\title{
Alphabetisches Verzeichnis der Professoren
}




\section{A}

\section{Abegg, Johann Friedrich}

1790-1794 Phil. Fak.

Klassische Philologie

1818-1840 Theol. Fak.

Praktische Theologie

* 30. Nov. 1765 Roxheim (bei Bad Kreuznach)

$\dagger$ 16. Dez. 1840 Heidelberg

ref.

V Johann Friedrich A. (1718-1789) Pfarrer

M Catharina Juliane geb. Beck (1737-1810)

(27. Dez. 1790 Elisabeth (Lisette) Charlotte geb. De Prée (1771-1817)

(25. April 1822 Franziska Wilhelmina geb. Maurer verw. Dupré (1789-1876), s. Ebert (2003), Stumm (2012) S. 690 (Register)

$\mathrm{K} \quad 8 \mathrm{~S}, 2 \mathrm{~T}$ (aus 1. Ehe), $1 \mathrm{~S}, 1 \mathrm{~T}$ (aus 2. Ehe)

Vw Schwäger: Georg Ludwig Konrad (seit 1831 von) Maurer (1790-1872) Jurist, Rechtshistoriker, 1847 bayer. Staats- und Reichsrat sowie Justiz- und Außenminister, s. NDB 16 (1990) S. 435 f., WBIS. - Luise Maurer (1794-1863) Ehefrau von: (siehe) Leopold Gmelin.

$L b$ Seit SS 1784 Studium der Philologie, Theologie an U Halle-Wittenberg, SS 1786 an UH (ohne Matrikeleintrag); 14. Juni 1786 theol. Examen; 26. Juni 1786 Ordination; anschl. beigeordneter Vikar und Hauslehrer bei Pfarrer Philipp Jakob Hilspach (1735-1812; s. Biundo (1968) S. 192) in Neckargemünd.

H: Seit Aug. 1789 Konrektoratsverweser, 2. Nov. 1789-Aug. 1794 Rektor des Ref. Gymnasiums (heute: Kurfürst-Friedrich-Gymnasium „KFG“).

UH: 24. Dez. 1789 zum SS 1790 Ern. zum a. o. Prof. für Klassische Philologie.

Boxberg (Baden): Seit 22. Aug. 1794 Pfarrer und Inspektor; als Inspektor auch Mitglied der Pfälzischen Synode; 24. April-Mitte Aug. 1798 Aufent- halt u. a. in Königsberg (Preußen), s. hierzu J. F. A.: Reisetagebuch von 1798 ... (1976) (unter W) und Vollert (2014) (unter $L$ ).

Leimen und Sandhausen (bei H): Seit 22. Febr. 1799 Inspektor (Dekan) und Pfarrer.

Karlsruhe: Seit 29. Aug. 1807 a. o. Mitglied im Rang e. Geistlichen Rats, seit 1. Juni 1810 korr. Mitglied im Rang e. Kirchenrats des Prot. Oberkirchenratskollegiums.

Welschneureut (heute: Stadtteil von Karlsruhe): Seit 29. Aug. 1807 Pfarrer.

H: Seit 5. Jan. 1808 II. Pfarrer an Peterskirche; seit Juni 1814 II. Pfarrer, 15. April 1823-1840 (†) I. Pfarrer an Heiliggeistkirche mit e. jährl. Einnahme von 1556 Gulden und 21 Kreuzer (Stand: 1832), s. hierzu UAH RA 6718 fol. 14r. • In dieser Zeit:

UH: 18. April 1818 Dr. theol.; seit WS 1818/19 Privat-Dozent; seit 14. Okt. 1819 o. Prof. für Praktische Theologie mit e. Jahresbesoldung von 60o.Gulden (Stand: 1833); 23. Okt. 1818-1840 (†) Direktor des neuerrichteten Theologisch-Homiletischen Seminars, s. hierzu Chronologische Geschichte der Seminarien an UH in: UAH RA 6122 fol. 71r-73v.

1828 Prorektor der UH; 1825, 1829, 1835 Dekan der Theol. Fak. der UH

E 1836 Ritter des Ordens vom Zähringer Löwen.

Qu UAH PA 1288; RA 5906, 6139, 6718 fol. 5v, 6r, 14 r u. ö.; Theol. Fak. 3 (alte Signatur: H-I-175/2) fol. 118v. GLA Abt. 205, Fasz. 140. • Briefe: UBH. • Nachlaß: Archiv des Germanischen Nationalmuseums Nürnberg.

$W$ Predigt-Versuch über das Allgemeine der Sokratischen Lehrart. Heidelberg 1793. Predigt über Römer 15,13, gehalten am 20. October 1816. Heidelberg 1817 - J.F.A. Reisetagebuch von 1798. Hrsg. von Walter und Jolanda Abegg ... Frankfurt/M. 1976. 
L Ullmann, Carl: J.F.A. - eine Charakteristik. Heidelberg (?) 1841. ADB 1 (1875) S. 4f.; Badische Biographien 1 (1875) S. 1 f.; WBIS. • Johann Jacob Abegg 1685-1744. Vorfahren und Nachkommen. Hrsg. von Hans-Christian Brandenburg und Michael Müller-Stüler. Meerbusch 2004. S. 185-187. • BBKL XXVII (2007) Sp. 1-5. • Schwinge, Gerhard: Schwarz, Marheineke, Ewald, A., Hüffell. Zur Vorgeschichte des ersten badischen Predigerseminars in Heidelberg zwischen 1807 und 1818 bzw. 1818 und 1838 in: Praktische Theologie und Landeskirchengeschichte ... Hrsg. von Johannes Ehmann. Berlin 2008. S. 281-292. - Stumm (2012) S. 690 (Register). • Vollert, Michael P.: Zwei Reisetagebücher aus den Jahren 1798 und 1905. Unveröffentlichtes Manuskript 2014 (Ausdruck im UAH); Ders.: Johann Heinrich Voß ... J.F. A. ... Zwei Gelehrte an der Universität Heidelberg im frühen 19. Jahrhundert. Rheinbach 2017.

$P$ Bildarchiv UAH; graph. Slg. UBH.

\author{
Abert, Hermann Joseph (Kurzbiographie) \\ * 25. März 1871 Stuttgart \\ $\dagger$ 13. Aug. 1927 Stuttgart \\ ev.-luth.
}

„Das Staatsministerium hat unterm 04. 03.1920 beschlossen, seine Entschließung vom 16. August 1919 Nr. 2245, durch die der a. o. Professor an der Universität Halle/S., Dr. Hermann Abert, zum etatm. a.o. Professor für Musikwissenschaft an der Universität Heidelberg auf 1. April d. J. [als Nachfolger von Philipp Wolfrum] ernannt worden ist, auf Ansuchen des Genannten zurückzunehmen" (aus: UAH H-IV-102/146 fol. 556r). Abert nimmt zum WS 1920/21 das Ordinariat für Musikwissenschaft in Leipzig, 1923 das in Berlin an. Anstelle Aberts erhält Theodor Kroyer 1920 die Heidelberger Professur.

\section{Qu UAH H-IV-102/146 fol. 556r.}

W Johann Joseph Abert (1832-1915). Sein Leben und seine Werke. Leipzig 1916. 2. Aufl. Bad Neustadt/Saale 1983/84. - Wolfgang Amadeus Mo- zart. Eine Biographie. 2 Bde. Leipzig 1919-1921. • Gesammelte Schriften und Vorträge. Hrsg. von Friedrich Blume. Halle/S. 1929. Nachdr. Tutzing 1968.

$L$ NDB 1 (1953) S. 18; WBIS. • Gedenkschrift für H. A. Von seinen Schülern. Hrsg. von Friedrich Blume. Halle/S. 1928. Nachdr. Tutzing 1974. Funk, Karl Josef: H. A. Musiker, Musikwissenschaftler, Musikpädagoge. Stuttgart 1994. • Ruf, Wolfgang: H.A. und die Händel-Renaissance in: Händel-Jahrbuch. Kassel 2002. S. 221-231. Salomon, Maynard: Who wrote H. A.s W. A. Mozart? in: The journal of musicology - a quarterly review of music history, criticism, analysis, and performance practice. Berkeley (California) 2008. S. 318-337. • Catalogus prof. Halensis online; Professorenkatalog Leipzig online.

\section{Ackermann, Jacob Fidelis}

1805-1815 Med. Fak.

Anatomie, Physiologie

* 23. April 1765 Rüdesheim

$\dagger \quad$ 28. Okt. 1815 Rüdesheim kath.

V Bernardus A. (1709-1790) Gastwirt und Weinberg-Besitzer, Schöffe

M Maria Loretta geb. Fink (1732-1779)

๑ 10. Mai 1795 Maria Eva Thekla geb. Linn $\left({ }^{\star} 1767\right)$ Scheidung 1815

$\mathrm{K} \quad 2 \mathrm{~S}, 1 \mathrm{~T}$

Lb Seit 1784 Studium an U Würzburg, anschl. Mainz.

U Mainz: 8. Mai 1787 Dr. med.; 5. Mai 1788 anatomische Inaugural-Dissertation.

1788-1789 Studienreisen durch Deutschland, Österreich, Italien, Schweiz.

U Mainz: Seit 1789 Privat-Dozent für Gerichtliche Medizin und Medizinalpolizei (= Theorie des staatlichen Gesundheitswesens); seit 1792 o. Prof. für Botanik; Okt. 1792 Einzug der franz. Revolu- 
tionstruppen; Juli 1793 Rückeroberung der Stadt durch preußische Truppen; Flucht.

Rüdesheim: Anfang 1794 aus gesundheitlichen Gründen Rückkehr in seine Geburtsstadt.

Mainz: Seit Aug. 1794 Untersuchung von kurfürstl. Behörden über e. politische Agitation A.s während der Mainzer Republik von März bis Juli 1793; 22. Dez. 1795 kurfürstl. Urteil untersagt A. als Anhänger der franz. Revolution u.a. jegliche Praxis „in den Kurlanden und (erklärt ihn) für unfähig zu allen Diensten in dem Mainzer Kurstaate“ (aus: Mathy (1986) S. 66); A. führt Rehabilitationsprozeß mit Erfolg; 12. Dez. 1797 Wiederberufung an U; 1798 nach Aufhebung der U Ern. zum Präsidenten der allg. Versammlung der Prof. an neu errichteter Zentral- und Spezialschule sowie Präsident der Verwaltungskommission des U-Fonds; seit 1798 Prof. für Anatomie und Physiologie an „École spéciale de médecine de Mayence“.

Jena: Seit SS 1804 o. Prof. für Anatomie und Chirurgie an $\mathrm{U}$ und Mit-Direktor der Herzoglich Med.-Chirurg. Krankenanstalt; 1804 Ruf an U Moskau abgelehnt.

UH: 12. Febr. 1805 Ern. zum o. Prof. in Nachf. von Karl Friedrich Posselt; Mitte Juli 1805 Dienstantritt; 23. Okt. 1805-1815 ( $\dagger$ ) außerdem (Gründungs-)Direktor des Anatomischen Theaters und der Inneren Poliklinischen Anstalt im ehemaligen Dominikanerkloster an der Ecke Hauptstrasse/ Brunnengasse (1815-1826 Schließung des „Institutum policlinicum medico chirurgicum" aus finanziellen Gründen); 30. Jan. 1812 Ministerium des Innern überträgt A. allerdings nur kurzzeitig das Amt des provisorischen Direktors des Botanischen Gartens in Nachf. von Wilhelm Gottlob Kastner (seit 1812 Direktor: Franz Schelver), s. hierzu UAH RA 6883 fol. 7 r-14r.

12. Juni 1810-18. April 1811 Prorektor der UH; 1809, Jan.-Okt. 1815 Dekan der Med. Fak. der UH.

$\mathrm{Zu}$ den Aufgaben der Poliklinischen Anstalt, siehe Almanach der Universität Heidelberg auf das Jahr 1813 ... Hrsg. von Julius Lampadius. Heidelberg 1812. S. $196 \mathrm{f}$.
1804 Herzogl. Sachsen-Weimarischer Hofrat; 1805 Kurfürstl. Badischer Geh. Hofrat

E Mitglied: Gesellschaft naturkundiger Freunde in Westfalen, Schweizerische Gesellschaft der Ärzte Bern, Med. Gesellschaft Erlangen, 1812 Akademie der Wissenschaften Berlin.

Qu UAH PA 1286; RA 6165 (1815-1816: Kauf von Instrumenten und Präparaten aus dem Nachlaß von J. F. A.). • GLA Abt. 205, Fasz. 141. • Ergebnislose Anfrage: Universitätsarchiv Mainz.

$W$ Commentatio de nervorum opticorum inter se nexu in: Blumenbachs medicinische Bibliothek 3 (1788) S. 337, 706. - De discrimine sexuum praeter genitalia. Diss. Mainz 1788. - Versuch einer physischen Darstellung der Lebenskräfte organisierter Körper. 2 Bde. Frankfurt/M. 1797-180o. 2. Aufl. 1805. Der Scheintod und das Rettungsverfahren. Frankfurt/M. 1804. • Die Gall'sche Hirn-, Schedelund Organen-Lehre vom Gesichtspunkte der Erfahrung aus beurtheilt und widerlegt. Heidelberg 1806. Siehe auch Hofmann (2004) S. $141 \mathrm{ff}$.

MHG 1805 Klinische Annalen der Herzoglichen medicinisch-chirurgischen Krankenanstalt in Jena.

L Schief, Axel: J.F.A. Diss. Heidelberg 1969. • Chronik Ärzte H (1985) S. 120, 209; WBIS. • Mathy, Helmut: J.F.A. und die Französische Revolution in: Ders.: Entschlüsselte Schilder - Straßennamen auf dem Campus ... Mainz 1986. S. 63-71. • Heidelberg im säkularen Umbruch (1987) S. 557 (Register); Zimmermann/Drüll (199o) S. 28 u. ö. • Göttert, Rolf: Er pries den Wein als Medizin ... in: Rheingauer Gestalten gestalten den Rheingau. Hedwig Witte und Rolf Göttert stellen markante Rheingauer vor. Geisenheim 1991. - Schweigard (2000) S. 129-131 u.ö.; Kirschke (2001) S. 445 (Register). Hofmann, Marion: Der Arzt J.F.A. ... und seine Vorstellungen vom "Scheintod“. Diss. Regensburg 2004. S. 83-93 u. ö. • Zimber, Peter: Er brachte den Schinderhannes mit nach Heidelberg: ... J. F. A. ... in: RNZ (22. April 2008) Nr. 94, S. 3. Zimmermann/Neuper (2008) S. 256 (Register). - Voß, Heinz-Jürgen: Making Sex Revisited: Dekonstruktion des Geschlechts aus biologischmedizinischer Perspektive. Bielefeld 2010. S. $144 \mathrm{f}$. 
u. ö. Hier freut sich der Tod (2013) S. 50-57, 103 u. ö.; Doll (2014) S. 248-251 u.ö.; Doll/Kirsch/ Eckart (2017) S. 9, 16, 20, 106.

$P$ Bildarchiv UAH; Chronik Ärzte $\mathrm{H}$.

\section{Affolter, Friedrich Xaver}

1897-1920 Jur. Fak.

1920-1921 (Honorar-Prof.) Jur. Fak.

Römisches Recht, Privatrecht

* 10. Febr. 1862 Solothurn

$\dagger \quad$ 02. Febr. 1923 Wiesloch (bei Heidelberg)

kath., nach 1871 altkath., seit 1909 prot.

V Urs Josef A. ( $\left.{ }^{*} 1822\right)$ Oberamtmann

M Rosalie geb. Grolimund (1834-1882)

๑ 11. April 1891 Elisabeth geb. Rössel ( $\left.{ }^{*} 1866\right)$

$\mathrm{K} \quad 2 \mathrm{~S}$ (davon $1 \mathrm{~S}$ im 1 . Weltkrieg $\not \times$ ), $1 \mathrm{~T}$

Lb UH: Seit WS 1881/82 Studium; 26. Febr. 1885 Dr. iur.

H: 1884 Kurzlebige Errichtung e. Privatschule für Rechts- und Volkswirtschaftswissenschaften.

Antwerpen: 1885 Vertreter Deutschlands in int. Konferenz für proportionale Volksvertretung.

UH: 30. Juni 1897 Habilitation; seit 14. Febr. 1901 nichtetatm. a.o. Prof.; seit WS 1902/03 Lehrauftrag für Römisches Recht und Dt. Bürgerliches Recht mit e. jährl. Vergütung von 1500.- Mark; seit WS 1908/og Lehrauftrag auch für Int. Privatrecht; seit 29. Febr. 1920 o. Honorar-Prof.; seit SS 1921 Entbindung von Lehrverpflichtungen an UH aus Krankheitsgründen.

Qu UAH PA 1285; RA 4943, 5209, 5252, 7655; Acc. 40/11. GLA Abt. 235, Fasz. 1722.

W Das römische Institutionensystem, sein Wesen und seine Geschichte. Heidelberg 1897. - Das intertemporale Recht. 2 T. Leipzig 1902-1903. • System des deutschen bürgerlichen Übergangsrechts. Leipzig 1903. - System des badischen Verwal- tungsrechts. Karlsruhe 1904. - Die Persönlichkeit des herrenlosen Sklaven. Leipzig 1913. • Die Friedensentschließung des Reichstags und die Kriegsschuldfrage. Berlin 1919.

$L$ Wer ist's (1922) S. 8 f.; Jansen (1992a) S. 163 (Register); Schroeder (2010) S. 346-349; Historisches Lexikon der Schweiz online (2011), s. http://www. hls-dhs-dss.ch/textes/d/D15825.php; Deutsche Biographie, s. https://www.deutsche-biographie.de/gn d11600942X.html [04. Nov. 2017].

$P$ Bildarchiv UAH.

\author{
Ahrens, Hans \\ siehe Ahrens, Johannes
}

\section{Ahrens, Johannes (Hans) Karl Friedrich}

1919-1920 Med. Fak.

Zahnheilkunde

* 26. März 1883 Schwerin

$\dagger \quad$ 23. Juli 1920 Heidelberg ev.

V Johannes Carl Christian A. (*1848) Kaufmann M Sophie Luise Agneta geb. Kruse ( $\left.{ }^{*} 1854\right)$

๑ 8. April 1908 Else geb. Jablonowsky (1885-1961) K $\quad 1$ T

Lb U München: Seit WS 1903/o4 Studium; 1906 ärztl. Approbation; 21. Dez. 1906 Dr. med.; 1907 zahnärztl. Approbation; Assistent am Zahnärztl. Inst.: seit 1. Mai 1908 in Konservierender Abt., seit 1912 in Chirurg. Abt.; 3. April 1913 Habilitation; seit 13. Jan. 1919 nichtetatm. a. o. Prof. - In dieser Zeit:

1915-1918 Kriegsdienst.

UH: Seit 25. Jan. 1919 etatm. a. o. Prof. und Direktor des Zahnärztl. Inst. als Nachf. von Gottlieb Port.

E 1917 Türkischer Eiserner Halbmond; 1918 Ritterkreuz des österr. Franz-Josef-Ordens. 
Qu UAH PA 808, 3109. - GLA Abt. 235, Fasz. 1723. Auskunft: Landeskirchliches Archiv Schwerin - Kirchenbuchstelle.

$W-$

$L$ Christian, Paul: Heidelberg und die moderne Medizin seit dem 1. Weltkrieg in: Ruperto Carola 5. Jg., Nr. 9/10 (1953) S. 51. • Bauer/Langsch (1991) S. 382 online; Deutsche Biographie, s. https:// www.deutsche-biographie.de/gnd1012763730.html [06.11. 2017].

\section{Alewyn, Richard}

1932-1933 Phil. Fak.

Neuere Deutsche Literatur

* 24. Feb. 1902 Frankfurt/M.

$\dagger$ 14. Aug. 1979 Prien (Bayern)

ev.

V George A. (1870-1937) Fabrikbesitzer

M Mathilde geb. Schmitz gesch. A. verh. Spier (1880-1945) Hausfrau

๑ 1928 Nelly geb. Ferch (* 1902) Scheidung 1951

๑ 1952 Marianne geb. Schroeter (1913-1971) Hausfrau

K $\quad 2$ T

Lb Seit 1920 Studium der Germanistik, Philosophie, Klassischen Philologie an U Frankfurt/M., anschl. Marburg, München, 24. April 1923-29. Mai 1925 H; 30. Juli 1925 Dr. phil. an UH.

U Berlin: 1926-1931 Stipendiat der Notgemeinschaft der dt. Wissenschaft; seit 1929 wiss. Assistent am Deutschen Seminar; 13. Febr. 1931 Habilitation für Dt. Philologie.

UH: Seit 30. Juli mit Wirkung vom 1. Okt. 1932 planm. a. o. Prof. am Deutschen Seminar als Nachf. von Friedrich Gundolf; 17. Jan. 1933 Antrittsvorlesung; 12. Aug. 1933 Versetzung in den Ruhestand ohne Pensionsanspruch aufgrund des Gesetzes zur „Wiederherstellung des Berufsbeamtentums“; Nov. 1933 Übersiedlung nach Frankreich.
Seit Dez. 1933 Gastprof. für Dt. Literatur (Rockefeller-Stipendiat) am Institut d'Études Germaniques an Sorbonne in Paris; seit Juni 1935 Aufenthalt in Österreich als Privat-Gelehrter; Aug. 1938 Flucht zunächst nach Ascona; Nov.-Dez. 1938 Gastvorträge an U of Cambridge und University College in London; Febr. 1939 Emigration in die USA.

Flushing (Stadtteil von Queens, e. Stadtbezirk von New York City): Seit Mitte 1940 Associate Prof., seit 1948 Full Prof. am Queens College; 1947-1948 Forschungsreise nach Europa, u. a. Gast-Prof. an U Marburg und Köln; 1948 Rückkehr nach Deutschland.

U Köln: Seit 2. Mai 1949 o. Prof. für Dt. Philologie.

FU Berlin: Seit 2. Nov. 1955 o. Prof.; Ruf an U Göttingen abgelehnt.

U Bonn: 1. Mai 1959-31. März 1967 (Emeritierung)

o. Prof. für Neuere Dt. Sprache und Literatur.

Gastprofessuren u.a.: 1960 Harvard U in Cambridge (Massachusetts), 1967/68 Columbia U in New York; 1971 Max Kade Distinguished Guest Prof. an U of Kansas in Lawrence.

E Mitglied: 1964 Dt. PEN-Zentrum, 1966 Akademie der Wissenschaften zu Göttingen, 1967 Dt. Akademie für Sprache und Dichtung Darmstadt; 1966 Ehrenmitglied der Modern Language Association of America.

Qu UAH PA 3114; Quästurakte Rep. 27-4. • GLA Abt. 235, Fasz. 1724. - Briefwechsel Gottfried Benn - R.A. 1951-1956 in: Berliner Hefte zur Geschichte des literarischen Lebens 5 (2003) S. 2550. Nachlaß: DLA Marbach, s. hierzu Fink, Heidrun: Der Nachlaß von R.A. ... in: Mitteilungen Marbacher Arbeitskreis für Geschichte der Germanistik, H. 4 (1992) S. 16-18; Int. Germanistenlexikon 1 (2003) S. 21. • Auskunft: Herr Dr. Michael Schroeter, Prien.

W Johann Beer. Studien zum Roman des 17. Jahrhunderts. Aus dem Nachlass hrsg. von Klaus Garber ... 2. Aufl. Heidelberg 2012. • Bibliographie in: 
Festschrift für R. A. (1967); s. auch Garber (2000), Int. Germanistenlexikon 1 (2003) S. 19 f.

HG Seit 1958 Literatur und Leben.

MHG 1957-1961 Euphorion.

$L$ Festschrift für R.A. Hrsg. von Herbert Singer und Benno von Wiese. Köln u. a. 1967. Verzeichnis Bonn (1968) S. 2. Gruenter, Rainer: Nachruf in: Euphorion (1979) Bd. 73, H. 3. In memoriam R.A. Reden, gehalten am 5. Dez. 1979. Hrsg. von Beda Allemann u. a. Bonn 1981. $\bullet$ R. A. Mit unveröffentl. Dokumenten und Fragmenten aus dem Nachlaß und e. Beitrag von Klaus Garber. Ausstellung der UB der Freien Universität Berlin ... Berlin 1982. (Ausstellungsführer der UB der FU Berlin. 6.) - Dictionary of Emigrés 2 (1983) S. 16; Mussgnug (1988) S. 171-181 u.ö.; DBE 1 (1995) S. 86. • Garber, Klaus: R.A. in: Wissenschaftsgeschichte Germanistik (2000) S. 211-220. HempelKüter, Christa: Germanistik zwischen 1925 und 1955 ... Berlin 200o. S. 23f., 64-66, 197 f. u.ö. • Szabó, Anikó: Vertreibung, Rückkehr, Wiedergutmachung: Göttinger Hochschullehrer im Schatten des Nationalsozialismus ... Göttingen 2000. S. 252, 256 f. u. ö. - Göttinger Gelehrte 2 (2001) S. 654 f.; Int. Germanistenlexikon 1 (2003) S. 18-21. • Seng, J.: Aufrichtiges Gespräch. Zum Briefwechsel zwischen Ernst Beutler und R. A. in: Goethezeit - Zeit für Goethe ... Festschrift für Christoph Perels ... Hrsg. von Konrad Feilchenfeldt u.a. Tübingen 2003. Garber, Klaus: Zum Bilde R. A.s. München 2005. Das Projekt Empfindsamkeit und der Ursprung der Moderne. R. A.s Sentimentalismusforschungen und ihr epochaler Kontext. Hrsg. von Klaus Garber und Ute Széll. München 2005. • Weber, Regina: Das „Internationale Germanistenlexikon 1800-1950" und die emigrierten Germanisten. Verlust und Neuerfindung von Identität im Zeichen des Exils am Beispiel von ..., R. A. und Bernhard Blume in: Autobiografie und wissenschaftliche Biografik. München 2005. S. 86-101. • Reinhart, Max: Der Detektiv in der Geschichte: R.A. und das Problem der Frühen Neuzeit in: Daphnis. Zs. für mittlere deutsche Literatur und Kultur der frühen Neuzeit (1400-1750). Amsterdam 2006. S. 381-428. - UH im Nationalsozialismus (2006) S. 360, 362, 365; Hausmann (2008) S. 787 (Register); 100 Jahre Germanistik in Ham- burg (2011) S. 252 f., 447 u. ö.; Lexikon jüdischer Einwohner Hs (2011) S. 28; Riecke (2016) S. 141 (Register); Deutsche Biographie, s. https://www. deutsche-biographie.de/gnd11850181X.html [04.11. 2017].

$P$ Bildarchiv UAH.

\section{Altmann, Sally (seit 1927: Altmann, Salomon Paul)}

1910-1922 Phil. Fak.

1922-1929 (1933) (Honorar-Prof.) Phil. Fak.

Nationalökonomie

* 27. Juni 1878 Berlin

$\dagger \quad$ 07. Okt. 1933 Achern (Baden)

mosaisch

V Wilhelm (?) A., Kaufmann

M Johanna geb. Hirsch

( 5. Nov. 1906 Dr. Elisabeth geb. Gottheiner (1874-1930) Sozialpolitikerin, seit 1908 Dozentin (wohl erste Hochschuldozentin Deutschlands), seit 1925 Titular-Prof. an Handelshochschule Mannheim, s. NDB 1 (1953) S. 227; Günther, Rosmarie: Eine vorbildliche Netzwerkerin - E. A.-G. ... in: Mannheimer Geschichtsblätter 20 (2010) S. 21-34.

$\mathrm{K}$ Keine.

Lb Seit WS 1898/99 Studium der Philosophie, Naturwiss., Staatswiss. an U Berlin, anschl. Freiburg/ Br.; 22. Febr. 1906 Dr. phil. an U Berlin.

Frankfurt/M.: 1906-1908 Wiss. Beamter an Handelskammer; seit WS 1907/08 außerdem nebenamtl. Dozent für Volkswirtschaftslehre an Handelshochschule Mannheim.

Handelshochschule Mannheim: Seit SS 1909 hauptamtl. Dozent für Volkswirtschaftslehre; seit 3o. Juni 1910 a. o. Prof.; 25. Jan. 1923-1. Okt. 1930 (Emeritierung aus Krankheitsgründen) o. Prof. • In dieser Zeit:

UH: 30. Nov. 1910 Habilitation; seit 1. Aug. 1917 nichtetatm. a.o. Prof.; seit 31. Aug. 1922 o. Hono- 
rar-Prof.; seit WS 1929/30 aus Krankheitsgründen Entbindung von Lehrverpflichtungen; Apr. 1933 Entlassung aufgrund des „Gesetzes zur Wiederherstellung des Berufsbeamtentums“.

Achern: Seit 1931 Aufenthalt in Heil- und Pflegeanstalt Illenau.

Qu UAH PA 3116. • GLA Abt. 235, Fasz. 1727.

$W$ Die Kriegsfürsorge in Mannheim. Mannheim 1916. Soziale Mobilmachung. Mannheim 1916. • Gegenwartsaufgaben des wirtschaftswissenschaftlichen Hochschulunterrichts. Mannheim 1927.

L Kürschner (1928/29) Sp. 21; WBIS; HandelsHochschule Mannheim 1907-1932 (1932) S. 22. • Kurzbiographien zur Geschichte der Juden 19181945. Hrsg. von Joseph Walk. München 1988. Köster, Roman: Die Wissenschaft der Außenseiter. Die Krise der Nationalökonomie in der Weimarer Republik. Göttingen 2011. - Deutsche Biographie, s. https://www.deutsche-biographie.de/ pnd11629518X.html [22. 06. 2018].

P Portrait-Zeichnung von 1930 im UA Mannheim.

\section{Altmann, Salomon Paul}

s. Altmann, Sally

\section{Amann, Julius}

1875-1879 Jur. Fak.

Römisches Recht

* 17. Dez. 1838 Freiburg/Br.

$\dagger \quad$ 31. Okt. 1879 Heidelberg

kath.

V Johann A. (1799-1879) Buchbinder

M Theresia geb. Klausmann (1799-1885)

( Maria geb. Linkenbach

$\mathrm{K}$ unbekannt.
Lb Seit WS 1858/59 Studium der Medizin an U Freiburg/Br., anschl. Würzburg, München; Herbst 1865 ärztl. Staatsexamen in München.

U Freiburg/Br.: Seit WS 1865/66 Studium der Rechtswiss.; 1870/71 Feldarzt während des Deutsch-Französischen Krieges; 19. Jan. 1875 Dr. iur.

UH: 31. Juli 1875 Habilitation; seit 26. Juni 1878 a. o. Prof.

E 1871 Ritterkreuz II. Klasse des Ordens vom Zähringer Löwen.

Qu UAH PA 3117. GLA Abt. 205, Fasz. 144 f.

$W$ Die Berechnung der Falcidia bei Vereinigung mehrerer Erbtheile durch Accrescenz oder Potestas ... Leipzig 1876. • Die Grundsätze der heutigen Pandektenkritik geprüft an der sogenannten Lex Gallus. München 1878. •Über den Begriff des procurator und mandatarius nach römischem Recht. Heidelberg 1879.

L J.A. in: Heidelberger Familienblätter Nr. 94 (26. Nov. 1879) S. 374 f. - Biographie in: Autoren der Bunsenbibliothek (2009 online). Schroeder (2010) S. 331f.; Deutsche Biographie, s. https:// www.deutsche-biographie.de/gnd116296631.html [04.11. 2017].

\section{Andreae, Philipp Victor Achilles}

1884-1894 Phil. Fak.

Geologie, Paläontologie

* 14. Nov. 1859 Frankfurt/M.

$\dagger$ 17. Jan. 1905 Hildesheim ev.

V Achilles A. (1820-1888) Bankier, Handelsmann in Frankfurt/M.

M Alharda Alexandrine geb. Freiin von der Borch (1836-1917)

œ 25. März 1896 Margarethe geb. von Wasmer (1874-1921); in 2. Ehe $\varnothing 1906$ Heinrich Bolten-Baeckers (1871-1938), u.a. Bühnenautor, 
Filmregisseur, Produzent, Librettist (u. a. von „Das ist die Berliner Luft" und „Schenk mir doch ein kleines bisschen Liebe“), s. Weniger, Kay: Das große Personenlexikon des Films. Die Schauspieler, Regisseure ... des 20. Jahrhunderts. Berlin 2001. Bd. 1. S. 459.

K $2 \mathrm{~S}$

Vw Onkel: Dr. iur. Dr. med. Dr. phil. h.c. (187o U Straßburg) Hermann Victor A. (1817-1889) Sprach- und Religionsforscher, s. NDB 1 (1953) S. 280, WBIS, BBKL I (1990) Sp. 165.

Lb Seit SS 1879 Studium der Naturwiss. an U Straßburg, anschl. Berlin, Bonn, Straßburg.

Straßburg: 21. Febr. 1883 Dr. phil. an U; seit 1883 Volontär bei geologischer Landesaufnahme.

UH: 18. Juli 1884 Habilitation; seit 7. Juli 1887 a.o. Prof.; WS 1890/91 Studienreisen in den Orient und nach Nordafrika; seit 7. März 1891 etatm. a. o. Prof.

Hildesheim: Seit 1. Juni 1894 Direktor des RoemerMuseums (heute: Roemer- und Pelizaeus-Museum).

Qu UAH PA 1294; RA 6489; Fak.-Akten H-IV102/105 fol. 55r, 58r, 7or u. ö., H-IV-102/107 fol. 28r u. ö. GLA Abt. 235, Fasz. 1731. Briefe: UBH.

$W$ Beitrag zur Kenntnis des Elsässer Tertiärs. $2 \mathrm{~T}$. Straßburg 1883-1884. • Führer durch die Gesteinssammlung des Roemer-Museums. Hildesheim 1896.

$L$ Biogr. Jahrbuch 10 (1905) Sp. 139 (Anhang); NDB 1 (1953) S. 281-282 (mit Werkverz.); WBIS; Jansen (1992a) S. 163 (Register); Genealogie der Familie Andreae, s. http:/gw.geneanet.org/bemi ha?lang=fr; $\mathrm{p}=$ philipp+victor+achilles; $\mathrm{n}=$ andreae; Autoren der Bunsenbibliothek (2009 online); Hessische Biografie, s. http://www.lagis-hessen.de/ pnd/116309415 (Stand: 10. April 2010).

$P$ Bildarchiv UAH; graph. Slg. UBH.

\section{Andreas, Willy Ludwig}

1923-1946, 1948, 1949 Phil. Fak.

Neuere Geschichte

* 3o. Okt. 1884 Karlsruhe

$\dagger$ 10. Juli 1967 Litzelstetten (heute: Stadtteil von Konstanz)

ev.

V Ludwig A. (1851-1906) Immobilien-Kaufmann

M Elise geb. Schnepf

$\varnothing$ 30. April 1921 Gertrud (Gerta) geb. Marcks (1897-1985) T von: (siehe) Erich M. [d. Ä.]

$\mathrm{K} \quad 1 \mathrm{~S}, 2 \mathrm{~T}$

Vw Schwager: Erich Marcks [d. J.] $\left({ }^{\star} 1891\right.$ X 1944) Berufsoffizier, zuletzt 1944 General der Artillerie, s. Jacobsen, Otto: E.M. Soldat und Gelehrter. Göttingen 1971; NDB 16 (1990) S. 125; Siegfried A. Kaehler: Briefe 1900-1963. Hrsg. von Walter Bußmann, Günther Grünthal. Boppard 1993. S. 482 (Register); Briefe von General E. M. an seinen Schwager Willy Andreas zu Beginn des Zweiten Weltkrieges in: Nachlaß von W. A. im GLA Karlsruhe.

Lb Seit WS 1903/04 Studium der Geschichte, Philosophie, Germanistik, Ökonomie an U Grenoble, seit SS 1904 München, SS 1905 Berlin, WS 1905/06SS 1907 H; Juli 1907 Rigorosum, 7. Febr. 1908 (Datum der Promotionsurkunde) Dr. phil. an UH.

U Freiburg/Br.: WS 1907/08 Forts. des Studiums; 18. März 1908 Staatsexamen.

Konstanz: Seit 30. Mai 1908 Lehramtspraktikant am Gymnasium.

Karlsruhe: Seit 22. Okt. 1908 wiss. Mitarbeiter bei Badischer Histor. Kommission.

U Marburg: 27. Juli 1912 Habilitation für Neuere Geschichte; seit WS 1912/13 Privat-Dozent.

TH Karlsruhe: Seit 18. Juli 1914 Lehrauftrag; seit 1. Aug. 1914 nichtetatm. a. o. Prof.

1914-1918 Kriegsfreiwilliger. 
U Rostock: Seit 7. Mai 1916 etatm. a. o. Prof. für Geschichte; 1919 Ruf als o. Prof. an TH Karlsruhe abgelehnt; seit 1. Juli 1919 persönlicher Ordinarius.

U Berlin: Seit SS 1922 o. Prof. für Verfassungs-, Verwaltungs- und Wirtschaftsgeschichte.

UH: Seit SS 1923 o. Prof. und Mit-Direktor des Histor. Seminars als Nachf. von Hermann Oncken; Sommer/Herbst 1924 Ablehnung der Stelle des Personalreferenten für Universitäten im Preußischen Kultusministerium Berlin, s. hierzu auch Otto Regenbogen; 1929 Ruf an U Göttingen abgelehnt; seit SS 1933 Mit-Direktor des Histor. Seminars, Abt. für Mittlere und Neuere Geschichte; 18. Febr. 1946 Entlassung gemäß Erlaß der amerik. Militärregierung (Spruchkammerverfahren vom März 1947: nicht belastet und nicht betroffen); 22. Juni 1948 Wiedereinstellung als planm. o. Prof.; 1. Juli 1948 Ruhestand; 4. Juni 1949 Wiederernennung zum o. Prof.; 1. Nov. 1949 Emeritierung.

U Tübingen: 1949-1951 Vertreter des Ordinariats für Geschichte.

U Freiburg/Br.: WS 1952/53 Gastvorlesungen; seit 15. April 1955 Honorar-Prof.

1932/33 Rektor der UH; 1927/28 Dekan der Phil. Fak. der UH

Siehe auch Anhang Sporteinrichtungen an $U H$ 1910-1933 und ihre Mitglieder

$E$ Mitglied der Akademie der Wissenschaften: 1934 München, 1942 Berlin. 1959 D. theol. UH und Dr. iur. h. c. Freiburg/Br.

Qu UAH PA 308, 3123f.; Fak.-Akte H-IV-102/149 fol. 2or; B-1015/3 vom 19. Sept. 1933; B-0747/1 vom 14. Aug. 1947; Studentenakte. - Briefe: UBH. Nachlaß: GLA Karlsruhe.

$W$ Geschichte der badischen Verwaltungsorganisation und Verfassung in den Jahren 1802-1818. Leipzig 1913. Deutschland vor der Reformation. Stuttgart 1932. 7. Aufl. 1972. • Das Zeitalter Napoleons und die Erhebung der Völker. Heidelberg 1943. Erw. Neubearb. 1955. • Carl August von Wei- mar. Stuttgart 1953. - Siehe Hauck, Dorothea: Verzeichnis der Schriften von W. A. ... in: ZGORh 105. Jg. (1957) S. 295-324.

HG Gespräche Bismarcks. Bd. 1: Bis zur Aufrichtung des Deutschen Reiches. Berlin 1924. 2. Aufl. 1924. Bd. 2: Bis zur Entlassung Bismarcks. Berlin 1926. 2. Aufl. 1926. Bd. 3: Von der Entlassung bis zum Tode Bismarcks. Berlin 1926. (Otto von Bismarck: Die gesammelten Werke. Bde. 7-9.)

L Kühn, Johannes: W. A. in: Ruperto Carola 6. Jg., Nr. 15/16 (1954) S. 65 f. • Facius, Friedrich: Nekro$\log$ in: Historische Zeitschrift 207 (1969) S. 525528; Ders.: W. A. in: ZGORh 124. Jg. (1976) S. 369377. - Catalogus prof. Marburgensis 2 (1979) S. 461 f.; Badische Biographien N.F. II (1987) S. 47; Weber (1987) S. 8 f.; Mussgnug (1988) S. 297 (Register); Heiber II,1 (1992) S. 649 (Register); Heiber II,2 (1994) S. 831 (Register); Jansen (1992) S. 407 (Register); Historikerlexikon ( $\left.{ }^{2} 2002\right)$ S. 6 f.; Grüttner (2004) S. 14; Kriegstagebuch K. Hampe (2007) S. 942 (Register); BBKL XXIX (2008) Sp. 46-75; Hausmann (2008) S. 787 (Register); WBIS; Grewolls (2011). - Engehausen, Frank: "Schweineschmalzstullenfresser" und „Hopfenjauchekonsument“. Zwei anonyme Kommentare zu den "rassischen Säuberungen“ an der Universität Heidelberg 1933 in: Onlineportal „Geschichte der Landesministerien in Baden und Württemberg in der Zeit des Nationalsozialismus", s. http:// ns-ministerien-bw.de/2015/11/schweineschmalz stullenfresser-und-hopfenjauchekonsument-zweianonyme-kommentare-zu-den-rassischen-saeu berungen-an-der-universitaet-heidelberg-193/ (abgerufen am 2. Nov. 2015). - Spenkuch (2016) S. 1307 (Register); Deutsche Biographie, s. https:// www.deutsche-biographie.de/gnd118649213.html [04.11. 2017].

$P$ Bildarchiv UAH; graph. Slg. UBH; Ruperto Carola; Badische Biographien. 


\section{Anschütz, Gerhard}

1900-1908, 1916-1933 Jur. Fak.

Dt. Staats- und Rechtsgeschichte, Dt. Reichs- und

Landesstaatsrecht, Verwaltungsrecht, Kirchen-

recht, Polizeiwissenschaft

* 10. Jan. 1867 Halle/S.

$\dagger$ 14. April 1948 Heidelberg

ev.

V August A. (1826-1874) seit 1851 Privat-Dozent und seit 1855 a. o. Prof. Bonn, seit 1859 o. Prof. Greifswald, seit 1862 o. Prof. für Rechtswiss. Halle-Wittenberg, s. ADB 46 (1902) S. 16, WBIS, Catalogus prof. Halensis online

M Anna geb. Volkmann (1832-1901) T von Alfred Wilhelm V. (1801-1877), u.a. 1844-1876

o. Prof. für Pathologie und Physiologie HalleWittenberg, s. Catalogus prof. Halensis online, Professorenkatalog Leipzig online; Zimmer, Heinz-Gerd: Profiles in Cardiology: A.W.V. in: Clinical Cardiology 28 (2005) S. $546 \mathrm{f}$. Schwester von Richard von V. (1830-1889), u. a. seit 1867 o. Prof. für Chirurgie Halle-Wittenberg, s. Trieder, Simone: R. von V. - Chirurg und Literat. Halle/S. 2006; Catalogus prof. Halensis online

( 4. Sept. 1896 Elisabeth geb. Herold (1873-1932), s. Gesamtausgabe Gustav Radbruch 17 (1991) S. 88 u. ö.

K 1 T, 2 S: u. a. Dr. iur. Hans A. (1901-1980) Jurist; Ehemann von Elisabeth Charlotte (Liselotte) geb. Fraenkel verw. Köster (1902-1992) T von: (siehe) Albert F. - Siehe Albert Fraenkel ... Hrsg. von Peter Drings u. a. Landsberg/Lech 2004. S. 407 (Register); Lexikon jüdischer Einwohner Hs (2011) S. 115.

Lb SS 1886 Studium an U Genf, seit WS $1886 / 87$ Leipzig, WS 1887/88 Berlin, seit SS 1888 Halle-Wittenberg; 9. Juli 1889 I. Staatsprüfung am Oberlandesgericht in Naumburg; 10. Jan. 1891 Dr. iur. an U Halle-Wittenberg.

Referendar: Seit Juli 1889 Bitterfeld, seit Frühjahr 1890 Halle/S., seit Okt. 1891 u. a. bei Bezirksregierung Merseburg; 7. Juli 1894 II. Staatsprüfung in Berlin; Aug. 1894-Jan. 1899 zunächst Regierungs- assessor, anschl. Staatskommissar in Wittenberg, Berlin und zuletzt Stettin.

U Berlin: 6. Aug. 1896 Habilitation für Staatsrecht.

U Tübingen: 16. Jan. 1899 Ern. zum o. Prof.

UH: 30. Juli 1900 Ern. zum o. Prof. als Nachf. von Georg Meyer; 3. Okt. 1900 Vereidigung.

U Berlin: Seit WS 1908/o9 o. Prof. für Öffentl. Recht.

UH: 14. Dez. 1915 Ern. zum 1. Okt. 1916 o. Prof. als Nachf. von Fritz Fleiner; 1920 Ruf an U Leipzig abgelehnt; 1. April 1933 auf eigenen Antrag der Amtspflichten enthoben.

1922/23 Rektor der UH; 1921/22 Wahlsenator der UH; 1902/03, 1907/08, 1918/19, 1925/26 Dekan der Jur. Fak. der UH

1946 Mitglied des Verfassungsausschusses für Württemberg-Baden

1910 Geh. Justizrat; 1916 Geh. Hofrat

E 1899 Dr. rer. pol. h.c. Tübingen. 1904 Fürstl. Lippischer Hausorden II. Klasse; 1906 Ritterkreuz I. Klasse des Ordens vom Zähringer Löwen; 1912 Königl. Preußischer Roter Adler-Orden IV. Klasse. 1947 Ehrensenator der Universität Heidelberg.

Qu UAH PA 735, 3133; RA 6656, 6679, 6762. GLA Abt. 235, Fasz. 1734. • Briefe: UBH. $\bullet$ Reden dt. Gelehrter (1999) S. 55-60. Mitteilungen: Herr Dr. Klaus Anschütz, Heidelberg. Aus meinem Leben. Hrsg. ... von Walter Pauly. 2. Aufl. Frankfurt/M. 2008. (Autobiogr.)

$W$ Die gegenwärtigen Theorien über den Begriff der gesetzgebenden Gewalt und den Umfang des königlichen Verordnungsrechts nach preußischem Staatsrecht. Tübingen 1900. 2. Aufl. 1901. • Meyer, Georg: Lehrbuch des deutschen Staatsrechtes. 6. und 7. Aufl. bearb. von Gerhard Anschütz. Leipzig 1905 und München 1914-1919. 8. Aufl. 2005. Die Verfassungsurkunde für den PreuBischen Staat. Berlin 1912. - Die Verfassung des 
Deutschen Reichs vom 11. VIII. 1919. Berlin 1920. 14. Aufl. 1933. Nachdr. 1960. - Das preußischdeutsche Problem. Tübingen 1922. • Siehe hierzu Schroeder (2010) S. $404 \mathrm{ff}$.

MHG Handbuch des deutschen Staatsrechts. 2 Bde. Tübingen 1930-1932. Nachdr. 1998.

L NDB 1 (1953) S. 307 (mit Werkverz.). • Böckenförde, Ernst Wolfgang: G. A. in: Semper apertus 3 (1985) S. 167-185. • Mussgnug (1988) S. 297 (Register); Badische Biographien N.F. III (1990) S. 6-8; Jansen (1992) S. 407 (Register); Heiber II,2 (1994) S. 831 (Register); WBIS; Stolleis (2002) S. 419 (Register). Gesamtausgabe Gustav Radbruch 20 (2003) S. 175 (Register); Wirtschaftswiss. Fak. Tübingen I (2004) S. 332-339; Kriegstagebuch K. Hampe (2007) S. 942 (Register). • Groh, Kathrin: Demokratische Staatsrechtslehrer in der Weimarer Republik ... Tübingen 2010. S. 42 ff. - Heun, Werner: G.A. ... in: Festschrift 200 Jahre Juristische Fakultät der ... Universität zu Berlin ... Hrsg. von Stefan Grundmann ... Berlin u. a. 2010. S. 455476. Schroeder (2010) S. 399-409 u. ö. - Leo, Paul Christopher: Wilhelm Groh ... Hamburg 2012. S. 115-117. - Anderheiden, Michael: G. A. als Wegbereiter des heutigen Positivismus in: Heidelberger Thesen zu Recht und Gerechtigkeit (2013) S. 323-344. - Intellektuelle in Heidelberg (2014) S. 423 (Register); Spenkuch (2016) S. 1307 (Register). - Schroeder, Klaus-Peter: „Nationalismus und Demokratie gehören zusammen“. G. A.: Einsichten und Ansichten eines Heidelberger Staatsrechtslehrers im Ersten Weltkrieg in: UH während des Ersten Weltkriegs (2017) S. 241-258.

$P$ Bildarchiv UAH; NDB.

\section{Arnold, Philipp Friedrich}

1826-1835, 1852-1873 Med. Fak. 1826-1835, 1852-1873 Anatomie, 1826-1835, 1852 1858 auch Physiologie

* o9. Jan. 1803 Edenkoben (Rheinpfalz)

$\dagger \quad$ o4. Juli 1890 Heidelberg

ev.
V Zacharias A. (1767-1840) Gutsbesitzer

M Susanne Margaretha geb. Brünings (17681833) Enkelin von Christian Brünings (s. Drüll (1991) S. 13) und T von Konrad Ludwig B., Kirchenrat, 1771-1781 Pfarrer an Peterskirche in $\mathrm{H}$, s. Seiner Churfürstlichen Durchleucht zu Pfalz etc. Hof- und Staats-Kalender für das Jahr 1781 ... München 1781. S. 184; Wundt, Friedrich Peter: Geschichte und Beschreibung der Stadt Heidelberg. Bd. 1. Mannheim 1805. Nachdr. Heidelberg 1997. S. 419.

(26. April 1830 Ida Eberhardina geb. von Go(c)k (1811-1868) T von Carl Christoph Friedrich G. (1776-1849) Halbbruder Friedrich Hölderlins (1770-1843), u.a. 1817-1842 Hof- und Domänenrat, s. Dickenberger, Udo, Pfäfflin, Waltraud und Friedrich: Der Stuttgarter Hoppenlau-Friedhof als literarisches Denkmal. Marbach/Neckar 1992. S. 218-220.

K 5, u.a. T: Ida A. (1831-1909) Ehefrau von: (siehe) Carl Gegenbaur. S: (Siehe) Julius A.

Vw Bruder: Joseph Wilhelm A. (1801-1873) seit 1827 Privat-Dozent UH, seit 1835 a.o. Prof. für Pathologische Physiologie Zürich, 1841-1866 niedergelassener Arzt in H, s. NDB 1 (1953) S. 383, WBIS, Emundts-Trill (1997) S. 240. • Neffe: (Siehe) Wilhelm Wundt.

Lb UH: Seit SS 1821 Studium; 7. Sept. 1825 Dr. med.; Frühjahr-Herbst 1826 Studienreise nach $\mathrm{Pa}-$ ris; 1826 Habilitation für Medizin; seit 23. Okt. 1826 Hilfsprosektor mit e. jährl. Besoldung von 400.Gulden, seit 7. Nov. 1828 Prosektor am Anatom. Inst.; seit 27. Nov. 1832 a. o. Prof. mit Besoldung; seit 1. Juni 1833 Besoldungszulage von 200.- Gulden „unter der Verpflichtung, Vorlesungen über vergleichende Anatomie zu halten und die Vervollständigung der anatomischen Sammlungen zu besorgen" (aus: Schreiben vom 1. Mai 1833 in: UAH PA 1298).

U Zürich: 6. Dez. 1834 (Ern.) zum 1. April 1835 o. Prof.

U Freiburg/Br.: Seit 3. März 1840 o. Prof.

U Tübingen: 9. Nov. 1844 Ern. zum o. Prof. für Anatomie, Pathologie und Physiologie; SS 1845 Amtsantritt. 
UH: 30. Juli 1852-30. Sept. 1873 (Ruhestand) o. Prof. für Anatomie und 1852-1858 für Physiologie (A.s Nachf. wird 1858 Hermann von Helmholtz) sowie 1852-1873 Direktor der Anatom. und 18521858 der Physiolog. Anstalt (auch: Inst.) als Nachf. von Jacob Henle.

1854/55 Prorektor der UH; 1853, 1858, 1863/64, 1869/70 Dekan der Med. Fak. der UH

1852 Geh. Hofrat

E Mitglied: 1856 Naturhistor.-Med. Verein H, 1860 Dt. Akademie der Naturforscher Leopoldina Halle/S. 1870 Ritterkreuz I. Klasse des Ordens vom Zähringer Löwen.

Qu UAH PA 1298; RA 6189, 6592, 6783, 6900. • Siehe auch Archiv der Dt. Akademie der Naturforscher Leopoldina Halle/S.

$W$ Icones nervorum capitis. Zürich u.a. 1834 . 2. Aufl. 1860. Tabulae anatomicae. Zürich, Stuttgart 1838-1842. - Lehrbuch der Physiologie des Menschen. 4 Bde. Freiburg/Br. 1845-1851.

L NDB 1 (1953) S. 383 f. (mit Werkverz.); Hirsch 1 $\left({ }^{3} 1962\right)$ S. 210 f.; Chronik Ärzte H (1985) S. 120. • Hildebrand, R.: The cranial nerves as living morphotic entities - F.A.'s Icones nervorum capitis ... in: Acta Neurochirurgica (Wien) 92 (1988) S. 5-14. Pantel/Bauer (1990) S. 89. - Schnalke, T.: P.F. A. in: Der Pathologe 12(1) (1991) S. 48 f. • Lekakis, G. K.: P. F. A., Ludvig Levin Jacobson and their contribution to head and neck anatomy in: Journal of Laryngology and Otology 117(1) (2003) S. 2831. - Seidler/Leven (2007) S. 183 f.; WBIS; Freudenberg (2010) S. 142-144 u. ö.; Hier freut sich der Tod (2013) S. 65-68; Doll (2014) S. 257-261 u.ö.; Doll/ Kirsch/Eckart (2017) S. 41, 109.

$P$ Bildarchiv UAH; graph. Slg. UBH; NDB; Chronik Ärzte $H$.

\section{Arnold, Julius}

1863-1907 Med. Fak.

1863-1866 Histologie, Anatomie; 1866-1907 Pa-

thologische Anatomie

* 19. Aug. 1835 Zürich

$\dagger \quad$ O2. Febr. 1915 Heidelberg ev.

V (siehe) Friedrich A. (1803-189o)

M Ida Eberhardina geb. von Go(c)k (1811-1868)

( 29. Sept. 1874 Bianca geb. Muth (1853-1915)

K $\quad 1$ S, 2 T

Vw Halbbruder des Großvaters mütterlicherseits: Friedrich Hölderlin (1770-1843).

Lb UH: Seit WS 1854/55 Studium; Staatsexamina: 1858 Innere Medizin, Okt. 1859 Chirurgie, Geburtshilfe; 14. Nov. 1859 Dr. med.; 1860-1861 Studienreisen, u. a. nach Prag, Wien, Berlin; 9. Febr. 1863 Habilitation für Histologie; seit Okt. 1863 Assistent am Anatom. Inst. (Direktor: Vater Friedrich A.); WS 1865/66 Assistent am Patholog. Inst. der U Berlin; seit 15. April 1866 a. o. Prof. für Patholog. Anatomie mit e. jährl. Besoldung von 8oo.Gulden an UH; 1866-1907 Direktor des neuerrichteten Patholog.-Anatom. Inst.; Frühjahr 1870 Ruf an U Bern abgelehnt; seit 14. Mai 1870 (I.) o. Prof. für Patholog. Anatomie (II. Prof.: Theodor von Dusch) mit e. Besoldungszulage von 200.- Gulden; Rufe an U abgelehnt: 1872 Kiel, 1882 Wien; jährl. Besoldung: seit März 1872 250o.- Gulden, seit Jan. 1882 700o.- Mark, seit Jan. 1907 7500.(plus Wohnungsgeld von 1200.- Mark); 1. April 1907 Ruhestand (Ruhegehalt: 6525.- Mark). • In dieser Zeit:

H: 1861-1866 Niederlassung als praktischer Arzt.

1888 Prorektor der UH; 1877/78, 1886/87, 1896/97 Dekan der Med. Fak. der UH

1880 Hofrat; 1882 Geh. Hofrat; 1884 Geh. Rat II. Klasse; 1907 Wirkl. Geh. Rat (Exzellenz)

E 1880 Mitglied der Dt. Akademie der Naturforscher Leopoldina Halle/S.; 1909 Mitglied der Akademie der Wissenschaften H. - Kommandeur- 
kreuz I. Klasse: 1899 des Ordens vom Zähringer Löwen, 1903 des Ordens Berthold I.

Qu UAH PA 812, 1299; RA 5225, 6175, 6785. Mitschrift A.s von den Vorlesungen Adalbert Ducheks im SS 1857, siehe UAH Acc. 30/12. - Siehe auch Archiv der Dt. Akademie der Naturforscher Leopoldina Halle/S.

$W$ Die Bindehaut der Hornhaut und der Greisenbogen. Heidelberg 1860. • Anatomische Beiträge zu der Lehre von den Schußwunden. Heidelberg 1873. Untersuchungen über Staubinhalation und Staubmetastase. Leipzig 1885. • Über den Kampf des menschlichen Körpers mit den Bakterien in: Akademische Rede zum Geburtsfeste des höchstseligen Grossherzogs Karl Friedrich am 22. Nov. 1888 ... gehalten. Heidelberg 1888. S. 1-46. Über feinere Strukturen und die Anordnung des Glykogens in den Muskelfaserarten des Warmblüterherzens. Heidelberg 1909. Bibliographie 1860-1905 in: Festschrift für Professor J. A. Hrsg. von Ernst Schwalbe. Jena 1905. S. 778-795.

$L$ Heidelberger Prof. aus dem 19. Jhdt. 2 (1903) S. 72-76; Wer ist's (1906) S. 24. - Ernst, Paul: J. A. in: Münchener med. Wochenschrift 11 (1915) S. 370-372. Stübler (1926) S. 327; Arnim 1 (1944) S. 36; Hirsch $1\left({ }^{3} 1962\right)$ S. 211 f.; Hoche (1969) S. 86 f.; Chronik Ärzte H (1985) S. 120, 209 f.; WBIS; Pantel/Bauer (1990) S. 94-99; Jansen (1992a) S. 163 (Register); Dhom (2001) S. 354-361 u. ö.; Von der Forschung gezeichnet (2007) S. 107 u. ö;; Autoren der Bunsenbibliothek (2009 online); Deutsche Biographie, s. https://www.deutsche-biographie. de/gnd116208627.html [04.11.2017]; Doll/Kirsch/ Eckart (2017) S. 62.

$P$ Bildarchiv UAH; graph. Slg. UBH; Chronik Ärzte H.

\section{Arnsperger, Hans Rudolf Emil Ludwig}

1903-1911 Med. Fak.

Innere Medizin

* 04. Okt. 1872 Karlsruhe

$\dagger$ o8. Febr. 1955 Karlsruhe ev.

V Carl Ludwig Friedrich A. (1837-1907) seit 1877 Ministerialrat im badischen Ministerium des Innern, seit 1881 im Ministerium der Justiz, des Kultus und Unterrichts, seit 1895 auch Direktor des Oberschulrats Karlsruhe, s. Badische Biographien 6 (1935) S. 106-108

M Rosa Ernestine Wilhelmine geb. BischoffDeurer (1840-1877)

œ 18. Aug. 1930 Else geb. Thürmer (1879-vor 1955)

$\mathrm{K} \quad 1 \mathrm{~S}$

Vw Brüder: Walther A. (1871-1902) 1897-1900 Privat-Dozent für Philosophie UH, anschl. TH Hannover, s. UAH PA 1303; Bronisch, Johannes: Der Mäzen der Aufklärung: Ernst Christoph von Manteuffel und das Netzwerk des Wolffianismus. Berlin 2010. S. 20, 28 u. ö. - Siehe Ludwig A.

$L b$ Seit SS 1891 Studium an U Freiburg/Br., München, SS 1894-WS 1895/96 H; Febr. 1893 Physikum an U Freiburg.

H: WS 1895/96 Staatsexamen; 11. März 1896 Approbation; 17. Juli 1896 Dr. med. an U.

Moabit (heute: Ortsteil von Berlin): Seit Mai 1897 Volontärarzt am Städtischen Krankenhaus.

UH: Seit Okt. 1897 Assistenzarzt am Patholog.Anatom. Inst.; seit Okt. 1898 Volontärarzt an Med. U-Klinik.

Freiburg/Br.: Seit Okt. 1901 Assistenzarzt an Psychiatr. Klinik und am Patholog.-Anatom. Inst.; Jan. 1902 Studienaufenthalt in Paris.

April-Juli 1902 Schiffsarzt bei Norddeutschem Lloyd; seit Juli 1902 Studienaufenthalt in London. 
UH: Okt. 1902-Okt. 1903 Assistenzarzt an Med. U-Klinik; 18. Juli 1903 Habilitation; seit Okt. 1903 Leiter des Röntgenlaboratoriums der Med. U-Klinik; seit 25. März 1909 nichtetatm. a. o. Prof.; WS 1910/11 letzte Vorlesungsankündigung; SS 1911 von UH beurlaubt.

Dresden-Friedrichstadt: 1911-1937 Direktor der Inneren Abt. des Städtischen Krankenhauses.

Qu UAH PA 1301. • GLA Abt. 235, Fasz. 1737.

W Die Röntgenuntersuchung der Brustorgane und ihre Ergebnisse für Physiologie und Pathologie. Leipzig 1909. - Die Röntgendiagnostik der Lungenkrankheiten. Leipzig 1910. • Die Röntgenuntersuchung des Magen-Darmkanals und ihre Ergebnisse für Physiologie und Pathologie. Leipzig 1912.

$L$ Stübler (1926) S. 315; Wer ist's (1935) S. 36 f.; WBIS. • Die Professoren der Medizinischen Fakultät Carl Gustav Carus Dresden und ihrer Vorgängereinrichtungen 1814-2004. Hrsg. von Caris-Petra Heidel und Marina Lienert. München 2004. • Deutsche Biographie, s. https://www.deutschebiographie.de/gnd1012764192.html [04.11. 2017].

$P$ Bildarchiv UAH.

\section{Arnsperger, Ludwig Herbert Gustav Emil}

1906-1912 Med. Fak.

Chirurgie

* 23. Okt. 1877 Karlsruhe

$\dagger$ 20. April 1970 Karlsruhe

ev.

V Carl Ludwig Friedrich A. (1837-1907), siehe Hans Arnsperger

M Rosa Ernestine Wilhelmine geb. BischoffDeurer (1840-1877)

๑ 16. April 1912 Gertrud Wilhelmine Maria geb. Eltze (1878-1957)

$\mathrm{K}$ unbekannt

Vw Brüder: siehe Hans A.
Lb WS 1895/96 Studium an UH, SS 1896 Berlin, WS 1896/97-SS 1897, SS 1899-WS 1900/o1 H.

UH: 27. Febr. 1901 Approbation; 9. Mai 1901 Dr. med.; Assistenzarzt: seit Juni 1901 Kurhaus in St. Blasien, seit Okt. 1901 Patholog. Inst. der UH, seit April 1901 Chirurg. U-Klinik; 2. März 1906 Habilitation; SS 1906-WS 1906/o7 I. Assistenzarzt (Leiter) an klinischer Ambulanz der Chirurg. U-Klinik in Nachf. von Walther Petersen; SS 1907-SS 1908 I. klinischer Assistenzarzt an Chirurg. UKlinik als Nachf. von Friedrich Voelcker; seit WS 1908/o9 I. Assistenzarzt an klinischer Ambulanz der Chirurg. U-Klinik als Nachf. von Voelcker; seit 23. Febr. 1912 nichtetatm. a. o. Prof.; 31. März 1912 aus Lehrkörper ausgeschieden.

Karlsruhe: 1912-1953 Leitender Arzt des gesamten alten und neuen St. Vincentius-Krankenhauses.

E 1952 Verdienstkreuz der Bundesrepublik Deutschland.

Qu UAH PA 1302. - Briefe: UBH. - Auskunft: Stadtarchiv Karlsruhe (Signatur: 19. 8/StS 20/ Band 2 - 433).

$W$ Über die Indikation zur Gastroenterostomia posterior antecolica in: Bruns Beiträge für Chirurgie 56 (1908). • Der gegenwärtige Stand der Pathologie und Therapie der Gallensteinkrankheit. Halle/S. 1911. (Sammlung zwangloser Abh. aus dem Gebiete der Verdauungs- und Stoffwechselkrankheiten. Bd. 3. H. 8.)

$L$ Stübler (1926) S. 320; Chirurgen-Verzeichnis $\left({ }^{4} 1958\right)$ S. $13 \mathrm{f}$.

$P$ Bildarchiv UAH. 


\section{Aschaffenburg, Gustav}

1895-1901 Med. Fak.

Psychiatrie

* 23. Mai 1866 Zweibrücken (Pfalz)

$\dagger \quad$ 02. Sept. 1944 Baltimore (Maryland) mosaisch, seit ca. $1901 \mathrm{ev}$.

V Lazarus (Louis) A. (1828/29-1914) Kaufmann, Lehrer des Talmud

M Julie geb. Feibes (1843-1929)

$\varnothing$ 23. Febr. 1901 Marie (Maja) Thecla geb. Nebel (1878-1965) Lehrerin

K 3 T, 1 S: Dr. phil. Hans Georg Franz A. (Pseudonym: George Amberg) (1901-1971), u.a. 1924-1928 Bühnendirektor bei Festspielen in Köln, Darmstadt und H, 1943-1948 Kurator des Tanzarchivs des Museum of Modern Art in New York, 1966-1971 Prof. für Filmwissenschaften New York, s. WBIS; Room, Adrian: Dictionary of Pseudonyms - 13000 assumed names and their origins. 5th ed. Jefferson (North Carolina) 2010. S. 24.

Lb SS 1885 Studium an UH, seit WS $1885 / 86$ Würzburg, SS 1887 Freiburg/Br., WS 1887/88 Berlin, WS 1888/89 H, seit SS 1889 Straßburg; 7. März 1887 Physikum in Würzburg; 2. März 1890 Staatsexamen in Straßburg; 10. Mai 1890 Dr. med. an U Straßburg.

Ausbildung in Psychiatrie und Neurologie: Seit Mai 1890 Wien, Jan.-Juli 1891 Paris.

UH: 6. Juli 1891-31. März 1901 Assistent an Akad. Irrenklinik; Jan. 1894-März 1901 stellvertr. Direktor der Irrenklinik (Direktor: Emil Kraepelin); 11. Dez. 1895 Habilitation; seit 20. März 1900 nichtetatm. a.o. Prof.; 1. März 1901 auf eigenen Antrag $\mathrm{U}$ verlassen.

Halle/S.: 1. April 1901-31. Aug. 1904 Leitender Arzt der Beobachtungs-Abt. für geisteskranke Verbrecher im Strafgefängnis; April 1901 Umhabilitation an U Halle-Wittenberg.

Köln: Seit 1. Okt. 1904 „konsultierender Prof.“, seit 1. Juni 1906 o. Prof. an neugegründeter Akademie für Praktische Medizin, die 1919 als Med. Fak. der wiedererrichteten U übernommen wird; 19061919 Leitender Arzt der Irrenanstalt Lindenburg in K.-Lindenthal, seit 1919 Teil der U.

U Köln: Seit Juli 1919 o. Prof. und Direktor der Psychiatr. Klinik, 1928 umbenannt in „Psychiatr. und Nervenklinik“; 1928-1934 auch Mit-Direktor des ersten deutschen Inst. für Kriminalwissenschaften; 31. März 1934 auf eigenen Antrag Emeritierung; 14. Febr. 1936 rückwirkend zum 31. Dez. 1935 Entziehung der Lehrbefugnis aus rassischen Gründen.

Emigration: Jan. 1939 Schweiz, Sept. 1939 USA.

Baltimore: Seit 1939 psychiatrischer Konsiliar an e. Privatklinik, dem Mount Hope Retreat, und Research Prof. an Johns-Hopkins-U.

E 1942 Ehrenmitglied der American Psychiatric Association. 1926 Dr. iur. h.c. UH; 1932 Dr. phil. h.c. Würzburg.

Qu UAH PA 1304; Fak.-Akten H-II-867/2, H-II868/4 (Ehrenpromotion). - GLA Abt. 235, Fasz. 1740. • Briefe: UBH. Auskunft: Universitätsarchiv Köln. Mitteilungen von Familienangehörigen.

$W$ Das Verbrechen und seine Bekämpfung. Heidelberg 1903. 3. Aufl. 1923. • Die Beziehungen des sexuellen Lebens zur Entstehung von Nerven- und Geisteskrankheiten in: Dt. med. Wochenschrift 53 (1906) S. 1793-1798. - Die Sicherung der Gesellschaft gegen gemeingefährliche Geisteskranke. Ergebnisse einer i. A. der Holtzendorff-Stiftung gemachten Studienreise. Berlin 1912. - Psychiatrie und Strafrecht. Köln 1928. (Kölner Universitätsreden. 19.) - Verminderte Zurechnungsfähigkeit in: Reichsgerichtspraxis im dt. Rechtsleben 5 (1929). - Bibliographie in: Busse (1991) S. 228249.

G, HG 1904-1936 Monatsschrift für Kriminalpsychologie und Strafrechtsreform.

HG 1911-1923 Handbuch der Psychiatrie; 19121930 Bibliothek der Kriminalistik. 
L NDB 1 (1953) S. 410. - Hentig, Hans von: Pioneers in Criminology in: Journal of Criminal Law, Criminology and Police Science, vol. 42, no. 2 (August 1954). - Seifert, Dorothea: G. A. als Kriminologe. Jur. Diss. Freiburg/Br. 1981. • Dictionary of Emigrés 2 (1983) S. 35 f.; Chronik Ärzte H (1985) S. 121; WBIS; Golczewski (1988) S. 473 (Register). • Busse, Falk: G.A. Leben und Werk. Med. Diss. Leipzig 1991. - Kreuter, Alma: Deutschsprachige Neurologen und Psychiater. 1. Bd. München 1996. • Wetzell, Richard: Inventing the Criminal - A History of German Criminology 1880-1945. Chapel Hill u. a. 2000. Die Juristen der Universität Bonn im „Dritten Reich“. Hrsg. von Mathias Schmoeckel. Köln u. a. 2004. • Peiffer (2004) S. 1128 (Register); Catalogus prof. Halensis online.

\section{Asher, Georg Michael}

1863-1869 (1874) Jur. Fak.

Römische Rechtsgeschichte

* 03. Aug. 1827 St. Petersburg

$\dagger$ 12. Juli 1905 Paris

mosaisch

V Adolph A. (eigentlich: Abraham Isaac Ascher) (180o-1853), u. a. Juwelenhändler in Russland, Antiquar, seit 1830 Inhaber e. int. Buchhandlung in Berlin, s. ADB 1 (1875) S. 619, Jüdische National-Biographie 1 (1925) S. 169 f., WBIS; Jacobson, Jacob: Die Judenbürgerbücher der Stadt Berlin 1809-1851. Berlin 1962. S. 241f.; Keiderling, Thomas: A.A. ... Ein jüdischer Buchhändler mit englischem Sortiment in: Berlinische Monatsschrift 8 (1996) S. 55-59.

M Anna geb. Friedeberg ( $† 1867)$

$\infty$ unverheiratet.

Lb Berlin: 1845-1851 Buch- und Antiquariatsbuchhandelslehre; 1851-1854 Studium an U.

1854-1862 "Antiquarbuchhändler“ in Deutschland, Belgien, Niederlande, Frankreich, Schweiz, Schweden, Norwegen, Dänemark, Großbritannien; in dieser Zeit: 3. Aug. 1855 Dr. iur. an UH.
UH: 30. Juli 1863 Habilitation; seit 5. Mai 1869 a. o. Prof.; seit Okt. 1869 Beurlaubung; 1870/71 Kriegsfreiwilliger (Krankenpfleger) während des Deutsch-Französischen Krieges; 1871-Juni 1874 Beurlaubung für Studienaufenthalt in Russland; 1874 Verzicht auf seine Professur.

Paris: 1874 (Übersiedlung)-1905（†） Privat-Gelehrter.

Qu UAH PA 1305; Fak.-Akte H-II-111/50. • GLA Abt. 205, Fasz. 146.

$W$ Henry Hudson, the navigator. London 186o. • Die Begründung des Ususfructus. Berlin 1862. • Rechtsgeschichtliche Studien. Berlin 1862.

L Jüdische National-Biographie 1 (1925) S. 171; WBIS; Schroeder (2010) S. 208f.; Deutsche Biographie, s. https://www.deutsche-biographie.de/g nd117765457.html [04.11. 2017].

\section{Askenasy, Eugen}

1872-189o Phil. Fak.

1890-1897 Nat.-Math. Fak.

1897-1903 (Honorar-Prof.) Nat.-Math. Fak.

Botanik

* 05. Mai 1845 Tarnopol (Kaisertum Österreich; heute: Ternopil, Ukraine)

$\dagger \quad$ 24. Aug. 1903 Sölden (Ötztal, Österreich)

口 Frankfurt/M.

mosaisch

V N.N. $(\dagger 1887)$ Arzt

M Maria geb. Raffalovik (†1859)

œ unverheiratet.

Lb Seit 1859 landwirtschaftl. Studien, auch Tätigkeit in Zuckerfabrik und Brauerei u. a. in Durlach (heute: Stadtteil von Karlsruhe).

Studium der Botanik: 1862 Land- und Forstwirtschaftl. Akademie Hohenheim (heute: Stadtteil 
von Stuttgart), 1863 Königl. Preußische Landwirtschaftl. Akademie in Poppelsdorf (heute: Ortsteil von Bonn).

UH: Seit WS 1864/65 Forts. des Studiums; 3. Nov. 1866 Dr. phil.; 23. Okt. 1872 Habilitation; seit 27. Jan. 1881 a. o. Prof.; seit 23. Dez. 1897 Honorar-Prof.; SS 1903 letzte Vorlesungsankündigung über Pflanzenphysiologische Übungen, wöchentlich 2-stündig.

1904 Stiftung des Askenasy-Stipendiums für Botanik und Zoologie an der Universität Heidelberg, s. UAH RA 5203, $5309 \mathrm{f}$.

E Mitglied: 1904 Senckenbergische Naturforschende Gesellschaft Frankfurt/M., Naturhistor. Verein H, Dt. Botanische Gesellschaft, 1886 Dt. Akademie der Naturforscher Leopoldina Halle/S.

Qu UAH PA 1293; RA 6501; Fak.-Akte H-IV102/67. GLA Abt. 76, Fasz. 9866. • Briefe: UBH. • Siehe auch Archiv der Dt. Akademie der Naturforscher Leopoldina Halle/S.

$W$ Beiträge zur Kritik der Darwinschen Lehre. Leipzig 1872. - Über das Saftsteigen in: Verh. des Naturhistor. Vereins Heidelberg N.F. 5 (1895) S. 325-345.

L NDB 1 (1953) S. 417 (mit Werkverz.); Autoren der Bunsenbibliothek (2009 online); WBIS.

$P$ Bildarchiv UAH; graph. Slg. UBH; NDB.

\section{Auwers, Karl Friedrich von}

1889-189o Phil. Fak. 1890-190o Nat.-Math. Fak. Chemie

* 16. Sept. 1863 Gotha

$\dagger$ 03. Mai 1939 Marburg

ev.
V Arthur (seit 1912: von) A. (1838-1915), u.a. Berlin: seit 1866 Prof. für Astronomie an U und Astronom der Akademie der Wissenschaften sowie 1878-1912 Sekretar der Physikal.-Math. Klasse der Akademie, s. NDB 1 (1953) S. 462 f., Krafft (2007), WBIS

M Henriette Marie geb. Jacobi (1837-1917)

๑ 8. April 1893 Pauline Cäzilia Elisabeth geb. Koch (1870-1941)

K 2 T, 1 S: Otto von A. (1895-1949) seit 1924 Physiker in Forschungslaboratorien der Siemens-Werke in Berlin, seit 1935 Privat-Dozent für Physik Berlin, seit 1943 apl. Prof., seit 1946 o. Prof. Bergakademie Clausthal, s. NDB 1 (1953) S. 463, Biogr. Enzyklopädie Naturwissenschaftler 1 (2003) S. 28, WBIS.

Lb Seit SS 1881 Studium der Naturwiss. an UH, seit WS 1882/83 Berlin.

U Berlin: 12. Aug. 1885 Dr. phil.; seit Okt. 1886 Privat-Assistent von August Wilhelm von Hofmann (1818-1892).

U Göttingen: Seit April 1887 Privat-Assistent von (siehe) Victor Meyer.

UH: Seit Okt. 1889 Privat-Assistent von Meyer; 16. Dez. 1889 Habilitation; seit 25. Jan. 1894 nichtetatm. a.o. Prof.; seit 1. Jan. 1899 I. Assistent am Chemischen Laboratorium als Nachf. von Ludwig Gattermann; seit 21. April 1900 etatm. a. o. Prof.

U Greifswald: Seit 20. Aug. 1900 o. Prof. und Direktor des Chemischen Inst.

U Marburg: Seit 1. Okt. 1913 o. Prof. und Direktor des Chemischen Inst.; 1929 Emeritierung.

1913 Geh. Reg.-Rat

E Mitglied: 1909 Dt. Akademie der Naturforscher Leopoldina Halle/S., Dt. Chemische Gesellschaft. • 1926 Dr.-Ing. E.h. TH Dresden.

Q $u$ UAH PA 1291; RA 6886; Fak.-Akte H-IV102/124. - GLA Abt. 235, Fasz. 1742. • Briefe: UBH. Siehe auch Archiv der Dt. Akademie der Naturforscher Leopoldina Halle/S. 
$W$ Die Entwicklung der Stereochemie. Heidelberg 1890. Tabellen zur Berechnung der theoretischen Molekularrefraktionen organischer Verbindungen. Berlin 1914.

L NDB 1 (1953) S. 463 (mit Werkverz.); Jansen (1992a) S. 163 (Register); Biogr. Enzyklopädie
Naturwissenschaftler 1 (2003) S. 27; Stolz (2003) S. 19 f.; Autoren der Bunsenbibliothek (2009 online); WBIS; Grewolls (2011).

P Bildarchiv UAH; graph. Slg. UBH. 


\section{B}

\section{Baehr}

siehe Bähr

\section{Bähr, Johann Christian Felix}

1819-1872 Phil. Fak.

Klassische Philologie

* 13. Juni 1798 Darmstadt

$\dagger \quad$ 28. Nov. 1872 Heidelberg ref.

V Johannes B. (1767-1828), u. a. 1799 Pfarrer an Heiliggeistkirche in $\mathrm{H}$, seit 1803 Inspektor der Diözese Unterheidelberg, seit 1818 Superintendent von $\mathrm{H}$, seit 1826 Prälat der Vereinigten Ev.-prot. Kirche im Großherzogtum Baden, s. Wüstenberg, Ulrich: Karl Bähr (1801-1874). Ein badischer Wegbereiter für die Erneuerung und die Einheit des ev. Gottesdienstes. Göttingen 1996. S. 23-28 u. ö.; DBETh 1 (2005) S. 79

M Johanette Philippine geb. Koch (1779-1829)

$\varnothing$ 10. April 1827 Julie Albertine geb. Schneider (1797-1829)

$\infty$ 3. Febr. 1834 Sophie Rosalie Josephine Luise geb. Reinbold $\left({ }^{*} 1803\right)$

$\mathrm{K}$ keine

Vw Bruder: D. theol. Karl B. (1801-1874), u.a. Pfarrer, 1843-1861 (Ruhestand) Oberkirchenrat der Ev. Landeskirche in Baden, s. DBETh 1 (2005) S. 79; Wüstenberg, Ulrich: K. B. in: Lebensbilder aus der Ev. Kirche in Baden im 19. und 2o. Jahrhundert. Bd. II: Kirchenpolitische Richtungen. Hrsg. von Johannes Ehmann. Heidelberg 2010. S. 57-76.

Lb UH: Seit WS 1815/16 Studium der Theologie, anschl. der Klassischen Philologie, Geschichte; 26. Juni 1819 Dr. phil.; 18. Sept. 1819 Habilitation; WS 1819/20 Beginn seiner Vorlesungen; Rufe abgelehnt: 1821 Kantonsschule Aarau (Kanton Argau), 1826 als Direktor des Gymnasiums Clausthal (heu- te: C.-Zellerfeld); seit 5. Juli 1821 a. o. Prof.; 1822 Anfangsgehalt von 200.-, 1872 Endgehalt von 2400.- Gulden pro anno; seit 15. Juni 1826 o. Prof.; 1830-1832 (als 1. Vertreter der Phil. Fak. neben Carl Rau) Mitglied der Bibliotheks-Kommission; 21. Juni 1845-WS 1863/64 Direktor des Philolog. Seminars als Nachf. von Georg Friedrich Creuzer, SS 1864-1. Juli 1865 Mit-Direktor (zus. mit Hermann Köchly) des genannten Seminars. - In dieser Zeit:

UBH: 6. Dez. 1832 (Ern.)-1872 Oberbibliothekar (Vorstand) als Nachf. von Joseph Eiselein; 7. Jan. 1833 Dienstantritt.

1835/36, 1855/56 Prorektor der UH; 1830, 1836, 1842, 1850, 1862/63 Dekan der Phil. Fak. der UH

1836 Hofrat; 1844 Geh. Hofrat

E 1845 Ritter, 1869 Kommandeur II. Klasse des Ordens vom Zähringer Löwen; 1869 Komturkreuz des Franz-Joseph-Ordens; 1869 Ritterkreuz I. Klasse des Ludwigsordens (Hessen).

Qu UAH PA 1307; RA 5961, 5972, 6859; Fak.-Akte H-IV-102/14. GLA Abt. 205, Fasz. 149. Briefe, Nachlaß: UBH. • Briefe von Heidelberger Gelehrten an Franz Joseph Mone. Hrsg. von Friedrich von Weech in: ZGORh 57. Jg. (1903) S. 464-469.

$W$ Geschichte der römischen Litteratur. Karlsruhe 1828. 2. Aufl. 1832. 3 Supplement-Bde. Karlsruhe 1836-1840. 4. Aufl. 1868-1870. Bd. 4: 1872. • Zur Geschichte der Wegführung der Heidelberger Bibliothek nach Rom im Jahre 1623. Heidelberg 1872.

Redakteur Seit 1834 (Mit-Redakteur), seit 1847 (Redakteur) Heidelberger Jahrbücher der Literatur

L ADB 1 (1875) S. 769-772 (mit Werkverz.); Badische Biographien 1 (1875) S. 32-35; WBIS; Bader (1925) S. 7. - Vogeler, Hellmut: J.C. F. B. als Oberbibliothekar der Universitätsbibliothek Heidelberg ... in: Bibliothek und Wiss. 7 (1970) S. 41137. - Wüstenberg, Ulrich: Karl Bähr (1801-1874). Ein badischer Wegbereiter für die Erneuerung und die Einheit des ev. Gottesdienstes. Göttingen 
1996. S. 419 (Register). - Handbuch der historischen Buchbestände in Deutschland. Hrsg. von Bernhard Fabian. Hildesheim 2003.

$P$ Bildarchiv UAH; graph. Slg. UBH.

\section{Baethgen, Friedrich Jürgen Heinrich}

1920-1927 Phil. Fak.

Geschichte

* 30. Juli 1890 Greifswald

$\dagger$ 18. Juni 1972 München ev.

V Friedrich Wilhelm Adolph B. (1849-1905), seit 1884 Prof. für Alttestamentliche Theologie Kiel, seit 1888 Halle-Wittenberg, seit 1889 o. Prof. Greifswald, seit 1895 Berlin, s. NDB 1 (1953) S. 531, WBIS, BBKL I (1990) Sp. 341f., Tilitzki 1 (2012) S. 36

M Molly Luise geb. Schmidt ( ${ }^{*} 1862 \uparrow$ nach 1945$)$

$\infty$ unverheiratet

Vw Schwester: Eva Frieda Agnes B. (1897-1967) Ehefrau von: (siehe) Ernst Wahle.

Lb Studium: Seit WS 1908/o9 UH, seit SS 1910 Berlin, seit SS $1912 \mathrm{H}$.

UH: Seit 1913 etatm. Assistent am Histor. Seminar; 2. Jan. 1914 Dr. phil.; 3. Mai 1920 Habilitation; 19211923 außerdem Mitarbeiter an Monumenta Germaniae Historica; seit 17. Juli 1924 nichtplanm. a. o. Prof. In dieser Zeit:

Ende 1914-Mai 1917 Kriegsdienst; Mai 1917-März 1919 Hilfsarbeiter in Presse-Abt. des AuslandsAmts in Berlin.

Seit 1. April 1927 II. Sekretär am Preußischen Histor. Inst. in Rom und Honorar-Prof. an U Berlin.

U Königsberg (Preußen): Seit 1929 o. Prof.
München: 1947-1958 Präsident der Monumenta Germaniae Historica; seit 1948 Honorar-Prof. an U.

E Mitglied der Akademie der Wissenschaften: 1944 Berlin, 1950 München (1956-1964 Präsident), 1959 Leipzig. 1955 Dr. phil. h.c. Rom.

Qu UAH PA 3168. • GLA Abt. 235, Fasz. 1743. • Nachlaß: Archiv der Monumenta Germaniae Historica in München.

W Beiträge zur Geschichte Cölestins V. Halle/S. 1934. • Der Engelpapst. Leipzig 1943. Europa im Spätmittelalter. Berlin 1951. Mediaevalia. 2 Bde. Stuttgart 1960.

Bearb. 1937-1968 Hampe, Karl: Deutsche Kaisergeschichte in der Zeit der Salier und Staufer. Nachdr. der 12. Aufl. Darmstadt 1983.

HG 1932-1935 Königsberger Histor. Forschungen. 1935-1939 Neue Dt. Forschung der Mittelalterlichen Geschichte.

MHG 1941-1954 Int. Bibliography of Historical Science.

L Arnim 1 (1944) S. 49, 3 (1978) S. 60; Weber (1987) S. 21f.; Jansen (1992) S. 407 (Register); Fuhrmann (1996) S. 203 (Register); Kriegstagebuch K. Hampe (2007) S. 943 (Register). • Fuhrmann, Horst: F. B. Besinnung und Neuanfang in: Denker, Forscher und Entdecker: eine Geschichte der Bayerischen Akademie der Wissenschaften in historischen Porträts. Hrsg. von Dietmar Willoweit ... München 2009. S. 337-355. - Grewolls (2011). • Lemberg, Joseph: Der Historiker ohne Eigenschaften. Eine Problemgeschichte des Mediävisten F. B. Frankfurt/M. 2015. - Spenkuch (2016) S. 1307 (Register); Deutsche Biographie, s. https:// www.deutsche-biographie.de/gnd118646338.html [06.11. 2017].

$P$ Bildarchiv UAH.

U Berlin: Seit 1939 o. Prof. 
Baeyer, Johann (Hans) Emil (seit 1885: Ritter von)

1918-1933 (1934) Med. Fak.

Orthopädie

* 28. Febr. 1875 Straßburg

$\dagger \quad$ 21. Jan. 1941 Düsseldorf

ev.

V Adolf Ritter von B. (1835-1917) seit 1860 Privat-Dozent, seit 1866 a.o. Prof. an U Berlin sowie 1860-1872 Lehrer am Gewerbeinstitut Berlin, seit 1872 o. Prof. an U Straßburg, 18751915 o. Prof. für Chemie an U München; 1905 Nobelpreis für Chemie, siehe NDB 1 (1953) S. 534-536, Naumann (2003) S. 3, 61, Autoren der Bunsenbibliothek (2009 online), WBIS; Fischer, Marta: Lebendige Verbindungen. Biobibliographisches Lexikon der Biochemiker zwischen Deutschland und Russland im 19. Jahrhundert. Aachen 2013. S. 11-14. $\bullet$ Siehe auch Hans Knorr: Eintrag unter $M$ [utter]

M Adelheid (Lida) geb. Bendemann (1847-1910), siehe Naumann (2003) S. 3

๑ 16. März 1903 Hildegard Karoline Luise geb. Merkel (1882-1958), siehe Gästebuch der Hildegard von Baeyer. Heidelberg 1918-1958 online unter http://www.hildegard-vonbaeyer. net () 2010 Cornelius von Baeyer für die Nachkommen); T von Johannes Merkel (18521909) seit 1877 Privat-Dozent und seit 1881 a.o. Prof. Halle-Wittenberg, 1881 o. Prof. Rostock, 1885-1909 o. Prof. für Römisches, Deutsches und Bürgerliches Recht Göttingen, siehe Catalogus prof. Gottingensium (1962) S. 52, 77, WBIS, NDB 17 (1994) S. 147f., Catalogus prof. Halensis online, Catalogus prof. Rostochiensium online

K 1 T, 3 S: Walter Ritter von B. (1904-1987) Prof. für Medizin H, siehe Drüll (2009) S. $88 \mathrm{f}$. D Dr. med. Erich Ritter von B. (1909-1990) Mediziner, s. Weirich, Angela, Hoffmann, Georg F.: E. von B. ... Medizinstudent in der Weimarer Republik und Porträtzeichner von Professoren der Heidelberger Universität in: Heidelberg. Jahrbuch zur Geschichte der Stadt 2012. Heidelberg 2011. Jg. 16. S. 165-176. • Dr. phil. nat. Hans Jakob Ritter von B. (1912-1998), u. a. Telekommunikationstechniker, siehe Rü- rup (2008) S. 150f., http://www.vonbaeyer. net/sites/vonbaeyer.net/hansjakob/index.ht $\mathrm{ml}$; Ehemann von Renata geb. Freudenberg (1911-1977), s. http://www.vonbaeyer.net/sites/ vonbaeyer.net/renata/biography.html; $\mathrm{T}$ von Ernst F. (1884-1967) (Vetter von: (siehe) Karl F.) seit 1917 Privat-Dozent UH, seit 1922 a.o. Prof. Marburg, 1934-1937 (Ruhestand aus rassischen Gründen) o. Prof. Marburg, 1938-1954 Ordinarius für Pädiatrie Basel, s Bernhard, Michael: Der Pädiater E. F. ... Marburg 2001. • Siehe auch Naumann (2003) S. 14, 53, 57, 63

Vw Schwester: Eugenie von B. (1869-1952) Ehefrau von Oskar Piloty $\left({ }^{*} 1866\right.$ × 1915$)$ seit 1899 Prof. für Anorganische Chemie München, s. NDB 20 (2001) S. 446; Neffe: (siehe) Hans Knorr: Eintrag unter $M[$ utter]. - Siehe auch Genealogisches Handbuch des in Bayern immatrikulierten Adels. Hrsg. Vereinigung des Adels in Bayern ... Stegaurach 1980. Bd. XIII. S. 612 ff.; Naumann (2003) S. 2-6, Drüll (2009) S. 88 .

Lb Studium: WS $1896 / 97$, SS 1899 , SS 1900-SS 1901 U München, SS 1897/98-WS 1898/99, WS 1899/1900, WS 1900/o1 Jena; 12. Juli 1901 Approbation und Dr. med. München; April 1901-Aug. 1902 Assistent am Physiolog. Inst. der U Göttingen; Okt. 1902-März 1903 Studienreisen nach H, Breslau, Wien.

U München: 1. Mai 1903-1908 Volontär-Assistent für Orthopädie an Chirurg. Klinik; 28. April 1908 Habilitation für Chirurgie; 19. Dez. 1908 Aufnahme in Med. Fak. als Privat-Dozent; seit Jan. 1911 Leiter der Orthopäd. Abt. des Krankenhauses links der Isar; seit 31. Jan. 1915 a. o. Prof. • In dieser Zeit:

1914-1918 Kriegsdienst.

U Würzburg: 16. Juli 1917 Ern. zum etatm. a. o. Prof. für Orthopädie und Direktor des König-LudwigHauses.

UH: Seit 1. Okt. 1918 etatm. a. o. Prof. und Direktor der Orthopäd. Anstalt, seit Dez. 1922 (Gründungs-)Direktor der neugebauten Orthopäd. Anstalt in H-Schlierbach, siehe hierzu auch Friedrich Endemann und Ernst Walz; 22. März 1919 Ern. zum o. Prof.; seit Okt. 1929 (Gründungs-)Direktor 
des neuen Landeskrüppelheims "Wielandheim“ in H-Schlierbach (siehe hierzu auch Oscar Vulpius); 21. Okt. 1933 mit Wirkung vom 1. März 1934 Versetzung in Ruhestand aus rassischen Gründen, bis dahin mit sofortiger Wirkung Entbindung und Beurlaubung von Lehre und Leitung der Orthopäd. Klinik.

1934 Gastvorlesungen in USA und Großbritannien.

Düsseldorf: 1935-1941 Privat-Praxis für Orthopädie.

1926/27 Dekan der Med. Fak. der UH

Siehe auch Anhang Sporteinrichtungen an UH 1910-1933 und ihre Mitglieder

E 1917 Badisches Kriegsverdienstkreuz; 1918 König Ludwig Kreuz.

Qu UAH PA 826, 3171; B-3182/1 (Juli 1954) S. 3-6. • Mitteilungen: Herr Prof. Dr. Walter Ritter von Baeyer $(\dagger)$ und Herr Dr. Alexander von Baeyer, Starnberg.

$W$ Orthopädische Behandlung der Nervenkrankheiten in: Curschmann, Hans und Kramer, Franz: Lehrbuch der Nervenkrankheiten. Berlin 1925. • Der lebendige Arm. Jena 1930. - Über Bewegung des Menschen. Zur Lehre der Synapsis in: Zs. für Anatomie und Entwicklungsgeschichte 110 (1940). Siehe auch Naumann (2003) S. 64-81.

L Kürschner (1931) Sp. 127; Arnim 3 (1978) S. 61; Universität Würzburg (1982) S. 858; Chronik Ärzte H (1985) S. 121; Jansen (1992a) S. 163 (Register). • Naumann, Peter: H. von B. - Leben und Werk. Diss. Würzburg 2003. Kriegstagebuch K. Hampe (2007) S. 943 (Register). - Über H. von B. in: Goerig, M., Goetz, A. E.: Mitarbeiter und Herausgeber mit jüdischer Herkunft der ersten dt. Anästhesiezeitschriften in: Der Anaesthesist 9 (2010) S. 838 u. o. - Deutsche Biographie, s. https://www. deutsche-biographie.de/gnd11603792X.html [o6. 11. 2017].

$P$ Bildarchiv UAH; Chronik Ärzte H.

\section{Baisch, Bernhard}

1912-1921 Med. Fak.

Chirurgie

* 13. Juni 1880 München

$\dagger$ 05. Dez. 1945 Karlsruhe ev.

V Hermann B. (1846-1894) Landschafts- und Tiermaler, seit 1881 Prof. an Akademie der Künste Karlsruhe, s. ADB 46 (1902) S. 189 f., Badische Biographien 5 (1906) S. 27 f., WBIS; Mülfarth, Leo: Kleines Lexikon Karlsruher Maler. Karlsruhe 1987.

M Anna geb. Cox

$\varnothing$ 15. Sept. 1908 Maria geb. Pfeiffer $\left({ }^{\star} 1881 \dagger\right.$ nach 1945)

K $1 \mathrm{~T}$

Lb Seit WS 1898/99 Studium an U Freiburg/Br., seit WS 1899/1900 H.

UH: 27. Juli 1903 Staatsexamen; 13. Febr. 1904 Dr. med.; Assistent: seit Sept. 1904 Chirurg. U-Klinik, seit Okt. 1908 Orthopäd. Poliklinik in München, seit Mai 1909 Chirurg. U-Klinik der UH; 1909/101921 Leiter der Orthopäd. Ambulanz der Chirurg. U-Klinik in Nachf. von Oscar Vulpius; 1. Aug. 1912 Habilitation; seit 17. Juli 1918 nichtetatm., seit 1920 nichtplanm. a. o. Prof. In dieser Zeit:

1914-1918 Kriegsdienst.

Karlsruhe: 1921-1945 Facharzt für Chirurgie und Orthopädie am St. Vincentius-Krankenhaus.

Siehe auch Anhang Sporteinrichtungen an $U H$ 1910-1933 und ihre Mitglieder

E Prinzregent Luitpold-Medaille.

Qu UAH PA 820, 3175; RA 6789; Fak.-Akte H-III111/145. GLA Abt. 235, Fasz. 1750.

$W$ Bau und Mechanik des normalen Fusses und des Plattfusses. Stuttgart 1913. 
$L$ Stübler (1926) S. 320; WBIS.

$P$ Bildarchiv UAH.

\section{Barazetti, August Caesar Joseph}

1884-1897 Jur. Fak.

Zivilprozeßrecht, Franz. Zivilrecht, Badisches

Landrecht

* 13. Jan. 1844 Mannheim

$\dagger \quad$ 05. Juli 1907 Fribourg (Schweiz)

kath.

V Dr. iur. Alexander B. (1805-1886) Obergerichtsadvokat, Kirchenfiskalanwalt

M Josephine geb. Fretten ( ${ }^{*} 1810 \nmid$ nach 1886$)$

๑ 18. Sept. 1880 Sophie geb. Le Monnier (18581929) Schriftstellerin, s. WBIS; T von Anton Ritter von Le M. (1819-1873) erster Wiener Polizeipräsident, s. WBIS

K $2 \mathrm{~S}, 2 \mathrm{~T}$

Lb WS 1863/64 zunächst Studium der Romanischen Sprachen und Literaturgeschichte an U Bonn, seit SS 1864 Studium der Rechtswiss. H; Promotion zum Dr. iur. (kein Nachweis an UH).

Mannheim: Volontär: seit Jan. 1869 Großherzogl. Amtsgericht, seit Febr. 1870 Großherzogl. Bezirksamt; seit 2. Mai 1870 Sekretariatspraktikant des Großen Kreis- und Hofgerichts; April 1871 II. Staatsprüfung in Karlsruhe.

Konstanz: Seit Mai 1871 Gehilfe am Großherzogl. Bezirksamt; seit Ende 1871 Assessor in einer Anwaltspraxis.

Rechtsanwalt: 1873-1884 Mannheim, 1884-1887 H.

UH: 16. Mai 1884 Habilitation, s. UAH H-II-111/91 fol. 48-73; seit 28. Nov. 1889 a.o. Prof.; 10. Sept. 1897 auf eigenen Antrag Entlassung.

Genf: Seit 1897 Aufenthalt ohne Berufsausübung.

Fribourg: Seit 1900 o. Prof. für Römisches Recht.
Qu UAH PA 1308; Fak.-Akte H-II-111/91. • GLA Abt. 235, Fasz. 1752 f.

$W$ Einführung in das französische Civilrecht und das badische Landrecht ... Frankfurt/M. 1889. 2. Aufl. 1894. - Das Eherecht mit Ausschluß des ehelichen Vermögensrechts nach dem Code Napoleon und dem badischen Landrecht. Hannover 1895. - Der Vorentwurf zum ersten und zweiten Teil des Schweizerischen Civilgesetzbuches. Bern 1898.

$L$ Badische Biographien 6 (1935) S. 789; Jansen (1992a) S. 163 (Register); WBIS; Schroeder (2010) S. 335-337; Deutsche Biographie, s. https://www. deutsche-biographie.de/gnd116050403.html [06. 11. 2017].

$P$ Bildarchiv UAH; graph. Slg. UBH.

\section{Barry, Roger (bis 1796: CM)}

1804, 1805, 1809-1811 (Hofastronom) Phil. Fak.

Astronomie

* 30. Sept. 1752 Spincourt (bei Verdun)

$\dagger \quad$ 25. Okt. 1813 Mannheim kath.

V N.N.

M N.N.

( unverheiratet.

Lb Paris: 3. Okt. 1769 Eintritt in CM (Congregatio Missionis, Kongregation der Mission, auch Lazaristenorden; 1796 Erlöschen des Ordens in der Kurpfalz); 4. Okt. 1771 Ablegung der Gelübde.

Lehrer an Seminaren der CM: Seit 1774 für Mathematik in Noyon (bei Compiègne), seit 1776 für Theologie in Sens, seit 1783 in Noyon; seit 1785 Direktor des Theol. Seminars in Toul.

Paris: Seit Ende 1787 Studien der Sternkunde bei Joseph-Jérôme de Lalande (1732-1807).

Mannheim: Seit Dez. 1788 Vertreter des Hofastronomen Peter Ungeschick (†April 1790, s. Drüll 
(1991) S. 159 f.), 12. April 1790 Ern. zum Hofastronomen als Nachf. von Ungeschick an Kurfürstl. (bis 1806, 1806-1813 Großherzogl.) Sternwarte; 17931801 Unterbrechung der Messungen während der Koalitionskriege; Ende April-Mitte Mai 1799 nach Eroberung Mannheims durch franz. Truppen Inhaftierung wohl aufgrund e. Kolportage von Andreas Traitteur (s. Drüll (1991) S. 156-158), B. habe zwei franz. Emigranten vor ihrer Verhaftung und drohenden Erschießung versteckt gehalten; Mai 1799 Freispruch durch Kriegsgericht und Weggang von Mannheim; Sept. 1799 Rückkehr nach Rückzug der Franzosen als Hofastronom.

UH: WS 1804/05 (Vorlesung: „Theorie der Sternkunde“), SS 1805, SS 1809-SS 1811 Hofastronom B. „ertheilt in der Kenntniß und Beobachtung des gestirnten Himmels praktischen Unterricht [u.a.] auf der ... Sternwarte zu Mannheim“ (aus: Anzeige der Vorlesungen ... zu Heidelberg WS 1809/10. Heidelberg 1809. S. 24).

E 1792 A.o. Mitglied der Kurpfälz. Akademie der Wissenschaften Mannheim; 1807 Mitglied der Akademie der Wissenschaften München.

Qu UAH PA 1313; RA 6583, 6635. - GLA Abt. 205, Fasz. 150, 493. - Ergebnislose Anfrage: Stadtarchiv Mannheim.

$W$ Astronomische Beobachtungen in: Journal des Savans (1789). Beobachtungen des Uranus und des Jupiters in: Histoire de l'Académie des Sciences pour 1789. Tome X. Paris (1793).

$L$ Meusel 5. Bd., 5. Ausg. (1820) Sp. 81 f. (mit Werkverz.); Poggendorff 1 (1863) Sp. 106 (mit Werkverz.). Moschick, Paul: R.B.s Sternverzeichnis nach den Beobachtungen am Mauerquadranten der Sternwarte zu Mannheim 1807-1811. Rostock 1905. - Mathy, Ludwig: R. B. der Hofastronom ... in: Mannheimer Geschichtsblätter 27. Jg. (1926) S. 122-127, 141-149. - Kistner (1930) S. 4347; Haas (1960) S. 70-72 u. ö. • Budde, Kai: Sternwarte Mannheim ... 1772-1880. Heidelberg u.a. 2006. S. 94-123 u. ö. - WBIS. - Saltin, Günther: Geschichte der Orden und Kongregationen in Mannheim. Hauptteil 2 in: Reiner Albert, Günther Saltin: Katholisches Leben in Mannheim.
Bd. 1. Von den Anfängen bis zur Säkularisation. Ostfildern 2009. S. 454 f. u. ö. • Deutsche Biographie, s. https://www.deutsche-biographie.de/gnd 116059974.html [06.11.2017].

\section{Bartholomae, Friedrich Christian Leonhard}

1909-1924 Phil. Fak.

Vgl. Sprachwissenschaft, Sanskrit

* 21. Jan. 1855 Zum Forst in Limmersdorf bei Kulmbach, Oberfranken (heute: Ortsteil von Thurnau)

$\dagger \quad$ 09. Aug. 1925 Langeoog ev.

V Johann Leonhard B. (1812-1859) Revierförster

M Eleonore Friederike Nanette geb. Aichinger (1821-1903)

๑ 12. Dez. 1891 Anna Ida geb. von Briesen (18641941)

K $\quad 1 S\left({ }^{*} 1894 \times 1915\right)$

Lb Seit 1872 Studium der Iranistik, Indogermanistik an U München, anschl. Erlangen, Leipzig; 15. Juni 1877 Dr. phil. an U Leipzig.

U Halle-Wittenberg: 12. März 1879 Habilitation; seit 18. Jan. 1884 nichtetatm. a. o. Prof.

U Münster: Seit 1. Okt. 1885 etatm. a. o. Prof.

U Gießen: Seit 21. April 1898 o. Prof.

U Straßburg: Seit 1. April 1909 o. Prof.

UH: Seit 1. Okt. 1909 o. Prof. als Nachf. von Hermann Osthoff; 1. Okt. 1909 Begründer und 19091924 Direktor des Sprachwiss. Seminars im Erdgeschoß der Alten U; 1. April 1924 Emeritierung.

1918/19 Rektor der UH; 1917 Wahlsenator H; 1910/ 11, 1920/21 Dekan der Phil. Fak. der UH

1909 Geh. Hofrat; 1919 Geh. Rat II. Klasse

Siehe auch Anhang Sporteinrichtungen an UH 1910-1933 und ihre Mitglieder 
E Korr. Mitglied der Kaiserl. Akademie der Wissenschaften St. Petersburg; 1909 Mitglied der Akademie der Wissenschaften H. • 1891 Königl. Preußische Rettungsmedaille am Band; 1907 Ritterkreuz II. Klasse des Großherzogl. Hessischen Philippsordens; 1912 Ritterkreuz I. Klasse des Ordens vom Zähringer Löwen.

Qu UAH PA 1314; RA 6433, 6863; Fak.-Akte H-IV102/138; Acc. 40/11. • GLA Abt. 235, Fasz. 1755. • Nachlaß Bartholomaeiana in: Bayerische Staatsbibliothek München.

$W$ Studien zur indogermanischen Sprachgeschichte. 2 Bde. Halle/S. 189o. - Altiranisches Wörterbuch. Straßburg 1904. - Die Zendhandschriften der Königl. Hof- und Staatsbibliothek in München. München 1915.

HG Die Universität Heidelberg ihren Toten des großen Kriegs zum Gedächtnis ... Akad. Trauerfeier in der Universitätskirche. Heidelberg 1919.

L Kürschner (1925) Sp. 36; NDB 1 (1953) S. 609 (mit Werkverz.). - WBIS; Jansen (1992a) S. 163 (Register); Wennemuth (1994) S. 632 (Register); Kriegstagebuch K. Hampe (2007) S. 944 (Register); 100 Jahre Germanistik in Hamburg (2011) S. 86, 448; Catalogus prof. Halensis online; Riecke (2016) S. 44, 71, 78.

$P$ Bildarchiv UAH; graph. Slg. UBH.

\section{Bartsch, Karl Friedrich Adolf Konrad}

1871-1886 (1888) Phil. Fak.

Germanische und Altromanische Philologie

* 25. Febr. 1832 Sprottau (Schlesien; heute: Szprotawa, Polen)

$\dagger \quad$ 19. Febr. 1888 Heidelberg ev.

V Karl Friedrich Wilhelm B. (1792-1839) Vermessungsrevisor, später Steuereinnehmer

M Friederike geb. von Winterfeld (18oo-1872)

(1) 29. Sept. 1858 Sofie geb. Marx

K $3 \mathrm{~S}, 1 \mathrm{~T}$
Lb Seit WS 1849/50 Studium der Klassischen Philologie an U Breslau; Studium der Älteren dt. Literatur und der Romanistik: seit 1851 an U Berlin, anschl. Halle-Wittenberg; 12. März 1853 Dr. phil. an U Halle-Wittenberg.

Seit Mai 1853 Bibliotheksstudien in Paris, London, Oxford; 1854-1855 Gesellschafter des Freiherrn Friedrich von der Leyen-Blömersheim.

Nürnberg: Seit Herbst 1855 Kustos am Germanischen Nationalmuseum.

U Rostock: 29. Dez. 1857 Ern. zum o. Prof. der Dt. und Neueren Literatur; 8. Mai 1858 Dienstantritt; 11. Juni 1858 Gründer des ersten Germanist. Seminars an einer deutschen $\mathrm{U}$.

UH: 14. Jan. 1871 Ern. zum o. Prof. als Nachf. von Adolf Holtzmann mit e. jährl. Besoldung von 300o.- Gulden; Ostern 1871 Dienstantritt; SS 1873Febr. 1888 (Gründungs-)Direktor des Seminars für Neuere Sprachen (1878 Umbennung in: Germanisch-Romanisches Seminar), s. hierzu Lehmann (1967) S. 232 f.; 1872 und 1873 Rufe an U Breslau abgelehnt; seit Dez. 1886 Beurlaubung aus gesundheitlichen Gründen (Stellvertr.: Hermann Osthoff).

1881 Prorektor der UH; 1872/73 Dekan der Phil. Fak. der UH

1871 Hofrat; 1873 Geh. Hofrat; 1886 Geh. Rat II. Klasse

Siehe auch Adolf Holtzmann

E Ritterkreuz des Nordsternordens; Ritterkreuz des Hausordens der Wendischen Krone; Königl. Preußischer Kronenorden III. Klasse; 1877 Ritterkreuz I. Klasse des Königl. Sächsischen Albrechtsordens; 1878 Ritterkreuz des Ordens der Italienischen Krone; 1880 Ritterkreuz I. Klasse, 1881 Eichenlaub zum Ritterkreuz des Ordens vom Zähringer Löwen.

Qu UAH PA 1315; RA 5278, 6418, 6839; Fak.-Akte H-IV-102/73. • GLA Abt. 76, Fasz. 9868. • Briefe: UBH; Hugo Schuchardt Archiv, Universität Graz. • 
Briefwechsel der Brüder Grimm mit K. B., Franz Pfeiffer und Gabriel Riedel. Kritische Ausgabe. Bd. 2. Hrsg. von Günter Breuer ... Stuttgart 2002. • Nachlaß: UBH. - Jugenderinnerungen. Hrsg. von Hans-Joachim Koppitz. Würzburg 1966. (Autobiogr.)

$W$ Untersuchungen über das Nibelungenlied. Wien 1865. - Chresthomatie de l'ancien français. Leipzig 1866. - Deutsche Liederdichter des 12.14. Jahrhunderts. Stuttgart 1879.

HG, Übers. Reinfried von Braunschweig. Mittelhochdeutscher Text. Stuttgart 1871. Nach K. B. neu hrsg. und übers. von Elisabeth Martschini. Kiel 2017.

HG 1869-1888 Germania: Zs. für dt. Altertumskunde.

L NDB 1 (1953) S. 613 (mit Werkverz.); Lehmann (1967) S. 219-222; WBIS; Biogr. Lexikon für Mecklenburg 2 (1999) S. 35-38; Int. Germanistenlexikon 1 (2003) S. 88-90; Ein Knab auf schnellem Roß (2006) S. 92-94. - Meves, Uwe: K. B. und die Gründung des ersten Germanistischen Seminars ... in: Von lon der wisheit. Gedenkschrift für Manfred Lemmer. Hrsg. von Kurt Gärtner ... Sandersdorf 2009. S. 154-175. Kalkhoff (2010) S. 352 (Register). - Kuhnle, Till R.: Das Mittelalter übersetzen: der Philologe K. B. in: Dante Alighieri: Die göttliche Komödie in der Übersetzung von K. B. ... Eingeleitet und kommentiert von Till R. Kuhnle. Wiesbaden 2010. - Grewolls (2011). • Krätzner, Anita: Von Christian Wilbrandt zu K. B. Institutionalisierung und Disziplinierung der Germanistik in Rostock in: Wissen im Wandel. Disziplinengeschichte im 19. Jhdt. ... Hrsg. von Gisela Boeck ... Rostock 2011. S. 61-76. Catalogus prof. Rostochiensium online; Riecke (2016) S. 141 (Register).

$P$ Bildarchiv UAH; graph. Slg. UBH; NDB.

\section{Bassermann, Gustav Heinrich}

1876-1909 Theol. Fak.

Praktische Theologie

* 12. Juli 1849 Frankfurt/M.

$\dagger$ 29. Aug. 1909 Samaden (Schweiz) ev.

V Friedrich Daniel B. (1811-1855) Verlagsbuchhändler, Politiker, s. NDB 1 (1953) S. 624 f., Gelehrte in der Revolution (1998) S. 236 (Register), Lengemann (2000) S. 69 f., Stumm (2012) S. 690 (Register); Briefe: UBH

M Emilie geb. Karbach (1811-1872)

$\infty$ 17. April 1873 Helene geb. Alt (1850-1913)

$\mathrm{K} \quad 2 \mathrm{~T}$ (davon $1 \mathrm{~T}$ früh $\dagger$ ): Maria (Marie) Clara B. (1876-1953) verh. Freifrau von Campenhausen, 1910-1953 mit Lehrkursen u. a. über Vortragskunst an Phil. Fak. von UH beauftragt, s. UAH PA 3462, 6133, 668o; Türck, Verena: M. von C. - Ein Kurzporträt der ersten Frau im Lehrbetrieb der UH in: Wissenschaft als weiblicher Beruf? (2008) S. 7

Vw Neffe: Hans Frhr. von Campenhausen, s. Drüll (2009) S. 143f. - Weitere Vw, s. auch Lengemann (2000) S. 69.

Lb Seit SS 1867 Studium an U Jena, SS 1870 Zürich, seit WS 1870/71 H; 1872 II. theol. Examen in H; seit 1872 Predigtamtskandidat in Baden(-Baden); seit 28. Jan. 1873 Hilfsprediger in Arolsen.

U Jena: 1. April 1876 Lizentiatenprüfung und Privat-Dozent.

UH: Seit 19. April 1876 a. o. Prof. (mit Staatsdienereigenschaft) als Nachf. von Hermann Schultz mit e. Jahresgehalt von 2500.- Mark, siehe hierzu $Z$; 29. Juli 188o Ern. zum o. Prof.; SS 1884-WS 1894/95 Direktor des Ev.-Prot. Theol. Seminars als Nachf. von Daniel Schenkel; SS 1884-SS 1909 I. U-Prediger zunächst an Peterskirche (im Sommer) und an Providenzkirche (im Winter, da beheizbar) als Nachf. von Schenkel, seit 1896 an Peterskirche, die die Funktion der U-Kirche übernimmt, s. hierzu UAH RA 6132; Rufe abgelehnt: 1885 Oberhofprediger und Generalsuperintendent der Gothaischen Landeskirche, 1892 Hauptpastor an St. Nikolaikirche in Hamburg; SS 1895 Aufteilung des Ev.-Prot. 
Theol. Seminars in Praktisch-Theol. Seminar und Wiss.-Theol. Seminar: SS 1895-SS 1909 Direktor des Praktisch-Theol. Seminars.

1896 Prorektor der UH; 188o/81, 1885/86, 189o/91, 1896/97, 1902/03, 1907/o8 Dekan der Theol. Fak. der UH

Seit 1881 Mitglied der Badischen Generalsynode in Karlsruhe

1883 Mitbegründer des Allg. Ev.-Prot. Missionsvereins, s. hierzu Buß, Ernst: Zur Vorgeschichte des Allg. Ev.-Prot. Missionsvereins in: OstasienJahrbuch. Nr. 3. Berlin 1924. S. 63-78. • Siehe auch Friedrich Nippold

$Z$ „Die Theologische Facultät hat sich ... dafür ausgesprochen: daß die erledigte Professur (des Hermann Schultz) wieder in die beiden besonderen Lehrfächer der neutestamentlichen Exegese und praktischen Theologie geschieden [werde], die erste als Hauptfach anzusehen (sei) und ... einem Ordinarius verliehen werden muß; für die zweite dagegen eine jüngere Kraft als Extraordinarius in Vorschlag zu bringen sei; die Aufgabe dieser zweiten Lehrstelle wird auch dahin bestimmt, daß darin die Mitwirkung beim Universitätsgottesdienst wie beim Seminarunterricht und Vorlesungen über praktische Theologie umfaßt sind ..." (aus: Bericht des Engeren Senats der $\mathrm{UH}$ an das Ministerium des Innern vom 12. März 1876 in: UAH RA 6718 fol. 42 r).

1896 Kirchenrat; 1903 Geh. Kirchenrat

E 1883 D. theol. Zürich. 1885 Ritterkreuz I. Klasse, 1902 Ritterkreuz I. Klasse mit Eichenlaub vom Orden des Zähringer Löwen.

Qu UAH PA 1316; RA 5210, 6127, 6135, 6718. • Matrikel Zürich (1999) Nr. 3743. • Briefe, Nachlaß: UBH; s. hierzu Karcher, Stefan: Nachlass H. B. Datenbank (2017) online unter doi:10.11588/data/ PFZXUD.

$W$ Handbuch der geistlichen Beredsamkeit. Stuttgart 1885. - Geschichte der evangelischen Gottesdienstordnung in badischen Landen. Stuttgart
1891. Zur Frage des Unionskatechismus. Tübingen, Leipzig 1901. - Wie studiert man evangelische Theologie? Stuttgart 1905. - Was ist der Mensch, dass du seiner gedenkst? Akademische Predigten von H. B. Hrsg. von Helene Bassermann und Otto Frommel. Leipzig 1911.

MHG 1881-1909 Zs. für praktische Theologie.

L Bassermann, Ernst: Wilhelm Bassermann ... und seine Nachkommen. Mannheim 1905. Bassermann'sche Familien-Nachrichten. Mannheim 1910. H. 4, S. 15. Hartmann, Carl: H. B. Vortrag gehalten im Wiss. Predigerverein. Karlsruhe 1912. • Waldeck 4 (1923) S. 112; RGG 1 ( $\left.{ }^{2} 1928\right)$ S. 793; Musik in Heidelberg (1985) S. 248 (Register); BBKL I (1990) Sp. 411; WBIS; Lebensbilder aus der ev. Kirche (2007) S. 522 (Register). Deutsche Biographie, s. https://www.deutsche-biographie.de/gnd 116080116.html [06.11.2017]. - Karcher, Stefan: Die Anfänge der Universitätsgottesdienste in der Heidelberger Peterskirche (Heidelberger Universitätsprediger (Online Dokumentation)). Theol. Fak. der UH. Online-Ressource (2017), s. https:// www.uni-heidelberg.de/fakultaeten/theologie/for schung/predigtforschung/universitaetsprediger/ universitaetsgottesdienste-in-der-peterskirche. html; Ders.: H.B. und die Grundlegung der akademischen Predigt. Diss. Heidelberg (2018 in Vorbereitung).

$P$ Bildarchiv UAH; graph. Slg. UBH.

\section{Bauer, Johannes Christian Ludwig August}

1910-1929 Theol. Fak.

Praktische Theologie

* 12. Sept. 1860 Wiesloch (Baden)

$\dagger$ 10. Jan. 1933 Heidelberg

ev.

V Friedrich Karl B. (1832-1920) Pfarrer, später Kirchenrat, s. Badische Biographien N.F. I (1982) S. $29 \mathrm{f}$.

M Wilhelmine Auguste Henriette Louise geb. Pampel (1835-1889)

๑ 16. Okt. 1884 Minna geb. Ringwald (1862-1928)

$\mathrm{K} \quad 2 \mathrm{~S}, 2 \mathrm{~T}$ 
Lb Seit WS 1878/79 Studium an U Erlangen, anschl. Leipzig, Basel, SS 1881-WS 1881/82 H; Ostern 1881 I., Okt. 1882 II. Prüfung in Karlsruhe; 19. Nov. 1882 Ordination in Lahr.

Vikar: Seit Nov. 1882 Emmendingen, seit Pfingsten $1883 \mathrm{H}$, zuletzt Freiburg/Br.

Freiburg/Br.: Seit 1888 Pfarrer am Landesgefängnis.

U Marburg: Seit Febr. 1890 Eigenstudien; 9. Aug. 1892 Lizentiatenprüfung; Aug. 1892 Habilitation; seit 5. Sept. 1902 a. o. Prof.; seit 21. Juli 1906 etatm. a. o. Prof.

U Königsberg (Preußen): Seit 15. Juli 1907 (1. Okt. 1907 Dienstbeginn) o. Prof. als Nachf. von (siehe) Heinrich Bassermann.

UH: 22. Dez. 1909 Ern. zum o. Prof. und Direktor des Praktisch-Theol. Seminars als Nachf. von Bassermann; seit 28. Dez. 1909 Lehrauftrag für christliche Archäologie und christliche Kunstgeschichte; 1. April 1910 Amtsantritt; 1912 Ruf an U Leipzig abgelehnt; 31. März 1929 Emeritierung. • In dieser Zeit:

Karlsruhe: Mitglied: 1914-1918 der Badischen Generalsynode, 1919 der verfassunggebenden Landessynode, 1920-1932 der ev. Kirchenregierung in Baden.

1915/16 Prorektor der UH; 1912/13, 1917/18, 1922/23, 1928 Dekan der Theol. Fak. der UH

1921 Begründer der Ev. Kirchenhistorischen Kommission in Baden (Publikationsorgan: Veröffentlichungen der ev. Kirchenhistorischen Kommission in Baden. Frankfurt/M., Heidelberg 1921-1922. 3 Bde., damit Erscheinen eingestellt).

1912 Geh. Kirchenrat

Siehe auch Anhang Sporteinrichtungen an UH 1910-1933 und ihre Mitglieder

E 1904 O. Mitglied der Königl. Gesellschaft für Wiss. und schöne Literatur Göteborg; 1920 Mitglied der Akademie der Wissenschaften H. 1904
D. theol. Marburg. 1916 Ritterkreuz I. Klasse des Ordens vom Zähringer Löwen.

Qu UAH PA 3203; RA 617, 6400; Acc. 40/11. • GLA Abt. 235, Fasz. 1757. • Briefe: UBH. • Nachlaß: Ev. Oberkirchenrat - Landeskirchliches Archiv Karlsruhe; UBH.

W Predigten über Worte Jesu. Tübingen 1903. • Schleiermacher als patriotischer Prediger. Gießen 1908. - Die Agendenreform der Gegenwart. Tübingen 1911. - Zur Geschichte des Bekenntnisstandes der vereinigten ev.-prot. Kirche im Großherzogtum Baden. Heidelberg 1915.

HG Die Union 1821. Urkunden und Dokumente. Heidelberg 1921. (Veröffentlichungen der ev. Kirchenhistorischen Kommission in Baden. 1.)

$L$ Catalogus prof. Marburgensis 1 (1927) S. 62; NDB 1 (1953) S. 640f. • Roth, Erich: Des Lebens Anfang und Aufstieg in: Ein Leben für die Kirche. Hrsg. von Fritz Hauß u.a. Karlsruhe 1960. S. 1731. BBKL I (1990) Sp. 418 f.; Jansen (1992) S. 407 (Register); Fix (1994) S. 72-79; Personenlexikon zum dt. Protestantismus (2006) S. 28; Kriegstagebuch K. Hampe (2007) S. 944 (Register); Badische Biographien N.F. VI (2011) S. 16-18; Tilitzki 1 (2012) S. 782 (Register).

$P$ Bildarchiv UAH.

Beck, Bernhard Ferdinand Berthold Rudolph (seit 1884: von Beck)

1894-1901 Med. Fak.

Chirurgie

* 23. Sept. 1863 Freiburg/Br.

$\dagger$ 29. Dez. 1930 Karlsruhe kath.

V Dr. med. Bernhard Oktav (seit 1884: von) B. (1821-1894) chirurg. Militärarzt, zuletzt Generalmajor, s. NDB 1 (1953) S. 696, WBIS

M Mathilde Freiin geb. von und zu Bodmann (1837-1871) 
( 10. April 1897 Maria geb. Pfeilsticker $\left({ }^{*} 1874\right.$ $\dagger$ nach 1941)

K $\quad 2 \mathrm{~T}$

Vw Großvater: Karl Joseph B. (1794-1838), u.a. seit 1821 o. Prof. für Chirurgie, Ophthalmologie, Gerichtliche Arzneikunde Freiburg/Br., s. Nachlaß in UB Freiburg/Br; Baumgärtner, Karl Heinrich: Gedächtnisrede auf K. J.B. bei dessen akad. Totenfeier ... Freiburg 1954. Nachdr. der Ausg. von 1839; WBIS.

Lb Seit WS $1882 / 83$ Studium an U Freiburg/Br., SS $1887 \mathrm{H}$, seit WS $1887 / 88$ Göttingen.

U Göttingen: 1889 II. Staatsexamen; 1889 Dr. med.

Seit 1889 ärztl. Fortbildung in Wien und Berlin.

UH: 1890-1897 Assistent an Chirurg. U-Klinik; 24. Febr. 1894 Habilitation; seit 23. Nov. 1896 nichtetatm. a.o. Prof.; SS 1901 letzte Vorlesungsankündigung „Über Nachbehandlungen von Verletzungen und Operationen“; 1901 aus Liste der akad. Lehrer gestrichen.

Karlsruhe: 1897-1930 Chefarzt der Chirurg. Abt. und 1898-1930 Direktor des Städtischen Krankenhauses.

Geh. Hofrat

Qu UAH PA 1324. - Nachlaß: Universitätsbibliothek Freiburg/Br.

$W$ Beiträge zur Pathologie und Chirurgie des Gehirns. Tübingen 1894. • Über zwei interessante Fälle von Magenchirurgie in: Dt. med. Wochenschrift 8 (1894).

L Stübler (1926) S. 319. • Gothaisches Genealogisches Taschenbuch der Adeligen Häuser. Gotha 1941. Teil B. S. 26. - Stumpf, Ludwig: B. von B. in: Biographiensammlung. Karlsruhe 1965. S. 19-21. Leier, Wolfgang Andreas: Der Anteil Heidelbergs an der Entwicklung der Magenchirurgie. Diss. Heidelberg 1977. • Chronik Ärzte H (1985) S. 121 f.; WBIS; Deutsche Biographie, s. https://www.deutsche-biographie.de/gnd120066599.html [06.11. 2017].
$P$ Bildarchiv UAH; graph. Slg. UBH; Leier; Chronik Ärzte H.

\section{Beck, Karl Maria Otto Hans}

1913-1942 Med. Fak.

Hals-, Nasen-, Ohrenheilkunde

* $\quad$ 04. März 1880 Bonndorf (Schwarzwald)

$\dagger \quad$ o6. März 1942 Heidelberg

口 Mannheim

kath.

V Dr. phil. h.c. (1907 der UH) Otto Julius B. (1846-1908) Amtmann, seit 1891 Oberbürgermeister von Mannheim, s. UAH H-IV-767/2; NDB 1 (1953) S. 707; Strobel, Engelbert: Oberbürgermeister O.J.B. in: Badische Heimat: mein Heimatland. Zs. für Landes- und Volkskunde ... Freiburg/Br. 1982. H. 2. S. 227-293; Geschichte der Stadt Mannheim. Hrsg. von Michael Caroli, Ulrich Nieß. Bd. 2: 1801-1914. Ubstadt-Weiher 2007. S. 505-594 u. ö.

M Amalie geb. Raouloff (1859-1937)

๑ 2. März 1914 Alexia Ludovica Antonia geb. Gräfin von Sternberg-Rudelsdorf $\left({ }^{*} 1879\right)$

K $\quad 2 \mathrm{~S}$

Lb Seit SS 1900 Studium an UH, seit SS 1902 Straßburg, anschl. München, Berlin; 1902-1903 Militärdienstpflicht als Einjährig-Freiwilliger in Straßburg; 1905 Staatsexamen in H; 24. Nov. 1905 Dr. med. an UH.

1905-1906 Assistent zunächst am German Hospital in London, anschl. am Inst. für Experimentelle Therapie in Frankfurt/M.; 1906-1907 Oberarzt der Landwehr I beim 1. Schweren Reiterregiment in München.

UH: Assistent: Seit Herbst 1907 am Patholog. Inst., seit Okt. 1908 an U-Klinik für Ohren-, Nasen- und Kehlkopfkranke; 4. März 1913 Habilitation; seit 26. Febr. 1919 nichtetatm., 1920-1931 nichtplanm. a.o. Prof.; seit 1920 Oberarzt an U-Hals-, Nasen-, Ohrenklinik; seit 14. April 1931 o. Prof. und Direktor der U-Klinik für Ohren-, Nasen- und Ohrenkranke als Nachf. von Werner Kümmel. • In dieser Zeit: 
H: 1921-1931 Niedergelassener Facharzt.

Bei einer Entzündung der Stirnhöhle kann die Stirnhöhlenpunktion nach „Kümmel-Beck“ angewendet werden: durch die Bohrung einer Öffnung zur Stirnhöhle hin wird der angestaute Eiter oder Schleim abgesaugt.

\section{Qu UAH PA 830, 3232.}

$W$ Experimentelle Untersuchungen über den Einfluß von Bakterientoxinen und Giften auf das Gehörorgan. Wiesbaden 1913. - Erkrankungen der Nase und Nebenhöhlen im Kindesalter in: Handbuch der Hals-, Nasen-, Ohrenheilkunde 2 (1926).

HG Archiv für Ohrenheilkunde und Erkrankungen der oberen Luftwege.

L Stübler (1926) S. 324; Kürschner (1940/41) Sp. 79; Fischer 1 ( $\left.{ }^{3} 1962\right)$ S. 87; Chronik Ärzte H (1985) S. 121; WBIS; Jansen (1992a) S. 163 (Register); Badische Biographien N.F. IV (1996) S. 20-22; Lehrstätten der Oto-Rhino-Laryngologie (1996) S. 16o, 295 (Register); Deutsche Biographie, s. https:// www.deutsche-biographie.de/gnd129870218.html [06.11.2017].

P Bildarchiv UAH; Chronik Ärzte H.

\section{Becker, August}

1907-1946 Nat.-Math. Fak.

(Theoretische) Physik; 1914-1917 Radiologie

* 19. Febr. 1879 Osterburken (Baden)

$\dagger$ 16. Jan. 1953 Heidelberg

ev.

V Friedrich August B. (1838-1897) Gendarmeriewachtmeister

M Christiane geb. Heintzmann ( $\dagger$ vor 1897)

œ 29. Dez. 1903 Maria Auguste geb. Roth (18781961)

K $1 \mathrm{~S}\left(X_{1} 1945\right), 1 \mathrm{~T}$
Lb Studium der Mathematik, Naturwiss. an U: Seit WS 1897/98 H, SS 1899 Kiel, seit WS 1899/1900 H; Febr. 1901 Staatsexamen für Lehramt an Mittelschulen in Karlsruhe; 2. Aug. 1901 Dr. phil. nat. an UH.

U Kiel: Juni 1901-Okt. 1907 Assistent von (siehe) Philipp Lenard am Physikal. Inst.; 9. Mai 1905 Habilitation.

UH: Seit 1. Okt. 1907 (Umhabilitation) Privat-Dozent und Assistent von Lenard am Physikal. Inst.; seit 11. Nov. 1907 nichtetatm. a. o. Prof.; 1907 Ruf an TH Hannover abgelehnt; seit 29. Dez. 1913 etatm., 1920-1935 planm. a. o. Prof. und Leiter des Theoretisch-Physikalischen Apparats; 1914-1917 auch Dozent für Radiologie; seit 6. Juni 1935 o. Prof. und Direktor des Philipp Lenard-Inst. als Nachf. von Walther Bothe; 14. Dez. 1945 Emeritierung zum 31. März 1946; 18. Febr. 1946 Entlassung gemäß Erlaß der amerikanischen Militärregierung; 1. Okt. 1951 Emeritierung. • In dieser Zeit:

1915-1916 Kriegsdienst. - 1929 Mitglied der Radium-Kommission des Reichsarbeitsministeriums in Berlin.

1937-1939 Dekan der Nat.-Math. Fak. der UH

E 1935 Ausw. Mitglied der Balneologischen und Klimatologischen Gesellschaft Prag; 1937 Mitglied der Akademie der Wissenschaften $\mathrm{H}$.

Qu UAH PA 3235 f.; RA 6465f., 6886, 6898; Rep. 40-374. • GLA Abt. 235, Fasz. 1438. • Briefe: UBH.

$W$ Ein neuer Emanationsmeßapparat für direkte Ablesung in: Zs. für Instrumentenkunde 30 (1910). • Über die Elektrizitätsentwicklung durch Änderung flüssiger Oberflächen in Gasen in: Jahrbuch der Radioaktivität und Elektronik 9 (1912). • Über radioaktive Normalpräparate als Grundlage der Emanationsmessung in: Strahlentherapie 14 (1922) S. 707-714.

$L$ Professoren Kiel (1956) S. 216; Jansen (1992a) S. 163 (Register); WBIS. - Schmidt-Schönbeck (2011) S. 75 f. u. ö. Kipnis, Alexander: Biographie A. B. online unter http://www.kipnis.de/index2.ph 
p?option $=$ com_content $\&$ do_pdf $=1 \&$ id $=13 \quad$ (abge rufen am 8. April 2014; Ausdruck im UAH). Deutsche Biographie, s. https://www.deutsche-bio graphie.de/gnd116102586.html [06.11. 2017].

$P$ Bildarchiv UAH.

\section{Becker, Carl Heinrich}

1902-1908 Phil. Fak.

Orientalische Philologie

* 12. April 1876 Amsterdam

$\dagger$ 10. Febr. 1933 Berlin ev.

V Carl Wilhelm Ferdinand B. (1821-1897) Bankier und Konsul der Stadt Frankfurt/M. in Amsterdam, s. Michaelis/Morgenstern ... (2013) S. 45-59 u. ö.

M Julie geb. Schöffer (1839-1917), s. ebd. S. 59-61 u. ö. - T von Conrad Heinrich S. (1815-1878) Großkaufmann (Kaffeehändler), Wahlkonsul der Stadt Frankfurt/M. in Amsterdam, Mitglied im preußischen Abgeordnetenhaus, s. ebd. S. $19-36$ u. 0 .

( 14. März 1905 Hedwig geb. Schmid (18841971), s. ebd. S. 68,71 f., 81, 171-176 u. ö.

K 1 T, 2 S: u. a. Hellmut B. (1913-1993) Jurist, Bildungspolitiker, s. Conze, Eckart u. a.: Das Amt und die Vergangenheit. Dt. Diplomaten im Dritten Reich ... München 2010; Michaelis/ Morgenstern ... S. 107-113 u. ö.; Raulff, Ulrich: Kreis ohne Meister. Stefan Georges Nachleben. München 2012. S. 535 (Register).

Vw Großvater: Karl Ferdinand B. (1775-1849) Arzt, Pädagoge, Sprachwissenschaftler, s. NDB 1 (1953) S. 710 f., Michaelis/Morgenstern ... S. 47-49 u. ö.

Lb Seit SS 1895 Studium der Theologie, Religionskunde, Assyriologie, Orientalischen Sprachen an U Lausanne, seit WS 1895/96 H; 30. Okt. 1899 Dr. phil. an UH.
WS 1899/1900-SS 1900 Forts. des Studiums, vor allem der Arabistik an U Berlin; seit Herbst 1900 Studienreisen, u. a. Spanien, Marokko, Süditalien, Ägypten, Sudan, Griechenland, Türkei.

UH: 3. Mai 1902 Habilitation; 1906 Ruf an College Aligarh (Indien) abgelehnt; seit 2. Juli 1906 nichtetatm. a. o. Prof.

Hamburg: Seit 1. Okt. 1908 o. Prof. für Geschichte und Kultur des Vorderen Orients am neugegründeten Kolonial-Inst.

U Bonn: Seit 1. Sept. 1913 o. Prof. für Geschichte und Sprachen des Orients.

Berlin: Seit 26. Juni 1916 Personalreferent für Universitäten am preußischen Kultusministerium; seit April 1919 Unterstaatssekretär als Nachf. von Max Hermann Baege (1875-1939), 1921-1925 Staatssekretär im preußischen Kultusministerium; April-Nov. 1921 (per interim), 18. Febr. 1925-Jan. 1930 (Rücktritt) preußischer Minister für Wiss., Kunst und Volksbildung (Ziel: Schaffung e. einheitlichen Bildungssystems).

U Berlin: 23. Nov. 1916 Ern. zum o. Honorar-Prof.; 3o. Nov. 1916 Erteilung des Lehrauftrags für Geschichte der islamischen Völker; 23. April 1930 Ern. zum o Prof. und Direktor des Inst. für Semitistik und Islamkunde.

Mitbegründer: 1920 Dt. Hochschule für Politik, 1926 Preußische Dichterakademie; 1925 Initiator für 15 neuerrichtete deutsche Pädagogische Akademien

1932 Mitglied einer Völkerbundskommission für China

1916 Geh. Reg.-Rat

E 1919 Dr. phil. h.c. Bonn, 1924 D. theol. Königsberg (Preußen), 1927 Dr. med. h.c. Marburg, 1929 D. theol. Debrecen. 1902 Jubiläumsmedaille des Großherzogs Friedrich I. von Baden. 
Qu UAH PA 1326. • GLA Abt. 235, Fasz. 1773. • Calder, William M.: Der Briefwechsel Werner Jaegers mit C.H. B. (1918-1932) in: Philologus. Zs. für antike Literatur und ihre Rezeption. Berlin 2009. S. 310-348. - Kestenberg, Leo: Gesammelte Schriften. Teil 1: Briefe von und an Adolf Kestenberg ... und C.H. B. Freiburg/Br. u. a. 2010. Dokumente über C.H.B., s. Bibliothek für Bildungsgeschichtliche Forschung (BBF) online unter www.bbf.dipf. de und Zentralbibliothek für Wirtschaftswissenschaften (ZBW) online unter http://zbw.eu/beta/ p2o/person/1271. - Nachlaß: Geheimes Staatsarchiv Preußischer Kulturbesitz, Berlin. • Auskunft: Herr Dr. Ulf Morgenstern, Friedrichsruh.

W Gedanken zur Hochschulreform. Leipzig 1919. 2. Aufl. 1920. - Islamstudien. 2 Bde. Leipzig 19241932. - Die pädagogische Akademie im Aufbau unseres nationalen Bildungswesens. 1.-5. Aufl. Leipzig 1926-1930.

\section{G, HG 1910-1933 Der Islam.}

$L$ NDB 1 (1953) S. 711 (mit Werkverz.); Verzeichnis Bonn (1968) S. 14 f.; WBIS; Heiber 1 (1991) S. 632 (Register); BBKL XXV (2005) Sp. 42-46. • Morrone, Giovanni: Incontro di civiltà. L'Islamwissenschaft di C.H.B. Neapel 2006. - Kriegstagebuch K. Hampe (2007) S. 944 (Register). • KlinkhardtLexikon Erziehungswissenschaft. Hrsg. von KlausPeter Horn u. a. Bad Heilbrunn 2011. Bd. 1. S. 95 f. • Bonniot, Béatrice: Homme de culture et républicain de raison: C.H.B. ... Frankfurt/M. 2012. • Gibt es noch eine Universität? Zwist am Abgrund - eine Debatte in der Frankfurter Zeitung 1931/32. Hrsg. von Dieter Thomä. Konstanz 2012. Raulff, Ulrich: Kreis ohne Meister. Stefan Georges Nachleben. München 2012. S. 535 (Register). Böhmer, Bert: Zum 8o. Todestag des preuBischen Kultusministers C.H.B. Friedrichsruh 2013. Typoskript. Michaelis, Kristina, Morgenstern, Ulf: Kaufleute, Kosmopoliten, Kunstmäzene: Die Gelnhäuser Großbürgerfamilien Becker und Schöffer. Katalog zur Ausstellung. Gelnhausen 2013. S. 63-85, 162-165, 199-203 u. ö.

$P$ Bildarchiv UAH; NDB; Michaelis/Morgenstern (2013). - Finnisch-Ugrisches Seminar der U Göttingen.

\section{Becker, Otto Heinrich Enoch}

1868-189o Med. Fak.

Augenheilkunde

* 03. Mai 1828 Ratzeburg

$\dagger \quad$ o6. Febr. 1890 Heidelberg

$\square \quad$ Ratzeburg (Domfriedhof) ev.

V Dr. phil. Ulrich Justus Hermann B. (1791-1843) zunächst Konrektor, seit 1830 Gymnasial-Prof., seit 1839 Rektor der Domschule in Ratzeburg, s. WBIS, Grewolls (2011)

M Mathilde Anna Rosalie geb. Hufeland (17941863) T von Gottlieb H. (1760-1817) Prof. für Rechtswiss., u. a. 1788-1803 U Jena, 1803-1806 Würzburg, 1806-1808 Landshut; 1808-1812 Senatspräsident und Bürgermeister von Danzig, seit 1816 o. Prof. Halle-Wittenberg, s. NDB 10 (1974) S. $7^{*}$, WBIS; Rohls, Michael: Kantisches Naturrecht und historisches Zivilrecht: Wissenschaft und bürgerliche Freiheit bei G. H. Baden-Baden 2004.

$\infty$ 2. Febr. 1864 Helene geb. Figdor $\left({ }^{*} 1840 \dagger\right.$ nach 1890)

K 2 S, 1 T: Margaretha Alberta Emma Helena B. (1866-1932) Ehefrau von: (siehe) Ernst Walz

Vw Bruder: Eberhard B. (1823-1897), u. a. 186o1865 Lehrer des späteren Großherzogs von Mecklenburg Adolf Friedrich V. (1848-1914), 1865-1897 Pastor in Mirow, s. Grewolls (2011).

Lb Seit 1847 zunächst als Stipendiat Studium der Theologie an U Erlangen; seit 1848 Studium der Naturwiss., Mathematik an U Berlin.

Wien: Seit 1851 Hauslehrer; seit 1854 Studium der Medizin an U; April 1859 Dr. med.; seit 1860 Sekundärarzt am Königl.-Kaiserl. Allg. Krankenhaus; seit 1864 Assistent an U-Augenklinik; 1867 Habilitation.

UH: Seit 3. Aug. 1868 o. Prof. und Direktor der UAugenklinik in Nachfolge von Hermann Knapp.

1876 Prorektor der UH; 1875/76, 1884/85 Dekan der Med. Fak. der UH 
1878 Hofrat; 1884 Geh. Hofrat; 1886 Geh. Rat II. Klasse

Siehe auch Karl Zangemeister: Eintrag unter Z[itat]

E 1882 Kommandeurkreuz II. Klasse mit Eichenlaub des Ordens vom Zähringer Löwen.

Qu UAH PA 1327; RA 6307, 6787. • Briefe: UBH.

$W$ Atlas der pathologischen Topographie des $\mathrm{Au}-$ ges. 3 Lfg. Wien 1874-1878. - Pathologie und Therapie des Linsensystems. Leipzig 1875. - Photographische Abbildungen von Durchschnitten gesunder und kranker Augen. Heidelberg 18751876. Zur Anatomie der gesunden und kranken Linse. Wiesbaden 1883.

HG Donders, Franciscus Cornelis: Die Anomalien der Refraktion und Accomodation des Auges ... Wien 1866.

$L$ ADB 46 (1902) S. 326 f.; Heidelberger Prof. aus dem 19. Jhdt. 2 (1903) S. 197-205; Stübler (1926) S. 322; Hoche (1969) S. 102f.; Chronik Ärzte H (1985) S. 122; WBIS; Pantel/Bauer (1990) S. 9698. - Steffen, Uwe: Zwei bedeutende Ratzeburger: ... Ulrich Becker und ... O. B. in: Lauenburgische Heimat. Zs. des Heimatbund und Geschichtsvereins Herzogtum Lauenburg. Ratzeburg 2005. S. 50-56. Grewolls (2011).

$P$ Bildarchiv UAH; graph. Slg. UBH; Chronik Ärzte H.

\section{Beer, Georg Gottfried}

1910-1934 Theol. Fak.

Alttestamentliche Exegese

* 12. Nov. 1865 Schweidnitz (Schlesien; heute: Świdnica, Polen)

$\dagger$ 16. Febr. 1946 Heidelberg

$\square$ Neckargemünd ev.
V Karl Gottfried B. (1810-1865) Leutnant

M Marie Mathilde geb. Scholz (1830-1919)

( 27. Dez. 1900 Emma (Emmy) Berta geb. Müller (1867-1943)

K $\quad 1$ S, 1 T

Lb Seit WS 1884/85 Studium der Theologie, Philosophie an U Berlin; 18. Febr. 1888 Dr. phil. an U Leipzig; 1888 1. theol. Examen.

Erbach: Seit 1888 Lehrer an Nassauischer Realschule und Predigtamtskandidat.

U Bonn: 6. Aug. 1891 Lizentiatenprüfung.

U Breslau: 21. Mai 1892 Habilitation für Altes Testament.

U Halle-Wittenberg: 22. Juli 1895 Habilitation und Dr. theol.; seit WS 1895/96 Privat-Dozent.

Straßburg: Seit WS 1900/o1 etatm. a. o. Prof. an U und Gymnasiallehrer.

UH: 22. Dez. 1909 Ern. zum o. Prof. am Wiss.Theol. Seminar; 20. April 1910 Vereidigung; 31. März 1934 Emeritierung; SS 1934 Vertreter seiner Professur.

1921/22 Rektor der UH; 1913/14, 1918/19, 1923/24, 1928/29, 1932/33 Dekan der Theol. Fak. der UH

Siehe auch Anhang Sporteinrichtungen an $U H$ 1910-1933 und ihre Mitglieder

E Mitglied: Wiss. Gesellschaft Straßburg, 1925 Akademie der Wissenschaften H. 1908 D. theol. Marburg.

Qu UAH PA 3250; RA 5225. - GLA Abt. 235, Fasz. 1777. • Briefe: UBH. - Auskunft: Ev. Oberkirchenrat - Landeskirchliches Archiv - Karlsruhe; Universitätsarchive Leipzig und Bonn.

W Der Text des Buches Hiob. Marburg 1897. • Pascha oder das jüdische Osterfest. Tübingen 1911. • Hebräische Grammatik. 2 T. Berlin 1920-1921. 2. Aufl. 1952. 1955. Die Bedeutung des Ariertums für die israelisch-jüdische Religion in: Reden ge- 
halten bei der Jahresfeier der UH ... am 22. Nov. 1921 ... Heidelberg 1922. II. Teil. S. 2-36. - Siehe auch BBKL XXXIII (2012).

L RGG 1 ( $\left.{ }^{2} 1927\right)$ S. 850; Jansen (1992a) S. 44, 83; Fix (1994) S. 80-84; Personenlexikon zum dt. Protestantismus (2006) S. 31; WBIS; Klee, Personenlexikon (2007); BBKL XXXIII (2012) Sp. 109-151; Deutsche Biographie, s. https://www.deutschebiographie.de/gnd116107596.html [06. 11. 2017].

$P$ Bildarchiv UAH.

\section{Behaghel, Wilhelm Maximilian Otto}

1878-1883 Phil. Fak.

Germanische Philologie

* O3. Mai 1854 Karlsruhe

$\dagger \quad$ o9. Okt. 1936 München

ㅁ Gießen

ev.

V Felix B. (1822-1888) Oberkirchenrat, s. WBIS

M Pauline Luise Nanette geb. Wielandt (18271901)

$\infty$ 2. Aug. 1887 Clara Elisabeth Maria Dorothea geb. Zöller (1866-1924)

K 1 T, 1 S: Eduard Felix Otto B. (1895-1961) 19321946 a. o. Prof. für Chemie Gießen, s. WBIS, Kürschner (1961) S. 98

Vw Großvater: Johann Georg B. (1797-1861) 18281861 Prof. am Lyceum in $\mathrm{H}$; Nachlaß in UB Freiburg/Br. (NL 13); s. Ehmann, Wilhelm: Der Thibaut-Behaghel-Kreis in: Archiv für Musikforschung 3 (1938) S. 428-457, 4 (1939) S. 21-67; Das „Goldene Buch“ des KFG (1994) S. 35. Onkel: Wilhelm Jakob B. (1824-1896), u. a. 1861-1896 Prof. für Rechtswiss. Freiburg/ Br., s. WBIS, Zeiler (2009) S. 519 (Register).

Lb Seit WS 1873/74 Studium an UH, anschl. Göttingen, seit 10. Mai 1875 H, dann Paris.

UH: 22. April 1876 Dr. phil.; 1877 philolog. Staatsexamen; 16. Jan. 1878 Habilitation; seit 16. Jan. 1882 a. o. Prof.
U Basel: Seit 9. Juni 1883 o. Prof.

U Gießen: Seit 30. Juni 1888 o. Prof. als Nachf. von (siehe) Wilhelm Braune; 1893 Ruf an U Freiburg/ Br. abgelehnt; 1. Okt. 1925 Emeritierung.

Die „Behaghelschen Gesetze“ beschreiben Grundprinzipien der Stellung von Wörtern und Satzgliedern in einem Satz.

1897 Geh. Hofrat; 1918 Wirkl. Geh. Rat

E Mitglied der Akademie der Wissenschaften: 1912 München, 1928 Göttingen. 1924 Dr. iur. h.c. Gießen. 1934 Goethe-Medaille für Kunst und Wissenschaft; 1934 Goldener Ehrenring des Allg. dt. Sprachvereins. 1907 Kommandeurkreuz II. Klasse des Ordens vom Zähringer Löwen.

Qu UAH PA 1339; Fak.-Akte H-IV-102/149 fol. 2V (1926 keine Ehrenpromotion, sondern Diplomerneuerung). GLA Abt. 235, Fasz. 1778. • Briefe: UBH. - Teil-Nachlaß: UB Gießen (siehe Bayerer, Wolfgang G.: Findbuch zum Nachlass O.B. Giessen 1993); UBH (Signatur: Heid. Hs. 3664).

$W$ Die deutsche Sprache. Leipzig 1886. 12. Aufl. 1955. Geschichte der deutschen Sprache. Straßburg 1891. 5. Aufl. 1928. - Deutsche Syntax. Eine geschichtliche Darstellung. 4 Bde. Heidelberg 1923-1932.

MG, $M H G$ 1880-1936 Literatur-Blatt für Germanische und Romanische Philologie. $1888-1892$ Germania: Zs. für dt. Altertumskunde. - 19241933 Gießener Beiträge zur dt. Philologie.

L NDB 1 (1953) S. 747 f. (mit Werkverz.); Lehmann (1967) S. 223f.; Gießener Gelehrte (1982) S. 29-37. Ramge, Hans: O. B. und das Deutsche Seminar in: Panorama - 400 Jahre Universität Giessen ... Hrsg. ... von Horst Carl. Frankfurt/M. 2007. S. 108-113; Ders.: O. B. Philologe und Sprachautorität in: Mitteilungen des oberhessischen Geschichtsvereins 97 (2012) S. 195-220, s. auch online http://nbn-resolving.de/urn/resolver.pl?urn= urn:nbn:de:hebis:26-opus-112545. - Hennig, Mathilde: Mündlichkeit und Schriftlichkeit bei O. B. (2. Fassung). UB Gießen 2016. (Behagheliana. 1.) On- 
line-Ressource, s. http://nbn-resolving.de/urn/re solver.pl?urn=urn:nbn:de:hebis:26-opus-120772. Riecke (2016) S. 142 (Register).

$P$ Bildarchiv UAH; NDB. - Portraitgemälde und -büste in U Gießen.

\section{Behrens, Behrend Walter}

1926-1932 Med. Fak.

Pharmakologie

* 23. Mai 1895 Gießen

$\dagger$ 30. Dez. 1969 Gut Hilperdingen in Walsrode (Niedersachsen)

ev.

V Dietrich B. (1859-1929) seit 1884 Privat-Dozent Greifswald, seit 1890 a. o. Prof. Jena, seit 1891 o. Prof. für Romanistik Gießen, s. Kredel, Elisabeth, Gottschalk, Walter: D. B. in: Schönbohm, Bernhard: Bekannte und berühmte Jeverländer ... Jever 1981; Gießener Gelehrte (1982) S. 38-46; WBIS

M Dorothea Fahlberg (1861-1939)

( 28. Aug. 1923 Ella Marie geb. Tyedmers-Middoge $\left({ }^{*} 1899\right)$

$\mathrm{K}$ keine.

Lb U Gießen: Seit SS 1914 zunächst Studium der Landwirtschaft, Tierheilkunde, dann der Medizin; Dez. 1920 med. Staatsexamen.

U Gießen: April 1921-März 1922 Assistent an Med. Klinik; 9. Aug. 1922 Dr. med.

U Königsberg (Preußen): April 1922-Sept. 1925 Assistent am Pharmakolog. Inst.; 30. Juni 1925 Habilitation.

UH: Seit Okt. 1925 Assistent am Pharmakolog. Inst.; 25. Febr. 1926 Umhabilitierung; 4. Aug. 1930 Ern. zum apl. a. o. Prof.
Berlin: Seit 1. April 1932 apl. a. o. Prof. an U; 1934/35 nebenamtl. Referent im Reichs- und Preußischen Ministerium für Wiss., Erziehung und Volksbildung; seit 22. Febr. 1935 Referent im Reichserzie-

U Kiel: 3. April 1935-30. Sept. 1964 (Emeritierung) o. Prof. und Direktor des Pharmakolog. Inst.

1938-1947 Vorsitzender der Dt. Pharmakologischen Gesellschaft mit Sitz in Berlin-Charlottenburg

Qu UAH PA 834, 3253. • GLA Abt. 235, Fasz. 1779.

$W$ Über den Einfluß der Verdünnungsflüssigkeit auf das Zählresultat bei Erythrocytenzählungen in: Pflügers Archiv für die gesamte Physiologie 195 (1922) S. 266-287.

HG 1934-1944 Sammlung von Vergiftungsfällen.

MHG 1928-1944 (Erscheinen eingestellt) Schmerz, Narkose und Anaesthesie.

$L$ Professoren Kiel (1956) S. 88. • Zetler, Gerhard: In memoriam B. B. in: Universität Kiel ... Forschungen und Berichte aus der Christian-Albrechts-Universität zu Kiel. Neumünster 1970. S. 94 f. - Kürschner (1980) S. 199, (1983) S. 4817; Arnim 3 (1981) S. 95; WBIS; Lindner/Lüllmann (1996) S. 165 u. ö.

$P$ Bildarchiv UAH.

\section{Bekker, Ernst Immanuel}

1874-1908 Jur. Fak. 1908-1909 (Honorar-Prof.) Jur. Fak.

Römisches Recht, Dt. Bürgerliches Recht

* 16. Aug. 1827 Berlin

$\dagger \quad$ 29. Juni 1916 Heidelberg ev. 
V August Immanuel B. (1785-1871) seit 1810 a. o. Prof., seit 1811 o. Prof. für Klassische Philologie Berlin, s. NDB 2 (1955) S. 24 f.; Schröder, Wilt Aden: I.B., der unermüdliche Herausgeber vornehmlich griechischer Texte in: Die modernen Väter der Antike ... Hrsg. von Annette M. Baertschi ... Berlin u. a. 2009. S. 329-368. Nach der sog. Bekker-Zählung wird noch heute die Gesamtausgabe Aristoteles' zitiert.

M Sophia Patricia Juana Maria del Rosario Dorothea geb. Simon (1799-1885) leibliche T e. Kaufmanns aus Cadiz, Pflege-T des Heinrich Christoph von Willrich (1759-1827) Pastor, s. Schröder, Wilt Aden ... (2009) S. 335 Anm. 25, 365

œ 1887 Ottilie geb. Barnewitz verw. Quistorp (1826-1907)

$\infty$ 15. März 1911 Helene geb. Sulzer verw. Zorn (1868-1919)

K 1 Stief-T, s. UAH Rep. 14-134.

Lb SS 1844 Studium an U Berlin, seit WS 1844/45 H, seit WS 1845/46 Berlin.

Berlin: 1847 Examen; seit 1847 Auskultator (s. Levin Goldschmidt: Eintrag unter $L b$ (1851)) am Kammergericht; 17. Febr. 1849 Dr. iur. utr. an U.

1849-1852 Offizier im Regiment Kolberg (Pommern).

U Halle-Wittenberg: 1853 Habilitation; seit 1854/55 a.o. Prof.

U Greifswald: Seit Juni 1857 o. Prof.

UH: 11. Juli 1874 Ern. zum o. Prof. als Nachf. von Bernhard Windscheid; 19. Okt. 1874 Vereidigung; 1874-1879 Beisitzer des Spruchkollegiums der Jur. Fak.; 1. Okt. 1908 Emeritierung mit gleichzeitiger Ern. zum Honorar-Prof.; WS 1908/o9 letzte Vorlesungsankündigung.

1886/87 Prorektor der UH; 188o/81, 1899 Wahlsenator H; $1877 / 78,1884 / 85,1889 / 901895 / 96$ Dekan der Jur. Fak. der UH

1874 Geh. Hofrat; 1884 Geh. Rat II. Klasse; 1903 Geh. Rat I. Klasse (Exzellenz)
$E$ Mitglied der Akademie der Wissenschaften: 1897 Berlin, 1909 H. 1909 Dr. phil. h.c. UH. • 1899 Großkreuz, 1908 Goldene Kette zum Großkreuz des Ordens vom Zähringer Löwen. 1899 Ehrenbürger der Stadt Heidelberg.

Qu UAH PA 1341; RA 6149, 6762. • UA Freiburg/ Br. B 110/405, S. 337 f. GLA Abt. 235, Fasz. 3232. Briefe: UBH.

$W$ Die processualische Consumption im classischen römischen Recht. Berlin 1853. • Von deutschen Hochschulen. Allerlei, was da ist und was da sein sollte. Berlin 1869 (anonym erschienen). • Die Aktionen des römischen Privatrechts. 2 Bde. Berlin 1871-1873. - System des heutigen Pandektenrechts. 2 Bde. Weimar 1886-1889. • Grundbegriffe des Rechts und Mißgriffe der Gesetzgebung. Berlin 1910.

MG 1857 Jahrbuch des gemeinen deutschen Rechts.

MHG Seit 1881 Zs. der Savigny-Stiftung für Rechtsgeschichte, Romanistische Abt.

L NDB 2 (1955) S. 25; Jammers (1964) S. 277 u. ö.; Badische Biographien N.F. I (1982) S. 38; Jansen (1992) S. 407 (Register). - Handbuch der historischen Buchbestände in Deutschland. Hrsg. von Bernhard Fabian. Hildesheim 2003. Die modernen Väter der Antike. Die Entwicklung der Altertumswissenschaften an Akademie und Universität im Berlin des 19. Jahrhunderts. Hrsg. von Annette M. Baertschi ... Berlin 2009. S. 329-368. • Kalkhoff (2010) S. 352 (Register); Schroeder (2010) S. 245-252 u. ö. (S. 247: irrtümlich Geburtsjahr 1828 statt 1827 angegeben); Grewolls (2011). - A. F. J. Thibaut ... Bürger und Gelehrter. Hrsg. von Christian Hattenhauer ... Tübingen 2017. S. 103-111.

$P$ Bildarchiv UAH (Gips-Totenmaske und -Hand); graph. Slg. UBH; NDB; Badische Biographien. 


\section{Benecke, Ernst Wilhelm}

1865-1872 Phil. Fak.

Geologie, Paläontologie

* 16. März 1838 Berlin

$\dagger \quad$ o6. März 1917 Straßburg

ev.

V Dr. phil. Viktor B. (1809-1852/53) Privatlehrer, 1840-1848 Gutsbesitzer, Privat-Gelehrter

M Em(m)eline geb. Schunck ( $\dagger$ in den 7oer Jahren des 19. Jhdts)

(2) 25. Juli 1866 Emilie Caroline Luise Emma geb. Fallenstein (1846-1922), s. Kaesler (2014) S. 220, 227, 480; Schwester der Mutter von: (siehe) Alfred und Max Weber

K 3 S: u. a. Wilhelm B. (1868-1946) Privat-Dozent: seit 1896 Straßburg, seit 1899 Kiel; a. o. Prof.: seit 1907 Kiel, seit 1909 Bonn, seit 1911 Berlin; o. Prof. für Botanik: seit 1914 Berlin, 1917-1935 Münster, s. Verzeichnis Bonn (1968) S. 17 f., WBIS. $\bullet 7$ T: u. a. Marie Ida Lili B. (18731956) und Auguste Henriette B. (1874-1952) Schwägerinnen von: (siehe) Georg Schmidt (1860-1935)

Vw siehe NDB 2 (1955) S. $41^{*}$.

Lb Seit 18. Okt. 1857 Praktikant in der Grube Reden in Landsweiler-Reden (Saarland; heute: Ortsteil von Schiffweiler); seit Mai 1859 Mitarbeiter im Erzbergwerk in Clausthal; hier auch Studium an der Bergschule.

Halle/S.: Juli 1859-März 186o (vorzeitiger Abbruch wegen Schwerhörigkeit) Militärdienstpflicht als Einjährig-Freiwilliger; hier gleichzeitig Studium an U Halle-Wittenberg.

Forts. des Studiums an U: SS 1860 Würzburg, WS 1860/61 und SS 1861 Berlin, seit WS 1861/62 Heidelberg.

UH: 10. Mai 1862 Dr. phil.

1862-1865 Eigenstudien u.a. in München; 1864 Reise nach England.

UH: 28. Juni 1865 Habilitation; seit 11. Febr. 1869 a. o. Prof.
U Straßburg: 20. April 1872 Ern. zum o. Prof. für Geognosie, Geologie, Paläontologie; 31. März 1907 Emeritierung. • In dieser Zeit:

Straßburg: 1873-1907 Direktor der Commission für die Geologische Landesuntersuchung von Elsass-Lothringen.

17. Aug. 1871: Gründungsmitglied des Oberrheinischen Geologischen Vereins im ehemaligen Bad-Hotel Rothenfels im heutigen Gaggenau-Bad Rotenfels

E Mitglied: 1900 Akademie der Wissenschaften Berlin, 1889 Königl. Gesellschaft der Wissenschaften in Göttingen.

Qu UAH PA 1352. GLA Abt. 76, Fasz. 9876.

$W$ Über die Trias in Elsaß-Lothringen und Luxemburg. Straßburg 1875-1877. Geognostische Beschreibung der Umgebung von Heidelberg. Straßburg 1879-1881. Geologischer Führer durch das Elsaß. Straßburg 1900. Bibliographie in: Wilckens (1919) S. 10-12.

HG 1865-1876 Geognostisch-paläontologische Beiträge.

MHG 1879-1884 Neues Jahrbuch für Mineralogie, Geologie und Paläontologie.

$L$ Wilckens, Otto: Nachruf in: Jahresberichte und Mitteilungen des Oberrheinischen Geologischen Vereines N.F. 8 (1919) S. 6-10. • NDB 2 (1955) S. 41 f. (mit Werkverz.); WBIS; Mitgl. der Akad. der Wiss. Göttingen (2001) S. 35 (hier unter: Beneke); Roth (2001) S. 705 (Register); Kaesler (2014) S. 227 f., 392; Riecke (2016) S. 12.

$P$ Bildarchiv UAH; NDB. 


\section{Bergstraesser, Arnold Adolf Eberhard Karl Maximilian}

1928-1934 Phil. Fak.

1934 Wirtschaftswiss. Fak.

1935 (1936) Staats- und Wirtschaftswiss. Fak.

Staatswissenschaften, 1932-1936 auch Auslandskunde

* 14. Juli 1896 Darmstadt

$\dagger$ 24. Febr. 1964 Freiburg/Br.

ev.

V Arnold B. (1841-1897) Verlagsbuchhändler, Landtagsabgeordneter, s. Hessische Abgeordnete 1820-1933. Biogr. Nachweise für die Landstände des Großherzogtums Hessen ... Bearb. von Hans Georg Ruppel ... Darmstadt 1980. S. 62 f.; WBIS

M Ernestine geb. Brandeis (1869-1944) Hofschauspielerin (Künstlername: Erna Brand)

$\infty$ 28. Aug. 1925 Erika Emma Johanna geb. Sellschopp (1900-1977)

$\mathrm{K} \quad 1 \mathrm{~S}, 1 \mathrm{~T}$

Lb 1914-1918 Kriegsdienst; 1915 Immatrikulation für Rechtswiss. und Kameralwiss. an U Tübingen für 2 Semester; SS 1919 Studium der Staatswiss., Geschichte, Volkswirtschaftslehre sowie des Öffentl. Rechts an U Berlin, WS 1919/20-SS 1921 München, WS 1921/22-SS 1923 H.

UH: 9. Jan. 1924 Dr. phil.; seit 1. April 1922 Hilfsassistent am Volkswirtschaftl. Seminar, 1924 umbenannt in Inst. für Sozial- und Staatswissenschaften, seit 1. April 1924 Assistent am o.g. Inst. für Sozial- und Staatswiss.; 23. Mai 1928 Habilitation; seit 1. April 1932 a. o. Prof. für Auslandskunde (Eberhard-Gothein-Professur für Staatswissenschaften und Auslandskunde) am o.g. Inst.; WS 1932/33 Lehrauftrag an Dt. Hochschule für Politik in Berlin; seit Mai 1934 Mitglied der neuerrichteten Wirtschaftswiss., seit Jan. 1935 der Staatsund Wirtschaftswiss. Fak.; WS 1935/36 auf eigenen Antrag beurlaubt; Febr. 1936 Zurückziehung des Urlaubsantrags für das SS 1936 wird B. vom Minister des Kultus und Unterrichts nicht gestattet; 10. Aug. 1936 Entzug der Lehrbefugnis aus rassischen Gründen; 30. Sept. 1936 Entlassung; 1937 Flucht nach Frankreich und Emigration.
Kalifornien: Seit Okt. 1937 Unterricht am Scripps College in Claremont; Dez. 1941-Febr. 1942, Sept. 1942-Jan. 1943 Internierung durch das FBI, Alien Enemy Control Unit, als vermeintlicher NaziSpion, s. hierzu Schmitt (1997) S. 175 f.

Illinois: 1944-1952 Prof. für German Cultural History am Department of Germanic Languages and Literatures der U of Chicago; in dieser Zeit: 1950 Gastprof. an U Frankfurt/M.

U Erlangen: WS 1952/53-SS 1953 Kommissar. Vertreter der o. Professur für Amerikanische Kulturgeschichte.

UH: Wiederaufnahme als nichtplanm. a.o. Prof. für SS 1954 geplant, s. hierzu Schultes (2010) S. $610-612$.

U Frankfurt/M.: 1954 Ruf abgelehnt.

U Freiburg/Br.: Seit SS 1954 o. Prof. für Wiss. Politik und Soziologie.

U.a. Mitbegründer und seit 1924 Geschäftsführer des Akademischen Austauschdienstes (AAD), dem Vorläufer des 1931 gegründeten Dt. Akademischen Auslandsdienstes (DAAD); 1955-1959 Direktor des Forschungsinstituts der Dt. Gesellschaft für Auswärtige Politik; 1960-1964 Mitglied und Vorsitzender der dt. UNESCO-Kommission; 1960 Initiator der Forschungsstelle für Weltzivilisation in Freiburg/Br.

Qu UAH PA 260, 324, 3276; Studentenakte. • Die Tübinger Studierenden 1818-1918. Ältere Studentenakten ... im UA Tübingen. - Nachlaß: Bundesarchiv Koblenz.

$W$ Landwirtschaft und Agrarkrise in Frankreich in: Schmollers Jahrbuch für Gesetzgebung, Verwaltung und Volkswirtschaft im Deutschen Reich 52 (1928). - Staat und Wirtschaft Frankreichs. Stuttgart 1930. - Politik in Wissenschaft und Bildung. Freiburg/Br. 1961. Weltpolitik als Wissenschaft. Geschichtliches Bewußtsein und politische Entscheidung. Hrsg. von Dieter Oberndörfer. Köln, Opladen 1965 (mit Bibliogr.). 
L Arnim 1 (1944) S. 93; Wer ist wer (1962) S. 94; Dictionary of Emigrés 2 (1983) S. 92. - Krohn, Claus-Dieter: Der Fall B. in Amerika in: Exilforschung 4 (1984) S. 254-275. - Mussgnug (1988) S. 297 (Register); Jansen (1992) S. 407 (Register); Brintzinger (1996) S. 397 (Register). - Schmitt, Horst: Ein „typischer Heidelberger im Guten wie im Gefährlichen“ ... in: Heidelberger Sozial- und Staatswissenschaften (1997) S. 167-196. • Blomert (1999) S. 317-328 u. ö. • Boerner, Peter: A. B. und die "Aspen convocation“ von 1949: Visionen e. besseren Welt im Namen Goethes in: Goethe im Exil ... Hrsg. von Gert Sautermeister ... Bielefeld 2002. S. 281-297. - Sarkisyanz, Emanuel: A.B. ... zum vierzigjährigen Gedenken. Vom Bekennertum zum Professorentum, vom Umgang mit Deutschlands Idealismus, Romantik und Jugendbewegung ... Hamburg 2004. - Freiburger Phil. Fak. (2006) S. 575-589 u.ö. • Söllner, Alfons: Normative Verwestlichung? Die politische Kultur der frühen Bundesrepublik und A. B. in: Ders.: Fluchtpunkte. Studien zur politischen Ideengeschichte des 20. Jhdts. Baden-Baden 2006. S. 181-200. - Liebold, Sebastian: Starkes Frankreich - instabiles Deutschland. Kulturstudien von Curtius/Bergstraesser und Vermeil ... Berlin u.a. 2008. - Schultes (2010) S. 52-54, 313 ff. u. ö.; Lexikon jüdischer Einwohner Hs (2011) S. 49. Oberndörfer, Dieter: Zur Geschichte des A.-B.Instituts. Eine Dokumentation und persönliche Erinnerungen. Freiburg/Br. 2011. - Behrmann, Günter C.: A. B., die Heidelberger Staats- und Sozialwissenschaften und Georges „Staat“ im Europa der Zwischenkriegszeit in: „Kreis aus Kreisen“. Der George-Kreis im Kontext deutscher und europäischer Gemeinschaftsbildung. Hrsg. von Bruno Pieger ... Hildesheim 2016. S. 475-546; Ders.: Biographische Forschung als disziplinengeschichtliches Korrektiv. Wissenschaftshistorische Bemerkungen zur Bergstraesser-Forschung in: Biographie und Politologie. Hrsg. von Thomas Noetzel ... Marburg 2016. S. 15-35. • Detjen, Joachim: A. B. - Befähigung zum politischen Urteilen und Förderung weltpolitischen Bewusstseins in: Ders.: Politische Erziehung als Wissenschaftsaufgabe. Das Verhältnis der Gründergeneration der deutschen Politikwissenschaft zur politischen Bildung. Baden-Baden 2016. S. 103-162. • Deutsche Biographie, s. https://www.deutsche-biographie. de/gnd118656147.html [06.11. 2017]. • Liebold, Se- bastian: Ein konservativer Humanist? A. B. in der frühen Bundesrepublik in: Neugründung auf alten Werten? Konservative Intellektuelle und Politik in der Bundesrepublik. Baden-Baden 2017. S. 101-127.

$P$ Bildarchiv UAH.

\section{Bergsträsser, Gotthelf}

1923-1926 Phil. Fak.

Orientalische Philologie

* 05. April 1886 Oberlosa (heute: Stadtteil von Plauen)

$\dagger$ 16. Aug. 1933 durch Absturz bei e. Bergtour am Watzmann

$\square$ Berchtesgaden

ev.-luth.

V Karl Friedrich Wilhelm B. (1836-1895) Pfarrer

M Emma Albine geb. Springer (1858-1915)

๑ 10. Jan. 1921 Marie Luise geb. von Loeben (1895-1942)

K $\quad 3 \mathrm{~T}$

Lb Leipzig: Seit WS 1904/o5 Studium der Philosophie, Sprachwissenschaft, Klassischen und Semitischen Philologie an U; 29. Mai 1908 Prüfung für höheres Lehramt.

Dresden: Seit 1. Juni 1908 Vikar an e. Gymnasium; 29. Sept. 1908 staatl. Stenographielehrerprüfung; seit 1. Juni 1909 „nicht ständiger wiss. Lehrer“ für Klassische Sprachen am Vitzthumschen Gymnasium (aus: Adressbuch für Dresden und seine Vororte. Dresden 1910. 2. T.S. 96).

Leipzig: 27. Febr. 1911 Dr. phil. an U; seit 16. April 1911 Gymnasiallehrer; 30. Okt. 1912 Habilitation für Semitische Sprachen an U; Febr.-Juli 1914 Studienreisen: Türkei, Syrien, Palästina, Ägypten.

U Konstantinopel (heute: Istanbul): Nov. 1915Nov. 1918 o. Prof.

U Berlin: Seit SS 1919 etatm. a. o. Prof.

U Königsberg (Preußen): Seit WS 1919/20 o. Prof. 
U Breslau: Seit SS 1922 o. Prof.

UH: Seit WS 1923/24 O. Prof. als Nachf. von Carl Bezold.

U München: Seit SS 1926 o. Prof. für Semitische Philologie und Islamwissenschaft; WS 1929/30, WS 1931/32 Gastvorlesungen an U Kairo.

E Mitglied der Akademie der Wissenschaften: 1925 H, 1926 München.

Qu UAH PA 3277. • Briefe: UBH. • G.-B.-Archiv in: Berlin-Brandenburgische Akademie der Wissenschaften.

$W$ Sprachatlas von Syrien und Palästina. Leipzig 1915. Gesenius' Hebräische Grammatik. 29. Aufl. 2 Bde. Leipzig 1918-1929. Nachdr. Hildesheim u.a. 1995. - Einführung in die semitischen Sprachen. München 1928. Nachdr. Ismaning 1993.

$L$ NDB 2 (1955) S. 92 f. (mit Werkverz.); WBIS; BBKL I (1990) Sp. 520; Jansen (1992a) S. 163 (Register). - Der Islam im öffentlichen Recht des säkularen Verfassungsstaates. Hrsg. von Stefan Muckel. Berlin 2008. - Lory, Pierre: Book review: The History of the Qur'ān, written by Theodor Nöldeke, Friedrich Schwally, G. B. ... in: Arabica. Leiden 2014. S. 798-80o.

$P$ Bildarchiv UAH; NDB.

\section{Beringer, Kurt}

1927-1933 Med. Fak.

Psychiatrie

* 24. Juni 1893 Ühlingen (Schwarzwald; heute: Ü.-Birkendorf)

$\dagger$ 11. Aug. 1949 Freiburg/Br. kath.

V Emil August B. (1864-1928) Fabrikant

M Wilhelmine geb. Binder (1865-1943)

๑ 30. März 1921 Dr. med. Cornelie Gertrud Anna Elsa Martha geb. Dreves (1895-1974)

K 1 T
Lb Studium: WS 1911/12-WS 1913/14 UH, SS 1914 Kiel, WS 1914/15 H.

1915-1918 Kriegsdienst; Herbst 1919 Staatsexamen in H; 28. Nov. 1919 Approbation in H.

UH: 1919-1920 Assistent an Med. U-Klinik; 1. März-31. Dez. 1920 Volontärassistent an Psychiatr. Klinik und Med. U-Klinik; 30. April 1920 Dr. med.; Jan. 1921-Okt. 1932 Assistent an Psychiatr. Klinik; 1924-1925 (mit Unterbrechungen) auch Nervenarzt in Karlsruhe; 18. Febr. $1927 \mathrm{Ha}-$ bilitation; 1928-1929 Mitglied der dt.-russischen Syphilis-Expedition in Burjato-Mongolei; seit 23. März 1932 planm. a. o. Prof.

U München: 30. Jan. 1933 Ern. zum nichtplanm. a. o. Prof. und Oberarzt der Psychiatr. und Nerven-Klinik.

U Freiburg/Br.: Seit 1. April 1934 o. Prof. und Direktor der Psychiatr. und Nerven-Klinik; Rufe an U abgelehnt: 1938 Köln, 1939 Prag, 1941 Straßburg, 1945 Frankfurt/M.; 25. April 1945 Wahl zum Dekan der Med. Fak. (bis 1946/47).

Qu UAH PA 838, 3278; Fak.-Akte H-III-862/31. • Nachlaß: Universitätsarchiv Freiburg/Br.

$W$ Der Mescalinrausch. Seine Geschichte und Erscheinungsweise. Berlin 1927. Nachdr. 1969. • Bedeutung der Rauschgiftversuche für die Klinik in: Schweizer Archiv für Neurologie und Psychiatrie 28 (1931). Die syphilidogenen Erkrankungen des Nervensystems bei den Burjato-Mongolen in: Archiv für Psychiatrie und Nervenkrankheiten 104 (1935). - Störungen des Antriebs in: Zs. für die gesamte neurologische Psychiatrie 171 (1941).

MG 1928 Zs. „Der Nervenarzt“.

L Arnim 1 (1944) S. 93, 3 (1961) S. 44; Kürschner (1950) Sp. 121. - Ruffin, Hanns: K. B. † in: Dt. Zs. für Nervenheilkunde 164 (1950) S. 199-208. • Hermle, Leo: Biobibliographie K. B. Freiburg/Br. 1980. - Chronik Ärzte H (1985) S. 122; WBIS. • Hermle, L., Degkwitz, R.: Bibliographic remarks on K. B. in: Nervenarzt 10 (Okt. 1989) S. 651-656. Badische Biographien N.F. III (1990) S. 39-41. • 
K.B. und die Heidelberger Drogenforschung der 2oer Jahre. Hrsg. von Werner Pieper. Darmstadt 1999. - Rauscherleben in Psychiatrie und Philosophie. Die Selbstversuche von Walter Benjamin und K. B. in: Medizin und Kultur: ärztliches Denken und Handeln im Dialog zwischen Naturund Geisteswissenschaften ... Hrsg. von Giovanni Maio ... Stuttgart u. a. 2001. S. 151-159. • Peiffer (2004) S. 1130 (Register). • Schott, H.: Medizingeschichte(n): Ärztlicher Selbstversuch - Meskalinrausch in: Dt. Ärzteblatt 102(38) (2005) S. 41. • Seidler/Leven (2007) S. 858 (Register). Haack, Hans-Peter, Haack, Carmen: Atlas zur Entwicklung der Psychiatrie. Leipzig 2010. Deutsche Biographie, s. https://www.deutsche-biographie.de/ gnd116134682.html [06.11.2017].

$P$ Bildarchiv UAH.

\section{Bernstein, Julius}

1865-1871 Med. Fak.

Physiologie

* o8. Dez. 1839 Berlin

$\dagger \quad$ o6. Febr. 1917 Halle/S.

mosaisch, später konf.-los

V Aaron David B. (1812-1884) Schriftsteller (Pseudonym: A. Rebenstein), Mitbegründer der Berliner Jüdischen Reformgemeinde, $s$. NDB 2 (1955) S. 133, Encyclopaedia judaica 3 (2007) S. 476-478; A. B. in seiner Zeit. Briefe und Materialien. Hrsg. von Julius H. Schoeps. Hildesheim u. a. 2010.

M Caroline geb. Bernstein (1812-1854), s. Tennstedt, Florian: Arbeiterbewegung und Familiengeschichte bei Eduard Bernstein und Ignaz Zadek ... in: IWK. Int. Wiss. Korrespondenz zur Geschichte der dt. Arbeiterbewegung ... Hrsg. von Henryk Skrzypczak. Berlin 1982. 18. Jg. S. 479.

๑ Sophie geb. Levy (1856-1923) Pianistin und Komponistin
K mehrere, u.a. Felix B. (1878-1956), u.a. 19211934 (Entzug der Lehrbefugnis aus rassischen Gründen) o. Prof. für Mathematik an U Göttingen, u. a. 1936-1943 Prof. für Biostatistik an New York U, s. O'Connor, John J., Robertson, Edmund F.: F. B. in: MacTutor History of Mathematics archive online unter http:// www-history.mcs.st-andrews.ac.uk/Biograph ies/Bernstein_Felix.html; Catalogus prof. Halensis online; Bismarck, M., Schmerling, S.: F. B.: Ein ehemaliger Privatdozent der ... Universität Halle-Wittenberg in: Reports on Didactics and History of Mathematics 24 (2007).

Vw Vetter: Eduard B. (1850-1932) sozialdemokratischer Politiker und Theoretiker, s. UAH RA 7328; NDB 2 (1955) S. 133f., WBIS; Tennstedt (1982) S. 451-481.

Lb Seit WS 1858/59 Studium an U Breslau, seit SS 1860 Berlin.

Berlin: 1. Aug. 1862 Dr. med. an U; 1863 II. Staatsexamen und Approbation; 1863-1865 Niederlassung als praktischer Arzt.

UH: Seit 1. April 1865 Assistent am Physiolog. Inst.; 6. Juli 1865 Habilitation; seit 4. März 1869 a. o. Prof.

U Berlin: Seit WS 1871/72 a. o. Prof.

U Halle-Wittenberg: 21. Okt. 1872-1911 (Ruhestand) o. Prof. und 1881-1911 (Gründungs-)Direktor des Physiolog. Inst.

1898 Geh. Medizinalrat

E 1875 Mitglied der Dt. Akademie der Naturforscher Leopoldina; Korr. Mitglied der Pariser Akademie der Wissenschaften. - Königl. Preußischer Roter Adler-Orden III. Klasse; Kronen-Orden III. Klasse.

Qu UAH PA 1361; RA 6191. • Briefe: UBH. • Siehe auch Archiv der Dt. Akademie der Naturforscher Leopoldina Halle/S.

$W$ Untersuchungen über den Erregungsvorgang im Nerven- und Muskelsystem. Heidelberg 1871. • Untersuchungen an dem Physiologischen Institut 
in Halle. Halle/S. $1888 \mathrm{ff}$. Lehrbuch der Physiologie des tierischen Organismus. Stuttgart 1894. 3. Aufl. 1910. - Untersuchungen zur Thermodynamik der bioelektrischen Ströme in: Archiv für die gesamte Physiologie des Menschen und der Tiere 92 (5. Nov. 1902) S. 521-562.

L Jüdische National-Biographie 1 (1925) S. 353; Encyclopaedia judaica 4 (2007). - Seyfarth, ErnstAugust und Peichl, Leo: Vor 100 Jahren: J.B. ... formuliert seine Membrantheorie in: Neuroforum - Zs. der Neurowissenschaftlichen Gesellschaft 4 (2002) S. 274-276. • Autoren der Bunsenbibliothek (2009 online); Catalogus prof. Halensis online. - Fischer, Marta: Akteure und Agentien. Bibliographisches Lexikon der Pharmakologen zwischen Deutschland und Russland im 19. Jahrhundert. Aachen 2014. S. 15-17. Deutsche Biographie, s. https://www.deutsche-biographie.de/gnd 11865652X.html [06. 11. 2017]. - Schwartze, Dieter: Der Physiologe J. B. Erinnerung zum 10o. Todestag - was ist geblieben? in: Ärzteblatt Sachsen-Anhalt. Offizielles Mitteilungsblatt der Ärztekammer Sachsen-Anhalt. Magdeburg 2017. S. 49.

\section{$P$ Bildarchiv UAH.}

\section{Bernthsen, Heinrich August}

1879-1887 Phil. Fak.

1919-1925 (Honorar-Prof.) Nat.-Math. Fak.

Chemie

* 29. Aug. 1855 Krefeld

$\dagger$ 26. Nov. 1931 Heidelberg

ev.

V Heinrich Friedrich B. (1821-1913) Schreiner, später Bauunternehmer

M Maria Sybilla geb. Pot(t)gies(s)er (1823-1903)

@ 17. März 1884 Maria Magdalena geb. von Haubenschmied (1863-1927) Schriftstellerin, s. Hacker, Lucia: Schreibende Frauen um 1900: Rollen - Bilder - Gesten. Berlin 2007. S. 31 und Anm. 23. - T von Ferdinand Ritter von H. (1808-189o) zuletzt 1879-1884 Präsident des Oberlandesgerichts München, s. WBIS; Mader, Franz: Tausend Passauer. Passau 1995. S. 90.
K 1 S (1888-1919) sowie $1 \mathrm{~S}$ und $1 \mathrm{~T}$ als Jugendliche $\dagger$

Vw Schwester: Dr. phil. Sophie B. (1857-1936), s. UAH Studentenakte; Stifterin des gleichnamigen Fonds, aus dem 1937 erstmals Stipendien „an begabte, würdige und tüchtige Studierende, auch an Promovierte ... des Chemischen Instituts, ... des Physikalisch-Chemischen Instituts, ... des Englischen ... und Historischen Instituts ... der Universität Heidelberg ... zur Förderung ihrer Studien und zur Hilfeleistung für ihren Übergang vom Studium in einen Beruf " vergeben wurden (und noch werden: an Studenten der Anglistik, s. http://www.as.uniheidelberg.de/studium/usa-kanada/sophiebernthsen.php; abgerufen am 12. April 2018), aus: UAH B-9706/1; s. hierzu auch B-9706/2-3.

Lb 17. Okt. 1871-16. März 1874 Studium der Mathematik, Naturwiss. an U Bonn, 1874-1875 H; 1874 Lehramtsprüfung in Bonn.

U Bonn: 1875-1877 Assistent am Chemischen Labor; 17. Juni 1876 Dr. phil.; 5. Juni 1878 Oberlehrerexamen.

UH: 9. Jan. 1879 Habilitation; seit 22. Mai 1883 a. o. Prof.

Ludwigshafen: Seit 23. Juli 1887 Leiter der wiss. Abt. des Hauptlabors der Badischen Anilin- und Sodafabrik (BASF); seit 1897 auch Gesamtleitung der wiss.-technischen Forschung und des Patentwesens; 1918 Ruhestand.

UH: Seit 1. Aug. 1919 o. Honorar-Prof.; SS 1925 letzte Vorlesungsankündigung.

Geh. Hofrat

E 1924 Mitglied der Akademie der Wissenschaften H; 1928 Ehrenmitglied des Vereins Dt. Chemiker. 1925 Dr-Ing. E.h. TH Berlin-Charlottenburg; 1926 Dr. phil. nat. h.c. UH.

Qu UAH PA 1362, 3285; B-9707. Briefe: UBH. • Auskunft: Nordrhein-Westf. Personenstandsarchiv Rheinland, Brühl; Stadtarchiv Krefeld; Universitätsarchiv Bonn. • Sammlung von Vorträgen 
und biogr. Unterlagen im: Archiv der BASF, Ludwigshafen. • Fünfzig Jahre Tätigkeit in chemischer Wissenschaft und Industrie. Leipzig 1925. (Autobiogr. als Manuskript gedruckt.)

$W$ Studien in der Methylenblaugruppe. Heidelberg 1885. - Kurzes Lehrbuch der organischen Chemie. Braunschweig 1887. 18. Aufl. 1925.

$L$ NDB 2 (1955) S. 142 f. (mit Werkverz.). Pötsch, Winfried R. u. a.: Lexikon bedeutender Chemiker. Leipzig 1988. S. 116 f. • Jansen (1992a) S. 164 (Register). Die BASF - eine Unternehmensgeschichte. Hrsg. von Werner Abelshauser. 2. Aufl. München 2003. S. 731 (Register). Badische Biographien N.F. V (2005) S. 15 f. Biographie in: Meilensteine der Chemie 2005 in: Nachrichten aus der Chemie 53 (Jan. 2005) Ausg. 1, S. 11-18. - Autoren der Bunsenbibliothek (2009 online).

$P$ Bildarchiv UAH; graph. Slg. UBH; NDB.

\section{Besseler, Heinrich Theodor}

1928-1945 Phil. Fak.

Musikwissenschaft

* 02. April 1900 Hörde (heute: Stadtteil von Dortmund)

$\dagger \quad$ 25. Juli 1969 Leipzig

kath., dann ev., zuletzt freireligiös

V Dr. Heinrich B., Chemiker

M Anna geb. Born, Hausfrau

$\infty$ 17. Dez. 1925 Hildegard geb. Schwartz $\left({ }^{*} 1897\right.$ $\dagger$ nach 1982)

$\mathrm{K}$ keine.

Lb Seit SS 1918 Studium der Philosophie, Mathematik an U Bonn; Juni-Dez. 1918 Kriegsdienst.

U Freiburg/Br.: SS 1919-SS 1921 Forts. des Studiums; seit WS 1920/21 auch Studium der Musikwiss.: WS 1921/22 Wien, seit SS 1922 Freiburg; 19221923 Assistent am Musikwiss. Seminar; 30. Juli 1923 Dr. phil.; Herbst 1923-Herbst 1925 Eigenstudien an U Göttingen; 3. Nov. 1925 Habilitation Freiburg.
UH: 1. März 1928-Okt. 1945 (Entlassung gemäß Erlaß der amerikanischen Militärregierung) planm. a. o. Prof. und Direktor des Musikwiss. Inst. als Nachf. von Hans Joachim Moser; Sept. 19436. Jan. 1945 Kriegsdienst, s. hierzu Schipperges (2005) S. 208-214; 1944 Ruf an U Graz abgelehnt. • In dieser Zeit:

Mannheim: Seit 18. Nov. 1933 Prof. an Städtischer Hochschule für Musik und Theater.

Berlin: 21. Jan. 1935-24. Juni 1939 (Amtsenthebung) zudem Sekretär des Amtlichen Ausschusses zur Betreuung der dt. Musikdenkmale am Staatl. Inst. für Musikforschung, s. hierzu Schipperges, S. 173-194; 26. Juni 1939-31. Dez. 1944 (SchlieBung) ehrenamtl. Schriftführer im Ausschuss für das Archiv für Musikforschung am Staatl. Institut.

U Freiburg/Br.: WS 1941/42, SS 1942 zugleich Vertreter des Musikwiss. Lehrstuhls.

Für die Zeit 1945-1949, s. Schipperges (2005) S. $251-298$.

U Jena: Seit 1. Juli 1949 o. Prof. und Direktor des Musikwiss. Seminars.

U Leipzig: 1. Jan. 1957-31. Aug. 1965 (Emeritierung) o. Prof. und Direktor des Inst. für Musikwiss.

E 1955 Mitglied der Sächsischen Akademie der Wissenschaften Leipzig. 1967 Doctor of Human Letters der U of Chicago. 1960 Nationalpreis für Wissenschaft und Technik (III. Klasse).

Qu UAH PA 326, 329o f. Briefe: UBH. • Nachlaß: Universitätsarchiv Leipzig.

$W$ Die Musik des Mittelalters und der Renaissance. Handbuch der Musikwissenschaft. Hrsg. von Ernst Bücken. Potsdam 1931. Bourdon und Fauxbourdon. Leipzig 1950. 3. Aufl. 1965. • Fünf echte Bildnisse Johann Sebastian Bachs. Kassel, Basel 1956. Das musikalische Hören der Neuzeit. Berlin 1959. Bibliographie in: Schipperges (2005) S. $427-435$. 
HG Altniederländische Motetten. Kassel 1929. 3. Aufl. 1965. 1932-1939 Heidelberger Studien zur Musikwissenschaft.

MHG 1952-1969 Archiv für Musikwissenschaft.

L Riemer, Otto: H. B. zum Gedächtnis in: Ruperto Carola 21. Jg., Bd. 47 (1969) S. 392 f. • Lowinsky, Edward E.: H. B. † in: Journal of the American Musicological Society Vol. XXIV, No. 3 (1971) S. 499502. - Grüß, Hans: H. B. in: Namhafte Hochschullehrer der Karl-Marx-Universität Leipzig ... Bd. 1. Leipzig 1982. S. 48-53. - Heiber 1 (1991) S. 632 (Register); Jansen (1992a) S. 164 (Register); Professorenkatalog Leipzig online. - Schipperges, Thomas: Die Akte H. B. ... Musikwissenschaft und Wissenschaftspolitik in Deutschland 1924-1949. München 2005. - Freiburger Phil. Fak. (2006) S. 420 f., 897 u. ö. - Schipperges, Thomas: H. B. und seine Schule in Jena 1950 bis 1957 in: Musikwissenschaft und Vergangenheitspolitik: Forschung und Lehre im frühen Nachkriegsdeutschland. München 2015. S. 353-380. - Deutsche Biographie, s. https:// www.deutsche-biographie.de/gnd118662570.html [06.11.2017].

$P$ Grüß (1982).

\section{Bessel Hagen, Friedrich (Fritz) Carl}

1886-1897 (1899) Med. Fak.

Chirurgie

* O2. Jan. 1856 Charlottenburg (heute: Ortsteil von Berlin)

$\dagger$ 20. Dez. 1945 Charlottenburg ev.

V Wilhelm Hermann Adolf Hagen (1820-1894), u.a. 1854-1871 Stadtrat, 1862-1876 Mitglied des Preußischen Abgeordnetenhauses, 18671877 Reichstags-Mitglied, s. WBIS, NDB 7 (1966) S. $471^{*}$ (Artikel: Hagen, Carl Ernst Bessel); Preussens Weg in die politische Moderne: Verfassung - Verwaltung - politische Kultur zwischen Reform und Reformblockade. Hrsg. von Bärbel Holtz, Hartwin Spenkuch. Berlin 2001. S. 179 .
M Johanna Louise Amalie geb. Bessel (18261856) $\mathrm{T}$ von Dr. h.c. Friedrich Wilhelm B. (1784-1846), u.a. seit 1810 o. Prof. für Astronomie Königsberg (Preußen), s. NDB 2 (1955) S. 179 f.; Lavrinovič, Kazimir K.: F. W. B. ... Aus dem Russischen übers. von Katja Hansen-Matyssek und Heinz Matyssek. Basel u. a. 1995; Fischer, Ernst Peter: Die Erforschung des Himmels von Aristoteles bis Stephen Hawking. München 2009. S. 153-161.

œ 14. Okt. 1887 Auguste Emilie Helene geb. Frentzel (1868-1945) T von Adolf Emil F. (1833-1905), u.a. Geh. Kommerzienrat, seit 1897 Mitglied des Preußischen Herrenhauses, 1901-1905 Präsident des Dt. Handelstages, s. Biggeleben, Christof: Das „Bollwerk des Bürgertums": die Berliner Kaufmannschaft 18701920. München 2006. S. 456 (Register).

K 1 T, 3 S: u.a. Erich Paul Werner B.H. (18981946), u. a. seit 1931 a. o. Prof. für Mathematik Bonn, s. Verzeichnis Bonn (1968) S. 21; Neuenschwander, Erwin: Der Nachlass von Erich B. H. im Archiv der Universität Bonn in: Historia mathematica 20 (1993) S. 382-414.

Vw Bruder: Carl Ernst B.H. (1851-1923), u.a. 1884-1888 a.o. Prof. für Angewandte Physik und Direktor des Elektrotechnischen Labors Polytechnikum Dresden, seit 1887 leitender Elektroingenieur der Kaiserl. Marine in Kiel und Admiralitätsrat, 1893-1918 (Rücktritt) Direktor der II. Abt. der Physikalisch-Technischen Reichsanstalt in Charlottenburg, s. NDB 7 (1966) S. 471; Die Professoren der TU Dresden 1828-2003. Bearb. von Dorit Petschel. Köln 2003. S. 311.

Lb Seit WS 1876/77 Studium der Medizin, Anthropologie an U Königsberg, WS 1878/79-WS 1879/80 Berlin, seit SS 1880 Königsberg; 29. Juni 1881 Approbation; 15. Juli 1881 Dr. med. an U Königsberg.

Assistent: U.a. seit 1882 U-Frauenklinik in Berlin, seit 1883 Städtisches Krankenhaus in Friedrichshain (bei Berlin).

UH: Seit 8. Dez. 1885 Assistent an Chirurg. U-Klinik; 24. Jan. 1886 Habilitation; seit 30. Sept. 1889 a.o. Prof.; SS 1897 letzte Vorlesungsankündigung; seit WS 1897/98 von UH beurlaubt; SS 1899 aus dem Lehrkörper der U ausgeschieden. 
Worms: Mai 1891-1897 Direktor des Städtischen Krankenhauses.

Berlin-Charlottenburg: 1897-1922 Leiter der Chirurg.-Gynäkolog. Abt. sowie Direktor des Städtischen Krankenhauses Westend.

1914-1918 Kriegsdienst.

E 1888 Mitglied der Dt. Akademie der Naturforscher Leopoldina Halle/S.

Qu UAH PA 1367; RA 5226. - Siehe auch Archiv der Dt. Akademie der Naturforscher Leopoldina Halle/S.

W Zur Kritik und Verbesserung der Winkelmessungen am Kopfe, nebst einer Mitteilung über den Verlauf und die Ursachen der normalen Synostose am Schädel in: Archiv für Anthropologie (1881); Der Schädel Immanuel Kant's in: ebd. (1881). • Über die Pathologie des Klumpfußes in: Verhandlungen des 14. Chirurgenkongresses (1885).

L Almanach Heidelberg (1886) S. 125; Wer ist's (1935) S. 113; Arnim 1 (1944) S. 100; Fischer $1\left({ }^{3} 1962\right)$ S. 108; WBIS; Chronik Ärzte H (1985) S. 122; Jansen (1992a) S. 164 (Register). • Broghammer, Herbert u. a.: F.C.B.H., Chirurg und Anthropologe ... in:. Zentralblatt für Chirurgie 122 (1997) S. 11521157. - Raffensperger (2012) S. 164, 295 u. ö.; Deutsche Biographie, s. https://www.deutsche-biographie.de/gnd11615456X.html [06.11. 2017].

$P$ Bildarchiv UAH.

\section{Bessel-Hagen}

siehe Bessel Hagen

\section{Bettmann, Siegfried}

1897-1935 Med. Fak. 1897-1908 Innere Medizin, (1904-1908) 19081935 Haut- und Geschlechtskrankheiten

* 16. Juni 1869 Bayreuth

$\dagger$ 19. Okt. 1939 Zürich mosaisch, seit $1915 \mathrm{ev}$.

V Jacob Siegfried B., Privatier

M Pauline geb. Kupfer

๑ 21. März 1901 Rosa geb. Friedmann $\left({ }^{*} 1881\right.$ $\dagger$ nach 1961)

K 1 S, s. Lexikon jüdischer Einwohner Hs (2011) S. 51f.; Reichert, Folker: Hans B.s Freitod und das Ende der deutsch-jüdischen Symbiose in: ZGORh 159. Jg. (2011) S. 531-553. 2 T: u. a. Dr. phil. Annemarie B. (1902-1989) Ehefrau von Hajo Holborn (1902-1969), u.a. 1926-1931 Privat-Dozent für Geschichte an UH, seit 1938 Prof. an Yale U in New Haven (Connecticut), s. NDB 9 (1972) S. 522; Friedrich Meinecke. Akademischer Lehrer und emigrierte Schüler ... Hrsg. von Gerhard Albert Ritter. München 2006. S. 47-56 u. ö.

Vw Enkelin: Hanna geb. Holborn verh. Gray $\left({ }^{*} 1930\right)$ Prof. für Geschichte: 1964-1974, $1978-$ 1993 U of Chicago, 1974-1978 Yale U, s. Chambers Biographical Dictionary. Edinburgh 2002. S. 632 .

Lb Seit WS 1888/89 Studium an UH, WS 1890/91 Berlin, seit SS $1891 \mathrm{H}$.

UH: 1893 Staatsexamen; 1. Dez. 1893 Dr. med.; Assistent: seit 1894 Med. Poliklinik, 1895-1908 Med. U-Klinik; 22. Dez. 1897 Habilitation für Innere Medizin; 1899-1908 Leiter der Abt./Ambulanz für Haut- und Geschlechtskrankheiten an Med. U-Klinik; 5. Aug. 1901 Ern. zum a. o. Prof.; seit 13. Aug. 1904 Lehrauftrag für das Fach Hautund Geschlechtskrankheiten; seit 13. Aug. 1908 etatm. a. o. Prof. für Haut- und Geschlechtskrankheiten und bis 1935 Direktor der von B. und Wilhelm Erb gegründeten U-Haut- und Hautpoliklinik; seit 22. März 1919 persönlicher Ordinarius auf dem neueingerichteten Lehrstuhl für Dermatologie; 1. Okt. 1926 Ern. zum planm. Ordinarius; seit 6. April 1933 aus rassischen Gründen Beurlaubung, 
die am 28. April 1933 ohne Angabe e. Grundes wieder aufgehoben wird; Okt. 1934 Antrag auf Emeritierung, dem zum 1. April 1935 stattgegeben wird.

1938 Emigration in die Schweiz; B. stirbt vor seiner geplanten Ausreise in die USA.

1924/25 Dekan der Med. Fak. der UH

E 1903 Korr. Mitglied der Dermatologischen Gesellschaft Wien. 1910 Friedrich-Luisen-Medaille.

Qu UAH PA 839, 3292; RA 6270, 6811; Fak.-Akte H-III-111/121. • Briefe: UBH.

$W$ Die ärztliche Überwachung der Prostituierten in: Handbuch der sozialen Medizin (1905). E Einführung in die Dermatologie. Wiesbaden 1914. • Geschlechtsleben und Hygiene. Leipzig 1923.

L Kürschner (1931) Sp. 192 f., (1935) Sp. 90; Fischer 1 ( $\left.{ }^{3} 1962\right)$ S. 109 f.; Chronik Ärzte H (1985) S. 122; Mussgnug (1988) S. 297 (Register); Badische Biographien N.F. III (1990) S. 44-46; Jansen (1992) S. 407 (Register); Kriegstagebuch K. Hampe (2007) S. 946 (Register); Altmeyer (2011 online); Lexikon jüdischer Einwohner Hs (2011) S. 51. Reichert, Folker: Hans Bettmanns Freitod und das Ende der deutsch-jüdischen Symbiose in: ZGORh 159. Jg. (2011) S. 533 f. u. ö. • Deutsche Biographie, s. https://www.deutsche-biographie.de/ gnd116156147.html [06.11. 2017].

$P$ Bildarchiv UAH.

\section{Bezold, Ernst Christian Carl}

1894-1922 Phil. Fak.

Orientalische Philologie

* 18. Mai 1859 Donauwörth

$\dagger \quad$ 21. Nov. 1922 Heidelberg

ev.

V Dr. iur. Ernst Justus B. (1822-1885) Bezirksgerichtsrat

M Viktoria Katharina geb. Then (1837-1905)
(28. April 1888 Adele geb. Bursian (1860-1936) T von Conrad B. (1830-1883), u. a. seit 1858 a.o. Prof. für Klassische Altertumswissenschaften Leipzig, seit 1861 Tübingen, seit 1864 o. Prof. Zürich, seit 1869 Jena, seit 1874 München, s. ADB 47 (1903) S. 401-406, WBIS, Professorenkatalog Leipzig online

$\mathrm{K}$ keine.

Lb Seit 1877 Studium der Semitistik an U München, seit 1879 Leipzig, 188o/81 Straßburg; 188o Dr. phil. an U Leipzig; 1882 Studienreise nach Großbritannien.

U München: 23. April 1883 Habilitation; 1883-1885 Privat-Dozent.

London: Seit 1885/86 Katalogisierungsarbeiten im Britischen Museum im Auftrag der englischen Regierung.

UH: Seit 13. März 1894 o. Prof. als Nachf. von Rudolph Brünnow und Direktor des Orientalischen Seminars; 1914-1919 Direktor des Ägyptolog. Inst. als Vertreter von Hermann Ranke.

1916/17 Prorektor der UH; 1897, 1915 Wahlsenator H; 1901/O2, 1919/2o Dekan der Phil. Fak. der UH

1923 Verkauf der B.schen Bibliothek an das Orientalische Seminar der UH

1908 Geh. Hofrat; 1917 Geh. Rat II. Klasse

Siehe auch Anhang Sporteinrichtungen an UH 1910-1933 und ihre Mitglieder

$E$ Mitglied der Akademie der Wissenschaften: 1908 München, 1909 H. 1901 Dr. iur. h.c. Glasgow; 1917 D. theol. UH. 1902 Ritterkreuz I. Klasse des Ordens vom Zähringer Löwen.

Qu UAH PA 1373; RA 6437, 6588, 6861; Acc. 40/11. Briefe, Nachlaß: UBH.

$W$ Catalogue of the Cuneiform Tablets in the Kouyundjik Collection of the British Museum. 5 Bde. London 1889-1899. Ninive and Babylon. Leipzig 1903. 4. Aufl. 1926. • Babylonisch-assy- 
risches Glossar. Hrsg. von Albrecht Götze und Adele Bezold. Heidelberg 1926. Bibliographie in: Zs. für Assyriologie ... N. F. 1 (1924) S. 57-72.

MG, HG 1884-1922 Zs. für Keilschriftforschung und verwandte Gebiete, seit 1886 u.d. T.: Zs. für Assyriologie und vorderasiatische Archäologie.

L NDB 2 (1955) S. 212 f. (mit Werkverz.); BBKL I (1990) Sp. 574; Jansen (1992a) S. 164 (Register); Wennemuth (1994) S. 632 (Register); Badische Biographien N. F. VI (2011) S. 23-25.

$P$ Bildarchiv UAH; graph. Slg. UBH.

\section{Bischoff, Gottlieb Wilhelm}

1825-1854 Phil. Fak.

Botanik

* 21. Mai 1797 Dürkheim (heute: Bad D.)

$\dagger$ 11. Sept. 1854 Heidelberg ev.-luth.

V Johann Carl Christoph B. (1769-1834) Apotheker

M Susanna Maria geb. Petry verw. Bechtel († vor 1809)

$\infty$ 29. Sept. 1831 Henrietta Charlotta Wilhelmina geb. Heddäus (1801-1840)

$\mathrm{K} \quad 2 \mathrm{~S}, 2 \mathrm{~T}$

$L b$ Seit 1816 zunächst Ausbildung in elterlicher Apotheke in Dürkheim; anschl. Aufenthalt in Kaiserslautern bei Verwandten; hier Botanik-Unterricht bei Wilhelm Daniel Joseph Koch (1771-1849; Arzt und Florist, s. Wagenitz, Gerhard: W. D. J. K. ein Altmeister der Floristik in: Hoppea - Denkschriften der Regensburgischen Botanischen Gesellschaft 61 (2000) S. 833-852); seit 1819 Ausbildung im Zeichnen an Akademie der Bildenden Künste in München.

Seit 3. Mai 1821 Studium zunächst der Pharmazie, anschl. auch der Naturwiss. und Botanik an U Erlangen, seit 1823 München; 5. Mai 1823 pharma- zeutisches Examen in München; 1823 Dr. phil. an U Erlangen; seit 1823 botanische Eigenstudien in Dürkheim.

H: Spätherbst 1824-Frühjahr 1833 (?) Lehrer an Privat-Lehranstalt für Knaben.

UH: 20. März 1825 B. erhält Erlaubnis vom Engeren Senat der U, Vorlesungen über Pharmazie halten zu dürfen (aus: UAH PA 1368; Verzeichniss der sämmtlichen Studirenden auf der UH im SS 1831, S. 8); seit 1. April 1833 a. o. Prof. mit e. jährl. Besoldung von 110o.- Gulden in Nachf. von Franz Joseph Schelver, s. UAH RA 6883; seit 14. Nov. 1839 o. Prof.; seit 11. Mai 1847 außerdem wiss. Direktor des Botanischen Gartens zwischen heutigem Bismarck- und Adenauerplatz als Nachf. von Johannes Metzger (siehe zu Metzger: Franz Schelver) und in Nachf. von Schelver, s. hierzu RA 5629 fol. 61r,v, Wissenschaftsatlas der UH (2011) S. 237.

1856: Ersteigerung des von B. angelegten Herbariums durch den amerikanischen Studenten Evan Pugh (1828-1864): es bildet heute den Grundstock des Herbariums der Pennsylvania State University in State College; s. hierzu Traverse, Alfred: Dr. Pugh's Herbarium in: Journal of the Botanical Research Institute of Texas 7 (2013) S. 751-764.

Siehe auch Franz Schelver (hier: Zitat (2))

E 1826 Mitglied der Dt. Akademie der Naturforscher Leopoldina Halle/Saale; Mitglied: Königl. Botanische Gesellschaft Regensburg, Med.-Botanische Gesellschaft London, Naturforschende Gesellschaft Mannheim, Apothekenverein im nördlichen Deutschland.

Qu UAH PA 1368 f.; RA 5355, 5629 fol. 47r,v u. ö., 6883. Matrikel Erlangen (1918) S. 39. GLA Abt. 205, Fasz. 159. - Nachlaß: UBH. - Siehe auch Archiv der Dt. Akademie der Naturforscher Leopoldina Halle/S.

$W$ Die botanische Kunstsprache in Umrissen. Nürnberg 1822. • Die kryptogamischen Gewächse mit besonderer Berücksichtigung der Flora Deutschlands und der Schweiz. Nürnberg 1828. • Handbuch der botanischen Terminologie und Sys- 
temkunde. 3 Bde. Nürnberg 1830-1844. - Lehrbuch der Botanik. 3 Bde. Stuttgart 1834-1840.

$L$ NDB 2 (1955) S. 263. • Hentze, Bernd-Walter W.: G. W. B. ... Diss. Heidelberg 1975. WBIS; Thomas (1985) S. 164-169; Carl (2004) S. 60 f.; Wissenschaftsatlas der UH (2011) S. $236 \mathrm{f}$.

P Bildarchiv UAH; graph. Slg. UBH; NDB.

\section{Bischoff, Theodor Ludwig Wilhelm (seit 1870: von Bischoff)}

1835-1843 Med. Fak.

Vgl. Anatomie, Pathologische Anatomie, Physiologie

* 28. Okt. 1807 Hannover

$\dagger$ 05. Dez. 1882 München ev.

V Ernst Christian Heinrich B. (1781-1861), u.a. seit 1818 a. o., 1819-1861 o. Prof. für Pharmakologie Bonn, s. Verzeichnis Bonn (1968) S. 25, WBIS, Renger (1982) S. 292 (Register), Giese (1990) S. 3-30, 233 u.ö., Hessische Biografie, s. http://www.lagis-hessen.de/pnd/116193093 (Stand: 12. Nov. 2016)

M Juliane geb. Amelung gesch. Hufeland (17711845), s. Giese (1990) S. 5 f., 11, 13 f., 19, 26. - Jan. 1807 Trennung, Sommer 1807 Scheidung von Christoph Wilhelm Hufeland (1762-1836), u. a. seit 1801 königl. preußischer Leibarzt und erster Arzt an der Charité, seit 1809 o. Prof. für Medizin an U Berlin, s. WBIS, NDB 10 (1974) S. 1-7; Hufeland, Günther: C.W.H. ... Bad Langensalza 2002.

$\infty$ 10. April 1839 Cunigunda (Kunigunde) Maria Sophia Dorothea geb. Tiedemann verw. Fohmann (1809-1889) T von: (siehe) Friedrich T.; Witwe von Vincenz Fohmann (1794-1837), u. a. 1819-1826 Prosektor am Anatomischen Theater der UH, seit 1827 Prof. für Anatomie Lüttich, s. UAH PA 9909, WBIS, Freudenberg (2010) S. 152-154 u. ö., Doll (2014) S. 277-281

$\mathrm{K} \quad 3 \mathrm{~S}, 3 \mathrm{~T}$
Lb U Bonn: 12. Okt. 1826-SS 1830 Studium der Medizin, Naturwiss., Philosophie; 28. Nov. 1829 Dr. phil.

UH: Seit Okt. 1830 Forts. des Studiums der Medizin; 16. Jan. 1832 Dr. med., s. hierzu UAH HIII-111/29.

Berlin: 9. Aug. 1832 Approbation als Arzt, Geburtshelfer und Operateur; seit Spätherbst 1832 Assistent an Königl. U-Entbindungsanstalt.

U Bonn: 10. Sept. 1833 Habilitation für Physiologie.

UH: Seit 17. Mai 1835 Privat-Dozent mit e. jährl. Gehalt von 350.- Gulden; 1836 Ruf an U Basel abgelehnt; seit 13. Mai 1836 a. o. Prof. in Nachf. von Friedrich Sigismund Leuckart mit e. jährl. Besoldung von 6oo.- Gulden; 9. Febr. 1843 Ern. durch Großherzog Leopold zum o. Prof. (ohne Gehaltserhöhung und ohne Berechtigung zur Abnahme von Prüfungen) gegen den Beschluß der Fak., die behauptet, ... daß „ungeachtet des gegenwärtigen großen Umfanges der anatomischen und physiologischen Wissenschaften, dieselben durch Herrn Geheimenrath [Friedrich] Tiedemann auf die völlig genügende und würdigste Weise vertreten sind“ (aus: UAH PA 1375).

U Gießen: Seit 22. Sept. 1843 (Ern.) o. Prof. für Physiologie mit e. jährl. Gehalt von 1400.- Gulden und seit 8. Nov. 1844 auch für Anatomie; 1843/441855 Direktor des Physiolog. und Anatom. Inst.

U München: 8. Dez. 1854 Ern. zum SS 1855 o. Prof. für Anatomie (bis 30. April 1878) und Physiologie (bis 1863) sowie $1855-1878$ (Ruhestand) Konservator der Anatom. Anstalt.

E 1843 Mitglied der Dt. Akademie der Naturforscher Leopoldina Halle/S.; Mitglied der Akademie der Wissenschaften: 1848 Wien, 1853 Göttingen, 1854 Berlin, 1857 München. • 1844 Sömmerringpreis.

Qu UAH PA 1375; RA 6595; Fak.-AkteH-III-111/29. Teil-Nachlaß: Hessisches Staatsarchiv in Darmstadt. - Siehe auch Archiv der Dt. Akademie der Naturforscher Leopoldina Halle/S. Ergebnislose 
Anfrage: Ev.-luth. Stadtkirchenverband - Kirchenbuchamt - in Hannover. - Auskunft: Stadtarchiv München (Sterberegister von 1882: Bestätigung des Geburtsortes Hannover); Universitätsarchiv Bonn. - Selbstbiographie. Kiel 1925.

$W$ Entwicklungsgeschichte der Säugetiere und des Menschen. Leipzig 1842. - Der Harnstoff als Maß des Stoffwechsels. Gießen 1853. - Entwicklungsgeschichte des Rehes. Gießen 1854. - Die Gesetze der Ernährung des Fleischfressers. Leipzig 1860. (Mitverf.) - Das Studium und die Ausübung der Medicin durch Frauen. München 1872 (B. spricht hier von der „geistigen Minderwertigkeit"der Frau).

L Verzeichnis Bonn (1968) S. 25; Chronik Ärzte H (1985) S. 122, 211f.; Pantel/Bauer (1990) S. 87 f. • Giese, Christian: T.L.W. von B. ... Anatom und Physiologe. Habil.-Schrift. Gießen 1990. - Mitgl. der Akad. der Wiss. Göttingen (2001) S. 41. Giese, Christian: T.L.W.B. und der Beginn der naturwiss.-experimentellen Medizin in Gießen in: Die Medizinische Fakultät der Universität Gießen 1607-2007. Stuttgart 2007. S. 197-217. • Freudenberg (2010) S. 146-148 u. ö.; Doll (2014) S. 307 f. u. ö.; Doll/Kirsch/Eckart (2017) S. 29, 31.

P Bildarchiv UAH; Chronik Ärzte H.

\section{Blessing, Georg Joseph}

1920-1933 (1934) Med. Fak.

Zahnheilkunde

* 24. Dez. 1882 Freiburg/Br.

$\dagger$ 10. Dez. 1941 München

kath.

V Alexander B. (1837-1914) Kaufmann

M Elisabeth geb. Leo (1848-1936)

$\infty$ 16. Aug. 1912 Adeline Charlotte geb. Barry (1887-1961)

$\mathrm{K} \quad 2 \mathrm{~S}, 1 \mathrm{~T}$
Lb Seit WS 1903/04 Studium der Medizin, Zahnheilkunde, Naturwiss. an U Freiburg/Br., anschl. Straßburg, München; 1906 Approbation in Freiburg; 1906 Dr. med. dent. an U Freiburg; 24. Febr. 1911 Dr. phil. an U Bern.

Assistent an Zahnärztl. U-Kliniken: Seit 1907 Freiburg, seit 1911 Tübingen.

Leiter der Zahnärztl. Kliniken: 1912-1914 an Akademie für praktische Medizin Düsseldorf, 19141917 Braunschweig; 1915 Habilitation für Gewerbehygiene an TH Braunschweig; 1917-1918 Kriegsdienst; 1919 Ruf an U Hamburg abgelehnt.

U Rostock: 1919 Umhabilitation; 1920 Ruf an U Jena abgelehnt; seit 1920 nichtetatm. a. o. Prof. und Abt.-Vorstand der U-Klinik.

UH: Seit 1. Okt. 1920 planm. a. o. Prof. und Direktor des Zahnärztl. Inst. (1921 Umbenennung in Zahnärztl. U-Poliklinik, Mai 1927 in Zahnärztl. Klinik und Poliklinik der U, s. hierzu Bauer/Langsch (1991) S. 383 f. online) als Nachf. von Johannes Ahrens; seit 31. Jan. 1924 persönlicher Ordinarius; seit 18. Juli 1930 planm. o. Prof.; 2.-7. Mai 1933 Schutzhaft nach e. vom nationalsozialistischen Dt. Studentenbund inszenierten Aufruhrs während seiner Vorlesung, s. hierzu UAH PA 988; 4. Mai 1933 Beurlaubung durch Minister des Kultus ... wegen angeblicher Unterschlagung von öffentl. Geldern und Erhebung unberechtigter Studentengebühren (Anklage erweist sich später als unbegründet); Sept. 1933 B. steht vor der Wahl, entweder seine Emeritierung zu beantragen oder e. Disziplinarverfahren auszulösen; Juli 1934 B. stellt Antrag auf Emeritierung aus gesundheitlichen Gründen; 1. Dez. 1934 Emeritierung; Juni 1935 B. stellt Antrag auf Wiederaufnahme seiner Vorlesungstätigkeit; Rektor Wilhelm Groh lehnt ab mit der Begründung, B. passe sich als Mitglied der Dt. Zentrumspartei nicht dem neuen nationalsozialistischen „Geist“ an der sich „erneuernden Universität“ an.

1924: B. ist erster Ordinarius für Zahnheilkunde an der Universität Heidelberg 
E 1921 Dr. med. dent. h.c. UH.

Qu UAH PA 988, 3317. - GLA Abt. 235, Fasz. 1798. Mitteilungen: Frau Dr. Carmen Ehrnsperger-Blessing $(\dagger)$.

W Das zahnärztliche Staatsexamen. 2 Bde. München 1911. 2. Aufl. 1926. - Zur Bakteriologie und antibakteriellen Therapie der Pyorrhoea alveolaris. Leipzig 1911. (Sammlung von Vorträgen aus dem Gebiete der Zahnheilkunde. H. 5.) - Allg. und spezielle Bakteriologie des Mundes und der Zähne. Leipzig 1915. - Diagnostisch-therapeutisches Vademecum für die zahnärztliche Praxis. Leipzig 1921. 6. Aufl. 1923.

L Kürschner (1928/29) Sp. 184, (1940/41) Sp. 142; Mussgnug (1988) S. 297 (Register). - Bauer/ Langsch (1991) S. 382-387 online; Jansen (1992) S. 407 (Register); Jansen (1992a) S. 164 (Register); Kristen (1996) S. 224f.; UH im Nationalsozialismus (2006) S. 1031-1037 u. ö. - Über G. B. in: Leo, Paul Christopher: Wilhelm Groh ... Hamburg 2012. S. 117-123. - Catalogus prof. Rostochiensium online; Deutsche Biographie, s. https://www. deutsche-biographie.de/gnd116201738.html [06.11. 2017].

$P$ Bildarchiv UAH.

\section{Blochmann, Friedrich Johann Wilhelm}

1885-189o Phil. Fak.

1890-1891 Nat.-Math. Fak.

Zoologie

* 21. Jan. 1858 Karlsruhe

$\dagger$ 22. Sept. 1931 Tübingen ev.

V Friedrich B., Küblermeister

M Katharina Johanna geb. Zobel

$\infty$ 1. Okt. 1891 Marie Anna Mathilde geb. Winkelmann (1865-1942) T von: (siehe) Eduard W.

K 3 S, 2 T

Lb Polytechnikum Karlsruhe: Seit 1877 Studium der Architektur.
UH: Seit WS 1879/80 Studium der Zoologie; 3. März 1881 Dr. phil.; 1881-1891 Assistent am Zoolog. Inst.; 28. Nov. 1885 Habilitation; seit 1. März 1888 a. o. Prof.

U Rostock: Seit 29. Mai 1891 o. Prof. der Zoologie und Vgl. Anatomie, Direktor der Zoolog. Sammlungen und des Inst. für Zoologie.

U Tübingen: WS 1898/99-SS 1924 (Emeritierung) o. Prof., Direktor des Zoolog. Inst. und der Zoolog. Schausammlung.

E Dr. rer. nat. h.c. Tübingen.

Qu UAH PA 1328; RA 5226, 6577, 6901. - Staatsarchiv Basel [!]: Personalakten (Signaturen: PA 212a T 2 III 3 (1891), PA 212a T 2 XXX 26-34 (19151920)). Briefe: UBH.

$W$ Die mikroskopische Pflanzen- und Thierwelt des Süßwassers. 2 T. 1886-1891. T. 2: 2. Aufl. 1895. • Untersuchungen über den Bau der Brachiopoden. $2 \mathrm{~T}$. Jena $1892-1900$.

$L$ NDB 2 (1955) S. 309; WBIS; DBE 1 (1995) S. 575; Catalogus prof. Rostochiensium online; Biogr. Enzyklopädie Naturwissenschaftler 1 (2003) S. 75; Grewolls (2011).

$P$ Bildarchiv UAH; graph. Slg. UBH.

\section{Blum, Johann Reinhard}

1828-1877 Phil. Fak.

Mineralogie, Geologie

* 28. Okt. 1802 Hanau

$\dagger \quad$ 22. Aug. 1883 Heidelberg ev.-luth.

V Friedrich Carl B. (1748-1826), u. a. 1771-178o Expedient am Ev.-luth. Konsistorium in Hanau, seit 1780 Konsistorialregistrator, seit 1782 Sekretär, seit 1786 Assessor bei der Steuer- und Landkassendirektion, 1799-1811 Konsistorialrat, seit 1814 Kurfürstl. Steuerrat, seit 1819 Kurhessischer Geheimer Steuerrat, s. WBIS 
M Johanna Wilhelmine geb. Blum (1765-1824)

$\infty$ 12. Okt. 1843 Helene geb. Marx (1814-1888)

K 1 S, 1 T: Helene Amalia Charlotte B. (18461930) Ehefrau von: (siehe) Wilhelm Kühne

Vw Schwester: Louise Johanna geb. B. (1787-1824) Ehefrau von: (siehe) Karl Caesar Ritter von Leonhard. - Bruder: Karl Ludwig B. (17961869) 1823-1826 Kustos an UB Berlin, 18261851 (Ruhestand) o. Prof. für Geographie, Statistik, Geschichte Dorpat, seit 1852 Wohnsitz in $\mathrm{H}$, s. ADB 2 (1875) S. 738 f., WBIS; Über K.L.B. in: Jakob Michael Reinhold Lenz im Urteil dreier Jahrhunderte ... Hrsg. von Peter Müller ... Bern 2005. S. 682 (Register).

Lb Seit SS 1821 Studium der Kameralwiss. an UH, seit WS 1823/24 Marburg; 1825 kameralistische Staatsprüfung in Marburg.

UH: Seit 1825 Eigenstudium der Mineralogie; 17. März 1828 Dr. phil.; 12. Juli 1828 Habilitation; seit 8. Nov. 1838 a. o. Prof.; seit 15. Juni 1845 a. o. Prof. mit e. Jahresgehalt von 300.- Gulden; seit 1848 jährl. Gratifikation von 200.- Gulden; WS 1850/51-SS 1864 Direktor der Schülerschen Mineraliensammlung (siehe unten) mit e. jährl. Besoldungszulage von 300.- Gulden; seit 1. Nov. 1850 jährl. Besoldungszulage von 200.- Gulden; seit 2o. Okt. 1856 o. Prof.; WS 1864/65-SS 1877 Direktor des „Mineralien-Kabinets“; 1. Okt. 1877 auf eigenen Antrag Ruhestand.

1863 Wahlsenator der UH; 1861 Dekan der Phil. Fak. der UH

Blum stellt 1864 die erste große mineralogisch-petrographische Sammlung im Westflügel des Heidelberger Friedrichsbaus in der Hauptstraße 4751 auf; sie ist ein Geschenk des Jenenser Bergrates Gustav C. Schüler an die Universität 1850 und umfasst insgesamt 15000 Mineralien.

1870 verkauft B. seine eigene Sammlung von über 1700 Pseudomorphosen für 3000.- Dollar an das im 1866 gegründeten Peabody Museum untergebrachten Mineralogical Cabinet of Yale College in New Haven (Connecticut) (heute unter dem Namen: „Blum pseudomorph collection“), s. hier- zu Brush, George Jarvis: Mineralogical Department in: Annual Report of the Yale Sheffield Scientific School 6 (1870/71) S. 3.

17. Aug. 1871: Gründungsmitglied des Oberrheinischen Geologischen Vereins im ehemaligen Bad-Hotel Rothenfels im heutigen Gaggenau-Bad Rotenfels

1871 Hofrat; 1877 Geh. Hofrat

E 1868 Ritterkreuz I. Klasse, 1878 Kommandeurkreuz II. Klasse des Ordens vom Zähringer Löwen.

Qu UAH PA 1329; RA 5815 und 6487 f. (betreffen Mineraliensammlung), 6593, 6895; Fak.-Akte H-IV-102/23. • GLA Abt. 205, Fasz. 160. • Briefe: $\mathrm{UBH}$.

$W$ Lehrbuch der Oryktognosie. Stuttgart 1833. • Die Pseudomorphosen des Mineralreichs. Stuttgart 1843. Handbuch der Lithologie und Gesteinslehre. Erlangen 1860.

L ADB 47 (1903) S. 22 f. (mit Werkverz.); Ruuskanen (2008) S. 141 f.; WBIS.

$P$ Bildarchiv UAH; graph. Slg. UBH; Mineralogisch-Petrographisches Inst. der UH.

\section{Bluntschli, Johann Caspar}

1861-1881 Jur. Fak.

Staatsrecht, Politik, Verwaltungsrecht

* 07. März 1808 Zürich

$\dagger$ 21. Okt. 1881 Karlsruhe

口 Heidelberg

ev.

V Hans Caspar B. (1774-1860) Kerzen- und Seifenfabrikant

M Anna Katherina geb. Koller (1785-1840)

œ 7. März 1831 Emilie geb. Vogel (1808-1876) 
K 4 T (1 T früh †): u.a. Emilia Luisa (Luise) B. $\left({ }^{\star} 1832 \dagger\right.$ nach 1898 in der Schweiz) Ehefrau von Karl von Hecker (1827-1882) seit 1853 Privat-Dozent Berlin, seit 1858 o. Prof. für Geburtshilfe Marburg, seit 1859 München, s. Vannahme, Benedikt: K. von H. ... Biobibliographie eines Münchner Geburtshelfers und Gynäkologen. Diss. München 2010 (online). • $3 \mathrm{~S}(1 \mathrm{~S}$ früh $\dagger)$ : u. a. Alfred Friedrich B. (18421930) 1870-1881 Architekt zahlreicher Bauten in Frankfurt/M., 1881-1915 o. Prof. für Architektur am Polytechnikum in Zürich, s. WBIS; Altmann, Bernd: Mein Motto fürs Leben bleibt Renaissance. Der Architekt A.B. Phil. Diss. Trier 2000 (mit Abb. und Bibliographie; online).

Vw Enkel: Sohn des o.g. Architekten Alfred Friedrich B.: Hans B. (1877-1962), u. a. 1915 Verleihung des Titels „Prof.“, seit 1919 o. Prof. für Anatomie und Entwicklungsgeschichte am Senckenbergischen Anatomischen Inst. der U Frankfurt/M., 1933-1942 (Emeritierung) o. Prof. Bern, s. Organ (1993) S. 146 (Register).

$L b$ Vor 1827 Studium am Politischen Institut in Zürich; seit Okt. 1827 Studium an U Berlin, seit Sept. 1828 Bonn; 29. Aug. 1829 Dr. iur. an U Bonn; Sept. 1829-März 1830 Aufenthalt in Paris.

Zürich: Seit April 1830 Auditor (auch Auditeur: Jurist) am Amtsgericht, anschl. Sekretär bei der Regierungskommission des Innern, zuletzt bei der Kommission für administrative Streitigkeiten; 1831-1833 Gerichtsschreiber und Notar am Bezirksgericht.

U Zürich: 26. Jan. 1833-15. Okt. 1836 a. o. Prof. für Römisches Recht an neugegründeter U; 1836 Ruf an U Brüssel abgelehnt; 15. Okt. 1836-23. Febr. 1848 o. Prof. $\bullet$ In dieser Zeit:

Zürich: 1833-1839 Rechtskonsulent der Stadt und Rechtsrat des Kaufmännischen Direktoriums; 1839-1845 Mitglied des Eidgenössischen Staatsrats; u. a. auch 1837-1845 Mitglied des Großen Rats des Kantons.

U München: 8. Nov. 1848 Ern. zum o. Prof. des Dt. Privatrechts.
UH: Seit 2. Nov. 1861 zum WS 1861/62 o. Prof. als Nachf. von Robert von Mohl; 1861-1879 (Auflösung) Beisitzer des Spruchkollegiums der Jur. Fak.; seit 1871 (zus. mit Carl Knies) Direktor des neueingerichteten Staatswiss. Seminars; seit 1863 u. a. Vorstand der akad. Krankenhauskommission als Nachf. von Carl Rau. • In dieser Zeit:

Karlsruhe: 1861-1868, 1869-1870, 1879-1880 Mitglied der I. Kammer, 1873-1876 Mitglied und 1. Vizepräsident der II. Kammer des Badischen Landtags; 1867, 1871, 1876, 1881 Präsident der Badischen Generalsynode.

1870/71, 1877/78 Prorektor der UH; 1864/65, 1870/71, 1874/75, 1880/81 Dekan der Jur. Fak. der $\mathrm{UH}$

1863 Mitbegründer des Dt. Protestantenvereins, siehe hierzu auch Richard Rothe

1873 Mitbegründer des „Institut de Droit International“

1839 Reg.-Rat; 1861 Hofrat; 1863 Geh. Rat III. Klasse

E Korr. Mitglied der Académie des sciences morales et politiques Paris. 1879 Dr. phil. h.c. UH. • Maximiliansorden für Wissenschaft und Kunst. • Ritter des Michaelsordens; 1861 Komtur des Sächsischen Albrecht-Ordens.

Qu UAH PA 1331; RA 184, 5716, 6761. GLA Abt. 205, Fasz. 161. - Briefe: UBH. - Familienarchiv Bluntschli in: Katalog der Handschriften der Zentralbibliothek Zürich. 3. Bd. Familienarchive. Bearb. von Jan-Pierre Bodmer. Zürich 1996. S. 37-74 u. ö. - Der Redaktionsbriefwechsel der Hallischen, Deutschen und Deutsch-Französischen Jahrbücher 1837-1844. Hrsg. von Martin Hundt. Bd. 1: Der Briefwechsel um die Hallischen Jahrbücher. Berlin 2010. Apparat: S. 256 (Register). - Denkwürdiges aus meinem Leben. 3 T. Nördlingen 1884 . (Autobiogr.)

$W$ Staats- und Rechtsgeschichte der Stadt und Landschaft Zürich. 2 T. Zürich 1838-1839. Allgemeines Staatsrecht. 2 Bde. München 1851-1852. 
6. Aufl. 1885. • Deutsches Privatrecht. 2 Bde. München 1853. 3. Aufl. 1864. • Privatrechtliches Gesetzbuch für den Kanton Zürich. Zürich 1854-1856. • Das moderne Völkerrecht der zivilisierten Sta[a]ten als Rechtsbuch dargestellt. Nördlingen 1868. 3. Aufl. 1878 (siehe hierzu Hattenhauer, Christian: Kein chocolate-cream soldier: J. C. B. ... und sein „Modernes Völkerrecht der civilisirten Staten als Rechtsbuch dargestellt" (1868) in: Privatrecht, Wirtschaftsrecht, Verfassungsrecht. Privatinitiative und Gemeinwohlhorizonte in der europäischen Integration ... Hrsg. von Cordula Stumpf ... Baden-Baden 2015. S. 953-960). • Lehre vom modernen Staat. 5. Aufl. 3 T. Stuttgart 1875. 6. Aufl. 2 T. 1885-1886.

$M H G$ Kritische Überschau für Gesetzgebung und Rechtswiss., seit 1859 u.d.T.: Kritische Vierteljahrsschrift für Gesetzgebung und Rechtswiss. • 1857-1870 Deutsches Staatswörterbuch. 11 Bde. Verkürzte Neuausgabe: 3 Bde. 1869-1873.

$L$ Baier (1937) S. 184-188; NDB 2 (1955) S. 337 f.; Kosch (1963) S. 129; WBIS; Hinz (2000) S. 44-46. Röben, Betsy: J.C.B., Francis Lieber und das moderne Völkerrecht 1861-1881. Baden-Baden 2003. • Jayme, Erik: J. K. B. und das int. Privatrecht - Zu e. Brief B.s an den Fürsten Bibesco ... in: Humaniora (2006) S. 135-144. • Wölky, Guido: Roscher, Waitz, B. und Treitschke als Politikwissenschaftler. Spätblüte und Untergang eines klassischen Universitätsfaches in der zweiten Hälfte des 19. Jahrhunderts. Diss. Bochum 2006. Baur (2009) S. $196 \mathrm{f}$. u. ö. Metzner, Carolin: J. C. B. Leben, Zeitgeschehen und Kirchenpolitik 1808-1881. Frankfurt/M. u. a. 2009. - Keßler, Ewald: J. C. B. ... in: Lebensbilder aus der Ev. Kirche in Baden im 19. und 2o. Jahrhundert. Bd. II: Kirchenpolitische Richtungen. Hrsg. von Johannes Ehmann. Heidelberg 2010. S. 111-138. - Schroeder (2010) S. 215-223. • Müller-Graff, Peter-Christian: Recht überwindet Grenzen: Thibaut, B., Goldschmidt und andere Heidelberger in: Heidelberger Thesen zu Recht und Gerechtigkeit (2013) S. 67-94. • Prettenthaler-Ziegerhofer, Anita: J. C. B. ... in: Klassiker des europäischen Denkens: Friedens- und Europavorstellungen aus 700 Jahren europäischer Kulturgeschichte. Baden-Baden 2014. S. 359-365.

$P$ Bildarchiv UAH; graph. Slg. UBH; NDB (1955); Keßler (2010) S. 110.

\section{Boeckh}

siehe Böckh

\section{Böckh, Philipp August}

1807-1811 Phil. Fak.

1807-1811 Klassische Philologie; 1809-1811 Eloquenz

* 24. Nov. 1785 Karlsruhe

$\dagger$ 03. Aug. 1867 Berlin ev.-luth.

V Georg Matthäus B. (1735-1790) Notar, Hofratssekretär

M Marie Salome geb. Hörner/Hörnes (1745-1815)

๑ 4. Okt. 1809 Dorothea (Dorette) Eleonora Wilhelmina Carolina geb. Wagemann (17901829), s. Poiss (2009) S. 106 Anm. 109; Schwester von: (siehe) Georg W.

๑ 18. Sept. 1830 Anna Louisa geb. Taube gesch. Hoffmann (1790-1864)

K $\quad 2$ T (eine T früh $\dagger$ ), 3 S: u. a. Richard Georg Friedrich B. (1824-1907), u. a. 1875-1902 Direktor des Statistischen Amts Berlin, seit 1881 a. o. Prof., seit 1895 o. Honorar-Prof. für Statistik U Berlin, s. NDB 2 (1955) S. 367, WBIS

Vw Onkel: Christian Gottfried Friedrich B. (17321792) Theologe und pädagogischer Schriftsteller, s. ADB 2 (1875) S. 783, WBIS. • Groß-Neffe: (siehe) Eugen von Jagemann. • Enkel von August B.s Schwester Dorothea: (siehe) Bernhard Stark.

Lb U Halle/S.: Seit April 1803 Studium; 15. März 1807 Dr. phil.

Berlin: 1806-1807 Lehrer am Gymnasium zum Grauen Kloster und Privat-Lehrer.

UH: 28. Nov. 1807 Habilitation; seit 27. Okt. 1807 a.o. Prof. mit Besoldung; 1809 Ruf an U Königsberg (Preußen) abgelehnt; zwischen 21. Febr. und 16. Juni 1809 Ern. zum o. Prof. für Eloquenz und nur SS 1809 Mit-Direktor (zus. mit Friedrich Heinrich Christian Schwarz) des Philolog.-Pädagog. (auch: Pädagog.-Philolog.) Seminars als 
Nachf. von Friedrich Creuzer, der im Aug. 1809 an UH zurückkehrt; 5. Sept. 1810 Ruf an U Berlin.

U Berlin: 23. April 1811 (Dienstantritt)-April 1867 (Ruhestand) o. Prof. für Klassische Philologie („eloquentiae et poeseos prof. publicus"); 1812 (Begründer)-1867 Direktor des Philolog. und 18191867 auch des Pädagog. Seminars.

1830 Geh. Reg.-Rat

E Mitglied der Akademie der Wissenschaften: Turin, Amsterdam, Kopenhagen, 1814 Berlin, 1820 München, 1830 Göttingen, 1855 Wien. 11828 Ritter des Königl. Preußischen Roten Adlerordens III. Klasse; 1867 Orden pour le Mérite für Wissenschaften und Künste. 1857 Ehrenbürger von Berlin.

Qu UAH PA 1334; RA 4921, 6122 fol. 71r u. ö., 6372, 6634; Fak.-Akte H-IV-102/2 fol. 9r,v, 93 u. ö. • GLA Abt. 205, Fasz. 162. - Der Redaktionsbriefwechsel der Hallischen, Deutschen und Deutsch-Französischen Jahrbücher 1837-1844. Hrsg. von Martin Hundt. Bd. 1: Der Briefwechsel um die Hallischen Jahrbücher. Berlin 2010. Apparat: S. 256 (Register). Nachlaß: UBH; s. auch Kalliope. Auskunft: Kirchenbuchstelle im Ev. Zentralarchiv Berlin (Totenbuch St. Matthäus 1867).

$W$ Pindari opera quae supersunt. Leipzig 18111821. Staatshaushaltung der Athener. Berlin 18171840. 3. Aufl. 1886. Corpus inscriptionum Graecarum. Berlin 1828-1877. A. B's gesammelte kleine Schriften. Leipzig 1858-1874.

MHG 1809-1811 Heidelbergische Jahrbücher der Literatur.

$L$ Verzeichnis im Jahre 1845 in Berlin lebender Schriftsteller und ihrer Werke. Berlin 1846. S. 3034. Crusius, Otto: A.B. und Sigmund von Reizenstein in ihrem Briefwechsel in: Heidelberger Prof. aus dem 19. Jhdt. 1 (1903) S. 355-405. • NDB 2 (1955) S. $366 \mathrm{f}$. (mit Werkverz.). - Schneider, Bernd: A. B. Altertumsforscher, Universitätslehrer und Wissenschaftsorganisator im Berlin des 19. Jahrhunderts. Ausstellung zum 200. Geb.... in der Staatsbibliothek Preussischer Kulturbesitz.
Wiesbaden 1985. Heidelberg im säkularen Umbruch (1987) S. 557 (Register); BBKL XIX (2001) Sp. 18o-189. Italiensehnsucht - kunsthistorische Aspekte eines Topos. Hrsg. von Hildegard Wiegel. München u. a. 2004. 200 Jahre Heidelberger Romantik (2008) S. 207-223. - Poiss, Thomas: Die unendliche Aufgabe. A.B. als Begründer des Philologischen Seminars in: Die modernen Väter der Antike. Die Entwicklung der Altertumswissenschaften an Akademie und Universität im Berlin des 19. Jahrhunderts. Hrsg. von Annette M. Baertschi ... Berlin 2009. S. 45-72; Ders.: A. B. als Universitätspolitiker in: Netzwerke des Wissens - das intellektuelle Berlin um 180o. Hrsg. von Anne Baillot. Berlin 2011. S. 85-112. - Kalkhoff (2010) S. 352 (Register); Geschichte U Berlin (2012) Bd. 1, S. 659 (Register). - A. B.: Philologie, Hermeneutik und Wissenschaftspolitik. Hrsg. von Christiane Hackel, Sabine Seifert. Berlin 2013.

$P$ Bildarchiv UAH; NDB.

\section{Boehm, Karl}

1900-1913 Nat.-Math. Fak.

Mathematik

* 29. April 1873 Mannheim

$\dagger \quad$ 07. März 1958 Kressbronn am Bodensee kath., seit 1904 konf.-los

V Joseph Anton B. $\left({ }^{*} 1824\right)$ Kaufmann

M Julia Henriette geb. Kley ( $\left.{ }^{*} 1837\right)$

E Elly geb. Meyer-Elles (1865-1939) Übersetzerin, s. Kürschners Literatur-Kalender (1926) Sp. 93

K unbekannt.

Lb UH: Seit WS 1891/92 Studium der Chemie, seit SS 1892 Studium der Mathematik; 1. Aug. 1896 Dr. phil. nat.; März 1897 Staatsexamen für höheres Lehramt in Karlsruhe; 1897-1900 Eigenstudien in $\mathrm{H}$ und Mannheim; 7. Juli 1900 Habilitation; seit 25. Nov. 1904 nichtetatm. a. o. Prof.

U Königsberg (Preußen): Seit WS 1913/14 o. Prof. 
TH Karlsruhe: 1. April 1917-1936 (Emeritierung) o. Prof

Kressbronn: Seit 1937 Wohnsitz.

E 1916/17 Mitglied der Dt. Akademie der Naturforscher Leopoldina Halle/S.; 1929 Mitglied der Akademie der Wissenschaften H. 1953 Ehrenbürger der TH Karlsruhe.

Qu UAH PA 1342. - Briefe: UBH; Universitätsarchiv Freiburg/Br. - Siehe auch Archiv der Dt. Akademie der Naturforscher Leopoldina Halle/S.

$W$ Elliptische Funktionen. 2 Bde. Berlin 19081910. Begriffsbildung. Karlsruhe 1922. • Über lineare Differentialgleichungen mit konstanten Koeffizienten und einer Störungsfunktion. Berlin 1931.

L Kürschner (1926) Sp. 154, (1928) Sp. 198, (1961) S. 2365; Wer ist wer (1955) S. 102; Poggendorff 7a (1956) S. 216; Kern (1992) S. 43-45 u. ö. • Renteln, Michael von: Die Mathematiker an der TH Karlsruhe (1825-1945). 2. Aufl. Karlsruhe 2002. S. 25-38 u. ö. Tilitzki 1 (2012) S. 784 (Register); Deutsche Biographie, s. https://www.deutsche-biographie. de/gnd116220023.html [06.11.2017].

$P$ Bildarchiv UAH.

Bois-Reymond, David Paul Gustave Du siehe Du Bois-Reymond, Paul

\section{Boll, Franz Johann Evangelista}

1908-1922 (1924) Phil. Fak.

Klassische Philologie

* o1. Juli 1867 Rothenburg ob der Tauber

$\dagger \quad$ 03. Juli 1924 Heidelberg

kath.
V Johann Georg B. (1836-1915) Oberlandesgerichtsrat

M Maria geb. Nusser (1840-1921)

( 4. Okt. 1895 Ida geb. Schwarzenbach (18671923) T von Valentin S. (1830-189o) seit 1854 Privat-Dozent Würzburg, seit 1862 o. Prof. für Chemie an U Bern, s. Hörmann, Ursula C.: Die akad. Ausbildung der Apotheker im Kanton Bern. Diss. Bern 1998. S. 132-139; WBIS. K $\quad 1 \mathrm{~S}$

Lb Seit WS 1885/86 Studium an U Berlin, seit 1887 München.

München: 7. März 1891 Dr. phil.; Okt. 1891 Prüfung für Lehramt an höheren Schulen; seit Dez. 1891 Praktikant, seit Juli 1892 etatm. Assistent, seit Juli 1894 Sekretär, 1898-1903 Leiter der Handschriften-Abt. an Königl. Bayer. Hof- und Staatsbibliothek.

U Würzburg: Seit SS 1903 o. Prof.

UH: Seit 14. Juli 1908 o. Prof. als Nachf. von Albrecht Dieterich und Mit-Direktor (bis SS 1918 zus. mit Fritz Schöll, bis SS 1921 mit Otto Weinreich, WS 1921/22 mit Karl Meister) des Philolog. Seminars; 1921 Rufe an U Berlin und Wien abgelehnt; seit SS 1922 aus Krankheitsgründen beurlaubt.

1923 Rektor der UH; 1909/10 Dekan der Phil. Fak. der UH

1916 Geh. Hofrat

$E$ Mitglied der Akademie der Wissenschaften: 1907 München, 1909 H, 1917 Göttingen, 1922 Bologna. Dr. phil. h. c. Padua.

Qu UAH PA 3361; RA 6827; Rep. 16. - GLA Abt. 235, Fasz. 1817. - Briefe: UBH. - Heilen, Stephan: Wilamowitz und F.B. Ein Gelehrtenbriefwechsel 1894-1923 in: Wilamowitz und kein Ende ... William M. Calder III zum 70. Geb. ... Hrsg. von Markus Mülke. Hildesheim 2003. S. 87-160. - TeilNachlaß: UBH. - Familienarchiv: Staatsbibliothek zu Berlin. 
$W$ Sphaera. Neue griechische Texte und Untersuchungen zur Geschichte der Sternbilder. Leipzig 1903. Nachdr. Hildesheim 1967. Aus der Offenbarung Johannis. Leipzig, Berlin 1914. • Sternglaube und Sterndeutung. Die Geschichte und das Wesen der Astrologie. Leipzig 1918. 4. Aufl. 1931. Siehe Gärtner (2000) S. 85 ff.

L NDB 2 (1955) S. 432. • Gärtner, Helga: „Finsternisse" und die Heidelberger Klassische Philologie: F. B. in: „Stürmend auf finsterem Pfad ... “ ... Hrsg. von Helga Köhler ... Heidelberg 200o. S. 83-98. • Kriegstagebuch K. Hampe (2007) S. 947 (Register); WBIS.

$P$ Bildarchiv UAH.

\section{Bonhoeffer, Karl Ludwig}

1904 Med. Fak.

Psychiatrie

* 31. März 1868 Neresheim (Schwäbische Alb)

$\dagger$ 04. Dez. 1948 Berlin

ev.

V Friedrich Ernst Philipp Tobias B. (1828-1907) Landgerichtspräsident, s. Neumärker (1990) S. $13-15$

M Julie Eugenie Wilhelmine geb. Tafel (18421936), s. Neumärker, S. 12 f.

๑ 5. März 1898 Paula geb. von Hase (1876-1951) T von Karl August von H. (1800-189o) seit 1828 a. o. Prof. Leipzig, seit 1829 a. o. Prof. Jena, seit 1830 o. Prof. für Theologie Breslau, s. NDB 8 (1969) S. 19 f., Neumärker, S. 42; Pältz, Eberhard: „Für Recht und Freiheit" , „Aufrichtigkeit und Treue": zum Lebenswerk und Vermächtnis des Jenaer Theologen K. A. von H. ... in: Beiträge zur Hase'schen Familiengeschichte. Hrsg. vom Vorstand des Familienverbandes von Hase. Mainz 1994. Bd. 1. S. 9-46.

K 4 T, 4 S: u. a. Karl Friedrich B. (1899-1957), u. a. 1934-1947 o. Prof für Chemie Leipzig, s. Deichmann (2001) S. 580 (Register), Rürup (2008) S. 520 (Register), Geschichte U Leipzig 3 (2010) S. 958 (Register). Klaus B. (19011945 hingerichtet) Jurist, Widerstandskämpfer, s. Bonhoeffer, Emmi: Bewegende Zeugnisse e. mutigen Lebens. Hrsg. von Sigrid Grabner ... Reinbek ‥ 2006. • Dietrich B. (1906-1945 hingerichtet) Theologe, Widerstandskämpfer, s. Metaxas, Eric: B. - Pastor, martyr, prophet, spy ... Nashville 2010; Schlingensiepen, Ferdinand: D. B. Biographie. München 2010; Tietz, Christiane: D. B. ... München 2013; Nachlaß in Staatsbibliothek zu Berlin. - Siehe auch Leibholz-Bonhoeffer, Sabine: Vergangen, erlebt, überwunden ... 3. Aufl. Wuppertal-Barmen 1969; Neumärker (1990) S. 184-211.

$L b$ Seit Herbst 1886 Militärzeit; seit SS 1887 Studium an U Tübingen, WS 1889/90 Berlin und SS 1890 München, seit WS 1890/91 Tübingen; Febr. 1892 Staatsexamen und Approbation in Tübingen; 1892 Dr. med. an U Tübingen.

U Breslau: Seit 1. Jan. 1893 Assistenzarzt an Psychiatr. U-Klinik; 26. Okt. 1897 Habilitation; März 1898-Sept. 1903 Leiter der Beobachtungsstation für geisteskranke Häftlinge (Gefängnispsychiater); seit Dez. 1902 a. o. Prof.; seit Juli 1903 o. Prof.

U Königsberg (Preußen): Seit 1. Okt. 1903 persönlicher o. Prof. und Direktor der Psychiatr. Klinik und Nervenpoliklinik.

UH: SS 1904 o. Prof. und Direktor der U-Irrenklinik als Nachf. von Emil Kraepelin.

U Breslau: Seit WS 1904/05 o. Prof. und Direktor der Psychiatr. und Nervenklinik.

U Berlin: 1912-1936 (Emeritierung) o. Prof. und Direktor der Psychiatr. und Nervenklinik der Charité; Rufe an U abgelehnt: 1917 Tübingen, 1924 München; 1936-1938 Vertreter seines Lehrstuhls nach Emeritierung; 29. Jan. 1946 Berufung zum o. Prof. ohne Lehrverpflichtungen.

Berlin: 1942 Ern. zum a.o. Mitglied des wiss. Senats des Heeres-Sanitätswesens.

1913-1915, 1916-1932, 1933-1940 Vorsitzender der Berliner Gesellschaft für Psychiatrie und Neurologie 
1897: Entdecker des „Bonhoeffer-Zeichen“ als Symptom des Muskelzuckens bei Chorea („Veits$\left.\tan z^{\prime \prime}\right)$

1908 Geh. Medizinalrat

E 1936 Mitglied der Dt. Akademie der Naturforscher Leopoldina Halle/S.; 1948 Ehrenmitglied der Berliner Gesellschaft für Psychiatrie und Neurologie.

Qu UAH PA 1347. - GLA Abt. 235, Fasz. 1819. • Siehe auch Archiv der Dt. Akademie der Naturforscher Leopoldina Halle/S. • Lebenserinnerungen in: K. B. zum 10o. Geb. ... Hrsg. von Jürg Zutt ... Berlin u. a. 1969. S. 8-107. Leibholz-Bonhoeffer, Sabine: Weihnachten im Hause Bonhoeffer. 13. Aufl. Gütersloh 2005.

$W$ Die symptomatischen Psychosen im Gefolge von akuten Infektionen und inneren Erkrankungen. Leipzig, Wien 1910. Inwieweit kommen psychogene Krankheitszustände vor, die nicht der Hysterie zuzurechnen sind? in: Allg. Zeitschrift für Psychiatrie 68 (1911). • Nervenärztliche Erfahrungen und Eindrücke. Berlin 1941. Bibliographie in: Kreuter 1 (1996) S. 161-164.

HG 1912-1939 Monatsschrift für Psychiatrie und Neurologie. A Archiv für Psychiatrie und Nervenkrankheiten. A Allg. Zeitschrift für Psychiatrie.

MHG Die psychiatrischen Aufgaben bei der Ausführung des Gesetzes zur Verhütung erbkranken Nachwuchses. Mit e. Anhang: Die Technik der Unfruchtbarmachung. Klinische Vorträge im erbbiologischen Kurs. Berlin 1934.

$L$ Stübler (1926) S. 325; Große Nervenärzte 1 (1956) S. 17-26; Chronik Ärzte H (1985) S. 122f. • Totgeschwiegen 1933-1945. Die Geschichte der K.-B.Nervenklinik ... Berlin 1988. S. 207-218 u. ö. $•$ Neumärker, Klaus-Jürgen: K. B. Leben und Werk eines deutschen Psychiaters und Neurologen in seiner Zeit. Leipzig 1990. - Medizin und Gesundheitspolitik (1991) S. 328 (Register); WBIS; Schmeiser (1994) S. 412 u. ö. - Gerrens, Uwe: Medizinisches Ethos und Theologische Ethik: Karl und Dietrich B. in der Auseinandersetzung um Zwangssterili- sation und „Euthanasie“ im Nationalsozialismus. München 1996. Kreuter 1 (1996) S. 160-164; Peiffer (2004) S. 1132 (Register). D Der Wert menschlichen Lebens. Medizinische Ethik bei Dietrich B. und Karl B. Hrsg. von Christof Gestrich ... Berlin 2006. Roelcke, Volker: Politische Zwänge und individuelle Handlungsspielräume: K. B. und Maximinian de Crinis im Kontext der Psychiatrie im Nationalsozialismus in: Die Charité im Dritten Reich. Hrsg. von Sabine Schleiermacher ... Paderborn 2008. S. 67-84. Hennig, Falko: K. B. und das Gesetz zur Verhütung erbkranken Nachwuchses in: Der Eisbär in der Anatomie: Geschichten aus 300 Jahren Charité. Berlin 2010. S. 106-112. • Tilitzki 1 (2012) S. 784 (Register); Deutsche Biographie, s. https://www.deutsche-biographie.de/gnd11 8661442.html [06.11. 2017].

P Bildarchiv UAH; Chronik Ärzte H.

Bonifacius a Sancto Wunibaldo (1782-1802: OCD)

Bonifacius (Bonifaz) vom heiligen Wunibald

siehe Schnappinger, Franz Martin

\section{Bopp, Karl Friedrich}

1906-1915, 1919-1934 Nat.-Math. Fak.

Mathematik

* 28. März 1877 Rastatt

$\dagger \quad$ 05. Dez. 1934 Heidelberg

kath.

V Gustav B. (1828-1889) Arzt

M Anna Maria geb. Lindemann (1845-1907)

(2) 8. Aug. 1903 Bertha Luise geb. Ortmayer (18791931)

$\mathrm{K}$ keine.

Lb Seit WS 1895/96 Studium der Physik, Chemie, Zoologie, anschl. Mathematik, Philosophie an U Straßburg, seit SS 1900 H; 9. Juni 1902 Dr. phil. nat. an UH; 1902-1906 Eigenstudien. 
UH: 21. Juli 1906 Habilitation; 26. Juni 1915 Ern. zum nichtetatm. a. o. Prof. in Nachf. von Moritz Cantor; SS 1919 Antritt der nichtetatm. a.o. Professur; seit SS 1919 Lehrauftrag für Geschichte der Mathematik, Politische Arithmetik und Versicherungswesen; 1920-1934 nichtplanm. a.o. Prof. • In dieser Zeit:

1915-1918 Kriegsdienst.

Qu UAH PA 3366. - GLA Abt. 235, Fasz. 1820. Briefe, Nachlaß: UBH.

$W$ Drei Untersuchungen zur Geschichte der Mathematik. Berlin 1929. - Zur Geschichte des math. Instituts der Universität Heidelberg in: Tätigkeitsbericht der Math. Fachschaft an der Universität Heidelberg (1931) S. 18 f. - Siehe Bibliographie in: Badische Biographien N. F. VI (2011) S. 42.

L Kürschner (1931) Sp. 261f. (mit Werkverz.); WBIS. - Lorey, Wilhelm: K. B. † in: Jahresbericht der Dt. Mathematiker-Vereinigung (1935) Bd. 45, S. 116-119. - Über K. B. in: Der Briefwechsel von Johann I. Bernoulli. Hrsg. von der Naturforschenden Gesellschaft in Basel. Basel 1955. Bd. 1. S. 46-48. Kern (1992) S. 45 f. u. ö.; Badische Biographien N.F. VI (2011) S. 41 f.; Deutsche Biographie, s. https://www.deutsche-biographie.de/gnd11 7620610.html [06.11.2017].

\section{Bornträger, August Friedrich}

1849-189o Phil. Fak.

1890-1902 (1905) Nat.-Math. Fak.

Chemie, Pharmazie, Kristallographie

* o6. Jan. 1820 Clausthal (heute C.-Zellerfeld)

$\dagger$ 13. Febr. 1905 Heidelberg ev.

V Heinrich August Carl B. (1787-1845) Hüttenbeamter

M Juliane Charlotte geb. Erbrich (1793-1854)

๑ 9. Jan. 1851 Johanna geb. Ayle (1816-1873)

K $\quad 1 \mathrm{~T}$
Lb Seit ca. 1838 pharmazeutische Ausbildung in Bodenburg (bei Hildesheim; heute: Ortsteil von Bad Salzdetfurth); seit 1841 Apotheker in Hamburg.

U Göttingen: Seit 1843 Studium der Chemie, Botanik, Pharmazie, Mathematik, Kristallographie, Mineralogie, Physik, Chemie; seit 1844 Assistent am Chemischen Laboratorium.

UH: SS 1845-WS 1846/47 Immatrikulation an Phil. Fak.; 23. April 1846 Dr. phil.; 1846-1857 Assistent am Chemischen Laboratorium; 21. Dez. $1849 \mathrm{Ha}$ bilitation; seit 8. Mai 1857 a.o. Prof.; WS 1901/o2 B.s letzte Ankündigung von „Praktisch-chemischen Übungen im Laboratorium an den ersten fünf Wochentagen und Experimentalpharmacie“ im Vorlesungsverzeichnis.

1846 wohnt B. wohl bei e. Verwandten seiner Mutter in Heidelberg, dem Schreiner Heinrich Ayle in der Märzgasse. Ayle ist - laut Allgemeine Encyclopädie der Wissenschaften und Künste ... hrsg. von Johann Samuel Ersch ... Leipzig 1834. 2. Section ... 11. T., S. 102 - dafür bekannt, dass er Abtritte u.a. in Krankenhäusern an der Wand montieren kann, sogar direkt neben dem Bett, die „nicht die geringsten Ausdünstungen und sogar in ihren Abführungsröhren nicht die mindeste Spur hinterlassen“.

E 1902 Ritterkreuz I. Klasse des Ordens vom Zähringer Löwen.

Qu UAH PA 1337 (vermisst); RA 6496, 7128; Fak.Akte H-IV-102/42 fol. 141r-144r. • GLA Abt. 235, Fasz. 1821. • Briefe: UBH. - Auskunft: Stadtarchiv Heidelberg (Geburtsjahr 1820).

$W-$

L Biogr. Jahrbuch 10 (1905) Sp. 149; Badische Biographien 6 (1935) S. 791; WBIS.

$P$ Graph. Slg. UBH. 


\section{Bothe, Walther Wilhelm Georg Franz}

1932-1934 Nat.-Math. Fak.

(1934-1946 (Honorar-Prof.) Nat.-Math. Fak.)

1946-1950 (1953) Nat.-Math. Fak.

Experimentalphysik

* o8. Jan. 1891 Oranienburg (bei Berlin)

$\dagger \quad$ o8. Febr. 1957 Heidelberg ev.

V Friedrich B., Uhrmacher

M Charlotte geb. Hartung, Schneiderin

$\infty$ 6. Juli 1920 Barbara geb. Below (1893-1951) T von N. Below, Stadtingenieur in Moskau (griechisch-orthodox)

K $\quad 2 \mathrm{~T}$

Lb Berlin: Seit WS 1908/o9 Studium der Mathematik, Naturwiss. an U; 29. April 1913 Staatsexamen für Lehramt an höheren Schulen; 1. Juni 1913-1. Juni 1918 Assistent im Laboratorium für Radioaktivität an Physikal.-Technischer Reichsanstalt; 15. Juli 1914 Dr. phil. an U.

16. Sept. 1914-23. Juli 1915 Kriegsdienst als Freiwilliger; 23. Juli 1915-28. Juli 1920 („aus Sibirien entwichen“, s. UAH PA 3378) in russischer Kriegsgefangenschaft.

Physikal.-Technische Reichsanstalt Berlin: Juli 1920 Wiederaufnahme der Tätigkeit als Regierungsrat (Ern. rückwirkend vom 1. Juni 1918); Okt. 1925-Okt. 1930 Leiter des Laboratoriums für Radioaktivität. • In dieser Zeit:

U Berlin: 27. Juli 1925 Habilitation; seit 3. Juni 1929 nichtbeamteter a. o. Prof.

U Gießen: Seit 1. Nov. 1930 o. Prof. und Direktor des Physikal. Inst.

UH: 9. Juli 1932 Ern. zum o. Prof. und Direktor des Physikal. und Radiolog. Inst. als Nachf. von Philipp Lenard; 1. Okt. 1932 Dienstantritt; 18. Febr. 1933 Antrittsvorlesung; Nov. 1934 Ruf an U Göttingen abgelehnt; 17. Jan. 1934 B. bittet um Entlassung aus dem badischen Staatsdienst zum 1. April 1934, um Berufung an das Kaiser-Wilhelm Inst. zu folgen; 22. Febr. 1934 B. zieht sein Entlassungs- gesuch zurück, da die endgültige Genehmigung vom Reichsministerium des Innern für den Wechsel noch nicht vorliegt; 3.-31. März 1934 Dienstbehinderung durch Krankheit; 22. März 1934 Bestätigung des Entlassungsgesuchs durch Reichsminister des Innern; seit 1. April 1934 o. HonorarProf.; 1934-1946 keine Vorlesungsankündigungen; Aug. 1936 Ruf an U Leipzig abgelehnt; 29. Juni 1937 „Nachweis des abgelegten Treugelöbnisses gegenüber dem Führer Adolf Hitler" vor Rektor Ernst Krieck, in: UAH PA 3378; 2./3.-4. Juni 1945 Inhaftierung durch Amerikaner; 15. Jan. 1946 Entlassung durch amerik. Militärregierung; 25. Febr. 1946 Wiedereinsetzung (s. UAH B-3029/13); 30. April 1946 Ern. zum o. Prof. und Direktor des (I.) Physikal. U-Inst. (hauptamtlich) und (in Personalunion) Direktor der seit 1934 von ihm geleiteten Abt. am Kaiser-Wilhelm-Inst. (nebenamtlich; siehe unten); 22. Juli 1948 Berufung zum wiss. Berater für die Militärregierung des Landes Württemberg-Baden; SS 1950 letzte Vorlesungsankündigung; seit 28. März 1951 Beamter auf Lebenszeit; 3. Juli 1953 auf eigenen Antrag Entlassung aus Staatsdienst. • In dieser Zeit:

Kaiser-Wilhelm-Inst. (seit 1951 Max-Planck-Inst.) für med. Forschung in H: 1. April 1934-1957 Direktor des Inst. für Physik als Nachf. von Wilhelm Hausser; Vorträge: u. a. Aug. 1938 Cambridge, Juni 1939 Chicago.

1954 Nobelpreis für Physik (zus. mit Max Born (1882-1970)), s. http://www.nobelprize.org/nobel_ prizes/physics/laureates/1954/bothe-bio.html

Anmerkung des NS-Studentenführers Hans Himmel $\left({ }^{*} 1897 \dagger\right.$ nach 1970$)$ auf e. Brief des Rektors Wilhelm Groh vom 24. Jan. 1934, in dem Groh den Weggang B.s von der Universität bedauert: „B. wird ja wohl Honorarprofessor werden und deshalb ist wohl größeres Gelobe nicht am Platze" (aus: UAH PA 3378).

1943 baut B. zusammen mit seinem Assistenten Wolfgang Gentner (siehe Drüll (2009) S. 218f.) das erste Zyklotron (Teilchenbeschleuniger) in Deutschland. 1943 nimmt er es in seinem Institut für Physik am Kaiser-Wilhelm-Institut für med. Forschung in $\mathrm{H}$ in Probebetrieb. 
Jan. 1948-Okt. 1950 Vorsitzender der Physikalischen Gesellschaft Württemberg-Baden-Pfalz

E Mitglied der Akademie der Wissenschaften: 1932 Leipzig, 1933 Göttingen, 1939 Berlin, 1946 H; 1944 Korr. Mitglied der Dt. Akademie der Luftfahrtforschung (für die Dauer von 5 Jahren); 1952 Ritter der Friedensklasse des Ordens Pour le Mérite für Wissenschaften und Künste; 1953 MaxPlanck-Medaille; 1955 Ehrenmitglied des Verbandes Dt. Physikal. Gesellschaften; 1955 Großes Verdienstkreuz. • 1940 Kriegsverdienstkreuz II. Klasse.

Qu UAH PA 3378 f.; B-3029/2, B-3029/13, B-3029/ 17a. Archiv der Max-Planck-Gesellschaft Berlin: PA Bothe (II. Abt. Rep. 1A) und Nachlaß.

W Atlas typischer Nebelkammerbilder ... Berlin 1940. (Mitverf.) • Künstliche Radioaktivität durch thermische Neutronen bei den seltenen Erden. Göttingen 1944. - Der Physiker und sein Werkzeug. Berlin 1944. - Die Streuung von Elektronen in schrägen Folien. Heidelberg 1952.

L Fleischmann, Rudolf: Zur Entdeckungsgeschichte der künstlichen Kern-y-Strahlung in: Die Naturwiss. 38 (1951); Ders.: W.B. in: ebd. 44 (1957). - Poggendorff 7a (1956) S. 24of. • Hahn, Otto: Gedenkworte für W.B. in: Orden pour le Mérite für Wissenschaft und Künste. Bd. 2: Reden und Gedenkworte. Berlin 1956/57. MaierLeibnitz, Heinz: W. B. in: Semper apertus 3 (1985) S. 405-415. - Jansen (1992a) S. 164 (Register). • Hoffmann, Dieter u. a.: W.B. - Wissenschaftler in vier Reichen. Berlin 1995. Cornwell (2004) S. 562 (Register); Kazemi (2006) S. 29-32; UH im Nationalsozialismus (2006) S. 1247 (Register). • Bonolis, Luisa: W. B. and Bruno Rossi: The birth and development of coincidence methods in cosmic-ray physics in: American journal of physics 79 (2011) 11, S. 1133-1150. - Wissenschaftsatlas der UH (2011) S. 250-252; Deutsche Biographie, s. https://www. deutsche-biographie.de/gnd119335956.html [06.11. 2017].

$P$ Bildarchiv UAH. - Bildarchiv des Archivs der Max-Planck-Gesellschaft Berlin.
Boucke, Ewald August (Pseudonym: Waldow, Erich)

1921-1928 Phil. Fak. 1928-1937 (1938) (Honorar-Prof.) Phil. Fak. Neuere Dt. und Skandinavische Literatur

* 15. Aug. 1871 Bremerhaven

$\dagger$ 05. Jan. 1943 Heidelberg ev.

V Friedrich Wilhelm B. (1834-1921) Lehrer, s. Schmitt (2015) S. $11 \mathrm{f}$.

M Bertha Emilia geb. Geburek (1842-1884), s. Schmitt, S. $11 \mathrm{f}$.

$\varnothing$ 10. Okt. 1896 Florence geb. Benedikt (18661944), s. Schmitt, S. 83,87 f., 91 u. ö.

$\mathrm{K}$ keine

Vw Bruder: Oswald Friedrich (Fred) B. $\left({ }^{*} 1875\right.$ $\dagger$ nach 1936) Instructor of the Commerce and Finance program, anschl. Prof. of Economics an Pennsylvania State U in State College, s. Stark, Werner: History and historians of political economy. Ed. by Charles M. A. Clark. New Brunswick, London 1994. S. 289 (Register); Schmitt (2015) S. 15 f. u. ö.

Lb SS 1890 Studium an U Jena, seit WS 1890/91 Breslau, seit SS 1892 Freiburg/Br.; 1894 Rigorosum, 5. Febr. 1895 (Datum der Promotionsurkunde) Dr. phil. an U Freiburg.

Ann Arbor (Michigan): Seit 1896 Instructor, 19061911 Assistant Prof., 1911-1912 Junior Prof., 19125. März 1918 (unbefristete Beurlaubung nach Eintritt der USA in 1. Weltkrieg) Full Prof. of German an $U$ of Michigan; in dieser Zeit vier Rufe abgelehnt, u. a. Harvard U in Cambridge (Massachusetts) und U of Chicago (Illinois).

Sommer 1920 Rückkehr nach Europa; seit Sept. 1920 in Freiburg/Br.; hier erfolgloser Habilitationsversuch („meine Bemühungen ... wegen etwaiger Habilitation ... haben vorläufig zu nichts geführt, da ich von dem Ordinarius, Herrn Professor [Friedrich Ottomar Eduard] Wilhelm, auf mein Schreiben keine Antwort erhielt" (aus: Schmitt (2015) S. 27). 
UH: 4. Mai 1921 Habilitation; seit 21. Juli 1921 nichtplanm. a.o. Prof.; 21. Febr. 1924 Bewilligung e. Lehrauftragsvergütung durch Ministerium des Kultus und Unterrichts; seit 9. Aug. 1928 o. Honorar-Prof; 14. Aug. 1928 Ministerium stimmt dem Vorschlag des Engeren Senats der U auf Ern. B.s zum Ordinarius zu; die Ern. unterbleibt wohl aus Altersgründen; Reisen: seit Juli 1936 USA, Sept. 1936-Anfang 1937 Japan; WS 1936/37 Beurlaubung von U; 11. Febr. 1937 Versetzung in Ruhestand zum 31. März 1937 in Folge Erreichung der Altersgrenze; 19. April 1937 Verlängerung des Lehrauftrags bis einschl. WS 1937/38.

Die Florence und Ewald Boucke-Stiftung unterstützte 1950-1953/54 unbemittelte Studenten der Musikwissenschaft, s. Schmitt (2015) S. 95 f.

Q $u$ UAH PA 3384; B-5981/1f., B-8910/208, B9522. - GLA Abt. 235, Fasz. 1823. • Nachlaß: UBH. • Auskunft: Universitätsarchiv Freiburg/Br. - Lebensernte. Privatdruck. Heidelberg 1938. (Autobiogr.)

$W$ Wort und Bedeutung in Goethes Sprache. Berlin 1901. (Literar-historische Forschungen. 20.) • Goethes Weltanschauung auf historischer Grundlage. Stuttgart 1908. - Aufklärung, Klassik und Romantik. Braunschweig 1925. • Bibliographie in: Schmitt (2015) S. $97 \mathrm{f}$.

HG Heinrich Heine. Werke. 12 Bde. Berlin 19281930.

L Kürschner (1940/41) Sp. 181; WBIS; Jansen (1992a) S. 164 (Register); UH im Nationalsozialismus (2006) S. 362, 364. • Schmitt, Nicolai Johann: E. August(us) B. Germanist und Schriftsteller zwischen "Neuer Welt" und „Vaterland“ 1871-1943. Heidelberg 2015. • Riecke (2016) S. 142 (Register); Deutsche Biographie, s. https://www.deutschebiographie.de/gnd116271981.html [06.11.2017].

$P$ Bildarchiv UAH.

\section{Brackenhöft, Theodor}

1839-1861 Jur. Fak.

Zivilprozeßrecht, Zivilrecht, Handelsrecht

* 13. Mai 1801 Eutin

$\dagger \quad$ 22. Mai 1861 Heidelberg

ev.-luth.

V Erich Christoph B. ( $†$ nach 1833) Buchhalter

M N.N.

unverheiratet.

Lb Seit 4. Mai 1827 Studium der Rechtswiss. an U Kiel, WS 1827/28-SS 1829 H; 8. Sept. 1829 Dr. iur. an $\mathrm{UH}$.

Hamburg: 1829-1832 Advokat.

Kiel: 4. Mai 1833 Erneut Immatrikulation („zum 2. Mal inscribiert") zum Studium der Rechtswiss. an U (Alter: 31 [!] Jahre); 10. Okt. 1833 Staatsexamen; 1833-1839 Eigenstudien.

UH: 11. Okt. 1839 Habilitation; 1840-1861 a.o. Beisitzer des Spruchkollegiums der Jur. Fak; seit 9. Juli 1852 a. o. Prof.

Qu UAH PA 1383. - Matrikel Kiel (1915) S. $216 \mathrm{f}$. (hier Geb.-Datum und -ort: 13.05.1801 Eutin), 268f. (Matrikeleintrag vom 04.05.1833). Briefe: UBH. • Ergebnislose Anfragen: Ev.-Luth. Kirchenkreis Ostholstein in Neustadt (kein Nachweis in Eutiner Taufbüchern 180o-1815); Erzbistum Hamburg - Erzbischöfliches Generalvikariat - Abt. Recht, Diözesanarchiv/Zwischenarchiv in Hamburg (kein Nachweis im Taufbuch der Lübecker kath. Gemeinde, zuständig für Eutiner Katholiken).

$W$ Die Identität und materielle Connexität der Rechtsverhältnisse. Göttingen 1839. - Erörterungen über die Materien des allgemeinen Theils von Linde's Lehrbuch des deutschen gemeinen Civilprocesses. Leipzig 1842. • Die Grundlagen des gemeinen deutschen Rechts. Würzburg 1851.

$L$ ADB 3 (1876) S. 233; WBIS; Jammers (1964) S. $56 \mathrm{f} ., 177$; Schroeder (2010) S. $108 \mathrm{f}$. 


\section{Brandt, Samuel David Friedrich Ludwig}

1877-1904 Phil. Fak. 1904-1919 (1935) (Honorar-Prof.) Phil. Fak.

Klassische Philologie

* o1. Mai 1848 Saarbrücken

$\dagger$ 18. Aug. 1938 Heidelberg

ev.

V Martin Gottlieb Wilhelm B. (1818-1894) Direktor e. Höheren Töchterschule

M Auguste Mathilde geb. Neustetel (1822-1894) $\mathrm{T}$ von Regine (Julie) Jolberg geb. Zimmern verw. Neustetel (180o-1870) Begründerin u. a. von Kindertagesstätten, s. WBIS, NDB 10 (1974) S. 585 f.; Hauff, Adelheid M. von: Regine Jolberg ... Leben, Werk und Pädagogik. Das ganze Wesen der Kinderpflege ist Liebe. Heidelberg 2002; BBKL XXI (2003) Sp. 718-727; Bruder von Regine Jolberg: (siehe) Sigmund Zimmern

๑ 16. Aug. 1881 Elisabeth geb. Säbel (1857-1934)

K 4 S: u.a. Otto B. (1892-1935), u. a. seit 1928 planm. a.o. Prof., 1934-1935 Prof. für Neuere Geschichte Erlangen, s. NDB 2 (1955) S. 533, Willett (2001) S. 195, 199 u. ö., Professoren Erlangen (2009) S. $22 \mathrm{f}$.

Vw Bruder: Dr. phil. Paul Eduard Karl B. (18611932) (Pseudonym: Hans Licht) Gymnasiallehrer und -direktor, Kunsthistoriker; Verfasser von: Sehen und Erkennen - Eine Anleitung $\mathrm{zu}$ vergleichender Kunstbetrachtung. Leipzig 1910. 13. Aufl. Stuttgart 1968; siehe WBIS; Wiesenthal, Max: P. B. † in: Das humanistische Gymnasium 43 (1932) S. 135 f.

Lb Seit WS 1867/68 Studium der Theologie, Philologie an U Berlin, seit WS 1868/69 Halle-Wittenberg, seit SS 1870 Bonn; 1870/71 Kriegsteilnahme während des Deutsch-Französischen Krieges; Ostern 1871 I. theol. Examen in Koblenz.

1871-1873 Lehrer im Hause des Färbereibesitzers August Weyermann auf Schloß Hagerhof in (Bad) Honnef; 31. Mai 1872 Dr. phil. an U Leipzig; 1. Febr. 1873 Oberlehrerprüfung in Bonn; SS 1873-SS 1874 Forts. des Studiums der Philologie an UH.
Seit Herbst 1877 Hilfslehrer, seit 1883 Prof. am Lyceum, 1894 (Umbenennung)-1913 (Pensionierung) am Gymnasium (heute: Kurfürst-FriedrichGymnasium „KFG“). • In dieser Zeit:

UH: 30. Juli 1877 Habilitation; 1878-1919 Assistent am Philolog. Seminar; seit 4. Jan. 1883 a. o. Prof.; 1904-1919 Leiter des Philolog. Proseminars; seit 26. Febr. 1904 Honorar-Prof.; seit 21. Febr. 1908 o. Honorar-Prof.; SS 1919 letzte Vorlesungsankündigung; 31. Dez. 1935 Entziehung der Lehrbefugnis aus rassischen Gründen.

1917 Geh. Hofrat

E 1923 O. Mitglied der Wiss. Gesellschaft Straßburg. 1899 D. theol. UH. 1905 Ritterkreuz I. Klasse des Ordens vom Zähringer Löwen.

Qu UAH PA 3392; RA 6375, 6827. GLA Abt. 235, Fasz. 1825. • Briefe: UBH.

$W$ Eclogae poetarum Latinorum. Leipzig 1881. 3. Aufl. 1910. Eumenius von Augustodunum. Freiburg/Br. 1882. • Siehe auch Das „Goldene Buch“ des KFG (1994) S. $99 \mathrm{f}$.

HG Lucii Caeli Firmiani Lactanti opera omnia. 3 Bde. Leipzig 1890-1897.

L Kürschner 1 (1925) Sp. 97, (1931) Sp. 289; WBIS; NDB 2 (1955) S. 533; Jansen (1992a) S. 164 (Register); Das "Goldene Buch" des KFG (1994) S. 98-100 u. ö.; Deutsche Biographie, s. https:// www.deutsche-biographie.de/gnd116406933.html [06.11. 2017].

P Bildarchiv UAH; graph. Slg. UBH.

Saarbrücken: 1874-1877 Gymnasiallehrer. 


\section{Brauer, August Ludolph}

1897-1904 Med. Fak.

Innere Medizin

* 01. Juli 1865 Rittergut Hohenhausen (Kreis Thorn; heute: Toruń, Polen)

$\dagger$ 25. Nov. 1951 München

ev.

V August Wilhelm B. (1840-1926) Landwirt, Kaufmann

M Josephine Emma geb. Chopard (1841-1873)

$\infty$ 14. Sept. 1897 Juliane (Julie) geb. Fritsch (18771945) $T$ von Heinrich F. (1844-1915), u.a. 1883-1910 o. Prof. für Gynäkologie Bonn, s. Verzeichnis Bonn (1968) S. 82, Catalogus prof. Halensis online, WBIS

$\mathrm{K} \quad 3 \mathrm{~S}, 2 \mathrm{~T}$

Lb Seit WS 1885/86 Studium an U Bonn, anschl. Marburg, München, Freiburg/Br.

Freiburg/Br:: WS 1891/92 Staatsexamen; Frühjahr 1892 Dr. med. an U.

1892-1894 Schiffsarzt.

Assistent an Med. Poliklinik: Seit April 1894 Bonn, seit Jan. 1895 H, Okt. 1895-Juli 1896 Bonn.

UH: Seit Aug. 1896 Assistent an Med. Ambulanz; 31. Juli 1897 Habilitation; seit 5. Aug. 1901 nichtetatm. a. o. Prof.

U Marburg: Seit 16. Aug. 1904 etatm. a. o. Prof. und bis 1910 Leiter der Med. Poliklinik; seit 14. Aug. 1905 persönlicher Ordinarius; 1. Okt. 1905-1910 Direktor der Med. U-Klinik; seit 2. Juni 1906 etatm. o. Prof.; 1910 Ruf an U Greifswald abgelehnt.

Hamburg-Eppendorf: 1. Jan. 1911-1934 (Ruhestand) Direktor des Allg. Krankenhauses; 19141918 beratender Internist in Polen, Palästina, Türkei.

U Hamburg: 1919-1934 (Ruhestand) o. Prof. • In dieser Zeit:
Hamburg: 1927 Begünder des Instituts für medizinische Forschung auf dem Gebiet der Luftfahrt, 1931 umbenannt in Institut für Luftfahrtmedizin und Klimaforschung, s. hierzu Harsch, Viktor: L.B., German aeromedical pioneer in: Aviation, Space, and Environmental Medicine 75 (2004) S. 705-707.

Frankfurt/M.: 1936 Gründer und bis 1942 Vorsitzender des „Forschungsinstituts für Arbeitsgestaltung, Altern und Aufbrauch e. V." mit jeweils einer Abt. in Frankfurt und Wiesbaden, s. hierzu Magistratsakten (Signatur 8.978) zum Forschungsinstitut für Arbeitsgestaltung ... e. V., Wiesbaden (19361942) im Institut für Stadtgeschichte Frankfurt/M.

München: Seit 1947 Direktor des Tuberkulose-Forschungs-Instituts.

E 1910 Korr. Mitglied der Königl.-Ungarischen Gesellschaft der Ärzte in Budapest; Korr. Mitglied der Akademie: Stockholm, Florenz, Rom, Kopenhagen; 1932 Mitglied der Dt. Akademie der Naturforscher Leopoldina Halle/S.

Qu UAH PA 1384; Fak.-Akte H-III-111/126 fol. 96r-133v. - GLA Abt. 235, Fasz. 1827. - Briefe: UBH. - Siehe auch Archiv der Dt. Akademie der Naturforscher Leopoldina Halle/S.

$W$ Die Erfolge der Cardiolysis in: Münchener Med. Wochenschrift 14 (1902). - Die Erkennung und Verhütung des Fleckfiebers und Rückfallfiebers. Würzburg 1915. 2. Aufl. 1916. Die Ruhr, ihr Wesen und ihre Behandlung. Berlin 1918. 2. Aufl. 1922. Die Herzchirurgie unter Berücksichtigung der physiologischen Fragestellungen in: Brauer, Ludolph u. a.: Handbuch der normalen und pathologischen Physiologie VII, 2 (1920). • Die wissenschaftlichen Grundlagen der Lungenkollapstherapie. Hamburg 1930.

MHG 1938 Zeitschrift für Luftfahrtmedizin. • Handbuch der Tuberkulose. Leipzig 1914. 3. Aufl. 1923.

$L$ NDB 2 (1971) S. 540 f.; Catalogus prof. Marburgensis 2 (1979) S. 206 f.; Chronik Ärzte H (1985) S. 123; WBIS. - Bedenbecker, Claudia: L. B. ... als 
Internist und Wissenschaftsreformer. Werdegang und Anfangsjahre als Ärztlicher Direktor des Allg. Krankenhauses Eppendorf in Hamburg. Med. Diss. Hamburg 2015. Online unter http://nbn-resolving. de/urn/resolver.pl?urn=urn:nbn:de:gbv:18-75329

$P$ Bildarchiv UAH.

\section{Braun, Christian Heinrich}

1875-1884 Med. Fak.

Chirurgie

* 18. Febr. 1847 Beerfelden (bei Erbach, Hessen)

$\dagger$ 10. Mai 1911 Göttingen

ㅁ Heidelberg

ev.

V Ludwig Albrecht B. (1797-1869) Pfarrer, s. WBIS

M Luise Katharine geb. Rinck (2. Ehefrau)

$\infty$ Klara Julie Adelheid Kathinka Elisabetha geb. von Dusch (1854-1887), s. Stumm (2012) S. 22; T von: (siehe) Theodor von $\mathrm{D}$.

$\mathrm{K} \quad 1 \mathrm{~S}, 2 \mathrm{~T}$

Lb Seit WS 1864/65 Studium an U Gießen, anschl. Berlin; 1869-1870 Konservator am Patholog.-Anatom. Inst. der U Gießen; 1870/71 Unterarzt während des Deutsch-Französischen Krieges.

U Gießen: 1. Okt. 1871-1. April 1874 Prosektor am Anatom. Inst. und Assistent am Physiolog. Inst.; 6. Febr. 1872 Dr. med.; 23. Febr. 1872 Approbation; 3. Mai 1873 Habilitation für Anatomie.

UH: Okt. 1874-Okt. 1879 Assistent an Chirurg. UKlinik; 31. Juli 1875 Habilitation für Chirurgie; seit 28. Dez. 1878 a. o. Prof.; seit Okt. 1879 Assistent an Chirurg. Poliklinik.

Mannheim: Seit 1. Mai 1884 dirigierender Arzt der Chirurg. Abt. am Städtischen Krankenhaus.

U Jena: Seit WS $1884 / 85$ o. Prof. und Direktor der Chirurg. Klinik.
U Marburg: Seit SS 1888 o. Prof. und Direktor der Chirurg. Klinik.

U Königsberg (Preußen): Seit WS 1890/91 o. Prof. und Direktor der Chirurg. Klinik.

U Göttingen: Seit 1. Dez. 1895 o. Prof. und Direktor der Chirurg. Klinik und Poliklinik.

1891 Medizinalrat; 1894 Geh. Medizinalrat

E 1888 Mitglied der Dt. Akademie der Naturforscher Leopoldina Halle/S.

Qu UAH PA 1385. Siehe auch Archiv der Dt. Akademie der Naturforscher Leopoldina Halle/S.

$W$ Über Gastro-Enterostomie und gleichzeitig ausgeführte Entero-Anastomose in: Verh. der Dt. Gesellschaft für Chirurgie 21 (1892) und in: Langenbecks Archiv für Chirurgie 45 (1893). • Über den Verschluß eines perforierten Magengeschwürs durch Netz in: Zentralblatt für Chirurgie 24 (1897). - Demonstration eines Präparates einer elf Monate nach der Ausführung der GastroEnterostomie entstandenen Perforation des Jejunum in: Verh. der Dt. Gesellschaft für Chirurgie 28 (1899).

$L$ Catalogus prof. Marburgensis 1 (1927) S. 195 f.; WBIS; Catalogus prof. Gottingensium (1962) S. 77; Leier (1977) S. 94-100; Chronik Ärzte H (1985) S. 123. Semler, Norbert: Leben und Wirken des Chirurgen C.H.B. Diss. Göttingen 1989. - Tilitzki 1 (2012) S. 784 (Register); Deutsche Biographie, s. https://www.deutsche-biographie.de/gnd116406 933.html [06.11. 2017].

P Leier (1977); Tilitzki 1 (2012). 


\section{Braun, Friedrich Wilhelm Stefan Jacob}

1917-1923 Theol. Fak.

Kirchengeschichte

* 29. Juli 1873 Aglasterhausen (bei Mosbach, Baden)

$\dagger$ 19. April 1923 Neckargemünd ev.

V Karl Ludwig B. (1831-1882) Steuerkommissär

M Susanna Margaretha geb. Mangold

( 24. Nov. 1908 Elise geb. Müller $\left({ }^{\star} 1879\right)$

$\mathrm{K} \quad 2 \mathrm{~S}, 1 \mathrm{~T}$

Lb Seit WS 1893/94 Studium an UH, seit WS 1894/95 Halle-Wittenberg, seit WS 1895/96 Erlangen, WS 1896/97-WS 1897/98 H; Frühjahr 1898 theol. Staatsexamen in Karlsruhe; 1898 Ordination.

H: 1898 Erzieher des Prinzen Wilhelm Ernst von Sachsen-Weimar-Eisenach (1876-1923).

Seit 1899 Vikar in Donaueschingen; seit 1901 Stadtvikar in Baden-Baden; seit 1905 Tätigkeit im Sekretariat des Oberkirchenrates in Karlsruhe; 19061908 Pfarrverwalter in verschiedenen Orten.

U Straßburg: 1907 Lizentiatenprüfung.

Pfarrer: Seit 1. Dez. 1908 Michelfeld (bei Sinsheim), Juli 1917-April 1923 Neckargemünd. • In dieser Zeit:

UH: 28. Juli 1917 Habilitation; seit 1. Okt. 1917 Repetent an Theol. Fak. mit e. Vergütung von jährl. 1000.- Mark; seit 1. Okt. 1917 „Lehrauftrag zur Suppletur im theol. Unterricht insbesondere auf dem Gebiete der Kirchengeschichte" mit e. Jahresvergütung von 2000.- Mark (aus: UAH RA 6754 fol. 9r); seit 12. Okt. 1917 nichtetatm. a. o. Prof. in Nachf. von Hermann Strathmann; 1920-1923 ( $\dagger)$ nichtplanm. a. o. Prof.
Qu UAH PA 3397; RA 5182, 5218, 5225, 6753f. • GLA Abt. 235, Fasz. 1829.

$W$ Die Bedeutung der Concupiscenz in Luthers Leben und Lehre. Berlin 1908. • Der Krieg und das christliche Gewissen. Karlsruhe 1915. • Siehe auch BBKL.

$L$ Badisches Pfarrerbuch 2 (1939) S. 75; Jansen (1992a) S. 164 (Register); Fix (1994) S. 121-123; BBKL XVII (200o) Sp. 164-171; Deutsche Biographie, s. https://www.deutsche-biographie.de/gnd 1020053208.html [06.11. 2017].

$P$ Bildarchiv UAH.

\section{Braune, Theodor Wilhelm}

1888-1919 Phil. Fak.

1919-1921 (Honorar-Prof.) Phil. Fak.

Germanische Philologie

* 20. Febr. 1850 Großthiemig (Brandenburg)

$\dagger$ 10. Nov. 1926 Heidelberg ev.

V Gottfried Wilhelm B. (1810-1874) Pfarrer

M Marie Henriette geb. Elste $\left({ }^{\star} 1822\right)$

๑ 29. Sept. 1879 Sophie Elisabeth Luise geb. Lange (1858-1920/21) T von Christian Conrad Ludwig L. (1825-1885), u. a. seit 1855 o. Prof. für Klassische Philologie Prag, seit 1859 Gießen, seit 1871 Leipzig, s. WBIS, Professorenkatalog Leipzig online

K $3 \mathrm{~T}$ (davon 2 T vorzeitig †): Gertrud B. (18841973), s. Die Pfälzische Landesbibliothek 19211971. Aus Geschichte und Gegenwart. Hrsg. von Wolfgang Metz. Speyer 1971. S. 61f.; Ehefrau von: (siehe) Robert Petsch. 2 S (davon $1 \mathrm{~S}$ früh $\dagger$ ): Hermann B. (1886-1977), u. a. seit 1924 a.o. Prof., 1927-1955 o. Prof. für Chemie TH Hannover, s. Wer ist wer (1962) S. 161, WBIS 
Vw Schwäger: Konrad Johann Friedrich Wilhelm (von) Lange (1855-1921), u. a. seit 1893 Prof. für Kunstgeschichte Königsberg (Preußen), seit 1894 Tübingen, s. NDB 13 (1982) S. 550 f.; Mieh lich, Almut: K.L. Mitbegründer des Bundes für Heimatschutz in Württemberg in: Schwäbische Heimat 55 (2004) S. 202-205; Skladny, Helene: Ästhetische Bildung und Erziehung in der Schule ... 2. Aufl. München 2012. S. 217242. - Ludwig Gustav Lange (1863-1936) Physiker, s. WBIS, NDB 13 (1982) S. $551 \mathrm{f}$.

Lb U Leipzig: Seit 1869 Studium; 16. Juli 1872 Dr. phil.; 1873-1880 Kustos an UB; 30. Okt. 1874 Habilitation; seit 5. Febr. 1877 a. o. Prof.; seit 1. Jan. 188o a. o. Prof. mit Staatsdienereigenschaft.

U Gießen: Seit 20. März 188o o. Prof. für Dt. Sprache und Literatur (Nachf.: (siehe) Otto Behaghel); Rufe an U abgelehnt: Kiel, SS 1887 Halle-Wittenberg, WS 1887/88 Tübingen.

UH: 24. März 1888 Ern. zum o. Prof. für Germanische Sprache und Literatur sowie zum Direktor, seit 21. Juli 1890 Mit-Direktor (zus. mit Friedrich Neumann) des Germanisch-Romanischen Seminars als Nachf. von Karl Bartsch mit e. jährl. Besoldung von „600o.- Mark nebst dem gesetzlichen Wohnungsgeldzuschuß von 66o.- Mark, dem Ersatz der Umzugskosten im Reservalbetrag von 1000.- Mark und des Einkaufsgeldes in die Witwenkasse" (aus: Brief des Ministeriums der Justiz, des Kultus und Unterrichts in Karlsruhe vom 28. März 1888 in: UAH RA 6839); 1. Okt. 1919 Ruhestand, gleichzeitig Ern. zum o. Honorar-Prof.; SS 1921 letzte Vorlesungsankündigung.

1904/05 Prorektor der UH; 1891, 1903 Wahlsenator der UH; 1896/97, 1916/17 Dekan der Phil. Fak. der $\mathrm{UH}$

1917-1923 Vorstand der Akademischen Lesehalle in Heidelberg

1902 Hofrat; 1905 Geh. Hofrat; 1917 Geh. Rat II. Klasse

E Mitglied der Akademie der Wissenschaften: Straßburg, 1904 München, 1909 H, 1919 Göttin- gen. 1899 Ritterkreuz I. Klasse, 1910 Ritterkreuz mit Eichenlaub des Ordens vom Zähringer Löwen.

Qu UAH PA 1387; RA 6113, 6419, 6839; Fak.-Akte H-IV-102/119 fol. 126v, 127r; B-6124 (Lesehalle). • GLA Abt. 235, Fasz. 1830. Briefe: UBH.

W Althochdeutsches Lesebuch. Halle/S. 1875. 12. Aufl. 1952. - Gotische Grammatik. Halle/S. 1880. 20. Aufl. 2004. Althochdeutsche Grammatik. 2 T. Halle/S. 1886. 15. Aufl. 2004. • Die Handschriftenverhältnisse des Nibelungenliedes in: Beiträge zur Geschichte der dt. Sprache und Literatur 25 (1900) S. 1-220, 27 (1902) S. 542-564, 36 (1910) S. $540-551$.

MG, $M H G$ 1874-1926 Beiträge zur Geschichte der dt. Sprache und Literatur.

$L$ NDB 2 (1955) S. 558 f. (mit Werkverz.); Lehmann (1967) S. 225-227, 234; Burkhardt (1976) S. 38 f. u. ö. - Fromm, Hans: W. B. in: Beiträge zur Geschichte der dt. Sprache und Literatur 100 (1978) H. 1, S. 4-39. • Jansen (1992a) S. 164 (Register); Wennemuth (1994) S. 632 (Register); Int. Germanistenlexikon 1 (2003) S. 265 f. Wilhelm Scherer: Briefe und Dokumente aus den Jahren 1853 bis 1886. Hrsg. ... von Mirko Nottscheid ... Göttingen 2005. S. 418 (Register). Kriegstagebuch K. Hampe (2007) S. 947 (Register); 100 Jahre Germanistik in Hamburg (2011) S. 86 f., 451 u.ö.; Professorenkatalog Leipzig online; Riecke (2016) S. 142 (Register).

$P$ Bildarchiv UAH; NDB.

\section{Braus, Daniel Abraham Otto Hermann}

1901-1921 Med. Fak.

Anatomie

* 15. Aug. 1868 Burtscheid (heute: Stadtteil von Aachen)

$\dagger$ 28. Nov. 1924 Würzburg

ㅁ Heidelberg

ev. 
V Dr. med. Otto Berthold Ernst Alexander B. (1835-1906) Arzt

M Bertha Ernestine geb. Lamberts (1844-1914)

( 25. Febr. 1899 Elisabeth (Lisbeth) Caroline Hermine Cäcilie geb. Fürbringer (1879-1929), s. über Elisabeth Braus in: Im Schaffen geniessen: der Briefwechsel der Kulturwissenschaftler Eberhard und Maria Luise Gothein ... Hrsg. von Michael Maurer ... Köln 2006. S. 447, 449, 647; T von: (siehe) Max F.

K 3 T: u. a. Hedwig B. verh. Haller-Braus (190o1989) Bildhauerin, s. Atelier Hermann Haller: Bellerivestrasse/Höschgasse Zürich. Hrsg. von der Präsidialabteilung der Stadt Zürich zur Ausstellung der Werke von Hermann Haller und Hedwig Braus ... Zürich 6. Juli bis 24. September 1989; Ehefrau von Hermann Haller (1880-1950) Schweizer Bildhauer, s. Apel, Maria-Theresia: H.H. Leben und Werk. Münster 1996.

Lb Seit WS 1888/89 Studium an U Jena; 24. Febr. 1890 ärztl. Vorprüfung in Jena; seit SS 1890 Forts. des Studiums an U Bonn, SS $1891 \mathrm{H}$, seit WS 1891/92 Jena.

Militärdienstpflicht als Einjährig-Freiwilliger: 1. April-1. Okt. 1890 Bonn, 1. April-1. Okt. 1893 Aachen.

U Jena: 23. Sept. 1892 Dr. med.; 4. März 1893 Staatsprüfung; seit 1. April 1894 Assistent am Anatom. Inst.; Juli 1896 Habilitation.

U Würzburg: Seit 1. Okt. 1899 Privat-Dozent und Prosektor am Inst. für Embryologie, Histologie und Vgl. Anatomie.

UH: Seit 6. März 1901 a. o. Prof. und Prosektor am Anatom. Inst.; seit 24. Mai 1912 o. Prof. und Direktor des Anatom. Inst. als Nachf. von Max Fürbringer.

U Würzburg: 1. Okt. 1921-28. Nov. 1924 ( $\dagger$ ) o. Prof. und Direktor des Anatom. Inst.

1914/15 Dekan der Med. Fak. der UH

Siehe auch Johannes Rissom: Eintrag unter Z[itat] (3)
E 1903/04 Mitglied der Dt. Akademie der Naturforscher Leopoldina Halle/S.; 1916 Mitglied der Akademie der Wissenschaften $\mathrm{H}$.

Qu UAH PA 852, 3398; RA 6169, 6173, 6783f.; Fak.-Akte H-III-621/1. • Briefe H.B.s in: Ernst Haeckel Online-Briefedition - Inst. für Geschichte der Medizin ... der U Jena. • Teil-Nachlaß: UB Frankfurt/M.; UBH, siehe hierzu Verzeichnis des Teil-Nachlasses Hermann Braus - Heid. Hs. 3915. Bearb. von Angelika Günzburger. UB Heidelberg 1985. Siehe auch Archiv der Dt. Akademie der Naturforscher Leopoldina Halle/S. • Mitteilungen: Frau Margret von Eichmann geb. Braus ( $\dagger$ ), Heidelberg.

$W$ Die Entstehung der Nervenbahnen. Leipzig 1911. (Sammlung wiss. Vorträge auf dem Gebiet der Naturwiss. und der Medizin. 3.) - Anatomie des Menschen. 2 Bde. Berlin 1921-1924. Bd. 3: 1932 (fortgeführt von Curt Elze). Bd. 1: 3. Aufl. 1954. Bd. 2: 3. Aufl. 1956. Bd. 3: 2. Aufl. 1960.

$L$ Dem Gedächtnis an H.B. von Schülern und Freunden gewidmet. Berlin 1925. (Wilhelm Roux' Archiv für Entwicklungsmechanik der Organismen. 106.) • König, Fritz: H. B. †in: Verhandlungen der Physikalisch-Medizinischen Gesellschaft zu Würzburg. N.F. 50,3. Würzburg 1925. S. 100123. NDB 2 (1955) S. 562 f. (mit Werkverz.); Chronik Ärzte H (1985) S. 123; WBIS. • Jansen (1992a) S. 164 (Register); Goerttler 2 (2004) S. 20; Kriegstagebuch K. Hampe (2007) S. 947 (Register); Doll (2014) S. 261-263 u. ö.; Hier freut sich der Tod (2013) S. 75-79, 105 u. ö. • Über H.B. in: Muschong, Nikolaus: Hans Virchow ...: Leben und Werk eines Anatomen und Anthropologen. Göttingen 2013. S. 505 (Register). • Doll/Kirsch/Eckart (2017) S. 60, 113.

$P$ Bildarchiv UAH; NDB; Chronik Ärzte H. 


\section{Bredig, Georg}

1901-1910 Nat.-Math. Fak.

Physikalische Chemie

* o1. Okt. 1868 Glogau (Niederschlesien; heute: Głogów, Polen)

$\dagger$ 24. April 1944 New York

mosaisch, später ev.

V Max B. (1842-1899) Kaufmann

M Ernestine geb. Troplowitz (1847-1930)

@ 3. Jan. 1901 Rosa geb. Fraenkel (1877-1933)

$\mathrm{K} \quad 1 \mathrm{~S}, 1 \mathrm{~T}$

Lb SS 1886 Studium der Naturwiss. an U Freiburg/ Br., WS 1886/87-1894 Studium der Chemie, Physik an U Berlin, 1899-1901 auch Studium der Medizin an U Leipzig; 7. März 1894 Dr. phil. an U Leipzig; 1894-1895 Eigenstudien in Amsterdam, Paris, Stockholm.

U Leipzig: Seit 1. Nov. 1895 Assistent am Physikalisch-Chemischen Inst.; 9. Febr. 1901 Habilitation.

UH: Seit WS 1901/o2 etatm a. o. Prof. (erster Fachvertreter für Physikalische Chemie) und Abt.-Vorsteher am Chemischen Laboratorium.

ETH Zürich: Seit SS 1910 o. Prof. und Leiter des Labors für Physikalische Chemie und Elektrochemie.

TH Karlsruhe: Seit 1. Okt. 1911 o. Prof. für Physikalische Chemie und Elektrochemie; 1933 Anfeindungen wegen „undeutscher und schädlicher $\mathrm{Ge}$ sinnung“; 1. Okt. 1933 Emeritierung.

Nov. 1938 kurzzeitige Verhaftung; Herbst 1939 Ausreise in die Niederlande; 1939/40 Entziehung der dt. Staatsangehörigkeit; Frühjahr 1940 Emigration in die USA; 19. Aug. 1940 Aberkennung des Doktorgrades laut dem Gesetz über die Führung akademischer Grade vom 7. Juni 1939.

1898 Begründer der Katalyse-Forschung
E Mitglied der Akademie der Wissenschaften: Leningrad, 1920 Amsterdam, 1924 (1938 Ausschluß) H, 1930 München. 1929 Dr. h.c. U Rostock; 1930 Dr. sc. techn. h.c. ETH Zürich.

$Q u$ UAH PA 1388; RA 6499, 6886. Briefe: UBH. • „Seinen Freunden zur Erinnerung“. Selbstverlag o. O. 1938. (Autobiogr.)

W Anorganische Fermente. Leipzig 1901. • Über die Chemie der extremen Temperaturen. Leipzig 1901. Denkmethoden der Chemie. Leipzig 1923.

HG 1905-1926 Handbuch der angewandten physikalischen Chemie.

L Kürschner (1926) Sp. 190, (1928/29) Sp. 242, (1935) Sp. 147; Dictionary of Emigrés 2 (1983) S. 149 f.; Jansen (1992a) S. 164 (Register). - Wehefritz, Valentin: Pionier der physikalischen Chemie: ... G. B. ... Ein deutsches Gelehrtenschicksal im 20. Jahrhundert. Dortmund 1998. - G. B. und Wilhelm Ostwald in ihren Briefen. Hrsg. von Karl Hansel ... Großbothen 2002. (Mitteilungen der Wilhelm-Ostwald-Gesellschaft ... Sonderheft. 4.) • Vertriebene Mitgl. der Akad. der Wiss. H (2009) S. 3-9; Badische Biographien N. F. VI (2011) S. 4447; Deutsche Biographie, s. https://www.deutschebiographie.de/gnd116469307.html [06.11. 2017].

$P$ Bildarchiv UAH; Vertriebene Mitgl. (2009).

\section{Brie, Siegfried}

1866-1874 Jur. Fak.

Staats- und Kirchenrecht, Staats- und Rechtsgeschichte

* 21. Jan. 1838 Hamburg

$\dagger \quad$ 03. Dez. 1931 Breslau (heute: Wrocław, Polen) mosaisch, später ev.

V Samuel Isaac B. (†vor 1856) Partikulier, Kaufmann

M Jeanette geb. Bromberg

œ 1875 Sophie geb. Schenkel (1850-1887) T von: (siehe) Daniel S. 
( 1889 Emma geb. Karsten, T von Gustav K. (1820-190o), u.a. 1847-1894 o. Prof. für Mineralogie und Physik Kiel, s. NDB 11 (1977) S. 304 f., Biogr. Lexikon für Schleswig-Holstein 12 (2006) S. 249-253; Kröger, Uwe: G.K. und der Anfang einer Eichverwaltung in Schleswig-Holstein 1859 in: Natur- und Landeskunde: Zs. für Schleswig-Holstein ... Husum 2009. S. 16-21.

K 2 T: u.a. Dr. phil. Maria B. verh. Dedo-Brie (1877-1960) Schriftstellerin, u. a. von Novellen, Erzählungen und Gedichten, u. a. „Savonarola in der deutschen Literatur“ (Diss., 1903), „Das Fenster ins Blaue“ (Gedichte, 1939), s. Dt. Literatur-Lexikon - 20. Jhdt. (2003) Bd. 4. Sp. 234. 2 S: u. a. Friedrich Daniel Wilhelm B. (1880-1948), u.a. 1910-1937 (Zwangsemeritierung) o. Prof. für Anglistik Freiburg/Br., 1945 (Rückberufung und Wiedereinsetzung)-1948 o. Prof. ebd., s. NDB 2 (1955) S. 610f.; Hausmann, Frank-Rutger: Anglistik und Amerikanistik im 3. Reich. Frankfurt/M. 2003. S. 446 f.; Vertriebene Mitgl. der Akad. der Wiss. H (2009) S. 11-16.

Lb Seit SS 1856 Studium an UH, seit WS 1857/58 Leipzig, anschl. Berlin; Dez. 1861 Dr. iur. an U Berlin.

Berlin: 1862-1864 Redakteur der Berliner Allg. Zeitung.

UH: 1864-1866 Eigenstudien; 27. Okt. 1866 Habilitation; 6. Sept. 1869 Ern. zum a. o. Prof.

U Rostock: Seit SS 1874 o. Prof.

U Breslau: 1878-1921 o. Prof.

$E$ D. theol.; Dr. rer. pol. h.c.

Qu UAH PA 1391; RA 5278. • Briefe: UBH. • Nachlaß: UB Breslau. - Auskunft: Stadtarchiv Schaffhausen. Mitteilungen: Herr Prof. Dr. Johannes Schenkel, Universität Heidelberg.

W Der Bundesstaat. Abt. 1: Geschichte der Lehre vom Bundesstaat. Leipzig 1874. (Mehr nicht erschienen.) - Theorie der Staatenverbindungen.
Stuttgart 1886. • Die Lehre vom Gewohnheitsrecht. Breslau 1889.

L Kürschner (1928/29) Sp. 251, (1931) Sp. 314, (1935) Sp. 1681; WBIS; Hausmann (2003) S. 446 f.; Schroeder (2010) S. 329-331; Grewolls (2011); Deutsche Biographie, s. https://www.deutschebiographie.de/gnd116507942.html [06.11.2017]; Schroeder (2017) S. 151-157.

$P$ Bildarchiv UAH.

\section{Brinkmann, Carl}

1923-1934 Phil. Fak.

1934 Wirtschaftswiss. Fak.

1935-1942 Staats- und Wirtschaftswiss. Fak.

Nationalökonomie, Finanzwissenschaft

* 19. März 1885 Tilsit (Ostpreußen; heute: Sowetsk, Russische Föderation)

$\dagger$ 20. Mai 1954 Oberstdorf ev.

V Carl B. (1855-1901) Rechtsanwalt; Bürgermeister: 1854-1900 Königsberg (Preußen), 19001901 Berlin, s. Kullnick, Heinz: Berliner und Wahlberliner. Personen und Persönlichkeiten in Berlin 1640-1914. Berlin 1961.

M Eva geb. Krieger, s. Wirtschaftswiss. Fak. Tübingen I (2004) S. 567

๑ 28. Okt. 1915 Eva geb. Strupp $\left({ }^{*} 1894\right)$ Scheidung 1921

๑ 21. März 1921 Johanna (Hanna) geb. Wernicke verw. Ahrens (1898-1954)

K $1 S(† 1941)$

Lb SS 1903 Studium an U Freiburg/Br., seit WS 1903/o4 Göttingen, 1904-1906 Oxford (RhodesStipendium), seit WS 1906/o7 Berlin; 4. Aug. 1908 Dr. phil. an U Berlin.

U Freiburg/Br.: 7. Febr. 1913 Habilitation für Mittlere und Neuere Geschichte.

Berlin: 1915-1923 Legationsrat im Auswärtigen Amt. • In dieser Zeit: 
U Berlin: 7. Jan. 1920 Umhabilitierung und Verleihung der venia legendi für Nationalökonomie; seit 1921 a. o. Prof. für Wirtschaftswiss.

UH: Seit 1. Okt. 1923 o. Prof. als Nachf. von Emil Lederer und Mit-Direktor am Volkswirtschaftl. Seminar (1924 umbenannt in Inst. für Sozial- und Staatswissenschaften), seit 1933 Direktor (als Nachf. von Alfred Weber) des Inst. für Sozial- und Staatswiss. an Phil. Fak., seit Mai 1934 an der neuerrichteten Wirtschaftswiss., seit Jan. 1935 an der Staatsund Wirtschaftswiss. Fak.; WS 1927/28 Gast-Prof. an U Kiel; Okt. 1928-März 1929 Studienreise USA.

U Berlin: 1. April 1942-31. März 1945 (Entlassung) o. Prof.; 1. Jan. 1946-31. März 1947 Lehrstuhlvertr. an U Erlangen.

U Tübingen: 1. April 1947-31. März 1953 (Emeritierung) o. Prof. für Wirtschaftslehre und Soziologie; SS 1953-WS 1953/54 Vertreter seines Lehrstuhls.

E Mitglied der Akademie der Wissenschaften: 1931 H, 1949 München.

Qu UAH PA 3402. • Briefe: UBH.

$W$ Weltpolitik und Weltwirtschaft im 19. Jahrhundert. Bielefeld 1921. 2. Aufl. 1936. - Wirtschaftsund Sozialgeschichte. München 1927. 2. Aufl. 1953. Soziologische Theorie der Revolution. Göttingen 1948. - Siehe Wirtschaftswiss. Fak. Tübingen I (2004) S. 569-574.

L Handels-Hochschule Mannheim 1907-1932 (1932) S. 26; Wirtschaftswiss. Hochschullehrer (1938) S. 28, 331-335 (Bibliographie bis 1937); Professoren Kiel (1956) S. 53 f.; Kosch (1963) S. 164; Jansen (1992) S. 407 (Register); Brintzinger (1996) S. 397 (Register). - Körner, Heiko: C. B. Eine wissenschaftsbiographische Skizze in: Heidelberger Sozial- und Staatswissenschaften (1997) S. 159165. - Wirtschaftswiss. Fak. Tübingen I (2004) S. 567-575 u.ö.; Schultes (2010) S. 123-128 u.ö.; WBIS. - Köster, Roman: Die Wissenschaft der Außenseiter. Die Krise der Nationalökonomie in der Weimarer Republik. Göttingen 2011. - Spenkuch (2016) S. 1309 (Register); Deutsche Biogra- phie, s. https://www.deutsche-biographie.de/gnd11 6520515.html [06.11. 2017].

$P$ Bildarchiv UAH.

\section{Broemser, Philipp}

1930-1934 Med. Fak.

Physiologie

* 20. Juli 1886 Rüdesheim/Rhein

$\dagger$ 11. Nov. 1940 München kath.

V Georg Joseph B. (1846-1916) Arzt

M Anna Friederike geb. Engel (1849-1924)

๑ 15. Sept. 1927 Maria geb. Kunst (1885-1970)

$\mathrm{K}$ keine.

Lb Seit SS 1905 Studium an U Marburg, anschl. Freiburg/Br., München, Berlin, Marburg.

Marburg: 4. Mai 1910 Staatsexamen; 1. Juni 1911 Dr. med. an $\mathrm{U}$.

Berlin: 16. Juni 1911 Approbation.

U München: Seit 1. Aug. 1911 Assistent, 1. April 1919-31. März 1925 Konservator am Physiolog. Inst.; 8. März 1918 Habilitation; seit 16. Okt. 1922 a. o. Prof. In dieser Zeit:

1914-1918 Kriegsdienst.

U Basel: Seit 1. April 1925 o. Prof.

UH: Seit 20. Jan. 1930 o. Prof. und Direktor des Physiolog. Inst. als Nachf. von August Pütter.

U München: Seit SS 1934 o. Prof. und Direktor des Physiolog. Inst. und der Physiolog. Sammlung.

WS 1933/34 Dekan, 1. April 1934 erneut Wahl zum Dekan der Med. Fak. der UH, seit Mai 1934 Dekan: Carl Schneider (siehe Drüll (2009) S. 557 f.) 
E Mitglied der Akademie der Wissenschaften: 1932 H, 1940 München; 1938 Mitglied der Dt. Akademie der Naturforscher Leopoldina Halle/S.

Qu UAH PA 854, 3411. - GLA Abt. 235, Fasz. 1840. - Siehe auch Archiv der Dt. Akademie der Naturforscher Leopoldina Halle/S. • Rektoratsreden - online.

$W$ Neue Methoden der Blutdruck- und Blutstromstärkemessung in: Zs. für Biologie 86 (1927), 88 (1928); Bestimmung des Herzschlagvolumens in: ebd. 90 (1930). - Kurzgefaßtes Lehrbuch der Physiologie. Leipzig 1934. 2. Aufl. 1938. • Grundlagen der Haemodynamik in: Luftfahrtmedizinische Abhandlungen (1938).

MHG 1909-1940 Zs. für Kreislaufforschung.

L NDB 2 (1955) S. 630; Chronik Ärzte H (1985)

S. 123; Zimmermann/Drüll (1990) S. 49 u. ö.; Jansen (1992) S. 407 (Register); Heiber II,2 (1994) S. 833 (Register); Grüttner (2004) S. 29; UH im Nationalsozialismus (2006) S. 1248 (Register); Klee, Personenlexikon (2007) S. 76; WBIS.

$P$ Bildarchiv UAH; NDB; Chronik Ärzte H.

\section{Bronn, Heinrich Georg}

1821-1862 Phil. Fak.

Landwirtschaftslehre, Technologie, Gewerbewissenschaft, Paläontologie, Forstwesen, Zoologie

* o3. März 1800 Ziegelhausen (heute: Stadtteil von Heidelberg)

$\dagger \quad$ 05. Juli 1862 Heidelberg kath.

V Georg Ernst B. (1762-1820) Oberförster

M Elisabeth Margarete geb. Herzberger ( $†$ 1832)

$\infty$ 22. April 1835 Luise geb. Penzel

K ${ }_{4} \mathrm{~S}, 1 \mathrm{~T}$
Vw Bruder: Valentin Heinrich B. (1796-1834) WS 1822/23-SS 1825 Privat-Dozent für Forsttaxation, Forstbotanik, Naturgeschichte der Tiere und Enzyklopädie der Forstwissenschaft UH, seit WS 1825/26 o. Prof. für Forst- und Landwirtschaft Lüttich, seit 1832 o. Prof. für Forstwiss. und Vorstand der neugegründeten Forstschule des Polytechnikums Karlsruhe, s. WBIS, Deutsche Biographie, https://www. deutsche-biographie.de/pnd118178768.html [08.12. 2017].

Lb UH: Seit WS 1817/18 Studium der Philosophie; seit SS 1818 Studium der Kameralwiss.; 24. Jan. 1821 Dr. phil.; 5. Mai 1821 Habilitation; 1824-1827 Studienreisen: Frankreich, Schweiz, Italien; seit 11. Okt. 1827 a.o. Prof. mit Besoldung; Juli-Okt. 1829 Studienreise nach Schweden; seit 24. April 1833 Direktor des Zoolog. Kabinetts als Nachf. von Friedrich Tiedemann; seit 23. Jan. 1838 o. Prof.

\section{Prorektor der UH}

B. übersetzt 1860 erstmals Charles Darwins „Origin of Species“ (1859 erschienen) ins Deutsche (Titel: Über die Entstehung der Arten im Thier- und Pflanzen-Reich durch natürliche Züchtung oder Erhaltung der vollkommensten Rassen im Kampfe um's Daseyn).

1845 Hofrat

$E$ Mitglied: 1832 Dt. Akademie der Naturforscher Leopoldina Halle/S., 1858 Akademie der Wissenschaften München. 1861 Wollaston-Medaille der Geological Society of London. Ritter des Ordens vom Zähringer Löwen.

Qu UAH PA 1393; RA 5342-5344, 5628 f., 5633, 6038 u. o.; Fak.-Akte H-IV-102/16 fol. 43r-48v, 53r, 103r-107r. - GLA Abt. 205, Fasz. 170. • Briefe: UBH. Nachlaß: Germanisches Nationalmuseum Nürnberg. - Siehe auch Archiv der Dt. Akademie der Naturforscher Leopoldina Halle/S.

$W$ System der urweltlichen Pflanzentiere ... Heidelberg 1825 . Ergebnisse meiner naturhistorischöconomischen Reisen. 2 T. Heidelberg, Leipzig 1826-1832. Gaea Heidelbergensis oder Mineralo- 
gische Beschreibung der Gegend von Heidelberg. Heidelberg, Leipzig 1830. - Lethaea Geognostica. Stuttgart 1834. 2. Aufl. 1838. Bronn's Klassen und Ordnungen des Tierreichs. 6 Bde. Leipzig 18591876.

MHG 1830-1862 Jahrbuch für Mineralogie, Geognostik und Petrefaktenkunde.

$L$ NDB 2 (1955) S. 633f. (mit Werkverz.). Baron, Walter: Zur Stellung von H. G. B. in der Geschichte des Evolutionsgedankens in: Sudhoffs Archiv für Geschichte der Medizin und der Naturwissenschaften 45 (1961). • Hoppe, Reinhard: Über H.B. in: 750 Jahre Ziegelhausen. Heidelberg 1970. S. 4245. - Schumacher, Ingrid: Die Entwicklungstheorie des Heidelberger Paläontologen und Zoologen H. G. B. ... Eine naturwissenschaftlich begründete Lehre über das Entstehen und Vergehen der Organismen, ihr Nachweis und ihre Zusammenfassung in allgemeinen geologisch-paläontologischen und morphologisch-systematischen Gesetzmässigkeiten. Diss. Heidelberg 1975. Schmitt (1978) S. 72 u. ö. Moeller, Heinz Friedrich: Zoologisches Museum der Universität Heidelberg. In Zusammenarbeit mit Westermanns Monatshefte. Braunschweig 1985. S. 26 f., 35 f. u. ö. - Querner, Hans: H.G.B. und seine Entwicklungslehre in: Semper apertus 2 (1985) S. 531-540. - WBIS; Weinmann (1999) S. 228; Goerttler 2 (2004) S. 22. • Gliboff, Sander: H. G. B., Ernst Haeckel and the origins of German Darwinism. Cambridge (Massachusetts) 2008.

$P$ Bildarchiv UAH; graph. Slg. UBH.

\section{Brühl, Julius Wilhelm}

1888-189o (Honorar-Prof.) Phil. Fak. 1890-1910 (Honorar-Prof.) Nat.-Math. Fak. Chemie

* 13. Febr. 1850 Warschau (heute: Warszawa, Polen)

$\dagger \quad$ 05. Febr. 1911 Heidelberg (Suizid) mosaisch, später ev.
V Ludwig B. (1821-1867) Industrieller

M Emma geb. Bamberg

๑ 1880 Lili geb. Bamberger (1857-1931)

$\mathrm{K} \quad 1 \mathrm{~S}, 1 \mathrm{~T}$ (früh $\dagger$ )

$L b$ Seit 1868 Studium der Chemie am Polytechnikum Zürich, seit WS 1870/71 Studium auch der Physik an U Berlin.

Polytechnische Schule (seit $188 \mathrm{o}$ TH) Aachen: 1873-1879 Assistent für „Reine Chemie“ am Chemischen Labor; ca. 1874 Habilitation (vor Promotion); 1875 Dr. phil. an U Göttingen.

Technische Akademie Lemberg (heute: Lwiw, Ukraine): Seit Dez. 1879 zunächst Stellvertr., seit 23. Aug. 1880 o. Prof. für Chemische Technologie; Frühjahr 1882 schwere Lungenblutung.

Freiburg/Br.: Seit 1884 Wohnsitz (zur Rekonvaleszenz).

UH: 17 . Nov. 1887 Ern. zum SS 1888 Honorar-Prof. als Nachf. von August Bernthsen; 21. Febr. 1908 Ern. zum o. Honorar-Prof.; SS 1910 B.s letzte Ankündigung im Vorlesungsverzeichnis.

E Mitglied der Kaiserl. Akademie der Wissenschaften Krakau; 1904 Ehrenmitglied der Royal Institution of Great Britain. - Dr. of Science h.c.: 1904 U Cambridge, 1908 Dublin. 1910 Ritterkreuz I. Klasse des Ordens vom Zähringer Löwen.

Qu UAH PA 1397; RA 6499, 6886. • GLA Abt. 235, Fasz. 1842. - Briefe: in: Handschriften, Autographen ... der Staats- und Universitätsbibliothek Göttingen. - Nachlaß: UBH (Signatur: Heid. Hs. 3833). - Auskunft: Hochschularchiv der TH Aachen; Universitätsarchive Göttingen (Phil. Prom. 161, 73) und Freiburg/Br.

$W$ Chemie der fünfgliedrigen heterocyclischen Systeme mit Kohlenstoff-, Sauerstoff-, Schwefel-, Selen- und Stickstoffatomen. Braunschweig 1898. (Mitbearb.) - Chemie der sechsgliedrigen heterocyclischen Systeme. Braunschweig 1899. (Mitbearb.) - Die Entwicklung der Spectrochemie. 
Vortrag gehalten vor der Royal Institution zu London am 26. Mai 1905. (German Edition.) Berlin 1905. Nachdr. Whitefish (Montana) 2010. - Siehe auch Badische Biographien, WBIS.

L NDB 2 (1955) S. 663; WBIS; Badische Biographien N.F. V (2005) S. 31-33; Ruuskanen (2008) S. 108 f.; Autoren der Bunsenbibliothek (2009 online).

$P$ Bildarchiv UAH; NDB; Badische Biographien.

\section{Brünnow, Rudolph Ernst}

1890-1893 Phil. Fak.

(1893-1904 (Honorar-Prof.) Phil. Fak.)

Orientalische Philologie

* o7. Febr. 1858 Ann Arbor (Michigan)

$\dagger$ 14. April 1917 Bar Harbor (Maine) ev.

V Franz Friedrich Ernst B. (1821-1891), u. a. seit 1851 erster Observator an Sternwarte Berlin, seit 1854 Direktor der neuerrichteten Sternwarte in Ann Arbor (Michigan) und Dozent an der 1852 von Henry Phil(l)ip Tappan (siehe unten) gegründeten Ann Arbor School of Astronomers ebd., später stellvertr. Direktor des Dudley-Observatoriums in Schenectady (New York); 1866-1874 Direktor der Sternwarte und Prof. für Astronomie Trinity College in Dublin, s. Hönig, W.: Worte am Sarge des Herrn F. F.E. B. gesprochen ... in Heidelberg. Heidelberg 1891; NDB 2 (1955) S. 667, WBIS; Plotkin, Howard: Henry Tappan, F.B. and the founding of the Ann Arbor School of Astronomers, 1852-1863 in: Annals of Science 37 (1980) No. 3, S. 287-302; Biographical Encyclopedia of Astronomers. Editor-in-chief Thomas Hockey ... New York 2007. S. 179 f.
M Rebecca (Barbie) Lloyd geb. Tappan (18361893), s. Broome Semans (2009) S. 361-363 u. ö. - T von Henry Phil(l)ip T. (1805-1881) Prof. für Philosophie U of the City of New York, 1852 Begründer der Ann Arbor School of Astronomers und 1852-1863 (Entlassung) erster Präsident der U of Michigan in Ann Arbor, danach Wohnsitz in Vevey, s. Perry, Charles M.: H.P.T. Philosopher and University President. Ann Arbor 1933; Wilbee, Victor R.: The Religious Dimensions of Three Presidencies in a State University: Presidents Tappan, Haven and Angell at the University of Michigan. Ann Arbor 1967; Plotkin (1980), Broome Semans (2009) S. 558 (Register)

$\infty$ 1. Juni 1894 Marguerite geb. Beckwith (18721907), s. Broome Semans, S. 107, 488, 492 $\mathrm{K} \quad{ }_{2} \mathrm{~S}, 3 \mathrm{~T}$

Lb Seit ca. 1877 Studium am St. Columba’s College in Whitechapel (bei Dublin), Trinity College in Dublin, anschl. an U Basel, Tübingen, Straßburg; 1880-189o Privat-Gelehrter in Straßburg, Vevey, Oxford und H; 1882 Dr. phil. an U Straßburg.

UH: Seit 12. März 1890 a. o. Prof. mit Staatsdienereigenschaft in Nachf. von Gustav Weil (siehe auch Heinrich Thorbecke); seit 12. Juli 1891 o. Prof.; 15. Okt. 1893 auf eigenen Antrag aus Lehrkörper ausgeschieden; Okt. 1893-Mai 1904 Honorar-Prof. (in der genannten Zeit in den Vorlesungsverzeichnissen als „beurlaubt“ eingetragen).

Seit 6. Okt. 1893 Aufenthalt in New York; seit ca. 1897 Domizil auf dem Familiensitz in Vevey, Chalet Beauval (s. hierzu Ballif, Laurent: Les bains de Vevey ... Lausanne 1997).

1895, 1897, 1898 Studienreisen zus. mit (siehe) Alfred von Domaszewski nach Syrien, Jordanien und in den Libanon (Photos von diesen Reisen, s. Archaeological Archives der Princeton U online).

Princeton U (New Jersey): Seit 1910 o. Prof.

E 1904 Ritterkreuz I. Klasse des Ordens vom Zähringer Löwen. 
Qu UAH PA 1400; RA 6861. - GLA Abt. 235, Fasz. 1843. • Briefe: UBH. • Rudolf-Ernest Brünnow Papers 1876-1897 in: Princeton University Library.

$W$ A classified list of all simple and compound cuneiform ideographs ... Leiden 1889. - Klassischarabische Chrestomathie aus Prosaschriftstellern. Berlin 1911. 8. Aufl. 2008.

MHG R.B. und Alfred von Domaszewski: Die Provincia Arabia. 3 Bde. Straßburg 1904-1909.

L Rogers, Robert William: R.E.B., Gentleman and Scholar ... in: Methodist review (Jan.-Febr. 1918) S. 66-75 (in Princeton University Library). • Enciclopedia italiana 7 (1930) S. 978. • Über R. B. in: Lebenserinnerungen. Berlin 1937/38. Hrsg. von Thomas Ruska. Online veröffentlicht, s. http://julius.ruska.de/lebenserinnerungen.html/index. html. 38. Kapitel (Stand: 03. Sept. 2001). Who was who in America 1 (1968) S. 156. Kornrumpf, Hans-Jürgen und Jutta: Fremde im Osmanischen Reich 1826-1912/13. Bio-bibliographisches Register. 2. Aufl. Stutensee 1998. • Broome Semans, Barbara u. a.: John Broome and Rebecca Lloyd. Vol. I: Their descendants and related families ... Selbstverlag in USA 2009. S. 361-363 u.ö. • Deutsche Biographie, s. https://www.deutsche-biographie. de/gnd116751851.html [06.11.2017].

$P$ Bildarchiv UAH; graph. Slg. UBH.

\section{Bubnoff, Nicolai von}

1911-1914/15, 1918-1946 Phil. Fak. 1946-1958 (Honorar-Prof.) Phil. Fak. Philosophie, Russische Geistesgeschichte

* $\quad$ 07. Jan. 1880 St. Petersburg

$\dagger$ 04. Aug. 1962 Heidelberg griechisch-kath.

V Dr. med. Nicolai Dmitrijewitsch von B. (18371889) Arzt, u.a. auch Regiments- und Leibarzt des Prinzen Alexander von Oldenburg (18441932)
M Marie Henriette geb. Türstig (1853-1928) Gesellschafterin der Prinzessin Therese von Oldenburg (1852-1883)

๑ 15. Sept. 1923 Hertha Gertrud Cornelia Sophie geb. Kirch (1895-1985)

K $2 \mathrm{~S}$

Vw Bruder: Serge von B. (1888-1957), u. a. seit 1929 o. Prof. für Geologie, Paläontologie Greifswald, seit 1950 Humboldt-U Berlin, s. Lexikon Greifswalder Hochschullehrer (2004) S. 31 f.; Kaemmel, Thomas: S. von B. ... Zu seinem Leben, seiner Leistung und seiner Wirkung ... in: Zs. für geologische Wissenschaften (2007) S. 231-251; Wer war wer in der DDR? Hrsg. von Helmut Müller-Enbergs ... 5. Ausg. Bd. 1. Berlin 2010. S. 185; Grewolls (2011).

Lb St. Petersburg: Seit 1898 Studium an U; Mai 1902 Staatsexamen bei Histor.-Philolog. Prüfungskommission.

Seit WS 1902/03 Forts. des Studiums an U Leipzig, anschl. Freiburg/Br., WS 1907/o8-SS 1908 H; 23. Nov. 1908 Dr. phil. an UH; 1908-1911 Eigenstudien in Freiburg, Bonn, München, H.

UH: 1. Juli 1911 Habilitation; 1914/15 Internierung als russischer Staatsangehöriger; 2. Dez. 1918 Wiedergestattung der Abhaltung von Vorlesungen und Übungen; 20. Mai 1919 Lektor für russische Sprache; 2. Juni 1921 Einbürgerung in badischen Staatsverband; 26. Okt. 1921 vereidigter Dolmetscher für Russisch; seit 17. Juli 1924 nichtplanm. a.o. Prof.; 1932-1956 Leiter des ursprünglich von der Josefine und Eduard von Portheim-Stiftung für Wissenschaft und Kunst eingerichteten Slavischen Inst. in $\mathrm{H}$, Augustinergasse 5, das nach der Aufgabe als Stiftung 1931 als U-Inst. eingerichtet wird; 19361951 Leiter der Russischen (Slawistischen) Abt. des Dolmetscher-Inst.; seit 28. Nov. 1939 apl. Prof.; seit 24. Dez. 1946 Honorar-Prof.; WS 1957/58 letzte Ankündigung e. wöchentlichen 2-stündigen Vorlesung über „Geschichte der neueren Philosophie von Descartes bis Leibniz“. • In dieser Zeit:

Wirtschaftshochschule Mannheim: Nov. 1946März 1950 (Ruhestand) Planm. a. o. Prof. 
Qu UAH PA 344, 3420; RA 5029. • Briefe: UBH. • Teil-Nachlass: UAH. Ivanov, Vjaceslav: Dichtung und Briefwechsel aus dem deutschsprachigen Nachlass. Hrsg. von Michael Wachtel. Mainz 1995. S. 311 (Register).

W Zeitlichkeit und Zeitlosigkeit ... Heidelberg 1911. - Friedrich Nietzsches Kulturphilosophie und Umwertungslehre. Leipzig 1923. • Östliches Christentum. 2 Bde. München 1923-1925. (Mitverf.) - Kultur und Geschichte im russischen Denken der Gegenwart. Breslau, Leipzig 1927. • Russische Sprachlehre. Heidelberg 1931. 9. Aufl. 1949.

L Kürschner (1954) Sp. 272; WBIS; Badische Biographien N.F. I (1982) S. 83-85 (mit Werkverz.); Jansen (1992a) S. 164 (Register); Tilitzki 2 (2002) S. 1447 (Register); Engehausen (2008) S. 65 f. • Leaman, George, Simon, Gerd .... SD [Sicherheitsdienst] über Philosophie-Professoren, s. http:// homepages.uni-tuebingen/gerd.simon/philosophendossiers.pdf (abgerufen am 14. Aug. 2017). Deutsche Biographie, s. https://www.deutschebiographie.de/gnd116817429.html [06.11. 2017].

$P$ Bildarchiv UAH.

\section{Buddenbrock-Hettersdorff, Wolfgang Freiherr von}

1914-1920 Naturwiss.-Math. Fak.

Zoologie

* 25. März 1884 Bischdorf (heute: Biskupice, Polen)

$\dagger$ 11. April 1964 Mainz

ev.

V Richard Freiherr von B.-H. (1831-1891) Landrat, Gutsbesitzer

M Elisabeth Anna geb. von Herder (1850-1930)

๑ 10. März 1922 Gertrud Paula Marie-Luise geb. von Rohr (1900-2000)

K 2 S (beide 1945 X $), 3 \mathrm{~T}$

Vw Urgroßvater: Johann Gottfried von Herder (1744-1803) Dichter.
Lb Seit WS 1902/03 Studium des Maschinenbaufachs an TH (Berlin-)Charlottenburg; seit Aug. 1905 Ingenieur bei der Gesellschaft für drahtlose Telegraphie in Berlin; seit SS 1906 Studium der Zoologie an U Jena, SS 1907-SS 1909 H.

UH: 1. März 1910 Dr. phil. nat.; seit 1. Aug. 1910 wiss. Assistent am Zoolog. Inst.; 17. Jan. 1914 Habilitation für Zoologie; seit 29. Febr. 1920 nichtetatm. a. o. Prof. • In dieser Zeit:

1914-1918 Kriegsdienst (1919 Entlassung).

U Berlin: Seit ca. Aug. 1920 erster Assistent am Zoolog. Inst.; 31. Aug. 1921 Umhabilitation.

U Kiel: Seit 20. Nov. 1922 (mit Wirkung vom 1. April 1923) o. Prof. für Zoologie und Vgl. Anatomie sowie Direktor des Zoolog. Inst.; Rufe an U abgelehnt: 1926 Wien, 1933 Leipzig.

U Halle-Wittenberg: Seit 1. März 1936 (Zwangsversetzung) o. Prof. für Biologie und Direktor des Zoolog. Inst. (Begründung der Versetzung, s. Catalogus prof. Halensis online).

U Wien: Seit 1. April 1942 o. Prof. und Direktor des Zoolog. Inst.; 1945 Ausweisung.

U Marburg: WS 1945/46 Vertreter des Lehrstuhls für Zoologie.

U Mainz: 15. Mai 1946-31. März 1954 (Emeritierung) o. Prof. für Zoologie, insbesondere Vgl. Physiologie und Direktor des Zoolog. Inst.

E Mitglied: 1936 Dt. Akademie der Naturforscher Leopoldina Halle/S., 1944 Österr. Akademie der Wissenschaften Wien; 1950 Ehrenmitglied der Akademie der Wissenschaften und der Literatur Mainz. 1964 Dr. rer. nat. h. c. U Tübingen. 1949 Universitätsmedaille Kiel. • Siehe auch Kürschner (1966).

Qu UAH PA 1404; RA 6577. - Siehe auch Archiv der Dt. Akademie der Naturforscher Leopoldina Halle/S. - Mitteilungen: Frau Elisabeth Serra geb. von Buddenbrock-Hettersdorff, Collioure (Pyrénées-Orientales), Frankreich. 
$W$ Grundriß der vergleichenden Physiologie. o. O. 1928. 2 Bde. 2. Aufl. 1937-1939. - Vergleichende Physiologie. 6 Bde. Basel 1950-1967. • Bibliographie in: Gattermann/Neumann (2005) S. $101 \mathrm{f}$.

$L$ Wer ist wer (1951) S. 80; Lehrkörper Berlin (1955) S. 26; Professoren Kiel (1956) S. 165. Nachruf in: Almanach der Österr. Akademie der Wissenschaften 114 (1964) S. 377-380. - Kürschner (1966) S. 297. - Dokumentation zur Österr. Akademie der Wissenschaften 1847-1972 ... Bearb. von Ludmilla Krestan und Klaus Wundsam. Wien 1972. S. 17. Catalogus prof. Marburgensis 2 (1979) S. 781. - Vertriebene Wissenschaftler der Christian-Albrechts-Universität zu Kiel (CAU) nach 1933 ... Hrsg. von Ralph Uhlig. Bearb. von Uta Cornelia Schmatzler und Matthias Wieber. Frankfurt/M. 1991. - Heiber (1992) S. 290, 438, 443 f., (1994) S. 387, 410 f., 415 u. ̈̈.; Jansen (1992a) S. 164 (Register); DBE 2 (1995) S. 192; Lexikon der Naturwissenschaftler (2000) S. 69. - Eberle, Henrik: Die Martin-Luther-Universität [Halle] in der Zeit des Nationalsozialismus 1933-1945. Halle/S. 2002. S. 153, $159 \mathrm{f}$. Catalogus prof. Halensis online; Gattermann/Neumann (2005) S. 95-101. Kiel-Lexikon. Hrsg. von Doris Tillmann ... 2. Aufl. Neumünster 2011. - Deutsche Biographie, s. https:// www.deutsche-biographie.de/gnd105026042.html [06.11.2017].

$P$ Bildarchiv UAH.

\section{Bütschli, Otto Johann Adam}

1878-189o Phil. Fak.

1890-1919 Nat.-Math. Fak.

Zoologie, Paläontologie

* o3. Mai 1848 Frankfurt/M.

$\dagger \quad$ 02. Febr. 1920 Heidelberg

口 Karlsruhe

ev.

V Friedrich Rudolph B. (1806-1863) Konditor

M Philippine Caroline geb. Culmann (1812-1880)

$\infty$ 14. Aug. 1878 Hedwig Sophie Wilhelmine geb. Hoffmann (1856-1879)
(4. Juni 1881 Mathilde geb. Lange (1856-1930)

K 3 T, s. UAH Rep. 40-34.

Lb Polytechnische Schule Karlsruhe: Seit 1864 Studium der Mineralogie, Chemie und Paläontologie; 1865-1866 Assistent.

UH: WS 1866/67 und WS 1867/68 Forts. des Studiums; seit 1867 Assistent von (siehe) Robert Wilhelm Bunsen; 5. Dez. 1867 Dr. phil.

1868 Militärdienstpflicht als Einjährig-Freiwilliger; seit Frühjahr 1869 Eigenstudien in Leipzig, seit Herbst 1869 in Frankfurt/M.; 1870/71 Kriegsdienst während des Deutsch-Französischen Krieges.

U Kiel: Seit 1872 Assistent am Zoolog. Inst.

Frankfurt/M.: 1874 Eigenstudien.

Polytechnische Schule Karlsruhe: 17. Okt. $1876 \mathrm{Ha}-$ bilitation für Zoologie; 1876-1878 Privat-Dozent.

UH: 9. Febr. 1878 Ern. zum o. Prof. und Direktor des Zoolog. Inst. und Museums nebst Paläontolog. Museum und Abt. für landwirtschaftl. Tierlehre als Nachf. von Alexander Pagenstecher; Rufe an U abgelehnt: 1882 Rostock, 1883 Königsberg (Preußen), 1884 München, Straßburg; 1. April 1919 Ruhestand.

1883/84, 1894 Wahlsenator der UH; Dekan: 1885/86 Phil. Fak., 1895/96, 1901/02, 1906/07, 1912/13 Nat.Math. Fak. der UH

1884 Hofrat; 1896 Geh. Hofrat; 1908 Geh. Rat II. Klasse; 1919 Wirkl. Geh. Rat

E 1888 Mitglied der Dt. Akademie der Naturforscher Leopoldina Halle/S.; Mitglied der Akademie der Wissenschaften: 1889 Göttingen, 1897 Berlin, 1900 München, 1904 Wien, 1909 H; Ehrenmitglied: 1899 Physikalisch-Medizinische Societät Erlangen, 1903 U Moskau. 1909 Dr. of Science h.c. Cambridge (Großbritannien); 1909 Dr. h.c. Jena. 1913 Bayer. Maximiliansorden für Wissenschaft und Kunst. 1914 Kommandeurkreuz II. Klasse des Ordens vom Zähringer Löwen. 
Qu UAH PA 1409; RA 6578, 6900f. - GLA Abt. 235, Fasz. 1855. • Briefe: UBH. • Nachlaß: UAH; Fotoarchiv Otto Bütschli: Deutsches Museum München. Siehe auch Archiv der Dt. Akademie der Naturforscher Leopoldina Halle/S. - Mitteilungen: Frau Lucia Rosa Groos (Enkelin), Karlsruhe.

$W$ Beiträge zur Kenntnis der freilebenden Nematoden in: Verh. der Kaiserl. Leopoldinisch-Carolinischen Akademie der Naturforscher 36 (1873) Nr. 5, S. 1-124. - Studien über die ersten Entwicklungsvorgänge der Eizelle, die Zellteilung und die Konjugation der Infusorien in: Abh. der Senckenbergischen Naturforschenden Gesellschaft 10 (1876) S. 215-452. Protozoa. Abt. 1-3 in: Bronn's Klassen und Ordnungen des Tierreichs. Leipzig 1880-1889. - Mechanismus und Vitalismus. Leipzig 1901. Bibliographie, siehe Beneke, Klaus: O. B. ... online.

L NDB 3 (1957) S. 6 (mit Werkverz.). - Willer, Wilfried: O.B. in: Ruperto Carola 19. Jg., Bd. 41 (1967) S. 329-333. - Bütschli, August: Goetheplatz-Erinnerungen ... Hrsg. von Wolfgang Klötzer ... 3. Aufl. Frankfurt/M. 1979. S. 8, 111 f. • Moeller, Heinz Friedrich: Zoologisches Museum der Universität Heidelberg. In Zusammenarbeit mit Westermanns Monatshefte. Braunschweig 1985. S. 231 f., 37 f. u. ö. Jansen (1992a) S. 164 (Register); Wennemuth (1994) S. 633 (Register). Beneke, Klaus: O. B. ... und die Wabenstruktur des Protoplasmas der Schäume und Gele, siehe unter: http:// www.uni-kiel.de/anorg/lagaly/group/klausSchi ver/buetschli.pdf (Ausdruck im UAH). • Goerttler 2 (2004) S. 25; Badische Biographien N.F. V (2005) S. 42-44. Beckmann, Anett: Mentalitätsgeschichtliche und ästhetische Untersuchungen der Grabmalsplastik ... Karlsruhe 2006. S. 172. • Birn (2012) S. 28, 45. Fokin, Sergei: O. B. and his Russian students in: Science in Russia. Published by the Russian Academy of Science. Vol. 2. Moskau 2012. S. 89-94; Ders.: O. B.: Where we will genuflect in: Protistology - An Int. Journal - 8 (1) (2013) S. 22-35.

$P$ Bildarchiv UAH; graph. Slg. UBH; NDB (1957); Willer (1967).

\section{Buhl, Heinrich}

1875-1884 Jur. Fak.

1884-1886 (Honorar-Prof.) Jur. Fak.

1886-1907 Jur. Fak.

Römisches Recht, Zivilprozeßrecht, Französisches

Zivilrecht, seit 1884 auch Badisches Landrecht

* $\quad$ 02. Juni 1848 Deidesheim (Pfalz)

$\dagger \quad$ 04. Febr. 1907 Luxor (Ägypten)

口 Deidesheim

kath., (nach) 1871 altkath.

V Franz Peter B. (1809-1862) Politiker, s. NDB 3 (1957) S. 11

M Josephine geb. Jordan (1813-1872)

(2). Nov. 1876 Elisabeth geb. von Struckoff (1854-1914)

$\mathrm{K}$ keine

Vw Bruder: Franz Armand B. (1837-1896) Politiker, s. NDB 3 (1957) S. 10 f.

Lb Seit WS 1865/66 Studium der Philosophie, Rechtswiss. an UH, seit WS 1867/68 Göttingen, anschl. Berlin?, Würzburg; 1869 I. jur. Staatsexamen.

Zweibrücken: 1869-1872 Rechtspraktikant.

UH: 22. Dez. 1869 Dr. iur.; 1872 II. jur. Staatsexamen; 1872-1875 Eigenstudien; 29. Mai 1875 Habilitation; seit 26. Juni 1878 a. o. Prof.; 1884 Ruf an U Kiel abgelehnt; seit 18. Aug. 1884 Honorar-Prof.; seit 20. Aug. 1886 o. Prof. in Nachfolge von Achilles Renaud. • In dieser Zeit:

Karlsruhe: 1903-1904 Mitglied der I. Kammer des Badischen Landtags als Vertreter der UH.

1902 Prorektor der UH; 1886/87, 189o/91, 1897/98, 1904/o5 Dekan der Jur. Fak. der UH

Buhl vermacht seine Barockvilla in der Heidelberger Hauptstraße 234 (Nähe Karlstor) der UH, die die Räume heute für Empfänge und kulturelle Veranstaltungen nutzt. Im östlichen Nebenhaus (Hauptstraße 236) ist jetzt ein Studentenwohnheim untergebracht, s. Semper apertus 5 (1985) S. 311-322.

1902 Hofrat; 1903 Geh. Hofrat 
E 1899 Ritterkreuz I. Klasse mit Eichenlaub des Ordens vom Zähringer Löwen.

Qu UAH PA 1412; RA 6149, 6761f. u. ö.; Fak.-Akte H-II-111/70.

W Zur Rechtsgeschichte des deutschen Sortimentsbuchhandels. Heidelberg 1879. - Africans Quaestionen und ihr Verhältniß zu Julian in: Zeitschrift der Savigny-Stiftung 2 (1881). • Römisches Recht und bürgerliches Gesetzbuch. Heidelberg 1902. Zur Geschichte der Universität Heidelberg unter Großherzog Friedrich I. Heidelberg 1902.

L NDB 3 (1957) S. 10; Jansen (1992a) S. 164 (Register). - Parks und Gärten im Rhein-NeckarDreieck ... [u. a. der Buhl'sche Park]. Texte von Heinrich Wawrik und Paul Weißer. Schwetzingen 1996. Baur (2009) S. $187 \mathrm{f}$. Coulin, ChristianKarl: Karl August Heinsheimer ... Frankfurt/M. u. a. 2009. - Schroeder (2010) S. 269-272 u. ö.; Deutsche Biographie, s. https://www.deutsche-bio graphie.de/gnd117153427.html [06.11. 2017].

P Bildarchiv UAH; graph. Slg. UBH.

\section{Bulmerincq, August Michael von}

1882-189o Jur. Fak.

Allg. Staatsrecht, Völkerrecht, Politik

* 12. Aug. (31. Juli st.v.) 1822 Riga (Russisches Kaiserreich; heute: Rīga, Lettland)

$\dagger$ 18. Aug. 189o Stuttgart

ㅁ Heidelberg ev.

V Eberhard Michael von B. (1787-1870) Kaufmann

M Charlotte geb. Kriegsmann ( $† 1884$ )

$\infty$ 18. Okt. 1851 Mathilde Ebba Natalie geb. Hern$\operatorname{mar}(\mathrm{c}) \mathrm{k}(1832-1920)$

$\mathrm{K}$ keine.

Lb Seit 1841 Studium an U Dorpat; seit 1845 Studienaufenthalte in: Königsberg (Preußen), Berlin, Bonn, $1847 / 48 \mathrm{H}$.
Riga: Seit 16. Juli 1848 Auskultant des Stadtrats und seit 27. Okt. 1848 Notar des Rats-LandvogteiGerichts; 18. Okt. 1850-25. Mai 1853 Sekretär des Städtischen Kriminalgerichts und des Departments in Bauernsachen.

U Dorpat (heute Tartu, Estland; bis 1889 einzige dt.sprachige U im Russischen Kaiserreich): 1849 Magisterprüfung in Rechtswiss.; 14. Jan. $1854 \mathrm{Ha}-$ bilitation; 1856 [sic] Dr. iur.; seit 3. Sept. 1856 a. o. Prof.; seit 26. Juli 1858 o. Prof.; 1875 Ruhestand.

Wiesbaden: 1875-1881 Privat-Gelehrter.

UH: 19. Dez. 1881 (Ern.) zum SS 1882 o. Prof. und Direktor des Staatswiss. Seminars als Nachf. von Johann Caspar Bluntschli.

1883/84 Dekan der Jur. Fak. der UH

1873 Mitstifter des „Institut de droit international“ in Genf

1858 Hofrat; 1862 Collegienrat; 1874 Wirkl. Staatsrat; 1881 Geh. Rat II. Klasse

E 1864 St. Stanislaus-Orden II. Klasse; 1870 St. Anna-Orden II. Klasse; 1875 Ritterkreuz des Schwedischen Nordsternordens; 1882 Komturkreuz des Ordens der Krone von Italien; 1889 Ritterkreuz I. Klasse mit Eichenlaub des Ordens vom Zähringer Löwen.

\section{Qu UAH PA 1413; RA 6761. Briefe: UBH.}

$W$ Das Asylrecht in seiner geschichtlichen Entwicklung ... Unveränderter Neudr. der Ausg. von 1853. Vaduz 1989. - Die Systematik des Völkerrechts von Hugo Grotius bis auf die Gegenwart. Dorpat 1858. Praxis, Theorie und Codification des Völkerrechts. Leipzig 1874. • Das Völkerrecht oder internationale Recht in: Marquardsen's Handbuch des öffentlichen Rechts der Gegenwart 1,2 (1884) S. 177-384.

L ADB 47 (1903) S. 348-350; WBIS. - Handbuch der historischen Buchbestände in Deutschland. Hrsg. von Bernhard Fabian. Hildesheim 2003. • Macalister-Smith, Peter: Bio-bibliographical key 
to the membership of the Institut de Droit International 1873-2001 in: Journal of the History of International Law 5 (1) (2003) S. 77-159. • Mälksoo, Lauri: The context of international legal arguments „Positivist“. International law scholar A. von B. ... and his concept of politics in: Journal of the history of international law (2005) S. 181-209.

$P$ Bildarchiv UAH; graph. Slg. UBH.

\section{Bunsen, Robert Wilhelm Eberhard}

1852-1889 Phil. Fak.

Chemie

* 30. März 1811 Göttingen

$\dagger$ 16. Aug. 1899 Heidelberg ev.-luth.

V Christian B. (1770-1837) seit 1797 Kustos der UB, seit 1805 a. o., seit 1814 o. Prof. für Ästhetik Göttingen, s. Catalogus prof. Gottingensium (1962) S. 106, WBIS

M Auguste Friederike geb. Quensel (1775-1853)

(1) unverheiratet

Vw siehe Hoß-Hitzel (2003) S. 9-11.

Lb U Göttingen: Seit SS 1828 Studium der Naturwiss.; 17. Okt. 1831 Dr. phil.; Mai 1832-Sept. 1833 Studienreisen in Deutschland, Frankreich, Schweiz, Österreich; 25. Jan. 1834 Habilitation.

Kassel: Seit 30. März 1836 Lehrer an Höherer Gewerbeschule.

U Marburg: Seit 7. Aug. 1839 (Versetzung durch Tausch e. Marburger Chemieprofessors an die Gewerbeschule) a.o. Prof. und stellvertr. Leiter des Chemischen Inst.; seit 29. Juli 1841 o. Prof. mit e. jährl. Besoldung von 650.- Talern; seit 11. Nov. 1841 Direktor des Chemischen Inst.; Mai-Oktober 1846 Studienreise durch Island; 1850 Rufe an U abgelehnt: Halle-Wittenberg, $\mathrm{H}$.

U Breslau: Seit 4. April 1851 o. Prof.; Frühjahr 1851 Ruf an UH zunächst erneut abgelehnt.
UH: 6. Aug. 1852 (Dienstantritt Ende Sept.) Ern. zum o. Prof. als Nachf. von Leopold Gmelin und Direktor des Chemischen Laboratoriums in Nachfolge von Wilhelm Delffs mit e. Jahresgehalt von 2700.- Gulden; 1863 Ruf an U Berlin abgelehnt; 1. Aug. 1889 auf eigenen Antrag Ruhestand.

1854, 1864/65 Dekan der Phil. Fak. der UH

1860 entwickeln Gustav Robert Kirchhoff und B. die Spektralanalyse, s. hierzu Hübner, Klaus: Gustav Robert Kirchhoff ... Ubstadt-Weiher 2010. S. 118-136 u. ö.

1852 Hofrat; 1863 Geh. Rat III. Klasse; 1868 Geh. Rat II. Klasse; 1881 Geh. Rat I. Klasse

E Mitglied: 1839 Gesellschaft zur Beförderung der gesammten Naturwiss. Marburg, 1851 Dt. Akademie der Naturforscher Leopoldina Halle/S.; Mitglied der Akademie der Wissenschaften: 1848 Wien, 1853 München, 1855 Göttingen. • Dr. phil. h. c.: 1874 Leiden, 1878 Pavia. 1874 Becquerel-Medaille. 1863 Ehrenbürger der Stadt Heidelberg.

$\mathrm{Q} u$ UAH PA 1414; RA 5177, 5684, 5717, 6488, 6495, 6572, 6817, 6886. • GLA Abt. 76, Fasz. 989o. • Vorlesungsnachschrift von unbekannter Hand über die „Experimental-Chemie“ nach R. B. von 1880/81 in: UAH KE-117. • Briefe: UBH. • „ ... der Himmel bewahre Sie vor einer socialistischen Herrschaft!“ Briefe von R.W.B. an Théophile Jules Pelouze ... in der Universitätsbibliothek Marburg. Hrsg. ... von Fritz Krafft. Marburg 1996. - Hoß-Hitzel, Stephanie B.: „Es lebt sich himmlisch in Heidelberg“. R.W.B. und seine Korrespondenz. Diss. Heidelberg 2003. - Stock, Ch.: R.W.B.s Korrespondenz vor dem Antritt der Heidelberger Professur (1852). Stuttgart 2007. - Nachlaß: UBH; Universitätsbibliothek Marburg. - Siehe auch Archiv der Dt. Akademie der Naturforscher Leopoldina Halle/S.

$W$ Theorie der zusammengesetzten Radicale in: Annalen der Chemie und Pharmacie 24 (1855) ff. • Gasometrische Methoden. Braunschweig 1857. 2. Aufl. 1877. - Chemische Analyse durch Spektralbeobachtungen in: Annalen der Physik und Chemie (1860) Bd. 110, No. 6, S. 161-189. (Mitverf.) Neu hrsg. von Gabriele Dörflinger. 2013 
online publiziert unter: http://nbn-resolving.de/ urn:nbn:de:bsz:16-heidok-156578. - Gesammelte Abhandlungen von R. B. Hrsg. von Wilhelm Ostwald und Max Bodenstein. 3 Bde. Leipzig 1904. • Bibliographie in: Hoß-Hitzel (2003) S. 318-326.

L Mayer, Adolf: Bunseniana. Eine Sammlung von humoristischen Geschichten aus dem Leben von R. B. ... Heidelberg 1904. • Badische Biographien 1 (1906) S. 860-862. • Über R. B. in: Roscoe, Henry E.: Ein Leben der Arbeit. Erinnerungen. Leipzig 1919. S. 358 (Register). - Smith (1949) S. 43 f.; NDB 3 (1957) S. 18-20; Catalogus prof. Gottingensium (1962) S. 138; WBIS. - Freudenberg, Karl: Die Studienreise R.B.s nach BerlinParis-Wien 1832/33 in: Heidelberger Jahrbücher 6 (1962) S. 111-181. • Eberhardt (1990) S. 206 (Register). Eckhardt, Wilhelm A.: R. W. B. und die Höhere Gewerbeschule in Kassel in: Hessisches Jahrbuch für Landesgeschichte 44 (1994) S. 55-69. Heilmann, Arnt: R.W.B. in Breslau in: Würzburger medizinhistorische Mitteilungen. Würzburg
2000. S. 239-254. Von der Forschung gezeichnet (2007) S. 108f. u. ö. Eine Bibliothek als beredte Zeugin eines umfassenden Wandels des wiss. Weltbilds, s. Autoren der Bunsenbibliothek (2009 online). • Hübner, Klaus: Gustav Robert Kirchhoff. Das gewöhnliche Leben eines außergewöhnlichen Mannes. Ubstadt-Weiher 2010. S. 302 (Register). • R.W.B. und sein Heidelberger Laboratorium ... Hrsg. von der Gesellschaft Dt. Chemiker. Broschüre. Frankfurt/M. 2011. - Wissenschaftsatlas der UH (2011) S. 96-98; Birn (2012) S. 191 (Register). Petrik, Marek: Friedrich August Genth aus Wächtersbach und die Entdeckung der ersten $\mathrm{NiO}-$ Kristalle am Marburger chemischen Institut unter R. W. B. Göttingen 2013.

$P$ Bildarchiv UAH; graph. Slg. UBH. 1908 Denkmal von Hermann Volz, aufgestellt in $\mathrm{H}$ vor dem Psychologischen Institut, Hauptstraße 47-51. 


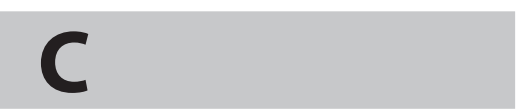

\section{Cantor, Moritz Benedikt}

1853-1877 Phil. Fak.

1877-1890 (Honorar-Prof.) Phil. Fak.

1890-1913 (Honorar-Prof.) Nat.-Math. Fak.

Mathematik

* 23. Aug. 1829 Mannheim

$\dagger \quad$ 09. April 1920 Heidelberg

mosaisch

V Isaak Bendix C. († 1885) Kaufmann

M Nanette geb. Schnapper

$\infty$ 23. Aug. 1868 Telly geb. Gerothwohl (18471873)

K 1 S: Dr. iur. Otto C. (1869-7. April 1920). 1 T: Cläre Jeanette Adelheide C. (1873-1951) 9. Jan. 1944-27. Juni 1945 im KZ Theresienstadt (heute: Terezín, Tschechien); Ehefrau von Dr. phil. Rudolf Horn (1878-1939), u. a. 1929-1932 Direktor der Mädchenrealschule (heute: Hölderlin Gymnasium) in H, 1932-1933 (Entlassung aufgrund der mosaischen Herkunft seiner Ehefrau) Gymnasial-Prof. in Emmendingen; 1929-1933 Mitglied der II. Kammer des Badischen Landtags in Karlsruhe; siehe Studentenakte im UAH; Nachlaß im GLA Karlsruhe; Badische Landtagsprotokolle in: Badische Landesbibliothek Karlsruhe; Festschrift zum 10o-jährigen Bestehen der Schule: Hölderlin Gymnasium Heidelberg 1877-1977. Heidelberg 1977.

Lb Seit WS 1848/49 Studium der Mathematik, Physik und Chemie an UH, seit WS 1849/50 Göttingen, seit Frühjahr 1851 H; 6. Mai 1851 Dr. phil. an UH; Eigenstudien: seit Anfang 1852 Berlin, seit Herbst $1852 \mathrm{H}$.

UH: 30. April 1853 Habilitation; seit 9. Nov. 1863 a. o. Prof.; seit 30. Juli 1877 Honorar-Prof.; seit 21. Febr. 1908 o. Honorar-Prof.; 15. Aug. 1913 auf eigenen Antrag Ruhestand (Grund: „Meine Au- gen versagen mir mehr und mehr den Dienst, und ich kann nicht mehr erkennen, was ich selbst nur wenig über Kopfeshöhe an die Tafel geschrieben habe“, aus: Brief vom 19. Mai 1913 in: UAH PA 1416).

$Z 1877$ bittet C. in einem Schreiben an die Phil. Fak. um seine Beförderung an der UH: Engerer Senat befürwortet sein Gesuch in e. Schreiben an das Ministerium des Innern vom 18. Juli 1877: „In voller Anerkennung der rühmlichen literarischen Leistungen und der zur Genüge bewiesenen Lehrtätigkeit des Petenten erlauben wir uns in Übereinstimmung mit der philosophischen Facultät den von letzterer gestellten Antrag, es möge dem Professor Dr. Cantor der Charakter als Professor honorarius verliehen werden, aufs wärmste hohem Ministerium zu empfehlen“" (aus: PA 1416). Bereits am 30. Juli verleiht Großherzog Friedrich I. C. „den Charakter als Professor honorarius" (siehe Brief vom 6. Aug. 1877 in: PA 1416).

Knapp drei Monate nach dem Tod des a. o. Mathematik-Professors Friedrich Rummer stellt C. im Nov. 1882 das Gesuch, es „möge [ihm] für Abhaltung von elementar-mathematischen Vorlesungen das hierfür dem Professor Rummer bisher pro Semester gewährte Honorar von 400.- Mark hochgeneigt bewilligt werden" (aus: Brief des Engeren Senats an das Ministerium der Justiz, des Kultus und Unterrichts vom 2. Dez. 1882 in: PA 1416). Diese Bitte wird gewährt; C. stellt ordnungsgemäß nach jedem Semester einen Antrag auf Auszahlung der 400.- Mark; diese Anträge sind lückenlos bis SS 1892 einschließlich dokumentiert (siehe PA 1416).

Mitglied der Alten Leipziger Burschenschaft 1849 (siehe hierzu Grimm, Horst, Besser-Walzel, Leo: Die Corporationen. Frankfurt am Main 1986).

1894 Hofrat; 1902 Geh. Hofrat

Siehe auch Friedrich Rummer

E Mitglied: 1877 Dt. Akademie der Naturforscher Leopoldina Halle/S., 1901 Petersburger Akademie der Wissenschaften, 1901 Istituto Veneto di Scienze, Lettere ed Arti in Venedig, 1909 Akademie der 
Wissenschaften H. 1886 Ritterkreuz I. Klasse des Ordens vom Zähringer Löwen; 1913 Ritterkreuz des Ordens Berthold I.

Qu UAH PA 1416; RA 6142, 6508, 6679; Fak.-Akten $\mathrm{H}-\mathrm{IV}-102 / 47$ fol. 48r-5or, 57r-64r, H-IV-102/ 57 fol. 412r-416r. - GLA Abt. 235, Fasz. 1862. • Briefe: UBH. - Nachlaß: UBH, s. Postkarten und Briefe von Gustaf Enestrom an M.C. Aus dem in der Universitätsbibliothek Heidelberg verwahrten Nachlass M. C.s. Signatur: Heid. Hs. 4028,107. Abschrift: Gabriele Dörflinger, s. http://www.ub.uniheidelberg.de/archiv/21477 (Jan. 2014). Siehe auch Archiv der Dt. Akademie der Naturforscher Leopoldina Halle/S. • Auskunft: Frau Inge Puschmann, Karlsruhe.

$W$ Über ein weniger gebräuchliches CoordinatenSystem. Frankfurt/M. 1851 (gedr. Diss. in: UAH H-IV-102/47 unter fol. 63r eingeheftet). - Mathematische Beiträge zum Kulturleben der Völker. Halle/S. 1863. • Die römischen Agrimensoren und ihre Stellung in der Geschichte der Feldmeßkunst. Leipzig 1876. - Vorlesungen über Geschichte der Mathematik. 4 Bde. Leipzig 1880-1908. Nachdr. 1965. Politische Arithmetik oder die Arithmetik des täglichen Lebens. Leipzig 1898. 2. Aufl. 1903. Reprint Charleston (South Carolina) 2010. Karl Wilhelm von Feuerbach. Heidelberg 1910. Neu hrsg. von Gabriele Dörflinger. Heidelberg 2010. • Siehe auch Verzeichnis der mathematischen Werke, Abhandlungen und Recensionen des Hofrat ... M. C. Zus.gestellt von Maximilian Curtze in: Zs. für Mathematik und Physik. Suppl. 14 (1899) S. $625-650$.

HG 1877-1918 Abhandlungen zur Geschichte der Mathematischen Wissenschaften.

$L$ Bopp, Karl: M.C. †. Gedächtnisrede, gehalten im Math. Verein zu Heidelberg am 19. Juni 1920. Neu hrsg. von Gabriele Dörflinger. UB Heidelberg 2005. Online-Ausg. • NDB 3 (1957) S. 129 (mit Werkverz.); WBIS. - Lützen, Jesper und Purkert, Walter: Conflicting tendencies in the historiography of mathematics: M.C. and H. G. Zeuthen in: The history of modern mathematics. Ed. by Eberhard Knobloch und David E. Rowe. Vol. 3: Images, ideas, and communities. Boston u.a. 1994. S. 142. Badische Biographien N.F. V (2005) S. 44f. •
Eneström, Gustav: M.C.s Vorlesungen über Geschichte der Mathematik aus der Sicht seines Kritikers Gustaf Eneström. Rezensionen, Artikel und Briefe zus.gestellt von Gabriele Dörflinger. UB Heidelberg 2014, s. http://www.ub.uni-heidelberg. de/archiv/16473. Mathematik in der Heidelberger Akademie der Wissenschaften zus.gestellt von Gabriele Dörflinger. Ein Projekt der Fachinformation Mathematik der Universitätsbibliothek Heidelberg, s. http://www.ub.uni-heidelberg.de/ archiv/16931 (Stand: April 2014). Homo Heidelbergensis mathematicus online.

$P$ Bildarchiv UAH; graph. Slg. UBH; NDB.

\section{Capaun, Carl Franz Otto \\ siehe Karlowa}

\section{Carius, Georg Ludwig (Louis)}

1856-1865 Phil. Fak.

Chemie

* 24. Aug. 1829 Barbis (heute: Stadtteil von Bad Lauterberg im Harz)

$\dagger \quad$ 24. April 1875 Marburg ev.-luth.

V August Martin C. (1788-1840), u.a. seit 1821 Pastor in Barbis, s. WBIS (hier unter: Carius, N.N.)

M Dorothea Friederike geb. Wallis (1794-1836)

๑ 28. Aug. 1861 Henriette geb. Bach (1833-1864)

๑ 13. Mai 1869 Selma Elfriede Johanna geb. Ranke (1844-1943) T von Ernst Constantin R. (1814-1888), u. a. seit 1850 Prof. für Theologie Marburg, s. Catalogus prof. Marburgensis 1 (1927) S. 46, NDB 21 (2003) S. 139; Nichte von Leopold (von) Ranke (1795-1886), u.a. 18341871 o. Prof. für Geschichte Berlin, s. NDB 21, S. 140-142; Boldt, Andreas: Das Leben und Werk L. von R. Oxford, Bern 2016; Über die Gelehrtenfamilie Ranke, s. ebd. S. 138-140.

$\mathrm{K} \quad 1 \mathrm{~S}, 2$ weitere $\mathrm{K}$ früh $\dagger$. 
Lb Seit 1846 Apothekerlehre in Goslar, anschl. Mitarbeiter in e. pharmazeutischen Laboratorium in Lüneburg; 1850 Maturitätsprüfung.

Studium der Naturwiss. an U: Seit 1850 Göttingen, seit 10. Jan. $1853 \mathrm{H}$.

UH: 1. Dez. 1852-Ende 1858 Assistent am Bunsenschen Chemischen Laboratorium; 7. Okt. 1853 Dr. phil.; 15. Dez. 1855 Habilitation; SS 1856 erste Ankündigung von Vorlesungen; Ende 1858 Einrichtung e. kleinen eigenen Labors; seit 22. Juli 1861 a. o. Prof.

U Marburg: Seit 22. Nov. 1865 o. Prof. und Direktor des Chemischen Inst.

Qu UAH RA 6496. GLA Abt. 205, Fasz. 175.

$W$ Beitrag zur Theorie der mehrbasischen Säuren, besonders auch deren Sulfo-Derivate. Heidelberg 1861. Neue Synthese aromatischer Säuren. Marburg 1868 .

L Ladenburg, Albert: L.C. †. o. O. 1875. - Poggendorff 3 (1898) S. 235; Catalogus prof. Marburgensis 1 (1927) S. 464 f.; WBIS. Pötsch, Winfried R. u. a.: Lexikon bedeutender Chemiker. Leipzig 1988. S. 78. Von der Forschung gezeichnet (2007) S. 110 u. ö.; Autoren der Bunsenbibliothek (2009 online). Kurze Übersicht über die Entwicklung des Fachs Chemie an der ... U Marburg von 1609 bis zur Gegenwart. Hrsg. vom Dekanat des Fachbereichs Chemie. 3. Aufl. Marburg 2009. S. 7, 13 f. (s. www.chemie.uni-marburg.de/dekanat/chemie. pdf).

$P$ Bildarchiv UAH.

\section{Cartellieri, Alexander Georg Maximilian}

1899-1902 Phil. Fak.

Geschichte

* 19. Juni 1867 Odessa

$\dagger$ 16. Jan. 1955 Jena

ev.-luth.
V Leopold C. (1828-1903) Kaufmann, dt. Konsul in Odessa

M Cölestine geb. Manger (1831-1918)

๑ 23. Juli 1894 Margarete geb. Ornold (18701931)

K $1 \mathrm{~T}, 4 \mathrm{~S}$ (davon $1 \mathrm{~S}$ früh $\dagger$ ), u. a. Dr. Wolfgang C. (1901-1969), u. a. 1959-1966 Staatssekretär, zuletzt im Bundesministerium für Wissenschaftliche Forschung, s. Wer ist Wer (1967) S. 262; Nachlaß im Bundesarchiv Koblenz

Vw Bruder: (siehe) Otto C.

Lb Seit SS 1887 Studium der Geschichte, Philosophie, Philologie an U Tübingen, anschl. Leipzig, Berlin; 21. Dez. 1891 Dr. phil. an U Leipzig.

Karlsruhe: Seit 6. Jan. 1892 Hilfsarbeiter bei Badischer Histor. Kommission; 7. Nov. 1893 Lehramtsprüfung in Berlin; seit 23. Dez. 1893 etatm. Hilfsarbeiter, April 1895-Sept. 1898 Archiv-Assessor am GLA.

UH: 15. Febr. 1899 Habilitation für Mittlere und Neuere Geschichte; seit 20. Febr. 1902 nichtetatm. a. o. Prof.

U Jena: Seit Okt. 1902 a. o. Prof.; Ruf an U Rostock abgelehnt; seit Okt. 1904 o. Prof.; 1935 Emeritierung (1948-1952 ohne Ruhegehalt).

1913 Geh. Hofrat

E 1933 Mitglied der Akademie der Wissenschaften Leipzig.

Qu UAH PA 1420. GLA Abt. 235, Fasz. 1863. Nachlaß: Universitäts- und Landesbibliothek Jena. • Erinnerungen. II. T.: Heidelberger Eindrücke und Dozenten 1899-1902. Jena 1948. Masch. geschr. Ex. in: Landesarchiv Schleswig-Holstein, Abt. 399.130, Nr. 132. - A.C.: Tagebücher eines deutschen Historikers. Vom Kaiserreich bis in die Zweistaatlichkeit (1899-1953). Hrsg., ... bearb. von Matthias Steinbach und Uwe Dathe. München 2014.

W Philipp II. August, König von Frankreich. 4 Bde. Leipzig 1899-1922. Geschichte der neueren Revolutionen vom englischen Puritanismus 
bis zur Pariser Kommune (1642-1871). Leipzig 1921. - Weltgeschichte als Machtgeschichte (3821190). 5 Bde. München 1927-1941, 1972.

$L$ Festschrift für A.C. zum 6o. Geb. Weimar 1927. • Kürschner (1931) Sp. 386. - Nachruf in: Historische Zeitschrift 179 (1955) S. 663 (mit Werkverz.). • Steinbach, Matthias: „Ich bin wirklich ein Leidtragender des Krieges ..." Die Universität Jena und der Zusammenbruch der int. Gelehrtenwelt 19141918 unter ... Berücksichtigung des Historikers A.C. in: Zwischen Wissenschaft und Politik. Studien zur Jenaer Universität im 20. Jhdt. Hrsg. von Herbert Gottwald und Matthias Steinbach ... Jena 2000. S. 25-46; Ders.: Des Königs Biograph: A.C. Historiker zwischen Frankreich und Deutschland. Frankfurt/M. u. a. 2001. • Müller, Heribert: „Aber das menschliche Herz bleibt, und darum können wir historisch kongenial verstehen ..." Anmerkungen zu e. Biographie des Jenaer Historikers A.C. in: Zs. des Vereins für Thüringische Geschichte. Jena 2001. S. 337-352. - Kämpferische Wissenschaft: Studien zur Universität Jena im Nationalsozialismus. Hrsg. von Uwe Hoßfeld u. a. Köln u. a. 2003. S. 913-917, 929 f. u. ö. •WBIS; Wolgast (2010) S. $172 \mathrm{f}$. Steinbach, Matthias: Die aus Urkunden und Akten gekelterten Weine sind Schlaftrunke. A.C. als Karlsruher Archivar in seinen Tagebüchern und Erinnerungen in: ZGORh 160. Jg. (2012) S. 493-559. Deutsche Biographie, s. https://www. deutsche-biographie.de/gnd116462558.html [06.11. 2017].

P Bildarchiv UAH; Festschrift (1927).

\section{Cartellieri, Wilhelm Ernst Otto}

1904-1924 Phil. Fak. 1925, 1928-1930 Phil. Fak.

Geschichte

* 23. Jan. 1872 Odessa

$\dagger$ 13. April 1930 Basel

ev.
V Leopold C. (1828-1903) Kaufmann, dt. Konsul in Odessa

M Cölestine geb. Manger (1831-1918)

( 10. Aug. 1918 Eva Valeska Hedwig geb. Schröter (1892-1965), s. Kriegstagebuch K. Hampe (2007) S. 995 (Register)

K 2 S: u.a. Diether C. $\left({ }^{*} 1919\right)$ Psychologe, 1969 Referent für Wehrpsychologie im Bundesverteidigungsministerium. 2 T: u. a. Gudula C. verh. Ehmig (1929-2009) seit 1960 Sprachlehrerin an Folkwang-Hochschule Essen, s. Parsons, O. J.: Visitors from West-Germany: Mrs. Gudula Ehmig-C. and daughter Cäcilia. German speech teacher enjoys spokane visit in: The Spokesman-Review vom 25. Sept. 1965, S. 2; in 2. Ehe verh. mit Hans Georg Siebeck (1911-1990) 1936-1976 Leiter des Verlages J.C.B. Mohr, heute: Mohr Siebeck GmbH \& Co. KG Tübingen

Vw Bruder: (siehe) Alexander C.

Lb Seit 1892 Studium der Geschichte, Nationalökonomie, Philologie, Philosophie an U Freiburg/ Br., anschl. Berlin, SS 1893 H, seit WS 1893/94 Berlin.

Berlin: 18. Dez. 1897 Dr. phil.; 1. Juni 1898-31. März 1904 Mitarbeiter an Monumenta Germaniae Historica; 1899 Studienreise nach Italien.

UH: 30. April 1904 Habilitation; 1907/08 Studienreisen nach Belgien, Frankreich, Italien, England; seit 7. Febr. 1910 nichtetatm., 1920-31. März 1924 nichtplanm. a.o. Prof.; seit Okt. 1922 außerdem nichtplanm. Bibliothekar an UBH; SS 1925, WS 1928/29-WS 1929/30 Lehrauftrag als nichtplanm. a. o. Prof. erneuert. In dieser Zeit:

1914-1916 Kriegsdienst; März 1916-Mai 1918 Beamter in Archivsektion der Politischen Abt. des Generalgouvernements Belgien in Brüssel.

GLA Karlsruhe: Seit 1. April 1924 planm. Archivrat unter der Bedingung, ,die Verbindung mit der Universität Heidelberg zu lösen", s. hierzu Wolgast (2010) S. 174 f.; seit 1. April 1928 Oberarchivrat.

Siehe auch Johannes Rissom: Eintrag unter $Z[\mathrm{i}-$ tat] (1) 
Qu UAH PA 3464; RA 6421, 6847; Fak.-Akten H-IV-102/136, H-IV-102/139. • GLA Abt. 235, Fasz. 1864. Nachlaß: UBH.

$W$ Abt Suger von Saint-Denis, 1081-1151. Berlin 1898. Nachdr. 1965. Geschichte der Herzöge von Burgund. Leipzig 1910. Heidelberger Erinnerungsstätten. Heidelberg 1922. - The Court of Burgundy [Am Hofe der Herzöge von Burgund. Basel 1926]. London 1929. Reprint 1996. - Siehe auch Kriegstagebuch K. Hampe (2007) S. 950 (Register).

L Krebs, Manfred: O.C. in: ZGORh 83. Jg. (1931) S. 345-349. - NDB 3 (1957) S. 16of. (mit Werkverz.); WBIS; Fuhrmann (1996) S. 205 (Register); Wolgast (2010) S. 173-175; Badische Biographien N. F. VI (2011) S. 58-61.

\section{$P$ Bildarchiv UAH.}

\section{Caspari, Otto Heinrich Gotthold}

1869-1895 Phil. Fak.

Psychologie, Anthropologie

* 24. Mai 1841 Berlin

$\dagger \quad$ 28. Aug. 1917 Heidelberg

mosaisch, nach $1864 \mathrm{ev.}$

V Ludwig Heinrich C., Kaufmann

M Minna geb. Dietze

๑ 30. Okt. 1865 Agnes geb. Hintsche (1842-1923)

$\mathrm{K} \quad 2 \mathrm{~S}, 3 \mathrm{~T}$

Lb Seit 1861 Studium zunächst - auf Wunsch des Vaters - der Kameral- und Staatswiss., dann der Philosophie, Naturwiss., auch Psychologie an U Greifswald, anschl. Berlin, seit 5. Nov. 1862 München, seit 26. Okt. 1863 Göttingen; 14. März 1864 Dr. phil. an U Göttingen (Prädikat: rite, s. UAH H-IV-102/69 fol. 113v, eigenhändiger Lebenslauf).

Seit SS 1864 Studium der psycholog. Pathologie und Psychiatrie an U Berlin, seit Anfang 1866 Jena; Mitte 1866 Rückkehr ins Elternhaus in Berlin aufgrund des Preußisch-Österr. Krieges.
UH: 6. Aug. 186818 Professoren der Phil. Fak. beschließen "gegen drei Stimmen ... Herrn Dr. Caspari (zu seinem Gesuch um Zulassung zur Habilitation in der Philosophie) zu erklären, daß die Facultät zwar den Fleiß und die eingehende Beschäftigung mit philosophischen Fragen nicht verkennt, welche er $[=\mathrm{C}$.] in seiner Schrift an den Tag lege, daß sie aber in derselben Schärfe der Begriffe, Strenge des wissenschaftlichen Verfahrens, Klarheit und Correctheit der Darstellung zu sehr vermisse, um sie als Habilitationsschrift anerkennen zu können" (aus: UAH H-IV-102/69 fol. 187r); 5. Nov. 1869 Habilitation für Philosophie mit dem Prädikat „hinreichend befähigt“, s. UAH PA 1422; 29. Dez. 1877 Ern. zum a.o. Prof. gegen den Willen der Fak.; Ministerium des Innern begründet die Verleihung, dass 1. mit diesem Titel keinerlei Rechte verbunden sind, 2. seine „literarische Regsamkeit nicht bezweifelt" werden kann und 3. ihm ohne die Verleihung des Titels das „weitere Fortkommen in der academischen Laufbahn ... abgeschnitten" würde (aus: Brief vom 17. April 1877 in: UAH PA 1422); 1884-1894 Gesuche um Ern. zum a. o. Prof. mit Staatsdienereigenschaft werden von der Phil. Fak. mit der Begründung fehlender Geldmittel abgelehnt; 1890/91 C.s Gesuch um Versetzung in die Naturwiss.-Math. Fak. wird von dieser abgelehnt, s. hierzu PA 1422; C. erhält einmalige Vergütungen vom Ministerium der Justiz, des Kultus und Unterrichts: 21. Mai 1893 von 1200.- Mark, 24. März 1895 von 80o.- Mark „im Hinblick auf seine akademische Wirksamkeit" (aus: PA 1422); 22. Juli 1895 C. wird die „Berechtigung zur Lehrtätigkeit entzogen und der Charakter als außerordentlicher Professor verlustig erklärt" wegen „öffentliches Aergerniß erregenden Verhaltens ... in Heidelberg in sittlicher Erziehung, insbesondere über ... [sein] Verhältniß zu der früheren Dienstmagd Barbara Dunst", die die Mutter der o. g. 5 Kinder ist und die von C. als seine anerkennt werden (Zitate aus: RA 1129 fol. ir und PA 1422 letzte Seite).

H: Nach 1895 freier Schriftsteller.

Mitglied der Heidelberger Freimaurerloge Ruprecht zu den fünf Rosen 
Qu UAH PA 1422; RA 1129; Fak.-Akten H-IV-102/ 69 fol. 111r-133r, 187 r u. ö., H-IV-102/72 fol. $7 \mathrm{r}-21 \mathrm{r}$ u. ö. - GLA Abt. 235, Fasz. 1866; Literarische Einsendungen von O.C., s. GLA 60 Nr. 178. • Briefe: UBH. • Auskunft: Stadtarchiv Heidelberg.

$W$ Die psychophysische Bewegung in Rücksicht der Natur ihres Substrats. Leipzig 1869. • Die Urgeschichte der Menschheit mit Rücksicht auf die natürliche Entwicklung des frühesten Geisteslebens. 2 Bde. Leipzig 1873. 2. Aufl. 1877. • Der Zusammenhang der Dinge. Gesammelte philosophische Aufsätze. Breslau 1881. • Drei Essays über Grund- und Lebensfragen der philosophischen Wissenschaft. Heidelberg 1886. 2. Aufl. 1888. • Die Bedeutung des Freimaurertums für das geistige Leben. Berlin 1889. 4. Aufl. 1930. Das Problem über die Ehe! Frankfurt/M. 1899. 2. Aufl. u.d. T.: Die soziale Frage über die Freiheit der Ehe mit Berücksichtigung der Frauenbewegung vom phil.-histor. Gesichtspunkt. Frankfurt/M. 1905. Aufsatz über die Lösung der Judenfrage in: Die Lösung der Judenfrage. Eine Rundfrage veranstaltet von Dr. Julius Moses. Berlin, Leipzig 1907. S. 83-86. • Das Erkenntnisproblem mit Rücksicht auf die gegenwärtig herrschenden Schulen. Hamburg 1909.

MHG 1877-1886 Kosmos - Zeitschrift für einheitliche Weltanschauung auf Grund der Entwicklungslehre...

$L$ Almanach Heidelberg (1886) S. 142; Wer ist's (1914) S. 244; WBIS; Hinz (2000) S. 46. • Die Kulturgeschichte der Prähistorie: Völkerpsychologische und darwinistische Deutungen bei O.C. in: Mehr, Christian: Kultur als Naturgeschichte: Opposition oder Komplementarität zur politischen Geschichtsschreibung 1850-1890? Berlin 2009. S. 123-130. - Deutsche Biographie, s. https:// www.deutsche-biographie.de/gnd11646805X.html [06.11. 2017].

$P$ Bildarchiv UAH; graph. Slg. UBH.

\section{Chelius, Franz Carl (seit 1866: von Chelius)}

1847-1873 Med. Fak.

Chirurgie

* $\quad$ 06. Sept. 1821 Heidelberg

$\dagger$ o6. Juni 1899 Ahrweiler

$\square$ Heidelberg kath.

V (siehe) Maximilian Joseph C.

M Anna Maria geb. Freiin von Sensburg (17971867) $\mathrm{T}$ von Ernst Philipp Freiherr von S. (1765-1831) badischer Staatsrat, s. Badische Biographien 2 (1875) S. 295-298

๑ 2. Jan. 1850 Anna Maria Josepha Eleonora geb. Minet (1830-1896)

K 2 S, 2 T: u.a. Barbara Warinka Maria (von) C. (1856-1949) Urgroßmutter von Claus von Amsberg (1926-2002) 1966-2002 Prinz der Niederlande.

Lb UH: Seit WS 1838/39 Studium; 7. Dez. 1843 Dr. med.; Frühjahr 1844 Staatsexamen; 20. Juli 1844 Approbation.

1844-1846 Bildungsreisen nach Kiel, Kopenhagen, Berlin, Prag, Wien, Paris, London, Oxford, Edinburgh, Dublin.

UH: 23. Jan. 1847 Habilitation; 1847-1864 Assistent an Chirurg. U-Klinik; seit 9. Juli 1852 a.o. Prof.; seit 21. Aug. 1857 a. o. Prof. mit e. Jahresgehalt von 40o.- Gulden; Febr.-Okt. 1864 während des Deutsch-Dänischen Krieges Arzt im preußischen Hauptquartier; 15. April 1873 auf eigenen Antrag aus Lehrkörper ausgeschieden. • In dieser Zeit:

H: 1846-1873 Privat-Praxis; 1864-1873 Gründer und Leiter e. Privatklinik für chirurgische Kranke und Leiter des Frauenpfründnerhauses (= St. Anna-Hospital); 1870/71 während des Deutsch-Französischen Krieges leitender Arzt in den zu Lazaretten umfunktionierten Räumen seiner Privatklinik und des Anna-Hospitals.

Dresden: 1873-1877 o. Prof. an Königl. Sächsischer Chirurgisch-medicinischer Akademie. 
H: 1877 Gründer und 1877-1896 Leiter e. PrivatKlinik für Chirurgie und Frauenkrankheiten (Hauptstraße 22, Seitenflügel); Okt. 1890-1896 (zus. mit Hermann Lossen) Chirurg an neuerrichteter Privatklinik Josephshaus.

Ahrweiler: Seit 1896 Wohnsitz aus gesundheitlichen Gründen.

1876 Badischer Hofrat

E 1850 Ritter des Großherzogl. Hessischen Ludwig-Ordens I. Klasse; 1871 Ritterkreuz I. Klasse des Ordens vom Zähringer Löwen; 1879 Komturkreuz des Hausordens der Wendischen Krone.

Qu UAH PA 1427. • GLA Abt. 205, Fasz. 182 f. • Briefe: UBH.

$W$ Über die Amputation im Fußgelenke. Heidelberg 1846. - Über das Staphylom der Hornhaut. Heidelberg 1847.

$L$ Biogr. Jahrbuch 4 (1899) Sp. 133; Pagel (1901) Sp. 320; Badische Biographien 5 (1906) S. 98 f.; Chronik Ärzte H (1985) S. 123; WBIS; Deutsche Biographie, s. https://www.deutsche-biographie.de/gnd 116496908.html [06.11. 2017].

$P$ Bildarchiv UAH; Chronik Ärzte H.

\section{Chelius, Maximilian Joseph (seit 1866: von Chelius)}

1817-1864 Med. Fak.

Chirurgie, seit 1818 auch Augenheilkunde

* 16. Jan. 1794 Mannheim

$\dagger$ 17. Aug. 1876 Heidelberg kath.

V Christoph Ernst C. (1754-1808) Chirurg, Accoucheur

M Ottilia Josepha geb. Boehm (1764-1825)

( 22. April 1819 Anna Maria geb. Freiin von Sensburg (1797-1867), siehe Franz Chelius

K 1 T, 4 S (davon $1 \mathrm{~S}$ früh $\dagger$ ), u. a. (siehe) Franz C.
Vw Enkel: Oskar von C. (1859-1923) Offizier, Generaladjutant des letzten dt. Kaisers, auch Komponist, s. WBIS; Afflerbach, Holger: Der Dreibund. Europäische Großmacht- und Allianzpolitik vor dem Ersten Weltkrieg. Wien 2002. S. 522 f.; MGG (Personenteil) 4 ( $\left.{ }^{2} 2003\right)$, Bayerisches Musiker-Lexikon online, Digitales Archiv der thüringischen Staatsarchive.

Lb UH: Seit WS 1808/og Studium; 8. Febr. 1812 Dr. med.

Seit 1812 Eigenstudien in praktischen Krankenanstalten: München, danach Landshut.

Ingolstadt: 1813 Spitalarzt.

$1813 / 14$, erneut 1815 Regimentsarzt bei den badischen Truppen in den Befreiungskriegen.

Karlsruhe: 1814 Lazarett-Arzt nach dem Ersten Pariser Frieden; 3. Sept. 1814 Lizenz als Heilarzt.

1815-1817 Studienreisen nach Wien, Göttingen, Berlin, Halle/S., Leipzig, Würzburg, Jena, Paris.

UH: Seit 20. Okt. 1817 a. o. Prof. für Chirurgie; seit 1. Mai 1818 (Begründer und) Direktor der Chirurg. Klinik im Akad. Hospital im ehem. Dominikanerkloster an der Ecke Hauptstrasse/Brunnengasse; seit 17. Nov. 1818 o. Prof. für Chirurgie und Augenheilkunde; 1819 Umzug des Hospitals mit der Chirurg. Klinik in den Marstall (heute: Neckarstaden 2-6), 1844 in die Seminarstr. 2 in das ehem. Seminarium Carolinum (heute: Sitz der U-Verwaltung); 29. Okt. 1864 auf eigenen Antrag Ruhestand.

1834, 1846 Prorektor der UH; 1823, 1828, 1834, 1839, 1843, 1851, 1857, 1862/63 Dekan der Med. Fak. der $\mathrm{UH}$

Von 1831 bis 1905 ist das Palais Morass in Heidelberg, Hauptstraße 97 im Besitz der Familie Chelius, s. Kurpfälzisches Museum im Palais Morass. Ein Führer von Carl Ludwig Fuchs und Sigrid Wechssler. Heidelberg 1989. S. 18, 26 f. u. ö.

1820 Hofrat; 1826 Geh. Hofrat; 1841 Geh. Rat II. Klasse 
E 1858 Mitglied der Dt. Akademie der Naturforscher Leopoldina Halle/S. - Großkreuz des Ordens vom Zähringer Löwen; 1862 Kommandeurkreuz der französischen Ehrenlegion. 1841 Ehrenbürger der Stadt Heidelberg.

Qu UAH PA 1428; RA 5098, 5629, 6183, 6280, 6789, 6887 u. ö.; GF 145 f. • GLA Abt. 205, Fasz. 176-181. • M.J. Chelius: Gehörkrankheiten. Vorlesungsmitschrift vom WS 1825/26 im UAH (Signatur: Acc. 30/oo). Briefe: UBH. - Nachlaß: UAH (Signatur: Rep. 138). Siehe auch Archiv der Dt. Akademie der Naturforscher Leopoldina Halle/S.

$W$ Handbuch der Chirurgie. 2 Bde. Heidelberg 1822. 8. Aufl. 1857. Handbuch der Augenheilkunde. 2 Bde. Stuttgart 1839-1843. - Bibliographie in: Eckert (1967) S. 92-194.

MHG 1825-1834 Klinische Annalen. • 1828-1834 Neue Jahrbücher der teutschen Medicin und Chirurgie. 1835-1848 Medicinische Annalen.

$L \mathrm{NDB}_{3}$ (1957) S. 196 f. (mit Werkverz.). • Eckert, Cornelius: M.J. von C., Gründer der Chirurgischen U-Klinik Heidelberg. Diss. Heidelberg 1967. - Dt. Geschlechterbuch 175 (1977) S. 50 ff.; Leier (1977) S. 21-26; Schmitt (1978) S. 72 u.ö.; Chronik Ärzte H (1985) S. 123, 212 f.; Semper apertus 2 (1985) S. 192 (Register); WBIS. • Handbuch der historischen Buchbestände in Deutschland. Hrsg. von Bernhard Fabian. Hildesheim 2003. • Prückner (2004) S. 302 (Register); Stumm (2012) S. 692 (Register); Doll/Kirsch/Eckart (2017) S. 34.

$P$ Bildarchiv UAH; graph. Slg. UBH; Chronik Ärzte H.

\section{Cohn, Georg Ludwig}

1876-1886 Jur. Fak. 1886-1892 (Honorar-Prof.) Jur. Fak.

Deutsche Rechtsgeschichte, Preußisches Recht

* 19. Sept. 1845 Breslau (heute: Wrocław, Polen)

$\dagger$ 16. Febr. 1918 Zürich

mosaisch

V Samuel Löbel C., Kaufmann

M Philippine geb. Falk

๑ 2. Sept. 188o Margareta geb. Levin (1859-1941)

K 2 T: u.a. Dr. oec. Elsbeth C., 1907 Namensänderung in Georgi (1882-1975) Lehrerin, Schriftstellerin. 2 S: Walter C., dann Änderung in Georgi (1889-1920) seit 1919 Privat-Dozent für Immunologie Frankfurt/M., s. DBE 3 (2006) S. 758. - Felix C., dann Änderung in Georgi (1893-1965) 1920-1923 Assistent am Institut für Krebsforschung H, 19231933 Chefassistent an U-Klinik und seit 1924 Privat-Dozent für Neurologie Breslau, 19331946 Direktor der psychiatr. Privatklinik Bellevue in Yverdon-les-Bains (Kanton Waadt); U Basel: 1946-1951 Sekundärarzt an Psychiatr. U-Klinik Friedmatt, seit 1948 a. o. Prof., 19511965 o. Prof. und Vorsteher der Neurolog. UPoliklinik, s. WBIS, DBE 3 (2006) S. 757

Vw Bruder: Hermann C. (1838-1906) 1866-1906 Begründer und Direktor e. Augenklinik in Breslau, seit 1868 Privat-Dozent, seit 1874 a.o. Prof. für Augenheilkunde ebd., s. Pagel (1901) Sp. $335 \mathrm{f}$; Jüdische National-Biographie 1 (1925) S. 580; Christmann, Günter: Augenarzt und Schulhygieniker ... H.C. in: Ärzteblatt Sachsen 2 (2007) S. 8of.; WBIS. • Großneffe: Ludwig Hamburger (1901-1970), u.a. bis 1939 Privat-Dozent für Dt. Zivil- und Handelsrecht an U Genf, s. Meyer-Pritzl (200o) S. $372 \mathrm{f}$.

Lb Breslau: 1861-1863 Banklehrling; 1864 Maturitätsprüfung.

Seit SS 1864 Studium an U Breslau, anschl. Berlin; 1866/67 Staatsexamen; 1867-1874 im preußischen Justizdienst tätig, zuletzt als Kreisrichter; 1868 Dr. iur. an U Greifswald; 1874-1876 Eigenstudien. 
UH: 10. Juni 1876 Habilitation; seit 1. Juli 1878 a.o. Prof.; seit 1. Aug. 1886 Honorar-Prof.; 1890 Ruf an U Tokio abgelehnt; WS 1891/92 letzte Vorlesungen.

U Zürich: Seit 3. März 1892 o. Prof. für Dt. Privatrecht, Rechtsgeschichte, Handels-, Wechsel- und Versicherungsrecht; SS 1892 Vorlesungsbeginn.

E Mitglied der Accademia delle Lettere Padua und von anderen wiss. Gesellschaften.

Qu UAH PA 1442; Fak.-Akte H-II-111/83. • Auskunft: Universitätsarchiv Göttingen; Universitätssowie Stadtarchiv Zürich.

$W$ Zur Lehre vom Check in: Zs. für vgl. Rechtswissenschaft 1-3 (1877-1882). • Die Gesetze Hammurabis. Zürich 1903. • Der Kampf um den Wechselprotest. Berlin 1905.

$M G 1877$ Zs. für vgl. Rechtswissenschaft.

L Almanach Heidelberg (1886) S. 112; Wer ist's (1914) S. 230. - Egger, August: Nekrolog G. C. in: Universität Zürich - Rektoratsreden und Jahresberichte. April 1917-Ende März 1918. Zürich 1918. S. 64-68. - Jüdische National-Biographie 1 (1925) S. 579; WBIS; Schroeder (2010) S. 333-335; Ders. (2017) S. 172-178; Deutsche Biographie, s. https:// www.deutsche-biographie.de/gnd116629304.html [06.11. 2017]. • Verzeichnis der Dozenten der Universität Zürich SS 1833-WS 1937/38 (in der Reihenfolge des Eintrittes in die Fakultät bzw. in die höhere Stellung in derselben). Bearb. von F. Peter, s. http://www.archiv.uzh.ch/dam/jcr:00000ooo-1 92d-6565-ffff-ffffb128fc2a/uzh_dozierendenver zeichnis_1833-1933.pdf. S. 962 (hier: 17. Febr. 1918 als Todesdatum genannt; abgerufen am 23. März 2018).

P Bildarchiv UAH; graph. Slg. UBH; Egger (1918).

\section{Cohnheim, Otto Heinrich} (seit 1917: Kestner)

1898-1913 Med. Fak.

Physiologie, Physiologische Chemie

* 30. Mai 1873 Breslau (heute: Wrocław, Polen)

$\dagger \quad$ 21. Febr. 1953 Hamburg mosaisch, (vor) $1898 \mathrm{ev.}$

V Friedrich Julius C. (1839-1884), u. a. seit 1868 o. Prof. für Pathologie Kiel, seit 1872 Breslau, seit 1878 Leipzig, s. NDB 11 (1977) S. 556, Dhom (2001) S. 788 (Register), Professorenkatalog Leipzig online; Briefe in UBH

M Martha Fanny Therese geb. Lewald (18521919)

๑ 2. Juni 1906 Eva Marie Mathilde geb. Barth (1882-1973) Sängerin

K $\quad 1$ S, 4 T: u. a. Felicitas Anna Maria Dora C./K. verh. Kukuck (1914-2001) Komponistin, s. Lexikon verfolgter Musiker und Musikerinnen der NS-Zeit. Hrsg. von Claudia Maurer Zenck und Peter Petersen ... Hamburg $2005 \mathrm{ff}$. online; Hamburgische Biografie. Personenlexikon hrsg. von Franklin Kopitzsch ... Göttingen 2008. S. 203-205; Sprenger, Cordula: F. K. als Komponistin von Solo- und Chorliedern. Marburg 2008; Nachlass im Archiv Frau und Musik in Frankfurt/M. - Siehe auch Fischer (2012) S. 49.

Lb Seit SS 1891 Studium an U Leipzig, seit WS 1893/94 H, seit WS 1894/95 Leipzig; 25. Jan. 1896 Staatsprüfung in Leipzig.

UH: 26. Juni 1896 Dr. med.; Jan.-Mai 1897 Volontär-Assistent an Med. U-Klinik; seit Mai 1897 Assistent am Physiolog. Inst.; 22. Dez. 1898 Habilitation für Physiologie; seit 24. Juni 1903 nichtetatm. a.o. Prof.; 1904 Gast-Prof. an Boston U (Massachusetts); Studienaufenthalte: WS 1900/o1 Biolog. Station in Neapel, WS 1905/o6 Hygienisches Inst. der U Berlin, 1908-1913 (im Jahr jeweils für einige Monate) Zoolog. Station in Neapel.

Hamburg: Seit 1. Juni 1913 Oberarzt und Vorsteher der Physiolog. Abt. des Allg. Krankenhauses Eppendorf. • In dieser Zeit: 
1914-1918 Kriegsdienst.

U Hamburg: 5. Mai 1919-31. März 1934 (Entlassung) o. Prof. an neugegründeter U und Direktor des Physiolog. Inst.; 30. Juni 1934 Ruhestand aus rassischen Gründen; Emigration.

Großbritannien: 1935-1939 Wiss. Arbeiten u. a. am Rowett Research Institute in Bucksburn (bei Aberdeen); Nov. 1939-Mai 1940 wiss. Arbeiten am Royal Sea Bathing Hospital in Margate (Kent); Mai-Nov. 1940 Internierung auf Isle of Man als „enemy alien“; seit Dez. 1940 Lehrer u.a. an School of Agriculture in Cambridge.

Hamburg: Mai 1949 Remigration; 6. Juni 1946 Emeritierung an U rückwirkend zum 1. Mai 1945.

1901 Entdecker von Erepsin, einem eiweißabbauenden Verdauungsenzym

Qu UAH PA 1445; RA 6191, 6902; Fak.-Akten HIII-111/149, H-III-111/15of. u.ö. • GLA Abt. 235, Fasz. 1872. • Briefe: UBH. - Auskunft: Staatsarchiv Hamburg.

W Chemie der Eiweißkörper. Braunschweig 1900. 4. Aufl. 1924. Trypsin und Erepsin in: HoppeSeyler's Zs. für Physiologische Chemie (1902) Bd. 36, H. 1, S. 13-19. Harn und Harnabsonderung in: Zuntz, Nathan: Lehrbuch der Physiologie des Menschen. Leipzig 1909. 4. Aufl. 1931. • Die Ernährung des Menschen. Berlin 1924. 3. Aufl. 1928. (Mitverf.)

L NDB 11 (1977) S. 555f. (mit Werkverz.). - Matthews, D.M.: O.C. - The forgotten physiologist in: British Medical Journal 2 (1978) S. 618f. • Hochschulalltag im „Dritten Reich“ - U Hamburg 3 (1991) S. 1261 f. u.ö.; Jansen (1992a) S. 164 (Register). Villiez, Anna von: Verfolgt und vertrieben. Aus der Serie „Einzelschicksale jüdischer Ärzte in Hamburg im Nationalsozialismus." O. K. und die Ärzte-Emigration nach Großbritannien in: Hamburger Ärzteblatt. Zs. der Ärztekammer Hamburg ... Hamburg 2006. S. 223. - Nicolaysen, Rainer: K. (bis 1917 Cohnheim), O.H. in: Hamburgische Biografie. Göttingen 2008. 4. Bd. S. 190192. Fischer (2012) S. 49-53.

\section{Conradi, Johann Wilhelm Heinrich}

1814-1823 Med. Fak.

Pathologie, Therapie (Innere Medizin)

* 22. Sept. 1780 Marburg/Lahn

$\dagger \quad$ 17. Juni 1861 Göttingen ev.-luth.

V Johann Ludwig C. (1730-1785), u. a. seit 1765 a.o., seit 1774 o. Prof. für Rechtswiss. Marburg, s. Catalogus prof. Marburgensis 1 (1927) S. 115 f., NDB 3 (1957) S. 340, WBIS

M Anna Florentine geb. Seipp (1751-1835)

( 29. Mai 1806 Johanna Friederica geb. Schraidt (1785-1823)

๑ 18. April 1824 Johanna Marie Ernestine geb. Schulze (1799-1857) T von Gottlob Ernst S. (auch genannt: Aenesidemus-Schulze) (17611833), u.a. seit 1788 o. Prof. für Philosophie Helmstedt, 1810-1833 Göttingen, s. Catalogus prof. Gottingensium (1962) S. 106, WBIS; Hoyos Jaramillo, Luis Eduardo: Der Skeptizismus und die Transzendentalphilosophie. Dt. Philosophie am Ende des 18. Jahrhunderts. Freiburg/Br. 2008. S. 99-224.

$\mathrm{K} \quad 7 \mathrm{~S}, 1 \mathrm{~T}$

Lb U Marburg: Seit SS 1797 Studium; 13. Jan. 1802 Dr. med.; Ostern 1802 Habilitation; seit 17. Aug. 1803 a.o. Prof.; seit 11. Jan. 1805 o. Prof.; seit 1809 Leiter der Poliklinik; seit 1812 Direktor der stationären Klinik im Akad. Krankenhaus.

UH: 26. Mai 1814 Ern. zum o. Prof. als Nachf. von Stephan Zipf; 1814 (Begründer)-1823 Leiter des Med.-Klinischen Inst. (Med. Klinik) im Akad. Spital/Hospital im ehemaligen Dominikanerkloster an der Ecke Hauptstrasse/Brunnengasse; 1818 Umzug des Akad. Hospitals mit der Med. Klinik in den Marstall (heute: Neckarstaden 2-6); WS 1814/ 15 Dienstantritt; Rufe an U abgelehnt: 1818 Bonn, 1821 Marburg, Anfang 1823 Göttingen.

U Göttingen: WS 1823/24-17. Juni 1861 (†) o. Prof. für Allg. Therapie und 1823-1853 Leiter des Poliklinischen Inst.; Ostern 1837-1853 Direktor des Akad. Krankenhauses. 
1818 Prorektor der UH; 1817 Dekan der Med. Fak. der UH

1815 Hofrat; 1820 Geh. Hofrat; 1852 Obermedizinalrat

E 1823 Mitglied der Akademie der Wissenschaften Göttingen. 1853 Dr. phil. h. c. Göttingen.

Qu UAH PA 1448. • GLA Abt. 205, Fasz. 187f. • Briefe: UBH.

$W$ Handbuch der allgemeinen Pathologie. Marburg 1811. 6. Ausg. 1841. - Handbuch der speziellen Pathologie und Therapie. 2 Bde. Marburg 1811-1816. 4. Aufl. 1831-1833. • Über das medizinisch-klinische Institut in dem akademischen Hospital zu Heidelberg. Heidelberg 1817. - Kritik der medizinischen Lehre des Dr. Broussais. Heidelberg 1821. 2. Ausg. 1823. - Handbuch der allgemeinen Therapie. Kassel 1833.

L NDB 3 (1957) S. 340 (mit Werkverz.); Catalogus prof. Gottingensium (1962) S. 75. Haselhorst, Klaus: J.W.H.C. Med. Diss. Göttingen 1964. • Schmitt (1978) S. 72 u. ö.; Renger (1982) S. 293 (Register); Chronik Ärzte H (1985) S. 124, 214; WBIS; Stumm (2012) S. 692 (Register); Mitgl. der Akad. der Wiss. Göttingen (2001) S. 60 (hier Todesdatum: 16. Juni); Prückner (2004) S. 302 (Register). Zimmermann, Volker: „Eine Medicinische Facultät in Flor bringen“. Zur Geschichte der Medizinischen Fakultät der ... Universität Göttingen. Göttingen 2009. S. 32, 41 u. ö. • Bauer/Ho (2016) S. $22 \mathrm{f}$.

$P$ Bildarchiv UAH; graph. Slg. UBH; NDB; Chronik Ärzte H.

\section{Cramer, Moritz Eduard}

1891-1898 (1902) Med. Fak.

Hygiene

* 23. Aug. 1863 Solothurn (Schweiz)

$\dagger$ 19. Jan. 1902 Aachen

ev.

V Heinrich C. (1831-1893) Direktor: seit 1861 Anstalt Rosenegg in Solothurn, seit 1873 Städtische Irrenanstalt Lindenburg bei Köln, seit 1874 Irrenheilanstalt Marburg und seit 1874 a. o. Prof., seit 1877 o. Prof. für Psychiatrie an U Marburg, s. Catalogus prof. Marburgensis 1 (1927) S. 268; Nolte, Karen: Gelebte Hysterie: Erfahrung, Eigensinn und psychiatrische Diskurse im Anstaltsalltag um 1900. Frankfurt/M. 2003. S. 36-48 u. ö.

M Emma geb. Den(n)inger (1834-1894)

( 1. Juni 1895 Magda Emma Bertha geb. von Schmidt (1864-1944) T von Ernst Albert von S. (1845-1921), u. a. 1884-1919 o. Prof. für Pharmazeutische Chemie Marburg, s. Catalogus prof. Marburgensis 1 (1927) S. 484, WBIS

K $1 \mathrm{~S}$

Vw Brüder: August C. (1860-1912), u. a. seit 1897 a. o. Prof. für Psychiatrie und 1900-1912 Direktor der Provinzial-Irrenanstalt Göttingen, s. NDB 3 (1957) S. 391, Catalogus prof. Gottingensium (1962) S. 77, 94; WBIS; Nolte (2003) S. 157 f. u. ö.; Fangerau, Heiner: Politik und Nervosität: Gründung und Betrieb der ersten deutschen Volksnervenheilstätte „Rasemühle" bei Göttingen zwischen 1903 und 1914 in: Krankenhauspsychiatrie 16 (2005) S. 25-32. • Karl C. (1862-1937) 1901-1928 dirigierender Arzt der orthopäd.-chirurg. Abt., anschl. Klinik im Bürgerhospital Köln, seit 1904 Dozent, seit 1908 Prof. für orthopäd. Chirurgie an Akademie für praktische Medizin ebd., 1919-1928 planm. a.o. Prof. an Med. Fak. der U Köln, s. Kürschner (1935) Sp. 203, WBIS; Glimpel, Gisa: K.C. und die Orthopädie in Köln. Diss. Köln 1975.

Lb U Marburg: Seit SS 1883 Studium; 21. Jan. 1888 Staatsexamen; 7. Juli 1888 Dr. med.; 1888-1891 Eigenstudien. 
UH: Seit 2. Sept. 1891 Assistent am Hygien. Inst.; 14. Dez. 1891 Habilitation; seit 11. Juli 1896 nichtetatm. a.o. Prof.; WS 1898/99-WS 1901/o2 Entbindung von Lehrverpflichtungen aus Krankheitsgründen.

Qu UAH PA 1452; RA 6212; Fak.-Akte H-III-111/ 118 fol. 139r-15or (Habilitation). • Auskunft: Standesamt Marburg; Stadtarchiv Würzburg.

$W$ Die Zusammensetzung der Bacterien in ihrer Abhängigkeit von dem Nährmaterial ... München 1892. - Die Messung der Sonnenstrahlung in hygienischer Hinsicht. Sonderdruck. Berlin 1894. • Hygiene. Ein kurzes Lehrbuch für Studierende und Ärzte. Leipzig 1896. • Über die Beschaffenheit des Heidelberger Trinkwassers. Heidelberg 1896.

$L$ Biogr. Jahrbuch 7 (1902) Sp. 22*; Badische Biographien 6 (1935) S. 792; Chronik Ärzte H (1985) S. 124; WBIS.

\section{Creuzer, Georg Friedrich}

1804-1809, 1809-1845 Phil. Fak.

Philologie und Alte Historie

* 10. März 1771 Marburg/Lahn

$\dagger$ 16. Febr. 1858 Heidelberg ev.-luth.

V Christoph Andreas Joachim Leonhard C. (1726-1772) Buchbindermeister, später Steuereinnehmer

M Philippine Eleonore geb. Bang (1734-1795)

๑ 6. Okt. 1799 Sophia (Sophie) Eleonora geb. Müller verw. Leske (1758-1831), s. Gersdorff (2006) S. 280 (Register); Witwe von Nathanael Gottfried Leske (1751-1786) seit 1774 PrivatDozent, seit 1775 a. o. Prof. für Naturgeschichte, seit 1778 o. Prof. für Ökonomie Leipzig, 1786 o. Prof. für Kameralwiss. Marburg, s. Catalogus prof. Marburgensis 1 (1927) S. 437 Anm., WBIS; Otto, Hans-Werner u. a.: Zum 250. Geb. von N. G. L. in: Berichte der Naturforschenden Gesellschaft Oberlausitz 10 (2002) S. 109-113.
๑ 9. Nov. 1831 Anna Jacobina geb. Sebastian verw. Weber (1803-1889) T von: (siehe) Friedrich Jacob Christian S.; Witwe von Karl Josef Weber (1798-1831) Privat-Dozent für Rechtswiss. UH, s. Emundts-Trill (1997) S. 237

K 1 Stief-S, 1 Stief-T: Eleonore Wilhelmine geb. Leske ( $\dagger$ vor 1853) Ehefrau von Johann Christian Zimmermann (1786-1853) UH: seit 10. Juni 1805 Privat-Lehrer für Mathematik in Theorie und Praxis, Geognosie oder Allg. Naturgeschichte der Erde, 17. Mai 1807 Dr. phil.; SS 1809 Privat-Dozent für Mathematik, Physik und Baukunst U Marburg; Berg- und Forstamt Clausthal: seit Herbst 1809 Eisenhüttenregistrator, seit 1818 Bergschreiber, seit 1827 Bergsekretär, seit 1839 Bergrat, 1853 Oberbergrat; in dieser Zeit u.a. auch Dozent für Mathematik, Mineralogie, Geognosie und Bergbaukunde an Bergschule für die Harzdivision in Clausthal; 1846-1853 Planer des Ernst-August-Stollens von Gittelde (heute: Ortsteil von Bad Grund am Harz) bis Clausthal, e. Wasserlösungsstollen zum Abführen des Grubenwassers des Oberharzer Bergbaus, seit 2010 Weltkulturerbe der UNESCO, s. Emundts-Trill (1997) S. 313 (hier irrtümlich 1784 statt 1786 als Geb.-Jahr angegeben); Müller, Georg: Dr. phil. J.C.Z. ... Eine ungewöhnliche Karriere im Oberharzer Bergbau. Clausthal-Zellerfeld 2012. Online, s. https://www.deutsche-digitale-bibliothek.de/binary/2GV3XTNTHBLPW JZ6M33GBSTSX5XDPN6TZ/full/1.pdf (abgerufen am 30. Dez. 2017; S. 11: hier wurde Herrn Georg Müller von der Verfasserin irrtümlich der 16. statt 17. Mai 1807 als Promotionsdatum mitgeteilt); Professorenkatalog Marburg, s. http://www.uni-marburg.de/uniarchiv/pkat/ details?id=9872 (Stand: 11. Nov. 2016)

Vw Vetter: Leonhard Christoph Andreas C. (17681844) Marburg: seit Mai 1794 (Begründer zus. mit F.C.) Vorsteher e. Erziehungs-Anstalt, 1801-1822 Pfarrer, 1803-1844 o. Prof. für Philosophie an U und 1821-1844 Konsistorialrat, s. Catalogus prof. Marburgensis 1 (1927) S. 292, WBIS; Tafani, Daniela: C.A.L.C.: a discussione della dottrina morale di Kant alla fine del Settecento. Genua 1999; Gersdorff (2006) S. 280 (Register). 
Lb Seit SS 1789 Studium zunächst der Theologie, dann der Philosophie, Philologie, Alten Geschichte an U Marburg, seit Herbst 1790 Jena, seit Herbst 1791 Marburg.

Marburg: Mai 1794 Begründer zus. mit seinem Vetter Christoph Andreas Leonhard C. und 17941798 Lehrer e. Eleven-Instituts (Erziehungs-Anstalt).

Leipzig: SS 1798 Forts. des Studiums an U und Hauslehrer.

U Marburg: WS 1797/98, WS 1798/99 C. hält Privatvorlesungen (Privatissima); 9. Okt. 1799 Dr. phil. an U Tübingen (in absentia); seit 1799 Privat-Dozent an U Marburg; seit 21. Okt. 1800 a.o. Prof. für Griechische Sprache mit Besoldung; seit 31. Okt. 1802 o. Prof. für Eloquenz, Dichtkunst, Griechische Literatur; 1803/04 Rufe an U Wilna und Würzburg abgelehnt.

UH: Seit 4. April 1804 o. Prof.; 1805 Rufe an U Fulda und Landshut abgelehnt, s. hierzu Kayser (1923) S. 56-59; seit 1807 (Mitbegründer und) Mit-Direktor (bis 1810 zus. mit Friedrich Heinrich Christian Schwarz) des Philolog.-Pädagog. (auch: Pädagog.Philolog.) Seminars, s. hierzu UAH RA 6122.

U Leiden: SS 1809 Berufung zum o. Prof. für Griechische Sprache.

UH: 1. Aug. 1809 Zurückberufung als o. Prof.; 1809-1810 Mit-Direktor des Philolog.-Pädagog. Seminars, SS 1810 Trennung in ein Philolog. Seminar unter C. (Leiter bis Mai 1845) und ein Pädagog. (-Katechetisches) Seminar unter Schwarz, s. hierzu GLA Abt. 235, Fasz. 326o; Rufe an U abgelehnt: Göttingen, Kiel, Bonn und München; 1. Mai 1845 auf eigenen Antrag Ruhestand.

1807, 1814, 1822/23 Dekan der Phil. Fak. der UH

Ein von Freunden und Schülern Creuzers am 3o. Dez. 1834 gestiftetes Konvolut von griechischen und römischen Münzen, Gemmen und Abgüssen, das „Antiquarium Creuzerianum“, bildet u. a. den Grundstock der späteren Heidelberger archäologischen Universitätssammlung, siehe hierzu Carl Zell. C.s eigene archäologische Sammlung, die erstmals der Universität Heidelberg im Januar 1847 zur Acquisition angeboten (s. hierzu UAH RA 6387) und später für die großherzogliche Sammlung erworben wird, ist heute im Badischen Landesmuseum Karlsruhe untergebracht.

Über C.s tragische Verbindung zu Karoline von Günderrode (1780-1806) zwischen 1804 und 1806, s. Gedichte, Prosa, Briefe. Hrsg. von Hannelore Schlaffer. Stuttgart 1998; Gersdorff (2006); Stauf, Renate: „... rette Dich, setze mich aus ans Ufer“. Aporien der romantischen Liebe im Briefwechsel zwischen K. von G. und F. C. in: SchreibLust: der Liebesbrief im 18. und 19. Jahrhundert. Hrsg. von Renate Stauf ... Berlin 2013. S. 165-186.

1806 Hofrat; 1818 Geh. Hofrat; 1826 Geh. Rat II. Klasse

E Mitglied der Akademie der Wissenschaften: 1808 München, 1844 Göttingen, 1848 Wien; 1825 Mitglied der Académie des Inscriptions et BellesLettres Paris. 1815 D. theol. UH; 1844 Dr. iur. h.c. UH. 1849 Orden pour le Mérite für Wissenschaften und Künste; 1853 Maximiliansorden für Wissenschaft und Kunst. 1834 Kommandeur des Ordens vom Zähringer Löwen; 1837 Ritter der französischen Ehrenlegion. - 1844 Ehrenbürger der Stadt Heidelberg.

Qu UAH PA 1453; RA 1118, 6122 fol. 71r u.ö., 6372, 6387 u. ö. • GLA Abt. 205, Fasz. 189, 536. • Briefe: UBH. Briefe F.C.s an Savigny (1799-1850). Hrsg. von Hellfried Dahlmann. Berlin 1972. • Briefwechsel deutschsprachiger Philosophen 17501850. Hrsg. von Norbert Henrichs ... bearb. von Horst Weeland. München u. a. 1987. Bd. 1. Nachlaß: UBH; Badische Landesbibliothek Karlsruhe. • Mitteilungen: Herr Prof. Dr. Henning Freund, Ev. Hochschule Tabor in Marburg und Herr Dr. Nicolas Zenzen, Universität Heidelberg. • Aus dem Leben eines alten Professors. Leipzig 1848. (Autobiogr.)

$W$ Das akademische Studium des Alterthums, nebst e. Plane der humanistischen Vorlesungen und des Philolog. Seminarium auf der Universität Heidelberg. Hrsg. ... von Jürgen Paul Schwindt. Heidelberg 1807. Faks.-Ausg. Heidelberg 2007. 
Symbolik und Mythologie der alten Völker, besonders der Griechen. Leipzig 1810-1812. 3. Aufl. 18361843. Nachdr. Hildesheim 1973. - Zur Geschichte der griechischen und römischen Literatur. Leipzig 1847. Zur Geschichte der klassischen Philologie seit Wiederherstellung der Literatur. Frankfurt/M. 1854.

MHG Studien. 6 Bde. Heidelberg 1805-1811 (zus. mit Carl Daub), s. hierzu Ein Knab auf schnellem Roß (2006) S. 67. 1807-1809 Heidelbergische Jahrbücher der Literatur.

$L$ Catalogus prof. Marburgensis 1 (1927) S. 334; NDB 3 (1957) S. 414f. (mit Werkverz.); WBIS. Sohnle, Werner: G.F.C.s „Symbolik und Mythologie“ in Frankreich. Göppingen 1972. - Münch, Marc Mathieu: La "Symbolique“ de F.C. Paris 1976. Heidelberg im säkularen Umbruch (1987) S. 558 (Register). Hölscher, Tonio: G. F. C. in: Archäologenbildnisse (1988). Kirschke (2001) S. 445 (Register); Ein Knab auf schnellem Roß (2006) S. 12 f., 69 u. ö. - Gersdorff, Dagmar von: „Die Erde ist mir Heimat nicht geworden." Das Leben der Karoline von Günderrode. Frankfurt/M. 2006. S. 280 (Register). - Lenhart, Volker: F. H.C. S. und die Gründung des Philolog.-Pädagog. Seminars 1807. Vortrag auf der Jubiläumsveranstaltung „200 Jahre institutionalisierte wiss. Pädagogik und Lehrerbildung an der Universität Heidelberg“, online unter www2.ibw.uni-heidelberg.de/feldevaluation o9/jubilaeum.pdf vom 24. April 2007. - F.C. ... Begleitband zur Ausstellung in der UBH ... Hrsg. von Frank Engehausen u. a. Heidelberg 2008. 200 Jahre Heidelberger Romantik (2008) S. 281-298. • Dönike, Martin: Altertumskundliches Wissen in Weimar. Berlin 2013. S. 498 (Register). - Objekte erzählen Geschichte(n) (2016) S. 124-130 u. ö.; Riecke (2016) S. 11, 116.

$P$ Bildarchiv UAH; graph. Slg. UBH; NDB; Archäologenbildnisse (1988).

\section{Cropp, Friedrich}

1813-1820 Jur. Fak.

Römisches Recht, Deutsches Recht

* 05. Juli 1790 Moorburg (heute: Stadtteil von Hamburg)

$\dagger \quad$ 08. Aug. 1832 Lübeck ev.-luth.

V Paul Lorenz C. (1759-1830) Pastor

M Helena Maria geb. Caarstens (1765-1845)

๑ 25. Sept. 1814 Maria Elisabetha geb. Speyerer (1782-1854)

$\mathrm{K} \quad 2 \mathrm{~S}, 2 \mathrm{~T}$

$L b$ Seit 13. Mai 1810 Studium an U Göttingen.

UH: 30. Sept. 1811 Immatrikulation; 10. Juli 1813 Dr. iur.; 19. Juli 1813 Bewilligung der facultas legendi; seit 23. April 1814 a. o. Prof. mit e. Jahresgehalt von 200.- Gulden in Nachf. von Arnold Heise; 1814 Ruf an U Kiel abgelehnt; 1815-1820 a. o. Beisitzer des Spruchkollegiums der Jur. Fak.; 15. Febr. 1817 Ern. zum o. Prof. als Nachf. von Heise; Rufe an U abgelehnt: 1817 Gießen, Königsberg (Preußen), Tübingen, 1818 Jena, 1819 Halle-Wittenberg; 17. Aug. 1820 auf eigenen Antrag aus Lehrkörper ausgeschieden.

Lübeck: 1820-1832 Richter am Oberappellationsgericht der vier Freien Städte des Dt. Bundes.

1818 Dekan der Jur. Fak. der UH

1820 Hofrat

Qu UAH PA 1455. GLA Abt. 235, Fasz. 642. Matrikel Göttingen (1937) S. 498. • Briefe: UBH.

$W$ Loca juris Romani selecta ... Heidelberg 1815. • Abhandlung über den Diebstahl nach dem älteren Recht der Freien Städte Hamburg, Lübeck und Bremen in: Criminalistische Beiträge 2 (1825). • Juristische Abhandlungen mit Entscheidungen des Oberappellationsgerichts der vier freien Städte Deutschlands. Hamburg 1830 (zus. mit Arnold Heise). 
$L$ ADB 4 (1876) S. 610-612; Lautenschlager (1933) S. 645 f., 652-661; Jammers (1964) S. 177 u. ö.; Renger (1982) S. 153; Weisert (1991) S. 126 u. ö.; WBIS; Schroeder (2010) S. 117-120.

\section{Crusius, Otto Karl Friedrich Hermann}

1898-1903 Phil. Fak.

Klassische Philologie

* 20. Dez. 1857 Hannover

$\dagger$ 29. Dez. 1918 München ev.

V Otto Carl Siegismund C. (1794-1860 oder 1861) Consistorial-Commissär (Beauftragter der kirchlichen Behörde)

M Sophie Charlotte Elisabeth geb. Winkelmann (1825-1900)

๑ 5. Okt. 1885 Franziska Elisabeth Dorothea geb. von Bihl (1858-1939)

K $\quad 1$ T, 2 S: u. a. Friedrich Alfred Ernst Alexis C. ( ${ }^{*} 1897$; ermordet 1941 in Tötungsanstalt Hartheim in Alkoven bei Linz, Österreich) Gymnasiallehrer und Altphilologe, Autor von: Römische Metrik: Eine Einführung. München 1929. 8. Aufl. 2006.

Vw Onkel: Gottlob Christian C. (1785-1848) Schullehrer, Sprach- und Literaturwissenschaftler, s. ADB 4 (1876) S. 631; Pökel, Wilhelm: Philologisches Schriftsteller-Lexikon. Leipzig 1882.

Lb Seit Ostern 1875 Studium an U Leipzig.

Herbst 1877-1878 Hauslehrer bei e. dt.-amerik. Familie (in dieser Zeit: Reisen nach Süddeutschland, Italien, Südfrankreich und Paris).

U Leipzig: SS 1878 Forts. des Studiums; 23. Dez. 1879 Dr. phil.

Dresden-Neustadt: April 1880-April 1881 Provisorischer Gymnasialoberlehrer am Königl. Gymnasium.

Leipzig: 3. Aug. 188o Oberlehrerprüfung; April 1881-April 1882 Militärdienstpflicht als Einjährig-
Freiwilliger; seit April 1882 wiss. Hilfslehrer, April 1885-1886 ständiger Oberlehrer an Thomasschule. In dieser Zeit:

U Leipzig: 29. März 1883 Habilitationskolloquium; 4. Mai 1883 Erteilung der venia legendi; seit 15. April 1884 Assistent am Philolog. Seminar; Ostern 1886 Ruf als a. o. Prof. an U Jena abgelehnt.

U Tübingen: Seit 19. März 1886 o. Prof. als Nachf. von (siehe) Erwin Rohde und Mit-Direktor des Philolog. Seminars; 1898 Ruf an U Halle-Wittenberg abgelehnt.

UH: Seit 15. April 1898 o. Prof. als Nachf. von Rohde und Mit-Direktor (zus. mit Fritz Schöll) des Philolog. Seminars; 1899 Ruf an U Wien abgelehnt. • In dieser Zeit:

H: 1898-1903 Mitglied des Oberschulrats.

U München: April 1903-Dez. 1918 o. Prof. und Direktor des Philolog. Seminars. • In dieser Zeit:

München: 1903-1918 Mitglied des Oberschulrats; 1915-1918 Generalkonservator der Sammlungen des bayer. Staates.

1899/190o Dekan der Phil. Fak. der UH

1899 Geh. Hofrat

$E$ Mitglied der Akademie der Wissenschaften: 1903 München, 1911 Wien. • Dr. h. c. der U: Athen, Dublin. 1889 Königl. Württ. Erinnerungsmedaille in Silber.

Qu UAH PA 1456; RA 6827. - UA Leipzig PA 390. GLA Abt. 76, Fasz. 9903. Briefwechsel zwischen Eduard Meyer und O.C. in: Gert Audring: Aufbereitung wichtiger Briefbestände aus dem Nachlass Eduard Meyers online, s. http://www. kohring-digital.de/briefe-eduard-meyer.html (abgerufen am 15. Sept. 2014). - Nachlaß: Bayerische Staatsbibliothek München (Nachlaßrepertorium von 1970/72, s. http://bsbdok.digitale-sammlun gen.de/general/item/bsbdok:101057:2/component/ bsbdok:101056/Nachlassverzeichnis_Crusiusiana. pdf). 
$W$ Beiträge zur griechischen Mythologie und Religionsgeschichte. Leipzig 1886. Untersuchungen zu den Mimiamben des Herondas. Leipzig 1892. • Delphische Hymnen. Göttingen 1894. - Erwin Rohde. Ein biographischer Versuch ... Tübingen 1902. Wie studiert man klassische Philologie? München 1911.

HG 1889-1918 Philologus.

MHG 1910-1918 Das Erbe der Alten.

$L$ Preisendanz, Karl: O.C. † in: Jahresbericht für Altertumswissenschaft 185 B - Nekrologe (1920). • Pfeiffer, Rudolf: O.C. $\dagger$ in: Dt. Biogr. Jahrbuch. Bd. 2: 1917-1920. Stuttgart 1928. S. 237-243. NDB 3 (1957) S. 432 (mit Werkverz.); WBIS. Kössler, Franz: Berufsbiographien aus Schul-Jahresberichten und Schulprogrammen 1825-1918 mit Veröffentlichungsverzeichnissen. UB GieBen 2008. (Giessener Elektronische Bibliothek, s. http://geb.uni-giessen.de/geb/volltexte/2008/61 09/(Band)). • Die Leipziger Rektoratsreden 18711933. Hrsg. von Franz Häuser. Bd. 1. Berlin 2009. S. 353,413 .

$P$ Bildarchiv UAH; graph. Slg. UBH; NDB.

Curtius, Ernst Robert (Taufnamen; später hinzugefügt: Gustav Tassilo)

1924-1929 Phil. Fak.

Romanische Philologie

* 14. April 1886 Thann (Deutsches Reich; heute: Frankreich)

$\dagger$ 19. April 1956 Rom

ㅁ Freiburg/Br.

ev.

V Friedrich C. (1851-1933) Präsident des Direktoriums und des Oberkonsistoriums der Kirche Augsburgischer Konfession in ElsaßLothringen

M Louise geb. von Erlach-Hindelbank (18571919)

๑ 15. Febr. 1930 Ilse Wilhelmine geb. Gsottschneider (1907-2002)
$\mathrm{K}$ keine

Vw Großvater: Ernst C. (1814-1896), u.a. Lehrer, seit 1844 a. o. Prof. Berlin, seit 1855 Prof. Göttingen, seit 1868 o. Prof. für Archäologie Berlin, s. NDB 3 (1957) S. 446 f., WBIS; Wrede, Henning: Olympia, E.C. und die kulturgeschichtliche Leistung des Philhellenismus in: Die modernen Väter der Antike. Die Entwicklung der Altertumswissenschaften an Akademie und Universität im Berlin des 19. Jahrhunderts. Hrsg. von Annette M. Baertschi ... Berlin 2009. S. 165-208. - Schwestern: Olympia Christa C. (1887-1979) Ehefrau von: (siehe) Viktor von Weizsäcker; weitere Vw, s. Int. Germanistenlexikon 1 (2003) S. 353. - Greda C. (1889-1972) seit 1912 Ehefrau von Werner Picht (1887-1965) Soziologe, Schriftsteller, Vater von: (siehe) Georg P. in: Drüll (2009) S. 464 f.; Raulff, Ulrich: Kreis ohne Meister. Stefan Georges Nachleben. München 2012. S. 541 (Register).

Lb U Straßburg: Seit WS 1903/04 Studium des Sanskrit, der Vgl. Sprachwiss., der Neueren Philologie; SS 1904 sowie WS 1905/o6 Studium an U Berlin und WS 1911/12 an UH; 19. Dez. 1908 Staatsexamen; 28. Febr. 1910 Dr. phil.

1910-1911 Wehrdienst.

U Bonn: 22. Okt. 1913 Habilitation; seit 15. Dez. 1919 a. o. Prof. In dieser Zeit:

Aug. 1914-Mai 1916 Kriegsdienst.

U Marburg: Seit SS 1920 o. Prof.

UH: 21. Dez. 1923 (Ern.) zum 1. April 1924 o. Prof. als Nachf. von Friedrich Neumann und Mit-Direktor (zus. mit Leonardo Olschki) des Romanischen Seminars; u. a. Aug.-Okt. 1924 Studienreisen nach Frankreich und Italien.

Rufe abgelehnt: 1920 TH Dresden, 1928 U Frankfurt/M., 1928 Köln, 1930 Leipzig, 1946 Hamburg und Tübingen.

U Bonn: Seit WS 1929/30 o. Prof.; 30. April 1951 Emeritierung. 
E Mitglied der Medieval Academy of America; Mitglied der Akademie der Wissenschaften: 1941 Göttingen, 1944 München. • 1951 Dr. iur. h.c. Glasgow; 1954 Dr. phil. h.c. Sorbonne Paris. 1950 Lessing-Preis Hamburg; 1952 Friedensklasse des Ordens Pour le Mérite für Wissenschaften und Künste.

Qu UAH PA 3499. • GLA Abt. 235, Fasz. 1874. • Briefe: UBH. E. R.C. Briefe aus einem halben Jahrhundert. Eine Auswahl. Hrsg. und kommentiert von Frank-Rutger Hausmann. Baden-Baden 2015. • E. R. C. - Max Rychner. Freundesbriefe 1922-1956. In Zusammenarbeit mit Claudia Mertz-Rychner hrsg. ... von Frank-Rutger Hausmann. Frankfurt/M. 2015. • Nachlaß: Universitätsbibliothek Bonn; s. auch Int. Germanistenlexikon 1 (2003) S. 355.

$W$ Die literarischen Wegbereiter des neuen Frankreich. Potsdam 1919. 2. Aufl. 1920. 4. Aufl. u.d. T.: Französischer Geist im 20. Jahrhundert. Bern 1952. 2. Aufl. 1960. - Die französische Kultur ... Stuttgart 1930. - Deutscher Geist in Gefahr. Stuttgart 1932. 5.-6. Tsd. 1933. - Europäische Literatur und lateinisches Mittelalter. Bern 1948. 3. Aufl. 1961. Siehe Richards, Earl Jeffrey: Modernism, medievalism and humanism. A research bibliography on the reception of the works of E. R.C. Tübingen 1983; Int. Germanistenlexikon 1 (2003) S. 354.

$L$ NDB 3 (1957) S. 447 f. (mit Werkverz.); Verzeichnis Bonn (1968) S. 49; Catalogus prof. Marburgensis 2 (1979) S. 482 f.; WBIS. - E. R. C. Werk, Wirkung, Zukunftsperspektiven. Hrsg. von Walter Berschin ... Heidelberg 1989. - Kosmopolis der Wissenschaft. E. R.C. und das Warburg Institut. Briefe und andere Dokumente. Hrsg. von Dieter Wuttke. Baden-Baden 1989. • „In Ihnen begegnet sich das Abendland“ ... Hrsg. von WolfDieter Lange. Bonn 1990. - Jansen (1992) S. 408 (Register); Ders. (1992a) S. 164 (Register). • Lausberg, Heinrich: E. R. C. Aus dem Nachlaß hrsg. ... von Arnold Arens. Stuttgart 1993. - Hoeges, Dirk: Kontroverse am Abgrund: E.R.C. und Karl Mannheim ... Frankfurt/M. 1994. Klemperer (1999) S. 925 (Register). - Hausmann, Frank-Rutger: Unangreifbare Großordinarien: Karl Vossler und E.R.C. in: Ders.: „Vom Strudel der Ereignisse verschlungen“. Deutsche Romanistik im
„Dritten Reich“. Frankfurt/M. 20oo. • Hergemöller, Bernd-Ulrich: Mann für Mann. Ein biographisches Lexikon. Frankfurt/M. 2001. S. 178. - Int. Germanistenlexikon 1 (2003) S. 353-355. • Wissenschaftler im George-Kreis. Die Welt des Dichters und der Beruf der Wissenschaft. Hrsg. von Bernhard Böschenstein ... Berlin 2005. Hausmann (2008) S. 792 (Register). Liebold, Sebastian: Starkes Frankreich - instabiles Deutschland. Kulturstudien von Curtius/Bergstraesser und Vermeil ... Berlin 2008. - Kalkhoff (2010) S. 38-40 u. ö. Hausmann, Frank-Rutger: E. R.C. und die Mittellateinische Philologie in: Mittellateinisches Jahrbuch 48 (2013) S. 181-206; Ders.: C., Goethe und Jaspers oder E.R.C. als Goetheforscher in: Offener Horizont. Jahrbuch der Karl-JaspersGesellschaft. Göttingen 2014. S. 72-105. - Intellektuelle in Heidelberg (2014) S. 423 (Register). • Raulff, Ulrich: Im Spiegel Schlegels: E. R.C. und die Konversion als Lebenstraumspiel in: Figuren der Konversion: Friedrich Schlegels Übertritt zum Katholizismus im Kontext. Hrsg. von Winfried Eckel ... Paderborn 2014. S. 337-352. - Riecke (2016) S. 87-89. - Wieckenberg, Ernst-Peter: „Wer den Weg nach Paris abschneidet, muß den nach Rom öffnen“. E.R.C. ideenpolitische Wende in den frühen dreißiger Jahren in: Die akademische "Achse Berlin-Rom“? Der wissenschaftlich-kulturelle Austausch zwischen Italien und Deutschland 1920 bis 1945. Hrsg. von Andrea Albrecht ... München 2017 S. 133-152.

P Bildarchiv UAH; Archäologenbildnisse (1988).

\section{Curtius, Gustav Tassilo}

siehe Curtius, Ernst Robert

\section{Curtius, Ludwig Michael}

1920-1928 Phil. Fak.

(1928-1954 (Honorar-Prof.) Phil. Fak.)

Archäologie

* 13. Dez. 1874 Augsburg

$\dagger$ 10. April 1954 Rom

kath. 
V Dr. med. Ferdinand C. (1844-1919) Arzt

M Therese geb. Göhl (1855-1939)

$\infty$ 11. Juni 1921 Editha geb. Wyneken gesch. von Fransecky (1885-1932), s. Giovannini (1998) S. 274

K 2 T

Lb Seit WS 1894/95 Studium der Rechtswiss., Nationalökonomie, Philosophie an U München, seit WS 1895/96 Berlin; seit WS 1896/97 Studium der Archäologie an U München, anschl. Rom, München.

München: Seit 1. Okt. 1900 Aushilfsassistent, seit 16. Okt. 1903 Assistent am Königl. Antiquarium; 12. Febr. 1902 Dr. phil.

Athen: Seit Sept. 1904 Stipendiat des Archäolog. Inst. des Deutschen Reichs.

München: Seit 16. April 1906 Kustos am Museum für Abgüsse klassischer Bildwerke; 21. Nov. 1907 Habilitation für Klassische Archäologie an U.

U Erlangen: 7. Juli 1908 Ern. zum a.o. Prof.; seit 24. Dez. 1908 auch Direktor des Archäolog. Seminars und der Kunstsammlung; seit 1./2. Jan. 1913 o. Prof. • In dieser Zeit:

1914-1918 Kriegsdienst.

U Freiburg/Br:: Seit 1. Okt. 1918 o. Prof. und Direktor des Archäolog. Inst.

UH: Seit 1. April 1920 o. Prof. und Direktor des Archäolog. Inst. als Nachf. von Friedrich von Duhn; 1925 Ruf an U Köln abgelehnt; 1925/26 Ausgrabungen in Aegina (Griechenland); seit 16. April 1928 o. Honorar-Prof.; seit WS 1928/29 keine Vorlesungsankündigungen mehr.

Rom: April 1928-Sept. 1937 Erster Direktor des Dt. Archäolog. Inst.

1924/25 Dekan der Phil. Fak. der UH

Siehe auch Friedrich von Duhn
$E$ Mitglied der Akademie der Wissenschaften: 1921 H, 1934 Göttingen, 1935 München. 1927 Dr. iur. h.c. Camerino (Italien). • Orden pour le Mérite für Wissenschaften und Künste; s. auch Professoren Erlangen (2009) S. 34.

Qu UAH PA 3501. GLA Abt. 235, Fasz. 1876. • Nachlaß: Archiv des Germanischen Nationalmuseums Nürnberg; Dt. Archäolog. Inst. Rom. • Deutsche und antike Welt. Lebenserinnerungen. Stuttgart 1950.

$W$ Die antike Kunst. 2 Bde. Berlin 1923-1938. 3. unver. Aufl. 1959. Die Wandmalerei Pompejis. Leipzig 1929. Interpretationen von sechs griechischen Bildwerken. Bern 1947. - Torso - Verstreute und nachgelassene Schriften von L.C. Ausgewählt, hrsg. ... von Joachim Moras. Stuttgart 1957. Schriften von L.C. Eine Bibliographie zus. gestellt ... von Reinhard Lullies. Mainz 1979.

L Pasquali, Giorgio: Storia dello spirito tedesco nelle memorie d'un contemporaneo [= L. C.]. Florenz 1953. NDB 3 (1957) S. 449; Glockner (1969) S. 272 (Register); Weiland (1988) S. 672-674; Jansen (1992) S. 408 (Register); Ders. (1992a) S. 164 (Register). - Eine hervorragend nationale Wissenschaft (2001) S. 224-227 u. o.. • Willett (2001) S. 6o, 135 u. ö.; Freiburger Phil. Fak. (2006) S. 126129, 907 u. ö.; Killy Literaturlexikon 2 (2008) S. 523; Professoren Erlangen (2009) S. 33 f.; WBIS. • Faber, Richard: Ein katholischer Preuße: der deutschnationale Archäologe L.C. in: A propos: Kulturwissenschaftliche Miszellen von und für Richard Faber. Hrsg. von Christine Holste, Barbara von Reibnitz. Würzburg 2013. S. 155-159. - Lebensbilder. Klassische Archäologen und der Nationalsozialismus. Hrsg. von Gunnar Brands und Martin Maischberger. Rahden/Westf. 2016. Bd. 2. S. 79111. Objekte erzählen Geschichte(n) (2016) S. 187194 u. ö.

P Bildarchiv UAH; Archäologenbildnisse (1988). 


\section{Curtius, Julius Wilhelm Theodor}

1898-1926 Nat.-Math. Fak.

Chemie

* 27. Mai 1857 Duisburg

$\dagger \quad$ o8. Febr. 1928 Heidelberg

ev.-luth.

V Julius C. (1818-1885) Fabrikbesitzer

M Sophie geb. Ohlenschlager (1828-189o)

(o) unverheiratet

Vw Neffe: Dr. iur. Julius C. (1877-1948), u.a. 1919 Initiator und Vorsitzender e. Ortsgruppe der Deutschen Volkspartei (DVP) sowie 1919-1921 Fraktionsvorsitzender des Stadtrats in H; Berlin: 1921-1926 Rechtsanwalt, 1920-1932 Abgeordneter der DVP im Reichstag, 1926-1929 Reichswirtschaftsminister, 1929-1931 Reichsaußenminister, 1932 Ausschluß aus der DVP, 1932-1943 Vermögensverwalter, Rechtsanwalt, Landwirt; seit 1946 Rechtsanwalt in H, s. NDB 3 (1957) S. 445, WBIS; Rödder, Andreas: Stresemanns Erbe. J.C. und die deutsche Außenpolitik 1929-1931. Paderborn 1996.

Lb Seit WS 1876/77 Studium der Musik, Philosophie, Naturwiss. an U Leipzig; 1877-1878 Militärdienstpflicht als Einjährig-Freiwilliger; seit SS 1879 Studium der Chemie an UH.

U Leipzig: Seit 1880 Forts. des Studiums; 26. Juli 1882 Dr. phil.

München: Seit Okt. 1884 Assistent am Chemischen Laboratorium der Königl. Akademie der Wissenschaften.

U Erlangen: 10. März 1886 Habilitation für Chemie; seit 17. April 1886 I. Assistent und Abt.-Leiter am Chemischen Laboratorium.

U Kiel: 23. Dez. 1889 Ern. zum o. Prof.; 1889-1897 Direktor des Chemischen Inst.; Rufe abgelehnt: 1889 Clark-University in Worcester (Massachusetts), 1890 TH Karlsruhe, 1892 U Würzburg, 1895 Tübingen.

U Bonn: 5. Jan. 1897 Ern. zum o. Prof.; 1897-1898 Direktor des Chemischen Inst.
UH: 27. Dez. 1897 Ern. zum o. Prof. und Direktor des Chemischen Laboratoriums als Nachf. von Victor Meyer; SS 1898 Vorlesungsbeginn; 23. April 1898 Vereidigung; 1902 Ruf an U Kiel abgelehnt; 31. März 1924 auf eigenen Antrag der Amtspflichten enthoben; SS 1924-WS 1925/26 Vertreter seines Lehrstuhls.

1905 Prorektor der UH; 1903/04 Wahlsenator der UH; 1902/03, 1909/10, 1914/15, 1920/21 Dekan der Nat.-Math. Fak. der UH

1918-1920 Präsident der Dt. Chemischen Gesellschaft

1895 Geh. Reg.-Rat; 1897 Geh. Rat II. Klasse

Siehe auch Johannes Rissom: Eintrag unter $L[\mathrm{e}] b[$ enslauf $]$

$E$ Mitglied der Akademie der Wissenschaften: 1907 München, 1909 H, 1919 Göttingen. • 1908 Dr. med. h.c. U Erlangen; 1927 Dr.-Ing. E.h. TH Karlsruhe. 1899 Ritterkreuz, 1908 Kommandeurkreuz II. Klasse des Ordens Berthold I.; 1903 Kommandeurkreuz II. Klasse des Ordens vom Zähringer Löwen; s. auch Professoren Erlangen (2009) S. 35 .

Qu UAH PA 3503. - GLA Abt. 235, Fasz. 20195. • Briefe: UBH. • Freunde in der Zeit des Aufbruchs der Chemie: der Briefwechsel zwischen T.C. und Carl Duisberg. Hrsg. von Margot Becke-Goehring. Berlin 1990. - Teil-Nachlaß: UAH (Signatur: KE 114: Nachlaß-Splitter 1871-1917); UBH, siehe Verzeichnis des Nachlasses T. C.: Sign.: Heid. Hs. 4070. Bearb. von Günter Kern. UBH 1992; Werksarchiv der Bayer AG Leverkusen.

W Diazo- und Diazoamidoverbindungen der Fettreihe in: Berichte der Dt. Chemischen Gesellschaft 17 (1884); Darstellung von Hydrazin aus Aldehydammoniak in: ebd. 23 (1890). • Stickstoffwasserstoffsäure in: Journal für praktische Chemie 43 (1891). - Über das Vorkommen von Formaldehyd in Pflanzen. Heidelberg 1912 (Mitautor: Hartwig Franzen). - Teil-Bibliographie in: Stupp-Kuga, Ieva: Personalbibliographien von Professoren und Dozenten der Chemie an der Universität Erlangen 
im Zeitraum von 1851 bis 1900 ... Med. Diss. Erlangen 1971. S. 160-187.

MHG Geschichte des Chemischen UniversitätsLaboratoriums seit der Gründung durch Bunsen. Zur Feier der Enthüllung des Bunsendenkmals in Heidelberg. Hrsg. von T.C. und Johannes Rissom. Heidelberg 1908. - 1915-1925 Journal für praktische Chemie.

L Darapsky, August: T.C. zum Gedächtnis in: Journal für Praktische Chemie 125 (1930) S. 1-22. • Klucker, Christian: Erinnerungen eines Bergführers. Erlenbach-Zürich 1930. Neuaufl. 2010. • Smith (1949) S. 57 f.; NDB 3 (1957) S. 445 f.; Verzeichnis Bonn (1968) S. 49; Poggendorff 7a (1971) S. 142 f. - Ziegler, Manfred: Betrachtungen zum Leben und Werk von T.C. in: Ruperto Carola 83/ 84 (1991) S. 91-103. - Jansen (1992a) S. 164 (Register); Wennemuth (1994) S. 633 (Register); Badische Biographien N. F. V (2005) S. 49-51; Professoren Erlangen (2009) S. 34 f. • Runde, Ingo: „Es giebt sehr viel zu tun, nur fehlen die älteren Praktikanten für die Doctorarbeiten“. Anmerkungen zu T.C. und der chemischen Forschung im Ersten Weltkrieg in: UH während des Ersten Weltkriegs (2017) S. 337-343.

$P$ Bildarchiv UAH; graph. Slg. UBH.

\section{Czerny, Vincenz}

1877-1906 Med. Fak. 1906-1913 (Honorar-Prof.) Med. Fak. Chirurgie

* 19. Nov. 1842 Trautenau (heute: Trutnov, Tschechien)

$\dagger \quad$ 03. Okt. 1916 Heidelberg

kath., seit 1871 altkath.

V Vincentius Ignatius C. (1802-1885) Apotheker

M Barbara (Betty) Franziska geb. Schmidt (18151895)

๑ 8. Mai 1872 Luise Amanda geb. Kussmaul (1853-1929) T von: (siehe) Adolf K.
K 1 T: Margarete (Gretel) C. (1880-1968) verh. Stein-Czerny, Ehefrau von Fritz Stein (18791961), u.a. seit 1919 a.o., seit 1928 o. Prof. für Musikwissenschaft Kiel, seit 1933 Direktor der Staatl. Musikhochschule Berlin, 1934-1940 Leiter des Amtes für Chorwesen und Volksmusik der Reichsmusikkammer, März-Mai 1945 Leiter des Staatl. Inst. für dt. Musikforschung, nach 1945 Präsident des Verbands für ev. Kirchenmusik, s. Prieberg, Fred K.: Handbuch Deutsche Musiker 1933-1945. CD-ROMLexikon. Kiel 2004. S. 6.817-6.818; Klee, Kulturlexikon (2007) S. 588. 3 S: u. a. Siegfried C. (1889-1979) Porträtist, s. S.C. - Ein Malerleben. München 1971. - Siehe auch Pfeiffer (2004) S. 155

Vw Enkel: Max Martin Stein (1911-2001) Konzertpianist seit 1936 Berlin, seit 1939 Breslau, seit 1947 Lehrer am Robert-Schumann-Konservatorium Düsseldorf, 1970-1997 Kuratoriumsmitglied der Elsa-Reger-Stiftung.

$L b$ Seit 1860 Studium der Zoologie an U Prag.

U Wien: Seit WS 1862/63 Studium der Medizin; 19. Dez. 1866 Staatsexamen und Promotion zum Dr. med.; seit Ostern 1867 Assistent an Augenklinik, anschl. am Patholog. Inst., seit 1868 an Chirurg. U-Klinik; 1870/71 Lazarettarzt in Weißenburg (Elsaß) während des Deutsch-Französischen Krieges; 1871 Habilitation; seit Juni 1871 o. Prof.

U Freiburg/Br.: 17. Nov. 1871 Ern. zum o. Prof. und Direktor der Chirurg. Klinik; 1873 Ruf an U Innsbruck abgelehnt.

UH: 28. Dez. 1876 Ern. zum SS 1877 o. Prof. und Direktor der Chirurg. U-Klinik (bis 1906) als Nachf. von Gustav Simon; Rufe an U abgelehnt: 1877, 1879 Prag, 1882 Würzburg, 1894 Wien; 20. Febr. 1906 Antrag C.s auf Errichtung, 17. März 1906 Senatsbeschluß der U zur Errichtung des Inst. für Experimentelle Krebsforschung; 25. Sept. 1906-1. Okt. 1916 (Gründungs-)Direktor des Inst. für (Experimentelle) Krebsforschung, e. Heil- und Pflegeanstalt für 47 Krebskranke („Samariterhaus“) und zwei wiss. Abt. (Biolog.-Chemische und Histo-Parasitolog. Abt.), Voßstraße 3; 1. Okt. 1906 Pensionierung; seit 20. Nov. 1906 o. Honorar-Prof.; SS 1913 letzte Vorlesungsankündigung. 
1903/o4 Prorektor der UH; 1881, 1901/o2 Wahlsenator der UH; 1878/79, 1887/88, 1897/98 Dekan der Med. Fak. der UH

Präsident: 1901 Dt. Gesellschaft für Chirurgie, 1908 Int. Gesellschaft für Chirurgie, 1918 Int. Gesellschaft für Krebsforschung

1877 Hofrat; 1879 Geh. Hofrat; 1882 Geh. Rat II. Klasse; 1903 Geh. Rat I. Klasse; 1914 Generalstabsarzt (General à la suite)

E 1909 Mitglied der Akademie der Wissenschaften H; Ehrenmitglied: 1903 Dt. Gesellschaft für Chirurgie, 1908 Gesellschaft für Natur- und Heilkunde Dresden. 1894 Kommandeurkreuz I. Klasse, 1906 Großkreuz I. Klasse des Ordens vom Zähringer Löwen. • 1912 Ehrenbürger der Stadt Trautenau.

Qu UAH PA 866, 1458; RA 5236, 5669, 6269, 6331, 6789. - Briefe: UBH. - Aus meinem Leben in: Ruperto Carola 41 (1967) S. 214-244 (gekürzte Autobiogr. mit Werkverz.).

$W$ Versuche über Kehlkopfexstirpation in: Wiener Med. Wochenschrift 27 (1870); Über die Aus- rottung des Gebärmutterkrebses in: ebd. $45 \mathrm{ff}$. (1879). - Das Heidelberger Institut für experimentelle Krebsforschung. Tübingen 1912. • Bibliographie in: Badische Biographien N. F. VI (2011) S. $71 \mathrm{f}$.

$L$ NDB 3 (1957) S. 461; Krebs/Schipperges (1968) S. 58-66; Hoche (1969) S. 89; Leier (1977) S. 7-12, 28-30 u. ö.; Chronik Ärzte H (1985) S. 124, 214 ff. • Amberger, Herbert, Amberger-Larmann, Mechthild: Krebschirurgie in Heidelberg ... Berlin 1986. - Jansen (1992a) S. 164 (Register); 100 Jahre Krebsforschung (2000) S. 31-36 u.ö.; Peiffer (2004) S. 1135 (Register); UH im Nationalsozialismus (2006) S. 1249 (Register); Seidler/Leven (2007) S. 231f. u. ö. • Lindner, Cornelia: V.C. Pionier der Chirurgie, chirurgischen Onkologie und integrierten Krebsforschung. Freiburg/Br. 2009. • Badische Biographien N.F. VI (2011) S. 66-72. • Schmidt, Christel: „In scientia salus“. Krebsforschung in Heidelberg ... in: Heidelberg. Jahrbuch zur Geschichte der Stadt 2014. Heidelberg 2013. Jg. 18. S. 139-142.

$P$ Bildarchiv UAH; graph. Slg. UBH; NDB; Chronik Ärzte $H$. 


\section{Darapsky, August Joseph}

1903-1912 Nat.-Math. Fak.

Chemie

* O3. Mai 1874 Mainz

$\dagger$ 26. April 1942 Aschaffenburg

口 Heidelberg

kath.

V Heinrich Gottlob Martin D. (1816-1889) Obergerichtsrat

M Agnes Maria Philippina geb. Gerlach (18281911)

$\infty$ N.N.

$\infty$ 17. April 1928 Maria Klara geb. Müller († nach 1942)

K 1

Vw Neffe: Emil Heinrich D. (1906-1944) Studienassessor, 1943 Inhaftierung wegen „Wehrkraftzersetzung“, 1944 gehängt, s. Die Märtyrer von Wöllstein. Hrsg. von Heinrich Holtmann. Gau-Algesheim 1996. S. 196 (Register); Antweiler, Bernd: Reichspogromnacht November 1938 in Wöllstein ... Hrsg. von der Ortsgemeinde Wöllstein. Ausstellung vom 9. Nov. 2013. S. 34 f. - Nichte: Dr. Elisabeth (Ella) D. (1913-1998), Schwester von Emil D., 1939-1943 Archivarin, 1943-1945 Inhaftierung, 1945-1976 Oberarchivrätin im Stadtarchiv Mainz, s. Die Märtyrer von Wöllstein ... (1996) S. 196 (Register); Blick auf Mainzer Frauengeschichte. Mainzer Frauenkalender 1991-2012. Ein Lesebuch. Hrsg. von der Landeshauptstadt Mainz. Hauptamt - Frauenbüro und Öffentlichkeitsarbeit. Mainz 2012. S. $21 \mathrm{f}$.

Lb Seit SS 1893 Studium an U Freiburg/Br., anschl. München, Straßburg, Bonn, SS 1898, WS 1898/ $99 \mathrm{H}$.

UH: 8. Juni 1899 Dr. phil.; seit Herbst 1899 Assistent am Chemischen Laboratorium; 2. Mai 1903 Habilitation; seit 13. Mai 1908 nichtetatm. a. o. Prof.

Köln: Seit WS 1912/13 hauptamtl. Prof. für Chemie und Chemische Technologie an Städtischer Handels-Hochschule.

U Köln: Seit 1. Juli 1919 o. Prof. und Direktor des Chemischen Inst. an Phil. Fak. der neugegründeten U Köln; 30. Sept. 1939 Emeritierung.

Qu UAH PA 1461; RA 6496. - Teil-Nachlaß: Historisches Archiv der Stadt Köln. Mitteilungen: Frau Dr. Elisabeth Darapsky ( $†)$, Mainz.

$W$ Bernthsen, Heinrich August: Kurzes Lehrbuch der organischen Chemie. 11. Aufl. bearb. in Gemeinschaft mit A.D. Braunschweig 1911. 14. Aufl. 1919. • Über optisch aktive Hydrazinosäuren. Heidelberg 1913. - Theodor Curtius zum Gedächtnis in: Journal für Praktische Chemie 125 (1930) S. 1-22; Über Isatosäurediazid in: ebd. 147 (1936) S. 43-52. (Mitverf.) - Teil-Bibliographie in: Corsten, Hermann: Das Schrifttum der zur Zeit an der Universität Köln wirkenden Dozenten. Köln 1938. S. 464-466.

MHG 1921-1941 Journal für praktische Chemie.

L Kürschner (1928/29) Sp. 346, (1940/41) Sp. 28o. • Heimbüchel, Bernd: Die neue Universität. Selbstverständnis - Idee und Verwirklichung in: Heimbüchel, Bernd, Papst, Klaus: Kölner Universitätsgeschichte. Bd. 2. Köln, Wien 1988. S. $516 \mathrm{f}$. • WBIS; Jansen (1992a) S. 164 (Register); Deutsche Biographie, s. https://www.deutsche-biographie. de/gnd116027231.html [06.11. 2017].

$P$ Bildarchiv UAH.

\section{Daub, Carl}

1796-1836 Theol. Fak.

Dogmatik, Exegese

* 20. März 1765 Kassel

$\dagger \quad$ 22. Nov. 1836 Heidelberg

ref. 
V George (?) D., hochfürstlicher Marställer, s. Einwohner und Familien der Stadt Kassel. Eheschließungen, Geborene, Verstorbene 1731-1839. Bearb. von Helmut Thiele. Kassel 1986. S. 127.

M Anna Elisabeth geb. Schaub (?)

$\infty$ 20. April 1801 Charlotte Wilhelmine Sophie geb. Blum (1776-1837), s. Gersdorff (2006) S. $158,163,214$

K 4 S, 6 T: u. a. Wilhelmine Marie D. (1802-1870) Ehefrau von: (siehe) Wilhelm Dittenberger [sen.]

Vw Enkel: Wilhelm Dittenberger [jun.] (18401906) Altertumsforscher, Epigraphiker, s. NDB 3 (1957) S. 522; Zimmermann, Hans-Dieter: W.D. ... in: Jahrbuch für Hallische Stadtgeschichte 2006. Halle/S. 2006. S. 264-269. Emilie Dittenberger (1841-1901) Ehefrau von: (siehe) Heinrich Weber.

Lb U Marburg: Seit 28. April 1786 Studium der Philologie, Philosophie, Geschichte, Theologie; 1789 theol. Examen; seit SS 1790 Stipendiatenmajor (Tutor für Theologie-Studenten der Stipendiatenanstalt) und Privat-Dozent.

Hohe Landesschule Hanau: 15. Juni 1794 Ern. zum II. Prof. für Philosophie; 6. Jan. 1796 Entlassung.

UH: 13 . Nov. 1795 Ern. zum II. Prof. an Theol. Fak.; Mai 1796 erstmals in der „Anzeige der Vorlesungen ... im Sommerhalbenjahre vom 12. May 1796 bis zu Ende Septembers 1796 auf der Hohen Schule zu Heidelberg" genannt; 1803 Ruf an U Würzburg abgelehnt; seit 25. Juni 1805 I. Prof. als Nachf. von Daniel Ludwig Wundt; Rufe an U abgelehnt: 1816 Breslau, 1818 Bonn.

1816, 1824/25 Prorektor der UH; 1797, 1799, 1803, $1805,1808,1811,1814,1817,1820,1823,1827,1833$ Dekan der Theol. Fak. der UH

1805 Kirchenrat; 1810 Geh. Kirchenrat

E Vor 18. Okt. 1797 D. theol. UH, siehe hierzu Intelligenzblatt der Allg. Literatur-Zeitung Nr. 130 vom 18. Okt. 1797, Sp. 1081; 1827 Dr. phil. h.c. Marburg.
Qu UAH PA 1462; RA 1118, 5355, 5622, 6126, 6592, 6633, 6718 fol. 3v, 4r, 10v, 11r u. ö. • GLA Abt. 205, Fasz. 194f., 536. - Briefe: UBH. • Auskunft: Landeskirchliches Archiv Kassel; Ev. Oberkirchenrat Landeskirchliches Archiv - Karlsruhe.

W Lehrbuch der Katechetik. Frankfurt/M. 1801. • Judas Ischarioth oder das Böse im Verhältniß zum Guten. 2 Bde. Heidelberg 1818-1819. • Die dogmatische Theologie jetziger Zeit. Heidelberg 1833 . C.D.s philosophische und theologische Vorlesungen. Hrsg. von Philipp Konrad Marheineke und Theophor Wilhelm Dittenberger. Berlin 1838-1844.

MHG Studien. 6 Bde. Heidelberg 1805-1811 (zus. mit Friedrich Creuzer), s. hierzu Ein Knab auf schnellem Roß (2006) S. 67.

$L$ Catalogus prof. Marburgensis 1 (1927) S. 331f. • Mitteilungen der Hessischen Familiengeschichtlichen Vereinigung. Darmstadt 1942-1944. Bd. 7. H. 1-6. S. 149. Nr. 50. NDB 3 (1957) S. 522 (mit Werkverz.); Renger (1982) S. 294 (Register); Heidelberg im säkularen Umbruch (1987) S. 558 (Register). - Wagner, Falk: Die vergessene spekulative Theologie. Zur Erinnerung an C.D. anläßlich seines 150. Todesjahres. Zürich 1987. BBKL I (1990) Sp. 1231; Kirschke (2001) S. 446 (Register); Ein Knab auf schnellem Roß (2006) S. 24 u. ö. • Gersdorff, Dagmar von: „Die Erde ist mir Heimat nicht geworden." Das Leben der Karoline von Günderrode. Frankfurt/M. 2006. S. 280 (Register). $\bullet$ Hessische Biografie, s. http://www.lagis-hessen.de/ pnd/118820141 (Stand: 6. März 2013).

P Bildarchiv UAH; graph. Slg. UBH.

\section{Deissmann, Gustav Adolf}

1897-1908 Theol. Fak.

Neutestamentliche Exegese und Kritik

* 07. Nov. 1866 Langenscheid/Lahn (bei Diez)

$\dagger$ 05. April 1937 Wünsdorf (bei Berlin; heute: Ortsteil von Zossen)

ev. 
V Adolf D. (1832-1900) Pfarrer, s. WBIS

M Emilie Sophie Luise Ernestine geb. Rullmann (1833-1906)

๑ 18. April 1895 Henriette Elisabeth geb. Behn (1873-1955) T von Theodor August B. (18161886) Kaufmann, Reeder, 1840 Mitbegründer des ersten dt. Handelszentrums in Singapur, heute u.d.N.: Behn Meyer Chemicals Co.

K $3 \mathrm{~S}, 2 \mathrm{~T}$

Lb Seit SS 1885 Studium an U Tübingen, SS 1888 Berlin, seit WS 1888/89 am Theol. Seminar der Ev. Landeskirche in Nassau in Herborn; hier I. theol. Examen; 1890 II. theol. Examen in Wiesbaden.

Dausenau (bei Bad Ems): Seit 1. Dez. 1890 Vikar.

U Marburg: 1891 Dr. theol.; April 1892-März 1895 Repetent an Stipendiatenanstalt; 20. Okt. 1892 Lizentiatenprüfung und Habilitation.

Seit 1. April 1895 Pfarrer in Herborn und seinen heutigen Stadtteilen Hörbach und Hirschberg sowie Sinn im Dilltal (bei Herborn) und Lehrer am Theol. Seminar in Herborn.

UH: 18. Juli 1897 Ern. zum o. Prof. als Nachf. von Carl Holsten; 11. Okt. 1897 Vereidigung; 1897-1908 Direktor der Neutestamentl. Abt. am Wiss.-Theol. Seminar als Nachf. von Holsten; April-Juni 1906 Studienreisen nach Griechenland, Kleinasien.

U Berlin: SS 1908-SS 1935 (Emeritierung) o. Prof. für Neues Testament als Nachf. von Bernhard Weiss, Vater von: (siehe) Johannes Weiss; 1909 Studienreisen in Kleinasien, Syrien, Palästina, Ägypten; 1922 Ruf als Landesbischof von Nassau nach Wiesbaden abgelehnt; 1926-1928 Teilnahme an Ausgrabungen des Österr. Archäolog. Inst. Wien in Ephesus (Kleinasien).

1899/1900, 1905/o6 Dekan der Theol. Fak. der UH

1904: Initiator (zus. mit (siehe) Albrecht Dieterich) des Heidelberger Eranos-Kreises, einem Kollegentreffen zur Erörterung religionswissenschaftlicher Fragen

1904 Heidelberger Stadtverordneter
Sept. 1914: D. unterschreibt neben 92 anderen Wissenschaftlern, Schriftstellern und Künstlern das sog. „Manifest der 93“, e. Aufruf vor allem gegen den Vorwurf der deutschen Kriegsschuld und der Kriegsgreuel in Belgien sowie für die Identität von deutscher Kultur und deutschem Militarismus.

U.a. 1924 und 1925 Mitglied des Int. Komitees Life and Work. • Seit 1929 Mitglied des Ökumenischen Rates für Praktisches Christentum

Am 26. und 27. April 2013 fand ein Symposium über: A.D. - Ein (zu Unrecht) fast vergessener Theologe und Philologe - statt; Veranstalter: Theologische Fakultät der Humboldt-Universität zu Berlin sowie Zentral- und Landesbibliothek Berlin.

Nach 1908 Geh.-Rat

E 1898 D. theol. Marburg; Dr. of Divinity: 1906 Aberdeen, 1911 St. Andrews (Schottland), 1912 Manchester, 1929 Oxford. - 1906 Ritterkreuz I. Klasse des Ordens vom Zähringer Löwen.

Qu UAH PA 1463. - GLA Abt. 235, Fasz. 188o. • Briefe: UBH. - Horsley, G.H.R.: The origin and scope of Moulton and Milligan's vocabulary of the Greek Testament, and D.s planned New Testament Lexicon. Some unpublished letters of G.A.D. to J.H. Moulton. Paper. Int. Conference on Religion. Melbourne (July 1992), pdf-Datei (Ausdruck im UAH); Ders.: An unpublished Septuaginta papyrus from the Nachlass of A.D. in: Archiv für Papyrusforschung 39 (1993) S. 35-38. - Nachlaß: Zentral- und Landesbibliothek Berlin.

W Bibelstudien. Marburg 1895. - Licht vom Osten. Tübingen 1908. 4. Aufl. 1923. • Paulus. Eine kulturund religionsgeschichtliche Skizze. Tübingen 1911. 2. Aufl. 1925. - Deutscher Schwertsegen. Kräfte der Heimat fürs reisige Heer. Stuttgart, Berlin 1915. 3. Aufl. 1915. - Die Stockholmer Weltkirchenkonferenz. Berlin 1926. Neues Testament und Rassenfrage (1933), s. hierzu: Liebing, Heinz: Die Marburger Theologen und der Arierparagraph in der Kirche. Marburg 1977. S. 16-19. 
HG 1914-1921 Evangelische Wochenbriefe, s. auch Golling, Ralf: Schriftstücke entdeckt: „Evangelische Wochenbriefe" des Theologieprofessors A.D. in: Tagesspiegel-Sonderseiten der Humboldt-Universität Berlin vom 10. April 2004 (s. https://www. hu-berlin.de/pr/medien/publikationen/regelmaessig/tsp/sso4/deissmann_html).

$L$ Catalogus prof. Marburgensis 1 (1927) S. 71; NDB 3 (1957) S. 571 f.; WBIS; TRE 8 (1981) S. 406408; BBKL I (1990) Sp. 1248f. • Wirth, Günter: A.D. und der Arierparagraph in: Deutsches Pfarrerblatt 91 (1991) S. 508-510. - Markschies, Christoph: A. D. - ein Heidelberger Pionier der Ökumene in: Zs. für neuere Theologiegeschichte 12 (2005) S. 47-89. - Gorny, Ernst-Dieter: Einführung zur Person A.D., s. http://www.gornyonline.de/deissmann/ vom 2. Nov. 2007 (hier auch Bibliographie; Ausdruck im UAH). - Meinhardt, Ernst-Otto: A.D. - Ein Wegbereiter der Weltchristenheit ... Theol. Diss. Hamburg 2009. - Gerber, Albrecht: D. the Philologist. Berlin, New York 2010. Hogeterp, Albert L. A.: New Testament Greek as popular speech in: Zs. für die neutestamentliche Wissenschaft (2011) S. 178-200. Kurzbiographie, s. https://chran.theologie.hu-berlin.de/history/histo ry-nt (abgerufen am 30. Juni 2014). TroeltschGesamtausgabe 19 (2014) S. 502 (Register).

$P$ Bildarchiv UAH; graph. Slg. UBH; NDB.

\section{Delffs, Friedrich Wilhelm Hermann}

1840-1853 Phil. Fak.

1853-1889 Med. Fak.

Chemie

* 21. April $1812 \mathrm{Kiel}$

$\dagger$ 17. März 1894 Heidelberg

ev.

V Detlev Lorenz D. ( ${ }^{*}$ 1770) Kaufmann

M Louise Eleonore Adolphine geb. von Kamptz ${ }^{*}$ 1779)

( Friederike Charlotte Adolphine Antoinette geb. De Vicq von Tholen (1817-1866), s. Martin, Alison E. (2009) S. 158 Anm. 16
K 3 S: siehe hierzu UAH Rep. 14-158. 1 T: Sophie Louisa D. (1844-1911) Übersetzerin, s. Blos (1914) S. 37; Martin, Alison E.: Raabe's „English Prophet": Sofie D. and the English translation of Abu Telfan in: Wilhelm Raabe: Global themes - international perspectives. Ed. by Dirk Göttsche and Florian Krobb. London 2009. S. 149-158.

$L b$ U Kiel: Seit 12. April 1831 Studium der Medizin, Naturwiss., Philosophie; 1834 Dr. phil.

Seit 1834 Mitglied des Offiziers-Corps Rendsburg (Schleswig-Holstein); 1834-1840 Eigenstudien; in dieser Zeit hält D. auch Privat-Vorlesungen u. a. in Kiel und Schleswig.

UH: 1. April 1840 Habilitation an Phil. Fak.; seit 20. Jan. 1843 a. o. Prof.; Okt. 1846 D. beantragt vergeblich eine von der Fak. unterstützte o. Professur für Chemie an der Phil. Fak.; seit 1. Juli 1847 Jahresgehalt von 300.- Gulden; Dez. 1849 D. stellt erneut mit Unterstützung der Fak. und des Engeren Senats e. Gesuch um Verleihung e. Ordinariats für Chemie an Phil. Fak.; der Chemiker Leopold Gmelin (Med. Fak.) urteilt negativ über die wiss. Leistung D.s; das hat zur Folge, daß das Innenministerium erst im Sept. 1852 eine - anschl. auch negative - Entscheidung über den Antrag trifft, s. hierzu Roß (1997) S. 471f., 476; 1851 Friedrich Henle und Carl Sebastian Pfeufer schlagen für die Nachf. des entpflichteten Gmelin u. a. Robert Bunsen und Justus von Liebig (1803-1873) vor (Nachf. Gmelins wird 1852 Bunsen an der Phil. Fak.); Mai 1851-Aug. 1852 provisorischer Leiter des Chemischen Labors als Nachf. Gmelins, s. UAH RA 6816; Nov. 1852, erneut Jan. und März 1853 Phil. und Med. Fak. sowie der Engere Senat stellen den Antrag an das Ministerium auf ein Ordinariat für Chemie an der Med. Fak. und die Einrichtung e. Labors für D.; D. selbst schreibt in e. weiteren Gesuch, sollte ihn die Regierung nicht zum o. Prof. ernennen, bäte er zu Ostern 1853 um seine Entlassung; seit 23. April 1853 o. Prof. an Med. Fak. mit e. Besoldungszuschuß von 500.- Gulden zusätzlich zu dem seit 1847 gezahlten Jahresgehalt von 300.- Gulden sowie der Einschränkung, kein eigenes Labor von U zur Verfügung gestellt zu bekommen; D. bezieht zunächst die ehem. Gmelinschen Laborräume im Dominikanerkloster an der Ecke 
Hauptstrasse/Brunnengasse (Abriß 1855), anschl. die im gegenüberliegenden Haus zum Riesen in der Hauptstraße 52; 1863 D. erhält Laborräume im Friedrichsbau, dem auf dem Gelände des Dominikanerklosters errichteten Neubau, siehe UAH RA 6202; WS 1864/65 erstmals im Adressbuch der UH als Direktor des 2ten Chemischen Laboratoriums genannt (bis 1889); 1872 Jahresgehalt von 180o.Gulden, 1888 von 400o.- Mark; 1. Sept. 1889 Ruhestand.

1856, 1861, 1866/67, 1871/72 Dekan, 1867/68 Prodekan der Med. Fak. der UH

Siehe auch Ludwig Posselt

Qu UAH PA 1465; RA 5815, 5823, 6202, 6280, 6494, 6572, 6612, 6886 u. ö. - Matrikel Kiel (1915) S. 250 f. - Briefe: UBH. - Auskunft: Ev. Kirchenbuchamt Heidelberg (Taufbuch 1841-1846); Stadtarchiv Heidelberg.

$W$ Die anorganische Chemie in ihren Grundzügen dargestellt. Kiel 1839. 3. Aufl. 1854. • Die reine Chemie, in ihren Grundzügen dargestellt. 2 T. Erlangen 1839. 3. Aufl. 1854-1855. Stöchiometrischer Commentar zur Pharmacopoea Badensis. Heidelberg 1842. Siehe auch Roß (1997) S. 482 f.

$L$ Poggendorff 3 (1898) S. 348; Badische Biographien 5 (1906) S. 907; Thomas (1985) S. 171. Roß, Rudolf Stefan: Der Chemiker W.D. und die Institutionalisierung der Medizinischen Chemie an der Universität Heidelberg im 19. Jhdt. in: Würzburger medizin-histor. Mitteilungen 16 (1997) S. 467485. - Stumm (2012) S. 69-71 u. ö.; Deutsche Biographie, s. https://www.deutsche-biographie.de/ gnd116058188.html [06.11. 2017].

$P$ Bildarchiv UAH; graph. Slg. UBH.

\section{Dennig, Emil Adolf Theodor Helmut}

1925-1931 (1932) Med. Fak.

Innere Medizin

* 13. Juli 1895 Tübingen

$\dagger \quad$ o1. Febr. 1973 Stuttgart ev.

V Adolf Friedrich D. (1858-1931), u. a. seit 1896 a. o. Prof. für Innere Medizin Tübingen, seit 1902 niedergelassener Arzt in Stuttgart, s. Fischer $1\left({ }^{3} 1962\right)$ S. 308 , WBIS

M Klara Johanna Margaretha geb. Posse(h)1 (1858-1937)

( 6. Nov. 1926 Marianne Gertrud Elisabeth geb. Wittmers (1899-1943)

$\infty$ 15. Aug. 1944 Dr. med. Margarete Elisabeth Katharina geb. Jank $\left({ }^{*} 1912\right)$

K $\quad 3 \mathrm{~S}, 5 \mathrm{~T}$

Lb Seit WS 1913/14 Studium an U Tübingen, 1917 München, anschl. erneut Tübingen, WS 1918/19 H, SS 1919 Tübingen; 1914-1916 Kriegsdienst; Juli 1917 Physikum in München; Nov. 1919 Staatsexamen in Tübingen.

U Tübingen: Jan.-Juli 1920 Medizinalpraktikant am Physiolog. Inst.; Juli 1920 Dr. med.; Aug. 1920 Approbation.

UH: Seit Okt. 1920 Volontär, seit April 1921 Hilfsassistent, seit Okt. 1921 Assistent an Med. U-Klinik; 11. Mai 1925 Habilitation; Studienaufenthalte: Okt.Dez. 1925 Physiolog. Inst. in Cambridge (Großbritannien), Febr.-Okt. 1928 Physiolog.-Chemisches Inst. in Boston (Massachusetts); seit 15. März 1930 nichtplanm. a. o. Prof.; SS 1931-SS 1932 beurlaubt; Mai 1932 aus Lehrkörper ausgeschieden.

Stettin: Seit Mai 1931 Chefarzt der Inneren Abt. des Städtischen Krankenhauses.

Berlin: Seit Aug. 1934 Chefarzt der Inneren Abt. des Rudolf-Virchow-Krankenhauses in Wedding und seit Nov. 1934 Direktor der Inneren Abt. und der Med. U-Klinik des Krankenhauses in Moabit; 1935-1945 außerdem apl. Prof. an Friedrich-Wilhelms-U. • In dieser Zeit: 
1939-1941 Kriegsdienst.

Stuttgart: 1946-1971 Ärztlicher Direktor des KarlOlga-Krankenhauses und Chefarzt der Inneren Klinik.

U Tübingen: 1964-1973 Honorar-Prof.

1964 Gründungsmitglied der Süddeutschen Gesellschaft für Innere Medizin

E 1966 Großes Verdienstkreuz.

Qu UAH PA 876, 3537, 9144. • GLA Abt. 235, Fasz. 1883. Auskunft: Archiv der Hansestadt Lübeck; Standesamt Korntal-Münchingen (Sterbedatum des Vaters Adolf Friedrich D.: 03. Okt. 1931 in Lübeck); Standesamt Stuttgart.

W Innervation der Harnblase. Berlin 1926. Dringliche Krankheiten in der Inneren Medizin. Stuttgart 1942. 4. Aufl. 1963. • Sulfonamide, Penicillin, Streptomycin in der inneren Medizin. Berlin 1949. 2. Aufl. 1949. (Mitverf.)

(M)HG Broglie, Maximilian: Lehrbuch der inneren Medizin. 2 Bde. Stuttgart 1950. 8. Aufl. 1969.

L Kürschner (1940/41) Sp. 291, (1950) Sp. 332, (1961) S. 308, (1980) S. 614; WBIS. - Todesanzeige in: Dt. Med. Wochenschrift 98 (1973) S. 406. Chronik Ärzte H (1985) S. 124; Deutsche Biographie, s. https://www.deutsche-biographie.de/gnd 104526912.html [06.11.2017].

P Bildarchiv UAH; Chronik Ärzte H.

Dereser, Thaddäus Anton (1777-1802: Thaddäus a Sancto Adamo OCD)

1797-1798, 1799-1807 Theol. Fak., kath. Abt.

Orientalische Sprachen, Bibelhermeneutik

* 03. Febr. 1757 Fahr (Bayern; heute: Ortsteil von Volkach)

$\dagger$ 16. Juni 1827 Breslau (heute: Wrocław, Polen) kath.
V Johannes Adam D., Weinbauer

M Anna Maria geb. N. N.

(1) unverheiratet.

Lb U Würzburg: Seit WS 1772/73 Studium der Philosophie; 1776 Dr. phil.; 1777-1779 Studium der Theologie.

OCD: 1776-1779 Novize im Kloster der Unbeschuhten Karmeliten in Würzburg; 18. Okt. 1777 Profeß im Noviziat der Dt. Provinz des Ordens in Köln; 11. März 178o Priesterweihe in Mainz; 1802 Austritt aus dem Orden.

UH: Seit 6. Dez. 1779 Forts. des Studiums der Theologie.

OCD: 1780-1783 Lektor der Philosophie und Theologie am Ordenshaus in $\mathrm{H}$.

Kurkölnische U Bonn: Seit 11. Nov. 1783 o. Prof. für "Scriptur und Orientalische Sprachen" an neugegründeter U; 11. Nov. 1783 Verleihung des theol. Dr.-Titels durch Maximilian Friedrich, Kurfürst von Köln; 1. Nov. 1791 Entlassung auf eigenen Antrag.

Straßburg: 27. Nov. 1791 D. legt Eid auf Zivilkonstitution ab; damit war er vom Papst suspendiert und konnte nur noch in der franz. Kirche als Geistlicher wirken; seit WS 1791/92 o. Prof. für Orientalische Sprachen und Bibelexegese an U und Prediger am Münster; seit 17. Nov. 1792 auch Superior des bischöflichen Priesterseminars; seit Aug. 1793 außerdem konstitutioneller Pfarrer in Scherwiller (Elsaß); 28. Okt. 1793-13. Nov. 1794 Haft und Verurteilung zur Guillotine aufgrund D.s Ablehnung der Constitution civile du clergé während der Jakobinerherrschaft; 1795 nach Sturz der Jakobiner, Reise nach Paris; Febr. 1796 mit Erlaubnis der franz. Regierung Ausreise nach Würzburg; hier als Lehrer i. A. des Ordens tätig; Mai 1796 Lossprechung von Suspension durch päpstl. Reskript.

UH: Seit 4. Febr. 1797 substituierter Lehrer für Orientalische Sprachen und Bibelhermeneutik; 1798 auf mehrfache Aufforderung der Oberkuratel an Akad. U-Senat , anstelle des Paters Thaddaeus ein anderes Subject [für den Lehrstuhl der Orientalischen Sprachen] in Vorschlag zu bringen", lau- 
tet die Erwiderung, man sei „außer Stand gesezet" e. anderen als D. vorzuschlagen (s. hierzu den die Vorgänge zus.fassenden Brief des Dekans vom 27. März 1799 in: UAH PA 1466); 1798-1799 Vortragsreisen („litterarische Wanderschaft“ aus: PA) in Süddeutschland und der Schweiz; 7. April 1799 Ern. zum o. Prof. für Orientalische Sprachen als Nachf. von Joannes a Cruce (s. Drüll (1991) S. 78 8o) mit e. jährl. Besoldung von 150.- Gulden nach Tod Kurfürst Carl Theodors; März 1802 Verleihung des Tischtitels durch Kurfürst Max IV. Joseph; 1802 Austritt aus Karmelitenorden; 23. Febr. 1803 erzwungene Ablehnung der Rufe an U Königsberg (Preußen) (Besoldung hier: 600.- Gulden) und Gießen (11. März 1803) aufgrund verweigerter Zustimmung von Kurfürst (und späterem Großherzog) Karl Friedrich; 19. März 1803 D. erhält jährl. Besoldung von 110o.- Gulden; 29. März 1807 Verlegung der kath. Abt. der Theol. Fak. nach Freiburg/Br.

U Freiburg: Seit April 1807 (Versetzung) o. Prof. für Orientalische Sprachen und Bibelexegese.

Karlsruhe: Seit 30. April 1810 Stadtpfarrer auf Befehl Karl Friedrichs; 1. Juli 1811 D. hält e. vom Erbprinzen Karl und der Regierung mißverstandene Trauerrede auf Karl Friedrich, in der D. - bezogen auf die Wahl der Beamten - von Karl „unparteiische [religiöse] Gerechtigkeit" fordert; D. muß aufgrund dieser Respektlosigkeit die Stadt am nächsten Tag verlassen; er lehnt Versetzung an Großherzogl. Lyceum in Konstanz als Prof. für Alte Sprachen ab; Reisen in der Schweiz.

Luzern: Seit 11. Okt. 1811 Regens des bischöflichen Priesterseminars und Lehrer am Lyceum; D. ist als erfolgreicher und von der Regierung angesehener Ausländer vielfältigen Verleumdungen durch neidische Kollegen ausgesetzt, kann aber in allen Fällen seine Unschuld nachweisen; 26. Febr. 1814 nach Staatsstreich Entlassung durch neue Regierung.

H: Seit 1814 Privat-Gelehrter; April 1814 Ruf an U Breslau erreicht D. nicht, da das nach Luzern gesandte Schreiben ihm nicht nach $\mathrm{H}$ nachgeschickt wurde.

U Breslau: Seit 8. Nov. 1815 o. Prof. für Bibelexegese und Dogmatik sowie Domherr.
Zur Theologischen Fakultät, katholische Abteilung an UH, s. Weisert/Drüll/Kritzer (2007) S. 48, 53

1803: Diskussion über (die letztendlich erfolgte) Anerkennung des Dr.-Titels, den D. 1786 auf der vom Kaiser allein bestätigten und privilegierten Universität Bonn erwarb, die eigentlich e. „päpstlichen Vollmacht zur Creirung eines Doctors bedürfe“, s. PA 1466.

1805 Badischer Geistlicher Rat

Qu UAH PA 1466; RA 6209, 6746 u. ö. $\bullet$ GLA Abt. 205, Fasz. 196, 655, 660, 658. Briefe: UBH (unter: Dereser, Anton). $\bullet$ Rechenschaft über mein Betragen vor und in der Revolution ... Straßburg vom 20. Okt. 1795 (UB Straßburg).

$W$ Necessitas linguarum orientalium ad sacram scripturam intelligendam, vindicandam, ac fidei dogmata probanda. Köln 1783. - Das Deutsche Brevier. 4 Bde. Heilbronn 1811.

HG 1808 Katholisches Gebetbuch.

L Hegel, Eduard: T. A. D.s Studium und Lehrtätigkeit an der Universität Heidelberg in: Archiv für mittelrheinische Kirchengeschichte 4. Jg. (1952) S. 229-253. NDB 3 (1957) S. 605; Brandl (1978) S. 41 f.; Renger (1982) S. 294 (Register). - Kammerer, Louis: T. A. D. in: Nouveau dictionnaire de biographie alsacienne. Fédération des Sociétés d'Histoire ... d'Alsace. Strasbourg 1986. Fasz. 7. S. 625 f. • Weisert (1991) S. 121, 13of. u. ö.; Burkard (1995) S. 253 (Register); „Chronik des Barfüsser Karmelitenkloster" (1998) S. 34f., 219-231 u. ö.; Schweigard (2000) S. 268-276; WBIS; BBKL XXXII (2011) Sp. 222-229.

$P$ Bildarchiv UAH; graph. Slg. UBH. 


\section{Deurer, Ernst Ferdinand Friedrich Wilhelm}

1833-1851 Jur. Fak.

Römisches und Preußisches Recht

* 26. Juli 1812 Kandern (Schwarzwald)

$\dagger$ 31. Juli 1873 Darmstadt

kath.

V Wilhelm Johann Constantin D. (1780-1858) vor 1810 Amtsschreiber, seit 1810 Amtmann, seit 1822 Oberamtmann, vor 1832 Geh. Rat, seit 1835 Stadtdirektor in Heidelberg, s. UAH RA 5138; Großherzogl. Badische Regierungsblätter vom 20. 01.1810, Nr. 30 vom 01.12.1819, 1822 Blatt Nr. 2 vom 16.01.1822; Briefwechsel Karl Josef Anton Mittermaier - Hermann Fitting. Hrsg. ... von Lieselotte Jelowik. Frankfurt/M. 2000. S. 114 und Anm. 1.

M Maria Antoinetta geb. Dietz (1781-1861)

( 3. April 1845 Sophie Elisabetha Barbara Wilhelmine geb. Kayser (1825-1892)

K 4 S: u. a. Ernst D. (1846-1912) Komponist, s. Kurzgefaßtes Tonkünstler-Lexikon. Hrsg. von Paul Frank und Wilhelm Altmann. 15. Aufl. Wilhelmshaven 1971. 2 T: u.a. Sophie D. (1848-1921) in 1. Ehe $\varnothing$ Paul Gordan (18371912), u. a. 1875-1910 (Ruhestand) o. Prof. für Mathematik Erlangen, s. NDB 6 (1964) S. 646, WBIS; in 2. Ehe $\infty$ Wilhelm Filehne (18441927), u. a. 1886-1911 (Ruhestand) o. Prof. für Arzneimittellehre Breslau, s. NDB 5 (1961) S. 146, WBIS. - Siehe auch Waldeck (1920) S. $37 \mathrm{f}$.

Lb Studium: Seit 4. Nov. 1829 UH, SS 1832 Göttingen, seit WS $1832 / 33 \mathrm{H}$.

UH: 25. März 1833 Dr. iur.; 15. April 1833 Bewilligung der facultas legendi; 1837-1851 Beisitzer des Spruchkollegiums der Jur. Fak.; seit 7. April 1841 a. o. Prof.

U Gießen: 11. Aug. 1851-10. Jan. 1868 o. Prof.

Qu UAH PA 1469; Fak.-Akte H-II-111/28. • Briefe: UBH. • Briefe deutscher und Schweizer Germanisten an Karl Joseph Anton Mittermaier. Hrsg. ... von Lieselotte Jelowik. Frankfurt/M. 2001. S. 347 und Anm. 4. Auskunft: Herr Volker G. Scheer, Freiburg/Br.

$W$ Dissertatio inauguralis annotationes nonnullas ad legem II. de origine juris exhibens. Heidelberg 1833. Grundriß für äussere Geschichte und Institutionen des römischen Rechts. Heidelberg 1849.

$L$ Wechmar (1846) S. 251. - Die Familie Deurer in: Waldeck, Florian: Alte Mannheimer Familien. Mannheim 1920. S. 29-38, hier: S. 37 f. • Jammers (1964) S. 56, 177 u. ö.; Schroeder (2010) S. $107 \mathrm{f}$.

$P$ Bildarchiv UAH; NDB.

\section{De Wette, Wilhelm Martin Leberecht}

1807-1810 Theol. Fak.

Exegese

1807-1810 Phil. Fak.

Semitische Sprachen (Hebräisch, Arabisch, Sy-

risch)

* 12. Jan. 1780 Ulla (bei Weimar; heute: Ortsteil von Nohra)

$\dagger$ 16. Juni 1849 Basel ev.-luth.

V Johann August De W. (1744-1812) Pfarrer

M Margaretha Dorothea Christiana geb. Schneider $(\dagger 1819)$

$\infty$ April 1805 Eberhardine Magdalene Henriette geb. Boye (1775-1806)

( 4. Okt. 1809 Henrietta geb. Frisch gesch. Beck (1774-1825) 1819-1825 getrennt von de W. mit den Kindern in Heidelberg lebend; nach 1825 leben die Kinder bei ihrem Vater in Basel

(1833/34 Sophie geb. Streckeisen verw. von Mai (1788-1867)

K $1 \mathrm{~S}, 1 \mathrm{~T}, 1$ Stief-S, 1 Stief- $\mathrm{T}$

$L b$ U Jena: Seit 21. Okt. 1799 zunächst Studium der Rechtswiss., anschl. der Philosophie und Theologie; 11. März 1805 Promotion zum Dr. phil.; seit WS 1805/06 Privat-Dozent an Phil. Fak.; 1805-1807 auch Redakteur bei der Jenaischen Allg. Literaturzeitung. 
UH: Seit SS 1807 a. o. Prof. mit e. jährl. Besoldung von 500.- Gulden als Nachf. von Thaddäus Dereser; SS 1807-SS 1810 auch Vorlesungen an Phil. Fak. in „Orientalischer Philologie“ laut „Anzeigen der Vorlesungen“; seit Herbst 1809 o. Prof.

U Berlin: Seit 30. Aug. 1810 o. Prof. mit e. jährl. Besoldung von 1500.- Talern; 2. Okt. 1819 Entziehung der Lehrbefugnis an U und Ausweisung aus Preußen aufgrund e. Trostbriefs de W.'s an die ihm näher bekannte Mutter von Karl Ludwig Sand nach dessen Hinrichtung, s. hierzu Actensammlung über die Entlassung des Professors de W. vom theologischen Lehrstuhl in Berlin. Zur Berichtigung des öffentlichen Urtheils von ihm selbst herausgegeben. Leipzig 1820.

Weimar: Seit 1819 Privat-Gelehrter; 1820 Reisen u. a. in die Schweiz, nach Böhmen und Tirol.

U Basel: Seit März 1822 o. Prof.; 13. Mai 1822 Beginn seiner Vorlesungen; 1846 Studienreise nach Italien.

Basel: 1829 Verleihung der Bürgerrechte der Stadt; Mitglied des Kirchen- und Schulrates.

E 1813 D. theol. Breslau.

Qu UAH PA 2438; RA 6080, 6633. GLA Abt. 205, Fasz. 567. - Briefe: UBH. - Teil-Nachlaß: Öffentliche Bibliothek der Universität Basel. • Auskunft: Universitätsarchiv Jena.

$W$ Beiträge zur Einleitung in das Alte Testament. 2 Bde. Halle/S. 1806-1807. Biblische Dogmatik des Alten und Neuen Testaments. Berlin 1813. 3. Aufl. 1831. Lehrbuch der hebräisch-jüdischen Archäologie. Leipzig 1814. 4. Aufl. 1864. • Lehrbuch der historisch-kritischen Einleitung in das Alte und Neue Testament. 2 Bde. Berlin 1817-1826. Bd. 1: 8. Aufl. Berlin 1869; Bd. 2: 6. Aufl. 1860. • Vorlesungen über die Sittenlehre. 3 Bde. Berlin 1819-1823. - Lehrbuch der christlichen Dogmatik in ihrer historischen Entwicklung. 2 Bde. Berlin 1821-1831. 3. Aufl. 1840. Reprint Charleston (South Carolina) 2012. - Theodor oder: Des Zweiflers Weihe. 2 Bde. Berlin 1822. 2. Aufl. 1828. • Das Wesen des christlichen Glaubens vom Standpunkte des Glaubens dargestellt. Basel 1846.
HG Briefe Martin Luthers. 5 Bde. Berlin 18251828.

MHG 1819-1822 Theologische Zeitschrift (zus. mit Friedrich Schleiermacher). 3 H. (mehr nicht erschienen), siehe hierzu Friedrich Daniel Ernst Schleiermacher: Theologisch-dogmatische Abhandlungen und Gelegenheitsschriften. Hrsg. von Hans-Friedrich Traulsen ... Berlin 1990. Einleitung. (Friedrich Schleiermacher. Kritische Gesamtausgabe ... Bd. 10.)

L Wechmar (1846) S. 254; Keller (1913) S. 175 f.; Schneider (1913) S. 206. - Staehelin, Ernst: Dewettiana: Forschungen und Texte zu W.M.L. de W.s Leben und Werk. Basel 1956. NDB 3 (1957) S. 628; WBIS. Hanschin, Paul: W. M.L. de W. als Prediger und Schriftsteller. Basel 1958. • Smend, Rudolf: W.M.L. de W. in: Deutsche Alttestamentler in drei Jahrhunderten. Göttingen 1989. • BBKL I (1990) Sp. 1277 f. - Rogerson, John W.: W.M.L. de W. Founder of modern biblical criticism: an intellectual biography. Sheffield (South Yorkshire) 1992. • W.M.L. de W. Ein Universaltheologe des 19. Jahrhunderts. Hrsg. von Hans-Peter Mathys, Klaus Seybold. Basel 2001 (mit Bibliographie). - Saupe, Paul: Geboren vor 225 Jahren in Ulla bei Weimar der Theologe W.M.L. de W. in: Palmbaum. Literarisches Journal aus Thüringen. Bucha bei Jena 2003. S. 162-167. Buntfuss, Markus: Die Erscheinungsform des Christentums: zur ästhetischen Neugestaltung der Religionstheorie bei Herder, Wackenroder und De Wette. Berlin 2004. - Geschichte U Berlin (2012) Bd. 1, S. 660 (Register); Klippel (2012) S. 369. - Meier, Nikolaus: Kunst, Kirche, Museum in Basel. Die Sammlerin Emilie Linder, der Theologe W.M. L. de W., der Kunsthistoriker Georg Schmidt in: Emilie Linder (17971867). Malerin, Mäzenin, Kunstsammlerin. Hrsg. von Patrick Braun ... Basel 2013. S. 264-284. • Iff, Markus: Religionsphilosophie und Theologie. Rudolf Ottos Bezug auf W.M.L. de W. in: Rudolf Otto: Theologie - Religionsphilosophie - Religionsgeschichte. Hrsg. von Jörg Lauster ... Berlin 2014. S. 191-202.

$P$ Bildarchiv UAH; NDB. 


\section{Dibelius, Martin Franz}

1915-1947 Theol. Fak.

Neutestamentliche Exegese und Kritik

* 14. Sept. 1883 Dresden

$\dagger$ 11. Nov. 1947 Heidelberg

ev.-luth.

V Franz Wilhelm D. (1847-1924) Superintendent, später Oberhofprediger, s. NDB 3 (1957) S. $631 \mathrm{f}$.

M Martha Concordia geb. Hoffmann (1853-1887)

$\infty$ 10. Juli 1908 Dorothea (Dora) geb. Colma (1883-1960)

K $\quad 2$ T, 3 S: u. a. Ulrich D. (1924-2008) Musikpublizist und Rundfunkredakteur, s. Loeckle, Wolf: Lordsiegelbewahrer der Qualität: Der Musikschriftsteller U.D. in: neue musikzeitung (2004) Nr. 11; Auf den Faltenwurf des Starkritikers pfiff er ... in: FAZ vom 30. April 2008.

Lb Seit 1901 Studium der Theologie, Philosophie an U Neuchâtel, anschl. Leipzig, Tübingen, Berlin; 13. Juli 1905 Dr. phil. an U Tübingen.

1905-1914 Gymnasiallehrer zunächst in Berlin, anschl. in Charlottenburg. • In dieser Zeit:

U Berlin: 29. Febr. 1908 Lizentiaten-Promotion; 10. Febr. 1910 Habilitation; 1910-1914 Privat-Dozent.

UH: 24. Dez. 1914 Ern. zum o. Prof. als Nachf. von Johannes Weiss am Wiss.-Theol. Seminar; 20. April 1915 Vereidigung; 30. Aug.-25. Okt. 1916 Kriegsdienst; Rufe an U abgelehnt: 1928 Hamburg, 1929 Bonn, 1940 Chicago, 1947 Berlin; 1937 Untersagung dienstlicher Auslandsreisen durch Reichserziehungsminister (1938 Entzug des Reisepasses); April-Dez. 1945 Mitglied des Dreizehnerausschusses zum Wiederaufbau der UH.

1927/28 Rektor, Juni-Sept. 1928 Prorektor der UH; 1926/27 Wahlsenator der UH; 1919/20, 1924/25, 1945 Dekan der Theol. Fak. der UH

1918-1930 aktives Mitglied der Deutschen Demokratischen Partei
Siehe auch Anhang Sporteinrichtungen an UH 1910-1933 und ihre Mitglieder

E 1926 O. Mitglied der Akademie der Wissenschaften H (1945-1947 Sekretar). D. theol.: 1915 Berlin, 1937 St. Andrews (Schottland).

Qu UAH PA 241, 3545f.; RA 4814, 5225, 6722. • GLA Abt. 235, Fasz. 1884f. • Briefe, Nachlaß: UBH; s. hierzu Werner, Wilfried: Zum Nachlaß von M. D. in der UBH in: Ruperto Carola 41. Jg., H. 80 (1989) S. 67. - Zeit und Arbeit in: Die Religionswissenschaft der Gegenwart in Selbstdarstellungen. Hrsg. von Erich Stange. Bd. 5. Leipzig 1929. (Autobiogr.)

$W$ An die Kolosser, Epheser, an Philemon. Tübingen 1911. 3. Aufl. 1953. An die Thessalonicher. Tübingen 1911. 3. Aufl. 1937. • Die Formgeschichte des Evangeliums. Tübingen 1919. 3. Aufl. 1961. • Botschaft und Geschichte. Gesammelte Aufsätze. Hrsg. von Günther Bornkamm. 2 Bde. Tübingen 1953-1956. - M.D.: Selbstbesinnung des Deutschen. Hrsg. von Friedrich Wilhelm Graf. Tübingen 1997.

L NDB 3 (1957) S. 632 (mit Werkverz.). - Fix, Karl Heinz: M.D., die Politik seiner Zeit und zwei Theologenberufungen $1930 / 31$ und 1946 in: ZGORh 138. Jg. (1990) S. 496-504. Heiber (1991) S. 633 (Register); Jansen (1992) S. 408 (Register); Ders. (1992a) S. 164 (Register); Fix (1994) S. 93-116; Reutter (1994) S. 62 u. ö.; Badische Biographien N.F. IV (1996) S. 52-55; WBIS. • Graf, Friedrich Wilhelm: M.D. über eine Zerstörung der Bürgerlichkeit in: Zs. für neuere Theologiegeschichte 4 (1997) H. 1, S. 114-153; Ders.: Zur Lebensgeschichte M.D.s in: M.D.: Selbstbesinnung des Deutschen ... (1997) S. 50-93 (siehe Gesamttitel unter $W$ ). - Friedrich Naumann in seiner Zeit. Hrsg. von Rüdiger vom Bruch. Berlin 2000. S. 295-303 u. ö. - Geiser, Stefan: Verantwortung und Schuld. Studien zu M.D. Münster u. a. 2001. Besier, Gerhard: M.D. - an internationally renowned German New Testament scholar under National Socialism in: Kirchliche Zeitgeschichte. Int. Zs. für Theologie und Geschichtswissenschaft. Göttingen 2004. S. 339-351. - Personenlexikon zum dt. Protestantismus (2006) S. 58; UH 
im Nationalsozialismus (2006) S. 1249 (Register); Kriegstagebuch K. Hampe (2007) S. 953 (Register). Bauspieß, Martin: Geschichte und Erkenntnis im lukanischen Doppelwerk. Leipzig 2012. Bringeland, Hans: Religion und Welt. M.D. ... 3 Bde. Berlin 2013-2014. - Theißen, Gerd: M. D. ... in: Jahresheft der Theologischen Fakultät der Universität Heidelberg. Heidelberg 2014. S. 94-102. • Merk, Otto: Die evangelische Kriegsgeneration in: Merk, Otto: Wissenschaftsgeschichte und Exegese. Bd. 2: Gesammelte Aufsätze 1998-2013. Hrsg. von Roland Gebauer ... Berlin 2015. S. 3-68. • Keßler, Ewald: Ehrenpromotion für einen Gegner der NSRassenlehre. Ein Vorschlag des Theologen ... M. D. 1935 in: Heidelberg. Jahrbuch zur Geschichte der Stadt 2017. Heidelberg 2016. Jg. 21. S. 137-147.

$P$ Bildarchiv UAH; NDB.

\section{Dierbach, Johann Heinrich}

1817-1845 Med. Fak.

Botanik, Rezeptierkunst, Materia medica (Arzneimittellehre)

* 23. März 1788 Heidelberg

$\dagger$ 11. Mai 1845 Heidelberg ev.-luth.

V Jacob Friederich D. (1735-1794) Buchbinder der UH, s. UAH PA 1470

M Anna Margaretha geb. Bastian (1754-1797)

$\infty$ 4. Nov. 1820 Maria Elisabetha geb. Münch (1796-1843)

K $6 \mathrm{~T}$ (davon 2 unehelich geboren, s. hierzu Keidel (1983) S. 20 f.)

Lb H: Vor 1804 Lehrling in U-Apotheke; pharmazeutisches Examen; nach 1804-1816 "praktischer" Pharmazeut u. a. 1814 in U-Apotheke (siehe hierzu Wilhelm Mai).

UH: Seit 24. Okt. 1812 Studium; 1816 Dr. med.; 1816 Approbation; 29. Okt. 1817 Habilitation für Botanik und Rezeptierkunst; 1817 D.s Gesuch um Benutzung des Botanischen Gartens hinter dem ehemaligen Dominikanerkloster an der Ecke Hauptstrasse/Brunnengasse für seine Vorlesungen wird vom Senat der U abgelehnt; seit 9. März 1820 a. o. Prof. mit e. jährl. Besoldung von 200.- Gulden; seit Jan. 1823 Zulage von jährl. 200.- Gulden; zwischen 1824 und 1833 mehrere erfolglose Bitten um Gehaltszulage; 1832 D.s Gesuch um Übertragung der Professur für Botanik des verstorbenen Mediziners Franz Schelver wird vom Innenministerium mit der Begründung abgelehnt, für dieses Ordinariat sei kein Mediziner, sondern ein Angehöriger der Phil. Fak. vorgesehen (Nachf. Schelvers wird 1828 der Gärtner und 1843 der zum Garten-Direktor ernannte Johannes Metzger, s. UAH PA 1987 f. (zu Metzger, siehe Franz Schelver), danach 1847-1854 Gottlieb Wilhelm Bischoff); seit 1. April 1833 jährl. Erhöhung seiner Besoldung um 200.- Gulden, damit Jahresgehalt von insgesamt 6oo.- Gulden.

Qu UAH PA 1471; RA 5628 f., 6595, 6883; Fak.-Akte H-III-111/15. • GLA Abt. 205, Fasz. 199.

$W$ Flora Heidelbergensis. Plantas sistens in praefectura Heidelbergensi ... 2 T. Heidelberg 18191820. - Die Arzneimittel des Hippokrates. Heidelberg 1824. Nachdr. 1969. - Die neuesten Entdeckungen in der materia medica. $4 \mathrm{Bde}$. Heidelberg 1828-1847. 2. verm. Aufl. des 1. Bd. 1837. • Flora mythologica oder Pflanzenkunde in Bezug auf Mythologie und Symbolik der Griechen und Römer. Ein Beitrag zur ältesten Geschichte der Botanik, Agricultur und Medicin. Frankfurt/M. 1833. Reprint 2013. Codex medicamentarius Germanorum. Heidelberg 1845.

HG 1841 Pharmacopoea Badensis.

$L$ Hesperus (1831) S. 143. $\bullet$ Meurer, Friedrich: Kurze biographische Skizze des Professors ... H. D. in: Archiv der Pharmazie 111 (1850) S. 96-98. NDB 3 (1957) S. 654 f.; WBIS. - Keidel, Jochen: J.H.D. Ein Beitrag zu Leben und Werk des Heidelberger Hochschullehrers. Diss. Marburg 1983 (mit Werkverz.). - Chronik Ärzte H (1985) S. 125; Thomas (1985) S. 627 (Register). 


\section{Dieterich, Wilhelm Albrecht Julius}

1903-1908 Phil. Fak.

Klassische Philologie

* o2. Mai 1866 Hersfeld (heute: Bad H.)

$\dagger$ o6. Mai 1908 Heidelberg ev.

V Hermann Wilhelm Albrecht D. (1820-1889) 1850-1885 Gymnasiallehrer in Hersfeld

M Henriette Friederike Charlotte geb. Münscher (1830-1873) T von Wilhelm M. (1795-1872) 1832-1867 Gymnasialdirektor in Hersfeld; Enkelin von: Wilhelm M. (1766-1814), s. Eintrag unter $V w$ [Urgroßvater]

œ 8. März 1899 Marie geb. Usener (1867-1931) T von Hermann U. (1834-1905) o. Prof. für Klassische Philologie: seit 1863 Greifswald, 18661902 Bonn, s. Verzeichnis Bonn (1968) S. 319, BBKL XII (1997) Sp. 965-979; Niesen, Josef: Bonner Personenlexikon. 3. Aufl. Bonn 2011.

K $2 \mathrm{~S}$

Vw Urgroßvater: Wilhelm Münscher (1766-1814) seit 1792 o. Prof. für Theologie Marburg, s. WBIS, BBKL XXI (2003) Sp. 1044-1048. W.M.s Mutter: Katharine Elisabeth geb. Schröder (1735-1807) T von Johann Joachim S. (1680-1756), u. a. seit 1713 Prof. für Orientalische Sprachen und Kirchengeschichte Marburg, s. WBIS; Bickert, Hans Günther: Der Armenologe J.J.S. Leben und Wirken e. bedeutenden Gelehrten aus der Schwalm in: Zs. des Vereins für Hessische Geschichte und Landeskunde 116 (2011) S. 163-195.

Vw Vetter: Karl Münscher (1871-1936), u.a. seit 1909 Prof. für Klassische Philologe Münster, s. WBIS.

$L b$ Seit SS 1884 Studium zunächst der Theologie (auf Wunsch des Vaters), anschl. der Klassischen Philologie an U Leipzig, seit SS 1886 Bonn (u.a. Student bei Hermann Usener); 14. Aug. 1888 Dr. phil. an U Bonn; Mai 1889 Prüfung für höheres Lehramt; Herbst 1889-189o Proband am Ev. Gymnasium in Elberfeld (heute: Wuppertal-E.).
U Marburg: 24. Okt. 1891 Habilitation; März 1894Frühjahr 1895 Studienreisen nach Griechenland, Italien und in das Osmanische Reich; seit 18. Juli 1895 etatm. a. o. Prof. und Direktor des Philolog. Seminars.

U Gießen: Seit 3. April 1897 o. Prof.

UH: Seit 1. April 1903 o. Prof. als Nachf. von Otto Crusius und Mit-Direktor (zus. mit Fritz Schöll) des Philolog. Seminars; 1903-1908 auch Mitglied des Oberschulrats; 1907 Ruf an U Halle-Wittenberg abgelehnt.

1905/o6 Dekan der Phil. Fak. der UH

1904: Initiator (zus. mit (siehe) Adolf Deissmann) des Heidelberger Eranos-Kreises, einem Kollegentreffen zur Erörterung religionswissenschaftlicher Fragen

1907 Geh. Hofrat

E Ritter des Ordens vom Zähringer Löwen.

Qu UAH PA 1472; RA 6375. - Briefe: UBH. • Nachlaß: Universitätsarchiv Bonn.

W Abraxas. Studien zur Religionsgeschichte des späteren Altertums. Leipzig 1891. Nachdr. Aalen 1973. Reprint Whitefish (Montana) 2010. • Eine Mithrasliturgie. Leipzig 1903. Mutter Erde. Ein Versuch über Volksreligion. Leipzig 1905. 3. Aufl. 1925. Nachdr. Hamburg 2013.

HG 1904-1908 Archiv für Religionswissenschaft.

$L$ Catalogus prof. Marburgensis 1 (1927) S. 341; NDB 3 (1957) S. 669f.; WBIS; Glockner (1969) S. 272 (Register). - Marchand, Suzanne: „From Liberalism to Neoromanticism: A.D., Richard Reitzenstein, and the religious turn in fin-de-siècle German Classical Studies" in: Out of Arcadia. Classics and Politics in Germany in the Age of Burckhardt, Nietzsche and Wilamowitz. Ed. by Ingo Gildenhard and Martin Ruehl. London 2003. S. 129-160. - Zu A.D.s Rekonstruktion ursprünglicher Denkformen in: Wessels, Antje: Ursprungszauber - Zur Rezeption von Hermann Useners 
Lehre von der religiösen Begriffsbildung ... Berlin 2003. S. 96-128. 100 Jahre Germanistik in Hamburg (2011) S. 112, 453 .

$P$ Bildarchiv UAH; NDB.
Qu UAH PA 1475, 3562; Fak.-Akten H-IV-102/49, H-IV-102/52. • Briefe: UBH.

$W$ Das System der Staatsanleihen im Zusammenhang der Volkswirtschaft betrachtet. Heidelberg 1855. Die Besteuerung der Aktiengesellschaften in Verbindung mit der Gemeinde-Besteuerung. Köln 1859. • Die Volkswirtschaft und ihr Verhältnis zu Gesellschaft und Staat. Frankfurt 1864.

L Schüler, Manfred: C.D. und die Theorie des Staatskredits in der 2. Hälfte des 19. Jahrhunderts. Diss. Köln 1961. • Über C. D. in: Thym, Wolf-Reimar: Öffentliche Ausgaben und öffentliche Schuld. Diss. Erlangen-Nürnberg 1968 (mit Werkverz.). • Verzeichnis Bonn (1968) S. 55. - Glaeser, Rolf: C.D. ... A pioneering and unorthodox thinker on public debt and fiscal policy in: European economists of the early 2oth century. Vol. 2: Studies of neglected continental thinkers of Germany and Italy. Cheltenham 2003. S. 81-103. - Deutsche Biographie, s. https://www.deutsche-biographie.de/g nd116117095.html [06.11. 2017].

$P$ Bildarchiv UAH.

UH: 2. Aug. 1853 Dr. phil.; 1853-1854 Eigenstudien in Berlin, anschl. H; 11. Jan. 1856 Habilitation.

Köln: Sommer 1859-Winter 1861 Sekretär des Centralvereins der Rheinisch-Westphalischen Actiengesellschaften.

U Bonn: WS 1859/6o-WS 1861/62 Privat-Dozent.

UH: Seit SS 1862 Privat-Dozent; seit 26. Juni 1863 a. o. Prof. - In dieser Zeit:

Polytechnikum Karlsruhe: 1864-1865 Prof.

U Marburg: WS 1867/68-SS $1884(\dagger)$ o. Prof.; SS 1869 und SS 1870 von U beurlaubt für Gast-Professur an Königl. Gewerbeakademie in Berlin. • In dieser Zeit:

Berlin: Seit 1868 Mitglied der Kommission zur Prüfung des Staatshaushalts; 1868-1872 Abgeordneter des Preußischen Landtags; 1870 Mitglied der Kommission für Finanzen und Zölle.

\section{Dinckler, Max}

siehe Dinkler

\section{Dinkler, Carl Max}

189o-1896 Med. Fak.

Innere Medizin

* 27. April 1863 Königsee (Thüringen; heute: Ortsteil von Königsee-Rottenbach)

$\dagger$ 05. März 1929 Aachen ev.

V Christian Hermann D. (1830-1907) Arzt

M Amalie Auguste Elwire Thecla geb. Harraß (1840-1932)

๑ Elisabeth Wilhelmine Emilie geb. Meyer

K unbekannt. 
Lb Seit WS 1882/83 Studium an U Erlangen, anschl. Jena, WS $1884 / 85-S S 1885 \mathrm{H}$, seit WS 1885 / 86 Halle-Wittenberg; 4. Nov. 1886 Dr. med. an U Halle-Wittenberg.

UH: 18. Febr. 1887 Staatsexamen; Febr. 1888-1895 klinischer Assistenzarzt an Med. U-Klinik (Akad. Krankenhaus); 4. Aug. 1890 Habilitation; seit 1. Juni 1895 nichtetatm. a. o. Prof.

Aachen: Okt. 1896-März 1929 Leiter der Inneren Abt. des Ev. Luisenhospitals.

1902 Mitbegründer der Rheinisch-westfälischen Gesellschaft für Innere Medizin und Nervenheilkunde

Qu UAH PA 1476; Fak.-Akte H-III-111/110.

$W$ Über Bindegewebs- und Gallengangsneubildung in der Leber bei chronischer Phosphorvergiftung ... Halle/S. 1887. • Zur Lehre von der Sclerodermie. Leipzig 1891.

L Pagel (1901) Sp. 395; Stübler (1926) S. 315; Fischer $1\left({ }^{3} 1962\right)$ S. 317 . Koppen, Bodo von: 100 Jahre Ev. Krankenhausverein zu Aachen Luisenhospital. 1867-1967. Aachen 1967. S. 96. Chronik Ärzte H (1985) S. 125. • Strohmeyer, Georg u. a.: Geschichte der Inneren Medizin in Nordrhein-Westfalen. 100 Jahre Rheinisch-Westfälische Gesellschaft für Innere Medizin. Paderborn 2004. S. 35-61. • Deutsche Biographie, s. https://www.deutsche-biographie.de/gnd116137770.html [06.11. 2017].

$P$ Bildarchiv UAH; graph. Slg. UBH; Koppen (1967).

\section{Dittenberger, Theodor}

s. Dittenberger, Theophor Wilhelm

\section{Dittenberger, Theophor Wilhelm [sen.]}

1833-1852 Theol. Fak.

Theologie

* $\quad$ o1. Mai 1807 Teningen (bei Emmendingen, Baden)

$\dagger \quad$ o1. Mai 1872 Weimar

ev.

V Theophor Simon Friedrich D. (1766-1842), u. a. seit 1807 Pfarrer an Providenzkirche in $\mathrm{H}$

M Johanna Auguste geb. Schmidt

๑ 15. März 1838 Wilhelmine Marie geb. Daub (1802-1870) T von: (siehe) Carl D.

K 4 S: u.a. Wilhelm D. [jun.] (1840-1906) seit 1865 Lehrer an verschiedenen Gymnasien, seit 1874 o. Prof. für Klassische Philologie HalleWittenberg, siehe NDB 3 (1957) S. 522; Zimmermann, Hans-Dieter: W. D. ... in: Jahrbuch für Hallische Stadtgeschichte 2006. Halle/S. 2006. S. 264-269; Catalogus prof. Halensis online. 1 T: Emilie D. (1841-1901) Ehefrau von: (siehe) Heinrich Weber.

Lb Seit WS 1826/27 Studium der Theologie, auch Philologie an UH, seit SS 1830 Halle-Wittenberg; 13. Juli 1831 theol. Prüfung in Karlsruhe; anschl. Pfarrvikar in $\mathrm{H}$.

UH: 13. Dez. 1832 Lizentiatenprüfung; 26. Okt. 1833 Habilitation; 1833/34 Bildungsreise durch Deutschland und Dänemark; seit 6. Febr. 1838 a. o. Prof. sowie II. Lehrer am 18. Mai 1838 eröffneten Predigerseminar und damit verbunden 31 . Juli 1838-SS 1852 II. U-Prediger (I. U-Prediger: Richard Rothe bis WS $1848 / 49$, seit SS 1851 Daniel Schenkel) an Peterskirche (im Sommer) und an Providenzkirche (im Winter, da beheizbar); seit 7. Mai 18470. Prof. für Praktische Theologie. • In dieser Zeit:

H: 31. Juli 1838-Aug. 1852 Pfarrverweser der Heiliggeist-Gemeinde.

Weimar: Aug. 1852-April 1872 Oberhofprediger und städtischer Oberpfarrer.

1850 Dekan der Theol. Fak. der UH 
1852 Großherzogl. Sächsischer Kirchenrat, 1863 Geh. Kirchenrat

E 1846 D. theol. UH, s. hierzu UAH Fak.-Akten Theol. Fak. 26 fol. 26, 31, 111 und Theol. Fak. 66 fol. 8 o.

$Q u$ UAH PA 1477; RA 6126f., 6133, 6612, 6718 fol. 8v, 9r, 67r-69r u. ö. GLA Abt. 205, Fasz. 202. • Briefe: UBH. - Auskunft: Ev. Kirche in Mitteldeutschland - Landeskirchenarchiv Eisenach (Sterbeeintrag im Totenbuch der ev. Gemeinde Weimar 1872). - Biographie, von ihm selbst verfaßt. 3 H. Mannheim 1839-1841.

$W$ Über Predigerseminarien. Heidelberg 1835. • Die Universität Heidelberg im Jahre 1804. Ein Beitrag zu ihrer Geschichte. Heidelberg 1844. • Votum in der theologischen Facultät der Universität Heidelberg über den durch Pastor Dulon angeregten Kirchenstreit in Bremen. Heidelberg 1852. • Zeitpredigten in den Kirchen zu Weimar gehalten. Weimar 1854 .

MG 1854 Protestantische Kirchenzeitung für das ev. Deutschland.

MHG Philosophische und theologische Vorlesungen. Hrsg. von Philipp Konrad Marheineke und T.W.D. 8 Bde. Heidelberg 1838-1843.

$L$ ADB 5 (1877) S. 261f. (Todesjahr irrtümlich mit 1871 angegeben); Badische Biographien 1 (1875) S. 189-193; Badisches Pfarrerbuch 2 (1939) S. 116; WBIS; BBKL I (1990) Sp. 1334f. (Todesjahr irrtümlich mit 1871 angegeben).

$P$ Bildarchiv UAH; graph. Slg. UBH.

\section{Dittrich, Georg Paul Max}

1897-1913 Nat.-Math. Fak.

Chemie

* o9. Sept. 1864 Görlitz

$\dagger \quad$ 05. Juni 1913 Heidelberg

ev.

V Oskar D. (1830-1885) Regierungs-Geometer bzw. -Feldmesser

M Liddy geb. Schelle (1833-1916)

๑ 3. April 1902 Helene geb. Schultz (1880-1979)

K $\quad 1$ S, 2 T

Lb Studium der Naturwiss. an U: WS 1886/87 Leipzig, SS 1887 München, WS 1887/88-SS 1888 H, WS 1888/89-SS 1889 Göttingen, WS 1889/90-SS $1890 \mathrm{H}$.

UH: 9. Mai 1890 Dr. phil. nat.; 1890-1891 Assistent am Chemischen Laboratorium.

H: 1891-1893 Hilfsarbeiter an Großherzoglich Badischer Geologischer Landesanstalt.

UH: 1893-1895 Studium der Nahrungsmittelchemie (ohne Immatrikulationsnachweis); 1894-1895 Assistent am Chemischen Laboratorium; 1895 Approbation als Nahrungsmittelchemiker; 1896/971913 Leiter des Chemischen und Bakteriolog. Unterrichts- und Untersuchungslaboratoriums in der Brunnengasse 14; 29. Mai 1897 Habilitation für Chemie; seit 14. Febr. 1903 nichtetatm. a. o. Prof.

Qu UAH PA 1478; RA 6398, 7725. • Adreßbuch der Stadt H 1890-1913 - online. Mitteilungen: Frau Gerda Dittrich $(\dagger)$.

W Anleitung zur Gesteinsanalyse. Leipzig 1905. • Chemisches Praktikum. 2 Bde. Heidelberg 19061908. - Chemische Experimentierübungen für Studierende und Lehrer. Heidelberg 1911.

$L$ NDB 4 (1959) S. 4; WBIS; Jansen (1992a) S. 164 (Register); DBE 2 (2005) S. 651.

$P$ Bildarchiv UAH. 


\section{Dochow, Carl Hermann Franz}

1907-1932 Jur. Fak.

Internationales Öffentliches Recht

* 27. Jan. 1875 Halle/S.

$\dagger$ 19. April 1932 Heidelberg ev.

V Adolph Heinrich D. (1844-1881) seit WS 1871/ 72 Privat-Dozent H, seit WS 1872/73 Prof. für Rechtswiss. Halle-Wittenberg, s. UAH PA 1480, ADB 47 (1903) S. 736 f.; Nachruf in: Liszt, Franz von: Strafrechtliche Aufsätze und Vorträge. Bd. 1: 1875-1891. Berlin 1905. S. 79-89.

M Philippine Amalie Charlotte Mathilde geb. Keidel ( $†$ 1927)

$\infty$ unverheiratet.

Lb U Halle-Wittenberg: Seit 1897 Studium; 1900 Dr. phil.

Halle/S.: Seit 1. Sept. 1900 wiss. Hilfsarbeiter, seit 1. Jan. 1901 II. Sekretär an Handelskammer.

Berlin: April 1902-Sept. 1904 Sekretär von Hans Hermann Freiherrn von Berlepsch (1843-1926; 1890-1896 preußischer Minister für Handel und Gewerbe); 1. Okt. 1904-31. März 1905 wiss. Hilfsarbeiter am Statistischen Amt.

UH: 24. April 1906 Dr. iur.; 29. April 1907 Habilitation; WS 1910/11 Lehrauftrag als Vertreter des Ordinarius für Verfassungs- und Verwaltungsrecht an TH Karlsruhe; seit 7. April 1914 Bibliothekar am Jur. Seminar; seit 3. Juni 1915 nichtetatm., 1920$1932(\dagger)$ nichtplanm. a. o. Prof. In dieser Zeit:

1914-1918 Kriegsdienst; SS 1920-WS 1931/32 nebenamtl. Dozent an Handelshochschule Mannheim.

E 1918 Ritterkreuz II. Klasse mit Schwertern des Ordens vom Zähringer Löwen.

Qu UAH PA 3575; RA 5029, 6113, 6149, 6762. • Briefe: UBH.
$W$ Die Kriminalität im Amtsbezirk Heidelberg. Berlin 1906. - Vereinheitlichung des Arbeiterschutzrechtes durch Staatsverträge. Berlin 1907. • Die Organisation der auswärtigen Verwaltung nach deutschem Recht in: Annalen des Deutschen Reichs für Gesetzgebung, Verwaltung ... München 1914. S. 630-638. Verwaltung und Wirtschaft. Berlin 1921. 2. Aufl. 1923. - Gewerbeordnung für das Deutsche Reich. Berlin 1922. 2. Aufl. 1926. Landwirtschaftsrecht. Breslau 1927.

Bearb. Meyer, Georg: Lehrbuch des deutschen Verwaltungsrechts. 3. und 4. Aufl. München 19101915.

L Kürschner (1928/29) Sp. 388; Jansen (1992a)

S. 164 (Register); Stolleis (2002); Schroeder (2010)

S. 354 f. Bode, Matthias von: Die auswärtige Kulturverwaltung der frühen Bundesrepublik. Eine Untersuchung ihrer Etablierung zwischen Norminterpretation und Normgenese. Tübingen 2014. S. 166 f. u. ö. Deutsche Biographie, s. https://www. deutsche-biographie.de/gnd116151714.html [06.11. 2017].

$P$ Bildarchiv UAH.

\section{Dohna-Schlodien, Alexander Georg Theobald Burggraf und Graf zu}

1920-1926 Jur. Fak.

Strafrecht, Strafprozeßrecht

* 29. Juni 1876 Potsdam

$\dagger$ 25. Dez. 1944 Bonn ev.-ref.

V Hannibal Graf zu D.-S. (1838-1914) Generalleutnant

M Helene geb. Fürstin Maurokordatos (18461924)

( 24. Sept. 1906 Elisabeth geb. von PommerEsche (1882-1969) T von Albert von P.-E. (1837-1903), u. a. 1890-1897 Oberpräsident der Provinz Sachsen, s. Die preußischen Oberpräsidenten 1815-1945. Hrsg. von Klaus Schwabe. Boppard/Rhein 1985. 
K 1 S, 5 T: u.a. Dagmar zu D.-S. (1907-1995) Bildhauerin; Ehefrau von Wolf Graf von Baudissin (1907-1993), u.a. General, seit 1979 Prof. und 1971-1984 (Gründungs-)Direktor des Inst. für Friedensforschung und Sicherheitspolitik an U Hamburg, s. W. Graf von B. Modernisierer zwischen totalitärer Herrschaft und freiheitlicher Ordnung. Hrsg. von Rudolf J. Schlaffer ... München 2007. - Dr. Ruth zu D.-S. (1908-2000) Physikerin; Ehefrau von Karl Hermann Knoke (1909-1994) Jurist und Diplomat, s. WBIS; Wiegeshoff, Andrea: „Wir müssen alle etwas umlernen“. Zur Internationalisierung des Auswärtigen Dienstes der Bundesrepublik Deutschland (1945/51-1969). Göttingen 2013. S. $428 \mathrm{f}$.

Lb Seit 1895 Studium an U Rom, anschl. Lausanne, Freiburg/Br., Berlin.

U Berlin: 29. Dez. 1898 Staatsexamen; 13. Mai 1902 Dr. iur.

Seit Dez. 1898 Referendardienst; 1899-1900 Militärdienstpflicht als Einjährig-Freiwilliger; Okt. 1900-Sept. 1902 Doktorand am Kriminalistischen Seminar der U Berlin.

U Halle-Wittenberg: Seit Okt. 1902 Eigenstudien; 24. Okt. 1904 Habilitation.

U Königsberg (Preußen): Seit 24. Sept. 1906 etatm. a. o. Prof.; seit 10. Febr. 1913 o. Prof. In dieser Zeit:

Herbst 1906-Frühjahr 1909 Wiss. Begleiter des Prinzen August Wilhelm von Preußen (18871949) in Bonn, Straßburg und Potsdam, s. hierzu Machtan, Lothar: Einen Doktor für den Prinzen ... in: DIE ZEIT (22. Okt. 2009) Nr. 44.

1914-1916 Kriegsdienst; seit Mai 1916 Arbeit im Zivilberuf und Berichterstatter am a.o. Kriegsgericht; seit Dez. 1917 Leiter der Justizabt. der Militärbezirksverwaltung Litauen-Süd in Bialystok (heute: Polen); 28. Sept.-28. Nov. 1918 Abkommandierung als Prorektor an U Dorpat; 28. Nov. 1918-7. Jan. 1919 (Entlassung) Kriegsdienst.
UH: 13. Febr. 1920 Ern. zum o. Prof.; Rufe abgelehnt: 1923 U Frankfurt/M., 1925 Kiel.

U Bonn: 1. Aug. 1926-30. Sept. 1939 (Emeritierung) o. Prof.; Okt.-Dez. 1939 Lehrstuhlvertretung an U Erlangen-Nürnberg; 1940-1941 Vertreter seines Lehrstuhls aufgrund Lehrkräftemangel.

1921/22 Dekan der Jur. Fak. der UH

1919/20 Abgeordneter der Nationalversammlung in Weimar; 1920 Wahl zum Reichstagsabgeordneten für den Wahlkreis Ostpreußen (DVP) (Niederlegung des Mandats nach Annahme des Rufes an UH), s. hierzu „Akten der Reichskanzlei. Weimarer Republik“ online, s. http://www.bundesarchiv.de/aktenreichskanzlei/1919-1933/oooo/adr/ getPPN/119136783/

E Königl. Preußischer Roter Adler-Orden IV. Klasse.

Qu UAH PA 744, 3580. - GLA Abt. 235, Fasz. 1897. Briefe: UBH; siehe auch Kalliope.

W Die Rechtswidrigkeit. Halle/S. 1905. - Das Strafprozeßrecht. Berlin 1913. 3. Aufl. 1929. Recht und Irrtum. Mannheim 1925. - Der Aufbau der Verbrechenslehre. Bonn 1936. 4. Aufl. 1950. Kernprobleme der Rechtsphilosophie. Mit e. Nachwort von Erik Wolf. Nachdr. der Ausg. von 1940. Darmstadt 1959.

$L$ NDB 4 (1959) S. 53 f.; WBIS; Verzeichnis Bonn (1968) S. 57; Heidelberger Strafrechtslehrer (1986) S. 275-284; Jansen (1992) S. 408 (Register); Ders. (1992a) S. 164 (Register). • Escher, Alfred: Neukantianische Rechtsphilosophie, teleologische Verbrechensdogmatik und modernes Präventionsstrafrecht. Eine biographische und wissenschaftsgeschichtliche Untersuchung über A. Graf zu D. ... Berlin 1993. Morell, Alexander: A. Graf zu D. in: Die Juristen der Universität Bonn im „Dritten Reich“. Hrsg. von Mathias Schmoeckel. Köln 2004. S. 105-136. - Zwischen Diktatur und Neubeginn. Die Universität Bonn im "Dritten Reich“ und in der Nachkriegszeit. Hrsg. von Thomas P. Becker. Göttingen 2008. Parashu, Dimitrios: Jurist(en) im Porträt: A. Graf zu D.-S. ... und Dimi- 
trios S. Mavrokordatos (1821-1873) in: Recht und Politik (2011) Bd. 47, Nr. 4, S. 238-241. - Tilitzki 1 (2012) S. 786 (Register). - Dohna, Lothar Graf zu: Die Dohnas und ihre Häuser. Profil einer europäischen Adelsfamilie. Unter Mitwirkung von Alexander Fürst zu Dohna $(\dagger)$... 2 Bde. Göttingen 2013. - Maus (2013) S. 458 (Register); Catalogus prof. Halensis online.

$P$ Bildarchiv UAH.

\section{Doller, Johannes Lorenz (Ex-SJ)}

1779 (1779-1805) Phil. Fak.

Ästhetik

$\approx$ 03. Okt. 1750 Bretten (bei Karlsruhe)

$\dagger$ 30. Jan. 1820 Mainz

kath.

V Lorenz D. (1711-1781) Kaufmann

M Maria Benedicta Sperlin (†1770)

Lb UH: 5. Dez. 1766 Studium an Phil. Fak.; 7. Sept. 1767 Bakkalaureat-, 7. Sept. 1768 Magisterexamen.

SJ: 1768 Eintritt in Jesuitenorden in Mainz; in Diensten des Ordens: 1768 Mainz, 1770-1773 H; 14. Sept. 1770 Ablegung der einfachen Gelübde.

1773 - nach Aufhebung des Ordens - Studium der Theologie, Rechtswiss.; gleichzeitig Lehrer und Hofmeister junger Adeliger.

UH: Seit 22. Jan. 1779 a. o. Prof.; Juli 1779 D. wird aus Krankheitsgründen auf einige Jahre von UH beurlaubt; 1779-1805 Beibehaltung des Titels und der Rechte seiner Professur; 1805 Wiederbesetzung seiner Professur durch (siehe) Aloys Schreiber. - In dieser Zeit:

1779-1805 Hofmeister bei Johann Maria Rudolf Graf Waldbott von Bassenheim (1731-1805); seit 1805 Privatier u.a. in Bruchsal, zuletzt in Mainz.
$Z$ Seiner Bewerbung um die a.o. Professur für Ästhetik 1778 legt D. Kurfürst Carl Theodor eine „Erklärung desjenigen“ bei, „was ich unter dem Namen eines Professors der schönen Wissenschaften zu lehren gesinnt bin: Ich verstehe unter den schönen Wissenschaften die Redekunst und die Dichtkunst ... Die Aesthetik oder die Philosophie der schönen Künste und Wissenschaften lehret ..., welcher der wahre Zweck dieser Künste und Wissenschaften sey, sie beweiset, daß er kein anderer als die Erweckung erhöhter Empfindungen seyn könne, sie bestimmt daraus die Natur dieser Wissenschaften; sie untersuchet alsdann die Natur der Empfindungen; sie theilet sie in obere und niedere, ergötzende und verdrießliche u.s.w.; ... sie sucht philosophische Grundsätze auf, aus welchen sie erkläret, woher jener Einfluß entstehe, was für Empfindungen angenehm oder unangenehm sind ... Auf diese Lehren folgt die Abhandlung von den Gegenständen, die tauglich sind durch die sinnliche Erkenntniß, Empfindungen zu erwecken ... Es werden Bemerkungen über diese Gegenstände gegeben, wenn sie in der Natur vorhanden sind, andere, wenn sie gedichtet werden und der Vorzug von beyden unterschieden ... In diesem [besonderen] Theil [der Vorlesungen] also muß zu erst der Unterschied der schönen Künste und Wissenschaften angezeiget und bey den letztern das, was beide gemein und jede besonders hat, bestimmet, die Grenzen zwischen Redner und Dichter gezeichnet werden, dann kann von einer jeden ins besondere von ihrer Geschichte, Beschaffenheit, Nutzen und Vortrefflichkeit, von der Erfindung, Anordnung, Ausarbeitung, Ausdrucke gehandelt, wieder die besondern Gattungen der Reden und Gedichte vorgenommen und die einer jeden eigne Regel angegeben werden ... Man erkenne hieraus, daß ich nicht zu viel gesaget habe, da ich behauptete, daß diese Wissenschaft zu Heidelberg auf der Hohen Schule noch nicht gelehret wird. Sollte ... auch Herr Professor [Johannes Carl Casimir] Wund zufälliger weise ästhetische Anmerkungen beybringen, so thut er es doch nicht in dem ganzen Umfange. Er ließt den Batteux [Charles B. (1713-1780)] vor und es bleibt zuletzt doch noch wahr, daß diese Professur in Betracht des Katholischen Theiles neu wäre ... “ (aus: GLA Abt. 205, Fasz. 204). 
Qu UAH PA 1482. - GLA Abt. 205, Fasz. 204; Toepke 4 (1903) S. 232 unter Toller, Laurentius. • Auskunft: Kath. Pfarramt Bretten (Taufbuch); Stadtarchiv Mainz (Sterberegister).

$W$ Beleuchtung der Schrift: Werden die Jesuiten auch in Teutschland wieder aufkommen? Bamberg, Würzburg 1815. - Zeugnisse aus allen Jahrhunderten bis auf d[as] J[ahr] 1815 für die Gewalt der Kirche und ihres Oberhauptes ... Frankfurt/M. 1816. Historisch-Kritische Versuche zur Beleuchtung der Reformation Luthers und ihrer Geschichte. Von e. Wahrheitsfreunde [d.i. J. L. D.]. Luthers kath. Monument oder kritische Betrachtung verschiedener Urtheile kath. oder unter Katholiken gerechneter Schriftsteller über Luther und seine Reformation. Frankfurt/M. 1817. - Siehe auch WBIS.

HG Der Jesuitenfeind. Pendant zur Zeitschrift: Die Jesuiten. Für alle Jene, die noch auf das Sprüchlein achten: Audiatur et altera pars, zu deutsch: Höre man doch auch den andern Theil. Hrsg. von dem Verf. der Zeugnisse für die Gewalt der Kirche und ihres Oberhauptes. Frankfurt/M. 1817.

L WBIS; Deutsche Biographie, s. https://www. deutsche-biographie.de/pnd132398818.html [14.03. 2018].

\section{Domaszewski, Alfred von}

1887-1924 Phil. Fak.

Alte Geschichte

* 3o. Okt. 1856 Temeswar (Ungarn; heute: Timişoara, Rumänien)

$\dagger \quad$ 25. März 1927 München

kath.

V Viktor von D. (1821-1882) Offizier, zuletzt Major, Ingenieur, s. Wettel (1931) S. 6-8

M Pauline geb. Preyss, T von Medizinalrat Dr. Georg P. (1810-1884), s. Grillparzer, Franz: Sämtliche Werke - Ausgewählte Briefe, Gespräche, Berichte. Bd. 2. Darmstadt 1960. S. 233-235.

( ) unverheiratet.
Lb U Wien: Seit WS 1875/76 Studium der Klassischen Philologie, Alten Geschichte, Archäologie; 12. Mai 1882 Dr. phil.; 23. März 1885 Habilitation. • In dieser Zeit:

Wien: 1879 Prüfung für das höhere Lehramt; 18801882 Probekandidat, 1883-1884 Lehrer am akad. Gymnasium; u.a. 1882 im Auftrag der Königl. Akademie der Wissenschaften Berlin Reise nach Kleinasien; 23. Nov. 1884-31. Juli 1887 Custosadjunkt an der Antikensammlung des Kunsthistor. Museums.

UH: 6. April 1887 Ern. zum a. o. Prof. am Archäolog. Inst., WS 1889/90-WS 1893/94 am „Archäolog. Inst. einschl. der Abt. für Alte Geschichte (und für Neuere Kunst)“; seit 1. Sept. 1887 jährl. Besoldung von 2700.- Mark und Wohnungsgeldzuschuß; seit 19. Febr. 1891 o. Prof.; SS 1894 erstmals im Adressbuch der UH als Vorstand der Abt. für Alte Geschichte genannt; u. a. 1895, 1897, 1898 Studienreisen zus. mit (siehe) Rudolph Brünnow nach Syrien, Jordanien und in den Libanon (Photos von diesen Reisen, s. Archaeological Archives der Princeton U online); 1901 Ruf an U München abgelehnt; SS 1918 aus Krankheitsgründen von U beurlaubt; 31. März 1924 Emeritierung.

Hamburg-Eppendorf: 1926-1927 Aufenthalt wegen seines Gichtleidens im Neuen Allg. Krankenhaus.

München: Jan. 1927 Übersiedlung.

1900/o1 Dekan der Phil. Fak. der UH

1902 Hofrat; 1906 Geh. Hofrat

E Korr. Mitglied: 1883 Dt. Archäolog. Inst. (1889 o. Mitglied), 1885 Zentralkommission für Erforschung und Erhaltung der Kunst- und historischen Denkmale; Mitglied der Akademie der Wissenschaften: 1920 H, 1923 Wien. - Dr. iur. h.c. • 1889 Ritterkreuz I. Klasse, 1913 Ritterkreuz mit Eichenlaub des Ordens vom Zähringer Löwen; 1890 Offizierskreuz der Italienischen Krone. 
Q $u$ UAH PA 3583; RA 5225, 6112, 6394, 6847. • Briefe: UBH; Universitäts- und Landesbibliothek ... Halle/S. (Signatur: Yi 20 I D 1043-1083).

$W$ Die Rangordnung des römischen Heeres. Bonn 1908. 3. Aufl. Köln 1981. Abhandlungen zur römischen Religion. Leipzig 1909. Hildesheim 1977. • Geschichte der römischen Kaiser. 2 Bde. Leipzig 1909. 3. Aufl. 1920.

MHG Rudolph Brünnow und A. von D.: Die Provincia Arabia. 3 Bde. Straßburg 1904-1909.

L Kürschner (1926) Sp. 314. • Nachruf in: Almanach der Akademie der Wissenschaften Wien (1927) S. 279-308 (mit Werkverz.). - Wettel, Franz: A. von D. Ein Erinnerungsblatt zum 75 -jährigen Gedächtnistage seiner Geburt. Temeswar 1931. (Deutsch-Banater Volksbücher. 56.) - Hofmann, Harald: A. von D. in: Jahresbericht über die Fortschritte der klassischen Altertumswissenschaft (1935) S. 115-143. - Schmitthenner, Walter: A. von D. in: Ruperto Carola 8. Jg., Bd. 19 (1956) S. 116 f. • Weber (1987) S. 106 f.; Geschichte Histor. Seminar UH (1992) S. 221f.; Jansen (1992) S. 408 (Register); Ders. (1992a) S. 164 (Register); Wennemuth (1994) S. 633 (Register); Asketischer Protestantismus (2005) S. 301 (Register); Kriegstagebuch K. Hampe (2007) S. 953f. (Register); WBIS; Autoren der Bunsenbibliothek (2009 online). Deutsche Biographie, s. https://www.deutsche-biographie. de/gnd116175516.html [06.11.2017].

$P$ Bildarchiv UAH; graph. Slg. UBH; Ruperto Carola.

\section{Dresel, Gustav Ernst Gerhard}

1915-1926 Med. Fak.

Hygiene, Bakteriologie

* 03. Sept. 1885 Buckau (heute: Stadtteil von Magdeburg)

$\dagger \quad$ 25. Sept. 1964 Freiburg/Br.

ev.
V Carl Edmund Otto D. (1851-1887) Kaufmann

M Charlotte Wilhelmine Jenny geb. Osten $\left({ }^{*} 1861\right.$ $\dagger$ nach 1923)

๑ 3. Nov. 1911 Ilse geb. Koenenkamp (1889-1982) $\mathrm{K}$ keine.

Lb Seit SS 1905 Studium an U Straßburg, anschl. Berlin, Kiel, Bonn, SS 1908-WS 1909/10 H.

UH: 2O. Juni 1910 Staatsexamen; Juli 1910-Juli 1911 Praktikant an Innerer Klinik und am Hygien. Inst.; 12. Juli 1910 Dr. med.; 1911-1926 Assistent am Hygien. Inst.; 1910-1912 Studium der Staats- und Kameralwiss.; 3. Juli 1913 Dr. phil.; 8. Juli 1915 Habilitation für Hygiene; seit 29. März 1921 a.o. Prof. (1921/22 gewähltes Mitglied des Engeren Senats); seit Ende April 1924 (nach dem Tod von Hermann Kossel) kommissar. Direktor des Hygiene-Inst. sowie des Untersuchungsamts für ansteckende Krankheiten, das dem Hygiene-Inst. angegliedert ist; 1925 Rufe an U abgelehnt: Gießen, Dresden, Königsberg (Preußen). • In dieser Zeit:

H: Aug. 1914-Sept. 1918 Kriegsdienst als Leiter des Medizinaluntersuchungsamts für Infektionskrankheiten.

U Greifswald: Seit 1. Juni 1926 o. Prof. und Direktor des Hygien. Inst.; 1933 Ruf an U Göttingen abgelehnt.

U Leipzig: Seit 1. Mai 1934 o. Prof.; 1936-1945 Beauftragter des Sicherheitsdienstes für Med. Fak. (seit 1936 Mitglied der SS); 1945 Verhaftung durch amerik. Militärregierung; 1945-1947 Berufsverbot (als Mitläufer eingestuft).

Bremen: Seit Jan. 1948 wiss. Berater in e. chemischen Fabrik; seit April 1949 Betriebsarzt und Personalchef in e. Speditions-Firma; 1950-1956 Inhaber e. bakteriologisch-serologischen Untersuchungs-Inst.

UH: 27. Juni 1958 Verleihung der Rechtsstellung e. emeritierten o. Prof.

21. Mai 1921: Mitbegründer der Mensa academica H; 1922 Initiator des U-Sportplatzes, Jahnstraße in $\mathrm{H}$ 
Siehe auch Anhang Sporteinrichtungen an UH 1910-1933 und ihre Mitglieder

Qu UAH PA 883, 3593 f. • GLA Abt. 235, Fasz. 1903.

$W$ Soziale Fürsorge, eine Übersicht für Studierende und Sozialtätige. Berlin 1918. 2. Aufl. 1922. • Lehrbuch der Hygiene. Berlin 1928. - Grundriß der Gesundheitslehre für Volksschullehrer. Osterwieck/Harz 1932. Epidemiologie des Typhus abdominalis in: Mikrobiologie, Immunbiologie und Grenzgebiete 1 (1933). - Siehe Lexikon Greifswalder Hochschullehrer (2004) S. 48.

L Handels-Hochschule Mannheim 1907-1932 (1932) S. 29; Fischer $1\left({ }^{3} 1962\right)$ S. 330. Gara, P. F. de: In memoriam E. G.D. in: Med. Klinik 60 (1965) S. 775. - Kürschner (1966) S. 419-420; WBIS; Chronik Ärzte H (1985) S. 125; Jansen (1992) S. 408 (Register); Ders. (1992a) S. 164 (Register); Lexikon Greifswalder Hochschullehrer (2004) S. 48; Professorenkatalog Leipzig online; Sächsische Biografie online.

\section{$P$ Bildarchiv UAH; Chronik Ärzte $\mathrm{H}$.}

\section{Driesch, Hans Adolf Eduard}

1909-1912 Nat.-Math. Fak.

1912-1916 Phil. Fak.

1916-1920 (Honorar-Prof.) Phil. Fak.

1918-1920 Phil. Fak.

Naturphilosophie, Zoologie, Parapsychologie,

Psychologie; 1918-1920 Philosophie

* 28. Okt. 1867 Kreuznach (heute: Bad K.)

$\dagger$ 16. April 1941 Leipzig

ev.

V Paul Friedrich D. (1830-1869) Kaufmann (Gold- und Silberwaren)

M Josephine geb. Raudenkolb (1824-1887) T von Joseph R. (kath.), Cellist in der Hofkapelle Schwerin
(0) 23. Mai 1899 Margaret(h)e geb. Reifferscheidt (1874-1946) Schriftstellerin, s. NDB 4 (1959) S. 125 f.; T von Franz R., Inhaber e. Bankgeschäfts und von Reisebüros

K 1 T, 1 S: Curt D. (1904-1988) Komponist, Musikschriftsteller, s. WBIS, Bieber (2014) S. 370 und Anm. 410.

Lb Seit SS 1886 Studium der Naturwiss., Zoologie an U Freiburg/Br., seit 1887 Jena, anschl. München, Jena; Juli 1889 Dr. phil. an U Jena.

Studienreisen u.a.: Aug. 1889-189o Großbritannien, Ceylon, Indien, Schweiz, 1893-1894 Asien.

Privat-Gelehrter: Herbst 1891-1900 (mit wenigen Unterbrechungen) an Zoolog. Station in Neapel, seit 1900 in $\mathrm{H}$.

U of Aberdeen (Schottland): 1907-1908 GiffordLecturer.

UH: 29. Okt. 1909 Habilitation für Naturphilosophie an Nat.-Math. Fak.; seit 3. Okt. 1911 nichtetatm. a. o. Prof.; 25. Jan. 1912 Übertritt in Phil. Fak.; SS 1915 Vorlesung über „Logik“ in Vertretung des erkrankten Wilhelm Windelband mit e. Vergütung von 60o.- Mark; 30. Okt. 1915 Lehrauftrag für e. 4-stündige Vorlesung im WS 1915/16 über "Logik der empirischen Wirklichkeit" und Übertragung der vertretungsweisen Leitung des Phil. Seminars für verstorbenen Windelband; seit 3. Febr. 1916 o. Honorar-Prof.; 1918 Ruf an U Dorpat abgelehnt; seit 1. Okt. 1918 etatm. a. o. Prof. für Philosophie unter Belassung des Titels eines o. Honorar-Prof. als Nachf. von Emil Lask.

U Köln: Seit SS 1920 o. Prof.

U Leipzig: Febr. 1921-Okt. 1933 (Emeritierung aufgrund des Gesetzes zur „Wiederherstellung des Berufsbeamtentums“) o. Prof.; 1922-1923 GastProf. an U in Peking, anschl. Vortragsreisen in Japan und den USA; 1926-1928 Gast-Prof. an U of Wisconsin in Madison, anschl. Universidad de Buenos Aires.

Driesch gilt als der Begründer der Klon-Forschung 
1947: Gründung der Hans-Driesch-Gesellschaft für Philosophie und Parapsychologie in Regensburg

2013: Erstmals Verleihung des Hans-Driesch-Wissenschaftspreises durch die Universität Witten/ Herdecke; „der jährlich zu vergebende und mit 500o.- Euro dotierte Preis will mutige und innovative Wissenschaftler fördern" (zitiert von der Homepage der U Witten/Herdecke).

E Mitglied: 1904 Dt. Akademie der Naturforscher Leopoldina Halle/S., Kaiserl. Akademie der Wissenschaften Krakau, 1911 Linnean Society of London, 1917 Akademie der Wissenschaften H; Ehrenmitglied der Phil. Gesellschaft Utrecht sowie Budapest; 1913 Mitglied, 1926-1928 Präsident der Society for Psychical Research London. 1910 Dr. iur. h.c. Aberdeen; 1923 Dr. med. h.c. Hamburg; 1923 Dr. rer. nat. h. c. Nanking.

Qu UAH PA 1487; RA 6859. GLA Abt. 235, Fasz. 1905. - Briefe: UBH; Universitätsbibliothek Leipzig. $\bullet$ Siehe auch Archiv der Dt. Akademie der Naturforscher Leopoldina Halle/S. - Lebenserinnerungen ... München, Basel 1951. (Autobiogr.)

$W$ Die Biologie als selbständige Grundwissenschaft und das System der Biologie. Leipzig 1893. 2. Aufl. 1911. - Analytische Theorie der organischen Entwicklung. Leipzig 1894. • Der Vitalismus als Geschichte und als Lehre. Leipzig 1905. 3. Aufl. 2012. Philosophie des Organischen. Leipzig 1908. 4. Aufl. 1928. Neuaufl. 2009. - Ordnungslehre. Jena 1912. 3. Aufl. 1923. Wirklichkeitslehre. Leipzig 1917. 3. Aufl. 1930. Parapsychologie. München 1932. 4. Aufl. 1984. Reprint 2015. Bibliographie in: Miller, Thomas: Konstruktion und Begründung ... (1991).

MHG 1934-1936 Character and Personality - Int. Quarterly of Psychodiagnostics and Allied Studies.

L NDB 4 (1959) S. 125f. - Mocek, Reinhard: Wilhelm Roux. H.D. Jena 1974 (mit Werkverz.). • Müller, Werner A.: Von der Seele zur Information. H.D., Jakob von Uexküll ... und die Entwicklung der gegenwärtigen Biologie im Spannungsfeld von
Mechanismus und Vitalismus in: Semper apertus 3 (1985) S. 299-325. - Miller, Thomas: Konstruktion und Begründung. Zur Struktur und Relevanz der Philosophie H.D.s. Hildesheim 1991. Jansen (1992) S. 408 (Register). - Seng, Thomas: Weltanschauung als verlegerische Aufgabe: der Otto Reichl Verlag 1909-1954. Berlin 1993. S. 573 (Register). Mocek, Reinhard: Die werdende Form. Eine Geschichte der kausalen Morphologie. Marburg 1998. - BBKL XIX (2001) Sp. 181-195; Tilitzki 1 (2002) S. 567 f. u. ö.; Peiffer (2004) S. 1136 f. (Register). Leben und Geschichte: Anthropologische und ethnologische Diskurse der Zwischenkriegszeit. Hrsg. von Thomas Keller ... München 2006. Sächsische Lebensbilder. Hrsg. von Gerald Wiemers. Bd. 6, Teilbd. 1. Stuttgart 2009. S. 167-186. Lembert, Alexandra: Deutsche Wissenschaft im int. Kontext: Der Leipziger Philosoph H.D. und Großbritannien in: Anglosachsen: Leipzig und die englischsprachige Kultur. Hrsg. von Stefan Welz, Fabian Dellemann. Frankfurt/M. 2010. S. 99-116. Bieber, Hans-Joachim: SS und Samurai: Deutschjapanische Kulturbeziehungen 1933-1945. München 2014. S. 1252 (Register). - Elstner, Michael: Jenseits der Entwicklungsphysiologie - Curt Herbst im Spiegel seiner Korrespondenz mit H.D. Ulm 2014. Diss. Online, s. urn:nbn:de:bsz:289vts-87950 (abgerufen am 7. März 2018). - Professorenkatalog Leipzig online.

$P$ Bildarchiv UAH; NDB.

\section{Du Bois-Reymond, David Paul Gustave}

1865-187o Phil. Fak.

Mathematik

* O2. Dez. 1831 Berlin

$\dagger \quad$ 07. April 1889 Freiburg/Br.

ㅁ Berlin-Schöneberg ref.

V Felix-Henri Du B. (1782-1864) Reg.-Rat, Abt.Leiter im preußischen Außenministerium, Sprachwissenschaftler, s. NDB 4 (1959) S. 146, WBIS (hier auch weitere $V w$ ) 
M Wilhelmine (Minette) geb. Henry (1789-1865) Bildhauerin, s. NDB 4, S. $146^{*}$; Enkelin von Daniel Nikolaus Chodowiecki (1726-1801) Kupferstecher, Maler, s. Hinrichs, Ernst, Zer nack, Klaus: D. C. ... Kupferstecher, Illustrator, Kaufmann. Tübingen 1997. - Netzwerke des Wissens. Das intellektuelle Berlin um 1800. Hrsg. von Anne Baillot. Berlin 2011.

๑ 23. Sept. 1876 Henriette geb. Massute (18421909)

K $1 \mathrm{~S}$

Vw Bruder: Emil Heinrich Du B.-R. (1818-1896), u.a. seit 1855 o. Prof. für Physiologie Berlin, s. NDB 4 (1959) S. 146-149, WBIS, Hoche (1969) S. 73 f.; Ruff, Peter: E. du B.-R. Leipzig 1997; Beneke, Klaus: E. H. Du B.-R. in: Beiträge zur Geschichte der Kolloidwissenschaften. Mitteilungen ... Nehmten 1999. VIII. S. 92-105; Peiffer (2004) S. 1137 (Register); Der IgnorabimusStreit. Hrsg. von Kurt Bayertz ... Hamburg 2012. S. 1-26 u. ö. - Briefe in UBH; Ernst Wilhelm von Brücke. Briefe an E. Du B.-R. Hrsg. ... von Hans Brücke ... 1. T. Graz 1978; E. Du B.R. ... Anton Dohrn (1840-1909): Briefwechsel. Hrsg. von Christiane Groeben ... Berlin 1985.

Vw Vetter: Alfred E. Hoche (1865-1943), u.a. 1902-1933 Prof. für Psychiatrie und Neurologie Freiburg/Br., s. Müller-Seidel, Walter: A.E.H. - Lebensgeschichte im Spannungsfeld von Psychiatrie, Strafrecht und Literatur. München 1999. • Neffe: Claude Du B.-R. (18551925), u.a. seit 1891 Privat-Dozent für Augenheilkunde Berlin, 1907-1919 Lehrer für Physiologie und propädeutische Medizin an Dt. Medizinschule für Chinesen in Shanghai, s. WBIS; Reisen in chinesischer Geschichte und Gegenwart. Erfahrungen, Berichte, Zeugnisse. Hrsg. von Mechthild Leutner ... Wiesbaden 2008. S. 135-140 u. ö.

Lb Vor WS 1852/53 Studium zunächst der Medizin an U Berlin und WS 1852/53-SS 1853 Zürich, dann Studium der Mathematik an U Königsberg (Preußen), anschl. Berlin.

Berlin: 1859 Dr. phil. an U; 1860 Examen für höheres Lehramt; 1861-1865 Lehrer u.a. am FriedrichWerderschen Gymnasium.
UH: 3. Mai 1865 Habilitation; seit 16. Sept. 1868 a. o. Prof.

U Freiburg/Br.: 31. Dez. 1869 (Ern.) zum SS 1870 o. Prof.

U Tübingen: Seit 20. Jan. 1874 o. Prof.

TH Berlin-Charlottenburg: Seit WS 1884/85 o. Prof. für Höhere Mathematik an Abt. V für Allg. Wissenschaften, insbesondere für Mathematik und Naturwissenschaften.

E Mitglied: 1874 Akademie der Wissenschaften München, 1883 Dt. Akademie der Naturforscher Leopoldina Halle/S.

Qu UAH PA 3046; Fak.-Akte H-IV-102/64. • Matrikel Zürich (1999) Nr. 1694. - Briefe von Karl Weierstrass an P. du B.-R. Hrsg. von Gösta MittagLeffler in: Acta mathematica 39 (1923) S. 199-225. • Dokumente einer Freundschaft. Briefwechsel zwischen Hermann von Helmholtz und E. du B.-R. 1846-1894. Bearb. von ... Christa Kirsten ... Berlin 1986. Nachlaß: Staatsbibliothek zu Berlin. • Siehe auch Archiv der Dt. Akademie der Naturforscher Leopoldina Halle/S. • Auskunft: Universitätsarchiv TU Berlin (Codex Professorum).

$W$ Eine neue Theorie der Convergenz und Divergenz von Reihen mit positiven Gliedern in: Journal für die reine und angewandte Mathematik 76 (1873) S. 61-91; Über lineare partielle Differentialgleichungen 2. Ordnung in: ebd. 104 (1889) S. 241301. Die allgemeine Functionentheorie. Tübingen 1882. Über die Grundlagen der Erkenntnis in den exacten Wissenschaften. Tübingen 1890.

$L$ Hardy, Godfrey H.: Orders of infinity. The ,infinitärcalcül“ of P. du B.-R. Cambridge (New York) 1910. Nachdr. 2015. - NDB 4 (1959) S. 148 (mit Werkverz.); Homo Heidelbergensis mathematicus online. Sonar, Thomas: 3000 Jahre Analysis: Geschichte, Kulturen, Menschen. Berlin 2011. S. 575 f.

$P$ Über die Grundlagen der Erkenntnis ... (1890). 


\section{Duchek, Adalbert}

1856-1858 Med. Fak.

Allg. und Spezielle Pathologie und Therapie, Phy-

sikal. Diagnostik

* o1. Dez. 1824 Prag

$\dagger$ 02. März 1882 Wien

ㅁ Weidling (heute: Ortsteil von Klosterneuburg) kath.

V N.N., Arzt

M N.N.

$\infty$ Marie geb. von Riedel $\left({ }^{*} 1835 \dagger\right.$ nach 1900$) \mathrm{T}$ von Joseph Gottfried Ritter von R. (1803-1870) seit 1837 Primararzt an Irrenanstalt Prag, seit 1851 Direktor der Irrenheilanstalt Wien, s. Biogr. Lexikon des Kaiserthums Oesterreich (1874) Bd. 26, S. 95-98 (online); Czeike, Felix: Historisches Lexikon Wien. Wien 1995. Bd. 4.

$\mathrm{K}$ unbekannt.

Lb Prag: Seit WS 1843/44 Studium an U; 9. Aug. 1848 Dr. med. an U; seit 9. Juni 1848 Sekundar-Arzt am Allg. Krankenhaus; seit 1. Okt. 1851 Assistent an II. Med. U-Klinik.

U Lemberg (heute: Lwiw, Ukraine): Seit 8. Sept. 1855 o. Prof. für Spezielle Pathologie, Therapie und Klinik.

UH: 5. Juli 1856 Ern. zum (I.) o. Prof. für Pathologie und Therapie (II. Lehrer: Theodor von Dusch) und Direktor des Akad. Krankenhauses (ehem. I. und II. Med. U-Klinik) als Nachf. von Karl Ewald Hasse (und Friedrich Puchelt); D. lehnt e. „Vereinbarung [mit von Dusch] über die zu treffende Unterrichts- und Geschäftstheilung ab" (aus: UAH PA 1493); 22. Nov. 1856 Ministerium des Innern verfügt daraufhin: D. liest über Allg. und Spezielle Pathologie und Therapie sowie (auf eigenen Wunsch) über Physikal. Diagnostik (siehe auch $Z) ; 1856$ mit der Übernahme des Direktoriums der I. Med. U-Klinik war bislang auch die Übertragung der Leitung der Poliklinik verbunden; so übernimmt D. automatisch auch die PoliklinikLeitung; in e. Schreiben des Ministeriums des Innern vom 30. Dez. 1856 wird ihm daraufhin nach- drücklich mitgeteilt, daß die Vergabe dieses Amtes nur dem Staat obliegt; das Ministerium bzw. Großherzog Friedrich I. setzen als neuen Direktor und Nachf. von Hasse am 27. Dez. 1856 Theodor von Dusch ein, s. hierzu UAH RA 6280; 23. März 1858 Niederlegung seiner Ämter.

Wien: $1858-1871$ o. Prof. an Med.-Chirurg. Josephs-Academie, e. Bildungsanstalt für Feldärzte im Rang e. Militärakademie.

U Wien: 1871-1882 o. Prof. für Klinische Medizin und Direktor der I. Med. U-Klinik im Allg. Krankenhaus.

$Z$ In dem o.g. Schreiben des Ministeriums vom 22. Nov. 1856 heißt es zum Konflikt Duchek/von Dusch weiter: „Hiebei veranlasst man den engern Senat, den beiden für die pathologischen Fächern ernannten Lehrern ein kollegialisches, einmüthiges, sich gegenseitig unterstützendes und förderndes Zusammenwirken zu empfehlen, indem nur auf diesem Wege die ihnen gemeinschaftliche Aufgabe in der wünschenswerthen, für die Universität ersprießlichen Weise gelößt werden kann" (aus: PA 1493).

1873 Hofrat

Qu UAH PA 1488, PA 1493 (Theodor von Dusch); RA 6804, 6280. - GLA Abt. 205, Fasz. 207. - Mitschrift Julius Arnolds von den Vorlesungen A.D.s im SS 1857, siehe UAH Acc. 30/12.

$W$ Handbuch der speciellen Pathologie und Therapie. 3 Lfg. Erlangen 1862-1873. • Scorbut (Scharbock), scorbutus in: Handbuch der allg. und speciellen Chirurgie (1876) 1, 2. Abt. A.

MHG 1861-1870 Wiener med. Jahrbücher.

$L$ Pagel (1901) Sp. 419; Stübler (1926) S. 313; Chronik Ärzte H (1985) S. 125; WBIS. - Czeike, Felix: Historisches Lexikon Wien. Wien 1995. Bd. 2. S. 105f. - Tragl, Karl Heinz: Chronik der Wiener Krankenanstalten. Wien 2007. S. 63-66 u. ̈. • Deutsche Biographie, s. https://www.deutsche-bio graphie.de/gnd11765731X.html [06.11. 2017]. 
P Bildarchiv UAH; Chronik Ärzte H. - Gedenkstatue von Josef Grünhut, Universitätsring 1, Wien (Universitätsarkaden).

\section{Dümgé, Carl George}

1805-1814 Phil. Fak.

Vaterländische Geschichte

* 23. Mai 1772 Heidelberg

$\dagger \quad$ 27. Febr. 1845 Karlsruhe kath.

V Georg D. (1721-1796) Advokat, Oberamts-Registrator, s. UAH RA 8068

M Maria Anna geb. Redinger (1735-1804)

( 27. Juli 1815 Maria Anna geb. Fischer (17681822)

๑ 10. Aug. 1841 Caroline geb. Resch $\left({ }^{*} 1806\right)$

$\mathrm{K}$ vermutlich keine.

Lb Seit WS 1788/89 Studium an UH; seit 1794 Privatier.

UH: 21. Sept. 1805 Habilitation; seit 17. Juni 1811 außerdem Bibliothekar an UB; seit 19. Dez. 1811 a. o. Prof.

GLA Karlsruhe: Seit 27. Jan. 1814 Assessor; vor 1819 Ablehnung mehrerer Gesuche D's um Rückversetzung nach H; 1819 Ern. zum Archivrat.

H: Seit Febr. 1819 vom GLA beurlaubt zur Mitarbeit und -herausgabe des Archivs der Gesellschaft für ältere dt. Geschichtskunde (Redakteur); 11. April 1822 Zurückberufung an GLA Karlsruhe.

GLA Karlsruhe: 2. Juli 1822-19. Dez. 1844 (Ruhestand) Archivrat (nach 1822 zunehmende Schwerhörigkeit).

E 1820 Mitglied der Akademie der Wissenschaften München; 1837 Korr. Mitglied des Histor. Vereins für das Großherzogtum Hessen. 1810 Dr. phil. h.c. UH.
Qu UAH PA 1489; RA 5896, 6065; Fak.-Akte H-IV-102/5. Toepke 4 (1903) S. IV-V. • GLA Abt. 76, Fasz. $1715-1717$.

W Symbolik germanischer Völker in einigen Rechtsgewohnheiten. Heidelberg 1812. - Siehe auch Klein (1992) S. 232-256, 261-263.

Bearb. Regesta Badensia. Urkunden des Großherzoglich Badischen General-Landes-Archives von den ältesten Zeiten bis zum Schlusse des zwölften Jahrhunderts ... Karlsruhe 1836.

HG Allgemeines diplomatisches Archiv für die neueste Zeitgeschichte enthaltend e. vollständige Sammlung aller bekannt gewordenen und ferner bekannt werdenden Actenstücke seit Entstehen des gegenwärtigen europ. Staatenbundes wider Frankreichs Uebermacht. Heidelberg 1814.

MHG 1819-1822 Archiv der Gesellschaft für ältere dt. Geschichtskunde. 4 Bde. Nachdr. Hannover 1977.

L ADB 5 (1877) S. 459; WBIS. - Klein, Michael: Aus den Anfängen der "Monumenta Germaniae Historica“: K. G.D. ... in Berichten und Selbstzeugnissen in: ZGORh 140. Jg. (1992) S. 221-265. • Fuhrmann (1996) S. 205 (Register). - Schwarzmaier, Hansmartin: Die Anfänge der kritischen Geschichtswissenschaft am Oberrhein: C.G.D. und Franz Joseph Mone in: Das Mittelalterbild des 19. Jhdts. am Oberrhein. Hrsg. von Hansmartin Schwarzmaier u. a. Stuttgart 2004. S. 31-45. Wolgast (2010) S. 165-168; Riecke (2016) S. 8.

\section{Dümge, Karl Georg}

siehe Dümgé, Carl George 


\section{Duhn, Friedrich Carl von}

1880-1919 Phil. Fak. 1919-1930 (Honorar-Prof.) Phil. Fak. Archäologie

* 17. April 1851 Lübeck

$\dagger$ 05. Febr. 1930 Heidelberg ev.

V Dr. iur. Carl Alexander von D. (1815-1904) Oberlandesgerichts-Rat

M Anna Margarethe geb. Heineken (1821-1902)

$\infty$ 18. Sept. 1880 Florence geb. Wolffson (18601881)

$\varnothing$ 7. Sept. 1882 Marie Babette Josefine Anna geb. von Böckmann (1857-1928)

K 3 S (davon $1 S \times$ 1914), 2 T: Clara von D. (1886-1973) Ehefrau von Fritz Burger $\left({ }^{*} 1877\right.$ X 1916) Maler, seit 1906 Privat-Dozent, seit 1915 a. o. Prof. für Kunstgeschichte U München, s. Hauck, Rolf M.: F. B. ... Kunsthistoriker und Wegbereiter der Moderne am Beginn des 20. Jahrhunderts. Diss. München 2005; Filippi, Elena: F. B. ... Arte come critica - critica come arte; tendenze e ragioni della disciplina storico-artistica agli inizi del XX secolo. Rom 2016; Seele, Heide: Auch er träumte vom Gesamtkunstwerk: Das Kurpfälzische Museum Heidelberg ehrte den vor 100 Jahren gestorbenen F. B. ... in: RNZ vom 18./19. Juni 2016, S. 15. Maria Elisabeth von D. (1896-1966) Ehefrau von Dr. phil. (U Münster; 1940 Ausbürgerung und Aberkennung des Dr.-Titels) Friedrich (Fritz) Jakob Hepner (1890-1970), u. a. seit 1925 Tätigkeit im Reichsaußenministerium, dann Tätigkeit im Reichsarchiv Berlin, zugleich Inhaber e. Fotofirma, 1934 Emigration nach England, 1949 als Prof. für Kommunikationsgeschichte am Anthropolog. Inst. London erwähnt, s. Die Rückkehr der dt. Geschichtswissenschaft in die „Ökumene der Historiker". Hrsg. von Ulrich Pfeil. München 2008. S. 235; Gertzen, Otto: Gedenkblatt für F. J.H. in: flurgespräche - Universität Münster, s. http://www.flurgespraeche.de/wp-content/ uploads/2017/06/Gedenkblatt_Hepner-Fritz. pdf (Ausdruck im UAH); s. auch Kriegstagebuch K. Hampe (2007) S. 949 und 954 (Register).
Vw Enkelin: Dr. phil. Lili Fehrle-Burger geb. Burger (1907-1991) Literatur-, Kunst- und Kulturhistorikerin, 1937 Dozentin an der Frauen-U Wellesley College (Massachusetts), 1939 Dozentin am Heidelberg College, 1967 Mitbegründerin und 1976-1991 Erste Vorsitzende der Heidelberger Goethe-Gesellschaft, s. Nachlass UBH (Heid. Hs. 4075); Seele, Heide: Urgestein des Heidelberger Kulturlebens in: RNZ vom 13. Febr. 2007, Ruuskanen (2008) S. 158; T von (siehe oben Eintrag unter $K$ [inder]) Fritz Burger (1877-1916) und Ehefrau von Dr. Hans Fehrle (1914-1996) 1949-1980 stellvertr. Leiter des G. Braun Verlags Karlsruhe, Sohn von: (siehe) Eugen F.

Lb U Bonn: Seit 1869 Studium; 6. Aug. 1874 Dr. phil.

1875-1879 Studienreisen nach Italien, Sizilien, Griechenland, u. a. $1875-1876$ als Stipendiat am Dt. Archäolog. Inst. in Rom.

\section{U Göttingen: 28. Juni 1879 Habilitation.}

UH: 7. Febr. 188o Ern., seit 6. April 1880 o. Prof. und Direktor des Archäolog. Inst. als Nachf. von Carl Bernhard Stark mit e. Jahresbesoldung von 2500.- Mark, s. UAH RA 6828; Studienreisen u. a.: März-April 1890 Troja, Febr.-Mai 1896 Sizilien und Nordafrika; SS 1919 Ruhestand und gleichzeitig Ern. zum Honorar-Prof.; WS 1929/30 letzte Vorlesung.

1911/12 Prorektor der UH; 1886/87, 1895/96, 1915/16 Dekan der Phil. Fak. der UH

D. erweitert durch Neuerwerbungen die Heidelberger Archäologische Sammlung antiker Kleinkunst (heute: Antikenmuseum und Abguss-Sammlung im Neuen Kollegiengebäude, Marstallhof 4) zu einer der bedeutendsten Lehrsammlungen an deutschen Universitäten. Er erschließt 1887 erstmals die Abguss-Sammlung mit fast 500 Exponaten durch einen Katalog, der bis 1913 in sechs Auflagen erscheint.

U.a. Mitarbeiter bei dem vom Architekten und Baurat Louis Jacobi (1836-1910) geleiteten und von Kaiser Wilhelm II. geförderten Wiederaufbau der 
Saalburg, e. ehemaligen Kastells des römischen Limes bei Bad Homburg vor der Höhe. 1912: Wilhelm II. besucht - in Anerkennung der archäolog. Verdienste - von D. in seinem Haus in der Werrgasse 7 in Heidelberg.

Sept. 1914: F. von D. unterschreibt neben 92 anderen Wissenschaftlern, Schriftstellern und Künstlern das sog. „Manifest der 93“, e. Aufruf vor allem gegen den Vorwurf der deutschen Kriegsschuld und der Kriegsgreuel in Belgien sowie für die Identität von deutscher Kultur und deutschem Militarismus.

1902 Hofrat; 1905 Geh. Hofrat; 1917 Geh. Rat II. Klasse

Siehe auch Anhang Sporteinrichtungen an $U H$ 1910-1933 und ihre Mitglieder

E Mitglied: 1907 Kaiserl. Russische Archäolog. Gesellschaft, 1908 Reale Accademia dei Lincei Rom, 1909 Akademie der Wissenschaften H. $\bullet 1889$ Ritter I. Klasse des Ordens vom Zähringer Löwen; 1890 Offizierskreuz des Ordens der Hl. Mauritius und Lazarus; 1910 Griechischer Erlöserorden.

Qu UAH PA 1491; RA 5942, 6392, 6394f., 6828. • GLA Abt. 235, Fasz. 1907. - Briefe: UBH. - Nachlaß: Dt. Archäologisches Institut Berlin. - Auskunft: Universitätsarchiv Göttingen. - Mitteilungen: Frau Dr. Lili Fehrle-Burger ( $\dagger$ ), Heidelberg; Herr Dr. Nicolas Zenzen, Universität Heidelberg.

W Antike Bildwerke in Rom. Leipzig 1881-1882. • Pompeji, eine hellenistische Stadt in Italien. Leipzig 1906. 2. Aufl. 1910. - Italische Gräberkunde. 2 Bde. Heidelberg 1924-1939.

$L$ NDB 4 (1959) S. 180; Catalogus prof. Gottingensium (1962) S. 142. F. von D. in: Zwischen Olymp und Acheron. Hrsg. von Editha Wolf-Crome. Freiburg/Br. u. a. 1971. - Hölscher, Tonio: F. von D. in: Archäologenbildnisse (1988) S. 100 f.; Jansen (1992) S. 408 (Register); Ders. (1992a) S. 164 (Register); WBIS; Badische Biographien N.F. IV (1996) S. 69 f.; Kriegstagebuch K. Hampe (2007) S. 954 (Register); Ruuskanen (2008) S. 157-159; Objekte erzählen Geschichte(n) (2016) S. 21, 146-153, 170$178,180-185$ u. ö.

$P$ Bildarchiv UAH; graph. Slg. UBH; NDB; Archäologenbildnisse.

\section{Du Moulin Eckart auf Bertoldsheim, Richard Maria Ferdinand Graf}

1894-1898 Phil. Fak.

Geschichte

* 27. Nov. 1864 Leipzig

$\dagger \quad$ o1. April 1938 Bertoldsheim (Oberbayern; heute: Ortsteil von Markt Rennertshofen)

- Schloß Bertoldsheim (Familiengruft) kath.

V Eduard Graf Du M.E. (1834-1902) Majoratsherr

M Karoline geb. Meyer (1838-1895)

( 25. Sept. 1894 Bertha geb. Berger (1866-1949)

K 2 T, 1 S: Dr. iur. Karl Leon Graf Du M.E. (190o1991), u.a. 1930-1932 Leiter des Nachrichtendienstes der SA, 1934-1936 Inhaftierung im KZ Lichtenburg in Prettin (heute: Ortsteil von Annaburg in Sachsen-Anhalt) wegen angeblicher Homosexualität, s. Spruchkammerbescheid 1/2 Bl. 2, 2/1 Bl. 112 im Inst. für Zeitgeschichte München; Hergemöller, BerndUlrich: Mann für Mann. Ein biographisches Lexikon. Frankfurt/M. 2001. S. 193 f.

Lb Seit WS 1882/83 Studium an U Würzburg, anschl. Leipzig, München, Breslau, Berlin, Paris; 1886 Dr. phil. an U Breslau.

UH: 2. Aug. 1894 Habilitation; seit 19. Aug. 1897 nichtetatm. a. o. Prof.

TH München: Seit WS 1898/99 a.o. Prof.; 19001930 o. Prof.

Vorsitzender: Bayerischer Gauverband des Alldeutschen Verbandes (vor 1904-1914), Dt. Kampfbund gegen die Kriegsschuldlüge

1923 Geh. Reg.-Rat 
Qu UAH PA 2024; RA 6617. Auskunft: Historisches Archiv der TU München. - Betrachtungen und Erlebnisse. München 1912. (Autobiogr. Skizzen.)

$W$ Bayern unter dem Ministerium Montgelas. München 1895. - Der historische Roman in Deutschland und seine Entwicklung. Berlin 1905. Cosima Wagner. München 1914. 3. Aufl. 1924. • Bismarck, der Mann und das Werk. Stuttgart 1915. Vom alten Germanien zum neuen Reich. Stuttgart 1925. Geschichte der deutschen Universitäten. Stuttgart 1929. Nachdr. 1976.

HG Neue Briefe Hans von Bülows. München 1927.

L Kürschner (1931) Sp. 525f., (1935) Sp. 930; Wer ist's (1935) S. 328; WBIS; Deutsche Biographie, s. https://www.deutsche-biographie.de/gnd108824 713.html [06.11. 2017].

\section{Dungern, Emil Freiherr von}

1906-1913 Med. Fak.

Hygiene

* 26. Nov. 1867 Würzburg

$\dagger \quad$ 04. Sept. 1961 Ludwigshafen (am Bodensee) ev.

V Otto Ernst Friedrich Wilhelm Karl Freiherr von D. (1831-1911) Hauptmann, HerzoglichNassauischer und Großherzoglich Luxemburgischer Kammerherr

M Olga geb. Baronin Grotthuß (1845-1924)

( 27. Febr. 1919 Hedwig geb. Bauer verw. Haaß $\left({ }^{*} 1873\right)$ Witwe von Robert Haaß (1847-1905) Heimatdichter, u. a. 1888-1905 Leiter des Chemisch-Technischen Laboratoriums, 1896 Ern. zum Prof. TH Karlsruhe, s. Badische Dichter. Ein Sammelbuch badischer Lyrik bis auf die jüngste Zeit. Hrsg. von Albert Geiger. Karlsruhe 1905.

$\mathrm{K}$ keine.
Vw Großvater: Emil August Viktor Freiherr von D. (1802-1862), u. a. seit 1842 Herzoglich Nassauischer Geheimer Rat, Ministerialdirektor, seit 1844 Staatsminister, seit 1852 Bundestagsgesandter. - Siehe Hessische Biografie http:// www.lagis-hessen.de/pnd/118980386 (Stand: 21. Jan. 2017).

Lb Seit WS 1887/88 Studium an U Freiburg/Br., anschl. München, Freiburg/Br., Berlin.

U Freiburg/Br.: 13. Mai 1892 Dr. med.; 30. Nov. 1892 Approbation; Dez. 1892-Sept. 1893 Assistent am Hygien. Inst.

Okt. 1893-April 1894 Eigenstudien in Paris; Sept. 1894-März 1895 Assistent am Inst. für Infektionskrankheiten in Berlin.

U Freiburg/Br:: 19. Juni 1896 Habilitation für Bakteriologie und Hygiene; seit 30. Nov. 1902 a. o. Prof.

UH: Seit 6. April 1906 a. o. Prof. und Leiter (zus. mit Theodor Wasielewski) der Wiss. (Biologisch-Chemischen) Abt. am neugegründeten Inst. für Experimentelle Krebsforschung im Samariterhaus, s. hierzu auch Vincenz Czerny; Jahresvergütung von 3200.- Mark (aus: UAH PA 1490 vom 3. Febr. 1913).

Hamburg-Eppendorf: März 1913-Okt. 1918 Direktor des Inst. für Experimentelle Krebsforschung.

Ludwigshafen: Seit 1918 Wohnsitz.

D.s Blutgruppen-Forschungen gemeinsam mit seinem Schüler Ludwig Hirschfeld/Hirszfeld (18841954) führen 1910 zu neuen Erkenntnissen auf dem Gebiet der Vaterschaftsbestimmung

E 1947 Dr. med. h.c. U Freiburg/Br. • 1912 Königl. Bayer. Verdienstorden vom Hl. Michael II. Klasse.

Qu UAH PA 886, 1490; RA 6331. - GLA Abt. 235, Fasz. 1908.

$W$ Beitrag zur Histologie der Nebennieren bei Morbus Addisoni ... Freiburg 1892. • Die Anti- 
körper. Jena 1903. Das Wesen der bösartigen Geschwülste. Leipzig 1907. (Mitverf.) • Über Nachweis und Vererbung biochemischer Strukturen in: Zs. für Immunitätsforschung und experimentelle Therapie (1910) Bd. 4, S. 531-546 (zus. mit Ludwig Hirschfeld); Über Vererbung gruppenspezifischer Strukturen des Blutes in: ebd. (1910) Bd. 6, S. 284292 (zus. mit L. Hirschfeld); Über gruppenspezifische Strukturen des Blutes in: ebd. (1911) Bd. 8, S. 526-562 (zus. mit L. Hirschfeld).

$L$ Wer ist's (1935) S. $328 \mathrm{f}$; Fischer $1 \quad\left({ }^{3} 1962\right)$ S. 340 f.; Chronik Ärzte H (1985) S. 125. • Wagner, Gustav, Mauerberger, Andrea: Krebsforschung in Deutschland: Vorgeschichte und Geschichte des Deutschen Krebsforschungszentrums ... Berlin 1989. S. 35-37 u. ö. • Jansen (1992a) S. 164 (Register); Seidler/Leven (2007) S. 787; WBIS; Friedrich (2009) S. 75 f. u. ö. • Ludwik Hirszfeld: The Story of One Life. Translated and edited by Marta A. Balińska and William H. Schneider. Rochester 2010. S. 455 (Register). • Geserick, Gunther, Wirth, Ingo: Genetic Kinship Investigation from Blood Groups to DNA Markers in: Transfusion Medicine and Hemotherapy (2012 June) 39(3) S. 163-175. • Deutsche Biographie, s. https://www.deutsche-biographie.de/gnd116251875.html [06.11. 2017].

$P$ Bildarchiv UAH.

\section{Dusch, Theodor Georg Carl von (seit 1881: Freiherr von Dusch)}

1854-189o Med. Fak. 1854-1856 Allg. Pathologie; WS 1856/57-SS 1862 Pathologische Anatomie, seit WS 1862/63 Allg. Pathologie und Therapie, Kinderheilkunde (wichtigste Krankheiten des kindlichen Alters mit klinischen Demonstrationen)

* 17. Sept. 1824 Karlsruhe

$\dagger$ 13. Jan. 1890 Heidelberg kath., (nach) 1871 altkath.
V Alexander Anton von D. (1789-1876) Laufbahn im badischen Staatsdienst: 1815-1851 (Ruhestand) in verschiedenen Ministerien in Karlsruhe, u.a. 1843-1849 Minister des Großherzoglichen Hauses und der auswärtigen Angelegenheiten Badens, s. NDB 4 (1959) S. 204 f.; Handbuch der Baden-württ. Geschichte ... Hrsg. von Hansmartin Schwarzmaier ... Stuttgart 1992. Bd. 3. S. 95-97, 99 u. ö.; Zegowitz, Bernd: Der Politiker als Gelegenheitsdichter: A. von D.s Arbeiten für und über das Theater in: Von der Spätaufklärung zur Badischen Revolution ... Hrsg. von Achim Aurnhammer ... Freiburg/Br. 2010. S. 607-620.

M Maria Anna geb. von Weiler (1787-1858)

๑ 10. Aug. 1849 Johanna Auguste geb. Gmelin (1823-1897) T von: (siehe) Leopold G.

K $\quad 1$ S, 2 T: u. a. Klara Julie Adelheid Kathinka Elisabetha von D. (1854-1887) Ehefrau von: (siehe) Heinrich Braun. - Siehe Stumm (2012) S. 22

Vw Neffe: Alexander Frhr. von D. (1851-1923), u.a. 1905-1917 Staatsminister und Präsident des badischen Staatsministeriums, s. Badische Biographien N.F. V (2005) S. 55-58.

Lb Seit SS 1842 zunächst Studium der Rechtswiss. an U Freiburg/Br., seit SS 1843 Studium der Medizin an $\mathrm{UH}$.

UH: Herbst 1846-Herbst 1847 Assistenzarzt an Chirurg. U-Klinik; 1. Nov. 1847 Dr. med.

Karlsruhe: Staatsprüfungen: 18. Dez. 1846 für Innere Medizin, 12. Juli 1847 für Chirurgie und Geburtshilfe.

April-Aug. 1848 Feldarzt bei Großherzogl. Badischem Armee-Corps.

Mannheim: Aug. 1848-1854 Niederlassung als praktischer Arzt (Armenarzt).

UH: 24. Okt. 1854 Habilitation für Allg. Pathologie; seit 20. Okt. 1856 II. Lehrer der Pathologie mit dem Charakter e. a.o. Prof. (I. Lehrer: o. Prof. Adalbert Duchek) mit e. jährl. Besoldung von 40o.- Gulden; Duchek lehnt e. „Vereinbarung [mit von Dusch] über die zu treffende Unterrichts- und Geschäftstheilung ab“ (aus: UAH PA 1493; siehe hier- 
zu auch A. Duchek); 22. Nov. 1856 Ministerium des Innern verfügt: von D. liest über Patholog. Anatomie; seit 27. Dez. 1856 (bis 189o) Direktor der nunmehr von der Med. U-Klinik getrennten Poliklinik als Nachf. von Karl Ewald Hasse; 17. Mai 1870 Ern. vom Ministerium des Innern zum II. o. Prof. für Pathologie (I. Prof.: Julius Arnold) gegen den Willen der Med. Fak., die zu dieser Berufung von der Behörde nicht gefragt wurde, s. hierzu PA 1493: Schreiben vom 17., 19., 20., 30. Juni 1870; Dez. 1870-März 1871 Leiter e. Reservelazaretts in Karlsruhe-Durlach; seit 12. Dez. 1882 Besoldungserhöhung von 300.- Mark zu seinem jährl. Grundgehalt von 3200.- Mark. • In dieser Zeit:

H: 2. Juli 186o-189o (Mitbegründer) I. Direktor der Kinderheilanstalt, seit April 1864 u.d. N. Luisen-Heilanstalt (II. Direktor seit 1861: (siehe) Zacharias Oppenheimer), seit Nov. 1885 mit Sitz in H-Bergheim, Luisenstraße 5 (s. hierzu auch Wilhelm Posselt und Theodor Plitt). Die Anzeige zur Eröffnung der Kinderheilanstalt lautete 1860: „Vom 2. d[ieses] M[onats = Juli] an kann die Aufnahme von kranken Kindern stattfinden. Bei derselben wird durchaus kein Unterschied in Betreff der Confession und der Herkunft gemacht. Armuth und Mangel an der nöthigen Pflege befähigen zur unentgeltlichen Aufnahme, soweit es die Mittel gestatten. Die Anmeldungen geschehen täglich in der Wohnung der beiden ärztlichen Directoren.

Die ärztlichen Directoren: Dr. von Dusch, Plöckstraße Nr. 79, Dr. [Alfred] Flad [bis 1861, s. 150 Jahre Pädiatrie in H (2010) S. 11, 32-34, 39; Nachf. Flads: Zacharias Oppenheimer], LeopoldstraBe 43."

1879 Prorektor der UH; 1876/77, 1885/86 Dekan der Med. Fak. der UH

1880 Hofrat

Siehe auch Adalbert Duchek
E 1864 Mitglied der Dt. Akademie der Naturforscher Leopoldina Halle/S. • 1867 Ritterkreuz I. Klasse, 1871 Ritterkreuz I. Klasse mit Eichenlaub, 1885 Kommandeurkreuz II. Klasse des Ordens vom Zähringer Löwen.

Qu UAH PA 1493; RA 5094, 5527, 6269, 6280, 6804; Fak.-Akte H-III-111/107 fol. 83r-88r u. ö. • GLA Abt. 76, Fasz. 9907 f. • Siehe auch Archiv der Dt. Akademie der Naturforscher Leopoldina Halle/S. - Ergebnislose Anfrage: Stadtarchiv Heidelberg (zu Alfred Flad).

$W$ Untersuchungen und Experimente als Beitrag zur Pathogenese des Icterus und der akuten gelben Atrophie der Leber. Leipzig 1854. - Lehrbuch der Herzkrankheiten. Leipzig 1868. • Die Krankheiten der Kreislauforgane. Tübingen 1878. (Mitverf.) (Handbuch der Kinderkrankheiten. Hrsg. von Carl Gerhardt. 4. 1. Abt.) • Über Kinderheilkunde und deren Unterricht auf Universitäten. Rede ... am 22. Nov. 1879. Heidelberg 1879.

L NDB 4 (1959) S. 205; Hoche (1969) S. 99-102; WBIS; Riese (1977) S. 409 (Register); Chronik Ärzte H (1985) S. 125 f., 216 ff. • Wille, Lutz: Universitäts-Kinderklinik Luisen-Heilanstalt zu Heidelberg 1860-1985 in: Der Kinderarzt 16. Jg., Nr. 7 (1985) Sp. 1000-1002. • Pantel/Bauer (1990) S. 8991, 98 u. ö.; 150 Jahre Pädiatrie in H (2010) S. 3140; Stumm (2012) S. 693 (Register; S. 22: als Vermählungsmonat Okt. genannt); Bauer/Ho (2016) S. $27-33$.

$P$ Bildarchiv UAH; graph. Slg. UBH; Wille (1985); Chronik Ärzte H. 


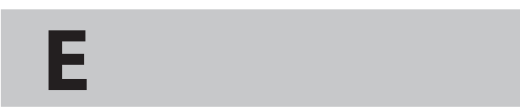

\section{Ebler, Erich Jakob}

1905-1915 Nat.-Math. Fak.

Chemie

* o8. März 188o Mannheim

$\dagger$ 23. Jan. 1922 München

mosaisch, zwischen 1901 und 1905 ev. getauft

V Emil E. (1853-1933) Kaufmann (mosaisch), s. Hampe (2016) S. 2 f. u. o.

M Emma geb. Lewy (1857-1883)

๑ 7. April 1904 Marie geb. Scherr (1876-1942) Scheidung am 29. Juni 1920; T von Johannes S. (1817-1886) 1848-1849 Abgeordneter der II. Kammer der württ. Landstände für Geislingen; 1849 Flucht in die Schweiz; seit 1850 Privat-Dozent an U Zürich, seit 1852 PrivatGelehrter in Winterthur, seit 1860 o. Prof. für Literatur, Geschichte am Eidg. Polytechnikum Zürich, s. ADB 31 (1890) S. 125-130, WBIS; Raberg, Frank: Biographisches Handbuch der württ. Landtagsabgeordneten 1815-1933 ... Stuttgart 2001. S. 780.

(15. April 1921 Anna (Anni) Pauline geb. Schild verw. Schwarz

K 2 T: Gertrud Elena E. (1906-1969) Lehrerin. Annemarie Emma Elisabeth E. (1910-2004) Ehefrau von Hermann Hampe (1904-1979) Sohn von: (siehe) Karl H.; s. auch UAH Rep. 14-223.

Lb WS 1898/99-WS 1901/02 Studium der Chemie, Physik, Mineralogie, Botanik, Zoologie, Mathematik an UH; Ostern 1901 Teilnehmer e. Ferienkurses für physico-chemische Messungen am Physikal.-Chemischen Inst. der U Leipzig.

UH: 1. Mai 1902 Dr. phil. nat.; seit April 1900 Hilfsassistent, April 1901-31. März 1915 Assistent an Anorganischer Abt. des Chemischen Laboratoriums; 1. Okt. 1903-17. März 1904 Militärdienst („wegen Fußleidens als dienstunbrauchbar entlassen“, aus: UAH PA 1496); 8. Mai 1905 Habilitation; seit 15. Juni 1910 nichtetatm. a. o. Prof.; WS 1912/ 13-SS 1915 Lehrauftrag für e. 2-stündige radiologische Experimental-Vorlesung; seit Herbst 1912 Vorstand der Anorganischen Abt. am Chemischen Laboratorium.

1914-1918 Kriegsdienst.

U Frankfurt/M.: 9. Febr. 1915 Ern. zum etatm. a.o. Prof. für Analytische und Organische Chemie; seit 19. Aug. 1920 o. Prof.

1912 Entdecker e. neuen Verfahrens zur Gewinnung von Radium. Das Verfahren wird am 4. März 1912 als amerik. Patent mit der Nr. US 1059531 eingetragen und am 22. April 1913 veröffentlicht unter dem Titel: Process for the preparation, isolation, and enrichment of radium and other radio-active substances. Die Rechte für die Verfahrensanwendung erwirbt eine englische Gesellschaft gegen Bezahlung von einer Million Mark an E. unter der Bedingung, daß er sich mit diesem Betrag an der Gesellschaft beteiligt (aus: Heidelberger Zeitung vom 26. Jan. 1914, in: PA 1496).

E. begeht in München während einer Reise am 23. Jan. 1922 Selbstmord wohl aufgrund von Langzeitschäden durch eine Giftgasverletzung im 1. Weltkrieg; er wird am 27. Jan. 1922 auf dem Münchner Ostfriedhof bestattet.

E 1915 Eisernes Kreuz II. Klasse; 1917 Ritterkreuz II. Klasse des Ordens vom Zähringer Löwen.

Qu UAH PA 1496; RA 6469, 6499, 6886, 6898. • GLA Abt. 235, Fasz. 1913. - Briefe: UBH. - Auskunft: Stadtarchiv Zürich; Frankfurt/M.: Universitätsarchiv (Abt. 4, Nr. 1147, Bl. 7: Bericht über E.s Suizid und seine Feuerbestattung in München), Stadtarchiv, Senckenbergische Bibliothek sowie Standesamt. - Mitteilungen: Herr Dr. Thomas Hampe, Bonn.

$W$ Über die Radioaktivität der Maxquelle in Bad Dürkheim an der Haardt in: Verhandlungen des Naturhistorisch-Medicinischen Vereins zu Heidelberg N.F. 9 (1908) S. 87 ff. • E., E., Knoevenagel, 
Emil: Praktikum des anorganischen Chemikers. 2. Aufl. Leipzig 1909. - E., E., Bender, Wilhelm: Über die Behandlung der "Rohsulfate“ bei der Fabrikation des Radiums und des Mesothoriums in: Sitzungsberichte der Heidelberger Akademie der Wissenschaften. Math.-Naturwiss. Klasse. Abt. A. Heidelberg 1913.

$L$ Über E.E. in: Henrich, Ferdinand: Die chemische Technologie der Radioelemente in: Ders.: Chemie und chemische Technologie radioaktiver Stoffe. Berlin 1918. S. 274-344. • Hahn, F.: E. E. zum Gedächtnis in: Zs. für angewandte Chemie 35. Jg. (7. März 1922) Nr. 19, S. 109 f. • Poggendorff 5 (1925) S. 319; WBIS. • Hampe, Thomas: Aus der Geschichte meines Großvaters E.E., Chemiker. Masch.geschr. Manuskript. Bonn 2016 (Ausdruck im UAH). - Deutsche Biographie, s. https://www. deutsche-biographie.de/gnd101280830o.html [06. 11. 2017].

\section{$P$ Bildarchiv UAH.}

\section{Eckardt, Hans Felix von}

1926-1933, 1946-1957 Phil. Fak.

Soziologie, Publizistik

* 22. Dez. 1890 Riga (Russisches Kaiserreich; heute: Rīga, Lettland)

$\dagger \quad$ 24. Dez. 1957 Heidelberg ev.

V Johannes von E. (1850-1936) Oberlehrer, Publizist; Bruder von Julius von E. (1836-1908), u. a. seit 1860 Sekretär des Landeskonsistoriums von Livland, seit 1870 Redakteur des Hamburgischen Correspondenten und der Hamburger Börsenhalle, seit 1885 in diplomatischen Diensten, u. a. Generalkonsul: seit 1892 in Stockholm, 1900-1907 Zürich, s. WBIS, NDB 4 (1959) S. 282; Hamburgische Biografie: Personenlexikon. Hrsg. von Franklin Kopitzsch ... Hamburg 2003. Bd. 2. S. 111.

M Hedwig geb. Karum (1867-1934)
Q 10. April 1917 Gertrude geb. Dannheisser (1895-1987), s. Briefe in UBH; Korrespondenz, s. Gilman, Sander L.: Inscribing the other. Lincoln 1991. S. 239-241 u. ö.; Hermann Broch: Briefe an Erich von Kahler (1940-1951). Hrsg. von Paul Michael Lützeler. Berlin 2010. Scheidung 1927; seit 1936 Ehefrau von: (siehe) Emil Lederer

๑ 13. Juni 1931 Marianne geb. Jaffé (1905-1991), s. Demm (2014) S. 244 (Register); T von: (siehe) Edgar J.

K $\quad 2 \mathrm{~S}, 3 \mathrm{~T}$

Lb Studium der Rechtswiss. an U: Seit SS 1912 Moskau, SS 1913 Berlin, WS 1913/14-SS 1914, 19. Jan. 1915-SS $1917 \mathrm{H}$.

1914 Erwerb der dt. Staatsangehörigkeit; 1915-1918 freiwilliger Kriegsdienst.

UH: 9. Mai 1919-24. Okt. 1919 Studium der Nationalökonomie; 9. Dez. 1919 Dr. phil.

Hamburg: Jan. 1920-Sept. 1926 Referent für Osteuropa am Weltwirtschaftsarchiv; außerdem Redakteur des Hamburgischen Wirtschaftsdienstes. • In dieser Zeit:

U Hamburg: 10. Dez. 1925 Habilitation für Praktische und Theoretische Nationalökonomie.

UH: Seit 11. Okt. 1926 nichtplanm. a.o. Prof.; seit 1927 (Gründer) Leiter des Inst. für Zeitungswesen; 11. April 1933 Entlassung aufgrund des Gesetzes zur „Wiederherstellung des Berufsbeamtentums“; 20. Febr. 1934 Entziehung der Lehrbefugnis aus politischen Gründen.

Kaufm. Angestellter: Seit 1934 Telefonbau und Normalzeit AG in Frankfurt/M., 1938-1942 BBC in Mannheim, anschl. in Frankfurt/M.

München: Seit Sept. 1945 Delegierter des Bayer. Ministerpräsidenten im Kultusministerium.

UH: 15. Mai 1946 Reaktivierung als a.o. Prof. und Leiter des Inst. für Publizistik; 8. Juli 1946-24. Dez. $1957(\dagger)$ planm. a. o. Prof. • In dieser Zeit:

Frankfurt/M.: Seit 1949 Senator der Europäischen Akademie. 
Qu UAH PA 371, 2640, 3614f.; Rep. 13, Rep. 121. Briefe: UBH.

W Grundzüge der Politik. Breslau 1927. - Rußland. Leipzig 1930. - Iwan der Schreckliche. Frankfurt/M. 1941. 2. Aufl. 1947. • Russisches Christentum. München 1947. • Die Macht der Frau ... Kultursoziologische Skizzen. Stuttgart 1949.

$H G$ Friedrich von Gentz: Staatsschriften und Briefe. 2 Bde. München 1921. • Freiheit und Würde des Menschen. Stimmen aus drei Jahrtausenden. München 1947. • Politisches Lesebuch. Stuttgart 1948 .

L Kürschner (1950) Sp. 384; WBIS. • Haacke, Wilmont: H. von E. - 30 Jahre Professor in: Publizistik 1 (1956) S. 362-365. • Pöschl, Viktor: H.F. von E. † in: Ruperto Carola 10. Jg., Bd. 23 (1958) S. 160 f. - Int. Soziologenlexikon. Hrsg. von Wilhelm Bernsdorf ... Stuttgart 1980. 2. Aufl. Bd. 1. S. 108. Mussgnug (1988) S. 297 (Register); Jansen (1992) S. 408 (Register); Ders. (1992a) S. 164 (Register); Hausmann (2006) S. 89-92 u. ö. • Südkamp, Elisabeth: Das Institut für Zeitungswesen im Haus Buhl und H. von E. in: Heidelberg. Jahrbuch zur Geschichte der Stadt 2014. Heidelberg 2013. Jg. 18. S. 25-29. • Demm (2014) S. 244 (Register); Riecke (2016) S. 69, 97; Deutsche Biographie, s. https://www.deutsche-biographie.de/gnd 11634766X.html [06.11.2017].

$P$ Bildarchiv UAH; Ruperto Carola.

\section{Edlbacher, Siegfried Augustin Johann}

1919-1932 Med. Fak.

Physiologie

* $\quad$ 07. März 1886 Linz (Österreich)

$\dagger \quad$ 05. Juni 1946 Basel (Suizid)

口 Salzburg ev., seit 1917 kath.

V Dr. iur. Maximilian E. (1835-1893) Rechtsanwalt, Landtags- und Reichstagsabgeordneter, s. WBIS

M Johanna geb. von Risch (1854-1935)
๑ 15. Sept. 1917 Valerie geb. Kabella (1892-Mai 1946)

K unbekannt.

Lb WS 1906/o7 Studium der Chemie, Physik, Botanik, Zoologie, Philosophie an U Wien, seit SS 1907 Graz, WS 1908/o9 Gießen, SS 1909 Jena, seit WS 1909/10 Graz; 16. Mai 1911 Dr. phil. nat. an U Graz.

Assistent: SS 1911 Chemisches Laboratorium der Handelshochschule in Berlin, seit WS 1911/12 Medizinisch-Chemisches Inst. der U Innsbruck.

UH: Seit 15. April 1913 Assistent am Physiolog. Inst.; 31. Juli 1919 Habilitation; seit SS 1924 Lehrauftrag für Physiolog. Chemie; seit 12. Dez. 1924 nichtplanm. a. o. Prof. - In dieser Zeit:

Okt.-Dez. 1914, Aug. 1915-Okt. 1916 Kriegsdienst.

U Basel: Seit WS 1932/33 o. Prof. für Physiolog. Chemie und Vorsteher der Physiologisch-Chemischen Anstalt.

E 1946 Dr. med. h.c. U Basel.

Qu UAH PA 887, 3625; RA 6191. • GLA Abt. 235, Fasz. 1915.

$W$ Handbuch der biologischen Arbeitsmethoden. Berlin 1927. (Mitverf.) - (Kurzgefasstes) Lehrbuch der physiologischen Chemie. Berlin 1929. 15. Aufl. 1963. Praktikum der physiologischen Chemie. Heidelberg 1932. 2. Aufl. 1940.

$L$ NDB 4 (1959) S. 314; WBIS. • Rintelen, Friedrich: Geschichte der medizinischen Fakultät in Basel 1900-1945. Basel 1980. S. 328-333. Chronik Ärzte H (1985) S. 126; Jansen (1992a) S. 164 (Register); Badische Biographien N. F. VI (2011) S. 81-84.

$P$ Bildarchiv UAH.

\section{Edler von Weidenbach}

siehe Weidenbach, Christoph 


\section{Ehrenberg, Philipp Hans}

1910-1924 (1933) Phil. Fak.

Philosophie

* o4. Juni 1883 Altona (heute: Stadtteil von Hamburg)

$\dagger$ 31. März 1958 Heidelberg

mosaisch, seit 1909 ev.

V Otto E. (1849-1928) Bankier

M Emilie (Emmi) geb. Fischel (1859-1941)

( 26. Juli 1913 Else Anna geb. Zimmermann (1890-1970) e. der ersten deutschen Gymnasiallehrerinnen

K 1 T, 1 S: Andreas (Andrew) E. (1926-2010), u. a. 1970-1993 Prof. of Marketing an London Business School, 1993-2005 Research Prof. an London South Bank University, s. https:// www.geni.com/people/Andrew-Ehrenberg/6 ooooooo12291327782 (abgerufen am 27. Dez. 2017; Ausdruck im UAH)

Vw Bruder: Victor E. (1891-1976) seit 1922 Privat-Dozent für Alte Geschichte Frankfurt/M., seit 1929 o. Prof. Prag, Febr. 1939 Flucht vor Einmarsch dt. Truppen in Prag nach Großbritannien, 1941-1945 Temporary Lecturer in Classics am King's College in Newcastle upon Tyne (s. hierzu Brodersen, Kai: „To write history and to live history are two very different things". V.E. in Newcastle upon Tyne 1941-1945 in: Die Antike außerhalb des Hörsaals. Hrsg. von Kai Brodersen. Münster 2003. S. 165-168), seit 1946 o. Prof. University of London, s. Ehling, Kay: „Vielleicht werde ich auch einmal wieder Deutschland besuchen können. "Ein Brief V. E.s vom 20. Febr. 1947 in: Historia 53 (2004) S. 121-128. • Victor E.s Söhne: Sir Geoffrey Rudolph Elton (Geburtsname: Gottlieb Rudolf Ehrenberg) (1921-1994) britischer Historiker und Lewis Richard Benjamin Elton (Geburtsname: Ludwig R. B. Ehrenberg) $\left({ }^{*} 1923\right)$ britischer Bildungsforscher (Vater von Ben Elton $\left({ }^{*} 1959\right)$ britischer Schriftsteller, Bühnenautor und Komiker), s. Wikipedia
Vw Vettern: Rudolf E. (1884-1969) seit 1877 PrivatDozent für Handelsrecht und Dt. Privatrecht Göttingen; o. Prof.: seit 1882 Rostock, seit 1887 Göttingen, 1911-1922 (Emeritierung) Leipzig, s. NDB 4 (1959) S. $351 \mathrm{f}$; Wehefritz, Valentin: Naturforscher, Philosoph, Theologe ... R. E. ... Ein dt. Gelehrtenschicksal im 20. Jahrhundert. UB der TU Dortmund. Dortmund 2016. (Universität im Exil. 8.); Professorenkatalog Leipzig online. - Dr. phil. Franz Louis August Rosenzweig (1886-1929) Religionsphilosoph, u. a. 1920-1922 Leiter des Freien Jüdischen Lehrhauses in Frankfurt/M., s. WBIS, BBKL VIII (1994) Sp. 698-703; Casper, Bernhard: F.R., Ferdinand Ebner und Martin Buber ... Freiburg/Br. 2017.

Vw Zu weiteren Vw, s. Brakelmann 1 (1997) S. 1318,364 .

Lb SS 1902 Studium der Rechts- und Staatswiss. an U Göttingen, seit WS 1902/03 Berlin, seit SS 1904 $\mathrm{H}$; seit SS 1905 Studium der Nationalökonomie, Philosophie an U München; 12. Juni 1906 Dr. oec. publ. an U München; seit Okt. 1906 Militärdienstpflicht als Einjährig-Freiwilliger in Kassel.

UH: Seit WS 1908/o9 Forts. des Studiums der Philosophie; 23. April 1909 Rigorosum, 17. Dez. 1909 (Datum der Promotionsurkunde) Dr. phil.; 24. Okt. 1910 Habilitation; seit 1909/10 Eigenstudien in Theologie; seit 11. Juni 1918 nichtetatm., seit 1920 nichtplanm. a.o. Prof.; SS 1924-WS 1932/33 von U beurlaubt; April 1933 Verzicht auf venia legendi. - In dieser Zeit:

1914-1918 Kriegsdienst; seit SS 1922 Studium der Theologie an U Münster; 1923 I., 1924 II. theol. Examen ebd.; 1. Aug. 1923-1. Febr. 1924 Lehrvikar in $\mathrm{H}$.

Bochum: Seit 1. Juni 1924 Hilfspfarrer, seit 8. Juni 1924 o. Pfarrer; 1. Juli 1937 Amtsenthebung.

9. Nov. 1938 Deportation ins KZ Sachsenhausen; März 1939 Entlassung durch Intervention und Bürgschaft des Bischofs von Chichester, George Kennedy Allen Bell (1883-1958), und mit dem Versprechen auszuwandern; Mai 1939 Emigration nach Großbritannien; u.a. als Seelsorger dt. Ge- 
fangener in engl. Lagern tätig; 1947 Rückkehr nach Deutschland.

April 1947-Sommer 1950 Mitarbeiter im Volksmissionarischen Amt der Ev. Kirche von Westfalen, u. a. in Gladbeck und Bethel.

\section{H: Seit 1954 Wohnsitz.}

1919-1920 Sozialdemokratisches Mitglied des Heidelberger Stadtrats

1919 Mitbegründer des Badischen Volkskirchenbundes, s. hierzu Vollmer, Antje: Die Neuwerkbewegung. Zwischen Jugendbewegung und religiösem Sozialismus. Freiburg/Br. 2016. S. 173 ff.

1993 wurde die Hans-Ehrenberg-Gesellschaft in Bochum gegründet; sie „informiert über Leben und Werk von H.E. und einiger Zeitgenossen, ediert die Schriften der H.E. Gesellschaft, ... veranstaltet wissenschaftliche Tagungen und Symposien und fördert Forschungsarbeiten aus den Bereichen der Systematischen Theologie und der kirchlichen Zeitgeschichte" (zitiert aus: http:// www.clio-online.de, hier: Stichwort EhrenbergGesellschaft; abgerufen am 6. Nov. 2017).

Seit 2000 wird alle zwei Jahre der mit 5000.- Euro dotierte Hans-Ehrenberg-Preis verliehen, s. hierzu https://hansehrenberg.info/2017/03/12/hans-ehren berg-preis/

Qu UAH PA 3634; Studentenakte. GLA Abt. 235, Fasz. 1918. - Nachlaß: Landeskirchliches Archiv der Ev. Kirche von Westfalen in Bielefeld; s. auch Brakelmann 1 (1997) S. 339. Autobiography of a German pastor. London 1943. (H.E. Autobiographie eines deutschen Pfarrers und weitere Zeugnisse aus der NS-Zeit. Hrsg. von Günter Brakelmann. Waltrop 1999.)

$W$ Die Parteiung der Philosophie. Studien wider Hegel und Kantianer. Leipzig 1911. 2. Aufl. Essen 1998. Deutschland im Schmelzofen. Berlin 1932. • Luthertum, ökumenisch und deutsch. Gütersloh 1947. Die Paradoxien des Evangeliums. München 1957.
HG 1919-1920 Christliches Volksblatt.

$L$ Ebner, Ferdinand: Die Wirklichkeit Christi in: Der Brenner. Österr. Kulturzeitschrift. 10. Folge (Herbst 1926) S. 9, 14, 21 u.ö. - RGG $2\left({ }^{2} 1928\right)$ S. 42. Bauks, Friedrich Wilhelm: Die Pfarrer in Westfalen von der Reformationszeit bis 1945. Bielefeld 1980. S. 113 (mit Werkverz.). Mussgnug (1988) S. 297 (Register); Jansen (1992) S. 408 (Register); Ders. (1992a) S. 164 (Register). - Potthast, Karl Heinz: Christ sein und Jude bleiben? H.P.E. in: Konfrontation und Koexistenz. Zur Geschichte des dt. Judentums. Hrsg. von Renate Heuer, Ralph-Rainer Wuthenow. Frankfurt/M. 1996. S. 208-223. • Brakelmann, Günter: H.E. Ein judenchristliches Schicksal in Deutschland. Bd. 1: Leben, Denken und Wirken 1883-1932. Bd. 2: Widerstand, Verfolgung und Emigration 1933-1939. Waltrop 1997. 1999. - BBKL XIX (2001) Sp. 201219; Handschuhsheimer Friedhof 3 (2002) S. 88 f.; Tilitzki 2 (2002) S. 1449 (Register). Das Erbe des Theologen H.E. ... Hrsg. von Manfred Keller und Jens Murken. Münster 2009. - Lexikon jüdischer Einwohner Hs (2011) S. 90 f. • H.E. als Grenzgänger zwischen Philosophie und Theologie. Hrsg. von Traugott Jähnichen, Andreas Losch. Kamen 2017. (Hans Ehrenberg Studien. Bd. 1. = Schriften der Hans Ehrenberg-Gesellschaft. Bd. 26.) • Deutsche Biographie, s. https://www.deutsche-biographie.de/gnd118688200.html [06.11. 2017].

$P$ Bildarchiv UAH.

\section{Ehrismann, Gustav Adolph}

1897-1909 Phil. Fak.

Deutsche Philologie

* 08. Okt. 1855 Pforzheim

$\dagger \quad$ o9. Sept. 1941 Hamburg-Othmarschen

ㅁ Heidelberg

ev.

V Johann Friedrich E. (1809-1882) Bijouteriefabrikant

M Caroline geb. Kämpff (1820-1869)

$\infty$ 11. Febr. 1892 Emma geb. Pregi(t)zer (18641936) 
K 2 S: u. a. Otfried E. (1898-1945), u. a. seit 1938 a. o. Prof. für Hygiene, Bakteriologie Hamburg, s. WBIS.

Lb WS 1872/73-WS 1874/75 Studium der Chemie am Polytechnikum Karlsruhe; SS 1875-SS 1880 Studium der Klassischen Philologie, Germanistik, Romanistik an UH, unterbrochen SS 1877-SS 1878 Leipzig; 4. Aug. 188 o Dr. phil. an UH; Privat-Gelehrter (aus gesundheitlichen Gründen): seit 1881 in Pforzheim, seit $1894 \mathrm{H}$.

UH: 8. Mai 1897 Habilitation für Dt. Philologie; seit 4. Juli 1901 a. o. Prof.; WS 1904/05-WS 1908/o9 Lehrauftrag für Altdeutsche Übungen am Germanisch-Romanischen Seminar.

U Greifswald: 23. April 1909-31. März 1924 (Emeritierung) o. Prof.; 1911 Ruf an U Graz abgelehnt.

Wohnsitze: Seit 1924 H, seit 1934 Berlin-Grunewald, seit 1938 Othmarschen.

1911 Geh. Reg.-Rat

$E$ Mitglied der Akademie der Wissenschaften: 1923 Berlin, 1924 Göttingen, 1932 München. 1930 Dr. phil. h.c. UH.

Qu UAH PA 1503; RA 6419, 6839; Fak.-Akte H-IV-102/93 fol. 33or. • GLA Abt. 235, Fasz. 1919. • Nachlaß, s. Int. Germanistenlexikon 1 (2003). • Auskunft: Ev. Oberkirchenrat - Landeskirchliches Archiv - Karlsruhe (Kirchenbücher der Stadtkirche Pforzheim).

W Geschichte der deutschen Literatur bis zum Ausgang des Mittelalters. 2 T. München 1918-1935. Neudr. 1966. Der Geist der deutschen Dichtung im Mittelalter. Leipzig 1925. • Siehe Int. Germanistenlexikon 1 (2003).

$L$ NDB 4 (1959) S. 359 f.; Lehmann (1967) S. 230232; Burkhardt (1976) S. 41 u. ö. Ehrismann, Otfrid: Die Stille der Provinz. G.E. - Germanist in Greifswald (1909-1924) in: Mediävistische Literaturgeschichtsschreibung. G.E. zum Gedächtnis ... Hrsg. von Rolf Bräuer ... Göppingen 1992. S. 1750. Badische Biographien N.F. IV (1996) S. 70-
72; Int. Germanistenlexikon 1 (2003); Lexikon Greifswalder Hochschullehrer (2004) S. 51; Ruuskanen (2008); 100 Jahre Germanistik in Hamburg (2011) S. 112, 209, 454. • WBIS; Riecke (2016) S. 143 (Register).

$P$ Bildarchiv UAH; NDB.

Eiselein, Joseph (auch: Eiselein, Josua)

1830 (1827-1836) Phil. Fak.

Geschichte, Geographie

* 18. März 1791 Engen (im Hegau)

$\dagger$ 30. Mai 1856 Geisingen (bei Donaueschingen) kath., seit $1823 \mathrm{ev.}$

$\mathrm{V}$ Ignatius $\mathrm{E}$.

M Marianne geb. Dietrich

$\infty$ 14. Sept. 1826 Antonie geb. Rehsteiner (18031877) (Trennung) 1859-1877 Aufenthalt in der Heil- und Pflegeanstalt Illenau in Achern

K 5, u. a. 2 T (davon 1 T: Nonne), 2 S: Friedrich E. (1829-1900) 1863-1889 Gymnasial-Prof. (seit 1853 kath.), s. Badische Biographien 5 (1906) S. 141-143; Karl E. (1831-1899) zuletzt Landgerichtspräsident, s. ebd. S. 143-145, WBIS.

$L b$ Donaueschingen: Nach Lehrerausbildung seit Okt. 1816 provisorischer, seit März 1818 etatm. Gymnasiallehrer, Ende 1818-1826 Gymnasialpräfekt mit e. jährl. Besoldung von 8oo.- Gulden. • In dieser Zeit:

Donaueschingen: Seit 1816 Sekretär und Cassier bei der Gesellschaft der Freunde vaterländischer Geschichte und Naturgeschichte an den Quellen der Donau; seit 1818 Bibliothekar in Diensten von Karl Egon II. Fürst zu Fürstenberg (1796-1854); Herbst 1818 Priesterweihe; 1819-1823 (Entlassung aufgrund Niederlegung des Priesteramtes) Hofkaplan.

Durlach (heute: Stadtteil von Karlsruhe): Seit 1826 I. Lehrer am Pädagogium.

UBH: Seit 13. Sept. 1827 I. Oberbibliothekar (Vorstand) an UBH als Nachf. von Franz Joseph Mone 
mit e. jährl. Besoldung von 1200.- Gulden; 18301832 Einsetzung e. Bibliothekskommission, deren Anordnungen E. mehrfach nicht befolgt, s. hierzu UAH K-Ia-o61; 6. Dez. 1832 (von U erzwungener) Ruhestand (s. hierzu Vogeler (1970) S. 5456) unter Belassung der Befugnis, Vorlesungen halten zu dürfen; 7. Jan. 1833 Niederlegung seines Amts als I. Oberbibliothekar; 15. Okt. 1835 Verurteilung zu e. 6-monatigen Aufenthalt in e. Arbeitshaus aufgrund „Unterschlagung und Dienstgelübdebruchs während seiner Dienstzeit“ (aus: K-Ia-061); 10. März 1836 Urteil wird aufgehoben, stattdessen zum 1. Mai 1836 Entlassung aus dem Staatsdienst und Streichung seines Ruhegehalts. In dieser Zeit:

UH: Seit 13. Sept. 1827 Prof.; E. erhält den Prof.-Titel, um den akad. Lehrern rangmäßig gleichgestellt zu sein; laut den Vorlesungsverzeichnissen liest E. nur im SS 1830 über "Geschichte und Physische und Politische Geographie der Länder und Staaten Amerikas".

Privat-Gelehrter: Seit 1836 in Konstanz, nach 1845 in Geisingen.

Qu UAH PA 1508f.; RA 5355, 5972, 6038, 6108; K-Ia-o61. • Briefe: UBH. • Auskunft: Kath. Stadtpfarramt in Engen.

$W$ Die Sprichwörter und Sinnreden des deutschen Volkes in alter und neuer Zeit. Zum ersten Mal aus den Quellen geschöpft ... Freiburg/Br. 1840. Die reimhaften, anklingenden und ablautartigen Formeln der hochdeutschen Sprache in alter und neuer Zeit ... Leipzig 1841. • Grundlinien der deutschen Sprachlere in Reimversen abgefasst nach Jacob Grimms Grammatik. Konstanz 1845. • Deutsche Sprachlere für Schulen. Konstanz 1846. • Geschichte und Beschreibung der Stadt Konstanz und ihrer nächsten Umgebung. Konstanz 1851.

HG Johann Winckelmanns sämtliche Werke ... 12 Bde. Donaueschingen 1825-1829. - Jacob Grimms Grammatik der hochdeutschen Sprache unserer Zeit. Konstanz 1843.
$L$ Wechmar (1846) S. 251; Bader (1925) S. 53; WBIS. • Vogeler, Hellmut: Johann Christian Felix Bähr als Oberbibliothekar der Universitätsbibliothek Heidelberg ... in: Bibliothek und Wissenschaft 7 (1970) S. 41-137, hier besonders S. 54-56. Joseph (Josua) E. in: Denecke, Ludwig: Jacob Grimm und sein Bruder Wilhelm. Stuttgart 1971. S. 92, 94. Über J.E. in: Harris, Martin: Joseph Maria Christoph Freiherr von Lassberg 1770-1855. Briefinventar und Prosopographie. Heidelberg 1991. S. 258. - Kessler, Martina D.: Viel Köche versaltzen den Brey und Bey viel Hirten wird übel gehütet. Diachrone Betrachtung der Variantenvielfalt phraseologischer Formen ... Frankfurt/M. 2010. S. 465 f. u. ö. - Siefert, Hugo: Vor 222 Jahren wurde der badische Professor Joseph Josua E. geboren in: Verein für Geschichte und Naturgeschichte der Baar: Schriften des Vereins für Geschichte und Naturgeschichte der Baar 56 (2013) S. 27-52. • Deutsche Biographie, s. https://www.deutsche-bio graphie.de/gnd116426292.html [06.11. 2017].

\section{Eiselein, Josua}

siehe Eiselein, Joseph

\section{Eisenlohr, August Adolf}

1869-1885 Phil. Fak. 1885-1902 (Honorar-Prof.) Phil. Fak.

Altägyptische Philologie

* o6. Okt. 1832 Mannheim

$\dagger$ 24. Febr. 1902 Heidelberg ev.

V Dr. med. Wilhelm Ludwig E. (1786-1848) Arzt M Auguste geb. Catoir (1803-1873)

๑ 1859 Pauline geb. André (1840-1860)

( 17. Aug. 188o Sophie Ferdinande geb. Schreiber verw. Schlehner (1847-1935)

K 2 S: u. a. Friedrich (Fritz) E. (1881-1957), u. a. 1921-1944 o. Prof. für Chemie Königsberg (Preußen), s. NDB 4 (1959) S. 417, Lexikon Greifswalder Hochschullehrer (2004) S. 51 f., Tilitzki 1 (2012) S. 787 (Register) 
Vw Bruder: (siehe) Friedrich E. • Onkel: Wilhelm E. (1799-1872) Physiker, s. NDB 4 (1959) S. 418, WBIS. - Vetter: August E. (1833-1916), u.a. 1892-1900 Präsident des badischen Innenministeriums, s. Badische Biographien N.F. IV (1996) S. 72-74.

Lb Seit WS 1850/51 Studium der Theologie an UH, seit WS 1851/52 Göttingen, SS $1853 \mathrm{H}$; anschl. Eigenstudien in Chemie an UH; nach 1853 E. betreibt auf ärztlichen Rat Landwirtschaft.

H: 1860-1873 Nennung E.s als Chemiker im Einwohner-Verzeichniß der Stadt Heidelberg, zunächst in der Leopoldstraße 21, ca. 1863-1873 in westlicher Hauptstraße 78; 1873 Umzug in Neuenheimer Straße 26a, zuletzt 1902 in Neuenheimer Landstraße 12 wohnhaft. - In dieser Zeit:

UH: 17 . Nov. 1860 Dr. phil.; 1865 Eigenstudien der chinesischen und ägyptischen Sprache; 8. Mai 1869 Habilitation für Altägyptische Sprachkunde; seit 18. Dez. 1872 a. o. Prof.; seit 10. Jan. 1885 HonorarProf.; Nov. 1891 Antrag E.s auf Genehmigung zur "Abhaltung eines kartographischen Lehrkurses“ im SS 1892 wird von Phil. Fak. und Engerem Senat abgelehnt, s. UAH RA 6428 fol. 1r; WS 1901/o2 ( $\dagger$ ) letzte Vorlesungsankündigung. • In dieser Zeit:

Studienreisen nach Ägypten: WS 1869/70, WS 1884/85, Jan.-März 1885; SS 1872 Studienreise in die Niederlande und nach Großbritannien, „um die dort befindlichen Sammlungen ägyptischer Alterthümer zu studiren“ (aus: Brief vom 6. Mai 1872 in: UAH PA 1510).

Qu UAH PA 1510; RA 6428; Fak.-Akten H-IV102/57 fol. 422r-428r, H-IV-102/76 fol. 105r-11or. Briefe: UBH.

W Der große Papyrus Harris ... Vortrag ... Leipzig 1872. Aus dem großen Papyrus Harris (3 T.) in: Zs. für ägyptische Sprache und Alterthumskunde (Mai/Juni 1873) S. 49-58, ebd. (Sept./Okt. 1873) S. 98-103, ebd. (Nov./Dez. 1873) S. 154-16o. • On the political condition of Egypt before the reign of Ramses III ... in: Transactions of the Society of Biblical Archaeology (1872) Vol. I, S. 355-384. • Ein altbabylonischer Felderplan. Leipzig 1896.
Übers. Ein mathematisches Handbuch der alten Ägypter. (Papyrus Rhind des British Museum.) 2 Bde. Leipzig 1877. Neudr. Walluf bei Wiesbaden 1972 .

MHG Corpus papyrorum Aegypti à Eugène Revillout et A. E. editum. 4 Fasz. Paris 1885-1902.

$L$ NDB 4 (1959) S. 417 (mit Werkverz.); WBIS. • Helck, Wolfgang, Otto, Eberhard: Kleines Lexikon der Ägyptologie ... 4. Aufl. Wiesbaden 1999. S. 220.

$P$ Bildarchiv UAH; graph. Slg. UBH; NDB.

\section{Eisenlohr, Friedrich}

1854-189o Phil. Fak.

1890-1904 Nat.-Math. Fak.

Mathematik, seit 1872 auch Physik

* 16. Juli 1831 Mannheim

$\dagger \quad$ 21. Juli 1904 Heidelberg ev.

V Dr. med. Ludwig Wilhelm E. (1786-1848) Arzt

M Auguste geb. Catoir (1803-1873)

(25. Juli 1857 Mathilde geb. Schlehner (18361859)

2. Mai 1878 Pauline geb. Schlehner (1839-1908)

K $\quad 1 \mathrm{~T}$

Vw Bruder: (siehe) August E.

Lb Seit WS 1849/50 Studium an UH, seit WS 1850/ 51 Göttingen; 21. Okt. 1852 Dr. phil. UH; WS 1852/ 53-WS 1853/54 Immatrikulation an U Berlin; zwischen 1853 und 1854 auch Eigenstudien in Gießen und Göttingen.

UH: 11. Dez. 1854 Habilitation; seit 3. Mai 1872 a. o. Prof., ca. Mai 1892-21. Juli 1904 (†) nichtetatm. a. o. Prof. auch für Physik.

$Z$ Am 12. März 1872 stellt der derzeitige Dekan der Heidelberger Phil. Fak., Bernhard Stark, an Engeren Senat den Antrag auf Verleihung der außerordentlichen Professur an E. mit der Begründung: „... Seine Vorlesungen behandelten bisher Mecha- 
nik, theoretische Optik, Methode der kleinsten Quadrate, Wahrscheinlichkeitsrechnung, Differential- und Integralrechnung, das Potential und daneben gab er [auch] Privatissima in dem bezeichneten Lehrbereich. Ist nun auch sein Lehrerfolg kein besonders glänzender zu nennen, seine Zuhörerzahl bewegt sich ... durchschnittlich zwischen drei und acht, wozu auch die Natur der vorgetragenen Fächer unmittelbar mit beigetragen hat, so ist derselbe ... bei seiner Tätigkeit ein anerkennswerter ..." (aus: UAH PA 1511). Knapp zwei Monate später erhält E. die beantragte Professur.

Seit 1875 Heidelberger Stadtrat

Siehe auch Julius Ruska

E 1896 Ritterkreuz I. Klasse mit Eichenlaub des Ordens vom Zähringer Löwen.

Qu UAH PA 1511; Fak.-Akten H-IV-102/48 Nr. XXXIV, H-IV-102/49 Nr. 41 fol. 194, H-IV-102/50 Nr. 1.21, H-IV-102/74 Nr. 61 fol. 296. GLA Abt. 76, Fasz. 1952.

$W$ Untersuchungen über Variations-Rechnung. Mannheim 1853.

$L$ Poggendorff 3 (1898) S. 402 (mit Werkverz.). Über F.E. in: Heffter, Lothar: Beglückte Rückschau auf neun Jahrzehnte: ein Professorenleben. Freiburg/Br. 1952. S. 35. NDB 4 (1959) S. 417; WBIS; Math. Institute in Deutschland (1989) S. 163, 166; Kern (1992) S. 8, 28 f. u. ö.; Deutsche Biographie, s. https://www.deutsche-biographie.de/gnd 137315945.html [06.11. 2017].

$P$ Bildarchiv UAH.

\section{Ellinger, Philipp}

1921-1932 Med. Fak.

Pharmakologie

* 18. Juni 1887 Frankfurt/M.

$\dagger$ 12. Sept. 1952 London

mosaisch

V Leo E. (1852-1916) Handelsmann, Mitbegründer der Metallgesellschaft AG in Frankfurt/M., Kommerzienrat, s. Bibliographie zur Geschichte der Frankfurter Juden 1781-1945. Bearb. von Hans-Otto Schembs. Frankfurt/M. 1978. S. 434.

M Emma geb. Ruben (1854-1927)

( 12. Sept. 1911 Elisabeth geb. Guttmann (18921983)

K $\quad 2 \mathrm{~S}, 1 \mathrm{~T}$

Vw Vetter: Alexander E. (1870-1923), u.a. 19141923 o. Prof. für Pharmakologie U Frankfurt/M., s. NDB 4 (1959) S. 457 f., Lindner/ Lüllmann (1996) S. 177 u. ö., Juden der Frankfurter U (1997) S. 84-86. - Neffe: Friedrich Philipp E. (1900-1962) seit 1932 Privat-Dozent für Radiologie Berlin, Emigration: 1936 Dänemark, 1938 USA, u. a. seit 1948 Direktor der Pharmazeutischen und Radiobiologischen Abt. am US Naval Medical Research Inst. in Bethesda (Maryland), s. WBIS.

Lb WS 1905/06, SS 1906 Studium der Medizin, Zoologie an U München, WS 1906/o7-SS 1909 Studium der Medizin, Chemie H, WS 1909/10-WS 1910/11 Studium der Chemie, Physik, Mineralogie Greifswald; 2. März 1911 Dr. phil. nat. U Greifswald.

UH: 1913 Staatsexamen; 23. Febr. 1914 Dr. med.; seit Okt. 1912 Volontärassistent, Okt. 1913-Febr. 1932 planm. Vollassistent am Pharmakolog. Inst.; 18. Nov. 1921 Habilitation; seit 11. Aug. 1925 nichtplanm. a. o. Prof.; kommissar. Direktor des Pharmakolog. Inst.: Nov. 1924-Dez. 1925 in Nachf. von Rudolf Gottlieb, Mai 1929-April 1930 in Nachf. von Hermann Wieland. • In dieser Zeit:

Aug. 1914-Dez. 1918 Kriegsdienst.

Med. Akademie Düsseldorf: 11. Febr. 1932 Ern. zum o. Prof. und Direktor des Pharmakolog. Inst.; 
Juni 1933 zwangsweise Beurlaubung; 1. Jan. 1934 Ruhestand ohne Gehalt (Amtsenthebung aus rassischen Gründen).

Großbritannien: Frühjahr 1934 Emigration; Forscher: seit 1934 Division of Nutrition, Lister Institute, Roebuck House in Cambridge und 19421952 Lister Inst. of Preventive Medicine in London; 1937-1938 Studienreise nach Ägypten; 1939 Erwerb der britischen Staatsangehörigkeit.

Med. Akademie Düsseldorf: 1. Juni 1950 Zuerkennung des Status e. o. Prof. und der Emeritierungsbezüge.

Qu UAH PA 893, 3654; RA 6204; Fak.-Akte HIII-111/158. • GLA Abt. 235, Fasz. 1924.

$W$ E., P., Hirt, August: Eine Methode zur Beobachtung lebender Organe mit stärksten Vergrößerungen im Lumineszenzlicht in: Handbuch der biologischen Arbeitsmethoden. Abt. 5, T. 2, H. 15, Lfg. 341. (o. J.) - Handbuch der experimentellen Pharmakologie. 2. Bd. 1. Hälfte. Berlin 1920. • Siehe Baden-Württ. Biographien V (2013) S. 89-93.

L Kürschner (1928/29) Sp. 461. Nachrufe in: The Lancet 2 (1952) Nr. 16, Nature 171 (1953) Nr. 4351. • Poggendorff 7a (1956) S. 496; WBIS; Lindner/Lüllmann (1996) S. 178 u. ö. (hier irrtümlich Geburtsjahr: 1888). Jakobs, Guido, Bayer, Karen: Vertriebene jüdische Hochschullehrer - Rückkehr erwünscht? in: Nach der Diktatur. Die Medizinische Akademie Düsseldorf vom Ende des Zweiten Weltkriegs bis in die 196oer Jahre. Hrsg. von Wolfgang Woelk u. a. Essen 2003. S. 115-137. • Löffelholz, K., Trendelenburg, U.: Verfolgte deutschsprachige Pharmakologen 1933-1945. 2. Aufl. Frechen 2008. S. 78. • Baden-Württ. Biographien V (2013) S. 89-93; Deutsche Biographie, s. https:// www.deutsche-biographie.de/gnd137315066.html [06.11. 2017].

$P$ Bildarchiv UAH.

\section{Elsenhans, Theodor Friedrich}

1902-1909 Phil. Fak.

Philosophie

* $\quad$ 07. März 1862 Stuttgart

$\dagger$ 03. Jan. 1918 Dresden

ev.

V August Friedrich E. (1827-1883) Prof. an Realanstalt Stuttgart

M Christiane Wilhelmine Pauline geb. Heß (1836-1888)

๑ 27. Aug. 1895 Bertha geb. Häberlein $\left({ }^{\star} 1877\right)$, s. Briefe in: Archiv des Verlages J.C.B. Mohr (Paul Siebeck), Tübingen. Signatur: Nachlaß 488, A 0381, 5, Bl. 231-237.

K $1 S(X 1916)$

Vw Onkel: Johann Michael E. (1803-1882) Pfarrer in Klosterreichenbach (heute: Ortsteil von Baiersbronn), 4. Jan. 1849 Gründer des Volksvereins ebd., daraufhin Enthebung seines Pfarramts als angeblicher Anstifter zum Aufruhr, Verurteilung zu knapp 2-jähriger Festungshaft, 1856 (Wiedereinsetzung)-1864 Pfarrer in Niederhofen (heute: Ortsteil von Schwaigern); Ernst E. (1815-1849 standrechtlich erschossen) Journalist, 1848/49 Teilnehmer der dt. Revolution, s. Schwäbische Lebensbilder ... Stuttgart 1957. Bd. VI. S. 350-366; WBIS; Back, Nikolaus: Revolution in Württemberg 1848/49. Schwaben im politischen Aufbruch. Karlsruhe 2014 .

Lb U Tübingen: Seit WS 1880/81 Studium der Philosophie, Theologie; 25. Febr. 1886 (Rigorosum) Dr. phil.

1885-1889 Vikar, u.a. in Wangen (heute: Stadtbezirk von Stuttgart), anschl. Repetent am Ev.Theol. Seminar in Maulbronn und Blaubeuren; Frühjahr 1885 1. theol., 1888 2. theol. Dienstprüfung in Tübingen.

Leutkirch (Allgäu): Seit 1890 Diakon; 1890 Studienreisen nach Norddeutschland, Großbritannien, Norwegen.

Riedlingen (Württemberg): Seit 1891 Stadtpfarrer. 
UH: 25. Okt. 1902 Habilitation für Philosophie; seit 21. Juli 1908 nichtetatm. a. o. Prof. In dieser Zeit:

H: 1902 Gründer e. Höheren Knabeninstituts.

TH Dresden: Seit 1. April 1909 o. Prof. für Philosophie, Pädagogik und Direktor des Pädagog. Seminars.

1.-5. September 1908 Generalsekretär des 3. Int. Kongresses für Philosophie in Heidelberg

Qu UAH PA 1514. - GLA Abt. 235, Fasz. 1922. • Briefe: UBH; Archiv des Verlages J.C.B. Mohr (Paul Siebeck), Tübingen. Signatur: Nachlaß 488, A 0326,3, Bl. 115-200 in: Staatsbibliothek zu Berlin.

$W$ Psychologie und Logik zur Einführung in die Philosophie. Leipzig 1890. 7. Aufl. 1936. Fries und Kant. 2 T. Gießen 1906. Charakterbildung. Leipzig 1908. 3. Aufl. 1920. Lehrbuch der Psychologie. Tübingen 1912. 3. Aufl. 1939.

L NDB 4 (1959) S. 464 (mit Werkverz.). - Herrmann, Joachim: Über T.E. Als Manuskript gedruckt in: Informationen der TU Dresden o2 (1989). - Professoren TU Dresden (2003) S. 187. • Stein, Edith: „Freiheit und Gnade“ und weitere Beiträge zu Phänomenologie und Ontologie (1917 bis 1937) ... Freiburg/Br. 2014. S. 300 ff.

\section{Elze, Curt}

1912-1921 Med. Fak.

Anatomie

* 16. Febr. 1885 Halle/S.

$\dagger$ 09. April 1972 Kassel

ev.

V Dr. theol. [!] Curt E. (1852-1937) Rechtsanwalt, Notar, 1934 Initiator der Dt. Anwalt- und Notarversicherung, s. hierzu http://www.danv. de/de/DANV/DANV/Elze-Hilfe; Gsänger, Johannes: Über C. E. in: Carl Wolpers - ein rheinischer Notar in: notar - Monatsschrift für die gesamte notarielle Praxis 1 (2011) S. 3-11, hier: S. 5-7 u. o.
M Lina geb. Frenkel (1857-1936)

(D) 23. Febr. 1916 Annemarie geb. Keil ( $\left.{ }^{*} 1892\right)$

K 2 T, 2 S: u. a. Martin E. $\left({ }^{\star} 1927\right)$, u. a. $1967-1976$ o. Prof. für Neues Testament und Kirchengeschichte Hamburg, 1976-1980 Pfarrer an Matthäuskirche Aschaffenburg, seit 1980 Honorar-Prof. U Würzburg, s. Kürschner (1983) S. 839; 500 Jahre Theologie in Hamburg: Hamburg als Zentrum christlicher Theologie ... Hrsg. von Johann Anselm Steiger. Berlin 2005. S. 441 u. ö.; Hamburger Professorinnen- und Professorenkatalog online, s. https://www.hpk. uni-hamburg.de/resolve/id/cph_person_oooo 1384 (abgerufen am 20. Aug. 2017)

Vw Bruder: Walter E. (1891-1979) Offizier, Jagdpilot, Lyriker, seit 1928 Privat-Dozent, seit 1929 Lehrbeauftragter, 1933-1945 (Amtsenthebung) o. Prof. für Geschichte und Kriegsgeschichte an Friedrich-Wilhelms-U Berlin, 1954 Anerkennung als Emeritus U Freiburg/Br., s. Vitzthum, Wolfgang Graf: Preusse im GeorgeKreis: W.E. in: Theorie und Geschichte der Wirtschaft. Festschrift für Bertram Schefold. Hrsg. von Volker Caspari. Marburg 2009. S. 331-357; Raulff, Ulrich: Kreis ohne Meister. Stefan Georges Nachleben. München 2012. S. 537 (Register); Reichherzer, Frank: „Alles ist Front!" Wehrwissenschaften in Deutschland und die Bellifizierung der Gesellschaft vom Ersten Weltkrieg bis in den Kalten Krieg. Paderborn 2012. S. 513 (Register).

Lb Seit SS 1903 Studium an U Freiburg/Br., anschl. Halle-Wittenberg; Dez. 1907 ärztl. Prüfung in Halle.

U Freiburg/Br.: Jan.-Dez. 1908 Praktikum an Med. U-Klinik und am Anatom. Inst.; 18. Dez. 1908 Dr. med.

U Wien: Seit Okt. 1909 Prosektor am Anatom. Inst.

UH: Seit Okt. 1912 Prosektor am Anatom. Inst.; 18. Dez. 1912 Habilitation; seit 24. Okt. 1918 nichtetatm., seit 1920 nichtplanm. a.o. Prof. - In dieser Zeit:

1914-1916 Kriegsdienst. 
U Gießen: Seit SS 1921 planm. a.o. (persönlicher o.) Prof.

U Rostock: Seit WS 1921/22 o. Prof. und Direktor des Anatom. Inst.

U Gießen: WS 1936/37-WS 1939/40 o. Prof.

U Würzburg: SS 1940-WS 1951/52 (Emeritierung) o. Prof. und Direktor des Anatom. Inst.; 1945 kurzzeitige Entlassung auf Befehl der amerik. Militärregierung, s. hierzu Elze, Curt: Ich über mich (1962) S. 586.

Qu UAH PA 894, 1515; RA 6169, 6173. GLA Abt. 235, Fasz. 1923. - Rektoratsreden online. Nachlaß: UB Würzburg. - Mitteilungen: Herr Prof. Dr. Martin Elze, Hamburg. • E., C.: Ich über mich in: Hippokrates - Wiss. Medizin und praktische Heilkunde im Fortschritt der Zeit (1962) 33. Jg., H. 1, S. 583-587.

$W$ Vergleichende funktionelle Pathologie. Radebeul 1929. Braus, Hermann und fortgeführt von E., C.: Anatomie des Menschen. 3. Bd. Berlin 1932. Bd. 1: 3. Aufl. 1954. Bd. 2: 3. Aufl. 1956. Bd. 3: 2. Aufl. 1960. Der Einfluß der Heidelberger Anatomen auf den Wandel der Anatomie in den letzten 100 Jahren. Berlin 1951. - Der menschliche Körper. Berlin 1966.

Bearb. Die Krankheiten der Speiseröhre und des äußeren Halses. München 1929.

MHG 1934-1968 Zs. für Anatomie und Entwicklungsgeschichte. 1934-1968 Ergebnisse der Anatomie und Entwicklungsgeschichte.

L Kürschner (1970) S. 584 (mit Werkverz.); WBIS. - Schmidt, W.: In memoriam C.E. in: Anatomischer Anzeiger (1976) 140(1-2) S. 1-8. Gießener Gelehrte (1982) S. 383 f., 1003; Voswinckel (2002) S. 368 f.; Buddrus/Fritzlar (2007) S. $122 \mathrm{f}$.; Medizinische Fakultät U Gießen (2007) S. 614 u. ö.; Grewolls (2011); Doll (2014) S. 274-277 u. ö.; Catalogus prof. Rostochiensium online.

$P$ Bildarchiv UAH.

\section{Endemann, Friedrich}

1904-1924 Jur. Fak.

Römisches und Dt. Bürgerliches Recht

* 24. Mai 1857 Fulda

$\dagger$ 31. Okt. 1936 Heidelberg ev.

V Wilhelm Samuel E. (1825-1899), u.a. o. Prof. für Handels- und Prozessrecht, Rechts- und Wirtschaftsgeschichte: seit 1862 Jena, 18751895 Bonn, s. NDB 4 (1959) S. 491 f.; Wirtschaft und Wirtschaftstheorien in Rechtsgeschichte und Philosophie. Hrsg. von Jean F. Kervégan ... Frankfurt/M. 2004. S. 163-185; Maus (2013) S. 458 (Register)

M Kathinka Anna Dominica geb. Pult (18341909)

( 27. Dez. 1888 Emilie Dorothea geb. Caspersen (1864-1918)

K $2 \mathrm{~S}$

Vw siehe Hofer (1993) S. 16 f.

Lb Seit WS 1877/78 Studium an U Jena, anschl. Bonn, Berlin, Bonn; 22. Mai 1880 Referendarexamen in Köln; 1880-1886 Referendar; 1. April 1882 Dr. iur. an U Bonn.

Berlin: Seit 13. Jan. 1886 Gerichts-Assessor; 1886 Zurückziehung der Habilitationsarbeit, siehe hierzu Hofer (1993) S. 20 f.; 17. Okt. 1886 Habilitation.

U Königsberg (Preußen): Seit 18. Okt. 1888 a.o. Prof.; seit 20. Aug. 1892 o. Prof.

U Halle-Wittenberg: 19. Juni 1895 Ern. zum o. Prof.

UH: 24. März 1904 Ern. zum o. Prof. als Nachf. von Otto Karlowa; 1918 E. ist bei der Errichtung der Heidelberger Orthopädischen Anstalt maßgeblich beteiligt (s. auch Ernst Walz und Hans Ritter von Baeyer), siehe hierzu Hofer (1993) S. 40; 31. März 1924 Emeritierung. • In dieser Zeit:

1914-1915 Kriegsdienst.

1917/18 Prorektor der UH; 1908/o9, 1915/16, 1920/21 Dekan der Jur. Fak. der UH 
1909 Mitglied der literarischen Sachverständigenkammer für Württemberg, Baden und Hessen

Neben Leo Koenigsberger und Wilhelm Windelband ist E. maßgeblich an der Gründung der Heidelberger Akademie der Wissenschaften 1909 beteiligt, siehe hierzu UAH Acc. 40/11, Hofer (1993) S. $40-43$.

1905 Geh. Hofrat; 1918 Geh. Rat II. Klasse

Siehe Johannes Rissom: Eintrag unter $Z$ [itat] (2) und Anhang Sporteinrichtungen an UH 1910-1933 und ihre Mitglieder

E 1909 Ehrenmitglied der Akademie der Wissenschaften H. 1924 Dr. med. h.c. UH. 1909 Ritterkreuz I. Klasse des Ordens vom Zähringer Löwen; 1910 Kommandeurkreuz des Königl. Belgischen Ordens Leopold II.

Qu UAH PA 748, 3635 f.; RA 5225, 5799, 6113, 6762, 7728; Fak.-Akte H-II-348/2. • GLA Abt. 235, Fasz. 1926. Briefe: UBH.

$W$ Rechtswirkungen der Ablehnung einer Operation. Berlin 1893. - Lehrbuch des bürgerlichen Rechts. 3 Bde. Berlin 1898-1899. 9. Aufl. 19031920. - Römisches Privatrecht. Berlin 1923. Bibliographie in: Hofer (1993) S. 168-178.

$L$ Handels-Hochschule Mannheim 1907-1932 (1932) S. 27. • Ulmer, Eugen: Gedächtnisrede auf F.E. Heidelberg 1938. (Heidelberger Universitätsreden. N.F. 3.) - NDB 4 (1959) S. 491 (mit Werkverz.); WBIS; Gesamtausgabe Gustav Radbruch 17 (1991) S. 455 (Register); Jansen (1992) S. 408 (Register); Ders. (1992a) S. 165 (Register). • Hofer, Sibylle: Zwischen Gesetzestreue und Juristenrecht - Die Zivilrechtslehre F.E.s. Baden-Baden 1993. Wennemuth (1994) S. 633 (Register); Kriegstagebuch K. Hampe (2007) S. 955 f. (Register); Schroeder (2010) S. 310-315 u. ö.; Tilitzki 1 (2012) S. 787 (Register).

$P$ Bildarchiv UAH; NDB.

\section{Enderlen, Eugen}

1918-1932 (1933) Med. Fak.

Chirurgie

* 21. Jan. 1863 Lehen (heute: Stadtteil von Salzburg)

$\dagger$ 07. Juni 1940 Stuttgart

口 Salzburg

ev.

V Karl Julius E. (1833-1916) Ingenieur, Direktor der Städtischen Gasfabrik

M Marie Wilhelmine geb. Sixt (1835-1912)

๑ 6. Dez. 1919 Friederike Sofie geb. Sandel (18631942)

$\mathrm{K}$ keine.

Lb Seit WS 1882/83 Studium an U München, anschl. Greifswald, Marburg.

Okt. 1884-März 1885, Okt. 1887-März 1888 Militärdienstpflicht als Einjährig-Freiwilliger.

U München: Juni 1887 Rigorosum, 23. Febr. 1888 (Datum der Promotionsurkunde) Dr. med.; 14. Juli 1887 Approbation; Assistent: seit Okt. 1887 am Bakteriolog. Inst., April 1888-Okt. 1891 am Patholog. Inst., Nov. 1891-Febr. 1894 an Chirurg. U-Klinik.

U Greifswald: Sept. 1894-Juli 1896 Assistent an Chirurg. U-Klinik; 26. Juni 1895 Habilitation.

U Marburg: Aug. 1896-Sept. 1904 Assistent sowie Okt. 1896-Sept. 1904 Sekundärarzt an Chirurg. UKlinik; seit 21. Okt. 1896 (Umhabilitierung) PrivatDozent; 11. Jan. 1899 Ern. zum a. o. Prof.

U Basel: 26. Sept. 1904 Ern. zum o. Prof. und Direktor der Chirurg. Klinik; WS 1904/05 Dienstantritt.

U Würzburg: 15. Febr. 1907 Ern. zum o. Prof. und Direktor der Chirurg. Klinik sowie Oberarzt der Chirurg. Abt. am Juliusspital in W.; SS 1907 Dienstantritt; 1911 Ruf an U Königsberg (Preußen) abgelehnt. • In dieser Zeit:

1914-1916 Kriegsdienst. 
UH: Seit 1. Okt. 1918 o. Prof. und (bis 31. März 1933) Direktor der Chirurg. U-Klinik als Nachf. von Max Wilms; 31. März 1932 Zurruhesetzung, seit 1. April 1933 endgültiger Ruhestand.

Stuttgart: Seit 1933 Wohnsitz.

1920/21 Dekan der Med. Fak. der UH

1925 Vorsitzender der Dt. Gesellschaft für Chirurgie

1911 Königl. Bayer. Geh. Hofrat; 1918 Badischer Geh. Hofrat

E Ehrenmitglied der Deutschen (1933), der Schweizer und Griechischen Gesellschaft für Chirurgie; Korr. Mitglied der Amerikanischen und Pariser Gesellschaft für Chirurgie.

Qu UAH PA 869, 3664; RA 6789. - GLA Abt. 235, Fasz. 1928. Briefe: UBH.

$W$ Transplantation von Gefäßen und Organen in: Dt. Zs. für Chirurgie 99 (1909). (Mitverf.) • Parabiose durch Gefäßnaht in: Beiträge zur klinischen Chirurgie 70 (1910). (Mitverf.) - Anatomie der Struma und Kropfoperation in: Zeitschrift für angewandte Anatomie 3 (1918). (Mitverf.) - Bibliographie in: Haubold (1969) S. 29-36.

$L$ Catalogus prof. Marburgensis 1 (1927) S. 200; NDB 4 (1959) S. 494f. (mit Werkverz.); WBIS. • E.E. ... Hrsg. von Werner Wachsmuth. Berlin u. a. 1963. Krebs/Schipperges (1968) S. 78-84, 124 u. ö. - Haubold, Burkhardt: E.E. Med. Diss. Heidelberg 1969. - Leier (1977) S. 31-34; Chronik Ärzte H (1985) S. 126, 218. • Linder, Fritz, Amberger, Mechthild: Chirurgie in Heidelberg in: Semper apertus 4 (1985) S. 200-203. Jansen (1992a) S. 165 (Register); Eckart (2000) S. 84f.; Peiffer (2004) S. 1143 (Register); Badische Biographien N.F. VI (2011) S. 90-95; Grewolls (2011).

$P$ Bildarchiv UAH; graph. Slg. UBH; NDB; Chronik Ärzte H.

\section{Engelhard, Felix Hermann Herbert}

1921-1945 Jur. Fak.

Strafrecht, Strafprozeßrecht

* 07. Mai 1882 Mannheim

$\dagger$ 19. Dez. 1945 Heidelberg ev.

V Emil E. (1854-1920) 1874-1908 Tapeten-Fabrikant, Geh. Kommerzienrat; 1909-1918 Mitglied der I. Kammer des badischen Landtags, 1911-1920 Präsident der Handelskammer Mannheim, s. WBIS, Badische Biographien N.F. I (1982) S. 107

M Helene Katharine Margareta geb. Grohe (18581919)

(26. Aug. 1922 Sybille Louisa Emma Fanny Ernestine geb. Berten (1888-1962)

K $1 \mathrm{~T}$

Lb Seit WS 1900/o1 Studium an U München, WS 1901/o2 H, seit SS 1902 Berlin, seit SS 1903 H; Frühjahr 1904 I. jur. Staatsprüfung in Karlsruhe.

Seit 3. Mai 1904 Rechtspraktikant in Mannheim; 13. April 1905 Dr. iur. an UH; Spätjahr 1909 II. jur. Staatsprüfung in Karlsruhe.

Gerichtsassessor: 17. Nov. 1909-1. Febr. 1914 (auf eigenen Antrag Entlassung aus badischem Staatsdienst) zunächst Mannheim, anschl. Bonndorf (Schwarzwald), Konstanz, zuletzt Freiburg/Br.; 1910/11 und 1913/14 Studienaufenthalt am Kriminalist. Inst. in Berlin.

1914-1918 Kriegsdienst (seit Ende Sept. 1915 in russischer Kriegsgefangenschaft; 1918 Flucht aus sibirischem Lager).

Mannheim: 1919-1925 Rechtsanwalt.

UH: 12. März 1921 Habilitation; WS 1921/22-WS 1922/23 Lehrauftrag an U Kiel (Vertreter des Lehrstuhl-Inhabers für Strafrecht (siehe) Gustav Radbruch); SS 1923-WS 1924/25 Lehrauftrag an U Frankfurt/M.; seit 21. Juni 1923 nichtplanm. a.o. Prof.; seit 15. April 1925 planm. a. o. Prof.; 1929 Ruf an U Prag abgelehnt; nur im Trimester 1941 von UH beurlaubt. 
E 1915 Kommandeurkreuz II. Klasse des Ordens vom Zähringer Löwen.

Qu UAH PA 749, 3667. - GLA Abt. 235, Fasz. 1930. - Über H.E. in: Gustav Radbruch: Briefe. Hrsg. von Erik Wolf. Göttingen 1968. Nr. 100, 156, 217. Mitteilungen: Frau Gertrud Durand-Engelhard.

$W$ Kann Betrug begangen werden durch Vorspiegelung einer gesetzeswidrigen oder unsittlichen Gegenleistung? Heidelberg 1905. D Das ChantageProblem im geltenden und künftigen deutschen Strafrecht in: Strafrechtliche Abhandlungen (1912) H. 151. - Die Ehre als Rechtsgut im Strafrecht. Mannheim 1921. Einführung in das Strafrecht an Hand von Rechtsfällen. Heidelberg 1946. 2. Aufl. u.d. T.: Strafrecht. Die Lehre vom Verbrechen an Hand von Rechtsfällen. Hrsg. von Gustav Radbruch. Heidelberg 1948.

L Kürschner (1940/41) Sp. 373. - Radbruch, Gustav: Nachruf in: Süddeutsche Juristenzeitung Jg. 1 (1946) Nr. 8/9. - WBIS; Jansen (1992a) S. 165 (Register); Schroeder (2010) S. 481-486 u. ö.; Deutsche Biographie, s. https://www.deutsche-biographie.de/gnd116488883.html [06.11. 2017].

$P$ Bildarchiv UAH.

\section{Erb, Carl August}

1814-1816 Jur. Fak. 1814-1816 Pandekten, Juristische Enzyklopädie und Methodologie 1816-1844 Phil. Fak. 1816-1844 Logik, Philosophie, Anthropologie, Psychologie, Physische Geographie, Biologie, Physiologie, Metaphysik, Mathematik, 1840-1844 Pandekten [!]

* o1. Febr. 1791 Heidelberg

$\dagger$ 05. Febr. 1873 Schwetzingen ref.

V (siehe) Ludwig E. (1743-1824)

M Louisa geb. Rittmann (1749-1791)

$\infty$ unverheiratet
Vw Neffe: (siehe) Wilhelm E. (1840-1921).

Lb Seit WS 1807/08 Studium an UH, seit 25. März 1812 Göttingen.

U Göttingen: 14. Sept. 1812 Dr. iur.; seit WS 1812/13 Privat-Dozent für Rechtswiss.

UH: 28. Febr. 1814 Annahme als Privat-Dozent an Jur. Fak. „nach gehöriger Habilitation“, aber die „Anzeige seiner Vorlesungen im Lections Catalog ist gleich zu gestatten“ (aus: Brief vom Ministerium des Innern vom 28. Febr. 1814 in: UAH PA 1518); seit 26. Mai 1814 a. o. Prof. für Rechtswiss. mit e. Jahresgehalt von 200.- Gulden; Okt. 1815 E.s Entlassungsgesuch „durch eine unglückliche Gemüthsstimmung [hervorgerufen als] ... Folge theils von seiner bisherigen Kränklichkeit, theils von unangenehmen häuslichen Vorfällen veranlasst, wird abgewiesen" (aus: Schreiben vom Akademischen Directorium vom 6. Nov. 1815 in: PA 1518); SS 1816 letzte Vorlesungsankündigung an Jur. Fak.; seit 24. Juni 1816 a. o. Prof. an Phil. Fak. mit e. jährlichen Gehaltszulage von 40o.- Gulden; seit 27. Okt. 1820 zweiter o. Prof. für Philosophie unter der Bedingung, „dass die Einführung desselben [als Ordinarius] bis zur völligen Herstellung seiner Gesundheit aufzuschieben und [er] ... bis dahin von der Theilnahme an den Geschäften der Facultät zu dispensiren sey" (aus: Brief vom Ministerium des Innern vom 28. Nov. 1830 in: PA 1518); WS 1832/33 Vorlesungsankündigungen u. a. über "Jus divinum und humanum, verglichen nach allen Zweigen der Rechts- und Staatswissenschaft; Cursorische Lectüre medicinischer und naturwissenschaftlicher Schriften in schwedischer, französischer, spanischer und portugiesischer Sprache"; WS 1840/41-SS 1844 Vorlesungsankündigungen u. a. über „Classische Prosodie der Zeitsylben und ihrer einzelnen Schlag- und Beilaute im Lateinischen und Griechischen; Pandekten [!]“; 25. April 1844 Pensionierung.

Bamberg: 1852 Gründer e. chrono-astronomischen Anstalt mit Sternwarte zur Durchführung „der Gleichzeitigkeit des bürgerlichen oder Kalendertages ohne Unterscheidung der geographischen Länge, gleichzeitigen Anfang, gleichzeitiges Ende, gleichbenannte Eintheilung in Stunden, Bestrebungen, die Zeit für ganze Länder zu reguliren“ 
(aus: Anonymus ... (1852), s. hierzu weiter ebd.); 1854 Verlegung des Wohnsitzes von $\mathrm{H}$ nach Bamberg.

E. ist bis 1844 Besitzer des 1719 von dem Theologen Johannes Christian Kirchmejer (siehe Drüll (1991) S. 84 f.) erbauten, heute noch bestehenden Barockgebäudes an der Ecke Grabengasse/Seminarstaße (heute: Restaurant und Hotel Romer). E. soll von der Galerie des Innenhofes Flugversuche unternommen haben, die ebenso misslangen wie seine Experimente, mit Schwimmschuhen den Neckar zu überqueren (aus: Hepp, Frieder: Kunstwerk des Monats: Karl Weysser (1833-1904): Alte Poststation mit Blick in die Seminarstraße, 1900, Öl/Leinwand - Kurpfälzisches Museum der Stadt Heidelberg. Redaktion: Ulrike Pecht ... Heidelberg 2012. Nr. 327). Seit 1844 wohnt Erb zunächst in der Heidelberger Seminarstraße (s. Adress-Kalender der Stadt Heidelberg für das Jahr 1844. Heidelberg 1844. S. 36) und von 1846 bis zu seinem Weggang 1854 in der Klingentorstraße (s. Adreß-Kalender sämmtlicher Bewohner der Stadt Heidelberg für 1846. Heidelberg 1846. S. 40).

Qu UAH PA 1518; RA 6612, 6761. • GLA Abt. 205, Fasz. 219. - Matrikel Göttingen 1 (1937) S. 515. • Briefe: UBH.

W Zur Mathematik und Logik. Heidelberg 1821. • Forschungen über Geschlechts-Natur. Heidelberg 1824. Mittheilung eines ersten Entwurfes zu einer aero- und hydrodynamischen Gesellschaft, oder Gesellschaft für Luft und Wasser nach meinen Erfindungen. Heidelberg 1824.

L Wechmar (1846) S. 251; WBIS. • Anonymus: Bestrebungen, die Zeit für ganze Länder zu reguliren in: Polytechnisches Journal (1852) Bd. 126, Miszelle 2, S. 236 f. Catalogus prof. Gottingensium (1962) S. 66; Schroeder (2010) S. $120 \mathrm{f}$.

\section{Erb, Johann Ludwig}

1787-1791 Phil. Fak.

1787-1791 Finanz- und Staatswirtschaft, 1787-1791

Polizeiwissenschaft

1812 Staatswirtschaftl. Sektion

1812-1822 (Honorar-Prof.) Staatswirtschaftl. Sek-

tion

1822 (Honorar-Prof.) Phil. Fak.

1812-1822 Polizeiwissenschaft

* 03. Mai 1743 Wiesloch (Baden)

$\dagger \quad$ 25. Juni 1824 Heidelberg

ev.

V Johann Ludwig E. $\left({ }^{*} 1703\right)$ Schulmeister

M Maria Elisabetha geb. N.N.

¿ Louisa geb. Rittmann (1749-1791)

๑ 24. Mai 1796 Elisabetha Friderike Conradina geb. Rittmann ( ${ }^{*} 1770 \dagger$ vor 1840$)$

K 4 T, 5 S: u.a. (siehe) Carl August E.

Vw Enkel: (siehe) Wilhelm E.

Lb WS 1760/61 Studium der Theologie an UH, seit 1761 Utrecht; seit 1763 Hofmeister in Den Haag; vor 1767 Forts. des Studiums an U Utrecht; 1767 Immatrikulation an U Leipzig als Hofmeister von Johann Graf von Meermann (1753-1816), 1769 an U Göttingen zum Studium der Rechtswiss.; 1774 Dr. iur. an U Leiden; 1774-1776 Begleiter Meermanns auf Reisen durch England, Schottland, Frankreich, Italien, Schweiz, Süddeutschland.

U Leiden: 1777-1780 Privat-Vorlesungen über Rechtskunde und Geometrie; 1778 Ruf an U Groningen abgelehnt.

1780-1783 Lehrer/Begleiter der Prinzen zu SolmsHohensolms-Lich; 1784 Ern. zum Hofrat des Herzogtums Pfalz-Zweibrücken.

UH: 28. Sept. 1784 E. lehnt Lehrstuhl für Schöne Wissenschaften als Nachf. von Johannes Carl Casimir Wundt (s. Drüll (1991) S. 174-178) ab, da er auf die „höchstungewöhnliche und erniedrigende Bedingung einer vorläufigen Prüfung “, die mit der Vergabe der Lektur verbunden ist, „zur Erfüllung deroselben Antragens herabzulassen " nicht gewillt ist; Professur erhält Jacob Johann Fauth (aus: UAH PA 1519). 
Staatswirtschafts Hohe Schule H und Phil. Fak. der UH: 1786 Annahme des Rufes an Staatswirtschafts Hohe Schule, die mit Phil. Fak. der U personell verbunden ist; Frühjahr 1787-WS 1790/91 (Niederlegung der Professur aus gesundheitlichen Gründen) a. o. Prof. als Nachf. von Ludwig Benjamin Martin Schmidt (siehe Drüll (1991) S. 135).

H: 1791-1812 Privat-Gelehrter.

UH: Seit 24. Febr. 1812 Privat-Dozent für Polizeiwiss. an Staatswirtschaftl. Sektion (Mai 1803 Einführung der Staatswirtschaftl. Sektion nach Eingliederung der "Staatswirtschafts Hohe Schule“ $\mathrm{H}$ in UH); 23. Juli 1812 Bestellung zum HonorarProf.; SS 1822 letzte Vorlesungsankündigung; Mai 1822 Zusammenlegung der Staatswirtschaftl. Sektion mit Phil. Fak.

Mannheim (?): 1791-1803 (?) Pfarrer/Prediger (?).

Zur Staatswirtschaftl. Sektion der UH, siehe Heinrich Eschenmayer und Ludwig Wallrad Medicus: Einträge unter $Z$ [itat]

E 1787 o. Mitglied der Kurpfälzischen Physikalisch-Ökonomischen Gesellschaft; 1803 Mitglied der Batavischen Gesellschaft der Wissenschaften zu Haarlem. 1786 Dr. phil. h. c. UH.

Qu UAH PA 1519. GLA Abt. 205, Fasz. 139, 216218. - Auskunft: Ev. Oberkirchenrat - Landeskirchliches Archiv - Karlsruhe.

W Fürst und Volk einander näher geführt durch Gerechtigkeit. Mannheim 1799. - Unterwerfung unter Gottes weise Regierung in Zeiten der Noth. Heidelberg 1817. Die allgemeine Wasser-Noth. Aufruf an die verschonten Einwohner Badens zur Wohltätigkeit. Heidelberg 1824.

L Schneider (1913) S. 333 f., 338; Baumgarten (1997) S. 94, 97; WBIS.

\section{Erb, Wilhelm Heinrich}

1865-1880, 1883-1907 Med. Fak.

Pathologie, Therapie

* 30. Nov. 1840 Winnweiler (Pfalz)

$\dagger \quad$ 29. Okt. 1921 Heidelberg

ev.

V Friedrich E. (1797-1868) Forstmeister, Sohn von: (siehe) Ludwig E.

M Sophie geb. Hof(f)meister (1803-1895)

œ 1870 Bertha Karoline geb. Her(r)mann (18481873)

๑ 28. März 1876 Anna Auguste Wilhelmine geb. Gass (1855-1928) T von: (siehe) Wilhelm G.

$\mathrm{K} \quad 4 \mathrm{~S}(1 \mathrm{~S} \times 1914,1 \mathrm{~S}$ in jüngeren Jahren $\dagger)$, s. Badische Biographien N. F. VI (2011) S. 99

Vw Onkel: (siehe) Carl August E.

Lb Studium: WS 1857/58, WS 1858/59-WS 1860/61 UH, SS 1858 Erlangen, SS 1861-SS 1862 München.

U München: 1861-1862 Assistent am Patholog. Inst.; 1862 med. Examen; 27. Okt. 1864 Dr. med.

UH: Seit Okt. 1862 Assistent an Med. U-Klinik; 18. Nov. 1865 Habilitation für Pathologie; seit 25. Febr. 1869 a. o. Prof.

U Leipzig: Seit 1. April 1880 o. Prof. für Spezielle Pathologie und Therapie und Direktor der Med. Poliklinik, s. Steinberg, H., Wagner, A.: W.E.'s years in Leipzig (1880-1883) and their impact on the history of neurology in: European Neurology 70 (2013) S. 267-275.

UH: 27. Sept. 1882 Ern. zum o. Prof. für Pathologie und Therapie und Direktor der Med. U-Klinik als Nachf. von Nikolaus Friedreich; April 1883 Dienstantritt; 1. April 1907 Ruhestand; 1908 (mit Siegfried Bettmann als Direktor) Mitbegründer der UHaut- und Hautpoliklinik. • In dieser Zeit:

H: 1883-ca. 1915 Internist in Privatpraxis.

1893 Prorektor der UH; 189o/91, 1900/o1 Dekan der Med. Fak. der UH 
1876 Mitbegründer der Wanderversammlung Südwestdeutscher Neurologen und Psychiater

1891-1915 Heidelberger Stadtverordneter

1907 Mitbegründer und 1. Vorsitzender der Gesellschaft Dt. Nervenärzte, s. hierzu Rüdel, Reinhardt: W.E., Gründer und erster Vorsitzender der Gesellschaft Dt. Nervenärzte in: Fortschritte der Neurologie - Psychiatrie. Sonderheft 1, 69. Jg. (Aug. 2001) S. S11-S17.

Entdecker der Sehnenreflexe, Erforscher der Krankheiten des peripheren Nervensystems und des Rückenmarks, Mitbegründer der Elektrotherapie und Begründer der modernen Neurologie

1885 Erbauer der am Heidelberger Adenauer Platz 2 stehenden Villa, s. hierzu „Vergoldete Leisten wurden einfach übermalt": Als Leferenzvilla bekannt - Von Prof. Erb erbaut - ... in: RNZ vom 8. Aug. 1996, Nr. 182, S. 5.

1886 Hofrat; 1888 Geh. Hofrat; 1893 Geh. Rat II. Klasse; 1907 Wirkl. Geh. Rat (Exzellenz)

E 1887 Mitglied der Dt. Akademie der Naturforscher Leopoldina Halle/S.; 1901 Korr. Mitglied des Vereins für Innere Medizin Berlin; 1909 Mitglied der Akademie der Wissenschaften H; Ehrenmitglied: 1902 Gesellschaft der Irrenärzte und Neurologen von Kasan, 1902 Clinical Society of London, 1904 New York Academy of Medicine. 1894 Verdunpreis. 1888 Ritterkreuz I. Klasse mit Eichenlaub des Ordens vom Zähringer Löwen; 1893 Komturkreuz II. Klasse des Herzogl. Sachsen-Ernestinischen Hausordens.

Qu UAH PA 898, 1520; RA 5140, 6804. GLA Abt. 235, Fasz. 1936. - Briefe: UBH. - E.s Privatarchiv im Universitätsarchiv Leipzig. $\bullet$ Siehe auch Archiv der Dt. Akademie der Naturforscher Leopoldina Halle/S.

W Zur Pathologie und pathologischen Anatomie peripherischer Paralysen in: Dt. Archiv für klinische Medizin 4 (1867), 5 (1868). Handbuch der Krankheiten der peripheren cerebrospinalen Nerven. Leipzig 1874. 2. Aufl. 1878. Handbuch der
Elektrotherapie. Leipzig 1882. 2. Aufl. 1886. Über die wachsende Nervosität unserer Zeit. Heidelberg 1894.

MG, MHG 1891 Deutsche Zeitschrift für Nervenheilkunde.

L NDB 4 (1959) S. 562. - Doerr, Wilhelm: W.E. zum Gedächtnis in: Heidelberger Jahrbücher 10 (1966) S. 22-28; Vogel, Paul: Die Heidelberger neurologische Schule. Friedreich - Erb - Hoffmann in: ebd. 14 (1970) S. 77-81. Hoche (1969) S. 87f. u. ö.; WBIS; Chronik Ärzte H (1985) S. 126, 219 f. Bryan, Bettina: W.E. ... und seine elektrotherapeutische Station an der Medizinischen Klinik in Heidelberg in: Schriftenreihe der Dt. Gesellschaft für Geschichte der Nervenheilkunde. Hrsg. von K.A. Bushe [!] ... Bd. 1. Würzburg 1996. • Meinck (2004) S. 26-28; Peiffer (2004) S. 1144 (Register). - Kühlmann, Wilhelm: „Nervosität“ als Epochensyndrom. Zur Pathographie und Therapie der "Moderne“ in einer Heidelberger Rede (1893) des Neurologen W.E. in: Figurationen der literarischen Moderne ... Heidelberg 2007. S. 191201. Sarikcioglu, Levent and Arican, Ramazan Yavuz: W.H.E. ... and his contributions to neuroscience in: Journal of Neurology, Neurosurgery and Psychiatry (Juli 2007) 78(7), S. 732. Ruuskanen (2008) S. 65 f. Personenlexikon der Sexualforschung. Hrsg. von Volkmar Sigusch und Günter Grau. Frankfurt/M. 2009. S. 147. Professorenkatalog Leipzig online; Badische Biographien N. F. VI (2011) S. 99-103. • Eckardt, Wolfgang U.: Illustrierte Geschichte der Medizin: Von der französischen Revolution bis zur Gegenwart. Berlin 2011. S. 173176. Averbeck, Hubertus: Von der Kaltwasserkur bis zur physikalischen Therapie ... Bremen 2012. S. 119, 267, 689 u. ö. Eckart, Wolfgang U.: Nervöse Zeiten - W.E. und „sein“ Zeitalter der Neurasthenie im Kontext in: Psyche im Fokus (2014) Ausg. 2, S. 33-36. - Wagner, A., Steinberg, H.: W.E. ... in: Neurologie an der Universität Leipzig. Beiträge zur Entwicklung des klinischen Fachgebietes von 1880 bis 1985 . Hrsg. von A. Wagner und H. Steinberg. Leipzig 2015. S. 70-106.

$P$ Bildarchiv UAH; graph. Slg. UBH; NDB; Heidelberger Jahrbücher (1966); Chronik Ärzte H. 


\section{Erdmannsdörffer, Bernhard}

1874-1901 Phil. Fak.

Geschichte

* 24. Jan. 1833 Altenburg (Thüringen)

$\dagger \quad$ o1. März 1901 Heidelberg

ev.

V Friedrich Eduard E. (1797-1873) Kauf- und Handelsherr

M Marianne Sophie geb. Zinkeisen (180o-1839)

$\varnothing$ 28. Aug. 1874 Anna Maria Sophia geb. Lenz (1854-1892), s. Aly (2011) S. 182, 316

๑) nach 1892 Antonie geb. Lenz (1836-1917)

K 1 S: (siehe) Otto E. (1876-1955). 4 T: u. a. Friederike (Frieda) Johanna E. (1879-1963) Gesangslehrerin, s. Kriegstagebuch K. Hampe (2007) S. 900; Hannah E. (†1910) Malerin und Sophie E., 1. und 2. Ehefrau von Heinrich Lilienfein (1879-1952) Schriftsteller, s. NDB 14 (1985) S. $556 \mathrm{f}$.

Vw Bruder: Adolph E. (1845 im Stoßdegen-Duell erstochen), siehe Thieme, Friedrich: Das Studentengrab [A.E.s] in Wöllnitz in: Altes und Neues aus der Heimat - Beilage zum Jenaer Volksblatt (1934-1936) 6. Folge, S. 135 f.

Lb U Jena: Seit SS 1852 Studium der Philologie, Geschichte, Philosophie; 13. April 1855 Dr. phil.

Seit 1857 Hauslehrer zunächst in Ostpreußen, dann in Venedig (hier auch Eigenstudien).

U Jena: 12. Juni 1858 Zulassung zum Examen pro magisterio und pro venia legendi (Habilitation) für Geschichte; 23. Juni 1858 Dispens von Staatsprüfung; 25. Okt. 1858 Probevorlesung zum Thema: Über den Interdictstreit zwischen Papst Paul V. und der Republik Venedig im Jahr 1605; 26. Okt. 1858 Magisterdiplom.

München: Seit Herbst 1859 Hilfsarbeiter bei Histor. Kommission; 1859/6o Aufenthalt in Italien.

U Berlin: 1861 Umhabilitation; seit 1863 außerdem Dozent für Geschichte an Kriegsakademie in B.; 1869 Ruf an U Dorpat abgelehnt; seit 13. Sept. 1869 a. o. Prof.
U Greifswald: 27. Dez. 1870 Ern. zum o. Prof. für Neuere Geschichte.

U Breslau: Seit 29. Juli 1873 o. Prof.

UH: Seit 25. Jan. 1874 o. Prof. als Nachf. von Heinrich von Treitschke; WS 1889/9o (Etatisierung des Seminars)-WS 1895/96 Mit-Direktor (zus. mit Eduard Winkelmann), SS 1896 Direktor, seit WS 1896/97 Mit-Direktor (zus. mit Dietrich Schäfer) des Histor. Seminars.

1884/85 Prorektor der UH; 1878/79, 1891/92 Dekan der Phil. Fak. der UH

1886 Hofrat; 1892 Geh. Hofrat

E Mitglied: Badische Histor. Kommission Karlsruhe, Histor. Kommission München, 1897 Akademie der Wissenschaften Berlin und München. • 1894 Verdun-Preis. 1899 Kommandeurkreuz II. Klasse des Ordens vom Zähringer Löwen.

Qu UAH PA 1521; RA 6847. - Rektoratsreden online. Briefe: UBH. - Nachlaß: Bundesarchiv Berlin. Im Schaffen genießen. Der Briefwechsel der Kulturwissenschaftler Eberhard und Marie Luise Gothein [u. a. mit B.E.]. Hrsg. von Michael Maurer ... Köln 2006. S. 672 (Register). • Wilhelm Dilthey: Briefwechsel 1852-1882 [u.a. mit B.E.]. Hrsg. von Gudrun Kühne-Bertram ... Bd. 1. Göttingen 2011. S. 327 f. u. ö. • Auskunft: Universitätsarchiv Jena. - Mitteilungen von Familienangehörigen.

W Graf Georg Friedrich von Waldeck. Berlin 1869. Nachdr. Charleston (South Carolina) 2012. • Politische Korrespondenz Karl Friedrichs von Baden 1783-1806. 5 Bde. Heidelberg 1888-1901. • Deutsche Geschichte vom Westfälischen Frieden bis zum Regierungsantritt Friedrichs des Großen. 2 Bde. Berlin 1892-1893. Neudr. 1932. Nachdr. Paderborn 2013. Mirabeau. Leipzig 1900. Kleinere historische Schriften. Mit e. biogr. Geleitwort hrsg. von Heinrich Lilienfein. Berlin 1912.

MHG 1864-1884 Urkunden und Actenstücke zur Geschichte des Kurfürsten Friedrich Wilhelm von Brandenburg. 
$L$ NDB 4 (1959) S. 574 f. (mit Werkverz.); Weber (1987) S. 134 f.; Giesselmann (1992) S. 86-9o u. ö. - Wolgast, Eike: Die Sicht des Alten Reiches bei Treitschke und E. in: Imperium Romanum ... Hrsg. von Matthias Schnettger. Mainz 2002. S. 169188. Aly, Götz: Warum die Deutschen? Warum die Juden? Gleichheit, Neid und Rassenhass 180o1933. Frankfurt/M. 2. Aufl. 2011. S. 182 f., 316. $\bullet$ Grewolls (2011); WBIS; Kaesler (2014) S. 998 (Register).

$P$ Bildarchiv UAH; graph. Slg. UBH.

\section{Erdmannsdörffer, Otto Heinrich}

1926-1949 Nat.-Math. Fak.

Mineralogie, Petrographie

* 11. März 1876 Heidelberg

$\dagger$ 18. April 1955 Heidelberg

ev.

V (siehe) Bernhard E.

M Anna Maria Sophia geb. Lenz (1854-1892), s. Aly, Götz: Warum die Deutschen? Warum die Juden? Gleichheit, Neid und Rassenhass 180o1933. Frankfurt/M. 2. Aufl. 2011. S. 182, 316.

( 23. Sept. 1909 Margot Lucia Klara Albertine geb. Pistor (1887-1954)

K $\quad 2 \mathrm{~T}$

Lb Seit WS 1895/96 Studium an UH, seit SS 1897 Straßburg; 23. April 1901 Dr. phil. nat. an UH.

TH Berlin-Charlottenburg: Okt. 1900-Febr. 1901 Assistent am Mineralogisch-Geologischen Inst.

Berlin: Seit 1. April 1901 Hilfsgeologe, seit 1. Juni 1911 Bezirksgeologe an Preußischer Geologischer Landesanstalt. • In dieser Zeit:

U Berlin: 25. Juli 1908 Habilitation; 1908-1912 Privat-Dozent.

TH Hannover: Seit 27. April 1912 a. o. Prof.; seit WS 1912/13 o. Prof. für Mineralogie und Geologie. • In dieser Zeit:
19. Juli 1915-18. Nov. 1918 Kriegsdienst.

UH: Seit SS 1926 o. Prof. und Direktor des Mineralogisch-Petrographischen Inst. als Nachf. von Ernst Wülfing; 1. April 1949 Emeritierung.

1932 Rektor der UH; 1927/28, 1933/34, 1934/35 Dekan, Mai-Sept. 1946 stellvertr. Dekan der Nat.Math. Fak. der UH

Siehe auch Anhang Sporteinrichtungen an $\mathrm{UH}$ 1910-1933 und ihre Mitglieder

E 1940 Mitglied der Dt. Akademie der Naturforscher Leopoldina Halle/S.; Mitglied der Akademie der Wissenschaften: 1925 Göttingen, 1926 H; 1937 Ehrenmitglied der Royal Geological Society of Cornwall. 1953 Hans Stille-Medaille der Dt. Geologischen Gesellschaft.

Qu UAH PA 3685; RA 6847; Rep. 40-393; Fak.-Akte H-IV-102/131. GLA Abt. 235, Fasz. 1939. • Siehe auch Archiv der Dt. Akademie der Naturforscher Leopoldina Halle/S.

W Grundlagen der Petrographie. Stuttgart 1924. • Die Rolle der Anatexis in: Sitzungsberichte der Heidelberger Akademie der Wissenschaften. Math.Naturwiss. Klasse (1939). - Die Diorite des Bergsträsser Odenwaldes in: Heidelberger Beiträge zur Mineralogie und Petrographie I (1947); Magmatische und metasomatische Prozesse in Graniten in: ebd. I (1948).

HG 1947-1955 Heidelberger Beiträge zur Mineralogie und Petrographie.

MHG 1948-1955 Mineralogie und Petrographie in Einzeldarstellungen.

L Kürschner (1940/41) Sp. 379, (1950) Sp. 424. • Hoenes, Dieter: O.H.E. in memoriam in: Contributions to Mineralogy and Petrology Vol. 4, Nr. 5 (Sept. 1954) S. I-XI. - Lehrkörper TH Hannover (1956) S. 52; WBIS; Badische Biographien N. F. II (1987) S. 79 f.; Jansen (1992) S. 408 (Register); Ders. (1992a) S. 165 (Register); Wennemuth (1994) S. 633 (Register); Wagenbreth (1999) S. 96, 153, 181; 
Deutsche Biographie, s. https://www.deutsche-bio graphie.de/gnd116531444.html [06.11. 2017].

$P$ Bildarchiv UAH; graph. Slg. UBH; Lehrkörper TH Hannover; Badische Biographien.

\section{Erhard, Johann Simon}

siehe Erhardt

\section{Erhardt, Johann Simon}

1823-1829 Phil. Fak.

Philosophie

* 30. März 1776 Ulm

$\dagger$ 22. Juni 1829 Heidelberg

ev.

V Johann Ulrich E. (1745-1821) Schuhmacher

M Agnesia geb. Nusser (1743-1804)

( 30. März 1812 Wilhelmina geb. Freiin von Racknitz (1793-1876)

K $\quad 4 \mathrm{~S}, 1 \mathrm{~T}$

Lb SS 1803 Studium der Theologie an U Tübingen, seit 20. Okt. 1803 Altdorf, seit 16. April 1804 Würzburg („der Theologie Beflissener"); phil. Magisterexamen.

Nach 1804 Privat-Lehrer in Haunsheim, dann München; seit Jan. 1809 Lehrer an Studienschule in Schweinfurt; seit Febr. 1810 Oberprimär-(Gymnasial-)Lehrer in Ansbach; seit 1811 Prof. für Philosophie am Realinstitut in Nürnberg.

U Erlangen: Seit 22. März 1817 Privat-Dozent.

U Freiburg/Br.: 26. Aug. 1817 Ern. zum o. Prof.

UH: 3. Okt. 1822 Ern. zum o. Prof. als Nachf. von Joseph Hillebrand; 23. April 1823 Beginn der Gehaltszahlung.
1827/28 Prorektor der UH; 1826 Dekan der Phil. Fak. der UH

1821 Hofrat

Qu UAH PA 1522. - GLA Abt. 205, Fasz. 220221. Matrikel Würzburg (1980) S. 864.

$W$ Vorlesungen über die Theologie und das Studium derselben. Erlangen 1810. - Philosophische Encyclopädie, oder System der gesammten wiss. Erkenntnisse. Freiburg 1818. Grundlage der Ethik. Freiburg 1821. Einleitung in das Studium der gesammten Philosophie. Heidelberg 1824.

$L$ Weyermann, Albrecht: Neue Nachrichten von Gelehrten und Künstlern aus Ulm. Ulm 1829. S. 86 f. ADB 6 (1877) S. 201; Willett (2001) S. 56; Professoren Erlangen (2009) S. 44; WBIS.

\section{Erlanger, Raphael Slidell Freiherr von}

1893-1897 Nat.-Math. Fak.

Zoologie

* 23. Juli 1865 Paris

$\dagger \quad$ 29. Nov. 1897 Heidelberg

ㅁ Frankfurt/M.

kath.

V Emil Frhr. von E. (1832-1911) Bankier, s. Mendelssohn, Gabriele: Die Familie Erlanger. Bankiers, Mäzene, Künstler ... Ingelheim 2005.

M Mathilde geb. Slidell (1842-1927) T von John S. (1793-1871) amerik. Politiker und Geschäftsmann, s. Dictionary of Louisiana Biography 2 (1988) S. $746 \mathrm{f}$.

$\infty$ 18. Nov. 1894 Mary Charlotte Frances Roslyne geb. Blennerhassett (1876-1963), s. Howell, P. A.: Galway, Mary ... in: Australian Dictionary of Biography 14 (1996). - $1913 \varnothing$ Sir Henry Lionel Galway (1859-1949) Gouverneur von Kolonien in Nigeria, Gambia u.a., s. Gailey, Harry A.: Historical Dictionary of the Gambia. Lanham (Maryland) 1999.

$\mathrm{K} \quad 1 \mathrm{~S}, 1 \mathrm{~T}$ 
Vw siehe NDB 4 (1959) S. 593* (Artikel: Erlanger, Raphael Frhr. von (1806-1878)).

$\mathrm{Lb}$ Seit WS 1886/87 Studium der Medizin an U Bonn, seit SS 1887 auch Studium der Zoologie, Botanik, Physik, Chemie H, SS 1888 Bonn, WS 1888/ 89 Berlin, seit SS 1889 H; 3. März 1891 Dr. phil. nat. an UH; Forts. des Studiums: SS 1891 Zoolog. Inst. H, Jan.-Juli 1892 Zoolog. Station Neapel.

UH: 3. März 1893 Habilitation; SS 1893-SS 1894 Forschungsaufenthalt an Zoolog. Station in Neapel; seit 23. April 1897 a. o. Prof.

1903-1905: Familie von Erlanger unterstützt finanziell den Bau der Pfarrkirche St. Raphael in Heidelberg-Neuenheim zum Gedenken an R. Frhr. von E.

\section{Qu UAH PA 1523. GLA Abt. 76, Fasz. 9912.}

$W$ Beiträge zur Morphologie der Tardigraden. T. 1: Zur Embryologie eines Tardigraden: Macrobiotus macronyx Dujardin in: Morphologisches Jahrbuch 22 (1895) S. 491-513. Mit zwei separaten Farbtafeln. - Zur sog. japanischen Aufklebemethode in: Zs. für wiss. Mikroskopie und für mikroskopische Technik 12 (1895) S. 186 f. - Die neuesten Ansichten über die Zellteilung und ihre Mechanik in: Zoolog. Centralblatt III. Jg., Nr. 2 (1896). • Über den sog. Nebenkern in den männlichen Geschlechtszellen der Insekten in: Zoolog. Anzeiger 496 (1896). Bibliographie in: Jungbluth (2011) S. 169-172.

L ADB 48 (1904) S. 397; Badische Biographien 5 (1906) S. 908; WBIS; Jansen (1992a) S. 165 (Register). Mendelssohn, Gabriele: Die Familie Erlanger. Bankiers - Mäzene - Künstler ... Ingelheim 2005. S. 86 f. u. o. $\bullet$ Mach, Martin: Baron R.S. von E. und die Bärtierchen-Schwanzplatte in: Das Bärtierchen-Journal Nr. 82 (April 2007) online, s. http://www.baertierchen.de/apr2007.html (Ausdruck im UAH). • Jungbluth, Jürgen H.: Raphael Slidell Frhr. von E. ... in: Carolinea. Beiträge zur naturkundlichen Forschung in Südwestdeutschland ... Bd. 69. Karlsruhe 2011. S. 165-173.

$P$ Bildarchiv UAH.

\section{Erlenmeyer, Richard August Carl Emil}

1857-1868 Phil. Fak.

Chemie

* 28. Juni 1825 Wehen (bei Wiesbaden; heute: Stadtteil von Taunusstein)

$\dagger$ 22. Jan. 1909 Aschaffenburg

口 Heidelberg

ev.

V Dr. Johann Friedrich Albrecht E. (1794-1856) Stadtpfarrer, Dekan

M Maria Elisabeth geb. Hanekroth (1794-1864)

$\infty$ 2. Sept. 1850 Auguste Sophia geb. Hengstenberg (1830-1897)

K 1 T: Maria E. (1859-1941) Ehefrau von Hermann Dingler (1846-1935), u. a. 1889-1910 o. Prof. für Botanik an Forstlicher Hochschule Aschaffenburg, s. Möbius, Martin: Nachruf in: Berichte der Dt. Botanischen Gesellschaft, Sonderdruck, 54,2 (1936) S. 122-139; WBIS, NDB 3 (1957) S. 729. 1 S: Emil E. (1864-1921), u. a. Prof. für Chemie: seit 1893 U Straßburg, 1907-1921 Kaiserlich-Biologische Anstalt Berlin-Dahlem, s. Lepsius, B.: Nachruf in: Berichte der dt. chemischen Gesellschaft 54 (5) (1921) S. A107-A113; WBIS; NDB 4 (1959) S. 594*

Vw Neffe: Dr. med. Albrecht E. (1849-1926) leitender Direktor an den von seinem Vater (und Bruder von Emil E.) Adolph E. (1822-1877) 1848 gegründeten Erlenmeyer'schen Anstalten für Gemüts- und Nervenkranke in Bendorf, s. NDB 4 (1959) S. 594, WBIS; Schmitt, Robert: A.E. - ein Lebensbild in: Heimatkalender für den Landkreis Koblenz (1963) S. 69 f.

Vw Enkel: Hugo Dingler (1881-1954) (S von Hermann D. (1846-1935) siehe oben), u.a. seit 1920 a. o. Prof. U München, 1932-1934 (Emeritierung) o. Prof. für Philosophie TH Darmstadt, 1934-1936, 1940-1945 (Suspendierung) Lehrbeauftragter an Math.-Naturwiss. Sektion U München, 1936-ca. 1942 auch Mitarbeiter der Forschungsgemeinschaft Dt. Ahnenerbe („Das Ahnenerbe“), e. Einrichtung der Schutzstaffel (SS), s. Hugo-Dingler-Archiv in der Hofbibliothek Aschaffenburg, NDB 3 (1957) S. 729 f., Klee, Personenlexikon (2007) S. 112. 
Lb Seit SS 1845 Studium der Medizin, Pharmazie, Chemie an U Gießen, SS 1846 H, SS 1847 Gießen.

Seit 1847 zunächst Hilfsassistent, anschl. Assistent am Chemischen Inst. der U Gießen, dann am Chemischen Laboratorium Fresenius in Wiesbaden; 1849 pharmaz. Staatsexamen in Nassau/Lahn.

1849-1850 Besitzer e. Apotheke in Katzenelnbogen (Rheinland-Pfalz); 14. März 1851 Dr. phil. an U Gießen; 1850-1855 Inhaber e. Apotheke in Wiesbaden; zugleich Chemie-Lehrer an Handels- und Gewerbeschule ebd.

H: Seit 1855 Wohnsitz; Einrichtung e. Privat Untersuchungs-Labors für die Düngemittelindustrie.

UH: 2. Mai 1857 Habilitation; seit 28. März 1863 a. o. Prof.

München: 26. Sept. 1868-31. März 1883 (aus gesundheitlichen Gründen vorzeitiger Ruhestand auf eigenen Antrag) o. Prof. am Polytechnikum (seit $1877 \mathrm{TH}$ ); auch Berater u. a. bei damaliger Bayer. AG für chemische und landwirtschaftlichchemische Fabrikate in Heufeld in Oberbayern (heute: Clariant AG).

Privat-Gelehrter: Seit 1883 in Frankfurt/M., seit 1885 in Wiesbaden, seit 1886 erneut in Frankfurt/M., 1893-1909 in Aschaffenburg; u.a. 18931897 Mitarbeiter im Labor der Forsthochschule ebd.

1860 entwickelt E. den nach ihm benannten Erlenmeyerkolben

E 1870 Mitglied der Akademie der Wissenschaften München. Ehrenpromotionen: 1901 Gießen; 1905 München, 1905 (Dr. phil. nat.) UH. 1865 Russischer St. Anna Orden III. Klasse.

Qu UAH PA 1524. - Briefe: UBH. - Nachlaß: Deutsches Museum von Meisterwerken der Naturwissenschaft und Technik in München/Archiv.

$W$ Lehrbuch der organischen Chemie. 3 Bde. Leipzig 1867-1894. (sowohl Verf. als auch Mitverf.) - Aufgabe des chemischen Unterrichts ge- genüber Wissenschaft und Technik. München 1871. • Über den Einfluß des Freiherrn Justus von Liebig auf die Entwicklung der reinen Chemie. München 1874. • Bemerkungen über Examina und Ausbildung der technischen Chemiker. Heidelberg 1898. - Bibliographie in: Conrad, Max: Nachruf für E. E. ... (1910) S. 3659-3664.

(M)HG 1859-1865 Kritische Zeitschrift für Chemie und Pharmacie.

Mit-Redakteur, MHG 1871-1883 Liebigs Annalen der Chemie.

$L$ Conrad, Max: Nachruf für E.E. in: Berichte der dt. chemischen Gesellschaft 43 (1910) S. 36453659. - Smith (1949) S. 81f.; NDB 4 (1959) S. 594 f. (mit Werkverz.); WBIS. Meyer, Rita: E. E. ... als Chemiehistoriker und sein Beitrag zur Entwicklung der Strukturchemie. Diss. München 1984. • Schwedt, Georg: Liebig und seine Schüler: Die neue Schule der Chemie. Berlin 2002. S. 266 u. ö. DBE 3 (2006) S. 124; Von der Forschung gezeichnet (2007) S. 111f. u. ö.; Autoren der Bunsenbibliothek (2009 online). - Biographie E.E. in: Fischer, Marta: Lebendige Verbindungen. Biobibliographisches Lexikon der Biochemiker zwischen Deutschland und Russland im 19. Jahrhundert. Aachen 2013. S. 46-48.

$P$ Bildarchiv UAH; NDB.

\section{Ernst, Paul}

1888-1900, 1907-1928 Med. Fak.

Pathologische Anatomie

* 26. April 1859 Zürich

$\dagger$ 18. Dez. 1937 Heidelberg ref.

V Friedrich E. (1829-1911) Arzt, 1860-1863 auch a. o. Prof. für Medizin und Leiter der Chirurg. U-Poliklinik Zürich, s. Matrikeledition der U Zürich 1833-1924. Ed. von Ulrich Helfenstein. Online (Jahr 1847, Nr. 1182); Fischer $1\left({ }^{3} 1962\right)$ S. 373 f., WBIS

M Anna Elisabetha geb. von Muralt (1833-1876) 
Ø 18. Aug. 1900 Ida Cuntz geb. Stienen (18551930) T von Caspar S. (†1870), u.a. Preußischer Konsul, seit 1868 Generalkonsul des Norddeutschen Bundes in Ancona

@ 14. März 1933 Anna geb. von Scherer, T von Otto von S., Geh. Reg.-Rat

$\mathrm{K}$ keine

Vw Alexander von Muralt (1903-1990) seit 1933 Privat-Dozent an UH, 1936-1968 Ordinarius für Physiologie an U Bern, s. UAH PA 1087, 5130; WBIS, Historisches Lexikon der Schweiz online.

Lb U Zürich: Seit WS 1877/78 Studium; SS 1882 Staatsprüfung; Assistent: seit 1882 Patholog. Inst., seit 1884 Med. U-Klinik; 10. Sept. 1884 Dr. med.

U Berlin: Seit Herbst 1885 Assistent von Robert Koch (1843-1910) im Laboratorium des Hygienischen Inst.

UH: 1. Sept. 1886-15. März 1900 Assistent von Julius Arnold am Patholog.-Anatom. Inst.; 21. Dez. 1888 Habilitation für Pathologie und Bakteriologie; seit 6. Aug. 1893 a. o. Prof.

U Zürich: Seit 15. März 1900 o. Prof.

UH: 1. Febr. (Ern.) zum 1. April 1907 o. Prof. und Direktor des Patholog.-Anatom. Inst. als Nachf. von J. Arnold; 1908-1928 Lehrauftrag für Geschichte der Medizin als Nachf. von Ernst Schwalbe; 31. März 1928 Emeritierung.

1908/o9, 1918/19 Dekan der Med. Fak. der UH

1914 Geh. Hofrat

E 1903 Mitglied der Gelehrten Gesellschaft in Zürich; 1933 Mitglied der Dt. Akademie der Naturforscher Leopoldina Halle/S.; 1916 Mitglied der Akademie der Wissenschaften H. • 1910 Ritterkreuz I. Klasse des Ordens vom Zähringer Löwen.

Qu UAH PA 899, 3693. - GLA Abt. 235, Fasz. 1942. Staatsarchiv Basel-Stadt (Signatur: PA 212a T 2 XXXIX 34). • Briefe: UBH. • Teil-Nachlaß: UAH; darin: Lebenslauf. Masch.geschr. Manu- skript (Signatur: Acc. 30/12). - Siehe auch Archiv der Dt. Akademie der Naturforscher Leopoldina Halle/S.

$W$ Über Kern- und Sporenbildung bei Bacterien. Leipzig 1888. - Wege und Wanderungen der Krankheitsstoffe. Zürich 1901. Mißbildungen des Nervensystems in: Die Morphologie der Mißbildungen des Menschen und der Tiere. Ein Handund Lehrbuch für Morphologen, Physiologen, prakt. Aerzte und Studierende. Unter Mitwirkung zahlreicher Fachgenossen begründet von ... Ernst Schwalbe hrsg. von Gg. B. Gruber. III. T. 2. Abt. Jena 1909. S. 67-252.

HG Die Missbildungen der einzelnen Organe und Organsysteme in: Die Morphologie der Mißbildungen des Menschen und der Tiere ... T. 3. Abt. 3. Jena $1927[-1958]$.

L Schmincke, A.: P.E. zum 70. Geb. in: Münchener med. Wochenschrift 16 (1929) Beilage. • Kürschner (1931) Sp. 612, (1935) Sp. 291; Fischer 1 $\left({ }^{3} 1962\right)$ S. 374; Chronik Ärzte H (1985) S. 126, 220 f.; WBIS; Jansen (1992a) S. 165 (Register). - Wieser, Andreas: Der Pathologe P.E. ... Diss. Dietikon 1993. Becker, Volker: Pathologie: Beständigkeit und Wandel ... Berlin 1996. S. 31f. u. ö. • Dhom (2001) S. 378-381 u. ö.; UH im Nationalsozialismus (2006) S. 1250 (Register).

$P$ Bildarchiv UAH; graph. Slg. UBH; Chronik Ärzte H.

\section{Eschenmayer, Philipp Christoph Heinrich}

1805-1820 Staatswirtschaftl. Sektion

Staatswirtschaft

* 31. Juli 1763 Neuenbürg (bei Pforzheim)

$\approx$ o1. Aug. 1763

$\dagger \quad$ o2. Juli 1820 Heidelberg ev.-luth.

V Jacob Heinrich E., Stadt- und Amtspfleger M Agnesia Catharina geb. Traub 
๑ Louisa Friedericia geb. von Wogau (17771832); seit 1822 Ehefrau von: (siehe) Christian von Langsdorf(f)

$\mathrm{K}$ keine

Vw Bruder: Adolph Carl August (seit 1813: von) E. (1768-1852), u.a. seit 1811 a. o. Prof. für Medizin und Philosophie und 1818-1836 o. Prof. für Praktische Philosophie Tübingen, s. NDB 4 (1959) S. 644; Maier, Sonja: Der Einfluss der Fichteschen Philosophie in der Medizin bei A. ... E. Med. Diss. Tübingen 2009. Print-ondemand.

Lb H: Seit WS 1785/86 Studium an „Staatswirtschafts Hohe Schule“, die mit Phil. Fak. der U personell verbunden ist.

Seit 1789 Hauptmann und Regimentsquartiermeister; seit 1798 Posthalter/Postverwalter in Plochingen; 21. Jan. 1800 Verhaftung wegen Landesverrats; 29. Okt. 1801 Haftentlassung; danach wohl Aufenthalt in Stuttgart; 1804 Verbannung aus Stuttgart, s. Landesarchiv Baden-Württemberg, Abt. Staatsarchiv Ludwigsburg, D 51 Bü 368.

UH: Seit WS 1805/o6 Privat-Dozent (Mai 1803 Einführung der Staatswirtschaftl. Sektion, siehe hierzu auch Stieda (1906) S. 131-138 u. ö.); seit 23. Febr. 1807 a. o. Prof.; seit 6. Mai 1811 o. Prof.; 1. Nov. 1812 Dr. phil.

1813, 1818 Direktor der Staatswirtschaftl. Sektion der UH

1816/17: Erfolgreiche Eingabe E.s bei Wilhelm I., König von Württemberg, wegen angeblich zu Unrecht erlittener Misshandlungen und Verluste, s. hierzu Landesarchiv Baden-Württemberg, Abt. Hauptstaatsarchiv Stuttgart, E 31.

$Z$ Die Staatswirtschaftliche Sektion an der UH besteht von Mai 1803 (Eingliederung der „Staatswirtschafts Hohe Schule“ in U als Staatswirtschaftl. Sektion) bis Mai 1822 als „eine eigene, von der allgemeinen Section oder philosophischen Facultät abgesonderte Abtheilung ..., welche gleich den 4 eigentlichen sogenan(n)ten Facultäten bis jetzt noch Jura Corporis separati genieße; so hätten die, welche als Privat-Lehrer [= Privatdozenten] staatswirthschaftliche Vorlesungen halten wollten, sich dazu bey der staatswirthschaftlichen Section vorschriftsmäßig zu habilitieren, gleichviel, ob dieselben vorher schon bey einer oder mehrern der 4 Facultäten $\mathrm{zu}$ Vorlesungen sich habilitiert hätten oder nicht ..." (aus: Auszug Großherzogl. Badischen Geheimenraths-Protokolls. Polizeydepartement ... Karlsruhe, den 22. Juny 1807 in: UAH RA 5952). - Siehe hierzu auch Ludwig Wallrad Medicus: Eintrag unter $Z$ [itat].

Im Auszug aus dem „Geheimenraths-Protokoll. Polizeydepartement" vom 17. März 1808 wird der Wahlmodus des Direktors der Staatswirtschaftlichen Sektion festgelegt: „... Seine Königl. Hoheit [haben] unterm 14. Merz gnädigst genehmigt, dass auch bey der Staatswirthschaftl. Section in Heidelberg, welche einen Theil der Phylosophischen Facultät, aber auch zugleich ein eigenes Ganzes unter Vorstand eines Directors ausmacht, nach dem Beyspiel des Decanats-Wechsels bey den Facultäten, die Abwechselung in diesem Directorium nach den Vorschriften der academischen Gesetze eingeführt werden, und daher die außerordentlichen Professoren nicht zum Directorium zuzulassen, und der Director so wenig als der Decan als solcher, Mitglied des Senats seyen“ (aus: UAH RA 5953).

Am 13. Mai 1822 ergeht der kuratorische Erlaß, die Staatswirtschaftliche Sektion mit der Philosophischen Fakultät der UH zu „vereinen“" (siehe Brief des von 1821 bis 1822 für die UH zuständigen Kurators Karl Philipp von Zyllnhardt (1779-1828) an den Engeren Senat vom 20. Juli 1822 mit der Aufforderung, die Vollziehung der Zusammenlegung anzuzeigen, in: RA 5952). - Siehe auch Neuhaus (2014) S. 50-56 u. ö.

Geh. Rat

Zur Einführung der Staatswirtschaftlichen Sektion an $\mathrm{UH}$ 1803, siehe auch Ludwig Wallrad Medicus: Eintrag unter $Z$ [itat]

E 1820 Ritter des Ordens der Württ. Krone.

Qu UAH PA 1525; RA 1119; Fak.-Akte H-IV-102/o7 fol. 178r, v, 182r, 183r. • GLA Abt. 205, Fasz. 223. • Briefe: UBH. 
$W$ Anleitung zu einer systematischen Einrichtung des Staats-Rechnungswesens und zur Kenntnis der dahin einschlagenden Rechte. 2 Bde. Heidelberg 1807. - Vorschlag zu einem einfachen SteuerSysteme. Heidelberg 1808. • Über die Consumptionssteuer. Heidelberg 1813. • Über das formelle Prinzip der Staatswirtschaft als Wissenschaft und Lehre. Heidelberg 1815.

Redakteur 1808-1809 Die Rheinische BundesZeitung.

$L$ Heidelbergische Jahrbücher der Literatur (1813) 6. Jg., 2. Hälfte, hierin: Intelligenzblatt 1813 , Nr. 1, S. 1; Stieda (1906) S. 140 f. u. ö. • H. E. in: Hölzle, Erwin: Das alte Recht und die Revolution. München 1931. S. 238 Anm. 1. Greiner, Karl: Die Post in Württemberg unter Herzog, Kurfürst und König Friedrich in: Archiv für dt. Postgeschichte 2 (1962) S. 17-51. • WBIS. • Jenetzky, Johannes: System und Entwicklung des materiellen Steuerrechts in der wissenschaftlichen Literatur des Kameralismus 1680-1840 ... Berlin 1978. S. 64f., 74-76, 154 f., 229 f. u. ö. • Neuhaus (2014) S. 72-74 u. ö.

\section{Ewald, August Georg Carl}

1880-1921 Med. Fak. 1921-1922 (Honorar-Prof.) Med. Fak. Physiologie

* o7. Juni 1849 Darmstadt

$\dagger \quad$ 03. Febr. 1924 Heidelberg ev.

V Ludwig (Louis) Wilhelm E. (1813-1881) Obersteuer-Direktor, Geh. Rat, siehe Hessische Biografie, s. http://www.lagis-hessen.de/de/ subjects/idrec/sn/bio/id/2731 (Stand: 28. Juni 2013)

M Karoline Henriette geb. Schleiermacher (18181889) T des Dr. Ludwig Johann S. (1785-1844) Ober-Baudirektor, s. Hessische Biografie http://www.lagis-hessen.de/pnd/118608053 (Stand: 10. Okt. 2012)
(16. Sept. 1886 Maria geb. Müller (1857-1942)

K 2 S: u.a. Otto E. (1890-1964), u.a. seit 1935 Oberarzt und Leiter der Bestrahlungs-Abt. am Samariterhaus in H, seit 1939 auch PrivatDozent für Radiologie UH, 31. Okt. 1945 Entlassung durch amerik. Militärregierung, nach 1945 ohne Einkommen, seit 1. März 1951 Rentenauszahlung von 474.- DM aufgrund Strahlenschädigung während seines Dienstes im Samariterhaus, s. UAH PA 903, 3701

Vw Ur-Großvater: (siehe) Ludwig E. • Enkelin: Renate E. (1930-2018) Ehefrau von Peter Schenck (1930-1995) 1973-1992 Prof. für Klinische Radiologie UH, s. Drüll (2009) S. 527.

Lb Seit WS 1867/68 Studium der Naturwiss. an Phil. Fak. der UH, seit WS 1869/70 Berlin; Sommer 1870 Physikum in Berlin.

U Bonn: Seit 1870 Forts. des Studiums; 28. Juni 1873 Dr. med.; 5. Jan. 1874 Approbation.

UH: 1874-1901 Assistent am Physiolog. Inst.; 23. Okt. 188 o Habilitation; seit 26. Juli 1883 a. o. Prof.; 1886 Ruf an U Santiago (Chile) abgelehnt; seit 1. Okt. 1901 Mitarbeiter „zur Unterstützung des Direktors des Physiologischen Instituts bei der Leitung der praktischen Arbeiten im Institut" (aus: Schreiben des Ministeriums für Justiz, Kultus und Unterricht an Engeren Senat der UH vom 19. Juli 1901 in: UAH PA 902); seit 15. März 1921 o. Honorar-Prof.; SS 1921 letzte Vorlesungsankündigung.

Qu UAH PA 1, 902, 3700; RA 5278, 6191, 6633, 6808. GLA Abt. 235, Fasz. 1946. • Briefe: UBH.

$W$ E., A. und Kühne, Wilhelm: Die Verdauung als histologische Methode. Heidelberg 1877 . Über den Modus der Nervenverbreitung im elektrischen Organ von Torpedo und die Bedeutung desselben für die Physiologie der Entladung des Organs. Heidelberg 1881. - Über pigmenthaltige Knorpelzellen. Heidelberg 1919.

$L$ Stübler (1926) S. 310; WBIS; Fischer 1 ( $\left.{ }^{3} 1962\right)$ S. 380; Chronik Ärzte H (1985) S. 126 f.; Jansen (1992a) S. 165 (Register). - Hessische Biografie, s. http://www.lagis-hessen.de/pnd/116612568 (Stand: 
3. Febr. 2011); Deutsche Biographie, s. https://www. deutsche-biographie.de/gnd116612568.html [06.11. 2017].

$P$ Bildarchiv UAH; graph. Slg. UBH.

\section{Ewald, Johann Ludwig}

1805-1808 Theol. Fak.

Moral- und Pastoraltheologie

* 16. Sept. 1748 Dreieichenhain (bei Offenbach im Fürstentum Isenburg; heute: Stadtteil von Dreieich)

$\dagger$ 19. März 1822 Karlsruhe ref.

V Georg Ernst E. (†1772) fürstl. Isenburgischer Amtskeller

M Maria Charlotte geb. Vigelius (1719-1751/52)

$\infty$ 10. Sept. 1775 Rahel Gertraud geb. du Fay (1749-1831)

$\mathrm{K} 5$ (davon $1 \mathrm{~S}$ früh $\dagger$ )

Vw Ur-Enkel: (siehe) August E.

Lb 4. Okt. 1766 Immatrikulation an U Marburg, anschl. Forts. des Studiums in Göttingen; 17681770 Hofmeister der Prinzen von Hessen-Philippsthal.

1770 Pfarrer in Götzenhain (heute: Stadtteil von Dreieich) für kurze Zeit; seit 1770 Pastor in Ravolzhausen (heute: Ortsteil von Neuberg im MainKinzig-Kreis).

Offenbach/M.: 1773-1781 II. Pfarrer.

Detmold: 1781-1796 Lippe-Detmoldischer Hofprediger und Generalsuperintendent; in dieser Zeit auch Gründer des ersten lippischen Lehrerseminars.

Bremen: 19. Juli 1796-25. Febr. 1802 II. Pfarrer an Stephanskirche. In dieser Zeit:
U Marburg: 1796 E. sucht um e. Promotion an Theol. Fak. in absentia und „ohne die gewöhnliche[n] Specimina" nach; Fak. antwortet, dies sei ohne landgräfliche Einwilligung nicht möglich; Reskript vom 28. Okt. 1796 erlaubt - nach Einreichen e. von der Fak. unterstützten und erfolgreichen Gesuchs an den Landesherrn - die (Ehren-) Promotion; 10. Dez. 1796 D. theol.

Bremen: Seit 26. Febr. 1802 Gymnasial-Prof. für Praktische Philosophie; 1804 Studienreise in die Schweiz (Besuch von Johann Heinrich Pestalozzi (1746-1827) Pädagoge).

UH: Seit 13. April 1805 0. Prof.; WS 1807/08 letzte Vorlesungsankündigung über „Theol. Encyclopädie und Moraltheologie“ im „Vorlesungs-Catalog", s. hierzu UAH RA 6633 zwischen 5. Okt. und 5. Nov. 1807.

Karlsruhe: 17. Okt. 1807 (Berufung)-1821 Geistlicher Ministerialrat, Mitglied des Kirchenrats und der Badischen Generalsynode.

Jan.-Sept. 1807 Dekan der Theol. Fak. der UH

Zur Vermählung E.s mit Rahel Gertrud du Fay dichtet Goethe im Sept. 1775 „In allen guten Stunden“, 1810 von Carl Friedrich Zelter (1758-1832) vertont; siehe Goethes Leben von Tag zu Tag: Generalregister: Namenregister ... Hrsg. von Siegfried Seifert ... Berlin 2011. Bd. 9. S. 108.

Kirchenrat

E 1796 D. theol. Marburg.

Qu UAH RA 4596, 5902, 6633. - GLA Abt. 205, Fasz. 225-226. - Briefe: UBH. - Auskunft: Universitätsarchiv Marburg (Protokollbuch der Theol. Fak. 307a Nr. 437).

$W$ Über Predigerbeschäftigung und Predigerbetragen. Lemgo 1783. - Lesebuch für die Landschulen. 3 T. Lemgo, Duisburg 1788-1793. • Über Revolutionen, ihre Quellen und die Mittel dagegen. Berlin 1792. - Die Kunst, ein gutes Mädchen, eine gute Gattin, Mutter und Hausfrau zu werden. 2 Bde. Bremen 1798. 5. Aufl. 1815. - Der 
gute Jüngling, gute Gatte und Vater, oder Mittel, um es zu werden. 2 Bde. Frankfurt/M. 1804. • Einige Fragen und noch mehr unläugbare Wahrheiten, Juden- und Menschenleben betreffend. Karlsruhe 1820. - Einiges Geschichtliche, woran bei einer bevorstehenden Vereinigung der beiden protestantischen Kirchen wohl erinnert werden darf, mit Winken auf ihre Zweckmässigkeit. Heidelberg 1821. - Projüdische Schriften aus den Jahren 1817-1821. Mit Nachträgen zur Ewald-Bibliographie hrsg. von Johann Anselm Steiger. Heidelberg 200o. Hamburg im Jahre 1798. Ein Bericht von J.L.E. mitgeteilt von Reinhold Pabel in: Hamburgische Geschichts- und Heimatblätter 14,10 (2002) S. 217-220.

HG 1793-1796 Urania für Kopf und Herz, s. hierzu Schwinge (1994) S. 58 f. $\bullet 1800-1805$ Christliche Monatsschrift, s. ebd. S. 169-173 u. ö.

MHG 1815-1819 Zs. zur Nährung christlichen Sinnes.

L Keller (1913) S. 171; Schneider (1913) S. 111; WBIS; NDB 4 (1959) S. 693 f. • Schwinge, Gerhard: Jung-Stilling als Erbauungsschriftsteller der Erweckung ... Göttingen 1994. S. 360 (Register). • Steiger, Johann Anselm: Neues über den lippischen Generalsuperintendenten J.L.E. ... Forschungsergebnisse und Thesen in: Lippische Mitteilungen aus Geschichte und Landeskunde. Bielefeld 1995. S. 107-118; Ders.: J.L.E. Rettung eines theologischen Zeitgenossen. Göttingen 1996. Kirn, Hans-Martin: Deutsche Spätaufklärung und Pietismus: ihr Verhältnis im Rahmen kirchlich-bürgerlicher Reform bei J.L.E. ... Göttingen 1998. • Killy Literaturlexikon 3 (2008) S. 338 f. • Schwinge, Gerhard: Schwarz, Marheineke, E., Abegg, Hüffell. Zur Vorgeschichte des ersten badischen Predigerseminars in Heidelberg zwischen 1807 und 1818 bzw. 1818 und 1838 in: Praktische Theologie und Landeskirchengeschichte ... Hrsg. von Johannes Ehmann. Berlin 2008. S. 281-292. • Steiger, Johann Anselm: J.L.E. Ein politischer Schriftsteller, Reformpädagoge, Volksaufklärer, protestantischer Kirchenmann und Apologet des Judentums in: Literarisches Leben im dt. Südwesten von der Aufklärung bis zur Moderne. Bd. 2: Von der Spätaufklärung zur badischen Revolution ... Hrsg. von Achim Aurnhammer ... Freiburg/Br. 2010. S. 65-
90; Ders.: „einen ... unpartheyischen Lehrer der kirchlichen Dogmatik“. Ein Brief des reformierten Karlsruher Kirchenmannes J. L. E. an Carl Ullmann (1796-1865) in: Jahrbuch für badische Kirchen- und Religionsgeschichte. Stuttgart 2011. S. 41-55. Hessische Biografie, s. http://www.la gis-hessen.de/pnd/11919619o (Stand: 13. Mai 2014).

$P$ Bildarchiv UAH; graph. Slg. UBH; NDB.

\section{Eymer, Heinrich Christian}

1917-1924, 1930-1934 Med. Fak.

Gynäkologie, Geburtshilfe

* 11. Juni 1883 Frankfurt/M.

$\dagger$ 16. Mai 1965 München ev.

V Christian E. (1851-1919) Schulrektor

M Minna Maria Margarethe Elise geb. Bornemann (1855-1946)

๑ 10. Sept. 1919 Dr. med. Alma geb. Klinker (1888-1971)

K 1 T, 1 S: Karl-Peter E. (1920-1999), u.a. apl. Prof. für Innere Medizin München, s. Informationsdienst der Ludwig-Maximilians-Universität München 3 (1999) Bl. 2.

Lb Studium: SS 1902 U Marburg, WS 1902/03-SS 1904 und WS 1905/06-WS 1906/07 H, WS 1904/ 05-SS 1905 München; 11. Juli 1907 Staatsexamen in $\mathrm{H}$.

UH: Aug. 1907-April 1908 Medizinalpraktikant an U-Frauenklinik; 31. Juli 1908 Dr. med.; 15. Aug. 1908 Approbation; Aug. 1908-Jan. 1919 Assistent an U-Frauenklinik; zwischenzeitlich Hospitationen, u. a. Nov. 1912-Mai 1913 am Hygien. Inst. der U Frankfurt/M., am Patholog. Inst. der U Straßburg; 26. Febr. 1917 Habilitation; seit Febr. 1919 Oberarzt an U-Frauenklinik als Nachf. von Maximilian Neu; seit 7. Dez. 1921 nichtplanm. a. o. Prof.

U Innsbruck: SS 1924-SS 1930 o. Prof. und Direktor der Frauenklinik. 
UH: Seit WS 1930/31 o. Prof. und Direktor der U-Frauenklinik als Nachf. von Carl Menge; seit 4. Okt. 1930 auch Kreisoberheb(e)arzt für Mannheim, $\mathrm{H}$ und Mosbach.

U München: 1. Mai 1934 (Ern.)-15. Nov. 1945 o. Prof. und Direktor der U-Frauenklinik sowie der Hebammenschule; seit 15. Nov. 1945 Suspension von Ämtern; zwischen 5. und 15. Jan. 1946 Einsetzung als kommissar. Leiter der U-Frauenklinik; 27. Juli 1946 zweite Dienstenthebung; seit 1. April 1948 erneut kommissar. Leiter der U-Frauenklinik; 12. Aug. 1948 (Wiedereinsetzung)-1. Okt. 1954 (Emeritierung) o. Prof. und Direktor der U-Frauenklinik.

1931/32 Dekan der Med. Fak. der UH

1952-1953 Präsident der Dt. Gesellschaft für Gynäkologie und Geburtshilfe

E Ehrenmitglied der Dt. Gesellschaft für Gynäkologie und Geburtshilfe. - Großes Verdienstkreuz zum Verdienstorden.

Qu UAH PA 904, 3702f.; Fak.-Akte H-III-111/89. • GLA Abt. 235, Fasz. 1947. Mitteilungen: Herr Prof. Dr. Karl-Peter Eymer ( $\dagger$ ); Herr Prof. Dr. Erich Kuß, München.

$W$ Über die Behandlung gutartiger gynäkologischer Blutungen mit radioaktiven Substanzen in: Strahlentherapie 10 (1920). - Über Schwangerschaft und Geburt nach Uterusresection in: Zen- tralblatt für Gynäkologie 3 (1921). • Die Röntgenstrahlen in Gynäkologie und Geburtshilfe. Hamburg 1922. - Die Eingriffe zur Unfruchtbarmachung der Frau in: Gesetz zur Verhütung erbkranken Nachwuchses vom 14. Juli 1933 nebst Ausführungsverordnungen. Hrsg. von Arthur Gütt u. a. München 1934. - Siehe auch Buttron (1981) S. 116.

MHG 1934-1954 Münchener Med. Wochenschrift, s. Buttron, S. 116.

L Kürschner (1966) S. 503; Buttron (1981) S. 114116; Chronik Ärzte H (1985) S. 127; Zander (1991) S. 64-66; Jansen (1992a) S. 165 (Register); Kuß (2000) S. 283-388; WBIS. • Bröer, Ralf: Frauenheilkunde im Dienst der Eugenik - Ärztliche Karrieren an der U-Frauenklinik Heidelberg im Nationalsozialismus in: Geburtshilfe und Frauenheilkunde 64 (2004) S. 1090-1097. UH im Nationalsozialismus (2006) S. 1251 (Register); Klee, Personenlexikon (2007) S. 142f.; WBIS; Universität München im Dritten Reich 2 (2008) S. 525 und Anm. 35, 568. Albrecht, Pavla: H.E. - eine ärztliche Karriere zwischen Ehrgeiz, Eugenik und Nationalsozialismus in: Rechte Karrieren in München ... Hrsg. von Marita Krauss. München 2010. S. 297-310. • Ludwig, H.: Lokale Spuren eines Jahrhunderts: Die I. Frauenklinik der LudwigMaximilians-U München ... in: Der Gynäkologe 1 (2011) S. 64-70, hier: S. 64-66. Deutsche Biographie, s. https://www.deutsche-biographie.de/gnd11 7701505.html [06.11. 2017].

$P$ Bildarchiv UAH; Chronik Ärzte H. 


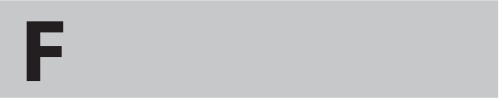

Fauth, Johann Jacob

1784-1807 Theol. Fak.

Eloquenz, Kirchengeschichte

* 1757 Neustadt/Weinstraße

$\approx$ 30. Sept. 1757 Mülheim (heute: Stadtteil von Köln)

$\dagger$ 20. Nov. 1807 Heidelberg

口 Peterskirche in westl. Kapelle der Südseite (heute: Glaskapelle)

ref.

V Franz Philipp F. ( ${ }^{*}$ ca. 1728) Kaufmann

M Anna Catharina geb. N.N.

$\infty$ 26. Sept. 1793 Henrietta geb. de Pre (1769-1808 oder 1824)

K 2 S (u. a. Carl Philipp F. (†1824) cand. theol.), $1 \mathrm{~T}$

Vw Bruder: Johann Philipp F. (1754-1836) Kaufmann, Bankier; zur Genealogie, s. Gruch, J.: Die ev. Pfarrerinnen und Pfarrer im Rheinland. Bonn 2013. II. Nr. 3227. - Enkel von J. P. F.: Franz Friedrich Christian F. (1841-1905), u. a. seit 1879 Oberlehrer, seit 1885 Prof. und seit 1901 Direktor des König-Wilhelm-Gymnasiums Höxter, s. Kuhlemann, Frank-Michael, Schmuhl, Hans-Walter: Beruf und Religion im 19. und 20. Jahrhundert. Stuttgart 2003. S. 100 u. ö.; Kössler, Franz: Personenlexikon von Lehrern des 19. Jahrhunderts. Giessener Elektronische Bibliothek. Bd. 6. Reprint 2008 (online).

Lb 1773-1776 Studium der Theologie an UH; danach Ausbildung zum Vikar.

Wiener Neustadt: Vor 1780 Vikar.

Innere Stadt Wien: 18. April 1783 Antrittspredigt als Vikar an der am 25. Dez. 1784 offiziell eröffneten Kirche „Ev. Pfarrgemeinde Helvetisches Bekenntnis (H. B.) “ in der Dorotheergasse.
UH: 10. Nov. 1784 F. legt das von Kurfürst Carl Theodor vor Übernahme der Professur verlangte Eignungsexamen ab; 21. Nov. 1784 Ern. zum a.o. Prof. in Nachf. von Johannes Carl Casimir Wundt, s. Drüll (1991) S. 174-178. In dieser Zeit:

H: 1786-1807 II. Pfarrer an Peterskirche.

1783-1803 Mitglied des Illuminatenordens (Ordensname: Chrysostomus), s. Die Protokolle der Wiener Freimaurerloge "Zur wahren Eintracht" (1781-1785). Hrsg. von Hans-Josef Irmen. Frankfurt/M. 1994. S. 350.

Siehe auch Ludwig Erb

E 7. Nov. 1786 D. theol. UH.

Qu UAH PA 1535; RA 759 fol. 297r, v, RA 3185. Acta secularium (1787) S. 166, 170 f.; Toepke IV (1903) S. 336 Anm. 5, 630-632, 643. - Deutschland: Geburten und Taufen 1558-1898. Index FamilySearch, siehe https://familysearch.org/pal:/ MM9.1.1/NCPF-5RD (abgerufen am 11. März 2018).

W Programma de communi scientiarum vinculo. Heidelberg 1789. • Programma de eo, quod iustum est circa librorum editiones insciis ac invitis primis editoribus repetitas. Heidelberg 1791. • Programma de bonis litteris a principibus Palatinis ac inprimis a Carolo Friderico adamatis ... Heidelberg 1803 .

L Keller (1913) S. 82; Schneider (1913) S. 25; WBIS; Badisches Pfarrerbuch 2 (1939) S. 154. • Ev. Gemeinde H.B. in Wien. [Jubiläumsfestschrift.] Hrsg. von Peter Karner. Wien 1986. - Über J.F. in: Editio 2009. Int. Jahrbuch für Editionswissenschaft ... hrsg. von Rüdiger Nutt-Kofoth u. a. Tübingen 2009. Bd. 23. S. 68 und Anm. 109. $\bullet$ Über das Werk F.s „De eo, quod iustum est circa librorum editiones ..." in: Gieseke, Ludwig: De librorum digitalisatione in: Zs. für Urheber- und Medienrecht (2010) H. 5, S. 424-426. 


\section{Feer, Walter Emil}

1907-1911 Med. Fak.

Kinderheilkunde

* 05. März 1864 Aarau (Schweiz)

$\dagger$ 21. Okt. 1955 Zürich

ref.

V Emil F. (1833-1869) Seidenband-Fabrikant

M Louise geb. Großmann (1840-1922)

$\infty$ 1. Okt. 1891 Rosa Louisa geb. Sulzer (18691955) T von Albert S.-Grossmann (1841-1910) Großindustrieller, s. Matschoß, Conrad: Die Geschichte der Firma Gebrüder Sulzer in Winterthur und Ludwigshafen/Rhein. Berlin 1910.

$\mathrm{K} \quad 2 \mathrm{~S}, 2 \mathrm{~T}$

Lb SS 1884 Studium an U München, seit WS 1884/85 Basel, SS 1886 München, WS 1886/87-SS 1887 H, seit WS $1887 / 88$ Basel; 1889 med. Staatsexamen in Basel; WS $1889 / 90$ Forts. des Studiums an U Wien; 11. März 1890 Dr. med. an U Basel.

Basel: 1890-1891 Assistenzarzt am Kinderspital; Nov. 1891-1907 erster praktizierender Kinderarzt, auch Allgemeinmediziner; 1905 u. a. Gründer des Vereins für Säuglingsfürsorge. • In dieser Zeit:

U Basel: 12. März 1894 Habilitation für Kinderheilkunde; 1894-1907 Privat-Dozent.

UH: Seit 1. Febr. 1907 nichtetatm. a.o. Prof. und Direktor der U-Kinderklinik Luisen-Heilanstalt als Nachf. von Oswald Vierordt (bisherige Teilung in I. und II. Direktorat entfällt ab 1907); 13. Aug. 1908-1. April 1911 etatm. a. o. Prof.

U Zürich: 16. Juli 1910 Ern. zum etatm. a. o. Prof. (persönlicher Ordinarius) und Direktor des Kinderspitals; SS 1911 Beginn seiner Lehrtätigkeit; seit 21. März 1912 o. Prof.; 15. April 1929 Emeritierung und Ern. zum Honorar-Prof.; 1929-1945 Präsident des Komitees des Kinderspitals.

F. ist 1908 der erste etatisierte Heidelberger Professor für Kinderheilkunde; erster Ordinarius wird sein Nachfolger Ernst Moro 1919
E Mitglied: 1925 Königl. Gesellschaft der Ärzte in Budapest, 1933 Dt. Akademie der Naturforscher Leopoldina Halle/S.; Ehrenmitglied: Schweizerische Gesellschaft für Pädiatrie, Dt. Gesellschaft für Kinderheilkunde, Interstate Postgraduate Medicine in London, Schweizerische Akademie der med. Wissenschaften.

Qu UAH PA 906, 1543; RA 6797. - GLA Abt. 235, Fasz. 1951. - Siehe auch Archiv der Dt. Akademie der Naturforscher Leopoldina Halle/S.

W Diagnostik der Kinderkrankheiten. Berlin 1921. 6. Aufl. 1951. - Eine eigenartige Neurose des vegetativen Nervensystems beim Kleinkind [Feersche Krankheit] in: Ergebnisse der inneren Medizin und Kinderheilkunde 24 (1923) S. 100-122. - Siehe hierzu auch Kunz (1987) S. 39-69 (mit Bibliographie).

G, HG Lehrbuch der Kinderheilkunde. 1.-14. Aufl. Jena 1911-1942. 27. Aufl. 1993.

MHG 1912-1929 Jahrbuch für Kinderheilkunde und physische Erziehung.

$L$ NDB 5 (1961) S. 45 (mit Werkverz.); WBIS; Chronik Ärzte H (1985) S. 127. • Wille, Lutz: Universitäts-Kinderklinik (Luisen-Heilanstalt) zu Heidelberg 1860-1985 in: Der Kinderarzt 16. Jg., Nr. 7 (1985) Sp. 1006. - Kunz, Roland: Der Kinderarzt E. F. ... Med. Diss. Zürich 1987. 150 Jahre Pädiatrie in H (2010) S. $46 \mathrm{f}$.

$P$ Bildarchiv UAH; NDB; Chronik Ärzte H.

\section{Fehling, Ferdinand}

1906-1920 Phil. Fak.

Mittlere und Neuere Geschichte

* 11. Nov. 1875 Lübeck

$\dagger$ 08. Dez. 1945 Waldhilsbach (heute: Ortsteil von Neckargemünd)

口 Waldhilsbach ev.-luth. 
V Dr. iur. Dr. phil. h.c. Dr. rer. pol. h.c. Ferdinand F. (1847-1927) Advokat, Notar, seit 1896 Justiz- und Finanzsenator, 1917-1920 Bürgermeister von Lübeck, s. Aus meinem Leben. Erinnerungen und Aktenstücke. Lübeck 1929; Nachlass im Stadtarchiv Lübeck; NDB 5 (1961) S. 46 f.; Lübecker Lebensläufe. Hrsg. von Alken Bruns. Neumünster 1993. S. $118 \mathrm{ff}$. - Onkel: Hermann Christian (von) F. (1811-1885) seit 1839 Lehrer, 1841-1883 (Ruhestand) Hauptlehrer (Prof.) für Chemie und Technologie an Vereinigter Real- und Gewerbeschule, seit 1876 TH Stuttgart; 1848 Veröffentlichung der Nachweisreaktion der quantitativen Bestimmung von Zucker z. B. im Harn (Fehling-Probe), s. NDB 5 (1961) S. 47. - Vetter: Hermann F. (1847-1925) seit 1872 Assistent und Oberarzt an U-Frauenklinik Leipzig, 1876 Habilitation Leipzig, seit 1877 Direktor der Landes-Hebammen-Anstalt Stuttgart; o. Prof. für Gynäkologie, Geburtshilfe: seit 1887 Basel, seit 1894 Halle/S., 1901-1918 Straßburg, 1919 Ausweisung aus Elsaß, s. Württembergische Biographien 1 (2006) S. 73 f., Catalogus prof. Halensis online

M Ada Marie Caroline geb. Geibel (1853-1906), Lebensskizzen, s. hierzu Briefe u. a. von Emanuel G. (in Privatbesitz); T von Emanuel G. (1815-1884) Lyriker, s. N.N. (†): Eine Jugendliebe E. G.s [= Cäcilie Wattenbach (1815-1883), Schwester von: (siehe) Wilhelm W.] in: Die Gartenlaube. Hrsg. von Adolf Kröner. Leipzig 1888. H. 4, S. 67; Kohut, Adolph: E.G. als Mensch und Dichter. Mit ungedruckten Briefen, Gedichten und e. Autobiographie G.s. Berlin 1915. Nachdr. Bremen 2017. S. 90-99; Göhler, Christine: E.G. Ein Lebensbild in Selbstzeugnissen und Berichten seiner Freunde. Schellhorn 1992; E. G. Aufstieg und Fall eines Umstrittenen. Das Magazin zur Ausstellung. Hrsg. von Birte Lipinski ... Lübeck 2015.

( 23. Okt. 1914 Margarete (Grete) Elisabeth Casimira geb. Planck (1889-1917), s. Kriegstagebuch K. Hampe (2007) S. 957 (Register); T von Max P. (1858-1947) 1919 Nobelpreisträger für Physik; siehe auch Georg Wagemann: Eintrag unter $\infty$ [Ehefrau], $V w$ [Schwestern, Neffe]

( 1. Febr. 1919 Emma Ottilie Agnes geb. Planck (1889-1919), Zwillingsschwester von 1. Ehefrau, s. Kriegstagebuch, S. 914
K 2 T, s. ebd. S. 957 (Register)

Vw Großmutter: Anna Emilie Fehling geb. Oppenheimer (1803-1885) $\mathrm{T}$ von Jacob Ams(ch)el O. (1778-1845), u. a. bis 1818 Teilhaber des Bankhauses Heckscher \& Co. in Hamburg, s. Ahrens, Gerhard: Jüdische Heiratspolitik. Hanseatische Bezüge in e. unterdrückten Heine-Gedicht in: Der Wagen. Lübecker Beiträge zur Kultur und Gesellschaft. Hrsg. von Manfred Eickhölter. Lübeck 2008. S. 166182; Deutsche Biographie, https://www.deutsche-biographie.de/pnd137692838.html [27.12. 2017]. - Siehe auch UAH H-IV-102/137 fol. 106r, v.

Vw Bruder: u. a. Jürgen F. (1885-1968) 1922-1944 (mit Unterbrechungen) Spielleiter am Berliner Staatstheater, 1949-1952 Theaterregisseur, Schauspieler in München; 1944 Aufnahme in die sog. Gottbegnadeten-Liste, e. Namenliste von 1041 Künstlern, die auf Grund ihrer künstlerischen Leistung vom Wehrmacht- und Arbeitseinsatz freigestellt waren; s. Jürgen-Fehling-Archiv im Archiv der Akademie der Künste in Berlin; Gründgens, Gustaf: Für J. F. durch Himmel und Hölle. Er trieb jeden Schauspieler zum Äußersten ... in: DIE ZEIT Nr. 12 vom 18. März 1960; J. F. Der Regisseur ... Ausstellung in der Akademie der Künste vom 28. Okt. bis 26. Nov. 1978. [Katalogkonzeption: Rudolf Noelte ...] Berlin 1978. 2. Aufl. 1985; „Liebt das Theater ..." Der Regisseur J.F. Buch und Regie: Jürgen Moeller. VHS-Kassette. Portrait. BRD 1985; Das Theater des deutschen Regisseurs J. F. ... hrsg. von Gerhard Ahrens. Berlin 1985; Unterm Notdach: Nachkriegsliteratur in Berlin 1945-1949. Hrsg. von Ursula Heukenkamp. Berlin 1996. S. 566 (Register); Heilmann, Matthias: Leopold Jessner - Intendant der Republik: Der Weg eines deutsch-jüdischen Regisseurs aus Ostpreußen. Tübingen 2005. S. 442 (Register); Rühle, Günther: Theater in Deutschland 1887-1945. Seine Ereignisse - seine Menschen. 2. Aufl. Frankfurt/M. 2007; Hamburgische Biografie 5 (2010) S. 113 f., Deutsche Biographie, https://www.deutsche-biographie.de/pn d118799975.html [25.12.2017]. 
Lb Seit SS 1894 Studium der Philosophie, Volkswirtschaftslehre, Politik an U Bonn, 30. Okt. 189522. März 1899 Berlin, 29. April 1899-20. April $1900 \mathrm{H}$.

Berlin: 31. Juli 1900 Rigorosum, 15. Dez. 1900 (Datum der Promotionsurkunde) Dr. phil. („magna cum laude") an U; 1. Okt. 1900-30. Sept. 1901 Militärdienstpflicht als Einjährig-Freiwilliger im 3. hanseatischen Infanterieregiment Nr. 162 zu Lübeck; seit Okt. 1901 Mitarbeiter in der Kommission für die Herausgabe der Urkunden und Aktenstücke zur Geschichte des Kurfürsten Friedrich Wilhelm von Brandenburg.

UH: 5. Mai 1906 Habilitation, s. UAH H-IV102/137 fol. 104r-122r; seit 3. Juni 1912 nichtetatm. a.o. Prof.; 15. Okt. 1914 Ministerium des Kultus und Unterrichts teilt Histor. Seminar mit, dass wir ,auf den Antrag, ... F. einen Lehrauftrag zur Abhaltung von Übungen ... (Proseminar) zu erteilen, nach Schluß des Krieges zurückkommen" werden (aus: UAH RA 6421); SS 1919 Beurlaubung von UH ,zum Zweck wissenschaftlicher Arbeiten auf dem Gebiet der brandenburgisch-preußischen Geschichte in Berlin" (aus: Brief vom 26. April 1919 in: UAH PA 1544); 27. April 1920 erneut Bitte F.s um Beurlaubung, da ,ich mich infolge meines erschütterten Gesundheitszustandes der Ausübung einer ersprießlichen Lehrtätigkeit in diesem Semester [= SS 1920] nicht gewachsen fühle. Als Hauptgrund dieses Versagens darf ich das persönliche Missgeschick anführen, das mich durch den Tod meiner Frau betroffen [!] hat" (aus: PA 1544). In dieser Zeit:

Seit 1914 Kriegsdienst; April 1918-Ende Juli 1919 (Auflösung des Amtes) Kommandierung an das Kriegspresseamt, Abt. „Fremde Presse“ in Berlin.

U Hamburg: 26. Juli 1920 Umhabilitation; seit WS 1920/21 Privat-Dozent; seit 4. Juli 1931 nichtbeamteter a. o. Prof.; seit Ende Jan. 1935 Beurlaubung bis auf weiteres; 16. Aug. 1937 Lehrbefugnis aus rassischen Gründen entzogen (nichtarische Großmutter väterlicherseits: Anna Emilie F. geb. Oppenheimer). • In dieser Zeit:
Aufenthalte: 16. Juli-20. Okt. 1923 Heilanstalt in Lübeck-Strecknitz (Diagnose: manisch-depressiv); 23. Juni-1. Sept. 1930 Provinzial- und Pflegeanstalt Lengerich in Westfalen; Nov./Dez. 1932 Sanatorium Neufriedenheim in München; seit 27. Dez. 1934 geschlossene Aufnahmeabteilung für Geisteskranke des Karlshospitals in Kassel, 4. Juni 19357. Juli 1937 als Pensionär im Diakonenheim des Ev. Vereins für Innere Mission in Kassel, seit 7. Juli 1937 Gasthof bei Kassel, anschl. in Lollar (bei Gießen), 17. Aug. 1937-17. Aug. 1938 Psychiatrie- und Nervenklinik der U Giessen.

Aufenthalte in von Bodelschwinghschen Anstalten (heute: Stiftungen) Bethel: Seit 17. Aug. 1938 Haus Morija in Gadderbaum (heute: Stadtbezirk von Bielefeld), 13. Okt. 1939-19. Sept. 1940 Haus Heidegrund in der damaligen Betheler Zweiganstalt Eckardtsheim (heute: Ortsteil von Sennestadt im Stadtbezirk von Bielefeld).

Langenhorn (bei Hamburg): 19. Sept. 1940 (Überweisung auf Wunsch der Familie)-8. Aug. 1943 Aufenthalt in Heil- und Pflegeanstalt.

Scheuern (heute: Stadtteil von Nassau an der Lahn): Seit 8. Aug. 1943 Aufenthalt in Heil-, Erziehungs- und Pflegeanstalt; 27. März 1945 Flucht während e. Fliegeralarms.

Aufenthalte: Nach März 1945 zunächst Gaiberg (bei $\mathrm{H}$ ), zuletzt Waldhilsbach.

E Eisernes Kreuz II. Klasse; 1915 Hanseatenkreuz.

Qu UAH PA 1544; RA 6069, 6421; Quästurakte Rep. 27-304; Fak.-Akte H-IV-102/137; Studentenakte. - GLA Abt. 235, Fasz. 1952. - Archiv der Hansestadt Lübeck - Familienarchiv Fehling - FA Fehling II.; Geheimes Staatsarchiv Preußischer Kulturbesitz Berlin. - Ergebnislose Anfrage: Stadtarchiv Nerckargemünd. - Auskunft: Ev. Kirchengemeindeamt - Kirchenbuchamt - Heidelberg; Stadtarchiv Heidelberg; von Bodelschwinghsche Stiftungen Bethel - Hauptarchiv - Bielefeld; Staatsarchiv Hamburg (Bestand 361-6, Sign. IV 2427); Universitätsarchiv der Humboldt-Universität Berlin. 
$W$ Frankreich und Brandenburg in den Jahren 1679-1684. Leipzig 1906. • Die europäische Politik des Großen Kurfürsten 1667-1688. Leipzig 1910. • Kaiser Friedrich II. und die römischen Cardinäle in den Jahren 1227-1239. Berlin 1901. Nachdr. 1965.

L Kürschner (1931) Sp. 306; Jansen (1992) S. 408 (Register); Ders. (1992a) S. 165 (Register); Kriegstagebuch K. Hampe (2007) S. 957 (Register); 100 Jahre Geschichtswissenschaft in Hamburg (2011) S. 112, 115 Anm. 77; Reichert (2015) S. 230 f., 239 f., 242. - Inama-Knäblein, Alexandra B., Drüll, Dagmar: F.-Biographie (Arbeitstitel; 2018 in Vorbereitung).

\section{$P$ Bildarchiv UAH.}

\section{Fehr, Hans Adolf}

1917-1924 Jur. Fak.

Deutsches Recht, Deutsche Rechtsgeschichte,

Bürgerliches Recht, Handelsrecht

* o9. Sept. 1874 St. Gallen

$\dagger$ 21. Nov. 1961 Muri (bei Bern)

ev.

V Dr. Adolf Konrad F. (1842-1894) Arzt

M Bertha Amalie Mathilde geb. Hofer (18461929)

๑ 7. Juni 1903 Nelly geb. Hoffmann (1877-1927)

๑ 1. Juni 1949 Dagmar Ida Felizitas geb. Vaniory gesch. Kohlschütter (1910-1984)

K $2 \mathrm{~S}, 1 \mathrm{~T}$

Vw Schwager: Dr. phil. et med. Hans Prinzhorn (1886-1933) 1919-1921 Assistent an Psychiatr. U-Klinik H; in dieser Zeit, unterstützt von Karl Wilmanns, legt P. eine Sammlung von Kunstwerken Geisteskranker an, s. NDB 20 (2001) S. 730 f.; Zwischen Wahnsinn und Kunst. Die Sammlung Prinzhorn. Dt. Film von 2007. Regie Christian Beetz; Prinzhorn, Hans: Bildnerei der Geisteskranken. 7. Aufl. Wien 2011. • 2001: Eröffnung des Museums „Sammlung Prinzhorn" in der Heidelberger Voßstraße 2.

Lb Seit 1894 Studium an U Würzburg, seit SS 1896 Bonn, anschl. Berlin, Bern; 18. Juli 1899 Dr. iur. an U Bern.
Paris: 1899-1901 Attaché an Schweizerischer Gesandtschaft.

U Leipzig: 1. Nov. 1904 Habilitation; SS 1905-WS 1906/o7 im Vorlesungsverzeichnis genannt.

U Jena: 27. Juli 1906 Ern. zum a.o. Prof.; 27. Okt. 1906 Vereidigung; 11. Aug. 1907 Ern. zum o. Prof.

U Halle-Wittenberg: 13. Jan. 1912 Ern. zum o. Prof.; 1917 Ruf an U Bonn abgelehnt.

UH: 15. Mai 1917 Ern. zum o. Prof. als Nachf. von Richard Schroeder.

U Bern: SS 1924-SS 1944 (Emeritierung) o. Prof.

Dem 1918 gestifteten (s. hierzu Kraus (1999) S. 435) Institut für geschichtliche Rechtswissenschaft, Germanistische Abt., der Universität Heidelberg ist das sogenannte Fehr-Archiv als Sonderbestand angegliedert. Diese von F. angelegte Sammlung umfaßt 645 Bilddokumente mit Abbildungen des mittelalterlichen und frühneuzeitlichen Prozeßund Strafvollstreckungswesens.

1917 Geh. Hofrat

$E$ Mitglied der Akademie der Wissenschaften: Madrid, $1918 \mathrm{H}$.

Qu UAH PA 752, 3723f.; RA 6762; Quästurakte Rep. 27-306; Rep. 40-394. - GLA Abt. 235, Fasz. 1955. Amtliches Personalverzeichnis der ... Universität zu Bonn für das Sommer-Halbjahr 1896. Bonn 1896. S. 27. - Briefe: UBH. - Mein wissenschaftliches Lebenswerk. Bern 1945. (Autobiogr.)

$W$ Deutsche Rechtsgeschichte. Berlin 1921. 6. Aufl. 1962. - Kunst und Recht. 3 Bde. Zürich 19231936. Humor im Recht. Bern 1946. Vom Leben in der Gemeinde. Stuttgart 1948. 5. Aufl. 1965. • Emil Nolde, ein Buch der Freundschaft. Köln 1957.

MHG 1936-1950 Zeitschrift für das gesamte Handelsrecht und Konkursrecht. - Archiv für Rechtsund Wirtschaftsphilosophie. 
L Gönnenwein, Otto: H.F. zum 8o. Geb. in: Ruperto Carola 6. Jg., Nr. 15/16 (1954) S. 63 f. Kürschner (1961) S. 423. - Who's who in Switzerland. Ed. by Stephen Taylor. Genf 1961. S. 95. • Beyerle, Franz: Kunst und Recht. H.F. Leben und Schriften in: Das Bodenseebuch. Ein Buch für Land und Leute ... Hrsg. von Guntram Brummer. Kreuzlingen 1964. 39. Jg. S. 36-38. • Rechtsgeschichte im Nationalsozialismus ... Hrsg. von Michael Stolleis und Dieter Simon. Tübingen 1989. S. 119, 121-123 u. ö. • Jansen (1992) S. 408 (Register). Paul, Hanns Christian: Ein ungewöhnlicher Freund Fraengers: der Rechtshistoriker H.F. in: Neue Kunst - Lebendige Wissenschaft. Hrsg. von Susanne Himmelheber ... Heidelberg 2004. S. 111122. - Lieberwirth, Rolf: H.F. in: Handwörterbuch zur dt. Rechtsgeschichte. Hrsg. von Albrecht Cordes u. a. 2. Aufl. Berlin 2008. Bd. 1. Sp. 1451 f. • Impressionist, modern works on paper ... Properties from the Hans Fehr collection and various sources. London 2009 [Auktionskatalog von Christie's]. - Catalogus prof. Halensis online; Schroeder (2010) S. 413-417 u. ö.; WBIS. • Lenzner, Ulf: H.A.F. ... in: Rechtsgelehrte der Universität Jena aus vier Jahrhunderten. Jena 2012. S. 215-233; Ders.: H. F. und Emil Nolde - Ein Juraprofessor als Kunstmäzen oder Facetten einer Freundschaft in: Juristen hinter Literatur und Kunst ... Berlin 2013. S. 37-58. - Rechtsgelehrte der U Jena (2012) S. 215233. - Schroeder, Klaus-Peter: H.F. - Wegbereiter der Rechtsikonographie in: Heidelberger Thesen zu Recht und Gerechtigkeit (2013) S. 255-266. • Deutsche Biographie, s. https://www.deutsche-bio graphie.de/gnd116433868.html [06.11.2017].

$P$ Bildarchiv UAH; Ruperto Carola; NDB.

\section{Fehrle, Joseph Eugen}

1913-1945 Phil. Fak. 1913-1934 Klassische Philologie, 1934-1945 Volkskunde

* $\quad$ 07. Aug. 1880 Stetten (im Hegau; heute: Ortsteil von Engen)

$\dagger \quad$ o8. Mai 1957 Heidelberg

kath., seit ca. 1914 ev.-luth.
V Johann F. (1851-1931) Hauptlehrer

M Martina geb. Wick (1858-1933)

๑ 10. Sept. 1910 Erna geb. Küster (1892-1950)

K 2 T, 1 S: siehe Friedrich von Duhn ( Vw).

Lb UH: Seit WS 1900/o1 Studium der Philologie, Archäologie, Geschichte; 16. Jan. 1908 Dr. phil.; 29. April 1908 Prüfung für höheres Lehramt in Karlsruhe.

H: Seit Mai 1908 Lehramtspraktikant am Großherzogl. Gymnasium; Jan.-April 1909 vom Schuldienst beurlaubt für Eigenstudien und Studienreise nach Italien.

UH: Seit 15. April 1909 Lektor für Latein und Griechisch; 7. Juli 1913 Habilitation für Klassische Philologie; seit 25. März 1919 nichtetatm., 1920-1934 nichtplanm. a.o. Prof.; seit 16. März 1926 außerdem Lehrauftrag für Volkskunde; WS 1933/34 Lehrauftrag für Volkskunde an TH Karlsruhe; SS 1934-WS 1934/35 Lehrauftrag für Volkskunde an U Freiburg/Br.; seit 8. Mai 1934 persönlicher Ordinarius für Volkskunde und Juli 1934-Juli 1938 (Mit-)Direktor (zus. mit Friedrich Panzer bis SS 1936) des Deutschen Seminars; seit Herbst 1935 Leiter der neueingerichteten „Lehrstätte der deutschen Volkskunde an der UH“, der e. Volkskundliche Lehrschau, die Landesstelle Baden des „Atlas der Dt. Volkskunde“ (1929 von F. initiiert und anfänglich in der Heidelberger Werderstraße 34 untergebracht, seit 1934 an UH) und die Landesstelle Baden der „Dt. Flurnamenforschung“ (ebenfalls von F. initiiert und seit 1934 an UH) angegliedert sind; 6. Mai 1936 Ern. zum o. Prof. für Deutsche Volkskunde rückwirkend vom 1. Juli 1935; Herbst 1941 Ruf an Reichs-U Straßburg abgelehnt; 11. Mai 1942 außerdem Lehrauftrag für Religionswissenschaft; 3. Juli 1945-23. Mai 1947 Internierungshaft; 19. Nov. 1945 Entlassung gemäß Erlaß der amerikanischen Militärregierung; 16. Jan. 1950 als Mitläufer eingestuft; 1. Okt. 1950 Emeritierung. • In dieser Zeit:

1914-1918 Kriegsdienst.

H: 1925-1945 Leiter des von der Josefine und Eduard von Portheim-Stiftung für Wissenschaft und Kunst (1941 umbenannt in Heidelberger Stiftung 
für Kunst und Wissenschaft) eingerichteten Inst. für Volkskunde im Palais Weimar in der Hauptstraße 235 .

Karlsruhe: Seit 14. März 1933 zunächst ehrenamtlicher kommissar. Leiter, seit 1. Mai 1933 Ministerialrat und Leiter der Hochschul-Abt. im Ministerium des Kultus und Unterrichts; Sept. 1935 auf eigenen Antrag Entlassung; Aug. 1934-1944 Führer der Verwaltungs-Akademie Baden.

Berlin: 18. Mai 1937-31. März 1942 Nebenamtl. Mitglied des Reichsjustizprüfungsamtes in Berlin.

München: 1944-1945 Ehrenamtlicher Leiter der Abt. Volkskunde an Dt. Akademie.

22. Okt. 1943-31. März 1945 Prorektor der UH; 1942/43 Dekan der Phil. Fak. der UH

E Mitglied der Wiener Gesellschaft für Volkskunde; 1932 Mitglied der Badischen Histor. Kommission; Mitglied der Akademie der Wissenschaften: 1934 H (1946 (?) aus der Mitgliederliste gestrichen), 1955 Bologna. 1942 Ehrensenator der Universität Heidelberg.

$\mathrm{Q} u$ UAH PA 387, 3729; RA 5233, 6395, $6876 \mathrm{f}$; B-3027/2, B-3029/17a. GLA Abt. 235, Fasz. 1959. • Briefe: UBH. - Mitteilungen: Ehepaar Dres. Hans Fehrle $(\dagger)$ und Lili Fehrle-Burger $(\dagger)$, Heidelberg. • Diathek-Sammlung Fehrle im Ludwig-Uhland-Institut für Empirische Kulturwissenschaft der Universität Tübingen.

$W$ Die kultische Keuschheit im Altertum. Gießen 1910. Nachdr. Berlin 1966. - Deutsche Feste und Jahresbräuche. Leipzig 1916. 4. Aufl. 1936. • Badische Volkskunde. Heidelberg 1924. Unveränd. Nachdr. Frankfurt/M. 1979. • Deutsche Hochzeitsbräuche. Jena 1937. • Feste und Volksbräuche im Jahresverlauf europäischer Völker. Kassel 1955. Lateinische Grammatik. 6 T. Heidelberg 1965-1967. Bibliographie in: Frohmüller (2013) S. $87-99$.

HG 1927-1939 Bausteine zur Volkskunde und Religionswissenschaft. 1927-1943 Oberdeutsche Zs. für Volkskunde. • Seit 1931 Badische Flurnamen.
MHG Seit 1926 Zs. Volk und Rasse.

HG, Übers. Publius Cornelius Tacitus: Germania. München 1929. 4. Aufl. 1944.

$L$ Badische Biographien N.F. I (1982) S. 112-114. • Niederdräing, Martin: Zur Geschichte der Universität Heidelberg: E.F. Masch.geschr. Zulassungsarbeit. Heidelberg 1983. • Assion, Peter: „Was Mythos unseres Volkes ist". Zum Werden und Wirken des NS-Volkskundlers E.F. in: Zs. für Volkskunde 81 (1985) S. 220-244. • Mussgnug (1988) S. 297 (Register); Heiber II,1 (1992) S. 652 (Register); Heiber II,2 (1994) S. 835 (Register); Jansen (1992) S. 408 (Register); Ders. (1992a) S. 165 (Register); Wennemuth (1994) S. 633 (Register); Heidelberg 1945 (1996) S. 101 u.ö.; Schlichtenberger (1998) S. 248 (Register); Remy (2002) S. 181-185; Grüttner (2004) S. 46; Freiburger Phil. Fak. (2006) S. $320 \mathrm{ff}$; UH im Nationalsozialismus (2006) S. 355-357 u. ö.; Engehausen (2008) S. 70 f. u. ö. • Schirrmacher, Arne: Philipp Lenard: Erinnerungen eines Naturforschers ... Berlin 2010. • Frohmüller, Moritz: E. F. und die deutsche Volkskunde in Heidelberg. Magisterarbeit am Histor. Seminar der Universität Heidelberg. Heidelberg 2013. (Ex. im UAH.) - Riecke (2016) S. 143 (Register); Deutsche Biographie, s. https://www.deutsche-biographie.de/gnd116434171.html [06.11.2017].

$P$ Bildarchiv UAH; Badische Biographien.

\section{Fischer, Ernst Kuno Berthold}

1850-1853, 1872-1903 (1906) Phil. Fak.

Philosophie

* 23. Juli 1824 Sandewalde (Schlesien; heute: Sądowel, Polen)

$\dagger \quad$ 05. Juli 1907 Heidelberg

ev.

V Karl Theodor F. (1787-1878) Superintendent, Pastor

M Charlotte geb. von Corvin-Wiersbitzki (17981826) 
$\infty$ 1. Sept. 1852 Maria geb. Le Mire (1824-1882)

( 26. Aug. 1884 Christiane Louise geb. Kirchhoff verw. Stilling (1832-1903), s. Neergaard, Steen: J.P. Jacobsen og Skandinavisk forening i Rom (2008) S. 13-18, besonders S. 18 Anm. 57 (Ausdruck im UAH)

K 1 S, 2 T, s. NDB 5 (1971) S. $199^{*}$

Vw Onkel: Otto Julius Bernhard von CorvinWiersbitzki (1812-1886) Schriftsteller, Freiheitskämpfer, s. BBKL I (1990) Sp. $1137 \mathrm{f}$; Reinhard, Stefan: Die Darstellung der Revolution von 1848/49 in den Lebenserinnerungen von Carl Schurz und O. von C. Frankfurt/M. 1999. Enkelin: Dr. Marie geb. Clauss (18821963) Ärztin, s. Marzolff, Renate: Die Enkelin des Philosophen ... in: Heidelberg. Jahrbuch zur Geschichte der Stadt 2010. Heidelberg 2009. Jg. 14. S. 47-73.

Lb Studium der Philologie, Philosophie, Theologie an U: seit SS 1844 Leipzig, seit SS 1845 Halle-Wittenberg; 19. März 1847 Dr. phil. an U HalleWittenberg.

Pforzheim: Jan. 1848-Aug. 1850 Hauslehrer.

UH: 26. Okt. 1850 Habilitation; 1. Juli 1853 Entzug der venia legendi durch Ministerialreskript, hier ohne Angabe von Gründen (e. der Gründe war der Vorwurf, pantheistische Lehren zu verbreiten).

1853-1856 Eigenstudien; Ende 1856 Verweigerung der Habilitation an U Berlin durch preußisches Ministerium, obwohl Habilitationskolloquium bereits stattgefunden hatte; kurz danach Zulassung als Privat-Dozent ebd. durch königl. Kabinettsordre; F. tritt Dozentur nicht an.

U Jena: Seit Dez. 1856 o. Honorar-Prof.; seit 1. Okt. 1857 o. Prof.; 1857, 1858 Rufe an UH abgelehnt.

UH: Seit 9. Juli 1872 o. Prof. als Nachf. von Eduard Zeller; Rufe an U abgelehnt: 1870 und 1872 Wien, 1875 Leipzig, 1881 Berlin; seit WS 1903/04 aus Krankheitsgründen beurlaubt; seit SS 1905 keine Vorlesungsankündigungen mehr; 1. Okt. 1906 auf eigenen Antrag Ruhestand.

1875/76 Prorektor der UH
Vor 1872 Geh. Hofrat; 1872 Geh. Rat II. Klasse; 1886 Geh. Rat I. Klasse

Siehe auch Wilhelm Windelband

E 1885 Korr. Mitglied der Königl. Akademie der Wissenschaften zu Berlin; 1902 Ehrenmitglied der Phil. Gesellschaft St. Petersburg. - 1904 Dr. iur. h.c. Königsberg (Preußen); 1904 Dr. phil. nat. h.c. UH. 1875 Kommandeurkreuz II. Klasse mit Eichenlaub, 1882 Großkreuz des Ordens vom Zähringer Löwen; 1895 Großkreuz des Großherzoglich-Sächsischen Hausordens vom weißen Falken; 1902 Großkreuz, 1903 Goldene Kette zum Großkreuz des Ordens Berthold I. 1894 Ehrenbürger der Stadt Heidelberg.

Qu UAH PA 1553; Fak.-Akte H-IV-102/46 Nr. 73; Acc. 37/16; GF 5. Briefe, Nachlaß: UBH. - Auskunft: Universitätsarchiv Halle/Saale.

$W$ Logik und Metaphysik. Stuttgart 1852. 2. Aufl. 1865. Nachdr. 1983. - Geschichte der neuern Philosophie. 11 Bde. Mannheim u.a. 1854-1904. Mehrere Aufl./Ausg. (siehe hierzu Hülsewiesche (1989)). Über den Witz in: K. F.: Kleine Schriften. Reihe 1,2. 2. Aufl. Heidelberg 1889. S. 6o-198.

L NDB 5 (1961) S. 199 (mit Werkverz.); Glockner (1969) S. 272 (Register). • Schulz, Eberhard Günter: Das Talent der philosophiehistorischen Darstellung bei den Schlesiern Rudolf Haym und K.F. in: Für unser Schlesien. Hrsg. von Helmut Neubach ... München 1985. S. 240-253. • Wiehl, Reiner: Heidelberger Philosophie zwischen Kantianismus und Hegelianismus in: Semper apertus 2 (1985) S. 409-431. - Hülsewiesche, Reinhold: System und Geschichte. Leben und Werke K. F.s. Frankfurt/M. 1989. (Bibliogr.: S. 163-189.) - WBIS; Jansen (1992a) S. 165 (Register). - Gruzenberg, O.S.: K. F.: Kritisch-biographischer Essay (übers. von Alla Meissner) in: Heidelberger Professoren in russischer Sicht. Dokumente aus der Zeit um 1900. Hrsg. von Willy Birkenmaier. Heidelberg 2000. S. 32-45. - Ruuskanen (2008) S. 125 f. - Schmidt, Jürgen W.: Zum akademischen Werdegang des schlesischen Philosophen K.F. ... Die Vorgeschichte seiner Berufung nach Jena 1853-1856 in: Fachprosaforschung - Grenzüberschreitungen 4/5 
(2008/o9). Baden-Baden 2010. S. 433-449. Dietrich, Rainer: Warum witzige Werbung weniger wirkt. Ein Essay zu K.F. „Über den Witz“ in: Texte. Seit 1386. Gedichte - Kurzprosa - Sprachdaten von Wissenschaftlerinnen und Wissenschaftlern der UH in der Akad. Mittagspause vorgestellt. Ekkehard Felder, Ludger Lieb (Hrsg.) ... Heidelberg 2016. S. 57-68. Riecke (2016) S. 143 (Register).

$P$ Bildarchiv UAH; graph. Slg. UBH; NDB.

\section{Fischler, Franz Josef Benedikt}

1906-1914 Med. Fak.

Innere Medizin

* 15. März 1876 Wiesloch (Baden)

$\dagger \quad$ 26. Juni 1957 München altkath.

V Dr. med. Eduard F. ( $†$ nach 1884) Arzt

M Emilie geb. Knauff (1839-1884)

œ unverheiratet.

Lb Studium: WS 1895/96 UH, SS 1896 Freiburg/ Br., seit WS 1896/97 Leipzig, WS 1898/99-WS 1899/ $1900 \mathrm{H}$; Juli 1900 Approbation in H; 1900-1901 Militärdienstpflicht als Einjährig-Freiwilliger.

UH: April 1901-Sept. 1902 Assistent am Patholog.Anatom. Inst.; 3. Juni 1902 Dr. med.; Okt. 1902Jan. 1914 Assistent an Med. U-Klinik; 17. Nov. 1906 Habilitation; seit 5. Aug. 1912 nichtetatm. a. o. Prof.; Febr. 1914 auf eigenen Antrag Verzicht auf venia legendi.

1914-1917 Kriegsdienst.

München: Seit 1918 Vorstand der Abt. für Krankenversorgung am Städtischen Lebensmittelamt; 1921-1932, 1946-1956 wiss. Mitarbeiter am Pharmaz. Inst. der U und an Dt. Forschungsanstalt für Lebensmittelchemie; 27. Juli 1926 Promotion zum Dr. phil. an U.
Qu UAH PA 3768. • GLA Abt. 235, Fasz. 1967.

$W$ Die Entstehung der Lebercirrhose nach experimentellen und klinischen Gesichtspunkten in: Kinderheilkunde 3 (1909). • Anleitung zum Praktikum der analytischen Chemie. München 1941. 6. Aufl. 1954. (Mitverf.) • Anleitung zur Harnanalyse. München 1943. 5. Aufl. 1966.

$L$ NDB 5 (1961) S. 215 f. (mit Werkverz.); WBIS. • Franz Fischler in: Dt. Forschungsanstalt für Lebensmittelchemie. 1918-1978. Garching 1978.

$P$ Bildarchiv UAH; NDB.

\section{Fleiner, Fritz}

1908-1915 Jur. Fak.

Dt. Staats- und Rechtsgeschichte, Dt. Reichs- und Landesstaatsrecht, Verwaltungsrecht, Kirchenrecht

* 24. Jan. 1867 Aarau (Kanton Aargau)

$\dagger$ 26. Okt. 1937 Ascona (Kanton Tessin) ev.

V Albert F. (1826-1877) Zementfabrikant

M Léontine geb. Zschokke (1834-1905) Enkelin von Heinrich Z. (1771-1848) Schriftsteller, s. BBKL XV (1999) Sp. 1588-1595

@ 16. März 1896 Fanny geb. Veith (1870-1957), s. Schroeder (2010) S. $303 \mathrm{f}$.

$\mathrm{K}$ keine

Vw Vetter: siehe Wilhelm F.

Lb Seit SS 1887 Studium an U Zürich, anschl. Leipzig, Berlin; 13. Dez. 1890 Dr. iur. utr. an U Zürich; 1891 II. Staatsexamen in Aarau; Nov. 1891-Sommer 1892 Studienaufenthalt in Paris.

U Zürich: 9. Juli 1892 Habilitation für Kirchenrecht; seit 6. Mai 1895 a. o. Prof.

U Basel: Seit 2. Juni 1897 o. Prof. für Öffentl. Recht und Kirchenrecht. 
U Tübingen: Seit 10. Jan. 1906 o. Prof. für Verwaltungslehre, Verwaltungsrecht und Allg. Staatsrecht.

UH: Seit 14. Juli 1908 o. Prof. als Nachf. von Gerhard Anschütz; Rufe an U abgelehnt: 1909 Bern, 1913 Zürich.

U Zürich: WS 1915/16-WS 1935/36 (Emeritierung) o. Prof. für Staats-, Verwaltungs- und Kirchenrecht.

1912/13 Dekan der Jur. Fak. der UH

1910-1915 Mitglied des Bezirksrats von Heidelberg

E 1913 Ritterkreuz I. Klasse des Ordens vom Zähringer Löwen. - Weitere Ehrungen, siehe Wirtschaftswiss. Fak. Tübingen 1 (2004) S. $368 \mathrm{f}$.

Qu UAH PA 1559; RA 6762. • GLA Abt. 235, Fasz. 1970. Briefe: UBH. • Nachlaß: Universitätsbibliothek Zürich.

$W$ Verwaltungsrechtsfälle für den akademischen Gebrauch. Tübingen 1908. 3. Aufl. 1929. - Institutionen des deutschen Verwaltungsrechts. Tübingen 1911. 2. fotomechanischer Neudr. der 8. Aufl. 1963. Das Schweizerische Bundesstaatsrecht. Tübingen 1923. Unveränd. Nachdr. der Neubearb. von 1949. Zürich 1978. Bundesstaatliche und gliedstaatliche Rechtsordnung. Verwaltungsrecht der öffentlichen Anstalt. Berichte von F. F., Josef Lukas u.a. Berlin 1929. Reprint 2013. - Tradition, Dogma, Entwicklung als aufbauende Kräfte der schweizerischen Demokratie. Zürich 1933. • Ausgewählte Schriften und Reden. Hrsg. von Fanny Fleiner. Zürich 1941. - Siehe Wirtschaftswiss. Fak. Tübingen 1 (2004) S. 369-371.

L Kürschner (1935) Sp. 333. Giacometti, Zaccaria: F. F. in: Schweizerische Juristen-Zeitung 34, 10 (1937). - Deutsches Familienarchiv 17 (1961); Universität Zürich (1983) S. 312 f.; Wirtschaftswiss. Fak. Tübingen 1 (2004) S. 366-372. - Müller, Roger: Verwaltungsrecht als Wissenschaft. F. F. ... Frankfurt/M. 2006. Schroeder (2010) S. 297-304 u. ö.;
Deutsche Biographie, s. https://www.deutsche-bio graphie.de/gnd1186839oX.html [06.11.2017]; UH während des Ersten Weltkriegs (2017) S. 37-39 u.ö.

P Bildarchiv UAH; graph. Slg. UBH.

\section{Fleiner, Wilhelm Albert}

1888-1905 Med. Fak. 1905-1906 (Honorar-Prof.) Med. Fak. 1906-1924 Med. Fak. Innere Medizin

* 06. Dez. 1857 Schopfheim (Breisgau)

$\dagger$ 26. Juli 1926 Heidelberg ev.

V Wilhelm F. (1828-1889) Apotheker, 1871-1872 Mitglied der II. Kammer des Badischen Landtags, s. WBIS

M Christine geb. Stein (1830-1918)

(1) 27. Sept. 1884 Luise Emma Margarete geb. Keller (1860-1943)

K $2 \mathrm{~T}$

Vw Vetter: siehe Fritz F.

$L b$ 16. Jan. 1877 Apothekergehilfenprüfung in Karlsruhe; Apothekergehilfe: 1877-1878 Lausanne, 1878-1879 Schopfheim.

April-Okt. 1879 Eigenstudium der lateinischen und griechischen Sprache für die im Herbst 1880 abgelegte Reifeprüfung in Karlsruhe; seit WS 1879/ 80 Studium an UH, SS 1882 Kiel, WS 1882/83-WS 1883/84 UH; 17. Jan. 1884 Approbation in Karlsruhe; 1886 staatsärztl. Prüfung ebd.

UH: 12. Febr. 1884 Dr. med.; 1884-1892 Assistent: zunächst Patholog.-Anatom. Inst. der UH, anschl. U-Frauenklinik in Berlin, zuletzt Ambulanz der Med. U-Klinik H; 14. Jan. 1888 Habilitation; seit 29. Juli 1892 nichtetatm. a. o. Prof.; 1904 Ruf an U Greifswald abgelehnt; seit 17. Jan. 1905 o. HonorarProf.; 3. Nov. 1906-31. März 1924 (Emeritierung) o. Prof. und Direktor der Med. Poliklinik als Nachf. von Oswald Vierordt; SS 1924 Vertreter seines Lehrstuhls. • In dieser Zeit: 
H: 1888 Niederlassung als Arzt; seit 1888 Internist am Diakonissenhaus, seit 1891 auch am St. Josefshaus.

1912/13 Dekan der Med. Fak. der UH

1896-1923 Konsiliarius u.a. der badischen großherzoglichen Familie

1896 Hofrat; 1905 Geh. Hofrat

E 1891 Kommandeurkreuz des Ordens Danilos I. von Montenegro; 1900 Ritterkreuz des Ordens Berthold I.; 1906 Friedrich-Luisen-Medaille; 1907 Königl.-Preußischer Kronenorden II. Klasse; 1907 Kommandeurkreuz II. Klasse mit Eichenlaub des Ordens vom Zähringer Löwen; 1914 Kommandeurkreuz I. Klasse des Königl. Schwedischen Nordsternordens.

Qu UAH PA 911, 3777; RA 6177, 6804, 7438; Fak.Akte H-III-111/96 Nr. 35. • GLA Abt. 235, Fasz. 1971.

W Zur Pathologie der Addison'schen Krankheit in: Berliner Klinische Wochenschrift 51 (1889). • Lehrbuch der Erkrankungen der Verdauungsorgane. Stuttgart 1896. - Über das Körperliche und Seelische in Diagnose und Behandlung in: Jahreskurse für ärztliche Fortbildung (März 1912).

$L$ Thannhauser, S. J.: W.F. † in: Münchener Med. Wochenschrift 73 (1926) S. 2130. - Fleiner, Elisabeth: W.F. Lebensbild eines deutschen Arztes. Heidelberg 1939 (mit Werkverz.). - Fischer 1 $\left({ }^{3} 1962\right)$ S. 416; Chronik Ärzte H (1985) S. 127; WBIS; Jansen (1992a) S. 165 (Register); Bauer/Ho (2016) S. 38-46; Deutsche Biographie, s. https:// www.deutsche-biographie.de/gnd1012263673.html [06.11.2017].

$P$ Bildarchiv UAH; Chronik Ärzte H.

\section{Fossmann}

siehe Vossmann

\section{Fraenkel, Julius Albert}

1928-1933 (Honorar-Prof.) Med. Fak. Innere Medizin

* O3. Juni 1864 Mußbach (heute: Stadtteil von Neustadt/Weinstraße)

$\dagger \quad$ 22. Dez. 1938 Heidelberg

$\square$ Ruvigliana bei Lugano (bis 1947)

$\square$ Heidelberg (Ehrengrab) mosaisch, seit 1896 prot.

V Jacob F. (1836-1905) Weinhändler, s. A.F. ein Arztleben in Licht und Schatten (2004) S. 17, 20-22 u. ö.

M Emilia (Emma) geb. Deutsch (1838-188o)

๑ 22. Okt. 1896 Erna geb. Thorade (1873-1968), siehe Lexikon jüdischer Einwohner Hs (2011) S. 114. - Schwester von Willa T. (1871-1962) Sozialpolitikerin, Frauenrechtlerin, s. WBIS

K 2 T: Dr. Annemarie F. (1897-1967) Volkswirtschaftlerin, bis 1933 (Entlassung) Leiterin des ev. Jugend- und Wohlfahrtsdienstes in $\mathrm{H}$. • Elisabeth Charlotte (Liselotte) F. (1902-1992) Volksschullehrerin; Ehefrau von Hans Anschütz (1901-1980) Jurist, S von (siehe) Gerhard A. - Siehe A. F. ein Arztleben, S. 38 f., $51 \mathrm{f}$. u. ö., Lexikon jüdischer Einwohner Hs, S. 115.

Lb Seit SS 1883 Studium an U München, seit 1885 Straßburg; 1888 Staatsexamen in Straßburg; $1888-$ 1890 Assistenzarzt an U-Frauenklinik in München (1889/90 Unterbrechung durch Tuberkulose-Erkrankung mit anschl. Kuraufenthalten u.a. auch in der Schweiz); Winter 1890/91 kurzzeitig Assistenzarzt in Berlin bei Georg Cornet (1858-1915), e. Mitarbeiter Robert Kochs (1843-1910), um bei Erprobung des gegen Tuberkulose 1890 entwickelten (unwirksamen) Medikaments Tuberkulin mitzuwirken.

Badenweiler: 1891-1914 Leitender Arzt an der seit 1903 zur „Diätetischen Kuranstalt“ erweiterten Villa Hedwig als Nachf. von Adolf Weil (s. hier$\mathrm{zu}$ „Eine raffiniert humane Kur": Hermann Hesse [und sein Arzt A. F.] in Badenweiler ... 3. Aufl. Schliengen 2012; weitere Patienten F.s sind: Karl Jaspers, Elisabeth Eleonore Anna Justine „Elly“ Heuss-Knapp (1881-1952) Ehefrau von Theodor Heuss); seit 11. Mai 1891 niedergelassener prakti- 
scher Landarzt (aus: Gewerbeanmeldung bei der Gemeinde); 1903-1920 auch (Gründer und) Leiter der „Villa Paul“ für Lungenkranke sowie 19051920 Leiter des Hildakrankenheims, s. hierzu A. F. ein Arztleben (2004) S. 90-95; 21. März 1914 preußischer Minister des Innern verleiht F. „in Anerkennung Ihrer wissenschaftlichen Leistungen das Prädikat Professor ..." (aus: A.F. ein Arztleben, S. 35); 1920 Verkauf seiner Privat-Villa. • In dieser Zeit:

UH: 1893-1905 F. arbeitet jeweils in den Wintermonaten am Pharmakolog. Inst.

H: 1902 Erste Erwähnung von „Fränkel, Alb., Dr. med., Bunsenstr. 12" im Adressbuch der Stadt Heidelberg ... für das Jahr 1902. Heidelberg 1902. S. 134; seit 1905 praktizierender Arzt („Fränkel, Alb., Dr. med., Arzt, Bergheimer Str. 27a, Tel. 1098“ laut Adressbuch der Stadt Heidelberg ... für das Jahr 1905. Heidelberg 1905. S. 160); 1934 letzte Erwähnung als Arzt im Stadt-Adreßbuch der Kreishauptstadt Heidelberg ... für das Jahr 1934. Heidelberg 1934. S. 252; Sept. 1938 Entziehung der Approbation aus rassischen Gründen. • In dieser Zeit:

H: 1914-1918 Kriegsdienst als Stabsarzt und Leiter e. Beobachtungslazaretts in Neuenheim und Internist des XIV. Armeekorps.

H: Seit 1920 zunächst beratender Arzt, 1928-18. April 1933 (sofortige Beurlaubung, angeordnet durch Sonderkommissar für das Gesundheitswesen in Baden) Leiter des Tuberkulose-Krankenhauses (heute: Thoraxklinik) in Rohrbach; 8. Aug. 1927-1. Juni 1933 (Kündigung durch Gesellschaftsversammlung) (Mitbegründer und) Ärztl. Direktor des Mittelstands-Sanatoriums Speyerershof $\mathrm{GmbH}$, Gemeinnützige öffentl. Krankenanstalt, heute: Schmieder-Kliniken.

UH: Seit 26. März 1928 o. Honorar-Prof. mit e. Lehrauftrag für Tuberkulose; 20. April 1933 Beurlaubung von der Lehre durch U; 2. Mai 1933 Befreiung von der Lehre durch Kultusministerium auf eigenen Antrag; 2. Aug. 1933 Lehrbefugnis aus rassischen Gründen entzogen (Gesetz zur „Wiederherstellung des Berufsbeamtentums").
1906: Erfinder und Entwickler der intravenösen Strophanthintherapie bei der Behandlung von Herzinsuffizienz

Im Sept. 1933 schreibt Ehefrau Erna F. in einem Brief: „Ins Ausland können wir aus finanziellen Gründen ... nicht, so gern wir gehen würden“ (aus: A. F. ein Arztleben (2004) S. 56 Anm. 197).

Der mexikanische Maler Diego Rivera (1886-1957) verewigt F. 1943/44 auf e. Wandgemälde über „Die Geschichte der Kardiologie“ im Treppenhaus des Nationalen Instituts für Kardiologie in MexikoStadt.

2004: Aufstellung einer Bronze-Büste F.s (Künstler: Helmut Heinze) im Park der Heidelberger Thoraxklinik

E 1914 Verleihung des Professoren-Titels. 1920 Ehrenbürger der Stadt Badenweiler.

Qu UAH PA 912, 3791; Rep. 40-395. GLA Abt. 235, Fasz. 1974. - Briefe: UBH. - Nachlaß: Stadtarchiv Mannheim, s. hierzu Boehringer Mannheim übergibt Nachlaß A. F.s dem Stadtarchiv Mannheim in: Der Archivar (1996) Jg. 49, H. 1, S. 88. • Auskunft: Frau Dr. Andrea Köster, Heidelberg.

$W$ Diagnostik und allgemeine Symptomatologie der Lungenkrankheiten in Vorlesungen für Ärzte und Studierende. Wien 189o. Spezielle Pathologie und Therapie der Lungenkrankheiten. Handbuch für Ärzte und Studierende. Wien 1904. • Strophanthintherapie. Berlin 1933. • Der Weg zur rationellen Therapie. Leipzig 1933. Bibliographie in: A. F. ein Arztleben (2004) S. 396-405.

L Kürschner 5 (1935) Sp. 344. - Den Unvergessenen. Opfer des Wahns 1933-1945. Hrsg. von Hermann Maas ... Heidelberg 1952. • A. F.: Arzt und Forscher. Gedenkausgabe ... zus.gestellt von Georg Weiss. Mannheim 1963. 2. Aufl. 1964. • WBIS; Chronik Ärzte H (1985) S. 127, $221 \mathrm{ff}$ - Ehmann, M.: Das Lebenswerk von A.F. reicht weit über die Entdeckung der Strophanthintherapie hinaus ... Heidelberg 2001. Krauß, Martin: A. F. und die Gründung des Krankenhauses Speyerershof in: Heidelberg. Jahrbuch zur Geschichte der 
Stadt 2002. Heidelberg 2002. Jg. 7. S. 131-141. A. F. ein Arztleben in Licht und Schatten ... Hrsg. von Peter Drings u. a. Landsberg/Lech 2004. • Schadt, Jörg: A. F. - Arzt und Forscher ... in: Jahresbericht Verein für Naturkunde Mannheim. N.F. H. 8 für die Jahre 2002-2004. Mannheim 2005. S. 147158. Kriegstagebuch K. Hampe (2007) S. 958 (Register); Siegmund-Schultze (2009) S. 463 (Register); Badische Biographien N. F. VI (2011) S. 118123; Lexikon jüdischer Einwohner Hs (2011) S. 114.

$P$ Bildarchiv UAH; Chronik Ärzte H; A.F. ein Arztleben (2004).

\section{Frank, Erich}

1923-1928 Phil. Fak.

Philosophie

* o6. Juni 1883 Prag

$\dagger \quad$ 22. Juni 1949 Amsterdam (Niederlande)

mosaisch, später kath.

$\mathrm{V}$ Aloys F. (1835-1886)

M Regine geb. Eisler (1843-1919)

unverheiratet.

Lb Seit SS 1905 Studium an U Berlin, anschl. Freiburg/Br., 1907 Wien, WS 1907/o8-WS 1908/o9 H; Frühjahr 1911 Prüfung für höheres Lehramt in Karlsruhe.

H: Seit 1911 Probekandidat, seit 1912 Volontär am Gymnasium; 12. Mai 1911 Promotion zum Dr. phil. an $\mathrm{U}$.

Aug. 1914-Nov. 1918 Kriegsdienst.

April-Dez. 1919 Lehramtspraktikant am Gymnasium in Freiburg/Br.; 1. Jan. 1920-31. Juni 1922 Studienurlaub.

Seit 1. Juli 1922 Lehramtspraktikant am Gymnasium in H; 1924-1928 Gymnasiallehrer in Mannheim. • In dieser Zeit:

UH: 5. Mai 1923 Habilitation; seit 2. Aug. 1927 nichtplanm. a. o. Prof.
U Marburg: 3. Nov. 1928-31. Dez. 1935 (Zwangsemeritierung und Publikationsverbot aus rassischen Gründen) o. Prof. für Philosophie und Pädagogik; Inhaftierung; Ende 1938 Emigration in die USA.

Cambridge (Massachusetts): 1939-1949 Research Fellowship an Harvard University. • In dieser Zeit:

Bryn Mawr (Vorort von Philadelphia, Pennsylvania): Frühjahr 1940, 1942-1943 Visiting Prof., 19431948 Faculty Member am Bryn Mawr College.

Philadelphia: 1948-1949 (†) Appointed Prof. an U of Pennsylvania; Juni 1949 Ferienaufenthalt in Amsterdam.

Qu UAH PA 3792; Studentenakte. • Briefe: UBH.

$W$ Das Prinzip der dialektischen Synthesis und die Kantische Philosophie. Berlin 1911. Plato und die sog. Pythagoreer. Halle/S. 1923. Nachdr. 1962. Philosophical understanding and religious truth. London, New York 1945. (Dt. Übers.: Philosophische Erkenntnis und religiöse Wahrheit. Stuttgart 1950.) - Wissen, Wollen, Glauben. Gesammelte Aufsätze zur Philosophiegeschichte und Existentialphilosophie. Hrsg. von Ludwig Edelstein. Zürich, Stuttgart 1955.

L Glockner (1969) S. 272 (Register); Catalogus prof. Marburgensis 2 (1979) S. 498; WBIS. - E. F. in: Biographical Dictionary of North American Classicists. Ed. by Ward W. Briggs. Westport (Connecticut), London 1994. S. 195 f. - Kersting, Christa: Pädagogik im Nachkriegsdeutschland. Wissenschaftspolitik und Disziplinentwicklung 1945 bis 1955. Bad Heilbrunn 2008. S. 122, 164 und Anm. 279. - Tilitzki 2 (2012) S. 1450 (Register). • Über E. F. in: Dostal, Robert: History of the Department of Philosophy. Homepage of Bryn Mawr College, s. http://www.brynmawr.edu/philosophy/history2. html. 


\section{Franke, Karl}

1912-1919 Med. Fak.

Chirurgie

* 29. Nov. 1879 Driburg (Westfalen; heute: Bad

D.)

$\dagger$ 29. Juni 1959 Achern (Baden)

ev.

V August F. (1849-1924) Holzhändler

M Wilhelmine geb. Garschagen (1847-1934)

$\varnothing$ 2. Aug. 1914 Hedwig geb. Luckenbach (18891977)

K 4, u.a. Dietrich F. (1921-2008) seit 1957 Facharzt für Chirurgie, seit 1963 Privat-Dozent für Chirurgie Marburg, 1965-1986 Chefarzt der Chirurg. Klinik des Krankenhauses Bruchsal, 1965 Umhabilitation an UH, 1969-1989 apl. Prof. H, s. UAH PA 7810, 10317; WBIS, Kürschner (1983) S. 1017.

Lb U München: Seit SS 1900 Studium; 21. Jan. 1905 med. Staatsexamen; 1905 Volontärarzt, 1907-1908 Assistenzarzt an Chirurg. U-Klinik; 1906 Dr. med.; 20. Sept. 1906 Approbation.

UH: Seit Mai 1908 Assistenzarzt an Chirurg. UKlinik; 27. Juni 1912 Habilitation; seit 17. Juli 1918 nichtetatm. a. o. Prof. • In dieser Zeit:

1914-1918 Kriegsdienst.

Achern: 1. April 1919-1953 Chefarzt der Chirurg. Abt. am Städtischen Krankenhaus.

E 1911 Prinz-Regent-Luitpold-Medaille in Bronze.

Qu UAH PA 914, 1568. GLA Abt. 235, Fasz. 1977. Mitteilungen: Herr Prof. Dr. Dietrich Franke (†).

$W$ Über die Lymphgefäße der Lunge, zugleich ein Beitrag zur Erklärung der Baucherscheinungen bei Pneumonie. Leipzig 1912. • Über die Behandlung alter Knochenfisteln nach Schußfrakturen in: Berliner klinische Wochenschrift 39 (1916).
L Stübler (1926) S. 320; Chirurgen-Verzeichnis $\left({ }^{4} 1958\right)$ S. 215; WBIS; Krebs/Schipperges (1968) S. $123 \mathrm{f}$.

$P$ Bildarchiv UAH.

\section{Franzen, Hartwig Heinrich}

1904-1912 Nat.-Math. Fak.

Chemie

* 21. März 1878 Nortorf (bei Neumünster, Schleswig-Holstein)

$\dagger$ 14. Febr. 1923 Karlsruhe ev.

V Hartwig F., Kaufmann, dann Pflanzenbutterfabrikant

M Helene geb. Sindt

( 2). Sept. 1902 Maria Caroline geb. Geiger (1882-1964)

K $\quad 1 \mathrm{~S}, 1 \mathrm{~T}$

Lb Vor 1897 Mitarbeiter in väterlicher Fabrik.

Kopenhagen: WS 1897/98 Studium am Jörgen'schen Inst. für Gärungsphysiologie.

UH: Seit SS 1898 Studium (gegen den Willen des Vaters); 30. Juli 1901 Dr. phil. nat.; 1901-1912 Assistent am Chemischen Laboratorium; 26. Nov. 1904 Habilitation; Herbst-Winter 1904 Aufenthalt am Gärungschemischen Inst. der Versuchs- und Lehrbrauerei in Berlin; seit 4. April 1910 nichtetatm. a. o. Prof.

TH Karlsruhe: 8. Juni 1912-14. Febr. 1923 Etatm. a. o. Prof. für Organische Chemie. In dieser Zeit: 1915-1918 Kriegsdienst.

Qu UAH PA 1569; RA 6496, 6898; Fak.-Akte H-V$1 / 58$.

W Gasanalytische Übungen: ein Hilfsbuch für das gasanalytische Praktikum. Leipzig 1907. Über die Bildung der Aminosäuren in den Pflanzen und 
über die Einwirkung von Formaldehyd auf Cyankalium. 2 T. Heidelberg 1910. Curtius, Theodor, F., H.: Ein Versuch zur Synthese des Blätteraldehydes (Hexylenaldehyds). Heidelberg 1914. • Über die chemischen Bestandteile grüner Pflanzen. Heidelberg 1921.

$L$ Wer ist's (1922) S. 420; WBIS; Deutsche Biographie, s. https://www.deutsche-biographie.de/gnd11 671968o.html [06.11. 2017].

$P$ Bildarchiv UAH; graph. Slg. UBH.

\section{Freudenberg, Karl Johann}

1926-1946, 1946-1955 Nat.-Math. Fak. Chemie

* 29. Jan. 1886 Weinheim/Bergstraße

$\dagger \quad$ 03. April 1983 Heidelberg ev.

V Hermann Ernst F. (1856-1923) Teilhaber und Mit-Direktor der Fa. Freudenberg mit Sitz in Weinheim, heute: Freudenberg SE

M Helene geb. Siegert (1855-1939) T von August Friedrich S. (1820-1883), u. a. seit 1872 Prof. an Königlich-Preußischer Kunstakademie Düsseldorf, s. WBIS

(D 30. Juli 1910 Doris geb. Nieden (1887-1967)

$\mathrm{K} \quad 2 \mathrm{~S}$ (beide $\mathrm{S}$ im 2. Weltkrieg $X$ ), 3 T: u.a. Herta F. (1916-2011) Ehefrau von Hans Plieninger (1914-1984), u.a. 1960-1979 Prof. für Chemie an UH, s. Drüll (2009) S. $467 \mathrm{f}$.

Vw Bruder: u.a. Richard F. (1892-1975) 1914-1972 Teilhaber und Mit-Direktor der Fa. Freudenberg, u.a. 1919 bis 1925 Abgeordneter im Badischen Landtag, s. Exner, Konrad: R. F. ... als Abgeordneter der DDP von 1919 bis 1925 in Karlsruhe in: hierzuland. Das Regio-Magazin von Rhein, Neckar und Main 26. Jg. (2011) Nr. 44, S. 29-36 (Zs. im UAH). • Vetter: Ernst F. (1884-1967), s. Hans Ritter von Baeyer: Eintrag unter $K$ [inder].

Lb Seit SS 1904 Studium der Naturwiss. an U Bonn; 1. Okt. 1905-1. Okt. 1906 Militärdienstpflicht als Einjährig-Freiwilliger in Ludwigsburg.
U Berlin: Herbst 1907-Ostern 1910 Forts. des Studiums; Juni 1910 Dr. phil.; seit Juli 1910 Assistent am Chemischen Inst.

U Kiel: Seit 1. April 1914 Assistent am Chemischen Inst.; 16. Juli 1914 Habilitation; seit 4. Aug. 1919 nichtplanm. Prof. • In dieser Zeit:

1914-1918 Kriegsdienst.

U München: Seit 2. Nov. 1920 nichtplanm. Prof.

U Freiburg/Br.: Seit 1. Okt. 1921 planm. a. o. Prof.

TH Karlsruhe: Seit 1. Okt. 1922 o. Prof. und Direktor des Chemischen Inst.; Nov. 1922 Ruf an U Wien abgelehnt.

UH: 1. April 1926-31. März 1955 (Emeritierung) o. Prof. und Direktor des Chemischen Inst. als Nachf. von Theodor Curtius; 1931 Gast-Prof. an U of Wisconsin-Madison und $\mathrm{U}$ of Baltimore (Maryland); 1. April 1938-1945 Leiter des Inst. für die Chemie des Holzes und der Polysaccharide, e. ForschungsInst. des Vierjahresplanes, dem Reichsamt für Wirtschaftsausbau (Reichswirtschaftsministerium) unterstellt; April-Dez. 1945 Mitglied des Dreizehnerausschusses zum Wiederaufbau der UH; 24.-27. Jan. 1946 Inhaftierung durch amerik. Militärbehörde, siehe hierzu Rückblicke auf ein langes Leben (1999) S. 248-251; 14. Febr. 1946 Entlassung auf Befehl der amerik. Militärregierung, s. hierzu UAH B-3029/13, PA 3802; 23. Sept. 1946 Wiedereinstellung durch den Präsidenten des Landesbezirks Baden; 21. Nov. 1947 „Der Präsident des Landesbezirks Baden hat mit Entschließung vom 10. Nov. 1947 aufgrund der von der Militärregierung Heidelberg mit Schreiben vom 11. Aug. 1947 erteilten Bestätigung der rechtskräftig ergangenen Entscheidung der Spruchkammer Heidelberg vom 8. Aug. 1946 [Freispruch] ... den Obengenannten [Freudenberg] ... für die Wiedereinstellung im öffentlichen Dienst vom 4. Dez. 1946 unter Berufung in das Beamtenverhältnis auf Lebenszeit als planm. o. Prof. der Chemie an der Universität Heidelberg wieder in den Dienst eingestellt" (aus: UAH PA 3802).

1949/50 Rektor der UH; 1931/32, April 1945-Jan. 1946 stellvertr. Dekan der Nat.-Math. Fak. der UH 
1951-1956 Heidelberger Stadtrat

1953-1957 Vorsitzender des Vorstands der Heidelberger Volkshochschule

Siehe auch Richard Kuhn und Ernst Wilke

$E$ Mitglied der Akademie der Wissenschaften: 1925 H, 1935 Göttingen, 1936 München; 1940 Mitglied der Dt. Akademie der Naturforscher Leopoldina Halle/S.; 1963 ausw. Mitglied der Royal Society London. 1952 Emil-Fischer-Medaille; 1966 Großes Bundesverdienstkreuz mit Stern.

Qu UAH PA 3801-3805. Briefe: UBH. - TeilNachlaß: UAH (Signatur: Rep. 14); UBH, s. Verzeichnis des Teil-Nachlasses K. F.: Signatur: Heid. Hs. 4071. Bearb. von Günter Kern. UBH 1992. • Siehe auch Archiv der Dt. Akademie der Naturforscher Leopoldina Halle/S. - Mussgnug, Dorothee (Bearb.): K. J.F. - Lebenserinnerungen in: Heidelberger Jahrbücher 32 (1988) S. 151-187. • Rückblicke auf ein langes Leben: Erinnerungen des Chemikers K. J. F. Heidelberg 1999. (Autobiogr.)

W Stereochemie. Wien 1933. Tannin. Cellulose. Lignin. Berlin 1933. Organische Chemie. Heidelberg 1938. 14. Aufl. 1982. Constitution and Biosynthesis of Lignin. Heidelberg, New York 1968.

$L$ Professoren Kiel (1956) S. 218. - Schildknecht, Hermann Karl: K.F. 90 Jahre alt in: Ruperto Carola 57 (1976) S. 105. • Cramer, Friedrich: Leben und Werk von K. F. in: Heidelberger Jahrbücher 28 (1984) S. 57-72. • WBIS; Mussgnug (1988) S. 297 (Register); Jansen (1992a) S. 165 (Register); Wennemuth (1994) S. 634 (Register); Baden-Württ. Biographien III (2002) S. 87-90. • Schmitt, Uta: Poesie in der Architektur - Die Villa Freudenberg ... in: Unser Museum. Mitteilungen des Förderkreises des Museums Weinheim. Weinheim 2002. Nr. 13. S. 30-43. Kipnis, Alexander: Biographie K. F. online unter http://www.kipnis.de/index.php?option $=$ com_content $\&$ task $=$ view $\&$ id $=155 \&$ Itemid $=26$ (Stand: 21. Okt. 2012; Ausdruck im UAH). Deutsche Biographie, s. https://www.deutsche-biographie.de/gnd116773758.html [06.11. 2017].

$P$ Bildarchiv UAH.

\section{Freund, Wilhelm Hermann}

1916-1924 Med. Fak. 1916-1918 Innere Medizin, 1918-1924 Pharmakologie

* 11. Aug. 1882 Breslau (heute: Wrocław, Polen)

$\dagger$ 14. Okt. 1944 (Ermordung) KZ Auschwitz (heute: Oświęcim, Polen)

mosaisch

V Dr. iur., 1901 Dr. iur. h.c. (U Breslau) Wilhelm Salomon F. (1831-1915) Rechtsanwalt, Notar, 1871-1915 Stadtverordneter von Breslau, 1876-1879 Mitglied des preußischen Abgeordnetenhauses (national-liberal), 1879-1881 Mitglied des Reichstags, 1884-1914 Vorsteher der Schlesischen Anwaltskammer, 1885-1915 Stadtverordneten-Vorsteher von Breslau, seit 1901 Ehrenbürger der Stadt Breslau, s. WBIS; Hamburger, Ernest: Juden im öffentlichen Leben Deutschlands: Regierungsmitglieder, Beamte ... Tübingen 1968. S. 296-298; Haunfelder, Bernd: Die liberalen Abgeordneten des deutschen Reichstags 1871-1918. Münster 2004. S. 143.

M Clara geb. Immerwahr (1845-1914)

$\infty$ unverheiratet

K 1 Adoptiv-T.

$L b$ Seit SS 1900 Studium der Chemie und Medizin an U Freiburg/Br., anschl. Breslau, München.

U Breslau: Seit WS 1903/04 Forts. des Studiums; 15. März 1906 Dr. phil. nat.; 15. Febr. 1908 ärztl. Staatsprüfung.

Wiesbaden: Aug. 1908-April 1909 Praktikant an Innerer Abt. des Städtischen Krankenhauses.

UH: 15. Febr. 1909 Approbation; 30. Juni 1909 Dr. med.; seit Aug. 1909 Assistent an Med. U-Klinik; 15. Dez. 1916 Habilitation für Innere Medizin; seit Dez. 1918 Assistent am Pharmakolog. Inst.; Dez. 1918 Verleihung der venia legendi für Pharmakologie; seit 7. Dez. 1921 nichtplanm. a. o. Prof. • In dieser Zeit:

1914-1918 Kriegsdienst als Lazarettarzt. 
U Münster: Seit WS 1924/25 o. Prof. und (Gründungs-)Direktor des Pharmakolog. Inst.; 1925 Ruf an UH abgelehnt; 30. März-Okt. 1933 Beurlaubung von U: SA-Sturmführer und Adjutant der SA-Standarte 13 verbietet F. Lehrtätigkeit und Aufenthalt in den Diensträumen; Sept. 1934 F. leistet Diensteid der Beamten auf Adolf Hitler; 1. Jan. 1936 Berufsverbot und endgültige Entlassung von U; 3. Okt. 1939 Emigration in die Niederlande.

Amsterdam: Nach 1939 Mitarbeiter in e. pharmazeutischen Firma; 1940 dt. Besetzung der Niederlande; 1941 Einstellung der Ruhegehalts-Zahlung wegen „Volks- und Staatsfeindlichkeit“ sowie Einzug seines gesamten Vermögens.

Deportationen: 26. Nov. 1942 Sammellager Westerbork (Niederlande), 18. Jan. 1944 KZ Theresienstadt (heute: Terezín, Tschechien), 12. Okt. 1944 KZ Auschwitz.

E Kriegsverdienstkreuz des Großherzogs von Baden.

Qu UAH PA 917, 3806; RA 6204. - GLA Abt. 235, Fasz. 1981. "Es wird alles gut werden“. Der Briefwechsel zwischen dem jüdischen Pharmakologen H.F. und seinem Schüler Willy König 19251939. Hrsg. von Ingeborg Huhn und Ursula Kilian. Münster 2010.

W Über Fieber durch Blutplättchenzerfall in: Dt. Archiv für Klinische Medizin 106 (1912). • Über die pharmakologischen Wirkungen des defibrinierten Blutes in: Archiv für experimentelle $\mathrm{Pa}$ thologie und Pharmakologie 88 (1920); Studien zur unspezifischen Reiztherapie in: ebd. 91 (1921).

L WBIS; Kürschner (1935) Sp. 352; Universität Münster (1980) S. 296, 299; Fischer 1 ( $\left.{ }^{3} 1962\right)$ S. 446; Chronik Ärzte H (1985) S. 128. • Möllenhoff, Gisela, Schlautmann-Overmeyer, Rita: Jüdische Familien in Münster 1918-1945. Biographisches Lexikon. Münster 1995. Lindner/Lüllmann (1996) S. 186 u. o. (hier: Sterbeort Mauthausen). • Löffelholz, Konrad, Trendelenburg, Ulrich: Verfolgte deutschsprachige Pharmakologen 1933-
1945. 2. Aufl. Frechen 2008. Deutsche Biographie, s. https://www.deutsche-biographie.de/gnd14 3517007.html [06.11. 2017].

$P$ Bildarchiv UAH.

\section{Freymond, Emile}

1883-189o Phil. Fak.

Romanische Philologie

* o9. Juli 1855 Breslau (heute: Wrocław, Polen)

$\dagger$ 09. Mai 1918 Prag ref.

V Charles F., Lehrer für franz. Sprache und Lektor an U Breslau

M N.N.

@ N.N. geb. Strasser (†1918)

$\mathrm{K}$ unbekannt.

Lb Seit 1876 Studium an U Breslau, anschl. Berlin, Straßburg; Frühjahr 1881 Dr. phil. an U Straßburg; 1881/82 Eigenstudien in Breslau.

UH: 31. Juli 1883 Habilitation, s. hierzu UAH H-IV102/101 fol. 92r-119r; seit 27. Juli 1884 a. o. Prof. in Nachfolge von Eugen Laur; 1889 Ruf an U Krakau abgelehnt; 10. Mai 189o Entlassung aus badischem Staatsdienst auf eigenen Wunsch.

U Bern: Seit WS 1890/91 o. Prof.; WS 1901/o2 letzte Erwähnung im Vorlesungsverzeichnis.

U Prag: 22. Sept. 1901 Ern. zum o. Prof.

Qu UAH RA 5226, 5278, 6418. GLA Abt. 205, Fasz. 232. Briefe: Krumbacheriana I in: Bayerische Staatsbibliothek München; Universitäts- und Landesbibliothek Sachsen-Anhalt in Halle/S. • Teil-Nachlaß: Archiv der Karls-Universität Prag. • Auskunft: Universitätsarchiv Bern; Archiv der Karls-Universität Prag.

$W$ Über den reichen Reim bei altfranzösischen Dichtern bis zum Anfang des XIV. Jahrhunderts. Halle/S. 1882. - Jongleurs und menestrels. Halle/S. 
1883. Précis de littérature française du moyen âge. Paris 1886. - Artus' Kampf mit dem Katzenungetüm. Eine Episode der Vulgata des Livre d'Artus, die Sage und ihre Lokalisierung in Savoyen. Halle/S. 1899. - Eine Prager Handschrift der Lamentations de Matheolus und des Livre de Leesce in: Prager Deutsche Studien 8 (1908) S. 565-583. - Siehe hierzu auch: Nachruf in: Bericht über das Studienjahr ... (1918) S. 8.

L Almanach Heidelberg (1886) S. 146; Wer ist's (1914) S. 46o. - Jaberg, Karl: Emil (sic!) F. in: Archiv für das Studium der neueren Sprachen und Literaturen 137 (1918) S. 218f. • Nachruf in: Bericht über das Studienjahr 1917-18. Erstattet vom Prorektor ... Anton Elschnig. Prag 1918. S. 17 f. • WBIS; Kalkhoff (2010) S. 41; Wissenschaftsatlas der UH (2011) S. 109. - Fryba, Annette: Philologie et linguistique romanes. Institutionnalisation des disciplines dans les universités suisses (18721945). Leuven u. a. 2013. S. 193 f. • Le Fèvre, Jehan: The Book of Gladness - Le Livre de Leesce: A 14th Century Defense of Women. Translated, annotated ... by Linda Burke. English, French. Jefferson (North Carolina), London 2013. S. 24, 27, 121 u. ö.

$P$ Bildarchiv UAH; graph. Slg. UBH. - Staatsarchiv des Kantons Bern.

\section{Friedreich, Nikolaus Anton}

1858-1882 Med. Fak.

1858-1882 Pathologie, Therapie

* 31. Juli 1825 Würzburg

$\dagger \quad$ o6. Juli 1882 Heidelberg

kath., (nach) 1871 altkath.

V Johann Baptist F. (1796-1862) seit 1820 a.o., 1830-1833 (Enthebung seines Amtes aufgrund „Renitenz, Rechthaberei und Aufruhr“: F. setzt sich für e. geheime Senatswahl ein) o. Prof. für Heilkunde Würzburg, seit 1833 Inhaber von verschiedenen Physikaten (e. obrigkeitlich bestellter Arzt), 1850-1855 (Ruhestand) o. Prof. Erlangen, s. NDB 5 (1961) S. 458 f., WBIS, Grimm (Aug. 2001) S. S8

M Anna Catharina geb. Bolle (1795-1862)
(21. Aug. 1854 Josephine geb. Lauck $\left({ }^{*} 1823\right)$

$\mathrm{K}$ keine

Vw Großvater: Nicolaus Anton F. (1761-1836), u.a. seit 1795 a. o. Prof. für Allg. Therapie, seit 1796 Ordinarius für Praktische Heilkunde Würzburg, s. Enzyklopädie Medizingeschichte. Hrsg. von Werner E. Gerabek u. a. Berlin 2005. S. $440 \mathrm{f}$.

Lb Würzburg: Seit WS 1844/45 Studium an U, SS 1847 an UH, seit WS $1847 / 48$ erneut Würzburg; 22. Aug. 1850 Dr. med. an U und Approbation; April 1850-April 1853 Assistenzarzt an Med. Klinik im Juliusspital.

U Würzburg: 1. Nov. 1853 Habilitation; seit 16. Mai 1857 a. o. Prof.

UH: Seit 1. Febr. 1858 o. Prof. und Direktor der Med. U-Klinik als Nachf. von Adalbert Duchek; WS 1862/63-WS 1864/65 auch Vorlesungen über Pathologische Anatomie; Mitinitiator des 1876 neu erbauten Akad. Krankenhauses in der Bergheimer Straße, von 1844 bis 1876 in der Seminarstraße 2 im ehem. Seminarium Carolinum (heute: Sitz der U-Verwaltung) gelegen. • In dieser Zeit:

H: 1858-1882 Niedergelassener Arzt.

1867 Prorektor der UH; 1862, 1872/73, 1881/82 Dekan der Med. Fak. der UH

1863 dokumentiert F. erstmals e. nach ihm benannte Krankheit, die F.-Ataxie, e. degenerative Erkrankung des Zentralnervensystems

1882 erhält die Universitätsbibliothek Heidelberg 4983 Bände aus dem Besitz F.s, siehe hierzu Handbuch der historischen Buchbestände in Deutschland. Hrsg. von Bernhard Fabian. Hildesheim 2003.

Hofrat; 1872 Geh. Hofrat; 1875 Geh. Rat II. Klasse

E 1880 Mitglied der Dt. Akademie der Naturforscher Leopoldina Halle/S. • Ritterkreuz I. Klasse, 1869 Kommandeurkreuz II. Klasse, 1881 Großkreuz des Ordens vom Zähringer Löwen; 1876 
Kommandeurkreuz I. Klasse des Königl.-Schwedischen Polarstern-Ordens; 1880 Kommandeur I. Klasse nebst Stern des Herzogl.-Anhaltischen Hausordens Albrechts des Bären. • 1869 Ehrenbürger der Stadt Heidelberg.

Qu UAH PA 1576; RA 5879, 6269, 6785, 6804. • GLA Abt. 205, Fasz. 236. - Briefe: UBH. - Siehe auch Archiv der Dt. Akademie der Naturforscher Leopoldina Halle/S. - Auskunft: Kath. Matrikelamt Würzburg.

$W$ Die Krankheiten des Herzens in: Virchows Handbuch der speciellen Pathologie und Therapie Bd. V, 2. Abt. (1861). 2. Aufl. 1867. Zur Diagnose der Herzbeutelverwachsung in: Rudolf Virchows Archiv für patholog. Anatomie und Physiologie 29 (1864) S. $296 \mathrm{ff}$ - Die Heidelberger Baracken für Kriegsepidemien während des Feldzuges 1870 und 1871. Heidelberg 1871. • Über progressive Muskelatrophie, über wahre und falsche Muskelhypertrophie. Berlin 1873. - Über Ataxie mit besonderer Berücksichtigung der hereditären Formen in: Rudolf Virchows Archiv für patholog. Anatomie ... 68 (1876) und 70 (1877). - Beiträge zur physikalischen Untersuchung der Blutgefäße in: Dt. Archiv für klinische Medizin 21 (1878) S. 205 ff.

$L$ NDB 5 (1961) S. 458 f.; WBIS; Krebs/Schipperges (1968) S. 47, 198. - Janßenharms, Friderike: Theorie und Praxis der Herzkrankheiten bei N.F. Med. Diss. Heidelberg 1969. - Vogel, Paul: Die Heidelberger neurologische Schule: FriedreichErb-Hoffmann in: Heidelberger Jahrbücher 14 (1970) S. 73-77. - Chronik Ärzte H (1985) S. 128, 223. Grimm, Tiemo: N. F., der erste Heidelberger "Neurologe“ in: Fortschritte der Neurologie, Psychologie (Aug. 2001) Sonderheft 1, 69. Jg., S. S8S1o. Meinck (2004) S. 24f. • Enzyklopädie Medizingeschichte. Hrsg. von Werner E. Gerabek u. a. Berlin 2005. S. 440 f. Ärztelexikon (2006) S. $129 \mathrm{f}$.

$P$ Bildarchiv UAH; graph. Slg. UBH; NDB; Vogel (1970).

\section{Fries, Jakob Friedrich}

1805-1816 Phil. Fak.

Philosophie, Metaphysik, Naturrecht, Mathe-

matik, seit 1812 auch Experimentalphysik

* 23. Aug. 1773 Barby an der Elbe

$\dagger$ 10. Aug. 1843 Jena

ref.

V Dr. phil. [!] Peter Konrad F. (1720-1783) Pfarrer

M Christiana Sophia geb. Jäschke (1738-1798)

๑ 1806 Caroline Louise Victorie geb. Erdmann (1787-1819)

(1820 Eleonore geb. Leporin (1780-1842)

$\mathrm{K}{ }_{4} \mathrm{~S}, 4 \mathrm{~T}$, siehe NDB.

Lb Seit 1795 Studium zunächst der Rechtswiss., anschl. der Philosophie, Mathematik, Naturwiss. an U Leipzig, seit 1795/96 Jena; seit Herbst 1797 Hauslehrer in Zofingen (Schweiz).

U Jena: 1800 Eigenstudien; 21. Febr. 1801 phil. Disputation; 31. Okt. 1801 Habilitation für Philosophie; Frühjahr 1803-Herbst 1804 Studienreisen in Deutschland, Österreich, Schweiz, Frankreich, Italien; seit März 1805 a. o. Prof.

UH: 16. April 1805 Berufung; Ende Mai 180517. Sept. 1816 (Weggang) o. Prof.; SS 1812 Übertragung der Professur für Experimentalphysik als Nachf. von Wilhelm Gottlob Kastner nebst 18131816 Direktorat des Physikal. Kabinetts als Nachf. von Adolph Suckow (s. UAH RA 6459).

U Jena: Seit WS 1816/17 o. Prof. für Philosophie, Mathematik, Physik; 1819-1824 Suspendierung von U (unter Belassung des Gehalts) im Zusammenhang mit seiner Teilnahme am Wartburgfest und Verstrickung in die Untersuchungen um die Ermordung von August Kotzebue im Zuge der Karlsbader Beschlüsse (in dieser Zeit Aufenthalt in Holland); 1824 Wiederannahme als Prof. für Mathematik, Physik, 1838 - nach Lehrverbot - auch wieder für Philosophie.

1813 Prorektor der UH; 1810, 1815 Dekan der Phil. Fak. der UH (1815 protestiert der seit 1804 an der UH lehrende Ordinarius für Philosophie, Ferdi- 
nand Christoph Weise, gegen die Übertragung des Dekanats an J.F., „da der Turnus mich traf“, siehe weiter UAH RA 6600 vom 17. Jan. 1815).

Siehe auch Ferdinand Christoph Weise: Eintrag unter $Q u$ [ellen]

$E$ Mitglied der Akademie der Wissenschaften: 1808 München, 1812 Berlin.

Qu UAH PA 1578; RA 4921, 5437 (Verbot des Sonderdrucks einer antijüdischen Rezension von J.F. 1816), 6459, 7129. • GLA Abt. 205, Fasz. 237. Briefe: UBH. - Teil-Nachlaß: Thüringer Universitätsund Landesbibliothek Jena; Goethe- und Schiller-Archiv, Weimar; Universitätsarchiv Tübingen (Bestand Familienarchiv Gerland).

$W$ Über die Gefährdung des Wohlstandes und Charakters der Deutschen durch die Juden. Heidelberg 1816 (siehe hierzu Sigmund Zimmern: Eintrag unter $W$ [erke], Z.s Erwiderung von 1816). • Von deutscher Staatsverfassung. 1. Abt. des Buches Von Deutschem Bund ... Mit e. Nachwort hrsg. von Gerald Hubmann. Nachdr. der Ausg. 1816. Heidelberg 1997. - Die allgemeinen Lehren der Lebensweisheit und die Tugendlehre. Heidelberg 1818. Nachdr. Aalen 1970. • F. F. Sämtliche Schriften nach den Ausgaben letzter Hand zus.gestellt, eingeleitet und mit e. Fries-Lexikon versehen von Gert König und Lutz Geldsetzer. 29 Bde. Aalen 1964-2011 (Bde. 30-33: 2018 in Vorbereitung).

L Günther (1858) S. 227 f. - Koenigsberger, Leo: Zur Erinnerung an J.F.F. Heidelberg 1911. - Lautenschlager (1933) S. 645, 661-663; Ders.: Die Berufung des Philosophen J. F. F. ... nach Heidelberg in: ZGORh 89. Jg. (1937) S. 142-153. Cube, Felix von: Die Auffassungen J. F. F.' und seiner Schule über die phil. Grundlagen der Mathematik und ihr Verhältnis zur Grundlagentheorie. Diss. Stuttgart 1957. NDB 5 (1961) S. 6o8f.; Renger (1982) S. 296 (Register); WBIS; Heidelberg im säkularen Umbruch (1987) S. 515-527 u. ö. Kraft, Hans: J.F.F. im Urteil der Philosophiegeschichtsschreibung. Diss. Düsseldorf 1980. - Science in Germany ... Ed. by Kathryn M. Olesko. Philadelphia 1989. S. 17-35. - J. F. F. - Philosoph, Naturwissenschaftler und Mathematiker. Verhandlungen des
Symposions Probleme und Perspektiven von J.F. F. Erkenntnislehre und Naturphilosophie vom 9.-11. Okt. 1997 an der Friedrich-Schiller-Universität Jena. Hrsg. von Wolfram Hogrebe und Kay Herrmann. Frankfurt/M. 1999. - Petrak, Peter: Ethik und Sozialwissenschaft: der Einfluß der Philosophie J.F.F. auf das Konzept einer normativen Sozialwissenschaft Gerhard Weissers. Regensburg 1999. Herrmann, Kay: Mathematische Naturphilosophie in der Grundlagendiskussion. J.F.F. und die Wissenschaften. Göttingen 2000. • Hubmann, Gerald: Sittlichkeit und Recht: die jüdische Emanzipationsfrage bei J.F.F. und anderen Staatsdenkern des Deutschen Idealismus in: Antisemitismus bei Kant und anderen Denkern in der Aufklärung ... Hrsg. von Horst Gronke. Würzburg 2001. S. 125-152. - Kirschke (2001) S. 446 (Register). Bentzel-Sternau, Karl Christian Ernst von: Anti-Israel. Eine projüdische Satire aus dem Jahre 1818 nebst den antijüdischen Traktaten Friedrich Rühs' und J. F. F.' (1816). Hrsg. und mit e. Nachwort versehen von Johann Anselm Steiger. Heidelberg 2004. Naturphilosophie nach Schelling (2005) S. 181-220. - Grundl, Wolfgang: Die psychische Anthropologie von J.F.F. - eine historisch-systematische Diskussion zur Philosophie des Geistes. Diss. Würzburg 2006. Bonnet, Christian: L'autre école de Iena - critique, métaphysique et psychologie chez J. F. F. Paris 2013.

$P$ Bildarchiv UAH; graph. Slg. UBH; NDB. $\bullet 1873$ Büste am Fürstengraben in Jena.

\section{Froboese, Siegfried Waldemar Curt}

1923-1929 Med. Fak.

Pathologie

* 03. Mai 1891 Treptow (heute: Alt-Treptow, Ortsteil von Berlin)

$\dagger \quad$ 16. Juli 1994 St. Gilgen am Wolfgangsee (Salzburg-Umgebung)

ev., später konf.-los

V Eugen F. (1858-1937) Spediteur

M Selma geb. Sachse (1859-1939) 
(D) 17. Febr. 1917 Dr. med. Felicia Johanna Adele geb. Thiele (1890-1971) Ärztin; Scheidung

@ 21. März 1936 Margarete (Grete) geb. Eweler $\left({ }^{*} 1899\right)$ Geigerin; s. Beethoven, Ludwig van - Schottische Lieder op. 108, Sänger: Dietrich Fischer-Dieskau, Violine: Grete EwelerFroboese ... Schallplatten-Aufnahme von 1952 für RIAS Berlin; Neueinspielung auf CD. Audite 2008.

K $\quad 1$ S, 2 T

Lb Berlin: Seit SS 1910 Studium an U; 27. Aug. 1915 med. Hauptprüfung; 28. Aug. 1916 Approbation; 18. Okt. 1916 Promotion zum Dr. med. an U; 19161919 Assistent am Patholog. Inst. des Rudolf-Virchow-Krankenhauses; 1920 Eigenstudien.

U Königsberg (Preußen): Seit Febr. 1921 Assistenzarzt am Anatom. Inst.

UH: Seit April 1921 Assistenzarzt am Patholog.-Anatom. Inst.; 7. Nov. 1923 Habilitation; seit 12. Febr. 1929 nichtplanm. a. o. Prof.

Berlin: 1. Okt. 1929-31. Mai 1959 Direktor des Patholog. Inst. des Städtischen Krankenhauses in Spandau; seit 1934 Dozent an Berliner Akademie für ärztl. Fortbildung und Mitglied des Lehrkörpers der Staatsmed. Akademie; 1946-1948 Rufe an U abgelehnt: Halle-Wittenberg, Greifswald, Rostock, Leipzig; seit 1. Mai 1954 Honorar-Prof. an FU in Dahlem.

Seit 1959 Wohnsitz in St. Gilgen.

E 1959 Ehrenvorsitzender der Berliner Gesellschaft für Pathologie; 1960 Ehrenmitglied der Berliner Med. Gesellschaft.

Qu UAH PA 920, 3826. - GLA Abt. 235, Fasz. 2007. Auskunft: Landesarchiv Berlin (Med. Berufsakte Arzt C.F. (Signatur: B Rep. 012 Nr. 1470)). Mitteilungen: Herr Prof. Dr. Curt Froboese $(\dagger)$. Blick in die eigene Vergangenheit. Selbstverlag 1961. (Autobiogr.)

W Heterochromie und Katarakt. Berlin 1916. Die Verfettung des Endometriums. Beitrag zur normalen und pathologischen Anatomie der Ute- russchleimhaut in: Rudolf Virchows Archiv für patholog. Anatomie und Physiologie und für klinische Medizin. Berlin 1924. Bd. 250. S. 296-342; Ursache der fetalen Peritonitis (Meconiumperitonitis) in: ebd. Berlin 1928. Bd. 269. S. 595-601. Rudolf Virchow. Stuttgart 1953. - Über 50 Jahre Arzt in: Therapie der Gegenwart (1971) H. 4, S. $604 \mathrm{ff}$.

L Trautmann, Fritz: Vita von ... C. F. in: Berliner Medizin - Organ für die gesamte praktische und theoretische Medizin. Berlin 1962. H. 17. XIII. Jg. • Chronik Ärzte H (1985) S. 128. • Doerr, Wilhelm: C.F. 100 Jahre alt in: Der Pathologe (Mai 1991) Bd. 12, Nr. 3 .

$P$ Bildarchiv UAH.

\section{Frommel, Karl Otto}

1912-1918 Theol. Fak. 1918-1937 (Honorar-Prof.) Theol. Fak.

Praktische Theologie

* 14. Mai 1871 Heidelberg

$\dagger \quad$ 31. Juli 1951 Heidelberg ev.

V Wilhelm F. (1829-1897), u.a. 1867-1893 Prof. am Lyceum in $\mathrm{H}$, s. Badische Biographien 5 (1906) S. 18of., Das „Goldene Buch“ des KFG (1994) S. 88 u. ö.

M Lina geb. von Steinbeis (* nach 1833) T von Dr. phil. h.c. Ferdinand von S. (1807-1893) württ. Wirtschaftspolitiker, s. Siebertz, Paul: F. von S. Ein Wegbereiter der Wirtschaft. Stuttgart 1952; Alberti, Günter von: F.S. und die Gewerbeförderung im Königreich Württemberg. 2. Aufl. Stuttgart 2001; Raberg, Frank: Biografisches Lexikon für Ulm und Neu-Ulm 1802-2009. Ostfildern 2010. S. $421 \mathrm{f}$.

๑ 1. Aug. 1899 Helene geb. Helbing (1872-1959) T von Albert H. (1837-1914), u.a. 1903-1914 Präsident des Oberkirchenrats der Ev. Landeskirche in Baden, s. Badische Biographien N.F. IV (1996) S. 128-130 
K 3 S: u.a. Wolfgang F. (1902-1986) Schriftsteller, Rundfunkredakteur, u. a. 1934-1935 Lehrbeauftragter für Politische Pädagogik U Greifswald, s. Baumann, Günter: Dichtung als Lebensform. W.F. zwischen George-Kreis und Castrum Peregrini. Würzburg 1995; Hergemöller, Bernd-Ulrich: Mann für Mann. Ein biographisches Lexikon. Frankfurt/M. 2001. S. 255-257; Raulff, Ulrich: Kreis ohne Meister. Stefan Georges Nachleben. München 2012. S. 537 (Register). - Gerhard F. (1906-1984) Komponist, u. a. 1960-1971 Kompositionslehrer an Musikhochschule Frankfurt/M., s. Ausstellungskatalog G. F. Heidelberg 1987; Klee, Kulturlexikon (2007) S. $167 \mathrm{f}$.

Vw Groß-Onkel: Justinus Kerner (1786-1862) Dichter, Arzt, s. NDB 11 (1977) S. 524-527. • Onkel: Emil F. $(1828-1896)$, u.a. $1872-1895$ Hofprediger und Militäroberpfarrer des kaiserlichen Gardekorps Berlin, s. BBKL II (1990) Sp. 143 f.

Lb Seit SS 1891 Studium der Theologie, Philosophie, Geschichte, Musikwiss. an U Erlangen, 4. Mai 1892-10. Okt. 1893 H, seit WS $1893 / 94$ Berlin; 1895 theol. Hauptprüfung; 1. Juni 1898 Dr. phil. an $\mathrm{UH}$.

Leipzig: Seit 1895 Hilfsprediger an ref. Kirche.

Karlsruhe: Seit 1897 provisorischer Hofvikar des badischen Großherzogs; seit 1899 Hofvikar, seit 1901 Hofdiakon, seit 1906 Hofprediger; 1906 Ruf als Hofprediger nach Meiningen abgelehnt.

H: Seit 1907 Stadtpfarrer der II. Christuspfarrei als Nachf. von Adolf Schmitthenner, Vater von: (siehe) Heinrich S.; 1910-1937 Stadtpfarrer der I. Christuspfarrei; 1918 Ruf als Oberhofprediger nach Weimar abgelehnt. $\bullet$ In dieser Zeit:

UH: Seit 16. März 1907 e. der Hauptlehrer am Praktisch-Theol. Seminar mit e. jährl. Honorar von 80o.- Mark; 17. Juli 1912 Habilitation; seit 6. Sept. 1912 nichtetatm. a. o. Prof.; seit 15. Okt. 1912 „Erweiterung der Lehraufgabe“ am PraktischTheol. Seminar mit e. jährl. Vergütung von 2400.Mark (aus: Brief des Ministeriums des Kultus und Unterrichts vom 22. Nov. 1912 in: UAH RA 6127); 1914-1918 Seelsorger in Lazaretten; seit 24. Okt.
1918 o. Honorar-Prof.; SS 1937 letzte Vorlesungsankündigung; 30. Sept. 1937 Ruhestand.

1914-1932 Vertreter der Landeskirchl. Vereinigung in der Synode der Landeskirche in Baden

1928 Kirchenrat

Siehe auch Johannes Rissom: Eintrag unter $Z[\mathrm{i}-$ tat] (3)

E 1909 Lic. theol. h.c. und 1915 D. theol. UH. • 1903 Ritterkreuz II. Klasse mit Eichenlaub des Ordens vom Zähringer Löwen.

Qu UAH PA 3830; RA 6127, 6754. - GLA Abt. 235, Fasz. 148. Briefe: UBH; siehe auch Kalliope.

W Mannelin, das Schattenbild einer Jugend. Berlin 1910. Vom inwendigen Leben. Predigten. Tübingen 1913. Franz Theremin. Beitrag zur Theorie und Geschichte der Predigt. Tübingen 1915. Ausgewählte Gedichte. Heidelberg 1947.

L WBIS; NDB 5 (1961) S. 660; Jansen (1992a) S. 165 (Register); Fix (1994) S. 85-92; BBKL XVI (1999) Sp. 538-542; Personenlexikon zum dt. Protestantismus (2006) S. 82; Kriegstagebuch K. Hampe (2007) S. 959 (Register); Lebensbilder aus der ev. Kirche in Baden (2007) S. 525 (Register); Deutsche Biographie, s. https://www.deutsche-biographie. de/gnd116839856.html [06.11. 2017].

$P$ Bildarchiv UAH; NDB.

\section{Fuchs, Christian Joseph (Geburtseintrag: Fuchs, Christian)}

1861-1865 Med. Fak.

Veterinärkunde

* 13. Febr. 1801 Zülpich (Hauptort des franz. Kantons Zülpich; bei Euskirchen)

$\dagger$ 10. Nov. 1871 Karlsruhe kath. 
V Johann Wilhelm Fuchs

M Maria Katharina geb. Langenhovels

@ Katharina geb. Bolkenius ( $†$ nach 1871)

$\mathrm{K}$ mind. $1 \mathrm{~S}$

Lb Zülpich: Vor Jan. 1820 Lehrling, anschl. Gehilfe in e. Apotheke.

Seit 4. Jan. 1820 Studium der Medizin an U Bonn; WS 1822/23-1825 Studium der Tierheilkunde an U Berlin; 1827 als Kandidat der Tierheilkunde bezeichnet.

Zülpich: 20. Febr. 1827 Genehmigung e. Veterinärpraxis; $1827-1829$ Tierarzt.

1830 Tierärztl. Staatsprüfung.

1831-1839 Kreistierarzt für die Kreise Montjoie, Malmedy und Schleiden (bei Aachen).

Berlin: Ostern 1839-Febr. 1843 Lehrer/Repetitor an der Königl. Thierarzneischule.

1843 Departements-Tierarzt im Reg.-Bezirk Bromberg (Provinz Posen).

Karlsruhe: 1843-186o (Aufhebung der Schule und Pensionierung) Dozent, seit 1846 auch Prof. an Tierarzneischule; 1849-1861 Hauptlehrer an der Höheren Beschlagschmied-Schule in Gottesaue; 1860 Ern. zum Beirat der großherzogl. Sanitätscommission.

UH: 25. Jan. 1861 Ern. zum a.o. Prof. mit e. Jahresgehalt von 150.- Gulden seit 21. Juni 1861.

Karlsruhe: 4. März 1865-1870 o. Mitglied des Obermedizinalrats.

Sept. 1852 Präsident der Versammlung deutscher Tierärzte in Schwerin

1861 Großherzogl. Medizinalrat

Qu UAH PA 1583. - Auskunft: Standesamt Karlsruhe (Sterbebuch von 1871); Archiv der Stadt Zülpich (Geburts-Akt Christian Fuchs vom 13. Pluriose im 9. Jahr der Fränkischen Republik).
$W$ Die schädlichen Einflüsse der Bleibergwerke auf die Gesundheit der Hausthiere, insbesondere des Rindviehes: mit Rücksicht auf die im Auftrage eines hohen Ministeriums der geistlichen, Unterrichts- und Medicinal-Angelegenheiten an der Thierarzneischule in Berlin angestellten Versuche mit Bleierzen beim Rindvieh. Berlin 1842. Handbuch der allgemeinen Pathologie der Haussäugethiere. Berlin 1843. - Über die Pflichten gegen die Thiere, mit Rücksicht auf das badische Strafgesetz gegen Thierquälerei. Ein Vortrag gehalten ... behufs der Anregung zur Bildung eines Vereins zum Schutze der Thiere. Karlsruhe 1852. - Das Seelenleben der Thiere, in's Besondere der Haussäugethiere im Vergleich mit dem Seelenleben des Menschen. Vorträge, gehalten zu Karlsruhe in der Gesellschaft „Eintracht“ im Winter 1853/54 in: Archiv für Thierheilkunde. Bd. 21. H. 3. Erlangen 1855. Pathologische Anatomie der Haussäugethiere. Leipzig 1859. • Allgemeine Lehre der Seuchen und ansteckenden Krankheiten der Haussäugethiere. Leipzig 1862. • F., C. J., Pagenstecher, Heinrich Alexander: Die Trichinen: nach Versuchen im Auftrage des Großherzoglich Badischen Handelsministeriums, ausgeführt am Zoologischen Institute in Heidelberg. Leipzig 1865. 2. Aufl. 1866. Bibliographie in: Thierärztliche Mittheilungen. Karlsruhe 1872. 7. Jg., Nr. 1 und 2.

G, HG: 1844-1849 Thierärztliche Zeitung, Karlsruhe.

$L$ WBIS. - Nachruf in: Thierärztliche Mittheilungen. Karlsruhe 1871. 6. Jg. Nr. 12. S. 179-183. • Driesch, Angela von den, Peters, Joris: Geschichte der Tiermedizin: 5000 Jahre Tierheilkunde. Stuttgart 2003. S. 161. - Johann Wilhelm Carl Ludwig: Der Kreis Lechenich um 1826. Preußische Bestandsaufnahme des Landes und seiner Bevölkerung. Bearb. von Sabine Graumann. Köln 2008. S. 21 und Anm. 120. 


\section{Fuchs, Karl Wilhelm}

1863-1872 (1876) Phil. Fak.

Mineralogie, Geognosie

* 18. Aug. 1837 Mannheim

$\dagger$ 25. Juli 1886 Karlsruhe

- Mausoleum Hauptfriedhof Mannheim ev.

V Friedrich Jakob F., Partikulier

M Karoline Luise Juliane Friedrike geb. Dyckerhoff (1809-1872)

$\infty$ unverheiratet.

Lb Seit WS 1856/57 Studium an UH, seit WS 1857/ 58 Göttingen, WS 1859/60-SS $1860 \mathrm{H}$.

UH: Seit 1859 Assistent am Chemischen Laboratorium; 7. Febr. 1860 Dr. phil.; 26. Jan. 1863 Habilitation; seit 9. Jan. 1868 a. o. Prof.; 1872-1874 Gewährung e. 2-jährigen Studien-Urlaubs: Erforschung der vulkanischen Natur der Insel Ischia für die ital. Regierung; 1874-1876 Abwesenheit ohne Erlaubnis der U; 22. Juni 1876 aus der Liste der akad. Lehrer an $\mathrm{U}$ gestrichen.

Seine testamentarische Stiftung über 20000.Goldmark (Kaufkraft heute $350000 €$ ) erfolgte zweckgebunden an seine Geburtsstadt Mannheim für die Anlage des späteren Unteren Luisenparks, des ältesten Teils der heutigen grossen Parkanlage. Den gleichen Betrag setzte er für die Errichtung seines Mausoleums fest (aus: Wikipedia: Fuchs, Karl); siehe Die Friedhöfe in Mannheim. Wegweiser zu den Grabstätten bekannter Mannheimer Persönlichkeiten. Hrsg. vom Fördererkreis historischer Grabstätten. Mannheim 1992.

Qu UAH PA 1581; Fak.-Akte H-IV-102/57. Auskunft: Stadtarchiv Mannheim (Zweitschrift des ev. Taufbuches 1837); Standesamt Karlsruhe (Sterbebuch von 1886).

$W$ Tafeln zur Bestimmung der Mineralien durch das Löthrohr. Heidelberg 1867. 3. Aufl. 189o. • Anleitung zum Bestimmen der Mineralien. Heidelberg 1868. 5. Aufl. 1907. - L'isola d'Ischia: monografia geologica. Florenz 1872. • Die künstlich dargestellten Mineralien, nach G. Rose's Krystallo-chemischen Mineralsysteme geordnet. Haarlem 1872. Statistik der Erdbeben von 1865-1885. Wien 1886 .

L Poggendorff 3 (1898) S. 484. - Mitgliederverzeichnis des Schwarzburgbundes. Hrsg. von Leopold Petry. 4. Aufl. Bremerhaven 1908. S. 149.

\section{Fuchs, Immanuel Lazarus}

1875-1884 Phil. Fak.

Mathematik

* 05. Mai 1833 Moschin (heute: Mosina, Polen)

$\dagger$ 26. April 1902 Berlin mosaisch, seit $1860 \mathrm{ev}$.

V Rafael F., Lehrer

M Caecilie geb. Katz ( $†$ vor 1860)

( ca. 1868 Marie geb. Anders (1849-1917)

K 2 T: u. a. Clara F. (1869-1954) Ehefrau von Ludwig Schlesinger (1864-1933 Zwangspensionierung) o. Prof. für Mathematik: seit 1897 Klausenburg, seit 1911 Budapest, 1911-1930 Gießen, s. ÖBL online 10 (1994) S. 197. 4 S: u.a. Richard F. (1873-1945) seit 1901 Studienrat, seit 1906 Privat-Dozent, seit 1922 Dozent, 1923/241938 (Entlassung) a.o. Prof. für Mathematik an TH Berlin-Charlottenburg, s. NDB 5 (1961) S. 675 f., WBIS, Math. Institute in Deutschland (1989) S. 23

Vw Enkelin: Hildegard Schlesinger (1903-1969) Physikerin, seit 1963 Nachfolgerin auf der Professur für Semitische Sprachen und Biblische Geschichte (!) am Hebrew Union College Cincinnati (Ohio) ihres Ehemannes Julius Lewy (1895-1963) 1930-1933 persönlicher Ordinarius für Assyriologie an U Gießen, 1936-1963 Prof. am Hebrew Union College, s. Gießener Gelehrte 2 (1982) S. 626-633.

Lb 1853 Hauslehrer von (siehe) Leo Koenigsberger in Posen (heute: Poznań, Polen).

U Berlin: Seit SS 1854 Studium; 2. Aug. 1858 Dr. phil. 
Berlin: 19. März 1859 Prüfung für höheres Lehramt; seit 1860 Hilfslehrer; 26. März 1864-23. Mai 1867 Lehrer, zuletzt an Friedrichs-Werderscher Gewerbeschule; 23. Mai 1867-1869 Lehrer an Artillerie- und Ingenieurschule. • In dieser Zeit:

U Berlin: Aug. 1865 Habilitation; seit 7. Dez. 1866 a. o. Prof.

U Greifswald: Seit 3. Febr. 1869 o. Prof. als Nachf. von Leo Koenigsberger; seit 22. März 1869 zugleich Dozent an Königl. Staats- und Landwirtschaftl. Akademie in Eldena (heute: Ortsteil von Greifswald).

Göttingen: Seit 23. Jan. 1874 o. Prof.

UH: Seit 8. Jan. 1875 o. Prof. und Mit-Direktor (zus. mit Georg Quincke) des Math.-Physikal. Seminars als Nachf. von Koenigsberger.

U Berlin: Seit SS 1884 o. Prof. und Mit-Direktor des Math. Seminars.

1876/77 Dekan der Phil. Fak. der UH

Geh. Rat

E 1883 Mitglied der Dt. Akademie der Naturforscher Leopoldina Halle/S.; Mitglied der Akademie der Wissenschaften: 1874 Göttingen, 1884 Berlin, 1898 München. 1883 Ritterkreuz I. Klasse des Ordens vom Zähringer Löwen.

Qu UAH PA 1582; RA 6508. - GLA Abt. 76, Fasz. 9922. - Briefe: UBH. - Siehe auch Archiv der Dt. Akademie der Naturforscher Leopoldina Halle/S.

$W$ Zur Theorie der linearen Differentialgleichungen mit veränderlichen Coefficienten in: Jahresbericht über die Städtische Gewerbeschule im Friedrichs-Werder ... Berlin 1865. S. 3-38. • Über den Zusammenhang zwischen Cometen und Sternschnuppen ... Greifswald 1873. • Über Funktionen zweier Variabeln, welche durch Umkehrung der Integrale zweier gegebener Funktionen entstehen. Göttingen 1881. - Zur Theorie der Abelschen Funktionen in: Sitzungsberichte der Königlich Preussischen Akademie der Wissen- schaften zu Berlin (1897) S. 6o8-621. • Über einige Thatsachen in der mathematischen Forschung des 19. Jahrhunderts. Rede ... Berlin 1900. - Zur Theorie der linearen Differentialgleichungen. Berlin 1901. Gesammelte Werke. Hrsg. von Richard Fuchs und Ludwig Schlesinger. 3 Bde. Berlin 19041909. Bibliographie online, s. http://www-history. mcs.st-andrews.ac.uk/Extras/Fuchs_publications. html (Ausdruck im UAH).

HG 1892-1902 Crelles Journal für die reine und angewandte Mathematik.

$L$ NDB 5 (1961) S. 675; WBIS; Math. Institute in Deutschland (1989) S. 282 (Register); Biogr. Enzyklopädie Naturwissenschaftler 1 (2003) S. 257; „Aller Männerkultur zum Trotz" (2008) S. 34, 61, 100. Jüdische Mathematiker in der deutschsprachigen akademischen Kultur. Hrsg. von Birgit Bergmann, Moritz Epple. Berlin 2009. S. 53-55 u. ö. - Grewolls (2011). • Der Mathematiker L. F.: eine biographische Anthologie aus Nachrufen und biographischen Artikeln von Meyer Hamburger, Carl von Voit, Georg Wallenberg u. a. zus.gestellt von Gabriele Dörflinger. UBH 2012, s. http://www. ub.uni-heidelberg.de/archiv/14284; Heidelberger Texte zur Mathematikgeschichte: L.F. ... Materialsammlung, zus.gestellt von Ders. UBH 2016, s. Homo Heidelbergensis mathematicus online.

$P$ Bildarchiv UAH; graph. Slg. UBH; NDB.

\section{Fühling, Johann Joseph}

1872-188o Phil. Fak.

Landwirtschaftslehre

* $\quad$ 02. Aug. 1825 Köln

$\dagger \quad$ 02. Nov. 1884 Heidelberg

kath.

V Wilhelm F. $\quad\left({ }^{*} 1777\right)$ Weinwirt, Ökonom (= Landwirt)

M Gertrud geb. Liermann

$\infty$ unverheiratet.

Lb Vor 1855 landwirtschaftl. Lehre in väterlicher Ackerwirtschaft und Handelsgärtnerei; anschl. 
Verwalter der brüderlichen „Butzweiler Höfe“ (Butzweiler, heute: im Stadtteil Köln-Ossendorf).

U Bonn: 2. Nov. 1855 Immatrikulation für Ökonomie als Johann Fühling aus Butzweiler.

(Bonn-)Poppelsdorf: Seit 1856 Forts. des Studiums an Königl. Höherer Landwirtschaftl. Lehranstalt; 8. Aug. 1857 landwirtschaftl. Abgangsprüfung.

Rheinland: Zwischen 1857 und 1859 Schriftsteller und Vortragender über landwirtschaftl. Themen; Promotion zum Dr. phil. (U unbekannt).

(Bonn-)Poppelsdorf: 1859 (kurzzeitig) Probevorlesungen über Landwirtschaftl. Statistik und über Trockenlegung des Bodens an Königl. Höherer Landwirtschaftl. Lehranstalt.

Jüchen (bei Grevenbroich): 1859 Lehrer, 18601863 Rektor der im Nikolauskloster eingerichteten Ackerbauschule.

Köln: 1863-1868/69 Wohnsitz; nach 1863-1868/ 69 Direktor der Sektion Volkswirtschaft im Rheinischen Landwirtschaftl. Verein für Credit- und Genossenschaftswesen; 1863-1867 Mitglied des Preußischen Abgeordnetenhauses in Berlin für den Wahlkreis Neuß-Grevenbroich-Krefeld.

Berlin: 1868/69-ca. 1870 Wohnsitz; 1868/69-ca. 1870 Direktor der Norddeutschen Grundcreditbank; 1867-1870 auch Mitglied des Reichstags des Norddeutschen Bundes; 1868 Ruf an U Kiel auf Lehrstuhl für Landwirtschaft abgelehnt.

Köln: (Nach) 1870 Wohnsitz; hier hauptsächlich Fachschriftsteller.

UH: 3. Juli 1872 Ern. zum o. Prof.; 8. Okt. 1872 Vereidigung; 22. April 1876 Annahme der Statuten durch das Ministerium des Innern für das von $\mathrm{F}$. errichtete Landwirtschaftl. Seminar/Inst., s. hierzu UAH RA 6573; 1. Nov. 1880 auf eigenen Antrag Versetzung in Ruhestand nach Schlaganfall; 1880 Aufhebung des Landwirtschaftl. Inst., s. hierzu UAH H-IV-102/92 fol. 15r-23r.

1872 Hofrat; 1880 Geh. Hofrat
Qu UAH PA 1584; RA 6573, 689of.; Fak.-Akte H-IV-102/75. • GLA Abt. 205, Fasz. 238. • Amtliches Verzeichniß des Personals und der Studirenden der Königl. Rheinischen ... Universität zu Bonn. WS 1855/56-SS 1857. Digitalisat. • Ergebnislose Anfrage: Karlsruher Institut für Technologie (KIT) - KIT-Archiv. Auskunft: Nordrhein-Westf. Personenstandsarchiv Rheinland, Brühl (Geburtsurkunde von 1825); GLA in Karlsruhe.

W Der praktische Rübenbauer. Bonn 1860. 3. Aufl. 1877. - Oekonomik der Landwirthschaft oder System der landwirthschaftlichen Betriebslehre. Grundriß für Vorlesungen über landwirthschaftliche Betriebslehre. Berlin, Leipzig 1876. Neuauflage u.d.T.: Ökonomik der Landwirthschaft oder allgemeine Landwirthschaftslehre. Mit e. Bild des Verfassers. Hrsg. von Theodor Fühling [Neffe]. Berlin 1889.

Redakteur 1864-1874 Neue landwirthschaftliche Zeitung (Glogau), 1874-1922 (Erscheinen eingestellt) u.d.T.: Fühling's Landwirthschaftliche Zeitung (Stuttgart).

HG, Redakteur 1874-1884 Fühling's Landwirthschaftliche Zeitung.

$L$ Hirth's Parlaments-Almanach. Ausg. 6 vom 20. Okt. 1867. Berlin 1867. S. 39 f. und Ausg. 8 vom 15. April 1869. Berlin 1869. S. 152. - J.J.F. in: Thiel's landwirthschaftlichem Konversations-Lexikon. 1. Suppl.-Bd. Leipzig 1884. S. 63 f. (hier irrtümlich 1. Aug. als Geb.-Tag genannt). A Almanach Heidelberg (1886) S. 86, 240. Künzel, Franz, Koll, Otto: Festschrift zur Feier des 50-jährigen Bestehens der ... landwirthschaftlichen Akademie Poppelsdorf. Bonn 1897. S. 143. - WBIS. • Böhm, Wolfgang: Biographisches Handbuch zur Geschichte des Pflanzenbaus. München 1997. S. 76. • Autoren der Bunsenbibliothek (2009 online); Deutsche Biographie, s. https://www.deutsche-biographie. de/gnd133463087.html [06.11. 2017].

$P$ Thiel's landwirthschaftl. Konversations-Lexikon (1884) S. 63. 


\section{Fürbringer, Max Karl}

1876-1879, 1901-1912 Med. Fak.

Anatomie

* 30. Jan. 1846 Wittenberg

$\dagger \quad$ o6. März 1920 Heidelberg ev.

V Karl F. (1814-1870) Kreisgerichts-Direktor

M Hermine geb. Gumprecht (1821-1899)

๑ 3. März 1878 Fanny geb. Bassermann (18561891)

K $\quad 1$ S, 1 T: Elisabeth (Lisbeth) Caroline Hermine Cäcilie F. (1879-1929) Ehefrau von: (siehe) Hermann Braus

Vw Bruder: Paul Walther F. (1849-1930) seit 1879 a.o. Prof. für Haut- und Kinderkrankheiten, 1886-1903 Direktor der Inneren Abt. des Krankenhauses Friedrichshain Berlin, s. NDB 5 (1961) S. 690 f., WBIS, Lexikon der Naturwissenschaftler (2000); Personenlexikon der Sexualforschung. Hrsg. von Volkmar Sigusch und Günter Grau. Frankfurt/M. 2009. S. 216220 u. ö.

Lb Seit WS 1865/66 Studium der Mathematik, Naturwiss. an U Jena, seit 1867 Berlin; 20. Dez. 1869 Dr. phil. an U Berlin.

U Jena: Seit SS 1870 Studium der Medizin; 18701873 Assistent am Anatom. Inst.; 21. März 1874 med. Staatsexamen. • In dieser Zeit:

Juli-Dez. 1870 Kriegsdienst während des DeutschFranzösischen Krieges.

U Erlangen: 1874 Dr. med.

UH: 1874-1879 Prosektor am Anatom. Inst. als Nachf. von (siehe) Heinrich Braun; 5. Mai 1876 Habilitation; seit 28. Dez. 1878 a. o. Prof.

U Amsterdam: Seit 16. Juli 1879 o. Prof. und Direktor des Anatom. Inst.

U Jena: Seit WS 1888/89 o. Prof.
UH: Seit SS 1901 o. Prof. und Direktor des Anatom. Inst. als Nachf. von Carl Gegenbaur; 1. Okt. 1912 Ruhestand.

1901 Geh. Hofrat; 1910 Geh. Rat II. Klasse

E 1881 Mitglied der Dt. Akademie der Naturforscher Leopoldina Halle/S.; Mitglied der Akademie der Wissenschaften: 1900 Berlin, 1903 München, 1909 H; 1903 Korr. Mitglied der Senckenbergischen Naturforschenden Gesellschaft Frankfurt/ M. 1896 Ritter I. Klasse des GroßherzoglichSächsischen Hausordens vom weißen Falken; 1903 Ritterkreuz I. Klasse mit Eichenlaub des Ordens vom Zähringer Löwen.

Qu UAH PA 922, 1585; RA 6783. - Briefe: UBH; Anatom. Sammlung der UH. - Teil-Nachlaß: UBH; Universitätsbibliothek Frankfurt/M. • Siehe auch Archiv der Dt. Akademie der Naturforscher Leopoldina Halle/S.

$W$ Untersuchungen zur Morphologie und Systematik der Vögel. 2 T. Amsterdam 1888. • Über die spino-occipitalen Nerven der Selachier und Holocephalen und ihre vergleichende Morphologie in: Festschrift zum 70. Geb. von Carl Gegenbaur. Leipzig 1897. Das Zungenbein der Wirbeltiere, insbesondere der Reptilien und Vögel. Hrsg. von Hermann Braus. Berlin 1922.

$L$ NDB 5 (1961) S. 690 (mit Werkverz.); WBIS. • Mocek, R.: Die Kontroverse M.F. - Hans Driesch zur Frage des Verzichts auf englische wissenschaftliche Ehrungen in: Arbeitsblätter zur Wissenschaftsgeschichte. Hrsg. von R. Mocek. H. 5. HalleWittenberg 1979. • Chronik Ärzte H (1985) S. 128; Lexikon der Naturwissenschaftler (2000); Goerttler 1 (2003) S. 53; Peiffer (2004) S. 1147, 1154 (Register); Badische Biographien N.F. VI (2011) S. 126128; Hier freut sich der Tod (2013) S. 72-74 u. ̈.; Doll (2014) S. 281-283; Doll/Kirsch/Eckart (2017) S. $45-48,53,112$.

$P$ Bildarchiv UAH; graph. Slg. UBH; NDB; Chronik Ärzte H. 


\section{Fürstner, Carl Ludwig}

1878-1891 Med. Fak.

Psychiatrie

* $\quad$ 07. Juni 1848 Strasburg (Uckermark, Brandenburg; heute: Mecklenburg-Vorpommern)

$\dagger$ 25. April 1906 Straßburg (Elsaß, Deutsches Reich) ev.-luth.

V Carl David F. (1813-1873) Arzt

M Albertine Auguste Amalie geb. Kauffmann

œ 1878 Therese geb. Hecht $\left({ }^{*} 1850\right)$

$\mathrm{K}$ unbekannt.

Lb Seit WS 1866/67 Studium der Medizin an U Würzburg, anschl. Berlin; 1870/71 Feldassistenzarzt während des Deutsch-Französischen Krieges; 25. Nov. 1871 Dr. med. an U Berlin.

U Greifswald: Seit 1871 Assistent am Patholog. Inst.

Berlin: 1873-1877 Oberarzt an Irren-Abt. der Königl. Charité.

Stefansfeld (Elsaß; heute: Ortsteil von Brumath): Seit 1877 Arzt an Irrenanstalt.

UH: 14. Nov. 1877 Ern. zum SS 1878 o. Prof. und seit 15. Okt. 1878 (Eröffnung der Klinik) erster Direktor der Großherzoglich Badischen U-Irrenklinik (Psychiatr. Klinik) (Irrenanstalt unterstand dem Ministerium des Innern, die Psychiatr. Klinik als Unterrichtsinstitut der UH dem Kultusministerium, s. Hoche (1969) S. 105, auch S. 112-123).

U Straßburg: Seit 1. April 1891 o. Prof. und Direktor der Psychiatr. Klinik.

1879/80, 1889/9o Dekan, Febr.-Sept. 1881, AprilSept. 1882 Prodekan der Med. Fak. der UH

Die Badische U-Irrenklinik (Psychiatr. Klinik) in Heidelberg war 1878 die erste in Deutschland für den Unterricht im Rahmen einer Universität errichtete Irrenanstalt, siehe hierzu Hoche (1969) S. 103.

1889 Hofrat
E 1887 Ritterkreuz I. Klasse des Ordens vom Zähringer Löwen.

Qu UAH PA 1587; RA 6315, 6809.

$W$ Über Schwangerschafts- und Puerperalpsychosen in: Archiv für Psychiatrie 5 (1875) S. 505-543. • Die Psychiatrie in der neuen Prüfungsordnung in: Berliner klinische Wochenschrift 20 (1883) S. $477 \mathrm{f}$. Über Irrenkliniken an der Hand eines Berichtes über den Betrieb der Universitäts-Irrenklinik zu Heidelberg während der Jahre 1878-1883. Heidelberg 1885. •Über das Verhalten des Körpergewichts bei Psychosen in: Dt. Archiv für klinische Medizin 46 (1890) S. 273-284. - Zur Pathologie und pathologischen Anatomie der progressiven Paralyse ... in: Archiv für Psychiatrie 14 (1892) S. 83 ff.; Über multiple Sklerose und Paralysis agitans in: ebd. 30 (1898) H. 1. Zur Pathologie der progressiven Paralyse in: Monatsschrift für Psychiatrie und Neurologie XII (1902) S. 409-422.

MHG Archiv für Psychiatrie.

$L$ Hoche, Alfred: C.F. in: Archiv für Psychiatrie 41 (1906) S. V-XIII. - NDB 5 (1961) S. $700 \mathrm{f}$. (mit Werkverz.); Hoche (1969) S. 103-106, 120 f.; Chronik Ärzte H (1985) S. 128; WBIS; Kreuter 1 (1996). - Engstrom, Eric J.: Clinical Psychiatry in Imperial Germany: A History of Psychiatric Practice. Ithaca 2003. S. 292 (Register). - Müller-Küppers (2004) S. 14f. - Universitätskolloquien zur Schizophrenie. Hrsg.: Hanns Hippius. Darmstadt 2004. Bd. 2. S. 3-14. - Grewolls (2011). Entgrenzungen des Wahnsinns: Psychopathie und Psychopathologisierungen um 1900. Hrsg. von Heinz-Peter Schmiedebach. Berlin 2016. S. 304 (Register).

$P$ Bildarchiv UAH; graph. Slg. UBH; NDB; Chronik Ärzte H.

Fürstner, Karl

s. Fürstner, Carl 


\section{G}

\section{Gaedeke, Arnold Heinrich}

1870-1882 Phil. Fak.

Geschichte

* 04. Nov. 1844 Königsberg (heute: Kaliningrad, Russische Föderation)

$\dagger$ 07. Okt. 1892 Dresden ev.

V Friedrich Heinrich G. (1811-1895) Bankier

M Henriette Charlotte Antoinette geb. Lorck (1819-1885)

๑ 17. Okt. 1871 Sophie Friederike geb. Meßling (1847-1927)

K $2 \mathrm{~S}$

Vw Bruder: Heinrich Konrad G. (1843-1912) Bankier, Industrieller, s. NDB 6 (1964) S. 16 f.

Lb Seit 1864 Studium der Geschichte, Kunstgeschichte an U Königsberg (Preußen), Berlin, seit SS 1865 H, SS 1866 Göttingen, WS 1866/67-SS $1867 \mathrm{H}$.

UH: 7. Mai 1867 Dr. phil.; 1. Juni 1870 Habilitation; 1871 Eigenstudien in Wien; seit 24. Jan. 1877 a.o. Prof. • In dieser Zeit:

1870/71 Kriegsdienst während des Deutsch-Französischen Krieges.

Dresden: Seit SS 1882 o. Prof. am Polytechnikum, 1890 umbenannt in Sächsische TH.

Qu UAH PA 1588. GLA Abt. 76, Fasz. 9926. • Briefe: UBH. • Briefe an A.G. in: Fläschendräger, Werner: Der Historiker Wilhelm Maurenbrecher ... in: Leipziger Beiträge zur Universitätsgeschichte. Hrsg. von ... Horst Hennig. Leipzig 1988. H. 2. S. 50-56. Nachlaß: UAH. Mitteilungen: Frau Dr. Hannah Gaedeke ( $†$ ), Heidelberg.
$W$ Die Politik Österreichs in der spanischen Erbfolgefrage. 2 Bde. Leipzig 1877. Maria Stuart. Heidelberg 1879. - Wallensteins Verhandlungen mit den Schweden und Sachsen. 1631-1634. Frankfurt/M. 1885. - Siehe auch Verstreute Schriften. Hrsg. von Hannah Gaedeke. (Heidelberg 1982; in UBH: Signatur Heid. Hs. 4014.)

$L$ Über A.G. in: Oncken, Wilhelm: Beiträge zur neueren Geschichte. Giessen 1885. Reprint 2011. S. 34-45, 51, 59-65, 79. Gaedeke, Hannah: A.G. Leben und Werk. 2 Bde. Grunern-Staufen 1983-1984. Masch.geschr. Ex. in UBH (Signatur: Heid. Hs. 4003). - Weber (1987) S. 164. - Klaus, W.: A.G. ... in: SLB-Kurier: Nachrichten aus der Sächsischen Landesbibliothek Dresden ... (1993) S. 10 f. 175 Jahre TU Dresden: Geschichte der TU Dresden 1828-2003. Hrsg. von Reiner Pommerin. Köln 2003. S. 72, 81. • Professoren TU Dresden (2003) S. 250 f.; Deutsche Biographie, s. https:// www.deutsche-biographie.de/gnd116329246.html [06.11. 2017].

\section{$P$ Bildarchiv UAH.}

\section{Gambsjaeger, Franz Anton Wilhelm}

1782-1816 Jur. Fak.

1782-1802 Geschichte der in Deutschland geltenden Rechte, 1802-1809 Geschichte des römischen Rechts, 1782-1814 Pandekten, 1782-1816 (kath. und prot.) Kirchenrecht, 1782-1807 Peinliches Recht (= Strafrecht), 1805-1806 Institutionen, 1805-1816 Bürgerliches Recht, 1809-1814 Badisches Landrecht (Code Napoléon)

* 04. Sept. 1752 Heidelberg

$\dagger \quad$ o6. Aug. 1816 Heidelberg kath.

V Franz G.

M Maria Elisabetha geb. N.N.

$\infty$ 25. Febr. 1781 Maria Anna geb. Speck (17601799)

K 1 T

Lb UH: 16. Dez. 1767 Immatrikulation als „auditor logices“; 7. Sept. 1768 Bakkalarexamen, 7. Sept. 
1769 Magisterexamen an Phil. Fak., kath. Abt.; nach 1769 Studium der Rechtswiss., auch an U Göttingen.

UH: $1776 / 77$ Jur. Lizentiatenexamen; seit 9. Juni 1777 Korrepetitor an Jur. Fak.; 23. Mai 1782 Ern. zum a.o. Prof.; seit 16. Juni 1789 o. Prof.; 1804 Berufung als Assessor an Badisches Oberhofgericht im Bruchsaler Schloß abgelehnt; bis 1816 Beisitzer des Spruchkollegiums der Jur. Fak.

180o/o1 Rektor, 1812/13 Prorektor der UH; 1791, 1796, 1801, 1808, 1814 Dekan, Jan.-Dez. 1815 Prodekan (für Johann Ludwig Klüber, s. UAH RA 793 S. 68) der Jur. Fak. der UH

1808 Beisitzer des Akademischen Gerichts in Heidelberg

1805 Wirkl. Oberhofgerichtsrat

E 7. Nov. 1786 Dr. iur. utr. h.c. UH.

Q $u$ UAH PA 1591; RA 4921, 6766 (Brief vom 3. April 1799); GF 7. Acta secularium (1787) S. 166, 227 f.; Toepke 4 (1903) S. 239 Anm. 2, 240, 515f. • GLA Abt. 205, Fasz. 239f., 666. • Briefe: UBH. • Auskunft: Kath. Kirchenbuchamt Heidelberg.

$W$ Testamentum in genere, in specie inofficiosum una cum remediis juris. Heidelberg 1803 . Programma circa conditionem seu affimativam seu negativam religionis ultimae voluntati insertam num pro adjecta aut non adjecta habendam ... Heidelberg 1812 . Ius ecclesiasticum in usum praelectionum. 2 Bde. Heidelberg 1815.

$L$ Janson, Franz: Freymüthige Bemerkungen über den von ... F. W. G. an der hohen Schule zu Heidelberg gewagten Beweis ... Heidelberg 180o. • ADB 8 (1878) S. 358 (hier irrtümlich 1753 statt 1752 als Geburtsjahr genannt); Keller (1913) S. 83-86; Jammers (1964) S. 177 u. ö.; Weisert (1991) S. 121 u. ö.; Schweigard (2000); WBIS; Schroeder (2017) S. $31 \mathrm{f}$.

\section{Gans, Oscar}

1919-1930 Med. Fak.

Dermatologie

* o6. Febr. 1888 Dormagen

$\dagger$ 28. Mai 1983 Limpsfield-Oxted (Surrey, England)

口 Limpsfield-Oxted mosaisch, später ev.

V Isaak G. (1846-1909) Viehhändler

M Henriette geb. Herz (1857-1929)

( 8. Sept. 1914 Bertha Adolfine Friedericke geb. Schweers (1890-1980), siehe Briefwechsel zwischen Eduard Spranger und Käthe Hadlich ... (Eintrag unter $Q u[$ ellen])

K $\quad 1 \mathrm{~S}, 1 \mathrm{~T}$

Lb 1907-1908 Militärdienstpflicht als EinjährigFreiwilliger bei 9. Rheinischen Infanterie-Regiment in Bonn; Studium an U: seit SS 1907 Bonn, anschl. Berlin, zuletzt Freiburg/Br.

U Freiburg/Br.: März 1912 Staatsprüfung; 13. Dez. 1912 Dr. med.; Juni 1913 Approbation.

U Hamburg: Juli 1913-Juni 1914 Assistenzarzt an U-Klinik.

U Freiburg: Juli 1914-Anfang Jan. 1919 Assistenzarzt an U-Hautklinik. • In dieser Zeit:

1914-1918 Kriegsdienst.

UH: Seit 6. Jan. 1919 Assistenzarzt, seit 17. Mai 1921 Oberarzt an U-Hautklinik; 30. Sept. 1919 Habilitation für Dermatologie und Venerologie; 1924 von U beurlaubt für Lehrauftrag an Med. Akademie in Düsseldorf; seit 12. Dez. 1924 nichtplanm. a.o. Prof.; Nov.-Dez. 1926 Vorlesungen an Mayo Clinic in Rochester (Minnesota); WS 1929/1930 letzte Vorlesungsankündigung.

U Frankfurt/M.: Jan. 1930 Ern. zum o. Prof. und Direktor der U-Hautklinik; SS 1930 Dienstantritt; 31. März 1934 Entlassung aus rassischen Gründen; 1934 Emigration nach Indien. 
Bombay: 1935-1949 Privat-Praxis und wiss. Tätigkeit an State Institutes; 1935-1949 Vorstandsmitglied des jüdischen Hilfsvereins; Rufe an U abgelehnt: 1946 München und Frankfurt/M.

U Frankfurt/M.: 1949-1959 (Emeritierung) o. Prof. und Direktor der Dermatologischen Klinik.

Comano im Tessin: Seit 1959 Wohnsitz.

Limpsfield-Oxted: Nach 1980 Wohnsitz.

1953-1960 Präsident der Dt. Dermatologischen Gesellschaft (DDG)

Der 1983 von der DDG gestiftete Oscar-Gans-Preis gehört zu den bedeutendsten Wissenschaftspreisen in der Dermatologie

E Korr. Mitglied der Italienischen Gesellschaft für Dermatologie und Syphiligraphie; Ehrenmitglied der Dermatologischen Gesellschaft St. Louis und Cleveland; 1956 Mitglied der Dt. Akademie der Naturforscher Leopoldina Halle/S. 1958 Dr. med. h.c. UH. 1957 Großes Bundesverdienstkreuz.

Qu UAH PA 925, 3863. - GLA Abt. 235, Fasz. 2020. Briefwechsel zwischen Eduard Spranger und Käthe Hadlich. Hrsg. von Karin Priem ... Bibliothek für Bildungsgeschichtliche Forschung des DIPF (Deutsches Institut für Internationale Pädagogische Forschung), online unter http://bbf.dipf. de/digitale-bbf/editionen/spranger-hadlich/per son-g. - Siehe auch Archiv der Dt. Akademie der Naturforscher Leopoldina Halle/S. - Mitteilungen: Herr Eduard Breimann, Dormagen. Lebenserinnerungen (Manuskript; Signatur: MS 325) im Institut für Zeitgeschichte, München.

$W$ Histologie der Hautkrankheiten. Berlin. Bd. 1: 1925. 2. Aufl. 1955. Bd. 2: 1927. 2. Aufl. 1957. • Syphilis: Primäreffekte, Exantheme und Enantheme in: Handbuch der Haut- und Geschlechtskrankheiten 16, T. 1 (1930). (Mitverf.)

$L$ Universität Gießen 1 (1907) S. 427; Bader (1925) S. 70; Dictionary of Emigrés 2 (1983) S. 357; Kürschner (1983) S. 1124f.; Chronik Ärzte H
(1985) S. 128; WBIS. - Krücke, Wilhelm: Nachrufe auf Hubert Harbauer, ..., O. G. ... Wiesbaden 1987. Juden der Frankfurter U (1997) S. 110-113. • Scholz, Albrecht: Geschichte der Dermatologie in Deutschland. Berlin 1999. Dhom (2001) S. $691 \mathrm{f}$. u. ö. Breimann, Eduard: Das Dorf Dormagen und seine Menschen. 2. Aufl. Neuss 2008. S. 192194. Hammerstein, Notker: Die Johann Wolfgang Goethe-Universität Frankfurt am Main. Bd. 1: Von der Stiftungsuniversität zur staatlichen Hochschule. Göttingen 2012. S. 899 (Register). Benzenhöfer, Udo: Die Universitätsmedizin in Frankfurt am Main von 1914 bis 2014. Münster 2014. S. 165 f. u. ö. Wernig, Carina: Dormagen ehrt berühmten Sohn der Stadt in: Neuß-Grevenbroicher Zeitung vom 12. Dez. 2016. - Deutsche Biographie, s. https://www.deutsche-biographie.de/gnd1164113 92.html [06.11.2017].

$P$ Bildarchiv UAH; graph. Slg. UBH.

\section{Gass, Friedrich Wilhelm Joachim Christian}

1868-1887 (1889) Theol. Fak.

Kirchengeschichte, Symbolik, Dogmatik, Ethik

* 28. Nov. 1813 Breslau (heute: Wrocław, Polen)

$\dagger \quad$ 21. Febr. 1889 Heidelberg ev.

V D. theol. und Dr. phil. h.c. Joachim Christian G. (1766-1831) seit 1795 Feldprediger, seit 1807 Prediger an Marienkirche Berlin, seit 1810 Konsistorialrat, seit 1811 o. Prof. für Theologie Breslau, s. ADB 8 (1878) S. 394-396, WBIS, BBKL II (1990) Sp. 181; s. auch Eintrag unter $H G$ [Herausgeber]

M Wilhelmine Elisabeth geb. Stavenhagen ( ${ }^{\star}$ ca. 1778)

๑ Johanna geb. Krieger $\left({ }^{*} 1823 \dagger\right.$ nach 1886$)$

K 1 S, 2 T: u.a. Anna Auguste Wilhelmine G. (1855-1928) Ehefrau von: (siehe) Wilhelm Erb.

Lb Seit WS 1832/33 Studium an U Breslau, seit WS 1834/35 Halle-Wittenberg, seit WS 1835/36 Berlin; 1836 Rückkehr nach Breslau. 
U Breslau: 31. Jan. 1838 Dr. phil.; 9. Nov. 1839 theol. Lizentiatenprüfung; 21. Dez. 1839 Habilitation; seit 2. Sept. 1846 a. o. Prof.

U Greifswald: Seit SS 1847 a. o. Prof.; 1847-1861 Bibliothekar an UB; seit 14. Aug. 1855 o. Prof. für Systematische Theologie.

U Gießen: Seit 12. Sept. 1861 o. Prof. für Systematische Theologie.

UH: 23. Dez. 1867 Ern. zum SS 1868 o. Prof. als Nachf. von Richard Rothe und e. der Hauptlehrer am Ev.-Prot. Theol. Seminar mit e. jährl. Besoldung von 280o.- Gulden, s. UAH RA 6718 fol. 29r, v; SS 1887 letzte Vorlesungsankündigung; 8. Nov. 1888 Ministerium der Justiz, des Kultus und Unterrichts in Karlsruhe teilt dem Engeren Senat der UH mit, „daß leider eine Besserung in dem Befinden des Herrn Professor Dr. Gass in dem Maße nach ärztlicher Voraussicht nicht zu erwarten ist, daß Herr Gass seine akademische Lehrthätigkeit wieder unbehindert würde aufnehmen können" (aus: Brief vom 8. Nov. 1888 in: RA 6718); Nachf.: (siehe) Ludwig Lemme. $\bullet$ In dieser Zeit:

Karlsruhe: 1871, 1876, 1881 Teilnehmer der Badischen Generalsynode als Vertreter der Theol. Fak. der UH.

1869/70, 1873/74, 1876/77, 1881/82 Dekan der Theol. Fak. der UH

1885 Kirchenrat

E 1854 D. theol. Greifswald. 1874 Ritterkreuz I. Klasse des Ordens vom Zähringer Löwen.

Qu UAH PA 1596; RA 184, 6718. GLA Abt. 235, Fasz. 2017. Briefwechsel zwischen Eduard Spranger und Käthe Hadlich. Hrsg. von Karin Priem u. a. Bibliothek für Bildungsgeschichtliche Forschung des DIPF (Deutsches Institut für Internationale Pädagogische Forschung), online unter http://bbf. dipf.de/digitale-bbf/editionen/spranger-hadlich/ person-g.
W Gennadius und Pletho, Aristotelismus und Platonismus in der Griechischen Kirche, nebst einer Abhandlung über die Bestreitung des Islam im Mittelalter. Breslau 1844. Geschichte der protestantischen Dogmatik in ihrem Zusammenhange mit der Theologie überhaupt. 4 Bde. Berlin 18541867. Reprint 2015-2017. • Die Lehre vom Gewissen. Ein Beitrag zur Ethik. Berlin 1869. Symbolik der griechischen Kirche. Berlin 1872. • Optimismus und Pessimismus. Der Gang der christlichen Welt- und Lebensansicht. Berlin 1876. Geschichte der christlichen Ethik. 3 Bde. Berlin 1881-1887.

$H G$ Friedrich Schleiermachers Briefwechsel mit Joachim Christian Gass. Berlin 1852.

MG, MHG Seit 1875 Zeitschrift für Kirchengeschichte.

MHG Henke, Ernst Ludwig Theodor: Neuere Kirchengeschichte. Nachgelassene Vorlesungen. 3 Bde. Halle/S. 1874-1880.

$L$ Badische Biographien 4 (1891) S. 527-536. • Gass, Elisabeth: Erinnerungen an Heinrich von Treitschke: seine Freundschaft mit W.G. in: Zeitwende - Kultur, Kirche, Zeitgeschehen. Neuendettelsau 1928. - WBIS; BBKL II (1990) Sp. 182; DBE 3 (2006); Grewolls (2011).

P Bildarchiv UAH; graph. Slg. UBH.

\section{Gatterer, Christoph Wilhelm Jacob}

1787-1803 Phil. Fak.

1803-1822 Staatswirtschaftl. Sektion

1822-1823 Phil. Fak.

Kameralwissenschaften, Ökonomische Wissenschaften, Landwirtschaft, Forstwissenschaft, Diplomatik

* 29. Nov. 1759 Göttingen

$\approx$ 02. Dez. 1759

$\dagger$ 11. Sept. 1838 Heidelberg ev.-luth. 
V Johann Christoph G. (1727-1799), u.a. 17591799 o. Prof. für Geschichte Göttingen, s. WBIS, NDB 6 (1964) S. 89-91, Geschichtswissenschaft in Göttingen (1987) S. 19-22 u. ö.; Debus, Karl Heinz: Der Gatterer-Apparat [Sammlung]. Speyer 1998; Göttinger Gelehrte 1 (2001) S. 40 f.; Gierl, Martin: Das Alphabet der Natur und das Alphabet der Kultur im 18. Jhdt. Botanik, Diplomatik, Linguistik und Ethnographie nach Carl von Linné, J. C. G. ... in: NTM. Zs. für Geschichte der Wissenschaften, Technik und Medizin. Basel 2010. S. 1-27.

M Helena Barbara geb. Schubert (1728-1806)

( 9. April 1787 Justina Amalia geb. Klingsöhr (1767-1863)

K $\quad 2 \mathrm{~T}$

Vw Schwester: Philippine Magdalene G. verh. Engelhard (1756-1831) Dichterin, s. ADB 6 (1877) S. 136 f.; Stummann-Bowert, Ruth: Johann Gottlob Nathusius in Althaldensleben und die Familie Engelhard in Kassel: Kulturelle Beziehungen und verwandtschaftliche Verbindungen in: Jahresschrift der Museen des Ohrekreises. Haldensleben 1994. Bd. 1. S. 20-35; Kleßmann, Eckart: Universitätsmamsellen: fünf aufgeklärte Frauen zwischen Rokoko, Revolution und Romantik. Frankfurt/M. 2008; P.E. geb. Gatterer ... „Laß die Dichtkunst mich begleiten bis zum letzten Lebensgang“. Ausgewählte Gedichte. Ein bürgerliches Frauenleben zwischen Spätaufklärung und Biedermeier. Hrsg. von Ruth Stummann-Bowert. Würzburg 2008.

Lb U Göttingen: 3. Jan. 1778 Immatrikulation; ca. 1784-1787 Dozent für Mineralogie, Naturkunde; 1785 als Assessor der Königl. Societät der Wiss. und des Königl. Histor. Inst. Göttingen sowie Mitglied der Kurpfälz. Meteorologischen Societät zu Mannheim genannt (Titelblatt in: Anzeige seiner Vorlesungen für diejenigen, welche den Harz mit Nutzen bereisen wollen. Göttingen 1785); 19. März 1787 Dr. phil.

Staatswirtschafts Hohe Schule H und Phil. Fak. der UH: 17. Febr. 1787 Ern. zum o. Prof. für Kameralwiss., insbesondere „Ökonomische Wissenschaften“ als Nachf. von Johann Heinrich Jung(-Stilling) (s. Drüll (1991) S. 81) nach Verlegung der „Kameral
Hohe Schule“ Lautern (heute: Kaiserslautern) 1784 nach $\mathrm{H}$ und Angliederung als Staatswirtschafts Hohe Schule an Phil. Fak. der UH; SS 1787 Amtsantritt; 1788-1797 G. hält jedes zweite Semester, 1797-1804 jedes Semester, im SS 1821 seine letzte forstwiss. Vorlesung, s. hierzu Neuhaus (2014) S. 57 und Anm. 296; seit 1797 auch Vorlesungen über Diplomatik in Nachfolge von Johannes Schwab (s. Drüll (1991) S. 141); Mai 1803 Einführung der Staatswirtschaftl. Sektion nach Eingliederung der „Staatswirtschafts Hohe Schule“ H in U.

UH: Seit Mai 1803 o. Prof. an Staatswirtschaftl. Sektion; Rufe an U abgelehnt: 1803 Moskau, 1804 Würzburg; 1812 als Direktor des Schlossgartens in $\mathrm{H}$ genannt, s. hierzu UAH RA 6883 fol. 12r; nach 1812 G. legt das Amt des Garten-Direktors nieder, „weil er sich durch verschiedene Maasnahmen von höherer Behörde gekränkt" fühlt; er macht sich zum Grundsatz, „bis zu seiner Pensionirung den Schlossgarten nicht mehr zu betreten“ (aus: UAH RA 5629 fol. 25V, 26r); 17. Jan. 1822 auf eigenen Antrag von allen Amtsgeschäften an U befreit; Mai 1822 Zusammenlegung der Staatswirtschaftl. Sektion mit Phil. Fak.; 23. Juli 1823 Ruhestand.

1792, 1798, 1801 Dekan der Phil. Fak. der UH; 1808/ o9, 1814 Direktor der Staatswirtschaftl. Sektion der UH; zur Staatswirtschaftl. Sektion der UH, siehe Heinrich Eschenmayer und Ludwig Wallrad Medicus: Einträge unter $Z$ [itat]

1818: Wilhelm I., König von Württemberg, veranlasst den Ankauf der G.schen Bibliothek für Universitätsbibliothek Tübingen

1790 Wirkl. Bergrat; 1805 Oberforstrat

E 1782 Mitglied der Akademie der Wissenschaften Göttingen; 1805 Korr. Mitglied der Generalforstkommission. - Ritter des Ordens vom Zähringer Löwen. • Siehe hierzu auch Ollrogg (1981) S. 30.

Qu UAH PA 1598; RA 297, 6519-6523 u.ö.; G-II65/1, G-II-65/2 (Schlossgarten in H). • GLA Abt. 205, Fasz. 244-246, 1117. - Toepke 4 (1903) S. 348 Anm. 2. Prozesssachen Freiburg 1489-1867. Bearb. von Stefan Hanke. UA Freiburg/Br. 1997. S. 17: Verleumdungsprozess, Signatur: 8o, Vorsi- 
gnatur 1: III i 72, Laufzeit: 1807; Titel: Forderungen von 302 Gulden 45 Kreuzer der Heidelberger Professoren Georg Adolf Suckow, Gutterer [wohl Christoph Wilhelm Gatterer] und Martin Tobias Engelbert Semer gegen die katholische Kirchenkommission. - Briefe: UBH. - Auskunft: Universitätsarchiv Göttingen; Ev.-luth. Kirchenbuchamt Göttingen; Ev.-luth. Pfarramt Clausthal.

$W$ Anleitung, den Harz und andere Bergwerke mit Nutzen zu bereisen. 5 T. Göttingen 1785-1792. Auch u.d.T.: Beschreibung des Harzes ... 2 Bde. Nürnberg 1792-1793. - Abhandlung von dem Handelsrange der Russen. Mannheim 1789. A Allgemeines Repertorium der forstwissenschaftlichen Literatur nebst beygefügten kritischen Bemerkungen über den Werth der einzelnen Schriften. 2 Bde. Ulm 1796. Neudr. Amsterdam 1972. Allgemeines Repertorium der mineralogischen, berg- und salzwerkswissenschaftlichen Litteratur. 2 Bde. Gießen 1798-1799.

HG 1790-1794 Technologisches Magazin. 1796 1807 Neues Forstarchiv.

L ADB 8 (1878) S. 409 f.; Stieda (1906) S. 128 u. ö;; Catalogus prof. Gottingensium (1962) S. 134; NDB 6 (1964) S. 91. • Ollrog, Wolfgang: C. W. J. G. ... in: Archiv für Sippenforschung 81/82 (1981) S. 28-34. • Lessing, Hans-Erhard: Technologen an der Universität Heidelberg in: Semper apertus 2 (1985) S. 116-120. - Weisert (1991) S. 122, 128 u. ö.; WBIS; Carl (2004); DBE 3 (2006); Neuhaus (2014) S. 57$63,69,73$ f., $76,85,195,287,353$.

P Bildarchiv UAH; graph. Slg. UBH.

\section{Gattermann, Friedrich August Ludwig}

1889-189o Phil. Fak.

1890-1900 Nat.-Math. Fak.

Chemie

* 20. April 1860 Goslar

$\dagger$ 20. Juni 1920 Freiburg/Br.

ev.
V Heinrich Friedrich Wilhelm G. $\left({ }^{*} 1827\right)$ Bäckermeister

M Marie Dorothea Louise geb. Creutzburg $\left({ }^{*} 1838\right)$

๑ 7. März 1893 Katharina (Käthe) Auguste geb. Krausse $\left({ }^{\star} 1869\right)$ Scheidung 1918

K $1 \mathrm{~T}$

Lb April 1880-März 1881 Militärdienstpflicht als Einjährig-Freiwilliger; hier gleichzeitig seit SS 1880 Studium an U Leipzig; seit SS 1881 Forts. des Studiums an UH, WS 1882/83 Berlin, seit SS 1883 Göttingen.

U Göttingen: 18. Febr. 1885 Dr. phil.; 1885-1889 Assistent am Allg. Chemischen Labor von (siehe) Victor Meyer; 28. Juni 1886 Habilitation.

UH: Seit 7. Juni 1889 a.o. Prof. und stellvertr. Direktor des Chemischen Laboratoriums (Leiter: V. Meyer); 1897 Ruf an U Bern abgelehnt; seit 30. Dez. 1898 etatm. a. o. Prof.

U Freiburg/Br.: Seit 24. März 1900 o. Prof. und Direktor des Chemischen Labors an Phil. Fak.

Über die Gattermann Reaktion (1890), Gattermann-Koch Reaktion (1897), Gattermann Aldehyd Synthese (1898) und Gattermann-Synthese (1906), s. Laue, Thomas, Plagens, Andreas: Namenund Schlagwort-Reaktionen der Organischen Chemie. 5. Aufl. Wiesbaden 2006. S. 149-152.

1914 Geh. Hofrat

E 1888 Mitglied der Dt. Akademie der Naturforscher Leopoldina Halle/S.; 1909 Mitglied der Akademie der Wissenschaften H. 1892 Ritterkreuz II. Klasse mit Eichenlaub des Ordens vom Zähringer Löwen.

Qu UAH PA 1599; RA 5851, 6497, 6886. - Briefe: UBH. - Siehe auch Archiv der Dt. Akademie der Naturforscher Leopoldina Halle/S.

$W$ Über die Einwirkung von Phosgen auf Salmiak, eine Synthese aromatischer Säuren in: Berichte der Dt. Chemischen Gesellschaft 20 (1887); Über Thionaphthen in: ebd. 26 (1893); Eine Synthese aroma- 
tischer Aldehyde in: ebd. 30 (1897), 31 (1898). • Die Praxis des organischen Chemikers. Leipzig 1894. 43. Aufl. 1982. - Tabelle zur Berechnung der volumetrischen Stickstoff-Bestimmungen. Leipzig 1906.

L Jacobson, Paul Heinrich: L. G. in: Berichte der Dt. Chemischen Gesellschaft (1921) 54. Jg., Nr. 6, S. 115-141. - Smith (1949) S. 94 f.; NDB 6 (1964) S. 91 (mit Werkverz.); Badische Biographien N.F. V (2005) S. 89-91; Autoren der Bunsenbibliothek (2009 online).

$P$ Bildarchiv UAH; graph. Slg. UBH; NDB.

Gedan, K. (Pseudonym)

siehe Kossmann, Robby

\section{Gegenbaur, Carl}

1873-1901 Med. Fak.

Anatomie

* 21. Aug. 1826 Würzburg

$\dagger \quad$ 14. Juni 1903 Heidelberg

kath., (nach) 1871 altkath.

V Franz Joseph G. (1792-1872) Rentamtmann

M Elisabeth Karoline geb. Roth (180o-1866)

๑ Ostern 1863 Emma Anna Margaretha geb. Streng (1834-1864)

๑ 18. März 1869 Ida geb. Arnold (1831-1909) T von: (siehe) Friedrich A.

K $\quad 1$ S, 2 T: u.a. Elisabeth (Else) G. (1871-1947) Aquarellmalerin, s. WBIS.

Lb U Würzburg: Seit WS 1845/46 zunächst Studium der Philosophie, dann der Medizin.

Würzburg: 1850-1852 Assistenzarzt am Juliushospital (in dieser Zeit Studienreise, u. a. nach Berlin).

U Würzburg: 15. April 1851 Dr. med.; 1852-1853 Studienreise nach Sizilien; 28. Jan. 1854 Habilitation für Anatomie und Physiologie.
U Jena: Seit Sept. 1855 a. o. Prof. für Zoologie; seit 15. Sept. 1858 o. Prof. für Anatomie und bis 1862 für Zoologie; 1872 Ruf an U Straßburg abgelehnt.

UH: Seit 26. Juni 1873 o. Prof. und Direktor des Anatom. Inst. als Nachf. von Friedrich Arnold; 1877/78 Ruf an U Amsterdam abgelehnt; 1. April 1901 Ruhestand.

1873/74, 1882/83, 1895/96 Dekan der Med. Fak. der $\mathrm{UH}$

1873 Geh. Hofrat; 1877 Geh. Rat II. Klasse

E 1857 Mitglied der Dt. Akademie der Naturforscher Leopoldina Halle/S.; Mitglied der Akademie der Wissenschaften: 1864 Leipzig, 1870 München, 1891 Göttingen, 1897 Wien, 1900 Berlin; 1884 ausw. Mitglied der Royal Society London. 1885 Maximilians-Orden für Wissenschaft und Kunst; 1896 Copley-Medaille. 1875 Ritterkreuz I. Klasse, 1877 Eichenlaub zum Ritterkreuz I. Klasse, 1883 Kommandeurkreuz II. Klasse, 1885 Stern zum Kommandeurkreuz, 1899 Großkreuz des Ordens vom Zähringer Löwen. • 1899 Ehrenbürger der Stadt Heidelberg.

$Q u$ UAH PA 1603f.; RA 5819; GF 106-110, 136 f. • GLA Abt. 235, Fasz. 2021. • Briefe: UBH. • Nachlaß: UAH (Signatur: Rep. 95). - Anatomische Sammlung der UH. - Siehe auch Archiv der Dt. Akademie der Naturforscher Leopoldina Halle/S. • Erlebtes und Erstrebtes. Leipzig 1901. (Autobiogr.)

$W$ Grundzüge der vergleichenden Anatomie. Leipzig 1859. 2. Aufl. 1870. Grundriß der vergleichenden Anatomie. Leipzig 1874. 2. Aufl. 1878. Nachdr. Saarbrücken 2007. Lehrbuch der Anatomie des Menschen. 2 Bde. Leipzig 1883. 8. Aufl. 1909. • Vergleichende Anatomie der Wirbeltiere mit Berücksichtigung der Wirbellosen. 2 Bde. Leipzig 1898-1901. Gesammelte Abhandlungen von C. G. 3 Bde. Leipzig 1912.

G, HG 1875-1902 Morphologisches Jahrbuch, e. Zs. für Anatomie und Entwicklungsgeschichte, s. hierzu Doll/Kirsch/Eckart (2017) S. 112. 
$L$ NDB 6 (1964) S. 130 f.; Hoche (1969) S. 85f.; WBIS; Chronik Ärzte H (1985) S. 128, 223-225; Stolz (2003) S. 94-96. Hoßfeld, Uwe: C. G. Deutscher vergleichender Anatom, Morphologe und Zoologe ... in: Lexikon der bedeutenden Naturwissenschaftler. Hrsg. von Dieter Hoffmann ... Heidelberg 2004. 2. Bd. S. 88. • Peiffer (2004) S. 1148 (Register). •Wagner, Günther: C. G. ... Pionier der Vergleichenden Anatomie und Förderer von Ernst Haeckel in: Wegbereiter der modernen Medizin. Jenaer Mediziner aus drei Jahrhunderten ... Jena 2004. S. 115-142. - Ärztelexikon (2006) S. 137. • Contributions to the History of Herpetology. Ed. by Kraig Adler ... Vol. 2. Saint Louis 2007. Hier freut sich der Tod (2013) S. 69-71, 105 u. ö.; Doll (2014) S. 283-288 u. ö.; Doll/Kirsch/Eckart (2017) S. 44-46, 96 (Gegenbaur-Sammlung), 111.

$P$ Bildarchiv UAH; graph. Slg. UBH; NDB; Chronik Ärzte H.

\section{Geiger, Philipp Lorenz}

1818-1824 Phil. Fak.

1824-1836 Med. Fak.

Pharmazie, Arzneimittellehre, Theoretische und

Pharmazeutische Chemie

* 29. Aug. 1785 Freinsheim (Pfalz)

$\dagger$ 19. Jan. 1836 Heidelberg

ref.

V Johannes G. (1752-1816) Pfarrer, s. Badisches Pfarrerbuch 2 (1939) S. 190

M Maria Louisa geb. Hecht (1751-1824)

$\varnothing$ 4. April 1811 Anna Barbara geb. Fol(t)z verw. Sachs (1768-1824) Witwe des Karlsruher Stadtapothekers Christoph Gottfried Sachs, s. hierzu Thomas (1985) S. 269-274

$\infty$ 24. Jan. 1826 Auguste Ernestine geb. Rinck (1794-1859), s. Thomas, S. 274-277

K $\quad 2$ S, 4 T, s. Thomas, S. 276, 290-306

Vw siehe Thomas, S. 79, 277-280, 306-310, 561563.

Lb Apothekerlehrling: Ende 1798-Aug. 1799 Adelsheim, Ostern 1800-Ostern $1804 \mathrm{H}$; Apothekergehilfe (sog. Servierzeit): seit Ostern 1804
H, seit Ostern 1805 Rastatt, seit Ostern 1807 Lindau; Ende Sept. 1807 pharmazeutisches Examen in Karlsruhe.

Karlsruhe: Herbst 1807-Juni 1814 Verwalter der Sachs'schen Stadtapotheke. In dieser Zeit:

UH: 2. Mai 1810-Frühjahr 1811 Studium der Pharmazie.

Lörrach (bei Weil am Rhein): Febr. 1812-Dez. 1826 Inhaber der Löwenapotheke (seit Dez. 1813 Verwalter: Schwager Fol(t)z).

H: 28. März 1814-1. Sept. 1821 Besitzer der U-Apotheke als Nachf. von: (siehe) Johann Wilhelm Mai; seit SS 1816 Privat-Vorlesungen über Allg. Botanik und Med. Pflanzenkunde in Räumen der U-Apotheke, Hauptstr. 110.

UH: 24. Juli 1817 Dr. phil.; 1. April 1818 Habilitation an Phil. Fak.; 25. Okt. 1824 Ern. durch Großherzog Ludwig I. zum a. o. Prof. für Pharmazie an Phil. Fak.; 30. Dez. 1824 Beschluß des Engeren Senats, die Professur für Pharmazie an die Med. Fak. zu verlagern; seit 23. Juli 1826 jährl. Besoldung von 400.- Gulden, seit 1. Febr. 1835 jährl. Zulage von 200.- Gulden.

E Mitglied: Mineralogische Gesellschaft Jena, Medico-botanical Society of London. 1827 Dr. med. h. c. Marburg.

Qu UAH PA 1605; RA 5355, 660o; Fak.-Akten H-III-111/22, H-IV-102/13 fol. 105r u. ö.; GF 40. • GLA Abt. 205, Fasz. 248. Briefe, Nachlaß: UBH.

$W$ Handbuch der Pharmacie zum Gebrauche bei Vorlesungen und zum Selbstunterrichte für Ärzte, Apotheker und Droguisten. Heidelberg. Bd. 1: 1824. 5. Aufl. 1837-1843. Bd. 2. 2 T.: 1827-1829. 2. Aufl. 1838-1843. Versuche mit Conium maculatum in: Magazin für Pharmacie 35 (1831) S. 72-85, 259286. - Darstellung des Atropins in: Annalen der Pharmacie 5 (1833) S. 43-81 und ebd. 6 (1833) S. 4465. (Mitverf.); Über einige neue giftige organische Alkalien in: ebd. 7 (1833) S. 269-280. - Pharmacopoea universalis. 2 T. Heidelberg, Wien 18351845. 
$L$ Donat (1913) S. 189f. - Ein Brief Justus Liebigs aus dem Geiger-Archiv in: Ruperto Carola 10. Jg., Bd. 24 (1958) S. 137-139. NDB 6 (1964) S. 147; Schmitt (1978) S. 72 u. ö. - Keidel, Jochen: Johann Heinrich Dierbach. Ein Beitrag zu Leben und Werk des Heidelberger Hochschullehrers. Diss. Marburg 1983. S. 44-47 u. ö. - Thomas (1985) (mit Werkverz.); Dies.: P.L.G. und Justus Liebig: „... alles um des verdammten Geldes wegen?" Berührungspunkte - Zusammenarbeit und Freundschaft - Entwicklungslinien in: Gießener Universitätsblätter. Gießen 1987. S. 13-31, s. http:// geb.uni-giessen.de/geb/volltexte/2013/949o/index. html. • Eberhardt (1990) S. 206 (Register); Kirschke (2001) S. 446 (Register); Stumm (2012) S. 96$101 \mathrm{u} . \ddot{\mathrm{o}}$.

$P$ Bildarchiv UAH; graph. Slg. UBH; NDB. • Siehe auch Thomas (1985) S. 283-286.

\section{Geiler, Karl Hermann Friedrich}

1921-1928 Jur. Fak.

1928-1939 (Honorar-Prof.) und 1946-1947 (Ho-

norar-Prof.) Jur. Fak.

1947-1953 Jur. Fak.

1921-1939 Gesellschaftsrecht, Steuerrecht; 1946 1953 Int. Recht

* 10. Aug. 1878 Schönau im Schwarzwald

$\dagger$ 14. Sept. 1953 Heidelberg

ev.

V Karl G. (1851-1906) Amtsrichter, später Oberstaatsanwalt, s. Badische Biographien 6 (1935) S. $108 \mathrm{f}$.

M Anna geb. Piristi

( 22. Dez. 1904 Charlotte Mathilde geb. Hirsch (1881/82-1942), siehe Lexikon jüdischer Einwohner Hs (2011) S. 127

K $2 \mathrm{~T}$, siehe ebd.

Lb Seit WS 1896/97 Studium an U Freiburg/Br., anschl. Berlin, seit SS 1899 H; 1903 II. Staatsprüfung in Karlsruhe.

1903-1904 Badischer Gerichtsreferendar; 1904 Dr. iur. an UH.
Mannheim: 1904-1953 Rechtsanwalt; 1908-1933 nebenamtlicher Dozent für Rechtswissenschaft an der von ihm mitbegründeten Handelshochschule; 1916 Verlegung des Wohnsitzes nach $\mathrm{H}$.

In dieser Zeit:

1914-1918 Kriegsdienst.

UH: 26. Febr. 1921 Habilitation für Gesellschaftsrecht; seit 3. März 1921 nichtplanm. a. o. Prof. für Steuerrecht; seit 18. Juni 1928 o. Honorar-Prof.; SS 1939 letzte Vorlesungsankündigung; 17. Juli 1939 Entzug der Lehrbefugnis aus rassischen Gründen (nichtarische Ehefrau).

Wiesbaden: 16. Okt. 1945-20. Dez. 1946 Ministerpräsident des Staates Groß-Hessen.

UH: 15. Jan. 1946 Wiedereinsetzung als HonorarProf.; seit 23. Juni 1947 nichtbeamteter persönlicher Ordinarius.

15. Aug. 1948-26. Juli 1949 Rektor und 1949/50 Prorektor der UH

1948 Präsident der neugegründeten Europäischen Akademie (später umbenannt in Deutsche Europa-Akademie, 1954 aufgelöst und vom Institut für Europäische Politik übernommen)

E Mitglied der Unesco, Sektion Erziehung. 1953 Großes Bundesverdienstkreuz. 1915 Ritterkreuz II. Klasse mit Eichenlaub und Schwertern des Ordens vom Zähringer Löwen. 1953 Ehrensenator der Universität Heidelberg.

Qu UAH PA 753, 3883 f.; RA 5029. • Briefe: UBH. • Nachlaß: Hessisches Hauptstaatsarchiv Wiesbaden.

$W$ Gesellschaftliche Organisationsformen des neuen Wirtschaftsrechts. Mannheim 1919. 2. Aufl. 1922. Körperschaftssteuergesetz vom 30. III. 1920. Systematisch erläutert ... und mit e. Anhang über Gesellschaftsformen und Steuerrecht. Mannheim 1921. Erg.-Bd. 1923. - Beiträge zum modernen Recht. Mannheim 1933. - Geistige Freiheit und so- 
ziale Gerechtigkeit. Wiesbaden 1947. Siehe auch Badische Biographien N. F. III (1990) S. 103.

$L$ Handels-Hochschule Mannheim 1907-1932 (1932) S. 26. • Thiess, Frank: K. G. zum Gedächtnis in: Ruperto Carola 5. Jg., Nr. 11/12 (1953) S. 19 f.; Weber, Friedrich: K. G. in: ebd. S. 21 f.; Kuntz, Edwin: Ein Unvergessener in: ebd. 10. Jg., Bd. 24 (1958) S. 10 f. NDB 6 (1964) S. 151; Badische Biographien N.F. III (1990) S. 99-103; WBIS. • Mühlhausen, Walter: K.G. und die Universität Heidelberg 1920-1953 ... in: Nassauische Annalen 110 (1999) S. 315-344. * Hausmann (2006) S. 26-28 u. ö.; Baur (2009) S. 244f.; Schroeder (2010) S. 737 (Register); Lexikon jüdischer Einwohner Hs (2011) S. 127. Weis, Stefanie: Leben und Werk des Juristen K.G. ... Hamburg 2013. Hessische Biografie, s. http://www.lagis-hessen.de/pnd/102038015 (Stand: 27. Jan. 2017); Schroeder (2017) S. 333-339.

$P$ Bildarchiv UAH; graph. Slg. UBH; Ruperto Carola (1953); NDB.

\section{Gelzer, Heinrich Carl Guido}

1873-1878 Phil. Fak.

Alte Geschichte

* o1. Juli 1847 Berlin

$\dagger$ 11. Juli 1906 Jena

ref.

V Johann Heinrich G. (1813-1889), u.a. 18441851 o. Prof. für Geschichte Berlin, 1853-1870 Hrsg. der Protestantischen Monatsblätter für innere Zeitgeschichte, seit 1860 Berater Großherzogs Friedrich I. von Baden, 1866 Ern. zum Badischen Staatsrat, s. NDB 6 (1964) S. 177 f., Historisches Lexikon der Schweiz online (2003)

M Julie geb. Sarasin (1825-1912)

$\infty$ 12. Sept. 1876 Emilie Klara geb. Thurneysen (1853-1919) T von Dr. Eduard ThurneysenGemuseus (1824-1900) Präsident des Appellationsgerichts in Basel
K 2 T: u.a. Emily G. (1877-1906) Ehefrau von Friedrich („Fritz") Karl Adolf Koegel (18601904) Schriftsteller, Komponist, Unternehmer, s. Hoffmann, David Marc: Zur Geschichte des Nietzsche-Archivs. Berlin 1991. S 135-232, 407423 („Koegel-Exzerpte“) u. ö.; Schäfer, Wilhelm: Die Missgeschickten ... neu hrsg. von Christoph Knüppel ... Bielefeld 2011. • 1 S: Heinrich Johann Eduard G. [jun.] (1883-1945) seit 1918 a.o., seit 1928 o. Prof. für Romanistik Jena, s. Hausmann (2008) S. 413, 417 u. ö.; Nachlaß: U- und Landesbibliothek Jena Vw Schwager: (siehe) Hermann Schultz.

Lb Seit 1865 Studium an U Basel, seit 1867 Göttingen.

Göttingen: 1869 Oberlehrerexamen; 1. Juli 1869 Dr. phil. an U.

Basel: 1. Okt. 1869-1873 Gymnasiallehrer; u. a. 1871 Reise durch Kleinasien. • In dieser Zeit:

U Basel: 1872 Habilitation für Alte Geschichte; 1872-1873 Privat-Dozent.

UH: 2. Aug. 1873 Ern. zum a.o. Prof. mit Staatsdienereigenschaft.

U Jena: 24. Juni 1878 Ern. zum o. Prof. für Klassische Philologie und Alte Geschichte.

1878 Geh. Hofrat

E 1875 Korr. Mitglied des Archäolog. Inst. des Deutschen Reichs in Rom; 1894 o. Mitglied der Königl. Sächsischen Gesellschaft der Wiss. Leipzig; 1899 Mitglied der Bayer. Akademie der Wissenschaften München. $\bullet 1897$ D. theol. Gießen.

Qu UAH PA 753, 3883f.; RA 639o. GLA Abt. 76, Fasz. 9929a. - Briefe: UBH. - Werkmanuskript „Die Chronographien des Sextus Julius Africanus' " in U- und Landesbibliothek Jena, s. hierzu Krönung, Thomas: Die Wiederentdeckung des Manuskripts von H. G. zur kritischen Edition der Chronographien des Julius Africanus in: WeltZeit. Christliche Weltchronistik aus zwei Jahrtausenden in Beständen der Thüringer Universitäts- 
und Landesbibliothek Jena. Berlin 2005. S. 20-31. Auskunft: Universitätsarchiv Gießen. • Geistliches und Weltliches aus dem türkisch-griechischen Orient. Selbsterlebtes und Selbstgesehenes. Leipzig 1900. (Autobiogr.)

$W$ Sextus Julius Africanus und die byzantinische Chronographie. 3 Bde. Leipzig 1880-1898. • Die Genesis der byzantinischen Themenverfassung. Leipzig 1899. • Ausgewählte kleine Schriften. Hrsg. von Heinrich Gelzer [jun.]. Leipzig 1907.

MG 1893 Byzantinische Zeitschrift.

L Zeitgenossenlexikon (1905) Sp. 432 f. - Nachruf in: Byzantinische Zs. 16 (1907) S. 417-429 (mit Werkverz.). - NDB 6 (1964) S. 178. • Herz, Heinz: H.G. Beiträge zu seinem Welt- und Geschichtsbild in: Helikon 17 (1977) S. 302-308. Nietzsche Briefwechsel. Kritische Gesamtausgabe. Hrsg. von Giorgio Colli ... Bd. 4. T. 2: Briefe an Friedrich Nietzsche: Mai 1872-Dezember 1874. Berlin 1978. S. 265 f. (hier: Brief von Otto Ribbeck an Nietzsche über G.). - Historisches Lexikon der Schweiz online (2003); BBKL XXIV (2005) Sp. 681-685; Deutsche Biographie, s. https:/www.deutsche-biogra phie.de/gnd104123966.html [07.11. 2017].

$P$ Bildarchiv UAH; Geistliches und Weltliches (Autobiogr.).

\section{Gensler, Johann Caspar}

1816-1821 Jur. Fak.

Juristische Praxis (praktische Rechtswissenschaft), Zivil- und Strafprozeßrecht

* 14. Sept. 1766 Ostheim vor der Rhön (Unterfranken)

$\dagger \quad$ 18. Nov. 1821 Heidelberg ev.-luth.

V Georg Christian G. ( $\left.{ }^{*} 1728\right)$ Kantor, Schuldiener

M Anna Susanna geb. Hoffmann

๑ Hieronyma Carolina geb. Heiligenstett/Heyligenstädt (1780-1845)

K 2
Vw Schwager: (siehe) Jacob Roux.

Lb 1789-1791 Studium an U Jena.

Seit 1791 Hauslehrer; nach 1792 Advokat in Eisenach, anschl. Syndikus in Ostheim; vor 1800 Konsulent und Justizbeamter in Diensten des Grafen Julius von Soden (1754-1831; Schriftsteller, Publizist, Politiker, s. Hanke, Peter: Ein Bürger von Adel. Leben und Werk des J. von S. Würzburg 1988).

U Jena: 1801 Dr. iur.; seit 1801 Privat-Dozent; 26. Aug. 1805 Ern. zum o. Prof. für Institutionen; SS 1813 Rektor.

UH: Dez. 1815 Ern. zum 1. April 1816 o. Prof. als Nachf. von Christoph Martin; 1816-1821 Beisitzer des Spruchkollegiums der Jur. Fak.; Rufe an U abgelehnt: 1818 Bonn, 1819 Erlangen.

1819 Dekan der Jur. Fak. der UH

1805 Justizrat; 1809 Hofrat; 1818 Geh. Justizrat

Qu UAH PA 1608. • GLA Abt. 205, Fasz. 249 f. • Auskunft: Ev.-Luth. Pfarramt in Ostheim vor der Rhön (Taufbuch von 1766); Ev. Kirchengemeindeamt Heidelberg (Totenbuch von 1821).

$W$ Anleitung zur gerichtlichen Praxis in bürgerlichen Rechtsstreitigkeiten verbunden mit theoretischen Darstellungen und Bemerkungen. Hrsg. von Karl Eduard Morstadt. 2 Bde. Heidelberg 18211825. - Rechtsfälle für die Civil-Praxis. Heidelberg 1817. 2. vervollst. Ausg. von Eduard Morstadt. Heidelberg 1833. - Sammlung von Rechtsfällen zur Beurtheilung und förmlichen Bearbeitung in academischen Übungs-Collegien. 3 H. Heidelberg 1817. • Beitrag zur Lehre von der Diligenz und Culpa nach den Begriffen der römischen Rechtsgelehrten. Heidelberg 1819. 3. Aufl. 1839. • Dr. J. C. G.s ... vollständiger Commentar über Martin's Civilprocess-Lehrbuch. Hrsg. von Karl Eduard Morstadt. 2 Bde. Heidelberg 1825.

MHG 1818-1821 Archiv für zivilistische Praxis.

$L$ Dem Andenken des verewigten Herrn J. C. G. ... Heidelberg 1822. • Günther (1858) S. 80; Jammers 
(1964) S. 177 u. ö.; Heidelberger Strafrechtslehrer (1986) S. gf.; Weisert (1991) S. 126 u. ö.; Schroeder (2010) S. 122-125 u. ö; Deutsche Biographie, s. https://www.deutsche-biographie.de/gnd1165424 03.html [07.11. 2017].

$P$ Bildarchiv UAH; graph. Slg. UBH.

\section{Georgi}

s. Cohn

\section{Gerhard, Gustav Adolf}

1908-1913 Phil. Fak.

Klassische Philologie

* 14. April 1878 Konstanz

$\dagger$ 24. Okt. 1918 Wien

ev.

V Gustav Adolf G., Bahnverwalter

M Sophie geb. Kramer

$\infty$ 25. Sept. 1908 Fanny geb. Schaefer $\left({ }^{*} 1876\right)$

$\mathrm{K} \quad 2 \mathrm{~S}, 2 \mathrm{~T}$

Vw Enkel: Wiltrud geb. Fuchs $\left({ }^{*} 1945\right)$, u. a. $1973-$ 1977 Dozentin für Chor- und Orchesterleitung an Universidad Austral de Chile, seit 1977 Kantorin und Organistin an Matthäikirche in Düsseldorf, 1989-2005 Kirchenmusikdirektorin an St. Marien in Osnabrück, s. Wikipedia. - Reimund G. (1979-2006 Doppelname: Gerhard-Multhaupt) $\left({ }^{*} 1952\right)$, u.a. $1985-1994$ Wiss. Mitarbeiter und Projektleiter am Heinrich-Hertz-Institut für Nachrichtentechnik Berlin, seit 1994 U-Prof. für Sensorik und seit 1996 für Angewandte Physik kondensierter Materie an neugegründeter Math.-Naturwiss. Fak. U Potsdam, seit 2014 Senator der $\mathrm{U}$, s. http://physik.cosmos-indirekt.de/Phy sik-Schule/Reimund_Gerhard (abgerufen am 25. Aug. 2017). • Anselm G. $\left({ }^{*} 1958\right)$, u. a. seit 1992 Hochschuldozent an U Münster, seit 1994 o. Prof. für Musikwissenschaft an U Bern, s. http://www.musik.unibe.ch/ueber_uns/perso nen/prof_dr_gerhard_anselm/index_ger.html (abgerufen am 25. Aug. 2017).
Lb Seit WS 1894/95 Studium der Klassischen Philologie an UH; 18. März 1902 Staatsprüfung für höheres Lehramt in H; 22. Juni 1903 Dr. phil. an UH.

UBH: Juli 1901-Febr. 1913 a.o. Hilfsarbeiter an Handschriften-Abt. • In dieser Zeit:

April 1902-Okt. 1906 Lehramtspraktikant in H; Okt. 1906-April 1907 Teil der Militärdienstpflicht als Einjährig-Freiwilliger; seit 9. April 1907 Gymnasiallehrer, u.a. 1. Jan. 1908 (Versetzung nach) Tauberbischofsheim; Schuljahr 1908/og beurlaubt; 10. Sept. 1909 auf eigenen Antrag Entlassung aus Schuldienst.

UH: 27. Juli 1907 Habilitation; SS 1908 erste, WS 1912/13 letzte Vorlesungsankündigung; seit 21. Juli 1911 nichtetatm. a. o. Prof.

Franz-Josephs-U Czernowitz: Seit SS 1913 etatm. a. o. Prof.; Aug. 1914 Schließung der U nach Einmarsch der Russen; SS 1918 Ern. zum o. Prof. nach Wiedereröffnung der U. $\bullet$ In dieser Zeit:

Wien: 1914-1918 Kriegsdienst als Mitarbeiter in e. Ministerium.

Qu UAH PA 38f., 1609; RA 6375. • GLA Abt. 235, Fasz. 1984. - Auskunft: Ev. Kirchengemeindeamt in Konstanz (Taufbuch von 1878).

$W$ Untersuchungen zur Geschichte des griechischen Briefes. Heidelberg 1901. Phoinix von Kolophon. Texte und Untersuchungen. Leipzig 1909. Der Tod des grossen Pan. Heidelberg 1915.

$H G$ Griechisch-literarische Papyri: Ptolemäische Homerfragmente. Heidelberg 1911. (Veröffentlichungen aus der Heidelberger Papyrus-Sammlung. IV,1.) • Griechische Papyri: Urkunden und literarische Texte aus der Papyrus-Sammlung der Universitätsbibliothek Heidelberg. Heidelberg 1938 (posthum erschienen). (Veröffentlichungen aus den badischen Papyrus-Sammlungen. 6.)

$L$ NDB 6 (1964) S. 277 f.; WBIS. 


\section{Gervinus, Georg Gottfried}

1830-1835 Phil. Fak. 1844-1848 (1853) (Honorar-Prof.) Phil. Fak. Geschichte

* 20. Mai 1805 Darmstadt

$\dagger$ 18. März 1871 Heidelberg ev.-luth.

V Georg Gottfried G. (1765-1837) Gerber, Lederhändler, Gastwirt

M Anna Maria Margarethe geb. Schwarz (17721837)

( 3. Sept. 1836 Victoria/Victorie geb. Schelver (1820-1893) Musikerin, siehe Badische Biographien 5 (1906) S. 198-202, Pfeiffer (2004) S. 156 f.; Baar, Regina: V.G. - Leben und Wirken der Ehefrau und Witwe in: G. G. G. ... Gelehrter - Politiker (2005) S. 73-84 (mit P); T von: (siehe) Franz Schelver

$\mathrm{K}$ keine.

Lb Seit 1819 Buchhändlerlehre in Bonn, seit 1820 Kaufmannslehre; anschl. Angestellter in e. Modeund Schnittwarenhandlung in Darmstadt.

Seit 1823 Selbststudium; 1825 Maturitätsprüfung.

Seit SS 1825 Studium der Philologie, Geschichte an U Gießen, seit 26. April $1826 \mathrm{H}$.

Frankfurt/M.: Herbst 1827-Anfang 1829 Lehrer am Erziehungsinstitut Gutermann.

H: 1829-1830 Hauslehrer bei der englischen Familie Hunter.

UH: 30. Mai 1829 Dr. phil.; 27. Aug. 1830 Habilitation; 1832-1833 Studienreise durch Italien; 1833 auch als Privat-Lehrer für Geschichte an e. Mädchen-Pensionat in H erwähnt; 18. April 1835 Ern. zum a.o. Prof. für Geschichte; 2. Sept. 1835 Antrittsrede; 29. Dez. 1835 auf eigenen Antrag Entlassung aus badischem Staatsdienst.

U Göttingen: Seit SS 1836 o. Prof. für Geschichte, Literatur; 11./12. Dez. 1837 als e. der „Göttinger Sieben“" nach dem Protest gegen den Verfassungs- bruch König Ernst Augusts von Hannover Amtsenthebung und des Königreichs Hannover verwiesen.

Seit Dez. 1837 Aufenthalt in Darmstadt; Dez. 1837 Ruf an U Zürich abgelehnt; 4. März 1838-Ende April 1839 Reise über Frankreich nach Italien, s. hierzu Baar, Regina: Flucht ins Land der Schönheit. Briefwechsel zwischen G. G. G. und Karl Hegel auf ihrem Weg aus den politischen Konflikten des deutschen Vormärz nach Italien - und zurück (1837-1839) ... Heidelberg 2008.

H: Okt. 1839-1844 Privat-Gelehrter; Nov. 1839Juni 1844 Besitzer des Hauses Felseck in der heutigen Neuenheimer Landstraße 38; 1844-1863 häufig wechselnde Wohnsitze.

UH: 8. Juni 1844 Ern. zum Honorar-Prof.; 1845 Ruf an U Jena abgelehnt; SS 1848 letzte Vorlesung, auch wenn WS 1848/49 Vorlesungen G.s über „Neueste Geschichte seit 1815 dreimal wöchentlich“ angekündigt werden (aus: Anzeige der Vorlesungen der ... Universität zu Heidelberg ..., welche im Winter-Halbjahr 1848/49 ... gehalten werden sollen. Heidelberg 1848. S. 15); 1848-1849 Aufenthalt in Italien; 7. Juli 1853 Entziehung der „verliehene[n] Bewilligung zu[r] Haltung von Vorlesungen“ (aus: UAH H-IV-102/49 fol. 195v), siehe hierzu Abschnitt: Febr. 1853 Anklage wegen Hochverrats ... • In dieser Zeit:

Frankfurt/M.: 31. März-3. April 1848 Mitglied des Vorparlaments; 3. April-8. Mai 1848 Vertrauensmann der Hansestädte im Siebzehnerausschuß des Bundestages; 18. Mai-31. Juli 1848 (Austritt) Abgeordneter in Nationalversammlung.

H: 1853-1871 Privat-Gelehrter; 1863-1871 Eigentümer des Hauses Leopoldstraße 5 (heute: FriedrichEbert-Anlage 5); 1866-1867 Aufenthalt in Italien. • In dieser Zeit:

Febr. 1853 Anklage wegen Hochverrats vor dem Hofgericht in Mannheim, s. hierzu G. G. G. ... Gelehrter - Politiker (2005) S. 118-122; 8. März 1853 Freispruch vom Vorwurf des Hochverrats, aber G. wird „der Gefährdung der öffentlichen Ruhe und Ordnung durch die Presse" für schuldig befunden (siehe hierzu: Der Hochverratsprozeß gegen Ger- 
vinus (1967)); Strafmaß: 2 Monate Gefängnis und Bezahlung der Prozeßkosten; G. legt Widerspruch ein; 16. April 1853 Oberhofgericht in Mannheim schlägt das Urteil aus formalen Gründen nieder; 21. Mai 1853 Gericht verzichtet auf weitere Verfolgung der Angelegenheit; 7. Juli 1853 trotzdem Entziehung der „verliehene[n] Bewilligung zu[r] Haltung von Vorlesungen" an UH.

1856 Mitbegründer der bereits 1860 wieder aufgelösten Deutschen Händel-Gesellschaft

1845 Hofrat

$E$ Mitglied der Akademie der Wissenschaften: 1845 Berlin, 1848 Wien, 1861 Göttingen, 1863 München.

Qu UAH PA 1614; RA 5683 (Stiftung e. GervinusBüste 1914), RA 6595; Fak.-Akten H-IV-102/24 fol. 118r-13or, H-IV-102/25 fol. 102r, 210r, 22or-221r, H-IV-102/49 fol. 195r, v. - GLA Abt. 205, Fasz. 254. - Wagner, Jonathan F.: G. über die Einigung Deutschlands. Briefe aus den Jahren 1866-1870 in: ZGORh 121. Jg. (1973) S. 371-392. • G.G.G. nach der Revolution. Der Wandel e. enttäuschten Liberalen zum radikalen Republikaner. Sechs Briefe aus den Jahren 1849-1851. Hrsg. von Jonathan F. Wagner in: Darstellungen und Quellen zur Geschichte der dt. Einheitsbewegung ... 10 (1978) S. 153-188 (auch: Sonderdruck Heidelberg 1978). • Der Redaktionsbriefwechsel der Hallischen, Deutschen und Deutsch-Französischen Jahrbücher 1837-1844. Hrsg. von Martin Hundt. Bd. 1: Der Briefwechsel um die Hallischen Jahrbücher. Berlin 2010. Apparat: S. 262 (Register). Nachlaß: UBH. • G. G. G.' Leben. Von ihm selbst. 1860, gedruckt Leipzig 1893. (Autobiogr.)

$W$ Geschichte der Angelsachsen im Überblick. Frankfurt/M. 1830 (s. hierzu UAH H-IV-102/24 fol. 161r-162r). Geschichte der poetischen National-Literatur der Deutschen. 5 Bde. Leipzig 18351842. Ab 4. Aufl. u. d. T.: Geschichte der deutschen Dichtung. 5. Aufl. 1874. Grundzüge der Historik. Leipzig 1837. Briefe „Vom Rheine“ in: Deutsche Zeitung vom 21. Nov. 1848 bis 24. Mai 1849 . Geschichte des 19. Jahrhunderts seit den Wiener Verträgen. 8 Bde. Leipzig 1855-1866.
G 1834 Deutsche Jahrbücher.

Redakteur 1. Juli 1847-31. Juli 1848 „Deutsche Zeitung".

$L$ Catalogus prof. Gottingensium (1962) S. 107; NDB 6 (1964) S. 335-338. - Der Hochverratsprozeß gegen Gervinus. Hrsg. von Walter Boehlich. Frankfurt/M. 1967. - Carl, Rolf-Peter: Prinzipien der Literaturbetrachtung bei G. G. G. Bonn 1969. • Hübinger, Gangolf: G.G.G. Historisches Urteil und politische Kritik. Göttingen 1984. • Ebling, Wolfgang: G.G.G. ... und die Musik. München 1985. - Wolgast, Eike: Politische Geschichtsschreibung in Heidelberg ... in: Semper apertus 2 (1985) S. 166-173. - Weber (1987) S. 170 f.; Giesselmann (1992) S. 78-84 u.ö.; Best/Weege (1996) S. 153; Gelehrte in der Revolution (1998) S. 11-40; Jansen (2000) S. 181-214; Göttinger Gelehrte 1 (2001) S. 182 f.; Roth (2001) S. 708 (Register); Jansen (2002) S. 166-185. • G. G. G. ... Gelehrter - Politiker - Publizist. Bearb. von Frank Engehausen ... Heidelberg 2005. Kilchmann, Esther: Verwerfungen in der Einheit ... München 2009. Kreutz, Wilhelm: G.G.G. und Ludwig Häusser - politische Professoren in: Von der Spätaufklärung zur Badischen Revolution ... Hrsg. von Achim Aurnhammer ... Freiburg/Br. 2010. Bd. 2. S. 111-126. • Kaesler (2014) S. 998 (Register); Riecke (2016) S. 144 (Register). - Siehe auch http://www.rzuser. uni-heidelberg.de/ jv8/vlgk-alt/ressourcen/7_per sonen/Gervinus/blic1848.htm; http://www.ub.uniheidelberg.de/helios/fachinfo/www/gesch/Gesch Erg/Felseck.htm.

$P$ Bildarchiv UAH; graph. Slg. UBH; NDB.

\section{Gessler, Hans}

1923-1930 Med. Fak.

Innere Medizin

* 02. Sept. 1890 Stuttgart

$\dagger$ 03. Juni 1966 Berchtesgaden ev. 
V Friedrich Wilhelm G. (1850-1925) Hofkammerpräsident

M Helene Mathilde geb. Bach (1863-1913)

(16. April 1921 Else geb. Rüdiger $\left({ }^{*} 1894\right)$

K 1 T, 1 S: Ulrich G. (1922-1990) 1965-1987 Chefarzt der IV. Med. Klinik Nürnberg und Ordinarius für Innere Medizin sowie Gründer des Inst. für Nephrologie U Erlangen-Nürnberg, s. Kürschner (1987) S. 1288.

Lb Seit WS 1907/08 Studium an U Tübingen, anschl. Kiel, München.

München: 1914 Dr. med. an U; Aug. 1914 Staatsprüfung; Sept. 1914 Approbation.

1914-1919 Kriegsdienst.

UH: 1920-1926 Assistenzarzt an Med. U-Klinik; 26. Jan. 1923 Habilitation; 1926-1930 Oberarzt an Med. U-Klinik; seit 4. Aug. 1927 nichtplanm. a.o. Prof.

Wuppertal-Barmen: Seit Nov. 1930 Chefarzt der Inneren Abt. des Städtischen Krankenhauses; Juli 1945 Entlassung gemäß Erlaß der Militärregierung.

Radevormwald: 1949-1957 (Ruhestand) Leiter der Inneren Abt. des Johanniter-Krankenhauses.

Qu UAH PA 936, 3900. GLA Abt. 235, Fasz. 1986.

$W$ Die Homöopathie im Rahmen der Gesamtmedizin. Stuttgart 1937. (Mitverf.)

L Stübler (1926) S. 316; Kürschner (1931) Sp. 831. • H.G. in: Bergische Morgenpost Nr. 202 vom 1. Sept. 1955, Nr. 226 vom 28. Sept. 1957.

$P$ Bildarchiv UAH.
Gierke, Otto Friedrich (seit 1911: von Gierke)

1884-1887 Jur. Fak.

Deutsches Recht

* 11. Jan. 1841 Stettin (heute: Szczecin, Polen)

$\dagger$ 10. Okt. 1921 Charlottenburg (heute: Ortsteil von Berlin)

ev.

V Julius G. (1807-1855), u. a. Stadtsyndikus, 1848 preußischer Landwirtschaftsminister, anschl. Appellationsgerichtspräsident

M Concordia Therese geb. Zitelmann (18091855)

$\infty$ 2. April 1873 Marie Cäcilie Elise (Lili) geb. Loening (1850-1936) Schwester von: (siehe) Richard Loening

K 3 T: u. a. Anna von G. (1874-1943) Sozialpädagogin, Politikerin der DNVP, siehe WBIS, BBKL XXIII (2004) Sp. 517-527; Paul, Erika: Zwischen Sozialgeschichte und Fluchtort. Das Landjugendheim Finkenkrug und seine mutigen Frauen. Berlin 2013. - Hildegard von G. (1880-1966) Sozialpädagogin, s. Hoffmann, Erika: Zwei Wegbereiterinnen sozialer Arbeit: H. von G. ... in: Mädchenbildung und Frauenschaffen 5 (1961) S. 11-16; Maier, Hugo: Who is who der Sozialen Arbeit. Freiburg/Br. 1999. S. 201f. 3 S: u. a. Julius Karl Otto von G. (1875-1960) 1925-1938, 1945-1960 o. Prof. für Rechtswiss. Göttingen, s. NDB 6 (1964) S. 373 f.; Szabó, Anikó: Vertreibung, Rückkehr, Wiedergutmachung: Göttinger Hochschullehrer im Schatten des Nationalsozialismus ... Göttingen 2000. S. 147-149; Schenk, Günter, Meÿer, Regina: Biographische Studien über die Mitglieder des Professorenzirkels „Spirituskreis". Halle/S. 2007; Catalogus prof. Halensis online; Tilitzki 1 (2012) S. 790 (Register). - Edgar Otto Konrad von G. (1877-1945) 1911-1938, 1939-1944 Prof. für Bakteriologie und Leiter des Pathologisch-Bakteriolog. Inst. TH Karlsruhe, s. NDB 6 (1964) S. 373, WBIS, Badische Biographien N. F. VI (2011) S. 137-140. Siehe auch: Goldenes Buch der Burschenschaft Allemannia zu Heidelberg. Festschrift Teil I ... Hrsg. von Wolf-Diedrich Reinbach. Heidelberg 2006. S. 31-34 (Otto von G. sen.), S. 328- 
330 (Julius von G.), S. 334 f. (Edgar von G.), S. 402 f. (Otto von G. jun.).

Lb WS $1857 / 58$ Studium an U Berlin, seit SS 1858 H, SS 1860 Berlin; 21. Aug. 1860 Dr. iur. an U Berlin; nach bestandenen jur. Staatsexamina: seit Sept. 1860 Auskultator (s. Levin Goldschmidt: Eintrag unter $L b$ (1851)), seit April 1862 Referendar, seit Mai 1865 Assessor am Appellationsgericht in Stettin.

U Berlin: Ostern 1867 Habilitation; 1871 Ruf an U Zürich abgelehnt; seit 10. März 1871 a. o. Prof.

U Breslau: 13. Dez. 1871 Ern. zum o. Prof.; 1884 Ruf an U Göttingen abgelehnt.

UH: Seit 11. Juli 1884 o. Prof. als Nachf. von Achilles Renaud.

U Berlin: Seit 30. Juni 1887 o. Prof.

1896 Mitglied der Gründungskommission des Deutschen Rechtswörterbuchs

Weitgehend ablehnend zum Frauenstudium äußert sich G. in e. umfangreichen Gutachten auf der Grundlage seiner Organismustheorie, die er in Bd. 1 des deutschen Genossenschaftsrechts (s. Eintrag unter $W$ [erke]) 1868 darlegt, s. Zeiler (2009) S. 66 Anm. 74.

Geh. Justizrat; 1884 Geh. Hofrat

E Mitglied der Akademie der Wissenschaften: 1903 München, 1916 Wien. • Friedensklasse des Ordens Pour le Mérite für Wissenschaften und Künste.

Qu UAH PA 1615; RA 5480, 6761. • Briefe: UBH. • Nachlaß: Staats- und Landesbibliothek Göttingen. Mitteilungen: Herr Dr. Gerhart von Gierke (†), Türkenfeld.

$W$ Das deutsche Genossenschaftsrecht. 4 Bde. Berlin 1868-1913. Neudr. 1954. - Johannes Althusius und die Entwicklung der naturrechtlichen Staatstheorien. Breslau 1880. 5. Aufl. 1958. Deutsches Privatrecht. 3 Bde. München 1895-1917.
Nachdr. der 3 Bde. Leipzig 2010. Bd. 4: Familienrecht. Aus dem Nachlaß hrsg. von Karl Kroeschell und Karin Nehlsen-von Stryk. Berlin 2010. • Der germanische Staatsgedanke. Berlin 1919.

L NDB 6 (1964) S. 374f. (mit Werkverz.); WBIS. • Retter, Hein: Reformpädagogik und Protestantismus im Übergang zur Demokratie. Frankfurt/M. 2007. S. 613-628. Gutachten zum Promotions- und Habilitationsverfahren von ... O.G. in: Max Weber Gesamtausgabe. Hrsg. von Gerhard Dilcher ... Abt. 1. Bd. 1. Tübingen 2008. S. 98 ff. • Zeiler (2009) S. 520 (Register). • Berliner Juristische Fakultät (2010) S. 399 (Register). • Jander, Heiko: Komplementär und Kommanditist in der verbandsrechtlich verselbständigten Kommanditgesellschaft ... Baden-Baden 2010. S. 50-53. • Schroeder (2010) S. 263-265 u. ö. - Thiessen, Jan: O. von G. in: Festschrift 200 Jahre Jur. Fak. der ... Universität zu Berlin ... Hrsg. von Stefan Grundmann ... Berlin 2010. S. 343-374. • Lobinger, Thomas: O. von G., Hugo Sinzheimer und der Tarifvertrag im dt. Arbeitsrecht in: Heidelberger Thesen zu Recht und Gerechtigkeit (2013) S. 179206. - Maus (2013) S. 458 (Register). Schwab, Dieter: Naturrecht und Rechtsidee. Historische Reflexionen im Anschluss an eine Rektoratsrede von O. von G. Naturrecht und Staat in der Neuzeit ... Hrsg. von Jens Eisfeld ... Tübingen 2013. S. 543-558. Löhnig, Martin: Wer war eigentlich ... O. von G.? in: Ad legendum - die Ausbildungszeitschrift aus Münsters Juridicum. Münster 2016. S. 329-332. - Dilcher, Gerhard: Historische Sozialwissenschaft als Mittel zur Bewältigung der Moderne: Max Weber und O. von G. im Vergleich in: Die Germanisten und die historische Rechtsschule: bürgerliche Wissenschaft zwischen Romantik, Realismus und Rationalisierung ... Frankfurt/M. 2017. S. 415-442.

$P$ Bildarchiv UAH; graph. Slg. UBH; NDB. 


\section{Glafey, Hugo}

1924-1930 Nat.-Math. Fak.

Chemie

* 26. Okt. 1862 Glauchau (Sachsen)

$\dagger$ o1. Jan. 1945 Meißen

ev.

V Robert G. ( $†$ nach 1927) (Textil-)Kaufmann

M Marie Christine geb. Leonhardt

@ 18. März 1889 Ottilie Henriette Elise geb. Puhlmann ( ${ }^{*} 1869 \dagger$ nach 1945 ); seit (vor) 1944 getrennt lebend

K $1 S$

Lb Studium: Seit SS 1879 Technische Staatslehranstalt in Chemnitz, seit WS 1882/83 Königl. Polytechnikum in Dresden; 1886 Diplomabschlußprüfung (Diplom zum Fabrik-Ing.) am Polytechnikum Dresden.

Berlin: Seit 21. April 1885 technischer Hilfsarbeiter (1. Mai 1885 Beeidigung), seit 1. April 1889 etatm. technischer Hilfsarbeiter, seit 23. Mai 1896 Reg.-Rat, 7. April 1921-1924 Ober-Reg.-Rat am Reichspatentamt; 1898-1905 außerdem Lehrer für Maschinenbau; 1902-1903 zudem Lehrer an Webschule; 1904-1914 Lehrer an Hauptlehranstalt für Zollbeamte. • In dieser Zeit:

TH Berlin-Charlottenburg: 14. Jan. 1915 Habilitation; seit 12. Jan. 1924 nichtbeamteter a. o. Prof. für Textiltechnik und -industrie auf dem Lehrgebiet Arbeitsmaschinen in Abt. III für Maschinen-Ingenieurwesen (seit 1922 Fak. III für Maschinenwirtschaft, Fachabt. für Maschinenbau).

UH: Seit 8. Aug. 1924 nichtplanm. a.o. Prof.; 30. Sept. 1930 auf eigenen Antrag U verlassen.

In den 2oer und zoer Jahren des 20. Jahrhunderts ist G. Schriftleiter der Melliand-Textilberichte, e. textiltechnischen Fachzeitschrift mit Sitz in Frankfurt/M.

1906 Geh. Reg.-Rat
E Königl. Preußischer Roter Adler-Orden IV. Klasse; Kronen-Orden III. Klasse.

Qu UAH PA 3915. • GLA Abt. 235, Fasz. 1991. • Auskunft: Universitätsarchiv TU Berlin (Codex Professorum); Staatsarchiv Leipzig (Sterbe-Zweitbuch des Standesamts Meißen 1945. Bd. 1. Bestand 22000: Standesamt-Zweitbücher der Gemeinden Sachsens, Nr. 7066).

W Die Rohstoffe der Textilindustrie. Leipzig 1909. 2. Aufl. 1921. Spinnen und Zwirnen. Leipzig 1911. 2. Aufl. 1928. Krieg und Textilindustrie. Berlin 1915. - Wirkerei und Strickerei ... Berlin 1927. (Mitverf.) - Maschinen für die Gewinnung und das Verspinnen der Baumwolle. Berlin 1931.

Mitbearb. Technologie der Wolle. Chemische Technologie und mechanische Hilfsmittel für die Veredlung der Wolle. Berlin 1938.

HG Textil-Lexikon. Handwörterbuch der gesamten Textilkunde. Stuttgart 1937.

L H.G. 70 Jahre alt in: Melliand-Textilberichte (1932). Kürschner (1935) Sp. 403; Wer ist's (1935) S. 496; WBIS.

$P$ Bildarchiv UAH.

\section{Glockner, Hermann Michael}

1924-1933 Phil. Fak.

Philosophie

* 23. Juli 1896 Fürth

$\dagger \quad$ 11. Juli 1979 Braunschweig

口 Frauenchiemsee kath.

V Sebastian G. (1871-1954) Volksschullehrer, später Schulrat

M Kunigunde geb. Wegemer (1873-1933)

( 14. Febr. 1925 Dr. med. Maria geb. Hilpert (1897-1977) Ärztin

$\mathrm{K}$ keine. 
Lb Nov. 1915-Dez. 1918 Kriegsdienst (nach e. Unfall 1916 zum Sanitätsdienst in Erlanger Lazaretten abkommandiert).

U Erlangen: Seit SS 1916 Studium der Philosophie, auch Medizin; 19. Juni 1919 Dr. phil.

Seit WS 1919/20 Studium der Philosophie an UH, seit WS 1921/22 Studium der Medizin, Philosophie an U München, WS 1922/23 Studium der Philosophie an $\mathrm{UH}$.

UH: 3. Mai 1924 Habilitation; 1930 Ruf an U Erlangen scheitert am Einspruch der dortigen Theol. Fak. aufgrund kath. Konfession G.s; 4. Aug. 1930 Ern. zum nichtbeamteten a.o. Prof. durch Staatsministerium mit e. monatl. Privat-Dozenten-Stipendium von brutto 320.- Reichsmark (aus: UAH PA 3919).

U Gießen: Seit 1. Nov. 1933 o. Prof.; 1943 Ruf an U Graz abgelehnt; 6. Dez. 1944 nach Bombenangriff Zerstörung der G.schen Wohnung und all seiner Habe.

Dez. 1944-1951 Aufenthalt in ehemaliger Militärbaracke in Trohe (heute: Ortsteil von Buseck) bei Gießen; Ende März 1946 Schließung der U Gießen und damit auch Aussetzen der Gehalts-Zahlung; 1. April 1949 G. prozessiert gegen das Land Hessen und wird zum 1. April 1949 mit Pension in Ruhestand an U Gießen versetzt.

Gießen: 1949-WS 1950/51 Lehrauftrag für Philosophie an Nachfolgerin der U Gießen, der seit Mai 1946 bestehenden Justus-Liebig-Hochschule für Bodenkultur und Veterinärmedizin.

TH Braunschweig: Seit 4. Aug. 1951 planm. a.o. Prof.; 10. Okt. 1951-30. Aug. 1964 (Emeritierung) o. Prof.

1930 Mitbegründer des Int. Hegelbundes; seit 1963 Mitglied des Willibald-Pirckheimer-Kuratoriums

E 1955 O. Mitglied der Braunschweiger Wiss. Gesellschaft. - 1930 Kuno-Fischer-Preis der UH; 1966 Willibald-Pirckheimer-Medaille; 1971 Goldene Bürgermedaille der Stadt Fürth.
Qu UAH PA 3919. - GLA Abt. 235, Fasz. 1993. • Nachlaß: Stadtarchiv Fürth im Schloß Burgfarrnbach; siehe Trapp, Marianne: Der Nachlaß des Philosophen H.G. in: Zs. für philosophische Forschung 37 (1983) H. 1, S. 138-140. • Heidelberger Bilderbuch. Bonn 1969. (Autobiogr.)

W Die Abenteuer des Geistes. Stuttgart 1938. 3. Aufl. 1947. Einführen in das Philosophieren. Berlin 1944. 3. Aufl. 1951. Die europäische Philosophie von den Anfängen bis zur Gegenwart. Stuttgart 1958. Gegenständlichkeit und Freiheit. 2 Bde. Bonn 1963-1966. Das Selbstbewußtsein. Eine Einführung in die Fundamentalphilosophie. Bonn 1972. 2. Aufl. 1973. • Bibliographie in: Rationalität, Phänomenalität, Individualität. Hrsg. von Wolfgang Ritzel. Bonn 1966. S. 375-388.

HG Georg Wilhelm Friedrich Hegel. Sämtliche Werke. Auf Grund des von Ludwig Boumann ... besorgten Originaldruckes im Faks.-Verfahren neu hrsg. von H.G. 20 Bde. Stuttgart 1927-1940. In mehreren Aufl. erschienen.

MHG 1934-1944 Zeitschrift für Deutsche Kulturphilosophie.

$L$ Gießener Gelehrte (1982) S. 298-308; WBIS; Jansen (1992) S. 409 (Register); Ders. (1992a) S. 165 (Register); Tilitzki 1 (2002) S. 619f. u. ö.; Klee, Personenlexikon (2007) S. 187; 100 Jahre Germanistik in Hamburg (2011) S. 212, 223f., 456; Deutsche Biographie, s. https://www.deutsche-biographie.de/gn d118695444.html [07.11. 2017].

$P$ Bildarchiv UAH; Gießener Gelehrte.

Glück, Christian Wilhelm Maximilian Hugo 1899-1940 Nat.-Math. Fak. Botanik

* 13. Dez. 1868 Windsheim (Mittelfranken; heute: Bad W.)

$\dagger \quad$ 28. Sept. 1940 Heidelberg ev. 
V

Christian Karl Friedrich G. (1826-1886) Land gerichtsrat

M Charlotte Rosalie geb. Reinsch (1842-1917)

(0) 7. Sept. 1922 Helene geb. Peschko $\left({ }^{*} 1886 \dagger\right.$ nach 1964), s. UAH B-3469/2

$\mathrm{K}$ unbekannt

Vw Christian Friedrich von G. (1755-1831), u.a. seit 1784 Prof. für Pandekten an U Erlangen, siehe WBIS.

Lb Seit WS 1890/91 Studium an U Erlangen, anschl. Freiburg/Br., Erlangen, München; 19. Dez. 1894 Dr. phil. an U München; Febr. 1895-März 1897 Forts. des Studiums an U Halle-Wittenberg.

Assistent am Botanischen Inst.: Seit April 1897 UH, seit Mai 1897 U München.

UH: 25. Febr. 1899 Habilitation; seit 14. Febr. 1903 nichtetatmäßiger a.o. Prof.; 1914-1917 außerdem Aushilfs-Lehrer an Höherer Mädchenschule (heute: Hölderlin Gymnasium) in H; Herbst 1924 Studienreise nach Nordamerika; seit 17. März 1936 mit Neuordnung des Herbariums des Botanischen Inst. beauftragt.

E Korr. Mitglied des Naturhistorischen Vereins Nürnberg; Mitglied des Botanischen Vereins Regensburg; Mitglied der Academy of Sciences Philadelphia (USA).

Qu UAH PA 3920 f., 10048. • GLA Abt. 235, Fasz. 20208. • Briefe: UBH.

$W$ Biologische und morphologische Untersuchungen über Wasser- und Sumpfgewächse. 4 Bde. Jena 1905-1924. - Blatt- und blütenmorphologische Studien. Jena 1919.

L Kürschner (1940/41) Sp. 536; WBIS; Jansen (1992a) S. 165 (Register); Best/Weege (1996); Deutsche Biographie, s. https://www.deutsche-biogra phie.de/gnd116681926.html [07.11. 2017].

$P$ Bildarchiv UAH.

\section{Gmelin, Leopold}

1813-1851 Med. Fak.

Chemie, auch Pharmakologie

* $\quad$ 2. Aug. 1788 Göttingen

$\dagger$ 13. April 1853 Heidelberg ev.

V Johann Friedrich G. (1748-1804), u. a. seit 1775 Prof. für Botanik, Chemie, Medizin Göttingen, s. NDB 6 (1964) S. 481, WBIS, Göttinger Gelehrte 1 (2001) S. 58 f., Kirschke (2001) S. 446 (Register)

M Rosine Luise geb. Schott (1755-1828), s. Stumm (2012) S. 696 (Register)

๑ 1. Okt. 1816 Luise geb. Maurer (1794-1863), s. Stumm, S. 696 (Register). - Schwester von Franziska Wilhelmina M. verw. Dupré (17891876) Ehefrau von: (siehe) Johann Friedrich Abegg

K $\quad 1$ S, 3 T: u.a. Luise Julie G. (1817-1896) Mutter von: (siehe) Adolf Mayer (1843-1942). 1837 erhält e. der Töchter „Sonnabends historischen Unterricht" von (siehe) Friedrich Christoph Schlosser, s. UAH H-IV-102/33 fol. 62r. - Siehe Mayer, Julie: Kinder- und Jugenderinnerungen ... Abschrift des handschriftl. Originals von 1886. Frankfurt/M. 1965; Stumm, S. 700 (Register). - Johanna Auguste G. (18231897), siehe Stumm, S. 693 (Register); Ehefrau von: (siehe) Theodor von Dusch. • Siehe Stumm, S. 20-23.

Vw Vettern: Ferdinand Gottlieb G. (1782-1848), u. a. seit 1810 o. Prof. für Naturgeschichte, $\mathrm{Me}$ dizin Tübingen, s. WBIS. • Christian Gottlob G. jun. (1792-1860), u. a. seit 1817 o. Prof. für Chemie und Pharmazie Tübingen, s. WBIS. • Siehe auch NDB 6 (1964) S. 476-478, Stumm, S. 3 f., 300, 553 u. ö.

Lb Tübingen: 1804-1805 Tätigkeit in der in Gmelinschem Besitz befindlichen U-Apotheke; seit 29. Okt. 1804 Studium der Chemie, Medizin, auch Mathematik an U.

U Göttingen: Seit 24. Okt. 1805 Forts. des Studiums; Sommer 1809 med. Examen. 
U Tübingen: Seit 26. Okt. 1809 Forts. des Studiums; 10. März 1811 Flucht nach Österreich aufgrund e. drohenden Untersuchung seiner Beteiligung an e. Duell, s. hierzu Stumm (2012) S. 12-14.

Seit März 1811 Aufenthalt in Wien; 1. April 1812 (Datum der Promotionsurkunde, s. Stumm, S. 106) Dr. med. an U Göttingen (in absentia); März 1812März 1813 Studienreise durch Italien.

UH: 24. Juni 1813 Habilitation für Medizin und Chemie; seit 26. Sept. 1814 a. o. Prof.; WS 1814/15 Studienreise nach Paris; 8. Jan. 1816 Ern. zum Direktor des Chemischen Laboratoriums; Rufe an U abgelehnt: 1817 Berlin, 1835 Göttingen; seit 24. Okt. 1817 o. Prof. für Chemie; 12. April 1851 Ruhestand.

1830 Prorektor der UH; 1822, 1827, 1833, 1838, 1841, 1850 Dekan der Med. Fak. der UH

1817: G. ist erster Ordinarius nur für das Fach Chemie an der Universität Heidelberg

Am 14. Juli 1988, anläßlich des 200. Geburtstags von G., erscheint eine Sonderbriefmarke mit seinem Brustbild

1820 Hofrat; 1828 Geh. Hofrat; 1851 Geh. Rat II. Klasse

Siehe auch Wilhelm Delffs und Ludwig Posselt

E 1823 Mitglied der Dt. Akademie der Naturforscher Leopoldina Halle/S.; 1819 Mitglied der Pharmazeutischen Gesellschaft St. Petersburg; Mitglied der Akademie der Wissenschaften: 1819 München, 1827 Berlin, 1830 Göttingen, 1848 Wien. $\bullet 1832$ Dr. phil. h.c. UH.

$Q u$ UAH PA 1619; RA 5680, 5814, 6202, 6493, 6886 u. ö. • GLA Abt. 205, Fasz. 255. • Briefe: UBH. • Siehe auch Archiv der Dt. Akademie der Naturforscher Leopoldina Halle/S. • Mitteilungen: Frau Marianne König-Gmelin ( $†$ ).

$W$ Handbuch der (theoretischen) Chemie. 3 Bde. Frankfurt/M. 1817-1819; seit 1872 u.d. T.: (GmelinKraut's) Handbuch der Chemie. 8. Aufl. ca. 760 Bde. 1924-1997. (1990-1997 (eingestellt) Fortfüh- rung u.d.T.: Gmelin Handbook of Inorganic and Organometallic Chemistry; s. Schulz, Hedda und Georgy, Ursula: Von CA bis CAS online: Datenbanken in der Chemie. 2. Aufl. Berlin 1994. S. 314 (Register)). - Versuche über die Wege, auf welchen Substanzen aus dem Magen und Darmkanal ins Blut gelangen, über die Verrichtung der Milz und die geheimen Harn-Wege. Heidelberg 1820. • Tiedemann, Friedrich, G., L.: Die Verdauung nach Versuchen. 2 Bde. Heidelberg 1826-1827. 2. Aufl. 1831 (siehe hierzu: Mehlan, Willi: Das Werk von Friedrich Tiedemann und L.G.: Die Verdauung nach Versuchen. Diss. Bonn 1976). • Bibliographie in: Stumm (2012) S. 175-181.

$L$ Smith (1949) S. 105f.; NDB 6 (1964) S. 480 f.; Schmitt (1978) S. 72 u.ö.; Thomas (1985) S. 9397. Dorsch, Rudi: L. G., Begründer der Chemie ... in: Ruperto Carola Jg. 41, H. 79 (1989) S. 65-76. • Fluck, Ekkehard: L. G. - Ein Heidelberger Chemiker und sein Werk in: Heidelberger Jahrbücher 33 (1989) S. 89-106. Eberhardt (1990) S. 206 (Register); Kirschke (2001) S. 446 (Register). - Roß, R. Stefan: Das Wissenschaftsverständnis Friedrich Tiedemanns ... und L.G.s ... in: Fachprosaforschung - Grenzüberschreitungen Bd. 4/5, 2008/o9 (2010) S. 187-212. - Stumm, Petra Renate: L. G. ... Leben und Werk eines Heidelberger Chemikers. Diss. Heidelberg 2012 (auch online). • Doll/Kirsch/ Eckart (2017) S. 107.

$P$ Bildarchiv UAH; graph. Slg. UBH; NDB.

\section{Göppert, Ernst}

1895-1912 Med. Fak.

Anatomie

* 04. Jan. 1866 Breslau (heute: Wrocław, Polen)

$\dagger$ 23. März 1945 Marburg

ev.

V Heinrich Robert G. (1838-1882) seit 1863 Privat-Dozent, seit 1865 a. o. Prof., $1868-1873$ o. Prof. für Rechtswiss. Breslau, seit 1874 Vortragender Rat im preußischen Kultusministerium Berlin, s. ADB 49 (1904) S. 454f., WBIS, Maus (2013) S. 458 (Register) 
M Gertrude Elise geb. Landsberg ( $† 1917)$

(2). Mai 1899 Alice geb. Schuchard $\left({ }^{*} 1878\right)$

K 2 S

Vw Großvater: Heinrich Robert G. (1800-1884) seit 1831 a. o. Prof., seit 1839 o. Prof. für Botanik Breslau, s. NDB 6 (1964) S. 519 f., WBIS; Willisch, Norbert: H.R.G. zum Gedächtnis in: Schlesischer Kulturspiegel 44 (2009) S. 54f.; Nachlaß: Berlin-Brandenburgische Akademie der Wissenschaften Berlin

Vw Brüder: Dr. iur. Heinrich G. (1867-1937), u. a. seit 1906 Vortragender Rat im preußischen Ministerium für Handel und Gewerbe, seit 1909 Staatskommissar der Berliner Börse, Unterstaatssekretär: seit 1914 im Handelsministerium, 1917-1919 Reichswirtschaftsamt; 1919-1935 (Emeritierung) Inhaber der Stiftungsprofessur (ohne Habilitation) für Industrie- und Handelsrecht Bonn, s. Die Juristen der Universität Bonn im „Dritten Reich“. Hrsg. von Mathias Schmoeckel. Wien 2004. S. 233250 u. ö. Friedrich G. (1870-1927), u. a. seit 1909 a. o. Prof., seit 1919 o. Prof. für Kinderheilkunde Göttingen, s. WBIS; Vater von: Maria G. verh. Goeppert-Mayer (1906-1972) Ordinaria für Physik: seit 1946 U of Chicago, seit 1960 U of California in La Jolla; 1963 Nobelpreisträgerin (u. a. zus. mit Hans Jensen, s. Drüll (2009) S. 310f.) für Physik (Entdeckung der nuklearen Schalenstruktur), s. NDB 16 (1990) S. 549 f.; Wuensch, Daniela: Der letzte Physiknobelpreis für eine Frau? M. G.-M.: Eine Göttingerin erobert die Atomkerne ... Göttingen 2013.

Lb Seit SS 1885 Studium an UH, seit WS 1887/88 Berlin, SS 1889 H; 189 o Staatsexamen in H; 14. Juli 1890 Dr. med. an UH.

U Jena: 1891-1892 Assistent am Zoolog. Inst. bei Ernst Haeckel (1834-1919).

UH: Seit 1892 Assistent am Anatom. Inst.; 19011912 Prosektor am genannten Inst.; 23. Okt. 1895 Habilitation; seit 20. März 1900 nichtetatm. a.o. Prof.; 1905-1912 Abt.-Vorstand des Anatom. Inst.
U Frankfurt/M.: Seit Frühjahr 1914 kommissar. Direktor des Anatom. Inst., WS 1914/15-SS 1919 o. Prof. und Direktor des genannten Inst. - In dieser Zeit:

1914-1915 Kriegsdienst.

U Marburg: Seit 1. Okt. 1919 o. Prof. und Direktor des Anatom. Inst.; 1921 Ruf an U Breslau abgelehnt; 1. April 1934 Emeritierung; bis 30. Sept. 1943 kommissar. Vertreter seines Lehrstuhls.

E 1904 Mitglied der Dt. Akademie der Naturforscher Leopoldina Halle/S.

Qu UAH PA 1621; RA 6169, 6173. • Siehe auch Archiv der Dt. Akademie der Naturforscher Leopoldina Halle/S.

$W$ Untersuchungen zur Morphologie der Fischrippen. Leipzig 1895. • Blutgefäßsystem. Leipzig 1913. (Lehrbuch der Anatomie des Menschen. Hrsg. von Carl Gegenbaur. Bd. 3. 8. Aufl.) - Nervensystem, Haut- und Sinnesorgane. München 1940. (Mitverf.) (Benninghoff, Alfred: Lehrbuch der Anatomie des Menschen. 2. Bd. 2. T.)

HG 1924-1930 Jahrbuch für Morphologie und mikroskopische Anatomie. 1931-1939 Handbuch der vergleichenden Anatomie der Wirbeltiere.

$L$ Catalogus prof. Marburgensis 2 (1979) S. 241f.; WBIS; Jansen (1992a) S. 165 (Register); Doll (2014) S. 288-291; Deutsche Biographie, s. https://www. deutsche-biographie.de/gnd116720158.html [07.11. 2017]; Doll/Kirsch/Eckart (2017) S. 46, 57-59, 92.

$P$ Bildarchiv UAH.

U Marburg: Seit 1. Okt. 1912 etatm. a. o. Prof. 


\section{Görres, Johann Jakob Joseph (Kurzbiographie)}

1807-1808 (Privatlehrer) Phil. Fak.

Philosophie in ihrer Totalität, Ästhetik, Bau des Himmels, Organopöie (Physiologie oder Physik der organischen Natur), Psychologie, Spekulative Physik, Hygiene

* 25. Jan. 1776 Koblenz

$\dagger$ 29. Jan. 1848 München

UH: 17. Sept. 1806 Erteilung der Lehrerlaubnis aufgrund seiner bisherigen schriftstellerischen Tätigkeit; SS 1807 erstmals als Privatlehrer (= PrivatDozent) in "Anzeige der Vorlesung“ genannt; SS 1808 letzte Nennung im Vorlesungsverzeichnis; kein Prof. an UH.

Qu UAH PA 1622. - Der Redaktionsbriefwechsel der Hallischen, Deutschen und Deutsch-Französischen Jahrbücher 1837-1844. Hrsg. von Martin Hundt. Bd. 1: Der Briefwechsel um die Hallischen Jahrbücher. Berlin 2010. Apparat: S. 262 (Register).

$L$ Heidelberg im säkularen Umbruch (1987) S. 560 (Register); Emundts-Trill (1997) S. 275 f.; Ein Knab auf schnellem Roß (2006) S. 74-78 u. o.; Redl (2013) S. 858-861 u. ö.; Riecke (2016) S. 9 f., 13.

\section{Götze, Albrecht Ernst Rudolf}

1922-1930 Phil. Fak.

Vgl. Sprachwissenschaft, Semitische Philologie

* 11. Jan. 1897 Leipzig

$\dagger$ 15. Aug. 1971 Garmisch-Partenkirchen

- New Haven (Connecticut)

(vor) 1921 ev.-luth., dann konf.-los

V Dr. med. Rudolf G. (1863-1920) 1900 Begründer der Nervenheilstätte Naunhof bei Leipzig, seit 1908 Oberarzt und Medizinalrat an Heilund Pflegeanstalt Heppenheim, 1920 Leiter der Landes-Heil- und Pflegeanstalt Alzey, s. WBIS, Maier-Metz (2015) S. 13
M Elsa geb. Römmler, s. Maier-Metz, S. 13

$\infty$ 11. Nov. 1922 Frida Maria Emma geb. Schirbel $\left({ }^{\star} 1896\right)$ Korrespondentin

$\mathrm{K} \quad 1 \mathrm{~S}, 2 \mathrm{~T}$

Vw Bruder: Raimund (Raimundo) G. (1899-1990), u. a. 1938-1943 Direktor des Physics Dept. der Universidad de los Andes in Bogotá (Kolumbien), s. Hilton, Ronald: Who's Who in Latin America. Part III. Columbia, Ecuador and Venezuela. Stanford (California) 1951. S. 128; Prata, E.: R. G. † in: Ciencia e Ingeniería (1990) Vol. 20, No 1. Siehe Maier-Metz, S. $13 \mathrm{f}$.

Lb SS 1915 Studium der Philologie an U München, seit WS 1915/16 Leipzig, WS 1918/19-SS 1919 H, WS 1919/20 Berlin; Mai 1916-Nov. 1919 Kriegsdienst.

UH: SS 1920-WS 1920/21 Forts. des Studiums; 15. Febr. 1921 Dr. phil.; 1. Mai 1921-31. März 1930 Assistent am Sprachwiss.(-Oriental.) Seminar; 28. Okt. 1922 Habilitation für Vgl. Sprachwissenschaft und für Semitische Philologie; SS 1926 Eigenstudien in Berlin; seit 2. Aug. 1927 nichtplanm. a. o. Prof.; SS 1928-WS 1928/29 Lehrstuhlvertr. für Semitische Philologie an U Göttingen; SS 1929 Lehrauftrag für Vorlesungen aus dem Gebiet des Arabischen und Syrischen an UH.

U Marburg: 13. Jan. 1930 Berufung zum SS 1930 als o. Prof. für Semitische Sprachen und Orientalische Geschichte; 23. Nov. 1933 Entlassung laut $\$ 4$ des Gesetzes zur „Wiederherstellung des Berufsbeamtentums“" (wegen politischer Unzuverlässigkeit; G. trat öffentlich für (siehe) Emil Gumbel ein); bis Ende Febr. 1934 Auszahlung der Dienstbezüge.

1933/34 Lehrbeauftragter an U Kopenhagen und 1934 Gastprof. an U Oslo; 1934 Emigration via London in die USA.

Yale U in New Haven (Connecticut): Seit Sept. 1934 Visiting Prof.; seit 1936 William Laffan Prof. für Assyriologie und Babylonische Literatur; 1946 Ruf an U Marburg abgelehnt.

Bagdad: 1947-1956 Direktor der Baghdad School of the American Schools of Oriental Research.

Yale U in New Haven: 1956-1965 (Emeritierung) Sterling Prof. 
E Mitglied der Akademie der Wissenschaften Kopenhagen.

Qu UAH PA 3935; Fak.-Akte H-IV-103/1 S. 22, Nr. 182; Studentenakte. • GLA Abt. 235, Fasz. 1996.

$W$ Kleinasien zur Hethiterzeit. Eine geographische Untersuchung. Heidelberg 1924. • Hattušiliš. Der Bericht über seine Thronbesteigung nebst den Paralleltexten. Leipzig 1925. Nachdr. Darmstadt 1967. Neue Bruchstücke zum großen Text des Hattušiliš und den Paralleltexten. Leipzig 1930. Die Annalen des Muršiliš. Leipzig 1933. Nachdr. Darmstadt 1967. - Kulturgeschichte des Orients. Abschnitt 3,1: Kleinasien. München 1933. 2. Aufl. 1957. Nachdr. 1974. - Hethiter, Churriter und Assyrer. Hauptlinien der vorderasiatischen Kulturentwicklung im 11. Jahrtausend vor Chr. Geb. Oslo 1936. Old Babylonian omen texts. New Haven 1947. The laws of Eshnunna. New Haven 1956. Cuneiform texts from various collections. Ed. by Benjamin R. Foster. New Haven 2009. Bibliographie in: Journal of Cuneiform Studies XXVI (1974) S. $2-15$.

HG Verstreute Boghazköi-Texte. Marburg 1930.

MHG 1947-1971 Journal of Cuneiform Studies.

$L$ Zum Tod von A.G. in: Bulletin of the American Schools of Oriental Research 206 (1972) S. 3-6, Journal of the American Oriental Society 92 (1972) S. 197-203, Archiv für Orientforschung 24 (1973) S. 243-245. - Catalogus prof. Marburgensis 2 (1979) S. 505 f.; Dictionary of Emigrés 2 (1983) S. 387. Brenner, Arthur D.: Emil J. Gumbel: Weimar German Pacifist and Professor. Boston 2001. S. 222 (Register). $\bullet$ WBIS. • Maier-Metz, Harald: Entlassungsgrund: Pazifismus. A. G., der Fall Gumbel und die Marburger Universität 1930-1946. Münster 2015. - Deutsche Biographie, s. https:// www.deutsche-biographie.de/gnd116740256.html [07.11. 2017].

P Archiv für Orientforschung (1973); Maier-Metz (2015).

\section{Goldschmidt, Heinrich Jacob}

1896-1901 Nat.-Math. Fak.

Chemie

* 04. Dez. 1857 Prag

$\dagger \quad$ 20. Sept. 1937 Oslo mosaisch

V Salomon G. (1823-1902) Fabrikant

M Julie geb. Porges Edle von Portheim (18281894)

@ 27. März 1887 Amélie geb. Köhne (1864-1929)

K 1 S: Victor Moritz G. (1888-1947) seit 1909 Privat-Dozent, seit 1914 Prof. für Kristallographie, Mineralogie, Petrographie Oslo, 1929-1935 (auf eigenen Wunsch Entlassung) Göttingen, 1935 Emigration nach Oslo, von dort 1942 Flucht zunächst nach Schweden, 1943 nach Großbritannien, seit ca. 1943 Mitarbeiter u.a. am Macaulay Land Use Research Inst. in Aberdeen, 1946 Rückkehr nach Oslo, s. NDB 6 (1964) S. 618 f., WBIS; Fure, Jorunn Sem: Bürger der Wissenschaftspolitik: V.M.G. in: Skandinavien als Zuflucht für jüdische Intellektuelle: 1933-1945. Hrsg. von Izabela A. Dahl und Jorunn Sem Fure. Berlin 2014. S. 268-299.

Lb Seit 1876 Studium an U Wien, anschl. Graz, Prag; 1881 Dr. phil. an U Prag.

Polytechnikum Zürich: Seit WS 1881/82 Privat-Dozent; seit 11. Aug. 1885 Honorar-Prof.

U Amsterdam: Seit 1894 Privat-Dozent am van't Hoffschen Laboratorium.

UH: 18. Juli 1896 Habilitationsgesuch unter Erlaß der Formalitäten, zugleich Gesuch um a. o. Professur; 22. Aug. 1896 Ern. zum nichtetatm. a. o. Prof.; Ende WS 1900/o1 Weggang.

U Oslo: 23. Nov. 1900 (Ern. zum SS 1901)-SS 1927 (Emeritierung) o. Prof.

1929-1935 Wohnsitz in Göttingen; 1935 Emigration nach Oslo. 
E Mitglied: 1880 Dt. Chemische Gesellschaft, 1930 Akademie der Wissenschaften Göttingen, Dänische und Norwegische Akademie der Wissenschaften. 1911 Königl. Norwegischer Sankt OlavsOrden mit Schwertern.

Qu UAH PA 1623; RA 6886.

$W$ Leitfähigkeit und katalytische Wirkung mittelstarker Säuren in Methylalkohol in: Zs. für physikalische Chemie 117 (1925), 129 (1927). (Mitverf.); Veresterung der Ameisensäure in Methylalkohol in: ebd. 143 (1929). (Mitverf.) • Siehe auch WBIS.

$L$ Poggendorff 7a (1958) S. 235; WBIS; Dictionary of Emigrés 2 (1983) S. 394; Lexikon bedeutender Chemiker (1988); Göttinger Gelehrte 2 (2001) S. $428 \mathrm{f}$. Encyclopaedia Judaica. 2nd ed. Detroit 2007. Bd. 7. S. 718. Deutsche Biographie, s. https:// www.deutsche-biographie.de/gnd11675639X.html [07.11. 2017].

$P$ Bildarchiv UAH.

\section{Goldschmidt, Levin}

1855-1870 Jur. Fak.

Römisches Recht, Pandekten, Handels-, See- und Wechselrecht

* 30. Mai 1829 Danzig (heute: Gdańsk, Polen)

$\dagger$ 16. Juli 1897 Wahlershausen (heute: Stadtteil von Kassel)

ㅁ Berlin mosaisch

V David G., Kaufmann

M Henriette geb. Laser

$\varnothing$ 3. April 1856 Adele geb. Herrmann (†1916); s. Briefe in UBH

$\mathrm{K}$ keine

Vw Großnichte: (siehe) Gertrud (Gerta) von Ubisch.

Lb Seit SS 1847 Studium der Medizin, seit SS 1848 Studium der Rechtswiss. an U Berlin, anschl. Bonn, seit WS 1849/50 H, WS 1850/51 Berlin; Zulassung zur Promotion wird M. an U Berlin auf- grund seiner Glaubenszugehörigkeit verweigert, s. hierzu Schroeder (2010) S. 176.

U Halle-Wittenberg: 27. Mai 1851 Dr. iuris civilis.

Seit 1851 Appellationsgerichts-Auskultator während der ersten gerichtlichen Ausbildungsstufe für Juristen, seit März 1853 Appellationsgerichts-Referendar in Danzig, zuletzt in Marienwerder; wegen seiner Konfession wird G. in Preußen nicht die Habilitation erlaubt („verfassungswidrig“), s. hierzu Weyhe (1996) S. 55-6o.

UH: 10. März 1855 Habilitation; seit 25. Mai 1860 a. o. Prof. ohne Gehalt; Dez. 1865 Ruf an U Wien abgelehnt; seit 27. Febr. 1866 o. Prof. (ohne Nennung e. Fachs) mit e. Besoldung von 10oo.- Gulden, aber ohne Berechtigung zur Abnahme von Prüfungen in "Examinationscommission" und Übernahme des Dekanamtes, s. hierzu Weyhe, S. 83-90; $1866-$ 1870 Beisitzer des Spruchkollegiums der Jur. Fak.; seit 31. Juli 1869 Mitglied der Prüfungskommission; SS 1870 letzte Vorlesungsankündigung.

Leipzig: 3. Jan. 1870 (Ern.)-1. Juli 1875 Rat am neueingerichteten Bundesoberhandelsgericht des Norddeutschen Bundes; Rufe an U abgelehnt: 1872 Berlin, später Straßburg, H.

U Berlin: Seit Okt. 1875 o. Prof. auf dem ersten im Deutschen Reich eingerichteten Lehrstuhl für Handelsrecht; 1889/90 erster Dekan mosaischen Glaubens; SS 1892 Vertreter des erkrankten G.s: Max Weber; 1892 Niederlegung der Vorlesungstätigkeit aus gesundheitlichen Gründen. • In dieser Zeit:

Berlin: 1875-1877 Reichstagsmitglied der Nationalliberalen Partei.

G. ist 1866 der erste Ordinarius mosaischen Glaubens an e. deutschen Juristenfakultät und $1870 \mathrm{der}$ erste jüdische Reichsbeamte im Norddeutschen Bund; siehe auch Adolf Weil und Sigmund Zimmern

Geheimer Justizrat

E Dr. h.c. Bologna. 
Qu UAH PA 1624; RA 5815, 6761; Fak.-Akte H-II111/50 fol. 241-354 (Erlaubnis zur Habilitation 1855) u. ö. GLA Abt. 76, Fasz. 9931. Briefe: UBH.

$W$ Encyclopädie der Rechtswissenschaft im Grundriß. Heidelberg 1862. * Handbuch des Handelsrechts. 2 Bde. Erlangen 1864-1883. 3. Aufl. 1891. - System des Handelsrechts mit Einschluß des Wechsel-, See- und Versicherungsrechts. Stuttgart 1887. 4. Aufl. 1892. Universalgeschichte des Handelsrechts. Stuttgart 1891. • Vermischte Schriften. Aus dem Nachlaß hrsg. von Hermann Veit Simon. 2 Bde. Berlin 1901. Bibliographie in: Weyhe (1996) S. 546-578.

G, HG 1858 Zeitschrift für das gesammte Handelsrecht.

$L$ Jammers (1964) S. 177 u. ö.; NDB 6 (1964) S. 617 f. (mit Werkverz.). • Landwehr, Götz: Die Handelsrechtswissenschaft an der Universität Heidelberg im 19. Jahrhundert in: Semper apertus 2 (1985) S. 61-83. - Dt. Juristen jüdischer Herkunft (1993) S. 215-230; WBIS. - Weyhe, Lothar: L. G. Ein Gelehrtenleben in Deutschland ... Berlin 1996. • Gutachten zum Promotions- und Habilitationsverfahren von ... L. G. in: Max Weber Gesamtausgabe. Hrsg. von Gerhard Dilcher ... Abt. 1. Bd. 1. Tübingen 2008. S. $98 \mathrm{ff}$. Baur (2009) S. 181-185. • Schön, Wolfgang: Recht und Ökonomie bei L.G. in: Festschrift für Karsten Schmidt zum 70. Geburtstag. Hrsg. von Georg Bitter ... Köln 2009. S. 1427-1446. - Schmidt, Karsten: L. G. in Berlin. Eine Skizze über die Berliner Universitätsjahre 1875-1897 ... in: Festschrift 200 Jahre Jur. Fak. der ... Universität zu Berlin ... Hrsg. von Stefan Grundmann ... Berlin 2010. S. 327-342. • Schroeder, Klaus-Peter: L. G. ... vom Heidelberger Rechtsprofessor zum Richter am Bundesoberhandelsgericht in: Festschrift für Dietrich Pannier. Hrsg. von Detlev Fischer ... Köln 2010. S. 171180. - Schroeder (2010) S. 174-185; Maus (2013) S. 115, 302, 386. - Müller-Graff, Peter-Christian: Thibaut, Bluntschli, G. und andere Heidelberger in: Heidelberger Thesen zu Recht und Gerechtigkeit (2013) S. 67-94. • Kaesler (2014) S. 998 (Register); Schroeder (2017) S. 82-115.

$P$ Bildarchiv UAH; NDB.

\section{Goldschmidt, Victor Mordechai}

1888-189o Phil. Fak.

1890-1909 Nat.-Math. Fak.

1909-1933 (Honorar-Prof.) Nat.-Math. Fak.

Mineralogie, Kristallographie

* 10. Febr. 1853 Mainz

$\dagger \quad$ o8. Mai 1933 Salzburg

$\square$ Heidelberg

mosaisch, seit ca. 1888 ev.

V Salomon Benedikt G. (1818-1906) Eisenhandel en gros, Bankgeschäft

M Josefine geb. Porges (seit 1841: Porges Edle von Portheim) (1822-1869)

๑ 28. Dez. 1888 Leontine Lola geb. Porges (seit 1879: Porges Edle von Portheim) (1863-1942 Suizid vor ihrer Deportation ins KZ) Kusine, siehe Schlichtenberger (1998) S. 248 (Register), Lexikon jüdischer Einwohner Hs (2011) S. 135

K keine.

Lb Seit WS 1870/71 Studium der Ingenieurwiss. an Gewerbe-Akademie in Berlin, seit Herbst 1871 an Königl. Sächsischer Bergakademie Freiberg; 1874 Examen als Hütten-Ing. ebd.; 1874-1875 Militärdienstpflicht als Einjährig-Freiwilliger.

Bergakademie Freiberg: Seit 1875 Assistent für Hüttenkunde, Probierkunst und Lötrohranalyse.

1878-1882 Studium der Chemie, Paläontologie an U München; in dieser Zeit: SS 1879 Immatrikulation an UH; 6. Aug. 188 o Dr. phil. an UH.

1882-1887 Eigenstudien an U Wien.

UH: 24. Febr. 1888 Habilitation; seit 6. Aug. 1892 nichtetatm. a.o. Prof.; WS 1893/94-WS 1894/95 Weltreise; 1895/96 Gründer und Finanzier des privaten Mineralogisch-Kristallogr. Inst., zunächst in der Akademiestraße 1, seit 1926/27 in der Hauptstraße 48; seit 7. Jan. 1909 o. Honorar-Prof.; SS 1933 letzte Vorlesungsankündigung; das im April 1933 an G. adressierte Schreiben mit der Mitteilung seiner Beurlaubung von $U$ als „Angehöriger der jüdischen Rasse ohne Rücksicht auf die konfessionelle Zugehörigkeit“ (aus: UAH PA 3943) aufgrund des Erlasses zur Aufrechterhaltung für Sicherheit 
und Ordnung wird an die U zurückgeschickt, da sich G. seit dem 30. Jan. 1933 in Österreich aufhält und dort erkrankt ist.

1919 Gründer der Josefine und Eduard von Portheim-Stiftung für Wissenschaft und Kunst in Heidelberg, s. hierzu Engehausen, Frank: Die Josefine -und-Eduard-von-Portheim-Stiftung für Wissenschaft und Kunst 1919-1955. Heidelberger Mäzenatentum im Schatten des Dritten Reiches. Heidelberg 2008.

Die Mineral- und Gesteinssammlung im mineralogischen Teil des Heidelberger Museums des Instituts für Geowissenschaften sind aus dem Fundus bedeutender Sammlungen, u. a. auch aus der von G. zusammengestellt.

31. März 2012: Umbenennung der Heidelberger Treitschkestraße in Goldschmidtstraße (siehe Heinrich Treitschke); s. hierzu auch „Was lange währt, ist endlich gut: Treitschkestraße ist jetzt umbenannt" in: RNZ vom 2. April 2012.

1913 Geh. Hofrat

E 1913 Mitglied der Akademie der Wissenschaften H; 1933 Ehrenmitglied der Dt. Mineralog. Gesellschaft. 1903 Dr. h. c. Queens University Kingston (Großbritannien); 1922 Dr.-Ing. E.h. 1913 Ritterkreuz I. Klasse des Ordens vom Zähringer Löwen.

Qu UAH PA 3943; GF 70. • Briefe: UBH. $\bullet$ Nachlaß: UAH (Signatur: Rep. 44). - Auskunft: Stadtarchiv Würzburg (Friedhofbelegungsbücher bzw. Totenbücher).

$W$ Index der Kristallformen der Mineralien. 3 Bde. Berlin 1886-1891. - Kristallographische Winkeltabellen. Berlin 1897. Über harmonische Analyse von Musikstücken in: Annalen der Naturphilosophie 3 (1904). Der Diamant. Eine Studie. Heidelberg 1911. (Mitverf.) - Atlas der Kristallformen. 9 Bde. Heidelberg 1913-1923. Materialien zur Musiklehre. 6 T. Heidelberg 1923-1925. (Heidelberger Akten der von Portheim-Stiftung. Bde. 5, 8, 9, 11, 14, 15.) - Atomgewicht und Atombau, Raum und Raumsinn, Blutumlauf durch Contakt-Pro- motion und Pulsieren. Heidelberg 1925. (Heidelberger Akten der von Portheim-Stiftung. Bd. 12.)

G, HG 1913-1926 Beiträge zur Kristallographie und Mineralogie.

$L$ Den Unvergessenen. Opfer des Wahns 19331945. Hrsg. von Hermann Maas ... Heidelberg 1952. NDB 6 (1964) S. 612. Amstutz, Gerhard Christian: G., V. in: Dictionary of Scientific Biography 5 (1972) S. 455 f. - Hesse, Erich: V.G. in: Heidelberger Jahrbücher 25 (1981) S. 43-56. Berdesinski, Waldemar: V.G. in: Semper apertus 2 (1985) S. 506-515. • Jansen (1992a) S. 165 (Register); Schlichtenberger (1998); Hinz (2000) S. 47. • Handbuch der historischen Buchbestände in Deutschland. Hrsg. von Bernhard Fabian. Hildesheim 2003. • Rösler, Hans Jürgen: Der Kristallograph V.G. ... Seine Jugendjahre und seine Beziehungen zu Berlin und Freiberg. Freiberg 2004. Badische Biographien N. F. V (2005) S. 9698. - Marzolff, Renate: Leontine und V.G. Gründer der von-Portheim-Stiftung. Bürger in Heidelberg 1889-1942. Heidelberg 2007. - Engehausen (2008). Vom Wissen der Dinge - aus den ethnographischen Sammlungen der Portheim-Stiftung. Hrsg. von Stefan Dietrich und Margareta Pavaloi. Heidelberg 2008. Lexikon jüdischer Einwohner Hs (2011) S. 135 f. Mathematik in der Heidelberger Akademie der Wissenschaften zus.gestellt von Gabriele Dörflinger. Ein Projekt der Fachinformation Mathematik der Universitätsbibliothek Heidelberg, s. http://www.ub.uni-heidelberg.de/archiv/16931 (Stand: April 2014).

$P$ Bildarchiv UAH. 


\section{Gothein, Eberhard}

1904-1923 Phil. Fak.

Nationalökonomie, Finanzwissenschaft

* 29. Okt. 1853 Neumarkt (Schlesien; heute: Środa Śląska, Polen)

$\dagger$ 13. Nov. 1923 Berlin

口 Heidelberg

ev.

V Hugo Gottheiner, später Gothein (1815-1861) Arzt

M Marie geb. Ehm (1818-1870)

(1) 14. März 1885 Dr. phil. h.c. (1931 der UH) Marie Luise geb. Schröter (1863-1931) Schriftstellerin, Kunsthistorikerin, s. Demm (2014) S. 245 (Register), ,Es ist schon eine wunderbare Zeit, die ich jetzt lebe" (2014). - Briefe in UBH

K 4 S (davon $1 S$ X 1914): u. a. Werner G. (18901968) bildender Künstler, s. Badische Biographien N.F. III (1990) S. 107 f. - Percy G. (1896-1944 im KZ Hamburg-Neuengamme umgekommen) Schriftsteller, s. Badische Biographien N.F. I (1982) S. 140 f.; Hergemöller, Bernd-Ulrich: Mann für Mann. Ein biographisches Lexikon. Frankfurt/M. 2001. S. 294-296; Karlauf, Thomas: Stefan George ... München 2008; Raulff, Ulrich: Kreis ohne Meister. Stefan Georges Nachleben. München 2012. S. 537 (Register); Demm (2014) S. 245 (Register), „Es ist schon eine wunderbare Zeit, die ich jetzt lebe", S. 11 f. u. ö.

Vw Bruder: Georg G. (1857-1940) Politiker, s. WBIS.

$L b$ Seit WS 1872/73 Studium der Philosophie, Geschichte, Volkswirtschaftslehre an U Breslau, SS 1874-SS 1875 H, seit WS 1875/76 Breslau.

Breslau: 10. Juli 1877 Dr. phil., 1878 Habilitation, 1878-1884 Privat-Dozent für Geschichte an U; seit 1879 auch Gymnasiallehrer.

U Straßburg: 1884 Umhabilitation für Nationalökonomie, s. hierzu Enzenauer (2005) S. 10 und Anm. 9.

TH Karlsruhe: Seit 1885 o. Prof. für Nationalökonomie.
U Bonn: Seit 18. März 1890 o. Prof. für Nationalökonomie; 1901-1903 auch Lehrer an der von G. mitgegründeten Handelshochschule in Köln.

UH: 17. Dez. 1903 Ern. zum o. Prof. als Nachf. von Max Weber; SS 1904 Vorlesungsbeginn; seit 1904 Lehrauftrag für Kulturgeschichte; 31. März 1923 Emeritierung. • In dieser Zeit:

1907 (Mitbegründer)-1923 Nebenamtlicher Dozent an der Handelshochschule in Mannheim; 1912-1919 Stadtverordneter von H; 1919-1921 Mitglied in der Verfassunggebenden Badischen Nationalversammlung in Karlsruhe.

1914/15 Prorektor der UH; 1917/18 Dekan der Phil. Fak. der UH

1906 Geh. Hofrat; 1915 Geh. Rat II. Klasse

Siehe Johannes Rissom: Eintrag unter $Z$ [itat] (3)

Siehe auch Anhang Sporteinrichtungen an $U H$ 1910-1933 und ihre Mitglieder

$E$ Mitglied der Akademie der Wissenschaften: 1909 H, 1916 München. • Dr. iur. h.c. • Königl. Preußischer Roter Adler-Orden IV. Klasse; Preußischer Kronenorden III. Klasse.

$Q u$ UAH PA 3948; RA 182, 6113, 6573, 6679, 6867; Quästurakten Rep. 27-421f.; Fak.-Akte u.a. H-IV102/153. - Briefe: UBH. - Im Schaffen genießen. Der Briefwechsel der Kulturwissenschaftler Eberhard und Marie Luise G. Hrsg. von Michael Maurer ... Köln u. a. 2006; Cser, Andreas: Vom Weltkrieg bis zum demokratischen Neubeginn. Zum Briefwechsel zwischen Eduard und Marie Luise G. in den Jahren 1914 bis 1923 in: Homo heidelbergensis. Festschrift für Klaus-Peter Schroeder ... Hrsg. von Pirmin Spieß. Neustadt/Weinstr. 2017. S. 263277. Briefwechsel zwischen Eduard Spranger und Käthe Hadlich. Hrsg. von Karin Priem u. a. Bibliothek für Bildungsgeschichtliche Forschung des DIPF (Deutsches Institut für Internationale Pädagogische Forschung), online unter http://bbf.dipf. de/digitale-bbf/editionen/spranger-hadlich/per son-g. • Nachlaß: UBH. 
$W$ Kulturentwicklung Süditaliens in Einzeldarstellungen. Breslau 1886. - Die Aufgaben der Kulturgeschichte. Leipzig 1889. - Wirtschaftsgeschichte des Schwarzwaldes ... Straßburg 1892. - Ignatius von Loyola und die Gegenreformation. Halle/S. 1895. - Geschichtliche Entwicklung der Rheinschiffahrt im 19. Jhdt. Leipzig 1903. Schriften zur Kulturgeschichte der Renaissance, Reformation und Gegenreformation. Hrsg. von Edgar Salin. 2 Bde. München 1924.

MHG 1909-1910 Heidelberger volkswirtschaftliche Abhandlungen.

$L$ Gothein, Marie Luise: Lebensbild von E.G. Stuttgart 1931. - Handels-Hochschule Mannheim 1907-1932 (1932) S. 25; Baier (1937) S. 170-206; NDB 6 (1964) S. 654-656 (mit Werkverz.); Verzeichnis Bonn (1968) S. 93; Badische Biographien N. F. II (1987) S. 102-105; Geschichte Histor. Seminar UH (1992) S. 167-169, 185 ff.; Jansen (1992) S. 409 (Register); Ders. (1992a) S. 165 (Register); Wennemuth (1994) S. 634 (Register); Brintzinger (1996) S. 398 (Register). - Zuschlag, Christoph: „... eine Ebene des geistigen Gemeinschaftslebens ...." Wilhelm Fraenger und die Gotheins in: Neue Kunst - Lebendige Wissenschaft. Hrsg. von Susanne Himmelheber, Karl Ludwig Hofmann. Heidelberg 2004. S. 123-129. • Asketischer Protestantismus (2005) S. 155-184 u. ö.; Enzenauer (2005) S. 9-15 u.ö. - Cser, Andreas: E. G. ... in: Heidelberg. Jahrbuch zur Geschichte der Stadt 2006/07. Heidelberg 2006. Jg. 11. S. 57-82. - Kriegstagebuch K. Hampe (2007) S. 961 (Register). • Maurer, Michael: E. G. Leben und Werk zwischen Kulturgeschichte und Nationalökonomie. Köln 2007. (Bibliographie: S. 372-378.) • Ruuskanen (2008) S. 192 f.; Schönhärl (2009) S. 457 (Register); WBIS; Demm (2014) S. 245 (Register). • „Es ist schon eine wunderbare Zeit, die ich jetzt lebe“. Die Heidelberger Gelehrte Marie Luise Gothein ... Eine Ausstellung der Universitätsbibliothek Heidelberg. (Katalog.) Hrsg. von Maria Effinger ... Heidelberg 2014. S. 87-89 u. ö. - Intellektuelle in Heidelberg (2014) S. 424 (Register). - Cser, Andreas: Krieg aus der Perspektive des Friedens. Zum Briefwechsel und zur Publizistik E. G.s zwischen 1914 und 1918 in: UH während des Ersten Weltkriegs (2017) S. 185-213.
$P$ Bildarchiv UAH; Bronze-Totenmaske im UAH; NDB; Badische Biographien.

\section{Gotschlich, Emil Carl Anton Constantin}

1926-1935, (1941-1942) Med. Fak.

Hygiene

* 28. März 1870 Beuthen (heute: Bytom, Polen)

$\dagger$ 19. Dez. 1949 Heidelberg kath.

V Dr. Emil G. (1838-1877) Gymnasialoberlehrer M Maria Luise geb. Kinne (1845-1914)

œ 11. Juni 1898 Rosa geb. Kaufmann (1872-1934)

K $1 \mathrm{~S}, 1 \mathrm{~T}$

Vw Enkel: Emil Claus G. $\left({ }^{\star} 1935\right)$, u. a. seit 1960 Mitarbeiter im Labor für Bakteriologie und Immunologie, seit 1978 Prof. für Bakteriologie und Leiter des Labors für bakterielle Pathogenese und Immunologie sowie 1996-2005 Vizepräsident für Medical Sciences der Rockefeller U in New York; 1966/68 entwickelt E. C. G. e. Impfstoff gegen Meningitis C, s. https://www. rockefeller.edu/our-scientists/emeritus-facul ty/937-emil-c-gotschlich/\#content (abgerufen am 26. Aug. 2017).

Lb U Breslau: Seit WS 1889/9o Studium; 1894 med. Staatsexamen; 1894 Approbation; 28. April 1894 Dr. med.; Jan. 1894-Sept. 1896 Assistent am HygieneInst.

Alexandrien: Okt. 1896-Dez. 1914 (Ausweisung durch englische Militärbehörde) Direktor des Städtischen Gesundheitsamtes und ägyptischer Abgeordneter des Int. Gesundheits- und Quarantäneamtes (auf Empfehlung von Robert Koch (1843-1910), s. Grüntzig, Johannes W., Mehlhorn, Heinz: R.K. Seuchenjäger und Nobelpreisträger. Heidelberg 2010); 1903 Verleihung des Titels „Prof.“ durch preußisches Ministerium der Geistlichen, Unterrichts- und Medizinalangelegenheiten in Berlin.

Halle/S.: Jan.-Juni 1915 Stellvertr. Direktor des Hygien. Inst. 
Saarbrücken: 1. Juni 1915-31. März 1917 Direktor des Preußischen Inst. für Hygiene und Infektionskrankheiten und fachärztlicher Beirat bei Armeekorps.

U Gießen: 31. Jan. 1917 Ern. zum SS 1917 o. Prof. und Direktor des Hygien. Inst.; 1924 Ruf nach Alexandrien abgelehnt.

UH: 4. Dez. 1925 Ern. zum SS 1926 o. Prof. und Direktor des Hygiene-Inst. als Nachf. von Hermann Kossel; seit 1926 auch Leiter des dem Hygiene-Inst. angegliederten badischen Untersuchungsamtes für ansteckende Krankheiten; 31. März 1935 Entbindung von amtl. Verpflichtungen; SS 1935 Vertreter seines Lehrstuhls.

Ankara: Nov. 1935-Nov. 1941 Direktor des ZentralHygiene-Inst.

UH: WS 1941/42 und SS 1942 G. hält Vorlesungen über Hygiene in Vertretung von Ernst Rodenwaldt.

1930 Rektor der UH; 1927/28 Dekan der Med. Fak. der UH

Siehe auch Anhang Sporteinrichtungen an $U H$ 1910-1933 und ihre Mitglieder

E 1926 Mitglied der Akademie der Wissenschaften H; 1928 Mitglied der Dt. Akademie der Naturforscher Leopoldina Halle/S. • 1940 Goethe-Medaille für Kunst und Wissenschaft. • Türkisch-Osmanischer Orden III. Klasse; Königl. Griechischer Erlöserorden. • 28. März 1945 Ehrensenator der Universität Heidelberg, siehe UAH PA 1275.

Qu UAH PA 940f., 1275, 3949. - GLA Abt. 235, Fasz. 1487. • Briefe: UBH. • Siehe auch Archiv der Dt. Akademie der Naturforscher Leopoldina Halle/S.

$W$ Leitfaden der Mikroparasitologie und Serologie. Berlin 1920. 2. Aufl. 1939. (Mitverf.) - Milch, Molkereiprodukte und Speisefette. Jena 1927. • Hygiene, Zivilisation und Kultur. Heidelberg 1929. • Hygiene in der modernen Türkei. Heidelberg 1943. - Bibliographie in: Gnädig (1999) S. 212-225.
HG 1926-1929 Handbuch der hygienischen Untersuchungsmethoden.

MHG 1938-1941 Türkische Zs. für Hygiene und experimentelle Biologie.

$L$ NDB 6 (1964) S. 657 f.; Gießener Gelehrte (1982) S. 261, 927, 1052; Chronik Ärzte H (1985) S. 129, 225 f.; Jansen (1992a) S. 165 (Register). • Nöske, Barbara: E. G. ... - sein Leben und wissenschaftliches Werk. Giessen 1996. Gnädig, Nicole: E. G. ... und die wissenschaftliche Hygiene. Med. Diss. Heidelberg 1999. • Eckart (2000) S. 82 f. • Roelcke, Volker: „Prävention“ in Hygiene und Psychiatrie zu Beginn des 20. Jahrhunderts: Krankheit, Gesellschaft, Vererbung und Eugenik bei Robert Sommer und E.G. in: Die Medizinische Fakultät der Universität Gießen 1607 bis 2007. Hrsg. von Volker Roelcke. Stuttgart 2007. Bd. 1. S. 395-416.

$P$ Bildarchiv UAH; NDB; Chronik Ärzte H.

\section{Gottfried, Carl}

siehe Gottfried, Karl

\section{Gottfried, Karl Julius Hermann}

1925-1926 Nat.-Math. Fak.

Chemie

1930-1934 Nat.-Math. Fak.

Mineralogie

* 16. April 1892 Kassel

$\dagger \quad$ 25. Mai 1973 Münden (heute: Hannoversch M.) ev.

V Friedrich Alfred Hugo G. $\left({ }^{\star} 1859\right)$ Großkaufmann

M Anna Elisabeth Margarete Friederike geb. Brandau (1859-1928)

( 22. Aug. 1916 Ina Hulda Adolfine Rosalie geb. Salomon(-Calvi) (1894-1979), s. UAH Rep. 7-17; Lexikon jüdischer Einwohner Hs (2011) S. 142, 367; T von: (siehe) Wilhelm Salomon. Scheidung (vor) 1937 
๑ 29. Mai 1943 Elsbeth Hedwig Margarete geb. Zühlke (*1902 † nach 1983)

$\mathrm{K} \quad 1 \mathrm{~T}$

Lb Okt. 1912 Eintritt als Fahnen-Junker in Armee; 1914-1918 Kriegsdienst.

UH: Seit WS 1918/19 Studium der Naturwiss.; 2. Mai 1922 Dr. phil. nat.; Mai 1922-März 1926 Assistent am Chemischen Laboratorium; 31. Okt. 1925 Habilitation für Chemie.

Kaiser-Wilhelm-Inst. für Silikatforschung BerlinDahlem: Seit April 1926 Stipendiat; seit 1. Jan. 1928 Leiter der Röntgen-Abt. am Inst.

UH: 30. Juli 1930 Umhabilitierung für Mineralogie; seit 15. Aug. 1931 nichtplanm. a.o. Prof.; 14. April 1934 Ministerium, Abt. Kultus und Unterricht teilt Rektor Wilhelm Groh Strafsache gegen G. wegen Diebstahls mit; 16. April 1934 auf eigenen Antrag Niederlegung der venia legendi; Begründung: Kriegsverwundung führte $\mathrm{zu}$ andauernden Kopfschmerzen, so dass die Arbeit nur mit „Hilfenahme von Medizinalien“ zu bewältigen war; „so kam es manchmal vor, dass ich ... nicht mehr wusste, was ich tat" (aus: UAH PA 3950); 8. Mai 1934 Ministerium teilt Groh mit, dass nach G.s Verzicht auf Lehrberechtigung von weiteren Schritten gegen ihn abgesehen wird.

Berlin: Nach 1934-1969 Referent für die Zs. „Chemisches Zentralblatt“.

Qu UAH PA 3950; Fak.-Akte H-V-4/32. • GLA Abt. 235, Fasz. 1998. Mitteilungen: Frau Elsbeth Gottfried geb. Zühlke ( $\dagger)$.

$W$ Über die Struktur von Silikaten. Coburg 1928. • Über die kontaktmetamorphen Gesteine des Baitonegebietes in der Adamellogruppe. Berlin 1930.

L Poggendorff 7a (1958) S. 244.

\section{Gottlieb, Rudolf}

1892-1924 Med. Fak. Pharmakologie

* o1. Sept. 1864 Wien

$\dagger \quad$ 31. Okt. 1924 Heidelberg mosaisch, seit Okt. 1892 ev.

V Julius G. (1834-1920) Kaufmann, Geldwechsler

M Josefine geb. Landauer (1837-1931)

๑ 9. März 1893 Susette Elisabeth Helene geb. Kühne (1873-1944) T von: (siehe) Wilhelm K.

K 2 S

Lb U Wien: Seit WS 1882/83 Studium der Medizin; 1887 Staatsexamen; 26. Juli 1887 Dr. med.; Sept. 1887-Sept. 1890 Assistent an I. Med. Klinik sowie am Inst. für Med. Chemie.

Assistent am Inst. für Pharmakologie: Seit $1889 \mathrm{U}$ Straßburg, 1890 U Marburg.

UH: Okt. 189o-März 1898 Assistent am Pharmakolog. Inst.; 11. Juli 1892 Habilitation; seit 11. Juli 1896 nichtetatm. a.o. Prof.; seit 31. März 1898 o. Prof. und Direktor des Pharmakolog. Inst. als Nachf. von Woldemar von Schröder; Rufe an U Innsbruck und Prag abgelehnt.

1913 Prorektor der UH; 1906/o7, 1917/18 Dekan der Med. Fak. der UH

1910 Geh. Hofrat

Siehe auch Anhang Sporteinrichtungen an $U H$ 1910-1933 und ihre Mitglieder

E 1911 Mitglied der Dt. Akademie der Naturforscher Leopoldina Halle/S.; 1913 Mitglied der Akademie der Wissenschaften H. • 1914 Ritterkreuz I. Klasse mit Eichenlaub des Ordens vom Zähringer Löwen.

Qu UAH PA 942, 1813; RA 1127, 6202, 6204, 6610, 6816; Fak.-Akte H-III-111/116. • Briefe: UBH. • Siehe auch Archiv der Dt. Akademie der Naturforscher Leopoldina Halle/S. 
$W$ Studien über die Wirkung des Pikrotoxins. Leipzig 1892. - Die experimentelle Pharmakologie als Grundlage der Arzneibehandlung. Berlin, Wien 1910. 7. Aufl. 1925. (Mitverf.) - Nachweis und Bestimmung des Adrenalins im Blut. Berlin 1925. (Mitverf.)

$L$ Wer ist's (1922) S. 506. • Krehl, Ludolf: R. G. † in: Dt. med. Wochenschrift (1924) S. 1835. • Meyer, Hans H.: R. G. Ein Nachruf in: Archiv für experimentelle Pathologie und Pharmakologie 105 (1925) S. I-XV. • Stübler (1926) S. 329; Chronik Ärzte H (1985) S. 129; WBIS; Jansen (1992a) S. 165 (Register); Lindner/Lüllmann (1996) S. 193 u. ö.; Kriegstagebuch K. Hampe (2007) S. 962 (Register); Ruuskanen (2008) S. 141f. • Staudacher, Anna: „... meldet den Austritt aus dem mosaischen Glauben“: 18 ooo Austritte aus dem Judentum in Wien, 1868-1914 ... Frankfurt/M. 2009. S. 205. Badische Biographien N.F. VI (2011) S. 149-152; Deutsche Biographie, s. https://www. deutsche-biographie.de/gnd116794259.html [07.11. 2017].

P Bildarchiv UAH; Chronik Ärzte H.

\section{Gradenwitz, Otto}

1909-1928 Jur. Fak.

Römisches und Dt. Bürgerliches Recht

* 16. Mai 186o Breslau (heute: Wrocław, Polen)

$\dagger \quad$ 07. Juli 1935 Berlin

mosaisch, seit ca. $1900 \mathrm{ev}$.

V Moritz G. (1827-1888) Bankier

M Luise geb. Berlé (1838-1924)

$\varnothing$ unverheiratet

Vw siehe NDB 13 (1982) S. $164^{*}$ (Artikel: Robert René Kuczynski).

Lb Seit 1876 Studium an U Breslau, anschl. Berlin, SS $1877 \mathrm{H}$, WS 1877/78 Leipzig, SS $1878 \mathrm{H}$, Berlin (?); 31. Juli 1880 Dr. iur. an U Berlin.

1879-1885 Referendar in Wiesbaden, anschl. Berlin. - In dieser Zeit:
1880-Sommer 1882 (durch Unfall dienstunfähig) Heeresdienst; Jan. 1881 Immanuel Bekker fordert G. zur Habilitation an UH auf; Sept. 1881 Offiziersexamen nicht bestanden; 30. Juli 1883 Gesuch um Erteilung der venia legendi an Jur. Fak. der UH (siehe UAH H-II-111/93 fol. 45r); 27. Nov. 1883 Otto Karlowa lehnt Habilitationsschrift ab (siehe H-II111/93 fol. 47v-5or); 21. Mai 1884 Dekan August von Bulmerincq notiert: „Auf Wunsch des Herrn Dr. Gradenwitz, welchen er mündlich gegen mich aussprach, ist der Sache kein weiterer Fortgang gegeben worden. Zwar wollte der Herr mir im Januar 1884 seine weiteren Entschluesse kund geben, hat es aber bis zum heutigen Tage nicht gethan" (aus: H-II-111/93 fol. 5or); 4. Dez. 1884 G. zieht seine Arbeit zurück (siehe H-II-111/93 fol. 43r).

U Berlin: 30. Okt. 1885 Habilitation; 1885-1895 Bearbeiter des Wörterbuchs der klassischen Rechtswissenschaft; seit 31. März 1890 nichtetatm. a.o. Prof.

U Königsberg (Preußen): Seit 30. Sept. 1895 etatm. a. o. Prof.; seit SS 1896 o. Prof.

\section{U Straßburg: Seit WS 1907/o8 o. Prof.}

UH: Seit 1. April 1909 o. Prof. als Nachf. von Leopold Wenger; 1. Okt. 1928 auf eigenen Antrag Ruhestand; Übersiedlung nach Berlin.

1913/14, 1919/20, 1924/25 Dekan der Jur. Fak. der $\mathrm{UH}$

Zum 1918 gestifteten Institut für geschichtliche Rechtswissenschaft, Romanistische Abt., der Universität Heidelberg, s. Kraus (1999) S. 435

Geh. Hofrat

E Mitglied der Akademie der Wissenschaften: 1909 H, 1933 München. - 1930 Dr. iur. h.c. Königsberg; 1930 Dr. phil. h.c. Berlin. 1904 Königl. Preußischer Roter Adler-Orden IV. Klasse; 1913 Ritterkreuz I. Klasse des Ordens vom Zähringer Löwen.

Qu UAH PA 756, 3953; Fak.-Akte H-II-111/93 fol. 43r-108r (Habilitationsschrift: fol. 51-108). Brie- 
fe: UBH. • Die Rechtswissenschaft der Gegenwart in Selbstdarstellungen. Hrsg. von Hans Planitz. Leipzig 1929. 3. Bd. S. 41-88. (Autobiogr.)

$W$ Einführung in die Papyruskunde. Leipzig 1900. Laterculi vocum Latinarum. Leipzig 1904. • Bismarcks letzter Kampf $1888-1898$... Berlin 1924. Heidelberger Index zum Theodosianus. Berlin 1925. Erg.-Bd. 1929.

L Kunkel, Wolfgang: O.G. in: Ruperto Carola 12. Jg., Bd. 28 (1960) S. 10-14. - NDB 6 (1964) S. 702 f. Seckel, Dietrich: Gradenwitz-Anekdoten in: Ruperto Carola 32. Jg., H. 64 (1980) S. 29-36. • Badische Biographien N.F. I (1982) S. 142-144. • Hermann, Johannes: O.G. in: Semper apertus 3 (1985) S. 136-147. - Jansen (1992a) S. 165 (Register); WBIS; Wennemuth (1994) S. 634 (Register); Schroeder (2010) S. 315-322 u. ö.; Tilitzki 1 (2012) S. 790 (Register). - Baldus, Christian: Die Auslegung nach dem Willen - und eine Heidelberger These von O. G. in: Heidelberger Thesen zu Recht und Gerechtigkeit. Hrsg. von Christian Baldus ... Tübingen 2013. S. 207-225; Ders.: Eigenwillig und differenziert: eine Lanze für O.G. in: Homo heidelbergensis. Festschrift für Klaus-Peter Schroeder ... Hrsg. von Pirmin Spieß. Neustadt/Weinstr. 2017. S. 295-304. • Schroeder (2017) S. 249-266.

$P$ Bildarchiv UAH; NDB.

\section{Gräff, Siegfried Wilhelm}

1921-1929 Med. Fak.

Pathologie

* 22. März 1887 Karlsruhe

$\dagger \quad$ 02. Nov. 1966 Burgberg (im Schwarzwald; heute: Ortsteil von Königsfeld) ev.-luth.

V Wilhelm Karl Hermann G. (1842/44-1920) Buchhändler

M Johanna geb. Rudolf ( ${ }^{*} 1860 \dagger$ nach 1920$)$

$\infty$ 8. April 1920 Hedwig (Heta) Emmi Elisabeth Maria geb. Aschoff $\left({ }^{*} 1898 \dagger\right.$ nach 1966$) \mathrm{T}$ von D. theol. (UH) Ludwig A. (1866-1942) seit 1894 Privat-Dozent Göttingen, o. Prof. für Pa- thologie: seit 1903 Marburg, 1906-1935 (Emeritierung) Freiburg/Br., s. Kürschner (1940/ 41) Sp. 39, WBIS, Seidler/Leven (2007) S. 857 (Register)

$\mathrm{K} \quad 3 \mathrm{~S}$ (davon $1 \mathrm{~S}$ früh $\dagger$ ), $1 \mathrm{~T}$ : Hildegard G. $\left.{ }^{*}{ }^{*} 1926\right)$ Ehefrau von Erich Lüddekens (19132004), u. a. 1964-1981 o. Prof. für Ägyptologie Würzburg, s. Thissen, Heinz-Josef, Zauzich, Karl-Theodor: E. L. ... in: Enchoria - Zs. für Demotistik und Koptologie 29 (2005) S. 1-3; Jördens, Andrea: E. L. ... in: Hermae. Scholars and Scholarship in Papyrology. II. Hrsg. von M. Capasso. Pisa-Roma 2010. S. 61.

Lb WS 1905/o6 Studium an U Straßburg, SS 1906 H, seit WS 1906/o7 Freiburg/Br., anschl. Leipzig, SS 1909-WS 1909/10 Berlin; 12. Dez. 1910 med. Staatsexamen in Freiburg/Br.; 1. Juni 1911-31. März 1912 Medizinalpraktikant im Diakonissenhaus und im Städtischen Krankenhaus in Karlsruhe; 19. Dez. 1911 Approbation in Freiburg/Br.

U Freiburg/Br.: 1. März 1912 Dr. med.; 1. April 191231. März 1913 Assistenzarzt am Patholog. Inst.; 1912 Erkrankung an Lungentuberkulose.

Davos: April-Aug. 1913 Kuraufenthalt; Sept. 1913März 1914 Assistenzarzt an e. Sanatorium.

U Halle-Wittenberg: Seit Frühjahr 1914 kurzzeitig Hospitant am Physiolog. Inst.

1914-1918 Militärischer Zivilarzt. • In dieser Zeit:

U Freiburg: Seit 1. April 1915 Assistenzarzt am Patholog. Inst.; SS 1916 vertretungsweise Leiter des Patholog. Inst.; 13. Juni 1917 Habilitation.

Berlin: 1. April-30. Sept. 1921 Eigenstudien am Urbankrankenhaus.

UH: 1. Okt. 1921-28. Febr. 1923 Assistenzarzt am Patholog.-Anatom. Inst.; 26. Okt. 1921 Umhabilitierung; seit 13. Okt. 1922 nichtplanm. a. o. Prof.; Febr. 1923-März 1925 Gastprof. u. a. am Patholog. Inst. der Niigata U (Japan); April-Juni 1925 Gastvorlesungen an U in Bunkyō, e. Bezirk in Tokio; SS 1928 Vertreter des Lehrstuhls für Pathologie an U Tübingen; Nov. 1928 Verleihung der Dienstbezeichnung „Prosektor“. 
Barmbeck (heute: Barmbek, Stadtteil von Hamburg): 1. März 1929-10. Jan. 1946 (Entlassung durch britische Militärregierung), 14. Nov. 1946 (Wiedereinstellung)-30. Sept. 1952 (Ruhestand) leitender Oberarzt (Prosektor) am Patholog. Inst. des Allg. Krankenhauses. • In dieser Zeit:

U Hamburg: Seit 15. Mai 1929 Privat-Dozent; 25. April 1930 Verleihung des Titels „Prof.“; 27. Juli 1939-2. Jan. 1946 (Entlassung durch britische Militärregierung) apl. a.o. Prof. für Patholog. Anatomie und Allg. Pathologie; 23.Okt. 1946 (Wiedereinstellung)-30. Sept. 1952 (Ruhestand) nichtplanm. a.o. Prof.

Rothenburgsort (heute: Stadtteil von Hamburg): 1953-1955 Leiter der Prosektur am Kinderkrankenhaus.

Seit 1955 Wohnsitz in Burgberg.

Nach seinem Japanaufenthalt werden auf Initiative und Vermittlung G.s dem 1913/14 angelegten Karlsruher Japangarten u.a. ein Shintô-Schrein mit Schutzlöwen von der Stadt Nagoya geschenkt, s. hierzu Schmidt, Horst: Der Japangarten in Karlsruhe ... Karlsruhe 2014.

1951 Mitbegründer, auch Leiter des Landesverbandes für Krebsforschung und Krebsbekämpfung Hamburg (heute: Hamburger Krebsgesellschaft e. V.)

E 1953 Ehrenmitglied der Norddeutschen Tuberkulose-Gesellschaft. 1962 Hufeland-Medaille.

Qu UAH PA 943, 3955; Rep. 40-399. - GLA Abt. 235, Fasz. 1999. - Amtliches Verzeichniß des Personals und der Studierenden der ... Universität zu Berlin. Auf das Sommerhalbjahr ... 1909. Berlin 1909. S. 108. • Auskunft: Bürgermeisteramt Königsfeld im Schwarzwald (Sterbebuch von 1966).

W Die Lungenphthise. 2 Bde. Berlin 1923. Atlas der Erkrankungen der oberen Luftwege. Leipzig 1933-1934. - Tod im Luftangriff. Ergebnisse pathologisch-anatomischer Untersuchungen anläßlich der Angriffe auf Hamburg in den Jahren 19431945. Hamburg 1948. 2. Aufl. 1955. - Medizinische und pathologisch-anatomische Forschung und Lehre. Hamburg 1950. - Pathologische Anatomie der Zahnheilkunde. Stuttgart 1961. (Mitverf.)

L Ricker, Gustav: Pathologie als Naturwissenschaft - Relationspathologie. Berlin 1924. S. 380 . • Fischer $1\left({ }^{3} 1962\right)$ S. 525; Kürschner (1966) Sp. 708 f.; WBIS. - Manz, A.: In memoriam S. W. G. in: Hamburger Ärzteblatt - Zs. der Ärztekammer Hamburg und der Kassenärztlichen Vereinigung Hamburg. Hamburg 1966. S. 384 f. • Selberg, Werner: In memoriam S. G. in: Verhandlungen der Dt. Gesellschaft für Pathologie 52 (1968) S. 583-591. • Pieper, Christine: Die Sozialstruktur der Chefärzte des Allgemeinen Krankenhauses Hamburg-Barmbek 1913-1945 ... Münster u. a. 2003. S. 196-199 u. ö. • Über S. G. in: Krämer, Elke: Leben und Werk von ... Günther Enderlein ... Sankt Goar 2006. S. $268 \mathrm{f}$. u. ö. Keitel, W.: S. G. in: Zs. für Rheumatologie 04 (2008) 67(2), S. 165-171. S. W. G. in: Hamburgische Biografie. Hrsg. von Franklin Kopitzsch ... Göttingen 2008. Bd. 4. S. 120-122.

\section{$P$ Bildarchiv UAH.}

\section{Grafe, Erich Eduard}

1910-1921 Med. Fak.

Innere Medizin

* 24. Febr. 1881 Berlin

$\dagger$ 16. Mai 1958 Florenz

ㄷlorenz

ev.

V Eduard G. (1855-1922), u.a. 1886-1888 a.o. Prof. Halle-Wittenberg, Ordinarius für Theologie: seit $1888 \mathrm{Kiel}$, seit 1890 Bonn, s. Verzeichnis Bonn (1968) S. 94, WBIS, Album Professorum der Ev.-Theol. Fakultät Bonn (1995) S. 197 f., Troeltsch-Gesamtausgabe 19 (2014) S. 503 (Register), Catalogus prof. Halensis online

M Anna geb. Weidenbusch (1859-1938)

๑ 27. März 1909 Anni geb. Hoffmann $\left({ }^{*} 1885\right)$

K $3 \mathrm{~S}$ 
Lb Seit WS 1899/1900 Studium an U Kiel, anschl. Bonn, SS 1902 H, zuletzt Berlin.

Bonn: 1901-1902 Militärdienstpflicht als Einjährig-Freiwilliger; 7. Juli 1904 med. Staatsexamen.

U Bonn: Seit Aug. 1904 Volontärassistent am Anatom. Inst.; seit Dez. 1904 Medizinalpraktikant an Med. U-Klinik; 7. Nov. 1904 Dr. med.; 1. März 1905 Approbation.

U Berlin: Assistent: seit Okt. 1905 Physiolog. Inst., seit März 1906 Hygien. Inst.

UH: Seit April 1907 Assistent an Med. U-Klinik; 27. Mai 1910 Habilitation; seit 21. März 1916 nichtetatm., 1920-1921 nichtplanm. a. o. Prof.; 1919-1921 Oberarzt an Med. U-Klinik. • In dieser Zeit:

1914-1915, 1918 Kriegsdienst (als Stabsarzt der Reserve Internist in Feld- und Reservelazaretten, zuletzt Stationsarzt der Nerven-Abt. im Reservelazarett in $\mathrm{H})$.

U Rostock: Seit 1. Okt. 1921 planm. a. o. Prof. und 1921-1926 Leiter der Med. Poliklinik; seit 14. Juli 1923 o. Prof.

U Würzburg: Seit 1. April 1926 o. Prof. und Direktor der Med. Nervenklinik (Luitpoldkrankenhaus); 18. Juli 1945 Entlassung; 3. Juli 1948 Wiedereinsetzung in e. Planstelle mit gleichzeitiger Versetzung in den Ruhestand; 1952/53 Zuerkennung des Status e. Emeritus.

Garmisch-Partenkirchen: Seit 1952 Wohnsitz; hier Arzt im Kurhotel Wigger.

1938 Präsident der Dt. Gesellschaft für Gastroenterologie, Verdauungs- und Stoffwechselkrankheiten. 1954 Vorsitzender der Dt. Gesellschaft für Ernährung

E 1956 Ehrenmitglied der Dt. Gesellschaft für Innere Medizin. 1951 Dr. med. h.c. Rostock. 1956 Rinecker-Medaille in Gold. - Eisernes Kreuz II. Klasse.
Qu UAH PA 944, 3958; Studentenakte. • Universitätsarchiv Würzburg PA 342. - GLA Abt. 235, Fasz. 2001. Auskunft: Marktarchiv in GarmischPartenkirchen.

W Die pathologische Physiologie des Gesamtstoffund Kraftwechsels bei der Ernährung des Menschen. München 1923. Hygiene der Lunge im gesunden und kranken Zustande. Stuttgart 1925. (Mitverf.) - Die Krankheiten des Stoffwechsels und ihre Behandlung. Berlin 1930. 2. Aufl. u.d. T.: Ernährungs- und Stoffwechselkrankheiten und ihre Behandlung. Berlin 1958.

L Kürschner (1931) Sp. 897f., (1940/41) Sp. 556f. • Reinwein, H.: E.G. † in: Münchener med. Wochenschrift (1958) S. 1941 f.; Ders. E. G. $\dagger$ in: Diabetes - Journal ed. by American Diabetes Association (Sept./Oct. 1959) vol. 8, no. 5, p. 398. Oberdisse, K.: Zum Tode E. G.s in: Dt. Med. Wochenschrift 84 (1959) S. 523 f. - Fischer 1 ( $\left.{ }^{3} 1962\right)$ S. 526; Chronik Ärzte H (1985) S. 129; WBIS; Jansen (1992a) S. 165 (Register); Catalogus prof. Rostochiensium online. Große bayerische biographische Enzyklopädie. Hrsg. von Hans-Michael Körner. München 2005. Bd. 1. S. 678. • Jenss, Harro, Lerch, Markus M.: Kurzbiographie E. G. in: Tagungen der Dt. Gesellschaft für Gastroenterologie, Verdauungs- und Stoffwechselkrankheiten (DGVS). Die Präsidenten von 1914 bis 2014. (Mit biographischen Skizzen.) Hrsg. im Auftrag der DGVS. Greifswald 2014. S. 25 u. ö. Deutsche Biographie, s. https://www.deutsche-biographie.de/gn d117553174.html [07.11. 2017].

$P$ Bildarchiv UAH.

\section{Grisebach, August Carl Eduard Rudolph Arnold}

1930-1937, 1947-1950 Phil. Fak.

Neuere Kunstgeschichte

* 04. April 1881 Berlin

$\dagger \quad$ 24. März 1950 Heidelberg

ev. 
V Hans Otto Friedrich Julius G. (1848-1904) Architekt, s. NDB 7 (1965) S. 99 f., WBIS; H. G. Architekt der Gründerjahre ... Bearb. von Ekhart Berckenhagen. Berlin 1974.

M Emmy geb. Hensel (1858-1936)

๑ 1913 Swanhild Kjelseth geb. Jörgensen (18861971) Scheidung 1924

( 22. Dez. 1924 Dr. phil. Hanna geb. Blumenthal (1899-1988) Kunsthistorikerin, siehe Potsdamer Tagebuch. Mit e. Nachwort von Hilde Domin. Heidelberg 1974. 2. Aufl. Magdeburg 2009 (Autobiogr. über die Zeit von Jan. 1945 bis Febr. 1946 in Potsdam sowie über H.G.s Aufenthalt in Kolumbien 1948); 20 Jahre (Graphisches) Kabinett H. G. Heidelberg 1971; Kurzbiographie in: G., H.: Der Heidelberger Bergfriedhof. Heidelberg 1981. S. 126; Lexikon jüdischer Einwohner Hs (2011) S. $144 \mathrm{f}$.

K 1 S: Hans G. (1926-1990), u.a. seit 1964 o. Prof. für Biochemie Freiburg/Br., s. Kürschner (1980) S. 1198; Hahlbrock, Klaus: Obituary: H.G. ... in: Zs. für Naturforschung C 3-4 (1990) S. 140-142. 2 T: Dr. med. Eveline G. (1922-2001) Ärztin; Ehefrau von Erich von Holst (1908-1962), u.a. 1946-1948 o. Prof. für Zoologie an UH, s. Drüll (2009) S. 288 f.; Entwicklung der Verhaltensbiologie und biologischen Kybernetik im 20. Jhdt. Zur 100. Wiederkehr des Geburtstags von E. von H. ... in: Disziplingenese im 20. Jahrhundert. Beiträge zur 17. Jahrestagung der DGGTB [Dt. Gesellschaft für Geschichte und Theorie der Biologie] in Jena 2008. Hrsg. von Michael und Joachim Kaasch. Berlin 2010. S. 11-26. - Dr. phil. Manon G. $\left({ }^{*} 1931\right)$ verh. Andreas-G., früher: Maren-G., Literaturwissenschaftlerin, u. a. 1980-1981 Vorstandssprecherin der niedersächsischen Partei Die Grünen, 1981-1984 e. der drei Bundesvorstandssprecher der Grünen, siehe Erlebte Geschichte erzählt. 19941997. Michael Buselmeier im Gespräch mit ... M. G. ... Heidelberg 200o; Lexikon jüdischer Einwohner Hs (2011) S. 145; Auffermann, Verena: Manon Maren-Grisebach: Auf dem Pfad grüner Tugend aus: DIE ZEIT Nr. 33 (1983), aktualisiert 22. Nov. 2012, s. http://www.zeit. de/1983/33/auf-dem-pfad-gruener-tugend
Vw Großvater: Heinrich August Rudolf G. (18141879) seit 1837 Privat-Dozent für Botanik, seit 1841 a. o. Prof., seit 1847 o. Prof. für allg. Naturgeschichte und Direktor des Botanischen Gartens Göttingen, s. NDB 7 (1965) S. 96 f., Göttinger Gelehrte 1 (2001) S. 164 f., WBIS.

Lb Seit SS 1900 Studium an U Berlin, München, Berlin.

Berlin: 13. Okt. 1906 Dr. phil.; 1906-1907 Volontär an Museen.

TH Karlsruhe: 20. Okt. 1910 Habilitation für Kunstgeschichte.

U Berlin: Seit 8. Febr. 1912 Privat-Dozent; 21. März 1918 a. o. Prof. In dieser Zeit:

Nov. 1915-Nov. 1918 Kriegsdienst.

TH Hannover: Seit 5. Sept. 1919 o. Prof.

U Breslau: Seit 29. Juni 1920 o. Prof.; 1929 Studien an Bibliotheca Hertziana in Rom.

UH: 18. Juli 1930 Ern. zum o. Prof. am Kunsthistor. Inst. als Nachf. von Carl Neumann; 1. Okt. 1930 Amtsantritt; 19. Juni 1937 Zwangspensionierung auf Grund des Gesetzes zur „Wiederherstellung des Berufsbeamtentums“ (Grund: nichtarische Ehefrau).

Seit 1937 Privat-Gelehrter in Timmendorf, Jan. 1945-Febr. 1946 in Potsdam; 1946 Rückkehr nach H.

UH: 5. März 1947 Umwandlung der Zwangspensionierung rückwirkend in e. Emeritierung.

1931-1933, 1947-1949 Vorsitzender des Heidelberger Kunstvereins

E 1947 Mitglied der Akademie der Wissenschaften $\mathrm{H}$.

Qu UAH PA 419, 3978-3980. - Briefe, Nachlaß: UBH. • A.G. ... Kunsthistoriker in Deutschland. Mit e. Edition der Briefe Heinrich Wölfflins an A. G. Hrsg. von Golo Maurer. Ruhpolding u.a. 2007. 
W Danzig. Leipzig 1908. Nachdr. Augsburg 1999. • Der Garten, eine Geschichte seiner künstlerischen Entwicklung. Leipzig 1910. Carl Friedrich Schinkel. Leipzig 1924. Nachdr. München 1981. • Die Kunst der deutschen Stämme und Landschaften. Wien 1946.

L Lehrkörper TH Hannover (1956) S. 99; NDB 7 (1965) S. 97 f. - Grisebach, Hanna: Der Heidelberger Bergfriedhof. Heidelberg 1981. S. 73-8o. • Mussgnug (1988) S. 297 (Register); Jansen (1992a) S. 165 (Register); Badische Biographien N.F. IV (1996) S. 109; Wendland (1999) T. 1, S. 243-245. Metzler Kunsthistoriker Lexikon (2007) S. 140143; Schubert (2008) S. 65-71; WBIS. • Groth, Katharina, Müller, Birgit: Kunstgeschichte um 1900 ein Vergleich beruflicher Werdegänge in: In der Mitte Berlins. 200 Jahre Kunstgeschichte an der Humboldt-Universität ... Hrsg. von Horst Bredekamp und Adam S. Labuda. Berlin 2010. S. 177188.

$P$ Bildarchiv UAH; graph. Slg. UBH; Lehrkörper TH Hannover (1956); NDB (1965); Grisebach (1981).

\section{Groh, Jakob Wilhelm}

1927-1937 (1939) Jur. Fak.

Arbeitsrecht, Bürgerl. Recht, Zivilprozeßrecht

* 13. Aug. 1890 Darmstadt

$\dagger$ 15. Jan. 1964 Karlsruhe

口 Darmstadt

ev.

V Jacob G. (1857-1914) Kaufmann

M Wilhelmine geb. Krämer (1867-1958)

(1) 14. Juli 1917 Ilse geb. Müller (1892-1970)

K $1 \mathrm{~S}\left({ }^{\star} 1922 \times \times 1944\right), 1 \mathrm{~T}$

Lb Seit WS 1909/10 Studium zunächst der Philosophie (2 Semester), anschl. der Rechtswiss. an U Freiburg/Br., seit 1911 Gießen; Dez. 1913 I., März 1919 II. Staatsprüfung.

13. Dez. 1913-März 1919 Referendar in Darmstadt; Febr. 1915-Nov. 1918 Kriegsdienst als ungedienter
Landsturmmann im Garnisonsdienst; 17. Jan. 1917 Dr. iur. an U Gießen.

Darmstadt: Seit 1. Mai 1919 Gerichtsassessor und Amtsrichter.

U Gießen: 1. Okt. 1920-31. März 1924 Assistent am Jur. Seminar; 3. Febr. 1922 Habilitation für Bürgerl. Recht, Arbeitsrecht; seit 1. April 1924 planm. a. o. Prof.

UH: 26. Nov. 1926 Ern. zum planm. a.o. Prof.; 1. April 1927 Amtsantritt; Ern.: 10. Mai 1928 persönlicher Ordinarius, 1. Okt. 1933 planm. o. Prof.; 1. April 1937-30. Sept. 1939 beurlaubt.

Berlin: 1. April 1937-30. Sept. 1941 Referent und stellvertr. Leiter des Amtes Wissenschaft im Reichsministerium für Wissenschaft, Erziehung und Volksbildung (REM); 1937-1940 Beisitzer des Reichsdienststrafhofs; seit 1. Okt. 1941 Referent zur besonderen Verwendung, 1942-1944 nebenamtlicher Referent im REM.

U Berlin: 1. Okt. 1939-1945 Ordinarius und seit 10. November 1941 Geschäftsführender Direktor des Jur. Seminars; seit 1. Okt. 1939 Beurlaubung vom Lehramt durch REM; 1. Okt. 1941 „Ihrem Wunsche folgend, sich wieder ausschließlich der Lehr- und Forschungstätigkeit an der Universität zu widmen", Entbindung von Ämtern im REM (aus: Schreiben des REM vom 30. Sept. 1941 in: UA Humboldt-U Berlin UK - G 201, Blatt 8); April 1942 Gastprof. an U Budapest; seit 22. Mai 1944 Entbindung von der Verpflichtung zur Abhaltung von Vorlesungen für SS 1944 aus gesundheitlichen Gründen; 5. März 1945 Aufforderung G.s durch Jur. Fak., am 13. März 1945 Vorlesungen in den Ferienwiederholungskursen an $\mathrm{U}$ zu beginnen (aus: UA Humboldt-U Berlin Jur. Fak. vor 1945, Nr. 513, Blatt 6); Mitte 1945 Entlassung.

Ende Januar 1944 (ausgebombt) Flucht nach Kirchmöser (heute: Ortsteil von Brandenburg an der Havel); Wohnsitz: zunächst Kirchmöser, seit Sommer 1946 Höxter (Westfalen), seit 1952 Karlsruhe.

1. Okt. 1933-31. März 1937 Rektor der UH; 1930/31, 1933 Dekan der Jur. Fak. der UH 
April 1934: Benennung als badischer Vertreter im Vorstand des Deutschen Museums in München

$Z$ In einem Brief vom 9. Febr. 1950 an die Heidelberger Universitätskasse schildert Groh seine Lebensumstände nach 1943: „Unser einziger Sohn ist [1944] gefallen, unser Hab und Gut ist in Berlin verbrannt, wo wir bis zum bitteren Ende aushielten. Im Sommer 1946 sind wir zu meiner Tochter nach Höxter gezogen. Ich lebte von Armenunterstützung, da ich wegen eines schweren Herzleidens für dienstunfähig erklärt wurde; meine Frau arbeitete als Fabrikarbeiterin. Jetzt hoffen wir, dass wir durch den Unterhaltszuschuss [der durch den Regierungspräsidenten in Detmold gewährt wird] ... wenigstens aus den gröbsten Sorgen herauskommen ..." (aus: UAH PA 3982).

Siehe auch Anhang Sporteinrichtungen an $U H$ 1910-1933 und ihre Mitglieder

E 1936 Ehrenmitglied der Königl. Rumänischen Gesellschaft der Geschichte der Medizin Bukarest. 1918 Hessisches Kriegsehrenzeichen; 1934 Ehrenkreuz für Kriegsteilnahme.

Qu UAH PA 757, 3982; Fak.-Akte H-II-319/3; B-1211; B-1221/1, B-1221/2. - GLA Abt. 235, Fasz. 2031. - Briefe: UBH. • Auskunft: Archiv der Humboldt-Universität Berlin.

W Deutsches Arbeitsrecht. Breslau 1924. • Sittenwidrige Erfüllungsvereitelung. Berlin 1932.

HG Typische Prozesse. Ein Zivilprozeßpraktikum zum Gebrauch bei akad. Übungen ... 8. Aufl. Berlin 1930.

MHG 1942-1945 Zs. für Zivilprozeß.

$L$ Handels-Hochschule Mannheim 1907-1932 (1932) S. 27; Kürschner (1940/41) Sp. 570, (1950) Sp. 639, (1961) S. 598; Wer ist wer (1962) S. 462; Mussgnug (1988) S. 297 (Register); Heiber I (1991) S. 636 (Register); Jansen (1992) S. 409 (Register); Ders. (1992a) S. 165 (Register); Heiber II,2 (1994) S. 837 (Register); Grüttner (2004) S. 64; Berliner U in NS-Zeit 1 (2005) S. 26-31; UH im Nationalsozialismus (2006) S. 1253 f. (Register); Klee, Per- sonenlexikon (2007) S. 202; WBIS; Schroeder (2010) S. 476-481 u. ö. • Leo, Paul Christopher: W.G. - Erster Rektor der Ruperto-Carola in der NS-Zeit. Diss. UH. Hamburg 2012. Deutsche Biographie, s. https://www.deutsche-biographie. de/gnd11686172X.html [07.11. 2017]. • Meier, Julia Christine: W. G. als Rektor der Universität Heidelberg - Uneingeschränkter ,Führer ' der Universität oder Rektor im polykratischen System? 1933-1937. Lehramtsarbeit. Heidelberg 2017 (Ausdruck im $\mathrm{UAH}$ ).

$P$ Bildarchiv UAH.

\section{Gross, Eberhard Rudolf}

1922-1924, 1925-1932 Med. Fak.

Physiologie

* $\quad$ 04. Sept. 1888 Maracaibo (Venezuela)

$\dagger$ 27. Sept. 1976 Bonn

ev.

V Rudolf G. (1851-1922) Kaufmann, Konsul

M Elisabeth geb. Schnars (186o-1927)

๑ 22. Dez. 1917 Paula geb. Buttersack (1892-1978)

K $\quad 1 \mathrm{~S}, 2 \mathrm{~T}$

Lb Seit SS 1908 Studium der Medizin an UH, seit WS 1909/10 Freiburg/Br., anschl. Leipzig, München, Freiburg/Br.

Freiburg/Br.: 1913 Staatsexamen; 8. Mai 1914 Dr. med. an U; 4. Sept. 1914 Approbation.

1914-1918 Kriegsdienst.

UH: 1. Febr. 1919-31. März 1924 Assistent am Physiolog. Inst.; 2. März 1922 Habilitation.

U Freiburg/Br.: Seit April 1924 Assistent am Physiolog. Inst.

UH: Seit April 1925 Assistent am Physiolog. Inst.; 29. März 1927-31. März 1932 nichtplanm. a.o. Prof. • In dieser Zeit: 
Ludwigshafen: 1. Okt. 1926-31. März 1932 Leiter des Gewerbehygienischen Labors der I. G. Farbenindustrie.

Wuppertal-Elberfeld: 1932-1945 Leiter des Gewerbehygienischen Laboratoriums, 1937-1945 Leiter des Industriehygienischen Labors der I.G. Farbenindustrie (Bayer AG); 1945 Internierung auf Schloß Kransberg bei Frankfurt/M.; 1945-1956 Leiter des Inst. für Toxikologie der Bayer AG. • In dieser Zeit:

U Bonn: Seit SS 1936 a. o. Prof. für Pharmakologie; 7. Nov. 1939-22. Mai 1962 (Entbindung vom Lehrauftrag) apl. Prof.; 1950-1955 Leiter der Abt. Gewerbe-Toxikologie am Pharmakolog. Inst.

Siehe auch Anhang Sporteinrichtungen an UH 1910-1933 und ihre Mitglieder

Qu UAH PA 946, 3985. Briefe: UBH. • Auskunft: Universitätsarchiv Bonn.

$W$ Über die Wirkung von Strophanthin und Digitoxin auf die Atmung des Kaninchens. Berlin 1914.

$L$ Verzeichnis Bonn (1968) S. 97; Kürschner (1980) S. 4458; WBIS; Schmaltz (2005) S. 670 (Register). Forsbach, Ralf: Die medizinische Fakultät der Universität Bonn im „Dritten Reich“. München 2006. S. 105.

\section{$P$ Bildarchiv UAH.}

\section{Gross, Walter}

1911-1921 Med. Fak.

Pathologische Anatomie

* 12. Jan. 1878 Waldkirch (Baden)

$\dagger$ 14. Sept. 1933 Münster/Westf. (Suizid) ev.

V Ferdinand G. $\left({ }^{*} 1848\right)$ Fabrikbesitzer

M Bertha geb. Doll ( $\left.{ }^{*} 1855\right)$ T von Karl D. (18271905) Theologe, seit 1874 Oberhofprediger, $s$. NDB 4 (1959) S. 60 f., WBIS
( 18. Jan. 1909 Dr. med. Margarethe Helene geb. Schmitzdorff (1882-1965) Ärztin

K 2 S: u. a. Walter Hatto G. (1913-1984), u. a. seit 1944 Dozent und seit 1952 apl. Prof. Göttingen, seit 1964 o. Prof. Gießen, 1968-1979 (Emeritierung) o. Prof. für Archäologie Hamburg, s. Kürschner (1983) S. 1312, WBIS, Göttinger Gelehrte 2 (2001) S. $686 \mathrm{f}$.

Lb SS 1897 Studium an U Lausanne, seit WS 1897/ 98 H, seit WS 1899/1900 Berlin, WS 1901/o2-SS $1902 \mathrm{H}$.

UH: 9. Febr. 1903 Staatsexamen; 1903-1904 Militärdienstpflicht als Einjährig-Freiwilliger; Assistent: seit April 1903 U-Kinderklinik Luisen-Heilanstalt, anschl. Patholog.-Anatom. Inst.; 16. Juli 1904 Dr. med.

Assistent: Seit 1904 Physiolog. Labor des Inst. für Experimentelle Medizin in St. Petersburg, seit 1906 II. Med. Klinik der U München.

UH: Seit 1908 Assistent am Patholog.-Anatom. Inst.; 31. Juli 1911 Habilitation für Allg. und Experimentelle Pathologie und Patholog. Anatomie; seit 27. Aug. 1917 nichtetatm., 1920-1921 nichtplanm. a. o. Prof. $\bullet$ In dieser Zeit:

1914-1918 Kriegsdienst; Sept.-Dez. 1918 Vorlesungen an U Dorpat.

U Greifswald: Seit 17. März 1921 o. Prof. und Direktor des Patholog. Inst.

U Münster: Seit WS 1924/25 o. Prof. und Direktor des Patholog. Inst.

E 1911 Prinz-Regent Luitpold-Medaille.

Qu UAH PA 947. - GLA Abt. 235, Fasz. 2035. • Auskunft: Universitätsarchiv Münster.

$W$ Experimentelle Untersuchungen über den $\mathrm{Zu}$ sammenhang zwischen histologischen Veränderungen und Funktionsstörungen der Nieren in: Beiträge zur patholog. Anatomie und zur allg. Pathologie 51 (1911) S. 528-575. • Über den Zusammenhang zwischen Farbstoffausscheidung und 
vitaler Färbung der Nieren in: Verh. der Dt. Patholog. Gesellschaft (1914) S. 123-128. • Zur Technik der Fettfärbung in: Zs. für wiss. Mikroskopie 47 (1930) S. 64-68. - Pathologische Anatomie der Typhus- und Paratyphusbazillenausscheider. Jena 1931.

$L$ Stübler (1926) S. 326 f; NDB 7 (1966) S. 145 f.; Universität Münster (1980) S. 296, 298; Chronik Ärzte H (1985) S. 129. - Lexikon Greifswalder Hochschullehrer (2004) S. 75f.; Huhn/Kilian (2011) S. 249 (Register; S. 234 lautet der Sterbeort irrtümlich Göttingen); Fischer (2012) S. 104-106. • Voß, Jonathan: Zum Gedenken an W.G. in: flurgespräche - Universität Münster, s. http://www. flurgespraeche.de/wp-content/uploads/2017/03/ Gedenkblatt_Walter_Gross_neu.pdf (hier auch Begründung für G.s Suizid).

$P$ Bildarchiv UAH.

\section{Grützmacher, Georg Konstans}

1893-1914 Theol.Fak.

Neues Testament, Kirchengeschichte

* 22. Dez. 1866 Berlin

$\dagger \quad$ 28. Febr. 1939 Münster ev.

V Ernst G., Kaufmann

M Ida Maria Karolina Konstantia geb. Fischer

๑ 14. März 1899 Erika Gisela Wilhelmina geb. Cuntz ( ${ }^{*} 1876 \dagger$ nach 1939$)$

K 1 T, 1 S: Dr. phil. Martin G. (1901-1994), u.a. seit 1934 Reg.-Rat und Begründer des Labors für Akustik an Physikalisch-Technischer Reichsanstalt (PTR) Berlin, 1945 Verlegung nach Göttingen, 1947 nach Braunschweig, 1950-1966 (Pensionierung) Direktor der Abt. Akustik an Physikalisch-Technischer Bundesanstalt (PTB) in Braunschweig, seit 1948 Honorar-Prof. für Physik an TH ebd., s. Zeitz, Katharina: Max von Laue ... Seine Bedeutung für den Wiederaufbau der dt. Wissenschaft nach dem 2. Weltkrieg. Stuttgart 2006. S. 131-137 u. ö.; WBIS
Vw Bruder: Richard G. (1876-1959) seit 1900 Vikar in Friedersdorf (Brandenburg; heute: Ortsteil der Gemeinde Vierlinden), 1901-1902 Inspektor am Theol. Studienhaus in Greifswald, seit 1902 Privat-Dozent ebd., seit 1903 a.o. Prof. und 1912-1924 (Ruhestand aus gesundheitlichen Gründen) o. Prof. für Systematische Theologie Erlangen, 1930-1945 wiss. Leiter der Lessing-Hochschule und 1945 Dozent an Volkshochschule Berlin, s. Professoren Erlangen (1993) S. 27, BBKL XVII (2000) Sp. 514-528; NS-Opfer unter Vorbehalt: homosexuelle Männer in Berlin nach 1945. Hrsg. von Andreas Pretzel. Münster 2002. S. $308 \mathrm{f}$, 335; Catalogus prof. Rostochiensium online.

Lb Seit 1886 Studium der Theologie, Geschichte an U Lausanne, anschl. Berlin, Halle-Wittenberg.

UH: 29. Febr. 1892 Dr. phil.; 30. Juli 1892 mündliche Prüfung, 24. Okt. 1892 theol. Lizentiatenprüfung; 27. März 1893 II. theol. Staatsexamen in Berlin; 21. Nov. 1893 Habilitation für Kirchengeschichte; 1893-1914 Repetent an Theol. Fak.; seit 23. Juli 1897 nichtetatm. a.o. Prof.; seit WS 1902/ o3 Lehrauftrag zur Abhaltung von Vorlesungen über badische Kirchengeschichte mit e. Jahresvergütung von 2000.- Mark (zuletzt 3000.- Mark) und „mit der weiteren Verpflichtung, im theologischen Unterricht, sofern es erforderlich wird, supplierend einzutreten“" (aus: UAH RA 6754 fol. 1r).

U Münster: WS 1914/15-WS 1934/35 o. Prof.

1917 Geh. Konsistorialrat

E 1914 D. theol. UH.

Qu UAH PA 1639; Fak.-Akte Theol. Fak. 54 fol. 109-110, 115-119, 131V, 227-253, 256-304. • GLA Abt. 235, Fasz. 2039.

W Die ev. Landeskirche des Großherzogtums Baden. Überblick über ihre Geschichte. Freiburg/ Br. 1898. - Hieronymus. Eine biographische Studie. 3 Bde. Berlin 1901-19o8. Neudr. Aalen 1969. • Der Sieg des Christentums über die Welt der Anti- 
ke. Berlin 1908. Die Bedeutung der Selbstbiographie für die Geschichte der christlichen Frömmigkeit. Halle/S. 1925.

HG Theologie der Gegenwart.

L Kürschner (1931) Sp. 948; Universität Münster (1980) S. 244, 246; Jansen (1992a) S. 165 (Register); BBKL XVII (2000) Sp. 508-514; Personenlexikon zum dt. Protestantismus (2006) S. 93; TroeltschGesamtausgabe 19 (2014) S. 503 (Register); Deutsche Biographie, s. https://www.deutsche-biographie.de/gnd1023958287.html [07.11. 2017].

$P$ Bildarchiv UAH.

\section{Gruhle, Hans Walther}

1913-1934 (1937) Med. Fak.

Psychiatrie, Psychopathologie, Med. Psychologie

* o7. Nov. 1880 Lübben (Niederlausitz)

$\dagger$ 03. Okt. 1958 Bonn

ev.

V Franz Karl Heinrich G. (1841-1922) Rechnungsrat

M Thekla Sidonie geb. Schumann (1848-1932)

$\infty$ 6. Mai 1922 Dr. phil. Atha geb. Nodnagel (18971973) T von Ernst Otto N. (1870-1909) Musikschriftsteller, Sänger, Komponist, s. NDB 7 (1966) S. 209*, WBIS

K 1 T, 1 S: Wolfgang G. $\left({ }^{*} 1924\right)$, u. a. seit 1960 Assistent am Inst. für Kernphysik, seit 1969 Privat-Dozent, 1974-1986 (Ruhestand) a.o. Prof. für Physik Köln, s. Kürschner (1983) S. 1329; Schmeh, Klaus: „Eine Ansammlung von spinnerten oder genialen Individuen“. EnigmaZeitzeugen berichten - Teil 1: W.G. in: Telepolis - Onlinemagazin vom 08. Aug. 2005.

Vw Schwester: Margarete G. (1876-1900) Gesangslehrerin am Konservatorium Dresden, s. WBIS.

Lb Seit SS 1899 Studium an U Leipzig, SS 1901 Würzburg; April-Okt. 1901 (Entlassung wegen e. nervösen Herzleidens) Militärdienstpflicht als Einjährig-Freiwilliger.
U München: Seit WS 1901/o2 Forts. des Studiums; Juli 1904 Staatsexamen und Approbation; Nov. 1904-April 1905 Mitarbeiter an Psychiatr. Klinik (Direktor: (siehe) Emil Kraepelin); 29. Jan. 1907 Dr. med., s. hierzu Böhnke (2008) S. 11f., 83-90.

UH: Seit Mai 1905 Volontärassistent, 1908-Febr. 1919 planm. Assistenzarzt an Psychiatr. Klinik; 1. Nov. 1910-1. Mai 1911 Beurlaubung für eigene wiss. Fortbildung an U Bonn und München, s. hierzu UAH H-III-111/156 fol. 134V; 3. März 1913 Habilitation für Psychiatrie und Med. Psychologie; seit 15. Febr. 1919 Oberarzt an Psychiatr., 1928 umbenannt in Psychiatr.-Neurolog. Klinik; seit 19. Febr. 1919 nichtetatm., seit 1920 nichtplanm. a. o. Prof.; seit SS 1921 Lehrauftrag für „Experimentelle Psychopathologie" mit e. Vorlesungshonorar von 300.- Mark pro Wochenstunde; seit 1921 auch Leiter der Sammlung Prinzhorn, s. hierzu Karl Wilmanns; seit Juli 1933 kommissar. Leiter der Psychiatr.-Neurolog. Klinik nach Entlassung von Wilmanns; SS 1934-WS 1936/37 Beurlaubung. $\bullet$ In dieser Zeit:

1916-1918 Kriegsdienst; 1927-1932 (Schließung) Lehrauftrag für „Normale Psychologie“ an Lehrerbildungsanstalt in Karlsruhe.

U Bonn: 25. April-1. Nov. 1934 (Entlassung aufgrund kritischer Äußerungen über die EugenikIdeologie) Vertreter des Ordinarius und stellvertr. Direktor der U-Nervenklinik.

Weißenau (heute: Ortsteil von Ravensburg): Seit 1. Febr. 1935 Assistenzarzt an Württ. Heil- und Pflegeanstalt.

Stuttgart: Seit 1. Juli 1935 Ober-Medizinalrat am Württ. Innenministerium.

Zwiefalten: 25. April 1936-Nov. 1939 Direktor der Württ. Heilanstalt.

Weißenau: Seit Nov. 1939 formaler Leiter der Württ. Heil- und Pflegeanstalt.

Winnenden (bei Stuttgart): Nov. 1939-April 1945 Kriegsdienst als Chefarzt des Nervenlazaretts. 
U Bonn: SS 1946-WS 1947/48 Lehrstuhlvertr. (Gast-Prof.) und kommissar. Leiter der U-Nervenklinik; 1947 Ruf an U Berlin abgelehnt; SS 1948-SS 1952 (Ruhestand) o. Prof. und Direktor der U-Nervenklinik; Febr. 1955-Dez. 1956 zunächst kommissar. Leiter, dann erneut Direktor der U-Nervenklinik.

Siehe auch Anhang Sporteinrichtungen an $U H$ 1910-1933 und ihre Mitglieder

E 1918 Eisernes Kreuz II. Klasse; Frontkämpferehrenkreuz.

Qu UAH PA 948, 3995; Rep. 40-399; Fak.-Akte HIII-111/156 fol. 133r-141r (Habilitation). GLA Abt. 235, Fasz. 2038. • Briefe: UBH. - Nachlaß: Bayer. Staatsbibliothek München, s. https://bsbdok.digi tale-sammlungen.de/general/item/bsbdok:123321/ component/bsbdok:123320/Nachlassverzeichnis_ Gruhle, Hans_Ana 612.pdf (abgerufen am 26. Aug. 2017). - Briefwechsel zwischen Eduard Spranger und Käthe Hadlich. Hrsg. von Karin Priem u.a. Bibliothek für Bildungsgeschichtliche Forschung des DIPF (Deutsches Institut für Internationale Pädagogische Forschung), online unter http://bbf. dipf.de/digitale-bbf/editionen/spranger-hadlich/ person-g. - Mitteilungen: Herr Prof. Dr. Wolfgang Gruhle, Bergisch-Gladbach.

$W$ Die Ursachen der jugendlichen Verwahrlosung und Kriminalität. Berlin 1912. - Säufer als Brandstifter. Berlin 1914. (Mitverf.: (siehe) Karl Wilmanns, Georg L. Dreyfus.) (Verbrechertypen. H. 2.) - Psychiatrie für Ärzte. Berlin 1918. 2. Aufl. 1922. - Selbstmord. Stuttgart 1940. - Verstehende Psychologie. Stuttgart 1948. 2. Aufl. 1956. Verstehen und Einfühlen. Gesammelte Schriften. Berlin 1953. Gutachtentechnik. Berlin 1955.

MG, MHG 1913-1914 Verbrechertypen. 3 H. (zus. mit Albrecht Wetzel). 1921 Psychologische Forschung - Zs. für Psychologie und ihre Grenzwissenschaften. - Psychiatrie der Gegenwart, Forschung und Praxis. Berlin 1960-1967.

$L$ Reventlow, Franziska Gräfin zu: Herrn Dames [= Gruhle] Aufzeichnungen oder Begebenheiten aus einem merkwürdigen Stadtteil. München
1913. Große Nervenärzte 3 (1963); NDB 7 (1966) S. 209 f.; Verzeichnis Bonn (1968) S. 98; Chronik Ärzte H (1985) S. 129 f.; Klüpfel/Graumann (1986) S. 33 u.ö. - Spiegelberg, Herbert: Phenomenology in Psychology and Psychiatry. A Historical Introduction. 2. Aufl. Evanston (Illinois) 1986. S. 99 u. ö. - Jansen (1992) S. 409 (Register). - Kreuter (1996) S. 482-485. • Über H.G. in: Opfer nationalsozialistischen Unrechts an der Universität Bonn ... Hrsg. von Klaus Borchard. Bonn 1999. S. 57 f. - Peiffer (2004) S. 1150 (Register). * Forsbach, Ralf: Die medizinische Fakultät der Universität Bonn im „Dritten Reich“. München 2006. S. 197-200. - Grüttner/Kinas (2007) S. 175 u. ö. • Böhnke, Claudia: H.W. G. Leben und Werk. Med. Diss. Bonn 2008. •... da liegt der riesige Schatten Freud's (2008) S. 199-207. - Wissenschaftsatlas der UH (2011) S. 244 f. • Gundlach, Horst: H. W. G. in: Deutschsprachige Psychologinnen und Psychologen 1933-1945. Hrsg. von Uwe Wolfradt u.a. Wiesbaden 2015. S. 149-151.

\section{$P$ Bildarchiv UAH.}

\section{Grupe, Eduard August Rudolf}

1919-1920 (Lehrbeauftragter)

1920-1932 (Honorar-Prof.) Jur. Fak.

Juristische Lexikographie, Grenzgebiete der

Rechtswiss., Geschichte des Altertums

* $\quad$ 04. Mai 1857 Göttingen
$+\quad$ 19. Mai 1935 Heidelberg
ev.

V Wilhelm G. (1831-1905) Reichseisenbahnbeamter

M Friederike Dorothea geb. Siebrecht (18271881)

๑ 23. Jan. 1886 Alma geb. Libeau $\left({ }^{*} 1859 \dagger\right.$ nach 1935)

K $\quad 1 \mathrm{~S}, 2 \mathrm{~T}$

Lb U Straßburg: Seit 1876 Studium der Klassischen Philologie; 25. Okt. 1879 Staatsprüfung; 4. Dez. 1884 Dr. phil. 
1879-1882 Hilfslehrer in Straßburg, anschl. Colmar, erneut Straßburg.

Pfalzburg (Lothringen; heute: Phalsbourg): 18821889 Lehrer.

Zabern (Elsaß; heute: Saverne): Seit 1889 Oberlehrer.

Buchsweiler (Elsaß; heute: Bouxwiller): Seit 29. Dez. 1896 Gymnasial-Prof.

Metz (Lothringen): Seit 1904 Gymnasial-Prof.

Buchsweiler: Seit Mai 1907 Direktor des Gymnasiums.

Metz: Febr. 1915-Dez. 1918 (Entlassung durch franz. Regierung) Direktor des Gymnasiums.

UH: Seit 3. Okt. 1919 Lehrauftrag für Juristische Lexikographie; seit 20. Aug. 1920 o. Honorar-Prof. für Grenzgebiete der Rechtswiss., Geschichte des Altertums; SS 1932 letzte Vorlesungsankündigung.

1902-1933 Bearbeiter des II. Bandes des Vocabularium jurisprudentiae Romanae im Auftrag der Akademie der Wissenschaften Berlin

1915 Geh. Studienrat

E 1917 Dr. iur. h.c. Straßburg. 1908 Königl. PreuBischer Roter Adler-Orden IV. Klasse.

Qu UAH PA 3999. GLA Abt. 235, Fasz. 2041. Briefe: UBH.

$W$ Die Gajanischen Institutionenfragmente in Justinians Digesten in: Zs. der Savigny-Stiftung für Rechtsgeschichte 16 (1895) S. 300-319. • Kaiser Justinian. Aus seinem Leben und seiner Zeit. Leipzig 1923.

$L$ NDB 7 (1966) S. 233; WBIS; Schroeder (2010) S. $493 \mathrm{f}$.

\section{Güntert, Hermann Georg Konrad}

1913-1921, 1926-1946 Phil. Fak.

Vgl. Indogermanische Sprachwissenschaft

* 05. Nov. 1886 Worms

$\dagger$ 23. April 1948 Heidelberg ev.

V Hermann G. (1859-1897) Kaufmann

M Johanna Katharina Sophie geb. Lack (18621941)

๑ 6. Okt. 1923 Gisela Sophie Emma Julie geb. Wachenfeld (1902-1987) T von Friedrich W. (1865-1928), u. a. 1899-1928 o. Prof. für Rechtswiss. Rostock, s. Kürschner (1926) Sp. 2064, Catalogus prof. Rostochiensium online

$\mathrm{K}$ keine.

Lb UH: Seit SS 1905 Studium der Klassischen Philologie, Germanistik, Indogermanistik; 6. April 1909 Staatsexamen in Latein, Griechisch und Deutsch als Hauptfächer für Lehramt an höheren Schulen; 11. Juli 1908 Rigorosum, 10. Juli 1909 (Datum der Promotionsurkunde) Dr. phil.

U Leipzig: WS 1909/10 Studium der Vgl. Indogerman. Sprachwiss.

H: 1909-1910 (mit Unterbrechung) Probekandidat, 15. Nov. 1910-4. Nov. 1918 Lehrer, 4. Nov. 1918-Okt. 1921 hauptamtlicher Prof. am Gymnasium (heute: Kurfürst-Friedrich-Gymnasium „KFG“"). In dieser Zeit:

UH: 8. Febr. 1913 Habilitation für Indogerman. Sprache und Altertumswiss.; seit 25. Febr. 1918 nichtetatm., seit 1920 nichtplanm. a. o. Prof.

U Rostock: Seit 23. Okt. 1921 planm. a. o. Prof. für Vgl. Indogerman. Sprachwiss. und Sanskrit; seit 1. April 1922 o. Prof.

UH: Seit SS 1926 o. Prof. und Direktor des Sprachwiss. Seminars als Nachf. von Christian Bartholomae; seit Nov. 1933 unbesoldeter Lehrauftrag für Germanenkunde; seit Juni 1938 stark eingeschränkte Lehrtätigkeit durch Schlaganfall; Dez. 1945 „mit Rücksicht auf seine schwere Erkrankung ... [wird] jedoch von einer Anordnung der 
Amtsenthebung abgesehen" (aus: UH im Nationalsozialismus (2006) S. 384); 31. März 1946 auf eigenen Antrag Emeritierung.

1928/29, 1933/34, 1934-1937 Dekan der Phil. Fak. der UH

1930 Vorsitzender des Vereins für das Deutschtum im Ausland

Siehe auch Johannes Stein

E Mitglied: Deutscher Germanistenbund, 1931 Akademie der Wissenschaften H. 1939 Kommandeurkreuz des Bulgarischen Ordens für Zivilverdienst.

Qu UAH PA 421, 4002; Fak.-Akte H-IV-757/4 fol. 653r. GLA Abt. 235, Fasz. 2042. Nachlaß: UBH. • Mitteilungen: Frau Gisela Güntert (†), Heidelberg.

$W$ Kalypso. Bedeutungsgeschichtliche Untersuchungen auf dem Gebiet der indogermanischen Sprachen. Halle/S. 1919. - Von der Sprache der Götter und Geister. Halle/S. 1921. • Grundfragen der Sprachwissenschaft. Leipzig 1925. 2. Aufl. bearb. von Anton Scherer. Heidelberg 1956. Am Nornenquell. Nordische Dichtungen. Leipzig 1933. - Der Ursprung der Germanen. Heidelberg 1934. Prometheus, der arische Heiland. Mythenspiel. Heidelberg 1938. - Geschichte der germanischen Völkerschaften. Leipzig 1943.

HG 1937-1942 Indogermanische Bibliothek: Abt. 1 und 3. 1938-1939 Zs. „Wörter und Sachen“.

MHG 1926-1937 Zs. „Wörter und Sachen“.

$L$ Goegginger, Wolf H.: H. G. als Religionsforscher in: Numen. Int. Review for the History of Religions (1967) S. 150-158. - Glockner, Hermann: Freunde in Heidelberg. Erinnerungen an H. G. in: Heidelberger Jahrbücher 17 (1973) S. 157-174. • Antiquitates Indogermanicae. Gedenkschrift für H. G. Hrsg. von Manfred Mayrhofer u. a. Innsbruck 1974 (mit Werkverz.). • WBIS; Jansen (1992) S. 409 (Register); Ders. (1992a) S. 165 (Register); Das „Gol- dene Buch“ des KFG (1994) S. 115f.; Hutton (1999) S. 407 (Register); UH im Nationalsozialismus (2006) S. 1254 (Register). - Lincoln, Bruce: H.G. in the 1930s. Heidelberg, Politics, and the Study of Germanic/Indogermanic Religion in: The Study of Religion under the Impact of Fascism. Ed. by Horst Junginger. Leiden 2008. S. 179-204. • Catalogus prof. Rostochiensium online; Riecke (2016) S. 145 (Register); Deutsche Biographie, s. https:// www.deutsche-biographie.de/gnd116911336.html [07. 11. 2017].

$P$ Bildarchiv UAH; Antiquitates Indogermanicae (1974).

\section{Gumbel, Emil Julius}

1923-1932 Phil. Fak.

Statistik

* 18. Juli 1891 München

$\dagger$ 10. Sept. 1966 New York

mosaisch, später konf.-los

V Hermann G. (1857-1916) Privatbankier

M Flora geb. Gumbel (1869-1917)

๑ Mai 1930 Marieluise geb. Czettritz gesch. Solscher (1892-1952) T des Generalmajors Hermann C. (1865-1946), s. Jansen (1991) S. 387

K 1 Adoptiv-S, 1 Stief-S

Lb U München: 1910-1914 Studium der Nationalökonomie, Mathematik; 1. Febr. 1913 Diplom für Versicherungsverständige; 1. Febr. 1913-1. Aug. 1914 Assistent am Seminar für Statistik und Versicherungswissenschaft; 28. Juli 1914 Dr. oec. publ.

Aug. 1914-Jan. 1915 (Beurlaubung „wegen Krankheit") Kriegsfreiwilliger.

Eintritt: Herbst 1915 Bund Neues Vaterland, April 1917 Unabhängige Sozialdemokratische Partei Deutschlands, 1920 (1928 Austritt, 1930 Wiedereintritt) SPD.

Berlin: 1. Febr. 1916-1. Mai 1918 Ingenieur in Flugzeugmeisterei Adlershof (bei Berlin); seit WS 1915/ 16 auch Studium der Physik an U; seit 1. Mai 1918 
Ingenieur bei Firma Telefunken; seit 1921 Lehrer an Betriebsräteschule des Allg. Dt. Gewerkschaftsbundes.

UH: 20. Jan. 1923 Habilitation für Statistik am Volkswirtschaftl. Seminar; 30. Juli 1924 Einleitung e. Disziplinarverfahrens; e. der Gründe dafür war der Satz G.s in e. Rede über die im Krieg „ich will nicht sagen - auf dem Felde der Unehre gefallen[en] ... - aber doch auf gräßliche Weise ums Leben" gekommenen Soldaten; 31. Juli 1924 Suspendierung von Lehrtätigkeit durch badischen Kultusminister; 6. Aug. 1924 Aufhebung der Suspendierung durch Kultusministerium; bis Mai 1925 Phil. Fak. leitet weitere disziplinarische Untersuchungen gegen G. ein; Okt. 1924 Vortragsreise durch Frankreich auf Einladung der franz. Liga für Menschenrechte, s. hierzu G.s Beschreibung seiner franz. Reiseeindrücke in: Jansen (1991) S. 292-296; Mai 1925-März 1926 auf eigenen Antrag Beurlaubung von $\mathrm{U}$. $\bullet$ In dieser Zeit:

Moskau: Mai-Sept. 1925 (unter Belassung seiner Lehrauftragsvergütung), 1. Okt. 1925-30. März 1926 (ohne Vergütung) Mitarbeiter am Marx-Engels-Institut.

UH: 16. Mai 1925 Beschluß der Phil. Fak. „in der Angelegenheit G." lautet: Die Fak. "glaubt eher ein solches Mitglied ertragen zu können, als Gefahr laufen zu dürfen, eine nicht von jeder Seite aus unangreifbare Ausschließung eines ihrer Mitglieder vorzunehmen" (s. weiter den in e. Broschüre gedruckten Beschluß in: UAH PA 4007); 26. Febr. 1929 Phil. Fak. lehnt Verleihung der Amtsbezeichnung a.o. Prof. an G. auf Anfrage des Ministeriums des Kultus und Unterrichts ab; in diesem Schreiben betont der Dekan, daß e. Verleihung des Titels seitens des Ministeriums „ohne Anregung der Fak. ... die Verletzung eines bis dahin unangefochtenen Gewohnheitsrechts" bedeuten würde (PA 4007); 4. Aug. 1930 Ern. zum a. o. Prof. durch das Staatsministerium; Nov. 1930, Febr. 1931 größere Protestversammlungen gegen Ern. G.s zum Prof. mit Teilnehmern u. a. aus der Vereinigung Heidelberger Verbindungen, der NSDAP und DNVP; Anfang 1932 Reise in die UdSSR; 27. Mai 1932 in Anspielung auf das auch „Kohlrübenwinter" genannte Hungerjahr 1917/18 äußert G. öffentlich, e. Kohlrübe sei als Kriegerdenkmal geeigneter als „eine leichtbekleidete Jungfrau mit Siegespalme in der Hand“; 15. Juni 1932 wiederholte Einleitung e. Disziplinarverfahrens durch Phil. Fak.; 5. Aug. 1932 Entziehung der venia legendi durch badisches Kultusministerium („Ruhestörer und Friedensbrecher des akad. Gemeinschaftslebens", s. hierzu weiter Jansen (1994) S. 218f.)

Aug.-Sept 1932 USA-Reise; WS 1932/33 Gastvorlesungen am Inst. Henri Poincaré der U Paris.

UH: 1. Febr. 1933 Ablehnung des Einspruchs G.s gegen seine Entlassung durch Kultusminister; 7. März 1933 Berliner Polizeipräsident erläßt Haftbefehl gegen G.; 23. Aug 1933 Ausbürgerung.

U Lyon: Seit 1934 Chargé de Recherches, seit 1936 Maître de Recherches am Math. Inst.; Mai-Okt. 1940 Flucht in die USA.

New York: 1940-1944 Stipendiat der RockefellerFoundation und Associate Prof. an New School for Social Research; u. a. seit 1945 Visiting Prof., 1947-1948 Associate Prof. am Brooklyn College; 1951-1952 Consultant Prof. an Stanford U; 19531966 Adjunct Prof. an School of English der Columbia U.

FU Berlin: Jeweils SS 1953-1956, 1959 Gast-Prof. • 1956 Einsetzung in die Rechtsstellung e. emeritierten Ordinarius.

1919 Mitbegründer des Friedensbundes der Kriegsteilnehmer. 1927-1932 Vorstandsmitglied der Dt. Liga für Menschenrechte

Seit 2016 trägt eine neueingerichtete Forschungsund Dokumentationsstelle am Moses Mendelssohn Zentrum Potsdam den Namen „Emil Julius Gumbel Forschungsstelle Antisemitismus und Rechtsextremismus", siehe hierzu Schoeps, Julius H.: Die E.J.G. Forschungsstelle stellt sich vor in: Mitteilungen der E. J. G. Forschungsstelle ... Potsdam (Jan. 2017) Ausgabe 1, S. 2.

E 1926 Korr. Mitglied des Timirjasew-ForschungsInst. Moskau und mehrerer math. Vereinigungen. 1949 Guggenheim-Preis. 
Qu UAH PA 4007; Fak.-Akte H-II-319/2; von B-3075/2 bis B-3075/10, von B-3075/12 bis B-3075/ 19; B-3182/6. - GLA Abt. 235, Fasz. 1890-1895. • Briefe: UBH. - The E. J. Gumbel collection. Political papers of an anti-Nazi scholar in Weimar and exile, 1914-1966. From the Archives of the Leo Baeck Institute. Editorial Advisor Arthur Brenner. New York City 1990. - Siehe auch Nachlaß Hans Schneider (1912-2010) im UAH.

$W$ Verschwörer. Beiträge zur Geschichte und Soziologie der nationalistischen Geheimbünde seit 1918. Wien 1924. Nachdr. 1979. • Vier Jahre politischer Mord. Wien 1924. Neuaufl. 1980. - Statistical theory of extreme values and some practical applications. New York 1954. - Statistics of Extremes. New York 1958.

$H G 1938$ Freie Wissenschaft.

$L$ Leisen, Adolf: Die Ausbreitung des völkischen Gedankens in der Studentenschaft der Weimarer Republik. Diss. Heidelberg 1964. • Über G. in: G., E. J.: Verschwörer. Nachdr. Heidelberg 1979. S. VXXVI. • Jansen, Christian: Der „Fall Gumbel“ und die Heidelberger Universität 1924-1932. Heidelberg 1981. - Pazifismus in der Weimarer Republik. Beiträge zur historischen Friedensforschung. Hrsg. von Karl Holl ... Paderborn 1981. • Olenhusen, Albrecht Götz von: Der Pazifist E. J. G. in: Vorgänge 62/63, H. 2/3 (1983) S. 172-176. • Jansen, Christian: E. J.G. - Ein Statistiker des Antimilitarismus in: Pazifismus zwischen den Weltkriegen. Hrsg. von D. Harth u.a. Heidelberg 1985. S. 31-42. - Mussgnug (1988) S. 297 (Register). - Eisfeld, Rainer: Ausgebürgert und doch angebräunt. Deutsche Politikwissenschaft 1920-1945. Baden-Baden 1991. • E.J.G. Auf der Suche nach Wahrheit ... Hrsg. von Annette Vogt. Berlin 1991. Heiber I (1991) S. 636 (Register). - Jansen, Christian: E. J. G. - Portrait eines Zivilisten. Heidelberg 1991. - Wittebur, Klemens: Die deutsche Soziologie im Exil. 19331945. Münster 1991. • Jansen (1992) S. 409 (Register); WBIS. - E. J. G. Akademische Gedächtnisfeier anlässlich des 100. Geburtstages ... Heidelberg 1993. Baden-Württ. Biographien II (1999) S. 173176. Brenner, Arthur D.: E. J. G.: Weimar German
Pacifist and Professor. Boston 2001. (Bibliographie S. 199-220). - Gatens, Rosanna M.: Prelude to Gleichschaltung: The university of Heidelberg and the E.J.G. controversies, 1924-1932 in: European history quarterly 31 (2001) Nr. 1, S. 65-100. Šejnin, Oskar B.: G., Einstein and Russia. Moskau 2003. Langkau-Alex, Ursula: Dokumente zur Geschichte des Ausschusses zur Vorbereitung e. deutschen Volksfront ... Berlin 2005. • Wegbereiter der Demokratie. Hrsg. von Manfred Asendorf. Stuttgart 2006. Gatens, Rosanna M.: Turnips and War Memorials: E. J. G.'s critique of German militarism, 1918-1933 in: Int. Social Science Review (March 22, 2008) online. - Siegmund-Schultze (2009) S. 464 (Register). - Jansen, Christian: Beethovenstraße 39. Hier wohnte ... G. in: Heidelberg. Jahrbuch zur Geschichte der Stadt 2014. Heidelberg 2013. Jg. 18. S. 209-212. • Homo Heidelbergensis mathematicus online; Intellektuelle in Heidelberg (2014) S. 129-139, 228f. - Maier-Metz, Harald: Entlassungsgrund: Pazifismus. Albrecht Götze, der Fall G. und die Marburger Universität 1930-1946. Münster 2015. - Fernández, Lexuri, Scherer, Matthias: E. J.G. Ein Statistiker der Extreme in: Risiko Manager. Fachzeitschrift für Risiko-Experten 05 (2016) S. 33-39. • Heither, Dietrich: „Ich wusste, was ich tat." E. J. G. und der rechte Terror in der Weimarer Republik. Köln 2016. - Deutsche Biographie, s. https://www.deutsche-biographie.de/ gnd118543563.html [07.11.2017].

$P$ Bildarchiv UAH.

Gundelfinger, Friedrich Leopold

siehe Gundolf, Friedrich

Gundolf, Friedrich Leopold (bis 1927:

Gundelfinger)

1911-1931 Phil. Fak.

Neuere Dt. Literatur

* 20. Juni 1880 Darmstadt

$\dagger \quad$ 12. Juli 1931 Heidelberg mosaisch 
V Dr. phil. Sigmund Gundelfinger (1846-1910) seit 1869 Privat-Dozent, seit 1873 a.o. Prof. für Mathematik Tübingen, 1879-1907 (Ruhestand) o. Prof. Polytechnikum Darmstadt, s. NDB 7 (1966) S. 315, WBIS

M Amalie geb. Gunz (1857-1922), s. Friedrich Gundolf - Elisabeth Salomon. Briefwechsel (2015) S. 792 (Register)

4. Nov. 1926 Dr. phil. Elisabeth Agnes geb. Salomon (1893-1958), s. Schönhärl (2009) S. 457 (Register); Lexikon jüdischer Einwohner Hs (2011) S. 149; Eschenbach, Gunilla, Schönhärl, Korinna: Salomon, Elisabeth Agnes (ab 1926 Gundolf) in: Stefan George und sein Kreis. Ein Handbuch. Hrsg. von Achim Aurnhammer u. a. Berlin 2012. Bd. 3. S. 1606-1608; Briefe in $\mathrm{UBH}$

K $\quad 1$ T (Mutter: Agathe geb. Mallachow gesch. Closson (1884-1983) Pianistin, s. Friedrich Gundolf - Elisabeth Salomon. Briefwechsel, S. 796 (Register)): Dr. Cordelia Ottilie G. (1917-2008) seit 1960 Dozentin für Italienische Sprache und Literatur an U of Melbourne (Australien), s. Matthiesen, Michael: Das Kind des Jüngers ... in: FAZ vom 12. Sept. 2008; Friedrich Gundolf - Elisabeth Salomon. Briefwechsel, S. 796 (Register).

Lb Seit WS 1898/99 Studium an U München, SS 1900 H, seit WS 1900/o1 Berlin; März 1903 Dr. phil. U Berlin; 1903-1911 schriftstellerische Tätigkeit in München, dann Darmstadt; 1907 Studienreise mit Stefan George nach Italien.

UH: 26. April 1911 Habilitation; seit 1. Aug. 1917 nichtetatm. a.o. Prof.; 1920 Ruf an U Berlin abgelehnt; seit 20. Aug. 1920 planm. a. o. Prof.; seit 25. Okt. 1920 erster Ordinarius für Neuere Dt. Literaturgeschichte. In dieser Zeit:

1916-1918 Kriegsdienst.

1929/30 Dekan der Phil. Fak. der UH

E 1929 Mitglied der Akademie der Wissenschaften H. 1917 Jakob-Minor-Preis; 1929 Goethepreis der Stadt Frankfurt/M.; 1930 Lessingpreis Hamburg.
Qu UAH PA 422, 4013; RA 6588; Rep. 40-399; Fak.-Akten H-IV-757/13 fol. 294 u. ö., H-IV-757/16 fol. 834 u. o.. - GLA Abt. 235, Fasz. 2044. • Briefe: UBH; DLA Marbach; Württ. Landesbibliothek Stuttgart. - Wolfskehl, Karl und Wolfskehl, Hanna: Briefwechsel mit F.G. Hrsg. von Karlhans Kluncker. 2 Bde. Amsterdam 1976-1977. • F. G. - Friedrich Wolters. Ein Briefwechsel aus dem Kreis um Stefan George. Hrsg. von Christophe Fricker. Köln 2009. - Friedrich Gundolf - Elisabeth Salomon. Briefwechsel (1914-1931). Im Auftrag des DLA Marbach hrsg. von Gunilla Eschenbach und Helmuth Mojem. Berlin 2015. Nachlaß: Institute of Germanic and Romance Studies der University of London; Württ. Landesbibliothek Stuttgart. • Mitteilungen: Frau Dr. Cordelia O. Gundolf ( $†$ ), Melbourne.

$W$ Shakespeare und der deutsche Geist. Berlin 1911. 9. Aufl. 1947. Neudr. 1959. - Stefan George in unserer Zeit. Heidelberg 1913. 3. Aufl. 1918. • Goethe. Berlin 1916. 13. Aufl. 1930. Nachdr. 1964. • Dichter und Helden. Heidelberg 1921. 2. Aufl. 1923. Shakespeare - sein Wesen und Werk. 2 Bde. Berlin 1928. 3. Aufl. 1949. Gedichte. Berlin 1930. Romantiker. 2 Bde. Berlin 1930-1931. - Anfänge deutscher Geschichtsschreibung von Tschudi bis Winckelmann. Aufgrund nachgelassener Schriften F. G.s bearb. und hrsg. von Edgar Wind. Amsterdam 1938. Neuausg. Frankfurt/M. 1992. Die deutsche Literärgeschicht: reimweis kurz fasslich hergericht. Hrsg. ... von Ernst Osterkamp. Heidelberg 2002. - Siehe Neutjens, Clemens: F.G. Ein bibliographischer Apparat. Bonn 1969. Loecker, Armand de: F. G. Bibliographie 1968-1980 in: Duitse Kroniek 33 (1983) S. 30-44.

HG Romantiker-Briefe. Jena 1907.

MHG 1910-1912 Jahrbuch für die geistige Freiheit.

L NDB 7 (1966) S. 319-321; Lehmann (1967) S. 229; Glockner (1969) S. 273 (Register). • Bock, Claus Victor: F. G. .... „Verblassendes Blendwerk“ oder "lebendiger Geist“ in: Heidelberger Jahrbücher 25 (1981) S. 33-42. • Schmitz, Viktor: F. G. und seine Schüler in: Ruperto Carola 33. Jg., H. 65/ 66 (1981) S. 47-56. - Kannellopoulus, Panajotis: Nachruf auf F. G. in: Ruperto Carola 34 Jg., H. $67 /$ 68 (1982) S. 106 f. - Sühnel, Rudolf: F. G. und der 
George-Kreis in: Semper apertus 3 (1985) S. 259284. - Badische Biographien N. F. II (1987) S. 111113; Jansen (1992) S. 409 (Register); Ders. (1992a) S. 165 (Register). O Osterkamp, Ernst: F. G. in: Wissenschaftsgeschichte Germanistik (2000) S. 162175. Hergemöller, Bernd-Ulrich: Mann für Mann. Ein biographisches Lexikon. Frankfurt/M. 2001. S. $312 \mathrm{f}$. - Thimann, Michael: "Caesars Schatten“. Die Bibliothek von F. G. Rekonstruktion und Wissenschaftsgeschichte. Heidelberg 2003. Kriegstagebuch K. Hampe (2007) S. 963 (Register). • Arrighetti, Anna Maria: Mensch und Werk in kritischen Publikationen des George-Kreises. Zu F.G.s "Goethe“ und zu Ernst Bertrams „Nietzsche - Versuch einer Mythologie“. Heidelberg 2008. - Schönhärl (2009) S. 457 (Register); 100 Jahre Germanistik in Hamburg (2011) S. 115 f., 457 u. ö.; 200 Jahre Berliner Germanistik (2011) S. 382 (Register). Grünbaum, Melitta: Begegnungen mit G. Hrsg. von Gunilla Eschenbach ... Marbach/Neckar 2012. - Raulff, Ulrich: Kreis ohne Meister. Stefan Georges Nachleben. München 2012. S. 537 (Register). Egyptien, Jürgen: F. G. in Heidelberg. Marbach/Neckar 2013. - Intellektuelle in Heidelberg (2014) S. 424 (Register). - Redl, Philipp: Dichtergermanisten der Moderne: Ernst Stadler, F.G. und Philipp Witkop zwischen Poesie und Wissenschaft. Köln 2016. • Riecke (2016) S. 145 (Register). • Egyptien, Jürgen: „... eine solche Einheit so zu erleben das ist schon einen Weltkrieg wert“. F. G. als Deuter des Ersten Weltkrieges, Goethe-Interpret und George-Jünger in: UH während des Ersten Weltkriegs (2017) S. 215-240.

$P$ Bildarchiv UAH; graph. Slg. UBH; NDB (1966); Heidelberger Jahrbücher (1981).

\section{Gutzwiller, Max Carl Joseph}

1926-1933 (1936) Jur. Fak.

Römisches und Dt. Bürgerliches Recht, Privatrecht

* o1. Okt. 1889 Basel

$\dagger$ o6. Febr. 1989 Muntelier (Kanton Fribourg, Schweiz)

kath.

V Karl Max Joseph G. (1856-1928) Bankier, Grossrat

M Emilie geb. Meyer (1868-1929), u. a. 1912-1921 erste Präsidentin des Schweizer Kath. Frauenbundes, 1912-1918 Präsidentin des Kath. Frauenbundes Baselstadt, s. Ueberschlag, E.: Frau Emilie G.-Meyer. Diplomarbeit an der sozial-caritativen Frauenschule. Luzern 1935; Mutter, C.: Frauenbild und politisches Bewusstsein im Schweizer Kath. Frauenbund. Freiburg im Üchtland 1987; Historisches Lexikon der Schweiz - online - vom 12. Dez. 2013

@ 29. Dez. 1921 Gisela geb. Strassmann (18961942), s. Lexikon jüdischer Einwohner Hs (2011) S. 151f.; T von Paul S. (1866-1938) 1900 Gründer und bis 1936 (zwangsweise SchlieBung und Verkauf) Leiter e. privaten Frauenund Geburtenklinik in Berlin, seit 1897 PrivatDozent, 1906 Verleihung des Titels „Prof.“, 1919-1935 (Entziehung der Lehrbefugnis) apl. Prof. für Gynäkologie Berlin, s. Strassmann, Wolfgang Paul: Die Strassmanns. Schicksale e. deutsch-jüdischen Familie über zwei Jahrhunderte. Frankfurt/M. 20o6; Lange-Quassowski, Jutta und Schneider, Volkmar: Eine bedeutende Ärztedynastie: Die Strassmanns. Berlin 2012. S. 13-26.

๑ Dez. 1943 Anne Marie geb. Meyer

K 3 T, 2 S: u.a. Martin Charles G. (1925-2014) Physiker: seit 1953 Exploration and Production Research Laboratory der Shell Oil Company in Houston (Texas), 1960-1963 Labor der IBM (Schweiz), 1963-1993 (Ruhestand) Thomas J. Watson Research Center in Yorktown Heights (New York); seit 1993 Adjunct Prof. of Physics an Yale U in New Haven (Connecticut), s. M.C.G.: A Biographical Memoir by M. V. Berry and D. Baeriswyl. National Academy of Sciences. Washington 2016, s. online www.nasonline.org/memoirs. 
Vw Vorfahr: Stephan G. (1802-1875) seit 1827 Anwalt und Parlamentsmitglied in Basel, Hauptführer der Baselbieter Revolution, die 1833 zur Trennung von Basel-Landschaft und BaselStadt führte (siehe hierzu auch Hermann Rauschenplat); 1833 Präsident des Verfassungsrats des neugegründeten selbständigen Kantons Basel-Landschaft, anschl. Präsident des Landrats und bis ca. 1845 Präsident des Regierungsrats, s. Birkhäuser, Kaspar: Der Baselbieter Politiker S. G. ... Liestal 1983; Historisches Lexikon der Schweiz - online - vom 18. März 2008

Vw Bruder: Ernest G. (1891-1976) Bankier, s. Coston, Henry: Dictionnaire des dynasties bourgeoises et du monde des affaires. Paris 1975; https://www.gutzwiller.ch/en/home/strategy. html (abgerufen am 26. Aug. 2017).

Lb Studium: SS 1909 U Basel, seit WS 1909/10 Freiburg im Üchtland (heute: Fribourg), seit 1910 Berlin, seit 1911 Bonn; 31. Dez. 1917 Dr. iur. utr. an U Bonn.

Bern: 1918 Mitarbeiter im Rechtsbüro der Eidgenössischen Abt. für Auswärtiges (Politisches Department).

Berlin: Aug. 1918 Eintritt in schweizerischen diplomatischen Dienst als Gesandtschaftsattaché; 1921 Rückversetzung nach Bern.

Freiburg im Üchtland: Seit WS 1921/22 a. o. Prof.; seit Juni 1924 o. Prof.

UH: 3. Febr. 1926 Ern. zum o. Prof. als Nachf. von Friedrich Endemann und (Mit-)Direktor (bis 1929 zus. mit Karl Heinsheimer, nach 1929 alleiniger Direktor) des Inst. für Ausländisches Recht, s. hierzu UAH H-II-554/1; 1. April 1926 Dienstantritt; 1933 Ruf an U Istanbul abgelehnt; Mai 1933 Vorlesungsboykott durch nationalsozialistisch gesinnte Fachschaftsvertreter; nach Mai 1933 keine Vorlesungstätigkeit mehr; seit WS 1933/34 auf eigenen Antrag Beurlaubung (bei voller Gehaltszahlung); 30. Juni 1936 Entpflichtung , auf sein Gesuch hin ... G. wünscht seinen Wohnsitz in der Schweiz zu nehmen“ (aus: UAH PA 4018): Weggang aus ras- sischen und politischen Gründen; 1937 auf eigenen Antrag außerdem Entbindung aus Reichs- und Landeszugehörigkeit.

St. Gallen: 1936-1937 Lehrer an Handelshochschule.

Freiburg im Üchtland: WS 1937/38-SS 1956 (Emeritierung) o. Prof.; seit 1956 Honorar-Prof.

UH: 1. April 1958 Gewährung der Rechtsstellung e. in Ruhestand versetzten o. Prof. rückwirkend vom 1. April $1951 \mathrm{im}$ Zuge e. Wiedergutmachungsverfahrens.

1927/28 Dekan der Jur. Fak. der UH

1947 Mitglied des Institut de Droit Int. • 1951 und 1956 Vertreter der Schweiz in den Sessionen der Haager Konferenz für Int. Privatrecht.

Präsident: 1952-1954 Int. Law Association London, 1962-1965 Schweizer Vereinigung für Int. Recht

E 1959 Dr. iur. h.c. Amsterdam.

Qu UAH PA 4018; RA 5029; Fak.-Akte H-II-552/ 1. Personalverzeichnis der Universität Basel für das Sommersemester 1909. Basel 1909. S. 19. • Briefe: UBH. • Siebzig Jahre Jurisprudenz. Erinnerungen eines Neunzigjährigen. Basel 1978. Nachdr. 1989. (Autobiogr. mit Werkverz.)

$W$ Die Gestaltung unseres Unterrichts im römischen Recht. Bern 1922. • Der Geltungsbereich der Währungsvorschriften. Fribourg 1940. - Beitrag zum Haager Internationalprivatrecht 1951. Fribourg 1951. (Mitverf.) • Elemente der Rechtsidee. Ausgewählte Aufsätze und Reden. Hrsg. von Anton Heini. Basel 1964. Bibliographie in: Wubbe, Felix: In memoriam M. G. ... (1993) S. 842.

HG 1949-1971 Zeitschrift für schweizerisches Recht.

$L$ Who's who in Switzerland (1955) S. 169f.; WBIS. Ansprachen aus Anlass der Einweihung des M.-G.-Saales am 28. Mai 1980. Hrsg. vom Inst. für Ausl. und Int. Privat- und Wirtschaftsrecht der 
UH. Heidelberg 1982. - Kürschner (1983) S. 1361; Mussgnug (1988) S. 297 (Register). - M.G. in: Schweizerisches Jahrbuch für int. Recht 47 (1990) S. 59-81. • Jansen (1992a) S. 165 (Register). • Wubbe, Felix: In memoriam M. G. ... in: Zs. der Savigny-Stiftung für Rechtsgeschichte - Romanistische Abt. (1993) Bd. 110, S. 842-845. - Baur (2009) S. 244 f.; Schroeder (2010) S. 468-476 u.ö.; Lexikon jüdischer Einwohner Hs (2011) S. 152. - Leo, Paul Christopher: Wilhelm Groh ... Hamburg 2012. S. 123-127. - Kronke, Herbert: M.G.: Universalgelehrter des Privatrechts und moralische Instanz in: Heidelberger Thesen zu Recht und Gerechtigkeit (2013) S. 463-484. • Deutsche Biographie, s. https://www.deutsche-biographie.de/gn d118543849.html [07.11.2017]; Schroeder (2017) S. $339-345$.

\section{$P$ Bildarchiv UAH.}

\section{Guyet, Carl Julius}

1824-1836 Jur. Fak.

Rechtsphilosophie, Römisches Recht, Zivilprozeßrecht

* 11. März 1802 Homburg vor der Höhe (heute: Bad H. vor der H.)

$\dagger \quad$ o8. April 1861 Jena ev.-luth.

V Julius Carl G. (†1807) Hauptmann, Ritter der Ehrenlegion, Geheimrat

M Dorothea geb. Loewe ( $†$ nach 1852) 1838-1852 als e. der „Erbleihherrn“ (Grundbesitzer) der Rosalino-Mühle in Oberursel genannt, s. Ochs, Bernd: Die Rosalino-Mühle - Papiermühle und Tapetenfabrik in Oberursel, Herzogtum Nassau 1812 bis 1848 in: Mitteilungen des Vereins für Geschichte und Heimatkunde Oberursel e. V. H. 51. Oberursel 2012. S. 63 f.

(17. April 1827 Adeline Hedwig Maria Caroline geb. Höfle $\left({ }^{\star} 1805\right)$

$\mathrm{K}$ mind. $2 \mathrm{~T}$

Vw (?) August Ernst Ludwig G., seit 1832 PrivatDozent und 1833-1839 Beisitzer des Spruchkollegiums der Jur. Fak. der UH, s. UAH PA 1642, Jammers (1964) S. 177 u. ö.
Lb Seit WS 1818/19 Studium an UH, SS 1822 Berlin; anschl. Studienreise.

UH: 13. März 1823 Dr. iur.; 11. April 1823 Habilitation; SS 1824 Beginn seiner Vorlesungen; seit Herbst 1825 a. o. Beisitzer, 1827-1836 Mitglied des Spruchkollegiums der Jur. Fak.; 1827 Ruf an U Dorpat abgelehnt; seit 11. Okt. 1827 a. o. Prof.

U Jena: WS 1836/37-WS 186o/61 (†) o. Prof. • In dieser Zeit:

Jena: Seit 1836 Rat am Gesamt-Oberappellationsgericht und seit 1856 Vorsitzender des Schöffenstuhls.

1843 Geh. Justizrat

Qu UAH PA 1643; RA 5355; GF 9. - GLA Abt. 205, Fasz. 261. • Briefe: UBH.

$W$ Abhandlungen aus dem Gebiete des Civilrechts. Heidelberg 1829. - Juristische Abhandlungen und Rechtsfälle. Jena 1847. (Mitverf.)

HG Anton Friedrich Justus Thibaut's Juristischer Nachlaß. 2 Bde. Berlin 1841-1842.

L ADB 10 (1879) S. 239; WBIS; Jammers (1964)

S. 177 u. ö.; Schroeder (2010) S. 100 f., 108.

$P$ Bildarchiv UAH. - Abb. in: Bauer, Joachim: „Rektor und Dekane im Jubiläumsjahr 1858. “James Marshall und sein Jenaer Universitätsgemälde in: Weimar-Jena: Die große Stadt - Das kulturhistorische Archiv 1/1 (2008) S. 53-58.

\section{György, Paul}

1923-1933 Med. Fak.

Kinderheilkunde

* 07. April 1893 Großwardein (Siebenbürgen, Ungarn; heute: Oradea, Rumänien)

$\dagger \quad$ o1. März 1976 Morristown (New Jersey) ev. 
V Dr. med. Meinhard G., Arzt

M Adele geb. Poppe

$\infty$ 23. Okt. 1920 Margaret (Grete) A. geb. John $\left({ }^{*} 1893 \dagger\right.$ nach 1976$)$

K 3 S (davon $2 \mathrm{~S} \uparrow$ vor 1976), s. Lexikon jüdischer Einwohner Hs (2011) S. 153.

Lb Seit 1912 Studium an U Berlin, anschl. München, Genf, Budapest; 1914-1918 Kriegsdienst.

U Budapest: Frühjahr 1915 Staatsexamen und Dr. med.; seit 1918 Assistent am Kinderkrankenhaus.

UH: Seit 1920 Assistent, seit 1925 Oberarzt an UKinderklinik Luisen-Heilanstalt; 1. März 1923 Habilitation; seit 4. Aug. 1927 nichtplanm. a. o. Prof.; 27. April 1933 Entlassung auf eigenen Antrag wegen antisemitischer Gesetzgebung („infolge der veränderten politischen Verhältnisse“, aus: UAH PA 4019, Brief G.s an den Engeren Senat vom 27. April 1933) und Emigration nach Großbritannien.

U of Cambridge: 1933-1935 Research Fellow in Nutrition Laboratory; 1935 Emigration in die USA.

Cleveland (Ohio): Seit 1935 Visiting Assistant Prof. für Kinderheilkunde, 1937-1944 Associate Research Prof. an Case Western Reserve U; 1935-1941 Kinderarzt am Babies' and Children's Hospital, am University Hospital und Rainbow Hospital.

Philadelphia (Pennsylvania): Seit 1944 Assosciate Research Prof. für Kinderheilkunde, seit 1946 Prof. für Klinische Kinderheilkunde, seit 1950 Prof. für Kinderernährung (of nutrition in pediatrics), 19541959 (Emeritierung) Prof. für Kinderheilkunde an $\mathrm{U}$ of Pennsylvania School of Medicine. In dieser Zeit:

Philadelphia: 1950-1957 Chefarzt am Hospital der U of Pennsylvania; 1957-1963 (Emeritierung) Chefarzt für Kinderheilkunde am Philadelphia General Hospital.

H: 1952-1976 Auswärtiges Mitglied des MaxPlanck-Instituts für medizinische Forschung.
E 1958 Dr. med. h.c. UH. 1951 Boden Award of the American Institute of Nutrition; 1962 Mickle Fellowship of the University of Toronto; 1968 Howland Award of the American Pediatric Society; 1975 National Medal of Science.

Qu UAH PA 950, 4019. GLA Abt. 235, Fasz. 2046.

$W$ Avitaminosen und verwandte Krankheitszustände. Berlin 1927. - Die Behandlung und Verhütung der Rachitis und Tetanie. Berlin 1929. • A hitherto unrecognized biochemical difference between human milk and cow's milk in: Pediatrics 11 (1953) S. 98-107. - Protecting the pre-school child; programmes in practice. London 1965. (Mitverf.) - Undialyzable growth factors for Lactobacillus bifidus var. Pennsylvanicus in: European Journal of Biochemistry 43 (1974) S. 29-33.

L Fischer $1\left({ }^{3} 1962\right)$ S. 556; WBIS. Barness, L. A., Tomarelli, R. M.: P. G. ... A biographical sketch in: The Journal of Nutrition 32 (1) (1979) S. 17-23. • Who was who in America 7 (1981) S. 244; Dictionary of Emigrés 2 (1983) S. 443; Chronik Ärzte H (1985) S. 130. - Wille, Lutz: Universitäts-Kinderklinik Luisen-Heilanstalt zu Heidelberg 1860-1985 in: Der Kinderarzt 16. Jg., Nr. 7 (1985) Sp. 1007. • Mussgnug (1988) S. 297 (Register); Eckart (2000) S. 90; 150 Jahre Pädiatrie in H (2010) S. 69 f.; Lexikon jüdischer Einwohner Hs (2011) S. 152 f.; Deutsche Biographie, s. https://www.deutsche-biogra phie.de/gnd125340222.html [07.11. 2017].

$P$ Bildarchiv UAH; Chronik Ärzte H.

Gystrow, Ernst (Pseudonym)

siehe Hellpach, Willy 


\section{H}

\section{Häberle, Daniel}

(1917-1934 Nat.-Math. Fak.)

1934 (Honorar-Prof.) Nat.-Math. Fak.

1932-1934 (Lehrbeauftragter) Nat.-Math. Fak.

Pfälzische Landeskunde auf geologischer

Grundlage

* o8. Mai 1864 Daubenbornerhof in Enkenbach (bei Kaiserslautern; heute: Ortsteil von Enkenbach-Alsenborn)

$\dagger$ 09. Juni 1934 Heidelberg

- Odernheim am Glan ev.

V Philipp H. (1815-1885) Gutsbesitzer

M Katherine geb. Mayer (1828-1903)

๑ 11. Febr. 1899 Emilie geb. Grossarth (18701941)

K 2 T

Vw siehe Häberle, Katharina: Die Geschichte der Familie Häberle. Daubenbornerhof von 1525 bis zur Gegenwart. Die Nachkommen der Töchter mit Stammbaum von 1902 bis 1904 aufgestellt von D.H., von der Verfasserin ergänzt und weitergeführt. Alsenborn 1969.

$L b$ Bis 1882 Schulbesuch bis zur Unterprima; 1883 Eintritt in Handelsmarine; 1884/85 Militärdienstpflicht als Einjährig-Freiwilliger bei Kriegsmarine, zuletzt im Rang e. Reserveoffiziers; anschl. Reisen auf Handels- und Kriegsschiffen nach Schweden, Großbritannien, Frankreich, Amerika, West- und Ostindien, Süd- und Ostasien, Australien, Neuseeland, Südsee; Ausbildung bei der Kriegsmarine zum Zahlmeister.

Deutsch-Ostafrika: 1888-189o Beteiligung innerhalb der Schutztruppe an der Niederwerfung des Araberaufstands.

Daressalam: Seit 1891 Reichskolonialbeamter, zuletzt Vorstand der Gouvernementshauptkasse der dt. Kolonialverwaltung; Sommer 1902 aus Krank- heitsgründen (Tropenkrankheit) auf eigenen Antrag Versetzung in Ruhestand unter Bewilligung e. Pension und Verleihung des Titels Kaiserl. Rechnungsrat; 1902 Rückkehr nach Deutschland.

UH: Dez. 1902-Jan. 1923 Aushilfe an U-Kasse; seit WS 1902/03 Studium der Geschichte, Geographie, Volkswirtschaft, Naturwiss.; 23. Juni 1908 Dr. phil. nat.; 26. April 1907-1933 freiwilliger wiss. Mitarbeiter am 1908 gegründeten Geologisch-Paläontolog. Inst.; 3. Aug. 1914-29. Dez. 1919 Kriegsdienst als Verwaltungsvorstand des Stadthallenlazaretts in H; 28. Dez. 1917 Verleihung des Titels „Prof.“; zwischen WS 1917/18 und WS 1931/32 keine Lehrveranstaltungen in Vorlesungsverzeichnissen nachgewiesen; seit SS 1932 Lehrbeauftragter für Pfälzische Landeskunde; seit 19. März 1934 o. Honorar-Prof. • In dieser Zeit:

Handelshochschule Mannheim: Seit 1918 Angestellter, 1924-1933 nebenamtl. Dozent.

H: 7. März 1921-1933 Bestellung zum Rechner der Portheim-Stiftung durch Badisches Ministerium des Kultus und Unterrichts, 1924/25-1934 Leiter des von der Josefine und Eduard von PortheimStiftung für Wissenschaft und Kunst eingerichteten Inst. für Pfälzische Landeskunde im Palais Weimar, Hauptstraße 235.

Seit 1915 Heidelberger Stadtverordneter, zunächst für die Nationalliberale, seit ca. 1918 für die Deutsche Demokratische Partei

1925 Gründungsmitglied der heute noch bestehenden Pfälzischen Gesellschaft zur Förderung der Wissenschaften in Speyer

Die vorwiegend aus Pfalz-Literatur bestehende Privatbibliothek H.s übernimmt 1925 die Pfälzische Landesbibliothek in Speyer, s. Die Pfälzische Landesbibliothek 1921-1971. Aus Geschichte und Gegenwart. Hrsg. von Wolfgang Metz. Speyer 1971. S. 61.

E Mitglied: 1916 Geographische Gesellschaft München, 1917 Histor. Verein der Pfalz Speyer, 1924 Mannheimer Altertumsverein, 1927 Geographi- 
sche Gesellschaft zu Würzburg. • 1898 Königl. Preußischer Kronenorden IV. Klasse.

Qu UAH PA 2542, 4031; RA 6480; GF 50. GLA Abt. 235, Fasz. 2050. Briefe: UBH. $\bullet$ Teil-Nachlaß: UBH; Pfälzische Landesbibliothek Speyer.

W Das Reichsland bei Kaiserslautern ... Kaiserslautern 1907. Pfälzische Bibliographie. 6 Bde. Speyer 1908-1928. Auswanderung und Koloniegründungen der Pfälzer im 18. Jahrhundert. Kaiserslautern 1909. - Die landeskundliche Literatur der Rheinpfalz ... Heidelberg 1909. • Die ortskundliche Literatur der Rheinpfalz ... Heidelberg 1910. Die Gesellschaft für Naturwissenschaft und Heilkunde zu Heidelberg (1818-1847) ... Heidelberg 1913. - Die Wüstungen der Rheinpfalz auf Grundlage der Besiedlungsgeschichte. Kaiserslautern 1921. Der Naturhistorisch-Medizinische Verein zu Heidelberg von 1907-1931 in: Festschrift zum 75-jährigen Bestehen des NaturhistorischMedizinischen Vereins zu Heidelberg am 24. Okt. 1931. Heidelberg 1931. S. 211-242.

G, HG 1905-1920 Pfälzische Heimatkunde, 19211933 u. d. T.: Pfälzisches Museum - pfälzische Heimatkunde.

L Salomon, Wilhelm: Das Geologisch-Paläontologische Institut der Universität Heidelberg im ersten Jahrzehnt seines Bestehens 1901-1911. Heidelberg 1911. S. 137-159. - Kürschner (1928/29) Sp. 787; WBIS. • Christmann, Ernst: D. H. zum 100. Geb. in: Jahrbuch zur Geschichte von Stadt und Landkreis Kaiserslautern 2 (1963/64) S. 122-126. • May, Hans Erich: D.H. in: Pfälzer Lebensbilder. Hrsg. von Hartmut Harthausen. Speyer 1996. Bd. 5. S. 171-230. Engehausen (2008); Wissenschaftsatlas der UH (2011) S. 129. Burkhart, Ulrich: Vor 80 Jahren: der Historiker und Landeskundler D. H. stirbt in Heidelberg in: Historische Schlaglichter 2014. - Institut für pfälzische Geschichte und Volkskunde. Kaiserslautern 2014 - online (Ausdruck im UAH). • Deutsche Biographie, s. https:// www.deutsche-biographie.de/gnd116358378.html [07. 11. 2017].

$P$ Bildarchiv UAH; graph. Slg. UBH.

\section{Häusser, Ludwig}

1840-1867 Phil. Fak.

Geschichte

* 26. Okt. 1818 Kleeburg (Unterelsaß; heute: Cleebourg, Grand Est)

$\dagger$ 17. März 1867 Heidelberg ref.

V Johann Jakob H. (1787-1820/21) Pfarrer

M Anna Maria Dorothea geb. Paniel (1795-1857)

$\infty$ 17. Sept. 1846 Eleonore Wilhelmine geb. Rettig (1823-1895)

$\mathrm{K} \quad 2 \mathrm{~S}, 2 \mathrm{~T}$

Lb Seit WS 1835/36 Studium der Philologie, Geschichte an UH, seit SS 1838 Jena.

H: 15. Okt. 1838 Philolog. Staatsprüfung; 20. März 1839 Dr. phil. an U.

Wertheim: 1839-1840 Lehrer am Gymnasium; Febr.-Juni 1840 Studienreise nach Paris.

UH: 31. Aug. 1840 Habilitation für Geschichte und Philologie; 7. Mai 1845 Ern. zum a.o. Prof.; seit 16. Nov. 1849 o. Prof.; Rufe an U abgelehnt: 1849 Zürich, 1855 Erlangen, 1860 Jena. • In dieser Zeit:

H: 1840-1867 Prof. am Lyceum (heute: KurfürstFriedrich-Gymnasium „KFG“); 1840-1859 Mitarbeiter u. a. bei Augsburger Allg. Zeitung.

31. März-3. April 1848 Mitglied des Frankfurter Vorparlaments; 1848-1850, 1860-1864 Mitglied der II. Kammer des Badischen Landtags in Karlsruhe; 1850 Abgeordneter des Erfurter Unionsparlaments.

1864/65 Prorektor der UH; 1855, 1866/67 Dekan der Phil. Fak. der UH

1860 Mitglied der Badischen Generalsynode in Karlsruhe

1865 Mitbegründer des Dt. Protestantenvereins

1861 Hofrat; 1865 Geh. Rat III. Klasse 
$E$ Mitglied der Akademie der Wissenschaften: 1848 München, 1865 Göttingen. • 1856 Göttinger Wedekind-Preis; 1862 Maximiliansorden für Wissenschaft und Kunst; 1864 Verdun-Preis. 1857 Ritter des Ordens vom Zähringer Löwen; 1860 Königl. Preußischer Roter Adler-Orden III. Klasse; 1861 Königl. Belgischer Leopoldorden; 1862 Preußischer Kronorden III. Klasse; 1864 Comthurkreuz des Großherzogl. Sächsischen Hausordens vom weißen Falken. 1 1860 Ehrenbürger der Stadt Heidelberg.

Qu UAH PA 1649; RA 5683 (Stiftung e. HäusserBüste 1914), 5724, 6847; Fak.-Akte H-IV-102/36 u. ö. - GLA Abt. 205, Fasz. 272. • Briefe: UBH. • Briefe von Heidelberger Gelehrten an Franz Joseph Mone. Hrsg. von Friedrich von Weech in: ZGORh 57. Jg. (1903) S. 474 f. - Teil-Nachlaß: UBH; Badische Landesbibliothek Karlsruhe.

$W$ Geschichte der rheinischen Pfalz nach ihren politischen, kirchlichen und literarischen Verhältnissen. 2 Bde. Heidelberg 1845. Nachdr. Speyer 1978. - Denkwürdigkeiten zur Geschichte der Badischen Revolution. Heidelberg 1851. • Deutsche Geschichte vom Tode Friedrichs des Großen bis zur Gründung des Deutschen Bundes. 4 Bde. Berlin 1854-1857. - Ludwig Häusser's Geschichte der französischen Revolution 1789-1799. Hrsg. von Wilhelm Oncken. Berlin 1867. 3. Aufl. 1891.

$L \quad \mathrm{NDB} 7$ (1966) S. 456-459; WBIS. • Wolgast, Eike: Politische Geschichtsschreibung in Heidelberg ... in: Semper apertus 2 (1985) S. 174-181. - Weber (1987) S. 198f.; Geschichte Histor. Seminar UH (1992) S. 179-182; Das „Goldene Buch“ des KFG (1994) S. 24 f.; Lengemann (200o) S. 154f. • Handbuch der historischen Buchbestände in Deutschland. Hrsg. von Bernhard Fabian. Hildesheim 2003. - Kreutz, Wilhelm: Georg Gottfried Gervinus und L.H. - politische Professoren in: Von der Spätaufklärung zur Badischen Revolution ... Hrsg. von Achim Aurnhammer ... Freiburg/Br. 2010. Bd. 2. S. 111-126. - Waibel, Lorenz: L. H. ... Kleindeutsche politische Geschichtsschreibung an der Universität Heidelberg. Hamburg 2014.

$P$ Bildarchiv UAH; graph. Slg. UBH; NDB.

\section{Hagen, Carl}

siehe Hagen, Karl

Hagen, Friedrich Carl

siehe Bessel Hagen, Friedrich

Hagen, Karl (auch: Carl)

1837-1849 Phil. Fak.

Geschichte

* 10. Okt. 1810 Dottenheim (Mittelfranken; heute: Ortsteil von Dietersheim)

$\dagger$ 24. Jan. 1868 Bern ev.

V Friedrich Wilhelm H. (1767-1837) Pfarrer, Gymnasial-Prof., s. WBIS

M Maria Christiane Elisabeth geb. Schmauß (1771-1858)

๑ 3. Nov. 1839 Anna Margaretha Johanna geb. Martius (1811-1844)

๑ 6. Juli 1845 Juliana Amalia geb. Hepp (180o1851)

K 1 S: Hermann H. (1844-1898) seit 1873 a.o., seit 1878 o. Prof. für Klassische Philologie Bern, s. NDB 7 (1966) S. 475 f.; Die Dozenten der Bernischen Hochschule. Ergänzungs-Bd. zu: Hochschulgeschichte Berns ... Bern 1984. S. 137 .

Lb Seit WS 1827/28 Studium der Theologie, Philologie an U Erlangen, anschl. Jena.

U Erlangen: Seit WS 1831/32 Studium der Philologie, Philosophie; 7. Juni 1833 Dr. phil.

München: 1833-1836 Hauslehrer und Lehrer.

U Erlangen: 17. Juli 1836 Habilitation.

UH: 25. Nov. 1837 „Öffentliche Disputation pro facultate legendi“ (aus: UAH PA 1653); 7. Mai 1845 Ern. zum a. o. Prof.; 12. Juni 1845 Vereidigung. • In dieser Zeit: 
31. März-3. April 1848 Mitglied des Frankfurter Vorparlaments; 1848-18. Juni 1849 Abgeordneter in Frankfurter Nationalversammlung; Mai-Juni 1849 Teilnehmer am badischen Aufstand.

H: 1848 Präsident des Demokratischen Vereins.

UH: 31. Aug. 1849 Entlassung aufgrund seiner politischen Tätigkeit in der Nationalversammlung.

H: 1849-1855 Privat-Gelehrter; 1853 Untersuchungsverfahren wegen Hochverrats.

Bern: 1855-1868 o. Prof. an U und Gymnasial-Prof.

Qu UAH PA 1653; RA 7643. Matrikel Erlangen (1918) S. 218. • GLA Abt. 205, Fasz. 262. • Briefe: UBH. Friedrich Fröbel und K. H. Ein Briefwechsel aus den Jahren 1844-1848. Hrsg. und bearb. von Erika Hoffmann. Weimar 1948.

$W$ Deutschlands litterarische und religiöse Verhältnisse im Zeitalter der Reformation. 3 Bde. Erlangen 1841-1844. Neudr. 1966. • Fragen der Zeit. 2 Bde. Stuttgart 1843-1845. Geschichte der neuesten Zeit vom Sturze Napoleons bis auf unsere Tage. 2 Bde. Braunschweig 1848-1851. • Die östliche Frage mit besonderer Rücksicht auf Deutschland. Frankfurt 1854. 2. Aufl. 1854. - Deutsche Geschichte von Rudolf von Habsburg bis auf die Zeit Friedrichs des Großen. 3 Bde. Frankfurt 18541858.

MG, MHG 1838-1839 Zeitschrift „Braga“.

L ADB 10 (1879) S. 341-343. - Haag, Ferdinand: Die Universität Heidelberg in der Bewegung von 1848/49. Diss. Heidelberg 1934. NDB 7 (1966) S. 476; WBIS. - Mühlpfordt, Günter: K.H. Ein progressiver Historiker im Vormärz über die radikale Reformation in: Jahrbuch für Geschichte 21 (1980) S. 63-101; Ders.: K. H. Vom Historiker der radikalen Reformation zum Radikaldemokraten in: Jahrbuch des Inst. für dt. Geschichte 9 (1980) S. 219-272. Wolgast, Eike: K. H. in der Revolution von $1848 / 49$... in: ZGORh 133. Jg. (1985) S. 279-300; Ders.: Politische Geschichtsschreibung in Heidelberg ... in: Semper apertus 2 (1985) S. 183-186. - Weber (1987) S. 199 f.; Best/Weege
(1996) S. 166 f.; Gelehrte in der Revolution (1998) S. 155-182. - Zepf, Robert: K. H. ... Historiker und Politiker in: Fränkische Lebensbilder. Neustadt/ Aisch 1998. Bd. 17. S. 185-207. - Siegmund-Schultze (2009) S. 461 (Register).

$P$ Bildarchiv UAH.

\section{Hahn, Karl August}

1840-1850 Phil. Fak.

Deutsche Sprache und Literatur

* 14. Juli 1807 Heidelberg

$\dagger$ 20. Febr. 1857 Wien ev.-luth.

V Johann Friedrich H. (1757-1810) Kirchschaffner

M Philippina Helena geb. Schimper (1766-1837) Postsekretärin, s. Toepke 5 (1904) S. 334

(1) Okt. 1843 Emilia Beck ( $\left.{ }^{*} 1817\right)$

$\mathrm{K} \quad 1 \mathrm{~S}, 2 \mathrm{~T}$

Lb Seit 20. April 1825 Studium der Philologie an UH, seit WS 1825/26 Halle-Wittenberg, seit 6 . Nov. $1826 \mathrm{H}$.

Seit 1830 Erzieher in St. Aubin (Kanton Freiburg, Schweiz); seit 1838 Eigenstudien in Wien und Berlin; 19. Okt. 1839 Dr. phil. an U Halle-Wittenberg.

UH: Mai 1840 Habilitation für Dt. Sprache und Literatur; seit 28. Mai 1847 a. o. Prof.

U Prag: 23. Nov. 1849 Ern. zum SS 1850 o. Prof. mit e. jährl. Gehalt von 8oo.- Gulden.

U Wien: $1851-1857$ o. Prof.

Hahns Habilitation 1840 ist die erste ausschließlich für Deutsche Sprache und Literatur an der Universität Heidelberg

Qu UAH PA 1655; Fak.-Akten H-IV-102/36, H-IV102/38 fol. 206r, H-IV-102/41 fol. 140r-142r. GLA Abt. 205, Fasz. 264. • Briefe von Heidelberger Ge- 
lehrten an Franz Joseph Mone. Hrsg. von Friedrich von Weech in: ZGORh 57. Jg. (1903) S. 471474. Auskunft: Universitätsarchiv Halle/S.

W Mittelhochdeutsche Grammatik. Frankfurt/M. 1842. 4. Ausg. 1884. - Neuhochdeutsche Grammatik. Frankfurt 1848. - Auswahl aus Ulfilas gothischer Bibelübersetzung. Heidelberg 1849. 3. Aufl. 1874. - Die echten Lieder von den Nibelungen nach Lachmanns Kritik ... Prag 1851. • Althochdeutsche Grammatik. Prag 1852. 5. Aufl. 1882. Siehe auch Burkhardt (1976) S. 232.

L ADB 10 (1879) S. 369; Lehmann (1967) S. 213215; WBIS; Burkhardt (1976) S. 30-32 u. ö. • Zur Geschichte und Problematik der Nationalphilologien in Europa ... Hrsg. von Frank Fürbeth ... Tübingen 1999. S. 450-452 u. ö. • Riecke (2016) S. 145 (Register).

\section{Haller, Béla (bis ca. 1882: Béla Graf Haller von Hallerstein)}

1894-1914 Nat.-Math. Fak.

Zoologie

* 28. April 1858 Székelykeresztúr, Siebenbürgen (Ungarn; heute: Cristuru Secuiesc, Rumänien)

$\dagger \quad$ 21. Juli 1914 Heidelberg unitarisch

V Josef Graf Haller von H. (1818-1889) Rittergutsbesitzer

M Anna geb. Kiss (1826-1874)

๑ 10. Nov. 1883 Gizella geb. Lázár de Szárhegy (1857-1887)

๑ 1888 Bertha geb. Perczel (1864-1931)

K 2 S (1. Ehe): Karl Graf Haller von H. $\left({ }^{\star} 1885\right.$ X 1917 bei Verdun). • Victor Graf Haller von H. (1887-1953) 1914-1919 Kriegsdienst, seit 1921 Privat-Dozent, seit 1925 a.o. Prof. für Anatomie Berlin, 1935-1938 (Versetzung in Ruhestand aus gesundheitlichen Gründen) o. Prof. Halle-Wittenberg, s. WBIS, Catalogus prof. Halensis online
K 1 S (2. Ehe): Ernö Graf Haller von H. ( ${ }^{*} 1891$ X 1915). 2 T (2. Ehe), u. a. Maria Gisela Gräfin Haller von H. (1894-1937) Ehefrau von Dr. iur. Ascan Klée Gobert (1894-1967) seit 1921 Kaufmann, seit 1927 Assekuradeur für Seeversicherungen, seit 1946 Senator der Hansestadt Hamburg und u.a. Präses der Kulturbehörde, auch Schriftsteller, s. Gobert, Ascan Klée: Zweimal Student in Heidelberg in: Ruperto Carola 10. Jg., Bd. 23 (1958) S. 123-126 (Autobiogr.); WBIS; Vater von Boy Gobert (1925-1986) Schauspieler, Regisseur, 19691980 Intendant des Thalia Theaters Hamburg, seit 1980 Generalintendant der Berliner Staatl. Schauspielbühnen, $1986(\dagger)$ designierter Direktor des Theaters in der Josefstadt Wien, s. WBIS; Blasche, Gerhard und Witt, Eberhard: Hamburger Thalia Theater - Boy Gobert. Hamburg 1980.

Lb Seit WS 1877/78 Studium der Medizin an UH, seit SS 1879 Studium der Naturwiss. Wien; 1882 Dr. phil. an U Wien.

Retersdorf bei Schäßburg, Kreis Hermannstadt in Siebenbürgen (heute: Retiş, Rumänien): 1882-1893 Wiss. Schriftsteller (zoolog. Eigenstudien) und Landwirt; Febr. 1893 Übersiedlung nach $\mathrm{H}$.

UH: 26. Okt. 1894 Habilitation; seit 20. Febr. 1898 a.o. Prof.; SS 1914 letzte Vorlesungsankündigung über Allg. Biologie der Tiere.

Um 1882 Grafentitel „aus eigenem Willen abgelegt", siehe hierzu UAH H-V-1/15 fol. 13r.

1894: „Ich besitze ein für mäßige Lebensansprüche und für die Erziehung der Kinder ausreichendes Vermögen“ (aus: H-V-1/15 fol. 13r).

Qu UAH PA 1657; RA 6617, 690o; Fak.-Akte H-V1/15 fol. 8r-26r. Briefe: UBH.

$W$ Beiträge zur Kenntnis der Textur des CentralNervensystems höherer Würmer. Wien 1889. • Lehrbuch der vergleichenden Anatomie. 2 Lfg. Jena 1902-1904. • Über den Großhirnmantel des Känguruh (Makropus rufus) ... Heidelberg 1911. • Über das Zentralnervensystem des Skorpions und 
der Spinne in: Sitzungsberichte der Heidelberger Akademie der Wissenschaften. Math.-Naturwiss. Klasse. Abt. B. Heidelberg 1912.

L WBIS; Peiffer (2004) S. 137 u.ö.

P Bildarchiv UAH; graph. Slg. UBH.

\section{Hallerstein}

siehe Haller

\section{Hammer, Carl Friedrich}

1898-1935 (1938) Med. Fak.

Innere Medizin

* 25. März 1863 Lingen (Ems)

$\dagger \quad$ O2. Juni 1939 Heidelberg

ev.

V Carl Friedrich Gottlob H. (1824-1896) Eisenhüttendirektor

M Henriette Dorothea Caroline geb. Sohle (18301895)

$\infty$ 21. Dez. 1889 Johanna geb. Boetel $\left({ }^{*} 1869 \dagger\right.$ nach 1939)

K $\quad 3 \mathrm{~S}, 1 \mathrm{~T}$

Lb Seit SS 1883 Studium an U Jena, anschl. Göttingen, Berlin, Jena; Sommer 1888 Staatsexamen in Jena.

U Jena: Seit Okt. 1889 Assistent an Med. Poliklinik; 10. Sept. 1890 Dr. med.

UH: Seit Okt. 1890 Assistent, Okt. 1897-Juni 1939 $(\dagger)$ Oberarzt an Med. Poliklinik; 4. März 1898 Habilitation; seit 29. Dez. 1903 nichtetatm., seit 1920 nichtplanm., seit 1935 nichtbeamteter a. o. Prof.; SS 1935 letzte Vorlesungsankündigung; SS 1938 letzte Nennung im Personalverzeichnis. • In dieser Zeit:
H: 1893-1939 Niedergelassener Arzt; 1925-1939 Direktor des Städtischen Anna-Hospitals in der Plöck Nr. 6 sowie Stadtschularzt.

1914-1918 Kriegsdienst.

E Georgischer Stern der Kaiserin Tamara; 1915 Ritterkreuz II. Klasse mit Eichenlaub und Schwertern vom Orden des Zähringer Löwen.

Qu UAH PA 956, 4065; RA 6281. - GLA Abt. 235, Fasz. 2059.

$W$ Zur Kasuistik der myopathischen und der spinalen Form der progressiven Muskelatrophie. Weimar 1890 .

$L$ Wer ist's (1935) S. 589; Fischer $1\left({ }^{3} 1962\right)$ S. 573; Chronik Ärzte H (1985) S. 130.

\section{Hampe, Karl Ludwig}

1903-1934 Phil. Fak.

Geschichte

* 03. Febr. 1869 Bremen

$\dagger$ 14. Febr. 1936 Heidelberg

ev.

V Heinrich Eduard H. (1817-1903) Buchhändler M Betty Friederike geb. Hütterot(t) (1834-1898)

$\varnothing$ 2. März 1903 Gertrud Martha Charlotte (Lotte) geb. Rauff (1883-1950), s. Kriegstagebuch K. Hampe (2007) S. 964 (Register); T von Hermann R. (1853-1942), u. a. seit 1889 Privat-Dozent für Geologie und Paläontologie, 1896 Verleihung des Titels „Prof.“ U Bonn, 1904-1922 (Emeritierung) o. Prof. TH Berlin, s. WBIS, Verzeichnis Bonn (1968) S. 237

K 3 T, 4 S: u.a. Hermann H. (1904-1970) Architekt, Leiter des Kirchenbauamts der Ev. Landeskirche in Baden, s. WBIS, UH im Nationalsozialismus (2006) S. 175, 214 u. ö.; Schwiegersohn von: (siehe) Erich Ebler. - Roland H. (1908-1981), u.a. 1957-1975 Prof. für Archäologie H, s. Drüll (2009) S. 253f. • Konrad H. (1928-2018) em. Prof. für Flöte an Hochschule für Musik Würzburg 
Vw Bruder: Theodor Eduard H. (1866-1933) Literatur- und Kunsthistoriker am Germanischen Nationalmuseum Nürnberg, s. NDB 7 (1966) S. 599 f. • Enkel: Michael H. $\left({ }^{*} 1935\right)$ Schauspiel- und Opern-Regisseur, Prof. an Musikhochschule Köln, s. H., M.: Alles Theater - Reden und Aufsätze ... Köln 200o; Opernschule. Für Liebhaber, Macher und Verächter des Musiktheaters. Köln 2015.

Lb Seit SS 1888 Studium an U Bonn, seit SS 1889 Berlin; 21. Juni 1893 Dr. phil. an U Berlin.

Berlin: 1893-1897 Mitarbeiter bei Monumenta Germaniae Historica; u.a. Juli 1895-Febr. 1896 Studienreise durch Großbritannien.

U Bonn: 24. Okt. 1898 Habilitation; seit 15. Febr. 1901 a. o. Prof.; 1902 Ruf an U Königsberg (Preußen) abgelehnt.

UH: 26. Jan. 1903 Ern. zum o. Prof. als Nachf. von Dietrich Schäfer; 1903-1933 Mit-Direktor des Histor. Seminars; 1914 Ruf an U Frankfurt/M. abgelehnt; 1917-1935 Mitglied der Zentraldirektion der Monumenta Germaniae Historica in Berlin; 1921 Ruf an U Berlin abgelehnt; seit SS 1933 Mit-Direktor des Histor. Seminars, Abt. für Mittlere und Neuere Geschichte; 1. April 1934 auf eigenen Antrag Ruhestand.

1924/25 Rektor der UH; 1907/o8, 1921/22 Dekan der Phil. Fak. der UH

1914 Geh. Hofrat

Siehe auch Anhang Sporteinrichtungen an UH 1910-1933 und ihre Mitglieder

E 1903 O. Mitglied der Badischen Histor. Kommission; Mitglied der Akademie der Wissenschaften: 1909 (korr., 1916 o.) H, 1925 Berlin, 1933 München. 1910 Ritterkreuz I. Klasse des Ordens vom Zähringer Löwen.

Qu UAH PA 4066; Fak.-Akte H-IV-102/134; RA 5111, 6421, 6847. GLA Abt. 235, Fasz. 2060. Reichert, Folker: Paul Kehr und K.H. über die Aufgaben der Monumenta Germaniae Historica nach dem Ersten Weltkrieg: ein Briefwechsel in: Deutsches Archiv für Erforschung des Mittelalters. Köln 2004. Bd. 6o. S. 549-569. - Nachlaß: UBH, s. Stange, Manfred: Verzeichnis des Nachlasses K. H. Heid. Hs. 4067. UB Heidelberg 1991, s. http:// digi.ub.uni-heidelberg.de/diglit/heidhs4067verz. • Mitteilungen: Herr Dr. Thomas Hampe, Bonn. • K. H. Kriegstagebuch 1914-1919. Hrsg. von Folker Reichert und Eike Wolgast. München 2004. 2. Aufl. 2007. - K. H. ... Selbstdarstellung ... Heidelberg 1969. (Autobiogr.)

$W$ Deutsche Kaisergeschichte in der Zeit der Salier und Staufer. Leipzig 1909. 11. Aufl. 1963. • Herrschergestalten des deutschen Mittelalters. Leipzig 1927. 2. Aufl. 1933. • Das Hochmittelalter. Geschichte des Abendlandes von 900-1250. Berlin 1932. 4. Aufl. 1953.

L NDB 7 (1966) S. 599 (mit Werkverz.); WBIS; Verzeichnis Bonn (1968) S. 104; Biogr. Wörterbuch zur dt. Geschichte 1 (1973) Sp. 1017. • Weber (1987) S. 202 f.; Badische Biographien N.F. III (1990) S. 115-118; Jakobs (1992) S. 52-65; Jansen (1992) S. 409 (Register); Ders. (1992a) S. 165 (Register); Fuhrmann (1996) S. 209 (Register); Historikerlexikon (2002) S. 134. - Reichert, Folker: Über K.H. in: Max Webers Abschied von Heidelberg in: Jahrbuch für U-Geschichte 5 (2002) S. 199-215. BBKL XXIV (2005) Sp. 759-761. • Reichert, Folker: Gelehrtes Leben. K.H., das Mittelalter und die Geschichte der Deutschen. Göttingen 2009; Ders.: „Die Wissenschaft ist ein großes Feuer“. K.H.s Mittelalter in Monarchie, Republik und Diktatur in: Jahrbuch der Akademie der Wissenschaften zu Göttingen (2011) S. 177-182; Ders. (2015) S. 229 f. u. ö.; Ders.: „Das Publizistische streifende Historiographie“: K. H. und die belgische Frage in: UH während des Ersten Weltkriegs (2017) S. 147167; Ders.: Tod und Verklärung. Das Professorengrab als biographisches Zeugnis, in: Historische Zeitschrift 306 (2018) (im Druck).

$P$ Bildarchiv UAH; NDB; Archäologenbildnisse (1988). 


\section{Hanno, Raphael Benjamin}

1822-1824 Theol. Fak.

Alttestamentliche Exegese (Bibelwissenschaft) 1824-1871 Phil. Fak. 1824-1871 Orientalische Philologie (Hebräische, Arabische und Chaldäische Sprach- und Literaturwiss.), Altertumskunde; 1826-1840 Philosophie, Moral, Ästhetik

* 07. Juni 1791 Hanau

$\dagger$ 28. Dez. 1871 Heidelberg

mosaisch, nach $1817 \mathrm{ev}$.

V Raphael H.

M N.N.

(2. Nov. 1817 Henriette Hertz (1791-1872)

$\mathrm{K} \quad 1 \mathrm{~S}, 1 \mathrm{~T}$

Lb Seit SS 1815 Studium der Theologie, Philologie an U Göttingen, anschl. Marburg.

U Marburg: WS 1814/15-SS 1815 Privat-Dozent für chaldäische Stellen in den biblischen Büchern Daniel und Esra sowie Erklärung der Sprüche Salomonis und der Psalmen, für Hebräische Archäologie und (als Privatissimum) Hebräische Sprache; 16. Mai 1816 Dr. phil.; 16. März 1831 [!] Dr. theol.

Hamburg: 1816-1817 Oberlehrer und Mit-Direktor an Israelitischer Freischule.

Landau: 1817-1822 Privatlehrer.

UH: 31. Mai 1822 Habilitation an Theol. Fak.; seit 4. März 1824 a. o. Prof. an Phil. Fak.; seit 23. April 1826 a. o. Prof. mit Besoldung; WS 1871 letzte Vorlesungsankündigung über Ausgewählte Psalmen.

Siehe auch Eduard Röth: Eintrag unter $Z$ [itat] (1)

Qu UAH PA 1668f. - GLA Abt. 205, Fasz. 267 • Briefe: UBH. - Auskunft: Stadtarchiv Heidelberg; Ev. Kirchengemeindeamt Heidelberg.

$W$ Erstlinge meiner Leyer: eine Neujahrsgabe an Günstige. Hamburg 1817 (hierzu s. Briefe an Goethe. Gesamtausgabe in Regestform. Bearb. von Manfred Koltes u.a. Weimar 2011. Bd. 8: 1818-
1819. Regest-Nr. 8/1036). - Gedichte. Heidelberg 1825. Die hebräische Sprache für den Anfang auf Schulen und Akademien. 2 Abt. Heidelberg 18251828. Amulete [!] für edle Menschen gegen Anfälle der Kleinmüthigkeit. Heidelberg 1827. • Das Schloß im Abendroth. Heidelberg 1828. • Frühlings- und Sommer-Spazierbüchlein. Heidelberg 1829. Liebe und Weisheit. Auswahl aus seinen hinterlassenen Schriften. Hrsg. von C. Fortlage. 2 T. Jena 1876.

$L$ Catalogus prof. Marburgensis 1 (1927) S. 428; Jüdische National-Biographie 2 (1927) S. $605 \mathrm{f}$. • Biographie in: Jüdische Gemeinden in Hessen. Hrsg. von Paul Arnsberg. Frankfurt/M. 1971. S. 329. - WBIS; Deutsche Biographie, s. https:// www.deutsche-biographie.de/gnd116454520.html [07.11. 2017].

\section{Hansen, Karl Michael Maria}

1923-1933 (1934) Med. Fak.

(1958) 1959-1962 (Honorar-Prof.) Med. Fak.

Innere Medizin

* 07. Mai 1893 Trier

$\dagger \quad$ 20. Okt. 1962 Neckargemünd kath.

V Michael H. (1851-1926) Kaufmann

M Maria geb. Neuerburg (1853-1921)

๑ 15. Okt. 1923 Maria Bertha geb. Sulzer $\left({ }^{*} 1899\right)$

K $\quad 3 \mathrm{~S}, 1 \mathrm{~T}$

$L b$ Seit SS 1911 Studium der Philosophie und Medizin an U Bonn, seit WS 1912/13 Studium der Medizin an U Würzburg, WS 1913/14 München, SS 1914-WS 1914/15 Göttingen; 2. Mai 1914 Physikum.

2. Aug. 1914-10. Nov. 1918 Kriegsdienst.

SS 1918 Forts. des Studiums der Medizin an U Gent, WS 1918/19-SS 1919 H; 6. Juni 1919 Staatsexamen; 7. Juni 1919 Approbation.

U Würzburg: Juli 1919-April 1920 Assistent am Physiolog. Inst.; 30. März 1920 Dr. med. 
UH: Mai 1920-Dez. 1925 Assistent an Med. U-Klinik; 30. Jan. 1923 Habilitation; Jan. 1926-Febr. 1929 Oberarzt an Med. U-Klinik; seit 4. Aug. 1927 nichtplanm. a.o. Prof.; Febr. 1933-Jan. 1934 von U beurlaubt; 21. März 1934 aus dem Verzeichnis der akad. Lehrer gestrichen. • In dieser Zeit:

H: März 1929-Jan. 1933 Leiter der Inneren Abt. des St. Josefskrankenhauses.

Lübeck: 1933-1957 Leiter des Allg. Krankenhauses, 1943 umbenannt in Städtisches Krankenhaus. • In dieser Zeit:

U Hamburg: WS 1942-SS 1957 apl. Prof.

Neckargemünd: Seit 1957 Wohnsitz.

UH: Seit 30. Juni 1958 Honorar-Prof.; WS 1959/60WS $1962(\dagger)$ Vorlesungsankündigungen.

1956 Präsident der Deutschen Gesellschaft für Innere Medizin

E Mitglied der Société française d’Allergie.

Qu UAH PA 958, 4078, 4108. • GLA Abt. 235, Fasz. 2061. Briefe: UBH.

$W$ Die einheimische Sprue und ihre Folgekrankheiten. Stuttgart 1936. (Mitverf.) • H., K., Staa, Hildegard von: Reflektorische und algetische Krankheitszeichen der inneren Organe. Leipzig 1938. 2. Aufl. u.d. T.: H., K., Schliack, Hans: Segmentale Innervation. Stuttgart 1962 (mit Werkverz.). • Sensibilitätsschema nach Dejerine. Leipzig 1940. 3. Aufl. 1955.

$M G, M H G$ Seit 1928 Der Nervenarzt.

HG Allergie. Leipzig 1940. 3. Aufl. Stuttgart 1957. 4. Aufl. u.d. T.: Lehrbuch der klinischen Allergie. Bearb. von E. Fuchs ... Stuttgart 1967.

L Kürschner (1961) S. 665; WBIS. • Findeisen, D. G.: K. H. † in: Allergie und Asthma 8 (Dez. 1962) S. 277 f. • Wer ist wer (1962) S. 513 • Christian, P.: In memoriam K.H. in: Nervenarzt 34 (Okt. 1963) S. 425 f. - Gronemeyer, V.: In memoriam K.H. in:
Allergologica XVIII (1963) S. 85-88. - Prausnitz, C.: K.H. in: Int. Archives of Allergy and Applied Immunology 22 (1963) S. 68. - Werner, M.: K.H. $\dagger$ in: Dt. Med. Wochenschrift 88 (Jan. 1963) S. 153155. Nelson, H.S.: Some highlights of the first century of immunotherapy in: Annals of Allergy, Asthma \& Immunology 107/5 (2011) S. 417-421. • Deutsche Biographie, s. https://www.deutsche-bio graphie.de/gnd116459530.html [07.11. 2017].

$P$ Bildarchiv UAH.

\section{Hartmann, Paul Richard}

1927-1930 Phil. Fak.

Orientalische Philologie

* o8. Juni 1881 Neunkirchen (heute: Ortsteil von Bad Mergentheim)

$\dagger$ 05. Febr. 1965 Berlin-Dahlem ev.

V Georg August Moriz H. (1846-1930) Pfarrer

M Thekla Luise geb. Schlaissing (1850-1926)

๑ 26. Febr. 1914 Johanna geb. Insinger $\left({ }^{\star} 1885\right)$

$\mathrm{K} \quad 2 \mathrm{~S}, 1 \mathrm{~T}$

Lb Seit WS 1899/9o Studium der Theologie an U Tübingen; Herbst 1904 I. theol. Staatsprüfung in Tübingen; seit WS 1904/05 Studium der Orientalistik an U Berlin.

U Tübingen: 1. Sept. 1905-30. Sept. 1910 Wiss. Hilfsarbeiter an UB; 22. Juni 1907 Dr. phil.

Leiden: 1. Okt. 1910-31. März 1913 Redakteur der „Enzyklopädie des Islam“.

U Kiel: 30. Mai 1914 Habilitation für Semitische Philologie; Dez. 1915-Juni 1916 Kriegsdienst; 18. Juli 1917 Verleihung des Titels „Prof.“.

U Leipzig: 28. Juli 1918 Ern. zum etatm. a.o. Prof. für Orientalistik.

U Königsberg (Preußen): 30. Juni 1922 Ern. zum 1. Okt. 1922 o. Prof. für Orientalistik. 
UH: 6. Aug. 1926 Ern. zum o. Prof. als Nachf. von Gotthelf Bergsträsser; 27. Jan. 1927 Vereidigung; SS 1929 Studienreise in die Türkei.

U Göttingen: Seit 14. März 1930 o. Prof. für Orientalistik.

Friedrich-Wilhelms-U (seit 1949: Humboldt-U) Berlin: 1. April 1936-30. Sept. 1951 (Emeritierung) o. Prof. für Arabistik und Islamkunde.

Berlin, Ost: April 1947-1956 Direktor des neugegründeten Inst. für Orientforschung an Dt. Akademie der Wissenschaften.

$E$ Mitglied der Akademie der Wissenschaften: Damaskus, Kopenhagen, 1939 Berlin; 1950 Ehrenmitglied der Dt. Morgenländischen Gesellschaft.

Qu UAH PA 4091. GLA Abt. 235, Fasz. 2063. Repertorium der Briefe aus dem Archiv Walter de Gruyter. Ausgewählt von Otto Neuendorff ... Berlin 1999. S. 112. Nachlaß: Staatsbibliothek zu Berlin.

$W$ Kleine Beiträge zur Epigraphik Anatoliens. Göttingen 1936. - Die Religion des Islam. Berlin 1944. - Zur Wiedergabe türkischer Namen und Wörter in den byzantinischen Quellen. Berlin 1952. Bibliographie in: Roemer (1967) S. 3 Anm. 11.

HG 1935-1961 (1944-1953 Erscheinen eingestellt) Orientalische Literaturzeitung. $1937-1950$ Porta Linguarum Orientalium.

$L$ Professoren Kiel (1956) S. 218; Kürschner (1961) S. 678; Catalogus prof. Gottingensium (1962) S. 117. Dietrich, Albert: R. H. ... in: Jahrbuch der Akademie der Wissenschaften in Göttingen (1965) S. 74-82. - Roemer, Hans Robert: R. H. in memoriam in: ZDMG 117 (1967) S. 1-10. • WBIS; Jansen (1992a) S. 166 (Register); Professorenkatalog Leipzig online; Deutsche Biographie, s. https://www. deutsche-biographie.de/gnd119489228.html [07.11. 2017].

\section{Hasse, Karl Ewald}

1852-1856 Med. Fak.

Pathologie, Therapie, Pathologische Anatomie

* 23. Juni 1810 Neustadt (heute: Stadtteil von Dresden)

$\dagger$ 19. Sept. 1902 Hannover prot.

V Friedrich Christian August H. (1773-1848), u. a. 1803-1828 o. Prof. für Moral und Geschichte an Königl.-Sächsischer Ritter- und Militärakademie Dresden, 1828-1848 o. Prof. für Histor. Hilfswissenschaften U Leipzig, s. Professorenkatalog Leipzig online

M Christiane Karoline geb. Demiani ( $†$ 1817)

๑ 4. Jan. 1841 Sophie geb. Campe $(\dagger 1879)$

$\infty$ Frühjahr 1880 Chlotilde geb. von BockumDolffs verw. Gräfin von Wedel ( $† 1888)$

K 2 T: u.a. Marianne H. $\left({ }^{*} 1865\right)$ Ehefrau von Dr. med. et phil. Ernst Ehlers (1835-1925), u. a. o. Prof. für Zoologie und Vgl. Anatomie: seit 1869 Erlangen, seit 1874 Göttingen, s. NDB 4 (1959) S. 346, WBIS, Göttinger Gelehrte 1 (2001) S. 208; Otto Hölder: Briefe an die Eltern $1878-1887$... Hrsg. von Stefan Hildebrandt ... Leipzig 2014. S. 289 (Register).

Lb Seit 1827 Studium an Med.-Chirurg. Akademie in Dresden, dann an U Leipzig; März 1833 Dr. med. an U Leipzig; 1833 Studienreisen: Paris, Wien, Prag.

U Leipzig: April 1836 Habilitation; 1836-1844 Prosektor; seit Herbst 1838 a. o. Prof. für Patholog. Anatomie. • In dieser Zeit:

Leipzig: Ostern 1836-1844 Repetent am JakobsSpital.

Zürich: Seit SS 1844 o. Prof. der Med. Klinik und Pathologie an U und 1844-1852 Direktor des Kantonsspitals.

UH: Seit 30. Juli 1852 o. Prof. und Direktor der I. Med. Klinik (SS 1852: bisheriges Med. Klinikum wird in I. und II. Med. Klinik aufgeteilt) in Nachf. für den erblindeten Friedrich Puchelt, der bis WS 1855/56 weiterhin im Adressbuch der U als Direktor der I. Med. Klinik, im SS 1856 bei der Zu- 
sammenlegung der beiden Kliniken zur Med. Klinik zus. mit Hasse als Mit-Direktor genannt wird; 1852-1856 Leiter der Poliklinik als Nachf. von Carl Pfeufer.

Göttingen: WS 1856/57-WS 1877/78 (Ruhestand) o. Prof. an U und Direktor des Ernst August-Hospitals.

1878 Wohnungswechsel zunächst nach Hameln, dann nach Hannover.

1854 Dekan der Med. Fak. der UH

1852 Hofrat; 1855 Geh. Hofrat

Qu UAH PA 1681; RA 5355, 6804. GLA Abt. 205, Fasz. 271. Sektionsberichte ab dem 2. Dez. 1852 aus der II. Med. Klinik Heidelberg in: UAH Acc. 30/12. Briefe: UBH. Erinnerungen aus meinem Leben. Leipzig 1893. 2. Aufl. 1902. (Autobiogr.)

W Anatomische Beschreibung der Krankheiten der Circulations- und Respirationsorgane. Leipzig 1841. Die Menschenblattern und die Kuhpockenimpfung, eine geschichtliche Skizze. Leipzig 1852. • Die Krankheiten des Nervensystems. Erlangen 1855. 2. Aufl. 1868.

L Obst, Hermann: K.E.H. - der Nestor der deutschen Kliniker. Hamburg 1900. - Stübler (1926) S. 312; Catalogus prof. Gottingensium (1962) S. 76. Über K.E. H. in: Hoepke, Hermann: Henles Meinungen über seine Kollegen in: Ruperto Carola 32. Jg., H. 64 (1980) S. 37 f., 40. - Chronik Ärzte H (1985) S. 13o f.; Pantel/Bauer (1990) S. 89. • Kitschmann, Urs: Der Internist K.E.H. ... seine Zürcher Jahre 1844-1852. Dietikon 1993. • WBIS; Professorenkatalog Leipzig online; Deutsche Biographie, s. https://www.deutsche-biographie.de/gn d119135809.html [07.11. 2017].

$P$ Bildarchiv UAH.

\section{Hatschek, Julius Karl}

1898-1905 Jur. Fak.

Öffentliches Recht

* 21. Aug. 1872 Czernowitz (heute: Tscherniwzi, Ukraine)

$\dagger$ 12. Juni 1926 Göttingen mosaisch, seit $1898 \mathrm{ev}$.

V Isidor H., Rechtsanwalt

M N.N.

$\infty$ 2. Sept. 1905 Lina geb. Lehrer ( $†$ nach 1926)

$\mathrm{K} \quad 2 \mathrm{~S}, 1 \mathrm{~T}$

Lb Seit WS 1890/91 Studium an U Leipzig, anschl. Czernowitz, Wien; WS 1894/95 Staatsexamen in Czernowitz; 8. Febr. 1895 Dr. iur. an U Czernowitz; 1895-1898 Eigenstudien in Wien, H, Wien.

UH: 28. Okt. 1898 Habilitation; SS 1900-SS 1901, SS 1902 Studienreisen nach Großbritannien; seit 29. Juni 1902 nichtetatm. a. o. Prof.

Posen (heute: Poznań, Polen): Seit WS 1905/06 a. o. Prof. an Preußischer Verwaltungs-Akademie; 1907-1909 beurlaubt.

Berlin: Seit 1907 Lehrender an Vereinigung für staatswissenschaftliche Fortbildung und „Hilfsarbeiter" im Preußischen Unterrichtsministerium.

U Göttingen: Seit 4. Juni 1909 a. o. Prof.; seit 1918 Lehrauftrag für englisches Recht; seit 23. April 1921 persönlicher Ordinarius für Staats-, Verwaltungsund Völkerrecht.

$\mathrm{Q} u$ UAH PA 1682; RA 5225, 6149, 7625; Fak.-Akte H-II-111/118. GLA Abt. 235, Fasz. 2065.

$W$ Englisches Staatsrecht mit Berücksichtigung der für Schottland und Irland geltenden Sonderheiten. 2 Bde. Tübingen 1906. - Englische Verfassungsgeschichte bis zum Regierungsantritt der Königin Viktoria. München 1913. Neudr. 1978. • Das Staatsrecht des Vereinigten Königreichs Großbritannien - Irland. Tübingen 1914. - Institutionen des deutschen und preußischen Verwaltungsrechts. Leipzig 1919. 2. Aufl. u.d. T.: Lehrbuch des 
deutschen und preußischen Verwaltungsrechts. Leipzig 1922. 8. Aufl. 1931. Deutsches und preußisches Staatsrecht. 2 Bde. Berlin 1922-1923. 2. Aufl. 1930. • Völkerrecht. Leipzig 1923.

MHG Wörterbuch des Völkerrechts und der Diplomatie. 3 Bde. Berlin 1924-1929.

L Kürschner (1926) Sp. 669; Catalogus prof. Gottingensium (1962) S. 54; NDB 8 (1969) S. 57 f. Katalog der Julius-Hatschek-Bibliothek in der Juristischen Fakultät der Universität Kyoto. Kyoto 1976. • Universität Czernowitz (1979) S. 310; WBIS. • Sattler, Andreas: J.H. ... Staatsrecht am Anfang der Weimarer Republik in: Rechtswissenschaft in Göttingen: Göttinger Juristen aus 250 Jahren. Göttingen 1987. S. 365-384. - Jansen (1992a) S. 166 (Register). • J.H., Staatsrechtler ... Reden anläßlich der Enthüllung einer Gedenktafel am 2. Juni 2008 in der Planckstrasse 8 [in Göttingen] in: Göttinger Jahrbuch. Göttingen 2008. - Staudacher, Anna L.: „... meldet den Austritt aus dem mosaischen Glauben": 18 ooo Austritte aus dem Judentum in Wien 1868-1914: Namen - Quellen - Daten. Frankfurt/M. 2009. S. 235. Schroeder (2010) S. 349 f.; Ders. (2017) S. 179-185.

$P$ Bildarchiv UAH.

\section{Hatzfeld, Anton Helmuth}

1932-1935 Phil. Fak.

(1961) 1962 (Honorar-Prof.) Phil. Fak.

Romanische Philologie

* 04. Nov. 1892 Dürkheim (heute: Bad D.)

$\dagger$ 18. Mai 1979 Washington D.C.

kath.

V Konrad H., Weinhändler

M Hortensia geb. Maas

๑ 6. Aug. 1924 Herta Maria geb. Scheitel (18931985), siehe Lexikon jüdischer Einwohner Hs (2011) S. 159

$\mathrm{K}$ keine.
Lb Studium der Romanistik, Anglistik an U: WS 1911/12, SS 1912 Grenoble, WS 1912/13 Berlin, SS 1913-WS 1914/15 München.

1914-1918 Kriegsdienst.

München: 30. April 1915 Dr. phil. an U; 1919 Staatsprüfung für höheres Lehramt; 1919-1922 Eigenstudien.

U Frankfurt/M.: 29. Juli 1922 Habilitation; WS 1928/29-SS 1929 Lehrstuhlvertr. an U Königsberg (Preußen); seit 20. Sept. 1929 nichtplanm. a. o. Prof.

UH: 17. Dez. 1931 Ern. zum SS 1932 planm. a. o. Prof. (persönlicher Ordinarius) und Direktor des Romanischen Seminars als Nachf. von Leonardo Olschki; 28. April-3. Mai 1933 Beurlaubung aufgrund des Gesetzes zur „Wiederherstellung des Berufsbeamtentums"; seit 25. Nov. 1935 Beurlaubung; 31. Dez. 1935 Entziehung der Lehrbefugnis und Zwangspensionierung aus rassischen Gründen.

Nov. 1938 Flucht nach Belgien; 1939-1940 GastProf. an U Louvain.

Catholic U of America in Washington: Seit 1940 Visiting Prof., 1942-1968 (Emeritierung) Full Prof. of Romance Languages and Literatures; $1945 \mathrm{Na}-$ turalisierung. • In dieser Zeit:

Gastprof.: 1960 UH, 1961 München.

UH: 13. März 1961 Ern. zum Honorar-Prof.; SS 1962 einzige Vorlesungsankündigung: Franz. Literaturgeschichte als Kunstgeschichte.

E 1950 Mitglied der Hispanic Society of America; 1959 Mitglied der Akademie der Wissenschaften München. 1959 Dr. h.c. Grenoble. 1962 Prix Saintour-Linguistique de l'Académie française.

Qu UAH PA 430, 4096.

$W$ Leitfaden der vergleichenden Bedeutungslehre. München 1924. 2. Aufl. 1928. "Don Quijote" als Wortkunstwerk. Leipzig 1927. A critical Bibliography of the new stilistics applied to the romance 
literatures 1900-1952. Chapel Hill 1953. - Der gegenwärtige Stand der romanistischen Barockforschung. München 1961. - Siehe auch Romanisten als Verfolgte des Nationalsozialismus (1989) S. $282 \mathrm{f}$.

MHG Literarhistorische Jahrbücher der Görresgesellschaft.

$L$ Pabst, Walter: H.H. in: Romanistisches Jahrbuch 5 (1952). - Frey, John: H.H. in: Orbis 9 (1962). - Linguistic and literary studies in honor of H.A.H. Ed. by Alessandro Santi Crisafulli. Washington 1964. * Kürschner (1966) S. 831 f., (1980) S. 4459; WBIS; Who was who in America 7 (1981) S. 26of.; Mussgnug (1988) S. 298 (Register). - Romanisten als Verfolgte des Nationalsozialismus (1989) S. 282-284; Jansen (1992a) S. 166 (Register); Carl (1998) S. 263; UH im Nationalsozialismus (2006) S. 438 f. u. ö.; Hausmann (2008) S. 798 (Register); Lexikon jüdischer Einwohner Hs (2011) S. 159; Deutsche Biographie, s. https://www. deutsche-biographie.de/gnd120617218.html [07.11. 2017].

$P$ Bildarchiv UAH; Romanisten als Verfolgte ... (1989) S. 284.

\section{Hausrath, Adolf (Pseudonym: George Taylor)}

1861-1864 Theol. Fak. 1867-1906 Theol. Fak.

Kirchengeschichte, Neutestamentliche Exegese

* 13. Jan. 1837 Karlsruhe

$\dagger \quad$ 02. Aug. 1909 Heidelberg ev.

V August H. (1806-1847) Hofdiakon

M Julie geb. Weltzien (1805-1881)

๑ 2. Sept. 1864 Henriette geb. Fallenstein (18401895), siehe Kaesler (2004) S. 999 (Register); Schwester von Helene F. (1844-1919) Mutter von: (siehe) Alfred und Max Weber
K 11, darunter 5 T, 2 S: Dr. phil. August H. (18651944), u.a. Gymnasial-Direktor, s. Das „Goldene Buch“ des KFG (1994) S. 114. - Hans H. (1866-1945), u.a. o. Prof. für Forstwiss.: seit 1904 TH Karlsruhe, 1920-1934 Freiburg/Br., siehe Nachlaß im UA Freiburg/Br; NDB 8 (1969) S. 127, WBIS. • T: u.a. Pauline (Paula) Helene Mathilde H. (1872-1958) Ehefrau von: (siehe) Georg Schmidt.

Lb Seit WS 1856/57 Studium der Theologie und Geschichte an U Jena, SS 1858 Göttingen, WS 1858/ 59 Berlin, SS 1859 H; Nov. 186o Staatsprüfung in H.

UH: 7. April 1861 Lizentiatenexamen; 24. Okt. 1861 Habilitation; SS 1864 letzte Vorlesungsankündigung. • In dieser Zeit:

H: 23. April 1862-30. April 1864 Stadtvikar.

Karlsruhe: Mai 1864-Okt. 1867 Assessor im Ev. Oberkirchenrat; 1867 Vertreter der Gemeinde H auf der Badischen Generalsynode.

UH: Seit 20. Okt. 1867 (Dienstantritt) a.o. Prof. in Nachf. von Carl Bernhard Hundeshagen; Rufe abgelehnt: 1871 als Hauptpastor an St. Jacobikirche in Hamburg, 1871 U Bern und 1874 Jena; seit 2. Nov. 1871 o. Prof. als Nachf. von Hundeshagen; 1871-1895 e. der Hauptlehrer am Ev.-Prot. Theol. Seminar; SS 1895 Aufteilung des Ev.-Prot. Theol. Seminars in Praktisch-Theol. Seminar und Wiss.Theol. Seminar: SS 1895-WS 1905/o6 Direktor der Kirchengeschichtl. Abt. am Wiss.-Theol. Seminar; 1. April 1906 Ruhestand. • In dieser Zeit:

Karlsruhe: 1889-189o Mitglied der I. Kammer des Badischen Landtags als Vertreter der UH.

1882/83, 1901/o2 Prorektor der UH; 1874/75, 1879/ 8o, 1884/85, 1889/9o, 1895/96, 1901/o2 Dekan der Theol. Fak. der UH

1886 Kirchenrat; 1899 Geh. Kirchenrat; 1906 Geh. Rat II. Klasse

E 1896 O. Mitglied der Badischen Histor. Kommission; 1909 Mitglied der Akademie der Wissenschaften H. 1871 D. theol. Wien; 1903 Dr. phil. 
h.c. UH. 1879 Ritterkreuz I. Klasse, 1885 Ritterkreuz I. Klasse mit Eichenlaub, 1902 Kommandeurkreuz II. Klasse des Ordens vom Zähringer Löwen. 1906 Ehrenbürger der Stadt Heidelberg.

Qu UAH PA 1664; RA 6718, 6728. • Briefe: UBH. • Nachlaß: Ev. Oberkirchenrat - Landeskirchliches Archiv - Karlsruhe.

W Der Apostel Paulus. Heidelberg 1865. 2. Aufl. 1872. Neutestamentliche Zeitgeschichte. 4 Bde. Leipzig 1868. 3. Aufl. 1879. - David Friedrich Strauß. 2 Bde. Heidelberg 1876-1878. • Richard Rothe und seine Freunde. 2 Bde. Berlin 19021906. Taylor, George (Pseudonym): Die Albigenserin. Leipzig 1902. • Luthers Leben. 2 Bde. Berlin 1905. 3. Aufl. 1913.

MG 1891 Neue Heidelberger Jahrbücher.

L NDB 8 (1969) S. 126 f.; Lebensbilder aus der ev. Kirche in Baden (2007) S. 526 (Register); Troeltsch-Gesamtausgabe 19 (2014) S. 503 (Register).

$P$ Bildarchiv UAH; graph. Slg. UBH; NDB.

\section{Hausser, Karl Wilhelm}

1929-1933 (Honorar-Prof.) Nat.-Math. Fak. Physik

* O2. März 1887 Mannheim

$\dagger \quad$ 04. Juni 1933 Heidelberg

ev.

V Karl H. (1850-1918) Lehrer, seit 1900 Syndikus der Handelskammer Mannheim

M Barbara (Babette) geb. Dickemann (1855-1925)

๑ 1918 Dr. Isolde geb. Ganswindt (1889-1951) Physikerin, 1929-1951 Abt.-Leiterin am Kaiser-Wilhelm/Max-Plack-Inst. für med. Forschung in H, s. PA und Nachlaß im Archiv der Max-Planck-Gesellschaft Berlin; NDB 8 (1969) S. 127 f.; Fuchs, Margot: I.H. ... Technische Physikerin und Wissenschaftlerin am Kaiser-Wilhelm-/Max-Planck-Inst. für med. Forschung, Heidelberg in: Berichte zur
Wissenschaftsgeschichte 17 (1994) S. 201-215; Vogt, Annette: Wissenschaftlerinnen in Kaiser-Wilhelm-Instituten. A-Z. 2. erw. Aufl. Berlin 2008. S. 70-72.

K 1 S: Karl Hermann H. (1919-2001), u. a. Prof. für Physik und 1966-1987 Direktor des Inst. für Physik am Max-Planck-Inst. für med. Forschung in $\mathrm{H}$ (in Nachf. seines Vaters), s. PA K.H.H. im Archiv der Max-Planck-Gesellschaft Berlin; Wer ist wer (1984) S. 475; Nachruf in: Physikalische Blätter 57 (2001) Nr. 5 , S. 65.

Lb Studium der Naturwiss.: WS 1905/06-SS 1906 U München, seit WS 1906/07 H.

UH: April 1910-März 1913 Assistent am Physikal. und Radiolog. Inst.; 29. April 1913 Dr. phil. nat.

TH Danzig: Sept. 1913-Aug. 1914 Assistent am Physikal. Inst.

Aug. 1914-Sept. 1915 Kriegsdienst.

Danzig: 1916 Leiter der Röntgenstation des Städtischen Krankenhauses.

Berlin: Seit Okt. 1916 Physiker am Röhrenlaboratorium von Telefunken; seit Juli 1919 Leiter des Physikalisch-Med. Laboratoriums bei Siemens \& Halske.

H: Sept. 1929 Begründer, 1930-1933 Direktor des Inst. für Physik am neugegründeten Kaiser-Wilhelm-Inst. für med. Forschung. • In dieser Zeit:

UH: Seit 6. Sept. 1929 o. Honorar-Prof.; SS 1933 letzte Vorlesungsankündigung.

E 1931 Mitglied der Akademie der Wissenschaften $\mathrm{H}$.

Qu UAH PA 4109; RA 6465. - Briefe: UBH. • Nachlaß: Archiv der Max-Planck-Gesellschaft Berlin. - Mitteilungen: Herr Prof. Dr. Karl Hermann Hausser ( $\dagger$ ). 
W Sonnenbrand und Sonnenbräunung in: Wiss. Veröffentlichungen des Siemens Konzerns 6 (1927). (Mitverf.) - Einfluß der Wellenlänge in der Strahlenbiologie in: Strahlentherapie 28 (1928). • Strahlung und Lichterythem. Leipzig 1934. (Mitverf.) • Lichtabsorption und Doppelbindung. 1.-6. Mitteilung in: Zs. für physikalische Chemie 29 (1935). (Mitverf.)

MG 1919 Zeitschrift für technische Physik.

L Kossel, Walther: Zum Gedächtnis an K. W. H. ... in: Strahlentherapie 48 (1933) S. 205-222. NDB 8 (1969) S. 128. Staab, Heinz A.: 50 Jahre KaiserWilhelm/Max-Planck-Inst. für med. Forschung Heidelberg in: Heidelberger Jahrbücher 24 (1980) S. 52 f., 56 u. ö. - Kipnis, Alexander: Biographie W.H. online unter http://www.kipnis.de/index. php/alexander/kurzbiografien/79-hausser-wilhel m-1887-1933-physiker-biophysiker (abgerufen am 3. Febr. 2010; Ausdruck im UAH).

$P$ NDB. $\bullet$ Bildarchiv des Archivs der Max-PlanckGesellschaft Berlin.

\section{Hedicke, Edmund Karl Robert}

1919-1939 Phil. Fak.

Kunstgeschichte

* 19. Sept. 1874 Breslau (heute: Wrocław, Polen)

$\dagger \quad$ 03. Juli 1957 Heidelberg

ev.

V Heinrich H. (1830-1911) Drogist

M Anna geb. Haselbach

( 26. Jan. 1908 Anni geb. Fischer (1877-1927)

๑ 16. Aug. 1932 Babette Auguste geb. Grämlich $\left({ }^{*} 1907\right)$

K $\quad 1 \mathrm{~S}, 1 \mathrm{~T}$

Lb Seit WS 1894/95 Studium der Rechtswiss. an U Breslau, anschl. Berlin, Freiburg/Br., München; 6. Aug. 1898 Dr. iur. an UH.
U Straßburg: Seit WS 1898/99 Studium der Kunstwiss.; 5. Mai 1913 Habilitation für Kunstgeschichte; 14. Juni 1914 Dr. phil. • In dieser Zeit:

1914-1918 Kriegsdienst.

UH: 21. Juni 1919 Umhabilitierung; seit 29. Febr. 1920 nichtplanm. a. o. Prof. am Kunsthistor. Inst.; 30. Sept. 1939 Ruhestand.

E 1910 Korr. Mitglied des Cercle Archéologique des Mons; 1922 Mitglied der Straßburger Wiss. Gesellschaft in Heidelberg.

Qu UAH PA 433, $4118 \mathrm{f}$.

$W$ Jacques Dubroeucq von Mons. Straßburg 1904. - Cornelis Floris und die Florisdekoration. Studien zur niederländischen und deutschen Kunst im XVI. Jahrhundert. 2 Bde. Berlin 1913. • Methodenlehre der Kunstgeschichte. Straßburg 1924 .

L Kürschner (1925) Sp. 366, (1928/29) Sp. 855, (1940/41) Sp. 665, (1950) Sp. 738f.; Wer ist wer (1955) S. 426; WBIS; Jansen (1992a) S. 166 (Register). - The Expressionist Turn in Art History: A Critical Anthology. Ed. by Kimberly A. Smith. Farnham 2014. S. 8 f., 34, 110f. • Maurer, Trude: „... und wir gehören auch dazu“: Universität und „Volksgemeinschaft“ im Ersten Weltkrieg. Göttingen 2015. S. 913-915. • Deutsche Biographie, s. https://www.deutsche-biographie.de/gnd1165637 53.html [07.11. 2017].

$P$ Bildarchiv UAH.

\section{Hegel, Georg Wilhelm Friedrich}

1816-1818 Phil. Fak.

Philosophie

* 27. Aug. 1770 Stuttgart

$\dagger$ 14. Nov. 1831 Berlin ev.-luth. 
V Georg Ludwig H. (1733-1799) RentkammerSekretär, zuletzt Rentkammer-ExpeditionsRat, s. Leopold von Ranke. Briefwechsel ... (2016) S. 383 (s. Eintrag unter $Q u$ [ellen])

M Maria Magdalena Louisa geb. Fromm (17411783), s. ebd.

(15. Sept. 1811 Maria Helena Susanna geb. Freiin von Tucher (1791-1855), s. ebd. und S. 564

K $\quad 1 \mathrm{~T}$ (früh $\dagger$ ), 1 unehelicher S: Ludwig Fischer (1807-1831), s. Lebensstationen Hegels (1991) S. 44 f., Jaeschke (2010) S. 26, 39 f. u. ö. 2 S: Karl H. (1813-1901), u. a. 1841-1848 a.o. Prof., 1848-1856 o. Prof. für Geschichte Rostock, 1856-1901 Ordinarius Erlangen, s. Biogr. Lexikon für Mecklenburg 2 (1999) S. 120f.; K.H. Historiker im 19. Jahrhundert. Hrsg. von Helmut Neuhaus. Erlangen 2001; Neuhaus, Helmut: K.H. - Ein (fast) vergessener Historiker des 19. Jahrhunderts in: Zwischen Wissenschaft und Politik ... Stuttgart 2001. S. 309-328; Kreis, Marion: K.H. Geschichtswissenschaftliche Bedeutung und wissenschaftsgeschichtlicher Standort. Göttingen 2012. Immanuel H. (1814-1891), u.a. 18651891 Konsistorial-Präsident der preußischen ev. Landeskirche Berlin und der Provinz Brandenburg, s. WBIS

Vw siehe NDB 8 (1969) S. $207^{*}$.

Lb U Tübingen: 27. Okt. 1788 Immatrikulation als „serenissimi stipendiarius“ des Theol. Stifts zum Studium der Philologie, Philosophie und Mathematik; 21. Sept. 1790 phil. Magisterexamen; seit WS 1790/91 auf Wunsch der Eltern Studium der Theologie am Theol. Stift; Juni 1793 theol. Disputation; 19./20. Sept. 1793 theol. Konsistorialprüfung in Stuttgart.

Hauslehrer: Seit Okt. 1793 Bern, seit Jan. 1797 Frankfurt/M., s. hierzu Lebensstationen Hegels (1991) S. 25-29, Jaeschke (2010) S. 9-18; in dieser Zeit außerdem Eigenstudien der Volkswirtschaft, Politik und Philosophie; Anfang 1801 Übersiedlung nach Jena.

U Jena: 27. Aug. 1801 Nach Abgabe e. Dissertation und Abhaltung e. Disputation Erlangung des Rechts, Vorlesungen in Philosophie als Privat-Dozent zu halten; seit Febr. 1805 a.o. Prof.; seit Juli 1806 jährl. Auszahlung von 100.- Talern durch
Kurfürst Friedrich August III. von Sachsen; Jan. 1807 vergebliche Bewerbung um Professur für Botanik und der damit verbundenen Stelle e. Verwalters des Botanischen Gartens.

Bamberg: Seit Mitte März 1807 leitender Redakteur der Bamberger Zeitung.

Nürnberg: Dez. 1808-1816 Rektor und Prof. der Vorbereitungs-Wissenschaften am Königl. Bayer. Egidiengymnasium; 1813-1816 Lokal-Schulrat und Referent in Schul- und Studiensachen bei Königl. Stadtkommissariat; 1816 Rufe abgelehnt: U Berlin auf das noch immer unbesetzte Ordinariat für Philosophie von Johann Gottlieb Fichte (17621814) und U Erlangen als o. Prof. für Philologie.

UH: 19. Aug. 1816 Ern. zum o. Prof. als Nachf. von Jakob Fries und seit 23. Okt. 1816 mit e. jährl. Gehalt von 1500.- Gulden; 28. Okt. 1816 Antrittsvorlesung, s. hierzu Lebensstationen Hegels (1991) S. 63 f.; Sept. 1818 Weggang.

U Berlin: WS 1818/19-1831 ( $\dagger$ ) o. Prof. als Nachf. von Fichte; 22. Okt. 1818 Antrittsvorlesung; 1829/ 30 Rektor.

Hegel wohnt von Januar 1817 bis September 1818 in der Plöck in Heidelberg; eine Gedenktafel an dem Gebäude, das sich an der Stelle des ehemaligen Wohnhauses befindet (heute eine Tiefgarage mit der Hausnummer 48-50), erinnert daran.

1958: Gründung des Hegel-Archivs durch das Land Nordrhein; das Archiv ist seit Jan. 2017 vollständig in das Forschungszentrum für Klassische Deutsche Philosophie/Hegel-Archiv in der Fakultät für Philosophie und Erziehungswissenschaft der Ruhr-Universität Bochum integriert. Seine Hauptaufgaben sind die Edition der Gesammelten Werke Hegels sowie die Förderung der Hegel-Forschung.

E 1803 Mitglied (II. Assessor) der Mineralog. Gesellschaft in Jena; 1804 Mitglied der Naturforschenden Gesellschaft Westfalens. - 1831 Königl. Preußischer Roter Adlerorden III. Klasse. 
Qu UAH PA 1683; RA 5683 (Stiftung e. Büste von G.W.F.H. durch Erben von Kuno Fischer 1907/ 08). GLA Abt. 205, Fasz. 275. - Matrikel Tübingen 3 (1953) S. 342. • Briefe: UBH. • Briefe von und an Hegel. 3. Aufl. hrsg. u. a. von Johannes Hoffmeister, Friedhelm Nicolin. 5 Bde. Hamburg 1969-1981. Hegel in Berichten seiner Zeitgenossen. Hrsg. von Günther Nicolin. Hamburg 1970. • Karl Rosenkranz: Briefe 1827-1850. Hrsg. von Joachim Butzlaff. Berlin 1994. S. 520 (Register). • Der Redaktionsbriefwechsel der Hallischen, Deutschen und Deutsch-Französischen Jahrbücher 1837-1844. Hrsg. von Martin Hundt. Bd. 1: Der Briefwechsel um die Hallischen Jahrbücher. Berlin 2010. Apparat: S. 264 (Register). • Leopold von Ranke. Briefwechsel. Historisch-kritische Ausg. Bd. 1: 1810-1825. Neu bearb. von Dietmar Grypa. Berlin 2016. S. 839 (Register). Materialien über und von G.W.F.H. in: Universitäts- und Landesbibliothek Jena, Bibliothek des Katechetischen Oberseminars Naumburg (Nachlass Tholuck), Hegel-Archiv Bochum, DLA Marbach, UB Tübingen. $\bullet$ Ziesche, Eva: Der handschriftliche Nachlass G.W.F.H.s und die Hegel-Bestände der Staatsbibliothek zu Berlin Preußischer Kulturbesitz. 2 T. Wiesbaden 1995. Auskunft: Frau Dr. Katharina Comoth, Köln.

W Phänomenologie des Geistes. Bamberg 1807. 6. Aufl. 1952. - Wissenschaft der Logik. 2 Bde. Nürnberg 1812-1816. 2. Aufl. 1932. • Encyclopädie der philosophischen Wissenschaften im Grundrisse. Heidelberg 1817. 3. Aufl. 1830. - Grundlinien der Philosophie des Rechts oder Naturrecht und Staatswissenschaft im Grundrisse. Berlin 1820. (Vgl. dazu den Sammelband von Ludwig Siep (Hrsg.): G.W.F.H.: Grundlinien der Philosophie des Rechts. 4. überarb. und erw. Aufl. 2017 (nach der 1. Aufl. 1997)). • Vorlesungen über die Philosophie der Geschichte. Berlin 1837. 4. Aufl. 1961. • Hegel - Gesammelte Werke. Hrsg. von der Nordrhein-Westfälischen Akademie der Wissenschaften und der Künste. Hamburg $1968 \mathrm{ff}$. - Hegels Gesammelte Werke. Katalog anläßlich des 31. Int. Hegel-Kongresses, 17.-20. Mai 2016 in Bochum ... mit einer vollständigen Übersicht aller Bände der „Akademieausgabe G.W.F. Hegel Gesammelte Werke“ sowie der Vorausedition „G.W.F. Hegel
Vorlesungen. Ausgewählte Nachschriften und Manuskripte“ und der „Hegel-Studien“, „Hegel-Studien Beihefte“. Hamburg 2016.

Redakteur 1816-1818 Heidelbergische/Heidelberger Jahrbücher der Literatur.

$L$ [Ist Prof. H. tatsächlich an der Cholera verstorben?] in: Tagebuch über das Verhalten der bösartigen Cholera in Berlin. Hrsg. von Albert Sachs. Eine Sammlung von Aufsätzen pathologisch-therapeutischen, gesundheitspolizeilichen und popular-medicinischen Inhalts in bezug auf den Verlauf der Epidemie im In- und Auslande seit dem 14. Sept. bis zum 31. Dez. 1831. Berlin 1831. Nr. 6o. Eintrag vom 23. Nov. 1831. S. 239-241 u. ö. • Glockner (1969) S. 273 (Register); NDB 8 (1969) S. 207-222 (mit Werkverz.). Helferich, Christoph: G. W. F. H. Stuttgart 1979. • Comoth, Katharina: Ein Dokument (mit Faks.) über H.s Aufenthalt in Heidelberg in: Hegel-Studien 20 (1985) S. $117 \mathrm{ff}$;; Dieselbe: Die Idee als Ideal. Trias und Triplizität bei H. Heidelberg 1986. - Fulda, Hans Friedrich: H.s Heidelberger Encyclopädie in: Semper apertus 2 (1985) S. 298-320. - Heidelberg im säkularen Umbruch (1987) S. 528-556 u. ö. • BBKL II (1990) Sp. 643-649; Lebensstationen Hegels (1991); Braun (1997) S. 144-178 u. ö.; Kirschke (2001) S. 447 (Register); WBIS. - Über G.W.F.H. in: Briese, Olaf: Angst in den Zeiten der Cholera ... Berlin 2003. S. 13-20, 199-205, 213-234 u. ö. • Hoffmann, Thomas Sören: G.W.F.H. - Eine Propädeutik. Wiesbaden 2004. (Übers.: A Propaedeutic. Translated by David Healan. Leiden 2015.) • Tannert, Ursula: H.s Nürnberger Ehefrau spendete ihrem Gatten viel Lob: Der Fürst der Denker war ein perfekter Ehemann in: Nürnberger Zeitung Nr. 248 (23. Okt. 2008) S. 1. Die modernen Väter der Antike. Die Entwicklung der Altertumswissenschaften an Akademie und Universität im Berlin des 19. Jahrhunderts. Hrsg. von Annette M. Baertschi ... Berlin 2009. S. 277-302. - Jaeschke, Walter: Hegel-Handbuch. Leben - Werk - Schule. 2. Aufl. Stuttgart 2010. Leszl, Walter: From Hegel to Zeller in: The Presocratics from the Latin middle ages to Hermann Diels ... Hrsg. von Oliver Primavesi ... Stuttgart 2011. S. 309-333. 200 Jahre Berliner Germanistik (2011) S. 382 (Register); Geschichte U Berlin (2012) Bd. 1, S. 661 (Register). • G. W. F. H. Hrsg. von Reinhard Hiltscher 
und Stefan Klingner. Darmstadt 2012. - Klippel (2012) S. 380 (Register); Gerhards (2013) S. 509 (Register). - Schnädelbach, Herbert: G.W.F.H. zur Einführung. 5. Aufl. Hamburg 2013. Comoth, Katharina: Im Angesicht des Meeres: H. auf der Insel Rügen in: Jahrbuch für Hegelforschung. Hrsg. von Helmut Schneider. Bd. 15-17. Sankt Augustin 2014. S. 135 f. - Intellektuelle in Heidelberg (2014) S. 425 (Register). Gögelein, Simon: Identität und Unterschied. Historisch-genetische Untersuchungen zu einem Kategorienpaar bei G.W.F.H. Berlin 2016.

$P$ Bildarchiv UAH. • Büsten im Hörsaal des Instituts für Philosophie der U Jena und im Senatssaal der Humboldt-U Berlin.

\section{Hegener, Julius Carl Anton Hugo}

1901-1910 (1911) Med. Fak.

Ohrenheilkunde

* 04. Juni 1870 Essen

$\dagger \quad$ 23. Nov. 1953 Wildungen (heute: Bad W.) kath.

$\mathrm{V}$ August H., Ingenieur

M Josephine geb. Nierfeld

( 8. Mai 1896 Paula Antonie Josephine Magdalene geb. Otto (1875-1959)

$\mathrm{K}$ 4, davon mindestens $2 \mathrm{~S}$

Lb Seit WS 1889/9o Studium zunächst der Physik, Mathematik, dann der Medizin an U Bonn, anschl. Freiburg/Br., Bonn.

U Bonn: 10. März 1894 Dr. med.; WS 1894/95 med. Staatsexamen; 1895-1896 Militärdienstpflicht als Einjährig-Freiwilliger.

Breslau: Seit April 1896 Volontärassistent am Patholog. Inst. der U; seit Okt. 1897 chirurg. Assistent am Krankenhaus Bethanien.
UH: April 1898-1904 Assistent an U-Ohrenklinik; 20. Juli 1901 Habilitation; seit 11. Juli 1909 nichtetatm. a. o. Prof.; seit WS 1910/11 Beurlaubung, SS 1911 Streichung aus dem Personalverzeichnis. In dieser Zeit:

H: 1904-1907 (Schließung der Klinik, „um sich mehr der wiss. Arbeit zu widmen", aus: UAH PA 1684) Leiter e. Privatklinik.

Hamburg: Okt. 1910-Okt. 1943 Niedergelassener Facharzt für Ohren-, Nasen- und Halskranke; 1914-1918 Kriegsdienst als Stabsarzt in verschiedenen Lazaretten; April 1918-März 1935 außerdem leitender Oberarzt der Hals-, Nasen-, OhrenAbt. und der Poliklinik am Allg. Krankenhaus St. Georg. • In dieser Zeit:

U Hamburg: 19. Mai 1919-31. März 1935 Apl. a. o. Prof. für Ohrenheilkunde, s. hierzu Friedrich Maurer: Eintrag unter $K[$ inder].

Qu UAH PA 1684; RA 6318, 6398. GLA Abt. 235, Fasz. 2069.

$W$ Krankhafte Veränderungen der Form und Stellung der Ohrmuschel. Wiesbaden 1901. • Theoretische und experimentelle Untersuchungen der Massagewirkung auf den Schallleitungsapparat. Wiesbaden 1901.

$H G$ Zeitschrift für Hals-, Nasen- und Ohrenheilkunde.

L Politzer, Adam: Geschichte der Ohrenheilkunde. Stuttgart 1907. Bd. 1. S. 248 u. ö. $\bullet$ Kürschner (1935) Sp. 504, (1954) Sp. 846. Loebell, E.: J.H. on his eightieth birthday in: Zs. für Rhinologie, Otologie und ihre Grenzgebiete (Juni 1950) 29(6) S. $306 \mathrm{f}$. Fischer $\left({ }^{3} 1962\right)$ S. 598; WBIS; Brusis (2002) S. $188 \mathrm{f}$. u. ö. Über J.H. in: Rouenhoff, Tanja: Carl Otto von Eicken: Vertreter der Hals-, Nasen- und Ohrenheilkunde in Giessen von 1910-1922. Zahnmed. Diss. Gießen 2003. S. 60-64 u. ö.

$P$ Bildarchiv UAH. 


\section{Heger, Johann Philipp}

1805-1811 Med. Fak.

Arzneikunde (auch: 1805-1811 Geschichte der Medizin, 1806-1811 Pathologie, Therapie, 18071810 Gerichtliche Medizin)

* 12. Sept. 1770 Otterberg (bei Kaiserslautern)

$\dagger \quad$ o7. Dez. 1816 Heidelberg

kath.

V Matthäus H., Stadtschultheiß, auch Schaffner zu Enkenbach, siehe Seiner Churfürstl. Durchleucht [!] zu Pfalz Hof- und Staatskalender für das Jahr 1781. München 1781. S. 144, 192.

M Magdalena geb. N.N.

$\infty$ unverheiratet.

Lb UH: Seit 3. Dez. 1788 Studium; ca. 1793 Dr. med.; nach 1793 Assistenzarzt.

Baden(-Baden): Seit 1803 ärztl. Assistentenstelle; Nov. 1805 H. erhält durch Kurfürstl. SanitätsCommission seine Entlassung als ärztl. Assistent.

UH: SS 1805 (Beginn: 6. Mai 1805) als Doktor und Privatlehrer erstmals in „Anzeige derjenigen Vorlesungen, welche im Sommerhalbenjahre 1805 auf der Ruprecht-Carolinischen Universität zu Heidelberg gehalten werden“, genannt; H. liest über den „Einfluß medizinischer Systeme auf den Geist der Heilkunde, in theoretischer und praktischer Hinsicht", morgens 6-7 Uhr und über „Kritische Kulturgeschichte der Heilkunde neuester Zeit nach eigenen Heften", abends 5-6 Uhr; seit Nov. 1805 a. o. Prof. für Arzneikunde ohne Gehalt; seit 19. Juni 1810 o. Prof. als Nachf. von Johann Jacob Loos mit e. Jahresbesoldung von 30o.- Gulden. • In dieser Zeit:

H: 1805-1811 Niedergelassener Arzt.

Amorbach: Seit 23. April 1811 Hofarzt des Fürsten von Leiningen, Emich Carl (1763-1814).

H: Nach Juli 1814 Wohnsitz; 1814-1816 erneut niedergelassener Arzt.
Qu UAH PA 1685. GLA Abt. 205, Fasz. $276 \mathrm{f}$.

$W$ Einleitungsprogramm zur Eröffnung seiner Vorlesungen über verschiedene Gegenstände der Heilkunde ... Heidelberg 1806.

$L$ Wechmar (1846) S. 252; Keller (1913) S. 190 f.; Schneider (1913) S. 331-333; Stübler (1926) S. 238 f.

\section{Heine, Carl Wilhelm (seit 1876: Ritter von Heine)}

1865-1869 Med. Fak.

Chirurgie

* 26. April 1838 Cannstatt (heute: Bad C.)

$\dagger$ 09. Sept. 1877 Cannstadt kath.

V Dr. Jacob H. (180o-1879) Orthopäde, 18291864 Besitzer und Direktor e. priv. Orthopäd. Heilanstalt in Cannstatt, Entdecker und Beschreiber der „Heine-Medin-Krankheit“ (Spinale Kinderlähmung), s. NDB 8 (1969) S. 282 f., Hansen (1993) S. 55-73

M Henriette Ludovike geb. Camerer (1807-1884)

$\infty$ unverheiratet

Vw siehe NDB 8 (1969) S. 285, Hansen (1993) S. 1954.

Lb Seit WS 1855/56 Studium der Medizin, Naturwiss. an U Tübingen, seit 1858 Würzburg, 1861 Tübingen.

Tübingen: 1861 Med. und naturwiss. Staatsexamen; Juni 1861 Dr. med. an U.

1861-1862 Studienreisen nach Wien (6 Monate), Berlin (3 Monate) und Prag (einige Wochen).

Stuttgart: Sommer 1862 Ärztl. Staatsprüfung und Approbation.

Cannstatt: Seit Sommer 1862 Assistent in väterlicher Orthopäd. Heilanstalt.

Hofrat 
Seit Okt. 1862 Bildungsreisen nach Paris (bis April 1863), London (8 Monate), anschl. Glasgow, Edinburgh, zuletzt Dublin.

Cannstatt: Winter 1863-Febr. 1864 erneut Assistent in väterl. Orthopäd. Heilanstalt.

Flensburg: Seit Febr. 1864 Assistenzarzt in preuBischen Feldspitälern während des Deutsch-Dänischen Krieges.

Berlin: Seit Winter 1864/65 Studienaufenthalt.

UH: Juli 1865-1867 Assistent an Chirurg. U-Klinik; 3. Nov. 1865 Habilitation; SS 1867-WS 1867/68 provisorischer Leiter der Chirurg. U-Klinik anstelle von Carl Otto Weber († Juni 1867); seit 20. Mai 1868 a. o. Prof.

U Innsbruck: Seit WS 1869/70 o. Prof. und Gründungs-Direktor der Chirurg. U-Klinik; 1870/71 Leiter e. Feldhospitals e. württ. Sanitätszuges in Nancy während des Deutsch-Französischen Krieges.

U Prag: Seit 1873 o. Prof., Gründer und Leiter der II. Chirurg. U-Klinik; seit Okt. 1876 österr. Staatsbürger.

Jan. 1877 Wahl zum Präsidenten der deutschen Ärzteschaft

E 1876 Erhebung in den österr. erblichen Ritterstand. 1864/65 Königl. Preußischer Roter Adler-Orden IV. Klasse; Alsenkreuz am Hohenzollernband; österr. Orden der Eisernen Krone; 1871 Eisernes Kreuz II. Klasse und bayer. Verdienstkreuz.

Qu UAH PA 1692. 3 Briefe, u. a. in: SchleswigHolsteinische Landesbibliothek in Kiel.

$W$ Resection des Kehlkopfes bei Laryngo-Stenose in: Archiv für klinische Chirurgie 7 (1866) S. 514-526. Die Schußverletzungen der unteren Extremitäten. Berlin 1866. Der Hospitalbrand (Gangraena diphtheritica) Wund-Diphtheritis in: Handbuch der allg. und speciellen Chirurgie (1874) Bd. 1, Abt. 2, S. 187-385.
L NDB 8 (1969) S. 285 (mit Werkverz.); WBIS. • Hekler, Hans: C.W.H. - Enkel des Lauterbacher Sonnenwirts - einer der großen Chirurgen des 19. Jahrhunderts in: D’Kräz. Beiträge zur Geschichte der Stadt und Raumschaft Schramberg. Heft 12 (1992) S. 17-25; online unter http:// www.hanshekler.de/ch/history/Heine/Carl_Wilhelm_Heine.pdf. (Stand: 2007). Hansen, Heinz: Die Orthopädenfamilie Heine. Leben und Wirken der einzelnen Familienmitglieder im Zeichen einer bedeutenden deutschen Familientradition des neunzehnten Jahrhunderts. Dissertation. Dresden 1993. Huber, Heinz: Geschichte der Medizinischen Fakultät Innsbruck und der medizinischchirurgischen Studienanstalt (1673-1938). Wien 2010. S. 365 (Register).

$P$ NDB; Hekler; Hansen.

\section{Heinsheimer, Karl August}

1903-1929 Jur. Fak.

Zivilprozeßrecht, Dt. Bürgerliches Recht, Han-

delsrecht

* 2o. Okt. 1869 Mannheim

$\dagger$ 16. Juni 1929 Heidelberg

mosaisch, seit $1899 \mathrm{ev}$.

V Maximilian (Max) H. (1832-1892), u. a. 18791892 Oberlandesgerichtsrat in Karlsruhe, s. Badische Biographien 5 (1906) S. 269 f.; Jüdisches Leben im Kraichgau. Zur Geschichte der Eppinger Juden und ihrer Familien. Hrsg. von den Heimatfreunden Eppingen e. V. Eppingen 2006. S. 138-142; Jüdische Persönlichkeiten im Kraichgau (2013) S. 119-122

M Anna geb. Rosenthal (1847-1882)

$\infty$ 11. Juli 1896 Anna Regina geb. Dreifus/Dreifuß (1875-1955), s. Lexikon jüdischer Einwohner Hs (2011) S. 162

$\mathrm{K} \quad 2 \mathrm{~S}$ (davon $1 \mathrm{~S}$ im 1 . Weltkrieg $X)$ ), $1 \mathrm{~T}$, s. Lexikon jüdischer Einwohner Hs, S. 163 
Vw Neffe: Dr. iur. (UH) Rudolf H. (ca. 1934 Änderung des Namens in: Uri Yadin) (1908-1985), u.a. 1931-1933 (Berufsverbot) Assistent an Jur. Fak. Berlin, 1933 Emigration; Jerusalem: 1936-1948 Rechtsanwalt, seit 1949 Direktor für Planung im Rechtswesen im israelischen Justizministerium, seit 1958 stellvertr. Generalstaatsanwalt; seit 1951 auch Dozent, seit 1970 Visiting Associate Prof. für Körperschaftsrecht, Verfassungsrecht Hebräische U Jerusalem, s. WBIS; Englard, Izhak: Uri Yadin - In memoriam in: Israel Law Review (1985) Nr. 4.

Lb Seit WS 1886/87 Studium an U Lausanne, anschl. Straßburg, Berlin, Leipzig, Freiburg/Br.; 1890 I. badische Staatsprüfung.

Dez. 1890-Juni 1894 Volontär am Bezirksamt in Waldkirch (im Breisgau), danach am Oberlandesgericht in Karlsruhe.

7. Juli 1891 Dr. iur. an U Leipzig; 29. Juni 1894 II. Staatsprüfung in Karlsruhe.

Seit 5. Juli 1894 Referendar bei Staatsanwaltschaft in Freiburg/Br., später am Amtsgericht in Mannheim.

Mosbach (Baden): Seit 5. Juni 1896 Amtsrichter.

H: Seit 11. März 1899 Landgerichtsassessor; 21. Juni 1901-4. April 1907 Landgerichtsrat.

UH: 28. Nov. 1903 Habilitation für Bürgerliches Recht und Zivilprozesse; seit 4. April 1907 o. Prof. als Nachf. von Heinrich Buhl; April 1917 Gründer und 1917-1929 Direktor (1918-1923 neben Karl Neubecker, 1924-1929 neben Max Gutzwiller) des gestifteten Seminars für Rechtswirtschaftliche und Rechtsvergleichende Studien im Haus Augustinergasse 9 in $\mathrm{H}$; das Seminar wird seit 1924 als Inst. der U unter der Bezeichnung Inst. für Ausländisches Recht geführt, s. hierzu UAH H-II-554/1.

Das Seminar für Rechtswirtschaftliche und Rechtsvergleichende Studien ist 1916 u.a. eine Stiftung des Großunternehmers und Mäzenen Carl Leopold Netter (1864-1922; s. NDB 19 (1999) S. 86 f., UH während des Ersten Weltkriegs (2017) S. 44); nach Minimierung des Stiftungsvermögens wäh- rend der Inflation wird das Institut von der $\mathrm{UH}$ seit 1924 teilfinanziert. - Siehe hierzu auch Karl Neubecker

1929 Rektor der UH; 1911/12, 1917/18 Dekan der Jur. Fak. der UH

1917 Geh. Hofrat

Siehe auch Anhang Sporteinrichtungen an UH 1910-1933 und ihre Mitglieder

E 1910 Ritterkreuz I. Klasse des Ordens vom Zähringer Löwen.

Qu UAH PA 759, 4140-4142; RA 1132, 5225, 5718, 6762. • GLA Abt. 235, Fasz. 2075. • Briefe: UBH.

W Typische Prozesse. Berlin 1906. 7. Aufl. 1927. • Praktische Übungen im Bürgerlichen Recht. Jena 1909. 5. Aufl. 1930. Handels- und Wechselrecht. Berlin 1924. 3. Aufl. 1930.

$H G$ Zivilgesetze der Gegenwart.

L Handels-Hochschule Mannheim 1907-1932 (1932) S. 26; NDB 8 (1969) S. 440 f. • Über K. H. in: Seckel, Dietrich: Gradenwitz-Anekdoten in: Ruperto Carola 32. Jg., H. 64 (1980) S. 34. • Jansen (1992) S. 409 (Register); Ders. (1992a) S. 166 (Register); WBIS. Coulin, Christian-Karl: K.A.H. Vom badischen Richter zum Lehrer an der Universität Heidelberg. Frankfurt/M. 2009. • Schroeder (2010) S. 738 (Register); Lexikon jüdischer Einwohner Hs (2011) S. 163; Schroeder (2017) S. 234249.

$P$ Bildarchiv UAH; graph. Slg. UBH; NDB. 


\section{Heinze, Carl Friedrich Rudolf}

1873-1896 Jur. Fak.

Strafrecht, Strafprozeßrecht, Kirchenrecht

* 10. April 1825 Saalfeld an der Saale (Thüringen)

$\dagger$ 18. Mai 1896 Heidelberg ev.-luth.

V Dr. phil. et theol. Johann Christian Carl H. (1797-1872), u. a. Konrektor am Lyzeum, seit 1835 Pfarrer, s. Schroeder (2010) S. 255 Anm. 103

M Henriette geb. Heumann (1802-1872)

(20. April 1857 Elise Henriette geb. von Zastrow (1834-1915)

$\mathrm{K} \quad 1 \mathrm{~S}$, mind. $2 \mathrm{~T}$ (davon $1 \mathrm{~T}$ früh $\dagger$ ), u. a. Margarethe Hedwig Elisabeth H. (1858-1928) Ehefrau von: (siehe) Richard Loening

Vw Bruder: Franz Friedrich Maximilian (Max) H. (1835-1909), u. a. 1875-1909 o. Prof für Geschichte der Philosophie Leipzig, s. NDB 8 (1969) S. 447, Professorenkatalog Leipzig online

Vw Neffe (S von Max H. (1835-1909)): Karl Rudolf H. (1865-1928), u.a. seit 1906 Landgerichtsdirektor in Dresden, 1907-1912 Mitglied des Reichstags (nationalliberal), seit 1914 Reichsgerichtsrat, 1915-1916 Mitglied der II. Sächsischen Kammer, 1916-1918 Unterstaatssekretär im Justizministerium in Konstantinopel, 1. Juli-8. Nov. 1918 sächsischer Justizminister, 1918/19 Mitbegründer der DVP, 1920-1928 Mitglied des Reichstags, 25. Juni 1920-4. Mai 1921 und 22. Nov. 1922-12. Aug. 1923 Reichsjustizminister, 1923 Reichskommissar in Sachsen, 1926-1927 Vorsitzender des Konsularobergerichts in Ägypten, s. Gustav Radbruch Gesamtausgabe. Bd. 16: Biographische Schriften. Bearb. von Günter Spendel. Heidelberg 1988. S. 444f.; „Akten der Reichskanzlei. Weimarer Republik" online, s. http://www.bundes archiv.de/aktenreichskanzlei/1919-1933/opa/a dr/adrhl/kap1_1/para2_172.html (abgerufen am 28. Aug. 2017).

$L b$ U Leipzig: Seit 20. Mai 1844 Studium der Rechtswiss., Kriminalistik; 1847 I., 1849 II., 1852 letzte Staatsprüfung.
Thüringen: Seit 1847 Volontär in Herzogl. Meiningischen Diensten; seit 3. Okt. 1850 Volontär, seit 1. Dez. 1850 provisorischer Staatsanwalt in Salzungen; planm. Staatsanwalt: seit 29. Dez. 1852 in Sonneberg, seit 7. Dez. 1853 am Kreisgericht in Hildburghausen.

Dresden: Seit 4. Sept. 1856 Stellvertr. des Oberstaatsanwalts am Königl. Sächsischen Oberappellationsgericht; seit 5. Nov. 1860 I. Staatsanwalt am Bezirksgericht.

U Leipzig: 4. April 1865 Ern. zum o. Prof. für Kriminalrecht, Strafrecht, Strafprozeß und Rechtsphilosophie; 1866-1871 Vertreter der U Leipzig in I. Kammer des Sächsischen Landtags in Dresden; 1870 Berufung an Hanseatisches Oberappellationsgericht in Lübeck abgelehnt; 1872 Konflikt mit sächsischer Regierung durch zu liberale Ansichten, s. hierzu Pawlischta (1998) S. 49 f.; 1872 Ruf an U Tübingen zunächst angenommen, dann abgelehnt.

UH: 7. Jan. 1873 Annahme des Rufes als o. Prof. und Nachf. von Emil Herrmann; 1873-1879 (Auflösung) Beisitzer des Spruchkollegiums der Jur. Fak.; 1875 Ruf an U Wien abgelehnt.

1883 Prorektor der UH; $1876 / 77,1882 / 83,1888 / 89$, 1894/95 Dekan der Jur. Fak. der UH

1870 Geh. Hofrat; 1873 Geh. Rat II. Klasse

$E 1865$ Dr. iur. h.c. Leipzig. 1874 Österr. Comthurkreuz des Franz-Josefs-Ordens; 1875 Kommandeurkreuz des Ordens vom Zähringer Löwen; 1893 Orden des Heiligen Stanislaus II. Klasse mit Stern.

Qu UAH PA 1691. - Briefe: UBH; Universitätsbibliothek Leipzig.

$W$ Ein deutsches Geschworenengericht. Leipzig 1865. Staatsrechtliche und strafrechtliche Erörterungen zu dem amtlichen Entwurfe eines Strafgesetzbuches für den Norddeutschen Bund. Leipzig 1870. - Hungarica. Freiburg/Br. 1882. - Siehe Bibliographie in: Pawlischta (1998) S. XVIII-XXI. 
L ADB 50 (1905) S. 153-155; Badische Biographien 5 (1906) S. 270-276; Jammers (1964) S. 177 u. ö.; Heidelberger Strafrechtslehrer (1986) S. 35-42. • Pawlischta, Udo: C.F.R.H. - Leben und Werk eines altliberalen Strafrechtslehrers ... Als Ms. gedr. Aachen 1998. Klietz, Guido: C. F. R.H. in: Rudolstädter Heimathefte ... H. 1/2 (2002) 48. Jg., S. 4244, H. 3/4 (2002) 48. Jg., S. 102. • WBIS; Baur (2009) S. 195 f. u.ö.; Professorenkatalog Leipzig online; Schroeder (2010) S. 255-258.

$P$ Bildarchiv UAH; graph. Slg. UBH.

\section{Heise, Georg Arnold}

1804-1814 Jur. Fak.

Kirchenrecht, Kirchengeschichte, Römisches

Recht

* 02. Aug. 1778 Hamburg

$\dagger \quad$ o6. Febr. 1851 Lübeck

ev.-luth.

V Ludwig Barthold H. (1749-1812) Kaufmann

M Marianne geb. Behrmann (1746-1801)

(0) 30. Sept. 1804 Elisabeth geb. Isenbart (17751831)

$\mathrm{K} \quad 1 \mathrm{~S}($ früh $\dagger), 3 \mathrm{~T}$ (davon $1 \mathrm{~T}$ früh $\dagger)$

Lb Seit Okt. 1798 Studium an U Jena, anschl. Göttingen.

U Göttingen: 16. Jan. 1802 Dr. iur.; seit 1. März 1802 a.o. Beisitzer des Spruchkollegiums; seit SS 1803 Privat-Dozent; 1804 Ruf an U Jena abgelehnt; seit 1804 a. o. Prof.

UH: 23. Juni 1804 Ern. zum o. Prof.; 29. Okt. 1804 Amtsantritt; 1804-1814 Beisitzer des Spruchkollegiums der Jur. Fak.; 1808 Ruf an Ludwig-Maximilians-U Landshut abgelehnt.

U Göttingen: 23. April 1814-31. März 1820 o. Prof. für Römisches Recht. • In dieser Zeit:
Hannover: Seit Mai 1818 Vortragender Rat im Justizdepartement; seit 1819 auch Abgeordneter der U Göttingen in II. Kammer der Ständeversammlung des Königreichs Hannover.

Lübeck: Seit April 1820 Präsident des Oberappellationsgerichts der vier Freien Städte des Dt. Bundes.

1808 Prorektor der UH; 1805, 1810 Dekan der Jur. Fak. der UH

1808 Justizrat; 1816 Hofrat

Qu UAH PA 1690; RA 4921, 6029. GLA Abt. 205, Fasz. 280. • Briefe: UBH. • Nachlaß: UBH (Signatur: Heid. Hs. 2128); Archiv der Hansestadt Lübeck im Bestand Familienarchiv Hach.

$W$ Grundriß eines Systems des gemeinen Civilrechts zum Behuf von Pandektenvorlesungen. Heidelberg 1807. 3. Aufl. 1819. Reprint Frankfurt/M. 2016. • Juristische Abhandlungen mit Entscheidungen des Oberappellationsgerichts der vier freien Städte Deutschlands. Hamburg 1830 (zus. mit Friedrich Cropp). • Heise's Handelsrecht. Hrsg. von August Wunderlich. Frankfurt/M. 1858.

MHG 1827-1830 Juristische Abhandlungen.

L Keller (1913) S. 182-184; Schneider (1913) S. 97; Lautenschlager (1933) S. 639 f. u. ö.; Jammers (1964) S. 177 u.ö.; NDB 8 (1969) S. 453f.; Biogr. Lexikon für Schleswig-Holstein 7 (1985) S. 97 f.; Heidelberg im säkularen Umbruch (1987) S. 561 (Register); Weisert (1991) S. 122 u. ö. • Ahrens, Gerhard: G.A.H. in: Lübecker Lebensläufe aus neun Jahrhunderten. Hrsg. von Alken Bruns. Neumünster 1993. S. 178-181. - Braunewell, Markus: G.A.H. Biographie und Briefwechsel mit Savigny und anderen. Diss. Frankfurt/M. 1999. - Kirschke (2001) S. 447 (Register); WBIS; Schroeder (2010) S. 2023 u. ö. • A.F.J. Thibaut ... Bürger und Gelehrter. Hrsg. von Christian Hattenhauer ... Tübingen 2017. S. 8-11 u. ö.

$P$ Bildarchiv UAH; graph. Slg. UBH; NDB. 
Hellpach, Willy Hugo (Pseudonym: Gystrow, Ernst)

1926-1951 (1952) (Honorar-Prof.) Phil. Fak. Allg. und Angewandte Psychologie, Sozial- und Völkerpsychologie

* 26. Febr. 1877 Oels in Schlesien (heute: Oleśnica, Polen)

$\dagger \quad$ o6. Juli 1955 Heidelberg ev.-luth.

V Hugo Rudolf Hermann H. († Aug. 1877) Kreisgerichts-Kalkulator

M Agnes Anna geb. Otto (1853-1930)

๑ 28. April 1904 Olga Johanna geb. Klim (18801948) kath.

$\mathrm{K}$ keine.

Lb Seit WS 1895/96 Studium der Psychologie, Philosophie, Medizin an U Greifswald, seit WS 1897/ 98 Leipzig; 23. Jan. 1900 Dr. phil. an U Leipzig; 1901 med. Staatsexamen und Approbation in Greifswald; Okt. 1900-Okt. 1901 Militärdienstpflicht als Einjährig-Freiwilliger in Greifswald, dann Jena.

UH: Okt. 1901-Sept. 1902 Volontärarzt an Psychiatr. U-Klinik; März-April 1902 abgebrochene Unterarztübung in Jena.

Berlin: Okt. 1902-Herbst 1903 Volontärarzt an Poliklinik.

UH: 10. Dez. 1903 Dr. med.

Karlsruhe: 1904-1922 Niedergelassener Nervenarzt. • In dieser Zeit:

TH Karlsruhe: 16. Febr. 1906 erste Habilitation für Psychologie an Phil. Fak. der UH für TH, s. hierzu Karl Jaspers; 25. Juni 1906 Erteilung der venia legendi für Psychologie an TH; seit 22. Dez. 1911 nichtetatm. a.o. Prof.; seit 1. April 1920 planm. a. o. Prof. und Direktor des neugegründeten Inst. für Sozialpsychologie; 19. Dez. 1922-1. Jan. 1926 o. Honorar-Prof.; 1923 Ruf an Handelshochschule Mannheim abgelehnt. • In dieser Zeit:

1914-1918 Kriegsdienst.
Karlsruhe: 1919 Eintritt in die Deutsche Demokratische Partei (DDP); 1920-1922 Stadtverordneter; 7. Nov. 1922-26. Dez. 1925 badischer Minister des Kultus und Unterrichts; seit Nov. 1923 stellvertr. badischer Staatspräsident, Nov. 1924-Nov. 1925 badischer Staatspräsident.

UH: 4. Jan. 1926 Ern. zum o. Honorar-Prof. mit Lehrauftrag für Allg. und Angewandte Sozialund Völkerpsychologie (Phil. Fak.); 8. Mai 1926 (Antrittsvorlesung)-17. Nov. 1951 (Beendigung der Vorlesungstätigkeit aus gesundheitlichen Gründen) H. kündigt in jedem Semester Vorlesungen an; WS 1943/44 (erste Erwähnung im Personalund Vorlesungsverzeichnis der UH (1943) S. 29)17. Nov. 1951 Leiter des Psycholog. Inst. (Nachf.: (siehe) Johannes Rudert in: Drüll (2009) S. 507f.); 1. Nov. 1952 Niederlegung der Professur. - In dieser Zeit:

Berlin: März 1925 Kandidat der DDP im 1. Wahlgang der Reichspräsidentenwahl; 1925-1930 (Rücktritt) stellvertr. Vorsitzender der DDP-Parteileitung; 20. Mai 1928-16. März 1930 (Niederlegung des Mandats) Reichstagsabgeordneter; 1928 1930 Mitglied des Reichsgesundheitsrates.

H.s Einstellung zum Nationalsozialismus, s. Kaune (2005) S. 332-341 u. ö.

E Mitglied: 1943 Akademie der Wissenschaften H, 1944 Dt. Akademie der Naturforscher Leopoldina Halle/S. 1952 Wilhelm-Wundt-Medaille; 1952 Großes Bundesverdienstkreuz; 1953 ParacelsusMedaille. - Eisernes Kreuz II. Klasse; Ritterkreuz II. Klasse des Ordens vom Zähringer Löwen.

Qu UAH PA 436, 4150 f.; Quästurakten Rep. 27494 f.; Rep. 40-401; Fak.-Akten H-III-145, H-IV102/150 Nr. 158; B-1266/4, B-6651/1. • GLA Abt. 235, Fasz. 6135. - Briefe: u. a. in UBH. - Nachlaß: GLA Karlsruhe. Siehe auch Archiv der Dt. Akademie der Naturforscher Leopoldina Halle/S. - Reden dt. Gelehrter (1999) S. 63-78. • Wirken in Wirren. 2 Bde. Hamburg 1948-1949. (Autobiogr.) • Hellpach-Memoiren 1925-1945. Hrsg. von Christoph Führ und Hans Georg Zier. Köln 1987. 
$W$ Die Grenzwissenschaften der Psychologie. Leipzig 1902. - Die geopsychischen Erscheinungen. Leipzig 1911. 4.-8. Aufl. u.d.T.: Geopsyche. 1935-1977. - Die Wesensgestalt der deutschen Schule. Leipzig 1925. 2. Aufl. 1926. • Politische Prognose für Deutschland. Berlin 1928. • Elementares Lehrbuch der Sozialpsychologie. Berlin 1933. Ab 2. Aufl. u.d.T.: Sozialpsychologie. 3. Aufl. 1951. • Einführung in die Völkerpsychologie. Stuttgart 1938. 2. Aufl. 1944. - Siehe Stallmeister, Walter: Willy Hellpach-Bibliographie. Hagen 1986.

HG Seit 1922 Sozialpsychologische Forschungen.

Redakteur 1907-1920 Ärztliche Mitteilungen des Leipziger Ärzteverbandes.

$L$ NDB 8 (1969) S. 487f. (mit Werkverz.). Gundlach, Horst: W.H. zum Gedächtnis in: Ruperto Carola 28./29. Jg., H. 58/59 (1976/77) S. 112 f.; Ders.: Freud schreibt an H. in: Psyche 31 (1977) S. 908934; Ders.: W.H., Attributionen in: Psychologie im Nationalsozialismus. Hrsg. von Carl Friedrich Graumann. Heidelberg 1985. S. 165-195. Chronik Ärzte H (1985) S. 131; Klüpfel/Graumann (1986) S. 29-31, 59-70 u. ö.; WBIS. - Lankenau, Klaus: W.H. - Ein Leben zwischen Politik und Wissen in: ZGORh 134. Jg. (1986) S. 359-375; Wolgast, Eike: Der demokratische Bürger als Politiker: Bemerkungen zum 3. Band der Erinnerungen von W.H. in: ebd. 136. Jg. (1988) S. 479-483. • W.H. Beiträge zu Werk und Biographie. Hrsg. von Walter Stallmeister ... Frankfurt/M. 1991. • Jansen (1992) S. 409 (Register); Wennemuth (1994) S. 635 (Register); Baden-Württ. Biographien II (1999) S. 209212. Müller, Kathrin: Die Geschichte des Psychologischen Instituts der Universität Heidelberg in den Jahren 1933-1980. Diplom-Arbeit. Heidelberg 200o. Jansen, Christian: W.H. Ein antiliberaler Demokrat kommentiert den Niedergang der Weimarer Republik in: Völkische Bewegung - Konservative Revolution - Nationalsozialismus ... Hrsg. von Walter Schmitz ... Dresden 2005. S. 209226. Kaune, Claudia-Anja: W.H. Biographie eines liberalen Politikers ... Frankfurt/M. 2005. Raehlmann (2005) S. 271 (Register); Ärztelexikon (2006) S. 159 f. • Müller, Leonhard: Wirken in Wirren: W.H. in: Badische Heimat: mein Heimatland. Zs. für Landes- und Volkskunde ... Freiburg/Br.
2006. S. 237-245. UH im Nationalsozialismus (2006) S. 543-555 u.ö.; Kriegstagebuch K. Hampe (2007) S. 967 (Register); Spenkuch (2016) S. 1313 (Register).

P Bildarchiv UAH; NDB; Chronik Ärzte H.

\section{Helmholtz, Hermann Julius Ferdinand (seit 1883: von Helmholtz)}

1858-1871 Med. Fak.

Physiologie

* 31. Aug. 1821 Potsdam

$\dagger \quad$ o8. Sept. 1894 Charlottenburg (heute: Charlottenburg-Wilmersdorf, Ortsteil von Berlin)

$\square$ Friedhof Wannsee ev.

V August Ferdinand Julius H. (1792-1859) Gymnasiallehrer, s. Stock/Lemmerich (2014) S. 3

M Caroline geb. Penne (1797-1854), s. ebd.

(26. Aug. 1849 Olga geb. von Velten (1827-1859)

๑ 16. Mai 1861 Anna geb. von Mohl (1834-1899), s. NDB 8 (1969) S. 501, Pfeiffer (2004) S. 154f.; T von: (siehe) Robert von $\mathrm{M}$.

K 2 T: Katharina (Käthe) H. (1850-1878) Ehefrau von Wilhelm von Branca (1844-1928), u. a. seit 1887 o. Prof. für Mineralogie, Geologie, Paläontologie Königsberg (Preußen), 1890-1895 (Niederlegung des Amtes aus gesundheitlichen Gründen) Tübingen, 1899-1917 (Ruhestand) Berlin, s. Tilitzki 1 (2012) S. 784 (Register); s. auch Gustav Kirchhoff: Eintrag unter $K$ [inder]. - Ellen von H. (1864-1941) Malerin, Ehefrau von Arnold (von) Siemens (18531918) Mitinhaber der Firma Siemens \& Halske, Politiker, s. WBIS. 3 S: u. a. Richard Wilhelm Ferdinand von H. (1852-1934) Eisenbahn-Ingenieur, s. NDB 8 (1969) S. 501 f. - Dr. phil. Robert von H. (1862-1889) Physiker, s. WBIS.

Lb Berlin: Seit WS 1838/39 Eleve des Königl. Med.Chirurg. Friedrich-Wilhelms-Inst.; Juni 1842 mündl. med. Examen ebd.; 2. Nov. 1842 Dr. med. ebd.; seit Okt. 1842 Unterchirurg an Charité; Okt. 1843-Sept. 1848 Eskadronchirurg und Militärarzt in Potsdam; Febr. 1846 Staatsprüfung als Arzt 
und Wundarzt am Friedrich-Wilhelms-Inst.; seit 2. Sept. 1848 Lehrer der Anatomie an Akademie der Künste und Gehilfe am Anatomisch-Zootomischen Museum.

U Königsberg: Seit 3. Juni 1849 a. o. Prof. für Physiologie und Pathologie mit Besoldung; seit 24. Jan. 1852 o. Prof.; 1853 Ruf an U Kiel abgelehnt.

U Bonn: Seit 27. März 1855 o. Prof. für Physiologie und Anatomie; 1857 Ruf an UH zunächst abgelehnt.

UH: Seit 17. April 1858 o. Prof. und Direktor des Physiolog. Inst. als Nachf. von Friedrich Arnold mit e. jährl. Gehalt von 360o.- Gulden; Okt. 1858 Dienstantritt; Sept. 1863 Bezug des Physiolog. Inst. und e. Dienstwohnung (Miete: 360.- Gulden) im neuerrichteten Friedrichsbau in der Hauptstraße 47-51 (auf dem Gelände des ehem. Dominikanerklosters), s. hierzu Hübner (2010) S. 142-148; Rufe an U abgelehnt: 1865 Wien, 1868 Bonn, 1871 Cambridge (Großbritannien).

U Berlin: Seit SS 1871 o. Prof. für Physik und Direktor des Physikal. Inst. mit e. jährl. Gehalt von 4000.- Talern (entspricht 7000.- Gulden).

Charlottenburg: Seit 4. April 1888 (Mitbegründer) Präsident der Physikalisch-Technischen Reichsanstalt.

1862 Prorektor der UH; 1860, 1865/66 Dekan der Med. Fak. der UH

1850 Erfinder des Augenspiegels, s. Dokumente zur Erfindung des Augenspiegels durch H. von H. im Jahre 1850. Hrsg. von Ernst Engelking. München 1950.

1845 Gründer und Mitglied der Physikalischen Gesellschaft Berlin

1858-1871 Vorsteher des Naturhistor.-Med. Vereins Heidelberg, s. hierzu Hübner (2010) S. 108 u. ö.

1869 Mitbegründer des Deutschen Alpenvereins

1861 Hofrat; 1865 Geh. Rat III. Klasse; 1868 Geh. Rat II. Klasse; 1891 Geh. Reg.-Rat
$E$ Mitglied der Akademie der Wissenschaften: 1857 Berlin, 1858 München, 1859 Göttingen, 1860 Wien. Dr. phil. h.c.: 1860 Berlin, 1878 Pavia. • 1867 Maximiliansorden für Wissenschaft und Kunst. - 1858 Ritterkreuz des Königl. Niederländischen Löwenordens; 1865 St. Stanislaus Orden II. Klasse; 1868 Kommandeurkreuz II. Klasse des Ordens vom Zähringer Löwen. 1869 Ehrenbürger der Stadt Heidelberg.

Qu UAH PA 1700; RA 184, 5815, 6189, 6808; GF 14. GLA Abt. 6o, Fasz. 22, Abt. 76, Fasz. 9939. • Briefe: UBH. - Dokumente einer Freundschaft. Briefwechsel zwischen $\mathrm{H}$. von $\mathrm{H}$. und Emil du Bois-Reymond 1846-1894. Bearb. von ... Christa Kirsten ... Berlin 1986. • Hörz, Herbert: Naturphilosophie als Heuristik? Korrespondenz zwischen H. von H. und Lord Kelvin (William Thomson). Marburg 2000. - Nachlaß: Berlin-Brandenburgische Akademie der Wissenschaften; Historische Instrumentensammlung am Johannes-Müller-Institut für Physiologie an der Humboldt-Universität zu Berlin; Deutsches Museum von Meisterwerken der Naturwissenschaft und Technik München/Archiv.

$W$ Über die Erhaltung der Kraft. Berlin 1847. • Lehre von den Tonempfindungen als physiologische Grundlage für die Theorie der Musik. Braunschweig 1863. 6. Aufl. 1913. Bibliographie in: Stock/Lemmerich (2014) S. 97-118. Philosophische und populärwissenschaftliche Schriften. Hrsg. von Michael Heidelberger, Helmut Pulte und Gregor Schiemann. 3 Bde. Hamburg 2017.

$L$ Verzeichnis Bonn (1968) S. 113; NDB 8 (1969) S. 498-501 (mit Werkverz.); Poggendorff 7a, Suppl. (1971) S. 267-277. Bringmann, Wolfgang u. a.: H. und Wundt an der Heidelberger Universität 1858 1871 in: Heidelberger Jahrbücher 20 (1976) S. 7988. Das Haus H. in: Kyczynski, Jürgen: Gelehrtenbiographien. Berlin 1977. S. 103-124. - Ernst Wilhelm von Brücke. Briefe an Emil Du Bois-Reymond. Hrsg. ... von Hans Brücke ... 1. T. Graz 1978. S. 298 (Register). • Chronik Ärzte H (1985) S. 131, 228 f.; Zimmermann/Drüll (1990) S. 4of. • H. von H. Vorträge e. Heidelberger Symposiums anläßlich des 100. Todestages. Hrsg. von Wolfgang U. Eckart und Klaus Volkert. Pfaffenweiler 1996. Werner, Franz: H.H.' Heidelberger Jahre 1858- 
1871. Berlin 1997; Ders.: Zum Tod des Physiologen H.H. in: ZGORh 146. Jg. (1998) S. 544-551. Beneke (1999) S. 106-150; Peiffer (2004) S. 1154 (Register); Naturphilosophie nach Schelling (2005) S. 237-274; Von der Forschung gezeichnet (2007) S. 112 f. u. ö. Ruoff, Michael: H. von H. Paderborn 2008. Autoren der Bunsenbibliothek (2009 online); Homo Heidelbergensis mathematicus online. - Hübner, Klaus: Gustav Robert Kirchhoff. Das gewöhnliche Leben eines außergewöhnlichen Mannes. Ubstadt-Weiher 2010. S. 304 (Register). Werner, Franz: Die Berufung von H. von $\mathrm{H}$. an die Universität Heidelberg. Digitale Ausgabe von Gabriele Dörflinger. Universitätsbibliothek Heidelberg. Heidelberg 2011, s. http://archiv. ub.uni-heidelberg.de/volltextserver/19571/. • Wissenschaftsatlas der UH (2011) S. 97-99; Fischer (2012) S. 116-118; Geschichte U Berlin (2012) Bd. 1, S. 661 (Register). - Araujo, Saulo de Freitas: Bringing new archival sources to Wundt scholarship: The case of Wundt's assistantship with $\mathrm{H}$. in: History of Psychology - American Psychological Association - 17 (2014) S. 50-59. - Stock, Armin, Lemmerich, Jost: H. von H. Ein Wegbereiter der wissenschaftlichen Psychologie. Würzburg 2014. • Hörz, Herbert: Alexander von Humboldt und $\mathrm{H}$. von $\mathrm{H}$. Aktuelle Ideen von zwei Geistesheroen des 19. Jahrhunderts in: El arte de crear memoria. Festschrift zum 8o. Geb. von Hans-Otto Dill. Hrsg. von Dorothee Röseberg ... Berlin 2015. S. 33936o. - Rheinberger, Hans-Jörg und Schöttler, Peter: Empirie vor Theorie. Leopold von Ranke und $H$. von H. in: Berlins wilde Energien. Porträts aus der Geschichte der Leibnizschen Wissenschaftsakademie. Hrsg. von Stephan Leibfried ... Berlin 2015. S. 190-211.

$P$ Bildarchiv UAH; graph. Slg. UBH; NDB; Chronik Ärzte H; Fischer (2012).

\section{Henle, Friedrich Gustav Jacob}

1844-1852 Med. Fak.

Pathologische Anatomie, Physiologie,

Vgl. Anatomie

* 19. Juli 1809 Fürth

$\dagger$ 13. Mai 1885 Göttingen

ev.-luth.

V Simon Wolf Jacob H. (mosaisch, seit $1821 \mathrm{ev.}$ mit Taufnamen: Wilhelm Simon H.) (17821856) Kaufmann

M Helene Sophie geb. Disbeck/Diespeck (17791836)

@ 10. März 1846 Elisabeth geb. Egloff (1821-1848), siehe „Mein geliebter, böser Schatz!“ Der Anatom und das Nähmädchen, eine Geschichte in Briefen. Zürich 2004.

œ 11. Aug. 1849 Marie Johanne Elise geb. Richter $\left({ }^{*} 1827\right)$

K 2 S, 4 T: u.a. Anna H. (1850-1923) Ehefrau von Friedrich Merkel (1845-1919), u. a. seit 1872 o. Prof. für Anatomie Rostock, seit 1883 Königsberg (Preußen), seit 1885 Göttingen, s. NDB 17 (1994) S. 145 f., WBIS, Tilitzki 1 (2012) S. 800 (Register). - Sophie H. (1852-1917) Ehefrau von Heinrich Ephraim Ulmann (18411931), u.a. seit 1870 Prof. für Geschichte U Dorpat, 1874-1912 o. Prof. Greifswald, s. Weber (1987) S. 611, WBIS, Grewolls (2011); North, Michael: Von Ernst Moritz Arndt zu Herbert Langer: Protagonisten der neueren Geschichte in Greifswald ... Stuttgart 2015. S. 83-97.

Vw Neffe: (Siehe) Fritz Schöll. - Großnichte: Dorothea (Dora) Johanna geb. Schöll (188o1967), s. Lexikon jüdischer Einwohner Hs (2011) S. 340; Ehefrau von: (siehe) Otto Regenbogen

Vw Enkel: Paul Merkel (1872-1943), u. a. seit 1909 a. o., seit 1916 o. Prof. für Rechtswiss. Greifswald, s. NDB 17 (1994) S. 145*, WBIS. - Marie geb. Ulmann (1873-1915) T von Sophie Ulmann geb. Henle und Heinrich Ulmann (siehe oben Eintrag unter $K[$ inder]), Ehefrau von: (siehe) Werner Kümmel.

Lb Seit 1828 Studium an U Bonn, seit SS 1830 H, seit SS 1831 Bonn; 4. April 1832 Dr. med. an U Bonn; 30. März 1833 Staatsexamen in Berlin. 
Berlin: 1834-1840 Prosektor an Med.-Chirurg. Militärakademie.

U Berlin: 1834-1840 Prosektor am Anatom. Inst.; 1837 Habilitation (Verzögerung seiner Habilitation durch Anklage 1834 auf Hochverrat wegen Teilnahme an der verbotenen Burschenschaftsbewegung während seiner Studentenzeit; Verurteilung zu 6-jähriger Haft sowie Ausstellung e. Unfähigkeitserklärung für den öffentlichen Dienst; nach mehrmonatiger Inhaftierung Rehabilitierung durch Intervention Alexander von Humboldts); 1837-1840 Privat-Dozent.

U Zürich: Seit 28. März 1840 o. Prof. für Anatomie und Physiologie sowie Direktor des Anatom. Inst.

UH: Seit 11. Jan. 1844 o. Prof. (II. Anatom. Lehrstuhl neben Friedrich Tiedemann); 1845-1852 Direktor des Physiolog. Inst.; seit Okt. 1849 auch Direktor des Anatom. Inst. als Nachf. von Tiedemann.

U Göttingen: Seit WS 1852/53 o. Prof. für Anatomie und Physiologie, s. hierzu Ude-Koeller, Susanne: "Geben Sie diese schönste Professur in Deutschland, nach welcher Viele die Hand ausstrecken, nicht aus Ihrer Hand“. J. H. in Göttingen 1852-1885 in: Göttinger Jahrbuch 58 (2010) S. 63-77.

1847 Dekan der Med. Fak. der UH

H. legt zwischen 1849 und 1852 Inventarbücher über die Heidelberger pathologischen und anatomischen Präparate an, siehe die Sammlungsbücher J.H.s in: Hier freut sich der Tod (2013) S. $104 \mathrm{f}$.

Entdecker u. a. der nach ihm benannten Henleschen Schleife in der Niere, s. hierzu Hier freut sich der Tod (2013) S. 88

1845 Hofrat; 1884 Geh. Ober-Medizinalrat

Siehe auch Friedrich Tiedemann
E 1858 Mitglied der Dt. Akademie der Naturforscher Leopoldina Halle/S.; Mitglied der Akademie der Wissenschaften: 1860 München, 1873 Berlin.

Qu UAH PA 1702. • GLA Abt. 205, Fasz. 281, Abt. 235, Fasz. 576. - Briefe: UBH. - Der Briefwechsel zwischen J.H. und Karl Pfeufer 1843-1869. Hrsg. von Hermann Hoepke [H.H.]. Wiesbaden 1970. Waldeyer, Wilhelm: Briefe an J. Henle 1863-1885. Hrsg. von H. H. in: Ruperto Carola 27. Jg., H. 55/56 (1975) S. 47-53, ebd. 28. Jg., H. 57 (1976) S. 43-54; H., H.: Henles Meinungen über seine Kollegen in: ebd. 32. Jg., H. 64 (1980) S. 37-41; Briefe des Physikers Philipp von Jolly an J. Henle (1853-1864). Hrsg. von H. H. in: ebd. 38. Jg., H. 75 (1986) S. 148 154. Geprüfte Liebe ... J. Henle und Elise Egloff in Familienbriefen (1843-1848). Hrsg. von Gunhild Kübler. Zürich u.a. 1987. - Nachlaß: Staatsund Universitätsbibliothek Göttingen. - Siehe auch Archiv der Dt. Akademie der Naturforscher Leopoldina Halle/S.

W Pathologische Untersuchungen. Berlin 1840. • Handbuch der rationellen Pathologie. 2 Bde. Braunschweig 1846-1853. Bd. 1: 3. Aufl. 1854. Bd. 2: 2. Aufl. 1855. Handbuch der systematischen Anatomie des Menschen. 3 Bde. Braunschweig 18551879.

MHG 1844-1869 Zs. für rationelle Medicin.

$L$ Catalogus prof. Gottingensium (1962) S. 76; NDB 8 (1969) S. 531f. (mit Werkverz.); Schmitt (1978) S. 72 u. ö.; Pantel/Bauer (1990) S. 88 f.; Zimmermann/Drüll (1990) S. 3of. u. ö.; Weinmann (1999) S. 228; Dhom (2001) S. 73-80; Göttinger Gelehrte 1 (2001) S. 166 f.; Peiffer (2004) S. 1155 (Register); Prückner (2004) S. 303 (Register); Ärztelexikon (2006). • Otis, Laura: Müller's lab. Oxford 2007. J.H. Bürgerliches Leben und „rationelle Medicin“. Eine Ausstellung im Klinikum Fürth ... Hrsg. von Fritz Dross, Kamran Salimi. Fürth 2009. - WBIS; Hier freut sich der Tod (2013) S. 61-65, 103-105 u. ö.; Doll (2014) S. 296-298; Bauer/Ho (2016) S. 25; Doll/Kirsch/Eckart (2017) S. $26,37,107$ u. ö.

$P$ Bildarchiv UAH; graph. Slg. UBH; NDB. 


\section{Hensel, Paul Hugo Wilhelm}

1898-1902 Phil. Fak.

Philosophie

* 17. Mai 1860 Groß-Barthen (Ostpreußen; heute: Barciany, Polen)

$\dagger$ o8. Nov. 1930 Erlangen ev.-luth.

V Sebastian H. (1830-1898) Gutsbesitzer, später Direktor der Berliner Baubank; Herausgeber von: Die Familie Mendelssohn. 1729 bis 1847. Nach Briefen und Tagebüchern. Berlin 1879. Nachdr. Frankfurt/M. 2002.

M Julie geb. von Adelson (1836-1901)

@ 12. März 1896 Katharina (Käthe) geb. Rosenhayn (1861-1910)

$\infty$ 16. Sept. 1917 Dr. Elisabeth geb. Schemmann gesch. Nelson (1884-1954)

$\mathrm{K} 1 \mathrm{~S}$ (aus 1. Ehe), $2 \mathrm{~T}$ (aus 2. Ehe): u.a. Dr. phil. Cécile H. (1923-2012) Journalistin, Historikern, 1967-1989 (Gründerin und) Vorsitzende der Mendelssohn-Gesellschaft, s. Schmitz, André: C. Lowenthal-H. ... Rede bei der Trauerfeier am 2. Febr. 2012 in der Potsdamer Friedenskirche, s. http://www.mendels sohn-gesellschaft.de/downloads/Nachruf_C $\% \mathrm{C}_{3} \%$ A9cile_Lowenthal-Hensel.pdf. • Siehe Mendelssohn, the Nazis and me. A renegade pictures production for BBC. Written and directed by Sheila Hayman. Houghton-le-Spring 2009. 1 DVD-Video.

Vw Großeltern: Fanny Zippora Hensel geb. Mendelssohn und Wilhelm H., siehe Carl Mendelssohn Bartholdy: Eintrag unter Vw [Tante]

Vw Schwester: Cécile H. (1858-1928) Ehefrau von Friedrich Leo (1851-1914) Prof. für Klassische Philologie: u. a. 1888-1889 U Straßburg, 18891914 Göttingen. - Siehe auch Die Mendelssohns in Berlin ... Bearb. von Rudolf Evers ... Berlin 1983. Homepage der MendelssohnGesellschaft in Berlin unter: http://www.men delssohn-remise.de/

Lb Berlin: Nach Privat-Unterricht 1876-1877 Besuch e. Handelsschule; seit 1877 Buchhändlerlehre; 1880-1881 Besuch des Köllnischen Gymnasiums mit anschl. Reifeprüfung.
U Berlin: Seit WS 1881/82 Studium der Philosophie, Geschichte.

U Freiburg/Br:: 1883-1885 Forts. des Studiums; 23. Okt. 1885 Dr. phil.; Okt. 1885-März 1888 Volontär an UB.

U Straßburg: 4. Aug. 1888 Habilitation; seit 21. März 1895 a. o. Prof.

UH: 20. Febr. 1898 Ern. zum nichtetatm. a. o. Prof.

U Erlangen: 1. Mai 1902 (Ern.)-1. Mai 1929 (Emeritierung) o. Prof. für Systematische Philosophie.

1923 Geh. Reg.-Rat

E 1922 Mitbegründer und Mitglied der Philosophischen Akademie Erlangen. 1922 Bayer. Verdienstorden vom Heiligen Michael IV. Klasse.

Qu UAH PA 1706. GLA Abt. 235, Fasz. 2079. • Briefe: UBH. • P.H. Sein Leben in seinen Briefen. Hrsg. von Elisabeth Hensel. Frankfurt/M. 1937.

W Thomas Carlyle. Stuttgart 1901. 3. Aufl. 1922. • Hauptprobleme der Ethik. Leipzig 1903. 3. Aufl. 1913. Religionsphilosophie. Göttingen 1934.

L Glockner (1969) S. 273 (Register); NDB 8 (1969) S. 561f. (mit Werkverz.); Willett (2001) S. 199, 291 u. ö.; Professoren Erlangen (2009) S. 88; WBIS; Kaesler (2014) S. 999 (Register). - Thiel, Christian: P.H. Der „Sokrates von Erlangen“ - Lebenskünstler und kritischer Philosoph. Berlin 2016.

$P$ Bildarchiv UAH; graph. Slg. UBH; NDB; Professoren Erlangen. 


\section{Herbst, Curt Alfred}

1901-1935 Nat.-Math. Fak.

Zoologie

* 29. Mai 1866 Meuselwitz (Herzogtum SachsenAltenburg; heute: Thüringen)

$\dagger$ 09. Mai 1946 Heidelberg ev.

V Heinrich Wilhelm H. (1829-1874) Fabrikant

M Henriette Ernestine geb. Martin (1832-1889)

$\infty$ unverheiratet.

Lb WS 1886/87 Studium der Naturwiss., Zoologie an U Genf, SS 1887-WS 1889/90 Studium der Naturwiss. und Medizin an U Jena.

1889-189o Studienreisen nach Ceylon, Java, Vorderindien.

U Jena: 10. Febr. 1890 Dr. phil.; seit Mai 1890 Assistent am Zoolog. Inst.

Seit Aug. 1890 Eigenstudien am Polytechnikum in Zürich; Herbst 1891-Frühjahr 1892 Eigenstudien an Zoolog. Station in Neapel.

UH: 27. April 1901 Habilitation; WS 1901/02, WS 1904/05 (von U beurlaubt) Eigenstudien an Zoolog. Station in Neapel; seit 3. Jan. 1906 nichtetatm. a. o. Prof.; seit 27. März 1919 o. Prof. und Direktor des Zoolog. Inst. und Museums (Sophienstraße 6) als Nachf. von Otto Bütschli; SS 1928-WS 1928/ 29 (beurlaubt) Eigenstudien an Zoolog. Station in Neapel; 31. März 1935 Ruhestand.

1921/22, 1926/27 Dekan der Nat.-Math. Fak. der $\mathrm{UH}$

1914-1919 Ausw. Mitglied des Kaiser-WilhelmInst. für Biologie in Berlin

E 1906 Mitglied der Dt. Akademie der Naturforscher Leopoldina Halle/S.; Mitglied der Akademie der Wissenschaften: Krakau, 1920 H. 1913 Dr. med. h.c. Halle-Wittenberg.
Qu UAH PA 4169; RA 6900, 6902. • GLA Abt. 235, Fasz. 2082. - Briefe: UBH; Universitätsbibliothek Leipzig. • Auskunft: Universitätsarchiv Jena.

$W$ Formative Reize in der tierischen Ontogenese. Leipzig 1901. Beitrag zur Entwicklungsphysiologie der Färbung und Zeichnung der Tiere in: Abh. der Akademie der Wissenschaften Heidelberg. Math.-Nat. Klasse (1919). - Untersuchung zur Bestimmung des Geschlechts in: Sitzungsberichte der Akademie der Wissenschaften Heidelberg. Math.-Nat. Klasse $(1928,1929)$.

L Kürschner (1931) Sp. 1126, (1940/41) Sp. 701; Arnim 1 (1944) S. 539; NDB 8 (1969) S. 593; WBIS. • Oppenheimer, Jane M.: C. H.s contributions to the concept of embryonic induction in: Developmental biology ... Vol. 7: A conceptual history of modern embryology. Ed. by Scott F. Gilbert. New York 1991. S. 63-90. Jansen (1992a) S. 166 (Register); Ärztelexikon (2006) S. 163. - Fangerau, Heiner: Spinning the scientific web: Jacques Loeb (1859-1924) und sein Programm ... Berlin 2010. S. 265 (Register). - Elstner, Michael: Jenseits der Entwicklungsphysiologie - C H. im Spiegel seiner Korrespondenz mit Hans Driesch. Diss. Ulm 2014.

$P$ Bildarchiv UAH.

\section{Herrigel, Eugen Viktor}

1922-1924, 1929-1930 Phil. Fak.

Philosophie

* 20. März 1884 Lichtenau (bei Baden-Baden)

$\dagger$ 18. April 1955 Garmisch-Partenkirchen ev.-luth.

V Gottlob H. (1850-1926) Volksschullehrer, s. UAH Rep. 51

M Christiane geb. Kiesel (1850-1915), s. ebd.

๑ Paula geb. Baronin von Beulwitz (1893-1924), s. ebd.

(15. Sept. 1925 Auguste (Gusty) Luise geb. Seefried (1887-1974), s. ebd.

K $\quad 1$ T (* und † o8. Aug. 1924), s. ebd. 
Lb UH: SS 1904-SS 1907 Studium der Theologie; 1908 theol. Hauptprüfung; seit WS 1908/o9 Studium der Philosophie; 17. Jan. 1912 Dr. phil.; seit 1918 Assistent am Phil. Inst.; 28. Okt. 1922 Habilitation; Mai 1924-Juli 1929 von UH beurlaubt; 2. Aug. 1927 Ern. zum nichtplanm. a. o. Prof.

In dieser Zeit:

1914-1918 Kriegsdienst.

Japan: 1924-1927 Dozent, 1927-1929 o. Prof. für dt. Philosophie an U Tōhoku in Sendai; 20. Juni 1929 Kyūdō-Prüfung (5. Dan).

U Erlangen: 1. Nov. 1929 (Ern.) zum SS 1930 o. Prof.; 1938-April 1944 Prorektor, Okt. 1944-April 1945 Rektor; 31. Mai-Dez. 1945 Ern. durch Militärregierung zum Prorektor; 14. Jan. 1946 Entlassung gemäß Erlaß der Militärregierung; 28. Juni 1948 Wiedereinsetzung als o. Prof. mit gleichzeitiger Versetzung in Ruhestand; 16. Dez. 1952 Emeritierung.

Garmisch-Partenkirchen: Seit April 1952 Wohnsitz.

1929 Kaiserl. Japanischer Geh. Rat

E 1940-1945 Mitglied der Bayer. Akademie der Wissenschaften München. • 1930 Dr. h.c. U Tōhoku in Sendai.

Qu UAH PA 4180. - Nachlaß: UAH (Signatur: Rep. 51). Auskunft: Marktarchiv Garmisch-Partenkirchen (Sterbeeintrag 1955); Universitätsarchiv Erlangen.

$W$ Die metaphysische Form. Eine Auseinandersetzung mit Kant. Tübingen 1929. - Zen in der Kunst des Bogenschießens. Konstanz 1948. 43. Aufl. 2003. - Der Zen-Weg. Aufzeichnungen aus dem Nachlaß. Hrsg. von Hermann Tausend. Mit e. Anhang bearb. von Gusty Herrigel. München 1958. 11. Aufl. 1990.

HG Emil Lask. Gesammelte Schriften. 3 Bde. Tübingen 1923-1924.
L Kürschner (1935) Sp. 529, (1940/41) Sp. 706, (1950) Sp. 783, (1961) S. 2374; Glockner (1969) S. 273 (Register). • Biographie in: Schorcht, Claudia: Philosophie an den bayerischen Universitäten 1933-1945. Erlangen 1990. S. 90-95. • Hecker, Hellmuth: Lebensbilder dt. Buddhisten. Band II: Die Nachfolger ... Konstanz 1992. • Heiber II,2 (1994) S. 199-203. Gülberg, Niels: E. H.s Wirken als philosophischer Lehrer in Japan in: Waseda-Blätter 4 (1997) S. 41-66, 5 (1998) S. 44-6o. • WBIS; Willett (2001) S. 134, 344 u. ö. Trimondi Victor, Trimondi, Victoria: E.H. - Ein überzeugter Nazi verfasst „Zen in der Kunst des Bogenschießens“ in: Hitler, Buddha, Krishna. Eine unheilige Allianz vom Dritten Reich bis heute. Wien 2002. S. 101-103. Grüttner (2004) S. 74. • Obereisenbuchner, Matthias: E. H. und der westliche Blick auf die fernöstliche Kultur. Vortrag gehalten bei der Tagung des Loslassens ... am 22./23. April 2005, online unter http://kyu-do.de/download/Herrigel_Kyudo. pdf. Klee, Personenlexikon (2007) S. 247; Professoren Erlangen (2009) S. 9of. (hier als Emeritierungsdatum der 8. Juli 1954 genannt). - Yamada, Shoji: Shots in the Dark: Japan, Zen, and the West (Buddhism and Modernity). Translated by Earl Hartman. Chicago 2009. - Deutsche Biographie, s. https://www.deutsche-biographie.de/gnd1167457 54.html [07.11. 2017].

$P$ Bildarchiv UAH; Professoren Erlangen (2009).

\section{Herrmann, Emil}

1868-1872 Jur. Fak.

Kriminalrecht, Kriminalprozeßrecht, Kirchenrecht

* 09. April 1812 Dresden

$\dagger$ 16. April 1885 Gotha

ev.

V Christian Friedrich Heinrich H., Oberauditor (auch Auditeur: Justizbeamter) des sächsischen Generalstabs, seit 1822 Kriegsgerichtsrat am Generalkriegsgerichtskollegium

M Henriette Wilhelmine Charlotte geb. Kaupisch

๑ 1837 Aline geb. Kaupisch (†1900)

K 11 . 
Lb U Leipzig: Seit WS 1829/30 Studium; 1832 Staatsexamen; 27. Febr. 1834 Dr. iur.; seit 8. März 1834 Privat-Dozent.

U Kiel: Seit 26. Juli 1836 a. o. Prof.; seit 25. Mai 1842 o. Prof.

U Göttingen: 3o. Nov. 1846 zum SS 1847 Ern. zum o. Prof.; in dieser Zeit auch 1849 Mitglied der I. Ständekammer des Königreichs Hannover als Vizepräsident der allg. Ständeversammlung in Hannover.

UH: 12. Dez. 1867 zum SS 1868 Ern. zum o. Prof. als Nachf. von Carl Joseph Anton Mittermaier; 18681872 Beisitzer des Spruchkollegiums der Jur. Fak.; in dieser Zeit auch 1869-1872 Mitglied der I. Kammer des Badischen Landtags in Karlsruhe.

Berlin: Okt. 1872-April 1878 (auf eigenen Antrag Austritt) Präsident des Ev. Oberkirchenrats der Altpreußischen Union, s. hierzu Bamberg, Albert von, H., E.: E.H. und sein Eintritt in die Leitung des Berliner Oberkirchenrats und sein Austritt in: Mitteilungen aus seinem schriftlichen Nachlaß. Halle/Saale 1906. S. 588-759; Schneider (2013).

Seit 1878 Wohnsitz in H, seit 1883 in Gotha.

1868/69 Dekan der Jur. Fak. der UH

1864-1872 Präsident des Deutschen Ev. Kirchentages

1873: Initiator der Konsistorialsynodalverfassung der Ev. Kirche der altpreußischen Union

1859 Hofrat; 1864 Geh. Justizrat; 1867 Geh. Rat III. Klasse; 1872 Geh. Rat II. Klasse; nach 1872 Wirkl. Geh. Rat

E 1847 Königl. Preußischer Roter Adler-Orden II. Klasse; 1851 Hannoveranischer Guelphenorden IV. Klasse; 1868 Ritterkreuz I. Klasse des Ordens vom Zähringer Löwen.

Qu UAH PA 1712; RA 6761. • Briefe: UBH. • Kirchenheim, Arthur: E.H. und die preußische Kirchenverfassung. Nach Briefen und meist unge- druckten Quellen. Berlin 1912. - Nachlaß: Geheimes Staatsarchiv Preußischer Kulturbesitz Berlin.

$W$ Zur Beurtheilung des Entwurfs eines Criminalgesetzbuchs für das Königreich Sachsen. Leipzig 1836. Die Stellung der Religionsgemeinschaften im Staate. Göttingen 1849. • Die notwendigen Grundlagen einer die konsistorialen und synodalen Ordnung vereinigenden Kirchenverfassung. Berlin 1862. - Das staatliche Veto bei Bischofswahlen, nach dem Rechte der oberrheinischen Kirchenprovinz. Heidelberg 1869.

HG, $M H G$ 1836-1885 Corpus juris civilis.

$L$ Professoren Kiel (1956) S. 33; Catalogus prof. Gottingensium (1962) S. 51; Jammers (1964) S. 177 u. ö.; NDB 8 (1969) S. 687 f. (mit Werkverz.); Heidelberger Strafrechtslehrer (1986) S. 34; WBIS; BBKL II (1990) Sp. 768 f. • Dvorak, Helge: Biographisches Lexikon der Deutschen Burschenschaft. Bd. I: Politiker. Teilbd. 2. Heidelberg 1999. S. 312. • Schroeder (2010) S. 252-255 u.ö. • Schneider, Bernd Christian: E.H. und die preußische Kirchenverfassung. Zwischen akademischen Idealen und dienstlichen Zwängen in: Protestantismus in Preußen. Bd. 3: Von der Mitte des 19. Jahrhunderts bis zum Ersten Weltkrieg. Hrsg. von Albrecht Beutel ... Frankfurt/M. 2013. S. 121-146.

$P$ Bildarchiv UAH; graph. Slg. UBH.

\section{Hesse, Ludwig Otto}

1856-1868 Phil. Fak.

Mathematik

* 22. April 1811 Königsberg (Preußen; heute: Kaliningrad, Russische Föderation)

$\dagger \quad$ 04. Aug. 1874 München

$\square$ Heidelberg ev.

V Johann Gottlieb H. (1781-1829) Seifenfabrikant

M Anna Karoline geb. Reiter (1788-1865) 
( 1841 Marie Sophie Emilie geb. Dulk (†1877) T von Friedrich Philipp D. (1788-1852) zunächst Apotheker, seit 1825 Privat-Dozent, seit 1833 o. Prof. für Chemie Königsberg (Preußen), s. NDB 4 (1959) S. 184 f. (unter D., Albert), WBIS $\mathrm{K} \quad 1 \mathrm{~S}$ (früh $\dagger$ ), $5 \mathrm{~T}$ (davon $1 \mathrm{~T}$ früh $\dagger$ ).

Lb Königsberg: Seit April 1832 Studium an U; Mai 1837 Oberlehrerexamen; 1837-1838 Lehramtskandidat; Sommer 1838 Studienreisen in Deutschland und Italien; Herbst 1838-Ende 1841 Lehrer an Provinzial-Gewerbeschule.

U Königsberg: 27. Jan. 1840 Dr. phil.; April 1840 Habilitation; seit 31. Okt. 1847 a. o. Prof. mit Besoldung.

U Halle-Wittenberg: Herbst 1855 Ern. zum o. Prof.; Jan. 1856 Amtsantritt.

UH: Seit 28. April 1856 o. Prof. als Nachf. von Ferdinand Schweins; 9. Sept. 1856 Vereidigung; 1868 Ruf an U Bonn abgelehnt.

Polytechnikum München: WS 1868/69-SS 1874 o. Prof.

186o Dekan der Phil. Fak. der UH

$E$ Mitglied der Akademie der Wissenschaften: 1856 Göttingen, 1859 Berlin, 1869 München; 1871 Ehrenmitglied der Mathematical Society London. $\bullet 1872$ Steiner-Preis.

Qu UAH PA 1720. • GLA Abt. 205, Fasz. 285. Rektoratsreden - online.

$W$ Über Kurven III. Klasse und Kurven III. Ordnung in: Journal für die reine und angewandte Mathematik 38 (1849); Über die Doppeltangenten der Kurven IV. Ordnung in: ebd. 49 (1855). • L. O.H.s gesammelte Werke. Hrsg. von der Math.Physikal. Classe der ... Akademie der Wissenschaften. München 1897. 2. Ed. Reproduction of the 1. Ed. New York 1972.

L Dyck, W., Gundelfinger, S. u.a.: O.H. - Lebenslauf in: L. O.H.s gesammelte Werke ... (1897) S. 711-721. NDB 9 (1972) S. 21 f. (mit Werkverz.). •
Haas, Karlheinz: L.O.H.: Mathematiker an der Universität Halle (1855-1856) ... in: Dictionary of scientific biography. New York 1981. Bd. 6. S. 356358. Hawkins, Thomas: H.'s principle of transfer and the representation of Lie algebras in: Archive for history of exact sciences 39 (1988/89) S. 4173. Math. Institute in Deutschland (1989) S. $198 \mathrm{f}$. u. ö.; Homo Heidelbergensis mathematicus online; WBIS. - H.'sche Normalenform einer Ebene in: Elemente der Mathematik: EdM. [Schulbuch.] Sachsen-Anhalt. Qualifikationsphase. Hrsg. von Heinz Griesel u. a. ... Braunschweig 2016. S. $314 \mathrm{f}$.

$P$ Bildarchiv UAH; graph. Slg. UBH; NDB.

\section{Hettner, Alfred Hermann}

1899-1905 Phil. Fak.

1905-1906 (Honorar-Prof.) Phil. Fak.

1906-1928 Phil. Fak.

Geographie

* o6. Aug. 1859 Dresden

$\dagger$ 31. Aug. 1941 Heidelberg ev.

V Hermann Julius Theodor H. (1821-1882) seit 1847 Privat-Dozent für Literaturgeschichte und Ästhetik UH, 1851-1855 a.o. Prof. für Ästhetik, Kunst- und Literaturgeschichte U Jena, seit 1855 o. Prof. an Akademie der bildenden Künste Dresden, 1869-1882 Prof. für Kunstgeschichte Polytechnikum Dresden., s. Lehmann (1967) S. 215, NDB 9 (1972) S. 32 f.; Schlott, Michael: H.H. Idealistisches Bildungsprinzip versus Forschungsimperativ. Zur Karriere eines „undisziplinierten Gelehrten“ im 19. Jahrhundert. Tübingen 1993; EmundtsTrill (1997) S. 279 f., Professoren TU Dresden (2003) S. 365, Riecke (2016) S. 145 (Register)

M Anna geb. Grahl (1838-1897)

( 14. Okt. 1899 Bertha Rohde (1878-1902), s. Franz Overbeck - Erwin Rohde. Briefwechsel. Hrsg. ... von Andreas Patzert ... Berlin 1990. S. 627 (Register); T von: (siehe) Erwin R.

๑ 27. Okt. 1925 Marie geb. Mall (1878-1955)

$\mathrm{K}$ keine. 
Lb Seit SS 1877 Studium der Geographie, Geologie, Philosophie, Völkerkunde, Nationalökonomie, Chemie, Physik an U Halle-Wittenberg, seit SS 1878 Bonn, seit SS 1879 Straßburg; 31. Okt. 1881 Dr. phil. U Straßburg; Nov. 1881 Forts. des Studiums an U Bonn; 1881/82 Assistent am Lehrstuhl für Geographie bei Ferdinand von Richthofen (1833-1905).

Kolumbien: Seit 1882 Lehrer im Hause des britischen Konsuls in Bogota; 1883-1884 Studienreise durch Kolumbien.

U Leipzig: Seit Herbst 1884 Eigenstudien; 29. Juni 1887 Habilitation.

1888-Spätjahr 1890 Forschungsreise nach Südamerika (Peru, Chile, Argentinien, Uruguay, Südbrasilien) im Auftrag der Generalverwaltung der Königlich Preußischen Museen.

U Leipzig: Seit Spätjahr 1890 erneut Privat-Dozent; seit 30. Mai 1894 nichtetatm. a. o. Prof.

U Tübingen: Seit WS 1897/98 nichtetatm. a.o. Prof.; 1898 Ruf an U Würzburg abgelehnt.

UH: Seit 1. März 1899 etatm. a. o. Prof. und SS 1899WS 1927/28 Direktor des neuerrichteten Geographischen Seminars; 25. März 1899 Vereidigung; 1905 Ruf an U Breslau abgelehnt; seit 10. April 1905 o. Honorar-Prof.; seit 4. Aug. 1906 Inhaber des neueingerichteten Lehrstuhls für Geographie; 1913-1914 Studienreisen: Sibirien, Ostasien, Java, Hinter- und Vorderindien, Ceylon (Vertreter: Franz Thorbecke, s. Heinrich Thorbecke: Eintrag unter $V w$ [Neffen]); 1. April 1928 Emeritierung.

1914/15 Dekan der Phil. Fak. der UH

1913 Geh. Hofrat

Siehe auch Johannes Rissom: Eintrag unter $Z[\mathrm{i}-$ tat] (3)

$E$ Mitglied der Akademie der Wissenschaften: 1910 H, 1930 Wien (1940 Aberkennung der Mitgliedschaft, 1945 posthume Wiederaufnahme). • 1929 Dr. rer. nat. h.c. UH. 1930 Cullum-Medail- le der American Geographical Society New York. • 1906 Ritterkreuz I. Klasse des Ordens vom Zähringer Löwen.

Qu UAH PA 4198; RA 5723, 6428, 6662, 6831, 6865; GF 139. GLA Abt. 235, Fasz. 2089, Abt. 466, Fasz. 8957. Teil-Nachlaß: UBH.

W Rußland. Eine geographische Betrachtung von Volk, Staat und Kultur. Leipzig 1905. 4. Aufl. 1921. • Englands Weltherrschaft. Leipzig 1915. 4. Aufl. 1928. Grundzüge der Länderkunde. 2 Bde. Leipzig 1921-1924. Bd. 1: 5. Aufl. 1932. - Der Gang der Kultur über die Erde. Leipzig 1923. 2. Aufl. 1929. • Die Geographie, ihre Geschichte, ihr Wesen und ihre Methoden. Breslau 1927. Vergleichende Länderkunde. 4 Bde. Leipzig 1933-1935.

\section{G, HG 1895-1935 Geographische Zeitschrift.}

$L$ Handels-Hochschule Mannheim 1907-1932 (1932) S. 27; NDB 9 (1972) S. 31 f. (mit Werkverz.); Badische Biographien N. F. I (1982) S. 17 o f. Plewe, Ernst: A.H. in: Semper apertus 2 (1985) S. 512530. - Jansen (1992) S. 409 (Register) - Wardenga, Ute: Geographie als Chorologie - A.H.s Versuch einer Standortbestimmung in: 100 Jahre Geographie an der Ruprecht-Karls-Universität Heidelberg (1895-1995). Hrsg. von Dietrich Barsch u.a. Heidelberg 1996. S.1-17; Dies.: Defining geography - the struggle and development of A.H.'s methodological construct in: Struggles over geography violence, freedom and development at the millennium. Hettner lectures 3. Ed. by M.J. Watts. Heidelberg 2000. S. 113-126. Enzenauer (2005) S. 28 f.; Kriegstagebuch K. Hampe (2007) S. 968 (Register). - Auf den Spuren H.s - Geographie in Heidelberg. Hrsg. von Peter Dippon, Bertil Mächtle u. a. Heidelberg 2008. Encyclopedia of Geography. Ed. by Barney Warf. Thousand Oaks (Kalifornien) 2010. Bd. 3. S. $1422 \mathrm{f}$. Fricke, Werner: A.H. - Forscher und Stubengelehrter. Reflektion über seine Rezeption anlässlich des A.-H.-Jubiläums in: Heidelberger Geographische Gesellschaft: HGG-Journal 23/2008 (2010) S. 5-21. • Peters, Karin: A.H.s Reisen in den kolumbianischen Anden (1882-1884). Überlegungen aus heutiger Sicht. Münster 2010. - Roskamm, Nikolai: Dich- 
te: Eine transdisziplinäre Dekonstruktion. Diskurse zu Stadt und Raum ... Bielefeld 2011. S. 104-108 u. ö. Professorenkatalog Leipzig online. - Dickinson, Robert E.: The Makers of Modern Geography ... London 2014. Kapitel 9 (ohne S.-Angaben).

$P$ Bildarchiv UAH; graph. Slg. UBH; Geographisches Inst. der UH.

\section{Heubner, Wolfgang Otto Leonhard}

1930-1932 Med. Fak.

Pharmakologie

* 18. Juni 1877 Leipzig

$\dagger \quad$ 26. Febr. 1957 Heidelberg

ev.-luth.

V Otto Johann Leonhard H. (1843-1926), u.a. 1894-1913 o. Prof für Kinderheilkunde Berlin, s. NDB 9 (1972) S. 38 f., Kneer (1989) S. 15 f., Professorenkatalog Leipzig online

M Martha geb. Haußner (1855-1934)

๑ 16. März 1907 Lisa geb. Lutteroth (1878-1966)

K 4 T, s. Kneer, S. 13, 23

Vw Großvater: Otto Leonhard H. (1812-1893) Jurist, Politiker, Dichter, s. WBIS; Matzerath, Josef: Aspekte sächsischer Landtagsgeschichte ... 1833-1868. Dresden 2007. * Weitere Vw, s. NDB 9 (1972) S. $38^{*}$ (unter Heubner, Leonhard).

Lb Sommer 1896 Militärdienst; seit WS 1896/97 Studium der Medizin an U Göttingen, seit 1898 Berlin; Febr. 1899 Physikum in Berlin; seit 1899 klinische Semester an U Marburg, Berlin, Straßburg; 1901 Staatsprüfung in Straßburg; 3. Juli 1901 Approbation ebd.; 1901 Assistent von (siehe) Albert Fraenkel in Badenweiler.

U Straßburg: Seit Frühjahr 1902 Assistent am Pharmakolog. Inst.; 1903 Dr. med.

Studium der Chemie: Seit 1905 U München, 1906 Zürich.

U Straßburg: Seit 1906 Assistent am Pharmakolog. Inst.; Juni 1907 Habilitation für Pharmakologie.
U Berlin: Seit 2. Juni 1908 (Antrittsvorlesung) Privat-Dozent und Assistent am Pharmakolog. Inst.

U Göttingen: Seit WS 1908/o9 a. o. Prof. und Direktor des Pharmakolog. Inst.; SS 1910-WS 1928/ 29 o. Prof. • In dieser Zeit:

1914-1916 Kriegsdienst; 1916-1918 Lehre und Forschung am Kaiser-Wilhelm-Inst. und an Heeresgasschule in Berlin.

Med. Akademie Düsseldorf: SS 1929-WS 1929/30 Direktor des Pharmakolog. Inst.; in dieser Zeit Amerika- und Kanadareise.

UH: 29. Nov. 1929 Ern. zum o. Prof. und Direktor des Pharmakolog. Inst. als Nachf. von Hermann Wieland (in Nachf. von Philipp Ellinger); 25. April 1930 Vereidigung.

Friedrich-Wilhelms-U Berlin: 1. April 1932-30. April 1949 (1. Emeritierung) o. Prof. und Direktor des Pharmakolog. Inst.; WS 1934/35 auf eigenen Antrag Vorlesungsbefreiung, s. hierzu Kneer (1989) S. 39f.; 1946-1949 Präsident des Wiss. Senats der Zentralverwaltung für das Gesundheitswesen der sowjetisch besetzten Zone in Berlin.

FU Berlin: Mai 1949-April 1953 (2. Emeritierung) o. Prof. und (Gründungs-)Direktor des Pharmakolog. Inst. an der Charité.

H: Seit 1954 Wohnsitz.

1911 Mitbegründer der Arzneimittelkommission der dt. Ärzteschaft

E 1921 Mitglied der Akademie der Wissenschaften Göttingen; seit 1922 korr., 1946-1950 (Austritt) o. Mitglied der Akademie der Wissenschaften Berlin. 1936 Mitglied der Dt. Akademie der Naturforscher Leopoldina Halle/S. 1928 Dr. med. vet. h.c. Tierärztl. Hochschule Hannover; 1952 Dr. med. h.c. U Göttingen; 1952 Dr. rer. nat. h.c. FU Berlin. 1954 Paracelsus-Medaille; 1956 Schmiedeberg-Plakette. 
Qu UAH PA 972, 4200; Rep. 40-402. - GLA Abt. 235, Fasz. 2093. - Teil-Nachlaß: 26 Tagebücher 1908-1956 im Archiv der Dt. Gesellschaft für experimentelle und klinische Pharmakologie und Toxikologie in Mainz. Masch.schriftl. transkribiert von Erich Muscholl.

W Genuß und Betäubung durch chemische Mittel. Berlin 1948. 2. Aufl. 1952. • Über Wanderung des DDT in Insektennerven. Berlin 1949. U Über lokale Reizwirkung. Göttingen 1950. Bibliographie in: Kneer (1989) S. 87-124.

HG 1926-1950 Handbuch der experimentellen Pharmakologie.

MHG 1910-1915 Therapeutische Monatshefte. 1946-1957 Naunyn-Schmiedebergs Archiv für experimentelle Pathologie und Pharmakologie.

$L$ Catalogus prof. Gottingensium (1962) S. 78 , 83; NDB 9 (1972) S. 39 f. - Kneer, Johanna Therese: W.H. Leben und Werk. Diss. Tübingen 1989. • Jansen (1992a) S. 166 (Register); Lindner/Lüllmann (1996) S. 206 u.ö.; Ärztelexikon (2006) S. 166 f. - Schagen, Udo: Von der Freiheit - und den Spielräumen - der Wissenschaft(ler) im Nationalsozialismus: W.H. und die Pharmakologen der Charité 1933-1945 in: Die Charité im Dritten Reich. Hrsg. von Sabine Schleiermacher ... Paderborn 2008. S. 207-228. - Fischer, Ernst Peter: Die Charité - Ein Krankenhaus in Berlin 1710 bis heute. München 2009. - Kessel, Nils: Biographie als Disziplinentradition: von der Idealisierung des Pharmakologen W.H. in: Medizin, Gesellschaft und Geschichte in: Jahrbuch des Instituts für Geschichte der Medizin der Robert Bosch Stiftung. Bd. 27/2008. Stuttgart 2009. S. 133-160. Huhn/ Kilian (2011) S. 249 (Register).

$P$ Bildarchiv UAH.

\section{Heyck, Eduard Karl Heinrich Bertold}

1892-1896 Phil. Fak.

Geschichte

* 30. Mai 1862 Doberan (Mecklenburg; heute: Bad D.)

$\dagger$ 11. Juli 1941 Ermatingen (Kanton Thurgau, Schweiz)

ev.

V Eduard Heinrich Wilhelm H. (1836-1903) Landmann, Gärtnereibesitzer, Privatier

M Adolphine Marie Louise Giese (1835-1912)

@ 1890 Marie (Maina) Elisabeth Heyck-Jensen geb. Jensen (1870-1940) Kunstmalerin, s. Fiedler, Friedrich: Aus der Literatenwelt: Charakterzüge und Urteile - Tagebuch. Hrsg. von Konstantin Asadowski. Göttingen 1996. S. 521 (Register). - T von Dr. phil. Wilhelm J. (1837-1911) Lyriker und Schriftsteller, s. NDB 10 (1974) S. 404-406; Magnussen-Petersen, Anna: Persönliche Begegnungen mit Klaus Groth, ... W. J., ... Adolph Menzel. Hrsg. von Karin Magnussen. Husum 1994; Saul, Nicholas: W.J. and Wilhelm Raabe: literary value, evolutionary aesthetics, and competition in the marketplace in: The German bestseller in the late nineteenth century. Ed. by Charlotte Woodford ... Rochester 2012. S. 58-76. Scheidung 1901

๑ 17. Nov. 1907 Gertrud geb. Schaumann (18861952)

K $\quad 1$ T, $3 \mathrm{~S}$ (davon $1 \mathrm{~S}$ und $1 \mathrm{~T}$ aus 1 . Ehe), u. a. Hans H. (1891-1972) Schriftsteller, Dichter, s. WBIS; Klee, Kulturlexikon (2007) S. 244. - Hartwig H. (1912-1982) apl. Prof. und Leiter der Neurolog. Abt. des Rudolf Virchow Krankenhauses Berlin, s. Kürschner (1976) S. 1241. • Siehe Heyck-Jensen families website unter http:// www.heyck-jensen.com/index.html

Lb WS 1880/81 Studium der Philologie, Vgl. Sprachwiss., Geschichte, auch Philosophie an U Leipzig, seit SS $1881 \mathrm{H}$, SS 1882 Jena, WS 1882/83WS $1884 / 85$ H; 27. Jan. 1885 Dr. phil. UH; 1 . Febr. 1885-1. April 1887 Hilfsarbeiter bei Badischer Histor. Kommission und am GLA in Karlsruhe. 
U Freiburg/Br.: 17. März 1887 Habilitation; seit 26. Febr. 1890 a. o. Prof.

UH: Seit 1. Okt. 1892 nichtetatm. a. o. Prof.

Donaueschingen: 1. Sept. 1896-31. März 1898 Vorstand der Fürstlich-Fürstenbergischen Archivund Bibliotheksverwaltung und Kunstsammlungen.

1898 Vortragsreisen u. a. nach Palästina, Brasilien; 1898-1909 freischaffender Gelehrter zunächst mit Wohnsitz in München, dann Berlin.

Ermatingen: Seit 1909 Privat-Gelehrter und Schriftsteller.

1899-1900 Vorsitzender der Gesellschaft der Bibliophilen

E 1891 Ehrenmitglied der Schweizerischen Geschichtsforschenden Gesellschaft; 1896 o. Mitglied der Badischen Histor. Kommission. - 1937 Goethemedaille für Kunst und Wissenschaft.

Qu UAH PA 1723; RA 7500; Fak.-Akte H-IV-102/ 107. - GLA Abt. 235, Fasz. 2095. • Fürstlich-Fürstenbergisches Archiv, Donaueschingen, Personalia, H. 69. - Nachlaß (auch von Wilhelm Jensen und Maina Heyck-Jensen): Schleswig-Holsteinische Landesbibliothek Kiel.

W Die Geschichte der Herzöge von Zähringen. Freiburg/Br. 1891. Nachdr. 1980. • Die Allgemeine Zeitung 1798-1898. Beiträge zur Geschichte der Presse. München 1898. • Bismarck. Bielefeld 1898. 5. Aufl. 1922. - Deutsche Geschichte: Volk, Staat, Kultur und geistiges Leben. 3 Bde. Bielefeld 19051906. Bd. 1: 2. Aufl. 1924.

HG 1893-1941 Allgemeines Deutsches Kommersbuch. - Seit 1897 Monographien zur Weltgeschichte.

$L$ Nachruf in: Zs. für Schweizerische Geschichte 22 (1942) S. 122 f. - Heyck, Hans: Zum Andenken an E.H. in: Der Convent (April 1954) Jg. 5, H. 4, S. 94-96. • Bielschowsky, Ludwig: E. H. - Ein deutscher Gelehrter, Liederdichter und Bibliophile in: Börsenblatt für den Dt. Buchhandel. Frankfurter Ausg. Nr. 17 (27. Febr. 1976) A39-A42. - WBIS; Autoren der Bunsenbibliothek (2009 online); Grewolls (2011); Dt. Literatur-Lexikon - 20. Jhdt. (2012) Bd. 18. Sp. 74-76. • Reusch, Nina: Populäre Geschichte im Kaiserreich: Familienzeitschriften als Akteure der deutschen Geschichtskultur 18901913. Bielefeld 2015. S. 8of., 268-271 u. ö. • Deutsche Biographie, s. https://www.deutsche-biographie.de/gnd116786167.html [07.11. 2017].

$P$ Bildarchiv UAH; graph. Slg. UBH.

\section{Hieber, Walter Otto}

1926-1933 Nat.-Math. Fak.

Anorganische Chemie

* 18. Dez. 1895 Stuttgart

$\dagger \quad$ 29. Nov. 1976 München prot.

V Dr. theol. Johannes (seit 1910: von) H. (18621951) seit 1892 Gymnasial-Prof., seit 1910 Direktor des Königl. Württ. Ev. Oberschulamts, u. a. seit 1898 Mitglied des Reichstags, 19201924 württ. Staatspräsident, s. WBIS; Raberg, Frank: Biographisches Handbuch der württ. Landtagsabgeordneten 1815-1933. Stuttgart 2001. S. 354-357; Reibel, Carl-Wilhelm: Handbuch der Reichstagswahlen 1890-1918. Bündnisse, Ergebnisse, Kandidaten. 2. Halb-Bd. Düsseldorf 2007. S. 1207-1210; Biographisches Lexikon zur Geschichte der dt. Sozialpolitik 1871-1945. Hrsg. von Eckhard Hansen und Florian Tennstedt. Kassel 2010. Bd. 1. S. 73 f.

M Mathilde Auguste geb. Schmid (1871-1946)

unverheiratet.

Lb Aug.-Sept. 1914 (Entlassung wegen Krankheit) Kriegsdienst.

U Tübingen: Seit WS 1915/16 Studium; 23. Jan. 1919 Dr. rer. nat.; Febr. 1919-Dez. 1924 Assistent am Chemischen Inst. (hier bei e. Unfall im Labor Verlust der rechten Hand); 2. Juli 1924 Habilitation. 
U Jena: Seit Jan. 1925 a. o. Prof. für AnorganischAnalytische Chemie, Assistent und Abt.-Leiter am Chemischen Laboratorium.

UH: Seit 20. Mai 1926 nichtplanm. a.o. Prof. und Assistent am Chemischen Inst.

TH Stuttgart: Seit Febr. 1933 a. o. Prof. und Abt.Vorsteher des Laboratoriums für Anorganische Chemie und Anorganisch-Chemische Technologie.

TH München: 1. April 1935-31. März 1964 (Emeritierung) o. Prof. und Vorsteher des AnorganischChemischen Laboratoriums; 1945 vorübergehende Entlassung durch amerik. Militärregierung.

Entdecker der Metallcarbonylwasserstoffe und der neuen Reaktionen und Synthesen von Metallcarbonylen sowie der Aufklärung ihrer Konstitution (Hiebersche Basenreaktion)

E Mitglied: 1944 Akademie der Wissenschaften München, 1956 Dt. Akademie der Naturforscher Leopoldina Halle/S., 1959 Chemical Society London. Dr. rer. nat. h.c.: 1958 UH, 1969 Würzburg. • 1951 Alfred-Stock-Gedächtnispreis der Gesellschaft der Dt. Chemiker.

Qu UAH PA 4205. • GLA Abt. 235, Fasz. 2096.

$W$ Bildungsweise und Metallsalzreaktion des Kobaltcarbonylwasserstoffs in: Zs. für anorganische und allgemeine Chemie 232 (1937) S. 17-38. (Mitverf.) - Einwirkungen organischer Schwefelverbindungen auf die Carbonyle von Eisen und Kobalt in: ebd. 235 (1937) S. 353-364. (Mitverf.) Siehe Bibliographie in: Fischer, Ernst Otto (1979) S. XXIX-XXXIX.

MHG 1943-1945 Zs. für anorganische und allgemeine Chemie. 1953-1976 Chemische Berichte.

$L$ Wer ist wer (1955) S. 468; Poggendorff 7a, 2 (1958) S. 486 f.; Kürschner (1976) S. 1247. • Fischer, Ernst Otto: In memoriam W.H. in: Chemische Berichte. Hrsg. von der Gesellschaft dt. Chemiker. Wein- heim 1979. 112. Jg., Nr. 2, S. XXI-XXVIII. • WBIS; Stolz (2003) S. 155f.; Baden-Württ. Biographien IV (2007) S. 146-148; Deutsche Biographie, s. https:// www.deutsche-biographie.de/gnd116796782.html [07.11. 2017]. • Werner, Helmut: Geschichte der anorganischen Chemie: Die Entwicklung einer Wissenschaft in Deutschland von Döbereiner bis heute. Weinheim 2017.

$P$ Bildarchiv UAH.

\section{Hillebrand, Heinrich Joseph}

1817-1822 Phil. Fak.

Philosophie

* 24. Aug. 1788 Groß Düngen (bei Hildesheim; heute: Ortsteil von Bad Salzdetfurth)

$\dagger \quad$ 25. Jan. 1871 Soden (heute: Bad S. am Taunus)

ㅁ Gießen kath., seit $1815 \mathrm{ev}$.

V Johann Christoph H. (1749-1827) Kötter, Wagner

M Anna Maria Angela geb. Büsse (1757-1827)

$\infty$ 1. April 1818 Barbara Katharina geb. Eschborn (1798-1823/24)

๑ 2. Juli 1825 Caroline geb. Hoffmann (18061847)

K mind. 2 T, 3 S: u. a. Julius Hubert H. (1819-1868) seit 1844 Privat-Dozent Gießen, seit 1850 Privat-Dozent, seit 1851 a. o. Prof. und 1860-1866 (Ruhestand aus gesundheitlichen Gründen) o. Prof. für Rechtswiss. Zürich, seit 1866 Honorar-Prof. Freiburg/Br., s. UAH PA 1726; ADB 12 (1880) S. 417 f., Zeiler (2008) S. 96 f., Ders. (2009) S. 520 (Register). Marie H. (18211894) Schulleiterin, s. Roland, Jean: M.H., ihr Leben und erziehliches Wirken. Gießen 1895; Hessische Biographie 1 (1918) S. 203-207. • Karl H. (1829-1884) Publizist, s. Encyclopædia Britannica 11. Ed. (1911), NDB 9 (1972) S. 147 f.; Laue, Nathalia: Bewegung und Bewegtheit ... Diss. Jena 2006. Bd. 1. S. 124-128 u. ö.; WBIS.

Lb Zunächst Studium der Theologie am Klerikalseminar des Gymnasiums Josephinum in Hildesheim, seit WS 1811/12 auch Studium der Philologie 
und der Orientalischen Sprachen an U Göttingen; seit 1812 Lehrer am Josephinum in Hildesheim; 1815 Entlassung aufgrund Konversion zum Protestantismus kurz nach Priesterweihe; seit 1816 Privatier und Hauslehrer in Würzburg.

UH: 14. Okt. 1817 H. erhält Erlaubnis, Vorlesungen zu halten; 21. Jan. 1818 Ern. zum a. o. Prof.; 8. Febr. 1818 Dr. phil.; seit 19. Okt. 1820 o. Prof. als Nachf. von Georg W. F. Hegel.

U Gießen: 19. Juli 1822 Ern. zum o. Prof.; WS 1822/ 23 Dienstantritt; 1824-1849 (1824-1838 Pädagogiarch $=$ Schulrektor) Gymnasiallehrer an Lateinschule; 25. Okt. 1850 Versetzung in Ruhestand zunächst ohne Pension aufgrund seiner liberalen Haltung. • In dieser Zeit:

Darmstadt: 1832-1849 Mitglied des großherzogl. Oberstudienrats; 1847-1856, 1862-1865 Abgeordneter verschiedener Wahlbezirke in II. Kammer der Hessischen Landstände; 1848 Präsident der II. Kammer.

1822 Dekan der Phil. Fak. der UH

1822 Hofrat

Qu UAH PA 1725; Fak.-Akten H-IV-102/12, H-IV102/13. GLA Abt. 205, Fasz. 290.

$W$ Deutschland und Rom oder: Über das Verhältnis der deutschen Nation zum römischen Stuhle. Frankfurt/M. 1818. • Der Organismus der philosophischen Idee in wissenschaftlicher und geschichtlicher Hinsicht. Dresden 1842. - Die deutsche Nationalliteratur seit dem Anfange des 18. Jahrhunderts. 3 T. Hamburg 1845-1846. 3. Aufl. 1875.

L ADB 12 (1880) S. 415-417; Universität Gießen 1 (1907) S. 432 f.; Lehmann (1967) S. 211 f;; Asmus (1974) S. 13-22 u. ö.; WBIS. • Hessische Abgeordnete $1820-1933$... Bearb. von Hans Georg Ruppel ... Darmstadt 1980. S. 135 f. - Mayer, Thomas Michael: Büchner und J.H. im Giessener Sommersemester 1834 in: Georg-Büchner-Jahrbuch. Berlin 1981. S. 195 f. - Wirkungen und Wertungen.
Adolph Frhr. Knigge im Urteil der Nachwelt ... Eine Dokumentensammlung ... Hrsg. von Michael Schlott ... Göttingen 1998. S. 108-111 u. ö. • Hessische Biografie, s. http://www.lagis-hessen.de/ pnd/116811919 (Stand: 11. März 2017).

\section{Hintzelmann, Paul Karl Ernst Friedrich}

(1902-1924 Phil. Fak.)

Romanistik

* 17. Dez. 1858 Grabow (Mecklenburg)

$\dagger \quad$ o7. Mai 1936 Heidelberg ev.

V Helmuth Christian H. (1825-1888) Amtssekretär, seit 1866 Amtsregistrator, siehe Landeshauptarchiv Schwerin, Sachakten Ministerium für Landwirtschaft, Domänen und Forsten, Signatur: $(5.12-4 / 2) 10228$

M Franziska geb. Ehrke ( ${ }^{\star} 1834 \dagger$ nach Sept. 1893)

( 10. Sept. 1885 Anna Johanna Karoline Wilhelmine geb. Stoppel $\left({ }^{*} 1860\right)$

K $\quad 1 \mathrm{~S}, 1 \mathrm{~T}$

Lb 1. April 1878-31. März 1879 Einjährig-Freiwilliger ohne militärische Charge in Rostock.

Seit SS 1878 Studium der Neueren, insbesondere der Romanischen Philologie an U Rostock, seit SS 1879 Berlin, 24. April 1880-11. Aug. 1882 UH; 23. Juli 1882 Dr. phil. an UH.

UBH: Seit 1. April 1882 Hilfsarbeiter mit e. Gehalt von monatlich 100.- Mark; 29. Juni 1882 Vereidigung; 1. Okt. 1882-5. Juli 1886 Kustos mit e. jährl. Besoldung von 18oo.- Mark; Febr. 1884 Zuschuß von 500.- Mark aus Stiftungsmitteln für e. bibliothekarische Bildungsreise nach Rostock, Berlin, Dresden, Leipzig, Halle/S. und Göttingen; seit 5. Juli 1886 (Vereidigung) (II. etatm.) Bibliothekar mit e. jährl. Gehalt von 2100.- Mark; seit 1. Juli 1902 I. etatm. Bibliothekar als Nachf. von Jacob Wille; 1. Febr. 1924 Ruhestand. • In dieser Zeit:

UH: 11. April 1902-1. Febr. 1924 (Ruhestand) Verleihung des Titels „Prof.“; 1902-1924 keine Vorlesungsankündigungen. 
Jährliche Gehaltsübersicht 1882-1912 an UBH:

1. April 1882: 1200.- Mark;

1. Okt. 1882: 1800.- Mark;

5. Juli 1886: 2100.- Mark;

1. April 1891: 3320.- Mark;

1. April 1894: 3720.- Mark;

1. Jan. 1900: 4200.- Mark;

1. Jan. 1903: 4700.- Mark;

1. Juli 1908: 6845.- Mark;

1. Juli 1912: 7450.- Mark ...

Gehaltsübersicht 1920-1922 (während der Inflation) an UBH:

Seit 1. April 1920: 24 900.- Mark

seit 1. Jan. 1921: 30 895.- Mark;

seit 1. Aug. 1921: 35 335.- Mark;

seit 1. Okt. 1921: 62 400.- Mark;

seit 1. Jan. 1922: 64 900.- Mark;

seit 1. April 1922: 80 80o.- Mark;

seit 1. Mai 1922: 102 900.- Mark;

seit 1. Juni 1922: 125 300.- Mark;

seit 1. Aug. 1922: 237 300.- Mark;

seit 1. Sept. 1922: 450 120.- Mark ...

Monatliche Gehaltsübersicht von 1924 an UBH:

Seit 1. Febr. 1924: 357,45 Mark;

seit 1. Juni 1924: 481,19 Mark;

seit 1. Nov. 1924: 490,88 Mark ... (aus: UAH PA 4224).

Qu UAH PA 48, 4224; RA 5972 f.; Fak.-Akte H-IV102/99 fol. 246r-25or.

Bearb. Heidelberg und Umgebung. Praktischer Reiseführer. 4. Aufl. Berlin 1908-1909.

HG Almanach der Universität Heidelberg für das Jubiläumsjahr 1886. Heidelberg 1886. • Die Matrikel der Universität Heidelberg. Teile IV - VII (17041870). Bearb. von Gustav Toepke ... Heidelberg 1903-1916.

L WBIS; Habermann et al. (1985) S. 149.

P Graph. Slg. UBH.

\section{Hippel, Eugen Adolph Arthur von}

1893-1909 Med. Fak.

Augenheilkunde

* 03. Aug. 1867 Königsberg (Preußen; heute: Kaliningrad, Russische Föderation)

$\dagger \quad$ 05. Juli 1939 Göttingen ref.

V Arthur Friedrich Wilhelm von H. (1841-1916) o. Prof. für Augenheilkunde: seit 1879 Gießen, seit 1890 Königsberg (Preußen), seit 1892 Halle-Wittenberg, 1901-1914 Göttingen, s. Catalogus prof. Gottingensium (1962) S. 77, NDB 9 (1972) S. 200, Catalogus prof. Halensis online, Tilitzki 1 (2012) S. 793 (Register)

M Olga Dorothea geb. Magnus (1846-19oo), s. Tilitzki 1, S. 548

$\infty$ 22. Sept. 1894 Gertrude Mathilde geb. Winkelmann (1874-1961) T von: (siehe) Eduard W.

$\mathrm{K} \quad 1 \mathrm{~S}, 2 \mathrm{~T}$

Vw Bruder: Robert von H. (1866-1951) o. Prof. für Rechtswiss.: seit 1895 Rostock, 1899-1935 Göttingen, s. Catalogus prof. Gottingensium (1962) S. 53, NDB 9 (1972) S. 201 f.; Dölling, Dieter: R. von H. - ein dt. Strafrechtswissenschaftler im Übergang vom 19. zum 20. Jahrhundert in: Rechtswissenschaft in Göttingen: Göttinger Juristen aus 250 Jahren. Göttingen 1987. S. 413-434; Schmeiser (1994) S. 411 u. ö., Grewolls (2011).

Lb Seit WS 1885/86 Studium an U Gießen, WS 1886/87 Berlin, seit SS 1887 UH, SS 1888 Gießen, seit WS $1888 / 89$ Göttingen; 25. Jan. 1890 Dr. med. an U Göttingen; 9. Febr. 1890 Staatsprüfung in Göttingen.

UH: Seit März 1890 Assistent am Patholog.-Anatom. Inst.; seit März 1891 Assistent an Med. U-Klinik; März 1892-Okt. 1909 Assistent an U-Augenklinik; 22. Juli 1893 Habilitation; seit 23. Dez. 1897 nichtetatm. a. o. Prof.

U Halle-Wittenberg: Seit WS 1909/10 o. Prof. und Direktor der U-Augenklinik; 1914-1915 Leiter e. Reservelazaretts. 
U Göttingen: 1915-1935 (Emeritierung) o. Prof. und Direktor der Augenklinik als Nachf. seines Vaters Arthur von $\mathrm{H}$.

Seit 1895 Erforscher einer Netzhautmißbildung, die heute als "von Hippel-Lindausches Syndrom“ bekannt ist, s. Beighton, Peter, Beighton, Greta: The Man behind the Syndrome. Berlin 1986. S. 231; Molino, D. u. a.: The history of von Hippel-Lindau disease in: Journal of Nephrology 19 (2006 MayJune) Suppl. 10, S. 119-123.

Geh. Medizinalrat

E 1912 Mitglied der Dt. Akademie der Naturforscher Leopoldina Halle/S.

Qu UAH PA 1731; RA 6177. • GLA Abt. 235, Fasz. 2100.

W Das Geschwür der Hirnhauthinterfläche. (Ulcus internum Corneae.) Halle/S. 190o. • Die Mißbildungen und angeborenen Fehler des Auges. Leipzig 1908. - Nussbaum, Moritz, H., E. von: Entwicklungsgeschichte des menschlichen Auges. 2. Bd. 1. Abt. 2. Aufl. Leipzig 1908. • Die Krankheiten der Sehnerven in: Handbuch der gesamten Augenheilkunde 398.-479. Lfg., T. 2, Bd. 7 (1922) S. 223-584. - Der jetzige Stand der Lehre von der Kurzsichtigkeit. Göttingen 1923.

MHG Albrecht von Graefe-Archiv für Ophthalmologie. Zentralblatt für die gesamte Ophthalmologie.

$L$ Catalogus prof. Gottingensium (1962) S. 78; NDB 9 (1972) S. 200 f.; Chronik Ärzte H (1985) S. 131; WBIS. - Vogel, Martin: E. von H. - Mediziner. Rede anläßlich der Enthüllung einer Gedenktafel am 23. Sept. 2004 in Göttingen, DüstereEichenweg 35 in: Göttinger Jahrbuch. Göttingen 2005. S. 157 f. - Surgical endocrinopathies: Clinical management and the founding figures. Ed. by Janice L. Pasieka ... Heidelberg 2015. S. 347-364. • Catalogus prof. Halensis online.

$P$ Bildarchiv UAH; graph. Slg. UBH; NDB; Chronik Ärzte H.

\section{Hirschel, Georg}

1907-1926 (1928) Med. Fak.

Chirurgie

* 11. Febr. 1875 Ludwigshafen

$\dagger \quad$ o9. April 1963 Heidelberg ev.

V Georg H. (†1897) Kaufmann, zuletzt Privatmann in $\mathrm{H}$

M Elise geb. Dangmann ( $† 1912 / 13$ ?)

œ 30. Dez. 1914 Rosa geb. Schmeicher $\left({ }^{*} 1884\right.$ $\dagger$ nach 1963)

$\mathrm{K} \quad 1 \mathrm{~S}$

Lb Studium: Seit SS 1896 UH, SS 1898 Bern, WS 1898/99 Berlin, SS 1899 München, WS 1899/1900WS $1900 / 01 \mathrm{H}$.

H: 23. Febr. 1898 Ärztl. Vorprüfung; 1901 med. Staatsexamen; 23. Juli 1901 Dr. med. an U.

Karlsruhe: Seit 1901 Assistent an Med. Abt. des Städtischen Krankenhauses.

UH: Seit Sept. 1902 Assistent (approbierter Arzt) am Patholog.-Anatom. Inst. im Akad. Krankenhaus; seit Mai 1903 Assistent (Volontärarzt), seit WS 1904/o5 klinischer Assistenzarzt, WS 1911/12WS 1914/15 I. klinischer Assistenzarzt an Chirurg. U-Klinik im Akad. Krankenhaus; 27. Juli 1907 Habilitation; seit 16. Juni 1913 nichtetatm., 1920-Febr. 1928 nichtplanm. a. o. Prof. an Chirurg. U-Klinik; 15. Okt.-15. Dez. 1914 stellvertr. Leiter der Chirurg. U-Klinik (für Max Wilms); SS 1915 Assistenzarzt an Ambulanz der Chirurg. U-Klinik; Febr. 1928 Entziehung der venia legendi und Streichung aus Verzeichnis der akad. Lehrer, da H. seit WS 1926/ 27 - trotz Ankündigung in den Vorlesungsverzeichnissen - nicht lehrt. In dieser Zeit:

WS 1915/16-WS 1918/19 Kriegsdienst; 1914-1953 Chefarzt der Chirurg. Abt. des St. Josefskrankenhauses in $\mathrm{H}$.

Qu UAH PA 977, 4234; RA 6588, 6789; Fak.-Akte H-III-111/135 fol. 232r-238r, 339r, 34or. • GLA Abt. 
235, Fasz. 2102. Briefe: Archiv des Verlages J. C. B. Mohr (Paul Siebeck) in Staatsbibliothek zu Berlin, Handschriften-Abt.

$W$ Über Strumitis bei Typhus abdominalis. Heidelberg 1901. - Der heutige Stand der operativen Therapie der akuten diffusen eitrigen Peritonitis. Tübingen 1907. - Lehrbuch der Lokalanästhesie. Wiesbaden 1913. 3. Aufl. 1923.

$L$ Chirurgen-Verzeichnis $\left({ }^{4}{ }^{4} 958\right)$ S. 348 ; Fischer 1 ( $\left.{ }^{3} 1962\right)$ S. 634 f.; Chronik Ärzte H (1985) S. 131; Jansen (1992a) S. 166 (Register). • Über G.H. in: Geschichte operativer Verfahren an den Bewegungsorganen. Hrsg. von Ludwig Zichner u.a. Darmstadt 200o. S. 176, 181-186. Goerig/Schulte am Esch (2012) S. 172 und Anm. 171; Deutsche Biographie, s. https://www.deutsche-biographie.de/gn d1012808335.html [07.11.2017].

$P$ Bildarchiv UAH.

\section{Hirt, August Erwin Theobald}

1925-1936 Med. Fak.

Anatomie

* 29. April 1898 Mannheim

$\dagger$ O2. Juni 1945 (Suizid) Schönenbach (heute: Ortsteil von Schluchsee)

口 Grafenhausen (Schwarzwald) ev., später konf.-los

V Johannes H. (1851-1923) Kaufmann

M Charlotte Maria Katharina geb. Rastberger $\left({ }^{*} 1870\right)$

๑ 7. Juli 1923 Frieda Maria geb. Häffner (18981944)

K $1 \mathrm{~S}(\dagger 1944), 1 \mathrm{~T}$

Lb 1914-1916 Kriegsfreiwilliger (verwundet mit schwerer Gesichtsverletzung); 1917 Reifeprüfung in Mannheim.

UH: Seit WS 1917/18 Studium; 5. Dez. 1921 Staatsexamen; 17. Jan. 1922 Dr. med.; 5. Dez. 1922 Approbation; seit April 1921 Praktikant, Dez. 1922-März 1936 Prosektor am Anatom. Inst.; 4. Mai 1925 Ha- bilitation; seit 15. März 1930 nichtplanm. a. o. Prof.; WS 1935/36 Vertreter des Fachs Anatomie an U Marburg.

U Greifswald: Seit SS 1936 a.o. Prof.; seit 16. Juli 1936 o. Prof.

U Frankfurt/M.: WS 1938/39-SS 1941 o. Prof. • In dieser Zeit:

Aug. 1939-April 1941 Kriegsdienst als Oberarzt.

Reichs-U Straßburg: WS 1941/42-Nov. 1944 o. Prof.; 1942-1943 Forschungsauftrag u. a. über Therapie von Kampfstoffverletzungen der Haut durch Senfgas am Inst. für wehrwiss. Zweckforschung des Schutzstaffel (SS)-Ahnenerbes, wiss. Abt. H (H für Hirt); Nov. 1944 Besetzung der Stadt durch amerik. und franz. Militär; 18. Dez. 1944 Erlaß des Reichsministers für Wissenschaft, Erziehung und Volksbildung zur Verlegung der Reichs-U Straßburg an U Tübingen.

U Tübingen: Dez. 1944-April 1945 Nach Evakuierung des Inst. nach Tübingen ist $\mathrm{H}$. e. anwesendes Mitglied des Straßburger Lehrkörpers, s. Vorlesungsverzeichnis der U Tübingen; April 1945 Flucht nach Schönenbach.

Hirt führt 1942-1944 Versuche mit Senfgas an Häftlingen des KZ Natzweiler-Struthof durch; er ist zudem maßgeblich an der Ermordung von jüdischen Häftlingen des KZ Auschwitz (heute: Oświęcim, Polen) beteiligt, s. hierzu Lang, HansJoachim: Die Namen der Nummern. Wie es gelang, die 86 Opfer eines NS-Verbrechens zu identifizieren ... Hamburg 2004.

Am 24. Dez. 1952 wird Hirt von e. Militärgericht in Metz zum Tode verurteilt - in Unkenntnis seines Selbstmordes.

Siehe auch Anhang Sporteinrichtungen an $U H$ 1910-1933 und ihre Mitglieder

Qu UAH PA 978, 4235; Fak.-Akte H-III-862/36. • GLA Abt. 235, Fasz. 2103. 
$W$ Eine Methode zur Beobachtung lebender Organe mit stärksten Vergrößerungen im Lumineszenzlicht in: Handbuch der biologischen Arbeitsmethoden. Abt. 5, T. 2, H. 15, Lfg. 341. (o. J.) (Mitverf.: Philipp Ellinger.) - Vergleichend-anatomische Untersuchungen über die Innervation der Niere in: Zs. für Anatomie und Entwicklungsgeschichte 73 (1924). - Mikroskopische Beobachtungen an lebenden Organen mit Demonstrationen (Intravitalmikroskopie) in: Naunyn-Schmiedeberg's Archives of Pharmacology (Dec. 1929) Vol. 147, Numbers 1-3. (Mitverf.: P. Ellinger.)

L Lachman, Ernest: Anatomist of infamy: A. H. in: Bulletin of the History of Medicine 51 (1977) S. 594602. Holocaust. Hrsg. von Jürgen Heideking. Tübingen 1982. S. $196 \mathrm{f}$. Schmaltz (2005) S. 670 (Register). - Wechsler, Patrick: La Faculté de Médecine de la „Reichsuniversität Straßburg“ (19411945) à l'heure nationale-socialiste. Diss. Straßburg 2005. - Kater, Michael H.: Das „Ahnenerbe“ der SS 1935-1945. Ein Beitrag zur Kulturpolitik des Dritten Reiches. 4. Aufl. München 2006. S. 503 (Register). UH im Nationalsozialismus (2006) S. 651-653; Marx (2008) S. 319-321 u.ö. • Benzenhöfer, Udo: A.H. Verbrecherische Menschenversuche mit Giftgas und „terminale“ Anthropologie in: Mengele, Hirt, Holfelder, Berner, von Verschuer, Kranz: Frankfurter Universitätsmediziner der NS-Zeit. Hrsg. von Udo Benzenhöfer. Münster 2010. S. 21-43 u. ö. • Lang, Hans-Joachim: Die Skelettsammlung des A.H. Ein Anatomieprofessor lässt morden in: Die Frauen von Block 10. Hamburg 2011. S. 182-192. • Müßig, Katrin: A. H. ... Leben und Werk. Diss. Regensburg 2014. $\bullet$ Deutsche Biographie, s. https://www.deutsche-biographie. de/gnd119339005.html [07.11.2017]; Doll/Kirsch/ Eckart (2017) S. 70.

\section{His, Rudolf}

1896-1904 Jur. Fak.

Rechtsgeschichte, Handelsrecht, Deutsches Privatrecht

* 15. Juli 1870 Basel

$\dagger \quad$ 22. Jan. 1938 Münster ev.

V Wilhelm H. d. Ä. (1831-1904) o. Prof. für Anatomie: seit 1857 Basel, seit 1872 Leipzig, s. NDB 9 (1972) S. 249, Peiffer (2004) S. 1156 (Register), Berliner U in NS-Zeit I (2005) S. 19, 41, 44, Geschichte U Leipzig 2 (2010) S. 916 (Register), Doll/Kirsch/Eckart (2017) S. 65, 114

M Elisabeth Vischer (1836-1924)

( 29. Sept. 1898 Hedwig Emilie Mathilde geb. Pfitzer (1876-1953), s. Oestmann (2014) S. 5 f., 17. - T von: (siehe) Ernst P.

K $\quad 1$ T, s. Oestmann, S. 6 und Anm. 37, 17

Vw Bruder: Wilhelm H. d. J. (1863-1934) o. Prof. für Innere Medizin: seit 1902 Basel, seit 1906 Göttingen, 1907-1932 Berlin, s. Catalogus prof. Gottingensium (1962) S. 77, NDB 9 (1972) S. 249, WBIS; Wormer, Eberhard J.: Syndrome der Kardiologie und ihre Schöpfer. München 1989. S. 117-124; Lechner, Anna: Leben und Lebenswerk von W.H. dem Jüngeren. Diss. Heidelberg 1998.

Lb Seit WS 1888/89 Studium an U Genf, anschl. Leipzig, Berlin, Leipzig, zuletzt Basel; 17. Juli 1892 Dr. iur. an U Basel; Juni-Okt. 1892 schweizerischer Militärdienst.

Paris: Nov. 1892-Nov. 1893 Attaché volontaire an Schweizer Gesandtschaft.

Seit Ende 1893 Eigenstudien an U Leipzig, seit $1894 \mathrm{H}$.

UH: 27. Nov. 1896 Habilitation; 1898-1901 Assistent am Jur. Seminar (bei (siehe) Richard Schroeder am Dt. Rechtswörterbuch); seit 21. Dez. 1900 nichtetatm. a. o. Prof.; seit WS 1902/03 Lehrauftrag für Geschichte und Grundzüge des Privatrechts mit e. jährl. Bezahlung von 1500.- Mark. 
U Königsberg (Preußen): Seit SS 1904 o. Prof. für Bürgerliches Recht.

U Münster: Seit 10. April 1908 o. Prof. mit e. jährl. Gehalt von 4400.- Mark und e. Wohnungsgeldzuschuss von 660.- Mark; Sommer 1915-Frühjahr 1918 Kriegsdienst als Oberleutnant in der Postprüfstelle e. Gefangenenlagers in Münster; 1920 Ruf an U Frankfurt/M. abgelehnt; WS 1935/36 Entpflichtung; SS 1936-WS 1936/37 Vertreter seines Lehrstuhls.

Qu UAH PA 1732; RA 6679. GLA Abt. 235, Fasz. 2104. Rektoratsreden - online. Briefe: UBH.

W Zur Rechtsgeschichte des thüringischen Adels in: Zs. des Vereins für Thüringische Geschichte und Altertumskunde. Jena 1904. Bd. 22. N.F. 14. S. 1-35. Neuaufl. Darmstadt 1965. Das Strafrecht des deutschen Mittelalters. 2 Bde. Leipzig 1920. Weimar 1935. Neudr. Aalen 1964. Geschichte des deutschen Strafrechts bis zur Karolina. München 1928. - Recht und Verfassung Westfalens im Mittelalter. Velen 1930.

$L$ Naendrup, Hubert: R. H. - ein Forscherleben im Dienste der deutschen Rechtsgeschichte. Münster 1941. NDB 9 (1972) S. 248 f. (mit Werkverz.); Arnim 3/4 (1978) S. 658; Universität Münster (1980) S. 271. - Steveling, Lieselotte: Juristen in Münster: Ein Beitrag zur Geschichte der Rechts- und Staatswissenschaftlichen Fakultät der ... Universität Münster. Münster 1999. S. 131-136, 163-169, 254-267 u. ö. Schroeder (2010) S. 344-346 u. ö.; Tilitzki 1 (2012) S. 793 (Register). • Oestmann, Peter: R.H. ... - ein Schweizer Strafrechtshistoriker in Münster in: Münsteraner Juraprofessoren. Hrsg. von Thomas Hoeren. Münster 2014. S. 30-69.

\section{Hitzig, Ferdinand}

1829-1833, 1861-1875 Theol. Fak.

Altes Testament

* 23. Juni 1807 Hauingen (heute: Ortsteil von Lörrach)

$\dagger$ 22. Jan. 1875 Heidelberg

ev.
V Ferdinand Sigismund H. (1775-1838) Pfarrer, s. Badisches Pfarrerbuch 2 (1939) S. 272

M Johanna geb. Brodhag(e)

@ Emma geb. Sievert (1808/09-1875)

K 1 T, 2 S: Ferdinand H. (1836-186o) zuletzt Bremer Obersteuermann bei der Marine. - Hermann H. (1843-1918), u.a. 1871-1873 Lehrer am Lyceum in $\mathrm{H}$ (heute: Kurfürst-FriedrichGymnasium „KFG“), seit 1878 (Habilitation) a. o. Prof. Bern, 1887-1917 o. Prof. für Klassische Philologie Zürich, s. Waser, Otto: H.H. in: Biogr. Jahrbuch für Alterthumskunde 42 (1922) S. 11-23; Das „Goldene Buch“ des KFG (1994) S. 91f.; Ehemann von Emilie geb. Steiner (1842-1919), s. https://www.myheritage.de/ names/emilie_steiner; Schwester von: (siehe) Heinrich Steiner

Vw Onkel: Friedrich Wilhelm H. (1767-1849) 1821 D. theol. UH, s. Badisches Pfarrerbuch 2, S. 272. Enkel: Hermann Ferdinand H. (18681911) seit 1892 Privat-Dozent, seit 1895 a.o. Prof., seit 1897 o. Prof. für Römisches Recht Zürich, s. H.F.H. ... in: Mélanges Paul Frédéric Girard. Études de droit romain dédiées à M.P.F. Girard à l'occasion du 6oe anniversaire ... Paris 1912; Die U Zürich 1833-1933 und ihre Vorläufer. Bearb. von Ernst Gagliardi ... Zürich 1938. S. 840 f.

Lb Seit WS 1824/25 Studium der Theologie, Philosophie an UH, seit WS $1825 / 26$ Halle-Wittenberg; Spätjahr 1827 theol. Staatsexamen in Karlsruhe; $1827-1829$ Kandidat der Theologie u.a. in Lörrach, seit 1828 in Göttingen; 13. April 1829 Dr. theol. an U Göttingen.

\section{UH: Seit WS 1829/30 Privat-Dozent.}

U Zürich: Seit SS 1833 o. Prof. für Altes, auch Neues Testament, außerdem Arabisch und später Sanskrit sowie Syrische Sprachen an neugegründeter U.

UH: 25. Jan. 1861 Ern. zum o. Prof. (eigentlich für Theologie und Philosophie) als Nachf. von Friedrich Umbreit an Theol. Fak. mit e. Jahresgehalt von 2300.- Gulden, s. UAH RA 6718 fol. 22r, v; 30. März 1861 Amtsantritt.

1866 Prorektor der UH; 1863/64, 1867/68, 1871/72 Dekan der Theol. Fak. der UH 
1871 Mitglied der Badischen Generalsynode in Karlsruhe, s. hierzu Kuhlemann, Frank-Michael: Bürgerlichkeit und Religion: zur Sozial- und Mentalitätsgeschichte der evangelischen Pfarrer in Baden 1860-1914. Göttingen 2002. S. 552 (Register).

1864 Kirchenrat; 1872 Geh. Kirchenrat

E 1831 D. theol. UH. 1862 Ritter des Ordens vom Zähringer Löwen.

Qu UAH PA 1733; GF 16. GLA Abt. 205, Fasz. 292. • Briefe, Nachlaß: UBH. • Auskunft: Universitätsarchiv Göttingen.

$W$ Die zwölf kleinen Propheten. Leipzig 1838. 3. Aufl. 1863. • Der Prophet Jeremia. Leipzig 1841. • Geschichte des Volkes Israel vom Anbeginn bis zur Eroberung Masada's im Jahr 72 nach Christus. 2 Bde. Leipzig 1869-1870. • F. H.s Vorlesungen über biblische Theologie und messianische Weissagungen des Alten Testaments. Hrsg. von Johann Jakob Kneucker. Karlsruhe 188o. S. 1-35.

L NDB 9 (1972) S. 276 (mit Werkverz.); WBIS; BBKL II (1990) Sp. 904 f. • Villiger, Verena: „Dem scheidenden Hitzig seine Freunde und Verehrer“: Gottfried Sempers Pokal für F.H. in: Zs. für schweizerische Archäologie und Kunstgeschichte (= Revue suisse d'art et d'archéologie ... ) 56 (1999) H. 1. S. 53-66 (mit P).

$P$ Bildarchiv UAH; graph. Slg. UBH; NDB.

\section{Hoepke, Hermann}

1923-1939, 1945-1946, 1946-1961 Med. Fak. Anatomie
* 13. Mai 1889 Eberswalde (Brandenburg)
$\dagger \quad$ 22. Dez. 1993 Heidelberg ev.

V Dr. Paul H. (1857-1929) Landgerichtsdirektor M Antoinette geb. Landois (1867-1935)
@ 18. März 1922 Gertrud Adele Hedwig geb. Proske $\left({ }^{*} 1897\right)$, siehe Lexikon jüdischer Einwohner Hs (2011) S. 183

K $\quad{ }_{1} \mathrm{~S}, 1 \mathrm{~T}$

Lb Seit SS 1909 Studium an U Freiburg/Br., SS 1910 Kiel, seit WS 1910/11 Freiburg, WS 1911/12 Marburg, SS 1912 Greifswald, WS 1912/13 München, seit SS 1913 Greifswald; 22. Juli 1911 Physikum in Freiburg; 23. Juli 1914 Staatsexamen in Greifswald; 1. Aug. 1914 Approbation; 1914-1918 Kriegsdienst; 25. Febr. 1918 Dr. med. an U Greifswald.

U Breslau: Seit 1. Jan. 1919 planm. Assistent am Anatom. Inst.

UH: Seit 1. Okt. 1921 planm. Assistent und I. Prosektor am Anatom. Inst.; 27. Febr. 1923 Habilitation; seit 4. Aug. 1927 nichtbeamteter a. o. Prof.; 31. März 1939 Vertragsende, da für H. kein Lehrstuhl an UH eingerichtet werden kann; AprilSept. 1939 Vertragsverlängerung, um H. die Möglichkeit zu geben, Verhandlungen mit U Adelaide und Istanbul zu führen, da er sonst mittellos würde; 1. Okt. 1939-31. März 1940 Beurlaubung zur Durchführung seiner Ausbildung als praktischer Arzt unter Weiterbezahlung der Bezüge; Dez. 1939 Reichs-Erziehungs-Ministerium erklärt Lehrbefugnis an UH für erloschen; 31. März 1940 endgültiges Ausscheiden; in dieser Zeit: 1. Sept. 193931. Dez. 1939 (von UH unter Weiterzahlung seiner Bezüge beurlaubt) Volontärassistent am Städtischen Krankenhaus in Lübeck.

H: 1. Febr. 1940-1945 Praktischer Arzt („,notdienstverordneter Arzt“, aus: UAH PA 4253).

UH: 8. Sept. 1945 Wiederverleihung des Titels eines a. o. Prof.; 1. Nov. 1945 o. Prof. und Direktor des Anatom. Inst.; 18. Febr. 1946 Entlassung gemäß Erlaß der amerik. Militärregierung; Febr.-Sept. 1946 Forts. der Vorlesungen; 4. Sept. 1946 Wiedereinsetzung als o. Prof.; Sept.-Nov. 1953 Vortragsreise in USA; 30. Sept. 1957 Emeritierung; WS 1957/ 58-SS 1961 weiterhin Vertreter seines Lehrstuhls. • In dieser Zeit:

Karlsruhe: SS 1948-SS 1961 Lehrauftrag an Akademie der Bildenden Künste. 
1947/48 Dekan der Med. Fak. der UH

1951-1968 Heidelberger Stadtrat; 1952-1968 Mitglied des Rundfunkrates Stuttgart

E 1959 Großes Verdienstkreuz des Verdienstordens; 1969 Bürgermedaille der Stadt Heidelberg; 1976 Paracelsus-Medaille.

Qu UAH PA 982, 2754, 4253-4257, 9680 f., 10350. • Briefe: UBH. • Teil-Nachlaß: UAH. Mitteilungen: Herr Prof. Dr. Hermann Hoepke ( $\dagger$ ), Heidelberg.

$W$ Lehrbuch über das Muskelspiel des Menschen. Jena 1936. 7. Aufl. 1979. - Leitfaden der Histologie des Menschen. Berlin 1950. Die Geschichte der Anatomie in Heidelberg. Berlin 1951. Zentrales und vegetatives Nervensystem. Stuttgart 1959. Alt Heidelberg. Heidelberg 1971. 3. Aufl. 1980.

HG, Bearb. Der Briefwechsel zwischen Jakob Henle und Karl Pfeufer 1843-1869. Wiesbaden 1970. Homers Odyssee. Baden-Baden 1975. Homers Ilias. Baden-Baden 1977.

$L$ Kantner, Max: Prof. H. 8o Jahre alt in: Heidelberger Jahrbücher 13 (1969) S. 18-22. - Zum 8o. Geb. von H.H. in: Fortschritte der Medizin 26. Jg. (1969) Nr. 13, S. 581 f. - Ackermann, Georg: H.H. zum 85. Geb. in: Ruperto Carola 26. Jg., H. 53 (1974) S. 100 f. - WBIS; Chronik Ärzte H (1985) S. 131, 232 ff.; Mussgnug (1988) S. 298 (Register); Jansen (1992a) S. 166 (Register); BadenWürtt. Biographien III (2002) S. 159-162; UH im Nationalsozialismus (2006) S. 655 f. u. ö.; Lexikon jüdischer Einwohner Hs (2011) S. 183; Deutsche Biographie, s. https://www.deutsche-biographie. de/gnd116931639.html [07.11.2017]; Doll/Kirsch/ Eckart (2017) S. 70, 84.

$P$ Bildarchiv UAH; Heidelberger Jahrbücher; Chronik Ärzte H.

\section{Hoffmann, Ernst}

1922-1935, 1945-1948 Phil. Fak.

Philosophie, Pädagogik

* 13. Jan. 188 o Berlin

$\dagger$ 28. Jan. 1952 Heidelberg

ev.

V Otto H. (1853-1930) Architekt, später Baurat, u. a. 1884 Erbauer der heute unter Denkmalschutz stehenden Landhausanlage „Burg“ als eigenes Wohnhaus an der Ecke Friedrich-Wilhelm-Platz/Schmargendorfer Straße in BerlinFriedenau, s. https://www.berlin.de/ba-tempel hof-schoeneberg/organisationseinheit/denk malschutz/denkmal-februar-2013.html (Ausdruck im UAH)

M Anna geb. Ranfft (1853-1927)

Q 12. Juli 1906 Dorothea geb. Zürcher (1882-1965) T von Emil Z. (1850-1926) seit 1873 Anwalt und Advokat, 1881-1926 Oberrichter, auch Präsident des Schwurgerichts, 1890-1923 o. Prof. für Strafrecht Zürich; Nachlaß in Zentralbibliothek Zürich; siehe Alder, Oscar: E.Z. $\ldots \dagger$ in: Appenzellische Jahrbücher 54 (1927) S. 75-8o; Holenstein, Stefan: E.Z. - Leben und Werk eines bedeutenden Strafrechtlers ... Zürich 1996.

K 1 (früh $\dagger$ ).

Lb Seit WS 1899/1900 Studium der Klassischen Sprachen, Philosophie an U Berlin, SS 1900 Studium der Philosophie an UH, WS 1900/o1 Göttingen, seit SS 1901 Berlin; 13. Dez. 1904 Staatsexamen für Klassische Sprachen und phil. Propädeutik in Berlin; 6. Mai 1905 Dr. phil. an U Berlin.

Berlin: Seit 1. April 1905 Ausbildung am Königl. Pädagog. Seminar; 7. April 1907-1. April 1922 Studienrat am Mommsen-Gymnasium in Charlottenburg; 1922 Ruf an U Hamburg abgelehnt. • In dieser Zeit:

Winter 1916/17 Kriegsdienst.

UH: Seit 6. April 1922 planm. a. o. Prof. und - neben Heinrich Rickert und Karl Jaspers - Direktor des Phil. Seminars; seit 2. Aug. 1927 (Einrichtung e. neuen Professur) o. Prof.; außerdem Lehrbeauf- 
tragter an Lehrerbildungsanstalt: 1927 in Karlsruhe, $1928 \mathrm{H}$; 1930 Ruf an U Jena abgelehnt; 1. Okt. 1935 Emeritierung auf eigenen Antrag, um der drohenden Amtsenthebung aus rassischen Gründen (,jüdischer Mischling“) zuvorzukommen; 14. Nov. 1935 Entbindung von amtlichen Verpflichtungen; WS 1945/46 Wiederaufnahme der Lehrtätigkeit; 31. März 1948 Entpflichtung. • In dieser Zeit:

H: Dez. 1927-Jan. 1952 (†) Gründer und Leiter der Forschungsstelle „Edition der Schriften von Nikolaus von Kues" (Cusanus-Commission) an der Heidelberger Akademie der Wissenschaften.

1931/32 Dekan der Phil. Fak. der UH

E 1928 Mitglied der Akademie der Wissenschaften H. 1950 D. theol. UH.

Qu UAH PA 451, 4263. • Briefe, Nachlaß: UBH.

$W$ Das Universum des Nikolaus von Cues. Heidelberg 1930. - Platon. Zürich 1950. Lizenzausg. 1961. • Pädagogischer Humanismus. 22 Vorträge und Abhandlungen. Hrsg. von Walter Rüegg und Arthur Stein. Zürich 1955. - Platonismus und christliche Philosophie. Gesammelte Abhandlungen und Vorträge zur Geschichte der Philosophie. Leben und Schriften E. H.s ... Hrsg. von ... HansGeorg Gadamer. Zürich 1960.

MHG Cusanus-Texte: Dies sanctificatus vom Jahre 1439. Heidelberg 1929. - Nicolai de Cusa. Opera omnia I: De docta ignorantia ... Leipzig 1932.

$L$ Wilpert, Paul: E. H. † in: Zs. für philosophische Forschung (1953) Bd. 7, Nr. 2, S. 265-275 (mit Bibliographie). Glockner (1969) S. 273f. (Register); NDB 9 (1972) S. 414 f. (mit Werkverz.); Arnim 3/4 (1978) S. 666 f.; WBIS. - Über E.H. in: Cassirer, Toni: Mein Leben mit Ernst Cassirer. Hildesheim 1981. S. 111-113 u.ö. • Mussgnug (1988) S. 298 (Register); Jansen (1992) S. 410 (Register); Ders. (1992a) S. 166 (Register); Wennemuth (1994) S. 635 (Register); Baden-Württ. Biographien III (2002) S. 163 f.; UH im Nationalsozialismus (2006) S. 1257 (Register); Vertriebene Mitgl. der Akad. der
Wiss. H (2009) S. 29-34. • Über E. H. in: Leo, Paul Christopher: Wilhelm Groh - Erster Rektor der Ruperto-Carola in der NS-Zeit. Diss. UH. Hamburg 2012. S. 149.

P Bildarchiv UAH; Vertriebene Mitgl. (2009). • Büste im Institut für Bildungswissenschaft der UH.

\section{Hoffmann, Johann}

1888-1910 Med. Fak.

1910-1914 (Honorar-Prof.) Med. Fak.

1914-1919 Med. Fak.

Neuropathologie

* 28. März 1857 Hahnheim (Rheinhessen)

$\dagger \quad$ o1. Nov. 1919 Heidelberg ev.

V Paul H. (1809-1878) Ackersmann und Landwirt, 1849-1852 Bürgermeister

M Maria Eva geb. Feldmann ( $† 1897)$

๑ 22. Juli 1902 Fanny Luise Johannette geb. Clemm verw. Giulini (1864-1946), s. Briefe in UBH; T von Dr. phil. August Ernst Carl Conrad C. (seit 1893 Ritter von) (1837-1910) 1865 Mitbegründer, seit 1885 Mitglied, 1897-1903 Vorsitzender des Aufsichtsrats der Badischen Anilin- und Sodafabrik (BASF) in Ludwigshafen, u. a. 1883-1899 Abgeordneter des Bayer. Landtags, 1897-1899 Präsident der Abgeordnetenkammer; 1886 Initiator zur Gründung der Pfälzischen Hypothekenbank AG, seit 1900 lebenslänglicher Reichsrat der Krone Bayern, seit 1908 Exzellenz, s. NDB 3 (1957) S. $286 \mathrm{f}$., Baden-Württ. Biographien V (2013) S. 497-500; Witwe von Paul Johann Baptist Giulini (1856-1899) Mit-Direktor der väterlichen Schwefelsäure-, Alaun- und Vitriolfabrik in Ludwigshafen, s. Baden-Württ. Biographien IV (2007) S. 102-104. • Weitere Vw, s. BadenWürtt. Biographien V (2013) S. 500-503

K keine.

Lb Seit SS 1877 Studium an UH, seit SS 1879 Straßburg, seit SS 188 o Berlin, seit SS $1881 \mathrm{H}$; Praktikant: SS 188 o Propädeutische Klinik und WS 188o/81 Chirurg. U-Klinik sowie auch Klinisches Inst. für 
Geburtshilfe in Berlin; WS 1881/82 Staatsexamen in $\mathrm{H}$; 1. April 1882 Approbation in Karlsruhe.

UH: Seit Juni 1882 Assistent an Med. U-Klinik; Frühjahr 1883 ärztl. Prüfung; 12. März 1883 Dr. med.; 16. Jan. 1888 Habilitation für Innere Medizin; seit 21. Jan. 1891 nichtetatm. a. o. Prof.; seit WS 1903/04 Leiter der Ambulanz für Nervenkrankheiten und ca. Mai 1907-1919 (†) Leiter der NervenAbt. in der Med. U-Klinik; seit SS 1907 Lehrauftrag für Neurologie, Elektrotherapie und -diagnostik, physikalische und chemische Diagnostik; Okt. 1907 Ern. zum Oberarzt; seit 22. März 1910 o. Honorar-Prof.; 4. Sept. 1914 „wegen Einberufung des Direktors der Klinik ... Prof. Dr. Krehl ... wird für die Dauer seiner Abwesenheit die Leitung der med. Klinik ... Hoffmann übertragen" (aus: UAH RA 6804); seit 15. Okt. 1914 etatm. a. o. Prof.; seit 22. März 1919 o. Prof.

Johann Hoffmann ist der erste Ordinarius für Neuropathologie an UH, s. hierzu Kuhn, Erich: J.H., erster ordentlicher Professor für Nervenpathologie in Heidelberg in: Fortschritte der Neurologie, Psychologie (Aug. 2001) Sonderheft 1, 69. Jg., S. S18-S22.

1896 Erstbeschreibung des „Hoffmann-Syndroms“ (hypothyreote Myotonie); vor 1904 Entdecker des sog. Knipsreflexes an den Fingern (Hoffmann'sches Zeichen)

1917 Geh. Hofrat

E 1903 Ritterkreuz I. Klasse vom Orden des Zähringer Löwen; 1906 Friedrich-Luisen-Medaille.

Qu UAH PA 984, 1738; RA 6269, 6588, 6803f.; Fak.-Akten H-III-111/104 fol. 177, 182r-217r, HIII-111/150 fol. 356r, H-III-574/1. - GLA Abt. 235, Fasz. 2110. Briefe: UBH. • Auskunft: Ev. Kirchengemeinde Selzen, Hahnheim in Köngernheim (Taufbuch von 1857).

W Zur Lehre von der Tetanie ... Leipzig 1888. • Über chronische spinale Muskelatrophie im Kindesalter auf familiärer Basis in: Dt. Zs. für Nervenheilkunde (1893); Weiterer Beitrag zur Lehre von der Tetanie in: ebd. 9 (1896) S. 278-290. - Siehe auch Kuhn ... (2001) S. S19-S21.

L Schönfeld, Walther: J.H. ... der Heidelberger Neurologe ... in: Ruperto Carola 14. Jg., Bd. 31 (1962) S. 184-188. - Vogel, Paul: Die Heidelberger neurologische Schule. Friedreich-Erb-Hoffmann in: Heidelberger Jahrbücher 14 (1970) S. 8184. Chronik Ärzte H (1985) S. 131; Jansen (1992a) S. 166 (Register). Kreuter, Alma: Deutschsprachige Neurologen und Psychiater. 2. Bd. München 1996. Meinck (2004) S. 28 f.; Ruuskanen (2008) S. 236 f. u. ö. Schmitt, H.P.: Größe im Schatten 150 Jahre J.H. ..., Nervenarzt und Hochschullehrer in: Nervenheilkunde (2008) Vol. 27, H. 3, S. 117-236. - Nezhad, Golnoush Sadat Mahmoudi, Dalfardi, Behnam: J.H. ... in: Journal of Neurology 9 (2014). Deutsche Biographie, s. https://www. deutsche-biographie.de/gnd116939532.html [07.11. 2017].

$P$ Bildarchiv UAH; Ruperto Carola; Heidelberger Jahrbücher; Chronik Ärzte H.

\section{Hofmeister, Wilhelm Friedrich Benedikt}

1863-1872 Phil. Fak.

Botanik

* 18. Mai 1824 Leipzig

$\dagger$ 12. Jan. 1877 Lindenau (heute: Stadtteil von Leipzig)

ev.-luth.

V Friedrich H. (1782-1864) Gründer (des heute noch existierenden Leipziger „Friedrich Hofmeister Musikverlag"): 1807 der Sortimentshandlung für Musikalien, nach 1807 des gleichnamigen Musikverlags, der musikalischen Leihanstalt und des Buchverlags in Leipzig; Hrsg.: seit 1816 Handbuch der musikalischen Literatur, seit 1830 Musikalisch-literarischer Monatsbericht, s. NDB 9 (1972) S. 467 f., WBIS

M Friederike geb. Seidenschnur (1783-1861)

$\infty$ 15. Nov. 1847 Agnes Amalia geb. Lurgenstein (1824-1870)

(26. Febr. 1876 Johanna geb. Schmidt 
$\mathrm{K} \quad 5 \mathrm{~S}, 4 \mathrm{~T}$ (davon $3 \mathrm{~S}$ und $1 \mathrm{~T}$ früh $\dagger, 2 \mathrm{~S}, 1 \mathrm{~T} \dagger$ vor $1876)$, u.a. Constanze H. $\left({ }^{*} 1859\right)$ verh. Ganzenmüller, s. Landesarchiv Baden-Württemberg, Abt. Staatsarchiv Ludwigsburg, F 215 Bü 214

Vw Schwester: Clementine H. (1826-1905) Schriftstellerin (Pseudonym: Clelie Betemann), s. Lexikon deutscher Frauen der Feder ... Hrsg. von Sophie Pataky. Berlin 1898. S. 1, 64; Friedrichs, Elisabeth: Die deutschsprachigen Schriftstellerinnen des 18. und 19. Jahrhunderts. Ein Lexikon. Stuttgart 1981; Ehefrau von Ambrosius Abel (1820-1878) Buchhändler und Verleger, seit 1852 Inhaber des Buchverlags von Friedrich Hofmeister, s. WBIS. - Enkel: Dr. phil. Wilhelm Ganzenmüller (1882-1955) Wissenschaftshistoriker, Verfasser des grundlegenden Werkes über „Die Alchemie im Mittelalter" (Paderborn 1938. Reprint Hildesheim 1967), s. NDB 6 (1964) S. 68, WBIS.

Lb Seit 1839 Volontär in Musikalienhandlung von August Cranz in Hamburg; autodidaktische Studien in Naturwiss., Sprachen und Musik.

Leipzig: Seit Ostern 1841 Fremdsprachen-Korrespondent im väterl. Geschäft, Febr. 1852-1863 zus. mit seinem Bruder Adolph Moritz H. (1802-1870) Leiter des väterl. Musikverlags; 1841-1863 Eigenstudien in Botanik, Privat-Gelehrter und Verfasser wiss. Werke; 1845 Studienreisen nach Bayern und Tirol.

UH: 31. Mai 1863 Ern. zum o. Prof. und Direktor des Botanischen Gartens (zwischen heutigem Bismarck- und Adenauerplatz) als Nachf. von Gottlieb Wilhelm Bischoff (in Nachf. von Johann Anton Schmidt als "provisorischem Direktor") durch ministeriellen Erlaß; 3. Aug. 1863 Vereidigung; 1867 Ruf an U Leipzig abgelehnt; seit 1871 auch Respizient (Berichterstatter) für den Schlossgarten in $\mathrm{H}$.

U Tübingen: 30. Mai 1872 Ern. zum o. Prof.; WS 1872/73 Vorlesungsbeginn; 18. Mai 1876 Schlaganfall; Sept. 1876 auf eigenen Antrag Enthebung von Professur.

Lindenau: Seit Okt. 1876 Wohnsitz.

1867 Entdecker der Zellteilung (Mitose) bei höheren Pflanzen
$E$ Mitglied der Akademie der Wissenschaften: 1859 München, 1870 Göttingen, 1874 Berlin; Mitglied: 1859 Dt. Akademie der Naturforscher Leopoldina Halle/S., 1873 American Academy of Arts and Sciences. 1851 Dr. phil. h.c. Rostock; 1867 Dr. med. h.c. Halle-Wittenberg. 1876 Goldene Boerhave Medaille.

Qu UAH PA 1742; RA 5633, 6883.

$W$ Die Entstehung des Embryos der Phanerogamen. Leipzig 1849. • Vergleichende Untersuchung der Keimung, Entfaltung und Fruchtbildung höherer Kryptogamen ... und der Samenbildung der Coniferen. Leipzig 1851. (Engl. Übers.: On the germination, development, and fructification of the higher Cryptogamia, and on the fructification of the Coniferae. Translated by Frederick Currey ... London 1862) - Die Lehre von der Pflanzenzelle. Leipzig 1867. Allgemeine Morphologie. Leipzig 1868.

MHG 1867-1868 Handbuch der physiologischen Botanik.

L Goebel, K. von: W.H. - Arbeit und Leben eines Botanikers des 19. Jahrhunderts. Mit biographischer Ergänzung von Frau Prof. Ganzenmüller geb. Hofmeister in: Große Männer - Studien zur Biologie des Genies. Bd. 8. Hrsg. von Wilhelm Ostwald. Leipzig 1924 (S. 131: irrtümlich 24. Mai als Todestag angegeben). NDB 9 (1972) S. $468 \mathrm{f}$. (mit Werkverz.); WBIS; Leins (1994) S. 55-57. • W.H. in: Isely, Duane: One Hundred and One Botanists. Ames (Iowa) 1994. S. 210-212. - Kaplan, D. R., Cooke, T. J.: The genius of W.H. The origin of causal-analytical research in plant development in: American Journal of Botany 83 (1996) S. 16471660. Frahm, Jan-Peter, Eggers, Jens: Lexikon deutschsprachiger Bryologen. 2. Aufl. Norderstedt 2001. Bd. 1. S. 202-204. - Wagenitz, Gerhard: W. H. in: Darwin \& Co. Eine Geschichte der Biologie in Portraits. Hrsg. von Ilse Jahn ... Bd. 1. München 2001. S. 332-334. - Autoren der Bunsenbibliothek (2009 online); Wissenschaftsatlas der UH (2011) S. 238. W. H. in: Wuketits, Franz M.: Außenseiter in der Wissenschaft: Pioniere - Wegweiser - Reformer. Berlin 2015. S. 239-242.

$P$ Bildarchiv UAH; graph. Slg. UBH; NDB. 


\section{Holsten, Carl Christian Johann}

1876-1897 Theol. Fak.

Neutestamentliche Exegese und Kritik

* 31. März 1825 Güstrow (Mecklenburg)

$\dagger$ 26. Jan. 1897 Heidelberg

ev.

V Christoph Diederich H. (1793-1865) Aktuar, Notar

M Dorothea Hanna (Johanna) Elisabeth geb. Krohn (1797-1853)

๑ 4. Okt. 1853 Ottilie Louise Johanna Henriette geb. Kippe (1835-1913)

$\mathrm{K} \quad 1 \mathrm{~S}, 1 \mathrm{~T}$

Lb Seit 31. Mai 1843 Studium der Theologie, Philosophie an U Leipzig, WS 1843/44 Jena, SS 1844WS 1844/45 Berlin, seit 14. April 1845 Rostock; Herbst 1849 I., Frühjahr 1852 II. theol. Examen in Rostock.

Rostock: Seit 7. April 1852 Lehrer für Religion, später auch für griechische und deutsche Literatur am Gymnasium („Große Stadtschule“); 1853 Dr. phil. an $\mathrm{U}$.

Bern: 16. Okt. 1869 (Ern.)-Juni 1871 Lehrer am Obern Gymnasium.

U Bern: Seit Ostern 1870 a. o. Prof. für Neues Testament; seit 21. Juni 1871 o. Prof.

UH: Seit 26. April 1876 o. Prof. als Nachf. von Hermann Schultz mit e. Jahresgehalt von 5400.- Mark, s. hierzu auch $Z$; 1. Okt. 1876 Vereidigung; 18761895 e. der Hauptlehrer am Ev.-Prot. Theol. Seminar; SS 1895 Aufteilung des Ev.-Prot. Theol. Seminars in Praktisch-Theol. Seminar und Wiss.-Theol. Seminar: SS 1895-1897 (†) Direktor der Neutestamentlichen Abt. am Wiss.-Theol. Seminar.

1887/88 Prorektor der UH; 1878/79, 1883/84, 1888/ 89, 1894/95 Dekan der Theol. Fak. der UH

$Z$ „Die Theologische Facultät hat sich ... dafür ausgesprochen: daß die erledigte Professur (des H. Schultz) wieder in die beiden besonderen Lehrfächer der neutestamentlichen Exegese und prak- tischen Theologie geschieden [werde], die erste als Hauptfach anzusehen (sei) und ... einem Ordinarius verliehen werden muß; für die zweite dagegen eine jüngere Kraft als Extraordinarius in Vorschlag zu bringen sei; die Aufgabe dieser zweiten Lehrstelle wird auch dahin bestimmt, daß darin die Mitwirkung beim Universitätsgottesdienst wie beim Seminarunterricht und Vorlesungen über praktische Theologie umfaßt sind ..." (aus: Bericht des Engeren Senats der UH an das Ministerium des Innern vom 12. März 1876 in: UAH RA 6718 fol. 42 r).

1890 Kirchenrat

E 1873 D. theol. Jena. 1886 Ritterkreuz I. Klasse, 1894 Ritterkreuz I. Klasse mit Eichenlaub, 1897 Kommandeurkreuz II. Klasse des Ordens vom Zähringer Löwen.

Qu UAH PA 1748; RA 6722. • Briefe: UBH. • Auskunft: Landeskirchliches Archiv - Kirchenbuchstelle - Schwerin.

W Zum Evangelium des Paulus und Petrus. Rostock 1868. Das Evangelium des Paulus. 2 T. Berlin 1880-1898. Die synoptischen Evangelien nach der Form ihres Inhalts. Heidelberg 1886.

$L$ Nachruf in: Akad. Mitteilungen für die Studierenden der Ruprecht-Karls-Universität Heidelberg 13 (1896/97). Programm der Trauer-Feier für den verstorbenen ... K. H. ... den 27. Jan. 1897. Heidelberg 1897. - RGG $2\left({ }^{2}{ }_{1928)}\right.$ S. 1998. • Becker, Julius: C.H. in: Die Grosse Stadtschule zu Rostock in $3^{1 / 2}$ Jahrhunderten: eine Jubiläumsschrift. Rostock 1930. S. 128. • WBIS; BBKL II (1990) Sp. $1006-$ 1008 (unter Holstein); Grewolls (2011); TroeltschGesamtausgabe 19 (2014) S. 504 (Register).

P Bildarchiv UAH; graph. Slg. UBH. 


\section{Holtzmann, Karl Adolf Wilhelm}

1852-187o Phil. Fak.

Deutsche Sprache und Literatur

* O2. Mai 1810 Karlsruhe

$\dagger$ 03. Juli 1870 Heidelberg ev.-prot.

V Johann Michael H. (1774-1820) GymnasialProf.

M Christine Sibylle Friederike geb. Fetzer (17761841)

( 1846 Luise geb. Wundt (1824-1858)

$\infty$ 24. Mai 1860 Margaretha Theresia Mathilde geb. Hilgard verw. Tittmann (1829-1912)

$\mathrm{K} \quad 2 \mathrm{~S}$ (aus 1. Ehe), $2 \mathrm{~T}$ (aus 2. Ehe), u. a. Louise H. (1864-1913) Ehefrau von: (siehe) Albrecht Kossel. - Stief-T: Emilie Thekla Mathilde Tittmann $\left({ }^{*} 1851 \dagger\right.$ nach 1919$)$ Ehefrau von: (siehe) Ernst Pfitzer

Vw Brüder: D. theol. (1856 UH) Julius H. (18041877) seit 1827 Gymnasiallehrer, seit 1847 I. Pfarrer an Heiliggeistkirche in $\mathrm{H}, 1861-$ 1877 Prälat der Ev. Landeskirche in Baden, s. WBIS. - Carl Alexander H. (1811-1865), u. a. seit 1831 Lehrer, seit 1851 Prof. für Physik und Mechanik Polytechnikum Stuttgart, s. NDB 9 (1972) S. 561 f.; Kohlhaas, Wilhelm: C. A. H. ... in: Lebensbilder aus Baden-Württemberg. Bd. 18. Stuttgart 1994. S. 285-298.

Vw Neffen: (siehe) Heinrich H. - Adolf H. (18381914) 1867-1897 Gymnasial-Prof., seit 1885 a. o. Prof., seit 1890 Honorar-Prof., seit 1908 o. Honorar-Prof. für Sanskrit und Vgl. Sprachwiss. Freiburg/Br., s. NDB 9, S. 559 f. - Siehe auch Schwarzmaier, Hansmartin: Walther Holtzmann (1891-1963) ... Abkömmling e. badischen Gelehrtenfamilie in: Eberbacher Geschichtsblatt 8 o (1981) S. 71-88.

Lb Seit 1828 Studium der Theologie an U HalleWittenberg, seit 1829 Berlin; Juni 1831 theol. Examen in Karlsruhe; seit 1831 Theologiekandidat in Kandern (Schwarzwald).

Seit Sommer 1832 Studium der Dt. und Orientalischen Philologie an U München, seit 1834 (mit kurzen Unterbrechungen) an U Paris.
Karlsruhe: Seit Nov. 1837 Gymnasial-Prof. und Erzieher der Prinzen Wilhelm und Karl von Baden mit e. jährl. Gehalt von 800.- Gulden; Besoldungszulagen: Okt. 1841 von 200.-, Aug. 1846 von 60o.-, Febr. 1848 von 200.- Gulden.

UH: 24. April 1852 Ern. zum ersten Ordinarius für Dt. Philologie in Nachf. von Karl Hahn mit e. Jahresbesoldung von 2600.- Gulden; 6. Mai 1852 Vereidigung, siehe hierzu $Z$ (1); WS $1868 / 69$ und SS 1869 Beurlaubung aus gesundheitlichen Gründen.

1857 Dekan der Phil. Fak. der UH

Z (1) H. wird am 6. Mai 1872 von F.C. Muth, damaligem „Kassier und Secretär" bei der KassenVerwaltung der UH in der Hauptstraße, vereidigt, nachdem $\mathrm{H}$. durch großherzogliche EntschlieBung zum Professor der Altdeutschen Sprache und Literatur am 24. April ernannt wurde. Die Eidesformel lautet: „Ich schwöre Treue dem regierenden Prinzen Friedrich von Baden und der Verfassung, Gehorsam dem Gesetze, des Fürsten wie des Vaterlandes Wohl nach Kräften zu befördern und überhaupt alle Pflichten des mir übertragenen Amtes gewissenhaft zu erfüllen, so wahr mir Gott helfe" (aus: UAH PA 1751). Die Bezeichnung des von $\mathrm{H}$. bekleideten Lehrstuhls wechselt: Der Engere Senat benennt H. in einem Schreiben vom 3. Mai 1852 als „Professor der deutschen Sprache und Literatur", in einem Bericht vom 10. Mai 1852 als „Lehrer der älteren deutschen Literatur und Sprache“. Holtzmann selbst schreibt 1852 in seinem Personalbogen „Professor der deutschen Sprache und Literatur", siehe hierzu PA 1751.

H. bietet zwischen 1852 und 1870 folgende Lehrveranstaltungen an (Auszüge aus: Anzeigen der Vorlesungen ... auf der ... Ruprecht-Carolinischen Universität zu Heidelberg ...):

Sanskritgrammatik, Geschichte der deutschen Literatur bis zu Ende des 15. Jahrhunderts (WS 1852/ 53); Erklärungen ausgewählter alt- und mittelhochdeutscher Stücke aus Wackernagels altdeutschem Lesebuch, Vergleichende Grammatik der indogermanischen Sprachen, Sanskrit, Über das Nibelungenlied (SS 1853); Erklärung des Nibelun- 
genliedes, Deutsche Grammatik, Sanskrit: erster Curs (SS 1858); Geschichte der deutschen Literatur, Sanskrit, Erklärung der älter[e]n Edda (WS 1861/ 62); Geschichte der deutschen Literatur von Anfang bis zu Schiller's Tod, Germanische Alterthümer mit Erklärung von Tacitus Germania, Sanskrit (WS 1864/65); Erklärung des Nibelungenliedes, Erklärung angelsächsischer Gedichte (SS 1870).

$Z$ (2) Nach H.s Tod stellt sich die Frage nach seinem Nachfolger; hierüber teilt das Ministerium des Innern in Karlsruhe dem Engeren Senat bzw. der Phil. Fak. der UH am 13. Dez. 1870 mit: „... Wir sind mit der philosophischen Facultät vollkommen darüber einverstanden, daß es sehr schwer fallen möchte, einen Gelehrten für die Universität $\mathrm{zu}$ erwerben, welcher sämmtliche von dem verstorbenen Hofrath Holtzmann vertretenen Fächer vorzutragen im Stande wäre ... Wir sind ... weit entfernt, das Gewicht der Gründe zu verkennen, mit welchem die philosophische Facultät in ihrer Darstellung vom 24. October d. J. den Antrag unterstützt, einerseits für das Sanskrit und überhaupt die altindische Sprache und Literatur nebst der vergleichenden Sprachkunde der indogermanischen Sprachen, andererseits für die deutsche und wo möglich auch die altromanische insbesondere altfranzösische Sprache und Literatur je eine künftige Lehrkraft zu berufen ... Die alsbaldige Berufung eines Lehrers für Sanskrit und die damit zusammenhängenden Fächer dürfte wohl zur Zeit nicht so dringlich geboten sein; denn diese Wissenschaften werden jetzt wenigstens durch einen außerordentlichen Professor vertreten, nachdem an Dr. [Salomon] Lefmann, welcher ... Sanskrit und vergleichende Sprachwissenschaften bisher mit Erfolg gelesen hat, jüngst dieser [a.o.] Character verliehen wurde ..." (aus: UAH RA 6839). Nachfolger H.s wird 1871 Karl Bartsch.

1843 Hofrat

E 1852 Dr. phil. h.c. UH, s. UAH H-IV-102/27 fol. 2V, 3r, v, 147, 158-159, 185-186, 204. 1846 Ritter des Ordens vom Zähringer Löwen; 1850 Ritter des Königl. Preußischen Roten Adlerordens I. Klasse.
Qu UAH PA 1751; RA 6839; Fak.-Akten H-IV102/45, H-IV-102/46, H-IV-102/48, H-IV-102/73. • GLA Abt. 205, Fasz. 299. Briefe: UBH. • Nachlaß: Badische Landesbibliothek Karlsruhe.

$W$ Über den griechischen Ursprung des indischen Thierkreises. Karlsruhe 1841. - Indische Sagen. Karlsruhe 1845-1847. 2. Aufl. 1855. Altdeutsche Grammatik. Bd. 1, Abt. 1.2. Leipzig 1870-1875.

L ADB 13 (1881) S. 16-18; Lehmann (1967) S. 215218; Burkhardt (1976) S. 33 f. u. ö.; WBIS. • Schwarzmaier, Hansmartin: W.H. ... in: Eberbacher Geschichtsblatt. Eberbach 1981. Folge 80. S. 77 ff. • Collinge, N.E.: The Laws of Indo-European. Amsterdam 1985. S. 91-99 u. o.. Riecke (2016) S. 146 (Register). - Textrevisionen: Beiträge der Int. Fachtagung der Arbeitsgemeinschaft für germanistische Edition, Graz 17.-20. Febr. 2016. Hrsg. von Wernfried Hofmeister, Andrea HofmeisterWinter ... Berlin 2017. S. 63-67.

P Bildarchiv UAH; graph. Slg. UBH.

\section{Holtzmann, Heinrich Julius}

1858-1874 Theol. Fak.

Neues Testament

* 17. Mai 1832 Karlsruhe

$\dagger$ 04. Aug. 1910 Baden-Baden

ev.

V Karl Julius H. (1804-1877) Pfarrer, später Hausgeistlicher der Großherzogl. Familie in Karlsruhe, s. Badische Biographien 3 (1881) S. 59-62

M Adelheid geb. Sprenger (1811-1893), siehe https://www.myheritage.de/names/adelheid_ sprenger

( 15. Aug. 1864 Sara Henriette Karoline (Lina) geb. Weber (1840-1889/97) Schwester von: (siehe) Heinrich Weber 
K 1 T: Adelheid H. (1866-1925) 1900 A. H. setzt das Frauenstudium in Baden durch, 19001914 Reichsvorsitzende des Vereins Frauenbildung-Frauenstudium, 1918 Mitbegründerin und 2. Vorsitzende der Deutschen Demokratischen Partei (DDP), s. Badische Biographien N. F. IV (1996) S. 285-287; Böttcher, Rudolf H.: 100 Jahre Frauenstudium - Adelheid Steinmann [geb. H.] in: Pfälzisch-Rheinische Familienkunde 14 (1999) S. 467. - Ehefrau von Gustav Steinmann (1856-1929) seit 1880 Privat-Dozent für Geologie und Paläontologie Straßburg, seit 1885 a. o. Prof. Jena, seit 1886 o. Prof. Freiburg/Br., seit 1906 o. Prof. und Direktor des Geologischen Inst. Bonn, s. Seibold, Eugen, Seibold, Ilse: G. S. ... Ein deutscher Ordinarius der Kaiserzeit in: Int. Journal of Earth Sciences Bd. 99, Suppl. 1 (2010) S. 3-15.

K 3 S: u.a. Robert H. (1873-1946) seit 1902 Privat-Dozent für Mittlere und Neuere Geschichte Straßburg, seit 1913 o. Prof. Gießen, seit 1916 Breslau, seit 1923 Halle-Wittenberg, 1930-1939 Berlin, s. NDB 9 (1972) S. 562, Catalogus prof. Halensis online. - Friedrich H. (1876-1948) Landesgewerbearzt, seit 1912 Privat-Dozent, seit 1919 a. o. Prof., seit 1939 apl. Prof. für Hygiene TH Karlsruhe, s. WBIS

Vw Onkel: (siehe) Adolf H. (1810-1870). Bruder: Adolf H. (1838-1914) 1867-1897 GymnasialProf., seit 1885 a.o. Prof., seit 1890 HonorarProf., seit 1908 o. Honorar-Prof. für Sanskrit und Vgl. Sprachwiss. Freiburg/Br., s. NDB 9, S. $559 \mathrm{f}$.

Lb WS 1850/51 Studium an UH, seit SS 1851 Berlin; Herbst 1854 theol. Staatsexamen in Berlin; 7. Dez. 1854-Ende 1857 Pfarramtskandidat in Badenweiler.

UH: 5. März 1858 Lizentiatenprüfung; auch Lehrer am Predigerseminar; April 1858 Habilitation; seit 3. Juni 1861 a. o. Prof.; 1865 Ruf an U Wien abgelehnt; seit 5. Okt. 1865 o. Prof. • In dieser Zeit:

Karlsruhe: 1867-1870 Mitglied der II. Kammer des Badischen Landtags.

U Straßburg: WS 1874/75-SS 1904 (Ruhestand) o. Prof.; 1875 Berufung zum Propst an St. Petri-Kirche in Berlin-Cölln abgelehnt.
Baden-Baden: Seit 1906 Wohnsitz.

1870/71 Dekan der Theol. Fak. der UH

1865 Mitbegründer des Protestantenvereins in Eisenach

H. bietet folgende Vorlesungen (in Auszügen) an der Theol. Fak. zwischen 1858 und 1874 laut den Anzeigen der Vorlesungen ... auf der ... RuprechtKarolinischen Universität zu Heidelberg an: Allgemeine Religionsgeschichte, Repetitorien und Examinatorien über exegetische und dogmatische Theologie (WS 1858/59); Erklärung des Evangeliums Johannis (SS 1859); Die Augsburgische Confession: historisch, dogmatisch und kirchenrechtlich erklärt, Über Schleiermacher, Katechetik, Examinatorien und Repetitorien über die Fächer der exegetischen und dogmatischen Theologie (SS 1860); Einleitung ins Neue Testament, Über Schleiermacher, Lehre vom Volksschulwesen (SS 1862); Erklärungen des Evangeliums und der Briefe des Johannes, Katechetik, Praktische Auslegung ausgewählter Stücke des neuen Testaments, Lehre vom Volksschulwesen mit Einführung in die Volksschule: erste Hälfte, Katechetische Übungen, Mittheilung und Analysiren von Predigten ausgezeichneter Kanzelredner seit der Reformation (WS 1864/65); Erklärung der synoptischen Evangelien, Katechetik, Mittheilungen und Analysen von Predigten, Lehre vom Volksschulwesen mit Einführung in die Volksschule (SS 1874).

E 1862 D. theol. Wien; 1897 Dr. phil. h.c. Straßburg.

Qu UAH PA 1750; RA 6127, 6718 fol. 3or-31v. • Briefe: UBH. Julius Wellhausen: Briefe. Hrsg. von Rudolf Smend ... Tübingen 2013. S. 862 (Register).

$W$ Kanon und Tradition. Ein Beitrag zur neuen Dogmengeschichte und Symbolik. Ludwigsburg 1859. - Die synoptischen Evangelien. Leipzig 1863. - Lehrbuch der historisch-kritischen Einleitung in das Neue Testament. Freiburg/Br. 1885. 3. Aufl. 1892. - Lehrbuch der neutestamentlichen Theologie. 2 Bde. Freiburg/Br. 1896-1897. 2. Aufl. 1911. Die Entstehung des Neuen Testaments. Halle/S. 1904. 2. Aufl. 1911. - Das Messianische Bewusstsein Jesu. Tübingen 1907. 
L NDB 9 (1972) S. 560 f. (mit Werkverz.); WBIS; BBKL II (1990) Sp. 1012-1014; TRE 15 (1993) S. 519522. Weinhardt, Joachim: Die Reorganisation der Theologischen Fakultät der Universität Straßburg im ersten Jahrzehnt nach dem deutsch-französischen Krieg 1870/71: Adolf Harnack, Paul Lobstein und andere "bekenntnistreue Lutheraner“ als Gegengewicht zu H. J.H. in: Journal of the history of modern theology 14 (2007) 2, S. 191-237. • Troeltsch-Gesamtausgabe 19 (2014) S. 504 (Register).

$P$ Bildarchiv UAH.

\section{Homburger, August Friedrich}

1911-1930 Med. Fak.

Psychiatrie

* 18. Dez. 1873 Frankfurt/M.

$\dagger \quad$ 29. Juni 1930 Frankfurt/M. mosaisch

V Michael H. (1843-1924) Kaufmann

M Auguste geb. Getz (1844-1873)

$\infty$ unverheiratet.

Lb Seit 1892 Studium an U Straßburg, WS 1894/95 UH, seit SS 1895 Straßburg.

Straßburg: 1. Juni 1897 Staatsprüfung; 1. Juli 1897 Approbation; 25. Febr. 1899 Dr. med. an U.

Frankfurt/M.: 1898-1899 Tätigkeit am Senckenbergischen Patholog. Inst.; Dez. 1899-März 1906 Assistent am Städtischen Siechenhaus und Arzt an Poliklinik für Nervenkranke; seit April 1906 niedergelassener Nervenarzt.

UH: Seit Nov. 1907 Assistenzarzt, später Oberarzt an Psychiatr. Poliklinik; 1. Aug. 1911 Habilitation; seit 27. Aug. 1917 nichtetatm., seit 1920 nichtplanm. a. o. Prof.; Okt. 1920-Juni 1930 ( $\dagger$ ) Leiter der Psychiatr. Poliklinik. • In dieser Zeit:

H: 1917 (Erste Nennung)-1930 niedergelassener Nervenarzt.
Gründer der ersten Heilpädagogischen Beratungsstelle an einer U-Klinik, und zwar 1917 an U-Kinderklinik Luisen-Heilanstalt in Heidelberg

2006 stiftet der Berliner Verein zur Durchführung neurowissenschaftlicher Tagungen e.V. den August-Homburger-Preis (Preis der Universität Würzburg) für besondere wissenschaftliche Leistungen in klinischer und grundlagenwissenschaftlicher Forschung zur Kinder- und Jugendpsychiatrie sowie Psychotherapie.

Qu UAH PA 989, 1753; RA 6326. - GLA Abt. 235, Fasz. 2117.

$W$ Lebensschicksale geisteskranker Strafgefangener. Berlin 1912. • Die körperlichen Erscheinungen der Kriegshysterie in: Münchener Med. Wochenschrift 29 (1916). • Vorlesungen über Psychopathologie des Kindesalters. Berlin 1926. Neuaufl. 1966.

MHG Zeitschrift für Kinderforschung.

L Kürschner (1928/29) Sp. 988. • Froboese, Felicia: Dem toten Lehrer und Freunde A.H. in: Zs. für Kinderforschung. Organ der Gesellschaft für Heilpädagogik und des Dt. Vereins zur Fürsorge für jugendliche Psychopathen. Langensalza 1930. S. $413-417$ - Fischer $1\left({ }^{3} 1962\right)$ S. 659. - Baeyer, Walter Ritter von: A.H. - Arzttum und soziale Verantwortung in: Heidelberger Jahrbücher 18 (1974) S. 89-93; Müller-Küppers, Manfred: Zur Lage der Kinder- und Jugendpsychiatrie heute in: ebd. 18 (1974) S. 94-100; Stutte, Hermann: A. H.s Bedeutung in der Geschichte der Kinderpsychiatrie in: ebd. 18 (1974) S. 83-88. • Chronik Ärzte H (1985) S. 132; WBIS. - Nissen, Gerhardt: Kulturgeschichte seelischer Störungen bei Kindern und Jugendlichen. Stuttgart 2005. S. 560 (Register). Deutsche Biographie, s. https://www.deutsche-biogra phie.de/gnd117529508.html [07.11. 2017].

P Bildarchiv UAH; Heidelberger Jahrbücher (1974). 


\section{Hoops, Johannes Ludwig}

1896-1934 Phil. Fak.

Englische Philologie und Germanische Altertumskunde

1941-1947 Phil. Fak.

Englische Philologie

* 20. Juli 1865 Rablinghausen (heute: Ortsteil von Bremen)

$\dagger$ 14. April 1949 Heidelberg

ev.

V Johann Jakob H. (1840-1916) Oberlehrer

M Gesine geb. Blanke (1839-1920)

$\infty$ 15. Aug. 1895 Ida Friederika Theodora Luise geb. Schultz (1871-1951)

K 1 T, 2 S: Walter Dietrich H. (1900-?), u. a. 19411945 Gesandtschaftsrat an Dt. Botschaft in Peking, zuletzt Konsul in Vancouver, s. UAH Rep. 40-371; Hausmann (2003) S. 90 ff. • Reinald H. $\left({ }^{\star} 1906 \times 1943\right)$, u. a. seit 1938 a. o. Prof., seit 1939 o. Prof. für Anglistik U Innsbruck, s. WBIS, Hausmann, S. 88-96.

Lb Seit SS 1885 Studium der Mathematik, Naturwiss. an U Jena, seit 1886 Neuere Sprachen, Geschichte an U Freiburg/Br.

Freiburg/Br.: 5. Okt. 1889 Dr. phil. an U; 12 . März 1890 Staatsexamen für höheres Lehramt; seit 19. April 1890 Lehramtspraktikant an Realschule.

H: Seit Febr. 1891 Lehramtspraktikant am Gymnasium.

U Tübingen: Seit 1. April 1893 Lektor der Englischen Sprache; seit 24. Dez. 1894 a. o. Prof.; 25. Juli 1895 Habilitation.

UH: Seit 1. März 1896 etatm. a. o. Prof. als Nachf. von Joseph Schick; 1901 Rufe abgelehnt: Akademie für Sozial- und Handelswiss. in Frankfurt/M. und Städtische Handelshochschule in Köln; seit 1. Jan. 1902 o. Prof. und bis 1924 Mit-Direktor (zus. mit Wilhelm Braune bis 1919 sowie bis 1923 mit Friedrich Neumann, 1920-1924 mit Friedrich Panzer) des Germanisch-Romanischen Seminars, Unterabteilung: Englisches Seminar [!]; Aug.-Okt. 1904 Studienreise nach Amerika; Rufe an U abgelehnt:
1910 Leipzig, 1913 Wien; seit 1. Apr. 1924 Direktor des Englischen Seminars, das Germanisch-Romanische Seminar wird aufgelöst; März-Nov. 1925 als erster dt. Austausch-Prof. an U of California in Berkeley; Gast-Prof.: SS 1930 U of California in B., Okt.-Dez. 1933 Johns-Hopkins-U in Baltimore (Maryland); 31. März 1934 Emeritierung; WS 1936/ 37 stellvertr. Direktor des Englischen Seminars. • In dieser Zeit:

1914-1916 Kriegsdienst.

Gastprof.: WS 1937/38 U of California in Los Angeles, SS 1937 U of California in Berkeley, SS 1938 U of Hawaii in Manoa.

UH: April 1941-Nov. 1945 Vertreter des LehrstuhlInhabers Harro Jensen (s. Drüll (2009) S. 311 f.), Nov. 1945-WS 1946/47 Vertreter des Lehrstuhls bis zur Ern. von Hermann Flasdieck (s. Drüll, S. 196 f.).

1920/21 Rektor der UH; 21./27. März-14. Aug. 1945 kommissar. Rektor der UH, s. hierzu auch Weisert/ Drüll/Kritzer (2007) S. 23; 1906/07, 1922/23 Dekan der Phil. Fak. der UH

1921 Begründer der Mensa academica und 1922 (gemeinsam mit Friedrich Panzer) der Ferienkurse für ausländische Studenten an UH. $1921 \mathrm{Be}-$ gründer und bis 1949 Geschäftsführer der „Gesellschaft der Freunde der Universität Heidelberg“

Siehe auch Anhang Sporteinrichtungen an $U H$ 1910-1933 und ihre Mitglieder

1910 Geh. Hofrat; 1913 Geh. Rat II. Klasse

$E$ Mitglied der Akademie der Wissenschaften: 1909 H, 1920 Wien, 1940 München; 1935 o. Mitglied der Königl. Gesellschaft der Wiss. Uppsala; 1936 Mitglied der Englischen Literarischen Gesellschaft von Japan an Kaiserl. U Tokio. 1940 Goethe-Medaille für Kunst und Wissenschaft. 1908 Ritterkreuz I. Klasse des Ordens vom Zähringer Löwen; 1915 Comturkreuz II. Klasse des Königl. Sächsischen Albrechtsordens. • 6. Sept. 1945 Ehrensenator der Universität Heidelberg. 
Qu UAH PA 429of.; RA 5186, 5225, 6113, 6824. • GLA Abt. 235, Fasz. 2118. • Briefe: UBH. • Mitteilungen von Familienangehörigen.

$W$ Waldbäume und Kulturpflanzen im germanischen Altertum. Straßburg 1905. Kommentar zum Beowulf. Heidelberg 1932. 2. Aufl. 1965. • Die Geschichte des Ölbaumes. Heidelberg 1944.

HG 1900-1943 Anglistische Forschungen. • 19001944 Englische Studien. - Reallexikon der germanischen Altertumskunde. 4 Bde. Straßburg 19111919. Neuaufl. in 35 Bden. Berlin 1968/72-2007.

L Flasdieck, Hermann: J.H. Rede bei der Gedenkfeier ... in: Neue Heidelberger Jahrbücher N.F. (1950) S. 1-18. - NDB 9 (1972) S. 606 f. (mit Werkverz.); Jansen (1992a) S. 166 (Register); Wennemuth (1994) S. 635 (Register); Badische Biographien N.F. IV (1996) S. 144f. - Reallexikon der Germanischen Altertumskunde ... Berlin 2000. Bd. 15. S. 109-111. Hausmann (2003) S. 237-247; Kriegstagebuch K. Hampe (2007) S. 970 (Register); WBIS; Riecke (2016) S. 43 f., 49, 71, 100.

$P$ Bildarchiv UAH.

\section{Horstmann, August Friedrich}

1867-1889 Phil. Fak. 1889-189o (Honorar-Prof.) Phil. Fak. 1890-1900 (1929) (Honorar-Prof.) Nat.-Math. Fak. Chemie

* 21. Nov. 1842 Mannheim

$\dagger \quad$ o8. Okt. 1929 Heidelberg ev.

V Georg Friedrich H. (1805-1876) Kolonialwaren-Großhändler

M Charlotte Friedericke geb. Köhler (1807-1893)

๑ 5. April 1873 Clotilde geb. Gernandt (18441921)

$\mathrm{K} \quad 4 \mathrm{~S}$ (davon $1 \mathrm{~S}$ früh $\dagger$ ), $1 \mathrm{~T}$
Lb Mannheim: 1857-1859 Besuch der Höheren Bürgerschule; Herbst 1859-Herbst 1862 kaufmännische Lehre im elterlichen Unternehmen Horstmann \& Köhler.

UH: Seit WS 1862/63 Studium; 25. Jan. 1865 Dr. phil.

1865 Eigenstudium der Thermodynamik an $\mathrm{TH}$ Zürich; Herbst 1865-Sommer 1867 Experimentalstudien an $\mathrm{U}$ Bonn.

UH: 2. Nov. 1867 Habilitation; seit 16. Febr. 1872 a.o. Prof.; 1875-1879 Experimentalarbeiten zur Bestätigung des Massenwirkungsgesetzes; seit 14. Nov. 1889 Honorar-Prof.; WS 1899/19oo letzte Ankündigung im Vorlesungsverzeichnis (aufgrund H.s Erblindung); seit 21. Febr. 1908 o. Honorar-Prof.

1881-1894 Referent der „Berichte der Dt. Chemischen Gesellschaft“

1910 Geh. Hofrat

E 1909 Mitglied der Akademie der Wissenschaften H; 1912 Ehrenmitglied: Dt. Chemische Gesellschaft, Dt. Bunsen-Gesellschaft für angewandte physikalische Chemie H, Naturhistor.-Med. Verein H. 1922 Dr.-Ing. E.h. TH Karlsruhe. 1893 Ritterkreuz I. Klasse des Ordens vom Zähringer Löwen.

Qu UAH PA 1754; Fak.-Akte H-IV-102/64 fol. 102r-106r u. ö. GLA Abt. 235, Fasz. 2120. Briefe: UBH. - Mitteilungen: Frau Gundel Treiber-Horstmann $(\dagger)$, Stuttgart. Lebenserinnerungen eines Kurzsichtigen. Masch.geschr. Manuskript von 1925. (Autobiogr.)

W Dampfspannung und Verdampfungswärme des Salmiaks in: Berichte der Dt. Chemischen Gesellschaft 2 (1869). - Über den II. Hauptsatz der mechanischen Wärme-Theorie und dessen Anwendung auf einige Zersetzungs-Erscheinungen in: Liebigs Annalen der Chemie, Suppl.-Bd. 8 (1872). Dissociation der Chlorsilber-Ammoniakverbindungen. Heidelberg 1877. - Theoretische Chemie. Braunschweig 1885. Abhandlungen zur Thermodynamik chemischer Vorgänge. Leipzig 1903. Nachdr. Paderborn 2013. 
L Smith (1949) S. 127; NDB 9 (1972) S. 644-645 (mit Werkverz.); WBIS. - Kipnis, Alexander: A.H. ... Eine große Übergangsfigur in der Geschichte der Physikalischen Chemie in: Gesellschaft Dt. Chemiker, Fachgruppe Geschichte der Chemie. Mitteilungen. Nr. 11 (1995) S. 26-44; Ders.: A.H. in: Badische Biographien N.F. IV (1996) S. 145-147 (siehe hier die Erklärung zu den unterschiedlichen Angaben über H.s Geburtsdatum: 21. oder 20. Nov. 1842); Ders.: A. H. und die physikalische Chemie. Berlin 1997 (mit Bibliographie und Bildern). - Jensen, William B.: A.H. and the origins of chemical thermodynamics in: Bulletin for the history of chemistry 34 (2009) 2, S. 8391. - Smith, Henry Monmouth: Torchbearers of chemistry: Portraits and brief biographies of scientists who have contributed to the making of modern chemistry. New York 2013. S. 126 f. u. ö.

$P$ Bildarchiv UAH; graph. Slg. UBH; NDB.

\section{Hülsen, Christian Karl Friedrich}

1917-1923 (Honorar-Prof.) Phil. Fak.

Archäologie

* 29. Nov. 1858 Charlottenburg (heute: Charlottenburg-Wilmersdorf, Ortsteil von Berlin)

$\dagger$ 19. Jan. 1935 Florenz

ev.

V Prof. Dr. Friedrich H. (1831-1896) Oberlehrer

M Caroline geb. Brand (1831-1917)

๑ 4. Juli 1892 Elisabeth geb. Frommel (1858-1919) T von Emil Wilhelm F. (1828-1896) ev. Theologe, Hofprediger, Dichter, s. NDB 5 (1961) S. 66o, BBKL II (1990) Sp. 134f. • Siehe hierzu auch: Den Freunden unseres Hauses zur Erinnerung an die Trauung unserer Kinder Christian und Elisabeth H. geb. Frommel zu Rom: 4. Juli 1892. Berlin 1892.

$\mathrm{K}$ Keine.

Lb U Berlin: Seit 1876 Studium; 15. März 188o Dr. phil.
1881-1882 Stipendiat des Dt. Archäolog. Inst. in Rom; 14. Febr. 1882 Lehramtsprüfung in Berlin; 1882-1885 Studienaufenthalt weiterhin in Italien.

Berlin: Seit 1. Okt. 1885 Probejahr zunächst am Friedrichs-Gymnasium, dann vom 1. April bis 30. Sept. 1886 am Progymnasium in Groß-Lichterfelde; seit 1. Okt. 1886-30. Sept. 1887 o. Lehrer am o.g. Progymnasium.

Rom: Okt. 1887-Sept. 1909 (Ruhestand) II. Sekretär des Königl. Dt. Archäolog. Inst.

Florenz: Seit Okt. 1909 Privat-Gelehrter.

Seit Juli 1914 Wohnsitz auf Schloß Hoheneck (bei Ludwigsburg).

UH: Seit 11. Aug. 1917 o. Honorar-Prof.; SS 1918 Lehrstuhlvertr. von Alfred von Domaszewski bei Prüfungen und stellvertr. Leiter der Abt. des Histor. Seminars für Alte Geschichte; SS 1923 letzte Vorlesungsankündigung.

H: 1920 Erste Erwähnung im Stadtbuch der Stadt Heidelberg ... für das Jahr 1920. Heidelberg 1920. S. 258 mit Wohnsitz in der Kaiserstr. 25; 1929 letzte Erwähnung im Stadtbuch der Stadt Heidelberg ... Heidelberg 1929. S. 217; in dieser Zeit Privat-Gelehrter.

Florenz: Seit 1929/30 Privat-Gelehrter.

E 1905 Mitglied der Accademia dei Lincei; Mitglied der Akademie der Wissenschaften: 1907 Berlin, 1912 München, 1918 H; Mitglied der RussischArchäolog. Gesellschaft; Korr. Mitglied des Institut de France in Paris. 1906 Dr. iur. h.c. Oxford.

Qu UAH PA 4320; RA 6847. - GLA Abt. 235, Fasz. 2124. - Archiv der Bibliothek für Bildungsgeschichtliche Forschung Berlin (Signatur Gut Lehrer (Personalunterlagen von Lehrkräften), 87977). • Briefe: UBH; siehe auch Kalliope. • Theodor Mommsen und Friedrich Althoff: Briefwechsel 1882-1903. Hrsg. ... von Stefan Rebenich und Gisa Franke. München 2012. S. 863 (Register). • Nachlaß: Dt. Archäologisches Institut Berlin. 
$W$ Formae Urbis Romae Antiquae. Berlin 1896. 2. Aufl. 1912. - Das Forum Romanum. Rom 1904. 2. Aufl. 1905. La pianta di Roma dell'anonimo Einsidlense in: Dissertazioni della Pontificia accademia romana di archeologia. Rom 1907. Ser. II, Tom. IX, S. 377-424. Reproduktion unter dem Titel: Note all'itinerario dell'anonimo Einsidlense. Ed. von Maria Elisa Garcia Barraco. Rom 2016. • Das Skizzenbuch des Giovannantonio Dosio. Berlin 1933 .

L NDB 9 (1972) S. 736 (mit Werkverz.); WBIS; Archäologenbildnisse (1988) S. $126 \mathrm{f}$. Coccia, Michele: Un brindisi per C.H. in: Strenna dei Romanisti 70 (2009) S. 185-196. - Geschichte der Altertumswissenschaften. Biographisches Lexikon. Hrsg. von Peter Kuhlmann und Helmuth Schneider. Stuttgart 2012. Sp. $598 \mathrm{f}$.

\section{Hundeshagen, Carl Bernhard}

1847-1867 Theol. Fak.

Neutestamentliche Exegese, Kirchengeschichte

* 3o. Jan. 1810 Friedewald (bei Bad Hersfeld)

$\dagger \quad$ o2. Juni 1872 Bonn

ev.

V Johann Christian H. (1783-1834) 1806-1821 kurhessischer Forstbeamter, u.a. 1821 o. Prof. für Forstwiss. U Tübingen, seit 1824 Gießen, s. UAH RA 5444; NDB 10 (1974) S. 63; Rozsnyay, Zoltán: J.C.H. in: Biographien bedeutender hessischer Forstleute. Wiesbaden 1990. S. 341352; Weimann, Hans-Joachim: J.C.H. Genie und Zorn im Vormärz. Remagen 2013.

M Eleonore Sophie geb. Hundeshagen ( $† 1822)$

$\varnothing$ unverheiratet

Vw siehe Weimann (2013) S. 15-22.

Lb Seit 23. Okt. 1825 Studium der Philosophie und Philologie an U Gießen; 28. Juni 1828 Relegation als Mitglied der Burschenschaft durch Großherzogl. Hessische Regierung; WS 1828/29 Forts. des Studiums an U Halle-Wittenberg.

U Gießen: Seit 21. April 1829 (nach Begnadigung) Studium der Theologie; 21. Okt. 1831 Dr. phil.;
22. Okt. 1831 Habilitation an Phil. Fak. ohne Abgabe e. Habilitationsschrift; 6. Mai 1833 theol. Lizentiatenprüfung; 1833 Habilitation an Theol. Fak.

U Bern: Seit WS 1834/35 a. o. Prof. für Kirchenund Dogmengeschichte; 1838, 1841, 1844 Deputierter auf Berner Generalsynode; seit 25. Nov. 1845 o. Prof.

UH: 23. April 1847 Ern. zum „Professor ordinarius der Theologie und Philosophie für das Fach der neutestamentlichen Exegese“" (aus: UAH RA 6718 fol. 16r) an Theol. Fak.; WS 1847/48 Beginn seiner Vorlesungen; 1849 Ruf an U Marburg abgelehnt.

U Bonn: WS 1867/68-1872(†) o. Prof.

1852, 1860 Prorektor der UH; 1849, 1853, 1857, 1861, 1864/65 Dekan der Theol. Fak. der UH

1848 Mitbegründer des Ev. Kirchentages, s. hierzu Bormuth, Daniel: Die Deutschen Evangelischen Kirchentage in der Weimarer Republik. Stuttgart 2007. S. 52 f. u. ö.

1850 Kirchenrat; 1859 Geh. Kirchenrat

E 1846 D. theol. Greifswald.

$\mathrm{Qu}$ UAH PA 1759; RA 319, 606, 6127, 6718 fol. 16r u. ö. - GLA Abt. 205, Fasz. 303. • Briefe: UBH. • Nachlaß: Universitäts- und Landesbibliothek Sachsen-Anhalt in Halle/S. • Auskunft: Universitätsarchiv Gießen.

$W$ Der deutsche Protestantismus, seine Vergangenheit und seine heutigen Lebensfragen im $\mathrm{Zu}$ sammenhang der gesamten Nationalentwicklung ... Frankfurt/M. 1847. 3. Aufl. 1850. Nachdr. Charleston (South Carolina) 2010. - Beiträge zur Kirchenverfassungsgeschichte und Kirchenpolitik, insbesondere des Protestantismus. Bd. 1 (mehr nicht erschienen). Wiesbaden 1864. Neudr. 1963. • Ausgewählte kleinere Schriften und Abhandlungen. Hrsg. von Theodor Christlieb. 2 Bde. Gotha 1874 .

MHG 1864-1872 Theologische Studien und Kritiken. 
L Riehm, Eduard Karl August: Zur Erinnerung an C. B. H. Gotha 1874. - Verzeichnis Bonn (1968) S. 129 f. Kössler, Franz: Verzeichnis der Doktorpromotionen an der Universität Gießen von 18011884. Gießen 1970; Ders.: Katalog der Dissertationen und Habilitationsschriften der Universität Gießen von 1801-1884. Gießen 1971. - Schmidt, Martin: K.B.H.s ... theologisch-politische Diagnose der Zeit im Jahre 1847 in: Heidelberger Jahrbücher 15 (1971) S. 20-56. • NDB 10 (1974) S. 63 f.; TRE 15 (1986) S. 701-703; BBKL II (1990) Sp. 11801182; Album Professorum der Ev.-Theol. Fakultät Bonn (1995) S. 286 (Register). - Gramley, Hedda: Christliches Vaterland - einiges Volk. Zum Protestantismus und Nationalismus von Theologen und Historikern 1848 bis 188 o in: Die Politik der Nation. Deutscher Nationalismus in Krieg und Krisen 1760 bis 1960 . Hrsg. von Jörg Echternkamp und Sven Oliver Müller. München 2002. S. 81-105. • Weimann, Hans-Joachim: Johann Christian Hundeshagen. Genie und Zorn im Vormärz. Remagen 2013. S. 21 f. u. ö. (S. 21: hier irrtümlich 10. statt 30. Jan. 1810 als Geburtsdatum genannt). Peschke, Franz: Der Heidelberger Indologe und Buddhologe ... Max Walleser und das Problem seines Ich. Eine Biographie. Print on demand (2017), s. http:// crossasia-repository.ub.uni-heidelberg.de/4032/1/ Walleser_10102017_End.pdf. S. 199.

$P$ Bildarchiv UAH; NDB.

\section{Hupfeld, Hans Rudolf Renatus}

1931-1950 Theol. Fak.

Praktische Theologie

* 03. Dez. 1879 Schleusingen (Thüringen)

$\dagger \quad$ 15. Febr. 1968 Heidelberg

ev.

V David H. (1836-1916) Superintendent

M Elisabeth geb. Müller (1842-1904) T von Julius M. (1801-1878) seit 1831 Privat-Dozent Göttingen, seit 1835 o. Prof. für Dogmatik Marburg, seit 1839 Halle-Wittenberg, s. WBIS, NDB 18 (1997) S. 326 f.; Willi, Hans-Peter: Unbegreifliche Sünde - „Die christliche Lehre von der Sünde" als Theorie der Freiheit bei J. M. Berlin 2003.
(24. Okt. 1907 Elisabeth Dorothea geb. Jäckel (1879-1967)

K $\quad 2 \mathrm{~S}, 3 \mathrm{~T}$

Vw Großvater: Hermann H. (1796-1866) seit 1824 Privat-Dozent Halle-Wittenberg, seit 1825 a.o. Prof., seit 1827 o. Prof. für Theologie und Orientalische Sprachen Marburg, 1843-1866 Halle-Wittenberg (1866 H.s Nachf.: (siehe) Eduard Riehm), s. NDB 10 (1974) S. 72 f., WBIS, BBKL II (1990) Sp. 1190 f.; Kaiser, Otto: Zwischen Reaktion und Revolution: H. H. ... - ein deutsches Professorenleben. Göttingen 2005.

$L b$ Seit SS 1898 Studium an U Tübingen, anschl. Halle-Wittenberg, Marburg, Greifswald; Okt. 1904 II. theol. Staatsexamen in Greifswald; 1904-1905 Besuch des Domkandidatenstifts in Berlin; 19. Mai 1906 Lizentiatenprüfung an U Greifswald.

1906 Ordination; seit Mai 1906 Domhilfsprediger in Berlin.

Pfarrer: Seit 1907 in Crossen (Sachsen; heute: Ortsteil von Erlau), seit Mai 1912 Barmen (heute: Stadtteil von Wuppertal), 1916-1918 Bonn. • In dieser Zeit:

Kriegsdienst: Seit 1914 Reservist in Köln, 1915-1916 Gouvernements-Pfarrer in Lille.

U Bonn: 8. Okt. 1919 Habilitation; seit 21. April 1925 nichtplanm. a. o. Prof.

U Rostock: Seit WS 1925/26 o. Prof.

UH: Seit 13. Juli 1931 o. Prof. und Direktor des Praktisch-Theol. Seminars als Nachf. von Johannes Bauer, s. hierzu Fix (1994) S. 219 u. ö.; April-Dez. 1945 Mitglied des Dreizehnerausschusses zum Wiederaufbau der U; 31. März 1950 Entpflichtung.

1947/48 Dekan der Theol. Fak. der UH

E 1923 D. theol. Bonn.

Qu UAH PA 247, 4329; Rep. 40-405. - GLA Abt. 235, Fasz. 2107. Briefe: UBH. 
W Die Ethik Johann Gerhards. Berlin 1908. Grundfragen christlicher Lebensgestaltung. Leipzig 1922. - Die Abendmahlsfeier, ihr ursprünglicher Sinn und ihre sinngemäße Gestaltung. Gütersloh 1935. - Liturgische Irrwege und Wege. Gladbeck 1952.

$L$ Eisinger, Walther: R.H. $\dagger$ in: Ruperto Carola 20. Jg., Bd. $43 / 44$ (1968) S. 34 f. • Verzeichnis Bonn (1968) S. 130; Arnim 3/4 (1978) S. 696; Fix (1994) S. 185-198; BBKL XIX (2001) S. 727-745;
Personenlexikon zum dt. Protestantismus (2006) S. 119; UH im Nationalsozialismus (2006) S. 1258 (Register); WBIS. - Merkel, Friedemann: R. H. in: Gottesdienst als Feld theologischer Wissenschaft im 20. Jahrhundert: deutschsprachige Liturgiewissenschaft in Einzelporträts. Münster 2011. S. 503512. - Catalogus prof. Rostochiensium online; Deutsche Biographie, s. https://www.deutsche-bio graphie.de/gnd11870821X.html [07.11. 2017].

$P$ Bildarchiv UAH; Ruperto Carola. 


\section{Ihne, Joseph Anton Friedrich Wilhelm}

1873-1883 Phil. Fak.

1883-1901 (Honorar-Prof.) Phil. Fak.

Englische Philologie

* 02. Febr. 1821 Fürth (Bayern)

$\dagger$ 21. Mai 1902 Heidelberg ev.

V Johann Wilhelm Christian Salomon I. ( $\left.{ }^{*} 1781\right)$ Kaufmann

M Anna Barbara geb. Braun $\left({ }^{\star} 1783\right)$

(2) 26. Mai 1847 Mary geb. Hull Allen (1818-189o)

K 1 T, 4 S: u. a. Dr. h.c. Ernst Eberhard (seit 1906: von) I. (1848-1917) Architekt, Kaiserl. Hofbaurat, u.a. 1889-1893 Erbauer des Schlosses Friedrichshof in Kronberg/Taunus im Auftrag der Witwe Kaiser Friedrichs III. (1831-1888), der ehem. Prinzessin von Großbritannnien Victoria (1840-1901); s. NDB 10 (1974) S. $128 \mathrm{f}$,, WBIS; Sander, Oliver: Die Rekonstruktion des Architekten-Nachlasses E. von I. ... Diss. Berlin 2000; Orth, Wolfgang (2006) S. $189 \mathrm{f}$. Anm. 7.

Lb Bonn: WS 1839/40-WS 1842/43 Studium an U; 17. März 1843 Dr. phil. an U; 1843 Oberlehrerprüfung.

Großbritannien: 1843-1846 Hauslehrer, u. a. Winter 1845/46 in London, Frühjahr 1846 in Schottland.

Elberfeld (heute: Wuppertal-E.): Seit 12. Mai 1847 zunächst Hilfslehrer, seit 7. Sept. 1847 I. o. Lehrer in Latein am heutigen Wilhelm-Dörpfeld-Gymnasium.

Liverpool: Herbst 1849-1854 Rektor des Mechanics Institute; 1854 (Gründer)-1863 Direktor e. eigenen privaten Tagesschule.

H: Seit 1863 Privat-Gelehrter.
UH: Seit 27. Febr. 1873 a. o. Prof.; seit März 1873 „als Hilfsarbeiter (am Seminar für Neuere Sprachen) (ist) beizuziehen für das Englische der a. o. Prof. ... Ihne" (aus: Brief des Ministeriums des Innern vom 5. März 1873 in: UAH RA 6418); seit 12. Juli 1874 a. o. Prof. (mit Staatsdienereigenschaft) mit e. Jahresgehalt von 8oo.- Gulden; seit 7. April 1883 Honorar-Prof.; WS 1883/84 Studienreise in Italien; 6. April 1901 Ruhestand.

1863 erwirbt I. das heute noch bestehende Haus Felseck in der Neuenheimer Landstraße 38 in Heidelberg; hier richtet er e. Begegnungsstätte für Engländer ein; so waren u. a. die späteren Könige Edward VII. und George V. (im Herbst 1892) als Prinzen Gäste des Hauses.

E 1893 Preußischer Kronenorden III. Klasse; 1893 Ritterkreuz I. Klasse des Ordens vom Zähringer Löwen; 1901 Ritterkreuz des Ordens Berthold I.

Qu UAH PA 4332; RA 6418, 6839, 6873. - Briefe: $\mathrm{UBH}$.

$W$ Forschungen auf dem Gebiet der römischen Verfassungsgeschichte. Frankfurt 1847. (Engl. Übers.: Researches into the history of the Roman constitution. London 1853. Nachdr. Buffalo (New York) 2001. Römische Geschichte. 8 Bde. Leipzig 1868-189o. Bde. 1 und 2: 2. Aufl. 1893-1896. (Engl. Übers. der Bde. 1-6: The History of Rome. London $1871 \mathrm{ff}$.) - A plea for the Emperor Tiberius in: Proceedings of the Literary and Philosophical Society of Liverpool (1856-1857). (Aus dem Engl. übers. und hrsg. von Wilhelm Schott: Zur Ehrenrettung des Kaisers Tiberius. Straßburg 1892.)

$L$ Badische Biographien 6 (1935) S. 591-595; WBIS. - Orth, Wolfgang: Von Elberfeld nach Liverpool. Der Althistoriker W.I. (1821-1902) in: Gesellschaft - Region - Politik. Festschrift für Hermann de Buhr ... Hrsg. von Jörg HentzschelFröhlings ... Norderstedt 2006. S. 181-192. • Wissenschaftsatlas der UH (2011) S. 109 f.; Deutsche Biographie, s. https://www.deutsche-biographie. de/gnd117127310.html [07.11. 2017].

$P$ Bildarchiv UAH; graph. Slg. UBH. 


\section{Jacobson, Paul Heinrich}

1889-189o Phil. Fak.

1890-1896 Nat.-Math. Fak.

Chemie

* 05. Okt. 1859 Königsberg (heute: Kaliningrad, Russische Föderation)

$\dagger$ 25. Jan. 1923 Berlin mosaisch, seit $1888 \mathrm{ev}$.

V Heinrich J. (1826-189o), u. a. seit 1873 Prof. für Experimentelle Pathologie und Leiter der Inneren Abt. des Jüdischen Krankenhauses in Berlin, s. ADB 50 (1905) S. 611f., WBIS

M Ernestine geb. Wolf(f) ( $\dagger$ in den goer Jahren des 19. Jhdts)

$\infty$ 8. Aug. 1891 Magdalene (Adda) Louise Bernhardine geb. Kreibohm (1867-1915) T von Carl Hermann Julius K. (1817-1880) ev. Pfarrer

$\mathrm{K}$ keine

Vw Großvater: Ludwig Jacobson (1795-1841) (ihm wurde als Jude die angestrebte akademische Karriere verwehrt) Gründer und Leiter des Orthopädischen Instituts in Königsberg (Preußen), s. ADB 50 (1905) S. 611f. • Onkel: Julius J. (1828-1889) 1873(-1889) erster Ordinarius für Augenheilkunde und 1877-1889 Direktor der ersten preußischen Augenklinik in Königsberg, s. NDB 10 (1974) S. 246 f., WBIS. • Bruder: Louis J. (1852-1905) Berlin: seit 1877 Ohrenarzt, 1896-1905 Direktor e. Privat-Poliklinik für Ohrenkrankheiten; seit 1888 auch Privat-Dozent, 1897-1905 Prof. für Ohrenheilkunde an U, siehe WBIS.

Lb Seit SS 1877 Studium der Chemie an U Berlin, seit SS $1879 \mathrm{H}$.

Berlin: Seit SS 188o Praktikant, 1882-1885 Assistent an Gewerbe-Akademie; 1. März 1882 Dr. phil. an U; seit 1885 Chemiker bei Kunheim \& Co. in Niederschöneweide (heute: Ortsteil von Berlin).
U Göttingen: Seit Frühjahr 1886 Assistent am Allg. Chemischen Labor bei (siehe) Victor Meyer; Febr. 1887 Habilitation.

UH: Mai 1889 Erteilung der venia legendi; seit 1890 auch Lehrauftrag für Pharmazeutische Chemie; seit 17. Dez. 1891 a. o. Prof.

Dt. Chemische Gesellschaft in Berlin: 1. Okt. 18961. Okt. 1911 Generalsekretär; 1911-1918 wiss. Leiter der Abt. für Chemische Sammel-Literatur.

U Berlin: 1921-1923 A. o. Prof. für Chemie.

1918 Geh. Reg.-Rat

Qu UAH PA 1765; RA 6886. Briefe: UBH.

$W$ Lehrbuch der organischen Chemie. 2 Bde. Leipzig 1891-1893. 2. Aufl. 1907-1913. (Mitverf.) • Der Dt. Chemischen Gesellschaft Tätigkeit für literarische Sammlung der Forschungsergebnisse in: Berichte der Dt. Chemischen Gesellschaft 51 (1918). Sonderheft.

HG Seit 1897 Berichte der Dt. Chemischen Gesellschaft.

$L$ Prager, Bernhard: P.J. $\dagger$ in: Berichte der Dt. Chemischen Gesellschaft 57 (1924) Nr. 8, S. 56-78, S. 79-81 (Bibliographie). Catalogus prof. Gottingensium (1962) S. 144; NDB 10 (1974) S. 247; WBIS; Autoren der Bunsenbibliothek (2009 online).

$P$ NDB.

Jacoby, Martin Johann

1901-1907 Med. Fak.

Pharmakologie

* 28. Jan. 1872 Berlin

$\dagger$ 18. Juli 1941 Manchester (Großbritannien) mosaisch

V Gustav J., Kaufmann

M Betty geb. Neumann 
(0) 1907 Margarete (Grete) geb. Orgler (18821987), u.a. Kindergärtnerin, Sozialarbeiterin, s. Indomitable Centenarian: The Margaret Jacoby Saga in: Association of Jewish Refugees in Great Britain Vol. XXXVII, Nr. 5 (May 1982) S. 1-3 u.ö. (Ausdruck im UAH); Kurzbiographien zur Geschichte der Juden ... (1988) S. 171; T von Julius O. (1829-1902) erster mosaischer Jurist in Posen, seit 1894 Vorsitzender der Anwaltskammer, Geh. Justizrat, s. WBIS

$\mathrm{K}$ keine.

Lb Seit WS 1890/91 Studium an U Freiburg/Br., anschl. Berlin; 30. April 1895 Dr. med. an U Berlin; Jan. 1896 Approbation in Freiburg.

U Berlin: Seit Mai 1896 Assistent und stellvertr. Oberarzt an II. Med. U-Klinik.

U Straßburg: Seit Okt. 1898 Assistent am Physiologisch-Chemischen Labor.

UH: Seit April 1900 Assistent am Pharmakolog. Inst.; 25. Juli 1901 Habilitation; seit 28. Mai 1906 nichtetatm. a. o. Prof.

Berlin: Seit 1907 Direktor der Biochemischen Abt. des Städtischen Krankenhauses Moabit; 10. Nov. 1933 Versetzung in Ruhestand aus rassischen Gründen; 1934-1938 ehrenamtl. Leiter des Chemischen Inst. am Jüdischen Krankenhaus.

1939 Emigration nach Großbritannien.

Qu UAH PA 1766; RA 6204. • GLA Abt. 235, Fasz. 2126.

$W$ Über das Aldehyde oxydirende Ferment der Leber und Nebenniere. Über die fermentative Eiweißspaltung und Ammoniakbildung bei Phosphorvergiftung in der Leber in: Hoppe-Seyler's Zs. 30/1+2 (1900) S. 135-181. - Über die Autolyse der Lunge in: Zs. für Physiologische Chemie 33 (1901) S. $126 \mathrm{f}$. Immunität und Disposition und ihre experimentellen Grundlagen. Wiesbaden 1906. • Einführung in die experimentelle Therapie. Berlin 1910. 2. Aufl. 1919. - Verteilung des Zuckers zwischen Blutzellen und Plasma in: Biochemische Zs. 244 (1932) S. 357-365. (Mitverf.); Wirkung der
Metalle auf Fermente in: ebd. 262 (1933) S. 181-184 und 267 (1933) S. 167 f.; Zusammensetzung des Reststickstoffes bei der experimentellen Uranvergiftung in: ebd. 281 (1935) S. $198 \mathrm{f}$.

$L$ Wer ist's (1928) S. 725, 10 (1935) S. 744; Poggendorff 7a, 2 (1958) S. 597. • Pross, Christian und Winau, Rolf: Nicht mißhandeln. Das Krankenhaus Moabit. Berlin 1984. S. 177 f. • WBIS. • Kurzbiographien zur Geschichte der Juden: 1918-1945. Hrsg. von Joseph Walk ... München 1988. S. 172. • Exodus von Wissenschaften aus Berlin: Fragestellungen, Ergebnisse, Desiderate. Entwicklungen vor und nach 1933. Hrsg. von Wolfram Fischer ... Berlin 1994. S. 304-307. - Deutsche Biographie, s. https://www.deutsche-biographie. de/gnd117610569.html [07.11. 2017].

P Bildarchiv UAH; Pross/Winau (1984).

\section{Jänecke, Ernst Georg Gustav}

1931-1955 (Honorar-Prof.) Nat.-Math. Fak.

Physikalische Chemie

* 04. März 1875 Alt-Warmbüchen (bei Hannover; heute: Ortsteil von Isernhagen)

$\dagger \quad$ 04. Jan. 1957 Heidelberg ev.

V Georg Friedrich William J. (1831-1908) zunächst Hof- und Ziegeleibesitzer, seit 1878 MitDirektor des (noch heute bestehenden) väterlichen Druckfarbenhersteller-Betriebs Gebr. Jänecke \& Fr[itz] Schneemann in Hannover

M Johanne Auguste Karoline geb. Warnecke (1844-1904)

๑ 7. Okt. 1909 Hedwig geb. Smend (1886-1920)

$\infty$ 8. Sept. 1921 Dr. phil. nat. Luise geb. Velde (1895-1966)

$\mathrm{K} 5 \mathrm{~S}$ (davon $1 \mathrm{~S}$ früh $\dagger$ und $3 \mathrm{~S}$ im 2. Weltkrieg $X), 1 \mathrm{~T}$

Lb Seit WS 1894/95 Studium an TH Hannover, WS 1895/96 U Göttingen, seit SS 1896 München, seit 1897 Berlin; 19. Dez. 1898 Dr. phil. an U Berlin. 
Hannover: 1. Dez. 1898-31. März 1899 Chemiker in (groß-)väterlicher Druckfarbenfabrik Gebr. Jänecke \& Fr. Schneemann; 1899-1900 Militärdienstpflicht als Einjährig-Freiwilliger.

TH Hannover: 1. April 1900-30. April 1905 Assistent am Anorganisch-Chemischen Laboratorium; 17. Febr. 1905 Habilitation.

Benthe (bei Hannover; heute: Ortsteil von Ronnenberg): 1. Mai 1905-28. Febr. 1906 Betriebsleiter des Kaliwerkes.

TH Hannover: 1. April 1906-30. April 1919 Assistent am Bauingenieur-Laboratorium; 20. April 1912-SS 1920 nichtetatm. a. o. Prof.

Oppau (heute: Stadtteil von Ludwigshafen): 1. Sept. 1920-1935 (Ruhestand) Leiter e. Forschungslaboratoriums bei Badischer Anilin- und Soda-Fabrik (heute: BASF).

\section{H: Seit 1921 Wohnsitz.}

UH: 4. Sept. 1931 Ern. zum o. Honorar-Prof.; SS 1955 letzte Vorlesungsankündigung.

E 17. Juli 1930 Dr.-Ing. E.h. TH Aachen.

Qu UAH PA 4353; Rep. 40-406. - GLA Abt. 235, Fasz. 2128. $\bullet$ Siehe auch Baden-Württ. Biographien III (2002) S. 176.

$W$ Gesättigte Salzlösungen vom Standpunkt der Phasenlehre. Halle/S. 1908. • Die Entstehung der deutschen Kalisalzlager. Braunschweig 1915. 2. Aufl. 1923. - Über das reguläre vierdimensionale Fünfzell. Berlin 1931. Etwas über die Schrumpfung der Erde. Berlin 1932. Kurzgefasstes Handbuch aller Legierungen. Berlin 1937. 2. Aufl. 1949. • Die Welt der chemischen Körper bei hohen und tiefen Temperaturen und Drucken. Weinheim 1950.

L Arnim 1 (1944) S. 599, 3 (1961) S. 283; WBIS; Baden-Württ. Biographien III (2002) S. 174-176; Deutsche Biographie, s. https://www.deutsche-bio graphie.de/gnd117059072.html [07.11. 2017].

$P$ Bildarchiv UAH.

\section{Jaffé, Edgar}

1904-1910 Phil. Fak.

Politische Ökonomie

* 14. Mai 1866 Hamburg

$\dagger$ 29. April 1921 München-Laim

mosaisch, seit 26. März 1882 prot.

V Isaac Joseph J. (1807-1890) Kaufmann

M Charlotte geb. Beer (1832-1888)

๑ 18. Nov. 1902 (Trennung 1910) Dr. phil. Elisabeth (Else) geb. Freiin Praetorius von Richthofen (1874-1973) 1900-1902 Fabrikinspektorin, s. UAH Rep. 197-152; Bertschinger-Joos, Esther: Frieda Gross und ihre Briefe an E. J. Ein bewegtes Leben im Umfeld von Anarchismus, Psychoanalyse und Bohème. Marburg 2014; Demm, Eberhard: E. J.-von R. Erfülltes Leben zwischen Max und Alfred Weber. Düsseldorf 2014; Kaesler (2014) S. 999 (Register); Friedrich Gundolf - Elisabeth Salomon. Briefwechsel (1914-1931). Im Auftrag des DLA Marbach hrsg. von Gunilla Eschenbach und Helmuth Mojem. Berlin 2015. S. 794 (Register).

K 3 S, s. Demm (2014) S. 245 (Register); darunter 1 Adoptiv-S: Peter J. (1907-1915) Sohn von Otto Gross (1877-1920) Psychiater, s. Personenlexikon der Sexualforschung. Hrsg. von Volkmar Sigusch und Günter Grau. Frankfurt/M. 2009. S. 244; Hergemöller, Bernd-Ulrich: Mann für Mann. Ein biographisches Lexikon. Frankfurt/M. 2001. S. 304f.; Demm (2014) S. 245 (Register), Kaesler (2014) S. 999 (Register). 1 T: Marianne J. (1905-1991), s. Demm (2014) S. 244 (Register); Ehefrau von: (siehe) Hans von Eckardt.

Lb Seit $1883 \mathrm{kaufm}$. Lehre in Deutschland, anschl. Frankreich, Spanien; 1888-1897 Teilhaber der väterlichen Firma in Manchester (Großbritannien).

Seit SS 1898 Studium der Philosophie, Geschichte, Nationalökonomie an U Berlin, SS 1901-SS 1902 H.

UH: 3. März 1902 Rigorosum, 7. Juli 1902 (Datum der Promotionsurkunde) Dr. phil.; 17. Dez. 1904 Habilitation für Politische Ökonomie; seit 30. Dez. 1908 nichtetatm. a. o. Prof.; seit SS 1909 Lehrauftrag „zur Abhaltung für 2-stündige Vorlesungen in 
jedem Semester über Geld- und Kreditwesen mit e. üblichen Honorar von 200.- Mark für die Wochenstunde" (aus: UAH H-IV-102/138 fol. 109r). In dieser Zeit:

Handelshochschule in Mannheim: SS 1908-SS 1910 Nebenamtlicher Dozent.

München: WS 1910/11-1914 A.o. Prof. für Geldund Kreditwesen an Handelshochschule und Lehrauftrag an U; 21. März-16. Okt. 1915 Wirtschaftssachverständiger bei dt. Zivilverwaltung in Belgien mit Sitz in Brüssel; 1915-1918 Wiederaufnahme der Lehrtätigkeit an Handelshochschule.

München: Nov. 1918 Gemeinsam mit Kurt Eisner (1867-21. Febr. 1919 ermordet) Aufruf zur Revolution; 8. Nov. 1918-21. Febr. 1919 Staatsminister der Finanzen im Kabinett Eisner; 1. März-17. März 1919 Staatsminister der Finanzen im Kabinett Martin Segitz (1853-1927); 07.-13. April 1919 gewählter Volksbeauftragter für Volkswirtschaft vom Revolutionären Zentralrat; 18. Juni 1919 nach dem Scheitern der Regierung - zwecks Verhinderung e. Prozesses gegen J. - Einweisung in Kuranstalt (Nervenheilanstalt) Neufriedenheim in M.-Laim wegen depressiver Gemütserkrankung.

Qu UAH PA 1768; Quästurakte, Vorlesungen betr., s. Rep. 27-643; Fak.-Akten H-IV-102/132 fol. 292r296r u. Ö., H-IV-102/136 fol. 218r-224V, H-IV-102/ 138 fol. 101r, 103r-109r; Studentenakte. GLA Abt. 235, Fasz. 2129. • Briefe: UBH. • Auskunft: Standesamt München. - Mitteilungen: Frau Anne Munding M.A., Generalredaktion der Max Weber-Gesamtausgabe, München.

W Das englische Bankwesen. Leipzig 1904. 2. Aufl. 1910. Volkswirtschaft und Krieg. Tübingen 1915. Finanz- und Steueraufgaben im neuen Deutschland. München 1919.

MHG 1904-1921 Archiv für Sozialwissenschaft und Sozialpolitik. • 1916-1919 Europäische Staatsund Wirtschaftszeitung.

$L$ Handels-Hochschule Mannheim 1907-1932 (1932) S. 25; NDB 10 (1974) S. 29of. • Schindler, Michael: E. J. als Publizist im Ersten Weltkrieg und als Finanzminister der Regierung Eisner. [o. O.] 1980. Universität Mannheim (1982) S. 294. • Bosls bayerische Biographie ... Hrsg. von Karl Bosl. Regensburg 1983. S. 390. - Menges, Franz: E. J. ... Nationalökonom und Finanzminister im Kabinett Kurt Eisner in: Geschichte und Kultur der Juden in Bayern. Lebensläufe. Hrsg. von Manfred Treml u. a. München 1989. S. 225-230. - Kriegstagebuch K. Hampe (2007) S. 971 (Register). • Roth, Guenther: Else von Richthofen, E.J. und ihre Kinder im Kontext ihrer Zeit in: Grenzüberschreitende Diskurse ... Hrsg. von Kay Waechter. Wiesbaden 2010. S. 301-319. Demm (2014) S. 245 (Register); Kaesler (2014) S. 999 (Register). Munding, Anne: E. J. ... Vom deutsch-jüdischen Unternehmer zum Finanzminister der bayerischen Revolution. Diss. München (März 2018 in Vorbereitung).

$P$ NDB.

\section{Jagemann, Friedrich Max Ludwig Eugen von}

1903-1926 (Honorar-Prof.) Jur. Fak.

Öffentliches Recht

* 25. Mai 1849 Karlsruhe

$\dagger$ 15. Aug. 1926 Heidelberg kath.

V Ludwig Hugo Franz von J. (1805-1853) Ministerialrat, s. ADB 13 (1881) S. 643-645; Briefe in $\mathrm{UBH}$

M Caroline geb. von Böckh (1820-1859) T von Christian Friedrich von B. (1777-1855) badischer Finanzminister, s. ADB 2 (1875) S. $783 \mathrm{f}$.

๑ 9. Juli 1874 Marie geb. von Sonntag (1850-1939)

K $1 \mathrm{~S}$ († 1909), $4 \mathrm{~T}$

Vw Groß-Onkel: (siehe) August Böckh.

Lb Seit WS 1867/68 Studium an U Berlin, anschl. Brüssel, WS 1869/70-SS $1870 \mathrm{H} ; 1870 / 71$ Kriegsdienst während des Deutsch-Französischen Krieges; Frühjahr 1872 I., Mai 1874 II. Staatsexamen in H; 1872 Hofjunker von Großherzog Friedrich I. von Baden (1856-1907); 23. April 1873 Dr. iur. UH. 
Gerichts-Referendar: Seit Herbst 1874 Bühl, anschl. Offenburg, zuletzt Freiburg/Br.

Mosbach (Baden): Seit 12. Mai 1877 Staatsanwalt, seit Herbst 1879 Landgerichtsrat.

Karlsruhe: Seit 1881 Ministerialassessor, 1882-1893 Ministerialrat im Ministerium der Justiz, des Kultus und des Unterrichts; seit 1881 auch stellvertr. Oberstaatsanwalt am Oberlandesgericht; 1882 außerdem Kammerherr Friedrichs I.; 1884 Beirat der Generalintendantur der großherzogl. Zivilliste.

Berlin: 1893-1903 (Abberufung) a. o. Gesandter von Baden und bevollm. Minister am Preußischen Hof sowie seit 1901 stellvertr. Bevollmächtigter im Bundesrat; 1. Okt. 1903 Ruhestand.

UH: Seit 16. Okt. 1903 o. Honorar-Prof.; WS 1925/ 26 letzte Vorlesungsankündigung. • In dieser Zeit:

H: 1914-1920 Leiter des Bezirksausschusses des Deutschen Roten Kreuz.

1894: Bei der baulichen Entwicklungsplanung der Karlsruher Justizvollzugsanstalt berät E. von J. Oberbaudirektor Josef Durm (1837-1919) maßgeblich

1892 Geh. Ober-Reg.-Rat; 1896 Geh. Rat II. Klasse; 1898 Wirkl. Geh. Rat

Qu UAH PA 762, 4356; RA 6761f. - GLA Abt. 235, Fasz. 2130. • Briefe: UBH. • Fünfundsiebzig Jahre des Erlebens und Erfahrens (1849-1924). Heidelberg 1925. (Autobiogr.)

W Handbuch des Gefängniswesens. 2 Bde. Hamburg 1888. (Mitverf.) - Die deutsche Reichsverfassung. Heidelberg 1904. - Zur Reichsfinanzreform. Heidelberg 1905. Das Großherzogtum Baden in allg. wirtschaftlicher und staatlicher Hinsicht dargestellt. Karlsruhe 1912. (Mitverf.)

L NDB 10 (1974) S. 293 f.; Jansen (1992) S. 410 (Register). - Acta Borussica. N.F. 1. Reihe. Die Protokolle des Preußischen Staatsministeriums 1817-
1934/38. Hrsg. von der Berlin-Brandenburgischen Akademie der Wissenschaften ... unter der Leitung von Jürgen Kocka ... Band 8/II. 21. März 1890-9. Okt. 1900 bearb. von Hartwin Spenkuch. Hildesheim 2003. S. 558. - Zeiler (2009) S. 129 f. (hier Rufname J.s: Eduard); Schroeder (2010) S. 340-342 u.ö.

$P$ Bildarchiv UAH; graph. Slg. UBH; NDB.

\section{Jannasch, Paul Ehrhardt}

1889-189o Phil. Fak.

1890-1919 Nat.-Math. Fak.

(1919-1921 (Honorar-Prof.) Nat.-Math. Fak.)

Chemie

* o2. Okt. 1841 Deutsch Ossig (heute: Ortsteil von Görlitz)

$\dagger \quad$ 20. März 1921 Heidelberg ev.

V Johann Moritz J. (1813-189o) Besitzer des Herrenhauses Oberhof in Deutsch Ossig

M Johanna Juliane geb. Apelt gesch. Arnold (1802-1876)

๑ 12. April 1893 Julie (Lulu) geb. Wagenmann (1860-1942), s. Scheidle, Ilona: „Fertige Tatsache spricht für sich!“ ... in: Heidelberg. Jahrbuch zur Geschichte der Stadt 2008. Heidelberg 2007. Jg. 12. S. 77; T von Julius August W. (1823-189o), u. a. seit 1861 o. Prof. für Theologie Göttingen, s. ADB 40 (1896) S. 477-479, Catalogus prof. Gottingensium (1962) S. 36, BBKL (2018 in Bearbeitung)

K 1 T, 1 S: Dr. phil. Adolf J. (1898-1984) 19271945 Redakteur im Berliner Propyläen Verlag, seit 1945 Reg.-Direktor und Leiter des Amts für Bildende Kunst im Senat von Berlin, 19551968 (?) Leiter der „Galerie des 20. Jahrhunderts“ Berlin, s. „So fing man einfach an, ohne viele Worte". Ausstellungswesen und Sammlungspolitik in den ersten Jahren nach dem 2. Weltkrieg. Hrsg. von Julia Friedrich ... Berlin 2013. S. 214-217 u. ö; Die Galerie des 20. Jahrhunderts in Berlin 1945-1968. Mit Beiträgen von Hanna Strzoda, ..., Alexander Jannasch ... Berlin 2015. 
Vw Schwager: (siehe) August Wagenmann. Enkel: Dr. iur. Alexander J. $\left({ }^{*} 1947\right)$, u. a. seit 1988 Richter am Verwaltungsgerichtshof BadenWürttemberg Mannheim, 1999-2012 (Ruhestand) Richter am Bundesverwaltungsgericht Leipzig.

Lb WS 1863/64 Studium an U Leipzig, seit SS 1864 Breslau, anschl. Greifswald, zuletzt Göttingen.

Assistent an Agrikulturchemischen Versuchsstationen: Seit Jan. 1867 in Halle/S., seit April 1867 bei der Königl. Landwirtschaftl. Akademie in Proskau (bei Oppeln).

U Göttingen: 9. Jan. 1869 Dr. phil.; 1869-1889 Assistent am Chemischen U-Labor; 3. Aug. 1883 Habilitation; 31. Dez. 1886 Verleihung des Titels „Prof.“; seit 14. Nov. 1888 a. o. Prof.

UH: Seit 7. Juni 1889 a. o. Prof.; 1889-1892 Assistent am Chemischen U-Laboratorium; seit 10. Mai 1892 etatm. a.o. Prof. und Abt.-Vorsteher am Laboratorium mit e. Jahresgehalt von 2400.- Mark und 620.- Mark Wohnungsgeld; WS 1918/19 letzte Vorlesungsankündigung; 1. April 1919 Ruhestand und Ern. zum Honorar-Prof.

E 1888 Mitglied der Dt. Akademie der Naturforscher Leopoldina Halle/S.; 1909 Mitglied der Akademie der Wissenschaften H. 1902 Ritterkreuz I. Klasse, 1912 Ritterkreuz I. Klasse mit Eichenlaub des Ordens vom Zähringer Löwen.

Qu UAH PA 1769; RA 6886. GLA Abt. 235, Fasz. 2131. - Teil-Nachlaß: UAH (50 Tagebücher P.J.s 1887-1921 sowie 1 Kladde mit Notizen über Phosphate von Jan. 1913). Mitteilungen: Herr Dr. iur. Alexander Jannasch (Enkel), Leipzig.

$W$ Praktischer Leitfaden der Gewichtsanalyse. Leipzig 1897. 2. Aufl. 1903. Nachdr. Charleston (South Carolina) 2010. - Verwendung des Ozons zur Ausführung quantitativer Analysen in: Journal für praktische Chemie 73 (1906). (Mitverf.); Quantitative Bestimmung der Borsäure in: ebd. 99 (1919). (Mitverf.)
$L$ Strecker, W.: P.J. in: Berichte der deutschen chemischen Gesellschaft (A and B Series) (1922) Bd. 55, H. 12, S. A194-A210. - Wer ist's (1922) S. 724; Arnim 1 (1944) S. 603; Catalogus prof. Gottingensium (1962) S. 126; WBIS; Jansen (1992a) S. 166 (Register); Deutsche Biographie, s. https:// www.deutsche-biographie.de/gnd11761119o.html [07.11. 2017]. - Werner, Helmut: Geschichte der anorganischen Chemie. Die Entwicklung einer Wissenschaft in Deutschland von Döbereiner bis heute. Weinheim 2017.

$P$ Bildarchiv UAH.

\section{Janson, Franz}

1789-1805 Jur. Fak.

Römisches Recht, Bürgerliches Recht, Dt. Staatsrecht, Juristische Praxis

$\approx$ 15. Sept. 1750 Waldböckelheim (Kurpfalz; heute: Rheinland-Pfalz)

$\dagger$ 15. Sept. 1816 Mannheim

kath.

V Josef J. (1713-1767) Kramer (Händler)

M Anna Catharina geb. Cornely (?)

$\infty$ unverheiratet.

Lb UH: Seit Dez. 1767 Studium; 1768 Bakkalaureatsexamen; 1786 Dr. iur.utr.

Seit 17. März 1773 Rechtspraktikant in Wetzlar; nach 1773 Syndikus des St. Andreas-Stifts und Reg.-Advokat in Worms; vor 1789 Geh. Kanzlist (Hof- und Reg.-Rat) des Fürstbischofs zu Speyer in Bruchsal.

UH: 8. Aug. 1789 Auf eigenen Antrag Ern. zum a. o. Prof. von kurpfälzischer Regierung gegen den Willen der Fakultät.

Schloß Bruchsal, seit 1810 (Verlegung) Schloß Mannheim: Seit 29. Juli 1805 Justizrat, 1808-1816 Hofgerichts-Rat am großherzogl. badischen Hofgericht. 
1782 Mitglied des Illuminatenordens (Ordensname: Lucius Apuleius)

Qu UAH PA 1774f.; RA 5774, 5921, 6208, 6219, 6766, 7281f. u. ö. - GLA Abt. 205, Fasz. 305 f. • Acta secularium (1787) S. 166, 227 f. • Auskunft: Bistumsarchiv Trier (Taufeintrag: Kirchenbuch 2 der Pfarrei St. Bartholomäus in Waldböckelheim, S. 13; Karbach, Franz Josef: Familienbuch der kath. Pfarrei Waldböckelheim 1677-1869. Spay 1994. Nr. 564).

$W$ Übersicht der Theorie der Rechte, des Processes und der juristischen Praxis. Mannheim 1789. Materialien zu einem künftigen Gesetzbuch für die Kurpfälzischen Lande, und zum Nachschlagen bey künftigen Vorlesungen über das Kurpfälzische Privat-Recht ... Heidelberg 1792. • Freymüthige Bemerkungen über den von ... Franz Wilhelm Gambsjaeger an der hohen Schule zu Heidelberg gewagten Beweis ... Heidelberg 1800.

L Biographie in: Stepf, Johann Heinrich: Gallerie aller juridischen Autoren von der ältesten bis auf die jetzige Zeit. Leipzig 1825. Bd. 4. S. 305 f. • Nachruf in: Mannheimer Intelligenzblatt Nr. 77 vom 24. Sept. 1816. - Wechmar (1846) S. 131; Keller (1913) S. 88 f.; Schneider (1913) S. 16 f.; Heidelberger Strafrechtslehrer (1986) S. 4 f.; Weisert (1991) S. 122 u. ö.; WBIS; Schroeder (2010) S. 15, 18, 20, 28.

\section{Jaspers, Karl Theodor}

1913-1937, 1945-1948 Phil. Fak.

Psychologie, Philosophie

* 23. Febr. 1883 Oldenburg

$\dagger \quad$ 26. Febr. 1969 Basel

ev.-luth.

V Karl Wilhelm J. (1850-1940) Amtshauptmann, später Bankdirektor, Landtagsabgeordneter, s. Biographisches Handbuch zur Geschichte des Landes Oldenburg. Hrsg. von Hans Friedl ... Oldenburg 1992.
M Henriette geb. Tantzen (1862-1941) T von Theodor Johann T. (sen.) (1834-1893) Politiker, u.a. 1872-1893 Mitglied des Oldenburgischen Landtags, s. Eckhardt, Albrecht: Von der bürgerlichen Revolution bis zur nationalsozialistischen Machtübernahme. Der oldenburgische Landtag und seine Abgeordneten 18481933. Oldenburg 1996. S. 109; WBIS

๑ 29. Sept. 1910 Gertrud geb. Mayer (1879-1974) ca. 1907 Pflegerin im Sanatorium Kohnstamm in Königstein, s. hierzu Kohnstamm, Peter: Lieder eines fahrenden Gesellen. Erinnerungen an vergangene Zeiten. Königstein 1994; Albert Fraenkel (2004) S. 59, 62, 149, Lexikon jüdischer Einwohner Hs (2011) S. 192, Schramm (2012) S. 98 f.; Briefe in UBH. - Bruder: Gustav Mayer (1871-1948) Journalist und Historiker, s. G.M. als deutsch-jüdischer Historiker in Krieg und Revolution 1914-1920. Tagebücher, Aufzeichnungen, Briefe. München 2009.

\section{K Keine.}

Lb Studium der Rechtswiss.: SS 1901 Immatrikulation an U Freiburg/Br. (April 1901 Abbruch des Studiums nach ärztl. Diagnose von Bronchiektase mit sekundärer Herzinsuffizienz), WS 1901/o2 H, SS 1902 München; anschl. Studium der Medizin: seit WS 1902/03 Berlin, seit 1903 Göttingen, seit SS $1906 \mathrm{H}$; 12. Juli 1907 Exmatrikulation an UH für Anmeldung zur Staatsprüfung; Sommer 1908 med. Staatsexamen in H; 8. Dez. 1908 Dr. med.; Gasthörer an UH: WS 1908/o9-WS 1911/12.

UH: Seit 18. Aug. 1908 Medizinalpraktikant an Innerer Klinik; Jan. 1909-Nov. 1916 Volontärassistent an Psychiatr. Klinik; 13. Dez. 1913 Habilitation für Psychologie an Phil. Fak., s. hierzu Willy Hellpach; seit 17. Nov. 1916 nichtetatm. a.o. Prof. für Philosophie; seit 1. April 1920 (17. Jan. 1920 Ern.) planm. a. o. Prof. für Philosophie als Nachf. von Hans Driesch; Rufe abgelehnt: 1921 Greifswald, Kiel, 1928 Marburg, 1929 Bonn; seit 1. Okt. 1921 (24. Juni 1921 Ern.) persönlicher Ordinarius für Philosophie und - neben Heinrich Rickert und seit 1922 Ernst Hoffmann - Mit-Direktor des Phil. Seminars; seit 1. April 1922 planm. o. Prof. als Nachf. von Heinrich Maier; 19. Juni 1937 Zwangsemeritierung aus rassischen Gründen.

H: 1937-1945 Privat-Gelehrter. 
UH: April-Dez. 1945 Mitglied des Dreizehnerausschusses zum Wiederaufbau der U; 14. Sept. 1945 Wiedereinsetzung als o. Prof.; 12. Dez. 1947 Berufung durch Beschluss des Regierungsrates des Kantons Basel-Stadt an U Basel, 23. März 1948 Ruf angenommen.

U Basel: Seit 1. April 1948 (Amtsantritt) o. Prof. für Philosophie einschließlich Psychologie und Soziologie; 30. Sept. 1961 Emeritierung auf Beschluss des Regierungsrates des Kantons Basel-Stadt.

Siehe auch Albert Fraenkel

E 1947 Mitglied der Akademie der Wissenschaften H. 1947 Dr. es lettres h.c. Lausanne; 1953 Dr. phil. h.c. UH. 1947 Goethepreis der Stadt Frankfurt/M.; 1958 Friedenspreis des Dt. Buchhandels; 1964 Orden pour le Mérite für Wissenschaften und Künste; 1965 Int. Friedenspreis Lüttich. 1946 Ehrensenator der Universität Heidelberg.

Qu UAH PA 460, 4369f.; RA 5035; Rep. 40-406; Fak.-Akte H-III-862/5; Studentenakte. GLA Abt. 235, Fasz. 2133. Briefe: UBH. $\bullet$ K. J. und Karl Heinrich Bauer: Briefwechsel 1945-1968. Hrsg. und erl. von Renato de Rosa. Berlin 1983. - K. J.: Italienbriefe 1902. Hrsg. von Suzanne Kirkbright. Heidelberg 2006. K. J.: Korrespondenzen. Hrsg. von M. Bormuth, C. Dutt, ... E. Wolgast. 3 Bde. Göttingen 2016. Auskunft: Staatsarchiv Basel-Stadt Präsidialdepartement - (Personaldossier der Universität über K. J. (StABS, UNI-REG 5d 2-1 (1) 153) sowie Dozentenkartei (StABS, Universitätsarchiv F 6.2)). Schicksal und Wille. Autobiogr. Schriften. Hrsg. von Hans Saner. München 1967. 2. Aufl. 1969.

W Allgemeine Psychopathologie. Berlin 1913. 8. Aufl. 1965 (siehe hierzu: Häfner, Heinz: K. J.: 100 Jahre „Allgemeine Psychopathologie“ in: Der Nervenarzt 11 (2013) S. 1281-1290). Psychologie der Weltanschauungen. Berlin 1919. 6. Aufl. 1971. Die geistige Situation der Zeit. Berlin 1931. 12. Aufl. 1971. Philosophie. 3 Bde. Berlin 1932. 4. Aufl. 1973. Die Idee der Universität. Berlin 1945. Neufassungen 1961 und 2000. Von der Wahrheit. München 1947. 4. Aufl. 1991. - Gesamtedition und Kommentierung der Werke von K. J., Edition der Briefe und des Nachlasses in Auswahl (For- schungsstelle K.-J.-Edition in der Heidelberger Akademie der Wissenschaften). Beginn des Editionsprojekts 2012.

MG, MHG 1945-1946 Zs. „Die Wandlung“ (u.a. mit Alfred Weber), siehe hierzu Waldmüller, Monika: „Die Wandlung. Eine Monatsschrift.“ Hrsg. von Dolf Sternberger unter Mitwirkung von K. J., ... Alfred Weber ... Marbach 1988; Oster, Patricia: Die Zeitschrift als Ort der Konstitution eines „transnationalen“ kulturellen Feldes. „Lancelot, Der Bote aus Frankreich“ und „Die Wandlung“ in: Am Wendepunkt - Deutschland und Frankreich um 1945 ... Hrsg. von Patricia Oster und Hans-Jürgen Lüsebrink. Bielefeld 2008. S. 231-248.

$L$ Gadamer, Hans Georg: K. J. † in: Ruperto Carola 21. Jg., Bd. 46 (1969) S. 50-56. Glockner (1969) S. 274 (Register). - Saner, Hans: K. J. in Selbstzeugnissen und Bilddokumenten. Hamburg 1970. 12. Aufl. 2005. - NDB 10 (1974) S. 362-365. - K. J. in seiner Heidelberger Zeit. Hrsg. von JoachimFelix Leonhard. Heidelberg 1983. Rosa, Renato de: Der Neubeginn der Universität 1945 in: Semper apertus 3 (1985) S. 543-566; Sternberger, Dolf: K. J. in: ebd. S. 285-298. - WBIS; BBKL II (1990) Sp. 1567-1578; Heiber I (1991) S. 638 (Register); Jansen (1992) S. 410 (Register); Ders. (1992a) S. 166 (Register); Giovannini (1998) S. 269-277. Bormuth, Matthias: Lebensführung in der Moderne - K.J. und die Psychoanalyse. Stuttgart 2002. Heidegger-Handbuch: Leben - Werk - Wirkung. Hrsg. von Dieter Thomä ... Stuttgart 2003. 2. Aufl. 2013. • Albert Fraenkel. Ein Arztleben ... Hrsg. von P. Drings u. a. Landsberg/Lech 2004. S. 138-154 u. ö. • Bock, Wolfgang J.: K.J. und Heidelberg in: Geschichte der Heidelberger Neurologie in: Deutsche Gesellschaft für Geschichte der Nervenheilkunde. 10. Bd. der Schriftenreihe. Würzburg 2004. S. 5369. - Peiffer (2004) S. 1159 (Register). - Teoharova, Genoveva: K. J.' Philosophie auf dem Weg zur Weltphilosophie. Würzburg 2005. Moraw (2008) S. 95-98. Existenz und Sinn: K. J. im Kontext ... Hrsg. von Anton Hügli u. a. Heidelberg 2009. K. J. im Schnittpunkt von Zeitgeschichte, Psychopathologie, Literatur und Film. Hrsg. von Dietrich von Engelhardt und Horst-Jürgen Gerigk. Heidelberg 2009. K. J. Grundbegriffe seines Denkens. Hrsg. von Hamid Reza Yousefi ... Reinbek 2011. • Lexikon jüdischer Einwohner Hs (2011) S. 192. - The 
Axial Age and Its Consequences. Ed. by Robert N. Bellah and Hans Joas. Cambridge (Massachusetts) 2012. Kuschel, Karl-Josef: Theodor Heuss, die Schoah, das Judentum, Israel: ein Versuch. Tübingen 2013. S. 251-256 u. ö. $\bullet$ One century of K. J' General Psychopathology. Ed. by Giovanni Stanghellini, Thomas Fuchs. Oxford 2013. • Hörner, Richard: K. J. und die Schuldfrage: Schuldfragen und fragwürdige Schuld. Bellheim 2014. Intellektuelle in Heidelberg (2014) S. 425 (Register). - K. J' philosophy and psychopathology. Ed. by Thomas Fuchs ... New York 2014. • Offener Horizont. Hrsg. von Matthias Bormuth. Jahrbuch der Karl JaspersGesellschaft (e. V. in Oldenburg). 2 Bde. Göttingen 2014-2015. Bakewell, Sarah: Das Café der Existenzialisten. Freiheit, Sein und Aprikosencocktails: mit Jean-Paul Sartre, Simone de Beauvoir, ..., K. J., Maurice Merleau-Ponty und anderen. Aus dem Engl. von Rita Seuß. München 2016. - Salomon, Reinhard: Auf der Grenze zwischen Religion und Wissenschaft, Philosophie und Theologie. Untersuchungen zur Position des Denkers bei K. J. und Paul Tillich. Marburg 2016. - Schibli, Sigfried: „Voller Hörsaal, Lust am Dozieren ...“ Auch ein Stück Basler Geschichte: Der Philosoph K.J. in seiner Korrespondenz in: Basler Zeitung (13. Aug. 2016) S. 14. - Kaegi, Dominic, Weidmann, Bernd: „Meine Hoffnung war, Deutschland möge ihn gewinnen“. K. J., der Erste Weltkrieg und die Philosophie in: UH während des Ersten Weltkriegs (2017) S. 99-121. Vom Ethos der Freiheit zur Ordnung der Freiheit. Staatlichkeit bei K. J. Hrsg. von KarlHeinz Breier, Alexander Gantschow. Baden-Baden 2017.

$P$ Bildarchiv UAH; graph. Slg. UBH; Ruperto Carola (1969).

\section{Jelke, Robert Johannes}

1919-1936, 1939-1946 Theol. Fak.

Systematische Theologie, Dogmengeschichte

* 31. März 1882 Frohse (Altmark; heute: Ortsteil von Schönebeck (Elbe))

$\dagger \quad$ o7. Juli 1952 Heidelberg ev.-luth.
V Robert Julius J. (1854-1915) Lehrer

M Alma Wilhelmine Sophie geb. Thieme (18611925)

( 28. Sept. 1909 Margarete geb. Schulz $\left({ }^{\star} 1886\right.$ $\dagger$ nach 1952)

K $1 \mathrm{~S}, 2 \mathrm{~T}$

$L b$ WS 1901/02 Studium der Theologie, Geschichte an U Halle-Wittenberg, seit SS 1902 Tübingen; 1905 I., 1907 II. theol. Prüfung in Dessau.

Dessau: 1908-1910 Hilfsprediger.

Saxdorf (bei Bad Liebenwerda; heute: Ortsteil von Uebigau-Wahrenbrück): 1910-1918 Pfarrer. • In dieser Zeit:

26. Jan. 1913 Lizentiatenprüfung an U Leipzig; 8. Okt. 1917 Dr. phil. an U Gießen.

U Halle-Wittenberg: Anfang 1919 Habilitation.

U Rostock: Seit April 1919 o. Prof.

UH: 16. Aug. 1919 Ern. zum o. Prof. am Wiss.-Theol. Seminar als Nachf. von Ludwig Lemme; WS 1919/ 20 Vorlesungsbeginn; 1935 Ruf an U Berlin abgelehnt; Mai 1936-31. März 1939 Beurlaubung von U, u. a. aufgrund e. Disziplinarverfahrens wegen Denunziation des Reichsstudentenführers Gustav Adolf Scheel (siehe Hachmeister, Lutz: Schleyer. Eine deutsche Geschichte. München 2004. S. 444 (Register); Prieschl, Martin: Der Gauleiter von Salzburg - G. A. Scheel (1907-1979) in: Loseblattsammelreihe $\mathrm{OeE}_{3} 8-45$ - Der Gauleiter von Salzburg ... (Juli 2016) Archiv Verlag Braunschweig) als Homosexuellen (außerdem ,sollte ich [R. J.] einen nationalsozialistischen Führer beleidigt und gesagt haben, ,die Juden kommen wieder in ihre Rechte '..." (aus: UAH B-3029/5), s. hierzu weiter UH im Nationalsozialismus (2006) S. 175f. Anm. 19 und S. 183 Anm. 93); WS 1936/37-WS 1938/39 Vertreter J.s: U-Dozent Lic. theol. Dr. phil. Helmut Thielicke (1908-1986; s. BBKL XI (1996) Sp. 11061113, TRE 33 (2002) S. 421-425); 1937 Widersetzung J.s gegen Beantragung seines Ruhestandes auf Aufforderung von Ministerium und U; 5. Nov. 1938 Freispruch durch Dienststrafkammer in Karlsruhe aufgrund nicht nachgewiesener Verleumdungsabsicht; 31. März 1946 Emeritierung. 
WS 1925/26-SS 1926, WS 1930/31-SS 1931, Okt. 1933-März 1934, April-Sept. 1934, Okt. 1934-März 1935 Dekan der Theol. Fak. der UH

1919-1932 Mitglied der Deutschnationalen Volkspartei

Siehe auch Anhang Sporteinrichtungen an $U H$ 1910-1933 und ihre Mitglieder

$\mathrm{Q} u$ UAH PA 248, 4378-4380; Fak.-Akte Theol. Fak. 97; B-3029/5; B-3029/17a. • GLA Abt. 235, Fasz. 2135-2141. • Auskunft: Universitätsarchiv HalleWittenberg.

$W$ Unter welchen Bedingungen können wir von religiöser Erfahrung sprechen? Halle/S. 1913. • Das Problem der Realität und der christliche Glaube. Eine Untersuchung zur dogmatischen Prinzipienlehre. Leipzig 1916. • Das religiöse Apriori und die Aufgaben der Religionsphilosophie. Gütersloh 1917. - Die Wunder Jesu. Leipzig 1922. • ReligionsPhilosophie. Leipzig 1927. - Vernunft und Offenbarung. Gütersloh 1932. - Eine heilige, allgemeine, christliche, deutsche Kirche. Leipzig 1941. Grundzüge der Religionspsychologie. Heidelberg 1948.

L RGG 3 ( $\left.{ }^{2} 1929\right)$ S. 65 (mit Werkverz.); Arnim 4 (1984) S. 735; BBKL III (1992) Sp. 20-22; Jansen (1992a) S. 166 (Register); Fix (1994) S. 126-130. • Wolfes, Matthias: Protestantische Theologie und moderne Welt. Berlin 1999. S. 292 und Anm. 113 u. ö. Personenlexikon zum dt. Protestantismus (2006) S. 124; UH im Nationalsozialismus (2006) S. 1258 (Register); Catalogus prof. Rostochiensium online. Bringeland, Hans: Religion und Welt: Martin Dibelius (1883-1947). Bd. 3: Dibelius im Dritten Reich und in der Nachkriegszeit. Berlin 2013. S. 12 Anm. 18, 50 und Anm. 169. Deutsche Biographie, s. https://www.deutsche-biographie. de/gnd117094706.html [07.11.2017].

$P$ Bildarchiv UAH.

\section{Jellinek, Georg}

1891-1911 Jur. Fak.

Allg. Staatsrecht, Völkerrecht, Politik

* 16. Juni 1851 Leipzig

$\dagger \quad$ 12. Jan. 1911 Heidelberg mosaisch, seit 1910 ev.-luth.

V Aron (später: Adolf) J. (1820-1893) Prediger und Oberrabbiner, Journalist, s. NDB 10 (1974) S. 391, Kempter (1998) S. 105-154, 256-26o u. ö., Georg Jellinek. Beiträge zu Leben und Werk (200o) S. 6o-65, 216-235

M Rosalie geb. Bettelheim (1832-1892)

๑ 17. Juli 1883 Camilla geb. Wertheim (18601940) 1900-1933 Leiterin e. Rechtsschutzstelle für Frauen und Mädchen in H, s. Kempter (1998) S. 626 (Register), Lexikon jüdischer Einwohner Hs (2011) S. 193; 1936 Verleihung des Dr. iur. h.c. UH, s. hierzu UAH H-II-867/ 2, H-II-868/4, B-1523/2; Nachlaß im Bundesarchiv Koblenz. - T von Gustav W. (18221888), u.a. seit 1865 Primararzt des neueröffneten Krankenhauses Rudolfstiftung und a.o. Prof. für Dermatologie und Syphilis Wien, s. WBIS, Kempter (1998) S. 198 Anm. 312, 198206

$\mathrm{K} 4 \mathrm{~S}$ (davon $2 \mathrm{~S}$ früh $\dagger$, s. Kempter, S. 248-250, 353 f.), u. a.: (siehe) Walter J.; 2 T: u.a. Dr. phil. Dorothea (Dora) Clara J. verh. Busch (Pseudonym: Eusebius Sandkorn) (1888-1992) Lehrerin, s. Kempter (1998) S. 623 (Register), Moraw (2008) S. 100 f., Ders. (2010) S. 197-222, Lexikon jüdischer Einwohner Hs (2011) S. 68-71

Vw Onkel: Herschel (später: Hermann) J. (18231848 hingerichtet) Journalist, Revolutionär, s. Kempter (1998) S. 25-98. • Geschwister: Emil J. (1853-1918) Geschäftsmann und Diplomat, s. Jellinek-Mercédès, Guy: Mein Vater - Der Herr Mercedes. Wien 1962; Kempter (1998) S. 358-364 u.ö. - Max Hermann J. (18681938) seit 1900 a.o. Prof., 1906-1934 o. Prof. für Dt. Sprache und Literatur Wien, s. Kempter, S. 294-300 u.ö., Int. Germanistenlexikon 2 (2003) S. 843 f., Riecke (2016) S. 43. - Siehe auch Kempter, S. 507-525. 
Lb Seit WS 1867/68 Studium der Philosophie, Geschichte, Rechtswiss. an U Wien, seit 14. Mai 1870 H, seit 1871 Wien, seit 1871/72 Leipzig; 19. Juni 1872 Dr. phil. an U Leipzig.

Wien: Dez. 1874-Jan. 1876 Concepts-Praktikant in der Statthalterei (e. Finanzaufsichtsbehörde); 1876 1879 Eigenstudien.

U Wien: 24. März 1874 Dr. iur. utr.; 1878 Gesuch um Habilitation wird zunächst von der Rechtsund Staatswiss. Fak. abgelehnt: J. habe noch „auf irgendeinem juristischen Gebiete Specialkenntnisse nachzuweisen“ (aus: Kempter (1998) S. 195 Anm. 297); 10. Juli 1879 Habilitation für Rechtsphilosophie; seit 8. Juni 1882 Lehrbefugnis für Allg. Staatsrecht und Völkerrecht; seit 9. Juni 1883 etatm. a.o. Prof. für Staatsrecht mit Lehrauftrag für Völkerrecht; 31. Aug. 1889 auf eigenen Antrag Austritt aus österr. Staatsdienst wegen Übergehung bei Ern. zum Ordinarius, s. hierzu Kempter, S. 250-253.

U Basel: 7. Dez. 1889 Ern. zum o. Prof. für Staatsrecht; SS 1890 Vorlesungsbeginn.

UH: Seit 11. Dez. 1890 o. Prof. als Nachf. von August von Bulmerincq; SS 1891 Vorlesungsbeginn; 24. April 1891 Vereidigung; 1891-1911 (†) Direktor des Staatswiss. Seminars als Nachf. von Bulmerincq.

1907 Prorektor der UH; 1896/97, 1903/04, Okt.Nov. 1909 Dekan der Jur. Fak. der UH

1902 Hofrat; 1905 Geh. Hofrat

E Mitglied der Akademie der Wissenschaften: Turin, 1909 H. • 1896 Ritterkreuz I. Klasse des Ordens vom Zähringer Löwen; 1901 OffizierEhrenkreuz des Fürstl. Hausordens zu Schaumburg-Lippe; 1907 Kommandeurkreuz III. Klasse des Ordens vom Weißen Elefanten (Siam); 1908 Ritterkreuz des Ordens Berthold I.

Qu UAH PA 1772; RA 251, 287, 6192, 6412, 6679, 6761f., 6772. • GLA Abt. 235, Fasz. 2142. • Briefe:
UBH. - Keller, Christian: Victor Ehrenberg und G. J. Briefwechsel 1872-1911. Frankfurt/M. 2005. • Mitteilungen von Familienangehörigen.

$W$ System der subjektiven öffentlichen Rechte. Freiburg/Br. 1892. Neudr. 1979. - Die Erklärung der Menschen- und Bürgerrechte. Leipzig 18951896. 4. Aufl. 1927. Allgemeine Staatslehre. Berlin 1900. 3. Aufl. 1914. Neudr. Bad Homburg vor der Höhe u.a. 1960. - Ausgewählte Schriften und Reden. 2 Bde. Berlin 1911. Neudr. 1970.

MHG Seit 1895 Staats- und völkerrechtliche Abhandlungen. - Seit 1902 Handbuch des öffentlichen Rechts. Seit 1908 Archiv für öffentliches Recht.

L NDB 10 (1974) S. 391f. (mit Werkverz.); Weisert (1991) S. 135 u. ö.; Jansen (1992a) S. 166 (Register); Dt. Juristen jüdischer Herkunft (1993) S. 355-368; Kempter (1998) S. 626 (Register). G Georg Jellinek. Beiträge zu Leben und Werk. Hrsg. von Stanley L. Paulson ... Tübingen 200o. Kistjakovskij, Bogdan A.: G.J. als Denker und Mensch (übers. von Alla Meissner) in: Heidelberger Professoren in russischer Sicht. Dokumente aus der Zeit um 1900. Hrsg. von Willy Birkenmaier. Heidelberg 2000. S. 76-84, 151f. - Asketischer Protestantismus (2005) S. 303 (Register). Jouanjan, Olivier: G. J. als Philosoph in: Rechtstheorie in rechtspraktischer Absicht ... Hrsg. von Ralph Christensen ... Berlin 2008. S. 135-154. • Zeiler (2009) S. 520 (Register). - Brugger, Winfried: G. J. als Sozialtheoretiker und Kommunitarist in: Der Staat - Zs. für Staatslehre und Verfassungsgeschichte ... Bd. 49, Nr. 3 (2010) S. 405-434. • Goller, Peter: „Für die Lehrkanzel des Staatsrechts werden ... einstimmig vorgeschlagen 1 loco ... G. J. ..." in: Ein Leben für Recht und Gerechtigkeit ... Festschrift für Hans R. Klecatsky. Hrsg. von Franz Matscher ... Wien 2010. S. 247-274. - Schroeder (2010) S. 739 (Register). - Danwerth, Christopher: Die prägenden Thesen und Ideen des G. J. in: Juristische Schulung. Zs. für Studium und Referendariat. München 2011. S. 406-410. - Bernstorff, Jochen von: G. J. and the origins of liberal constitutionalism in international law in: Goettingen journal of international law. Göttingen 2012. S. 659-675. - Brugger, Winfried: G. J.s Statuslehre in: Heidelberger Thesen zu Recht und Gerechtigkeit (2013) S. 227-254. • Faktizität 
und Normativität. G. J.s freiheitliche Verfassungslehre. Hrsg. von Winfried Brugger ... Tübingen 2016. Schroeder (2017) S. 209-233.

$P$ Bildarchiv UAH; graph. Slg. UBH; NDB; Kempter.

\section{Jellinek, Walter}

1929-1935, 1945-1955 Jur. Fak.

Öffentliches Recht

* 12. Juli 1885 Hütteldorf (heute: Teil des 14. Wiener Gemeindebezirks Penzing)

$\dagger \quad$ 09. Juni 1955 Heidelberg ev.

V (siehe) Georg J.

M Camilla geb. Wertheim (1860-1940), siehe ebd.

$\infty$ 3. April 1914 Irmgard Marie geb. Wiener (18911976)

K 2 S, 3 T, siehe Kempter (1998) S. 504-506 u. ö., Lexikon jüdischer Einwohner Hs (2011) S. 194.

Lb Seit WS 1903/04 Studium an UH, seit WS 1904/ O5 Freiburg/Br., WS 1905/06 Berlin, seit SS 1906 H; Herbst 1904-Herbst 1905 Militärdienstpflicht als Einjährig-Freiwilliger bei Feldartillerie in Freiburg; 1907 I. jur. Staatsprüfung.

Seit 29. April 1907 Rechtspraktikant am Amtsgericht in $\mathrm{H}$, anschl. am Großherzogl. Bezirksamt in Schwetzingen; Jan.-Juni 1908 Beurlaubung für Promotionsvorbereitung; 21. Mai 1908 Dr. iur. an U Straßburg.

Volontär: Seit 1. März 1909 Schwetzingen, seit 1. Jan. 1910 H; März 1910-Juni 1910 Hilfsarbeiter bei Stadtverwaltung in Freiburg/Br.

Karlsruhe: 31. März 1911 II. Staatsexamen; seit 1. April 1911 Gerichtsassessor am badischen JustizMinisterium.

U Leipzig: 12. Okt. 1912 Habilitation; Okt. 1912 Beginn seiner Vorlesungen als Privat-Dozent.
U Kiel: Seit 22. Okt. 1913 etatm. a.o. Prof.; seit 3. April 1919 o. Prof. - In dieser Zeit:

1914-1918 Kriegsdienst.

UH: 26. Nov. 1928 Ern. zum o. Prof. und Direktor des Jur. Seminars als Nachf. von Richard Thoma; SS 1929 Beginn seiner Vorlesungen; 10. Mai 1929 Vereidigung; u. a. Mai 1935 Vorlesungsboykott durch nationalsozialistisch gesinnte Fachschaftsvertreter; seit 1. Juli 1935 Beurlaubung von Lehrtätigkeit aus rassischen Gründen; 30. Okt. 1935 J. stellt erfolgloses Emeritierungsgesuch; 1. Jan. 19367. Sept. 1945 Zwangsruhestand; April-Dez. 1945 Mitglied des Dreizehnerausschusses zum Wiederaufbau der U; 14. Sept. 1945-9. Juni 1955 (†) (zum 30. Sept. 1955 war Emeritierung vorgesehen) o. Prof. und Direktor des Jur. Seminars; 1947-1955 URichter mit Disziplinargewalt über Studenten. • In dieser Zeit:

Karlsruhe: 1947-1955 Nebenamtl. o. Mitglied des Verwaltungsgerichtshofs Württemberg-Baden.

1929/30, 1. Okt. 1932-26. April 1933, 1946/47 Dekan der Jur. Fak. der UH

$\mathrm{Zu} \mathrm{J.s} \mathrm{Engagement} \mathrm{nach} 1945$ für den politischen und universitären Wiederaufbau, u.a. als Vorsitzender des Vereins „Studentenhilfe“, siehe Kempter (1998) S. 526-538

E Mitglied des Institut int. de droit public Paris.

Qu UAH PA 766, 4381f.; B-0747/1 vom 14. Aug. 1947. - Briefe: UBH. - W. J. - Carl Schmitt: Briefwechsel 1926 bis 1933. Hrsg. von Reinhard Mehring in: Schmittiana (2014) N. F. Bd. 2. S. 87-117. Mitteilungen von Familienangehörigen.

$W$ Der fehlerhafte Staatsakt und seine Wirkungen. Tübingen 1908. Nachdr. 1974. - Gesetz, Gesetzesanwendung und Zweckmäßigkeitserwägung. Tübingen 1913. Neudr. 1964. - Verwaltungsrecht. Berlin 1928. 2. Neudr. 1966. Die zweiseitigen Staatsverträge über Anerkennung ausländischer Zivilurteile. Berlin 1953. 
L NDB 10 (1974) S. 394 f. (mit Werkverz.); Mussgnug (1988) S. 58-61 u. ö.; Jansen (1992) S. 410 (Register); Ders. (1992a) S. 166 (Register); Ders. (1996). - Kempter (1998) S. 626 (Register); Ders.: Biographie und Typisierung ... „Die Jellineks“ in: Heidelberg. Jahrbuch zur Geschichte der Stadt 2000. Heidelberg 2000. Jg. 5. S. 332-335. • Pasemann, Birthe: W. J. und der Nationalsozialismus ... in: Kritische Justiz: Vierteljahresschrift für Recht und Politik. Baden-Baden 2005. S. 418-433. Baur (2009) S. 242-244; Hofer (2010) S. 187-189 u. ö.; Schroeder (2010) S. 739 (Register); Lexikon jüdischer Einwohner Hs (2011) S. 193f. • Leo, Paul Christopher: Wilhelm Groh ... Hamburg 2012. S. 131f. - Axer, Peter: Otto Mayer, W. J., Ernst Forsthoff und das Recht der öffentlichen Sachen in: Heidelberger Thesen zu Recht und Gerechtigkeit (2013) S. 267-285; Kahl, Wolfgang: W. J. und die schlichte Hoheitsverwaltung in: ebd. S. 345374. - Wiener, Christina: Kieler Fakultät und „Kieler Schule“. Die Rechtslehrer an der rechts- und staatswissenschaftlichen Fakultät zu Kiel in der Zeit des Nationalsozialismus und ihre Entnazifizierung. Baden-Baden 2013. S. 311 u. ö. - Spenkuch (2016) S. 1314 (Register); Schroeder (2017) S. 289-312.

\section{$P$ Bildarchiv UAH; NDB.}

\section{Jolly, Julius August Isaak}

1847-1861 Jur. Fak.

Staatsrecht; 1849-1861 auch Badisches Landrecht

* 21. Febr. 1823 Mannheim

$\dagger$ 14. Okt. 1891 Karlsruhe ev.

V Louis J. (1780-1853) Kaufmann, 1836-1849 I. Bürgermeister von Mannheim

M Marie Eleonore geb. Alt (1786-1859)

$\infty$ 18. Dez. 1852 Elisabeth geb. Fallenstein (18271901) Großtante von: (siehe) Alfred und Max Weber

K 2 T, 2 S: u. a. Julius J. (1856-1898), u. a. Staatsanwalt, seit 1895 Journalist, siehe Badische Biographien 5 (1906) S. 352-354
Vw Bruder: (siehe) Philipp (von) J. $\bullet$ Onkel: Isaac J. (1785-1852) 1835-1847 badischer Justizminister, s. Badische Biographien 1 (1875) S. $425 \mathrm{f}$., WBIS. - Neffen: (Siehe) Philipp (von) J.: Eintrag unter $K$ [inder].

Lb Seit WS 1840/41 Studium an UH, seit Herbst 1842 Berlin, seit WS 1843/44 H; Mai 1845 II. Staatsprüfung in Karlsruhe; seit 14. Juni 1845 Rechtspraktikant am Bezirksamt in Mannheim; 11. Juni 1845 Dr. iur. an UH.

Eigenstudien: Seit Sommer 1846 an U Leipzig, seit Herbst 1846 Bonn.

UH: 10. Juli 1847 Habilitation; 1848-1849 Flucht und Aufenthalt in Auerbach (heute: Bensheim-A.) vor Konskription; seit 8. Mai 1857 a. o. Prof.; SS 1861 letzte Vorlesungsankündigung.

Karlsruhe: Seit April 1861 Reg.-Rat, seit Juli 1862 Ministerialrat, Juli 1866-Febr. 1868 Präsident des Innenministeriums; 1868-1876 (Entlassung auf eigenen Antrag) Staatsminister der badischen Regierung; seit 30. Sept. 1876 Präsident der Oberrechnungskammer in Nachfolge von (siehe) Robert von Mohl; 1878 J. lehnt Stelle als Leiter des Finanzreferats im Reichskanzleramt in Berlin ab. • In dieser Zeit:

Karlsruhe: 1861-1868 Mitglied der I. Kammer, 1869-1876 Mitglied der II. Kammer des Badischen Landtags; seit 1866 auch Mitglied des Verwaltungsgerichtshofs.

E 1886 Dr. med. h.c. UH. 1869 Kommandeurkreuz I. Klasse des Ordens vom Zähringer Löwen; 1870 Königl. Preußischer Roter Adler-Orden I. Klasse; 1876 Großkreuz des Ordens vom Zähringer Löwen mit der goldenen Kette.

Qu UAH PA 1778; Fak.-Akte H-II-111/4O fol. 282r. • Briefe: UBH.

$W$ Über das Beweisverfahren nach dem Rechte des Sachsenspiegels. Heidelberg 1846. - Die badischen Gesetzentwürfe über die kirchlichen Verhältnisse. Heidelberg 1860. - Polizeistrafgesetzbuch und Gesetz über Gerichtsbarkeit und 
Verfahren in Polizeistrafsachen für Baden. $2 \mathrm{~T}$. Heidelberg 1867. (Mitverf.)

$L$ Hausrath, Adolf: Zur Erinnerung an J. J. Leipzig 1899. Knebel, Frieda, Kilian, Walter (Bearb.): Liste der Nachkommen des Jean Joly aus St. Denis les Rebais en Brie. Berlin 1937. S. 16 f. • NDB 10 (1974) S. 589-591; WBIS; Schroeder (2010) S. 202-204. Lepsius, Rainer M.: Max Weber und seine Kreise. Essays. Tübingen 2016. S. 174-176 u. ö.

$P$ Bildarchiv UAH; graph. Slg. UBH; NDB

Jolly, Johann Philipp Gustav (seit 1854: von Jolly)

1834-1854 Phil. Fak.

Mathematik, Physik

* 26. Sept. 1809 Mannheim

$\dagger$ 24. Dez. 1884 München ev.

V Louis J. (1780-1853) Kaufmann, 1836-1849 I. Bürgermeister von Mannheim

M Marie Eleonore geb. Alt (1786-1859)

( 1. Okt. 1839 Luise geb. Wüstenfeld (1821-1874), s. Briefe in UBH. - Schwester von Apollonia W. (1814-1843) Mutter von: (siehe) Theodor Leber

K 1 T, 5 S: u.a. Ludwig J. (1843-1905) 1872-1905 Prof. für Verwaltungsrecht Tübingen, s. WBIS, Wirtschaftswiss. Fak. Tübingen 1 (2004) S. 282285 u. ö. Friedrich J. (1844-1904) seit 1871 Privat-Dozent Würzburg, seit 1873 a.o. Prof. und seit 1875 o. Prof. Straßburg, seit 1890 o. Prof. für Psychiatrie und Nervenheilkunde Berlin, s. Arnim 1 (1944) S. 615, WBIS ( $P$ in Bildarchiv UAH). • Julius J. (1849-1932) U Würzburg: seit 1872 Privat-Dozent, seit 1877 a.o. Prof., 18861920 (Ruhestand) o. Prof. für Vgl. Sprachwissenschaften und Sanskrit, s. NDB 7 (1966) S. 591-607, Arnim 4 (1984) S. 745, WBIS

Vw Bruder: (siehe) Julius J. • Onkel: Isaac J. (17851852) 1835-1847 badischer Justizminister, s. Badische Biographien 1 (1875) S. 425 f., WBIS.
Lb Seit WS 1829/30 Studium der Mathematik, Physik an UH, anschl. Wien, Berlin.

UH: 20. Juni 1834 Dr. phil.; 7. Aug. 1834 Habilitation für Mathematik, Physik, Technologie; seit 14. Nov. 1839 a. o. Prof. für Mathematik mit e. jährl. Besoldung von 8oo.- Gulden; J. hält auch Vorlesungen über Physik; seit 29. Sept. 1846 o. Prof. für Physik und provisorischer Direktor des Physikal. Kabinetts mit e. jährl. Besoldung von 10oo.- Gulden und 400.- Gulden Mietzinsentschädigung; seit Okt. 1847 Direktor des genannten Kabinetts als Nachf. von Georg Wilhelm Muncke.

U München: WS 1854/55-SS 1884 Ordinarius für Physik.

Frankfurt/M.: 1861 Bayer. Bevollmächtigter in der Bundesversammlung.

1853 Dekan der Phil. Fak. der UH

1869-1884 (Gründungs-)Präsident der Münchner Geographischen Gesellschaft

1864 Konstrukteur u.a. einer Federwaage zur Bestimmung der Dichte fester, nicht wasserlöslicher Substanzen sowie 1879 /80 einer Bleikugel zur Bestimmung der Dichte der Erde, s. hierzu Soffel, Heinrich: „Er legte die Erde auf die Waage“. Der Physiker P. ... J. in: „Dem Geist alle Tore öffnen“. König Maximilian II. von Bayern und die Wissenschaft. Hrsg. von Ulrike Leutheusser ... München 2009. S. 93-104.

Geheimrat

E Mitglied der Akademie der Wissenschaften: 1856 München, 1864 Göttingen.

Qu UAH PA 1779; Fak.-Akten H-IV-102/30 fol. 84r, 87r; GF 19. • Briefe: UBH. • Nachlaß: GLA Karlsruhe.

W Principien der Mechanik. Stuttgart 1852. Die Physik der Molecularkräfte. München 1857. • Die Anwendung der Waage auf Probleme der Gravitation in: Abh. der Bayer. Akad. der Wiss. München. Math.-Physikal. Kl. XIII. Bd., I. Abt. (1878); 
Die Veränderlichkeit in der Zusammensetzung der atmosphärischen Luft in: ebd. XIII. Bd., II. Abt. (1879).

L Knebel, Frieda, Kilian, Walter (Bearb.): Liste der Nachkommen des Jean Joly aus St. Denis les Rebais en Brie. Berlin 1937. S. 15f. • NDB 10 (1974) S. 592; Homo Heidelbergensis mathematicus online. - Lohmann, Fritz: Unsere Vorfahren Jolly und Böhm. Stammtafeln, Notizen und Bilder. Eigenverlag. Bergisch-Gladbach 2009. - WBIS; Stumm (2012) S. 697 (Register).

\section{Jordan, Max}

1893-1909 Med. Fak.

Chirurgie

* 27. Mai 1864 Mannheim

$\dagger \quad$ 23. Nov. 1909 Heidelberg

mosaisch, später ev.

V Julius J. (1826-1899) Kaufmann, später Privatmann

M Maria geb. Levino $\left({ }^{*} 1841 \dagger\right.$ nach 1899$)$

$\infty$ 28. Febr. 1895 Frida geb. Fleischmann $\left({ }^{*} 1873\right)$

K $2 \mathrm{~S}$

Lb Seit WS $1882 / 83$ Studium an UH, SS 1885 Straßburg, WS 1885/86-SS 1886 H; Febr. 1887 Staatsexamen in H; Juli 1887 Dr. med. an UH.

Sept. 1887-Sept. 1888 Militärdienstpflicht als Einjährig-Freiwilliger, u.a. im 2. badischen Grenadier-Regiment; Okt.-Nov. 1888 Unterarzt-Übung in Rastatt.

UH: Seit Nov. 1888 Volontärarzt, WS 1890/91-WS 1894/95 klinischer Assistenzarzt an Chirurg. UKlinik; 5. Mai 1893 Habilitation; SS 1895-WS 1899/ 1900 Assistenzarzt an klinischer Ambulanz der Chirurg. U-Klinik als Nachf. von Georg Schmidt; seit 2. Jan. 1897 nichtetatm. a. o. Prof.; seit WS 1907/ o8 Chirurg, seit SS 1908 Leiter der Chirurg. Abt. der U-Kinderklinik Luisen-Heilanstalt als Nachf. von Hermann Lossen. • In dieser Zeit:
H: Seit 1900 Leiter einer Chirurg. Privat-Klinik (Kaiserstraße 8).

Qu UAH PA 1782. • Briefe: UBH.

$W$ Die Entwicklung der modernen Wundbehandlung. Heidelberg 1893. - Die akute Osteomyelitis mit besonderer Berücksichtigung ihres Verhältnisses zu den pyogenen Infektionen aufgrund klinisch-bakteriologischer Beobachtungen ... Tübingen 1893 .

$L$ Marwedel, Georg: M. J. † in: Münchener Medizinische Wochenschrift 57 (1910) S. 142 f. • Stübler (1926) S. 320; Arnim 1 (1944) S. 618; Fischer 1 $\left({ }^{3} 1962\right)$ S. 721; WBIS. - Leier, Wolfgang Andreas: Der Anteil Heidelbergs an der Entwicklung der Magenchirurgie. Diss. Heidelberg 1977. - Chronik Ärzte H (1985) S. 132; Jansen (1992a) S. 166 (Register); Deutsche Biographie, s. https://www. deutsche-biographie.de/gnd117656003.html [07.11. 2017].

P Bildarchiv UAH; Chronik Ärzte H.

\section{Jost, Gustav August Ludwig}

1919-1934 Nat.-Math. Fak.

Botanik

* 13. Nov. 1865 Karlsruhe

$\dagger \quad$ 22. Febr. 1947 Heidelberg

prot.

V Ludwig J. ( $\left.{ }^{*} 1826\right)$ Kaufmann

M Lina geb. Kammerer (1837-1919)

œ 20. Sept. 1894 Katharina geb. Reye (1869-1963)

$\mathrm{K} \quad 1 \mathrm{~S}, 4 \mathrm{~T}$

Lb WS 1883/84 Studium an UH, seit SS 1884 Straßburg; 9. Febr. 1887 Dr. phil. an U Straßburg; seit April 1887 Assistent am Botanisch-Pharmakognostischen Inst. der U Marburg.

U Straßburg: Seit Okt. 1887 Assistent am Botanischen Inst.; 20. Febr. 1891 Habilitation; seit 16. März 1894 a. o. Prof. 
Landwirtschaftl. Akademie (Bonn-)Poppelsdorf: Seit 6. Aug. 1907 etatm. a. o. Prof.

U Straßburg: Seit 15. Jan. 1908 o. Prof.; 1918 nach franz. Besetzung Elsaß-Lothringens Ausweisung.

UH: Seit 2. Jan. 1919 o. Prof. und Direktor des Botanischen Inst. (in der Bergheimer Straße 1) und Gartens im Neuenheimer Feld als Nachf. von Georg Klebs; Rufe an U abgelehnt: 1921 Erlangen, Marburg; 30. März 1934 Emeritierung.

1922/23, 1925/26 Dekan der Nat.-Math. Fak. der $\mathrm{UH}$

E Korr. Mitglied: Linnean Society London, Botanic Society Edinburgh, Botanic Society of America; Mitglied der Akademie der Wissenschaften: 1919 (1937 Austritt) H, 1925 Berlin, 1932 München; 1935 Mitglied der Dt. Akademie der Naturforscher Leopoldina Halle/S.

Qu UAH PA 4403f. • Briefe: UBH.

$W$ Vorlesungen über Pflanzenphysiologie. Jena 1904. 4. Aufl. 1923. (Mitverf.) • Führer durch den Botanischen Garten in Heidelberg. Heidelberg 1922. Die Entstehung der großen Entdeckungen in der Botanik. Heidelberg 1930.

MHG 1909-1920 Botanische Zeitung.

Mitbearb. Lehrbuch der Botanik für Hochschulen. 10.-16. Aufl. Jena 1910-1923.

L L. J. in: Overbeck, Fritz: Berichte der Dt. Botanischen Gesellschaft (1956) 68a, 2, S. 157-163. Verzeichnis Bonn (1968) S. 136; NDB 10 (1974) S. 630 f. (mit Werkverz.); Jansen (1992a) S. 166 (Register); WBIS; Leins (1994) S. 6of.; Wennemuth (1994) S. 635 (Register).

$P$ Bildarchiv UAH.

\section{Jung, Karl August}

1895-1898 (Lehrbeauftragter) Med. Fak.

1898-190o Med. Fak.

Zahnheilkunde

* 30. Juli 1868 Wetzlar

$\dagger$ 26. Aug. 1944 Berlin ev.

V Wilhelm J., Kaufmann

M Marie Amalie geb. Münch

$\infty$ unbekannt.

Lb U Berlin: Seit WS 1888/89 Studium; SS 1891-SS 1895 Assistent für konservierende Zahnheilkunde am Zahnärztl. Inst.; 20. Dez. 1892 Dr. med.; 1893/ 94 Studienreise in die USA.

UH: 16. Mai 1895 Erteilung e. Lehrauftrags für Zahnheilkunde; seit 1. Okt. 1895 Leiter des neugegründeten Zahnärztl. Inst. an Chirurg. U-Klinik; z. B. WS 1896/97 Vorlesungen über: Zahnärztl. Poliklinik (Extractionsübungen), Plombiercursus, Cursus der zahnärztl. Technik, Theoretische Zahnheilkunde (aus: Anzeige der Vorlesungen, welche im Winter-Halbjahr 1896/1897 auf der ... Universität zu Heidelberg gehalten werden sollen. Heidelberg 1896. S. 11); 24. Nov. 1898 Verleihung des Titels „Prof.“; 29. Mai 1900 auf eigenen Antrag Weggang von $\mathrm{U}$.

Berlin: 1900-1944 (?) Private Zahnarztpraxis. • In dieser Zeit:

1914-1918 Kriegsdienst.

E Ehrenmitglied der Dt. Zahnärzteschaft.

Qu UAH PA 1791. • GLA Abt. 235, Fasz. 2146. • Ergebnislose Anfragen: Archiv der HumboldtUniversität Berlin; Stadtarchive Heidelberg und Wetzlar. - Auskunft: Gemeindeverband Ev. Kirchengemeinden in Wetzlar.

$W$ Lehrbuch der zahnärztlichen Technik. Wien 1897. 3. Aufl. 1907. Anatomie und Pathologie der Zähne und des Mundes ... Wien 1898. • Das Fül- 
len der Zähne und die verwandten Arbeiten. Wien 1905. Laboratoriumskunde des Zahnarztes. Berlin 1905. 2. Aufl. 1921.

$L$ WBIS; Stübler (1926) S. 326; Fischer $1\left({ }^{3} 1962\right)$ S. 728; Chronik Ärzte H (1985) S. 132; Bauer/ Langsch (1991) S. 378-380 online. - 110 Jahre Zahnärztliches Institut Berlin 1884-1994. Festschrift. Hrsg.: Zentrum für Zahnmedizin Berlin. Berlin 1994. S. 26. Kristen (1996) S. 219 f. • Über K. J. in: Grzelkowski, Elke Rita: Friedrich Carl Ferdinand Busch (1844-1916), der erste Direktor des Zahnärztlichen Institutes der Friedrich-WilhelmsUniversität zu Berlin. Diss. Berlin 1998. S. 57 f. u. ö.

P Kristen (1996) S. 222.

\section{Jurasz, Anton Stanislaus}

1877-1908 Med. Fak.

Laryngologie

* 24. Nov. 1847 Spławie (bei Posen, Preußen; heute: Polen)

$\dagger$ 12. Aug. 1923 Posen (heute: Poznań) kath.

V Lorenz J. (1821-1894) Lehrer

M Anna geb. Przyjemska verw. Gawronska (18151893)

๑ 6. Sept. 1879 Carolina geb. Gaspey (1859-1940) T von Dr. phil. (UH) Thomas G. (1811-1871), u. a. 1850-1871 Privat-Dozent UH, s. EmundtsTrill (1997) S. 274f. (S. 274: Geb.-Datum 1811 irrtümlich verwechselt mit dem des Vaters 1788); Enkelin von Thomas G. (1788-1871) engl. Schriftsteller und Journalist, s. The Encyclopedia of Romantic Literature. General Editor: Frederick Burwick ... Vol. 1. Chichester 2012. S. $494 \mathrm{f}$.

K 4 T, 4 S: u.a. Anton Thomas Alexander J. (1882-1961), u. a. 1920-1939 (Emigration) Prof. für Chirurgie U Posen, seit 1940 U of Edinburgh, 1947 Emigration in die USA, s. WBIS; Magowska, Anita: A doctor facing turbulent times: Antoni Tomasz J., citizen of the world in: World Journal of Surgery 35 (2011) S. 21672171; Skolaut (2013) S. 134.
Lb Seit WS 1867/68 Studium an U Greifswald, anschl. Würzburg.

Greifswald: 14. März 1872 Approbation; 15. Aug. 1871 Dr. med. an U.

UH: Okt. 1872-April 1878 Assistent an Med. UPoliklinik; 16. Jan. 1877 Habilitation; WS 1877/781908 Leiter der Ambulatorischen Klinik für Kehlkopf-, Rachen- und Nasenkranke; seit 13. März 188 o a. o. Prof.; seit 23. Juli 1902 etatm. a. o. Prof. • In dieser Zeit:

H: 1878-1908 Niederlassung als praktischer Arzt.

U Lemberg (heute: Lwiw, Ukraine): Seit 1. Okt. 1908 o. Prof. und Mitbegründer der Klinik für Otolaryngologie.

U Posen: 1919-1920 (Ruhestand) o. Prof. an neugegründeter Adam-Mickiewicz-U und Organisator der Klinik für Laryngologie.

E 1902 Ritterkreuz I. Klasse des Ordens vom Zähringer Löwen; 1906 Friedrich-Luisen-Medaille.

Qu UAH PA 1794; RA 6319, 6795; Quästurakte Rep. 27-667. GLA Abt. 235, Fasz. 2147. Auskunft: Stadtarchiv Heidelberg. - Mitteilungen: Frau Arletta Juszkow, Bydgoszcz; Frau Eva und Herr Roman Bartwicki, Bad Vilbel.

$W$ Das systolische Hirngeräusch der Kinder. Heidelberg 1877. - Laryngoskopia i choroby krtani. Krakau 1878. Die Krankheiten der oberen Luftwege. Heidelberg 1891. - Geschichte der Laryngologie an der Universität Heidelberg. Würzburg 1908.

L Almanach Heidelberg (1886) S. 122; Pagel (1901) Sp. 833-834; Stübler (1926) S. 324; Arnim 1 (1944) S. 622. Schwab, Werner und Ey, Werner: Heidelberg als Wiege der vereinigten Oto-Rhino-Laryngologie und deren Geschichte in: Ruperto Carola 7. Jg., Nr. 18 (1955) S. 107-115. - Fischer $1\left({ }^{3} 1962\right)$ S. 730. - Ergetowski, Ryszard: Akta personalne Prof. Antoniego Stanislawa Jurasza w Heidelbergu 
i Karlsruhe in: Archiwum historii medycyny (1983) Bd. 46, H. 2, S. 215-235. • Chronik Ärzte H (1985) S. 132, 234; WBIS. - Boenninghaus, Hans-Georg: Hals-Nasen-Ohrenheilkunde im Wandel der Zeit in: Heidelberger Jahrbücher 33 (1989) S. 61-77. • Lehrstätten der Oto-Rhino-Laryngologie (1996) S. 157 f. (hier irrtümlich: Juracz statt Jurasz). • Lübbers, Wolf und Lübbers, Christian W.: Historische HNO-Instrumente und ihre Namensgeber. T. 1: "Too good to be forgotten" in: HNO-Nachrichten 43,3 (2013) S. 48 f. - Skolaut, Gabriela: Polnische Spuren in Heidelberg in: Heidelberg. Jahrbuch zur
Geschichte der Stadt 2014. Heidelberg 2013. Jg. 18. S. 131-134. Deutsche Biographie, s. https://www. deutsche-biographie.de/gnd118985051.html [07.11. 2017]. 80 lat Szpitala Uniwersyteckiego nr 1. im. dr. Antoniego Jurasza w Bydgoszczy. Śladami historii 1937-2017. Zespół redakcyjny Mieczysław Boguszyński, Arletta Juszkow ... Bydgoszcz 2017. (Dt. Übers.: 80 Jahre Dr. Anton Jurasz Universitätsklinikum Nr. 1 in Bromberg. Auf den Spuren der Geschichte 1937-2017.) S. 7-14 (P).

$P$ Bildarchiv UAH; graph. Slg. UBH; Ruperto Carola; Chronik Ärzte H. 


\section{Kaiser}

siehe auch Kayser

\section{Kahle, Bernhard Hermann}

1892-1910 Phil. Fak.

Germanische Philologie

* 25. Aug. 1861 Berlin

$\dagger \quad$ 09. Dez. 1910 Heidelberg

ev.

V Konrad K., Kreisgerichtsrat

M Rosalie geb. von Vormann

$\infty$ unverheiratet.

Lb SS 1881-SS 1886 (mit Unterbrechungen) Studium an UH, WS 1881/82 und SS 1884 Berlin.

UH: 7. Juli 1886 Dr. phil., s. hierzu UAH H-IV-102/ 112 fol. 286r-298v; 27. Febr. 1892 Habilitation; u.a. Sommer 1897 Studienreisen nach Dänemark und Island; seit 27. Mai 1898 a. o. Prof.; seit WS 1908/o9 Lehrauftrag für Skandinavische Philologie, Germanische Mythologie und Dt. Volkskunde.

Qu UAH PA 1795; Fak.-Akten H-IV-102/112 fol. 286r-298v, H-IV-102/113 fol. 286r; RA 6610.

$W$ Die Sprache der Skalden auf Grund der Binnen- und Endreime ... Strassburg 1892. • Altisländisches Elementarbuch. Heidelberg 1896. 2. Aufl. 1913. Nachdr. München 2015. • Isländische geistliche Dichtungen des ausgehenden Mittelalters. Heidelberg 1898. • Ein Sommer auf Island. Berlin 1900. Altwestnordische Namenstudien. Strassburg 1903.

L Badische Biographien 6 (1935) S. 691 f.; Arnim 1 (1944) S. 625; WBIS; Lehmann (1967) S. 230. • Handbuch der historischen Buchbestände in Deutschland. Hrsg. von Bernhard Fabian. Hildesheim 2003. - Riecke (2016) S. 38 f., 44, 76, 125; Deutsche Biographie, s. https://www.deutsche-bio graphie.de/gnd11602111X.html [07.11.2017].

$P$ Bildarchiv UAH; graph. Slg. UBH.

Kaiser, Karl (bis 7. Mai 1886: Nathan, Karl)

1893-1901 (1902) Med. Fak.

Physiologie

* 19. Dez. 1861 Hamburg

$\dagger \quad$ ca. 1933 Berlin

mosaisch, später konf.-los

V Wilhelm Nathan ( $\dagger$ 1887) Kaufmann

M N.N.

๑ 24. März 1888 Marie geb. Kohner $\left({ }^{\star} 1865\right)$

$\mathrm{K} \quad 2 \mathrm{~S}$

Lb UH: SS 1881 Immatrikulation als Karl Nathan aus Hamburg zum Studium der Philosophie.

Leipzig: 20. Okt. 1883-15. Juli 1887 Studium der Medizin an U; 4. Jan. 1888 med. Staatsexamen; 28. Febr. 1888 Dr. med. an U.

Hamburg: Seit 1888 approbierter Arzt.

H: Seit 1891 Wohnsitz.

UH: 2. März 1893 Habilitation; seit 5. Febr. 1897 nichtetatm. a. o. Prof.; 20. April 1901 K. „richtet die ergebene Bitte (an den Dekan der medizinischen Facultät), ihn wegen Fertigstellung einer größeren literarischen Arbeit von der Abhaltung der für dieses Semester [SS 1901] angekündigten Vorlesung dispensiren zu wollen" (aus: UAH PA 1797); 15. Okt. 1901 Urlaubsgesuch für zwei weitere Semester: „Von einer Berliner Elektrizitäts-Gesellschaft sind dem Unterzeichneten [K. K.] reiche Mittel zur Verfügung gestellt worden, um eine Reihe von Untersuchungen auszuführen, die an Resultate seiner biologischen Arbeiten anknüpfen und gewisse, die Elektrotechnik interessirende Probleme berühren. Dem Unterzeichneten ist dadurch ausgezeichnete Gelegenheit geboten, seine Kenntnisse und Erfahrungen auf dem Gebiete der Elektrochemie zu erweitern, was ihn später bei Wiederaufnahme seiner akademischen Thätigkeit von größtem Nutzen sein wird“ (aus: PA 1797); 10. Mai 1902 Engerer Se- 
nat lehnt K.s Gesuch um Verlängerung seines Urlaubs bis Ende des SS 1902 ab; 28. Mai 1902 „Die Mittheilung ..., dass die medizinische Facultät resp[ektive] der engere Senat mir einen weiteren Urlaub verweigert, bestimmt mich, die mir 1893 ertheilte venia legendi niederzulegen ..." (aus: PA 1797).

Berlin: Seit 1901 Mitarbeiter bei e. Elektrizitäts-Gesellschaft.

Qu UAH PA 1797; Fak.-Akte H-III-111/118. • Briefe: UBH. - Ergebnislose Anfragen: Geheimes Staatsarchiv - Preußischer Kulturbesitz - Berlin (PA-Akte); Historisches Archiv (hier: AEG-Archiv) Stiftung Dt. Technikmuseum Berlin; Siemens-Archiv, München; Bundesarchiv Referat R 3, Berlin (hier: Deutsch-Überseeische Elektrizitäts-Gesellschaft); Bundesarchiv Koblenz (hier: Deutsch-Überseeische Elektrizitäts-Gesellschaft); Staatsarchiv Hamburg (Geburtenbücher der Deutsch-Israelitischen Gemeinde Hamburg Jahrgang 1861) und Sterbebücher der hamburgischen Standesämter 1886-1900. - Auskunft: Universitätsarchiv Leipzig.

$W$ Untersuchungen über die Ursache der Rhythmicität der Herzbewegungen. München 1893.

Bearb. Halliburton, William Dobinson: Lehrbuch der chemischen Physiologie und Pathologie. Heidelberg 1894.

L Stübler (1926) S. 310; WBIS; Deutsche Biographie, s. https://www.deutsche-biographie.de/gnd11 6034653.html [07.11. 2017].

$P$ Bildarchiv UAH; graph. Slg. UBH.
Kallius, Erich Wilhelm Heinrich (bis 1870: Kuckuck)

1921-1935 Med. Fak.

Anatomie

* 03. Aug. 1867 Berlin

$\dagger \quad$ o1. Jan. 1935 Heidelberg ev.

V Prof. Dr. Albert Gottlob Samuel Kuckuck (ev.; 1870 Namensänderung in Kallius) (1840-1918) Studienrat, Oberlehrer am Königl. Gymnasium Berlin

M Anna Malwine Mathilde geb. Blume (18421917)

๑ 17. Sept. 1896 Gertrude geb. Giesinger (18711965)

K $2 \mathrm{~S}$

Lb Seit WS 1885/86 Studium an U Freiburg/Br., anschl. Berlin.

Berlin: 1891 Staatsexamen; 27. Febr. 1892 Dr. med. an $\mathrm{U}$.

U Göttingen: Seit 1. April 1892 Assistent am Anatom. Inst.

U Gießen: April-Sept. 1894 Prosektor am Anatom. Inst.

U Göttingen: 1. Okt. 1894-31. März 1907 Prosektor am Anatom. Inst.; 18. Okt. 1894 Habilitation für Anatomie; seit 20. Dez. 1895 nichtetatm. a. o. Prof.

U Greifswald: 1. April 1907-31. März 1917 o. Prof. • In dieser Zeit:

1914-1916 Kriegsdienst.

U Breslau: Seit 1. April 1917 o. Prof.

UH: Seit 26. Juli 1921 o. Prof. und Direktor des Anatom. Inst. als Nachf. von Hermann Braus; 10. Dez. 1921 Vereidigung; abgelehnte Rufe an U: Freiburg/Br., Göttingen, Königsberg (Preußen). 
1924 Rektor der UH; 1922/23, 1930/31, 26. April 1932-30. Sept. 1933, 1933/34, 1934/35 Dekan der Med. Fak. der UH

1917 Geh. Medizinalrat

$E$ Mitglied der Akademie der Wissenschaften: 1919 Uppsala, 1922 Göttingen, 1922 H; 1926 Mitglied der Dt. Akademie der Naturforscher Leopoldina Halle/S. • 1913 Königl. Preußischer Roter Adler-Orden IV. Klasse.

Qu UAH PA 1001, 4429; Quästurakten Rep. 27-533, Rep. 27-683; Fak.-Akte H-III-621/1; B-1211; F-II5230-11/9; Handakte HAW Nr. 241. GLA Abt. 235, Fasz. 2151. • Briefe: UBH. • Teil-Nachlaß: UBH (Signatur: Heid. Hs. 4151, 4132 IV, A-C). • Auskunft: Universitätsarchiv Göttingen. $\bullet$ Mitteilungen: Herr Ulrich Kallius.

$W$ Merkel, Friedrich, K., E.: Handbuch der gesamten Augenheilkunde. Bd. 1, Abt. 1, Kap. 1/2, T. 1: Anatomie und Physiologie. Makroskopische Anatomie des Auges. 2. Aufl. Leipzig 1910. Anatomie und bildende Kunst. München 1924.

Bearb. Merkel, Friedrich: Die Anatomie des Menschen. Einleitung, allg. Gewebelehre, Grundzüge der Entwicklungslehre ... 2. Aufl. München 1927.

HG 1923-1935 Zeitschrift für die gesamte Anatomie.

L Kürschner (1925) Sp. 465, (1935) Sp. 641; Wer ist's (1928) S. 759; Arnim 1 (1944) S. 627; WBIS; Catalogus prof. Gottingensium (1962) S. 83. - Hoepke, Hermann: Zum 100. Geb. von E. K. in: Ruperto Carola 19. Jg., Bd. 42 (1967) S. $116 \mathrm{f}$. Chronik Ärzte H (1985) S. 132, S. 234 f.; Jansen (1992) S. 410 (Register); Ders. (1992a) S. 166 (Register); Wennemuth (1994) S. 635 (Register); Lexikon Greifswalder Hochschullehrer (2004) S. 107 f. • Grundmann, Steffen: Der Anatom E. K. „... ein Lehrer von ungewöhnlichem Erfolg." Leben, Werk und Hochschulkarriere vom Kaiserreich bis zum Dritten Reich. Med. Diss. Greifswald 2008 (online). • Grewolls (2011); Huhn/Kilian (2011) S. 141f., 146; Hier freut sich der Tod (2013) S. 80-83, 114 u. ö.;
Doll (2014) S. 298-300 u. ö; Deutsche Biographie, s. https://www.deutsche-biographie.de/gnd1 16032499.html [07.11.2017]; Doll/Kirsch/Eckart (2017) S. 68, 116.

$P$ Bildarchiv UAH; UAH Rep. 14-589; Chronik Ärzte H.

\section{Kantor, Moritz \\ siehe Cantor}

\section{Kapp, Johann Georg Christian}

1839-1840 (Honorar-Prof.) Phil. Fak.

1840-1844 Phil. Fak.

Philosophie

* 18. März 1798 Bayreuth

$\dagger$ 31. Dez. 1874 Neuenheim (heute: Stadtteil von Heidelberg)

ev.

V Dr. phil. et theol. Johannes Georg K. (17391817) Gymnasial-Prof., Konsistorialrat, Hofprediger, s. ADB 15 (1882) S. 106, WBIS

M Henriette Sophie Ernestine geb. Müller

$\infty 1824$ Emilie Friederike geb. Schuster ( $\dagger$ vor 1874)

$\mathrm{K} \quad 1 \mathrm{~S}, 1 \mathrm{~T}$

Vw Neffe: Friedrich Kapp (1824-1884) Rechtsanwalt, Politiker, s. NDB 11 (1977) S. 134f., WBIS, Gelehrte in der Revolution (1998) S. $185 \mathrm{f}$.

Lb U Berlin: Seit 1816 Studium der Philosophie, Theologie.

U Erlangen: 1819 Dr. phil.; 23. Febr. 1823 Habilitation; seit 26. Juli 1824 a. o. Prof.; Reisen: 1825 Frankreich, 1829 Italien; 21. Dez. 1832 auf eigenen Antrag in „zeitlichen“ Ruhestand (1839 Entlassung); 1833 Übersiedlung nach $\mathrm{H}$.

H: Seit 1833 Privat-Gelehrter. 
UH: Seit 23. Mai 1839 Honorar-Prof.; seit 5. März 1840 o. Prof.; 25. April 1844 auf eigenen Antrag Dienstentlassung, s. hierzu Gelehrte in der Revolution, S. $186 \mathrm{f}$.

H: 1844-1874 Freier Schriftsteller. • In dieser Zeit:

Mitglied: 1846-1848 II. Kammer des Badischen Landtags in Karlsruhe, 31. März-3. April 1848 Vorparlament, 18. Mai-28. Juni 1848 (Austritt) Dt. Nationalversammlung in Frankfurt/M., s. hierzu K., C.: Die Gründe meines Austritts aus der Nationalversammlung. Darmstadt 1848; Gelehrte in der Revolution, S. 187-201.

1840 Hofrat

E 1828 Mitglied der Naturforschenden Gesellschaft Moskau, s. hierzu Professoren Erlangen (2009) S. 105.

Qu UAH PA 1803. - GLA Abt. 205, Fasz. 314. • Briefe: UBH. • Briefwechsel zwischen Ludwig Feuerbach und C. K. 1832-1848. Hrsg. ... von August Kapp. Leipzig 1876.

W Christus und die Weltgeschichte oder Sokrates und die Wissenschaft. Heidelberg 1823. • Über den Ursprung der Menschen und Völker nach der mosaischen Genesis. Nürnberg 1829.

$L$ Wechmar (1846) S. 133, 252, 313. C. K. in: Derwein, Herbert: Hoffmann von Fallersleben und Johanna Kapp. Fallersleben 1956. 2. Aufl. 1956. A Arnim 4 (1984) S. 771; Best/Weege (1996) S. 200 f.; Gelehrte in der Revolution (1998) S. 183-207; Professoren Erlangen (2009) S. 104 f.; WBIS; Deutsche Biographie, s. https://www.deutsche-biographie. de/gnd116053437.html [07.11. 2017].

$P$ Bildarchiv UAH; graph. Slg. UBH.
Karlowa, Carl Franz Otto (bis 1846: Capaun)

1872-1903 Jur. Fak.

Römisches Recht, Dt. Bürgerliches Recht

* 11. Febr. 1836 Bückeburg

$\dagger \quad$ 03. Jan. 1904 Leipzig

$\square \quad$ 11. Jan. 1904 Heidelberg ev.

V Dr. iur. Johann Hermann August Capaun (1846 Namensänderung in Karlowa) (18041875) Staatsarchivar, zuletzt OberappellationsRat, s. Briefe im Niedersächsischen Landesarchiv Bückeburg (Signatur: NLA BU E 53 Acc. 2002/021 Nr. 1); WBIS

M Sophia geb. Thornton (1802-1881)

œ 29. März 1873 Hermine Kunigunde Rosa Louise Betty geb. Leuckart (1851-1939) T von Rudolf L. (1822-1898; Neffe von: (siehe) Friedrich Sigismund Leuckart), u. a. 1869-1898 Prof. für Zoologie Leipzig, s. NDB 14 (1985) S. 372 f., WBIS, Geschichte U Leipzig 2 (2010) S. 918 (Register), Professorenkatalog Leipzig online

K 7 S: u.a. Rudolf K. (1876-1945), u. a. 1931-1934 Generalkonsul in Batavia auf Java (heute: Jakarta, Republik Indonesien), 1936-1939 Bediensteter im Auswärtigen Amt, Referat Kolonien, s. WBIS; „Akten der Reichskanzlei. Weimarer Republik“ - online

Vw Bruder: Emil Hermann K. (1835-1889 Suizid) Schauspieler, s. WBIS; Eisenberg, Ludwig: Großes biographisches Lexikon der deutschen Bühne. Leipzig 1903. S. 498.

Lb Seit SS 1854 Studium an U Göttingen, SS 1857SS 1858 Berlin.

Bückeburg: 1858-1862 Auditor (auch: Auditeur = Jurist) in Justizkanzlei.

U Bonn: 12. Juli 1862 Dr. iur.; 15. Nov. 1862 Habilitation.

U Greifswald: 8. Nov. 1867 Ern. zum o. Prof.

UH: 18. Jan. 1872 Ern. zum o. Prof. als Nachf. von Conrad Franz Rosshirt; 2. April 1872 Dienstantritt und Vereidigung; 1872-1879 (Auflösung) Beisitzer des Spruchkollegiums der Jur. Fak.; 1879 Ruf an 
U Würzburg abgelehnt; SS 1903, WS 1903/04 Anerkennung "als durch Krankheit dienstbehindert" (aus: UAH PA 1805); 1. Dez. 1903 jährl. Gehaltserhöhung von 700.- Mark und Entbindung von Lehrtätigkeit.

1878 Prorektor der UH; $1875 / 76,1881 / 82,1887 / 88$, 1893/94, 1901/o2 Dekan der Jur. Fak. der UH

1879 Hofrat; 1886 Geh. Hofrat; 1903 Geh. Rat II. Klasse

Siehe auch Otto Gradenwitz

E 1896 Ritterkreuz I. Klasse mit Eichenlaub, 1902 Kommandeurkreuz II. Klasse des Ordens vom Zähringer Löwen.

Qu UAH PA 1805. Briefe: UBH.

$W$ Der römische Civilprozeß zur Zeit der Legisaktionen. Berlin 1872. - Das Rechtsgeschäft und seine Wirkung. Berlin 1877. Neudr. 1968. • Römische Rechtsgeschichte. 2 Bde. Leipzig 1885-1901. Reprint Goldbach 1997.

L Almanach Heidelberg (1886) S. 110; Jammers (1964) S. 177 u. ö.; WBIS; Verzeichnis Bonn (1968) S. 141; Schroeder (2010) S. 243-245; Stumm (2012) S. 698 (Register); Deutsche Biographie, s. https:// www.deutsche-biographie.de/gnd116055723.html [07.11. 2017].

$P$ Bildarchiv UAH; graph. Slg. UBH.

\section{Kastner, Carl Wilhelm Gottlob}

1805-1812 Phil. Fak.

Experimentalchemie und -physik

* 31. Okt. 1783 Greifenberg (Pommern; heute: Gryfice, Polen)

$\dagger$ 13. Juli 1857 Erlangen

ev.-luth.
V Johann Friedrich Gottlob K. (1751-1829) Stadtschul-Rektor, Prediger

M Dorothea Juliane Susanne geb. Laurens (17601812), s. Kirschke (2001) S. 142 Anm. 632

๑ 7. Aug. 1806 Charlotta Franziska Susanne geb. Heddaeus (1785-1867), s. Kirschke, S. 142

K 5, s. Kirschke, S. 142 Anm. 629.

Lb Seit Ostern 1798 Apothekerlehrling in Swinemünde auf Usedom; seit Herbst 1801 Apothekergehilfe in Berlin; Ostern 1803-Ostern 1804 Verwalter e. Apotheke in Neustadt/Sachsen.

U Jena: Seit 29. April 1804 Studium der Medizin, Chemie, Pharmazie; 5. Nov. 1804 Dr. phil.; 15. März 1805 venia legendi für Chemie.

UH: Seit WS 1805/06 a.o. Prof.; seit 12. Febr. 1810 o. Prof.; seit 23. April 1810 Lehrbeauftragter für Botanik und provisorischer Direktor des Botanischen Gartens hinter dem ehemaligen Dominikanerkloster an der Ecke Hauptstrasse/Brunnengasse mit e. jährl. „Belohnung“ von 200.- Gulden als Nachf. von Franz Karl Zuccarini (und in Nachf. von Franz Schelver), s. UAH RA 6883 fol. 4r; 1811 Ruf als Lehrer am Lyzeum in Warschau abgelehnt.

U Halle/S.: 15. Febr. 1812 Berufung zum o. Prof. für Physik und Chemie; Jan. 1817 Bewerbung K.s auf den Lehrstuhl für Chemie und Physik an der 1818 wiedereröffneten U Bonn, s. hierzu Kirschke (2001) S. 192-194.

U Bonn: Juli 1818 Übertragung der Doppelprofessur für Chemie und Physik an K.; 9. Nov. 1818 Vorlesungsbeginn.

U Erlangen: 30. Nov. 1820 (Ern.)-13. Juli 1857 o. Prof. für Chemie, Physik und Pharmazie; Mai 1821 Dienstantritt.

1821 Hofrat

Siehe auch Franz Schelver 
E Mitglied der Akademie der Wissenschaften: 1812 Göttingen, 1820 München; 1816 Mitglied der Dt. Akademie der Naturforscher Leopoldina Halle/S. 1812 Dr. med. h. c. Gießen. $\bullet$ Siehe auch Professoren Erlangen (2009) S. $105 \mathrm{f}$.

Qu UAH PA 1806; RA 5814, 6459, 6883; Rep. 14295. GLA Abt. 205, Fasz. 315. Auskunft: Ev. Kirchengemeinde Ladenburg (Trauungsbuch von 1806).

$W$ Grundriß der Chemie. Heidelberg 1807. • Grundriß der Experimentalphysik. 2 Bde. Heidelberg 1809. 2. Aufl. 1822. • Chemisches Handwörterbuch. 2 Bde. Halle/S. 1813. Handbuch der Meteorologie. 2 Bde. Erlangen 1821-1825.

HG 1815-1824 Deutscher Gewerbsfreund. • 18241829 Archiv für die gesammte Naturlehre. 18301835 Archiv für Chemie und Meteorologie.

L Verzeichnis Bonn (1968) S. 142 f.; NDB 11 (1977)

S. 324; Renger (1982) S. 299 (Register); Willett (2001) S. 178, 272. - Kirschke, Martin: Karl W.G. Lehre im Konflikt mit dem preußischen Staat in: Christian Gottfried Nees von Esenbeck ... Leopoldina-Meeting am 20. ... Juni 2003 in Halle ... Dt. Akademie der Naturforscher Leopoldina. Halle/S. 2004. S. 201-214. - Professoren Erlangen (2009) S. 105 f.; WBIS; Stumm (2012) S. 698 (Register). • Werner, Helmut: Geschichte der anorganischen Chemie. Die Entwicklung einer Wissenschaft in Deutschland von Döbereiner bis heute. Weinheim 2017. S. 192, 238 u. ö.

\section{Kastner, Karl Wilhelm Gottlob}

siehe Kastner, Carl Wilhelm Gottlob

\section{Kautsky, Hans}

1928-1934 (Privat-Dozent) Nat.-Math. Fak. 1934-1936 (a. o. Prof.) Nat.-Math. Fak.

Anorganische Chemie

Kurzbiographie Kautskys, siehe Ernst Müller: Eintrag unter $L b$.

\section{Kayser, Karl Philipp}

1805-1827 Phil. Fak.

Klassische Philologie

* 18. Nov. 1773 Enzheim (heute: Ortsteil von Gundersheim, Rheinland-Pfalz)

$\dagger$ 18. Nov. 1827 Heidelberg ref.

V Peter Gregor K. (1722-1802) Pfarrer, s. Dreier, Bernhard, Weinknecht, Irmintraut: P.G.K. ... eine Selbstbiographie aus dem Jahre 1790 in: Blätter für pfälzische Kirchengeschichte und religiöse Volkskunde 56 (1989) S. 125-133.

M Catharina Sybilla geb. Obenauer (1741-1825)

( 13. April 1807 Gertrude (Trautchen) geb. Kaibel (1786-1843), Sängerin, ca. 1808-1843 (bis 1827 zus. mit K.P.K.) Betreiberin e. Schüler-Pensionats (Instituts), s. Aus gärender Zeit (1923) S. 80, Pfeiffer (2004) S. 156; s. auch Theodor Schliephake: Eintrag unter $\mathrm{Lb}$ (vor 1838). Bruder: Karl Ludwig Kaibel (1783-1864) Sänger (Bass), Theaterautor, Schauspieler: seit 1802 Breslau, 1808-1820 Mannheim, anschl. u. a. Hannover, seit 1835 Freiburg/Br., 18451856 Kassel, s. WBIS; Carl-Maria-von-WeberGesamtausgabe. Digitale Edition, http://www. weber-gesamtausgabe.de/Aooog53 (Version 1.4 vom 13. Okt. 2015; Ausdruck im UAH); $P$ im Bildarchiv UAH

K 5 T, 2 S: (siehe) Ludwig K. Georg Friedrich K. (1817-1857) Lehrer und Diakon, s. Badische Biographien 1 (1875) S. 452

Vw Vorfahren, s. Dreier/Weinknecht (1989) S. 125 f.

Lb U Göttingen: Seit WS 1790/91 Studium der Theologie, Philologie; seit Ostern 1792 Mitglied des Philolog. Seminars; 1793 theol. Lizentiatenprüfung.

Karlsruhe: Seit 9. Nov. 1793 Hauslehrer bei Johann Georg Schlosser (1739-1799; s. NDB 23 (2007) S. 101f.; Schwager Johann Wolfgang Goethes); 8. Jan. 1794 Flucht nach Vaals (Herzogtum Limburg; heute: Niederlande) während des 1. Koalitionskriegs (1792-1797).

Vaals: 17. Jan.-27. April 1794 Interims-Hofmeister. 
H: 27. Mai 1794 Dienstantritt als Praeceptor (Lehrer), seit 23. Juni 1794 zeitlicher Praeceptor, seit Aug. 1794 IV. Praeceptor, seit Dez. 1796 III. Praeceptor, seit 1796 I. Praeceptor, seit Herbst 1808 Prof., 13. Juli 1820-1827 alternierender Direktor (ref.) am Gymnasium, das am 21. Nov. 1808 aus dem ref. und kath. Gymnasium zum konfessionell „vereinigten“ Gymnasium zus.geschlossen wird; März 1805 Rufe an Gymnasien in Lübeck und Bremen abgelehnt. In dieser Zeit:

UH: Sept. 1794 Dominik Heddäus (1771-1795 Prof. für Theologie, ref. Abt. an UH, s. Drüll (1991) S. 57-59) bietet K. das durch Weggang von Johann Friedrich Abegg freigewordene Extraordinariat für Klassische Philologie an, um „die Professur den Protestanten zu erhalten“ (aus: Aus gärender Zeit (1923) S. 16); K. scheut „den damit verbundenen Aufwand" und lehnt ab, s. hierzu ebd. S. 16.

UH: 11. Mai 1805 Dr. phil.; seit SS 1805 Privat-Lehrer (Privat-Dozent); seit SS 1819 a. o. Prof.

UBH: Seit 26. Aug. 1805 Sekretär, seit Sept. 1818 Bibliothekar.

H: Um 1808-1827 Betreiber (zus. mit Ehefrau) e. Schüler-Pensionats (Instituts) in seinem Haus, später in e. Amtswohnung in der Hauptstraße, s. Aus gärender Zeit (1923) S. 80 und Anm. 228.

Seit 1795 Bibliothekar der Lesegesellschaft in Heidelberg

Qu UAH PA 1810. - GLA Abt. 205, Fasz. 318. Teil-Nachlaß: UAH (Signatur: Rep. 16/67-16/ 73); UBH; Badische Landesbibliothek Karlsruhe; Stadtarchiv Heidelberg (Tagebücher). • Aus gärender Zeit. Tagebuchblätter des ... Professors K. P. K. aus den Jahren 1793-1827. Hrsg. von Franz Schneider. Karlsruhe 1923. (Autobiogr.)

$W$ Bemerkungen über eine Stelle des Cicero. Heidelberg 1827. - Siehe Almanach Heidelberg (1813) S. $77 \mathrm{f}$.
HG Philitas: Fragmenta quae reperiuntur. Göttingen 1793. Erasmus von Rotterdam: Institutio hominis Christiani versibus hexametris. Heidelberg 1815.

L Badische Biographien 1 (1875) S. 447-449; Bader (1925) S. 123; WBIS. • Das "Goldene Buch“ des KFG (1994) S. 26 f. • Dreesen, Christine u. a.: „Gedanken über die Liebenswürdigkeit der Frauen“. Mädchenerziehung in Heidelberg in: Biedermeier in Heidelberg. Hrsg. von Carl Ludwig Fuchs u. a. Heidelberg 1999. S. 205f. u.ö. - Schankweiler, Franca Victoria: Wissenschaftskultur an der Wende vom 18. zum 19. Jahrhundert. Der Heidelberger Altphilologe K.P. K. ... in: Die Wittelsbacher und die Kurpfalz in der Neuzeit: Zwischen Reformation und Revolution. Hrsg. von Wilhelm Kreutz u. a. Regensburg 2013. S. 735-756. Deutsche Biographie, s. https://www.deutsche-biographie.de/gn d116090154.html [07.11. 2017].

$P$ Bildarchiv UAH.

\section{Kayser, Karl Ludwig}

1833-1872 Phil. Fak.

Klassische Philologie

* 03. Febr. 1808 Heidelberg

$\dagger \quad$ 05. Mai 1872 Heidelberg ev.

V (siehe) Karl Philipp Kayser (1773-1827)

M Gertrude geb. Kaibel (1786-1843), s. Karl Philipp Kayser: Eintrag unter $\infty$ [Ehefrau]

$\infty$ 27. März 1837 Carolina Ernestina (Lina) geb. Vollweiler (1818-1874); Scheidung 1853

$\infty$ 30. Sept. 1862 Sophie geb. Hilger (1836-1895) Gründerin e. Hauses für alleinstehende Frauen in $\mathrm{H}$

$\mathrm{K}$ mind. $1 \mathrm{~S}$

Lb UH: WS 1825/26 Immatrikulation zum Studium der Philologie; Sommer 1826 Studienreise nach Paris; nach 1826 wohl Forts. des Studiums.

H: Seit 1827 (nach Tod des Vaters) Privatlehrer. 
Sommer 1830 Theol. und philolog. Staatsexamen in Karlsruhe; 20. Dez. 1830 Dr. phil. an UH.

H: 1830-1833 Lehrer im elterlichen Pensionat und Eigenstudien.

UH: Mai 1833 Habilitation, siehe hierzu Eintrag unter $Z$ [itat]; seit 25. März 1841 a. o. Prof.; seit 9. Aug. 1855 jährl. Besoldung von 6oo.- Gulden, s. UAH RA 6828; seit 26. Sept. 1862 o. Prof. und seit SS 1866 Mit-Direktor (zus. mit Hermann Köchly) des Philolog. Seminars in Nachf. von Christian Bähr.

Z Friedrich Christoph Schlosser, Dekan der Heidelberger Phil. Fak., teilt am 5. Jan. 1833 seinen Kollegen in der Fak.-Sitzung über das vorgesehene Procedere bei der Habilitation K.s Folgendes mit: „Gesuch des Dr. Kaisers [!], seine Probevorlesung in dieser Woche halten zu dürfen: Ich habe ihm aufgegeben, sich mit dem Geheimrath [Georg Friedrich] Creuzer und Prof. [Christian] Bähr über die ihnen gelegene Zeit zu verständigen; er hat dieses gethan und ich schlage daher den Herren vor, sich am Sonnabend um 6 Uhr im Senatszimmer zur Anhörung der Vorlesung einzufinden. Die Aufgabe werden wir wohl am besten dem Herrn Geh. Rath Creuzer freundlich überlassen, da braucht der Pedell in der Kälte nicht so oft zu gehen“ ... Prof. Creuzer erklärt, er „werde also, wenn die übrigen Herrn einwilligen, dem Dr. Kaiser Samstags Morgens seine Aufgabe geben, sie von ihm in meinem Hause ausarbeiten lassen und mich Abends einfinden" (aus: UAH H-IV-102/29 fol. 3r, v). Gegen dieses Verfahren wenden sich [Carl] Rau und [Georg Wilhelm] Muncke sowie [Ferdinand] Schweins, denn sie sind der „Meinung, von der in unseren Habilitationsstatuten vorgeschriebenen Art, die Fragen zu bestimmen, nicht abzugehen, weil sonst das eine Beispiel für alle späteren Fälle entscheidend sein würde. Sonst einverstanden" (aus: H-IV-102/29 fol. 3v). Professor Schlosser teilt daraufhin mit: „Da, wie aus den beyliegenden Abstimmungen hervorgeht, die Majorität auf der Form besteht, so muß ich wieder [lies: wider] meine eigene Meinung den $\mathrm{H}$ [errn] Geh. Rath Creuzer ersuchen, drey Fragen in das Kästchen zu legen, aus denen die Herrn anschl[ießend] gefälligst eine auswählen werden. Ich werde sie hernach versiegelt dem $\mathrm{H}$ [errn] Geh. Rath Creuzer zustellen. Übrigens bleibt es bey der Ein- ladung auf Sonnabend um 6 Uhr" zur Anhörung der Vorlesung K.s im Senatszimmer (aus: H-IV102/29 fol. 5r). Prof. Creuzer stellt drei Fragen zur Wahl für die Prüfung, von der die erste einstimmig von den Kollegen angenommen wird:

„Frage über den Ursprung und Charakter der Biographie bei den Griechen als historischer Gattung" (aus: H-IV-102/29 fol. 5r, v).

E 1850 Mitglied der Akademie der Wissenschaften München. 1869 Ritterkreuz I. Klasse des Ordens vom Zähringer Löwen.

Qu UAH PA 1809; RA 6374, 6377, 6827 f.; Fak.-Akte H-IV-102/29 fol. 3r, v u. ö. • GLA Abt. 205, Fasz. 319. - Briefe: UBH; Bayer. Staatsbibliothek München; Universitäts- und Landesbibliothek Bonn; s. auch Kalliope. Nachlaß: Badische Landesbibliothek Karlsruhe (Nachlaß zum Teil im 2. Weltkrieg verbrannt), s. hierzu Syré, Ludger: Zwischen Bibliothek und Wissenschaft: Wilhelm Brambachs Briefe an Karl Dziatzko ... Berlin 2008. S. 67 und Anm. 40. - Auskunft: Ev. Kirchengemeindeamt Kirchenbuch - Heidelberg; Ev. Oberkirchenrat Landeskirchliches Archiv - Karlsruhe.

$W$ Lectiones Pindaricae. Heidelberg 1840. Reprint 2015. Hordeonius Lollianus geschildert nach einer noch nicht hrsg. athenischen Inschrift. Heidelberg 1841. De Pinacotheca quadam Neapolitana. Heidelberg 1844. - K. L.K.'s Homerische Abhandlungen. Hrsg. von Hermann Usener. Leipzig 1881.

HG M. Tullii Ciceronis opera quae supersunt omnia. Leipzig 1860-1869. - Flavii Philostrati opera auctiora. Leipzig 1870-1871.

$L$ Badische Biographien 1 (1875) S. 449-452; ADB 15 (1882) S. 513-518. - Über L. K. in: Wüstenberg, Ulrich: Karl Bähr (1801-1874). Ein badischer Wegbereiter für die Erneuerung und die Einheit des ev. Gottesdienstes. Göttingen 1996. S. 29-31, 45 u. ö.

$P$ Bildarchiv UAH; Gips-Totenmaske im UAH. 


\section{Kehrer, Erwin Karl Adolf}

1904-1910 Med. Fak.

Gynäkologie, Geburtshilfe

* 19. April 1874 Gießen

$\dagger$ 13. Dez. 1959 Heidelberg

ev.

V (siehe) Ferdinand K. (1837-1914)

M Emilie (Emmy) geb. Frisch (1849-1924) T von Carl Friedrich F. (1813-1886) GroßherzoglichHessischer Hofmaler und Hofrat, KaiserlichRussischer Hofmaler und Staatsrat, s. Stadtlexikon Darmstadt. Hrsg. vom Historischen Verein für Hessen. Redaktion: Roland Dotzert ... Stuttgart 2006. S. 278.

๑ 7. Juni 1905 Antonia geb. Schönle ( $†$ 1951)

๑ 26. Sept. 1958 Karoline Emma Hildegard geb. Stiens

$\begin{array}{lllll}K & \text { K } & 2 \mathrm{~T}\end{array}$

Vw Brüder: Hugo K. (1876-1967) seit 1909 PrivatDozent, 1915-1945 a. o. Prof. für Mittlere und Neuere Kunstgeschichte München, s. NDB 11 (1977) S. 400 f., WBIS; Kunstgeschichte nach 1945: Kontinuität und Neubeginn in Deutschland. Hrsg. von Nikola Doli u.a. Bonn 2006. S. 25 (online). - Ferdinand Adalbert K. (18831966), u.a. seit 1921 a.o. Prof. Breslau, 19251953 (Emeritierung) o. Prof. für Neurologie, Psychiatrie und Leiter der Psychiatr. und Nervenklinik Münster, s. Dicke, Jan Nikolas: Eugenik und Rassenhygiene in Münster zwischen 1918 und 1939. Berlin 2004. S. 58-73; Nervenärzte 2 (2006) S. 107-114, Ruuskanen (2008) S. 49 f., WBIS; Mamali, Ioanna: Psychiatrische und Nervenklinik Münster. Anfänge der Universitätspsychiatrie in Westfalen zur Zeit des Nationalsozialismus. Diss. Münster 2011. S. $29 \mathrm{ff}$.

Lb Seit WS 1893/94 Studium an UH, SS 1896 München, seit WS 1896/97 H; Juli 1898 Staatsexamen in H; Dez. 1899 Dr. med. an UH.

Seit 20. März 1899 Assistent am Anatomisch-Patholog. Inst. der UH; Assistent an U-Frauenklinik: seit Okt. 1899 H, seit Dez. 1899 Wien, seit April 1900 Freiburg/Br., seit Jan. 1901 Bonn.
UH: Jan. 1902-März 1910 Oberarzt an U-Frauenklinik und Leiter der Gynäkologisch-Operativen und der Ambulanten Abt. an o.g. Klinik; 9. Jan. 1904 Habilitation; seit 27. Nov. 1909 a. o. Prof.

U Bern: Seit 17. März 1910 o. Prof. und Direktor der U-Frauenklinik.

Dresden: Seit 26. Juli 1911 Direktor der KöniglichSächsischen Frauenklinik und Hebammenanstalt.

U Marburg: 28. Sept. 1925-31. Dez. 1939 (Ruhestand) o. Prof. und Direktor der U-Frauenklinik und Hebammenlehranstalt; nach Dez. 1939 weiterhin Vertreter seines Lehrstuhls und Leiter der Klinik.

1916 Ober-Medizinalrat; 1919 Geh. Medizinalrat

E Ehrenmitglied der Dt. Gesellschaft für Geburtshilfe und Gynäkologie. 1944 Goethe-Medaille für Kunst und Wissenschaft.

Qu UAH PA 1815. - GLA Abt. 235, Fasz. 2163. • Briefe: UBH.

$W$ Die Armlähmung bei Neugeborenen. Stuttgart 1934. - Der unvermutet schnelle Tod in Schwangerschaft, Geburt und Wochenbett. Stuttgart 1934. - Zur Geschichte des Kaiserschnitts in: Dt. med. Wochenschrift (1952).

MHG Archiv für Gynäkologie.

L NDB 11 (1977) S. 400; Catalogus prof. Marburgensis 2 (1979) S. 283f. - Damaschke, Astrid: Das Wirken von E. K. als Direktor der Königlich-Sächsischen Frauenklinik von 1911 bis 1925. Med. Diss. TU Dresden 1981. Arnim 4 (1984) S. 786; Chronik Ärzte H (1985) S. 132, 235f.; Zander (1991) S. 6o-62. Die Reden: Eröffnungsansprachen zu den Kongressen der Gesellschaft (für Gynäkologie und Geburtshilfe) 1886-1998. Hrsg. von Hans Ludwig. 2. Aufl. Heidelberg 1999. S. 451 (Register). - Klee, Personenlexikon (2007) S. 302; Hessische Biografie, s. http://www.lagis-hessen.de/pnd/ 
116093404 (Stand: 1. Juli 2016); Deutsche Biographie, s. https://www.deutsche-biographie.de/gnd 116093404.html [07.11. 2017].

$P$ Bildarchiv UAH; NDB; Chronik Ärzte H.

\section{Kehrer, Ferdinand Adolf}

1881-1902 Med. Fak.

Gynäkologie

* 16. Febr. 1837 Guntersblum (Rheinhessen)

$\dagger$ 16. Juni 1914 Heidelberg ev.

V Friedrich K. (1807-1888) praktischer Arzt, Kreisphysikus (Kreis-Amtsarzt)

M Elisabeth Luise geb. Baumann (1805-1891)

๑ 19. Juni 1873 Emilie (Emmy) geb. Frisch (18491924), s. Erwin Kehrer: Eintrag unter $M$ [utter]

K 1 T, 3 S: (siehe) Erwin K. (1874-1959) und Eintrag unter $V w$ [Brüder].

Lb U Gießen: Seit WS 1854/55 Studium; 22. Dez. 1859 Dr. med.; seit Dez. 1863 Assistent am Physiolog. Inst. und Prosektor am Anatom. Theater; 10. Febr. 1864 Habilitation für Geburtskunde; seit 22. Febr. 1868 a.o. Prof. für Theoretische Geburtshilfe; Rufe an U abgelehnt: Zürich, Würzburg, Erlangen; seit 27. April 1872 o. Prof. für Geburtshilfe. In dieser Zeit:

Gießen: 1860 Niederlassung als praktischer Arzt.

UH: 30. Dez. 1880 Ern. zum o. Prof. und (bis 1884) Direktor der Entbindungsanstalt im Weinbrennergebäude (Marstallhof 4 ) als Nachf. von Wilhelm Lange (Fach: Geburtshilfe); SS 1881 Dienstantritt; seit WS 1884/85 (Gründungs-)Direktor der U-Frauenklinik (Ecke Thibaut- und Voßstraße), s. hierzu Kubli, Fred: Festrede zum 1oojährigen Bestehen der U-Frauenklinik Heidelberg (12. Dez. 1884) in: Entwicklungen in Gynäkologie und Geburtshilfe. Hrsg. von G. Bastert ... Berlin 1991. S. 73-79; 1. Okt. 1902 Pensionierung. - In dieser Zeit:
1880-1902 Kreisoberheb(e)arzt für Mannheim, H, Mosbach.

1898/99 Prorektor der UH; 1888/89, 1899/190o Dekan der Med. Fak. der UH

K. ist 1881 erster Ordinarius für Gynäkologie an der Universität Heidelberg

1881 Mitbegründer des klassisch-konservativen Kaiserschnitts

1897 führt K. „die erste an die Öffentlichkeit gedrungene Unfruchtbarmachung zur Verhütung ,minderwertiger" Nachkommen" durch, s. Eckart, Wolfgang Uwe: Illustrierte Geschichte der Medizin: Von der französischen Revolution bis zur Gegenwart. 2. Aufl. Berlin 2011. S. 218.

19. April 1898 Mitbegründer und Erster Vorsitzender des Heidelberger Tierschutzvereins

1889 Hofrat; 1894 Geh. Hofrat; 1902 Geh. Rat II. Klasse

E 1887 Ritterkreuz I. Klasse, 1899 Kommandeurkreuz II. Klasse des Ordens vom Zähringer Löwen.

Qu UAH PA 1816; RA 5735, 5875, 6231; Fak.-Akten H-IV-102/133, H-IV-102/135. • GLA Abt. 235, Fasz. 2158. Mitteilungen: Frau Liselotte Moeller-Kehrer $(\dagger)$, Vevey.

$W$ Beiträge zur vergleichenden und experimentellen Geburtskunde. 6 H. Gießen 1864-1877. • Beiträge zur klinischen und experimentellen Geburtskunde und Gynäkologie. 2 Bde. Gießen 1879189o. Lehrbuch der Geburtshilfe für Hebammen. Gießen 1881. • Über ein modificiertes Verfahren beim Kaiserschnitte in: Archiv für Gynäkologie 19 (1882) H. 2, S. 177 ff. • Versuche über Kastration und Erzeugung von Hydrosalpinx in: Beiträge zur klinischen und experimentellen Geburtskunde und Gynäkologie. Gießen 1887. Bd. 2. S. 282-292. • Über Entstehung, Erscheinungen und Verhütung des Wochenfiebers. Heidelberg 1889. - Lehrbuch der operativen Geburtshilfe. Stuttgart 1891. 
$L$ Universität Gießen 1 (1907) S. 435 f.; Stübler (1926) S. 321; WBIS; NDB 11 (1977) S. 400; Buttron (1981) S. 64-72 u. ö.; Chronik Ärzte H (1985) S. 132 f., 236 f.; WBIS. • Zur Geschichte der Gynäkologie und Geburtshilfe: Aus Anlaß des 10ojährigen Bestehens der Dt. Gesellschaft für Gynäkologie und Geburtshilfe. Hrsg. von Lutwin Beck. Berlin 1986. S. 56-6o u. ö. $\bullet$ Zander, Josef: F. A. K. Begründer der Geburtshilfe und Gynäkologie und der „Frauenklinik“ in Heidelberg in: Entwicklungen in Gynäkologie und Geburtshilfe. Hrsg. von G. Bastert ... Berlin 1991. S. 60-62. • Jansen (1992a) S. 166 (Register). • Die Reden: Eröffnungsansprachen zu den Kongressen der Gesellschaft (für Gynäkologie und Geburtshilfe) 1886-1998. Hrsg. von Hans Ludwig. 2. Aufl. Heidelberg 1999. S. 451 (Register). • Ruuskanen (2008) S. 49 f. • LenzenSchulte, Martina: Wie der Kaiserschnitt zum Klassiker wurde in: FAZ vom 6. April 2014 online. • KlinikTicker - Online-Mitarbeitermagazin des Universitätsklinikums Heidelberg: „Ein Zimmer, 21 1/2 Schuh lang und 18 Schuh breit." Ein Streifzug durch die 250-jährige Geschichte der Hebammenschule in Heidelberg (16. Dez. 2016; abgerufen am 1. Okt. 2017). - Deutsche Biographie, s. https://www.deutsche-biographie.de/gnd11609346 3.html [07.11.2017].

$P$ Bildarchiv UAH; graph. Slg. UBH; Chronik Ärzte H.

\section{Kestner, Otto}

siehe Cohnheim

\section{Kindermann, Carl}

1894-19o6 Phil. Fak.

Nationalökonomie

* 10. Aug. 1860 Magdeburg

$\dagger \quad$ 21. April 1938 Schopfheim (Südschwarzwald) ev.

V Carl K. $\left({ }^{\star} 1810\right)$ Gerichtsassessor

M Alwine geb. Wodick
๑ 10. Nov. 1888 Henriette Anna geb. Maquet $\left({ }^{*} 1859\right)$

๑ 22. Sept. 1914 Frida geb. Huber verw. Sailer (1879-1940)

K $\quad 1$ S, 1 T (e. der K früh $\dagger)$.

Lb Seit WS 1877/78 Studium der Rechtswiss. an U Leipzig, SS 1881 Jena, anschl. Tübingen, SS 1883 Leipzig, zuletzt Berlin; 1881 Militärdienstpflicht als Einjährig-Freiwilliger in Jena.

Berlin: 1884 II. jur. Prüfung; 18. April 1885 Dr. iur. an $\mathrm{U}$.

Magdeburg: Seit 1885 Gerichtsreferendar.

UH: Seit ca. 1888 Eigenstudium der Nationalökonomie; 10. Mai 1889 Dr. phil.; zwischen 1889 und 1894 Eigenstudien in USA und Großbritannien; 27. Juli 1894 Habilitation; seit 23. Aug. 1899 nichtetatm. a.o. Prof.; 5. Dez. 1902 Aufnahme als ehem. preußischer Staatsangehöriger in badischen Staatsverband.

Stuttgart: WS 1906/o7-SS 1930 (Emeritierung) o. Prof. an Landwirtschaftl. Hochschule in Hohenheim und Lehrauftrag an Württ. Baugewerkschule (heute: Hochschule für Technik).

Wohnsitz: Zuletzt in Wehr (bei Schopfheim), Merianstraße 11 .

Qu UAH PA 1826; RA 6617, 6867; Fak.-Akte H-IV102/123 fol. 142r-145r. • GLA Abt. 235, Fasz. 2164. • Ergebnislose Anfrage: Stadtarchiv Bad Säckingen. - Auskunft: Stadtarchiv Heidelberg (Stadtrat H von 1902 Nr. 15 Fasc. 1); Archiv der Ev. Kirche der Kirchenprovinz Sachsen in Magdeburg; Stadtarchiv Schopfheim.

W Zur organischen Güterverteilung. 2 Bde. Leipzig 1894-1896. - Des deutschen Volkes Meisterjahre. Stuttgart 1916. 3. Aufl. 1919. - Die soziale Schöpferkraft im Aufbau Deutschlands und des Völkerlebens. München 1919. • Der Jungführer im deutschen Volksstaat. Leipzig 1930. 
L Kürschner (1931) Sp. 1434, (1935) Sp. 668; Wer ist's (1935) S. 811; WBIS; Klein (1968) S. 28, 81f. - Universität Hohenheim, Landwirtschaftliche Hochschule 1818-1968. Hrsg. von Günther Franz. Stuttgart 1968. S. 93 f. u. ö. • Über C. K. in: May, Georg: Mit Katholiken zu besetzende Professuren an der Universität Tübingen 1817-1945. Amsterdam 1975. S. 633 und Anm. 115. Heiber I (1991) S. 349-351 u. ö.; Württembergische Biographien 1 (2006) S. 132 f.; Deutsche Biographie, s. https://www.deutsche-biographie.de/gnd1161721 77.html [07.11. 2017].

$P$ Bildarchiv UAH.

Kirchenheim, Heinrich Adolf Paul Arthur von (Geburtsname: von Koscielski; 1875 Umbenennung)

1880-1924 Jur. Fak.

Allg. und Dt. Staats- und Strafrecht, auch Verwaltungs- und Kirchenrecht

* 15. April 1855 Berlin

$\dagger \quad$ 08. Jan. 1924 Heidelberg ev.

V Adolf von Koscielski, Major

M N.N. geb. Falkenstein

๑ 29. April 1878 Anna geb. Holberg (1855-1925)

$\mathrm{K} \quad 1 \mathrm{~S}, 4 \mathrm{~T}$

Lb Seit WS 1874/75 Studium an UH, anschl. Tübingen, Berlin; 26. Mai 1877 Staatsprüfung in Berlin; 2. Aug. 1877 Dr. iur. an U Tübingen.

Referendar am Kammergericht: Mai 1877-Mai 1879 Bernau bei Berlin, anschl. Berlin, zuletzt Breslau.

UH: 30. Okt. 188o Habilitation; SS 1883 Lehrstuhlvertretung an U Freiburg/Br.; seit 1. Aug. 1886 a.o. Prof., s. hierzu Schroeder (2010) S. 337 f.; 1896 Verurteilung zu e. Geldstrafe von 400.- Mark wegen Beleidigung e. Richters; 1914-1916 Kriegsdienst (Lazarettleiter; s. hierzu K., A. von: Bericht über das Vereinslazarett Diakonissenhaus in Heidelberg 1914-1920. Heidelberg [1920]); seit 1920 Lehrauftrag für Völkerrecht.

E 1893 Ehrenritter des Königl. Preußischen Johanniterordens; 1893 Kommandeur des Kaiserl. Russischen Stanislausordens II. Klasse.

Qu UAH PA 4493f.; RA 6762. - GLA Abt. 235, Fasz. 2167. Briefe: UBH.

$W$ Verwaltungspraktikum. Fälle und Fragen aus dem Gebiete des öffentlichen Rechts ... Stuttgart 1883. - Zur Reformation des Rechtsunterrichts. Leipzig 1887 . Schlaraffia politica. Geschichte der Dichtungen vom besten Staate. Leipzig 1892. (Anonym erschienen.) - Lehrbuch des Kirchenrechts. Bonn 1900. 2. Aufl. 1911. Emil Herrmann und die preußische Kirchenverfassung. Nach Briefen und anderen meist ungedruckten Quellen. Berlin 1912. (Rezension von Simon, Theodor in: Theologisches Literaturblatt. Leipzig 1912. S. 345.)

G, HG 1881-1924 Centralblatt für Rechtswissenschaft.

L Almanach Heidelberg (1886) S. 112f. • Der Fall des Professors von $\mathrm{K}$. in seiner Bedeutung für das Badische Beamtentum und die politischen Parteien Badens. Pforzheim 1897. Arnim 1 (1944) S. 649. Heinsheimer, Karl: A. von K. in: Ruperto Carola 7. Jg., Nr. 17 (1955) S. 76. • WBIS; Schroeder (2010) S. 337 f. Leucht, Robert: Dynamiken politischer Imagination: Die deutschsprachige Utopie von Stifter bis Döblin in ihren internationalen Kontexten, 1848-1930. Berlin 2016. S. 461 (Register). Deutsche Biographie, s. https://www. deutsche-biographie.de/gnd116181931.html [07.11. 2017].

P Bildarchiv UAH; graph. Slg. UBH. 


\section{Kirchhoff, Gustav Robert}

1854-1875 Phil. Fak.

Physik

* 12. März 1824 Königsberg (Preußen, heute: Kaliningrad, Russische Föderation)

$\dagger$ 17. Okt. 1887 Berlin

ev.

V Carl Friedrich K. (1778-1853) Landrichter, Justizrat

M Juliane Johanne Henriette geb. Wittke (17921853)

๑ 16. Aug. 1857 Clara geb. Richelot (1834-1869), s. Hübner (2010) S. 151-153; T von Friedrich Julius R. (1808-1875) seit 1832 a. o. Prof. (1843 Ruf an UH abgelehnt), 1843-1875 o. Prof. für Mathematik Königsberg (Preußen), s. ADB 28 (1889) S. 432 f., WBIS

( 6. Dez. 1872 Luise Genovefa Karolina Sophie geb. Bröm(m)el (1838-ca. 1906) bis Ende 1872 Oberaufsichtsführende an U-Augenklinik $\mathrm{H}$

K 2 S (davon $1 \mathrm{~S}$ früh $\dagger$ ), 2 T: u. a. Julia Clara Pauline (Paula) K. (1860-1932) Ehefrau von Wilhelm von Branca (1844-1928), u. a. seit 1887 o. Prof. für Mineralogie, Geologie, Paläontologie Königsberg, 1890-1895 (Niederlegung des Amtes aus gesundheitlichen Gründen) Tübingen, 1899-1917 (Ruhestand) Berlin, s. Tilitzki 1 (2012) S. 784 (Register); s. auch Hermann Helmholtz: Eintrag unter $K$ [inder]: Katharina (Käthe) H. (1850-1878); s. Tilitzki 1, S. 786 (Register)

Vw Brüder, s. Hübner, S. 22-24.

Lb U Königsberg: Seit SS 1842/43 Studium der Mathematik, Physik; 6. Sept. 1847 Dr. phil.

U Berlin: Seit Okt. 1847 Forts. des Studiums; 26. Juli 1848 Habilitation; 6. Jan. 1850 Weggang.

U Breslau: 1. Dez. 1849 Ern. zum a. o. Prof. und Mit-Direktor des Physikal. Kabinetts mit e. jährl. Besoldung von 40o.- Talern, seit Okt. 1851 von 500.- Talern, seit Jan. 1854 von 60o.- Talern; SS 1850 Verschiebung seines Vorlesungsbeginns auf WS 1850/51 aus Krankheitsgründen.
UH: 29. Sept. 1854 Ern. zum o. Prof. und Direktor des Physikal. Kabinetts als Nachf. von Philipp Jolly mit e. jährl. Besoldung von 1600.- Gulden und Mietzinsentschädigung von 400.- Gulden (bis April 1868); Sept. 1863 Bezug des Physikal. Kabinetts und e. Dienstwohnung (Miete: 200.Gulden) im neuerrichteten Friedrichsbau in der Hauptstraße 47-51 (auf dem Gelände des ehem. Dominikanerklosters), s. hierzu Hübner (2010) S. 142-148; seit 6. April 1868 jährl. Besoldung von 2200.- Gulden; seit WS 1869/70 (Begründer) MitDirektor (zus. mit Leo Koenigsberger) e. Math.Physikal. Seminars, s. hierzu Hübner, S. 156-159; 9. Juni 1870 Ruf an U Berlin abgelehnt; 14. Juni rückwirkend vom 1. April 1870 jährl. Besoldung von 3500.- Gulden, seit 1872 von 40oo.- Gulden, seit März 1874 von 60oo.- Gulden; Rufe abgelehnt: 1872 an U Würzburg, März 1874 als Direktor des in Planung stehenden Astrophysikalischen Observatoriums in Potsdam; 1. April 1875 Entlassung aus badischem Staatsdienst.

Königl. Preußische Akademie der Wissenschaften Berlin: Seit 1. April 1875 o. aktives Mitglied mit „dem ihm zustehenden gewöhnlichen Gehalt von 300.- Thalern [als o. Mitglied der Akademie sowie] eine[r] außergewöhnliche[n] Besoldung von 5500.- Thalern ... auf Lebenszeit" ... Mit dieser besonderen Besoldung soll K. „volle Muße für seine wissenschaftlichen Arbeiten" gewährleistet werden (aus: Hübner, S. 215); letztendlich zahlt die Akademie von den 5500.- Talern 3000.-, die restlichen 2500.- Taler das Finanzministerium, s. Hübner, S. 235-239.

U Berlin: Seit SS 1875 Inhaber der neueingerichteten o. Professur für Theoretische Physik ohne eigenes Inst.; 1877-1887 Mitglied der Bibliothekskommission, s. Hübner, S. 255-257.

Potsdam: 1875-1881 Mitglied der Direktion des Astrophysikalischen Observatoriums, s. Hübner, S. 226-228.

1865 Prorektor der UH; 1858, 1869/70 Dekan der Phil. Fak. der UH 
1860 entwickeln K. und Robert Wilhelm Bunsen die Spektralanalyse, s. hierzu Hübner, S. 118-136 u. ö.

1865 Hofrat; 1870 Geh. Hofrat; 1872 Geh. Rat II. Klasse

E 1857 Korr. Mitglied, 1870 ausw., 1875 o. Mitglied der Akademie der Wissenschaften Berlin; Mitglied der Akademie der Wissenschaften: 1861 München, 1862 Göttingen. 1862 Rumford-Medaille der Royal Society; 1876 Cothenius-Medaille der Dt. Akademie der Naturforscher Leopoldina Halle/S.; 1877 Maximiliansorden für Wissenschaft und Kunst; 1887 Prix Janssen der Académie des Sciences Paris (posthum). 1861 Ritterkreuz des Ordens der französischen Ehrenlegion; 1861 Ritter des Ordens vom Zähringer Löwen und Preußischer Kronenorden. • 1870 Ehrenbürger der Stadt Heidelberg. • Siehe hierzu auch Hübner (2010) S. 140 f.

$\mathrm{Q} u$ UAH PA 1827; RA 5683, 5815, 6189, 646of., 6898. • Briefe: UBH. • Ernst Wilhelm von Brücke. Briefe an Emil Du Bois-Reymond. Hrsg. ... von Hans Brücke ... 1. T. Graz 1978. S. 299 (Register). • Nachlaß: Badische Landesbibliothek Karlsruhe.

$W$ Beiträge $\mathrm{zu}$ den Verhandlungen des naturhistorisch-medicinischen Vereins zu Heidelberg. Bd. 1-3 (1857-1865). Zus.gest. von Gabriele Dörflinger. UBH. Heidelberg 2012 online, s. http:// www.ub.uni-heidelberg.de/archiv/13199. • Untersuchungen über das Sonnenspectrum und die Spectren der chemischen Elemente und weitere ergänzende Arbeiten. Neudr. der Ausgaben 18591863 ... Hrsg. von Hans Kangro. Osnabrück 1972. • K., G. R., Bunsen, R. W.: Chemische Analyse durch Spectralbeobachtungen. Wien 1861. Reprint Saarbrücken 2006. - Zur Geschichte der Spectralanalyse und der Analyse der Sonnenatmosphäre in: Poggendorffs Annalen 118 (1863) S. 94-111. Reprint Zürich 2008. • Über das Ziel der Naturwissenschaften. Prorektoratsrede an der Universität Heidelberg am 22. Nov. 1865. Heidelberg 1865. - Vorlesungen über mathematische Physik. 4 Bde. Leipzig 1876-1894. Mehrere Hrsg. und Aufl. - Gesammelte Abhandlungen. Leipzig 1882.
Nachtrags-Bd. Leipzig 1891. Reprint Saarbrücken 2006. - Zur Theorie der Lichtstrahlen in: Annalen der Physik 254 (4) (1883 [vorgelegt 1882]) S. 663695. (G. R. K.'s treatise „On the theory of light rays“ (1882). English translation, analysis and commentary. Editors: Klaus Hentschel, Ning Yan Zhu ... New Jersey 2017.) • Abhandlungen über Emission und Absorption. Leipzig 1898.

$L$ Smith (1949) S. 135 f.; NDB 11 (1977) S. 649653. - Urbig, Hans-Dieter: Philosophische und historische Untersuchungen über das Leben und Wirken von G. R. K. Ein Beitrag zur Erkenntnis der Evolution des Verhältnisses von Philosophie und Naturwissenschaft im 19. Jahrhundert. Diss. Humboldt-Universität. Berlin 1982. • Hennig, Jochen: Der Spektralapparat Kirchhoffs und Bunsens. Berlin 2003. Von der Forschung gezeichnet (2007) S. 115-117 u.ö. • Hübner, Klaus: G. R. K. Das gewöhnliche Leben eines außergewöhnlichen Mannes. Ubstadt-Weiher 2010. - Inan, Aziz S.: What did G.R.K. stumble upon 150 years ago? in: Proceedings of 2010 IEEE International Symposium on Circuits and Systems (ISCAS). Paris, France, 30 May-2 June 2010. Piscataway (New Jersey) 2010. S. 73-76. Homo Heidelbergensis mathematicus online; WBIS; Wissenschaftsatlas der UH (2011) S. 97-99. • Zur Erinnerung an G. R. K. Aufsätze von Robert von Helmholtz, August W. von Hofmann u. a. zus.gestellt von Gabriele Dörflinger. UB Heidelberg 2014 (online, s. http://www.ub.uniheidelberg.de/archiv/16631).

$P$ Bildarchiv UAH; graph. Slg. UBH; NDB.

\section{Kirschbaum, Johann Jacob Joseph}

1757 Jur. Fak.

Bürgerliches Recht und Kameralpraxis

1757-1761 Phil. Fak.

1757-1761 Natur- und Völkerrecht

1761-1804 Jur. Fak.

1761-1773 Gerichtliche Praxis; 1773-1804 Institutionen, Reichsprozeßrecht, Wechselrecht, Zivilprozeßrecht 
* 23. Juni 1721 Schallodenbach (bei Kaiserslautern)

$\dagger \quad$ o6. Juni 1804 Heidelberg kath.

V Johann Bonifaz K., Leser am Reichskammergericht, Domverwaltungsvorsteher

M Maria Anna geb. Hart (?)

( 15. Mai 1757 Maria Johanna Antonia geb. Hennemann $(\dagger 1766)$

๑ 19. Aug. 1766 Anna Maria Catharina geb. Otto (1743-1814)

K 4 T, 7 S: u. a. Joseph (seit 1814: von) K. (17581848), u. a. bis 1789 Lehrer des Völkerrechts an Kriegsschule in Paris, 1793-1805 Erzieher und Hofmeister von Ludwig Karl August Prinz von Bayern (1786-1868; 1825-1848 König Ludwig I.), s. Neuer Nekrolog der Deutschen. Hrsg. von Bernhard Friedrich Voigt. 27. Jg. (1849) 1. T. Weimar 1851. S. 30.

Lb U Mainz: Studium; 24. Mai 1746 Lizentiatenexamen in beiden Rechten.

Wetzlar: Seit 17. Juli 1749 Advokat am Reichskammergericht.

UH: 9. März 1757 Ern. zum a.o. Prof. für Bürgerliches Recht und Kameralpraxis an Jur. Fak.; 1757-1761 o. Prof. für Natur- und Völkerrecht an Phil. Fak.; 11. Nov. 1761-1773 o. Prof. für Gerichtliche Praxis als Nachf. von Johannes Joseph Alef (s. Drüll (1991) S. 3-5); auch U-Ökonomiekommissar; 1772 Dr. iur. an U Mainz; seit 1773 o. Prof. für Institutionen, Reichsprozeß-, Wechsel- und Zivilprozeßrecht; April 1804 Ruhestand.

1796/97 Rektor der UH; 1799-1802 Prokanzler der UH, siehe hierzu Weisert/Drüll/Kritzer (2007) S. 39 f.; $1765,1772,1778,1783,1788,1793,1798$ Dekan der Jur. Fak. der UH

1774 beauftragt die Oberkuratel K. und Franz Innozenz Gabriel Schoenmezel (Biographie siehe Drüll (1991) S. 138f.), eine „Verfassung der Heidelberger Universität aus den Archiv-Urkunden“ zu schreiben, siehe hierzu UAH RA 238.
Qu UAH PA 1829 f.; RA 724 f. [= A-160/77 (= I, 3, Nr. 94) fol. 127v, A-160/78 (= I, 3, Nr. 95) fol. 151r], 6766 (Brief vom 8. April 1799). - Winkelmann 1 (1886) S. 451,21; Toepke 4 (1903) S. 247 Anm. 3. • Verzeichnis der Studierenden der alten Universität Mainz. Hrsg. von Präsident und Senat der Johannes-Gutenberg-Universität Mainz. Lieferung 1. Wiesbaden 1979. S. 168. GLA Abt. 205, Fasz. 110 f., 139, 324-327, 1048.

$W$ Abhandlung über Real- und Idealkonkurrenz bei Vergehen. o. O. o.J. - Dissertatio inauguralis iuris publico-practici de revisione in causa appellabili, remedio appellationis neglecto penitus cessante. Heidelberg 1767. - Dissertatio juridica de concursu et cumulatione actionum tam de jure romano ... Heidelberg 1772.

L Almanach Heidelberg (1886) S. 90; Keller (1913) S. 82 f.; Schneider (1913) S. 16; Weisert (1991) S. 121 u. ö.; Schweigard (2000) S. 233-237 u. ö.; WBIS; Schroeder (2010) S. 14. - Kirschbaum, Wolfgang von: Homepage der Familie von Kirschbaum: Mosaiksteine einer vom Militär geprägten Familie, s. http://www.w-vk.de/?page_id=54 (abgerufen am 13. Sept. 2017). - Deutsche Biographie, s. https:// www.deutsche-biographie.de/gnd10288787X.html [07.11. 2017].

\section{Kissling, Karl Friedrich Josef}

1929-1940 (1945) (Honorar-Prof.) Med. Fak. Innere Medizin

* 14. März 1875 Allmendshofen (heute: Ortsteil von Donaueschingen)

$\dagger \quad$ o8. Sept. 1953 Baden-Baden kath.

V Karl K. († vor 1933) Oberförster

M Anna geb. Goeringer ( $\dagger$ nach 1933)

@ 15. März 1919 Emma Berta Anna geb. Pfeiffer $\left({ }^{*} 1884 \dagger\right.$ nach 1973$)$

$\mathrm{K}$ keine. 
Lb Seit WS 1893/94 Studium an U Freiburg/Br., anschl. Würzburg; 1895 Physikum in Würzburg.

U Tübingen: 3. Dez. 1896 Forts. des Studiums; Frühjahr 1899 med. Staatsexamen; 29. Mai 1899 Approbation; 14. Nov. 1899 Dr. med.; 20. Mai30. Sept. 1899 Hilfsassistent (Volontärarzt) an Psychiatr. Klinik.

1899-1900 Studien in Wien.

Hamburg-Eppendorf: Seit April 1901 Assistent, seit Jan. 1905 Sekundararzt der Inneren Abt. des Allg. Krankenhauses; 1. Okt. 1912-31. Okt. 1918 Oberarzt und Leiter der IV. Med. Abt. des Allg. Krankenhauses. • In dieser Zeit:

1914-1918 Kriegsdienst als Sanitätsoffizier.

Mannheim: 1. Nov. 1918-1. Jan. 1941 (Pensionierung) Amtierender Ärztl. Direktor und Chefarzt der Inneren Abt. des Städtischen Krankenhauses; seit Sept. 1939 Kriegsdienst als Chefarzt e. Lazarett-Abt. im Städtischen Krankenhaus; seit Jan. 1941 beratender Internist des Korpsarztes des Wehrkreises XII; Febr. 1945 Verlust seines Besitzes bei Luftangriffen. - In dieser Zeit:

UH: SS 1929-WS 1944/45 o. Honorar-Prof.; 3. Trimester 1940 letzte Vorlesungsankündigung.

Baden-Baden: Nach 1945 praktizierender Arzt.

\section{E Hamburgisches Hanseatenkreuz.}

Qu UAH PA 1014, 4504. - GLA Abt. 235, Fasz. 2170. Ergebnislose Anfragen: Standesamt Bruchsal; Standesamt Baden-Baden. • Auskunft: Universitätsarchiv Tübingen; Klinikum der Stadt Mannheim - Allg. Verwaltung und Organisation.

W Kopftrauma und Psychosen. Casuistische Beiträge. Tübingen 1899 .

L Kürschner (1935) Sp. 674, (1940/41) Sp. 903. Nachruf in: Der Bote vom Oberrhein. Zeitung für die Alten Herren ... des Corps Rhenania zu Freiburg/Br. Freiburg/Br. 1954. Nr. 9. S. 24-27. •
Chronik Ärzte H (1985) S. 133; Bauer (2002) S. 204 (Register); Deutsche Biographie, s. https://www. deutsche-biographie.de/gnd116193689.html [07.11. 2017].

\section{$P$ Bildarchiv UAH; Chronik Ärzte H.}

\section{Klaatsch, Hermann}

1890-1904 (1907) Med. Fak.

Menschliche Anatomie

* 10. März 1863 Berlin

$\dagger$ 05. Jan. 1916 Eisenach

口 unbekannt

ev.

V Dr. med. August Hermann Martin K. (18271885) Arzt, Geh. Sanitäts-Rat, s. ADB 51 (1906) S. 181

M Julie geb. Schwendler (1829-1895)

$\infty$ 1887/1888 Helene geb. Spangenberg; Scheidung nach 1896; T von Gustav S. (1828-1891) Historienmaler, u. a. seit 1869 Prof. an Akademie der Künste Berlin, s. ADB 55 (1910) S. 621-624, WBIS, Allg. Lexikon der Künstler 31 (1999)

K $1 \mathrm{~T}$

Lb SS $1881-$ SS 1882 und SS 1883 Studium an UH; 1882/83 Eigenstudien in Südfrankreich.

U Berlin: WS 1883/84-SS 1885 Forts. des Studiums; 1885 med. Staatsexamen in Berlin; 12. Okt. 1885 Dr. med.; seit März 1885 Assistent am Anatom. Inst.

UH: 1888-1896 Assistent am Anatom. Inst.; 26. Juli 1890 Habilitation; 1. Juni 1895-7. April 1907 nichtetatm. a. o. Prof.; Beurlaubungen: WS 1893/94, WS 1894/95 (1894 Studien an Zoolog. Station in Neapel, anschl. Messina), SS 1895, WS 1896/97-WS 1897/ 98, Jan. 1904 zunächst für 2 Jahre, Juli 1905 Verlängerung auf 3 Jahre. • In dieser Zeit u. a.:

1896-1904 Eigenstudien, Vorträge und Reisen: Frankreich, Belgien, Kroatien und Großbritannien; Febr. 1904-April 1907 auf Anregung seines Kollegen und Freundes (siehe) Otto Schoetensack Forschungsreise nach und durch Australien, 
um dort Belege für die ältesten Zeugnisse der Menschheit zu finden; teilfinanziert von e. Frankfurter Vertreter e. australischen Zinn-Minen-Gesellschaft sowie durch Sammlungs-Aufträge des Leipziger Völkerkundemuseums, des Hamburgischen Museums für Völkerkunde und des Kölner Rautenstrauch-Joest-Museums.

U Breslau: Seit 8. April 1907 etatm. a. o. Prof. für Anatomie, Anthropologie und Ethnographie, Kustos der Sammlungen des Anatom. Inst. der U und Direktor des Museums für Anthropologie und Völkerkunde; seit 1914 Leiter der neueröffneten Anthropologisch-Ethnologischen Sammlung.

Zwischen 1907 und 1910: K. ist Mitarbeiter u. a. von Otto Hauser (1874-1932), einem Schweizer Kunsthändler und Hobby-Archäologen, bei der Bergung des Skeletts eines Neandertalers im französischen Département Dordogne sowie von Otto Schoetensack bei der Bergung und wiss. Auswertung fossiler Hominidenfunde.

Von der insgesamt 2600 Objekte umfassenden Australiensammlung (Zahl 2600 : nach K.s eigenen Angaben) sind 892 Ethnographika seit 1908 dauerhaft im „Rautenstrauch-Joest-Museum Kulturen der Welt" in Köln durch eine Schenkung untergebracht; Ende 1907 fand dort eine Sonderausstellung mit dem gesamten Australienmaterial von K. statt, s. hierzu Erckenbrecht (2010). K.s private ethnographische Lehr- und Studiensammlung befindet sich im Staatlichen Völkerkundemuseum in Warschau.

E 1903 Mitglied der Dt. Akademie der Naturforscher Leopoldina Halle/S.

Qu UAH PA 1832; RA 6173. Briefe: UBH. Nachlaß und Australiensammlung: RautenstrauchJoest-Museum Köln; s. auch Erckenbrecht (2010) S. 27-46. Ergebnislose Anfragen: Ev. Kirche in Mitteldeutschland - Landeskirchenarchiv Eisenach; Stadtverwaltung Eisenach - SG Friedhofsund Bestattungswesen (Sterberegister beginnen ab 18. 09.1933). - Auskunft: Stadtarchiv Heidelberg (Meldekarte von H.K.); Universitätsarchiv der Humboldt-Universität zu Berlin; Stadtverwal- tung Eisenach - Amt für Bildung - Archiv (Sterbeeintrag: 05.01.1916 im Gasthof „Kaiserhof“ in Eisenach).

W Homo Aurignacensis Hauseri in: Prähistorische Zeitschrift 1 (1910) S. 273-338. • Die Entstehung und Erwerbung der Menschenmerkmale. 2 T. Wien 1911-1913. Grundzüge der Lehre Darwins. 4. neubearb. Aufl. von Adolf Heilborn. Mannheim 1919. Der Werdegang der Menschheit und die Entstehung der Kultur. Hrsg. von Adolf Heilborn. Berlin 1920. 2. Aufl. 1922.

$L$ H.K. als „Polygenist“: ein Nachruf von M.V.H. in: Polygenistische Beiträge. 1. Beilage, Nr. 2 (Frühjahr 1916) S. 1-6. • NDB 11 (1977) S. 697 f. (mit Werkverz.); WBIS. - Wegner, Dietrich, Klaatsch, Heinz: Hermann Klaatsch gegen Rudolf Virchow. Ein Berliner Wissenschaftler verhilft der Neandertalerforschung in Deutschland zum Durchbruch in: Acta praehistorica et archaeologica 35 (2003) S. 139-155. - Erckenbrecht, Corinna: Vom Forschungsziel zur Sammelpraxis - Die Australienreise und die völkerkundliche Sammlung H.K.s im Lichte neuer Quellen in: Kölner Museums-Bulletin. Berichte und Forschungen aus den Museen der Stadt Köln. Köln 2006. Nr. 3. S. 25-36; Dies.: Auf der Suche nach den Ursprüngen: die Australienreise des Anthropologen und Sammlers H.K. 1904-1907. Köln 2010. Hahn, Marcus: „Der Affe stammt vom Menschen ab“. Max Westenhöfer, H.K. und die Anthropologie-Rezeption Gottfried Benns in: Nach der Natur - After nature. Hrsg. von Franz J. Deiters. Freiburg/Br. 2010. S. 127-157. • Doll/Kirsch/Eckart (2017) S. 46.

$P$ Bildarchiv UAH; NDB. 


\section{Klages, Wilhelm August Hermann}

1900-1907 (1908) Nat.-Math. Fak.

Organische Chemie

* 19. Juni 1871 Hannover

$\dagger$ 27. Dez. 1957 Göttingen

ev.

V Heinrich K., Bäckermeister, später Privatmann

M Emma geb. Ryssel

(28. Aug. 1900 Mathilde Sophie geb. von Schenck (1875-1960)

$\mathrm{K} \quad 1 \mathrm{~S}, 2 \mathrm{~T}$

Lb 1887-1890/91 Nach Maturitätsprüfung Beginn e. kaufm. Lehre in e. Drogeriegeschäft in Hildesheim; anschl. Besuch e. Handelshochschule.

Studium der Naturwiss.: WS 1893/94-SS 1896 UH, anschl. kurzzeitig TH Hannover.

UH: Seit 15. April 1895 Assistent, seit Jan. 1896 Vorlesungs-Assistent, 1899-1903 Unterrichts-Assistent am Chemischen Laboratorium; 7. Jan. 1897 Dr. phil. nat.; 4. März 1900 Habilitation; seit 15. April 1903 Abt.-Vorsteher am Chemischen Inst.; seit 11. Juni 1904 nichtetatm. a. o. Prof.; WS 1907/o8-SS 1908 Beurlaubung; 1. Okt. 1908 Niederlegung der Lehrtätigkeit.

Ludwigshafen: Seit Okt. 1907 Chemiker bei Badischer Anilin- und Sodafabrik (heute: BASF).

Salbke (seit 1910: Stadtteil von Magdeburg): 19081927 Vorstands-Mitglied sowie Forschungs- und Technikdirektor der Saccharinfabrik AG vorm. Fahlberg, List \& Co.

Berlin: Okt. 1927-Dez. 1933 Geschäftsführendes Vorstands-Mitglied des Vereins Dt. Chemiker.

TH Berlin-Charlottenburg: 10. Juli 1928-30. Sept. 1936 Honorar-Prof. für Chemie im Lehrbereich Chemische Technologie der Fachabt. Chemie und Hüttenkunde in Fak. IV für Stoffwirtschaft (seit 1934 Fak. I für Allg. Wissenschaften, insbesondere für Mathematik, Naturwissenschaften und Wirtschaftswissenschaft).
Göttingen: Nach 1945 Wohnsitz.

Entwickler, u. a. 1920 von „Germisan“, einem Mittel zur Beizung von Saatgut

E 1902 Großherzogl. Badische Jubiläumsmedaille.

Qu UAH PA 1833; Rep. 40-408. - GLA Abt. 235, Fasz. 2171. Briefe: UBH; s. auch Kalliope. Auskunft: Universitätsarchiv TU Berlin (Codex Professorum).

$W$ Über optisch-active Benzolkohlenwasserstoffe in: Berichte der Dt. Chemischen Gesellschaft (1904) Jg. 37, H. 3, S. 649-655. (Mitverf.) - Schädlingsbekämpfung durch chemische Mittel in: Chemische Technologie der Neuzeit. Hrsg. von Franz Peters ... 4. Bd. 2. Aufl. Stuttgart 1933. S. 11241154. Stevia Rebaudiana, eine paraguayische Süßstoffpflanze in: Pharmazeutische Zentralhalle für Deutschland 90 (1951) S. 257-259.

$L$ Wer ist's (1935) S. 818; Poggendorff 7a (1957) S. 761; WBIS; Magdeburger biogr. Lexikon (online vom 09. Febr. 2005). - Maier, Helmut: Chemiker im „Dritten Reich“: Die Deutsche Chemische Gesellschaft und der Verein Deutscher Chemiker im NS-Herrschaftsapparat. Weinheim 2015. S. 705 (Register). Deutsche Biographie, s. https://www. deutsche-biographie.de/gnd117522988.html [07.11. 2017].

$P$ Bildarchiv UAH.

\section{Klebs, Albrecht Georg}

1907-1918 Nat.-Math. Fak.

Botanik

* 23. Okt. 1857 Neidenburg (Ostpreußen; heute: Nidzica, Polen)

$\dagger$ 15. Okt. 1918 Heidelberg ev.

V Emil K. (1821-1894) Staatsanwalt, später Konsistorialrat, s. WBIS

M Aurelie geb. Will 
@ 20. März 1888 Dr. phil. h.c. (U Tübingen) Luise Charlotte geb. von Sigwart (1865-1931) Ägyptologin, s. UAH Handakte HAW Nr. 869; NDB 11 (1977) S. 721, Demm (2014) S. 246 (Re gister); Wilhelm Dilthey: Briefwechsel. Bd. II: 1882-1895. Hrsg. von Gudrun Kühne-Bertram ... Göttingen 2015. S. 602 (Register); T von Christoph (seit 1875: von) S. (1830-1904), u.a. 1865-1903 (Ruhestand) o. Prof. für Philosophie Tübingen, s. Häring, Theodor: C.S. Tübingen 1930; WBIS, DBE 9 (2001) S. $325 \mathrm{f}$; Lange-Greve, Susanne: An der Grenze der Philosophie. Heinrich Maier 1867-1933. Philosoph - Psychologe - Pädagoge. Schwäbisch Gmünd 2014. S. 85 Anm. 6. - Schwester von Anna Sofie Elisabeth geb. Sigwart (1870-1953) Ehefrau von: (siehe) Heinrich Maier

K 1 T, 2 S, s. Kriegstagebuch K. Hampe (2007) S. 974 (Register)

Vw Bruder: Elimar K. (1852-1918) seit 1883 PrivatDozent Berlin, seit 1906 a. o. Prof., 1907-1914 (Entbindung von akad. Pflichten aus gesundheitlichen Gründen) o. Prof. für Alte Geschichte Marburg, s. Catalogus prof. Marburgensis 1 (1927) S. 348 f., WBIS.

Lb U Königsberg (Preußen): Seit WS 1874/75 Studium der Philosophie, Naturwiss., Kunstgeschichte.

U Straßburg: 1. Okt. 1878-30. Sept. 1880 Assistent am Botan. Inst.; 30. Jan. 1879 Dr. rer. nat.; zwischen 1880 und 1883 Militärdienstpflicht als EinjährigFreiwilliger in Straßburg.

U Tübingen: 1. April 1883-30. Sept. 1887 Assistent am Botan. Inst.; 26. Juli 1883 Habilitation.

U Basel: Seit 24. Sept. 1887 o. Prof.

U Halle-Wittenberg: Seit 6. Juli 1898 o. Prof. und Direktor des Botan. Inst.

UH: 20. Febr. 1907-15. Okt. 1918 (†) o. Prof., Direktor des Botan. Inst. und Gartens in der Bergheimer Straße (bis 1915) als Nachf. von Ernst Pfitzer; 8. Okt. 1907 Vereidigung; Forschungsreisen: WS 1910/11 Sibirien, Japan und auf Java, Indien, 1912
Südrußland, 1913 Ägypten; 1915 Verlegung des Botan. Gartens von der Bergheimer Straße ins Neuenheimer Feld.

1918 Wahlsenator UH; 1908/o9, 1913/14 Dekan der Nat.-Math. Fak. der UH

Begründer der botanischen Entwicklungsphysiologie

1907 Geh. Hofrat

$E$ Mitglied der Akademie der Wissenschaften: 1909 H, 1916 München. 1912 Ritterkreuz I. Klasse des Ordens vom Zähringer Löwen.

Qu UAH PA 4517; RA 5633. - GLA Abt. 235, Fasz. 2173. - Briefe: UBH. • Wilhelm Dilthey: Briefwechsel. Bd. II: 1882-1895. Hrsg. von Gudrun Kühne-Bertram ... Göttingen 2015. S. 602 (Register). Nachlaß: Staatsbibliothek zu Berlin.

$W$ Die Bedingungen der Fortpflanzung bei einigen Algen und Pilzen. Jena 1896. 2. Aufl. 1928. • Über die Fortpflanzungs-Physiologie der niederen Organismen ... Basel 1896. Nachdr. Charleston (South Carolina) 2010. - Willkürliche Entwicklungsänderungen bei Pflanzen. Jena 1903. • Über periodisch wachsende tropische Baumarten. Aus dem Nachlaß von G. K. Berlin 1926.

L NDB 11 (1977) S. 720 f. (mit Werkverz.). • Bopp, Martin: G. K. Wegbereiter der botanischen Entwicklungsphysiologie in: Semper apertus 3 (1985) S. 73-96. - WBIS; Jansen (1992a) S. 166 (Register); Bopp (1994) S. 89-94; Leins (1994) S. 59-61; Kriegstagebuch K. Hampe (2007) S. 974 (Register); Wissenschaftsatlas der UH (2011) S. 237 f.; Demm (2014) S. 246 (Register).

$P$ Bildarchiv UAH; NDB. 
Klein, Johann Friedrich Carl

1869-1877 Phil. Fak.

Mineralogie, Geognosie

* 15. Aug. 1842 Hanau

$\dagger \quad$ 23. Juni 1907 Charlottenburg (heute: Ortsteil von Berlin)

ev.

V Johann Georg Friedrich Ernst K. (1794-1857) Repositor

M Johanna Maria Margaretha geb. Klauhold

œ 10. Aug. 1869 Emma geb. Wehner († nach 1907)

K $\quad 1 \mathrm{~S}$

Lb Studium: Seit 1861/62 Land- und Forstwirtschaftl. Akademie Hohenheim (heute: Stadtteil von Stuttgart), anschl. U Berlin, seit WS 1865/66 Tübingen, SS 1867-SS $1868 \mathrm{H}$.

UH: 3. Nov. 1868 Dr. phil.; 17. Juli 1869 Habilitation; seit 2. Aug. 1873 a. o. Prof.

U Göttingen: 18. Febr. 1877 Ern. zum o. Prof. und Direktor des Mineralogisch-Petrographischen Inst.; 1884 Studienreise nach Italien (Ätna und Vesuv).

U Berlin: 1887-1907 o. Prof. und Direktor des Mineralogisch-Petrographischen Inst. und des Museums für Naturkunde.

1889 Geh. Bergrat

$E$ Mitglied der Akademie der Wissenschaften: 1877 Göttingen, 1887 Berlin; 1882 Mitglied der Dt. Akademie der Naturforscher Leopoldina Halle/S.; Mitglied der Mineralogischen Gesellschaft St. Petersburg.

Qu UAH PA 1836; Fak.-Akte H-IV-102/70 fol. 101r-107r. • Briefe: UBH.

$W$ Einleitung in die Krystallberechnung. Stuttgart 1875. Petrographische Untersuchungen einer Suite von Gesteinen aus dem Gebiet des Bolsener Sees in: Neues Jahrbuch für Mineralogie - Beilage (1889); Apatit und Pyromorphit in: ebd. (1902).
Bibliographie, s. Bibliothek der Berlin-Brandenburgischen Akademie der Wissenschaften online unter bibliothek.bbaw.de.

MHG 1879-1884 Neues Jahrbuch für Mineralogie.

$L$ Wolff, Ferdinand von: Nekrolog C.K. in: Centralblatt für Mineralogie (1907) S. 641-661 (P). • Arnim 1 (1944) S. 655; Catalogus prof. Gottingensium (1962) S. 110; WBIS. • Geschichte der Mikroskopie. Leben und Werk großer Forscher. Bd. III: Angewandte Naturwissenschaften und Technik. Hrsg. von Hugo Freund und Alexander Berg. Frankfurt/M. 1966. S. 235-239. - Göttinger Gelehrte 1 (2001) S. 222 f. * The History of Meteoritics and Key Meteorite Collections: Fireballs, Falls and Finds. Ed. by Joseph Home McCall ... London 2006. S. 144-146. • Das Kleinsche Polarisationsmikroskop-Polymeter. Beitrag von olaf.med (20. Sept. 2013), s. online http://www.mikrosko pie-forum.de/index.php?topic $=17504.0$ (Ausdruck im UAH).

P Bildarchiv UAH; Göttinger Gelehrte (2001).

\section{Klein, Gustav}

1931-1937 (1938) (Honorar-Prof.) Nat.-Math. Fak. Biologie

* 19. Aug. 1892 Kahlenbergerdorf (heute: Stadtteil von Wien)

$\dagger$ 03. Juli 1954 Zell am Harmersbach (Schwarzwald)

kath.

V Leopold K. (1867-1900) Beamter im Unterrichtsministerium

M Therese geb. Sturm $\left({ }^{\star} 1869\right)$

$\infty$ 12. Aug. 1929 Adele geb. Kretschmer gesch. Franke (1893-ca. 1940); bis 1927 (Scheidung) Ehefrau von Adolf Franke (1874-1964) U Wien: seit 1901 Privat-Dozent, seit 1914 a.o. Prof., 1920-1941 (Emeritierung) o. Prof. für Chemie, s. WBIS; Die wissenschaftliche Welt von gestern (2004) S. 251-254 
๑ vor 1946 Frieda Klein-Haas geb. Haas, Apothekerin ( $†$ nach 2003) 1939-1945 Leiterin des heute noch bestehenden Pflanzensaftwerkes Schönenberger in Magstadt (bei Sindelfingen)

$\mathrm{K}$ mindestens $1 \mathrm{~S}, 1 \mathrm{~T}$

Lb U Wien: Seit WS 1911/12 Studium der Botanik und Chemie; seit 12. Dez. 1912 Demonstrator, seit 14. Dez. 1913 Hilfs-Assistent, 1. Jan. 1919-30. Sept. 1920 a.o. Assistent am Pflanzenphysiolog. Inst.; 20. Dez. 1918 Dr. phil. • In dieser Zeit:

Aug. 1914-Dez. 1918 Kriegsdienst (Aug.-Nov. 1916 Versetzung in Rohstoffgruppe am Kriegsministerium in Wien).

U Wien: 1. Okt. 1920-18. Dez. 1924 o. Assistent am Pflanzenphysiolog. Inst.; 1921 Habilitation; 1924 Ruf an Deutsche TH Prag abgelehnt; seit 18. Dez. 1924 a. o. Prof. für Anatomie und Physiologie der Pflanzen; seit 1. März 1927 o. Prof. und Direktor des Pflanzenphysiolog. Inst.

Oppau (heute: Stadtteil von Ludwigshafen): Seit 15. Jan. 1930 Prokurist und Leiter des Biologischen Laboratoriums Oppau der I.G. Farbenindustrie AG; 19. Nov. 1936 fristlose Entlassung aus I. G. Farbenindustrie, s. hierzu $Z$.

UH: 17. Jan. 1931 Ern. zum o. Honorar-Prof.; 14. Sept. 1936 Ern. durch Reichs- und Preußischen Minister für Wiss., Erziehung und Volksbildung zum Mitglied der für den II. Int. Krebskongreß in Brüssel gebildeten dt. Abordnung am 20.-26. Sept. 1936; K. nimmt letztendlich nicht teil; 27. Mai 1937 Untersagung der Lehrtätigkeit durch Rektor Ernst Krieck; 2. Juli 1938 K. legt seine Honorarprofessur nieder: „Infolge geänderter Lebensumstände bin ich in absehbarer Zeit schon aus räumlichen Gründen nicht mehr in der Lage, an der Universität Heidelberg tätig zu sein“ (aus: UAH PA 4521).

Oberursel (Taunus): Um 1938 Wohnsitz.

Magstadt: Vor 1946 Mitarbeiter im Pflanzensaftwerk Schönenberger.

Zell am Harmersbach: 1946 Begründer (zus. mit seiner Frau Frieda) der Pharmazeutischen Fabrik Dr. Gustav Klein GmbH; Eigenanbau von Heil- pflanzen, Herstellung und Vertrieb von pflanzlichen Arzneimitteln, u.a. des heute noch gängigen Phytopharmakons Gastritol Liquid. Nach dem Tod K.s 1954 Übernahme der Firmenleitung durch Frieda K.-H.; 2012 Verkauf der Firma Dr. Gustav Klein an die Schweizer Alpen Pharma AG (die niederländische SanoPharm Nederland in Barneveld z. B. hat noch heute die vom Ehepaar K. entwickelten phytotherapeutischen Produkte in ihrem Programm).

Z 1936 erhält K. von der Direktion der I. G. Farbenindustrie AG die fristlose Kündigung u.a. aufgrund verschwenderischen Umgangs mit Geld für seine Krebsforschungen und verfälschten Testergebnissen bei Krebspatienten. 1937 klagt K. gegen seine fristlose Entlassung durch I. G. Farbenindustrie vor dem Arbeitsgericht Ludwigshafen; am 5. Okt. 1937 wird seine Klage vom Arbeitsgericht abgewiesen und K. geht am 19. Okt. 1937 in Berufung. Auch diese Klage wird niedergeschlagen (s. hierzu Unternehmensarchiv Ludwigshafen, BASF Rechtsabteilung Ludwigshafen, B4/904, B4/ 931, B4/933, B4/1879). In e. Brief des Rektors der UH, Ernst Krieck, an den Minister des Kultus und Unterrichts in Karlsruhe vom 9. April 1938 heißt es: „Die Klage des Professors Klein ist in beiden Instanzen abgewiesen. Aus den Urteilsgründen ergibt sich eindeutig, daß Klein sich durch sein Verhalten als Mensch und als Wissenschaftler auch für die Universität untragbar gemacht hat" (aus: UAH PA 4521).

In einem Rechtfertigungsschreiben an Rektor Krieck vom 30. Mai 1938 führt K. an: „Mir ist bekannt, daß auch zu Ihren Ohren Gerüchte gedrungen sind, die meinen wissenschaftlichen Ruf und meine persönliche Ehre betreffen. Ich nehme daher Gelegenheit, Ihnen mitzuteilen, daß ich nach längeren Mühen endlich die Möglichkeit gehabt habe, einen Herrn, der solche Dinge verbreitet hat, stellen zu können. Ich habe ihn daraufhin im Wege der Privatklage gerichtlich belangt. Er gab durch seinen Anwalt folgende Erklärung ab: ,... Mein Mandant erklärt hiermit ausdrücklich, daß er alle die Person Ihres Mandanten, des Herrn Prof. ... Klein, und seine wissenschaftlichen Leistungen betreffenden Äußerungen, in denen eine Beleidigung, Kränkung oder Herabsetzung der Person oder der wissenschaftlichen Leistungen 
gesehen werden könnte, mit dem Ausdruck tiefsten Bedauerns zurücknimmt ... Er erklärt, daß er keinen Anlaß noch Unterlagen gehabt habe noch habe, solche Behauptungen aufzustellen oder gar aufrecht zu erhalten, daß vielmehr die Äußerungen in der Erregung und unter alkoholischem Einfluß geschehen sind. Diese Erklärung bezieht sich insbesondere auf den nach der Angabe von Zeugen in diesem Zusammenhang gebrauchten Ausdruck: Hochstapler oder Hochstapelei ..." Weiterhin erklärt der Mandant, er habe keine Unterlagen über die K. ebenfalls vorgeworfenen Transaktionen oder Devisenverschiebungen nach dem Ausland, unrechtmäßige Aneignung von Patenten durch K. oder über gefälschte Statistiken oder Bestechungen von Assistenten auswärtiger Kliniken. K. hofft mit dieser Erklärung, „daß auch Anderen, die ähnliche Dinge verbreitet haben, das Handwerk gelegt wird." Inzwischen ist, so Klein, auch eine Amnestie erfolgt (aus: UAH PA 4521).

1929 Vizepräsident des Vereins zur Verbreitung naturwiss. Kenntnisse. • Präsidialmitglied der Österr. Gartenbaugesellschaft. - Mitglied des Ausschußrates des österr. Wiss. Klubs

E 1929 Ehrenmitglied des Naturwiss. Vereins der U Wien. 1927 Richard Lieben-Preis der Kaiserl. Akademie der Wissenschaften Wien. - Silberne Militärverdienstmedaille mit Schwertern; Silberne Tapferkeitsmedaille II. Klasse; VerwundetenMedaille.

Qu UAH PA 4521. - GLA Abt. 235, Fasz. 2175f. • Briefe: UBH. - Auskunft: Unternehmensarchiv Ludwigshafen.

W Praktikum der Histochemie. Berlin 1929. • Krebsdisposition, Krebsabwehr und ihre Diagnose in: Archiv für klinische Chirurgie 183 (1935) S. 194$2 \mathrm{O} 2$.

HG Handbuch der Pflanzenanalyse. Wien 1931.

Redakteur 1929 Österr. Botanische Zs.
$L$ Wer ist's (1935) S. 822; Arnim 1 (1944) S. 655, 4 (1984) S. 811; WBIS; Jansen (1992) S. 397. • Die wissenschaftliche Welt von gestern: die Preisträger des Ignaz L. Lieben-Preises 1865-1937 und des Richard Lieben-Preises 1912-1928; ein Kapitel österreichischer Wissenschaftsgeschichte in Kurzbiografien. Hrsg. von R. Werner Soukup ... Wien 2004. S. 255258 u. ö. Deutsche Biographie, s. https://www. deutsche-biographie.de/gnd117523208.html [07.11. 2017].

$P$ Die wissenschaftliche Welt von gestern, S. 255 .

\section{Klein, Karl}

siehe Klein, Carl

\section{Kleinschmidt, Arthur Karl August Paul} Wilhelm

1875-190o Phil. Fak.

Neuere Geschichte

* o8. April 1848 Wiesbaden

$\dagger$ 04. Aug. 1919 Starnberg am See ev.

V Karl Heinrich August Georg K. (1816-1847) Leutnant a.D., Mainzollamts-Accessist (Akzessist $=$ Anwärter)

M Marie Elise Charlotte Julie Henriette geb. Freiin von Ziegesar (1817-1896)

๑ 4. April 1903 Elisabeth Antonie geb. Freiin von Holzhausen (1863-1937)

K keine.

Lb UH: Seit WS 1868/69 Studium der Geschichte, Politik und Rechtswiss.; 19. Okt. 1872 Dr. phil.; 7. Mai 1875 Habilitation; seit 17. Febr. 1887 a. o. Prof.

Dessau: 1. Jan. 1901-1909 (Ruhestand) Direktor der Herzogl. Hofbibliothek.

Wohnsitz: Nach 1909 Eggenburg bei Graz, seit Okt. 1916 Starnberg.

1900 Hofrat 
Qu UAH PA 1842; Fak.-Akte H-IV-102/81. • GLA 60 Nr. 252. • Briefe: UBH. • Auskunft: Stadtarchiv in Starnberg am See.

W Rußlands Geschichte und Politik dargestellt in der Geschichte des hohen Adels. Kassel 1877. Reprint 2006. - Die Eltern und Geschwister Napoleons I. Berlin 1878. 2. Aufl. 1886. - Karl Friedrich von Baden. Heidelberg 1878. • Geschichte des Königreichs Westfalen. Gotha 1893. Nachdr. Kassel 1970. Bayern und Hessen. Berlin 1900. 2. Aufl. 1902. Katalog der Herzoglichen Hofbibliothek zu Dessau. Geschichte des Mittelalters und der Neuzeit. Hrsg. und mit Sach- und Namensverzeichnis versehen von Emil Weyhe. Dessau 1910. • Geschichte von Arenberg, Salm und Leyen 1789-1815. Gotha 1912.

L Almanach Heidelberg (1886) S. 148; Wer ist's (1914) S. 847; Arnim 1 (1944) S. 655; WBIS; Geschichte Histor. Seminar UH (1992) S. 324 (Register); Jansen (1992a) S. 166 (Register). • Renkhoff, Otto: Nassauische Biographie. 2. Aufl. Wiesbaden 1992. S. 399. - Militärische Erinnerungskulturen vom 14. bis zum 19. Jahrhundert ... Hrsg. von Horst Carl ... Göttingen 2012. S. 352 f. u. ö. • Deutsche Biographie, s. https://www.deutsche-biogra phie.de/gnd116218428.html [07.11. 2017].

$P$ Bildarchiv UAH; graph. Slg. UBH.

\section{Kleinschmidt, Emil Karl Rudolf}

1922-1928 Med. Fak.

Chirurgie

* o6. Febr. 1885 Wiesbaden

$\dagger \quad$ o7. Juni 1978 Mülheim (Ruhr) ev.

V Georg Ludwig Theodor K. (1825-1893) Kaufmann

M Dorothee Lisette Luise geb. Schellenberg (1847-1932), s. http://www.geni.com/people/ Dorothea-Kleinschmidt/6000oooo277110719 32 ( $P$; Ausdruck im UAH)
๑ 5. Aug. 1919 Luise Margarete geb. Sachs (18881982)

K 4, u.a.1S, 2 T

Lb U München: Seit WS 1904/05 Studium; 1910 Dr. med.; 1910 Approbation.

Med. Ausbildung: 1910-1914 Düsseldorf, anschl. Wiesbaden, München.

UH: Juli 1914-Sept. 1922 Assistent an Chirurg. UKlinik; 3. März 1922 Habilitation; 1922-1928 Oberarzt an Chirurg. U-Klinik; seit 29. März 1927 a.o. Prof. • In dieser Zeit:

1914-1918 Kriegsdienst.

Mülheim (Ruhr): 1928-1962 Chefarzt und Leiter der Chirurg. Abt. des Ev. Krankenhauses.

Qu UAH PA 1017, 4530. - GLA Abt. 235, Fasz. 2180.

$W$ Über Entstehung und Bau der Gallensteine in: Beiträge zur pathologischen Anatomie und allg. Pathologie 72 (1923). • Über die schmerzstillende Wirkung eines morphinartig wirkenden Codeinderivats „Dicodid“ in: Münchener Med. Wochenschrift 13 (1923). Zur Technik der Eckfistel in: Zentralblatt für Chirurgie 39 (1926).

$L$ Chirurgen-Verzeichnis ( $\left.{ }^{4} 1958\right)$ S. 422 f., $\left({ }^{5} 1969\right)$ S. 462 f.; WBIS. - Nachruf in: Westdeutsche Allgemeine Zeitung vom 14. Juni 1978. Deutsche Biographie, s. https://www.deutsche-biographie. de/gnd137216319.html [07.11. 2017].

$P$ Westdeutsche Allgemeine Zeitung.

\section{Klibansky, Raymond}

1932-1933 (Privat-Dozent) Phil. Fak.

Philosophie

* 15. Okt. 1905 Paris

$\dagger$ 05. Aug. 2005 Montreal mosaisch 
V Hermann K. (1870-1936) Kaufmann

M Rosa geb. Scheidt (1879-1979) Hausfrau

๑ 1989 Dr. Ethel geb. Groffier $\left({ }^{\star} 1935\right)$ Prof. i. R. der Faculty of Law McGill U Montreal

K $\quad 1 \mathrm{~T}$

Lb WS 1923/24 Studium der Philosophie, Klassischen Philologie, Archäologie an UH, seit SS 1924 Kiel, WS 1925/26 H, SS 1926-WS 1926/27 Hamburg, WS 1927/28 H.

H: SS 1927-WS 1932/33 Mitarbeiter bei Edition der Cusanus- und Meister Eckhart-Werkausgabe der Heidelberger Akademie der Wissenschaften, s. hierzu Mussgnug (1988) S. 40-43, 182 f. - In dieser Zeit:

UH: 26. Sept. 1929 Dr. phil.; 9. Juli 1932 Habilitation für Philosophie; seit 20. April 1933 von U beurlaubt; April 1933 Studienaufenthalt in Rom; Aug. 1933 Emigration nach London; 2. Aug. 1933 Entziehung der Lehrbefugnis.

London: Seit 1933 ehrenamtl. Dozent am King's College der U.

Oxford: 1936 (Umhabilitation)-1948 Prof. (Lecturer) für Philosophie am Oriel College der U; 1938-1939 Gastprof. für Religionsphilosophie an U of Liverpool.

London: 1941-1946 Chief Intelligence Officer der Political Warfare Executive am britischen Foreign Office; 1946/47-1948 Direktor am Warburg-Inst. der U.

McGill U Montreal: 1. Sept. 1948 (Ern.)-30. Sept. 1975 (Emeritierung) o. Prof. für Logik und Metaphysik; Gast-Prof.: 1950 Indiana U in Bloomington, 1953 U Rom; zahlreiche abgelehnte Rufe.

UH: 22. Okt. 1957 Verleihung der Rechtsstellung e. am 1. April 1951 in den Ruhestand versetzten, zum 1. April $1970 \mathrm{zu}$ emeritierenden o. Prof.; die Zeit zwischen dem 23. Okt. 1933 und 31. März 1951 wird als Dienstzeit im Sinne des Besoldungs- und Versorgungsrechts angerechnet; als Tag der Ern. zum o. Prof. gilt der 1. Okt. 1944.
Präsident: 1966-1969 Institut Int. de Philosophie in Paris, 1968-1972 Société Int. de Philosophie médiévale in Louvain-La-Neuve

E Mitglied: 1964 Akademie der Wissenschaften H, 1965 Mediaeval Academy of America, 1977 Accademia Nazionale dei Lincei, 1980 Accademia Ligure Genova, 1990 Dt. Akademie für Sprache und Dichtung in Darmstadt; 1981 Fellow, 1995 Honorary Fellow des Wolfson College Oxford; 1985 Honorary Foreign Member der American Academy of Arts and Sciences. Ehrenpromotionen: 1987 Marburg, 1995 Bologna. 1995 Großes Bundesverdienstkreuz; 1999 Grand officier de l'Ordre national du Québec; 2000 Companion of the Order of Canada. 1986 Ehrensenator der Universität Heidelberg.

Qu UAH PA 480, 7101; Rep. 27-578; Studentenakte; Handakte HAW Nr. 249. - Nachlaß: DLA Marbach. Mitteilungen: Eigene Angaben von April 2003; Frau Prof. Dr. Ethel Groffier, Quebec. - Erlebte Geschichte erzählt 1994-1997 ... Michael Buselmeier im Gespräch mit R. K. 15. Mai 1994. Heidelberg 2000. S. 9-29. • Erinnerung an ein Jahrhundert. Gespräche mit Georges Leroux. Frankfurt/M. 2001. (Dt. Übers. von: Le philosophe et la mémoire du siècle.) • R.K. De la philosophie à la vie. Film. Regie: Anne-Marie Tougas. Kanada 2002.

$W$ Bibliographie 1927-2002 im UAH. - K., R., Groffier, Ethel: Idées sans frontières. Histoire et structures de l'Institut international de philosophie. Paris 2005.

(M)HG Nicolai de Cusa. Opera omnia. Vol. I und II. Leipzig 1932. Vol. VII und XII. Hamburg 1970 und 1982.

L Dictionary of Emigrés 2 (1983) S. 632; Kröner (1983) S. 6o; Mussgnug (1988) S. 28of. u.ö. • Jakobs, Hermann: Laudatio zur 6ojährigen Wiederkehr der Ehrendoktorwürde ... in: Ruperto Carola 42. Jg., H. 82 (Dez. 1990) S. 161-164. • Blomert (1999) S. 29-31 u. ö.; Int. Biogr. Archiv (1999/ 2001). Evangelische Kirchenhistoriker im „Dritten Reich“. Hrsg. von Harry Oelke und Thomas Kaufmann. Gütersloh 2002. S. 194-197 u. ö. • Ti- 
litzki 1 (2002) S. 108, 315, 600-603 u. ö. • Günther, Horst: „Kosmopolit der Vernunft“. Nachruf in: Neue Zürcher Zeitung vom 15. Aug. 2005. • Halfwassen, Jens: R. K.: Erinnerungen an ein Jahrhundert in: Ruperto Carola 3 (2005) S. 30-36. - Melancholie. Ausstellung Melancholie ... 2005-2006 in Paris und Berlin. Zu Ehren von R.K. ... Ed. Jean Clair. Ostfildern-Ruit 2005. - Senger, Hans Gerhard: R. K. ... Skizze e. philosophischen Biographie in: Die Sermones des Nikolaus von Kues ... Akten des Symposions in Trier ... Trier 2005. S. XI-XXVIII. • Bubner, Rüdiger: Nachruf in: Jahrbuch HAW für 2005 (2006) S. 157 f. • UH im Nationalsozialismus (2006) S. 1259 (Register). • Weber, Regina: Der Philosophiehistoriker R.K. und die „Internationalisierung“ der Philosophie ... in: Weltanschauliche Orientierungsversuche im Exil. Hrsg. von Reinhard Andress u.a. Amsterdam 2010. S. 79-98; Dies.: R. K. in: Deutschsprachige Exilliteratur seit 1933. Hrsg. von John M. Spalek ... Berlin 2010. Bd. 3, Suppl. 1. S. 93-124. • Lexikon jüdischer Einwohner Hs (2011) S. 221 f. • Stephan, Regina: Aktivitäten der Warburg-Bibliothek, gespiegelt im Marbacher Nachlaß R. K. Dokumente über K.s Beziehungen zur Kulturwissenschaftlichen Bibliothek Warburg in dem 2007 dem Deutschen Literaturarchiv Marbach übergebenen Nachlass in: Bibliotheken und Sammlungen im Exil. Hrsg. von Claus-Dieter Krohn und Lutz Winckler. München 2011. S. 100-114. • R. K. ... La bibliothèque d'un philosophe. Catalogue accompagne l'exposition ... présentée à la Grande Bibliothèque du 13 novembre 2012 au 25 août 2013. Montréal 2013. - Deutsche Biographie, s. https:// www.deutsche-biographie.de/gnd118777378.html [07. 11. 2017].

$P$ Bildarchiv UAH.

\section{Klopstock, Alfred}

1926-1933 (1935) Med. Fak.

Immunitäts- und Serumforschung

* 05. Febr. 1896 Weißensee (heute: Ortsteil von Berlin)

$\dagger$ 04. April 1968 Tel Aviv mosaisch
V Dr. Martin K. $\left({ }^{*} 1865\right)$ Arzt

M Regina geb. Tietz (1875-1923)

( 20. Febr. 1924 Dr. med. Elisabeth geb. Scheyer (1899-1958), s. Rürup (2008) S. 244, Lexikon jüdischer Einwohner Hs (2011) S. 222

@ nach 1958 Ruth geb. Block, Ärztin und Vorstandsmitglied der Women's Int. Zionist Organization, s. Rürup (2008) S. 245

K 1 T, s. Lexikon jüdischer Einwohner Hs, S. 222.

Lb Seit SS 1914 Studium an U Gent, anschl. Berlin; Mai 1915-März 1919 Kriegsdienst und Gefangenschaft.

Berlin: Juli 1920 Med. Staatsexamen; Okt. 1920Juni 1921 Assistent am Patholog. Inst. des AugustaViktoria-Krankenhauses in Schöneberg; 7. März 1921 Dr. med. an U.

UH: Seit 1922 Volontär, 1. Okt. 1923-1931 Assistent an Wiss. Abt. am Inst. für Experimentelle Krebsforschung; 6. Juli 1926 Habilitation; SS 1928 Teilnahme an Syphilisexpedition nach Sibirien; WS 1928/29 Beurlaubung aus gesundheitlichen Gründen; seit 6. Juli 1931 a. o. Prof.; 6. April-3. Mai 1933 von U bis auf Weiteres beurlaubt; 5. Mai 1933 eine Wiedereinsetzung lehnt K. aus gesundheitlichen Gründen ab; 5. Aug. 1933 Entziehung der Lehrbefugnis gemäß des Gesetzes zur „Wiederherstellung des Berufsbeamtentums" „kommt nicht in Betracht, ... da ... K. im Weltkrieg bei der fechtenden Truppe an Kämpfen teilgenommen hat" (aus: UAH PA 4537); Sommer 1933 Emigration; 21. Febr. 1935 Streichung aus dem Verzeichnis der akad. Lehrer, da K. „weder beurlaubt, noch in den beiden letzten Semestern Vorlesungen gehalten hat" (aus: PA 4537).

Tel Aviv: Nach 1933 Gründer (zus. mit seiner Frau Elisabeth) e. privaten bakteriologischen Laboratoriums; 1956-1964 o. Prof. und Direktor der Abt. für Mikrobiologie (1959-1964 Rektor) an U.

UH: 1. Jan. 1954 K. erhält als Wiedergutmachung die Bezüge e. von seinen amtlichen Pflichten entbundenen a. o. Prof. 
Qu UAH PA 1019, 4537; B-3182/10. • GLA Abt. 235, Fasz. 2185. • Briefe: UBH.

W K., A. und Witebsky, Ernst: Zur Kenntnis der Antigenfunktion von Bakterienlipoiden in: Klinische Wochenschrift 3 (1927). - Sachs, Hans, K., A.: Methoden der Hämolyseforschung. Berlin 1928. - Untersuchungen über chemospezifische Antigene: Über die Eignung von Lipoiden zur Manifestation chemospezifischer Antigenfunktionen in: Zs. für Immunitätsforschung 57 (1928) S. 174. K., A. und Klopstock, Elisabeth: Zur neuesten Entwicklung der Theorie und Methode der Syphilisreaktionen in: Journal für Psychologie und Neurologie 39 (1929) S. 429. - Die Methoden zur Serodiagnostik der Syphilis. Berlin 1933. Klopstock, Elisabeth und K., A.: The first diagnosed outbreak of Q Fever in Israel ... in: The Journal of the American Medical Association (1949) Vol. 140, No. 13.

L Kürschner (1931) Sp. 1473, (1935) Sp. 688; Dictionary of Emigrés 2 (1983) S. 632 f.; Mussgnug (1988) S. 298 (Register); 100 Jahre Krebsforschung (2000) S. 47 f.; UH im Nationalsozialismus (2006) S. 1259 (Register); Rürup (2008) S. 525 (Register); WBIS; Friedrich (2009) S. 90 f., 117 f. u. ö.; Lexikon jüdischer Einwohner Hs (2011) S. 222; Deutsche Biographie, s. https://www.deutsche-biographie.de/gn d116234261.html [07.11. 2017].

\section{Klüber, Johann Ludwig}

1807-1817 Jur. Fak.

Staatsrecht

* 10. Nov. 1762 Tann (Rhön)

$\dagger$ 16. Febr. 1837 Frankfurt/M.

ev.-luth.

V Johannes K. (1723-1793) Notar, Sekretär, Archivar

M Philippine Charlotte geb. Calmberg (17401823)

( Herbst 1789 Josephine Christine geb. Zeizer (1772/73-1796)
K 5 (4 davon früh $\dagger$ ): Friedrich Adolf K. (17931858) Jurist, u.a. 1824-1828 Oberbürgermeister von Düsseldorf, seit 1832 Legations- und Kabinettsrat, seit 1836 Geh. Referendär (Berichterstatter), zuletzt bis 1839 Geh. Rat im badischen Staatsdienst, 1845-1849 Mitglied der I. Kammer des Badischen Landtags, 1849-1850 badischer Minister für Auswärtige Angelegenheiten und des Großherzogl. Hauses, s. ADB 16 (1882) S. 247

Vw Nachfahren: Robert von K. (1873-1919 ermordet) preußischer Oberstleutnant im Generalstab, s. Hildebrand, Karl-Friedrich und Zweng, Christian: Die Ritter des Ordens Pour le Mérite für Wissenschaften und Künste. Osnabrück 2003. Bd. 2, S. 361 f. • Harald von K. (1901-1978) Astrophysiker, s. NDB 12 (1979) S. 134f. - Karl Werner K. (1904-1991) Kulturhistoriker und Genealoge; s. auch Familienarchiv im GLA Karlsruhe.

Lb Seit 17. Mai 1780 Studium der Rechtswiss. an U Erlangen, WS 1780/81 Gießen, 1. Mai 1781-28. Okt. 1782 Leipzig; anschl. Reise u. a. durch Sachsen und Sachsen-Anhalt.

Westfalen: 1783-1784 Hofmeister und Advokat.

U Erlangen: 1784 Rückkehr; 13. April 1785 Dr. iur.; 14. April 1785 Verleihung der venia legendi für Rechte; Ern.: 10. Juni 1786 a. o. Prof., 2. Jan. 1787 o. (fünfter) Prof., noch 1787 vierter Prof., 1792-1804 dritter Prof.; 1790-1797 u.a. Ratgeber des Ministers Karl August Freiherrn von Hardenberg.

Karlsruhe: Herbst 1804-1817 Geh. Referendär und Prinzen-Erzieher am Badischen Hof sowie Ratgeber des Großherzogs.

UH: 4. Febr. 1807 Ern. zum o. (ersten) Prof.; 18071817 Beisitzer des Spruchkollegiums der Jur. Fak.; seit Ende 1807 Kurator der Sternwarte, (s. hierzu Budde, Kai: Sternwarte Mannheim ... Heidelberg 2006. S. 109 ff.); Sept. 1814-Juni 1815 Besucher des Wiener Kongresses; 1815 Aufenthalt in Frankfurt/M.; 1816 Berufung zum badischen Finanzminister abgelehnt; WS 1816/17 letzte Vorlesungsankündigung. 
Berlin: 8. Mai 1817-März 1824 als Königl. Preußischer Wirkl. Geh. Legationsrat Beisitzer im Departement des Staatskanzlers und im Ministerium für Auswärtige Angelegenheiten; 1822-1824 Aufenthalt in Frankfurt/M. als königl. Regierungscommissär; 1. April 1824 auf eigenen Antrag Dienstentlassung, s. hierzu Schroeder (1997) S. 1148 f.

Frankfurt: 1824-1837 Privatier.

1809, 1815 (Jan.-Dez. 1815 Prodekan: Franz Gambsjaeger, s. UAH RA 793 S. 68) Dekan der Jur. Fak. der UH

1795 Hofrat; 1808 Staats- und Geh. Kabinettsrat

E Mitglied: 1788 Akademie der Wissenschaften Erfurt, 1834 Académie des Sciences Morales et Politiques Paris. 3. Juni 1792 Dr. phil. h.c. Erlangen. $\bullet 1836$ Orden der franz. Ehrenlegion.

Qu UAH PA 1847; Acc. 29/05-12, Acc. 29/05-14. Matrikel Erlangen (1918) S. 87 und Anm. 14. GLA Abt. 205, Fasz. 334. - Nachlaß: GLA Karlsruhe; Stadtarchiv Baden-Baden.

$W$ Neue Litteratur des deutschen Staatsrechts. Erlangen 1791. Staatsrecht des Rheinbundes. Tübingen 1808. Die Akten des Wiener Congresses in den Jahren 1814/15. Bde. 1-8. Erlangen 1815-1819. Bd. 9. 1835. - Das öffentliche Recht des deutschen Bundes und der Bundesstaaten. Frankfurt/M. 1817. 2. Ausg. 1822. 4. Aufl. 1840. Droit des gens modernes de l'Europe. 2 Bde. Stuttgart 1819. 2. Aufl. 1851. • Europäisches Völkerrecht. 2 Bde. Stuttgart 1821-1822. 2. Aufl. ... ergänzt von Carl E. Morstadt. Schaffhausen 1851.

HG Schluß-Acte des Wiener Congresses, vom 9. Juni 1815, und Bundes-Acte oder Grundvertrag des teutschen Bundes, vom 8. Juni 1815 ... Erlangen 1815. 2. Aufl. 1818. 3. Aufl. 1830. 1816-1817 Staatsarchiv des deutschen Bundes.

$L$ Artikel über J.L.K. aus: Konversationslexikon der neuesten Zeit und Literatur. 13. Heft in: Der Unparteiische. Ein encyclopädisches Zeitblatt für Deutschland vom 13. Mai 1833. Bd. 1. Nr. 37. 1. Jg. S. 145-147. NDB 12 (1980) S. 133f. (mit Werk- verz.); WBIS; Professoren Erlangen (1993) S. 134 f. • Schroeder, Klaus-Peter: J. L. K. - Ein deutsches Gelehrtenleben in: Wirkungen europäischer Rechtskultur. Festschrift für Karl Kroeschell ... Hrsg. von Gerhard Köbler ... München 1997. S. 1107-1154. • Willett (2001) S. 110, 278 u. ö.; Baur (2009) S. 161 f. Deutsch, Andreas: Ein Geheimbund mit Lizenz zum Töten: der Anti-Illuminaten-Orden des J.L.K. Stuttgart 2010. Schroeder (2010) S. 38-42 u. ö. • Dochnahl, Helmut: J.L.K. ... Professor, Staatsmann und Publizist. Jur. Diss. Heidelberg 2015.

$P$ Bildarchiv UAH; Stich nach e. Original-Marmorbüste enthalten in: UAH Acc. 29/05-17.

\section{Klug, Wilhelm Josef}

\author{
1924-1933, 1939-1940 Med. Fak. \\ Chirurgie
}

* 13. Aug. 1889 Roßbach (Bayern)

$\dagger$ 19. Sept. 1940 Pforzheim

kath.

V Johann Baptist K. (1854-1912) Land- und Gastwirt

M Mathilde geb. Happ ( ${ }^{*} 1868 \dagger$ nach 1939)

( 15. April 1921 Josefine Hubertine Maria geb. Rolshoven $\left({ }^{*} 1895 \dagger\right.$ nach 1940$)$

$\mathrm{K} \quad 1 \mathrm{~S}, 1 \mathrm{~T}$

Lb Würzburg: Seit WS 1910/11 Studium an U; Sept. 1916 Staatsexamen; April 1917 Approbation; seit Okt. 1919 Assistent an Chirurg. U-Klinik; 1920 Dr. med. an U. In dieser Zeit:

1914-1916, Sept. 1917-Mai 1919 Kriegsdienst.

UH: Seit Nov. 1920 Assistent, Nov. 1922-Sept. 1933 Oberarzt an Chirurg. U-Klinik; 16. Jan. 1924 Habilitation; seit 12. Febr. 1929 nichtplanm. a. o. Prof.; SS 1933 kommissar. Direktor der Chirurg. U-Klinik für emeritierten Eugen Enderlen.

Pforzheim: Seit 15. Sept. 1933 Direktor der Chirurg. Abt. des Städtischen Krankenhauses; 1. April 1934$1940(\dagger)$ Direktor des gesamten Städtischen Krankenhauses. 
UH: Seit 2. Nov. 1939 außerdem nichtbeamteter a. o. (apl.) Prof.

Qu UAH PA 1020, 4541. • GLA Abt. 235, Fasz. 2188.

W Zur Wundbakterienflora in: Dt. med. Wochenschrift 1 (1921). • Über die Carotisdrüse in: Bruns' Beiträge zur klinischen Chirurgie 131,3 (1924). • Zur Therapie der progredienten Hidradenitis axillaris in: Münchener Med. Wochenschrift 22 (1924). - Die Hypophyse und der Zuckerhaushalt des Körpers in: Dt. Zs. für Chirurgie 212 (1928).

L Kürschner (1926) Sp. 953, (1928/29) Sp. 1184f., (1931) Sp. 1476; Stübler (1926) S. 320; Wer ist's (1935) S. 833; WBIS; Krebs/Schipperges (1968) S. 82, 125.

\section{Knapp, Jakob Hermann}

1860-1868 Med. Fak.

Augenheilkunde

* 17. März 1832 Dauborn (bei Limburg; heute: Ortsteil von Hünfelden)

$\dagger$ 30. April 1911 Mamaroneck (Westchester County, New York)

ev.

V Johann K. (1807-1875) Landwirt, Gutsbesitzer, u. a. 1867-1870, 1873-1875 Mitglied des PreuBischen Abgeordnetenhauses, 1871-1875 Mitglied des Dt. Reichstags, s. Rösner, Cornelia: Nassauische Parlamentarier ... T. 1. Der Landtag des Herzogtums Nassau 1818-1866. Wiesbaden 1997. S. 92; Haunfelder, Bernd: Die liberalen Abgeordneten des deutschen Reichstags 1871-1918 ... Münster 2004. S. $234 \mathrm{f}$.

M Elisabeth geb. Preußer (1807-1867)

๑ vor 1868 Adolfine geb. Becker $(\dagger 1874)$

๑ 26. Sept. 1877 Hedwig geb. Sacksofsky $\left({ }^{*} 1852\right)$

K $\quad 1 \mathrm{~S}, 3 \mathrm{~T}$

Lb Studium an U: SS 1851 München, seit WS 1851/ 52 Würzburg, seit WS 1852/53 Berlin, WS 1853/54 Leipzig, SS 1854 Zürich, WS 1854/55 Wien; 1854 Dr. med. Gießen; WS 1855/56 Staatsexamen in Gießen.
Eigenstudien (mit Unterbrechungen): seit Herbst 1856 Paris, seit Herbst 1857 London, seit Herbst 1858 Berlin, seit Sommer $1859 \mathrm{H}$.

UH: 24. Dez. 1859 Habilitation; SS 1860 Beginn seiner Vorlesungen als Privat-Dozent; Dez. 1864 K. bittet um Verleihung der Professur für Augenheilkunde; 19. Okt. 1865 Ern. zum a.o. Prof. für Ophthalmologie in Nachfolge von Maximilian von Chelius; 17. Jan. 1867 Ern. zum „Fachprof. für Augenheilkunde ... mit e. vom 1. Jan. 1866 beginnenden Besoldung von 8oo.- Gulden“ durch Großherzog Friedrich I. mit der Verpflichtung, den klinischen Unterricht „so lange als nicht von der Universität eine eigene Augenheilanstalt eingerichtet wird, in seinem Institut [= private Klinik für Augenkranke] gegen eine Staatsunterstützung von jährlichen 2000.- Gulden zu ertheilen“ (aus: Schreiben vom 22. Jan. 1867 in: UAH RA 6787); SS 1867 erste Erwähnung der 1862 von K. privat gegründeten Klinik für Augenkranke als U-Institut in der westlichen Hauptstraße 35 (aus: Adressbuch der Ruprecht-Karls-Universität in Heidelberg. Heidelberg 1867. S. 7); 12. Dez. 1866 Ablehnung des Antrags von K. auf Verleihung der o. Professur für Augenheilkunde, siehe $Z$ (2); 1867 Reise in die USA; 15. Aug. 1868 auf eigenen Antrag Entlassung von U; 1868 Emigration. • In dieser Zeit:

H: 1861-1868 Niederlassung als Arzt; 20. April 1862 Gründer e. privaten Klinik für Augenkranke/Augen(kranken)klinik/Augenheilanstalt, siehe hierzu $Z$ (1); Bewilligungen von jährlichen Staatsbeiträgen zur Erweiterung der privaten Klinik für Augenkranke/Augenheilanstalt: 1862 und 1863 von 1000.- Gulden, 1865 von 500.- Gulden, Jan. 1866 von 2000.- Gulden; SS 1867 erste Erwähnung der privaten Klinik für Augenkranke als U-Institut.

New York: 1869 Gründer des Ophthalmic and Aural Institute; seit 1882 Prof. am Medical College der New York U; 1888-1902 Prof. am College of Physicians and Surgeons der Columbia U.

Z (1) Im Okt. 1861 bittet K. die Med. Fak. um finanzielle Unterstützung bei der Errichtung e. privaten Augenklinik; sowohl Fak. als auch Engerer Senat schlagen eine „Unterstützung des Petenten aus Staatsmitteln“ vor, da ,ein ausdrücklicher Posten“ für solche „gemeinnüzige Unternehmen“ im 
U-Budget nicht vorgesehen seien (aus: UAH PA 1849 fol. 11r, 12 r, v). Am 9. Okt. 1862 teilt das Ministerium des Innern dem Engeren Senat mit, daß „im ausserordentlichen Budget für 1862 und 1863 ein Beitrag von 1000.- Gulden zur Erweiterung der Augenheilanstalt des Dr. Knapp in Heidelberg (als Staatsbeitrag) bewilligt worden ist“ (aus: PA 1849 fol. 18r). Am 23. Sept. 1863 bittet K. erneut um „Unterstützung seiner Augenklinik“ (aus: PA 1849 fol. 2or); sowohl Fak. als auch Engerer Senat, BauKommission und der Direktor der Chirurg.-Ophthalmolog. U-Klinik, Maximilian Chelius, lehnen e. Unterstützung aus U-Mitteln ab und halten es für „wünschenswerth, wenn de[m]selben eine Unterstützung aus Staatsmitteln zu theil würde" (aus: PA 1849 fol. 21r). 24. März 1865: Anfrage des Ministeriums des Innern bei Engerem Senat, „wie groß die Summe der erforderlichen Subvention sei und ob dieselbe durch das Aversum der chirurgischen Klinik getragen werden könne" (aus: PA 1849 fol. 24r). 24. Mai 1865: Antwort des Engeren Senats nach dem Bericht der Med. Fak.: „In Ermangelung einer akademischen Augenkrankenklinik hält es der Senat für ein dringendes Bedürfniß, daß die Anstalt des Dr. Knapp, die gegenwärtig noch Privatanstalt ist, nur eine geringe Staats-Unterstützung empfängt, den Zwecken der Universität diene; er findet daher, wie die medicinische Fakultät, einen jährlichen Beitrag aus Universitätsmitteln von etwa 2000.- Gulden gerechtfertigt. Ihm erscheint aber dieser Beitrag als durchaus ungenügend, um auch nur einen bescheidenen Zustand einer Augenheilanstalt zu fundiren und er glaubt, $\mathrm{da}$ mindestens noch eine ebenso große Summe aus Staats- oder Gemeinde-Mitteln hierzu erforderlich sein würde. Das Verhältniß des Institutes zur Universität wäre anschl[ießend] in ähnlicher Weise zu ordnen, wie das für das akademische Krankenhaus geschehen ist. Daß die Dotation der chirurgischen Klinik geschmählert würde, hält der Senat, wie die medicinische Fakultät, für nicht thunlich. Seit einer Reihe von Jahren hat das akademische Krankenhaus jährlich ein Defizit gehabt; das nun endlich hergestellte Gleichgewicht seiner Einnahmen und Ausgaben würde wiederum in Frage gestellt, wenn eine Verringerung des Aversums der chirurgischen Klinik stattfände“ (aus: PA 1849 fol. 27r, v). Am 4. Mai 1865 weist das Ministe- rium des Innern einen „Staatsbeitrag zur Augenheilanstalt" in Höhe von 500.- Gulden an (aus: PA 1849 fol. 26r).

Z (2) Im Nov. 1866 stellt K. für die Fortführung seiner privaten "Augenkrankenklinik“ und die Fortsetzung seiner Vorlesungen die Forderung an U, daß ihm die Fachprofessur für Augenheilkunde in der Eigenschaft eines o. Mitglieds der Med. Fak. übertragen wird; ansonsten droht er mit der Auflösung der Klinik und seinem Weggang von Heidelberg. Am 12. Dez. 1866 urteilt der Engere Senat: „... Erregt es aber unser gerechtes Befremden, daß Knapp, erst seit einem Jahre Extraordinarius, nun vom Staate mit so einem namhaften Zuschuß für seine Anstalt unterstützt, jetzt schon eine ordentliche Professur fordert und zwar mit angehängter Drohung, fortzugehen"; daraufhin beschließt der Engere Senat, „dem Antrag der Facultät auf ablehnende Entscheidung einmüthig“ beizutreten (aus: Schreiben vom 12. Dez. 1866 in: RA 6787). 1 3\%4 Jahre später emigriert K. in die USA.

E 1857 Korr. Mitglied der Société médicale allemande Paris.

Qu UAH PA 1849; RA 6307f., 6787. • GLA Abt. 205, Fasz. $336 \mathrm{f}$. Wilhelm Dilthey: Briefwechsel 1852-1911. Bd. 1: 1852-1882. Hrsg. von Gudrun Kühne-Bertram ... Göttingen 2011. S. 453, 455, 459.

$W$ Die Krümmung der Hornhaut des menschlichen Auges. Heidelberg 1860. • Über Krankenhäuser, besonders Augenkliniken. Heidelberg 1866. Die intraocularen Geschwülste nach eigenen klinischen Beobachtungen und anatomischen Untersuchungen. Heidelberg 1868. - On Cocaine and its use in ophthalmic and general surgery in: Archives of Ophthalmology and Otology 13 (1884) S. $402-448$.

G, HG 1879-1911 Archives of Ophthalmology. Reprint London 2015.

MG, $M H G$ 1869-1878 Archiv für Augen- und Ohrenkrankheiten (zus. mit (siehe) Salomon Moos). • 1869-1878 Archives of Ophthalmology and Otology. 
$L$ Handbuch der gesamten Augenheilkunde. Hrsg. von A. Graefe ... 2. Aufl. Berlin 1918. Bd. 14. T. 5-7. S. 122. Honegger, Heinrich, Hessler, Birgit: Die Gründung der ersten Augenklinik in Heidelberg durch J.H.K. Heidelberg 1970. - Reichle (1973) S. 35-38 u. ö. - Jaeger, Wolfgang: Historische Modelle zur Erklärung der Augenbewegungen in: Semper Attentus. Beiträge für Heinz Götze ... Hrsg. von Konrad F. Springer. Berlin 1977. S. 164168. NDB 12 (1980) S. 155; Chronik Ärzte H (1985) S. 133 ; WBIS.

\section{P NDB; Chronik Ärzte H.}

\section{Knauff, Franz Moritz}

1861-1909 Med. Fak.

1861-1868 Physikal. und med. Diagnostik, Hautkrankheiten; 1868-1909 Hygiene (Öffentl. Gesundheitspflege), Gerichtl. Medizin

* 23. Sept. 1835 Karlsruhe

$\dagger \quad$ 07. April 1920 Heidelberg

kath., (nach) 1871 altkath.

V Leopold Leonhard K. (†1883) Revisor

M Franziska geb. Hildenstab

œ unverheiratet.

Lb Seit WS 1853/54 Studium an UH, seit SS 1855 Würzburg, WS 1856/57-WS 1858/59 H.

H: Frühjahr 1858 Staatsprüfung für Innere Heilkunde; Herbst 1858 Staatsprüfung für Chirurgie und Geburtshilfe.

Mai-Okt. 1859 Oberarzt im Großherzogl. Badischen Armeecorps.

UH: 24. Okt. 1859 (Rigorosum) Dr. med.

Eigenstudien: Seit Anfang Nov. 1859 in Berlin, Mitte April 1860-Anfang Juli 186o Prag und Wien.

UH: Seit WS 1860/61 Assistent an Med. U-Klinik des Akad. Krankenhauses; 18. Nov. 1861 Habilitation; 18. Dez. 1867 Ern. zum a.o. Prof. für Hygiene und Gerichtl. Medizin (1868 erste Vorlesungs- ankündigung); 1872 Ruf als Reg.- und Medizinalrat nach Colmar abgelehnt; 1876 Gründungs-Direktor des Inst. für Gerichtl. Medizin; 1888 Ruf an U Hamburg abgelehnt; seit Jan. 1891 (Gründungs-) Direktor des Hygien. Inst. an der Ecke Voßstraße/ Thibautstraße 2; 30. Dez. 1891 (Ern.)-1. Okt. 1909 (Ruhestand) o. Prof.; 1903-1909 auch Direktor des Untersuchungsamtes für ansteckende Krankheiten, das dem Hygien. Inst. angegliedert ist. • In dieser Zeit:

H: 10. Juni 1868-1. Okt. 1909 Bezirksarzt.

1894/95, 1903/o4 Dekan der Med. Fak. der UH

1883 Hofrat; 1899 Geh. Hofrat; 1909 Geh. Rat II. Klasse

E 188 o Ritterkreuz I. Klasse, 1908 Kommandeurkreuz des Ordens vom Zähringer Löwen; 1903 Ritterkreuz des Ordens Berthold I.

Qu UAH PA 1022, 1851; RA 6152, 6179, 6674, 6792, 6794. - GLA Abt. 235, Fasz. 2189. • Briefe: UBH.

$W$ Das neue akademische Krankenhaus in Heidelberg. Mit einem Atlas von XXVIII Tafeln und einer Photographie ... München 1879.

L Almanach Heidelberg (1886) S. 120; Stübler (1926) S. 328; Hirsch 3 ( $\left.{ }^{3} 1962\right)$ S. 556; Chronik Ärzte H (1985) S. 133; WBIS; Klinikum UH (1986) S. 15, 38 f. u. ö.; Geschichte gerichtl. Medizin (1996) S. 238-240; Ruuskanen (2008) S. 119; Deutsche Biographie, s. https://www.deutsche-biographie.de/ gnd116250135.html [07.11.2017].

$P$ Bildarchiv UAH; graph. Slg. UBH; Chronik Ärzte H. 


\section{Kneucker, Johann Jakob}

1873-1909 Theol. Fak.

Alttestamentliche Exegese, Semitische Sprachen

* 12. Febr. 1840 Wenkheim (bei Tauberbischofsheim)

$\dagger$ 25. Dez. 1909 Heidelberg

ev.

V Jakob K., Landwirt

M Katharina geb. Thoma

œ 31. März 1869 Maria Magdalena geb. Edel $\left({ }^{*} 1844\right)$

K $1 \mathrm{~S}, 6 \mathrm{~T}$

Lb Seit WS 1861/62 Studium an UH; 1865 theol. Hauptprüfung in $\mathrm{H} ; 1865$ Ordination in Wertheim.

Vikar: Seit 1865 Kirchheim (heute: Stadtteil von H), seit 1869 Freiburg/Br.

Pfarrer: Seit Juli 1870 Neunkirchen, seit $1873 \mathrm{H}$, seit 3. Juni 1875 Ziegelhausen (heute: Stadtteil von H), Okt. 1883-Okt. 1906 (Ruhestand aus gesundheitlichen Gründen) Eppelheim (bei H); 1900 Mitbegründer des ersten Eppelheimer ev. Kindergartens. In dieser Zeit:

UH: 2. Mai 1873 Lizentiatenprüfung; seit ca. Mai 1873 Repetent an Theol. Fak.; Mai/Juni 1873 Dr. theol.; 30. Juni 1873 Habilitation; 26. Aug. 187925. Dez. 1909 (†) a.o. Prof.; seit April 1899 Erhöhung des Semesterhonorars von 400.- auf 500.Mark; um 1899 Remuneration (Gratifikation) von 8oo.- Mark. - In dieser Zeit:

H: 1894-Okt. 1906 Dekan der Diözese Oberheidelberg, siehe zu "Diözese Oberheidelberg" Vollständige Sammlung der Großherzoglich-Badischen Regierungsblätter von deren Entstehung 1803 bis Ende 1833 ... Bd. 1. Nr. XVI vom 21. Sept. 1821. Carlsruhe 1834. S. 1647.

E 1884 D. theol. Bern. 1904 Ritterkreuz I. Klasse des Ordens vom Zähringer Löwen.
Qu UAH PA 1852; RA 6753. Nachlaß: UBH.

$W$ Siloah: Quell, Teich und Thal in Jerusalem. Eine Dissertation. Heidelberg 1873. - Das Buch Baruch. Geschichte und Kritik, Übersetzung und Erklärung ... Leipzig 1879. • Die Anfänge des römischen Christenthums. Karlsruhe 1886. Die Gleichberechtigung des kirchlichen Liberalismus mit der kirchlichen Rechtgläubigkeit im Lichte des biblischen Christenthums ... Heidelberg 1898.

$H G$ Dr. Ferdinand Hitzig's Vorlesungen über biblische Theologie und messianische Weissagungen des Alten Testaments. Karlsruhe 188o.

L Almanach Heidelberg (1886) S. 106; Wer ist's (1908) S. 704. - Trautwein, Adolf: Zur Erinnerung an J.J.K. in: Protestantische Monatshefte Jg. 14 (1910) H. 4, S. 121-136. • Realencyclopädie für prot. Theologie 23 (1913); Badische Biographien VI (1935) S. 468-471; Arnim 1 (1944) S. 661; WBIS. • Steck, Odil Hannes: Das apokryphe Baruchbuch: Studien zu Rezeption und Konzentration „kanonischer" Überlieferung. Göttingen 1993. S. 67-70 u. ö. Handbuch der historischen Buchbestände in Deutschland. Hrsg. von Bernhard Fabian. Hildesheim 2003. Troeltsch-Gesamtausgabe 19 (2014) S. 504 (Register); Deutsche Biographie, s. https:// www.deutsche-biographie.de/gnd116253797.html [07.11. 2017].

P Bildarchiv UAH; graph. Slg. UBH.

\section{Knies, Carl Gustav Adolf}

1865-1896 Phil. Fak.

Staatswissenschaften

* 29. März 1821 Marburg

$\dagger \quad$ 03. Aug. 1898 Heidelberg ev.

V Ferdinand K. $\left({ }^{*} 1787\right)$ Polizei-Expedient

M Katharina Elisabeth geb. Becker (1790-1867)

$\infty$ 4. Mai 1850 Louise geb. Braun $\left({ }^{\star} 1830 \dagger\right.$ nach 1898) 
K 1 S: Max K. (1851-1917) Augenarzt, seit 1888 a. o. Prof. für Augenheilkunde U Freiburg/Br., s. Arnim 1 (1944) S. 662, WBIS. 2 T: u. a. Klara Bettina Marie K. (1852-1878) Ehefrau von: (siehe) Ernst Kuhn.

Lb U Marburg: Seit 1841 Studium zunächst der Philologie, Theologie, dann der Geschichte, Rechts- und Staatswiss.; 21. Febr. 1846 Dr. phil. und Habilitation für Geschichte und Staatswiss.; SS 1849 letzte Vorlesungen.

Höhere Gerwerbeschule (Polytechnikum) Kassel: 1. Okt. 1849-April 1851 Lehrer für Geschichte, Dt. Sprache, Statistik und Handelsgeographie.

U Marburg: Herbst 1851-Herbst 1852 Privat-Dozent für Nationalökonomie, Statistik, Finanzwiss., Handelsgeographie, Weltgeschichte seit 1815, Neueste Geschichte Europas, Geschichte von England, Irland und Nordamerika.

Kantonsschule Schaffhausen: Seit 7. Sept. 1852 Lehrer für Geschichte, Geographie und Eidgenössisches und Kantonales Staatsrecht.

U Freiburg/Br.: 26. Jan. 1855 Ern. zum SS 1855 o. Prof. für Kameralwiss.; SS 1865 letzte Vorlesungen. • In dieser Zeit:

Karlsruhe: 1861-1866 Mitglied der II. Kammer des Badischen Landtags; 9. Aug. 1862-1865 Direktor des Badischen Oberschulrats für Mittel- und Volksschulen und a.o. Mitglied des Ministeriums des Innern.

UH: 19. Okt. 1865 Ern. zum WS 1865/66 o. Prof.; 1871-1882 Mit-Direktor (zus. mit Johann Caspar Bluntschli ( $\uparrow 1881) ; 1882$ Nachf. Bluntschlis: August Bulmerincq) des neueingerichteten Staatswiss. Seminars; 24. Aug. 1896 Ruhestand. - In dieser Zeit:

Karlsruhe: 1877-1887 Mitglied, 1882 II. Vizepräsident der I. Kammer des Badischen Landtags.

1871/72 Prorektor der UH; 1870/71, 1888/89 Dekan der Phil. Fak. der UH

1865 Geh. Rat III. Klasse; 1877 Geh. Rat II. Klasse
E 1895 Ausw. Mitglied der Magyarischen Akademie der Wissenschaften Budapest. 1877 Dr. iur. h.c. Tübingen. 1869 Ritterkreuz I. Klasse, 1878 Kommandeurkreuz II. Klasse, 1886 Kommandeurkreuz I. Klasse des Ordens vom Zähringer Löwen; 1893 Komthurkreuz II. Klasse des Herzogl. Sachsen-Ernestinischen Hausordens.

Qu UAH PA 1853; RA 6867. • Briefe: UBH. • Im Schaffen genießen. Der Briefwechsel der Kulturwissenschaftler Eberhard und Marie Luise Gothein [u. a. mit C. K.]. Hrsg. von Michael Maurer ... Köln u.a. 2006. S. 676 (Register). • Ausdruck e. Briefes von K. im UAH aus der Privatsammlung von Briefen im Familienarchiv Dr. Karsten Weber, Mosbach. * Nachlaß: UBH.

$W$ Die Statistik als selbständige Wissenschaft. Kassel 1850. - Die politische Ökonomie vom Standpunkte der geschichtlichen Methode. Braunschweig 1853. 2. Aufl. u.d. T.: Die politische Ökonomie vom geschichtlichen Standpunkte. Braunschweig 1883. Geld und Credit. 3 Bde. Berlin 1873-1879. Nachdr. 1931.

HG Karl Friedrichs von Baden brieflicher Verkehr mit Mirabeau und Du Pont. 2 Bde. Heidelberg 1892.

L Almanach Heidelberg (1886) S. 127 f.; Hausrath (1899) S. 79-86 u. ö.; Catalogus prof. Marburgensis 1 (1927) Nr. 827; Baier (1937) S. 185, 195 f.; NDB 12 (1980) S. 182 f. (mit Werkverz.); WBIS. • Häuser, Karl: K. als Geldtheoretiker ... Düsseldorf 1996. • Yagi, Kiichiro: K. K. Heidelberg Lecture on Economics: An Introduction in: Kyoto University Economic Review Vol. 69, No. 1/2 (146/147) (April/ Oct. 2000) S. 1-12. - Trautwein, Michael: C. K. ... Erörterungen über den Kredit in: Die ältere historische Schule: wirtschaftstheoretische Beiträge und wirtschaftspolitische Vorstellungen. Berlin 2005. S. 73-106. Kaesler (2014) S. 1000 (Register). Rühl, Manfred: Journalismus und Public Relations: Theoriegeschichte zweier weltgesellschaftlicher Errungenschaften. Wiesbaden 2015. S. 65 f. u. ö.

$P$ Bildarchiv UAH; graph. Slg. UBH; NDB. 


\section{Knoevenagel, Heinrich Emil Albert}

1892-1921 Nat.-Math. Fak.

Organische Chemie

* 18. Juni 1865 Linden (heute: Stadtteil von Hannover)

$\dagger$ 11. Aug. 1921 Wilmersdorf (heute: Ortsteil von Berlin)

ㅁ Heidelberg ev.

V Dr. phil. Julius K. (1832-1914) Chemiker: Aug. 1860 Gründer e. Laboratoriums für chemische Präparate, anschl. Betreiber e. Lithographischen Anstalt in Hannover; auch Stenograf: K., J.: Neue abgekürzte Kurrentschrift für jedermann zum Selbstunterricht und für Schulen. Hannover 1886; s. Wer ist's (1908) S. 705; Hannoversches Biographisches Lexikon: Von den Anfängen bis in die Gegenwart. Hrsg. von Dirk Böttcher ... Hannover 2002. S. 145 (Eintrag: Haën, Eugen de).

M Friederike geb. Jacobi (aus der Familie H. Jacobi, Wagenfabrik mit Dampfbetrieb in Hannover-Linden)

(28. Sept. 1895 Anna Elisabeth geb. Wocher (1871-1943)

K 2 S (davon 1 S 1915 X), 1 T

Vw Onkel: Albert K. (1825-1907) 1856 Gründer der (1991 geschlossenen) A. Knoevenagel Maschinenfabrik, Eisengießerei und Kesselschmiede in Hannover-Hainholz, s. Hannoversches Biographisches Lexikon, S. $202 \mathrm{f}$.

$\mathrm{Lb}$ Seit WS $1884 / 85$ Studium der Naturwiss. an TH Hannover, seit 1886 U Göttingen, seit SS 1888 München, SS 1889 Göttingen; 17. Juni 1889 Dr. phil. an U Göttingen.

UH: Okt. 1889-Nov. 1900 Assistent am Chemischen Laboratorium; 27. Okt. 1892 Habilitation; seit 25. Okt. 1896 nichtetatm. a. o. Prof.; SS 1899 erstmals als Abt.-Vorsteher am Chemischen Laboratorium im Adressbuch der UH genannt (bis 1921); seit 30. Nov. 1900 etatm., 1920-1921 planm. a. o. Prof. In dieser Zeit:
1896 entdeckt K. die nach ihm benannte Knoevenagel-Kondensation, s. hierzu Römpp Lexikon Chemie. Hrsg. von Jürgen Falbe ... 10. Aufl. Bd. 3. Stuttgart 1999. S. 2182.

E 1914 Ritterkreuz I. Klasse des Ordens vom Zähringer Löwen.

Qu UAH PA 1854; RA 6886. GLA Abt. 235, Fasz. 219o. Briefe: UBH. Nachlaß der Familie Knoevenagel im Stadtarchiv Hannover.

$W$ Raumisomere Benzamarone in: Berichte der Dt. Chemischen Gesellschaft 26 (1893). • Praktikum des anorganischen Chemikers. Leipzig 1901. (Mitverf.) 3. Aufl. 1920. Die condensierende Wirkung organischer Basen in: Berichte der Dt. Chemischen Gesellschaft 35 (1902). • Siehe auch WBIS.

L NDB 12 (1980) S. 206 f. • Pötsch, Winfried R. u. a.: Lexikon bedeutender Chemiker. Leipzig 1988. S. 241 f. Jansen (1992a) S. 166 (Register); WBIS. • List, Benjamin: E. K. und die Ursprünge der Aminokatalyse in: Angewandte Chemie - Zs. der Gesellschaft Dt. Chemiker 122 (2010) S. 1774-1779. • Werner, Helmut: Geschichte der anorganischen Chemie: Die Entwicklung einer Wissenschaft in Deutschland von Döbereiner bis heute. Weinheim 2017.

$P$ Bildarchiv UAH; graph. Slg. UBH. - Medaillon mit Profil K.s im Chemischen Inst. der UH, s. http://www.uni-heidelberg.de/institute/fak12/texte/knoeve.html.

\section{Knorr, Hans Ferdinand}

1924-1930 Med. Fak.

Orthopädie

* 30. März 1887 Würzburg

$\dagger$ 04. Jan. 1930 Bern

$\theta \quad$ Heidelberg

ev.

1914-1918 Kriegsdienst. 
V Ludwig K. (1859-1921), u. a. seit 1884 PrivatDozent Erlangen, seit 1885 Würzburg, 18891921 o. Prof. für Chemie Jena, s. NDB 12 (1980) S. 218-220, WBIS; Stolz, Rüdiger, Hallpap, Peter: Die Ära L.K. in der Chemie an der Universität Jena in: „Klassische Universität“ und „Akademische Provinz“. Hrsg. von M. Steinbach, S. Gerber. Jena 2005. S. 379-398; Stolz, Rüdiger: „... und fragen Sie Ihren Arzt oder Apotheker ..." L. K. und die Entdeckung der ersten synthetischen Arzneimittel. Weimar 2012; Hallpap, Peter, Klupsch, Thomas: Prof. Dr. L.K. ... Die Wohnung in Jena in: Gesellschaft Deutscher Chemiker - Fachgruppe Geschichte der Chemie. Mitteilungen. Frankfurt/M. 2014. S. 65-88.

M Elisabeth geb. Piloty (1862-1940) Schwester von Oskar P. ( ${ }^{\star} 1866$ X 1915$)$ seit 1899 Prof. für Anorganische Chemie München, s. NDB 20 (2001) S. 446; Onkel: (siehe) Hans Ritter von Baeyer: Eintrag unter $V w$ [Schwester]

œ 8. Juni 1918 Ruth geb. Vollert $\left({ }^{\star} 1896 \dagger\right.$ nach 1930)

$\mathrm{K} \quad 1 \mathrm{~S}, 2 \mathrm{~T}$

Lb Seit WS 1905/06 Studium an U Jena, anschl. München, Breslau, München.

München: 4. März 1912 Staatsprüfung; 31. März 1913 Approbation; 3. Juni 1913 Dr. med. an U.

UH: Assistent: Seit Okt. 1913 an Chirurg. U-Klinik, seit Jan. 1919 am Patholog.-Anatom. Inst., seit Juni 1919 an Chirurg. U-Klinik, seit Aug. 1921 an UKinderklinik Luisen-Heilanstalt, Okt. 1921-März 1926 an Orthopäd. Klinik; 10. Nov. 1924 Habilitation; seit April 1926 Oberarzt an Orthopäd. Klinik; seit 11. Okt. 1929 nichtplanm. a. o. Prof. - In dieser Zeit:

1914-1918 Kriegsdienst.

Qu UAH PA 1023, 4559; Med. Fak.-Akten 19141927 fehlen. $\bullet$ GLA Abt. 235, Fasz. 2192. • Ergebnislose Anfrage: Standesamt Würzburg. - Auskunft: Zivilstandsamt II. Abt. Bern; Stadtarchiv Heidelberg.
$W$ Moderne Lehren über den traumatischen Schock in: Klinische Wochenschrift I (1922). • Zur Mechanik der Hüftmuskulatur in: Zs. für orthopädische Chirurgie 45, 1/2 (1924). Verfolgung des Heilverfahrens bei Knochen- und Gelenkbrüchen mit der Blutkörperchensenkungsprobe in: Dt. Zs. für Chirurgie 203-204, H. 1-6 (1927).

L Kürschner (1926) Sp. 962; Arnim 1 (1944) S. 663; WBIS.

\section{Koch, Adolf}

1884-1913 Phil. Fak.

1884-1896 Geschichte; 1895-1913 Journalistik

* 10. März 1855 Mutterstadt (Pfalz)

$\dagger$ 24. Nov. 1922 Dießen (am Ammersee) mosaisch

V Lazarus K., Geschäftsagent, Rechtskonsulent

M N.N. († nach 1885)

( 2. Jan. 1907 Harriette geb. Am Ende verw. Ludwig $\left({ }^{*} 1874\right)$

$\mathrm{K} 1 \mathrm{~S}$

Lb Seit WS 1877/78 Studium an U Leipzig, seit SS 1878 H; 24. Juli 188 o Dr. phil. an UH.

H: 1881-1886/87 Mitarbeiter von (siehe) Eduard Winkelmann am „Urkundenbuch der UH“ und an „Regesten der Pfalzgrafen 1214-1300“ im Auftrag der Badischen Histor. Kommission.

UBH: 29. Juni 1882 (Vereidigung)-1888 Hilfsarbeiter "namentlich für die Beaufsichtigung der Handschriftenräume und des Handschriftenzimmers sowie für die damit zusammenhängenden und sonstigen Geschäfte der Bibliotheksverwaltung" zuständig (aus: Schreiben vom 29. Juni 1882 in: UAH PA 48 (Paul Hintzelmann) und aus: Schreiben vom 13. Nov. 1883 in: UAH PA 57) mit e. jährl. Gehalt von 1300.- Mark (Besucherfrequenz des Handschriftenzimmers vom 1. Jan. bis 10. Mai 1882: 186 Personen, s. Schreiben vom 10. Mai 1882 in: PA 57); 28. März 1888 Verleihung des Titels e. Kustos der UB; 21. Jan. 1889 K. „... ist aus dem Bibliotheksdienst ausgeschieden, um im Auftrag des 
Großherzogl. Ministeriums bis Jan. 1891 das Universitätsarchiv unter Oberleitung des ... Oberbibliothekars ([siehe] Karl Zangemeister) neu zu ordnen" (aus: PA 57).

UH: 24. Okt. 1884 Habilitation für Geschichte; seit 18. Aug. 1888 a. o. Prof.; seit SS 1895 K. bietet (bis auf eine Ausnahme im WS 1895/96) ausschließlich nur noch Vorlesungen über „Geschichte der Presse und des Journalismus in Deutschland mit praktischen Demonstrationen“ gratis an sowie „Praktische Übungen zur Einführung in die Journalistik“; WS 1896/97 und SS 1897 Beurlaubung; 1897 Gründung des "Journalistischen Seminars"; WS 1898/ 99, erneut WS 1899/1900-SS 1901 Beurlaubung für Aufenthalte in Paris, siehe hierzu $Z$ (2); 28. Febr. 1913 venia legendi entzogen, u.a. weil K. „sich [1.] … 1912 gegenüber ... Max Weber einer großen Illoyalität schuldig gemacht [s. hierzu Obst (1987)], ... 2. ... durch Veröffentlichung eines Nekrologs über Kuno Fischer in der „Kölnischen Zeitung" vom 5. Juli 1907 ein Plagiat begangen" habe (aus: Brief des Engeren Senats an Kultusministerium vom 31. Jan. 1913 in: UAH RA 1130; s. hierzu auch UAH RA 1129, Kaesler (2014) S. 671-674). • In dieser Zeit:

H: Seit 1892 Redakteur, anschl. Redaktionsleiter des „Heidelberger Tageblatt“.

Köln: 1902-1904 Auch ständiger Korrespondent der Kölnischen Zeitung; WS 1903/04-WS 1904/ 05 Gastvorlesungen über Journalistik an Handelshochschule.

1915-1916 In politisch-diplomatischer Mission in Konstantinopel (heute: Istanbul); 1916-1920 (erster Schlaganfall) Mitarbeiter am Orientalischen Seminar in Berlin.

Z (1) 1888 erhält K. vom Börsenverein den Auftrag, eine Geschichte des deutschen Buchhandels bis zur Neuzeit abzufassen. Die Vorauszahlung für diesen Auftrag gibt K. aus, ohne daß er seine Arbeit beendet. Der Börsenverein verzichtet auf rechtliche Schritte gegen K., der argumentiert: „Wenn mir [wegen Krankheit] jede grosse geistige Arbeit durch die Ärzte untersagt wurde, und ich das Begonnene nicht vollenden konnte, ist das Treulosigkeit?" (Zitat aus: Obst (1987) S. 35.)
$Z$ (2) K. beantragt zwischen 1898 und 1901 wiederholt Urlaub von UH für Aufenthalte in Paris; Begründung u.a.: „Mitte dieses Monats [Nov. 1898] wird in Paris eine Journalistenschule eröffnet werden, die nach der von mir gemachten und vom diesjährigen internationalen Kongress der Presse in Lissabon gut geheißenen Vorschläge eingerichtet worden ist. Diese neue Schule der Vorbildung zum journalistischen Berufe genau kennen zu lernen, erscheint mir für meine Studien auf diesem Gebiete von Wichtigkeit ...", aus: Brief vom 8. Nov. 1898 in: UAH PA 1855.

Z (3) Am 28. Mai 1902 schreibt das Ministerium der Justiz, des Kultus und Unterrichts an Heidelberger Phil. Fak., es beabsichtige, K. pro Semester ein Honorar von 400.- Mark zu bewilligen für „sein Colleg über, Geschichte der Presse und des Journalismus in Deutschland', dem er später praktische Übungen zur Einführung in die Journalistik (zweistündig) hinzugefügt hat. Das Colleg und die Übungen erfreuen sich reger Beteiligung"; das Ministerium ersucht „Äusserung, ob hiergegen dortseits Bedenken bestehen" (aus: PA 1855); am 16. Juni 1902 antwortet Phil. Fak.: „... der College hat ... von den letzten 12 Semestern nur 5 an unserer Hochschule zugebracht, während welcher er drei Mal 1stündig und 2 Mal sstündig Vorlesungen und Übungen abhielt ..." Die Fak. bezweifelt, daß die Kochschen Vorlesungen und Übungen einen so hohen wissenschaftlichen Wert besitzen, daß eine Remuneration [Gratifikation] gerechtfertigt sei, zumal andere Dozenten in ihren Leistungen „Koch weit überlegen sind. Die Fakultät muß es deshalb - besonders auch im Hinblick auf die Verbindungen, die Dr. Koch mit der Presse hat, u[nd] auf die Enttäuschungen, welche zuerst die Bibliotheksverwaltung $u$. anschl[ießend] die deutsche Buchhändlerbörse bei Erledigung von Arbeiten erfahren haben, die s[eine]r Z[ei]t Dr. Koch gegen erhebliche mehrjährige Remunerationen übertragen wurden - ablehnen, irgendwelche Verantwortung für eine derartige Maßnahme zu tragen oder zu übernehmen" (aus: PA 1855); das Ministerium teilt K. mit Schreiben vom 27. Juni 1902 mit, daß „wir zu unserem lebhaften Bedauern von der Ausführung unserer Absicht, e. Honorar zu zahlen, Abstand nehmen mußten, da Phil. Fak. und Engerer Senat erhebliche Bedenken äußerten" (aus: PA 1855). 
Z (4) Im Nov. 1907 sind K. ,anlässlich der Vollendung des 20. Semesters der von mir ins Leben gerufenen und geleiteten „Praktischen Übungen zur Einführung in die Journalistik“ ... vom Verein deutscher Zeitungsverleger und einiger anderer Freunde der Sache 1500.- M[ark] zur Begründung e. Bibliothek für die Geschichte des Zeitungswesens [an UH] überreicht worden“" (aus: Brief vom 23. Nov. 1907 in: PA 1855); Prorektor der UH, Georg Jellinek, gestattet K. für die Aufstellung der Bibliothek „die Benutzung des in dem kleinen Sprechzimmer neben dem Auditorium XIII befindlichen Schrankes zu Lehrzwecken ... auf Widerruf" (aus: Brief vom 23. Nov. 1907 in: PA 1855).

E 1902 Ehrenmitglied des Vereins Dt. Redakteure.

Qu UAH PA 57, 1855; RA 1129 f., 5972, 6433, 7674; Fak.-Akten H-II-319/1, H-IV-102/93. - GLA Abt. 235, Fasz. 2195. Briefe: UBH.

$W$ Über den deutschen Orden und seine Berufung nach Preußen in: Sammlung von Vorträgen für das deutsche Volk. Heidelberg 1884. Bd. 12. Nr. 10. Prince Alexander of Battenberg. London 1887. Presse und öffentliche Meinung. Hannover 1908.

Mitbearb. Regesten der Pfalzgrafen am Rhein 1214-1508. Bd. 1: ... 1214-1400. Innsbruck 1894 (zus. mit Jacob Wille).

$L$ Prozeß Koch - Weber in: Heidelberger Zeitung Nr. 242-246, 14.-18. Okt. 1912. - Heidelberger Hochschul-Nachrichten Nr. 1 vom Okt. 1912. • Riese (1977) S. 184f., 375-377. - Obst, Bernhard: Ein Heidelberger Professorenstreit. Die Auseinandersetzung zwischen A.K. und Max Weber 19101914. Köln 1987. Geschichte Histor. Seminar UH (1992) S. 187 f.; Jansen (1992a) S. 166 (Register). • Qualität im Journalismus. Grundlagen, Dimensionen, Praxismodelle. Hrsg. von Hans-Jürgen Bucher ... Wiesbaden 2003. S. 49 u. ö. Radkau, Joachim: Max Weber. Die Leidenschaft des Denkens. München 2005. S. 1002 (Register). - Kaesler (2014) S. 671-674; Deutsche Biographie, s. https:// www.deutsche-biographie.de/gnd118827375.html [07.11. 2017]. - Zeitungsbriefe und Briefzeitungen oder Die Anfänge der Zeitung. Richard Grass- hoff (1877), Georg Steinhausen (1895), Karl Bücher (1893) und A. K. (1910). Eingeführt und kommentiert von Hans Wagner. Baden-Baden 2017.

$P$ Bildarchiv UAH; graph. Slg. UBH.

\section{Koch, Johann}

siehe Koch, Johannes

Koch, Johannes Philipp (auch: K., Johann; K., Johann Peter) (bis 1796: CM)

1789-1806 Phil. Fak.

Logik, Metaphysik

* o9. April 1763 Borsch (Thüringer Rhön; heute: Ortsteil der Stadt Geisa)

$\dagger \quad$ 27. Jan. 1843 Ötigheim (bei Rastatt)

kath.

V Philipp K. $\left({ }^{*} 1738\right)$ Bauer

M Maria Katharina geb. Dreis/Treis

$\infty$ unverheiratet

Vw siehe Hanna (2014) S. 93-95.

$L b$ 18. Dez. 1779 Immatrikulation am Priesterseminar in Fulda; seit 21. Nov. 1782 Studium der Theologie, Philosophie an UH.

CM: 27. Dez. 1787 Erteilung der niederen Weihen und Tonsur in der Congregatio Missionis (Kongregation der Mission, auch Lazaristenorden; 1796 Erlöschen des Ordens in der Kurpfalz); 22. März 1788 Diakon; 17. Mai 1788 Priesterweihe.

H: 1785-1789 Gymnasiallehrer.

UH: Seit 26. Sept. 1789 o. Prof. als Nachf. von Jakob Koller (siehe Drüll (1991) S. 88-90); seit (vor) WS 1805/o6 auch Vorlesungsankündigungen über Geschichte der Philosophie.

Ötigheim: 12. Nov. 1806-27. Jan. 1843 Pfarrer; seit 1810 auch Dekan des Kapitels in Gernsbach (bei Rastatt). 
1799 Rektor UH; 1793, 1799, 1805 Dekan, 1804, 1806 Prodekan der Phil. Fak. der UH

Siehe auch Jakob Schmitt

Qu UAH PA 1857; RA 3185, 3797, 6760, 6858. GLA Abt. 205, Fasz. 339.

$W$ Positiones selectae ex philosophia. 5 T. Heidelberg 1790-1798 (Rezension in: Würzburger Gelehrten Anzeigen 1 (1791) S. 268).

L Keller (1913) S. 109; Schneider (1913) S. 22; WBIS. - Motsch, Karl Eugen: Ein katholischer Kantianer an der Heidelberger Universität in: Historisches Jahrbuch 50 (1930) H. 1, S. 525-533. Haas (1960) S. 99. Hanna, Georg-Wilhelm: Die privilegierte Stellung der Koch-Brüder aus Borsch bei Geisa in: Buchenblätter - Beilage der Fuldaer Zeitung für Heimatfreunde Nr. 24, 87. Jg. (12. Dez. 2014) S. 93-95.

\section{Koch, Johann Peter}

siehe Koch, Johannes

\section{Koch, Ludwig Konrad Albert}

1878-189o Phil. Fak.

1890-1902 Nat.-Math. Fak.

1902-1929 (Honorar-Prof.) Nat.-Math. Fak.

Botanik

* 27. Jan. 1850 Darmstadt

$\dagger$ 18. Mai 1938 Heidelberg

ev.

V Johann Jacob K. (1805-1886) Rechtsanwalt

M Dorothea Wilhelmine geb. Schilling (18271907)

@ unverheiratet.

Lb Seit SS 1870 Studium an TH Darmstadt, WS $1872 / 73-\mathrm{SS} 1874 \mathrm{UH}$.
UH: 8. Aug. 1874 Dr. phil.; SS 1875-WS 1876/77 Assistent am Phytophysiolog. Inst. und Herbarium; 4. Juni 1877 Habilitation.

Königl. Landwirtschaftl. Akademie Proskau (heute: Prószków, Polen): SS 1877-SS 1878 Dozent und kommissar. Leiter des Pflanzenphysiolog. Inst.

UH: Seit WS 1878/79 Privat-Dozent; seit 7. Febr. 1882 a. o. Prof.; seit 15. März 1902 Honorar-Prof.; seit 21. Febr. 1908 o. Honorar-Prof.; WS 1928/29 letzte Vorlesungsankündigung.

E 1885 Mitglied der Dt. Akademie der Naturforscher Leopoldina Halle/S. • 1910 Ritterkreuz I. Klasse des Ordens vom Zähringer Löwen.

Qu UAH PA 4567. • GLA Abt. 235, Fasz. 2196. • Siehe auch Archiv der Dt. Akademie der Naturforscher Leopoldina Halle/S.

$W$ Die Entwicklungsgeschichte der Orobanchen. Heidelberg 1887. Mikrotechnische Mitteilungen. Über Einbettung, Einschluß und Färben pflanzlicher Objekte. Berlin 1892. • Pharmakognostischer Atlas. 2 T. Leipzig 1911-1912.

L Kürschner (1931) Sp. 1498; Wer ist's (1935) S. 845; WBIS. - Plant Tissue Culture: 100 years since Gottlieb Haberlandt. Ed. by Margit Laimer, Waltraud Rücker. Wien 2003. S. 68, 84, 88. • Deutsche Biographie, s. https://www.deutsche-biographie.de/gn d116273089.html [07.11. 2017].

$P$ Bildarchiv UAH; graph. Slg. $\mathrm{UBH}$. 


\section{Köchly, Hermann August Theodor}

1864-1876 Phil. Fak.

Klassische Philologie

* 05. Aug. 1815 Leipzig

$\dagger$ 03. Dez. 1876 Triest

ㅁ Heidelberg

ev.

V Heinrich August K. (1768-1821) Buchhändler

M Charlotte geb. de la Garde (1788-1832)

$\infty$ Sept. 1847 Anna Rosalie geb. Saling (18261895)

$\mathrm{K} \quad 2 \mathrm{~S}, 2 \mathrm{~T}$

Lb U Leipzig: 12. Sept. 1832-WS 1836/37 Studium; Herbst 1834 Dr. phil.

Saalfeld/Saale: Seit Mai 1837 Progymnasiallehrer.

Dresden: Seit Jan. 1840 Oberlehrer an Kreuzschule; seit 15. März 1849 Mitglied der II. Kammer der Sächsischen Ständeversammlung; 3.-9. Mai 1849 Befürworter des Dresdner Maiaufstands: geplanter Sturz König Friedrich August II. und Etablierung e. sächsischen Republik scheitern; Flucht.

Brüssel: Seit Mitte Mai 1849 Aufenthalt als politischer Flüchtling.

U Zürich: 7. Nov. 1849 Ern. zum o. Prof.; SS 1850 Dienstantritt.

UH: 25. Juli 1863 Ern. zum o. Prof.; 18. April 1864 Vereidigung; SS 1864 erste Vorlesungsankündigung; SS 1864-1. Juli 1865 Mit-Direktor (zus. mit Hermann Christian Bähr), Juli 1865-WS 1865/66 Direktor, seit SS 1866 Mit-Direktor (zus. mit Ludwig Kayser), SS 1872 Direktor, seit WS 1872/73 MitDirektor (zus. mit Otto Ribbeck) des Philolog. Seminars; seit Sept. 1876 Reisebegleiter des Erbprinzen von Sachsen-Meiningen nach Griechenland; aus gesundheitlichen Gründen Abbruch der Reise; auf dem Rückweg nach $\mathrm{H}$ verstorben. • In dieser Zeit:

Karlsruhe: 1867-1877 A. o. Mitglied des Oberschulrats.
1867/68 Dekan der Phil. Fak. der UH

1871-1874 Reichstags-Abgeordneter der Fortschrittspartei in Berlin

1872 Hofrat

E Mitglied der Akademie der Wissenschaften: 1861 Berlin, 1863 München. 1868 Ritterkreuz I. Klasse des Ordens vom Zähringer Löwen. 1859 Ehrenbürger der Stadt Zürich.

$Q u$ UAH PA 1859; RA 6374, 6827. GLA Abt. 205, Fasz. 340. - Briefe: UBH. - Der Redaktionsbriefwechsel der Hallischen, Deutschen und DeutschFranzösischen Jahrbücher 1837-1844. Hrsg. von Martin Hundt. Bd. 1: Der Briefwechsel um die Hallischen Jahrbücher. Berlin 2010. Apparat: S. 267 (Register). - Nachlaß: UBH; Staats- und Universitätsbibliothek Hamburg.

$W$ Zur Gymnasialreform. Theoretisches und Praktisches. Dresden 1846. - Geschichte des griechischen Kriegswesens. Aarau 1852. (Mitverf.) Neudr. Osnabrück 1973. Griechische Kriegsschriftsteller. 2 Bde. Leipzig 1853-1855. (Mitverf.) • Einleitung in Cäsars Kommentarien über den Gallischen Krieg. Gotha 1857. (Mitverf.) - Akademische Vorträge und Reden. 2 Bde. Zürich 1859. N.F. Heidelberg 1882. - Opuscula philologica. Edidit Godofredus Kinkel ... 2 Bde. Leipzig 1881-1882.

MHG Hesiodausgabe mit kritischem Apparat. Leipzig 1870.

L NDB 12 (1980) S. 294. Haunfelder, Bernd: Die liberalen Abgeordneten des deutschen Reichstags 1871-1918. Münster 2004. S. 237. - Hund, Martin: Noch einmal zu den Deutsch-Französischen Jahrbüchern in: Marx-Engels-Jahrbuch 2004 ... Berlin 2005. S. 125. - Hempel, Dirk: Literarische Vereine in Dresden: Kulturelle Praxis und politische Orientierung des Bürgertums im 19. Jahrhundert. Tübingen 2008. S. 302 (Register). Ruuskanen (2008) S. 130 f.

P Bildarchiv UAH; graph. Slg. UBH; NDB. 


\section{Koehler, Carl August}

1882-189o Phil. Fak. 1890-1914 Nat.-Math. Fak. 1914-1928 (Honorar-Prof.) Nat.-Math. Fak. Mathematik

* o6. März 1855 Mannheim

$\dagger$ 16. April 1932 Heidelberg ev.

V Jakob Friedrich K. ( $\left.{ }^{*} 1821\right)$ Kaufmann

M Margaretha Johanna Friederike Pauline geb. Chur $\left({ }^{*} 1832\right)$

@ 14. März 1883 Johanna Ameline geb. Roeder (1858-1934)

K $\quad 3 \mathrm{~S}, 1 \mathrm{~T}$

Lb Seit WS 1871/72 Studium der Chemie, Mathematik am Polytechnikum Karlsruhe, seit WS 1874/ 75 UH, WS 1876/77 Berlin, SS 1877-SS 1879 H; 1876-1877 Militärdienstpflicht als Einjährig-Freiwilliger in Berlin.

UH: 5. März 1879 Dr. phil.; anschl. Eigenstudien und Vorbereitung auf Habilitation in $\mathrm{H}$; 17. Juni 1882 Habilitation; seit 18. Aug. 1888 a.o. Prof.; 26. Aug. 1905 Ern. mit Wirkung vom 1. Okt. 1905 zum etatm. a.o. Prof. mit e. jährl. Gehalt von 2500.- Mark und 900.- Mark Wohnungsgeld; Nov. 1913 Antrag K.s auf Entlassung zum 1. April 1914; seit 29. Dez. 1913 (Ern. zum 1. April 1914) o. Honorar-Prof.; seit SS 1922 Lehrauftrag für Synthetische Geometrie und über Determinanten; SS 1928 letzte Vorlesungsankündigung.

1905 ist K. der erste etatmäßige a. o. Professor für Mathematik an der Universität Heidelberg

1918 Geh. Hofrat

E 1906 Ritterkreuz I. Klasse des Ordens vom Zähringer Löwen.

Qu UAH PA 1861; RA 6508; Fak.-Akten H-IV-102/ 89 fol. 303r-305r u. o., H-IV-102/98 fol. 28r, 32r, 35r u. ö. • GLA Abt. 235, Fasz. 2199.
$W$ Lehrbuch der analytischen Geometrie. Mitverf. von Bd. 1. Leipzig 1905. - Zur Theorie des F2-Gebüsches mit reellem Poltetraeder und des Kegelschnitt-Gebüsches in: Sitzungsberichte der Heidelberger Akademie der Wissenschaften. Math.-Naturwiss. Klasse. Abt. A. 5. Abh. (1913); Über das Raumfünfeck und über die projektive Einteilung der durch ein Raumfünfeck bestimmten Polarfelder in: ebd. 16. [!] Abh. (1913).

L Kürschner (1926) Sp. 974, (1928) Sp. 1210. • Nachruf in: Jahresbericht der Dt. MathematikerVereinigung (DMV) 44 (1934) S. 199-210 (mit P). • Poggendorff 6 (1937) S. 1350; Math. Institute in Deutschland (1989) S. 162 f., 166; Jansen (1992a) S. 167 (Register); WBIS; Kern (1992); Deutsche Biographie, s. https://www.deutsche-biographie. de/gnd116276886.html [07. 11. 2017].

$P$ Bildarchiv UAH; graph. Slg. UBH.

\section{Koehler, Carl August}

siehe Koehler, August

\section{Köhler, Walter}

siehe Köhler, Walther

\section{Köhler, Walther Erich}

1929-1936 Theol. Fak.

Kirchengeschichte

* 27. Dez. 1870 Elberfeld (heute: Stadtteil von Wuppertal)

$\dagger$ 18. Febr. 1946 Heidelberg ev.

V Louis Ferdinand K. (1840-1897) Versicherungs-Direktor

M Juliane Christine Therese geb. Schäfer (18441927)

œ 16. März 1899 Marie Dorothea Elisabeth geb. Niethammer (1875-1952)

K 2 T 
Lb Seit WS 1889/9o Studium der Theologie und Geschichte an U Halle-Wittenberg, WS 1890/91SS $1891 \mathrm{H}$, WS 1891/92 Straßburg, SS 1892-WS 1892/93 H, seit SS 1893 Bonn, SS 1894-WS 1894/95 H; 1893 I., 1895 II. Staatsexamen in Koblenz; 4. Nov. 1895 Dr. phil. an UH.

\section{Frankfurt/M.: Seit März 1896 Vikar.}

U Tübingen: Okt. 1897-Juni 1900 Wiss. Hilfsarbeiter an UB; 22. Juli 1898 theol. Lizentiatenprüfung.

U Gießen: 3. Nov. 1900 Habilitation für Kirchengeschichte; seit 12. Nov. 1904 a. o. Prof.

U Zürich: Seit 18. Febr. 1909 o. Prof. für Kirchenund Dogmengeschichte.

UH: 22. Jan. 1929 Ern. zum o. Prof. und Direktor des Kirchenhistor. Seminars als Nachf. von Hans von Schubert; 10. Mai 1929 Vereidigung; 31. März 1936 Ruhestand.

1929/30 Dekan der Theol. Fak. der UH

E Mitglied der Hugo-Grotius-Gesellschaft Amsterdam; 1931 Mitglied der Akademie der Wissenschaften H; 1932 o. Mitglied der Badischen Histor. Kommission. 1917 D. theol. Zürich und Oslo; 1933 Dr. iur. h. c. Zürich. 1941 Goethemedaille für Kunst und Wissenschaft.

Qu UAH PA 250, 4583. - GLA Abt. 235, Fasz. 2200. - Briefe: UBH; Sächsische Landesbibliothek - Staats- und Universitätsbibliothek Dresden; s. auch Kalliope.

$W$ Die Ablassinstruktion, die Bullen, Symbole, Concilien und die Mystiker. Erlangen 1900. Nachdr. Hildesheim 1984. Z Zwingli und Luther. Ihr Streit über das Abendmahl nach seinen politischen und religiösen Beziehungen. 2 Bde. Leipzig 1924. Gütersloh 1953. - Zürcher Ehegericht und Genfer Konsistorium. 2 Bde. Leipzig 1932-1942. • Dogmengeschichte als Geschichte des christlichen Selbstbewußtseins. 2 Bde. Zürich 1938-1951. Ernst Troeltsch. Tübingen 1941. Huldrych Zwing- li. Leipzig 1943. • Bibliographie W. K. ... Hrsg. vom Zwingli-Verein. Zürich 1940. - Werkverzeichnis, siehe auch TRE 19 (1990) S. 289.

HG, Redakteur 1903-1905 Religion in Vergangenheit und Gegenwart (seit 1908 u.d. T.: Religion in Geschichte und Gegenwart (RGG)).

MHG 1914-1946 Corpus Reformatorum.

$L$ Universität Gießen 1 (1907) S. 437. - Crous, Ernst: W.K. in: Mennonitische Geschichtsblätter. Hrsg. vom Mennonitischen Geschichtsverein. Bolanden 1949. Nr. 6. S. 31-33. - Roth, Ernst: W. K. in: Zs. für Kirchengeschichte 63 (1950) 222-238. NDB 12 (1980) S. 312 (mit Werkverz.); WBIS; TRE 19 (1990) S. 287-289; Jansen (1992a) S. 167 (Register). - Theologische Fakultäten im Nationalsozialismus. Hrsg. von Leonore Siegele-Wenschkewitz ... Göttingen 1993. S. 171-173. - Fix (1994) S. 155-169; RGG 4 ( $\left.{ }^{4} 2001\right)$ Sp. 1476 f. • Conrad, Ruth: Lexikonpolitik: die erste Auflage der RGG im Horizont protestantischer Lexikographie. Berlin 2006. S. 579 (Register). • UH im Nationalsozialismus (2006) S. 1259 (Register). - W. K. in: Historisches Lexikon der Schweiz 7 (2008) S. 326, s. http://www.hls-dhs-dss.ch/textes/d/D27078.php. • Krumm, Christian: Johan Huizinga, Deutschland und die Deutschen. Münster 2011. S. 322 (Register). Hammann, Konrad: Hermann Gunkel Eine Biographie. Tübingen 2014. S. 207-209.

$P$ Bildarchiv UAH; graph. Slg. UBH.

\section{Koenigsberger, Leo}

1869-1875, 1884-189o Phil. Fak. 1890-1914 Nat.-Math. Fak.

1914-1918 (Honorar-Prof.) Nat.-Math. Fak.

Höhere Mathematik

* 15. Okt. 1837 Posen

$\dagger$ 15. Dez. 1921 Heidelberg mosaisch, seit 1860 ev.

V Jakob K. (1807-1881) Kaufmann

M Henriette geb. Kantorowicz (1816-190o) 
(D 13. Aug. 1873 Sophie geb. Kappel (1848-1938) aus Charkiw; Briefe in UBH; Stiefschwester der Ehefrau von: (siehe) Eugen Laur; siehe hierzu Koenigsberger, Leo: Mein Leben (1919) S. 131

K 1 T, 1 S: Johann Georg K. (1874-1946), u.a. 1904-1935 (Ruhestand) etatm. bzw. planm. a.o. Prof. für Physik Freiburg/Br., Nov. 1918 Mitglied des Arbeiterrats in Freiburg, 1919-1921 Mitglied des badischen Landtags, s. Kürschner (1931) Sp. 1529, Badische Biographien N.F. V (2005) S. 149-151, Homo Heidelbergensis mathematicus online, WBIS.

Lb U Berlin: Seit SS 1857 Studium der Mathematik, Naturwiss.; 22. Mai 1860 Dr. phil.

Berlin: 1860 Staatsprüfung; seit 1860 Lehrer am Friedrich-Wilhelms-Gymnasium; seit April 1861 Lehrer am Kadettenkorps.

U Greifswald: Seit 28. Nov. 1863 a.o. Prof.; seit 9. Mai 1866 o. Prof.

UH: Seit 24. Dez. 1868 (Ern. zum SS 1869) o. Prof. als Nachf. von Otto Hesse mit e. Jahresgehalt von 200o.- Gulden; seit WS 1869/70 Begründer und Direktor (zus. mit Gustav Kirchhoff) des Math.Physikal. Seminars, s. hierzu Hübner (2010) S. 156159.

Polytechnikum Dresden: Seit SS 1875 o. Prof. mit e. jährl. Gehalt von 5000.- Gulden.

U Wien: Seit SS 1877 o. Prof.

UH: Seit 17. April 1884 o. Prof. als Nachf. von Lazarus Fuchs; April 1914 Ruhestand und gleichzeitig Ern. zum o. Honorar-Prof.; SS 1918 letzte Vorlesungsankündigung.

1895 Prorektor der UH; Dekan: 1889/9o der Phil. Fak., 1896/97, 1903/o4 der Nat.-Math. Fak. der UH

Im SS 1869 stellt Sofja Wassiljewna Kowalewskaja (1850-1891; seit 1884 o. Prof. für Mathematik an U Stockholm, s. hierzu Audin, Michèle: Remembering Sofya Kovalevskaya. London 2011; Kauf-
holz-Soldat, Eva: A Divergence of Lives. Zur Rezeption S. K. s. Diss. Mainz (2018 in Vorbereitung)) erfolgreich den Antrag, bei K. Vorlesungen zu hören, s. hierzu auch Hübner (2010) S. 159f., Birn (2012) S. 191 (im Register unter Königs- und Koenigsberger).

Neben Friedrich Endemann und Wilhelm Windelband ist K. maßgeblich an der Gründung der Heidelberger Akademie der Wissenschaften 1909 beteiligt, siehe hierzu UAH Acc. 40/11, Hofer (1993) S. 40-43.

1875 Geh. Hofrat; 1886 Geh. Rat II. Klasse; 1914 Wirkl. Geh. Rat

E Mitglied der Akademie der Wissenschaften: 1874 Göttingen, 1880 München, 1893 Berlin, 1909 H. 1902 Dr. phil. h.c. U Kristiania (heute: Oslo); 1918 Dr. phil. nat. h.c. Frankfurt/M. 1896 Kommandeurkreuz II. Klasse, 1903 Kommandeurkreuz I. Klasse mit Eichenlaub des Ordens vom Zähringer Löwen.

Qu UAH PA 1865. • GLA Abt. 235, Fasz. 2201. • Briefe: UBH; Brief-Sammlung: Universitätsbibliothek Göttingen. - Nachlaß: Staatsbibliothek zu Berlin; Universitätsbibliothek Göttingen. - Mein Leben. Heidelberg 1919. (Autobiogr.)

$W$ Lehrbuch der Theorie der Differentialgleichungen mit einer unabhängigen Variablen. Leipzig 1889. Die Prinzipien der Mechanik. Leipzig 1901. Hermann von Helmholtz. 3 Bde. Braunschweig 1902-1903. Nachdr. Hildesheim 2003.

$L$ Riese (1977) S. 411 (Register); NDB 12 (1980) S. 355 f.; Wennemuth (1994) S. 636 (Register); Biogr. Enzyklopädie Naturwissenschaftler 1 (2003) S. 481. 100 jüdische Persönlichkeiten aus Mecklenburg-Vorpommern ... Hrsg. vom Max-SamuelHaus ... Redakteur Frank Schröder. Rostock 2003. S. $101 \mathrm{f}$. Professoren TU Dresden (2003) S. 485 f; Badische Biographien N.F. V (2005) S. 151-153; Homo Heidelbergensis mathematicus online; WBIS. - Jüdische Mathematiker in der deutschsprachigen akademischen Kultur. Hrsg. von Birgit Bergmann, Moritz Epple. Berlin 2009. S. 1f., 36, 42 u. ö. Hübner, Klaus: Gustav Robert Kirchhoff. 
Das gewöhnliche Leben eines außergewöhnlichen Mannes. Ubstadt-Weiher 2010. S. 305 (Register). Mathematik in der Heidelberger Akademie der Wissenschaften zus.gestellt von Gabriele Dörflinger. Ein Projekt der Fachinformation Mathematik der Universitätsbibliothek Heidelberg, s. http:// www.ub.uni-heidelberg.de/archiv/16931 (Stand: April 2014).

$P$ Bildarchiv UAH; graph. Slg. UBH.

\section{Kopff, August Adalbert}

1907-1924, 1945-1947 (Lehrauftrag), 1947-1950

Nat.-Math. Fak.

Astronomie

* 05. Febr. 1882 Heidelberg

$\dagger \quad$ 25. April 1960 Heidelberg ev.

V Otto K. (1848-1888) Flaschnermeister

M Friederike geb. Hartenstein (1852-1933)

@ 2. Juni 1914 Margarethe geb. Hormuth (18911943), s. Briefe in UBH

K $2 \mathrm{~S}$

Lb UH: WS 1900/o1-WS 1903/o4 Studium der Naturwiss.

H: Seit Jan. 1901 Assistent an Landessternwarte (Astrophysikal. Inst.); 1904 Staatsexamen.

Pforzheim: 1904 Lehramtspraktikant an Oberrealschule.

H: Seit 1905 Assistent, 1912-1924 wiss. Beamter an Landessternwarte (Astrophysikal. Inst.).

UH: 26. Juli 1906 Dr. phil. nat.; 20. Juli 1907 Habilitation; 1912 Ruf nach Chile abgelehnt; seit 18. Nov. 1912 nichtetatm., 1920-1924 nichtplanm. a. o. Prof. - In dieser Zeit:

1914-1918 Kriegsdienst.
Berlin: Seit 26. Juli 1924 o. Prof. an U und Direktor des Astronom. Rechen-Inst. in Dahlem; 1945 Verlegung des Inst. nach $\mathrm{H}$.

H: Dez. 1945-Nov. 1954 (Entpflichtung) Direktor des Astronom. Rechen-Inst.; 1947-1950 Direktor der Landessternwarte. • In dieser Zeit:

UH: Seit 14. Dez. 1945 Lehrauftrag; 1. März 19478. Dez. 1950 (Ruhestand) planm. o. Prof.

1906 Entdecker eines nach ihm benannten Kometen und weiterer 66 Asteroiden; ein Mondkrater von $41 \mathrm{~km}$ Durchmesser trägt ebenfalls seinen $\mathrm{Na}$ men

1930-1939, 1949-1953 Vorstandsmitglied, 19391945 Vorsitzender der Astronomischen Gesellschaft

E 1936 Mitglied der Dt. Akademie der Naturforscher Leopoldina Halle/S.; Mitglied der Akademie der Wissenschaften: 1936 Berlin, 1939 Wien, 1947 H; Ehrenmitglied: 1949 American Astronomical Society und Sociedad Astronomica de Mexico; 1958 ausw. Mitglied der Accademia Nazionale dei Lincei Rom.

Qu UAH PA 4606. GLA Abt. 235, Fasz. 1492. Briefe: UBH. $\bullet$ Wielen, Roland, Wielen, Ute: A. K., die Relativitätstheorie und zwei Briefe Albert Einsteins an K. im Archiv des Astronomischen Rechen-Instituts. UBH. Heidelberg 2013, s. http:// www.ub.uni-heidelberg.de/archiv/15653. - Siehe auch Archiv der Dt. Akademie der Naturforscher Leopoldina Halle/S.

$W$ Grundzüge der Einsteinschen Relativitätstheorie. Leipzig 1921. 2. Aufl. 1923. Dritter Fundamentalkatalog des Berliner Astronomischen Jahrbuchs. T. 1: Veröffentlichungen des Astronomischen Rechen-Instituts Berlin-Dahlem 54 (1937). - Tafeln zur Reduktion des Systems des General Catalogue auf das System des FK 3. Berlin 1940. - Grundbegriffe der sphärischen Astronomie. Heidelberg 1952. (Mitverf.)

L NDB 12 (1980) S. 564 (mit Werkverz.). • Gondolatsch, F.: A.K. in: Mitteilungen der Astrono- 
mischen Gesellschaft 15 (1961) S. 5-16. - Fricke, Walter: Nachruf in: Astronomische Nachrichten 285 (1962) S. 284-286; Ders.: Die Neueinrichtung des Astronomischen Rechen-Instituts in Heidelberg. Heidelberg 1962. - Sweetser, T.H., Kiedron, K.: The Comet Rendezvous Asteroid Flyby Mission to Comet Kopff ... in: Advances in the Astronautical Sciences, Astrodynamics 71 (1989) S. 1133. - Lexikon der Naturwissenschaftler (2000) S. 249 f. - Wielen, Roland, Wielen, Ute: Astronomische Ephemeriden, Navigation und Krieg. Die erstaunliche Zusammenarbeit der EphemeridenInstitute von Deutschland, England, Frankreich und den USA im Zweiten Weltkrieg nach Dokumenten im Archiv des Astronomischen RechenInstituts. Edition der Dokumente. Astronomisches Rechen-Institut. Zentrum für Astronomie. Universität Heidelberg. Heidelberg 2016, s. http:// archiv.ub.uni-heidelberg.de/volltextserver/22021/ 7/Ephem-Austausch-1.pdf.

$P$ Bildarchiv UAH; NDB.

\section{Kopp, Hermann Franz Moriz}

1864-189o Phil. Fak.

Chemie

* 3o. Okt. 1817 Hanau

$\dagger$ 20. Febr. 1892 Heidelberg

ev.

V Dr. med. Johann Heinrich K. (1777-1858) seit 1802 Arzt, seit 1807 Prof. für Chemie, Physik und Naturgeschichte am Lyzeum (Athenaeum) Hanau, seit 1813 Medizinalrat, seit 1815 Hofrat, seit 1816 Garnisons-, Waisenhaus- und Stadtimpfarzt, seit 1824 Geh. Obermedizinalrat und Leibarzt des Kurfürsten von Hessen, s. ADB 16 (1882) S. 682 f., WBIS, Hessische Biografie, s. http://www.lagis-hessen.de/pnd/1001 97000 (Stand: 12. Febr. 2014)

M Maria Anna geb. Dittmann (1788-1824)

( 9. Sept. 1852 Johanna Louise geb. Tiedemann $\left({ }^{\star} 1825\right)$ Nichte von: (siehe) Friedrich T.
K 1 T: Theresa K., Ehefrau von Dr. phil. Dr. med. Eugen Albert Georg Baumann (1846-1896), u. a. seit 1882 a. o. Professor für Medizin Berlin, seit 1883 o. Prof. für Med. Chemie Freiburg/Br., s. NDB 1 (1953) S. 651; Spaude, Marion: E. A. B.: Leben und Werk. Zürich 1973; Lexikon bedeutender Chemiker (1988) S. 31; Von der physiologischen Chemie zur frühen biochemischen Arzneimittelforschung: der Apotheker und Chemiker E. B. Stuttgart 1996.

Vw Onkel: Karl Wilhelm K. (seit 1803 von K.) (1770-1844), u.a. seit 1804 Direktor der Gräflich-Solmsschen Rentkammer, seit 1815 Direktor der Hessisch-Darmstädtischen Hofkammer, seit 1821 Präsident der hessischen Oberfinanzkammer, 1841-1844 Finanzminister des Großherzogtums Hessen; seit 1835 lebenslängliches Mitglied der I. Kammer der Landstände des Großherzogtums Hessen, s. Hessische Abgeordnete 1820-1933. Erg.-Bd. ... Hrsg. von Hannelore Götz und Klaus-Dieter Rack. Darmstadt 1995; Hessische Biografie, s. http://www.lagis-hessen.de/de/subjects/idrec/ sn/bio/id/3192 (Stand: 6. März 2013).

Lb Seit SS 1836 Studium der Chemie, Physik an UH, seit WS 1837/38 Marburg; 1. Sept. 1838 Dr. phil. an U Marburg; 1838/39 Eigenstudien in Hanau.

U Gießen: Seit Herbst 1839 Mitarbeiter im Laboratorium von Justus Liebig (1803-1873); 27. März 1841 Habilitation für Physik und Chemie; seit 25. April 1843 a. o. Prof.; seit 1. Juli 1853 o. Prof. als Nachf. von Liebig.

UH: 26. Sept. 1863 Ern. zum o. Prof. (Neueinrichtung e. II. Ordinariats neben dem Lehrstuhl von Robert Bunsen); 30. März 1864 Vereidigung; Rufe an U Berlin und Leipzig abgelehnt; 1. Juli 1890 auf eigenen Antrag Ruhestand.

1869/70 Prorektor der UH; 1868/69, 1887/88 Dekan der Phil. Fak. der UH

Begründer der physikalischen Chemie

Geh. Hofrat 
E Mitglied der Akademie der Wissenschaften: 1855 Göttingen, 1859 München, 1867 Berlin; 1861 Mitglied der Dt. Akademie der Naturforscher Leopoldina Halle/S. 1856 Dr. med. h.c. Greifswald. 1863 Maximiliansorden für Wissenschaft und Kunst. 1861 Ritter des Ordens vom Zähringer Löwen; 1865 Ritterkreuz des Königl. Schwedischen Nordsternordens; 1870 Kommandeurkreuz II. Klasse des Ordens vom Zähringer Löwen.

Qu UAH PA 1868; RA 5817, 6886; Fak.-Akte H-IV102/63. - GLA Abt. 235, Fasz. 353. • Briefe: UBH. • Siehe auch Archiv der Dt. Akademie der Naturforscher Leopoldina Halle/S.

$W$ Geschichte der Chemie. 4 Bde. Braunschweig 1843-1847. Nachdr. 1931. 1966. - Einleitung in die Krystallographie und in die krystallographische Kenntnis der wichtigeren Substanzen. Braunschweig 1849 .

MHG 1847-1862 Jahresbericht über die Fortschritte der Chemie und verwandter Theile anderer Wissenschaften.

Redakteur 1851-1892 Annalen der Chemie und Pharmacie.

$L$ Ruska, Julius: H.K.: Historian of Chemistry in: Journal of Chemical Education 14 (1937). - Speter, Max: „Vater Kopp“. Bio-, Biblio- und Psychographisches von und über H.K. ... in: Osiris - a research journal devoted to the history of science and its cultural influences ... Chicago 1938. Nr. 5. S. 392-460. - Grund, Eva: H.F.M.K. in: Lebensbilder aus Kurhessen 3 (1942) S. 258-266; Smith (1949) S. 140 f.; NDB 12 (1980) S. 566-568; WBIS. • Hoppe, Brigitte, Kricman, Viktor A.: Dieser Junge will Chemie studieren. Das Leben und Wirken des Liebigschülers H.K. in: Kultur \& Technik. Das Magazin aus dem Dt. Museum. München 1995. S. 40-45. - Schwedt, Georg: Liebig und seine Schüler: Die neue Schule der Chemie. Berlin 2002. S. 270 u. ö. $\bullet$ Rocke, Alan J., K., H.: From the molecular world: A nineteenth-century science fantasy. Heidelberg 2012. Hessische Biografie, s. http://www.lagis-hessen.de/pnd/101304854 (Stand: 12. Febr. 2014).

P Bildarchiv UAH; graph. Slg. UBH; NDB.

\section{Kopp, Ulrich Friedrich}

1807-1808 Phil. Fak.

1808-1810 (Honorar-Prof.) Phil. Fak.

Diplomatik

* 18. März 1762 Kassel

$\dagger$ 25. März 1834 Marburg

口 27. März 1834 Marburg

ev.

V Dr. iur. Carl Philipp K. (1728-1777), u. a. seit 1756 Reg.-Rat, seit 1761 Oberappellationsgerichts-Rat, seit 1772 auch Direktor des Steuerkollegiums in Kassel sowie 1772-1776 Direktor der Handelskompanie in Karlshafen, seit 1774 Geh. Rat und OberappellationsgerichtsDirektor in Kassel, s. ADB 16 (1882) S. 69o, Hessische Biografie, s. http://www.lagis-hes sen.de/pnd/136421776 (Stand: 16. April 2013)

M Christiane Amalie geb. Stirn (1735-1813)

$\infty$ 24. Okt. 1790 Adolfine Conradine Christine geb. Laers $(1768-1833)$

K 1 T: Amalie K. $\left({ }^{*} 1792\right)$ Pianistin; Ehefrau von Josef Alexander Jakob Karl Magnus Dahmen (1783-1863) (Enkel von Wilhelm D. (17151773) 1742-1773 Prof. an Jur. Fak. der UH, s. Drüll (1991) S. 23f.), u.a. Geh. Sekretär am badischen Ministerium für Auswärtige Angelegenheiten, anschl. Reg.-Direktor des Unterrheinkreises, 1845-1849 Kurator der UH (s. hierzu Über Heidelberger U-Ämter (2013) S. 34,38 f., 46 f.), s. Badische Biographien 1 (1875) S. 156 f., WBIS. - Dahmen, Josef Alexander: Beleuchtung der in Nr. 316 bis 336 der Deutschen Zeitung enthaltenen Angriffe gegen die Universität Heidelberg, ihre Lehrer, Anstalten und ihren Curator. Von Letzterem am Schlusse seiner Geschäftsführung [verfasst]. Heidelberg 1849. 
Vw Brüder: Karl Friedrich (seit 1803: von) K. (1764-1837), u.a. 1798-1801 Hessen-Kasselischer Chargé d'affaires in Paris, 1818-1835 Kurhessischer Minister der Auswärtigen Angelegenheiten, s. Hessische Biografie http:// www.lagis-hessen.de/pnd/136421725 (Stand: 7. Sept. 2012). Dr. phil. h.c. Karl Wilhelm (seit 1802: von) K. (1770-1844), u.a. seit 1792 Hessen-Kasselischer Regimentsauditeur (Auditeur = Justizbeamter), seit 1797 Sekretär des Erbprinzen, seit 1802 Gräflich-Sayn-Wittgensteinischer Bergdirektor, seit 1804 FürstlichSolmsscher Regierungs- und Kammerdirektor in Lich, seit 1812 Großherzoglich-Hessischer Vizedirektor, seit 1815 Direktor der Hofkammer in Arnsburg, seit 1819 Geh. Referendär (Berichterstatter) und Geheimer Staatsrat im Finanzministerium Darmstadt, seit 1821 Präsident der Oberfinanzkammer, seit $1828 \mathrm{zu}$ gleich Zolldirektor, seit 1835 lebenslängliches Mitglied der I. Kammer der Kurhessischen Ständeversammlung, 1836-1846 Bundestagsgesandter, 1841-1844 Finanzminister und Präsident des Staatsrats, s. Hessische Biografie http://www.lagis-hessen.de/de/subjects/idrec/ sn/bio/id/3192 (Stand: 6. März 2013).

Lb Seit 1779 Studium der Rechtswiss. an U Göttingen; jur. Examen.

Kassel: Seit 1783 Regierungs-Assessor; seit 30. Juli 1788 Justizrat und Mitglied der Oberwege- (und Bau-)Kommission; seit 19. Nov. 1793 RegierungsRat; seit 3. Febr. 1797 Geh. Referendär und Landsekretär über alle inneren Landes- und Regierungsangelegenheiten; 24. Dez. 1802-Jan. 1804 (Entlassung auf eigenen Antrag aus gesundheitlichen Gründen) außerdem Leiter des Kurhessischen Hofarchivs; 18. März 1803-Jan. 1804 (auf eigenen Antrag Entlassung) Wirkl. Geh. Kabinettsrat.

Seit 1804 Wohnsitz in Göttingen; 1804-1805 Subdelegatus der kaiserl. Kommission in Coesfeld im ehemaligen Münsterschen Amt in Horstmar (bei Münster); u.a. Archiv- und Bibliotheksreisen in Deutschland, Frankreich, Holland und Schweiz.

H: Seit Nov. 1806 Wohnsitz.
UH: Seit SS 1807 Privat-Dozent; seit 19. März 1808 Honorar-Prof.; WS 1809/10 letzte Vorlesungsankündigung.

Mannheim: Seit 1810 Privat-Gelehrter.

Seit 1813 Wohnsitz in Karlsruhe; K. kehrt später nach Mannheim zurück; er stirbt 1834 während e. Besuchs in Marburg.

1801 Erteilung der Erlaubnis zur Annahme des Patents e. Königl. Preußischen Legationsrats

$E$ 18. Sept. 1804 Dr. iur. h.c. Göttingen; 1821 Dr. phil. h.c. 1820 Ritter des Königl. Preußischen Roten Adler-Ordens III. Klasse und Ritter des Kurfürstlich-Hessischen Löwen-Ordens I. Klasse; 1829 Groß-Kreuz des Welfen-Ordens.

Qu UAH PA 1869; GF 26. - GLA Abt. 205, Fasz. 343. - Briefe: UBH. - Auskunft: Ev. Gemeindeamt - Kirchenbuchstelle - Marburg (Sterberegister 1834); Ev. Kirchengemeindeamt Mannheim (Sterberegister 1833); Universitätsarchiv Göttingen (Promotionsalbum der Jur. Fak. 1804); Gesellschaft für Familienkunde in Kurhessen und Waldeck e. V. in Kassel.

$W$ Handbuch zur Kenntnis der Hessen-Casselischen Landesverfassung und Rechte. 7 T. Kassel 1796-1808. - Palaeographia critica. 4 Bde. Mannheim 1817-1829. • Bilder und Schriften der Vorzeit. 2 Bde. Mannheim 1819-1827. Index bibliothecae ab U. F. Koppio ... relictae. Katalog der hinterlassenen Bibliothek von U.F. Kopp dem Paläographen. Mannheim 1846.

$L$ Dt. Geschlechterbuch Bd. 96 (1937) S. 80, Anm. 31b; NDB 12 (1980) S. 568; WBIS; Hessische Biografie, s. http://www.lagis-hessen.de/pnd/ 100197035 (Stand: 25. März 2011). • Daniels, Peter T.: Wilhelm Gesenius, U.F. K., and the beginnings of semitic epigraphy in: Biblische Exegese und hebräische Lexikographie: das „Hebräisch-deutsche Handwörterbuch“ von Wilhelm Gesenius als Spiegel und Quelle alttestamentlicher und hebräischer Forschung, 200 Jahre nach seiner ersten Auflage. Berlin 2013. S. 155-168. 


\section{Kortüm, Johann Friedrich Christoph}

1840-1858 Phil. Fak.

Geschichte

* 24. Febr. 1788 Eichhorst (bei Neustrelitz/ Mecklenburg)

$\dagger$ 04. Juni 1858 Heidelberg ev.-luth.

V Carl Siegfried K. (1757-180o) Pfarrer

M Anna Catharina geb. Krüger

$\infty$ 17. Mai 1852 Anna Maria geb. Stumpf (18151863)

K 1 S (1843-1899; gemeinsamer S mit späterer Ehefrau), 1 T, s. Toepke 6 (1907) S. 474; Reichlin-Meldegg, Karl Alexander Frhr. von: Das Leben eines ehemaligen römisch-katholischen Priesters (1874) S. 191.

Lb Seit 20. Okt. 1806 Studium der Philologie, Geschichte an U Halle/S., seit Frühjahr 1807 Göttingen, seit Okt. $1808 \mathrm{H}$; 1810 bei dem Versuch, in Spanien gegen das napoleonische Frankreich zu kämpfen, Verhaftung als Spion in Rostock; 1810 Flucht in die Schweiz.

Schweiz: Seit 1810 Aufenthalt an Anstalt von Johann Heinrich Pestalozzi in If(f)erten (Kanton Waadt; heute: Yverdon-les-Bains); 1812-1817 Lehrer am Inst. Fellenbergs in Hofwyl; 1813-1814 freiwilliger preußischer Jäger in Befreiungskriegen; seit Ostern 1817 Lehrer für Latein und Griechisch an Kantonsschule in Aarau.

1818 Eigenstudien in Wien; seit 16. Febr. 1819 Gymnasial-Prof. für Geschichte in Neuwied; 1821 Weggang aufgrund Erteilung e. Ohrfeige an e. höheren Beamten, der Ernst Moritz Arndt (1769-1860) verunglimpfte.

U Basel: Seit 10. März 1821 Privat-Dozent für Geschichte und Statistik.

Hofwyl: Seit 1822/23 erneut Lehrer am Inst. Fellenbergs.

U Basel: Seit 1826 Privat-Dozent.
Bern: Seit 14. April 1832 Prof. an Akademie; seit 16. Juli 1834 o. Prof. für Geschichte an U.

UH: 16. Juni 1840 Ern. zum o. Prof.; WS 1840/41 Beginn seiner Vorlesungen.

1844, 1852 Dekan der Phil. Fak. der UH

$\mathrm{Z} \mathrm{Zu} \mathrm{seiner} \mathrm{Ernennung} \mathrm{als} \mathrm{Ordinarius} \mathrm{schreibt}$ K. am 9. Juli 1840 aus Bern an Prorektor und Mitglieder des Engeren Senats der Universität Heidelberg: „... Mit den innigsten Wünschen für das fernere Gedeihen einer wissenschaftlichen Anstalt, deren Bild in dem dankbaren Gemüthe ihres ehemaligen Zöglings niemals verlosch, und mit der Bitte um gefällige Nachsicht gegenüber einem Manne, welcher Jahre lang bei einem Teutschland stammverwandten, jedoch eigenthümlich ausgeprägten Volke willig die zweite Heimath fand, verbleibe Magnificenz! Hochverehrte Herren! Ihr ergebenster Dr. Friedr. Kortüm“ (aus: UAH PA 1870).

Qu UAH PA 1870; RA 5205, 6847. GLA Abt. 201, Fasz. 169. - Briefe: UBH. - Therese Huber: Briefe. Bd. 6.1: Juli 1815 bis September 1818. Bearb. von Petra Wulbusch. Hrsg. von Magdalene Heuser und Petra Wulbusch. Berlin 2011. S. 1367 (Register).

$W$ Entstehungsgeschichte der freistädtischen Bünde im Mittelalter und in der Neuzeit. 3 Bde. Zürich 1827-1829. • Römische Geschichte von der Urzeit Italiens bis zum Untergang des abendländischen Reichs. Zürich 1843. • Geschichte Griechenlands von der Urzeit bis zum Untergang des achäischen Bundes. 3 Bde. Heidelberg 1854. Geschichte Europas im Übergange vom Mittelalter zur Neuzeit. 2 Bde. Leipzig 1861. (Mitverf.)

$L$ Reichlin-Meldegg, Karl Alexander Frhr. von: F. K. ... Leipzig 1858; Ders.: Das Leben eines ehemaligen römisch-katholischen Priesters. Heidelberg 1874. S. 191-193. ADB 16 (1882) S. 730-732. • Vischer, Eduard: F.K. als Zeitgeschichtsschreiber in: Festgabe Leonhard von Muralt. Zürich 1970. • Semper apertus 2 (1985) S. 182 f.; Weber (1987) S. 319; WBIS. - Sehlke, Stephan: Pädagogen - Pastoren - Patrioten. Biographisches Handbuch zum Druckgut für Kinder und Jugendliche von Autoren 
und Illustratoren aus Mecklenburg-Vorpommern von den Anfängen bis einschließlich 1945. Norderstedt 2009. S. 204f. Grewolls (2011). Stamboom Kuurstra en Gordijn „J.F.C.K.“ [Stammbaum] online, s. https://www.genealogieonline.nl/stam boom-kuurstra-en-gordijn/I7865.php (abgerufen am 22. Sept. 2017).

$P$ Bildarchiv UAH.

Koscielski, Heinrich Adolf Paul Arthur von siehe Kirchenheim

\section{Kossel, Albrecht Carl Ludwig Martin Leonhard}

1901-1923 Med. Fak.

Physiologie

* 16. Sept. 1853 Rostock

$\dagger \quad$ 05. Juli 1927 Heidelberg ev.-luth.

V Albrecht K. (1827-1919) Kaufmann, Bankdirektor, Schiffsreeder, hannoverscher und preuBischer Konsul, s. Streib (1999) S. 7 Anm. 2 u. ö.

M Klara geb. Jeppe (1830-1911)

( 14. Nov. 1886 Louise geb. Holtzmann (18641913) $\mathrm{T}$ von: (siehe) Adolf $\mathrm{H}$.

$\mathrm{K} \quad 2 \mathrm{~T}$ (davon $1 \mathrm{~T}$ früh $\dagger$ ), $1 \mathrm{~S}$ : Walther K. (18881956), u. a. seit 1921 Prof. für Theoretische Physik U Kiel, seit 1932 TH Danzig, 19451953 (Emeritierung) U Tübingen, s. UAH PA 4620, B-3029/5; Briefe in UBH; NDB 12 (1980) S. 616 f., Manke (2011) S. 78 f., Schmidt-Schönbeck (2011) S. 81-85 u.ö., Spenkuch (2016) S. 1315 (Register)

Vw Bruder: (siehe) Hermann K. Enkel: Albrecht K. (1912-1999), u. a. 1965-1977 (Ruhestand) apl. Prof. für Pädiatrie an U-Klinik Tübingen, s. Kürschner (1996) S. 730, Manke, S. 79.

Lb WS 1872/73-WS 1873/74, SS 1875 und WS 1875/ 76 Studium der Medizin an U Straßburg, SS 1874, WS $1874 / 75$, SS 1876 und WS $1876 / 77$ Rostock;
15. Juli 1877 II. Staatsexamen in Rostock; 24. Juli 1877 Approbation in Schwerin; 30. April 1878 Dr. med. an U Rostock.

Militärdienst: Okt. 1874-März 1875, Aug. 188015. März 1881

U Straßburg: Okt. 1877-Okt. 1883 Assistent am Physiologisch-Chemischen Inst.; 2. Aug. $1881 \mathrm{Ha}-$ bilitation für Physiolog. Chemie und Hygiene.

U Berlin: 1. Okt. 1883-31. März 1895 Vorsteher der Chemischen Abt. des Physiolog. Inst. der Charité; 15. Dez. 1883 Habilitation für Anatomie, Physiologie; seit 22. Okt. 1887 a. o. Prof.

U Marburg: 6. Jan. 1895 Ern. zum o. Prof. für Hygiene; 8. Febr. 1895 durch ministeriellen Erlaß Umwandlung in e. o. Professur für Physiologie; seit 1. April 1895 Direktor des Physiolog. Inst.; 1897 Ruf an U Breslau abgelehnt.

UH: 21. Dez. 1900 Ern. zum SS 1901 o. Prof. und Direktor des Physiolog. Inst. als Nachf. von Wilhelm Kühne; April 1923 Emeritierung; SS 1923 Vertreter seines Lehrstuhls.

H: 1920 Gründer, 1921-1927 Leiter des Inst. für Eiweißforschung (Stiftung Fritz Behringer, s. hierzu UAH B-6481).

1908 Prorektor der UH; 1905/06, 1916/17 Dekan der Med. Fak. der UH

1907 Präsident des Int. Physiologenkongresses in Heidelberg

1910 Nobelpreis für Physiologie oder Medizin, s. http://www.nobelprize.org/nobel_prizes/medici ne/laureates/1910/

1970 ist der Kopf K.s auf einer Briefmarke in Schweden abgebildet

Gesellschaft Deutscher Chemiker richtet 2012 den Albrecht-Kossel-Preis, dotiert mit 7500.- Euro, ein; der Preis wird an Persönlichkeiten verliehen, die hervorragende Arbeit auf dem Gebiet der Biochemie geleistet haben, s. hierzu https://www. gdch.de/gdch/preise-und-auszeichnungen/gdchpreise.html 
1894 Geh. Medizinalrat; 1907 Geh. Hofrat; 1914 Geh. Rat II. Klasse

E 1887 Mitglied der Dt. Akademie der Naturforscher Leopoldina Halle/S.; Mitglied der Akademie der Wissenschaften: Paris, 1902 Stockholm, 1903 Turin, 1909 Kopenhagen, H, 1918 Göttingen. 1906 Dr. phil. h.c. Greifswald; Dr. of Science h.c.: 1904 U Cambridge, 1908 Dublin; 1909 Dr. med. h.c. Genf. 1903 Ritterkreuz I. Klasse des Ordens vom Zähringer Löwen.

Qu UAH PA 1027, 4618; RA 6808. GLA Abt. 235, Fasz. 1542. • Briefe: UBH. • Siehe auch Archiv der Dt. Akademie der Naturforscher Leopoldina Halle/S.

$W$ Leitfaden für medicinisch-chemische Curse. Berlin 1886. 8. Aufl. 1921. - Über die chemische Beschaffenheit des Zellkerns. Berlin 1910. (Nobel-Vortrag.) - Protamine und Histone. Hrsg. von Siegfried Edlbacher. Wien 1929.

HG 1895-1927 Hoppe-Seyler's Zs. für Physiologische Chemie.

$L$ Catalogus prof. Marburgensis 1 (1927) S. 245 f. • Sepke, Ilonka: Zur Geschichte der chemischen Abteilung am Physiologischen Institut der Berliner Universität (1877-1928). Die Beiträge von Theodor Schwann, A. K., ... und Hermann Steudel bei der Herausbildung der physiologischen Chemie als selbständige Wissenschaftsdisziplin. Diss. Humboldt-Universität. Berlin 1979. - NDB 12 (1980) S. 615f. (mit Werkverz.); Chronik Ärzte H (1985) S. 133, 238 f.; Zimmermann/Drüll (1990) S. 48 f.; Wennemuth (1994) S. 636 (Register); Biogr. Lexikon für Mecklenburg 2 (1999) S. 151f. • Streib, Tiana: Hermann Kossel. Biographie eines Hygienikers. Diss. Heidelberg 1999. - Eckart (2000) S. 81 f.; Ärztelexikon (2006) S. $196 \mathrm{f}$.; Badische Biographien N.F. VI (2011) S. 209-213; Manke (2011) S. 57-109; Wissenschaftsatlas der UH (2011) S. 222 f., 252; Fischer (2012) S. 134-137. - Framm, Edith, Framm, Joachim: A. K. - ein Nobelpreisträger aus Mecklenburg (Aug. 2018 in Vorbereitung).

$P$ Bildarchiv UAH; Chronik Ärzte H. - Tonbüste in Privatbesitz in $\mathrm{H}$.

\section{Kossel, Alexander August Richard} Hermann

1910-1925 Med. Fak.

Hygiene

* O2. Nov. 1864 Rostock

$\dagger$ 29. April 1925 Heidelberg ev.-luth.

V Albrecht K. (1827-1919) Kaufmann, Bankdirektor, Schiffsreeder, hannoverscher und preuBischer Konsul, s. Streib (1999) S. 7 Anm. 2 u. ö.

M Klara geb. Jeppe (1830-1911)

(10. Mai 1890 Mary Alexandrine geb. Horsfall (1863-1923)

$\mathrm{K} \quad 2 \mathrm{~T}$

Vw Bruder: (siehe) Albrecht K.

Lb Seit WS 1882/83 Studium an U Rostock, seit SS 1883 Tübingen, SS 1884 Rostock, seit WS 1884/85 Berlin; 27. Juli 1887 Dr. med. an U Berlin; 15. Juni 1888 Approbation in Berlin.

Berlin: Seit Okt. 1888 Assistent am Elisabeth-Kinderhospital; seit Jan. 1890 Assistent am Städtischen Krankenhaus Moabit; Sept. 1891-März 1899 Assistent von Robert Koch (1843-1910) am Königl. Preußischen Inst. für Infektionskrankheiten; Mitglied der Expedition zur Erforschung: u. a. 11. Aug.-2. Okt. 1898 der Malaria in Italien, Sept. 1899 der Pest in Portugal.

U Berlin: 13. Mai 1898 Verleihung des Titels „Prof.“.

Berlin: Seit März 1899 kommissar. Hilfsarbeiter, 1900-1904 Leiter des Bakteriolog. Laboratoriums am Kaiserl. Gesundheitsamt; 18. Dez. 1899 Ern. zum Reg.-Rat und Mitglied des Gesundheitsamtes.

U Gießen: 5. Nov. 1904 (Vereidigung)-April 1910 o. Prof. und Direktor des Hygien. Inst.; 1906 Berufung als Direktor e. neuen Zweigstelle des Kaiserl. Gesundheitsamtes in (Berlin-)Dahlem-Lichterfelde abgelehnt.

UH: 28. Okt. 1909 Ern. zum SS 1910 o. Prof. und Direktor des Hygien. Inst. sowie des Untersuchungsamtes für ansteckende Krankheiten, das dem Hy- 
gien. Inst. angegliedert ist; K. ist Nachf. von (siehe) Franz Knauff; 1916 Ruf an Königl. Inst. für Infektionskrankheiten in Berlin abgelehnt.

1920 Rektor der UH; 1911/12, 1921/22 Dekan der Med. Fak. der UH

1906-1920 Mitglied des Reichs-Gesundheitsrates in Berlin

1916 Geh. Hofrat

Siehe auch Anhang Sporteinrichtungen an $U H$ 1910-1933 und ihre Mitglieder

E 1914 Ritterkreuz I. Klasse des Ordens vom Zähringer Löwen.

Qu UAH PA 1028, 4619; RA 6794. GLA Abt. 235, Fasz. 2235.

$W$ Die Behandlung der Diphtherie mit Behring's Heilserum. Berlin 1895. - Tierische Tuberkulose und menschliche Lungenschwindsucht in: Dt. med. Wochenschrift 43 (1911). Siehe auch Bibliographie in: Streib (1999) S. 96-101.

$L$ Universität Gießen 1 (1907) S. 438. - Laubenheimer, Kurt: H.K. zum Gedächtnis in: Dt. med. Wochenschrift 24 (1925). • Fischer $2\left({ }^{3} 1962\right)$ S. 807; WBIS; Chronik Ärzte H (1985) S. 133 f.; Jansen (1992) S. 410 (Register); Ders. (1992a) S. 167 (Register). Streib, Tiana: H.K. Biographie eines Hygienikers. Diss. Heidelberg 1999. - Kriegstagebuch K. Hampe (2007) S. 975 (Register); Badische Biographien N. F. VI (2011) S. 213-216; Grewolls (2011); Manke (2011) S. 81f.; Deutsche Biographie, s. https://www.deutsche-biographie.de/gnd11 7538183.html [07.11. 2017]

P Bildarchiv UAH; Chronik Ärzte H.
Kossmann, Robby August (Pseudonym: Gedan, K.)

1873-189o Phil. Fak.

Zoologie

* 22. Nov. 1849 Danzig (heute: Gdańsk, Polen)

$\dagger$ 29. Sept. 1907 Berlin ev.

V Johann August K. († 1849) Rechtsanwalt M Julia Elfriede geb. Kuckhein

(1) 15. Okt. 1877 Elisabeth Luise geb. Dietze $\left({ }^{*} 1854\right)$

$\mathrm{K} \quad 2 \mathrm{~S}, 1 \mathrm{~T}$

Lb Seit SS 1868 Studium der Naturwiss. an UH, seit SS 1870 Jena, zuletzt Leipzig; 24. Okt. 1871 Dr. phil. an U Leipzig; 1871 Eigenstudien ebd., anschl. Würzburg; 1872 Studienreisen: Helgoland und Italien.

UH: 5. Aug. 1873 Habilitation; Okt. 1873-Mai 1876 Assistent am Zootomischen Inst.; Juli 1874-April 1875 Forschungsreise zum Roten Meer im Auftrag der Königl. Akademie der Wissenschaften Berlin; seit 1875/76 Leiter des Zootomischen Inst. und des Inst. für Landwirtschaftl. Tierlehre; seit 5. Dez. 1877 a. o. Prof.; Okt. 1880-Aug. 1881 Mitarbeiter an Zoolog. Station in Neapel; Sept.-Nov. 1883 Forschungsreise nach Mahón (Menorca) im Auftrag der Königl. Akademie der Wissenschaften Berlin; Mai 1890 auf eigenen Antrag aus Lehrkörper der $\mathrm{UH}$ ausgeschieden.

U Straßburg: SS 1890 Immatrikulation zum Studium der Medizin; 30. Juli 1890 ärztl. Vorprüfung.

U Göttingen: 1890 Forts. des Studiums; 16. Nov. 1892 Dr. med.; 22. Dez. 1902 ärztl. Staatsprüfung.

Berlin: Seit 1903 Assistent an mehreren Kliniken, dann bis 1907 niedergelassener Frauenarzt.

Unter seinem Pseudonym K. Gedan verfaßt Kossmann Essays, Märchen, Novellen und Dramen, u. a. Ein Mörder. Schauspiel in einem Aufzuge. Basel 1891. Im „Das Magazin für Litteratur" 60. Jg., Nr. 39, Berlin vom 26. Sept. 1891, S. 624 schreibt der Rezensent mit dem Kürzel F. über das Stück: „K. Gedan beruft sich auf dem Titelblatt auf ein 
früheres Werk: Francesco Carraciolo. Ob er sich bei späteren Veröffentlichungen auch als Verfasser des Schauspiels ,Ein Mörder' bekennen wird? In seinem Interesse wäre es nicht ratsam, da es kaum eine besondere Empfehlung wäre. Das vorliegende Werk ist weder sprachlich noch inhaltlich von irgend welcher Bedeutung..."

Qu UAH PA 1871; RA 5489, 6901; Fak.-Akten H-IV-102/77, H-IV-102/86. - GLA Abt. 76, Fasz. 9971. Emil du Bois-Reymond (1818-1896) Anton Dohrn (1840-1909): Briefwechsel. Hrsg. von Christiane Groeben ... Berlin 1985. S. 319 (Register). Nachlaß: Staatsbibliothek zu Berlin.

W Zoologische Ergebnisse e. im Auftrage der Königl. Academie der Wissenschaften zu Berlin ausgeführten Reise in die Küstengebiete des Rothen Meeres. Leipzig 1877. • Elemente der wissenschaftlichen Zoologie. München 1878. • Zur Histologie der Chorionzotten des Menschen. Diss. Leipzig 1892. Allgemeine Gynäcologie. Berlin 1903. • Züchtungspolitik. Schmargendorf bei Berlin 1905.

MHG Die Gesundheit, ihre Erhaltung, ihre Störungen, ihre Wiederherstellung. Ein Hausbuch ... Hrsg. von R. K. und Julius Weiss. Stuttgart 189o. • Mann und Weib. Ihre Beziehungen zueinander und zum Kulturleben der Gegenwart. Hrsg. von R. K. und Julius Weiss. 3 Bde. Stuttgart 1908.

$L$ Pagenstecher, H. Alexander: Über die von ... R.K. am Rothen Meere gesammelten Mollusken. Leipzig 1877. - Dennert, Eberhard: Die Wahrheit über Ernst Haeckel und seine Welträtsel: Nach dem Urteil seiner Fachgenossen beleuchtet. Halle/S. 1901. Nachdr. Bremen 2012. S. 40-47. • Biogr. Jahrbuch 12 (1907) Sp. 48 (Anhang); WBIS. • Hill, Andreas: Medizinische Debatten über sexuelle Abstinenz in Deutschland von 1903 bis 1918. Med. Diss. Lübeck 1996. - Schmersahl, Katrin: Medizin und Geschlecht: Zur Konstruktion der Kategorie Geschlecht im medizinischen Diskurs des 19. Jahrhunderts. Opladen 1998. S. 200, 322-324 u. ö. Benecke, Max: Dem Täter auf der Spur. So arbeitet die moderne Kriminalbiologie. Köln 2006. 5. Aufl. 2010. S. 328 (Register). • Personenlexikon der Sexualforschung. Hrsg. von Volkmar Sigusch und Günter Grau. Frankfurt/M. 2009. S. 375 u. ö. • Deutsche Biographie, s. https://www.deutsche-bio graphie.de/gnd116343583.html [07.11. 2017].

$P$ Graph. Slg. UBH.

\section{Kraepelin, Emil Wilhelm Magnus Georg}

1891-1903 Med. Fak.

Psychiatrie

* 15. Febr. 1856 Neustrelitz (Mecklenburg)

$\dagger \quad$ 07. Okt. 1926 München

$\square$ Heidelberg

ev.

V Karl Wilhelm K. (1817-1882) seit 1839 Opernsänger, Schauspieler am Hoftheater in Neustrelitz, seit 1848 Musiklehrer und Rezitator der Gedichte und Geschichten Fritz Reuters (1810-1874), s. ADB 17 (1883) S. 47 f., WBIS; Der Reuter-Rezitator K. K. in: Wagner, Annalise: Biographische Denkmale: Erinnerungen an fast vergessene Persönlichkeiten aus Mecklenburg und Vorpommern ... Neubrandenburg 1993 S. 32-35.

M Emilie Dorothea Auguste geb. Lehmann (18191896)

๑ 4. Okt. 1884 Ina Marie Wilhelmine geb. Schwabe (1863-1944)

$\mathrm{K} \quad 2 \mathrm{~S}, 6 \mathrm{~T}$ (davon beide $\mathrm{S}$ und $2 \mathrm{~T}$ früh $\dagger$ ), u. a. Antonie (Toni) K. (1887-1962) Ehefrau von: (siehe) Friedrich Schmidt

Vw Bruder: Dr. phil. Karl K. (1848-1915) seit 1873 Lehrer für Mathematik und Naturkunde an Höherer Bürgerschule Leipzig, seit 1887 Prof. an Realschule des Johanneums Hamburg, 1889-1914 Direktor des Naturhistor. Museums Hamburg, s. WBIS, NDB 12 (1980) S. 640 f.

Lb Seit SS 1874 Studium der Medizin an U Leipzig, seit SS 1875 Würzburg.

Würzburg: Juli 1877-Aug. 1878 Assistenzarzt am Julius-Spital; März 1878 Rigorosum, 1881 (Datum der Promotionsurkunde) Dr. med. an U; Juli 1878 II. med. Examen; 9. Aug. 1878 Approbation. 
Assistenzarzt: Seit Aug. 1878 an Kreisirrenanstalt in München, Febr. 1882-7. Juni 1882 (Kündigung) an Psychiatr. Klinik in Leipzig, s. hierzu Lamberti (1995) S. 142 f.; Steinberg, H.: Der Konflikt zwischen E. K. und Paul Flechsig. K.s Entlassung aus der Leipziger Irrenklinik und seine Habilitation in: Schriftenreihe der Dt. Gesellschaft für Geschichte der Nervenheilkunde 8 (2002) S. 301-322.

U Leipzig: 1882-1883 Assistenzarzt am Inst. für Experimentelle Psychologie; 21. Okt. $1882 \mathrm{Habi}-$ litation, s. hierzu Steinberg, H., Himmerich, H.: K.'s habilitation and his thesis - a pioneer work for modern systematic reviews, psychoimmunological research and categories of psychiatric diseases in: World Journal of Biological Psychiatry 14 (2013) S. $248-257$.

München: Seit Nov. 1883 II. Assistenzarzt an Kreisirrenanstalt; 3. Dez. 1883 Umhabilitierung an U.

Seit Aug. 1884 II. Arzt an Provinzial-Irrenheilanstalt in Leubus (Schlesien); seit Mai 1885 Oberarzt am Stadtkrankenhaus in Dresden.

U Dorpat (heute Tartu, Estland; bis 1889 einzige dt.sprachige U im Russischen Kaiserreich; 1889 einsetzende Russifizierung, u.a. mit Absetzung des Deutschen als Lehrsprache und Durchsetzung der russischen Sprache): Seit 1. Juli 1886 o. Prof. und Direktor der Klinik für Nerven- und Geisteskranke (s. hierzu Steinberg, Holger, Angermeyer, Matthias Claus: E. K's years at Dorpat as professor of psychiatry in nineteenth-century Russia in: History of Psychiatry 12 (2001) S. 297-327; Engmann, Birk, Steinberg, Holger: Die Dorpater Zeit von E. K. - Hinterließ dieser Aufenthalt Spuren in der russischen und sowjetischen Psychiatrie? in: Fortschritte der Neurologie - Psychiatrie 85 (11) (2017) S. 675-682); Okt. 1890 Ruf an UH.

UH: 5. Dez. 1890 Ern. zum o. Prof. und Direktor der Großherzoglich Badischen U-Irrenklinik (Psychiatr. Klinik) als Nachf. von Karl Fürstner; 24. April 1891 Vereidigung.

U München: WS 1903/04-SS 1922 (Pensionierung) o. Prof. und Direktor der Psychiatr. Klinik; 1904 Studienreise nach Südostasien und in die Südsee.
München: 1917-1926 Gründer und Vorstand der Dt. Forschungsanstalt für Psychiatrie, heute: MaxPlanck-Institut für Psychiatrie.

1891/92, 1901/o2 Dekan der Med. Fak. der UH

1917 Mitbegründer des Bayer. Landesvereins der dt. Vaterlandspartei

1928 Stiftung der goldenen Kraepelin-Medaille, verliehen von der Dt. Forschungsanstalt für Psychiatrie

1998 wird in Glen Oaks (New York) die Int. Kraepelin Society gegründet

1888 Kaiserlich Russischer Staatsrat; 1902 Hofrat; 1916 Geh. Hofrat

E Dr. phil. h.c.: 1919 Bonn, 1921 Königsberg (Preußen). 1916 König Ludwig-Kreuz für Heimatverdienste; 1918 Ehrenkreuz des Verdienstordens vom Heiligen Michael.

Qu UAH PA 1872; RA 6315f., 6809, 7419; GF 147. PA im Archiv der Max-Planck-Gesellschaft Berlin. - Briefe: UBH. - Fischel, Werner: Wilhelm Wundt und E.K. Gedanken über e. Briefwechsel in: Karl-Marx-Universität Leipzig 1409-1959. Leipzig 1959. Bd. 1. S. 382-391. - Der Briefwechsel zwischen Wilhelm Wundt und E. K. ... Hrsg. von Holger Steinberg. Bern 2002. • Teil-Nachlaß: UAH (Signatur: KE 109); Archiv des Max-Planck-Inst. für Psychiatrie München. - Mitteilungen: Frau Dr. Ursula Perkow ( $\dagger)$, Heidelberg, Urenkelin von E. K. Lebenserinnerungen. Hrsg. von Hanns Hippius u. a. Berlin 1983. (Autobiogr. mit Werkverz.) Edition Emil Kraepelin. Hrsg. von Wolfgang Burgmair, Eric J. Engstrom ... München 2000 ff. Bd. I: Persönliches, Selbstzeugnisse (200o), Bd. II: Kriminologische und forensische Schriften. Werke und Briefe (2001), Bd. III: Briefe I, 1868-1886 (2002), Bd. IV: Kraepelin in Dorpat, 1886-1891 (2003), Bd. V: Kraepelin in Heidelberg, 1891-1903 (2005), Bd. VI: Kraepelin in München I, 1903-1914 (2006), Bd. VII: Kraepelin in München II, 19141921 (2009), Bd. VIII: Kraepelin in München III, 1921-1926 (2013). 
$W$ Die Abschaffung des Strafmaßes. Stuttgart 1880. - Compendium der Psychiatrie. Ein Lehrbuch für Studierende und Ärzte. Leipzig 1883. Seit der 2. Aufl. u.d. T.: Psychiatrie. 9. Aufl. 1927. Einführung in die psychiatrische Klinik. Leipzig 1901. 4. Aufl. 1904. Werden, Sein, Vergehen. Gedichte. München 1928. Bibliographie, s. http://www. psych.mpg.de/1802369/bibliographie_kraepelin. pdf (abgerufen am 24. Sept. 2017).

HG Seit 1895 Psychologische Arbeiten.

$L$ Der Psychiater E. K. in: Das Carolinum 28. Jg., Nr. 35 (1962) S. 54-6o. - NDB 12 (1980) S. 640; Chronik Ärzte H (1985) S. 134, 239 f.; Klüpfel/ Graumann (1986) S. 14-28; Medizin und Gesundheitspolitik (1991) S. 330 (Register); Jansen (1992a) S. 167 (Register); Schmeiser (1994) S. 410 u. ö.; WBIS; Lamberti (1995) S. 140-153 u.ö. • Weber, Matthias M.: Von E.K. zu Ernst Rüdin: Die Dt. Forschungsanstalt für Psychiatrie 1917-1945 in: Schriftenreihe der Dt. Gesellschaft für Geschichte der Nervenheilkunde. Hrsg. von G. Nissen ... Bd. 2. Würzburg 1997. • Steinberg, H.: „Wie martert dieser Zwiespalt mich!“ Dem Menschen E. K. nachempfunden in seinen Gedichten in: Der Nervenarzt 73 (2002) S. 293-297. - Goerttler 2 (2004) S. 57 f.; Müller-Küppers (2004) S. 15 f.; Peiffer (2004) S. 1163 (Register). - Weber, Matthias M.: Lebensstil und ätiologisches Konzept: Rassenhygienische Tendenzen bei E. K. in: Sozialdarwinismus, Genetik und Euthanasie. Menschenbilder in der Psychiatrie. Hrsg. von Martin Brüne ... Stuttgart 2004. S. 71-91. • Ärztelexikon (2006) S. 197 f. • Schott, Heinz, Tölle, Rainer: Geschichte der Psychiatrie: Krankheitslehren, Irrwege, Behandlungsformen. München 2006. S. 603, 669 (Register). • Steinberg, H.: Die Bedeutung Wilhelm Wundts für E. K.s Person und Werk in: Schriftenreihe der Dt. Gesellschaft für Geschichte der Nervenheilkunde 13 (2007) S. 233-265. Badische Biographien N.F. VI (2011) S. 216-219. • Steinberg, H.: E. K. Experimental psychology as an auxiliary science in psychiatry and clinical empirical psychiatry as the foundation of modern psychiatry in: Pathfinders in international Psychology. Ed. by G. J. Rich, U.P. Gielen. Charlotte (North Carolina) 2015. S. 6578. Becker, Katrin: E. K.s Beiträge zur Schlafforschung. Diss. Leipzig 2016, s. online http://nbn- resolving.de/urn:nbn:de:bsz:15-qucosa-209202. Becker, K., Steinberg, H., Kluge, M.: E. K.'s concept of the phenomenology and physiology of sleep: First systematic description of chronotypes in: Sleep Medicine Reviews 27 (2016) S. 9-19. • Steinberg, H., Carius, D., Fontenelle, L. F.: K.'s views on obsessive neurosis: a comparison with the DSM-5 criteria for obsessive-compulsive disorder in: Revista Brasileira de Psiquiatria. São Paulo (Oct./Dec. 2017). Vol. 39, No. 4.

$P$ Bildarchiv UAH. • Bildarchiv des Archivs der Max-Planck-Gesellschaft Berlin.

\section{Krafft, Wilhelm Ludwig Friedrich Emil}

1888-189o Phil. Fak.

1890-1923 Nat.-Math. Fak.

1923 (Honorar-Prof.) Nat.-Math. Fak.

Organische und Anorganische Chemie

* 21. Febr. 1852 Bonn

$\dagger \quad$ 03. Juni 1923 Heidelberg

ev.

V Wilhelm Ludwig K. (1821-1897), u.a. Konsistorialrat und 1859-1896 o. Prof. für Kirchengeschichte Bonn, s. Verzeichnis Bonn (1968) S. 161, WBIS, NDB 12 (1980) S. 643

M Frieda geb. von Scheibler (1828-1906) Vorsitzende mehrerer Frauenvereine, Inhaberin der Königin-Louise-Verdienst-Medaille, s. WBIS

œ 1874 oder 1876 Helene geb. Aigroz (1854-1937) K 1 Adoptiv-T

Vw Ur-Ur-Großvater: Johann Gottlob Leidenfrost (1715-1794) Mediziner und Theologe („Leidenfrostsches Phänomen“), s. Kersken, Hartwig: J. G. L. in: Zur Geschichte der Universität Duisburg. Hrsg. von Dieter Geuenich ... Duisburg 2007. S. 306-311; WBIS.

Lb U Bonn: Seit WS 1869/70 Studium der Naturwiss.; 16. Nov. 1874 Dr. phil. • In dieser Zeit:

1870 (verwundet) Kriegsfreiwilliger im DeutschFranzösischen Krieg. 
Polytechnikum Zürich (heute: ETH): Seit Herbst 1874 Eigenstudien.

U Basel: Seit Herbst 1875 Assistent am Chemischen Inst.; 16. Nov. 1875 Habilitation; seit 1877 a. o. Prof.

UH: 15. Febr. 1888 Ern. zum a. o. Prof.; 1888-1922 Leiter e. der $\mathrm{U}$ angeschlossenen Privat-Labors; 21. März 1923 Ern. zum o. Honorar-Prof.

1879 findet K. eine Methode für einen stufenweisen Abbau von Carbonsäuren um jeweils ein CAtom (Krafftscher Carbonsäureabbau). 1895 entdeckt K. den Übergang von echten zu kolloidalen Lösungen bei den oberflächenaktiven Stoffen durch Mizellenbildung (Krafft-Punkt), s. Lauth, Günter Jakob, Kowalczyk, Jürgen: Einführung in die Physik und Chemie der Grenzflächen und Kolloide. Berlin 2016. S. 404.

E 1892 Mitglied der Dt. Akademie der Naturforscher Leopoldina Halle/S.

$\mathrm{Qu}$ UAH PA 4626; RA 5225, 6886; Quästurakten Rep. 27-676, Rep. 27-684; Fak.-Akte H-IV-102/ 119 fol. 32r, v. GLA Abt. 235, Fasz. 2236. Briefe: UBH. $\bullet$ Nachlaß: UAH. $\bullet$ Siehe auch Archiv der Dt. Akademie der Naturforscher Leopoldina Halle/S.

$W$ Kurzes Lehrbuch der Chemie: Anorganische Chemie. Wien 1891. 6. Aufl. 1915. Kurzes Lehrbuch der Chemie: Organische Chemie. Leipzig 1893. 4. Aufl. 1905. - Siede- und Sublimationspunktbestimmung, Destillieren und Sublimieren in: Staehlers Handbuch der Arbeitsmethoden in der anorganischen Chemie 3 (1913), 2 (1919). $\bullet$ Siehe auch Badische Biographien N. F. VI (2011).

$L$ NDB 12 (1980) S. 643 f. (mit Werkverz.); WBIS; Von der Forschung gezeichnet (2007) S. 117f. u. ö.; Autoren der Bunsenbibliothek (2009 online); Badische Biographien N. F. VI (2011) S. 219-222.

$P$ Bildarchiv UAH.

\section{Krause, Friedrich Ernst-August}

1919-1926 Phil. Fak.

Sinologie

* 23. Aug. 1879 Posen (heute: Poznań, Polen)

$\dagger$ 12. Dez. 1942 Heidelberg

ev., später konf.-los

V Theodor Adolf-August K., Generalmajor

M Anna geb. Braune

$\infty$ 5. April 1904 Elsa geb. Maiss $\left({ }^{*} 1879\right)$ Scheidung 14. Dez. 1921

C 5. April 1938 Luise Friederike Maria geb. Keese $\left({ }^{*} 1894 \dagger\right.$ nach 1942$)$

K $2 \mathrm{~S}$

Lb 10. März 1897-22. Mai 1919 Militärdienstzeit als aktiver Offizier (zuletzt Major). • In dieser Zeit:

U Berlin: Seit WS 1902/03 Studium der persischen, chinesischen und japanischen Sprache; Diplomprüfungen: 1910 japanisch, 1912 chinesisch; 19. Aug. 1914 Dr. phil.

1914-1918 Kriegsdienst.

UH: 19. Juli 1919 Habilitation; seit 17. Juli 1924 nichtplanm. a. o. Prof.

U Göttingen: Seit WS 1926/27 nichtbeamteter a. o. Prof. und Leiter des Sinolog. Seminars; SS 1930-SS 1934 beurlaubt; zum WS 1934/35 aus dem Lehrkörper ausgeschieden.

K. ist der erste Sinologe an der Universität Heidelberg

E 1938 Mitglied der Akademie der Wissenschaften Göttingen.

Qu UAH PA 4645. GLA Abt. 235, Fasz. 2240. Briefe: Staatsbibliothek zu Berlin. Teil-Nachlaß: Sächsisches Staatsarchiv Dresden (Archivalie im Bestand 22208 J.C. Hinrichs Verlag, Leipzig, Archival-Nr. 172).

$W$ Die Aufgaben und Methoden der Sinologie. Heidelberg 1919. - Ju-Tao-Fo. Die religiösen und 
philosophischen Systeme Ostasiens. München 1924. • Geschichte Ostasiens. 3 T. Göttingen 1925. • Siehe auch Hadamitzky, Wolfgang, Rudat-Kocks, Marianne: Japan-Bibliografie. Verzeichnis deutschsprachiger japanbezogener Veröffentlichungen. Reihe B: Aufsätze. Bd. 2/1: Japan-Bibliografie (19211930). München 2007. S. 26-29, 72-74, 86-89 u. ö.

$L$ Catalogus prof. Gottingensium (1962) S. 130. • Walravens, Hartmut: F.E. A. K., Major und Ostasienwissenschaftler - eine Bio-Bibliographie. Hamburg 1983. - WBIS; Jansen (1992a) S. 167 (Register). Zehl Romero, Christiane: Anna Seghers. Eine Biographie. 1900-1947. Berlin 2000. S. 129. • Li, Weijia: China und China-Erfahrung in Leben und Werk von Anna Seghers. Bern 2010. S. 250 (Register). - Kampen, Thomas: Sinologie im 20. Jahrhundert: Heidelberg - Deutschland - International. Heidelberg 2011. S. 14-16 u. ö. Maas, Utz: Sprachforschung in der Zeit des Nationalsozialismus: Verfolgung, Vertreibung, Politisierung und die inhaltliche Neuausrichtung der Sprachwissenschaft. Berlin 2016. S. 623 (Register). • Deutsche Biographie, s. https://www.deutsche-biographie.de/gnd118747142.html [07.11. 2017]. Peschke, Franz: Der Heidelberger Indologe und Buddhologe ... Max Walleser und das Problem seines Ich. Eine Biographie. Print on demand (2017) S. 237 f., s. http://crossasia-repository.ub.uni-heidelberg.de/ 4032/1/Walleser_10102017_End.pdf.

\section{Krause-Bakowski, Friedrich}

(seit 1931 als K.-B. im Stadt-Adreßbuch ... Heidelberg (1932) S. 304 aufgeführt)

siehe Krause, Friedrich

Krehl, August Albert Ludolf (seit 1904: von Krehl)

1907-1931 Med. Fak.

Pathologie, Therapie

* 26. Dez. 1861 Leipzig

$\dagger \quad$ 26. Mai 1937 Heidelberg

ev.
V Christoph Ludolf Ehrenfried K. (1825-1901), u. a. 1874-1899 (Ruhestand) o. Prof. für Orientalische Sprachen Leipzig, s. WBIS, NDB 12 (1980) S. 732 f., Professorenkatalog Leipzig online

M Julia geb. Wiesand (1832-1898)

œ 1888 Maria geb. Geibel (Scheidung vor 1906 aufgrund ihres Ehebruchs) T von Carl Friedrich Wilhelm G. (1806-1884) Buchhändler, seit 1866 Mitinhaber des Verlages Duncker \& Humblot in Berlin, s. ADB 49 (1904) S. 274, DBE 3 (2006) S. 717

(14. Sept. 1910 Elisabeth geb. Frohne verw. Koenig (1868-1942), siehe Leibrecht (2003) S. $101 \mathrm{f}$. u. ö.

K 1 S, 2 T: u. a. Eva (von) K. $\left({ }^{*} 1889\right)$ Ehefrau von Alfred Schwenkenbecher (1875-1963) PrivatDozent für Innere Medizin: 1904 Tübingen, 1904-1906 Straßburg, 1907 H; seit Okt. 1907 a. o. Prof. und Direktor der Med. Poliklinik Marburg, seit 1909 Direktor der Med. Klinik des Städtischen Krankenhauses Frankfurt/M., seit 1914 o. Prof. und Direktor der Med. Klinik der U Frankfurt/M., 1920-1949 (Ruhestand) o. Prof. und Leiter der Med. Poliklinik Marburg, s. UAH PA 2275; Catalogus prof. Marburgensis 2 (1979) S. 383 f., WBIS, Hessische Biografie, s. http://www.lagis-hessen.de/pnd/1174191 17 (Stand: 8. Aug. 2016)

Vw Großeltern, Urgroßvater: August K. (17841855), u. a. 1834-1853 (Ruhestand) o. Prof. für Theologie, U-Prediger Leipzig, s. WBIS, Geschichte U Leipzig 2 (2010) S. 917 (Register), Professorenkatalog Leipzig online; Ehemann von Luise geb. von Ammon, Tochter von Christoph Friedrich von A. (1766-1850), u.a. seit 1792 o. Prof. für Theologie Erlangen, seit 1794 Göttingen, seit 1804 Erlangen, seit 1813 Oberhofprediger und Oberkonsistorialrat in Dresden, s. WBIS, NDB 1 (1953) S. 253 f., BBKL I (1990) Sp. 148f.; Groß, Reiner: Als Oberhofprediger in der Ständeversammlung: C.F. von A. in: Landtagskurier - Sachsen, Landtag. Dresden 1993.

$L b$ WS $1880 / 81$ Studium an U Jena, SS $1881 \mathrm{H}$, seit WS 1881/82 Leipzig, anschl. Berlin, SS 1885-WS 1885/86 erneut Leipzig; med. Staatsprüfungen; 23. Dez. 1885 Approbation. 
U Leipzig: 1886-1892 Assistent an Med. U-Klinik; 1. März 1886 Dr. med.; 1888 Habilitation für Innere Medizin.

U Jena: 29. Okt. 1892 Vereidigung als a. o. Prof. und 1892-1899 Direktor der Poliklinik.

U Marburg: Seit WS 1899/19oo o. Prof. und Direktor der Poliklinik.

U Greifswald: Seit SS 1900 o. Prof. und Direktor der Med. U-Klinik.

U Tübingen: Seit SS 1902 o. Prof. und Direktor der Med. U-Klinik.

U Straßburg: Seit SS 1904 o. Prof. und Direktor der Med. U-Klinik.

UH: 28. Nov. 1906 Ern. zum o. Prof. und Direktor der Med. U-Klinik als Nachf. von Wilhelm Erb; SS 1907 Dienstantritt; Rufe an U abgelehnt: 1908 Wien, 1910 Leipzig, 1912 München; 31. März 1930 Ruhestand; SS 1930-WS 1930/31 Vertreter seines Lehrstuhls. • In dieser Zeit:

H: 1907-1931 Niedergelassener Arzt; 1929-1937 Geschäftsführender Direktor des von ihm initiierten Kaiser-Wilhelm-Inst. für med. Forschung und Leiter des dem Inst. angegliederten Patholog. Inst.

1914-1918 Kriegsdienst.

1907/o8 Dekan der Med. Fak. der UH

1906 Geh. Rat II. Klasse

E Mitglied: 1909 Akademie der Wissenschaften H, 1926 Dt. Akademie der Naturforscher Leopoldina Halle/S.; 1932 Orden pour le Mérite für Wissenschaften und Künste. 1906 Dr. phil. h.c. Greifswald; 1927 D. theol. Tübingen. 1904 Ehrenkreuz des Ordens der Württembergischen Krone mit persönlichem Adel; 1907 Großoffizierskreuz mit Stern des Königl. Siamesischen Ordens vom Weißen Elefanten; 1916 Kommandeurkreuz I. Klasse mit Schwertern des Ordens vom Zähringer Löwen; 1936 Adlerschild des Deutschen Reiches. 1922 Ehrenbürger der Stadt Heidelberg.
Qu UAH PA 1034, 4655; RA 6269, 6804. • GLA Abt. 235, Fasz. 2242. - Personalakte im Archiv der Max-Planck-Gesellschaft Berlin. - UA Jena Bestand M, Nr. 235, Bl. 7, 20 f. • Briefe: UBH. • L. K. Feldpostbriefe an seine Frau vom September 1914 bis September 1918. 2 Bde. Leipzig 1939. Eckart, Wolfgang U.: Der Krieg, das „Ärztliche“ und die Pathologische Physiologie - L. von K. in seinen Briefen an die Gattin, 1914-1918 in: UH während des Ersten Weltkriegs (2017) S. 259-278. - Siehe auch Archiv der Dt. Akademie der Naturforscher Leopoldina Halle/S.

$W$ Grundriß der allgemeinen klinischen Pathologie. Leipzig 1893. 2. Aufl. u.d. T.: Pathologische Physiologie. 1898. 13. Aufl. u. d. T.: Entstehung, Erkennung und Behandlung innerer Krankheiten. Leipzig 1930. 14. Aufl. 1934. • Die Erkrankungen des Herzmuskels und die nervösen Herzkrankheiten. Wien 1901. 2. Aufl. 1913. Krankheitsform und Persönlichkeit. Heidelberg 1929.

HG Deutsches Archiv für klinische Medizin. • Archiv für experimentelle Pathologie und Pharmakologie.

$L$ Catalogus prof. Marburgensis 1 (1927) S. 218; Handels-Hochschule Mannheim 1907-1932 (1932) S. 29; NDB 12 (1980) S. 733 f. • Staab, Heinz A.: 50 Jahre Kaiser-Wilhelm/Max-Planck-Inst. für med. Forschung Heidelberg in: Heidelberger Jahrbücher 24 (1980) S. 47-58 u. ö. • WBIS; Chronik Ärzte H (1985) S. 134, 240-242. • Jacob, Wolfgang: Medizinische Anthropologie in: Semper apertus 4 (1985) S. 122-160; Schettler, Gotthard: L.K. in: ebd. 3, S. 114-135. Jansen (1992) S. 410 (Register); Ders. (1992a) S. 167 (Register); Wennemuth (1994) S. 636 (Register); Eckart (2000) S. 86-88. - Leibrecht, Thomas: Die Villa Krehl in Heidelberg in: Heidelberg. Jahrbuch zur Geschichte der Stadt 2003/04. Heidelberg 2003. Jg. 8. S. 99-113. • Peiffer (2004) S. 1163 (Register); Ärztelexikon (2006) S. 199f.; Klee, Personenlexikon (2007) S. 338; Kriegstagebuch K. Hampe (2007) S. 975 (Register); Rürup (2008) S. 526 (Register); Grewolls (2011); Huhn/ Kilian (2011) S. 250 (Register); Wissenschaftsatlas der UH (2011) S. 116-118, 252. 
$P$ Bildarchiv UAH; graph. Slg. UBH; NDB; Chronik Ärzte H. • Bildarchiv des Archivs der MaxPlanck-Gesellschaft Berlin.

\section{Kroyer, Theodor}

1920-1922 (Honorar-Prof.) Phil. Fak.

1922-1923 Phil. Fak.

Musikwissenschaft

* o9. Sept. 1873 München

$\dagger$ 12. Jan. 1945 Wiesbaden (in e. Hotel)

kath.

V Anton K. ( $\left.{ }^{*} 1835\right)$ Strafanstalts-Direktor

M Marie geb. Pöller/Polier $\left({ }^{*} 1844\right)$

$\varnothing$ 21. Aug. 1920 Anna geb. Stockbauer (18771961)

$\mathrm{K}$ keine.

Lb Seit WS 1892/93 Studium zunächst der Theologie (auf Wunsch der Eltern) an U München, seit 1893 Studium der Musikwiss. an Akademie der Tonkunst in München, zuletzt an U München; 1897 Dr. phil. an U München.

München: 1897-1910 Musikreferent der Allg. Zeitung; 1900-1902 Lehrer an Dr. Kaims Musik-Institut.

U München: 30. Okt. 1902 Habilitation; seit 3. Juni 1907 nichtetatm. a. o. Prof.

UH: Seit 28. Juli 1920 planm. a. o. Prof. unter Verleihung der Amtsbezeichnung o. Honorar-Prof. als Nachf. von Philipp Wolfrum; 6. April 1922 Verleihung der Amtsbezeichnung und akad. Rechte e. o. Prof. (persönlicher Ordinarius).

U Leipzig: Seit WS 1923/24 o. Prof., Direktor des Musikwiss. Inst. und des Instrumenten-Museums sowie des Staatl. Forschungs-Inst. für Musikwissenschaft (als Nachf. von (siehe) Hermann Abert).

U Köln: 1. April 1932-30. Sept. 1938 (Emeritierung) o. Prof.; Begründer der Instrumentensammlung des Musikwiss. Inst.
1921 Initiator e. eigenen Ortsgruppe der Dt. Musikgesellschaft (Collegium musicum) in Heidelberg

Siehe auch Hermann Abert

Qu UAH PA 4673; RA 6134; Fak.-Akte H-IV-102/ 146 fol. 572, 574-582. - UA Köln (Findbuch, Zugang 44 (1991/92) S. 24. - GLA Abt. 235, Fasz. 2247. - Briefe: UBH; Universitätsbibliothek Leipzig; Münchner Stadtbibliothek; s. auch Kalliope. • Verzeichnis der aus dem Nachlaß von T.K. stammenden Briefe und Karten Max Regers an K. 19001904, die im November 1963 bei der Firma Hauswedell von der Staatlichen Bibliothek Regensburg ersteigert wurden. o. O. 1963. - Nachlaß: Bayer. Staatsbibliothek München.

$W$ Ludwig Senfl und sein Motettenspiel. München 1902. - Joseph Rheinberger. Regensburg 1916. • Walter Courvoisier. München 1929.

G 1925 Reihe „Publikationen älterer Musik“.

HG Max Weber. Die rationalen und soziologischen Grundlagen der Musik. München 1921.

L NDB 13 (1982) S. 92 f. • Finscher, Ludwig: Bachverein und Universität in: Ruperto Carola 74 (1986) S. 157 f. BBKL IV (1992) Sp. 696f. Arntz, Michael: Die Entwicklung der universitären Musikwissenschaft in Köln bis 1932, siehe http://www. uni-koeln.de/phil-fak/muwi/fricke/o49arntz.pdf. • WBIS. - Phleps, Thomas: Ein stiller, verbissener und zäher Kampf um Stetigkeit. Musikwissenschaft in NS-Deutschland und ihre vergangenheitspolitische Bewältigung in: Gesellschaft für Musikforschung. Musikforschung - Nationalsozialismus - Faschismus. Referate der Tagung Schloss Engers ... Hrsg. von Isolde von Foerster ... Mainz 2001. S. 471-488. MGG (Personenteil) 10 ( $\left.{ }^{2} 2003\right)$; Professorenkatalog Leipzig online. Bayerisches Musiker-Lexikon online. Hrsg. von Josef Focht, siehe http://bmlo.de/k102o (Stand: 10. April 2012). Leitmeir, Christian Thomas: Ein „Mann ohne Eigenschaften“? - T.K. als Ordinarius für Musikwissenschaft in Köln (1932-1938) in: 
Musikwissenschaft im Rheinland um 1930 ... Hrsg. von Klaus Pietschmann ... Berlin 2012. S. 93-136.

$P$ NDB.

\section{Kuckuck, Erich Wilhelm Heinrich}

siehe Kallius, Erich

Kübel, Johannes Matthaeus (SJ bis 1773)

1780 (Lehrer), 1781-1784 Phil. Fak.

1780-1784 Mathematik, Theologie

1784-1809 Jur. Fak.

Geistliches Recht

* 15. Nov. 1742 Herbstein (bei Fulda)

$\dagger$ 03. Jan. 1809 Heidelberg kath.

V Erasmus K. (1703-1750) Leinweber (?)

M Maria Magdalena geb. Ruhl (1715-1784)

$\infty$ unverheiratet.

Lb 1755-1757 Erlernung des Leinwebergewerbes; 1758-1759 Vorbereitungs-Unterricht für das Gymnasium; 1760-1765 Gymnasialbesuch in Fulda.

SJ: 14. Sept. 1764 Eintritt in Societas Jesu (Gesellschaft Jesu, Jesuitenorden; 1773 Aufhebung des Ordens); 1765-1768 Studium der Theologie am Jesuitenkolleg in Mainz; Lehrer am Gymnasium: seit 1768 Bruchsal, seit 1769 Fulda.

H: 1770-1773 (Aufhebung des Ordens) Prof. für Rhetorik am Gymnasium; 1773-1780 Präses der kurfürstl. Alumnen.

UH: 20. Jan. 1772 Immatrikulation zum Studium der Theologie; 24. Dez. 1776 Disputation zum Dr. phil.; seit 31. Okt. 1780 provisorischer Lehrer für Mathematik an Phil. Fak.; zwischen 1781 und 1782 Dr. theol.; 21. Nov. 1781 Ern. zum a. o. Prof. für Mathematik; 26. April 1783 Ern. zum o. Prof. für Mathematik als Nachf. von Christian Mayer (s. Drüll (1991) S. 99-101); seit 24. April 1784 o. Prof. für Geistliches Recht an Jur. Fak. als Nachf. von Franz Xaver Holl (s. Drüll (1991) S. 70); bis $1809(\dagger)$ Beisitzer des Spruchkollegiums der Jur. Fak.

1792/93 Rektor der UH; 1789, 1794, 1799, 1803, 1804? (oder Ignaz Wedekind) Dekan der Jur. Fak. der UH

K.s Bibliothek befindet sich seit 1809 in der Universitätsbibliothek Heidelberg, s. hierzu UAH K-Ia, $521 / 3$.

1805 Geistlicher Rat

E 7. Nov. 1786 Dr. iur. utr. h.c. UH.

Qu UAH PA 1881f.; Fak.-Akte H-II-111/2b fol. 23v. Acta secularium (1787) S. 166, 227 f.; Toepke 4 (1903) S. 264 u. ö. GLA Abt. 205, Fasz. 345.

$W$ Entwurf einer Vorlesung aus dem gemeinnützigsten Theile der practischen Mechanic. Heidelberg 1783. - Lehrsätze und Aufgaben aus der GröBenlehre. Heidelberg 1783. - Matthäus Kübel ... über die Geschichte bischöflicher Dispensen oder Beleuchtung des 3 ten pereirischen Satzes. 2. Aufl. Heidelberg 1788. Können ledige Katholiken, die nach protestantischen Gesetzen vom Bande geschiedene Protestanten ehelichen, ohne wider die Lehre der katholischen Kirche zu verstossen? Meersburg 1804.

$L$ Heidelbergische Jahrbücher der Literatur (1809) 2. Jg., Abt. 5,1, H. 8, hierin: Intelligenzblatt Nr. IX 1809, S. 33 f.; Wechmar (1846) S. 252, 288; Poggendorff 1 (1863) Sp. 1324; Keller (1913) S. 72-74; Schneider (1913) S. 15; Sommervogel IV (1960) Sp. 1268f.; Jammers (1964) S. 177 u. ö.; Brandl (1978) S. 140 (hier: Geb.-Tag 14. Nov.); Weisert (1991) S. 121 u. ö.; WBIS; Burkard (1995) S. 250 (Register). - Handbuch der historischen Buchbestände in Deutschland. Hrsg. von Bernhard Fabian. Hildesheim 2003. Baur (2009) S. 108f., 164, 349; Schroeder (2010) S. 15; Deutsche Biographie, s. https://www.deutsche-biographie.de/gnd100875 106.html [07.11. 2017]. 


\section{Küchler, Friedrich}

1919-1921 Theol. Fak.

Altes Testament

* 15. April 1874 Triest (Österreich-Ungarn; heute: Italien)

$\dagger$ 23. April 1921 Heidelberg

ev.

V Georg K. († vor 1918) Großkaufmann, s. Ein Schloss im Meer (2016)

M Johanna (?) geb. N.N. (1848-1941) (?)

๑ 1905 Eliza geb. Jeken (?) $\left({ }^{\star} 1878 \dagger\right.$ nach 1921$)$

$\mathrm{K} \quad 1 \mathrm{~S}, 1 \mathrm{~T}$

Lb Seit SS 1892 Studium der Philosophie (u.a. auch Assyriologie), Theologie an U Leipzig, anschl. Kiel, seit SS 1895 Leipzig, WS 1896/97-WS 1901/o2 Marburg; 1902 Dr. phil. an U Marburg; theol. Lizentiatenexamen.

U Berlin: 1906 Habilitation für Altes Testament; Nov. 1906-SS 1910 Privat-Dozent.

U Straßburg: Seit 1. Okt. 1910 etatm. a. o. Prof. für Altes Testament; 1914-1918 Kriegsdienst als Lazaretthilfsgeistlicher (Militärkrankenwärter); Dez. 1918 Schließung der U und Ausweisung als Deutscher.

UH: 30. April 1919 Genehmigung der Nostrifikation an Theol. Fak. für Alttestamentliche Wissenschaft; seit SS 1919 Lehrbeauftragter; 31. Mai 1921 Karlsruher Ministerium des Kultus und Unterrichts gewährt „dem früheren Strassburger a.o. Prof. ... K. für die der Universität Heidelberg während 2 $1 \frac{1}{2}$ Jahren durch Abhaltung von Vorlesungen geleisteten wertvollen Dienste nachträglich eine Vergütung von 2000.- Mark" (aus: UAH PA 4693); 21. Mai 1921 Reichsminister des Innern, Abt. für Elsaß-Lothringen in Lahr im Breisgau schreibt an UH, „daß den Erben die dem Verstorbenen infolge der Neuregelung der Bezüge der verdrängten elsass-lothringischen Beamten noch zustehenden Bezüge und der Witwe das Gnadenviertel demnächst angewiesen werden“ (aus: PA 4693).
Qu UAH PA 4693.

$W$ Beiträge zur Kenntnis der assyrischen Medizin. Phil. Diss. Marburg 1902. • Beiträge zur Kenntnis der assyrisch-babylonischen Medizin. Texte mit Umschrift, Übersetzung und Kommentar. Leipzig 1904. Hebräische Volkskunde. Tübingen 1906. • Die Stellung des Propheten Jesaja zur Politik seiner Zeit. Tübingen 1906. - Jahwe und sein Volk nach Jeremia in: Zs. für die alttestamentliche Wissenschaft. Berlin 1908. S. 81-109. - Das priesterliche Orakel in Israel und Juda in: Abhandlungen zur semitischen Religionskunde ... (1918) S. 285302. Siehe auch BBKL IV (1992).

MHG Abhandlungen zur semitischen Religionskunde. Festschrift für Wolf Wilhelm Graf von Baudissin. Gießen 1918.

$L$ RGG $3\left({ }^{2} 1929\right)$ Sp. 1330; BBKL IV (1992) Sp. 741f.; Fix (1994) S. 19, 131; Max Weber - Gesamtausgabe Band I/21,1 (2005) S. 1054 (Register). • Ein Schloss im Meer - Gästebuch der Familie von Hütterott. Bearbeitung und Kommentierung von Detlef Gaastra. Leipzig 2016. Deutsche Biographie, s. https://www.deutsche-biographie.de/gnd11 6581204.html [07.11. 2017].

\section{Kühne, Friedrich Wilhelm (Willy)}

1871-190o Med. Fak.

Physiologie

* 28. März 1837 Hamburg

$\dagger$ 10. Juni 1900 Heidelberg ev.

V Julius Ferdinand K. (1799-1871) SchifffahrtsDirektor

M Susette Amalie geb. Feige (1806-1888)

$\varnothing$ 12. Aug. 1872 Helene Amalia Charlotte geb. Blum (1846-1930) T von: (siehe) Reinhard B.

K 1 T: Susette Elisabeth Helene K. (1873-1944) Ehefrau von: (siehe) Rudolf Gottlieb.

Lb U Göttingen: Seit WS 1854/55 Studium der Medizin, Pharmakologie, Naturwiss.; 1856 Dr. phil. [!]; 1856-1857 Assistent am Physiolog. Inst. 
U Jena: 1857 Kurzzeitiger Aufenthalt.

U Berlin: Seit 1858 Assistent an Chemischer Abt. des Patholog. Inst.

Seit 1859 Studienaufenthalt in Paris, London, zuletzt seit Winter 1860 in Wien.

U Berlin: 1861-1868 Assistent und Leiter des Chemischen Labors am Patholog. Inst.

U Amsterdam: Jan. 1868 Ern. zum o. Prof.

UH: Seit 22. Febr. 1871 o. Prof. und Direktor des Physiolog. Inst. als Nachf. von Hermann Helmholtz; Rufe an U abgelehnt: 1873 Wien, 1892 Berlin.

1874/75, 1883/84 Dekan der Med. Fak. der UH

Schöpfer des Fachbegriffs „Enzym“; seine erste Nennung ist in: K., W.: Über das Verhalten verschidener organisirter und sog. ungeformter Fermente in: Verhandlungen des Naturhist.-med. Vereins zu Heidelberg (1877) N. F. 1, S. 190-193.

1871 Hofrat; 1873 Geh. Rat II. Klasse

$E$ Mitglied der Akademie der Wissenschaften: 1885 München, 1896 Stockholm, 1898 Berlin; 1892 Mitglied der Königl. Gesellschaft der Wissenschaften Uppsala. 1862 Dr. med. h. c. Jena. 1880 Ritterkreuz I. Klasse, 1886 Kommandeurkreuz II. Klasse, 1896 Kommandeurkreuz I. Klasse des Ordens vom Zähringer Löwen.

Qu UAH PA 1883, 4702-4704; RA 5710, 5816, 6189, 6808. Briefe: UBH. • Ernst Wilhelm von Brücke: Briefe an Emil Du Bois-Reymond. Hrsg. ... von Hans Brücke ... 1. T. Graz 1978. S. 300 (Register).

$W$ Lehrbuch der Physiologischen Chemie. 3 Lfg. Leipzig 1866-1868. - Über die Verdauung der Eiweißstoffe durch den Pankreassaft in: Virchows Archiv 39 (1867) S. 130-172; Über das Trypsin in: ebd. S. 194-198. - Zur Photochemie der Netzhaut in: Untersuchungen aus dem Physiolog. Institut der Universität Heidelberg. Bd. 1, H. 1 (1877)
S. 1-14. • Physiologie der Netzhaut in: Handbuch der Physiologie. Hrsg. von Ludimar Hermann ... Leipzig 1879. - Die motorische Nervenendigung, besonders nach Beobachtungen an Muskelquerschnitten ... Heidelberg 1884.

HG 1877-1882 Untersuchungen aus dem Physiolog. Institut der Universität Heidelberg. 4 Bde.

MHG Seit 1883 Zeitschrift für Biologie.

L Leber, Theodor: W.K. Gedächtnisrede gehalten bei der Enthüllung seines Denkmals [ReliefPlakette] im Physiologischen Institut zu Heidelberg am 20. Okt. 1901. Heidelberg 1901. • Schalck, Adolf: Das Leben und Wirken des Heidelberger Physiologen W.K. Diss. Med. Akademie. Düsseldorf 1940. - Hoche (1969) S. 86 f.; NDB 13 (1982) S. 202 f.; Chronik Ärzte H (1985) S. 123, 244f.; WBIS. Neurath, Hans und Zwilling, Robert: W.K. und die Anfänge der Enzymologie in: Semper apertus 2 (1985) S. 361-370. - Zimmermann/Drüll (1990) S. 41 f. Bauer, Axel W.: F. W. K. in: Enzyklopädie Medizingeschichte. Hrsg. von Werner E. Gerabek u. a. Berlin 2005. S. 812. Ruuskanen (2008) S. 141 f.; Autoren der Bunsenbibliothek (2009 online). Biographical Encyclopedia of Scientists. Third Edition. Ed. by John Daintith. Boca Raton (Florida) 2009. S. 431. • Birn (2012) S. 191 (Register); Fischer (2012) S. 147f. • Shepherd, Gordon M.: Foundations of the Neuron Doctrine. Oxford 2016. S. 326 (Register).

$P$ Bildarchiv UAH; Relief-Plakette im Inst. für Physiologie und Pathophysiologie der UH, Im Neuenheimer Feld 326; graph. Slg. UBH; NDB; Chronik Ärzte H.

\section{Kühne, Willy}

siehe Kühne, Friedrich Wilhelm 


\section{Kümmel, Werner Friedrich Franz}

1902-1907 Med. Fak.

1907-1919 (Honorar-Prof.) Med. Fak.

1919-1930 Med. Fak.

Ohrenheilkunde, seit 1908 auch Nasen- und Kehlkopfheilkunde

* 29. April 1866 Hildesheim

$\dagger$ 19. Nov. 1930 Heidelberg ev.

V Werner K. (1834-1893) Direktor e. Gas- und Wasserwerks

M Emilie geb. Schacht (1838-1887)

œ 3. März 1904 Marie geb. Ulmann (1873-1915) T von Sophie geb. Henle (1852-1917; T von: (siehe) Jacob H.) und von Heinrich Ephraim Ulmann (1841-1931), u.a. seit 1870 Prof. für Geschichte U Dorpat, 1874-1912 o. Prof. Greifswald, s. Weber (1987) S. 611, WBIS, Grewolls (2011); North, Michael: Von Ernst Moritz Arndt zu Herbert Langer: Protagonisten der neueren Geschichte in Greifswald ... Stuttgart 2015. S. 83-97.

$\infty$ 27. Sept. 1919 Irma geb. Holtzmann (18841980)

K 1 T, 3 S: u.a. Werner Georg K. (1905-1995), u. a. 1952-1973 Prof. für Theologie Marburg, s. Catalogus prof. Marburgensis 2 (1979) S. 32, Wer ist wer (1984) S. 727, BBKL XVIII (2001) Sp. 827f.; Otto Merk: Wissenschaftsgeschichte und Exegese: Gesammelte Aufsätze 1998-2013. Hrsg. von Roland Gebauer ... Berlin 2015. S. 271-286 u. ö.

Vw Bruder: Otto K. (1874-1952) Generaldirektor der Staatl. Museen Berlin, s. NDB 13 (1982) S. 211f. • Enkel: Werner Friedrich K. $\left({ }^{\star} 1936\right)$, u. a. 1976-1985 Prof., 1988-2004 Leiter des Medizinhistor. Inst. Mainz, s. Wer ist wer (1984) S. 726. - Hans Martin K. (1937-1986), u. a. 1980-1986 o. Prof. für Altorientalistik Marburg, s. Farber, Walter: Nekrolog in: Zs. für Assyriologie und Vorderasiatische Archäologie Bd. 77, H. 1 (1987) S. 1-6.

Lb Seit WS 1883/84 Studium an U Leipzig, anschl. Marburg, Straßburg.
Straßburg: Jan. 1888 Approbation; Febr. 1888 Staatsexamen; Herbst 1888 Dr. med. an U.

1888-1892 Assistent: Patholog. Inst. der U-Ohrenklinik in Straßburg, anschl. U-Ohrenklinik in Berlin.

U Breslau: Seit April 1892 Assistent an Chirurg. UKlinik; 20. Juli 1895 Habilitation für Chirurgie, besonders des Ohres und der oberen Luftwege; Okt. 1896-Febr. 1899 stellvertr. Leiter der Poliklinik für Ohren-, Nasen- und Kehlkopfkrankheiten; seit 4. Febr. 1899 etatm. a. o. Prof. und Direktor der Poliklinik für Ohren-, Nasen- und Kehlkopfkrankheiten; 1901 Ruf an U Straßburg abgelehnt.

UH: 10. Nov. 1902 (Ern.)-23. Dez. 1907 etatm. a. o. Prof.; WS 1902/03 Vorlesungsbeginn; seit 17. Jan. 1903 Direktor der neuerbauten U-Ohrenklinik (Otologische Klinik) in Voßstraße 7 als Nachf. von Adolf Passow, 1908-1930 Direktor der Klinik für Ohren-, Nasen- und Kehlkopfkranke nach Zusammenlegung der Otologischen Klinik und der Ambulatorischen Klinik für Kehlkopf-, Rachen- und Nasenkranke; 23. Dez. 1907-22. März 1919 Verleihung des Titels e. o. Honorar-Prof.; seit 15. Aug. 1908 Lehrauftrag auch für Nasen- und Kehlkopfheilkunde in Nachf. von Anton Jurasz; 22. März 1919 Verleihung der Amtsbezeichnung und Rechte eines o. Prof. (persönlicher Ordinarius); seit 1. Sept. 1926 planm. o. Prof.

1917 Geh. Hofrat

E 1910 Ritterkreuz I. Klasse des Ordens vom Zähringer Löwen.

Qu UAH PA 1041, 4705; RA 6795. GLA Abt. 235, Fasz. 2249. • Briefe: UBH. • Teil-Nachlaß: UAH.

$W$ Die Mißbildungen der Extremitäten durch Defekt, Verwachsung und Überzahl. Kassel 1895. • Über die vom Ohr ausgehenden septischen Allgemeininfektionen in: Mitteilungen aus den Grenzgebieten der Medizin und Chirurgie 30 (1907) 3. Suppl.-Bd. S. 169-217. - Die chronische Tonsillitis in: Zs. für Hals-, Nasen- und Ohrenheilkunde $4(1922 / 23)$ S. 446-472; Örtliche Erkrankungen der oberen Luftwege als Ursache oder 
Folge von allergischen Erscheinungen in: ebd. 20 (1928) S. 104-128. Die Erkrankungen des inneren Ohres und der psychogenen Hörstörungen. Stuttgart 1923.

L NDB 13 (1982) S. 213f. (mit Werkverz.); Chronik Ärzte H (1985) S. 134, 245-247; Jansen (1992a) S. 167 (Register); WBIS; Lehrstätten der Oto-Rhino-Laryngologie (1996) S. 158f., 304 (Register). • Issa, Miriam Charbel: Karl Adolf Passow und die Berliner Hals-Nasen-Ohrenheilkunde. Diss. Berlin 1999. S. 18 f., 21 f. u. ö.

P Bildarchiv UAH; NDB; Chronik Ärzte H.

\section{Künßberg, Eberhard Georg Otto Freiherr von}

1910-1928 Jur. Fak.

1929-1941 (Honorar-Prof.) Jur. Fak.

Deutsche Rechtsgeschichte, Rechtliche Volks-

kunde

* 28. Febr. 1881 Porohy (Galizien; heute: Ukraine)

$\dagger$ 03. Mai 1941 Heidelberg ev.

V Ulrich Freiherr von K. (1847-1923) Forstrat

M Julie Thekla geb. Mrozowski (1855-1885)

( 14. Okt. 1910 Dr. phil. Katharina geb. Samson (1883-1977) Biologin und Frauenrechtlerin, s. UAH Rep. 141 (Engisch); Petersen, Hilde: K. von K. † in: Ruperto Carola 30. Jg., H. 61 (Dez. 1978) S. 131; Moraw (2008) S. 109-113, Lexikon jüdischer Einwohner Hs (2011) S. 227-229, Riecke (2016) S. 86, Künßberg (2017) S. 15 (P)

K 3 T, 2 S: u. a. Dr. Ekkehard von K. (1913-2001), u. a. Mitbegründer und 1976-1978 Präsident des Royal College of General Practitioners in Edinburgh; s. Lexikon jüdischer Einwohner Hs (2011) S. 227.

Lb Wien: Seit WS 1899/190o Studium der Rechtswiss. an U; 9. Juli 1903 II. jur. Staatsprüfung; 22. März 1904 Dr. iur. an U.
U München: SS 1904-SS 1905 Studium der Geschichtl. Hilfswiss., Rechtsgeschichte.

H: Seit April 1905 zunächst Hilfsarbeiter, 19081917 Leiter zus. mit (siehe) Richard Schroeder (†1917), 1917-1941 Leiter der Herausgabe des Dt. Rechtswörterbuchs im Auftrag der Akademie der Wissenschaften Berlin, Dienstort H; seit 13. Sept. 1928 beamteter Prof. der genannten Akademie. • In dieser Zeit:

UH: 25. Juli 1910 Habilitation für Dt. Rechtsgeschichte; 1910 Ruf an U Neuchâtel (Schweiz) abgelehnt; 13. Juni 1916-12. Sept. 1928 a.o. Prof.; 16. Jan. 1929 Ern. zum o. Honorar-Prof.; 1929-1941 Vorlesungsankündigungen.

1915-1918 Kriegsdienst als (Gründer und) Leiter der ersten dt. Einarmschule für versehrte Soldaten in Ettlingen.

Aus der 1961 gegründeten E.-von-K.-Stiftung wird vorzugsweise einer auf dem Gebiet der histor. Rechtswissenschaften arbeitenden Nachwuchswissenschaftlerin der UH ein Förderpreis verliehen.

E 1924 Mitglied der Akademie der Wissenschaften $\mathrm{H} ; 1928$ o. Mitglied der Badischen Histor. Kommission. 1912 Königl. Preußischer Roter Adler-Orden IV. Klasse; Badisches Kriegshilfskreuz.

Qu UAH PA 61, 771, 4708. GLA Abt. 235, Fasz. 2250. Briefe: UBH; s. auch Kalliope. - Teil-Nachlaß: UBH; Forschungsstelle für Rechtsgeschichte der U Zürich; Historisches Seminar der U Münster.

$W$ Fibel für Einarmige und Ohnhändler. Karlsruhe 1915. 5. Aufl. 1946. - Rechtsbrauch und Kinderspiel. Heidelberg 1920. 2. Aufl. 1952. • Der Sachsenspiegel. Bilder aus der Heidelberger Handschrift. Heidelberg 1934. - Rechtliche Volkskunde. Freiburg/Br. 1936. - Flurnamen und Rechtsgeschichte. Weimar 1936.

MHG Deutsches Rechtswörterbuch. 3 Bde. Weimar 1914-1938. Unveränderter Nachdr. 1998. 
L ÖBL online 1815-1950 (1968) Bd. 4 (Lfg. 19) S. 327; NDB 13 (1982) S. 226 f. (mit Werkverz.); Badische Biographien N.F. III (1990) S. 163-166; Wennemuth (1994) S. 636 (Register); Rechtsvergleicher verkannt (2000) S. 251-262; UH im Nationalsozialismus (2006) S. 1261 (Register). • Schorsch, René: E. G. O. Frhr. von K. ... Vom Wirken eines Rechtshistorikers. Frankfurt/M. 2010. • Schroeder (2010) S. 740 (Register); 100 Jahre Germanistik in Hamburg (2011) S. 200 f., 207 f., 464 u.ö.; Lexikon jüdischer Einwohner Hs (2011) S. 227 f. • Schroeder, Klaus-Peter: Adolf Laufs, E. Frhr. von K. und die "Badische Einarmschule“ in: Medizinrecht 33. Jg., H. 11 (Nov. 2015) S. 790-792. • Riecke (2016) S. 45, 68, 70, 77, 86. Künßberg, Eberhard von: Die Entwicklung der deutschen Rechtssprache ... Baden-Baden 2017. S. 11-20, 24-28 u. ö. • Schroeder (2017) S. 325-333 (zu S. 325 Anm. 2: Dr. phil. Katharina von K. geb. Samson $\left({ }^{*} 1883\right)$ starb 1977 , die Begräbnisfeier fand im März 1978 statt).

$P$ Bildarchiv UAH; NDB.

\section{Kuhn, Ernst Wilhelm Adalbert}

1875-1877 Phil. Fak.

Vgl. Sprachwissenschaft, auch Sanskrit

* $\quad$ 07. Febr. 1846 Berlin

$\dagger$ 21. Aug. 1920 München

ev.

V Dr. phil. Adalbert Franz K. (1812-1881) seit 1841 Lehrer, seit 1856 Gymnasial-Prof., 1870-1880 (Ruhestand) Direktor des Cölnischen Gymnasiums Berlin; Sagenforscher, Begründer der vgl. Mythologie, seit 1852 (Mit-Begründer) (Mit-)Hrsg. der Zs. für vgl. Sprachforschung, s. NDB 13 (1982) S. 256, WBIS; Schmitt, Rüdiger: Epistolographischer Nachtrag zur Korrespondenz zwischen Jacob Grimm und A. K. in: Brüder-Grimm-Gedenken. Hrsg. von Ludwig Denecke. Bd. 10. Stuttgart 1993. S. 64-67; Int. Germanistenlexikon 2 (2003) S. 1030-1032; Hennies, Wolfram: Ein Schatz aus Sagen und Gebräuchen. Die märkischen Volkskundler A. K. und Wilhelm Schwartz forschten auch in Mecklenburg in: Schweriner Volkszeitung ... Mecklenburg-Magazin. Schwerin 2015. S. 25.
M Albertine geb. Schwartz; Schwester von Dr. phil. Wilhelm S. (1821-1899) seit 1844 Oberlehrer, seit 1862 Gymnasial-Prof. am Friedrichwerderschen Gymnasium Berlin; Direktor: seit 1864 in Neuruppin, seit 1872 FriedrichWilhelms-Gymnasium in Posen, 1882-1894 (Ruhestand) Luisengymnasium Berlin; 1894 Geh. Reg.-Rat, s. Friedel, Ernst: Nachruf in: Brandenburgia. Monatsblatt der Gesellschaft für Heimatkunde der Provinz Brandenburg zu Berlin. 8. Jg. 1899/19oo. Berlin 1900. S. 124130 (mit P); Feustel, Jan: Zu Fuß auf den Spuren märkischer Gespenster. W.S. und Adalbert Kuhn. Die Sagensammler in: Die Mark Brandenburg - Zs. für die Mark Brandenburg. Berlin 1998. Bd. 31, S. 34-37.

๑ 5. April 1877 Klara Bettina Marie geb. Knies (1852-1878) T von: (siehe) Carl Knies

๑ 28. Dez. 1880 Mathilde geb. Dormeyer (18561943)

K $\quad 1 \mathrm{~T}$

Lb Seit WS 1863/64 Studium an U Berlin, anschl. Tübingen.

U Halle-Wittenberg: 10. Juni 1869 Dr. phil.; 21. Jan. 1871 Habilitation.

\section{U Leipzig: SS 1873-SS 1875 Privat-Dozent.}

UH: Seit 26. Mai 1875 o. Prof. als Nachf. von Ernst Windisch.

U München: 1. April 1877-30. Sept. 1919 o. Prof. für Arische (= indische und iranische) Philologie und Vgl. Indogermanische Sprachwissenschaft.

Die K.sche Bibliothek mit ca. 6 ooo Bänden befindet sich in der UB München; sie umfaßt hauptsächlich sprachwissenschaftliche Werke, Grammatiken, Wörterbücher ... vorwiegend der indischen Sprachen und Dialekte (Sanskrit, Hindu, Pali, Singhalesisch u. a.) und der übrigen asiatischen Sprachen wie Jakutisch, Tibetisch, Mongolisch, auch Japanisch und Chinesisch. Die Bibliothek enthält außerdem Werke aus den Bibliotheken seines Vaters und seines Onkels Wilhelm Schwartz.

Geh. Hofrat 
$E$ Mitglied der Akademie der Wissenschaften: 1878 München, 1902 Wien. 1898 Bayer. Maximiliansorden für Wissenschaft und Kunst. - Ritter des Verdienstordens der Bayer. Krone.

Qu UAH PA 1885; RA 6863. • Vorlesungsverzeichnisse der U Leipzig SS 1873-SS 1875 online. • Briefe: UBH. - Schmitt, Rüdiger: E.K. und Vilhelm Thomsen: Aspekte ihres Forschens im Spiegel ihrer Korrespondenz. Kopenhagen 1990; Briefe und Dokumente von Albert Grünwedel. Hrsg. von Hartmut Walravens. Wiesbaden 2001. S. 1-102 u. ö.; Wilhelm Grube (1855-1908): Leben, Werk und Sammlungen des Sprachwissenschaftlers ... Bearb. von Hartmut Walravens und Iris Hopf. Wiesbaden 2007. S. 117-119 u. ö. • Nachlaß: Universitätsbibliothek München. Auskunft: Standesamt München (Sterbebuch von 1920; hierin Eintrag der Eheschließung vom 28. Dez. 1880 in Ellrich/Thüringen).

W Beiträge zur Pāli-Grammatik. Berlin 1875. • Barlaam und Joasaph. München 1893. Der Einfluß des arischen Indiens auf die Nachbarländer im Süden und Osten. München 1903. Siehe Zistl, Karl G.: Bibliographie der Schriften E. K.s in: Aufsätze zur Kultur- und Sprachgeschichte vornehmlich des Orients. E. K. zum 7o. Geb. ... Hrsg. von Carl Bezold und Lazian Scherman. Breslau 1916. S. XII-XXV.

G, HG 1883-1886 (Erscheinen eingestellt) Literaturblatt für Orientalische Philologie.

MHG 1873-1920 Zs. für vgl. Sprachforschung auf dem Gebiete der indogermanischen Sprachen (Mitbegründer der Zs. ist Adalbert Franz K.: siehe Eintrag unter $V$ [ater]). 1887-1894 Orientalische Bibliographie. 1895-1904 Grundriß der iranischen Philologie.

L Arnim 1 (1944) S. 701; Lehmann (1967) S. 224; NDB 13 (1982) S. 257; WBIS. • Handbuch der historischen Buchbestände in Deutschland. Bd. 10: Bayern - München. Hrsg. von Eberhard Dünninger ... T. 1. Hildesheim 1996. S. 119 f. • Die Schriften des Johannes von Damaskos. Bd. VI/1: Historia animae utilis de Barlaam et Joasaph (spuria). Einführung von Robert Volk. Berlin 2009. S. 27-31,
109-112 u. o.. Wilhelm, Friedrich: Zur Geschichte der Indologie an der Universität München in: 200 Jahre Indienforschung - Geschichte(n), Netzwerke, Diskurse. Hrsg. von Heidrun Brückner und Karin Steiner. Wiesbaden 2012. S. 209-211 u. ö.

\section{Kuhn, Richard}

1929-1945 (Honorar-Prof.) Nat.-Math. Fak. 1946-1950 (Honorar-Prof.) Nat.-Math. Fak. Chemie 1950-1967 Med. Fak.

Biochemie

* O3. Dez. 1900 Wien

$\dagger$ 31. Juli 1967 Heidelberg kath.

V Richard Clemens K. (1860-1935) Ingenieur, später Vorstand der Seebehörde in Triest

M Angelika geb. Rodler (1863-1945)

(1) 18. Dez. 1928 Daisy geb. Hartmann (19071976), siehe Schmaltz (2005) S. 364 u. ö.

K 4 T: u. a. Daisy Angelika K. $\left({ }^{\star} 1930\right)$ 1959-1992 Prof. für Mikrobiologie am Dept. of Biology der California State U in Northridge (Kalifornien). 2 S: Peter Richard K. (1932-2011), u. a. 1979-1997 o. Prof. für Allg. Maschinenkonstruktionslehre an U Karlsruhe, s. Kürschner (2001) S. 1776. - Hans-Jürg K. $\left({ }^{*} 1934\right)$ seit 2002 em. o. Prof. für Medizin im Bereich Humanmedizin, Abt. Morphologie an U Göttingen, s. Kürschner (1983) S. 2351, (2011) S. 2340.

Lb 19. Jan.-30. Nov. 1918 Kriegsdienst; seit WS 1918/19 Studium an U Wien, seit WS 1919/20 München.

U München: 22. Nov. 1922 Dr. phil.; 1922-1926 Assistent am Chemischen Inst.; 6. März 1925 Habilitation für Chemie.

ETH Zürich: Seit 1. Okt. 1926 o. Prof. für Allg. und Analytische Chemie; Rufe abgelehnt: 1928 U Wien, Stanford U (Kalifornien). 
UH: 6. Sept. 1929-31. Okt. 1945 o. Honorar-Prof. für Chemie an Nat.-Math. Fak.; Rufe abgelehnt: 1931 TH Berlin-Charlottenburg, 1936 U Berlin, 1937 Chicago; 31. Okt. 1945 (bis 1. Juli 1946) Entlassung von UH gemäß Erlaß der amerik. Militärregierung. • In dieser Zeit:

H: Okt. 1929-Juli 1967 Direktor der Abt. für Chemie am neugegründeten Kaiser-Wilhelm-Inst. (seit 1948 Max-Planck-Inst.) für med. Forschung; seit 26. Mai 1937 Übernahme der Geschäftsführung, 1. März 1938 Ern. zum Geschäftsführenden Direktor des Gesamt-Inst. als Nachf. von Ludolf von Krehl.

Berlin: Okt. 1939-1945 Leiter der Fachsparte Organische Chemie im Reichsforschungsrat und 1943/ 44 Giftgasforschung in Zus.arbeit mit Heereswaffenamt.

UH: 1. Juli 1946 Wiedereinsetzung als o. Honorar-Prof. für Chemie an Nat.-Math. Fak.; Rufe abgelehnt: 1950 Philadelphia U (Pennsylvania), U München; seit 10. Juni 1950 o. Prof. für Biochemie an Med. Fak., siehe hierzu $Z$.

1938 Nobelpreis für Chemie, s. http://www.nobel prize.org/nobel_prizes/chemistry/laureates/1938/; Annahme durch Reichs-Regierung verboten („Des Führers Wille ist unser Glaube“: handschriftliche Anmerkung K.s auf seinem Ablehnungs-Brief an die Königl. Schwedische Akademie der Wissenschaften vom 28. Nov. 1939, s. II. Abt. Rep. 1A PA Kuhn (Bd. 2) im Archiv der Max-Planck-Gesellschaft (MPG) Berlin); 1949 Entgegennahme des Preises.

Entdecker u. a. von Carotin, Lactoflavin (Vitamin $\mathrm{B}_{2}$ ) und Adermin (Vitamin $\mathrm{B}_{5}$ )

1938-1945 Präsident der Dt. Chemischen Gesellschaft; 1964-1965 Präsident der Gesellschaft Dt. Chemiker

1948-1966 Senator, seit 1966 Ehrensenator, 19551966 Vizepräsident der Max-Planck-Gesellschaft

$Z$ Kuhn schreibt in einem Brief vom 26. April 1950 an den Präsidenten der Max-Planck-Gesellschaft, Otto Hahn: Um Auseinandersetzungen mit dem seit 1926 an der Naturwissenschaftlich-Mathematischen Fakultät lehrenden Ordinarius für Chemie, Karl Freudenberg, zu vermeiden, „... erscheint (es) mir möglich dafür Voraussetzungen zu schaffen, daß wir beide, [Freudenberg und K.] als Angehörige zweier verschiedener Fakultäten mit abgegrenzten Wirkungsbereichen, die beide Teile befriedigen, im Rahmen der Universität Heidelberg koexistieren, ohne daß Herr Prof. Freudenberg das Gefühl haben müsste, durch mich beeinträchtigt und beengt zu werden ... So wie die Dinge jetzt liegen, wäre mir eine unter Druck zustandekommende Einschränkung von Prof. Freudenberg nicht recht ..." (aus: II. Abt. Rep. 1A PA Kuhn (Bd. 2) im Archiv der Max-Planck-Gesellschaft Berlin).

E Mitglied der Akademie der Wissenschaften: 1931 H, 1938 München, 1940 Wien, 1941 Berlin; 1936 Mitglied der Dt. Akademie der Naturforscher Leopoldina Halle/S. 1960 Dr. phil. h.c. Wien; 1961 Prof. h.c. Universidade Federal de Santa Maria (Brasilien); 1967 Dr. rer. nat. h.c. UH. • 1942 Goethe-Preis der Stadt Frankfurt; 1958 Orden pour le Mérite für Wissenschaften und Künste; 1964 Großes Bundesverdienstkreuz mit Stern und Schulterband.

Qu UAH PA 1040, 4717; Quästurakte Rep. 27752. - Briefe: UBH. - PA in II. Abt. Rep. 1A PA Kuhn (2 Bde.) und Nachlaß im Archiv der MaxPlanck-Gesellschaft Berlin; siehe auch Kazemi (2006) S. 165, 168f. • Siehe Archiv der Dt. Akademie der Naturforscher Leopoldina Halle/S. • Mitteilungen: Herr Prof. Dr. Hans-Jürg Kuhn, Göttingen.

$W$ Carotine und Carotinoide in: Forschung und Fortschritt 9 (1933) S. 426 f.; Wirkungen eines Vitamins in: ebd. (1934) S. 249. - Lactoflavin (Vitamin $B_{2}$ ) in: Zs. für angewandte Chemie 49 (1936) S. 6-10. (Mitverf.) - Das Vermächtnis Justus von Liebigs. München 1953.

L Staab, Heinz A.: 50 Jahre Kaiser-Wilhelm/MaxPlanck-Inst. für med. Forschung Heidelberg in: Heidelberger Jahrbücher 24 (1980) S. 54, 57 f., 61 u. ö. - NDB 13 (1982) S. 266-268 (mit Werkverz.); Chronik Ärzte H (1985) S. 134, 243 f. • Quadbeck, 
Günter: R.K. in: Semper apertus 3 (1985) S. 5572. - Oberkofler, Gerhard, Goller, Peter: R.K. ... Skizzen zur Karriere eines österreichischen Nobelpreisträgers. Innsbruck 1992. - WBIS; BadenWürtt. Biographien IV (1994) S. 196-198; Lexikon der Naturwissenschaftler (2000) S. 253; Deichmann (2001) S. 587 (Register); Grüttner (2004) S. 104; Schmaltz (2005) S. 671f. (Register); Kazemi (2006) S. 163-169; UH im Nationalsozialismus (2006) S. 168, 1193; Klee, Personenlexikon (2007) S. 350 f. Physiker zwischen Autonomie und Anpassung. Hrsg. von Dieter Hoffmann und Mark Walter. Weinheim 2007. S. 669 (Register). • Deichmann, Ute: Stellungnahme zu seinem politischen Verhalten während der NS-Zeit unter der Fragestellung: Kann Kuhn als Persönlichkeit Vorbildcharakter in der Chemie zuerkannt werden, online unter https://www.gdch.de/fileadmin/downloads/ Service_und_Informationen/Presse_OEffentlichkeitsarbeit/PDF/deich_kuhn.pdf. - Rürup (2008) S. 526 (Register); Wissenschaftsatlas der UH (2011) S. 133, 252. - Maier, Helmut: Chemiker im „Dritten Reich". Die Deutsche Chemische Gesellschaft und der Verein Deutscher Chemiker im NS-Herrschaftsapparat. Weinheim 2015.

$P$ Bildarchiv UAH; NDB; Chronik Ärzte H. • Bildarchiv des Archivs der Max-Planck-Gesellschaft Berlin.

\section{Kussmaul, Karl Philipp Adolf Konrad}

1856-1859 Med. Fak.

Heilmittellehre, Toxikologie, Psychiatrie, Gerichtliche Medizin, Pathologie

* 22. Febr. 1822 Graben (bei Karlsruhe; heute: Ortsteil von G.-Neudorf)

$\dagger$ 28. Mai 1902 Heidelberg ev.-luth.

V Philipp Jacob K. (1790-1850) Arzt

M Luise Katharina geb. Böhringer (1798-1846)

$\infty$ 1. Okt. 1850 Luise Amanda Jakobine geb. Wolf (1828-1898)

K 1 S: Eduard K. (1856-1881 ertrunken), 4 T (davon $1 \mathrm{~T}$ früh $\dagger$ ), u. a. Luise Amanda K. (18531929) Ehefrau von: (siehe) Vincenz Czerny.
Lb H: Seit WS 1840/41 Studium an UH; 15. Juni 1846 Approbation; 1846 wiss. Assistent an Med. UKlinik.

1847-1848 Eigenstudien in Wien, anschl. Prag; April 1848-Dez. 1849 Militärarzt.

Kandern (Schwarzwald): Seit März 1850 Landarzt; 1853 Aufgabe der Praxis aus gesundheitlichen Gründen.

U Würzburg: Seit 1853 Forts. des Studiums; 16. Aug. 1854 mündliche Prüfung, 10. März 1855 Promotionsurkunde zum Dr. med.

H: Seit Winter 1854 Eigenstudien; seit 30. April 1855 Physikatsassistent der Stadt.

UH: 14. Juli 1855 Habilitation für Arzneimittellehre, Psychiatrie, Gerichtliche Medizin, Anthropologie; WS 1856/57 erste Vorlesungsankündigung; 1857 als Assistenzarzt bezeichnet, siehe UAH PA 1778 (Julius Jolly); seit 8. Mai 1857 a. o. Prof.; seit 17. Juli 1858 a. o. Prof. mit e. Jahresgehalt von 400.- Gulden.

U Erlangen: Seit 1. Okt. 1859 o. Prof. für Arzneimittellehre und Staatsarzneikunde sowie Vorstand der Med. Klinik im U-Krankenhaus.

U Freiburg/Br.: 18. Aug. 1862 Berufung; seit 1. April 1863 o. Prof. für Innere Medizin.

U Straßburg: WS 1876/77-WS $1887 / 88$ o. Prof. für Innere Medizin.

H: Seit 1. Apr. 1888 Wohnsitz; 1889-1902 (Mitbegründer und) Leiter des Ev. Diakonissen-Krankenhauses (heute: Krankenhaus Salem).

1856 Mitbegründer des Naturhistorisch-Medizinischen Vereins in Heidelberg

Mehrere medizinische Begriffe tragen seinen $\mathrm{Na}$ men, z.B. die Kussmaul-Atmung, siehe hierzu Kotter, Claudia: Entdeckungsgeschichte frühkindlicher Reflexe unter Betrachtung der historischen Entwicklung der Reflexlehre. Freiburg/Br. 2012. S. 147-159. 
Erfinder der parodistischen Figur des „Biedermaier", siehe Das Buch Biedermaier. Gedichte von Ludwig Eichrodt und A.K. sowie von ihrem Vorbild, dem „alten Dorfschulmeister“ Samuel Friedrich Sauter. Gesammelt und hrsg. von Ludwig Eichrodt. Stuttgart 1911; siehe hierzu Schwabe, Heide: A.K. und die Entstehung der Epochenbezeichnung „Biedermeier“. Diss. Köln 1974.

Seit 2006 Verleihung der Kussmaul-Medaille von der Deutschen Gesellschaft für Rheumatologie an Wissenschaftler, die die Rheumatologie entscheidend geprägt haben

1891 Geh. Rat

E 1886 Cothenius-Medaille der Dt. Akademie der Naturforscher Leopoldina Halle/S. • 1898 Ehrenbürger der Stadt Heidelberg.

Qu UAH PA 1887; Fak.-Akte H-III-111/63; GF 27. • Briefe: UBH. - Teil-Nachlaß: Universitätsarchiv Freiburg/Br; s. auch Kluge (2002) S. $521 \mathrm{f}$. Auskunft: Universitätsarchiv Freiburg/Br. • Siehe auch Archiv der Dt. Akademie der Naturforscher Leopoldina Halle/S. - Jugenderinnerungen eines alten Arztes. Stuttgart 1899. 20. Aufl. 1960. (Autobiogr.) - Aus meiner Dozentenzeit in Heidelberg. Hrsg. von Vinzenz Czerny. Stuttgart 1903. 4. Aufl. München 1925.
$W$ Untersuchungen über das Seelenleben des neugeborenen Menschen. Leipzig 1859. 3. Aufl. 1896. • Von dem Mangel, der Verkümmerung und der Verdoppelung der Gebärmutter, von der Nachempfängnis und der Überwanderung des Eies. Würzburg 1859. - Über die Behandlung der Magenerweiterung durch eine neue Methode. Freiburg/Br. 1869. - Die Störungen der Sprache. Leipzig 1877. 4. Aufl. hrsg. ... von Hermann Gutzmann. Leipzig 1910.

$L$ Pagel (1901) Sp. 932-934; NDB 13 (1982) S. 344 f.; Chronik Ärzte H (1985) S. 134, 247 f. • Schindler, Fritz: Die zwei Leben des A.K. Filmporträt vom Südfunk. 1 Videokassette. Stuttgart 1985. • Professoren Erlangen (1999) S. 111 f.; Rastatt und die Revolution von 1848/49 (2001) S. 749 (Register). • Kluge, Friedrich: A. K. Arzt und Forscher, Lehrer der Heilkunst. Freiburg/Br. 2002. • Kluge, F. J., Matteson, E. L.: Klar denken, warm fühlen, ruhig handeln: A.K. ... und seine Bedeutung für die Medizin im 21. Jahrhundert in: Zs. für Rheumatologie 62 (2003) Nr. 5, S. 484-490. • Goerttler 2 (2004) S. 59 f.; Peiffer (2004) S. 1164 (Register); Ärztelexikon (2006). - Sedivy, Roland: Pathologie in Fallstudien. Historische Präparate neu betrachtet. Wien 2007. - Seidler/Leven (2007) S. 864 (Register). Wilkes, Johannes: A. K. und das Seelenleben der Neugeborenen in: Schriftenreihe der Dt. Gesellschaft für Geschichte der Nervenheilkunde 15 (2009) S. 287-294. • Freudenberg (2010) S. 159161 u. ö.

$P$ Bildarchiv UAH; graph. Slg. UBH. 


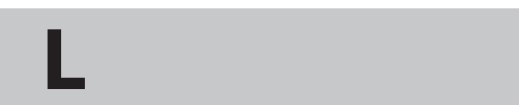

\section{Ladenburg, Albert}

1868-1873 Phil. Fak.

Chemie

* O2. Juli 1842 Mannheim

$\dagger$ 15. Aug. 1911 Breslau (heute: Wrocław, Polen) mosaisch, seit $1891 \mathrm{ev}$.

V Leopold L. (1809-1889) Advokat, s. NDB 13 (1982) S. 387

M Delphine geb. Picard (1814-1882), s. Lessing, Hans-Erhard: Delphine Ladenburg, Karl Gutzkow und die Draisens - Eine Mannheimer Begebenheit mit Folgen in: Mannheimer Geschichtsblätter 15 (2008) S. 6-21.

$\infty$ 19. Sept. 1875 Margarete geb. Pringsheim (18551909) T von Nathanael P. (1823-1894), u.a. seit 1864 a. o. Prof. Berlin, 1864 [!]-1868 (ausgeschieden aus gesundheitlichen Gründen) 0 . Prof. für Botanik Jena, anschl. Privat-Gelehrter in Berlin, s. NDB 20 (2001) S. $722 \mathrm{f}$.

K 3 S: u. a. Rudolf L. (1882-1952), u. a. 1932-1950 Prof. für Physik an Princeton U (New Jersey), s. Nachlaß im Archiv der Max-Planck-Gesellschaft Berlin; NDB 13 (1982) S. 391f., Spenkuch (2016) S. 1315 (Register).

$L b$ Seit Herbst 1858 Studium der Mathematik, seit Frühjahr 1860 Studium des Maschinenbaus und der modernen Sprachen am Polytechnikum Karlsruhe; seit WS 1860/61 Studium der Chemie an UH, WS 1862/63 Studium der Physik, Meteorologie und Geschichte an U Berlin.

UH: 3. Juni 1863 Dr. phil.; seit 1863 Assistent am Chemischen Laboratorium; Eigenstudien: Frühjahr 1865 Gent, danach London, 1866 Paris, 1867 H; 1. Febr. 1868 Habilitation; seit 30. März 1872 a. o. Prof.

U Kiel: 25. Okt. 1872 Ern. zum o. Prof.; SS 1873 Antritt seiner Professur; 1873-1889 (Gründungs-)Direktor des Chemischen Inst.
U Breslau: Seit 15. Aug. 1889 o. Prof.; 1. Okt. 1909 auf eigenen Antrag Ruhestand aus gesundheitlichen Gründen.

1889 Geh. Reg.-Rat

E 1880 Mitglied der Dt. Akademie der Naturforscher Leopoldina Halle/S.; 1886 Ehrenmitglied der Chemical Society London; Mitglied: 1909 Académie de Médicine Paris, 1910 Akademie der Wissenschaften Berlin. 1884 Dr. med. h.c. Bern. • Goldene Hanbury-Medaille.

Qu UAH PA 1888. • Briefe: UBH. Siehe auch Archiv der Dt. Akademie der Naturforscher Leopoldina Halle/S. - Lebenserinnerungen. Breslau 1912. (Autobiogr.)

$W$ Vorträge über die Entwicklungsgeschichte der Chemie in den letzten 100 Jahren. Braunschweig 1869. 3. Aufl. u.d. T.: Vorträge über die Entwicklungsgeschichte der Chemie von Lavoisier bis zur Gegenwart. Braunschweig 1902. 4. Aufl. 1907.

HG 1882-1889 Handwörterbuch der Chemie.

$L$ Lossen, Wilhelm: Offener Brief an A.L. und offene Anfrage an den Vorstand der Gesellschaft deutscher Naturforscher und Ärzte. Köln 1903. • Schell, Jakob Herman: Der Gottesglaube und die naturwissenschaftliche Welterkenntnis. Eine kritische Entgegnung auf A.L.s Vortrag in der 75. Naturforscherversammlung zu Kassel am 21. Sept. 1903. Bamberg 1904. 3. Aufl. 1904 [!]. • Waldeck, Florian: Ladenburg in: Alte Mannheimer Familien. Schriften der familiengeschichtlichen Vereinigung Mannheim. Mannheim 1920. Neudr. 1986. • NDB 13 (1982) S. 390 f. (mit Werkverz.); WBIS; Badische Biographien N.F. V (2005) S. 168-170 (hier Anm. zu L.s Geburtsdatum, ob 02. oder 03. Juli). • Von der Forschung gezeichnet (2007) S. 119f. u. ö. • Complete Dictionary of Scientific Biography ... Detroit 2008. Vol. 7. S. $551 \mathrm{f}$.

$P$ Bildarchiv UAH; NDB. 


\section{Landsberg, Georg}

1893-1904 Nat.-Math. Fak.

Mathematik

* 30. Jan. 1865 Breslau (heute: Wrocław, Polen)

$\dagger$ 14. Sept. 1912 Berlin-Tiergarten

口 unbekannt

mosaisch

V Bernhard L., Kaufmann

M Philippina geb. Buttermilch

$\infty$ unverheiratet.

Lb Seit WS 1884/85 Studium der Mathematik, Philosophie an U Breslau, seit WS 1886/87 auch Studium der Chemie Leipzig, seit SS 1887 erneut Breslau.

U Breslau: 19. Dez. 1889 Rigorosum, 29. März 1890 (Datum der Promotionsurkunde) Dr. phil.

1890-1893 Eigenstudien in Berlin und $\mathrm{H}$ (keine Immatrikulation an $\mathrm{UH}$ nachzuweisen).

UH: 29. April 1893 Habilitation; seit 17. Febr. 1897 nichtetatm. a. o. Prof.; seit SS 1900 Lehrauftrag für e. „4-stündige Vorlesung über darstellende Geometrie in einem Semester des Studienjahres" (aus: UAH PA 1895) mit e. Honorar von 500.- Mark; seit WS 1902/03 zusätzlicher Lehrauftrag für Höhere Mathematik.

U Breslau: Seit 17. Okt. 1904 etatm. a. o. Prof.

U Kiel: Seit 24. Okt. 1906 etatm. a. o. Prof.; 30. Jan. 1911 Ern. zum o. Prof.

Qu UAH PA 1895; RA 6508, 6616. Ergebnislose Anfragen: Bürger- und Ordnungsamt - Archiv der Meldebehörde - in Kiel; Centrum judaicum in Berlin: jüdisches Personenstandsregister (Begräbnisort). - Auskunft: Universitätsarchiv Kiel im Landesarchiv Schleswig-Holstein in Schleswig; Universitätsarchiv Leipzig; Landesarchiv in Berlin - Standesamt.
$W$ Theorie der algebraischen Funktionen von einer Variablen. Leipzig 1902. (Mitverf.) - Die Krümmung in der Variantenrechnung in: Math. Annalen 65 (1908); Theorie der Elementarteiler linearer Integralgleichungen in: ebd. 69 (1910); Flächen, die ein Kurvenbündel unter festem Winkel schneiden in: ebd. 72 (1912).

L Arnim 2 (1950) S. 13; Professoren Kiel (1956) S. 158; Math. Institute in Deutschland (1989) S. 285 (Register); Jansen (1992a) S. 167 (Register); Kern (1992) S. 100-103 u. ö.; WBIS. • Jüdische Mathematiker in der deutschsprachigen akademischen Kultur. Hrsg. von Birgit Bergmann, Moritz Epple. Berlin 2009. S. 234 (Register). - Homo Heidelbergensis mathematicus online; Deutsche Biographie, s. https://www.deutsche-biographie.de/gnd11 6690275.html [07.11. 2017].

$P$ Bildarchiv UAH; graph. Slg. UBH.

\section{Lange, Wilhelm}

1851-188o Med. Fak.

Geburtshilfe

* o8. Febr. 1813 Wilhelmshöhe (Böhmen; heute: Jizerka, Ortsteil von Kořenov, Tschechien)

$\dagger \quad$ 25. Febr. 1881 Heidelberg kath.

V Simon L., Revierförster

M Maria Anna geb. N.N.

œ Amalie geb. Platt ( $\dagger$ nach 1881)

$\mathrm{K} \quad 1 \mathrm{~S}, 1 \mathrm{~T}$

Lb U Prag: Seit WS 1831/32 Studium; 7. Nov. 1839 Approbation; 1839 Dr. med.; seit 27. Juli 1840 Hilfsassistent am Lehrstuhl für Geburtshilfe; seit 21. Aug. 1841 Praktikant am Allg. Krankenhaus in Prag; seit 23. Juni 1842 Assistent am Lehrstuhl für Geburtshilfe; 9. Okt. 1845 Habilitation für Frauenkrankheiten; seit 1845 Vorstand der Gynäkologischen Klinik.

U Innsbruck: Seit 23. April 1847 a. o. Prof.

U Prag: Seit 25. Okt. 1850 a. o. Prof. 
UH: Seit 20. Sept. 1851 o. Prof. und Direktor der Geburtshilflichen Klinik (vorher: Obstetrizische Klinik bzw. Entbindungsanstalt) als Nachf. von Franz Carl Naegelé; 1851, 1854, 1855 Rufe an U Prag abgelehnt; 30. Sept. 1880 Ruhestand. - In dieser Zeit:

1851-1880 Oberheb(e)arzt für den Unterrheinkreis als Nachf. von Franz Joseph [!] Naegelé.

1858 Prorektor der UH; 1855, 1859, 1864/65, 1870/71, 1880 Dekan der Med. Fak. der UH

1851 Hofrat; 1855 Geh. Hofrat; 1881 Geh. Rat II. Klasse

Siehe auch Franz Joseph Naegelé

E 1857 Ritterkreuz I. Klasse, 1865 Kommandeurkreuz, 1871 Kommandeurkreuz II. Klasse mit Eichenlaub des Ordens vom Zähringer Löwen.

Qu UAH PA 1904. - GLA Abt. 205, Fasz. 352354. Briefe: UBH.

W Lehrbuch der Geburtshülfe für Hebammen. Prag 1851. 5. Aufl. 1880. - Lehrbuch der Geburtshülfe, mit Berücksichtigung der gerichtsärztlichen Seite des Faches bearbeitet. Erlangen 1868.

L ADB 17 (1883) S. 653 f.; Badische Biographien 4 (1891) S. 245; Schmitt (1978) S. 73 f. u. ö.; Buttron (1981) S. 47-63; Chronik Ärzte H (1985) S. 134; WBIS; Zander (1991) S. 57 f. • Huber, Heinz: Geschichte der Medizinischen Fakultät Innsbruck und der medizinisch-chirurgischen Studienanstalt (1673-1938). Bearb. von Verena Plankl. Wien 2010. S. 129 f. u. ̈.

$P$ Bildarchiv UAH; graph. Slg. UBH.
Langsdorf(f), Carl Christian (seit 1804 (in Rußland geadelt): von Langsdorf(f))

1806-1834 Phil. Fak.

Mathematik, Technologie, Wasser-, Straßen- und Brückenbau

* 18. Mai 1757 Nauheim (heute: Bad N.)

$\dagger$ 10. Juni 1834 Heidelberg ev.-luth.

V Georg Melchior L. (1713-1767) Salinen-Rentmeister, s. Hessische Biografie http://www.la gis-hessen.de/pnd/1097291804 (Stand: 19. April 2017)

M Maria Margarethe geb. Koch verw. Möller (1716-1788), s. ebd.

๑ Dez. 1781 Christine Elisabeth Louise geb. Langsdorff (Kusine) (1761-1818) T des Archivrats Carl Wilhelm L.

( April 1818 Elisabetha Magdalena geb. Meyer verw. Glen(c)k (1754-1822)

( 4. Sept. 1822 Louisa Friedericia geb. von Wogau verw. Eschenmayer (1777-1832) Witwe von: (siehe) Heinrich Eschenmayer

(20. Juni 1832 Elisabeth Henriette geb. Schweickart/Schweickhard (1788-1858)

K 4 T: u.a. Eleonora Johannette Caroline von L. (1790-1828) Ehefrau von: (siehe) Ludwig Wallrad Medicus. 8 S: u. a. Gustav Wilhelm L. (1803-1847) Prof. für Mathematik, Physik an Polytechnischer Schule in St. Petersburg

Vw Bruder: Johann Wilhelm L. (1745-1827), u.a. 1775-1792 Kammer-Rat in Darmstadt mit Referat in Salzwerksangelegenheiten (Frühjahr 1777-1787 Bauleiter der Saline in Salzhausen (heute: Bad S., Stadtteil von Nidda)) und Fächern der Jurisprudenz und Mathematik, 1792-1803 Salinen-Direktor in Salzhausen, seit 1803 Geh. Kammer-Rat, seit 1808 Geh. Rat und Vize-Direktor, 1813-1820 (Ruhestand) zweiter Direktor des Hofkammerkollegs in Gießen, s. WBIS. - Urenkel: Eduard Study (1862-1930), u. a. seit 1894 a. o. Prof. Bonn, seit 1897 o. Prof. Greifswald, 1904-1927 (Emeritierung) o. Prof. für Mathematik Bonn, s. Hartwich, Yvonne: E.S. ... Ein mathematischer Mephistopheles im geometrischen Gärtchen. Diss. Mainz 2005. 
Lb Seit WS 1774/75 Studium der Rechtswiss., Mathematik, Philosophie an U Göttingen, seit WS 1776/77 Gießen.

Salzhausen: Ostern 1777-1781 zunächst Praktikant, anschl. besoldeter Mitarbeiter am Salinen-Ausbau unter der Leitung seines Bruders Johann Wilhelm.

U Erfurt: Anfang 1781 Dr. phil.

U Gießen: SS 1781 Privat-Lehrer (= Privat-Dozent) für Mathematik.

Mülheim (Ruhr): Seit Okt. 1781 Landrichter und Rentmeister.

Gerabronn (bei Crailsheim): Seit April 1784 Rat und Salineninspektor; Frühjahr 1795 Salzwerk-Inspektionsreise im Auftrag der Dänisch-Norwegischen Regierung nach Norwegen, Dänemark und Schweden.

U Erlangen: Seit 30. Aug. 1796 o. Prof. für Maschinenlehre und Technolog. Wiss., seit 1799 auch Mathematik; 1804 Ruf an UH abgelehnt.

U Wilna (Russisches Kaiserreich; heute: Vilnius, Litauen): Seit SS 1804 o. Prof. für Angewandte Mathematik.

UH: Seit 27. Mai 1806 o. Prof. in Nachf. von Johann Hermann Vossmann und als Nachf. von Ludwig Wallrad Medicus (s. Drüll (1991) S. 101f.).

1809 Prorektor der UH; 1808, 1813 Dekan der Phil. Fak. der UH

1784 Brandenburgischer Rat; 1804 Russischer Hofrat; 1806 Kurfürstl. Geh. Hofrat

E Mitglied: 1777 Hochfürstl. Hessische Gesellschaft in Homburg, Königl. Schwedische Patriotische Gesellschaft und Kurpfälz. Physikalisch-Ökonomische Gesellschaft, 1779 Churfürstlich-Mayntzische Gesellschaft oder Academie nützlicher Wissenschaften zu Erfurt, 1789 Physicalische Societät zu Lausanne, 1795 Academie der Wissenschaften zu Haarlem, 1804 Dt. Akademie der Naturforscher Leopoldina Halle/S.; Mitglied der Akademie der Wissenschaften: 1797 Göttingen, 1808 München. - Siehe auch Professoren Erlangen (2009) S. 121.

Qu UAH PA 1908; RA 4921. - GLA Abt. 235, Fasz. 652. - Briefe: UBH. - Siehe auch Archiv der Dt. Akademie der Naturforscher Leopoldina Halle/S. Auskunft: Stadtarchiv Erfurt.

$W$ Erläuterungen über die Kaestnerische Analysis des Unendlichen. Gießen 1778. - Manuskript e. Vortrags, 1780 gehalten in der Academie nützlicher Wissenschaften zu Erfurt (Signatur: ArBAA XI400, Bestell-Nr. 5/733-118 im Stadtarchiv Erfurt). Vollständige auf Theorie und Erfahrung gegründete Anleitung zur Salzwerkskunde. 5 Bde. Altenburg 1784-1796. • Lehrbuch der Hydraulik. Altenburg 1794. • Entwurf zu Vorlesungen über mehrere dem Kameralisten und Technologen wichtige Gegenstände. Altenburg 1798. - Grundlehren der Photometrie. 2 Bde. Erlangen 1803-1805. A Ausführliches System der Maschinenkunde ... 2 Bde. Heidelberg 1826-1828. • Über die Unsterblichkeit der menschlichen Seele. Ein Sendschreiben an den Herrn Prälat Hüffell in Karlsruhe. Heidelberg 1834. Siehe auch Volk (1934).

$L$ Über C. L. in: Reichlin-Meldegg, Karl Alexander Frhr. von: Das Leben eines ehemaligen römischkatholischen Priesters. Heidelberg 1874. S. 141143. ADB 17 (1883) S. 691f.; Universität Gießen 1 (1907) S. 440 (mit Werkverz.). • Langsdorff, Ludwig: Geschichte der Familie L. von 1550 bis 1850. Naumburg 1928. • Volk, Walter: K. C. von L.: sein Leben und seine Werke. Philippsburg 1934. Lessing, Hans-Erhard: Technologen an der Universität Heidelberg in: Semper apertus 2 (1985) S. 105131. Math. Institute in Deutschland (1989) S. 92, 160; WBIS; Professoren Erlangen (2009) S. $120 \mathrm{f}$; Neuhaus (2014) S. 69-72 u. ö.; Homo Heidelbergensis mathematicus online; Hessische Biografie, s. http://www.lagis-hessen.de/pnd/116728701 (Stand: 18. Mai 2017).

$P$ Bildarchiv UAH; graph. Slg. UBH. 


\section{Lask, Emil}

1905-1914 (1915) Phil. Fak.

Philosophie

* 25. Sept. 1875 Wadowice (Karpatenvorland, Kronland Königreich Galizien; heute: Polen)

X 26. Mai 1915 bei Turza-Mała (Russisches Kaiserreich; heute: Polen)

mosaisch, später ev.

V Leopold L. (1841-1905) seit 1885 (Gründer) Papier- u. Rohpappenfabrikant in Falkenberg/ Mark in Brandenburg

M Cerline geb. Kohn (1849-1921) Erzieherin, Lehrerin

$\infty$ unverheiratet

Vw Schwester: Berta L. (Pseudonym: Gerhard Wieland) (1878-1967) Dichterin, Theaterautorin, Journalistin; 1938 Emigration in die Sowjetunion, 1953 Rückkehr nach Ost-Berlin, s. NDB 13 (1982) S. 647 f.; Lexikon deutsch-jüdischer Autoren. Hrsg. vom Archiv Bibliographia Judaica ... München 2007. Bd. 15. S. 179188; Wedel, Gudrun: Autobiographien von Frauen: ein Lexikon. Köln 2010. S. 475; Wer war wer in der DDR? 5. Ausg. Bd. 1. Berlin 2010; Demm (2014) S. 7o f. (Register).

Lb Seit SS 1894 Studium zunächst der Rechtswiss., dann der Philosophie an U Freiburg/Br.; Okt. 1895Okt. 1896 Militärdienstpflicht als Einjährig-Freiwilliger; seit WS 1896/97 Forts. des Studiums an U Straßburg, 1898-1901 Freiburg/Br.; 1901 Rigorosum, 8. Juni 1902 (Datum der Promotionsurkunde) Dr. phil. an U Freiburg/Br.

1901-1905 Eigenstudien in Berlin und Falkenberg/ Mark.

UH: 19. Jan. 1905 Habilitation für Rechtsphilosophie; seit 7. Febr. 1910 nichtetatm. a. o. Prof.; seit 31. März 1913 etatm. a. o. Prof.; SS 1913-SS 1914 MitDirektor (zus. mit Wilhelm Windelband) des Phil. Seminars; seit Aug. 1914 Kriegsfreiwilliger.

Qu UAH PA 1905; RA 6432, 6859. GLA Abt. 235, Fasz. 2219. • Briefe, Nachlaß: UBH.
$W$ Fichtes Idealismus und die Geschichte. Diss. Heidelberg 1902. - Rechtsphilosophie. Heidelberg 1905. Die Logik der Philosophie und die Kategorienlehre. Tübingen 1910. - Die Lehre vom Urteil. Tübingen 1912. • E. L. Gesammelte Schriften. Hrsg. von Eugen Herrigel. 3 Bde. Tübingen 19231924. Reprint u.d. T.: Sämtliche Werke. 2 Bde. Jena 2002-2003.

L Glockner (1969) S. 274 (Register). • Höbe, Konrad: Zwischen Rickert und Heidegger. Versuch über e. Perspektive des Denkens von E.L. in: Phil. Jahrbuch 78. Jg., 2. Halbbd. (1971) S. 360376 (mit Werkverz.); Ders.: E. L.s Rechtsphilosophie in: Archiv für Rechts- und Sozialphilosophie LIX/2 (1973) S. 221-235. • Rosshoff, Hartmut: E. L. als Lehrer von Georg Lukács. Bonn 1975. • Anter, Andreas: Männer mit Eigenschaften: Max Weber, E. L. und Georg Simmel als literarische Figuren in Berta Lasks Roman „Stille und Sturm“ in: Siegreiche Niederlagen ... Hrsg. von Martin Lüdke ... Reinbek bei Hamburg 1992. S. 156-169. • Demmerling, Christoph: Logica trascendentale e ontologia fondamentale. E.L. e Martin Heidegger in: Rivista di Filosofia (1992) LXXXIII/2, S. 241-261. • Jansen (1992a) S. 167 (Register); WBIS; Heidelberg im Schnittpunkt intellektueller Kreise (1995) S. $378-$ 399. - Glatz, Uwe B.: E. L.: Philosophie im Verhältnis zu Weltanschauung, Leben und Erkenntnis. Würzburg 2001. Handbuch österreichischer Autorinnen und Autoren jüdischer Herkunft: 18. bis 20. Jhdt. Hrsg. von der Österr. Nationalbibliothek. Wien 2002. Bd. 1. S. 787 f. • Masi, Felice: E. L. Il pathos della forma. Macerata 2010. Badische Biographien N.F. VI (2011) S. 245-248. - Morrone, Giovanni: Valore e realtà. Studi intorno alla logica della storia di Windelband, Rickert e L. Soveria Mannelli 2013. Demm (2014) S. 246 (Register). • Redaelli, Roberto: E. L. Il soggetto e la forma. Macerata 2016 .

$P$ Bildarchiv UAH. 


\section{Laubenheimer, Kurt Karl Emil Gustav}

1910-1922 Med. Fak.

Hygiene, Bakteriologie

* 13. Dez. 1877 Gießen

$\dagger$ 09. Juli 1955 Frankfurt/M.

ev.

V August L. (1848-1904) seit 1873 Privat-Dozent, seit 1876 a.o. Prof. für Chemie Gießen, seit 1873 Chemiker, 1887-1903 Direktor und Vorstands-Mitglied der Farbwerke Hoechst, s. Flemming, Hans Walter: Einführung der Serologie in Hoechst durch A.L. Frankfurt/M. 1968; WBIS, NDB 13 (1982) S. 692 f., Hessische Biografie, s. http://www.lagis-hessen.de/pnd/ 116865768 (Stand: 9. Juli 2017)

M Maria Henriette Johanna Emilie geb. Koch (1849-1926)

$\infty$ 1. Sept. 1906 Norina geb. von Kilian $\left({ }^{*} 1883\right)$

$\mathrm{K} \quad 1 \mathrm{~S}, 1 \mathrm{~T}$

Vw Tante: Auguste Caroline Emilie geb. Koch (1853/57-1931) Ehefrau von Dr. phil. Dr. oec. publ. Wilhelm Stieda (1852-1933) seit 1876 Privat-Dozent Straßburg, seit 1878 a. o. Prof., seit 1879 o. Prof. für Nationalökonomie und Statistik Dorpat, seit 1882 Reg.-Rat am Statistischen Amt des Deutschen Reichs Berlin, seit 1884 o. Prof. für Staatswiss. Rostock, 1898-1923 (Emeritierung) o. Prof. für Nationalökonomie Leipzig, s. Bräuer, Karl: W. S. ein deutsches Gelehrtenleben. Altenburg 1933; Von den Anfängen bis zum 19. Jahrhundert. Bibliothek W.S., Carl Mennioke ... Frankfurt/M. 1961; Biographisches Lexikon zur Geschichte der deutschen Sozialpolitik. Bd. 1: Sozialpolitiker im Deutschen Kaiserreich: 1871-1918. Kassel 2010. S. 157; WBIS, Grewolls (2011). - Briefe, Nachlaß in UB Leipzig.

Vw Schwester: Auguste L. $\left({ }^{*} 1874\right)$ Ehefrau von Hans Koeppe (1867-1939) seit 1894 niedergelassener praktischer Arzt, seit 1898 Privat-Dozent für Kinderheilkunde, 1907-1933 (Emeritierung) o. Prof. für Kinderheilkunde und 1912-1933 Direktor der U-Kinderklinik Gießen; 1899 Begründer der ersten privaten Kinder-Poliklinik in Gießen, s. WBIS; H.K. in: Enke, Ulrike, Oehler-Klein, Sigrid: Professoren - Patienten - Studenten: die medizinische
Fakultät der Universität Gießen seit 1607. Ausstellungsband des Fachbereichs Medizin ... Gießen 2007. S. 146; Klein, Dagmar: Engagierter Kinderarzt ist nicht vergessen. H.K. war der Gründer der Kinderheilkunde in Gießen in: Uniforum. Zeitung der Justus-Liebig-Universität Gießen. Nr. 1/26 (Febr. 2015) S. 10.

Lb Seit SS 1898 Studium an UH, seit SS 1900 Gießen; 13. Dez. 1902 Approbation in Gießen.

U Gießen: Seit Jan. 1903 Volontär am Hygien. Inst.; 10. Mai 1903 Dr. med.

U Straßburg: Seit Juli 1903 Assistent an Med. Klinik.

Frankfurt/M.: Seit Okt. 1904 Assistent an Chirurg. Abt. des Städtischen Krankenhauses; seit Jan. 1906 Volontär am Patholog. Inst.

U Gießen: Juli 1906-März 1910 Assistent am Hygien. Inst.; 2. Mai 1909 Habilitation.

UH: Seit April 1910 Assistent am Hygien. Inst.; 29. April 1910 Umhabilitation; seit 5. Mai 1915 nichtetatm., 1920-1922 nichtplanm. a. o. Prof. In dieser Zeit:

1914-1918 Kriegsdienst.

Frankfurt/M.: 1922-1943 Planm. Mitglied und Leiter der Serolog. Abt. des Staatl. Inst. für Experimentelle Therapie (heute: Paul-Ehrlich-Inst.).

Qu UAH PA 1046, 4761; RA 6212, 6794, 6902. • GLA Abt. 235, Fasz. 2220.

W Phenol und seine Derivate als Desinfektionsmittel. Berlin 1909. - Fortschritte in der Desinfektion in: Therapeutische Monatshefte 28 (1914). • Wohnungsdesinfektion bei Tuberkulose in: Zs. für Hygiene und Infektionskrankheiten 77 (1914). • Allgemeine Bakteriologie und Sterilisationslehre. Jena 1915. Lehrbuch der Mikrophotographie und Mikroprojektion. Berlin 1920. 2. Aufl. 1931. 
L Kürschner (1950) Sp. 1172; Fischer $2\left({ }^{3} 1962\right)$ S. 870; Deutsche Biographie, s. https://www.deutsche-bio graphie.de/gnd117606278.html [07.11. 2017].

$P$ Bildarchiv UAH.

\section{Laur, Eugen}

1869-1885 Phil. Fak.

Französische Literatur

* 11. Febr. 1825 Breslau (heute: Wrocław, Polen)

$\dagger \quad$ nach Juni 1885 Heidelberg (?) christlich (kath.?)

V N.N. († vor 1845) Rentier

M N.N.

( vor 1873 N. N., Stiefschwester von Sophie geb. Kappel (1848-1938) aus Charkiw (Ukraine); Briefe in UBH; Ehefrau von: (siehe) Leo Koenigsberger; siehe hierzu Koenigsberger, Leo: Mein Leben. Heidelberg 1919. S. 131.

$\mathrm{K}$ unbekannt.

$L b$ Breslau: Ostern 1844 Maturitätsprüfung am Gymnasium zu St. Maria Magdalena zu Breslau; seit 1844 Studium an U.

UH: 28. April 1845 Immatrikulation zum Studium der Rechtswiss.; 10. Aug. 1845 Promotion zum Dr. phil., s. UAH H-IV-102/41 fol. 134r.

U Greifswald: Okt. 1851 Promotion zum Dr. iur. utr.

Seit ca. 1867 Aufenthalt in Paris; anschl. Journalist für norddeutsche Zeitungen.

UH: 14. Mai 1869 Habilitation für Französische Literatur, s. UAH H-IV-102/70 fol. 27or-281r; 21. April 1869 als Dr. phil. et utr. iur. genannt (in: UAH PA 1913); 5. März 1873 „als Hilfsarbeiter (am Seminar für neuere Sprachen) (ist) beizuziehen für das Französische der Privatdocent ... Laur" (aus: Brief des Ministeriums des Innern vom 5. März 1873 in: UAH RA 6418); 23. Dez. 1875 Ern. zum a. o. Prof.; Juni 1885 auf eigenen Antrag Weggang aus Krankheitsgründen („Lungencatarh“ aus: PA 1913).
Mitglied der Heidelberger Freimaurerloge Ruprecht zu den 5 Rosen (1873-1879 und 1880-1884 Meister vom Stuhl der Loge).

$W$ Eine Heirath „ad interim“. Novelle. Straßburg 1860. - Zwei Gräber. Novelle. Straßburg 1860. • Wie werden Moden gemacht? in: Die Gartenlaube (1867) H. 50, S. 794-796. - Louize Labé. Zur Geschichte der französischen Litteratur des XVI. Jahrhunderts. Straßburg 1873.

Qu UAH PA 1913; RA 6418; Fak.-Akten H-IV-102/ 41 fol. 134r, H-IV-102/70 fol. 266r-281r. - Adreßbuch der Stadt H 1870-1885 - online; Adreßbuch der UH - online. • Toepke V (1904) S. 758.

L Lehmann (1967) S. 222; Wikipedia; Kalkhoff (2010) S. 34 u. ö.

$P$ Bildersammlung UAH.

\section{Lauterborn, Robert}

1898-1918 Nat.-Math. Fak.

Zoologie

* 23. Okt. 1869 Ludwigshafen

$\dagger$ 11. Sept. 1952 Freiburg/Br.

ev.

V August L. (1840-1912) seit 1865 Lithograph, später Hofbuchdrucker, Buchhändler und Begründer der ersten Ludwigshafener Lokalzeitung; in 2. Ehe verh. mit Pauline geb. Gelbert $(\dagger 1911)$ Schwester von Elisabetha (Elise) Carolina geb. G., s. 50 Jahre Rheinforschung ... (2009) S. 15 f., 111 (Eintrag unter Qu)

M Elisabetha (Elise) Carolina geb. Gelbert (18431871)

$\infty$ unverheiratet.

Lb UH: Seit WS 1889/9o Studium der Naturwiss., vor allem Zoologie und Botanik; seit 1890 Praktikant am Zoolog. Inst.; 21. Juni 1897 Dr. phil. nat.; 30. Juli 1898 Habilitation; seit 14. Febr. 1903 nichtetatm. a. o. Prof. am Zoolog. Inst.; Reisen u. a.: Aug. 1907 Norwegen und Spitzbergen, März-April 1908 
Kanarische Inseln, März-April 1910 Algerien und Nordrand der Sahara; Aug. 1914-Aug. 1917 (Räumung des Lazaretts während des Krieges) mikroskopische und bakteriolog. Untersuchungen im Lazarett des Roten Kreuzes in Ludwigshafen; Frühjahr 1917 Ruf an U München abgelehnt.

TH Karlsruhe: Seit 11. Juni 1918 o. Prof. für Forstzoologie; WS 1918/19 Beginn seiner Vorlesungen; 1920 Verlegung der forstwiss. Ausbildung von Karlsruhe nach Freiburg/Br.

U Freiburg/Br.: Seit 19. Febr. 1920 (Versetzung) o. Prof.; Sept.-Okt. 1929 Italienreise; 30. Sept. 1935 Ruhestand.

1908-1945 Bayer. Staatsministerium des Innern setzt L. als "Aufsichtsorgan für die Reinhaltung der Gewässer" für die Pfalz ein

E 1937 Mitglied der Dt. Akademie der Naturforscher Leopoldina Halle/S.; 1952 Ehrenmitglied der Dt. Zoologischen Gesellschaft. - Dr. phil. nat. h.c.: 1948 Freiburg/Br., 1950 Basel. • 1948 Einar-Naumann-Plakette.

Qu UAH PA 1911; RA 6901. GLA Abt. 235, Fasz. 2221. Nachlaß: Universitätsbibliothek Freiburg/ Br. - Siehe auch Archiv der Dt. Akademie der Naturforscher Leopoldina Halle/S. - Auskunft: Stadtarchiv Ludwigshafen (Sterbebuch von 1871 für Mutter Elisabetha (Elise)). 50 Jahre Rheinforschung. Lebensgang und Schaffen eines deutschen Naturforschers - R.L. Hrsg.: RegioWasser e. V. Freiburg/Br. 2009. (Autobiogr.)

$W$ Die Verunreinigung der Gewässer und die biologischen Methoden ihrer Untersuchung. Ludwigshafen 1908. 2. Aufl. 1915. Die biologische Selbstreinigung unserer Gewässer in: Verh. des naturhistorischen Vereins der preußischen Rheinlande und Westfalens 68 (1911). G Gastrotricha, Rotatoria, Süßwasserfauna in: Handwörterbuch der Naturwissenschaft. Bde. 4, 8, 9 (1913). Der Rhein: Naturgeschichte eines deutschen Stromes ... 3 T. Freiburg/Br. und Ludwigshafen 1930-1938. - Bibliographie 1893-1951 in: 50 Jahre Rheinforschung (2009) S. 752-758.
HG Das Vogel-, Fisch- und Thierbuch des Straßburger Fischers Leonhard Baldner aus dem Jahre 1666. Ludwigshafen 1903.

L Willer, Wilfried: R.L. zum Gedächtnis in: Ruperto Carola 25. Jg., H. 52 (Dez. 1973) S. 95-101. • NDB 13 (1982) S. 738-740 (mit Werkverz.; S. 738: Angaben von Vornamen und Lebensdaten der Mutter unrichtig); WBIS. - Lange, Jörg: R.L. ... Ein Leben am Rhein. An Hand seiner unveröffentlichten Lebenserinnerungen wird ein Abriß des Lebens und des wissenschaftlichen Wirkens von R. L. gegeben in: Lauterbornia - Int. Zs. für Faunistik und Floristik des Süßwassers. Dinkelscherben 1990. H. 5, S. 1-25. • Lange, Jörg: R. L. - Ein Leben am Rhein in: Darwin \& Co. Eine Geschichte der Biologie in Porträts. Hrsg. von Ilse Jahn und Michael Schmitt. München 2001. Bd. 2. S. 180197. - Willer, Wilfried: R. L. in: Pfälzer Lebensbilder. Speyer 2001. Bd. 6. S. 261-280.

$P$ Bildarchiv UAH; NDB.

\section{Leber, Theodor Karl Gustav}

1890-1910 Med. Fak.

Augenheilkunde

* 29. Febr. 1840 Karlsruhe

$\dagger \quad$ 07. April 1917 Heidelberg ev.

V Johann Adam L. (1806-1884), u.a. seit 1844 Prof. am Lyceum in $\mathrm{H}$ (heute: Kurfürst-Friedrich-Gymnasium „KFG“), s. Reichle (1973) S. 5-9

M Apollonia geb. Wüstenfeld (1814-1843) Schwester von Luise W. (1821-1874) Ehefrau von: (siehe) Philipp Jolly

( 22. Aug. 1872 Alide geb. Wüstenfeld (18401880) Kusine

(26. Mai 1882 Ottilie (Olli) geb. Mejer (18491916) T von Otto M. (1818-1893) Prof. für Staats- und Kirchenrecht, u.a. seit 1851 Rostock, 1874-1883 Göttingen, s. NDB 16 (1990) S. 737, BBKL V (1993) Sp. 1178 f., Catalogus prof. Rostochiensium online

$\mathrm{K}$ keine 
Vw Onkel: (siehe) Philipp Jolly. - Neffe: Alfred Theodor Leber (1881-1954) Augen- und Tropenmediziner, s. Schmieg, Rainald: A.L., Begründer der dt. Tropenophtalmologie. Diss. Düsseldorf 1992; Grüntzig, Johannes W., Mehlhorn, Heinz: A. Th. L.: A pioneer in tropical ophthalmology. Missing in the South Seas - rediscovered in India in: Klinische Monatsblätter für Augenheilkunde 201 (Okt. 1992) S. 254-262; Dies.: Expeditionen ins Reich der Seuchen. Medizinische Himmelfahrtskommandos der dt. Kaiser- und Kolonialzeit. München 2005.

Lb Seit WS 1857/58 Studium an UH; 13. Okt. 1859 med. Vorexamen in Karlsruhe; 16. April 1862 Staatsprüfung ebd.

H: Frühjahr 1862-Frühjahr 1863 Assistent an der von (siehe) Hermann Knapp neugegründeten privaten Klinik für Augenkranke/Augen(kranken) klinik/Augenheilanstalt; 18. Juli 1862 Dr. med. an $\mathrm{UH}$.

Wien: Seit Frühjahr 1863 Assistent am Physiolog. Inst. der Med.-Chirurg. Militärakademie (Josephinum).

Paris: Seit 1. Nov. 1864 Assistent in e. Augenpraxis.

U Berlin: Seit Frühjahr 1867 Assistent an Augenärztl. Abt. der Charité; 29. Juli 1869 Habilitation.

U Göttingen: Seit 28. April 1871 a. o. Prof. mit e. Jahresbesoldung von 500.- Talern; 1873 Rufe an U Erlangen und Würzburg abgelehnt; 7. Juli 1873 Ern. zum o. Prof. und Direktor der Augenklinik mit e. Jahresgehalt von 1200.- Talern; 1878 Ruf an U Würzburg abgelehnt; seit 1. Jan. 1879 jährl. Gehaltserhöhung von 300.- Talern; 189o Ruf an U Leipzig abgelehnt.

UH: 12. April 1890 Ern. zum WS 189o/91 o. Prof. und Direktor der U-Augenklinik als Nachf. von Otto Becker; 1. Okt. 1910 auf eigenen Antrag Versetzung in Ruhestand.
1898/99 Dekan der Med. Fak. der UH

1887 Königl. Preußischer Geh. Medizinalrat; 1890 Geh. Rat II. Klasse

E 1888 Mitglied der Dt. Akademie der Naturforscher Leopoldina Halle/S.; 1909 Mitglied der Akademie der Wissenschaften H; 1917 o. Mitglied der Königl. Societät der Wiss. in Upsala. • 1896 Graefe-Medaille. 1881 Königl. Preußischer Roter Adler-Orden IV. Klasse; 1892 Ritterkreuz I. Klasse mit Eichenlaub, 1896 Kommandeurkreuz II. Klasse, 1903 Kommandeurkreuz I. Klasse des Ordens vom Zähringer Löwen.

Qu UAH PA 1047, 1910; RA 6307, 6787. GLA Abt. 235, Fasz. 2223. Briefe: UBH. $\bullet$ Nachlaß in Privatbesitz. - Siehe auch Archiv der Dt. Akademie der Naturforscher Leopoldina Halle/S.

$W$ Über Retinitis pigmentosa und angeborene Amaurose in: Graefes Archiv für Ophthalmologie 15 (1869) S. 1-25. - Die Zirkulations- und Ernährungsverhältnisse des Auges in: Handbuch der gesammten Augenheilkunde. Hrsg. von Alfred Graefe und Theodor Saemisch. Leipzig 1876. 2. neubearb. Aufl. Leipzig 1903. - L., T., Wagenmann, August: Infantile Necrose der Bindehaut mit letalem Ausgang durch allgemeine multiple Streptocokken-Invasion des Gefässystems in: Albrecht von Graefes Archiv für Ophthalmologie 34 (1888) Nr. 4, S. 250-271. • Die Entstehung der Entzündung und die Wirkung der entzündung-erregenden Schädlichkeiten ... Leipzig 1891. • Die Gründung der Heidelberger Universitäts-Augenklinik und ihre ersten Direktoren. Heidelberg 1903. Neue Untersuchungen über den Flüssigkeitswechsel des Auges in: Albrecht von Graefes Archiv für Ophthalmologie 64 (1906) S. 1-127. • Die Krankheiten der Netzhaut. 2 Bde. 2. Aufl. Berlin 1915-1916. - Bibliographien in: Reichle (1973) S. 67-70, Stahl (2016) S. 198-213.

MHG 1871-1917 Albrecht von Graefes Archiv für Ophthalmologie. 
$L$ Catalogus prof. Gottingensium (1962) S. 76; Reichle (1973); Chronik Ärzte H (1985) S. 135; NDB 14 (1985) S. 19 f. • Jaeger, W.: T.L. und die Begründung der Experimentellen Ophthalmologie in: Semper apertus 2 (1985) S. 321-331; Ders.: The foundation of experimental ophthalmology by T.L. in: Documenta Ophthalmologica 68 (1988) S. $71 \mathrm{ff}$; Autoren der Bunsenbibliothek (2009 online). - Stahl, Dorina Maren: Die Einführung der Chemotaxis der Leukozyten in die Medizin. Eine wissenschaftshistorische Analyse der Laborprotokolle T.L.s zur Entzündungsforschung. Med. Diss. Lübeck 2016.

$P$ Bildarchiv UAH; graph. Slg. UBH; NDB; Chronik Ärzte $H$.

\section{Lederer, Emil Hans}

1912-1931 Phil. Fak.

Nationalökonomie, Finanzwissenschaft

* 22. Juli 1882 Pilsen (heute: Plzeň, Tschechien)

$\dagger$ 29. Mai 1939 New York

mosaisch, seit $1907 \mathrm{ev}$.

V Philipp L., Kaufmann

M Sophie geb. Schwarzkopf

( 30. Okt. $1907 \mathrm{Em}(\mathrm{m}) \mathrm{y}$ Lederer-Seidler geb. Seidler (1879-1933), s. UAH RA 6412; Briefe in UBH; Spenkuch (2016) S. 726

๑ 1936 Gertrude geb. Dannheisser gesch. von Eckardt (1895-1987), s. Briefe in UBH; Korrespondenz, s. Gilman, Sander L.: Inscribing the other. Lincoln 1991. S. 239-241 u. ö.; Hermann Broch: Briefe an Erich von Kahler (1940-1951). Hrsg. von Paul Michael Lützeler. Berlin 2010. Bis 1927 Ehefrau von: (siehe) Hans von Eckardt $\mathrm{K}$ keine.

Lb Seit WS 1901/02 Studium der Rechtswiss., Nationalökonomie an U Wien, anschl. Berlin, Wien; Anfang 1906 Dr. iur. an U Wien.

1906-1907 Advokaturskandidat am Gericht in: Wien, dann Pilsen und zuletzt Brüx (Nordböhmen; heute: Most, Tschechien); 1907-1910 Sekre- tär des Niederösterreichischen Gewerbe-Vereins in Wien; seit 1910 Redakteur des Weber-Sombartschen Archivs für Sozialwissenschaft und Sozialpolitik, gedruckt in Tübingen; 1911 Dr. rer. pol. an U München.

UH: 3. Febr. 1912 Habilitation; Lehrauftrag: WS 1914/15 Praktische Nationalökonomie, SS 1915 Allg. Volkswirtschaftslehre; seit 25. Febr. 1918 nichtetatm. a.o. Prof.; 1920 Ruf an Handelshochschule Nürnberg abgelehnt; seit 20. Aug. 1920 planm. a.o. Prof.; 26. Aug. 1922 Verleihung von Titel und Rechten e. o. Prof.; Ende 1922 Ruf an U Leipzig abgelehnt; 27. Febr. 1923 Ern. zum o. Prof. als Nachf. von Eberhard Gothein und Mit-Direktor des Volkswirtschaftl. Seminars, 1924 umbenannt in Inst. für Sozial- und Staatswissenschaften; April 1923-März 1925 Gastprof. an Staatl. U in Tokio; 1929 Ruf an U Frankfurt/M. abgelehnt. • In dieser Zeit:

Dez. 1918-März 1919, erneut 1920-1921 Mitglied der Kommission zur Vorbereitung der Sozialisierung der Industrie (= Sozialisierungskommission) in Berlin; März 1919-März 1920 Mitglied und Direktor der volkswirtschaftl. Abt. in der österr. Staatskommission für Sozialisierung in Wien.

U Berlin: 10. Sept. 1931 Ern. zum o. Prof. durch ministeriellen Erlaß ohne Zustimmung und gegen den Willen der Fak.; 14. April 1933 Lehrbefugnis aus rassischen Gründen entzogen (Gesetz zur „Wiederherstellung des Berufsbeamtentums“); 1933 Emigration zunächst nach Japan, anschl. in die USA.

New York City: 1933 (Mitbegründer)-1939 Prof. an "University in Exile“ in der New School for Social Research, später Graduate Faculty of Political and Social Science.

Qu UAH PA 498, 4780; RA 6573, 6867. • GLA Abt. 235, Fasz. 2224. • Briefe: UBH.

$W$ Die Privatangestellten in der modernen Wirtschaftsentwicklung. Tübingen 1912. - Die sozialen Organisationen. Leipzig 1912. 2. Aufl. 1921. • Deutschlands Wiederaufbau und weltwirtschaftliche Neueingliederung durch Sozialisierung. Tü- 
bingen 1920. - Grundzüge der ökonomischen Theorie. Tübingen 1922. 3. Aufl. u. d. T.: Aufriß der ökonomischen Theorie. Tübingen 1931. Der neue Mittelstand in: Grundriß der Sozialökonomik. 9. Abt. 1. T. Tübingen 1926. S. 120-141. (Mitverf.) - L., E., Lederer-Seidler, Emy: Japan - Europa. Wandlungen im Fernen Osten. Frankfurt/M. 1929. - Technischer Fortschritt und Arbeitslosigkeit. Tübingen 1931. 2. Aufl. Genf 1938. Nachdr. Frankfurt/M. 1981. - Wirkungen des Lohnabbaus. Tübingen 1931. - The State of the masses. New York 1940. 2. Aufl. 1967. (Übers.: Der Massenstaat. Gefahren der klassenlosen Gesellschaft. Hrsg. ... von Claus-Dieter Krohn. Graz 1995.) - Kapitalismus, Klassenstruktur und Probleme der Demokratie in Deutschland 1910-1940. Ausgewählte Aufsätze ... Hrsg. von Jürgen Kocka ... Göttingen 1979. • Schriften zur Wissenschaftslehre und Kultursoziologie. Texte von E. L. hrsg. ... von Peter Gostmann und Alexandra Ivanova. Wiesbaden 2014.

L Handels-Hochschule Mannheim 1907-1932 (1932) S. 26; WBIS; Dictionary of Emigrés 2 (1983) S. 699 f.; NDB 14 (1985) S. 39 f. - Krohn, ClausDieter: Wissenschaft im Exil: deutsche Sozialund Wirtschaftswissenschaftler in den USA und die New School for Social Research. Frankfurt/M. 1987. Rutkoff, Peter M., Scott, William B.: Die Schaffung der „Universität im Exil“ in: Exil, Wissenschaft, Identität. Die Emigration deutscher Sozialwissenschaftler 1933-1945. Hrsg. von Ilja Srubar. Frankfurt/M. 1988. - Klingemann, Carsten: Das „Institut für Sozial- und Staatswissenschaften“ an der Universität Heidelberg zum Ende der Weimarer Republik und während des Nationalsozialismus in: Jahrbuch für Soziologiegeschichte 1990. Hrsg. von Heinz-Jürgen Dahme ... Opladen 1990. S. 79-120. - Jansen (1992) S. 411 (Register); Ders. (1992a) S. 167 (Register); Heidelberg im Schnittpunkt intellektueller Kreise (1995) S. 422-444; Brintzinger (1996) S. 398 (Register). Esslinger, Hans Ulrich: Interdisziplinarität. Zu E.L.s Wissenschaftsverständnis am Institut für Sozial- und Staatswissenschaften in: Heidelberger Sozial- und Staatswissenschaften (1997) S. 117-158. Behrend, Manfred: „Der Wandschirm, hinter dem nichts geschieht“. Bildung, Tätigkeit und Ende der ersten deutschen Sozialisierungskommission in: Beiträge zur Geschichte der Arbeiterbewegung H. 4, 40 Jg. (1998) S. 18-35. - Janssen, Hauke: Nationalökonomie und Nationalsozialismus ... Marburg 1998. S. 552 f. Z Zehl Romero, Christiane: Anna Seghers. Eine Biographie. 1900-1947. Berlin 2000. S. $126-$ 128. Hülsmann, Jörg Guido: Mises. The Last Knight of Liberalism. Auburn (Alabama) 2007. S. 1091 (Register). - Härpfer, Claudius: Humanismus als Lebensform: Albert Salomons Verklärung der Realität. Wiesbaden 2009. S. 12 f., 103 f., 113 f. • Max Weber-Gesamtausgabe. Bd. I/24: Wirtschaft und Gesellschaft. Entstehungsgeschichte und Dokumente. Hrsg. von Wolfgang Schluchter. Tübingen 2009. S. 272 (Register). Köster, Roman: Die Wissenschaft der Außenseiter. Die Krise der Nationalökonomie in der Weimarer Republik. Göttingen 2011. Gostmann, P., Ivanova, A.: E. L. in: Schriften zur Wissenschaftslehre und Kultursoziologie. Texte von E. L. ... Wiesbaden 2014. S. 737. Intellektuelle in Heidelberg (2014) S. 165-169 u. ö. Hagemann, Harald: Capitalist development, innovations, business cycles and unemployment Joseph Alois Schumpeter and E.H.L. in: Journal of evolutionary economics. Berlin 2015. Vol. 25 (1), S. 117-131. Spenkuch (2016) S. 1315 (Register).

$P$ Bildarchiv UAH; NDB.

\section{Lefmann, Salomon}

1866-1901 Phil. Fak. 1901-1912 (Honorar-Prof.) Phil. Fak.

Vgl. Sprachwissenschaft, Orientalische Philologie

* 25. Dez. 1831 Telgte (Westfalen)

$\dagger$ 14. Jan. 1912 Heidelberg

mosaisch

V Salomon L. († nach 1877) Metzger, Kaufmann, s. Geschichte der Stadt Telgte. Hrsg. ... von Werner Frese. Münster 1999. S. 508.

M Sabine geb. Adelsheim

(1) 31. Dez. 1874 Zilli geb. Blach (1843-1899)

$\infty$ 28. Okt. 1907 Cilly geb. Lefmann $\left({ }^{\star} 1880\right)$ aus Telgte 
K 1 T, 2 S: u. a. Dr. med. Gotthold L. $\left({ }^{*} 1880 \dagger\right.$ nach 1965) Mediziner, Internist, 1915-1933 Chefarzt des Vincentius-Krankenhauses H; 1933-1939 private Praxis mit Belegbetten im Vincentius; 1939 Emigration nach England, 1957 als Prof. für Medizin in London genannt, s. UAH Rep. 40-289; Medizin- und Stadtgeschichte im Herzen Heidelbergs. 90 Jahre Sankt Vincentius-Krankenhaus. Ausstellung anlässlich einer ökumenischen Zeichensetzung - der Übergabe der Trägerschaft von der kath. Heilig-Geist-Gemeinde an die Ev. Stadtmission Heidelberg. Verantwortlich: Gheorghe Stanomir. Heidelberg 2005. S. 10.

$L b$ L. erhält Unterricht an jüdischer Schule in Telgte, s. hierzu Eintrag unter Z[itat]; Studium am Lehrerseminar der Marks-Haindorf-Stiftung in Münster; Aug. 1851 Elementarlehrerexamen in Soest.

1851-1859 Elementarlehrer: Coesfeld, anschl. Oberdollendorf (heute: Stadtteil von Königswinter) und Lippstadt.

1859 Externe Matura-Prüfung am Gymnasium in Paderborn; SS 1860 Studium der Philosophie an U Münster, seit WS 1860/61 H, seit WS 1861/62 Berlin; 5. März 1864 Dr. phil. an U Berlin; L. erhält ohne Glaubenswechsel keine Anstellung als Gymnasiallehrer in Berlin; daher reist er zum Studium des Sanskrit nach Paris.

UH: 28. April 1866 Habilitation für Sanskrit und Vgl. Sprachwissenschaft; WS 1866/67-WS 1911/ 12 ununterbrochene Vorlesungsankündigungen (Ausnahme: SS 1873-SS 1874 Beurlaubung für Eigenstudien); seit 5. Dez. 1870 a.o. Prof.; seit WS 1891/92 Lehrbeauftragter für Sanskrit mit Honorar; seit 7. Dez. 1901 Honorar-Prof., seit 21. Febr. 1908 o. Honorar-Prof. für Sanskrit, Altindische Kultur- und Literaturgeschichte.

Leiter e. jüdischen Wohlfahrtsvereins in Heidelberg. 1887 Präsident des Armenfürsorge-Vereins Zedaka

$Z$ Telgte beherbergt im 19. Jahrhundert die größte jüdische Gemeinde im Kreis Münster und wird 1848 bzw. 1857 Sitz der Synagogengemeinde des genannten Kreises. Anfang des 19. Jahrhunderts erfolgt der Unterricht zeitweise in e. Schullokal durch e. fest angestellten Lehrer oder aber durch jüdische Wanderlehrer (siehe http://www.jüdi sche-gemeinden.de/index.php/gemeinden/s-t/19 19-telgte-ems-nordrhein-westfalen: Aus der Geschichte der jüdischen Gemeinden im deutschen Sprachraum, hier: Telgte).

Seit 2012 ist eine Straße nach Lefmann in Telgte benannt

1911 Hofrat

Siehe auch Adolf Holtzmann

$E$ Mitglied der Böhmischen Gesellschaft für Wissenschaft in Prag. 1902 Ritterkreuz I. Klasse des Ordens vom Zähringer Löwen.

Qu UAH PA 1914; RA 5226, 5278, 6081 u. ö. GLA Abt. 235, Fasz. 2226. Briefe: UBH; s. auch Kalliope. Nachlaß, siehe Lexikon deutsch-jüdischer Autoren (2007) S. 259.

W Über deutsche Rechtschreibung. Berlin 1871. • Lalita Vistara. Erzählung von dem Leben und der Lehre der Clâkya Simha. Berlin 1874. • Geschichte des alten Indiens. Berlin 1890. 2. Aufl. 1898. • Franz Bopp, sein Leben und seine Wissenschaft. 3 Bde. Berlin 1891-1897.

$L$ Nekrolog in: Chronik der Stadt Heidelberg (1912) Jg. XX, S. 217-219. • Wir machen die betrübende Anzeige, dass ... S. L. ... gestern verschieden ist. Die Beerdigung findet am Dienstag, den 16. Januar, nachmittags $3^{1 / 2}$ Uhr von der israelitischen Friedhofkapelle [auf dem Jüdischen Friedhof Bergfriedhof, Rohrbacher Straße 115 in $\mathrm{H}$ ] aus statt. Heidelberg 1912. • Judaica und Hebraica zum Teil aus den Bibliotheken der verstorbenen Herren ... S. L. in Heidelberg und ... Georg M. Caro in Zürich. Lagerkatalog J. Baer \& Co. Frankfurt/M. 1914. Bd. 625. - Lehmann (1967) S. 218 f.; NDB 14 (1985) S. 56 f. (mit Werkverz.); WBIS. - Lexikon deutsch-jüdischer Autoren ... Redaktionelle Leitung: Renate Heuer ... Bd. 15. Berlin 2007. S. 259261. Riecke (2016) S. 22-24.

$P$ Bildarchiv UAH; graph. Slg. UBH; NDB. 


\section{Leger, Thomas (Alfr(i)ed) Anton Martin}

(1810) 1811-1855 Phil. Fak.

Landbaukunst, Archäologie und Geschichte der Architektur, Zeichnungs- und Konstruktionslehre

* 10. März 1783 Neustadt/Weinstraße

$\dagger \quad$ 17. Febr. 1855 Heidelberg kath.

V Johann Adam L. ( $†$ nach 1821) 1777-1796 (mit Unterbrechungen) Stadtschreiber in Neustadt, (vor) 1794 als Geh. Sekretär genannt

M Maria Regina geb. Blum

$\infty$ 14. Okt. 1810 Maria Franziska geb. Gerlach (1789-1843)

๑ 8. Aug. 1844 Barbara Josepha Veronica geb. Maisch (1800-1855)

$\mathrm{K} \quad 7 \mathrm{~S}, 5 \mathrm{~T}$

Lb Seit 12. Dez. 1799 Studium der Philosophie, seit 1800 Studium der Mathematik, Physik an UH.

Karlsruhe: Seit 1805 Praktikant im Bauamt; seit 1806 Sekretär und Lehrer bei Graf Christian von Oberndorff (1762-1809; s. Christian Graf von O. und seine Familie in: Fetzer, Ralf: Die Grafen von O. Edingen-Neckarhausen 2005. S. 103-107); seit 1. Juli 1809 Großherzogl. badischer Architekt.

UH: Seit 6. Dez. 1810 Privat-Lehrer (Privat-Dozent); 23. Nov. 1811 Dr. phil. und Meister in den freien Künsten (Magister artium liberalium); SS 1811-WS 1854/55 Vorlesungsankündigungen, siehe Eintrag unter $Z$ [itat]; seit 26. April 1821 a. o. Prof.

Z Im SS 1821 hält L. beispielsweise u.a. montags, dienstags, donnerstags und freitags von 10 bis 11 oder von 4 bis 5 Uhr Übungen über „Perspectivische Zeichnungslehre und ihre Anwendung für Architecten und Landschaftsmaler auf Composition und Nachbildung der Natur: Dr. Leger nach eigenen Ansichten, Entdeckungen und Portefeuilles" (aus: Anzeige der Vorlesungen, welche im Sommerhalbenjahre 1821 auf der Großherzoglich Badischen Ruprecht Karolinischen Universität zu Heidelberg gehalten werden sollen. Die Vorlesungen werden den 3osten April eröffnet ... Heidelberg 1821. S. 26).
L. ist Schüler u.a. von Friedrich Weinbrenner (1766-1826) Architekt, zuletzt Oberbau-Direktor in Karlsruhe, s. Schumann, Ulrich Maximilian: F. W.: Klassizismus und "praktische Ästhetik“. Berlin 2010.

Luzerner Galerie Fischer Auktionen AG verkauft 2011 L.s Aquarell „Blick auf das Heidelberger Schloss"von 1804.

E 1822 O. Mitglied des Großherzogl. Badischen Landwirtschaftl. Vereins; 1823 Ehrenmitglied der Gesellschaft für ältere teutsche Geschichtsquellenkunde zu Frankfurt/M.

Qu UAH PA 1915; RA 5355, 6361. GLA Abt. 205, Fasz. 356 f. - Briefe: UBH; Universitätsbibliothek Leipzig (Adressat wohl Christian Ludwig Stieglitz (1756-1836) Jurist, Bauforscher). - Auskunft: Stadtarchiv Neustadt/Weinstraße (Taufeintrag ohne Nennung des Vornamens Alfred/Alfried).

$W$ Theorie der bürgerlichen Baukunst. Freiburg/ Br. 1811. Führer durch die Ruinen des Heidelberger Schlosses. Heidelberg 1816. 3. Aufl. 1857. De architectura rei publicae utilissima oratio. Mannheim 1822. - Des Professors Dr. Thomas Alfried Leger Erklärendes Verzeichniß der Denkmäler in der Graimbergischen Alterthümer-Sammlung des Heidelberger Schlosses. Hrsg. von Carl von Graimberg. Heidelberg 1838. - Führer für Fremde durch die Ruinen des Heidelberger Schlosses. Heidelberg 1849. 5. Aufl. hrsg. von Carl von Graimberg. Heidelberg 1860 .

$L$ Wechmar (1846) S. 252; WBIS. - Klein, Michael: Die Handschriften 65/1-1200 im Generallandesarchiv Karlsruhe. Wiesbaden 1987. S. 147 u. ö. • Fetzer, Ralf: Die Grafen von Oberndorff. EdingenNeckarhausen 2005. S. 103 u. ö. • Deutsche Biographie, s. https://www.deutsche-biographie.de/gnd11 6860669.html [07.11.2017].

P Bildarchiv UAH; graph. Slg. UBH. 
Lemcke, Carl Heinrich Gottlieb (seit 1896 persönlicher Adel: von Lemcke) (Pseudonym: Manno, auch Manus, Karl)

1862-1871 (1872) Phil. Fak.

Ästhetik, Literatur- und Kunstgeschichte

* 26. Aug. 1831 Schwerin

$\dagger \quad$ 07. April 1913 München

口 Kochel am See

kath. (?)

V Christian Ludwig L., Zimmermann

M Luise Sophie Marie geb. Henckhuss

@ 1862 Emilie geb. von Dessauer (1827-1905) T von Georg (1837: von) D. (1795-1870) Hofrat und Rechtsanwalt (siehe Madei (2009) S. 30 Anm. 42) Besitzer des Schlosses Aspenstein in Kochel am See, e. Künstler-Sommerquartier; u. a. ist Moritz von Schwind (1804-1871) hier Gast: 1858 entsteht das Ölgemälde „Morgenstunde" (heute: München, Schack-Galerie), das Emilie als junge Frau am Fenster in ihrem Zimmer im Schloß zeigt, s. Madei, Peter: "Fensterplatz" online unter http://linkszeit. de/wp-content/uploads/2012/o7/FENSTER $\mathrm{K}$ keine. PLATZ.pdf (2009) S. 30 f. (Ausdruck im UAH)

Lb 17. April 1852-16. Sept. 1854 Studium an U Göttingen, anschl. München (laut Toepke 6 (1907) keine Immatrikulation an UH); 12. Juli 1856 Dr. phil. an UH; nach 1856 Studienreisen durch Frankreich und Großbritannien; vor 1862 Eigenstudien in Berlin und München.

UH: 28. Nov. 1862 Habilitation; 16. Dez. 1862 Verleihung der venia legendi; seit 5. Aug. 1867 a.o. Prof.; WS 1869/70 Beurlaubung; Okt. 1871 genehmigter Antrag auf Beurlaubung für ein Jahr; 11. Jan. 1872 Entlassung auf eigenen Antrag, siehe hierzu Eintrag unter $Z$ [itat].

München: Seit Okt. 1871 Eigenstudien; seit 1872 Privat-Dozent für Neuere dt. Literaturgeschichte an $\mathrm{U}$.
Reichs-Akademie für Bildende Künste Amsterdam (Niederlande): Seit 1873 o. Prof. für Ästhetik und Kunstgeschichte.

Polytechnikum Aachen: Seit WS 1876/77 o. Prof.

Stuttgart: Frühjahr 1885-1903 o. Prof. für Kunstgeschichte am Königl. Polytechnikum und an Kunstschule sowie 1897-1903 Direktor der Königl. Gemäldegalerie.

München: 1903 Wohnsitzwechsel auf Wunsch seiner bereits schwerkranken Frau.

$Z$ Bernhard Stark, Dekan der Phil. Fak., schreibt am 16. Dez. 1871 anläßlich des Abschiedsgesuchs von L. an den Engeren Senat der UH: „... wir sprechen dabei das Bedauern der Fakultät über den Verlust einer tüchtigen regsamen Kraft für unsere Hochschule aus, deren Werth dieselbe erst kürzlich ... unter dem 8. Juli [durch die an das] großherz(ogliche) Ministerium des Innern gerichteten Anträge auf eine Gehaltsertheilung ausdrücklich anerkannt hat" (aus: UAH PA 1918).

1856 Mitbegründer des Münchner Dichterkreises „Die Krokodile“ (L.s Vereinsname: Hyäne), s. Die Krokodile. Ein Münchner Dichterkreis. Hrsg. von Johannes Mahr. Stuttgart 1987.

E 1885 Dr. phil. h.c. Padua. 1903 Komturkreuz II. Klasse des Friedrichsordens.

Qu UAH PA 1918. Auskunft: Universitätsarchive Stuttgart und Göttingen.

W Populäre Ästhetik. Leipzig 1865. 6. Aufl. u. d. T.: Ästhetik in gemeinverständlichen Vorträgen. 2 Bde. Leipzig 1890. Geschichte der deutschen Dichtung neuerer Zeit: Von Opitz bis Klopstock. Leipzig 1871. Neuausg. u. d. T.: Von Opitz bis Klopstock. Leipzig 1882. Manno, Karl: Beowulf. Roman. Berlin 1882. 3. Aufl. 1899. Ein süßer Knabe. Berlin 1884. 2. Aufl. 1886.

$L$ Jahresbericht des Königl. Polytechnikums zu Stuttgart für das Studienjahr 1884/85 (1885) S. 12. • Bericht der Königl. Technischen Hochschule in Stuttgart für das Studienjahr 1902/03 (1903) S. 19. 
Biogr. Jahrbuch 18 (1913) S. 177 f., Sp. 105. - Lemcke, Carl in: Heess, Wilhelm: Geschichtliche Bibliographie von Mecklenburg. Rostock 1944. Bd. 2. S. 1348. - Lehmann (1967) S. 218; WBIS; Riecke (2016) S. 22 f., 124; Deutsche Biographie, s. https:// www.deutsche-biographie.de/gnd116891211.html [07. 11. 2017].

$P$ Bildarchiv UAH.

\section{Lemme, Friedrich Wilhelm Christoph Ludwig}

1891-1919 Theol. Fak.

1919-1927 (Honorar-Prof.) Theol. Fak.

Systematische Theologie (Dogmengeschichte)

* o8. Aug. 1847 Salzwedel (Altmark)

$\dagger \quad$ 26. Okt. 1927 Heidelberg

ev.

V Heinrich L., Tischlermeister

M Marie Elise Helene geb. Schmidt

(O) 22. Mai 1877 Marie geb. Kulicke (1854-1926)

$\mathrm{K} \quad 1 \mathrm{~S}, 2 \mathrm{~T}$

Lb Berlin: Seit SS 1866 Studium der Theologie, auch Philosophie an U; April 1872 II. theol. Examen; 1872 kurzzeitig Alumnus des Domkandidatenstifts.

U Göttingen: Okt. 1872 Repetentenprüfung; seit Okt. 1872 Repetent am Theol. Seminar; 9. März 1874 theol. Lizentiatenprüfung.

Berlin: Seit Okt. 1874 Inspector adjunctus am Domkandidatenstift und Domhilfsprediger.

Breslau: April 1876-Sept. 1884 Inspektor des Studentenkonvikts Johanneum. • In dieser Zeit:

U Breslau: April 1876 Habilitation; seit Okt. 1881 a. o. Prof.

U Bonn: Seit 28. Juli 1884 o. Prof. für Systematik.
UH: 8. Sept. 1890 (Ern.) zum SS 1891-1. Okt. 1919 (Emeritierung) o. Prof. als Nachf. von Wilhelm Gass; 1891-1895 e. der Hauptlehrer am Ev.-Prot. Theol. Seminar; 1893/94 Ruf an U Königsberg (Preußen) abgelehnt, s. hierzu Tilitzki 1 (2012) S. 39 und Anm. 175f.; SS 1895 Aufteilung des Ev.Prot. Theol. Seminars in Praktisch-Theol. Seminar und Wiss.-Theol. Seminar: SS 1895-SS 1919 Direktor der Dogmengeschichtl. Abt. am Wiss. Theol. Seminar; 1896-1909 auch Lehrer am Praktisch-Theol. Seminar; SS 1909 auf eigenen Wunsch Entbindung von der Verpflichtung zur Abhaltung systematischer Übungen am Praktisch-Theol. Seminar, s. Schreiben des Ministeriums der Justiz, des Kultus und Unterrichts vom 29. Dez. 1908 in: UAH RA 6127; seit 26. Juli 1919 o. Honorar-Prof.; WS 1919/20-SS 1927 Vorlesungsankündigungen.

1892/93, 1897/98, 1903/04, 1908/o9, 1914/15 Dekan der Theol. Fak. der UH

1913 Mitinitiator der Christlich-nationalen Gruppe des Bundes gegen die moderne Frauenemanzipation. 1918 Mitbegründer des „Verein Theologisches Studienhaus Heidelberg“. • $\mathrm{Zu} \mathrm{L.s}$ antisemitischer Haltung, s. Fix (1994) S. 26-28.

1894 Kirchenrat; 1903 Geh. Kirchenrat

E 1884 D. theol. Breslau. 1908 Ritterkreuz I. Klasse mit Eichenlaub des Ordens vom Zähringer Löwen.

Qu UAH PA 4798; RA 6753. • GLA Abt. 235, Fasz. 2233. Briefe, siehe Kalliope.

$W$ Die Prinzipien der Ritschlschen Theologie und ihr Wert. Bonn 1891. Christliche Ethik. 2 Bde. Berlin-Lichterfelde 1905. Christliche Glaubenslehre. 2 Bde. Berlin-Lichterfelde 1918-1919. • Christliche Apologetik. Berlin 1922.

L Braun, Wilhelm, Göbel, Walter: Ein Gedenkwort und Bedenkwort zu seinem 70. Geburtstag. Karlsruhe 1917. Arnim 2 (1950) S. 41; Verzeichnis Bonn (1968) S. 175; BBKL IV (1992) Sp. 1407-1410; Jansen (1992) S. 411 (Register); Ders. (1992a) S. 167 (Register); Fix (1994) S. 17-28; WBIS. • Lessing, Eckhard: Geschichte der deutschsprachigen evan- 
gelischen Theologie von Albrecht Ritschl bis zur Gegenwart. Göttingen 2000. Bd. 1. S. 489 (Register). - Personenlexikon zum dt. Protestantismus (2006) S. 155; Troeltsch-Gesamtausgabe 19 (2014) S. 505 (Register); Deutsche Biographie, s. https:// www.deutsche-biographie.de/gnd116897244.html [07.11. 2017].

$P$ Bildarchiv UAH; graph. Slg. UBH.

\section{Lenard, Philipp Eduard Anton}

1896-1898, 1907-1922, 1922-1931 Nat.-Math. Fak. 1896-1898 Theoretische Physik, 1907-1931 Physik

* 07. Juni 1862 Preßburg (heute: Bratislava, Slowakei)

$\dagger$ 20. Mai 1947 Messelhausen (bei Bad Mergentheim)

kath., seit 1920 konf.-los

V Philipp Nerius L. von Lenardis (1812-1896) Weinhändler (Lenard \& Laban: Weingroßhandlung mit Schaumweinerzeugung nach französischer Art)

M Antonie geb. Baumann (1831-1865)

$\infty$ 14. Aug. 1897 Katharina (Katty) geb. Schlehner (1870-1946)

K $1 \mathrm{~S}(1900-1922), 1 \mathrm{~T}$

Lb Seit 1881 Studium der Naturwiss. an TH und als Gasthörer an U Wien (Immatrikulation an e. U war L. als Realschul-Absolvent nicht möglich), anschl. a. o. Hörer an U Budapest; hier wohl Nachholung der allg. Hochschulreife; seit 1882 Mitarbeiter in väterlicher Weinhandlung; WS $1883 / 84-$ SS 1884 Forts. des Studiums an UH, seit WS $1884 /$ 85 Berlin.

UH: WS $1885 / 86-S S 1886$ Forts. des Studiums; 9. Juli 1886 Dr. phil.; 1886-189o Assistent am Physikal. Kabinett.

U Breslau: Seit 1890 Assistent am Physikal. Inst.

U Bonn: Seit 1891 Assistent am Physikal. Inst.; 25. Jan. 1893 Habilitation.
U Breslau: Seit WS 1894/95 nichtetatm. a. o. Prof.

TH Aachen: Seit WS 1895/96 Dozent.

UH: 25. Okt. 1896 (Ern.) zum WS 1896/97 etatm. a. o. Prof.

U Kiel: Seit SS 1898 o. Prof. und Direktor des Physikal. Inst.

UH: Seit 25. Mai 1907 o. Prof. und Direktor des Physikal. Inst. als Nachf. von Georg Quincke sowie seit April 1909 Direktor des neugegründeten Radiolog. Inst.; 1914 Ruf an U Preßburg abgelehnt; 27. Juni 1922 militante Besetzung des Lenardschen Instituts durch Arbeiter und Studenten, nachdem L. die staatlich angeordnete Arbeitsruhe anläßlich des Begräbnisses von Walther Rathenau demonstrativ ignorierte; nach Einleitung e. Disziplinarverfahrens gegen L. durch den U-Senat erfolgt L.s Suspendierung; L. reicht daraufhin seinen Rücktritt ein; nach Interventionen von physikalischen Gesellschaften, Kollegen und Heidelberger Studenten werden sowohl Suspendierung als auch L.s Aufgabe der Professur zurückgenommen; 31. März 1931 Emeritierung.

Messelhausen: Seit Jan. 1945 Wohnsitz (im Dez. 1944 übersiedelt ein Teil des Ende 1941 neu eingerichteten Inst. für Weltpost- und Weltnachrichtenwesen der UH unter Leitung des planm. a.o. Prof. für Physik und Lenardschülers, Ludwig Wesch, nach M., s. hierzu Drüll (2009) S. 664f.).

1910/11, 1915/16 Dekan der Nat.-Math. Fak. der UH

1905 Nobelpreis für Physik, s. http://www.nobel prize.org/nobel_prizes/physics/laureates/1905/len ard-lecture.html

Sept. 1914: L. unterschreibt neben 92 anderen Wissenschaftlern, Schriftstellern und Künstlern das sog. „Manifest der 93“" e. Aufruf vor allem gegen den Vorwurf der deutschen Kriegsschuld und der Kriegsgreuel in Belgien sowie für die Identität von deutscher Kultur und deutschem Militarismus.

1933-1946 Senator der Kaiser-Wilhelm-Gesellschaft 
1907 Geh. Rat II. Klasse

Siehe auch Reinhard Mecke, Ferdinand Schmidt

$E$ Mitglied der Akademie der Wissenschaften: 1909 (1934 Austritt) H, 1909-1945, 1942-1945 Ehrenmitglied (1945 aus Mitgliederliste gestrichen) Berlin, 1917 Wien. 1903 Dr. med. h. c. UH; 1911 Dr. phil. h.c. U Oslo; 1922 Dr.-Ing. h.c. TH Dresden; 1942 Dr. phil. (?) h.c. U Preßburg. • 1896 Goldene Medaille der Royal Society London (Aug. 1914 Rückgabe der Medaille, s. hierzu Schönbeck (2017) S. 314f.); 1932 Franklin-Medaille; 1933 Adlerschild des Deutschen Reiches. 1912 Kommandeurkreuz II. Klasse des Ordens vom Zähringer Löwen. • 1933 Ehrenbürger der Stadt Heidelberg; 1942 Ehrensenator der Universität Heidelberg.

Qu UAH PA 480o-4803; RA 5683, 6465f., 6898; Fak.-Akte H-V-4/25 fol. 98 ff. $\bullet$ GLA Abt. 235, Fasz. 2202. - Briefe: UBH. - Nachlaß: Deutsches Museum München - Archiv; UBH; s. auch Kazemi (2006) S. 182, 184. • Schirrmacher, Arne: P. L.: Erinnerungen e. Naturforschers. Kritische annotierte Ausgabe des [Lenardschen] Originaltyposkriptes von 1931/1943. Berlin 2010.

$W$ Über die lichtelektrische Wirkung in: Annalen der Physik 8 (1902). - Über Kathodenstrahlen. Nobel-Vortrag. Leipzig 1906. 2. Aufl. 1920. • Über Relativitätsprinzip, Äther, Gravitation. Leipzig 1918. 3. Aufl. 1921. • Über Äther und Uräther in: Jahrbuch der Radioaktivität und Elektronik 17 (1921). 2. Aufl. 1922. - Große Naturforscher. Eine Geschichte der Naturforschung in Lebensbeschreibungen. München 1929. 6. Aufl. 1943. • Deutsche Physik. 4 Bde. Leipzig 1936-1937. 3. Aufl. 1942-1943. - Wissenschaftliche Abhandlungen aus den Jahren 1886-1932 ... 3 Bde. Leipzig 1942-1944. Bd. 4: Hrsg. und kritisch kommentiert von Charlotte Schönbeck. Diepholz 2003.

HG Heinrich Hertz. Gesammelte Werke. 3 Bde. Leipzig 1894-1895.

L Riese (1977) S. 412 (Register). • P.L.: Die Grenzen der Wissenschaft in: Mosse, George L.: Der nationalsozialistische Alltag. So lebte man unter Hitler. [Aus dem Engl. von Renate Becker.] Kö-
nigstein/Taunus 1978. S. 233-236. NDB 14 (1985) S. 193-195 (mit Werkverz.). - Neumann, Reinhard und Putlitz, Gisbert zu: P.L. in: Semper apertus 3 (1985) S. 374-404. • Badische Biographien N. F. II (1987) S. 184-187; Heiber I (1991) S. 640 (Register); Heiber II,1 (1992) S. 657 (Register); Heiber II,2 (1994) S. 842 (Register); Jansen (1992) S. 411 (Register); Ders. (1992a) S. 167 (Register). • Instrument - Experiment. Historische Studien ... Hrsg. von Christoph Meinel. Berlin 2000. S. 386408. Schönbeck, Charlotte: Albert Einstein und P.L.: Antipoden im Spannungsfeld von Physik ... Berlin 200o. Ausgewählte Literaturnachweise aus dem Bestand der Akademiebibliothek zu P.E.A.L. in: Berlin-Brandenburgische Akademie der Wissenschaften - Akademiebibliothek. Berlin 2002. S. 6-8. Cornwell (2004) S. 569 (Register); Grüttner (2004) S. 108. • Hoffmann, Dieter: Lenärd Fülop - P. L.: Von Preßburg nach Heidelberg: in: „... immer im Forschen bleiben!“ Hrsg. von Marc Schalenberg ... Stuttgart 2004. S. 337-350. • Kazemi (2006) S. 181-184. Kleinert, Andreas: Von Preßburg nach Heidelberg. P.L. und die Schwierigkeiten e. Biographie in: Die biographische Spur in der Kultur- und Wissenschaftsgeschichte. Hrsg. von Peter Zigman. Jena 2006. - UH im Nationalsozialismus (2006) S. 1261 (Register). • Physiker zwischen Autonomie und Anpassung. Hrsg. von Dieter Hoffmann und Mark Walter. Weinheim 2007. S. 670 (Register). • Schmidt-Schönbeck (2011) S. 67-75. • WBIS; Wissenschaftsatlas der UH (2011) S. 250-252 u. ö. • Kleinert, Andreas: Verdienste und Verfehlungen. Zum 150. Geb. von P.L. in: Physik Journal 11 (2012) Nr. 7, S. 51-54. • Konstruierte Wirklichkeit. P. L. ... Biografie - Physik - Ideologie. Katalog zur Sonderausstellung im Dt. Museum München. Hrsg. von Wilhelm Füßl und Johannes-Geert Hagmann. München 2012. • Intellektuelle in Heidelberg (2014) S. 426 (Register). Hillman, Bruce J., Ertl-Wagner, Birgit, Wagner, Bernd C.: The man who stalked Einstein. How Nazi scientist P. L. changed the course of history. Lanham 2015. - Spenkuch (2016) S. 1315 (Register); Schönbeck, Charlotte: Radikaler Wandel - P.L. ... in der Zeit des Ersten Weltkrieges in: UH während des Ersten Weltkriegs (2017) S. 297-336.

$P$ Bildarchiv UAH; graph. Slg. UBH; NDB (1985); Badische Biographien (1987). 


\section{Lenel, Walter}

1932-1933 (Honorar-Prof.) Phil. Fak.

Geschichte

* 03. Aug. 1868 Mannheim

$\dagger \quad$ 28. April 1937 Heidelberg

mosaisch, seit 1905 prot. (getauft von Albert

Schweitzer), später konf.-los

V Victor L. (1838-1917) Industrieller, s. NDB 14 (1985) S. 203, Friedhöfe in Mannheim (1992) S. $329 \mathrm{f}$.

M Helene geb. Michaelis (1844-1917)

๑ 17. Febr. 1906 Luise geb. Borckenhagen (18821982), 1947 Emigration in die USA, s. Lexikon jüdischer Einwohner Hs (2011) S. 239

K 3 T, 2 S: u. a. Fritz Victor L. (1907-2003) 1933 Emigration in die USA; u.a. 1947-1973 Prof. für Metallkunde am Rensselaer Polytechnic Institute Troy (New York), s. Schäfer-Richter, Uta, Klein, Jörg: Die jüdischen Bürger im Kreis Göttingen 1933-1945 ... Ein Gedenkbuch ... Göttingen 1992. S. 130; Szabó, Anikó: Vertreibung, Rückkehr, Wiedergutmachung: Göttinger Hochschullehrer im Schatten des Nationalsozialismus ... Göttingen 2000. S. 605 f. u. ö. • Edith L. (1909-1994), u. a. Prof. für Dt. Philologie am State College of New Jersey in Montclair (New Jersey), s. Lexikon jüdischer Einwohner Hs, S. 239. • Luise Antonie L. (1912-?) 1938 Emigration in die USA, u.a. Prof. für Dt. Philologie an Western-IllinoisState-U in Macomb (Illinois). Ludwig Moritz L. (1914-2002), u. a. Prof. für Musikwiss. am Muhlenberg College in Allentown (Pennsylvania). - Siehe Lexikon jüdischer Einwohner Hs, S. 239-241, Schroeder (2017) S. 150.

Vw Bruder: Richard L. (1869-1950) Industrieller, s. NDB 14 (1985) S. 203 f.; Müller, Carl-Jochen: R.L. in: Die höchste Auszeichnung der Stadt - 42 Mannheimer Ehrenbürger im Porträt. Mannheim 2002. S. $106 \mathrm{f}$. Onkel: Otto L. (1849-1935), u.a. seit 1907 o. Prof. für Römische Rechtsgeschichte an U Freiburg/Br., s. NDB 14, S. 204 f.; WBIS; Göppinger, Horst: Juristen jüdischer Abstammung im „Dritten Reich“. 2. Aufl. München 1990; Zeiler (2009) S. 521 (Register), Lexikon jüdischer Einwohner Hs, S. 241 (Berta Lenel)
Vw siehe auch Guide to the Fritz Victor Lenel Family Collection 1773-2010; AR 25424/MF 1125. Processed by Kevin Schlottmann as part of the Leon Levy Archival Processing Initiative, made possible by the Leon Levy Foundation. (C) 2011 Leo Baeck Institute, New York; online, s. http://digifindingaids.cjh.org/?pID=12 70511\#serI.

Lb Seit WS 1886/87 Studium der Rechtswiss. an U Straßburg, anschl. Leipzig.

Straßburg: Seit WS 1888/89 Studium der Geschichte an U; 27. Sept. 1893 Dr. phil. an U; 1893-1918 Privat-Gelehrter; 1918 Übersiedlung nach $\mathrm{H}$.

H: 1918-1937 Privat-Gelehrter, wohnhaft Plöck 48. - In dieser Zeit:

UH: Seit 16. Juli 1932 o. Honorar-Prof.; 2. Aug. 1933 Lehrbefugnis aus rassischen Gründen entzogen (Gesetz zur „Wiederherstellung des Berufsbeamtentums").

Qu UAH PA 4806. GLA Abt. 235, Fasz. 2203. • Briefe: UBH. - Mitteilungen: Herr Prof. Dr. Fritz Victor Lenel $(\dagger)$.

W Studien zur Geschichte Paduas und Veronas im 13. Jahrhundert. Straßburg 1893. - Venezianischistrische Studien. Straßburg 1911. • Enrico Dandolo. Als Manuskr. gedr. Heidelberg [1931].

L Kürschner (1931) Sp. 1710. - Nachruf in: Historische Zeitschrift 156,2 (1937). - WBIS; Zwischen Wissenschaft und Politik (2001) S. 391 und Anm. 26. - Reichert, Folker: Gelehrtes Leben. Karl Hampe, das Mittelalter und die Geschichte der Deutschen. Göttingen 2009. S. 256, $347 \mathrm{f}$. • Friedrich Meinecke: Neue Briefe und Dokumente. Hrsg. von Gisela Bock und Gerhard A. Ritter. München 2012. S. 664 (Register). • Deutsche Biographie, s. https://www.deutsche-biographie.de/gn d116899689.html [07.11. 2017]. 


\section{Leonhard, Gustav Alfons}

1842-1878 Phil. Fak.

Geologie, Mineralogie

* 22. Nov. 1816 München

$\dagger$ 27. Dez. 1878 Heidelberg

ev.

V (siehe) Karl Caesar Ritter von L.

M Louise Johanna geb. Blum (1787-1824) Schwester von: (siehe) Reinhard B.

$\infty$ unverheiratet (?).

Lb UH: Seit WS 1836/37 Studium der Mineralogie; 30. April 1840 Dr. phil.

1840-1842 Eigenstudien in Berlin, anschl. Studienreisen in Norddeutschland und Habilitationsvorbereitungen in $\mathrm{H}$.

UH: Juli 1842 Habilitation; seit 8. Mai 1857 a.o. Prof.; WS 1878 (†) letzte Vorlesungsankündigung.

Die Mineral- und Gesteinssammlung im mineralogischen Teil des Heidelberger Museums des Instituts für Geowissenschaften sind aus dem Fundus bedeutender Sammlungen, u. a. auch aus der L.schen Sammlung zusammengestellt.

Qu UAH PA 1920; RA 5355, 6488, 6592, 6645, 7302. • Briefe: UBH.

$W$ Handwörterbuch der topographischen Mineralogie. Heidelberg 1843. • Grundzüge der Geognosie und Geologie. Stuttgart 1851. 3. Aufl. 1874. • Grundzüge der Mineralogie für Schule und Haus. Stuttgart 1851. 2. Aufl. 1853. • Die quarzführenden Porphyre. Stuttgart 1851. 2. Aufl. 1855. • Die Mineralien Badens nach ihrem Vorkommen. Stuttgart 1855 .

MHG 1862-1878 Neues Jahrbuch für Mineralogie, Geognosie und Paläontologie (als Nachf. seines Vaters).
$L$ ADB 18 (1883) S. 307; Poggendorff 3 (1896) S. 796 f.; Wagenbreth (1999) S. 248 (Register); Autoren der Bunsenbibliothek (2009 online); WBIS. • Einheit und Vielfalt: Franz Ungers (180o-1870) Konzepte der Naturforschung im internationalen Kontext. Hrsg. von Marianne Klemun. Göttingen 2016. S. 207-209.

$P$ Bildarchiv UAH; graph. Slg. UBH.

\section{Leonhard, Karl Caesar Ritter von}

1818-1862 Phil. Fak.

Naturgeschichte der Erde, Kameralwissenschaften

* 12. Sept. 1779 Rumpenheimer Schloß (Rumpenheim, heute: Stadtteil von Offenbach)

$\dagger$ 23. Jan. 1862 Heidelberg

ev.

V Johann Conrad von L. (1745-1794) Gutsverwalter

M Catherine Susanne geb. Godeffroy (1741-1792)

( 1802 Louise Johanna geb. Blum (1787-1824) Schwester von: (siehe) Reinhard B.

$\infty$ 30. Jan. 1825 Sophie Charlotte geb. Willich (1790-1875)

K 3 T, 2 S: u.a. (siehe) Gustav L.

Lb Seit 1797 Studium der Kameralwiss., Mineralogie an U Marburg, seit 1799 Göttingen, anschl. Marburg; 1801 kameralwiss. Examen in Marburg.

Hanau: Seit 1801 Assessor an Landeskassen- und Steuerdirektion; 1809-1810 Referent im Berg-, Hütten- und Salinenfach und Oberpostdirektor; 25. Febr. 1810 Dr. phil. an U Halle/S.; seit Okt. 1810 Leiter der Domänenverwaltung des Großherzogtums Frankfurt; Jan. 1811 Versetzung in Ruhestand durch Großherzog Karl (= Karl Theodor von Dalberg) aufgrund von Verleumdungen und Intrigen; März 1812 Wiedereinsetzung in sein Amt auf großherzoglichen Befehl; Okt. 1813 nach der Restauration Amtsenthebung und Ankündigung seiner Rückversetzung zum Assessor an Landeskassen- und Steuerdirektion aufgrund fal- 
scher Verdächtigungen durch Kurfürst Wilhelm I. von Hessen-Kassel, L. habe Franzosen begünstigt; 1814 auf eigenen Antrag Entlassung aus hessischen Diensten.

München: Seit Dez. 1815 o. Mitglied und Geh. Rat an Math.-Naturwiss. Klasse der Akademie der Wissenschaften.

UH: Seit 14. April 1818 o. Prof.; zwischen 1820 und 1846 mehrwöchige Studienreisen u. a. in die Schweiz, nach Frankreich und Österreich; bis SS 1851 als Direktor des „Mineralogischen Kabinets“ im Adressbuch der Ruprecht-Karls-Universität genannt; WS 1861/62 (†) letzte Vorlesungsankündigung über Lehre vom Bergbau.

1823 Prorektor der UH; 1821, 1828, 1834, 1840, 1847 Dekan der Phil. Fak. der UH

1809 Kammer-Rat; 1812 Geh. Rat

$E$ Mitglied der Akademie der Wissenschaften: 1806 Göttingen, 1811 Sankt Petersburg, 1815 München; 1858 Mitglied der Dt. Akademie der Naturforscher Leopoldina Halle/S.; Mitglied der Gesellschaft naturforschender Freunde zu Berlin. 1822 Ritter des Königl. Schwedischen Nordstern-Ordens; 1847 Ritter des Ordens vom Zähringer Löwen.

Qu UAH PA 1919; RA 5355, 6487, 6488 (betr. Mineraliensammlung), 6645 (1818 Antrittsvorlesung), 6592, 7302. - GLA Abt. 205, Fasz. 359. - Briefe: $\mathrm{UBH}$; siehe "Goethe-Wörterbuch im Internet" unter www.gwb.uni-trier.de; siehe auch Kalliope. • Siehe Archiv der Dt. Akademie der Naturforscher Leopoldina Halle/S. • Aus unserer Zeit in meinem Leben. 2 Bde. Stuttgart 1854-1856. (Autobiogr.)

W Geschichtliche Darstellung der Schlacht bei Hanau am 30. Oktober 1813 ... Hanau 1813 (anonym erschienen). 3. Aufl. 1913. Reprint der 3. Aufl. Hanau 2013. • Propädeutik der Mineralien. Frankfurt/M. 1817. (Mitverf.) - Handbuch der Oryctognosie. Heidelberg 1822. 2. Aufl. 1826. - Die Basaltgebilde in ihren Beziehungen zu normalen und abnormalen Felsmassen. 2 Bde. Stuttgart 18311832. Geologie oder Naturgeschichte der Erde. 5 Bde. Stuttgart 1836-1845.

HG 1807-1830 Taschenbuch für die gesammte Mineralogie (nach 1830 u.d. T.: Neues Jahrbuch für Mineralogie, Geognosie und Petrefactenkunde).

MHG 1830-1862 Neues Jahrbuch für Mineralogie, Geognosie und Petrefactenkunde (nach 1862 u.d. T.: Neues Jahrbuch für Mineralogie, Geognosie und Paläontologie).

L ADB 18 (1883) S. 308-311; Arnim 2 (1952) S. 45; Schmitt (1978) S. 72 u. ö. - Kluth, Cornelia: K.C. von L. Mitbegründer der Wetterauischen Gesellschaft in: Jahresbericht der Wetterauischen Gesellschaft für Naturkunde 131.-132. Jg. (1981) S. 103-112. - Nowotny, Otto: Carl C. von L.s „Taschenbuch für die gesammte Mineralogie“... in: Cartographica Helvetica 9 (1994) S. 32-38. • Heinstein (1999) S. 98; Wagenbreth (1999) S. 248 (Register); Weinmann (1999) S. 220f.; Autoren der Bunsenbibliothek (2009 online); WBIS; Stumm (2012) S. 699 (Register).

P Bildarchiv UAH; graph. Slg. UBH; Kluth (1981).

\section{Leser, Emanuel}

1873-1914 Phil. Fak.

Nationalökonomie

* 26. Sept. 1849 Mainz

$\dagger \quad$ 20. Mai 1914 Heidelberg mosaisch

V Leo L. (1818-1900) Kaufmann, Rabbi und seit ca. 1856 Vorstandsmitglied der israelitischen Religionsgesellschaft in Mainz, s. L.L. $\dagger$ in: Der Israelit. Ein Centralorgan für das orthodoxe Judenthum. Hrsg. von Oskar Lehmann. Mainz 20. Sept. 1900.

M Olga geb. Oppenheimer ( $†$ nach 1900)

œ 13. Juli 1875 Ida geb. Rohr (1850-1904) 
K 1 T: Sophie L. (1876-1908), s. Willstätter $\left({ }^{2} 1958\right)$ S. 147-154, Photo: Tafel II; Ehefrau von Richard Willstätter (1872-1942) 1915 Nobelpreisträger für Chemie; seit 1905 o. Prof. für Chemie ETH Zürich, 1912-1916 Direktor des Kaiser-Wilhelm-Inst. für Chemie BerlinDahlem, 1916-1924 (Niederlegung der Professur) Ordinarius U München, 1939 Emigration in die Schweiz, s. Willstätter ( $\left.{ }^{2} 1958\right)$; Litten, Freddy: R. W. - Kurzbiographie, s. http://litten. de/fulltext/willst.htm (Stand: 8. März 2004). • 2 S: u. a. Dr. iur. Guido L. (1883-1942 Suizid) 1919-1933 (Entlassung) Amtsgerichtsrat, DDPPolitiker, 1919-1921 Mitglied der II. Kammer des badischen Landtags, s. Kurzbiographien zur Geschichte der Juden 1918-1945. Hrsg. von Joseph Walk ... Jerusalem 1988; Ehemann von Irmgard Meyer (1888-1942 Suizid) T von: (siehe) Victor M.

$L b$ WS 1867/68 Studium an UH, seit SS 1868 Göttingen; 1870 Dr. phil. an U Göttingen.

UH: 27. Okt. 1873 Habilitation; seit 1. April 1881 a.o. Prof.; seit SS 1894 Lehrauftrag für „Suppletur in den nationalökonomischen und finanzwissenschaftlichen Disciplinen unter Bewilligung einer Vergütung von jährlich 10oo.- Mark“, siehe hierzu UAH RA 6867 fol. 6r, v; SS 1914 letzte Vorlesungsankündigung über Die Börse und Börsengeschäfte.

Schenkung e. Teils der Privatbibliothek L.s (Bibliotheca Leseriana) an UBH, siehe hierzu UAH RA 5973; siehe auch Handbuch der historischen Buchbestände in Deutschland. Hrsg. von Bernhard Fabian. Hildesheim 2003.

E 1893 Ritterkreuz I. Klasse des Sachsen-Ernestinischen Hausordens.

Qu UAH PA 1923; RA 6867. - GLA Abt. 235, Fasz. 2204. • Briefe: UBH. • Mitteilungen von Familienangehörigen.

W Neckers zweites Ministerium. Mainz 1871. • Der Begriff des Reichthums bei Adam Smith. Heidelberg 1874. • Die Hypothekenbanken und ihre Jahresabschlüsse. Heidelberg 1879 . Untersuchungen zur Geschichte der Nationalökonomie. Jena 1881. Neudr. 2014. - Merkantilsystem in: Handwörterbuch der Staatswiss. Bd. 4 (1892); 3. Aufl.: Bd. 6 (1910). - Zur Geschichte der Prämiengeschäfte. Jena 1896.

HG David Ricardo's kleinere Schriften. Aus dem Englischen ins Deutsche übertragen und eingeleitet von E. L. Jena 1905. 2. Aufl. 1922.

L Wer ist's (1914) S. 988; Jüdische National-Biographie 4 (1929) S. 34f. - Willstätter, Richard: Aus meinem Leben. Hrsg. von A. Stoll. Weinheim 1949. 2. Aufl. 1958. S. 147-151 u. ö. • WBIS. • Coing, Marga: Die Bibliothek des Heidelberger Nationalökonomen E.L. und ihre Eingliederung in die Universitätsbibliothek Heidelberg in: Bibliothek und Wissenschaft 11 (1977) S. 72-117. • Braeuer, Walter: Biographie E.L.s. Reinbek 1981. (4 masch.geschr. Seiten (mit Bibliographie). Kopien im UAH.) - Meyer, Hans-Martin: Retrokatalogisierung der Bibliotheca Leseriana: Etappenziel Monographien erreicht in: Theke Aktuell - Für Heidelberger Bibliotheken von Heidelberger Bibliotheken 13. Jg. (2006) H. 2, S. 71 f. • Deutsche Biographie, s. https://www.deutsche-biographie. de/gnd116948485.html [07.11. 2017].

$P$ Bildarchiv UAH; graph. Slg. UBH.

\section{Leuckart, Friedrich Sigismund}

1822-1832 Med. Fak.

Pathologische Anatomie, Naturgeschichte, Zoo-

logie, Tierarzneikunde

* 26. Aug. 1794 Helmstedt

$\dagger \quad$ 25. Sept. 1843 Freiburg/Br. ev.-luth.

V Sigismund L. (1741-1826) Buchdruckereibesitzer

M Johanna Sophie Regine geb. Seemann (17571831)

(17. Mai 1838 Anna geb. Blank (kath.)

K $\quad 1 \mathrm{~S}, 2 \mathrm{~T}$ 
Vw Neffe: Rudolf L. (1822-1898), u. a. 1869-1898 Prof. für Zoologie Leipzig, s. NDB 14 (1985) S. 372 f., WBIS, Geschichte U Leipzig 2 (2010) S. 918 (Register), Professorenkatalog Leipzig online; T von Rudolf L.: Hermine Kunigunde Rosa Louise Betty L. (1851-1939) Ehefrau von: (siehe) Otto Karlowa.

Lb U Göttingen: Seit 1812 Studium der Medizin, Naturwiss.; 1816 Dr. med.

Seit 1816 Eigenstudien in Berlin, anschl. Breslau, Wien, Halle-Wittenberg, Paris.

UH: 2. Okt. (?) 1822 Habilitation für Medizin und Naturgeschichte; seit 21. Mai 1829 a. o. Prof.

U Freiburg/Br.: Seit 9. Aug. 1832 o. Prof. für Zoologie, Physiologie, Anatomie, Veterinärkunde.

E 1828 Mitglied der Dt. Akademie der Naturforscher Leopoldina Halle/S.

Qu UAH PA 1926. Auskunft: Pfarrei St. Martin im Erzbischöflichen Archiv Freiburg/Br. (Kath. Ehebuch 1838-1844); Ev. Oberkirchenrat - Landeskirchliches Archiv - Karlsruhe (Totenbuch 1843). - Siehe auch Archiv der Dt. Akademie der Naturforscher Leopoldina Halle/S.

$W$ Versuch einer naturgemäßen Eintheilung der Helminthen. Heidelberg 1827. - Asteroidengeschlecht „Cometula“ in: Heusinger's Zs. für organische Physik 3 (1829). • Über die Verbreitung der übriggebliebenen Reste einer vorweltlichen organischen Schöpfung. Freiburg/Br. 1835. • Untersuchungen über das Zwischenkieferbein des Menschen in seiner normalen und abnormen Metamorphose. Stuttgart 1840.

L Uppenkamp, Peter: Leben und Werk von F.S.L. Diss. Heidelberg 1973. - NDB 14 (1985) S. $371 \mathrm{f}$; Pantel/Bauer (1990) S. 87; Seidler/Leven (2007) S. 864 (Register); WBIS. - Möller, Daniel: Die Geschichte der Anthropologischen Sammlung Freiburg: Entstehung, Zusammenführung, Verlust. Marburg 2015. S. 45-47, $109 \mathrm{f}$.

$P$ Bildarchiv UAH; NDB.

\section{Levy, Ernst}

1928-1935 Jur. Fak.

Römisches und Dt. Bürgerliches Recht

* 23. Dez. 1881 Berlin

$\dagger$ 14. Sept. 1968 Davis (Kalifornien) mosaisch

V Robert L. (1850-1930) Kaufmann

M Betty geb. Landsberger (1858-1919)

๑ 21. Mai 1909 Marie geb. Wolff (1884-1974)

K $\quad 1$ S, 1 T: Brigitte Marianne L. (1912-1981), u.a. Prof. für Rechtswiss. an $\mathrm{U}$ of California in Davis, s. Ernst Levy und Wolfgang Kunkel. Briefwechsel 1922-1968 ... (2005) S. 15 Anm. 24; Ehefrau von Edgar Bodenheimer (19081991) Prof. für Rechtswiss. ebd., s. a.a.O. S. 11 Anm. 15. - Siehe auch Lexikon jüdischer Einwohner Hs (2011) S. 251

Vw Schwester: Anna L. (1885-1975) Ehefrau von James Simon (1880-1944 (Ermordung) KZ Auschwitz, heute: Oświęcim, Polen) Komponist, s. Verdrängte Musik - Berliner Komponisten im Exil. Hrsg. von Habakuk Traber und Elmar Weingarten. Berlin 1987. - Neffe: Ulrich Simon (1913-1997), u. a. 1972-1980 Prof. für Christliche Literatur am King's College London, s. Coggins, Richard: Obituary: The Reverend ... U.S. in: The Independent. London 16. Aug. 1997.

Lb Seit SS 1900 Studium an U Freiburg/Br., anschl. Berlin.

Berlin: Mai 1903 I. Staatsexamen; seit Mai 1903 Referendar am Amtsgericht in Charlottenburg; 29. Nov. 1906 Dr. iur. an U; Dez. 1908 II. Staatsexamen; Juli 1909-März 1913 Amtsrichter in Oranienburg (bei Berlin).

U Berlin: Mai 1914 Habilitation; 1918 Verleihung des Titels „Prof.“. • In dieser Zeit:

1916-1918 Kriegsdienst.

Frankfurt/M.: Seit SS 1919 a.o. Prof.; seit 20. Nov. 1919 o. Prof. (persönlicher Ordinarius); seit 1. Okt. 1920 planm. o. Prof. 
U Freiburg/Br.: Seit WS 1922/23 o. Prof.

UH: Seit 1. Okt. 1928 o. Prof. als Nachf. von Otto Gradenwitz; WS 1928/29 erste Vorlesungankündigung; 11. Mai 1929 Antrittsvorlesung; 1931 Ruf an U Bonn abgelehnt; 28. April-27. Juli 1933 von Lehrtätigkeit an $\mathrm{U}$ beurlaubt aus rassischen Gründen; 10. Mai 1935 erneute Beurlaubung; 4. Nov. 1935 L. stellt Antrag auf Entpflichtung; 31. Dez. 1935 Versetzung in Ruhestand; 1936 Emigration.

U of Washington in Seattle: 1936-Juni 1952 (Emeritierung) Prof.

UH: 1. April 1950 Emeritierung; WS 1952/53, SS 1959 Gastvorlesungen.

Wohnsitz: Seit Okt. 1956 Basel, seit Nov. 1966 Davis.

Okt. 1932-April 1933 Dekan der Jur. Fak. der UH

$E$ Mitglied der Akademie der Wissenschaften: 1926-1939 (aus Mitgliederliste gestrichen), 1947$1968(\dagger) \mathrm{H}, 1960$ Göttingen, 1962 München; 1958 Mitglied der Accademia Nazionale dei Lincei Roma. - Dr. iur. h.c. Frankfurt/M. und Athen; 1948 Dr. phil. h.c. UH. 1956 Großes Verdienstkreuz des Verdienstordens der BRD.

Qu UAH PA 774, 4820; Fak.-Akte H-II-552/2. Briefe: UBH. - Ernst Levy und Wolfgang Kunkel. Briefwechsel 1922-1968. Hrsg. von Dorothee Mussgnug ... Heidelberg 2005. Mitteilungen: Herr Dan Bodenheimer, San Diego (Kalifornien).

$W$ Die Konkurrenz der Aktionen und Personen im klassischen römischen Recht. 2 Bde. Berlin 1918-1922. Neudr. 1964. - Westen und Osten in der nachklassischen Entwicklung des römischen Rechts in: Zs. der Savigny-Stiftung für Rechtsgeschichte. Romanistische Abt. 49 (1929). - Weströmisches Vulgarrecht. Das Obligationenrecht. Weimar 1956. - Gesammelte Schriften. Hrsg. von Wolfgang Kunkel und Max Kaser. Köln 1963.

MHG 1926-1934 Zs. der Savigny-Stiftung für Rechtsgeschichte. Romanistische Abt.
$L$ Niederländer, Hubert: E.L. $\dagger$ in: Ruperto Carola 21. Jg., 46. Bd. (1969) S. 48 f. - Dictionary of Emigrés 2 (1983) S. 717; NDB 14 (1985) S. 403 f. (mit Werkverz.). - Misera, Karlheinz und Backhaus, Ralph: E. L. und das Vulgarrecht in: Semper apertus 3 (1985) S. 186-214. Mussgnug (1988) S. 298 (Register). - E.L. in: Juristen an der Universität Frankfurt am Main. Hrsg. von Bernhard Diestelkamp und Michael Stolleis. Baden-Baden 1989. S. 94-101. • Jansen (1992a) S. 167 (Register); Dt. Juristen jüdischer Herkunft (1993) S. 164f. u. ö.; Baur (2009) S. 242-244; Vertriebene Mitgl. der Akad. der Wiss. H (2009) S. 35-40; Schroeder (2010) S. 740 (Register); Lexikon jüdischer Einwohner Hs (2011) S. 250f. - Leo, Paul Christopher: Wilhelm Groh ... Hamburg 2012. S. 132-135. • Schroeder (2017) S. 275-288.

$P$ Bildarchiv UAH; NDB (1985); Vertriebene Mitgl. (2009).

Levy, Hermann Joachim (Pseudonym: Lint, Hermann)

1907-1919 (1920) Phil. Fak.

Nationalökonomie

* 22. Mai 1881 Berlin

$\dagger$ 16. Jan. 1949 Richmond (Stadtteil von London) ev.

V Martin L. (1836-1911) Bankier, auch Komponist, s. http://imslp.org/wiki/Category:Levy, _Martin (abgerufen am 17. Nov. 2015; Ausdruck im UAH)

M Elise Antonie geb. Rosenthal (1844-1902)

$\infty$ 1. Juni 1906 Berta geb. Stammler $\left({ }^{*} 1885\right) \mathrm{T}$ von Rudolf S. (1856-1938) seit 1882 a. o. Prof. Marburg, seit 1884 a. o. Prof. Gießen, seit 1885 o. Prof. Halle-Wittenberg, 1916-1923 o. Prof. für Römisches Recht, Rechtsphilosophie Berlin, s. WBIS, Catalogus prof. Halensis; Philosophisches Denken in Halle. Abt. 3. Bd. 5: Rechts- und politikphilosophische Denker: R. S., Rudolf Joerges ... Bearb. und hrsg. von Ingomar Kloos ... Halle/S. 2006. S. 29-85. • Siehe auch Richard Loening: Eintrag unter $V w$ 
@ 1924 Margarethe geb. Schlegel (1899-1987) Schauspielerin, s. Weniger, Kay: Zwischen Bühne und Baracke. Lexikon der verfolgten Theater-, Film- und Musikkünstler 1933-1945. Berlin 2008. S. $306 \mathrm{f}$. Siehe auch http://www. steffi-line.de/archiv_text/nost_film2ob4o/ 120_schlegel_margarete.htm (abgerufen am 24. Sept. 2017); Ausdruck im UAH

K $\quad 1 \mathrm{~S}$

Vw Schwester: Julie L. (1871-1953) Ehefrau von Arnold Reissert (1860-1945) 1884-1888 Redakteur der Berichte der Dt. Chemischen Gesellschaft, seit 1888 Privat-Dozent, seit 1900 Prof. für Chemie Berlin, 1898-1902 Reg.-Rat und Mitglied des Patentamtes Berlin, seit 1902 Privat-Dozent und seit 1914 Honorar-Prof. Marburg, s. WBIS.

Lb U München: Seit WS 1899/190o Studium; Juli 1902 Dr. rer. pol.

Eigenstudien: 1902-1903 Großbritannien, Mai 1904-März 1905 USA.

U Halle-Wittenberg: Juni 1905 Habilitation.

UH: 19. Okt. 1907 Umhabilitation; seit 7. Febr. 1910 nichtetatm. a.o. Prof.; WS 1919/20 Beurlaubung; 27. Febr. 1920 Verzicht auf venia legendi und Streichung aus Vorlesungs- und Personalverzeichnis.

In dieser Zeit:

Handelshochschule Mannheim: SS 1909-SS 1910 (Verzicht auf Lehrtätigkeit) Hauptamtl. Dozent für Volkswirtschaftslehre.

1914-1918 Kriegsdienst.

TH Berlin-Charlottenburg: Seit 1921 Privat-Dozent, seit 1923 nichtplanm. a. o. Prof. für Volkswirtschaftslehre, Fachabt. Wirtschafts- und Rechtswissenschaften in Fak. I für Allg. Wissenschaften, insbesondere für Mathematik, Naturwiss. und Wirtschaftswiss.; seit Mai 1933 zwangsweise Beurlaubung; Sept. 1933 Entziehung der Lehrbefugnis aufgrund des Gesetzes zur „Wiederherstellung des Berufsbeamtentums“.
England: 1934/35 Emigration; Dozent in Cambridge und London; seit 1945 Wohnsitz in London.

Qu UAH PA 1932; RA 6412. - Auskunft: Universitätsarchiv TU Berlin (Codex Professorum).

$W$ Die Not der englischen Landwirte zur Zeit der hohen Getreidezölle. Stuttgart 1902. • Monopole, Kartelle und Trusts in der englischen Industrie. Jena 1909. 2. Aufl. 1927. Die Grundlagen des ökonomischen Liberalismus in der Geschichte der englischen Volkswirtschaft. Jena 1912. 2. Aufl. u.d.T.: Der Wirtschaftsliberalismus in England. Jena 1928. - Lint, Hermann (Pseudonym): Die Frau im Traum. Berlin 1913. Die englische Wirtschaft. Berlin 1922. - Die Grundlagen der Weltwirtschaft. Leipzig 1924. 2. Aufl. 1931.

$L$ Jüdische National-Biographie 4 (1929) S. 69; Kürschner (1931) Sp. 1726, (1935) Sp. 804. • Handels-Hochschule Mannheim 1907-1932 (1932) S. 22. - Wer ist's (1935) S. 964; WBIS; Catalogus prof. Halensis online. - Berg, Nicolas: Kulturwirtschaftslehren gegen den Antisemitismus der Zeit: Die jüdischen Nationalökonomen Richard Ehrenberg, H.L. und Julius Hirsch in: Open Peer Review-Publication series „Nineteenth-Century Anti-Semitism in International Perspective“ (1. Dez. 2016), s. https://mws.hypotheses.org/37182 (abgerufen am 24. Sept. 2017). Deutsche Biographie, s. https://www.deutsche-biographie.de/gnd117670 448.html [07. 11. 2017].

$P$ Bildarchiv UAH.

\section{Lewald, Ernst Anton}

1813-1848 Theol. Fak.

Kirchengeschichte

* 20. März 1790 Hannover

$\dagger \quad$ 15. Jan. 1848 Heidelberg ev.-prot.

V Levi Salomon Michael David L. (1754-1805) Hofagent, Finanzrat, Hofbankier 
M Fradel geb. Me(n)delsheim ( $\dagger$ (vor) 1798) T von Herz Cerf Beer von Medelsheim, ursprüngl. Naphtali Ben Dov Beer (franz: Cerfbeer) (1726-1793), u. a. Pächter mehrerer Eisenwerke, Finanzier König Ludwig XV. (1710-1774), ca. 1767 Directeur général des fourages militaires, s. Warschawski, Max: Hirtz de Medelsheim dit Cerf Berr, représentant de la „nation juive" d'Alsace 1726-1793, s. http://judais me.sdv.fr/perso/cerfberr/index.htm (abgerufen am 25. Sept. 2017; Ausdruck im UAH); Szajkowski, Zosa: Jews and the French Revolutions of 1789,1830 and 1848 . New York 1970. S. 481 f. u. ö.

$\infty$ 11. April 1839 Albertine Wilhelmine Amalie geb. Kleinmann

K 2 S, s. NDB 14 (1985) S. 411*; 1 T: Hermine Henriette Amalie L. (1841-1911) Ehefrau von: (siehe) Wilhelm Oncken

Vw Enkel: u. a. Hans L. (1883-1963) seit 1910 Privat-Dozent für Bürgerl. und Römisches Recht Würzburg, seit 1911 a.o. und seit 1913 o. Prof. Lausanne, seit 1915 Frankfurt/M., seit 1920 Köln, seit 1923 Frankfurt/M., seit 1932 Berlin, 1935-1953 (Emeritierung) o. Prof. für Rechtsgeschichte und Privatrecht Basel, s. NDB 14 (1985) S. 411 f., Dt. Juristen jüdischer Herkunft (1993) S. 211 u. ö., Lösch (1999), WBIS; Breunung, Leonie, Walther, Manfred: Die Emigration deutschsprachiger Rechtswissenschaftler ab 1933. Ein bio-bibliographisches Handbuch. Bd. 1: Westeuropäische Staaten, Türkei, Palästina/Israel, lateinamerikanische Staaten, Südafrikanische Union. Berlin 2012. S. 275-290 u. ö.

Lb U Jena: Seit 1808 Studium; 1812 Habilitation „und ein Paar Semester hindurch daselbst Vorlesungen gehalten“ (aus: UAH RA 6718 fol. 11r).

UH: Seit 21. Juni 1813 Repetent und Privat-Dozent; 1816 Dr. phil.; 18. Febr. 1819 Ern. zum a. o. Prof.; seit 20. Nov. 1828 o. Prof.

1844/45 Prorektor der UH; 1831, 1838, 1841, 1845 Dekan der Theol. Fak. der UH

1844 Kirchenrat
E 1829 D. theol. UH.

Qu UAH PA 1933; PA 2371 (Friedrich Umbreit; hier L.s Brief vom 1. Jan. 1829); RA 6718 fol. 7v, 8r, 10v, 11r u. ö; Theol. Fak. 7 fol. 85-91, 95, Bd. 10 fol. 20, 23. GLA Abt. 235, Fasz. 334. Rektoratsreden online. • Briefe: $\mathrm{UBH}$.

$W$ Observationes philologicae ad casuum graecorum vim atque indolem illustrandam. Jena 1811 . Catechetischer Unterricht des Pfalzgrafen Friedrich V. ... eine nach der Reihenfolge der Fragen in dem Heidelbergischen Catechismus geordnete Erläuterung desselben im Geist und Styl der Reformationszeit. Heidelberg 1841. • De religionibus peregrinis apud veteres Romanos paulatim introductis. Heidelberg 1844.

$L$ Meusel 6. Bd., 5. Ausg. (1821) S. 523, 11. Bd., 5. Ausg. (1834) S. 405; WBIS; Deutsche Biographie, s. https://www.deutsche-biographie.de/gnd116969 474.html [07.11. 2017].

\section{Liebich, Bruno Arthur Franz Karl}

1913-1922 Phil. Fak.

Indische Philologie

* 07. Jan. 1862 Altwasser (heute: Stary Zdrój, e. Stadtteil von Wałbrzych (Waldenburg), Polen)

$\dagger \quad$ 04. Juli 1939 Breslau (heute: Wrocław, Polen) ev.

V Reinhold L., Mühlenbesitzer

M N.N.

@ 9. März 1901 Klasina geb. Humbert, T von Hermann Poppo H. (1838-1904) zunächst Kaufmannslehrling in Birmingham, seit 1863 Vertreter e. englischen Firma für landwirtschaftliche Maschinen in Breslau, anschl. Gründer e. eigenen Unternehmens und britischer Konsul, s. Smidt, Wolbert G.C.: Die Familie Humbert in: Biographisches Lexikon für Ostfriesland. Hrsg. von Martin Thielke. Bd. 2. Aurich 1997. S. 175 u. ö.

K $\quad 1 \mathrm{~S}, 1 \mathrm{~T}$ 
Lb Seit WS 1880/81 Studium an U Breslau, seit 1882 München, zuletzt Göttingen; 1885 Dr. phil. an U Göttingen.

U Breslau: 1886-1888 Volontär an UB; 27. Juni 1892 Habilitation; seit 17. April 1897 nichetatm. a. o. Prof.

UH: 10. Dez. 1912 Nostrifikation; seit 3. Jan. 1913 nichtetatm., 1920-1922 nichtplanm. a.o. Prof.; SS 1913 erste Vorlesungsankündigung.

U Breslau: SS 1922-WS 1927/28 (Emeritierung) o. Prof.

Qu UAH PA 1935; RA 6113, 6863. - GLA Abt. 235, Fasz. 2210.

W Das Cāndra-Vyākaraṇa. [Göttingen] 1895. (Sonderdruck aus: Nachrichten der Königl. Gesellschaft der Wissenschaften zu Göttingen. Philolog.-Histor. Klasse. H. 3.) • Die Wortfamilien der lebenden hochdeutschen Sprache als Grundlage für ein System der Bedeutungslehre. Breslau 1899. 2. Aufl. 1905. - Sanskrit-Lesebuch. Leipzig 1905. Nachdr. Stuttgart 2016. Zur Einführung in die indische einheimische Sprachwissenschaft. Heidelberg 1920. • Die vier indischen Āçrama's. Breslau 1936.

HG Kşīrataraniginī, Kşīrasvāmin's Kommentar zu Panini’s Dnātupāạtha. Breslau 1930.

$L$ NDB 14 (1985) S. 491 f. (mit Werkverz.; im NDBund Wikipedia-Artikel fehlt die Heidelberger Zeit 1912-1922); WBIS. Coward, Harold G., Raja, K. Kunjunni: The Encyclopedia of Indian Philosophies. Vol. 5: The Philosophy of the Grammarians. Princeton (New Jersey) 1990. S. 582 (Register).

$P$ Bildarchiv UAH.

\section{Liebmann, Karl Otto Heinrich}

1920-1935 Nat.-Math. Fak.

Mathematik

* 22. Okt. 1874 Straßburg

$\dagger$ 12. Juni 1939 München-Solln ev.

V Otto L. (1840-1912) seit 1872 Prof. für Philosophie Straßburg, seit 1882 Jena, s. NDB 14 (1985) S. 506-508, WBIS

M Julie Christine geb. Neumann (1842-1920) T von Karl Friedrich N. (1793-1870; mosaisch, seit 1816 prot.), u.a. Bibliophiler, Reisender, 1833-1852 Prof. für chinesische und armenische Sprache, Länder- und Völkerkunde München, s. ADB 23 (1886) S. 529 f., WBIS; Walravens, Hartmut: K.F.N. und Karl Friedrich August Gützlaff ...: zwei deutsche Chinakundige im 19. Jahrhundert. Wiesbaden 2001.

( 20. Dez. 1913 Natalie geb. Kraus (1890-1924) T von Carl K. (1851-1918), u. a. seit 1888 Prof. für Landwirtschaft, seit 1892 Direktor der Bayer. Hauptversuchsanstalt für Landwirtschaft, 1895 umbenannt in Königl. Bayer. Akademie für Landwirtschaft und Brauereien in Weihenstephan, 1902-1910 (Mitinitiator) Direktor der Bayer. Landessaatzuchtanstalt in Weihenstephan, 1901-1910 o. Prof. für Agrarwiss. TH München, s. NDB 12 (1980) S. 691f., WBIS

$\infty$ 6. April 1926 Helene Klara Hanna geb. Ehlers (1896-1984)

K 2 T, 2 S: u. a. Karl-Otto L., Attending Psychiatrist at Harbor Health Services, Associate Clinical Prof. of Psychiatry at Yale school of medicine in New Haven (Connecticut).

Lb Seit WS 1892/93 Studium an U Leipzig, seit 1894 Jena; 22. Nov. 1895 Dr. phil. an U Jena; 27. Juni 1896 Lehramtsprüfung in Jena.

U Göttingen: Seit 1896 Forts. des Studiums; 1. Okt. 1897-30. Sept. 1898 Assistent an Math. Modellsammlung.

U Leipzig: Okt. 1898-Okt. 1910 Assistent am Math. Inst.; 27. Okt. 1899 Habilitation; seit 25. Febr. 1905 nichtetatm. a. o. Prof. 
TH München: Seit WS 1910/11 etatm. a. o. Prof.; seit 26. Sept. 1915 o. Prof.

UH: Seit 30. Juni 1920 o. Prof. als Nachf. von Paul Stäckel; 28. Okt. 1920 Vereidigung; 2. Juni 1935 Emeritierungsgesuch (nach Boykott durch NSStudenten) aus gesundheitlichen Gründen; 1. Okt. 1935 Entbindung auf eigenen Antrag (aus rassischen Gründen) von amtl. Pflichten.

München-Solln: Seit 1936 Wohnsitz.

1925/26 Rektor der UH; 1923/24, 1928/29 Dekan der Nat.-Math. Fak. der UH

Adelheid Furtwängler (1863-1944; Mutter des Dirigenten Wilhelm F.) porträtiert L. 1932 in Öl. Sohn Karl-Otto L. schenkt das Gemälde 2008 der Universität Heidelberg; es befindet sich heute im Seifert-Raum des Mathematischen Instituts.

Siehe auch Anhang Sporteinrichtungen an $U H$ 1910-1933 und ihre Mitglieder

E 1909 Mitglied der Sächsischen Gesellschaft der Wissenschaften; Mitglied der Akademie der Wissenschaften: 1917 München, 1921 (1938 Austritt) H.

Qu UAH PA 4829. GLA Abt. 235, Fasz. 2211. Briefe: UBH.

$W$ Lehrbuch der Differentialgleichungen. Leipzig 1901. - Nichteuklidische Geometrie. Berlin 1908. 3. Aufl. 1923. - Synthetische Geometrie. Leipzig 1934.

Übers. Markow, Andrei Andrejewitsch: Wahrscheinlichkeitsrechnung (aus dem Russischen). Leipzig 1912.

$L$ NDB 14 (1985) S. 508; Math. Institute in Deutschland (1989) S. 285 (Register); Jansen (1992) S. 411 (Register); Ders. (1992a) S. 167 (Register); WBIS. • Bauer, Friedrich L.: Pringsheim, Liebmann, Hartogs. Schicksale jüdischer Mathematiker in München in: Sitzungsberichte der Bayer. Akademie der Wissenschaften. Math.-Naturwiss. Klasse. Jg. 1997. S. 1-32. - Sgries, Sören: Erinnerung an „dunkle Seiten“. Gedenkkolloquium für den jüdischen
Mathematiker H.L. in: RNZ (19. Juni 2008) Nr. 141, S. 5. - Vertriebene Mitgl. der Akad. der Wiss. H (2009) S. 41-46; Badische Biographien N.F. VI (2011) S. 258 f. - Über H.L. in: Leo, Paul Christopher: Wilhelm Groh ... Hamburg 2012. S. 147. • Professorenkatalog Leipzig online; Homo Heidelbergensis mathematicus online.

$P$ Bildarchiv UAH; Ölportrait von 1932 (siehe oben); NDB; Vertriebene Mitgl. (2009).

\section{Lieske, Georg Rudolf}

1914-1922 (1923) Nat.-Math. Fak.

Botanik

* o6. Sept. 1886 Dresden

$\dagger$ 16. Juli 1950 Hamburg ev.

V Otto L., Eisenbahnassistent

M Anna geb. Müller

$\infty$ N.N.

K mind. 1 S: Dr. med. Herbert L. (1923-2006) Facharzt für innere Medizin und Tropenkrankheiten in Hamburg.

Lb Seit Ostern 1906 Militärdienstpflicht als Einjährig-Freiwilliger; seit SS 1907 Studium an TH Dresden, seit WS 1908/o9 U Leipzig.

U Leipzig: 7. Febr. 1910 Dr. phil.; seit Okt. 1910 Assistent am Botanischen Inst.; 1911 Prüfung für höheres Lehramt in Leipzig.

Freiburg/Br.: Seit Okt. 1911 Assistent am Botanischen Inst.; Aug. 1912-März 1913 Forschungsreise durch Brasilien.

UH: Seit Okt. 1913 Assistent am Botanischen Inst.; 21. Febr. 1914 Habilitation; März-April 1914 Studien an Zoolog. Station in Neapel; seit 29. Febr. 1920 nichtplanm. a. o. Prof.; 1. April 1922 Beurlaubung für ein Jahr; Mai 1923 Streichung aus der Dozentenliste. $\bullet$ In dieser Zeit:

1914-1918 Kriegsdienst. 
Leverkusen: 31. März 1922-28. Febr. 1926 Leiter der Pflanzenschutz-Abt. der Bayer-AG.

Berlin: Seit 1926 Mitarbeiter an Biolog. Reichsanstalt.

Mülheim (Ruhr): Ende 1927-1934 Leiter der Biolog. Abt. am Kaiser-Wilhelm-Inst. für Kohlenforschung.

Seit Ende 1934 Leiter des Biolog. Forschungslabors der Norddeutschen Hefeindustrie (vormals Hefefabrik Wulf) in Dessau, ca. 1936 (Verlegung des Labors)-1950 in Hamburg.

Qu UAH PA 4834; RA 6502. • GLA Abt. 235, Fasz. 2212. Auskunft: Bayer Leverkusen, Werksverwaltung.

$W$ Morphologie und Biologie der Strahlenpilze. Berlin 1921. - Bakterien und Strahlenpilze. Berlin 1922. Kurzes Lehrbuch der allgemeinen Bakterienkunde. Berlin 1926.

$L$ Mäckel, Hans Georg: G. R.L. † in: Berichte der Dt. Botanischen Gesellschaft (Jan. 1963) Vol. 76,11, S. 163-169 (mit Werkverz.). - R.L. in: Pflanzenschutz-Nachrichten Bayer 32 (50) (1979/3) S. 466. Jansen (1992a) S. 167 (Register); Deutsche Biographie, s. https://www.deutsche-biographie.de/gnd11 771939o.html [07.11. 2017].

$P$ Bildarchiv UAH.

\section{Lilienthal, Karl Ludwig Julius von}

1896-1919 Jur. Fak. 1919-1923 (1924) (Honorar-Prof.) Jur. Fak.

Strafrecht, Strafprozeßrecht, Kirchenrecht

* 31. Aug. 1853 Elberfeld (heute: Stadtteil von Wuppertal)

$\dagger \quad$ 08. Nov. 1927 Heidelberg

ev.
V Ludwig Theodor Balduin von L. (1828-1893) Kaufmann, s. Baum, Marie-Luise: L. von L. in: Wuppertaler Biographien 6 (1966) S. 105-112

M Friederike Henriette geb. Seyd (1832-1884)

C 3. Juni 1879 Anna geb. Boehler (1857-1931)

$\mathrm{K} \quad 1 \mathrm{~S}, 2 \mathrm{~T}$

Vw Schwager: August Krohn (1840-1889), u.a. seit 1881 a. o. Prof. für Philosophie Halle-Wittenberg, seit 1884 o. Prof. Kiel, s. Catalogus prof. Halensis online.

Lb Berlin: Seit WS $1868 / 69$ Studium an U; Juni 1872 I. Staatsprüfung.

Elberfeld: 1872-1877 Referendar am Landgerichtsbezirk; 19. Febr. 1873 Dr. iur. an UH; 1877 II. Staatsprüfung; 9. Juli 1877-30. Aug. 1877 (Entlassung auf eigenen Antrag aus dem Justizdienst) Gerichtsassessor bei Staatsanwaltschaft.

U Halle-Wittenberg: 7. Aug. 1879 Habilitation für Strafrecht und Strafprozeß.

U Zürich: Seit WS 1882/83 o. Prof.

U Marburg: 23. Sept. (Ern.) zum 1. Okt. 1889 o. Prof.

UH: 10. Juni 1896 Ern. zum o. Prof. als Nachf. von Rudolf Heinze; 14. Okt. 1896 Vereidigung; 19021919 außerdem Hilfsrichter am Großherzogl. Landgericht in H; 1. Okt. 1919 Emeritierung mit gleichzeitiger Ern. zum o. Honorar-Prof.; SS 1923 letzte Vorlesungsankündigung; 4. Nov. 1924 Charakter als o. Honorar-Prof. abgelegt.

1912/13 Prorektor der UH; 1906, 1911 Wahlsenator H; 1898/99, 1900, 1905/06, 1909/10, 1913, 1914/15 Dekan der Jur. Fak. der UH

1902 Badischer Hofrat; 1905 Geh. Hofrat

Siehe auch Anhang Sporteinrichtungen an $U H$ 1910-1933 und ihre Mitglieder

E 1899 Ritterkreuz I. Klasse, 1910 Ritterkreuz mit Eichenlaub des Ordens vom Zähringer Löwen; 1913 Ritterkreuz des Ordens Berthold I. 
Qu UAH PA 775, 4835; RA 6761; Fak.-Akte H-II111/74 fol. 161r-163r. - GLA Abt. 235, Fasz. 2213. Briefe: UBH. - Mitteilungen von Familienangehörigen. - Die Rechtswissenschaft der Gegenwart in Selbstdarstellungen. Hrsg. von Hans Planitz. Leipzig 1929. 3. Bd. S. 89-124. (Autobiogr.)

W Hypnotismus und Strafrecht. Berlin 1887. Grundriß zur Vorlesung über deutsches Strafrecht. Marburg 1900. 4. Aufl. 1916. - Der Streit um die Strafrechtsreform. Heidelberg 1912. - Siehe Bibliographie in: Küper (1985) S. 402-405.

MHG 1881-1927 Zs. für die gesamte Strafrechtswissenschaft.

L Catalogus prof. Marburgensis 1 (1927) S. $138 \mathrm{f}$. Mittermaier, Wolfgang: K. von L. zum Gedächtnis in: Zs. für Sexualwissenschaft XIV (1927) S. 321323. Kaufmann, Arthur: Zum 100. Geb. von K. von L. in: Ruperto Carola 5. Jg., Nr. 11/12 (1953) S. 56 f. - Küper, Wilfried: Der Heidelberger Strafrechtslehrer K. von L. in: Semper apertus 2 (1985) S. 375-405. NDB 14 (1985) S. 558 f.; Heidelberger Strafrechtslehrer (1986) S. 145-194. • Lang, Stephan: Das strafrechtliche Lebenswerk K. von L.s. Diss. Heidelberg 1986. - Schroeder (2010) S. 282286; Catalogus prof. Halensis online.

$P$ Bildarchiv UAH; graph. Slg. UBH; Ruperto Carola; NDB.

\section{Lingenthal, von}

siehe Zachariae

Lint, Hermann (Pseudonym)

siehe Levy, Hermann
Loening, Jakob Bernhard Richard (bis 1857: Löwenthal)

1875-1882 Jur. Fak.

Zivilprozeßrecht, Strafrecht, Strafprozeßrecht

* 17. Aug. 1848 Frankfurt/M.

$\dagger$ 19. Sept. 1913 Jena

prot.

V Dr. phil. Zacharias Löwenthal (1810-1884) (mosaisch, seit 1847 prot.; 1857 Umbenennung in Carl Friedrich Loening) Verlagsbuchhändler, s. Der Redaktionsbriefwechsel der Hallischen, Deutschen und Deutsch-Französischen Jahrbücher 1837-1844. Hrsg. von Martin Hundt. Bd. 1: Der Briefwechsel um die Hallischen Jahrbücher. Berlin 2010. Apparat: S. 268 (Register); Frankfurter Biographie 1 (1994) S. 466 f., Schmuhl (2011) S. 6-10, 16 Anm. 70

M Anna Luise geb. Reinach (1812-1892)

(1) 12. Aug. 1877 Margarethe Hedwig Elisabeth geb. Heinze (1858-1928) T von: (siehe) Rudolf $H$.

K 4 S (davon: 1 S $1915 \not x, 1 \mathrm{~S}$ früh $\dagger$ ), 3 T: u.a. Lilli Katharina Hildegard L., Ehefrau von Wolfgang Stammler (1886-1965) Scheidung ca. 1936; seit 1909 Lehrer, 1911-1924 Oberlehrer in Hannover, seit 1914 Privat-Dozent, 1919-1924 apl. Prof. TH Hannover, 1914-1919 Kriegsdienst, Aug.-Dez. 1918 etatm. Dozent U Dorpat, Dez. 1918 Verleihung des Titels „Prof.“, seit 1921 nichtbeamteter a.o. Prof. TH Hannover, 1924-1936 (zwangsweise Versetzung in Ruhestand) o. Prof. für Dt. Sprach- und Literaturgeschichte Greifswald, Privat-Gelehrter: seit 1936 Berlin, seit 1948 in Hösbach (bei Aschaffenburg), 1951-1957 o. Prof. U Fribourg (Schweiz), s. WBIS; Schmid, Alfred A.: W.S. in: Naturanschauung im Mittelalter: Eröffnung der Wolfgang-Stammler-Gastprofessur für Germanische Philologie an der Universität Freiburg. Hrsg. von Walter Blank ... Freiburg/ Schweiz 1994. S. 11-16; Int. Germanistenlexikon 1 (2003) S. 1783-1786; Simon, Gerd u.a.: Chronologie Stammler, Wolfgang, s. http:// homepages.uni-tuebingen.de/gerd.simon/ ChrStammler.pdf (Stand: 12. Juli 2006; Ausdruck im UAH), NDB 25 (2013) S. 50 f.; S von Rudolf S. (1856-1938). - Siehe auch Schmuhl (2011) S. 16 
Vw Bruder: Edgar L. (1843-1919), u.a. seit 1886 o. Prof. für Staats-, Kirchen- und Völkerrecht Halle-Wittenberg, s. WBIS, Catalogus prof. Halensis online, Catalogus prof. Rostochiensium online, Schroeder (2017) S. 157-162. Schwester: Marie Cäcilie Elise (Lili) L. (18501936) Ehefrau von: (siehe) Otto (von) Gierke.

Vw Berta geb. Stammler $\left({ }^{*} 1885\right)$ T von Rudolf S. (1856-1938), s. Hermann Levy: Eintrag unter ( [1. Ehe] Schwester von Wolfgang S. (s.o. Eintrag unter $K$ [inder]). - Siehe Schmuhl (2011) S. 6, NDB 25 (2013) S. $49^{*}, 50^{*}$.

Lb Seit 28. April 1866 Studium an UH, anschl. Berlin; 4. Dez. 1869 Dr. iur. an U Berlin; 1870 Staatsexamen in Frankfurt/M.

Mai 1870-1873 Gerichtsreferendar in Frankfurt/ M.; 1. Aug. 1870-1. Aug. 1871 Kriegsteilnehmer als Einjährig-Freiwilliger im Deutsch-Französischen Krieg.

Bonn: 1873-April 1874 Referendar am Friedensund Landgericht.

UH: 31. Juli 1875 Habilitation; seit 1. Juli 1878 a.o. Prof.; 1881 Rufe an U Bonn und Gießen abgelehnt.

U Jena: 17. Nov. 1881 Ern. zum o. Prof.; 1. April 1882 Dienstantritt.

1912 Geh. Rat

Qu UAH PA 1941; Fak.-Akte H-II-111/83. • Auskunft: Ev. Kirchengemeindeamt Heidelberg (Traubuch 1877).

$W$ Der Vertragsbruch und seine Rechtsfolgen. Straßburg 1876. - Der Reinigungseid bei Ungerichtsklagen im deutschen Mittelalter. Heidelberg 1880. Die Widerklage im Reichs-Civilprocess. Berlin 1881. - Geschichte der strafrechtlichen $\mathrm{Zu}$ rechnungslehre. Jena 1893.
$L$ Wer ist's (1909) S. 851; Biogr. Jahrbuch 18 (1913) Sp. 107; Schroeder (2010) S. 332 f. • Schmuhl, Elisabeth: R. L. ... Ein Strafrechtsgelehrter der „Historischen Schule“. Leben und Werk. Stuttgart 2011. • Rechtsgelehrte der U Jena (2012) S. 171-192; Deutsche Biographie, s. https://www.deutsche-biographie.de/gnd117154466.html [07.11.2017]; Schroeder (2017) S. 168-171.

$P$ Bildarchiv UAH.

\section{Loeschcke, Hermann}

1929-1931 (Honorar-Prof.) Med. Fak.

Pathologie

* 13. Mai 1882 Dorpat (Russisches Kaiserreich; heute: Tartu, Estland)

$\dagger \quad$ 27. Sept. 1958 Rostock ev.

V Georg L. (1852-1915), u.a. Prof. für Archäologie Bonn, s. NDB 15 (1987) S. 61f.; Kinne, Johanna: Das Akademische Kunstmuseum der U Bonn unter der Direktion von G. L. ... Petersberg 2004.

M Katharine Emilie geb. Jäger (1852-1912) T von Gustav J. (1808-1871) Maler, seit 1847 Direktor der Kunstakademie Leipzig, s. ADB 13 (1881) S. 649 f., WBIS

( 20. Dez. 1910 Dr. phil. Thekla Eleonore Eva geb. Freytag (1877-1932) Enkelin von Matthias Jacob Schleiden (1804-1881), u. a. 1850-1863 o. Prof. für Naturwissenschaften (Botanik) Jena, s. Jahn, Ilse, Schmidt, Isolde: M.J.S. - Sein Leben in Selbstzeugnissen. Halle/S. 2005.

( 3). Sept. 1932 Marianne geb. Haeckel (18971947) Großnichte von Ernst H. (1834-1919) Zoologe, s. NDB 7 (1966) S. 423-425, WBIS

๑ 27. Mai 1949 Gerta geb. Haeckel (1900-1978) Schwester von Marianne $\mathrm{H}$.

K 7, u.a. Hans Hermann L. (1912-1986), u.a. 1964-1981 Prof. für Physiologie Bochum, s. Wer ist wer (1962) 14. Ausg., S. 921 (hier auch Vorfahren mütterlicherseits genannt), WBIS; Kiwull-Schöne, H.: Institute stellen sich vor: Zur Geschichte des Inst. für Physiologie der Ruhr-Universität Bochum (online) 
Vw Brüder: Gerhard L. (1880-Juli 1912), u.a. seit Juni 1912 a.o. Prof. für Theologie an U Göttingen, s. Lietzmann, Hans: G.L. in: Biogr. Jahrbuch 17. Jg. (1912) S. 43-45. - Siegfried L. (1883-1956) Archäologe, Abt.-Direktor am Landesmuseum Trier, s. WBIS. - Reinhard L. (1887-1920) Maler, s. WBIS.

Lb Seit WS 1901/o2 Studium an U Bonn, anschl. Berlin, Bonn.

Bonn: Jan. 1906 Staatsexamen; 22. Juli 1906 Approbation; 7. Febr. 1907 Dr. med. an U; Juli 1906April 1908 Assistent an Chirurgisch-Gynäkolog. Abt. des Krankenhauses der Friedrich-WilhelmStiftung.

Köln: Sept. 1908-April 1910 Assistent am Patholog. Inst. der Akademie für Praktische Medizin an U; 1910-1913 Prosektor am Patholog. Inst. und Vorsteher der Patholog. Abt. am Augusta-Hospital; 13. Okt. 1911 Habilitation für Allg. Pathologie und Patholog. Anatomie an U.

Mannheim: Okt. 1913-März 1931 Prosektor und Leiter des Patholog. Inst. der Städtischen Krankenanstalten. • In dieser Zeit:

UH: Seit März 1929 o. Honorar-Prof; 1929-1931 Vorlesungsankündigungen.

U Greifswald: 1. April 1931-1947 0. Prof.; nach dem Krieg vorübergehend Arbeitsverbot; L. darf aber weiterhin Forschungen durchführen, siehe hierzu Lexikon Greifswalder Hochschullehrer (2004) S. 145. - In dieser Zeit:

1939-1945 Kriegsdienst.

U Rostock: 15. April 1948-31. Aug. 1955 (Emeritierung) o. Prof.

E 1936 Mitglied der Dt. Akademie der Naturforscher Leopoldina Halle/S.; 1955 Mitglied der Dt. Akademie der Wissenschaften zu Berlin. 1956 Dr. med. h.c. Greifswald.
Qu UAH PA 1061, 4861. - GLA Abt. 235, Fasz. 2259. Rektoratsreden - online. Siehe auch Archiv der Dt. Akademie der Naturforscher Leopoldina Halle/S. - Mitteilungen: Herr Prof. Dr. Hans Hermann Loeschcke $(\dagger)$.

$W$ Über den Bau des Lungenacinus und der Lokalisation der Tuberkulose in ihm in: Brauers Beiträge zur Klinik der Tuberkulose 56 (1923). • Vorstellungen über das Wesen von Hyalin und Amyloid auf Grund serologischer Versuche in: Zieglers Beiträge zur Pathologie und pathologischen Anatomie 77 (1927). - Störungen des Luftgehalts der Lunge, Atelektase und Emphysem in: Henke-Lubarsch, Handbuch der speciellen Pathologie (1928). - Gesamtbild der Tuberkulose unter immunbiologischen Gesichtspunkten in: Zentralblatt der inneren Medizin 16 (1931).

L Kürschner (1931) Sp. 1786 f., (1950) Sp. 1237 f.; Handels-Hochschule Mannheim 1907-1932 (1932) S. 30; Wer ist wer (1958) S. 781. • Terbrüggen, August: Gedenkblätter. H. L. in: Verh. der Dt. Gesellschaft für Pathologie. Stuttgart 1959. S. 383-386 (mit Werkverz.). • Über H.L. in: Unschuld, Paul U.: Die Ärztin und der Maler. Carl Jung-Dörfler und Hedwig Danielewicz ... Düsseldorf 1994. S. 33 f., 8o f. u. ö. • Bauer (2002) S. 204 (Register). • Reddemann, Hans: H.L. in: Berühmte und bemerkenswerte Mediziner aus und in Pommern. Schwerin 2003. S. 105 f. - Lexikon Greifswalder Hochschullehrer (2004) S. 144f. (hier: Loeschke); Catalogus prof. Rostochiensium online; Deutsche Biographie, s. https://www.deutsche-biographie. de/gnd119516756.html [07.11.2017].

\section{Loewe, Siegfried Walter}

\author{
1929-1933 (Honorar-Prof.) Med. Fak. \\ (1951-1963 (Honorar-Prof.) Med. Fak.) \\ Pharmakologie
}

* 19. Aug. 1884 Fürth

$\dagger \quad$ 24. Aug. 1963 Salt Lake City (Utah) mosaisch

V Friedrich August L. (1849-1888) Bankdirektor M Clotilde geb. Blumenthal ( $\left.{ }^{\star} 1862\right)$ 
( 27. Okt. 1919 Ide Adelheid Victoria geb. Witte (1894-1971)

K $\quad 2$ S, 1 T

Lb Seit WS 1902/03 Studium der Medizin an U Freiburg/Br., anschl. Berlin, seit 1905 Studium der Chemie an U Straßburg, zuletzt München; Mai 1907 med. Staatsexamen in München.

U Straßburg: 1907-1910 Assistent am Physiolog.Chemischen Inst.; Juli 1908 Dr. med.; 1909-1910 Militärdienstpflicht als Einjährig-Freiwilliger.

U Leipzig: SS 1910-WS 1911/12 Studium der Physik, Chemie; seit April 1910 Leiter des Chemischen Labors der Psychiatr. Klinik und Mitarbeiter am Physikalisch-Chemischen Inst.

U Göttingen: Seit April 1912 Assistent am Pharmakolog. Inst.; Juli 1913 Habilitation für Pharmakologie; April 1915-1918 stellvertr. Direktor des Pharmakolog. Inst.; seit April 1918 a. o. Prof. • In dieser Zeit:

Aug. 1914-April 1915 Kriegsdienst.

U Tartu (Estland): Seit WS 1920/21 o. Prof. und Direktor des Inst. für Pharmakologie und Med. Chemie; 1922-1928 auch Leiter der Pharmakolog. Abt. des Estnischen Arzneimittel-Untersuchungsamtes in Tartu.

Mannheim: Aug. 1928-Aug. 1933 (Entlassung) Leiter des Hauptlaboratoriums und Hormon-Forschungs-Inst. der Städtischen Krankenanstalten. • In dieser Zeit:

UH: Seit 27. April 1929 o. Honorar-Prof.; 1929-1933 Vorlesungsankündigungen; 2. Aug. 1933 Entzug der Lehrbefugnis aus rassischen Gründen (Gesetz zur „Wiederherstellung des Berufsbeamtentums“).

1933 Ausreise in die Schweiz (mit e. estnischen Pass); 1935 Emigration in die USA.

New York: 1936-1945 Forschungs-Mitglied, u.a. im Labor des Mount Sinai Hospital; 1936-1943 Forschungsarbeiten am Montefiore Hospital.
Salt Lake City: 1946-1957 (Emeritierung) Research Prof. am Pharmakolog. Inst. der U of Utah.

UH: 15. Febr. 1951 Wiederverleihung des Titels e. o. Honorar-Prof.; 1951-1963 keine Vorlesungsankündigungen.

1925 Entdecker der weiblichen und 1927 der männlichen Sexualhormone im Pflanzenreich

Die nach den beiden ersten Leitern des Hauptlaboratoriums genannte Lesser-Loewe Foundation e. V. fördert biochemische und endokrinologische Forschung am Universitätsklinikum Mannheim; die Stiftung verleiht seit 2006 jährlich e. heute mit 5000.- Euro dotierten Lesser-Loewe-Wissenschaftspreis.

E Mitglied: 1930 Dt. Pharmakolog. Gesellschaft (1935 Streichung aus Mitgliederliste, 1958 Ehrenmitglied), 1932 Dt. Akademie der Naturforscher Leopoldina Halle/S., 1935 Academy of Science New York, 1955 Dt. Akademie der Wissenschaften Berlin. 1956 Dr. h.c. Greifswald.

Qu UAH PA 1062, 4864. - GLA Abt. 235, Fasz. 1524. Briefe: University of Utah Libraries, Special Collections. - Siehe auch Archiv der Dt. Akademie der Naturforscher Leopoldina Halle/S.

W Pharmakologie des Uterus in: Bethes Handbuch der normalen und pathologischen Physiologie 14 (1926). - Die quantitativen Probleme der Pharmakologie in: Ergebnisse der Physiologie 27 (1928) S. 47-187. - The marihuana problem in the city of New York. New York 1944. (Mitverf.)

MHG 1915-1921 Therapeutische Monatshefte.

$L$ Catalogus prof. Gottingensium (1962) S. 84; Dictionary of Emigrés 2 (1983) S. 741; Chronik Ärzte H (1985) S. 135 f.; NDB 15 (1987) S. 85 f.; Mussgnug (1988) S. 298 (Register). - Zur Geschichte der Endokrinologie und Reproduktionsmedizin. 256 Biographien und Berichte. Hrsg. von Gerhard Bettendorf. Berlin 1995. S. 355 f. • Lindner/Lüllmann (1996) S. 231 u.ö.; WBIS; Bauer (2002) S. 204 (Register); UH im Nationalsozialis- 
mus (2006) S. 10. • Löffelholz, K., Trendelenburg, U.: Verfolgte deutschsprachige Pharmakologen 1933-1945. 2. Aufl. Frechen 2008. S. 115. • Über S. L. in: Goerig, M., Goetz, A. E.: Mitarbeiter und Herausgeber mit jüdischer Herkunft der ersten dt. Anästhesiezeitschriften in: Der Anaesthesist 9 (2010) S. 834f. - Lexikon jüdischer Einwohner Hs (2011) S. $260 \mathrm{f}$.

$P$ Bildarchiv UAH; Chronik Ärzte H.

\section{Löwenthal, Richard}

siehe Loening

\section{Loos, Johann Jacob}

1802-1810 Med. Fak.

Arzneiwissenschaft

* 10. Nov. 1774 Heidelberg

$\dagger \quad$ 19. Sept. 1838 Heidelberg ev.

V Johann Martin L. (1743-1815) Konditor, Handelsmann

M Eva Katharina geb. Ammann (1750-1834)

( unverheiratet.

Lb Seit April 1794 Studium der Medizin an UH, anschl. Jena, Würzburg.

UH: 1800 Dr. med.; seit 1802 Privat-Lehrer (= Privat-Dozent); seit 10. April 1805 a. o. Prof. ohne Bezahlung; seit 1809 o. Prof.; 1810 Niederlegung der Professur aus Krankheitsgründen. • In dieser Zeit:

H: Niedergelassener Arzt; L. übt - aus gesundheitlichen Gründen - Praxis wohl nur vorübergehend aus (seit Anfang 1810 geistig umnachtet).

Goethe schreibt über L. am 1. Okt. 1814 aus Heidelberg an seine Frau Christiane: „... Ein wunderlicher Mann redete mich an, Nahmens Loos, ein Arzt, wollte Augusten [August, Sohn Goethes] gekannt haben. Ich erfuhr allerley von ihm“, aus: Goethes Leben von Tag zu Tag. Zürich 1993. Bd. 6: 1814-1820. S. 125.

Qu UAH PA 1947; RA 6341, 6635. GLA Abt. 205, Fasz. 371. - Ludwig Achim von Arnim. Briefwechsel 1805-1806. Hrsg. von Heinz Härtl ... T. 1: Text. Berlin 2011. S. 339, 653 .

$W$ Entwurf einer medicinischen Pharmakologie nach den Principien der Erregungstheorie. Erlangen 1802 . 2. Aufl. 1813. • Regeln zur Verlängerung des Lebens aus dem 17. Jahrhundert. Mannheim 1804. - Systematische Beschreibung der außer Gebrauch gekommenen Arzneimittel. Darmstadt 1808. Gedanken über den medicinischen Unterricht. Heidelberg 1810.

$L$ Stübler (1926) S. 237 f.; Krebs/Schipperges (1968) S. 25; Chronik Ärzte H (1985) S. 136; Semper apertus 2 (1985) S. 136; WBIS.

\section{Lossen, Friedrich Christian Hermann}

1872-1894 Med. Fak.

1894-1908 (Honorar-Prof.) Med. Fak.

Chirurgie

* o7. Nov. 1842 Emmershäuser Hütte (bei Limburg/Lahn; heute: Emmershausen, Ortsteil von Weilrod)

$\dagger \quad$ 27. Aug. 1909 Heidelberg kath.

V Josef Gotthard L. (1795-1866) Eisenhüttenbesitzer

M Marianne geb. Kathrein, s. Hessisches ArchivDokumentations- und Informationssystem (HADIS), Abt. 362/33 Wiesbaden B

๑ Maria geb. Beckers ( $\dagger$ nach 1909)

K 5, darunter mind. 2 S: u.a. Richard L. (18751952), u. a. seit 1912 Gymnasial-Prof. Karlsruhe, 1924-1934 H, s. Das „Goldene Buch“ des KFG (1994) S. $141 \mathrm{f}$. 
Vw Vetter: Dr. phil. Max L. (1842-1898) 1863 Gründer (1871 nach Übertritt zum Altkatholizismus Dimission) des Kath. Studentenvereins Arminia an U Bonn, 1882 Mitbegründer des Altkath. Studentenvereins Cheruskia Bonn; seit 1881 Sekretar der Bayer. Akademie der Wissenschaften München; s. Koschera, Daniel: „Hat sich jüngst ein neuer Verein von katholischen Studenten gebildet" - Bavaria und die Bonner Union 1844-1867. Ein Beitrag zur Frühzeit katholischer Studentenvereinigungen in Deutschland. Magisterarbeit am Histor. Seminar der U Köln. Köln 2004.

Lb Seit SS 1862 Studium an U München, seit SS 1864 Würzburg, SS 1866 Berlin; März 1866 Dr. med. an U Würzburg; nach 24. Juli 1866 freiwilliger Hilfsarzt im preußischen Feldlazarett nach Gefecht bei Tauberbischofsheim während des PreuBisch-Deutschen Krieges; WS 1866/67 Staatsexamen in Berlin; SS 1867-WS 1867/68 Eigenstudien in Berlin und Wien.

U Halle-Wittenberg: Ostern 1868-Ostern 1870 Assistent an Chirurg. U-Klinik.

1870/71 Arzt während des Deutsch-Französischen Krieges in Lazaretten in Mannheim, H, Karlsruhe.

UH: 1871-1875 Assistent an Chirurg. U-Klinik; 18. Nov. 1871 Habilitation; SS 1872 Beginn seiner Lehrtätigkeit; seit 14 . Okt. 1875 a. o. Prof.; SS 1876 zunächst inoffizieller (einmaliges Honorar von 1000.- Mark), WS 1876/77 offiziell bestellter Vertreter des Lehrstuhls für Chirurgie und interimistischer Leiter der Chirurg. U-Klinik (für Gustav Simon †) mit e. einmaligen Honorar von 1500.- Mark; 1884-1907 Leiter der Chirurg. Abt. und 1890-1906 II. Direktor (I. Direktor: Oswald Vierordt $\dagger$ 1906), 1906-1907 kommissar. Direktor der U-Kinderklinik Luisen-Heilanstalt (seit 1907 neuer Direktor: Emil Feer); seit 15. Aug. 1894 Honorar-Prof.; seit 21. Febr. 1908 o. Honorar-Prof.; SS 1908 letzte Vorlesungsankündigung Über Hernien, 2 Stunden wöchentlich. • In dieser Zeit:

H: Okt. 1890-1909 (zus. mit Franz Chelius bis 1896) Chirurg an neuerrichteter Privatklinik Josephshaus.
Nach ihm wird die Lossensche Regel bei der Vererbung der tödlichen Bluterkrankheit (Hämophilie) benannt (1877)

Langjähriger Vorsitzender der Heidelberger Sektion des Alpenvereins

1902 Hofrat

Qu UAH PA 1946. Adreßbuch der Stadt H 189o1909 - online. Briefe: UBH.

$W$ Die Bluterfamilie Mampel in Kirchheim bei Heidelberg in: Dt. Zs. für Chirurgie 7 (1876), 76 (1905). - Neurektomie des Trigeminus II nach osteo-plastischer Resection des Jochbeins nebst Vorschlag zu einer neuen Schnittführung in: Zentralblatt für Chirurgie Nr. 5 (1878).

Bearb. Hueter, Carl: Grundriß der Chirurgie. 2.7. Aufl. Leipzig 1883-189o.

L Stübler (1926) S. 319; Badische Biographien 6 (1935) S. 576-578. • Über H. L. in: Bonnet, Rudolf: Männer aus und in Nassau nebst einigen Frauen - ein Quellenweiser. Frankfurt/M. 1940. S. 83. Lossen, Heinz: Dr. med. H.L., seine Ahnen und Nachkommen. Darmstadt 1953. Chronik Ärzte H (1985) S. 136; WBIS; 150 Jahre Pädiatrie in H (2010) S. 40; Deutsche Biographie, s. https://www. deutsche-biographie.de/gnd117221163.html [07.11. 2017].

$P$ Bildarchiv UAH; graph. Slg. UBH; Chronik Ärzte $\mathrm{H}$.

\section{Lossen, Wilhelm Clemens}

1866-1877 Phil. Fak.

Chemie

* $\quad$ 08. Mai 1838 Kreuznach (heute: Bad K.)

$\dagger$ 29. Okt. 1906 Aachen

- Aachen

kath. 
V Dr. med. Valentin L. (1803/04-1884) Arzt

M Wilhelmine Charlotte geb. Mayer (1805-1844)

๑ 1868 (Aachen) Maria geb. Pelzer (1837-1908)

K 1 S, s. NDB 15 (1987) S. 202*

Vw Onkel: Carl Maximilian L. (1793-1861) Montanindustrieller, Oberberg-Rat, s. NDB 15 (1987) S. 200 f. • Bruder: Karl August L. (18411893), u.a. seit 1873 Landesgeologe an Preußischer Geologischer Landesanstalt Berlin, seit 188 o a.o. Prof. für Geologie U Berlin, s. Poggendorff 4 (1904) S. 917, WBIS, Wagenbreth (1999) S. 248 (Register).

Lb Seit WS 1857/58 Studium an U Gießen, seit 1859 Göttingen; Aug. 1862 Dr. phil. an U Göttingen; Assistent am Chemischen Labor: 1862 Polytechnikum Karlsruhe, 1863 Halle-Wittenberg (hier nur Zulassung von prot. Dozenten).

UH: 8. Febr. 1866 Habilitation; seit 20. Jan. 1870 a.o. Prof.

U Königsberg (Preußen): WS 1877/78-SS 1903 (Ruhestand) o. Prof. und Direktor des Chemischen Laboratoriums.

H: Seit 1904 Wohnsitz in Gaisbergstr. 4; 29. Okt. 1906 L. stirbt während e. Besuchs bei Verwandten in Aachen.

1895 Geh. Reg.-Rat

1865 Entdecker u.a. des Hydroxylamins, e. kristallinen anorganischen chemischen Verbindung; auch die Entdeckung des nach ihm benannten Lossen-Abbaus, e. chemischen Reaktion, geht auf seine Arbeiten zurück; siehe Zinner, Gerwalt: W.L. und die Entdeckung des Hydroxylamins vor 125 Jahren in: Chemiker-Zeitung 114,6 (1990) S. 197204.

1876 Gründungsmitglied der Görres-Gesellschaft zur Pflege der Wissenschaft, e. der ältesten (kath.) dt. Wissenschaftsgesellschaften mit Sitz in Bonn

E 1887 Mitglied der Dt. Akademie der Naturforscher Leopoldina Halle/S.
Qu UAH PA 1948; Fak.-Akte H-IV-102/66. Briefe: UBH. - Siehe auch Archiv der Dt. Akademie der Naturforscher Leopoldina Halle/S.

$W$ Über das Cocain. Diss. Göttingen 1862. • Fortsetzung der Untersuchungen über die Coca und das Cocain in: Annalen der Chemie und Pharmacie 121 (1862) S. 372-375 (Mitverf.: Friedrich Wöhler). Über das Hydroxylamin in: Zs. für Chemie. N.F. 1 (1865) S. 551. Formeln zur Berechnung des Molecularvolumens organischer Verbindungen in: Liebigs Annalen für Chemie 254 (1889); Auftreten polymorpher Modification bei Hydroxylaminderivat in: ebd. 281 (1894). - Ausbildung und Examina der Chemiker. Heidelberg 1897. • Der Anteil der Katholiken am akademischen Lehramt in Preußen. Köln 1900.

$L$ Wer ist's (1906) S. 725. Cohn, Lassar: W.L. † in: Berichte der Dt. Chemischen Gesellschaft 40 (1907) S. 5079-5086. Poggendorff 5 (1925) S. 768; WBIS; NDB 15 (1987) S. 202 (hier irrtümlich Berlin als L.s letzten Wohnsitz genannt). Grzybowski, A.: The history of cocaine in medicine and its importance to the discovery of the different forms of anaesthesia in: Klinika oczna (2007) 109(1-3) S. 101-105. [Artikel in polnischer Sprache.] - Tilitzki 1 (2012) S. 799 (Register).

$P$ Bildarchiv UAH.

\section{Lüttge, Willy Friedrich Otto}

1922-1928 Theol. Fak.

Systematische Theologie, Religionsphilosophie

* 11. Aug. 1882 Berlin

$\dagger \quad$ o6. Juni 1928 Heidelberg

ev.

V Udo L., Eisenbahnobersekretär

M Amanda geb. Eggebrecht ( $\dagger$ nach 1928)

$\infty$ 20. Okt. 1920 Margarethe geb. Thiel $\left({ }^{\star} 1894\right.$ $\dagger$ nach 1941), siehe Nachlaß von Dora Clauß in UBH (Signatur: Heid. Hs. 4127)

$\mathrm{K}$ keine. 
Lb Seit WS 1901/o2 Studium an U Berlin, seit Okt. 1905 am Predigerseminar in Wittenberg; 1905 I., 1908 II. theol. Prüfung vor Brandenburgischem Konsistorium; 29. Juli 1908 Lizentiatenprüfung an U Berlin.

Anfang 1909 Studienaufenthalt in Frankreich; Juni 1909 Ordination zum Hilfsprediger.

Hennickendorf (bei Berlin; heute: Ortsteil von Rüdersdorf): Seit 1. Juni 1909 Pfarrverwalter.

U Berlin: 1910 Habilitation mit e. Untersuchung über „Religion und Dogma. Ein Jahrhundert innerer Entwicklung im französischen Protestantismus“; seit SS 1911 Privat-Dozent; Dez. 1917 Verleihung des Titels „Prof.“; 1914-1919 Kriegsdienst: seit 1914 Militärlazarett-Pfarrer in Berlin, seit 1916 Festungsgarnisons-Pfarrer in Breslau, seit 1917 Pfarrer an Alter Garnisonskirche in Berlin-Mitte; Mai 1919 Wiederaufnahme seiner Lehrtätigkeit an U; seit 7. Dez. 1919 nichtetatm. a. o. Prof. für Theologie und Religionsphilosophie.

UH: Seit 4. Mai 1922 o. Prof. und Direktor der Systematischen Abt. am Wiss.-Theol. Seminar als Nachf. von Georg Wobbermin.

1926/27 Dekan der Theol. Fak. der UH

Siehe auch Anhang Sporteinrichtungen an $U H$ 1910-1933 und ihre Mitglieder

E 1921 D. theol. Königsberg (Preußen).

Qu UAH PA 4886; Acc. 37/16. - GLA Abt. 235, Fasz. 2268. Briefe, siehe Stader Jahrbuch. Hrsg. vom Stader Geschichts- und Heimatverein. N. F. 54 (1964) S. 37; Kalliope.

$W$ Die Trennung von Staat und Kirche in Frankreich. Tübingen 1912. - Das Christentum in unserer Kultur. Leipzig 1925. • Die Dialektik der Gottesidee in der Theologie der Gegenwart. Tübingen 1925. Evangelisches Christentum und deutsche Bildung. Berlin 1926. - Religion und Kunst. Gütersloh 1929 (posthum erschienen).
$L$ Kürschner (1928/29) Sp. 1465; RGG 3 ( $\left.{ }^{2} 1929\right)$ S. 1746 b; WBIS; Jansen (1992a) S. 167 (Register); Fix (1994) S. 132-134; BBKL XVI (1999) Sp. 966972. - Wolfes, Matthias: Protestantische Theologie und moderne Welt ... Berlin 1999. S. 292. • Die „Murren“ des Hans Freiherr von Campenhausen: „Erinnerungen, dicht wie ein Schneegestöber“. Autobiografie. Hrsg. von Ruth Slenczka. Norderstedt 2005. S. 96. Wissenschaftliche Sammlungen an der Humboldt-Universität zu Berlin „Sammlungsobjekte Kabinette des Wissens“, Personen, s. http://www.sammlungen.hu-berlin.de/dokumen te/17257/ (abgerufen am 27. Juli 2016). • Deutsche Biographie, s. https://www.deutsche-biographie. de/gnd117300365.html [07.11. 2017].

$P$ Bildarchiv UAH.

\section{Lurz, Friedrich Leonhard}

1925-1945 Med. Fak.

Chirurgie

* 03. März 1895 Unterwittighausen (bei Tauberbischofsheim; heute: Ortsteil von Wittighausen)

$\dagger \quad$ 04. März 1977 Mannheim

kath.

V Georg Philipp L. (1851-1915) Mühlenbesitzer

M Maria Barbara geb. Schmitt (1850-1921)

( 3. Sept. 1920 Lina geb. Luthringshausen $\left({ }^{*} 1895\right)$

K $\quad 1 \mathrm{~S}, 1 \mathrm{~T}$

Lb Seit WS 1914/15 Studium an U Würzburg, WS 1917/18 Immatrikulation an UH (seit Okt. 1917 Adresse: Kaiserslautern, Reservelazarett, seit Kriegsnotsemester 1919 private Wohnadressen in H); 1915-1918 Kriegsdienst.

UH: 8. Nov. 1919 Staatsexamen in H; 26. Febr. 1920 Dr. med.; seit 15. Nov. 1920 Assistent an Chirurg. U-Klinik; 29. Juli 1925 Habilitation; seit 4. Aug. 1930 nichtplanm. a. o. Prof.; seit 3. Nov. 1939 apl. Prof.; 31. Okt. 1945 Entlassung gemäß Erlaß der amerik. Militärregierung. • In dieser Zeit: 
Mannheim: Seit 16. Febr. 1930 Chefarzt am Theresien-Krankenhaus; 15. Okt. 1934-1962 Chefarzt der Chirurg. und Urolog. Abt. des Diakonissen-Krankenhauses.

Qu UAH PA 1063, 4890; B-3027/2, B-3029/6. GLA Abt. 235, Fasz. 2271. Mitteilungen: Herr Dr. med. Hans Lurz (†), Sohn.

$W$ Über Nierentransplantationen in: Dt. Zs. für Chirurgie 194 (1926) S. 25-49; Studien am Ureter. Ein Beitrag zur konservativen Uretersteinbehandlung in: ebd. 211 (1928) S. 58-61. • Ein Zeichen der Nierentuberkulose in: Zs. für Urologie (1929). L., L., Lurz, Hans: Der muskelschonende Lumbalschnitt in: Allg. und spezielle chirurgische Operationslehre. 2. Aufl. Bd. 8: Die Eingriffe an den Harnorganen, Nebennieren und männlichen Geschlechtsorganen. Hrsg. von N. Guleke, R. Zenker ... Berlin 1961. S. 98-103.

L Kürschner (1931) Sp. 1815, (1940/41) Sp. 102; Chirurgen-Verzeichnis $\left({ }^{4} 1958\right)$ S. 529, $\left({ }^{5} 1969\right)$ S. 568; WBIS. Über F. L. L. in: Familientreffen der Schule Lurz. Miltenberg 1980. Chronik Ärzte H (1985) S. 136; Jansen (1992) S. 395. Streiflichter aus der Geschichte der Urologie. Hrsg. von D. Schultheiss, P. Rathert, U. Jonas. Berlin 200o. S. 231. Halling, T., Bellmann, J., Fangerau, H.: L. L. ... The urologist and his instrument: A medical career during the 1930 s up to the 6os in Germany in: The Journal of Urology (2013) Vol. 189, No. 4, S. e450. • Urologie 1945-1990: Entwicklung und Vernetzung der Medizin in beiden deutschen Staaten. Hrsg. von Thorsten Halling, Friedrich Moll, Heiner Fangerau. Berlin 2015. S. 103, 114, 124. • Deutsche Biographie, s. https://www.deutsche-biographie.de/gn d1079040412.html [07.11. 2017].

P Bildarchiv UAH; Chronik Ärzte H.

\section{Lust, Franz Alexander}

1913-1920 Med. Fak.

Kinderheilkunde

* 28. Juli 188o Frankfurt/M.

$\dagger \quad$ 23. März 1939 Baden-Baden (Suizid)

mosaisch, seit 1920 getauft

V Martin L., Kaufmann

M Clara geb. Levi († nach März 1939)

๑ 29. Mai 1910 Lilly geb. Hamburger (1889-1992) Sängerin; 1939/40 Emigration in die USA, 1990, im Alter von 101 Jahren, Rückkehr nach Karlsruhe, s. Werner, Josef: Hakenkreuz und Judenstern (1988) S. 552 (Register); Mührenberg, Anke: Biographie Lilly Lust in: Blick in die Geschichte. Hrsg. vom Forum für Stadtgeschichte und Kultur. Nr. 67. Karlsruhe vom 24. Juni 2005 online (Ausdruck im UAH mit Photo).

K $\quad 1 \mathrm{~S}, 1 \mathrm{~T}$

Lb Seit WS 1899/1900 Studium an UH; Winter 1900/01 erstes militärisches Diensthalbjahr als Einjährig-Freiwilliger in München; WS 1900/o1 Forts. des Studiums an U München, seit SS 1901 Berlin, seit SS $1902 \mathrm{H}$.

H: 3. März 1904 Ärztl. Staatsexamen; 28. März 1904 Approbation.

UH: Assistent: März-Sept. 1904 Med. U-Klinik, anschl. Pharmakolog. Inst.; 8. Dez. 1904 Dr. med.

Berlin: Okt.-Nov. 1904 Absolvierung e. bakterio$\log$. Kurses am Inst. für Infektionskrankheiten.

Tarmstedt (Niedersachsen): Jan.-Juni 1905 Zweites militärisches Diensthalbjahr als Einjährig-Freiwilliger.

Wiesbaden: Seit 1. Sept. 1905 Assistent an Innerer Abt. des Städtischen Krankenhauses.

UH: Seit Okt. 1907 Assistent, seit Febr. 1919 Oberarzt an U-Kinderklinik Luisen-Heilanstalt; 31. Jan. 1913 Habilitation für Pädiatrie; 1914-1918 Kriegsdienst als Oberarzt an preußisch-badischer Kadettenschule im Kadettenkrankenhaus in Karlsruhe; 
seit 24. Febr. 1919 nichtetatm. a. o. Prof.; WS 1920/ 21 Beurlaubung von U, um sein „Amt in Karlsruhe vorzubereiten“" (aus: UAH PA 1064).

Karlsruhe: 1920-1. April 1933 (Entlassung aus rassischen Gründen) (Gründungs-)Direktor der Badischen Landesanstalt für Säuglings- und Kleinkinderfürsorge, e. Stiftung von Großherzogin Luise von Baden (1838-1923) am Durlacher Tor. In dieser Zeit:

Karlsruhe: 1918-1933 Vorstand/Geschäftsführer des Badischen Landesverbandes für Säuglingsund Kleinkinderfürsorge; 1920-1933 niedergelassener Kinderarzt; 1933-1938 (Berufsverbot) Kinderarzt mit Praxis in L.s Privatwohnung in der Bachstraße 19.

Baden-Baden: 1938-1939 Wohnsitz in Meisenkopfstraße 1; in dieser Zeit:

KZ Dachau: 10. Nov.-12. Dez. 1938 Deportation.

Karlsruhe: 1950 erhält die von L. geleitete Kinderklinik den Namen Franz-Lust-Kinderklinik; 1995 wird e. Straße am Städtischen Klinikum in FranzLust-Straße umbenannt

E Zwischen 1914 und 1918: Ehrenkreuz für Kriegsteilnehmer; Kriegsverdienstkreuz; Ritterkreuz des kaiserlich-österr. Franz-Joseph-Ordens.

Qu UAH PA 1064, 4892; RA 6330; Fak.-Akte HIII-111/156 fol. 121r-132r (Habilitation). GLA Abt. 235, Fasz. 2272.
$W$ Über den Wassergehalt des Blutes und sein Verhalten bei den Ernährungsstörungen der Säuglinge in: Jahrbuch für Kinderheilkunde 73 (1911). • Diagnostik und Therapie der Kinderkrankheiten. Wien 1918 (u.d. T.: Pädiatrische Diagnostik und Therapie ... 29. Aufl. München 1997). • Medikamentöse Therapie der Tuberkulose in: Handbuch der Kindertuberkulose (1929). • Erkrankungen der Nase und des Rachens in: Handbuch der Kinderheilkunde. Hrsg. von M. von Pfaundler ... 4. Aufl. Bd. 3. Berlin 1931. S. 52-282.

$L$ Kürschner (1931) Sp. 1816f.; Wer ist's (1935) S. 1010 f.; WBIS; Chronik Ärzte H (1985) S. 136 . Lutz, Wille: U-Kinderklinik Luisen-Heilanstalt ... 1860-1985 in: Der Kinderarzt 16. Jg., Nr. 7 (1985) Sp. 1006. Werner, Josef: Hakenkreuz und Judenstern. Das Schicksal der Karlsruher Juden im Dritten Reich. Karlsruhe 1988. S. 552 (Register). • Vom Großherzoglichen Viktoria-Pensionat zur FranzLust-Kinderklinik. 75 Jahre Kinder- und Kinderchirurgische Klinik Karlsruhe 1920-1995. Hrsg. von Frank Schindera. Karlsruhe 1995. Biographie von F. L. in: Mührenberg, Anke: Gedenkbuch für die Karlsruher Juden online unter http:/gedenkbuch.informedia.de/gedenkbuch.php?PID= 12\&name=2610\#top (Stand: Sept. 2005; Ausdruck im UAH). - Deutsche Biographie, s. https://www. deutsche-biographie.de/gnd1012556492.html [07. 11. 2017]. 
M

\section{Magnus, Rudolf}

1900-1908 Med. Fak.

Pharmakologie

* 02. Sept. 1873 Braunschweig

$\dagger \quad$ 25. Juli 1927 Pontresina (Schweiz)

$\theta$ Zürich (Feuerbestattung) mosaisch, seit ca. $1902 \mathrm{ev}$.

V Dr. iur. Otto M. (1836-1920) Rechtsanwalt

M Sophie geb. Isler (1840-1920)

@ 1902 Gertraut Helene geb. Rau (1875-1947)

$\mathrm{K} \quad 2 \mathrm{~S}, 3 \mathrm{~T}$

Vw Schwester: Helene Emma M. (1880-1971) Ehefrau von Ephraim Moses Lilien (1874-1925) Jugendstil-Künstler, Zeichner, Illustrator, Radierer, s. NDB 14 (1985) S. 550 f.; E. M. L.: Jugendstil, Erotik, Zionismus. Hrsg. von Oz Almog, Gerhard Milchram. Wien 1998.

Vw Großvater: Dr. phil. Meyer Isler (1807-1888) seit 1832 Bibliothekar, 1872-1883 Direktor der Hamburger Stadtbibliothek, s. Erinnerungen des Hamburger Bibliothekars M.I. ... Nach der Bearbeitung von Helene Lilien. Hrsg. von Erich Zimmermann in: Zeitschrift des Vereins für Hamburgische Geschichte. Hamburg 1961. S. 45-86 (Lebenserinnerungen); BadtStrauß, Bertha: M.I. Ein jüdisches Gelehrtenleben in: Der Morgen. Zweimonatsschrift hrsg. von Julius Goldstein. Berlin 1937-1938. H. 8. S. 337-343; Hamburgische Biografie 4 (2008) S. 167. Großmutter: Emma Isler geb. Meyer (1816-1886), s. Mueller, Sabine: Deutsche Jüdin - jüdische Deutsche? Untersuchungen zu einer weiblichen jüdischen Sozialisation im 19. Jahrhundert am Beispiel der Emma Isler geb. Meyer. Lehrerprüfungsarbeit. Universität Hamburg 1993.

Lb Seit SS 1893 Studium an UH, seit SS 1894 Berlin, anschl. München.
UH: 14. Jan. 1898 Dr. med.; 29. Jan. 1898 med. Staatsprüfung in H; seit Okt. 1898 Assistent am Pharmakolog. Inst.; 23. Juli 1900 Habilitation; Laborarbeiten in Semesterferien: 1901 U Edinburgh, 1902 und 1903 Zoolog. Station in Neapel; seit 18. März 1904 nichtetatm. a. o. Prof.; u. a. MärzApril 1908 Studienreise durch Großbritannien.

U Utrecht: WS 1908/o9-SS 1927 o. Prof. und Gründungs-Direktor des ersten niederländischen Pharmakolog. Inst.; Rufe an U abgelehnt: 1915 HalleWittenberg, 1924 Groningen und H. - In dieser Zeit:

Deutschland: Seit Okt. 1915 Kriegsdienst als Stabsarzt in e. Lazarett in Speyer und Juni 1916-1917 in Akademie für das militärärztliche Bildungswesen in Berlin.

1927 Nominierung M.s zusammen mit seinem Mitarbeiter Adriaan P.H. A. de Kleijn (1883-1949) für den Nobelpreis für Physiologie oder Medizin (Magnus-de Kleijn-Reflex, s. hierzu M., R. (†), Kleijn, A. de: Körperstellung, Gleichgewicht und Bewegung bei Säugern in: Handbuch der normalen und pathologischen Physiologie ... Hrsg. von A. Bethe ... 15. Bd. 1. Hälfte ... Berlin 1930. S. 29-87 sowie Schuck, H., Sohlman, R.: Nobel - The Man and his Prizes. 2. Aufl. Amsterdam 1962. S. 145, 311); M. stirbt vor der endgültigen Entscheidung.

E Mitglied: 1919 Königlich-Niederl. Akademie der Wissenschaften, 1925 Dt. Akademie der Naturforscher Leopoldina Halle/S. 1925 Bailey-Medaille des Royal College of Physicians London; 1928 (posthum) Hans Horst Meyer-Medaille der Österr. Akademie der Wissenschaften Wien.

Qu UAH PA 1955; Fak.-Akte H-III-111/132 fol. 108r-117v (Habilitation). GLA Abt. 235, Fasz. 2276. - Siehe auch Archiv der Dt. Akademie der Naturforscher Leopoldina Halle/S.

W Pharmakologie der Magen- und Darmbewegungen in: Ergebnisse der Physiologie (1903) 2. Jg., S. 637-672; Die Bewegungen des Verdauungskanals in: ebd. (1908) 7. Jg., S. 27-64. - Goethe als Naturforscher. Leipzig 1906. Einfaches pharmakologisches Praktikum für Mediziner. Ber- 
lin 1921. - Die Digitalis und ihre therapeutische Anwendung. Berlin 1923. (Mitverf.) - Körperstellung. Experimentell-physiologische Untersuchungen über die einzelnen bei der Körperstellung in Tätigkeit tretenden Reflexe ... Berlin 1924. (Russische Übers. 1962 und engl. Übers. 1987.)

L Kürschner (1926) Sp. 1195. - Heubner, Wolfgang: R.M. in: Naunyn-Schmiedebergs Archiv für Experimentelle Pathologie und Pharmakologie 128 (1928) S. 17-23. • Liljestrand, Göran: Nachruf auf R.M. in: Ergebnisse der Physiologie 29 (1929) S. 646-654. - Arnim 2 (1952) S. 106; Fischer $2\left({ }^{3} 1962\right)$ S. 973; WBIS. - Magnus, Otto: R.M. Physiologist and Pharmacologist 1873-1927. Amsterdam 2002. - Bein, Reinhard: R. M. in: Lebensgeschichten von Braunschweiger Juden ... Braunschweig 2016. S. 198-205. - Deutsche Biographie, s. https://www.deutsche-biographie.de/gn d116678976.html [07.11. 2017].

\section{$P$ Bildarchiv UAH.}

\section{Mai, Franz Anton}

1773-1789, 1796-1814 Med. Fak. 1773-1789, 1796-1814 Medizin (insbesondere Heilart der besonderen Krankheiten, Allg. Pathologie und (Spezielle) Therapie); 1785-1789, 17961810 Hebammenkunst

* 16. Dez. 1742 Heidelberg

$\dagger \quad$ 20. April 1814 Heidelberg kath.

V Johann(Joannis) Maggio (später eingedeutscht in Mai) (1720-1792) Schornsteinfeger

M Maria Magdalena geb. Nagel (1720-1786)

( Sylvia Seraphina geb. von Verschaffelt (17521807), siehe UAH RA 6043; T von Peter Anton von V. (1710-1793), u.a. seit 1752 kurpfälz. Architekt und Hof-Bildhauer, s. BBKL XII (1997) Sp. $1282-1288$

K 3 T (s. UAH PA 1957 Blatt aus dem Jahr 180o), u. a. Johanna Maria Anna M. (1784-1857) Ehefrau von: (siehe) Franz Carl Naegelé (17781851)
Vw Bruder: (siehe) Wilhelm M. - Enkel: (Siehe) Franz Joseph Naegelé (1810-1851).

Lb UH: 4. Dez. 1760 Immatrikulation zum Studium der Philosophie; 7. Sept. 1762 Magisterexamen; anschl. Studium der Medizin; 1765 ärztl. Lizenz; 13. Sept. 1766 Dr. med.

Mannheim: 23. Okt. 1766-1796 Erster Korrepetitor an der am 19. April 1766 durch Kurfürst Carl Theodor gegründeten Gebäranstalt und Hebammenschule; 1767/68-1796 Physikus (Amtsarzt) am Zucht- und Waisenhaus; 1770-1796 auch praktischer Arzt und Physikus der Oberschultheißerei in Oggersheim (heute: Stadtteil von Ludwigshafen); 8. März 1770-16. Mai 180o Mitglied des Consilium medicum, s. hierzu Hess (1988) S. 237239; 30. Juni 1781 Gründer der „Schule zur Erziehung wohl unterrichteter Krankenwärter“, 1789 nach $H$ verlegt; 1796 Wohnsitzwechsel von Mannheim nach $\mathrm{H}$. • In dieser Zeit:

UH: 24. März 1773 Ern. zum a. o. Prof. für Medizin, s. UAH PA 1957; seit 17. Mai 1785 o. Prof. für Med. Institutionen und Hebammenkunst als Nachf. von Franz Innozenz Schoenmezel (siehe Drüll (1991) S. $138 \mathrm{f}$.) mit e. jährl. Besoldung von 605.- Gulden, 1 Fuder Wein und 12 Malter Korn (Schoenmezel bietet bereits 1783 auf Bitten einiger Studenten e. Vorlesung über „Praktische Anleitung zur Hebammenkunst“ an); Anfang Mai 1789 M.s Ankündigung der Eröffnung e. „Öffentlichen Lehrschule für die Bildung vernünftiger Krankenwärter“ (aus: Anzeige der Vorlesungen, welche im Sommerhalbenjahre vom 11ten May bis zu Ende Septembers 1789 auf der hohen Schule zu Heidelberg gehalten werden. Heidelberg 1789. S. 10); WS 1789/90WS 1795/96 keine Lehrtätigkeit an U laut Anzeige der Vorlesungen der Badischen Ruprecht-KarlsUniversität zu Heidelberg; in dieser Zeit Vertreter: 1789-1796 Franz Karl Zuccarini (für Heilkunde), 1789-1792 Peter Theodor von Leveling (siehe Drüll (1991) S. 94f.) und 7. Mai 1792-30. April 1796 (mit Unterbrechungen) Franz Moser (für Hebammen-, Entbindungskunst).

Am Kurfürstl. Hof: 1772 Ern. zum Hof-Medicus mit e. Jahresgehalt von 200.- Gulden; 1772-1794 Leibarzt von Elisabeth Augusta (1721-1794), der ersten Gattin Kurfürst Carl Theodors, in Oggers- 
heim, seit 1793 in Weinheim, s. hierzu Mörz, Stefan: Die letzte Kurfürstin ... Stuttgart 1997. S. 135, 193 u. ö.

H: 1785-1789/93 Inhaber des Physikats bei geistlicher Güter-Administration als Nachf. von Franz Innozenz Schoenmezel (s. Drüll (1991) S. 138f.) mit e. Jahresgehalt von 150.- Gulden; bis 20. März 1802 Arzt an "Canzley und Hospital, die Sapienz" (siehe hierzu Protokolle des Bayerischen Staatsrats (2008) Bd. 2. S. 163); 1801 Gründer des „Lehr-Institut einer Sitten- und Gesundheits-Lehre für die weibliche Jugend“, s. hierzu Eintrag unter $Z$ (1).

UH: SS 1796 Forts. der Vorlesungen; 1805-1810 Direktor des Gebär-, Entbindungs- oder Accouchement-Hauses, dessen Verlegung von Mannheim nach $\mathrm{H}$ am 7. März 1805 auf Betreiben M.s in das ehemalige Dominikanerkloster Ecke Hauptstrasse/Brunnengasse erfolgt (1818 Umzug in das Weinbrennergebäude, Marstallhof 4); 1809/10 Besoldungszulage von 300.- Gulden; 28. März 180919. Nov. 1810 M. bleibt Oberdirektor des Entbindungshauses, „aber in Erwägung seiner Jahre und Verdienste so wie der angemessenen Befähigung des Prof. [Franz Carl] Naegelé [wird] die Beigebung des leztern dergestalt genehmigt, daß demselben hiedurch kein Anspruch auf interimistische besondere Belohnung oder künftig Vorzug bei Ergebung der Oberdirection zugehe" (aus: UAH PA 2037; 19. Nov. 1810 Nachf.: Schwiegersohn Franz Carl Naegelé); 16. März 1813 M.s Jahresbesoldung beträgt - nach Abzug der Zuwendungen an seinen Schwiegersohn (siehe hierzu $Z$ (3)) - 708.- Gulden sowie rund 9 Malter Korn und 15 Malter Spelz (aus: PA 1957); WS 1813/14 letzte Vorlesungsankündigung.

1798 Rektor der UH; 1787, 1795, 1799, 1803, 1807 , 1814 (bis 20. April) Dekan der Med. Fak. der UH

$Z$ (1) 1802 erhält $M$. auf seine Bitte eine jährliche Unterstützung von 100.- Gulden für sein im Vorjahr gegründetes „Lehr-Institut einer Sitten- und Gesundheits-Lehre für die weibliche Jugend“, s. hierzu Protokolle des Bayerischen Staatsrats ... Bd. 2, S. $234 \mathrm{f}$.
Z(2) M. bittet im Mai 1802 Kurfürst Maximilian IV. Joseph von Bayern um Verleihung des Lehrstuhls für Physiologie und Pathologie an seinen zukünftigen Schwiegersohn Franz Carl Naegelé - zunächst ohne Besoldung. Die Med. Fak. lehnt diesen Vorschlag ab, da „das vorgeschlagene Subject dem academischen Senat eben so wenig als der Medizinischen Fakultät bekannt sei“" (aus: PA 2037 vom 4. Aug. 1802). Im Okt. 1806 wird Naegelé der Schwiegersohn M.s; er erhält im Juni 1807 ein nicht besoldetes Extraordinariat für Pathologie, Physiologie und Geburtshilfe.

$Z$ (3) Am 8. März 1808 hält ein „Großherzoglich Badisches Geheimraths-Protokoll des Polizeydepartments" in Karlsruhe fest, Mai könne Naegelé mit 6oo.- Gulden aus seiner Besoldung unterstützen; auch nach dem Tod M.s soll Naegelé das Geld weiterhin erhalten (aus: PA 2037); dies geschieht allerdings nicht: Seit dem 19. Nov. 1810 ist Naegelé "Accouchements-Director“ als Nachfolger M.s, wobei „dem Prof. Naegelé jene 300.- Gulden, welche seinem Schwiegervater ... jüngsthin als Gehaltszulage bewilligt wurden, nunmehr an ihn, Professor Nägele, ... ausgezahlt werden sollen“, was auch erfolgt (aus: PA 2037 Brief des Akad. Direktoriums [= Prorektor der UH] in Heidelberg vom 7. Dez. 1810).

8. März 1769 Ern. zum Kurfürstl. Medizinalrat, siehe Toepke 4 (1903) S. 198 Anm. 5

1805 Geh. Rat

Siehe auch Franz Carl Naegelé, Stephan Zipf

E 1812 Dr. phil. h.c. UH.

Qu UAH PA 1957; RA 329, 3185, 4998, 5456, 6221, 6226, 6477, 6672, 8256 u. ö. - GLA Abt. 77, Fasz. 1206. Protokolle des Bayerischen Staatsrats 17991817. Hrsg. von der Historischen Kommission bei der Bayerischen Akademie München. Bd. 2: 18021807. Bearb. von Esteban Mauerer. München 2008. Nr. 25. S. 163 f., 234 f.: Protokoll der Geheimen Staatskonferenz vom 20. März 1802, Onlinefassung unter: http://138.246.100.12/str/res/Bd2_1802/ nr25. 
$W$ Stolpertus, ein junger Arzt am Krankenbette. 5 T. Mannheim 1777-1807. - Von dem Einfluß der Komödien auf die Gesundheit arbeitender Staatsbürger. Mannheim 1780. Vorbeugung wider das Wechselfieber in: Mannheimer Zeitung Nr. CXII (16. Sept. 1780) S. 461-464. • Vorbeugungsmittel wider den Kindermord. Mannheim 1781. - Medicinische Fastenpredigten oder Vorlesungen über Körper- und Seelen-Diätetik, zur Verbesserung der Gesundheit und Sitten. 2 Bde. Mannheim 1793. - Programma de necessitate partus quandoque praematurè vel solo manuum vel instrumentorum adjutorio promovendi. Heidelberg 1799. • Die Kunst, die Gesundheit der Handwerker gegen die Gefahren ihres Handwerks zu verwahren. Mannheim 1803. Versuch eines sittlich und körperlichen Maaßstabs für deutsche Hausväter bei der Wahl einer Braut für ihre wohlgezogenen Söhne. Heidelberg 1806.

$L$ Todten-Feyer bey dem Begräbnis des Herrn F.A.M. ... am 21. April 1814. Heidelberg 1814. 4 Bl. - Kistner (1930) S. 187-196 u.ö. • Friedrich, Renate-Marianne: F. A. M. ... Ein Beitrag zur Medizingeschichte der Aufklärung. Diss. Heidelberg 1968. - Seidler, Eduard: Lebensplan und Gesundheitsführung. F.A.M. und die medizinische Aufklärung in Mannheim. 2. Aufl. Mannheim 1979. (Schriftenreihe der Studienreihe Böhringer.) • Buttron (1981) S. 6-27; Chronik Ärzte H (1985) S. 136, 250. Schipperges, Heinrich: Ursprung und Schicksal der Medizinischen Fakultät in: Semper apertus 4 (1985) S. 67-69. - Hess, Christel: Absolutismus und Aufklärung in der Kurpfalz in: ZGORh 136. Jg. (1988) S. 237-239. Zander (1991) S. 49-52; Tröger (2008) S. 21-44. • KlinikTicker - OnlineMitarbeitermagazin des Universitätsklinikums Heidelberg: „Ein Zimmer, 21 1/2 Schuh lang und 18 Schuh breit.“ Ein Streifzug durch die 250-jährige Geschichte der Hebammenschule in Heidelberg (16. Dez. 2016; abgerufen am 1. Okt. 2017). • Doll/ Kirsch/Eckart (2017) S. $17 \mathrm{f}$.

$P$ Bildarchiv UAH; graph. Slg. UBH; Chronik Ärzte H. • Reiss-Engelhorn-Museum Mannheim.

\section{Mai, Johann (Joannis) Wilhelm}

1798-1822 Med. Fak.

Pharmazeutische Experimentalchemie, Arzneimittellehre

* 13. Aug. 1759 Heidelberg

$\dagger \quad$ 05. April 1827 Heidelberg kath.

V Johann(Joannis) Maggio (später eingedeutscht in Mai) (1720-1792) Schornsteinfeger

M Maria Magdalena geb. Nagel (1720-1786)

๑ Franziska geb. Fick (1766-1826)

K 2 T

Vw Bruder: (siehe) Franz Anton M.

Lb Paris: 1783-1785 (?) Studium der Chemie, Pharmazie „unter den berühmtesten Lehrern 2 Jahre lang am Jardin royal ... mit besonderem ungewöhnlichem Fleiß“ (aus: Bitt-Brief des Bruders Franz Anton M. an Akad. Senat um eine Anstellung Wilhelms vom 14. Febr. 1798 in: UAH PA 1956).

7. Juli 1788 Approbation als Apotheker in Mannheim; 1788-1789 Apotheker in Ladenburg.

Am Kurfürstl. Hof: 1789-1794 Kammerdiener bei Elisabeth Auguste (1721-1794), der ersten Gemahlin Kurfürst Carl Theodors in Oggersheim, seit 1793 in Weinheim.

H: 1795-1810 (Gründer und) Inhaber e. Apotheke (M. hat „eine neue Arzneibude ... und sein Laboratorium mit vielen Unkosten so geräumig erbauet, daß die Zöglinge der Heilkunde allen chymisch-pharmaceutischen Operationen mit Nuzen und Gemächlichkeit beiwohnen können“ (aus: Bitt-Brief des Bruders ... vom 14. Febr. 1798 in: PA 1956); 1797-1814 (Gründer und) Betreiber von „zum Vorteil und zur Gemächlichkeit der Heidelberger Einwohner errichteten warmen Heilbäder[n]“ (18oo Verlegung in die Hauptstraße 108), s. hierzu Donat (1913) S. 188 f.; Sept. 1800 (Erteilung des Privilegs für Bezeichnung)-28. März 1814 (Verkauf der Apotheke an (siehe) Philipp Lorenz Geiger) U-Apotheker in der Hauptstraße 110. In dieser Zeit: 
UH: 9. Febr. 1798 M. bittet Akad. Senat um die „durch Hintritt des seeligen Herrn Eidenbenz [Christian E., s. UAH PA 1506] erledigte Stelle als Universitaets-Chymicker" (aus: PA 1956); 10. März 1798 Ern. zum a.o. Prof.; seit 23. April 1804 jährl. Besoldung von 200.- Gulden; Mai 1810, Aug. 1811, April 1813, Juni 1814 erfolglose Gesuche um Erhalt des Ordinariats und e. Gehaltszulage (Antworten des Ministeriums des Innern lauten: „... daß weder einem noch dem andern Gesuche dermalen willfahrt werden könne“, aus: PA 1956); 24. Jan. 1822 auf eigenen Antrag Ruhestand (Großherzog Ludwig I. ordnet an, daß M.s Pension aus dem Staatspensionsfonds übernommen wird, s. Brief vom 1. Febr. 1822 in: PA 1956).

Qu UAH PA 1956; RA 295, 6958, 7657 u. ö. • GLA Abt. 205, Fasz. 77, 374 f.

W -

L Donat (1913) S. 186-189; Keller (1913) S. 99 f.; Schneider (1913) S. 20; Stübler (1926) S. 18of.; Thomas (1985) S. 53-59. - Deutsche ApotherBiographie. Hrsg. von Wolfgang-Hagen Hein, Holm-Dietmar Schwarz. Erg.-Bd. II. Bearb. von Karlheinz Bartels. Stuttgart 1997. S. 198. Kirschke (2001) S. 448 (Register; hier irrtümlich Geb.-Jahr mit 1760 angegeben).

$P$ Bildarchiv UAH.

\section{Maier, Heinrich Georg}

1918-1922 Phil. Fak.

Philosophie, Pädagogik

* $\quad$ 05. Febr. 1867 Heidenheim an der Brenz

$\dagger \quad$ 28. Nov. 1933 Berlin

ev.

V Johann Gottlieb M. (1840-1921) Seifensieder, s. Lange-Greve (2014) S. $10 \mathrm{f}$.

M Regina Barbara geb. Zeuner (1847-1921), s. ebd.
( 5. April 1902 Anna Sofie Elisabeth geb. Sigwart (1870-1953) T von Christoph (seit 1875: von) S. (1830-1904), u. a. $1865-1903$ (Ruhestand) o. Prof. für Philosophie Tübingen, s. Häring, Theodor: C.S. Tübingen 1930; WBIS, DBE 9 (2001) S. 325 f., Lange-Greve, S. 85 Anm. 6. • Schwester von Dr. phil. h.c. (U Tübingen) Luise Charlotte geb. von Sigwart (1865-1931) Ägyptologin, s. UAH Handakte HAW Nr. 869; NDB 11 (1977) S. 721, Demm (2014) S. 246 (Register); Wilhelm Dilthey: Briefwechsel. Bd. II: 1882-1895. Hrsg. von Gudrun KühneBertram ... Göttingen 2015. S. 602 (Register). Ehefrau von: (siehe) Georg Klebs

K 1 T: Prof. (= Ehrentitel) Dr. phil. Anneliese M. (1905-1971) Wissenschaftshistorikerin, s. NDB 15 (1987) S. 696 f.; Vogt, Annette: Wissenschaftlerinnen in Kaiser-Wilhelm-Instituten. 2. Aufl. Berlin 2008. S. 122-125; Lange-Greve, S. 75 f. 1 S: Dr. iur. Georg M. (1907-1945) 1933 Habilitation an Jur. Fak. Berlin, Verweigerung der Lehrberechtigung durch seine Ablehnung des Nationalsozialismus, nach 1933 Rechtsanwalt, s. Lange-Greve, S. $77 \mathrm{f}$.

Lb WS 1885/86-189o Studium der Philosophie, Theologie an U Tübingen; März 189o I., Juni 1893 II. theol. Examen; seit 13. Nov. 189o Vikar in Oberurbach (heute: Urbach); Sept. 1891-April 1894 Repetent am Ev.-Theol. Seminar in Blaubeuren.

U Tübingen: 10. März 1892 Dr. phil.; 16. April 18941896 Repetent/Aushilfslehrer am Ev. Seminar; 22. Aug. 1896 venia legendi für Philosophie; $1896-$ 1900 Privat-Dozent.

U Zürich: Seit WS 1900/o1 a. o. Prof.; seit 26. Sept. 1901 o. Prof.

U Tübingen: 11. Aug. 1902 Ern. zum o. Prof.; 22. Jan. 1903 Antrittsrede.

U Göttingen: Seit WS 1911/12 o. Prof.

UH: Seit 4. Juli 1918 o. Prof. mit Lehrauftrag für Pädagogik.

U Berlin: Seit SS 1922 o. Prof. 
1920-1922 Vorsitzender des Pädagogischen Vereins Heidelberg, s. hierzu Lange-Greve (2014) S. $50 \mathrm{f}$.

1916 Geh. Reg.-Rat; 1918 Geh. Hofrat

E Mitglied der Akademie der Wissenschaften: 1918 H, 1918 Göttingen, 1920 Kopenhagen, 1922 Berlin. 1927 Dr. iur. h.c. Tübingen.

Qu UAH PA 4909; RA 6859. • GLA Abt. 235, Fasz. 2281.

W Syllogistik des Aristoteles. 2 T. Tübingen 18961900. Psychologie des emotionalen Denkens. Tübingen 1908. • An der Grenze der Philosophie. Tübingen 1909. - Sokrates. Sein Werk und seine geschichtliche Stellung. Tübingen 1913. Neudr. 1964. - Das geschichtliche Erkennen. Göttingen 1914. Philosophie der Wirklichkeit. 3 T. Tübingen 1926-1935. - Siehe hierzu auch Lange-Greve (2014) S. 52-59.

$L$ Catalogus prof. Gottingensium (1962) S. 115; Glockner (1969) S. 275 (Register); Arnim 4 (1984) S. 1016; NDB 15 (1987) S. 694-696; Kriegstagebuch K. Hampe (2007) S. 980 (Register). L Lange-Greve, Susanne: An der Grenze der Philosophie. H.M. 1867-1933. Philosoph - Psychologe - Pädagoge. Schwäbisch Gmünd 2014.

Manno, Karl (Pseudonym)

Manus, Karl (Pseudonym)

siehe Lemcke, Carl

\section{Marcks, Coqui Erich [d. Ä.]}

1901-1907 Phil. Fak.

Neuere Geschichte

* 17. Nov. 1861 Magdeburg

$\dagger$ 22. Nov. 1938 Berlin ref.

V Albert M. (†1888) Regierungsbaumeister

$\mathrm{M}$ Therese geb. Coqui

๑ 12. Aug. 1889 Friederike geb. von Sellin (18651951), s. Kriegstagebuch K. Hampe (2007) S. 980 (Register)

K $\quad 3$ S (1 S im 1., 2 S im 2. Weltkrieg $X$ ), u. a. Erich M. [d.J.] $\left({ }^{*} 1891 X_{1944}\right)$ Berufsoffizier, zuletzt 1944 General der Artillerie, s. Jacobsen, Otto: E.M. Soldat und Gelehrter. Göttingen 1971; NDB 16 (1990) S. 125; Siegfried A. Kaehler: Briefe 1900-1963. Hrsg. von Walter Bußmann, Günther Grünthal. Boppard 1993. S. 482 (Register); Briefe von General E. M. an seinen Schwager Willy Andreas zu Beginn des Zweiten Weltkrieges in: Nachlaß von Willy Andreas im GLA Karlsruhe. 1 T: Gertrud (Gerta) M. (1897-1985) Ehefrau von: (siehe) Willy Andreas.

Lb Seit SS 1879 Studium an U Straßburg, anschl. Bonn, Berlin, Straßburg.

Straßburg: 28. März 1884 Dr. phil. an U; Juli 1884 Oberlehrerexamen.

April 1885-Juli 1886 Studienreisen durch Frankreich, Großbritannien.

U Berlin: Dez. 1887 Habilitation.

U Freiburg/Br.: Seit 24. Nov. 1892 o. Prof.

U Leipzig: 15. Jan. 1894 Ern. zum SS 1894 o. Prof.

UH: 6. Juli 1901 Ern. zum WS 1901/o2 o. Prof. und Direktor der neueingerichteten Abt. für Neuere Geschichte.

Wiss. Stiftung Hamburg: Seit WS 1907/08 o. Prof. und Inhaber der ersten Stiftungsprofessur; 1912 Gast-Prof. in USA. 
U München: Seit Aug. 1913 o. Prof.

U Berlin: Frühjahr 1922-1928 (Emeritierung) o. Prof.

1904/o5 Dekan der Phil. Fak. der UH

1922 (zus. mit Friedrich Meinecke (1862-1954), s. F.M. Akademischer Lehrer und emigrierte Schüler. Briefe und Aufzeichnungen 1910-1977. Hrsg. von Gerhard A. Ritter. München 2006): Ernennung zum Historiographen des preußischen Staates

1928 Gründungsmitglied der Historischen Reichskommission

Seit 1935 Mitglied des Ehrenrats des „Reichsinstituts für Geschichte des neuen Deutschlands“

1901 Geh. Hofrat

E Mitglied der Akademie der Wissenschaften: 1898 München, Leipzig, 1922 Berlin, 1936 Wien; 1901 o. Mitglied der Badischen Histor. Kommission. 1936 Adlerschild des Deutschen Reiches. • 1900 Ritterkreuz I. Klasse des Königl. Sächsischen Verdienstordens; 1903 Ritterkreuz I. Klasse mit Eichenlaub vom Orden des Zähringer Löwen.

Qu UAH PA 1961; RA 552, 614, 6421, 6847. • GLA Abt. 235, Fasz. 2291. - Teil-Nachlaß: GLA Karlsruhe; Bundesarchiv Koblenz.

W Kaiser Wilhelm I. Leipzig 1897. 8. Aufl. 1918. Königin Elisabeth von England und ihre Zeit. Bielefeld 1897. 3. Aufl. 1951. • Die Universität Heidelberg im 19. Jahrhundert. Heidelberg 1903. - Otto von Bismarck, ein Lebensbild. 2 Bde. Stuttgart 1909-1915. 23. Aufl. 1924. - England und Frankreich während des letzten Jahrhunderts. Stuttgart 1923. - Der Aufstieg des Reiches. Deutsche Geschichte von 1807-1871/72. 2 Bde. Stuttgart 1938. • Hindenburg. Mit Ergänzungen ... von Walther Hubatsch. Göttingen 1963.

HG 1895-1902 Leipziger Studien. - 1902-1908 Heidelberger Abhandlungen.
MHG Seit 1910 Historische Zeitschrift. • Meister der Politik. Eine weltgeschichtliche Reihe von Bildnissen. 3 Bde. Stuttgart 1922-1923 (zus. mit Karl Alexander von Müller). 2. Aufl. 1923-1924.

$L$ Nachruf in: Almanach der Akademie der Wissenschaften Wien 89 (1939) S. 286-290. • Arnim 2 (1952) S. 121. Andreas, Willy: Zum 100. Geb. von E.M. am 17. Nov. 1961 in: Ruperto Carola 13. Jg., Bd. 30 (1961) S. 156-158. • Über E.M. d. Ä. in: Jacobsen, Otto: E.M. Soldat und Gelehrter. Göttingen 1971. - WBIS; NDB 16 (1990) S. 122-125. • Nordalm, Jens: Historismus und moderne Welt. E. M. ... in der dt. Geschichtswissenschaft. Berlin 2003; Ders.: Vom Staatssozialismus zum Nationalsozialismus: der Historiker E. M. zwischen Bismarck und Hitler in: Universitäten und Studenten im Dritten Reich: Bejahung, Anpassung, Widerstand ... Berlin 2008. S. 55-73. Kriegstagebuch K. Hampe (2007) S. 98of. (Register). - Clio in Hamburg: Historisches Seminar Universität Hamburg 1907-2007. Hrsg. von Claudia Schnurmann. Berlin 2010. S. 12-15 u. ö. 100 Jahre Germanistik in Hamburg (2011) S. 133f., 466; Gerhards (2013) S. 511 (Register). Knorring, Marc von: E. M. und sein Bild der preußischen Geschichte in: Das Thema „Preußen“ in Wissenschaft und Wissenschaftspolitik vor und nach 1945. Hrsg. von Hans-Christof Kraus. Berlin 2013. S. 101-117. Professorenkatalog Leipzig online; Berg (2014) S. 567 (Register); Spenkuch (2016) S. 1316 (Register).

P Bildarchiv UAH; Ruperto Carola.

\section{Marheinecke Marheineke, Philip Konrad} siehe Marheineke, Philip(p) Conrad 


\section{Marheineke, Philip(p) Conrad}

1807-1811 Theol. Fak.

Neues Testament, Praktische Theologie, Dogma-

tik

* 23. April 1780 Hildesheim

$\dagger$ 31. Mai 1846 Berlin

ev.-luth.

V Christoph M. $\left({ }^{\star} 1740\right)$ Gastwirt

M Anna Maria Lowina geb. Harburg (1749-1823/ 24)

( nach Juli 1809 Philippine Thekla geb. Blum $(\dagger 1818)$

$\infty$ 29. Juni 1824 Charlotte Friederike geb. Meves (ca. 1799-1880)

K 5 (alle früh $\dagger$ aus 1. Ehe), 6 (aus 2. Ehe).

Lb U Göttingen: WS 1798/99-1802 Studium der Theologie, Philosophie, Philologie.

Seit 1802 Hauslehrer in Miltzow (bei Neustrelitz; heute: Groß-M.).

U Erlangen: 23. Juli 1803 Dr. phil.

U Göttingen: 1804 Repetent am Ev. Seminar.

U Erlangen: 27. Nov. 1804 Verleihung der venia legendi an Phil. Fak.; seit 10. Jan. 1805 a. o. Prof. für Philosophie, Geschichte der Moral, Kirchengeschichte und Philosophie sowie zweiter U-Prediger.

UH: 10. Febr. 1807 Ern. zum a. o. Prof.; 1809 Ruf an U Königsberg (Preußen) abgelehnt; 13. Sept. 1809 Ern. zum o. Prof.

U Berlin: 23. April 1811-1844 o. Prof. für Dogmatik und Kirchengeschichte. In dieser Zeit:

Berlin: 1820-1844 Pastor an der Dreifaltigkeitskirche.

1835 Oberkonsistorialrat
Qu UAH PA 1960; Theol. Fak. 6 fol. 106-107. • GLA Abt. 205, Fasz. 376. Karl Rosenkranz: Briefe 1827-1850. Hrsg. von Joachim Butzlaff. Berlin 1994. S. 526 (Register).

$W$ System des Katholicismus in seiner symbolischen Entwickelung. 3 Bde. Heidelberg 18101813. Christliche Symbolik. 3 Bde. Berlin 18101814. Neuaufl. 1897. Geschichte der teutschen Reformation. 2 Bde. Berlin 1816. 2. Aufl. 4 Bde. 1831-1834. - Grundlehren der christlichen Dogmatik. Berlin 1819. 2. Aufl. 1827. Einleitung in die öffentlichen Vorlesungen über die Bedeutung der Hegelschen Philosophie in der christlichen Theologie ... Berlin 1842. Unveränd. Nachdr. Frankfurt/M. 1983. • Reform der Kirche durch den Staat. Leipzig 1844. - Vorlesungen über das System der christlichen Dogmatik. Berlin 1847. - Siehe auch BBKL V (1993).

$L$ ADB 20 (1884) S. 338-340; Arnim 2 (1952) S. 123; RGG 4 ( $\left.{ }^{3} 1960\right)$ Sp. 744; NDB 16 (1990) S. 172-174; TRE 22 (1992) S. 109-115; BBKL V (1993) Sp. 805812; WBIS. - Rupprecht, Eva-Maria: Kritikvergessene Spekulation. Das Religions- und Theologieverständnis der spekulativen Theologie P.K.M.s. Frankfurt/M. 1993. - Wolff, Albrecht Titus: Spekulative Ekklesiologie. Das Verständnis der Kirche in der Dogmatik von P. K. M. Frankfurt/M. 1998. • Schwinge, Gerhard: Schwarz, M., Ewald, Abegg, Hüffell. Zur Vorgeschichte des ersten badischen Predigerseminars in Heidelberg zwischen 1807 und 1818 bzw. 1818 und 1838 in: Praktische Theologie und Landeskirchengeschichte ... Hrsg. von Johannes Ehmann. Berlin 2008. S. 281-292. • Professoren Erlangen (2009) S. 132. - Wagner, Falk: Der Gedanke der Persönlichkeit Gottes bei P.M. Repristination eines vorkritischen Theismus in: Neue Zeitschrift für systematische Theologie und Religionsphilosophie. Berlin 2009. S. 44-88. Geschichte U Berlin (2012) Bd. 1. S. 663 (Register). Ringleben, Joachim: P.K. M. ... - die Zuflucht im Begriff in: Stiftsgeschichte(n): 250 Jahre Theologisches Stift der Universität Göttingen (1765-2015). Göttingen 2015. S. 59-65.

$P$ Bildarchiv UAH.

E 1811 D. theol. UH. 


\section{Marquardsen, Johannes Heinrich Christian (seit 1888: von Marquardsen)}

1851-1861 Jur. Fak.

Strafrecht, Strafprozeßrecht, Staatsrecht, Privatund Handelsrecht, Englische Staats- und Rechtsgeschichte

* 25. Okt. 1826 Schleswig

$\dagger$ 30. Nov. 1897 Erlangen ev.-luth.

V Johann Gerhard Nicolaus M. (1798-1861) Gutsbesitzer, Weinhändler, Senator

M Anna Maria Friederica geb. Paulsen $\left({ }^{*} 1800\right.$ $\dagger$ nach 1861)

(1) 1852 Emilie geb. Wiss (1830-1899)

K 2 .

Lb Vor 1844 Lehre, danach Besuch der der dänischen Krone direkt unterstellten Domschule in Schleswig.

Studium: Seit 7. Nov. 1844 UH, seit 14. Mai 1846 Kiel, seit 5. Mai 1847 H; 2. Febr. 1848 Dr. iur. an UH.

Seit 1848 Eigenstudien in Großbritannien, Belgien.

UH: Nov./Dez. 1851 Habilitation, s. hierzu UAH PA 1963; seit 29. Mai 1860 a. o. Prof.

U Erlangen: SS 1861-30. Nov. 1897 o. Prof. • In dieser Zeit:

Mitglied: $1868-1870$ Dt. Zollparlament, 18701892 Bayer. Abgeordnetenkammer, 1871-1897 Dt. Reichstag, s. hierzu ausführlich Biographisches Lexikon zur Geschichte der dt. Sozialpolitik 18711945. Hrsg. von Eckhard Hansen und Florian Tennstedt. Kassel 2010. Bd. 1. S. 105f. u. ö.

1863: Mitbegründer der Bayer. Fortschrittspartei

E 1888 Verdienstorden der Bayer. Krone.
Qu UAH PA 1963. - Toepke 5 (1904) S. 746, 6 (1907) S. 45; Matrikel Kiel (1915) S. 360 f.; Achelis 2 (1966) Nr. 9757. GLA Abt. 205, Fasz. 377. • Nachlaß: Bundesarchiv Berlin.

$W$ Das Oberhaus von England und die Wissenschaft. Erlangen 1862. - Der Trentfall. Erlangen 1862.

MG 1855 Kritische Zeitschrift für die gesammte Rechtswissenschaft.

HG William M. Best's Grundzüge des englischen Beweisrechts ... Heidelberg 1851. - Das ReichsPreß-Gesetz vom 7. Mai 1874 mit Einleitung und Kommentar. Berlin 1875. 1883-1894 Handbuch des öffentlichen Rechts der Gegenwart.

L ADB 52 (1906) S. 216-218; Arnim 2 (1952) S. 126. Hirschfelder, Heinrich: Von H.M. zu Franz Fhr. Schenk von Stauffenberg. Die Entwicklung des Linksliberalismus und die Anfänge der „Fränkischen Nachrichten“ in Erlangen (1884) - ein Beitrag zur lokalen Parteien- und Pressegeschichte in: Erlanger Bausteine zur fränkischen Heimatforschung 39 (1991) S. 101-116. • Professoren Erlangen (1993) S. 144f.; WBIS; Willett (2001) S. 288, 325-328 u. ö.; Schroeder (2010) S. $205 \mathrm{f}$.

\section{Martin, Christoph Reinhard Dietrich}

1805-1816 Jur. Fak.

Strafrecht, Zivilprozeßrecht, Juristische Praxis

* 02. Febr. 1772 Bovenden (bei Göttingen)

$\dagger$ 13. Aug. 1857 Gotha prot.

V Siegmund Peter M., Reservatenkommissär (Beamter zur Überwachung der Einhaltung der landesherrlichen Reservatsrechte (Hoheitsrechte))

M Maria Margaretha geb. Ihringk

๑ Frühling 1798 Carolina Friederike Luise geb. Wagemann (1776-1843) Schwester von: (siehe) Georg W. 
K 3 T: u. a. Emilie Juliane Sophie M. (1799-1876), siehe Biographie Emilie Stark geb. M. in: Chronik der Familie Stark. Hrsg. von Dr. Hans C. Stark. Konstanz 1960. H. 5. S. 2-48; Mutter von: (siehe) Bernhard Stark. - Caroline Therese M. (1804-1830) Ehefrau von Ludwig Wilhelm Wahl (1795-1831) zunächst Lehrer für Mathematik, seit 1823 Privat-Dozent, seit 1824 a. o. Prof. für Philosophie, Mathematik Jena, s. WBIS. 3 S: u. a. Gustav Adolph M. (18021831) seit 1823 Privat-Dozent, seit 1826 a.o. Prof., 1831 o. Prof. für Rechtswiss. Jena, s. Günther (1858) S. 91f., WBIS. - Eduard Arnold M. (1809-1875), u.a. seit 1858 Prof. für Gynäkologie Berlin, s. Pagel (1901) Sp. 1098f., WBIS, Stumm (2012) S. 366. • Siehe auch Chronik der Familie Stark (1960) H. 5. S. 35 f. Anm. 57

Vw Enkel: (siehe) Bernhard Stark. August Eduard M. (1847-1933), u.a. 1899-1907 Prof. für Gynäkologie an U Greifswald, s. NDB 16 (1990) S. $284 \mathrm{f}$. Weitere Vw, s. NDB.

Lb U Göttingen: Sept. 1787-1792 Studium; 11. April 1796 Dr. iur.; seit Ostern 1796 Privat-Dozent und Beisitzer des Spruchkollegiums; seit 4. Juni 1802 a. o. Prof.; Rufe an U abgelehnt: 1802 Jena, $1804 \mathrm{H}$; 1805 Ern. zum o. Prof. In dieser Zeit:

Göttingen: Okt. 1790-1805 (?) Advokat und Patrimonialrichter.

UH: 25. Juni 1805 Ern. zum o. Prof. für Juristische Praxis als Nachf. von Franz Janson; WS 1805/06 Amtsantritt; M. liest - entgegen seines Lehrauftrags - hauptsächlich Strafrecht, Zivilprozeßrecht; Dez. 1805-1816 Vorsitzender des Spruchkollegiums der Jur. Fak., s. Jammers (1964) S. 30-35 u. ö.; 1806-1810 Mitglied des Akad. Gerichts; Nov. 1815 M. beantragt Entlassung, da er aufgrund e. Petition zur Beschleunigung der Einführung der versprochenen landständischen Verfassung 1815 in e. Untersuchung verwickelt war, die zwar mit Freispruch endete, ihn aber veranlaßt, um seine Entlassung nachzusuchen, die am 11. Jan. 1816 genehmigt wird (erst 1818 unterzeichnet Großherzog Karl von Baden (1786-1818) die geforderte neue liberale Landesverfassung, u.a. Zusicherung der Gleichheit vor dem Gesetz, Aufhebung der aus der Leibeigenschaft resultierenden Verpflichtungen (siehe hierzu Christoph Weidenbach: Eintrag unter $Z$ [itat] (2)) und Einsetzung e. Landtags (in der Verfassungsurkunde als Ständeversammlung bezeichnet), dessen Befugnisse sich von den früheren Landständen erheblich unterscheiden, s. hierzu Engehausen, Frank: Kleine Geschichte des Großherzogtums Baden 1806-1918. 3. Aufl. Karlsruhe 2012. S. 36-43).

Jena: WS 1816/17-WS 1841/42 o. Honorar-Prof. an U und 1816-1842 Richter am Thüringischen Oberappellationsgericht; u. a. zwischen 1820 und 1825 , erneut 1828 Unterbrechungen seiner Arbeit durch e. „lebensgefährliche Krankheit, welche, Dank sei es der Vorsehung, glücklich überstanden ist, allein eine, mehrere Jahre hindurch fortgesetzte Cur nothwendig machte“ (aus: Vorrede zur ersten Ausgabe des Lehrbuchs des Teutschen gemeinen Criminal-Rechts (1825)).

Seit 1842 Privatier in Mügeln (bei Oschatz); 18461848 Mitglied des Sächsischen Staatsgerichtshofs in Dresden; nach 1848 Wohnsitz in Gotha.

1807/o8 Prorektor der UH; 1806, 1811 Dekan der Jur. Fak. der UH

1805 Justizrat; 1816 Geh. Justizrat

Qu UAH PA 1965; RA 793 S. 72-74, RA 4921. • Matrikel Göttingen 1 (1937) S. 303. GLA Abt. 205, Fasz. 378. - Jenaer Studentenbriefe von Johannes Versmann. Mitgeteilt von Adolf Wohlwill, s. http:// agora.sub.uni-hamburg.de/subhh/cntmng;jsessionid $=6 \mathrm{E}_{5} 62528 \mathrm{~F}_{4465419} \mathrm{C}_{31056866 \mathrm{~A}} 6 \mathrm{C}_{904}$.jvm1 ?type $=$ pdf\&did $=$ c1:30416 (abgerufen am 27. Sept. 2017). Auskunft: Universitätsarchiv Jena.

$W$ Lehrbuch des Civilprocesses. Göttingen 1800. 4. Aufl. 1812. (Siehe hierzu Morstadt, Eduard: Materialkritik von Martin's Civilprocess-Lehrbuch. Zugleich auf eine Mitcommentation von dessen Gegenstand berechnet, ein und neunzig Entwuerfe. Heidelberg 1820. 2. Aufl. 1828; Dr. Johann Caspar Genslers ... vollständiger Commentar über Martin's Civilprocess-Lehrbuch. Hrsg. von Karl Eduard Morstadt. 2 Bde. Heidelberg 1825.) • Lehrbuch des teutschen gemeinen bürgerlichen Processes. Göttingen 180o. 13. Aufl. hrsg. nach dessen Tode von seinem Sohne Theodor Martin. Leipzig 1862. 
Rechtsgutachten und Entscheidungen des Heidelberger Spruchcollegiums. Heidelberg 1808. - Anleitung zum Referiren in Rechtssachen. Göttingen 1809. 3. Aufl. 1829. - Lehrbuch des teutschen gemeinen Criminalprocesses. Göttingen 1812. 5. Aufl. 1857. - Lehrbuch des teutschen gemeinen Criminalrechts ... Heidelberg 1825. 2. Aufl. 1829. Nachdr. 1985. - Vorlesungsnachschriften: Theorie des gemeinen teutschen Civilprocesses (Jena 1831-1832) 2 T. in: UB Leipzig (Signatur: Ms 0813 I und II).

HG 1816-1818 Rheinischer Merkur.

L Günther (1858) S. 87; Lautenschlager (1933) S. 636-663; Catalogus prof. Gottingensium (1962) S. 58. Maiwald, Manfred: Der Heidelberger Kriminalist Martin und die Strafrechtswissenschaft seiner Zeit in: Semper apertus 2 (1985) S. 197221. Heidelberger Strafrechtslehrer (1986) S. 59; Heidelberg im säkularen Umbruch (1987) S. 563 (Register); Weisert (1991) S. 122, 133 u. ö.; WBIS. • Kreutzmann, Marko: Zwischen ständischer und bürgerlicher Lebenswelt: Adel in Sachsen-Weimar-Eisenach 1770-1830. Köln 2008. S. 229. Schroeder (2010) S. 26-30; Stumm (2012) S. 294, 366.

$P$ Bildarchiv UAH; graph. Slg. UBH.

\section{Marwedel, Georg Ludwig Arthur}

1897-1901 Med. Fak.

Chirurgie

* 16. Febr. 1868 Paris

$\dagger$ 28. Aug. 1930 Aachen

ev.

V Georg Friedrich Christian Feodor M. (18191874) Fabrikant

M Emma geb. von Pfannenberg $\left({ }^{*} 1849 \dagger\right.$ nach 1891) nach 1874 Ehefrau von Medizinalrat Dr. med. Wilhelm Ludwig Zöller, Direktor der Kreis-Kranken- und Pflege-Anstalt in Frankenthal (Pfalz)

$\infty$ Rosa Emma geb. Voelcker $\left({ }^{*} 1874 \dagger\right.$ nach 1930$)$

$\mathrm{K}$ unbekannt.
Lb UH: Seit SS 1886 Studium; 17. Febr. 1891 Approbation; 1891-1901 Assistent an Chirurg. U-Klinik; 28. Juli 1892 Dr. med.; 10. Juli 1897 Habilitation; seit SS 1900 Leiter der klinischen Ambulanz an Chirurg. U-Klinik als Nachf. von Max Jordan; seit 21. Jan. 1901 nichtetatm. a. o. Prof.

Aachen: 1. Okt. 1901-31. Mai 1929 Leiter der Chirurg. Abt. des Ev. Luisenhospitals.

E 1892 Ehrenkreuz des Montenegrinischen Danilo-Ordens.

Qu UAH PA 1967; RA 4943; Fak.-Akte H-III-111/ 117. Auskunft: Standesamt Aachen (Sterbebuch 1930); Standesamt Frankenthal/Pfalz (Sterbebuch 1874).

$W$ Klinische Erfahrungen über den Wert des Murphy'schen Darmknopfes in: Langenbecks Archiv für Chirurgie 55 (1897). • Die Aufklappung des Rippenbogens zur Erleichterung operativer Eingriffe im Hypochondrium und im Zwerchfellkuppelraum in: Zentralblatt für Chirurgie 30 (1903). Grundriß und Atlas der allgemeinen Chirurgie. München 1905. 2. Aufl. 1923.

L Stübler (1926) S. 320; WBIS. - Koppen, Bodo von: 100 Jahre Ev. Krankenhausverein zu Aachen Luisenhospital. 1867-1967. Aachen 1967. S. 70, 98. • Krebs/Schipperges (1968) S. 202 u. ö.; Leier (1977) S. 49-52 u.ö.; Deutsche Biographie, s. https:// www.deutsche-biographie.de/gnd1029936315.html [07.11. 2017].

$P$ Bildarchiv UAH; Koppen.

\section{Marx, Hermann}

1909-1924 Med. Fak.

Ohrenheilkunde

* 05. Febr. 1877 Worms

$\dagger \quad$ o8. Dez. 1953 Würzburg

ev. 
V Dr. Rudolph M. (1835-1896) Gymnasial-Prof.

M Rosine (Rosa) Salome geb. Rasor (1853-1920/ 21)

$\infty$ N.N.

๑ 12. Aug. 1922 Hedwig geb. Sieben (1896-1981)

$\mathrm{K} \quad 1 \mathrm{~S}, 2 \mathrm{~T}$ (aus 2. Ehe).

Lb SS 1897 Studium an U Gießen, seit WS 1897/98 H, SS 1899 Bern, seit WS 1899/190o H; WS 1901/o2 Staatsexamen in H; 4. März 1902 Dr. med. an UH.

Seit April 1902 Assistent an e. Sanatorium in der Schweiz.

UH: Assistent: Seit Okt. 1902 Patholog. Inst., seit 1903 Chirurg. U-Klinik, seit 1904 Augenklinik, seit 1906 Ohrenklinik; SS 1907-WS 1909/10 Forts. des Studiums der Medizin; 24. Febr. 1909 Habilitation; WS 1911/12 Lehrstuhlvertr. für Rhino-Laryngologie an U Freiburg/Br.; seit 5. März 1915 nichtetatm., 1920-30. Sept. 1924 nichtplanm. a. o. Prof. - In dieser Zeit:

1914-1918 Kriegsdienst; 1918-1920 Leiter des Lazaretts für Hals-, Nasen- und Ohrenkranke und -verwundete in $\mathrm{H}$.

U Münster: Seit 1. Okt. 1924 erster Inhaber des Lehrstuhls für HNO-Heilkunde und Direktor der Hals-, Nasen- und Ohrenklinik.

U Würzburg: 1. April 1928-25. Juli 1945 (Enthebung seines Amtes durch Militärregierung) o. Prof. für Hals-, Nasen-, Ohrenheilkunde, Vorsteher der U-Klinik und Poliklinik für Ohren-, Nasen- und Kehlkopfkrankheiten und 1935-1945 Mitglied des Krankenhausausschusses des U-Klinikums; Okt. 1935-März 1947 Direktor des Luitpold-Krankenhauses (= U-Klinikum). • In dieser Zeit:

Würzburg: 1939-1945 Kriegsdienst als Chefarzt des Reservelazaretts im Luitpold-Krankenhaus und anderer Lazarette in Würzburg.

U Würzburg: 25. Juli 1945 (Wiedereinsetzung)15. März 1947 Kommissar. Leiter der U-Klinik und Poliklinik für Ohren-, Nasen- und Kehlkopfkrankheiten und Mitglied des Krankenhausausschusses des U-Klinikums.
E 1940 Mitglied der Dt. Akademie der Naturforscher Leopoldina Halle/S.; Ehrenmitglied der Dt. Gesellschaft der Hals-, Nasen- und Ohrenärzte (Stiftung e. Hermann Marx-Preises). 1918/19 Hanseatenkreuz.

Qu UAH PA 1070, 4936; Fak.-Akte H-III-111/138 fol. 279r-287r; Studentenakte. - GLA Abt. 235, Fasz. 2298. Siehe auch Archiv der Dt. Akademie der Naturforscher Leopoldina Halle/S. • Auskunft: Stadtarchiv Worms; Amt für öffentliche Ordnung in Würzburg; Universitätsarchiv Würzburg.

$W$ Unfallverletzungen des Ohres in: Handbuch der gesamten Unfallheilkunde. Hrsg. von Fritz König und Georg Magnus. Stuttgart 1934. • Kurzes Handbuch der Ohrenheilkunde. Jena 1938. 2. Aufl. 1947. Die Nasenheilkunde in Einzeldarstellungen. 6 Lfg. Jena 1947-1952.

HG 1929-1939 Der Hals-, Nasen- und Ohrenarzt.

L Stübler (1926) S. 324; Kürschner (1928/29) Sp. 1502. - Ein großer Arzt und Menschenfreund H. M. † in: Main Post Nr. 285 vom 9. Dez. 1953. • WBIS; Universität Münster (1980) S. 296; Arnim 4 (1984) S. 1044; Chronik Ärzte H (1985) S. 136. • Deuster, Christian von, Ptok, Martin: Zur Geschichte der Hals-Nasen-Ohrenheilkunde, insbesondere in Würzburg. Pattensen (Hannover) 1986. S. 54-56 u. ö. Feldmann, Harald: Bilder aus der Geschichte der Hals-Nasen-Ohrenheilkunde. Heidelberg 2003. S. 27, 139. - Deutsche Biographie, s. https://www.deutsche-biographie.de/gnd132009 51X.html [07.11. 2017].

$P$ Bildarchiv UAH.

Maurer, Friedrich Adolf Karl Wilhelm Alexander

1888-1901 Med. Fak.

Anatomie

* 10. Okt. 1859 Gießen

$+\quad$ o8. Juli 1936 Jena

ev. 
V Wilhelm Ludwig M. (1825-1906) Staatsanwalt, 1880-1897 Oberlandesgerichtsrat, s. WBIS

M Sidonie geb. Scharfenberg (1834-1903)

๑ 13. Aug. 1894 Marie geb. Fremery $\left({ }^{*} 1875\right)$

$\mathrm{K}$ mind. $3 \mathrm{~S}, 1 \mathrm{~T}$ : Elisabeth Marie Sidonie M. ( $\left.{ }^{*} 1897\right)$ Ehefrau von Hermann Gustav Runge (1887-1942) seit 1923 Privat-Dozent, seit 1924 nichtplanm. a.o. Prof. Jena, seit 1935 apl. a.o. Prof. für Ohrenheilkunde Hamburg (als Nachf. von: (siehe) Julius Hegener), s. Brusis (2002) S. 189 f. u. ö.

Lb Seit SS 1878 Studium der Philosophie, seit SS 1879 der Medizin an UH, WS 1880/81 Studium der Naturwiss. und Zoologie an TH Darmstadt, seit SS 1881 der Medizin an UH; WS 1882/83 med. Staatsexamen in $\mathrm{H}$.

U Jena: Jan. 1883-Juli 1884 Assistent am Anatom. Inst.

UH: 12. März 1883 Dr. med.; Okt. 1884-Sept. 1888 Assistent am Anatom. Inst.; 29. Juli 1888 Habilitation; seit Okt. 1888 Prosektor am Anatom. Inst.; seit 25. März 1893 nichtetatm. a.o. Prof.; Okt. 1900März 1901 Vertreter von Carl Gegenbaur.

U Jena: SS 1901-SS 1932 (Emeritierung) o. Prof. und Direktor der Anatom. Anstalt.

1908 Geh. Hofrat

E 1898 Mitglied der Dt. Akademie der Naturforscher Leopoldina Halle/S. • 1910 Ritter des Herzoglich Ernestischen Hausordens; 1913 Kommandeur des Ordens vom weißen Falken.

Qu UAH PA 1971; RA 6169; Fak.-Akte H-III-111/ 95. Siehe auch Archiv der Dt. Akademie der Naturforscher Leopoldina Halle/S.

W Grundzüge der vergleichenden Gewebelehre. Leipzig 1915. • Der menschliche Körper, sein Aufbau und seine Tätigkeit. Berlin 1923. • Das Gehirn Ernst Haeckels. Jena 1924. • Der Mensch und seine Ahnen. Berlin 1928.

Redakteur Seit 1901 Jenaische Zs. für Naturwissenschaft.
L Stübler (1926) S. 307; Kürschner (1931) Sp. 1879, (1935) Sp. 875; Wer ist's (1935) S. 1039; Anatomischer Anzeiger 85 (1938) S. 313-331; Fischer 2 ( $\left.{ }^{3} 1962\right)$ S. 1006; WBIS. - Wiederanders, Bernd, Zimmermann, Susanne: Buch der Docenten der Medicinischen Facultät zu Jena. Golmsdorf 2004. S. 51-57. • Hessische Biografie, s. http://www.lagishessen.de/pnd/116855150 (Stand: 5. Aug. 2014). • Deutsche Biographie, s. https://www.deutsche-bio graphie.de/gnd116855150.html [07.11. 2017].

$P$ Bildarchiv UAH; graph. Slg. UBH.

\section{Maydolf, Eduard (Pseudonym) \\ siehe Mayer, Adolf}

Mayer, Adolf Eduard (auch: Mayer-Gmelin, Adolf; Pseudonym: Maydolf, Eduard)

1868-1876 Phil. Fak.

Agrikulturchemie

* o9. Aug. 1843 Oldenburg (Oldenburg)

$\dagger \quad$ 25. Dez. 1942 Heidelberg

ev.

V Dr. Karl August M. (1808-1894) Gymnasiallehrer: seit 1840 Oldenburg, seit 1851 Mannheim, seit 1873 Direktor der höheren Bürgerschule (Realgymnasium) Karlsruhe

M Luise Julie geb. Gmelin (1817-1896) T von: (siehe) Leopold G.

(20. Dez. 1872 Johanna Maria Margaretha Sophia geb. Kolligs (1853-1938)

K 4 .

Lb Polytechnikum Karlsruhe: Seit WS 1860/61 Studium zunächst der allg. math. Wissenschaften, seit WS 1861/62 Studium der Chemie.

UH: 21. Okt. 1862 Immatrikulation; 11. Febr. 1864 Dr. phil. 
Belgien: Seit März 1864 Assistent am Chemischen Laboratorium der U Gent; seit Herbst 1864 M. „versucht ... [sich] in Belgien in der chemischen Technik“ (aus: UAH PA 1975); Herbst 1865 Rückkehr nach Deutschland.

U Halle-Wittenberg: Nov. 1865-Dez. 1866 Studium der Agrikulturchemie, Physiolog. Chemie sowie der Pflanzenkrankheiten; Jan.-Dez. 1866 Assistent am Chemischen Laboratorium.

Karlsruhe: 1. Jan. 1867-1. April 1868 Assistent an Landwirtschaftl. Versuchsstation; anschl. Vorbereitung, u.a. auch auf Habilitation im Landwirtschaftl. Laboratorium des Polytechnikums.

UH: 21. Nov. 1868 Habilitation; M. gründet 1868 ein Landwirtschaftl.-Analytisches Büro bzw. Institut in $\mathrm{H}$ (es wird wohl 1872 in das neueingerichtete Heidelberger Landwirtschaftl. Laboratorium integriert); Juli $1871 \mathrm{M}$. bittet Handelsministerium um finanzielle „Unterstützung, um das [Landwirtschaftl.-Analytische] Institut auszudehnen und vielleicht mit der Zeit zu einer Privat-Versuchsstation umzubilden“ (aus: PA 1975); Antwort des Ministeriums nicht überliefert; 23. Okt. $1872 \mathrm{Ge}-$ nehmigung des Ministeriums des Innern für Übertragung der Vorlesungen über Landwirtschaftl. Chemisches Gewerbe, bislang gehalten von Privat-Dozent für Chemie Dr. Friedrich Rose (18391925; s. UAH PA 2162, WBIS), an M.; SS 1872 (nach Verlegung der Landwirtschaftl. Schule von Karlsruhe an UH) Neueinrichtung e. Landwirtschaftl. Laboratoriums und Landwirtschaftl. Sammlungen (Direktor: Adolf Stengel); an diesem Laboratorium ist „mit der speciellen Leitung der agriculturchemischen Arbeiten betraut: Privatdocent Mayer" (aus: Adressbuch der UH vom SS 1872. Heidelberg 1872. S. 8); Jan. 1873 zunächst erfolgloses Gesuch M.s um Verleihung der a.o. Professur, siehe $Z$; 9. Dez. 1874 Professoren Ernst Pfitzer, Johann Joseph Fühling und Adolf Stengel befürworten nach eingeholten Gutachten von Robert W.E. Bunsen und Hermann Kopp die Verleihung der a.o. Professur an M. und bitten den Engeren Senat, M. diesbezüglich im Ministerium zu empfehlen (siehe Bericht der Phil. Fak. vom 9. Dez. 1874 in: PA 1975); seit 8. Jan. 1875 a. o. Prof.; 16. Nov. 1875 Gesuch M.s an das Ministerium des Innern um Verleihung der Staatsdienereigenschaft; 10. Jan. 1876
Prorektor Kuno Fischer lehnt Gesuch ab, da u.a. ökonomische Gründe dagegenstehen, wie z. B. die „Neugründung eines besonderen agriculturchemischen Laboratoriums“ (aus: PA 1975).

Wageningen (Niederlande): Seit 1. Aug. 1876 Lehrer, 1. Febr. 1877-1. Jan. 1903 (Pensionierung) Prof. an Nieuwe Rijks-Landbouwproefstation und (Gründungs-)Direktor der ersten niederländischen landwirtschaftl. Versuchsstation; seit 18. Sept. 1886 Mitglied der Staatl. Kommission für die Untersuchung des Zustandes der Landwirtschaft in den Niederlanden.

15. März 1905 Rückkehr nach Heidelberg und Wohnsitz in der Moltkestraße 7.

26. Juni 1880: Das von M. bis 1876 geleitete Heidelberger Agriculturchemische Laboratorium wird aufgelöst, Teile des Inventars gehen an das Polytechnikum in Karlsruhe und an das Chemische Laboratorium der UH, s. hierzu UAH RA 6572.

Z Um die Entscheidung über die Verleihung der außerordentlichen Professur auf Bitte Adolf Mayers im Januar 1873 treffen zu können, bittet der Dekan der Philosophischen Fakultät, Karl Bartsch, die zuständigen Fachkollegen Bunsen und Kopp (Chemie), Fühling und Stengel (Landwirtschaftslehre) sowie Pfitzer (Botanik) um ihre Gutachten über die bislang erschienenen Arbeiten des Antragstellers. So urteilt Bunsen, mit Einverständnis seines Kollegen Kopp, im Febr./März 1873 u. a.: Die Arbeiten Mayers „zeugen von vielseitigen Kenntnissen, großem Fleiße und eifriger, wissenschaftlicher Strebsamkeit, und wenn ein solches mit vielseitigen Kenntnissen verbundenes Streben allein als Maßstab bei Verleihung außerordentlicher academischer Professuren gelten dürften, so würde ich kein Bedenken tragen für empfehlende Befürwortung des Gesuchs des Dr. Mayer zu stimmen. Allein die Facultät hat bisher bei solchen Befürwortungen gleich wie bei der Beurtheilung selbst von Inauguraldisputationen und namentlich von Habilitationsschriften ein Hauptgewicht darauf gelegt, wie weit die aufzuweisenden Arbeiten auf selbstständigen exacten Untersuchungen beruhen oder nur als mehr oder weniger gelungene Zusammenstellungen und Besprechungen eines gegebenen Stoffes zu betrachten sind. In den naturwis- 
senschaftlichen Fächern, welche, wie die Chemie, auf einer rein experimentellen Basis fußen, sind Arbeiten der letzteren Art überhaupt von geringerer und zwar um so geringerer Bedeutung, je weniger deren Autor durch selbstständige weitere Forschungen auf naturwissenschaftlichem Gebiete sich die Fähigkeit erworben hat, zu einem richtigen Verständniß und zu einer gesunden, nicht von unreifen Auffassungen beeinflussten, kritischen Beurtheilung fremder Arbeiten, auf die er in Ermangelung mühsam erworbener eigener Erfahrungen und Erkenntnisse ... allein angewiesen sieht. Wenn sich daher von diesem Standpunkte aus, den die Facultät in Fällen der vorliegenden Art stets festgehalten hat, die beiden ersten Arbeiten des Dr. Mayer, bei welchen es viel um zweckmäßige Anordnung, kritischen Beitrag und zeitgemäße Darstellung eines von Anderen geschaffenen bereits vielfach bearbeitenten [!] Materials handelt, in Betracht ziehen, so kann ich dieselben nicht für geeignet halten, um auf Grund derselben die Verleihung einer außerordentlichen academischen Professur zu rechtfertigen ..." (aus: UAH H-IV102/76 fol. $314 \mathrm{r}-315 \mathrm{r})$.

Im zweiten Gutachten, Febr./März 1873 erstellt von Fühling im Einvernehmen mit Stengel, heißt es: Die Verdienste von „... Mayer's Lehrbuch der Agrikultur-Chemie (werden) leider durch scharfsinnige, aber in ihrer beißenden Schärfe über die Grenzen der Objektivität weit hinaus gehende Kritik wesentlich beeinträchtigt, umsomehr als häufig in ebenso ungerechter als durchaus ungesunder Weise Urtheile über Leistungen der hervorragendsten Männer der Wissenschaft ausgesprochen werden. Bemüht man sich von diesem Mangel an Objektivität im kritischen Theile des bezeichneten Werkes abzusehen, so kennzeichnen dessen Verdienste sich darin, dass Mayer's Lehrbuch den meisten derartigen Lehrbüchern gegenüber, die lediglich eine Reihe von Thatsachen aus dem Gebiete der Chemie, Physik, Mineralogie, Geognosie, Physiologie - häufig sogar ohne jeden inneren Zusammenhang und ohne geistige Verbindung - zusammenstellen, einen Gedanken scharf und präcis durchführt, den Gedanken nämlich, die Ernährung der Pflanze zu lehren und auf der Basis dieser Lehre eine Erklärung des Feldbaues zu errichten, und zwar in durchaus selbstständiger Weise ... Nach ihrer gewissenhaften
Überzeugung glauben die Unterzeichneten die Frage, ob sie für empfehlende Ueberweisung der Mayer'schen Bitte stimmen, ... mit „Ja“ beantworten zu müssen“ (aus: H-IV-102/76 fol. 316r, v).

Das dritte Gutachten, verfasst am 12. März 1873 von Pfitzer, unterstützt nur in dem Fall das Gesuch Mayers, wenn die Fakultät der Verleihung der außerordentlichen Professur zustimmen sollte, siehe hierzu H-IV-102/76 fol. 318r-319r.

Am 25. April 1873 zieht Dekan Bartsch das Fazit aus den Gutachten und berichtet an den Engeren Senat: „Der Privatdocent Dr. A. Mayer hat der philosophischen Facultät das angeschlossene an Gr[oßherzogliches] Ministerium des Innern gerichtete Gesuch um Charakterisierung als außerordentlicher Professor mit der Bitte überreicht, dasselbe befürwortend an das Ministerium gelangen zu lassen. Die Facultät sieht sich bei aller Anerkennung des fleißigen Strebens und der unleugbaren Begabung des Dr. Mayer auf Grund seiner bisherigen wissenschaftlichen Arbeiten und academischen Thätigkeit für jetzt nicht in der Lage, sein Gesuch zu befürworten, hegt aber die Zuversicht, dass es Dr. Mayer bei seinem Fleiß und Streben in nicht langer Zeit gelingen werde, so selbstständige wissenschaftliche Arbeiten auszuführen, wie sie die Facultät in Übereinstimmung mit den bisher gesteckten Anforderungen als Grundlage für Ertheilung der von ihm erbetenen Auszeichnung glaubt verlangen zu müssen" (aus: $\mathrm{H}-\mathrm{IV}$-102/ 76 fol. 32or). M. erhält knapp zwei Jahre später im Januar 1875 das Extraordinariat.

E 1924 Mitglied der Akademie der Wissenschaften H. Ehrenpromotionen: 1920 Hochschule für Bodenkultur Wien, 1923 Landwirtschaftl. Hochschule Berlin, 1926 Landbouwhogeschool Wageningen. 1942 Dr. Richard-Kißling-Preis der Int. Tabakwiss. Gesellschaft.

Qu UAH PA 1975; RA 6571f., 6890; Rep. 14-30, Rep. 14-229f.; Fak.-Akten H-IV-102/62, H-IV102/76. Los vom Materialismus! Bekenntnisse e. Alten Naturwissenschaftlers. Heidelberg 1906. (Autobiogr.) 
W Das Düngerkapital und der Raubbau. Eine wirthschaftliche Betrachtung auf naturwissenschaftlicher Grundlage. Heidelberg 1869. • Lehrbuch der Agrikulturchemie in Vorlesungen. 2 Bde. Heidelberg 1871. 7. Aufl. 1914-1927. Lehrbuch der Gärungschemie. Heidelberg 1874. 7. Aufl. 1926. • Die Lehre von den chemischen Fermenten oder Enzymologie. Heidelberg 1882. - Über die Mosaikkrankheit des Tabaks in: Die landwirtschaftlichen Versuchs-Stationen 32 (1886) S. 451-467. Die landwirtschaftlichen Versuchsstationen als Staatsinstitut. Beiträge zur Reform dieser Anstalten. Heidelberg 1896. - Die Bedeutung des Wissens vom Tode für die Genealogie der Religion in: Religion und Geisteskultur 4 (1910) S. 191-207. • Siehe Badische Biographien N. F. V (2005) S. $203 \mathrm{f}$.

W Maydolf, Eduard: Mephistos Wiederkehr: dramatische Weihnachtsdichtung ... Heidelberg 1909. Laokoon. Einaktig [!] Trauerspiel. Heidelberg 1925. - Mayer-Gmelin, Adolf: Singsang für Volk und Vaterland. [Gedichtsammlung.] Heidelberg (1940).

$L$ Die Familie Gmelin und die Naturwissenschaften ... Porträts, Briefe, zeitgenössische Dokumente, Veröffentlichungen. Katalog zur Gmelin-Gedächtnisausstellung durchgeführt vom Gmelin-Inst. in der Max-Planck-Gesellschaft im Dechema-Hause in Frankfurt/M. 25. Nov.-2. Dez. 1964. WBIS; NDB 16 (1990) S. 533 f. Böhm, Wolfgang: Biographisches Handbuch zur Geschichte des Pflanzenbaus. München 1997. S. 206 f. u. ö. • Discoveries in Plant Biology. Ed. by Shain-Dow Kung, ShangFa Yang. Singapore 1998. Vol. I. S. 106 f. $(P)$. Badische Biographien N.F. V (2005) S. 201-204. Fields' Virology. 5th edition. Editors-in-chief David Mahan Knipe, Peter M. Howley. Vol. 1. Philadelphia 2007. S. 4 f. u. ö. • Vlak, Just: A. M. ... en zijn betekenis voor de Virologie als wetenschap in: Gewasbescherming - Mededelingenblad van de Koninklijke Nederlandse Plantenziektekundige Vereniging - (Mai 2007) Jg. 38. Nr. 3. S. 81-85. Autoren der Bunsenbibliothek (2009 online). Neurovirology. Ed. by Alex C. Tselis, John Booss. Edinburgh 2014. S. 7 f. u. ö. (S. 7: Karikatur M.s als Faust). - Schulze, Reinhard: Der Koran und die Genealogie des Islam. Basel 2015. S. 110, 356. Kallio, Katri: The roles of Template RNA and Replica- tion Proteins in the Formation of Semliki Forest Virus Replication Spherules. Diss. Helsinki 2016. S. 1.

P Bildarchiv UAH; graph. Slg. UBH.

\section{Mayer-Gmelin, Adolf \\ siehe Mayer, Adolf}

\section{Mayer-Gross, Willy}

1924-1933 (1935) Med. Fak.

Psychiatrie

* 15. Jan. 1889 Bingen/Rhein

$\dagger$ 15. Febr. 1961 Birmingham (Großbritannien) mosaisch

V Marx Mayer (1857-1934) Weinhändler

M Mathilde geb. Gross (1869-1969), s. Erinnerungen der Binger Jüdin M. Mayer, online unter http://www.juedisches-bingen.de/ 96.o.html (Ausdruck im UAH)

๑ 3. April 1919 Carola geb. Meyer $\left({ }^{*} 1888 \dagger\right.$ nach 1976)

K 1 Adoptiv-S, s. Lexikon jüdischer Einwohner Hs (2011) S. 291

Vw Vetter: Bernhard Gross (1905-2002) Atomphysiker, s. Mascarenhas, Sergio: B.G. and his contribution to physics in Brazil in: Brazilian Journal of Physics. São Paulo 1999. Vol. 29, No. 2; Nachruf auf B. G., s. online unter http:// www.canalciencia.ibict.br/notaveis/livros/be rnhard_gross_44.html (Ausdruck im UAH).

$L b$ Seit WS 1909/10 Studium an U München, SS 1911-WS 1911/12 H; Mai 1912 Staatsexamen in H; 1. Aug. 1913 Dr. med. an UH.

UH: Seit 1912 Medizinalpraktikant, seit Juli 1913 Assistent, 1924-1933 Oberarzt an Psychiatr. U-Klinik, unterbrochen 1922-1923 durch Studienaufenthalt an der in e. ehem. Kloster untergebrachten Irrenanstalt in Rheinau (Kanton Zürich); 14. Mai 1924 Habilitation; seit 27. April 1929 nichtplanm. a.o. Prof.; 1929-1932 außerdem Dozent an 
Lehrerbildungsanstalt in H; seit 6. April 1933 Beurlaubung aus rassischen Gründen; 15. Juli 1933 Aufhebung der Beurlaubung, da M.-G. vom Kultusministerium als „Frontkämpfer im Sinne des Gesetzes zur Wiederherstellung des Berufsbeamtentums ... anerkannt" wird (aus: UAH PA 4965); 1. Okt. 1933-1. Nov. 1935 Genehmigung e. Urlaubs für Forschungsaufenthalt in England; 31. Dez. 1935 Entzug der Lehrbefugnis aus rassischen Gründen. In dieser Zeit:

1914-1918 Kriegsdienst.

London: Seit Nov. 1933 Commonwealth Research Fellow, 1934-1939 Rockefeller Research Fellow an Psychiatr. U-Klinik Maudsley Hospital; 1939 med. Staatsexamen für Immigranten in Glasgow.

Dumfries (Schottland): 1939-1954 (Pensionierung) Direktor des Dept. of Clinical Research am Chrichton Royal Mental Hospital, s. Cyril Greenland: At the Crichton Royal with W.M.-G. in: History of Psychiatry 13 (2002) S. 467-470.

Birmingham: 1955-1960 (Emeritierung) Senior Fellow an Abt. für Experimentelle Psychiatrie der Medical School; 1958, 1960 Gastprof. an U München und Hamburg; Anfang Febr. 1961 Umzugsvorbereitungen, um Leitung e. geplanten pharmakopsychiatrischen Forschungsstätte an Psychiatr. Klinik der UH zu übernehmen. • In dieser Zeit:

UH: 1. April 1954 Emeritierung; 15. Febr. 1955 Landgericht Stuttgart setzt - entgegen der Auffassung des Kultusministeriums - M.-G. in die Rechte e. emeritierten o. Prof. ein; Kultusministerium akzeptiert Urteil nicht und klagt bei Oberlandesgericht; 30. Sept. 1955 Streit wird in e. auBergerichtlichen Vergleich beigelegt, s. hierzu Nervenärzte (1998) S. 53; 11. Dez. 1958 Med. Fak. beschließt, „den mit den Bezügen, aber nicht mit den Rechten e. emeritierten o. Prof. ausgestatteten M.-G. auch die Rechte e. emeritierten Ordinarius zuzuerkennen“" (aus: PA 4965).

1951/52 und 1956/57 Psychiatrischer Spezialberater der Weltgesundheitsorganisation der Vereinten Nationen in Indien
E 1942 Fellow of the British Psychological Society; 1945 Member, 1951 Fellow of the Royal College of Physicians London. • Dr. h.c. U Lissabon.

Qu UAH PA 1072, 4965. - Teil-Nachlaß 19221956: Bethlem Royal Hospital Archives and Museum in Beckenham/Kent.

$W$ Selbstschilderungen der Verwirrtheit. Berlin 1924. Pathologie der Wahrnehmung in: Handbuch der Geisteskrankheiten 1 (1928) S. 351-507; Therapie in: ebd. 9 (1932) S. 595-605. Clinical Psychiatry. London 1954. 2. Aufl. 1959. (Mitverf.: E. Slater, M. Roth.) - Siehe hierzu Bibliographie in: Haas (1976) S. 55-68, Nervenärzte (1998) S. 48 ff.

MG 1928-1933 Zs. „Der Nervenarzt“.

L Kürschner (1931) Sp. 1888, (1935) Sp. 879; Arnim 2 (1952) S. 144, 3 (1961) S. 400, 4 (1984) S. 1057. • Baeyer, Walter Ritter von: W.M.-G. $\dagger$ in: Ruperto Carola 13. Jg., Bd. 29 (1961) S. 210 f. - Bradley, P. B., Elkes, Joel: W. M.-G. (15.1.1889-14. [!] 2. 1961) in: Psychopharmacology Vol. 2, Nr. 4 (1961) S. 221223. Fischer $2\left({ }^{3} 1962\right)$ S. 1011. • Jung, R.: W. M.-G. in: Archiv für Psychiatrie und Zs. für die gesamte Neurologie 203 (1962) S. 123-136. - Wer ist wer (1962) S. 984. Haas, Karl Ferdinand: W. M.-G. Leben und Werk. Diss. Mainz 1976 (S. 43: als Todestag der 16. Febr. genannt). - Dictionary of Emigrés 2 (1983) S. 793; Chronik Ärzte H (1985) S. 137. • Spiegelberg, Herbert: Phenomenology in Psychology and Psychiatry. A historical introduction. 2. Aufl. Evanston (Illinois) 1986. S. 97-99 u.ö. • WBIS; Mussgnug (1988) S. 298 (Register); Nervenärzte (1998) S. 47-54. • Cordás, Táki Athanássios: W.M.-G. ... in: Revista de Psiquiatria Clínica (2003) S. 116-120. • Universitätskolloquien zur Schizophrenie. Hrsg. von Hanns Hippius. Berlin 2004. Bd. 2. S. 6-9. • Shorter, Edward: A Historical Dictionary of Psychiatry. New York 2005. S. 171f. u.ö. • UH im Nationalsozialismus (2006) S. 910-912 u.ö. - Peters, Uwe Henrik: Lexikon Psychiatrie, Psychotherapie, Medizinische Psychologie ... 6. Aufl. München 2007. S. 335. - Lexikon jüdischer Einwohner Hs (2011) S. 291. • One century of Karl Jaspers' General Psychopathology. Ed. by Giovanni Stanghellini, Thomas Fuchs. Oxford 2013. - Shorter, Edward: What Psychiatry left out of the DSM-5: Historical mental disorders today. 
New York 2015. S. 39f., 119-121 u. ö. • Deutsche Biographie, s. https://www.deutsche-biographie. de/gnd116963409.html [07.11. 2017].

$P$ Bildarchiv UAH; Chronik Ärzte H.

\section{Mecke, Reinhard Robert Julius}

1930-1937 Nat.-Math. Fak.

Physikalische Chemie, Spektroskopie

* 14. Juli 1895 Stettin (heute: Szczecin, Polen)

$\dagger$ 30. Dez. 1969 Freiburg/Br. ev.

V Paul M. (ca. 1860-1939) Chemiker

M Elise-Marie geb. Schoenberg

$\varnothing$ 2. Sept. 1927 Dr. rer. nat. Maria Paula Ottilie geb. Guillery (1902-2002)

K 3 T, 6 S (davon $1 \mathrm{~S}$ früh $\dagger$ ): u. a. Dieter M. (19332013) seit 1969 Privat-Dozent, seit 1973 Prof. für Biochemie Freiburg/Br., 1974-2001 (Emeritierung) o. Prof. und 1980-2001 Direktor des Physiolog.-Chemischen Inst. Tübingen, s. Probst, Hansgeorg: Zum Tode von D. M. ... in: Newsletter Uni Tübingen aktuell Nr. 2 (2013).

Lb 1909-1912 Schulbesuch u. a. in Chicago; Sept.Dez. 1914 (krankheitsbedingte Entlassung wegen e. Herzfehlers) Kriegsfreiwilliger, u. a. im Gefecht von Langemarck bei Ypern.

Wiesbaden: Seit Jan. 1915 Tätigkeit im Chemischen Laboratorium Fresenius.

Seit SS 1915 Studium der Physik, Mathematik, Naturwiss. an U Freiburg, WS 1916/17 Bern, SS 1917?, 29. Sept. 1917-22. Febr. 1920 Marburg; 23. Juni 1919 Rigorosum, 16. Juli 1919 (Datum der Promotionsurkunde) Dr. phil. nat. an U Marburg.

U Münster: 1919/20 Assistent am PhysikalischChemischen Inst.

U Bonn: Seit Mai 1920 Assistent am Physikal. Inst.; 9. Mai 1923 Habilitation für Physik; seit 17. Dez. 1927 nichtplanm. a. o. Prof.
UH: Seit 1. Okt. 1930 nichtplanm. a. o. Prof.; 1934/35 stellvertr. Direktor des Physikalisch-Chemischen Inst. nach Weggang von Max Trautz; Aug. 1934 Berufungsverhandlungen zwischen Badischem Unterrichtsministerium und M. als Nachf. von Trautz; durch Intervention des Einstein-Gegners Philipp Lenard unterbleibt Bestätigung der Ern. durch Reichsministerium für Wissenschaft, Erziehung und Volksbildung (Lenard urteilt über M. u. a.: Er ist ,... der einzige in Heidelberg ..., der wissenschaftliche Charakterschwäche und Geschmacklosigkeit gezeigt habe, noch im WS 1932/ 33 Einsteins Relativitätstheorie zu behandeln“, aus: UH im Nationalsozialismus (2006) S. 1106); 1935 Nachf. von Trautz: Kurt Fischbeck, s. Drüll (2009) S. $195 \mathrm{f}$.

U Freiburg/Br.: Seit 1. Jan. 1937 (Schreiben vom 8. April 1937 rückwirkend ab 1. Jan. 1937) o. Prof. für Theoretische Physik und Direktor des Inst. für Physikal. Chemie, seit April 1942 o. Prof. für Physikal. Chemie und Direktor des o.g. Inst.; Nov. 1944 Zerstörung des Inst. durch Bombardierung, Verlegung nach Konstanz-Wallhausen (bis 1949); 1. April 1963 Emeritierung; SS 1963-Ende SS 1964 Vertreter seiner Professur. • In dieser Zeit:

Freiburg/Br.: Juli 1957-Juni 1968 (Pensionierung) Begründer und Direktor des Inst. für Elektrowerkstoffe der Fraunhofer Gesellschaft für Angewandte Forschung (bis März 1959 untergebracht im Inst. für Physikal. Chemie der U); seit 1968 Berater am genannten Inst. der Fraunhofer Gesellschaft.

E 1964 Mitglied der Dt. Akademie der Naturforscher Leopoldina Halle/S.; Ehrenmitglied: 1956 Indian Academy of Sciences Bangalore, 1962 Belgische Chemische Gesellschaft. 1959 Giacomo Ciamician-Medaille der U Bologna; 1962 Jean Servais Stas-Medaille der Belgischen Chemischen Gesellschaft; 1965 Bunsen-Denkmünze in Gold der Dt. Bunsengesellschaft für Physikalische Chemie.

Qu UAH PA 4971; Fak.-Akte H-V-4/29 Nr. 79. • Auskunft: Archiv der Philipps-Universität Marburg im Hessischen Staatsarchiv ebd. • Siehe auch Archiv der Dt. Akademie der Naturforscher Leopoldina Halle/S. 
$W$ Experimentelle und theoretische Untersuchungen über Kranzerscheinungen im homogenen $\mathrm{Ne}$ bel. Leipzig 1920. Das Bandenspektrum des Jods in: Annalen der Physik Bd. 376, Nr. 9-12 (1923) S. 104-134. - Leitfaden der praktischen Experimentalphysik. Berlin 1926. Bandenspektra und ihre Bedeutung für die Chemie. Berlin 1929. • Siehe Bibliographie in: Kipnis (2015) online.

$L$ Verzeichnis Bonn (1968) S. 191f.; Arnim 4 (1984) S. 1060; WBIS. • Kovner, M. A.: Development of Mecke's ideas in the scientific work of Soviet spectroscopists in: Journal of Molecular Structure 347 (1995) S. 19 f.; Lüttke, W., Nonnenmacher, G. A.A.: R.M. Scientific work and personality in: ebd. S. 1-18. • UH im Nationalsozialismus (2006) S. $1106 \mathrm{f}$. Das Institut für Elektrowerkstoffe in der Ära R. M. in: 50 Jahre Fraunhofer IAF (Institut für Angewandte Festkörperphysik) 1957-1967. Heller - schneller - stärker. Jubiläumsschrift. Redaktion Helga König ... Günter Weimann (verantwortlich) ... Freiburg/Br. 2007. S. 33-37 u. ö. • Jug, Karl: Zweihundert Jahre Entwicklung der Theoretischen Chemie im deutschsprachigen Raum. Berlin 2015. S. 80, 84 u.ö. - Kipnis, Alexander: Biographie R.M. online unter http://www.kipnis.de/ index.php/alexander/kurzbiografien/170-meckereinhard-1895-1969-physiker-physikochemiker (abgerufen am 23. April 2015; Ausdruck im UAH; irrtümlich Geb.-Datum mit 13. statt 14. Juli angegeben). Deutsche Biographie, s. https://www. deutsche-biographie.de/gnd116988533.html [07.11. 2017].

$P$ Bildarchiv UAH.

\section{Medicus, Ludwig Wallrad}

1795-1803 Phil. Fak. 1803-1822 Staatswirtschaftl. Sektion 1822-1840 Phil. Fak.

Staatswirtschaft, auch Mathematik

* 08. Aug. 1771 Mannheim

$\dagger$ 18. Sept. 1850 München luth.
V Friedrich Casimir M. (1736-1808) Arzt, 1774 Gründer und Direktor der „Kameral Hohe Schule Lautern" (heute: Kaiserslautern), die 1784 als Staatswirtschafts Hohe Schule an Phil. Fak. der UH verlegt wird, s. Hess (1988) S. 233

M Caroline Catharina geb. Koch (1745-1814)

๑ 11. Mai 1811 Eleonora Johannette Caroline geb. von Langsdorf(f) (1790-1828) T von: (siehe) Christian von $\mathrm{L}$.

K 2 S: u. a. Wilhelm M. (1819-1912) seit 1845 Lehrer für Naturkunde an Kreisgewerbeschule und Konservator des Naturhistor. Museums in Lautern, Naturforscher, s. Keiper, Johann: Friedrich Kasimir Medicus in: Mannheimer Geschichtsblätter 7 (1906) H. 2, Sp. 33 f., WBIS.

Lb Seit WS 1787/88 Studium der Staatswiss. an UH; 1791 Forts. des Studiums an Handlungs-Akademie in Hamburg.

Forstpraxis: Seit 1792 Rheinpfalz, seit 1793 Württemberg; in den Ferien Studienreisen u. a. nach Frankreich, 1794 in die Schweiz.

Staatswirtschafts Hohe Schule H und Phil. Fak. der UH: Seit 20. Dez. 1795 a.o. Prof. an "Staatswirtschafts Hohe Schule“, die mit Phil. Fak. der U personell verbunden ist; 1795-1804 als Bergrat Mitgl. des Kurfürstl. Oberbergamtes Mannheim; 1796 jährl. Besoldung von 400.- Gulden seitens UH, als Bergrat zusätzl. 300.- Gulden; 1802 Promotion zum Dr. phil.; Mai 1803 Einführung der Staatswirtschaftl. Sektion nach Eingliederung der „Staatswirtschafts Hohe Schule" in U; Mai 1822 Zusammenlegung der Staatswirtschaftl. Sektion mit Phil. Fak.

Ordinarius für Land-, Forstwirtschaft und Bergbaukunde an U: Seit 1804 Würzburg, seit 1806 Landshut, seit 1826 München.

Vor 1826 Mitbegründer des Landwirtschaftlichen Vereins in Bayern

1795 Bergrat; 1828 Hofrat

$Z$ In einem Schreiben vom 19. Juni 1803 legt M. einem nicht näher genannten Herrn Geh. Rat seine Überlegungen zu der nun auch geplanten administrativen und räumlichen Zusammenführung 
der "Staatswirtschafts Hohe Schule“ mit der Universität Heidelberg 1803 durch Einführung der Staatswirtschaftlichen Sektion dar:

„... Nunmehr aber, da das Edict erschienen ist, welches das künftige Schiksal unserer hohen Schule auf eine so zwekmäßige Art bestimt, durch welches die jezige Regierung sich den Ruhm der völligen Wiederherstellung und weitern Ausbildung dieser gesunkenen Lehranstalt auf eine so ausgezeichnete Art erwirbt, ... sei es mir um so mehr erlaubt, Euer Wohlgebohrenen meine Wünsche und Hofnungen vorzutragen, ... je mehr es mir wünschenswerth ist, auch an den aufsteigenden bessern Tage[n] einen zufriedenen und freudigen Antheil nehmen zu können, nachdem ich in den vergangenen so trüben Zeiten standhaft ausgehalten und der bessern Zukunft gehoft habe ...

Seit meiner Anstellung ... habe ich über folgende Fächer Vorlesungen gehalten: Encyklopädie der staatswirtschaftl. Wissensch[aft], ... Landwirthschaft, Forstwissenschaft, Bergwerkswissenschaft. In Hinsicht des lezteren Faches habe [ich] nicht sowohl Bergbau in Specie vorgetragen, sondern es in hiesiger Lage für zweckmäßiger gefunden, meine Zuhörer mit dem ganzen der bergmännischen Wissenschaften bekannt zu machen, wobei ich jedoch die Hauptrücksicht auf Geognosie ,Gebirgskunde und Bergbau selbst nehme. Handlungswissenschaft habe [ich] ebenfalls schon einigemale vorgetragen. Den für das kameralistische Fach so wichtigen integrirenden Theil der Rechnungswissenschaft habe [ich] mehrmalen angekündet, aber noch nie zu Stande gebracht. Über Anfangsgründe der reinen Mathematik habe [ich] dreimal Vorlesungen gehalten und bin dazu, so wie zum Unterrichte in der praktischen Geometrie und auch in der Mineralogie erbötig ...

Von den drei im Universitäts-Edicte bestimmten Bibliothekarstellen würde [ich] mit Vergnügen eine übernehmen, wenn es mir einigen Vortheil verschaffen könnte. - Übrigens bin ich äußerst begierig auf die Entscheidung der Frage, wegen der künftigen Bestimmungen unserer bei der bisherigen Staatswirthschafts hohen Schule befindlichen, in einem eigenen Gebäude aufgestellten Samlungen, [wie] Bibliothek, physik[alisches] Kabinet, Mineraliensamlung und Modellenkabinet; werden sie mit den geringen Universitätssamlungen der Art vereiniget werden oder abgesondert stehen bleiben? ... Unsere Bibliothek bei der Staatswirthschafts hohen Schule schränkt sich blos auf dieses Fach [= Staatswirtschaft] ein und enthält das vorzüglichste desselben, was bis auf den Zeitpunkt des Krieges in den verschiedenen Theilen des kameralistischen Faches herausgekommen ist; sie [= die Bibliothek] ist überdieß in der größten Ordnung und allen hiesigen Gelehrten und Studierenden von erprobtem Nuzen. Die Universitätsbibliothek ist eine nicht sehr bedeutende, ziemlich unordentliche Zusammenhäufung von gröstentheils alten Werken aus allen Fächern. Durch eine zu frühe Vereinigung beider [Bibliotheken] könnte die Unordnung der einen leicht auch auf die andere ausgedehnt und der Nuzen, den erstere [ $=$ Bibliothek der Staatswirtschafts Hohen Schule] jezt leistet, leicht gehem[m]t werden ..." (aus: GLA Abt. 205, Fasz. 382).

Zur Einführung der Staatswirtschaftlichen Sektion an UH 1803, siehe auch Heinrich Eschenmayer: Eintrag unter $Z$ [itat]

Qu UAH PA 1979. - Winkelmann 2 (1886) S. 292 Fasz. 382. - Protokolle des Bayerischen Staatsrats 1799-1817. Hrsg. von der Historischen Kommission bei der Bayerischen Akademie München. Bd. 2: 1802-1807. Bearb. von Esteban Mauerer. München 2008. Nr. 25. S. 164: Protokoll der Geheimen Staatskonferenz vom 20. März 1802, Onlinefassung unter: http://138.246.100.12/str/res/ Bd2_1802/nr25. • Bf.: UBH. • Auskunft: Registeramt des Ev.-Luth. Kirchengemeindeamts München (Sterberegister der Prot. Stadtpfarrei München); Ev. Oberkirchenrat - Landeskirchliches Archiv - Karlsruhe.

$W$ Forsthandbuch oder Anleitung zur deutschen Forstwissenschaft. Stuttgart 1802. - Entwurf eines Systems der Landwirtschaft. Heidelberg 1809.

$L$ Keiper, Johann: Friedrich Kasimir Medicus in: Mannheimer Geschichtsblätter 7 (1906) H. 2, Sp. 33. • Poller (1979) S. 200 f.; WBIS. • Die Ludwig-Maximilians-Universität in ihren Fakultäten ... Hrsg. von Laetitia Boehm und Johannes 
Spörl. Bd. 1. Berlin 1972. S. 131-144. • Hess, Christel: Absolutismus und Aufklärung in der Kurpfalz in: ZGORh 136. Jg. (1988) S. $234 \mathrm{ff}$. Biographie in: Hessische Biografie, s. http://www.lagis-hessen. de/pnd/100374794 (Stand: 15. Okt. 2010); Neuhaus (2014) S. 58 f. u. ö.

\section{Mehlhorn, Paul}

1884-1891 (Dozent), 1891-1893 Theol. Fak.

Kirchengeschichte

* O3. Jan. 1851 Gauern (bei Gera)

$\dagger \quad$ 05. Dez. 1919 Leipzig

ref.

V Johann M. (1814-1883) ev.-luth. Pfarrer

M Louise geb. Linke (1815-1900)

๑ 24. Mai 1877 Emma Louise geb. Besançon $\left({ }^{*} 1857\right)$

K 3 S, 3 T (davon $1 \mathrm{~T}$ früh $\dagger$ ): u. a. Helene M. (1883-1971) Photographin; Ehefrau von Rüdiger Berlit (1883-1939) expressionistischer Maler und Grafiker, s. R. B. und der Expressionismus in Leipzig. Hrsg. von Richard Hüttel und Hans-W. Schmidt. Leipzig 2010.

Vw Werner M. (1932-2009) Nachfahre in 3. Generation, u. a. 1971-200o o. Prof. für Physik an U Freiburg/Br., s. Kürschner (2001) S. 2052. • Nachfahre in 4. Generation (Sohn von Werner M.): u. a. Prof. Dr. Dr. h. c. Uwe M. $\left({ }^{\star} 1963\right)$, Assistenzarzt: seit 1991 U Köln, 1993-1996 U of Texas-Houston Medical Center; U Köln: 1996-1998 Assistenzarzt, seit 1998 Facharzt für Herzchirurgie, 1999 Habilitation, seit 2001 C 3-Prof., seit 2005 W 2-Prof.; seit 2007 W 2-Prof. U Mainz, seit 2015 Ärztl. Direktor und Chefarzt für Herzchirurgie der Helios Klinik für Herzchirurgie in Karlsruhe.

Lb Seit 22. April 1869 Studium der Theologie, Philosophie an U Jena, 24. April-6. Aug. 1872 Zürich.

1872-1873 Examensvorbereitungen; 5. Sept. 1873 theol. Vorprüfung, 4. Okt. 1875 Hauptprüfung in Altenburg; 15. Dez. 1873 Dr. phil. an U Jena.
Dresden: Seit 1873 provisorischer Lehrer, seit 8. Dez. 1874 Lehrer für Religion und Kirchengeschichte am Inst. Cachin.

Leipzig: Seit 7. Jan. 1875 provisorischer Oberlehrer, seit 1. April 1875 Oberlehrer am Nicolai-Gymnasium.

H: 15. Juli 1881-30. April 1893 Prof. am Lyceum (heute: Kurfürst-Friedrich-Gymnasium „KFG“). • In dieser Zeit:

UH: Seit WS 1884/85 Dozent; 1885-1893 e. der Hauptlehrer am Ev.-Prot. Theol. Seminar; seit 19. März 1891 nichtetatm. a. o. Prof.

Leipzig: Mai 1893-März 1918 (Ruhestand) II. Pfarrer der ev.-ref. Gemeinde.

1918 Kirchenrat

E Juli 1886 Theol. Lizenziat h.c. UH; 1893 D. theol. Jena.

Qu GLA Abt. 235, Fasz. 13375. A Auskunft: Universitätsarchiv Jena; Ev.-ref. Kirche Leipzig. • Mitteilungen: Herr Prof. Dr. Werner Mehlhorn ( $\dagger$ ), Freiburg/Br.

$W$ Heidelberger Universitätspredigten. Leipzig 1891. - Die Bibel, ihr Inhalt und geschichtlicher Boden. Leipzig 1877. 8. Aufl. 1914. • Leitfaden zur Kirchengeschichte für höhere Lehranstalten. Leipzig 1881; dann u.d.T.: Kirchengeschichte für höhere Schulen. 11. Aufl. 1925. • Grundriß der protestantischen Religionslehre. Leipzig 1883. 8. Aufl. 1918. - Aus den Quellen der Kirchengeschichte. 2 H. Berlin 1894-1899. Wahrheit und Dichtung im Leben Jesu. Leipzig 1906. Die Frauen unserer Reformatoren. Tübingen 1917.

$L$ Wer ist's (1914) S. 1094; Arnim 4 (1984) S. 1062; Das „Goldene Buch“ des KFG (1994) S. 96 (hier Todesdatum: o6. Dez.); WBIS. - In der Mitte der Stadt. Die ev.-ref. Kirche zu Leipzig ... Hrsg. von Hans-Jürgen Sievers. Leipzig 2000. S.112- 
114, 163. Deutsche Biographie, s. https://www. deutsche-biographie.de/gnd116993626.html [07.11. 2017].

$P$ Bildarchiv UAH; graph. Slg. UBH; In der Mitte der Stadt (2000) S. 163.

\section{Meister, Karl Max Richard}

1921-1950 Phil. Fak.

Klassische Philologie

* 22. Okt. 188 o Leipzig

$\dagger \quad$ 13. Sept. 1963 Heidelberg ev.

V Dr. phil. Richard M. (1848-1912) seit 1872 Lehrer, seit 1892 Prof., seit 1908 Studienrat für Griechisch und Latein an Nikolaischule Leipzig, s. WBIS; Meister, Karl: R. M. in: Indogermanisches Jahrbuch 1 (1914) S. 219-227 (mit Schriftenverzeichnis)

M Klothilde geb. Eckardt (1859-1945)

๑ 27. Sept. 1911 Margarete geb. Boyens (18881979)

K $\quad{ }_{1} \mathrm{~S}, 3 \mathrm{~T}$

Vw Brüder: Edwin M. (1884-1978), u. a. 1925-1945 Prof. für Textil- und Wärmetechnik TH Dresden, s. Arnim 4 (1984) S. 1066, Professoren TU Dresden (2003) S. 614 (hier 1970 als Todesjahr genannt). - Eckard M. $\left({ }^{*} 1885\right.$ \ 1914) $1913-$ 1914 Privat-Dozent für Rechtswiss. U Leipzig, 1914 Ruf an U Basel, s. Planitz, Hans: Nachruf in: Zs. der Savigny-Stiftung für Rechtsgeschichte - Germanistische Abt. 36 (1915) S. LVI-LX; WBIS

Vw siehe NDB 16 (1990) S. $727^{*}$.

Lb U Leipzig: Seit 1899 Studium; 22. Juni 1905 Dr. phil.; 1905 Staatsexamen in Leipzig.

Probekandidat, Gymnasiallehrer: 1906 Dresden, 1907-1909 Leipzig.

U Leipzig: Seit Sept. 1907 Assistent am Philolog. Inst.; 26. April 1909 Habilitation.
U Berlin: Seit Sept. 1909 Privat-Dozent und Assistent am Inst. für Altertumskunde; seit WS 1909/10 nichtetatm. a.o. Prof.

U Königsberg (Preußen): WS 1914/15 (Dienstantritt: SS 1916)-SS 1921 o. Prof. • In dieser Zeit:

Aug. 1914-1916 Kriegsdienst.

UH: Seit 5. Sept. 1921 o. Prof. als Nachf. von Otto Weinreich; WS 1921/22 Mit-Direktor (zus. mit Franz Boll), seit SS 1922 Direktor, SS 1925-SS 1933 Mit-Direktor (zus. mit Otto Regenbogen) des Philolog. (Pro-)Seminars im Weinbrennerbau, Marstallhof 4; WS 1933/34-WS 1935/36 Mit-Direktor (zus. mit Otto Regenbogen), seit SS 1936 Direktor, WS 1938/39-30. Nov. 1945 Mit-Direktor (zus. mit Hildebrecht Hommel, s. Drüll (2009) S. 289), seit SS 1946 Mit-Direktor (zus. mit Regenbogen) des Griechisch-Lateinischen Seminars (bis WS 1946/ 47), seit SS 1947 des Philolog. Seminars im Weinbrennerbau; 1927 Ruf an U Tübingen abgelehnt; WS 1941/42-SS 1943 Vertreter des Lehrstuhls für Klassische Philologie an U Freiburg/Br.; 31. März 1949 Emeritierung; SS 1949-SS 1950 Vertreter seines Lehrstuhls und des Direktorats des Philolog. Inst.

1931 Rektor der UH; 1926/27 Dekan der Phil. Fak. der UH

Siehe auch Anhang Sporteinrichtungen an $U H$ 1910-1933 und ihre Mitglieder

E 1924 Mitglied der Akademie der Wissenschaften $\mathrm{H}$.

Qu UAH PA 527, 4988 f. • Nachlaß: UBH. • Mitteilungen: Herr Dr. Ulrich Meister $(\dagger)$.

$W$ Lateinisch-griechische Eigennamen. H. 1: Altitalische und lateinische Eigennamen. Leipzig 1916. Die homerische Kunstsprache. Leipzig 1921. Die Tugenden der Römer. Rektoratsrede. Heidelberg 1930. Bibliographie in: Studien zur Sprache, Literatur und Religion der Römer. Hrsg. von Viktor Pöschl und Michael von Albrecht. Frankfurt/M. 1987. 
HG 1946-1963 Heidelberger Texte. Lateinische Reihe.

MHG 1925-1933 Gnomon - Kritische Zeitschrift für die gesamte klassische Altertumswissenschaft.

L Kürschner (1961) S. 1310; Gnomon (1964) S. 222224; NDB 16 (1990) S. 727 f.; WBIS; Jansen (1992) S. 411 (Register); Ders. (1992a) S. 167 (Register). • Gärtner, Hans Armin: K.M. ... und das Seminar für Klassische Philologie der Universität Heidelberg in: Eikasmós 4 (1993) S. 269-272; Pöschl, Viktor: K. M. ... in: ebd. S. 273 f. • Tilitzki 1 (2012) S. 800 (Register).

$P$ Bildarchiv UAH; graph. Slg. UBH.

\section{Mejer, Fedor Egorovič \\ Mejer, Fëdor Jegorovic \\ siehe Meyer, Friedrich}

\section{Mendel, David}

s. Neander, August

Mendelssohn Bartholdy, Carl (nach 1860:

Karl) Wolfgang Paul

1864-1868 Phil. Fak.

Neuere Geschichte

* $\quad$ 07. Febr. 1838 Leipzig

$\dagger \quad$ 23. Febr. 1897 Königsfelden bei Brugg (Kanton Aargau)

$\square$ Karlsruhe ev.

V Felix M. B. (1809-1847) Komponist, u.a. 18351847 Kapellmeister des Gewandhausorchesters Leipzig, s. MGG 9 (1961) S. 59-98; Todd, Ralph Larry: Mendelssohn: A Life in Music. Oxford 2003; 250 Jahre Familie M. (2014) S. 360 (Register)
M Cécile Charlotte Sophie geb. Jeanrenaud (1817-1853), s. Felix und Cécile M. B.: Das Tagebuch der Hochzeitsreise (1837) nebst Briefen an die Familien. Hrsg. von Peter Ward Jones. Übers. aus dem Engl. und Franz. von Thomas Schmidt-Beste. Zürich 1997; 250 Jahre Familie M. (2014) S. 360 (Register)

๑ 6. März 1869 Bertha geb. Eissenhardt (18481870), s. 250 Jahre, S. 360 (Register)

๑ 21. Okt. 1872 Mathilde geb. von Merkl (18481937), s. ebd.

$\mathrm{K} \quad 1 \mathrm{~T}$ (aus 1. Ehe), 1 Totgeburt, $1 \mathrm{~S}$ (aus 2. Ehe): Albrecht M.B. (1874-1936) seit 1901 PrivatDozent, seit 1904 a.o. Prof. Leipzig, seit 1905 o. Prof. Würzburg, 1920-1933 o. Prof. für Privatrecht, Zivilrecht Hamburg, auch 1919 Berater der Reichsregierung bei den Friedensverhandlungen in Versailles, 1923-1934 Leiter des Inst. für Auswärtige Politik, seit 1925 Richter am Haager Schiedsgericht, s. NDB 17 (1994) S. 62f., Professorenkatalog Leipzig online, WBIS, 100 Jahre Germanistik in Hamburg (2011) S. 19-22, 467 u. ö.; A. M.B. ... Jurist Friedensforscher - Künstler in: Rabels Zs. für ausländisches und int. Privatrecht 75 (2011) H. 1, S. 1-31.

Vw Tante: Fanny Zippora Mendelssohn ((18051847) 1816 ev. getauft: Fanny Cäcilie M.B.) Komponistin; seit 1829 Ehefrau von Wilhelm Hensel (1794-1861) Maler, s. LowenthalHensel, Cécile, Arnold, Jutta: Wilhelm Hensel ... Berlin 2004. \Zu Fanny M. B., s. NDB 17 (1994) S. 52 f.; Schleuning, Peter: Fanny Hensel ... Musikerin der Romantik. Köln 2007; Steinbeck, Anke: Jenseits vom Mythos Maestro. Dirigentinnen für das 21. Jhdt. Diss. Berlin 2010; Härtling, Peter: Liebste Fenchel! Das Leben der F.H.-M. in Etüden und Intermezzi. Köln 2011; Hensel, Sebastian: Hier fiel Mutter vom Esel. Reisen nach Italien mit den Eltern Wilhelm Hensel und Fanny ... Das Tagebuch von 1839/40 und die Zeichnungen von 1845 . Hrsg. von Wolfgang Dinglinger. Hannover 2011; 250 Jahre Familie M. (2014) S. 109-130, 355 (Register). - Fanny und Wilhelm Hensel sind Großeltern von: (siehe) Paul Hensel 
Vw Onkel: Paul Hermann M.-B. (1812-1874) seit 1838 Teilhaber, seit 1871 Seniorchef der Familienbank Mendelssohn \& Co. Berlin (Vormund von Carl und seinem Bruder Paul M. B.), s. Briefe in Staatsbibliothek zu Berlin, Musikabteilung, MA Nachlaß 17; WBIS, NDB 17 (1994) S. 45, 52*, 250 Jahre, S. 361 (Register); Panwitz, Sebastian: Das Haus des Kranichs. Die Privatbankiers von Mendelssohn \& Co. (1795-1938). Hrsg. von Peter Schüring. Berlin 2018.

Vw Geschwister, u. a. Bruder: Dr. phil. Paul M.B. d. Ä. (1841-1880) Chemiker, SS 1859-SS 1861, SS 1862-WS 1863/64 Studium an UH, 1867 $(-1880)$ Mitbegründer und -direktor der Gesellschaft für Anilinfabrikation $\mathrm{mbH}$ in Berlin-Rummelsburg, 1873 nach Aufkauf der „Chemischen Fabrik Dr. Jordan“ umbenannt in "Aktiengesellschaft für Anilinfabrikation“ (Agfa), s. UAH RA 5479: Disziplinarverfahren im April 1861 als Student der UH wegen Verhöhnen e. Kommilitonen sowie im Juni desselben Jahres wegen e. Auseinandersetzung zwischen P.M. B. und zwei Polizisten; Strafe: 3 Tage Karzerhaft; siehe NDB 17 (1994) S. 586o; Lackmann, Thomas: Das Glück der Mendelssohns - Geschichte einer deutschen Familie. Berlin 2005. Schwester: Elisabeth (Lili) M. B. (1845-1910), s. 250 Jahre, S. 204, 213 f.; Ehefrau von Adolf Wach (1843-1926) seit 1868 Privat-Dozent Königsberg (Preußen), Ordinarius für Kirchenrecht und Zivilprozeßrecht: seit 1869 Rostock, seit 1871 Tübingen, seit 1872 Bonn, 1875-1920 (Emeritierung) Leipzig, s. Schmidt, Gerold: Zur Erinnerung an den großen Prozeßrechtler A. W. in: Zs. für Zivilprozeß 100. (Jubiläums-)Bd. (1987) S. 3-10; WBIS; Unger, Dagmar: A. W. ... und das liberale Zivilprozeßrecht. Berlin 2005; Schmidt, AnnaBarbara: Und nebenbei Gewandhausdirektor: sie gehörten zu den Spitzen der Gesellschaft ... zu ihnen zählte A.W. in: Gewandhaus-Magazin ... Altenburg 2015. S. $44 \mathrm{f}$.

Lb U Berlin: WS 1856/57 Studium der Rechtswiss. auf Druck seines Onkels (siehe Eintrag oben unter Vw: Paul Hermann M.-B.).
UH: Seit SS 1857 Forts. des Studiums der Rechtswiss., aus eigenem Interesse auch Studium der Geschichte; 23. Juli 1859 Dr. iur.

1859-1864 Eigenstudien in griechischer Sprache und Geschichte: zunächst Berlin, Winter 1861/62 Göttingen, anschl. London, München, 1862 Griechenland; in dieser Zeit: 1860-1861 Militärdienstpflicht als Einjährig-Freiwilliger in Berlin, s. hierzu UAH RA 5478.

UH: 10. Febr. 1864 Dr. phil.; 12. März 1864 Habilitation; seit 5. Aug. 1867 a. o. Prof.; Jan. 1868 Ruf auf e. Extraordinariat an U Gießen abgelehnt.

U Freiburg/Br.: 18. März 1868 Ern. zum o. Prof.; Frühjahr 1872 M.s vierte und letzte Reise nach Griechenland; Herbst 1873 körperlicher Zusammenbruch wegen Gemütskrankheit (nervöse Reizbarkeit); 10. Nov. 1873 M. B. beantragt Entlassung aus Staatsdienst; Frühjahr 1874 auf eigenen Antrag Entlassung aus Krankheitsgründen.

Nach Herbst 1873 Übersiedlung nach Baden-Baden; seit Mai 1874 Aufenthalt in Heilanstalt für Epileptische Kranke der Höheren Stände in Görlitz (Diagnose: katatonische Schizophrenie); Nov. 1876-1897 (†) Aufenthalt in Kantonaler Heil- und Pflegeanstalt, e. Psychiatr. Klinik im ehem. Kloster Königsfelden bei Brugg.

Qu UAH PA 1982; RA 5478 (Disziplinarverfahren im Nov. 1860 als ehem. Student der UH wegen tätlicher Beleidigung e. Kommilitonen; M. B. entzieht sich der akad. Gerichtsbarkeit durch Eintritt in Militärdienst; Ausschluß M. B.s von UH für ein halbes Jahr nach seiner Entlassung aus Militärdienst); Fak.-Akten H-II-111/56 fol. 414-428, H-IV-102/62 fol. 206-213. - GLA Abt. 201, Fasz. 196. Teil-Nachlaß: Mendelssohn-Archiv Berlin (MA Nachlaß 1).

W Graf Johann Kapodistrias. Berlin 1864. - Geschichte Griechenlands von der Eroberung Konstantinopels ... 1453 bis auf unsere Tage. 2 T. Leipzig 1870-1874. Nachdr. Hildesheim 2004. Goethe und Felix Mendelssohn Bartholdy. Leipzig 1871. • Mirabeau in: Preußische Jahrbücher 31 (1873) S. 361-412. 
MHG (zus. mit Onkel Paul Hermann M.-B.) Felix Mendelssohn Bartholdy. Briefe aus den Jahren 1830-1847. 2 Bde. Leipzig 1863. Friedrich von Gentz. Briefe an Pilat. Ein Beitrag zur Geschichte Deutschlands im 19. Jahrhundert. 2 Bde. Leipzig 1868 .

L Badische Biographien 5 (1906) S. 553-559; Jüdische National-Biographie 4 (1929) S. 340; WBIS; Weber (1987) S. 377 f. - Gantzel-Kress, Gisela: M. B. 1838-1897 in: Mendelssohn-Studien 8 (1993) S. 197-225; Löschburg, Winfried: Der Philhellenismus - „die Religion der Jugend und des Alters" - K.M.B.s Geschichte Griechenlands und sein Briefwechsel mit Heinrich von Treitschke in: ebd. S. 227-235. - Lackmann, Thomas: Das Glück der Mendelssohns. Geschichte einer deutschen Familie. Berlin 2005. DBE 6 (2006) S. 890; Autoren der Bunsenbibliothek (2009 online). 250 Jahre Familie Mendelssohn. Beiträge des Kongresses Berlin, 20.-22. Juni 2012. Hrsg. von Sebastian Panwitz und Roland Dieter Schmidt-Hensel. Hannover 2014. S. 203-225. - Steiner, Elke Renate: Die anderen Mendelssohns. K. M. B. [Graphic Novel.] Reproduktion. Berlin 2015. - Deutsche Biographie, s. https://www.deutsche-biographie.de/ gnd1072631873.html [07.11. 2017].

$P$ Ölportrait M.B.s (um 1845) von Eduard Magnus (1799-1872) im Mendelssohn-Archiv Berlin (Depos. MG 112).

\section{Mendelssohn Bartholdy, Karl}

siehe Mendelssohn Bartholdy, Carl

\section{Menge, Carl Gustav August Friedrich David} Hermann

1908-1930 Med. Fak.

Geburtshilfe, Gynäkologie

* 18. Aug. 1864 Kreuznach (heute: Bad K.)

$\dagger$ o9. Okt. 1945 München ev.-luth.
V Gustav M. (1829-1895) Kaufmann

M Johanna geb. Schultze (1828-1908)

$\infty$ 29. Sept. 1898 Clara Julie Pauline geb. Siveke (1877-1968)

$\mathrm{K} \quad 2 \mathrm{~T}$

$L b$ Seit 1884 Studium an U München, anschl. Freiburg/Br., Leipzig; 1886 Physikum.

München: 30. Jan. 1889 Dr. med. an U; 31. Jan. 1889 Staatsexamen.

Berlin: Assistent: Sommer 1889 Hygien. U-Inst. bei Robert Koch (1843-1910), seit Herbst 1889 PrivatFrauenklinik.

Stettin: Seit 1890 Lehrer an Hebammenlehranstalt.

U Leipzig: Seit 15. Aug. 1892 Assistent an Frauenklinik; 26. Juni 1896 Probevorlesung als Privat-Dozent; seit 29. März 1901 a. o. Prof.

U Erlangen: Seit 1. Okt. 1904 o. Prof.

UH: Seit 21. Febr. 1908 o. Prof., Direktor der UFrauenklinik und Hebammenschule als Nachf. von Alfons von Rosthorn; Rufe an U abgelehnt: 1907 Tübingen, 1911 Bonn; 1. Okt. 1930 auf eigenen Antrag Emeritierung.

München: Seit 1931/32 Wohnsitz.

1909/10, 1919/20 Dekan der Med. Fak. der UH

1922-1923 Präsident der Dt. Gesellschaft für Gynäkologie und Geburtshilfe

1911 Geh. Hofrat

E Ehrenmitglied: Dt. Gesellschaft für Gynäkologie, Med. Gesellschaft Buenos Aires; 1926 Mitglied der Dt. Akademie der Naturforscher Leopoldina Halle/S. • 1944 Goethe-Medaille für Kunst und Wissenschaft.

Qu UAH PA 1073, 4990. • UA Leipzig PA 1500. GLA Abt. 235, Fasz. 2303. Siehe auch Archiv der Dt. Akademie der Naturforscher Leopoldina Hal- 
le/S. Mitteilungen: Frau Diplom-Ing. Barbara Helbich (Enkelin mütterlicherseits), Architektin, Hannover.

$W$ Bakteriologie des weiblichen Genitalkanales. 2 T. Leipzig 1897. (Mitverf.) - Die Therapie der chronischen Endometritis in der allgemeinen Praxis. Berlin 1901. Handbuch der Frauenheilkunde. Wiesbaden 1913. 5. Aufl. 1927. (Mitverf.) • Anatomie und topographische Anatomie. Entwicklungsgeschichte und Bildungsfehler der weiblichen Genitalien in: Handbuch der Gynäkologie. 3. Aufl. München 1930. Bd. 1,1. (Mitverf.) - Siehe Buttron (1981) S. $102 \mathrm{f}$.

MHG 1913-1922 Jahrbuch der Frauenheilkunde für Ärzte und Studierende.

L Kürschner (1940/41) Sp. 167; Arnim 2 (1952) S. 155, 4 (1984) S. 1071. - Runge, Hans: C. M. in: Ruperto Carola 8. Jg., Bd. 19 (1956) S. 113-115. • Fischer $2\left({ }^{3}{ }_{1962}\right)$ S. 1023. Pittroff, Rainer: Die Lehrer der Heilkunde der Universität Erlangen 1843-1943 und ihr Werdegang. Diss. Erlangen 1964. - Buttron (1981) S. 98-102 u. ö.; Chronik Ärzte H (1985) S. 137, 251f.; Zander (1991) S. 63f.; Professoren Erlangen (1999) S. 129; Kuß (2000); Kriegstagebuch K. Hampe (2007) S. 982 (Register); WBIS. • Deutsche Gesellschaft für Gynäkologie und Geburtshilfe. Vom Programm zur Botschaft. A short history (1886-2008) of the German Society of Gynecology and Obstetrics reviewing its 57 congresses. Hrsg. von Hans Ludwig und Walter Jonat. 2. Aufl. Düsseldorf 2008. - Thoms-Hoffmann, Ingrid: In der "Villa Menge" vom Geburtsstress erholen ... in: RNZ vom 23. April 2008, S. 7. Professorenkatalog Leipzig online; Deutsche Biographie, s. https:// www.deutsche-biographie.de/gnd116881585.html [07.11. 2017].

$P$ Bildarchiv UAH; Ruperto Carola; Chronik Ärzte H; Professoren Erlangen (1999) S. 129.

\section{Merton, Hugo Philip Ralph}

1913-1935 Nat.-Math. Fak.

Zoologie

* 18. Nov. 1879 Frankfurt/M.

$\dagger$ 23. März 1940 Edinburgh (Schottland) mosaisch, später ev.

V Albert Moses M. (1841-1880) Kaufmann

M Rosette Sabine geb. Stern (1846-1907)

( 20. Nov. 1909 Gertrud Pauline Anna geb. Oswalt $\left({ }^{*} 1888 \dagger\right.$ nach 1960$)$, s. Lebenserinnerungen in: UBH Heid. Hs 4029; Lexikon jüdischer Einwohner Hs (2011) S. 293

K 3S, s. ebd. S. 294.

Lb Seit WS 1898/99 Studium an U Bonn, anschl. Berlin, seit WS 1901/02 H; 21. Juli 1905 Dr. rer. nat. an UH; 1905-1906 Eigenstudien an Zoolog. Station in Neapel.

UH: Seit 1906 Assistent am Zoolog. Inst.

1907-1908 Forschungsreise zu den Molukken-Inseln i.A. der Senckenbergischen Naturforschenden Gesellschaft Frankfurt/M.

Frankfurt/M.: Seit 1909 stellvertr. Direktor des Senckenberg-Museums.

UH: 29. Okt. 1913 Habilitation; seit 29. Febr. 1920 nichtplanm. a.o. Prof.; seit 6. April 1933 Beurlaubung, die am 28. April 1933 zurückgezogen wird, „da er im Weltkrieg bei der fechtenden Truppe an Schlachten teilgenommen hat" (aus: UAH PA 4997); 31. Dez. 1935 Entzug der Lehrbefugnis aus rassischen Gründen. • In dieser Zeit:

1914-1918 Kriegsdienst.

U of Edinburgh: WS 1937/38 Gastdozent.

10. Nov. 1938-29. Nov. 1938 Verschleppung ins KZ Dachau; April 1939 Emigration.

U of Edinburgh: Seit 1939 Mitarbeiter am Institute of Genetics. 
E Mitglied des Vereins für Geographie und Statistik Frankfurt/M. - Eiserne Plakette der Senckenbergischen Naturforschenden Gesellschaft Frankfurt/M. Ritterkreuz mit Schwert vom Orden des Zähringer Löwen.

\section{Qu UAH PA 4997.}

$W$ Ergebnisse einer zoologischen Forschungsreise in die südöstlichen Molukken. Frankfurt/M. 1911. Beitrag zur Anatomie und Histologie von Temnocephala in: Zeitschrift für Zellforschung 34 (1911); Die Wanderungen der Geschlechtszellen in der Zwitterdrüse von Planorbis in: ebd. 10 (1930).

L Kürschner (1931) Sp. 1931. Ritchie, James: H. M. Obituary in: Nature 145 (1940) S. 924 f. • Gebäude der UH (1985) S. 463 f.; Deichmann (1992) S. 357 (Register); UH im Nationalsozialismus (2006) S. 1194-1196 u. ö.; Lexikon jüdischer Einwohner Hs (2011) S. 293f.; Deutsche Biographie, s. https:// www.deutsche-biographie.de/gnd116907436.html [07.11. 2017].

$P$ Bildarchiv UAH.

\section{Merx, Ernst Otto Adalbert}

1875-1909 Theol. Fak.

Altes Testament

* O2. Nov. 1838 Bleicherode (bei Erfurt)

$\dagger$ 04. Aug. 1909 Heidelberg ev.

V Wilhelm M. (1809-1843) Volksschullehrer, Prediger

M Eulalia geb. Hoche (1811-1908) Schriftstellerin, siehe Deutsche Dichterinen [!] ... Hrsg. von Heinrich Groß. Bd. 2. Berlin 1885. S. 72 ff.; Schwester: Louise Franziska H. verh. Aston (1814-1871) Schriftstellerin und Frauenrechtlerin, siehe Heinrich, Guido: Magdeburger biogr. Lexikon ... Magdeburg 2002.

$\varnothing$ Mai 1873 Sophie geb. Curtius verw. Döderlein (1841-1915)
K 2 T: Elisabeth M. (1874-1945) Krankenschwester; Ehefrau von: (siehe) Julius Ruska. • Gisela M. (1875-1965) Ehefrau von: (siehe) Maximilian Wolf

Vw siehe NDB 17 (1994) S. 194.

Lb Seit WS 1857/58 Studium der Orientalistik, Theologie an U Marburg, anschl. Halle-Wittenberg; 8. Okt. 1861 Dr. phil. an U Breslau.

U Berlin: Seit WS 1861/62 Forts. des Studiums; 1864 theol. Lizentiatenprüfung.

U Jena: 2. Mai 1865 Habilitation an Theol. Fak.; seit 1869 a. o. Prof.

U Tübingen: Seit WS 1869/70 o. Prof. für Semitische Sprachen an Phil. Fak.

U Gießen: Seit 3. Febr. 1873 o. Prof. für Altes Testament.

UH: Seit 10. April 1875 o. Prof. als Nachf. von Ferdinand Hitzig mit e. jährl. Besoldung von 6200.Mark, s. UAH RA 6718 fol. 39r, v; 1875-1895 e. der Hauptlehrer am Ev.-Prot. Theol. Seminar; SS 1895 Aufteilung des Ev.-Prot. Theol. Seminars in Praktisch-Theol. Seminar und Wiss.-Theol. Seminar: SS 1895-SS 1909 Direktor der Alttestamentlichen Abt. am Wiss.-Theol. Seminar.

1892/93 Prorektor der UH; $1877 / 78,1882 / 83,1887 /$ 88, 1893/94, 1900/01, 1906/07 Dekan der Theol. Fak. der UH

M. bricht am Grab seines Kollegen Adolf Hausrath tot zusammen.

1892 Geh. Hofrat; 1905 Geh. Rat II. Klasse

E 1909 Mitglied der Akademie der Wissenschaften H. 1871 D. theol. Jena. $\bullet 1893$ Komthurkreuz II. Klasse des Sachsen-Ernestinischen Hausordens.

Qu UAH PA 1985; RA 6718. - Briefe, Nachlaß: $\mathrm{UBH}$. 
W Grammatica syriaca. 2 T. Halle/S. 1867-1870. • Das Gedicht von Hiob. Jena 1871. • Die Prophetie des Joel und ihre Ausleger von den ältesten Zeiten bis zu den Reformatoren. Halle/S. 1879. - Idee und Grundlinien einer allg. Geschichte der Mystik. Heidelberg 1893. • Die Bücher Moses und Josua. Tübingen 1907 .

G 1867 Archiv für wiss. Erforschung des Alten Testaments.

HG The ecclesiastical history of Eusebius Pamphili, 265-339, bishop of Caesarea. Syriac text, edited from the manuscripts in London and St. Petersburg, with a collation of the ancient Armenian version .... and variant readings from other versions. London 1898. Reprint Amsterdam 1975.

Übers. Die vier kanonischen Evangelien nach ihrem ältesten bekannten Texte ... 2 T. Berlin 18971905 (hierzu siehe auch Julius Ruska: Eintrag unter $(M) H G)$. Die Evangelien des Markus und Lukas nach der syrischen im Sinaikloster gefundenen $\mathrm{Pa}$ limpsesthandschrift mit vier Originalaufnahmen Jerusalemischer Grabstätten in: Die vier kanonischen Evangelien nach ihrem ältesten bekannten Texte ... T. 2. Hälfte 2 [1]. Berlin 1905.

$L$ Universität Gießen 1 (1907) S. 444; Badische Biographien 6 (1935) S. 44-56; Arnim 2 (1952) S. 16o. Schmitthenner, A.: A. M. zum Gedächtnis in: Badische Pfarrvereinsblätter Nr. 2 (1959) S. 1-3. Hoche (1969) S. 84f. u. ö.; NDB 17 (1994) S. 194 f. - Otto, Eckart: Max Webers Studien des Antiken Judentums: Historische Grundlegung einer Theorie der Moderne. Tübingen 2002. S. 375 (Register). Handbuch der historischen Buchbestände in Deutschland. Hrsg. von Bernhard Fabian. Hildesheim 2003. - Asketischer Protestantismus (2005) S. 81 und Anm. 23, 82 u. ö.; Wischmeyer (2008) S. 468 (Register); WBIS. • Iff, Markus: Liberale Theologie in Jena. Ein Beitrag zur Theologie- und Wissenschaftsgeschichte des ausgehenden 19. Jahrhunderts. Berlin 2011. S. 399 (Register). Troeltsch-Gesamtausgabe 19 (2014) S. 505 (Register).

$P$ Bildarchiv UAH; graph. Slg. UBH.
Metzger, Johannes (1789-1852)

1812-1851 Gärtner der UH, siehe Kurzbiographie

bei Franz Schelver: Eintrag unter $Z$ [itat] (3)

\section{Meyer, Arthur Woldemar}

1918-1921 (1923) Med. Fak.

Chirurgie

* 16. März 1885 Wiesbaden

$\dagger$ 14. Nov. 1933 Berlin (Suizid)

口 Marburg

ev.-luth.

V Hans Horst M. (1853-1939) seit Mai 1881 Privat-Dozent Straßburg, o. Prof. für Pharmakologie: seit Okt. 1881 Dorpat, seit 1884 Marburg, 1904-1924 (Emeritierung) Wien, s. Medizin in Selbstdarstellungen 2 (1923) S. 139168, Arnim 2 (1952) S. 165, 4 (1984) S. 1082, Fischer $2\left({ }^{3} 1962\right)$ S. 1034, NDB 17 (1994) S. 317319; WBIS. - Nachlaß in David M. Rubenstein Rare Book \& Manuscript Library der Duke University in Durham (North Carolina)

M Dorothea (Doris) geb. Boehm(-Glaubitten) (1860-1902)

(1 1924/25? Luise Charlotte (Lotte) geb. Schiedmayer (1902-1933 vom Ehemann vor seinem Suizid erschossen) mosaisch; T von Max S. (1865-1941) Kommerzienrat und Mitinhaber der bis 2008 bestehenden Schiedmayer Pianofortefabrik in Stuttgart, heute fortgeführt u.d. N. Schiedmayer Celesta GmbH in Wendlingen

K 1 S (nach 1933 Adoptiv-S von Kurt Heinrich Meyer, s. Eintrag unter Vw [Bruder]): Johannes Horst M. (1926-2016) seit 1957 Dozent an Harvard University in Cambridge (Massachusetts), seit 1959 Assistant Prof., anschl. Associated Prof., 1984-2004 (Emeritierung) Fritz London Prof. für Physik an Duke University in Durham, s. World Who's Who in Science (1968) S. 1170, Homepage http://www.phy. duke.edu/ hm/LTM/ltm.html (abgerufen am 23. Aug. 2016; Ausdruck im UAH) 
Vw Bruder: Kurt Heinrich M. (1883-1952) seit 1911 Privat-Dozent für Chemie U München, seit 1917 Mitarbeiter am Kaiser-Wilhelm-Institut Berlin, seit 1918 Leiter der organischen Abt. des Chemischen U-Inst. München, seit 1921 Direktor der Forschungslabore der BASF Ludwigshafen, seit 1932 o. Prof. für Organische und Anorganische Chemie U Genf, s. NDB 17 (1994) S. 319 f.; Beneke, Klaus: Über K.H.M. in: Hermann Franz Mark ... Mitbegründer der Polymerwissenschaften, s. http://www. uni-kiel.de/anorg/lagaly/group/klausSchiver/ mark.pdf (2005) S. 5-9 u. ö. (Ausdruck im $\mathrm{UAH}$ ); Fischer, Edmond $\mathrm{H}$. and Piguet, $\mathrm{Al}-$ fred: Macromolecules and Enzymes: The Geneva heritage from K.H.M. and Edmond $\mathrm{H}$. Fischer in: Chimia 63 (2009) S. 835-838.

Vw Enkel: Dr. Christopher M. $\left({ }^{*} 1958\right)$ seit 1991 Physiker am National Institute of Standards and Technology, Thermometry Group in Gaithersburg (Maryland), s. http://www.nist. gov/pml/div685/grpo1/meyerstaff.cfm (abgerufen am 23. Aug. 2016; Ausdruck im UAH).

Lb Studium: SS 1904 UH, seit WS 1904/05 Wien, seit SS 1906 H; 19. Juli 1906 ärztl. Vorpüfung an UH; WS 1906/07 Forts. des Studiums an U Marburg, seit SS 1907 Wien, seit SS 1908 H; Juli 1909 Staatsexamen in $\mathrm{H}$.

UH: Assistent: Seit Okt. 1909 Med. U-Klinik, Okt. 1910-Dez. 1921 Chirurg. U-Klinik; 30. Juni 1909 Rigorosum, 7. Okt. 1910 (Datum der Promotionsurkunde) Dr. med.; 3. Okt. 1910 Approbation; 19121913 Teilnahme als Militärarzt im Balkankrieg auf bulgarischer Seite; seit 1914 Kriegsdienst als Chirurg "bei einer badischen Formation im Westen“ (aus: Lebenslauf vom 1. Jan. 1917 in: UAH PA 1074); Okt. 1915-1918 Kommandierung ,auf Wunsch ... des Königs Ferdinand [I. (1861-1948)] von Bulgarien und zur Dienstleistung als Leibarzt des Königs" in Sofia (aus: ebd.); 7. März 1917 Genehmigung auf Erteilung e. vorläufig befristeten venia legendi „mit der Auflage, ... die Probevorlesung spätestens ein halbes Jahr nach Beendigung des Krieges zu halten" (aus: PA 1074); 8. Juli $1918 \mathrm{Ha}-$ bilitation; seit 7. Dez. 1921 nichtplanm. a. o. Prof.; 30. Dez. 1921 Urlaubsgenehmigung befristet bis zum 1. Jan. 1923; 15. Juni 1923 aus Lehrkörper ausgeschieden.
Berlin: Seit 1. Jan. 1922 Leiter der II. Chirurg. Abt. des Krankenhauses Westend in Charlottenburg und Chirurg mit Belegbetten in Privatklinik Franziskus-Krankenhaus im Ortsteil Tiergarten.

George Bernard Shaw (1856-1950) war u.a. M.s Patient

M.s Schicksal ist das Grundmotiv im Drama „Professor Mamlock“ (Premiere 1934) des Schriftstellers und Arztes Friedrich Wolf (1888-1953).

E Eisernes Kreuz II. Klasse; Roter Adlerorden III. Klasse mit Schleife und Schwertern; Königl. Bulgarischer Tapferkeitsorden IV. Klasse; Sächsischer Albrechtsorden; Bayer. Militärverdienstorden mit Schwertern; Württ. Friedrichsorden mit Schwertern; Ritterkreuz vom Franz JosephsOrden mit Kreuz und Band; Königl. Bulgarischer Rote Kreuz Orden I. Klasse.

Qu UAH PA 1074, 1990; Fak.-Akte H-III-862/11 fol. 5r-7r; Studentenakte. - GLA Abt. 235, Fasz. 2279. - Auskunft: Hessisches Staatsarchiv Marburg (Bestand 925 Nr. 2233); Standesamt Wiesbaden (Geburtsnebenregister 1885. Bd. 1. S. 285 (online)). Mitteilungen: Frau Dr. Ulrike Eisenberg, Berlin; Herr Prof. Dr. Johannes Horst Meyer ( $\dagger$ ), Durham; Herr Rolf Schiedmayer, Wendlingen.

$W$ Über den Einfluß der Anaesthesie auf den Verlauf der Entzündungen in: Zentralblatt für Chirurgie (1920); Die Messung des elektrischen Widerstandes als Hilfsmittel bei der Lokalisation von Hirntumoren in: ebd. (1921). - Experimentelle Untersuchungen über Muskelkontrakturen nach fixierenden Verbänden in: Dt. Zs. für Chirurgie 162(1) (1921) S. 122-138; Erfolgreiche Trendelenburgsche Operation bei Embolie der Arteria pulmonalis in: ebd. 205(1) (1927) S. 1-21; Eine weitere (meine vierte) erfolgreiche Lungenembolieoperation (Neues zur Technik) in: ebd. 231(8) (1931) S. 586-592. - Operation großer Bauchnarbenbrüche in: Bruns' Beiträge zur klinischen Chirurgie 16o. Bd. H. 6 (8. Dez. 1934) S. 612-615 (posthum erschienen).

L Chirurgen-Kalender (1926) S. 219. Arzt, Leopold: A. M. $\dagger$ in: Wiener Klinische Wochenschrift 
Nr. 47, 46. Jg. (24. Nov. 1933) S. 1433 f. • Enderlen, Eugen: A. W. M. zum Gedächtnis in: Medizinische Klinik 50 (8. Dez. 1933) S. 1697. - Heidelberger Tageblatt vom 15. Nov. 1933; WBIS. - Voelcker, Fritz: Geleitwort zu der nachfolgenden Meyerschen Arbeit („Operation großer Bauchnarbenbrüche") in: Bruns' Beiträge zur klinischen Chirurgie 160. Bd., H. 6 (8. Dez. 1934) S. 610 f. • Fischer $2\left({ }^{3} 1962\right)$ S. 1032. - Ostrowski, Siegfried: Vom Schicksal jüdischer Ärzte im Dritten Reich in: Bulletin des Leo Baeck Instituts 6 (1963) S. 313-351. • Sakowsky, Hans-Jürgen: Die Chirurgische Klinik des Krankenhauses Westend von 1904 bis 1933 ... Med. Diss. FU Berlin. Berlin 1982. S. 42-51 u. ö. - Schober, Karl Ludwig: Tragik im Terror 1933: A. W. M. in: Deutsche Akademie der Naturforscher Leopoldina. Jahrbuch 1994. Stuttgart 1995. S. 489-508. • Schilde, Kurt: Opfer des NS-Terrors 1933 in Berlin. Biografische Skizzen in: Der Tag von Potsdam. Der 21. März 1933 und die Errichtung der nationalsozialistischen Diktatur. Hrsg. von Christoph Kopke und Werner Treß. Berlin 2013. S. 207f. • Raute, Michael: Jude - venia entzogen 1934. Schicksale deutsch-jüdischer Chirurgen nach 1933. Leipzig 2014. S. 49 f., 157. - Deutsche Biographie, s. https:// www.deutsche-biographie.de/gnd11936663o.html [07.11. 2017].

$P$ Bildarchiv UAH.

Meyer, Johann Friedrich Wilhelm Clemens Ludwig (auch: Waldeck, Friedrich Meyer von; Mejer, Fedor Egorovič; Mejer, Fëdor Jegorovic) (Pseudonym: Montan, Fredrik)

1880-1898 (1899) Phil. Fak.

Dt. Literaturgeschichte, Mythologie, Poetik

* 15. Mai 1824 Arolsen

$\dagger$ 16. Mai 1899 Heidelberg mosaisch, seit 20. Juni $1824 \mathrm{ev}$.

V Nathan M., Kaufmann, Lederfabrikant (mosaisch; 1827 getauft auf: Johann Georg M.); seit $1845 / 46$ verarmt

M Johannette geb. Eschersson (Ascherson)

$\infty$ Dorothe geb. von Bursy ( $\dagger$ nach 1899)
K mehrere T, s. ADB 52 (1906) S. 337. 3 S: Prof. Kunz M.(-Waldeck) (1859-1953) Genre- und Marinemaler, u. a. 1908-1910 Kunstlehrer in Dallas (Texas), s. WBIS. $\bullet$ Dr. phil. (Promotion an UH, s. UAH H-IV-102/111 fol. 296r-301r) Wolfgang Alexander M. genannt M.-Waldeck (1862-1914) 21. Okt. 1882 Immatrikulation an UH, s. UAH Studentenakte; Dramaturg: seit 1893 Mannheim, seit 1895 Berliner Theater in Berlin, 1896-1908 Hoftheater in Dresden, s. Wildberg, Bodo: Das Dresdner Hoftheater in der Gegenwart. Dresden 1902; WBIS. Alfred Wilhelm Moritz M. (seit April 1903 M.-Waldeck) (1864-1928) SS 1884 Immatrikulation an UH, s. UAH Studentenakte; 1884 Eintritt in dt. Kriegsmarine als Kadett, seit 1909 Kapitän zur See, zuletzt Vizeadmiral sowie 1911-1914 Gouverneur des dt. Schutzgebietes Kiautschou in China, 1914-1919 in japanischer Kriegsgefangenschaft, 1920 Abschied von Marine, s. Rangliste der Kaiserlich Deutschen Marine. Redaktion im Marine-Kabinet. Berlin 1914. S. 110; WBIS, Badische Biographien N.F. II (1987) S. 204 f.; Hildebrand, Hans H., Henriot, Ernest: Deutschlands Admirale 1849-1945. Die militärischen Werdegänge der See-, Ingenieur-, Sanitäts-, Waffen- und Verwaltungsoffiziere im Admiralsrang. Hrsg. von Dermot Bradley. Bd. 2. Osnabrück 1989. S 484f.; P: Eisengußmedaille von 1914 mit Büste von A.W.M.M. in: 500 Jahre Geschichte und Kunst im Spiegel der Medaille. Künker Auktion 247. Osnabrück 2014. S. 410.

Lb Seit WS 1840/41 Studium des Bergwesens an Bergschule zur Ausbildung von Steigern und Beamten in Clausthal (heute: C.-Zellerfeld); 18421843 Studium der Naturwiss., seit 1843 Studium der Literatur, Altertumskunde an U Berlin; Dez. 1845 Dr. phil. an U Berlin.

Lettland: Seit 1846 Hauslehrer bei Baron August von der Recke (1807-1861) auf Schloss Neuenburg (heute: Jaunpils), anschl. bei Johann Friedrich Otto Karl Reichsgraf von Medem (1801-1860) auf Schloss Alt-Autz (heute: Vecauce Manor).

Russisches Kaiserreich: Sommer 1849 Oberlehrerexamen der Deutschen und Lateinischen Sprache in Dorpat (heute: Tartu, Estland); seit 1849 
stellvertr. Leiter e. Knabenschule in Mitau (heute: Jelgava, Lettland); seit 1850 Privat-Gelehrter in Dorpat; Sommer 1851 Übersiedlung nach St. Petersburg.

St. Petersburg: Mai 1852-Mai 1874 Chefredakteur der „St. Petersburger Dt. Zeitschrift“; 18531856 Belagerung von St. Petersburg während des Krimkrieges (siehe Eintrag unter $E$ [hrungen]); 1853-1874 Lektor für Dt. Sprache und Literatur an U; 1858-1859 oder 1874 außerdem Oberlehrer an Hauptschule St. Petri.

Übersiedlung: 1874 nach Bonn, 1877/78 nach H; hier Eigenstudien.

UH: 3. Aug. 1880 Habilitation für Dt. Literaturgeschichte, Mythologie, Poetik ohne Habilitationsschrift aufgrund von M.s bisherigen Publikationen und seiner Lektortätigkeit an U St. Petersburg; seit 31. Juli 1882 a. o. Prof. am Germanisch-Romanischen Seminar; SS 1889, WS 1889/90, SS 1895 und WS 1895/96 (Kur wegen e. Herzleidens) Entbindung auf eigenen Antrag von akad. Funktionen; seit April 1898 Beurlaubung auf eigenen Antrag aus Krankheitsgründen.

1859 Gründungsmitglied des Verwaltungsrates der Dt. Schillerstiftung im Zweigverein in St. Petersburg

1865 Mitbegründer der Gesellschaft für wissenschaftliche Unterhaltung in St. Petersburg, s. Busch, Margarete: Das deutsche Vereinswesen in St. Petersburg vom 18. Jahrhundert bis zum Beginn des Ersten Weltkrieges in: Nordost-Archiv Zs. für Regionalgeschichte. Bd. 3. H. 1. Lüneburg 1994. S. 47.

1864 Kaiserl. Russischer Kollegienrat; 1895 Großherzogl. Badischer Hofrat

E 1856 Kaiserl. Russische Medaille „für den Staatsdienst in e. belagerten Stadt während des Krieges 1853-56“, s. Standesliste „Bekleidete Dienst-Stellen“ in: UAH PA 1991; 1859 Verdienstkreuz des Sächsisch-Ernestinischen Hausordens; 1862 Komthurkreuz II. Klasse des Kaiserl. Russischen Ordens des Hl. Stanislaus; 1870 Preußischer Kronenorden
III. Klasse; 1875 Komthurkreuz II. Klasse des Kaiserl. Russischen Ordens der Hl. Anna; 1888 Ritterkreuz I. Klasse des Ordens vom Zähringer Löwen; 1896 Fürstlich Waldeckscher Verdienstorden.

Qu UAH PA 1991; RA 6418f.; Fak.-Akte H-IV102/92. Adreßbuch der Stadt Heidelberg für das Jahr 1878. Heidelberg 1878. S. 122. • Heinrich VII. Prinz Reuß - Botschafter unter Bismarck und Caprivi. Briefwechsel 1871-1894. Hrsg. von James Stone und Winfried Baumgart ... Paderborn 2015. S. 112 f. Auskunft: Ev. Pfarramt Arolsen. • Unter dem russischen Scepter. Heidelberg 1894. (Autobiogr.)

$W$ Waldeck, Friedrich Meyer von: Die Erbin von Glengary. Schauspiel. St. Petersburg 1866. - Formenlehre der deutschen Dichtung. St. Petersburg 1868. Goethes Märchendichtungen. Heidelberg 1879. Geistiges Leben der St. Petersburger Deutschen in: Unsere Zeit. Dt. Revue der Gegenwart. Leipzig 1881. Bd. 2. S. 214-243.

Übers. Russische Erzählungen in deutscher Übersetzung. Heidelberg 1878.

L Almanach Heidelberg (1888) S. 144f.; Biogr. Jahrbuch 4 (1899) S. 218 f.; ADB 52 (1906) S. 333337; Badische Biographien 5 (1906) S. 915; Lehmann (1967) S. 222 f.; Burkhardt (1976) S. 37 f.; Int. Germanistenlexikon 1 (2003) S. 1210 f. • Hoffmann, Albrecht: F. M. von W. ... als Bergschüler und Schriftsteller im Harz in: Allg. Harzer BergKalender für das Jahr 2008. Clausthal-Zellerfeld 2007. Riecke (2016) S. 148 (Register).

$P$ Bildarchiv UAH. 


\section{Meyer, Christian Wilhelm Georg}

1889-190o Jur. Fak.

Staats- und Rechtsgeschichte, Reichs- und Landesstaatsrecht

* 21. Febr. 1841 Detmold

$\dagger \quad$ 28. Febr. 1900 Heidelberg ev.-luth.

V Georg Heinrich M. (1803-1866) Gastwirt, 1847-1861 Oberbürgermeister in Detmold, s. Bürgerbuch der Stadt Detmold von 1635-1885. Bearb. von Fritz Verdenhalven. Detmold 1977. S. 73 , Nr. 1569.

M Ida Sophie Wilhelmine geb. Caspari (18091842)

๑ 1873 Ernestine geb. Schotten (1849-1931) T von Carl S. (1821-1855) U-Syndicus Marburg, s. Catalogus prof. Marburgensis 1 (1927) S. 554 K $\quad 1 \mathrm{~T}$

$\mathrm{Lb}$ Seit SS 1860 Studium an U Jena, seit 9. Nov. $1861 \mathrm{H}$, anschl. Göttingen; 2. März 1863 Dr. iur. utr. an UH; 17. Juni 1863 II. Staatsprüfung in Detmold.

Seit Juli 1863 Auditor (auch: Auditeur = Justizbeamter) u. a. in Detmold, Schötmar (heute: Ortsteil von Bad Salzuflen); seit 1866 Hilfsarbeiter im Statistischen Bureau in Jena.

U Marburg: 21. Dez. 1867 Habilitation; 1869-1870 Studienreise in Großbritannien; seit 16. April 1872 a. o. Prof.

U Jena: Seit 24. Jan. 1875 o. Prof.; Rufe an U Marburg und Breslau abgelehnt. • In dieser Zeit:

1878, 1879 Abgeordneter der Stadt Jena im Landtag des Großherzogtums Sachsen-Weimar-Eisenach in Weimar; 1881-1889 Vertreter des Wahlkreises Weida-Jena im Reichstag in Berlin.

UH: 13. Dez. 1888 Ern. zum o. Prof. als Nachf. von Hermann Schulze; 30. April 1889 Amtsantritt; 1891-1899 Mitglied der I. Kammer des Badischen Landtags als Vertreter der UH in Karlsruhe.

1897 Prorektor der UH; 1891/92, 1899/Febr. 1900 (†) Dekan der Jur. Fak. der UH
1888 Hofrat; 1891 Geh. Hofrat; 1898 Geh. Rat II. Klasse

E 1878 Ritterkreuz I. Klasse des Großherzoglich Weimarischen Hausordens vom Weißen Falken; 1879 Königl. Preußischer Kronenorden III. Klasse.

Qu UAH PA 1992. • Ergebnislose Anfrage: Ev. Gemeindeamt Marburg (Ehebuch von 1873). A Auskunft: Nordrhein-Westfälisches Personenstandsarchiv Westfalen-Lippe in Detmold.

$W$ Grundzüge des norddeutschen Bundesrechtes. Leipzig 1868. Staatsrechtliche Erörterungen über die deutsche Reichsverfassung. Leipzig 1872 . Lehrbuch des deutschen Staatsrechts. Leipzig 1878. 7. Aufl. 1914/19. - Lehrbuch des deutschen Verwaltungsrechts. 2 Bde. Leipzig 1883-1885. 4. Aufl. 1913/15. - Staatsrechtliche Stellung der deutschen Schutzgebiete. Leipzig 1888. - Das parlamentarische Wahlrecht. Hrsg. von Georg Jellinek. Berlin 1901 (posthum erschienen).

$L$ Catalogus prof. Marburgensis 1 (1927) S. 147 f.; lehrer und Politiker aus Lippe in: Lippische Mitteilungen aus Geschichte und Landeskunde. Bielefeld 1993. S. 191-197. - Haunfelder, Bernd: Die liberalen Abgeordneten des dt. Reichstags 18711918 ... Münster 2004. S. 276 f. Schroeder (2010) S. 278-282. - Staatsrechtler des 20. Jahrhunderts. Hrsg. von Peter Häberle ... Berlin 2015. S. 29-46.

$P$ Bildarchiv UAH; graph. Slg. UBH.

\section{Meyer, Victor}

1889-189o Phil. Fak. 1890-1897 Nat.-Math. Fak.

Chemie

* o8. Sept. 1848 Berlin

$\dagger \quad$ 07./08. Aug. 1897 Heidelberg (Suizid) mosaisch, seit $1885 \mathrm{ev}$.

V Jakob M. (1816-1892) Kattunfabrikbesitzer

M Bertha geb. Meyer (1822-1895) 
(6) 1873 Hedwig geb. Davidson (1851-1936)

K $\quad 1$ S, 5 T (1 T früh $\dagger$ ): u. a. Elisabeth Johanna Maria Adolpha M. (1885-1969), s. UAH Rep. 14-117 (Brief vom 8. Okt. 1927), UAH B-3182/ 22; Lexikon jüdischer Einwohner Hs (2011) S. 442; Ehefrau von: (siehe) Karl Wilmanns. • Irmgard M. (1888-1942 Suizid) Ehefrau von Dr. iur. Guido Leser (1883-1942 Suizid) 19191933 (Entlassung) Amtsgerichtsrat, DDP-Politiker, 1919-1921 Mitglied des badischen Landtags, s. Kurzbiographien zur Geschichte der Juden 1918-1945. Hrsg. von Joseph Walk ... Jerusalem 1988; S von: (siehe) Emanuel Leser.

Vw Bruder: Richard M. (1846-1926), u.a. 18891918 o. Prof. für Chemie an TH Braunschweig, s. NDB 17 (1994) S. $312 \mathrm{f}$.

Lb Seit WS 1864/65 Studium der Chemie an U Berlin.

UH: Seit WS 1865/66 Forts. des Studiums; 13. Mai 1867 Dr. phil.; seit 1867 Assistent am Chemischen Laboratorium.

Königl. Gewerbeinstitut Berlin: Seit Herbst 1868 Assistent im Laboratorium von Adolf von Baeyer ((1835-1917) Vater von: (siehe) Hans Ritter von B.).

Polytechnikum Stuttgart: Seit 30. Aug. 1871 a.o. Prof.

Polytechnikum Zürich: Seit 10. Juni 1872 o. Prof. und Direktor des Analytischen Laboratoriums.

U Göttingen: 8. Dez. 1884 Ern. zum o. Prof. und Direktor des Allg. Chemischen Labors; SS 1885 Vorlesungsbeginn; Nov. 1888 Ruf an UH zunächst abgelehnt.

UH: Seit WS $1889 / 90$ o. Prof. und Direktor des Chemischen Laboratoriums als Nachf. von Robert Bunsen.

1892/93 Dekan der Nat.-Math. Fak. der UH

1888 Königl. Preußischer Geh. Reg.-Rat

Siehe auch Karl von Auwers (1887), Ludwig Gattermann (1885), Paul Jacobson (1886)
E 1882 Mitglied der Dt. Akademie der Naturforscher Leopoldina Halle/S.; Mitglied der Akademie der Wissenschaften: 1883 München, 1896 Berlin; 1895 Mitglied der Königl. Gesellschaft der Wissenschaften Upsala. 1891 Davy-Medaille der Royal Society London.

Qu UAH PA 1993; RA 6886 (29. Nov. 1888); Fak. Akte H-IV-102/67. PA im Archiv der MaxPlanck-Gesellschaft Berlin. - Nachlaß: Bibliothek des Dt. Museums München. - Siehe auch Archiv der Dt. Akademie der Naturforscher Leopoldina Halle/S.

$W$ Treadwell, Frederick Pearson, M., V.: Tabellen zur qualitativen Analyse. Hottingen-Zürich 1882. 13. Aufl. Wien 1932. - Langer, Carl, M., V.: Pyrochemische Untersuchungen. Braunschweig 1885. Darstellung der beta-Jodpropionsäure in: Berichte der Dt. Chemischen Gesellschaft 21 (1888). - Die Thiophengruppe. Braunschweig 1888. Chemische Probleme der Gegenwart. Heidelberg 1890. 2. Aufl. 1890. Märztage im kanarischen Archipel. Leipzig 1893. M., V., Jacobson, Paul Heinrich: Lehrbuch der organischen Chemie. 2 Bde. Leipzig 1893-1903. 2. Aufl. 1907-1910. Siehe NDB 17 (1994), WBIS.

L Katalog des V. M.schen Handapparates. Hrsg. von der Kekulé-Bibliothek der Farbenfabriken vorm. Friedr. Bayer \& Co. Leverkusen o. J. • Meyer, Richard, Meyer, Johanna: Aus V.M.s Jugendzeit. Als Manuscript für die Freunde. Braunschweig 1902. Badische Biographien 5 (1906) S. 872874. - Meyer, Richard: V.M. Leben und Wirken eines deutschen Chemikers und Naturforschers ... Leipzig 1917. • Smith (1949) S. 170 f.; Catalogus prof. Gottingensium (1962) S. 111; NDB 17 (1994) S. 313317; WBIS; Göttinger Gelehrte 1 (2001) S. $246 \mathrm{f}$. Beer, Günther: V.M. wirkte in Göttingen 18851889 in: Museumsbrief - Museum der Göttinger Chemie 21./22. 2002/2003 (2003) S. 26-39. Ruuskanen (2008) S. 164; Autoren der Bunsenbibliothek (2009 online). • V. M. ... Schlafloser Forscher in: Zankl, Heinrich, Betz, Katja: Trotzdem genial: Darwin, Nietzsche, Hawking und Co. Weinheim 2014. S. 65-73.

$P$ Bildarchiv UAH; graph. Slg. UBH; Göttinger Gelehrte 1 (2001) S. 247. Bildarchiv des Archivs der Max-Planck-Gesellschaft Berlin. 


\section{Meyerhof, Otto Fritz}

(1929) 1930-1935 (Honorar-Prof.) Med. Fak. (1949-1951 (Honorar-Prof.) Med. Fak.)

Physiologie

* 12. April 1884 Hannover

$\dagger \quad$ 06. Okt. 1951 Philadelphia (Pennsylvania) mosaisch, später konf.-los

V Felix M. (1849-1923) Kaufmann

M Bettina geb. May (1862-1915)

$\infty$ 4. Juni 1914 Hedwig geb. Schallenberg (18911954) Malerin, s. Rürup (2008) S. 269, Lexikon jüdischer Einwohner Hs (2011) S. 298

K 1 T, 2 S: Georg Gottfried, später George Geoffrey M. (1916-2003) Prof. für Ingenieurwiss. am Nova Scotia Technical College in Halifax (Kanada), s. Nachruf in: Bautechnik 8o (Nov. 2003) Nr. 11, S. 850 f., Lexikon jüdischer Einwohner Hs, S. $298 \mathrm{f}$. Walter Ernst M. (19222006) 1959-1992 Prof. für Physik an Stanford U (Kalifornien), s. NDB 17 (1994) S. 393*, Lexikon jüdischer Einwohner Hs, S. 299

Vw Vetter 2. Grades: Max M. (1874-1945), u.a. 1903-1911 Augenarzt in Kairo, 1911-1914 (Rückkehr nach Deutschland) Direktor der Augenklinik des Abbas-Hospitals in Kairo, 1914-1918 Kriegsdienst, seit 1918 Augenarzt in Hannover, 1922-1945 erneut Augenarzt in Kairo, s. NDB 17 (1994) S. 392 f.; Lehnert, Isolde: Zur Kur am Nil. Die Ägyptenreise von Max und Otto M. im Winter 1900/01. Wiesbaden 2017. - Vetter 2. Grades von Max M.: (siehe) Wilhelm Spiegelberg.

Lb Seit SS 1903 Studium der Medizin an U Freiburg/Br., anschl. Straßburg, Berlin.

UH: WS 1907/08-SS 1908 Forts. des Studiums; 1909 Staatsexamen in H; 7. Dez. 1909 Dr. med.; 1909-1910 Assistent im Labor der Med. U-Klinik.

Neapel: Nov. 1910-Juni 1911 Studien am Zoolog. Inst.

U Kiel: April 1912-März 1924 Assistent am Physiolog. Inst.; 9. Aug. 1913 Habilitation; 20. Sept. 1918 Verleihung des Titels „Prof.“; seit 31. Aug.
1921 nichtplanm. a.o. Prof.; WS 1922/23-WS 1923/ 24 Lehrauftrag für Physiolog. Chemie. In dieser Zeit:

1914-1915 Kriegsdienst;

Berlin-Dahlem: Seit April 1924 wiss. Mitglied des Kaiser-Wilhelm-Inst. für Biologie.

UH: 6. Sept. 1929 Ern. zum o. Honorar-Prof.; WS 1929/30, SS 1930 keine Vorlesungsankündigungen; WS 1930/31-SS 1935 Vorlesungen; seit 19. Nov. 1935 Beurlaubung; 31. Dez. 1935 Entzug der Lehrbefugnis aus rassischen Gründen.

H: 1929-1938 Direktor des Physiolog. Inst. am neugegründeten Kaiser-Wilhelm-Inst. für med. Forschung; Sept. 1938 Flucht zunächst in die Schweiz, anschl. nach Frankreich.

Paris: Seit 1938 Mitarbeiter am Inst. de Biologie et Physico-Chimie; Mai-Okt. 1940 Flucht über Portugal nach USA.

Philadelphia: Seit 1940 o. Prof. an School of Medicine der U of Pennsylvania.

UH: 1949 Erneute Ern. zum o. Honorar-Prof.; 1949-1951 keine Vorlesungsankündigungen.

1923 Nobelpreis für Physiologie oder Medizin (zus. mit Archibald Vivian Hill (1886-1977)), s. http:// www.nobelprize.org/nobel_prizes/medicine/lau reates/1922/meyerhof-facts.html

2001 Einweihung des dem U-Klinikum $\mathrm{H}$ angegliederten Otto-Meyerhof-Zentrums für ambulante Medizin und klinische Forschung, s. Schwarz, Michael: Forschung am ambulanten Patienten ... in: Unispiegel. Hrsg. von der Universität Heidelberg ... Nr. 3 (2001) S. 3.

E Korr. Mitglied der Med. Akademie Rom; 1931 (1937 Austritt, 1947 Wiederaufnahme) Mitglied der Akademie der Wissenschaften H; 1937 Mitglied der Königl. Gesellschaft London. • Dr. h.c. Edinburgh und weitere Ehrungen und Auszeichnungen. 
Qu UAH PA 1077, 5011; Fak.-Akte H-III-862/o6 fol. 288-293; Studentenakte (1900-1909/10). GLA Abt. 235, Fasz. 2285. - Nachlaß: University of Pennsylvania in Philadelphia. • Auskunft: Universitätsarchiv Freiburg/Br.

$W$ Beiträge zur psychologischen Theorie der Geistesstörungen. Göttingen 1910. • Über Goethes Methode der Naturforschung. Göttingen 1910. • Zur Energetik der Zellvorgänge. Göttingen 1913. • Über Hemmung von Fermentreaktionen durch indifferente Narkotica. Kiel 1913 (Habil.-Schrift). • Über die enzymatische Milchsäurebildung im Muskelextrakt in: Biochemische Zs. 178 (1926) S. 396. Die chemischen Vorgänge im Muskel. Berlin 1930. Siehe NDB 17 (1994) S. 395 f.

L Kürschner (1931) Sp. 1956, (1950) Sp. 1356. • Weber, Hans Hermann: O.M. in: Die Naturwissenschaften 39 (1952). • Hieronimus, Ekkehard: Theodor Lessing, O.M., Leonard Nelson. Bedeutende Juden in Niedersachsen. Hannover 1964. • Staab, Heinz A.: 50 Jahre Kaiser-Wilhelm/Max-PlanckInst. für med. Forschung Heidelberg in: Heidelberger Jahrbücher 24 (1980) S. 52-56 u. ö. • Dictionary of Emigrés 2 (1983) S. 814; Arnim 4 (1984) S. 1085. - Schweiger, Hans-Georg: O.M. in: Semper apertus 3 (1985) S. 357-373. Mussgnug (1988) S. 298 (Register); Zimmermann/Drüll (1990) S. 49 u. ö.; NDB 17 (1994) S. 393-396; Badische Biographien N.F. IV (1996) S. 212-215. • Schirmer, Ralf H., Gromer, Stephan: Zum 50. Todestag von O. M. ... - Der Aufbruch der Zellbiologie. Heidelberg 2004. Online unter http://www.rzuser.uniheidelberg.de/\%7Ehp $3 /$ Meyerhof.htm. - Kazemi (2006) S. 211-215. - UH im Nationalsozialismus (2006) S. 1263 (Register) • Werle, Dorit: Carl Neuberg - Wegbereiter der Biochemie. Unter Einbeziehung der Briefwechsel von Carl Neuberg mit Otto Warburg, ..., O.M. ... aus den Jahren 1909-1956. Diss. Halle-Wittenberg 2007. • Rürup (2008) S. 527 (Register). - Vertriebene Mitgl. der Akad. der Wiss. H (2009) S. 47-52; WBIS; Wissenschaftsatlas der UH (2011) S. 252. • Hofmann, Eberhard: O.M. - Humanist und Naturforscher. Von der Philosophie zum Nobelpreis in: Vorträge und Abhandlungen zur Wissenschaftsgeschichte ... Stuttgart 2016. S. 299-369.

$P$ Bildarchiv UAH; NDB 17 (1994); Vertriebene Mitgl. (2009).

\section{Mitteis, Heinrich Karl Ludwig}

1924-1934 Jur. Fak.

Deutsche Rechtsgeschichte, Bürgerliches Recht, Handelsrecht

* 26. Nov. 1889 Prag

$\dagger$ 23. Juli 1952 München kath.

V Ludwig Hermann M. (1859-1921) 188o-1886 Richter, seit 1884 zugleich Privat-Dozent für Römisches Recht U Wien, seit 1887 a.o. Prof.; Ordinarius: seit 1891 Prag, seit 1895 Wien, seit 1899 Leipzig, s. WBIS, NDB 17 (1994) S. 576 f.; Rupprecht, Hans-Albert: L.M. in: Hermae: Scholars and Scholarship in Papyrology. Ed. by Mario Capasso. Pisa 2007. S. 67-70; Geschichte U Leipzig 2 (2010) S. 919 (Register), Professorenkatalog Leipzig online

M Hermine Amalia geb. Luber (1858-1912)

@ 18. Dez. 1919 Mathilde (Liddy) geb. Abt (18881971)

$\mathrm{K}$ keine.

Lb Seit WS 1908/og Studium an U Leipzig, WS 1909/10 Berlin, seit SS 1910 Leipzig.

Leipzig: 9. Jan. 1912 Referendarexamen; Jan. 1912April 1913 Referendar; 17. Febr. 1913 Dr. iur. an U.

U Bonn: Seit Mai 1913 (Unterbrechung der Referendarzeit) Eigenstudien.

Referendar: 1914-1915 Amtsgerichte in Zwenkau und Leipzig sowie Landgericht in Leipzig.

26. April 1915-1918 Kriegsdienst.

U Halle/S.: 9. April 1919 Habilitation für Dt. Recht und Rechtsgeschichte; SS 1920 Lehrauftrag an U Köln; 1921 Ruf an U Frankfurt/M. abgelehnt.

U Köln: Seit 1. April 1921 o. Prof.

UH: 16. Juni 1924 Ern. zum o. Prof. als Nachf. von Hans Fehr; 1. Okt. 1924 Dienstantritt; 1928 Ruf an U Tübingen abgelehnt. 
U München: 27. März 1934 Ern. zum o. Prof.; 1935 Entbindung von seinen Pflichten.

U Wien: Seit 1. April 1935 o. Prof.; März 1938-Jan. 1940 Amtsenthebung.

U Rostock: Seit 4. Jan. 1940 (Versetzung) o. Prof.; 1945 Rückberufung an U München scheitert an Verschleppung der erforderlichen Umzugsgenehmigung durch amerik. Militärverwaltung, die erst am 27. Mai 1946 die Genehmigung erteilt.

U Berlin: Frühjahr 1946 Annahme der Professur; 1946/47 Rufe an U abgelehnt: Frankfurt/M., Wien, Tübingen, Göttingen, München, $\mathrm{H}$.

U München: 24. Dez. 1947 Ern. zum o. Prof.; 1. April 1948 Dienstantritt; 30. März 1952 Annahme e. Rufes an U Zürich zum WS 1952/53; M. stirbt vorher im Juli 1952 an e. Herzanfall.

1926/27, Okt.-Nov. 1933 (Absetzung nach Differenzen mit Rektor Wilhelm Groh; s. hierzu Brun (1991) S. 104-106, Schroeder (2010) S. 427) Dekan der Jur. Fak. der UH

1927 Mitbegründer des Dt. Rechtshistorikertages, s. hierzu Stolleis, Michael: Deutscher Rechtshistorikertag in: Handwörterbuch zur dt. Rechtsgeschichte. Berlin 2008. Bd. I. Sp. 990-992.

Siehe auch Anhang Sporteinrichtungen an UH 1910-1933 und ihre Mitglieder

E Mitglied der Akademie der Wissenschaften: 1925 H, 1945 Wien, 1946 Berlin, 1949 München; 1933 Mitglied der neugegründeten Akademie für Dt. Recht München. 1917 Eisernes Kreuz II. Klasse; 1918 Sächsisches Albrechtskreuz mit Schwert.

Qu UAH PA 778, 5033; Fak.-Akten H-II-319/3, H-II-553; B-0747/1 vom 14. Aug. 1947. GLA Abt. 235, Fasz. 2312. - Nachlaß: Universitätsbibliothek München.

$W$ Lehnrecht und Staatsgewalt. Weimar 1933. Nachdr. 1958. Grundriß des österreichischen Urheberrechts nach dem Bundesgesetz vom 9. April 1936. Wien 1936. - Die deutsche Königswahl. Ba-
den-Baden 1938. 2. Aufl. 1944. Nachdr. 1975. • Der Staat des hohen Mittelalters ... Weimar 1940. 8. Aufl. 1968. Deutsche Rechtsgeschichte. München 1949. 13. Aufl. 1974. Deutsches Privatrecht. München 1950. 6. Aufl. 1972. • Siehe Bibliographie in: Brun (1991) S. 199-207.

HG 1946-1952 Zeitschrift der Savigny-Stiftung für Rechtsgeschichte.

L Kürschner (1950) Sp. 1370. • Reicke, Siegfried: H.M. in: Ruperto Carola 7/8 (1952) S. 37 f. Nachruf in: Almanach der Akademie der Wissenschaften. Wien 1954. Bd. 104. S. 343-346. - Arnim 4 (1984) S. 1103. - Juristen im Portrait. Verlag und Autoren in 4 Jahrzehnten ... München 1988. S. 572583. • Brun, Georg: Leben und Werk des Rechtshistorikers H.M. unter besonderer Berücksichtigung seines Verhältnisses zum Nationalsozialismus. Frankfurt/M. 1991. - H.M. nach 100 Jahren ... Symposium ... in München ... Hrsg. von Peter Landau u. a. München 1991. Jansen (1992) S. 411 (Register); Ders. (1992a) S. 167 (Register); Heiber II,2 (1994) S. 844 (Register). • Diestelkamp, Bernhard: Drei Professoren der Rechtswissenschaft in bewegter Zeit: H.M. ... Stuttgart 2000. - Historikerlexikon (2002) S. $226 \mathrm{f}$.; Buddrus/Fritzlar (2007) S. 279-282. - Kortüm, Hans-Henning: Mittelalterliche Verfassungsgeschichte im Bann der Rechtsgeschichte zwischen den Kriegen - H.M. und Otto Brunner in: Das Lehnswesen im Hochmittelalter. Forschungskonstrukte - Quellenbefunde - Deutungsrelevanz. Hrsg. von Jürgen Dendorfer ... Ostfildern 2010. S. 57-78. • Schroeder (2010) S. 740 (Register). • Leo, Paul Christopher: Wilhelm Groh ... Hamburg 2012. S. 135-143. Wesel, Uwe, Beck, Hans Dieter: 250 Jahre rechtswissenschaftlicher Verlag C.H. Beck: 1763-2013. München 2013. S. 584 (Register).

P Bildarchiv UAH; Ruperto Carola. 


\section{Mittermaier, Carl Joseph Anton}

1821-1867 Jur. Fak.

Deutsches Strafrecht

* 04. Aug. 1787 München

$\approx$ 05. Aug. 1787

$\dagger \quad$ 28. Aug. 1867 Heidelberg kath.

V Joseph M. (1750-1797) Apotheker

M Catharina geb. Orthmayr (1759-1828)

๑ 1812 Margarethe geb. von Walther (1786-1869) Schwester von Philipp Franz von W. (17821849), u.a. seit 1818 Prof. für Chirurgie und Augenheilkunde U Bonn, seit 1830 leitender Arzt für Chirurgie und Augenheilkunde am Städtischen Krankenhaus München sowie Leibarzt König Ludwigs I. von Bayern, s. ADB 41 (1896) S. 121 f., WBIS

K 7, u. a. Philipp Franz M. (1817-1899) Baurat, s. Wagner-Hasel, Beate: Die Arbeit des Gelehrten. Der Nationalökonom Karl Bücher ... Frankfurt/M. 2011. S. 399 (Register). - Clara Antonia M. (1820-1855) 1839-1855 und Louise M. (1815-1872) 1857-1872: Ehefrauen von Friedrich Karl Konrad Christoph Frhr. von KrafftEbing (1807-1889) Jurist, seit 1848 Amtsvorstand, 1857-1861 (Ruhestand) Oberamtmann, s. Lehsten, Lupold von, Seibold, Gerhard: Das Freundschaftsalbum der Louise Mittermaier 1847-1857: ein bemerkenswertes Zeugnis des Familien- und Freundeskreises Karl Joseph Anton M.s aus der Paulskirchenzeit in: Archiv für Familiengeschichtsforschung. Limburg 2006. 10. Jg. H. 4. S. 242-267. • Dr. med. Karl M. (1823-1917) Arzt, s. WBIS; Handbuch der historischen Buchbestände in Deutschland. Hrsg. von Bernhard Fabian. Hildesheim 2003; Wagner-Hasel (2011) S. 52, 54f., 65. • Dr. iur. Franz Ludwig M. (1826-1891) Jurist, s. Wolfgang Mittermaier: Eintrag unter $V$ [ater]
Vw Enkel: u.a. Richard Frhr. von Krafft-Ebing (1840-1902) Neuropathologe, seit 1872 Prof. für Psychiatrie Straßburg, seit 1873 Prof. an $\mathrm{U}$ und bis $188 \mathrm{o}$ Leiter der Landesirrenanstalt in Graz, seit 1885 o. Prof. für Psychiatrie und Neurologie sowie Gründungs-Direktor des Sanatoriums Mariagrün in Graz, seit 1892 o. Prof. und Direktor der Psychiatr. Klinik der Landes-Irrenanstalt Wien, s. WBIS; Ammerer, Heinrich: Am Anfang war die Perversion. R. von K.-E. Psychiater und Pionier der modernen Sexualkunde. Wien 2011. - (Siehe) Wolfgang $M$.

Vw Enkelin: Emilie M. (1853-1909) T von Philipp Franz M. (1817-1899; siehe oben Eintrag unter $K$ [inder]) und Ehefrau von Karl Bücher (1847-1930) 1872-1878 Gymnasiallehrer in Dortmund und Frankfurt/M., seit 1878 Redakteur der Frankfurter Zeitung, seit 1881 PrivatDozent München, Ordinarius für Nationalökonomie und Statistik: seit 1882 Dorpat, seit 1883 Basel, seit 1890 TH Karlsruhe, 1892-1916 (Emeritierung) U Leipzig, s. WBIS, WagnerHasel (2011)

Vw siehe auch NDB 17 (1994) S. 584.

Lb Ludwig-Maximilians-U Landshut: Seit 9. Nov. 1805 Studium der Rechtswiss.; Sommer $1807 \mathrm{Ab}$ solutorium (Examen).

München: Seit 1807 Praktikant am Landgericht in M.-Au und Sekretär des Juristen Paul Johann Anselm Ritter von Feuerbach (1775-1833).

UH: Seit 13. April 1808 Forts. des Studiums als Stipendiat der bayer. Regierung; 29. März 1809 Dr. iur.

Ludwig-Maximilians-U Landshut: Seit 17. Nov. 1809 Privat-Dozent; 1811 Ruf an U Kiel abgelehnt; seit 16. Juli 1811 o. Prof. für Kriminalrecht und Kriminalprozeß mit e. jährl. Besoldung von 10oo.Gulden; 1818 Rufe an U Halle-Wittenberg und Jena abgelehnt.

U Bonn: Seit Okt. 1818 o. Prof. an neugegründeter U; u. a. 1820/21 Berufung an Oberappellationsgericht der vier Freien Städte des Dt. Bundes in Lübeck abgelehnt. 
UH: 1. Sept. 1821-28. Aug. $1867(\dagger)$ o. Prof. als Nachf. von Friedrich Cropp; 1821-1867 Beisitzer des Spruchkollegiums der Jur. Fak.; Rufe an U abgelehnt: 1826 München, 1831 Bonn; 1830-1832 Mitglied der Bibliotheks-Kommission. - In dieser Zeit:

Karlsruhe: 1826-1845 Mitglied der Badischen Gesetzgebungskommission; 1831-1840, 1846-1849 Mitglied, 1833-1840, 1846-1849 Präsident der II. Kammer des Badischen Landtags.

Frankfurt/M.: 31. März-3. April 1848 Präsident des Vorparlaments, 1848/49 Mitglied der Dt. Nationalversammlung.

1825, 1837 Prorektor der UH; 1826, 1830, 1834, 1838, 1841, 1845, 1850, 1855, 1861 Dekan der Jur. Fak. der $\mathrm{UH}$

M.s Bibliothek mit mehr als 4400 Werken in 8019 Bänden sowie ca. 6000 Dissertationen und Broschüren ist in der Heidelberger Universitätsbibliothek aufgestellt, s. hierzu Handbuch der historischen Buchbestände in Deutschland. Hrsg. von Bernhard Fabian. Hildesheim 2003.

Das ehemalige Wohnhaus M.s, e. der ältesten Barockbauten Heidelbergs, befindet sich in der Karlsstraße 8.

1811 Hofrat; 1821 Geh. Hofrat; 1826 Geh. Rat II. Klasse

E Mitglied mehrerer Akademien. 1862 Orden pour le Mérite für Wissenschaften und Künste. • 1848 Dr. iur. h.c. Prag; 1859 Dr. phil. h.c. UH; 1865 Dr. iur. h.c. Cambridge (Massachusetts). 1831 Kommandeurkreuz des Ordens vom Zähringer Löwen; 1841 Ritter der französischen Ehrenlegion; 1857 Comthurkreuz des Oldenburgischen Hausund Verdienstordens; 1861 Stern zum Kommandeurkreuz des Ordens vom Zähringer Löwen. • 1839 Ehrenbürger der Stadt Heidelberg.
Qu UAH PA 2004; RA 5437, 5628, 5683 (Stiftung e. Mittermaier-Büste 1914), 6387 u. ö.; GF 140. GLA Abt. 205, Fasz. 384-385. • Ausdruck e. Briefes von M. im UAH aus der Privatsammlung von Briefen im Familienarchiv Dr. Karsten Weber, Mosbach. Briefe deutscher und Schweizer Germanisten an K. J.A. M. Hrsg. ... von Lieselotte Jelowik. Frankfurt/M. 2001. • Briefwechsel K. J. A. M. - Robert von Mohl. ... Hrsg. von Dorothee Mussgnug. Frankfurt/M. 2005. Briefe Herrmann Theodor Goltdammers an K. J. A. M. Hrsg. und bearb. von Dorothee Mussgnug. Frankfurt/M. 2007. Briefe Leopold August Warnkönigs an K. J.A.M. 18331858. Hrsg. von Lieselotte Jelowik. Frankfurt/M. 2009. - Teil-Nachlaß: UAH (Signatur: KE 96); UBH; Bundesarchiv Berlin. • Auskunft: Archiv des Erzbistums München und Freising.

$W$ Anleitung zur Verteidigungskunst im dreifachen Criminalprocesse. Landshut 1814. 4. Aufl. 1845. - Lehrbuch des deutschen Privatrechts. Landshut 1821. - Grundsätze des gemeinen deutschen Privatrechts mit Einschluß des Handels-, Wechsels- und Seerechts. 2 Abt. Landshut 1824. 7. Aufl. 1847. • Die summarischen Verfahrensarten des gemeinen bürgerlichen Prozesses in Vergleichung mit den preussischen und französischen Civilverfahren ... 2. Auflage. Bonn 1840. - Die Mündlichkeit, das Anklageprinzip, die Öffentlichkeit und das Geschworenengericht. Stuttgart 1845. Das englische, schottische und nordamerikanische Strafverfahren. Erlangen 1851. • Der gegenwärtige Zustand der Gefängnißfrage. Erlangen 1860. - Siehe Nuzzo, Luigi: Bibliographie der Werke K. J. A. M. Frankfurt/M. 2004.

MG 1818-1867 Archiv für die civilistische Praxis. • 1846 Deutsche Zeitung.

MG, MHG 1828-1856 Kritische Zeitschrift für Rechtswissenschaft und Gesetzgebung des Auslandes.

HG 1817-1856 Neues Archiv des Criminalrechts.

L Arnim 2 (1952) S. 181; Jammers (1964) S. 177 u. ö. Landwehr, Götz: K. J. A. M. in: Heidelberger Jahrbücher 12 (1968) S. 29-55; Ders.: Die Handelsrechtswissenschaft an der Universität Heidelberg 
im 19. Jahrhundert in: Semper apertus 2 (1985) S. 61-83. Heidelberger Strafrechtslehrer (1986) S. 17-28, 43-115. - C. J. A. M. Symposium 1987 in Heidelberg. Vorträge und Materialien. Hrsg. von Wilfried Küper ... Heidelberg 1988. Beckenbauer, Alfons: Die Ludwig-Maximilians-Universität in ihrer Landshuter Epoche 1800-1826. München 1992. S. 377 (Register). • Fleckenstein, Martin: Die Todesstrafe im Werk C.J.A.M. ... Zur Entwicklungsgeschichte eines Werkbereichs und seiner Bedeutung für Theorie- und Methodenbildung. Frankfurt/M. 1992. NDB 17 (1994) S. 584f.; Biogr. Lexikon der U München 1 (1998) S. 281 ff.; Gelehrte in der Revolution (1998) S. 93-120. Koch, Arnd: C. J.A.M. und das Schwurgericht in: Zs. für neuere Rechtsgeschichte. Wien 2000. H. 2. S. 167-187. Kirschke (2001) S. 448 (Register). Borrmann, Kathrin: Gemeines dt. Privatrecht bei C.J.A.M. Baden-Baden 2009. C. J. A. M. ... Hrsg. von Werner Moritz und Klaus-Peter Schroeder. UbstadtWeiher 2009. - Schroeder, Klaus-Peter: „Aus Mittermaier wird schwerlich je etwas werden." Leben und Werk von C. J. A. M. ... in: Juristische Arbeitsblätter 41 (2009) 6, S. 433-435; Ders. (2010) S. 133142 (S. 134: irrtümlich 5. statt 4. Aug. als Geburtstag angegeben). - Keßler, Ewald: Der Jurist M. und der Altkatholizismus in: Int. Kirchliche Zeitschrift N.F. ... 101 (Juni 2011) H. 2. S. 116-136. • Stumm (2012) S. 700 (Register). Hess, Burkhard: C. J.A.M. - Zivilprozeßrecht in Europa vom 19. Jahrhundert bis in die Gegenwart in: Heidelberger Thesen zu Recht und Gerechtigkeit (2013) S. 143-160. Maus (2013) S. 459 (Register).

$P$ Bildarchiv UAH; graph. Slg. UBH.

\section{Mittermaier, Georg Gottfried Wolfgang}

1896 (Lehrbeauftragter) Jur. Fak.

1897-1900 Jur. Fak.

1947-1953 (Honorar-Prof.) Jur. Fak.

Strafrecht, Strafprozeßrecht, Zivilprozeßrecht

* 29. Mai 1867 Heidelberg

$\dagger \quad$ 28. Juli 1956 Heidelberg

ev.
V Dr. iur. Franz Ludwig M. (1826-1891) Jurist, Landwirt, Politiker; 1848-1854 Aufenthalt u.a. auf Madeira, um e. Lungenleiden auszukurieren (in Begleitung seines Bruders und Arztes Dr. med. Karl M. (1823-1917), s. WBIS, Wagner-Hasel (2011) S. 52, 54f., 65) 1854-1856 Landwirt auf dem Grenzhof, e. Weiler in $\mathrm{H}-$ Wieblingen, dann Übersetzer, 1863-1891 Mitarbeiter der Zeitschrift für das gesamte Handelsrecht; 1860 Gründer des Schützenvereins $\mathrm{H}$, seit 1882 Vorstandsmitglied der Stadtverordneten, 1886 Mitverantwortlicher bei Organisation der 500-Jahrfeier der UH, s. u.a. Briefe in UBH; Badische Biographien 5 (1906) S. 566-569, Wolf (1997) S. 10-16 u. ö.; WagnerHasel, Beate: Die Arbeit des Gelehrten: Der Nationalökonom Karl Bücher (1847-1930). Frankfurt/M. 2011. S. 52, 54.

M Marie geb. Joppert (1836-1909), s. Wolf (1997) S. 16

$\infty$ 23. Sept. 1899 Mathilde Clementine geb. Saunier (1867-1945), s. Hoffmann (2011) S. 125 f., 129. - Vormund und Stief-Vater: (siehe) Richard Schroeder

K $\quad 2 \mathrm{~S}, 1 \mathrm{~T}$

Vw Großvater: (siehe) Carl Joseph Anton M.

Vw Schwester: Bertha M. $\left({ }^{*} 1863 \dagger\right.$ nach 1927$)$ Ehefrau von Karl Ludwig Neumann (1854-1925) 1886-1891 Gymnasiallehrer, seit 1886 auch Privat-Dozent, seit 1891 a. o. Prof., seit 1896 Honorar-Prof., 1906-1919 (Emeritierung) o. Prof. für Geographie Freiburg/Br., s. Badische Biographien N.F. II (1987) S. 210 f.

Vw siehe auch Carl Joseph Anton Mittermaier.

Lb Seit WS 1885/86 Studium an UH, WS 1886/87 Berlin, seit SS 1887 H; Frühjahr 1889 Rechtspraktikantenprüfung in Karlsruhe.

H: Seit Mai 1889 Rechtspraktikant; 25. Jan. 189o Dr. iur. an U; 1890-1891 Militärdienstpflicht als Einjährig-Freiwilliger bei II. Badischem Grenadierregiment Nr. 110.

Karlsruhe: Frühjahr 1893 I., Mai 1893 II. Staatsexamen. 
Studienreisen: u.a. Juli-Dez. 1893 Nordamerika und anschl. kurzzeitig Großbritannien; Febr. 1894Dez. 1895 Referendar an verschiedenen Gerichten; seit Herbst 1894 Habilitations-Vorbereitungen.

UH: Mai-Okt. 1896 Lehrauftrag für Strafrecht anstelle des verstorbenen Rudolf Heinze; 25. Jan. 1897 Habilitation; seit 16. Aug. 1899 nichtetatm. a.o. Prof.

U Bern: Seit WS 1900/o1 o. Prof. und 1901 Begründer des Kriminalistischen Seminars.

U Gießen: 21. Febr. 1903 Ern. zum o. Prof.; 1914Ende 1916 Kriegsdienst als Freiwilliger, s. hierzu Wolf (1997) S. 18 f.; 1. Okt. 1933 auf eigenen Antrag Emeritierung, s. hierzu ebd. S. 33-37.

H: Seit Dez. 1933 Wohnsitz; Eigenstudien.

UH: Frühjahr 1947-SS 1949 Lehrauftrag für e. einstündige Vorlesung über Gefängniskunde; seit 24. Mai 1947 Honorar-Prof.; WS 1952/53 letzte Vorlesungsankündigung über Kriminalpolitik; Ende Nov. 1953 Schlaganfall mit Verlust der Lese- und Schreibfähigkeit sowie Sprachstörungen.

1923/24-1934 (Ausschluß) Mitarbeiter an der Reform des Reichsstrafgesetzbuches

1914 Geh. Justizrat

Qu UAH PA 779, 2005, 5035. • GLA Abt. 235, Fasz. 2313. Nachlaß: UBH.

$W$ Kritische Beiträge zur Lehre von der Strafrechtsschuld. Gießen 1909. - Wie studiert man Rechtswissenschaft? Stuttgart 1911. 2. Aufl. 1921. • Gefängniskunde. Berlin 1954. - Siehe auch Wolf (1997) S. 50-145.

L WBIS; Gießener Gelehrte 2 (1982) S. 658-671; Jansen (1992a) S. 167 (Register); NDB 17 (1994) S. 585 f. - Wolf, Jochen: Das Leben und das strafrechtliche Werk W.M.s. Frankfurt/M. 1997. • Schroeder (2010) S. 351-353 u. ö.

$P$ Bildarchiv UAH; graph. Slg. UBH; Gießener Gelehrte; WBIS.

\section{Moebius, Martin August Johannes}

1887-189o Phil. Fak.

1890-1893 Nat.-Math. Fak.

Botanik

* $\quad$ 07. Dez. 1859 Leipzig

$\dagger$ 25. Jan. 1946 Bad Homburg vor der Höhe ev.

V Dr. phil. Paul M. (1825-1889) Leipzig: 18481865 Gymnasiallehrer, 1852-1865 Direktor der neugegründeten Lehranstalt für buchhändlerische Wissenschaften, seit 1865 Direktor der ersten Bürgerschule; seit 1869 großherzogl. Schulrat (seit 1880 Oberschulrat) und Generalschul-Inspektor in Gotha, seit 1872 auch Mitglied des Großherzogl. Staatsministeriums ebd., s. ADB 52 (1906) S. 429 f., WBIS

M Julie geb. Marezoll (1823-189o) T von Theodor Gustav Ludwig M. (1794-1873) seit 1816 Privat-Dozent Jena, seit 1817 a.o. Prof., seit 1818 o. Prof. Gießen, 1837-1864 o. Prof. für Römisches Recht, Naturrecht Leipzig, s. ADB 20 (1884) S. 315 f., Professorenkatalog Leipzig online (Sohn von Johann Gottlob M. (1761-1828) seit 1789 U-Prediger, seit 1790 a. o. Prof. und Direktor des Predigerseminars Göttingen, seit 1794 Hauptpastor an dt. Petrikirche in Kopenhagen, seit 1803 Konsistorialrat, Superintendent und Oberpfarrer in Jena, s. ADB 20, S. $316 \mathrm{f} .$, WBIS)

(14. Okt. 1893 Anna geb. Loos (1865-1948)

K 1 S: Hans M. (1895-1977) 1929-1943 PrivatDozent Marburg, seit 1928 Kustos bei Staatl. Kunstsammlungen Kassel, 1943-1963 (Emeritierung) o. Prof. für Archäologie Würzburg (als Nachf. von Reinhard Herbig, s. Drüll (2009) S. 269f.), s. NDB 17 (1993) S. 604f.

Vw Großvater: August Ferdinand M. (1790-1868) Leipzig: seit 1815 Privat-Dozent, seit 1816 a.o. Prof., seit 1844 o. Prof. für Höhere Mechanik und Astronomie, seit 1816 Observator, seit 1820 Direktor der Sternwarte auf der Pleißenburg, s. WBIS, NDB 17 (1993) S. 6oo-603, Professorenkatalog Leipzig online 
Vw Onkel: August Theodor M. (1821-1890) 18451861 zunächst Assistent, dann Kustos an UB Leipzig, seit 1852 Privat-Dozent, seit 1859 a.o. Prof. Leipzig, 1865-1889 (Entpflichtung) o. Prof. für Nordische Philologie Kiel, s. Professoren Kiel (1956) S. 143, WBIS, NDB 17 (1993) S. $603 \mathrm{f}$.

Vw Bruder: Dr. med. et phil. Paul Julius M. (18531907) Leipzig: 1882-1888 Assistent an Neurolog.-Elektrotherapeutischen Abt. der Med. U-Poliklinik, 1883-1893 (auf eigenen Antrag Aufgabe der Dozentur) Privat-Dozent für Neurologie, 1879-1907 Privat-Praxis für Nervenkranke (Autor von: Über den physiologischen Schwachsinn des Weibes. Halle/S. 1900), s. Nachlaß in UB Leipzig; Steinberg, Holger: Zum 150. Geb. von P. J.M. in: Der Nervenarzt 75,1 (Jan. 2004) S. 97-100.

Lb Seit WS 1878/79 zunächst nur Hörer der Naturwiss., Chemie, Botanik an U Leipzig nach Erkrankung an e. Nervenleiden; Winter 1878/79 Vorbereitung auf Maturitätsprüfung in Gotha; Ostern 1880 Reifeprüfung.

UH: SS 1880-SS 1883 Studium; 19. Juli 1883 Dr. phil.

U Berlin: 1883-1886 Forts. des Studiums und Eigenstudien.

UH: Seit Okt. 1886 Assistent am Botanischen Inst.; 17. Dez. 1887 Habilitation; seit 17. Dez. 1891 nichtetatm. a.o. Prof.

Frankfurt/M.: 1893-1914 Dozent für Botanik und 1893-1928 Direktor des Botanischen Gartens am Senckenbergischen Institut.

U Frankfurt/M.: 1914-1928 (Emeritierung) o. Prof. und Direktor des Botanischen Inst.

Geh. Reg.-Rat

Qu UAH PA 2007; Fak.-Akten H-IV-102/101 fol. 291r-227r, H-IV-102/119 fol. 72r-87r. • Auskunft: Magistrat der Stadt Bad Homburg vor der Höhe (Sterbebuch 1946, Nr. 42).
$W$ Über nutzlose Eigenschaften der Pflanzen und das Prinzip der Schönheit in: Berichte der Deutschen Botanischen Gesellschaft 24,1 (1906) S. 5-12 (Sonderdruck). Mikroskopisches Praktikum für systematische Botanik. 2 Bde. Berlin 1912-1915. • Die Farbstoffe der Pflanzen. Berlin 1927. - Geschichte der Botanik von den ersten Anfängen bis zur Gegenwart. Jena 1937. 2. Aufl. Stuttgart 1968.

L Kürschner (1931) Sp. 1976 f., (1940/41) Sp. 202. • Wolff, Paul: Formen des Lebens. Botanische Lichtbildstudien. 120 Naturaufnahmen mit Vorbemerkungen und Hinweisen von M. M. Königstein im Taunus 1931. Neudr. 2002. • Armin 2 (1952) S. 183; WBIS. M. M. in: Berichte der Dt. Botanischen Gesellschaft 68a (1955) S. 1-8. • Böhm, Wolfgang: Biographisches Handbuch zur Geschichte des Pflanzenbaus. München 1997. S. 217. - Michels, Claudia: 1427 Menschen, die sich den Nazis widersetzten in: Frankfurter Rundschau vom 17. Juli 2004. - Ich sehe wunderbare Dinge. 100 Jahre Sammlungen der Goethe-Universität. Ausstellungskatalog ... Hrsg.: Charlotte Trümpler ... Ostfildern 2014. S. 41, $44 \mathrm{f}$. Deutsche Biographie, s. https://www.deutsche-biographie.de/gnd1 04274654.html [07.11. 2017].

$P$ Bildarchiv UAH; graph. Slg. UBH.

Mohl, Robert (seit 1837 persönlicher, seit 1871 erblicher Adel: von Mohl)

1847-1861 Jur. Fak.

Verwaltungsrecht, Allg. Staatsrecht

* 17. Aug. 1799 Stuttgart

$\dagger \quad$ in der Nacht vom 04. auf den 05. Nov. 1875 Berlin

ev.-luth.

V Dr. iur. Benjamin Ferdinand (von) M. (17661845) Reg.-Rat, seit 1831 Präsident des Oberkonsistoriums, s. NDB 17 (1994) S. 690* (hier: Geb.-Jahr 1767), WBIS

M Louisa Friederica geb. Autenrieth (1776-1843)

(21. Juni 1830 Pauline geb. Becher (1808-1894) 
K 2 S, 2 T: u.a. Anna von M. (1834-1899), s. NDB 8 (1969) S. 501, Pfeiffer (2004) S. 154 f.; Ehefrau von: (siehe) Hermann (von) Helmholtz

Vw Brüder: Julius M. (180o-1876) Prof. für Orientalistik am Collège de France Paris, s. ZDMG 31 (1877) S. IV-XIII, ADB 22 (1885) S. 57-59, WBIS. • Moritz M. (1802-1888) Nationalökonom, Wirtschaftspolitiker, s. Biogr. Handbuch der württ. Landtagsabgeordneten (2001). Hugo M. (1805-1872) seit 1835 o. Prof. für Botanik an U Tübingen, s. WBIS. - Siehe auch NDB 17 (1994) S. 690-692, Wirtschaftswiss. Fak. Tübingen 1 (2004) S. 173.

Lb Seit WS 1817/18 Studium der Rechts- und Staatswiss., Staatswirtschaft an U Tübingen, WS 1819/20-WS 1820/21 H, SS 1821 Tübingen; 27. Aug. 1821 Dr. iur. an UH; 1821-1824 Studienreisen nach Frankfurt/M., Göttingen, Paris.

U Tübingen: 30. März 1824 Ern. zum a. o. Prof. für Staatsrecht an Jur. Fak.; 25. März 1827-5. Dez. 1845 o. Prof. für Enzyklopädie der Staatswiss., Politik, Polizeiwiss., Staatsrecht an Staatswirtschaftl. Fak.; 20. Mai 1831 Dr. oec. publ. (ohne Diss. und Disputation an Staatswirtschaftl. Fak. aufgrund e. Erlasses des Kanzlers der U); Aug. 1836-1844 Oberbibliothekar an UB; 5 . Dez. 1845 Zwangsversetzung als Reg.-Rat nach Ulm wegen e. oppositionellen Wahlaufrufs, s. hierzu Wirtschaftswiss. Fak. Tübingen 1 (2004) S. 175 f.; 10. Dez. 1845 freiwilliger Austritt aus dem Staatsdienst.

Tübingen: 1846-1847 Freier Schriftsteller; seit 1846 Stadtrat; seit Herbst 1846 Mitglied der Abgeordnetenkammer des Württ. Landtags für Tuttlingen in Stuttgart; April-Sept. 1847 Studienreise nach England.

UH: Seit 19. April 1847 (Ern.) o. Prof. II. Klasse (d. h. ohne Teilnahmeberechtigung an den Fak.-Sitzungen und Doktorexamina); 1. Okt. 1847 Amtsantritt; 4. April 1851-30. Juni 1861 o. Prof. (I. Klasse, d.h. mit Teilnahmeberechtigung ...) in Nachfolge von Eduard Morstadt. • In dieser Zeit:

Frankfurt/M.: 31. März-3. April 1848 Mitglied des Vorparlaments; 1848-1849 Abgeordneter der Dt. Nationalversammlung; 9. Aug. 1848-10. Mai 1849 Reichsjustizminister.
Karlsruhe: 1857-1860 Mitglied der I. Kammer als Vertreter der UH, 1867-1872 Präsident der I. Kammer des Badischen Landtags.

Frankfurt/M.: 1861-1866 Badischer Gesandter am Dt. Bundestag.

München: 1866-Sept. 1871 Badischer Gesandter am Königl. bayer. Hof.

Karlsruhe: Okt. 1871-Nov. 1875 Präsident der Oberrechnungskammer.

Berlin: Jan. 1874-Nov. 1875 Mitglied des Reichstags für den Wahlkreis Donaueschingen.

1853 Prorektor der UH; 1853, 1859 Dekan der Jur. Fak. der UH

1847 Geh. Hofrat; 1861 Geh. Rat II. Klasse; 1867 Wirkl. Geh. Rat (Exzellenz)

E 1868 Mitglied der Akademie der Wissenschaften München. • 1871 Dr. phil. h.c. UH. • 1857 Ritter, 1861 Kommandeurkreuz II. Klasse des Ordens vom Zähringer Löwen. 1861 Ehrenbürger von Heidelberg sowie zahlreiche weitere Ehrungen und Auszeichnungen.

Qu UAH PA 2009. GLA Abt. 6o, Fasz. 285, 1390, Abt. 76, Fasz. 5366, 9829, Abt. 232, Fasz. 316 f., Abt. 233, Fasz. 23769. • Brief-Sammlung: Universitätsbibliothek Tübingen. • Ausdruck e. Briefes von M. im UAH aus der Privatsammlung von Briefen im Familienarchiv Dr. Karsten Weber, Mosbach. • Briefwechsel Karl Josef Anton Mittermaier - R. von M. ... Hrsg. von Dorothee Mussgnug. Frankfurt/M. 2005. - Der Redaktionsbriefwechsel der Hallischen, Deutschen und Deutsch-Französischen Jahrbücher 1837-1844. Hrsg. von Martin Hundt. Bd. 1: Der Briefwechsel um die Hallischen Jahrbücher. Berlin 2010. Apparat: S. 270 (Register). Nachlaß: Universitätsbibliothek Tübingen; Hauptstaatsarchiv Stuttgart; Bundesarchiv Koblenz. - Lebenserinnerungen. 1799-1875. 2 Bde. Stuttgart, Leipzig 1902. (Autobiogr.; Originalhandschrift in Universitätsbibliothek Tübingen.) 
W Das Staatsrecht des Königreichs Württemberg. 2 Bde. Tübingen 1829-1831. 2. Aufl. 1840. - Die Polizei-Wissenschaft nach den Grundsätzen des Rechtsstaats. 3 Bde. Tübingen 1832-1834. 3. Aufl. 1866. Geschichtliche Nachweisungen über die Sitten und das Betragen der Tübinger Studirenden während des 16. Jahrhunderts. Tübingen 1840. 3. Aufl. u.d.T.: Sitten und Betragen der Tübinger Studirenden ... Freiburg/Br. 1898. - Die Geschichte und Literatur der Staatswissenschaften ... 3 Bde. Erlangen 1855-1858. - Staatsrecht, Völkerrecht und Politik. 3 Bde. Tübingen 186o-1869. Nachdr. 1962. - Siehe Wirtschaftswiss. Fak. Tübingen 1 (2004) S. 180-184.

G, $M H G$ 1844-1875 Zs. für die gesamte Staatswissenschaft. - Siehe auch Wirtschaftswiss. Fak. Tübingen, S. 182.

L Cohn, Gustav: R.M. wider die Gleichstellung der Juden. Zur Kritik der neuesten Angriffe von einem getauften Juden. Berlin 1869. Bader (1925) S. 171. - Angermann, Erich: R. von M. ... Neuwied 1962. - Reichsminister R. M. und seine Wähler 1848/49. 19 Briefe aus der deutschen Nationalversammlung. Hrsg. von Bernhard Mann in: Zs. für Württ. Landesgeschichte 30 (1971) S. 327381. - Ehrle, Peter Michael: R. von M. als Leiter der Tübinger Universitätsbibliothek ... Tübingen 1975. - Grahe, Rolf-Jürgen: Meinungsfreiheit und Freizügigkeit. Eine Untersuchung zum Grundrechtsdenken bei R. von M. Diss. Münster 1981. • Weisert (1991) S. 128 u. ö. • Stöcker, Birgit: Die Gemeinwohltheorie R. von M.s als ein früher Ansatz des sozialen Rechtsstaatsprinzips. München 1992. NDB 17 (1994) S. 692-694; WBIS; Best/ Weege (1996) S. 243f.; Gelehrte in der Revolution (1998) S. 41-67. - Schulen der deutschen Politikwissenschaft. Hrsg. von Wilhelm Bleek und Hans J. Lietzmann. Opladen 1999. S. 105-129 u. ö. Biographisches Handbuch der württembergischen Landtagsabgeordneten $1815-1933$... Bearb. von Frank Raberg. Stuttgart 2001. S. 577. Wirtschaftswiss. Fak. Tübingen 1 (2004) S. 173-187 u.ö. • Jayme, Erik: Internationales Privatrecht: Ideengeschichte von Mancini und Ehrenzweig zum Europäischen Kollisionsrecht. Heidelberg 2009. S. 446 (Register). - Schroeder (2010) S. 167-174. • Stockinger, Thomas: R. von M.: Der Linksausleger im Reichsministerium - Alles andere als ein
Demokrat in: Achtundvierzig - Blog zur Edition der Akten der Provisorischen Zentralgewalt für Deutschland in der Revolution 1848/49 (25. März 2013), s. online https://achtundvierzig.hypotheses. org/160 (abgerufen am 30. Sept. 2017).

$P$ Bildarchiv UAH; graph. Slg. UBH; Wirtschaftswiss. Fak. Tübingen (2004) S. 187.

\section{Mohr, Ernst Wilhelm Max}

1900-1926 Nat.-Math. Fak.

Chemie

$$
\begin{aligned}
& \text { 30. Mai } 1873 \text { Dresden } \\
& \dagger \quad \text { 07. März } 1926 \text { Heidelberg } \\
& \text { ev. }
\end{aligned}
$$

V Otto Christian M. (1835-1918) zunächst BauIngenieur, 1873-1900 o. Prof. u. a. für Mechanik und Festigkeitslehre Polytechnikum/TH Dresden, s. NDB 17 (1994) S. 702 f., Professoren TU Dresden (2003) S. 638-640

M Anna Doris Christiane geb. Buresch ( $\dagger 1907)$

$\infty$ 28. Sept. 1901 Clara Maria Theodora geb. Hegener (1871-1923)

K $1 \mathrm{~S}, 1 \mathrm{~T}$

Lb TH Dresden: Seit SS 1891/92 Studium der Chemie; Okt. 1893 Diplomprüfung; Okt. 1893-Sept. 1894 Militärdienstpflicht als Einjährig-Freiwilliger; seit WS 1894/95 Forts. des Studiums an TH; Mai 1896 Schlußprüfung; Wechsel zur U Kiel, da TH erst 1900 das Promotionsrecht erhält.

U Kiel: Mai 1896 Immatrikulation; 1896-1897 Assistent am Chemischen Inst. bei (siehe) Theodor Curtius; 16. März 1897 Dr. phil.

U Bonn: Seit April 1897 Assistent am Chemischen Inst. bei Curtius.

UH: Seit April 1898 Assistent am Chemischen Laboratorium bei Curtius; 3. Nov. 1900 Habilitation, s. hierzu UAH H-V-I/56 Nr. 4; seit 3. Jan. 1906 nichtetatm., 1920-1926 (†) nichtplanm. a. o. Prof.; 28. Okt. 1908 als Abt.-Vorsteher am Chemischen Laboratorium erwähnt, s. UAH PA 5049; 1908 M. 
erkrankt an allmählicher Körperlähmung durch Verletzung des Rückenmarks; 1914 M. führt krankheitsbedingt seine letzten Experimentalforschungen im Labor selbst durch; 22. März 1923 Minister des Kultus und Unterrichts erteilt M. e. Lehrauftrag für e. einstündige Vorlesung über „Stereochemie“; 20. März 1925 Minister erteilt M. „dem gestellten Antrag entsprechend ... nachträglich für das WS 1924/25 e. Lehrauftrag " für e. zweistündige Vorlesung über "Geschichte der Chemie“ (aus: PA 5049); WS 1925/26 letzte Vorlesungsankündigung.

Qu UAH PA 5049; RA 7249; Fak.-Akte H-V-I/56 Nr. 4. GLA Abt. 235, Fasz. 2315. • Briefe: Universitätsbibliothek Freiburg/Br.

W Spaltbarkeitsbeweis ohne direkte Spaltung und ohne Zuhilfenahme optisch aktiver Substanzen in: Journal für praktische Chemie 71 (1905); Die Theorie des asymmetrischen Kohlenstoffatoms und das Pasteursche Prinzip in: ebd. 87 (1913); Die Baeyersche Spannungstheorie und die Struktur des Diamanten in: ebd. 98 (1918) S. 315; Modelle zur Erläuterung einiger Sätze der Symmetrielehre im stereochemischen Unterricht in: ebd. 105 (1922). • Zur Konformation des Cyclohexans: zwei Arbeiten von Hermann Sachse und drei Arbeiten von E. M. Eingeleitet und mit Anmerkungen versehen von Horst Remane. Leipzig 1987. - Siehe auch Badische Biographien VI (2011) S. $278 \mathrm{f}$.

L Kürschner (1926) Sp. 1298. - Nachruf in: Berichte der Dt. chemischen Gesellschaft 59 (1926). • Poggendorff 6 (1938) S. 176of.; Jansen (1992a) S. 167 (Register); NDB 17 (1994) S. 703 f.; Badische Biographien N. F. VI (2011) S. 276-279.

$P$ Bildarchiv UAH.

\section{Mollison, Theodor James}

1912-1918 Med. Fak.

Anatomie, Anthropologie, Urgeschichte

* 31. Jan. 1874 Stuttgart

$\dagger \quad$ o1. März 1952 München

ev.
V James M. (1810-1875) Kupferstecher

M Emma geb. Frank (1840-1892)

( 4. Aug. 1898 Dorothea Elisabeth geb. Pfalzgraf $\left({ }^{*} 1876\right)$

( 1925 Elisabeth geb. Gmelin gesch. Freudenberg (1879-1963) T von Wilhelm G. (1832-1901) Landgerichtsrat in Tübingen

K 1 T

Vw siehe NDB 18 (1997) S. 4f.*

Lb U Freiburg/Br.: Seit WS 1893/94 Studium; Sommer 1898 Approbation; Aug. 1898 Dr. med.

Frankfurt/M.: 1898-1902 Praktischer Arzt.

Seit 1902 Eigenstudien in Würzburg; 1904-1905 Studienreise durch Ostafrika.

U Zürich: Seit Frühjahr 1905 Assistent am Anthropolog. Inst.; 10. Febr. 1910 Habilitation.

Dresden: Seit Mai 1911 Leiter der Anthropolog. Abt. am Königl. Zoologisch-Anthropolog.-Ethnographischen Museum des Zwingers.

UH: 15. Nov. 1912 Umhabilitation; Nov. 1912-1918 Custos der Anthropolog. Sammlung am Anatom. Inst. und Assistent am genannten Inst.; seit 22. April 1916 nichtetatm. a. o. Prof.

U Breslau: Seit SS 1918 etatm. a. o. Prof. als Nachf. von: (siehe) Hermann Klaatsch; seit 1921 persönlicher Ordinarius.

München: 1. April 1926-31. März 1939 (Emeritierung) o. Prof. und Vorsteher des Anthropolog. Inst. der U sowie 1926-1944 Leiter der Anthropolog. Staatssammlung; 1939-1944 Vertreter seines Lehrstuhls an U.

Nach 1933 Vorsitzender der Münchner Gesellschaft für Rassenhygiene zur „Vervollkommnung der Rasse“

Seit 1950 Sachverständiger für Vaterschaftsgutachten der Dt. Gesellschaft für Anthropologie 
E 1933 Mitglied der Dt. Akademie der Naturforscher Leopoldina Halle/S. 1944 Goethe-Medaille für Kunst und Wissenschaft.

Qu UAH PA 1082, 2011; RA 6784 (hier wird M. als Lehrender für Urgeschichte genannt; Vorgänger: (siehe) Otto Schoetensack). GLA Abt. 235, Fasz. 2318. Siehe auch Archiv der Dt. Akademie der Naturforscher Leopoldina Halle/S.

$W$ Die Körperproportionen der Primaten in: Gegenbaurs morphologisches Jahrbuch 42 (1911) S. 79-302. - Technik und Methoden der physischen Anthropologie, Kraniologie und Osteologie in: Kultur der Gegenwart. Hrsg. von Paul Hinneberg. V. Abt. Anthropologie einschließlich naturwiss. Ethnographie. Leipzig 1923. S. 12-36. • Gattenwahl und Erbgut. München 1931. Rassenkunde und Rassenhygiene in: Erblehre und Rassenhygiene im völkischen Staat. Hrsg. von E. Rüdin. München 1934. S. 34-48.

HG 1926-1943 Anthropologischer Anzeiger.

L Kürschner (1931) Sp. 1989f. Nachruf in: Zs. für Morphologie und Anthropologie 45 (1953) S. 416432. - Oetteking, B.: The late professor T.M. in: Man - The journal of the Royal Anthropological Institute of Great Britain and Ireland (1953) Bd. 53, S. 196. Arnim 4 (1984) S. 1111; WBIS. • Ziegelmayer, Gerfried: 100 Jahre Anthropologie in München in: Würzburger medizinhistorische Forschungen 5 (1987) S. 245-269. - Kater, Michael H.: Doctors under Hitler. Chapel Hill 1989. S. 421 (Register). • NDB 18 (1997) S. 4-6. The Holocaust and History: The Known, the Unknown, the Disputed, and the Reexamined. Ed. by Michael Berenbaum and Abraham J. Peck. Bloomington 1998. S. 121, 131 Anm. 28. • Hossfeld, Uwe: Geschichte der biologischen Anthropologie in Deutschland. Von den Anfängen bis in die Nachkriegszeit. Stuttgart 2005. S. 501 (Register). - Klee, Personenlexikon (2007) S. 414 f.; Doll/Kirsch/Eckart (2017) S. 63.

$P$ Siehe NDB.

\section{Mone (auch: Money), Franz Joseph (Geburtsname: Monee)}

1817 („Doctor legens"), 1818-1827 Phil. Fak. Geschichte, auch Geschichte über Altdeutsche Sprache und Literatur

* 12. Mai 1796 Mingolsheim (heute: Bad M., Ortsteil von Bad Schönborn)

$\dagger$ 12. März 1871 Karlsruhe kath.

V Johann (Franz) Joseph Moonen/Mohnen (1765-1840) Landwirt, Kaufmann

M Anna Maria geb. Heilig (1774-1835)

$\infty$ 5. Okt. 1820 Sophie geb. Warnkönig, Schwester von Leopold August W. (1794-1866), u. a. seit 1817 Prof. für Pandekten Lüttich, seit 1827 Löwen, seit 1836 (Natur-, Staats- und Völkerrecht) Freiburg/Br., 1844-1856 (Kirchenrecht) Tübingen, s. ADB 41 (1896) S. $177 \mathrm{f}$;; Wild, Gisela: L. A. W. ... Ein Rechtslehrer zwischen Naturrecht und historischer Schule und ein Vermittler deutschen Geistes in Westeuropa. Karlsruhe 1961; Strobel, Engelbert: L.A.W. Bedeutender Rechtsgelehrter und „Westeuropäer" in: Badische Heimat: mein Heimatland. Zs. für Landes- und Volkskunde ... Freiburg/ Br. 1969. S. 190-192; Briefe L.A.W.s an Karl Josef Anton Mittermaier 1833-1858. Hrsg. ... von Lieselotte Jelowik. Frankfurt/M. 2009.

K 7, darunter 3 T, 3 S: u. a. Fridegar M. (18291900 ), u. a. $1855-1860$ (Entzug der venia legendi) Privat-Dozent für Geschichte H (s. Auszug aus den Fak.-Sitzungen vom 19. und 22. Dez. 1859, die Kritik F.M.s an Geschichtsschreibern betreffend, in: UAH PA 2014), seit 1862 Lehrer mit Staatsdienereigenschaft; Gymnasial-Prof.: seit 1863 Karlsruhe, 1868-1872 (Pensionierung) Rastatt; 1876 Entlassung aus dem Staatsdienst, s. Nachlaß im GLA Karlsruhe; Badische Biographien 5 (1906) S. $915 \mathrm{f}$., Emundts-Trill (1997) S. 297 f., Rastatt und die Revolution von 1848/49 (1999) S. 554 (Register), (2001) S. 750 (Register).

Lb UH: Seit 1814 Studium der Philologie, Geschichte; vor März 1817 Dr. phil. an UH (?); 7. März 1817 Erlaubnis, als „doctor legens im Fach der Geschichte" Vorlesungen zu halten (aus: UAH PA 
2013); 19. Dez. 1818 Habilitationsdisputation; 1819 Ruf an U Lüttich abgelehnt; seit 15. April 1819 a. o. Prof. mit e. jährl. Besoldungszulage von 300.- Gulden; seit 25. Jan. 1822 o. Prof. • In dieser Zeit:

UBH: Sept. 1818-Jan. 1822 Sekretär als Nachf. von Karl Philipp Kayser mit e. jährl. Gehalt von 400.Gulden; 13. März 1825-1827 I. Oberbibliothekar (Vorstand) der UB als Nachf. von Friedrich Christoph Schlosser mit e. jährl. Zulage von 200.- Gulden, s. UAH RA 5386.

U Löwen (seit 1815 Königreich der Vereinigten Niederlande, seit 1830 vorläufige belgische Regierung, seit 1831 Königreich Belgien): Seit WS 1827/ 28 o. Prof. für Geschichte und Statistik; 1831 Verlassen der $\mathrm{U}$ nach belgischer Revolution wegen Weigerung M.s, seinen dem König der Vereinigten Niederlande geleisteten Eid zu brechen.

\section{H: Nach 1831 Privatgelehrter.}

Karlsruhe: 1834 Leiter und Redakteur der Karlsruher Zeitung; 1835-1868 (Ruhestand) Direktor des GLA. - Der Nachfolger M.s am GLA, Karl Heinrich Roth von Schreckenstein (1823-1894), urteilt über seinen Amtsvorgänger: „So verdienstlich auch, in wissenschaftlicher Hinsicht, gelehrte Publikationen sind, so sind doch dieselben nicht in erste, sondern in zweite Linie zu stellen, wenn für die Auffindbarkeit der Archivalien noch so unendlich viel zu tun ist" (aus: GLA Abt. 450, Fasz. 108).

Zwischen 1817 und 1827 bietet M. folgende Vorlesungen an (Auszüge aus den Anzeigen der Vorlesungen ... auf der ... Ruprecht-Karolinischen Universität zu Heidelberg): Geschichte von Deutschland unter den schwäbischen Kaisern (SS 1817); Erklärung des Nibelungenliedes, Unterricht in der Altdeutschen Sprache (WS 1817/18); Geschichte der Reichsstädte, Heraldik und Wappenkunde, Deutsche Mythologie und Alterthümer (SS 1818); Allg. Geschichte des Mittelalters, Diplomatik, Cursorische Erklärung des Nibelungenliedes (WS 1818/19); Geschichte der deutschen Nationalliteratur (SS 1819); Deutsche Geschichte, Mythologie der germanischen, gallischen, britannischen und slavischen Völker, Erklärung des Nibelungenliedes (WS 1819/20); Statistik, Geschichte des Mit- telalters, Diplomatik und Heraldik (SS 1820); Statistik und Politik, Deutsche Geschichte, Erklärung der Nibelungen (WS 1820/21); Allg. Geschichte des Mittelalters, Diplomatik und Heraldik, Erklärung des Liedes vom Kaiser Otnit (SS 1821); Weltgeschichte der alten, mittleren und neuen Zeit, Teutsche Geschichte, Anleitung zum Verständnis der älteren teutschen Sprache (SS 1825); danach bis zu seinem Weggang 1827 lehrt M. über „Geschichte mit ihren Hülfs- und Nebenwissenschaften": Geschichte der nationellen [!] Cultur und Literatur im Mittelalter (SS 1827).

1836 Mitbegründer der „Badischen Gesellschaft für Zuckerfabrikation “ in Karlsruhe, 1837-1841 Vorsitzender des Aufsichtsrats mit Sitz in Waghäusel

1835 Geh. Archivrat

E Mitglied der Akademie der Wissenschaften: 1852 München, 1853 Wien.

Qu UAH PA 2013; RA 5168, 6036, 6601. - GLA Abt. 205, Fasz. 389. • Briefwechsel Johann Friedrich Böhmers mit F. J. M. und Fridegar Mone. Hrsg. von Friedrich von Weech in: ZGORh 55. Jg. (1901) S. 422-461; Briefe von Heidelberger Gelehrten an F. J.M. Hrsg. von Demselben in: ebd. 57. Jg. (1903) S. 458-492. - Briefwechsel der Brüder Jacob und Wilhelm Grimm mit Gustav Freytag, Moriz Haupt, Heinrich Hoffmann von Fallersleben und F.J.M. Hrsg. von Philip Kraut ... Stuttgart 2015. • Nachlaß: GLA Karlsruhe, s. GLA Online-Findmittel (2006) unter https://www2.landesarchiv-bw.de/ ofs21/olf/einfueh.php?bestand=15032\#_2.

$W$ Geschichte des Heidenthumes im nördlichen Europa. 2 Bde. Darmstadt 1822-1823. - Die katholischen Zustände in Baden. 2 Bde. Regensburg 1841-1843. - Schauspiele des Mittelalters. Karlsruhe 1846. Neudr. 1970. - Die gallische Sprache und ihre Brauchbarkeit für die Geschichte. Karlsruhe 1851 .

G, MHG 1850-1868 Zeitschrift für die Geschichte des Oberrheins (ZGORh). 
HG Badisches Archiv zur Vaterlandskunde in allseitiger Hinsicht. 2 Bde. Karlsruhe 1826-1827. • Lateinische Hymnen des Mittelalters. 3 Bde. Freiburg/Br. 1853-1855. Nachdr. 1964.

(M)HG Quellensammlung der badischen Landesgeschichte. Im Auftrag der Regierung. 4 Bde. Karlsruhe 1848-1867 (Bde. 3 und 4 zus. mit Sohn Fridegar M.).

L Mone, Fridegar: F. J.M.: Sein Leben, Wirken und seine Schriften. Freiburg/Br. 1871. Nachruf in: Almanach der Akademie der Wissenschaften Wien 21 (1871) S. 120. • Mone, Fridegar: F. J. M. und seine Ankläger. Freiburg/Br. 1872. A ADB 22 (1885) S. 165 f.; Bader (1925) S. 173; Arnim 2 (1952) S. 190; Lehmann (1967) S. 208f. • Haselier, Günther: F. J. M. ... in: Beiträge zur Landeskunde. Regelmäßige Beilage zum Staatsanzeiger für BadenWürttemberg. Nr. 3 (Juni 1971) S. 9-13. - Messmer, Willy: Archivdirektor F. J.M. und seine Zeit. Ein Stück badischer Geschichte. Östringen 1989. • Haymes, Edward R.: Richard Wagner and the Altgermanisten: Die „Wibelungen“ and F. J.M. in: Rereading Wagner. Ed. by Reinhold Grimm ... Madison 1993. S. 23-38. - WBIS; Fuhrmann (1996) S. 144, Anm. 20 und 36; NDB 18 (1997) S. 32 f. • Schwarzmaier, Hansmartin: Die Anfänge der kritischen Geschichtswissenschaft am Oberrhein: Carl Georg Dümgé und F. J.M. in: Das Mittelalterbild des 19. Jhdts. am Oberrhein. Hrsg. von Hansmartin Schwarzmaier u. a. Stuttgart 2004. S. 31-45. • Rödel (2005) S. 344, 345 Anm. 17 u.ö.; Wolgast (2010) S. 168-172; Riecke (2016) S. 148 (Register).

$P$ Bildarchiv UAH; graph. Slg. UBH; NDB.

\section{Monee, auch: Money}

siehe Mone, Franz Joseph

Montan, Fredrik (Pseudonym)

siehe Meyer, Friedrich

\section{Moos, Salomon}

1859-1891 Med. Fak. 1891-1895 (Honorar-Prof.) Med. Fak. 1859-1865 (mit Unterbrechungen) Spezielle Pathologie, Therapie, Psychiatrie, Gerichtliche Medizin, Krankheiten der Harn- und Geschlechtsorgane; 1861-1895 Ohrenheilkunde

* 15. Juli 1831 Randegg (bei Konstanz; heute: Gottmadingen)

$\dagger \quad$ 15. Juli 1895 Heidelberg

口 Karlsruhe (Jüdischer Friedhof, Kriegsstraße) mosaisch

V Wolf Moses M. (1799-1859)

M Elleonore geb. Wieler (ca. 1795-1848)

(D 1859 Sophie geb. Haas (1840-1904)

$\mathrm{K}$ keine.

Lb Seit WS 1851/52 Studium an UH, März-Aug. 1854 Prag, Aug.-Nov. 1854 Wien, WS 1854/55-WS $1855 / 56 \mathrm{H}$.

UH: Nov. 1854-1856 Assistent an Med. U-Klinik; 23. Juni 1856 Dr. med.; 21. Juli 1856 Approbation als praktischer Arzt, Wund- und Heb(e)arzt; 7. Aug. 1859 Habilitation; WS 1859/60 Bewilligung der Med. Fak. zur Abhaltung von Vorlesungen über Psychiatrie; seit 24. Aug. 1866 a. o. Prof.; 1870/71 Lazarettarzt während des Deutsch-Französischen Krieges; WS 1861/62 erstmals Ankündigung in „Anzeige der Vorlesungen ...“ e. wöchentlich zweimal stattfindenden Lektur über Ohrenheilkunde; SS 1865-SS 1895 aussschließlich Vorlesungen über Ohrenheilkunde (z. B. Übungen im Gebrauch des Ohrenspiegels); seit 28. Aug. 1891 Honorar-Prof. • In dieser Zeit:

H: Sept. 1856-1895 Praktischer Arzt; 1873 Gründer, 1873-1895 Leiter der Ambulatorischen Klinik für Ohrenkranke (Inst. für Ohrenkranke) in Bergheimer Straße 28.

M.s Bibliothek mit ca. 300 Titeln, 400 Broschüren und Dissertationen ist in der Universitätsbibliothek Heidelberg untergebracht, siehe hierzu Kata$\log$ zu Heid. Hs. 2784; siehe auch Handbuch der 
historischen Buchbestände in Deutschland. Hrsg. von Bernhard Fabian. Hildesheim 2003.

1889 Hofrat

E 1887 Mitglied der Dt. Akademie der Naturforscher Leopoldina Halle/S.

Qu UAH PA 2017; RA 4942, 5245 und 5309f. (Stiftung 1895), 5736, 6318. - Siehe auch Archiv der Dt. Akademie der Naturforscher Leopoldina Halle/S.

W Klinik der Ohrenkrankheiten. Wien 1866. • Beiträge zur normalen und pathologischen Anatomie und zur Physiologie der Eustachischen Röhre. Wiesbaden 1874. • Über Meningitis cerebrospinalis epidemica. Heidelberg 1881. Katalog der Sammlung mikroskopischer Präparate betreffend die normale und pathologische Histologie des Gehörorgans. Wiesbaden 1890.

MG, MHG 1869-1878 Archiv für Augen- und Ohrenheilkunde (zus. mit (siehe) Hermann Knapp); Forts. u.d. T.: 1878-1895 Zeitschrift für Ohrenheilkunde.

$L$ Pagel (1901) Sp. 1157 f; Badische Biographien 5 (1906) S. 916; Stübler (1926) S. 323 f.; Jüdische National-Biographie 4 (1929) S. 421; Arnim 2 (1952) S. 195; Hirsch $4\left({ }^{3} 1962\right)$ S. 256. • Über die Familie Moos in: Leo Baeck Institute New York Bibliothek und Archiv. Katalog. Hrsg. von Max Kreutzberger ... Tübingen 1970. Bd. 1. S. 441. C Chronik Ärzte H (1985) S. 137, 253 f.; NDB 18 (1997) S. 75 f. • Kette, Benjamin: Die Bedeutung des Archivs für pathologische Anatomie und Physiologie und klinische Medizin (Virchows Archiv) bei der Entwicklung und Etablierung des Fachgebietes der Hals-, Nasen- und Ohrenheilkunde im Zeitraum von 1847-1902 in Deutschland. Diss. Berlin 2015. S. 32-39, 53-57 u. ö.

$P$ Bildarchiv UAH; graph. Slg. UBH; Pagel; Chronik Ärzte $H$.

\section{Moro, Ernst Franz}

1911-1936 Med. Fak.

Kinderheilkunde

* o8. Dez. 1874 Laibach (Österreich; heute: Ljubljana, Slowenien)

$\dagger$ 17. April 1951 Heidelberg kath.

V Ludwig M. († 1878) Leinwandhändler

M Maria geb. Tonia $(\dagger 1880)$

๑ 1. Juni 1904 Margarethe (Grete) Mathilde geb. Hönigsvald/Hönigswald (1877-1962) Kunstmalerin, s. Lexikon jüdischer Einwohner Hs (2011) S. 303

K 1 S, 1 T, s. ebd. S. 304 .

Lb U Graz: Seit WS 1893/94 Studium zunächst der Botanik, dann der Medizin; 20. April 1899 Dr. med.; seit 1899 Assistent an U-Kinderklinik.

Wien: 1. April 1902-Ende März 1903 Assistent am St. Anna Kinderspital; 1903 (Begründer)-1906 Leiter e. privaten Säuglingsheims und Kindersanatoriums.

U Graz: 15. Jan. 1906 Habilitation.

U München: 15. Okt. 1906-31. März 1911 PrivatDozent und Oberarzt an U-Kinderklinik.

UH: Jan. 1911 Ern. zum etatm. a. o. Prof. und Direktor der U-Kinderklinik Luisen-Heilanstalt als Nachf. von Emil Feer; SS 1911 Beginn seiner Lehrtätigkeit; 22. März 1919 Amtsbezeichnung und Rechte e. o. Prof.; 1920 Ruf an U Zagreb abgelehnt; seit 1. Sept. 1926 planm. o. Prof.; 30. Okt. 1936 auf eigenen Antrag Emeritierung (Grund: Ehefrau jüdischer Herkunft). • In dieser Zeit:

H: 1911-1948 Kinderarzt in Privat-Praxis.

1925/26 Dekan der Med. Fak. der UH

1919: Moro ist der erste Ordinarius für Kinderheilkunde an UH; siehe hierzu auch Emil Feer 
1908 kreiert M. e. Suppe gegen Durchfall, besonders für Kinder: die noch heute bekannte Morosche Möhrensuppe; diese senkt die Säuglingssterblichkeit bei Durchfallerkrankungen erheblich; aktuell wurde nachgewiesen, daß die Suppe auch gegen resistente Keime wirkt. Das Rezept: 500 Gramm geschälte Karotten in 1 Liter Wasser eine Stunde kochen, anschließend im Mixer pürieren; diesen Brei erneut mit Wasser auf 1 Liter auffüllen und mit 3 Gramm Kochsalz würzen.

1918 beschreibt M. den nach ihm benannten Moro-Reflex, e. Klammer- und Umklammerungsreflex bei Säuglingen und Säugetieren.

E 1911 Korr. Mitglied der Münchner Gesellschaft für Kinderheilkunde; 1931/33 Mitglied der Dt. Akademie der Naturforscher Leopoldina Halle/S.; 1938 Ehrenmitglied der Rumänischen Gesellschaft für Kinderheilkunde und -fürsorge Klausenburg.

Qu UAH PA 1083, 5070; RA 6330, 6797; Rep. 40413. Auskunft: Stadtarchiv Heidelberg; Diözesanarchiv Wien; Nadškofijski arhiv Ljubljana. $\bullet$ Siehe auch Archiv der Dt. Akademie der Naturforscher Leopoldina Halle/S.

$W$ Über das Verhalten haemolytischer Serumstoffe beim Kind. Wiesbaden 1908. Experimentelle und klinische Überempfindlichkeit. Wiesbaden 1910. - Denkschrift zur Errichtung eines Zentralamtes für Mutter- und Kinderfürsorge im Großherzogtum Baden ... in: Zs. für Säuglings- und Kleinkinderschutz. Berlin 1917 (zus. mit Carl Temmerman Noeggerath). - Eczema infantum und Dermatitis seborrhoides. Berlin 1932. - Siehe Bibliographie in: Schief (1969) S. 99-113.

MHG Jahrbuch für Kinderheilkunde.

L Kürschner (1925) Sp. 685, (1950) Sp. 1391. • Kleinschmidt, Hans: E. M. $\dagger$ in: Monatsschrift Kinderheilkunde. Zs. für Kinder- und Jugendmedizin - Organ der Dt. Gesellschaft für Kinderheilkunde. Heidelberg 1951. S. 311f. - Randerath, Edmund: Gedenken an E.M. in: Ruperto Carola 4 (1951) S. 18. - Schief, Gerda: E. M. ... Diss. Heidelberg 1969. - Chronik Ärzte H (1985) S. 137, 254. - Wille, Lutz: U-Kinderklinik Luisen-Heil- anstalt ... in: Der Kinderarzt 16. Jg., Nr. 7 (1985) Sp. 1006f. - Jansen (1992a) S. 167 (Register). • Eckart, Wolfgang U.: E.M. in: Heidelberg. Jahrbuch zur Geschichte der Stadt 2002. Heidelberg 2002. Jg. 7. S. 233-251. - Weirich, Angela, Hoffmann, Georg F.: E. M. ... A great pediatric career started $\ldots$ in the shadows of nazi laws in: European Journal of Pediatrics 164 (2005) S. 599-606. UH im Nationalsozialismus (2006) S. 1264 (Register). - Adler, Alfred: Über den nervösen Charakter (1912): Grundzüge einer vergleichenden Individualpsychologie und Psychotherapie. Hrsg. von Karl Heinz Witte ... 2. Aufl. Göttingen 2008. S. 405 (Register). 150 Jahre Pädiatrie in H (2010) S. 47-54, 57-74; WBIS; Badische Biographien N.F. VI (2011) S. 282-286; Lexikon jüdischer Einwohner Hs (2011) S. 303f. • Rotzoll (2013) S. 205-208; Deutsche Biographie, s. https://www.deutschebiographie.de/gnd116929669.html [07.11. 2017].

$P$ Bildarchiv UAH; Terrakotta-Büste im UAH (als Depositum); graph. Slg. UBH; Ruperto Carola; Chronik Ärzte H.

\section{Morstadt, Carl Eduard}

1815-1850 Jur. Fak.

Dt. Privat- und Handelsrecht, Dt. Zivilprozeß-

recht, Staats- und Kirchenrecht, Staatswirtschaft

* 07. April 1792 Karlsruhe

$\dagger$ 10. Jan. 1850 Heidelberg ev.-luth.

V Georg Michael M., Kammerfourier (= Hofbeamter, mit Überwachung des Ordnungs- und Sicherheitsdienstes am Karlsruher Hof betraut)

M Friederica Jacobina geb. Pasterts/Pastart

(29. Juli 1819 Wilhelmine Magdalena geb. Piton (1788-1820)

$\infty$ 1. Juni 1830 Anna Amalia geb. Schragmüller/ Schwarzmüller

$\mathrm{K} \quad 1 \mathrm{~S}, 1 \mathrm{~T}$

Vw Schwester: Amalie M. gen. Neumann-Haizinger (180o-1884) Schauspielerin, s. Wurzbach, Constant von: Biographisches Lexikon des Kaiserthums Österreich. Wien 1861. Bd. 7. 
Lb Seit SS 1809 Studium an UH, Freiburg/Br.; 1812 Rechtspraktikantenprüfung in $\mathrm{H}$; 29. Aug. 1812 Dr. iur. an U Freiburg.

Karlsruhe: 1812-1816 Advokat.

UH: Seit 17. Aug. 1815 Privat-Dozent; seit 1815 auch Advokat in H; 27. Mai 1816 Jur. Fak. erteilt auf Antrag M.s Dispens von seiner Habilitationsdisputation; seit 5. Febr. 1819 a.o. Prof.; 22. Juni 1821 Engerer Senat genehmigt M. Vorlesungen über Nationalökonomie und Finanzwissenschaft; 20. Sept. 1824 Suspendierung durch Innenministerium für 6 Monate auf eigenen Antrag M.s zur Wiederherstellung seiner Gesundheit, s. hierzu Schroeder (2005) S. 221f.; 4. Nov. 1842 o. Prof. II. Klasse (d.h. ohne Teilnahmeberechtigung an den Fak.Sitzungen und Doktorexamina); 13. Nov. 1846 o. Prof. auf Veranlassung der badischen Regierung (I. Klasse, d.h. mit Teilnahmeberechtigung ...); seit Juli 1846 o. Mitglied des Spruchkollegiums der Jur. Fak.; 26. Jan. 1847 Niederlegung seiner Ämter im Spruchkollegium, in der Prüfungskommission und als Dekan, s. hierzu Schroeder (2005) S. $226 \mathrm{f}$.

1847 Dekan der Jur. Fak. der UH (Jan. 1847 Niederlegung seines Amtes; Jan.-Dez. 1847 Prodekan: Heinrich Zöpfl)

M.'s Streitigkeiten mit seinen Kollegen, der Fakultät, dem großherzoglichen Haus und der Regierung, s. Küper, Wilfried: Einige Nachrichten ... über den berüchtigten ... Karl E. M. in: Heidelberger Strafrechtslehrer (1986) S. 117-144 und Schroeder (2005) S. $216 \mathrm{ff}$.

Qu UAH PA 2020f.; RA 5437, 5954, 6765, 7643 u. ö.; GF 31. • GLA Abt. 235, Fasz. 656.

W Materialkritik von Martin's Civilprocess-Lehrbuch. Zugleich auf eine Mitcommentation von dessen Gegenstand berechnet, ein und neunzig Entwuerfe. Heidelberg 1820. 2. Aufl. 1828. • Vertheidigungen der Universitätsprofessoren gegen Dr. Diesterweg's Schmähungen und Recepte. Mannheim 1836. - Gemeindeutscher Civilproceß- schlüssel, pragmatisch-kritischer Commentar zu Linde's Civilproceßlehrbuch. Heidelberg 1847. • Polemisch-humoristische Leuchtkugeln in das deutsche Privatfürstenrecht oder humoristische Bekämpfung von Heffter's Irrlehren über Gewissensehe, heimliche Ehe und Mantelkindserbrecht. Heidelberg 1847. • E. M.s Inquisition auf den Rattenkönig-Spuk in Heidelberg ... Heidelberg 1849. Ausführlicher Commentar zu Feuerbach's Lehrbuch des gemeinen in Deutschland giltigen peinlichen Rechts. Hrsg. von Josef Schauberg. 2 T. Schaffhausen 1852-1855 (posthum erschienen). Nachdr. Goldbach 1997.

HG Siehe Johann Caspar Gensler und Christoph Martin: Einträge unter $W$ [erke].

$L$ Badische Biographien 4 (1891) S. 271-274; Heidelberger Strafrechtslehrer (1986) S. 33 f., 117-144. * Landwehr, Götz: Die Handelsrechtswissenschaft an der Universität Heidelberg im 19. Jahrhundert in: Semper apertus 2 (1985) S. 61-83. - WBIS; Schroeder (2005) S. 216-231; Humaniora (2006) S. 287 Anm. 2, 29of. u. ö.; Baur (2009) S. 171-180; Schroeder (2010) S. 150-156. - Djazayeri, Alexander: Die Geschichte der Giroüberweisung von den Anfängen im 19. Jahrhundert bis zum modernen Zahlungsdiensterecht. Göttingen 2011. S. 54 f. u. ö.

$P$ Bildarchiv UAH; graph. Slg. UBH.

\section{Morstadt, Karl Eduard}

siehe Morstadt, Eduard

\section{Moser, Franz Xaver}

1792-1794 („Correpetitor“) Med. Fak. 1792-1796 Entbindungskunst 1794-1821 Med. Fak. 1794-1821 Chirurgie, Anatomie; 1798-1812 Geburtshilfe

$\approx$ 23. Nov. 1747 Rottweil

$\dagger \quad$ o8. Sept. 1833 Heidelberg kath. 
V David M., Wundarzt

M Maria Anna geb. Dimbler (auch: Dimmler)

$\infty$ N.N. († vor 1833)

$\mathrm{K}$ unbekannt.

Lb Seit 1772 Studium an U Straßburg, anschl. Wien, Berlin.

Seit 1775 Unterchirurg bei Infanterie-Regiment in Berlin (?); seit 1777 Kompagnie-Chirurg in Mannheim.

H: 1788-1795 Regimentsarzt des I. Leib-DragonerRegiments; 1795-1799 Stabsmedikus im Feldspital im Kloster Neuburg (bei H). • In dieser Zeit:

UH: Seit 23. Jan. 1792 „Correpetitor“ (Repetitor) der Anatomie, Chirurgie; 7. Mai 1792-30. April 1796 (mit Unterbrechungen) Vorlesungen über Entbindungskunst nach [Johann Georg] Röderer's Anfangsgründen der Geburtshülfe ... von 10 bis 11 Uhr. Am Ende derselben werden praktische Uebungen am Fantome gemacht (aus: Anzeige der Vorlesungen der Badischen Ruprecht-Karls-Universität zu Heidelberg: Anzeige der Vorlesungen, welche im Sommerhalbenjahre ... 1795 auf der hohen Schule zu Heidelberg gehalten werden. Heidelberg 1795. S. 9) als Vertreter für Franz Anton Mai; 29. Nov. 1794 Ern. zum a. o. Prof. für Chirurgie, Anatomie; 1798-1812 (jeweils im SS) Vorlesungen über Geburtshilfe; 16. Febr. 1799 Ern. zum o. Prof. Chirurgie, Anatomie als Nachf. von Peter Theodor Leveling, s. Drüll (1991) S. 94f.; 24. Sept. 1799 Dr. med., s. hierzu UAH RA 6477 S. 64; 7. Mai 1821 Ruhestand.

1801, 1805, 1810, 1816 Dekan der Med. Fak. der UH

M. kündigt im WS 1796/97 die erste Vorlesung an UH über venerische Erkrankungen an; er erstellt Anfang des 19. Jahrhunderts auch die erste Liste mit allen Heidelberger anatomischen Präparaten, s. hierzu UAH K-IV/1-58/1.

Qu UAH PA 2022; RA 3185, 4999, 6226, 6477, 6737, 6779, 6781, 8162. • GLA Abt. 205, Fasz. 391 f. • Auskunft: Stadtarchiv Rottweil (Taufbuch); Kath. Kirchenbuchamt Heidelberg (Totenbuch).
$W$ Beantwortung der Frage, da das Elektrum ein starkes Reizmittel ist, so wird gefragt, ob dasselbe nicht auch zur Erweckung der Scheintoten angewendet werden könne. Mannheim 1790.

L Keller (1913) S. 98; Stübler (1926) S. 159-162; Chronik Ärzte H (1985) S. 137; WBIS; Jansen (1992a) S. 167 (Register). 100 Jahre Hautklinik Heidelberg ... Redaktion: Martin Hartmann. Heidelberg 2008. S. 4 (hier irrtümlich 1755 als Geburtsjahr genannt). Doll/Kirsch/Eckart (2017) S. 21.

\section{Moser, Hans Joachim}

1925-1927 Phil. Fak.

Musikwissenschaft

* 25. Mai 1889 Berlin

$\dagger$ 14. Aug. 1967 Berlin ev.

V Dr. phil.h.c. Andreas M. (1859-1925) zunächst Studium der Ingenieurwiss., Architektur u.a. TH Zürich; seit 1878 Schüler, seit 1879 Hilfslehrer an Königl. Akad. Hochschule für Musik Berlin, 1883 (nach wenigen Monaten Aufgabe aus gesundheitlichen Gründen) Konzertmeister am Nationaltheater Mannheim, anschl. privater Geigenlehrer, seit 1888 Dozent, 19001925 (Ruhestand) o. Prof. für Violine an Königl. Akad. Hochschule für Musik, 1918 umbenannt in Staatl. Akad. Hochschule für Musik Berlin, s. MGG 9 (1961) Sp. 624f., WBIS

M Edda geb. Elcho (1868-1930) T von Rudolf E. (1839-1923) 1862-ca. 1870 Aufenthalt in USA, u. a. als freiwilliger Kämpfer im Bürgerkrieg, Schauspieler, seit 1871 freier Schriftsteller und u. a. Redakteur der Berliner Volks-Zeitung, s. WBIS

๑ 2. Nov. 1916 Clara geb. Topp $\left({ }^{*} 1889\right)$ Scheidung 1935

๑ 15. Aug. 1935 Dorothea (Dorle) geb. Duffing (1906-2010) Schneidermeisterin, s. Moser, Edda, Voigt, Thomas: Ersungenes Glück. Erinnerungen und Gespräche. Leipzig 2011. S. 157 (Register). 
$\mathrm{K} \quad 2 \mathrm{~S}, 1 \mathrm{~T}$ (aus 1. Ehe). $3 \mathrm{~T}$ (davon $1 \mathrm{~T}$ früh $\dagger$ ) (aus 2. Ehe), u.a. Edda M. $\left({ }^{*} 1938\right)$ Kammersängerin; u.a. Leiterin von Meisterklassen: Europ. Akademie für Musik und Darstellende Kunst Montepulciano (Italien), Junge Münchner Philharmonie, Mozarteum Salzburg; Professorin auf Lebenszeit an Hochschule für Musik Köln, seit 2006 (Initiatorin) künstlerische Leiterin des „Festspiel der deutschen Sprache“ in Bad Lauchstädt, s. Riemann (1975) Erg.-Bd., S. 229, Wer ist wer (1984) S. 869; M., E., Voigt, Thomas: Ersungenes Glück ... Leipzig 2011. (Autobiogr.)

K 2 S (aus 2. Ehe): Jörg Giselher M. (1936-2015), u.a. 1974 Habilitation für Klinische Physiologie Freiburg/Br., 1987-2001 (Pensionierung) Prof. für Lasermedizin Düsseldorf. - Kai M. $\left({ }^{*} 1944\right)$, u.a. 1968-1972 Dozent für Violoncello an University of Texas in Austin; Mitglied: seit 1974 Symphonieorchester des Bayer. Rundfunks, 1974-1984 Bell'Arte Streichquartett, 1984-2003 Röhn Trio München

Vw Enkel (Söhne von Kai M. und Edith geb. Wiens $\left({ }^{*} 1950\right)$ kanadische Opern-, Lied- und Konzertsängerin (Sopran), s. http://www. edithwiens.com): Johannes M. $\left({ }^{\star} 1979\right)$ Cellist, seit 2012 Prof. an Hochschule für Musik Köln, 2017 Echo Klassik-Preisträger, s. http://www. johannes-moser.com. • Benjamin M. ( $\left.{ }^{*} 1981\right)$ Konzert- und Kammermusikpianist, s. http:// www.benjaminmoser.com

Vw siehe NDB 18 (1997) S. 191*; Moser, Edda, Voigt, Thomas: Ersungenes Glück ... Leipzig 2011. S. 157 (Register).

Lb Seit SS 1907 Studium der Musikwiss., Germanistik, Philosophie an U Marburg, seit WS 1908/o9 Leipzig, SS 1910 Rostock; Sommer 1910 Dr. phil. an U Rostock; 1910-1914 u.a. Sänger, Musikkritiker, Studienreisender in Frankreich und Italien; 19141918 Kriegsdienst.

U Halle/S.: 1. Nov. 1919 Habilitation; seit Juni 1923 nichtplanm. a. o. Prof.

UH: Seit 6. März 1925 planm. a. o. Prof. als Nachf. von Theodor Kroyer; 1926 Ruf an U Frankfurt/M. abgelehnt.
U Berlin: WS 1927/28-Okt. 1933 (Entlassung aufgrund dienstlicher Verfehlung, s. hierzu Grüttner/ Kinas (2007) S. 133 und Anm. 32) Honorar-Prof.

Berlin: Okt. 1927-Okt. 1933 (zwangsweise Versetzung in Ruhestand, s. oben) Direktor der Staatl. Akademie für Kirchen- und Schulmusik; 19331938 freier Schriftsteller.

Berlin, Reichsministerium für Volksaufklärung und Propaganda: Seit 1938 stellvertr. Leiter, 19401945 Generalsekretär der Reichsstelle für Musikbearbeitungen; 1940-1945 auch Vorsitzender des Künstlerischen Prüfungsamtes Abt. Musik der o.g. Reichsstelle.

Berlin: 1945-1947 Privat-Gelehrter.

U Jena: 1. Okt.-Ende Nov. 1947 (Suspendierung „wegen profaschistischer Vergangenheit“, aus: Huschke (2006) S. 340 Anm. 475; Entlassung nach zwei Monaten aufgrund seiner Tätigkeit im Propagandaministerium) o. Prof.

Weimar: 1. Okt.-Ende Nov. 1947 (Suspendierung, s. oben) Gründungs-Direktor der Abt. Musikwiss. an Staatl. Hochschule für Musik; seit 27. Sept. 1948 Auftragsarbeit für Monographie: „Goethe und die Musik“ anläßlich des Goethejahres 1949 (Bezahlung: 10 ooo.- Mark); 1948-1949 Privat-Gelehrter.

Berlin-West: 1949-1961 (Ruhestand) Direktor des Städtischen (ehemals Sternschen) Konservatoriums.

Am 29. Juni 1925 findet ein Liederabend „Alte Meister des deutschen Liedes“, vorgetragen von H. J.M., im Musik-Institut der U Tübingen statt; die Kritik über diesen Liederabend ist nachzulesen in: Weinreich, Otto: Ausgewählte Schriften. Bd. IV: Zur Musikwissenschaft 1909-1960. Konzertkritiken 1923-1933 und 1945-1952 ... Hrsg. von Günther Wille. Amsterdam 1975. S. 78-84 u. ö.

E 1931 D. theol. Königsberg (Preußen). • Eisernes Kreuz II. Klasse. 
Qu UAH PA 5073; Fak.-Akte H-IV-102/146 (1919: Beurteilung M.s durch Hermann Abert in: Schipperges (2005) S. 57 Anm. 14). GLA Abt. 235, Fasz. 1552. Nachlaß: Staatsbibliothek zu Berlin, Musik-Abt.; Musikwiss. Institut der Universität Köln; s. auch Inklusion \& Exklusion (2016) S. 175 und Anm. 14. - Mitteilungen: Herr Kai Moser, Krailling und Frau Prof. Edda Moser, Rheinbreitbach.

W Geschichte der deutschen Musik. 3 Bde. Stuttgart 1920-1924. 4. Aufl. 1926. - Corydon, das ist: Geschichte des mehrstimmigen Generalbaßliedes. 2 Bde. Braunschweig 1933. Nachdr. 1966. - Musiklexikon. 2 Bde. Berlin 1935. 4. Aufl. 1955. Neuaufl. 1968. Das deutsche Lied seit Mozart. 2 Bde. Berlin 1937. Rev. Ausg. 1966. Goethe und die Musik. Leipzig 1949 • Die ev. Kirchenmusik in Deutschland. Berlin 1954. Nachdr. 1978.

MHG 1928-1933 Zeitschrift für Schulmusik. • Gesamtausgabe von Carl Maria von Weber.

$L$ Wer ist wer (1955) S. 816; MGG 9 (1961) Sp. 625627; Kürschner (1966) S. 1650. • Söhngen, Oskar: H. J.M. zum Gedächtnis in: Die Musikforschung 21 (1968) H. 2, S. 154-157. - Brockhaus-RiemannMusiklexikon. Hrsg. von Carl Dahlhaus und Hans Heinrich Eggebrecht. Wiesbaden 1979. Bd. 2. S. 155. - WBIS; NDB 18 (1997) S. 191-193. • Über H. M. in: Schipperges, Thomas: Die Akte Heinrich Besseler ... München 2005. S. 57 f. u. ö. • Huschke, Wolfram: Zukunft Musik. Eine Geschichte der "Hochschule für Musik Franz Liszt“ in Weimar. Köln 2006. S. 587 (Register). • Grüttner/Kinas (2007) S. 133, 158; Klee, Kulturlexikon (2007) S. $417 \mathrm{f}$; Catalogus prof. Halensis online. - Moser, Edda, Voigt, Thomas: Ersungenes Glück. Erinnerungen und Gespräche. Leipzig 2011. S. 157 (Register). - Inklusion \& Exklusion: „Deutsche“ Musik in Europa und Nordamerika 1848-1945. Hrsg. von Sabine Mecking, Yvonne Wasserloos. Göttingen 2016. S. 171-190 u. ö.

$P$ Bildarchiv UAH.

\section{Moulin Eckart auf Bertoldsheim, Richard} Maria Ferdinand Graf Du

siehe Du Moulin Eckart auf Bertoldsheim, Graf Richard

\section{Muckermann, Ernst Johannes}

1909-1922 (1923) Nat.-Math. Fak. Chemie

* 15. Nov. 1874 Anholt (Westfalen; heute: Ortsteil von Isselburg)

$\dagger \quad$ o1. Nov. 1943 München kath.

V Sanitätsrat Dr. Clemens M. $\left({ }^{*} 1838\right)$ praktischer Arzt (Kopie seiner Diss. De scarlatina. Berlin 1862 im UAH)

M Johanna geb. Schulze-Gahmen

unverheiratet.

Lb Ostern 1891 Abgang von Königl. Gymnasium in Emmerich am Rhein mit Zeugnis für Obersekunda.

Radevormwald (Bergisches Land): Seit Ostern 1891 pharmazeutische Lehrzeit als Gehilfe; 1894 Gehilfenexamen.

1894-1897 Apotheker-Ausbildung zunächst in Radevormwald, dann in Mannheim, Zürich, Neuchâtel (Schweiz), Hamburg.

U Bonn: Seit SS 1897 Studium der Pharmazie, Medizin; Nov. 1898 pharmazeutische Staatsprüfung in Bonn; WS 1898/99 Studium der Chemie.

Berlin: SS 1899-WS 1899/190o Forts. des Studiums der Chemie, Medizin an U; 1. April 1899-1. April 1900 Militärdienstpflicht als Einjährig-Freiwilliger als Militärapotheker am Hygienisch-Chemischen Laboratorium der Kaiser-Wilhelms-Akademie für das militärärztliche Bildungswesen.

UH: SS 1900-WS 1901/o2 Forts. des Studiums der Chemie, Physik, Allg. Botanik, Medizin; 1. Juli 1902 (Rigorosum mit Note III = cum laude) Dr. phil. nat., s. hierzu Z; seit Okt. 1902 Privat-Assistent von 
(siehe) Theodor Curtius, SS 1903-März 1915 Unterrichts-Assistent am Chemischen Laboratorium; Mai 1904 Staatsexamen für Nahrungsmittelchemie; Ende Febr. 1907 Abitur („Maturum“) am humanistischen Gymnasium in Offenburg; 20. Jan. 1909 Habilitation; 14. Febr. 1913 ärztl. Vorprüfung; 1913/14 Lehrauftrag für Wasser- und Harnanalyse; seit 11. März 1915 nichtetatm., seit 1920 nichtplanm. a. o. Prof.; Mai 1917 med. Staatsexamen und ärztl. Approbation; SS 1919 Lehrauftrag für Nahrungsmittelchemie; 1. April 1922 Beurlaubung von einem Jahr; Mai 1923 auf eigenen Antrag aus Lehrkörper ausgeschieden. • In dieser Zeit:

\section{Aug. 1914-17. Dez. 1918 Kriegsdienst.}

München: Seit 1922 niedergelassener Facharzt.

Z Am 20. Juni 1902 schreibt M.s Doktorvater Theodor Curtius an die Kollegen der Heidelberger Naturwiss.-Math. Fakultät über die Qualifikation seines Promovenden: „Herr Apotheker Muckermann ist mir durch mehrjährige Studien bekannt. Er hat sich in jeder Weise während dieser Zeit ausgezeichnet. Ich kann Herrn M. bestens der Facultät zur Gewährung des Dispenses vom Reifezeugnis empfehlen ..." (aus: UAH H-V-3/2 Nr. 97).

Qu UAH PA 5080; RA 6496, 6886, 7655; Fak.-Akte H-V-3/2. GLA Abt. 235, Fasz. 2320. • Auskunft: Stadtarchiv Isselburg.

$W$ Über die Einwirkung von Hydrazinhydrat auf Bersteinsäuremonoäthylester, Succinaminsäure und Succinimid. Heidelberg 1902. • Über die Bildung von Nitroso-Pyrazolidonen und Pyrazolonen aus Hydraziden ungesättigter Säuren. Heidelberg 1908.

L Deutsche Biographie, s. https://www.deutschebiographie.de/gnd117147117.html [07.11. 2017].

$P$ Bildarchiv UAH.

\section{Müller, Ernst}

1909-1921, 1922-1945 Nat.-Math. Fak.

Anorganische und Organische Chemie

* 18. Febr. 1881 Esslingen

$\dagger$ 10. April 1945 Heidelberg (Suizid) ev.

V Christian Friedrich M. (1836-1914) Maschinen-Fabrikant, s. Firmenbestand von MüllerWeingarten AG (Fritz Müller) aus Esslingen im: Wirtschaftsarchiv Baden-Württ., Schloß Hohenheim in Stuttgart

M Christiane geb. Volland (1840-1911)

$\infty$ unverheiratet.

Lb Seit WS 1899/1900 Studium an TH Stuttgart, seit WS 1900/o1 UH.

UH: 6. Mai 1904 Dr. phil. nat.; seit Mai 1904 PrivatAssistent von Theodor Curtius, seit Okt. 1905 Vorlesungs-Assistent am Chemischen Laboratorium; 19. Febr. 1909 Habilitation; seit 11. März 1915 nichtetatm., seit 1920 nichtplanm. a. o. Prof.

U Köln: Seit WS 1921/22 planm. a.o. Prof. und Abt.-Vorsteher des Chemischen Inst.

UH: Seit 10. Febr. 1922 planm. a. o. Prof. als Nachf. von Emil Knoevenagel; 1936-1945 Leiter der Anorganischen Abt. am Chemischen Inst. als Nachf. von Hans Kautsky [ $L b$ Kautskys: (1891-1966) seit 1928 Privat-Dozent und seit 1934 nichtplanm. a.o. Prof. für Anorganische Chemie UH, 1936-1945 planm. a. o. Prof. Leipzig, 1945-1946 Zwangsevakuierung durch Amerikaner nach Weilburg, seit 1946 Lehrauftrag Marburg, seit 14. Juli 1949 Lehrauftrag Frankfurt/M., 11. Aug. 1949-1. Okt. 1959 (Emeritierung) o. Prof. Marburg, s. WBIS, Wikipedia].

In einer Notiz vom 10. April 1945 heißt es: „Soll sich vergiftet haben, weil er seine Wohnung auf Anordnung der Amerikaner räumen musste" (aus: UAH PA 5095).

Qu UAH PA 5095; RA 5212, 6496; Fak.-Akte H-V5/2 Nr. 49. GLA Abt. 235, Fasz. 2326. 
W Sonn, A., M., E.: Über eine neue Methode zur Umwandlung von Carbonsäuren in Aldehyde in: Berichte der dt. chemischen Gesellschaft 52 (1919) S. 1927-1934. - Einwirkung von Aluminiumchlorid auf Di- und Trichloräthylen in: Journal für praktische Chemie N.F. 133 (1932) S. 291-304. (Mitverf.); Verhalten einiger Abkömmlinge der Azidoessigsäure gegen Kaliumäthylat in: ebd. 152 (1939) S. 219-236. (Mitverf.)

L Kürschner (1940/41) Sp. 225; WBIS; Poggendorff 7a (1959) S. 362; Jansen (1992a) S. 167 (Register); UH im Nationalsozialismus (2006) S. $1153 \mathrm{f}$. Wang, Z.: Comprehensive Organic Name Reactions and Reagents. Hoboken (New Jersey) 2009. Vol. 2. S. 2625-2627 (über Sonn-Müller-Reaktion).

\section{$P$ Bildarchiv UAH.}

\section{Münter, Albert Heinrich}

1923-1934 (1936) Med. Fak.

Anthropologie

* 07. Dez. 1883 Herford (Westfalen)

$\dagger$ 19. Febr. 1957 London prot.

V Carl Heinrich M. (1832-1889) Kaufmann

M Charlotte Emilie Christine geb. Steinmeyer (1850-1904)

๑ 1916 N. N.; Scheidung 1918

( 27. Dez. 1920 Henrietta Mathilde geb. Schmidt $\left({ }^{*} 1888 \dagger\right.$ nach 1957$)$ „Kommunistin“, s. Grüttner/Kinas (2007) S. 175 Anm. 225

$\mathrm{K} \quad 1 \mathrm{~S}$

Lb Seit SS 1903 Studium der Theologie an U Erlangen, seit WS 1904/05 Berlin, WS 1906/07 Greifswald.

Westfalen: April 1907 Theol. Lizentiatenprüfung an U Münster; 1907-1908 Militärdienstpflicht als Einjährig-Freiwilliger; April 1908 Mitglied des Predigerseminars in Soest.
Bremen: Seit Ostern 1909 Erzieher; Herbst 1909 „infolge dogmatischer [dogmatisch-erzieherischer] Bedenken sah ich mich gezwungen, meinen Beruf aufzugeben“ (aus: Lebenslauf in: UA Münster Promotionsakte der Phil. Fak., Bestand 65 Nr. 1009).

U Münster: Seit WS 1909/10 Studium der Zoologie, Botanik, Anatomie; 26. Sept. 1912 Dr. phil.; Okt. 1912-April 1919 Assistent am Anatom. Inst. • In dieser Zeit:

1914-1918 Kriegsdienst.

UH: Seit Mai 1919 Assistent am Anatom. Inst.; WS 1920/21-1932/33 Kustos der Anthropolog. Sammlung im Anatom. Inst. (hier legt M. e. „germanische Skelettsammlung“ an); 17. Jan. 1923 Habilitation mit dem Thema „Altägypter und Kopten in Bezug auf negroide Komponenten beim Schädelbau"; seit 22. Jan. 1929 nichtplanm. a. o. Prof., siehe hierzu Z; WS 1933/34 letzte Vorlesungsankündigung; 15. Febr. 1934-1. Juli 1936 UrlaubsGenehmigung vom Minister des Kultus und Unterricht und der Justiz; Aug. 1936 aus Liste der akad. Lehrer der UH gestrichen, nachdem M. keinen neuen Beurlaubungsantrag stellt. • In dieser Zeit:

H: April 1921-1932/33 Leiter des von der Josefine und Eduard von Portheim-Stiftung für Wissenschaft und Kunst im Anatom. Inst. eingerichteten Anthropolog. Inst. in der Brunnengasse 1.

London: 1934-1936 Studienaufenthalt, u.a. am Royal College of Surgeons of England; 1936-ca. 1948 Lecturer am Anatomy Institute.

$Z$ In einem Brief vom 10. Nov. 1928 schlägt Erich Kallius die Verleihung des Titels eines apl./nichtplanm. a. o. Professors an M. dem Dekan der Med. Fak. vor; Kallius schreibt: „Seitdem die Fakultät diesen Antrag (auf Verleihung der a. o. Professur) [im Mai 1927 aufgrund fehlender eigenständiger wiss. Arbeiten] abgelehnt hatte, sind über die wissenschaftliche Arbeit des Herrn Münter folgende Angaben zu machen: Bekanntlich ist Herr M. mit einer umfassenden Bearbeitung über den Vorgang des Rassenwandels im Aegyptervolke beschäftigt und hat seit der zweiten Arbeit darüber (1927) eine weitere ausführliche Arbeit fertig gestellt, die in 
diesen Tagen erscheinen wird. Dass er unentwegt an demselben Thema fortgearbeitet hat, spricht für den Ernst, mit dem er seine wissenschaftlichen Aufgaben behandelt ... Ferner bearbeitet Herr M. erbbiologisch die Insassen der Badischen Blinden- und Taubstummen-Anstalten, der Marokkanerkinder von Mainz und Umgebung (streng geheim!!), die musikalische Begabung der Familien und Angehörigen des Thomanerchors in Leipzig etc. Das sind nicht nur Pläne, sondern ernsthafte Vorarbeiten ..." (aus: UAH PA 1086). Der Antrag hat Erfolg: am 22. Jan. 1929 erfolgt die Ernennung M.s zum nichtplanm. a. o. Professor.

Qu UAH PA 1086. GLA Abt. 235, Fasz. 2330, Abt. 235, Fasz. 5007 fol. 284r, v. $\bullet$ Brief-Sammlung: Archive of the Society for the Protection of Science and Learning, 1933-1987 in: Bodleian Library, University of Oxford. - Auskunft: Universitätsarchiv Münster.

$W$ Zur Stellung der Kopten zu den Altägyptern. Eine kraniometrische Studie in: Zs. für Anatomie und Entwicklungsgeschichte 74 (1924) S. 614-683, 78 (1926) S. 66-82; Zur Differentialdiagnose der Kopten in: ebd. 83 (1927) S. 113-221; Über den Vorgang des Rassenwandels im Ägyptervolke und über Charakter und Herkunft der ihm zugrundeliegenden ethnischen Elemente in: ebd. 88 (1929) S. 1-87. Zur Cro-Magnon-Frage in: Jahrbuch der badischen Lehrer (1926).

L Kürschner (1935) Sp. 948; WBIS; UH im Nationalsozialismus (2006) S. 658 f. u.ö.; Grüttner/ Kinas (2007) S. 175 u.ö. • Über H.M. in: Grundmann, Steffen: Der Anatom Erich Kallius ... Med. Diss. Greifswald 2008. S. 135 f., 142 u. ö. (online). • Hier freut sich der Tod (2013) S. 115 u.ö; Doll/ Kirsch/Eckart (2017) S. 63.

$P$ Bildarchiv UAH.

\section{Muncke, Georg Wilhelm}

1817-1847 Phil. Fak.

Physik

* 28. Nov. 1773 Groß-Hilligsfeld (heute: Stadtteil von Hameln)

$\approx$ 02. Dez. 1773

$\dagger$ 17. Okt. 1847 Großkmehlen (heute: Landkreis Oberspreewald-Lausitz)

ev.

V August Andreas M., Pastor

M Anna Carolina Elisabeth geb. Köring

( 1807 Johanna Louisa Philippine geb. Feder (1783/84-1846), s. Stumm (2012) S. 342, 350, 367

K 4 S: u.a. Georg August M. (*1809) 18331843 Privat-Dozent für Badisches Recht an Jur. Fak. der UH, s. UAH PA 2035; Jammers (1964) S. 177 u.ö., Emundts-Trill (1997) S. 229, Stumm, S. 344, 367. 1 T: Louisa Henrietta Carolina M. (1820-1877), siehe Stumm, S. 576; Ehefrau von: (siehe) Eduard Zachariae.

Lb Hannover: Vor 1796 Ausbildung, seit 6. Juni 1797 Lehrer, seit Herbst 1803 II. Direktor am Georgianum.

U Marburg: Seit 29. Aug. 1810 o. Prof. für Physik, Mathematik; 7. Sept. 1815 Dr. phil.

UH: 24. Dez. 1816 Ern. zum o. Prof. und Direktor des Physikal. Kabinetts als Nachf. von Jakob Fries (siehe hierzu UAH RA 6459, 6583); SS 1817 Beginn seiner Lehrtätigkeit; seit SS 1847 laut „Anzeige der Vorlesungen“",mit Urlaub abwesend'; M. hält sich bei seiner Tochter Louisa in Großkmehlen auf.

1819/20, 1839/40 Prorektor der UH; 1818, 1824, 1831, 1837, 1845 Dekan der Phil. Fak. der UH

1818 Hofrat; 1832 Geh. Hofrat; 1847 Geh. Rat III. Klasse

$E$ Mitglied der Akademie der Wissenschaften: 1826 St. Petersburg, Dorpat, 1830 Göttingen. 1841 Ritter des Ordens vom Zähringer Löwen. 
Qu UAH PA 2036. - GLA Abt. 205, Fasz. 400. Auskunft: Kirchenbuchamt - Stadtkirchenkanzlei - des Ev.-luth. Stadtkirchenverbandes Hannover (Taufbuch Groß-Hilligsfeld 1773); Ev. Kirchengemeinde Lindenau (Sterberegister Großkmehlen 1847 Nr. 18: „Es verstarb am 17. Oct. 1847 mittags 12 Uhr ... G. W. M. ... im Alter von 75 Jahren an Magenverhärtung“).

W Anfangsgründe der Naturlehre. 2 Abt. Heidelberg 1819-1820. - Die ersten Elemente der gesammten Naturlehre. Heidelberg 1825. 4. Aufl.
1842. Gehler's Physikalisches Wörterbuch. 11 Bde. Leipzig 1825-1845. (Mitbearb.) - Handbuch der Naturlehre. 2 Bde. Heidelberg 1829.

$L$ Poggendorff 2 (1863) S. 238f;; Catalogus prof. Marburgensis 1 (1927) S. 374f.; Schmitt (1978) S. 72 u. ö.; WBIS; Thomas (1985) S. 632 (Register); Stumm (2012) S. 701 (Register); Professorenkatalog Marburg, s. https://www.uni-marburg.de/uni archiv/pkat/details?id=9854 (Stand: 27. 7. 2016).

$P$ Bildarchiv UAH. 
Naegele

siehe Naegelé

\section{Naegelé, Franz Carl Joseph}

1807-1851 Med. Fak.

Pathologie, Physiologie, Geburtshilfe

$\approx$ 12. Juli 1778 Düsseldorf

$\dagger$ 21. Jan. 1851 Heidelberg

kath.

V Joseph N. (1741-1813), u. a. seit 1784 Direktor der Chirurg. Akademie in Düsseldorf; auch Stabschirurg, s. WBIS

M Magdalena geb. Winter ( $† 1807)$

$œ$ 19. Okt. 1806 Johanna Maria Anna geb. Mai (1784-1857) T von: (siehe) Franz Anton M.

K 5, mindestens 2 S: (siehe) Franz Joseph N. $\bullet$ Dr. iur. Maximilian N. (1818-1852) Privat-Dozent an Jur. Fak. der UH, s. Emundts-Trill (1997) S. 230 f., WBIS.

$L b$ Düsseldorf: Zunächst Prosektor und Repetitor der Anatomie an Chirurg. Akademie (s. oben Eintrag unter $V$ [ater]).

Vor 1800 Studium an U Straßburg, anschl. Freiburg/Br., zuletzt Bamberg; 1800 Dr. med. an U Bamberg; anschl. Studienreise.

Wuppertal: Seit 1801 Arzt in Barmen, auch Amtsphysikus (Amtsarzt) von Barmen und Beyenburg, Munizipalrat sowie Mitvorsteher (und Hauptstifter) e. allg. Armenanstalt.

UH: Seit 30. Juni 1807 a. o. Prof.; seit März 1808 N. erhält aus der Besoldung seines Schwiegervaters Franz Anton Mai e. Zuwendung von 6oo.- Gulden; 17. Nov. 1809 N. bittet Großherzog Karl Friedrich von Baden um ein Ordinariat; 10. Jan. 1810 Antwort des Ministeriums lautet, „daß er sich mit sei- nem Gesuch ... noch einige Zeit zu gedulden habe“ (aus: UAH PA 2037); April 1810 N. wiederholt seine Bitte um Vergabe e. Ordinariats; 19. Juni 1810 Ern. zum o. Prof.; seit 19. Nov. 1810 Direktor der Gebär- oder Entbindungsanstalt (seit WS 1834/35 umbenannt in Obstetrizische Klinik) mit e. Jahresgehalt von 300.- Gulden als Nachf. seines Schwiegervaters Franz Anton Mai sowie Hebammenlehrer; seit 23. Okt. 1811 jährl. Besoldungszulage von 200.- Gulden; 1818 Umzug der Entbindungsanstalt vom ehemaligen Dominikanerkloster an der Ecke Hauptstrasse/Brunnengasse in den Marstall (heute: Neckarstaden 2-6); seit 1. Febr. 1829 jährl. Besoldungszulage von 60o.- Gulden; 1829 Ruf an U Berlin abgelehnt. • In dieser Zeit:

25. Aug. 1813-29. Mai 1838 Oberheb(e)arzt des Neckar-, Main- und Tauberkreises, seit 1834 als Unterrheinkreis bezeichnet.

1826 Prorektor der UH; 1813, 1820, 1825, 1831, 1836, 1842, 1849 Dekan, April-Dez. 1814 Prodekan der Med. Fak. der UH

1813 urteilt Stephan Zipf, Ordinarius an der Med. Fak., über die Fähigkeiten Naegelés: „Mich gegen die Geschicklichkeit und wissenschaftlichen Kenntnisse des Prof. Naegelé nach meiner Überzeugung ausdrücken zu wollen, mögte zur Vermuthung einer persönlichen Gegenneigung führen; daß er aber die in gegenwärtigem Berichte auf den höchsten Grad [von ihm geforderten] gesteigerten [finanziellen] Erhebungen nicht verdiene, dieses glaube ich offen um so mehr bemerken zu müssen, da dafür eine überwiegende Autorität [= Mehrheit $]$ leicht aufzufinden wäre" (aus: Bericht des Engeren Senats der UH vom 6. März 1813 in: UAH PA 1957).

1852 erhält Universitätsbibliothek Heidelberg die N.sche Bibliothek, s. UBH Heid. Hs. 2784

1815 Hofrat; 1821 Geh. Hofrat; 1832 Geh. Rat II. Klasse

Siehe auch Franz Anton Mai

E 1813 Dr. phil. h.c. UH. - Kommandeur des Ordens vom Zähringer Löwen. 
Qu UAH PA 2037; RA 5355, 5837, 6221, 6227 f., 6792; Fak.-Akte H-III-111/7 fol. 18r. • Matrikel Freiburg/ Br. 1,2 (1955) S. 1026. GLA Abt. 205, Fasz. 404. • Schmitt, Viktor: Ein Briefwechsel zwischen Joseph Alexis Stoltz und F. C. N. ... Diss. Straßburg 1909.

$W$ Ueber den Zweck, Nutzen und die Einrichtung von Armenanstalten. Barmen 1807. - Über den Mechanismus der Geburt. Heidelberg 1818. 2. Aufl. 1822. Katechismus der Hebammen-Kunst. Heidelberg 1830. 6. Aufl. 1844. - Lehrbuch der Geburtshülfe. Heidelberg 1830. 14. Aufl. 1883. • Das schräg verengte Becken und über die wichtigsten Fehler des weiblichen Beckens überhaupt. Mainz 1839. Bibliographie in: Gotthold (1959) S. 45-48.

MHG 1825-1847 Heidelberger klinische (seit 1835 medizinische) Annalen.

$L$ ADB 23 (1886) S. 218 f; Heidelberger Prof. aus dem 19. Jhdt. 2 (1903) S. 116-128; Stübler (1926) S. 242-247. - Martin, Edith: Die Geburtshilfe in der Heidelberger Entbindungsanstalt während der Direktorialzeit Naegelés 1820-1850. Med. Diss. Heidelberg 1939. - Gotthold, Eberhard: F.C.N. Med. Diss. Heidelberg 1959. • Zander, Josef: Über ein Bildnis Goethes aus dem Besitz von F. K. N. in: Heidelberger Jahrbücher 14 (1970) S. 134-143. • Buttron (1981) S. 28-46; Chronik Ärzte H (1985) S. 138, 254 ff.; WBIS; Zander (1991) S. 52-57. • Zur Geschichte der Endokrinologie und Reproduktionsmedizin: 256 Biographien und Berichte. Hrsg. von Gerhard Bettendorf. Berlin 1995. S. 399. * NDB 18 (1997) S. 699 f.; Heinstein (1999) S. 98. • Klinkhammer, Gisela: Ärztetags-Sonderstempel zu Ehren von F. K. N. in: Dt. Ärzteblatt (2001) Jg. 98, H. 22, S. 84. • Prückner (2004) S. 304 (Register). David, M., Ebert, A. D.: Instrumente und ihre Namensgeber: F.C.N. ... und die Geburtszange ... in: Geburtshilfe und Frauenheilkunde 69 (2009) S. 307 f. - KlinikTicker - Online-Mitarbeitermagazin des Universitätsklinikums Heidelberg: "Ein Zimmer, 21 1⁄2 Schuh lang und 18 Schuh breit." Ein Streifzug durch die 250-jährige Geschichte der Hebammenschule in Heidelberg (16. Dez. 2016; abgerufen am 1. Okt. 2017). • Longo, Lawrence D., Reynolds, Lawrence P.: Wombs with a view: Illustrations of the gravid uterus from the Renaissance through the nineteenth century ... Basel 2016 . S. 214-216.
$P$ Bildarchiv UAH; graph. Slg. UBH; Stübler; Chronik Ärzte H.

\section{Naegelé, Franz Karl Anton Joseph} Hermann

1835-1851 Med. Fak.

Geburtshilfe, Geschlechtskrankheiten des Weibes, Gerichtliche Arzneikunde

* 22. Jan. 1810 Heidelberg

$\dagger \quad$ 05. Juli 1851 Heidelberg kath.

V (siehe) Franz Carl N.

M Johanna Maria Anna geb. Mai (1784-1857) T von: (siehe) Franz Anton M.

๑ 29. Sept. 1840 Franziska Friederica Constantine geb. Devens (1819-1865)

K $3 \mathrm{~S}$

Lb UH: Seit 12. April 1827 zunächst Studium der Philosophie, seit SS 1828 der Medizin; 29. Febr. 1832 Dr. med.; 23. Juni 1832 med. Staatsprüfung in H; 16. Aug. 1832-Aug. 1833 Assistenzarzt an Entbindungsanstalt; anschl. 1833-1834 Studienreisen nach Wien, Paris; seit Herbst 1834 Assistent des „Vorstehers der hiesigen Entbindungsanstalt [= Vater Franz Carl N.] beim klinischen Unterrichte sowie beim Unterrichte der Hebammen“ (aus: Brief N.s an das Ministerium des Innern vom 8. Febr. 1835 in: UAH PA 2038); April 1835 Habilitation; seit 8. Nov. 1838 a. o. Prof.; seit 31. Mai 1845 a. o. Prof. mit e. jährl. Besoldung von 200.- Gulden; nach 21. Jan.-5. Juli $1851(\dagger)$ Leiter und Verwalter der Entbindungsanstalt oder Geburtshilflichen Klinik; N. war als Nachf. seines Vaters vorgesehen (Nachf.: Wilhelm Lange). • In dieser Zeit:

H: 29. Mai 1838-5. Juli 1851 Oberheb(e)arzt des Unterrheinkreises als Nachf. seines Vaters Franz Carl N.

$\mathrm{Qu}$ UAH PA 2038; RA 5875, 6229; Fak.-Akte HIII-111/30 fol. 121r-140r. • GLA Abt. 205, Fasz. 405. 
$W$ De conglutinatione orificii uteri. Heidelberg 1835. Die geburtshülfliche Auscultation. Mainz 1838. Die Lehre vom Mechanismus der Geburt nebst Beiträgen zur Geschichte derselben. Mainz 1838. Commentatio de causa quadam prolapsus funiculi umbilicalis. Heidelberg 1839. - Lehrbuch der Geburtshülfe. Mainz 1843-1845. 8. Aufl. 1871.

$L$ Heidelberger Prof. aus dem 19. Jhdt. 2 (1903) S. 128-130; Stübler (1926) S. 270; WBIS; Arnim 2 (1952) S. 222. Gotthold, Eberhard: F. Carl N. Med. Diss. Heidelberg 1959. • Buttron (1981) S. 47; Chronik Ärzte H (1985) S. 138. • Zander, Josef: Die Bedeutung Heidelbergs für die Entwicklung der Gynäkologie und Geburtshilfe vom Beginn des 19. bis ins 20. Jahrhundert in: Entwicklungen in Gynäkologie und Geburtshilfe. Hrsg. von Gunther Bastert ... Berlin 1991. S. 47-72. • Prückner (2004) S. 59 f., 259. - Longo, Lawrence D., Reynolds, Lawrence P.: Wombs with a view: Illustrations of the gravid uterus from the Renaissance through the nineteenth century ... Basel 2016. S. 214. • Deutsche Biographie, s. https://www.deutsche-biographie.de/gnd131491083.html [07.11. 2017].

$P$ Bildarchiv UAH.

\section{Naegelé, Hermann}

siehe Naegelé, Franz Karl Anton Joseph Hermann

\section{Narath, Albert}

1906-1910 Med. Fak.

Chirurgie

* 13. Sept. 1864 Wien

$\dagger$ 14. Aug. 1924 Heidelberg

ev.

V Friedrich Albert N. (1827-1908) Privatier

M Johanna geb. Bauer (1834-1866)
( 26. Aug. 1897 Anna Louisa geb. Engelmann (1876-1924) T von Theodor Wilhelm E. (18431909) U Utrecht: seit 1871 a. o. Prof. für Medizin, seit 1877 Prof. für Allg. Physiologie, Vgl. Biologie, Histologie, Experimentelle Pharmakodynamie und Toxikologie, seit 1888 o. Prof. für Physiologie (als Nachf. seines Schwiegervaters Franciscus Cornelis Donders (auch: Frans Donders) (1818-1889), s. hierzu Leersum, Evert C. van: Het levenswerk van F.C. Donders. Haarlem 1932; Enzyklopädie Medizingeschichte. Berlin 2007. Bd. 1. S. 322), s. NDB 4 (1959) S. 517 f., WBIS

K 1 T, 2 S: u.a. Albert N. (1900-1974) Berlin: 1927-1945 Entwicklungsingenieur im Forschungslabor der AEG, 1931 übernommen von Telefunken, seit 1936 Privat-Dozent an TH, seit 1939 Dozent am Inst. für Angewandte Photochemie; seit 1946 Dozent, seit 1948 a.o. Prof. für Angewandte Photochemie TU Berlin; 1956 o. Prof. TH Aachen, im selben Jahr zurück an TU Berlin, 1965 Emeritierung ebd., s. Kürschner (1970) S. 2083, NDB 18 (1997) S. $734 \mathrm{f}$; Catalogus professorum - Professoren und Professorinnen der TU Berlin und ihrer Vorgänger, s. online https://cp.tu-berlin.de/per son $/ 802$

Vw Neffe: Peter Alfred N. (1891-ca. 1968), u.a. 1920-1935 Urologe an verschiedenen Krankenhäusern in H und Mannheim; New York: seit 1936 Lehrer für Urologie an Columbia U, seit 1938 Dozent, seit 1942 (Adjunct) Prof. an New York Polyclinic Medical School and Hospital, seit 1951 Arzt, seit 1954 Direktor der Urolog. Abt. am Northern Westchester Hospital Mount Kisco, s. UAH Studentenakte, Rep. 40414; WBIS.

Lb U Wien: Seit 1884 Studium der Medizin; Assistent und Prosektor: seit 1889 Anatom. Inst., seit Okt. 1891 Chirurg. Klinik; 14. Juni 1890 Dr. med.

U Utrecht: Seit 21. Febr. 1896 o. Prof.; Rufe an U abgelehnt: 1900 Königsberg (Preußen), 1901 Amsterdam.

UH: 26. Juni 1906 Ern. zum o. Prof. und Direktor der Chirurg. U-Klinik als Nachf. von Vincenz von Czerny; seit Okt. 1906 N. übernimmt zusätzlich Vorlesungen über Orthopädie, Heilgymnastik und 
Massage in Nachf. von Oscar Vulpius; 1. Okt. 1910 auf eigenen Antrag Ruhestand aus gesundheitlichen Gründen (Rückenmarkserkrankung).

1906 Geh. Hofrat

E 1902 Ritter des Niederländischen Löwenordens; 1910 Ritterkreuz I. Klasse mit Eichenlaub des Ordens vom Zähringer Löwen.

Qu UAH PA 1089, 5138; RA 6173, 6789; Fak.-Akte H-III-111/150 (2. Aug. 1906). - GLA Abt. 235, Fasz. 2338. - Chirurgie, Orthopädie, Röntgenologie, Zahnheilkunde: hierin neben mehreren Bibliotheken und Handapparaten die Bibliothek aus dem Besitze des Geh. Med.-Rats... A.N., Heidelberg. Antiquariatskatalog ... der Buchhandlung Gustav Fock. Leipzig 1930.

$W$ Über eine eigenartige Form von Hernia cruralis im Anschlusse an die unblutige Behandlung angeborener Hüftgelenksverrenkung in: Archiv für klinische Chirurgie 59 (1899) Nr. 2, S. 396424. - Der Bronchialbaum der Säugethiere und des Menschen. Stuttgart 1901. Zur Technik der Magen-, Darmoperationen. Der „Gastrophor“, ein Assistentensparer bei Magen-, Darmoperationen in: Archiv für klinische Chirurgie 71 (1903) Nr. 4, S. 901-910.

Redakteur 1910-1924 Deutsche Zeitschrift für Chirurgie.

L Stübler (1926) S. 320; Arnim 2 (1952) S. 225, 4 (1984) S. 1151; Fischer 2 ( $\left.{ }^{3} 1962\right)$ S. 1101; Krebs/ Schipperges (1968) S. 68-70. Narath, Albert jun.: Albert Narath. Kurzbiographie in: Ruperto Carola 20. Jg., Bd. 43/44 (1968) S. 174-186. - Leier (1977) S. 17 f., 81f. u. ö.; Chronik Ärzte H (1985) S. 138, 256; Semper apertus 4 (1985) S. 197 f.; NDB 18 (1997) S. 734*; WBIS. - Nigam, Vinod K., Nigam, Siddharth: Essentials of Abdominal Wall Hernias. New Delhi 2008. S. 191f. u. ö. VenenChirurgie: operative, interventionelle und konservative Aspekte ... Hrsg. von Wolfgang Hach ... Stuttgart 2013. S. 243-245 u. ö. Deutsche Biographie, s. https://www.deutsche-biographie.de/gnd116883 ogX.html [07.11. 2017].

$P$ Bildarchiv UAH; Chronik Ärzte H.

\section{Nathan, Karl}

siehe Kaiser

Neander, Johann August Wilhelm (bis Febr. 1806: Mendel, David)

1811-1813 Theol. Fak.

Kirchen- und Dogmengeschichte

* 17. Jan. 1789 Göttingen

$\dagger$ 14. Juli 1850 Berlin

mosaisch, seit 25. Febr. 1806 ev.

V Emanuel Mendel Gumprecht $\left({ }^{*} 1748 \dagger\right.$ nach 1813) Kaufmann

M Esther geb. Gottschalk (1752/55-1817/18)

$\infty$ unverheiratet.

$L b$ Seit SS 1806 Studium an U Halle/S., anschl. Göttingen.

Hamburg: 10. Nov. 1809 Kandidatenexamen; seit 1810 Predigtamtskandidat.

U Wittenberg: 1811 Theol. Lizentiatenprüfung.

UH: 4. Mai 1811 Habilitation; seit 16. April 1812 a. o. Prof.

U Berlin: 8. Jan. 1813 Ern. zum o. Prof. auf neueingerichtetem Lehrstuhl für Kirchengeschichte; SS 1813 Amtsantritt.

E 1839 Mitglied der Akademie der Wissenschaften Berlin.

Qu UAH PA 2040. GLA Abt. 205, Fasz. 408. Der Redaktionsbriefwechsel der Hallischen, Deutschen und Deutsch-Französischen Jahrbücher 1837-1844. Hrsg. von Martin Hundt. Bd. 1: Der Briefwechsel um die Hallischen Jahrbücher. Berlin 2010. Apparat: S. 271 (Register). Nachlaß, s. NDB 19 (1999) S. 10.

$W$ Über den Kaiser Julianus und seine Zeit. Heidelberg 1812. • Der heilige Bernhard und sein Zeitalter. Hamburg 1813. 3. Aufl. 1865. Neuausg. 1889. 
Genetische Entwicklung der vornehmsten gnostischen Systeme. Berlin 1818. - Allgemeine Geschichte der christlichen Religion und Kirche. 6 Bde. Hamburg 1825-1852. 4. Aufl. 1863-1865. Die mannigfachen Wege des Herrn in dem Werke der Bekehrung. Berlin 1829. - Geschichte der Pflanzung und Leitung der christlichen Kirche durch die Apostel. 2 Bde. Hamburg 1832. 4. Aufl. 1847. Das Leben Jesu Christi in seinem geschichtlichen Zusammenhange ... Hamburg 1837. 7. Ausg. 1874. • A. N. Dogmatik. Aus seinen Vorlesungen hrsg. von Paul Gloatz. Braunschweig 1898.

MHG Dt. Zeitschrift für christliche Wissenschaft und christliches Leben.

L ADB 23 (1886) S. 330-340. - Schneider, Karl Friedrich Theodor: A. N. Beiträge zu seinem Leben und Wirken. Schleswig 1894. Encyclopædia Britannica 11. Ed. (1911); Jüdische National-Biographie 4 (1929) S. 508 f. Hüttmann, Hilde: A. N. in seiner Jugendentwicklung. Diss. Hamburg 1936. • Arnim 2 (1952) S. 228. • Selge, Kurt-Victor: A. N. ein getaufter Hamburger Jude der Emanzipationsund Restaurationszeit als erster Berliner Kirchenhistoriker in: 450 Jahre Ev. Theologie in Berlin. Hrsg. von Gerhard Besier und Christof Gestrich. Göttingen 1989. S. 233-276. - Wechsler, Andreas: Geschichtsbild und Apostelstreit - e. forschungsgeschichtliche ... Studie ... Berlin 1991. S. 130134 u. ö. Kaufmann, Frank: Foundations of modern church history. New York 1992. - BBKL VI (1993) Sp. 518-520. Kuhn, Thomas K.: Der junge Alois Emanuel Biedermann. Lebensweg und theologische Entwicklung bis zur "Freien Theologie“ 1819-1844. Tübingen 1997. NDB 19 (1999) S. 10 f. (s. auch über N. in: NDB 22 (2005) S. 119 Artikel Rothe, Richard). - Der Pietismus im 19. und 20. Jhdt. Hrsg. von Ulrich Gäbler ... Göttingen 2000. - Wischmeyer (2008) S. 469 (Register). • Das Grabmal A. N. in: Unter jedem Grabstein eine Weltgeschichte ... Hrsg. vom Landesdenkmalamt Berlin. Berlin 2010. S. 77. - Schnurr, Jan Carsten: Weltreiche und Wahrheitszeugen: Geschichtsbilder der protestantischen Erweckungsbewegung in Deutschland 1815-1848. Göttingen 2011. S. 75-78 u. ö. - Gerber, Simon: Schleiermachers Kirchengeschichte. Tübingen 2015. S. 58f., 435-439.

$P$ Bildarchiv UAH; graph. Slg. UBH; NDB.

\section{Nebel, Daniel Wilhelm}

1766-1805 Med. Fak.

1766-1771 Medizin, insbesondere Chemie, 1771-

1805 Chemie und Pharmazie (Materia medica)

* o1. Jan. 1735 Heidelberg

$\dagger \quad$ 03. oder 05. Juli 1805 Heidelberg ref.

V Wilhelm Bernhard N. (1699-1748), u.a. 17281748 Prof. für Medizin H, s. UAH RA 8081, $8175,8178,8183,8185$ u.ö. (u. a. Nachlaß), Drüll (1991) S. $114 \mathrm{f}$.

M Maria Elisabetha geb. Wilhelmy (1705-1790), s. UAH RA 7191, 8166, 8174 u. ö.

(21. Aug. 1781 Maria Christina geb. Hettenbach (1738-1784), s. UAH RA 8177

๑ 6. April 1785 Catharina Elisabeth geb. Hettenbach (1753-1788)

K $1 \mathrm{~S}(1799 \mathrm{~N}$. nennt als Kind nur diesen Sohn in: UAH PA 2042 drittletztes Blatt): Johann Daniel N. (1785-1841) Arzt in H, s. Menzer, G.L.: Stammesgeschichte der Familie N. (1937) S. 28-30; WBIS

Vw Großvater: Daniel N. (1664-1733), u. a. 16881693 und 1707-1733 Prof. für Medizin, Botanik, Chemie H, s. UAH RA 1620, 5775, 5777, 5844 u. ö.; Drüll (1991) S. 113f.; Ehemann von Loysa Sara Catharina geb. de Spina (1678-1742) $\mathrm{T}$ von: Johannes de S. (1642-1689), u. a. 168o1689 Prof. für Institutionen H, s. Drüll (1991) S. 147 f. - Schwester: Christina Friederika N. (1733-1790), s. UAH RA 8174; Ehefrau von: Adam Jacob Friedrich Linck (ca. 1726-1758), u. a. 1753-1758 Prof. für Philosophie, Kirchengeschichte H, s. Drüll (1991) S. 95.

Lb 17. Dez. 1746 Immatrikulation an UH; 1749 Forts. des Studiums an U Göttingen, seit 1752 Leiden, anschl. Utrecht; 1756 Dr. phil. an U Utrecht (s. hierzu drittletzte Seite in UAH PA 2042); seit 1757 Praktika in Krankenhäusern in Straßburg.

UH: 21. Aug. 1758 Dr. med.

H: 1758-1805 Praktizierender Arzt; bis 18. März 1802 auch Arzt an "Canzley und Hospital“ (siehe hierzu Protokolle des Bayerischen Staatsrats (2008)). In dieser Zeit: 
UH: 5. April 1766 Ern. zum a. o. Prof. für Medizin, insbesondere Chemie (aus: Brief vom 15. April 1773 in: PA 2042) unter der Bedingung, „dass Er umb gehabung einiger Besoldung nirgendwo zu last des fisci academici behelligen solle" (aus: PA 2042); 15. Juli 1767-Aug. 1771 Verwalter der Professur für Anatomie, Chirurgie in Nachf. von Franz Joseph Oberkamp (s. Drüll (1991) S. 116f.) anstelle dessen noch in Ausbildung befindlichen jüngsten Sohnes Franz Philipp O. (s. ebd. S. 117f.); vor 13. April 1771 Ruf an U Harderwijk (Gelderland, Niederlande) abgelehnt; 13. April 1771 Ern. zum o. Prof. für Arzneikunst, besonders Chemie und Pharmazie mit e. jährl. Besoldung von 250.- Gulden; 8. Mai 1771 Verpflichtung und Aufnahme in den U-Senat; 1773 Besoldungszulage von 150.- Talern, 1 Fuder Wein und 12 Malter Korn; 18. Jan. 1788 letztes Schreiben von mehreren überlieferten Briefen N.s um Besoldungszulage, s. PA 2042.

In einem zu Ehren N.s gedruckten Totengedenkblatt heißt es über ihn: „Daß er sich gar nicht überhaben, sondern gegen jedermann liebreich, freundlich und sanftmüthig war, dass auch jedermann sich darüber verwundern musste, wie ohnerachtet der großen Gaben von Gott erlangt, er doch sich zu dem Geringen selbst herunter gelassen, und den Armen so wohl als den Reichen [als Arzt] besucht ..." In diesem Totengedenkblatt befindet sich auch ein von N. vor seinem Tod verfasster Appell an seine Hinterbliebenen: „Anrede des Selig-Verstorbenen an die hochbetrübte hinterlassene Frau Wittib und liebe Kinder ...", siehe PA 2042 nach Brief vom 28. Jan. 1788.

1777/78, 1793/94, 1801/02 Rektor der UH; 1774, 1778, 1782, 1786, 1790, 1794, 1798 Dekan der Med. Fak. der UH

E Mitglied: Akademie der Wissenschaften Paris, 1764 Kurpfälz. Akademie der Wissenschaften Mannheim.

Qu UAH PA 2042; RA 256, 264, 1116, 3185, 5781, 6685. GLA Abt. 205, Fasz. 409, 670. Toepke 4 (1903) S. 133. - Protokolle des Bayerischen Staatsrats 1799-1817. Hrsg. von der Historischen Kommission bei der Bayerischen Akademie München. Bd. 2: 1802-1807. Bearb. von Esteban Mauerer.
München 2008. Nr. 25: Protokoll der Geheimen Staatskonferenz vom 20. März 1802. Onlinefassung: http://138.246.100.12/str/res/Bd2_1802/ nr25. • Briefe: UBH; s. auch Kalliope.

$W$ Foetus ossei per quinquaginta quatuor annos extra uterum in abdomine detenti historia. München 1767 . Descriptio atque sectio anatomica infantis trimestris sine vesica urinaria nati. München 1782 . Siehe auch WBIS.

$L$ Keller (1913) S. 96 f.; Stübler (1926) S. 109-112. • Menzer, Georg-Ludwig: Stammesgeschichte der Familie Nebel. Leimen 1937. S. 24-28. - Krebs/ Schipperges (1968) S. 23; Chronik Ärzte H (1985) S. 138; WBIS; Wolgast (1986) S. 77; Deutsche Biographie, s. https://www.deutsche-biographie.de/gn d116901993.html [07.11. 2017].

$P$ Bildarchiv UAH; graph. Slg. UBH; Chronik Ärzte H.

\section{Neckel, Gustav Paul Karl Christoph}

1911-1920 Phil. Fak.

Nordische Philologie, Dt. Philologie

* 17. Jan. 1878 Wismar (Mecklenburg)

$\dagger$ 24. Nov. 1940 Dresden

$\theta$ Berlin

gottgläubig, vor 1933 konf.-los

V Gustav N. (1844-1923) Kaufmann, Fabrikbesitzer

M Amanda geb. Paetow (1854-1914)

$\infty$ 30. Sept. 1904 Hannah geb. von Wink (18811968), s. Zadow (2015) S. 40-42, 70 f.

K 2 T: Vera N. (1906-2002), s. Zadow, S. 9 f., $26-$ 32, 63, 141, 212 u. ö.; Ehefrau von Dr. phil. Astolf Zadow (1906-1945) Schriftsteller, s. Linthout, Ine van: Das Buch in der nationalsozialistischen Propagandapolitik. Berlin 2012. S. 125 f.; Zadow, S. 25 f., 33 f., 65 u. ö. - Dr. Ingrid N. (1920-1962) Chemikerin, s. ebd. S. 26-32, 41, 128 f., 141 u. ö. 
Lb Seit WS 1896/97 Studium an U München, SS 1898 Leipzig, seit WS 1898/99 Berlin; 26. Mai 1900 Dr. phil. an U Berlin.

Berlin: 10. Juni 1902 Prüfung für höheres Lehramt (Oberlehrerexamen) in Deutsch, Englisch und Latein; 1902-1904 wiss. Hilfslehrer.

1904-1911 Lehrer in Wismar, anschl. Oberlehrer an Realschule 2 in Breslau (heute: Wrocław, Polen). • In dieser Zeit:

U Breslau: 27. Juni 1909 Habilitation.

UH: 1. Aug. 1911 Nostrifikation; WS 1911/12 Erteilung e. bis 1920 geltenden Lehrauftrags für Skandinavische/Nordische Philologie als Nachf. von Robert Petsch; seit 25. Okt. 1911 a. o. Prof. für Nordische Philologie als Nachf. von Bernhard Kahle; WS 1919/20 letzte Vorlesungsankündigung. • In dieser Zeit:

1915-1916 Kriegsdienst.

U Berlin: Seit SS 1920 o. Prof. für Germanistische Philologie; 23. Sept. 1935 Erlaß des Reichs- und Preußischen Ministers für Wissenschaft, Erziehung und Volksbildung zur Zwangsversetzung N.s nach Göttingen (,$\ldots$ eine gegen N. gerichtete Intrige, bei der, wie man ungedruckten Quellen entnehmen kann, und wie noch lebende Zeitzeugen berichten, Privates und Politisches sich eigenartig vermischten“, s. hierzu weiter Paul, Fritz: Zur Geschichte der Skandinavistik (1985) sowie Zernack, Julia: G. N. in: See/Zernack (2004) S. 115-188).

U Göttingen: Seit 1. Okt. 1935 o. Prof. für Nordische Philologie und Gründungs-Direktor der Abt. für Nordische Philologie im Seminar für Dt. Philologie.

U Berlin: Zum 1. Nov. 1937 Rückberufung als o. Prof.; seit WS 1939/40 Beurlaubung aus gesundheitlichen Gründen; in dieser Zeit Aufenthalt in Privatnervenklinik Dr. Stoltenhoff in Dresden, s. hierzu Zernack (2004) S. 143-145.

1933 unterschreibt u.a. N. einen Aufruf ,an die Männer einer germanisch-deutschen Glaubensbewegung“; hieraus geht 1935 die „Deutsche Glau- bensbewegung" hervor, e. Zusammenschluß von verschiedenen Religionsgruppen, die sich vom Christentum lossagen und einen ,arisch-nordischen" Glauben etablieren wollen, s. hierzu Breuer, Stefan: Die Völkischen in Deutschland. Darmstadt 2008. S. 259.

Qu UAH PA 2046; RA 6839, 6879. GLA Abt. 235, Fasz. 2339. Mitteilungen: Herr Mario Zadow ( $†$ ) und Herr Martin Zadow, Hamburg.

$W$ Beiträge zur Eddaforschung mit Exkursen zur Heldensage. Dortmund 1908. Germanisches Heldentum. Jena 1915. 3. Aufl. 1936. Die altnordische Literatur. Leipzig 1923. Nachdr. 1963. • Altgermanische Kultur. Leipzig 1925. 2. Aufl. 1934. • Germanische Sagen von Göttern und Helden. Frankfurt/M. 1926. - Liebe und Ehe bei den vorchristlichen Germanen. Leipzig 1932. 3. Aufl. 1936. Kultur der alten Germanen. Potsdam 1934. - Vom Altertum zum Mittelalter. Leipzig 1935. Nachdr. 1964. • Siehe Schlottig, Kurt Helmut: G.N.s Werke und Schriften in: Beiträge zur Runenkunde und nordischen Sprachwissenschaft ... Hrsg. von K. H. Schlottig. Leipzig 1938. S. 176-192.

HG Edda. Heidelberg. Bd. 1: 1914. 3. Aufl. 1936. Bd. 2: 1927. 2. Aufl. 1936.

L Kürschner (1931) Sp. 2060, (1935) Sp. 957; Wer ist's (1935) S. 1130; Arnim 2 (1952) S. 229. Paul, Fritz: Zur Geschichte der Skandinavistik an der Georg-August-Universität Göttingen - Eine vorläufige Skizze - online (1985) unter: http://fami lie.neckel.info/images/PDF/Zur_Geschichte_der_ Skandinavistik.pdf (abgerufen am 12. Febr. 2016). NDB 19 (1999) S. 2of.; Int. Germanistenlexikon 2 (2003) S. 1311 f. Zernack, Julia: „Wenn es sein muß, mit Härte ...." Die Zwangsversetzung des Berliner Nordisten G. N. 1935 und die „Germanenkunde im Kulturkampf “ in: See, Klaus von, Zernack, Julia: Germanistik und Politik in der Zeit des Nationalsozialismus. Zwei Fallstudien: Hermann Schneider und G.N. Heidelberg 2004. S. 107-202. • Zadow, Mario Alexander: Erinnerungen 1927-1959. Karwe bei Neuruppin 2015. S. 40-42.

P Bildarchiv UAH; See/Zernack (2004) S. $107 \mathrm{f}$. 


\section{Neu, Maximilian}

1908-1933 Med. Fak.

Frauenheilkunde

* 05. April 1877 Freinsheim (Pfalz)

$\dagger \quad$ 22. Okt. 1940 Heidelberg (Suizid) mosaisch, seit $1918 \mathrm{ev}$.

V Lazarus N. (1824-1880) Kaufmann

M Wilhelmina geb. Reinhardt (1842-189o)

$\infty$ 25. Sept. 1912 Louise (Zilla) geb. Baruch (18851940 Suizid), s. Lexikon jüdischer Einwohner Hs (2011) S. 311

$\mathrm{K}$ keine.

Lb Seit SS 1897 Studium an UH, seit SS 1899 München, seit WS 1900/o1 H; 1899-1900 Militärdienstpflicht als Einjährig-Freiwilliger in Königl. Bayer. Armee in München.

3. März 1902 Ärztl. Staatsexamen in H; 6. März 1902 Dr. med. an UH; 1902-1903 Volontärassistent an Med. Klinik in Basel, anschl. an Diätetischer Kuranstalt in Badenweiler.

UH: Seit Nov. 1903 Volontärassistent, seit 1905 Assistent, Juni 1907-Febr. 1919 Oberarzt an U-Frauenklinik; 2. März 1908 Habilitation für Geburtshilfe und Frauenheilkunde; seit 10. Febr. 1914 nichtetatm., seit 1920 nichtplanm. a.o. Prof.; seit 20. April 1933 Beurlaubung bis auf weiteres aus rassischen Gründen; 22. Sept. 1933 Entziehung der Lehrbefugnis aufgrund des Gesetzes zur „Wiederherstellung des Berufsbeamtentums“; 1938 Entzug der Approbation. • In dieser Zeit:

H: 1920-1936/38 (totales Berufsverbot) Leiter e. Privat-Klinik für Geburtshilfe und Frauenkrankheiten in der Zähringer Straße 15.

2011 wird in Heidelberg in der Zähringer Straße 15 ein „Stolperstein“ für Maximilian und Louise Neu verlegt.
Qu UAH PA 1091, 5153; RA 5291, 5303; Quästurakte Rep. 27-913; Fak.-Akte H-III-111/139 fol. 312317; Studentenakte. • GLA Abt. 235, Fasz. 2341.

$W$ Die Stickoxydul-Sauerstoff-Narkose in: Archiv für klinische Chirurgie (1911) Bd. 95, H. 3. - Zur Therapie der Herzerkrankungen in der Schwangerschaft in: Verh. der dt. Gesellschaft für Gynäkologie (1913). - Die Diagnose der Schwangerschaft. Wiesbaden 1915. 2. Aufl. 1924.

L Arnim 2 (1952) S. 233; Fischer $2\left({ }^{3} 1962\right)$ S. 1107; Chronik Ärzte H (1985) S. 138; WBIS. - 50 Jahre Deutsche Gesellschaft für Anästhesiologie und Intensivmedizin ... Hrsg. von Jürgen Schüttler. Berlin 2003. S. 34 f. u. ö. $\bullet U H$ im Nationalsozialismus (2006) S. 850-852 u. o.; Grüttner/Kinas (2007) S. 174 u. ö.; Badische Biographien N.F. VI (2011) S. 292-294; Lexikon jüdischer Einwohner Hs (2011) S. 311. Rotzoll, Maike, Wiedemann, Klaus: Die „badische Judendeportation“ und das Schicksal von M. und Zilla N. in: Heidelberg. Jahrbuch zur Geschichte der Stadt 2012. Heidelberg 2011. Jg. 16. S. 249-254. • Deutsche Biographie, s. https:// www.deutsche-biographie.de/gnd1018913092.html [07.11.2017].

$P$ Bildarchiv UAH.

\section{Neubecker, Friedrich Karl}

1918-1923 Jur. Fak.

Vgl. Rechtswissenschaft, Int. Privatrecht

* 26. Juni 1872 Rodenbach (Pfalz)

$\dagger$ 31. Dez. 1923 Heidelberg ev.

V Adam N., Volksschullehrer

M Dorothea geb. Schölles (†1894)

๑ 15. Juli 1906 Renée geb. von Meyenburg $\left({ }^{*} 1885\right.$ $\dagger$ nach 1951) 
K 1 T, 1 S: Dr. phil. Ottfried N. (1908-1992) Schöpfer zahlreicher kommunaler und kirchlicher Wappen sowie Insignien akad. und militärischer Institutionen; seit 1927 Mitarbeiter des Reichskunstwarts, seit 1931 Mitarbeiter der Zigaretten-Industrie für WappenbilderSammelalben, 1944-1960/61 Vorsitzender des Heroldsausschusses für die Dt. Wappenrolle (DWR), seit 1952 Lehrbeauftrager für Kunstgeschichte FU Berlin, seit 1963 Lehrbeauftrager U Mainz, seit 1963 Direktor der „Allgemeinen Deutschen Wappenrolle“; 1963 Initiator, Mitgründer, Schriftführer, seit 1978 Präsident der Dt. Heraldischen Gesellschaft „WappenHerold“, Mainz, s. Arndt, Jürgen: Biographisches Lexikon der Heraldiker. Neustadt an der Aisch 1992. S. 382 f.; Hessische Biografie, s. http://www.lagis-hessen.de/pnd/11694594X (Stand: 8. Juli 2017).

$L b$ WS 1890/91 Zunächst Studium der Philologie, SS 1891 der Rechtswiss. an U München, seit WS 1891/92 Berlin; 23. Sept. 1895 Referendarexamen in Berlin.

Berlin: Seit 1895 Referendar; 22. Juli 1897 Dr. iur. an U; 1897-1902 Eigenstudien.

U Berlin: 11. Febr. 1902 Habilitation für Römisches und Dt. Bürgerl. Recht; seit 1909 nichtetatm. a.o. Prof.; seit 7. Nov. 1916 o. Honorar-Prof. • In dieser Zeit:

1914-1918 Kriegsdienst.

UH: Seit 16. Juli 1918 Inhaber der neueingerichteten Netterschen Stiftungsprofessur und 1918-1923 $(\dagger)$ Direktor (neben Karl Heinsheimer) des Seminars für Rechtswirtschaftliche und Rechtsvergleichende Studien im Haus Augustinergasse 9 (siehe hierzu Z); 1. Okt. 1918 Dienstantritt als o. (Stiftungs-)Prof.; 1921 Ruf an U Helsinki abgelehnt.

Okt.-Dez. 1923 (†) Dekan der Jur. Fak. der UH, s. hierzu Weisert/Drüll/Kritzer (2007) S. 68

$Z$ Professur und Seminar für Rechtswirtschaftliche und Rechtsvergleichende Studien sind 1916 eine Stiftung des Großunternehmers und Mäzens Carl Leopold Netter (1864-1922), s. NDB 19 (1999) S. 86 f.; das Seminar wird seit 1924 als Institut für Ausländisches Recht an der Jur. Fak. geführt und nach Minimierung des Stiftungsvermögens während der Inflation von UH teilfinanziert.

1918 Geh. Hofrat

E Ehrenmitglied der Real Academia de Jurisprudencia y Legislación de Madrid. - Serbischer St. Sava-Orden IV. Klasse.

Qu UAH PA 780, 5159. • GLA Abt. 235, Fasz. 1557.

$W$ Die Mitgift in rechtsvergleichender Darstellung. Leipzig 1909. Der Ehe- und Erbvertrag im internationalen Verkehr. Leipzig 1914. • Finnlands Eherechtsreform. Leipzig 1921. • Russisches und orientalisches Eherecht. Leipzig 1921.

$L$ Wer ist's (1922) S. 1103. - Abraham, Paul: K.N. Berlin 1925. (Bio-bibliographische Beiträge zur Geschichte der Rechts- und Staatswiss. Abt. Rechtswiss. 2.) - Rauchhaupt, F. W. von: K. N. $\dagger$ in: Zs. für vgl. Rechtswissenschaft 41 (1925) S. 276 f. • WBIS; Schroeder (2010) S. 417-421. Maus, Christian: Der ordentliche Professor und sein Gehalt. Die Rechtsstellung der juristischen Ordinarien an den Universitäten Berlin und Bonn zwischen 1810 und 1945 ... Göttingen 2013. S. 390 und Anm. 1168 u. ö. - Kraushaar, Felix: Aufbruch zu neuen Ufern. Die privatrechtlichen und rechtshistorischen Dissertationen der Berliner Universität im ersten Drittel des 20. Jahrhunderts im Kontext der Rechts- und Fakultätsgeschichte ... Berlin 2014. S. 523 (Register). Deutsche Biographie, s. https:// www.deutsche-biographie.de/gnd119223821.html [07.11. 2017].

$P$ Bildarchiv UAH. 


\section{Neumann, Carl}

1894-1903, 1911-1929 Phil. Fak.

Kunstgeschichte

* o1. Juli 186o Mannheim

$\dagger$ o9. Okt. 1934 Frankfurt/M.

口 Heidelberg

mosaisch, seit 17 . Juni $1887 \mathrm{ev.}$

V Jacob Samuel N. (1818-1895) Inhaber e. Kolonialwarengeschäfts en gros, s. Fink-Madera (1993) S. 13-15

M Nanny Emilia geb. Hirschhorn (1836-1909), s. ebd.

@ unverheiratet.

Lb Seit WS 1878/79 Studium der Klassischen Philologie, Geschichte, Philosophie an UH, seit WS 1879/80 Berlin, WS 1881/82 H; 26. April 1882 Dr. phil. an UH.

Eigenstudien: Frühsommer 1882 in Basel, seit Sommer 1882 München; 1884-1887 mehrere Studienreisen nach Italien, Griechenland, Ägypten, Palästina und Italien; 1887 Rückkehr nach Mannheim; in den Wintern 1888/89, 1889/9o und 189o/ 91 Reisen u. a. nach Athen, Konstantinopel, Ägypten, Palästina, Syrien und Rom; 1892-1893 Habilitationsvorbereitungen.

UH: 26. Mai 1894 Habilitation für Geschichte und Kunstgeschichte; seit 20. Juni 1897 nichtetatm. a. o. Prof.

U Göttingen: Seit 1. April 1903 a. o. Prof.; 1904 Rufe an U Breslau und TU Danzig abgelehnt.

U Kiel: Seit 1. Okt. 1904 persönlicher Ordinarius, s. hierzu Fink-Madera (1993) S. 24-33.

UH: 14. Jan. 1911 Ern. zum o. Prof. und Vorstand/ Direktor der Abt. für Neuere Kunst am Archäolog. Inst. (31. Juli 1916 Umbenennung in Kunsthistor. Inst. und Trennung vom Archäolog. Inst.) als Nachf. von Henry Thode; April 1911 Beginn seiner Lehrtätigkeit; nach 1918 schwere Depressionen mit „offenbar zum wiederholten Male“ Suizidversuchen: „Die Krankheit liegt in meiner Natur, aber die Auslösung hat immer auch eine äußere Ursa- che. Dieses Mal war es das nationale Unglück ...“ (aus: Fink-Madera (1993) S. 39 und Anm. 172); Nov. 1920 erneuter Suizidversuch; bis 1929 häufig dienstunfähig; 31. März 1929 Emeritierung; SS 1929 Vertreter seines Lehrstuhls.

1934 Übersiedlung nach Frankfurt/M. unter Beibehaltung seiner Wohnung in $\mathrm{H}$, Friedrichstraße 5 .

1913/14 Dekan der Phil. Fak. der UH

1907 Vorsitzender des Schleswig-Holsteinischen Kunstvereins

„Genieße Carl Neumann recht mit Bewusstsein, er ist ein seltener bunter Vogel mit seinem Gemisch von Geist und Witz, Zartheit, tiefer Empfindung und dabei wohl ab und an auch etwas Geziertheit ..." (aus: Friedrich Meinecke: Neue Briefe und Dokumente. Hrsg. von Gisela Bock und Gerhard A. Ritter; hier: Brief an Tochter Sabine Meinecke vom 22. Mai 1923. München 2012. S. 258 f.)

1917 Geh. Hofrat

E 1913 Mitglied der Akademie der Wiss. H. 1927 D. theol. UH. - 1909 Königl. Preußischer Roter Adler-Orden II. Klasse; 1914 Ritterkreuz I. Klasse des Ordens vom Zähringer Löwen.

Qu UAH PA 5198; RA 5683, 6398, 6448, 6850. • GLA Abt. 235, Fasz. 2343. • Bibliothek C. N. [Katalog.] Masch.geschr. Ex. 1935 in: UBH. • Nachlaß: UBH. • Die Kunstwissenschaft der Gegenwart in Selbstdarstellungen. Hrsg. von Johannes Jahn. Leipzig 1924. S. 33-76. (Autobiogr.)

$W$ Der Kampf um die neue Kunst. Berlin 1896. 2. Aufl. 1897. Rembrandt. 2 Bde. Stuttgart 1901. 4. Aufl. 1924. Heidelberg als Stadtbild. Heidelberg 1914. - Rembrandt: Handzeichnungen. München 1918. - Jacob Burckhardt. München 1927. • Bibliographie in: Fink-Madera (1993) S. 168-174.

$L$ Curtius, Ludwig Michael: Deutsche und antike Welt. Stuttgart 1950. S. 365 f. u.ö. • Professoren Kiel (1956) S. 156; WBIS. • Evers, Hans Gerhard: C. N. zum Gedenken in: Ruperto Carola 27 
(1960) S. 136-138. - Catalogus prof. Gottingensium (1962) S. 127; Glockner (1969) S. 275 (Register); Jansen (1992) S. 411 (Register); Ders. (1992a) S. 168 (Register). Czylin, Anna Maria: Henry Thode ... Leben und Werk. Frankfurt/M. 1993. S. 80, 125, 131, 187. - Fink-Madera, Andrea: C.N. 1860-1934. Frankfurt/M. 1993 (Abb. 14 zeigt (siehe) Philipp Wolfrum nicht C. N.). - Zehl Romero, Christiane: Anna Seghers. Eine Biographie. 19001947. Berlin 200o. S. 119, 122, 126, 133 f. • Hohenadl, Stefan: „... die Häute meines Herzens lösten sich.“ Anmerkungen zu C.N., einem Lehrer Wilhelm Fraengers an der Heidelberger Universität in: Neue Kunst - Lebendige Wissenschaft. Hrsg. von Susanne Himmelheber und Karl Ludwig Hofmann. Heidelberg 2004. S. 36-44. - Kriegstagebuch K. Hampe (2007) S. 984 (Register); Schubert (2008) S. 71f. u. ö.; Autoren der Bunsenbibliothek (2009 online); Lexikon jüdischer Einwohner Hs (2011) S. 313. - Über C. N. in: Kunstreligion. Bd. 2: Die Radikalisierung des Konzepts nach 1850. Hrsg. von Albert Meier u.a. Berlin 2012. S. 349-352. • Kaesler (2014) S. 1001 (Register). • Soroka, Tanja: C. N. ... „Rembrandt als Erlebnis und Forderung“, online unter http://www.kunstgeschichte.uni-kiel. de/de/geschichte-und-abschlussarbeiten/kik-carlneumann (abgerufen am 18. Aug. 2014) (Ausdruck im UAH). • Deutsche Biographie, s. https:// www.deutsche-biographie.de/gnd119132281.html [07.11.2017].

$P$ Bildarchiv UAH; graph. Slg. UBH; Ruperto Carola.

\section{Neumann, Friedrich (Fritz) Heinrich Georg}

1878-1882, 1890-1923 Phil. Fak. 1924-1930 (Lehrbeauftragter) Phil. Fak. Romanische Philologie; 1924-1930 Vulgärlateinische Sprachwissenschaft

* 23. April 1854 Warnemünde (Mecklenburg)

$\dagger \quad$ 03. Febr. 1934 Heidelberg

ev.-luth.

V Fritz N. († 1882) Kammermusikus

M Henriette geb. Plath (1824-1899)

(23. Mai 1882 Frida geb. Irion (1857-vor 1934)
K 2 S, 1 T, s. Kriegstagebuch K. Hampe (2007) S. 984 (Register).

Lb Seit WS 1872/73 Studium an U Berlin, WS 1874/ $75-\mathrm{SS} 1876 \mathrm{H}$.

UH: 11. Febr. 1876 Dr. phil.; 1876-1878 Hilfsarbeiter an UB; 5. April 1878 Habilitation für Romanische und Englische Sprache und Literatur; seit 16. Jan. 1882 a. o. Prof. für Romanische Philologie.

U Freiburg/Br.: Seit 6. Mai 1882 a.o. Prof. mit Staatsdienereigenschaft; seit 18. Juni 1883 o. Prof.

UH: Seit 4. Juni 1890 o. Prof. für Romanistik (in Nachf. von Emile Freymond) und bis 1923 MitDirektor (zus. bis Okt. 1919 mit Wilhelm Braune, 1902-1923 mit Johannes Hoops, 1920-1923 mit Friedrich Panzer) des Germanisch-Romanischen Seminars, Romanische Abt.; 1891 Ruf an U Gießen abgelehnt; 31. März 1923 Ruhestand; 1924-1930 Lehrbeauftragter für Vulgärlateinische Sprachwissenschaft.

1897/98 Dekan der Phil. Fak. der UH

N. ist der erste Ordinarius nur für Romanische Philologie an der Universität Heidelberg; seine Bibliothek mit 10 ooo-12 ooo Bänden ist heute zum Teil im Heidelberger Romanischen Seminar, zum Teil in der Universitätsbibliothek Heidelberg untergebracht, siehe hierzu Handbuch der historischen Buchbestände in Deutschland. Hrsg. von Bernhard Fabian. Hildesheim 2003.

1902 Hofrat; 1905 Geh. Hofrat

E 1909 Mitglied der Akademie der Wissenschaften H. 1926 Dr. phil. h.c. UH. 1899 Ritterkreuz I. Klasse, 1910 Ritterkreuz I. Klasse mit Eichenlaub vom Orden des Zähringer Löwen.

Qu UAH PA 5163; RA 6418f., 6840. - GLA Abt. 235, Fasz. 2342.

W Zur Laut- und Flexionslehre des Altfranzösischen hauptsächlich aus pikardischen Urkunden von Vermandois. Heidelberg 1878. • Die romanische Philologie, ein Grundriß. Leipzig 1886. 
MHG 1880-1929 Literaturblatt für germanische und romanische Philologie.

$L$ Wer ist's (1928) S. 1112; Kürschner (1931) Sp. 2075. Meier, Harri: F. N. zum 100. Geb. in: Ruperto Carola 17 (1955) S. 73 f. • Lehmann (1967) S. 234; Jansen (1992a) S. 168 (Register); Kriegstagebuch K. Hampe (2007) S. 984 (Register); Hausmann (2008) S. 807 (Register); Kalkhoff (2010) S. 36-38 u. ö.; Riecke (2016) S. 27, 41, 49.

$P$ Bildarchiv UAH; graph. Slg. UBH; Ruperto Carola.

\section{Neumann, Rudolf Otto}

1905-1910 Med. Fak.

Hygiene

* 29. Juni 1868 Seifhennersdorf (Sachsen)

$\dagger \quad$ 05. April 1952 Hamburg ev.

V Karl-Heinrich N. (1841-1918) Kantor

M Amalie Auguste geb. Augustin

( 1931 Elisabeth Minna Dorothea geb. Krützfeldt $(\dagger 1961)$

Vw Bruder: Bernhard N. (1867-1953), u. a. seit 1899 Privat-Dozent für Elektrochemie, Hüttenkunde, Probierkunst, seit 1904 Prof., seit 1906 apl. Prof. TH Darmstadt, 1914-1935 (Emeritierung) o. Prof. Breslau, nach 1945 o. Prof. Bergakademie Freiberg, seit 1948 kommissar. Leiter des Inst. für Organische Chemie ebd., 1951 Emeritierung, s. NDB 19 (1999) S. 135f., Hessische Biografie, s. http://www.lagis-hessen.de/ pnd/117551325 (Stand: 1. Mai 2017).

Lb Dresden: Seit 1886 pharmazeutische Ausbildung (ohne Reifeprüfung); 1889 pharmazeutisches Examen.

Seit 10. Mai 1890 Studium der Pharmazie, Chemie an U Greifswald, seit WS 1890/91 Leipzig; Okt. 1893 Apotheker-Staatsexamen in Leipzig.
U Erlangen: Seit WS 1893/94 Studium der Naturwiss.; Juni 1894 Dr. phil.

SS 1894 Studium der Medizin an U Würzburg; seit Juli 1894 Assistent am Hygienischen Inst. ebd.; WS 1894/95 Forts. des Studiums an U Straßburg, anschl. Berlin, Kiel; zwischenzeitlich Maturitätsprüfung; 1. März 1899 Dr. med. an U Würzburg; seit Okt. 1899 Hilfsarbeiter am Kaiserl. Gesundheitsamt in Berlin.

U Kiel: 1900-1902 Assistent am Hygienischen Inst.; 7. Juni 1902 Habilitation für Hygiene, Bakteriologie.

Hamburg: 1904 Abt.-Vorsteher am Hygienischen Inst.; 1904 Teilnahme an Expedition zum Studium des gelben Fiebers in Brasilien; seit Juli 1904 Assistent am Tropenhygienischen Inst. und am Seemannskrankenhaus.

UH: 6. Mai 1905 Umhabilitation; seit 12. Juni 1906 nichtetatm. a. o. Prof.; März-April 1908 Studien an Zoolog. Station in Neapel; 1909 Studienreise nach Ägypten (s. hierzu N., R.: Reise nach Ägypten über die Schweiz und Italien und Studienaufenthalt in Kairo 14.3.1909-5.5.1909. Bearb. und komm. von Felix Brahm. Bremen 2005); WS 1909/10 Lehrstuhlvertr. für emeritierten Franz Knauff.

U Gießen: 29. Dez. 1909 Ern. zum SS 1910 o. Prof. und Direktor des Hygienischen Inst.

U Bonn: SS 1914-SS 1922 o. Prof. und Direktor des Hygienischen Inst. In dieser Zeit:

1914-1918 Kriegsdienst als beratender Hygieniker.

U Hamburg: 1. Okt. 1922-30. Sept. 1935 (Emeritierung) o. Prof.; zwischen 1928 und 1931 Reisen nach Ostasien und in die USA; 1. Okt. 1935-30. Sept. 1937 kommissar. Vertreter seines Lehrstuhls. In dieser Zeit:

Hamburg: 1. Okt. 1922-30. Sept. 1935 (Entpflichtung) Direktor des Hygienischen Inst., 1923 umbenannt in Hygienisches Staatsinstitut, 1938 in Hygienisches Inst.; 1. Okt. 1935-30. Sept. 1937 kommissar. Direktor des Inst.; seit 1939 stellvertr. Mit-Direktor während des Feldeinsatzes seines 


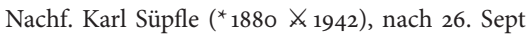
1942 (Süpfle fällt vor Stalingrad)-30. Sept. 1943 kommissar. Mit-Direktor des Hygienischen Inst.

Neumann hat von seinen Reisen eine $15000 \mathrm{Ob}$ jekte umfassende völkerkundlich-hygienische Sammlung zusammengetragen, die zum Teil im Hamburger Institut für Hygiene und Umwelt aufbewahrt wird.

1917 Geh. Medizinalrat

E 1933 Mitglied der Dt. Akademie der Naturforscher Leopoldina Halle/S.; Korr. Mitglied des Centro des Sciências, Letras e Artes São Paulo; 1943 Goethe-Medaille für Kunst und Wissenschaft. • 1910 Königl. Siamesischer Orden des Weißen Elefanten IV. Klasse; Orden der Rumänischen Krone III. Klasse; Kriegsverdienstkreuz.

Qu UAH PA 2049; RA 6794. • GLA Abt. 235, Fasz. 2344. - Siehe Nachlass Hans Harmsen N 1336/269 im Bundesarchiv Koblenz. - Siehe auch Archiv der Dt. Akademie der Naturforscher Leopoldina Halle/S. - Auskunft: Universitätsarchiv Greifswald; Institut für Hygiene und Umwelt Hamburg.

$W$ Die Bedeutung des Alkohols als Nahrungsmittel nach Stoffwechselversuchen am Menschen. Würzburg 1899 (siehe hierzu auch Rosemann, Rudolf: Über die angebliche eiweißsparende Wirkung des Alkohols. Eine kritische Besprechung der Arbeit von Dr. R. O. Neumann: Die Bedeutung des Alkohols ... in: Archiv für die gesammte Physiologie des Menschen und der Thiere. Hrsg. von E. F. W. Pflüger. Bonn 1899. Bd. 77. H. 7-8. S. 405424). Atlas und Grundriß der Bakteriologie und Lehrbuch der speziellen bakteriologischen Diagnostik. 2 T. München 1910. 7. Aufl. 1926-1927. • Atlas und Lehrbuch wichtiger tierischer Parasiten und ihrer Überträger mit besonderer Berücksichtigung der Tropenpathologie. München 1914. (Mitverf.) • Die im Kriege 1914-1918 verwendeten und zur Verwendung empfohlenen Brote, Brotersatz- und Brotstreckungsmittel unter Zugrundelegung eigener experimenteller Untersuchungen. Berlin 1920.
$L$ Geheimrat N. 6o Jahre in: Hamburger Fremdenblatt Nr. 178 vom 28. Juni 1928 (mit Photo). • WBIS; Arnim 2 (1952) S. 235, 4 (1984) S. 1165; Verzeichnis Bonn (1968) S. 210; NDB 19 (1999) S. $136 \mathrm{f}$. Hamburgische Biografie. Hamburg 2001. Bd. 1. S. 218 f. - Brahm, Felix: R.O.N. und seine Sammlung in: Hamburger Ärzteblatt. Zs. der Ärztekammer Hamburg und der Kassenärztlichen Vereinigung Hamburg. Hamburg 2002. S. 28; Ders.: R. O. N. Hygieniker, Zeichner, Sammler und Reisender 1868-1952. Hamburg 2003. • Steinmeier, Romy: „Hamburg hatte aber auch seine guten Seiten“. R. O.N. und das Hygienische Institut Hamburg. Bremen 2005.

\section{Niebergall, Friedrich Karl}

1903-1922 Theol. Fak.

Praktische Theologie

* 20. März 1866 Kirn (bei Bad Kreuznach)

$\dagger \quad$ 20. Sept. 1932 Marburg

ev.

V Jakob Philipp N., Realschuloberlehrer

M Anna Maria geb. Schug

( 20. Sept. 1892 Hedwig geb. Bremshey (18681948)

K 1 T, 5 S: u. a. Fritz N. $\left({ }^{*} 1894{ }{ }_{1918}\right)$, s. F. N.s Tagebuch unter http://www.europeana1914-1918. eu/de/contributions/612. Wilhelm N. (19041963), u. a. seit 1950 Privat-Dozent, 1956-1963 apl. Prof. für Wärme- und Kältetechnik am Inst. für Verfahrens- und Kältetechnik (seit 1959 Inst. für Kraftwerkstechnik und Apparatebau der Abt. Maschinenbau an Fak. V für Maschinenwesen) TH Berlin-Charlottenburg, u. a. seit 1950 auch wiss. Mitarbeiter der Abt. „Eis und Kälte“ bei der Rheinmetall-Borsig AG Berlin-Tegel, s. Arnim 4 (1984) S. 1171. Alfred N. (1909-1978), u. a. 1935-1946 Pfarrer in Marburg, seit 1955 Privat-Dozent Göttingen, 19591978 o. Prof. für Praktische Theologie und UPrediger sowie 1962-1964 Rektor Marburg, s. Catalogus prof. Marburgensis 2 (1979) S. 39, WBIS, BBKL (2018 in Vorbereitung) 
Vw Enkel: Hans-Helmut (Johannes; Buschi) N. (1938-1992) Jazzkomponist, Bassist, s. NDB 19 (1999) S. $215 \mathrm{f}$.

Lb Seit WS 1884/85 Studium an U Tübingen, anschl. Berlin, Bonn; Okt. 1889 II. theol. Prüfung in Bonn.

1890-1892 Provinzialpfarrvikar in Ohligs (heute: Stadtteil von Solingen); 1892-1903 Pfarrer in Kirn; 22. Juni 1902 Lizentiatenprüfung an U Gießen.

UH: 2. Mai 1903 Habilitation; seit 29. Mai 1908 nichtetatm., 1920-Apr. 1922 nichtplanm. a.o. Prof.; 21. Jan. 1909-15. April 1910 stellvertr. Lehrer für die beiden zurückgetretenen Ordinarien für Systematische Theologie, Ludwig Lemme und Ernst Troeltsch, am Praktisch-Theol. Seminar; N. übernimmt den „Unterricht im ... Seminar, insbesondere die Abhaltung der systematischen Übungen und des Universitätsgottesdienstes“ (aus: Brief des Ministeriums der Justiz, des Kultus und Unterrichts vom 29. Dez. 1908 in: UAH RA 6127) mit Bewilligung e. Semesterhonorars von 400.- Mark (aus: UAH RA 6754 fol. 4r); 28. Okt. 1909 ministerielle Bewilligung zur „Abhaltung von Vorlesungen über Geschichte und System der Pädagogik mit 4 Stunden wöchentlich mit dem üblichen Honorar von 200.- Mark für die Vortragsstunde sowie für die Übernahme von weiteren je $1^{1 / 2}$ Stunden Uebungen am praktisch-theologischen Seminar mit einem Honorar von 10o.- Mark für die Uebungsstunde“ (aus: RA 6754 fol. 3r); seit 15. April 1910 Lehrauftrag zur „Vertretung der praktischen Theologie in Vorlesungen und Übungen (letztere im [Praktisch-Theol.] Seminar) nach Vereinbarung mit dem Fachordinarius [Johannes Bauer] unter gleichzeitiger Verpflichtung zur Beteiligung am Universitätsgottesdienste gegen Bewilligung eines Semesterhonorars von 60o.- Mark“, seit 15. April 1914 von 1000.- Mark (aus: RA 6754 fol. $4 \mathrm{r}, 5 \mathrm{r}$ ).

U Marburg: Seit 7. April 1922 o. Prof. und U-Prediger.

Siehe Johannes Rissom: Eintrag unter Z[itat] (3)

Siehe auch Anhang Sporteinrichtungen an UH 1910-1933 und ihre Mitglieder
E 1910 D. theol. Berlin.

Qu UAH PA 5175; RA 6127, 6754. GLA Abt. 235, Fasz. 2346. Auskunft: Universitätsarchiv TU Berlin (Codex Professorum).

$W$ Wie predigen wir dem modernen Menschen? Tübingen. Bd. 1: 1902. 4. Aufl. 1920. Bd. 2: 1906. 3. Aufl. 1917. Bd. 3: 1921. Die paulinische Erlösungslehre ... Tübingen 1904. 2. Aufl. 1909. • Praktische Auslegung des Neuen Testaments. Tübingen 1909. 3. Aufl. 1923. - Jesus im Unterricht. Göttingen 1910. 5. Aufl. 1932. • Praktische Auslegung des Alten Testaments. 3 Bde. Göttingen 1912-1922. 2. Aufl. 1925. - Lebensinhalt. Ein Vermächtnis deutschen Glaubens. Berlin 1918. • Praktische Theologie. Lehre von der kirchlichen Gemeindeerziehung auf religionswissenschaftlicher Grundlage. 2 Bde. Tübingen 1918-1919. • Der neue Religionsunterricht. Methodik und Anleitung im Geiste der Arbeitsschule. 2 Bde. Langensalza 19221926. - Siehe BBKL VI (1993).

MHG Seit 1904 Praktische theologische Handbibliothek.

$L$ Catalogus prof. Marburgensis 2 (1979) S. 39; Arnim 4 (1984) S. 1171; Jansen (1992) S. 411 (Register); Ders. (1992a) S. 168 (Register); BBKL VI (1993) Sp. 708-717; Fix (1994) S. 29-51. • Emersleben, Lars: Kirche und praktische Theologie. Eine Studie über die Bedeutung des Kirchenbegriffes für die praktische Theologie anhand der Konzeptionen von ... F. N. Berlin 1999. - NDB 19 (1999) S. 214 f. (irrtümlich 30. statt 20. als Geb.- und Todestag angegeben); WBIS. • Schulte, Andrea: Welt als Thema der Religionspädagogik. Der Beitrag F. N.s. Waltrop 2002. - Kronhagel, Kristian Klaus: Religionsunterricht und Reformpädagogik. Otto Eberhards Beitrag zur Religionspädagogik in der Weimarer Republik. Münster 2004. S. 182-19o. • Personenlexikon zum dt. Protestantismus (2006) S. 185. - Schnepper, Arndt Elmar: Goldene Buchstaben ins Herz schreiben. Die Rolle des Memorierens in religiösen Bildungsprozessen. Göttingen 2012. S. 158-161 u. ö. Conrad, Ruth: Kirchenbild und Predigtziel. Eine problemgeschichtliche Studie zu ekklesiologischen Dimensionen der Homiletik. Tübingen 2012. S. 343-409 u. ö. • Troeltsch- 
Gesamtausgabe 19 (2014) S. 505 (Register). • F. N. Werk und Wirkung eines liberalen Theologen. Hrsg. von David Käbisch. Tübingen 2016.

\section{Nippold, Friedrich Wilhelm Franz}

1865-1872 Theol. Fak.

Kirchengeschichte

* 15. Sept. 1838 Emmerich

$\dagger \quad$ 03. Aug. 1918 Oberursel (Taunus) ev.

V Friedrich Wilhelm N. (†1882) Stadtrentmeister

M Helene geb. van Koetsveld (1805-1860)

( 11. Aug. 1863 Auguste geb. von Wahl-Kawast (1835-1903)

( 20. Aug. 1907 Marie Berta geb. Möhling verw. Schumacher (1847-1922), s. NDB 19 (1999) S. $284^{*}$

K 1 T, 2 S: u. a. Dr. iur. Otfried N. (1864-1938) seit 1889 Lehrer an Rechtsschule des Vereins für dt. Wissenschaften in Tokio, 1892-1905 (mit Unterbrechung) Rechtsanwalt in Thun und Bern, 1896-1898 im diplomatischen Dienst des Deutschen Reichs, seit 1905 Privat-Dozent für Völkerrecht an U Bern, 1911 Mitbegründer und bis 1914 Sekretär des Verbands für int. Verständigung in Frankfurt/M., 1914 Rückkehr nach Bern, 1919 Gründer der Schweizerischen Vereinigung für den Völkerbund und Mitglied der Eidg. Expertenkommission für den Völkerbund, 1920-1934 Präsident des Obersten Gerichtshofs und des Oberverwaltungsgerichts für das vom Völkerbund verwaltete Saargebiet in Saarlouis, 1934 Rückkehr in die Schweiz, 1927-1934 auch Prof. für Völkerrecht an U Bern, s. Nakai, Akio: O. N. und der Erste Weltkrieg. Kriegsursache und Kriegsschuld nach einem Schweizer Rechtsgelehrten in: Sophia University Repository for Academic (31.03.1996) S. 50-72; NDB 19 (1999) S. 284; Riehle, Bert: Eine neue Ordnung der Welt. Föderative Friedenstheorien im deutschsprachigen Raum zwischen 1892 und 1932. Göttingen 2009. S. 389 (Register). - Nachlass in Burgerbibliothek Bern.
Lb Seit WS 1856/57 Studium der Theologie, Philosophie an U Halle/S.; Mitte 1858 Rückkehr nach Emmerich aufgrund e. „eingetretene[n] doppelte[n] Unglücksfall[es] in meiner Familie" (aus: UAH PA 2054 fol. 6v).

U Bonn: 22. Okt. 1858-WS 1859/6o Immatrikulation; Ende SS 1859 Gewinner der Preisfrage „Über die verschiedenen Arten des Antinomismus in der ev. Kirche“; Nov. 1859 Aufgabe des Studiums durch ein „sich einstellendes Brustleiden, das so heftig auftrat, daß ich auf Befehl des Arztes ohne Verzug Bonn verlassen ... mußte. $\mathrm{Zu}$ Hause aber, wo meine Mutter an einer unheilbaren Krankheit dahinsiechte, konnte sich mein kränklicher Zustand nur noch verschlimmern, während mir zugleich alle Mittel fehlten, um den Wunsch des Arztes, daß ich ein südliches Klima aufsuchen sollte, nachkommen zu können“ (aus: PA 2054 fol. 7r).

Amsterdam: 1860 Einladung von holländischen Freunden nach A.: „... ich fand auf eine Art, an die ich bis dahin am wenigsten gedacht hatte, wieder eine Art von Beruf, woran ich mich aufraffen konnte ..." (aus: PA 2054 fol. 7r): Quellenstudien an Urkunden über den Antinomismus; in dieser Zeit: Sommer 1860 Dr. phil. an U Bonn.

Publikationstätigkeiten bei Aufenthalten: Winter $1860 / 61$ „durch geliehene Gelder ... in einem milderen Klima“ am Genfer See (aus: PA 2054 fol. 7v), Sommer und Herbst 1861 teils im Süden Frankreichs und teils in Emmerich, seit Jan. 1862 in Ägypten und Palästina (ich konnte „endlich dem Wunsche des Arztes ... [der] nur im ägyptischen Klima ... [möglichen] völlige[n] Genesung ... nachkommen, durch gnädigst bewilligte Unterstützungen Seiner Majestät“, König Wilhelm I. „und des (preußischen) Kultusministers“ (aus: PA 2054 fol. 7v); Sommer 1862 Erkrankung durch „syrisches typhöses Fieber ... Nach endlich erfolgter Genesung (war ich) über ein halbes Jahr zu jeder Thätigkeit unfähig, auch nachdem man mich Mitte September (1862) von Jerusalem nach Kairo zurücktransportiert hatte ... Nachdem ich endlich gegen Ende 1862 neue Arbeitskraft gewonnen [hatte], beschäftigten mich in den letzten Monaten meines ägyptischen Aufenthaltes theils eigentlich ägyptologische Studien, theils eine deutsche 
Bearbeitung der Scholtenschen Dogmatik“ [Johannes Henricus Scholten (1811-1885) niederländischer ref. Theologe] (aus: PA 2054 fol. 8r); Anfang Mai 1863 Rückkehr "nach einer abermals durch Fieber belohnten [!] Reise an den Suez Kanal nach Europa ..., wo ich durch glückliche Fügung der Umstände in den Stand gesetzt wurde, das eigene häusliche Leben [1863 Verehelichung], das ärztlicherseits für das beste Heilmittel meines Körperleidens erklärt worden war, sofort beginnen zu können“ (aus: PA 2054 fol. 8r).

Wiesbaden: Mitte 1863-Sept. 1864 Wohnsitz; in dieser Zeit Publikationstätigkeiten und Eigenstudien; Sept./Okt. 1864 Umzug nach H.

UH: 26. Nov. 1864 Theol. Lizentiatenprüfung; 28. Jan. 1865 Verleihung der venia legendi ohne Abgabe e. „Habilitationsdissertation, ... da schon mehrere, bei meinem Gesuch um Ertheilung des Licentiaten Grades mit vorgelegte Arbeiten von mir durch den Druck veröffentlicht sind" (aus: UAH Theol. Fak. 37 fol. 69r); 1865-1867 Privat-Dozent; 29. Nov. 1867 Ern. zum a. o. Prof.

U Bern: Seit 1. Jan. 1872 o. Prof.

U Jena: 26. April 1884-1. Okt. 1907 (Emeritierung) o. Prof.

1883 Mitbegründer des Allg. Ev.-Prot. Missionsvereins, s. hierzu Buß, Ernst: Zur Vorgeschichte des Allg. Ev.-Prot. Missionsvereins in: OstasienJahrbuch. Nr. 3. Berlin 1924. S. 63-78. - Siehe auch Heinrich Bassermann

1886 Mitbegründer des Ev. Bundes und Vorstandsmitglied des Gustav-Adolf-Vereins, ältestes ev. Hilfswerk in Deutschland (für ev. Minderheiten in der Diaspora) mit Sitz in Leipzig

\section{E 1870 Dr. h.c. Leiden.}

Qu UAH PA 2054; Fak.-Akten Theol. Fak. 37 fol. 1r-6ov, 67r-73r, 78r-79r, Theol. Fak. 40 Nr. 1522, 1534. - Nachlaß: Thüringer Universitäts- und Landesbibliothek Jena. • Auskunft: Universitätsarchiv Bonn; Universitätsarchiv Jena.
$W$ Die niederländischen Taufgesinnten in: Allg. kirchliche Zeitschrift (1861) S. 618-628. Handbuch der neuesten Kirchengeschichte. 5 Bde. Elberfeld 1867. 3. Aufl. 1880-1906. - Ursprung, Umfang, Hemmnisse und Aussichten der altkatholischen Bewegung. Berlin 1873. - Richard Rothe. 2 Bde. Wittenberg 1873-1874. 2. Aufl. 18771878. Ziele und Vorgeschichte des Ev. Bundes. Berlin 1889. Die Verschuldung des deutschen Protestantismus an der Oberherrschaft des Papsttums über das deutsche Reich. Leipzig 1899. • Die Wege nach Rom und die Los-von-Rom-Bewegungen. Bonn 1909.

Mitarbeiter Seit 1861 Protestantische Monatsblätter für innere Zeitgeschichte: Studien der Gegenwart für die ev. Länder deutscher Zunge.

$L$ F.N. zum Gedächtnis in: Int. Kirchliche Zeitschrift. N. F. der Revue internationale de théologie. Bd. 8 (1918) H. 4. S. 297-302. • Herderscheê, Jacobus: Levensbericht van F. N. in: Jaarboek van de Maatschappij der Nederlandse Letterkunde (1919) S. 31-42. - Mennonitisches Lexikon. Hrsg. von Christian Hege ... Bd. 3. Karlsruhe 1958. - RGG $4\left({ }^{3} 1960\right)$ Sp. 1498; WBIS; BBKL VI (1993) Sp. 950952; Wischmeyer (2008) S. 469 (Register). • Gerber, Stefan: Die Universität Jena 1850-1918 in: Traditionen - Brüche - Wandlungen. Die Universität Jena 1850-1995 ... Köln 2009. S. 197-200. • Lönnecker, Harald: „Das Thema war und blieb ohne Parallel-Erscheinung in der deutschen Geschichtsforschung“. Die Burschenschaftliche Historische Kommission ... und die Gesellschaft für Burschenschaftliche Geschichtsforschung e.V. (1898/1909-2009). Eine Personen-, Institutionsund Wissenschaftsgeschichte. Heidelberg 2009. S. 107 f. u. ö. - Deutsche Biographie, s. https:// www.deutsche-biographie.de/gnd117022012.html [07.11. 2017].

$P$ Bildarchiv UAH; graph. Slg. UBH. 


\section{Nissl, Franz Alexander}

1896-1918 Med. Fak.

Psychiatrie

* o9. Sept. 186o Frankenthal (Pfalz)

$\dagger$ 11. Aug. 1919 München

kath.

V Georg Joseph Michael Theodor N. (18241884) Gymnasiallehrer

M Maria Franzisca geb. Haas ( $† 1868)$

$\infty$ unverheiratet.

Lb U München: Seit WS 188o/81 Studium der Medizin; 23. Dez. 1884 Approbation; 31. Jan. 1885 Dr. med.

München: Seit 1. Jan. 1885 Assistent (von Bernhard von Gudden (1824-1886 im Starnberger See zus. mit König Ludwig II. von Bayern umgekommen) seit 1873 Ordinarius an U und Direktor der Oberbayer. Kreisirrenanstalt München, Verfasser des Gutachtens für die Entmündigung Ludwigs II.) an genannter Kreisirrenanstalt und Mit-Betreuer des psychisch kranken Prinzen Otto von Bayern (1848-1916) auf Schloß Fürstenried.

Blankenhain (bei Weimar): Seit Okt. 1888 Assistent am Carl-Friedrich-Hospital.

Frankfurt/M.: Seit 18. März 1889 II. Arzt an Städtischer Irrenanstalt.

UH: Nov. 1895-1904 Zunächst Assistenzarzt, anschl. Hilfsarzt an U-Irrenklinik; 12. Dez. 1896 Habilitation; WS 1898/99 (erstmals im Vorlesungsverzeichnis erwähnt)-WS 1917/18 Leiter des Anatom. Laboratoriums der U-Irrenklinik; Okt.-Dez. 1899 Studien an Zoolog. Station in Neapel; seit 21. Jan. 1901 nichtetatm. a. o. Prof.; 22. Juli 1904 Ern. zum WS 1904/05 0. Prof. und Direktor der UIrrenklinik (SS 1907 im Personalverzeichnis der UH erstmals als Psychiatr. Klinik bezeichnet) als Nachf. von Karl Bonhoeffer.

München: Seit 1. April 1918 o. Prof. an U und Vorstand der I. Anatom. Abt. an der von (siehe) Emil
Kraepelin gegründeten Dt. Forschungsanstalt für Psychiatrie, heute: Max-Planck-Institut für Psychiatrie.

1910/11 Dekan der Med. Fak. der UH

1890 führt N. u.a. die nach ihm benannte Färbetechnik bei Nervenzellen ein (Nissl-Färbung)

1914 Geh. Hofrat

E 1909 Mitglied der Akademie der Wissenschaften H. 1909 Friedrich-Luisen-Medaille; 1910 Ritterkreuz I. Klasse des Ordens vom Zähringer Löwen.

Qu UAH PA 1093, 2056; RA 5225, 6809, 7249. • GLA Abt. 235, Fasz. 2348.

$W$ Über eine neue hirnanatomische Methode speziell zur Feststellung der Lokalisationsverhältnisse der Nervenzellen in: Centralblatt für Nervenheilkunde und Psychiatrie (Juli 1894). • Der gegenwärtige Stand der Nervenzellenanatomie und -pathologie in: Allg. Zeitschrift für Psychiatrie 51 (1895). Die Verwertung des anatomischen Materials in Irrenanstalten in: Münchener Med. Wochenschrift 43 (1898). - Die Neuronenlehre und ihre Anhänger. Jena 1903. Zur Lehre der Lokalisation in der Großhirnrinde des Kaninchens. Heidelberg 1911. • Ein Fall von Paralyse mit dem klinischen Verlauf einer Dementia praecox. Berlin 1915.

$L$ Stübler (1926) S. 325. Cerletti, Ugo: Erinnerungen an F.N. Sonderdruck. München 1959. - Große Nervenärzte 2 (1959) S. 13-31; Arnim 4 (1984) S. 1177; Chronik Ärzte H (1985) S. 138, 257 f.; Jansen (1992a) S. 168 (Register). - Die Pathologen der Rheinpfalz. Hrsg. von Gerhard Bräunig und Wilhelm Doerr. Berlin 1994. S. 34-41 u. ö. • Wennemuth (1994) S. 637 (Register); WBIS; NDB 19 (1999) S. 29of.; Müller-Küppers (2004) S. 15; Peiffer (2004) S. 1171 (Register); Ärztelexikon (2006) S. 241f. - Enzyklopädie Medizingeschichte. Hrsg. von Werner E. Gerabek u. a. Berlin 2005. S. 1054.

$P$ Bildarchiv UAH; Große Nervenärzte; Chronik Ärzte H. 


\section{Noether, Max}

1870-1875 Phil. Fak.

Mathematik

* 24. Sept. 1844 Mannheim

$\dagger$ 13. Dez. 1921 Erlangen

mosaisch, seit Nov. 1920 konf.-los

V Hermann N. (1807-1894) Kaufmann

M Amalia (Malchen) geb. Würzburger (18121872)

$\varnothing$ 28. Aug. 1880 Ida Amalie geb. Kaufmann (1852-1915)

K 1 T: Amalie (Emmy) N. (1882-1935), u. a. 19221933 (Entziehung der Lehrbefugnis) a. o. Prof. für Mathematik an U Göttingen, seit 1933 Gast-Prof. am Bryn Mawr College in Bryn Mawr, e. Vorort von Philadelphia (Pennsylvania), s. „Des Kennenlernens werth“. Bedeutende Frauen Göttingens. Hrsg. von Traudel Weber-Reich. Göttingen 1993. S. 227-247; NDB 19 (1999) S. 320 f.; „Aller Männerkultur zum Trotz" (2008) S. 149-176 u. ö.; Göttinger Köpfe und ihr Wirken in die Welt. Hrsg. von Stine Marg und Franz Walter. Göttingen 2012. S. 7380; Riecke (2016) S. 42; Lexikon der Mathematik (2017) S. 71 f. 3 S: u. a. Fritz N. (18841941), u. a. 1922-1933 Prof. für Mathematik an TH Breslau, s. NDB 19, S. 321 f. - Siehe auch Siegmund-Schultze (2009) S. 467 (Register)

Vw Enkel: Gottfried N. (1915-1991), u. a. 1951-1968 Prof. für Math. Statistik an Boston U (Massachusetts), s. NDB 19, S. 322 f.

Lb UH: WS 1866/67-WS 1867/68 Studium der Mathematik, Physik; 5. März 1868 Dr. phil.

1868-1869 Eigenstudien an U Gießen, anschl. Göttingen; 1869/70 Habilitationsvorbereitung.

UH: 26. Nov. 1870 Habilitation; seit 25. Sept. 1874 a. o. Prof.

U Erlangen: Seit 1. April 1875 a. o. Prof.; seit 16. April 1888 o. Prof.; 1. April 1918 Befreiung von der Verpflichtung, Vorlesungen zu halten.
E Mitglied der Akademie der Wissenschaften: 1887 München, 1892 Göttingen, 1896 Berlin sowie weitere Auszeichnungen und Ehrungen.

Qu UAH PA 2059; Fak.-Akten H-IV-102/68 fol. 227r-229r, 232r, H-IV-102/73 fol. 29r, 3or. • Auskunft: Universitätsarchiv Erlangen. - Mitteilungen: Frau Dr. Cordula Tollmien, Hannoversch Münden.

$W$ Über einen Satz aus der Theorie der algebraischen Funktionen in: Math. Annalen 6 (1872) S. 351-359; Zur Theorie der Thetafunktionen von beliebig vielen Argumenten in: ebd. 16 (1879) S. 270-344. - Zur Grundlegung der Theorie der algebraischen Raumkurven. Preisschrift in: Abhandlungen der Preußischen Akademie der Wissenschaften (1882) S. 1-120. - Zur Theorie der Abelschen Differentialausdrücke und Funktionen in: Math. Annalen 37 (1890) S. 417-46o, 465499. Die Entwicklung der Theorie der algebraischen Funktionen in älterer und neuerer Zeit in: Jahresbericht der dt. Mathematiker-Vereinigung 3 (1894) S. 107-566 (gemeinsam mit Alexander Brill).

$L$ Wer ist's (1914) S. 1199. • Castelnuovo, G., Enriques, F., Severi, F.: M.N. (Nachruf mit Schriftenverzeichnis) in: Math. Annalen 93 (1925) S. 161181. Poggendorff 6 (1938) S. 1870; Arnim 2 (1952) S. 248; Math. Institute in Deutschland (1989) S. 286 (Register); NDB 19 (1999) S. 319 f.; Willett (2001) S. 200 f., 282; Badische Biographien N.F. V (2005) S. 216-218. • Jüdische Mathematiker in der deutschsprachigen akademischen Kultur. Hrsg. von Birgit Bergmann, Moritz Epple. Berlin 2009. S. 68f., 84-86 u. ö. - Professoren Erlangen (2009) S. 149 f.; Homo Heidelbergensis mathematicus online; WBIS. • Lexikon der Mathematik. Bd. 4: Moo bis Sch. Hrsg. von Guido Walz. 2. Aufl. Heidelberg 2017. S. $72 \mathrm{f}$.

$P$ Bildarchiv UAH.

1917 Geh. Hofrat 
Nohl, Ludwig Carl Friedrich

1860-1861 (1863), 1872-1885 Phil. Fak.

1860-1861 (1863) Ästhetik der Tonkunst

1872-1885 Geschichte und Ästhetik der Musik

(Musikwissenschaft)

* 05. Dez. 1831 Iserlohn

$\dagger$ 15. Dez. 1885 Heidelberg prot.

V Franz Ludwig N. (1801-1880) Advokat, Justizrat, s. Kayser, Andrea: F. L. N. - Ursachen und Verlauf der Revolution 1848/49 in: Iserlohn in der Revolution 1848/49 - Darstellungen und Quellen aus: Beiträge zur Geschichte Iserlohns. Iserlohn 2000.

M Constanze geb. Lecke (1802-1853), s. Schulte, Wilhelm: Iserlohn. Die Geschichte einer Stadt. Iserlohn 1937. Bd. 1. S. 350 f.

๑ Emma geb. Westberg (1839-1901/02)

K $5 \mathrm{~S}, 4 \mathrm{~T}$

Vw Bruder: Maximilian (Max) N. (1830-1863) Architekt, s. Schulte, Wilhelm (1937) S. 352-354; Aleweld, Norbert: M.N. in: Hermann Holtmeier: Markante Köpfe aus dem Märkischen Kreis. Iserlohn 1997.

Lb Seit WS 1849/50 („nach dem Wunsch meines Vaters“, aus: Lebenslauf vom 5. Dez. 1859 in: UAH PA 2060) Studium der Rechtswiss., auch „Architectur und Plastik“ an U Bonn, seit WS 1851/52 neben Rechtswiss. auch "Schöne Litteratur" an UH, seit WS 1852/53 Berlin; 1852 I. jur. Staatsexamen in Berlin.

Berlin: Seit 1852 jur. Ausbildung; außerdem Studium der Musikwiss. sowie Eigenstudien der „Museen und des Theaters, die mir zu häuslichen Studien in der Aesthetik die erforderlichen Anschauungen gewährten; schon damals im Jahre 1852, zu meinem jetzigen Berufe überzugehen, verhinderte mich der Wunsch meines Vater[s], der selbst Jurist ist“ (aus: Lebenslauf vom 5. Dez. 1859 in: PA 2060); 1856 II. jur. Staatsexamen; 1856 Studienreise („zur Wiederherstellung meiner körperlich sehr geschwächten und kranken“ Konstitution, aus: ebd.) nach Paris und Süd-Frankreich, nach Genua, Neapel und Rom („mein Gesundheitszustand verhinderte mich nur wenig an der
Betrachtung der Gegenstände, die für mein Interesse bedeutend waren“, aus: ebd.).

„Nach der Rückkehr ward mir der Wiedereintritt in den Staatsdienst vom Arzte nicht erlaubt. Nachdem ich eine Weile in meiner Vaterstadt [Iserlohn] gelebt, wiederum mit litterarischen Studien beschäftigt, mußte ich zur [Be]Hebung des Leidens, das immer noch nicht nachgelassen, einen Winter in Berlin zubringen und ergänzte dort meine musikalischen Studien, die ich bereits zur Universitätszeit unter Leitung des Professors [Siegfried Wilhelm] Dehn [(1799-1858), später auch bei e. Schüler Dehns, Friedrich Kiel (1821-1885)] dort begonnen hatte“ (aus: Lebenslauf vom 5. Dez. 1859 in: PA 2060).

H: Seit 1858 Wohnsitz; seit 1859 „Lehrer der Musik, Kettengasse 25“, s. Einwohner-Verzeichniß der Stadt Heidelberg nebst Angabe ihrer Wohnungen und Gewerbe in alphabetischer Ordnung für 1860 und 1861. Heidelberg 1860. S. 69.

UH: 10. März 1859 Dr. phil.; 12. März 1860 Habilitation für Ästhetik der Tonkunst, siehe hierzu $Z$; SS 1861 letzte Vorlesungsankündigung; WS 1861/62 und SS 1862 Beurlaubung aus Krankheitsgründen, s. hierzu PA 2060 (Frühling 1862 nach ärztlichem Rat mehrmonatige Erholung ohne ,jede Anstrengung des Geistes“, aus: Brief vom 1. Febr. 1862 in: PA 2060); Sommer 1862 Studium „auf der an musikalischen Schätzen überaus reichen Staatsbibliothek" in München (aus: Brief vom 1. Febr. 1862 in: ebd.); WS 1862/63 letzte Erwähnung als Mitglied des Lehrkörpers.

München: Seit Frühjahr 1863 Privatier, Schriftsteller.

U München: 1. Jan. 1865-1868 Ehrenprofessur, verliehen von König Ludwig II. von Bayern (18451886) für Geschichte und Ästhetik der Tonkunst in der philosophischen Fakultät ohne Lehrverpflichtung.

Badenweiler: 1868-1872 Privatier, Schriftsteller; 1868-1870 Studienreisen u.a. nach Wien, St. Petersburg. 
UH: Seit 22. Juli 1872 Privat-Dozent; Nov. 1873 Vortragsreise nach Budapest und Warschau; seit April 1875 Bewilligung e. jährl. Honorars von 1000.Mark für Abhaltung der Vorträge über Geschichte und Ästhetik der Tonkunst; 16. März 1877 Phil. Fak. und Engerer Senat lehnen N.s Gesuch um Verleihung e. a. o. Professur mit der Begründung ab, weil der Senat „erstens die Gründung einer Lehrstelle für Musik für unzweckmäßig und überflüssig erachtet, da es zweitens, wenn es sich um die Errichtung einer solchen Professur handeln sollte, den Petenten nicht als die hierzu geeignete Persönlichkeit betrachten könne, daher drittens im Hinblick auf dessen jüngste Schrift „Unsere geistige Bildung“ [Leipzig 1877] überhaupt eine Beförderung des Dr. Nohl an hiesiger Universität nicht empfehlen könne" (aus: Brief des Engeren Senats an Ministerium des Innern vom 16. März 1877 in: PA 2060); seit 17. März 1881 a. o. Prof. • In dieser Zeit:

Polytechnikum Karlsruhe: 4. Nov. 1875 Erteilung der Genehmigung zur Abhaltung von Vorlesungen über die Geschichte und Ästhetik der Tonkunst.

$Z$ Am 4. Febr. 1860 schreibt Otto Hesse, Dekan der Phil. Fak., zur Habilitation N.s über „Aestetik der Tonkunst" an den Engeren Senat der UH: „Das von Dr. Nohl gewählte Lehrfach ist zwar auf unserer Univ. ein neues, dessen technische Seite eher aus dem Gesichtskreise der Facultätsmitglieder liegt, aber die Facul. glaubt dennoch, das Gesuch des Dr. Nohl befürworten zu müssen, um einer neuen, sich erst bahnbrechenden Geistesrichtung die Gelegenheit zu bieten, sich auch auf unserer Universität Geltung zu verschaffen" (aus: UAH H-IV-102/57 fol. 12r).

Qu UAH PA 2060; RA 5237, 5278; Quästurakten Rep. 27-93o f.; Fak.-Akten H-IV-02/56 fol. 79r-85r, H-IV-102/57 fol. 3r-12r. • GLA Abt. 6o, Nr. 297. • Sowa, Georg: Zwölf Original-Briefe Franz Liszts an L.N. in: Fritz Kühn zum Gedächtnis aus: Beiträge zur Geschichte Iserlohns. Iserlohn 1968. • Nachlaß: Stadtarchiv Iserlohn. Staehelin, Martin: Die Beethoven-Materialien im Nachlaß von L.N. in: Beethoven-Jahrbuch. Bonn 1981. S. 201-220. • Beethoven's letters ... from the collection of Dr.
L. N. Ed. and transl. by Grace Jane Wallace. 2 Vol. Cambridge 2014. - Auskunft: Stadtarchiv Heidelberg. Mitteilungen: Herr Prof. Dr. Matthias Kruse, Stiftung Universität Hildesheim.

W Der Geist der Tonkunst. Frankfurt/M. 1861. • Beethoven's Leben. 3 Bde. Leipzig 1864-1877. 4. Aufl. 1922. Gluck und Wagner. Über die Entwicklung des Musikdramas. München 1870. • Musik und Musikgeschichte. Ansprache zur Eröffnung seiner [L.N.s] Lehrtätigkeit an der Großherzoglichen Polytechnischen Schule in Karlsruhe am 17. November 1875. Karlsruhe 1876 (S. 4-13: Lebensskizze L.N.s). - Mozart nach den Schilderungen seiner Zeitgenossen. Leipzig 1880. 4. Aufl. 1920. Allgemeine Musikgeschichte. Leipzig 1881. Beethoven. Leipzig 1882. B Briefwechsel zwischen Carl Maria von Weber und Thaddäus Susan. Abschrift nach den Veröffentlichungen von Friedrich Witthauer (1843) und L.N. (1882). Blätter des Gedenkens zus.gestellt von Friedrich Susan. Wien 1986.

$H G$ Briefe Beethovens. Stuttgart 1865. Mozart's Briefe. Nach den Originalen ... Salzburg 1865. • Neue Briefe Beethovens ... Stuttgart 1867.

L ADB 23 (1886) S. 755-757. - Schulte, Wilhelm: Iserlohn. Die Geschichte einer Stadt. Iserlohn 1937. Bd. 1. S. 354-357. MGG 9 (1961) Sp. 1551 f.; WBIS. • Hasch, Michael: C. F. L. N. ... Untersuchungen zu Leben und Wirken eines Iserlohner Musikhistorikers. Münster 1998. NDB 19 (1999) S. $324 \mathrm{f}$.

$P$ Bildarchiv UAH; graph. Slg. UBH.

\section{Nuhn, Johann Anton}

1842-1873 Med. Fak. 1873-1889 (Honorar-Prof.) Med. Fak.

Anatomie

* 21. Juni 1814 Schriesheim (bei Heidelberg)

$\dagger \quad$ 28. Juli 1889 Heidelberg

口 30. Juli 1889 ref. 
V Henrich N. $\left({ }^{*}{ }_{1784}\right)$ zunächst Schneidermeister, später Anatomiediener an $\mathrm{UH}$

M Anna Barbara Denzler/Dentzlin $\left({ }^{*} 1791\right)$

$\infty$ 12. Juli 1842 Caroline Boos († vor 1889; kath.)

$\mathrm{K} \quad 1 \mathrm{~T}$

Lb UH: Seit WS 1834/35 Studium; 19. Nov. 1838 Dr. med.; 5. Jan. 1842 Habilitation; seit Sommer 1844 Prosektor; seit 29. Sept. 1848 a. o. Prof.; seit 26. Okt. 1873 Honorar-Prof.; SS 1889 letzte Ankündigung im Vorlesungsverzeichnis.

Mitteilung von N.s Tochter Georgina an UH: „Mit grossem Schmerz mache ich ... die tieftraurige Mittheilung, dass mein Vater ... heute Nacht entschlafen ist. Heidelberg den 28. Juli 1889 ..." (aus: UAH RA 6170).

N. findet die nach ihm benannte Nuhn-, auch Blandin-Nuhn-Drüse (heute Glandula lingualis anterior genannt); er ist auch der Namensgeber des Nuhn-Fascientrichters (heute als Processus vaginalis fasciae transversalis bekannt).

E 1857 Mitglied der Gesellschaft Dt. Naturforscher und Ärzte. 1859 Goldene Medaille für Wissenschaft.
Qu UAH RA 6169 f.; Fak.-Akten H-III-111/40-42, H-III-111/48, H-III-111/55, H-III-111/82. • GLA Abt. 235, Fasz. 414. - Auskunft: Ev. Kirchengemeindeamt Schriesheim (Kopulationsbuch von 1812).

$W$ Über eine bis jetzt noch nicht näher beschriebene Drüse im Innern der Zungenspitze. Mannheim 1845. - Chirurgisch-anatomische Tafeln (Abt. I): Abbildungen der chirurgischen Anatomie des Kopfes und des Halses enthaltend. Mannheim 1846. - Erklärungen der chirurgisch-anatomischen Tafeln. Mannheim 1856. Lehrbuch der vergleichenden Anatomie ... 2 T. Heidelberg 1878. 2. Aufl. 1886. - Lehrbuch der practischen Anatomie als Anleitung zu dem Präpariren im Secirsale. Stuttgart 1882 .

L Stübler (1926) S. 305; Arnim 2 (1952) S. 254. • Über A.N. in: Hoepke, Hermann: Henles Meinungen über seine Kollegen aus: Ruperto Carola 32. Jg., H. 64 (1980) S. 4 of. • Chronik Ärzte H (1985) S. 138 f.; WBIS. • Enzyklopädie Medizingeschichte. Hrsg. von Werner E. Gerabek u. a. Berlin 2005. S. 1058. Freudenberg (2010) S. 165 u. ö.; Doll (2014) S. 312; Deutsche Biographie, s. https:// www.deutsche-biographie.de/gnd117587966.html [07. 11. 2017]; Doll/Kirsch/Eckart (2017) S. 29, 32. 


\section{O}

\section{Odenwald, Johann Karl Theodor}

1923-1945 Theol. Fak.

Systematische Theologie, Religionsphilosophie 1942-1945 (Lehrbeauftragter) Phil. Fak.

Religionsphilosophie

* o6. Juni 1889 Tauberbischofsheim

$\dagger \quad$ 09. Jan. 1970 Heidelberg

ev.

V Karl O. (1862-1907) Pfarrer, s. Badische Biographien 6 (1935) S. 806, WBIS

M Anna Henriette geb. Wegler

( 28. Mai 1938 Anna (verw.?) Andrès geb. Husser $\left({ }^{*} 1891 \dagger\right.$ nach 1970$)$

$\mathrm{K}$ keine.

Lb Seit WS 1911/12 Studium; 1914-1918 Kriegsdienst; Herbst 1919 II. Staatsexamen; 23. Juli 1921 Dr. theol.

Seckenheim (heute: Stadtteil von Mannheim): 1920-1923 Vikar.

UH: 28. April 1923 Habilitation; seit Sommer 1928 a. o. Prof.; seit 12. März 1929 o. Prof. am Wiss.Theol. Seminar als Nachf. von Willy Lüttge; seit 1. Mai 1942 auch Lehrbeauftragter für (Religions-) Philosophie an Phil. Fak.; ca. April 1945 Inhaftierung durch amerik. Militärbehörde als Sicherheitsdienst-Informant; 25. Okt. 1945 Entlassung von U gemäß Erlaß der Militärregierung; 13. Juni 1962 Verleihung der Rechtsstellung e. von seinen amtl. Verpflichtungen entbundenen o. Prof.

Nach 1945 Lehrer an einem Privat-Gymnasium.

1. Okt. 1931-1. Okt. 1932, April 1935-März 1945 Dekan der Theol. Fak. der UH

Qu UAH PA 254, 5204.
$W$ Friedrich Nietzsche und das heutige Christentum. Gießen 1926. - Protestantische Theologie. Überblick und Einführung. Berlin 1928. • Verkündigung und Theologie in neuer Wirklichkeit. Zur Sache der „Deutschen Christen“. Berlin 1934.

L Kürschner (1931) Sp. 2119, (1940/41) Sp. 298, (1966) S. 1764f.; Semper apertus 3 (1985) S. 623 (Register); Jansen (1992) S. 412 (Register); Ders. (1992a) S. 168 (Register); Fix (1994) S. 138-144; Meier (1996) S. 492 (Register); BBKL XVI (1999) Sp. 1162-1171; Personenlexikon zum dt. Protestantismus (2006) S. 188; UH im Nationalsozialismus (2006) S. 175-177, 180-193, 214-218 u. ö.; Klee, Personenlexikon (2007) S. 442; Wagner (2007) S. 357 u. ö.; WBIS. - Leo, Paul Christopher: Wilhelm Groh ... Hamburg 2012. S. 143-145. • Deutsche Biographie, s. https://www.deutsche-biographie. de/gnd122446194.html [07.11. 2017].

$P$ Bildarchiv UAH.

\section{Oechelhäuser, Wilhelm Friedrich Theodor} Adolf (seit 1883: von Oechelhäuser)

1887-1893 Phil. Fak.

Kunstgeschichte

* 17. Sept. 1852 Mülheim (Ruhr)

$\dagger \quad$ 03. Juni 1923 Dessau

$\square$ Dessau

ev.

V Wilhelm (1883 Nobilitierung: nur für seine Söhne angenommen) O.d. Ä. (1820-1902) seit 1852 Bürgermeister von Mülheim, 1857-1890 Leiter der Dt. Continental-Gas-Gesellschaft in Dessau, 1878-1893 Mitglied des Dt. Reichstags, s. WBIS, NDB 19 (1999) S. 421-423; s. auch Nachlaß Wolfgang von O. im Germanischen Nationalmuseum in Nürnberg

M Emma geb. R(h)einbach (1823-1876)

$\infty$ 5. Okt. 1878 Helene geb. von Maaßen (18551931) Enkelin von Karl Georg M. (1769-1834) preußischer Finanzpolitiker, s. NDB 15 (1987) S. $601 \mathrm{f}$.

$\mathrm{K} \quad 2 \mathrm{~S}, 2 \mathrm{~T}$ 
Vw Bruder: Wilhelm (von) O.d.J. (1850-1923) Kraftmaschinenkonstrukteur, u.a. seit 1881 Oberingenieur und 1890-1912 Generaldirektor der Dt. Continental-Gas-Gesellschaft als Nachf. seines Vaters, s. NDB 19 (1999) S. 423 f.

Lb Seit 1873 Studium des Baufachs, der Ingenieurwiss. an Bau-Akademie Berlin, anschl. TH Hannover; 1878 Bauführer-Examen in Berlin.

Berlin: 1878-1885 Bauführer, auch zeitweilig in Kassel; WS 1883/84-WS 1884/85 Studium der Archäologie an U; 1885 Dr. phil. an U; 1885/86 Verlegung des Wohnsitzes nach $\mathrm{H}$ : hier zunächst Privatier.

UH: 28. Mai 1887 Habilitation; seit 25. Aug. 1890 a. o. Prof.

Polytechnikum Karlsruhe: WS 1893/94-SS 1919 o. Prof.; Febr. 1915-Febr. 1916 Kriegsdienst als Freiwilliger im Militär-Gouvernement in Antwerpen. • In dieser Zeit:

Karlsruhe: 1900-1922 Vorsitzender der Baukommission für Denkmäler und Brunnengestaltung; 1913-1918 Mitglied der I. Kammer des Badischen Landtags als Abgeordneter des Polytechnikums; 1915-1919 Mitglied des Bürgerausschusses.

1902 Hofrat; 1904 Geh. Hofrat; 1917 Geh. Rat II. Klasse

E 1907 Prinzregent Luitpold-Medaille in Silber; 1913 Kommandeurkreuz II. Klasse des Ordens vom Zähringer Löwen; 1916 Ritterkreuz mit Schwertern des Ordens Berthold I.

Qu UAH PA 2065. GLA Abt. 235, Fasz. 2353. • Teil-Nachlaß: Germanisches Nationalmuseum Nürnberg; Bundesarchiv Koblenz.

$W$ Die Miniaturen der Universitätsbibliothek Heidelberg. 2 T. Heidelberg 1887-1895. D Das Heidelberger Schloß. Heidelberg 1891. 8. Aufl. 1987. • Der kunstgeschichtliche Unterricht an den deutschen Hochschulen. Karlsruhe 1902. Aus Anselm Feuerbachs Jugendjahren. Leipzig 1905. Krieg und Kunst. Karlsruhe 1915.
MHG 1896-1913 Die Kunstdenkmäler des Grossherzogtums Baden.

$L$ Wer ist's (1922) S. 1124. - Francke, Otto: Zum Heimgange der Brüder von O. in: Jahrbuch der Dt. Shakespeare-Gesellschaft 59/60 (1924). • Schwarzkopf, Christoph: A. von O. - ein Badener auf den Tagen für Denkmalpflege von 1900-1922 in: Denkmalpflege in Baden-Württemberg. Nachrichtenblatt der Landesdenkmalpflege 33 (2004) S. 13-22. Badische Biographien N.F. VI (2011) S. 295-298; Deutsche Biographie, s. https://www. deutsche-biographie.de/gnd117096563.html [07.11. 2017].

$P$ Bildarchiv UAH; graph. Slg. UBH.

\section{Oehme, Oskar Curt Alfred}

1928-1952 Med. Fak.

Innere Medizin

* 17. Dez. 1883 Dresden

$\dagger \quad$ 05. Okt. 1963 Heidelberg

ev.-luth.

V Geh. Sanitätsrat Prof. Dr. Emil Wilhelm O. (1847-1921) Arzt, Hausarzt der Königl.-Sächsischen Familie

M Auguste Anna Hilda geb. Muth

$\varnothing$ 16. Sept. 1914 Dr. med. Margarethe geb. Brauweiler ${ }^{*} 1898 \dagger$ nach 1963$)$

K $3 \mathrm{~T}$

Vw Ernst Ferdinand O. (1797-1855) seit 1825 Hofmaler in Dresden, s. WBIS, NDB 19 (1999) S. 432.

Lb Seit SS 1902 Studium an U Freiburg/Br., anschl. Leipzig, Berlin.

Freiburg/Br.: 6. Juni 1907 II. Staatsprüfung; 30. Juni 1908 Approbation.

U Leipzig: 4. Juli 1908 Dr. med.

Dresden: Seit Juli 1908 Assistent am Städtischen Krankenhaus. 
U Göttingen: Seit Okt. 1908 Assistent an Med. Poliklinik; 1913 Habilitation.

U Bonn: Seit 1913 Privat-Dozent und Oberarzt an Med. U-Klinik; 1918 Verleihung des Titels „Prof.“; 31. Aug. 1921 Ern. zum a. o. Prof.

UH: 5. Jan. 1928 Ern. zum planm. a. o. Prof. und Direktor der U-Poliklinik als Nachf. von Siegfried Thannhauser; 7. Febr. 1931 „... Die Ern. des planm. Prof. O. ... zum persönlichen Ordinarius muss aus grundsätzlichen Erwägungen zurückgestellt werden“ (aus: Schreiben des Ministers des Kultus und Unterrichts in: UAH PA 5205); 25. April 1932 Ern. zum persönlichen Ordinarius; April-Dez. 1945 Mitglied des Dreizehnerausschusses zum Wiederaufbau der U; 31. März 1952 Emeritierung.

H: 1946-1952 (?) Chefarzt der Heilanstalt Speyererhof; 1952-1957 Privat-Praxis im St. Josefskrankenhaus.

E 1937 Mitglied (1951-1953 Präsident) der Akademie der Wissenschaften H; 1957 Ehrenmitglied der Dt. Gesellschaft für Innere Medizin.

Qu UAH PA 1096, 5205; Rep. 40-415. - GLA Abt. 276-1 Nr. 25116, 235 Nr. 43019, 480 Nr. 8416.

$W$ Die Lymphe in: Handbuch der normalen und pathologischen Physiologie 6 (1925). Altern und Tod. Heidelberg 1944. - Die Bildung des Arztes. Heidelberg 1948. Goethe und der Arzt von heute. Stuttgart 1950. Am Wege gewachsen. Paralipomena. Heidelberg 1961.

L Jacobi, J.: Zum 7o. Geb. von C.O. in: Klinische Wochenschrift Jg. 31, H. 45/46 (1. Dez. 1953) S. 1112. • Catalogus prof. Gottingensium (1962) S. 96. Bauer, Karl Heinrich: C. O. † in: Jahrbuch 1963/64 der Heidelberger Akademie der Wissenschaften (1965) S. 53-55. - Int. Biogr. Archiv 10 (26. Febr. 1968); Verzeichnis Bonn (1968) S. 215; Chronik Ärzte H (1985) S. 139, 258; Jansen (1992a) S. 168 (Register); UH im Nationalsozialismus (2006) S. 1265 (Register); WBIS; Bauer/Ho (2016) S. 51-56; Deutsche Biographie, s. https://www.deutsche-biographie. de/gnd117098728.html [07.11. 2017].

\section{$P$ Bildarchiv UAH; Chronik Ärzte $\mathrm{H}$.}

\section{Oettingen, Karljohann Hans von}

1922-1931 (1933) Med. Fak.

Geburtshilfe, Gynäkologie

* 24. Juli 1891 Marburg

$\dagger \quad$ 03. Nov. 1953 Wiesbaden (Suizid) ev.

V Wolfgang von O. (1859-1943), u.a. seit 1888 Privat-Dozent für Kunstgeschichte Marburg, seit 1892 Prof. für Kunst- und Literaturgeschichte Kunstakademie Düsseldorf, seit 1897 Sekretär der Königl. Akademie der Künste Berlin, 1908-1918 Direktor des Goethe-Nationalmuseums und 1911-1918 Direktor des Goethe- und Schiller-Archivs Weimar, s. Catalogus prof. Marburgensis 1 (1927) S. 481, Kürschner (1935) Sp. 998, WBIS

M Caroline Marie Therese geb. Wilmanns (18581939), s. Oettingen, Hans von: Abenteuer meines Lebens. Irrwege und Einsichten eines Unbedachten. Berlin 1981. S. 41, 44 u. ö.

( 10. Mai 1917 Hildegard geb. de Greeff (18951932), s. Oettingen, S. 7-10, 37 f., 53-56 u. ö.

( 29. Juni 1933 Dr. med. Margot geb. Helferich (1899-1979) Fachärztin für Gynäkologie, u.a. 1931-1945 Oberärztin in Frauenklinik der Städtischen Krankenanstalten, nach 1945 Frauenärztin in Privat-Klinik in Wiesbaden, s. Oettingen, S. 65-70, 342-344 u. ö.

K 1 T, 2 S: u.a. Hans-Georg von O. (1919-1983) (Pseudonyme: Alexander von Mellin, H.G. von Reichenberg) zunächst Ausbildung zum Koloniallandwirt, seit 1939 Kriegsdienst, 1944 Verhaftung wegen Widerstands mit der Waffe gegen die Staatsgewalt, 1945 Verurteilung zu 6 Jahren Zuchthaus, 1945 nach geglückter Flucht Verhängung der Todesstrafe in Abwesenheit, 1946 Entlassung aus amerik. Kriegsgefangenschaft; nach 1946 u. a. Journalist und Verleger in Frankfurt/M., anschl. Unternehmensberater in Frankreich und der Schweiz, Nov. 1964 Verhaftung in Zürich wegen Spionage für DDR, Febr. 1966 Verurteilung zu 27 Monaten Haft, Mai 1966 vorzeitige Entlassung im Austausch gegen Ausreise einiger Schweizer Staatsbürger aus der DDR; seit 1966 Schriftsteller in Ost-Berlin, s. Oettingen, Hans von: Abenteuer meines Lebens ... Berlin 1981 (Autobiogr.); Wikipedia; $P$ im Bildarchiv UAH 
Vw Großvater: Georg Philipp von O. (1824-1916), u.a. seit 1854 Privat-Dozent, seit 1856 Leiter der U-Klinik, seit 1857 o. Prof. für Chirurgie, 1871-1879 (Ruhestand) o. Prof. für Augenheilkunde Dorpat, s. Saenger, Imma: G. P. von O., baltischer Arzt und Politiker. Med. Diss. FU Berlin. Berlin 1965; Oettingen, S. 40-46 u. ö.

Vw Enkelin: Sabine von O. $\left({ }^{*} 1962\right)$ Kostüm- und Bühnenbildnerin, Modedesignerin in Halle/S., siehe S. von O. 8oiger Jahre und 2009/2010. Ein Bilderbuch. Fotos: Jürgen Hohmuth. Berlin ca. 2010; http://www.sabinevonoettingen. de

Vw Gelehrtenfamilie, siehe hierzu NDB 19 (1999) S. $477^{*}$.

Lb SS 1911 Studium an U Berlin; 1. April-1. Aug. 1911 (Entlassung wegen e. Herzleidens) Militärdienstpflicht als Einjährig-Freiwilliger in Berlin; seit WS 1911/12 Forts. des Studiums an U München, seit WS 1912/13 Jena; Juli 1913 Physikum in Jena; WS 1913/14 Forts. des Studiums an U Marburg, SS 1914-WS 1915/16 H.

UH: Febr. 1916 Staatsexamen; 15. April 1916 Dr. med.

Medizinalpraktikant am Städtischen Krankenhaus: Seit April 1916 Erfurt, Jan.-April 1917 Weimar.

Seit Febr. 1917 Kriegsdienst als Unterarzt, seit Mai 1917 als Assistenzarzt der Reserve im Garnisonslazarett in Weimar, Sept.-Dez. 1918 (Entlassung) als Assistenzarzt.

UH: Seit 6. Jan. 1919 Assistent, seit 1924 Oberarzt an Frauenklinik; 26. Mai 1922 Habilitation; seit 29. März 1927 nichtplanm. a. o. Prof.; WS 1927/28-SS 1928 von UH beurlaubt. • In dieser Zeit:

Berlin: 15. Okt. 1927-15. Febr. 1928 Wiss. Mitarbeiter am Kaiser-Wilhelm-Institut.

UH: WS 1928/29 Forts. seiner Vorlesungen; seit Mai 1931 beurlaubt; 5. Sept. 1933 aus dem Lehrkörper ausgeschieden.
Wiesbaden: 1931-1945 (Absetzung durch amerik. Militärregierung) Direktor der Frauenklinik der Städtischen Krankenanstalten; anschl. Anklage vor amerik. Militärgericht wegen Durchführung von Zwangssterilisationen; O. lehnt Gericht als befangen $\mathrm{ab}$, „denn ich konnte beweisen, daß die Amerikaner schon 1868 Neger aus rassischen Gründen sterilisiert haben ... Zumindest haben sie mich laufenlassen“ (aus: Oettingen (1981) S. 343); nach 1945 Frauenarzt in Privat-Klinik im eigenen Haus.

Qu UAH PA 1098, 5209; Fak.-Akte H-III-862/21 fol. 177r-182r; Studentenakte. GLA Abt. 235, Fasz. 2356. Mitteilungen: Herr Arved von Oettingen, Wanfried.

$W$ Handbuch der Frauenheilkunde. Wiesbaden 1913. 5. Aufl. 1927. (Mitverf.) • Die perniciöse Anämie in der Schwangerschaft in: Zentralblatt für Gynäkologie 28 (1924); Der Salzstoffwechsel in der Plazenta in: ebd. 12 (1925); Zur Ninhydrinflockungsreaktion als Schwangerschaftsreaktion nach Vogel in: ebd. 40 (1926). Anatomie und topographische Anatomie, Entwicklungsgeschichte und Bildungsfehler der weiblichen Genitalien in: Handbuch der Gynäkologie 1,1 (1930). (Mitverf.)

L Gynäkologen-Kalender (1928) S. 203; Kürschner (1935) Sp. 998; Gynäkologen-Verzeichnis (1939) S. 349 f. • Müller-Werth, Herbert: 75 Jahre Städtische Krankenanstalten Wiesbaden. Wiesbaden 1954. S. 77 f. • Fischer 2 ( $\left.{ }^{3} 1962\right)$ S. 1141; WBIS. • Oettingen, Hans von: Abenteuer meines Lebens. Berlin 1981. S. 7-19, 28-33, 37 f., 48f., 51-56, 161 f., 314-316, 342-344, 357-360 u. ö.

$P$ Bildarchiv UAH.

\section{Olschki, Leonardo}

1913-1933 Phil. Fak.

Romanische Philologie

* 15. Juli 1885 Verona (Italien)

$\dagger \quad$ 07. Dez. 1961 Berkeley (Kalifornien) mosaisch 
V Leo Samuel O. (1861-1940) 1886 Gründer des Verlages Leo S. Olschki in Florenz, s. NDB 19 (1999) S. 528; Friedrich Gundolf - Elisabeth Salomon. Briefwechsel (1914-1931) (2015) S. 798 (Register)

M Pauline geb. Rosen (1862-1895)

๑ 17. Dez. 1923 Käte geb. Mosse (1900-1989), s. Lexikon jüdischer Einwohner Hs (2011) S. 316; T von Max M. (1873-1936), u.a. 1908 Verleihung des Titels „Prof.“ für Innere Medizin an Med. U-Poliklinik Berlin, s. NDB 18 (1997) S. $213^{*}$, WBIS

$\mathrm{K}$ keine

Vw siehe NDB 19 (1999) S. $527^{*}$.

Lb Seit 1903 Studium an U Florenz, anschl. Rom, München, Straßburg, SS 1906-SS 1908 H; 1. Dez. 1908 Dr. phil. an UH.

Lektor für Italienisch: Seit WS 1908/o9 Freiburg/ Br., seit 7. Mai 1909 H, seit WS 1909/10 Handelshochschule Mannheim, seit 1912 TH Darmstadt.

UH: 21. Juni 1913 Habilitation; seit 4. Sept. 1918 a. o. Prof.; 18. Jan. 1924 Amtsbezeichnung und Rechte eines o. Prof.; 1924-1929 Mit-Direktor (zus. mit Ernst Robert Curtius), 1929-1933 Direktor des Romanischen Seminars; seit 1. Mai 1930 o. Prof. als Nachf. von E. R. Curtius; SS 1933 letzte Vorlesungsankündigung; 12. Aug. 1933 Ruhestand aus rassischen Gründen.

Rom: 1933-1938 (Entlassung) Gast-Prof. an Königl. U; 1939 Emigration.

USA: 1939 Lehrtätigkeit an Johns-Hopkins-U Baltimore (Maryland); 1940/41 Substitute teacher für Spanisch am Sweet Briar College (Virginia); 19411942 Privat-Gelehrter, u. a. in Cambridge (Massachusetts); 1943-1944 Lehrer bei e. „Army language training program" in Eugene (Oregon); seit 1944 Lehrtätigkeit am Department of Oriental Language an U of California in Berkeley; 1950 Entlassung wegen Ablehnung des Loyalitätseids während der McCarthy-Ära.

Italien: 1950-1952 Wohnsitz.

USA: 1952 Aufhebung der Entlassung durch den California Supreme Court und Rückkehr.
UH: 28. Sept. 1953 Zuerkennung der Rechtsstellung e. von seinen amtl. Verpflichtungen entbundenen o. Prof.

Qu UAH PA 558, 5213; RA 6840, 6872. • Friedrich Gundolf - Elisabeth Salomon. Briefwechsel (19141931). Im Auftrag des DLA Marbach hrsg. von Gunilla Eschenbach und Helmuth Mojem. Berlin 2015. S. 798 (Register). - Nachlaß: Getty Research Institute in Los Angeles.

$W$ Paris nach den altfranzösischen nationalen Epen. Topographie, Stadtgeschichte und lokale Sagen. Heidelberg 1913. - Geschichte der neusprachlichen wissenschaftlichen Literatur. Bd. 1: Die Literatur der Technik und der angewandten Wissenschaften vom Mittelalter bis zur Renaissance. Heidelberg 1919. Bd. 2: Bildung und Wissenschaft im Zeitalter der Renaissance in Italien. Leipzig 1922. Bd. 3: Galilei und seine Zeit. Halle/S. 1927. Nachdr. Vaduz 1965. Die romanischen Literaturen des Mittelalters. Wildpark-Potsdam 1928. The genius of Italy. London 1950. Italien: Genius und Geschichte. Darmstadt 1958. - Siehe Izbicki, Thomas M.: L.O., a comprehensive bibliography in: La Bibliofilia 88,3 (1986) S. 297-308.

HG Dante Alighieri: La divina commedia. Heidelberg 1918. 2. Aufl. 1922.

L Kürschner (1931) Sp. 2127, (1935) Sp. 989; Handels-Hochschule Mannheim 1907-1932 (1932) S. 28. - Köhler, Erich: L.O. in: Ruperto Carola 31 (1962) S. 72 f. - Dictionary of Emigrés 2 (1983) S. 874; Arnim 4 (1984) S. 1204. Heitmann, Klaus: L. O. in: Ruperto Carola 74 (1986) S. 122-124. • Mussgnug (1988) S. 298 (Register); Romanisten als Verfolgte des Nationalsozialismus (1989) S. 310312; Jansen (1992a) S. 168 (Register); NDB 19 (1999) S. 527 f. Dörner, Anke: La vita spezzata. L. O. Ein jüdischer Romanist zwischen Integration und Emigration. Tübingen 2005. Hausmann (2008) S. 807 (Register); Kalkhoff (2010) S. 43-45 u. ö.; Lexikon jüdischer Einwohner Hs (2011) S. 316 f.; Intellektuelle in Heidelberg (2014) S. 427 (Register); Riecke (2016) S. 149 (Register).

P Bildarchiv UAH; Ruperto Carola (1962). 


\section{Oncken, Karl Hermann Gerhard}

1907-1923 Phil. Fak.

Neuere Geschichte

* 16. Nov. 1869 Oldenburg

$\dagger$ 28. Dez. 1945 Göttingen ev.

V Karl Gerhard O. (1839-1925) Hof-Kunsthändler

M Friederike Katherina Hermine geb. Krüger (1848-1903)

( 19. Sept. 1902 Anna Margarethe Karoline geb. Weber (1876-1954) Schwester von Dr. iur. Carl Wilhelm August W. (1871-1957), u.a. Bankier, 1918 Mitbegründer der Dt. Demokratischen Partei (DDP), 1930-1932 Abgeordneter im Reichstag, 1933 Emigration aus politischen Gründen nach Großbritannien, s. Frédéric, Stephan: Die Europavorstellungen im dt. und im franz. Widerstand gegen den Nationalsozialismus 1933/40 bis 1945. Hrsg. vom Histor. Inst. der Universität Stuttgart. Stuttgart 2002. S. 116, $120 \mathrm{ff}$. u. ö.

K 1 T, 2 S: u.a. Dr. phil. Dirk O. (1919-2015) Botschafter: 1972-1977 in Griechenland, 19771979 Indien, 1979-1984 Türkei, s. Int. Biogr. Archiv 48 vom 18. Nov. 1985

Vw Onkel: (siehe) Wilhelm Oncken. Enkelin: Dr. phil. Emily Haber geb. O. $\left({ }^{*} 1956\right)$ (T von Dirk O.) 2009-2011 Politische Direktorin des Auswärtigen Amts, seit 2011 Staatssekretärin im Auswärtigen Amt, seit Jan. 2014 Staatssekretärin im Bundesministerium des Innern, s. Sattar, Majid: E.H. Kleine Revolution am Werderschen Markt: Vom Sommer an wird sie die erste Frau sein, die den Apparat des Auswärtigen Amts leitet in: FAZ vom 28. Mai 2011; Int. Biogr. Archiv 37 vom 13. Sept. 2011.

Lb WS 1887/88 Studium an U Berlin, SS $1888 \mathrm{H}$, seit WS 1888/89 Berlin; 11. Aug. 1891 Dr. phil. an U Berlin.

Oldenburg: 1891-1895 Wiss. Hilfsarbeiter im Hausund Zentralarchiv.

Berlin: 28. Okt. 1897 Habilitation und 1897-1906 Privat-Dozent an U; seit Ostern 1904 Lehrer an
Königl. Kriegsakademie; WS 1905/o6 AustauschProf. an U of Chicago.

U Gießen: Seit SS 1906 o. Prof. und Direktor des Histor. Seminars als Nachf. von (siehe) Wilhelm Oncken.

UH: Seit 26. Juni 1907 o. Prof. als Nachf. von Erich Marcks [d. Ä.]; 1915-1918 Mitglied der I. Kammer des Badischen Landtags in Karlsruhe als Vertreter der UH als Nachf. von Ernst Troeltsch; Mai und Okt. 1921 Ruf an U Wien abgelehnt.

U München: Seit SS 1923 o. Prof. als Nachf. von Marcks.

U Berlin: 1. Okt. 1928-23. Juli 1935 (Datum der Entpflichtungsurkunde: Zwangsemeritierung aufgrund e. politisch-wiss. Rufmordes durch seinen ehem. Schüler, den fanatisch nationalsozialistisch gesinnten Walter Frank, s. hierzu Frank, W.: L'Incorruptible. Eine Studie über H. O. in: Völkischer Beobachter vom 3. Febr. 1935) o. Prof. als Nachf. von Marcks.

Göttingen: 1944 Evakuierung nach Ausbombung in Berlin.

1911/12 Dekan der Phil. Fak. der UH

1925 Mitbegründer der Deutschen Akademie, Vorgängerin der heutigen Goethe-Institute

1934-1935 Präsident der Histor. Reichskommission

1917 Geh. Rat; 1918 Geh. Hofrat

Siehe auch Johannes Rissom: Eintrag unter $Z[\mathrm{i}-$ tat] (3)

E 1907 Mitglied der Badischen Histor. Kommission; Mitglied der Akademie der Wissenschaften: 1909 H, 1919 Göttingen, 1922 Berlin, 1924 München. 1907 Ritterkreuz I. Klasse des Hessischen Verdienstordens Philipps des Großmütigen; 1912 Ritterkreuz I. Klasse des Ordens vom Zähringer Löwen. 
Qu UAH PA 5215; RA 615, 6847, 7699. - GLA Abt. 235, Fasz. 2357. - Briefe: UBH. - Reden dt. Gelehrter (1999) S. 112-121 u. ö. • Nachlaß: Staatsarchiv Oldenburg (siehe Findbuch zum Bestand „Nachlaß Professor Hermann Oncken“ ... Bearb. von Stefan Hartmann. Göttingen 1979). - Mitteilungen: Herr Dr. Philip Rosin, Universität Bonn.

W Ferdinand Lassalle. Stuttgart 1904. 5. Aufl. 1966. - Rudolf von Bennigsen. 2 Bde. Stuttgart 1910. Historisch-Politische Aufsätze und Reden. 2 Bde. München 1914. - Das alte und das neue Mitteleuropa. Gotha 1917. • Die Universität Heidelberg ihren Angehörigen im Felde - Weihnachten 1917. Heidelberg 1917. (Mitverf.) • Die Kriegsschuld unserer Feinde. Berlin 1918. Aus Rankes Frühzeit. Gotha 1922. - Das Deutsche Reich und die Vorgeschichte des Weltkriegs. 2 Bde. Leipzig 1933. • Cromwell. Vier Essays über die Führung einer Nation. Berlin 1935. 2. Aufl. 1952. - Nation und Geschichte. Reden und Aufsätze. 1919-1935. Berlin 1935. Die Sicherheit Indiens. Ein Jahrhundert englischer Weltpolitik. Berlin 1937. - Wandlungen des Geschichtsbildes in revolutionären Epochen in: Historische Zeitschrift 189 (1959) S. 124-138 (posthum erschienen).

MG 1892, 1894-1904 Redakteur des „Jahrbuch für das Herzogtum Oldenburg".

HG Die Rheinpolitik Kaiser Napoleons III. von 1863 bis 1870 und der Ursprung des Krieges von 1870/71. 3 Bde. Stuttgart 1926. Nachdr. 1967.

Bearb. Großherzog Friedrich I. von Baden und die deutsche Politik 1854-1871. 2 Bde. Stuttgart 1926-1927. Nachdr. 1966.

$L$ Universität Gießen (1907) S. 448; Kürschner (1928/29) Sp. 1720, (1940/41) Sp. 306; Arnim 2 (1952) S. 267, 4 (1984) S. 1205; WBIS. Hirsch, Felix: H. O. und Heidelberg in: Ruperto Carola 20. Jg., Bd. 47 (1969) S. 53-58. - Schwabe, Klaus: H.O. in: Deutsche Historiker. Hrsg. von Hans-Ulrich Wehler. Göttingen 1971. Bd. II. S. 81-97. • Boveri, Margret: Verzweigungen. Zürich 1977. S. 431 (Register). • Badische Biographien N. F. III (1990) S. 207-209. • Biographisches Handbuch zur Geschichte des Landes Oldenburg. Im Auftrag der Oldenburgischen Landschaft hrsg. von Hans Friedl ... Olden- burg 1992. S. 537-541. • Jansen (1992) S. 412 (Register); Ders. (1992a) S. 168 (Register); Wennemuth (1994) S. 637 (Register). - Cornelißen, Christoph: Politische Historiker und deutsche Kultur. Die Schriften und Reden von Georg von Below, H.O. und Gerhard Ritter im Ersten Weltkrieg in: Kultur und Krieg. Die Rolle der Intellektuellen, Künstler und Schriftsteller im Ersten Weltkrieg. Hrsg. von Wolfgang J. Mommsen ... München 1996. S. 119142. - Studt, Christoph: „Ein geistiger Luftkurort für deutsche Historiker“. H.O.s Austauschprofessur in Chicago 1905/06 in: Historische Zeitschrift 264 (1997) S. 361-389. NDB 19 (1999) S. 538 f. • Cornelißen, Christoph: H.O. ... in: Das Kaiserreich. Portrait einer Epoche in Biographien. Hrsg. von Michael Fröhlich. Darmstadt 2001. S. 388399. Historikerlexikon (2002) S. 242 f. • Ramm, Thilo: Ferdinand Lassalle. Der Revolutionär und das Recht. Berlin 2004. S. 41-43 u. ö. • Über H.O. in: Friedrich Meinecke: Akademischer Lehrer und emigrierte Schüler. Briefe und Aufzeichnungen 1910-1977. Hrsg. von Gerhard A. Ritter. München 2006. S. 512 (Register). Kriegstagebuch K. Hampe (2007) S. 986 (Register). • Lönnecker, Harald: „Das Thema war und blieb ohne Parallel-Erscheinung in der deutschen Geschichtsforschung“. Die Burschenschaftliche Historische Kommission ... und die Gesellschaft für Burschenschaftliche Geschichtsforschung e.V. (1898/1909-2009). Eine Personen-, Institutions- und Wissenschaftsgeschichte. Heidelberg 2009. S. 107 f. u. ö. • Gerhards (2013) S. 511 (Register); Berg (2014) S. 568 (Register); Reichert (2015) S. 229 f., 243 f. u. ö.; Spenkuch (2016) S. 1318 (Register). Engehausen, Frank: „vom politischen Nerv erfaßt und von nationaler Farbe durchleuchtet": H.O.s publizistisches Wirken im Ersten Weltkrieg in: UH während des Ersten Weltkriegs (2017) S. 169-183. • Rosin, Philip: H.O. und der Liberalismus in der Zeit des Kaiserreichs (Arbeitstitel) in: Jahrbuch für Liberalismusforschung 30. Jg. (2018 in Vorbereitung).

P Bildarchiv UAH; graph. Slg. UBH. 


\section{Oncken, Christian Friedrich Georg Wilhelm}

1862-1870 Phil. Fak.

Geschichte

* 19. Dez. 1838 Heidelberg

$\dagger$ 11. Aug. 1905 Gießen

ev.

V Anton Wilhelm O. (1803-1862) Advokat

M Maria Eleonora Carolina geb. Thaden (18141894)

๑ 7. Okt. 1865 Hermine Henriette Amalie geb. Lewald (1841-1911) T von: (siehe) Ernst Anton Lewald

K $\quad 1$ T

Vw Bruder: August O. (1844-1911), u.a. seit 1872 Privat-Dozent und seit 1877 a. o. Prof. für Nationalökonomie, Statistik an Hochschule für Bodenkultur Wien, seit 1877 a.o. Prof. an TH Aachen, 1878-1910 (Ruhestand) o. Prof. an U Bern, s. WBIS, NDB 19 (1999) S. 537. - Neffe: (Siehe) Hermann Oncken.

Lb Seit WS 1856/57 Studium der Geschichte, Philologie, Philosophie an UH, seit WS 186o/61 Göttingen, anschl. Berlin.

UH: 28. April 1860 Dr. phil.; 21. Mai 1862 Habilitation für Geschichte und Klassische Philologie; seit 12. Jan. 1866 a. o. Prof.

U Gießen: SS 1870-SS 1905 o. Prof. (sein Nachf. wird 1906 (siehe) Hermann Oncken); seit 1876 (Gründer und) Direktor des Histor. Seminars; Jan. 1873 Ruf an U Königsberg (Preußen) abgelehnt. • In dieser Zeit:

1873-1876 Mitglied der II. Kammer der Landstände des Großherzogtums Hessen; 1874-1877 zudem Mitglied des Dt. Reichstags.

1878 Mitinitiator des Oberhessischen Geschichtsvereins für Lokalgeschichte in Gießen, s. Klein, Dagmar: Enge Verbindungen zur Universität: 125 Jahre Oberhessischer Geschichtsverein. Initiative ging 1878 von den Professoren W. O. und Carl Gareis aus ... in: Justus-Liebig-Universität Gießen Uniforum. Gießen 2003.

1870 Geh. Rat; 1889 Geh. Hofrat

E 1880 Ritterkreuz I. Klasse des Verdienstordens Philipps des Großmütigen; 1897 Preußisches Kreuz der Komture des Hausordens der Hohenzollern; 1900 Komturkreuz des Ordens der Wachsamkeit oder vom weißen Falken; 1904 Komturkreuz II. Klasse des Verdienstordens Philipps des Großmütigen. - Siehe Verleihungsliste „Ehrenkreuz des Verdienstordens Philipps des Großmüthigen 1900-1918“. Bearbeiter: Dr. Lars Adler, Darmstadt. Stand: 20. April 2016, online http:// www.deutsche-gesellschaft-fuer-ordenskunde.de/ DGOWP/wp-content/uploads/2016/o4/Verleih_ Liste_Ehrenkreuz_Philipps-Orden_Adler.pdf (abgerufen am 8. Okt. 2017).

Qu UAH PA 2068; RA 6643 (Kriegsvorlesungen), 7050. Nachlaß: Universitätsbibliothek Gießen.

$W$ Athen und Hellas. Forschungen zur nationalen und politischen Geschichte der alten Griechen. 2 T. Leipzig 1865-1866. • Stadt, Schloß und Hochschule Heidelberg. Heidelberg 1869. 3. Aufl. 1885. • Die Staatslehre des Aristoteles in historisch-politischen Umrissen. 2 Bde. Leipzig 1870-1875. Neudr. 1964. - Österreich und Preußen im Befreiungskriege. 2 Bde. Berlin 1876-1879. Neudr. 1998. • Beiträge zur neueren Geschichte. Giessen 1885. Reprint 2011. Das Zeitalter des Kaisers Wilhelm. 2 Bde. Berlin 1890-1892. - Unser Heldenkaiser. Festschrift zum 100-jährigen Geburtstage Kaiser Wilhelms des Großen. Berlin 1897. 20. Aufl. 1898.

HG 1878-1893 Allgemeine Geschichte in Einzeldarstellungen in 44 Bden. 2. Aufl. 1895-1899. • 1881-1899 Gießener Studien auf dem Gebiet der Geschichte.

$L$ Universität Gießen (1907) S. 447 f.; Arnim 2 (1952) S. 267; Weber (1987) S. $425 \mathrm{f}$. - Lönnecker, Harald: „Das Thema war und blieb ohne Parallel-Erscheinung in der deutschen Geschichtsforschung". Die Burschenschaftliche Historische 
Kommission ... und die Gesellschaft für Burschenschaftliche Geschichtsforschung e.V. (1898/ 1909-2009). Eine Personen-, Institutions- und Wissenschaftsgeschichte. Heidelberg 2009. S. 30 f. u. ö.

$P$ Bildarchiv UAH.

\section{Oppenheimer, Zacharias Hugo}

1855-1904 Med. Fak.

Innere Medizin (Arzneimittellehre, Allg. Therapie, Hautkrankheiten)

* o8. Jan. 1830 Michelfeld (Baden)

$\dagger \quad$ 25. Juni 1904 Heidelberg mosaisch

V Seligmann (Sigmund) O. (1801-1872) Tuchfabrikant

M Jette geb. Levis (1806-1862)

๑ 4. März 1857 Mathilde geb. Frank (1833-1915)

K $1 \mathrm{~S}, 1 \mathrm{~T}$, s. Lexikon jüdischer Einwohner Hs (2011) S. 369.

Lb Seit 19. Okt. 1848 Studium an UH; Mai 1849 Teilnehmer am badisch-pfälzischen Aufstand; Juni 1849 nach Niederschlagung der Mairevolution Flucht in die Schweiz; Forts. des Studiums: seit Okt. 1849 U Würzburg, seit 22. Okt. 1851 H.

Frühjahr 1852 Chirurg. und geburtshilfliches Staatsexamen; Frühjahr 1853 Staatsprüfung für innere Heilkunde; anschl. 4-monatiger Studienaufenthalt in Paris.

UH: 1853-1854 Assistent an I. Med. U-Klinik; 3. Jan. 1855 Dr. med.; 30. April 1855 Habilitation; seit 26. Juni 1863 a. o. Prof. In dieser Zeit:

H: Mai 1854-1904 Niederlassung als praktischer Arzt, Wund- und Heb(e)arzt; 1861-189o II. Direktor der Kinderheilanstalt als Nachf. von Dr. Alfred Flad, seit April 1864 u.d.N. Luisen-Heilanstalt (I. Direktor: (siehe) Theodor von Dusch), seit Nov. 1885 mit Sitz in H-Bergheim, Luisenstraße 5.

1900 Hofrat
E 1892 Mitglied der Dt. Akademie der Naturforscher Leopoldina Halle/S.

Qu UAH PA 2070; Fak.-Akten H-III-111/61 fol. 238r-262r, H-III-111/62 fol. 81r-94v. • Siehe auch Archiv der Dt. Akademie der Naturforscher Leopoldina Halle/S.

$W$ Lehrbuch der physikalischen Heilmittel für Ärzte und Studierende der Medizin. 2 Lfg. Würzburg 1861-1863. •Über Rachitis. Heidelberg 1881. • Schmerz und Temperaturempfindung. Berlin 1893. Physiologie des Gefühls. Heidelberg 1899. • Bewußtsein - Gefühl. Eine psychologisch-physiologische Untersuchung. Wiesbaden 1903.

L Stübler (1926) S. 316, 324; Badische Biographien 6 (1935) S. 806; Hirsch 4 ( $\left.{ }^{3} 1962\right)$ S. 434; Hoche (1969) S. 99 f. - Biographie O.s in: Zander, Josef: Über ein Bildnis Goethes aus dem Besitz von Franz Karl Naegelé in: Heidelberger Jahrbücher 14 (1970) S. 136-139. • Chronik Ärzte H (1985) S. 139; WBIS; Jüdische Persönlichkeiten im Kraichgau (2013) S. 227-231. - Oppenheimer Family Tree online unter http://www.loebtree.com/oppz.html\#opp sig; siehe auch http://www.alemannia-judaica.de/ michelfeld_synagoge.htm (abgerufen am 10. Okt. 2017). - Deutsche Biographie, s. https://www.deut sche-biographie.de/gnd102652023.html [07.11. 2017].

$P$ Bildarchiv UAH; graph. Slg. UBH; Heidelberger Jahrbücher; Chronik Ärzte H.

\section{Oppermann, Hans August Karl}

1928-1934 Phil. Fak.

Klassische Philologie

* 13. Okt. 1895 Braunschweig

$\dagger$ 28. Aug. 1982 Tübingen

ev.

V Otto Gustav August O. (1862-1938) Stadtschuldirektor

M Margarethe Auguste Emilie geb. Wiedemann (1863-1918) 
(0) 10. Juli 1926 Dr. phil. Ella Maria geb. Borchers (1889-1959) Kunsthistorikerin

K 1 Sohn: Thomas O. ( $\left.{ }^{*} 1931\right)$, u.a. 1960-1967 Beamter der Europa-Abt. des Bundeswirtschaftsministeriums Bonn, 1967 Habilitation Hamburg, 1967-1999 (Emeritierung) o. Prof. für Öffentl. Recht und Auswärtige Politik Tübingen; 1985-1989 Vorsitzender der Dt. Gesellschaft für Völkerrecht; 1991-1993 Vorsitzender der Vereinigung Dt. Staatsrechtslehrer, 1999-2002 Präsident des Arbeitskreises Europ. Integration in Bonn, 2002-2003 Berater von Ministerpräsident Erwin Teufel im Europ. Verfassungskonvent, s. http://www.jura. uni-tuebingen.de/professoren_und_dozen ten/oppermann/lebenslauf/index_html (Ausdruck im UAH); O., T.: Meine sechs Jahrzehnte Öffentliches Recht in: Jahrbuch des Öffentl. Rechts der Gegenwart N.F. 62 (2014) S. 511527. (Autobiogr.)

Lb WS 1913/14 Studium an U Bonn, seit SS 1914 Berlin, seit WS 1915/16 Bonn; 1917-1918 Kriegsdienst.

U Bonn: 20. März 1920 Dr. phil.; 6. Nov. 1920 philolog. Staatsexamen.

1920-1922 Assistent am Philolog. Inst. der U Bonn, anschl. Greifswald.

(Bad) Godesberg: 1922-1925 Lehrer am Deutschen Kolleg, s. hierzu Das Deutsche Kolleg in Bad Godesberg. Beiträge zu seiner Geschichte. Bonn 1937.

U Greifswald: 3. Juni 1926 Habilitation.

UH: Seit Okt. 1928 Privat-Dozent und Assistent am Philolog. Seminar; seit 16. Sept. 1932 außerplanm. a.o. Prof.

U Freiburg/Br.: Seit 1. März 1934 a.o. Prof.; seit 1. Okt. 1935 o. Prof.

Reichs-U Straßburg: 23. Nov. 1941 (Eröffnung der Reichs-U)-Nov. 1944 (Besetzung der Stadt durch amerik. und franz. Militär) o. Prof.; 1944-1945 Zivilinternierung in Frankreich.
1945-1949 Mitarbeiter an Edition von Wilhelm Raabe. Sämtliche Werke. Braunschweiger Ausgabe.

Hamburg: Seit 1949 wiss. Angestellter, seit 1952 Studienrat am Christianeum in Othmarschen; 1954-1961 (Pensionierung) Leiter der Gelehrtenschule des Johanneums in Winterhude.

U Hamburg: 1959 Wiedereinsetzung in die Rechte eines emeritierten o. Prof.

Qu UAH PA 559, 5219. - Mitteilungen: Herr Prof. Dr. Thomas Oppermann, Tübingen.

W Caesar. Der Schriftsteller und sein Werk. Leipzig 1933. - Vergil. Frankfurt/M. 1938. - Caesar. Wegbereiter Europas. Göttingen 1958. 2. Aufl. 1963. 3. Aufl. 1977. • Johannes Gurlitt (1754-1827). Hamburg 1962. • Julius Caesar. Reinbek 1968. 20. Aufl. 2011. (Übers.: 1984, 1994 spanisch, 1997 koreanisch, 2001 japanisch.) - Wilhelm Raabe mit Selbstzeugnissen und Bilddokumenten. Hamburg 1970. 7. Aufl. Reinbek 2001. Bibliographie in: Das Johanneum. Magazin des Vereins der ehemaligen Schüler der Gelehrtenschule des Johanneums e. V. Hamburg 1982. S. 63-71.

HG 1962-1972 Jahrbuch der Raabe-Gesellschaft. • Römertum. Ausgewählte Aufsätze und Arbeiten aus den Jahren 1921 bis 1961. Darmstadt 1962. 4. Aufl. 1976. - Wege zu Vergil. Darmstadt 1963. 2. Aufl. 1976. Römische Wertbegriffe. Darmstadt 1967. 3. Aufl. 1983. Humanismus. Darmstadt 1970. 2. Aufl. 1977. - Wege zu Horaz. Darmstadt 1972.

L Kürschner (1935) Sp. 992, (1940/41) Sp. 308 f., (1950) Sp. 1492, (1954) Sp. 1716, (1966) S. 1779, (1980) S. 2815; WBIS. • H. O. ... in: Das Johanneum. Magazin des Vereins der ehemaligen Schüler der Gelehrtenschule des Johanneums e.V. Hamburg 1982. S. 71-73. Arnim 4 (1984) S. 1208. - Faber, Richard: Faschistische Vergil-Philologie, z. B. H. O. in: Hephaistos. Kritische Zs. zu Theorie und Praxis der Archäologie und angrenzender Gebiete. Berlin 1991. S. 111-133. - Malitz, Jürgen: Römertum im „Dritten Reich“. H.O. in: Imperium Romanum. Studien zu Geschichte und Rezeption ... Hrsg. von Peter Kneißl, Volker Losemann. Stuttgart 1998. S. 519-543. - Welker, Meinrad: Lexikon 
Greifswalder Hochschullehrer 1907-1932. Bad Honnef 2004. Bd. 3. S. 173 f. - Klee, Personenlexikon (2005) S. 444; Freiburger Phil. Fak. (2006) S. 303-364; UH im Nationalsozialismus (2006) S. 1265 (Register); Deutsche Biographie, s. https:// www.deutsche-biographie.de/gnd118736442.html [07. 11. 2017].

$P$ Bildarchiv UAH.

\section{Osann, Carl Alfred}

1887-189o Phil. Fak.

189o-1893, 1895-1897 (1898) Nat.-Math. Fak.

Geologie, Mineralogie

* 03. Dez. 1859 Hofheim in Unterfranken

$\dagger$ 06. Aug. 1923 Freiburg/Br. ev.

V Dr. Friedrich O. (1827-1885) praktischer Arzt, anschl. Landgerichtsarzt

M Emma geb. Lindenborn (1832-1914)

๑ 17. März 1921 Dr. Gertraud geb. Siehl (18951978) Mathematikerin, s. Abele, Andrea E. u. a.: Traumjob Mathematik! Berufswege von Frauen und Männern in der Mathematik. Basel 2004. S. 116; seit 1924 Ehefrau von Lothar Julius Wilhelm Heffter (1862-1962) seit 1891 a. o. Prof. für Mathematik Gießen, seit 1897 a. o. Prof. Bonn, seit 1904 o. Prof. TH Aachen, seit 1905 U Kiel, 1911-1931 Freiburg/Br., s. WBIS, Homo Heidelbergensis mathematicus online

$\mathrm{K}$ keine

Vw Großvater: Gottfried Wilhelm O. (1797-1866) seit 1823 Prof. für Chemie und Physik Dorpat, seit 1828 Würzburg, s. WBIS.

Lb UH: Seit WS 1877/78 Studium der Chemie, Physik, Mineralogie; 19. Febr. 1881 Dr. phil.; seit Okt. 1881 unbezahlter Mitarbeiter/Assistent am Mineralogisch-Geologischen Inst.

U Straßburg: April 1883-Sept. 1884 Studium der Geologie, Paläontologie.
UH: Okt. 1884-März 1887 Assistent am Mineralogisch-Geologischen Inst.; 3. Febr. 1887 Habilitation für Mineralogie und Geologie; WS 1887/ 88 und WS 1889 /90 von U beurlaubt für Studienreisen in Südspanien; seit 23. Mai 1891 a. o. Prof.; 13. Nov. 1892 Erteilung der Urlaubsgenehmigung für e. Studienaufenthalt in Texas (USA); WS 1892/ 93 zuächst letzte Vorlesungsankündigung.

Seit 1893 Feldforschung in Texas; seit Anfang 1894 Aufenthalte zur Aufarbeitung des mitgebrachten Gesteins: Großherzogl. Naturalienkabinett in Karlsruhe, seit Mitte 1894 Mineralog. Sammlung der U München.

UH: WS 1895/96 Wiederaufnahme seiner Vorlesungen; WS 1897/98 (von U beurlaubt) GastProf. an Städtischer Chemieschule in Mülhausen (Elsaß; heute: Mulhouse).

U Basel: Seit April 1898 Privat-Dozent für Kristallographie; seit März 1900 a. o. Prof.

U Freiburg/Br.: Seit SS 1903 etatm. a. o. Prof. und Direktor des Mineralog. Inst.; seit 8. Sept. 1904 o. Honorar-Prof.; seit 10. Aug. 1906 o. Prof.

1917 Geh. Hofrat

O.s Eruptivgesteinssammlung u.a. aus Texas mit über 5000 Exemplaren sowie 3000 Dünnschliffen befindet sich heute im Institut für Geo- und Umweltnaturwissenschaften - Mineralogie-Petrologie - der Universität Freiburg/Br. und ist einerseits Teil der regionalen Sammlung (digitalisiert) und andererseits Teil der fortlaufenden Dünnschliffsammlung (Zettelkasten).

E 1909 Mitglied der Akademie der Wissenschaften $\mathrm{H}$.

Qu UAH PA 2071; RA 6489, 6491; Fak.-Akte H-IV-102/94 fol. 188r-193r.

$W$ Geologische Specialkarte des Großherzogtums Baden. Geologische Aufnahmen von A. Andreae und A. O. Heidelberg 1895. 3. Aufl. Karlsruhe 1917. - Versuch einer chemischen Klassifikation der Eruptivsteine in: Tschermaks mineralog. und 
petrograph. Mitteilungen 19 (1900) S. 351-469, 20 (1901) S. 399-558, 21 (1902) S. 365-448, 22 (1903) S. 322-356, 403-436. - Beiträge zur chemischen Petrographie. 3 Bde. Stuttgart 1903-1916. • Die Mineralien Badens. Hrsg. von Gertraud Heffter verw. Osann. Stuttgart 1927.

L Nachruf in: Zentralblatt für Mineralogie (1924) S. 121f.; Arnim 2 (1952) S. 273; WBIS; Jansen (1992a) S. 168 (Register); Badische Biographien N.F. VI (2011) S. 298-301; Deutsche Biographie, s. https://www.deutsche-biographie.de/gnd117150o 53.html [07.11. 2017].

$P$ Bildarchiv UAH.

\section{Osthoff, Caspar Carl Heinrich Gottfried Emil Franz Hermann}

1877-1909 Phil. Fak.

Vgl. Sprachwissenschaft

* 18. April 1847 Billmerich (heute: Stadtteil von Unna)

$\dagger \quad$ 07. Mai 1909 Heidelberg ev.

V Franz O., Gutsbesitzer

M Lisette Theodore geb. Birnberg

๑or 1873 Henriette geb. Schölling $\left({ }^{\star} 1852\right)$

@ 14. März 1878 Emilie geb. Weeren $\left({ }^{*} 1857\right)$

K $\quad 2$ S, 2 T

Lb Seit WS 1865/66 Studium an U Bonn, seit SS 1867 Tübingen, WS 1868/69 Berlin, SS 1869 Bonn.

U Bonn: SS 1869 Dr. phil.; Herbst 1871 Prüfung für höheres Lehramt.

Kassel: Seit 1871 Lehramtspraktikant, seit 1872 Gymnasiallehrer.

Leipzig: Seit 1874 Privat-Gelehrter; 24. Juli 1875 Habilitationskolloquium an U; 21. Okt. 1875 Erteilung der venia legendi an $\mathrm{U}$.
UH: 17. Febr. 1877 Ern. zum a. o. Prof. (mit Staatsdienereigenschaft) mit e. Jahresgehalt von 2000.Mark; seit 29. Dez. 1877 o. Prof. als Nachf. von Ernst Kuhn; Dez. 1886-April 1888 stellvertr. Direktor des Germanisch-Romanischen Seminars für erkrankten Ordinarius Karl Bartsch ( $†$ Febr. 1888); Nachf. von Bartsch, s. Wilhelm Braune.

1899 Prorektor der UH; 1884/85, 1894/95 Dekan der Phil. Fak. der UH

1899 Hofrat; 1903 Geh. Hofrat

E Ehrenmitglied der Phil. Gesellschaft Budapest. • 1908 Ritterkreuz I. Klasse mit Eichenlaub des Ordens vom Zähringer Löwen.

Qu UAH PA 2072; RA 5278, 6839, 6863, 7418; Fak.-Akte H-IV-102/130 fol. 84r, v. • UA Leipzig PA 786. Notes for Latin grammar course given by Prof. H. O. Manuskript $1882-1883$ in: Otto Bremer class notes, 1882-1883, aufbewahrt in Bancroft Library - University of California in Berkeley (Kalifornien). - Lieber Freund ... Die Briefe H. O.s an Karl Brugmann 1875-1904 ... Hrsg. von Eveline Einhauser. Trier 1992.

$W$ Forschungen im Gebiete der indogermanischen nominalen Stammbildung. 2 T. Jena 1875-1876. Morphologische Untersuchungen. 6 Bde. Leipzig 1878-1910. (Mitverf.) • Zur Geschichte des Perfects im Indogermanischen ... Straßburg 1884.

$L$ Badische Biographien 6 (1935) S. 56-64; Arnim 2 (1952) S. 275. - H. O. in: Portrait of Linguists. Ed. by Thomas A. Sebeok. Vol. 1. Bloomington 1966. S. 555-562 u. ö. - Lehmann (1967) S. 224; Riese (1977) S. 412 (Register). • Gardt, Andreas: Geschichte der Sprachwissenschaft in Deutschland. Vom Mittelalter bis ins 20. Jahrhundert. Berlin 1999. S. 396 (Register). NDB 19 (1999) S. 627 f. • Leipziger Germanistik: Beiträge zur Fachgeschichte im 19. und 20. Jahrhundert. Hrsg. von Günther Öhlschläger ... Berlin 2013. S. 261 (Register). • Riecke (2016) S. 149 (Register).

$P$ Bildarchiv UAH; graph. Slg. UBH. 
$W$ De vera librorum juris feudalis Longobardici origine prolusio. Göttingen 1805. Lehrbuch des Lehnrechts. Nach des Verf. Tode hrsg. von Christian August Gottlieb Göde. Göttingen 1808. Neuaufl. 1837.

\section{Paetz, Carl Wilhelm}

1804-1805 Jur. Fak.

Staats- und Lehnrecht, Reichsgeschichte, Kriminalrecht

* 11. Juni 1781 Ilfeld (Südharz)

$\dagger$ 27. März 1807 Göttingen ev.

V Heinrich Alexander Günther P. (1734-1808) Direktor des ev. Gymnasiums im ehem. Prämonstratenserkloster in Ilfeld, s. Heerde, HansJoachim: Das Publikum der Physik. Lichtenbergs Hörer. Göttingen 2006. S. $478 \mathrm{f}$.

M N.N.

$\infty$ unverheiratet

Vw Bruder: Ludwig August P. (†1799), s. Heerde (2006) S. 479.

Lb U Göttingen: Seit 23. April 1798 Studium; 1801 Dr. iur.; seit 1801 Privat-Dozent; 1801-1802 a.o. Beisitzer des Spruchkollegiums.

U Kiel: Seit WS 1802/03 a. o. Prof. für Dt. Recht.

UH: Seit 1. Sept. 1804 o. Prof. und Beisitzer des Spruchkollegiums der Jur. Fak.

U Göttingen: Seit Herbst 1805 o. Prof. für Dt. Recht, Dt. Geschichte und Beisitzer des Spruchkollegiums.

Qu GLA Abt. 205, Fasz. 425. Ludwig Achim von Arnim. Briefwechsel 1805-1806. Briefwechsel III. T. 1: Text. Hrsg. von Heinz Härtl ... Berlin 2011. S. 1109 (Register). - Karl August Böttiger - Briefwechsel mit Christian Gottlob Heyne. Hrsg. ... von René Sternke und Klaus Gerlach. Berlin 2015. S. 737 f. (Register). - Auskunft: Ev.-luth. Kirchenbuchamt Göttingen.

$L$ Saalfeld, Friedrich: Geschichte der Universität Göttingen in dem Zeitraume von 1788 bis 1820 . Hannover 1820. Bd. 3. S. 71. • Allg. Encyklopädie der Wissenschaften. 3. Section (1837) S. 243 f.; Keller (1913) S. 182; Schneider (1913) S. 78; Kayser (1923) S. 59; Professoren Kiel (1956) S. 49; Catalogus prof. Gottingensium (1962) S. 50; Jammers (1964) S. 177 u. ̈.; Weisert (1991) S. 122 u. ö.; WBIS; Schroeder (2010) S. 19 f. u. ö.; Deutsche Biographie, s. https://www.deutsche-biographie.de/gnd116015 357.html [07.11. 2017].

\section{Pagenstecher, Heinrich Alexander}

1856-1863 Med. Fak.

Physiologie und Vgl. Anatomie, seit WS 1858/59

auch Zoologie

1863-1878 Phil. Fak.

Zoologie, Paläontologie, Vgl. Anatomie und Physiologie, Landwirtschaftl. Tierlehre

* 18. März 1825 Elberfeld (heute: Stadtteil von Wuppertal)

$\dagger \quad$ 04. Jan. 1889 Hamburg

ev.-luth.

V Dr. med. Heinrich Karl Alexander P. (17991869) Arzt, 1848/49 Mitglied der Frankfurter Nationalversammlung, 1862-1866 Mitglied der II. Kammer des Badischen Landtags in Karlsruhe, siehe Nachlaß im Bundesachiv Koblenz, Abt. Frankfurt; Best/Weege (1996) S. 255 f., WBIS, Erben (2011) S. 55-74

M Juliane (Julie) geb. Jung (1802-1872)

$\infty$ 22. Juli 1850 Eugenie geb. Aders (1829-1882), siehe Zur Silber-Hochzeit von A.P. und Eugenie ... Elberfeld 1875 (in: UBH Signatur A 2737 RES::1.1846-75).

๑ 1884 Maria Olga geb. Schwartze (1854-1928)

$\mathrm{K} \quad 4 \mathrm{~S}(1 \mathrm{~S}$ früh $\dagger)$ 
Vw Bruder: (siehe) Ernst P. • Siehe auch Nachkommenverzeichnis des Professors ... Ernst Gerhard P. und Frau Henriette geb. Otterbein. Flensburg 1939; Haering, Hans: Aus der Familie e. Herborner Professors [i.e. Heinrich Karl Alexander P. (1799-1869)] Emanzipation [seiner Tante Antoinette Wilhelmine Dapping geb. Otterbein (1769-1863)] um 1800 in: Mitteilungsblatt des Geschichtsvereins Herborn (1996) S. 1-18; NDB 20 (2001) S. $1^{*}$.

Lb Seit WS 1842/43 Studium der Medizin, Naturwiss. an U Göttingen, seit 5. Mai $1845 \mathrm{H}$, anschl. Berlin.

U Berlin: 29. Aug. 1846 Dr. med.; Approbationen: 3. Mai 1847 als praktischer Arzt und Operateur, 28. Aug. 1847 als Geburtshelfer.

Praktischer Arzt: Seit 1847 Elberfeld, seit 1848 (Badearzt) Salzbrunn (heute: Szczawno-Zdrój, Polen), 1849-1856 (Wuppertal-)Barmen.

UH: 18. Juli 1856 Habilitation an Med. Fak.; 1. Aug. 1862 Dr. phil. an U Tübingen; 20. Jan. 1863 Ern. zum a. o. Prof. für Zoologie, Paläontologie an Phil. Fak. und (bis 1878) Direktor des Zoolog. Inst. (Kabinetts) nebst Abt. für landwirtschaftl. Tierlehre als Nachf. von Heinrich Georg Bronn; seit 9. April 1866 o. Prof.; 27. April 1878 auf eigenen Antrag Versetzung in Ruhestand.

H: 1878-1882 Privat-Gelehrter.

Hamburg: Seit 31. Mai 1882 (Gründungs-)Direktor des Naturhistor. Museums.

1875/76 Dekan der Phil. Fak. der UH

E 1876 Mitglied der Dt. Akademie der Naturforscher Leopoldina Halle/S.

Qu UAH PA 2080; Fak.-Akte H-III-111/63. • Briefe: UBH. - Siehe auch Archiv der Dt. Akademie der Naturforscher Leopoldina Halle/S.

$W$ Beiträge zur Anatomie der Milben. 2 Bde. Leipzig 1860-1861. • Die Trichinen. Leipzig 1865. 2. Aufl. 1866. (Mitverf.) - Die Insel Mallorka ...
Leipzig 1867. (Spanische Übers. Palma 1876.) • Über den Ursprung einiger europäischer Schmetterlinge. Heidelberg 1875. - Allg. Zoologie oder Grundgesetze des thierischen Baues und Lebens. 4 Bde. Berlin 1875-1881. • Über die Thiere der Tiefsee in: Sammlung gemeinverständlicher wiss. Vorträge. Hrsg. von Rudolf Virchow u. a. Serie XIV. H. 313-325 (1879) S. 73-136.

L Arnim 2 (1952) S. 281. - Scheele, Irmtraut: Die Berufung von H. A. P. zum ersten Direktor des Naturhistor. Museums Hamburg in: Verh. des naturwiss. Vereins Hamburg N.F. 26 (1983) S. 5-27. • Moeller, Heinz Friedrich: Zoologisches Museum der Universität Heidelberg. In Zusammenarbeit mit Westermanns Monatshefte. Braunschweig 1985. S. 28 f., 36 f. u. ö. • Zimmermann/Drüll (1990) S. $31 \mathrm{f}$; NDB 20 (2001) S. $1 \mathrm{f}$.

$P$ Bildarchiv UAH; Scheele (1983); NDB.

\section{Pagenstecher, Ernst Adolph}

1851-1871 Jur. Fak.

Römisches Recht

* 30. Juni 1826 Elberfeld (heute: Stadtteil von Wuppertal)

$\dagger$ 10. Febr. 1901 Heidelberg ev.-luth.

V Dr. med. Heinrich Karl Alexander P. (17991869) Arzt, 1848/49 Mitglied der Frankfurter Nationalversammlung, 1862-1866 Mitglied der II. Kammer des Badischen Landtags in Karlsruhe, siehe Nachlaß im Bundesachiv Koblenz, Abt. Frankfurt; Best/Weege (1996) S. 255 f., WBIS, Erben (2011) S. 55-74

M Juliane (Julie) geb. Jung (1802-1872)

๑ 14. Mai 1853 Mathilde geb. Horstmann (18261865)

K 2 T

Vw Bruder: (siehe) Alexander P.

Lb Seit 5. Mai 1845 Studium an UH, seit 1846 Berlin; Frühjahr 1847 Freiwilliger im Kaiser Alexander-Garde-Infanterie-Regiment. 
U Bonn: 14. Aug. 1848 Dr. iur.; 1848 Forts. des Studiums an U Bonn; 1851 U verweigert Habilitierung P.s - wohl aufgrund der liberalen Haltung seines Vaters.

UH: 18. Okt. 1851 Habilitation; seit 25. Mai 1860 a. o. Prof.; 1862-1872 Beisitzer des Spruchkollegiums der Jur. Fak.; 24. Juli 1871 auf eigenen Antrag Entlassung, da Ern. zum o. Prof. als Nachf. von Carl Adolph von Vangerow ausbleibt.

\section{H: Seit 1871 Privatier.}

Qu UAH PA 2078; Fak.-Akte H-II-111/46 (hier: Ernst August P.). • „Deutschland Geburten und Taufen, 1558-1898“, database, FamilySearch https://familysearch.org/ark:/61903/1:1:ND2S-6R8: accessed 24 May 2016, Ernst Adolph Pagenstecher, 27 Juli 1826; citing; FHL microfilm 490,085.

$W$ Die römische Lehre vom Eigenthum in ihrer modernen Anwendbarkeit. 3 Abt. Heidelberg 18571859. Nachdr. Stockstadt/Main 2006. Neuaufl. BiblioLife 2010. • Pandekten-Praktikum zu Puchta's Pandekten und Girtanner's Rechtsfällen mit Hinweisung auf die Lehrbücher von Arndts und von Vangerow. Heidelberg 1860.

$L$ Badische Biographien 5 (1906) S. 917; Jammers (1964) S. 177 u. ö.; WBIS; Schroeder (2010) S. 207 f. (S. 207: irrtümlich Ernst August P. statt Ernst Adolph P.); Deutsche Biographie, s. https://www. deutsche-biographie.de/gnd116015586.html [07.11. 2017].

\section{Pagenstecher, Ernst August}

siehe Pagenstecher, Ernst Adolph

\section{Panzer, Friedrich Wilhelm}

1919-1920, 1920-1936 Phil.Fak.

Deutsche Philologie

* o4. Sept. 1870 Asch (heute: Aš, Tschechische Republik)

$\dagger$ 18. März 1956 Heidelberg ev.

V Johannes Gustav P. (1836-1923) Fabrikant

M Aurelia Klara geb. Holstein (1842-1873)

๑ 24. Sept. 1894 Helene Emilia Anna geb. Klaubert (1874-1952)

K 3 T: u.a. Hilde P. (1895-1985) Ehefrau von Hans Stempel (1894-1970), u.a. 1948-1964 Präsident der Pfälzischen Landeskirche, s. WBIS, BBKL XXXI (2010) Sp. 1292-1295. • 3 S: u.a. Wolfgang P. (1896-1983), u.a. 19361945 Prof. für Geographie H, s. Drüll (2009) S. $456 \mathrm{f}$, 100 Jahre Germanistik in Hamburg (2011) S. 212, 471

Vw Enkel: Wolf-Dieter Stempel $\left({ }^{*} 1929\right)$ seit 1962 Privat-Dozent und 1963 o. Prof. für Romanische Philologie Bonn, seit 1967 Konstanz, seit 1973 Hamburg, 1985-1994 (Emeritierung) München, s. Deutsche Biographie, https:// www.deutsche-biographie.de/pnd119165449. html [22.01.2018].

Lb WS 1888/89-WS 1893/94 Studium der Philologie, Geschichte, Kunstgeschichte, Archäologie, Philosophie an U Leipzig, anschl. Jena, Freiburg/ Br., München, Wien, Leipzig; Dez. 1892 Dr. phil. Leipzig.

U München: 3. Aug. 1894 Habilitation; 1894-1897 Privat-Dozent.

U Freiburg/Br.: Seit 30. Juni 1897 Privat-Dozent; seit 27. Febr. 1901 a. o. Prof.

Frankfurt/M.: Seit SS 1905 o. Prof. an Akademie für Sozial- und Handelswiss.; seit WS 1914/15 o. Prof. an neugegründeter U.

UH: Seit 10. Juli 1919 o. Prof. als Nachf. von Wilhelm Braune; 4. Okt. 1919 Vereidigung.

U Köln: SS 1920 o. Prof. 
UH: 14. Juli 1920 Ern. zum o. Prof.; seit 1920 MitDirektor (zus. mit Johannes Hoops (bis 1924) und Friedrich Neumann (bis 1923)) des GermanischRomanischen Seminars, Unterabteilung: Germanische Abt., Deutsches Seminar; 1. Apr. 1924-1934 (Gründungs-)Direktor des Deutschen Seminars, das Germanisch-Romanische Seminar wird aufgelöst; 1934-1936 Mit-Direktor (zus. mit Eugen Fehrle) des genannten Seminars; 1927 Ruf an U Berlin abgelehnt; 30. Sept. 1935 Emeritierung; WS 1935/36-SS 1936 Vertreter seiner Professur.

1926/27 Rektor der UH; 1925/26 Dekan der Phil. Fak. der UH

1922 Gründer (gemeinsam mit Johannes Hoops) der Ferienkurse für ausländische Studenten an UH

1912 Mitbegründer des Dt. Germanistenverbandes

1916 Geh. Reg.-Rat

Siehe auch Anhang Sporteinrichtungen an $U H$ 1910-1933 und ihre Mitglieder

E Mitglied der Dt. Gesellschaft der Wiss. und Künste Prag; Mitglied der Akademie der Wissenschaften: 1919 H (1941-1947 Präsident), 1937 Wien, 1949 München; 1942 Ehrenmitglied des Reichsinstituts für ältere dt. Geschichtskunde Berlin. • 1930 Brüder-Grimm-Gedenkmünze; 1940 Goethe-Medaille für Kunst und Wissenschaft. 1942 Ehrensenator der Universität Heidelberg.

Qu UAH PA 569, 5246f. - GLA Abt. 235, Fasz. 2365. - Nachlaß: UBH, siehe Günzburger, Angelika: Verzeichnis des Nachlasses F.P. 2 Bde. UBH 1984. Mitteilungen: Frau Dr. Marianne Mlacker geb. Panzer $(\dagger)$.

$W$ Hilde-Gudrun. Eine sagen- und literaturgeschichtliche Untersuchung. Halle/S. 1901. - Studien zur germanischen Sagengeschichte. 2 Bde. München 1910-1912. Deutschkunde als Mittelpunkt deutscher Erziehung. Frankfurt/M. 1922. Die Inschriften des deutschen Mittelalters. Leipzig 1938. - Studien zum Nibelungenliede. Frank-
furt/M. 1945. - Das Nibelungenlied. Entstehung und Gestalt. Stuttgart 1955. - Siehe auch WBIS, Int. Germanistenlexikon 2 (2003) S. $1366 \mathrm{f}$.

HG Die Kinder- und Hausmärchen der Brüder Grimm in ihrer Urgestalt. Berlin 1913. Neuausg. 1955. 2. Aufl. 1961. - Victor von Scheffel. Werke. 4 Bde. Leipzig 1919. • Siehe auch Int. Germanistenlexikon, S. $1366 \mathrm{f}$.

MHG 1913-1919 Zs. für den deutschen Unterricht. 1920-1924 Zs. für Deutschkunde.

$L$ Handels-Hochschule Mannheim 1907-1932 (1932) S. 28; Kürschner (1950) Sp. 1507 f. • Böckmann, Paul: Nachruf auf F. P. in: Heidelberger Akademie der Wissenschaften Jahresheft 1955/56. • Kienast, Richard: F. P. in: Ruperto Carola 8. Jg., Bd. 19 (1956) S. 102 f. • Nagel, Bert: F. P. in: Zs. für dt. Philologie 76 (1957); Ders.: In memoriam F. P. in: Ruperto Carola 12. Jg., Bd. 27 (1960) S. 142-144. • Arnim 4 (1984) S. 1230; Mussgnug (1988) S. 32, 67f., 99 Anm. 172 u. ö.; Jansen (1992) S. 412 (Register); Ders. (1992a) S. 168 (Register); Baden-Württ. Biographien I (1994) S. 262-264; WBIS; Wennemuth (1994) S. 637 (Register); Hutton (1999) S. 411 (Register). Kasten, Ingrid: F.P. in: Wissenschaftsgeschichte Germanistik (200o) S. 152-161. - NDB 20 (2001) S. 4of. - Lieb, Ludger: F. W. P. in: Enzyklopädie des Märchens ... Hrsg. von Rolf Wilhelm Brednich ... Bd. 10: Nibelungenlied - Prozeßmotive. Berlin 2002. S. 517-520. - Int. Germanistenlexikon 2 (2003) S. 1365-1367; 100 Jahre Germanistik in Hamburg (2011) S. 195-200, 211-216, 471 u. ö.; Riecke (2016) S. 149 (Register).

$P$ Bildarchiv UAH; graph. Slg. UBH; Ruperto Carola.

\section{Passow, Karl Adolf}

1896-1902 Med. Fak.

Ohrenheilkunde

* 12. Aug. 1859 Magdeburg

$\dagger \quad$ o7. Jan. 1926 Utrecht (Niederlande)

ev. 
V Arnold Thomas Gottfried P. (1829-1870) Gymnasial-Prof., s. Zur Erinnerung an A. P. in: Berliner Zeitung für Gymnasialwesen (1870) Bd. 24, S. 930-933; WBIS; Issa (1999) S. 3 f.

M Athenaea Thibeta geb. Ulrichs (1839-1913) Schriftstellerin, u. a. Autorin von: Die schwarzen Napoleone in Südafrika. Schilderungen des Lebens und der Sitten der Bantu-Völker, unter besonderer Berücksichtigung des Krieges der Engländer mit den Zulu. Leipzig 1886; Indische Volksmärchen. Stuttgart 1912. - T von Heinrich Nicolaus U. (1807-1843) 1837-1843 (Entlassung als dt. Beamter während nationalistischer Strömungen in Athen) o. Prof. für Lateinische Sprache U Athen, s. H.N.U. Der erste seines Faches in: Elsmann, Thomas: Im Schatten des Kaufmanns. Bremische Gelehrte 1600-1900. Bremen 2012. S. 152-171.

( 27. Sept. 1886 Marie Amélie geb. Freiin von Roepert (1862-1930)

K 1 T, 2 S: u.a. Arnold P. (1888-1966) seit 1923 Privat-Dozent, seit 1927 a.o. Prof. München, 1937-1945 (Entlassung durch Militärregierung) o. Prof., 1948 Wiedereinsetzung in die Rechte e. Emeritus für Augenheilkunde Würzburg, s. WBIS, Arnim 4 (1984) S. 1238; In nationalsozialistischen Gewässern: A.P. ... in: Geschichte der Augenheilkunde in Würzburg. Hrsg. von Michael Stolberg u. a. Pfaffenhofen 2007. S. 104-106; Friedel, Thomas: Über A.P. in: Karl Wessely - sein Leben, sein Wirken und sein Einfluß auf die Augenheilkunde in Deutschland und in der Welt. Diss. Würzburg 2008. S. 15 f., 24 und Anm. 79 u. ö.

Vw Schwester: Irene Gertrud P. (1863-1941) Ehefrau von Rudolf Christoph Eucken (1846-1926) zunächst Gymnasiallehrer, seit 1871 o. Prof. für Philosophie und Pädagogik Basel, 1874-1920 (Emeritierung) Jena; 1908 Nobelpreis für Literatur, s. NDB 4 (1959) S. 670-672; Beutin, Wolfgang: R.E. in: Preisgekrönte: Zwölf Autoren und Autorinnen von Paul Heyse bis Herta Müller. Ausgewählte Werke, sprachkritisch untersucht. Frankfurt/M. 2012. S. 55-76; Schäfer, Michael: Kapitalismus und Kulturkrise. Walter Eucken und die Philosophie R.E.s. Wirtschaft und Gemeinschaft. Konfessionelle und neureligiöse Gemeinsinnsmodelle im 19. und 20. Jahrhundert. Bielefeld 2014. S. 303318.
Vw Neffen: Arnold Eucken (1884-1950), seit 1911 Privat-Dozent Berlin, 1914-1918 Kriegsdienst; Ordinarius für Physikalische Chemie: seit 1919 Breslau, 1930-1950 Göttingen, s. BeckeGoehring, Margot, Eucken, Margaret: A.E. Chemiker - Physiker - Hochschullehrer. Glanzvolle Wissenschaft in zerbrechender Zeit. Berlin 1995; Göttinger Gelehrte 2 (2001) S. 434 f., Klee, Personenlexikon (2007) S. 140. • Walter Eucken (1891-1950 Suizid), seit 1921 Privat-Dozent Berlin; Ordinarius für Ökonomie: seit 1925 Tübingen, 1927-1950 Freiburg/Br., s. W. E. und sein Werk. Rückblick auf den Vordenker der sozialen Marktwirtschaft. Hrsg. von Lüder Gerken. Tübingen 2000; Dathe, Uwe, Goldschmidt, Nils: Wie der Vater, so der Sohn? Neuere Erkenntnisse zu W.E.s Leben und Werk anhand des Nachlasses von Rudolf Eucken in Jena in: ORDO - Jahrbuch für die Ordnung von Wirtschaft und Gesellschaft 54 (2003) S. 49-74; Dies.: Die größten Ökonomen: W.E. ... Stuttgart 2012; Zur Zukunft der sozialen Marktwirtschaft. 6o Jahre Walter Eucken Institut. Hrsg. von Lars P. Feld. Freiburg/Br. 2015. - Weitere Vw, siehe NDB 4 (1959) S. 670, $672 \mathrm{f}$.

Lb Berlin: Seit WS 1879/80 Studium am Medicinisch-chirurgischen Friedrich-Wilhelm-Inst., e. Anstalt zur Aus- und Weiterbildung von Militärärzten; Juni 1881 Physikum; 4. Aug. 1883 Dr. med.; 1885 Staatsexamen; 1891 Examen als Ohrenarzt. • In dieser Zeit:

Berlin: 1883-1892 Militärarzt.

Berlin: 1892-1894 Ärztl. Beirat der Reichskommission für Gesundheitspflege im Rheinstromgebiet; Stabsarzt (Abkommandierung): 1892 III. Med. Klinik, 1893-1894 Laryngolog. Klinik, 1894-1896 Ohrenklinik der Charité.

U Berlin: 1895 oder 1896 Habilitation (weder 1895 noch 1896 unter den Privatdozenten an U Berlin im Personalverzeichnis genannt).

UH: Seit 10. März 1896 nichtetatm. a. o. Prof. und Direktor des Inst. für Ohrenkranke in Bergheimer Straße 28; seit WS 1896/97 Leiter der Klinik und 
Poliklinik für Ohrenkranke mit 14 Betten in Bergheimer Straße 44 in Nachf. von Salomon Moos; seit 6. Dez. 1898 etatm. a. o. Prof.

U Berlin: Seit WS 1902/o3 etatm. a. o. Prof. und 1902-1922 Direktor der Klinik für Ohrenkrankheiten in der Charité, 1922-1926 Direktor der II. Hals-, Nasen-, Ohrenklinik und Poliklinik ebd. (Vereinigung der Fachgebiete Otologie und Laryngologie innerhalb e. I. und II. Hals-Nasen-Ohren-Klinik in der Charité); 1906-1926 auch Direktor der UKlinik und Poliklinik für Ohrenkrankheiten, 1912 umbenannt in U-Klinik und Poliklinik für Ohrenund Nasenkrankheiten; seit SS 1907 persönlicher Ordinarius; seit 1913 etatm. o. Prof. • In dieser Zeit:

1914/15 P. „steht als Generalarzt d[er] L[uftwaffe] im Felde" (aus: Königl. Friedrich-Wilhelms-Universität zu Berlin. Bericht über das Amtsjahr 1914/ 15 erstattet von dem Rektor Dr. Theodor Kipp. Berlin 1915. S. 18).

1902 Geh. Medizinalrat

P. ist behandelnder Ohrenarzt Kaiser Wilhelms II. (1859-1941); P. stirbt 1926 während eines Besuchs des früheren Regenten im Exil in den Niederlanden.

E Orden vom Zähringer Löwen; Kommandeur des Herzogl. Sachsen-Ernestinischen Hausordens.

Qu UAH PA 2084; RA 6318, 6795.

$W$ Ein Fall von Stenose des Conus arteriosus dexter mit Defect im Septum Ventriculorum in: Charité-Annalen 20 (1895) S. 219-233. • Eine neue Transplantations-Methode bei der Radikaloperation chronischer Mittelohrvereiterungen. Berlin 1895. - Die Verletzungen des Gehörorganes. Wiesbaden 1905. Trommelfellbilder. Ein Atlas für den praktischen Gebrauch. Jena 1912. Anleitung zu den Operationen am Gehörorgan, an den Tonsillen und in der Nase. Leipzig 1920. 3. Aufl. 1929. (Mitverf.)

MG 1908 Passow-Schaefer Beiträge zur praktischen theoretischen Hals-, Nasen- und Ohrenheilkunde.
L Stammliste K.W.-A. (1910) S. 249 f.; Wer ist's (1922) S. 1153; Kürschner (1925) Sp. 750 f. - Wagener, O.: Nachruf in: Archiv für Ohren-, Nasenund Kehlkopfheilkunde. Organ der Dt. Gesellschaft der Hals-, Nasen-, Ohrenärzte. Berlin 1926. S. 1-4. - Fischer 2 ( $\left.{ }^{3} 1962\right)$ S. 1178; Chronik Ärzte H (1985) S. 139, 259. ^ A. P. in: Akademische Lehrstätten und Lehrer der Oto-Rhino-Laryngologie in Deutschland im 20. Jahrhundert. Zus.gestellt und bearb. von Konrad Fleischer ... Hrsg. von der Dt. Gesellschaft für Hals-Nasen-Ohren-Heilkunde, Kopf- und Hals-Chirurgie ... Berlin 1996. S. 307 (Register). - Issa, Miriam Charbel: K. A.P. und die Berliner Hals-Nasen-Ohrenheilkunde. Diss. Berlin 1999. - Kirsch, Frank-Peter: Berliner Militärärzte im Labor 1870-1895. Diss. Med. Fak. Charité - Universitätsmedizin Berlin. Berlin 2009. S. 213, 234 u. ö. - Wagner, Frank: Beharrliche Einheit der Vielfalt: Das Ordinarienkollegium der Friedrich-Wilhelms-Universität zu Berlin 1809 bis 1945. Diss. Gießen 2012. S. 54, 134. • Wikipedia.

$P$ Chronik Ärzte H.

\section{Pauli, Wilhelm Eduard}

1926-1929 (1930) Med. Fak.

Innere Medizin (Angewandte medizinische

Physik)

* o1. Juni 1882 Ober-Ingelheim (heute: Stadtteil von Ingelheim am Rhein)

$\dagger \quad$ o1. Okt. 1950 Berlin ev.

V Carl P. (1852-1930) Grubenbesitzer

M Lina geb. Hirsch (1857-1939)

$œ$ unverheiratet

Vw Bruder: Richard P. (1886-1951) seit 1914 Privat-Dozent, seit 1919 Konservator, seit 1920 apl. Prof. für Psychologie und Religionsphilosophie am Psycholog. Inst. München, s. NDB 20 (2001) S. $123 \mathrm{f}$.

Lb Seit WS 1903/o4 Studium der Physik, Mathematik, Chemie an U Freiburg/Br., anschl. Straßburg, zuletzt Jena. 
U Jena: 4. Mai 1907 Dr. phil.; WS 1906/o7-SS 1907 Volontär-Assistent am Physikal. Inst.

UH: Assistent: Seit WS 1907/08 Physikal. und SS 1909-WS 1909/10 Radiolog. Inst.

U Jena: Seit Okt. 1910 Assistent am Physikal. Inst.; 18. Febr. 1911 Habilitation; Aug. 1914 (Freiwilliger)1916 (Entlassung als felddienstuntauglich infolge e. Verletzung) Kriegsdienst; seit 12. Jan. 1915 nichtplanm. a.o. Prof.; seit SS 1919 Abt.-Vorstand für Elektrizitätslehre an Physikal. Anstalt; 1920-1925 Beurlaubung „Zwecks Ausführung wiss. Arbeiten in München", aus: Standesliste in: UAH PA 5257 (tatsächlicher Grund für Weggang nach München waren „Eifersüchteleien, wie sie zwischen strebsamen jungen Gelehrten häufig vorkommen", aus: undatierter Brief (ca. Mai 1926 von Max Wien (1866-1938) 1911-1935 o. Prof. für Physik an U Jena) in: UAH PA 1104; 5. Okt. 1925 Bitte um Verlängerung des Urlaubs, da sich P. um Aufnahme in e. Med. Fak. e. U bemühe; Urlaub wird nicht gewährt, daraufhin Einreichung e. mehrmonatigen Krankschreibung; 24. Mai 1926 Antrag P.s auf Entlassung von $\mathrm{U}$ mit der Begründung, er wolle sich ausschließlich med. Studien widmen und keine physikal. Vorlesungen mehr halten; April 1926 aus Lehrkörper ausgeschieden. • In dieser Zeit:

U München: Seit WS 1920/21 Studium der Medizin; WS 1923/24 med. Staatsexamen; 1923-1924 Ableistung des praktischen Jahrs; 1924 Approbation und Dr. med.; vor Okt. 1926 u. a. Mitarbeiter an Chirurg. U-Poliklinik.

UH: Seit 1. Okt. 1926 Assistent an Med. U-Klinik; seit WS 1926/27 Lehrauftrag zur Abhaltung e. 2-stündigen Vorlesung über med. Physik mit e. Vergütung von 100.- Reichsmark für die Semesterwochenstunde; 16. Nov. 1926 Umhabilitation; seit 24. Jan. 1927 nichtplanm. a. o. Prof.; Beurlaubungen: 1. April-1. Okt. 1928 (Aufenthalt zur „Ausführung wiss. Arbeiten“ in Wien aus: PA 5257), 15. April 1929-15. April 1930 (Aufenthaltsort unbekannt); 15. April 1930 Austritt aus dem Lehrkörper auf eigenen Antrag.

U Jena: Seit SS 1930 a. o. Prof. für Physik.
Die fachliche Beurteilung P.s fällt bei drei überlieferten Beurteilungen positiv aus; „die einzige kleine Ausstellung ... an der Persönlichkeit [P.s] ... ist eine gewisse Neigung zum Misstrauen, die vielleicht auf die bei ,Verwachsenen' oft beobachtete Eigenschaft zurückzuführen sei, wiewohl dieses Gebrechen bei P. kaum in Erscheinung trete" (Äußerung Max Wiens in e. undatierten Brief (ca. Mai 1926) aus: PA 1104).

Qu UAH PA 1104, 5257. GLA Abt. 235, Fasz. 2370. - Auskunft: Universitätsarchiv Jena (Bestand D, Nr. 2228; Bestand M, Nr. 628; Bestand N, Nr. 47/1).

$W$ Lichtelektrische Untersuchungen an fluoreszierenden Substanzen in: Annalen der Physik 40 (1913). • P., E., Pauli, Richard (Bruder): Physiologische Optik, dargestellt für Naturwissenschaften. Jena 1918. - Einfluß normaler Kathodenstrahlen auf das lebende Gewebe in: Physikalische Zeitschrift 21 (1920).

L Poggendorff 5 (1925) S. 948; Kürschner (1926) Sp. 1425, (1931) Sp. 2173. - Schirrmacher, Arne: Philipp Lenard: Erinnerungen eines Naturforschers. Kritische annotierte Ausgabe des [Lenardschen] Originaltyposkriptes von 1931/1943. Berlin 2010. S. 216 und Anm. 756.

\section{Paulus, Heinrich Eberhard Gottlob}

1811-1844 Theol. Fak.

Exegese, Kirchengeschichte

* $\quad$ 01. Sept. 1761 Leonberg (bei Stuttgart)

$\dagger$ 10. Aug. 1851 Heidelberg ev.-prot.

V Gottlob Christoph P. (1727-1790) Diakon (1771 Amtsenthebung aufgrund phantasmagorischer Visionen); Autor der 1766 anonym erschienenen Streitschrift „Der Württembergische Solon", s. Schönwitz (2001) S. 10-15 u. ö.

M Maria Christine geb. Köstlin (1738-1767), s. Schönwitz, S. 12 
(2. Juni 1789 Karoline Friederike Elisabeth geb. Paulus (1767-1844) Kusine; Schriftstellerin (Pseudonym: Eleutherie Holberg), s. Schindel, Carl Wilhelm Otto August von: Die deutschen Schriftstellerinnen des 19. Jahrhunderts. Leipzig 1825. Bd. 2. S. 83-85; Waitz, Georg: Caroline (Schlegel-Schelling): Briefe an ihre Geschwister, ihre Tochter Auguste, die Familie ... Leipzig 1871. Bd. 2. S. $111 \mathrm{ff.}$ u. ö.; Unger, Rudolf: Ungedruckte Briefe Dorothea Schlegels an K. P. in: Neue Heidelberger Jahrbücher 17 (1913) S. 72-84; Schönwitz (2001) S. 26-28 u. ö.; Tilliette (2004) S. 588 (Register)

K 1 T: Sophie Caroline P. (1791-1847), s. Reichlin-Meldegg, Karl Alexander Frhr. von: Das Leben eines ehemaligen römisch-katholischen Priesters. Heidelberg 1874. S. 119 f.; Schönwitz, S. 77-84; Ehefrau von Prof. August Wilhelm Schlegel (1767-1845), u.a. Literaturhistoriker, s. NDB 23 (2007) S. 38-40; Paulin, Roger: Life of A. W. S. ... Cambridge (UK) 2016; Strobel, Jochen: A.W.S. im Dialog. Epistolarität und Interkulturalität. Paderborn 2016. - Die Ehe wird am 30. Aug. 1818 geschlossen; bereits nach wenigen Tagen trennt sich das Paar (ohne Scheidung) auf Geheiß des Vaters E.P., s. hierzu Mann für Mann. Biographisches Lexikon. Zur Geschichte von Freundesliebe und mannmännlicher Sexualität im dt. Sprachraum. Hrsg. von Bernd-Ulrich Hergemöller ... Berlin 2010. T. 2. S. 1044-1046.

K 1 S: Wilhelm P. (1802-1819), s. Schönwitz (2001) S. $84-88$

Vw siehe NDB 20 (2001) S. $135^{*}$.

Lb Schüler der Klosterschulen: Seit Okt. 1775 Blaubeuren, seit Nov. 1777 Bebenhausen (heute: Stadtteil von Tübingen).

U Tübingen: 3. Dez. 1777 Immatrikulation; 1. Dez. 1779 phil. Bakkalarexamen; 24. Sept. 1781 Magisterexamen.

Stift in Tübingen: Seit 1779 Stipendiat; 1784 theol. Examen.
1784-1786 Hauslehrer der Brüder seiner späteren Ehefrau in Schorndorf; 1786-1787 Vikar und Lehrer der 1. Schulklasse ebd.; 1787 Rückkehr ins Elternhaus aus gesundheitlichen Gründen.

Mai 1787-Nov. 1788 Studienreisen durch Deutschland, Holland, Großbritannien, Frankreich, finanziert vom Freiherrn Christian Heinrich von Palm (1736-1819), s. hierzu Bödeker, Hans Erich: H.E. G. P.' Tagebuch einer literarischen Reise (1787/ 1788). Eine Skizze in: Arbeitsgespräch „Reckahn, Mark Brandenburg“... Treffpunkte für Aufklärung, Volksaufklärung und Philanthropismus ... Bremen 2014. S. 235-246; 1789 kurzzeitig Repetent am Stift in Tübingen.

U Jena: Seit 15. April 1789 o. Prof. für Orientalische Sprachen an Phil. Fak. als Nachf. von Johann Gottfried Eichhorn (1752-1827), s. Brief der Theol. Fak. der UH an Engeren Senat vom 22. Jan. 1839 in: UAH PA 2087; 8. Aug. 1795 Dr. theol.; seit Okt. 1793 o. Prof. für Dogmatik und Exegese an Theol. Fak.

U Würzburg: Seit 20. Okt. 1803 o. Prof. für Theologie; 1804 Rufe an U Dorpat und Erlangen abgelehnt; Okt. 1806 (Würzburg fällt an Ferdinand III. von Toskana, Mai 1806-Juni 1814 an Großherzog von Würzburg) Weggang zunächst nach Stuttgart nach Aufhebung der Ev.-Theol. Fak. und Restituierung der Kath.-Theol. Fak.; 1806 Widerrufung der Ern. P.' zum o. Prof. an U in Altdorf bei Nürnberg aufgrund e. vernichtenden Urteils des Präsidenten der fränkischen Landesdirektionen Bamberg und Würzburg, Graf Friedrich von Thürheim (1763-1832), u. a. über P.s Vernachlässigung seiner Lehrtätigkeit an U sowie seiner Unkollegialität. • In dieser Zeit auch:

Würzburg: 1803-1806 Landesdirektions-Rat im Kurfürstentum Bayern.

Landesdirektions-Rat (vorherige Bezeichnung: Kreis-, Kirchen- und Schulrat) in Kirchen- und Schulsachen am Generalkommissariat: Seit Frühjahr 1807 Bamberg, seit Okt. 1808 Nürnberg.

UH: 13. Dez. 1810 Ern. zum o. Prof. der Theologie und Philosophie mit den Fächern Exegese und Kirchengeschichte mit e. Jahresgehalt von 2500.- 
Gulden und 500.- Gulden „für Zugskosten vom 23. April 1811 an ... aus der Universitätscasse" (aus: Brief des Akademischen Direktoriums [= Prorektor der $\mathrm{UH}$ ] an Bau- und Ökonomie-Kommission der UH vom 3. Jan. 1811 in: UAH RA 6718) als Nachf. von Wilhelm Martin Leberecht De Wette; SS 1811 Vorlesungsbeginn (P. lehrt nur an Theol. Fak.); 1813 P. erleidet lebensbedrohenden Schlaganfall, von dem er sich in den kommenden 2 Jahren wieder gut erholt; 1813-1815 keine Unterbrechung bei Ankündigungen der Vorlesungen; seit 23. Okt. 1818 Direktor des neuerrichteten Orientalisch-Exegetisch-Biblischen Seminars, s. hierzu die chronologische Geschichte der Seminarien an UH in: UAH RA 6122 fol. 71r-73v; 13. Jan. 1832 auf eigenen Antrag Entbindung von Vorlesungen: seit WS 1833/34 nur noch Ankündigung der Vorlesung „Geschichte des Urchristentums“; 25. April 1844 Ruhestand.

1814 Prorektor der UH; 1813, 1816, 1819, 1822, 1826, 1832 Dekan der Theol. Fak. der UH

1807 Kirchenrat; 1811 Geh. Kirchenrat

E Mitglied: 1789 Königl. Gesellschaft der Altertumsforscher London, 1808 Akademie der Wissenschaften München. 15. Mai 1823 Dr. iur. h.c. Freiburg/Br. 1839 Ehrenbürger der Stadt Heidelberg.

$Q u$ UAH PA 2087; RA 5460, 6122, 6718 fol. 2v, 3r, 1OV, 11r u. o..; GF 121; KE 219 (Vorlesungsmitschrift WS 1816/17 über Sprüche Salomos). - GLA Abt. 205, Fasz. 426, Abt. 235, Fasz. 660. Die Matrikeln der Universität Tübingen 1477-1817. Bd. 3: ... 17101817. Hrsg. von Heinrich Hermelink. Stuttgart 1953. S. 283. - Teil-Nachlaß: UBH; Deutsches Literaturarchiv Marbach. - Auskunft: Universitätsarchiv Jena (Bestand J, Nr. 33, Bl. 24-28; Bestand M, Nr. 190, Bl. 70). • Skizzen aus meiner Bildungsund Lebensgeschichte. Heidelberg 1839. (Autobiogr.)

$W$ Philologisch-kritischer Commentar über das Neue Testament. 4 Bde. Lübeck 18oo-1804. 2. Aufl. 1804-1808. Das Leben Jesu als Grundlage einer reinen Geschichte des Urchristentums. 2 Bde. Heidelberg 1828. Exegetisches Handbuch über die drei ersten Evangelien. 3 Bde. Heidelberg 18301833. 2. Aufl. 1842. - Die endlich offenbar gewordene positive Philosophie der Offenbarung oder Entstehungsgeschichte, wörtlicher Text, Beurtheilung und Berichtigung der von Schellingschen Entdeckungen über Philosophie überhaupt, Mythologie und Offenbarung des dogmatischen Christenthums im Berliner Wintercursus von 1841/42. Der allgemeinen Prüfung vorgelegt. Darmstadt 1843. - Zur Rechtfertigung der Deutschkatholischen gegen Klagen Römischgläubiger. Eine historische und staatsrechtliche Beleuchtung. Karlsruhe 1846. - Bibliographie in: Burchard (1985) S. $268-277$.

G, $M H G$ 1819-1831 Sophronizon oder unpartheiisch-freimüthige Beiträge zur neuern Geschichte, Gesetzgebung und Statistik der Staaten und Kirchen.

$L$ Julius, Gustav: Der Paulus-Schellingsche Streit in: Wigands Vierteljahrsschrift. Leipzig 1844. Bd. 1. S. 253-260. - Reichlin-Meldegg, Karl Alexander Frhr. von: H.E. G. P. und seine Zeit ... 2 Bde. Stuttgart 1853. Nachdr. Gloucester 2014. $\bullet$ Günther (1858) S. 213; Badische Biographien 2 (1875) S. 119129; Heidelberger Prof. aus dem 19. Jhdt. 1 (1903) S. 41-44. H. P. in: Hirsch, Emanuel: Geschichte der neueren ev. Theologie. Gütersloh 1953. 5. Bd. 4. Aufl. 1966. - Burchard, Christoph: H.E.G.P. in: Semper apertus 2 (1985) S. 222-297. Heidelberg im säkularen Umbruch (1987) S. 564 (Register); WBIS; BBKL VII (1994) Sp. 96-102; NDB 20 (2001) S. 135 f. Schönwitz, Ute: Er ist mein Gegner von jeher. Friedrich W.J. Schelling und H.E.G.P. Warmbronn 2001. - Steiger, Johann Anselm: H.E. G.P. ... zwischen Spätaufklärung, Liberalismus, Philosemitismus und Antijudaismus in: Zs. für bayerische Kirchengeschichte. Nürnberg 2001. S. 119-135. - RGG $6\left({ }^{4} 2003\right)$ Sp. 1065 f. • Tilliette, Xavier: Schelling. Biographie. Stuttgart 2004. S. 588 (Register.) - Mulzer, Martin: H.E.G.P., s. https:// www.bibelwissenschaft.de/stichwort/16843/ (Sept. 2012) (Ausdruck im UAH). Stumm (2012) S. 702 (Register). - Latifi, Kaltërina: „Verbotenes Recht“. H.E. G. P.' Auseinandersetzung mit dem Duell in: Heidelberg - Jahrbuch zur Geschichte 2015. Heidelberg 2014. Jg. 18. S. 221-230. Plathow, Michael: H. G. E. P. Säkularrede zum Reformationsjubiläum 
1817 in: Martin Luthers „Heidelberger Disputation“ und das Reformationsgedenken 2017 aus: Lutherjahrbuch. Organ der int. Lutherforschung ... Göttingen 2015. 82. Jg. S. 240-265, hier: S. 242-248.

$P$ Bildarchiv UAH; graph. Slg. UBH.

\section{Peltzer, Alfred}

1902-1911 (1912) Phil. Fak.

Kunstgeschichte

* 16. Aug. 1875 Krefeld

$\dagger$ 31. Dez. 1914 Pützchen (heute: Ortsteil von Bonn)

ev.

V Gustav P. (1844-1897) Samtfabrikbesitzer, s. NDB 20 (2001) S. 169

M Laura geb. ter Meer ( $\left.{ }^{*} 1850\right)$

(16. Aug. 1908 Luise geb. Roemer (1882-1961)

$\mathrm{K}$ keine

Vw Bruder: Walter P. (1880-1947), u.a. seit 1913 Vorstandsmitglied, seit 1927 Generaldirektor der Firma Peltzer Gebrüder AG, Sammetfabrik in Krefeld, s. WBIS

Vw siehe NDB 20 (2001) S. 170*.

Lb Krefeld: 1896-1897 Tätigkeit in elterlicher Firma auf Wunsch des Vaters.

Seit 27. April 1895 Studium an UH, seit SS 1896 Wien, 3. Mai 1897-SS 1899 Forts. des Studiums an UH; 16. Nov. 1899 Dr. phil. an UH.

Nov. 1899-1901 Studienreisen in Italien, Frankreich, Großbritannien, Italien, Belgien, Niederlande, Deutschland.

UH: 8. Nov. 1902 Habilitation; WS 1907/o8 Beurlaubung für e. Aufenthalt „im Interesse einer umfangreichen Arbeit in Rom“ (aus: Brief vom 10. Mai 1907 in: UAH PA 2089); seit 25. Juni 1909 nichtetatm. a.o. Prof.; Mitte Aug. 1911 „schwere nervöse“ Erkrankung und Einweisung in Nervenheilanstalt (aus: Brief vom 7. Sept. 1911 in: PA 2089); Dez. 1912 Aufgabe seiner Lehrtätigkeit aus gesundheitlichen Gründen.
Pützchen: 1911-1914 (†) Aufenthalt in Peiperscher Irrenanstalt.

Qu UAH PA 2089; Fak.-Akte H-IV-102/133. • GLA Abt. 235, Fasz. 2372. - Auskunft: Standesamt Krefeld-Mitte; Standesamt Bonn-Beuel (Sterbeeintrag 1914).

W Deutsche Mystik und deutsche Kunst. Straßburg 1899. (Rezensionen von: Bergner, Heinrich in: Theologische Literaturzeitung. Monatsschrift für das gesamte Gebiet der Theologie und Religionswissenschaft. Leipzig 1900. S. 153 f.; Bredt, Ernst Wilhelm in: Germanisches Nationalmuseum. Mitteilungen aus dem Germanischen Nationalmuseum (1902) S. 72.) • Über Malweise und Stil in der holländischen Kunst. Heidelberg 1903. • Albrecht Dürer und Friedrich II. von der Pfalz. Straßburg 1905. (Rezension von: Friedländer, Max J. in: Repertorium für Kunstwissenschaft 29 (1906) S. 91 f.) - Anthoni, der Meister vom Ottheinrichsbau zu Heidelberg. Heidelberg 1905. Heidelberg in der Kunstgeschichte des 19. Jahrhunderts. Heidelberg 1906.

HG Albrecht Dürer: Unterweysung der Messung mit dem Zirckel und Richtscheyt in Linien, Ebnen und gantzen Corporen. München 1908. Neudr. Wiesbaden 1970.

L NDB 20 (2001) S. 170*. - Fröschle, Hartmut: Goethes Verhältnis zur Romantik. Würzburg 2002. S. 116. Max Weber-Gesamtausgabe: Band II/9: Briefe 1915-1917. Hrsg. von Gerd Krumeich ... Tübingen 2008. S. 111 und Anm. 5 (hier verlässt P. 1912 Heidelberg zu Studien in Weimar). - Deutsche Biographie, s. https://www.deutsche-biogra phie.de/gnd142744158.html [07.11. 2017]. 


\section{Perels, Leopold Emil Erwin}

1905-1914, 1919-1928 Jur. Fak. 1928-1933 (Honorar-Prof.) Jur. Fak.

Deutsche Rechtsgeschichte, Bürgerliches Recht, Handels- und Seerecht

* 07. März 1875 Kiel

$\dagger \quad$ 25. März 1954 Périgueux (Frankreich)

口 Périgueux

ev.

V Dr. iur. Ferdinand P. (1836-1903), u.a. seit 1863 Garnisons-Auditeur (= Garnisons-Jurist), 1867-1877 Auditeur der Marinestation der Ostsee in Kiel, auch Lehrer für Völkerrecht, See- und Militärrecht an Marine-Akademie ebd., seit 1877 Wirkl. Admiralitätsrat, seit 1881 Geh. Militärrat, 1892-1901 (Pensionierung) Direktor des Verwaltungs-Departments des Reichsmarineamts Berlin und stellvertr. Bevollmächtigter im Bundesrat für Preußen, seit 1900 o. Honorar-Prof. für Seerecht U Berlin, seit 1901 Wirkl. Geh. Admiralitätsrat (Exzellenz), s. WBIS

M Anna geb. Volkmar (1849-1924) T von Leopold V. (1817-1864), u.a. seit 1845 AdvokatAnwalt am Revisions- und Kassationshof Berlin, Verteidiger von Beteiligten der 1848er Revolution, 1859 Gründungsmitglied der Juristischen Gesellschaft Berlin, s. Fijal, Andreas: Die Geschichte der Juristischen Gesellschaft zu Berlin in den Jahren 1859 bis 1933. Berlin 1990. S. $47 \mathrm{f}$.

๑ unverheiratet

Vw Brüder: Kurt P. (1878-1933 Suizid) seit 1903 Privat-Dozent Kiel, seit 1908 a. o. Prof. Greifswald, seit 1909 o. Prof. für Öffentl. Recht, Staatslehre U Hamburg, s. WBIS; Ipsen, Hans Peter: K.P. in: Lebensbilder hamburgischer Rechtslehrer ... Hamburg 1969. S. 69-74; Lexikon Greifswalder Hochschullehrer (2004) S. 179. • Ernst P. $\left({ }^{*} 1882 \dagger 1945\right.$ in Gestapohaft) seit 1911 Privat-Dozent, seit 1916 Prof., 19311938 (Zwangsemeritierung) persönlicher Ordinarius für Histor. Hilfswiss. Berlin, s. NDB 20 (2001) S. 181 f.; Oberling, Ines: E. P. ... Lehrer und Forscher an der Berliner Universität. Bielefeld 2005.
Vw Neffe, Sohn von Ernst P.: Friedrich Justus P. (1910-1945 erschossen) 1933 und 1936 nach rechtswiss. Staatsexamina aus rassischen Gründen keine Übernahme in Justizdienst, seit 1936 Rechtsberater der Bekennenden Kirche, Mitglied des Pfarrernotbundes, 1944 Verhaftung und Verurteilung durch Volksgerichtshof zum Tode, s. WBIS; Schreiber, Matthias: F.J.P. Ein Weg vom Rechtskampf der Bekennenden Kirche in den Politischen Widerstand. München 1989; NDB 20 (2001) S. 182; Perels, Joachim: Christlicher Widerstand gegen das Nazi-Regime - F. J. P. in: Die Rolle der Juristen im Widerstand gegen Hitler. Festschrift für F. J. P. Stiftung Adam von Trott, Imshausen e. V. (Hrsg.). Baden-Baden 2017. S. $49-66$.

Lb WS 1893/94 Studium an U Göttingen, SS 1894 H, WS 1894/95 Berlin, SS 1895 Kiel.

Berlin: 20. Nov. 1896 Referendarexamen; seit Dez. 1896 Referendar am Amtsgericht; 26. Juli 1898 Dr. iur. an U; Okt. 1898-Sept. 1899 Militärdienstpflicht als Einjährig-Freiwilliger im 2. Brandenburgischen Feldartillerie-Regiment; 4. Juni 1902 Assessorexamen; seit Juni 1902 Assessor am Amtsgericht, dann in Charlottenburg.

UH: 21. Dez. 1905 Habilitation; Mai 1907 Anklage wegen Hausfriedensbruch in Bahnhofswirtschaft, s. hierzu Schroeder (2015) S. 285-287; Juni 1907 Freispruch aufgrund seiner Schwerhörigkeit; seit 2. März 1912 nichtetatm. a. o. Prof.; Jan.-Sept. 1914 Beurlaubung; P. wird während seines SpanienUrlaubs vom Kriegsbeginn überrascht und kann nicht mehr nach Deutschland zurückkehren.

Barcelona: 4. Aug. 1914 Bewerbung, 1914-1919 stellvertr. Konsulatsverwalter am dt. Generalkonsulat; Herbst 1919 Rückkehr nach Deutschland.

UH: WS 1919/20 Forts. seiner nichtplanm. a. o. Professur; seit 18. Juni 1928 o. Honorar-Prof.; 30. Dez. 1928 Ablehnung e. von der Jur. Fak. an das Ministerium eingereichten Antrags auf Etablierung e. planm. Extraordinariats für P.; April-3. Mai 1933 Beurlaubung aufgrund des Gesetzes zur „Wiederherstellung des Berufsbeamtentums“; 18. Aug. 1933 Entzug der Lehrbefugnis aus rassischen Gründen; 
Ende 1933-Okt. 1940 P. erhält aus der jüdischen, privat unterstützten „Stiftung von 1916 für Rechtswirtschaftliche und Rechtsvergleichende Studien" an U e. monatl. Zuschuß von 282,50 Reichsmark; 22. Okt. 1940 Deportation nach Gurs (Südfrankreich). • In dieser Zeit:

Nov. 1903-Okt. 1940 Mitarbeiter am Dt. Rechtswörterbuch im Auftrag der Akademie der Wissenschaften Berlin, Dienstort Heidelberg; WS 1907/ o8-April 1933 nebenamtlicher Dozent an HandelsHochschule Mannheim.

Gurs: 1940-1945 (kein Entlassungsdatum in UAH PA genannt) Internierungslager; 25. Nov. 1941 Verlust der dt. Staatsangehörigkeit für alle deportierten Juden kraft 11. Verordnung zum Reichsbürgergesetz.

Périgueux: Seit 1945 Aufenthaltsort, letzter Wohnsitz im Hotel Fénélon; P. gelingt aufgrund seines schlechten Gesundheitszustandes und Paßschwierigkeiten (P. stellt keinen Antrag auf Wiedereinbürgerung) nicht mehr die Rückkehr nach Deutschland; 1950 P. erhält für „seine Arbeit (am Dt. Rechtswörterbuch) in der rückliegenden Zeit“ ein Honorar von 400.- DM, 1953 e. Honorar über 300.- DM („ein handschriftlicher Vertrag mit ... P. liegt nicht vor. Die Mitarbeit beruht auf einer alten mündlichen Abmachung“, aus: Brief des Heidelberger Leiters des Archivs des Dt. Rechtswörterbuchs Otto Gönnenwein (s. Drüll (2009) S. 226 f.) vom 11. Dez. 1953 an das Regierungs-Präsidium Nordbaden in Karlsruhe in: PA 5272).

UH: 1950-1954 Über die Wiedergutmachungspläne seitens der U, s. Schroeder (2015) S. 297-299.

Qu UAH PA 781, 5272; RA 6762. • GLA Abt. 235, Fasz. 1559, Abt. 456 E, Nr. 8900. - Auskunft: Universitätsarchiv Kiel im Landesarchiv SchleswigHolstein.

$W$ Strandungsdelikte im deutschen Recht. Breslau 1898. Die Handelsgerichtsordnung von Barcelona aus dem 15. Jahrhundert in: Zs. für das gesamte Handels- und Konkursrecht 85 (1921). - Wechselprotest und Wechselklagen. Mannheim 1929.
HG 1912-1933 Urkunden zur Geschichte des deutschen Privatrechts.

MHG 1930-1933 Jahrbuch des Jugendrechts.

L Kürschner (1931) Sp. 2183; Handels-Hochschule Mannheim 1907-1932 (1932) S. 26. • Weizsäcker, Wilhelm: L.P. † in: Ruperto Carola 6. Jg., Nr. 13/ 14 (1954) S. 49. - Mussgnug (1988) S. 200 (Register); Jansen (1992a) S. 168 (Register); UH im Nationalsozialismus (2006) S. 264-266 u. ö.; Lexikon jüdischer Einwohner Hs (2011) S. 331. • Leo, Paul Christopher: Wilhelm Groh ... Hamburg 2012. S. 145-147. - Schroeder, Klaus-Peter: Entrechtet, deportiert, vergessen: Der Heidelberger Rechtsgelehrte L.P. in: ZGORh 163. Jg. (2015) S. 277299. Riecke (2016) S. 45, 86 f.; Deutsche Biographie, s. https://www.deutsche-biographie.de/g nd116078537.html [07.11.2017]; Schroeder (2017) S. $186-208$.

$P$ Bildarchiv UAH; Ruperto Carola.

\section{Perron, Oskar}

1914-1922 Nat.-Math. Fak.

Mathematik

* $\quad$ 07. Mai 1880 Frankenthal (Pfalz)

$\dagger \quad$ 22. Febr. 1975 München ev.

V Jakob Heinrich August P. (1850-1925) Bankier

M Augusta geb. Leinenweber (1857-1924)

(1) 28. Juli 1906 Hermine geb. Perron (1883-1961)

K $\quad 3 \mathrm{~T}$

Vw Bruder: Heinrich P. $\left({ }^{*} 1881 \not x\right.$ Aug. 1918) Fabrik-Direktor, Ehemann von Ellen geb. Benz (1890-1973) T von Carl B. (1844-1929) Ingenieur und Automobil-Konstrukteur, s. NDB 2 (1955) S. 57-59; Grünewald, Martin, Williamson, Willy Harold: C. B., ein Leben für das Automobil. Kehl am Rhein 2013.

Lb Seit WS 1898/99 Studium an U München, anschl. Berlin; 1902 Dr. phil. nat. an U München; 1902 Lehramtsprüfung; anschl. Studienaufenthalte in Göttingen und Tübingen. 
U München: 1906 Habilitation.

U Tübingen: Seit 1910 etatm. a. o. Prof.

UH: 18. Dez. 1913 (Ern.)-30. Sept. 1922 o. Prof. als Nachf. von Leo Koenigsberger; 17. April 1914 Vereidigung. $\bullet$ In dieser Zeit:

1914-1918 Kriegsdienst.

U München: WS 1922/23-WS 1950/51 (Emeritierung) o. Prof. (als Nachf. von Alfred Pringsheim (1850-1941), s. NDB 20 (2001) S. 724 f., Schwiegervater von Thomas Mann); 1943 Wegzug nach DieBen am Ammersee, s. hierzu Zwei Briefe und eine Erklärung von Oskar Perron (1946) aus Dießen am Ammersee, Haus 292, vom 16. Sept. 1946 online unter http://www.ahnendaten.de/materialien/ fritz_lettenmeyer_briefe_perron.html (Homepage von Ulrich Kretschmer, München, abgerufen am 12. Okt. 2017); 1944 Ausbombung des P.schen Hauses in München; 1949 Rückkehr nach München; 196o letzte Vorlesungsankündigung.

1919/20 Dekan der Nat.-Math. Fak. der UH

1928 Bayer. Geh. Rat

$E$ Mitglied der Akademie der Wissenschaften: 1917 H, 1924 München; 1919 Mitglied der Dt. Akademie der Naturforscher Leopoldina Halle/S.; 23. Nov. 1940 Wahl zum Korr. Mitglied der Naturwiss.-Math. Klasse der Sächsischen Akademie der Wissenschaften zu Leipzig; „seine Mitgliedschaft wurde nicht vollzogen, weil das sächsische Volksbildungsministerium seine Zuwahl nicht zur Bestätigung an das Reichserziehungsministerium in Berlin weitergeleitet hat", s. hierzu Wiemers, Gerald: Die Sächsische Akademie der Wissenschaften zu Leipzig 1846-1996. Zur Organisationsform ihrer Mitglieder in: Neues Archiv für Sächsische Geschichte 67 (1996) S. 179-199, hier S. 193. Ehrendoktorate der U: 1956 Tübingen, 1960 Mainz. • Mitglied der Sektion Bayerland des Deutschen Alpenvereins.

Qu UAH PA 2091. • GLA Abt. 235, Fasz. 2374. • Briefe: Mathematisches Institut der Universität München. - Siehe auch Archiv der Dt. Akademie der Naturforscher Leopoldina Halle/S. • Auskunft: Stadtarchiv Frankenthal (Pfalz).

$W$ Die Lehre von den Kettenbrüchen. 2 Bde. Leipzig 1913. 3. Aufl. 1954-1957. Nachdr. 1977. • Irrationalzahlen. Berlin 1921. 4. Aufl. 1960. Algebra. 2 Bde. Berlin 1927. 3. Aufl. 1951. Nichteuklidische Elementargeometrie der Ebene. Stuttgart 1962.

L Kürschner (1931) Sp. 2185, (1950) Sp. 1526f., (1966) S. 1819 f. - Huther, Karl: Lebensbild O. P. in: Frankenthaler Zeitung. Sonderdruck (Mai 1966). • Schmidt, Hermann: Nachruf in: Jahrbuch der Bayer. Akademie der Wissenschaften (1976). • Frank, Evelyn: O.P. ... in: Journal of Number Theory (June 1982) Vol. 14, Issue 3, S. 281-291. • Arnim 4 (1984) S. 1258; WBIS. - Morlock, Walther: Die Perrons, eine pfälzische Hugenotten-Familie in: Die Rheinpfalz. Aktuelle Nachrichten aus der Pfalz vom 11. Juni 1985. Heinhold, Josef: O.P. in: Jahresbericht der Dt. Mathematiker-Vereinigung 90 (1988) S. 184-199 (mit Bibliographie). • Litten, Freddy: O.P. - Ein Beispiel für Zivilcourage im Dritten Reich in: Frankenthal einst und jetzt (1995) Nr. 1/2, S. 26-28. NDB 20 (2001) S. 196 f. • Bauer, Friedrich L., Haenel, Christoph: Übersehene numerische Aspekte in der Geschichte der Kettenbrüche. Dem Andenken an O.P. München 2007. Physiker zwischen Autonomie und Anpassung. Hrsg. von Dieter Hoffmann und Mark Walter. Weinheim 2007. S. 671 (Register). Bauer, Friedrich L.: Historische Notizen zur Informatik. Berlin 2009. S. 448 (Register). • Siegmund-Schultze (2009) S. 467 (Register); Homo Heidelbergensis mathematicus online. Hashagen, Ulf: Ein ausländischer Mathematiker im NS-Staat: Constantin Carathéodory als Professor an der Universität München. München 2010. - Mathematik in der Heidelberger Akademie der Wissenschaften zus. gestellt von Gabriele Dörflinger. Ein Projekt der Fachinformation Mathematik der Universitätsbibliothek Heidelberg, s. http://www.ub.uni-hei delberg.de/archiv/16931 (Stand: April 2014).

P Bildarchiv UAH; Huther (1966). 


\section{Petersen, Hans Albert}

1913-1921 Med. Fak.

Anatomie

* 28. Nov. 1885 Othmarschen (heute: Stadtteil von Hamburg)

$\dagger$ 29. Jan. 1946 Gmund am Tegernsee ev.

V Albert P. (1841-1916) Architekt, u. a. der 1900 eingeweihten Christuskirche Othmarschen, s. Lange, Ralf: Architekturführer Hamburg. Stuttgart 1995. S. 331 (Register).

M Hermine Emilie Louise geb. Jürgens verw. Lange (1854-1936)

$\infty$ unverheiratet.

$L b$ U Jena: Seit WS 1905/06 Studium der Naturwiss., auch Medizin; 9. Mai 1908 Dr. phil.

U Berlin: Seit 1908 Studium der Medizin; Sommer 1910 med. Staatsprüfung; 1910-1912 Studien am Physiolog. Inst.; 11. Dez. 1911 Dr. med.; 25. April 1912 Approbation.

UH: Seit Nov. 1912 Assistent, Juli 1914-Sept. 1921 Oberarzt am Anatom. Inst.; 6. Nov. 1913 Habilitation für Vgl. Anatomie; seit 29. März 1919 nichtetatm., seit 1920 nichtplanm. a.o. Prof. - In dieser Zeit:

1914-1918 Kriegsdienst als Truppen- und Lazarettarzt.

U Gießen: Seit WS 1921/22 planm. a. o. Prof., Prosektor und Leiter des Anatom. Inst.

U Würzburg: Seit SS 1925 o. Prof. und Vorsteher der Anatom. Anstalt als Nachf. von (siehe) Hermann Braus; 1939 auf eigenen Wunsch Emeritierung aus gesundheitlichen Gründen (Formalinallergie).

E 1940 Mitglied der Akademie der Wissenschaften München. 1920 Georg-Hermann-von-Meyer-Preis.
Qu UAH PA 1107, 2092; RA 6173. - GLA Abt. 235, Fasz. 2375. - Nachlaß: Universitätsbibliothek Würzburg. • Auskunft: Staatsarchiv Hamburg (Namen und Lebensdaten der Mutter Hermine aus: 741-4, K 4518).

$W$ Bänderkinematik. Versuch einer Theorie der Bandverbände. Heidelberg 1918. • Histologie und mikroskopische Anatomie. 3 Abschnitte. München 1922-1924. - Grundriß der Histologie und mikroskopischen Anatomie des Menschen. Berlin 1936. 4. Aufl. 1950. Die Eigenwelt des Menschen. Leipzig 1937. 2. Aufl. 1947. • Die Probleme der Zellenlehre und die ihrer Geschichte. Jena 1940.

L Kürschner (1950) Sp. 2429; WBIS; Gießener Gelehrte 1 (1982) S. 383; Arnim 4 (1984) S. 1262; NDB 20 (2001) S. 255.

$P$ Siehe NDB.

\section{Petersen, Gustav Adolph Walther}

1897-1906 Med. Fak.

Chirurgie

* 30. Okt. 1867 Ichenberg (bei Eschweiler; damalige Grube)

$\dagger$ 04. Jan. 1922 Sterbeort unbekannt ev.

V Carl Richard P. (1829-1884) Hüttendirektor

M Marie geb. Förster ( $†$ nach 1884)

œ 13. Febr. 1897 Anna geb. Frank $\left({ }^{\star} 1875\right)$

K $3 \mathrm{~T}$

Lb Seit WS 1886/87 Studium an U München, anschl. Leipzig, Kiel, Berlin, Bonn.

U Bonn: 5. März 1890 Dr. med.; WS 1890/91 med. Staatsexamen; 1891-1892 Militärdienstpflicht als Einjährig-Freiwilliger; seit April 1892 Assistent an U-Hautklinik.

U Zürich: Seit April 1893 Assistent am Patholog. Inst. 
U Berlin: Seit Anfang 1895 Tätigkeit am Bakteriolog. Inst.

UH: Seit Mai 1895 Assistent, 1901-1904 Leiter der klinischen Ambulanz an Chirurg. U-Klinik als Nachf. von Georg Marwedel; 30. Okt. 1897 Habilitation für Chirurgie; seit 13. Aug. 1901 nichtetatm. a. o. Prof.; SS 1904-SS 1905 (von U beurlaubt) Chefarzt e. Sanitätsexpedition im Russisch-Japanischen Krieg.

Leipzig-Lindenau: 20. Febr.-Ende März 1906 Oberarzt der Chirurg. Abt. des Diakonissenhauses.

U Leipzig: Seit März 1906 Privat-Dozent; SS 1906SS 1909 aus Krankheitsgründen von U beurlaubt; P. kündigt nur im SS 1907 e. 2-stündige Veranstaltung über Allgemeine Chirurgie „privatim“ im Vorlesungsverzeichnis an. In dieser Zeit:

Gaschwitz (heute: Stadtteil von Markkleeberg, Sachsen): Seit Ende März 1906 Aufenthalt in Heilanstalt Hartheck, e. privaten Sanatorium für wohlhabende Nerven- und Gemütskranke, 1892 gegründet und geleitet von Dr. Hugo Schütz (†1923).

Nach 1909 Einweisung in e. Nervenheilanstalt.

E 1901 Ritterkreuz II. Klasse mit Eichenlaub des Ordens vom Zähringer Löwen.

Qu UAH PA 2093; RA 5718, 6301. • UA Leipzig PA 1534. - Briefe: UBH; Staatsbibliothek zu Berlin. • Ergebnislose Anfragen: Stadtarchiv und Staatsarchiv Leipzig; Kirchliches Archiv Leipzig: Ev.Luth. Kirchgemeindeverband; Ev. Kirchengemeindeamt Eschweiler. A Auskunft: Krankenhausarchiv des Ev. Diakonissenkrankenhauses Leipzig.

$W$ Über Immunisirung und Serumtherapie bei der Staphylomykose. Tübingen 1897. Anatomische und chirurgische Beiträge zur Gastro-Enterostomie in: Bruns Beiträge zur Chirurgie 27 (1900). - Über Darmverschlingung nach der Gastro-Enterostomie in: Langenbecks Archiv für Chirurgie 62 (1900). • Über die operative Behandlung akuter Magenblutungen in: Zentralblatt für Chirurgie 29 (1902).
L Leier (1977) S. 78 f. u. ö.; WBIS. • Kütterer, Gerhard: Lebensdaten verdienter Persönlichkeiten in den ersten Jahrzehnten der Röntgenologie. 2. Aufl. Norderstedt 2015. S. 431. - Deutsche Biographie, s. https://www.deutsche-biographie.de/gn d11612340o.html [07.11. 2017].

$P$ Bildarchiv UAH (Signatur: Pos III 00185; hier auch Lebenslauf und Bibliographie bis 1902 vorhanden).

\section{Petsch, August Ferdinand Robert}

1904-1911 Phil. Fak.

Deutsche Philologie

* 04. Juni 1875 Berlin

$\dagger$ 10. Sept. 1945 Hamburg ev.

V August P. (1836-1874) Hauptlehrer

M Hedwig geb. Lehmann $\left({ }^{*} 1843 \dagger\right.$ nach 1904$)$

$\infty$ 4. April 1911 Gertrud geb. Braune (1884-1973), s. Die Pfälzische Landesbibliothek 1921-1971. Aus Geschichte und Gegenwart. Hrsg. von Wolfgang Metz. Speyer 1971. S. 61f.; T von: (siehe) Wilhelm B.

$\mathrm{K}$ keine.

Lb Berlin: Seit WS 1893/94 Studium der Germanistik, Philosophie an U; 1897-1898 Hilfsarbeiter an Königl. Bibliothek.

U Würzburg: Ostern 1898-1900 Eigenstudien; Sommer 1898 Rigorosum, Herbst 1898 (Promotionsurkunde) Dr. phil.; 23. Juni 1900 Habilitation; 1900-1904 Privat-Dozent. • In dieser Zeit:

Würzburg: Sept. 1900-Sept. 1904 Lehrer an Sophienschule, e. Privatanstalt für höhere weibliche Bildung; Okt. 1904-Okt. 1905 Beurlaubung vom bayerischen Staatsdienst.

TH Karlsruhe: 26. Juli 1904 (Umhabilitation)16. Okt. 1904 (Verzicht) Privat-Dozent. 
UH: Seit 3. Dez. 1904 Privat-Dozent; seit 22. Aug. 1907 nichtetatm. a.o. Prof.; seit SS 1909 Lehrauftrag für Altdeutsche Übungen am Germanisch-Romanischen Seminar als Nachf. von Gustav Ehrismann; 24. Juli 1911 Dekan der Phil. Fak., Christian Bartholomae, lädt gesamte akad. Korporation zur Abschieds-Feier P.s mit Abendessen (Preis des Gedecks 2,50 Mark; Anzug: Straßenanzug) ins Restaurant Schwarzes Schiff in Neuenheim ein (der Theologe Hans Schubert schreibt auf $\mathrm{Zu}$ - bzw. Absageliste: „Leider durch eine frühere Zusage [anderweitig] verhindert - bedaure lebhaft", aus: UAH PA 2096 letztes Blatt).

University of Liverpool (Großbritannien): WS 1911/12-1914 (Kriegsausbruch) o. Prof. für Germanische Philologie; Sommer 1914 Ruf an Königl. Akademie zu Posen (heute: Poznań, Polen).

Königl. Akademie zu Posen: 1914-1919 (Aufhebung der Akademie) Ordinarius; in dieser Zeit: freiwilliger Hilfslehrer an e. Oberrealschule in Posen.

U Hamburg: 16. Juli 1919 Ern. zum a. o. Prof.; seit 1. Okt. 1919 planm. a. o. Prof. für Neuere Dt. Literatur an neugegründeter U; 1. Juli 1923-31. März 1945 (Entbindung von amtlichen Pflichten) o. Prof. für Dt. Literaturgeschichte und Allg. Literaturwiss. und Direktor des Literaturwiss. Seminars; 1926 Ruf an U Prag abgelehnt; Mai 1945 Suspendierung durch britische Besatzungsbehörden; Sept. 1945 Versetzung in Ruhestand.

1924 Mitbegründer der Hamburger Goethe-Gesellschaft

E Mitglied: Abt. für Dt. Schrifttum der Akademie zur wiss. Erforschung und zur Pflege des Deutschtums, Dt. Akademie München, Dt. Gesellschaft für Philologie, Schwäbischer Schillerverein Marbach/ Neckar.

Qu UAH PA 2096; RA 6839. - GLA Abt. 235, Fasz. 2376. - Teil-Nachlaß: Staats- und Universitätsbibliothek Hamburg; s. auch Int. Germanistenlexikon 2 (2003) S. 1391. - Auskunft: Staatsarchiv Hamburg.
$W$ Freiheit und Notwendigkeit in Schillers Dramen. München 1905. Deutsche Dramaturgie. Von Lessing bis Hebbel. Hamburg 1912. 2. Aufl. 1921. Gehalt und Form. Dortmund 1925. • Wesen und Formen der Erzählkunst. Halle/S. 1934. 2. Aufl. 1942. - Tristan und Isolde. Eine Einführung in Richard Wagners musikalische Tragödie. Hamburg 1938. - Die lyrische Dichtkunst - Ihr Wesen und ihre Formen. Halle/S. 1939. • Einführung in Goethes „Faust“. Hamburg 1941. 3. Aufl. 1949. • Wesen und Formen des Dramas. Halle/S. 1945. • Bibliographie in: Vom Geist der Dichtung (1949) S. 381408; siehe auch Int. Germanistenlexikon 2 (2003) S. 1390 f., Müller (2011) S. 114 Anm. 19.

MHG Schillers Werke. 2. Ausgabe. 15 Bde. Leipzig 1922. Goethes Werke. Festausgabe zum hundertjährigen Bestehen des Bibliographischen Instituts ... 1826-1926 ... 18 Bde. Leipzig 1926. - Siehe hierzu Int. Germanistenlexikon, S. 1390 f.

L Kürschner (1931) Sp. 2199, (1940/41) Sp. 356, (1950) Sp. 2422; Wer ist's (1935) S. 1200; WBIS. • Vom Geist der Dichtung. Gedächtnisschrift für R.P. Hrsg. von Fritz Martini. Hamburg 1949. • Burkhardt (1976) S. 4of. • Eggensperger, Klaus: Versuch über R.P. Der Übergang zur nazigermanistischen Praxis und seine ideologietheoretischen Voraussetzungen. Magisterarbeit. Typoskript. Hamburg 1985. - Leech, Thomas Hale: Approaches to narrative in German. The critical theories of Ernst Hirt, R.P., Eberhard Lämmert, and Franz Stanzel. Phil. Diss. The University of Texas at Austin 1985. - Röhrs, Hermann: Nationalsozialismus, Krieg, Neubeginn. Eine autobiogr. Vergegenwärtigung aus pädagogischer Sicht. Frankfurt/M. 1990. S. 63-65. - Hochschulalltag im „Dritten Reich“ - U Hamburg (1991) Bd. 2. S. 707-734 u.ö.; Int. Germanistenlexikon 2 (2003) S. 1389-1391; Hamburgische Biographie 3 (2006) S. 292-294; Klee, Personenlexikon (2007) S. 456. - Müller, HansHarald: R. P. Sein akademischer Werdegang und die Begründung der Allgemeinen Literaturwissenschaft in Hamburg in: 100 Jahre Germanistik in Hamburg (2011) S. 107-124. • Riecke (2016) S. 149 (Register). - Vordermayer, Thomas: Bildungsbürgertum und völkische Ideologie. Konstitution und gesellschaftliche Tiefenwirkung eines Netzwerks völkischer Autoren (1919-1959). Berlin 2016. 
S. 121 u. ö. - Deutsche Biographie, s. https://www. deutsche-biographie.de/gnd11613469o.html [07.11. 2017].

$P$ Bildarchiv UAH.

\section{Pfeiffer, Friedrich Georg}

(1917) 1918-1922 Nat.-Math. Fak.

Angewandte Mathematik

* O2. Mai 1883 Augsburg

$\dagger \quad$ 21. Dez. 1961 Stuttgart (Verkehrsunfall) ev.

V Johann Friedrich P. ( $†$ vor 1916) seit 1896 Besitzer der 1804 gegründeten Brauerei Fischzug Petri in Augsburg, zuletzt Privatier

M Margaretha Augusta Elisabetha geb. Rosenecker

( 13. Aug. 1921 Frida Clara geb. Brauer verw. Vogt (1888-1962) T von Ernst Adolf B. (18511934) seit 1876 Privat-Dozent TH Berlin-Charlottenburg; o. Prof. für Maschinenkunde: seit 1883 TH Darmstadt, 1892-1919 (Ruhestand) TH Karlsruhe, s. Kürschner (1931) Sp. 292, WBIS; Zur Geschichte des Maschinenbaus an der Technischen Universität Darmstadt. Hrsg. von Manfred Hampe, Gerhard Pahl. Düsseldorf 2008. S. 1f. - Witwe von: (siehe) Wolfgang Vogt

K 2 T

Lb TH München: Seit WS 1901/o2 Studium; 1903 Vorprüfung für Ingenieurstudium; 1905 Lehramtsprüfung für die Fächer Mathematik und Physik; 1905 2. Staatsexamen für Lehramtskandidaten (Mathematik und Physik).

TH München: Seit 1905 Assistent am Math. Inst.; 19. Juli 1907 Dr. sc. techn.

U Göttingen: Seit 1908 Assistent am Inst. für Angewandte Mathematik.
TH Danzig: Seit 1910 Assistent am Math. Inst.; 1912 Habilitation.

U Halle/S.: Seit 1. Dez 1912 (Umhabilitation) Privat-Dozent mit Lehrauftrag für Angewandte Mathematik. - In dieser Zeit:

Kriegsdienst (eigene Angaben aus: UAH PA 2098): Aug.-Sept. 1914 Kriegsdienst (Landsturm mit Waffe), im Sept. 1914 für felddienstuntauglich erklärt; Nov. 1915-März 1916 nach Kriegsvermessungsvorschrift (Kr. V.) Ausbildung bei Feldartillerie-Regiment 75 in Halle/S.; Ende März-Ende Aug. 1916 im Felde bei 2. Bataillon FeldartillerieRegiment 75; seit Juli 1916 überzähliger Gefreiter; bis Anfang Sept. 1916 Versetzung zum stellvertr. Generalstab in Berlin, seit Anfang Sept. 1916 Versetzung in Vermessungs-Abt. 21, anschl. Abt. 8; 24. Nov. 1918 Entlassung.

UH: 30. Dez. 1916 Ern. mit Wirkung vom 1. April 1917 zum etatm. a. o. Prof. als Nachf. von Wolfgang Vogt mit e. Jahresgehalt von 2500.- Mark; WS 1918/ 19 Vorlesungsbeginn; seit 1. April 1920 Jahresgehalt als planm. a. o. Prof. von 13 200.- Mark, seit 1. Jan. 192122 044.- Mark, seit 1. Okt. 192155200 Mark; April 1921 Ruf an TH Aachen abgelehnt; 4. Mai 1921-31. März 1922 persönlicher o. Prof. mit e. Jahresgehalt von 29599.- Mark (seit 1. Okt. 1921), 60 10o.- Mark (seit 1. Jan. 1922).

TH Stuttgart: 1. April 1922-1. April 1951 (Emeritierung) o. Prof. für höhere Mathematik und Differentialgeometrie.

E 1925 Mitglied der Dt. Akademie der Naturforscher Leopoldina Halle/S.; 1925-1929 Mitglied der Dt. Physikalischen Gesellschaft.

Qu UAH PA 2098. GLA Abt. 235, Fasz. 2380. • Siehe auch Archiv der Dt. Akademie der Naturforscher Leopoldina Halle/S.; Auskunft: Standesämter Stuttgart und Augsburg.

$W$ Numerische Auflösung spezieller linearer Gleichungen in: Sitzungsberichte der Akademie der Wissenschaften Heidelberg 17 (1920). Elastokinetik in: Handbuch der Physik. Hrsg. von Hans 
Geiger und Karl Scheel. Berlin 1928. Bd. 6. Über Gleitreibung bei Systemen materieller Punkte in: Festschrift der TH Stuttgart ... Berlin 1929. • Differentialgleichungen der transversalen Stabschwingungen in: Zs. für angewandte Mathematik und Mechanik 25/27 (1947) S. 83-91.

L Kürschner (1931) Sp. 2207, (1961) S. 1533, (1966) S. 2822; Poggendorff 7a (1959) S. 550; WBIS. • Zum Gedenken an Otto Cranz, ..., F. .., ... Stuttgart 1963. S. 49-51. - Math. Institute in Deutschland (1989) S. 287 (Register); Jansen (1992a) S. 168 (Register). - Böttcher, Karl-Heinz, Maurer, Bertram: Stuttgarter Mathematiker. Geschichte der Mathematik an der Universität Stuttgart von 1829 bis 1945 in Biographien ... Stuttgart 2008. S. 183-187 u. ö. • Homo Heidelbergensis mathematicus online; Catalogus prof. Halensis online (30. April 2015); Deutsche Biographie, s. https://www.deutsche-bio graphie.de/gnd116163011.html [07.11. 2017].

$P$ Bildarchiv UAH.

\section{Pfeufer, Carl Sebastian (Geburtsname: Pfeuffer; seit 1855: von Pfeufer)}

1844-1852 Med. Fak. Innere Medizin (Pathologie, Therapie, Semiotik)

* 22. Dez. 1806 Bamberg

$\dagger$ 13. Sept. 1869 Pertisau (Achensee; Tirol)

ㅁ München

kath.

V Christian P. (1780-1852), u. a. seit 1801 Prof. für Medizin U Bamberg (1803 Aufhebung der U), seit 1804 Landgerichtsphysikus, seit 1814 Leiter des Krankenhauses in Bamberg, s. Steiner (1998) S. $6 \mathrm{f}$.

M Margarethe geb. Ellermann (178o-1813)

๑ 5. Okt. 1834 Ottilie Adele geb. von Hardegg (1812-1874)

$\mathrm{K} \quad 1 \mathrm{~S}($ früh $\dagger), 1 \mathrm{~T}$
Vw Halbbruder: Sigmund Heinrich P. (seit 1867 Ritter von P., seit 1881 Freiherr von P.) (18241894) seit 1858 Polizeioberkommissär, seit 1862 Polizeipräsident in München, seit 1867 Reg.-Präsident der Pfalz, 1871-1881 bayer. Innenminister, 1881-1894 Reg.-Präsident von Oberbayern, s. Carl (2004) S. 669 f.; Die Regierungspräsidenten von Oberbayern im 19. und 2o. Jhdt. Hrsg. im Auftrag von Reg.-Präsident Werner-Hans Böhm durch Stephan Deutinger ... München 2005.

Lb Seit 1. Nov. 1824 Studium an U Erlangen, seit 1825 Würzburg; 1828 med. Examen in Würzburg.

Seit 1828 Mitarbeiter im Krankenhaus in Bamberg, anschl. Assistent an Med. Klinik des Juliusspitals in Würzburg; 1831 Dr. med. an U Würzburg.

Frühjahr-Sept. 1831 Assistent am Allg. Krankenhaus in München; Sept. 1831 „Proberelation“ (fachspezifisches Examen); Ende 1831 Mitglied einer Cholera-Kommission für Oder-Gebiete und Magdeburg; Frühjahr 1832 Eigenstudien zu Choleraepidemien in Wien und Ungarn.

München: 1832-1836 Niederlassung als praktischer Arzt.

1836 Regierungskommissar bei Bekämpfung der Cholera-Epidemie in Mittenwald; seit Sept. 1836 Landgerichtsarzt in Au (bei München); 1837 auf Befehl König Ludwigs I. von Bayern Arzt für dt. Künstler während der Choleraepidemie in Rom.

U Zürich: WS 1840/41-WS 1843/44 o. Prof.; 1843 Rufe an U abgelehnt: Tübingen und UH, s. hierzu Steiner (1998) S. $12 \mathrm{f}$.

UH: Seit 11. Jan. 1844 o. Prof. (II. Lehrstuhl für Innere Medizin neben Friedrich Puchelt) als Nachf. von Theodor Bischoff; 1844-1852 Mit-Direktor (zus. mit Friedrich Puchelt) der Med. Poliklinik (P. ist für die Vorstadt, Puchelt für die Stadt zuständig); 1845 Ruf an U Tübingen abgelehnt; 31. März3. April 1848 Mitglied des Frankfurter Vorparlaments. 
München: 23. April 1852 Ern. zum o. Prof. für Therapie und Klinik an $\mathrm{U}$ und Oberarzt der II. Med. Abt. des Allg. Krankenhauses mit e. jährl. Gehalt von (1855) 10 ooo.- Talern; 1852 außerdem II. ärztl. Referent am Ministerium des Innern; 1855 Ruf an U Göttingen abgelehnt.

\section{Dekan der Med. Fak. der UH}

1858: P. setzt u.a. eine neue bayerische Prüfungsordnung durch, die zur erheblichen Verbesserung der ärztlichen Ausbildung beiträgt.

In den Innsbrucker Nachrichten Nr. 211, 16. Jg. (16. Sept. 1869) heißt es unter „Lokales und Verschiedenes: Plötzlicher Todfall. Am 13. d[iese]s [Monats] fiel Obermedizinalrath Dr. Pfeifer [!] aus München, gerade als er im Begriffe, von der Pertisau nach der Scholastika und Tegernsee zurückzufahren, beim Einsteigen in das Schiff am Ufer des Sees vom Schlage getroffen in Gegenwart seiner Frau und Tochter leblos nieder".

1845 Hofrat

E 1858 Mitglied der Dt. Akademie der Naturforscher Leopoldina Halle/S. - Kommandeur II. Klasse des Albrechtsordens des Königreichs Sachsen; 1854 Ritter I. Klasse des Verdienstordens vom Hl. Michael; 1855 Ritter des Verdienstordens der Bayer. Krone (hiermit verbunden war der persönliche Adel). • 1854 Goldene Ehrenmünze der bayerischen Ärzteschaft.

Qu UAH PA 2099; RA 6269, 6783, 6804. Matrikel Erlangen (1918) S. 366. - GLA Abt. 205, Fasz. 429. - Briefe: UBH. - Hoepke, Hermann: Der Briefwechsel zwischen Jakob Henle und K. P. $1843-$ 1869. Wiesbaden 1970. $\bullet$ Siehe auch Archiv der Dt. Akademie der Naturforscher Leopoldina Halle/S. • Ergebnislose Anfrage: Archiv des Erzbistums München und Freising in München. - Auskunft: Archiv des Erzbistums Bamberg (Taufbucheintrag von 1806 der Pfarrei St. Martin: Carolus Sebastianus Pfeuffer); Amt der Tiroler Landesregierung Abteilung Tiroler Landesarchiv in Innsbruck; Herr Johann Walser - Chronik Eben - in Maurach am Achensee.
$W$ Beiträge zur Geschichte des Petechial-Typhus. Diss. Bamberg 1831. Zum Schutze wider die Cholera. Heidelberg 1849. 3. Aufl. 1854.

MG, $M H G$ 1844-1869 Zs. für rationelle Medicin.

$L$ Kerschensteiner, Josef: Das Leben und Wirken des C. von P. Augsburg 1871 (mit Werkverz.). • ADB 25 (1887) S. 661f.; WBIS; Chronik Ärzte H (1985) S. 139, 259 f. - Steiner, Marcus: K. von P. Biographie und Ergographie. Diss. Heidelberg 1998. - Fast 60 Menschen raffte die Cholera 1836 in Mittenwald dahin. Nach e. Bericht von Dr. K.P., königlicher Gerichtsarzt aus München in: 's goldene Landl - Heimatbeilage für die Täler an der Loisach, Isar und Ammer. München 2001. Nr. 31, S. 128, Nr. 32, S. 132. • Enzyklopädie Medizingeschichte. Hrsg. von Werner E. Gerabek u.a. Berlin 2005. S. 1135. Ärztelexikon (2006) S. 259; Bauer/Ho (2016) S. $25 \mathrm{f}$.

P Bildarchiv UAH; graph. Slg. UBH.

\section{Pfeuffer}

siehe Pfeufer

\section{Pfitzer, Ernst Hugo Heinrich}

1872-189o Phil. Fak.

1890-1906 Nat.-Math. Fak.

Botanik

* 26. März 1846 Königsberg (Preußen; heute: Kaliningrad, Russische Föderation)

$\dagger \quad$ 03. Dez. 1906 Heidelberg ev.

V Hugo P. (1818-1858) Buchhändler, seit 1844 Teilhaber des Verlags- und Sortiments-Buchhandels J.H. Bon und Pfitzer, seit 1846 als Pfitzer \& Heilmann geführt (existiert noch 1878)

M Minna geb. Krüger

๑ 14. März 1874 Emilie Thekla Mathilde geb. Tittmann $\left({ }^{*} 1851 \dagger\right.$ nach 1910$)$ Stief-T von: (siehe) Adolf Holtzmann 
K 4 T: u.a. Hedwig Emilie Mathilde P. (18761953), s. Oestmann, Peter: Rudolf His ... - ein Schweizer Strafrechtshistoriker in Münster in: Münsteraner Juraprofessoren. Hrsg. von Thomas Hoeren. Münster 2014. S. 5 f., 17. - Ehefrau von: (siehe) Rudolf His.

Lb Seit SS 1863 Studium der Naturwiss., Botanik an U Königsberg (Preußen), WS 1865/66-SS 1866 Berlin, WS 1866/67 Königsberg; 9. April 1867 Dr. phil. an U Königsberg; 26. Juni 1867-SS 1868 Immatrikulation an UH; seit 1868 Habilitationsvorbereitungen in Bonn.

U Bonn: 12. Juni 1869 Habilitation (Antrittsvorlesung).

UH: 21. Juli 1872 Ern. zum o. Prof. und Direktor des Botanischen Gartens mit (Phytophysiolog.) Inst. und Herbarium zwischen heutigem Bismarck- und Adenauerplatz (bis 1876) als Nachf. von Wilhelm Hofmeister mit e. jährl. Besoldung von 2 200.- Gulden; 1876-1906 Direktor des neu angelegten Botanischen Gartens in der Bergheimer Straße im Bereich der heutigen alten LudolfKrehl-Klinik (Nr. 58), s. hierzu Wissenschaftsatlas (2011) S. 237 f.; 1872-1899, 1899-März 1907 Respizient der Forstbotanischen Anlagen im Schlossgarten in H; Rufe an U abgelehnt: 1888 Göttingen und Berlin; Jahresbesoldung: seit 24. März 1888 von 5660.- Mark, seit 1. April 1903 von 6500.Mark, seit 1. Juli 1905 von 6 700.- Mark.

1889 Prorektor der UH; 1880/81 Dekan, April-Juni 1882 Prodekan der Phil. Fak. der UH; 1891/92, 1898/ 99, 1901/02, 1905/06 Dekan der Nat.-Math. Fak. der UH

1885-1892, Nov. 1899-1900 Präsident des Naturhistor--Med. Vereins Heidelberg

1903-1906 Vizepräsident der Freien Vereinigung der Systematiker und Pflanzengeographen, s. hierzu Bericht über die Zusammenkunft der Freien Vereinigung der Systematischen Botaniker und Pflanzengeographen zu Berlin vom 16. bis 19. Sept. 1903. Leipzig 1903.

1889 Hofrat; 1894 Geh. Hofrat
E 1873 Korr. Mitglied der Botanic Society of Edinburgh; 1880 Mitglied der Dt. Akademie der Naturforscher Leopoldina Halle/S.; 1899 Mitglied der Akademie der Wissenschaften Berlin. 1886 Ritterkreuz I. Klasse des Ordens vom Zähringer Löwen; 1899 Kommandeurkreuz des Kaiserl.-Russischen St. Anna-Ordens II. Klasse.

Qu UAH PA 2101; RA 6883. GLA Abt. 235, Fasz. 1561. Briefe, siehe Darwin Correspondence Project online http://www.darwinproject.ac.uk/se$\operatorname{arch} /$ ?keyword=pfitzer\&tab $=$. Cambridge University Library. Cambridge (Großbritannien). • Siehe auch Archiv der Dt. Akademie der Naturforscher Leopoldina Halle/S. - Auskunft: Universitätsarchiv Bonn.

$W$ Über die Schutzscheide der deutschen Equisetaceen. Königsberg 1867. - Untersuchungen über Bau und Entwicklung der Bacillariaceen (Diatomaceen) in: Bonner Botanische Abh. aus dem Gebiet der Morphologie und Physiologie Bd. 1, H. 2 (1871). - Der Botanische Garten der Universität Heidelberg. Ein Führer für dessen Besucher mit einem Plane des Gartens. Heidelberg 1880. • Grundzüge einer vergleichenden Morphologie der Orchideen. Heidelberg 1882. • Entwurf einer natürlichen Anordnung der Orchideen. Heidelberg 1887. • Übersicht des natürlichen Systems der Pflanzen. Heidelberg 1894. 2. Aufl. 1902. O Orchidaceae-Pleonandra mit 157 Einzelbildern in $41 \mathrm{Fi}$ guren. Leipzig 1903. (Mitverf.) Neudr. 1959.

$L$ Tischler, Georg: E.P. $\uparrow$ in: Verhandlungen des Naturhist.-Med. Vereins zu Heidelberg N.F. 8 (1904-1908) S. 397-425 (mit Bibliographie). • Badische Biographien VI (1935) S. 387-390; Arnim 2 (1952) S. 321; Verzeichnis Bonn (1968) S. 225; Leins (1994) S. 57 f.; WBIS; NDB 20 (2001) S. 340 f.; Wissenschaftsatlas (2011) S. 238. Alt, Wolfgang, Sauer, Klaus Peter: Biologie an der Universität Bonn. Eine 200-jährige Ideengeschichte. Göttingen 2016. S. $78 \mathrm{f}$.

P Bildarchiv UAH; graph. Slg. UBH. 


\section{Pierson, Allard}

1869-1874 Theol. Fak.

Historische Theologie

* 08. April 1831 Amsterdam

$\dagger$ 27. Mai 1896 Gut Velhorst in Almen (bei Zutphen, Gelderland, Niederlande)

- Zutphen

ev.

V Jan Lodewijk Gregory P. (1806-1873) Kaufmann, Anhänger der Erweckungsbewegung "Réveil"

M Ida geb. Oijens (1808-1860) Autorin von frommen Schriften

( 23. Febr. 1854 Pauline Hermina Elisabeth geb. Gildemeester (1831-1900)

K 3 S, 4 T: u.a. Adriana Margaretha (Etha) P. (1866-1946) 1911 Vorsitzende des Ev. Arbeiterinnenvereins in Emden; Ehefrau von Dr. David Abraham Kool (1863-1945) 1895-1914 (Zerstörung durch Großbrand) Direktor der niederländischen Heringsfischerei AG „Neptun" (mit zeitweise 28 Segel-Loggern) in Emden und zugleich Konsul der Niederlande für Ostfriesland; 1907 Mitglied, 1909 Vorsitzender des Aufsichtsrates, 1914-1916 wirtschaftl. Leiter der Freien Schulgemeinde Wickersdorf, s. hierzu Dudek, Peter: „Versuchsacker für eine neue Jugend." Die Freie Schulgemeinde Wickersdorf 1906-1945. Bad Heilbrunn 2009. S. 38 f., 105 u. ö.

Vw Brüder: Hendrik P. (1834-1923) Prediger, s. Schram, Peter Leendert: H.P. Een hoofdstuk uit de geschiedenis van de inwendige zending. Kampen 1968; Leeuw, N. de: Niet door kracht of door geweld, maar door mijn geest zal het geschieden. Dominee Pierson en het liberale denken van gelovigen in: Liberaal Reveil 53 (2012) S. 104-107. Nicolaas Gerard P. (1839-1909), u. a. 1868-1891 Bank-Direktor, 1891-1894, 1897-1901 Finanzminister, 27. Juli 1897-28. Juni 1901 (Rücktritt) Premierminister der Niederlande, 1905-1909 Mitglied der II. Kammer des Parlaments (Staten-Generaal), s. Nieuw Nederlandsch biografisch woordenboek. Onder redactie van P. J. Blok, P.C. Molhuysen. Leiden 1921. T. 5. S. 506-508.
Lb U Utrecht: Seit WS 1849/50 Studium der Theologie, Philologie; 8. Febr. 1854 Dr. theol.

Pfarrer: Seit 1853 in Löwen (Belgien), seit Sept. 1857 in Waalsche Gemeente Rotterdam.

H: 1865-1869 Eigenstudien.

UH: 4. Febr. 1869 Genehmigung des Ministeriums des Innern, P. zur Habilitation „unter Erlassung der herkömmlichen Vorbedingungen" zuzulassen (aus: UAH PA 2107); seit 8. Juli 1870 a. o. Prof., s. hierzu auch $Z$ (1); seit 1. Juni 1873 "Aushilfe für den I. U-Prediger [Daniel Schenkel] und nach Bedürfniß auch (Lehrer) am [Ev.-Prot.] Theol. Seminar" mit e. jährl. Gehalt von 300.- Gulden (aus: PA 2107), s. hierzu $Z$ (2); 4. Juli 1874 Entlassung auf eigenen Antrag.

Utrecht: 1874-1877 Eigenstudien.

U Amsterdam: 1877-1895 o. Prof. für Archäologie, Neuere Philologie, Ästhetik, Kunstgeschichte am bisherigen Athenaeum Illustre, 1877 Umbenennung in $\mathrm{U}$.

$Z$ (1) Am 1. April 1868 wünscht Dekan Ferdinand Hitzig im Namen der Theol. Fak. der UH, ,eine so tüchtige wissenschaftliche Kraft wie Dr. Pierson für die Universität" zu gewinnen. Am 9. April 1868 stellt daraufhin der Engere Senat den Antrag an das Ministerium des Innern, P. gleich bei seiner Berufung entweder den Charakter als a.o. Prof. oder Honorar-Prof. zu verleihen aufgrund seiner „in der wissenschaftlichen Welt so anerkannten Bedeutung“. Das Ministerium antwortet am 24. Juni, man sehe „sich nicht veranlaßt, den gestellten Antrag höchsten Orts empfehlend vorzulegen“" (aus: PA 2107). Eine Begründung für die Absage ist nicht überliefert. Am 4. Juli 1870 leitet der Engere Senat einen wiederholten Antrag der Theol. Fak. an das Ministerium weiter, P. nun endlich eine a. o. Professur zu verleihen, da er „durch seine ausgedehnteren littärerischen Leistungen einer solchen Anerkennung in hohem Grade würdig erscheint" (aus: PA 2107). 4 Tage später erfolgt seine Ernennung.

$Z$ (2) Am 6. Mai 1873 beantragt Dekan Daniel Schenkel im Namen der Theol. Fak. unter Um- 
gehung des Engeren Senats direkt bei dem Ministerium ein Jahresgehalt von 300.- Gulden für Pierson. Begründung: „Seit nahezu drei Jahren hat (er) als außerordentlicher Professor mit ungewöhnlichem Erfolge an unserer Fakultät gewirkt. Besonders wußte er durch eine glückliche Lehrgabe seine Zuhörer an sich zu fesseln. Außerdem hat er im theologischen Seminar unentgeldlichen Unterricht ertheilt und im Universitätsgottesdienst durch seine geist- und gemüthvollen Vorträge eine zahlreiche Zuhörerschaft um sich gesammelt ..." (aus: PA 2107). Ab 1. Juni 1873 erhält P. e. Anstellung als Gehilfe am Ev.-Prot. Theol. Seminar mit e. Vergütung von 300.- Gulden.

Archäologische Funde aus der Antike, die P. von seinen Reisen aus dem Mittelmeerraum mitbrachte, und eine von ihm zwischen 1877 und 1895 angelegte Sammlung von Gipsabgüssen bilden den Grundstock für das Allard Pierson Museum, e. archäologischen Museum der Universität Amsterdam, Oude Turfmarkt 127; das Museum wurde zu Ehren P.s auch in seiner Funktion als erstem Archäologie-Professor an der Universität nach ihm benannt.

Qu UAH PA 2107; RA 6718. Auskunft: Universiteit van Amsterdam, Historische Commissie.

$W$ Eene Levensbeschouwing. Haarlem 1875. $\bullet$ Studien over Johannes Kalvijn. 3 Bde. Amsterdam 1881-1891. Geestelijke voorouders. Studien over onze beschaving. 6 Bde. Haarlem 1887-1913.

L Allard Pierson herdenking op 23 mei 1946. Groningen 1946. Arnim 2 (1952) S. 328; WBIS (mit Bibliographie). - Barnard, Marcel: Een weemoedige tint. Agnosticisme en estheticisme bij A.P. Diss. Universiteit Amsterdam. Meppel 1987. Molendijk, Arie L.: De levensbeschouwing van A.P. in: Nederlands theologisch tijdschrift 65 (2011) S. 18-36. - Tussen religieus gevoel en kritisch denken. Vijf Franse preken von Allard Pierson. Editie en vertaling: Johannes Trapman. Hilversum 2014. S. 7-54. - Deutsche Biographie, s. https:// www.deutsche-biographie.de/gnd12342920X.html [07.11. 2017].

$P$ Tussen religieus gevoel (2014) S. 48.
Plitt, Jakob Theodor

1854-1860 Theol. Fak.

Kirchenrecht, Pastorallehre

* $\quad$ 04. April 1815 Königsfeld (Schwarzwald)

$\dagger \quad$ 27. Mai 1886 Dossenheim (bei Heidelberg) ev.

V Johann Jakob P. (1781-1837) 1792 Aufnahme in Herrnhuter Gemeine; u. a. Lehrer in Brüdergemeinen: seit 1800 Unitäts-Knabenanstalt in Niesky (Oberlausitz), seit 1803 Pädagogium auf Schloss Barby in Barby, seit 1807 Pädagogium und Dozent am Theol. Seminar in Niesky; seit 1812 Mit-Prediger in Gnadau (heute: Ortsteil von Barby), seit 1813 Sozietätsarbeiter in Altona, seit 1814 Prediger und Inspektor der Pensionsanstalten in Königsfeld, 1821-1834 (Niederlegung des Amts aus Krankheitsgründen) Gemeinhelfer und Prediger in Neudietendorf (heute: Ortsteil von Nesse-Apfelstädt, Thüringen)

M Agnes Salome geb. Schumann (1789-1825) um 1812 Lehrerin in Brüdergemeine in Niesky, seit 1821 Witwenpflegerin in Gemeine Neudietendorf; Enkelin von Theophil(us) Salomo S. (1719-1760) Missionar der Herrnhuter Brüdergemeine, u. a. 1748-176o in Guyana, s. Teil des Nachlasses Walter Lehmann im Ibero-Amerikanischen Institut Preußischer Kulturbesitz Berlin (Signatur: Y/3117 [8]); Quandt, Christlieb: Nachricht von Suriname und seinen Einwohnern. Amsterdam 1968. S. 110 ff.; Reutter, Georg: Wilhelm von Humboldts linguistisches System. Seine Position in der Geschichte der Sprachwissenschaft. Berlin 2006. S. 201. - T von Christian Ludwig S. (17491794) (S von o. g. Theophil(us) Salomo S. (17191760)) Missionar der Herrnhuter Brüdergemeine, u. a. seit $1786 \mathrm{im}$ „Brüdergarten“ in Porayar in Trankebar/Tranquebar (Südindien; heute: Tharangambadi), siehe seinen Bericht: In acht Monaten nach Ostindien: Durch den Atlantik und den Pazifik 1785/86 in: Wege in die Welt. Reiseberichte aus 250 Jahren Brüdermission. Hrsg. von Hartmut Beck. Erlangen 1992. S. 46-60. 
( 23. Febr. 1842 Bertha geb. von Scheibler verw. Pastor (1804-1864), s. Album Professorum der Ev.-Theol. Fakultät Bonn (1995) S. 83 Anm. 6

๑ 29. Juni 1868 Emilie (Emy) Bernhardine Caroline geb. von Westhoven (1829-1909), s. ebd.

$\mathrm{K} \quad 1 \mathrm{~S}$ (früh $\dagger$ ), $1 \mathrm{~T}$ (s. auch ebd. S. 84 Anm. 16), 2 Totgeburten aus 1. Ehe; $1 \mathrm{~T}$ aus 2. Ehe, s. ebd.

Lb Schulausbildung in Herrnhuter Anstalten in Neudietendorf und Nieski; seit 1834 Studium der Theologie am Seminar der Herrnhuter Brüdergemeine in Gnadenfeld (heute: Pawłowiczki, Polen), seit 1835 auch Studium der arabischen und syrischen Sprachen an U Berlin; Lehrer an Herrnhuter Erziehungsanstalten: seit 1837 Neuwied, 1840 Gnadau; nach P.s Verlobung Austritt aus Herrnhuter Brüdergemeine nach Bekenntniserklärung zur ev.-prot. Kirche Badens.

UH: Seit 31. Okt. 1840 Forts. des Studiums der Theologie; 1840-1841 Mitglied des Predigerseminars; Dez. 1841 theol. Staatsprüfung in Karlsruhe.

Neckargemünd: 1841/42 Vikar.

Karlsruhe: Seit April 1842 Pfarrverweser, seit 1845 Stadtpfarrer. • In dieser Zeit:

Reisen: 1846 London, 1848 Belgien, England und Schottland, 1849 Südbaden und Frankfurt/M.

Bonn: Seit Mai 1850 II. Pfarrer; 1851 Reise durch Palästina, s. hierzu seine „Skizzen aus einer Reise nach dem heiligen Land.“ Karlsruhe 1853.

UH: 1853-1860 II. U-Prediger an Peterskirche (im Sommer) und an Providenzkirche (im Winter, da beheizbar) sowie II. Direktor (I. Direktor: Daniel Schenkel) des Predigerseminars als Nachf. von Wilhelm Dittenberger; 28. Okt. (?) 1854 Lizentiatenprüfung; 15. Dez. 1854 Habilitation unter Erlaß der Inauguraldisputation; seit 14. Dez. 1855 a. o. Prof. • In dieser Zeit:

H: 1853-186o Stadtpfarrer an Heiliggeistkirche.

U Bonn: 18. Febr. 1860 Ern., seit 5. Mai 1860 o. Prof., Direktor des Homiletischen Seminars und U-Prediger; 26. Mai 1866 auf eigenen Antrag Niederle- gung seiner Ämter aufgrund des (unbestätigten) Verdachts auf Hinwendung P.s zum kath. Glauben nach Veröffentlichung von Briefauszügen, in denen er über e. Rom-Reise mit Audienz beim Papst und Teilnahme an kath. Zeremonien berichtete, s. hierzu Album Professorum der Ev.-Theol. Fakultät Bonn (1995) S. 84-86.

22. Febr. 1867 Wiederaufnahme in die Reihe der badischen ev. Landesgeistlichen.

Dossenheim: Seit 26. Aug. 1867 Pfarrer.

1846: Teilnehmer bei der Gründung der Evangelical Alliance in London, s. hierzu Mann, Carl, P., T.: Der evangelische Bund - die zu Liverpool und London gehaltenen Conferenzen über christliche Vereinigung. Basel 1847. Nachdr. 2010.

1854 gründet $\mathrm{P}$. gemeinsam mit seiner Frau Bertha e. privates Kinderhospital in Heidelberg, das 1860 ins Diakonissenkrankenhaus nach Karlsruhe verbracht wird; s. hierzu auch Wilhelm Posselt und Theodor von Dusch

1855 „Oppositions“deputierter (gegen Einführung e. lutherisch-konfessionellen Agende anstelle der Unions-Agende) auf Badischer Generalsynode in Karlsruhe

Zur Herrnhuter Brüdergemeine siehe auch Daniel Heinrich Willy

E 1860 D. theol. UH.

Qu UAH PA 2109; RA 6127. - Toepke 5 (1904) S. 654. - Briefe: UBH. • Ausdruck e. Briefes von P. im UAH aus der Privatsammlung von Briefen im Familienarchiv Dr. Karsten Weber, Mosbach. • Nachlaß: Universitätsarchiv Bonn; Generallandesarchiv Karlsruhe (Plitts Tagebuchbericht „Erinnerungen“ von Anfang Mai bis Ende Aug. 1849 und später). Mitteilungen: Herr Olaf Nippe, Unitätsarchiv - Moravian Archives Herrnhut - in Herrnhut (Dienerblatt des Vaters Johann Jakob Plitt). 
$W$ De Cyrilli Hierosolymitani orationibus quae exstant catecheticis. Heidelberg 1855. - Die Pastoralbriefe. Praktisch ausgelegt. Berlin 1872. - Katechismus-Unterricht nach dem Katechismus für die ev.-prot. Kirche im Großherzogtum Baden. Lahr 1883. Siehe hierzu auch BBKL XXXVI (2015).

$L$ Verzeichnis Bonn (1968) S. 229; Album Professorum der Ev.-Theol. Fakultät Bonn (1995) S. 82-86 u. ̈. - Matz, Lothar: J. T. P. ... in: Theologie als Vermittlung. Bonner evangelische Theologen des 19. Jahrhunderts im Porträt. Rheinbach 2003. S. 94-100. - Wischmeyer, Johannes: Theologiae facultas. Rahmenbedingungen, Akteure und Wissenschaftsorganisation prot. Universitätstheologie ... 1850-1870. Berlin 2008. 150 Jahre Pädiatrie in H (2010) S. 31; WBIS. • Railton, Nicholas: Pietismus und Revolution. Der badische Pfarrer J.T.P. ... und seine Beziehung nach England ... Hrsg. von Gerhard Schwinge. Heidelberg 2012. - Arbeitsgemeinschaft für geschichtliche Landeskunde am Oberrhein e.V. (522.) Protokoll über die Arbeitssitzung am 11. Mai 2012. Vortrag von Dr. Gerhard Schwinge ... über Pietismus und Revolution: J.T.P., s. http://www.ag-landeskun de-oberrhein.de/index.php?id=p522v (Ausdruck im UAH). • BBKL XXXVI (2015) Sp. 1008-1017; Deutsche Biographie, s. https://www.deutsche-bio graphie.de/gnd103086404.html [07.11. 2017].

$P$ Bildarchiv UAH.

\section{Pockels, Friedrich Carl Alwin}

1900-1913 Nat.-Math. Fak.

Theoretische Physik

* 18. Juni 1865 Vicenza (Italien)

$\dagger$ 29. Aug. 1913 Heidelberg

ev.

V Theodor P. (1830-1906) Hauptmann

M Alwine geb. Becker (1838-1914) Hausfrau

๑ 8. Sept. 1900 Anna Elisabeth geb. Hartig (18771958)

K $\quad 1 \mathrm{~T}$
Vw Schwester: Dr. Ing. E.h. (Verleihung 1932 TH Braunschweig) Agnes Luise Wilhelmine P. (1862-1935), u. a. 1882 Erfinderin der sog. Schieberinne, s. Briefe und Tagebuch „Lebensereignisse“ im Archiv der TU Braunschweig; Pockels, Elisabeth: Ein gelehrtes Geschwisterpaar in: Zs. der Oberhessischen Gesellschaft für Natur- und Heilkunde 24 (1949) S. 303-307 (P); NDB 20 (2001) S. 555; Kurre, Diana, Köhnke, Gunda: Agnes Pockels' Experimente - Nobelpreiswürdige Forschung am Küchentisch. Rekonstruktionsversuche mit der Schieberinne des Agnes-Pockels-SchülerInnen-Labors der TU Braunschweig. Arbeit für Wahlpflichtfach Pharmaziegeschichte im SS 2007, online http://www.pharmtech.tu-bs. de/pharmgesch/typoz/fileadmin/Dokumen te/WPF-Experimente-_berarbeitet.pdf (Ausdruck im UAH); Winzer, Nicole, Rühl, Kirsten: Agnes Pockels: Biographie - Nobelpreiswürdige Forschung am Küchentisch ... Arbeit für Wahlpflichtfach Pharmaziegeschichte im SS 2007, online http://www.pharmtech.tu-bs. de/pharmgesch/typoz/fileadmin/Dokumente/ WPF_Biographie_Agnes_Pockels-1.pdf (Ausdruck im UAH); Beneke, Klaus: A.L.W.P. ... Forschende Hausfrau; bedeutende Grundlagenforschungen auf dem Gebiet der Grenzund Oberflächenchemie (Langmuir-PockelsWaage), online unter http://www.uni-kiel.de/ anorg/lagaly/group/klausSchiver/pockels.pdf (mit Bibliogr. und $P$; Ausdruck im UAH).

Lb Seit WS 1883/84 Studium an TH Braunschweig, anschl. U Göttingen, Freiburg/Br., Göttingen.

U Göttingen: Dez. 1888 Dr. phil.; Nov. 1889 Prüfung für Lehramt an höheren Schulen in Göttingen; April 1889-März 1896 Assistent am Physikal. Inst.; Febr. 1892 Habilitation; 1892-1896 PrivatDozent.

TH Dresden: Seit April 1896 a. o. Prof. und Adjunkt am Physikal. Inst.

UH: Seit 2. März 1900 etatm. a. o. Prof.

Qu UAH PA 2110. - Mitteilungen: Frau Anna Pockels (†), Tochter. 
$W$ Über den Einfluß elastischer Deformationen, speciell einseitigen Druckes, auf das optische Verhalten krystallinischer Körper. Diss. Leipzig 1889. - Die partielle Differential-Gleichung $\Delta \mathrm{u}+$ $\mathrm{k} 2 \mathrm{u}=0$ und deren Auftreten in der mathematischen Physik. Leipzig 1891. - Lehrbuch der Kristalloptik. Leipzig 1906. Nachdr. New York 1968. Ergebnisse der neueren Erdbebenforschung in bezug auf die physikalische Beschaffenheit des Erdinneren in: Geologische Rundschau 1 (1910).

HG 1908-1913 Beiblätter zu den Annalen der Physik.

L Catalogus prof. Gottingensium (1962) S. 144; Professoren TU Dresden (2003) S. 725; WBIS; Deutsche Biographie, s. https://www.deutsche-bio graphie.de/gnd116247401.html [07.11. 2017].

$P$ Bildarchiv UAH.

\section{Poppen, Hermann Meinhard}

1920-1952 Phil. Fak.

Musikwissenschaft

* o1. Jan. 1885 Heidelberg

$\dagger$ 10. April 1956 Heidelberg

ev.

V Hermann Julius P. (1850-1909) Baurat

M Maria geb. Sexauer (1852-1918)

$\infty$ 12. Okt. 1913 Bertha Emilie (Emmy) geb. Felber (1890-1986), s. Musik in Heidelberg (1985)

S. 249 (Register); Seele, Heide: Emmi [!] P. † in: RNZ Nr. 107 vom 12. Mai 1986

K $\quad 4$ S (davon: $1 \mathrm{~S}$ früh $\dagger, 1 \mathrm{~S} 1944$ vermißt)

Vw Nichte: Irmgard geb. Poppen (1924-1963) Cellistin, s. Fischer-Dieskau, Dietrich: Nachklang - Ansichten und Erinnerungen. Stuttgart 1987; Ehefrau von Dietrich Fischer-Dieskau (1925-2012) Bariton, s. Neunzig, Hans A.: D. F.-D. ... Berlin 2005; Oesterreichisches Musiklexikon online (8. Juli 2013). Enkel: Christoph P. $\left({ }^{*} 1956\right)$ Dirigent, seit 2003 Prof. für Violine und Kammermusik an Hochschule für Musik und Theater München, siehe Wikipedia.
Lb Seit WS 1903/04 Studium der Theologie an UH, seit WS 1905/o6 Berlin, anschl. Kiel; SS 1907 Forts. des Studiums der Theologie an UH, WS 1907/08SS 1909 Studium der Musikwiss. an UH; 1906 I., 4. Nov. 1907 II. theol. Staatsexamen in Karlsruhe; 1913 auf eigenen Antrag Streichung aus der Liste der Pfarramtskandidaten.

UH: SS 1910-Mai 1914 Assistent am Musik-Institut.

Meiningen: 1. Jan.-31. Juli 1912 Musikstudium bei Max Reger und 1913-1914 dessen Assistent.

U Jena: 23. Mai 1914-1918 Akad. Musikdirektor; in dieser Zeit: 1914-1918 Kriegsdienst.

Karlsruhe: 15. Juni 1918-1. Sept. 1919 (Versetzung in einstweiligen Ruhestand) (letzter) HofkirchenMusikdirektor; 1918-1919 (erster) Landeskirchenmusikdirektor der badischen Landeskirche; seit 19. Febr. 1921 Lehrauftrag an TH.

UH: 7. Juni 1919 Dr. phil.; 1. Sept. 1919-21. März 1952 (Ruhestand) Akad. U-Musikdirektor am Musik-Institut als Nachf. von Philipp Wolfrum; WS 1920/21 Beginn seiner Vorlesungen; 26. Juli 1928 Verleihung des Titels „Prof.“; SS 1952 Vertreter seines Lehrfachs. In dieser Zeit:

H: Mai 1931 (Gründer)-1956 Direktor des Ev. Kirchenmusikal. Inst. in der Leopoldstraße 62 (heute: Hochschule für Kirchenmusik der Ev. Landeskirche in Baden); 1936 Verleihung der Bezeichnung Landeskirchen-Musikwart auf Beschluß des Ev. Oberkirchenrates; Sept. 1944 kurzzeitige SchlieBung des Ev. Kirchenmusikal. Inst. durch Verfügung des Landesleiters der Reichsmusikkammer.

H: 1. Sept. 1919-1956 Städtischer Musikdirektor sowie Chorleiter des Bachchors als Nachf. von Wolfrum; 1952-1955 Chorleiter des Heidelberger Liederkranz, s. Hundertfünfzig Jahre Heidelberger Liederkranz 1839-1989. Bearb. von Alfred Vogel ... Heidelberg 1989. 
Seit 1938 Mitglied des Ausschusses der Ev. Kirche in Deutschland zur Abfassung des Ev. Kirchengesangbuchs

E 1955 D. theol. UH. $\bullet 1950$ Ehrenbürger der Stadt Heidelberg.

Qu UAH PA 5336; RA 6134, 6660; Studentenakte. • GLA Abt. 235, Fasz. 1889. - Briefe: Staatsarchiv Leipzig (im Bestand des Leipziger Musikverlages C.F. Peters). - Nachlaß: Hochschule für Kirchenmusik Heidelberg, s. Luchterhandt, Gerhard: 75 Jahre im Zeitraffer ... in: hfk aktuell „Hochschule für Kirchenmusik Heidelberg“ - Nachrichten - H. 2 (Okt. 2007) S. 30 f. • Mitteilungen: Herr Ministerialrat a. D. Volkmar Poppen $(\dagger)$.

W Max Reger. Leipzig 1918. 3. Aufl. 1947. • Das erste Kurpfälzer Gesangbuch und seine Singweisen. Lahr 1938. - Siehe Badische Biographien N. F. II (1987) S. 220.

MG, Schriftleiter 1925-1930 Ev. Kirchenmusik in Baden.

Mitbearb. (Orgel-)Choralbuch zum Ev. Kirchengesangbuch der ... Ev. Landeskirche Baden ... Karlsruhe 1952. 2. Aufl. Karlsruhe 1955. 4. Aufl. 1980.

HG Walther, Johann Gottfried: Orgelchoräle. Auswahl für den gottesdienstlichen Gebrauch. Kassel 1930. 5. Aufl. 1964. • Orgelvorspiele zum Ev. Kirchengesangbuch. Berlin 1953. 3. Aufl. 1961.

MHG Geistlich und weltlich. Gesänge für 4-stimmigen gemischten Chor ... Heidelberg 1914.

$L$ Reger, Elsa: Mein Leben mit und für Max Reger. Leipzig 1930. MGG 10 (1962) Sp. 1450 (mit Werkverz.). - Weg und Werk. Eine Festgabe zum 70. Geb. von H. M. P. Hrsg. von Otto Riemer. Heidelberg 1965. • Riemann (1975) Erg.-Bd., S. 401; Musik in Heidelberg (1985) S. 249 (Register). • Finscher, Ludwig: Bachverein und Universität in: Ruperto Carola 74 (1986) S. 157 f. • Badische Biographien N.F. II (1987) S. 219 f.; WBIS. • Schubert, Werner: H.M.P. als Musikwissenschaftler in: Die Hochschule für Kirchenmusik der Ev. Landeskirche in Baden, Heidelberg, ehemals Kir- chenmusikalisches Institut (1931-2006) und ihr Gründer H. M. P. ... Festschrift ... Hrsg. von Renate Steiger. Heidelberg 2006. S. 49-57. - UH im Nationalsozialismus (2006) S. 194f. u. ö. • Schlage, Thomas: H.M.P. ... in: Lebensbilder aus der ev. Kirche in Baden (2007) S. 332-363. D Deutsche Biographie, https://www.deutsche-biographie.de/ gnd116268387.html [07.11. 2017]; BBKL (März 2018 in Vorbereitung).

$P$ Bildarchiv UAH; Badische Biographien.

\section{Port, Gottlieb Albert Julius}

1901-1918 Med. Fak.

Zahnheilkunde

* 24. Okt. 1867 München

$\dagger \quad$ 31. Okt. 1918 Heidelberg ev.

V Dr. Julius P. (1834-1905) seit 1859 Militärarzt in Würzburg und München, anschl. Oberstabsarzt I. Klasse und Vorstand des Operationskurses in München, zuletzt bis 1896 (Abschied) Generalarzt, s. WBIS

M Wilhelmine geb. Müller

(12. April 1893 Amalie Luise Christiane Albertine geb. Seidel (1868-1946)

K $2 \mathrm{~S}$

Vw Zwillingsbruder: Konrad P. (1867-1957) seit 1897 Facharzt für Chirurgie und Orthopädie in Nürnberg, seit 1918 a.o. Prof., 1929-1935 (Emeritierung) o. Prof. für Orthopädie Würzburg, s. WBIS, DBE 2 (2007) S. 36.

Lb München: Seit WS 1885/86 Studium an U; 1891 Approbation als Arzt; 1891 Approbation als Zahnarzt; 26. Juni 1891 Dr. med.

1891-1896 Aktiver bayer. Militärarzt in Bayreuth, dann München.

U München: 20. Juni 1896 Habilitation; 1897 dreimonatige Studienreise zu Zahnärztl. Inst. in Deutschland, der Schweiz, Österreich (Wien), Großbritannien (London) und USA (u. a. College 
of Dental Surgery in Philadelphia, Pennsylvania); seit 1. Febr. 1900 I. Lehrer und Leiter der Zahntechnischen Abt. am Zahnärztl. Inst.

UH: Seit 6. März 1901 nichtetatm. a.o. Prof. und Leiter, 21. Juli 1902-1918 (†) Direktor des Zahnärztl. Inst. als Nachf. von Carl Jung; 3. Sept. 19061918 etatm. a. o. Prof. mit e. jährl. Einkommen von 3400.- Mark, seit 1. Juli 1908 4350.- Mark, seit 1. Okt. 1912 4700.- Mark; 1907 Ruf an U Leipzig abgelehnt. • In dieser Zeit:

H: Seit Okt. 1908 Leiter der neugegründeten Städtischen Schulzahnklinik, s. Chronik der Stadt Heidelberg 1907-1909 (1913) 15.-17. Jg., S. 107f.; 1914-1918 Kriegsdienst als Lazarettarzt für Kieferverletzte.

E 1907 Ritterkreuz I. Klasse vom Orden des Zähringer Löwen; 1916 Kriegsverdienstkreuz; 1917 Eisernes Kreuz am schwarz-weißen Bande.

Qu UAH PA 1111, 5338; RA 6362, 7652. • GLA Abt. 235, Fasz. 2388.

$W$ Mechanische Veränderungen an den Kiefern und der Zahnstellung infolge von Erkrankungen der benachbarten Organe. München 1896. Über die Röntgenphotographie in der Zahnheilkunde. Leipzig 1909. (Mitverf.) • Lehrbuch der Zahnheilkunde. Wiesbaden 1915. (Mitverf.) 6. Aufl. 1951.

HG 1903-1914 Index der dt. zahnärztl. Literatur und der zahnärztl. Bibliographie.

$L$ Stübler (1926) S. 326; Fischer $2\left({ }^{3} 1962\right)$ S. 1237. • Goerke, Heinz: 75 Jahre Deutsche Röntgengesellschaft. Stuttgart 1980. S. 9. - Arnim 4 (1984) S. 1309; Chronik Ärzte H (1985) S. 139; Klinikum UH (1986) S. 209 f.; Bauer/Langsch (1991) S. 380382 online; Kristen (1996) S. 220-223. Kütterer, Gerhard: Ach, wenn es doch ein Mittel gäbe, den Menschen durchsichtig zu machen wie eine Qualle! Die Röntgentechnik in ihren ersten beiden Jahrzehnten - ein besonders faszinierendes Stück Medizin- und Technikgeschichte, dargestellt in $\mathrm{Zi}$ taten. Norderstedt 2005. S. 197 u. ö. $\bullet$ DBE 2 (2007)
S. 35 f. - Hippele, Stephanie: Die Münchner Chirurgen Julius Fessler (1862-1937) und Paul Ziegler (1864-1911) und die Besetzung des ersten Zahnmedizinischen Lehrstuhls an der Ludwig-Maximilians-Universität München. Med. Diss. München 2012. S. 44-47. Kütterer, Gerhard: Lebensdaten verdienter Persönlichkeiten in den ersten Jahrzehnten der Röntgenologie. 2. Aufl. Norderstedt 2015. S. 443.

$P$ Bildarchiv UAH.

\section{Posselt, Carl Friedrich}

SS 1804 Med. Fak. WS 1804 Phil. Fak.

Allgemeine Naturgeschichte, Vergleichende Anatomie und Physiologie

* o1. Sept. 1780 Karlsruhe

$\dagger \quad$ 02. Dez. 1804 Heidelberg ev.-luth.

V Johann Friedrich P. (1752-1789) Hof- und Reg.-Rat, s. Posselt, William: Gottfried Posselt 1693-1768. Sein Leben, seine Vorfahren und seine Nachkommen ... München 1926. S. 134, 173, 193; Vierneisel, Emil: Ernst Ludwig P. in: ZGORh 88. Jg. (1936) S. 244 Anm. 1

M Johanna Catharina geb. Neydecker/Neudecker $(\dagger 1803)$

$œ$ unverheiratet

Vw Urgroßvater: Gottfried P. (1693-1768), s. Posselt, William (1926). - Onkel: Dr. iur. Ernst Ludwig P. (1763-1804), u. a. Journalist, Chefredakteur, Hof-Historiograph, s. ADB 26 (1888) S. 461-464; Posselt, William (1926) S. 193-195; Vierneisel, Emil: Ernst Ludwig P. in: ZGORh 88. Jg. (1936) S. 243-271, Forts.: ebd. 91. Jg. (1939) S. 444-499; Oesterle, Kurt: Der Redakteur in Flammen. Revolutionärer Feuerkopf und Pionier des politischen Journalismus: E. L.P. zeigte den Deutschen, wie man eine moderne Zeitung macht in: DIE ZEIT Nr. 25 vom 09. Juni 2004; Goethes Leben von Tag zu Tag: Generalregister ... (2011) S. 320 (Register). 
Lb Seit 30. März 1798 Studium an UH, anschl. Jena; 8. Okt. 1800 Dr. med. an U Jena.

H: 1800-1804 Niedergelassener Arzt; zwischen 1801 und 1803 Studienaufenthalt in Wien.

UH: Anfang 1804 Ern. zum a.o. Prof. mit e. jährl. Besoldung von 400.- Gulden; P. kündigt folgende Vorlesungen an: SS 1804 an Med. Fak.: Allgemeine reine Naturgeschichte, Vgl. Anatomie und Physiologie, samstags oder sonntags botanische und zoologische Excursionen publice in umliegende Gegenden, im WS 1804 († 02. Dez. 1804) an Phil. Fak.: Allgemeine reine Naturgeschichte, Vgl. Anatomie und Physiologie (aus: Anzeigen der Vorlesungen der ... Universität ... SS 1804 und WS 1804/05).

Qu UAH RA 5332, 8267. • GLA Abt. 205, Fasz. 432.

$W$ Tentamina circa anatomiam forficulae auriculariae Linn. icone illustrata. Diss. Jena 180o. Beiträge zur Anatomie der Insekten. Tübingen 1804.

L Donat (1913) S. 168; Schneider (1913) S. 81; Stübler (1926) S. 185 f. - Über C.F.P. in: Vierneisel, Emil: Ernst Ludwig P. in: ZGORh 88. Jg. (1936) S. 244 Anm. 1. WBIS. • Goethes Leben von Tag zu Tag: Generalregister: Namenregister - Register der Werke Goethes ... Hrsg. von Siegfried Seifert. Berlin 2011. S. 320 (Register). Deutsche Biographie, s. https://www.deutsche-biographie.de/gnd11 6277076.html [07.11. 2017].

\section{Posselt, Louis}

siehe Posselt, Ludwig

\section{Posselt, Ludwig (Louis) Friedrich}

1842-1847 Phil. Fak. 1847-1849 (1851) Med. Fak.

Pharmazie, Pharmazeutische Chemie

* 22. Nov. 1817 Heidelberg

$\dagger$ 21. Aug. 1880 Heidelberg ev.

V Carl Ludwig P. (1782-1845) Apotheker, 18311835, 1839-1845 Mitglied der II. Kammer des Badischen Landtags in Karlsruhe, s. Donat (1913) S. 168; Posselt, William: Gottfried Posselt 1693-1768. Sein Leben, seine Vorfahren und seine Nachkommen ... München 1926. S. $196-198$.

M Susanna Carolina geb. Anderst (1788-1876)

$\infty$ unverheiratet

Vw Bruder: (siehe) Wilhelm P.

Lb H: Vor 1836 praktische und theoretische Apotheker-Ausbildung; 1836 Apotheker-Gehilfenexamen.

1836-1838 Apotheker-Gehilfe, u. a. auch in Frankreich.

UH: 9. Mai 1838 Immatrikulation; 5. Juni 1839 pharmazeutisches Staatsexamen; 1839-1841 Assistent am Chemischen Laboratorium; 16. Dez. 1840 Dr. phil.

Sommer 1841 Untersuchung des Mineralwassers in Malsch (bei Karlsruhe); anschl. Studienreise durch die Schweiz.

U Gießen: WS 1841/42 Assistent am Chemischen Laboratorium.

UH: 28. Mai 1842 Habilitation an Phil. Fak.; seit 5. Febr. 1847 a. o. Prof. an Med. Fak.; März 1849 (nach Scheitern der 1848er Revolution) Beurlaubung auf $2^{1 / 2}$ Jahre zu e. wiss. Reise nach Kalifornien und Mexiko; während P.s Abwesenheit Vertreter seines Faches: Leopold Gmelin und Wilhelm Delffs, s. Brief vom 26. Febr. 1849 in: UAH PA 2112; 1851 Verlängerung der Beurlaubung für ein weiteres $1 / 2$ Jahr; Okt. 1851 aus der Liste der akad. Lehrer gestrichen. • In dieser Zeit: 
H: 27. April 1845-März 1849 General-ApothekenVisitator.

Nach März 1849 Aufenthalt u.a. in Kalifornien und Mexiko; u. a. Besuch von Minen in Nuevo León, e. Bundesstaat im Nordosten Mexikos (siehe hierzu: Louis P's Kreuz- und Querzüge durch Mexiko ... Heidelberg 1882); 1861 Rückkehr aus Mexiko; anschl. Aufenthalt bei seinem Neffen Ernst Karl Ludwig P. (siehe Wilhelm Posselt: Eintrag unter $K$ [inder]) in Bradford (West Yorkshire, England).

H: Seit 1869/7o Privatmann in der Grabengasse 14 am Ludwigsplatz (heute: U-Platz); in diesem Haus wohnen auch seine Mutter und Bruder Wilhelm; 16. März 1875 (Wahl)-21. Aug. 188o Stadtrat.

P. vermacht der Stadt Heidelberg testamentarisch Geld für den Bau eines „Lusthäuschens mit Aussichtsturm, die Posseltslust", aus rotem Sandstein, umgeben von einem kleinen Park mit Teich, Fontäne und Grotte, s. Stadtarchiv Heidelberg AA 317/10 (Laufzeit 1879-1926). 1895 in der Nähe des Kohlhofs auf dem Königsstuhl in Heidelberg errichtet, wird die Posseltslust kurz vor dem endgültigen Zerfall 2008/o9 grundlegend restauriert.

Qu UAH PA 2112; Fak.-Akte H-IV-102/36. GLA Abt. 205, Fasz. 433. Einwohner-Verzeichniß der Stadt Heidelberg für $1851 \ldots$ bis 1879 , s. http:// www.ub.uni-heidelberg.de/helios/digi/hdadressbuch.html. - Auskunft: Stadtarchiv Heidelberg (Geburtseintrag im Standesbuch der ev.-luth. Gemeinde Heidelberg (1810-1822) S. 205).

$W$ Tabellarische Übersicht der qualitativen chemischen Analyse. Heidelberg 1845. Die analytische Chemie tabellarisch dargestellt. Heidelberg 1846. Mina de Dolores, Vallecillo in: The Mining Magazine, devoted to Mines, Mining Operations, Metallurgy ... Vol. V. New York 1855. S. 112 f., 175179. - Louis P's Kreuz- und Querzüge durch Mexiko und die Vereinigten Staaten von Nord-Amerika. Nach Tagebuchaufzeichnungen bearb. von Felix Maurer. Heidelberg 1882. - Siehe auch Escamilla, Francisco Omar: Louis Posselt (2010) S. 46of.
L Poggendorff 2 (1863) Sp. 508. • Posselt, William: Gottfried Posselt 1693-1768. Sein Leben, seine Vorfahren und seine Nachkommen ... München 1926. S. $198 \mathrm{f}$. Apotheker-Biographie 2 (1978) S. 507f.; Thomas (1985) S. 170-172; Zimmermann/Drüll (1990) S. 31. - Roß, Rudolf Stefan: Der Chemiker Wilhelm Delffs und die Institutionalisierung der Medizinischen Chemie an der Universität Heidelberg im 19. Jhdt. in: Würzburger medizin-histor. Mitteilungen 16 (1997) S. 469471. - Schwedt, Georg: Liebig und seine Schüler. Die neue Schule der Chemie. Berlin 2002. S. 273 u. ö. Ruuskanen (2008) S. 42 f. Escamilla, Francisco Omar: Louis Posselt ..., sus ires y venires por México y su representación en el congreso de Químicos de Karlsruhe (1860) in: Alemania y e México independiente. Percepciones mutuas, 18101910. Karl Kohut, Alicia Mayer ... (Eds.). Ciudad de México 2010. S. 437-466.

\section{Posselt, Wilhelm Heinrich Christian}

1839-1854, 1858-1864 Med. Fak. 1839-WS 1853/54 Von den Krankheiten des kindlichen Alters mit praktischer Anleitung, Arzneimittellehre, Receptierkunst; nur SS 1843 Allg. Pathologie und Therapie; seit 1858 Med. Kasuistik am Krankenbett

* 14. Sept. 1806 Weinheim

$\dagger \quad$ 21. Jan. 1877 Heidelberg ev.

V Carl Ludwig P. (1782-1845) Apotheker, Landtagsdeputierter, s. Donat (1913) S. 168, Posselt, William: Gottfried Posselt 1693-1768. Sein Leben, seine Vorfahren und seine Nachkommen ... München 1926. S. 196-198.

M Susanna Carolina geb. Anderst (1788-1876)

$\infty$ 5. Juni 1834 Anna Babette geb. Landfried (1812-1867) T von Philipp Friedrich L., 18061820 Bierbrauermeister (seit 1804 Inhaber des Patents) im Gasthaus „Zum weißen Schwanen“ in H, Hauptstraße 143, s. Offenberg, Volker von: Prost Heidelberg! Die Geschichte der Heidelberger Brauereien und Bierlokale. Heidelberg 2005. S. 61f. u. ö. 
K 4 T (2 T früh †), 1 S: Ernst Karl Ludwig P. (18381907) 1858 (Gründer)-1883 Direktor e. Kommissionsgeschäfts in der Textilbranche u.d.N. Ernst Posselt in Bradford (West Yorkshire, England), 1883 (Gründer)-1896 Direktor von mehreren Textilfabriken, u. a. in Warschau und Riga; 1907 Stiftung seiner 148 Gemälde meist holländischer Meister an die Stadt $\mathrm{H}$, siehe Stadtarchiv H, Signatur UA 210/12 (Laufzeit 1907-1910); diese Bilder bilden den Grundstock der Gemälde-Abteilung des Kurpfälzischen Museums (2007 Neueröffnung der Sammlung Posselt), s. Posselt, William: Gottfried Posselt 1693-1768. Sein Leben, seine Vorfahren und seine Nachkommen ... München 1926. S. 202-205.

Vw Bruder: (Siehe) Ludwig P.

Lb UH: WS 1825/26-SS 1831 Studium; 1829-1831 Assistent an Med. U-Klinik; 27. Okt. 1831 Dr. med.

1831 Staats- und Akademische Prüfung (Approbation als praktischer Arzt, Wundarzt und Geburtshelfer) in $\mathrm{H}$ und Karlsruhe.

1831-1833 Eigenstudien in Würzburg und Paris.

H: 1833-1877 Niederlassung als praktischer Arzt. • In dieser Zeit:

UH: 7. Mai 1839 Habilitation; im SS 1840 Vorlesungsankündigungen: Arzneimittellehre mit Receptierkunst, Über Scheintod, Leichenhäuser und Kirchhöfe sowie Die wichtigern Kinderkrankheiten mit Übungen in der Auscultation und Percussion unter Benutzung seiner Kinderheilanstalt (auch WS 1840/41-Ende WS 1843/44); seit 15. Febr. 1844 a.o. Prof. in Nachf. von Friedrich Jacob Christian Sebastian; 1845 Ruf an U Dorpat abgelehnt; SS 1854-SS 1858 keine Vorlesungsankündigungen (Grund unbekannt); 24. Nov. 1864 Beendigung seiner Lehrtätigkeit auf eigenen Antrag.

H: 1840/42-1844 (?) Begründer und Leiter der ersten Privat-Kinderklinik, s. hierzu auch Theodor Plitt und Theodor von Dusch; 16. Sept. 1840: Schreiben der Sanitätscommission an Ministe- rium des Innern mit der Bitte P.s „um die Erlaubnis, Arzneimittel für kranke Kinder auf Kosten des Armenfonds ... verschreiben“ zu dürfen; Ministerium weist Bitte ab mit dem Hinweis, daß die Kostenübernahme aus dem genannten Fonds „ein Recht ist, welches allein dem polyclinischen Institute der Universität zugestanden werden kann und nicht geschmälert werden darf " (aus: Brief vom 22. Sept. 1840 in: UAH PA 2113); Juli 1842 Gesuch P.s um „Begründung und Beförderung einer Kinderheilanstalt", s. Brief vom 6. Juli 1842 in: PA 2113; Aug. 1842 Ablehnung des Antrags durch Akad. Senat und Med. Fak. mit der Begründung, e. Zustimmung "für die besondere Errichtung und Dotirung einer Kinderheilanstalt bei den Verhältnissen einer kleineren Stadt und der Zusammenhaltung unserer Fonds" nicht geben zu können (aus: Brief vom 31. Aug. 1842 in: PA 2113); 1842 Errichtung der P.schen „ambulatorischen und poliklinischen Privat-Heilanstalt" in H, s. hierzu Brief vom 27. Mai 1843 in: PA 2113. Diese Kinderheilanstalt war wohl in Posselts Wohnhaus in der Haspelgasse untergebracht. Am 27. Mai 1843 schreibt P. in einem Brief an das Ministerium des Innern: „... In der Aussicht auf eine hochgefällige hinlängliche Unterstützung zu meiner Kinderheilanstalt habe ich mir ein Haus begonnen zu bauen, wo ich meine Vorlesungen zu halten, pathologisch-clinische Untersuchungen in einem besonderen Laboratorium anzustellen und einige Krankenzimmer für arme Kinder wo möglich einzurichten gedenke ..." (aus: PA 2113). Dieses Haus stand am Ludwigsplatz (heute U-Platz) in der Grabengasse 14 (siehe hierzu auch Ludwig Posselt). Nach dem WS 1843/44 bietet P. u.a. Vorlesungen über „Kinderkrankheiten mit Anleitung am Krankenbett" an; hier heißt es allerdings nicht mehr unter Benutzung seiner Kinderheilanstalt. Diese Formulierung könnte das Ende der Heilanstalt aufzeigen.

1875 schenkt P. seine Bibliothek über Kinderheilkunde der Heidelberger Luisen-Heilanstalt

\section{E Goldene Staatsmedaille.}

Qu UAH PA 2113; Fak.-Akte H-III-111/28. • GLA Abt. 205, Fasz. 434f. - Auskunft: Stadtarchiv Heidelberg (es ließ sich allerdings kein Hinweis zu P.s 
Privat-Kinderklinik ermitteln, weder in den Akten des Stadtarchivs noch in den Ratsprotokollen 1841-1842).

$W$ De pleurae ossificatione. Heidelberg 1839 .

L Posselt, William: Gottfried Posselt 1693-1768. Sein Leben, seine Vorfahren und seine Nachkommen ... München 1926. S. 199f. - Stübler (1926) S. 312. - König, Paul: Die Entdeckung des reinen Nikotins im Jahre 1828 an der Universität Heidelberg durch Reimann und Posselt. Bremen 1940. • Chronik Ärzte H (1985) S. 140. - Myers, Richard L.: The 100 most important chemical compounds: A reference guide. Westport 2007. S. 192. 150 Jahre Pädiatrie in H (2010) S. 31, 37. Schaefer, Bernd: Natural products in the chemical industry. Heidelberg 2014. S. 482. Deutsche Biographie, s. https:// www.deutsche-biographie.de/gnd1012808467.html [07.11. 2017]. - Pagliaro, Ann Marie, Pagliaro, Louis A.: Women's drug and substance abuse. A comprehensive analysis and reflective synthesis. 2nd ed. London 2017.

P Bildarchiv UAH; graph. Slg. UBH; König (1940).

\section{Precht, Carl Christian Julius}

1897-1901 Nat.-Math. Fak.

Physik

* 28. Juni 1871 Bremen

$\dagger \quad$ 09. Juli 1942 Hannover ev.-luth.

V Friedrich Ernst P. (1843-1887) Steindruckereibesitzer

M Flora Clara geb. Westendörpf (1845-1917)

œ 26. Jan. 1899 Johanna geb. van Eck $\left.{ }^{*} 1873\right)$ Scheidung 1921

๑ 5. Aug. 1921 Anna Maria Elisabeth geb. van Jindelt $\left({ }^{*} 1890\right)$
K 1 S, 2 T: u.a. Gerritje P. (1899-1994) Diplom-Chemikerin, u.a. 1954-1970 Bundesvorsitzende des Verbands Dt. Frauenkultur, s. Hildebrandt, Irma: Erinnerung an die Ehrenvorsitzende Gerritje Meldau in: 120 Jahre Frau und Kultur - Verbandszeitschrift - 1 (2016) S. 12 f.; Ehefrau von Robert Meldau (1891-1978) Staubtechniker; seit 1926 niedergelassener Patentanwalt in Berlin, 1945 Flucht aus dem Ostsektor, anschl. Wiedereröffnung der Kanzlei in Harsewinkel (bei Münster), seit 1961 in Gütersloh, heute u.d. N. Meldau - Strauß - Flötotto \& Neisen; u. a. auch 1950-1966 Honorar-Prof. für Geschichte des gewerblichen Rechtsschutzes und über Technik des Industriestaubs TH Hannover, s. NDB 17 (1994) S. 12 f.; Maier, Helmut: Chemiker im „Dritten Reich“. Die Dt. Chemische Gesellschaft und der Verein Dt. Chemiker im NSHerrschaftsapparat. Weinheim 2015 (online); Nachlaß im Stadtarchiv Gütersloh.

Lb SS 1889 Studium an UH, seit WS $1889 / 90$ Berlin, WS 189o/91 H, seit SS 1891 Bonn; 25. Febr. 1893 Dr. phil. an U Bonn.

Münster (Westfalen): Seit 1892 Assistent am Physikal. Inst. der Akademie.

UH: 1894-1901 Assistent am Physikal. Inst.; 30. Jan. 1897 Habilitation; seit 9. Juni 1900 nichtetatm. a. o. Prof.

TH Hannover: Seit 15. Aug. 1901 Dozent für Experimentalphysik und Photographie; seit 17. Okt. 1901 a. o. Prof.; seit 3. April 1906 o. Prof. für Experimentalphysik und Leiter des Physikal. Inst.; 31. März 1935 vorzeitige Emeritierung aus Krankheitsgründen auf eigenen Antrag, s. hierzu Jung (2013) S. 103-106.

Tierärztl. Hochschule Hannover: 1924-1934 Honorar-Prof.

Qu UAH RA 6398, 6465, 6898. - Auskunft: Niedersächsisches Hauptstaatsarchiv Hannover (PA Precht). 
W Aufnahme gegen die Sonne mit der Sonne im Bilde in: Photographische Rundschau 16 (1902). Strahlungsenergie von Radium in: Annalen der Physik 21 (1906) S. 595-601. • Schallausbreitung in geschlossenen Räumen in: Verh. der Dt. Physikal. Gesellschaft 3 (1922); Über elektrische Pausen in: ebd. 12 (1931) S. $11 \mathrm{f}$.

L Kürschner (1931) Sp. 3448; Lehrkörper TH Hannover (1956) S. 18; Poggendorff 7a (1959) S. 622. • Festschrift zum 150jährigen Bestehen der Universität Hannover. Bd. 2: Catalogus professorum 1831-1981. Stuttgart 1981. - Jansen (1992a) S. 168 (Register). Schirrmacher, Arne: Philipp Lenard: Erinnerungen eines Naturforschers. Kritische annotierte Ausgabe des Originaltyposkriptes von 1931/1943. Berlin 2010. S. 115, 165. • Jung, Michael: „Voll Begeisterung schlagen unsere Herzen zum Führer". Die Technische Hochschule Hannover und ihre Professoren im Nationalsozialismus. Books on Demand. Norderstedt 2013. S. 373 (Register). Deutsche Biographie, s. https://www. deutsche-biographie.de/gnd116281278.html [07.11. 2017].

P Lehrkörper TH Hannover (1956).

\section{Preisigke, Friedrich}

1915-1924 (Honorar-Prof.) Jur. Fak.

Papyruskunde

* 14. Febr. 1856 Dessau

$\dagger \quad$ o8. Febr. 1924 Heidelberg

Konf. unbekannt

V N.N., Postbedienter

M N.N.

๑ 8. Jan. 1884 Klara geb. Naumann ( $†$ nach 1924)

K $\quad 1$ S, 1 T, s. Jördens (2007) S. 62.

Lb März 1877 Reifeprüfung am Dom-Gymnasium in Magdeburg; seit März 1877 Eleve, anschl. Beamter bei dt. Post- und Telegraphenverwaltung in Magdeburg, u. a. auch in Gröbzig (heute: Ortsteil der Stadt Südliches Anhalt), seit 1881 Berlin und 1888-1893 Hamburg; 1887 höhere Telegraphenverwaltungsprüfung.
Berlin: 1893-1904 Telegraphen-Direktor des Kaiserl. Stadt-Fernsprechamtes 6; 1899-1902 Studium der Altertumswiss. an U; Juli 1903 Dr. phil. an U Halle-Wittenberg.

Straßburg: 1. Mai 1904-31. Mai 1915 (Ruhestand aus gesundheitl. Gründen auf eigenen Antrag) Telegraphen-Direktor des Kaiserl. Telegraphenamtes; u.a. Winter 1908/o9 Studienreise durch Ägypten. • In dieser Zeit:

U Straßburg: 18. Sept. 1913-1. Juni 1915 (Ruhestand) Honorar-Prof. für Papyruswissenschaft an Phil. Fak.

UH: 7. April 1915 Ern. zum o. Honorar-Prof. an Jur. Fak. auf Betreiben von Otto Gradenwitz (s. hierzu Jördens (2007) S. 6of.) und 1919 Begründer des Papyrus-Inst. (siehe unten); Lehrauftrags-Vergütungen für Papyruskunde während der Inflation: seit WS 1920/21 3000.- Mark, seit WS 1921/22 28 ooo.- Mark, seit SS 192242 ooo.- Mark, seit WS 1922/23 108 ooo.- Mark, seit 1. Juli 1923420 750.Mark pro Semester für 4 Stunden Lehre wöchentlich; Papyrus-Inst. erhält auf Anfrage P.s vom Ministerium des Kultus und Unterrichts e. Zuschuß: am 31. Juli 1923 von 9 Millionen Mark „für sachliche Bedürfnisse und zur Beschaffung von Heizstoffen“, am 2. Okt. in Höhe von 8o Millionen (aus: UAH PA 5352).

Im Okt. 1919 richtet P. in Räumen seiner PrivatWohnung, Gaisbergstraße 101, das Papyrus-Institut ein; er erhält dafür einen jährl. Mietzins über 6oo.- Mark von UH ausbezahlt (aus: UAH RA 782).

1926 wird P.s Bibliothek an die Berliner Papyrussammlung verkauft, s. hierzu Jördens (2007) S. 57 Anm. 1.

1915 Geh. Post-Rat

E 1915 Mitglied der Akademie der Wissenschaften H. 1910 Dr. iur. h. c. UH.

Qu UAH PA 782, 5352 (eigenhändiger Eintrag: Geburtsort Dessau). GLA Abt. 235, Fasz. 2392. • Ergebnislose Anfragen: Archiv der Ev. Landeskirche 
Anhalts in Dessau-Roßlau (Kirchenbücher sind aus dieser Zeit vernichtet; auch kein Geburtseintrag in den später angefertigten (und unvollständigen) Ersatzregistern von Dessau St. Marien und St. Georg zu finden); Bischöfliches Ordinariat Magdeburg - Bistumsarchiv, s. http://data.matriculaonline.eu/de/deutschland/magdeburg.

$W$ Girowesen im griechischen Ägypten. Straßburg 1910. - Fachwörter des öffentlichen Verwaltungsdienstes Ägyptens in den griechischen Papyrusurkunden der ptolemäisch-römischen Zeit. Göttingen 1915. Antikes Leben nach den ägyptischen Papyri. Leipzig 1916. 2. Aufl. 1925. - Namenbuch, enthaltend alle griechischen, lateinischen, ägyptischen, hebräischen, arabischen ... Menschennamen, soweit sie sich in griechischen Urkunden ... Ägyptens vorfinden. Heidelberg 1922. Nachdr. Amsterdam 1967. - Siehe auch Jördens (2007) S. $56 \mathrm{ff}$.

HG Seit 1913 Sammelbuch griechischer Urkunden aus Ägypten.

$L$ Bell, H.I.: F.P. $(\dagger)$ in: The Journal of Egyptian Archaeology (July 1924) Vol. 10, No. 2, S. 172 f. • Nachruf in: Jahresbericht über die Fortschritte der klassischen Altertumswissenschaft 233 (1931) S. 100-102. - LeMarquand, Grant: An issue of relevance. A comparative study of the story of the bleeding woman ... New York 2004. S. 62-65 u. ö. - Jördens, Andrea: F.P. in: Hermae: Scholars and Scholarship in Papyrology. Ed. by Mario Capasso. Pisa 2007. S. 57-66. - Berichtigungsliste der griechischen Papyrusurkunden aus Ägypten. Hrsg. von H. A. Rupprecht ... 12. Bd. Leiden 2009. S. 173 f., 252 u. ö. Schroeder (2010) S. 494496. • Jördens, Andrea: F. P. in: Geschichte der Altertumswissenschaften. Biographisches Lexikon. Hrsg. von Peter Kuhlmann und Helmuth Schneider. Stuttgart 2012. Sp. 1016-1018. Deutsche Biographie, s. https://www.deutsche-biographie.de/gn d116281871.html [07.11. 2017].

$P$ Jördens (2007) S. 57.
Preuschen, Erwin Friedrich Wilhelm Ferdinand

1914-1918 Theol. Fak.

Neutestamentliche Theologie, Alte Kirchengeschichte

* o8. Jan. 1867 Lißberg (heute: Stadtteil von Ortenberg, Hessen)

$\dagger \quad$ 25. Mai 1920 Hausen (heute: Ortsteil von Pohlheim, Hessen)

ev.

V Erwin Franz P. (1823-1868) Pfarrer, Zeichner, u. a. seit 1850 Vikar in (Darmstadt-)Arheilgen, seit 1852 Verwalter, 1859-1868 Pfarrer in Lißberg, s. Baur, Wilhelm: Lebenserinnerungen. Darmstadt 1911. S. 39-41 u. ö.; WBIS; Haberkorn, Eva: Zeichenkunst im Verborgenen: E.F.P. Familienarchiv Preuschen neu im Hessischen Staatsarchiv Darmstadt in: Archivnachrichten aus Hessen. Hrsg.: Hessische Staatsarchive ... Wiesbaden 2014. S. 15-17; Hessische Biografie, s. http://www.lagis-hes sen.de/pnd/1102262277 (Stand: 1. Juni 2016)

M Wilhelmine Johannette geb. Beckurts

(6) 6. April 1899 Julie geb. Has (188o-1945)

K 3 S: u.a. Gerhardt P. (1908-2004) DiplomLandwirt, u. a. 1940-1950 (Gründer und) Leiter des Inst. für Landwirtschaftl. Arbeitswissenschaft der Kaiser-Wilhelm-Gesellschaft zur Förderung der Wissenschaften in Breslau, 1945 Verlegung nach Imbshausen (heute: Ortsteil von Northeim, Niedersachsen) und 1950-1976 u. d. N. Inst. für Landarbeit und Landtechnik der Max-Planck-Gesellschaft in Bad Kreuznach; 1944-1945 Privat-Dozent Breslau, 1945 Flucht, 1956-1974 apl. Prof. am Inst. für Wirtschaftslehre des Landbaus an Landwirtschaftl. Hochschule (seit 1967 U) Hohenheim (heute: Stadtteil von Stuttgart), 1969-1988 Vizepräsident der Gesellschaft für Geschichte des Weines, s. Nachlaß im Hessischen Staatsarchiv Darmstadt; Lebenserinnerungen. Landwirtschaft im 20. Jahrhundert. Niebüll 2002 (Autobiogr.); WBIS; DBE 8 (2007) S. 72; Hohenheimer Themen. Zs. für kulturwiss. Themen. Hrsg. von Ulrich Fellmeth, Harald Winkel $(\dagger)$... Die akademischen Lehrer an der Uni- 
versität Hohenheim 1968 bis 2005. Bearb. von Ulrich Fellmeth ... 15./16. Jg. 2006/2007. Sonderband. Stuttgart-Hohenheim 2008. S. $343 \mathrm{f}$.

Lb U Gießen: 8 Mai 1886 Immatrikulation zum Studium der Theologie, auch Philosophie; 8. Aug. 1889 I. theol. (Fak.-)Examen („examen pro facultate docendi“, aus: UAH PA 2117).

Friedberg: Herbst 1889-Herbst 1890 Ausbildung im Predigerseminar.

U Gießen: 9. Dez. 1890 Lizentiatenexamen an Theol. Fak.

Darmstadt: 31. März 1891 II. theol. Examen = Definitorialprüfung („examen pro ministerio“, aus: PA 2117).

Berlin: 1891-1893 Wiss. Hilfsarbeiter in Kirchenväterkommission an Akademie der Wissenschaften.

In hessischem Kirchendienst: Okt. 1893-Okt. 1897 Pfarrstellenverwalter in Steinbach (heute: Ortsteil von Fernwald) und Wieseck (heute: Stadtteil von Gießen) sowie in Eberstadt (heute: Stadtteil von Lich bei Gießen), anschl. Adjunkt in Bessungen (heute: Stadtteil von Darmstadt), zuletzt Pfarrer an Hofkirche in Darmstadt. • In dieser Zeit:

U Gießen: 8. März 1895 Dr. phil.

Darmstadt: Seit 9. Okt. 1897 Gymnasial-Prof. am Ludwig-Georgs-Gymnasium.

Hirschhorn/Neckar: 25. April 1908-März 1918 Pfarrer mit e. Jahresgehalt von 490o.- Mark (Stand: 1. Juli 1912). • In dieser Zeit:

UH: 25. Juli 1914 Habilitation; seit 11. Febr. 1915 nichtetatm. a.o. Prof.; WS 1914/15 Vertreter des verstorbenen Ordinarius Johannes Weiss mit e. "Honorar und Reisekostenentschädigung" von 900.- Mark (aus: PA 2117); SS 1917 Entbindung von Verpflichtung zur Abhaltung von Vorlesungen; WS 1917/18 letzte Vorlesungsankündigung.

U Gießen: Seit SS 1918 nichtetatm. a.o. Prof. für Territorialkirchengeschichte; Mai 1920 P.s plötzli- cher Tod an e. Magenleiden vereitelt geplante Berufung zum o. Prof. für Neues Testament. • In dieser Zeit:

Hausen (bei Gießen): 12. Dez. 1917 Berufung zum 1. April 1918 Pfarrer.

E 13. Nov. 1904 D. theol. Gießen.

Qu UAH PA 2117; RA 6722; Fak.-Akte H-I-22o/3. • GLA Abt. 235, Fasz. 2393. - Nachlaß: Hessisches Staatsarchiv Darmstadt (Korrespondenz, Familienpapiere, Kriegstagebücher 1914-1918). • Auskunft: Universitätsarchiv Gießen.

W Harnack, Adolf und P., E.: Geschichte der altchristlichen Literatur. 2 Bde. Leipzig 1893-1904. • Mönchtum und Sarapiskult. Darmstadt 1899. 2. Ausg. 1903. • Vollständiges griechisch-deutsches Handwörterbuch zu den Schriften des Neuen Testaments ... Gießen 1910. 6. Aufl. hrsg. von Kurt und Barbara Aland. Berlin 1988. Griechischdeutsches Taschenwörterbuch zum Neuen Testament. Gießen 1919. 8. Aufl. Berlin 2005. - Siehe auch BBKL VII (1994).

G, HG 1900 Zeitschrift für neutestamentliche Wissenschaft.

HG Tertullian. De paenitentia. De pudicitia. Tübingen 1910. Nachdr. Frankfurt/M. 1968.

$L$ Krüger, G.: E. P. † in: Zs. für neutestamentliche Wissenschaft Bd. 19 (Jan. 1920) H. 1, S. 97-102. • WBIS; Lexikon für Theologie und Kirche 8 (1963) Sp. 731; BBKL VII (1994) Sp. 938-941. Markschies, Christoph: Origenes und sein Erbe ... Berlin 2007. S. 112-118 u. ö. - Brennecke, Hanns Christof: „Patristik“ oder „altchristliche Literaturwissenschaft“? Eine historische Leitwissenschaft der protestantischen Theologie in Deutschland am Beginn des 20. Jahrhunderts in: Zs. für Antikes Christentum (2011) Bd. 15, S. 7-46, online unter https://www. degruyter.com/downloadpdf/j/zach.2011.15.issue1/zac.2011.002/zac.2011.002.pdf. • Deutsche Biographie, s. https://www.deutsche-biographie.de/gn d116283203.html [07.11. 2017]. 


\section{Probst, Johann Maximilian Alexander}

1836-1841 Phil. Fak.

1841-1842 Med. Fak.

Pharmazie, Chemie

* 12. März 1812 Sickingen (heute: Flehingen, e. Ortsteil von Oberderdingen im Kraichgau)

$\dagger$ 15. Febr. 1842 Heidelberg ev.

V Jacob P., Handelsmann

M Elisabetha geb. Rittmann

$\infty$ unverheiratet.

Lb Seit 1827 Apothekerlehre in Lauffen am Neckar; 1829/30 Apotheker-Gehilfenexamen; anschl. Apothekergehilfe in Stuttgart, danach Aschaffenburg; 10. Okt. 1832 Apothekerlizenz in Karlsruhe.

Seit SS 1832 Studium an UH; während e. Bildungsreise Gasthörer an U und Polytechnischer Schule: seit SS 1833 München, anschl. Wien (1 Jahr); seit 1834/35 Studienreise zu Fabriken und Hüttenwerken in Österreich, Ungarn, Galizien, Schlesien, Sachsen; Forts. des Studiums an U Berlin (2 Semester).

UH: 11. März 1836 Dr. phil.; 4. Mai 1836 Habilitation an Phil. Fak.; seit Mai 1836 Vertreter des Lehrstuhls für Pharmazie und Chemie von Philipp Lorenz Geiger; seit 23. März 1838 außerdem General-Apotheken-Visitator des badischen Unterrheinkreises; 5. Juni 1840 Genehmigung e. Antrags von P. auf Errichtung e. Pharmazeutischen Inst. an Med. Fak.; seit 22. Juli 1841 a. o. Prof. an Med. Fak.

Qu UAH PA 2119; Fak.-Akte H-IV-102/32 fol. 77r. GLA Abt. 205, Fasz. 438.

$W$ Die Zaisenhäuser Schwefelquellen. Heidelberg 1836. Das Apotheker-Taxwesen - durch eine auf statistische Nachweisungen begründete Kritik des teutschen Apotheken-Institutes, beleuchtet in seinen nächsten Beziehungen zu Staat, Publikum und practischer Medicin. Heidelberg 1838. Chemische Untersuchungen des Chelidonium majus und des Glaucium luteum in: Repertorium für die Pharmacie. Hrsg. von ... Dr. Buchner. 65. Bd.
Nürnberg 1839. - Beleuchtung der Verhältnisse der teutschen Apotheken zum Staate, zur Gesetzgebung und zum Arzte. Gelegentlich des Entwurfs einer neuen Medicinalordnung für Baden, unter Mitwirkung des Ausschusses des badischen Apothekervereins. Heidelberg 1841.

Mitbearb. Pharmacopoea Badensis. Heidelberg 1841.

$L$ Nekrolog in: Correspondenz-Blatt des Pharmaceutischen Vereins im Großherzogthum Baden Nr. 11 (1842) Beilage. S. 17-22. - Poggendorff 2 (1863) Sp. 533; WBIS. • Wankmüller, Armin: Pharmazieprofessor Dr. J.M. A. P. ... in Heidelberg in: Tübinger apothekengeschichtliche Abhandlungen. Nr. 26. Stuttgart 1972. - Apotheker-Biographie 2 (1978) S. 508 f.; Thomas (1985) S. 163, 167-170; Eberhardt (1990) S. 208 (Register); NDB 20 (2001) S. 734 f.; Stumm (2012) S. 702 (Register).

P Bildarchiv UAH; graph. Slg. UBH.

\section{Puchelt, Friedrich August Benjamin}

1824-1856 Med. Fak.

(eigentlich: Arzneikunde) Innere Medizin (Pathologie, Therapie)

* 27. April 1784 Bornsdorf (heute: Ortsteil von Heideblick, Spreewald)

$\dagger \quad$ 02. Juni 1856 Heidelberg ev.

V Friedrich August P. († ca. 1790) Pfarrer

$M$ Luise geb. Burscher

๑ vor 1814 Gottliebe Auguste geb. Leistner (17931860)

K 3 T, 3 S: u.a. Benno Rudolf P. (1814-1870) seit 1841 Privat-Dozent für Praktische Medizin (Semiotik, Auskultation, Diagnostik) an UH, später praktischer Arzt, s. UAH PA 2120; Emundts-Trill (1997) S. 257f. • Ernst Sigismund P. (1820-1885) Reichsgerichtsrat, s. Badische Biographien 4 (1891) S. 321-323, ADB 53 (1907) S. 137-139, WBIS. 
Lb U Leipzig: Seit 11. Mai 1804 Studium der Philosophie und Medizin; 11. März 1807 med. Bakkalaureat; 15. Nov. 1809 med. Lizentiatenexamen; 28. Febr. 1811 Dr. phil.; 5. April 1811 Dr. med.; 1811 Habilitation für Pathologie, Therapie; 1812 Gründer und 1812-1824 Leiter e. medizinisch-poliklinischen Ordination mit klinischer Studentenausbildung im Jakobshospital am Rosental; seit 1815 a. o. Prof.; 1814-1824 außerdem Kustos der Gehlerschen Bibliothek in UB; seit 15. Nov. 1820 o. Prof. für Pathologie, Therapie. • In dieser Zeit:

Leipzig: Seit 1808 Assistent von Dr. W. Sachse, e. niedergelassenen praktischen Arzt; nach 1811 Arzt der Armenanstalt.

UH: Seit 23. April 1824 (Ern.) o. Prof. (eigentlich für Arzneikunde) und Direktor des Med. Klinikums als Nachf. von Johann W.H. Conradi mit e. jährl. Besoldung von 180o.- Gulden; 1826-1844 Direktor der Poliklinik in Nachf. von Jacob Fidelis Ackermann; 1830-1832 Mitglied der Bibliotheks-Kommission; Jan. 1844-Juli 1852 Direktor der I. Med. Klinik in Seminarstraße 2 im ehem. Seminarium Carolinum (heute: Sitz der U-Verwaltung); 18441852 Mit-Direktor zus. mit Carl Pfeufer der Med. Poliklinik (Pfeufer ist für die Vorstadt, Puchelt für die Stadt zuständig); seit April 1844 Zulage von 200.- Gulden zu seinem jährl. Gehalt von 180o.Gulden; Juni 1844, Okt. 1852, erneut 1854 vergebliche Gesuche P.s um befristete Dispension von Klinikleitung; 23. März 1852 P. kündigt eigene StarOperation an; Vertreter während seiner Abwesenheit: sein Sohn Benno Rudolf P. (siehe oben Eintrag unter $K$ [inder]); 30. Juli 1852 Karl Ewald Hasse übernimmt für erblindeten P. die Direktion des (I.) Med. Klinikums und der Poliklinik; SS 1856 letzte Vorlesungsankündigung und letzte Nennung als Direktor (neben Hasse) des (I.) Med. Klinikums.

1838, 1850 Prorektor der UH; 1829, 1835, 1840, 1845, 1852 Dekan der Med. Fak. der UH

1826 Hofrat; 1838 Geh. Hofrat

E 1835 Mitglied der L'Académie de médicine. 1845 Ritter des Ordens vom Zähringer Löwen.
Qu UAH PA 2121; RA 5355, 6269. • GLA Abt. 205, Fasz. 439. - Auskunft: Ev. Oberkirchenrat - Landeskirchliches Archiv - Karlsruhe; Universitätsarchiv Leipzig (u. a. PA 4343, Phil. Fak. B 128a).

$W$ Das Venensystem in seinen krankhaften Verhältnissen. Leipzig 1818. •Über die Homöopathie. Berlin 1820. - Beiträge zur Medicin als Wissenschaft und Kunst. Leipzig 1823. - Die individuelle Konstitution und ihr Einfluß auf die Entstehung und den Charakter der Krankheiten. Leipzig 1823. System der Medizin in Umrissen dargestellt. 4 Bde. Heidelberg 1826-1832. 2. Aufl. 1835. • Die Hautkrankheiten in tabellarischer Form dargestellt. Heidelberg 1836 .

MHG 1825-1833 Heidelberger klinische Annalen.

L ADB 26 (1888) S. 684; Bader (1925) S. 199; Stübler (1926) S. 263-266; Schmitt (1978) S. 72 u.ö.; WBIS; Chronik Ärzte H (1985) S. 140, 261 f. • Henkelmann, Thomas: Die medizinische Klinik im 19. Jahrhundert in: Semper apertus 2 (1985) S. 326o. - Mülker, Petra: F. A. B.P. ... Biographie und Ergographie ... Diss. Heidelberg 1992. (S. 7: hier Todesjahr der Ehefrau mit 1862 angegeben.) Tuchman, Arleen Marcia: Science, medicine, and the State in Germany. The case of Baden 1815-1871. New York 1993. S. 25 f., 127 u.ö. • 110 Jahre Universitätsklinik und Poliklinik für Kinder und Jugendliche in Leipzig. Hrsg. von Wieland Kiess ... Basel 2003. S. 106. - Prückner (2004) S. 304 (Register); Professorenkatalog Leipzig online; Bauer/ Ho (2016) S. 23 f.

$P$ Bildarchiv UAH; graph. Slg. UBH; Mülker (1992).

\section{Pütter, August Franz Robert}

1923-1929 Med. Fak.

Physiologie

* o6. April 1879 Stralsund

$\dagger$ 11. März 1929 Heidelberg

ev. 
V Ernst August Ferdinand P. $\left({ }^{*} 1836 \dagger\right.$ nach 1913$)$ Richter

M Mariane Karoline Charlotte Mathilde geb. Münchmeyer $\left({ }^{*} 1846 \dagger\right.$ vor 1913$)$

( 14. Juni 1913 Gisela Elisabeth Ida Valerie geb. Zitelmann (1881-1959) Bildhauerin, s. Heidelberg um 1900 ... Ausstellungskatalog aus Anlaß des 60o-jährigen Jubiläums der UH ... Heidelberg 1986. S. 51 Nr. 51.9; Über Gisela Pütter in: Paul Clemen ... Katalog zur Ausstellung anlässlich seines 125. Geb. Bonn 1991. S. 150 u.ö.; Ruuskanen (2008) S. 76 Anm. 106. - T von Konrad Ernst Z. (1852-1923), u. a. 1883-1921 o. Prof. für Rechtswiss. Bonn, s. Verzeichnis Bonn (1968) S. 348, WBIS, Grewolls (2011)

K $\quad 2$ T, 2 S: u. a. siehe Pütter, Dietrich: Shivering on the Precipice. Life as a prisoner of war in the Soviet Union - online, s. dpuetter.com (abgerufen am 20. Febr. 2018).

Lb Seit WS 1898/99 Studium der Medizin, Naturwiss. an U Jena, anschl. Breslau; 27. Juli 1901 Dr. phil. an U Breslau; 5. Mai 1903 med. Staatsexamen in Breslau.

U Göttingen: 1903-1911 Assistent am Physiolog. Inst.; 6. März 1904 Dr. med.; 21. Dez. 1904 Habilitation; 7. April 1909 Verleihung des Titels „Prof.“; SS 1910 Ordinariatsvertreter an U Bonn.

U Bonn: 1911-1922 Assistent am Physiolog. Inst.; 31. Aug. 1921-17. Febr. 1922 nichtplanm. a. o. Prof. In dieser Zeit:
1914-1918 Kriegsdienst.

U Kiel: Seit 18. Febr. 1922 nichtplanm. a. o. Prof.

UH: Seit 21. Aug. 1923 o. Prof. und Direktor des Physiolog. Inst. als Nachf. von Albrecht Kossel; 1923 Ruf an U Kiel abgelehnt.

E 1924 Mitglied der Akademie der Wissenschaften $\mathrm{H}$.

Qu UAH PA 1115, 5364. GLA Abt. 235, Fasz. 2394.

W Organologie des Auges. Leipzig 1908. 2. Aufl. 1912. - Vergleichende Physiologie. Jena 1911. Die Dreidrüsentheorie der Harnbereitung. Berlin 1926.

$L$ Wöhlisch, Edgar: Dem Gedächtnis A.P. in: Ergebnisse der Physiologie (1929) Vol. 28,1. S. 690692. Catalogus prof. Gottingensium (1962) S. 95; Verzeichnis Bonn (1968) S. 232; Chronik Ärzte H (1985) S. 140; Zimmermann/Drüll (1990) S. 49 u. ö. Reddemann, Hans: Berühmte und bemerkenswerte Mediziner aus und in Pommern. Schwerin 2003. - Prüll, C., Maehle, A., Halliwell, R.: A short history of the drug receptor concept. Basingstoke 2009. S. 87 f. u. o. • Grewolls (2011); Deutsche Biographie, s. https://www.deutschebiographie.de/gnd116307919.html [07.11. 2017].

$P$ Bildarchiv UAH; Chronik Ärzte H. 


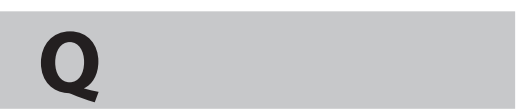

\section{Quincke, Georg Hermann}

1875-189o Phil. Fak.

1890-1907 Nat.-Math. Fak.

Physik

* 19. Nov. 1834 Frankfurt/Oder

$\dagger$ 13. Jan. 1924 Heidelberg

ev.

V Dr. Hermann Q. (1808-1891) Arzt, Geh. Medizinalrat, s. Medicinisches Schriftsteller-Lexicon. Bearb. von A. C. P. Callisen. Reprint of the edition Copenhagen 1830-1845. Nieuwkoop 1963. Bd. 15. S. 287.

M Louise Jeannette Marie geb. Gabain (18131891)

( 27. Mai 1863 Rebecca geb. Rieß (1836-1924) T von Peter Theophil R. (1804-1883) Physiker, s. ADB 28 (1889) S. 584-586; P.T.R.: Das erste jüdische Akademiemitglied [1842] in: Pieper, Herbert: „Ungeheure Tiefe des Denkens, unerreichbarer Scharfblick und die seltenste Schnelligkeit der Kombination." Zur Wahl Alexander von Humboldts in die Académie Royale des Sciences et Belles-Lettres zu Berlin. 4. Aufl. Berlin 2009. S. 48-57.

K 3 S (davon $1 S \times 1870$ Schlacht bei Beaumont); u. a. Friedrich (Fritz) Q. (1865-1934), 18911896 Betriebsleiter bei Chemischer Fabrik Rhenania AG in Stolberg (Rheinland), seit 1898 Betriebsleiter, seit 1905 Prokurist, seit 1912 stellvertr. Vorstandsmitglied bei Friedr[ich] Bayer et comp[agnie] in Elberfeld, 1921-1933 (Emeritierung) o. Prof. für Technische Chemie TH Hannover, s. Lehrkörper TH Hannover (1956) S. 33. 1 T: Therese Q. (1867-1952), s. Lexikon jüdischer Einwohner Hs (2011) S. 318
Vw Bruder: Heinrich Irenäus Q. (1842-1922), u. a. o. Prof. für Innere Medizin: seit 1873 U Bern, 1878-1908 (Emeritierung) Kiel, s. NDB 21 (2003) S. 48 f.; Locher, Wolfgang: H.Q. ... Vielfacher Erfinder und Arzt, doch bekannt für ein Ödem in: Der Kassenarzt (2008) Nr. 2, S. 28. Enkel: Prof. Dr. Hermann Q. (19011982) seit 1934 Chefarzt am Dt. Krankenhaus in Istanbul, s. UAH PA 1114, B-3182/17; WBIS, Mussgnug (1988) S. 299 (Register), Lexikon jüdischer Einwohner Hs (2011) S. 338.

$L b$ Studium der Physik, Chemie und Mathematik an U: seit WS 1852/53 Königsberg (Preußen), WS 1854/55-WS $1855 / 56$ H, 18. Okt. 1856-30. Sept 1858 Berlin. • In dieser Zeit:

Berlin: April 1857-März 1858 Militärdienstpflicht als Einjährig-Freiwilliger.

U Berlin: 7. Aug. 1858 Dr. phil.; Juli 1859 Habilitation; 1859-1865 Privat-Dozent. • In dieser Zeit:

Berlin: Seit 1. Okt. 1860 Lehrer für math. Physik, seit 3. März 1869 o. Lehrer (Prof.) an GewerbeAkademie; 1862-1865 auch Lehrer für Chemie und Physik an Bau-Akademie.

\section{U Berlin: Seit 27. Juni 1865 a. o. Prof.}

U Würzburg: Seit 22. Mai 1872 o. Prof.

UH: 9. Jan. 1875 Ern. zum o. Prof., Direktor des Physikal. Inst. und Mit-Direktor (zus. mit Immanuel Fuchs) des Math.-Physikal. Seminars als Nachf. von Gustav Kirchhoff; 1892, 1897 Ruf als Mitglied des Kuratoriums der Physikal.-Technischen Reichsanstalt Berlin abgelehnt; 1. Okt. 1907 Ruhestand.

H: Nach Okt. 1907 Forts. seiner Arbeiten im Privatlabor.

7. April 1885-27. April 1886 Prorektor der UH; Dekan: 1879/8o Phil. Fak., 189o/91, 1897/98, 1904/05 Nat.-Math. Fak. der UH 
1866 Erfinder des nach ihm benannten Quinckeschen Interferenzrohres u. a. zur Messung akustischer Schallwellen

1886 Geh. Hofrat; 1894 Geh. Rat II. Klasse

E Mitglied der Akademie der Wissenschaften: 1866 Göttingen, 1873 München, 1879 Berlin, 1909 H; 1879 ausw. Mitglied der Royal Society London. • Ehrendoktorate: U Würzburg, Oxford, Glasgow, Cambridge; 1914 Dr. phil. h.c. UH. • 1897 Goldene Cothenius-Medaille der Dt. Akademie der Naturforscher Leopoldina Halle/S. • 1885 Ritterkreuz I. Klasse, 1892 Kommandeurkreuz II. Klasse, 1902 Kommandeurkreuz I. Klasse des Ordens vom Zähringer Löwen; 1913 Preußischer Kronenorden II. Klasse mit Stern.

Qu UAH PA 2122; RA 467, 6461, 6898. GLA Abt. 235, Fasz. 2397. Ernst Wilhelm von Brücke. Briefe an Emil Du Bois-Reymond. Hrsg. ... von Hans Brücke ... 1. T. Graz 1978. S. 304 (Register). • Siehe auch Archiv der Dt. Akademie der Naturforscher Leopoldina Halle/S.
$W$ Bildung von Schaumwänden, Beugungsgittern und Perlmutterfarben durch Belichtung von Leimchromat, Kieselsäure, Eiweiß usw. in: Annalen der Physik 13 (1904); Eisbildung und Gletscherkorn in: ebd. 15 (1904). • Erwärmung und Spaltung von Gläsern und Kristallen durch elektrische Longitudinalschwingungen in: Kolloid-Zeitschrift 33 (1923). - Siehe auch Badische Biographie N.F. V (2005) S. $229 \mathrm{f}$.

L Poggendorff VI (1938) S. 2101f. • Über G. Q. in: Rave, Paul Ortwin: Karl Friedrich Schinkel: Lebenswerk. Berlin 1962. T. 3. S. $206 \mathrm{f}$ - WBIS; Arnim 4 (1984) S. 1335; NDB 21 (2003) S. 47 f.; Goerttler 2 (2004) S. 84; Badische Biographie N.F. V (2005) S. 228-230.

$P$ Bildarchiv UAH; graph. Slg. UBH. 


\section{Radbruch, Gustav Lambert}

1903-1914, 1926-1933, 1945-1948 Jur. Fak. Strafrecht, Strafprozeßrecht, Rechtsphilosophie

* 21. Nov. 1878 Lübeck

$\dagger \quad$ 23. Nov. 1949 Heidelberg ev.

V Georg Bernhard Heinrich R. (1841-1922) Kaufmann, s. Aus den Lebenserinnerungen G.B.R.s ... 1857-1861 in: Vaterstädtische Blätter - Zeitung der Vaterstädtischen Vereinigung Lübeck (1922) Nr. 20-23.

M Emma geb. Prahl (1842-1916)

( 28. Sept. 1907 Lina geb. Götz (1887-1970) Scheidung 1913; s. Gesamtausgabe Gustav Radbruch 17 (1991) S. 462 u.ö., Demm (2014) S. 247 (Register)

( 9. Nov. 1915 Lydia geb. Schenk gesch. Aderjahn (1888-1974), s. Hüterin eines großen geistigen Erbes in: Heidelberger Tageblatt vom 15. Jan. 1968

K $\quad 1$ T (1915-1939), $1 \mathrm{~S}\left({ }^{\star} 1918 \times \times 1942\right)$.

Lb Seit SS 1898 Studium an U München, anschl. Leipzig, Berlin; 20. Mai 1901 I. jur. Prüfung am Königl. Kammergericht in Berlin; 4. Sept. 1901-2. Jan. 1904 (auf eigenen Antrag Entlassung) Gerichtsreferendar in Lübeck; 27. Mai 1902 Dr. iur. an U Berlin.

UH: 16. Dez. 1903 Habilitation; 1903-1910 PrivatDozent; seit 7. Febr. 1910 nichtetatm. a. o. Prof. • In dieser Zeit:

Mannheim: Seit 1906 Lehrbeauftragter, WS 1907/ o8-WS 1913/14 nebenamtl. Dozent an Handelshochschule.

U Königsberg (Preußen): 31. März 1914 Ern. zum etatm. a.o. Prof. • In dieser Zeit:

23. Nov. 1915-4. Dez. 1918 Kriegsdienst.
U Kiel: Seit 1. April 1919 etatm. a.o. Prof. für Öffentl. Recht, Rechtsphilosophie, Staatslehre und Verwaltungsrecht an Rechts- und Staatswiss. Fak.; 1919 Ruf an U Köln abgelehnt; 1. Okt. 1919-30. Sept. 1926 o. Prof. für Strafrecht, Strafprozeß, Kriminalpolitik, Rechtsphilosophie, Völkerrecht; 13.-18. März 1920 von Unterstützern des Kapp-Putsches in Schutzhaft genommen. • In dieser Zeit:

Berlin: Seit Juni 1920 Reichstagsabgeordneter (seit 1918 Mitglied der SPD); 26. Okt. 1921-22. Nov. 1922, 13. Aug.-4. Okt. 1923, 6. Okt.-3. Nov. 1923 Reichsminister der Justiz.

UH: 27. Juli 1926 Ern. (mit Wirkung vom 1. Okt.) o. Prof. und Direktor des Jur. Seminars als Nachf. von Alexander Graf zu Dohna-Schlodien; Rufe an U abgelehnt: 1929 Hamburg und Frankfurt/M., 1931 Berlin; 8. Mai mit Wirkung vom 1. Aug. 1933 Entlassung aus politischen Gründen.

6. Juni 1934 Berufung zum o. Prof. für Strafrecht von Sept. 1934 bis Aug. 1935 an U Kaunas (Litauen); 31. Aug. 1934 Absage der Berufung auf Druck des Auswärtigen Amtes; April 1935-Mai 1936 Forschungsaufenthalt in Oxford (Großbritannien); Febr. 1937 Ablehnung e. Lehrauftrags für Rechtsphilosophie an U Zürich auf Druck des Auswärtigen Amtes; 1937-1945 Eigenstudien.

UH: April-Dez. 1945 Mitglied des Dreizehnerausschusses zum Wiederaufbau der U; 7. Sept. 1945 Wiedereinsetzung als o. Prof. unter Berufung in das Beamtenverhältnis auf Lebenszeit mit Wirkung vom 1. April 1945; 8. Jan. 1946 Wiedereröffnung des Lehrbetriebs; 30. Sept. 1948 Emeritierung.

Stuttgart: Anfang 1949 Wahl in Staatsgerichtshof für das Land Württemberg-Baden.

WS 1928/29-SS 1929, 6. Juni 1945-4. Aug. 1946 Dekan der Jur. Fak. der UH

1931-1933 Senator der Kaiser-Wilhelm-Gesellschaft Berlin zur Förderung der Wissenschaften

Mai 1949: Gründungsmitglied des Heidelberger Juristenkreises, s. hierzu Glahé, Philipp: Amnes- 
tielobbyismus in der frühen Bundesrepublik. G. R., Hellmut Becker und ihr Einsatz für NS-Verbrecher im „Heidelberger Juristenkreis“. Magisterarbeit am Histor. Seminar der UH (2017; Ex. im UAH).

E 1947 Mitglied der Akademie der Wissenschaften H; 1949 Korr. Mitglied der Accademia delle Scienze di Bologna; 1949 Ehrenmitglied des Dt. Juristentages Köln. 1948 Dr. phil. h.c. UH und Göttingen.

Qu UAH PA 783, 5385f. - Teil-Nachlaß: UBH; Landesarchiv Schleswig-Holstein in Schleswig; Stadtarchiv Kiel. - Nachlaßverzeichnis G. R. ... Bearb. von Manfred Stange ... Heidelberg 2001. • Reden dt. Gelehrter (1999) S. 8-87. - Der innere Weg. Aufriß meines Lebens. Hrsg. von Lydia Radbruch. Stuttgart 1951. 2. Aufl. 1961. (Autobiogr.)

W Geburtshilfe und Strafrecht. Jena 1907. - Einführung in die Rechtswissenschaft. Leipzig 1910. 13. Aufl. 1980. - Grundzüge der Rechtsphilosophie. Leipzig 1914. 8. Aufl. 1973. - Ihr jungen Juristen! Berlin 1919. Kulturlehre des Sozialismus. Stuttgart 1922. 4. Aufl. 1970. Paul Johann Anselm Feuerbach. Ein Juristenleben. Wien 1934. 3. Aufl. 1969. Elegantiae Juris Criminalis. Sieben Studien zur Geschichte des Strafrechts. Basel 1938. 2. neubearb., erw. Aufl. 1950. Goltsche, Friederike: Der Entwurf eines Allg. Dt. Strafgesetzbuches von 1922 (Entwurf Radbruch). Berlin 2010. - Gesamtausgabe Gustav Radbruch ... 20 Bde. Heidelberg 1987-2003.

$L$ Handels-Hochschule Mannheim 1907-1932 (1932) S. 26; Professoren Kiel (1956) S. 4of.; Badische Biographien N.F. I (1982) S. 223-225. Otte, Holger: G. R.s Kieler Jahre 1919-1926. Frankfurt/M. 1982. Laufs, Adolf: G.R. in: Semper apertus 3 (1985) S. 148-166. • Heidelberger Strafrechtslehrer (1986) S. 195-274; WBIS; Mussgnug (1988) S. 299 (Register); Heiber I (1991) S. 642 (Register); Jansen (1992) S. 412 (Register); Ders. (1992a) S. 168 (Register); BBKL VII (1994) Sp. 1189-1195. • Ott, Ulrich: Biographia mentalis ... in: Der Ort der Bücher .. Hrsg. von Uwe Jochum. Konstanz 1996. S. 28-31 u. ö. NDB 21 (2003) S. 83-86. - Neumann, Ulfrid: Wissenschaftstheorie der Rechtswissenschaft bei Hans Kelsen und G. R. ... in: Hans Kelsen. Staats- rechtslehrer und Rechtstheoretiker des 20. Jahrhunderts. Hrsg. von Stanley L. Paulson ... Tübingen 2005. S. 35-57. Scheuren-Brandes, Christoph M.: Der Weg von nationalsozialistischen Rechtslehren zur Radbruchschen Formel ... Paderborn 2006. UH im Nationalsozialismus (2006) S. 1267 (Register). Wegbereiter der Demokratie. 87 Porträts. Hrsg. von Manfred Asendorf. Stuttgart 2006. Jurists uprooted. German-speaking émigré lawyers in twentieth-century Britain. Ed. by Jack Beatson. Oxford 2007. Klein, Martin: Demokratisches Denken bei G. R. Berlin 2007. Olenhusen, Albrecht Götz von: G. R. - Wissenschaft zwischen Recht und Macht. Freiburg/Br. 2010. - Le Bouëdec, Nathalie: G. R. Juriste de gauche sous la République de Weimar. Québec 2011. • Rechts- und Staatsphilosophie des Relativismus. Pluralismus, Demokratie und Rechtsgeltung bei G. R. Hrsg. von Walter Pauly. Baden-Baden 2011. - Tilitzki 1 (2012) S. 804 (Register). - Dannecker, Gerhard: Die Radbruchsche Formel und ihre Rezeption durch die Rechtsprechung in: Heidelberger Thesen zu Recht und Gerechtigkeit (2013) S. 421-442; Hillenkamp, Thomas: G. R. - Eine Suche nach Alternativen zum Strafrecht in: ebd. S. 401-420. - Intellektuelle in Heidelberg (2014) S. 277-291. • Laage, Clea: Gesetzliches Unrecht. Die Bedeutung des Begriffs für die Aufarbeitung von NS-Verbrechen. Die Rezeption der R.schen Formel in Rechtsprechung und Rechtslehre nach 1945. Frankfurt/M. 2014. • Dahm, Jochen: G.R. - Recht muss Gerechtigkeit erstreben in: Vordenkerinnen und Vordenker der Sozialen Demokratie. 49 Porträts. Bonn 2015. S. 269-275. - Die Natur des Rechts bei G.R. Hrsg. von Martin Borowski und Stanley L. Paulson. Tübingen 2015. • Neumann, Ulfrid: „Methodendualismus" in der Rechtsphilosophie des Neukantianismus. Positionen zum Verhältnis von Sein und Sollen bei G. R. in: Wert und Wahrheit in der Rechtswissenschaft. Im Gedenken an Gerhard Sprenger. Stuttgart 2015. S. 25-40. • Pölzer, Jule Franca: Entlassungen an der Universität Heidelberg im Dritten Reich am Beispiel von G. R. und Artur Rosenthal. Seminararbeit. UH 2015. • Schlaudt, Oliver: Der Relativismusstreit als Streit um die Aufklärung. Eine historische Fallstudie zu aktuellem Gebrauch: G. R. und Hugo Dingler 1934. Berlin 2015. • Böttcher, Hans-Ernst: Der Lübecker Jurist G. R. - aktueller denn je oder: G. R. Rechtsphilosoph, Strafrechtler ... in: Welche Reform 
braucht das Strafverfahren? 39. Strafverteidigertag, Lübeck ... 2015. Berlin 2016. S. 341-371. • Grote, Stefan: G. R. und Gustav Friedrich Hartlaub. Eine Gelehrtenfreundschaft in finsterer Zeit in: Heidelberg. Jahrbuch zur Geschichte der Stadt 2017. Heidelberg 2016. Jg. 21. S. 149-160. - Mattutat, Liza: Die vertrackte Urteilsform. Ein Argument zur Frage der Rechtsgeltung mit und gegen Hans Kelsen, G. R. und Carl Schmitt. Marburg 2016. • Spenkuch (2016) S. 1318 (Register). • Eichenhofer, Eberhard: Juristen und Sozialstaat in der Weimarer Republik in: Soziales Recht. Wiss. Zs. für Arbeits- und Sozialrecht. Frankfurt/M. 2017. S. 2-19. • Glahé, Philipp: Übergesetzliches Recht und gesetzliches Unrecht. Leben und Werk G. R.s in: Eikasia. Revista de filosofia 78 (2017) S. 113-125. Hirte, Chris: Funde in Erich Mühsams Tagebüchern: Erich Mühsam und G. R. in: Rassismus, Antisemitismus, politische Gewalt und Verfolgung. Hrsg.: ErichMühsam-Gesellschaft ... Lübeck 2017. S. 98-136. • Köpcke-Duttler, Arnold: „Triumph der Pädagogik über das Strafrecht?" Die pädagogische Bedeutung der Jugendstrafe (Friedrich Wilhelm Foerster) und die Kritik der Gewalt der Strafordnung (G. R.) in: Zs. für Jugendkriminalrecht und Jugendhilfe. Hannover 2017. S. 236-241. - Küper, Wilfried: G. R. ... Leben und Lehre in Heidelberg in: Ders.: Strafrechtliche Beiträge zu Rechtsgeschichte und Rechtsphilosophie. Hrsg. von Michael Hettinger und Jan Zopfs. Tübingen 2017. S. 168-186. Schroeder (2017) S. 136-140.

$P$ Bildarchiv UAH; graph. Slg. UBH; Badische Biographien.

\section{Ramsauer, Carl Wilhelm}

1909-1921 Nat.-Math. Fak.

Physik, Radiologie

* o6. Febr. 1879 Osternburg (heute: Stadtteil von Oldenburg)

$\dagger$ 24. Dez. 1955 Berlin

口 Paulinenaue (Havelländisches Luch) ev.
V Carl R. (1818-1883) Pfarrer

M Auguste Charlotte Henriette geb. Frerichs (1837-1901)

๑ 9. Sept. 1919 Meta geb. Braun (1893-1946)

๑ 7. Mai 1949 Charlotte geb. Fischer $\left({ }^{\star} 1908\right)$

K 2 S, 1 T, 1 Adoptiv-T

Vw Großvater: Johannes R. (1790-1848) Lehrer, s. Ramsauer, Helene: J. R. und Pestalozzi in: Oldenburger Jahrbuch 83 (1983) S. 49-86.

Lb Seit SS 1897 Studium der Mathematik, Physik an U München, SS 1898 Tübingen, WS 1898/99-SS 1900 Berlin.

Jever (Ostfriesland): Aug. 1900-April 1901 Lehrer am Marien-Gymnasium.

U Kiel: SS 1901-SS 1902 Forts. des Studiums; 31. Jan. 1903 Dr. phil. nat. (Datum der Promotionsurkunde).

Kiel: Seit April 1902 wiss. Hilfsarbeiter, April 1903April 1906 Assistent am Kaiserl. Torpedo-Laboratorium; Mai 1906 Oberlehrerprüfung; 1906-1907 Militärdienstpflicht als Einjährig-Freiwilliger.

UH: Seit Okt. 1907 Assistent am Physikal. Inst.; April 1909-März 1921 wiss. Mitarbeiter am Radiolog. Inst.; 14. Juli 1909 Habilitation (Probevortrag); 30. Okt. 1909 Antrittsvorlesung; seit 6. Dez. 1915 nichtetatm., seit 1920 nichtplanm. a.o. Prof. • In dieser Zeit:

Aug. 1914-Dez. 1918 Kriegsdienst.

TH Danzig: SS 1921-SS 1928 o. Prof. und Direktor des Physikal. Inst.

Berlin-Reinickendorf: 1. Okt. 1928-30. Sept. 1945 Direktor e. neugegründeten Forschungslabors, seit Okt. 1945 freier Mitarbeiter bei der Allg. Elektrizitäts-Gesellschaft (AEG). • In dieser Zeit:

TH, seit 1946 TU Berlin-Charlottenburg: Seit 10. März 1931 Honorar-Prof. für Physik an Fak. I für Allg. Wissenschaften, insbesondere Mathematik, Naturwissenschaften und Wirtschaftswissenschaft; 1. April 1946-30. Sept. 1952 (Emeritierung) o. Prof. für Experimentalphysik und 
Direktor des Physikal. Inst. in Abt. B für Physik der Fak. I für Allg. Ingenieurwissenschaften (seit 1949: Fak. II).

Seit 1937 stellvertr. Mitglied des AEG-Vorstands

1940-1945, 1949-1951 Vorsitzender der Dt. Physikalischen Gesellschaft

1989 stiftet die AEG Aktiengesellschaft den CarlRamsauer-Preis

1919-1921 Entdecker des sog. Ramsauer-Effekts, s. R., C.: Über den Wirkungsquerschnitt der Gasmoleküle gegenüber langsamen Elektronen in: Annalen der Physik (1921) 4. Folge, Bd. 64, Nr. 6, S. 513-540.

E 1937 Korr. Mitglied der Dt. Akademie der Luftfahrtforschung. 1950 Dr. rer. nat. h.c. TH Karlsruhe. 1954 Großes Bundesverdienstkreuz. 1954 Ehrensenator der TU Berlin.

Qu UAH PA 2125. GLA Abt. 235, Fasz. 2398. • Auskunft: Universitätsarchiv TU Berlin (Codex Professorum). Mitteilungen: Frau Prof. Dr. Helene Ramsauer ((1905-2001) 1956-1973 Prof. für Ev. Theologie und Religionspädagogik an $\mathrm{PH}$ Oldenburg (entfernte Vw)). Physik - Technik - Pädagogik. Erfahrungen und Erinnerungen. Karlsruhe 1949 - Über meine wissenschaftliche Tätigkeit in: Fridericiana - Mitteilungen für die Vereinigung ehemaliger Studenten der TH Karlsruhe (1952) Nr. 1-2, S. 65 f. (Autobiogr.)

W Direkte magnetische Methode zur Bestimmung der lichtelektrischen Geschwindigkeits-Verteilung in: Annalen der Physik (1914) 4. Folge, Bd. 45, Nr. 23, S. 1121-1159. - Kritik der Relativitätstheorie. [Vortrag in der 13. Sitzung am 15. Nov. 1922] in: Naturforschende Gesellschaft Danzig. Schriften. N.F. 16. 1922 (1923) H. 1. S. 15. • Wirkungsquerschnitt der Edelgase gegenüber langsamen Elektronen. Hrsg. von Ernst Brüche. Leipzig 1954. (Mitverf.) - Siehe Baden-Württ. Biographien VI (2016).

HG 1956-1957 Physik in Einzelberichten.
MHG Seit 1931 Zeitschrift für technische Physik.

L Kürschner (1940/41) Sp. 419f., (1950) Sp. 1615; Poggendorff 7a (1959) S. 668 f. - Gobrecht, Heinrich: C. R. in: Berlinische Lebensbilder. Berlin 1987. Bd. 1. S. 263-275. - Hoffmann, Dieter: C.R., die Dt. Physikalische Gesellschaft ... in: Rüstungsforschung im Nationalsozialismus. Hrsg. von Helmut Maier. Göttingen 2002. S. 273-304. • Grüttner (2004) S. 135. - Weiss, Burghard: Forschung zwischen Industrie und Militär. C. R. und die Rüstungsforschung am Forschungsinstitut der AEG in: Physik-Journal 12 (2005) S. 53-57. - Physiker zwischen Autonomie und Anpassung. Hrsg. von Dieter Hoffmann und Mark Walter. Weinheim 2007. S. 671 (Register). • WBIS; Baden-Württ. Biographien VI (2016) S. 383-388; Spenkuch (2016) S. 1319 (Register).

$P$ Bildarchiv UAH; Poggendorff.

\section{Ranke, Heinrich Johannes Hermann}

1910-1937, 1946-1950 Phil. Fak.

Ägyptologie

* 05. Aug. 1878 Balgheim (Schwaben; heute: Ortsteil von Möttingen)

$\dagger$ 22. April 1953 Freiburg/Br. ev.-luth.

V Dr. theol. Friedrich Gotthilf Leopold Paul Emil R. (1842-1918), u.a. Hauptpastor und Senior des Geistlichen Ministeriums Lübeck, siehe WBIS, Deutsche Biographie, https:// www.deutsche-biographie.de/pnd116328967. html [22.12. 2017]

M Julia Wilhelmine Auguste geb. von Bever (1850-1924)

$\infty$ 24. Sept. 1906 Marie Elisabeth geb. Stein (18731964) Gesellschaftsmalerin, s. Kriegstagebuch K. Hampe (2007) S. 989 (Register), Lexikon jüdischer Einwohner Hs (2011) S. 339

K 1 T (1908-1927), 2 S: 1. S † 1933 (Suizid), 2. S XX 1941, s. Lexikon jüdischer Einwohner, S. 340 
Vw Großonkel: Leopold (seit 1865 von) R. (17951886), u. a. seit 1825 a.o. Prof. und $1834-1871$ o. Prof. für Geschichte Berlin; 1841 Ern. zum Historiographen des Preußischen Staates, s. WBIS, NDB 32 (2003) S. 140-142; Henz, Günter Johannes: L. von R. in Geschichtsdenken und Forschung ... 2 Bde. Berlin 2014. • Heinrich Friedrich R. (1798-1876) Lehrer und Pfarrer, seit 1840 o. Prof. für Dogmatik Erlangen, 1841-1873 (I.-III.) (Ober-)Konsistorialrat, s. WBIS, BBKL VII (1994) Sp. 1355f.; Muhlack, Ulrich: Die Brüder Leopold und Heinrich R. im Spannungsfeld von evangelischer Erweckung und historischem Denken in: Geschichtsbewusstsein und Zukunftserwartung in Pietismus und Erweckungsbewegung. Hrsg. von Wolfgang Breul ... Göttingen 2013. S. 192220. - Ernst Constantin R. (1814-1888), u.a. 1850-1888 o. Prof. für Kirchengeschichte und Neutestamentliche Exegese Marburg, s. Hitzig, Henriette: E. C. R. Professor der Theologie zu Marburg: Ein Lebensbild. Leipzig 1906; ADB 53 (1907) S. 199-205, WBIS

Vw Onkel: Heinrich (seit 1891 Ritter von) R. (18301909), u.a. seit 1859 Privat-Dozent, seit 1863 Honorar-Prof., seit 1874 a.o. Prof. für Pädiatrie U München, 1866-1886 Leiter der Pädiatrischen Poliklinik im Reisingerianum, 18861905 Direktor der U-Kinderklinik München, s. WBIS, NDB 21 (2003) S. 138-140. Johannes R. (1836-1916) seit 1863 Privat-Dozent, seit 1869 a.o. Prof. und seit 1886 o. Prof. für Anthropologie und Allg. Naturgeschichte U München sowie Vorstand der Anthropologisch-Praehistorischen Sammlungen des Staats in München, s. WBIS, NDB 21 (2003) S. 142-144

Vw Brüder: (siehe) Otto R. • Friedrich R. (18821950), u. a. seit 1921 o. Prof. für Germanistik Königsberg (Preußen), 1930-1937 Breslau, seit 1938 Basel, s. NDB 21 (2003) S. 144*; Brednich, Rolf-Wilhelm: F. R. in: Enzyklopädie des Märchens ... Berlin 2004. Bd. 11. Sp. 203-207; Historisches Lexikon der Schweiz online 10 (2011).

Lb Seit WS 1897/98 Studium der Theologie an U Göttingen, anschl. Greifswald, seit WS 1899/1900 Studium der Orientalischen Sprachen, Ägyptologie an U München; 10. Jan. 1902 Dr. phil. an U München.
Philadelphia: 1902-1905 Harrison Research Fellow an Assyriolog. Abt. des Museums der U of Pennsylvania.

Berlin: Juli 1905-Aug. 1910 Assistent an Ägyptologischer Abt. der Königl. Museen.

UH: 29. Okt. 1910 Habilitation für Ägyptologie; seit 16. Dez. 1910 nichtetatm. a. o. Prof.; seit 1. April 1911 Vertreter der Ägyptologie; seit 22. April 1911 etatm., 1920-1922 planm. a.o. Prof.; 1911 Begründer und Direktor des Ägyptolog. Inst.; Nov. 1912-Mai 1913 Ausgrabungsarbeiten in Amarna (Ägypten; hier Fund der Büste der Nofretete, s. hierzu Schlögl, Hermann A.: Nofretete. Die Wahrheit über die schöne Königin. München 2013. S. 9-11 u. ö.); seit 6. Dez. 1922 o. Prof.; 1924 Ruf an U Bonn abgelehnt; 1929-1930 Forschungsreise nach Ägypten; WS $1932 / 33$, SS 1938 Gast-Prof. an U of Wisconsin in Madison; 27. Juli 1937 zwangsweise Versetzung in den Ruhestand aus politischen Gründen (Verdacht auf Begünstigung e. Fahnenflüchtigen, s. hierzu UAH PA 60o); seit Nov. 1939 keine Auszahlung des Ruhegehalts. • In dieser Zeit:

1914-1918 Kriegsdienst.

Philadelphia: WS 1938/39-WS 1941/42 Visiting Prof. an U of Pennsylvania.

Mai 1942 Rückkehr nach Deutschland als Privatgelehrter mit Wohnsitz in Bollschweil (bei Freiburg/Br.) bis 1945/46.

UH: 1. Juni 1946 Emeritierung mit den Rechten e. aktiven Prof.; SS 1946-Ende 1950 Lehraufträge mit vollem Gehalt und Leiter des Ägyptolog. Inst.; WS $1948 / 49$, SS 1949 Gast-Kurator an U of Pennsylvania in Philadelphia; Jan.-Juni 1951 Gast-Prof. an Faruq-U in Alexandrien (Ägypten); $1951 \mathrm{Ab}-$ lehnung weiterer Lehrtätigkeit an UH aus gesundheitlichen Gründen.

Freiburg/Br.: Seit 1951 Wohnsitz.

April 1947-Juli 1948 Dekan der Phil. Fak. der UH

Die Sammlung des Ägyptologischen Instituts der Universität Heidelberg wird 1910 von R. begonnen und bis heute fortgeführt 
Witwe R.s verkauft die Bibliotheken der RankeBrüder (450o Bde.) an die Universitätsbibliothek Saarbrücken

Siehe auch Anhang Sporteinrichtungen an $U H$ 1910-1933 und ihre Mitglieder

E Korr. Mitglied des Dt. Archäologischen Inst. Berlin; 1913 (1939 Ausschluß, 1946 Restitution) Mitglied der Akademie der Wissenschaften $\mathrm{H}$; 1925 Mitglied der Kommission für das Dt. Inst. für Ägyptische Altertumskunde Kairo.

Qu UAH PA 600, 5400; RA 6437, 6795, 6821. GLA Abt. 235, Fasz. 1566, 2401-2402. - Briefe: UBH; Staatsbibliothek zu Berlin.

W Altägyptische Tierbilder. Leipzig 1925. • Die ägyptischen Personennamen. 2 Bde. Glückstadt 1935-1949. Medizin und Chirurgie im alten Ägypten. Heidelberg 1948. - Meisterwerke der ägyptischen Kunst. Basel 1948. Lizenz-Ausg. 1952.

L Kürschner (1950) Sp. 1617. Schaefer, Hans: Gedenken an H. R. in: Ruperto Carola Jg. 5, Nr. 9/10 (1953) S. 95. - Nachruf in: ZDMG 105 (1955) S. 2126. - Gesamtausgabe Gustav Radbruch 17 (1991) S. 490 (Register); Jansen (1992a) S. 168 (Register); BBKL VII (1994) Sp. 1323 f.; NDB 21 (2003) S. 144 f.; UH im Nationalsozialismus (2006) S. 1267 (Register); Vertriebene Mitgl. der Akad. der Wiss. H (2009) S. 59-64; Lexikon jüdischer Einwohner Hs (2011) S. 339 f. - Vogt, Heribert: Ein Heidelberger Forscher entdeckte Nofretete in: Rhein-NeckarZeitung Nr. 209 vom 9. Sept. 2013. S. 34.

$P$ Bildarchiv UAH; Vertriebene Mitgl. (2009).

\section{Ranke, Ernst August Otto}

1908-1917 Med. Fak.

Psychiatrie

* $\quad$ 01. April 188 o Lübeck

X 04 . Mai 1917

- Aussonce (dt. Soldatenfriedhof in der Region Champagne-Ardenne) ev.-luth.

V Dr. theol. Friedrich Gotthilf Leopold Paul Emil R. (1842-1918), u.a. Hauptpastor und Senior des Geistlichen Ministeriums Lübeck, siehe WBIS, Deutsche Biographie, https:// www.deutsche-biographie.de/pnd116328967.ht $\mathrm{ml}$ [22.12.2017]

M Julia Wilhelmine Auguste geb. von Bever (1850-1924)

$\infty$ 20. Sept. 1905 Charlotte Thekla Else geb. Zittel verw. Schmidt (1872-1935)

K 2 S, 1 Adoptiv- $T$

Vw Vorfahren und Brüder: siehe Hermann R.

Lb Seit WS 1899/1900 Studium an U Göttingen, anschl. München, Kiel, SS 1903 H; 7. Juli 1904 Staatsprüfung; 23. Juli 1904 Dr. med. an UH.

München: Seit Aug. 1904 Hilfsarzt an Psychiatr. Klinik.

Wiesloch (bei Heidelberg): Okt. 1905-Nov. 1906 Hilfsarzt an Heil- und Pflegeanstalt.

UH: Seit Dez. 1906 Assistent an Psychiatr. U-Klinik; 17. Juli 1908 Habilitation; seit 27. Aug. 1914 nichtetatm. a. o. Prof. • In dieser Zeit:

1914-1917 ( Х ) Kriegsdienst im bayer. LandsturmInfanterie-Bataillon Rosenheim.

E 1916 Hanseatenkreuz.

Qu UAH PA 1118 f., 5401f.; RA 5225. - GLA Abt. 235, Fasz. 2399 f.

$W$ Beiträge zur Lehre von der Meningitis tuberculosa. Gotha 1906. • Über Gehirnveränderungen bei der angeborenen Syphilis. Jena 1908. 
$L$ Tiefbewegt teilen wir mit, dass der a.o. Prof. O.R., Bataillonsarzt in einem E.-I.-Regiment am 4. Mai 1917 gefallen ist. Heidelberg 1917. • Stübler (1926) S. 326; WBIS; Gesamtausgabe Gustav Radbruch 17 (1991) S. 490 (Register). - Kreuter, Alma: Deutschsprachige Neurologen und Psychiater. 3. Bd. München 1996. • Peiffer (2004) S. 1177 (Register); UH im Nationalsozialismus (2006) S. 1267 (Register).

\section{Rasch, Gustav}

1920-1933 (Honorar-Prof.) Nat.-Math. Fak.

Angewandte Elektrizität

* o1. Aug. 1863 Mainz

$\dagger \quad$ o9. Febr. 1939 Neckargemünd

kath., nach 1871 altkath.

V Wilhelm Georg R. (1826-1901) Weingutsbesitzer

M Mathilde Katharine geb. Wittekind (1835-1913)

( 16. Juni 1891 Sophie Karoline Elisabeth geb. Macco $\left({ }^{*} 1869\right)$

$\mathrm{K} \quad{ }_{1} \mathrm{~S}, 1 \mathrm{~T}$

Lb Seit WS 1881/82 Studium u.a. der Elektrotechnik an TH Darmstadt, anschl. U Würzburg, TH München; Okt. 1883-Okt. 1884 Militärdienstpflicht als Einjährig-Freiwilliger; 15. Febr. 1888 Dr. phil. an U Würzburg.

Aachen: Seit 1889 Ingenieur bei Dt. Elektrizitätswerken.

Gera: Seit 1891 Betriebs-Leiter der elektrischen Straßenbahn- und Lichtanlage.

TH Karlsruhe: 13. Juni 1893 Habilitation für Elektrotechnik; seit WS 1893/94 Lehraufträge für Elektrische Bahnen, Starkstromanlagen und Elektrische Haushaltsanlagen. - In dieser Zeit:

Karlsruhe: 1894-1899 Städtischer Elektrotechniker, u.a. für Planung zur Elektrifizierung der Pferdebahnstrecke Durlach - Mühlburger Tor zuständig.
TH Aachen: Seit 1. Okt. 1899 Dozent; 1902 Verleihung des Titels „Prof.“; 1. April 1905-1. Okt. 1917 (Ruhestand) II. etatm. o. Prof. für Elektrotechnik.

UH: 16. Okt. 1920 Ern. zum o. Honorar-Prof.; WS 1932/33 letzte Vorlesungsankündigung.

1917 Geh. Reg.-Rat

E 1924 Mitglied der Akademie der Wissenschaften H. 1905 Roter Adler-Orden IV. Klasse. 1926 Ehrenbürger der TH Karlsruhe.

Qu UAH PA 5403. • GLA Abt. 235, Fasz. 2403.

$W$ Über die Berechnung der oberirdischen $\mathrm{Zu}$ leitung, des Stromverbrauchs und der Leitungsverluste elektrischer Bahnen. Karlsruhe 1893. • Stromvertheilung für elektrische Bahnen. Berlin 1898. - Regelung der Motoren elektrischer Bahnen. Berlin 1899. •Über die Verwendbarkeit von Mehrphasensystemen höherer Ordnungszahl zu Fernübertragungen elektrischer Energie in: Annalen der Physik 372, 5-8 (1922) S. 359-373. • Das kreisförmige Drehfeld in: Archiv für Elektrotechnik 21 $(1928 / 29)$.

L Kürschner (1931) Sp. 2313f.; Poggendorff 7a (1959) S. 676; WBIS. • Hoepke, Peter: Zur Entstehungsgeschichte der Elektrotechnik an der Universität Karlsruhe (TH). PDF-Datei von ca. 1995, s. https://www.etit.kit.edu/rd_download/Zur_Entstehungsgeschichte_der_Elektrotechnik(1).pdf (Ausdruck im UAH). • König, Wolfgang: Technikwissenschaften. Die Entstehung der Elektrotechnik aus Industrie und Wissenschaft 1880 und 1914. Bd. 1: Technik interdisziplinär. Chur 1995. S. 385 (Register). - DBE 8 (2007) S. 183f.; Deutsche Biographie, s. https://www.deutsche-biographie.de/gn d1012294897.html [07.11.2017]. 


\section{Rathgen, Karl Friedrich Theodor}

1900-1907 Phil. Fak.

Nationalökonomie, Finanzwissenschaft

* 19. Dez. 1856 Weimar

$\dagger \quad$ o6. Nov. 1921 Hamburg

ev.

V Bernhard R. (1802-1880), u.a. 1849-1850 Schleswig-Holsteinischer Justizminister, seit 1852 Kammergerichtsrat in Berlin, seit 1853 Mitglied des Rats im Ministerium in Weimar, 1859-1879 Präsident der Generalablösungskommission (e. Kommission, eingesetzt für die gesetzliche Ablösung der Verpflichtungen der Bauern gegenüber ihren Grund- und Leibherren) in Weimar, s. WBIS

M Cornelia Margarete geb. Niebuhr (1822-1878)

T von Barthold Georg N. (1776-1831), u. a. seit 1810 Dozent (ohne Studienabschluß) für Geschichte an neugegründeter U Berlin, 18161823 preußischer Gesandter am Apostolischen Stuhl, seit 1825 o. Prof. für Altertumswissenschaften Bonn, s. NDB 19 (1999) S. 219-221; Varvaro, Mario: Der ,Glücksstern' N.s und die Institutionen des Gaius. Deutsch-italienische Wissenschaftspolitik im frühen 19. Jahrhundert. 2. Aufl. Heidelberg 2014.

(23. Mai 1895 Emilie (Emmy) Henriette Frieda Natalie geb. Müller $\left({ }^{\star} 1867\right)$, s. Nachlass Werner von Melle in Staats- und Universitätsbibliothek Hamburg; Im Schaffen geniessen (2006) S. 679 (Register)

K 3 T, s. WBIS

Vw siehe NDB 19, S. $219^{*}$.

Lb Seit WS 1876/77 Studium der Rechtswiss., Nationalökonomie an U Straßburg, anschl. Halle/S., Leipzig, Berlin; 1. März 188o Referendarexamen in Naumburg; 1881 Dr. rer. pol. Straßburg.

Reichs-U Tokio: April 1882-April 1890 o. Prof. für Staatswissenschaften.

1890 Studienreise durch USA.

U Berlin: 21. Jan. 1892 Habilitation für Nationalökonomie.
U Marburg: Seit 27. Sept. 1893 nichtetatm. a.o. Prof.; seit 1. April 1894 etatm. a.o. Prof.; seit 28. März 1895 o. Prof. für Staatswissenschaften.

UH: 17. Mai 1900 Ern. zum o. Prof. mit e. Jahresgehalt von 6500.- Mark zuzüglich 760.- Mark Wohnungsgeld und einmalig 1200.- Mark für Umzugskosten, zunächst als Vertreter des erkrankten Max Weber, seit Okt. 1903 als Nachf. Webers.

Kolonial-Institut Hamburg: Seit WS 1907/o8 o. Prof. für Nationalökonomie am neugegründeten Institut; WS 1913/14 Austausch-Prof. an Columbia-U in New York; 1914 Studienreisen durch Mittelamerika und Westindien.

U Hamburg: 10. Mai 1919-1921 ( $\dagger$ ) o. Prof. und 1919/20 Rektor an neugegründeter U, in der das Kolonial-Institut aufgeht.

1902/o3 Dekan der Phil. Fak. der UH

E 1903 O. Mitglied der Badischen Histor. Kommission. 1890 Offizier des japanischen Verdienstordens; 1900 Preußischer Roter Adler-Orden IV. Klasse; 1903 Ritterkreuz I. Klasse des Ordens vom Zähringer Löwen.

Qu UAH PA 2126; RA 6412, 6679, 6867. • GLA Abt. 235, Fasz. 2404. • Auskunft: Landeskirchliches Archiv der Ev. Kirche von Kurhessen-Waldeck in Kassel (hier: Traubuch der ref. Universitäts- und Garnisongemeinde zu Marburg, S. 117).

W Japans Volkswirtschaft und Staatshaushalt. Leipzig 1891. - Die Auswanderung als wirtschaftliches Problem in: Schmollers Jahrbuch 30 (1906). • Staat und Kultur der Japaner. Bielefeld 1907. • Die Verfassung und Verwaltung Japans in: Allgemeine Verfassungs- und Verwaltungsgeschichte. Leipzig 1911. S. 114-135. • Belgiens auswärtige Politik und der Kongo in: Preußische Jahrbücher 162 (1915). • Siehe Schenck (1997) S. 385 f.

$L$ Catalogus prof. Marburgensis 1 (1927) S. 442; Arnim 2 (1952) S. 383. - Schenck, Paul-Christian: Der deutsche Anteil an der Gestaltung des modernen japanischen Rechts- und Verfassungswesens. Deutsche Rechtsberater im Japan der Meiji- 
Zeit. Stuttgart 1997. S. 39 f., 59-61, 72 f., 234, 258 f., 294-296, 338 f., 385 f., 395. - Matsuo, Nobushige: 50 "Sachsen“ in Japan, 1649-1998 in: Okayama Economic Review Vol. 30, No. 1 (1999) S. 117158. Im Schaffen geniessen: der Briefwechsel der Kulturwissenschaftler Eberhard und Marie Luise Gothein. Hrsg. von Michael Maurer ... Köln 2006. S. 679 (Register). • Kriegstagebuch K. Hampe (2007) S. 989 (Register). • Witte, Barthold C.: K. R. ... Nationalökonom und Gründungsrektor der Universität Hamburg. Reden, gehalten beim Akademischen Festakt zum 150. Geburtstag am 24. Januar 2007 ... Universität Hamburg, Fakultät Wirtschafts- und Sozialwissenschaften. Typoskript. Hamburg 2009. Nozaki, Toshiro: K. R. in seiner Jugendzeit (1856-1876) in: Journal of the Faculty of Sociology. Kyoto, Bukkyo University 51 (Sept. 2010) S. 55-74. 100 Jahre Germanistik in Hamburg (2011) S. 13 f., 17 f., 473. • Takii, Kazuhiro: Das System der Kaiserlichen Universität und K. R. in: The Zinbun Gakuho - Journal of Humanities 84. Kyoto 2011. S. 219-246. Kreis, Hannah, Schefold, Bertram: Die Einführung des Gedankenguts der Deutschen Historischen Schule in Japan. K. R. und Noburu Kanai - eine weitreichende LehrerSchüler-Beziehung und die Gründung des Japanischen Vereins für Sozialpolitik in: Der Einfluss deutschsprachigen wirtschaftswissenschaftlichen Denkens in Japan ... Hrsg. von Heinz D. Kurz. Berlin 2012. S. 29-46. - Hessische Biografie, s. http://www.lagis-hessen.de/pnd/116337427 (Stand: 19. Dez. 2016); Deutsche Biographie, s. https:// www.deutsche-biographie.de/gnd116337427.html [07.11.2017].

$P$ Bildarchiv UAH; graph. Slg. UBH. - Witte, Barthold C.: Ansprache aus Anlaß der Übergabe seines (= Karl Rathgens) Bildes an die Universität Hamburg am 24. Sept. 1987. Typoskript. Hamburg 1987.

\section{Rau, Carl Daniel Heinrich}

1822-1870 Phil. Fak.

Nationalökonomie

* 23. Nov. 1792 Erlangen

$\dagger$ 18. März 1870 Heidelberg ev.-luth.

V Johann Wilhelm R. (1745-1807) 1779-1807 Prof. für Theologie an U Erlangen, s. Meusel Bd. 3, 5. Ausg. (1811) S. 106, Haupt (2005) S. 4 f. u. ö.

M Karoline Henriette Hedwig geb. Hübener (1760-1813)

๑ 7. Okt. 1818 Amalie geb. Fischer (1799-1873)

K 1 T, 3 S: u.a. Ludwig R. (1821-1892) Privat-Dozent: WS 1845/46-SS 1849 für Frauenkrankheiten, Geburtshilfe an Med. Fak. und WS 1852/53-WS 1854/55 für Landwirtschaftl. Betriebslehre und Tierzucht an Phil. Fak. der UH; seit 1855 Prof. für Landwirtschaft an Landund Forstwirtschaftl. Akademie Hohenheim (heute: Stadtteil von Stuttgart), seit 1863 badischer Ministerialrat, 1872-1882 Direktor der Land- und Forstwirtschaftl. Akademie Hohenheim, s. UAH PA 2129; Klein (1968) S. 107, Emundts-Trill (1997) S. $259 \mathrm{f}$.

Vw Schwester: Johanna R. (1786-1856) 1820 Begründerin e. Höheren Töchterschule in Erlangen, s. Willett (2001) S. 264.

Lb U Erlangen: SS 1808-WS 1811/12 Studium der Kameralwiss.; 19. März 1812 Dr. phil.; seit SS 1812 Privat-Dozent für Kameralwiss.; 27. Juli 1816 venia legendi; Dez. 1818-Febr. 1822 Bibliothekar an UB; Rufe an U abgelehnt: 1818 Berlin und Gießen; seit 29. Mai 1818 a. o., seit 20. Dez. 1818 o. Prof.; 1821 Ruf an U Jena abgelehnt. • In dieser Zeit:

Erlangen: 1814-1817 Gymnasiallehrer.

UH: 28. Febr. 1822-18. März 1870 o. Prof.; WS $1822 / 23$ erste Vorlesungsankündigung; Rufe an U abgelehnt: 1826 München, 1828 Göttingen und Halle-Wittenberg, 1842 Berlin und Bonn; 18301832 (als 2. Vertreter der Phil. Fak. neben Christian Bähr) Mitglied der Bibliotheks-Kommission; 24. Nov.-20. Dez. 1855 provisorischer Direktor des Botanischen Gartens zwischen heutigem Bis- 
marck- und Adenauerplatz in Nachf. von Gottlieb Wilhelm Bischoff, s. UAH RA 5631; bis 1863 auch Vorstand der akad. Krankenhauskommission; WS 1869/70 letzte Vorlesung über Ausgewählte Abschnitte der Volkswirtschaftspolitik. - In dieser Zeit:

Karlsruhe: 1833-1840 Mitglied der I. Kammer des Badischen Landtags als Vertreter der UH.

Frankfurt/M.: 31. März-3. April 1848 Mitglied des Vorparlaments.

1831, 1847 Prorektor der UH; 1829, 1835, 1841, 1848, 1862 Dekan der Phil. Fak. der UH

1822 Hofrat; 1832 Geh. Hofrat; 1845 Geh. Rat II. Klasse

E 1862 Mitglied der Dt. Akademie der Naturforscher Leopoldina Halle/S.; Mitglied der Akademie der Wissenschaften: Paris, Brüssel, 1849 Wien. • Dr. iur. h.c.: 1843 Erlangen, 1865 Wien; 1862 Dr. phil. h.c. Tübingen. 1862 Stern zum Kommandeurkreuz des Ordens vom Zähringer Löwen; 1866 St. Anna-Orden II. Klasse. 1862 Ehrenbürger der Stadt Heidelberg.

$\mathrm{Q} u$ UAH PA 2128; RA 5631, 5633, 5815, 5961, 6476, 6867, 7964. - Matrikel Erlangen (1918) S. 382. • GLA Abt. 205, Fasz. 443-444. - Briefe, Kolleghefte: UBH; siehe auch Kalliope. Briefe von Heidelberger Gelehrten an Franz Joseph Mone. Hrsg. von Friedrich von Weech in: ZGORh 57. Jg. (1903) S. 477 f. Nachlaß: UAH (Signatur: Rep. 43; auch auf Mikrofilm, Signatur: MF 6 und MF 18). Siehe auch Archiv der Dt. Akademie der Naturforscher Leopoldina Halle/S. • Mitteilungen von Familienangehörigen. • Die vierzig Tage in Heidelberg. Erinnerungen an den badischen Aufstand im Sommer 1849. Bearb. von Gerd Wippermann u.a. Ubstadt-Weiher 1999. (Tagebuch.)

$W$ Über das Zunftwesen und die Folgen seiner Aufhebung. Leipzig 1816. 3. Aufl. 1820. Lehrbuch der politischen Ökonomie. 3 Bde. Heidelberg 18261837. Bd. 1: 8. Aufl. 1869. Bd. 2: 5. Aufl. 1862. Bd. 3:
6. Aufl. 1871. • Über die Landwirtschaft der Rheinpfalz und insbesondere in der Heidelberger Gegend. Heidelberg 1830.

HG 1835-1852 Archiv der politischen Ökonomie und Polizeiwissenschaft.

$L$ Nachruf in: Almanach der Akademie der Wissenschaften Wien 20 (1870) S. 141-143. - Stieda (1906) S. 145 f. u. ö. Carl Mengers erster Entwurf zu seinem Hauptwerk „Grundsätze“, geschrieben als Anmerkungen zu den „Grundsätzen der Volkswirthschaftslehre" von Karl H. R. Hrsg. und bearb. von Emil Kauder und Helene Kauder. Tokio 1963. • Sinewe, Klaus: K.H.R. Diss. Nürnberg 1965. • Eberl/Marcon (1984). - Haupt, Gabriele: K.H.R. Ein Beitrag zur Sozialgeschichte der Professorenschaft im 19. Jahrhundert. Diss. Heidelberg 2005 (online). Professoren Erlangen (2009) S. $168 \mathrm{f}$. Rosner, Peter: Die Entwicklung ökonomischen Denkens: Ein Lernprozess. Berlin 2012. S. 230-235 u. ö.

P Bildarchiv UAH; graph. Slg. UBH.

\section{Rauchhaupt, Simon Moritz Berthold Friedrich-Wilhelm von}

(1922) 1923-1946 Jur. Fak.

Ausländisches Recht, Vgl. Rechtswissenschaft

* 13. Aug. 1881 Forsthaus Wersk (Kreis Flatow; heute: Złotów, Polen)

$\dagger$ 28. Jan. 1989 Heidelberg

ev.

V Berthold von R. (1848-1911) Förster, s. Kaiserjagd vor hundert Jahren ... (1998) S. 14, $17 \mathrm{f}$. (siehe unter $\mathrm{Qu}$ )

M Susanna geb. Nitzsche (1861-1942)

( 11. März 1911 Ada Catherine geb. Cameron (1877-1944), s. ebd. S. 14, 17 f.

K $1 \mathrm{~S}$

Lb U Berlin: Seit WS 1901/o2 Studium der Rechtswiss., Volkswirtschaft, Philosophie.

UH: 7. Aug. 1906 Dr. iur.; 2. Okt. 1907 Dr. phil. 
1907-1910 Eigenstudien in Frankreich, Spanien, Großbritannien; 1911-1914 Privat-Gelehrter in Berlin; 1914-1915 Zivil-Dolmetscher im Kriegsgefangenenlager in Döberitz in Brandenburg (heute: Dallgow-D.).

Hamburg: 1915-1919 Wiss. Hilfsarbeiter, 1917-1919 auch Referent und Dezernent bei Kommission für Auslandsgesetze im Seminar für Öffentliches und Kolonial-Recht.

Aufenthalte: 1919, 1925 Den Haag (Niederlande), 1920-1924 (mit Unterbrechungen) Madrid und La Laguna (Teneriffa). • In dieser Zeit:

U Madrid: 19. Mai 1921 Licenciado en Derecho.

UH: 14. Juli 1922 Habilitation unter der Voraussetzung, von R. 1. e. „bessere berufliche Stellung in Spanien zu ermöglichen" und 2. von R. hält Vorlesungen nur in den SS an UH, in den WS an U Madrid (dort auch Wohnsitz bis 1924), s. hierzu auch Z; SS 1923, SS 1924, WS 1924/25-8. Jan. 1946 Lehrtätigkeit an UH; SS 1926 (von UH beurlaubt), u. a. Fak.-Mitglied der U von Chile in Santiago de Chile und (bis Nov. 1926) Vortragsreisen in Hispano-Amerika, s. hierzu von R.s Reisebericht in: UAH PA 5410; seit 6. Sept. 1929 nichtbeamteter a. o. Prof.; seit 21. Okt. 1939 apl. Prof.; 8. Jan. 1946 Entlassung gemäß Erlaß der amerik. Militärregierung.

Nach 1946 weiterhin wiss. tätig, hauptsächlich in Nord-, Südamerika, Spanien, Frankreich, Niederlande; seit 1958 Eigenstudien in Mathematik, Physik, Astronomie, Weltraumrecht und mehr.

Seit 1968 Mitglied der Abt. Luftrecht des Inst. für Handels- und Schiffsrecht der Universidad de Buenos Aires.

1934-1945 Vorsitzender des Heidelberger Ev. Diakonissenvereins

$Z$ Juristische Fakultät der UH bittet Engeren Senat in einem Schreiben vom 28. Juni 1922, die vereinbarte Absprache mit von R., nur während des Sommersemesters in $\mathrm{H}$ zu lesen, „nicht als Hindernis zu betrachten; (die Fakultät) ist im Gegenteil der Meinung, daß die Anwesenheit von R.s in Madrid in Anbetracht der nahen Beziehungen zu den dortigen politischen und wissenschaftlichen Kreisen für die gegenseitige Annäherung der beiden Länder und einen etwa daraus resultierenden Austausch geistiger Werte von Bedeutung werden könnte“ (aus: UAH PA 5410).

E Mitglied der Grotius-Stiftung München; 1922 Ehrenmitglied der Real Academia Española Madrid; Mitglied: 1923 Real Academia de Ciencias Morales y Políticas Madrid, Dt. Kommission für Weltraumforschung, 1968 Abt. Luftrecht des Inst. für Handels- und Schiffsrecht der U Buenos Aires. 1976 Dr. iur. h.c. Universidad Complutense de Madrid. 1970 Oberth-Medaille in Gold.

Qu UAH PA 5410f. - Nachlaß: UBH (Signatur: Heid. Hs. 4178). - Eigene Angaben von 1984 sowie Mitteilungen von Familienangehörigen. $\bullet$ Kaiserjagd vor hundert Jahren in: Kindheit im Kaiserreich ... Hrsg. von Rudolf Pörtner. Düsseldorf 1998. S. 13-19. (Autobiogr.)

$W$ Handbuch der deutschen Wahlgesetze und Geschäftsordnungen. München 1916. - Geschichte der spanischen Gesetzesquellen von den Anfängen bis zur Gegenwart. Heidelberg 1923. • Die Rechte Europas in ihrer rechtsgenetischen Gestalt und pragmatischen Auswertung. 2 Bde. München 1931-1932. - Völkerrecht. München 1936. • Über die christlichen Ritterorden, insbesondere den Johanniterorden. Heidelberg 1953. (Masch. geschr.) - Zur Geschichte der Familie von R. insbesondere Quellen, Herkunft, Wappen, Generationenaufbau und Personenbestand. Selbstverlag 1954. A short report on the law of outer space. Masch.geschr. Manuskript. Int. Institute of Space Law of the Int. Astronautical Federation 7 th Colloquium. Warschau 9.-10. Sept. 1964. • Bestandsaufnahme neuerer "principios generales“ im spanischen Recht in: Ibero-amerikanisches Archiv (Berlin) N.F. 3 (1977) 4, S. 365-376. Aufsätze über Weltraumrecht, siehe UBH Heid. Hs. 4178. - Siehe Priewe, Gerd D.: Bibliographie F. W. von R. Als Manuskript gedr. Berlin 1982.

Bearb. Handbuch der deutschen Verfassungen. 2. Aufl. München 1913.

MHG 1966-1969 Zs. „Astronautik“. 
$L$ Arnim 4 (1984) S. 1352; Kürschner (1987) S. 3618; WBIS; Jansen (1992) S. 412 (Register). • Über F. von R. in: „Pressemappe 20. Jahrhundert“ - Personenarchiv der Dt. Zentralbibliothek für Wirtschaftswissenschaften (ZBW). Stolleis (2002) S. 381, 398. - Steck, Peter K.: Zwischen Volk und Staat. Das Völkerrechtssubjekt in der deutschen Völkerrechtslehre (1933-1941). Baden-Baden 2003. S. 7o f. • Schroeder (2010) S. 604-610; Website der Familie, s. www.von-rauchhaupt.de (abgerufen am 17. Sept. 2014).

$P$ Bildarchiv UAH.

\section{Rauschenblatt}

siehe Rauschenplat

\section{Rauschenplat, Ernst Johann Hermann} (auch: Armin, Arminius) von

1848-1849 (1850) Phil. Fak.

Klassische Philologie

* o6. Okt. 1807 Alfeld (Leine) auf Familiengut Sellenstedt

$\dagger \quad$ 21. Dez. 1868 Alfeld

ev.-luth.

V Friedrich von R. (1769-1841) Landrat, Erbund Gerichtsherr, Districts-Commissair in Alfeld, Rittmeister, Besitzer des Guts Sellenstedt ebd., s. Mahrenholtz (1985) S. 21; Straubel, Rolf: Biographisches Handbuch der preußischen Verwaltungs- und Justizbeamten 17401806/15. T. 2. München 2009. S. 774.

M Juliane Sophie Dorothee geb. Berghof(f) (17821872)

@ unverheiratet

Vw Bruder: Dr. iur. August von R. (1811-1878) zuletzt Oberstleutnant, s. Mahrenholtz, S. 22, Lent (1998) S. 152, 162

Vw Hellmuth Frhr. von R. (seit 1947 u.d. N. Fritz Eberhard) (1896-1982) politischer Journalist, s. Mahrenholtz, S. 26, NDB 21 (2002) S. 209 f. • Siehe auch Mahrenholtz, S. 5-27.
Lb 1823-1826 Schüler des Königl. Pädagogiums (Klosterschule) in Ilfeld (Südharz).

Seit 24. April 1826 Studium der Rechtswiss. an U Göttingen, WS 1828/29-WS 1829/30 Berlin; 1829 Mitglied des Corps Hildeso-Guestphalia in Göttingen.

Göttingen: 17. März 1830 Dr. iur. und Privat-Dozent an Jur. Fak. der U; 8. Jan. 1831 H. von R. ist e. der Anführer des Bürgeraufstands gegen die Obrigkeit mit Übernahme des Stadtregiments für wenige Tage, s. hierzu auch Göttingen: Geschichte einer Universitätsstadt (2002) S. 62-67 u. ö.; Mitte Jan. 1831 nach Niederschlagung des Aufstands Flucht nach Straßburg.

Straßburg: Mitte Jan. 1831-April 1847 Wohnsitz mit Unterbrechungen:

27. Mai-1. Juni 1832 Teilnehmer des Hambacher Fests; anschl. Reise durch Süddeutschland als Emissär, „theils, um für die Ausbreitung des Preßvereins $[=$ Deutscher Vaterlandsverein zur Unterstützung der Freien Presse, kurz: Deutscher Preßund Vaterlandsverein] zu wirken, theils um sich nach dem Stande der Revolution in Deutschland zu erkundigen“ (aus: Wagemann (1839) S. 27); außerdem „hatte [H. von R.] im Sommer 1832 die Studenten in Heidelberg und Tübingen besucht und terroristisch-revolutionäre Grundsätze gepredigt“ (aus: ebd. S. 37).

Straßburg: 1832/33 Rückkehr.

Frankfurt/M.: März 1833 H. von R. („aus Straßburg" angereist, s. Wagemann, S. 46) ist e. der Anführer bei Vorbereitung und Durchführung des Frankfurter Wachensturms am 3. April, einem gescheiterten Überfall von ca. 50 Aufständischen auf die Haupt- und Konstablerwache zur Auslösung e. Revolution; erneut Flucht nach Frankreich; hier Ausweisung.

Schweiz: Nach 3. April 1833 Aufenthalt in Liestal (bei Basel). - Unruhen in Diepflingen (bei Basel) wegen Kontroversen in der Bürgerschaft, entweder zum Kanton Basel-Stadt oder zum Kanton Basel-Landschaft zu gehören (1833 führt sog. Basler Kantonstrennung zur gewaltsamen Trennung des 
ehem. Kantons Basel in die beiden o. g. Kantone, s. hierzu Heußler, Abraham: Die Trennung des Kantons Basel. 2 Bde. Zürich 1839-1842); 20. Mai 1833 H. von R. ist Mitinitiator und -verfasser e. Memorials, das Diepflingen zur neutralen und unabhängigen "Republik Diepflingen“ erklärt (am 29. Mai Aufhebung).

Bern: (Vor?) WS 1833/34-SS 1834 Privat-Dozent für Enzyklopädie der Rechtswiss. an Akademie (sein Nachf.: Philipp Jakob Siebenpfeiffer (17891845) Jurist, Journalist, Initiator des Hambacher Festes 1832). - In dieser Zeit:

29. Jan. 1834 Aufbruch von Bern nach Italien, s. $Z$ (1); 2./3. Febr. 1834 Teilnehmer an Giuseppe Mazzinis (1805-1872; italienischer Freiheitskämpfer) gescheitertem Aufstand in Savoyen im damaligen Königreich Sardinien zur Gründung e. nationalen italienischen Republik; bis Anfang Febr. 1834 in "Kriegsgefangenschaft", siehe $Z$ (1); anschl. Rückkehr an Akademie in Bern.

Zürich: Anfang 1835 kurzzeitig Leiter des Handwerkervereins.

Bern: Seit 9. April 1835 Aufenthalt.

Spanien: Frühling 1835 Fußreise von Bern nach Barcelona; Herbst 1835-Mai 1836 Freiwilliger im Ersten Carlistenkrieg (1833-1840) auf Seiten der Liberalen und des Militärs (als Cristinos oder Isabelinos bezeichnet), die e. Trennung von Kirche und Staat sowie e. zentralistischen Staat fordern; anschl. Flucht in die Schweiz.

Mai 1836 Verhaftung in der Schweiz, anschl. Ausweisung.

Straßburg: Okt. 1837 Rückkehr, s. Brief vom 16. Okt. 1838 in: Archives Du Bas Rhin (ADBR) 15 MS 2; hier angeblich Studium der Medizin an $U$ unter falschem Namen, s. ebd.

21. Aug. 1838 H. von R. kehrt heimlich in die Schweiz zurück (aus: Brief des Direktors der Police générale du Royaume vom 21. Aug. 1838 an den Straßburger Präfekten in: ADBR 15 MS 2).
Straßburg: Nach Aug. 1838 (Rückkehr)-April 1847 Aufenthalt als politischer Flüchtling; 1839-1842 Beschäftigung im Stadtarchiv mit mittelalterlicher Kunst und Quellenwerken der deutschen Rechtsgeschichte; H. von R. hofft vergeblich, das franz. Bürgerrecht zu erhalten (bei Besetzung e. Archivstelle wird ihm ein Franzose vorgezogen); in dieser Zeit wohl auch Privat-Lehrer der deutschen Sprache.

Kehl: 17. April 1847 Verhaftung; 24. April 1847 Verfügung über seine sofortige Freilassung; Gründe für Inhaftierung und Freilassung H. von R.s, s. $Z$ (2).

Seit Ende April 1847 Aufenthalt in Freiburg/Br.; 10. Juli 1847 Zurückweisung des zunächst vom Ministerium des Großherzogl. Hauses und der auswärtigen Angelegenheiten genehmigten Auslieferungsantrags H. von R.s wegen Hochverrats zwecks Rückführung in seine Heimat, das Königreich Hannover, durch Großherzogl. Ministerium der Justiz in Karlsruhe, s. hierzu $Z$ (4).

Straßburg: 1847/48 Rückkehr; Febr. 1848 Teilnehmer an Februar-Revolution, s. hierzu $Z$ (3); 22. Juli 1848 Inhaftierung aus Sicherheitsgründen; 27. Juli 1848 Ausweisung.

UH: 26. Mai 1848 Ern. zum a.o. Prof., s. hierzu auch $Z$ (5); 31. Aug. 1848 Verpflichtung H. von R.s mit Eröffnung der „statutenmäßigen Verbindlichkeit, binnen eines halben Jahres a dato entweder eine lateinische Antrittsrede oder ein lateinisch geschriebenes Programm durch den Druck bekannt zu machen" (aus: UAH PA 2132); WS 1848/ 49 Vorlesungsankündigungen über Erklärung der Annalen des Tacitus sowie Über den Einfluß des römischen Rechts im Mittelalter; SS 1849-SS 1850 keine Vorlesungstätigkeit; WS $1850 / 51$ aus dem Verzeichnis der akad. Lehrer gestrichen.

Frankfurt/M.: 1848 Teilnehmer des Vorparlaments, siehe Verhandlungen des Deutschen Parlaments. 1. Lieferung. Offizielle Ausgabe ... Frankfurt/M. 1848. S. 8, hier: Rauschenplat, Wilhelm, Hannover.

1848/49 H. von R., eingesetzt im Polizeidienst, bekämpft republikanische Freischaren in Baden; 1849 - nach Amnestierung - Rückkehr ins Kö- 
nigreich Hannover; hier zunächst Aufenthalt in Hildesheim, anschl. in seiner Geburtsstadt Alfeld („... der Gram über ein vergebliches Leben nagte an seinem Gehirn, er endete im Irrsinn" aus: Freytag, Gustav: Erinnerungen aus meinem Leben. Leipzig 1887. Nachdr. Berlin 2014. S. 117).

$Z$ (1) Brief H. von R.s vom 17. Febr. 1834 an den Berner Erziehungsrat, seine Abwesenheit Jan./ Febr. 1834 von der Akademie erklärend: „Ich verließ Bern am 29. v[origen] M[onats = Jan.] in Folge erhaltener Einladung an einem Zuge nach Italien theil zu nehmen; eine Einladung, die ich um so weniger ablehnen mochte, als mehre[re] meiner Freunde, schon seit längerer Zeit durch gleiche Schicksale mir eng verbunden, mitzogen. Während ich früher aus verschiedenen Gründen muthmaßte, die beabsichtigte Expedition werde erst im Frühling (zur Zeit der akademischen Ferien) stattfinden, erhielt ich jetzt die endliche Aufforderung zum Aufbruch so kurze Zeit vorher, daß mir, noch dazu mit vielen eiligen Anordnungen für meine Landsleute beschäftigt, wenig oder gar keine Zeit und Muße übrig blieb, meine eignen Angelegenheiten ordnungsgemäß zu erledigen. Jedoch hatte Dr. Siebenpfeiffer sich bereit erklärt, falls ich bis zum $3 \mathrm{t}$ [en] $\mathrm{d}$ [ieses] M[onats] noch nicht zurückgekehrt sein sollte, die Fortsetzung meiner Vorlesungen $\mathrm{zu}$ übernehmen, was ich so anschl. dem Herrn Bühler, einem meiner Zuhörer, einige Stunden vor meiner Abreise mit der Bitte um Benachrichtigung meiner übrigen Zuhörer mittheilte. Dabei glaubte ich, es werde sogleich in den ersten Tagen zur Entscheidung kommen, ob man das ganze Unternehmen aufzugeben oder einen längere[n] Feldzug voraus zusehen haben werde; in welchem letztern Fall ich den verehrl[ichen] Erziehungsrath $\mathrm{zu}$ ersuchen gedachte, die Fortsetzung meiner Vorlesungen durch Dr. Siebenpfeiffer zu bestätigen. Daß sich aber der ganze Zug in eine Art von Kriegsgefangenschaft auflösen werde, sah ich eben so wenig voraus, wie das Nichteintreten des Dr. Siebenpfeiffer.

Sollte nun der verehrliche Erziehungsrath die angeführte Erklärung zu einer Rechtfertigung nicht für genügend erachten, so scheint jedoch eher Grund vorhanden zu sein, mir die Eröffnung anderweitiger Vorlesungen $\mathrm{zu}$ versagen als die
Fortsetzung der bereits begonnenen ..." (aus: Universitätsarchiv Bern BB.IIIb.456 fol. 1r-2r).

Z (2) Am 24. April 1847 schreibt Großherzoglich Badisches Hofgericht des Mittel-Rhein-Kreises in Rastatt an Großherzoglich Hochpreisliches Justizministerium in Karlsruhe über die Verhaftung $\mathrm{H}$. von R.s: „... Unter dem 9.ten d[ieses] M[onats] [1847] wurde Dr. Johann Ernst Hermann von Rauschenplat auf den Grund des in den Fahndungsblättern vom Jahr 1834 gegen denselben erlassenen Ausschreibens in Kehl von der Gendarmerie verhaftet.

Nach Schreiben des Praefecten und Maire zu Straßburg vom 14. d. M. [1847] hält sich Dr. von Rauschenplat seit dem Jahr 1831 in Straßburg auf; derselbe hat sich hiernach waehrend dieses Zeitraums untadelhaft aufgeführt, und wird von dem Maire bei der Redaction des unter Autorität der Stadt herauszugebenden Codex diplomaticus von Straßburg beschäftigt.

Bei der Verhaftung fand man bei Dr. von Rauschenplat ausser ganz bedeutungslosen geschichtlichen Notizen zwei Gedichte: „Bei des Storchen Wiederkehr" von Hoffmann von Fallersleben [August Heinrich Hoffmann, bekannt als $\mathrm{H}$. von F. (1798-1874), u.a. auch politischer Flüchtling] und „An die Schleswig Holsteiner“ unterzeichnet „ein Straßburger" und einen gedruckten, eine OctavSeite haltenden Auszug aus dem Sachsenspiegel, Tacitus und Reichsabschieden, das deutsche ständische Wesen betreffend.

Da diese Drucksachen durchaus unverfänglichen Inhalts sind, das Gedicht „An den Storch“ ist nicht politischer Natur, das „An die Schleswig Holsteiner" ohne allen Ausfall auf das Bestehende; die geschichtlichen Auszüge sind meist in altdeutscher und lateinischer Sprache: so erbat sich das Bezirksamt Kork von Großherzoglichem Ministerium des Innern die Materialien, durch welche das Ausschreiben der Verhafteten veranlaßt worden und auf welche eine Untersuchung sich etwa gründen ließe.

Hierauf wurden dem Bezirksamte vom Großherzoglichen Ministerium des Innern, den Dr. von Rauschenplat betreffende Auszüge mitgetheilt, und zwar aus der „Zusammenstellung der Gegenstände aus den in Deutschland geführten Untersuchungen bezüglich des politischen Treibens in der Schweiz, insbesondere der Verbindung „Das 
junge Teutschland“" auf den der Bundes-CentralBehörde bis 14. Januar 1836 zugekommenen Acten, ferner aus dem von Regierungsstatthalter [Jakob Emanuel] Roschi [(1778-1848)] erstatteten „Bericht an den Regierungs-Rath der Republik Bern, betreffend die politischen Umtriebe ab Seite [aufseiten] politischer Flüchtlinge und anderer Fremder in der Schweiz, insbesonderer Rücksicht auf den Canton Bern 1836" sowie auch auf diese Schriften selbst.

Nach der ersten Schrift soll Rauschenplat Mitglied der Carbonari [italienischer Geheimbund für eine einheitliche, unabhängige Republik, 1833 Zerschlagung und Aufgehen in der Volksbewegung "Junges Italien“], dagegen stets ein Gegner des "jungen Teutschlands“" gewesen sein, auch einmal versucht haben, die deutschen Handwerker in Straßburg „politisch zu enthusiasmiren“. In der zweiten Schrift wird Dr. von Rauschenplat ... als vorzüglich kraeftig und muthig geschildert, auch soll derselbe ein Rundschreiben zu einer Generalversammlung der politischen Flüchtlinge in Grenchen [im Kanton Solothurn] untersignirt, auch einen Einfall in Teutschland, insbesondere [in] das Großherzogthum Baden beabsichtigt haben.

Das Bezirksamt Kork verhoerte hierauf den Dr. von Rauschenplat über die in den angeführten Schriften enthaltenen Anzeigen, deren Wahrheit derselbe jedoch schlechthin in Abrede stellte.

In dieser Lage wurde von dem Bezirksamt Kork diese Sache hieher vorgelegt.

Der Gerichtshof verfügte sofort die Entlassung des Dr. von Rauschenplat aus dem Verhaft und erkannte, daß die Untersuchung zu beruhen habe. Die Gründe sind folgende:

Eine alsbaldige Auslieferung wegen früherer Vergehen an Han[n]over erschien nicht als statthaft, weil nach dem Bundesbeschluß vom 14. October 1836 die Auslieferung nur auf Verlangen des betreffenden Staates zu geschehen hat; ein solches Verlangen aber gegenwärtig nicht vorliegt.

Die von dem Großherzoglichen Ministerium des Innern mitgetheilten, sorgfaeltig dahier geprüften Anzeigen, sind aber so unbestimmter Art und so wenig näher motivirt, daß auf den Grund dieser Angaben anderer politischer Flüchtlinge eine Specialuntersuchung nicht eingeleitet werden kann.
Aus diesen Gründen wurde das Beruhen der Untersuchung ausgesprochen und Dr. von Rauschenplat aus dem Verhaft entlassen, wovon wir unter Vorlage der Acten und unter Anschluß einer Abschrift der unterm heutigen an das Amt Kork erlassenenen Verfügung sammt der Beurkundung über die Abstimmung Einem Hochpreislichen Justizministerium ehrerbietige Anzeige erstatten" (aus: GLA Abt. 234 Nr. 1911).

$Z$ (3) Laut Bericht des Straßburger Präfekten an französischen Innenminister erschien $H$. von R. als einer der führenden Männer in der Februarrevolution 1848 in Straßburg, um gegen die republikanischen Aufständischen zu kämpfen. H. von R. „legte die Uniform der französischen Nationalgarde an; dadurch entstand ihm gegenüber eine Ablehnung seitens der Nationalgarde von Straßburg, die das Tragen der Uniform durch einen Ausländer als Zeichen der Zersetzung und Zerstörung empfand“ (aus: Brief des Straßburger Präfekten an den Innenminister Antoine Marie Jules Sénard (1800-1885) vom 24. Juli 1848 in: ADBR 3 M 77). „Am 22. Juli 1848 entstand am Morgen zwischen 7 und 10 Uhr ein Tumult vor dem Haus, in dem R. logierte. Es rotteten sich einige hundert Einwohner der Stadt zusammen, ... beschimpften ihn mit üblen Beleidigungen, tumultartiges Geschrei erhob sich, die öffentliche Ruhe im ganzen Viertel war gestört und selbst der Aufenthalt des politischen Flüchtlings vor Ort konnte eine gewisse Gefahr mit sich bringen. Um ihm gegen jegliche Tätlichkeiten Schutz zu bieten, gab der Präfekt den Befehl, ihn ins Gefängnis zu befördern; R. stimmte dem Aufenthalt gern zu und bat auch am nächsten Tag um Asyl, bis er am 27. Juli 1848 um 3 Uhr morgens in einer Kutsche in Begleitung von Gendarmen zu Pferd und zwei weiteren Gendarmen im Innern der Kutsche aus Straßburg ausgewiesen wurde; R. versicherte dem Präfekten, er habe nicht die Absicht, wieder einen Fuß nach Straßburg zu setzen" (aus: Brief des Straßburger Präfekten an den Innenminister vom 28. Juli 1848 in: ADBR 3 M 77).

Z (4) Alexander Anton von Dusch (1789-1876, Vater von: (siehe) Theodor von Dusch), Minister des Großherzoglichen Hauses und der auswärtigen Angelegenheiten in Karlsruhe, verfügt am 5. Juli 1847 gegenüber Großherzoglichem Minis- 
terium der Justiz: „Gelegentlich der im April d.J. zu Kehl erfolgten Arretirung des Rubricaten [von Rauschenplat] hatte sich die K[öniglich] Hannoverische Gesandtschaft hieher gewendet und um Constatirung der Identität des Individuums mit dem gleichnamigen Theilhaber an den Göttinger Unruhen gebeten. Inzwischen war bei Eingang dieser Note die Freilassung des Arrestanten bereits erfolgt, und wir konnten daher unsere Erwiderung nur dahin abgeben, daß die Gleichheit der Person mit höchster Wahrscheinlichkeit anzunehmen, daß aber von Rauschenplatt [!] hierlands gar nicht wegen seiner Theilnahme an den Göttinger Unruhen, sondern wegen invicirter Complicität an den im Jahr 1834 in der Schweiz vorgefallenen revolutionären Umtrieben zur Fahndung ausgeschrieben sey - daß derselbe übrigens nach vorliegenden glaubwürdigen Zeugnissen inzwischen sich von seinen früheren verbrecherischen Verbindungen ganz losgesagt haben solle, daß eine weitere Fahndung auf denselben nur auf besondere und actenmäßig belegte Requisition des competenten Hannoverischen Gerichts erfolgen werde.

Hiermit ist nun die abschriftlich anliegende Acte des K. Hannoveranischen Gesandten [18421851 Bundestags-Gesandter für Hannover: Frhr. Ernst August von Lenthe (1799-1856)] vom 30. v[origen] $\mathrm{M}$ [onats] an uns gelangt, in Bezug auf welche wir im Allgemeinen die Verpflichtung von $\mathrm{Gr}$ [oßherzoglicher] Regierung anerkennen, den Bundesbeschluß vom 5. Juli $1832 \mathrm{Nr}$. 8, Prot[ocoll der] 24. Sitzung $\$ 231$ gemäß eine Auslieferung eintreten zu lassen" (aus: GLA Abt. 234 Nr. 1911).

Gegen die Verfügung Alexander Anton von Duschs vom 5. Juli 1847, auf Antrag des Bundestags-Gesandten für Hannover, Frhr. Ernst August von Lenthe, die genehmigte Auslieferung von Rauschenplats wegen Hochverrats an Hannover betreffend, wendet sich das Karlsruher Justizministerium: In einem Schreiben vom 10. Juli 1847 erwidert Justizminister Christoph Trefurt (17901861), „daß zur Begründung des Auslieferungsbegehrens die Vorlage eines von dem zuständigen Gerichts ergangenen Fahndungssschreibens erforderlich sei“ (aus: GLA Abt. 234 Nr. 1911).
Z (5) Am 21. April 1848 teilt Carl Rau, Dekan der Heidelberger Phil. Fak., über den Werdegang $\mathrm{H}$. von R.s dem anfragenden Kurator der UH, Joseph Alexander Dahmen (1783-1863) Folgendes mit: „Dr. Rauschenplat hat als Dr. juris in Göttingen vor dem Aufstande, später auch kürzere Zeit an der Berner Akademie mit Beifall juridische Vorlesungen gehalten. Es ist bekannt, daß jugendliche Kühnheit und Freiheitsliebe ihn zur Theilnahme an verschiedenen gewagten Unternehmungen trieben, doch versichern diejenigen, welche ihn näher kennen, daß er in seinem früheren, an Abenteuern reichen Leben stets einen ehrenhaften Charakter bewiesen habe.

In seinem langen Aufenthalte zu Strasburg hat er sich mit wissenschaftlichen Arbeiten, vorzüglich mit der Herausgabe einer Urkundensammlung aus dem dortigen Archive beschäftigt, wovon der 1. Band unter dem Titel Codex diplomaticus der Stadt Strasburg erschienen ist. Zwei Mitglieder der Facultät, die seit längerer Zeit mit ihm bekannt sind, haben sich von seinen gründlichen Kenntnissen in der Geschichte des Mittelalters und in der römischen Literatur überzeugt und halten ihn für vollkommen befähigt, eine akademische Lehrstelle zu bekleiden. Hierauf gestützt, ist die Facultät einer Anstellung des Dr. Rauschenplat als Professor extraordinarius ... nicht entgegen [!].

Sollte jedoch dem Dr. Rauschenplat eine Besoldung zugedacht werden, so müßten wir daran erinnern, daß sein Lehrfach schon mehrfach besetzt ist, und daß die jetzige Universitätsdotation noch nicht zugereicht hat, um unseren Professoren, die durch Schriften und im Lehrfache sich längere Zeit hindurch Verdienste erworben haben, Besoldungen zu ertheilen. Ein Mitglied der Facultät [Anm.: leider nicht namentlich genannt!] stimmt gegen die Anstellung des Dr. Rauschenplat" (aus: UAH PA 2132).

Carl Adolph von Vangerow, Dekan der Heidelberger Jur. Fak., ebenfalls zur Stellungnahme über $\mathrm{H}$. von R.s Qualifikation von Dahmen aufgefordert, schreibt am 4. Mai 1848: „... Dr. Rauschenplat steht in dem Rufe eines scharfsinnigen, klassisch gebildeten Mannes, und als Jurist hat sich derselbe durch eine gut geschriebene Inaugural-Dissertation, die nicht, wie die meisten anderen Schriften dieser Art, ein blos ephemeres Dasein hat, vortheilhaft bekannt gemacht: 
De Rauschenplat, de onere probandi in act[ione] negatoria. Gött[ingen] 1831 [!] (c[on]f[er] Vangerow's [Lehrbuch der] Pandekt[en] Bd. I. S. 708 u. S. 717).

Welchen Studien sich Dr. Rauschenplat nach seinem Weggang von Göttingen in seinem spätern vielbewegten Leben zugewendet hat, weiß ich nicht. Sollten dies die Klassische Literatur der Alterthümer und die Rechtsgeschichte gewesen sein, so zweifle ich nicht, daß er als Lehrer in diesen Fächern erfolgreich wirken wird“ (aus: PA 2132).

Personenbeschreibung H. von R.s, festgehalten in einem Brief eines Agenten des Département du Haute-Rhin, Division. Bureau. Analyse - Police - in Colmar an den Straßburger Präfekten vom 8. Okt. 1838:

„Größe 1,70 m, braune Haare etwas gelockt, hohe Stirn ..., blonde Augenbrauen, hellblaue Augen, mittelgroßer Mund, leicht rundes Gesicht, blasser Teint, eine horizontale Narbe von zwei Zoll auf der Stirn“" (aus: ADBR 15 MS 2).

2012 wurden zwei mannshohe Skulpturen aus Bronze und Stahl am Göttinger Alten Rathaus enthüllt, vom Künstler, dem Hüttlinger Diplom-Bildhauer Andreas Welzenbach, betitelt: Die Göttinger Erhebung. Dargestellt ist auf der linken Seite ein Schemel auf einer Art Hubstange; diesen Sockel habe er bewusst leer gelassen, sagte Welzenbach, er müsse noch besetzt werden; rechterhand ist $\mathrm{H}$. von R. als Schwarzer Ritter in Playmobil-Optik auf einem Schemel zu sehen - freilich „karikaturhaft“ dargestellt, wie der Künstler betonte, s. hierzu weiter Göttinger Tageblatt vom 22. Dez. 2011 und Fuhrmann, Andreas: Frustabbau dank der „Göttinger Erhebung“ in: ebd. vom 20. Juli 2012.

Qu UAH PA 2132. GLA Abt. 205, Fasz. 446, Abt. 234 Nr. 1911. Archives Du Bas Rhin (ADBR) in Straßburg: 15 MS 2, 3 M 77 (Übers. der franz. Quellen: Frau Johanna Vasseur, Heidelberg). - Briefe: Universitätsbibliothek Kassel. - Auskunft: Universitätsarchiv Bern; Ev.-luth. St. Nicolai Kirchengemeinde in Alfeld (Leine).
$W$ De onere probandi in negatoria actione. Göttingen 1830. Briefe über Frankreich und Deutschland. Straßburg 1840. 12 Seiten. Siehe auch NDB 21 (2003) S. 209.

HG Die geheimen Beschlüsse der Wiener Kabinets-Konferenzen vom Jahr 1834. Nebst Anhang: Die geheime preussische Denkschrift vom Jahr 1822. Straßburg 1844.

$L$ Wagemann, Friedrich Moritz von: Darlegung der Haupt-Resultate aus den wegen der revolutionären Complotte der neueren Zeit in Deutschland geführten Untersuchungen. Auf den Zeitabschnitt mit Ende Juli 1838. Frankfurt/M. 1839. • Freytag, Gustav: Erinnerungen aus meinem Leben. Leipzig 1887. Nachdr. Berlin 2014. S. 70, 83, 106, 115-117. - Wiltberger, Otto: Die deutschen politischen Flüchtlinge in Straßburg von 18301849. Berlin 1910. S. 215 (Register). Catalogus prof. Gottingensium (1962) S. 67; WBIS. - Mahrenholtz, Hans: Die Familie R. in Niedersachsen in: Familienkundliche Kommission für Niedersachsen und Bremen ... Forschungsberichte. N.F. Bd. 2. Hannover 1985 S. 21 f. Huber, Ernst Rudolf: Deutsche Verfassungsgeschichte seit 1789 . Bd. II.: Der Kampf um Einheit und Freiheit 1830 bis 1850. 3. Aufl. Stuttgart 1988. S. 88 f., 128 f., 165-167 u. ö. Oberschelp, R.: Politische Geschichte Niedersachsens 1803-1866. Hildesheim 1988. S. 100 ff. Weiß, Egbert: Corpsstudenten in der Paulskirche in: Einst und Jetzt. Jahrbuch des Vereins für corpsstudentische Geschichtsforschung. München 1990. Sonderheft 1990. S. 50. Weiß, Joachim: Revolutionäre und demokratische Bewegungen in Deutschland zwischen 1789 und 1849. Eine Untersuchung $\mathrm{zu}$ Geschichtsdarstellung und Geschichtsbild in deutschen Schulgeschichtsbüchern der Weimarer Republik und der nationalsozialistischen Zeit. Hildesheim 1991. S. 73-75 u. ö. • Lent, Dieter: Ein braunschweigisches Studentenporträtalbum in: Braunschweigisches Jahrbuch für Landesgeschichte 79 (1998) S. 162-166. • Göttingen: Geschichte einer Universitätsstadt. Bd. 2: Vom Dreissigjährigen Krieg bis zum Anschluss an Preussen - Der Wiederaufstieg einer Universitätsstadt (1648-1866). Hrsg. von Ernst Böhme, Rudolf Vierhaus ... Göttingen 2002. S. 1133 (Register). • NDB 21 (2003) S. 208 f. Geschichte Niedersachsens ... 4. Bd.: Vom Beginn des 19. Jahrhunderts 
bis zum Ende des Ersten Weltkriegs. 2 T. Hrsg. von Stefan Brüdermann. Göttingen 2016. S. 108 f. u. ö.

$P$ Skizzenbüchlein aus dem Umfeld des Hambacher Festes mit 25 zeitgenössischen Original-Porträts. Straßburg 1832/1836 (im Besitz der Stiftung Hambacher Schloss in Neustadt/Weinstraße).

\section{Redwitz, Erich Oskar Maximilian Anton Freiherr von}

1919-1922 Med. Fak.

Chirurgie

* $\quad$ 02. April 1883 Bamberg

$\dagger$ 07. Sept. 1964 Seeseiten am Starnberger See (heute: Gemeinde Seeshaupt) kath.

V Maximilian (Max) Heinrich Joseph Frhr. von R. auf Schmölz und Theisenort (1858-1920) Seconde Lieutenant, zuletzt General der Kavallerie und Hofmeister des Prinzen Ludwig Ferdinand von Bayern (1859-1949)

M Rosalie (Rosa) geb. Freiin von Redwitz (18641947)

๑ 16. Sept. 1911 Olga geb. Küttner (1887-1976)

$\mathrm{K}$ keine

Vw Großvater: Oskar Frhr. von R. (1823-1891) Dichter, s. BBKL XXIII (2004) Sp. 1161-1164.

Lb 1902-1903 Militärdienstpflicht als EinjährigFreiwilliger; seit WS 1903/04 Studium an U München, SS 1907 Kiel, seit WS 1907/o8 München.

München: Nov. 1908 Ärztl. Prüfung; Dez. 1908 Dr. med. an $\mathrm{U}$.

Medizinalpraktikant: Seit Jan. 1909 Patholog. Inst. der U München, März-Okt. 1909 Städtisches Krankenhaus in Hamburg-Eppendorf.

U München: Seit Jan. 1910 Volontärarzt am Anatom. Inst.

Wien: Aug. 1910-Sept. 1911 Operationszögling an I. Chirurg. U-Klinik; anschließend 4-monatiges
Volontariat am Allg. Krankenhaus; in dieser Zeit auch Forts. des Studiums an U.

U Würzburg: Seit 1. April 1912 Assistent an Chirurg. U-Klinik; Aug. 1914-Dez. 1918 Kriegsdienst als Sanitätsoffizier; Nov. 1916 Habilitation.

UH: Seit 1. Febr. 1919 Oberarzt an Chirurg. U-Klinik; 21. März 1919 Umhabilitierung; seit 7. Dez. 1921 nichtplanm. a. o. Prof.

U München: Seit WS 1922/23 planm. a. o. Prof. und Direktor der Chirurg. Poliklinik.

U Bonn: 1. April 1928-31. März 1952 (Emeritierung) o. Prof. und Direktor der Chirurg. U-Klinik; 1933 Ruf an UH abgelehnt; WS 1952/53 vertretungsweise mit weiterer Wahrnehmung seines Lehrstuhls und Leitung der U-Klinik beauftragt. • In dieser Zeit:

Bonn: 1928-1952 Leiter des St. Johannes-Hospitals; 1. Jan. 1938 Oberstabsarzt der Reserve und Beratender Chirurg.

1928-1944 Gutachter des gerichtsärztlichen Ausschusses der Rheinprovinz

1950 Präsident der Dt. Gesellschaft für Chirurgie

E 1925 Ehrenmitglied der Interstate Postgraduate Medical Association of North-America; 1957 Ehrenmitglied der Dt. Gesellschaft für Chirurgie. • 1916 König Ludwig-Kreuz; 1944 Kriegsverdienstkreuz I. Klasse. - 1953 Großes Bundesverdienstkreuz.

Qu UAH PA 1124, 5419.

$W$ Die Pathogenese des peptischen Geschwürs des Magens und der oberen Darmabschnitte. Stuttgart 1928. (Mitverf.) - Die chirurgische Behandlung des Magen- und Zwölffingerdarmgeschwürs. Stuttgart 1955.

$H G$ Erste Hilfe. Unterrichtsbuch des Dt. Roten Kreuzes für die Sanitätsausbildung. 10. neu bearb. Aufl. Mainz 1958. 
MHG Lehrbuch der Chirurgie. 2 Bde. 10. Aufl. Jena 1951. 11. Aufl. 1956.

$L$ In memoriam Prof. E. Frhr. von R. Reden, gehalten am 13. Febr. 1965 bei der Gedenkfeier der Med. Fak. der ... Universität Bonn ... Bonn 1966. • Verzeichnis Bonn (1968) S. 237 f.; WBIS. • Forsbach, Ralf: Die Medizinische Fakultät der Universität Bonn im „Dritten Reich“. München 2006. S. 247-263 u. ö. Z Zwischen Diktatur und Neubeginn: Die Universität Bonn im „Dritten Reich“ und in der Nachkriegszeit. Hrsg. von Thomas Becker. Bonn 2008. S. 253-255, 269 f. u. ö. • Deutsche Biographie, s. https://www.deutsche-biographie. de/gnd116389656.html [07.11. 2017].

P Bildarchiv UAH; Verzeichnis Bonn (1968).

\section{Regenbogen, Otto}

1925-1935, 1945-1959 Phil. Fak.

Klassische Philologie

* 14. Febr. 1891 Neumarkt, Niederschlesien (heute: Środa Śląska, Polen)

$\dagger \quad$ 08. Nov. 1966 Heidelberg ev.

V Otto Albrecht Johann Heinrich R. (1855-1925) seit 1878 praktizierender Tierarzt, seit 1880 Assistent an Tierarzneischule Hannover; Kreistierarzt: seit 1889 Neumarkt, seit 1893 Gleiwitz; seit 1895 Departement- und Kreistierarzt in Gumbinnen (heute: Gussew, Russische Föderation); seit 1898 Dozent, $1899-1923$ o. Prof. für Pharmakologie und Toxikologie an Tierärztl. Hochschule Berlin, s. Hinz, W.: O.R. † in: Tierärztliche Rundschau 31. Jg. (1925) Nr. 26, S. 452; O.R. in: Geschichte des Corps Normannia Hannover 1859-1915. Lippstadt 1959. S. 105.

M Caroline geb. Spies

$\infty$ 3. Sept. 1929 Dorothea (Dora) Johanna geb. Schöll (1880-1967), s. Lexikon jüdischer Einwohner Hs (2011) S. 340; T von: (siehe) Fritz S.; Großnichte von: (siehe) Jacob Henle

$\mathrm{K}$ keine.
Lb Seit SS 1909 Studium an U Berlin, SS 1910 Göttingen, seit WS 1910/11 Berlin; 20. Mai 1914 Dr. phil. an U Berlin; 28. und 29. Juni 1915 I. Prüfung für Lehramt an höheren Schulen in Berlin.

Kriegsdienst: Jan. 1915-Febr. 1916 (Entlassung wegen Thrombose) freiwilliger Krankenpfleger, Nov. 1916-April 1917 (erneut Entlassung wegen Krankheit) bei 1. Garde-Fußartillerie-Regiment.

Berlin: Seit Mai 1916 Kandidat des höheren Lehramts, seit April 1918 Hilfslehrer, April 1919-März 1923 Oberlehrer (Studienrat) am Mommsen-Gymnasium.

U Berlin: Sommer 1920 Habilitation; seit 21. März 1923 nichtplanm. a. o. Prof.

UH: 24. Sept. 1924 Ern. zum SS 1925 o. Prof. als Nachf. von Franz Boll; Mit-Direktor (zus. mit Karl Meister): SS 1925-SS 1933 Philolog. Seminar, WS 1933/34-WS 1935/36 Griechisch-Lateinisches Seminar im Weinbrennerbau, Marstallhof 4; Okt. 1924 Ablehnung des ,ihm nach Herrn [siehe Willy] Andreas angebotene[n] Personalreferat[s] im Preußischen Kultusministerium ... in besonders uneigennütziger Weise" (aus: UAH H-IV-102/149 fol. 2or); 1931 Ruf an U Basel abgelehnt; 19. Sept. 1935 Minister des Kultus und Unterrichts leitet gegen R. ein Disziplinarverfahren ein, ,weil er die ihn als Beamten obliegende Pflicht, die sein Beruf erfordert, verletzt hat" (aus: UAH PA 5426): R. gab die Abstammung seiner Ehefrau als „ev. arisch“ an, „obgleich er wusste, dass sie Nichtarierin im Sinne des Gesetzes zur Wiederherstellung des Berufsbeamtentums war und ursprünglich auch der jüdischen Religion angehört hatte" (aus: Auszug e. Briefes des Ministers des Kultus und Unterrichts vom 19. Sept. 1935 in: PA 5426; siehe hierzu auch Z); Mai 1937 R. wird „wegen Dienstvergehens zur Strafe des Verweises und zu e. Geldstrafe von 300 Reichsmark verurteilt" (aus: UAH PA 605; zum Prozeßhergang, siehe PA 5426); 18. Dez. 1933 ministerieller Entschluß zur Versetzung in den $\mathrm{Ru}-$ hestand zum 1. April 1934 aus rassischen Gründen; Sept. 1935 R. wird „vorläufig seines Amtes unter Kürzung seines Diensteinkommens um 20 vom Hundert enthoben" (aus: PA 605 S. 1); 23. Sept. 1937 zum 1. Jan. 1938 endgültige Versetzung in den Ru- 
hestand aufgrund des Gesetzes zur „Wiederherstellung des Berufsbeamtentums".

H: 1938-1945 Privat-Gelehrter und Publizist.

UH: April-Dez. 1945 Mitglied des Dreizehnerausschusses zum Wiederaufbau der U; 7. Sept. 1945 mit Wirkung vom 1. April 1945 Wiedereinsetzung in frühere Rechte e. o. Prof. und Mit-Direktor (bis WS 1948/49 zus. mit Karl Meister), seit SS 1949 Direktor, seit WS 1950/51 Mit-Direktor (zus. mit Viktor Pöschl, s. Drüll (2009) S. 470 f.) des Philolog. Seminars (WS 1933/34-WS 1946/47 umbenannt in Griechisch-Lateinisches Seminar); 1946 Ruf an (Humboldt-)U Berlin abgelehnt; Frühjahr 1953 Gastprof. an U Uppsala; 31. März 1959 Emeritierung.

Juni 1945-Juli 1946, Aug. 1946-März 1947 Dekan der Phil. Fak. der UH

Z Am 27. Juni, wiederholt am 30. Aug. 1935, schreibt Rektor Wilhelm Groh erfolglos an den Minister des Kultus und Unterrichts: „... gestatte ich mir auf den Erlaß vom 18. Juni 1935 ... den von Professor Regenbogen ausgefüllten Fragebogen nebst Anlage vorzulegen. Aus dem Anlagebericht [Regenbogens vom 24. Juni 1935, s. UAH PA 5425] ergibt sich, daß Professor Regenbogen anscheinend nicht die Tatsache der nachträglichen Taufe der Großmutter seiner Frau kannte, daß er aber über deren nichtarische Abstammung unterrichtet war. In dem vom Reichswissenschaftsministerium ausgegebenen Personalbogen hat Prof. Regenbogen bei seiner Ehefrau angegeben: evangelisch, arisch. Ich bitte um Ermächtigung, dies in "nichtarisch" abändern zu dürfen, und gestatte mir anzuregen, eine entsprechende Berichtigung bei dem im Besitz des Reichswissenschaftsministeriums befindlichen Personalbogens $\mathrm{zu}$ erlassen [veranlassen]“ (aus: PA 5425).

E Mitglied: 1929 Akademie der Wissenschaften H (Sekretar 1947-1951), 1946 Dt. Akademie der Wissenschaften zu Berlin, 1953 Königl. Schwedische Akademie der Wissenschaften Stockholm. 1916 Rote Kreuz-Medaille III. Klasse; 1965 Komturkreuz des griechischen Georg I. Ordens; 1966 GroBes Bundesverdienstkreuz.
Qu UAH PA 605, 2924, 5425 ff.; Rep. 40-418. • Auskunft: Erzbischöfliches Dompfarramt in Freiburg/Br. (Totenbücher).

W Was erwarten Schule und Universität auf dem Gebiete des altsprachlichen Unterrichts voneinander? in: Neue Wege zur Antike. Leipzig 1927. Bd. 6. Schmerz und Tod in den Tragödien Senecas in: Vorträge der Bibliothek Warburg 7 (1927/ 28). Leipzig 1930. S. 167-218 [= O.R. Kleine Schriften. München 1961. S. 409-462]. - Theophrastos von Eresos. Stuttgart 1940. Politische Reden des Thukydides. Leipzig 1949. O. R. Kleine Schriften. Hrsg. von Franz Dirlmeier. München 1961.

Übers. Thukydides: Politische Reden. Leipzig 1949.

MHG Orient und Antike.

L Kürschner (1966) S. 1942 f. • Pöschl, Viktor: In memoriam O. R. in: Ruperto Carola 18. Jg., Bd. 40 (1966) S. 197f. • Gundert, Hermann: O.R. in: Heidelberger Jahrbücher 11 (1967) S. 27-39. • Jansen (1992) S. 412 (Register); Ders. (1992a) S. 168 (Register); WBIS. - Pöschl, Viktor: O.R. in: Eikasmos ... Miscellanea di studi in onore di Ernst Vogt ... Bd. IV. Bologna 1993. S. 293f. - Wennemuth (1994) S. 637 (Register). - Remy, Stephen P.: The Heidelberg myth: The nazification and denazification of a German university. Cambridge (Massachusetts) 2002. - Freiburger Phil. Fak. (2006) S. 303-364; UH im Nationalsozialismus (2006) S. 1267 (Register); Lexikon jüdischer Einwohner Hs (2011) S. 340 f.; Deutsche Biographie, s. https:// www.deutsche-biographie.de/gnd118743821.html [07.11. 2017].

$P$ Bildarchiv UAH; Ruperto Carola. 


\section{Reichlin-Meldegg, Karl Alexander Maria Freiherr von}

1832-1877 Phil. Fak.

1832 Religions- und Kirchengeschichte; 1832-1877 Philosophie, Sprachen, Logik, Metaphysik, Geschichte des Mittelalters und der Neuzeit, Enzyklopädie, Psychologie, Ästhetik, Geschichte der Philosophie, Geschichte der deutschen Nationalliteratur, Rhetorik

* 22. Febr. 1801 Grafenau (bei Waidhaus, Oberpfalz)

$\dagger \quad$ 15. Febr. 1877 Heidelberg

kath., seit $1832 \mathrm{ev}$.

V Joseph Alexander Reichs-Frhr. von R.-M. (1771-1812) Auditor (auch Auditeur: Justizbeamter), Anwalt, seit 1807 Justiz-, anschl. Hofgerichtsrat

M Maria Augusta Sidonia geb. Leuthin (17771826)

(1) 31. Mai 1832 Babette geb. Molitor (1805-1874)

$\mathrm{K} \quad 1 \mathrm{~T}$ (früh $\dagger$ ), $3 \mathrm{~S}$ (davon $2 \mathrm{~S}$ früh $\dagger$ ): Kuno Frhr. von R.-M. (1836-1894) SS 1866-SS 1892 (WS 1892/93-SS 1894 aus Krankheitsgründen beurlaubt) Privat-Dozent für Philosophie H, s. UAH PA 2135, RA 5268; R.-M., Karl Alexander Frhr. von: Das Leben eines ehemaligen römisch-katholischen Priesters (1874) S. 146 (siehe unter $Q u$ )

Vw siehe NDB 21 (2003) S. $317 \mathrm{f}$.

Lb U Freiburg/Br.: Seit WS 1815/16 Studium der Philosophie; seit WS 1817/18 Studium der kath. Theologie; 17. Mai 1821 Rigorosum zum Dr. theol. et iur. can.; 3. April 1822 theol. Lizentiatenexamen.

Meersburg am Bodensee: April-Aug. 1822 Kandidat des Bischöflichen Seminars.

7. Febr. 1822 Aufnahme in Weltpriesterstand; 28. Sept. 1822 Erteilung der niederen, 26. März 1823 der höheren Weihen in Rottenburg am Neckar.

Freiburg/Br.: 22. Okt. 1822-1825 Gymnasial-Prof. und Schulseelsorger.
U Freiburg/Br.: 15. Mai 1823 (Datum der Promotionsurkunde) Dr. theol. et iur. can.; seit 12. Aug. 1825 Dozent für Kirchengeschichte an Theol. Fak.; seit 28. Febr. 1828 a. o. Prof. für Theologie und Kirchengeschichte mit e. Gehalt von 8oo.- Gulden; 1830 Ruf an U Gießen abgelehnt; seit 4. Jan. 1830 o. Prof. an Theol. Fak.; auch Praeses des akad. Sittenephorats, e. erzieherischen Einrichtung für Studenten; 2. Aug. 1831 Bitte um Versetzung von Theol. in Phil. Fak. auf erledigte Professur für Histor. Hilfswiss. („seine freisinnige Haltung hatte ihm Tadel und Konflikte mit der erzbischöflichen Kurie eingebracht“, aus: Lehmann (1967) S. 213; so weigerte sich R.-M., auf Anweisung des Freiburger Erzbischofs Bernhard Boll (1756-1836), u.a. seine kirchenkritische Veröffentlichung: Geschichte des Christentums von seinem Ursprung bis zur neuesten Zeit ... (1831) zurückzuziehen; s. hierzu auch sein „Sendschreiben an Seine Gnaden, den Hochwürdigsten Herrn Erzbischof von Freiburg D. Bernhard Boll, in Beziehung auf das bei der römisch-katholischen Priesterweihe zu beschwörende Glaubensbekenntniß. Freiburg/Br. 1832" sowie den Artikel hierüber in: Theologisches Literaturblatt ... (9. Mai 1834) Sp. 433-438); seit 2. Febr. 1832 o. Prof. für Histor. Hilfswiss. an Phil. Fak.; Febr. 1832 Austritt aus kath. Kirche und Aufgabe der Professur (siehe $Z$ ).

Freiburg/Br.: 29. Febr. 1832 Übertritt zum Protestantismus, s. hierzu Eisenlohr, Jacob Friedrich: Akt des Übertritts und der Aufnahme des Dr. K. A. Frhr. von R.-M. ... aus der römisch-katholischen in die evangelisch-protestantische Kirche, nebst seinem Glaubensbekenntniß, abgelegt den 20. [richtig: 29.] Februar 1832 in der evangelischen Stadtpfarrkirche zu Freiburg. Bekannt gemacht von Dekan und Stadtpfarrer Eisenlohr, mit seiner eigenen gehaltenen Rede. Freiburg/Br. 1832.

UH: 12. April 1832 Erlaubnis, über „phil[osophische] Gegenstände und über Sprachen Collegien“ zu halten mit e. "Sustentationsgehalt von 8oo.- Gulden“, das bis Ostern 1833 von U-Kasse Freiburg/Br. auszuzahlen ist (aus: UAH PA 2136; s. auch $Z$ ); 22. Juni 1832 Beginn seiner Vorlesungen; SS 1834 R.-M. hat 38 Hörer in seinen Vorlesungen bei insgesamt 73 Studenten an Phil. Fak.; zwischen 1833 und 1835 erfolglose Anfragen R.-M.s um Auszahlung e. Besoldung; März 1836 Jahresgehalt von 
8oo.- Gulden „aus der durch das Ableben des a.o. Prof. der Philosophie [Heinrich] Schmidt [richtig: Schmid] daselbst erledigten Besoldung" (aus: PA 2136); seit 28. Mai 1839 a. o. Prof. für Philosophie mit e. Jahresgehalt von 8oo.- Gulden; seit 24. März 1840 o. Prof.; Jahresbesoldung: seit Jan. 1847 von 1200.- Gulden, seit Jan. 1862 von 140o.- Gulden, seit Nov. 1870 von 1600.- Gulden, zuletzt 1877 von 3600.- Mark und 660.- Mark Wohnungsgeldzuschuß; WS 1871/72 Beurlaubung, weil R.-M. „nahezu ganz erblindet [ist] und in der nächsten Zeit einer Operation sich zu unterwerfen gedenkt“" (aus: PA 2136); WS 1876/77 letzte Vorlesungsankündigung.

1843, 1851, 1863/64 Dekan der Phil. Fak. der UH

Z Am 27. Febr. 1832 trifft Großherzog Leopold von Baden (1790-1852) nachfolgende Entschließung über das weitere Schicksal R.-M.s nach dessen Austritt aus der katholischen Kirche: „... Der Professor von Reichlin hat durch das übergebene Sendschreiben an den Erzbischof, worin er die wesentlichen Lehren der katholischen Kirche verwirft und sich von solchem lossagt, so anschl. durch die hinzugekommene Erklärung, daß er zur evangelischen Kirche übergehen wolle, sein Staatsdienerverhältniß [an der U Freiburg] freiwillig aufgelöst. In Folge dieser Auflösung hört seine Anstellung als Professor und die Auszahlung der Besoldung an ihn auf.

In Berücksichtigung aller Verhältnisse sind jedoch Seine Königliche Hoheit gnädigst geneigt, demselben eine temporäre Unterstützung von 600 Gulden jährlich aus der Universitätskasse Freiburg zu bewilligen unter der ausdrücklichen Bedingung jedoch, daß er sich unverweilt nach Heidelberg begebe, und sich vor der Hand daselbst ruhig, still und ohne in irgendeiner Hinsicht Ursache $\mathrm{zu} \mathrm{Be}$ schwerden zu geben, aufhalte.

Das Ministerium hat diese Entschließung der Universität sowie dem Freiherrn von Reichlin eröffnen zu lassen, dessen Gehalt zu sistiren, und wenn er die vorgedachte Bedingung zu erfüllen verspricht und erfüllt, die bewilligte Sustentation ihm anzuweisen, auch zu[r] Wiederbesetzung der erledigten Professur [in Freiburg] die geeignete Einleitung $\mathrm{zu}$ treffen und das Resultat se[iner] Z[ei]t vorzulegen“ (aus: PA 2136 fol. 1v). R.-M. hat zunächst die großherzoglichen Auflagen erfüllt, denn er erhält am 12. April 1832 die Erlaubnis, Kollegien an UH abhalten zu dürfen. Doch bereits am 14. Aug. desselben Jahres beschwert sich das Heidelberger kath. Stadtdekanat über Äußerungen R.-M.s in einer „mit besonderer Erlaubniß des hochsprießlichen Curatoriums ... öffentliche[n Vorlesung] „Über das Verhältniß der Philosophie der Neuzeit zu den sogenannten Brod-Wissenschaften“, die er vor einem „sehr gemischten $\mathrm{Pu}$ blikum“ hielt. Es habe „... nicht nur durch eine unwürdige Art der Polemik, wie dieselbe durch ein Beispiel in dem communicirten Berichte belegt worden ist, [bei] den Katholiken der verschiedensten Claßen hiesiger Einwohner starkes Ärgerniß gegeben, sondern auch durch ihren eigenthümlichen in fortlaufenden, nicht selten höchst anstöBigen Witzeleien sich gefallenden, den Ernst und die Würde der Wissenschaft durchaus verletzenden Ton, insonderheit in christlich religiöser Beziehung bei den Anhängern jeder Confession und bei der ganzen akademischen Corporation, wir dürfen sagen, wahrhafte Entrüstung hervorgebracht" (aus: PA 2136). In einer durch Prorektor Friedrich Umbreit vorgenommenen Vernehmung werden R.-M. am 4. Okt. 1832 acht strittige, von ihm öffentlich gemachte Äußerungen, vorgelegt, zu denen er Stellung nehmen kann; seine Antworten sind im Protokoll festgehalten, s. hierzu PA 2136; R.-M., K. A. Frhr. von: Das Leben eines ehemaligen römisch-katholischen Priesters (1874) S. 135-140.

Ministerium des Innern untersagt R.-M. am 12. Okt. 1832 bis auf weiteres die Abhaltung von Vorlesungen über Kirchengeschichte. Daraufhin werden mehrere Studierende vorstellig mit der Bitte, R.-M. zumindest im laufenden Semester zu gestatten, seine kirchengeschichtlichen Vorlesungen fortzusetzen. Am 15. Febr. 1833 folgt das Ministerium dem Vorschlag des Engeren Senats der UH, R.-M. weiterhin die Vorlesungen über Kirchengeschichte zu untersagen. Außerdem ordnet das Ministerium am 17. Dez. 1832 an, R.-M. habe „künftig nur immatriculirte Studenten in seine Vorlesungen zuzulassen und seine Vorträge so einzurichten ..., daß keinerlei Aergerniß mehr entstehen könne, indem auf die erste gegründete Beschwerde weitere Maasregeln genommen würden" (aus: PA 2136).

1874 Hofrat 
E 1827 Mitglied der Historischen Gesellschaft zu Freiburg/Br. 19. Mai 1832 Dr. phil. h. c. Freiburg. • 1873 Ritterkreuz I. Klasse des Ordens vom Zähringer Löwen.

Qu UAH PA 2136; RA 6594, 6859, 7302; Fak.-Akte H-IV-102/132 fol. 293V, 294r, 693r. • GLA Abt. 205, Fasz. 448 f., Abt. 235, Fasz. 240. - Auskunft: Archiv des Bistums Passau. • R.-M., K. A. Frhr. von: Das Leben eines ehemaligen römisch-katholischen Priesters. Heidelberg 1874. (Autobiogr.)

$W$ Die Theologie des Magiers Manes und ihr Ursprung. Frankfurt/M. 1825. - Geschichte des Christentums von seinem Ursprung bis zur neuesten Zeit. Zum Gebrauche bei akademischen Vorlesungen über allgemeine christliche Religions- und Kirchengeschichte. Freiburg/Br. 1831. • Psychologie der Menschen mit Einschluß der Somatologie und der Lehre von den Geisteskrankheiten. 2 Bde. Heidelberg 1837-1838. • Bedenken eines süddeutschen Krebsfeindes über Schellings erste Vorlesung in Berlin (15. Nov. 1841). Stuttgart 1842 (anonym erschienen). • Die deutschen Volksbücher von Johann Faust, dem Schwarzkünstler, und Christoph Wagner, dem Famulus, nach Ursprung, Verbreitung, Inhalt, Bedeutung und Bearbeitung mit steter Beziehung auf Göthe's Faust und einigen kritischen Anhängen. Stuttgart 1848. • Heinrich Eberhard Gottlob Paulus und seine Zeit. 2 Bde. Stuttgart 1853. Nachdr. Gloucester 2014. • Friedrich Kortüm. Leipzig 1858. • Geschichte Europas im Übergange vom Mittelalter zur Neuzeit. 2 Bde. Leipzig 1861. (Mitverf.) - System der Logik nebst Einleitung in die Philosophie. 2 Bde. Wien 1870 .

HG Hautz, Johann Friedrich: Geschichte der Universität Heidelberg. Nach handschriftlichen Quellen nebst den wichtigsten Urkunden von J.F. Hautz. Nach dessen Tode hrsg. von K. A. von R.M. 2 Bde. Mannheim 1862-1864.

$L$ Wider römische Verketzungssucht. Gutachten eines aufrichtigen Kanonisten über die von der kath. Kirchenzeitung des D. Göschl und dem allgemeinen Religions- und Kirchenfreunde des D. Benkert erhobene Anklage gegen ... von R.-M. zu Freiburg. Leipzig 1831. • Geiger, Franz: Bemerkun- gen über das Sendschreiben des ... von R.-M. ... an seine Gnaden den hochwürdigsten Herrn Erzbischof zu Freiburg. Freiburg/Br. 1832. Artikel über Frhr. von R.-M.s „Sendschreiben an Seine Gnaden, den Hochwürdigsten Herrn Erzbischof von Freiburg ..." (1832) in: Theologisches Literaturblatt. Zur allgemeinen Kirchenzeitung. Nr. 55 (9. Mai 1834) Sp. 433-438. - ADB 27 (1888) S. 681f.; Arnim 2 (1952) S. 392; Lehmann (1967) S. 212 f.; WBIS; BBKL VII (1994) Sp. $1506 \mathrm{f}$; EmundtsTrill (1997) S. 363 (Register); NDB 21 (2003) S. 317 f. - Schmich, Tobias: Der Freiburger Kirchenhistoriker K. A. Frhr. von R.-M. Ein Beispiel für Kirchenkritik zur Zeit der Spätaufklärung in: Kirchengeschichte - Frömmigkeitsgeschichte - Landesgeschichte ... Remscheid 2008. S. 265281. Riecke (2016) S. 14, 18, 22.

$P$ Bildarchiv UAH; graph. Slg. UBH.

\section{Reinhard, Georg August Ferdinand}

1804-1822 Staatswirtschaftl. Sektion

1822-1829 Phil. Fak.

Polizei-, Finanzwissenschaft, Handelslehre, Theorie und Praktik der Staatsverwaltung

* 1773 Herzogtum Mecklenburg

$\dagger \quad$ 25. Febr. 1829 Heidelberg ref.

V N.N.

M N.N.

$\infty$ unverheiratet

$\mathrm{K}$ mindestens eine uneheliche T: Ferdinande Auguste Reinhard genannt Lauter, s. UAH RA 5355 .

$L b$ U Jena: 30. April 1792 Immatrikulation e. „Georg[ius] Aug[ustus] Reinhard, Megapolita$\mathrm{n}[\mathrm{us}]^{\text {“. }}$

UH: Seit 15. März 1804 a.o. Prof. (Mai 1803 Einführung der Staatswirtschaftl. Sektion nach Eingliederung der "Staatswirtschafts Hohe Schule" in UH); seit 23. April 1805 o. Prof. mit e. Jahresgehalt von 8oo.- Gulden; 28. Nov. 1812 Dr. phil.; seit 26. April 1822 auf eigenen Antrag von allen Fak.- 
Geschäften befreit; Mai 1822 Zusammenlegung der Staatswirtschaftl. Sektion mit Phil. Fak.; WS 1828/ 29 letzte Vorlesungsankündigung.

1810, 1816, 1821 Direktor der Staatswirtschaftl. Sektion der UH; zur Staatswirtschaftl. Sektion der UH, siehe Heinrich Eschenmayer und Ludwig Wallrad Medicus: Einträge unter $Z$ [itat]

1821 Hofrat

E Korr. Mitglied der Staatswirtschaftl. Gesellschaft zu Erlangen.

Qu UAH PA 2137; RA 5355, 6633, 7168; Fak.-Akten H-IV-102/7 fol. 4 r, 203-209, 212, H-IV-102/ 12 fol. 84 r. - GLA Abt. 205, Fasz. 450. • Ergebnislose Anfrage: Ev--Luth. Stadtkirchengemeinde Gotha. - Auskunft: Ev. Kirchengemeindeamt Heidelberg; Thüringer Universitäts- und Landesbibliothek Jena.

$W$ Versuch eines Grundrisses der Staatswirtschaftslehre. Mannheim 1805.

L Meusel 3. Bd., 5. Ausg. (1811) S. 126. Heidelbergische Jahrbücher der Literatur (1813) 6. Jg., 2. Hälfte, hierin: Intelligenzblatt 1813 , Nr. 1, S. 1. • Wechmar (1846) S. 153; Stieda (1906) S. 139, $142 \mathrm{f}$. u. ö.; Keller (1913) S. 204; Weisert (1991) S. 128 u. ö.

\section{Renaud, Johannes Achilles}

1851-1884 Jur. Fak.

Deutsches Privatrecht, Bürgerliches Prozeßrecht, Code civil (Badisches Landrecht), Kirchenrecht

* 14. Aug. 1819 Wiflisburg (heute: Avenches, Kanton Waadt)

$\dagger \quad$ 05. Juni 1884 Heidelberg ref.

V Karl Albert R., Pfarrer

M Victorine Micheline geb. Hollard
( 17. Mai 1864 Caroline Christiane Henriette geb. Hergenhahn $\left({ }^{*} 1840 \dagger\right.$ nach 1886$) \mathrm{T}$ von August H. (1804-1874) Jurist, Politiker, s. NDB 8 (1969) S. $608 \mathrm{f}$.

K $1 \mathrm{~T}$

Lb Seit 4. April 1838 Studium an U Bern, seit 28. Okt. 1839 H, WS 1840/41 Berlin.

UH: 1. Mai 1841 Immatrikulation; 1841 Promotion zum Dr. iur.

Paris: 1841-1842 Studienaufenthalt.

U Bern: Seit 1842 Privat-Dozent für Franz. Zivilrecht; seit 17. Okt. 1845 a. o. Prof.

U Gießen: Seit 27. Sept. 1848 o. Prof.

UH: Seit 2. Juni 1851 o. Prof. (I. Klasse, d.h. mit Teilnahmeberechtigung an den Fak.-Sitzungen und Doktorexamina) als Nachf. von Eduard Morstadt; 15. Okt. 1851 Dienstantritt; seit 1851 Beisitzer, 1867-1879 (Auflösung) Vorsitzender des Spruchkollegiums der Jur. Fak.; Rufe an U abgelehnt: 1867 Bern, 1873 Straßburg. • In dieser Zeit:

Karlsruhe: 1873-1879 Mitglied der I. Kammer des Badischen Landtags als Vertreter der UH.

1857/58, 1872/73 Prorektor der UH; 1856, Jan.-Sept. 1862, 1866/67, 1871/72, 1879/8o Dekan der Jur. Fak. der UH

1855 Hofrat; 1866 Geh. Hofrat; 1867 Geh. Rat III. Klasse; 1873 Geh. Rat II. Klasse

E 1867 Ritterkreuz I. Klasse, 1873 Kommandeurkreuz II. Klasse des Ordens vom Zähringer Löwen.

Qu UAH PA 2140; Fak.-Akte H-II-111/36. - Toepke 5 (1904) S. 627, 662. - Datenbank der Studierenden 1834-1914 der Universität Bern. Online erschienen unter http://apps.uniarchiv.unibe.ch/ syscomm/images/mata/364_395.gif. - GLA Abt. 205, Fasz. 451. - Briefe deutscher und Schweizer Germanisten an Karl Josef Anton Mittermaier. Hrsg. ... von Lieselotte Jelowik. Frankfurt/M. 2001. S. 488 (Register). Teil-Nachlaß: UBH. 
$W$ Lehrbuch des gemeinen deutschen sowie des in der allg. deutschen Wechsel-Ordnung enthaltenen Wechselrechts. Gießen 1854. 3. Aufl. 1868. • Über das Recht der Actiengesellschaften. Leipzig 1863. 2. Aufl. 1875. - Lehrbuch des gemeinen deutschen Civilprozeßrechts mit Rücksicht auf die neueren Civilprozeßgebungen. Der ordentliche Civilprozeß. Leipzig 1867. 2. Aufl. 1873. Nachdr. Frankfurt/M. 1987. - Das Recht der Stillen Gesellschaften und der Vereinigungen zu einzelnen Handelsgeschäften für gemeinschaftliche Rechnung. Hrsg. von Paul Laband. Heidelberg 1885. • Rechtliche Gutachten von A. R. Hrsg. von Theodor Hergenhahn. 2 Bde. Mannheim 1886.

L Karlowa, Otto: Worte gesprochen am Sarge des Herrn ... A.R. in: Heidelberger Familienblätter Nr. 47 (11. Juni 1884) S. 185-187. • Badische Biographien 4 (1891) S. 342-347; Arnim 2 (1952) S. 399; Jammers (1964) S. 61 u. ö. • Landwehr, Götz: Die Handelsrechtswissenschaft an der Universität Heidelberg im 19. Jahrhundert in: Semper apertus 2 (1985) S. 61-83. - Weisert (1991) S. 128 f. u. ö.; WBIS; Schroeder (2010) S. 210-215 u. ö.

$P$ Bildarchiv UAH; graph. Slg. UBH.

\section{Ribbeck, Johannes Carl Otto}

1872-1877 Phil. Fak.

Klassische Philologie

* 23. Juli 1827 Erfurt

$\dagger \quad$ 18. Juli 1898 Leipzig

ev.

V Ernst Friedrich Gabriel R. (1783-186o) Generalsuperintendent, Schulrat, s. ADB 28 (1889) S. 8o1f.

M Ulricke Juliane geb. Natan ( $\uparrow 1880)$

( 23. Sept. 1854 Emma geb. Baeyer (1831-1902), s. Moritz Lazarus und Heymann Steinthal (1986) S. 812 (Register), siehe unter $Q u$; Franz Overbeck - Erwin Rohde. Briefwechsel. Hrsg. ... von Andreas Patzert ... Berlin 1990. S. 637 (Register), siehe unter $Q u$

$\mathrm{K}$ keine.
Vw Bruder: Woldemar R. (1830-1902) Altphilologe, u.a. 1875-1902 Direktor des Ascanischen Gymnasiums Berlin, s. WBIS; Das Grabmal von W. R. in: Unter jedem Grabstein eine Weltgeschichte ... Hrsg. vom Landesdenkmalamt Berlin. Berlin 2010. S. 99.

Lb Seit SS 1845 Studium an U Berlin, seit SS 1846 Bonn, seit WS 1847/48 Berlin; 25. Mai 1849 Dr. phil. an U Berlin; Nov. 1849 Staatsexamen in Bonn; Mai 1849-März 1850 Aufenthalt im Elternhaus in Berlin.

Probejahr als Lehrer: Seit April 1850 am Gymnasium in Bonn, seit Okt. 1850 am Joachimsthalschen Gymnasium in Berlin.

Berlin: April 1851-Sept. 1852 Hilfslehrer am Joachimsthalschen Gymnasium; Okt. 1852-Sept. 1853 Studienaufenthalt gemeinsam mit befreundetem Schriftsteller Paul Heyse (1830-1914) in Italien; seit Okt. 1853 Hilfslehrer am Joachimsthalschen und am Friedrich-Wilhelmstädtischen Gymnasium sowie Mitglied des Seminars für gelehrte Schulen.

Elberfeld (heute: Stadtteil von Wuppertal): Seit Okt. 1854 II. o. Lehrer am (heutigen Wilhelm-Dörpfeld-)Gymnasium.

U Bern: Seit 26. März 1856 a. o. Prof.; 1859 Ruf an U Gießen abgelehnt; seit April 1859 o. Prof. und Direktor des Philolog. Seminars. • In dieser Zeit:

Bern: 1856-1859 Lehrer für Alte Sprachen am oberen Gymnasium; 1856-1859 Regierungs-Rat des Kantons Bern; 1859-1861 Lehrer der Alten Sprache an Kantonsschule.

Basel: Seit April 1861 Prof. und Mit-Direktor des Philolog. Seminars an U und Lehrer der Griechischen Sprache am Pädagogium; 1862 Ruf an U Marburg abgelehnt.

U Kiel: Seit 20. Okt. 1862 o. Prof. für Klassische Philologie und Beredsamkeit sowie Direktor des Philolog. Seminars.

UH: 21. Juli 1872 Ern. zum o. Prof. als Nachf. von Ludwig Kayser und Mit-Direktor (zus. mit Hermann Köchly) des Philolog. Seminars; 8. Okt. 1872 
Vereidigung; 13. Jan. 1876 jährl. Zulage von 485,71 Mark zu seinem Jahres-Grundgehalt von 6514,29 Mark (= 3800.- Gulden) (aus: UAH PA 2143).

U Leipzig: 5. Jan. 1877 (zum SS 1877) Ern. zum o. Prof. und Mit-Direktor des Königl. Philolog. Seminars.

Okt. 1873-März 1874 Dekan der Phil. Fak. der UH, s. hierzu PA 2143 (1874).

Siehe auch Karl Zangemeister: Eintrag unter $Z[\mathrm{i}-$ tat]

1874 Hofrat; 1876 Geh. Hofrat

E Mitglied der Akademie der Wissenschaften: St. Petersburg, 1877 Leipzig, 1887 München, 1888 Göttingen, 1896 Berlin. 1876 Ritterkreuz I. Klasse des Ordens vom Zähringer Löwen.

Qu UAH PA 2143; RA 5972, 6827. • UA Leipzig PA 843. O. R. Ein Bild seines Lebens aus seinen Briefen 1846-1898. Hrsg. von Emma Ribbeck. Stuttgart 1901. Moritz Lazarus und Heymann Steinthal. Die Begründer der Völkerpsychologie in ihren Briefen ... hrsg. von Ingrid Belke. Tübingen 1986. Bd. II/2. S. 812 (Register). • Franz Overbeck - Erwin Rohde. Briefwechsel. Hrsg. ... von Andreas Patzert ... Berlin 1990. S. 637 (Register). • Auskunft: Archiv und Bibliothek des Ev. Ministeriums zu Erfurt.

$W$ Der echte und der unechte Iuvenal. Eine kritische Untersuchung. Berlin 1865. Anfänge und Entwicklung des Dionysoscultus in Attika. Kiel 1869. Die römische Tragödie im Zeitalter der Republik. Leipzig 1875. Nachdr. Norderstedt 2016. • Friedrich Wilhelm Ritschl. Ein Beitrag zur Geschichte der Philologie. 2 Bde. Leipzig 1879-1881. • Geschichte der römischen Dichtung. 3 Bde. Stuttgart 1887-1892. Bd. 1: 2. Aufl. 1894. Bd. 2: 2. Aufl. 1900. Scaenicae Romanorum poesis fragmenta .. 2 Bde. 3. Ausg. Leipzig 1897-1898. - Reden und Vorträge. Leipzig 1899.

MHG 1876-1898 Rheinisches Museum.
$L$ Wachsmuth, Curt: Worte zum Gedächtnis an O.R. Leipzig 1898. Hausrath, Adolf: Zur Erinnerung an O. R. in: Deutsche Rundschau 28. Jg. (Febr. 1902) H. 5. ADB 53 (1907) S. 329-340; Arnim 2 (1952) S. 407; Professoren Kiel (1956) S. 143; WBIS. - Dilthey, Wilhelm: Zur Geistesgeschichte des 19. Jahrhunderts: Portraits und biographische Skizzen ... 3. Aufl. Hrsg. von Ulrich Herrmann. Göttingen 1991. S. 259-264. • Professorenkatalog Leipzig online.

$P$ Bildarchiv UAH; graph. Slg. UBH. • O. R. Ein Bild seines Lebens aus seinen Briefen (1901) mit 2 Portraits nach Zeichnungen von Paul Heyse.

\section{Rickert, Heinrich John}

1916-1934 Phil. Fak.

Philosophie

* 25. Mai 1863 Danzig (heute: Gdańsk, Polen)

$\dagger \quad$ 25. Juli 1936 Heidelberg

口 Danzig

ev.

V Heinrich Edwin R. (1833-1902) Redakteur, 1866 Mitbegründer der Nationalliberalen Partei, u.a. seit 1874 Reichstags-Abgeordneter, 1880 Mitbegründer der Liberalen Vereinigung („Sezessionisten“), s. Haunfelder, Bernd: Die liberalen Abgeordneten des deutschen Reichstags 1871-1918. Münster 2004. S. 334 f.; WBIS, NDB 21 (2003) S. $549 \mathrm{f}$.

M Annette geb. Stoddart (1839-1889)

$\infty$ 5. Aug. 1888 Sophie geb. Keibel (1864-1951) Bildhauerin; Schwester von Franz K. (18611929) U Freiburg/Br.: seit 1898 Privat-Dozent für Anatomie, seit 1892 a. o. Prof., seit 1900 etatm. a. o. Prof., seit 1912 o. Honorar-Prof.; Ordinarius: 1914-1918 Straßburg, seit Mai 1919 Königsberg, 1922-1929 Berlin und Direktor des Anatomisch-Biolog. Inst. ebd., s. NDB 11 (1977) S. 401 f., WBIS

K 4 S, s. Glockner (1969) S. 276 (Register), Kriegstagebuch K. Hampe (2007) S. 991 (Register)

Vw siehe NDB 21 (2003) S. 550*. 
Lb Vor Herbst 1877 Privat-Unterricht in Danzig, anschl. in Berlin; Herbst 1877-Ostern 1884 Schüler am Gymnasium zum Grauen Kloster in Berlin (Abgang ohne Reifezeugnis); SS 1884-WS 1884/85 Hörer an Phil. Fak. der U Berlin; 1885 Ablegung der Reifeprüfung.

Studium der Philosophie, Nationalökonomie, Physiologie: SS 1885 U Straßburg, WS 1885/86 Bern, SS 1886 Zürich, seit WS 1886/87 Straßburg; Sommer 1888 Dr. phil. an U Straßburg (Doktorvater: (siehe) Wilhelm Windelband).

Herbst 1888 Rückkehr nach Berlin; Dez. 1889 Übersiedlung nach Freiburg/Br. aus gesundheitlichen Gründen.

U Freiburg/Br.: Juli 1891 Habilitation; WS 1891/ 92 Beginn seiner Vorlesungen; seit 16. Nov. 1894 a. o. Prof.; 1896 Ruf an U Rostock abgelehnt; seit 13. Sept. 1896 o. Prof.; seit 1903 Direktor des Psycholog. Laboratoriums.

UH: 30. Dez. 1915 Ern. zum o. Prof. als Nachf. von Wilhelm Windelband; 1. April 1916 Dienstantritt; 1916-1932 Direktor - neben Karl Jaspers und seit 1922 Ernst Hoffmann - des Phil. Seminars; Nov. 1917 Ruf an U Wien abgelehnt; 1. April 1932 Emeritierung; SS 1932-WS 1933/34 Vertreter seines Lehrstuhls.

H: 1927-1933 Mitglied der Cusanus-Kommission der Akademie der Wissenschaften.

2000 Gründung der „Heinrich Rickert-Forschungsstelle " an der Universität Düsseldorf durch Prof. Rainer A. Bast; Ziel der Forschung ist die Herausgabe "Sämtliche Werke“ Rickerts, s. hierzu http://www.phil-fak.uni-duesseldorf.de/philo/ri ckert/ (abgerufen am 17. Febr. 2016).

1910 Geh. Hofrat

E Mitglied der Akademie der Wissenschaften: 1909 H, 1917 München, 1934 Berlin; Okt. 1931 Mitglied der Accademia Nazionale dei Lincei in Rom. 1924 Dr. iur. h.c. Königsberg; 1928 Dr. h.c. der Kulturwissenschaften TH Dresden; 1933 D. theol. UH. 1933 Goethe-Medaille für Kunst und
Wissenschaft. 1906 Ritterkreuz I. Klasse des Ordens vom Zähringer Löwen; 1918 Ritterkreuz des Ordens Berthold I.

Qu UAH PA 3346; RA 6859. GLA Abt. 235, Fasz. 2414. Matrikel Zürich (1999) Nr. 7562. Aus dem Leben eines Satyrs. Otto Erich Hartleben: Briefe und Postkarten an H.R. Hrsg. von Wolfgang Rasch. Bargfeld 1997. - Nachlaß: UBH. • Mitteilungen: Herr Prof. Dr. Rainer A. Bast, Universität Düsseldorf.

$W$ Zur Lehre von der Definition. Freiburg/Br. 1888. 3. Aufl. 1929. - Der Gegenstand der Erkenntnis. Freiburg/Br. 1892. 6. Aufl. 1928. • Die Grenzen der naturwissenschaftlichen Begriffsbildung. Eine logische Einleitung in die historischen Wissenschaften. Tübingen 1896 und 1902. 5. Aufl. 1929. Nachdr. Hildesheim 2007. - Fichtes Atheismusstreit und die Kantische Philosophie. Eine Säkularbetrachtung. Berlin 1899. Kulturwissenschaft und Naturwissenschaft. Freiburg/Br. 1899. 7. Aufl. 1926. Das Eine, die Einheit und die Eins. Tübingen 1924. Grundprobleme der Philosophie: Methodologie, Ontologie, Anthropologie. Tübingen 1934. Reprint Saarbrücken 2006. - Philosophische Aufsätze. Hrsg. von Rainer A. Bast. Tübingen 1999. - Die Grenzen der naturwissenschaftlichen Begriffsbildung. Eine logische Einleitung in die historischen Wissenschaften. Hrsg. von Rainer A. Bast. Hildesheim 2007.

MG, MHG Seit 1924 Heidelberger Abhandlungen zur Philosophie und ihrer Geschichte, s. hierzu Knappenberger-Jans, Silke: Verlagspolitik und Wissenschaft. Der Verlag J.C.B. Mohr (Paul Siebeck) im frühen 20. Jahrhundert. Wiesbaden 2001. S. 230 f. u. ö.

L Arnim 2 (1952) S. 411; Glockner (1969) S. 276 (Register). Wiehl, Reiner: Heidelberger Philosophie zwischen Kantianismus und Hegelianismus in: Semper apertus 2 (1985) S. 409-431. J Jansen (1992) S. 412 (Register); Ders. (1992a) S. 168 (Register); BBKL VIII (1994) Sp. 256-260; WBIS. • Über H.R. in: Heinrich Rickert: Philosophische Aufsätze. Hrsg. von Rainer A. Bast. Tübingen 1999. S. 437 f. NDB 21 (2003) S. 550-552; Kriegstagebuch K. Hampe (2007) S. 990 f. (Register); Schönhärl (2009) S. 459 (Register). Dewalque, Arnaud: 
Être et jugement. La fondation de l'ontologie chez H. R. Hildesheim 2010. Massimilla, Edoardo: Max Weber zwischen H.R. und Johannes von Kries. Drei Studien. Aus dem Italienischen übers. von Charlotte Voermanek. Köln 2012. Morrone, Giovanni: Valore e realtà. Studi intorno alla logica della storia di Windelband, R. e Lask. Soveria Mannelli 2013. - Intellektuelle in Heidelberg (2014) S. 427 (Register); Kaesler (2014) S. 1002 (Register); Troeltsch-Gesamtausgabe 19 (2014) S. 506 (Register). Methodologie, Erkenntnistheorie, Wertphilosophie. H.R. und seine Zeit. Hrsg. von Anna Donise ... Würzburg 2016. - Fahrenberg, Jochen: Geschichte des Instituts für Psychologie in Freiburg von der Vorgeschichte der Psychologie bis ca. 2000, s. PsyDok http://hdl.handle.net/ 20.500.11780/3775 (Stand: Aug. 2017).

$P$ Bildarchiv UAH; NDB.

\section{Riehm, Eduard Carl August}

1858-1862 Theol. Fak.

Altes Testament

* 20. Dez. 1830 Diersburg (heute: Ortsteil von Hohberg, bei Offenburg)

$\dagger \quad$ 05. April 1888 Giebichenstein (heute: Stadtteil von Halle/S.)

- Stadtgottesacker in Halle/S. ev.

V Isaak Heinrich R. (1799-1861) Pfarrer, zuletzt Dekan, s. Isaak Riehm (1799-1881) und seine Frau Charlotte geb. Rinck ... mit ihren rund 700 Nachkommen sowie Isaaks selbstgeschriebene Lebenserinnerung. Ein Familienbuch. Hrsg. ... von Joachim Breitner. Mannheim 2011 (Privatdruck).

M Charlotte geb. Rin(c)k (1803-1884)

$\infty$ 19. April 1855 Elise Auguste geb. Löschcke (1833-1866)

๑ 31. März 1869 Anna Maria Ottilie geb. Braune (1850-1936)

K 7 (aus 1. Ehe), 6 (aus 2. Ehe) davon 5 früh $\dagger$, s. auch DBE 8 (2007) S. $403 \mathrm{f}$.
Lb Seit WS 1848/49 Studium der Theologie, auch Philologie an UH, seit SS 1850 Studium der Theologie an U Halle-Wittenberg.

UH: Seit Ostern 1852 Mitglied des Ev.-Prot. Predigerseminars; 1. Juli 1853 theol. Staatsexamen; 17. Dez. 1853 Lizentiatenprüfung.

Karlsruhe: Seit 15. Nov. 1853 Stadtvikar in Durlach; 10. Jan. 1854 Ordination.

Mannheim: 20. Aug. 1854-27. März 1858 (Entlassung auf eigenen Antrag) Militärprediger und -seelsorger.

UH: 14. Juni 1858 Habilitation; seit 3. Juni 1861 a. o. Prof.; Mai 1862 Ruf an U Greifswald abgelehnt.

U Halle-Wittenberg: 11. Aug. 1862 Ern. zum a.o. Prof.; seit WS $1866 / 67$ o. Prof. als Nachf. von Hermann Hupfeld, Großvater von: (siehe) Renatus Hupfeld; Rufe u. a. an U abgelehnt: Dez. 1862 Kiel, 1876 Leipzig, 1879 Tübingen; auch Ablehnung des Amts als Generalsuperintendent von Westpreußen.

Seit 1878 Mitglied, seit 1885 Vorstand der Sächsischen Provinzial- und der Generalsynode

E 1864 D. theol. Halle-Wittenberg.

Qu UAH PA 2147; RA 6127. GLA Abt. 205, Fasz. 452. Nachschrift e. R.schen Vorlesung zum Alten Testament vom WS $1884 / 85$, s. Katalog der Handschriften der Universitäts-Bibliothek Leipzig. N.F. Bd. 1 ... T. 3 beschrieben von Detlef Döring. Wiesbaden 2003. S. 156. Albrecht Ritschl, Wilhelm Herrmann: Briefwechsel 1875-1889. Hrsg. von Christophe Chalamet ... Tübingen 2013. S. $515 \mathrm{f}$. (Register). Teil-Nachlaß im Nachlaß von Karl Bernhard Hundeshagen in Universitäts- und Landesbibliothek Sachsen-Anhalt in Halle/S. A Auskunft: Rat der Stadt Halle/S.

W Die Gesetzgebung Mosis im Lande Moah. Gotha 1854. - Der Lehrbegriff des Hebräerbriefes. 2 Bde. Basel 1858-1859. 2. Aufl. 1867. Die messianischen Weissagungen, ihre Entstehung, ihr zeitgeschichtlicher Charakter und ihr Verhältnis zur 
neutestamentlichen Erfüllung. Gotha 1875. 2. Aufl. 1885. (Engl. Übers. Edinburgh 1876.) • Der biblische Schöpfungsbericht. Halle/S. 1881.

HG Handwörterbuch des biblischen Altertums. 2 Bde. Bielefeld 1884. 2. Aufl. 1893-1894.

MHG 1865-1888 Theologische Studien und Kritiken.

$L$ ADB 30 (1890) S. 72-74; Badische Biographien 4 (1891) S. 353-355. Erinnerungen an unsern Vater, den ordentlichen Professor der Theologie E. R., zus.gestellt von Hermann Riehm. Halle/S. 1905. • Realencyclopädie für prot. Theologie 16 (1905) S. 776-783; WBIS. - Stephan, Christian: Die stumme Fakultät. Biographische Beiträge zur Geschichte der Theologischen Fakultät der Universität Halle. Dössel 2005. S. 63-66. - DBE 8 (2007) S. 403; Catalogus prof. Halensis online; BBKL (2018 in Vorbereitung).

\section{Riese, Friedrich Alexander}

1864-1868 (1869) Phil. Fak.

Klassische Philologie

* o2. Juni 1840 Frankfurt/M.

$\dagger$ 08. Okt. 1922 Frankfurt/M. ev.

V Johannes R., Kaufmann, Bankdirektor

M Dorothea geb. Weise

๑ vor 1870 Anna Hulda geb. Kampf (1843-1922)

$\mathrm{K} \quad 1 \mathrm{~S}, 2 \mathrm{~T}$

Lb Seit SS 1859 Studium anfangs der Theologie, dann der Philologie an U Erlangen, seit 1861 Bonn.

U Bonn: 5. Aug. 1862 Dr. phil.

Berlin: 7. März 1863 Staatsexamen für das höhere Schulamt; 1863-1864 Referendar am Friedrichswerderschen-Gymnasium.

UH: 21. Okt. 1864 Habilitation; seit 6. April 1868 a. o. Prof.; WS 1868/69, SS 1869 Beurlaubung.
Frankfurt/M.: Seit 1. April 1869 zunächst stellvertr. Lehrer, dann o. Lehrer, 1879-1. Okt. 1901 (Ruhestand) Oberlehrer am Städtischen Gymnasium.

1887-1893 I. Vorsitzender des Vereins für Geschichte und Altertumskunde

E 1911 Mitglied des Kaiserl. Dt. Archäologischen Instituts.

Qu UAH PA 2148; Fak.-Akte H-IV-102/69 fol. 8r14r u. o.. Briefe im Nachlaß Karl Praechters im Universitätsarchiv Halle/S. • Hermann Diels, Hermann Usener, Eduard Zeller: Briefwechsel. Hrsg. von Dietrich Ehlers. Berlin 1992. S. 534 (Register). Auskunft: Stadtarchiv Frankfurt/M.

W Die Idealisierung der Naturvölker des Nordens in der griechischen und römischen Literatur. Heidelberg 1875. • Das Rheinische Germanien in der antiken Litteratur. Leipzig 1892. Nachdr. Groningen 1969. Siehe auch Cahn (1925) S. 2-5.

HG Anthologia Latina sive Poesis Latinae supplementum. 2 Bde. Leipzig 1869-1870. Geographi Latini minores. Heilbronn 1878. Nachdr. Hildesheim 1964. - Die Gedichte des Catullus. Leipzig 1884. - Das rheinische Germanien in den antiken Inschriften. Leipzig 1892. 2. Aufl. 1913. Nachdr. 1969. - Publius Ovidius Naso: Carmina. 3 Bde. Leipzig 1871-1874/1899.

$L$ Wer ist's (1914) S. 1374; WBIS. - Cahn, Julius: Nachruf in: Archiv für Frankfurts Geschichte und Kunst. 4. Folge. 2. Bd. Hrsg. von Otto Ruppersberg. Frankfurt/M. 1925. S. 1-5. - Deutsche Biographie, s. https://www.deutsche-biographie.de/ gnd116544791.html [07. 11. 2017]. 


\section{Rissom, Johannes Carl}

1911-1924 (Kursleiter)

1922-1934 (Lehrkursleiter) (Phil. Fak.)

Leibesübungen

* 30. Nov. 1868 Bunge (heute: Holzbunge bei Rendsburg)

$\dagger \quad$ 02. Juni 1954 Heidelberg ev.-luth.

V Heinrich Hugo R. (1834-1901) Gutsbesitzer, zuletzt Rentner

M Johanna Maria geb. Claussen-Stuck († vor 1935)

( 23. Mai 1899 Agnes Henriette Catharine geb. Green (1873-1900)

$\mathrm{K}$ keine

Vw Ferdinand R. (* 1979) Nachfahre in 3. Generation, Diplom-Sportwissenschaftler, seit 2004 Ressortleiter Int. Jugendarbeit bei Dt. Sportjugend im Dt. Olympischen Sportbund e. V., Frankfurt/M.

Lb Okt. 1891-Sept. 1892 Militärdienstpflicht als Einjährig-Freiwilliger; seit 1892 Studium zunächst der Theologie, dann der Chemie an U Kiel, anschl. Bonn; Assistent von (siehe) Theodor Curtius am Chemischen Inst. bzw. Labor: seit Ostern 1896 Kiel, seit Ostern 1897 Bonn.

UH: SS 1898-April 1926 (Weggang von Curtius) Wiss. Hilfsarbeiter, Verwaltungs-Assistent und Sekretär am Chemischen U-Laboratorium; 12. März 1898 Dr. phil. nat.; 10. Mai 1901 mit Wirkung vom 1. Mai 1899 Verleihung der Eigenschaft e. Beamten ohne etatm. Anstellung; seit 1. Aug. 1902 planmäßiger Beamter; Jahresgehalt: seit 1. Juli 1904 von 2100.- Mark, seit 1. Juli 1907 von 2350.-, seit 1. Juli 1908 von $2785 .-$, seit 1. Juli 1912 von 3485.- Mark; 13. Dez. 1919 Vereidigung als etatm. Beamter; Jahresgehalt: seit 1. Jan. 1921 von $27722 .-$ Mark, seit 1. April 1922 von 78 300.-, seit 1. Sept. 1922 von 447 620.- Mark, seit 1. Nov. 1924 (nach Beendigung der Inflation im Nov. 1923) von 618,12 Rentenmark. • In dieser Zeit:

Ausbildung zum Turnlehrer: 1898 Teilnehmer an e. staatlichen Turnlehrerkursus; 1898 Turnlehrerexamen.
UH: SS 1911-SS 1924 Kursleiter für Ausbildung von Studenten als Leiter von Spielen und volkstümlichen Übungen; WS 1911/12-WS 1933/34 Ausbilder von Turnlehrern (Turnlehrerbildung), siehe hierzu Z (1); 1918 Verleihung des Titels „Prof.“; 1922-1934 Lehrkursleiter; seit April 1926 hauptamtlicher Leiter für Ausbildung der Turnphilologen; WS 1926/ 27-WS 1928/29 Ausbilder von Schwimmlehrern; seit 26. Juli 1928 Prof. der Besoldungsgruppe A2c; WS 1931/32-WS 1933/34 (Gründungs-)Direktor des Instituts für Leibesübungen; 28. Febr. $1934 \mathrm{Ru}$ hestand. $\bullet$ In dieser Zeit auch:

Seit April 1910 Mitglied, April 1926-Sept. 1933 hauptamtlicher Geschäftsführer des Akad. Ausschusses für Leibesübungen an $\mathrm{UH}$, siehe hierzu Z (2); Mitglied: WS 1911/12-WS 1933/34 Kommission für die Prüfung der Turnlehrer an UH, WS 1921/22-SS 1933 Dozentenausschuß für Leibesübungen an $\mathrm{UH}$.

Mai 1915-April 1919: „Leiter der von mir [J.R.] als Heilfaktor eingeführten körperlichen Ausbildung der Einarmer und Einbeiner in dem großen Lazarett in Ettlingen ... von Mai 1915 bis April 1919, wohin ich jeden Mittwoch gefahren bin" (aus: Fragebogen vom 11. April 1933 in: UAH PA 5482).

1898 Gründer der Dozenten-(Turn-)Riege an UH

1899 Gründer und Ehrenmitglied der ATV HassoRhenania Heidelberg

Z (1) Mit Genehmigung des Ministeriums der Justiz, des Kultus und Unterrichts vom 26. Okt. 1910 wird erstmals ein Kurs zur Ausbildung von Turnlehrern an der UH angeboten („Turnlehrerbildungskurs"). Mit gebührenfreien Vorlesungen und Übungen sind folgende a. o. Professoren beauftragt: seit SS 1911 Siegfried Schoenborn (Anatomie, Physiologie) und seit WS 1911/12 Otto Cartellieri (Turngeschichte); außerdem seit SS 1911 J.R. (Methodik und Systematik des Turnens sowie Gerätekunde) und U-Fechtlehrer Dr. Hermann Wehlitz (Leitung des praktischen Turnens und des methodischen und didaktischen Turnens), s. hierzu PA 5482 und Anhang Sporteinrichtungen an $U H$ 1910-1933 und ihre Mitglieder 
Z (2) April 1910: Gründung des Akad. Ausschusses für Leibesübungen an UH mit Vorsitzendem Hans von Schubert (als Prorektor) und den Mitgliedern Friedrich Endemann (Jurist), Ludwig Sütterlin (Philologe), R. sowie Dr. Hermann Wehlitz (U-Fechtlehrer; ${ }^{*} 1861$, s. UAH PA 6270, 9931; Zur Geschichte des Greifswalder Sportinstituts. Herausgeberkollegium: Peter Hirtz (Leitung), Gerhard Grasmann ... Lubmin 2013. S. 16-20); s. Anhang Sporteinrichtungen an UH 1910-1933 und ihre Mitglieder

Z (3) 1914-1918: Mitglied des „Ausschuß zur Veranstaltung Vaterländischer Volksabende in Stadt und Land“, u. a. mit Hermann Braus, Otto Frommel, Friedrich Niebergall, Alfred Hettner, Eberhard Gothein, Hermann Oncken, Hans von Schubert, Ernst Walz, s. hierzu Reichert (2001) S. $504 \mathrm{ff}$.

1921-1925 Mitglied des Deutschen Hochschulamts für Leibesübungen in Berlin

E Ehrenmitglied der Deutschen Turnerschaft. Eisernes Kreuz II. Klasse am weißen Band; Badisches Kriegsverdienstkreuz; Rote Kreuz-Medaille. 1953 Bundesverdienstkreuz.

$\mathrm{Q} u$ UAH PA 5482; RA 5654, 6095, 6097, 6099, 6100, 6496. GLA Abt. 235, Fasz. 1571. • Auskunft: Archiv der ATV Ditmarsia Kiel. - Mitteilungen: Herr Dr. Hans-Wolf Rissom, St. Augustin.

$W$ Leibesübungen der Einarmer und Einbeiner in: Körper und Geist 22 (1916). • Untersuchung über den Stand der Leibesübungen an den deutschen Hochschulen in: Monatsschrift für Turnen, Spiel und Sport 11 (1921). • Die Ausbildung der Studenten als Turn- und Sportlehrer an den deutschen Hochschulen in: Leibesübungen an deutschen Hochschulen. Handbuch für den deutschen Akademiker. Hrsg. von Lothar Berger. Göttingen 1922. S. 148-153. Die Entwicklung der Leibesübungen an der Universität Heidelberg in: Monatsschrift für Turnen, Spiel und Sport 12 (1924).
MHG Geschichte des Chemischen UniversitätsLaboratoriums seit der Gründung durch Bunsen. Zur Feier der Enthüllung des Bunsendenkmals in Heidelberg. Hrsg. von Theodor Curtius und J.R. Heidelberg 1908.

$L$ Wer ist's (1935) S. 1308. - Brossmer, Karl: J.R. Vorkämpfer studentischer Leibesübungen und des sportphilologischen Studiums in: Leibesübungen Sportarzt - Erziehung 8 (1951) S. 208f. - Nachruf in: 33. Rundschreiben des Altherrenverbandes der ATV Ditmarsia Kiel (Aug. 1954) S. 6 f. (mit autobiogr. Auszügen; Ausdruck im UAH). Mussgnug, Dorothee (Bearb.): Karl Johann Freudenberg - Lebenserinnerungen in: Heidelberger Jahrbücher 32 (1988) S. 157. Reichert (2001) S. 498, 504, 517 f. • Court, Jürgen: Deutsche Sportwissenschaft in der Weimarer Republik und im Nationalsozialismus. Bd. 2: Die Geschichte der Deutschen Hochschule für Leibesübungen 1919-1925. Berlin 2014. S. 204, 306, 314 u.ö. - Deutsche Biographie, s. https:// www.deutsche-biographie.de/gnd1012297403.html [07.11. 2017].

$P$ Bildarchiv UAH.

\section{Rodenwaldt, Ernst Robert Carl}

1919-1921, 1935-1945, 1948-1950 Med. Fak.

Hygiene, Bakteriologie

* 05. Aug. 1878 Berlin

$\dagger \quad$ 04. Juni 1965 Ruhpolding

ㅁ Villingen (heute: Villingen-Schwenningen) ev.

V Dr. phil. Robert R. $\left({ }^{*} 1846\right)$ Gymnasial-Prof., s. Müller, Hans-Harald, Nottscheid, Mirko: Wissenschaft ohne Universität, Forschung ohne Staat: Die Berliner Gesellschaft für Deutsche Literatur (1888-1938). Berlin 2011. S. 457.

M Katharina Auguste Emilie geb. Luther $\left({ }^{*} 1858\right)$ Lehrerin

๑ 4. Juli 1906 Katharine Martha Elisabeth geb. Katierske (1885-1957)

K $\quad 1 \mathrm{~S}, 1 \mathrm{~T}$ 
Vw Bruder: Gerhart R. (1886-1945 (Suizid)), u.a. seit 1932 o. Prof. für Archäologie an U Berlin, s. NDB 21 (2003) S. 698 f.; Sünderhauf, Es ther Sophia: „Am Schaltwerk der deutschen Archäologie“ - G. R.s Wirken in der Zeit des Nationalsozialismus in: Jahrbuch des Dt. Archäolog. Instituts 123 (2008) S. 283-362.

Lb Berlin: April 1897-Sept. 1901 Ausbildung an Kaiser-Wilhelms-Akademie für das militärärztliche Bildungswesen; 3. März 1900 Turnlehrerprüfung.

Okt. 1901-April 1903 Unterarzt bei Thüringischem Infanterie-Regiment.

25. Febr. 1903 Approbation; 26. Nov. 1904 Dr. med. an U Halle-Wittenberg.

Seit 18. April 1903 Assistenzarzt e. Kürassier-Regiments in Breslau; seit 21. Juli 1905 Oberarzt im Sanitätsamt des III. Armeekorps in Berlin; 1. Nov. 1907-24. Febr. 1910 Spezialausbildung am Inst. für Schiffs- und Tropenkrankheiten in Hamburg; 20. Juni 1908 kreisärztliche Staatsprüfung in Berlin.

Togo (Westafrika): Seit Febr. 1910 beamteter Regierungsarzt.

Berlin: 25. Febr. 1912 Kommandierung zur Dienstleistung im Reichskolonialamt; 25. Febr. 1914 Versetzung in Sanitätsamt des III. Armeekorps; in dieser Zeit wohl Verleihung des Titels „Prof.“.

Kriegsdienst: Seit 1. Aug. 1914 als Stabsarzt Adjutant des Armeearztes der IV. Armee in Flandern; Okt. 1915-März 1919 (Rückkehr) beratender Hygieniker der V. Kaiserlich-Osmanischen Armee in Kleinasien.

UH: 29. Sept. 1919 Habilitation; 10. Okt. 1919 Genehmigung des badischen Ministeriums des Kultus und Unterrichts für Beibehaltung des in PreuBischen Diensten verliehenen Prof.-Titels; April 1921 Verzicht auf venia legendi.

Indonesien: Mai 1921-Sept. 1934 Inspektor des Volksgesundheitsdienstes von Ostjava in Niederländisch-Indischen Diensten; 1932-1934 Direktor des Eijkman-Inst. für Volksgesundheit in Bata- via (heute: Djakarta); 1933 Bewerbung als Direktor des Inst. für Schiffs- und Tropenkrankheiten Hamburg scheitert.

U Kiel: Seit 18. Sept. 1934 o. Prof.

UH: 28. Okt. 1935-31. Okt. 1945 (Entlassung gemäß Erlaß der amerik. Militärregierung) o. Prof. und Direktor des Hygiene-Inst. als Nachf. von Emil Gotschlich; März 1936-1945 Leiter der Serologischen (Wiss.) Abt. am Inst. für Experimentelle Krebsforschung als Nachf. von Hans Sachs; Ablehnungen: 1936 Leitung des Reichsinstituts für Erbforschung in Berlin-Dahlem, Ruf auf Lehrstuhl für Rassenhygiene 1936 an U München und 1941 an Reichs-U Straßburg. • In dieser Zeit:

26. Aug. 1939-März 1945 Beratender Tropenhygieniker bei der Heeresführung und 1. Febr. 1940März 1945 Leiter des Tropenmed. Inst. an Militärärztlicher Akademie in Berlin (1943 Ern. zum Generalarzt).

30. März 1945 Gefangennahme in H; Ende 1945Febr. 1946 als Kriegsgefangener Betreuer e. dt. Kriegsgefangenenlazaretts in England; für die Zeit 1946-1948, s. Kiminus (2002) S. 147-163.

UH: Seit 1. Nov. 1948 Lehrauftrag für Hygiene und vertretungsweise Leiter des Hygienischen [!] Inst.; WS 1949/50 letzte Vorlesungsankündigung; 27. Nov. 1951 rückwirkend zum 1. April 1948 Emeritierung.

Ruhpolding: Seit 1954 ständiger Wohnsitz.

Okt. 1939-Juni 1942 Dekan der Med. Fak. der UH

E Mitglied: 1937 Akademie der Wissenschaften H, 1940 Dt. Akademie der Naturforscher Leopoldina Halle/S.; Ehrenmitglied: 1953 Societa Italiana di Medicina Sociale, 1962 Dt. Gesellschaft für Tropenhygiene. 1963 Dr. phil. h.c. Tübingen. 1907 Südwestafrika-Medaille; 1914 Königl. Preußischer Roter Adler-Orden IV. Klasse; 1916 Osmanischer Mecidiye-Orden III. Klasse. 
Qu UAH PA 1133 f., 5490 f. • Siehe auch Archiv der Dt. Akademie der Naturforscher Leopoldina Halle/S. • Ein Tropenarzt erzählt sein Leben. Stuttgart 1957. (Autobiogr.)

W Seuchenkämpfe. Heidelberg 1921. • Die Mestizen von Kisar. 2 Bde. Batavia 1927. • Einführung in die Hygiene und Seuchenlehre. Stuttgart 1936. 5. verm. Aufl. 1943. (Mitverf.) - Tropenhygiene. Stuttgart 1938. 6. Aufl. 1966. • Probleme des Städtebaus in Kolonialländern. Stuttgart 1941. Bibliographie in: Kiminus (2002) S. 183-200.

MHG 1952-1961 Welt-Seuchen-Atlas.

$L$ Professoren Kiel (1956) S. 88; Kürschner (1966) S. 2006. - Jusatz, Helmut: E. R. als Begründer der geo-medizinischen Forschung in: Heidelberger Jahrbücher 14 (1970) S. 23-51 (mit Werkverz.). • Chronik Ärzte H (1985) S. 140 f., 262 f.; WBIS; 100 Jahre Krebsforschung (2000) S. 48. - Kiminus, Manuela: E. R. Leben und Werk. Diss. Heidelberg 2002. - Zinke, Dieter: Generalarzt der Reserve ... E. R. unter: http://forum.axishistory.com/viewtop ic.php $\mathrm{f}=5 \& \mathrm{t}=108964 \& \mathrm{p}=960376 \&$ hilit $=$ Roden waldt (16. Febr. 2004; Ausdruck im UAH). - Enzyklopädie Medizingeschichte. Hrsg. von Werner E. Gerabek u.a. Berlin 2005. S. 1256 f. - UH im Nationalsozialismus (2006) S. 1268 (Register). • E.R. in: Lischke, Ralph-Jürgen: Biographisches Lexikon zur Geschichte der Demographie. Personen des bevölkerungswissenschaftlichen Denkens im deutschsprachigen Raum vom 16 . bis zum 20. Jahrhundert. Berlin 2007. S. 249. - Klee, Personenlexikon (2007) S. 501f.; Friedrich (2009) S. 145-153 u. ö.

$P$ Bildarchiv UAH; Ruperto Carola; Heidelberger Jahrbücher; Chronik Ärzte H.

\section{Röder, Karl David August}

1839-1879 Jur. Fak.

1879 (Honorar-Prof.) Jur. Fak.

Zivil- und Kriminalrecht, Staatsrecht, Naturrecht,

Staatslehre, Rechtsphilosophie, Strafrecht, Völ-

kerrecht

* 23. Juni 1806 Darmstadt

$\dagger$ 20. Dez. 1879 Heidelberg ev.-luth.

V Franz R. (1774-1840), u. a. seit 1798 Seconde Lieutenant, seit 1817 Major, seit 1827 Oberstlieutenant, s. WBIS, Schwieters (1964) S. 10-12

M Wilhelmine (Mina) geb. Krämer ( $† 1811)$

œ 19. April 1836 Bertha Margarethe Marie Sophie geb. Zammin(g)er/Zimmler (1813-1869)

K $\quad 2$ S, 3 T, s. Blos (1914) S. 37.

Lb Seit WS 1822/23 Studium zunächst der Humaniora (vor allem Klassische Philologie), dann der Rechtswiss. an U Göttingen, SS $1826 \mathrm{H}$; Herbst 1826 I., WS 1828/29 II. jur. Staatsexamen in Gießen; seit Ende 1826 Akzessist (Anwärter) im hessischen Staatsdienst, u. a. im Sekretariat des Hofgerichts in Darmstadt und an weiteren verschiedenen Gerichten.

Darmstadt: Seit Jan. 1828 provisorischer, seit Jan. 1830 „definitiv angestellter“ Akzessist am Hofgericht.

U Gießen: 7. Mai 1830 Dr. iur.; Herbst 1830 Habilitation, s. hierzu Schwieters (1964) S. 19 Anm. 45; seit Herbst 1830 R. „widmet sich (als Dr. legens) mit Liebe dem Lehrfach in der Rechts- und Staatswissenschaft" (aus: Lebenslauf R.s vom 20. Nov. 1838 in: UAH PA 2152); 1837 Publikation von R.s Buch "Grundzüge der Politik des Rechts. Erster Teil: Einleitung. Allgemeine Staatsverfassungslehre" (mehr nicht erschienen); hierauf Verdächtigung R.s revolutionärer Umtriebe seitens des Kanzlers der $\mathrm{U}$, daraufhin u. a. Untersagung von Vorlesungen über Strafrecht und Rechtsphilosophie, s. hierzu Schwieters, S. 24-29; R. erklärt, kein Interesse an "der verstümmelten venia docendi“ zu haben (aus: ebd. S. 28); s. hierzu weiter Eintrag unter $Z$ [itat]. 
UH: 3. Jan. 1839 Umhabilitation; SS 1839 Beginn seiner Lehrtätigkeit; seit 14. April 1842 a.o. Prof.; seit 1. Nov. 1855 (nach mehreren ergebnislosen Gesuchen um Gehalt) jährl. Besoldung von 500.Gulden, seit 1. Nov. 1872 jährl. Zulage von 100.Gulden; 31. März 1879 Verleihung des Charakters e. Honorar-Prof. nach mehrmaligen erfolglosen Anträgen R.s auf ein Ordinariat. - In dieser Zeit:

31. März-3. April 1848 Mitglied des Frankfurter Vorparlaments.

U Madrid: April 1877 Verleihung des Titels „Profesor honorario“, s. hierzu Schwieters, S. 6o-62.

$Z$ Am 2o. Nov. 1838 bittet R., zurzeit noch PrivatDozent an der U Gießen, das Ministerium des Innern in Karlsruhe erfolgreich um eine Anstellung an UH; er hat „... vor Allem aber ... das Verlangen, [die] Ausübung des Lehrberufs [in einem] weniger beschränkten Wirkungskreis zu finden, als eine so kleine Universität wie Gießen ihm gewähren kann, [und den] Wunsch, ... künftighin an einer großartigern, glorreichen und namentlich nicht, wie Gießen, fast bloß noch von Inländern und Brodstudenten besuchten, endlich an literärischen Hülfsmitteln und ächt wissenschaftlichem Geist reichen Hochschule wirken zu dürfen ..." (aus: PA 2152). Am 28. Dez. 1838 erfolgt die ministerielle Genehmigung zur Umhabilitation an UH.

Qu UAH PA 2152; Fak.-Akte H-II-111/34. GLA Abt. 205, Fasz. 453. - Toepke 5 (1904) S. 322 . Nachlaß: UBH (Signaturen: Heid. Hs. 999, 3600, 3607). - Auskunft: Ev. Kirchengemeindeamt Darmstadt. - Streiflichter auf mein Leben und Streben, besonders in Bezug auf die Lehre Krauses. Unveröffentl. Manuskript in UBH (Signatur: Heid. Hs 3607,2). (Autobiogr.)

W Grundzüge der Politik des Rechts. Darmstadt 1837. - Grundzüge des Naturrechts oder der Rechtsphilosophie. Heidelberg 1846. 2. Aufl. 1863. (Spanische Übers. 1879.) • Zur Rechtsbegründung der Besserungsstrafe. Heidelberg 1846. • Die Verbesserung des Gefängnißwesens mittelst der Einzelhaft. Prag 1856. - Der Strafvollzug im Geist des Rechts. Leipzig 1863. • Besserungsstrafe und Besserungsanstalten als Rechtsforderung. Leipzig
1864. - Die herrschenden Grundlehren von Verbrechen und Strafen in ihren inneren Widersprüchen. Wiesbaden 1867. Bibliographie in: Schwieters (1964) S. 248-258.

L Badische Biographien 3 (1881) S. 130-132; Blos (1914) S. 34-37 u. ö. - Weiss, Walter: K.D.A.R. Rechtsphilosoph, Kriminalist, Mensch. Ein Beitrag zum Naturrecht des 19. Jahrhunderts. Diss. Heidelberg 1950. Arnim 2 (1952) S. 425; WBIS. • Lithner, Klas: K.R., ein vergessener Gefängnisreformator in: Zs. für die gesamte Strafrechtswissenschaft (1961) Bd. 73, H. 3, S. 487-509. • Schwieters, Joseph: K. D. A. R. Ein biographischer Beitrag zur Geschichte des Strafvollzugs. Diss. Münster 1964. Heidelberger Strafrechtslehrer (1986) S. $30-$ 33. Landau, Peter: Die rechtsphilosophische Begründung der Besserungsstrafe. Karl Christian Friedrich Krause und K.D.A.R. in: Strafgerechtigkeit. Festschrift für Arthur Kaufmann zum 70. Geb. Hrsg. von Fritjof Haft ... Heidelberg 1993. S. 473-485. NDB 21 (2003) S. 709. • Nielsen, Eike: Die Ehe zwischen Recht und Sitte. Naturrechtliche Stimmen des 19. Jahrhunderts zur Beziehung zwischen Mann und Frau in der Ehe: Eduard Gans, K.D.A.R. und Heinrich Ahrens in: Frauenrecht und Rechtsgeschichte. Die Rechtskämpfe der deutschen Frauenbewegung. Hrsg. von Stephan Meder ... Köln 2006. S. 99-110. • Rabe, Christine Susanne: Gleichwertigkeit von Mann und Frau. Die Krause-Schule und die bürgerliche Frauenbewegung im 19. Jahrhundert. Köln 2006. S. 237 (Register). Riedel, Tanja-Carina: Gleiches Recht für Frau und Mann. Die bürgerliche Frauenbewegung und die Entstehung des BGB. Köln 2008. S. 36-38 u. ö. - Schroeder (2010) S. 101-104 u. ö.; Klippel (2012) S. 109, 184 u. ö.

$P$ Bildarchiv UAH. 


\section{Röhrer, Friedrich}

1920-1938 (1945) Nat.-Math. Fak.

Geologie, Paläontologie

* o8. Sept. 1885 Baden-Baden

$\dagger$ 14. Juli 1945 Konstanz

ev.

V Leonhard R. (1859-1908) Kellner, später Gastwirt

M Anna Rebekka Johanna geb. Hohe (1858-1924)

๑ 3. Aug. 1914 Emma Friederike (Frida) geb. Gund (1891-1953)

K $\quad 1 \mathrm{~S}, 1 \mathrm{~T}$

Lb UH: Seit WS 1904/o5 Studium der Mathematik und Naturwiss.; März 1909 Staatsexamen für höheres Lehramt in Karlsruhe; 2. Mai 1916 Dr. phil. nat.

Lehramtspraktikant an Oberrealschule: Seit 21. April 1909 in H (heute: Helmholtz-Gymnasium), seit 13. Sept. 1910 in Pforzheim, seit April 1919 in Schwetzingen; 20. Febr. 1920 Verbeamtung. - In dieser Zeit:

4. März 1916-12. Dez. 1918 Kriegsdienst.

UH: 10. Mai 1920 Habilitation; SS 1920 Beginn seiner Vorlesungen; SS 1923-WS 1934/35 Lehrauftrag zur Abhaltung e. 2-stündigen Vorlesung über Hydrologie; SS 1923 Auszahlung von 6 ooo.- Mark „zur Bestreitung der Fahrtkosten von Mannheim (= Wohnsitz) nach Heidelberg und zurück im Semester" (aus: UAH PA 2547); seit 11. Aug. 1925 nichtplanm./nichtbeamteter a.o. Prof.; seit SS 1935 Erweiterung des Lehrauftrags für Hydrologie auf das „Lehrgebiet der angewandten Geologie“ am Geologisch-Paläontolog. Inst. (aus: PA 2547); WS 1933/34 Vorlesung über „Angewandte Geologie im Rahmen der Wehrwissenschaft“; SS 1938 letzte Vorlesungsankündigung; seit 3. Nov. 1939 apl. Prof. • In dieser Zeit weitere Lehrtätigkeiten:

Mannheim: 1. Okt. 1920 Ern. zum Prof. am Realgymnasium; seit SS 1922 Dozent, WS 1926/2730. Sept. 1933 (Überführung der Handelshochschule an $\mathrm{UH}$ ) nebenamtlicher Dozent für Geographie und Geologie an Städtischer Handelshochschule.
H: WS 1928/29-WS 1931/32 (Schließung) Prof. an Lehrerbildungsanstalt; vor 1938 Oberstudienrat an Knabenoberschule, nach 1940 an Robert-BunsenSchule (heute Bunsen-Gymnasium).

Kriegsdienst: 17. Juli 1938-15. Okt. 1939 Stabsgeologe bei Luftverteidigungszone West, Abschnitt V („Westwall“); 27. Sept. 1939 Ern. zum RegierungsBaurat auf Kriegsdauer, anschl. Kriegsverwaltungsrat, seit 24. Juni 1943 „Regierungs-Baurat der Reserve im Range wie ein Major in der Reserve der Beamten des Heeres“ (aus: PA 5493).

Konstanz: (Nach) Mai/vor Aug. 1945 Abordnung als Oberstudienrat an Oberschule.

E 1918 Eisernes Kreuz II. Klasse; 1934 Ehrenkreuz für Frontkämpfer; 1939 Westwallehrenzeichen; 1940 Kriegsverdienstkreuz II. Klasse.

Qu UAH PA 2547, 5493. - GLA Abt. 235, Fasz. 2421. Briefe: Universitätsbibliothek Freiburg/Br. • Auskunft: Standesamt Schwetzingen.

$W$ Die gemeinen Klüfte und die Harnische in: Jahresberichte und Mitteilungen des Oberrheinischen Geologischen Vereines. N. F. (1916) Bd. 6. H. 1. S. 8-85 (Diss.). • Beiträge zur Hydro-Geologie des nördlichen Schwarzwaldes ... in: Verh. des naturwiss. Vereins Karlsruhe (1922/23). • Über Quellenuntersuchungsmethoden in: Gas- und Wasserfach (1923).

L Kürschner (1931) Sp. 2406; Handels-Hochschule Mannheim 1907-1932 (1932) S. 27. Prinz, Emil, Kampe, Robert: Handbuch der Hydrologie. 2. Bd.: Quellen (Süßwasser- und Mineralquellen). Berlin 1934. S. 23 f., 39, 132 f., 28of. • Deutsche Biographie, s. https://www.deutsche-biographie.de/ gnd116582308.html [07.11.2017].

$P$ Bildarchiv UAH. 


\section{Röth, Eduard Maximilian}

1840-1858 Phil. Fak.

Philosophie, Orientalistik (Sanskrit)

* 12. Okt. 1807 Hanau

$\dagger \quad$ 07. Juli 1858 Heidelberg

ref.

V Heinrich R. (1779-1812) Volksschullehrer

M Katharina geb. Kalbhenn

$\infty$ 11. April 1848 Metha Magdalena Johanna geb. Bach ( $†$ nach 1871)

K $4 \mathrm{~S}, 2 \mathrm{~T}$

Lb U Gießen: Seit 1825 Studium der Theologie; 1828 theol. Fakultäts-Examen.

Frankfurt/M.: 1828-1835 Privat-Studien der semitischen Literatur, auch der "talmudisch rabbinische[n] Litteratur" bei e. "gelehrten Rabbiner" (aus: UAH PA 2154 fol. 1r).

U Marburg: 1835 Promotion zum Dr. phil.

Paris: 1836-Frühjahr 1840 Eigenstudien der orientalischen Sprachen („Paris, (der) Mittelpunkt der orientalischen Studien“, aus: PA 2154 fol. 1v).

UH: 8. Aug. 1840 Habilitation (Ministerium des Innern schreibt am 6. Juni 1840: Aufgrund der bisherigen Veröffentlichungen R.s, Erlassung des üblichen Habilitations-Kolloquiums, „auf die Erlassung der Disputation aber könne man nicht eingehen", aus: PA 2154 fol. 7 r), s. hierzu auch $Z$ (1); 12. Okt. 1845 Gesuch R.s um Verleihung e. a.o. Professur, hierin e. inhaltliche Beschreibung seiner Studien und Vorlesungen, s. PA 2154 fol. 16r17r; seit 16. Jan. 1846 a. o. Prof.; 23. Jan. 1846-Sommer 1848 Auszahlung e. ständigen Gratifikation über 300.- Gulden im laufenden Semester gegen die Verpflichtung, Vorlesungen über das Sanskrit zu halten; seit 13. Aug. 1850 o. Prof.; SS $1852 \mathrm{Be}$ urlaubung „,behufs der Wiederherstellung seiner Gesundheit" (aus: PA 2154 fol. 39r); April und Mai 1855 Urlaubsreise nach England und in die Niederlande; 1855 Auszahlung e. jährl. Gehalts von 500.Gulden; seit 1. Nov. 1855 Besoldungszulage von 300.- Gulden.
1856 Dekan der Phil. Fak. der UH

Z (1) Am 26. Juni 1840 teilt R. dem Dekan mit, er habe die verlangten Thesen (siehe hierzu UAH H-IV-102/36 fol. 12or, v) für seine Habilitation der Fakultät vorgelegt, „was aber die Opponenten betrifft, so muß ich zu meinem Leidwesen bemerken, daß es mir nicht gelungen ist, in der philosophischen Fakultät einen Herrn zu finden, dem es seine Geschäfte erlaubt hätten, mir zu opponiren ..." (aus: PA 2154 fol. 8r). Der Orientalist Raphael Hanno entschuldigt sich in seinem Schreiben vom 30. Juni 1840 an den Dekan, aufgrund seiner angeschlagenen Gesundheit nicht als Opponent zur Verfügung zu stehen. Außerdem „liegt auch das Fach des Petenten - Chinesisch und Sanskrit fern genug von dem meinigen" (aus: PA 2154 fol. 1or).

Ähnlich wie Hanno antwortet auch sein Fachkollege Gustav Weil in einem vom 30. Juni datierten Brief: „... die von Herrn Dr. Röth ... mitgetheilten Theses (gehören) nicht ins Gebiet der arabischen, persischen und türkischen Philologie, mit [dem] der Unterzeichnete sich speziell beschäftigt, sondern mehr in das der Theologie und Geschichte der Philosophie. Uebrigens leidet Unterzeichneter schon seit mehrer[e]n Monaten an einer Heiserkeit, die ihm nicht gestattet, laut und öffentlich zu sprechen" (aus: PA 2154 fol. 12r).

Die Philosophische Fakultät schlägt daraufhin am 5. Juli 1840 vor, R. die Disputation zu erlassen, s. PA 2154 fol. 13r, v. Der Engere Senat entscheidet, daß „unter Communication mit der theol. Fakultät, Opponenten für Dr. Röth auszumitteln" seien (aus: PA 2154 fol. 14r). Am 8. Aug. 1840 ist in den Akten der Phil. Fak. die kurze Notiz zu finden, „Engerem academischem Senate geben wir ... Nachricht, daß Dr. Röth heute disputirt hat; der Actus fiel zur Zufriedenheit der Facultät aus" (aus: PA 2154 fol. 15r). Wer der/die Opponent/en letztendlich gewesen ist/sind, ist weder in der Personal- noch in der Fakultätsakte verzeichnet.

$Z$ (2) Am 4. Nov. 1854 „geruht [Großherzog Ludwig II.] das diesseitige Staatsministerium allergnädigst zu ermächtigen ..., die Unwiderruflichkeit der Anstellung des Professors Dr. Röth in Heidelberg mit dem Ablaufe seines fünften Probejahres, 
wenn bis dahin sich nicht Grund zu anderweiter Verfügung ergeben sollte, auszusprechen" (aus: PA 2154 fol. 42r).

$Z$ (3) In der von der Universität Heidelberg aufgegebenen R.schen Todesanzeige wird angekündigt, daß bei der Beerdigung „die Begleitung der Leiche $\mathrm{zu}$ Wagen vom Trauerhause [Grabengasse 8] aus stattfinden wird“ (aus: PA 2154 fol. 47r).

Qu UAH PA 2154; RA 6859; Fak.-Akte H-IV-102/ 36 fol. 12or-122r. • Mitschrift der Vorlesung „Darstellung und Critik des Hegelschen Systems“, gehalten im SS 1845 von E. M. R. in: Hegelsches System und badische Revolution. Eine unbekannte Heidelberger Vorlesungsmitschrift Joseph Victor von Scheffels. Aus dem Nachlass hrsg. ... von Marcel Krings in: ZGORh 159. Jg. (2011) S. 477-498.

$W$ Geschichte unserer abendländischen Philosophie. 2 Bde. Mannheim 1846-1858. 2. Aufl. 1862. • Die Proklamation des Amasis an die Cyprier bei der Besitznahme Cyperns durch die Ägypter um die Mitte des 6. Jahrhunderts vor Christi Geburt. Paris 1855 .

L Über E. R. in: Reichlin-Meldegg, Karl Alexander Frhr. von: Das Leben eines ehemaligen römischkatholischen Priesters. Heidelberg 1874. S. 187f. • Badische Biographien 2 (1875) S. 209 f.; ADB 29 (1889) S. 348; Lehmann (1967) S. 213; WBIS; DBE 8 (2007) S. 496.

\section{Rohde, Erwin}

1886-1898 Phil. Fak.

Klassische Philologie

* o9. Okt. 1845 Hamburg

$\dagger$ 11. Jan. 1898 Heidelberg

ev.

V Dr. Franz Adolph R. (1813-1866) Arzt

M Bertha Maria Wilhelmina geb. Schleiden (1813-1882), s. Franz Overbeck - Erwin Rohde. Briefwechsel. Hrsg. ... von Andreas Patzert ... Berlin 1990. S. 638 (Register).
( 8. Aug. 1877 Valentine geb. Framm (1859-1901), s. ebd. S. 638 f. (Register)

K 2 T: u.a. Bertha R. (1878-1902), s. ebd. S. 627 (Register); Ehefrau von: (siehe) Alfred Hettner. 2 S (davon $1 \mathrm{~S}$ früh $\dagger$ ): Erwin R. [jun.] (1881-1915 Davos) seit 1910 Privat-Dozent für Pharmakologie an UH, s. UAH PA 1137, 2156, RA 6204, Nachlaß im UAH; Gottlieb, Rudolf: E. R. $\dagger$ in: Verhandlungen des naturhistorischmedizinischen Vereins zu Heidelberg. N.F. 13 (1914-1917) H. 2, S. 482-495; Stübler (1926) S. 330 (unter Rhode); Franz Overbeck - E.R. Briefwechsel, S. 638 (Register); Kriegstagebuch K. Hampe (2007) S. 245. - 1912 Vergabe des Zinsertrags der HDer Jubiläums-Stiftung an E. R. [jun.], s. hierzu UAH RA 5225.

Lb SS 1865 Studium an U Bonn, WS 1865/66 Leipzig, seit WS 1867/68 Kiel.

U Kiel: 9. März 1869 Dr. phil.; 1869-1870 Studienreise durch Italien; Herbst 1870 Habilitation; seit 20. April 1872 a. o. Prof.

U Jena: 14. Febr. 1876 Ern. zum o. Prof.

U Tübingen: 12. Juli 1878 Ern. zum o. Prof. (Nachf. 1886: (siehe) Otto Crusius).

U Leipzig: 18. Dez. 1885 Ern. zum SS 1886 o. Prof.; 30. Sept. 1886 Entlassung auf eigenen Antrag.

UH: 16. Juni 1886 Ern. zum o. Prof. als Nachf. von Curt Wachsmuth und Mit-Direktor (zus. mit Fritz Schöll) des Philolog. Seminars mit e. Jahresgehalt von 8950.- Mark zuzüglich 660.- Mark Wohnungsgeldzuschuß; 2. Nov. 1886 Vereidigung; Jan./ Febr. 1897 Ruf an U Straßburg abgelehnt; 22. Febr. 1897 Besoldungserhöhung auf 9300.- Mark.

1894 Prorektor der UH; 1892/93 Dekan der Phil. Fak. der UH

Nach dem Tod R.s 1898 wird sein Heidelberger Kollege Fritz Schöll Vormund der unmündigen Kinder, s. hierzu Supplementa Nietzscheniana. Hrsg. von Wolfgang Müller-Lauter und Karl Pestalozzi. Bd. 2: Hoffmann David M.: Zur Geschichte des Nietzsche-Archivs: Elisabeth Förster- 
Nietzsche, Fritz Koegel ... Chronik, Studien und Dokumente. Berlin 1991. S. 34 f.

Umbenennung der Heidelberger Klosestrasse in Erwin Rohde-Strasse auf Anregung von (siehe) Carl Neumann 1916, s. hierzu UAH RA 5683

1886 Geh. Hofrat; 1894 Geh. Rat II. Klasse

E Mitglied des Philologischen Vereins Heidelberg; Mitglied der Akademie der Wissenschaften: 1886 Leipzig, 1897 München.

Qu UAH PA 2155; RA 5683, 6827 (Berufung 1886 und Tod 1898). - Briefe, Teil-Nachlaß: UBH, s. auch NDB 21 (2003) S. 762. - Friedrich Nietzsches Briefwechsel mit E.R. Hrsg. von Elisabeth Förster-Nietzsche und Fritz Schöll. Berlin 1902. 3. Aufl. 1923. - Franz Overbeck - E. R. Briefwechsel. Hrsg. ... von Andreas Patzert ... Berlin 1990. S. 638 (Register). - Friedrich Nietzsche: Sämtliche Briefe. Kritische Studienausgabe ... Hrsg. von Giorgio Colli ... 2. Aufl. München 2003. Bd. 8 (Gesamtregister). Bestebreurtje, Frank Peter: „Unser Rohde“. Der Briefwechsel zwischen Franz Overbeck und Otto Crusius in: Philologus - Zs. für antike Literatur und ihre Rezeption 156 (2012) H. 2, S. 346-387. E. R.: Briefe aus dem Nachlass. Bd. 1: Briefe zwischen 1865 und 1871. Hrsg. von Marianne Haubold ... Hildesheim 2015. Ergebnislose Anfrage: Landesarchiv Schleswig-Holstein in Schleswig (Vernichtung der Akten der Phil. Fak. Kiel im 2. Weltkrieg). - Auskunft: Frau Hedwig Däuble-Rohde (†), Karlsruhe.

$W$ Afterphilologie. Zur Beleuchtung des von ... Ulrich von Wilamowitz-Möllendorff herausgegebenen Pamphlets: „Zukunftsphilologie!“. Sendschreiben e. Philologen an Richard Wagner. Leipzig 1872. - Der griechische Roman und seine Vorläufer. Leipzig 1876. 3. Aufl. 1914. Psyche. Seelencult und Unsterblichkeitsglaube der Griechen. 2 T. Freiburg/Br. 1890-1894. 8. Aufl. 1921. - Kleine Schriften. 2 Bde. Tübingen 1901. Nachdr. 1969. Bd. 1: Beiträge zur Chronologie, Quellenkunde und Geschichte der griechischen Litteratur. Bd. 2: Beiträge zur Geschichte des Romans und der Novelle, zur Sagen-, Märchen- und Alterthumskun- de. Bibliographie in: E. R.: Briefe aus dem Nachlass. Bd. 1 (2015) S. 13-28.

HG Friedrich Creuzer und Caroline von Günderode. Briefe und Dichtungen. Heidelberg 1896.

$L$ Crusius, Otto: E.R. Ein biographischer Versuch ... Tübingen 1902. - Arnim 2 (1952) S. 430; Professoren Kiel (1956) S. 180. E. R. in: Sächsische Akademie der Wissenschaften Leipzig. Jahrbuch 1960-1962. Berlin 1964. S. 142. • Däuble, Hedwig: Friedrich Nietzsche und E.R. in: Nietzsche Studien 5 (1976) S. 321-354. • Cancik, Hubert: E. R., ein Philologe der Bismarckzeit in: Semper apertus 2 (1985) S. 432-501. Cohen-Halimi, Michèle: Querelle autour de „La naissance de la tragédie“: écrits et lettres de Friedrich Nietzsche, Friedrich Ritschl, E. R., Ulrich von Wilamowitz-Möllendorff, Richard et Cosima Wagner ... Paris 1995. • Treiber, Hubert: Freunde [u. a. E. R.] in: Nietzsche-Handbuch: Leben - Werk - Wirkung. Hrsg. von Henning Ottmann. Stuttgart 2000. S. 38-40. - WBIS; NDB 21 (2003) S. 761 f. • Eichberg, Ralf: Freunde, Jünger und Herausgeber. Zur Geschichte der ersten Nietzsche-Editionen. Frankfurt/M. 2009. S. 25-33 u. ö. Literatur der Antike und Philologie der Neuzeit. Ausgewählte Schriften von Ernst Vogt. Hrsg. von Erich Lamberz. Berlin 2013. S. 612 (Register). Schröder, Wilt-Aden: E. R. in: TeuchosBiogramm, Sammlung: Philologische Biographien, s. http://www.teuchos.uni-hamburg.de/interim/ prosop/Rohde.Erwin.html (30. Okt. 2013). • Professorenkatalog Leipzig online. Breuer, Stefan: Max Weber, das Charisma und E.R. in: Zs. für Religions- und Geistesgeschichte (2015) S. 1-16. • Taunton, Gwendolyn: Nietzsche - The Physician of Culture in: SydneyTrads - Weblog of the Sydney Traditionalist Forum (30. April 2016), s. online sydneytrads.com/2016/04/30/2016-symposiumgwendolyn-taunton (Ausdruck im UAH). - E. R.: Psyché. Le culte de l'âme chez les grecs et leur croyance à l'immortalité. Traduction française d'Auguste Reymond, édition revue, corrigée et augmentée par Alexandre Marcinkowski ... Paris 2017.

P Bildarchiv UAH; graph. Slg. UBH. 


\section{Rosenbusch, Harri}

siehe Rosenbusch, Heinrich

\section{Rosenbusch, Carl Heinrich (genannt: Harri) Ferdinand}

1878-189o Phil. Fak.

1890-1908 Nat.-Math. Fak.

Mineralogie, Geologie

* 24. Juni 1836 Einbeck

$\dagger$ 20. Jan. 1914 Heidelberg ev.-luth.

V Georg Heinrich Wilhelm R. (1808-1843) Waisenlehrer

M Luise Friederike Henriette geb. Püschel $\left({ }^{\star} 1812\right.$ $\dagger$ nach 1843) Handarbeitslehrerin

(21. Sept. 1869 Wilhelmine Auguste geb. Müller (1845-1929)

K 1 S (früh $\dagger$ ), 1 Pflege-S (1850-1877), s. Toepke 6 (1907) S. 601 Nr. 119; Borges, Dain Edward: The Family in Bahia, Brazil 1870-1945 (Familie Vianna-Bandeira). Stanford (California) 1992.

Lb U Göttingen: Seit WS 1855/56 Studium der Philologie, Theologie.

Bahia (Brasilien): 1857-1862 Hauslehrer.

Seit 1862 Studium der Naturwiss. an U Freiburg/ Br., 1865/66 H (ohne Immatrikulationseintrag), 1866-1868 Freiburg/Br.

U Freiburg/Br.: 8. Mai 1868 Dr. phil.; 7. Dez. 1868 Habilitation für Petrographie an Phil. Fak.; 1869 Aufenthalt in Rio de Janeiro; seit WS 1869/70 Privat-Dozent; seit 22. Dez. 1871 a. o. Prof.

Straßburg: Seit 1. Mai 1873 a. o. Prof. für Petrographie an U und geschäftsführendes Mitglied der „Kommission für die Geologische Landesuntersuchung für Elsaß-Lothringen“.

UH: 8. Sept. 1877 Ern. zum o. Prof. als Nachf. von Reinhard Blum und Direktor des MineralogischGeologischen Inst. mit e. jährl. Besoldung von 6ooo.- Mark; 27. März 1878 Vereidigung; 1883 Ruf an U Straßburg abgelehnt; 30. Sept. 1908 Ruhestand. • In dieser Zeit:

H: 12. Juli 1888-31. März 1907 (Pensionierung) (Gründungs-)Direktor der Großherzoglich Badischen Geologischen Landesanstalt mit e. jährl. „Funktionsgehalt“ von 3000.- Mark (Stand: 1888); 20. Dez. 1888 Errichtung, 1907 Übersiedlung der Landesanstalt nach Karlsruhe; siehe auch Adolf Sauer.

1900 Prorektor der UH, siehe hierzu Adolf Stengel; Dekan: 1883/84 der Phil. Fak., 1894/95, 1900/o1, 1907/08 der Nat.-Math. Fak. der UH

R.s Gesteins- und Mineralsammlungen bilden u. a. den Grundstock für das Museum des Heidelberger U-Instituts für Geowissenschaften

17. Aug. 1871: Gründungsmitglied des Oberrheinischen Geologischen Vereins im ehemaligen Bad-Hotel Rothenfels im heutigen Gaggenau-Bad Rotenfels

1888 Geh. Bergrat; 1902 Geh. Oberbergrat; 1903 Geh. Rat II. Klasse

$E$ Mitglied der Akademie der Wissenschaften: 1882 Göttingen, 1885 Stockholm, 1887 Berlin, 1902 München, 1904 Wien, 1909 H. 1903 WollastonMedaille der Geological Society of London. • 1894 Kommandeurkreuz des Ordens vom Zähringer Löwen; 1901 Kommandeurkreuz II. Klasse, 1908 Stern zum Kommandeurkreuz II. Klasse des Großherzogl. Ordens Berthold I.

Qu UAH PA 2163; RA 6895 (Mineralog. Inst.). • Vorlesungsmitschrift 1881/82 über Mineralogie in Mineralog. Bibliothek der U Basel. - Auskunft: Ev.-luth. Kirchenbuchamt in Einbeck (Niedersachsen).

$W$ Mikroskopische Physiographie der Mineralien und Gesteine. Ein Hülfsbuch bei mikroskopischen Gesteinsstudien. 2 Bde. Stuttgart 1873-1877. 3. Aufl. 1892-1896. (Engl. Übers.: Microscopical physiography of the rock-making minerals. An aid to the microscopical study of rocks ... Trans- 
lated and abridged ... by Joseph Paxson Iddings. British Library. Historical Print Editions. London 2011.) - Ein neues Mikroskop für mineralogische und petrographische Untersuchungen in: Neues Jahrbuch für Mineralogie (1876) S. 504-513. • Die Steiger Schiefer und ihre Contactzone an den Graniten von Barr-Andlau und Hohwald in: Abh. zur geologischen Specialkarte von Elsass-Lothringen Bd. 1, H. 2 (1877) S. 79-393. Hülfstabelle zur mikroskopischen Mineralbestimmung. Stuttgart 1888. Elemente der Gesteinslehre. Stuttgart 1898.

$L$ Milch, Ludwig: H.R. $\dagger$ in: Zs. der Dt. Geologischen Gesellschaft 66 (Jan. 1914) S. 129-159. • Wülfing, Ernst Anton: Zur Erinnerung an H.R. Heidelberg 1914. - Erdmannsdörffer, Otto H.: C.H.F. R. zu seinem 10o. Geb. in: Sitzungsberichte der Heidelberger Akademie der Wissenschaften. Math.-Naturwiss. Klasse. Abh. 3. (1936). Arnim 2 (1952) S. 438, 4 (1984) S. 1415. - Ramdohr, Paul: H.R. ... in: Geschichte der Mikroskopie. Leben und Werk großer Forscher. Bd. III: Angewandte Naturwissenschaften und Technik. Hrsg. von Hugo Freund und Alexander Berg. Frankfurt/M. 1966. S. 343-348. - Badische Biographien N.F. I (1982) S. 229 f.; Wolgast (1986) S. 120; WBIS; Wagenbreth (1999) S. 252 (Register); NDB 22 (2005) S. $65 \mathrm{f}$. Iddings, Joseph Paxson: Recollections of a Petrologist. Ed. by Davis A. Young. Boulder (Colorado) 2015. S. 218 (Register). - History of Geoscience. Celebrating 50 years of INHIGEO [International Commission on the History of Geological Sciences]. Ed. by W. Mayer ... Geological Society.

$P$ Bildarchiv UAH; graph. Slg. UBH. - Büste R.s von Prof. Dr. Hans Kindermann (1911-1997) im mineralog. Teil des Museums für Geowissenschaften der UH, INF 235.

\section{Rosenthal, Artur}

1922-1935 Nat.-Math. Fak. Angewandte Mathematik

* 24. Febr. 1887 Fürth (Mittelfranken)

$\dagger \quad$ o9. oder 15. Sept. 1959 Lafayette (Indiana) mosaisch

V Otto R. $\left({ }^{*} 1856\right)$ Kaufmann

M Jette geb. Heilbronner (1866-1946), s. Vertriebene Mitgl. der Akad. der Wiss. H (2009) S. 69 f., Lexikon jüdischer Einwohner Hs (2011) S. $357 \mathrm{f}$.

( unverheiratet.

$L b$ Seit WS 1905/o6 Studium an U und TH München, auch U Göttingen.

München: 22. Juli 1909 Dr. phil. an U; Okt. 1907 I., Okt. 1909 II. Lehramtsexamen; 1909-1911 Assistent am Math. Inst. der TH.

U München: 27. Juli 1912 Habilitation; seit Nov. 1920 nichtplanm. a. o. Prof. In dieser Zeit:

30. April 1917-3. Dez. 1918 Kriegsdienst.

UH: 15. Aug. 1922 Ern. zum planm. a. o. Prof. in Nachf. von Friedrich Pfeiffer; 27. Okt. 1922 Vereidigung; 1930 Ruf an U Gießen abgelehnt; 20. Mai 1930 Verleihung der Amtsbezeichnung und der akad. Rechte e. o. Prof.; 23. Mai 1932 Ern. zum o. Prof.; seit 6. April 1933 Beurlaubung aus rassischen Gründen, die am 28. April 1933 wieder aufgehoben wird „wegen Teilnahme an Gefechtshandlungen im Weltkrieg" (aus: UAH PA 5515); 2. Juni 1935 R. stellt Antrag auf Emeritierung mit Bericht über studentischen Boykott seiner Vorlesungen; seit 1. Okt. 1935 Entbindung von amtl. Pflichten; 31. Dez. 1935 Entzug der Lehrbefugnis.

KZ Dachau: 11. Nov.-10. Dez. 1938 Inhaftierung.

Juli 1939 Ausreise in die Niederlande mit Genehmigung der Behörden bis 1941; 1940 Emigration in die USA.

U of Michigan in Ann Arbor: Seit 1940 Lecturer und Research Fellow. 
U of New Mexico in Albuquerque: Seit 1942 Lecturer, seit 1943 Assistant Prof., seit 1946 Associate Prof.

Purdue-U in West Lafayette (Indiana): 1947-1957 Prof. In dieser Zeit:

UH: 5. Sept. 1949 R. verzichtet auf den ihm angebotenen Lehrstuhl für Mathematik als Nachf. von William Threlfall (s. Drüll (2009) S. 619f.); 8. Dez. 1953 Wiedergutmachungsbescheid des Kultusministeriums Baden-Württ. beurkundet R. die Rechtsstellung e. von seinen amtlichen Verpflichtungen entbundenen o. Prof. mit Wirkung vom 1. April 1949.

Okt. 1932-April 1933 (Niederlegung des Amts) Dekan der Nat.-Math. Fak. der UH

E 1930 (1937 Austritt) Mitglied der Akademie der Wissenschaften $\mathrm{H}$.

Qu UAH PA 5515; Fak.-Akte H-V-4/31 Nr. 47; B-3182/19.

$W$ Neuere Untersuchungen über Funktionen reeller Veränderlichen in: Enzyklopädie der mathematischen Wissenschaft (1924). - Set Functions. Albuquerque 1948. (Mitverf.) Introduction to the theory of measure and integration. Stillwater 1955.

L Jüdische National-Biographie 5 (1930) S. 246; Kürschner (1931) Sp. 2424; Poggendorff 7a (1958) S. 815. Nachruf in: Jahresbericht der Dt. Mathematiker-Vereinigung 63 (1960) S. 94-96, 73 (1971/ 72) S. 167. - Dictionary of Emigrés 2 (1983) S. 989; WBIS; Mussgnug (1988) S. 299 (Register); Math. Institute in Deutschland (1989) S. 288 (Register); Jansen (1992a) S. 168 (Register); Wennemuth (1994) S. 638 (Register); Jung (1999) S. 9-11, 2123, 34-40; Siegmund-Schultze (2009) S. 468 (Register); Vertriebene Mitgl. der Akad. der Wiss. H (2009) S. 65-71; Lexikon jüdischer Einwohner Hs (2011) S. 357; Homo Heidelbergensis mathematicus online. - Leo, Paul Christopher: Wilhelm Groh ... Hamburg 2012. S. 147. Mathematik in der Heidelberger Akademie der Wissenschaften zus.gestellt von Gabriele Dörflinger. Ein Projekt der Fachinformation Mathematik der Universitätsbiblio- thek Heidelberg, s. http://www.ub.uni-heidelberg. de/archiv/16931 (Stand: April 2014). • Pölzer, Jule Franca: Entlassungen an der Universität Heidelberg im Dritten Reich am Beispiel von Gustav Radbruch und A.R. Seminararbeit. Universität Heidelberg 2015.

P Bildarchiv UAH; Vertriebene Mitgl. (2009).

\section{Rosshirt, Johann Conrad Eugen Franz}

1819-1870 Jur. Fak.

Strafrecht, Römisches Recht, Staats- und Rechtsgeschichte, Kirchenrecht; 1842-1849 auch Badisches Landrecht

* 26. Aug. 1793 Oberscheinfeld (bei Bamberg)

$\dagger \quad$ 05. Juni 1873 Heidelberg kath.

V Adam Franz R. (1754-1821) Amtsvogt, zuletzt Rentamtmann (Vorstand e. Behörde der landesherrlichen Finanzverwaltung)

M Maria Eva geb. Österreicher (ca. 1760-1805)

( 15. Mai 1819 Eva Josefine geb. Stenger (17971873)

K 1 T, 1 S: Franz R. (1820-1887) Jurist (Oberhofgerichtsrat, Oberhofgerichtskanzler); 1859 1860, 1863-1870, 1881-1887 Mitglied der II. Kammer des Badischen Landtags in Karlsruhe, 1884-1887 Mitglied des Dt. Reichstags, s. DBE 8 (2007) S. 553, WBIS

Vw Bruder: Johann Eugen R. (1795-1872), u.a. 1833-1868 o. Prof. für Geburtshilfe Erlangen, s. Professoren Erlangen (1999) S. 155f., DBE 8 (2007) S. 553, WBIS.

$L b$ 13. Nov. 1809 Immatrikulation als Student der Philosophie an Ludwig-Maximilians-U Landshut; seit 16. Nov. 1810 Studium der Rechtswiss. an U Erlangen; 15 . Sept. 1812 Dr. iur. utr. ebd.

1812-1816 Praktika an Gerichts- und Polizeibehörden; 1815 Auskultatorexamen (s. hierzu Levin Goldschmidt: Eintrag unter $L b(1851))$ in Bayreuth. 
U Erlangen: Seit 3. Juni 1817 bereits Privat-Dozent für Rechts- und Staatswissenschaften; 16. März 1818 Habilitation; seit 1. Okt. 1818 a. o. Prof.

UH: Dez. 1818 Ern. zum SS 1819 o. Prof.; Rufe abgelehnt: 1818/19 Ludwig-Maximilians-U Landshut, 1823 Tübingen; 1819-1827, 1834-1867 Beisitzer des Spruchkollegiums der Jur. Fak.; 20. Juni $1870 \mathrm{Ru}$ hestand. In dieser Zeit:

Karlsruhe: 1825-1828 Mitglied der II. Kammer des Badischen Landtags als Vertreter der Stadt Heidelberg.

1829, 1833, 1841, 1861 Prorektor der UH; 1822, 1825, 1829, 1833, 1837, April-Dez. 1840, 1844, 1849, 1854, 1860, 1865/66 Dekan der Jur. Fak. der UH

1821 Hofrat; 1833 Geh. Hofrat; 1862 Geh. Rat II. Klasse

E 1825 Ritterkreuz, 1847 Kommandeurkreuz II. Klasse des Ordens vom Zähringer Löwen; 1845 Komtur des päpstlichen Gregorordens.

Qu UAH PA 2164. - Matrikel Erlangen (1918) S. 404 und Anm. 14. GLA Abt. 205, Fasz. 455, Abt. 233, Fasz. 21926. Briefe von Heidelberger Gelehrten an Franz Joseph Mone. Hrsg. von Friedrich von Weech in: ZGORh 57. Jg. (1903) S. 478-484.

$W$ Lehrbuch des Criminalrechts. Heidelberg 1821. Nachdr. Goldbach 1996. - Geschichte und System des deutschen Strafrechts. 3 Bde. Stuttgart 1838 1839. Nachdr. Goldbach 1996. • Über das System der Verträge. Heidelberg 1839. • Grundriß zum Kirchenrecht der Katholiken und Protestanten. Heidelberg 1850. - Dogmengeschichte des Civilrechts. Heidelberg 1853. Nachdr. Stockstadt am Main 2006. - Äußere Encyklopädie des Kirchenrechts oder die Haupt- und Hilfswissenschaften des Kirchenrechts. 2 Bde. Heidelberg 1865-1867.

HG 1831 Zs. für Civil- und Criminalrecht in gleichmäßiger Rücksicht auf Geschichte und Anwendung des Rechts auf Wissenschaft und Gesetzgebung.
L Jäck, Joachim Heinrich: Zweites Pantheon der Literaten und Künstler Bambergs ... 2. Aufl. Bamberg 1843 (hier Geburtsname der Ehefrau: Banzer/Panzer). - ADB 29 (1889) S. 260-262; Arnim 2 (1952) S. 441; Jammers (1964) S. 177 u. ö.; Heidelberger Strafrechtslehrer (1986) S. 14-16. - Weigle, Regina Barbara: Die Staatsrechtslehrer an der Universität Heidelberg im 19. Jahrhundert. Frankfurt/M. 1986. S. 47-49. • Weisert (1991) S. 127 u. ö.; WBIS; Baur (2009) S. 128 f., 161-165, 173-177 u. ö.; Schroeder (2010) S. 130-133 u. ö.

P Bildarchiv UAH; graph. Slg. UBH.

\section{Rost, Franz Paul Wilhelm Karl Theodor}

1914-1923 Med. Fak.

Chirurgie

* 28. Mai 1884 Naumburg/Saale

$\dagger$ 23. Febr. 1935 Mannheim ev.

V Dr. Paul Heinrich Wilhelm R., Stabsarzt, Regierungs- und Geheimer Medizinalrat im Ministerium zu Rudolstadt

M Klara Friederike Dorothee geb. Beyme

$\infty$ 1. Aug. 1912 Frieda Marie geb. Baumann $\left({ }^{*} 1888\right)$

$\mathrm{K} \quad 2 \mathrm{~S}, 1 \mathrm{~T}$

Lb Seit SS 1903 Studium an U Tübingen, WS 1905/o6 Leipzig, SS 1906 Königsberg, WS 1906/07 Straßburg, SS 1907-WS 1907/08 H; Juni 1908 ärztl. Staatsprüfung in $\mathrm{H}$.

Medizinalpraktikant/Assistent während des praktischen Jahres: Seit Juli 1908 Hygien. Inst. der UH, März-Juni 1909 Innere Abt. des Städtischen Krankenhauses in Wiesbaden.

UH: 22. Dez. 1908 Dr. med.; 1. Juli 1909 Approbation; seit 15. Sept. 1909 Assistent am Anatom. Inst. 
Dresden: Seit 1. Okt. 1910 Assistent am Patholog.Anatom. Inst. des Friedrichstädter Krankenhauses.

UH: Seit Sept. 1911 Assistent, seit 27. Mai 1919 Oberarzt an Chirurg. U-Klinik; 13. Juni 1914 Habilitation; seit 26. Juli 1919 nichtetatm., seit 1920 nichtplanm. a. o. Prof.

Mannheim: 1. Febr. 1923-23. Febr. 1935 (†) Leiter der Chirurg. Abt. des Städtischen Krankenhauses.

$Z$ „An den operativen Zwangssterilisationen, die nach dem Gesetz zur Verhütung erbkranken Nachwuchses vom 14. Juli 1933 vorgenommen wurden, beteiligten sich die Chefärzte der [Mannheimer] Chirurgischen und der Geburtshilflich-Gynäkologischen Abteilung der Städtischen Krankenanstalten, [u. a.] ... Franz Rost ... " (aus: Bauer, Axel W.: Festvortrag aus Anlass des Jubiläums „300 Jahre öffentliches Gesundheitswesen in Mannheim" im Großen Hörsaal des Mannheimer Universitätsklinikums am 21. April 2002. Hrsg. vom Universitätsklinikum Mannheim. Broschüre. Mannheim 2002. S. 8).

Erfinder des Granugenol-Öls (= Wundöl)

Geh. Rat

Qu UAH PA 7, 1140, 5520; RA 6173, 6789; Fak.-Akten H-III-111/152 fol. 16r, H-III-111/157 fol. 64r-72r, H-III-862/05 fol. 293r-298r. • GLA Abt. 235, Fasz. 2427. Auskunft: Rat des Kreises Naumburg, Bezirk Halle/S. (Geburtsurkunde 1884).

W Gesicht und Mundhöhle in: Lehrbuch der Kriegschirurgie. Hrsg. von August Borchard und Victor Schmieden. Leipzig 1912. 2. Aufl. 1919. • Beitrag zur Lehre von der chronischen Obstipation und ihrer chirurgischen Behandlung in: Centralblatt für die Grenzgebiete der Medizin und Chirurgie 28 (1915). - Streptokokkenserum als Prophylaktikum gegen Erysipel in: Münchener Med. Wochenschrift 17 (1918); Über den Verlauf der Sehnenscheidenphlegmonen bei Syringomyelie in: ebd. 51 (1918). • Pathologische Physiologie des Chirurgen. Leipzig 1920. 4. Aufl. 1938 u.d.T.: Pathologische Physiologie chirurgischer Erkrankungen (posthum erschienen; Mitverf.). (Engl. Übers.: The Pathological Physiology of Surgical Diseases. Philadelphia 1923.)

L Chirurgen-Kalender (1926) S. 276; Kürschner (1931) Sp. 2431 f., (1935) Sp. 1139; Wer ist's (1935) S. 1330; Fischer 2 ( $\left.{ }^{3} 1962\right)$ S. 1329 f.; WBIS; Bauer (2002) S. 55, 57, 83. 50 Jahre Deutsche Gesellschaft für Anästhesiologie und Intensivmedizin. Tradition und Innovation. Hrsg. von Jürgen Schüttler. Berlin 2003. S. 53, 64. - DBE 8 (2007) S. 555. Klinda, Gergely: Zur Geschichte der Pneumenzephalographie. Diss. Med. Fak. Charité. Berlin 2010. S. 56 f., 196. Bauer, Axel W.: Die Zwangssterilisationen während des Nationalsozialismus und das Mahnmal als Ort des Gedenkens. Vortrag im Rahmen der Übergabe des Mahnmals für die Opfer der Zwangssterilisationen in Mannheim ... am 5. März 2015. S. 5-7, siehe unter: http:// www.akjustiz-mannheim.de/Rede/Prof/Axel/Bau er/zwangssterilisationen.pdf (Ausdruck im UAH).

\section{Rosthorn, Alfons Edler von}

1902-1908 Med. Fak.

Geburtshilfe, Gynäkologie

* 19. Sept. 1857 Oed im Piestingtal (heute: Ortschaft von Waldegg im Bezirk Wiener Neustadt-Land)

$\dagger$ 09. Aug. 1909 Seckau (Kärnten)

- Stein (heute: Ortschaft von Viktring im Stadtbezirk Klagenfurt)

ev.

V Joseph Edler von R. (1816-1886) Industrieller, Gewerbe-Inspektor, s. ÖBL online 9 (1988) S. 271

M Josephine geb. Freiin von Manndorff (18401890)

๑ 17. Juli 1899 Helene geb. Wiet (1871-1939)

$\mathrm{K}$ keine 
Vw Bruder: u.a. Dr. phil. Arthur von R. (18621945) Diplomat und Schriftsteller, seit 1922 Honorar-Prof. für Sinologie an U Wien, s. ÖBL online 9 (1988) S. 269 f., NDB 22 (2005) S. $101 \mathrm{f}$ - Schwester: u. a. Helene von R. (18651929) Philantropin, s. ÖBL online 5 (1970) S. 7of.; Ehefrau von Ernst Lecher (1856-1926) (S von Zacharias Konrad L. (1829-1905) Schriftsteller, Journalist, s. ÖBL online 5, S. 71, NDB 14 (1985) S. $24^{*}$ ) seit 1884 Privat-Dozent Wien, seit 1891 a.o. und seit 1893 o. Prof. Innsbruck, 1909-1925 o. Prof. für Physik Wien, s. NDB 14 (1985) S. 24f. • Über die Familie R. in: Wurzbach, Constant von: Biographisches Lexikon des Kaiserthums Österreich. Wien 1874. 27. T. S. 85-89; ÖBL online 9 (1988) S. 269-272.

Lb U Wien: Seit WS 1876/77 Studium der Philosophie, Zoologie, seit 1880 Medizin; 1885 med. Staatsprüfung; März 1885 Dr. med.; Assistent: seit 1882 Anatom. Inst., seit 1885 Chirurg. Inst.

U Graz: Seit 1887 Assistent an Chirurg. Klinik.

U Wien: Seit 1888 Assistent an U-Frauenklinik; 1891 Habilitation.

U Prag: Seit Okt. 1891 Privat-Dozent und Leiter der U-Frauenklinik; seit 6. März 1892 a. o. Prof.; seit 8. Jan. 1894 o. Prof.

U Graz: Seit SS 1899 o. Prof. und Direktor der Frauenklinik; Rufe an U Groningen und Utrecht abgelehnt.

UH: Seit 28. Sept. 1902 o. Prof. und Direktor der U-Frauenklinik als Nachf. von Ferdinand Kehrer; Rufe abgelehnt: U Basel, Königsberg (Preußen), Straßburg, München.

U Wien: Seit SS 1908 o. Prof. und Leiter der II. UFrauenklinik.

1904/o5 Dekan der Med. Fak. der UH

1902 Geh. Hofrat

Siehe auch Julius Schottländer: Eintrag unter $Z[\mathrm{i}-$ tat]
E Mitglied: Geburtshilfliche Gesellschaft Leipzig, Société d’obstétrique, de gynécologie et de pédiatrie de Paris. 1905 Ritterkreuz I. Klasse des Ordens vom Zähringer Löwen.

Qu UAH PA 2166. • GLA Abt. 235, Fasz. 2428. • Auskunft: Archiv der Universität Wien.

$W$ Die Erkrankungen der weiblichen Geschlechtsorgane. 2 Bde. Wien 1896-1906. (Mitverf.) - Die Erkrankungen des Beckenbindegewebes in: Veitsches Handbuch 3,2 (1899). • Die Universitätsfrauenklinik in Heidelberg. Heidelberg 1904. (Mitverf.) • Siehe Buttron (1981) S. 86-9o.

$L$ A. von R. in memoriam in: Monatsschrift für Geburtshülfe und Gynäkologie 30 (1909) S. 260279 (mit Werkverz.). • Freund, W. A.: Macht der Zahlen in: Leben und Arbeit. Berlin 1913. S. 140 f. • Stübler (1926) S. 321; Fischer $2\left({ }^{3} 1962\right)$ S. 1330 f.; Buttron (1981) S. 83-97; Chronik Ärzte H (1985) S. 141. Zur Geschichte der Gynäkologie und Geburtshilfe. Aus Anlaß des 10ojährigen Bestehens der Deutschen Gesellschaft für Gynäkologie und Geburtshilfe. Hrsg. von Lutwin Beck. Berlin 1986. S. 188, 290 f., 296 u. ö. • ÖBL online 9 (1988) S. 269; WBIS; Zander (1991) S. 62f.; Dhom (2001) S. 625 f., 628; NDB 22 (2005) S. 101*. • Pickel, Hellmuth: Medizingeschichte - A. von R. - ein Liebling Asklepios' in: Gyn-Aktiv. Fachmagazin für Gynäkologie und Geburtshilfe 05 (2011). - Deutsche Biographie, s. https://www.deutsche-biographie.de/gn d116633905.html [07.11. 2017].

$P$ Bildarchiv UAH; graph. Slg. UBH.

\section{Rothacker, Erich Emil}

1920-1929 Phil. Fak.

Philosophie

* 12. März 1888 Pforzheim

$\dagger$ 10. Aug. 1965 Bonn

ev. 
V Emil Theodor R. (1855-1917) Großkaufmann, Schmuckhändler

M Julie Dorothea geb. Müller (1865-1952) Kolloratursängerin

$\infty$ 11. Nov. 1913 Elisabeth Mathilde Ferdinande Käthe geb. Bunger (1889-1969) Malerin

K 1 S: Johann Adam R. $\left({ }^{*} 1921\right.$ X 1941).

Lb Seit WS 1907/08 Studium der Philosophie, Naturwiss., Medizin an U Kiel, WS 1908/o9 Straßburg, seit SS 1909 München, anschl. Tübingen; 29. April 1912 Dr. phil. an U Tübingen; Forts. des Studiums an U: seit SS 1912 München, SS 1913-WS 1913/14 Berlin; 1914-1916 Eigenstudien.

1916-1918 Kriegsdienst.

UH: Seit 1919 Eigenstudien; 17. Jan. 1920 Habilitation; seit 1. Sept. 1920 Assistent am Phil. Seminar; nur SS 1923 Vorlesungsankündigung an Theol. Fak.: Übungen über Neuere Versuche, das "Wesen“ der Religion zu bestimmen, $1 \frac{1}{2}$ Stunden wöchentlich; seit 11. Sept. 1924 nichtplanm. a. o. Prof.

U Bonn: 25. Okt. 1928 zum SS 1929 Annahme des Rufes auf planm. a.o. Professur für Philosophiegeschichte; 23. Nov. 1928 zum SS 1929 Ern. zum o. Prof. für Philosophie und bis 1931 auch Lehrauftrag für Psychologie; 1929-1954 (Mit-)Direktor des Phil. Seminars und des Psycholog. Inst.; März 1945 Suspendierung durch amerik. Militärregierung; 17. Juni 1946 Wiedereinsetzung an U; seit Jan. 1947 erneute Suspendierung, s. hierzu Stöwer (2012) S. 294-296; 7. Nov. 1947 Wiederaufnahme der Lehrtätigkeit; 31. März 1954 Ruhestand. • In dieser Zeit:

Berlin: 8.-ca. 19. April 1933 Leiter der Abt. für Volksbildung im Reichsministerium für Volksaufklärung und Propaganda.

1939-1940 Kriegsdienst als Wehrmachtspsychologe.

E 1949 Mitglied der Akademie der Wissenschaften und Literatur Mainz.
Qu UAH PA 5526. - GLA Abt. 235, Fasz. 2430. • Mehring, Reinhard: Der Briefwechsel zwischen E. R. und Carl Schmitt 1933-1960 in: Deutsche Zs. für Philosophie. Berlin 2015. Bd. 63. S. 727-741. • Nachlaß: Universitäts- und Landesbibliothek Bonn. Auskunft: Standesamt Pforzheim. • Heitere Erinnerungen. Frankfurt/M. 1963. (Autobiogr.)

$W$ Einleitung in die Geisteswissenschaften. Tübingen 1920. 2. Aufl. 1930. Nachdr. 1972. • Logik und Systematik der Geisteswissenschaften. München 1927. 2. unveränd. Nachdr. 1970. - Geschichtsphilosophie. München 1934. • Die Schichten der Persönlichkeit. Leipzig 1938. 9. Aufl. Bonn 1988. Probleme der Kulturanthropologie. Bonn 1948. 3. Aufl. 1968. Philosophische Anthropologie. Bonn 1964. 3. Aufl. 1970. Gedanken über Martin Heidegger. Bonn 1973. "Das Buch der Natur“. Materialien und Grundsätzliches zur Metapherngeschichte. Aus dem Nachlaß hrsg. und bearb. von Wilhelm Perpeet. Bonn 1979.

MHG 1923-1944, 1949-1955 Dt. Vierteljahrsschrift für Literaturwissenschaft und Geistesgeschichte.

L Verzeichnis Bonn (1968) S. 251; Glockner (1969) S. 276 (Register); Arnim 4 (1984) S. 1422; Jansen (1992) S. 412 (Register); BBKL VIII (1994) Sp. 752756; Heiber II,2 (1994) S. 847 (Register); Heidelberg im Schnittpunkt intellektueller Kreise (1995) S. 170-182. • Böhnigk, Volker: Kulturanthropologie als Rassenlehre. Nationalsozialistische Kulturphilosophie aus der Sicht des Philosophen E.R. Würzburg 2002. - NDB 22 (2005) S. 117 f.; Klee, Personenlexikon (2007) S. 510; Hausmann (2008) S. 810 (Register). - Rudinger, Georg, Stöwer, Ralph: Die Psychologie an der Universität Bonn im Nationalsozialismus in: Zwischen Diktatur und Neubeginn (2008) S. 159-183. Tremmel, Frank: „Menschheitswissenschaft" als Erfahrung des Ortes. E.R. und die deutsche Kulturanthropologie. München 2009. Dyk, Silke van, Schauer, Alexandra: „... daß die offizielle Soziologie versagt hat". Zur Soziologie im Nationalsozialismus ... Essen 2010. S. 117 f. - Dokumentation der Debatte zur Tagung „E. R. und die Begriffsgeschichte“ vom 22.11. 2012-23.11.2012 in Berlin in: Forum Inter- 
disziplinäre Begriffsgeschichte. 1. Jg. 2. Ausg. Berlin 2012. Stöwer, Ralph: E. R. Sein Leben und seine Wissenschaft vom Menschen. Göttingen 2012.

$P$ Bildarchiv UAH.

\section{Rothe, Richard}

1837-1849, 1854-1867 Theol. Fak.

Neues Testament, Dogmatik

* 28. Jan. 1799 Posen (heute: Poznań, Polen)

$\dagger \quad$ 20. Aug. 1867 Heidelberg ev.-luth.

V Ernst Friedrich Wilhelm R. (1766-1844) Auditeur (= Justizbeamter), Finanzbeamter, u.a. 1822 in Breslau

M Charlotte Bernhardine Sophie geb. Müller $(\dagger 1833)$

$\infty$ 10. Nov. 1823 Luisa Wilhelmina Juliana geb. von Brück (1803-1861) Schwägerin von Leonhard Heubner (1780-1853), u. a. 1817-1853 Direktor des Predigerseminars in Wittenberg, s. auch BBKL II (1990) Sp. 795 f.

$\mathrm{K}$ keine

Vw siehe auch NDB 9 (1972) S. $38^{*}$ (unter Leonhard Heubner).

Lb Seit SS 1817 Studium der Theologie, auch Philosophie und Geschichte an UH, WS 1819/20-SS
Wittenberg: Seit Okt. 1828 (IV.) Prof., seit 1832 II. Direktor (I. Direktor: Leonhard Heubner) am Predigerseminar; zwischen 1832 und 1837 Rufe an U abgelehnt: Greifswald und Halle/S.

UH: Seit 27. April 1837 o. Prof. mit e. jährl. Besoldung von 2800.- Gulden und I. Direktor des am 18. Mai 1838 eröffneten Predigerseminars und damit auch I. U-Prediger an Peterskirche (im Sommer) und an Providenzkirche (im Winter, da beheizbar) in H; WS 1837/38 Dienstantritt; WS 1848/ 49 letzte Vorlesung. • In dieser Zeit:

Karlsruhe: 1843 Mitglied der Badischen Generalsynode.

U Bonn: 25. Sept. 1848 Berufung zum SS 1849 o. Prof. für Praktische Theologie; 6. Mai 1849 Antrittspredigt; Sept. 1853 eine von R. unerwünschte Ern. zum Konsistorialrat in Koblenz.

UH: 12. Nov. 1853 Ern. zum SS 1854 o. Prof. als Nachf. von Carl Ullmann mit e. jährl. Besoldung von 280o.- Gulden; 1854-1867 e. der Hauptlehrer am Ev.-Prot. Predigerseminar. In dieser Zeit:

Karlsruhe: 1855, 1861, 1867 Mitglied der Badischen Generalsynode; seit 1861 a. o. Mitglied des Ev. Oberkirchenrats; 1863-1866 Mitglied der I. Kammer des Badischen Landtags.

1848 Prorektor der UH; Jan.-Febr. 1839, 1842, 1846, 1856, 1860, 1862/63, 1866/67 Dekan der Theol. Fak. der UH

Dez. 1837: Einrichtung e. Fonds von 660o.- Gulden für die Errichtung e. Ev.-Prot. Predigerseminars in Heidelberg, s. hierzu UAH PA 2167 fol. 1 . Rückkehr ins Elternhaus; Anfang-Ende 1823 Hilfsprediger. • In dieser Zeit:

Berlin: Herbst 1823 II. theol. Prüfung; 12. Okt. 1823 Ordination in Nikolaikirche.

Rom: 1823 Ern., Jan. 1824-Mai 1828 preußischer Gesandtschaftsprediger.
1863 Begründer des Deutschen Protestantenvereins zusammen mit (siehe) Johann Caspar Bluntschli und (siehe) Daniel Schenkel

1844 Kirchenrat; 1853 Geh. Kirchenrat

E 1837 D. theol. UH. 
Qu UAH PA 2167; RA 6126f., 6718 fol. 8v, 9r. • GLA Abt. 205, Fasz. 457. Henß, Walter: R. R. und Karl Ullmann, ihr späteres Verhältnis beleuchtet aufgrund von Briefen Rothes in: ZGORh 122. Jg. (1974) S. 311-330. Nachlaß: UBH (Signatur: Heid. Hs. 2914-2975).

$W$ Die Anfänge der christlichen Kirche und ihre Verfassung. Wittenberg 1837. Reprint Frankfurt/M. 1963. • Denkschrift der Eröffnung des ev.prot. Predigerseminars zu Heidelberg. Heidelberg 1838. Theologische Ethik. 3 Bde. Wittenberg 18451848. 2. Aufl. in 5 Bden. 1867-1872. Zur Dogmatik. Gotha 1863. 3. Aufl. 1898. - Nachgelassene Predigten. Hrsg. von Daniel Schenkel und Johannes Bleek. 3 Bde. Elberfeld 1868-1869. - Dogmatik. Hrsg. von Daniel Schenkel. 3 Bde. Heidelberg 1870. - Stille Stunden. Aphorismen aus Rothe's Nachlaß. Hrsg. von Friedrich Nippold. Wittenberg 1872. Vorlesungen über Kirchengeschichte. Hrsg. von Hermann Weingarten. 2 Bde. Heidelberg 18751876. Gesammelte Vorträge und Abhandlungen R. R.s aus seinen letzten Lebensjahren. Eingeleitet von Friedrich Nippold. Elberfeld 1886.

L Nippold, Friedrich: R.R. 2 Bde. Wittenberg 1873-1874. 2. Aufl. 1877-1878. - Hausrath, Adolf: R. R. und seine Freunde. 2 Bde. Berlin 1902-1906. Verzeichnis Bonn (1968) S. 252. • Schmidt, Martin: R.R. als umfassender Denker in: Heidelberger Jahrbücher 13 (1969) S. 34-47; Henß, Walter: R.R.s Berufung nach Heidelberg 1837 in: ebd. 17 (1973) S. 175-189; Ders.: Drei Aktenstücke zur Berufung R. R.s nach Heidelberg 1837 in: ZGORh 137. Jg. (1989) S. 486-492. • BBKL VIII (1994) Sp. 759823; Album Professorum der Ev.-Theol. Fakultät Bonn (1995) S. 70-72 u. ö. • Krötke, Heike: Selbstbewusstsein und Spekulation. Eine Untersuchung der Spekulativen Theologie R. R.s unter besonderer Berücksichtigung des Verhältnisses von Anthropologie und Theologie. Hrsg. von Hans-Walter Schütte. Berlin 1999. - Osthof, Friederike: In deinem Lichte schauen wir das Licht. Die Wahrnehmung Gottes im Spiegel menschlichen Handelns. Zum theologischen Denken R. R.s in seinen Briefen, seinen Predigten und in der Theologischen Ethik. Bern 1999. - WBIS; NDB 22 (2005) S. 119 f. - Weyel, Birgit: Praktische Bildung zum Pfarrberuf. Das Predigerseminar Wittenberg und die Entstehung einer zweiten Ausbildungsphase evangelischer Pfarrer in Preussen. Tübingen 2006. S. 302 (Register). Bümlein, Klaus: R. R. und seine Freunde links des Rheins in: Praktische Theologie und Landeskirchengeschichte ... Berlin 2008. S. 305-314. - Rendtorff, Trutz: „Weltgeschichtliches Christentum“ - R.R. Theologische Ortsbestimmung für die Moderne in: Zs. für neuere Theologiegeschichte (2010) S. 1-19. - Ehmann, Johannes: R.R. und der Akademisch-Theologische Verein - Umbrüche in Universität und badischer Landeskirche nach 1860 in: Jahrbuch für badische Kirchen- und Religionsgeschichte. Stuttgart 2014. Bd. 7. S. 37-49. • Troeltsch-Gesamtausgabe 19 (2014) S. 506 (Register). • Exner, Konrad: R. R. Mitglied der Ersten Kammer des badischen Landtags in: Hierzuland - Das Regio-Magazin von Rhein, Neckar \& Main 32 (2017) S. 34-42. • Karcher, Stefan: Die Anfänge der Universitätsgottesdienste in der Heidelberger Peterskirche (Heidelberger Universitätsprediger (Online Dokumentation)). Theol. Fak. der UH. Online-Ressource (2017), s. https://www.uni-heidelberg.de/fa kultaeten/theologie/forschung/predigtforschung/ universitaetsprediger/universitaetsgottesdienstein-der-peterskirche.html (Biographie R.s 2018 in Vorbereitung).

$P$ Bildarchiv UAH; graph. Slg. UBH. • Büste in Heidelberger Peterskirche.

\section{Roux, Jacob Wilhelm Christian}

1819-1830 Phil. Fak.

Anatomische Zeichnungskunst, Figuren- und

Landschaftszeichnen

* 13. April 1771 Jena

$\dagger \quad$ 22. Aug. 1830 Heidelberg ev.

V Heinrich Friedrich R. (1728-1791) U-Fechtmeister, franz. Sprachmeister, s. Roux (1928) S. 4, 4of.

M Johanna Magdalena geb. Bittermann (17411821), s. ebd. S. 41, 94

( 19. April 1801 Pauline Johanna Georgia geb. Heiligenstett/Heyligenstädt (1772-1823), s. ebd. S. 52 
@ 10. Febr. 1825 Susanna Charlotte Mariana Wil helmina geb. Wippermann (1793-1862), s. ebd. S. 52,62

K 2 T (davon $1 \mathrm{~T}$ früh $\dagger$ ): Emilie R. (1808-1872), s. ebd. S. 62; Ehefrau von: Karl Friedrich Ludwig Löw Freiherr von und zu Steinfurth (1803-1868), u.a. 1826/27-1833 Privat-Dozent an UH, anschl. Richter, s. Emundts-Trill (1997) S. 228, WBIS; Rösner, Cornelia: Nassauische Parlamentarier ... T. 1. ... Wiesbaden 1997. S. 106. 2 S (davon 1 S früh $\dagger$ ): Carl Ernst Heinrich R. (1826-1894) Landschafts- und Tiermaler, s. WBIS, Roux, S. 62-64, Allg. Le xikon der Künstler 29 (1999) S. 122, NDB 22 (2005) S. $148^{*}$

Vw Großvater: François R. (1674-1750) Verfasser e. dt.-franz. Wörterbuchs, s. Roux, S. 20-37 u. ö., NDB 22 (2005) S. 148. • Schwager: (siehe) Johann Caspar Gensler.

Lb Jena: Seit 12. Dez. 1791 Studium der Mathematik, Naturwiss., Anatomie an U; 1797-1803 u.a. Zeichner für Vorlagen von Abb. des menschlichen Körpers für das Werk „Tabulae anatomicae“ des Anatomen und Chirurgen Justus Christian Loders (1753-1832, s. NDB 15 (1987) S. 7-10).

Dresden: 1798, 180o, 1801, 1802 und 1807 Studienaufenthalte mit Unterbrechungen; u.a. Schüler von Johann Christian Klengel (1751-1824; seit 1802 Prof. an Kunstakademie, s. Fröhlich, Anke: „Glücklich gewählte Natur ...“: J.C.K. ... Hildesheim 2005).

Jena und (seit 1809 auch) Weimar: Seit ca. 1801 Maler (privater Zeichenmeister) und Radierer (Studien- und Auftragsarbeiten in Porträt- und Landschaftsmalerei; Bekanntschaft mit Goethe); 7. Febr. 1813 als Lehrer am privaten Zeicheninstitut (Christoph Gotthilf Immanuel) Oehmes mit e. jährl. Vergütung von 12 Scheffel Korn und Gerste in Jena genannt, s. „Gelehrte“ Wissenschaft (2008) S. 292 und Anm. 39. - In dieser Zeit:

U Jena: 1806 Dr. phil.; seit 1808 externer Zeichenlehrer für die Unterweisung der Studierenden in den naturwissenschaftlichen Disziplinen; SS 18131819 festangestellter Lehrer der anatomischen Zeichenkunst; in dieser Zeit: u.a. 1813-April 1814 Flucht vor franz. Truppen in die Schweiz, April
1816-Frühjahr 1817 Aufenthalt in H; 1817-1819 Mitbegründer und Mit-Direktor e. Privat-Zeichenschule („Kunstschule“) in Jena.

UH: Seit 4. März 1819 (Ern.) a.o. Prof. mit e. Jahresgehalt von 8oo.- Gulden.

Über R.s Lehrmethoden im Zeichnen, s. „Gelehrte“ Wissenschaft (2008) S. 294-297.

Qu UAH PA 2168. • GLA Abt. 205, Fasz. 458 f. • Auskunft: Ev.-Luth. Kirchengemeinde - Stadtkirchenamt - Jena; Ev. Oberkirchenrat - Landeskirchliches Archiv - Karlsruhe; Universitätsarchiv Jena.

$W$ Malerische Ansichten aus der Gegend der Universitätsstadt Jena. Radierungen von J. R. Jena 1806. 2. Aufl. Text von Christian Gottfried Schütz ... Jena 1979. • Die Farben. Ein Versuch über Technik alter und neuer Malerei. 3 H. Heidelberg 18241829. - Beitrag zur Vervollkommnung der Technik in mehreren Zweigen der Malerei. Heidelberg 1828. - Entdeckungen aus dem Gebiete der physikalischen Farbenlehre. Heidelberg 1829.

L ADB 29 (1889) S. 409f. • Roux, Paul: Die Fechtmeisterfamilien Kreußler und Roux. Jena 1911. • Roux, Oscar: Der Réfugié François Roux, seine Ahnen und Nachkommen. Geschichte der Familie Roux in Biographien, mit einem Anhang. Jena 1928. S. 49-52 u. ö. • Weisert (1991) S. 126 u. ö. Heinstein, Patrick: Mir ist um Wahrheit zu thun ... J. W. C. R. Die Heidelberger Jahre des fast vergessenen Künstlers in: Badische Heimat: mein Heimatland. Zs. für Landes- und Volkskunde ... Freiburg/Br. 1994. 74. Jg. S. 495-509. - Schmeiser (1994) S. 408 u.ö.; Allg. Lexikon der Künstler 29 (1999) S. 122; WBIS; Heinstein (1999); NDB 22 (2005) S. 148 f; Ein Knab auf schnellem Roß (2006) S. 18. Maatsch, Jonas: Loders Anatomischer Atlas in: Ereignis Weimar. Anna Amalia, Carl August und das Entstehen der Klassik 17571807. Anlässlich der Ausstellung vom 1. April bis 4. Nov. 2007 im Schlossmuseum Weimar. Leipzig 2007. S. 270. "Gelehrte“ Wissenschaft. Das Vorlesungsprogramm der Universität Jena um 1800. Hrsg. von Thomas Bach ... Stuttgart 2008. S. $285 \mathrm{f}$. 
Anm. 13, 290-297. - Kunst und Handwerk in Weimar: Von der Fürstlichen Freyen Zeichenschule zum Bauhaus. Hrsg. von Kerrin Klinger. Weimar 2009. S. 40, 100-106 u. ö.

$P$ Siehe NDB.

\section{Rüdel, Marcellian (Taufname: Michael) OFM}

1798-1804 Theol. Fak., kath. Abt.

Moraltheologie, Orientalische Sprachen

* 04. Juni 1758 Kestert (Rhein-Lahn-Kreis)

$\dagger$ 25. Aug. 1830 Forst (bei Bruchsal, Baden) kath.

$\mathrm{V}$ N.N.

M N.N.

๑ unverheiratet.

Lb OFM: Seit 1776 Mitglied des Franziskanerordens; 9. Juni 1781 Ordination.

U Mainz: 1782-1786 Hörer der Theologie (ohne Matrikeleintrag); Studienassistent.

Aachen: 1786-1789 Lektor der Orientalischen Sprachen und Philosophie.

Düsseldorf: 1789-1791 Lektor für Kirchengeschichte.

Koblenz: 1791-1793 Lektor der Heiligen Schrift (Kirchengeschichte) und Morgenländischen Sprachen.

UH: 10. März 1794 Ern. zum Substituten des Ordinarius Albertin Schott, OFM (s. Drüll (1991) S. 139) als Nachf. von Arnold Wagner (s. ebd. S. 163 f.); Mai 1795 Dr. theol.; 10. Juni 1797 Gesuch Schotts an Kurfürst Carl Theodor um Ern. R.s zu seinem Nachfolger, s. UAH PA 2170; seit 9. Juni 1798 o. Prof. als Nachf. von Schott; seit 27. Juni 1798 jährliche Zahlung „aus den höchst Churfürstlichen Schenkungsgelder gedachtem Lehrstuhl anklebig[en] hundert fünfzig Gulden“ (aus: UAH PA 2170); 9. Jan.-Ende April 1799 Vorlesungen auch über Kirchengeschichte in Vertretung von Caspar Schmitz (aus: PA 2170); 25. Aug. 1804 Entlassung mit e. Pension von 40o.- Gulden.

Religionslehrer am Lyzeum: Seit 26. Nov. 1804 Baden (heute: Baden-Baden), seit 1808 Rastatt.

Forst: Seit 1814 Pfarrer.

1801 Dekan der Theol. Fak. der UH, kath. Abt., s. hierzu Weisert/Drüll/Kritzer (2007) S. 48

Z Am 30. Juli 1797 nimmt der Direktor des „Seminarium Carolinum“, einem Seminarienhaus für kath. Theologie-Studenten in Heidelberg, Lorenz Zerdurstinger (1797-1799 Ordinarius für Pastoraltheologie und Geistliche Beredsamkeit an UH, s. Drüll (1991) S. 181f.), zur anstehenden Ernennung R.s zum Ordinarius für Moraltheologie in einem „Votum particulare“ gegen die positive „FakultätsÄußerung über das Gesuch“ Stellung: „Die Rede ist hier von der Professur der theologischen Moral, welche ihrem Inhalte nach von der größten Wichtigkeit in der theologischen Fakultät ist. Nach der Meinung Votantis [i.e. Zerdurstinger, der ein Veto einlegt] muß der Lehrer der Moraltheologie mit der philosophischen Moral innigst vertraut sein, und die theologische Moral zuerst nach festen, allgemein giltigen moralischen Grundsätzen, übrigens gut theologisch und ächt katholisch, vortragen, und anschl. erst die Kasuistik darauf gründen, ohne daß die ganze Moral in einem Vortrage der Kasuistik bestehe. Dadurch würde dieses Gute bezweket, daß die jungen geistlichen Zöglinge in der Sittenlehre selbst nach den großen Bedürfnissen unserer Zeiten ihrer seits fest gegründet und in Stand gesezet würden, nicht nur fremde Sünden zu beurtheilen: sondern auch durch erhöhte tugendhafte Gesinnungen zu erst zu guten Menschen gebildet zu werden, ehe sie an der Bildung ihrer Mitmenschen arbeiten.

So viel als Unterzeichneter den Supplicirenden Herrn D[r.] Marcellian Rüdel mittelbar und unmittelbar kennt: so scheint ihm derselbe bei allen seinen guten Eigenschaften den oben aufgestellten Forderungen eines öffentlichen Morallehrers bis daher nur einseitig entsprochen zu haben. 
Unterzeichneter will durch diese Erklärung den übrigen persönlichen Eigenschaften des Herrn D. Marcellian um so weniger in etwas zu nahe tretten, als er denselben als einen recht braven und orthodoxen Mann schätzet, welcher ihm auch aus diesem Grunde besonders noch verehrlich ist, weil er durch besonderen Fleis und erbauliches ordensgeistliches Betragen selbst seinen klösterlichen Herrn Mitbrüdern zum besten Beispiele dienen kann.

Da einem zeitlichen Director eines geistlichen Seminariums nichts so nahe am Herzen liegen muß, als die Bildung und Vervollkommnung seiner Untergebenen: so hielt ich es für [meine] Pflicht, diese Bemerkungen vorzulegen.

Bei dieser Gelegenheit muß ich Pflichten halber noch erinnern, daß wenigstens der zu ernennende Herr Lehrer an ein zwekmäsigeres Schulbuch der Moral als die zeitherigen uralten D. Cuer und Antoine [Cuer, Moritz: Theologia dogmatica et moralis ... Münster 1778 und Antoine, Paul-Gabriel: Theologia moralis universa ... Venedig 1749] gewesen sind, angewiesen werden wolle" (aus: PA 2170).

Der Akademische Senat verlangt daraufhin von den Mitgliedern der Theol. Fak. einen "gutachtlichen Bericht" über „eine schickliche Auswahl ... eines für die christliche Sitten Lehre schicklicheren Lehrbuches als auch über andere etwa zur besseren Aufnahme des theologischen Studiums Katholischer seits nothwendige reformen ..." (aus: Brief des Dekans der Theol. Fak. Joannes a Cruce (s. Drüll (1991) S. 78-80) vom 22. Aug. 1797 in: PA 2179); siehe hierzu weiter die Berichte vom 23. Aug. 1797 in: PA 2170.

Qu UAH PA 2170; RA 6746. GLA Abt. 205, Fasz. $463 \mathrm{f}$.

$W$ Prima theologiae christianae principia et selectas de jure et justitia positiones: cum subjunctis polemico-criticis ex historia ecclesiastica parergis. Koblenz 1782. Institutiones et hermeneutica in S. Scripturam ... Mainz 1784. (Mitverf.) • Positiones selectae ex philosophia. Heidelberg 1790.

$L$ Freiburger Diöcesan-Archiv. Organ des kirchlich-histor. Vereins für Geschichte, Alterthums- kunde ... der Erzdiöcese Freiburg. Freiburg/Br. 1883. 16. Bd. S. 287. - Keller (1913) S. 69; Schneider (1913) S. 11. - Über M.R. in: Rhenania Franciscana. Sondernummer: Unsere Toten. Düsseldorf 1941. S. 145. Kullmann (1951) S. 262 f. • Der Regularklerus in den Kölner Bistumsprotokollen. 1661-1825. 1. Teil zus.gestellt von Jakob Torsy. Siegburg 1985. S. 467. - Burkard (1995) S. 252 (Register); BBKL XXXVIII (2017) Sp. $1224 \mathrm{f}$.

\section{Rüdel, Michael}

siehe Rüdel, Marcellian

\section{Rüger, Ludwig Paul Emil}

1923-1934, 1946-1955 Nat.-Math. Fak.

Geologie, Paläontologie

* 10. Aug. 1896 Wittuna (Steinkohlenbergwerk bei Pilsen; heute: Vytůn̆, Tschechien)

$\dagger$ 15. Mai 1955 Heidelberg

ev., später konf.-los

V Emil R. (1869-1928) Berg-Ingenieur, Bergwerks-Direktor

M Olga Emanuela geb. Freiin von Frey (18681938)

$\infty$ 25. Sept. 1923 Dr. Pauline Amalie geb. Haas $\left({ }^{*} 1896 \dagger\right.$ nach 1961) Paläontologin

$\mathrm{K}$ keine.

Lb 5. Febr. 1915-6. Dez. 1918 Kriegsdienst, zuletzt als Kriegsgeologe.

UH: Seit WS 1918/19 Studium; 1. März 192130. Sept. 1923 Hilfsassistent am Geologisch-Paläontolog. Inst.; 16. Dez. 1921 Rigorosum, 8. April 1922 (Datum der Promotionsurkunde) Dr. phil. nat.; 1. Okt. 1923-21. Jan. 1934 Voll-Assistent am Geologisch-Paläontolog. Inst.; 27. Okt. 1923 Habilitation; seit 7. Aug. 1929 nichtplanm. a. o. Prof.; seit WS 1931/32 Lehrauftrag für Paläontologie; 22. Jan. 1934 Beurlaubung für Vertretung von Wilfried von Seidlitz (1880-1945; 1919-1945 Prof. für Geologie an U Jena, 1933-1936 Präsident der Preußischen Geolog. Landesanstalt in Berlin) an U Jena. 
U Jena: 23. Jan. 1934-31. Juli 1944 Planm. a. o. Prof. am Geolog. Inst.; seit 1. Okt. 1943 planm. a. o. Prof. an Reichs-U Straßburg als Vertreter des Lehrstuhls für Geologie für den verstorbenen Otto Rudolph Wilckens (1876-1943).

Reichs-U Straßburg: 14. Okt. 1944 (Ern.) rückwirkend vom 1. Aug. 1944 „bis zur Besetzung“ der Stadt durch amerik. und franz. Militär im Nov. 1944 (aus: Standesliste in: UAH PA 5544) o. Prof. und Direktor des Geolog. Inst. mit e. Jahresgehalt von 9 30o.- Reichsmark.

U Jena: 1. Nov. 1944-13. April 1945 (Schließung der U) o. Prof.; 24. Juni 1945-31. Jan. 1946 Zwangsevakuierung nach Heidenheim an der Brenz auf Befehl der amerik. Militärregierung.

U Marburg: 1. Febr.-31. Juli 1946 Kommissar. Vertreter des Lehrstuhls für Geologie, Paläontologie.

UH: 24. Juni 1946 Ern. zum 1. Aug. 1946 o. Prof. und Direktor des Geologisch-Paläontolog. Inst. als Nachf. von Julius Wilser (s. Drüll (2009) S. 671f.) mit e. Jahres-Grundgehalt von $11600 .-$ Reichsmark und e. Kolleggeld-Garantie von 30oo.Reichsmark; 1. Okt. 1946 Erteilung der Zuzugsgenehmigung nach H; WS 1946/47 Beginn seiner Vorlesungen; 8. Febr. 1947 Vereidigung; Rufe an U abgelehnt: Prag, München, Mainz.

1946/47 Dekan, 1947/48 Prodekan der Nat.-Math. Fak. der UH

$E$ Mitglied der Akademie der Wissenschaften: 1947 H, 1952 München. - Teil-Nachlaß: Universitätsbibliothek Freiburg/Br.

Qu UAH PA 2548, 5544; Rep. 40-420; GF 155 . GLA Abt. 235, Fasz. 2432.

$W$ Geologischer Führer durch Heidelbergs Umgebung. Heidelberg 1928. • Die baltischen Länder. Estland, Lettland und Litauen. Heidelberg 1934. • Die Bodenschätze Großdeutschlands sowie Polens und der Slowakei. München 1937. 2. Aufl. 1939. • Bibliographie 1917-1954 in: UAH PA 2548 und Jahresberichte und Mitteilungen des oberrheinischen geologischen Vereins. Stuttgart 1957. N. F. Bd. 39.
L Ramdohr, Paul: L. R. in: Ruperto Carola 7. Jg., Nr. 17 (1955) S. 15. • Jahrbuch der Bayer. Akademie der Wissenschaften (1956) S. 229-233. Catalogus prof. Marburgensis 2 (1979) S. 886. - Mayer, Gaston: Badische Paläontologen. 1. Nachtrag (Ergänzungen und Berichtigungen) in: Mitteilungen des badischen Landesvereins für Naturkunde und $\mathrm{Na}$ turschutz N. F. 12 (28. Febr. 1981) H. 3/4, S. 254. • Badische Biographien N. F. II (1987) S. 231 f. Henke, Klaus-Dietmar: Die amerikanische Besetzung Deutschlands. 2. Aufl. München 1996. S. 763 f., 768. Wagenbreth (1999) S. 153, 183; Deutsche Biographie, s. https://www.deutsche-biographie.de/gn d116675497.html [07.11. 2017].

$P$ Bildarchiv UAH; Jahrbuch der Bayer. Akademie; Badische Biographien.

\section{Ruge, Georg Hermann}

1879-1883 Med. Fak.

Anatomie

* 19. Juni 1852 Berlin

$\dagger \quad$ 21. Jan. 1919 Zürich ev.

V Dr. Ludwig Magnus Wilhelm R. (1812-1897) Arzt, siehe R., L.M.W.: Erinnerungen aus meinem Leben ... Berlin 1889. Nachdr. Boston 2006.

M Maria Luise Caroline Philippine geb. Mayer (1825-1908) T von Dr. Carl Wilhelm M. (17951868) Gynäkologe und 1844 Gründer der heute noch bestehenden Gesellschaft für Geburtshilfe und Gynäkologie in Berlin, s. ADB 21 (1885) S. 122-124, WBIS

๑ 25. März 1885 Ernestine geb. Bänzinger (18641960), s. Organ (1993) S. 152 (Register)

$\mathrm{K}$ keine

Vw Bruder: Carl R. (1846-1926), u.a. 1882-1912 Direktor des Patholog. Inst. an U-Frauenklinik Berlin, 1896-1912 Prof. für Gynäkologie Berlin, s. Fischer $2\left({ }^{3} 1962\right)$ S. 1341, WBIS, Dhom (2001) S. 796 (Register) 
Vw Onkel: Arnold R. (1802-1880) Philosoph, politischer Publizist, s. NDB 22 (2005) S. 236-238, Geschichte U Leipzig 2 (2010) S. 921 (Register); Reinalter, Helmuth: A. R. ... Vom Radikalen Burschenschafter zum achtundvierziger Demokraten in: Akteure eines Umbruchs. Männer und Frauen der Revolution von 1848/ 49. Hrsg. von Helmut Bleiber u. a. Berlin 2003. S. 563-617; Der Redaktionsbriefwechsel der Hallischen, Deutschen und Deutsch-Französischen Jahrbücher 1837-1844. Hrsg. von Martin Hundt. Bd. 1: Der Briefwechsel um die Hallischen Jahrbücher. Berlin 2010. • Großneffe von Arnold R. (1802-1880): Arnold R. (18811945) 1910-1920 (Entziehung der Lehrbefugnis) Privat-Dozent für Philosophie an $\mathrm{UH}$, 1934-1945 (Entlassung) Archivrat am GLA Karlsruhe, s. UAH PA 613, 5550 f., RA 6432, 6859, 7231 und 7239, B-1266/1, B-3075/1, B-6631, B-8904, B-8910/191; Heidelberg im Schnittpunkt intellektueller Kreise (1995) S. 45 f., 58 f., 124, 129-133 u.ö., Badische Biographien N.F. IV (1996) S. 244-247; Himmlers Hexenkartothek. Das Interesse des Nationalsozialismus an der Hexenverfolgung. [Wiss. Großprojekt zur Erforschung der Hexenverfolgung.] Hrsg. von Sönke Lorenz u.a. Bielefeld 1999. S. 3545; Reichert (2001) S. 498 u. ö., Wolgast (2010) S. $175-177$.

Vw Onkel mütterlicherseits: Rudolf Virchow (1821-1902), u. a. seit 1856 o. Prof. für Pathologie an U Berlin, s. Goschler, Constantin: R. V. Köln 2002; R. V. ... Hrsg. von Christian Andree. Hildesheim 2009; Bauer, Axel W.: R. V. ... in: Universitas 65, Nr. 763 (2010) S. 34-53. Siehe auch Organ (1993) S. 13-16.

Lb Seit WS 1870/71 Studium an U Jena, anschl. Berlin; 4. Dez. 1875 Dr. med. an U Berlin; 1876 Staatsexamen in Berlin.

UH: Seit Herbst 1876 Assistent am Anatom. Inst.; 7. Juli 1879 Habilitation; seit 26. Juli 1883 a. o. Prof.

U Amsterdam: Seit WS 1883/84 a. o. Prof.; 5. Sept. 1888 Ern. zum o. Prof.

U Zürich: Seit 22. Juli 1897 (Ern.) o. Prof. und Leiter des Anatom. Inst.
E 1887 Mitglied der Dt. Akademie der Naturforscher Leopoldina Halle/S.

Qu UAH PA 2172; RA 5278, 6169, 6901. Briefe, Teil-Nachlaß: Schweizerische Nationalbibliothek in Bern, s. https://www.helveticarchives.ch/resultatliste.aspx. - Siehe auch Archiv der Dt. Akademie der Naturforscher Leopoldina Halle/S. • Auskunft: Ev. Zentralarchiv - Kirchenbuchstelle Berlin; Universitätsarchiv Zürich.

$W$ Untersuchungen über die Gesichtsmuskulatur der Primaten. Leipzig 1887. Anleitungen zu den Präparierübungen an der menschlichen Leiche. 2 T. Leipzig 1888. 5. Aufl. 1921. • Die Körperformen des Menschen in ihrer gegenseitigen Abhängigkeit und ihrem Bedingtsein durch den aufrechten Gang. Leipzig 1918. - Siehe auch Organ (1993) S. 137-140.

L Cloetta, Max: G.R. in: Jahresbericht der Universität Zürich (1918/19) S. 58-61. • Stübler (1926) S. 307; Fischer 2 ( $\left.{ }^{3} 1962\right)$ S. 1341f.; Universität Zürich (1983) S. 576 f.; WBIS; Jansen (1992) S. 412 (Register); Ders. (1992a) S. 168 (Register); Organ (1993); Doll (2014) S. 319-323 u. ö.; Kaesler (2014) S. 670-673. - Flatau, Elke: Der wissenschaftliche Autor. Aspekte seiner Typologisierung am Beispiel von Einstein, Sauerbruch ... Wiesbaden 2015. S. 207-209 u. o. - Deutsche Biographie, s. https:// www.deutsche-biographie.de/gnd119156865.html [07. 11. 2017]; Doll/Kirsch/Eckart (2017) S. 46, 112.

P Bildarchiv UAH; graph. Slg. UBH; Cloetta (1918/ 19). - Schweizerische Nationalbibliothek in Bern (Signatur: GS-FOTO-PORT-RUGE_GEORG-1).

\section{Rummer, Friedrich}

1863-1882 Phil. Fak.

Mathematik

* 1815 Plittersdorf (heute: Stadtteil von Rastatt)

$\dagger$ 11. Sept. 1882 Neuenheim (heute: Stadtteil von Heidelberg)

ev. 
V Friedrich R., Wasser- und Straßenbauingenieur M N.N.

@ Margarethe geb. Schwaner († vor 1882)

$\mathrm{K}$ mind. $1 \mathrm{~T}$

Lb Vor 1837 badischer Portepeefähnrich; 1837 Secondeleutnant im II. Badischen Infanterieregiment; 1839 Quittierung des Dienstes.

H: 1841-1882 Lehrer bzw. Prof. am Lyceum und an Höherer Bürger- und Gewerbeschule. • In dieser Zeit:

UH: Bereits vor 1863 hält R. Privat-Vorlesungen (s. Brief vom 9. Aug. 1865 in: UAH PA 2173); 9. Nov. 1863 Ern. zum a.o. Prof.; 15. März 1878 Bewilligung e. Honorars von 400.- Mark pro Semester (bis zu seinem Tod).

Am 15. Okt. 1863 antwortet das Ministerium des Innern auf einen Antrag der Heidelberger Phil. Fak. und des Engeren Senats, R., um ihm „Gelegenheit zu geben, anstatt des bisher an Studirende ertheilten Privatunterrichts Vorlesungen an der Universität zu halten“, eine a.o. Professur „ohne Verwilligung einer Besoldung“ zu verleihen: „... Da nun Prof. Rummer möglicherweise nicht geneigt sein könnte, ein unbesoldetes Ehr[en]amt an der Universität zu übernehmen, derselbe auch ein Gesuch um Ernennung zum außerordentlichen Professor bisher nicht gestellt hat, so wird der engere Senat veranlasst, hierüber mit ihm ins Benehmen zu treten, und ihn eventuell zur Einreichung eines Gesuches um Charakterisirung als außerordentlicher Professor an der Universität zu veranlassen“ (aus: PA 2173); nachdem R. sein Gesuch eingereicht hat, erfolgt die Ernennung zum a. o. Prof.; er verpflichtet sich, 6-8 Stunden wöchentlich Kollegien über Mathematik zu halten (aus: PA 2173). Am 22. Juli 1865 stellt R. vergeblich den Antrag auf „Verwilligung eines Gehalts als Belohnung für seine Lehrtätigkeit" (aus: Brief des Ministeriums des Innern vom 21. Sept. 1865 in: PA 2173). Nachdem er am 15. Juni 1877 erneut e. Antrag auf Besoldung stellt, befürwortet der Engere Senat am 17. Juli 1877 ein „Funktionsgehalt" für R., die Höhe des Betrages soll das Ministerium festsetzen; die Remuneration soll er für seine elementar-mathematischen Vorlesungen für die Studierenden der Kameralwiss. erhalten (aus: Brief des Engeren Senats vom 17. Juli
1877 in: PA 2173); am 15. März 1878 bewilligt das Ministerium ein Honorar von 400.- Mark pro Semester.

Im SS 1878 hält R. wöchentlich 12 Stunden Vorlesungen über „Stereometrie (2-stündig, 7 Zuhörer), Trigonometrie (3-stündig, 5 Zuhörer), praktische Geometrie (2-stündig, 3 Zuhörer), auch Differential- und Integralrechnung mit Anwendungen (5-stündig, 4 Zuhörer)" (aus: Brief vom 29. Juli 1878 in: PA 2173).

Siehe auch Moritz Cantor: Eintrag unter Z[itat]

$\mathrm{Q} u$ UAH PA 2173; siehe auch PA 1416 (Cantor); RA 6679; Fak.-Akte H-IV-102/62 fol. 28r.

$W$ Lehrbuch der Elementargeometrie. Heidelberg 1841. 2. Aufl. 1848. - Lehrbuch der Trigonometrie. Heidelberg 1845. 2. Aufl. 1867. • Die Buchstabenrechnung und Lehre von den Gleichungen. 2 T. Heidelberg 1847. 5. Aufl. 1881. - Neue Lehrsätze über eine krumme Linie. Heidelberg 1868.

$L$ Wechmar (1846) S. 78, 267. • Über F. R. in: Heffter, Lothar: Beglückte Rückschau auf neun Jahrzehnte. Ein Professorenleben. Freiburg/Br. 1952. S. 35. Math. Institute in Deutschland (1989) S. 163; Kern (1992) S. 71 u.ö.

$P$ Bildarchiv UAH.

\section{Ruska, Julius Ferdinand}

1911-1927 Phil. Fak.

Semitische Philologie

* $\quad$ 09. Febr. 1867 Bühl (bei Baden-Baden)

$\dagger$ 11. Febr. 1949 Schramberg (Schwarzwald) kath., seit Jan. 1897 ev.

V Ferdinand R. (1826-1901) Hauptlehrer

M Julie geb. Saas (1832-189o)

( ) 5. Aug. 1899 Elisabeth geb. Merx (1874-1945; ev.) Krankenschwester; T von: (siehe) Adalbert M. (ev.) 
K 4 S (1 S früh †), u.a. Ernst R. (1906-1988) seit 1949 Leiter der Abt. für Elektronenmikroskopie am Fritz-Haber-Inst. der Max-Planck-Gesellschaft in Berlin-Dahlem, seit 1955 u.d.N. Inst. für Elektronenmikroskopie am FritzHaber-Inst., seit 1955 auch wiss. Mitglied der Max-Planck-Gesellschaft; 1949 Ern. zum Prof. FU Berlin, 1959 auch an TU Berlin; 1986 Nobelpreisträger für Physik, s. Nachlaß in Staatsbibliothek zu Berlin; NDB 22 (2005) S. $297 \mathrm{f}$. Helmut R. (1908-1973) 1938-1945 Leiter (zus. mit seinem Schwager Bodo von Borries) des Laboratoriums für angewandte Elektronenmikroskopie bei Siemens \& Halske AG Berlin-Spandau, 1948-1951 Prof. U Berlin und Leiter der Abt. für Mikromorphologie an Dt. Akademie der Wissenschaften Berlin-Buch bzw. am Max-Planck-Inst. für physikalische Chemie und Elektro-Chemie Berlin-Dahlem, 1952-1958 Leiter der Abt. für Mikromorphologie New York State Dept. of Health und u. a. Associate Prof. Union U in Albany (New York), seit 1958 Direktor des Inst. für Biophysik und Elektronenmikroskopie an Med. Akademie (seit 1965 U) Düsseldorf, s. UAH PA 5560, NDB 22 (2005) S. 298; Gelderblom, Hans R., Krüger, Detlev H.: H.R.: His role in the evolution of electron microscopy in the life sciences, and especially virology in: Advances in Imaging and Electron Physics. Ed. by Peter W. Hawkes ... Amsterdam 2014. Vol. 182. S. 1-94.

K 2 T: u.a. Hedwig R. (1912-2008) Lehrerin; Ehefrau von Bodo von Borries (1905-1956), u. a. 1938-1945 Leiter (zus. mit seinem Schwager Ernst Ruska) des Laboratoriums für angewandte Elektronenmikroskopie bei Siemens \& Halske AG Berlin-Spandau, 1948 Gründer des Rheinisch-Westf. Inst. für Übermikroskopie in Düsseldorf, seit 1949 Honorar-Prof. an Med. Akademie ebd., seit 1953 o. Prof. TH Aachen, s. Ruska, Ernst: Nachruf in: Zs. für wiss. Mikroskopie und für mikroskopische Technik 3/63 (1957) S. 129-132; NDB 22 (2005) S. 296*

Vw Schwager: (siehe) Maximilian Wolf. Siehe auch Lebenserinnerungen (1937/38) Kapitel 1: Vorfahren und weitere Familie.
Lb Seit WS 1884/85 Studium der Mathematik, Naturwiss., Philosophie, Philologie an U Straßburg, seit 5. Mai 1886 H, WS 1887/88 Berlin; 28. April 1888 Rückkehr an UH; 15. März 1889 math.-naturwiss. Staatsexamen in $\mathrm{H}$.

Baden-Baden: Seit Winter 1888 Aufenthalt im Elternhaus in Badenscheuern (heute: Ortsteil von B.-B.); seit Sept. 1889 Volontär am Gymnasium; Nov. 1889-Jan. 1890 Lehrer-Vertreter am Progymnasium mit Realabteilungen in (Karlsruhe-)Durlach.

Oberrealschule (heute: Helmholtz-Gymnasium) in H: Seit Herbst 1890 Lehramtspraktikant, seit 28. März 1896 Prof. (siehe hierzu Z); seit 1. Okt. 1909 Beurlaubung; 12. Sept. 1910 auf eigenen Antrag Austritt aus Schuldienst unter Verzicht auf Pension. • In dieser Zeit:

UH: Seit WS 1890/91 Hörer der Orientalischen Philologie, Theologie; 19. Dez. 1895 Rigorosum, 29. Febr. 1896 (Datum der Promotionsurkunde) Dr. phil.; 1896-ca. 1898 Hörer der Mineralogie und Geologie; 4. Nov. 1911 Habilitation für Orientalische Philologie; 1913-Ende 1914 Beurlaubung aus Krankheitsgründen (nervöser Zusammenbruch); seit 30. Dez. 1915 nichtetatm., 1920-1927 nichtplanm. a. o. Prof.; seit SS 1924 Lehrauftrag für "Geschichte der Wissenschaft im Orient"; 19241927 (Stillegung des Inst.) auch Leiter des von der Josefine und Eduard von Portheim-Stiftung für Wissenschaft und Kunst eingerichteten Inst. für Geschichte der Naturwissenschaften in $\mathrm{H}$, zunächst Augustinergasse 5, dann Hauptstraße 48. • In dieser Zeit:

H: 1915 Rückkehr als Lehrer aus finanziellen Gründen, 21. Sept. 1917 (Ern.)-1. April 1924 Prof. mit e. anfänglichen Jahresgehalt von 4960.- Mark am Gymnasium (heute: Kurfürst-Friedrich-Gymnasium „KFG“).

U Berlin: Seit WS 1927/28 Honorar-Prof. und Leiter des zu begründenden Inst. für Geschichte der Naturwiss., das 1930 im Inst. für die Geschichte der Medizin und Naturwiss. an der Charité aufgeht; 1931-1938 Abt.-Vorsteher an diesem Inst. 
Schramberg: Während der Bombenangriffe auf Berlin 1943 Übersiedlung zu den Schwiegereltern seines Sohnes Ernst in den Schwarzwald.

$Z$ „Bei meiner Anstellung als Professor [für math.naturwiss. Fächer] an der [Heidelberger] Oberrealschule [1896] wurde mir auf Betreiben eines Mitglieds des Beirates [(siehe) Friedrich Eisenlohr, Stadtrat, 1872-1904 (nichtetatm.) a.o. Prof. für Mathematik und Physik an UH] das Versprechen abgenommen, mich auf keinen Fall zu habilitieren. Da eine Weigerung zugleich meine Versetzung von Heidelberg nach sich gezogen hätte, fügte ich mich und mußte mich durch das Vertrauen des Direktors [Robert] Salzer [(1831-1896) 1872-1896 Direktor der Oberrealschule] entschädigt finden, der mir sogleich den mineralogisch-geologischen Unterricht in Oberprima übertrug" (aus: eigenhändigem Lebenslauf von 1911 in: UAH PA 5561). In seinen Lebenserinnerungen schreibt R., der Einwand gegen seine Ernennung zum Oberrealschul-Professor wäre gewesen, er würde in absehbarer Zeit den Lehrerberuf aufgeben, um die universitäre Laufbahn einzuschlagen.

E 1927 Mitglied der Dt. Akademie der Naturforscher Leopoldina Halle/S. - Dr. phil. h.c. (U unbekannt).

Qu UAH PA 5561; K-Ia-671/13. - GLA Abt. 235, Fasz. 2437. Nachlaß: Ruska Familienarchiv, Bahnhofstrasse 8, 12207 Berlin. Siehe auch Archiv der Dt. Akademie der Naturforscher Leopoldina Halle/S. - Auskunft: Standesamt in Bühl. - Mitteilungen: Herr Thomas Ruska, Berlin. - Lebenserinnerungen. Berlin 1937/38. Hrsg. von Thomas Ruska. Online veröffentlicht, s. http://julius.ruska. de/lebenserinnerungen.html/index.html (Stand: 03. Sept. 2001).

$W$ Die Wirbeltiere, nach den Anforderungen des Lehrplans der badischen Oberrealschulen. Heidelberg 1902. Seit 4. Aufl. u.d.T.: Tierkunde in aufsteigender Darstellung ... Leipzig 1915. 5. Aufl. 1921. Geologische Streifzüge in Heidelbergs Umgebung ... Leipzig 1908. - Leitfaden der Mineralogie. Leipzig 1910. 2. Aufl. 1921. Das Steinbuch des Aristoteles. Heidelberg 1912. - Tabula Smaragdina. Ein Beitrag zur Geschichte der hermetischen Li- teratur. Heidelberg 1926. - Turba Philosophorum. Ein Beitrag zur Geschichte der Alchemie. Berlin 1931. - Das Buch der Alaune und Salze. Berlin 1935. - Studien zu den chemisch-technischen Rezeptsammlungen des Liber Sacerdotum. Berlin 1935. - Siehe auch Das „Goldene Buch“ des KFG (1994) S. 134f., NDB 22 (2005) S. 297. Chronologisches Verzeichnis der Arbeiten J. R.s, s. http://ju liusruska.digilibrary.de/digital_library.html (abgerufen am 10. Okt. 2016; Ausdruck im UAH).

(M)HG 1909-1912 (1913-1914) Pädagogisches Archiv. Merx, Adalbert: Das Evangelium des Johannes in: Die vier kanonischen Evangelien nach ihrem ältesten bekannten Texte ... Mit Register für das ganze Werk nach dem Tode des Verfassers hrsg. von J. R. Teil 2. Hälfte 2 [2]. Berlin 1911.

L Kürschner (1928/29) Sp. 1997, (1935) Sp. 1154, (1940/41) Sp. 530. - Kraus, Paul: J.R. in: Osiris. Published by the University of Chicago Press on behalf of The History of Science Society. Chicago 1938. Bd. 5. S. 4-40 (mit Werkverz.). - WBIS; Arnim 2 (1952) S. 457, 4 (1984) S. 1437; Jansen (1992a) S. 168 (Register); Das "Goldene Buch“ des KFG (1994) S. 131-135. - Hanisch, Ludmila: Die Nachfolger der Exegeten. Deutschsprachige Erforschung des Vorderen Orients in der ersten Hälfte des 20. Jahrhunderts. Wiesbaden 2003. S. 231 (Register). - NDB 22 (2005) S. 295-297; Kriegstagebuch K. Hampe (2007) S. 992 (Register); Engehausen (2008) S. 37, 55. - Siehe auch Homepage des Ruska-Familienarchivs unter http://julius.ruska. de/frame.html (abgerufen im Mai 2015). • Deberling, Oliver: Das vergessene Heiligtum: Wie aus einem israelischen Heiligtum der Heilige Gral wurde. Norderstedt 2017. S. 459 f. u. ö.

$P$ Bildarchiv UAH. 


\section{Ruth, Carl Friedrich Emil}

1844-1869 Phil. Fak.

Neuere Sprachen

* 14. Febr. 1809 Hanau

$\dagger$ 28. Aug. 1869 Heidelberg prot.

V Johann Heinrich R. ${ }^{*}{ }^{*}$ 1779) Privat-Lehrer, Erziehungsrat

M Friederike Sophie geb. Beykert

(16. Sept. 1833 Ida Susanne Emilie geb. Pickford (1809-1845) Harfinistin

$\mathrm{K}$ keine.

Lb Seit 1828 Studium an U Marburg, anschl. München.

UH: Seit 30. April 1832 Forts. des Studiums; 18. Dez. 1832 Dr. phil.; 23. Dez. 1837 Staatsexamen im Fach Französisch in Karlsruhe; seit 4. April 1838 Erlaubnis, engl. und franz. Vorlesungen an UH zu halten (aus: UAH PA 2175).

Florenz: 1840-1844 Direktor einer prot. Erziehungs-Anstalt.

UH: 21. Febr. 1844 Ministerium des Innern gestattet R., „Unterricht in der französischen und italienischen Sprache zu ertheilen, daß er sich aber ordnungsmäsig zu habilitieren habe, wenn er Vorlesungen über Literaturgeschichte an der Univer-
Habilitation nach bestandenem Kolloquium und gehaltener Probevorlesung, jedoch - mit ministerieller Genehmigung - ohne Disputation (aus: PA 2176); 25. Okt. 1847 R. bewirbt sich um Professorentitel, erhält aber nicht die „Fürsprache der Fakultät" (siehe hierzu PA 2176 vom 18. Nov. 1847); 18. Dez. 1867 Ern. zum a.o. Prof. (,jetzt einstimmig und ohne irgend eine Einwendung" seitens der Fak.; R. war mittlerweile der älteste Privat-Dozent der U, aus: PA 2176).

$Q u$ UAH PA 2175f.; Fak.-Akten H-IV-102/27 fol. 95r-98r, H-IV-102/40 fol. 94r. - Toepke V (1904) S. 482. GLA Abt. 205, Fasz. 461.

$W$ Geschichte der italienischen Poesie. 2 Bde. Leipzig 1844-1847. Studien über Dante Allighieri. Ein Beitrag zum Verständniss der Göttlichen Komödie. Tübingen 1853. (Ital. Übers.: Studi sopra Dante Allighieri per servire all'intelligenza delle Divina Commedia. Venedig 1865. Riferimento: Milano 2008.) - Geschichte des italienischen Volkes unter der Napoleonischen Herrschaft als Grundlage einer neuesten Geschichte Italiens. Leipzig 1859. - Geschichte von Italien vom Jahr 1815 bis 1850.2 Bde. Heidelberg 1867.

L Almanach Heidelberg (1886) S. 95; Kalkhoff (2010) S. 33f. u. o.; Wissenschaftsatlas der UH (2011) S. 109; Riecke (2016) S. 8; Deutsche Biographie, s. https://www.deutsche-biographie.de/gnd11 6711833.html [07.11. 2017]. 


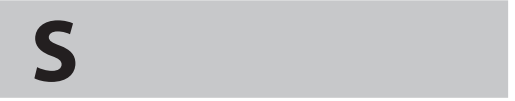

Saar, Anton

siehe Sar

\section{Sachs, Hans}

1920-1933 (1935) Med. Fak.

Immunitäts- und Serumforschung

* o6. Juni 1877 Kattowitz (Oberschlesien; heute: Katowice, Polen)

$\dagger$ 23. März 1945 Dublin

mosaisch

V Elias S., Industrieller (Kattowitzer AG für Eisenhüttenbetrieb), Bankgründer

M Flora geb. Hausdorff

(13. April 1905 Adelheid Sophie Charlotte (Lotte) geb. Grelling (1884-1978), siehe UAH Rep. 40-441; Lexikon jüdischer Einwohner Hs (2011) S. 365, Holfter/Dickel (2017) S. 445 (Register)

$\mathrm{K} \quad 1 \mathrm{~S}, 1 \mathrm{~T}$, siehe Lexikon jüdischer Einwohner, S. 365 , Holfter/Dickel, S. 288

Vw siehe NDB 22 (2005) S. 332*

$\mathrm{Lb}$ Seit WS 1895/96 Studium an U Freiburg/Br., anschl. Breslau, Berlin; 1899 Staatsexamen in Berlin; 1900 Dr. med. an U Leipzig; seit 1900 Volontär am Senckenbergischen Patholog. Inst. in Frankfurt/M.

Frankfurt/M.: Seit April 1901 Assistent, seit April 1905 Mitglied, Dez. 1907 Verleihung des Titels „Prof.", seit April 1910 etatm. wiss. Mitglied am Inst. für Experimentelle Therapie; 14. Jan. 191531. Aug. 1920 stellvertr. Direktor des genannten Inst.; 30. Sept. 1914-31. Aug. 1920 außerdem a. o. Honorar-Prof. an neugegründeter U.

UH: 20. Febr. 1920-31. Dez. 1935 Planm. a. o. Prof. mit Amtsbezeichnung e. o. Prof. und Direktor der Wiss. Abt. am Inst. für Experimentelle Krebsfor- schung; 15. Nov.-5. Dez. 1923 Studienaufenthalt am Serum-Inst. in Kopenhagen; 6. April 1933 Beurlaubung aus rassischen Gründen; 28. April 1933 Wiedereinsetzung zur kommissar. Weiterführung der Amtsgeschäfte ohne Lehrerlaubnis; 7. Okt. 1935 Beurlaubung mit sofortiger Wirkung; 31. Dez. 1935 Versetzung in den Ruhestand aus o.g. Gründen. • In dieser Zeit:

H: 1930-1935 (eigene Abmeldung) Wiss. Mitglied des Kaiser-Wilhelm-Inst. (KWI) für med. Forschung.

Dez. 1938 Emigration über Großbritannien (Ankunft in Harwich am 27. Dez.), anschl. Aufenthalt in London, 20. Apr. 1939 Ankunft in Irland, dann Wohnsitz in Rathmines, e. Vorort von Dublin.

Dublin: Nach 1939 Mitarbeiter am Dept. of Bacteriology des Trinity College.

1928/29 Dekan der Med. Fak. der UH

E 1932 Mitglied der Dt. Akademie der Naturforscher Leopoldina Halle/S.; 1927 Korr. Mitglied der Gesellschaft für Mikrobiologie Wien. 1930 Ludwig Darmstädter-Preis mit der Paul Ehrlich-Plakette.

Qu UAH PA 1144, 5570; Quästurakte Rep. 271141. GLA Abt. 235, Fasz. 1578. • Siehe auch Archiv der Dt. Akademie der Naturforscher Leopoldina Halle/S.

$W$ Die Hämolysine und ihre Bedeutung für die Immunitätslehre. Wiesbaden 1902. • Über die Beziehung zwischen Toxin und Antitoxin und die Wege ihrer Erforschung. Leipzig 1905. (Mitverf.) • Die Hämolysine und die cytotoxische Sera ... Wiesbaden 1907. Über die Beziehung des Kobragiftes zu den roten Blutzellen in: Münchener Med. Wochenschrift (1908). S., H., Georgi, Walter: Zur Serodiagnostik der Syphilis mittels Ausflockung durch cholesterinierte Extrakte in: Medizinische Klinik - Zs. für innere Medizin in Klinik und Praxis (1918) Bd. 14, Nr. 33, S. 805-809. - S., H., Klopstock, Alfred: Methoden der Hämolyseforschung. Berlin 1928. Probleme der pathologischen Physiologie im Lichte neuerer immunbiologischer Be- 
trachtung. Wien 1928. Antigene und Antikörper in: Handbuch der normalen und pathologischen Physiologie (1929) Bd. 13, S. 405-462.

MHG Zs. für Immunitätsforschung und experimentelle Therapie.

L Stübler (1926) S. 300; Kürschner (1928/29) Sp. 2005 f., (1931) Sp. 2474 f., (1935) Sp. 1159 f. $\bullet$ Obituary: H.S. in: The Lancet (28. April 1945) Vol. 245, Issue 6348, page 547 (hier Todestag 23. März). • Dictionary of Emigrés 2 (1983) S. 1007; Arnim 5 (1985) S. 3; Chronik Ärzte H (1985) S. 141; Mussgnug (1988) S. 64 f., 153 u. ö.; Jansen (1992a) S. 168 (Register); Juden der Frankfurter U (1997) S. 323325; Eckart (2000) S. 91; 100 Jahre Krebsforschung (2000) S. 47 f. u. ö.; NDB 22 (2005) S. 332 (hier Todestag 25. März); Rürup (2008) S. 530 (Register; S. 310: hier Todestag 28. März); WBIS; Friedrich (2009) S. 89-108, 123-131 u. ö.; Lexikon jüdischer Einwohner Hs (2011) S. 365. • Holfter, Gisela, Dickel, Horst: An Irish Sanctuary. German-speaking Refugees in Ireland 1933-1945. Berlin 2017. S. 445 (Register).

$P$ Bildarchiv UAH; Chronik Ärzte H.

\section{Sachße, Carl}

siehe Sachsse, Karl Robert

\section{Sachsse, Karl Robert}

1835-1859 Jur. Fak.

Deutsches Privatrecht, Kirchenrecht, Staats- und Rechtsgeschichte

* 13. Jan. 1804 Leipzig

$\dagger \quad$ 27. Dez. 1859 Heidelberg ev.

V Johann Daniel S., Hausvater (Leiter e. Anstalt, e. Heims)

M Rosina Friederike geb. Rupp

œ 1841 Johanna Mathilde geb. Unrein (18161872)

$\mathrm{K}$ keine.
Lb U Leipzig: Seit WS 1821/22 Studium der Mathematik, Philosophie, anschl. Rechtswiss.; 1. März 1827 Dr. phil.; WS 1829/30-WS 1833/34 Abhaltung von Lehrveranstaltungen an Jur. Fak., s. Vorlesungsverzeichnisse der U Leipzig.

UH: 24. Aug. 1834 Dr. iur.; SS 1835 (ohne Habilitation) erstmals als Privat-Dozent in „Anzeige der Vorlesungen ... der Ruprecht-Carolinischen Universitaet ..." genannt; seit 16. Jan. 1846 a. o. Prof. • In dieser Zeit:

UBH: Seit 29. Jan. 1835 Bibliotheksgehilfe; 18. Jan. 1838-Dez. 1859 II. Bibliothekssekretär (aus: UAH PA 2121 (Puchelt, Friedrich)).

Qu UAH PA 2179; RA 6765; Fak.-Akte H-II-111/ 29. GLA Abt. 205, Fasz. 466. Auskunft: Universitätsarchiv Leipzig.

$W$ Das Lied von dem Winter. [Gedichtet auf Buchhändler Anton Winter.] Heidelberg 1840. • Historische Grundlagen des deutschen Staatsund Rechtslebens. Heidelberg 1844. $\bullet$ Sachsenspiegel oder sächsisches Landrecht ... Heidelberg 1848. Reprint Holzminden 2007. Das Beweisverfahren nach deutschem mit Berücksichtigung verwandter Rechte des Mittelalters. Erlangen 1855.

$L$ Badische Biographien 2 (1875) S. 228; ADB 30 (189o) S. 145 f.; Bader (1925) S. 219; WBIS; Schroeder (2010) S. $104 \mathrm{f}$.

\section{Salin, Edgar}

1920-1927 Phil. Fak.

Volkswirtschaft, Staatswissenschaften

* 10. Febr. 1892 Frankfurt/M.

$\dagger$ 17. Mai 1974 Veytaux (bei Montreux, Schweiz) mosaisch

V Alfred Bernhard S. (1859-1948) Industrieller M Paula Auguste geb. Schiff (1871-1952) 
@ 22. März 1922 Antonie Charlotte geb. Trützschler von Falkenstein (1903-1987), s. Schönhärl (2009) S. 459 (Register); Scheidung 1938

( 10. Sept. 1949 Isolde Maria Gertrud geb. Baur (*1915)

K $\quad{ }_{1} \mathrm{~S}, 1 \mathrm{~T}$

Lb 1910 Reise durch die USA nach Alaska, s. hierzu E.S.: Im Sonderzug nach Alaska. Tagebuch einer amerikanischen Reise 1910. Hrsg. von Paul Hugger. Zürich 2004.

SS 1910 Studium der Rechtswiss., Kameralwiss., auch Philosophie an UH, seit WS 1910/11 München, anschl. Berlin, SS 1912-SS 1913 UH; 6. Febr. 1914 Dr. phil. an UH.

Aug. 1914-März 1918 Kriegsdienst; 7. Sept. 19185. Febr. 1919 Referent an Dt. Gesandtschaft in Bern.

UH: Seit Febr. 1919 Assistent am Volkswirtschaftl. Seminar, 1924 umbenannt in Inst. für Sozial- und Staatswiss.; 25. Okt. 1920 Habilitation für Volkswirtschaft; seit 24. Juni 1924 a. o. Prof. (EberhardGothein-Professur für Staatswiss. und Auslandskunde) am Inst. für Sozial- und Staatswiss.; SS 1927 Vertreter des freien Ordinariats für Staatswiss. an U Kiel.

U Basel: 26. Juli 1927 Ern. zum o. Prof.; seit 1929 Vorsitzender des Ständigen Staatl. Einigungsamtes des Kantons Basel-Stadt; SS 1946-SS 1947 Gastvorlesungen an UH; 31. März 1963 Emeritierung.

1925 Mitbegründer der 1935 aufgelösten FriedrichList-Gesellschaft, die 1954 von S. als List-Gesellschaft neu gegründet wird.

E 1963 Fellow des Weizmann Inst. Rehovot (Israel). 1962 Bundesverdienstkreuz I. Klasse; 1962 Goetheplakette der Stadt Frankfurt/M.

Qu UAH PA 5578; RA 5029. - Briefe: UBH. • Dreyer, Wilfred: „Sehr verehrter Herr Kollege Salin ..." Handlungsalternativen deutscher Soziologen im NS-Staat im Spiegel des Briefwechsels von E. S. in: Parteien, Kulturen und Konflikte ... Hrsg. von Stefan Immerfall. Wiesbaden 200o. S. 51-82. Friedrich Gundolf - Elisabeth Salomon. Brief- wechsel (1914-1931). Im Auftrag des DLA Marbach hrsg. von Gunilla Eschenbach und Helmuth Mojem. Berlin 2015. S. 799 (Register). - Nachlaß: Universitätsbibliothek Basel. - Mitteilungen von Familienangehörigen.

$W$ Geschichte der Volkswirtschaftslehre. Berlin 1923. 4. Aufl. 1951. - Wege und Ziele der Arbeitsbeschaffung im Kanton Basel-Stadt. Gutachten in: Ratschlag und Entwurf zu einem Gesetz über dringliche Maßnahmen zur Milderung der Wirtschaftskrise im Kanton Basel-Stadt (1936). Jakob Burckhardt und Nietzsche. Basel 1938. 2. Aufl. 1948. • Ökonomie der Atomkraft. Köln 1955. • Politische Ökonomie. Geschichte der wirtschaftspolitischen Ideen von Platon bis zur Gegenwart. Tübingen 1967.

\section{G 1958 Marketing Research Institute „Prognos“.}

MHG 1947-1974 Int. Zs. für Sozialwissenschaften „Kyklos“.

$L$ Professoren Kiel (1956) S. 53; Kürschner (1970) S. 2520; Who's who in Switzerland (1972/73) S. 602. Schmitz, Victor A.: In memoriam E.S. in: Ruperto Carola 27. Jg., H. 54 (März 1975) S. 9294. - Jansen (1992) S. 412 (Register); Brintzinger (1996) S. 399 (Register). • Janssen, Hauke: Nationalökonomie und Nationalsozialismus. Die dt. Volkswirtschaftslehre in den dreißiger Jahren. Marburg 1998. S. 575 f. • NDB 22 (2005) S. 372 f. • Raulff, Ulrich: Kreis ohne Meister. Stefan Georges Nachleben. München 2009. S. 541 (Register). • Schönhärl (2009) S. 72-83 u.ö.; Schultes (2010) S. 613 f. u. ö. - Köster, Roman: Die Wissenschaft der Außenseiter: Die Krise der Nationalökonomie in der Weimarer Republik. Göttingen 2011. S. 360 (Register). - Reichert, Folker: Hans Bettmanns Freitod und das Ende der deutsch-jüdischen Symbiose in: ZGORh 159. Jg. (2011) S. 534-536 u. ö. • Schefold, Bertram: Politische Ökonomie als „Geisteswissenschaft“ in: Studien zur Entwicklung der ökonomischen Theorie. Hrsg. von Harald Hagemann. Bd. 26. Berlin 2011. S. 149-210. - Tagungsbericht: Neue Städte für einen neuen Staat. E.S. und das „Israelprojekt“ der List Gesellschaft, 02.12. 2011-04.12.2011 Berlin in: H-Soz-Kult (19.05. 2012), s. www.hsozkult.de/conferencereport/id/ 
tagungsberichte-4234; s. hierzu: Neue Städte für einen neuen Staat: Die städtebauliche Erfindung des modernen Israel und der Wiederaufbau in der BRD. Eine Annäherung. Hrsg. von Karin Wilhelm, Kerstin Gust. Bielefeld 2013. • Demm (2014) S. 247 (Register); Intellektuelle in Heidelberg (2014) S. 427 (Register). - Berman, Russell A.: E. S. and social theory in the circle around Stefan George in: Telos (2016) Nr. 176, S. 121-142. • Riecke (2016) S. 61.

$P$ Bildarchiv UAH.

\section{Salis, Arnold von}

1929-1940 Phil. Fak.

Klassische Archäologie

* 29. Juli 1881 Liestal (Kanton Basel-Landschaft)

$\dagger \quad$ 02. April 1958 Zürich ref.

V D. theol. Jakob Arnold von S. (1847-1923), u. a. 1891-1897 letzter Antistes (= Vorstand; Ehrentitel, 1897 abgeschafft), 1897-1921 Hauptpfarrer am Basler Münster, s. BBKL XX (2002) Sp. 1260 f.

M Maria/Marie geb. Haegler (1859-1924), s. Staatsarchiv Basel-Stadt LA 1924

๑ 8. April 1920 Helene Eleonore geb. von der Mühll (1887-1975) Schwester von Peter von der M. (1885-1970) 1918-1952 o. Prof. für Griechische Literatur und Sprache Basel, s. Historisches Lexikon der Schweiz online

$\mathrm{K} \quad{ }_{1} \mathrm{~S}, 3 \mathrm{~T}$

Lb Seit WS 1900/o1 Studium der Literaturgeschichte, Klassischen Philologie und Archäologie, Kunstgeschichte an U Basel, seit SS 1902 Bonn, anschl. Berlin, zuletzt Basel; 23. Juni 1905 Dr. phil. an U Basel.

Nov. 1905-Ende Febr. 1907 Studien- und Ausgrabungsreisen nach Griechenland und Kleinasien.

Assistent: Seit April 1907 Histor. Museum in Basel, seit Nov. 1907 Pergamon Museum in Berlin.
Bonn: Seit Mai 1908 Assistent am Akad. Kunstmuseum; 13. Jan. 1909 Habilitation an U; WS 1909/ 10 Lehrauftrag an U Greifswald.

U Rostock: Seit 9. Juli 1910 a. o. Prof. für Klassische Archäologie und Direktor der Archäolog. Sammlung und des Münzkabinetts.

U Münster: Seit WS 1916/17 o. Prof.

UH: 16. Nov. 1928 zum SS 1929 Ern. zum o. Prof. für Klassische Archäologie und Direktor des Archäolog. Inst. als Nachf. von Ludwig Curtius.

U Zürich: Seit WS 1940/41 o. Prof; WS 1941/421948 Lehrauftrag an U Basel; 1947/48 Beurlaubung (= Dispensierung); 30. Sept. 1948 Emeritierung; 1948-1951 Vertreter seines Lehrstuhls; 1951 Ern. zum Honorar-Prof. • In dieser Zeit:

U Freiburg/Br.: 1950-1951 Gastprof.

1932/33 Dekan der Phil. Fak. der UH

1914-1916 Mitglied der Zentraldirektion des Dt. Archäologischen Instituts Berlin

E 1931 Mitglied der Akademie der Wissenschaften $\mathrm{H}$.

Qu UAH PA 5579. • GLA Abt. 235, Fasz. 2442. • Teil-Nachlaß: Universitätsbibliothek Basel; Staatsarchiv Basel-Stadt; Frau Helene und Herr Walter Voegeli-von Salis, Zollikon. Mitteilungen: Herr Dr. Nicolas Zenzen, Universität Heidelberg.

W Der Altar von Pergamon. Berlin 1912. Die Kunst der Griechen. Leipzig 1919. 4. Aufl. 1953. • Neuere Darstellungen griechischer Sagen. 2 Bde. Heidelberg 1935-1937. Antike und Renaissance. Zürich 1947. - Auswahlbibliographie in: Jucker (1958) S. $436 \mathrm{f}$.

$L$ Jucker, Hans: A. von S. $\uparrow$ in: Schweizer Monatshefte 38 (1958) S. 432-437. - Verzeichnis Bonn (1968) S. 256; Universität Münster (1980) S. 417; Arnim 5 (1985) S. 9; WBIS; Archäologenbildnisse (1988) S. 210f.; Jansen (1992a) S. 168 (Register); Grewolls (2011); Historisches Lexikon der 
Schweiz online; Catalogus prof. Rostochiensium online. Panteleon, Ioannis Andreas: Eine Archäologie der Direktoren. Die Erforschung Milets im Namen der Berliner Museen 1899-1914. Paderborn 2015. S. 231-238 u. ö. • Objekte erzählen Geschichte(n) (2016) S. 197-205 u.ö.; Deutsche Biographie, s. https://www.deutsche-biographie.de/gn d116764201.html [07.11. 2017].

$P$ Bildarchiv UAH.

\section{Salomon, Wilhelm Hermann (seit 1923: Salomon-Calvi)}

1897-1934 (1935) Nat.-Math. Fak.

1897-1901 Geologie, Mineralogie; seit 1901

Stratigraphie und Paläontologie; seit 1908 Geo-

logie und Paläontologie

* 15. Febr. 1868 Berlin

$\dagger$ 15. Juli 1941 Ankara

口 Ankara

mosaisch, seit 1892 kath.

V Adolf S. (1827-1895) Fabrikant

M Hulda geb. Potocky-Nelken (1837-1892)

C 1. Juli 1893 Rosalia geb. Calvi (1869-1914), s. Ruuskanen (2008) S. 211 f., Lexikon jüdischer Einwohner Hs (2011) S. 367

$\mathrm{K} \quad 2 \mathrm{~S}, 2 \mathrm{~T}$, s. Lexikon jüdischer Einwohner Hs, S. 367; u.a. Ina Hulda Adolfine Rosalie S. (1894-1979), s. UAH Rep. 7-17; Lexikon jüdischer Einwohner Hs, S. 142, 367; Ehefrau von: (siehe) Karl Gottfried.

Lb Seit WS 1886/87 Studium an ETH Zürich, anschl. U Berlin, Leipzig, 1891-1893 München; 23. Jan. 1891 Dr. phil. an U Leipzig; seit Okt. 1893 Assistent am Mineralog. Inst. in Pavia (Italien).

UH: 18. März 1897 Genehmigung des Karlsruher Ministeriums der Justiz, des Kultus und Unterrichts zur Habilitation; 15. Juni 1897 Erteilung der venia legendi für Geologie und Mineralogie; seit April 1897 Assistent am Mineralog.-Geolog. Inst.; seit 18. Febr. 1899 nichtetatm. a. o. Prof.; seit 29. April 1901 etatm. a.o. Prof. und (bis 1908) Direktor des Stratigraphischen und Paläontolog.
Inst.; 1908-1934 Leiter des Geologisch-Paläontolog. Inst.; 1912 Ruf an TH Hannover abgelehnt; 31. März mit Wirkung vom 1. April 1913 Ern. zum o. Prof:; Rufe an U abgelehnt: 1913 Leipzig, 1919 München; 28. April 1933 Beurlaubung aus rassischen Gründen wird zunächst ausgesetzt; 4. Aug. 1934 unter dem Eindruck der antijüdischen Demütigungen auf eigenen Antrag Rücktritt von seinen Ämtern, um Ruf an U Ankara anzunehmen; 22. Aug. 1934 Ausreise in die Türkei; 31. Dez. 1935 Entzug der venia legendi aus rassischen Gründen.

Landwirtschaftl. Hochschule Ankara: WS 1934/351936 o. Prof. für Geologie und Mineralogie, Gründer und Direktor des Geologischen Inst.

Ankara: 1936-1941 Direktor der geolog. Landesanstalt der Türkei im Landwirtschaftsministerium; Planer e. modernen zentralen Wasserversorgung.

1918/19, 1924/25, 1930/31 Dekan der Nat.-Math. Fak. der UH

1913 Geh. Hofrat

E Mitglied der Akad. der Wiss.: 1916 (1938 aus der Liste der Mitglieder gestrichen) H, 1919 München; 1928 Korr. Mitglied der Real Academia de Ciencias y Artes de Barcelona. 1912 Ritterkreuz I. Klasse des Ordens vom Zähringer Löwen. • 1926 Ehrenbürger der Stadt Heidelberg (1933 aus der Liste der Ehrenbürger gestrichen).

Qu UAH PA 2549, 5580; RA 5368, 6480, 6491, 6888, 6895; GF 51; Acc. 17/03. GLA Abt. 235, Fasz. 2443.

W Kriegsgeologie. Heidelberg 1915. Die Erbohrung der Heidelberger Radium-Sol-Therme und ihre geologischen Verhältnisse. Berlin 1927. (Mitverf.) Epeirophorese. 2 T. Berlin 1930. Die Bedeutung der Bodenschätze und Bodenformen für Deutschlands politische, kulturelle und wirtschaftliche Entwicklung. Heidelberg 1933. - Die permokarbonischen Eiszeiten. Leipzig 1933.

HG 1929-1934 Badische Geologische Abhandlungen. 
L Kürschner (1931) Sp. 2482, (1935) Sp. 1162; Handels-Hochschule Mannheim 1907-1932 (1932) S. 27; Arnim 2 (1952) S. 469, 3 (1961) S. 513. • Pfannenstiel, Max: Zum Gedächtnis an W.S.-C. in: Ruperto Carola 23 (1957) S. 165-168; Becke, Margot, Pfannenstiel, Max: Gedenkfeier zum 10o. Geb. .. in: ebd. 43/44 (1968) S. 246-26o. - Dictionary of Emigrés 2 (1983) S. 1013; Mussgnug (1988) S. 73-75, 143 f.; WBIS; Jansen (1992) S. 412 (Register); Ders. (1992a) S. 168 (Register); Wennemuth (1994) S. 638 (Register). Mumm, Hans-Martin: Die Erschließung der Thermalquelle ... in: Heidelberg. Jahrbuch der Stadt 2000, Jg. 5 (2000) S. 55-76. • UH im Nationalsozialismus (2006) S. 1181-1188 u. ö.; Kriegstagebuch K. Hampe (2007) S. 992 (Register). Marzolff, Renate: Leontine und Victor Goldschmidt. Gründer der von-Portheim-Stiftung. Bürger in Heidelberg 1889-1942. Heidelberg 2007. Vertriebene Mitgl. der Akad. der Wiss. H (2009) S. 73-78; Lexikon jüdischer Einwohner Hs (2011) S. $366 f$. Orth, Karin: Die NS-Vertreibung der jüdischen Gelehrten. Die Politik der Deutschen Forschungsgemeinschaft und die Reaktionen der Betroffenen. Göttingen 2016. S. 167170 u. ö. - Deutsche Biographie, s. https://www. deutsche-biographie.de/gnd116767340.html [07.11. 2017].

$P$ Bildarchiv UAH; graph. Slg. UBH; Ruperto Carola; Vertriebene Mitgl. (2009).

\section{Salomon-Calvi, Wilhelm Hermann}

s. Salomon, Wilhelm

\section{Salz, Arthur}

1909-1919, 1924-1933 Phil. Fak.

Nationalökonomie

* 31. Dez. 1881 Staab bei Pilsen (heute: Stod, Tschechien)

$\dagger$ 10. Aug. 1963 Worthington (Vorort von Columbus, Ohio)

mosaisch
V Heinrich S. (1852-1902) Landwirt, Fabrikbesitzer, s. Die Juden und Judengemeinden Böhmens (1934) S. 609

M Rosa geb. Popper (†1906)

๑ 2. April 1912 Sophie (Soscha) geb. Kantorowicz (1887-1960), s. Schönhärl (2009) S. 460 (Register). - Schwester von Ernst K. (1895-1963), u.a. 1951-1963 Prof. für Geschichte am Institute for Advanced Study in Princeton (New Jersey), s. E. K. Erträge der Doppeltagung Institute for Advanced Study, Princeton ... Universität Frankfurt. Stuttgart 1997; Hergemöller, Bernd-Ulrich: Mann für Mann. Ein biographisches Lexikon. Frankfurt/M. 2001. S. 405-407; Schönhärl (2009) S. 458 (Register); Raulff, Ulrich: Kreis ohne Meister. Stefan Georges Nachleben. München 2012. S. 539 (Register); Friedrich Gundolf - Elisabeth Salomon. Briefwechsel (1914-1931) (2015) S. 799 (Register)

K 1 S, 2 T, s. Lexikon jüdischer Einwohner Hs (2011) S. 368.

Lb Seit WS 1900/o1 Studium der Philosophie, Kameralwiss., Rechtswiss. an U Berlin, anschl. München; 31. März 1905 Dr. rer. cam. an U München; 1905-1907 Tätigkeit im väterlichen Betrieb in Staab; seit WS 1907/o8 Forts. des Studiums an U Wien, anschl. Prag.

UH: 8. Mai 1909 Habilitation; auch Dozent an Mannheimer Handelshochschule; 7. Juli 1914 Ablehnung der Einleitung e. von S. beantragten Disziplinarverfahrens gegen sich selbst aufgrund e. Streites mit Paul Sander (1866-1919; a.o. Prof. für Wirtschaftsgeschichte an U Prag), der Salz u.a. des Plagiats in seinem Werk „Geschichte der böhmischen Industrie in der Neuzeit" beschuldigt (s. hierzu Sanders Rezension in: Deutsche Literaturzeitung für Kritik der int. Wissenschaft. Berlin 1913. S. 2675-2681 sowie Weischenberg, Siegfried: Max Weber und die Entzauberung der Medienwelt: Theorien und Querelen - eine andere Fachgeschichte. Wiesbaden 2012. S. 311); 11. Juni 1918 Ern. zum nichtetatm. a.o. Prof.; 27. März 1919 auf eigenen Antrag Entlassung. • In dieser Zeit: 
Seit Febr. 1915 Kriegsdienst in Ersatzbatterie des k.u.k. Feldkanonenregiments Nr. 4 in Wiener Neustadt; April 1916-ca. April 1917 als Militärbevollmächtigter in Konstantinopel (heute: Istanbul).

München: Mai 1919 Verhaftung, Juni 1919 wegen Beihilfe zum Hochverrat angeklagt und freigesprochen, s. hierzu Meyer-Leviné, Rosa: Leviné. Leben und Tod e. Revolutionärs ... München 1972.

1921-1924 Dozent an Akademie der Arbeit in der U Frankfurt/M.

Baden-Baden: Vor 1924-1929 Wohnsitz.

UH: 7. Jan. 1924 Erneuerung der venia legendi durch ministerielle Genehmigung und Einreihung unter nichtplanm. a.o. Prof.; auch Dozent an Handelshochschule in Mannheim; SS 1927, 1929-1933 Lehrauftrag für Volkswirtschaftslehre in Vertretung von Sally Altmann; 20. April 1933 Beurlaubung aufgrund des Gesetzes zur „Wiederherstellung des Berufsbeamtentums“; 28. Sept. 1933 Entzug der Lehrbefugnis aus rassischen Gründen.

Cambridge (Großbritannien): Sept. 1933 Ankunft; Dez. 1933-Aug. 1934 Gastprof. an U.

Columbus (Ohio): Seit 1934 Gastprof., 1937-1952 (Emeritierung) Full Prof. für Nationalökonomie an Ohio State U.

UH: 1949/50 S. stellt Antrag auf Wiedergutmachung; Jan. 1954 Ablehnung der „Klage [von Salz] wegen Wiedergutmachung eines Schadens im wirtschaftlichen Fortkommen" als unbegründet durch Landesamt für Wiedergutmachung in Karlsruhe (aus: UAH PA 5581); Sept. 1955 Kultusministerium gewährt e. monatliche finanzielle Unterstützung, seit Juli 1959 Auszahlung der Bezüge e. Emeritus.

E 1952 Dr. phil. h.c. UH. • Eisernes Kreuz II. Klasse; Goldenes Verdienstkreuz; Eiserner Halbmond.

Qu UAH PA 614, 5581; RA 6412; Rep. 40-421. • Friedrich Gundolf - Elisabeth Salomon. Briefwechsel (1914-1931). Im Auftrag des DLA Mar- bach hrsg. von Gunilla Eschenbach und Helmuth Mojem. Berlin 2015. S. 799 (Register). N Nachlaß: Leo Baeck Institute in New York (Arthur Salz Collection, Signatur: AR 6288 Box I-IV).

W Beiträge zur Geschichte und Kritik der Lohnfondstheorie. Stuttgart 1905. • Geschichte der böhmischen Industrie in der Neuzeit. München 1913. • Für die Wissenschaft gegen die Gebildeten unter ihren Verächtern. München 1921. • Der Begriff der Elastizität in der theoretischen Nationalökonomie in: Archiv für Sozialwissenschaft und Sozialpolitik 57 (1927). - Das Wesen des Imperialismus. Umrisse einer Theorie. Leipzig 1931.

MHG 1930-1933 Heidelberger Studien aus dem Inst. für Sozial- und Staatswissenschaften.

L Jüdische National-Biographie 5 (1930) S. 344; Handels-Hochschule Mannheim 1907-1932 (1932) S. 26. - Die Juden und Judengemeinden Böhmens in Vergangenheit und Gegenwart ... Bd. 1. Hrsg. von Hugo Gold. Brünn 1934. S. 6o8-610. • Kürschner (1950) Sp. 1733f., (1961) S. 1729, (1966) S. 2074. - Antrick, Otto: Die Akademie der Arbeit in der Universität Frankfurt/M. Darmstadt 1966.

S. 35, 39, 6o. • Bollmus (1973) S. 28-30 u. ö.; Dictionary of Emigrés 2 (1983) S. 1015; Mussgnug (1988) S. 299 (Register); WBIS. • Wittebur, Klemens: Die deutsche Soziologie im Exil 1933-1945 ... Münster 1991. S. 71 f. u.ö. • Jansen (1992) S. 412 (Register); Ders. (1992a) S. 168 (Register); Brintzinger (1996) S. 400 (Register). Biographisches Handbuch der deutschsprachigen wirtschaftswissenschaftlichen Emigration nach 1933. Hrsg. von H. Hagemann ... München 1999. Bd. 2. S. 600-603. • Max Weber - Gesamtausgabe Abt. 2. Bd. 8 (2003) S. 885 (Register). • Fried, Johannes: Zwischen „Geheimem Deutschland“ und "geheimer Akademie der Arbeit“. Der Wirtschaftswissenschaftler A.S. in: Geschichtsbilder im George-Kreis. Wege zur Wissenschaft. Hrsg. von Barbara Schlieben u.a. Göttingen 2004. S. 249-302. - UH im Nationalsozialismus (2006) S. 557 f.; Kriegstagebuch K. Hampe (2007) S. 992 (Register); Schönhärl (2009) S. 58-70 u. ö.; Schultes (2010) S. 54 f. u.ö. • Köster, Roman: Die Wissenschaft der Außenseiter. Die Krise der Nationalökonomie in der Weimarer Republik. Göttingen 2011. - Lexikon jüdischer Ein- 
wohner Hs (2011) S. 368. Stefan George und sein Kreis. Ein Handbuch. Hrsg. von Wolfgang Braungart ... Berlin 2012. Bd. 3. S. 1609-1612. • Demm (2014) S. 247 (Register); Spenkuch (2016) S. 1320 (Register); Deutsche Biographie, s. https://www. deutsche-biographie.de/gnd116767820.html [07.11. 2017].

$P$ Bildarchiv UAH.

\section{Samassa, Paul Anton Franz}

1893-1897 Nat.-Math. Fak.

Zoologie

* 15. Sept. 1868 Laibach (heute: Ljubljana, Slowenien)

$\dagger$ 17. Aug. $1941 \mathrm{Graz}$

kath.

V Albert S. (1833-1917) Glockengießer, Schiffsarmaturenfabrikant, s. ÖBL online $1815-1950$ (1988) Bd. 9 (Lfg. 45) S. 405 f.

M Anna Friderica geb. Gregel $\left({ }^{*} 1837\right)$

$\infty$ N.N.

Vw siehe ÖBL online, S. 405-407.

Lb Seit 1886 Studium der Medizin, Naturwiss. an U Graz, seit SS 1888 Würzburg, SS 1889 München, WS 1889/9o Wien, seit SS 1900 München.

U München: 1890 Dr. med.; 4. Juli 1891 Dr. phil.

UH: 25. April 1893 Habilitation; 1. Nov. 1893-1. Okt. 1894 Eigenstudien an Zoolog. Station in Neapel; seit 23. April 1897 nichtetatm. a. o. Prof.; 16. Okt. 1897 aus gesundheitlichen Gründen auf eigenen Antrag UH verlassen.

München: Seit 1899 Journalist und Chefredakteur der „Münchner Neuesten Nachrichten“.

Berlin: 1900-1908 Schriftleiter der „Alldeutschen Blätter“; 1904-1905, 1908 Reisen nach Afrika.

1909 Übersiedlung nach Klosterneuburg (bei Wien); 1914 politischer Berater des Erzherzogs Franz Ferdinand von Österreich; Herbst 1918
Übersiedlung auf e. Weingut bei Bozen; 1938 Ausweisung aus Italien nach Österreich als Anhänger der irredentistischen (terre irredente $=$,unerlöste Länder") Bewegung.

Seit 1899 Mitglied, auch Vorstandsmitglied im Alldeutschen Verband. - 1920 Gründungsmitglied der Großdeutschen Partei

Qu UAH PA 2182. - GLA Abt. 235, Fasz. 2521. • Teil-Nachlaß: Bundesarchiv Berlin; Dt. Zentralarchiv Potsdam; Österr. Staatsarchiv Wien.

$W$ Untersuchungen über das centrale Nervensystem der Cladoceren. Bonn 1891. - Das neue Südafrika. Hamburg 1905. 2. Aufl. 1928. • Der Völkerstreit im Habsburgerstaat. Leipzig 1910. - Die deutsch-österreichische Politik während des Krieges. Graz 1917. - Vom Sprachen-Lernen. Reichenberg 1917.

$L$ Wer ist's (1914) S. 1435, (1928) S. 1320. • Schödl, Günter: P.S. Ein biographischer Beitrag zur Vorgeschichte des "extremen Nationalismus“ in Deutschland und Österreich in: Südostdeutsches Archiv 21 (1978) S. 75-104. - ÖBL online 1815-1950 (1988) Bd. 9 (Lfg. 45) S. 407f.; NDB 22 (2005) S. 404 f.; WBIS. - Walkenhorst, Peter: Nation - Volk - Rasse. Radikaler Nationalismus im Deutschen Kaiserreich 1890-1914. Göttingen 2007. S. 399 (Register).

\section{Sar, Anton (bis 1796: CM)}

1791-1804 Theol. Fak., kath. Abt.

Dogmatik

1804-1817 Phil. Fak.

Französische Sprache

* o1. Jan. 1747 Metz

$\dagger \quad$ 05. März 1817 Heidelberg kath.

V N.N.

M N.N.

$\infty$ unverheiratet. 
Lb CM (Congregatio Missionis, Kongregation der Mission, auch Lazaristenorden; 1796 Erlöschen des Ordens in der Kurpfalz): 17. Aug. 1763 Eintritt in Kongregation in Paris; 18. Aug. 1765 Ablegung der Gelübde; nach Aug. 1765-1791 Lehrer der Philosophie und Theologie am Seminar, später auch Vorstand des Seminars in Metz. - Promotion zum Dr. theol.

UH: Seit 1791 zunächst Vertreter der Professur für Moraltheologie (Professur erhält Albertin Schott, s. Drüll (1991) S. 139) und Vertreter der Professur für Dogmatik; Mai 1791-1804 II. Prof. für Dogmatik als Nachf. von Antoine Joseph Patou(x) (s. Drüll (1991) S. 119; 1804 erhält Franz Martin Schnappinger I. Professur) an Theol. Fak.; im SS 1895 beispielsweise „wird Herr Prof. Sar in seinen Vorlesungen jeden Tag der Woche, den Mittwoch ausgenommen, von 3 bis $4 \mathrm{Uhr}$, nach beendigter Lehre von der Wahrheit der christlichen Religion die theologischen Grundprincipien abhandeln" (aus: Anzeige der Vorlesungen, welche im Sommerhalbenjahre 1795 auf der hohen Schule zu Heidelberg gehalten werden, S. 3); 1804-1817 Inhaber der neueingerichteten Professur für Franz. Sprache an Phil. Fak.

1794, 1798, 1803 Dekan der Theol. Fak. der UH, kath. Abt., siehe hierzu Weisert/Drüll/Kritzer (2007) S. 48

$Z$ Mit dem Tod des Karmeliten Joannes a Cruce (siehe Drüll (1991) S. 78-80), Professor für Dogmatik an der Heidelberger Theol. Fak., am 4. Mai 1799 ist „die Stelle eines academischen Senators aus der theologischen Fakultät katholischer Seits erledigt worden; die Ordnung (trifft) zwar den Professor Sar, derselbe aber (ist) als ein geborener Franzos der deutschen Sprache bis daher nur in soweit mächtig, daß er Alles ziemlich gut Geschriebene, auch alles Gedruckte lesen und verstehen, selbst auch demjenigen ohne Anstand folgen kann, was deutlich ausgesprochen wird. In jenen (Senats-)Verhandlungen aber, welche eilig abgelesen oder geschwind flüßig vorgetragen werden, (befürchtet) [er], einigen Aufenhalt zu verursachen; so hat sich Herr Professor Bonifacius a S[anc] to Wunibaldo [= Franz Martin Schnappinger], welcher im Lehralter unmittelbar folget, bereit gefunden, statt des Professors Sar im Senate so lange zu erscheinen, bis sich derselbe wird alle erforderliche Sprachübung verschaffet haben.

... Herr Prof. Bonifacius überläßt demselben [= Sar] freiwillig alle Senats-Ehrenweingelder $\mathrm{u}[\mathrm{nd}] \mathrm{d}[$ er]gleichen; selbst im Falle, die Rectorstelle auf diese Art den Herrn Professor Bonifacius treffe, auch die fünfzig fl[orentiner] Rectors-Besoldung, doch die Turnusgelder und die Hälfte der Matrikelgelder wird Herr Professor Sar dem Herrn Professor Bonifacius, solange derselbe die Stelle des ersteren im Senate vertreten wird, überlassen“" (aus: Brief von Bonifacius (= Schnappinger) an den Akademischen Senat vom 14. Mai 1799 in: UAH RA 902). Bis zum Wechsel Sars 1804 von der Theol. an die Phil. Fak. wird er von F. M. Schnappinger im Akad. Senat der UH vertreten.

\section{Qu UAH PA 2178; RA 902, 5905, 6635.}

$W$ Manières allemandes de parler français. Heidelberg 1808.

$L$ Wechmar (1846) S. 253 (hier: Sax, Anton); Schneider (1913) S. 8 f. (hier: Saar, Anton); Haas (1960) S. 67f., 113; Burkard (1995) S. 252 (Register). Saltin, Günther: Geschichte der Orden und Kongregationen in Mannheim. Hauptteil 2 in: Reiner Albert, Günther Saltin: Katholisches Leben in Mannheim. Bd. 1. Von den Anfängen bis zur Säkularisation. Ostfildern 2009. S. 459. - Kalkhoff (2010) S. 33 u. ö.; Riecke (2016) S. 8.

\section{Sartorius, Johann Baptist}

1842/43-1848 Jur. Fak.

Kirchenrecht, Zivilrecht

* 05. März 1798 Würzburg

$\dagger$ 21. März 1884 Würzburg kath.

V Adam Joseph S. (1747-1810) Verwaltungsrat und Stadt-Baumeister

M Margaretha Isabella geb. Bleiter (1768-1852)

$\infty$ 20. Aug. 1836 Louise geb. Rahn (1812-1884)

$\mathrm{K} \quad 2 \mathrm{~S}, 3 \mathrm{~T}$ 
Lb Würzburg: 1823 Staatskonkursprüfung; Accessist (Akzessist $=$ Anwärter): seit 1823 Stadtgericht, Nov. 1825-1833 (Verlegung des Gerichts nach Aschaffenburg) Appellationsgericht für den Untermainkreis.

UH: Febr. 1833 Promotion zum Dr. iur.

U Zürich: Seit SS 1833 Privat-Dozent; 16. Okt. 1836 Erteilung der von S. erbetenen Erlaubnis durch König Ludwig I. von Bayern zur Übernahme e. Professur in Zürich; SS 1837-SS 1841 a. o. Prof. für Allg. Staatsrecht mit besonderer Rücksicht auf die Institutionen der Schweiz an Staatswiss. Fak.

UH: 26. Febr. 1842 Engerer Akad. Senat schlägt auf das Gesuch S.' um Annahme als Prof. an UH vor, S. „weder als professor honorarius noch als professor extraordinarius zuzulassen, zumal man nur seine sehr günstigen schriftstellerischen Arbeiten, nicht aber seine Lehrergaben kennt, dagegen ihm $\mathrm{zu}$ gestatten, ... Vorlesungen $\mathrm{zu}$ halten, und den Titel eines Professors [zu führen]; sein Eintrag soll im Vorlesungsverzeichnis nach dem der a.o. Professoren und vor dem der Privatdozenten erfolgen“" (aus: UAH PA 2152 (Karl Röder)); SS 1843 erstmals als Prof. im Vorlesungsverzeichnis genannt; Juli 1845-Aug. 1848 Beisitzer des Spruchkollegiums der Jur. Fak.

Aschaffenburg: Seit 1. Okt. 1848 Assessor am Appellationsgericht für Unterfranken und Aschaffenburg.

Eichstätt: 3. Juni 1858-21. April 1862 (Ruhestand) Rat am Appellationsgericht für Mittelfranken.

Würzburg: Seit 28. April 1865 Wohnsitz in der Kapuzinerstraße 5 .

Die von der Zentralbibliothek Zürich übernommene Aufstellung der Juristischen Bibliothek geht auf J. B. Sartorius zurück

Qu UAH PA 2184, PA 2152 (Karl Röder). • GLA Abt. 235, Fasz. 581. • Ergebnislose Anfragen: Staatsarchiv Bern; Diözesanarchiv Würzburg; Standesamt Eichstätt. - Auskunft: Stadtarchiv Würzburg; Bayer. Hauptstaatsarchiv München (Signaturen:
MJu 19741, Gesandtschaft Karlsruhe 1496, MA 73488); Universitätsarchiv Zürich.

$W$ Zu-Rhein, Friedrich August von, S., J.B.: Sammlung merkwürdiger Rechtsfälle Bayerns. 2 Bde. Erlangen 1830-1831. - Organon des vollkommenen Friedens. Zürich 1837. • Die Lehre von der Widerklage nach dem gemeinen teutschen Civilprozesse. Erlangen 1838. - Bücher-Verzeichnis der juristischen Bibliothek in Zürich. Zürich 1840. - Revision der Lehre von der Aktenversendung in: Zs. für Civilrecht und Proceß 14 (1840) S. 219-256. Gesammelte Rechtsfälle für die Civil-Praxis an deutschen Universitäten. Erlangen 1844. - Die Mundart der Stadt Würzburg. Würzburg 1862. Unveränd. Neudr. Wiesbaden 1968. Vaduz 1989.

$L$ Ter Meulen, Jacob: Der Gedanke der Internationalen Organisation in seiner Entwicklung. 2. Bd.: 1789-1889. 1. Stück: 1789-1870. Den Haag 1929. S. 238-252. - Die Universität Zürich 1833-1933 und ihre Vorläufer. Bearb. von Ernst Gagliardi u.a. Zürich 1938. S. 8. - Jammers (1964) S. 55 Anm. 63, 177. • Foerster, Rolf Hellmut: Europa. Geschichte e. politischen Idee ... München 1967. S. 345. • Wehberg, Hans: Ideen und Projekte betr. die Vereinigten Staaten von Europa ... Bremen 1984. S. 17. • Falk, Ulrich: In dubio pro amico? Zur Gutachtenpraxis im gemeinen Recht in: forum historiae iuris. Internet-Zs. für Rechtsgeschichte (14. Aug. 200o), s. http://fhi.rg.mpg.de/articles/pdf-files/ooo8falk. pdf. - Option Europa: deutsche, polnische und ungarische Europapläne des 19. und 20. Jahrhunderts. Hrsg. von Włodzimierz Borodziej ... Göttingen 2005. Bd. 1. S. 62. Riehle, Bert: Eine neue Ordnung der Welt. Föderative Friedenstheorien im deutschsprachigen Raum zwischen 1892 und 1932. Göttingen 2009. S. 231 u. ö. 


\section{Sauer, Gustav Adolf}

1894-1900 Nat.-Math. Fak.

Geologie, Bodenkunde

* 10. Juli 1852 Weißenfels/Saale

$\dagger$ 02. Mai 1932 Stuttgart

ev.

V Gustav Adolf S. († vor 1896) Kaufmann

M Bertha geb. Laumann

$\infty$ 31. Mai 1882 Sophie Alexandrine Bertha Emilie Caroline geb. Knauth (1860-1930)

K 1 T, 3 S: u. a. Eberhard S. (1886-1967) seit 1922 Privat-Dozent, seit 1928 a.o. Prof. für Technische Chemie und Kolloidchemie, seit 1935 Lehrbeauftragter für Technische Kolloidchemie TH Stuttgart, s. WBIS, DBE (2007) S. 712.

Lb Seit SS 1872 Studium an U Leipzig, anschl. Halle/S.

Halle/S.: 1876 Dr. phil.; seit 1876 Privat-Assistent am Paläontolog. Inst.

Leipzig: Seit 1877 Assistent, seit 1879 Sektionsgeologe an Königl. Sächsischer Geologischer Landesanstalt.

H: 1888-1900 Landesgeologe an Großherzoglich Badischer Geologischer Landesanstalt, siehe auch Heinrich Rosenbusch. • In dieser Zeit:

UH: 14. Juli 1894 Habilitation; seit 12. Febr. 1898 nichtetatm. a.o. Prof.; 15. Okt. 1900 auf eigenen Antrag aus Lehrkörper ausgeschieden.

TH Stuttgart: WS 1900/o1-WS 1922/23 o. Prof. für Mineralogie und Geologie und Vorstand des Geolog.-Mineralog. Inst. • In dieser Zeit:

Stuttgart: 11. Aug. 1903-Frühjahr 1923 Vorstand der neugegründeten Geologischen Abt. des Königl. Württ. Statistischen Landesamts.

1914-1918 Kriegsfreiwilliger, u. a. als Kriegsgeologe an der Westfront in den Vogesen sowie an der bulgarischen Front im Wardartal.
E 1885 Mitglied der Dt. Akademie der Naturforscher Leopoldina Halle/S.; Ehrenmitglied: 1921 Oberrheinischer Geologischer Verein und Verein für vaterländische Naturkunde in Württemberg. • 1896 Ritterkreuz I. Klasse des Ordens vom Zähringer Löwen.

Qu UAH PA 2186. GLA Abt. 235, Fasz. 2446. • Siehe auch Archiv der Dt. Akademie der Naturforscher Leopoldina Halle/S.

$W$ Untersuchungen über phonolithische Gesteine der Canarischen Inseln. Diss. Halle/S. 1876. Mineralkunde als Einführung in die Lehre vom Stoff der Erdrinde. 7 Abt. Stuttgart 1905-1907. Die Ausnützung der Torfmoore. Stuttgart 1920. (Mitverf.) - Siehe Bibliographie in: Bräuhäuser (1933) S. XI-XV.

$L$ Wer ist's (1914) S. 1441; Kürschner (1931) Sp. 2494. - Bräuhäuser, Manfred: A.S. † in: Jahresberichte und Mitteilungen des Oberrheinischen geologischen Vereins. N.F. Bd. XXII. Jg. 1933. Stuttgart 1933. S. IX-XV. - Arnim 2 (1952) S. 478; WBIS; Wagenbreth (1999) S. 253 (Register). Bach, Ingo: Der Geologe und Mineraloge A.S. - eine biographische Skizze in: Weißenfelser Heimatbote - Weißenfelser Zs. für Heimatgeschichte und Kultur (2007) H. 2. DBE (2007) S. 711. • Sachs, Oliver: Die Erforschung und Namensgebung von "Suevit“ in: Jahresberichte und Mitteilungen des Oberrheinischen Geologischen Vereins 93 (2011) S. 77-88. Kölbl-Ebert, Martina: From local patriotism to a planetary perspective. Impact crater research in Germany, 1930s-1970s. Farnham 2015. S. 82 f. Deutsche Biographie, s. https://www. deutsche-biographie.de/gnd116976861.html [07.11. 2017].

$P$ Bildarchiv UAH.

\section{Sax, Anton}

siehe Sar 


\section{Schäfer, Johann Heinrich Dietrich}

1896-1903 Phil. Fak.

Mittelalterliche Geschichte, Hilfswissenschaften

* 16. Mai 1845 Bremen

$\dagger$ 12. Jan. 1929 Berlin-Steglitz

口 Berlin-Dahlem

ev.

V Johann Dietrich S. (1814-1855) Hafenarbeiter

M Anna Dorothea geb. Wellingh(a)usen (18091897) Dienst- und Waschfrau

๑ 21. Mai 1875 Wilhelmine Sophie Juliane geb. Theobald (1847-1924)

K 2 S, 4 T, siehe NDB 22 (2005) S. 504* - U.a. Anne (Anni) Julia S. (1878-1957) zwischen 1898 und 1906 Sekretärin von D.S. („Vaters Hilfe"), s. Lebenserinnerungen von Frau Anni Kalähne geb. S. in: Nachlaß D.S. im Staatsarchiv Bremen; u. a. Nov. 1918 Begründerin des Dt. Bürgerlichen Frauenbundes in Danzig mit 6oo Mitgliedern, 1920-1933 Landtagsabgeordnete im Danziger Volkstag für die DNVP, 1933 kurzzeitige Inhaftierung, 1945 Flucht aus Danzig nach Schleswig, s. über Anni K. geb. S. in: Ich bin der letzte Preusse. Der politische Lebensweg des konservativen Politikers Kuno Graf von Westarp (1864-1945). Hrsg. von Larry Eugene Jones und Wolfram Pyta. Kön 2006. S. 93 und Anm. 46; Paletschek, Sylvia: Historiographie und Geschlecht in: Eroberung der Geschichte: Frauen und Tradition. Hrsg. von R. Johanna Regnath. Hamburg 2007. S. 105-127, hier S. 110 und Anm. 14. - Seit 1906 Ehefrau von Alfred Kalähne (1874-1946) 1902 Habilitation an UH, seit 1906 a.o. Prof., seit 1921 planm. a. o. Prof. und seit 1923 o. Prof. für Photophysik und Photographie TH Danzig, s. UAH PA 1799; WBIS.

Lb Bremen: Seit April 186o Ausbildung am Volksschullehrer-Seminar; März 1863 Seminarabgangsprüfung; seit April 1863 Volksschullehrer; Febr. 1865 II. Lehrerprüfung; Herbst 1865-1868 Lehrer an Privat-Realschule; Frühling 1867 Englisch-Examen vor Prüfungskommission für höhere Schulen.
Seit SS 1868 Studium der Philologie, Geschichte an U Jena, WS 1869/70-SS $1870 \mathrm{H}$.

31. Juli 1870-30. März 1871 Freiwilliger im DeutschFranzösischen Krieg.

1871 Forts. des Studiums an U Göttingen; 9. Dez. 1871 Rigorosum, 27. April 1872 (Datum der Promotionsurkunde) Dr. phil. an U Göttingen; Mai 1872 Staatsprüfung für den Unterricht an höheren Schulen in Bremen.

Bremen: Seit 1. April 1872 Hilfslehrer, 1. Okt. 18721. Okt. 1876 o. Lehrer an Hauptschule.

Lübeck: Seit 24. April 1876 Mitarbeiter im Hansischen Geschichts-Verein; Okt. 1876-Sept. 1877 Archivreisen im Auftrag des Vereins.

U Jena: Seit WS 1877/78 a. o. Prof. für Mittelalterliche, auch Neuere Geschichte, Geographie, Hilfswiss.; seit 19. Juni 1880 o. Honorar-Prof.; seit WS 1883/84 o. Prof.

U Breslau: Seit SS 1885 o. Prof.; 1888 Ruf an U Halle-Wittenberg abgelehnt.

U Tübingen: Seit WS 1888/89 o. Prof.

UH: Seit 10. Juni 1896 o. Prof. als Nachf. von Eduard Winkelmann; 14. Okt. 1896 Vereidigung; Direktor des Histor. Seminars: 1896-1901 zus. mit Bernhard Erdmannsdörffer, SS 1901 Direktor, seit WS 1901/o2 zus. mit Erich Marcks [d. Ä.], seit WS 1902/o3 zus. mit Karl Hampe; seit Juli 1901 Direktor der neueingerichteten Abt. für Mittelalterliche Geschichte; 1901 Ruf an U Straßburg abgelehnt. • In dieser Zeit:

1901-1902 Mitglied der I. Kammer der Badischen Landstände als Vertreter der UH.

U Berlin: 9. Nov. 1902 Ern. zum o. Prof.; SS $1903-$ WS 1920/21 (Ruhestand) o. Prof. und Direktor des Histor. Seminars.

1898/99 Dekan der Phil. Fak. der UH 
U.a. 1915 (Mitbegründer)-1918 Vorsitzender des Unabhängigen Ausschusses für einen deutschen Frieden, s. hierzu: Lexikon zur Parteiengeschichte ... Hrsg. von Dieter Fricke ... Leipzig 1986. Bd. 4. S. 203-206; Bruendel, Steffen: Volksgemeinschaft oder Volksstaat: Die „Ideen von 1914 “ und die Neuordnung Deutschlands im Ersten Weltkrieg. Berlin 2003. S. 76-80 u. ö.

1917 Mitbegründer der Deutschen Vaterlandspartei (DVLP)

1901 Badischer Geh. Hofrat; 1902 Geh. Rat II. Klasse

$E$ Mitglied der Akademie der Wissenschaften: Kopenhagen, Stockholm, Upsala, 1894 Göttingen, 1903 Berlin, 1908 München; 1896 o. Mitglied der Badischen Histor. Kommission. - 1915 D. theol. Berlin. 1899 Königl. Preußischer Kronen-Orden III. Klasse; 1902 Ritterkreuz I. Klasse des Ordens vom Zähringer Löwen.

Qu UAH PA 2190; RA 6421, 6847. GLA Abt. 235, Fasz. 2454. - Repertorium der Briefe aus dem Archiv Walter de Gruyter. Ausgewählt von Otto Neuendorff. Bearb. von Anne-Katrin Ziesak. Berlin 1999. S. 255 f. • Teil-Nachlaß: Staatsarchiv Bremen; s. auch Ackermann (2004) S. 33-35. - Mein Leben. Berlin 1926. (Autobiogr.)

$W$ Deutschland zur See. Jena 1897. Nachdr. der 2. Aufl. von 1897. Bremen 2012. • Die Hanse. Bielefeld 1903. 4. Aufl. 1943. Die Weltgeschichte der Neuzeit. 2 Bde. Berlin 1907. 11. Aufl. 1922. - Die deutsche Geschichte. 2 Bde. Jena 1910. 10. Aufl. 1932. - Aufsätze, Vorträge und Reden. 2 Bde. Jena 1913. Bismarck, ein Bild seines Lebens und Wirkens. Berlin 1917. Neuaufl. 1935. - Staat und Welt. Berlin 1923. Osteuropa und wir Deutschen. Berlin 1924 .

HG Hanserecesse 1477-1530. 9 Bde. Leipzig 18811913. Württembergische Geschichtsquellen. 3 Bde. Stuttgart 1894-1896. Abhandlungen zur Verkehrs- und Seegeschichte. Berlin 1908-1913.
$L$ D.S. und sein Werk. Darstellungen von Rudolf Häpke ... Hrsg. von Kurt Jagow. Berlin 1925. • Bremische Biographie (1969) S. 433-435 (mit Werkverz.). - Bütfering, Elisabeth: D.S. als politischhistorischer Publizist vor dem Ersten Weltkrieg. Magisterarbeit. Tübingen 1972. - Berliner Historiker (1985); Weber (1987) S. 498-500; Jakobs (1992) S. 49-52; WBIS. - Pitz, Ernst: D.S. als Hanseforscher in: Hansische Geschichtsblätter 114 (1996) S. 141-166. - Ackermann, Jens P.: D.S. Politischer Historiograph des wilhelminischen Zeitalters. Diss. Jena 2002. • Schwarzwälder, Herbert: Das Große Bremen-Lexikon. Bremen 2003. - Ackermann, Jens P.: Die Geburt des modernen Propagandakrieges im Ersten Weltkrieg. D.S. ... Frankfurt/M. 2004. - Württembergische Biographien 1 (2006) S. 221-223; Kriegstagebuch K. Hampe (2007) S. 993 (Register). Geschichte der Universität zu Berlin 1810-2010. Bd. 4: Genese der Disziplinen ... Hrsg. von Heinz-Elmar Tenorth und Rüdiger vom Bruch. Berlin 2010. S. 573 (Register). Badische Biographien N.F. VI (2011) S. 338-341 (S. 338: irrtümlich 1913 statt 1903 als Aufnahmejahr in die Preußische Akademie der Wissenschaften $\mathrm{zu}$ Berlin genannt); Gerhards (2013) S. 512 (Register).

P Bildarchiv UAH; Bremische Biographie.

\section{Schapira, Hermann (Taufname: Hirsch)}

1883-189o Phil. Fak.

1890-1898 Nat.-Math. Fak.

Mathematik

* o4. Aug. 1840 Erschwilken (Russland; heute: Eržvilkas, Litauen)

† o8. Mai 1898 Köln (während e. Reise an Lungenentzündung)

ㅁ 10. Mai 1898 Köln

1953 Überführung nach Jerusalem mosaisch

V Salomon S.

M Eva geb. Schapira

( 1877/78 Clara geb. Blank (†1914/15)

K unbekannt. 
Lb Ausbildung zum Rabbiner („meine Erziehung genoss ich von meinem Vater, welcher sie fast auf das Talmudstudium beschränkte. In der hebräischen Bibliothek desselben lernte ich jedoch schon als Kind mathematische und astronomische Schriften kennen, welche in mir ein lebhaftes Interesse für die Mathematik erweckten. Dem Rabinatsstudium gewidmet, musste ich meine Lieblingswissenschaft geheim und privatim pflegen. 1867 gab ich schließlich meine erreichte Rabbinatscarriere auf", aus: UAH H-IV-102/94 fol. 163r).

Erschwilken: 1860-1867 Rabbiner.

Berlin: Seit 1868 Studium an Gewerbe-Akademie.

1871 Rückkehr nach Russland aus gesundheitlichen und finanziellen Gründen („Mittellosigkeit zwang mich ..., 1871, ohne das Studium vollendet zu haben, wieder nach Russland zu gehen, wo ich, nach einer Genesung von einer langwährigen und gefährlichen Krankheit, als Buchhalter, Correspondent und Controlleur [bis 1878 in Odessa] zu wirken gezwungen war", aus: $\mathrm{H}-\mathrm{IV}-102 / 94$ fol. 163r); Sommer 1878 Rückkehr nach Deutschland.

UH: Seit WS 1878/79 Forts. des Studiums; 17. Dez. 188 o Dr. phil.; 6. Juni 1883 Habilitation; seit 31. Juli 1887 a. o. Prof.

1884 Gründer des ersten nationaljüdischen Vereins "Zion“ in Deutschland in Heidelberg, s. hierzu weiter Dokumente zur Geschichte des deutschen Zionismus 1882-1933. Hrsg. ... von Jehuda Reinharz. Tübingen 1981. S. 10 und Anm. * sowie S. 575 (Register).

Qu UAH PA 2194; RA 6508; Quästurakte Rep. 27-1169; Fak.-Akten H-IV-102/94 fol. 16or-17or, H-IV-102/101. • Teil-Nachlaß im Bestand des „Leo Baeck Institute“ im Jüdischen Museum Berlin.

W Darstellung der Wurzeln einer allgemeinen Gleichung $\mathrm{n}=$ Grades mit Hülfe von Cofunctionen aus Potenzreihen in elementarer Behandlungsweise. Leipzig 1883. - Theorie der Congruenzen. Berlin 1889. - Theorie allgemeiner Cofunktionen und einige ihrer Anwendungen. Leipzig 1892.
Übers. Mischnath ha-mmiddoth (Lehre von den Maassen). Aus e. Manuscripte der Münchener Bibliothek, bezeichnet Cod. Hebr. 36. Als erste geometrische Schrift in hebräischer Sprache hrsg. ... von M. Steinschneider. Ins Deutsche übers. ... von H.S. in: Zs. für Physik und Mathematik 25 (1880) S. $1-56$.

L Cantor, Maurizio: Necrologio Ermanno Schapira in: Bolletino di bibliografia e storia delle scienze matematiche (1898) 1, S. 106-109. (Übers.: Cantor, Moritz: Nachruf H.S. Deutsch von Gabriele Dörflinger. UBH 2013 (online.)) - ADB 53 (1907) S. 732-733; Jüdische National-Biographie 5 (1930) S. 392 f. - Jaffe, Leib: The life of H.S. An autobiographical fragment and selections from Schapira's writings. Jerusalem 1939. - H. S., father of the J.N. F. (Jewish National Fund). New York 1962. • WBIS; Math. Institute in Deutschland (1989) S. 163, 166; Jansen (1992a) S. 169 (Register); Kern (1992) S. 95-100 u. ö. - Jüdische Mathematiker in der deutschsprachigen akademischen Kultur. Hrsg. von Birgit Bergmann, Moritz Epple. Berlin 2009. S. 235 (Register). Corry, Leo, Schappacher, Norbert: Zionist internationalism through number theory. Edmund Landau at the opening of the Hebrew University in 1925 in: Science in context 23(4) (2010) S. 427-471, hier S. 441-444 u. ö. • Wissenschaftsatlas (2011) S. 300-302; Homo Heidelbergensis mathematicus online. Studies on Steinschneider. Moritz Steinschneider and the emergence of the science of judaism in nineteenth century Germany. Ed. by Reimund Leicht, Gad Freudenthal. Leiden 2012. S. 46of., 465.

$P$ Bildarchiv UAH; graph. Slg. UBH.

\section{Schapira, Hirsch}

siehe Schapira, Hermann 


\section{Schelver, Franz Friedrich Maria Joseph} Liborius

1807-(1827) 1832 Med. Fak.

Zoologie mit vgl. Physiologie und Anatomie, Physiologie des Menschen, Philosophie der Botanik, Pathologie und Therapie (bis WS 1811/12), System der wiss. Medizin, Geschichte der Medizin, Magnetismus, Psychologie, Geschichte und Heilart der Gemütskrankheiten, Anthropologie

SS 1807 , WS $1807 / 08$, SS 1809-WS 1817/18, WS 1818/19-SS 1821, SS 1822, SS 1823-SS 1825, SS 1826 , SS 1827-SS 1828, SS 1829, SS 1830 Phil. Fak. System der Naturphilosophie, Mineralogie, Geognosie, Botanik, Physiologie (System) der Gewächse

* 23. Juli 1778 Osnabrück

$\approx$ 24. Juli 1778

$\dagger$ 30. Nov. 1832 Heidelberg kath.

V Dr. iur. Friedrich Joseph S. (1732-1795) Ritterschaftssekretär

M Maria Lydia Joanna Catherina Franciska geb. van $\mathrm{Be}(\mathrm{e}) \operatorname{sten}\left({ }^{*} 1752\right)$

$\infty$ Theodora geb. Meyer

$\infty$ 12. Juli 1815 Maria Margaretha geb. Schwartze verw. von der Horst (1779-1830)

$\mathrm{K} \quad 1 \mathrm{~S}$ (früh $\dagger$ ), 1 Stief-T, 2 T: u. a. Victoria/Victorie S. (1820-1893) (Ehefrau von: (siehe) Georg Gottfried Gervinus) Musikerin, siehe Badische Biographien 5 (1906) S. 198-202, Pfeiffer (2004) S. 156 f.; Baar, Regina: V.G. - Leben und Wirken der Ehefrau und Witwe in: Georg Gottfried Gervinus ... Gelehrter - Politiker - Publizist. Bearb. von Frank Engehausen ... Heidelberg 2005. S. 73-84 (mit $P$ ).

Vw Siehe Müller (1992) S. 15.

Lb Studium der Medizin: Seit 20. April 1796 U Jena, seit 16. Okt. 1797 Göttingen; 4. Okt. 1798 Dr. med. an U Göttingen.

Osnabrück: Ende 1798-Sept. 1801 Arzt.

U Kiel: 9. Sept. 1801 Immatrikulation als Dr. med. Franz Schelver.
U Halle/S.: Seit 1801/o2 Privat-Dozent für Pathologie und Therapie, auch Naturphilosophie.

U Jena: 11. Juni 1803 Ern. zum a. o. Prof. für Medizin und Direktor des Botanischen Gartens; Okt. 1806 bei Plünderung Jenas durch franz. Soldaten Ausraubung S.s „bis aufs Hemd“ (aus: Müller (1992) S. 32 f.); Flucht.

UH: Seit SS 1807 o. Prof. an Med. Fak.; 1807-1830 (mit Unterbrechungen) auch Vorlesungen an Phil. Fak.; 15. Jan.-23. April 1810 provisorischer Direktor des Botanischen Gartens hinter dem ehemaligen Dominikanerkloster (an der Ecke Hauptstrasse/ Brunnengasse) in Nachf. von Franz Karl Zuccarini, s. UAH RA 6883 fol. 2r und $Z$ (1); 1812-1827 (Enthebung durch ministeriellen Erlaß) Direktor des Botanischen Gartens als Nachf. von Wilhelm Gottlob Kastner (und in Nachf. von Jacob Fidelis Ackermann, s. RA 6883 fol. 12r), s. hierzu auch Müller, S. 44-55, Wissenschaftsatlas der UH (2011) S. 236 f.; Dez. 1827 Ausschluß von Fak.-Geschäften durch ministeriellen Erlaß nach Beschwerden der Fak. über das „uncollegialische u. statutenwidrige Benehmen" S.s (aus: Müller, S. 40); S. kann jedoch weiterhin Vorlesungen halten; 1832 S.s jährl. Besoldung beträgt 1100.- Gulden (aus: UAH PA 2197 fol. 25r).

1812, 1819 Dekan der Med. Fak. der UH

$Z$ (1) Vom 15. Jan. bis 23. April 1810 überträgt das Ministerium des Innern S. „die Direction der botanischen Gärten einstweilen nur provisorisch und mit dem ausdrücklichen Beysatze, daß ihm dieses keinen Titel für die Zukunft geben soll, es wäre anschl[ießend], daß, worüber binnen $14 \mathrm{Ta}$ gen näh[e]ren Gutachten entgegen gesehen wird, der Prof. Kastner nicht für vorzüglich zu dieser Direction angesehen werden könnte" (aus: RA 6883 fol. 2 r).

$Z$ (2) In einem Rückblick auf die Geschichte des Botanischen Gartens und seiner Direktoren heißt es 1844 über S.: Es gab einen „Professor der Botanik, [der] Direktor des Bot[anischen] Gartens war, welcher notorisch keine spezielle Pflanzenkenntniß besaß und zuletzt an Geisteskrankheit litt ... Vom Jahre 1828 an (war) gar kein Professor der Botanik als Direktor der Gärten [nämlich des Bota- 
nischen und Schlossgartens] angestellt ..., theils weil man unter den zwey vorhandenen Dozenten der Botanik, unter welchen sich kein Ordinarius befand, keinem einen Vorzug geben wollte, theils weil man vielleicht an eine baldige auswärthige $\mathrm{Be}$ rufung dachte, theils endlich, weil mit der Anlage des neuen Botanischen Gartens [1834 Aufgabe des alten Botanischen Gartens hinter dem ehemaligen Dominikanerkloster und Anlegung e. neuen zwischen heutigem Bismarck- und Adenauerplatz] ein Zeitraum ganz außergewöhnlicher Verhältnisse eintrat, in welcher [der Gärtner Johannes] Metzger faktischer Direktor in technischer wie in wissenschaftlicher Hinsicht war und bisher [1844] geblieben ist ..." (aus: UAH RA 5629 fol. 25v, 26r).

$Z$ (3) Johannes Metzger (1789-1852) war seit Nov. 1812 U-Gärtner in Heidelberg; 1830 erfolgte seine Ernennung zum Garten-Inspektor, 1843 zum Garten-Direktor. M. war nach 1812 bis 1851 auch für den Schlossgarten verantwortlich. Nach Schelver bekleidete M. von 1828 bis 1847 das Amt e. provisorischen Direktors des Botanischen Gartens, s. hierzu RA 5629 fol. 26r. 1844 wurde in einer neuen Garten-Ordnung das Amt geteilt: in einen technischen und einen wissenschaftlichen Direktor (hierzu siehe die Entwürfe für die Gartenordnung von 1844 in: RA 5629 fol. 25r-6or). M. übte beide Ämter aus bis zur Ernennung von Gottlieb Wilhelm Bischoff 1847 zum wiss. Direktor (bis 1854). M. blieb von 1847 bis zu seiner Ernennung zum Direktor des großherzogl. Gartens in Karlsruhe 1851 der technische Garten-Direktor (zu Metzger, s. UAH PA 1987 f., WBIS). Nachfolger M.s wurde im Mai 1851 für die „Besorgung des Botanischen Gartens und des Schlossgartens provisorisch" der Gärtner Christoph Lang, zuletzt 1887 erwähnt (aus: PA 1988; zu Lang, s. UAH PA 1896).

1821 Badischer Hofrat

E 1816 Mitglied der Dt. Akademie der Naturforscher Leopoldina Halle/S., Mitglied der Physikalischen Gesellschaft Göttingen.

Qu UAH PA 2197; RA 4921, 5628f., 5894, 6459, $6487,6592,6635,6883,7986$, 8016; G-II-63/1-GII-63/10 (Botanischer Garten). - GLA Abt. 205, Fasz. 471. Johann Wolfgang Goethe: Tagebücher.
Bd. V,2. 1813-1816. Kommentar. Hrsg. von Wolfgang Albrecht. Stuttgart 2007. S. 565 f., 711, 737, 741, 814f. - Siehe auch Archiv der Dt. Akademie der Naturforscher Leopoldina Halle/S. • Auskunft: Dompfarramt Osnabrück (Taufbuch); Bischöfl. Generalvikariat Osnabrück; Thüringer Universitäts- und Landesbibliothek (Abt. Handschriften) Jena; Universitätsarchiv Kiel im Landesarchiv Schleswig-Holstein in Schleswig.

$W$ Versuch einer Naturgeschichte der Sinnesorgane der Insecten und Würmer. Göttingen 1798. • Kritik der Lehre von den Geschlechtern der Pflanzen. 3 T. Heidelberg 1812-1823. - Lebens- und Formgeschichte der Pflanzenwelt. Heidelberg 1823.

L Wechmar (1846) S. 253; Günther (1858) S. 226; ADB 31 (1890) S. 30; Chronik Ärzte H (1985) S. 141. - Schipperges, Heinrich: Ursprung und Schicksal der Medizinischen Fakultät in: Semper apertus 4 (1985) S. 7of. - Müller, Klaus-Dieter: Franz Joseph S. ... Romantischer Naturphilosoph, Botaniker und Magnetiseur im Zeitalter Goethes. Stuttgart 1992. Müller-Jahncke, Wolf-Dieter (zus. mit Klaus-Dieter Müller): „Ich war im Tempel des Weltgeistes“. F. J.S. als Magnetiseur in Heidelberg in: Pharmazeutische Zeitung 138 (1993) H. 6, S. 2328. - Pieper, Werner: Im Tempel des Weltgeistes. F. J.S., der Wunderheiler in: Pieper, Werner: Highdelberg. Zur Kulturgeschichte der Genussmittel - am Beispiel einer berauschenden Stadt. Löhrbach im Odenwald 200o. Kirschke (2001) S. 449 (Register). Bach, Thomas: F.J.S. in: Naturphilosophie nach Schelling. Hrsg. von Thomas Bach und Olaf Breidbach. Stuttgart-Bad Cannstatt 2005. S. 595-626. Bürger, Bauern und Soldaten. Napoleons Krieg in Thüringen 1806 in Selbstzeugnissen: Briefe ... Hrsg. von Birgitt Hellmann. Weimar 2005. S. 75 f. u. ö. - Naturphilosophie nach Schelling (2005) S. 595-626; WBIS; Zimmermann/Neuper (2008) S. 218 f. u. ö.; Stumm (2012) S. 703 (Register).

$P$ Bildarchiv UAH; Chronik Ärzte H.

\section{Schelver, Franz Joseph}

siehe Schelver, Franz 


\section{Schenkel, Daniel Georg}

1851-1884 Theol. Fak.

Theologie, Philosophie

* 21. Dez. 1813 Dägerlen (bei Winterthur, Kanton Zürich)

$\dagger$ 19. Mai 1885 Heidelberg

ev.

V Johannes S. (1783-1828) Landgeistlicher, s. Schenkel, Daniel: J.S., Pfarrer zu Unterhallau in der Schweiz. Ein Denkmal auf dem Grabhügel eines Verborgenen vor der Welt. Hamburg 1837.

M Helena geb. Kraus(s) (1790-1841)

( 26. Jan. 1843 Maria Magdalena geb. von Waldkirch (1821-1906)

$\mathrm{K} \quad{ }_{4} \mathrm{~S}$ (davon $1 \mathrm{~S}$ früh $\dagger$ ), 2 T: u. a. Sophie S. (18501887) Ehefrau von: (siehe) Siegfried Brie

Vw Nachfahre: Johannes S. ( $\left.{ }^{\star} 1954\right)$ seit 2002 Privat-Dozent, seit 2012 apl. Prof. am Inst. für Physiologie und Pathophysiologie der UH und Leiter der Kryokonservierung am DKFZ.

Lb U Basel: Seit 1832 Studium der Theologie, Philosophie.

Schaffhausen: 1835 Theol. Examen; 1835 Predigtamtskandidat, 1836 Stadtvikar.

U Göttingen: 1836 Forts. des Studiums der Theologie; 1838 Lizentiatenprüfung.

Basel: 27. Sept. 1838 Habilitation an U; 1839-1842 Gymnasial-Hilfslehrer und Redakteur der „Basler Zeitung“.

Schaffhausen: 10. Juni 1841 (Berufung)-1849 I. Stadtpfarrer an Münsterkirche; Frühjahr 1842 Amtsantritt.

U Basel: 1846 Dr. theol.; seit 21. Nov. 1849 o. Prof.

UH: Seit 8. März 1851 o. Prof., I. Direktor des Ev.Prot. Predigerseminars, seit WS 1867/68 als Ev.Prot. Theol. Seminar bezeichnet und I. U-Prediger an Peterskirche (im Sommer) und an Providenz- kirche (im Winter, da beheizbar) als Nachf. von Richard Rothe mit e. Jahresgehalt von 2800.- Gulden; 8. Mai 1851 Vereidigung; 1859 Ruf an U Bonn abgelehnt; 16. April 1884 Ruhestand.

1856 Prorektor der UH; 1854, 1858, Jan.-Sept. 1862, 1865/66, 1868/69, 1872/73, 1875/76 Dekan der Theol. Fak. der UH

1863 Mitbegründer des Deutschen Protestantenvereins, siehe hierzu auch Richard Rothe

1858 Kirchenrat

E 1884 Kommandeurkreuz II. Klasse des Ordens vom Zähringer Löwen.

Qu UAH PA 2199; RA 6718 fol. 18r, v. GLA Abt. 205, Fasz. 472. - Briefe: UBH. - Ausdruck e. Briefes von S. im UAH aus der Privatsammlung von Briefen im Familienarchiv Dr. Karsten Weber, Mosbach. - Der Redaktionsbriefwechsel der Hallischen, Deutschen und Deutsch-Französischen Jahrbücher 1837-1844. Hrsg. von Martin Hundt. Bd. 1: Der Briefwechsel um die Hallischen Jahrbücher. Berlin 2010. Apparat: S. 275 (Register). • Auskunft: Stadtarchiv Schaffhausen; Staatsarchiv Basel-Stadt. - Mitteilungen: Herr Prof. Dr. Johannes Schenkel, Universität Heidelberg.

$W$ Wesen des Protestantismus, aus den Quellen des Reformationszeitalters dargestellt. Schaffhausen 1846-1851. Das Prinzip des Protestantismus. Schaffhausen 1852. - Christliche Dogmatik vom Standpunkt des Gewissens aus dargestellt. Wiesbaden 1858. Charakterbild Jesu. Wiesbaden 1864 . 4. Aufl. 1873. - Das Christusbild der Apostel und der nachapostolischen Zeit. Leipzig 1879.

G 1860 Allgemeine kirchliche Zeitschrift.

$L$ Badische Biographien 4 (1891) S. 383-400; Heidelberger Prof. aus dem 19. Jhdt. 1 (1903) S. 119127. - Schib, Karl: D.S. in: Schaffhauser Biographien des 18. und 19. Jahrhunderts. Thayngen 1956. Bd. 1. S. 326-330. BBKL IX (1995) Sp. 150-153; Wischmeyer (2008) S. 469 (Register). Ehmann, Reinhard: D.S. ... Liberaler Kirchenpolitiker und Agitator in: Lebensbilder aus der Ev. Kirche 
in Baden im 19. und 20. Jahrhundert. Bd. II: Kirchenpolitische Richtungen. Hrsg. von Johannes Ehmann. Heidelberg 2010. S. 169-198. - Noordveld-Lorenz, Dorothea-Henriette: Gewissen und Kirche. Zum Protestantismusverständnis von D.S. Tübingen 2014. Karcher, Stefan: Die Entstehung der Universitätsgottesdienste (1838). Theol. Fak. der UH. Online-Ressource (2017), s. http:// www.uni-heidelberg.de/fakultaeten/theologie/for schung/predigtforschung/universitaetsprediger/ wissenschaft-und-verkuendigung.html\#.

$P$ Bildarchiv UAH; graph. Slg. UBH.

\section{Scherrer, Hans}

siehe Scherrer, Johannes

\section{Scherrer, Johannes (genannt: Hans)}

1866-1917 Phil. Fak.

Geschichte, Nationalökonomie, Gesellschaftswissenschaften

* 29. Dez. 1828 Speyerdorf (heute: Lachen-Speyerdorf, Ortsteil von Neustadt/Weinstraße)

$\approx$ o1. Jan. 1829

$\dagger$ 19. Febr. 1917 Heidelberg ev.-prot.

V Karl Friedrich S. (1795-1865) Leinenweber, dann Ackersmann

M Christina geb. Wetzel (1791-1874)

(14. Mai 1866 Johanna Philippine geb. Hirschel (1843-1875) 1866-1875 Betreiberin e. BildungsAnstalt in H, Leopoldstraße 52

$\infty$ 21. Jan. 1890 Karolina (Lina) Katharina geb. Eckenroth verw. Hussenet (1836-1922) 1899 erstmals, 1917/18 letztmals als Betreiberin e. Anstalt für moderne Sprachen in der Neuenheimer Landstraße 52 (seit 1915 Nr. 58) genannt (s. Adreßbuch der Stadt H für 1899, S. 180, Adreßbuch ... für 1917, S. 309)
K $3 \mathrm{~S}$ (davon $1 \mathrm{~S}$ früh $\dagger$ ): Dr. med. Anton Friedrich S. (1867-1909) praktischer Arzt. - Karl Friedrich Adam S. (1869-1936) vor 1914 Tierarzt in Tauberbischofsheim, anschl. Hornberg (Schwarzwald), auch Kreistierarzt in Lukow (heute: Łuków, Polen), seit 1919 Kreistierarzt in H; 1919-1936 Bewohner des Hauses Neuenheimer Landstraße 58 (s. Adreßbuch der Stadt H für 1919, S. 315, Adreßbuch ... für 1936, S. 397). 2 T: u. a. Käthe S. ( $\left.{ }^{*} 1870\right)$, siehe $Z$ (3).

Lb Seit 1841 Besuch der Lateinschule in Neustadt/Weinstraße; ca. 1843-1845 (Abbruch) praktische Vorbereitung auf Lehrerberuf in Böhl (heute: Böhl-Iggelheim) und Neustadt; anschl. Forts. der Schulausbildung in oberer Klasse der Lateinschule in Neustadt und Privat-Unterrichtung zur Vorbereitung auf die Maturitätsprüfung; Herbst 1847 Wechsel in höhere Klasse des Gymnasiums in Zweibrücken; Herbst 1848 Abbruch der Schulausbildung; S. hätte „gründliche[r] Nachhilfe von ... erfahrenen Gymnasiallehrern bedurft", um das Abschlußexamen ablegen zu können; er „scheute ... die großen Kosten meiner Eltern wegen und hoffte vergebens, ohne dieselben fortzukommen. Im Sturm der politischen Ereignisse von 1848 mit fortgerissen, wurde das Wesentliche versäumt und das Schuljahr verstrich" ohne Examensabschluß (aus: UBH Heid. Hs. 4148 I,2); 1849 S. nimmt Privatstunden in $\mathrm{H}$ und ist Hörer an $\mathrm{UH}$.

Studium der Rechtswiss.: 25. Jan. 1850 Immatrikulation an UH („limitirt wegen Mangels des Maturitätszeugnisses“, s. Toepke 6 (1907) S. 102 und Anm. 2), seit WS 1850/51 München (s. hierzu Z (4)); WS 1851/52-WS 1854/55 Forts. des Studiums der Rechtswiss. und der Philosophie an UH; 9. Dez. 1854 Dr. iur. an UH.

1855-1857 Studienreisen: Großbritannien, Frankreich, Belgien. $\bullet$ In dieser Zeit:

Brüssel: Redakteur an der 1831 gegründeten Zeitschrift „L'Indépendance Belge“; 1857 Erzieher der beiden natürlichen Söhne Leopolds I., des ersten Königs von Belgien, der Barone von Eppinghoven Georg (1849-1904) und Arthur (1852-1940). 
UH: Seit WS 1858/59 Studium der Geschichte (ohne Immatrikulation); 15. März 1864 Promotion zum Dr. phil.

Nassau: Seit Sommer 1864 Ordnung und Katalogisierung der Bibliothek des ehemaligen preuBischen Staatsministers Heinrich Friedrich Karl Reichsfreiherr vom und zum Stein (1757-1831) auf dem Steinschen Schloß; Ende 1864/Anfang 1865 Rückkehr nach $\mathrm{H}$.

UH: 10. Jan. 1866 Habilitation; seit 1. Aug. 1886 a. o. Prof. ohne etatm. Besoldung; SS 1917 S.s letzte Vorlesungsankündigung über „Versuche über die Lösung der sozialen Frage“ (einstündig) kann er nicht mehr erfüllen $(\dagger)$ • In dieser Zeit:

UBH: 23. Okt. 1872-30. Juni 1873 Volontär (S. „hat in dieser Stellung die Expeditionsgeschäfte besorgt“, aus: Brief vom 30. Juni 1873 in: UAH PA 77); S. vertritt Ende 1872 den durch Krankheit ausfallenden Bibliothekar Carl Ernst Thibaut (18071881), siehe Anton Friedrich Justus Thibaut: Eintrag unter $K$ [inder]; Juni 1873 S. erhält e. einmalige Zahlung von 70o.- Gulden für e. „aushülfsweise Dienstleistung“ (aus: Brief vom 4. Juni 1873 in: PA 77).

Z (1) Am 19. Mai 1890 Eröffnung des Konkursverfahrens über das Vermögen von S., nachdem durch „eine für seinen Neffen übernommene Bürgschaft nach Eintritt des Konkurses auch [S.] seinerseits“ in Konkurs getrieben wird (aus: Brief vom 24. Juli 1890 in: UAH PA 2200). Am 12. Juli 1890 wird „auf Antrag des Konkursverwalters sowie des Gläubigerausschusses das Konkursverfahren ... eingestellt, da eine den Kosten des Verfahrens entsprechende Konkursmasse nicht vorhanden ist“ (aus: PA 2200).

Ein Gesuch S.s um Gewährung einer finanziellen Unterstützung wird am 17. Juli 1907 vom Ministerium der Justiz, des Kultus und Unterrichts abschlägig beschieden, da „zu unserm Bedauern keine Mittel (im Hochschulbudget) zur Verfügung stehen" (aus: PA 2200). S.s Gesuch wird von der Phil. Fak. unterstützt, „allerdings gestattet sich die Fakultät ehrerbietigst zu bemerken, daß die Erteilung eines Lehrauftrags an ... S. ihres Erachtens nicht angebracht wäre“; eine Begründung für die Ablehnung ist in der PA nicht genannt (aus: Brief vom 21. Juni 1907 in: PA 2200).

$Z$ (2) Am 2. Jan. 1910 berichtet S. an den Senat der UH, daß „mir seit zwei Monaten infolge von Überarbeitung meine Kopfnerven so sehr erschüttert worden sind, daß ich wegen häufiger Schwindelanfälle alle geistige Arbeit einstellen mußte, so schwer es mir ankam. Sollte sich [!] mit der Zeit eine derartige Besserung eintreten, daß ich meine vorgenommenen Arbeiten wieder aufnehmen und wenigstens zum Teil vollenden kann, so will ich meinem Schöpfer dankbar sein und mit Freuden noch tun, was möglich ist“" (aus: PA 2200).

Z (3) Am 16. Sept. 1914 schreibt der damalige Privat-Dozent für Psychiatrie, (siehe) August Homburger, an einen Herrn Geheimrat, möglicherweise an den Prorektor Eberhard Gothein, daß die Familie von S. „durch den Ausbruch des Krieges in eine schwere Notlage geraten ist. Die beiden alten Leute [J.S. und seine Frau Lina] haben bisher eine Pension geführt, die fast ausschließlich von Ausländern besucht war. Mit dem Kriege ist ihnen dieser Rückhalt ihres wirtschaftlichen Daseins genommen. Andere Einnahmen sind nicht vorhanden; wohl aber Schulden; diese wachsen noch dadurch an, daß einige Juden nicht abreisen konnten und auch kein Geld zu erhalten vermögen. Bisher hat man diese Mieter aus Rücksicht im Hause behalten.

Bei den Eltern wohnt eine Tochter, Frau [Anna Katharina Christine Regina genannt Käthe] Wolcott (mit 4 Kindern), welche mit einem amerikanischen Philologen [Henry Riggs Wolcott seit 1892] verheiratet ist. Die Einnahmen des Mannes in Amerika reichen zum Unterhalt der ganzen Familie kaum aus; er ist, soweit mir bekannt ist, ein eigenartiger, wahrscheinlich abnorm phantastischer, religiös sektiererisch gerichteter Mensch, der seiner Familie kein gutes Oberhaupt gewesen ist. Frau W., die ich seit Jahren kenne, ist eine außerordentlich tüchtige und fleißige Frau und eine vortreffliche Erzieherin der Kinder. Sie ist, ebenso wie die Kinder, amerikanische Staatsbürgerin; sie mußte sich jetzt entschließen, in den nächsten Tagen die letzte Überfahrtsgelegenheit zu benutzen. Die Mittel zur Reise sind von einer Anzahl ihr zugetaner Leute aufgebracht worden. Frau W. führ- 
te eigentlich in den letzten $1^{1 / 2}$ Jahren die Pension der Eltern; diese sind geistig und körperlich nicht mehr rüstig genug, einem solchen großen Haushalt vorzustehen. Vor einiger Zeit konnte ich mich selbst von der fortschreitenden geistigen Hilflosigkeit Professor Scherrers überzeugen.

Es ist meiner Überzeugung nach hier dringend erforderlich, so bald als möglich Schritte zu tun, um einem Verkommen der alten Leute vorzubeugen. Vielleicht ist es Ihnen, sehr geehrter Herr Geheimrat, möglich, bei der Fakultät bez[iehungs] w[eise] dem akademischen Senat die Sache zur Sprache zu bringen ..." (aus: PA 2200).

Zwischen 1914 und 1917 erhält S. mehrfach finanzielle Unterstützungen vom Ministerium des Kultus und Unterrichts und aus der Buhl-Stiftung, siehe hierzu PA 2200.

$Z$ (4) Im Nachlaß S.s in der UBH (Signatur: Heid. Hs. $4148 \mathrm{I}, 12$ ) findet sich ein Nachruf auf S., verfaßt 1917 von e. Pfarrer Schäfer aus Speyerdorf, der - entgegen den eigenen biographischen Angaben S.s in seinem Nachlaß - den Lebenslauf des Verstorbenen zwischen 1848 und 1857 folgendermaßen schildert:

1848 wird S. das Reifezeugnis verweigert aufgrund S.s Denunziation gegenüber dem „preußischen Exekutionsheer als Mitglied des politisch anrüchigen Neustadter Turnvereins" [= Turn- und Sportgemeinde 1846 e. V., Neustadt an der Weinstraße]. S. versucht daraufhin vergeblich, die Maturitätsprüfung mit Privatunterricht in Heidelberg nachzuholen. Ihm gelingt im SS 1849 die Immatrikulation an der UH zum Studium der Philosophie, 1850 wechselt er dann nach München. Hier verweigert man ihm 1851 die Annahme zur phil. Staatsprüfung, und er kehrt nach $\mathrm{H}$ zurück zum Studium der Rechtswissenschaft. Soweit der Nachruf des Speyerdorfer Pfarrers.

S. ist mehrjähriger ehrenamtlicher Leiter des 1863 in $\mathrm{H}$ gegründeten Arbeiterbildungsvereins, s. Brief vom 29. März 1914 in: PA 2200.
Qu UAH PA 77, 2200; RA 5972; Fak.-Akten H-IV102/62, H-IV-102/66, H-II-111/49. - GLA Abt. 235, Fasz. 2463. - Nachlaß: UBH (Signatur: Heid. Hs. 4148; in seinen "Erinnerungen“ schreibt J.S. über sein Geb.-Datum: „... geboren vom zoten auf den 31ten Dezember 1828"; laut Kirchenbuch von Speyerdorf ist der 29. Dez. 1828 sein GeburtsTag, der 1. Jan. 1829 der Tauf-Tag). • Mitteilungen: Herr Gerhard Scherrer (Urgroßneffe), Wörth am Rhein; Frau Nordhild Scherrer-Wild (Urenkelin), Freiburg/Br.

W Die Gallier und ihre Verfassung. Heidelberg 1865. Soziologie und Entwicklungsgeschichte der Menschheit. 2 Bde. Innsbruck 1905-1908. • Der Aufstand in Baden und der Rheinpfalz 1849. Gautzsch bei Leipzig 1911. - Grundsätze und Gesetze der Soziologie. Leipzig 1914.

$L$ Biogr. Jahrbuch 2 (1917-1920) S. 670. - Int. Soziologenlexikon. Hrsg. von Wilhelm Bernsdorf. 2. Aufl. 1980. - WBIS; Deutsche Biographie, s. https://www.deutsche-biographie.de/gnd10128084 75.html [07.11. 2017].

$P$ Bildarchiv UAH; Nachlaß in UBH.

\section{Schick, Joseph}

1893-1896 Phil. Fak.

Englische Philologie

* 21. Dez. 1859 Rißtissen (heute: Stadtteil von Ehingen/Donau)

$\dagger$ 13. Febr. 1944 München kath.

V Bartholomäus S. (1820-1895) Schreiner und Landwirt

M Rosa geb. Kutter (1833-1896)

(2) 20. April 1892 Mary Arnold geb. Butcher (18581940) Vw mütterlicherseits von Matthew Arnold (1822-1888) Lyriker, Kulturkritiker, seit 1857 Prof. für Poesie an U of Oxford (England), s. Pratt, Linda Ray: M. A. revisited. New York 2000. 
K 1 T: Philippine S. (1893-1970) Konzertpianistin, Komponistin, u.a. 1946-1956 Lektorin für Musiktheorie und Anglistik U München, s. WBIS; Brühs, Regina D., Messmer, F. u.a.: P.S. Leben und Wirken. Tutzing 2005 (mit Werkverz., Diskographie, Bibliogr.); Bellinger/Regler-Bellinger (2012) S. 152 f. u.ö. - Nachlaß im Literaturarchiv der Monacensia in Stadtbibliothek München.

Lb 1877-1879 Studium der Mathematik, Naturwissenschaften und Neueren Sprachen an U Tübingen, anschl. München, WS 1883/84 Polytechnikum Stuttgart; 1884 Lehrerexamen.

1884-1887 Eigenstudien in England, u. a. in Devonshire.

U Berlin: 1887-1889 Forts. des Studiums der Anglistik, Germanistik, Allg. Sprachwissenschaft, Indologie, Romanistik und Arabistik; 21. Dez. 1889 Dr. phil. (Hauptfach: Anglistik); Sommer $1891 \mathrm{Ha}-$ bilitation.

U Bonn: Seit 1892 Privat-Dozent und Lektor.

UH: Seit 19. Mai 1893 nichtetatm. a.o. Prof.; seit 1. April 1894 etatm. a.o. Prof. mit e. Jahresgehalt von 2500.- Mark zuzüglich Wohnungsgeld von 620.- Mark.

U München: SS 1896-SS 1925 (Emeritierung) o. Prof. • In dieser Zeit:

1911-1912 Kaiser-Wilhelm-Prof. an Columbia-U in the City of New York; anschl. Weltreise; 1914 Kriegsfreiwilliger.

1926 Geh. Rat

E 1913 (1938 Austritt) Mitglied der Akademie der Wissenschaften München. 1912 Dr. of Letters h.c. der Columbia-U New York. 1939 Goethe-Medaille für Kunst und Wissenschaft.

Qu UAH PA 2204; RA 6824, 6850. • Briefe: UBH. • Im Schaffen genießen. Der Briefwechsel der Kulturwissenschaftler Eberhard und Marie Luise Gothein. Hrsg. von Michael Maurer ... Köln u.a.
2006. S. 680 (Register). - Nachlaß: Universitätsbibliothek München.

W Thomas Kyd's Spanish tragedy. Berlin 1903. 5. Aufl. 1928. - Nikolaus Lenau und die schwäbischen Dichter in ihren persönlichen, literarischen und dichterischen Beziehungen. Straßburg 1908. Drei Genies und ein Talent in: Shakespeare-Jahrbuch. Weimar 1936. Bd. 72. S. 42-78.

HG Corpus Hamleticum. 5 Bde. Berlin, Leipzig 1912-1938.

MHG 1897-1912 Literarhistorische Forschungen. • 1897-1914 Münchener Beiträge zur romanischen und englischen Philologie. - Widmann, Wilhelm: Hamlets Bühnenlaufbahn (1601-1877). Aus dem Nachlass hrsg. von J. S. und Werner Deetjen. Leipzig 1931.

L Verzeichnis Bonn (1968) S. 262; Riese (1977) S. 107 (irrtümlich: S., Karl statt Joseph); WBIS. • Handbuch der historischen Buchbestände in Deutschland. Bayern. Teil 1 (München). Hrsg. von Eberhard Dünninger. Bearb. von Irmela Holtmeier ... Hildesheim 1996. S. 140. - Tabataba-Vakili, Jutta (Großnichte J.S.s): Zum 150. Geb. von Prof. J.S. ... in: Rißbote - Ehingen direkt - Mitteilungsblatt der Großen Kreisstadt Ehingen (Donau) 51. Jg., Nr. 51-53 vom 18. Dez. 2009. S. 6 f. • Bellinger, Gerhard J., Regler-Bellinger, Brigitte: Schwabings Ainmillerstraße und ihre bedeutendsten Anwohner ... 2. Aufl. Norderstedt 2012. S. 152154 u. ö. - Deutsche Biographie, s. https://www. deutsche-biographie.de/gnd117226408.html [07.11. 2017].

$P$ Bildarchiv UAH; graph. Slg. UBH.

\section{Schliephake, Friedrich Wilhelm Theodor}

1857-1871 Phil. Fak.

Philosophie

* 28. April 1808 Dörnten (bei Goslar; heute: Ortsteil von Liebenburg)

$\dagger \quad$ o8. Sept. 1871 Heidelberg ev. 
V Christian Heinrich David S. (†1817) Pfarrer; nach dem Tod des Vaters 1817 ist S.s Vormund Leonhard Karl Heinrich Steyerthal (17841848) 1812-1848 Pastor zu Othfresen und Heissum bei Hildesheim

M Sophie Dorothea geb. Keller

vor 1848 Justine Petronella Franziska geb. de Gronckel ( $\dagger$ (vor) 1867)

$\infty 1867$ Friederike Elisabeth Therese geb. Reinbeck ( $\dagger$ nach 1880), s. FamilySearch (https:// familysearch.org)

$\mathrm{K}$ mindestens $3 \mathrm{~S}, 1 \mathrm{~T}$, s. https://familysearch. org/ark:/61903/1:1:NZ2D-9MY (abgerufen am 1. Nov. 2017).

Lb 1. Mai 1827 (Immatrikulation unter Vorlage e. philolog. Zeugnisses der Herzogl. Großen Schule in Wolfenbüttel)-5. Nov. 1831 (Exmatrikulation) Studium an U Göttingen; 1831 S. beteiligt sich am Göttinger Aufstand gegen die örtliche Regierung und Polizeibehörde; Aufstand wird militärisch niedergeschlagen; 1833 Dr. phil. an U Göttingen (?).

Dresden: Nach 1833 Kunststudien an Technischer Bildungsanstalt.

Vor 1839 Privat-Lehrer: Erziehungsanstalt von Prof. Zipf in Hanau, anschl. Kayser'sches Institut in $\mathrm{H}$, s. Karl Philipp Kayser: Eintrag unter $\infty$ [Ehefrau].

Brüssel: Seit 6. Juli 1839 a.o. Prof. für Literatur an Université Libre und Lehrer an École normale mit e. Jahresgehalt von 180o.- Franken.

Wiesbaden: 1843-1856 Erzieher und Lehrer der Kinder aus 2. Ehe des Herzogs Wilhelm I. von Nassau (1792-1839) am Herzogl. Nassauischen Hof mit e. Jahresgehalt von 1200.- Gulden; Dez. 1842 Ablehnung des Gesuchs S.s um Übertragung e. Professur für Philosophie an UH (siehe $Z$ ).

Idstein: März 1856-Nov. 1857 (auf eigenen Antrag Entlassung) Direktor des Herzogl. Nassauischen Zentral-Staatsarchivs mit e. Besoldung von jährl. 2100.- Gulden („nämlich: 1500.- Gulden Staatsbesoldung und 600.- Gulden Pension nebst Dienstwohnung und 200.- Gulden Zulage jährlich“, aus: Dienststellen-Bogen in: UAH PA 2211).
UH: Seit 9. März 1857 a. o. Prof. „unter Erlassung der vorgeschriebenen Habilitation“ (aus: Brief des Ministeriums des Innern vom 12. März 1857 in: PA 2211); 1. Dez. 1857 Vereidigung.

Z Am 27. Sept. 1842 stellt S. aus Brüssel den Antrag für die Übertragung e. Professur für Philosophie an UH; die Ablehnung begründet die Phil. Fak. am 10. Nov. 1842 damit, daß „der Bittsteller durch irgend eine gelehrte Schrift sich noch nicht bekannt gemacht hat und ebenso auch seine Leistungen als Lehrer und seine Lehrtätigkeit der $\mathrm{Fa}$ cultät durchaus unbekannt sind; so kann sie das Gesuch desselben ... keineswegs zur Gewährung empfehlen“" (aus: UAH RA 6859).

1845 Herzogl. Nassauischer Hofrat; 1855 Geh. Hofrat

Qu UAH PA 2211; RA 6859. GLA Abt. 205, Fasz. 476. Briefe UBH; s. auch Kalliope. - Der Redaktionsbriefwechsel der Hallischen, Deutschen und Deutsch-Französischen Jahrbücher 1837-1844. Hrsg. von Martin Hundt. Bd. 1: Der Briefwechsel um die Hallischen Jahrbücher. Berlin 2010. Apparat: S. 275 (Register). - Ergebnislose Anfrage: Universitätsarchiv Göttingen (eine Göttinger philosophische Promotion konnte nicht nachgewiesen werden). - Auskunft: Ev. Kirchengemeindeamt Liebenburg (Taufbuch 1808 der Gemeinde Dörnten).

W Gedichte. Göttingen 1831. - Kaiser Heinrich IV. Ein Trauerspiel. Mannheim 1841. (Rezension hierzu u. a. in: Zeitung für die elegante Welt. 41. Jg. Nr. 133 (10. Juli). Leipzig 1841. S. 529-531.) • Literarische Übersichten in: Die Grenzboten. Blätter für Deutschland und Belgien ... Nr. 1. Brüssel, Frankfurt/M. 1842. S. 107-124. - Die Grundlagen des sittlichen Lebens. Wiesbaden 1855. Einleitung in das System der Philosophie. Wiesbaden 1856. Geschichte von Nassau von den ältesten Zeiten bis auf die Gegenwart, auf der Grundlage urkundlicher Quellenforschung. 4 Bde. Wiesbaden 18641875 (Bde. 4-7 fortgeführt von Karl Menzel). • Über Friedrich Fröbels Erziehungslehre, deren wissenschaftliche Begründung und Fortbildung in: Philosophische Monatshefte Bd. 4, H. 6 (März 1870) S. 487-509. 2. Aufl. (in Buchform) Berlin 1871. 
L Oesterley, Georg Heinrich: Geschichte der Universität Göttingen in dem Zeitraume vom Jahre 1820 bis ... 1837. Göttingen 1838. S. 117. • Vanderkindere, Leon: L’Université de Bruxelles. Notice historique, faite à la demande du Conseil d'administration. Brüssel 1884. S. 60 u.ö. - ADB 31 (1890) S. 519 f.; Philosophen-Lexikon 2 (1950) S. 464; WBIS. - Ureña, Enrique M.: Philosophie und gesellschaftliche Praxis. Wirkungen der Philosophie K.C.F. Krauses in Deutschland (18331881). Stuttgart 2001. - Rabe, Christine Susanne: Gleichwertigkeit von Mann und Frau. Die KrauseSchule und die bürgerliche Frauenbewegung im 19. Jahrhundert. Köln 2006. S. 237 (Register).

$P$ Bildarchiv UAH.

\section{Schlosser, Friedrich Christoph}

1817-1861 Phil. Fak.

Geschichte

* 17. Nov. 1776 Jever (Ostfriesland)

$\dagger \quad$ 23. Sept. 1861 Heidelberg

ev.

V Carl Wilhelm S. (1727-1783) Advokat

M Weyke Maria geb. Mehrings (1735-1794)

(28. März 1827 Louise Henriette geb. Hoffmann (1791-1862), s. Leopold von Ranke. Briefwechsel (2016) S. 743

$\mathrm{K}$ keine.

Lb U Göttingen: Seit 18. März 1795 (Immatrikulation) Studium der Theologie, Klassischen Philologie, Staatswissenschaften.

Varel (bei Wilhelmshaven): Dez. 1797-Juni 1798 Erzieher der Kinder des Grafen Bentink-Rhone.

Juni 1798 I. Theol. Examen in Jever; anschl. mehrmonatige Verwaltung e. Pfarrstelle.

Hauslehrer/Erzieher: 1798-180o Othmarschen (heute: Stadtteil von Hamburg), 180o-1807 im Hause des Kaufmanns Georg Meyer in Frankfurt/M.
Jever: 1808-1809 Konrektor an Provinzialschule (heute: Mariengymnasium).

U Gießen: 25. Dez. 1809 Dr. phil.

Frankfurt/M.: 1810-1817 Gymnasiallehrer; 1812 Ruf an UH abgelehnt; 1812-1814 (Auflösung) Prof. für Geschichte und Geschichte der Philosophie am Großherzogl. Lyzeum; seit 1814 Stadtbibliothekar.

UH: Seit 26. Aug. 1817 o. Prof. und I. Oberbibliothekar (Vorstand) der UB als Nachf. von Friedrich Wilken; Juli-Nov. 1822 Studienreise nach Paris; 4. März 1825 Rücktritt als Direktor der UB, s. hierzu UAH RA 5386; Studienreisen: Mai-Juni 1834 Paris, Aug.-Okt. 1836 Italien; 1840 Ruf an U Brüssel abgelehnt.

1820, 1827, 1833, 1839 Dekan der Phil. Fak. der UH

1817 Hofrat; 1823 Geh. Hofrat; 1832 Geh. Rat II. Klasse

E 1840 Mitglied der Königl. Akademie der Wissenschaften Kopenhagen. 1857 Dr. iur. h.c. UH. • 1854 Maximiliansorden für Wissenschaft und Kunst; 1860 Orden pour le Mérite für Wissenschaften und Künste. 1844 Ritter, 1845 Kommandeur des Ordens vom Zähringer Löwen. 1852 Ehrenbürger der Stadt Heidelberg.

Qu UAH PA 2212; RA 5048, 5960, 6847 u. ö.; Fak.-Akte H-IV-102/33 u.ö. • GLA Abt. 205, Fasz. 477. - Briefe: UBH; siehe auch NDB 23 (2007) S. 104. - Der Redaktionsbriefwechsel der Hallischen, Deutschen und Deutsch-Französischen Jahrbücher 1837-1844. Hrsg. von Martin Hundt. Bd. 1: Der Briefwechsel um die Hallischen Jahrbücher. Berlin 2010. Apparat: S. 275 (Register). • Leopold von Ranke. Briefwechsel. Historisch-kritische Ausg. Bd. 1: 1810-1825. Neu bearb. von Dietmar Grypa. Berlin 2016. S. 743 f. - Teil-Nachlaß: $\mathrm{UBH}$; Stadt- und Universitätsbibliothek Frankfurt/M.; Badische Landesbibliothek Karlsruhe. • Selbstbiographie in: Zeitgenossen. Biographien und Charakteristiken. Neue Reihe. Nr. XX. Leipzig 1826 . 
$W$ Leben des Theodor Beza und des Peter Martyr Vermili. Heidelberg 1809. - Geschichte der bilderstürmenden Kaiser des oströmischen Reiches. Frankfurt/M. 1812. - Weltgeschichte in zusammenhängender Erzählung. 4 Bde. Frankfurt/M. 1815-1841. Geschichte des 18. Jahrhunderts. 2 Bde. Heidelberg 1823; neu bearb. u.d.T.: Geschichte des 18. Jahrhunderts und des 19. bis zum Sturz des französischen Kaiserreiches. 6 Bde. 2. Aufl. Heidelberg 1836-1848. 3. Aufl. 7 Bde. 1843-1848. 4. Aufl. 8 Bde. 1853-1860. Universalhistorische Uebersicht der alten Welt und ihrer Cultur. 3 Bde. Frankfurt/M. 1826-1834. • Weltgeschichte für das deutsche Volk. 19 Bde. Frankfurt/M. 1844-1857, s. hierzu weiter Gottlob, Michael: F.C.S. ... Weltgeschichte für das deutsche Volk in: Hauptwerke der Geschichtsschreibung. Hrsg. von Volker Reinhardt. Stuttgart 1997. S. 574-577. Dante. Studien. Leipzig 1855.

MHG 1830-1835 Archiv für Geschichte und Literatur.

L Lorenz, Ottokar: Der Historiker F.C.S. und die Geschichtsschreibung. Nachdr. der Ausg. von 1868. Hamburg 2011. ADB 31 (1890) S. 533-541; Goedeke 6 (1898) S. 328-331. • Gölter, G.: Die Geschichtsauffassung F.C.S.s. Diss. Heidelberg 1966 (mit Werkverz.). - Haar, Karl Heinz: Die Bibliothek des ... F. C. S. in: Bibliothek und Wiss. 8 (1972) S. 1-92. - Wolgast, Eike: Politische Geschichtsschreibung in Heidelberg ... in: Semper apertus 2 (1985) S. 158-166. Weber (1987) S. 518. Gottlob, Michael: Geschichtsschreibung zwischen Aufklärung und Historismus. Johannes von Müller und F.C.S. Frankfurt/M. 1989. - Dilthey, Wilhelm: Zur Geistesgeschichte des 19. Jahrhunderts. Portraits und biographische Skizzen ... 3. Aufl. Hrsg. von Ulrich Herrmann. Göttingen 1991. S. 37-52. • Fuhrmann (1996) S. 144 und Anm. 20. Handbuch der historischen Buchbestände in Deutschland. Hrsg. von Bernhard Fabian. Hildesheim 2003. - Sellier-Bauer, Ellen-Charlotte: F.C.S. Ein deutsches Gelehrtenleben im 19. Jahrhundert. Göttingen 2004. - WBIS; NDB 23 (2007) S. 104; Stumm (2012) S. 704 (Register).

$P$ Bildarchiv UAH; graph. Slg. UBH.
Schmid, Friedrich Alfred (seit 1942: Schmid Noerr)

1905-1916 (1919) Phil. Fak.

Philosophie

* 30. Juli 1877 Durlach (heute: Stadtteil von Karlsruhe)

$\dagger$ 12. Juni 1969 Percha (heute: Ortsteil von Starnberg)

ev.

V Alfred S. (1838-1926) Ökonomierat, u. a. Landwirtschafts-Inspektor und Vorstand der Landwirtschaftl. Winterschule: seit 1888 in Tauberbischofsheim, seit 1900 in Freiburg/Br., s. GLA Abt. 236, Nr. 18670; WBIS

M Amalie geb. Noerr (1843-1913)

๑ 1919 Claire (Cläre) geb. Rosenberger genannt Schmid-Romberg (1880-1960) Scheidung 1939; Schauspielerin, s. Max Weber - Gesamtausgabe Bd. II/9: Briefe 1915-1917 (2003) S. 858, Kriegstagebuch K. Hampe (2007) S. 994 (Register)

๑ 13. Dez. 1941 Elisabeth geb. von Bültzingslöwen (1909-1978) Musikerin

$\mathrm{K} 1 \mathrm{~T}$ (aus 1. Ehe), $1 \mathrm{~T}$ (aus 2. Ehe), $2 \mathrm{~S}$ (aus 2. Ehe): Wulf Schmid Noerr $\left({ }^{*} 1944\right)$ Schauspieler (u. a. an Theatern in München, Landshut, Wien; in TV-Serien und Filmen), Autor, Pianist, Komponist. - Gunzelin Schmid Noerr $\left({ }^{*} 1947\right)$, u. a. 1977-1996 Leiter des MaxHorkheimer-Archivs der U-Bibliothek Frankfurt/M., seit 1991 Privat-Dozent, 1998-2002 Prof. für Philosophie U Frankfurt/M. und FH Darmstadt, 2002-2015 Prof. für Sozialphilosophie und Sozialethik am Fachbereich Sozialwesen der Hochschule Niederrhein in Mönchengladbach, s. Wikipedia.

Lb Seit WS 1896/97 Studium zunächst der Germanistik, seit WS 1897/98 der Philosophie, Literaturgeschichte, Nationalökonomie und - auf väterlichen Wunsch - auch der Rechtswiss. an U Freiburg/Br., seit WS 1898/99 H (Herbst 1899 Aufgabe des rechtswiss. Studiums mit väterlichem Einverständnis), seit WS 1899/190o Straßburg, seit WS 1900/o1 Freiburg/Br.; Juli 1902 Dr. phil. an U Freiburg/Br. 
Nach Juli 1902 S. ist „teils einiger Erholung bedürftig, teils mit der nochmaligen Überarbeitung [seiner] Dissertation beschäftigt, die [er] bis zum Ende des Jahres 1903 zum Druck“ bringt (aus: Lebens- und Bildungsgang in: UAH PA 2215); seit Frühjahr 1904 Eigenstudien in Berlin.

UH: 7. Juni 1905 Habilitation; WS 1909/10 Beurlaubung für „Vorarbeiten zu einer umfangreicheren, philosophischen Untersuchung“ (aus: Brief vom 3. Juni 1909 in: PA 2215); seit 21. Dez. 1911 nichtetatm. a. o. Prof.; SS 1915 Lehrauftrag für Vorlesung über „Geschichte der Philosophie im 19. Jhdt." mit e. Vergütung von 8oo.- Mark in Vertretung des erkrankten Wilhelm Windelband; 30. Okt. 1915 Lehrauftrag für e. 4-stündige Vorlesung im WS 1915/16 über „Antike Philosophie“ für verstorbenen Windelband; SS 1916 letzte Vorlesungsankündigung; WS 1916/17-SS 1917 Beurlaubung „zum Zwecke von Studien in auswärtigen Bibliotheken und Anstalten“ (aus: Brief vom 30. Mai 1916 in: PA 2215); WS 1917/18 Kriegsdienst (im vaterländischen Hilfsdienst); SS 1918-SS 1919 Beurlaubung; 13. Okt. 1919 Urlaubsgesuch „wird mit Rücksicht auf die [in den Akten nicht überlieferte] unzureichende Begründung abgelehnt" und damit Streichung S.s aus Liste der akad. Lehrer.

Freier Schriftsteller: Nach 1916 zunächst in München, 1918-1969 ( $\dagger$ ) in Percha; 1933-1936 Publikationsverbot.

S. entwirft 1937 eine Reichsverfassung sowie 1939 ein Aktionsprogramm zur Beseitigung der HitlerHerrschaft.

E 1927 Lyrikpreis der Fastenrath-Stiftung Köln; 1929 Carl-Schünemann-Preis Bremen; 1958 Johann-Peter-Hebel-Gedächtnispreis. • 1963 Bundesverdienstkreuz.

Qu UAH PA 2215; RA 4946 (12. Dez. 1898 Einweisung S.s wegen Gonorrhoe in Med. U-Klinik H), 6859 (1915 Lehrstuhlvertretung); Rep. 40-479. • Nachlaß: Literaturarchiv Marbach. - Auskunft: Bundesarchiv Koblenz (Signatur: SgY 15/V 244/1 unter Schmidt, A.). - Mitteilungen: Herr Prof. Dr. Gunzelin Schmid Noerr, Frankfurt/M. Ein Leben im Gedicht. München 1961. (Autobiogr.)
$W$ Straßen und Horizonte. Gedichte. Leipzig 1917. - Zum Entwurf einer neuen Hochschulverfassung in: Der Wagenlenker. Organ des Reichsbundes Geistiger Arbeiter. 1. Jg. Nr. 2. München 1919. - Frau Perchtas Auszug. Ein mythischer Roman. Berlin 1928. • Perchta und Karl. Leipzig 1928. Nachdr. Pöcking 2002. • Ehre und Glück des Volkes. 1933 Publikationsverbot vor Erscheinen. • Dokument des Widerstandes: Entwurf einer deutschen Reichsverfassung. Geschrieben im Sommer 1937 in: Voran und beharrlich (Burschenschaft Teutonia) H. 33/34. Freiburg/Br. 1961. S. 1-12 (siehe hierzu Hoffmann (1985) S. 230-233). - Das Licht der Gefangenen ... Mythische Erzählungen. München 1947. - Ewige Mutter Europa. Der Mythos vom Europäer. Oldenburg 1949. • Die Hohenstaufen. Mythos und Sage. Stuttgart 1955. • Der Mystiker. Wesensbeschreibung eines menschlichen Urbildes. München-Pasing 1967 (Rezension hierzu, s. Schindler, Werner in: Ruperto Carola 19. Jg., Bd. 42 (Dez. 1967) S. 324-326).

HG Vom Wunder der Seele. Eine Auswahl aus den Traktaten und Predigten von Meister Eckhart ... Leipzig 1936. Mehrere Nachdr., zuletzt Stuttgart 2011.

$L$ Weber, Marianne: Max Weber. Ein Lebensbild. Tübingen 1926. 3. Aufl. 1984. S. 371 f. Arnim 2 (1952) S. 504, 5 (1985) S. 54; Wer ist wer (1962) S. 1364f.; Kürschners Literatur-Kalender (1967) S. 815 f. - Zentner, Wilhelm: Zum Tode von F. A.S.N. in: Ruperto Carola 21. Jg., Bd. 47 (1969) S. 59-61. Hagen, Wilhelm: Auftrag und Wirklichkeit ... München-Gräfeling 1978. S. 55 f., 6o64 (Entwurf e. zukünftigen U-Verfassung 1918/ 19). Hoffmann, Peter: Widerstand - Staatsstreich - Attentat. Der Kampf der Opposition gegen Hitler. 4. Ausg. München 1985. S. 123, 230233, 703. Horn, Elfriede: Weltweiser und Gelehrter. F.A.S.N. in: Dies.: Geehrt - geliebt - vergessen? Melsungen 1985. S. 143-146. •Über F. A. S. N. in: Der Johann-Peter-Hebel-Preis 1936-1988. Bearb. von Manfred Bosch. Waldkirch 1988. S. 168176. Dahms, Hans-Joachim, Neumann, Michael: Sozialwissenschaftler und Philosophen in der Münchner Räterepublik in: Jahrbuch für Soziologiegeschichte (1992) S. 115-146. • Jansen (1992) S. 412 (Register); Ders. (1992a) S. 169 (Register). 
Stummeyer, Bettina: Wie ein rätselhaftes Fabelwesen. Der Schriftsteller und Mystiker F. A. S. N. Bayer. Rundfunk. Manuskript. München 2002. • Bottlenberg-Landsberg, Maria Theodora von dem: Die Weissen Blätter. Eine konservative Zeitschrift im und gegen den Nationalsozialismus. Berlin 2012. S. 163 f., 301-303. - Deutsche Biographie, s. https:// www.deutsche-biographie.de/gnd117457558.html [07.11. 2017].

P Bildarchiv UAH; Ruperto Carola.

\section{Schmid, Johann Heinrich Theodor}

1830-1836 Phil. Fak.

Philosophie, Religionsphilosophie

* 24. Juni 1799 Jena

$\dagger$ 29. Jan. 1836 Heidelberg ev.

V Carl Christian Erhard S. (1761-1812), s. Günther (1858) S. 214 f., NDB 23 (2007) S. 139 f., Johannes Schmid's Nachkommen (2013) S. 151164 u.ö.; seit 1785 Dozent für Philosophie, Theologie, Moralphilosophie an U Jena, seit 1791 o. Prof. für Logik, Metaphysik Gießen, seit 1793 o. Prof. für Philosophie, Diakon der Stadtkirche und Garnisonsprediger Jena, seit 1798 o. Prof. für Theologie ebd. als Nachf. seines nachmaligen Schwiegervaters Johann Wilhelm Schmid (1744-1798), s. ADB 31 (1890) S. $672 \mathrm{f}$, Johannes Schmid's Nachkommen, S. 137-150, WBIS

M Bernhardine Sophie Friedericke geb. Schmid (1778-1822), s. Johannes Schmid's Nachkommen, S. 103-106 u.ö.; T von Johann Wilhelm Schmid (1744-1798) Jena: zunächst Garnisonsprediger und Diakon an St. Michael, 1783-1798 Prof. für Theologie an U (s.o. Eintrag unter $V$ [ater])

( 1830 Bertha geb. Kraus(s)e (1810-1839), s. Johannes Schmid's Nachkommen, S. 298, 367
K $\quad 2$ S, 1 T (davon $1 \mathrm{~S}$ und $\mathrm{T}$ früh $\dagger$ ): „... verstorbener Prof. Schmid (hat) zwar keine Kinder, wohl aber eine Wittwe hinterlassen, welche sich in gesegneten Leibes-Umständen befindet ..." (in: Brief vom 18. Febr. 1836 aus: UAH PA 2217), s. UAH RA 5355; Johannes Schmid's Nachkommen, S. 367

Vw Ur-Großvater: Jesaias Friedrich Weissenborn (1673-1750), u. a. seit 1713 a. o. Prof., 1724-1742 o. Prof. für Theologie Jena, seit 1722 auch Superintendent, s. WBIS

Vw Bruder: Reinhold Leonhard S. (180o-1873) 1833-1869 Prof. des Römischen Rechts Bern, s. Johannes Schmid's Nachkommen, S. 367 u. ö.

Lb U Jena: Seit 1817 Studium der Philosophie, Theologie, Geschichte; 1820/21 ein Jahr Festungshaft, s. hierzu $Z$.

1821 Theol. Kandidatenexamen in Weimar; 22. Okt. 1821-Ende SS 1822 Forts. des Studiums der Kirchengeschichte an U Göttingen; 19. Dez. 1822 Rigorosum, 23. Dez. 1822 (Datum der Promotionsurkunde) Dr. phil. an U Jena, s. hierzu UA Jena, Bestand M, Nr. 250.

U Jena: Juni 1829 S. bittet U um Erlaubnis, an Theol. Fak. Vorlesungen halten zu dürfen; mit Reskript vom 9. Okt. 1829 Erteilung der Erlaubnis für H. S. bzw. seinen Bruder Reinhold S., Vorlesungen an Theol. bzw. Jur. Fak. halten zu können, s. UA Jena, Bestand A, Nr. 422; zuvor Verweigerung seitens der Fak. aufgrund S.s Beziehungen zur Burschenschaft, s. Z; 23. Nov. 1829 Habilitation für Philosophie; Dez. 1829 S. bittet U um Erlaubnis, Vorlesungen in Kirchengeschichte halten $\mathrm{zu}$ dürfen, s. UA Jena, Bestand J, Nr. 102, 131.

UH: 22. April 1830 Ern. zum a. o. Prof. an Phil. Fak. mit e. Jahresgehalt von 10oo.- Gulden als Nachf. von Johann Simon Erhardt; WS 1830/31 Vorlesungsbeginn; 13. Juli 1832 Gesuch S.s, auch Vorlesungen über Dogmatik und Theologische Moral an Theol. Fak. lesen zu dürfen, wird sowohl von $\mathrm{UH}$ als auch vom Ministerium des Innern abgelehnt, weil „man wünsche, daß der Petent zur Belebung des Studiums der Philosophie dem ihm bei seiner Vocation gewordenen Berufe sich mit ungetheilter Kraft widmen“ soll (aus: UAH PA 2217); Aug. 1833-April 1834 Beurlaubung „zu e. Reise in 
die Heimath und zur Wiederherstellung seiner Gesundheit" aufgrund e. , anhaltenden Brustübels“ (aus: Brief vom 2. Nov. 1833 in: PA 2217).

Z S. wird - ebenso wie sein Bruder Reinhold aufgrund der Mitgliedschaft im Jünglingsbund in der Burschenschaft nach den Karlsbader Beschlüssen 1819/20 zu 6 Jahren Haft verurteilt, anschl. auf 1 Jahr Festungshaft begnadigt.

Siehe auch Karl Alexander Freiherr von ReichlinMeldegg

Qu UAH PA 2217; RA 5355, 6593. - Briefe: u.a. Thüringer Universitäts- und Landesbibliothek Jena. - Die Handschriften der Thüringer Universitäts- und Landesbibliothek Jena. Bd. II: Die mittelalterlichen lateinischen Handschriften der Signaturreihen außerhalb der Electoralis-Gruppe. Beschrieben von Bettina Klein-Ilbeck und Joachim Ott ... Wiesbaden 2009. S. 310 f. Auskunft: Universitätsarchiv Jena.

$W$ Der Mysticismus des Mittelalters in seiner Entstehungsperiode. Jena 1824. Versuche einer Metaphysik der inneren Natur. Leipzig 1834. • Über Schleiermachers Glaubenslehre. Leipzig 1835. • Vorlesungen über das Wesen der Philosophie und ihre Bedeutung für Wissenschaft und Leben für denkende Leser. Stuttgart 1836.

$L$ Reichlin-Meldegg, K. A. Frhr. von: Das Leben H.S.s ... in kurzem Umrisse dargestellt. Heidelberg 1836. Wechmar (1846) S. 253 (unter Schmidt, Heinrich); Badische Biographien 2 (1875) S. 275; Philosophen-Lexikon 2 (1950) S. 467. • Friedrich Schleiermacher. Kritische Gesamtausgabe ... Hrsg. von Günter Meckenstock ... Abt. 1. Schriften und Entwürfe. Bd. 15. Register zur I. Abt. erstellt von Lars Emersleben ... Addenda und Corrigenda zur I. Abt. Berlin 2005. S. 148 (Register). • Stamm-Buch der Jenaischen Burschenschaft. Die Mitglieder in der Urburschenschaft 1815-1819. Bearb. von Peter Kaupp. Köln 2005. S. 98 f. - Johannes Schmid's Nachkommen. Bd. 2: 400 Jahre Thüringer Familiengeschichte - fürstliche Beamte und Gelehrte. Erweitere Neuaufl. der Erstausg. von 1897. Bearb. und hrsg. von Wendelin Koehler. Recklinghausen 2013. S. 298-308 u. ö.
Schmid Noerr, Friedrich Alfred

s. Schmid, Alfred

\section{Schmidt, Franz Adolf}

1876-189o Phil. Fak.

1890-1913 Nat.-Math. Fak.

1913-1914 (Honorar-Prof.) Nat.-Math. Fak.

Geologie, Metallurgie

* 27. Febr. 1836 Karlsruhe

$\dagger$ 30. Jan. 1917 Heidelberg

kath., später konf.-los

V Franz Peter S. (1804-1870) Secretair des Großherzogl. Ministeriums des Innern, kath. Kirchen-Section, seit 1838 Hofgerichtsrat in Mannheim, s. Toepke VI (1907) S. 383

M Barbara Carolina geb. Walther (1813-1857)

$\infty$ unverheiratet.

Lb Polytechnikum Karlsruhe: 1855-1858 Studium der Mathematik, Physik, Chemie, Geognosie, Mineralogie.

Bergakademie Freiberg: 1858-1860 Studium der Metallurgie und Bergwerkswissenschaft.

Mannheim: 1859 Berg- und hüttenmännisches Staatsexamen.

UH: 8. Mai 1860 Immatrikulation; 4. Aug. 1860 Dr. phil.

Böhmen: Seit 1860/61 Tätigkeit als Metallurg bzw. Geologe.

Kandern (Schwarzwald): 1862 Assistent bei Hüttenverwaltung.

Zizenhausen (bei Konstanz; heute: Ortsteil von Stockach): 1863-1866 Vorstand der Hüttenverwaltung des Eisenwerks.

USA: 1867-1871 Hütten-Ingenieur am Bessemer Stahlwerk in Troy (bei Albany, New York); 18721875 Geologe am Department of Natural Resour- 
ces' Missouri Geological Survey („geologische Aufnahme des Staates Missouri“ aus: UAH H-IV102/82 Nr. 35).

UH: 4. März 1876 Habilitation für Geologie, Metallurgie als „badischer Berg- und Hütten-Praktikant“ (aus: Brief vom 13. Jan. 1876 in: UAH PA 2219); seit 7. Jan. 1881 a.o. Prof.; Jan. 1885-Febr. 1902 Lehrauftrag für Chemische Technologie mit e. Honorar von 300.- Mark pro Semester; seit 11. Dez. 1913 o. Honorar-Prof.; SS 1914 letzte Vorlesungsankündigung.

S.s " Geologist's field notebooks“, die er zwischen 1872 und 1874 während seiner Tätigkeit am Department of Natural Resources' Missouri Geological Survey schrieb, werden im Missouri Department of Natural Resources, Post Office Box 176, 1101 Riverside Drive, Jefferson City, MO 651020176 aufbewahrt.

Im Mai 1907 schenkt S. dem Stratigraphischen und Paläontologischen Institut der UH „seine Sammlung von Erzen und technologischen Produkten ... Diese eine ganze Reihe von Seltenheiten und Unikaten enthaltende Sammlung hat einen beträchtlichen Wert und ist die Frucht einer jahrzehntelangen Sammeltätigkeit. An die Schenkung ist nur die Bedingung geknüpft, dass die Erze zu Lebzeiten des Gebers in derselben Ordnung aufbewahrt, nicht mit fremdem Material vermischt werden und dem Geber zugänglich bleiben. Es ist schwierig, einen Geldwert für die Sammlung anzugeben, da es sich bei einer ganzen Reihe von Stücken um Seltenheitswerte handelt. Immerhin glaube ich mit einer Schätzung von eintausend Mark der Wirklichkeit nahe zu kommen ..." (aus: Brief des Instituts-Direktors Wilhelm Salomon an den Engeren Senat vom 31. Mai 1907 zur Weiterleitung an das Ministerium der Justiz, des Kultus und Unterrichts in Karlsruhe, in: UAH RA 6480). Am 7. Juni 1907 erteilt das Ministerium die Genehmigung zur Annahme der S.schen Schenkung.

E 1916 Ritterkreuz I. Klasse des Ordens vom Zähringer Löwen.

Qu UAH PA 2219; RA 6480; Quästurakte Rep. 271225; Fak.-Akten H-IV-102/57 Nr. 44, H-IV-102/
82 Nr. 35 f. - Toepke VI (1907) S. 383. Auskunft: Kath. Pfarrei St. Stephan in Karlsruhe (Taufbuch).

$W$ Die Blei- und Zink-Erz-Lagerstätten von Südwest-Missouri. Heidelberg 1876. • Zinkerzlagerstellen von Wiesloch in: Verh. des NaturhistorischMed. Vereins Heidelberg 2 (1880); Geologie des Münstertales. 3 T. in: ebd. 3 (1886), 4 (1887), 6 (1889). - Auszug aus der geologischen Beschreibung des Heidelberger Schloßgebäudes. Heidelberg 1886. (Exemplar im UAH.) - Siehe auch Badische Biographien, S. $345 \mathrm{f}$.

$L$ WBIS; Badische Biographien N.F. VI (2011) S. 344-346; Deutsche Biographie, s. https://www. deutsche-biographie.de/gnd104085584.html [07.11. 2017].

$P$ Bildarchiv UAH; graph. Slg. UBH.

\section{Schmidt, Bruno Wilhelm}

1898-1903 (1905) Jur. Fak.

Staats- und Völkerrecht

* 21. Juni 1865 Leipzig

$\dagger$ 07. Juli 1905 Lindhardt (bei Leipzig; heute: Ortsteil von Naunhof)

ev.-luth.

V Carl Wilhelm S. (1834-1887) Besitzer des Hotels Sedan, Blücherstr. 1, vis-à-vis Hauptbahnhof Leipzig; Postkarte mit lithographischer Abb. der Hotelfassade und Werbetext („120 Zimmer, hydraulischer Personen-Aufzug, Telephon-Verbindung ..."), s. Stadtgeschichtliches Museum Leipzig (Inventar-Nr. Doubl. 350, GOS-Nr. soo26353)

M Henriette Friederike geb. Säuberlich, 18871900 Besitzerin des o.g. Hotels

( unbekannt.

Lb SS 1885 Studium an UH, WS 1885/86 Leipzig, SS 1886 H, WS 1887/88 Berlin, WS 1886/87, SS 1887, SS 1888 -WS $1889 / 90$ Leipzig.

Leipzig: 189o-1896 Führung des elterlichen Hotelbetriebs nach Tod des Vaters. • In dieser Zeit: 
U Leipzig: 23. Jan. 1890 Rigorosum, 30. Jan. 1893 (Datum der Promotionsurkunde) Dr. iur.; 18961897 Eigenstudien.

UH: 24. Jan. 1898 Habilitation; 26. Mai 1902 Antrag des Engeren Senats an Ministerium für Justiz, Kultur und Unterricht um Verleihung der a.o. Professur an S.; 29. Juni 1902 Ern. zum nichtetatm. a.o. Prof.; WS 1902/o3 letzte Vorlesungsankündigung; seit SS 1903 Beurlaubung wegen „schwerem Gelenkrheumatismus“ (aus: Brief vom 5. Okt. 1903 in: UAH PA 2220).

Qu UAH PA 2220; Fak.-Akten H-II-111/116 fol. 47r-134r (hier auch Habilitationsschrift eingebunden), H-II-111/123 fol. 264r-265r. • Auskunft: Sächsisches Staatsarchiv Leipzig; Stadtarchiv Leipzig (Sterbeeintrag 1887).

$W$ Über einige Ansprüche auswärtiger Staaten auf gegenwärtiges deutsches Reichsgebiet. Leipzig 1894. Der Staat. Eine öffentlich-rechtliche Studie. Leipzig 1896. - Das Gewohnheitsrecht als Form des Gemeinwillens. Leipzig 1899. • Über die völkerrechtliche Clausula rebus sic stantibus, sowie einige verwandte Völkerrechtsnormen. Leipzig 1907. S. 1-226 (posthum erschienen).

$L$ Biogr. Jahrbuch 10 (1905) S. 244; WBIS; Stolleis 2 (1992) S. 451 Anm. 166 f.; Schroeder (2010) S. 350 f.; Deutsche Biographie, s. https://www.deutschebiographie.de/gnd133218643.html [07.11. 2017].

\section{Schmidt, August Ferdinand}

1922-1937 Nat.-Math. Fak.

Physik

* o9. März 1889 Mainz

$\dagger$ 21. Sept. 1960 Stuttgart

kath.

V Ferdinand S., Proviantamtsinspektor

M Therese geb. Mayer

C 1. Aug. 1914 Johanna Elisa geb. Becker (18861973)

$\mathrm{K}$ mindestens $1 \mathrm{~S}$
Lb Seit WS 1907/o8 zunächst Studium der Rechtswiss. an U Gießen.

UH: Seit WS 1908/og Studium der Naturwiss.; seit 1911 Assistent, 1921-1937 wiss. Mitarbeiter am Physikal. und Radiolog. Inst. (bis 1931 bei Philipp Lenard); 25. Nov. 1913 Dr. phil. nat.; 28. Okt. 1922 Habilitation; seit 5. Nov. 1927 nichtplanm. a.o. Prof.

TH Stuttgart: Seit 30. Nov. 1937 planm. a.o. Prof. für Grundlagen der Physik, Direktor des I. Physikal. Inst. und des mit der TH verbundenen Bodensee-Laboratoriums in Friedrichshafen am Bodensee; 1. April 1938-1. Dez. 1945 (Entlassung auf Anordnung der Militärregierung) o. Prof. • In dieser Zeit:

Friedrichshafen am Bodensee: Okt. 1941-1945 Abkommandierung durch Nachrichtenmittel-Versuchskommando Kiel der Kriegsmarine an Bodensee-Laboratorium zur Untersuchung der Ausbreitung von Schallwellen im Bodensee; 1945 Rückkehr nach Stuttgart.

1928-1933 Mitglied der Dt. Physikalischen Gesellschaft

$\mathrm{Qu}$ UAH Fak.-Akten H-V-4/21, H-V-5/11. • GLA Abt. 235, Fasz. 2471. - Briefe: UBH. - Auskunft: Stadtarchiv Heidelberg.

W Phosphoreszenz und Fluoreszenz. 2 Bde. Leipzig 1928. (Mitverf.) • Über die von einer LenardFensterröhre mit Platinansatz ausgehenden Röntgenstrahlen in: Physikalische Zeitschrift 36 (1935) S. $283-288$.

L Poggendorff 7a (1960) S. 159; Kürschner (1961) S. 1808. Physics and national socialism. An anthology of primary sources ... Ed. by Klaus Hentschel. Basel 1996. Reprint 2011. S. XLV, 341 u. ö. • Dörfel, Günter: „Selbstdarstellung und Legendenbildung um das Müller-Unkelsche Lenard-Rohr“ in: Int. Zs. für Geschichte und Ethik der Naturwissenschaften, Technik und Medizin (N.T.M.) 8 (2000) S. 244-258, hier S. 245. - Gemeinschaftsforschung, Bevollmächtigte und der Wissenstransfer. Die Rolle der Kaiser-Wilhelm-Gesell- 
schaft im System kriegsrelevanter Forschung des Nationalsozialismus. Hrsg. von Helmut Maier. Göttingen 2007. S. 237-240, 242 f., 245 u. ö. • Hentschel, Klaus: The Mental Aftermath. The Mentality of German Physicists 1945-1949. Oxford 2007. S. 92 f. u. ö. - Physiker zwischen Autonomie und Anpassung. Die Deutsche Physikalische Gesellschaft im Dritten Reich. Hrsg. von Dieter Hoffmann und Mark Walker. Weinheim 2007. S. 384 Anm. 76. - Deutsche Biographie, s. https://www. deutsche-biographie.de/gnd117502898.html [07.11. 2017].

\section{Schmidt, Karl Friedrich}

1921, 1924-1939 (1941) Nat.-Math. Fak.

Chemie

* o8. Aug. 1887 Heidelberg

$\dagger$ 30. Okt. 1971 Sulzbach (heute: Stadtteil von Weinheim)

ev.

V Traugott Christian S. (1855-1931) Lehrer, später Gymnasial-Prof. für Altphilologie

M Anna Maria Barbara Elisabeth geb. Löchner (1857-1940)

$\infty$ 2. Aug. 1915 Antonie (Toni) geb. Kraepelin (1887-1962) Scheidung 1942; $\mathrm{T}$ von: (siehe) Emil K.

( 27. Nov. 1942 Anna Maria geb. Hoyer gesch. Sundwall (1894-1969) 3. von 4 Ehefrauen von Johannes Sundwall (1877-1966) seit 1907 Dozent für Alte Geschichte, Griechische und Römische Literatur U Helsinki, seit 1919 Prof. Åbo Akademi in Turku (Finnland), 1921-1945 Prof. U Helsinki, s. Grumach, Ernst: J. S. † in: Kadmos - Zs. für vor- und frühgriechische Epigraphik 6 (1967) S. 1-5.

$\mathrm{K} \quad 3 \mathrm{~S}, 2 \mathrm{~T}$ (aus 1. Ehe).

Lb U München: Seit SS 1906 Studium der Medizin und Chemie; 1908-1909 Militärdienstpflicht als Einjährig-Freiwilliger.
UH: SS 1910-SS 1912 Forts. des Studiums; Okt. 1912-Aug. 1921 Assistent am Chemischen Laboratorium; 20. Okt. 1912 Rigorosum, 21. Jan. 1913 (Datum der Promotionsurkunde) Dr. phil. nat.; 22. Jan. 1921 Habilitation. • In dieser Zeit:

2. Aug. 1914-Nov. 1918 Kriegsdienst.

Åbo Akademi in Turku: Seit 3. Sept. 1921 Lektor, seit 10. Juni 1922 planm. a. o. Prof. für Organische Chemie.

UH: 12. Dez. 1924 Erneuerung der venia legendi; seit 20. April 1925 nichtplanm./nichtbeamteter a. o. Prof.; WS $1934 / 35$ und WS $1935 / 36$ keine Vorlesungsankündigungen; 29. Nov. 1937 Ausfall der angekündigten einstündigen Vorlesung über Geschichte der Chemie aufgrund e. „längerdauernden Erkrankung "S.s (aus: UAH PA 5685); WS 1938/ 39 letzte Vorlesungsankündigung; 31. Okt. 1940 S. stellt keinen Antrag auf Übernahme als „Dozent neuer Ordnung" wie es das Reichshabilitationsgesetz vom 17.02.1939 verlangt (bei der Bearbeitung dieses Antrags durch das Reichsministerium für Wissenschaft, Erziehung und Volksbildung wurde die fachliche Eignung, aber vor allem die politische Einstellung des Petenten überprüft); 8. Jan. 1941 Reichsministerium erklärt daraufhin S.s „Tätigkeit als nichtbeamteter a.o. Prof. ... mit sofortiger Wirkung für erloschen, da Sie nicht beabsichtigen, sich zum außerplanmäßigen Professor [bzw. zum Dozenten neuer Ordnung] ernennen zu lassen“ (aus: PA 5685). • In dieser Zeit:

Ludwigshafen/Rhein: Mai 1926-April 1936 o. Mitglied im Vorstand der (Chemischen Fabrik) Knoll AG.

H: Seit 1939, noch 1962 Privat-Gelehrter mit eigenem chemischen Labor in enger Zusammenarbeit mit der Knoll AG.

Sulzbach: 1936 Erwerb e. Gutes mit Viehbestand und Obstanlagen, das S. zu e. Musterhof aufbaut; seit 1969 auch Wohnsitz.

1923 Entdecker des unter dem Handelsnamen "Cardiazol“ bekannten bicyclischen Tetrazol-Derivats, Pentetrazol, einem Herz- und Kreislaufarzneimittel, seit 1926 weltweit von der Fa. Knoll AG 
vertrieben; 1982 Entzug der Zulassung durch die Food and Drug Administration in Silver Spring (Maryland). - Siehe hierzu auch über die nach S. benannte Schmidt-Reaktion: S., K.F.: Über den Imin-Rest in: Berichte der Dt. Chemischen Gesellschaft A/B, 57 (1924) S. 704-706; Laue, Thomas, Plagens, Andreas: Namen- und Schlagwort-Reaktionen der Organischen Chemie. 5. Aufl. Wiesbaden 2006. S. 297-300.

1927 Mitbegründer der Dt. Gesellschaft für Kreislaufforschung (1931/32 Austritt), s. hierzu Baumann, Timo: Die Dt. Gesellschaft für Kreislaufforschung im Nationalsozialismus 1933-1945. Berlin 2017. S. $90 \mathrm{f}$.

E Okt. 1914 Eisernes Kreuz II. Klasse, Mai 1918 I. Klasse; Ritterkreuz II. Klasse mit Schwertern vom Orden des Zähringer Löwen; Juni 1918 Hohenzollern Ehrenkreuz III. Klasse mit Schwertern; Abzeichen für Verwundete in mattweiss; Ehrenkreuz für Frontkämpfer.

Qu UAH PA 5685. - GLA Abt. 235, Fasz. 2473. • Mitteilungen: Frau Dr. Ursula Perkow ( $†$ ), Heidelberg, Urenkelin von Emil Kraepelin.

$W$ Über stickstoffhaltige Siebenringe. Heidelberg 1921. - Über die Bildung von Hydrazin, Hydroxylamin und Anilin aus Stickstoffwasserstoffsäure. Åbo Akademi, Turku 1923. - Über die Einwirkung von $\mathrm{NH}$ auf organische Verbindungen in: Angewandte Chemie 36 (1923) S. 511. • Die Einwirkung von Sulfurylazid auf Benzol in: Berichte der Dt. chemischen Gesellschaft 58 (1925) Abt. B, S. 2409-2412. S., K. F., Hildebrandt, Fritz, Krehl, Ludolf: Über „Cardiazol“, ein in wässriger Lösung subcutan injizierbares neues Analepticum in: Klinische Wochenschrift 4 (1925) S. 1678-1680. Mitteilung über die Auswertung des Digipuratums in: Dt. med. Wochenschrift 54 (1928) S. 830. - Entstehungsgeschichte bekannter Heilmittel. Cardiazol in: Münchener Med. Wochenschrift 82 (1935) S. 1489-1491. - Toxikologie der Stickstoffwasserstoffsäure in: Naunyn-Schmiedebergs Archiv für experimentelle Pathologie und Pharmakologie 187 (1937) S. 155-162.
L Kürschner (1940/41) Sp. 625. K. F. S. wird 70 in: Heidelberger Tageblatt vom 27. Aug. 1957. - WBIS; Badische Biographien N.F. II (1987) S. 241-243; Deutsche Biographie, s. https://www.deutsche-bio graphie.de/gnd137749775.html [07.11. 2017].

P Bildarchiv UAH; Badische Biographien.

\section{Schmidt, Georg Benno}

1888-1932 Med. Fak.

Chirurgie

* 18. März 186o Leipzig

$\dagger \quad$ o2. Juni 1935 Heidelberg ev.

V Benno Gottlob S. (1826-1896) seit 1853 PrivatDozent, seit 1865 a. o. Prof., seit 1887 o. Honorar-Prof. für Chirurgie Leipzig, siehe WBIS, Professorenkatalog Leipzig online

M Luise Eleonore geb. Berger

$\infty$ 8. April 1893 Pauline (Paula) Helene Mathilde geb. Hausrath (1872-1958) T von: (siehe) Adolf H.; Kusine von: (siehe) Alfred und Max Weber

$\mathrm{K} \quad$ 1S, $1 \mathrm{~T}$ (Adoptiv-Kinder)

Vw Brüder: Arthur Benno S. (1861-1940), u.a. seit 1887 Privat-Dozent für Dt. Recht, Leipzig, seit 1889 o. Prof. für Dt. Rechtsgeschichte, Kirchenrecht, Völkerrecht Gießen, 1913-1931 (Emeritierung) o. Prof. für Dt. Recht, Kirchenrecht Tübingen, s. Württembergische Biographien 2 (2011) S. 248-250; Ehemann von Marie Ida Lili geb. Benecke (1873-1956) T von (siehe) Wilhelm B. - Martin Benno S. (18631949), u. a. 1913-1934 (Emeritierung) o. Prof. für Pathologie Würzburg, siehe WBIS, Dhom (2001) S. 364-366; Ehemann von Auguste Henriette geb. Benecke (1874-1952) T von (siehe) Wilhelm B.

Lb Seit WS 1879/80 Studium an U Freiburg/Br., 1880-1884 Leipzig.

Leipzig: WS 1883/84 Med. Staatsexamen; Jan. 1884 Approbation; 5. März 1884 Dr. med. an U; seit 1884 II. Prosektor am Anatom. U-Inst. 
UH: 1885-1895 I. Assistent an Chirurg. U-Klinik; 3. März 1888 Habilitation; seit 10. Nov. 1902 nichtetatm., 1920-1932 nichtplanm. a.o. Prof.; 19091932 außerdem Leiter der Chirurg. Abt. der U-Kinderklinik Luisen-Heilanstalt als Nachf. von Max Jordan; 1. Febr. 1932 Aufgabe der Lehrtätigkeit aus Gesundheitsgründen. • In dieser Zeit:

1895-1923 Leiter e. privaten Chirurg.-Gynäkolog. Klinik in H; 1914-1918 Kriegsdienst; 1923-1932 (?) Leiter der Chirurg. Station im Ev. Diakonissenhaus (heute: Krankenhaus Salem) in H.

E Badischer Friedrich-Luisen-Orden; Rote KreuzMedaille III. und II. Klasse; Montenegrinischer Orden Danilos I. für die Unabhängigkeit der schwarzen Berge I. Klasse.

Qu UAH PA 1157, 5682. • Briefe: UBH. • Auskunft: Standesamt Heidelberg.

$W$ Beiträge zur Gallenblasen-Chirurgie. Jena 1896. - Kurzgefaßtes Lehrbuch der Chirurgie. Leipzig 1901.

L Stübler (1926) S. 319 f.; Kürschner (1931) Sp. 2593; Wer ist's (1935) S. 1405; Fischer $2\left({ }^{3} 1962\right)$ S. 1396; Chronik Ärzte H (1985) S. 141f.; Jansen (1992a) S. 169 (Register); WBIS; 150 Jahre Pädiatrie in H (2010) S. 47; Deutsche Biographie, s. https://www. deutsche-biographie.de/gnd117506044.html [07.11. 2017].

$P$ Bildarchiv UAH; graph. Slg. UBH.

\section{Schmidt, Johann Anton}

1852-1863 Phil. Fak.

Botanik

* o6. Mai 1823 Hamburg

$\dagger$ 21. Jan. 1905 Elberfeld (heute: Stadtteil von Wuppertal)

口 Hamburg ev.
V Hinrich S. (1778-1852) Kaufmann, Senator

M Agatha Henriette Dorothea geb. Luis (17831857)

๑ 31. März 1860 Anna Wilhelmine (Minna) geb. Nürnberg (1831-1904)

K $\quad 1 \mathrm{~T}$

Lb Zunächst Lehre zum Gärtner und Samenhändler.

Seit SS 1848 Studium der Philosophie an UH, seit WS 1849/50 Göttingen; 18. Okt. 1850 Dr. phil. an U Göttingen; 1850-1852 Eigenstudien, u.a. Jan.April 1851 auf Inselgruppe Kap Verde vor Küste Westafrikas.

UH: 10. Jan. 1852 Habilitation; 29. Nov. 1855 Ern. zum a.o. Prof. in Nachf. des Ordinarius Gottfried Wilhelm Bischoff, s. UAH RA 6883; seit 29. Dez. 1855 außerdem „provisorischer“ Direktor des Botanischen Gartens als Nachf. von Bischoff und in Nachf. von Carl Rau, s. hierzu UAH RA 5631; seit 1859 jährl. Besoldung von 400.- Gulden; 11. Aug. 1863 Weggang von $U$ auf eigenen Antrag nach Ern. von Wilhelm Hofmeister zum Ordinarius für Botanik und Direktor des Botanischen Gartens.

Privat-Gelehrter in Stadtteilen von Hamburg: Seit 1863 Bergedorf, seit 1867 Hamm, zuletzt wohl Horn.

Elberfeld: 1904 Umzug zu seiner Tochter.

E Mitglied: 1852 Dt. Akademie der Naturforscher Leopoldina Halle/S., 1852 Naturforschende Gesellschaft der Rheinpfalz, 1853 Naturwiss. Gesellschaft für die preußischen Rheinlande und Westfalen, 1853 Norddeutscher Apothekerverein.

Qu UAH PA 2221, 2223; RA 5631, 5633, 6883; Fak. Akte H-IV-102/48. - Siehe auch Archiv der Dt. Akademie der Naturforscher Leopoldina Halle/S.

$W$ Beiträge zur Flora der Cap Verdischen Inseln. Heidelberg 1852. • Flora von Heidelberg ... Heidelberg 1857. Repr. Stockbridge (Massachusetts) 2013. - Anleitung zur Kenntniß der natürlichen Familien der Phanerogamen. Stuttgart 1865. 2. Ausg. 1870 . 
L Biogr. Jahrbuch 10 (1905) Sp. 244. - Pfitzer, E.: J.A.S. in: Berichte der Dt. Botanischen Gesellschaft Bd. 23 (Mai 1905) S. 21-24. - WBIS. • J.A.S. in: Hamburgisches Geschlechterbuch. Limburg/Lahn 1966. Bd. 11, S. 377 f. • Göttinger Biologen 1737-1945. Eine biogr.-bibliogr. Liste. Hrsg. von Gerhard Wagenitz. Göttingen 1988. S. 155 f. • Quattrocchi, Umberto: CRC World dictionary of plant names. Common names, scientific names, eponyms ... Boca Raton (Florida) 1999. S. 2417. • Frahm, Jan-Peter, Eggers, Jens: Lexikon deutschsprachiger Bryologen. Norderstedt 2001. Bd. 1. S. 465 f. - Mabberley, David J.: Mabberley's plantbook. A portable dictionary of plants ... New York 2008. S. 316 u. ö. • Deutsche Biographie, s. https:// www.deutsche-biographie.de/gnd117507083.html [07.11.2017].

\section{Schmincke, Alexander}

1928-1945, 1947-1949 Med. Fak.

Allg. Pathologie, Patholog. Anatomie

* 18. Sept. 1877 Nürnberg

$\dagger \quad$ 26. Aug. 1953 Heidelberg

ev.

V Albrecht S., Kaufmann

M Emilie geb. Kümmell

๑ 10. Mai 1913 Hedwig geb. Behr (1888-1964)

K $\quad 3 \mathrm{~T}$

Lb Seit WS 1896/97 Studium an U Marburg, SS 1898 Würzburg, WS 1898/99 Marburg, seit SS 1899 Würzburg, siehe hierzu S.s Mitschriften von Vorlesungen in: UAH Acc. 30/12; 1. Okt. 1898-1. Febr. 1899 („als dienstbeschädigt entlassen“, aus: Standesliste in: UAH PA 5701 auf S. 2) Militärdienstpflicht als Einjährig-Freiwilliger.

Würzburg: 1901 Med. Staatsexamen; Febr. 1901 Approbation.

U Würzburg: Febr. 1901 Dr. med.; 1. Febr. 19011910 Assistent: U-Ohrenklinik, anschl. Anatom. dann Patholog. Inst.; Juli 1907 Habilitation.
U München: 1. Okt. 1910-1. Okt. 1921 Assistent am Patholog. Inst.; WS 1910/11-Aug. 1912 Privat-Dozent; seit Aug. 1912 nichtetatm. a.o. Prof. - In dieser Zeit:

6. Sept. 1914-24. Nov. 1918 Kriegsdienst, u.a. seit 15. Juli 1915 als Armeepathologe; 22. Aug. 1918 Verleihung des Charakters als Stabsarzt.

U Graz: WS 1921/22 o. Prof.

U Tübingen: 7. März 1922 Ern. zum 1. April 1922 o. Prof. und Direktor des Patholog. Inst.

UH: 26. März 1928 Ern. zum o. Prof. und Direktor des Patholog. Inst. als Nachf. von Paul Ernst; 11. Mai 1928 Vereidigung; 25. Okt. 1945 Ablehnung der von S. eingereichten Beantragung seiner Emeritierung durch Präsidenten der Landesregierung Baden, Abt. für Kultus und Unterricht in Karlsruhe; 31. Okt. 1945 Entlassung von UH gemäß Erlaß der amerikanischen Militärregierung; 16. Mai 1947 Bitte der Med. Fak. an Hochschulverwaltung, die Wiederanstellung von S. bei Militärregierung zu erwirken („S. ist hier nicht mehr länger zu entbehren ... (Er) ist ein Gelehrter von Weltruf von noch völlig ungebrochener Arbeitskraft ...", aus: UAH PA 5701); 6. Aug. 1947 Genehmigung der Wiedereinstellung als o. Prof.; seit 18. Aug. 1947 Wiedereinsetzung als Vorstand des Patholog. Inst.; 30. Sept. 1948 Emeritierung; 1. Okt. 1948-30. Sept. 1949 Vertreter seines Lehrstuhls und stellvertr. Leiter des Patholog. Inst. (Nachfolger: Edmund Randerath, s. Drüll (2009) S. 481 f.).

1929/30 Dekan der Med. Fak. der UH

Eine von S. entdeckte charakteristische Krebsform für den Nasen-Rachenraum ist bekannt u.d.N. Schmincke-Tumor, s. S., A.: Über lymphoepitheliale Geschwülste in: Beiträge zur patholog. Anatomie und zur allg. Pathologie 68 (1921) S. 161-169.

Siehe auch Anhang Sporteinrichtungen an UH 1910-1933 und ihre Mitglieder

E 1921 Korr. Mitglied der Gesellschaft für Kinderheilkunde München; 1921 Korr. Mitglied, 1933 Ehrenmitglied der ärztlichen Vereinigung München; 
1939 Mitglied der Akademie der Wissenschaften H. 1917 Eisernes Kreuz II. Klasse; 1935 Ehrenkreuz für Kriegsteilnehmer; 1941 Kriegsverdienstkreuz II. Klasse mit Schwertern.

Qu UAH PA 1160, 5701; Rep. 40-423. GLA Abt. 235, Fasz. 2477. - Teil-Nachlaß: UAH (Signatur: Acc. 30/12).

$W$ Histopathologischer Befund in Roseolen der Haut bei Wolhynischem Fieber in: Münchener med. Wochenschrift 64 (1917) S. 961. - Zur Lehre von den krankhaften Gewächsen in: Rudolf Virchows Archiv für patholog. Anatomie und Physiologie und für klinische Medizin 227 (1920). (Mitverf.) - Methoden zum Studium der Pathologie des Wachstums und der Entwicklung in: Handbuch der biologischen Arbeitsmethoden. Hrsg. von Emil Abderhalden. Abt. 8: Methoden der experimentellen morphologischen Forschungen. T. 1,1 (1924) S. 697-79o.

L Kürschner (1950) Sp. 1830. - Randerath, Edmund: A.S. in: Ruperto Carola 5. Jg., Nr. 11/12 (1953) S. 22 f.; Ders.: A. S. in: Ruperto Carola 9. Jg., Bd. 21 (1957) S. 142 f. - Doerr, Wilhelm: A. S. zum Gedächtnis in: Zentralblatt für allg. Pathologie und patholog. Anatomie. Jena 1954. S. 1-9. - Fischer 2 ( $\left.{ }^{3} 1962\right)$ S. 1399; WBIS; Arnim 5 (1985) S. 60; Chronik Ärzte H (1985) S. 142, 266; Jansen (1992a) S. 169 (Register); Dhom (2001) S. 796 (Register); Deutsche Biographie, s. https://www.deutsche-bio graphie.de/gnd130906050.html [07.11. 2017].

P Bildarchiv UAH; Ruperto Carola (1953); Chronik Ärzte H (1985).

\section{Schmitt, Jakob Ildefons Richard (bis 1796: $\mathrm{CM})$}

1786-1807 Phil. Fak. 1786-1788 Kritische Philosophie, Logik, Metaphysik; 1788-1792 Mathematik; 1792-1796 Mathematik, Philosophie; 1796-1807 Mathematik, Philosophie, Physik, Naturgeschichte

$\approx$ 29. Jan. 1762 Fulda

$\dagger$ o2. Dez. 1816 Mannheim kath.
V Georg Adam S. ( $\left.{ }^{*} 1732\right)$ Kantor

M Maria Catharina geb. Keller $\left({ }^{*} 1729\right)$

$\infty$ unverheiratet.

Lb CM (Congregatio Missionis, Kongregation der Mission, auch Lazaristenorden; 1796 Erlöschen des Ordens in der Kurpfalz): 24. Okt. 1785 Erteilung der niederen Weihen und Tonsur; seit 27. Dez. 1785 Subdiakon; seit 10. Juni 1786 Diakon; 22. Dez. 1787-1796 Priester. • In dieser Zeit:

\section{H: Vor 1786 Gymnasiallehrer.}

UH: Seit 1786 a. o. Prof. für Logik, Metaphysik in Nachf. von Johannes Michael Schwoll (s. Drüll (1991) S. 143); seit 23. Aug. 1788 o. Prof. für Mathematik als Nachf. von Peter Ungeschick (siehe Drüll, S. 159 f.) ,und zugleich ... Adjunctus auf dahiesiger Kurfürstlicher Sternwarte" (aus: Ernennungsschreiben vom 23. Aug. 1788 in: UAH PA 2226); seit 7. Mai 1792 Ankündigung von Vorlesungen auch über "Weltweisheit" (u.a. Philosophie Kants, Moralphilosophie, theoretische und praktische Philosophie) als Nachf. von Franz Heinrich Schneider (siehe Drüll, S. 136f.); seit 4. Febr. 1796 Übertragung der Lehrstellen der Physik und Naturgeschichte sowie Besorgung des Physikalischen und Naturalien-Kabinetts als Nachf. von Johannes Schwab (siehe Drüll, S. 141 f.; hier Korrektur: ${ }^{\star} 1731$ Scheinfeld in Mittelfranken, nicht in Thüringen); S. hat „in den achtziger und neunziger Jahren das Naturrecht auf unserer hohen Schule öffentlich mit allgemeinem Beifalle dem zahlreichsten Auditorium beinah jährlich vorgetragen“ (aus: Brief des Rektors Johannes Koch vom 9. April 1799 in: UAH RA 6858); 28. April 1799 Phil. Fak. stellt ergebnislos den Antrag, die ,erledigte Stelle eines öffentlichen Lehrers des Naturrechts [Johannes Adam Völlinger, s. Drüll, S. 161 f.; Rother, Wolfgang: Die Wirtschaftslehre J. A. V.s. ... in: Geld. Phil., literaturwiss. und ökonom. Perspektiven. Hrsg. von Josette Baer ... Basel 2013. S. 141-163] mit der Lehrstelle des zeitlichen Professoris der Philosophie in der Person des Herrn Prof. Schmitt [zu] vereinige[n], und die [anschließend] wieder zu besetzende Lehrstelle der Physik und Mathematik dem Professor Herrn Johannes Koch [zu] übertragen ..." (aus: RA 6858); WS 1806/07 letzte Vorlesungsankündigung. 
U Freiburg/Br.: Seit WS 1807/08 (erster Nachweis in den Vorlesungsverzeichnissen) o. Prof. für Praktische Philosophie und Logik; in dieser Zeit auch Schulrat; WS 1816 Beurlaubung aus Krankheitsgründen.

1794/95 Rektor der UH; 1787, 1791, 1797, 1803 Dekan der Phil. Fak. der UH

1805 Geistlicher Rat

Siehe auch Joannes a Cruce (s. Drüll (1991) S. 78) und Jakob Koller (s. ebd. S. 88 f.)

Qu UAH PA 2226; PA 1857 (Koch, Johannes); RA 6858, 8359. - GLA Abt. 205, Fasz. 481. • Auskunft: Kath. Stadtpfarramt St. Blasius Fulda (Taufbücher).

$W-$

L Wechmar (1846) S. 256; Keller (1913) S. 77, 110; Schneider (1913) S. 23; Haas (1960) S. 99; Math. Institute in Deutschland (1989) S. 160.

\section{Schmitthenner, Heinrich Wilhelm}

1919-1928 Phil. Fak.

Geographie

* O3. Mai 1887 Neckarbischofsheim

$\dagger$ 18. Febr. 1957 Marburg

ev.

V Adolf S. (1854-1907), u.a. 1893-1907 Stadtpfarrer in $\mathrm{H}$ und 1893-1907 Lehrer am Ev.Prot. Predigerseminar UH, Heimatdichter (Verfasser von u. a.: Das deutsche Herz. Stuttgart 1908. 3. Aufl. 1999), s. UAH Acc. 37/16; Badisches Pfarrerbuch 2 (1939) S. 541 f., BBKL XXVI (2006) Sp. 1351-1354

M Aline geb. Wagner (1857-1922)

( 8. April 1921 Luise Johanna Emilie geb. Ruppenthal (1896-1980)

K $\quad 2 \mathrm{~T}$
Vw Ur-Ur-Großvater, s. Schmitthenner, Adolf: Das Tagebuch meines Urgroßvaters. Freiburg/ Br. 1908. 3. Aufl. 1922.

Vw Bruder: (siehe) Paul S.

Lb Seit WS 1908/o9 Studium der Geographie, Geologie, Volkswirtschaftslehre, Soziologie an UH, seit SS 1910 Berlin, SS 1911-SS 1913 H; 16. Dez. 1912 Rigorosum, 16. Juli 1913 (Datum der Promotionsurkunde) Dr. phil. an UH; Forschungsreisen: 1912 Nordafrika, 1913/14 Ostasien.

1914-1918 Kriegsgeologe.

UH: 8. Febr. 1919 Habilitation; seit 1920 Assistent am Geographischen Inst.; seit 25. Juli 1923 nichtplanm. a.o. Prof.; 1925 Forschungsreise nach China.

U Leipzig: Seit SS 1928 planm. a.o. Prof. für Kolonialgeographie und Direktor des Kolonialgeographischen Inst.; 1928 Ruf an U Innsbruck abgelehnt; seit 27. Dez. 1928 persönlicher Ordinarius; seit 11. Mai 1936 o. Prof. für Geographie und Direktor des Geographischen Inst.; Apr. 1945 Wahl zum Dekan der Math.-Naturwiss. Abt. der Phil. Fak.; 23. Juni 1945-Ende Nov. 1945 Zwangsevakuierung durch amerik. Besatzung nach Weilburg, s. hierzu: Aus einem Brief von H.S. an seine Brüder vom 26. Juni 1945 in: Wiemers, Gerald: Die Amerikaner verlassen Leipzig. Vor 50 Jahren. Zwangsumsiedlung von Wissenschaftlern nach Weilburg/Lahn in: Universität Leipzig - Mitteilungen und Berichte für die Angehörigen und Freunde der Universität Leipzig (Juli 1995) H. 5/95, S. 19-21.

U Marburg: Seit 1. Jan. 1946 Lehrstuhlvertreter, 1. Aug. 1946-30. Sept. 1954 (Emeritierung) o. Prof.

E Mitglied: 1934 Akademie der Wissenschaften Leipzig, 1939 Dt. Akademie der Naturforscher Leopoldina Halle/S.

Qu UAH PA 239, 5707. - Teil-Nachlaß: Bundesarchiv Koblenz; Leibniz-Institut für Länderkunde Leipzig; Bundesforschungsanstalt für Landeskunde und Raumordnung Bad Godesberg; Universität Marburg. - Siehe auch Archiv der Dt. Akademie der Naturforscher Leopoldina Halle/S. 
$W$ Tunesien und Algerien. Die Landschaft und ihre Bewohner. Stuttgart 1924. - Chinesische Landschaften und Städte. Stuttgart 1925. Die Typen der Kolonialgebiete in: Koloniale Rundschau (1932). • China im Profil. Leipzig 1934. • Lebensräume im Kampf der Kulturen. Leipzig 1938. 2. Aufl. 1951. - Studien über Carl Ritter. Frankfurt/M. 1951. - Probleme der Schichtstufenlandschaft. Marburg 1956.

HG 1935-1944 Geographische Zeitschrift.

L Plewe, Ernst: H.S. Eine Würdigung anlässlich seines 70. Geb. Marburg 1957. - Brosche, KarlUlrich und Schultz, Hans-Dietrich: Probleme der Schichtstufenlandschaft. S.s Theorie im Lichte neuerer Forschungen, insbesondere in NordDeutschland in: Geographische Zs. 6o. Jg., H. 3 (3. Quartal 1972) S. 241-269. - Catalogus prof. Marburgensis 2 (1979) S. 896 f.; Badische Biographien N.F. II (1987) S. 243 f. - H.-S.-Gedächtnisschrift zu seinem 100. Geb. Hrsg. von Helmut Blume ... Stuttgart 1987. UH im Nationalsozialismus (2006) S. 1270 (Register); Lebensbilder aus der ev. Kirche (2007) S. 532 (Register); NDB 23 (2007) S. $248 \mathrm{f}$; WBIS; Geschichte U Leipzig 3 (2010) S. 966 (Register); Professorenkatalog Leipzig online; Sächsische Biografie online. Spang, Christian W.: Karl Haushofer und Japan. Die Rezeption seiner geopolitischen Theorien in der deutschen und japanischen Politik ... München 2013. S. 995 (Register). • Gutberger, Hansjörg: Raumentwicklung, Bevölkerung und soziale Integration. Forschung für Raumplanung und Raumordnungspolitik 19301960. Wiesbaden 2017. S. 535 (Register).

P Bildarchiv UAH; Badische Biographien.

\section{Schmitthenner, Ludwig Wilhelm Martin Paul}

1928-1945 Phil. Fak. 1928-1937 Geschichte des Kriegswesens 1937-1945 Wehrpolitik, Wehrwissenschaft

* 02. Dez. 1884 Neckarbischofsheim

$\dagger$ 12. April 1963 Heidelberg

ev.
V Adolf S. (1854-1907), siehe Heinrich S.

M Aline geb. Wagner (1857-1922)

๑ 28. April 1910 Emma/Emilie geborene Grimmel(-Landfried) (1890-1978) Hausfrau

$\mathrm{K}$ keine

Vw siehe Heinrich S.

Vw Bruder: (siehe) Heinrich S.

Lb Militärische Laufbahn 1904-1920:

Seit 1904 Fahnenjunker, seit 1905 Leutnant; 19121914 Studium an Kriegsakademie in Berlin; seit 1913 Oberleutnant; 1914-1918 Kriegsdienst; seit 1915 Hauptmann; 1920 Verabschiedung als Major.

Akademische Laufbahn 1919-1945:

UH: 8. Febr. 1919 (Kriegsnotsemester)-SS 1921 Studium der Philosophie, Geschichte; 2. Mai 1922 Dr. phil.; 3. Nov. 1928 Verleihung der venia legendi für Geschichte des Kriegswesens; 16. Mai 193330. Sept. 1937 planm. a. o. Prof. für Geschichte mit besonderer Berücksichtigung der Kriegsgeschichte und der Wehrkunde; Sept. 1933 Begründer der „Abt. für Geschichte mit besonderer Berücksichtigung der Kriegsgeschichte" am Histor. Seminar, seit 1936 u.d.N. „Kriegsgeschichtliches/Wehrgeschichtliches Seminar“; 1937 Ablehnung e. Berufung als Generaldirektor der preußischen Staatsarchive; seit 1. Okt. 1937 Ordinarius für Wehrpolitik und Wehrwissenschaft; 30. März 1945 Schließung der U; 30. April 1945 Entlassung aus Hochschuldienst durch amerik. Militärregierung; 19. Juni 1945 Verhaftung; 22. Aug. 1945 Entscheidung des U-Senats, sich von 13 „Repräsentanten extremen Nazitums“ zu trennen, darunter S. • In dieser Zeit:

Politische Laufbahn 1925-1945:

Karlsruhe: 1925-1933 Mitglied der II. Kammer des Badischen Landtags; Badisches Staatsministerium: seit 11. März 1933 Staatskommissar, seit 6. Mai 1933 Staatsrat, seit Ende Sept. 1933 Staatsminister ohne Geschäftsbereich; 4. Juni 1940-1945 mit der Wahrnehmung der Geschäfte des Badischen Ministers des Kultus und Unterrichts beauftragt.

Straßburg:

1940-1945 Leiter der Abt. Erziehung, Unterricht und Volksbildung des Chefs der Zivilverwaltung im Elsaß. 
Kriegsteilnahme:

Seit 29. Aug. 1939 Oberstleutnant im Generalstab und bis 1. Jan. 1940 Regimentskommandeur im Westen; seit Jan. 1940 beurlaubt.

Lebenslauf nach Juni 1945:

19. Juni 1945 Verhaftung in H; bis Mai 1946 Aufenthalt in verschiedenen amerik. Internierungslagern, Mai 1946-16. Sept. 1947 im franz. Gefängnis in Baden-Baden; nach Entlassung bis 15. Dez. 1948 mehrere Krankenhausaufenthalte; nach erfolglosen Gesuchen S.s auf Auszahlung e. Ruhegehalts, Fortschreiten „der Krankheit und Verelendung (- nicht zuletzt auf Grund [S.s] psychischer Verfassung -), so dass die Entnazifizierung immer wieder hinausgezogen werden mußte, weil Prof. S. den Belastungen einer Verhandlung in diesem Zustand nicht gewachsen war. Inzwischen konnte Prof. S. nach Abschluß des Entnazifizierungsverfahrens mit Hilfe eines von privater Seite erhaltenen Darlehns mehrere Kuren und Erholungsaufenthalte finanzieren und sich soweit restaurieren, dass seine Dienstfähigkeit als wiederhergestellt betrachtet werden kann" (aus: Brief vom 12. August 1952 in: UAH PA 5710); 20. März 1951 Einstellung des Spruchkammerverfahrens; Gewährung der Rechtsstellung: seit 1. Okt. 1950 eines in Ruhestand versetzten außerordentlichen Professors, seit 12. März 1964 (posthum) eines planmäßigen Ordinarius der UH.

1. Nov. 1938-März 1945 Rektor der UH (stellvertr. Rektor während S.s kriegsbedingter Abwesenheit vom 29. Aug. bis 31. Dez. 1939 ist Karl Bilfinger; im März 1945 beauftragt S., bevor er zwischen dem 21. und 27. März Heidelberg verläßt, den Emeritus Johannes Hoops mit der Vertretung, die dieser bis zum 14. August 1945 innehat).

Seit 1. Okt. 1933 (rückdatiert von Aug. 1934) Mitglied der NSDAP; seit Okt. 1934 Mitglied des Schutzstaffel (SS)-Oberabschnitts Rhein, seit 15. Sept. 1935 Standartenführer, 1944 SS-Brigadeführer (= Generalmajor).

1935 Mitglied des neugebildeten Stadtrats in Heidelberg, s. Kommunalwahlen in Heidelberg 18751984. Hrsg. von Rolf Maier. Heidelberg 1984. S. 8 o.
E 1914 Eisernes Kreuz II. und 1915 I. Klasse; 1914 Orden vom Zähringer Löwen; 1918 Bremer Hanseatenkreuz; 1934 Ehrenkreuz für Frontkämpfer.

Qu UAH PA 624, 5708-5710; Rep. 26-9; Quästurakten Rep. 27-1209f. - Rektoratsreden - online (2007). • Briefe: UBH; DLA Marbach. • Auskunft: Ev. Kirchengemeindeamt Heidelberg. - Lebenserinnerungen von L.W.M.P.S. in: Abt. 150.028: Familiennachlaß Schmitthenner ... Bearb. von Walter Schnaiter. Landeskirchliches Archiv in Karlsruhe (Aug. 2013) Nr. 504-507. - Siehe auch Lennartz (1999) S. 652.

$W$ Die Ansprüche des Adels und Volks der Stadt Rom auf Vergebung der Kaiserkrone während des Interregnums. Berlin 1923. Nachdr. Vaduz 1965. • Wehrhaft und frei: Die deutsche Wehr von den Anfängen bis zur Gegenwart. Langensalza 1934. 3. Aufl. 1943. - Volkstümliche Wehrkunde. Langensalza 1935. 2. Aufl. 1937. Politik und Kriegführung in der neueren Geschichte. Hamburg 1937. 2. Aufl. 1943. - Goethe und der Oberrhein. Straßburg 1944. • Bibliographie 1929-1942 in: UAH PA 5709; siehe Badische Biographien N.F. III (1990) S. 242 f., Lennartz (1999) S. 652 f.

$L$ WBIS; Badische Biographien N.F. III (1990) S. 239-243; Heiber I und II (1992-1994); Histor. Seminar H (1992) S. 289-294; Jansen (1992) S. 243 f., 249 f. u. ö.; Jansen (1992a) S. 41, 113 f., 155f.; Heidelberg 1945 (1996) S. 97 f., 101, 104 u. ö.; DBE 9 (1998) S. 34f. • Lennartz, Ulrike: P. S., badischer Staatsminister in: Die Führer der Provinz. NS-Biographien aus Baden und Württemberg. Hrsg. von Michael Kißener u. a. 2. Aufl. Konstanz 1999. S. 623-653. Hausmann (2003) S. 241 f. u.ö.; Grüttner (2004) S. 152; Wolgast (2004) S. 16of.; Klee (2005) S. 549; Reichs-U Strasbourg (2005) S. 75, 88, 244-246. - Schipperges, Thomas: Die Akte Heinrich Besseler ... Musikwissenschaft und Wissenschaftspolitik in Deutschland 1924-1949. München 2005. S. 209, 259, 409 u. ö. • Freiburger Phil. Fak. 1920-1960 (2006) S. 995; UH im Nationalsozialismus (2006) S. 1270 (Register); NDB 23 (2007) S. 248*, 249; Drüll (2009) S. 554f. • Reichherzer, Frank: „Alles ist Front!" Wehrwissenschaften in Deutschland und die Bellifizierung der Gesellschaft vom Ersten Weltkrieg bis in den Kalten Krieg. Paderborn 2012. S. 514 (Register). Geißler, 
Stefan Walter: Soldaten und Wissenschaftler. P.S. und das Kriegsgeschichtliche Seminar der Universität Heidelberg. Staatsexamensarbeit für das Lehramt an Gymnasien. Heidelberg 2014 (online), s. http://www.ub.uni-heidelberg.de/archiv/18145. • Deutsche Biographie, s. https://www.deutschebiographie.de/gnd118759906.html [07.11.2017]. Fichtenau, Viktor: P. S. „Universität als Stätte wehrpolitischer Erziehung" in: Täter, Helfer, Trittbrettfahrer. Bd. 7: NS-Belastete aus Nordbaden und Nordschwarzwald. Hrsg. von Wolfgang Proske. Gerstetten 2017. S. 257-271.

$P$ Bildarchiv UAH; siehe auch Badische Biographien N. F. III (1990) S. 243.

\section{Schmitz, Caspar (Taufname: Michael) (bis 1802: OFM)}

1789-1792 Theol. Fak., kath. Abt.

Kirchenrecht

1792-1794 Jur. Fak.

Kirchenrecht

1794-1804 Theol. Fak., kath. Abt.

Kirchengeschichte

* 26. Nov. 1760 Aachen

$\dagger$ 29. Juli 1835 Walldürn (Baden)

kath.

V N.N.

M N.N.

$\infty$ unverheiratet.

Lb OFM (Franziskanerorden): 1781-1802 (Austritt) einfacher Priester ohne Ordination; seit 25. Mai 1782 Subdiakon, seit 5. April 1785 Diakon; 1788-1790 Studienassistent und Korrepetitor am Konvent im Franziskanerkloster auf heutigem Karlsplatz in $\mathrm{H}$.

UH: 26. Aug. 1786 Immatrikulation zum Studium der Theologie; Aug. 1786 theol. Bakkalarexamen; 6. Sept. 1792 Dr. theol. (aus: Intelligenzblatt der Allg. Literatur-Zeitung Nr. 132 vom 10. Nov. 1792, Sp. 1082); 13. Aug. 1788-19. Febr. 1794 Assessor an
Theol. Fak. als Nachf. von Hermellus Müller mit e. „gewöhnlichen jährlichen Bezug von zehn Gulden“ (aus: UAH PA 2229), s. hierzu Drüll (1991) S. 110 f. (zu H. Müller) sowie 203f. (zu Assessor).

UH, Theol. Fak.: Seit 30. Sept. 1789 a. o. Prof. für Kirchenrecht; SS 1790 S. hält zwei Semester lang Vorlesungen über Moraltheologie für den erkrankten und am 8. Febr. 1791 verstorbenen Hermellus Müller; Mai 1791 Ablehnung e. Antrag S.s auf „Verleihung eines ordentlichen Lehrstuhls in dem Canonischen Rechte oder Kirchengeschichte " durch Kurfürst Carl Theodor (aus: Brief vom 10. Juni 1791 in: PA 2229).

UH, Jur. Fak.: Seit 25. Jan. 1792 a. o. Prof. für Kirchenrecht; 1. Dez. 1793 vergebliche Bittschrift S.s um Vergabe des Ordinariats für Moraltheologie als Nachf. von Albertin Schott (siehe Drüll (1991) S. 139); 1. Jan. 1794 erfolgreiche Bewerbung S.s um die "ordentliche Lehrstelle für Kirchengeschichte“ des verstorbenen Louis Alioz (s. Drüll, S. 6).

UH, Theol. Fak.: Seit 19. Febr. 1794 o. Prof. für Kirchengeschichte als Nachf. von Alioz; 15. Dez. 1798 ergebnisloser Antrag S.s auf Verleihung des Akad. Senatorsitzes, der mit dem Oeconomie-Commissariats-Amt verbunden ist; Inhaber dieses Amtes ist der zuletzt im Vorlesungsverzeichnis im SS 1795 genannte Prof. für Zivil- und Militärbaukunst sowie der Praktischen Geometrie, Andreas Traitteur (s. Drüll, S. 156 f.); dieser soll - laut S. - demnächst aus dem Amt entlassen werden (s. hierzu Brief S.s vom 15. Dez. 1798 in: PA 2229); 23. Jan. 1799 Rektor Johannes Koch gibt in e. Brief an Oberkuratel über Vergabe des Senatssitzes an S. zu bedenken, daß die „Anzahl der Glieder umgestoßen würde oder ... ein wirkliches Senatsglied alsdann weichen müßte" (aus: PA 2229; siehe hierzu auch Anton Sar (Z)); 15. Dez. 1798-24. März 1799 Reise S.s „in gewissen Universitaets Geschäften“ nach München zu Kurfürst Carl Theodor ( $\dagger 16$. Febr. 1799) (aus: UAH PA 2170 (Marcellian Rüdel); siehe hierzu auch Brief S.s vom 30. Jan. 1804 in: PA 2229); 9. Jan.-Ende April 1799 Vertreter S.s an U ist M. Rüdel; 17. Jan. 1804 wohl vergebliche Forderung S.s an Akad. Senat um Auszahlung der ihm zugesicherten 642 Gulden und 22 Kreuzer für seine Auslagen während seiner Dienstreise 1798/99 nach 
München, s. auch Briefwechsel zwischen Akademie bzw. Engerem Senat und S. wegen dieser nicht gezahlten Diäten in: PA 2229.

Amorbach: Seit 30. Okt. 1804 Schulrat und Geh. Rat, später Wirklicher Geh. Rat und Kabinettsrat in Fürstlich-Leiningischen Diensten; 1814/15 leiningischer Bevollmächtigter auf Wiener Kongreß.

Walldürn: 1809-1835 Pfarrer.

1796, 1800 Dekan der Theol. Fak. der UH, kath. Abt., siehe hierzu Weisert/Drüll/Kritzer (2007) S. 48

1797 Kurbayer. Wirkl. Geistlicher Rat

Qu UAH PA 2229; RA 4998 (Verhandlungen S.s in München mit Vollmacht der UH vom 27. Nov. 1798; darin: gedrucktes Conclusum der ReichsFriedensdeputation vom 15. Okt. 1798), 5969, 6215-6217, 6218, 6746, 6779; Theol. Fak. Nr. 75; GF Nr. 80. GLA Abt. 205, Fasz. 484-486. Ergebnislose Anfragen: Kath. Pfarramt Walldürn; Adelsarchiv Grafen zu Leiningen in Amorbach (seit 2003 geschlossen).

$W$ Vaticinium Danielis, animadversionibus hermeneutico-criticis illustratum. Heidelberg 1786.

L Keller (1913) S. 69 f.; Schneider (1913) S. 11. Über C.S. in: Rhenania Franciscana. Sondernummer: Unsere Toten. Düsseldorf 1941. S. 129 f. • Kullmann (1951) S. 255, 259. Der Regularklerus in den Kölner Bistumsprotokollen. 1661-1825. 1. Teil zus.gestellt von Jakob Torsy. Siegburg 1985. S. 477. • Burkard (1995) S. 253 (Register). - Organisation und innere Ausgestaltung des Deutschen Bundes 1815-1819. Bearb. von Eckhardt Treichel. Berlin 2016. S. 245-247 und Anm. 9.

\section{Schmitz, Michael}

siehe Schmitz, Caspar

\section{Schmiz}

siehe Schmitz

\section{Schnappinger, Bonifaz Martin}

siehe Schnappinger, Franz Martin

Schnappinger, Franz Martin (1782-1802:

Bonifacius a Sancto Wunibaldo, Bonifacius

(Bonifaz) vom heiligen Wunibald OCD)

1792-1807 Theol. Fak., kath. Abt.

1792-1807 Exegese, 1799-1807 Dogmatik

$\approx$ 05. Okt. 1762 Neuburg/Donau

$\dagger$ 06. Dez. 1832 Freiburg/Br.

kath.

V Friedrich S., Weinschröter

M Maria Anna geb. Zeller

( unverheiratet.

Lb Neuburg/Donau: Vor 1782 Studium der Humaniora und Philosophie.

OCD Würzburg: 28. Jan. 1782 Eintritt in Karmelitenorden; seit 1782 Studium der Theologie an U; 24. Sept. 1785 Priesterweihe; seit 1785 Lektor der Theologie im Karmelitenkloster.

Karmelitenkloster in H: 1792-1802 Lektor der Theologie; 1799-1802 Prior; 28. Aug. 1802 auf eigenes Ansuchen Austritt aus dem Karmelitenorden.

UH: Seit Nov. 1792 o. Prof. für Exegese; 1795 Dr. theol., s. hierzu UAH RA 6477 S. 7; 3. Febr. 1795April 1804 Repetitor für Theologie der kurfürstl. Alumnen; nach Mai 1799 Prof. für Dogmatik als Nachf. von Joannes a Cruce (s. Drüll (1991) S. 78 80); 10. Mai 1802 Verleihung des Tischtitels durch Kurfürst Max IV. Joseph; Jan. 1804 nach Neuorganisation der U Inhaber der I. Professur für Dogmatik; 1807 Verlegung der kath. Abt. der Theol. Fak. nach Freiburg/Br.

U Freiburg/Br.: Ostern 1807-Herbst 1821 o. Prof. für Dogmatik; 25. Juni 1819 40 Studierende der 
Theologie fordern einen zweiten, jüngeren Prof. für Dogmatik; 30. Juni 1819 Theol. Fak. bescheinigt S., er habe „in der Seelsorge einen seinen Talenten, seiner Liebe für alles Gute und seinem ganzen Charakter gewiß mehr angemessenen Wirkungskreis als in seiner gegenwärtigen Stellung " an der U (aus: Nekrolog (1876) S. 307).

S. bewirbt sich auf e. Pfarrei; 13. Sept. 1821 Ern. zum Pfarrer in Bräunlingen (bei Donaueschingen); er tritt Stelle aus gesundheitlichen Gründen nicht an; seine Bitte an U Freiburg/Br., e. Teil seines Pensionsgeldes zu zahlen, lehnt $U$ mit der Begründung ab, S. sei kein Mitglied der U mehr; er erhält nach längeren Verhandlungen eine Absenzbewilligung, s. hierzu weiter Nekrolog (1876) S. 309.

\section{Freiburg/Br.: Nach Herbst 1821 Privatier.}

1804 Prorektor der UH; 1795, 1799, 1804, 1807 Dekan der Theol. Fak. der UH, kath. Abt., s. hierzu Weisert/Drüll/Kritzer (2007) S. 48, 53; Mai 1799 S. erklärt sich bereit, Anton Sar als Mitglied im Akad./Engeren Senat der UH eine Zeit lang zu vertreten, siehe hierzu A. Sar: Eintrag unter $Z$ [itat].

1805 Geistlicher Rat

$\mathrm{Q} u$ UAH PA 2231; PA 2229 (Schmitz, Caspar; hier: Brief S.s von März/April 1804); RA 902, 6477 S. 7. • GLA Abt. 205, Fasz. 116 f., 487 f., 658.

$W$ Die heilige Schrift des Neuen Bundes ... 4 Bde. Mannheim 1797-1799. 3. Aufl. 1817. Nachdr. 1818. Grundlage aller Religion und Religionsphilosophie. Heidelberg 1805. (Rezension von: Wachter, Karl in: Archiv für die Pastoralkonferenzen in den Landkapiteln des Bisthums Konstanz. Konstanz, Freiburg/Br. 1805. S. 154-159.) - Entwurf der catholisch-christlichen Religions- und Dogmengeschichte $\mathrm{zu}$ akademischen Vorlesungen. Karlsruhe 1807. - Über Erziehung, Aufklärung, Zeitgeist, zugleich auch über Philosophie, Christenthum und Kirche ... Augsburg 1818. 2. Aufl. 1826.

$L$ Reichlin-Meldegg, Karl Alexander von: Das Leben eines ehemaligen römisch-katholischen Priesters. Heidelberg 1874. S. 31-33. - Nekrolog in: Freiburger Diözesan-Archiv 10 (1876) S. 306310. - Badische Biographien 3 (1881) S. 143 f.; Keller (1913) S. 63-65; Schneider (1913) S. 9; WBIS; Brandl (1978) S. 221; Burkard (1995) S. 247 (Register). "Chronik des Barfüsser Karmelitenkloster" (1998) S. 34 f. u. ö.; Deutsche Biographie, s. https:// www.deutsche-biographie.de/gnd100267963.html (4. Nov. 2017); BBKL (April 2018 in Vorbereitung).

\section{Schneegans, Edouard Schneegans, Frédéric Edouard} siehe Schneegans, Friedrich

\section{Schneegans, Friedrich Eduard}

1897-1915 Phil. Fak.

Romanische Philologie

* 05. Mai 1867 Straßburg

$\dagger$ 11. März 1942 Saint-Gaudens (Dép. Haute-Garonne, Frankreich)

ev.

V Karl Friedrich S. (1822-1890) Gymnasialdirektor, s. Veil, Heinrich: Zum Gedächtnis von K. F. S., Direktor des Prot. Gymnasiums ... Straßburg 1890.

M N.N. geb. Jung, T von Andreas J. (1793-1863) Bibliothekar und Prof. für Theologie an U Straßburg, s. ADB 14 (1881) S. 693 f., WBIS

(1) 1903 Anna geb. Lichtenberger, s. Kriegstagebuch K. Hampe (2007) S. 994 (Register); T von Ernest Charles L. (1847-1913) Prof. für Germanische Philologie an U Paris, s. WBIS, IdRef, https://www.idref.fr/o66878950 (abgerufen am 5. Nov. 2017)

$\mathrm{K}$ mind. $2 \mathrm{~S}$

Lb U Straßburg (Deutsches Reich): Seit WS 1885/ 86 Studium; 1891 Dr. phil.; Juli 1891 Staatsexamen für höheres Lehramt.

UH: Seit Okt. 1892 Lektor der Franz. Sprache am Germanisch-Romanischen Seminar mit e. jährl. Besoldung von 1500.- Mark; 1. Mai 1897 Habilitation; seit 16. Nov. 1900 nichtetatm. a. o. Prof. und 
Lehrbeauftragter für Romanische Philologie, insbesondere für Neufranzösisch; 1901/o2 Ruf als etatm. a.o. Prof. an U Erlangen abgelehnt; seit 23. Juli 1902 etatm. a.o. Prof. für Neuere Romanistik mit e. Jahresgehalt von 3200.- Mark und 900.Mark für Wohnungsgeld; 30. Sept. 1915 auf eigenen Antrag U verlassen, um seine Familie der nationalistischen Strömung nicht weiter auszusetzen.

U Neuenburg (Neuchâtel, Schweiz): Seit SS 1916 o. Prof.

Straßburg (Frankreich): Seit 1919 Gymnasial-Prof.

U Straßburg: Seit 1926 a. o. Prof.; 1928-1936 (Emeritierung) o. Prof.

Qu UAH PA 2233; RA 5225, 6840, 6874. • GLA Abt. 235, Fasz. 2479, 3352.

$W$ Die Volkssage und das altfranzösische Heldengedicht. Heidelberg 1896. Le théâtre édifiant aux XIVe et XVe siècle, dans poèmes et récits de la Vieille France. Paris 1928. - Le décor du livre alsacien au XVe et au XVIe siècle dans l'Humanisme en Alsace. Paris 1939.

Übers. Lettres d'un soldat. Briefe eines Soldaten. Dt. Übertragung von F. S. Zürich 1918.

L Hoepffner, Ernest: Frédéric Edouard S. in: Mémorial des années 1939-1945. Strasbourg 1947. (Publications de la Faculté des Lettres de l'Université de Strasbourg. 103.) S. 87-97. Riese (1977) S. 106; Jansen (1992a) S. 169 (Register); Kriegstagebuch K. Hampe (2007) S. 994 (Register); Kalkhoff (2010) S. 42 f. u. o.; Wissenschaftsatlas der UH (2011) S. 125; UH während des Ersten Weltkriegs (2017) S. 36 f. u. ö. (S. 36: Habilitation 1897 statt 1893); IdRef, s. https://www.idref.fr/o3454 7487 (abgerufen am 05.11. 2017); Deutsche Biographie, s. https://www.deutsche-biographie.de/gnd1 o1123728.html [07.11. 2017].

P Bildarchiv UAH; Hoepffner (1947).

\section{Schöberlein}

siehe Schoeberlein

\section{Schoeberlein, Ludwig Friedrich}

1850-1855 Theol. Fak.

Neutestamentliche Exegese, Systematische Theo-

logie, Philosophie

* o6. Sept. 1813 Colmberg (bei Ansbach)

$\dagger \quad$ o8. Juli 1881 Göttingen ev.-luth.

V Mathäus Michael S., Rechnungsbeamter

M Margarethe geb. Köhler

$\infty$ 4. Juni 1849 Elisabeth geb. Katianer († vor 1881)

K 4 .

Lb Seit WS 1830/31 Studium der Theologie und Philologie an U München, seit 10. Nov. 1832 Erlangen; 1835 I. theol. Examen in Ansbach.

Bonn: Seit Herbst 1835 Hauslehrer bei Moritz August von Bethmann Hollweg (1795-1877; u. a. seit 1829 o. Prof. und $1842-1848$ Kurator der U Bonn, 1858-1862 preußischer Kultusminister, s. BBKL I (1975) Sp. 565 f., Hessische Biografie, s. http://www.lagis-hessen.de/pnd/118510339 (Stand: 14. Juli 2017)).

1838 Vikar in Fürth-Poppenreuth; seit 7. Dez. 1838 Stadtvikar in München; seit Sommer 1841 Badeprediger in (Bad) Kissingen.

U Erlangen: 31. Okt. $1841-5$. Sept. 1850 Repetent am Theol. Seminar; 10. Febr. 1849 Habilitation; seit 16. Mai 1850 Privat-Dozent für Theologie, insbesondere Dogmatik. • In dieser Zeit:

Erlangen: Seit 17. Dez. 1848 Gymnasiallehrer für Hebräische Sprache.

UH: Seit 6. Sept. 1850 a. o. Prof. und "Aushilfe“ am Ev.-Prot. Predigerseminar mit e. Jahresgehalt von 1200.- Gulden und e. Remuneration (Gratifikation) von jährl. 200.- Gulden "sowie eine Zu[zu]gskostenvergütung von 400 Gulden ..., welch' 
letztere jedoch im Falle des Wegzugs von Heidelberg vor einem fünfjährigen Aufenthalte daselbst rückzuersetzen wäre" (aus: UAH RA 6718 fol. 17r).

U Göttingen: Seit WS 1855/56 o. Prof. für Systematische Theologie und Liturgiewissenschaft; 1878 Verleihung des Abt-Titels der luth. Benediktinerabtei Bursfelde (bei Hannoversch-Münden) als Senior der Theol. Fak.

1862 Konsistorialrat

E 1850 Lic. theol. h.c. und 1853 Dr. phil. h.c. Erlangen. 1879 Ritterkreuz des Ordens Heinrichs des Löwen I. Klasse.

Qu UAH PA 2238; RA 6718. Matrikel Erlangen (1918) S. 451. GLA Abt. 205, Fasz. 491. Briefe: UBH. - Nachlaß: Staats- und Universitätsbibliothek Göttingen. - Städtler, Heike: Der wissenschaftliche Nachlaß von L. F. S. ... Ein Beispiel für die Erstellung von Nachlaßverzeichnissen an wiss. Bibliotheken. Diplomarbeit 1992.

$W$ Die Grundlehren des Heils entwickelt aus dem Prinzip der Liebe. Stuttgart 1848. • Über den liturgischen Ausbau des Gemeindegottesdienstes in der deutschen evangelischen Kirche. Gotha 1859. • Musica sacra für höhere Lehranstalten, Kirchenchöre ... Göttingen 1869. 7. Aufl. 1931. • Die Musik im Cultus der evangelischen Kirche. Heidelberg 1881. Das Princip und System der Dogmatik. Heidelberg 1881.

MG, MHG 1876-1881 „Siona“: Monatsschrift für Liturgie und Kirchenmusik zur Hebung des gottesdienstlichen Lebens.

HG Schatz des liturgischen Chor- und Gemeindegesangs ... aus den Quellen ... des 16. und 17. Jahrhunderts geschöpft ... 3 Bde. Göttingen 1865-1872. Nachdr. 1928.

$L$ Catalogus prof. Gottingensium (1962) S. 36. • Trillhaas, Wolfgang: Abt L.S. als Systematiker in: Jahrbuch der Gesellschaft für Niedersächsische Kirchengeschichte ... Hannover 1964. S. 198-212. •
Professoren Erlangen (1993) S. 69; BBKL IX (1995) Sp. 596 f. Sandberger, Wolfgang: Das Bach-Bild Philipp Spittas. Ein Beitrag zur Geschichte der Bach-Rezeption im 19. Jahrhundert. Stuttgart 1997. S. 322 (Register). - Schulz, Frieder: Synaxis. Beiträge zur Liturgik ... hrsg. von Gerhard Schwinge. Göttingen 1997. S. 128-131 u. ö. • Müller, F.: Wer war L.S.? in: Zs. für Gottesdienst und Kirchenmusik 5 (2006) S. 18. - Wischmeyer (2008) S. 470 (Register); WBIS; Deutsche Biographie, s. https:// www.deutsche-biographie.de/gnd116852976.html [04. Nov. 2017].

$P$ Bildarchiv UAH; graph. Slg. UBH.

\section{Schöll, Fritz Gustav Adolf}

1877-1918 Phil. Fak.

Klassische Philologie

* 08. Febr. 1850 Weimar

$\dagger$ 14. Sept. 1919 Rottweil/Neckar

口 Heidelberg

ev.

V Dr. Adolf Gustav S. (1805-1882), u. a. seit 1842 Prof. für Archäologie Halle-Wittenberg, seit 1843 Direktor der Kunstanstalten zu Weimar, seit 1861 Oberbibliothekar ebd., s. NDB 23 (2007) S. $363^{*}$; Burgmann, G.: A. S. - ein Sudetenländer als Oberbibliothekar in Weimar in: Der Vertriebene (2007) H. 4, S. 25.

M Johanna geb. Henle (1816-1894) Schwester von: (siehe) Jacob H.

@ 1879 Clara geb. Krieger (1857-1913)

K 1 T: Dorothea (Dora) Johanna S. (1880-1967), s. Lexikon jüdischer Einwohner Hs (2011) S. 340; Ehefrau von: (siehe) Otto Regenbogen

Vw Bruder: Rudolf S. (1844-1893) o. Prof. für Klassische Philologie: seit 1873 Greifswald, seit 1874 Jena, seit 1876 Straßburg, 1885-1893 München, s. NDB 23 (2007) S. 363 f.; zu weiteren Vw, s. ebd. S. $363^{*}$.

$L b$ Seit Ostern 1869 Studium an U Göttingen, seit WS 1871/72 Leipzig; Okt. 1870-Juli 1871 Kriegsfreiwilliger im Deutsch-Französischen Krieg; 1873 philolog. Staatsexamen; 3. Juni 1874 Rigorosum, 
16. Juni 1875 (Datum der Promotionsurkunde) Dr. phil. an U Leipzig; 1874-1875 Eigenstudien in Jena.

U Leipzig: Seit Ostern 1875 Adjunkt am RussischPhilolog. Seminar; 2. Aug. 1876 Habilitationskolloquium; 25. Okt. 1876 Erteilung der venia legendi.

UH: 31. Mai 1877 Ern. zum o. Prof. als Nachf. von Otto Ribbeck; 2. Okt. 1877 Vereidigung; WS 1877/78-WS 1885/86 Mit-Direktor (zus. mit Curt Wachsmuth), SS 1886 Direktor, WS 1886/87 MitDirektor (zus. mit Erwin Rohde), SS 1898 Direktor, seit WS 1898/99 Mit-Direktor (zus. mit Otto Crusius), seit SS 1903 Mit-Direktor (zus. mit Albrecht Dieterich), SS 1908 Direktor, seit WS 1908/o9 MitDirektor (zus. mit Franz Boll) des Philolog. Seminars; 30. Sept. 1918 Ruhestand mit e. jährl. Ruhegehalt von 8100.- Mark.

1890 Prorektor der UH; 1882/83, 1893/94, 1908/o9 Dekan der Phil. Fak. der UH

Nach dem Tod seines Heidelberger Kollegen Erwin Rohde 1898 wird S. Vormund der unmündigen Kinder Rohdes, s. hierzu Supplementa Nietzscheniana. Hrsg. von Wolfgang Müller-Lauter und Karl Pestalozzi. Bd. 2: Hoffmann David M.: Zur Geschichte des Nietzsche-Archivs. Elisabeth Förster-Nietzsche, Fritz Koegel ... Chronik, Studien und Dokumente. Berlin 1991. S. $34 \mathrm{f}$.

1891 Hofrat; 1902 Geh. Hofrat; 1918 Geh. Rat II. Klasse

E 1909 Mitglied der Akademie der Wissenschaften H. 1903 Ritterkreuz des Ordens Berthold I.; 1910 Kommandeurkreuz II. Klasse, 1918 Stern zum Kommandeurkreuz des Ordens vom Zähringer Löwen.

Qu UAH PA 2239; RA 5186, 5278, 6827, 6859; Fak.Akte H-IV-102/143 fol. 177r u.ö. • Vorlesungsverzeichnisse der U Leipzig WS 1876/77, SS 1877 Phil. Fak., Altklassische Philologie - online. GLA Abt. 235, Fasz. 2487. - Franz Overbeck - Erwin Rohde. Briefwechsel. Hrsg. ... von Andreas Patzert ... Berlin 1990. S. 640 (Register).
W De accentu linguae Latinae. Leipzig 1875. • Analecta Plautina. Leipzig 1877. (Mitverf.) - Menanders Perinthia in der Andria des Terenz. Heidelberg 1912.

MHG Heidelberger Professoren aus dem 19. Jahrhundert. 2 Bde. Heidelberg 1903. - Plautus, Titus Maccius: Comoediae ... Bd. I,1. Leipzig 1884; Bd. I,5: 1881; Bde. III,2 und III,3: 1887; III,5: 1889; IV,1: 1890. - Varro, Marcus Terentius: De lingua Latina ... Leipzig 1910. - Friedrich Nietzsches Briefwechsel mit Erwin Rohde. Hrsg. von Elisabeth Förster-Nietzsche und F.S. Berlin 1902. 3. Aufl. 1923.

$L$ Wer ist's (1914) S. 1509; Biogr. Jahrbuch 2 (19171920) S. 733. • Boll, Franz: Gedächtnisfeier für ... F.S. und für die im Kriege gefallenen Mitglieder des Philologischen Seminars an der Universität Heidelberg. Ansprache am 2. Nov. 1919. Als Ms. gedruckt. Heidelberg 1919 (im UAH). • Goetz, Georg: F. S. in: Biogr. Jahrbuch für Alterthumskunde. 40. Jg. Leipzig 1920. S. 84-102. - WBIS; Arnim 2 (1952) S. 515; Kriegstagebuch K. Hampe (2007) S. 994 (Register); Deutsche Biographie, s. https:// www.deutsche-biographie.de/gnd101767595.html [07.11.2017].

$P$ Bildarchiv UAH; graph. Slg. UBH.

\section{Schönborn}

siehe Schoenborn

\section{Schoenborn, Joachim Alfons Siegfried}

1904-1917 Med. Fak.

Innere Medizin

* 31. Dez. 1874 Königsberg (Preußen, heute: Kaliningrad, Russische Föderation)

$\dagger$ 11. März 1966 Remscheid (Nordrhein-Westfalen)

ev. 
V Carl Wilhelm S. (1840-1906), u. a. seit 1871 o. Prof. für Chirurgie Königsberg (Preußen), seit 1886 Würzburg, s. Fischer $2\left({ }^{3} 1962\right)$ S. 1405 f., WBIS, Tilitzki 1 (2012) S. 807 (Register)

M Rosa geb. Küstner

Ф 31. März 1909 Gertrud geb. von Schubert (1888-1971), s. Kriegstagebuch K. Hampe (2007) S. 995 (Register); T von: (siehe) Hans (von) $\mathrm{S}$.

K 2 S, 2 T

Vw Bruder: (siehe) Walther S.

Lb Seit WS 1892/93 Studium an U Würzburg, Freiburg/Br., Würzburg, SS 1895-WS 1897/98 H; 24. Febr. 1897 Dr. med. an U Würzburg; Febr. 1898 Staatsprüfung in $\mathrm{H}$.

UH: Seit Jan. 1899 Assistent an Med. U-Klinik; 2. Juli 1904 Habilitation für Innere Medizin; seit 15. Juni 1910 nichtetatm. a. o. Prof.; WS 1916/17 letzte Ankündigung von Lehrveranstaltungen im Vorlesungs-Verzeichnis; SS 1917 beurlaubt. • In dieser Zeit:

1914-1915 Kriegsdienst.

Posen (heute: Poznań, Polen): Seit 1917 Leiter des Städtischen Krankenhauses.

Remscheid: 1919-1947 Leitender Chefarzt der Städtischen Krankenanstalten und Chefarzt der Med. Klinik dieser Anstalten.

Siehe auch Johannes Rissom: Eintrag unter Z[itat] (1) und Anhang Sporteinrichtungen an $U H$ 1910-1933 und ihre Mitglieder

Qu UAH PA 1165, 2241. GLA Abt. 235, Fasz. 2488. Auskunft: Historisches Zentrum - Archiv Remscheid (D_11_1_590).

W Gefrierpunkts- und Leitfähigkeits-Bestimmungen. Ihr praktischer Wert für die innere Medizin. Wiesbaden 1904. - Die Lumbalpunktion und ihre Bedeutung für Diagnose und Therapie. Heidelberg 1905. Klinischer Atlas der Nervenkrankheiten. Heidelberg 1908. (Mitverf.)
$L$ Stübler (1926) S. 315; Fischer $2\left({ }^{3} 1962\right)$ S. 1406; WBIS; Kriegstagebuch K. Hampe (2007) S. 995 (Register); Deutsche Biographie, s. https://www. deutsche-biographie.de/gnd11764515X.html [07.11. 2017].

\section{$P$ Bildarchiv UAH.}

\section{Schoenborn, Joachim Carl Walther}

1908-1915, 1919-1920 Jur. Fak. Öffentliches Recht, Völkerrecht

* 19. Juli 1883 Seebad Neuhäuser (heute: Metschnikowo, Ortsteil von Baltijsk, Russische Föderation)

$\dagger \quad$ 07. Mai 1956 Kiel

ev., nach 1936 gottgläubig

V Carl Wilhelm S. (1840-1906), siehe Siegfried S.

M Rosa geb. Küstner

Q unverheiratet

Vw Bruder: (siehe) Siegfried S.

Lb Seit WS 1901/o2 Studium an U Würzburg, seit WS 1902/03 Freiburg/Br., seit WS 1903/04 $\mathrm{H} ;$ 19. April 1905 I. Staatsprüfung in Karlsruhe; 12. Nov. 1906 Dr. iur. an UH.

6. Okt. 1905-April 1908 (Beurlaubung; Dez. 1909 auf eigenen Antrag Entlassung) Rechtspraktikant, u.a. am Amtsgericht in H, Staatsanwaltschaft in Mannheim, Stadtverwaltung in Freiburg/Br.

UH: 3. Aug. 1908 Habilitation; seit 1914 auch Lehrender an Handelshochschule in Mannheim; SS 1915 (Beurlaubung von UH) Lehrtätigkeit an U Tübingen; 3. Juni 1915 Ern. zum nichtetatm. a. o. Prof.; seit 18. Okt. 1915 erneut Beurlaubung von UH. • In dieser Zeit:

U Konstantinopel (heute: Istanbul): 17. Nov. 19151. Dez. 1918 o. Prof. für Öffentl. Recht; Nov. 1918 Entlassung nach Unterzeichnung des Waffenstillstandsabkommens der türkischen Regierung mit den Alliierten; danach möglicherweise Internierung; 12. Jan. 1919 Rückreise nach $H$. 
UH: SS 1919 Wiederaufnahme der Lehrtätigkeit als nichtetatm. Prof.; ca. Juni 1919 Ruf an U Greifswald abgelehnt.

U Kiel: 8. Nov. 1919 (zum SS 1920) Ern. zum persönlichen Ordinarius für Öffentl. Recht; seit 1. April 1927 o. Prof.; Ende SS 1944 Schließung der U; Ende Nov. 1944 kurzzeitige Abordnung S.s an U Erlangen durch ministerielle Anordnung; 1945 Beteiligung am Wiederaufbau der Kieler Rechts- und Staatswiss. Fak.; Nov. 1945 Wiedereröffnung der U; 30. Sept. 1951 Entpflichtung; 1951-1952 Lehrbeauftragter für Staats- und Verwaltungsrecht, Völkerrecht. • In dieser Zeit:

Freie Hansestadt Bremen: 1949-1953 Mitglied des Staatsgerichtshofs.

Qu UAH PA 789, 2242. - GLA Abt. 235, Fasz. 2489. Briefe: UBH.

$W$ Studien zur Lehre vom Verzicht im öffentlichen Recht. Tübingen 1908. - Die Besetzung von Veracruz. Stuttgart 1914. - Recht und Technik im modernen Seekriegsrecht. Kiel 1929.

MHG 1911 Die staatsrechtlichen Gesetze Badens.

L Handels-Hochschule Mannheim 1907-1932 (1932) S. 26; Professoren Kiel (1956) S. 41; WBIS. • Martens, Claus-Nis: W.S. ... ein Staatsrechtslehrer in den verfassungsrechtlichen Epochen unseres Jahrhunderts. Frankfurt/M. 1990. - Stolleis 4 (2002) S. 44, 57 f. - Hammer, Andreas: Staatenfolge und Staatennachfolge. Theorie und Praxis der Nachfolge in öffentlichen Schulden. Baden-Baden 2006. S. 88 f. u. ö. • Kieler Gelehrtenverzeichnis 1919-1965 online; Kriegstagebuch K. Hampe (2007) S. 995 (Register). - Otto, Martin: Von der Eigenkirche zum Volkseigenen Betrieb: Erwin Jacobi (1884-1965). Arbeits-, Staats- und Kirchenrecht zwischen Kaiserreich und DDR. Tübingen 2008. S. 59 und Anm. 7. - Schroeder (2010) S. 353 f. u. ö.; Deutsche Biographie, s. https://www. deutsche-biographie.de/gnd118938134.html [07.11. 2017].

P Kieler Gelehrtenverzeichnis 1919-1965 online.

\section{Schoetensack, Carl Friedrich Otto}

1904-1910 Nat.-Math. Fak.

Anthropologie, Urgeschichte

* 12. Juli 1850 Stendal

$\dagger \quad$ 23. Dez. 1912 Ospedaletti (Ligurien)

口 1938 Heidelberg

ev.

V Dr. phil. Heinrich August S. (1812-1891) Gymnasial-Prof.

M Julie geb. Würger (1804-1870) Verfasserin von: Mein Führer und Tröster. [Sammlung von Bibelzitaten.] Lahr/Baden. 2. Aufl. 1913.

๑ 9. Mai 1878 Marie Luise geb. Schneider (18561938)

K 2 S: u.a. August Otto S. (188o-1957) o. Prof. für Rechtswiss.: seit 1913 Basel, seit 1922 Tübingen, 1935-1947 (Emeritierung) Würzburg, s. WBIS; Benkert, Christopher: Die Juristische Fakultät der Universität Würzburg 1914 bis 1960. Ausbildung und Wissenschaft im Zeichen der beiden Weltkriege. Würzburg 2005. S. 201-203 u. ö. - Ehemann von: Theophanie Marie Luise geb. Bülow, T von Oskar Robert Arthur von B. (1837-1907) o. Prof. für Rechtswiss.: seit 1872 Tübingen, 1885-1892 (vorgezogener Ruhestand) Leipzig, s. NDB 2 (1955) S. 739, Professorenkatalog Leipzig online.

Lb Hamburg: 1868-1870 Drogisten-Lehre; seit 1870 kaufmännischer Gehilfe im Bruntschen Wollgeschäft.

Göttingen: April 1873-Okt. 1877 (Löschung des Firmennamens im Gesellschaftsregister) Mitteilhaber der chemischen Fabrik Saame \& Co.

Ludwigshafen: 2. Okt. 1877 Mitbegründer der Firma „Hofmann \& Schoetensack, Chemische Fabrik Ludwigshafen“, seit Nov. 1881 umbenannt in „Chemische Fabrik vormals Hofmann u. Schoetensack AG" mit Hauptsitz in Mannheim und Werk in Ludwigshafen; 1883 Verkauf der Fabrikanteile aus gesundheitlichen Gründen (Atemwegserkrankung) und Umzug nach Freiburg/Br. 
Seit 1885 Studium zunächst der Mineralogie, Geologie, Anthropologie und Philosophie, dann auch der Zoologie, Paläontologie und Anatomie an U Freiburg/Br., anschl. Straßburg.

U Freiburg/Br.: 10. Jan. 1886 Dr. phil.; Nov. $1886-$ 1888 Leiter des Museums für Urgeschichte und Völkerkunde; 1888 Umzug nach H.

H: 1888-1904 Privat-Gelehrter; ca. 1899 Abiturprüfung.

UH: 30. Juli 1904 Habilitation für Anthropologie, insbesondere Urgeschichte; seit 16. Aug. 1909 nichtetatm. a. o. Prof.; seit WS 1910/11 auf eigenen Antrag Beurlaubung aus gesundheitlichen Gründen.

1908 beschreibt S. erstmals den ein Jahr zuvor in der Sandgrube "Grafenrain" bei Mauer in der Nähe von Heidelberg gefundenen, ca. 600 ooo Jahre alten Unterkiefer e. Menschen und nennt diesen Urmenschen „Homo Heidelbergensis“.

Siehe auch Hermann Klaatsch und Theodor Mollison: hier Eintrag unter $Q u[$ ellen]

E 1909 Korr. Mitglied der Società italiana d'Antropologia Florenz; 1909 Mitglied der Société d'anthropologie Brüssel; Mitglied der Berliner Gesellschaft für Anthropologie, Ethnologie und Urgeschichte.

Qu UAH PA 2245; RA 6784; Fak.-Akte H-V-4/2 Nr. 67; GF 73. • Briefe: UBH. $\bullet$ Nachlaß: UAH (Signatur: Rep. 11). Mitteilungen von Nachfahren.

$W$ Die geschliffenen Steinwerkzeuge aus der neolithischen Schicht vom Schweizersbild. Zürich 1896. Beiträge zur Kenntnis der neolithischen Fauna Mitteleuropas. Heidelberg 1904. • Der Unterkiefer des Homo Heidelbergensis aus den Sanden von Mauer bei Heidelberg. Leipzig 1908. Nachdr. 2006. - Siehe auch Schoetensack, Wolfgang und Jürgen (1997) S. 69 f.
L O.S. in: Gummel, Hans: Forschungsgeschichte in Deutschland. Berlin 1938. S. 456. Kraatz, Reinhart: Homo erectus heidelbergensis ... in: Semper apertus 4 (1985) S. 258-273. - Schoetensack, Wolfgang und Jürgen: Das Leben von ... O.S. in: Homo heidelbergensis von Mauer. Das Auftreten des Menschen in Europa. Hrsg. von Günther A. Wagner ... Heidelberg 1997. S. 62-70. O. S. in: Wiehle, Martin: Altmark-Persönlichkeiten. Biografisches Lexikon der Altmark ... Oschersleben 1999. S. 155. - Goerttler 2 (2004) S. 98. • Homo heidelbergensis: Schlüsselfund der Menschheitsgeschichte. Hrsg. von Günther A. Wagner ... Darmstadt 2007. NDB 23 (2007) S. 436f. • Vom Menschen der Urzeit. 100 Jahre Homo heidelbergensis. Ein Bildband zum Jubiläum 2007. Themenheft 3/2009 der Zeitschrift Palaeos - Menschen und Zeiten. Hrsg. von Homo heidelbergensis von Mauer e. V. Mauer 2009. U Über O.S. in: Erckenbrecht, Corinna: Auf der Suche nach den Ursprüngen. Die Australienreise des Anthropologen und Sammlers Hermann Klaatsch 1904-1907. Köln 2010. S. 49 f. u. ö. Andruchowicz, Angelika: Blumenstraße 1 [Haus von O.S. in H] in: Heidelberg. Jahrbuch zur Geschichte der Stadt 2014. Heidelberg 2013. Jg. 18. S. 165-167. - Deutsche Biographie, s. https://www.deutsche-biographie.de/gnd11 6889977.html [04. Nov. 2017].

$P$ Bildarchiv UAH.

\section{Schott, Hermann Simon}

1871-1877 Jur. Fak.

Handels-, Wechsel-, See- und Versicherungsrecht

* o6. April 1842 Knittelsheim (bei Bellheim, Pfalz)

$\dagger \quad$ 25. Nov. 1895 Breslau (heute: Wrocław, Polen) kath.

V Peter S. $\left({ }^{*} 1815\right)$ Bauer

M Apollonia geb. Hörner

$\infty$ unbekannt.

Lb Seit WS 1862/63 Studium an U München, seit 27. Okt. 1863 H; 19. Juni 1867 Dr. iur. an U München. 
UH: 23. Nov. 1871 Habilitation; seit 25. Febr. 1875 a. o. Prof.

U Kiel: Seit SS 1877 o. Prof.

U Dorpat (heute: Tartu, Estland; bis 1889 einzige dt.sprachige U im Russischen Kaiserreich): Seit WS 1885/86 o. Prof.

U Breslau: 9. Dez. 1886 Ern. zum o. Prof. zum SS 1887.

1885 Russischer Staatsrat

Qu UAH PA 2250; Fak.-Akte H-II-111/72.

$W$ Der obligatorische Vertrag unter Abwesenden. Heidelberg 1873. • Das ius prohibendi und die formula prohibitoria. Leipzig 1889.

L WBIS; Professoren Kiel (1956) S. 36; Schroeder (2010) S. 331; Deutsche Biographie, s. https://www. deutsche-biographie.de/gnd116923512.html [04.11. 2017].

\section{Schott, Sigmund Albert Julius}

1907-1921 Phil. Fak.

Politische Ökonomie, Statistik, Nationalökonomie

* 10. Okt. 1868 Leipzig

$\dagger \quad$ 19. Nov. 1953 Heidelberg

口 Hauptfriedhof Mannheim (Ehrengrab)

ev.

V Bernhard Ernst Eugen S. $\left({ }^{*} 1841\right)$ Prokurist, 1884-1887 stellvertr. Direktor der Badischen Anilin- und Sodafabrik in Stuttgart

M Pauline Hermine Johanna geb. Reuß

๑ 9. Mai 1894 Hedwig Helene Sophie geb. Thorade (1874-1939)

K 2 S, s. Reichshandbuch der dt. Gesellschaft ... Bd. 2. Berlin 1930. S. 339.

Vw Siehe Wer ist's (1935) S. 1437.

Lb Seit WS 1887/88 Studium der Nationalökonomie an U München, anschl. Leipzig.
Leipzig: 11. Aug. 1890 Dr. phil. an U; 189o-1892 Volontärassistent am Statistischen Amt.

Oldenburg: 1892-1895 Wiss. Hilfsarbeiter, 18961897 Reg.-Assessor am Großherzogl. Statistischen Bureau.

Mannheim: 1897-1934 (Pensionierung) Direktor des Statistischen Amts; auch für kurze Zeit Leiter des Arbeitsamts und der Abendakademie. • In dieser Zeit:

UH: 23. Nov. 1907 (Ern.)-11. Nov. 1921 a. o. Prof.; 30. Nov. 1907 Habilitation unter Erlaß aller Formalitäten außer öffentl. Antrittsvorlesung; Rufe an drei U abgelehnt.

Mannheim: Seit SS 1908 Studiendirektor im Nebenamt, WS 1928/29-SS 1933 persönlicher Ordinarius an Handelshochschule.

Geh. Rat

E 1905 Mitglied des Int. Statistischen Instituts London. 1933 Dr. rer. oec. h.c. Handelshochschule Mannheim. 1907 Ritterkreuz I. Klasse des Ordens vom Zähringer Löwen. • 1949 Ehrenbürger der Stadt Mannheim.

Qu UAH PA 635, 5763. - Matrikel München online (WS 1887/88) S. 81. - GLA Abt. 235, Fasz. 2491. - Nachlaß: Stadtarchiv Mannheim. Auskunft: Stadtarchiv Mannheim; BASF-Archiv Ludwigshafen; Wirtschaftsarchiv Baden-Württ., Stuttgart.

$W$ Kapitalanlage. Volkstümliche Anleitung zu zweckmäßiger und vorteilhafter Vermögensverwaltung ... Freiburg/Br. 1904. 3. Aufl. 1905. • Alte Mannheimer Familien. Mannheim 1910. Statistik. Leipzig 1913. 3. Aufl. 1923. • Die Opernaufführungen der dt. Bühnen und des ... Nationaltheaters in Mannheim ... 1901-1911 ... Mannheim 1913. - Der Mehlverbrauch ausgewählter Haushaltungen in Mannheim ... Anfang 1915. Mannheim 1915. Statistische Bemerkungen zum Ergebnis der Nationalwahlen in Mannheim. Mannheim 1919. • Ausgewählte Schriften. Hrsg. von der Stadtverwaltung Mannheim ... Mannheim 1957. 
L Kürschner (1931) Sp. 2658, (1935) Sp. 1246; Handels-Hochschule Mannheim 1907-1932 (1932) S. 24; Wer ist's (1935) S. 1437. • Flaskämper, P.: S. S. $\dagger$ in: Revue de l'Institut Int. de Statistique (1953) Vol. 21, No. 3, S. 211. • Universität Mannheim (1982) S. 298; Arnim 5 (1985) S. 73; Badische Biographien N.F. III (1990) S. 248; Friedhöfe in Mannheim (1992) S. 87; Enzenauer (2005) S. 15f.; WBIS; Deutsche Biographie, s. https://www.deutsche-biographie.de/gnd117007161.html [04.11. 2017].

$P$ Bildarchiv UAH.

\section{Schottländer, Julius Gustav Adam}

1893-1908 Med. Fak.

Gynäkologie

* 31. März 1860 St. Petersburg

$\dagger$ 29. Mai 1917 Kiel

$\square$ Wien (?)

ev.-luth.

V Julius Adolf August S. (1815-1874) Fabrikdirektor (mosaisch, 1831 lutherisch getauft in St. Nikolai, Berlin), s. Amburger (1986) S. 256259

M Sophie Therese geb. Schott (1815-1887), s. ebd. S. $259 \mathrm{f}$.

( 27. Juli 1889 Elisabeth (Elsa) Molly geb. von Antropoff (1866-1945); Briefe in UBH

K $\quad 2 \mathrm{~S}$

Lb SS 1880-SS 1884 Studium an UH, WS $1884 / 85$ München, SS 1885-WS 1885/86 H. • In dieser Zeit:

H: SS 1882 Physikum; 1. Okt. 1882-1. April 1883 Militärdienstpflicht als Einjährig-Freiwilliger (1. Hälfte); WS 1885/86 Staatsexamen; Febr. 1886 Approbation.

UH: Nov. 1886-Dez. 1887 Assistenzarzt an UFrauenklinik; 27. Jan. 1888 Dr. med.

Mai-Dez. 1888 Forts. der Militärdienstpflicht als Einjährig-Freiwilliger Arzt bzw. Unterarzt in Kiel bei der Marine; 1901 Beförderung zum Stabsarzt der Seewehr der Reserve.
Assistenzarzt: Seit 1888 Anatom. Inst. der U Kiel, seit 1889 Privat-Anstalt für Frauenkrankheiten in Berlin; 1890-1892 Eigenstudien, u. a. an der Hans Kehrschen Privatklinik in Halberstadt.

UH: 11. Jan. 1893 Habilitation; seit Okt. 1893 Mitglied der Prüfungs-Kommission für das med. Staatsexamen; Beurlaubungen: WS 1893/94 aufgrund Ischias-Erkrankung, SS 1895 „behufs Vollendung einer größeren wissenschaftlichen Arbeit, ferner zum Zwecke einer wissenschaftlichen Studienreise, endlich zur Kräftigung meiner Gesundheit" (aus: Brief vom 19. April 1895 in: UAH PA 2251); seit 19. Mai 1897 nichtetatm. a. o. Prof.; WS 1897/98-WS 1899/1900 Beurlaubung („... Ich habe mich von meiner Erkrankung [an Neurasthenie (= Nervenschwäche)] leider noch immer nicht völlig erholt und Herr Geh. Rath [s. Wilhelm] Erb, der mir erlaubt hat, mich auf ihn zu berufen, hat mir von der Wiederaufnahme meiner Berufsgeschäfte durchaus abgerathen“, aus: Brief vom 30. April 1898 in: PA 2251); seit Okt. 1903 Leiter des Labors der U-Frauenklinik.

U Wien: Febr. 1908-Mai $1917(\dagger)$ Begründer und Leiter des Labors an II. U-Frauenklinik, s. hierzu $Z$; seit Febr. 1908 Privat-Dozent, 1911-1917 nichtetatm. a.o. Prof. an Med. Fak. • In dieser Zeit:

Kiel: Seit Aug. 1914 Kriegsdienst als Leiter des Statistischen Rapportsbureau des Sanitätsamts der Ostseestation der Königl. Dt. Marine, 1915-1917 $(\dagger)$ Oberstabsarzt und Leiter e. Lazaretts.

Z S. hat 1908 "die Absicht, Herrn Geh. Hofrat Dr. [siehe: Alfons Edler] von Rosthorn nach Wien zu folgen und zwar ... als Laboratoriumsvorstand ... an der neuerbauten Frauenklinik daselbst" (aus: Bericht des Engeren Senats der UH an das Ministerium der Justiz, des Kultus und Unterrichts vom 28. Febr. 1908 in: PA 2251).

E 1902 Gedenkmünze zum Regierungsjubiläum Großherzogs Friedrich I. von Baden; 1903 Seewehr-Dienstkreuz; Eisernes Kreuz II. Klasse.

Qu UAH PA 2251; Fak.-Akten H-III-111/105, HIII-111/118. - Auskunft: Archiv der Universität Wien; Stadtarchiv Kiel. 
$W$ Über den Graaf'schen Follikel, seine Entstehung beim Menschen und seine Schicksale bei Menschen und Säugethieren. Bonn 1893. - Über Eierstocktuberkulose. Jena 1897. - Zur Kenntnis des Uteruskarzinoms. Monographische Studie über Morphologie, Entwicklung, Wachstum nebst Beiträgen zur Klinik der Erkrankung. Berlin 1912. (Mitverf.) - Zur Theorie der Abderhaldenschen Schwangerschaftsreaktion, sowie Anmerkungen über die innere Sekretion des weiblichen Genitales in: Zentralblatt für Gynäkologie (1914) S. 425. • Zur histologischen Wertung und Diagnose der Radiumveränderungen beim Uteruskarzinom in: Strahlentherapie V (1915) S. 604. Bibliographie in: Wertheim (1917) S. $269 \mathrm{f}$.

$L$ Biogr. Jahrbuch 2 (1917-1920) S. 671f. • Wertheim, E.: J.S. † in: Monatsschrift für Geburtshülfe und Gynäkologie 46 (1917) S. 268-271. • Stübler (1926) S. 321; Jüdische National-Biographie 5 (1930) S. 462; Arnim 2 (1952) S. 519; Fischer 2 ( $\left.{ }^{3} 1962\right)$ S. 1408 f. - Amburger, Erik: Deutsche in Staat, Wirtschaft und Gesellschaft Russlands. Die Familie Amburger in St. Petersburg 1770-1920. Wiesbaden 1986. S. 259 f. - WBIS; ÖBL online 11 (1997) S. 154f.; Dhom (2001) S. 625f., 628, 658. • Pickel, H.: J.S.s Werk über das Uteruskarzinom wird 100 in: Ärztewoche 47 (2011) S. 28 f.; Ders.: J. S. „Zur Kenntnis des Uteruskarzinoms" in: Der Gynäkologe 4 (2011). - Deutsche Biographie, s. https:// www.deutsche-biographie.de/gnd117015148.html [07.11. 2017].

$P$ Bildarchiv UAH; graph. Slg. UBH.

\section{Schrade, Hubert Joseph}

1926-1940 Phil. Fak.

Neuere Kunstgeschichte

* 30. März 1900 Allenstein (heute: Olsztyn, Polen)

$\dagger$ 25. Nov. 1967 Freiburg/Br.

ㅁ Heidelberg

kath.
V Franz S. († 1952) Lehrer

M Margarethe geb. Hoppe

๑ ca. 1927 Anna geb. Benninghof (ca. 1884-1939)

( 28. Aug. 1940 Inge geb. Wolff $\left({ }^{\star} 1919 \dagger\right.$ nach 1989) Reichsstudentinnenschaftsführerin, s. UAH Studentenakte von 1937

$\mathrm{K} \quad 1 \mathrm{~S}, 1 \mathrm{~T}$

Vw Bruder: Leo S. (1903-1964), u. a. seit 1929 Privat-Dozent für Musikwissenschaft U Königsberg (Preußen), 1938 Emigration, seit 1943 Gastprof., seit 1948 o. Prof. für Musikgeschichte Yale U in New Haven (Connecticut), 19581964 o. Prof. U Basel, s. Gattungen der Musik in Einzeldarstellungen. Gedenkschrift L.S. Hrsg. von Wulf Arlt ... Bern 1973; WBIS; Marx, Hans Joachim: „... ein jüngerer Gelehrter von Rang". L. S.s frühe Jahre bis zur Emigration in die USA (1938) in: Die Musikforschung 67. Jg. (2014) S. 251-269.

Lb WS 1918/19 Zunächst Studium der Medizin an U Königsberg, seit Febr. 1919 Studium der Literatur- und Kunstgeschichte, Philosophie an U Berlin, seit SS $1920 \mathrm{H}$.

UH: 9. Nov. 1922 Rigorosum, 14. Mai 1923 (Datum der Promotionsurkunde) Dr. phil.; 19. Mai 1926 Habilitation für Kunstgeschichte; seit 4. Nov. 1931 nichtplanm. a. o. Prof.; seit 20. März 1936 rückwirkend zum 1. Febr. 1935 planm. a. o. Prof. (= persönlicher Ordinarius); seit 17. Jan. 1938 mit Wirkung vom 1. Jan. 1938 o. Prof.

U Hamburg: Seit 1. Sept. 1940 o. Prof. und Direktor des Kunstgeschichtl. Seminars.

Reichs-U Straßburg: 1. Aug. 1941 (Ern.)-8. Mai 1945 (Entlassung) o. Prof.; 23. Nov. 1941 Eröffnung der Reichs-U; Nov. 1944 Besetzung der Stadt durch amerik. und franz. Militär; 18. Dez. 1944 Erlaß des Reichsministers für Wissenschaft, Erziehung und Volksbildung zur Verlegung der Reichs-U Straßburg an U Tübingen.

U Tübingen: SS 1945 S. wird im Vorlesungsverzeichnis als in Tübingen anwesendes Mitglied des Straßburger Lehrkörpers bezeichnet.

Freiburg/Br.: Seit Mai 1945 Wohnsitz; Mai 1945Okt. 1954 ohne Amt. 
U Tübingen: 21. Okt. 1954-31. März 1965 (Emeritierung) o. Prof. und Leiter des Kunsthistor. Inst.

April 1937-Okt. 1939 Dekan der Phil. Fak. der UH, s. auch Weisert/Drüll/Kritzer (2007) S. 27, 106

Siehe auch Johann Sölch: Eintrag unter Z[itat] (2)

E 1936 Mitglied der Akademie der Wissenschaften $\mathrm{H}$.

Qu UAH PA 636, 5766; Fak.-Akten H-IV-102/149, H-IV-757/17 fol. 175. • GLA Abt. 235, Fasz. 2492. • Briefe: UBH.

$W$ Tilman Riemenschneider. 2 Bde. Heidelberg 1927. Ikonographie der christlichen Kunst. Berlin 1932. - Das deutsche Nationaldenkmal ... München 1934. - Schicksal und Notwendigkeit der Kunst. Leipzig 1936. Bauten des Dritten Reiches. Leipzig 1937. - Heidelberg und das Neckartal. Berlin 1941. - Der verborgene Gott. Gottesbild und Gottesvorstellung in Israel und im Alten Orient. Stuttgart 1949. - Götter und Menschen Homers. Stuttgart 1952. Malerei des Mittelalters. 2 Bde. Köln 1958-1963.

HG 1939-1943 Das Werk des Künstlers.

$L$ Wer ist wer (1962) S. 1408; Kürschner (1966) S. 2224; Braune Universität (1965) S. 84-90. • Lenz, Hermann: Andere Tage. Köln 1968. S. 154 (Grauerbach = August Grisebach, der Bärtige $=$ H.S.). • Nachruf in: Attempto. Tübinger U-Zeitschrift. H. 27/28 (1968) S. 131f. Arnim 5 (1985) S. 74; Auch eine Geschichte der UH (1985) S. 337-345; Jansen (1992) S. 413 (Register); Ders. (1992a) S. 169 (Register). Erwin Panofsky: Beiträge des Symposions Hamburg 1992. Hrsg. von Bruno Reudenbach ... Berlin 1994. S. 1f. und Anm. 1-3. Wennemuth (1994) S. 638 (Register); Universitäten im Nationalsozialismus (2004) S. 65-67. • Hille, Nicole: Das Kunsthistorische Institut der Universität Tübingen und die Berufung von H.S. zum Ordinarius im Jahr 1954 in: Schwerpunkt. Kunstgeschichte an den Universitäten in der Nachkriegszeit. Hrsg. von Martin Papenbrock. Göttingen 2006. S. 171194. - UH im Nationalsozialismus (2006) S. 1270
(Register); Klee, Kulturlexikon (2007) S. 545; Ders., Personenlexikon (2007) S. 558; Metzler Kunsthistoriker Lexikon (2007) S. 393-395. • Kunstgeschichte im „Dritten Reich“. Theorien, Methoden, Praktiken. Hrsg. von Ruth Heftrig ... Berlin 2008. Schubert (2008) S. 71-83 u. ö.; Universität Tübingen im Nationalsozialismus (2010) S. 291301. Bohde, Daniela: Der politische Hintergrund der „politischen Ikonologie“. Von H.S. zu Reinhart Koselleck in: Reinhart Koselleck und die politische Ikonologie. Hrsg. von Hubert Locher und Adriana Markantonatos. Berlin 2013. S. 210-227. • Heftrig, Ruth: Fanatiker der Sachlichkeit: Richard Hamann und die Rezeption der Moderne in der universitären Kunstgeschichte 1930-1960. Berlin 2014. - Riecke (2016) S. 54, 73 f.; Deutsche Biographie, s. https://www.deutsche-biographie.de/gnd 117015709.html [07.11.2017]; Doll/Kirsch/Eckart (2017) S. 60.

\section{$P$ Bildarchiv UAH.}

Schreiber, Aloys (später zusätzlicher Vorname: Wilhelm; Pseudonym: Sirius, Julius)

1805-1813 Phil. Fak.

Ästhetik, Geschichte der deutschen Poesie und

Kunst, auch Natur- und Völkerrecht

* 12. Okt. 1761 Kappelwindeck (heute: Stadtteil von Bühl, Baden)

$\dagger$ 21. Okt. 1841 Oos (heute: Stadtteil von BadenBaden)

kath.

V Ignaz S. († 1787) Kaufmann und Zunftmeister der Bühler Krämerzunft

M Maria Katharina geb. Seuther/Seither (17371819)

๑ 1793 Maria Anna geb. Jo(u)bert (1770-1852)

K 1 T, 7 S (davon 2 S früh $\dagger$ ): u. a. Guido S. (17991871) 1829-1851 Prof. für Geometrie am Polytechnikum Karlsruhe, s. WBIS, Badische Biographien 2 (1875) S. 280 f. 
Lb Seit 11. Okt. 1781 Studium der Theologie an U Freiburg/Br. (ohne Studienabschluss); 1784 Lehrer für Ästhetik sowie Bibliotheksverwalter am Lyzeum, dem ehem. Jesuitengymnasium in Baden(Baden); 1788 Entlassung wegen e. Affäre mit seiner späteren Frau.

Mainz: 1788-1793 Theaterschriftsteller und -kritiker sowie Hofmeister und Hauslehrer bei Kurmainzer Staatsminister Graf Clemens August von Westphalen-Fürstenberg (1753-1818); u.a. Sommer 1791 Reisebegleiter, s. hierzu S.s „Bemerkungen auf einer Reise von Strasburg bis an die Ostsee. Im Sommer 1791. Erste Hälfte: bis Mainz. 2. Hälfte: von Frankfurt bis an die Ostsee. Leipzig 1793-1794“ (anonym erschienen).

Baden(-Baden): Seit 1793 schriftstellerisch tätig.

Rastatt: 1797-1799 Berichterstatter während des Reichs-Friedens-Kongresses (Hrsg. u.a. von: Handbuch des Congresses zu Rastatt. 3 Bde. Rastatt 1798-1799; Rastatter Congreß-Blatt und wöchentliche Nachrichten. Rastatt 1797-1798 (s. hierzu auch $Z)$ ).

Baden(-Baden): Seit Ende 1799 Hilfslehrer, 23. April 1801-Ende Okt. 1805 Gymnasial-Prof. für Klassische Literatur am Lyzeum; Ostern 1804 vorgesehener Dienstantritt an UH mit e. Gehalt von 70o.- Gulden und 10 Malter Früchte; Besoldung reicht S. nicht aus, so dass das Ministerium ihm vorschlägt, ein weiteres Jahr auf der Stelle als Gymnasial-Prof. zu bleiben, danach Aufstockung seines Gehalts auf 1000.- Gulden.

UH: Seit WS 1805/o6 o. Prof. als Nachf. von Lorenz Doller; 1. Juni 1807 Dr. phil., siehe UAH H-IV-102/ 2 fol. 46r; WS 1812/13 letzte Erwähnung im Vorlesungsverzeichnis.

Karlsruhe: Seit 1813 Hofhistoriograph und Archivar am badischen Hof; 16. Sept. 1825 Pensionierung.

Baden(-Baden): Seit Frühjahr 1826 Privatier.

1809 Dekan der Phil. Fak. der UH
$Z$ Eine Inhalts-Übersicht des „Rastatter CongreßBlatt und wöchentliche Nachrichten “ veröffentlicht durch Hofbuchdrucker Sprinzing, Rastatt ist abgedruckt in: Das Reich der Todten, enthaltend politische Gespräche der Todten; politische Reden nebst geheimen Briefwechsel zwischen den Lebendigen und den Todten. 12. Bd. 12. Jg. Nr. 97 (5. Dez. 1797) S. 789 f. und Beilage zu Nr. 100 (16. Dez. 1797) S. $822 \mathrm{f}$.

Ein Teil der im Oktober 1809 von S. an die Universität Heidelberg für 1200.- Gulden verkauften Kupferstichsammlung befindet sich in der Universitätsbibliothek (Signatur Heid. HS 2678 - Sammlung Schreiber), s. hierzu Handbuch der historischen Buchbestände in Deutschland. Hrsg. von Bernhard Fabian. Hildesheim 2003.

A.S. schrieb das Libretto zu Giacomo Meyerbeers (1791-1864) erster komponierter Oper „Jephtas Gelübde“. Die Oper wurde am 23. Dez. 1812 im Hoftheater in München uraufgeführt.

1813 Hofrat

E Mitglied der Gelehrten Gesellschaft Avignon.

$\mathrm{Q} u$ UAH PA 2253; RA 5437, 6027, 6029, 6046, 6065. Matrikel Freiburg/Br. 1,2 (1955) S. 886 Nr. 6 und Anm. (hier Bühl als Geburtsort genannt). • GLA Abt. 205, Fasz. 494-496. • Briefe: UBH. • Auskunft: Kath. Pfarramt Stiftskirche in BadenBaden (Totenbuch).

W Die Harfe. Operette. Offenbach 1793, s. hierzu Rezension in: Oberdeutsche allg. Litteraturzeitung. Salzburg 8. Juli 1793. 6. Jg. Stück LXXX. Sp. 61 f. • Malerische Ansichten des Rheins von Mainz bis Düsseldorf. Frankfurt/M. 1806. 2. Aufl. Heidelberg 1818. (Franz. Übers.: Voyage pittoresque sur le Rhin depuis Mayence jusqu'à Düsseldorf. Frankfurt/M. 1807.) • Comoedia Divina. Mit drei Vorreden von Peter Hammer, Jean Paul und dem Herausgeber [A. S.]. Mannheim (?) 1808. Neudr. 1907. Nachdr. der Ausg. 1808 mit e. Nachwort von Armin Schlechter. Heidelberg 2010. - Lehrbuch der Ästhetik. Heidelberg 1809. - Badische Geschichte. Karlsruhe 1817. - Poetische Werke. 3 Bde. Tübingen 1817. Handbuch für Reisende am Rhein. 
Heidelberg 1818. 5. Aufl. 1841. Deutschland und die Deutschen. Von den ältesten Zeiten bis zum Tode Karls des Großen. Karlsruhe 1823. 2. Ausg. 1835. - Franz Schubert [Vertonung von Texten von]: Friedrich Schlegel, ..., J.W. von Goethe, F. von Schiller, A.S. ... FonoTeam. Hamburg 2005. 2 CDs. Bibliographie in: „weder Kosmopolit noch Spießbürger" (2006) S. $68 \mathrm{f}$.

HG 1788 Tagebuch der Mainzer Schaubühne, Forts. u. d. T.: Dramaturgische Blätter. $1802-1803$ Allg. Kunst-Zeitung. 1806-1808 Badische Wochenschrift zur Belehrung und Unterhaltung für alle Stände. 1809-1812 Heidelberger Taschenbuch, seit 1816 fortgesetzt u.d.T.: Cornelia. Taschenbuch für deutsche Frauen. 1812 Vaterländische Blätter. 1827-1828 Damen-Bibliothek. • Siehe hierzu auch „weder Kosmopolit noch Spießbürger" (2006) S. 34-43 u. ö.

L Hub, Ignaz: Deutschland's Balladen- und Romanzen-Dichter ... Karlsruhe 1846. S. 115-118. • Wechmar (1846) S. 253; Badische Biographien 2 (1875) S. 279 f.; Keller (1913) S. 208-210; Schneider (1913) S. 86 f. Biehler, Otto: A. S. in: ZGORh 94. Jg. (1942) S. 598-675 (mit Werkverz.). • Heggen, Alfred: Ein bislang unbekannter Reisebericht über Paderborn aus dem Jahre 1794 in: Westfälische Zeitschrift - Zs. für vaterländische Geschichte und Altertumskunde 133 (1983) S. 77-83, online http://www.lwl.org/westfaelische-geschichte/ txt/wz-6024.pdf (abgerufen am 8. Nov. 2017). WBIS; Rastatt und die Revolution von 1848/49 (1999) S. 556 (Register); Kirschke (2001) S. 449 (Register). „weder Kosmopolit noch Spießbürger" - Der badische Dichter und Heidelberger Professor ... A.S. Hrsg. von Claudia Rink. Ubstadt-Weiher 2006 (S. 9: Bühl-Oberbrück [bis 1824 bei der Pfarrei Kappelwindeck] als Geburtsort angegeben). 200 Jahre Heidelberger Romantik (2008) S. 13-15, 389-413; Riecke (2016) S. 8-10. • Heidelberger Geschichtsverein e.V.: Biographie S.s online: http://www.s197410804.online.de/Menschen/SchreiberAloys/schreiberbio.htm (abgerufen am 9. Nov. 2017).

$P$ Bildarchiv UAH; Biehler (1942); Heidelberger Geschichtsverein e. V. online.

\section{Schreiber, Ludwig}

1906-1933 Med. Fak. Augenheilkunde

* 24. Febr. 1874 Schrimm (heute: Śrem, Polen)

$\dagger \quad$ 04. Okt. 1940 Heidelberg mosaisch, (vor) $1933 \mathrm{ev}$.

V Jacob S. (†1894) Buchhändler

M Caroline geb. Schreiber

œ 14. Sept. 1909 Charlotte geb. Kunst (1886-1945 (Ermordung) KZ Auschwitz, heute: Oświęcim, Polen), s. Lexikon jüdischer Einwohner Hs (2011) S. 376

K 2 S, s. ebd.

Lb U Königsberg (Preußen): Okt. 1893-Febr. 1898 Studium; Juli 1895 Physikum; Juni 1898 (Rigorosum) Dr. med.

1. Okt. 1898-13. Nov. 1899 Militärdienstpflicht als Einjährig-Freiwilliger, u. a. im I. Schweren ReiterRegiment zu München.

U Königsberg (Preußen): 3. Nov. 1898 Ärztliches Staatsexamen; Assistent: seit Nov. 1899 Anatom. Inst., seit April 1900 Patholog.-Anatom. Inst.

Berlin: Volontärarzt: Seit 1. April 1902 I. Innere Abt. des Stadtkrankenhauses am Urban, seit 1. Aug. 1902 U-Augenklinik.

UH: Seit 1. Okt. 1902 II. Assistent an U-Augenklinik, seit 1. Jan. 1905 I. Assistent an Ambulanz und der U-Augenklinik; 1. Juni 1906 Habilitation; seit 21. Nov. 1907 Oberarzt an Augenklinik mit apl. Beamteneigenschaft; seit 8. Juni 1912 nichtetatm., seit 1920 nichtplanm. a. o. Prof.; 1. Aug. 1914-11. Nov. 1918 Kriegsdienst als Oberarzt im Lazarett in UAugenklinik („meine wiederholten Bemühungen, den Krieg an der Front mitzumachen, konnten wegen Arbeitsüberlastung der Klinik nicht berücksichtigt werden“, aus: UAH PA 5772); seit 20. April 1933 „bis auf Weiteres als a.o. Professor der Universität beurlaubt" (aus: UAH PA 1169); 2. Aug. 1933 Entziehung der Lehrbefugnis aus rassischen Gründen. • In dieser Zeit: 
H: Seit 1. Okt. 1909 niedergelassener Augenarzt; 1938 letzte Erwähnung (siehe Stadt-Adreßbuch der Kreishauptstadt Heidelberg ... Heidelberg 1938. S. 258) als Arzt in Privatpraxis, Sophienstraße $7 b$; 1939 Umzug in die Mozartstraße 13, s. Adreßbuch für die Städte Heidelberg, Wiesloch und Umgebung. Heidelberg 1940. S. 263; der Eintrag lautet jetzt: Schreiber, Ludwig Israel Dr. Prof. a. D.

E 1905 Bayrische Jubiläumsmedaille; ca. 1916 Kriegsverdienstkreuz.

Qu UAH PA 1169, 5772. • GLA Abt. 235, Fasz. 2495.

W Mitosenbildung der Ganglienzellen in: Graefes Archiv für Ophthalmologie (1910); Über Heilungen von Netzhautablösung und die rheumatische Netzhautablösung in: ebd. (1920). • Die Krankheiten der Augenlider. 3. Aufl. unter Zugrundelegung der J. von Michelschen Darstellung. Berlin 1924.

L Stübler (1926) S. 323; Kürschner (1931) Sp. 2666; Chronik Ärzte H (1985) S. 142; Mussgnug (1988) S. 35, 54, 136; Jansen (1992a) S. 169 (Register); UH im Nationalsozialismus (2006) S. 1271 (Register); Lexikon jüdischer Einwohner Hs (2011) S. 376 f.; Deutsche Biographie, s. https://www.deutsche-bio graphie.de/gnd136711553.html [09.11.2017].

$P$ Bildarchiv UAH; Chronik Ärzte H.

\section{Schröder}

siehe auch Schroeder

\section{Schroeder, Richard Carl Heinrich}

1888-1917 Jur. Fak.

Deutsches Recht, Handels-, See- und Wechsel-

recht, Rechtsgeschichte, Privatrecht

* 19. Juni 1838 Treptow (Treptow an der Tollense; heute: Altentreptow, Mecklenburg-Vorpommern)

$\dagger \quad$ 03. Jan. 1917 Heidelberg

ev.
V Ludwig S. (1802-1869 (Suizid)) Justizrat, s. Webler (2005) S. 22 f., 69 u. ö.

M Eleonora Ida geb. Kölling (1804-1864), s. ebd. S. 106 f. u. ö.

(18. Mai 1866 Anna geb. Hugo $(\dagger 1884)$

( 4. April 1895 Fri(e)da Sofie Klara Wilhelmine geb. Forster verw. Hoffmann (1852-1930), s. Hoffmann (2011) S. 138-140

K 3 S, 3 T: u. a. Gertraud S. (1870-1957), s. Hoffmann, S. 125f.; Ehefrau von: (siehe) Hermann Wunderlich. 1 Stief-S, 1 Stief-T: Mathilde Clementine geb. Saunier (1867-1945), s. Hoffmann, S. 125 f., 129; Ehefrau von: (siehe) Wolfgang Mittermaier; s. auch UAH Rep. 40-423, Webler, S. 68 f., 98 u. ö., NDB 23 (2007) S. 572

Vw siehe NDB.

Lb Seit Ostern 1857 Studium der Rechtswiss. und Sprachwiss. an U Berlin, seit 28. April 1860 Göttingen, WS 1860/61 Berlin; 1. Febr. 1861 Dr. iur. an U Berlin.

Stettin: Seit 1. April 1861 Auskultator (s. Levin Goldschmidt, Eintrag unter Lb (1851)) am Stadtgericht, 15. Sept. 1862-31. Juli 1863 Referendar am Appellations- und Kreisgericht. • In dieser Zeit:

Berlin: April 1861-März 1862 Militärdienstpflicht als Einjährig-Freiwilliger bei Garde-Füsilier-Regiment.

U Bonn: 28. Okt. 1863 Habilitation; seit 14. Mai 1866 a.o. Prof.; 1866-1870 außerdem Lehrer an Landwirtschaftl. Akademie in (Bonn-)Poppelsdorf; 1. Jan. 1868 Ern. zum a. o. Prof. mit Besoldung; seit 12. März 1870 o. Prof.

U Würzburg: Seit SS 1873 o. Prof.

U Straßburg: 8. Febr. 1882 Ern. zum o. Prof.

U Göttingen: 17. Dez. 1884 Ern. zum o. Prof.; 1887 Ruf an U Breslau abgelehnt.

UH: 18. Juli 1887 Ern. zum o. Prof. als Nachf. von Otto Gierke; 4. April 1888 Vereidigung; 1894 Ruf an U Bonn abgelehnt. • In dieser Zeit: 
H: Seit 1897 Leiter, 1908-1917 zus. mit (siehe) Eberhard Frhr. von Künßberg Leiter der Herausgabe des Dt. Rechtswörterbuchs im Auftrag der Akademie der Wissenschaften Berlin, Dienstort H.

1891 Prorektor der UH; 1892/93, 1900/01, 1906/o7, 1910/11 Dekan der Jur. Fak. der UH

1887 Geh. Hofrat; 1899 Geh. Rat II. Klasse

1897 Mitglied der Gründungskommission für die Herausgabe des Dt. Rechtswörterbuchs

$E$ Mitglied der Akademie der Wissenschaften: 1892 München, 1895 Amsterdam, 1900 Berlin, 1909 H. 1893 Dr. phil. h.c. Göttingen; 1908 Dr. rer. pol. h. c. Münster. 1879 Ritterkreuz I. Klasse des Bayerischen Verdienstordens vom Hl. Michael; 1903 Kommandeurkreuz II. Klasse mit Eichenlaub und Stern des Ordens vom Zähringer Löwen.

Qu UAH PA 790, 2256; GF 43; RA 5225, 5481, 6192, 6761f., 6850. - GLA Abt. 235, Fasz. 2496. • Briefe, Nachlaß: UBH. $\bullet$ Mitteilungen: Frau Katharina Jahn-Busch, Vendersheim.

W Geschichte des ehelichen Güterrechts ... 4 T. in 2 Bden. Stettin 1863-1874. Neudr. Aalen 1967. • Niederländische Kolonien in Norddeutschland zur Zeit des Mittelalters. Berlin 188o. • Die Franken und ihr Recht. Weimar 1881. - Lehrbuch der deutschen Rechtsgeschichte. Leipzig 1889. 7. Aufl. 1932. - Deutsche Rechtsgeschichte. 2 Bde. Berlin 1912-1913. 2. Aufl. Bd. 1: 1929.

HG Das allg. deutsche Handelsgesetzbuch und die allg. deutsche Wechselordnung ... aus: Corpus iuris civilis für das Deutsche Reich und Österreich. 2 T. Bonn 1876-1877. 2. Ausg. 188o. 8. Aufl. Bonn 1896.

MHG Deutsches Rechtswörterbuch. Bd. 1. Weimar 1914. Unveränderter Nachdr. 1998.

$L$ Catalogus prof. Gottingensium (1962) S. 52; Verzeichnis Bonn (1968) S. 280; WBIS. - Webler, Meike: Leben und Werk des ... R.C.H.S. Ber- lin 2005. NDB 23 (2007) S. 572-574; Schroeder (2010) S. 272-278 u. ö.; Riecke (2016) S. 45.

$P$ Bildarchiv UAH; graph. Slg. UBH.

\section{Schröder, Woldemar Paul Victor von}

189o-1898 Med. Fak.

Pharmakologie

* o6. Sept. 1850 Dorpat (25. Aug. st. v.) (Russisches Kaiserreich; heute: Tartu, Estland)

$\dagger \quad$ 28. Jan. (16. Jan. st. v.) 1898 Heidelberg ev.

V Julius von S. (1808-1888) GouvernementsSchuldirektor

M Marie geb. von Schrenck (1817-1895)

( ) 3. Nov. 1896 Ulrike Elisabeth geb. Mannkopff (1873-1940) T von Emil Wilhelm M. (18361918), u.a. 1867-1905 o. Prof. für Medizin an U Marburg, s. Catalogus prof. Marburgensis 2 (1979) S. 313, WBIS

K 1 T

Vw Brüder: Julius von S. (1843-1895), u.a. Prof. für Chemie an Forstakademie Tharandt, Leopold von S. (1851-1920), u. a. seit 1899 o. Prof. für Indologie an U Wien und Theodor von S. (1853-1903), u.a. Direktor des Augenhospitals in St. Petersburg, s. NDB 23 (2007) S. 551f., WBIS.

Lb U Dorpat (bis 1889 einzige dt.sprachige $\mathrm{U}$ im Russischen Kaiserreich): 1869-1871 Studium der Medizin.

1871-1874 Studium krankheitshalber unterbrochen; in dieser Zeit: Ausbildung zum Photographen in Berlin; Photograph: 1872 in Dorpat, 18731874 in Riga.

U Dorpat: 1874-1877 Studium der Chemie; 1877 Staatsexamen in Chemie; 1878 Magisterprüfung in Chemie.

U Leipzig: 1879-188o Forts. des Studiums der Medizin und Mitarbeiter am Physiolog. Inst.; 13. Nov. 1880 Dr. rer. nat. an U Tübingen. 
U Straßburg: 1880-189o Assistent am Pharmakolog. Inst.; 1882 Dr. med.; 1884 oder 1886 Habilitation für Pharmakologie.

UH: Seit 31. Juli 1890 o. Prof. und Direktor des Pharmakolog. Inst. als Nachf. von Wilhelm Delffs.

1893/94 Dekan der Med. Fak. der UH

E 1892 Korr. Mitglied der Bayer. Akademie der Wissenschaften München.

Qu UAH PA 2257; RA 6816; Rep. 21-64 (Nachruf); Quästurakte Rep. 27-1227. • Universitätsarchiv Tübingen (Promotion: Signatur 136/7). - GLA Abt. 235, Fasz. 2497.

$W$ Über die Verwandlung des Ammoniaks in Harnsäure im Organismus des Huhns in: The virtual laboratory. Essays and resources on the experimentalization of life. Berlin 1878. S. 228-240. • Über die Bildung der Harnsäure im Organismus des Huhns. Diss. Tübingen 1880. - Über die Bildungsstätte des Harnstoffs in: Archiv für experimentelle Pathologie und Pharmakologie 15 (1882) S. 364-40o; Die Bildung des Harnstoffs in der Leber in: ebd. 19, 4-5 (1885) S. 373-386.

L Biogr. Jahrbuch 5 (1900) Sp. 57; Stübler (1926) S. 329; Fischer $2\left({ }^{3}{ }^{1962)}\right.$ S. 1412; Chronik Ärzte H (1985) S. 142; Lindner/Lüllmann (1996) S. $259 \mathrm{f}$. u. ö.; WBIS. • Extrakorporale Zirkulation in Theorie und Praxis. Hrsg. von Rudolf J. Tschaut. 2. Aufl. Lengerich 2005. S. 19 f., 26. Deutsche Biographie, s. https://www.deutsche-biographie.de/gnd101429 4231.html [09.11. 2017].

$P$ Bildarchiv UAH; graph. Slg. UBH; Chronik Ärzte H.

\section{Schuberg, August}

1894-1908 Nat.-Math. Fak.

Zoologie

* 29. Mai 1865 Karlsruhe

$\dagger$ 24. April 1939 Stuttgart ev.

V Georg S., Brauereibesitzer

M Sophie geb. Fahrer

œ 21. März 1903 Ida geb. Hoffmann (1880-1945)

$\mathrm{K} \quad 1 \mathrm{~T}$

Lb Seit WS 1883/84 Studium der Naturwiss., Mathematik an UH, WS 1886/87 Straßburg; 4. März 1887 Dr. phil. an UH; 1. April 1887-1. April 1888 Militärdienstpflicht als Einjährig-Freiwilliger.

U Würzburg: April 1888-April 1892 Assistent am Zoolog. Inst.; 1890 Staatsexamen in Mathematik und Naturwiss. für Lehramt an Mittelschulen; 1891 Habilitation für Zoologie.

TH Karlsruhe: Seit WS 1893/94 Privat-Dozent und Assistent am Zoolog. Inst.

UH: Seit WS 1894/95 Privat-Dozent; WS 1894/95WS 1907/08 Assistent am Zoolog. Inst.; seit 25. Juni 1896 nichtetatm. a. o. Prof.; seit SS 1902 Lehrauftrag für Systematische Zoologie, insbesondere zur Abhaltung e. wöchentlich dreistündigen Vorlesung über die einheimische Fauna, verbunden mit Bestimmungsübungen und Exkursionen mit e. Honorar pro Semester von 400.- Mark; März-April 1903 Arbeiten an Zoolog. Station in Neapel; Nov. 1907 Ruf an Kaiserl. Gesundheitsamt in Berlin angenommen (s. hierzu auch Theodor Wasielewski); 1. Febr.-1. April 1908 Beurlaubung von U für zunächst 2-monatige Probedienstleistung in Berlin.

Berlin: Seit 1. Febr. 1908 Mitglied auf Probe, 5. Mai 1908-ca. 1930 bestalltes Mitglied des (Kaiserl.) Gesundheitsamts und Vorsteher des Laboratoriums für Protozoenforschung.

1908 Reg.-Rat 
E Korr. Mitglied des Naturhistorisch-Med. Vereins Heidelberg; Mitglied der Dt. Zoolog. Gesellschaft Berlin.

Qu UAH PA 2258; RA 5186, 6577, 6617, 6902. GLA Abt. 235, Fasz. 2499. • Briefe: UBH.

$W$ Über den Bau und die Funktion der Haftapparate des Laubfrosches. Wiesbaden 1891. • Die Coccidien aus dem Darme der Maus in: Verh. des Naturhistorisch-Med. Vereins Heidelberg (1896). • Zoologisches Praktikum. Bd. 1 [mehr nicht erschienen]: Einführung in die Technik des Zoologischen Laboratoriums. Leipzig 1910.

$L$ Wer ist's (1922) S. 1409, (1935) S. 1446 f.; Arnim 2 (1952) S. 524; Deutsche Biographie, s. https://www. deutsche-biographie.de/gnd117107794.html [09.11. 2017].

P Ruperto Carola 19. Jg., Bd. 41 (1967) S. 319.

\section{Schubert, Hans Georg Wilhelm (seit 1878: von Schubert)}

1906-1928 Theol. Fak.

Kirchengeschichte

* 12. Dez. 1859 Dresden

$\dagger \quad$ o6. Mai 1931 Heidelberg

ev.

V Gustav S. (seit 1878: von S.) (1824-1907) Generalleutnant, Militärschriftsteller, s. G. von S. Lebenserinnerungen. Hrsg. von Hans von S. Stuttgart 1909; Nachlaß im Bundesarchiv Freiburg/Br.

M Mathilde geb. Barth (1825-1894) Schwester von Johann Heinrich B. (1821-1865), u. a. Afrikaforscher, s. NDB 1 (1953) S. 602 f.; H. B. Ein Forscher in Afrika. Leben - Leistung - Wirkung. Hrsg. von Heinrich Schiffers. Wiesbaden 1967; Kremer, Peter: Literatur von und über H. B. in: H. B.: Corinthiorum commercii et mercaturae historiae particula. In dt. und engl. Übersetzung. Heinrich-Barth-Institut. Köln 2002. S. 163-216; Wikipedia
( 24. Mai 1887 Bertha Elisabeth Gertrud geb. Köppern (1860-1946)

K 2 S, 5 T: u.a. Gertrud von S. (1888-1971), s. Kriegstagebuch K. Hampe (2007) S. 995 (Register); Ehefrau von: (siehe) Siegfried Schoenborn. - Dr. Erika von S. (1904-2002) Kunsthistorikerin, Historikerin, s. Wischmeyer, Wolfgang: Nachruf auf E. Dinkler-von S. in: Christliche Ethik - Ev. Ethik ... Hrsg. von Ulrich H.J. Körtner. Neukirchen 2004. S. 119122; Ehefrau von: Erich Dinkler (1909-1981), u.a. 1963-1977 Prof. für Neutestamentliche Theologie und Christl. Archäologie an UH, s. Drüll (2009) S. $162 \mathrm{f}$.

Lb SS 1878 Studium der Germanistik, Geschichte, Klassischen Philologie, Staats- und Rechtswiss. an U Leipzig, seit WS 1878/79 Bonn, seit WS 1879/ 8o Straßburg, SS 1881 Zürich, WS 1881/82 Leipzig, seit SS 1882 Straßburg, SS 1883-SS 1884 Tübingen; 27. März 1884 Dr. phil. an U Straßburg; WS 1884/ 85-SS 1886 Studium der Theologie an U HalleWittenberg.

Hamburg-Horn: Jan. 1887-Okt. 1891 Lehrer und Oberhelfer an Anstalten des Rauhen Hauses, e. Stiftung der Diakonie für straffällig gewordene oder sozial gefährdete Kinder und Jugendliche. • In dieser Zeit:

Nov. 1889 II. Theol. Prüfung und 22. Nov. 1889 Ordination am Domstift in Berlin; 189o Prüfung für höheres Lehramt in Halle/S.

U Straßburg: 11. März 1891 Ern. zum a. o. Prof. für Kirchengeschichte.

U Kiel: Seit 10. Febr. 1892 o. Prof.; 26. Aug. 1897-30. Sept. 1906 zudem Konsistorialrat im SchleswigHolsteinischen Landeskonsistorium in Kiel; 1906 Ruf an U Berlin abgelehnt.

UH: 21. Mai 1906 Ern. zum o. Prof. als Nachf. von Adolf Hausrath; 1. Okt. 1906 Vereidigung; 19061928 Direktor der Kirchengeschichtl. Abt./des Kirchengeschichtl. Seminars am Wiss.-Theol. Seminar als Nachf. von Hausrath; 1916 Rufe an U Berlin und Bonn abgelehnt; 31. März 1928 Ruhestand. 
1910/11 Prorektor der UH; 1909/10, 1915/16, 1920/21, 1922, 1927/28 Dekan der Theol. Fak. der UH

Verbandsvorsteher der Brüderschaft vom Rauhen Hause Schleswig-Holstein und Mecklenburg; 1897 Begründer und Vorsitzender des Vereins für Schleswig-Holsteinische Kirchengeschichte; 19171931 Mitglied der Preußischen Kommission zur Erforschung der Geschichte von Reformation und Gegenreformation; 1918-1931 Vorsitzender des Vereins für Reformationsgeschichte

1906 Geh. Kirchenrat; 1916 Geh. Rat II. Klasse

Siehe auch Johannes Rissom: Eintrag unter Z[itate] (2) und (3)

E 1906 O. Mitglied der Badischen Histor. Kommission; 1909 Gründungsmitglied der Akademie der Wissenschaften H; Mitglied: 1920 Dt. Gesellschaft für Missionswissenschaft Hamburg, 1926 Herder-Gesellschaft Riga. - 1892 D. theol. Straßburg; 1917 Dr. iur. h.c. Leipzig. 1910 Ritterkreuz I. Klasse mit Eichenlaub des Ordens vom Zähringer Löwen.

$\mathrm{Q} u$ UAH PA 5787 f.; RA 617, 624 und 5669 (Handakten von S.), 5111, 5670, 6448, 6728; Fak.-Akte Theol. Fak. 91; GF 54 f.; Acc. 40/11 (HAW-Akten). • Matrikel Zürich (1999) Nr. 6161. • GLA Abt. 235, Fasz. 2500. - Briefe: UBH. - Teil-Nachlaß: UAH (Signatur: Rep. 156); UBH; Bundesarchiv Freiburg/ Br.; s. hierzu auch NDB 23 (2007) S. 614. - Auskunft: Universitätsarchiv der Martin-Luther-Universität Halle-Wittenberg in Halle/S. - Mitteilungen von Familienangehörigen.

W Die evangelische Trauung. Berlin 189o. • Grundzüge der Kirchengeschichte. Tübingen 1904. 11. Aufl. 1950. Geschichte der christlichen Kirche im Frühmittelalter. Tübingen 1921. • Der Kampf des geistlichen und weltlichen Rechts in: Sitzungsberichte der Heidelberger Akademie der Wissenschaften. Phil.-Histor. Klasse. Abh. 2. Heidelberg 1926/27. • Die Anfänge der ev. Bekenntnisbildung bis 1529/30. Leipzig 1928. - Lazarus Spengler und die Reformation in Nürnberg. Hrsg. von Hajo Holborn. Leipzig 1934 (mit Werkverz.). - Siehe auch BBKL IX (1995) Sp. 1041.
L Scheel, Otto: H. von S. zum Gedächtnis. Leipzig 1931. - Professoren Kiel (1956) S. 8 f.; RGG 5 $\left({ }^{3} 1961\right)$ Sp. 1549 f.; WBIS; Jansen (1992) S. 413 (Register); Ders. (1992a) S. 169 (Register). - Theologische Fakultäten im Nationalsozialismus. Hrsg. von Leonore Siegele-Wenschkewitz und Carsten Nicolaisen. Göttingen 1993. S. 169-171 u.ö. • Fix (1994) S. 52-71; Wennemuth (1994) S. 638 (Register); BBKL IX (1995) Sp. 1040f. - Schilling, Johannes: H. von S. und die Anfänge des Vereins für Schleswig-Holsteinische Kirchengeschichte in: Verein für Schleswig-Holsteinische Kirchengeschichte. Schriften des Vereins ... 2. Neumünster 1997. S. 1635. TRE 30 (1999) S. 563-565. - Theologische Fakultäten an staatlichen Universitäten in der Perspektive von Ernst Troeltsch, Adolf von Harnack und H. von S. Hrsg. von Hartmut Kress ... Waltrop 2004. Personenlexikon zum dt. Protestantismus (2006) S. 229; Kriegstagebuch K. Hampe (2007) S. 995 (Register); NDB 23 (2007) S. 613 f.; Moeller (2008) S. 46-59.

$P$ Bildarchiv UAH; graph. Slg. UBH.

\section{Schürmaier}

siehe Schürmayer

\section{Schürmayer, Ignaz Heinrich}

1848-1849 Med. Fak.

Staats-Arzneikunde (Gerichtsmedizin)

$\approx$ 04. Febr. 1802 Freiburg/Br.

$\dagger$ 24. Mai 1881 Freiburg/Br. kath.

V Johann Baptist Hermann S., Hufschmied, Hammerwerkbesitzer

M Johanna geb. Rieder

๑ Maria Theresia geb. Madamé (†1866)

K 3 .

Lb U Freiburg/Br.: WS 1817/18-WS 1822/23 Studium; 1825 und 1826 Lizenz als Arzt der Gesamtheilkunde; 30. Aug. 1830 Dr. med. 
Renchen (Ortenaukreis, bei Appenweier): Seit 1825 praktischer Arzt.

Emmendingen: Seit April 1829 Amts-Chirurg (Amts-Wundarzt) im Großherzogl. Oberamt E.

Bonndorf im Schwarzwald: Seit 1836 Amtsarzt (Physikus).

Emmendingen: Seit 1837 Physikus; seit 1843 Medizinalrat. • In dieser Zeit:

1835-1846 (?) Erster Sekretär des neugegründeten Vereins Großherzogl. Badischer Medizinalbeamter für Beförderung der Staatsarzneikunde in Offenburg.

UH: 10. Juni 1848 Ern. zum o. Prof., s. hierzu Z; 1. Okt. 1848 Dienstantritt; 31. Aug. 1849 auf eigenen Antrag Zurückversetzung als Oberamtsarzt nach Emmendingen. In dieser Zeit:

H: 1848-1849 Amtsphysikus (Amtsarzt).

Mannheim: 1848-1849 Medizinalreferent am Großherzogl. Hofgericht.

Emmendingen: 1849-1872 (Pensionierung) Oberamtsarzt. • In dieser Zeit:

Freiburg/Br.: 1849-1872 Medizinalreferent am Großherzogl. Kreis- und Hofgericht.

Freiburg/Br:: Nach 1872 praktischer Arzt und Privat-Gelehrter.

$Z$ Ministerium des Innern in Karlsruhe gibt der Regierung des Unterrheinkreises in Mannheim am 14. Juni 1848, die Ernennung S.s betreffend, nachfolgende Anweisungen (der Unterrheinkreis setzt sich 1832-1864 aus den Ämtern des Neckarkreises, des Main- und Tauberkreises zusammen): „Seine Königliche Hoheit ... haben ... geruht, dem Medicinalrath Physikus Dr. Schürmayer in Emmendingen das Physikat Heidelberg mit der Verpflichtung zur Haltung von Vorträgen über die Fächer der Staats-Arzneikunde an der dortigen Universität zu übertragen und denselben demgemäß zugleich zum ordentlichen Professor dieser Fächer, jedoch mit Entbindung von den Fakultätsgeschäften zu ernennen, sofort ihm eine Lokalzulage von zweihundert Gulden und einem aus der Univ[ersitäts-] Kasse zu beziehenden jährlichen Functionsgehalt von vierhundert Gulden zu verwilligen. Hiervon wird die Kreis-Regierung zur weiteren Eröffnung in Kenntniß gesetzt ..." (aus: UAH PA 2261).

1861 Geheimer Hofrat

E Mitglied: Vor 1831 Naturforschende Gesellschaft zu Freiburg/Br., Großherzogl. Badischer Landwirthschaftlicher Verein. - Kommandeur II. Klasse des Zähringer Löwen-Ordens; 1869 Kaiserlich-Russischer Orden des Heiligen Stanislaus und Komturkreuz des Ordens der Heiligen Anna; Päpstlicher St. Gregorius-Orden. • 1869 Ehrenbürger der Stadt Emmendingen.

Qu UAH PA 2261. - Briefe: UBH. - Auskunft: Universitätsarchiv Freiburg/Br. (Signaturen: A 66/ 5, A 85/41).

$W$ Gerichtlich-medicinische Klinik oder Praktischer Unterricht zur Untersuchung und Begutachtung gerichtlich-medicinischer Fälle. Karlsruhe 1844. Handbuch der medicinischen Policei. Erlangen 1848. 2. Aufl. 1856. Theoretisch-practisches Lehrbuch der gerichtlichen Medicin ... Erlangen 1850. 4. Aufl. 1874.

MG, MHG 1836-1846 Annalen der Staatsarzneikunde (1846-1872 u.d.T.: Vereinte dt. Zeitschrift für die Staatsarzneikunde).

$L$ Badische Biographien 4 (1891) S. 433 f.; Stübler (1926) S. 280; Hirsch $5\left({ }^{3} 1962\right)$ S. 152; Semper apertus 1 (1985) S. 178f.; WBIS; ÖBL online 11 (1998) S. 296; Biogr. Enzyklopädie Mediziner 2 (2002) S. 564 f.

$P$ Bildarchiv UAH. 


\section{Schürmeier, Schürmeyer}

siehe Schürmayer

\section{Schultz, Ernst Andreas Heinrich Hermann}

1874-1876 Theol. Fak.

Neutestamentliche Exegese, Praktische Theologie

* 30. Dez. 1836 Lüchow (südliches Wendland)

$\dagger$ 15. Mai 1903 Göttingen

ev.-luth.

V Wilhelm S. (1805-1857) Anwalt, s. Ulrich (1988) S. $6 \mathrm{f}$.

M Luise geb. Wiehen (1809-1871)

(15. Mai 1861 Auguste geb. Lorenzen ( $\dagger 1878)$

$\infty$ 18. Okt. 1880 Julie geb. Gelzer († nach 1903), s. Ulrich, S. 33; T von Johann Heinrich G. (18131889), u. a. $1844-1851$ o. Prof. für Geschichte Berlin, 1853-1870 Hrsg. der Protestantischen Monatsblätter für innere Zeitgeschichte, seit 1860 Berater Großherzogs Friedrich I. von Baden, seit 1866 Badischer Staatsrat, s. NDB 6 (1964) S. 177 f., Historisches Lexikon der Schweiz online (2003)

K $1 \mathrm{~S}$ (aus 1. Ehe), s. hierzu Ulrich, S. 33-35, Deutsche Biographie https://www.deutsche-bio graphie.de/gnd117201677.html [09.11.2017]. • 4 T (aus 1. Ehe): u. a. Antonie S. (1863-1903) Ehefrau von Dr. phil. Johannes Geffcken (1861-1935) seit 1889 Lehrer am WilhelmGymnasium in Hamburg, 1907-1935 (ohne Habilitation) o. Prof. für Klassische Philologie Rostock, s. Merck, Heinrich: Begegnungen und Begebnisse. Hamburg 1958. S. 35-38; NDB 6 (1964) S. 128 f., Hamburgische Biografie 6 (2012) S. 103f., Catalogus prof. Rostochiensium online. - Elisabeth S. (1870-1955) Ehefrau von William Wrede (1859-1906), u. a. seit 1891 Privat-Dozent Göttingen, seit 1893 a. o. Prof., seit 1895 o. Prof. für Neutestamentliche Exegese Breslau, s. BBKL XIV (1998) Sp. 88-98; Wojtkowiak, Heiko: W.W. in: Stiftsgeschichte(n). 250 Jahre Theologisches Stift der Universität Göttingen (1765-2015). Göttingen 2015. S. 141-153.
K 4 (aus 2. Ehe), davon $2 \mathrm{~K}$ früh $\dagger, 2 \mathrm{~S}$ : Hermann S. [jun.] $\left({ }^{*} 1881 X_{1915}\right)$ seit 1910 Privat-Dozent für Klassische Philologie Göttingen, s. Nachlaß in Staats- und Universitätsbibliothek Göttingen (Signatur: Cod. Ms. H. Schultz); Ulrich (1988) S. 35. • Johann Heinrich S. (1884-1970) Erfinder der von ihm 1926 zunächst als ,autogene Organübungen“, 1932 als „Autogenes Training" benannten autosuggestiven Entspannungsübungen; u. a. 1914-1918 Kriegsdienst, seit 1915 Privat-Dozent, seit 1919 a. o. Prof. für Psychiatrie und Nervenheilkunde Jena, seit 1920 Chefarzt und wiss. Leiter des Lahmann-Sanatoriums auf dem Weißen Hirsch bei Dresden, seit 1924 niedergelassener Nervenarzt in Berlin, 1936-1945 stellvertr. Direktor des Dt. Instituts für psycholog. Forschung und Psychotherapie sowie Leiter der dortigen Poliklinik Berlin; nach 1945 niedergelassener Nervenarzt ebd., 1959 Gründer der Dt. Gesellschaft für Ärztl. Hypnose und Autogenes Training, s. Ulrich, S. 25, NDB 23 (2007) S. $700 \mathrm{f}$.

Vw Schwager: (siehe) Heinrich Gelzer. Siehe auch NDB 6 (1964) S. $177^{*}$, NDB 23, S. $700^{*}$.

Lb Seit SS 1853 Studium der Theologie, Philosophie an U Göttingen, seit SS 1854 Erlangen, seit SS 1855 Göttingen; Herbst 1856 I. theol. Prüfung vor Konsistorium in Göttingen.

Hamburg: 1856-1858 Hauslehrer.

U Rostock: 1858 Promotion zum Dr. phil.

U Göttingen: Seit 4. April 1859 Repetent am Collegium theologicum repetentium (heute: Theol. Stift); 12. Febr. 1861 vorzeitige Erteilung der venia legendi von Theol. Fak. für zwei Jahre, um Ankündigung seiner Veranstaltungen noch im Vorlesungsverzeichnis für SS 1861 zu sichern; 16. Febr. 1861 öffentliche Disputation zur Habilitation und zum theol. Lizentiatenexamen; 11. Febr. 1863 Verlängerung der Lehrbefugnis ohne zeitliche Begrenzung.

U Basel: Seit SS 1864 o. Prof. für Alttestamentliche Theologie; 1870-1872 auch Mitglied des Baseler Kirchenrats. 
U Straßburg: Seit WS 1872/73 o. Prof.; 1874 Ruf an U Berlin abgelehnt.

UH: 21. Juli 1874 Ern. zum o. Prof. als Nachf. von Heinrich Holtzmann mit e. Jahresbesoldung von 490o.- Gulden, s. UAH RA 6718 fol. 32r, v; 5 . Okt. 1874 Vereidigung; 15. April 1876 Entlassung auf eigenen Antrag.

U Göttingen: Seit SS 1876 o. Prof. für Systematische Theologie, Exegetische und Praktische Theologie; auch U-Prediger (bis 1902); 1890 Verleihung des Abt-Titels der luth. Benediktinerabtei Bursfelde (bei Hannoversch-Münden) als Senior der Theol. Fak.; seit Febr. 1903 keine Vorlesungsankündigungen aus gesundheitlichen Gründen.

„Die Theologische Facultät hat sich ... dafür ausgesprochen: daß die erledigte Professur (des H. Schultz) wieder in die beiden besonderen Lehrfächer der neutestamentlichen Exegese und praktischen Theologie geschieden [werde], die erste als Hauptfach anzusehen (sei) und ... einem Ordinarius verliehen werden muß; für die zweite dagegen eine jüngere Kraft als Extraordinarius in Vorschlag zu bringen sei; die Aufgabe dieser zweiten Lehrstelle wird auch dahin bestimmt, daß darin die Mitwirkung beim Universitätsgottesdienst wie beim Seminarunterricht und Vorlesungen über praktische Theologie umfaßt sind ..." (aus: Bericht des Engeren Senats der UH an Ministerium des Innern vom 12. März 1876 in: RA 6718 fol. 42r); siehe hierzu auch Heinrich Bassermann und Karl Holsten.

1881 Konsistorialrat

\section{E 1865 D. theol. U Göttingen.}

Qu UAH PA 2262; RA 6718 fol. 41r, v u. ö. • Wilhelm Dilthey: Briefwechsel. Bd. 1: 1852-1882. Hrsg. von Gudrun Kühne-Bertram ... Göttingen 2011. S. 925 (Register). - Julius Wellhausen: Briefe. Hrsg. von Rudolf Smend ... Tübingen 2013. S. 879 (Register). - Ernst Troeltsch. Kritische Gesamtausgabe. Bd. 19: Briefe II (1894-1904). Hrsg. von Friedrich Wilhelm Graf ... Berlin 2014. S. 507 (Register).
$W$ Die Voraussetzungen der christlichen Lehre von der Unsterblichkeit. Göttingen 1861. Alttestamentliche Theologie. Frankfurt/M. 1869. 5. Aufl. 1895. - Die Stellung des Glaubens zur heiligen Schrift. Karlsruhe 1869. 2. Aufl. 1877. • Grundriß der evangelischen Dogmatik. Göttingen 1890. 2. Aufl. 1892. Grundriß der christlichen Apologetik. Göttingen 1894. - Bibliographie in: Ulrich (1988) S. 206-226.

$L$ Catalogus prof. Gottingensium (1962) S. 36 f.; WBIS. - Ulrich, Peter: H.S.' „Alttestamentliche Theologie" im Zusammenhang seines Lebens und Werkes. Diss. Göttingen 1988. • BBKL XVII (2000) Sp. 1254-1258. • Rudolf Otto: Theologie - Religionsphilosophie - Religionsgeschichte. Hrsg. von Jörg Lauster ... Berlin 2014. S. 206 f., 214-216. • Schäfer, Christian: Alfred Rahlfs (1865-1935) und die kritische Edition der Septuaginta. Eine biographisch-wissenschaftsgeschichtliche Studie. Berlin 2016. S. 518 (Register). Deutsche Biographie, s. https://www.deutsche-biographie.de/gnd1190581 97.html [09.11. 2017].

$P$ Universitätsbibliothek Gießen.

\section{Schultze, Julius Friedrich}

1876-1887 Med. Fak.

Innere Medizin

* 17. Aug. 1848 Rathenow (Brandenburg)

$\dagger$ 14. Okt. 1934 Bonn ev.

V Johann Friedrich S. (*1806) Ziegeleibesitzer, Landwirt

M Karoline Augustine geb. Zander ( $\left.{ }^{*} 1813\right)$

๑ 1890 Margarethe geb. Heubach (1870-1959) T von Rudolf H. ( $† 1895)$ Rechtsanwalt, Teilhaber und Schwiegersohn des Gründers der Heidelberger Zementfabrik Gebr. Schifferdecker (heute: HeidelbergCement), Johann Philipp Schifferdecker (1811-1887), siehe NDB 22 (2005) S. $751 \mathrm{f}$.

$\mathrm{K} \quad 3 \mathrm{~S}, 1 \mathrm{~T}$ 
Lb WS 1867/68-WS 1870/71 Studium an U Berlin; $1870 / 71$ Kriegsfreiwilliger als Unterarzt in e. Lazarett in Berlin während des Deutsch-Französischen Krieges; 1871 Forts. des Studiums an U Bonn.

UH: 13. Nov. 1871 Dr. med.; SS 1872 Staatsprüfung; seit WS 1871/72 Assistent an Med. U-Klinik; 3. Aug. 1876 Habilitation; seit 13. März 188 o a. o. Prof.

U Dorpat (heute: Tartu, Estland; bis 1889 einzige dt.sprachige U im Russischen Kaiserreich; 1889 einsetzende Russifizierung, u.a. mit Absetzung des Deutschen als Lehrsprache und Durchsetzung der russischen Sprache): Seit WS 1887/88 o. Prof. und Direktor der Med. U-Klinik; 1888 Ruf als Direktor an Krankenhaus Hamburg-Eppendorf abgelehnt.

U Bonn: WS 1888/89-SS 1918 o. Prof. und Direktor der Med. U-Klinik.

1903 Mitbegründer der Rheinisch-Westfälischen Gesellschaft für Innere Medizin und Nervenheilkunde in Köln, s. hierzu Geschichte der Inneren Medizin in Nordrhein-Westfalen. 100 Jahre Rheinisch-Westfälische Gesellschaft für Innere Medizin 1903-2003. Hrsg. von Georg Stromeyer u.a. Paderborn 2004.

1900 Geh. Medizinalrat; 1918 Geh. Obermedizinalrat

E Ehrenmitglied der Gesellschaft Dt. Nervenärzte; 1887 Mitglied der Dt. Akademie der Naturforscher Leopoldina Halle/S.; 1899 ausw. Mitglied der Psychiatr. und Neuropatholog. Gesellschaft Moskau. 1928 Ehrenbürger der Stadt Bonn.

Qu UAH PA 2263; Fak.-Akten H-III-111/79, HIII-111/85. - Siehe auch Archiv der Dt. Akademie der Naturforscher Leopoldina Halle/S. - Medizin in Selbstdarstellungen 2 (1923) S. 193-215. (Autobiogr.)

$W$ Über den mit Hypertrophie verbundenen progressiven Muskelschwund und ähnliche Krankheitsformen. Wiesbaden 1883. • Über die Heilwirkung der Electrizität bei Nerven- und Muskelleiden.
Wiesbaden 1892. Lehrbuch der Nervenkrankheiten. Stuttgart 1898. - Die Krankheiten der Hirnhäute und die Hydrocephalie. Wien 1901. Humor und Satire aus dem Gebiet der Medizin. München 1928.

MHG 1891 Dt. Zeitschrift für Nervenheilkunde.

$L$ Nonne, Max: F. S. $\dagger$ in: Journal of Neurology 135 $(1934 / 35)$ Nr. 3-4, S. 81-89 (P). • Stursberger, Hugo: F. S. in: Chronik der ... Universität zu Bonn für das akad. Jahr 1933/34 ... Jg. 59. N. F. Jg. 48. Bonn 1935. S. 14-20. A Arnim 2 (1952) S. 529; Fischer $2\left({ }^{3} 1962\right)$ S. 1419 f.; Verzeichnis Bonn (1968) S. 284; WBIS. • The Founders of Child Neurology. Edited by Stephen Ashwal. San Francisco 1990. S. 582-586 u. ö. • Peiffer (2004) S. 1172 (Register). • Coch, Werner: F.S. - Arzt aus Rathenow ... in: Rathenower Heimatkalender 2012. Havelländischer Kreiskalender. 56. Jg. Rathenow 2011. S. 41-44. • Deutsche Biographie, s. https://www.deutsche-biographie.de/gn d11721428o.html [09.11. 2017].

\section{Schultze, Fritz}

siehe Schultze-Rhonhof, Friedrich

\section{Schultze-Rhonhof, Friedrich (Fritz)}

Max Edgar Rudolf Jonathan (bis 1919/20:

Schultze)

1924-1934 Med. Fak.

Geburtshilfe, Gynäkologie

* o9. Juni 1892 Kattowitz (heute: Katowice, Polen)

$\dagger \quad$ o1. Nov. 1951 Herford/Westfalen ev.

V August Schultze (1856-1903) Fabrikdirektor, s. Beiträge zur Geschichte der Familie (2006) S. 48

M Barbara geb. Bieregel (1858-1914)

๑ 3. März 1924 Margarete (Grete) Emilie geb. Faßmann (1895-1985) 
K 1 T, 2 S: u. a. Dr. phil. Friedrich-Carl S.-R. (19252014), u. a. 1964-1990 Direktor der Volkshochschule in Münster/Westfalen, 1982-2004 Vorstandsvorsitzender der Stiftung Schlesien (Oldenburg), seit 2005 Mitglied des Stiftungsrats, s. Graeve, Jutta: Schlesien lehren und lernen. F.-C. S.-R. in: Kulturpolitische Korrespondenz, Berichte, Meinungen, Dokumente. Hrsg.: Stiftung Dt. Kultur im östlichen Europa. 1300. Ausg. vom 20. Okt. 2010. S. 13; Wikipedia. Siehe auch Beiträge zur Geschichte der Familie (2006) S. 51.

Lb Seit WS 1910/11 Studium an U Berlin, SS 1913 Göttingen, seit WS 1913/14 Berlin; März 1913 Physikum an U Berlin.

3. Aug. 1914-31. Aug. 1919 Kriegsdienst (Sept. 1918Jan. 1919 in englischer Gefangenschaft).

Berlin: 26. März 1918 Staatsexamen und Approbation; April 1918 Dr. med. an U; 1. Sept. 1919-31. Mai 1921 Assistenzarzt an Innerer Abt. des Stubenrauch-Kreiskrankenhauses in Lichterfelde.

UH: Seit Juni 1921 Assistenzarzt, Mai 1931-1934 Oberarzt an U-Frauenklinik mit e. Monatsgehalt von 458.- Reichsmark; 6. Mai 1924 Habilitation; seit 15. März 1930 nichtplanm. a. o. Prof.; seit 1. Juli 1934 stellvertr. Direktor der U-Frauenklinik nach Weggang von Heinrich Eymer.

U Breslau: Seit 1. Nov. 1934 o. Prof. für Geburtshilfe und Gynäkologie sowie Direktor der U-Frauenklinik; Febr.-6. Mai 1945 (Einnahme der Stadt durch Rote Armee) Auflösung der U.

Ditfurt (bei Halberstadt): Seit Frühjahr 1945 Aufenthalt.

Herford: Seit 1947 Frauenarzt in e. Privatklinik.

Bünde: Seit Juli 1950 niedergelassener Frauenarzt.

1. Aug. 1946-1951 (†) Mitglied der Ärztekammer Westfalen-Lippe
E Zwischen 1914 und 1918 Eisernes Kreuz I. und II. Klasse.

Qu UAH PA 1172, 5803 (hier eigenhändige Eintragung der Verehelichung mit 3. März 1924). • GLA Abt. 235, Fasz. 2504. Auskunft: Standesamt Herford. Mitteilungen: Herr Dr. Justus SchultzeRhonhof, Karlsruhe.

W Schwangerschaft und Lungentuberkulose in: Archiv für Gynäkologie 128 (1926) S. 563-616. • S.-R., F., Bachl, E.: Über den Wert der chemischen Reaktion des Scheideninhalts für die Diagnose der Gonorrhoe in: Dt. Med. Wochenschrift 53 (1927) S. 189f. Lungentuberkulose und Schwangerschaft in: Ergebnisse der gesamten Tuberkuloseforschung 3 (1931). (Mitverf.) • Hansen, Karl, S.-R., F.: Tuberkulose als Grenzgebiet der Geburtshilfe und Gynäkologie in: Monatsschrift für Geburtshilfe und Gynäkologie 97 (1934) S. 354-363. Menge, Carl, S.-R., F.: Über inguinale Sterilisierung in: Dt. Med. Wochenschrift 61 (1935) S. 621-623.

MHG Archiv für Gynäkologie.

L Gynäkologen-Verzeichnis (1939) S. 438 f.; Kürschner (1940/41) Sp. 720, (1950) Sp. 1897; WBIS; Scholz/Barth/Pappai/Wacker (2005) S. 528 u. ö. Beiträge zur Geschichte der Familie SchultzeRhonhof gesammelt von Christiane Schultze ... Bonn 2006. S. 49 (hier Hochzeitsdatum: 4. März 1924). UH im Nationalsozialismus (2006) S. 1271 (Register). • Eckart, Wolfgang U.: Frau und Frauenheilkunde im Nationalsozialismus. Anmerkungen zum Themenfeld, offene Fragen in: Herausforderungen. 100 Jahre Bayerische Gesellschaft für Geburtshilfe und Frauenheilkunde. Hrsg. von C. Anthuber ... Stuttgart 2012. S. 87-94, hier S. 93; Frobenius, Wolfgang: Die Wiederbesetzung der gynäkologisch-geburtshilflichen Lehrstühle in Bayern nach 1945 in: ebd. S. 149-185, hier S. 160. Deutsche Biographie, s. https://www.deutsche-bio graphie.de/gnd12831303X.html [09.11. 2017].

$P$ Bildarchiv UAH. 


\section{Schulze-Gaevernitz, Hermann Johann} Friedrich von

s. Schulze, Hermann

\section{Schulze, Hermann Johann Friedrich (seit 1888: von Schulze-Gaevernitz)}

1878-1888 Jur. Fak.

Dt. Reichs- und Landesstaatsrecht, Dt. Reichsund Rechtsgeschichte, Verwaltungsrecht, Polizeiwissenschaft

* 23. Sept. 1824 Jena

$\dagger \quad$ 27. Okt. 1888 Heidelberg

ev.

V Friedrich Gottlob S. (1795-1860), u. a. Prof. für Staats- und Kameralwiss. an U Jena, s. NDB 23 (2007) S. $720 \mathrm{f}$.

M Bertha geb. Sturm (1799-1857), s. NDB 23, S. $720^{*}$

๑ April 1863 Luise geb. Milde (1841-1923) T von Karl August M. (1805-1861) Textilindustrieller und preußischer Handelsminister, s. WBIS, NDB 17 (1994) S. $504 \mathrm{f}$.

K 1 S: Gerhart (von) S.(-G.) (1864-1943) Politiker und seit 1896 o. Prof. für Nationalökonomie an U Freiburg/Br., 1927 Mitbegründer der Löwenberger Arbeitsgemeinschaft, s. NDB 23, S. 722 f., WBIS, BBKL XXVI (2006) Sp. 13661371, Kriegstagebuch K. Hampe (2007) S. 996 (Register), DBE 9 (2008) S. 291, Zeiler (2008) S. $159 . \bullet 4$ T: u. a. Marie S., Ehefrau von: (siehe) Hans Hinrich Wendt

Vw Enkel (Kinder von Gerhart (von) S.(-G.)): Dr. phil. Ruth von S.-G. (1898-1993) Religionsund Altertumswissenschaftlerin am British Museum London, s. „Es ist wichtig, dass diese jungen Menschen mit Kultur aufwachsen!“ Hommage an R. von S.-G., s. http://www.fa den-der-ariadne.de/ariad2/ruth.html (Ausdruck im UAH). • Gero von S.-G. (1901-1970) 1925 Emigration in die USA, seit 1928 Investmentbanker in New York, seit 1939 Export-Import-Kaufmann in Bern (und Verwalter des in der Schweiz befindlichen Vermögens seines Schwagers Edmund Stinnes), 1941-1945 Geheimdienstagent im Dienst von Allen Welsh
Dulles' (1893-1969), Gesandter und Leiter des nach Kriegsbeginn gegründeten US-Nachrichtendienstes Office of Strategy Services (OSS) in Bern, s. S.-G., G. von, Dulles, Allen: Unternehmen Sunrise. Die geheime Geschichte des Kriegsendes in Italien. Düsseldorf 1967; Baden-Württ. Biographien I (1994) S. 343-345, Deutsche Biographie, s. https://www.deutsche-biographie.de/gnd129442186.html [10.11. 2017]. - Margiana von S.-G. (1904-1989) 2. Ehefrau von Dr.-Ing. Edmund Hugo Stinnes (1896-1980) 1924-1925 Mitinhaber des väterl. Konzerns Stinnes AG, Aufsichts- und Verwaltungsratsmitglied mehrerer Unternehmen, ca. 1935 Emigration, anschl. Prof. für Nationalökonomie am Haverford College (Pennsylvania), s. Wikipedia, NDB 25 (2013) S. $355^{*}$. Weitere Vw, siehe NDB 23 (2007) S. $721^{*}$.

Lb Seit 1841 Studium an U Jena, anschl. Leipzig, Berlin; 1845 Staatsexamen in Jena; seit 1845 Justizdienst in Meiningen.

U Jena: 1846 Dr. iur.; 1846 Eigenstudien in Wien und Berlin; 21. Aug. 1847 Habilitation; seit 26. Febr. 1850 a.o. Prof.; 1852 Studienreisen nach Großbritannien, Frankreich, Belgien.

\section{U Breslau: Seit 8. Juni 1857 o. Prof.}

UH: Seit 14. Nov. 1877 o. Prof. als Nachf. von Heinrich Zöpfl; 29. April 1878 Vereidigung; 1878-1879 (Auflösung) Beisitzer des Spruchkollegiums der Jur. Fak. • In dieser Zeit:

Karlsruhe: 1881-1888 Mitglied der I. Kammer des Badischen Landtags als Vertreter der UH.

1878/79, 1885/86 Dekan der Jur. Fak. der UH

Berlin: 1869 Berufung zum Kronsyndikus und damit verbunden Ern. zum lebenslänglichen Mitglied des Preußischen Herrenhauses (= I. Kammer des preußischen Landtags). - Seit 1875 Mitglied der ev. Generalsynode.

1855 Hofrat; 1870 Geh. Justizrat; 1877 Geh. Rat II. Klasse 
E 1879 Mitglied des Instituts für int. Recht. 1855 Ritterkreuz des Portugiesischen Christus-Ordens; ca. 1855 Roter Adlerorden; 1876 Ritterkreuz I. Klasse mit Eichenlaub des Ordens vom Zähringer Löwen; 1876 Komturkreuz II. Klasse des Braunschweigischen Ordens Heinrichs des Löwen; 1877 Komturkreuz des Sachsen-Ernestinischen Hausordens.

Qu UAH PA 2266. GLA Abt. 235, Fasz. 9028. Briefe: UBH. - Auskunft: Ev.-Luth. Kirchengemeinde - Gemeindekirchenrat - Jena.

$W$ Das Recht der Erstgeburt in den deutschen Fürstenhäusern und seine Bedeutung für die deutsche Staatsentwicklung. Jena 1851. - Die staatsrechtliche Stellung des Fürstenthums Neuenburg in ihrer geschichtlichen Entwickelung und gegenwärtigen Bedeutung. Jena 1854. 3. Aufl. 1857. • Die Hausgesetze der regierenden deutschen Fürstenhäuser mit geschichtlich-staatsrechtlichen Einleitungen. 3 Bde. Jena 1862-1883. - Das Preußische Staatsrecht auf Grundlage des Deutschen Staatsrechts. 2 Bde. Leipzig 1870-1877. 2. Aufl. 18881890. Lehrbuch des deutschen Staatsrechts. 2 Bde. Leipzig 1883-1886. Bibliographie in: Ott (2008).

$L$ Günther (1858) S. 104f.; Almanach Heidelberg (1886) S. 107; Badische Biographien 4 (1891) S. 417-433; Jammers (1964) S. 177 u. ö.; NDB 23 (2007) S. 721 f. - Schroeder, Klaus-Peter: H. von S.-G. ... Preußischer Kronsyndikus und Heidelberger Staatsrechtslehrer in: Staat - Wirtschaft - Gemeinde. Festschrift für Werner Frotscher ... Hrsg. von Gilbert H. Gornig ... Berlin 2007. S. 111-127. • Ott, Sina: Der ... Staatsrechtslehrer und preußische Kronsyndikus H. von S.-G. Leben und Werk. Hamburg 2008. Schroeder (2010) S. 258-263 u.ö.; Deutsche Biographie, s. https:// www.deutsche-biographie.de/gnd118152343.html [10.11. 2017].

$P$ Bildarchiv UAH; graph. Slg. UBH.

\section{Schuster, Ernst Albert Karl Heinrich}

1930-1933 (Honorar-Prof.) Phil. Fak.

1933-1934 Phil. Fak.

1934 Wirtschaftswiss. Fak.

1935-1946 Staats- und Wirtschaftswiss. Fak.

Volkswirtschaftslehre

* 20. April 1893 Wilhelmshaven

$\dagger$ 13. Juli 1979 Karlsruhe ev.-luth.

V Albert Friedrich Johann S., Werftinspektor

M Johanna Gesine Gerhardine geb. Sints ( $\dagger$ vor 1920)

$\infty$ 9. April 1920 Ottilie Sophie Carla geb. Reese (1897-1981) Scheidung 1924

๑ 3. Juni 1927 Dr. Helene (Lena) Elisabeth Therese geb. Kaden $\left({ }^{*} 1898\right)$

K $1 S$

Lb Seit WS 1913/14 Studium der Geschichte, Philosophie, Volkswirtschaftslehre an U Kiel; 19141916 (schwerverwundet als kriegsuntauglich entlassen) Kriegsfreiwilliger.

Kiel: Seit 1916 Hilfsarbeiter, seit Febr. 1918 Assistent, Juni 1919-1923 Direktorialassistent am Inst. für Seeverkehr und Weltwirtschaft. - In dieser Zeit:

U Kiel: Dez. 1917 Dr. sc. pol.; 7. März 1921 Habilitation für wirtschaftl. Staatswissenschaften; SS 1922 Vertreter an U Münster; seit Febr. 1923 Lehrauftrag für Gewerbe- und Sozialpolitik.

U Tübingen: 1. Nov. 1923 Umhabilitierung; 13. März 1926 Ern. zum nichtplanm. a. o. Prof.

Mannheim: 7. März 1927 (Ern.)-30. Sept. 1933 o. Prof. für Volkswirtschaftslehre an Handelshochschule.

UH: Seit 4. Aug. 1930 o. Honorar-Prof.; 18. Mai 1934 rückwirkend zum 1. Nov. 1933 Ern. zum o. Prof. nach Beschluß, Handelshochschule Mannheim an UH zu überführen; Mai 1934 Errichtung zunächst der Wirtschaftswiss., Jan. 1935 der Staats- und Wirtschaftswiss. Fak.; 1934-1946 Leiter des Inst. für Volkswirtschaftslehre und Statistik; 
1936-1946 Leiter der Hochschularbeitsgemeinschaft für Raumforschung (HAG) am genannten Inst. (siehe hierzu Gutberger, Hansjörg: Raumentwicklung, Bevölkerung und soziale Integration. Forschung für Raumplanung und Raumordnungspolitik 1930-1960. Wiesbaden 2017. S. 87f., 9o, 412); 16. Jan. 1946 Entlassung gemäß Erlaß der amerik. Militärregierung.

Köln: 1951-1961 Mitglied der Geschäftsführung des Deutschen Industrie-Instituts (seit 1973: Institut der deutschen Wirtschaft). • In dieser Zeit:

U Köln: WS 1955/56-SS 1960 Lehrauftrag für Int. Wirtschaftspolitik.

UH: 17. Jan. 1961 Verleihung der Rechtsstellung e. von seinen amtl. Verpflichtungen entbundenen o. Prof.

April-Aug./Sept. 1945 stellvertr. Dekan der Staatsund Wirtschaftswiss. Fak. der UH

$\mathrm{Qu}$ UAH PA 282, 641, 5818f. • Auskunft: Universitätsarchiv Köln; Standesämter in Stade und Wilhelmshaven.

$W$ Der Wirtschaftskrieg. Die Maßnahmen und Bestrebungen des feindlichen Auslandes zur Bekämpfung des deutschen Handels ... Bd. 1: England. Jena 1917. (Mitverf.) - Das Einkommen. Eine kritische Untersuchung. Tübingen 1926. • Monoindustrielle Agglomeration. Die Schuhindustriestadt Pirmasens. Würzburg 1940. • Zur lohnpolitischen Situation. Köln 1953. 4. unveränderte Aufl. 1953 [!]. (Deutsches Industrie-Institut Köln. Schriftenreihe. Bd. 3.)

L Handels-Hochschule Mannheim 1907-1932 (1932) S. 23; Wirtschaftswiss. Hochschullehrer (1938) S. 235, 795f. (Bibliographie bis 1937). Heinzmann, Helmut: Das Volkseinkommen. Kritische Betrachtungen ... von 1926 unter ... Berücksichtigung der Schriften von E.S. Masch. geschr. Diss. Tübingen 1951. - Arnim 2 (1952) S. 534; Professoren Kiel (1956) S. 64. • Akademie für Deutsches Recht 1933-1945. Protokolle der Ausschüsse ... Bd. III,3: Ausschuß für Personen-, Vereins- und Schuldrecht. 1934-1936 ...
Hrsg. ... von Werner Schubert. Berlin 1990. S. 78. • Brintzinger (1996) S. 400 (Register); WBIS. • Kotowski, Mathias: Die öffentliche Universität. Veranstaltungskultur der ... Universität Tübingen in der Weimarer Republik. Stuttgart 1999. S. 49 f. u. ö. - UH im Nationalsozialismus (2006) S. 1271 (Register); Schultes (2010) S. 75-77, $321 \mathrm{ff}$. u. ö.; Deutsche Biographie, s. https://www.deutsche-bio graphie.de/gnd133669564.html [10.11.2017].

\section{Schwalbe, Ernst Theodor Karl}

1900-1908 Med. Fak.

Pathologie, Patholog. Anatomie, seit 1903 auch

Geschichte der Medizin

* 26. Jan. 1871 Berlin

$\dagger$ 17. März 1920 Schutow (heute: Ortsteil von Rostock)

ev.-luth.

V Prof. Dr. phil. Bernhard S. (1841-1901) zuletzt Direktor des Dorotheenstädtischen Realgymnasiums Berlin, s. Kurzes Lebensbild in: Schwalbe, Bernhard Georg: Grundriß der Astronomie. Braunschweig 1904. S. V-VII; Hahn, Hermann: Handbuch für physikalische Schülerübungen. 2. Aufl. Berlin 1913. S. 466469 u. ö.

M Elisabeth geb. Kelting

๑ 4. April 1899 Johanna geb. Gempp ( $\left.{ }^{\star} 1871\right)$

K $2 \mathrm{~S}, 3 \mathrm{~T}$

Vw Onkel: Gustav Albert S. (1844-1916) PrivatDozent: seit 1870 Halle/S., seit 1871 Freiburg/ Br.; seit 1872 Assistenz-Prof. Leipzig, seit 18730. Prof. für Anatomie Jena, seit 1881 Königsberg, seit 1883 Straßburg, s. Fischer $2\left({ }^{3} 1962\right)$ S. 1424, WBIS

Vw Enkelin: Dr. Renate Neumüllers-Klauser geb. Klauser (1925-2014) Historikerin, 1963-1990 Mitglied der Inschriftenkommissionen der Akad. der Wiss. H und der Sächsischen Akad. der Wiss. sowie Leiterin der Forschungsstelle „Deutsche Inschriften“ an Akad. der Wiss. $\mathrm{H}$; Verleihung des Ehrentitels „Professor" von UH; Bearb.: Die Inschriften der Stadt und des Landkreises Heidelberg. Stuttgart 1970; siehe Biographie unter http://www.sl97410804.on line.de/Personen/neumuellers.htm. 
Lb Seit WS 1890/91 Studium an U Straßburg; Ostern 1892 Physikum ebd.; Ostern-Herbst 1892 Militärdienstpflicht als Einjährig-Freiwilliger in Berlin (erstes Diensthalbjahr); seit WS 1892/93 Forts. des Studiums an UH, WS 1893/94 Berlin, SS 1894 H; März 1895 med. Staatsexamen in H; 24. Mai 1895 Dr. med. an UH; Aug. 1895-März 1896 Forts. der Militärdienstpflicht als Einjährig-Freiwilliger (Mai 1896 Beförderung zum Assistenzarzt der Reserve).

Seit April 1896 Assistenzarzt am Patholog.-Anatom. Inst. der UH; Okt.-Dez. 1896 Reise nach Ägypten als Begleiter e. erkrankten Freundes; Assistenzarzt: seit Jan. 1897 erneut Patholog.-Anatom. Inst. der UH, seit April 1897 Anatom. Inst. der U Straßburg.

H: Ostern 1898 Rückkehr und Eigenstudien; Assistenzarzt: seit Sept. 1898 Ambulanz der Med. UKlinik, seit Jan. 1899 St. Josefshaus, seit April 1899 Diakonissenhaus, seit Herbst 1899 erneut St. Josefshaus.

UH: April 1900-Aug. 1907 I. Assistenzarzt am Patholog.-Anatom. Inst. bei (siehe) Julius Arnold; 13. Juli 1900 Habilitation; WS 1903/04 erste Ankündigung e. Vorlesung über Ausgewählte Kapitel aus der Geschichte der Medizin; 2. Febr. 1906 Erteilung der Lehrerlaubnis für Geschichte der Medizin durch Akad. Senat mit e. Honorar von 200.Mark für die Vorlesungs- und 10o.- Mark für die Übungsstunde (Nachf. 1908: Paul Ernst), s. $Z$ (1); seit 10. März 1904 nichtetatm. a. o. Prof.; 1907 Verlegung des Wohnsitzes nach Karlsruhe; WS 1907/ o8 letzte Vorlesungsankündigung.

Karlsruhe: Seit 1. Sept. 1907 Leiter (Prosektor) des Patholog.-Bakteriolog. Inst. des Städtischen Krankenhauses.

U Rostock: Seit SS 1908 o. Prof. für Allg. Pathologie und Patholog. Anatomie und Direktor des Patholog. Inst.; Sommer 1912 Ruf an U Königsberg (Preußen) abgelehnt.

$Z$ (1) Erfolgreicher Antrag des Heidelberger Anatomen Julius Arnold vom 18. Dez. 1905 auf Einführung eines Lehrauftrags für Geschichte der
Medizin: „... An der Ruperto Carola traegt Herr Professor extraordinarius E. Schwalbe seit einigen Semestern über Geschichte der Medicin vor; auch literarisch hat er sich durch ein kleines Buch bethaetigt, das allgemeine Anerkennung gefunden hat. Ich erlaube mir deshalb den Antrag zu stellen, Herrn Professor E. Schwalbe einen Lehrauftrag für dieses Fach zu ertheilen mit der Auflage, in dem einen Semester eine 1-2stündige Vorlesung, in dem anderen historische Leseübungen abzuhalten. Eine jaehrliche Remuneration [= Belohnung, Gratifikation] von 500.- bis 600.- Mark schien mir angemessen. Ich bitte die Mitglieder der medicinischen Facultaet diesen Antrag zu unterstützen und an den Engeren Senat gelangen zu lassen“" (aus: UAH PA 2269).

Am 8. Juli 1907 erwidert das Ministerium der Justiz, des Kultus und Unterrichts auf ein befürwortendes Schreiben der Med. Fak. und des Engeren Senats der UH, die Fortführung des Lehrauftrags für Geschichte der Medizin betreffend: „... wir haben ernste Bedenken gegen die sich immer mehr einbürgernde Uebung, dass Privatdozenten der medizinischen Fakultät, die in den Krankenhäusern benachbarter Städte Stellungen als Aerzte oder Prosektoren inne haben, ihre Dozentur an der Universität fortsetzen. Wie die medizinische Fakultät richtig hervorhebt, geht in solchen Fällen der Zusammenhang und das Zusammenarbeiten mit den Fachvertretern der Universität vollständig verloren, und die akademische Stellung wird bei diesen Privatdozenten zur Dekoration.

Wenn wir nun auch dagegen, dass solche Privatdozenten trotz ihrer anderweitigen Beschäftigung und ihres auswärtigen Wohnsitzes ihre Beziehung zur Universität beibehalten, unter der Voraussetzung, dass Fakultät und Senat damit einverstanden sind, zunächst nichts einwenden wollen, so können wir doch in solchen Fällen die unter andern Verhältnissen erteilten Lehraufträge nicht aufrecht erhalten. Wir beabsichtigen auch in diesem Falle den Lehrauftrag auf Schluss des Semesters zurückzuziehen, zumal ein Bedürfnis nach der Vorlesung nach dem schlechten Besuch nicht vorzuliegen scheint" (aus: PA 2269). Nachdem Fakultät und Senat sich für die Fortsetzung des Lehrauftrags aussprechen, setzt $\mathrm{S}$. bis zu seinem Weggang nach Rostock die medizinhistorischen Vorlesun- 
gen und Übungen bis zum Ende des WS 1907/08 fort. - Siehe hierzu auch Hugo Starck: Eintrag unter $L b(\mathrm{UH})$

Z (2) S. wird am 17. März 1920 als Hauptmann und Führer einer Zeitfreiwilligenabteilung bei einem Feuergefecht mit Rostocker streikenden Arbeitern vor Rostock erschossen, siehe hierzu Rostocker Arbeiter schlagen den Kapp-Putsch nieder ... Rostock ca. 1955. S. 65. S. hinterläßt neben der Witwe fünf minderjährige Kinder.

E 1902 Regierungs-Jubiläums-Medaille Großherzog Friedrichs I. von Baden.

Qu UAH PA 2269; RA 4763f., 6177; Fak.-Akte HIII-111/123. GLA Abt. 235, Fasz. 2520. Auskunft: Stadtarchiv Rostock (standesamtlicher Sterbeeintrag 1920). Mitteilungen: Frau Dr. Renate Neumüllers-Klauser $(\dagger)$, Heidelberg.

$W$ Untersuchungen zur Blutgerinnung. Beiträge zur Chemie und Morphologie der Coagulation des Blutes. Braunschweig 1900. - Vorlesungen über Geschichte der Medizin. Jena 1905. 3. Aufl. 1920. Die Doppelbildungen. Jena 1907. Kleinlebewesen und Krankheiten. Jena 1908. Der Krieg als Erzieher. Über Volksernährung im Kriege und andere Kriegsnotwendigkeiten ... Zum Besten der Nähstube des Frauenvereins (Kriegs-NotstandsHilfe). Rostock 1915. Bibliographie in: Hanser, R.: E. S. ... in: Verhandlungen der Deutschen Pathologischen Gesellschaft (1937) S. 553-555.

HG Festschrift für Julius Arnold. Jena 1905. • 1906-1909 Die Morphologie der Mißbildungen des Menschen und der Tiere. 3 T. Jena 1906-1909.

MHG Handbuch der allgemeinen Pathologie und der pathologischen Anatomie des Kindesalters. 2 Bde. in 5 Abt. Wiesbaden 1912-1924.

$L$ Biogr. Jahrbuch 2 (1917-1920) S. 760; Stübler (1926) S. 327; WBIS. - Nekrolog in: Deutsches biographisches Jahrbuch. Hrsg. vom Verband der Deutschen Akademien. Bd. 2: 1917-1920. Stuttgart 1928. S. 760. Willgeroth, Gustav: Die mecklenburgischen Ärzte von den ältesten Zeiten bis zur Gegenwart. Schwerin 1929. S. 309. • Engel, Els- bet: Einige Cephalothoracopagi bei Säugetieren. Berlin 1931. S. 704-706, 722. • Hanser, R.: E.S. ... in: Verhandlungen der Deutschen Pathologischen Gesellschaft ... Berlin 1937. S. 549-555 (Ausdruck im UAH; S. 549: hier irrtümlich 20. Jan. als Geb.Tag genannt). Arnim 2 (1952) S. 535. Über E.S. in: Handbuch der Inneren Medizin. 4. Aufl. Neurologie. 1. T. Bearb. von R. Brun ... Berlin 1953. S. 1438 (Register). - Rostocker Arbeiter schlagen den Kapp-Putsch nieder. Die vorliegende Arbeit wurde von Mitarbeitern des Instituts für Gesellschaftswissenschaften an der Universität Rostock geschaffen. Verfasserkollektiv: Günter Heidorn (Leiter), Rudolf Kretschmar ... Hrsg. von der Bezirksleitung Rostock der Sozialistischen Einheitspartei Deutschlands/SED, Abt. Agitation und Propaganda. Rostock ca. 1955. S. 66-68, 75-77. • Schönfeld, Walther: Medizingeschichtliche Vorlesungen in Heidelberg im 19. und 20. Jahrhundert bis zur Errichtung des planmäßigen Extraordinariats für Geschichte der Medizin in: Heidelberger Jahrbücher 5 (1961) S. 104-113. • Fischer $2\left({ }^{3} 1962\right)$ S. 1424. Polzin, Martin: Kapp-Putsch in Mecklenburg. Junkertum und Landproletariat in der revolutionären Krise nach dem 1. Weltkrieg. Rostock 1966. S. 122, 311 Anm. 3. Chronik Ärzte H (1985) S. 142. D'Orazio, Ugo: E. S. ... - Ein Kapitel aus der Geschichte "nicht professioneller" Medizingeschichte in: Eine Wissenschaft emanzipiert sich. Die Medizinhistoriographie von der Aufklärung bis zur Postmoderne. Hrsg. von Ralf Bröer. Pfaffenweiler 1999. S. 235-247. - Nizze, Horst: Pathologie in Rostock in: Verhandlungen der Dt. Gesellschaft für Pathologie 88 (2004) S. 10-25. Eckerl, Michael Lukas: Nötig oder nützlich? Legitimierungsstrategien der deutschsprachigen Medizingeschichte im 20. und 21. Jahrhundert. Med. Diss. Ulm 2014. S. 17, 32 f., 40 f., 64 f., 67, 109. • Catalogus prof. Rostochiensium online (hier als Todestag 16. statt 17. März angegeben); Deutsche Biographie, s. https://www.deutsche-biographie.de/gnd11 7342203.html [10.11. 2017].

$P$ Bildarchiv UAH. 


\section{Schwarz, Friedrich Heinrich Christian}

1804-1837 Theol. Fak.

Neues Testament, Pädagogik

* 30. Mai 1766 Gießen

$\dagger \quad$ 03. April 1837 Heidelberg ev.-luth.

V Johann Georg Gottlieb S. (1734-1788), u.a. 1771-1773 a.o. Prof. für Theologie Gießen, seit 1777 Pfarrer in Alsfeld, s. WBIS; Friedrich Heinrich Christian Schwarz: Lehrbuch der Erziehungs- und Unterrichtslehre. Besorgt von Hans-Hermann Groothoff ... Paderborn 1968. S. $380 \mathrm{of}$.

M Maria Wilhelmina Hedwig geb. Strecker (17401819)

$\infty$ 13. April 1792 Johanne Magdalene Margarethe geb. Jung (1773-1826) T von Johann Heinrich Jung gen. Stilling (1740-1817) Schriftsteller, Arzt, u. a. $1784-1787$ Prof. an UH, s. Drüll (1991) S. 80-82; Merk, Gerhard: Jung-Stilling e. Umriß seines Lebens. 2. Aufl. Siegen 2013; Waldenmaier, Hermann: H.J.-S. Einer nur weiß Weg und Ziel. Das Leben e. ungewöhnlichen Menschen. Stuttgart 2013; J.H. J.-S. „... weder Calvinist noch Herrnhuter noch Pietist“. Fromme Populartheologie um 180o. Hrsg. von Veronika Albrecht-Birkner. Leipzig 2017.

K 10, u.a. Wilhelm S. (1793-1873) Pfarrer, s. Pfeiffer (2004) S. 157; Schwinge, Gerhard: Traditionelle Christlichkeit und liberaler Geist in: Mannheimer Geschichtsblätter 21/2011 (2011) S. 11-30.

Vw Siehe Schwinge (2011) S. 20-23.

Lb Gießen: Seit Frühjahr 1783 Studium der Theologie, Philosophie, Philologie an U; 1785/86 theol. Kandidaten-Examen.

Alsfeld: Frühjahr 1786 Rückkehr nach A. wegen "häuslicher Pflichten“; Ostern 1788 Ordination als Freiprediger; seit März 1788 Hilfsprediger als Nachf. seines verstorbenen Vaters.
Hessen: Seit Herbst 1788 Pfarrer in Dexbach (heute: Ortsteil von Biedenkopf bei Marburg); seit Sommer 1795 II. Pfarrer in Echzell (bei Friedberg); seit Frühjahr 1798 Pfarrer in Münster (heute: Stadtteil von Butzbach).

UH: 9. Aug. 1804 Ern. zum o. Prof., s. hierzu UAH RA 6718 fol. 4V, 5r; seit SS 1807 (Mitbegründer und) Mit-Direktor (bis 1810 zus. mit Friedrich Creuzer) des Philolog.-Pädagog. (auch: Pädagog.-Philolog.) Seminars, s. UAH RA 6122; SS 1810 Trennung in ein Philolog. Seminar unter Creuzer und ein Pädagog.(-Katechetisches) Seminar unter S. (Leiter bis 1837), s. hierzu GLA Abt. 235, Fasz. 3260; seit 1809 außerdem Sekretär des Ephorats (Aufsichtsgremium über das sittliche Verhalten und den Fleiß der Akademiker und Studenten); Rufe abgelehnt: 1809 als Superintendent und Ordinarius nach Greifswald, 1818 U Bonn, 1834 Berlin. • In dieser Zeit:

H: Seit ca. 1807 Direktor der Ev.-Luth. Schule, s. RA 6122 fol. 2 r.

1788-1820 (Gründer und) Vorsteher einer „häuslichen Erziehungsanstalt“, die er „von Ort zu Ort verpflanzte“, s. RA 6122 fol. 2r; WBIS.

1811, 1820, 1836 Prorektor der UH; 1806, Sept.-Dez. $1807,1809,1812,1815,1818,1821,1824,1828,1834$ Dekan der Theol. Fak. der UH

1821 Abgeordneter der Badischen Generalsynode in Karlsruhe

1805 Kirchenrat; 1819 Geh. Kirchenrat

E 1790 Mitglied der Literarischen Gesellschaft zu Mainz. Mai 1807 D. theol. UH; nach 1807 Dr. phil. h. c. Marburg.

$Q u$ UAH PA 2272; RA 6372, 6718 fol. 4v, 5r, 10v, 11r u. Ö.; Theol. Fak. 5 fol. 3-4. GLA Abt. 205, Fasz. 498, 536, Abt. 235, Fasz. 2506. • Briefe: UBH. • Jean Pauls Sämtliche Werke ... Band 6: Briefe an Jean Paul 1809-1814. Hrsg. von Angela Steinsiek und Michael Rölcke. Berlin 2012. S. 54, 142, 384, 553, 
1060, 1064, 1072 u.ö. • Auskunft: Ev. Kirchengemeindeverband Gießen. - Autobiographisches in: Strieder, Friedrich Wilhelm: Grundlage zu einer hessischen Gelehrten- und Schriftsteller-Geschichte. 14. Bd. Cassel, Marburg 1804; Forts. in: Justi, Karl Wilhelm: Forts. zu Strieder's Hessischer Gelehrten- und Schriftsteller-Geschichte ... 19. Bd. Marburg 1831. S. 607-622. - Schwarz, Lina: Erinnerungen aus mündlichen Mitteilungen meiner Eltern Schwarz. Heidelberg 1863.

$W$ Grundriß einer Theorie der Mädchenerziehung in Hinsicht auf die mittleren Stände ... Jena 1792. 2. Aufl. u.d. T.: Grundsätze der Töchtererziehung für die Gebildeten. Jena 1836. Gebrauch der Pestalozzischen Lehrbücher beim häuslichen Unterricht und in Volksschulen. Gießen 1804. • Lehrbuch der Pädagogik und Didaktik. Heidelberg 1805. 3. Aufl. u.d.T.: Lehrbuch der Erziehungsund Unterrichtslehre. Heidelberg 1835. 2 Bde. 8. Aufl. 1880-1882. Neudr. 1968. Evangelischchristliche Ethik. Heidelberg 1821. 2 Bde. 3. Aufl. 1836-1837. - Das Leben in seiner Blüte, oder Sittlichkeit, Christentum und Erziehung in ihrer Einheit. Leipzig 1837.

$M G$ 1808 Heidelbergische Jahrbücher der Literatur.

HG 1824-1827 Jahrbücher der Theologie und theologischen Nachrichten.

MHG 1819-1829 Freimütige Jahrbücher für das Volksschulwesen.

L Arnim 2 (1952) S. 536. Schwarz, Maria: Die Lehrtätigkeit meiner Vorfahren Johann Heinrich Jung und F.H.C.S. an der Universität Heidelberg. Freiburg/Br. 1961. (Sonderdruck im UAH.) • F.H.C.S. Lehrbuch der Erziehungs- und Unterrichtslehre. Besorgt von Hans-Hermann Groothoff ... Paderborn 1968. S. 373-477. - Lenhart, Volker: Die Pädagogik als wiss. Disziplin an der Ruprecht-Karl-Universität Heidelberg 1803-1970 in: Heidelberger Jahrbücher 15 (1971) S. 151-156. • Handbuch der historischen Buchbestände in Deutschland. Hrsg. von Bernhard Fabian. Hildesheim 2003. • WBIS; RGG 7 ( $\left.{ }^{4} 2004\right)$ • Gersdorff,
Dagmar von: „Die Erde ist mir Heimat nicht geworden. "Das Leben der Karoline von Günderrode. Frankfurt/M. 2006. S. 283 (Register). - Lenhart, Volker: F.H.C.S. und die Gründung des Philolog.-Pädagog. Seminars 1807. Vortrag auf der Jubiläumsveranstaltung „200 Jahre institutionalisierte wiss. Pädagogik und Lehrerbildung an der Universität Heidelberg“, online unter www2. ibw.uni-heidelberg.de/feldevaluationog/jubilae um.pdf vom 24. April 2007. - Schwinge, Gerhard: „Freundlich und ernst“. F.H.C.S. Theologieprofessor und Pädagoge ... Heidelberg 2007; Ders.: Int. Wissenschaftsaustausch um 1830. Ein Beispiel: ... F.H.C.S. in: Zs. für Religions- und Geistesgeschichte 6o. Jg., H. 4 (2008) S. 330-343; Ders.: S., Marheineke, Ewald, Abegg, Hüffell. Zur Vorgeschichte des ersten badischen Predigerseminars in Heidelberg zwischen 1807 und 1818 bzw. 1818 und 1838 in: Praktische Theologie und Landeskirchengeschichte ... Berlin 2008. S. 281-292. • BBKL XXXIII (2012) Sp. 1221-1226. Ehmann, Johannes: Die badischen Unionskatechismen. Vorgeschichte und Geschichte vom 16. bis 20. Jhdt. Stuttgart 2013. S. $192 \mathrm{ff}$.

P Bildarchiv UAH; graph. Slg. UBH.

\section{Schwarzacher, Walther Friedrich Rupert Maria}

1927-1936 Med. Fak.

Gerichtsmedizin

* 03. April 1892 Salzburg-Mülln

$\dagger$ 04. Juli 1958 Wien

kath.

V Friedrich S. (1864-1944) Rechtsbeamter, Reg.Rechnungs-Revident (österr. Amtstitel für e. Beamten), Hofrat

M Franziska geb. Zimmermann (1869-1939)

(1) 14. Mai 1922 Hedwig geb. Peyrer von Heimstatt (1895-1973) 
K 3 S: Wolfgang S. (1922-1997) Architekt, s. Tragl, Karl Heinz: Chronik der Wiener Krankenanstalten. Wien 2007. S. 570. - Walther S. $\left({ }^{*} 1925\right)$ The Queen's University of Belfast (Nord Irland): seit 1951 Lector für Sedimentologie, Stratigraphie und Mineralogie, seit 1964 Reader für Sedimentologie, 1975-1991 (Emeritierung) o. Prof. für Math. Geologie, s. Whitten, E.H. Timothy: Association Announcements. Second William Christian Krumbein/Medallist: W.S. in: Mathematical Geology (1978) Vol. 10, No. 4, S. 391 f. Hans Georg (Jürg) S. $\left({ }^{\star} 1928\right)$ seit 1959 Privat-Dozent für Anatomie, Histologie und Embryologie U Basel, seit 1961 Wien, seit 1966 Prof. für Anatomie Gießen, seit 1969 Bonn, 1971-1996 (Emeritierung) Ordinarius für Embryologie und Histologie U Wien

Vw Enkel: Dr. Trude Schwarzacher ( $\left.{ }^{*} 1956\right)$ 19942000 Research Project Leader am John Innes Centre in Norwich (Großbritannien), 20012014 Lecturer am Dept. of Biology, seit 2015 Honorary Lecturer am Dept. of Genetics der University of Leicester. - Stephan Wolfgang S. $\left({ }^{*} 1959\right)$ seit 2012 Privat-Dozent für Anatomie U Frankfurt/M. - Walther S. $\left({ }^{*} 1964\right)$ seit 1991 Lecturer, Reader, Prof. für Physik an University of Bristol (Großbritannien), s. http://www. bristol.ac.uk/physics/people/walther-schwar zacher/index.html (abgerufen am 11. Nov. 2017).

Lb 1911-1912 Militärdienstpflicht als EinjährigFreiwilliger.

SS 1912 Studium zunächst der Mathematik, Physik am Polytechnikum Wien; seit WS 1912/13 Studium der Medizin an U Wien; 1. Aug. 1914-Dez. 1918 Kriegsdienst; seit WS 1918/19 Forts. des Medizin-Studiums an U Graz; Nov. 1919 Staatsexamen in Graz.

U Graz: Seit 1. Jan. 1920 Assistenzarzt, seit 1. April 1924 o. Assistenzarzt (Prosektor) am Inst. für Gerichtliche Medizin; 2. März 1920 Dr. med.; 22. Sept. 1923 Habilitation; 1923-1927 Privat-Dozent; 1923/ 24 Beurlaubung zu Studienzwecken an Inst. für Gerichtliche Medizin und Inst. für PhysikalischChemische Biologie in Wien. • In dieser Zeit:
Graz: Herbst 1920-Herbst 1927 Beeideter Sachverständiger und Landesgerichtsarzt am Oberlandesgericht.

UH: 11. Nov. 1927 Ern. zum WS 1927/28 planm. a. o. Prof. und Direktor des neugegründeten Inst. für Gerichtliche Medizin; 1. Febr. 1928 Antrittsvorlesung; SS 1928-WS 1935/36 S. hält Vorlesungen über „Gerichtliche Medizin für Juristen mit Demonstrationen“ an Med. Fak.; 7. Febr. 1931 „Die Ern. des planm. Prof. ... S. zum persönlichen Ordinarius muss aus grundsätzlichen Erwägungen zurückgestellt werden“" (aus: Schreiben des Ministers des Kultus und Unterrichts in: UAH PA 5205 (Oehme); siehe hierzu auch Z); 20. März 1932 Ruf an U Halle-Wittenberg abgelehnt; 22. April 1932 Ern. zum o. Prof.; SS 1930-WS 1931/32 Gastvorlesungen für Gerichtliche Medizin an Med. Fak. der U Freiburg/Br.; WS 1935/36 letzte Vorlesungsankündigung an $\mathrm{UH}$. $\bullet$ In dieser Zeit:

26. März 1928-1936 Gerichtsarzt in den Bezirken der Landgerichte H, Mannheim, Mosbach, Karlsruhe sowie ständiges Mitglied des gerichtsärztlichen Ausschusses.

U Graz: 1. März 1936 Ern., seit SS 1936 persönlicher o. Prof. und Direktor des Inst. für Gerichtl. Medizin; 31. Aug. 1938 Entlassung aufgrund S.s. antinationalsozialistischer Einstellung.

Seekirchen am Wallersee (Österreich): 1938-1945 Privat-Gelehrter (math.-physikal. Forschungen).

Salzburg: 11. Juni 1945-6. Febr. 1946 Prosektor und Leiter der bakteriolog.-serolog. UntersuchungsAnstalt an Landeskranken-Anstalten.

U Graz: SS 1945 Rückberufung und Wiedereinsetzung als o. Prof.

U Wien: 1. Okt. 1946 (Ern.)-1958 (†) o. Prof. und Direktor des Inst. für Gerichtl. Medizin.

$Z$ Der Heidelberger Ordinarius für Pathologie Alexander Schmincke schlägt S. zur Verleihung des Titels e. o. Professors in einem Brief vom 17. Dez. 1930 an Rektor Karl Meister vor: „... Die Gründe, die mich zu meinem Antrag bewegen, sind sachlicher wie persönlicher Art. Zur Sache lässt sich an- 
führen, dass die gerichtliche Medizin sich immer mehr als für den Medizinstudierenden grundsätzlich wichtiges Unterrichtsfach erweist. Der Arzt braucht nicht nur gerichtlich-medizinische, sondern vor allem auch sozial-medizinische Kenntnisse, die ihm in den Kollegien über gerichtliche Medizin vermittelt werden. Der immer mehr zunehmenden Bedeutung des Fachs ist ja auch von der Fakultät dadurch Rechnung getragen, dass der Vertreter der gerichtlichen Medizin als Prüfer im Doktorexamen figuriert. Die Tendenz der deutschen Aerzteschaft geht dahin, grundsätzlich auch die Prüfung für gerichtliche Medizin im Staatsexamen zu fordern. Die Bedeutung des Fachs ist also eine derartige, dass seine Vertretung durch einen Ordinarius in der Fakultät berechtigt erscheint.

Herr Prof. S. hat sich während seiner Tätigkeit in Heidelberg durch sein wissenschaftliches und persönliches Auftreten eine ausgezeichnete Position geschaffen. Er hat auch dadurch grosse Verdienste, dass er die gerichtliche Medizin des ganzen Landes Baden an Heidelberg verknüpft hat, da er zugleich auch den gerichtlich-medizinischen Unterricht in Freiburg gibt. Von seinen Fachgenossen wird er hochgeschätzt, was schon auch daraus hervorgeht, daß er bei den Vakanzen der letzten Zeit in lebhafteste Erwägung gezogen wurde. Seine persönlichen und wissenschaftlichen Qualitäten sind derartige, dass der Vorschlag zum persönlichen Ordinarius hierdurch die gebührende Unterlegung erfährt" (aus: UAH PA 1177). 1932, knapp $2^{1 / 2}$ Jahre nach diesem Schreiben - nach Ablehnung eines Rufes an die Universität Halle-Wittenberg - erfolgt die Ernennung S.s zum Ordinarius.

E 1946 Mitglied der Österr. Akademie der Wissenschaften Wien (ebenfalls Mitglieder der Akademie: S.s Söhne Walther jun. und Hans Georg). • 1918 Bronzene und silberne Militärverdienstmedaille mit Schwertern.

Qu UAH PA 1177, 5835. Mitteilungen: Herr Prof. em. Dr. Walther Schwarzacher, Belfast; Frau Dr. Trude Schwarzacher, Leicester.
$W$ Die Anwendung der spektrophotometrischen Blutuntersuchung in der gerichtlichen Medizin in: Dt. Zeitschrift für die gesamte gerichtliche Medizin 1 (1922), 2 (1923). • Über traumatische Markblutungen des Gehirns in: Journal für Psychiatrie und Neurologie (1923). - Die Methoden der forensischen Haaruntersuchung in: Handbuch der biologischen Arbeitsmethoden. Hrsg. von Emil Abderhalden. 4. Abt., T. 12, 2. Hälfte (1934) S. 157176. Beiträge zur Physik des Messerstiches in: Sitzungsberichte der Akademie der Wissenschaften in Wien. Math.-Naturwiss. Klasse. Abt. IIa. 151. Bd. H. 7 und 8. Wien 1942. S. 170-196.

HG 1946-1958 Wiener Beiträge zur gerichtlichen Medizin.

$L$ Reuter, Fritz: W.S. als Forscher und Lehrer in: Beiträge zur Gerichtlichen Medizin 19 (1952) S. 2 ff. - Kürschner (1931) Sp. 2742, (1954) Sp. 2191, (1961) S. 2390. - Nachruf in: Almanach der Akademie der Wissenschaften Wien (1958) S. 431-440 (mit Werkverz.). - Nachruf in: Wiener klinische Woche 70 (1958) S. 983 f. - Reuter, Fritz: W. S. $\dagger$ in: Dt. Zs. für gerichtliche Medizin 48 (1959) S. 181187 (mit Werkverz.). • Fischer 2 ( $\left.{ }^{3} 1962\right)$ S. $1427 \mathrm{f}$;; Chronik Ärzte H (1985) S. 142; Jansen (1992a) S. 169 (Register) - Geschichte gerichtl. Medizin (1996) S. 442-444 u. ö.; WBIS.

$P$ Bildarchiv UAH; Chronik Ärzte H.

\section{Schweins, Franz Ferdinand}

1810-1856 Phil. Fak.

Mathematik

* 24. März 1780 Fürstenberg (bei Paderborn)

$\dagger \quad$ 15. Juli 1856 Heidelberg kath.

V Franz S. (1745-1813) Schreinermeister

M Gertrud geb. Weitekamp (1753-1824)

$\infty$ 22. Nov. 1826 Catharina Barbara geb. Bellosa (1790-1869)

$\mathrm{K} \quad 1 \mathrm{~T}$ 
Lb Kassel: 1801 Studium an Akademie der Zeichnenden Künste.

Göttingen: Seit 1802 Studium der Mathematik an U; Sept. 1806-April 1809 Privat-Lehrer für verschiedene elementarmath. Gegenstände; 9. März 1807 Dr. phil. an U.

Darmstadt (?): 1809/10 Aufenthalt.

UH: Seit 5. Febr. 1810 Privat-Dozent; seit 5. Sept. 1811 a. o. Prof.; 1815 Ruf an U Greifswald abgelehnt; 4. Jan. 1816 Ern. zum persönlichen o. Prof.; seit 1835 o. Prof. als Nachf. von Christian von Langsdorf(f).

1843 Prorektor der UH; 1819, 1825, 1832, 1838, 1846 Dekan der Phil. Fak. der UH

1821 Hofrat; 1844 Geh. Hofrat; 1851 Geh. Rat II. Klasse

E 1843 Ritterkreuz des Ordens vom Zähringer Löwen.

Qu UAH PA 2273; RA 126, 5005, 6475 f., 6595, 8362 u. ö. GLA Abt. 205, Fasz. 500.

$W$ Geometrie nach einem neuen Plane bearbeitet, aus den Schriften der alten und neuen gesammelt ... 2 Bde. Göttingen 1805-1808. Handbuch der Geodäsie. Gießen 1811. • Analysis. Heidelberg 1820. Theorie der Differenzen und Differentiale ... Heidelberg 1825 .

$L$ Badische Biographien 2 (1875) S. 293; ADB 33 (1891) S. 364; Keller (1913) S. 206 f.; Catalogus prof. Gottingensium (1962) S. 136; WBIS; Math. Institute in Deutschland (1989) S. 289 (Register). Cantor, Moritz: F.S. und Otto Hesse. Neu hrsg. von Gabriele Dörflinger. UB Heidelberg 2009, s. online http://www.ub.uni-heidelberg.de/archiv/12978. • Deutsche Biographie, s. https://www.deutsche-bio graphie.de/gnd117402966.html [10.11. 2017].

$P$ Bildarchiv UAH; graph. Slg. UBH.

\section{Sebastian, Friedrich Jacob Christian}

1814-184o Med. Fak.

Pathologie, Therapie, Semiotik

* 24. Nov. 1771 Heidelberg

$\dagger \quad$ 25. Sept. 1840 Heidelberg ev.-luth.

V Dionysius S. (1739-1795) Arzt

M Jacobina Catharina geb. Berthold

œ Henriette Maria geb. Goßmann (1785-1874)

K 1 S, 1 T: Anna Jacobina S. (1803-1889) in 1. Ehe verh. mit Karl Josef Weber (1798-1831) PrivatDozent für Rechtswiss. UH, s. Emundts-Trill (1997) S. 237; in 2. Ehe verh. mit (siehe) Friedrich Creuzer.

Lb Seit Dez. 1788 Studium an UH; vor 1793 Studium an Gebäranstalt in Mannheim (s. hierzu Franz Anton Mai); 18. März 1793 Dr. med. an UH.

Chirurgie-Major: 1793 Regiment Oranien-Friesland, 1794 Regiment Randwyk.

Leiden: Nach 1795 Lehrer an Militärärztlicher Schule.

Walcheren (Insel der Provinz Seeland): Vor 1810 Leiter e. Militärhospitals; 1810 Quittierung des Militärdienstes aus gesundheitlichen Gründen.

Leiden: Seit 1810 Wohnsitz.

H: Seit 1811 Wohnsitz.

UH: Seit 3. März 1814 a. o. Prof.; seit 25. Juni 1816 o. (zweiter) Prof.; 1823-1824 kommissar. Leiter des Med.-Klinischen Inst. bzw. der Med. Klinik im Akad. Hospital in Nachf. von Wilhelm Heinrich Conradi.

1821, 1826, 1832 Dekan der Med. Fak. der UH

1825 Hofrat 
Qu UAH PA 2277, 2285; RA 6477 S. 59 (1799). GLA Abt. 205, Fasz. 502.

$W$ Onderzoek der gronden, voor eene Veronderstelde Wederopneming van Zenuwvrocht door de Watervaten, en der nuttige Gevolgen, welke daaruit voor de Genees- en Heelkunde zouden kunnen afgeleid worden. Amsterdam 1811. Über die Sumpfwechselfieber ... Karlsruhe 1815. • Grundriß der allgemeinen pathologischen Zeichenlehre. Darmstadt 1819.

$L$ Badische Biographien 2 (1875) S. 294f.; Stübler (1926) S. 262 f.; Chronik Ärzte H (1985) S. 143; WBIS. - Mülker, Petra: Friedrich A.B. Puchelt ... Biographie und Ergographie ... Diss. Heidelberg 1992. S. 8, 11, 108. - Prückner (2004) S. 23, 264; Deutsche Biographie, s. https://www.deutsche-bio graphie.de/gnd100271820.html [10.11. 2017].

$P$ Bildarchiv UAH; graph. Slg. UBH; Chronik Ärzte H.

\section{Seeger, David Dionysius Friedrich Josef}

1805-1813 Staatswirtschaftl. Sektion

Kameralwissenschaft, Staatswirtschaftliche Politik

* 07. Dez. 1781 Stuttgart

$\dagger$ 20. Dez. 1813 Heidelberg

ev.-luth.

V Joseph Gottlieb S., Rent- bzw. Hofkammersecretair

M Josepha Friederica geb. Rall

$\infty$ 15. Sept. 1805 Friederica Dorothea Loysa geb. Wundt (1782-1809) T von: (siehe) Johannes Carl Casimir W. (1744-1784), u. a. 1776-1784 o. Prof. für Schöne Wissenschaften, Philosophie, Kirchengeschichte an UH, s. UAH RA 1117, 6716; Drüll (1991) S. 174-178, Maesel (1997) S. 241 u. ö.

$\mathrm{K}$ keine.

Lb UH: Seit 17. Okt. 1801 Studium der Kameralwiss.
Ellwangen: Seit 1803 Hofkammersecretair und Taxcontrolleur.

UH: Seit 1805 a.o. Prof. (Mai 1803 Einführung der Staatswirtschaftl. Sektion nach Eingliederung der "Staatswirtschafts Hohe Schule" $\mathrm{H}$ in UH); seit 24. Nov. 1810 o. Prof.; 1812 Dr. phil.

1812 Direktor der Staatswirtschaftl. Sektion der UH; zur Staatswirtschaftl. Sektion der UH, siehe Heinrich Eschenmayer und Ludwig Wallrad Medicus: Einträge unter $Z$ [itat]

Qu UAH PA 2279; RA 6600, 6634. - Toepke IV (1903) S. 376 („aliter von Seeger“). GLA Abt. 205, Fasz. 503.

$W$ System der Wirtschaftslehre. Karlsruhe 1807. Entwurf der Staatswissenschaft. Heidelberg 1810. Versuch über das vorzüglichste Abgabensystem. Gekrönte Preisschrift. Heidelberg 1811. 3. Aufl. Karlsruhe 1815.

$L$ Heidelbergische Jahrbücher der Literatur (1813) 6. Jg., 2. Hälfte, hierin: Intelligenzblatt 1813 , Nr. 1, S. 1; Wechmar (1846) S. 253; Stieda (1906) S. $141 \mathrm{f}$. u. ö.; Keller (1913) S. 204; Schneider (1913) S. 120; WBIS. • Jenetzky, Johannes: System und Entwicklung des materiellen Steuerrechts in der wissenschaftlichen Literatur des Kameralismus 16801840 ... Berlin 1978. S. 114f., 194-196, 222 f. u. ö. • Neuhaus (2014) S. 72 f. u. ö.

\section{Seidel, Paul Erich}

1914-1932 Med. Fak.

Augenheilkunde

* 30. Dez. 1882 Apolda

$\dagger \quad$ 26. Febr. 1946 Jena

ev.

V Dr. Gustav Heinrich S. (1848-1909) praktischer Arzt, Wundarzt, Geburtshelfer, SanitätsRat

M Melanie Therese Emilie Helene geb. Bürgel $\left({ }^{*} 1860 \dagger\right.$ nach 1909$)$ 
(0) 16. Sept. 1909 Ilse geb. Wiedemann $\left({ }^{*} 1887\right)$ $\mathrm{T}$ von Paul W., Wollwarenfabrikant und Mitinhaber der Fa. Christian Zimmermann \& Sohn, Apolda

K $\quad 1 \mathrm{~S}, 1 \mathrm{~T}$

Lb April-Okt. 1902 Halbjährige Militärdienstpflicht als Einjährig-Freiwilliger in Berlin („zweite Hälfte wegen Überschreitung der gesetzlich vorgeschriebenen Frist infolge Blinddarmentzündung nicht abgedient“ aus: Lebenslauf in: UAH PA 5854).

Seit WS 1902/03 Studium an Kaiser-WilhelmsAkademie für das militärärztliche Bildungswesen in Berlin, SS 1904 an U Berlin, seit WS 1904/o5 Erlangen, anschl. Straßburg, Leipzig, zuletzt Jena.

U Jena: 1907 Dr. med.; Mitte Mai 1907 Staatsexamen; seit Mitte Mai 1907 Assistent an U-Kliniken.

Apolda: 1. Nov. 1908-1. April 1910 Praktischer Arzt in Vertretung des erkrankten Vaters.

U Jena: Seit 1. April 1910 Assistent an Augenklinik.

UH: Seit 1. Okt. 1910 Klinischer Assistent, SS 1919WS 1931/32 Klinischer Oberarzt an U-Augenklinik; 8. Nov. 1911 Verleihung der Beamteneigenschaft; 27. April 1914 Habilitation; seit 26. Juli 1919 nichtetatm., 1920-1932 nichtplanm. a.o. Prof. - In dieser Zeit:

1914-1918 Kriegsdienst.

U Jena: 1. April 1932-1946 (†) o. Prof. und Direktor der Augenärztlichen Klinik und Poliklinik.

Qu UAH PA 1179, 5854. GLA Abt. 235, Fasz. 2511.

$W$ Über Lidbildung mittelst übertragener stielloser Hautlappen. Diss. Jena 1907. - Methoden zur Bestimmung des intraokularen Druckes in: Handbuch der biologischen Arbeitsmethoden Abt. 5, T. 6, H. 7 (1927). • Tränenorgane in: Handbuch der speziellen pathologischen Anatomie und Histologie 11 (1931) S. 281-358.

$L$ Stübler (1926) S. 323; Kürschner (1935) Sp. 1293 , (1940/41) Sp. 1273; WBIS; Fischer $2\left({ }^{3} 1962\right)$ S. 1435;
Chronik Ärzte H (1985) S. 143. „Im Dienst an Volk und Vaterland“. Die Jenaer Universität in der NS-Zeit. Hrsg. von Uwe Hoßfeld ... Köln 2005. S. 138, 160, 162. Rohrbach, Jens Martin: Augenheilkunde im Nationalsozialismus. Stuttgart 2007. S. 69,71 .

\section{Semer, Martin Tobias Engelbert}

1786-1803 Phil. Fak.

1803-1822 Staatswirtschaftl. Sektion

1822-1835 Phil. Fak.

Nationalökonomie, Statistik, Staatswirtschaft

* Nov. 1759 Schongau (Oberbayern)

$\dagger$ 18. Jan. 1837 Heidelberg kath.

V Ulrich S., Weingastgeber

M N.N.

( unverheiratet

Vw Bruder: Georg Franz Xaver S. (1755-1805) 1772-1783 (Austritt) Jesuit, seit 1781 a. o. Prof., seit 1783 o. Prof. für Staats- und Lehnrecht, Rechtsgeschichte, Natur-, Staats- und Völkerrecht Ingolstadt, s. Biogr. Lexikon der U München T. I (1998) S. 395 f., WBIS.

Lb Seit 8. Nov. 1781 Studium an „Kameral Hohe Schule“ zu Lautern (heute: Kaiserslautern); vor 1786 Advokat in Straubing (bei München).

Staatswirtschafts Hohe Schule H und Phil. Fak. der UH: Seit 9. Okt. 1786 a. o. Prof. (1784 Verlegung der „Kameral Hohe Schule“ zu Lautern nach H und Angliederung als Staatswirtschafts Hohe Schule an Phil. Fak. der UH); seit 18. Nov. 1790 o. Prof. mit e. Besoldung von 300.- Gulden in Nachfolge von Ludwig Erb; Mai 1803 Eingliederung der „Staatswirtschafts Hohe Schule“ in U als Staatswirtschaftl. Sektion.

UH: Seit Mai 1803 o. Prof. an Staatswirtschaftl. Sektion; Mai 1822 Zusammenlegung der Staatswirtschaftl. Sektion mit Phil. Fak.; seit Mai 1822 o. Prof. an Phil. Fak.; zwischen SS 1830 und zuletzt SS 1835 einstündige wöchentliche Vorlesungsankündigungen über „Physiokratie, nach Anlei- 
tung der Staatswirthschaftslehre von [Theodor Anton Heinrich] Schmalz, Berlin 1818“, s. Anzeige der Vorlesungen der Badischen Ruprecht-KarlsUniversität zu Heidelberg ..., welche im Sommerhalbenjahre 1830 ... auf der ... Universität zu Heidelberg gehalten werden sollen. Heidelberg 1830. S. 18 f., ... im Sommerhalbenjahre 1835 ..., S. 16. • In dieser Zeit:

UBH: Sommer 1805-Herbst 1808 Bibliothekar als Nachf. von Peter Wolfter (1803-18o8 Einsetzung e. Kommission, deren Mitglieder die Bibliothek unmittelbar leiten; 1808 Einsetzung e. I. Oberbibliothekars als Vorstand der UB (s. Friedrich Wilken), Kommission wird 1830 wieder eingesetzt, s. Joseph Eiselein).

1794, 1796, 1800 Dekan der Phil. Fak. der UH; 1809, 1815, 1819, 1820 Direktor der Staatswirtschaftl. Sektion der UH; zur Staatswirtschaftl. Sektion der UH, siehe Heinrich Eschenmayer und Ludwig Wallrad Medicus: Einträge unter $Z$ [itat]

Mitglied des Illuminatenordens in (Kaisers-)Lautern (Ordensname: Calendion)

1805 Kurpfälz. Hofkammer-Rat

E 1819 Dr. phil. h.c. UH.

Qu UAH PA 2281f.; Fak.-Akte H-IV-102/14. • UA Freiburg/Br. Bestand A 0053. GLA Abt. 205, Fasz. 139, 504f. • Prozesssachen Freiburg 1489-1867. Bearb. von Stefan Hanke. UA Freiburg/Br. 1997. S. 17: Verleumdungsprozess, Signatur: 80, Vorsignatur 1: III i 72, Laufzeit: 1807; Titel: Forderungen von 302 Gulden 45 Kreuzer der Heidelberger Professoren Georg Adolf Suckow, Gutterer [wohl Christoph Wilhelm Gatterer] und Martin Tobias Engelbert Semer gegen die katholische Kirchenkommission. Auskunft: Kath. Kirchenbuchamt Heidelberg (Sterbebuch 1837).

$W$ Über die Bürgeraufnahme in Städten und Flecken. Mannheim 1791 (UBH: Kriegsverlust). • Über die Natur und Bestimmungsgründe der Na-
tional-Emsigkeit. Ein Beitrag zur theoretischen Staatskunde in: Vorlesungen der Churpfälzischen physikalisch-ökonomischen Gesellschaft in Heidelberg. Von dem Winter 1789 bis 1790 ... 5. Bd. 2. T. Mannheim 1791. S. 1-106. • Über die Polizeiverwaltung in Städten, deren Bewohner aus verschiedenen Volksklassen bestehen. Mannheim 1792 (UBH: Kriegsverlust). • Beitrag zur näheren Bestimmung des Begriffes der eigentlichen Staatswirthschaft und ihres Gebietes. Mannheim 1794.

L Wechmar (1846) S. 253; Stieda (1906) S. 128, 139, 144 u. ö.; Keller (1913) S. 106 f.; Schneider (1913) S. 146-148; Bader (1925) S. 247 f. • Leitschuh, Max: Die Matrikeln der Oberklassen des Wilhelmsgymnasiums in München. Bd. 1. München 1970 (hier: 1777 Absolvent). • Poller (1979) S. 386 (Register); Kreutz (1991) S. 136 und Anm.; WBIS. - Ziekow, Jan: Über Freizügigkeit und Aufenthalt. Paradigmatische Überlegungen zum grundrechtlichen Freiheitsschutz in historischer und verfassungsrechtlicher Perspektive. Tübingen 1997. S. 97 und Anm. 226. - Schroeder (2005) S. 220; Neuhaus (2014) S. 51, 71 u. ö.

\section{Seng, Alfred}

1887-1907 Jur. Fak.

1907-1926 (Honorar-Prof.) Jur. Fak.

Französisches Zivilrecht, Zivilprozeßrecht

* 26. Okt. 1851 Lahr/Schwarzwald

$\dagger \quad$ 29. März 1934 Heidelberg

口 Lahr

prot.

V Carl S., praktischer Arzt

M Julie geb. Pannifex (1827-1857), s. Chronica des Hauses Pannifex ... verfasst und der Familie gewidmet von Michael Conrad Theodor Hug. Lahr (Baden) 1913. S. 16, s. http://brigit tegastelancestry.com/pannfex.htm (abgerufen am 26. Dez. 2017)

๑ Elena Tempe geb. Doer (1857-1944), s. Kriegstagebuch K. Hampe (2007) S. 997 (Register)

K 1 S, 1 T: Tempe S. (1883-1929) Ehefrau von August Heisler (1881-1953) Landarzt, s. NDB 8 (1969) S. 457. 
Lb Seit WS 1869/70 Studium an UH, seit WS 1870/ 71 Berlin, anschl. Erlangen.

Seit 1878 Assessor, 1879-1884 (Pensionierung) badischer Amtsrichter; seit 1886 Wohnsitz in H.

UH: 30. Juni 1887 Dr. iur.; 22. Juli 1887 Habilitation; seit 17. Dez. 1891 nichtetatm. a. o. Prof.; seit 4. April 1907 o. Honorar-Prof.; 16. Nov. 1922 auf eigenen Antrag Aufgabe des Lehramts aus Krankheitsgründen; seit WS 1922/23 weiterhin Vorlesungsankündigungen; WS 1923/24 Erteilung e. Lehrauftrags „Einführung in die Wohlfahrtspflege (soziale Fürsorge), insbesondere der Jugend" durch Engeren (Akad.) U-Senat; laut Vorlesungsverzeichnissen sind diese Vorlesungen für e. gröBeren Zuhörerkreis bestimmt; WS 1925/26 letzte Vorlesungsankündigung.

1905-1912 als Heidelberger Stadtrat genannt (s. Adressbuch der Stadt Heidelberg nebst den Stadtteilen Neuenheim ... für das Jahr 1905. Heidelberg 1905. S. 248 und Adreßbuch ... für das Jahr 1912. Heidelberg 1912. S. 308).

1918 Geh. Hofrat

E 1902 Ritterkreuz I. Klasse des Ordens vom Zähringer Löwen.

Qu UAH PA 792, 2283; Fak.-Akte H-II-111/98. GLA Abt. 235, Fasz. 2515. • Bf.: Universitätsbibliothek Freiburg/Br. - Auskunft: Stadtarchiv Heidelberg.

$W$ Die Sachmiete nach dem Code civil. Lahr 1887. Grundzüge des französischen Zivilrechts und des badischen Landesrechts. Halle/S. 1904. • Grundzüge des badischen Landesprivatrechts. Halle/S. 1912.

$L$ Wer ist's (1928) S. 1458 f.; Kürschner (1931) Sp. 2777; WBIS; Schroeder (2010) S. 339 f.; Deutsche Biographie, s. https://www.deutsche-biographie. de/gnd117656747.html [19.11. 2017].

$P$ Bildarchiv UAH; graph. Slg. UBH.

\section{Serr, Hermann Jakob}

1924-1935, 1939-1965 Med. Fak.

Augenheilkunde

* 26. Aug. 1895 Glarus (Schweiz)

$\dagger$ 21. März 1972 München

prot.

V Dr. Hermann Gottlieb S. $\left({ }^{\star} 1860 \nmid\right.$ nach 1944$)$ Arzt

M Anna Friederike Josefine geb. Heer $\left({ }^{*} 1873\right.$ $\dagger$ nach 1944)

$\infty$ 26. Okt. 1926 Anna geb. Gsottschneider $\left({ }^{*} 1901\right)$, s. hierzu $Z(1)$

$\mathrm{K} \quad 1 \mathrm{~S}, 1 \mathrm{~T}$ (früh $\dagger$ ).

$L b$ WS 1914/15 Studium an U Bern, SS 1915-WS 1919/20 (mit Unterbrechungen) München. - In dieser Zeit:

1. März 1915-15. Dez. 1918 Kriegsteilnehmer zunächst bei Kraftfahr-Ersatz-Abt. in München, zuletzt als Feldhilfsarzt.

München: Jan. 1918 Ärztl. Vorprüfung; 27. April 1920 Staatsexamen; anschl. Praktikant an II. Med. Klinik; 27. Jan. 1921 Approbation als Arzt.

U München: 15. Febr-15. Juli 1921 Volontärassistent an Augenklinik; 3. März 1921 Dr. med.

UH: Seit 15. Aug. 1921 Volontärarzt, seit 1. Juli 1922 Hilfsassistenzarzt, seit 1. Sept. 1922 o. Assistent, seit 1. April 1932 Oberarzt an U-Augenklinik als Nachf. von Erich Seidel (1910-1935 Direktor: August Wagenmann); 25. Juli 1924 Habilitation; seit 15. Okt. 1929 nichtplanm. und nichtbeamteter a.o. Prof.; SS 1935-WS 1938/39 von UH beurlaubt. • In dieser Zeit:

U Jena: SS 1935-WS 1938/39 Inhaber der Carl Zeiss-Stelle, e. Assistentenstelle an U-Augenklinik (1932-1946 Direktor: Erich Seidel), s. hierzu Z (2); seit SS 1935 auch Vorlesungstätigkeit; Dez. 1937 Teilnehmer des Int. Ophthalmologenkongresses in Kairo; 1937 ergebnislose Verhandlungen über Berufung S.s an U Ankara. 
UH: SS 1939 Wiederaufnahme der Vorlesungen; Aug. 1939 Gesuch S.s an Rektor um Ern. zum apl. Prof. neuer Ordnung; 25. Okt. 1939 Ern. zum apl. Prof.; Dez. 1946 Ruf an U Jena abgelehnt; SS 1965 letzte Vorlesungsankündigung als apl. Prof. • In dieser Zeit:

H: 11. April 1939-1965 Niedergelassener Augenarzt.

1939-1945 Kriegsteilnehmer als Feldhilfsarzt.

München: Seit 28. Okt. 1965 Wohnsitz.

Z (1) Am 23. Okt. 1926 schreibt S. an Friedrich Panzer, Rektor der UH: „... Ich wurde leider in die Notwendigkeit versetzt, meine für Anfang Oktober geplante Hochzeit auf Ende des Monats zu verschieben, da die baulichen Arbeiten meiner Wohnung [im Kreuzpfad 9 in Handschuhsheim] nicht rechtzeitig fertiggestellt worden sind. Die Studenten werden durch meine Abwesenheit keine Einbusse erleiden, da Herr Prof. Seidel die in diese Zeit fallende erste Kollegstunde übernommen hat ..." (aus: UAH PA 5854: Erich Seidel).

$Z$ (2) Von 1935 bis 1939 ist S. Inhaber der Carl Zeiss-Stelle an der U-Augenklinik Jena, die „eine alljährlich neu zu beantragende Assistentenstelle (ist). Und wenn ich auch de facto Oberarztfunktionen an der Klinik ausübe, so bin ich auf dem Papier doch Assistent, was solange nicht ins Gewicht fällt, als ich gleichsam als Gast (Beurlaubter der Universität Heidelberg) die Gelegenheit wahrnehme, mit der Firma Zeiss zusammen gewisse praktisch wichtige optische Fragen zu studieren bzw. zu bearbeiten ..." (aus: Brief vom 21. Aug. 1938 an Hans Runge, Dekan der Med. Fak. der UH, in: UAH PA 10413; Biographie Runges, s. Drüll (2009) S. $511 \mathrm{f}$. .).

E 1918 Eisernes Kreuz II. Klasse; 1934 Ehrenkreuz für Frontkämpfer.

$\mathrm{Q} u$ UAH PA 1182, 5872, 10413. - GLA Abt. 235, Fasz. 2501.
$W$ Blutbeschaffenheit und Glaukom in: Graefes Archiv für Ophthalmologie 114 (1924); Zur Frage des Kausalzusammenhanges zwischen Pupillenweite und Augendruck in: ebd. 121 (1928); Zur Analyse der spontanen Pulserscheinung in den Netzhautgefäßen mit Filmaufnahmen in: ebd. 137 (1937). • Bibliographie 1921-1939 in: UAH PA 5872.

MHG Axenfeld, Theodor: Lehrbuch und Atlas der Augenheilkunde. 9. Aufl. Jena 1949. 10. Aufl. Jena 1958.

L Kürschner (1950) Sp. 1944, (1961) S. 1940; WBIS.

$P$ Bildarchiv UAH.

\section{Siebeck, Richard}

1912-1924, 1931-1934, 1941-1952 Med. Fak.

Innere Medizin

* 10. April 1883 Freiburg/Br.

$\dagger$ 15. Mai 1965 Heidelberg ev.

V Dr. phil. h.c. (Freiburg/Br.) D. theol. (Gießen) Paul S. (1855-1920) Verlagsbuchhändler; Briefe in UBH, s. auch Kalliope; s. WBIS, NDB 24 (2010) S. 315 f., Troeltsch-Gesamtausgabe 19 (2014) S. 507 (Register)

M Thekla Elisabeth geb. Landerer (1857-1919), s. Troeltsch-Gesamtausgabe, S. 507 (Register)

@ 20. Sept. 1909 Agnes geb. von Müller (18851922), s. Kriegstagebuch K. Hampe (2007) S. 997 (Register); T von Karl von M. (18521940), u.a. 1903-1922 o. Prof. für Theologie Tübingen, s. WBIS, RGG ( $\left.{ }^{4} 2002\right)$ Sp. $1572 \mathrm{f}$, Catalogus prof. Halensis online

( 5. April 1923 Marie Therese Lina Wilhelmine geb. Rümelin (1892-1994) T von Max (von) R. (1861-1931), u.a. 1895-1931 o. Prof. für Rechtswiss. Bonn, s. WBIS, NDB 22 (2005) S. 225

K 2 T, 2 S: u.a. Robert S. (1921-1970), u.a. seit 1967 o. Prof. für Ophthalmologie Bonn, s. Verzeichnis Bonn (1968) S. 292, NDB 24 (2008) S. $317^{*}$

Vw siehe NDB 24, S. 315-317. 
Lb Seit WS 1901/o2 Studium an U Tübingen, anschl. Freiburg/Br., Berlin; Dez. 1906 Staatsexamen in Tübingen; 1907-1908 Praktikant: Chirurg. Klinik Tübingen, Med. U-Klinik H, Physiolog. Inst. Kopenhagen.

UH: 22. Okt. 1907 Dr. med; seit Okt. 1908 Assistent, Febr. 1919-April 1924 Oberarzt an Med. UKlinik; 8. Nov. 1912 Habilitation; seit 17. Juli 1918 nichtetatm. a.o. Prof.; Nov. 1921-1924 Leiter des Versorgungsärztlichen Beobachtungskrankenhauses in H. • In dieser Zeit:

1914-1918 Kriegsdienst.

U Bonn: Seit 1. Mai 1924 persönlicher Ordinarius und Direktor der Med. U-Poliklinik; 1930 Ruf an U Graz abgelehnt.

UH: Seit 1. April 1931 o. Prof. und Direktor der I. Med. U-Klinik als Nachf. von Ludolf von Krehl.

U Berlin: Seit 1. April 1934 o. Prof. und Direktor der Med. U-Klinik der Charité als Nachf. von Wilhelm His (1863-1934), Bruder von: (siehe) Rudolf His. • In dieser Zeit:

Berlin: 1939 o. Mitglied des Wiss. Senats für das Heeressanitätswesen.

UH: Seit 1. Okt. 1941 o. Prof. und Direktor der Ludolf-Krehl-Klinik als Nachf. von Johannes Stein; 30. Sept. 1951 Emeritierung; 1. Okt. 1951-18. Nov. 1952 Vertreter seines Lehrstuhls.

1932/33 Dekan der Med. Fak. der UH

E 1938 Mitglied der Dt. Akademie der Naturforscher Leopoldina Halle/S.; 1941 Ehrenmitglied der Anatomisch-Klinischen Gesellschaft Bukarest; 1942 Mitglied der Akademie der Wissenschaften H. - Dr. med. h.c. Bukarest; 1952 D. theol. UH. 1955 Paracelsus-Medaille.

$Q u$ UAH PA 1185, 5881-5883. - Siehe auch Archiv der Dt. Akademie der Naturforscher Leopoldina Halle/S. - Mitteilungen: Herren Dr. Eberhard Siebeck (†) und Dr. h.c. Georg Siebeck, Tübingen.
$W$ Beurteilung und Behandlung der Nierenkranken auf der Grundlage der klinischen Pathologie. Tübingen 1920. Probleme des Wasserhaushaltes in der Physiologie und in der klinischen Medizin in: Pflügers Archiv 201 (1923) S. 25 ff. • Lehrbuch der Inneren Medizin. Berlin 1931. 7. Aufl. Berlin 1949. Beurteilung und Behandlung Herzkranker. Berlin 1939. 3. Aufl. 1947. Medizin in Bewegung. Stuttgart 1949. 3. Aufl. 1983.

$L$ Medicus viator. Fragen und Gedanken am Wege R.S.s ... Hrsg. von Paul Christian ... Tübingen u. a. 1959. Verzeichnis Bonn (1968) S. 291 f. MedWelt. Die Medizinische Welt - Aus der Wissenschaft in die Praxis (1983) 34. Bd., 11. H., S. 347-353. Chronik Ärzte H (1985) S. 143, 269-270. • Jacob, Wolfgang: Medizinische Anthropologie in: Semper apertus 4 (1985) S. 122-160. - Baier, Hartmut: R.S. und Karl Barth - Medizin und Theologie im Gespräch. Die Bedeutung der theologischen Anthropologie in der Medizin R.S.s. Göttingen 1988. • Jansen (1992a) S. 169 (Register); Berliner U in NSZeit I (2005) S. 41, 44 u. ö. • Engelhardt, K.: R. S. an important exponent of the "Heidelberg School“. A look back at a great physician in the 4 oth year after his death in: Dt. Med. Wochenschrift 130 (19) (Mai 2005) S. 1227-1229. - UH im Nationalsozialismus (2006) S. 1271 (Register); Klee, Personenlexikon (2007) S. 581; NDB 24 (2008) S. $317 \mathrm{f}$.; Wissenschaftsatlas der UH (2011) S. 118 f., 132; Gerstengarbe (2012) S. 550 (Register); Troeltsch-Gesamtausgabe 19 (2014) S. 507 (Register). Roelcke, Volker: Forschungsbericht. R.S. und die Medizin im Nationalsozialismus. Haltung und Handeln bis 1945 und in der Nachkriegszeit. Im Auftrag der Dt. Gesellschaft für Psychoanalyse, Psychotherapie, Psychosomatik und Tiefenpsychologie (DGPT). Institut für Geschichte der Medizin. Universität Gießen. Stand: 25. Okt. 2016, s. http://www.dgpt. de/fileadmin/download/Geschichte_der_DGPT/ Roelcke_2016_Siebeck_25_10_2016.pdf. • Deutsche Biographie, s. https://www.deutsche-biogra phie.de/gnd118765140.html [21.11. 2017].

P Bildarchiv UAH; Chronik Ärzte H. 


\section{Sillib, Karl Rudolf}

(1908-1924 Phil. Fak.)

(1924) 1925-1932 (Honorar-Prof.) Phil. Fak.

Buch- und Bibliothekswesen

* 27. Febr. 1869 Mannheim

$\dagger$ 23. Okt. 1946 Badenweiler

ㅁ Lipburg (heute: Ortsteil von Sehringen bei Badenweiler)

prot.

V Carl Eduard S. (1829-1898) Kaufmann

M Sophia Dorothea geb. Krebs (1833-1919)

@ 19. Mai 1900 Gertrud geb. Glatz (1881-1951)

$\mathrm{K} \quad 1 \mathrm{~T}$

Lb WS 1887/88 Studium der Philosophie an UH, seit SS 1888 Berlin, anschl. Greifswald, WS 1889/ 90-SS $1891 \mathrm{H} ; 25$. April 1892 Dr. phil. an UH.

UBH: Seit 1. Mai 1893 Volontär, seit 1. Aug. 1894 a. o. wiss. Hilfsarbeiter mit e. jährl. Besoldung von 1200.- Mark; seit 1. Mai 1896 Kustos mit e. jährl. Vergütung von 160o.- Mark; seit 1. Mai 1897 beamteter Kustos; seit 1. Jan. 1898 jährl. Gehalt von 1900.- Mark; seit 4. Aug. 1902 II. etatm. Bibliothekar mit e. Einkommen von jährl. 2900.- Mark als Nachf. von Paul Hintzelmann; seit 11. Juni 1904 jährl. Einkommen von 3400.- Mark; 1914-1920 Reserve-Lazarett-Delegierter; Okt. 1915 Genehmigung des Ministeriums des Kultus und Unterrichts, die Dienstbezeichnung „Vorstand der Handschriften-Abt." im Personalverzeichnis der U hinzuzufügen; Nov. 1915 Ruf als Bibliotheksvorstand an TH Karlsruhe abgelehnt; 1. April 1920 Verleihung der Bezeichnung „Oberbibliothekar“; 1 . April 19221. Juni 1934 (Ruhestand) Direktor der UB als Nachf. von Jacob Wille; 1929-1934 Verwalter des U-Archivs als Vorstand der Handschriften-Abt. der UB als Nachf. von Wille; Juni-Sept. 1934 Vertreter seiner Stelle als ehem. Vorstand. In dieser Zeit:

UH: 7. Juli 1908 Verleihung des Titels „Prof.“; seit 13. Febr. 1924 o. Honorar-Prof.; 1925-1932 S. liest jeweils in den Sommersemestern abwechselnd über Die Geschichte des Buches mit Erläuterungen an Handschriften und Drucken sowie Geschichte der abendländischen Schrift. • In dieser Zeit:
H: 1908-1911 Ehrenamtl. Konservator der städtischen Kunst- und Altertümersammlung; 19081922 ehrenamtl. Vorstand der Kunst- und Altertumsdenkmäler für den Amtsbezirk H.

Am 6. Juni 1901 schreibt S. an das Ministerium der Justiz, des Kultus und Unterrichts, man möge seine Forderung der Umwandlung der Kustosstelle in eine etatm. Bibliothekarsstelle erfüllen. Dabei ist die Verleihung des Bibliothekartitels weniger relevant für ihn als vielmehr die etatm. Anstellung bei der UBH. „Für den Fall, (dass) auch dies Mal mein Wunsch nicht erfüllt würde, (wäre) für mich damit die Veranlassung zum Austritt aus der Bibliothek gegeben ..." (aus: UAH PA 87). Das Kultusministerium antwortet am 13. Dez. 1901, man sei ernstlich bemüht, seine Forderung zu erfüllen, aber die allgemeine Finanzlage lasse noch nicht einmal einen Budgetnachtrag 1902/03 zu. Man hoffe aber, im Budget 1904/05 „die neue etatmässige Bibliothekarstelle für den verdienten Bibliothekbeamten durchzusetzen“ (aus: PA 87). S. wird - entgegen der ministeriellen Ankündigung - bereits am 4. Aug. 1902 zum etatm. Bibliothekar ernannt: der bisherige (I.) Bibliothekar Jacob Wille rückt 1902 durch den Tod des UB-Vorstands Karl Zangemeister auf dessen Stelle nach; Willes Posten erhält der bisherige (II.) Bibliothekar Paul Hintzelmann, so daß S. zum (II.) etatm. Bibliothekar ernannt werden kann.

1929: S. ersteigert einen Teil des „Wunderhorn“Materials, bestehend aus 246 Briefen und über 2000 Liedern und Sinnsprüchen (UBH-Signatur: Heid. Hs. 2110-2119), s. hierzu Ein Knab auf schnellem Roß (2006) S. 94 u. ö.

$Q u$ UAH PA 87 f., 5901; RA 5972 f. • GLA Abt. 235, Fasz. 2529.

W Machiavellis Stellung zu Deutschland. Heidelberg 1892. - Schloß Favorite und die Eremitagen der Markgräfin Franziska Sibylla Augusta von Baden-Baden. Heidelberg 1914. 2. Aufl. 1929. • S., R., Lohmeyer, Karl: Heidelberg. Leipzig 1927. (Stätten der Kultur. 36.) • Die Geschichte der Handschrift in: Die Manessische Liederhandschrift ... Faksimile-Ausg. Leipzig 1929. S. 5-43. Rechenschaftsbericht über meine Tätigkeit als Direktor der UBH 
in: UAH PA 88. - Siehe Nokk, Sascha: Arbeiten von R.S. in: Neue Heidelberger Jahrbücher N.F. (1936) S. 90-92.

MHG Die Manessische Liederhandschrift ... Faksimile-Ausg. Leipzig 1929.

Schriftleiter 1928-1935 Zeitschrift für die Geschichte des Oberrheins.

L Kürschner (1931) Sp. 2801f., (1940/41) Sp. 787. • Lautenschlager, Friedrich: R.S. - ein Gedenkblatt in: ZGORh 97. Jg. (1949) S. 349-356. - Lohmeyer, Karl: Erinnerungen. „Dem Süden zu“. Eine Wanderung aus alten rheinisch-fränkischen Bürgerhäusern nach dem Land jenseits der Berge. Aus dem Nachlaß hrsg. von Karl Schwingel ... Heidelberg 1960. S. $254 \mathrm{f}$. Habermann et al. (1985); Jansen (1992a) S. 169 (Register); WBIS. • Handbuch der historischen Buchbestände in Deutschland. Hrsg. von Bernhard Fabian. Hildesheim 2003. Ein Knab auf schnellem Roß (2006) S. 94 u. ö.; UH im Nationalsozialismus (2006) S. 9699. - Universitätsbibliothek Heidelberg. Katalog der Inkunabeln der Universitätsbibliothek Heidelberg, des Instituts für Geschichte der Medizin und des Stadtarchivs Heidelberg. T. 1. Bearb. von Armin Schlechter und Ludwig Ries. Wiesbaden 2009. S. 6 f., 78 f. u. ö. • Runde (2012) S. 262; Riecke (2016) S. 67; Deutsche Biographie, s. https:// www.deutsche-biographie.de/gnd 11738593 X.html [21.11.2017].

P Bildarchiv UAH; graph. Slg. UBH.

Simon, Christoph Jacob Gustav Ludwig Friedrich

1867-1876 Med. Fak.

Chirurgie

* 29. Mai 1824 Darmstadt

$\approx$ 29. Juni 1824

$\dagger \quad$ 28. Aug. 1876 Neuenheim (heute: Stadtteil von Heidelberg)

ev.
V Johan Georg S. (1781-1847) Rentmeister

M Marie Philippine Luise Catharine geb. Scriba (1786-1845) 1834 schwerer Schlaganfall

๑ 3. Okt. 1860 Wilhelmine geb. Dingeldey (18281908)

K $2 \mathrm{~S}$

$\mathrm{Lb}$ Seit WS 1842/43 Studium an U Gießen, seit 31. Mai 1845 H, seit SS 1846 Gießen; Ende 1847 med. Examen in Gießen; Frühjahr 1848 Dr. med. an U Gießen.

Darmstadt: Seit 1848 Militärarzt, Herbst 1858-1861 Oberarzt im hessischen Truppen-Korps, u. a. auch Sommer 1849 während der badischen Revolution in Rastatt; 1851-1852 Studienaufenthalt in Paris, s. hierzu Illustrierte Geschichte der Urologie (2004) S. 98-100; 1848-1861 auch Arzt in sog. Armenpraxis; 1853 Mitbegründer und 1853-1861 Chirurg an Privat-Hospital für Chirurgische und AugenKranke.

U Rostock: 28. Febr. 1861 Ern. zum a.o. Prof.; 4. Sept. 1861 Ern. zum o. Prof. und Direktor der Chirurg. Klinik, zuletzt mit e. jährl. Besoldung von 2450.- Gulden; 1864-Anfang 1866 zeitweise Unterbrechung seiner klinischen Tätigkeit wegen e. Hüftgelenkserkrankung; Ende Juni-Sept. 1866 Reservelazarett-Leiter in Berlin während des PreuBisch-Deutschen Krieges.

UH: 11. Okt. 1867 Ern. zum WS 1867/68 o. Prof. und Direktor der Chirurg. U-Klinik als Nachf. von Otto Weber mit e. jährl. Besoldung von 3000.-, zuletzt von 5657.- Gulden; 1868/69 Ruf an U Greifswald abgelehnt, siehe hierzu UAH RA 6286; 1870/71 Generalarzt der Badischen Reservelazarette während des Deutsch-Französischen Krieges; SS 1876 Beurlaubung aus gesundheitlichen Gründen (thorakales Aortenaneurysma mit tödlichem Verlauf).

1868/69 Dekan der Med. Fak. der UH

$\mathrm{Zu}$ seiner Zeit ist S. ein berühmter Urochirurg, der 1869 die erste erfolgreiche Entfernung einer Niere (Nephrektomie) durchführt, siehe hierzu Gustav Simons Aufsatz über Exstirpation einer Niere am Menschen in: Deutsche Klinik 22 (1870) 
S. 137 f. - Erweiterung und Austastung der weiblichen Harnröhre wird heute noch "Simonisierung“" genannt.

Die Bedeutung S.s zeigt sich auch anläßlich seines Todes in einem am 29. August 1876 von Großherzog Friedrich I. von Baden per Badischer Staats-Eisenbahnen aufgegebenen Kondolenz-Telegramms - einem eher selten in den Akten des UAH vorkommenden Schriftstücks - an Heidelberger Prorektor Otto Becker mit dem Wortlaut: „S[eine] K[önigliche] H[ohei]t der Großherzog läßt dem Herrn Prorector den Ausdruck seiner aufrichtigen tiefgefühlten Theilnahme zukommen an dem schweren Verlust, den die Universität durch das Ableben des Hofraths Simon erlitten hat" (aus: UAH PA 2291).

1872 Mitbegründer der bis heute bestehenden Dt. Gesellschaft für Chirurgie in Berlin

Seit 1998 verleiht die Südwestdeutsche Gesellschaft für Urologie e.V. die Gustav Simon-Medaille an Wissenschaftler, die die Urologie in Deutschland maßgeblich beeinflusst haben; erster Empfänger der Medaille ist der Heidelberger Ordinarius für Urologie Lars-Erik Röhl (1920-1999), s. Drüll (2009) S. $498 \mathrm{f}$.

1868 Badischer Hofrat

E Mitglied: Schwedische Medizinische Gesellschaft, Geburtshilfliche Gesellschaft zu London, Société de Chirurgie Paris, Gynäkolog. Gesellschaft in Boston; Ehrenmitglied der Gesellschaft für Natur- und Heilkunde in Dresden. - Großherzogl.-Hessisches Ritterkreuz I. Klasse; Kaiserl.Russischer St. Annen-Orden; 1867 Preußischer Kronen-Orden III. Klasse; Hausorden der Wendischen Krone.

Qu UAH PA 2291 (hier Standesliste mit eigenhändigem Eintrag des Geburts-Datums mit 03. statt 29. Mai 1824); RA 6286, 6789. GLA Abt. 205, Fasz. 506. Auskunft: Ev. Kirche in Hessen und Nassau, Kirchenverwaltung - Zentralarchiv - Referat für Archiv- und Bibliothekswesen in Darmstadt (Kirchenbuch 1824 der Stadtkirchengemeinde Darmstadt, Kirchenbuch 1860 der Ev. Militärgemeinde ebd.). - Familiengrab: Bergfriedhof Heidelberg (hier Geburts-Datum irrtümlich mit 30. Mai 1824 angegeben).

$W$ Über Schußwunden. Gießen 1851. • Über die Heilung der Blasenscheidenfisteln; Beurtheilung der Operation autoplastique par glissement von Jobert de Lamballe in Paris. Neue Methode der Naht, die Doppelnaht (Entspannungs- und Vereinigungsnaht), zur Vereinigung der Fistelränder. Gießen 1854. - Über die Operation der Blasenscheidenfisteln durch die blutige Naht und Bemerkungen über die Heilung der Fisteln, Spalten und Defecte, welche an anderen Körpertheilen vorkommen. Rostock 1862. Mitteilungen aus der Chirurgischen Klinik zu Rostock. Prag 1868. Exstirpation einer Niere am Menschen. Vorläufige Mitteilung in: Deutsche Klinik. Zeitung für Beobachtungen aus dt. Kliniken und Krankenhäusern 22 (1870) S. 137 f. $\bullet$ Chirurgie der Nieren. 2 T. Stuttgart 1871-1876.

L ADB 34 (1892) S. 369-371; Pagel (1901) Sp. 1595-1598; Stübler (1926) S. 318 f.; Krebs/Schipperges (1968) S. 50-56. Gibson, T.: G. S. ... Simon$\operatorname{art}(\mathrm{s})(\mathrm{z})$ of the band? in: British Journal of Plastic Surgery (Oct. 1977) Vol. 30,4, S. 255-260. - Leier, Wolfgang Andreas: Der Anteil Heidelbergs an der Entwicklung der Magenchirurgie. Diss. Heidelberg 1977. Chronik Ärzte H (1985) S. 143, 271f.; Semper apertus 4 (1985) S. 192 f.; WBIS; Zander (1991) S. 59 f. - Moll, Friedrich H., Rathert, P.: The surgeon and his intention: G.S. ..., his first planned nephrectomy and further contributions to urology in: World Journal of Urology (June 1999) 17(3), S. 162-167. - Streiflichter aus der Geschichte der Urologie. Hrsg. von Dirk Schultheiss ... Berlin 1999. S. 17-20 u. ö. (S. 17: irrtümlich Geburts-Datum mit 13. März angegeben). - Illustrierte Geschichte der Urologie. Hrsg. von Jürgen Konert und Holger G. Dietrich ... Berlin 2004. S. 98-107 u. o.

$P$ Bildarchiv UAH; graph. Slg. UBH; Pagel; Chronik Ärzte H.

Sirius, Julius (Pseudonym)

siehe Schreiber, Aloys 


\section{Sölch, Johann (Hans) Georg}

1928-1935 Phil. Fak.

Geographie

* 16. Okt. 1883 Wien

$\dagger$ 10. Sept. 1951 Kitzbühel

口 Wien

kath.

V Johann Christof S. (1852-1934) Direktor des österr. k. u. k. Schulbuchverlages, Reg.-Rat

M Anna geb. Franke (1861-1924)

$\varnothing$ 16. Juli 1908 Berta Anna geb. Buchhorn ( ${ }^{*} 1885$ $\dagger$ nach 1951) mosaisch

K 1 T, s. Lexikon jüdischer Einwohner Hs (2011) S. 391 .

Lb Seit WS 1902/03 Studium der Geographie, Geologie, Geschichte, Alten Sprachen an U Wien, anschl. Bern, Graz; Juni 1906 Lehramtsprüfung (= Staatsexamen) für höheres Lehramt (Hauptfächer: Geographie und Geschichte) in Wien; 16. März 1906 Dr. phil. an U Wien; 1906 wegen Kurzsichtigkeit vom Militärdienst zurückgestellt.

U Leipzig: Seit 1. Jan. 1907 Assistent am Geographischen Inst.; 31. Juli 1907 „selbst um Entlassung angesucht wegen $\mathrm{zu}$ starker dienstl[icher] Inanspruchnahme“, aus: Personalbogen in: UAH PA 5916 letzte Seite.

Wien: Seit 15. Sept. 1907 Hilfslehrer am Staatsgymnasium.

Graz: 1. Sept. 1908-30. Sept. 1920 Zunächst Gymnasiallehrer, dann Gymnasial-Prof.; Jan. 1912 Lehramtsergänzungsprüfung (Hauptfach: Latein); „Kriegsdienst: 1915, 16. Juli-16. Okt. in Garnison, anschl. für unabkömmlich erklärt" (aus: Standesliste in: PA 5916); während des Krieges auch Lehrer am Mädchengymnasium; außerdem Dozent an Lehrerakademie und Mitglied der Prüfungskommission für Volks- und Berufsschule. • In dieser Zeit:

U Graz: 1. Okt. 1917 Habilitation für Geographie; WS 1917/18-SS 1920 Privat-Dozent.
U Innsbruck: 5. Sept. 1920 Ern. zum WS 1920/21 o. Prof. und Begründer e. Seminars für Alpengeographie.

UH: 29. März 1928 Ern. zum o. Prof. und Direktor des Geographischen Seminars als Nachf. von Alfred Hettner mit e. Grundgehalt von 12600 .Mark, Unterrichtsgeld von 2800.- Mark sowie ein „bei der Berufung zugesicherter Reisekostenzuschuß (für geographische Studienreisen) von jährl. 6oo.- Mark" (aus: Personalbogen in: PA 5916 letzte Seite; siehe auch $Z$ (1)); u. a. WS 1931/32 Beurlaubung für Studienreisen nach Frankreich und Großbritannien, s. hierzu Brief S.s an Ministerium des Kultus und Unterrichts in Karlsruhe vom 7. Juni 1931 in: PA 5916; WS 1933/34 S. hält auch Wirtschaftsgeographische Übungen an Handelshochschule in Mannheim ab; $1935, \ldots$ Politische Verhältnisse nötigten S., einen Ruf an die Universität Wien anzunehmen", aus: Nachruf auf J.S. in: Rhein-Neckar-Zeitung vom 21. Sept. 1951.

U Wien: Seit 1. Mai 1935 o. Prof. und Direktor des Geographischen Inst.; 1939 Beurlaubung, bald darauf Pensionierung, siehe hierzu auch $Z$ (2); 19391945 weiterhin Direktor des Geographischen Inst.

U Wien: 5. Sept. 1947 Wieder-Ern. zum o. Prof. und Direktor des Geographischen Inst.; 1947-1948 Rektor.

1930/31 Dekan der Phil. Fak. der UH

Z(1) 1928 - vor Annahme des Rufes an UH schildert S. in einem 5-seitigen Brief Badischem Ministerium für Kultus und Unterricht in Karlsruhe die in seinen Augen katastrophalen Zustände des Heidelberger Geographischen Seminars in der Augustinergasse 15; u. a. schreibt er: „... So war ich also bei meinem Besuch in Heidelberg in meinen Erwartungen schwer enttäuscht. Die Grundfrage, die hier zuerst gelöst werden muß, ist die Raumfrage. Ich kenne weitaus die meisten geographischen Seminare der deutschen und österreichischen Hochschulen und etliche andere ausländische. Ich muß aber ausdrücklich erklären, daß im Raum und an zweckmäßiger Raumeinteilung nur wenige hinter Heidelberg zurückstehen und muß sagen, daß in dieser Hinsicht die derzeitigen Verhältnisse einer Universität vom Range 
und vom Ruf Heidelbergs, an die berufen zu werden jeder Gelehrte sich als eine Ehre anrechnen muß, so durchaus nicht entsprechen, daß es sich jeder gründlich zu überlegen gezwungen ist, ob er nicht trotzdem die Berufung besser ablehnen solle, um sich nicht eine minderwertige Arbeitsstätte für eine besser ausgestattete einzutauschen. Wenn man also Wert darauf legt, zur Arbeit an diesem Platze und zur Leitung des Seminars eine vollwertige Kraft zu gewinnen, wenn man sich nicht etwa mit einem jungen Mann begnügen will, der froh ist, aus dem beengten Kreise seines Privatdozentendaseins heraus eine Professur zu erlangen und daher keine weiteren Ansprüche stellt, sondern mit allem zufrieden ist, so wird man nimmermehr darum herumkommen können, dem geographischen Seminar der Universität Heidelberg Räume und Ausstattung zur Verfügung zu stellen, wie sie der derzeitigen Stellung und den heutigen Aufgaben der geographischen Wissenschaft entsprechen und wie sie der altberühmten Universität würdig sind“ (aus: UAH PA 240).

Erst fünf Jahre später nach Abfassen dieses Briefes, im SS 1933, zieht das nun als Geographisches Institut bezeichnete ehemalige Seminar von der $\mathrm{Au}$ gustinergasse in die Neue Universität, Eingang Seminarstraße ein.

Z (2) Josef Bürckel (1895-1944), 1938-1940 Wiener Reichskommissar für die Wiedervereinigung Österreichs mit Deutschem Reich, bittet Paul Schmitthenner (siehe Drüll (2009) S. 554f.), Rektor der Universität Heidelberg, in einem Schreiben vom 29. März 1939 um Stellungnahme zur politischen Einschätzung Sölchs. Bürckel berichtet selbst: „Der Dekan der philosophischen Fakultät der Universität Wien hat mit Rücksicht auf die hervorragenden fachlichen Eigenschaften des Professors Sölch darum gebeten, - Sölch ist jüdisch versippt - für diesen Dozenten eine Ausnahme nach $\$_{3}$ der Berufsbeamtenverordnung von 1939 in die Wege zu leiten $\left[\$_{3}\right.$ betraf die Entfernung von Juden, jüdischen Mischlingen und jüdisch versippten Beamten aus dem Öffentlichen Dienst]. Für die Zeit seiner Tätigkeit in Heidelberg wird Sölch vom Personalamt des Gaues Baden der NSDAP eindeutig günstig beurteilt ..." (aus:
UAH PA 654). Schmitthenner schickt am 11. Mai 1939 die Stellungnahme des Dekans der Phil. Fak., (siehe) Hubert Schrade, zurück: „Professor Sölch hat sich während seines Heidelberger Aufenthaltes als eindeutig rechts eingestellt gezeigt. Er hat nicht nur immer wieder, wo es nötig war, gegen die demokratisch-jüdischen Mitglieder der Fakultät Stellung genommen, sondern sich auch ganz besonders in dem berüchtigten Fall Gumbel mit dem Vorgehen der Studenten identisch erklärt. Von unserer Seite her ist also kein Bedenken gegen die Einleitung des beabsichtigten Verfahrens zu Gunsten von Professor Sölch zu erheben“ (aus: PA 654). 1939 erfolgt S.s Pensionierung, bis 1945 bleibt er weiterhin im Amt als Direktor des Wiener Geographischen U-Instituts.

1951 Präsident der Österr. Geographischen Gesellschaft

$E$ Mitglied der Akademie der Wissenschaften: 1932 H, 1937 Wien; Ehrenmitglied des Schubertbundes; o. Mitglied der Wiss. Gesellschaft Innsbruck. Dr. iur. h. c. Glasgow.

Qu UAH PA 240, 654, 5916. - GLA Abt. 235, Fasz. 2534. - Über J. S. in: Leidlmair, Adolf: Hans Kinzl. Im Licht seines Briefwechsels, Lebenslaufes und persönlicher Erinnerungen in: Beiträge - Innsbrucker Bericht (2003) o7, S. 148 f., 153 f. u. ö. • Auskunft: Archiv der Universität Wien.

W Geographischer Führer durch Nordtirol. Berlin 1924. - Die Landformung der Steiermark. Graz 1928. - Der Rückzug der letzten Vergletscherung. Berlin 1932. Die Landschaften der Britischen Inseln. 2 Bde. Wien 1951-1952.

$L$ Wer ist's (1935) S. 1511 f.; Arnim 2 (1952) S. 581. • Nachruf in: Almanach der Akademie der Wissenschaften Wien (1954) S. 370-386 (mit Werkverz.). Jansen (1992) S. 413 (Register); Ders. (1992a) S. 169 (Register); WBIS; Wennemuth (1994) S. 638 (Register). • Grüttner/Kinas (2007) S. 175 u. ö.; Lexikon jüdischer Einwohner Hs (2011) S. 391. - Pfefferle, Roman, Pfefferle, Hans: Glimpflich entnazifiziert. Die Professorenschaft der Universität Wien von 1944 in den Nachkriegsjahren. 
Göttingen 2014. S. 94, 266, 303. - Deutsche Biographie, s. https://www.deutsche-biographie.de/gn d117451770.html [23.11. 2017].

$P$ Archiv der Universität Wien.

\section{Sommerfeld, Heinrich Adolf}

1924-1930 (Lehrbeauftragter) Phil. Fak.

1930-1933 (Honorar-Prof.) Phil. Fak.

1933-1934 Phil. Fak.

1934 Wirtschaftswiss. Fak.

1935-1939 Staats- und Wirtschaftswiss. Fak.

1924-1930 Betriebswirtschaftslehre

1930-1934 Nationalökonomie

1935-1939 Betriebswirtschaftslehre

* o9. Juli 1884 Dessau (heute: Stadtteil von Dessau-Roßlau)

$\dagger$ 13. Dez. 1950 Hünfeld (Hessen) ev.-luth.

V Heinrich S. (1847-1923) Gärtnereibesitzer

M Emma geb. Ruthe (1853-1933)

( 4. Aug. 1914 Antonie Marie Emilie geb. Bettzieche (1890-1968)

$\mathrm{K} \quad \mathrm{S}$

Lb Köthen (Anhalt): 1899-1905 Ausbildung am Lehrerseminar; 1905 Volksschullehrerprüfung am Lehrer-Seminar; seit 1905 Volksschullehrer.

Dessau: Seit 1907 Mittelschullehrer; 1. April 19081912 Gewerbeschullehrer; 1910-1912 Studium an Maschinenbauschule.

Leipzig: Seit SS 1912 Studium der Wirtschaftswiss., Rechtswiss. und Technischen Chemie an Handelshochschule; 1914 Handelslehrer-Diplomprüfung.

4. Aug. 1914-8. April 1918 Kriegsdienst (2. März 1915 verwundet bei Ypern, seit 15. Okt. 1915 Leutnant im Kriegsbekleidungsamt in Leipzig); 19161918 angeblich auch Revisor in e. Revisions-A.G. in Berlin.
U Leipzig: 8. Jan.-13. Okt. 1917 Immatrikulation zum Studium der Kameralwiss.; 14. Nov. 19178. Juni 1918 Studium der Rechtswiss. und Kameralwiss.

UH: 18. Okt. 1917 Immatrikulation, am 31. Okt. 1917 Anmeldung zurückgezogen; 19. Juni 1918 Immatrikulation, am 20. Juni 1918 Anmeldung erneut zurückgezogen; 27. Juni 1918 Rigorosum, 5. Juli 1918 (Datum der Promotionsurkunde) Dr. phil.

Friedrichs-Polytechnikum in Köthen: Seit WS 1918/19 Dozent für Betriebswirtschaftslehre.

Mannheim: Seit SS 1920 hauptamtlicher Dozent (Prof.) für Betriebswirtschaftslehre und Leiter des Privatwirtschaftl. Seminars; seit SS 1921 auch Leiter des Betriebswiss. Instituts an Handelshochschule; 10. Dez. 1926 (Ern.)-1. Nov. 1933 (Auflösung) o. Prof. an Handelshochschule. In dieser Zeit auch:

UH: SS 1924-SS 1930 Lehrauftrag für Betriebswirtschaft; seit 4. Aug. 1930 o. Honorar-Prof.; 1. Nov. 1933-1. Apr. 1939 o. Prof. nach Auflösung der Handelshochschule in Mannheim; Mai 1934 Errichtung zunächst der Wirtschaftswiss., Jan. 1935 der Staats- und Wirtschaftswiss. Fak.; 1935 Ruf an U Köln abgelehnt.

H: 1935 Referent für Ausbildung und Presse im Stab des Kreisjägermeisters (S. ist selbst Kreisjägermeister des Jagdkreises $\mathrm{H}$ ).

TH und U Breslau: Seit SS 1939 o. Prof.; seit 1939 Leiter vieler ballistischer Lehrgänge, zuletzt im Rang e. Oberstleutnants; Febr-6. Mai 1945 (Einnahme der Stadt durch Rote Armee) Auflösung von TH und U; Verlust seines Besitzes.

Nach 1945 Leitender Angestellter in e. Industriekonzern; Febr. 1947 als Wohnsitz Hünfeld genannt (aus: UAH PA 657).

Lehrauftrag: 1948 U Göttingen, 1949 U Köln als Vertreter des Lehrstuhlinhabers für Treuhandund Revisionswirtschaft.

1938/39 Dekan der Staats- und Wirtschaftswiss. Fak. der UH 
E Ritterkreuz vom Albrechtsorden; Eisernes Kreuz II. Klasse; 1934 Ehrenwinkel für ehemalige Stahlhelm-Angehörige.

Qu UAH PA 284, 657, 5927. GLA Abt. 235, Fasz. 2538. Auskunft: Universitätsarchiv Leipzig.

$W$ Die Wertansätze in der Inventur mit Berücksichtigung steuerlicher Vorschriften. Berlin 1921. 2. Aufl. 1923. - Die Goldmarkbuchhaltung, ihre Grundlagen und Technik. Berlin 1923. 2. Aufl. 1924. Die Technik des börsenmäßigen Termingeschäfts ... Berlin 1923. 2. Aufl. 1929. • Der Unternehmer als Verwalter vom Volksvermögen. Hamburg 1934 .

L Kürschner (1928/29) Sp. 2301f., (1931) Sp. 2828 f., (1940/41) Sp. 805, (1950) Sp. 1973, (1954) Sp. 2730. • Handels-Hochschule Mannheim 1907-1932 (1932) S. 23; Wirtschaftswiss. Hochschullehrer (1938) S. 212f., 753-756 (Bibliographie bis 1937). • Dürrhammer, Wilhelm: Nachruf für ... H. S. in: Zs. für Handelswissenschaftliche Forschung N. F. 3 (1951) S. 140. Arnim 2 (1952) S. 585 • Helwig, Hellmuth: Bekannte Betriebswirtschaftler aus dem Kreise des Corps Hermunduria, Leipzig, zu MannheimHeidelberg. Bio-Bibliographien von Karl von der Aa, ..., H. S. Manuskript. Mannheim 1958. (Ex. in UB Mannheim.) - Gablers Wirtschafts Lexikon. Hrsg. von Reinhold Sellien und Helmut Sellien. 10. Aufl. Bd. 5. Wiesbaden 1980. Sp. 1226 f. • Universität Mannheim (1982) S. 94, 273, 299; WBIS; Brintzinger (1996) S. 400 (Register). - Mantel, Peter: Betriebswirtschaftslehre und Nationalsozialismus. Eine institutionen- und personengeschichtliche Studie. Wiesbaden 2009. S. 924 (Register). • Schultes (2010) S. 264 u. ö.; Deutsche Biographie, s. https://www.deutsche-biographie.de/gnd138878 82X.html [23.11. 2017].

Sonntag, Carl Richardt

s. Sontag, Richard

\section{Sontag, Karl Richard}

1865-1872 Jur. Fak.

Strafrecht, Strafprozeßrecht

* o6. Febr. 1835 Magdeburg

$\dagger$ 26. März 1910 Karlsruhe (?)

ev.

V Johann Gottlieb Sonntag, Kaufmann

M Christiane geb. Bieber

$\infty$ unbekannt.

$L b$ Seit WS 1855/56 Studium an U Berlin, SS 1857 H, seit WS $1857 / 58$ Berlin; 15 . Juni 1860 Dr. iur. an U Halle-Wittenberg.

Halle/S.: Juni-Dez. 1860 Auskultator (s. Levin Goldschmidt: Eintrag unter $L b$ (1851)) am Kreisgericht.

Berlin: 1861-1864 Eigenstudien.

UH: 4. Febr. 1865 Habilitation für Strafrecht; seit 18. Dez. 1867 a. o. Prof.; 1872 Ruf an U Basel abgelehnt.

U Freiburg/Br.: Seit April 1872 o. Prof.; 1881 Ruf an U Gießen abgelehnt; April 1892 Versetzung in Ruhestand aus gesundheitlichen Gründen. - In dieser Zeit:

Karlsruhe: 1883-1884 Mitglied der I. Kammer des Badischen Landtags.

1881 Geh. Hofrat

E 1881 Ritterkreuz I. Klasse des Ordens vom Zähringer Löwen.

Qu UAH PA 2298 (eigenhändige Unterschrift: Karl Richard Sontag); Fak.-Akte H-II-111/63. • Ergebnislose Anfragen zum Sterbeort: Ev. Oberkirchenrat - Landeskirchliches Archiv - Karlsruhe; Universitätsarchiv Freiburg/Br.; Archiv und Bibliothek der Kirchenprovinz Sachsen in Magdeburg sowie Stadtarchiv Magdeburg. - Auskunft: Ev. Superintendentur - Kirchenbuchstelle - Magdeburg (im Geburtsregister 1835 als Carl Richardt 
Sonntag eingetragen); Archiv und Bibliothek der Kirchenprovinz Sachsen in Magdeburg (Taufeintrag von Richard Sonntag am 23. März 1835 in der Magdeburger Johanniskirche).

$W$ Die Entlassung gegen Caution im deutschen Strafverfahren. Heidelberg 1865. - Die Festungshaft. Ein Beitrag zur Geschichte des deutschen Strafensystems und zur Erläuterung des Reichsstrafrechts. Leipzig 1872. - Die Redaktionsversehen des Gesetzgebers insbesondere auf strafrechtlichem Gebiet. Freiburg/Br. 1874 .

$L$ Zeiler (2008) S. 35-39; Ders. (2009) S. 523 (Register); Schroeder (2010) S. 209 f.; Deutsche Biographie, s. https://www.deutsche-biographie.de/gn d117637866.html [23.11. 2017].

$P$ Bildarchiv UAH; graph. Slg. UBH.

\section{Spek, Josef}

1920-1947 Nat.-Math. Fak.

Zoologie

* 27. Mai 1895 Sächsisch-Regen (Siebenbürgen; heute: Reghin, Rumänien)

$\dagger$ 21. Febr. 1964 Rostock ev.

V Julius Gustav S. (1844-1910) Oberförster

M Mathilde Emilie geb. Wachner (1855-1914)

$\infty$ unverheiratet.

Lb UH: Seit WS 1913/14 Studium der Naturwiss.; 1914 „im Kriege als nicht geeignet zurückgestellt“ (aus: Fragebogen vom 14. Juli 1937 in: UAH PA 5933); seit 1. Juni 1917 wiss. Privat-Assistent von (siehe) Curt Herbst; 27. Okt. 1916 Dr. phil. nat.; Okt. 1918-Okt. 1936 I. Assistent am Zoolog. Inst. (s. hierzu auch Z); 26. April 1920 Habilitation; 1923-1924 auch Leiter des von der Josefine und Eduard von Portheim-Stiftung für Wissenschaft und Kunst eingerichteten Biomechanischen Inst. in H, Märzgasse 2 (Nachf.: Franz Weidenreich); Herbst 1925, 1. Okt. 1928-30. April 1929 Beurlaubung für wiss. Arbeiten an Zoolog. Station in Neapel; 11. Aug. 1925-18. Okt. 1939 nichtplanm. und nichtbeamteter a.o. Prof.; 1934 Ruf an Tongji-U in Shanghai abgelehnt; seit 1. Nov. 1936 Lehrauftrag für Vorlesungen und Übungen zu Protoplasma und Zellforschung; seit 18. Okt. 1939 apl. Prof. unter Berufung in Beamtenverhältnis; WS 1943/44 Vertreter des Lehrstuhlinhabers für Zoologie an U Greifswald; SS 1944 S. erhält nach Rückkehr des Greifswalder Ordinarius e. „ehrenvolle Einladung der Fakultät, noch ein Semester zu bleiben“, die S. annimmt (aus: Brief vom 14. April 1944 in: PA 5933); 1946 Ruf an U Halle/S. abgelehnt. • In dieser Zeit:

Okt. 1932-Sept. 1933 Studienurlaub: New York U, danach Washington Square College der New York U, seit 27. Mai 1933 Marine Biological Laboratory in Woods Hole (Massachusetts). - Beurlaubungen für wiss. Untersuchungen: Sept.-Okt. 1936 Zoolog. Station in Neapel, Sept.-Okt. 1937 Station für Meeresbiologie in Rovigno d'Istria (Italien; heute: Rovinj, Kroatien); Sept./Okt. 1938 Beurlaubung für entwicklungsphysiologische Versuche an Zoolog. Station in Neapel.

U Rostock: 1. Juli 1947-SS 1960 (Emeritierung) o. Prof. und Direktor des Zoolog. Inst.

Z Ludwig Wesch (siehe Drüll (2009) S. 664f.) stellt als Naturwiss.-Math. Fachabteilungsleiter der Heidelberger Dozentenschaft ein Gutachten über S. am 28. Nov. 1935 aus; hierin heißt es u. a.: „Prof. Spek ist der Typ des reinen Wissenschaftlers. Auf seinem Fachgebiet hat er eine geradezu glänzende Begabung entwickelt und sich auch allenthalben durchgesetzt. Hauptsächlich seine Protoplasmauntersuchungen waren richtungweisend. Wissenschaftlich ist Prof. Spek in jeder Hinsicht zu empfehlen. Ueber seine Person selbst ist noch zu sagen, dass er sich gegenüber der Aussenwelt vollkommen abschliesst und nur seinen Studien lebt. Aus diesem Grunde dürfte es auch immer, hauptsächlich bei den Studenten, zu einer gewissen Ablehnung von Prof. Spek kommen, obwohl seine pädagogischen Fähigkeiten nicht von der Hand zu weisen sind.

Politisch hat sich Prof. Spek in keiner Weise betätigt, was schon aus seiner gesamten Veranlagung hervorgeht. Nach dem Umsturz hat er sich ebenfalls sehr zurückgehalten, obwohl mir bekannt ist, dass er durchaus positiv auf dem Boden 
der nationalsozialistischen Weltanschauung steht. Eine Verlängerung seiner Assistententätigkeit ist unbedingt zu befürworten. Es wäre jedoch sehr wünschenswert, wenn Prof. Spek in angemessener Zeit entsprechend seinen Fähigkeiten eingesetzt werden könnte, hier wiederum wäre an eine Berufung an ein Kaiser-Wilhelm-Institut zu denken ..." (aus: UAH PA 5933).

Qu UAH PA 5933, 9988; RA 6577; Rep. 40-422. • GLA Abt. 235, Fasz. 2539.

$W$ Experimentelle Beiträge zur Kolloidchemie der Zellteilung. Dresden 1920. Die physiologischen Wechselwirkungen zwischen Kern und Plasma in: Lehrbuch der Allg. Physiologie. Hrsg. von Ernst Gellhorn. Leipzig 1931. S. 433-455. Neue experimentelle Studien über das Problem der Reaktion des Protoplasmas in: Protoplasma (1933) Bd. 20, S. 376-406. (Mitverf.) - Bibliographie 1918-1935 in: UAH PA 5933; siehe auch NDB 24 (2010) S. 656.

MG, MHG 1926-1945, 1950-1964 Zs. „Protoplasma“.

L Kürschner (1931) Sp. 2842, (1940/41) Sp. 811, (1961) S. 1975. - Arndt, E. A.: J. S. 65 Jahre alt in: Protoplasma (Juni 1961) Bd. 53, Nr. 2, S. 291-293 (mit Werkverz.). - J.S. $\dagger$ in: Verh. der Dt. Zoolog. Gesellschaft 30. Mai-5. Juni 1966. Göttingen 1967. S. 610-612. • Jansen (1992a) S. 169 (Register); WBIS; Engehausen (2008) S. 36, 46 u. ö.; NDB 24 (2010) S. 656; Catalogus prof. Rostochiensium online.

$P$ Bildarchiv UAH; siehe hier auch Das Zoologische Institut - eine Bilder-Chronik. Herrn Prof. Dr. Paul Krüger zugeeignet. Heidelberg, am 18. Dezember 1936.

\section{Spengel, Leonhard (seit 1875: von Spengel)}

1842-1847 Phil. Fak.

Philologie, Altertumskunde

* 24. Sept. 1803 München

$\dagger$ o8. Nov. 1880 München kath.

V Leonhard S., nach 1803 Pächter des 1803 aufgehobenen Klosters Andechs

M Anna Maria geb. Münch

œ 8. Jan. 1837 Josepha Euphrosyna geb. Klob $(1812-1852)$

K 7, u.a. Gymnasial-Prof. Dr. phil. Andreas S. (1838-1905) klassischer Philologe, zuletzt 18861902 (Ruhestand) Rektor des Königl. humanistischen Gymnasiums in Passau (heute: Gymnasium Leopoldinum), s. WBIS.

Lb München: Seit 1821 Studium am Lyceum; 1823 Lehrerexamen für höheres Schulfach.

Seit 1823 Eigenstudien mit Staatsstipendium in Leipzig, $1825-1826$ in Berlin; 1826 Ruf an U Kiel abgelehnt.

Gymnasium in München: Seit Herbst 1826 Lektor, 1830-1842 Gymnasial-Prof. In dieser Zeit:

U München: Seit 1826 II. Vorstand des Philolog. Inst.; 20. oder 28. März 1827 Dr. phil.; 1827 Habilitation; WS 1827/28-WS 1841/42 Privat-Dozent.

UH: Seit 26. Febr. 1842 o. Prof.

U München: Seit WS 1847/48 o. Prof.

$E$ Mitglied der Akademie der Wissenschaften: 1835 München, 1842 Berlin, 1860 Göttingen.

Qu UAH PA 2300; RA 5355, 6827. GLA Abt. 205, Fasz. 509. - Teil-Nachlaß: Bayerische Staatsbibliothek (Repertorium Spengeliana von 1920) und Universitätsarchiv München; Pfälzische Landesbibliothek Speyer (Signatur: Hs. 346).

$W$ Über die Poetik des Aristoteles. München 1847. Rhetores graeci. 3 Bde. Leipzig 1853-1856. 
Das philologische Seminar in München und die Ultramontanen. München 1854. - Demosthenes' Vertheidigung des Ktesiphon. Ein Beitrag zum Verständniß des Redners. München 1862. • Aristotelische Studien. 2 Bde. München 1864-1866.

$L$ Festgabe zum Doktorjubiläum des Herrn Professors ... L. von S. Neudr. der Ausg. München 1877. Aalen 1981. Nekrolog in: Biographisches Jahrbuch für Altertumskunde. Hrsg. von Conrad Bursian. Jg. 3. Berlin 188o. • Christ, Wilhelm: Gedächtnisrede auf L. von S. München 1881. • Über L. S. in: Ludwig Steub über sich selbst. Breslau 1883. Kapitel 19. ADB 35 (1893) S. 115-117; Meyers Großes Konversations-Lexikon. Leipzig 1909. Bd. 18. S. 714. Bosls bayerische Biographie ... Hrsg. von Karl Bosl. Regensburg 1983. • WBIS. •CentaurenGeburten“. Wissenschaft, Kunst und Philosophie beim jungen Nietzsche. Hrsg. von Tilman Borsche u. a. Berlin 1994. S. 535 (Register).

\section{Spiegelberg, Wilhelm}

1919-1920 (Lehrbeauftragter) Phil. Fak. 1920-1923 (Honorar-Prof.) Phil. Fak. Ägyptologie

* 25. Juni 1870 Hannover

$\dagger \quad$ 23. Dez. 1930 München mosaisch, seit 1910 prot.

V Eduard S. (1837-1910) Bankier

M Antonie geb. Dux (1846-1902)

$\infty$ 4. April 1899 Marie Hermine Elisabeth (Lise) geb. von Recklinghausen (1872-1948) T von Friedrich Daniel von R. (1833-1910) o. Prof. für Patholog. Anatomie: seit SS 1865 Königsberg, seit WS 1865/66 Würzburg, 1872-1906 (Ruhestand) Straßburg, s. NDB 21 (2003) S. 236 f. - Bruder: Heinrich von R. (1867-1942) Arzt, Blutdruckforscher, Philosoph, 1914-1918 Lazarettarzt in Straßburg, anschl. bis zu seinem Tod im Haushalt seiner Schwester Lise Spiegelberg wohnend, s. WBIS; H. von R. Vom Lebenssinn und Weltsinn. Hrsg. von Herbert Spiegelberg. St. Louis 1977; Nachlaß in Bayer. Staatsbibliothek München
K 3 S: u. a. Erwin S. (1901-1938 Suizid) seit 1926 Chemiker an Dt. Forschungsanstalt für Lebensmittelchemie München, 1936 Emigration, anschl. Prof. an Universidade Federal do Rio de Janeiro, s. Boveri, Margret: Verzweigungen. Zürich 1977. S. 97 f., 100 u. ö. - Herbert S. (1904-1990) Philosoph, Philosophiehistoriker; 1933 Emigration zunächst in die Schweiz, 1938 USA, anschl. Dozent Swarthmore College (Pennsylvania) und Lawrence $\mathrm{U}$ in Appleton (Wisconsin), 1963-1971 (Emeritierung) Prof. Washington U St. Louis (Missouri), s. NDB 24 (2010) S. 682

Vw siehe auch NDB 17 (1994) S. 392 f. (Artikel: Max Meyerhof, Vetter von W.S. und Vetter 2. Grades von (siehe) Otto Meyerhof).

Lb Seit SS 1888 Studium an U Straßburg, seit 1889 Berlin, 1890 Straßburg; Sommer 1890-Anfang 1891 Studien in Liverpool und London; Nov. 1891 Dr. phil. an U Straßburg; 1891/92 Forts. des Studiums für ein Semester an U Paris; 1892-1894 Habilitationsvorbereitungen in Paris, dann Berlin und anschl. Straßburg.

U Straßburg: 1894 Habilitation; seit 1895 Studien und Teilnehmer bei Ausgrabungen in Ägypten, besonders Theben; seit 1899 a. o. Prof.; seit 27. Juli 1899 (Gründungs-)Direktor des Inst. für Ägyptologie; 1907 Ruf an U Wien abgelehnt; seit 1907 o. Prof.; 1907-1911 mehrere Aufenthalte für Ausgrabungen in Theben; 1914-1917 Kriegsdienst als Zivildienstleistender im Kriegs-Bibliotheksdienst; 1918 nach franz. Besetzung Elsaß-Lothringens Niederlegung der Lehrtätigkeit; Febr. 1919 Ausweisung als „feindlicher Ausländer" und Konfiszierung des S.schen Hauses von franz. Regierung als Reparationszahlung gemäß dem Versailler Vertrag.

UH: Seit 28. Mai 1919 Lehrbeauftragter („Prof. S. wird zunächst ohne förmliche Eintretung in den Lehrkörper der Universität seine Tätigkeit aufnehmen und sich in der Ankündigung seiner Vorlesungen als Beauftragter Dozent (ordentlicher Professor der Universität Straßburg) zu bezeichnen haben", aus: Brief des Ministeriums des Kultus und Unterrichts vom 28. Mai 1919 an Senat der UH in: UAH PA 5937); WS 1919/20-SS 1923 Vorlesungsankündigungen; seit 9. April 1920 o. Honorar-Prof. („Die Ernennung zum o. Honorar- 
professor ist nur eine Rangverleihung, mit dem keinerlei staatliche Einkünfte verbunden sind“, Auskunft des Engeren Senats der UH auf Anfrage des Reichsministers des Innern, Abt. für ElsaßLothringen, Zweigstelle Lahr im Breisgau vom 24. April 1920 zur Ernennung S.s zum HonorarProf. aus: PA 5937).

U München: Seit WS 1923/24 o. Prof. und Begründer des Ägyptologischen Seminars; 1927, 1928, 1929, 1930 Studienaufenthalte in Ägypten.

Über die schlechte finanzielle Situation S.s als ehemaligem Ordinarius der Straßburger $U$ und jetzigem Lehrbeauftragter an der Universität Heidelberg gibt ein Schreiben des Reichsfinanzministeriums an das preußische Ministerium für Wissenschaft, Kunst und Volksbildung vom 15. April 1919 Auskunft: „... Sobald ein Strassburger Professor in ein anderes Amt (sei es auch nur als unbesoldeter Honorarprofessor) übertritt, ... muss davon ausgegangen werden, dass das bisherige Beamtenverhältnis und der daraus sich ergebende Anspruch auf Gehalt und sonstige Bezüge erlischt. Insbesondere verliert er damit Anspruch auf Ruhegehalt, und er kann auch nicht verlangen, dass ihm der Unterschied zwischen seinem bisherigen Gehalt und dem ... niedrigeren Gehalt der neuen Stelle nachgezahlt wird ... Die endgültige Entscheidung [über eine finanzielle Unterstützung S.s] muss den Verhältnissen nach dem Friedensschluß vorbehalten bleiben“ (aus: PA 5937).

Im Februar und März 1930 begleitet S. Thomas und Katja Mann während ihres Aufenthaltes in Kairo und Umgebung, s. hierzu Grimm, Alfred: Joseph und Echnathon. Thomas Mann und Ägypten. Ausstellungskatalog Museum Villa Stuck. 2. Aufl. München 1993. S. 25-48.

1924 Geh. Reg.-Rat

E Mitglied der Akademie der Wissenschaften: 1919 H, 1924 München.

Qu UAH PA 5937. GLA Abt. 235, Fasz. 2540.
$W$ Studien und Materialien zum Rechtswesen des Pharaonenreiches der Dynastien XVIII-XXI. Hannover 1892. A Arbeiter und Arbeiterbewegung im Pharaonenreich unter den Ramessiden. Straßburg $1895 . \bullet$ Geschichte der ägyptischen Kunst bis zum Hellenismus. Leipzig 1903. Ägyptologische Randglossen zum Alten Testament. Leipzig 1904. Der Aufenthalt Israels in Ägypten im Lichte der ägyptischen Monumente. Straßburg 1904. 4. Aufl. 1904 [!]. • Die Schrift und Sprache der alten Ägypter. Leipzig 1907. - Die sogenannte demotische Chronik. Leipzig 1914. • Der ägyptische Mythus vom Sonnenauge. Berlin 1915.

$H G$ Ägyptische und andere Graffiti aus der thebanischen Nekropolis. Heidelberg 1921. Koptisches Handwörterbuch. Heidelberg 1921. (Westendorf, Wolfhart: Koptisches Handwörterbuch bearb. auf der Grundlage des Koptischen Handwörterbuchs von W.S. 2. Aufl. Heidelberg 2008.) • Demotische Grammatik. Heidelberg 1925.

$L$ Wer ist's (1928) S. 1493; Kürschner (1931) Sp. 1879 f.; Arnim 2 (1952) S. 593; WBIS. • Grimm, Alfred: W.S. als Sammler. Veröffentlichung anläßlich der Gedächtnisausstellung „W.S. als Sammler“ zum 125. Geb. des Ägyptologen W.S. in der Staatlichen Sammlung Ägyptischer Kunst München, 24. April-16. Juli 1995. München 1995. NDB 24 (2010) S. 682 f. - Spiegelberg, Richard: W.S. A life in Egyptology. Published 2015. Online unter https://oi.uchicago.edu/sites/.../wilhelm_spiegel berg_memoir.pdf 5 (Ausdruck im UAH). • Gertzen, Thomas L.: Judentum und Konfession in der Geschichte der deutschsprachigen Ägyptologie. Berlin 2017. S. 226 (Register); Ders.: W. Leeser S. ... Der Ägyptologe hinter den Josephsromanen. Vaterstetten 2017.

P Spiegelberg (2015) S. 3. 


\section{Sponeck, Carl Friedrich Christian Wilhelm Graf von}

1806-1822 Staatswirtschaftl. Sektion

1822-1827 Phil. Fak.

Forst- und Jagdwissenschaft

* o9. Juli 1762 Osterholz in der Gemarkung Pflugfelden (heute: Stadtteil von Ludwigsburg)

$\dagger \quad$ 04. Okt. 1827 Heidelberg ref.

V Friedrich Ludwig Graf von S. (1725-1792), u. a. Kammerherr, Oberforstmeister und Verwalter des Oberforsts Schorndorf mit Amtssitz im Jagdschloß (in) Engelberg (heute: Stadtteil von Winterbach bei Stuttgart), s. auch http://www. genealogy.com/ftm/v/o/n/Gottfried-H-Vonsponneck/GENE32-0002.html (abgerufen am 24. Nov. 2017)

M Dorothea Christina geb. Pfister (1734-1791)

$\infty$ Caroline geb. Geigel

K 1 T

Lb $1778-1783$ Ausbildung an Karlsschule in Stuttgart, s. hierzu Hauptstaatsarchiv Stuttgart, Findbuch A 272 Bü 281; anschl. Studienreisen; seit 1784 Forstpraktikant, u. a. im Oberforst Schorndorf.

1785-1793 Chef des Herzogl.-Württ. Leibjägerkorps und der Jägergarde in Hohenheim (heute: Stadtteil von Stuttgart); 1793 Ern. zum Herzogl.Württ. Oberforstmeister; seit 1794 Oberforstmeister am Hof in Ludwigsburg; Oberforstmeister der Oberforstbezirke: seit Herbst 1796 Blaubeuren, seit 1797 Altensteig, Sommer 1801-1805 Neuenbürg, s. hierzu auch http://www.landesarchiv-bw. $\mathrm{de} / \mathrm{plink} / \mathrm{f}=1-4070 \& \mathrm{a}=\mathrm{fb}$.

UH: Seit SS 1806 a. o. Prof. (Mai 1803 Einführung der Staatswirtschaftl. Sektion nach Eingliederung der "Staatswirtschafts Hohe Schule“ H in UH); seit 2. Aug. 1808 o. Prof.; Mai 1822 Zusammenlegung der Staatswirtschaftl. Sektion mit Phil. Fak.

1811, 1817, 1822 (bis Mai) Direktor der Staatswirtschaftl. Sektion der UH; zur Staatswirtschaftl. Sektion der $\mathrm{UH}$, siehe Heinrich Eschenmayer und Ludwig Wallrad Medicus: Einträge unter $Z$ [itat]
$E$ Mitglied der Societät der Forst- und Jagdkunde zu Waltershausen. • Nov. 1811 Dr. phil. h.c. UH. • 1811 Goldene Verdienstmedaille des Großherzogs von Frankfurt.

Qu UAH PA 2302. GLA Abt. 205, Fasz. 510. • Briefe: siehe Kalliope. - Ergebnislose Anfrage: Landeskirchliches Archiv Stuttgart. - Auskunft: Landesarchiv Baden-Württemberg in Stuttgart (Geb.-Datum 09. Juli 1762 aus: Abschrift aus dem Pflugfelder Taufbuch). - Sammlung naturhistorischer ... Jäger-Beobachtungen ..., welche theils von dem Herausgeber selbst ... und ... von seinem verstorbenen Vater gemacht worden sind. Hrsg. von Carl Friedrich Graf von S. Heidelberg 1824 (teilw. Autobiogr.).

$W$ Forstwissenschaftliche und botanische Abhandlungen und Bemerkungen. Heidelberg 1807. Über die Anlegung, Einrichtung und den Nutzen der Holzgärten und Holzmagazine in forstlicher und staatswirthschaftlicher Hinsicht. Heidelberg 1816. • Über den Schwarzwald. Heidelberg 1817. Reprint hrsg. von Bernd Bendix. Remagen 2015. Über die Veräußerung von Staatswaldflächen zu landwirthschaftlichem Gebrauch. Heidelberg 1823. Handbuch des Floßwesens, vorzüglich für Forstmänner, Kameralisten und Forstbeamte. Stuttgart 1825 . Siehe auch Lindner, Kurt: Bibliographie der deutschen und der niederländischen Jagdliteratur von 1480 bis 1850 . Berlin 1976. Sp. 661-664.

L ADB 35 (1893) S. 259 f.; Stieda (1906) S. 139f., 146-148 u. ö.; Arnim 2 (1952) S. 595; Weisert (1991) S. 128 u. ö.; WBIS; Neuhaus (2014) S. 67-69, 72-77, 118 Anm. 578, 287 f., 350 u. ö. $\bullet$ Stinglwagner, Gerhard u. a.: Das Kosmos Wald- und Forstlexikon. 5. Aufl. Stuttgart 2016. S. 823 f. u. ö.

\section{Stäckel, Paul Gustav}

1913-1919 Nat.-Math. Fak.

Mathematik

* 20. Aug. 1862 Berlin

$\dagger$ 12. Dez. 1919 Heidelberg

ev.

1808 Badischer Oberforstrat 
V Ernst Gustav S. († 1908) Direktor e. höheren Mädchenschule, Schulrat

M Marie Elisabeth geb. Ringel ( $† 1869)$

$\infty$ 7. Mai 1891 Eleonore Elisabeth geb. Lüdecke (1869-1937/38)

K $\quad 2 \mathrm{~S}, 1 \mathrm{~T}$

Lb U Berlin: Seit WS 188o/81 Studium der Mathematik, Physik, Philosophie, Psychologie, Pädagogik, Geschichte; 10. Aug. 1885 Dr. phil.

Berlin: Juli 1886 Oberlehrerprüfung; Okt. 1886Sept. 1887 Militärdienstpflicht als Einjährig-Freiwilliger; Okt. 1887-Sept. 1888 Probelehrer im pädagog. Probejahr am Königl. Wilhelms-Gymnasium; 1888-1891 Eigenstudien.

U Halle/S.: 21. Febr. 1891 Habilitation; 1891-1895 Privat-Dozent.

U Königsberg (Preußen): 10. Juli 1895 Ern. zum a. o. Prof.; 1. Okt. 1895 Dienstantritt.

U Kiel: 4. Jan. 1897 Ern. zum persönlichen o. Prof.; 1. April 1897 Dienstantritt; 16. Okt. 1899 Ern. zum o. Prof.

TH Hannover: 9. Jan. 1905 Ern. zum o. Prof.; 1. April 1905 Dienstantritt.

TH Karlsruhe: 26. März 1908 Ern. zum o. Prof. • In dieser Zeit:

Karlsruhe: Seit 1911 Mitglied des Landesschulrats.

UH: 3. Jan. 1913 Ern. zum o. Prof. auf den neueingerichteten II. Lehrstuhl für Mathematik zunächst bis 1914 neben Leo Koenigsberger, 1914-1919 neben Oskar Perron; 1. April 1913 Dienstantritt. - In dieser Zeit:

1914-1916 Kriegsdienst.

1916/17 Dekan der Nat.-Math. Fak. der UH

1908 Geh. Hofrat
E 1895 Mitglied der Dt. Akademie der Naturforscher Leopoldina Halle/S.; Mitglied der Akademie der Wissenschaften: 1906 Göttingen, 1911 H. 1905 Österr. Kaiserl. Orden der Eisernen Krone III. Klasse; 1911 Ritterkreuz I. Klasse des Ordens vom Zähringer Löwen.

Qu UAH PA 2304; RA 6452. • GLA Abt. 235, Fasz. 2544. - Briefe: UBH; Universitätsarchiv Gießen, hier im Nachlass Friedrich Engel. • Siehe auch Archiv der Dt. Akademie der Naturforscher Leopoldina Halle/S.

$W$ Elementare Dynamik der mathematischen Wissenschaft in: Encyclopädie der mathematischen Wissenschaft IV,1 (1908). • Die Darstellung gerader Zahlen als Differenzen und Summen von Primzahlen. Berlin 1922. (Mitverf.) • Siehe Homo Heidelbergensis mathematicus online (Stand: Sept. 2008).

HG Bernoulli, Johann: Variationsrechnung ... Hrsg. von Paul Stäckel. Leipzig 1894. Nachdr. Darmstadt 1976. - Die Theorie der Parallellinien von Euklid bis auf Gauss. Eine Urkundensammlung zur Vorgeschichte der nichteuklidischen Geometrie ... Leipzig 1895. - Wolfgang und Johann Bolyai. Geometrische Untersuchungen. $2 \mathrm{~T}$. Leipzig 1913.

MHG Borel, Émile: Die Elemente der Mathematik. 2 Bde. Leipzig 1909. 2. Aufl. Bd. 1: 1913. Bd. 2: 1920.

$L$ Biogr. Jahrbuch 2 (1917-1920) S. 734. • Goldbeck, Ernst: P.S. zum Gedächtnis in: Int. Monatsschrift für Wissenschaft, Kunst und Technik XIII (1919) Sp. 439-450. - Perron, Oskar: P.S. Heidelberg 1920. - Arnim 2 (1952) S. 598; Professoren Kiel (1956) S. 154; Math. Institute in Deutschland (1989) S. 161 und 289 (Register); Lexikon bedeutender Mathematiker (1990). - Renteln, Michael von: P.S. ... Mathematiker und Mathematikhistoriker in: Überblicke Mathematik (1996/97). Hrsg. von Albrecht Beutelspacher u. a. Wiesbaden 1996. S. 151-160. Pfister, Felix: Das Gauss'sche Prinzip und das Lagrange'sche. Notizen zu e. kaum beachteten Arbeit P.S.s in: Zs. für angewandte Mathematik und Mechanik 77 (1997) S. 7-12. Renteln, Michael von: Die Mathematiker an der TH Karlsruhe (1825-1945). 2. Aufl. Karlsruhe 2002. S. 337- 
346. Kriegstagebuch K. Hampe (2007) S. 998 (Register); Homo Heidelbergensis mathematicus online; WBIS; Catalogus prof. Halensis online. Studien zur Wissenschafts- und zur Religionsgeschichte. Hrsg. von der Akademie der Wissenschaften zu Göttingen. Berlin 2011. S. 225-227, 233238, 252 f. u. ö. - Tilitzki 1 (2012) S. 628 f.; NDB 25 (2013) S. 16 f. - Weszely, Tibor: János Bolyai. Die ersten 200 Jahre. Aus dem Ungarischen von Manfred Stern. Basel 2013. S. 9-11, 20-22, 120-124, 219 ff. u. o.. Mathematik in der Heidelberger Akademie der Wissenschaften zus.gestellt von Gabriele Dörflinger. Ein Projekt der Fachinformation Mathematik der Universitätsbibliothek Heidelberg, s. http://www.ub.uni-heidelberg.de/archiv/16 931 (Stand: April 2014).

$P$ Das Fotoalbum für Weierstraß ... Kommentiert von Reinhard Bölling ... Braunschweig 1994. Abb. 29.1 .

\section{Stählin, Karl August Adolf Eduard}

1905-1914 Phil. Fak.

Mittlere und Neuere Geschichte

* 21. Jan. 1865 Breitenau (heute: Ortsteil von Feuchtwangen)

$\dagger$ 29. Aug. 1939 Berlin ev.-luth.

V Otto S. (1826-1868) Pfarrer

M Karoline geb. Bomhard (1828-1906)

๑ Frühjahr 1894 Frida geb. Forster (1871-1944)

$\mathrm{K} \quad 1 \mathrm{~S}, 3 \mathrm{~T}$

Vw Vettern: Otto S. (1868-1949) seit 1894 Gymnasiallehrer, seit 1908 o. Prof. für Klassische Philologie und Pädagogik Würzburg, 1913-1935 (Emeritierung) Erlangen, s. Deutsche Biographie, https://www.deutsche-biographie.de/pn d117202649.html [18.12.2017]. Wilhelm S. (1883-1975), u. a. seit 1926 o. Prof. für Praktische Theologie Münster, 1945-1952 Bischof der Ev.-Luth. Kirche in Oldenburg, s. Via vitae. Lebenserinnerungen. Kassel 1968; BBKL X (1995) Sp. 1115-1120
Vw Neffe 2. Grades: Gustav S. (1900-1985) seit 1930 Privat-Dozent für Neues Testament Leipzig, seit Okt. 1932 Dozent an Ev.-Luth. Theol. Hochschule Madras (heute: Chennai) in Indien, 1939 Rückkehr an U Leipzig, 1943-1945 Lehrstuhlvertr. Wien, seit 1946 o. Prof. Erlangen, 1952-1968 (Emeritierung) o. Prof. Mainz, s. Lexikon für Theologie und Kirche $9\left({ }^{3} 2000\right)$ Sp. 919 f.; S von Otto S.; Urenkel von Heinrich Ranke (1830-1909) Prof. für Kinderheilkunde, e. Neffen von Leopold von R. (1795-1886) Prof. für Geschichte und seit 1841 Historiograph des Preußischen Staates). - Großneffe 2. Grades: Traugott S. $\left({ }^{\star} 1934\right.$; S von Gustav S.) Emeritus für Praktische Theologie an Kirchlicher Hochschule Bethel in Bielefeld

Vw siehe Stählin, Otto: Die Familie S. aus Memmingen. Hrsg. [und ergänzt] von Friedrich Stählin. Neustadt/Aisch 1959.

Lb 1883-189o Militärische Ausbildung.

München: 1890-1893 Ausbildung als Leutnant an Kriegsakademie; 1894-1896 Adjutant (Oberleutnant) des Bezirkskommandos in Bamberg sowie der II. Infanterie-Brigade München; 1896 Kommandierung in Zentralstelle des Generalstabs; 1896-1899 Beurlaubung, Herbst 1899 Pensionierung vom Militär.

U Leipzig: Seit 1896 Studium der Geschichte, 18971901 auch Kunstgeschichte; 6. Febr. 1902 Dr. phil.

Eigenstudien: 1902-1905 Berlin, anschl. Paris, dann London.

UH: 10. Mai 1905 Habilitation; seit 7. Febr. 1910 nichtetatm. a. o. Prof.; März-Aug. 1910 Aufenthalt in St. Petersburg, s. hierzu K. S.: Reisebericht aus Rußland 1910. Briefe an seine Frau. Hrsg. von Gertrud Engels. Diessen/Ammersee 1968; SS 1914 Lehrstuhlvertr. an TH Karlsruhe.

U Straßburg: 16. Juni 1914 (Ern.)-1918 (nach franz. Besetzung Elsaß-Lothringens Niederlegung der Lehrtätigkeit) o. Prof. für Neuere Geschichte. • In dieser Zeit:

1914-1917 Kriegsdienst. 
U Leipzig: Seit 1919 o. Honorar-Prof. für Osteuropäische Geschichte.

U Berlin: 1920-1933 o. Prof. für Osteuropäische Geschichte und Direktor des Seminars für Osteuropäische Geschichte und Landeskunde.

Qu UAH PA 2305; RA 6421, 6847. GLA Abt. 235, Fasz. 2545. - Briefe: UBH. - Nachlaß: Geheimes Staatsarchiv Preußischer Kulturbesitz Berlin. Mitteilungen: Herr Prof. em. Dr. Traugott Stählin (Großneffe 2. Grades), Bielefeld.

$W$ Sir Francis Walsingham und seine Zeit. Heidelberg 1908. - Geschichte Elsass-Lothringens. München 1920. • Jacob von Stählin. Ein biographischer Beitrag zur deutsch-russischen Kulturgeschichte des 18. Jahrhunderts. Leipzig 1920. - Peter der Große. Stuttgart 1922. 2. Aufl. 1923. - Geschichte Rußlands von den Anfängen bis zur Gegenwart. 5 Bde. Stuttgart 1923-1939. Nachdr. 1961.

MHG Alexander Puschkin in seinen Briefen. Königsberg 1927.

Übers. Der Briefwechsel Iwans des Schrecklichen mit dem Fürsten Kurbskij (1564-1579). Eingeleitet und aus dem Altrussischen übertragen von K.S. unter Mitwirkung von Karl Weyer. Leipzig 1921.

L Kürschner (1925) Sp. 10oof., (1931) Sp. 2864, (1935) Sp. 1339; WBIS. Andreas, Willy: K. S. in: Historische Zeitschrift 163 (1941) S. 82-99. • Weber, Wolfgang: Biographisches Lexikon zur Geschichtswissenschaft in Deutschland, Österreich und der Schweiz. Die Lehrstuhlinhaber für Geschichte von den Anfängen des Faches bis 1970. Frankfurt/M. 1984. Weber (1987) S. 567 f. Hackl, Othmar: Die Bayerische Kriegsakademie (18671914). München 1989. S. 580. - Geschichte Histor. Seminar UH (1992) S. 326 (Register). - Flick, Caroline: Werner Hegemann (1881-1936). Stadtplanung, Architektur, Politik. Ein Arbeitsleben in Europa und den USA. T. 2. München 2005. S. 1253 (Register). - Große Bayerische Biographische Enzyklopädie. Hrsg. von Hans-Michael Körner. München 2005. Bd. 3. S. 1872. $\bullet$ Hundert Jahre Osteuropäische Geschichte. Vergangenheit, Gegenwart und Zukunft. Herausgeber Dittmar Dahl- mann. Stuttgart 2005. S. 21-23, 30 f. u. ö. $•$ Kriegstagebuch K. Hampe (2007) S. 998 (Register); Professorenkatalog Leipzig online. Maurer, Trude: „... und wir gehören auch dazu“. Universität und „Volksgemeinschaft“ im Ersten Weltkrieg. Göttingen 2015. S. 1205 (Register). • Deutsche Biographie, s. https://www.deutsche-biographie.de/gn d117202614.html [26.11. 2017].

P Bildarchiv UAH; K. S.: Reisebericht aus Rußland 1910. Briefe an seine Frau (1968).

\section{Starck, Alfred Wilhelm Hugo}

1899-1925 (1928) Med. Fak.

Innere Medizin

* 27. April 1871 Eichstetten am Kaiserstuhl

$\dagger$ 30. Mai 1956 Karlsruhe ev.

V Alfred S. (1834-1918) Notar

M Emilie geb. von Ziegler (1849-1918)

$\infty$ 14. Sept. 1901 Hedwig Luise Bertha geb. Scriba (1879-1952)

K 2 T, 2 S: u. a. Dr.-Ing. Dietrich S. (1909-2004), u. a. 1947-1970 (Gründungs-)Direktor e. heute in 3. Generation geführten Firma für industrielle Isoliertechnik, der „Unternehmensgruppe Dr. Starck“ in Siegburg

Vw Schwester: Camilla S. (1869-1936) Ehefrau von: (siehe) Oscar Vulpius.

Lb 1890/91 Militärdienstpflicht als Einjährig-Freiwilliger in H (erstes Diensthalbjahr); seit WS 1890/ 91 Studium an UH, WS 1893/94 Berlin, seit SS $1894 \mathrm{H}$.

UH: Juli 1892 Physikum („tentamen physicum“); Juli 1895 Staatsexamen; 28. Okt. 1895 Dr. med.; seit Okt. 1895 Volontär-Assistent an Chirurg. U-Klinik.

Seit Ende Aug. 1896 Schiffsarzt.

UH: Seit April 1897 Assistenzarzt, Okt. 1904-Mai 1905 Oberarzt an Med. U-Klinik; 1898/99 Militärdienstpflicht als Einjährig-Freiwilliger bei Kai- 
serl. Marine (zweites Diensthalbjahr); 22. Juli 1899 Habilitation; seit 26. Nov. 1903 nichtetatm., 192024. Febr. 1928 nichtplanm. a. o. Prof.; Mai 1905 S. stellt erfolgreich Antrag an U-Senat auf Fortsetzung seiner Lehrtätigkeit trotz Berufung als Chefarzt nach Karlsruhe; 1915-1918 Kriegsdienst als Marine-Oberstabsarzt (Chefarzt e. Kriegs-Lazarett-Abt.); SS 1925 S. hält letzte Vorlesungen laut Quästurakte, s. UAH Rep. 27-1263; 24. Febr. 1928 Entziehung der venia legendi, da S. seit zwei Semestern keine Vorlesungen gehalten hat und damit Streichung aus Verzeichnis der akad. Lehrer; 1933 und 1934 erfolglose Anträge S.s auf Wiederverleihung der venia legendi.

Karlsruhe: 11. Mai 1905-31. Mai 1945 Chefarzt der Med. Abt., 8. Jan. 1931-31. Mai 1945 leitender ärztl. Direktor des Städtischen Krankenhauses.

1912 Gründungsmitglied, 1934-1938 und 1951-1952 Vorsitzender des Verbands der Krankenhausärzte Deutschlands e. V.

Seine bekannteste Erfindung ist der Starcksche Dilatator, eine Dehnsonde mit reusenförmigem Spreizmechanismus zur Erweiterung einer verengten Speiseröhre (1907), s. hierzu Lübbers, Wolf, Lübbers, Christian W.: Mit dem Regenschirm durch die Speiseröhre. Die Crux mit dem Reflux in: HNO-Nachrichten 46(1) (2016) S. 48-50.

Siegfried Wagner (1869-1930), Sohn Richard Wagners, war e. der Patienten S.s; mit der Wagnerschen Familie verband S. e. lebenslange Freundschaft, s. auch Haase-Mühlbauer, Susanne: Axel Starck verleiht Instrument: Siegburger übergibt Stipendiatin Guaneri-Cello [aus dem Erbe seines Großvaters Hugo Starck] in: Generalanzeiger Region Siegburg vom 16. Mai 2017 (Ausdruck im UAH).

Siehe auch Ernst Schwalbe: Eintrag unter $Z$ (1) (1907)

Qu UAH PA 1192, 5957; Quästurakte Rep. 271263; Fak.-Akte H-III-111/125. • GLA Abt. 235, Fasz. 2547. Mitteilungen: Herren Dr.-Ing. Dietrich Starck $(\dagger)$ und Dipl.-Ing. Michael Starck (Urenkel), Siegburg.
W Die Divertikel der Speiseröhre. Leipzig 190o. • Die direkte Besichtigung der Speiseröhre. Ösophagoskopie. Ein Lehrbuch für den Praktiker. Würzburg 1905. 2. Aufl. u.d. T.: Lehrbuch der Ösophagoskopie. Würzburg 1914. • Die Krankheiten der Speiseröhre. Darmstadt 1952.

L Kürschner (1926) Sp. 1896, (1931) Sp. 2872; Stübler (1926) S. 315; WBIS; Fischer 2 ( $\left.{ }^{3} 1962\right)$ S. 1738. • Nachruf in: Biographiensammlung des Städtischen Klinikums Karlsruhe. Karlsruhe 1965. S. 2326. - Lott, Doris: Mein Karlsruhe. Geschichten aus der Fächerstadt. 2. Aufl. Karlsruhe 2002. S. 77-84. - Deutsche Biographie, s. https://www. deutsche-biographie.de/gnd117213330.html [26.11. 2017].

$P$ Bildarchiv UAH.

\section{Stark, Carl Bernhard}

1855-1879 Phil. Fak.

Archäologie, Kunstgeschichte

* o2. Okt. 1824 Jena

$\dagger$ 12. Okt. 1879 Heidelberg

ev.

V Carl/Karl Wilhelm S. (1787-1845) seit 1813 a.o. Prof. und Leibmedikus des Herzogs Carl August von Sachsen-Weimar-Eisenach, seit 1826 o. Prof. für Pathologie Jena, s. ADB 35 (1893) S. 491 f.; Bauer, Axel W.: Das öffentliche Krankenhaus als wissenschaftliche Bildungs-Anstalt. K.W.S. ... und sein Konzept eines Akademischen Lehrkrankenhauses aus dem Jahre 1839 - Anspruch und Wirklichkeit in: Bausteine der Medizingeschichte ... Hrsg. von Eduard Seidler ... Stuttgart 1984. S. 9-17; Ders.: Die Krankheitslehre von K. W. S. ...: Ontologische Pathologie als Analogiemodell. Medizin im Biedermeier zwischen Naturphilosophie und Naturwissenschaft in: Sudhoffs Archiv 69 (1985) S. 129-153; Zimmermann/Neuper (2008) S. 232-234 u. o. 
M Emilie Juliane Sophie geb. Martin (1799-1876), siehe Biographie Emilie Stark geb. M. in: Chronik der Familie Stark. Hrsg. von Dr. Hans C. Stark. Konstanz 1960. H. 5. S. 2-48; T von: (siehe) Christoph Martin

( 23. Mai 1850 Wilhelmine Johanna geb. Walther (1826-1900)

K $\quad{ }_{1} \mathrm{~S}, 3 \mathrm{~T}$

Vw Großvater: Johann Christian S. (auch: Starck, Starke) (1753-1811) seit 1779 a.o. Prof. für Medizin, seit 1784 o. Prof. und Vize-Direktor, seit 1794 Direktor der Entbindungsstation Jena; seit 1786 auch Leibarzt der Herzogin Anna Amalia und des Herzogs Carl August von Sachsen-Weimar-Eisenach sowie Hausarzt von Friedrich Schiller und der Familie von Johann Wolfgang von Goethe, s. Hesse, Volker: J. C. Stark d. Ä. ... Der Arzt Goethes und Schillers in: Wegbereiter der modernen Medizin. Jenaer Mediziner aus drei Jahrhunderten ... Hrsg. von Christian Fleck u.a. Jena, Quedlinburg 2004. S. 73-80; Zimmermann/Neuper (2008) S. $228 \mathrm{f}$. u. ö.; Nöthlich, Rosemarie, Hellmann, Birgitt: Neue Einblicke in das Leben des Mediziners J.C.S. ... Unbekannte Briefe in: Weimar-Jena: Die große Stadt. Das kulturhistorische Archiv 7/1 (2014) S. 72-87. • Großvater: (siehe) Christoph Martin. - Großmutter: Dorothea geb. Böckh, Schwester von: (siehe) August B. • Siehe auch NDB 25 (2013) S. $72^{*}$.

Vw Geschwister: Agnes Amalie S. (1827-1864) Ehefrau von Franz Xaver Wegele (1823-1897) seit 1849 Privat-Dozent und seit 1851 Prof. Jena, seit 1857 o. Prof. für Geschichte Würzburg, seit 1858 Mitherausgeber der ADB, s. Petersohn, Jürgen: F.X.W. und die Gründung des Würzburger Histor. Seminars (1857) in: Universität Würzburg (1982) S. 483-537; WBIS. • Helene Selma S. (1838-1887) Ehefrau von Friedrich Klopfleisch (1831-1898) U Jena: seit 1859 Privat-Dozent, 1875-1896 a.o. Prof. für Kunstgeschichte, seit 1894 ausschließlich für Prähistorische Archäologie; 1863-1896 Begründer und zunächst ehrenamtlicher, seit 1878 besoldeter Leiter des Germanischen Museums zu Jena, s. WBIS; Neumann, Gotthard: F. K. ... Begründer der thüringischen Urgeschichtsforschung in: Mannus - Zs. für Deutsche Vor- geschichte 24 (1932) S. 134-146; Peschel, Karl: F. K. als Ausgräber. Die „Rhönreise“ des Jahres 1882 in: Ethnographisch-Archäologische Zs. 22 (1981) S. 397-431.

Lb Seit SS 1842 Studium der Philosophie, Philologie an U Jena, seit WS 1843/44 Leipzig, seit WS $1844 / 45$ Jena.

U Jena: Herbst 1845 Magister-Examen in Philosophie und Promotion zum Dr. phil.; 1846 philolog. Examen.

1845-1847 Eigenstudien in Berlin und Jena; Juli 1847-Mai 1848 Studienreise nach Italien.

U Jena: Herbst 1848 Habilitation; seit 1850 a.o. Prof.; seit Herbst 1851 außerdem Vize-Direktor des Archäolog. Museums; Herbst 1852 Studienreisen nach Belgien und Frankreich.

UH: 9. Aug. 1855 Ern. zum o. Prof. für Archäologie als Nachf. von Carl Zell mit e. „beginnenden“ jährl. Besoldung von 1500.- Gulden, s. UAH RA 6828; SS 1860 erstmalige Nennung e. Archäolog. Sammlung unter Leitung von S. im Vorlesungsverzeichnis (aus: Adreßbuch der Ruprecht-KarlsUniversität. Heidelberg 1860. S. 6; s. hierzu auch Carl Zell) in Augustinergasse 15, 3. Stock des UBGebäudes, seit WS $1870 / 71$ in Augustinergasse 7 zu ebener Erde; 1863 Ruf an U Dorpat abgelehnt; 29. Okt. 1866 Genehmigung des Entwurfs e. Statuts für das Archäolog. Inst. durch Ministerium des Innern an Engeren U-Senat, s. hierzu UAH RA 6387; seit SS 1867 als Direktor des Archäolog. Inst. genannt, s. „Anzeige der Vorlesungen ... im Sommer-Halbjahr 1867 ...", S. 11; Aug. 1871-März 1872 Studienreise nach Griechenland, s. hierzu S., B.: Nach dem griechischen Orient. Heidelberg 1874. Nachdr. 2014.

15. April 1873-7. April 1874, 1. Okt. 1874-30. März 1875 Prorektor der UH; Dez. 1858-Dez. 1859, 1. Okt. 1871-30. Sept. 1872 Dekan der Phil. Fak. der UH

S. baut die Archäologische Sammlung (heute: Antikenmuseum und Abguss-Sammlung im Neuen Kollegiengebäude, Marstallhof 4) der UH auf, s. hierzu auch Universitätssammlungen in Deutschland. Das Informationssystem zu Sammlungen 
und Museen an deutschen Universitäten. Ein Projekt des Hermann von Helmholtz-Zentrums für Kulturtechnik, Humboldt-Universität zu Berlin. Leitung: Dr. Cornelia Weber, unter: http://www. universitaetssammlungen.de/sammlung/250/ge schichte.

1875 Hofrat

E Mitglied: 1851 Histor. Verein von Thüringen, 1854 Königl. Sächsische Gesellschaft der Wiss. Leipzig; 1852 o. Mitglied der Académie archéologique de Belgique. 1874 Ritterkreuz I. Klasse des Ordens vom Zähringer Löwen.

Qu UAH PA 2306f.; RA 5815, 6387, 6828. - GLA Abt. 205, Fasz. 511. - Briefe: UBH; s. auch Kalliope. Auskunft: Ev. Pfarramt Hanau (Traubuch 1850 der Marienkirche ebd.). Mitteilungen: Herr Prof. Dr. Erich Kuß, München; Herr Dr. Nicolas Zenzen, Universität Heidelberg.

$W$ Kunst und Schule. Zur deutschen Schulreform. Jena 1848. Forschungen zur Geschichte des hellenistischen Orients. Gaza und die philistäische Küste. Jena 1852 . Städteleben, Kunst und Alterthum in Frankreich. Jena 1855. Niobe und die Niobiden in ihrer literarischen, künstlerischen und mythologischen Bedeutung. Leipzig 1863. • Ladenburg am Neckar und seine römischen Funde. Bonn 1868. - Systematik und Geschichte der Archäologie der Kunst. Leipzig 188o. Nachdr. München 1969. - Vorträge und Aufsätze aus dem Gebiet der Archäologie und Kunstgeschichte. Nach dem Tode des Verf. hrsg. von Gottfried Kinkel. Leipzig 1880. Siehe auch NDB 25 (2013) S. 73.

$L$ Günther (1858) S. 277 f.; Badische Biographien 3 (1881) S. 178-181; ADB 35 (1893) S. 488-49o; WBIS. - Hölscher, Tonio: C.B.S. in: Archäologenbildnisse (1988) S. 49 f. - Ruuskanen (2008) S. 132 f.; NDB 25 (2013) S. 72 f.; Objekte erzählen Geschichte(n) (2016) S. 18-20, 130 f., 135-138 u. ö.

$P$ Bildarchiv UAH; graph. Slg. UBH; Archäologenbildnisse (1988).

\section{Stein, Johannes}

1926-1941 Med. Fak.

Innere Medizin

* 26. Juli 1896 Orsoy/Niederrhein (heute: Stadtteil von Rheinberg)

$\dagger$ 27. März 1967 Bonn ev.

V Emil S. $\left({ }^{*} 1859\right)$ Pfarrer

M Bertha Luise geb. Schlingensiepen $\left({ }^{\star} 1865\right)$

$\varnothing$ 1. März 1923 Magdalena geb. Frenzel (19021985)

K $\quad 2 \mathrm{~S}, 3 \mathrm{~T}$

Lb 1914-1918 Kriegsdienst; seit WS 1918/19 Studium an U Münster, anschl. Bonn.

Bonn: Dez. 1921 Staatsexamen; 1922 Dr. med. an U.

UH: Seit 1922 Assistent, 1926-1934 Oberarzt an Med. U-Klinik und Neurolog. Klinik; 8. Nov. 1926 Habilitation für Innere Medizin und Neurologie; seit 6. Juli 1931 a. o. Prof.; 8. Jan. 1934 Erteilung der Genehmigung i.A. des Ministers des Kultus, des Unterrichts und der Justiz, Abt. Kultus und Unterricht, durch (siehe) Eugen Fehrle, S. mit der Leitung des Psycholog. Inst. zu betrauen „und ihm ein Beirat, bestehend aus den Professoren [Hermann] Güntert und Dr. [Carl] Schneider [s. Drüll (2009) S. 557 f.] beigegeben wird“ (aus: Klüpfel/ Graumann (1986) Abb. 19); seit 1. April 1934 o. Prof. und Direktor der Med. U-Klinik.

Reichs-U Straßburg: 1. April 1941 Ern. zum WS 1941/42 o. Prof.; Nov. 1944 Besetzung der Stadt durch amerik. und franz. Militär.

Ende 1944-1948 Franz. Kriegsgefangenschaft.

Bonn: 1950-1954 Chefarzt des Johanniter-Krankenhauses.

Okt. 1933-März 1935 Kanzler, April 1935-März 1937, Mai 1937-Sept. 1938, Dez. 1938-Juni 1941 Prorektor der UH, s. hierzu Weisert/Drüll/Kritzer (2007) S. $26 \mathrm{f}$. 
Qu UAH PA 1195, 5967. - GLA Abt. 235, Fasz. 2551. Mitteilungen: Frau Magdalena Stein ( $†$ ).

W Zur Geschichte der Deutschen Universität Straßburg. Festschrift aus Anlass der feierlichen Wiederaufnahme der Lehr- und Forschungstätigkeit an der Reichsuniversität Strassburg. Straßburg 1941. 2. Aufl. 1942. (Mitverf.)

$L$ Wer ist's (1935) S. 1542. - Nachruf in: Der Westen 17. Jg., Nr. 5 (Okt. 1967) S. 2. • Klüpfel/Graumann (1986); Grüttner (2004) S. 167. • Marx, Jens Th.: J.S. et l'enseignement médical à la Reichsuniversität de Strasbourg in: Les Reichsuniversitäten de Strasbourg et de Poznan et les résistances universitaires 1941-1944 ... Textes réunis par Christian Baechler ... Strasbourg 2005. S. 115-126. • Uhlmann, Angelika: Die medizinische Fakultät der Reichsuniversität Straßburg und die Menschenversuche im KZ Natzweiler-Struthof in: Medizin im Nationalsozialismus und das System der Konzentrationslager. Beiträge eines interdisziplinären Symposiums. Hrsg. von Judith Hahn ... Frankfurt/M. 2005. S. 165-187. • UH im Nationalsozialismus (2006) S. 1272 (Register); Klee, Personenlexikon (2007) S. 599 f.; Marx (2008) S. 298-300; Deutsche Biographie, s. https://www.deutschebiographie.de/gnd1076135749.html [27.11.2017].

$P$ Bildarchiv UAH (Zeichnung).

\section{Steiner, Gabriel}

1919-1935 Med. Fak.

Psychiatrie

* 26. Mai 1883 Ulm

$\dagger$ 10. Aug. 1965 Detroit (Michigan) mosaisch

V Simon S. (1853-1938) Kaufmann, siehe http:// www.hohenemsgenealogy.at

M Fanni geb. Nathan (1858-1937), siehe ebd.

œ 1923 Greta geb. (Spanjer-)Herford $\left({ }^{*} 1889 \dagger\right.$ † vor 1965), siehe Lexikon jüdischer Einwohner Hs (2011) S. 399

$\mathrm{K}$ keine.
Lb Seit WS 1901/o2 Studium an U München, anschl. Würzburg, Freiburg/Br., Straßburg; Dez. 1907 Staatsprüfung in Straßburg; 1908 Absolvierung des praktischen Jahres: Innere Abt. des Bürgerspitals in Straßburg, dann Heil- und Pflegeanstalt Illenau in Achern.

U Freiburg/Br.: Seit 1909 Assistenzarzt an Psychiatr. Klinik.

U Straßburg: 1910-1919 Assistenzarzt an U-Klinik für Geistes- und Nervenkrankheiten; 30. März 1910 Dr. med.; 10. Nov. 1913 Habilitation für Psychiatrie und Neurologie. • In dieser Zeit:

1914-1918 Kriegsdienst als freiwilliger Arzt.

H: 1919-1936 Nervenarzt in Privatpraxis. • In dieser Zeit:

UH: 10. Juli 1919 Umhabilitation für Psychiatrie; 1919-1933 Assistenzarzt an Psychiatr. U-Klinik; WS 1919/20-SS 1933 Leiter des Patholog.-Anatom. Laboratoriums der Psychiatr. U-Klinik als Nachfolger von Franz Nissl; seit 2. Febr. 1920 nichtplanm. a.o. Prof.; Okt. 1921 Angebot e. Lehrauftrags für Experimentelle Pathologie und Histopathologie des Zentralnervensystems von Med. Fak. der U Breslau an S.; Okt. 1921 Antrag des Dekans der Med. Fak. der UH, (siehe) Karl Wilmanns, an Med. Fak., e. Lehrauftrag für S. an UH bei der Regierung zu erwirken, um ihn zu halten (siehe hierzu $Z) ;$ 2. Dez. 1921 erneuter Antrag Wilmanns auf Erteilung e. Lehrauftrags für S. an Med. Fak.; Febr. 1922 endgültige Ablehnung des Antrags durch Ministerium des Kultus und Unterrichts; dafür erhält S. ab 1. Jan. 1922 rückwirkend für die Dauer seiner Beschäftigung an $U$ ein Aversum von jährl. 14 400.- Mark; 30. Juli 1923-SS 1933 Bewilligung e. einstündigen Lehrauftrags für Experimentelle $\mathrm{Pa}-$ thologie und Histopathologie des Zentralnervensystems durch Erlaß des Unterrichtsministeriums; seit 20. April 1933 Beurlaubung aufgrund „Aufrechterhaltung der Sicherheit und Ordnung .... Privatdozenten mit Lehrauftrag nicht arischer $\mathrm{Ab}$ stammung sind zu beurlauben und das Dienstverhältnis ... zu kündigen ..." (aus: UAH PA 1196); Juli 1933 „... da Prof. Steiner Frontkämpfer [gewesen] ist, wird die ausgesprochene Kündigung zurückgenommen“ (aus: PA 5969); 1. Nov. 1934- 
1. Mai 1935 Beurlaubung für wiss. Arbeiten auf dem Gebiet der multiplen Sklerose an Columbia $\mathrm{U}$ in New York und Woman's Medical College in Philadelphia; 31. Dez. 1935 Lehrbefugnis aus rassischen Gründen entzogen; 15. Okt. 1936 Emigration in die USA.

New Orleans (Louisiana): Seit Febr. 1937 Visiting Lecturer an Medical School.

Detroit (Michigan): Seit Juli 1937 Lecturer, 19421953 (Emeritierung) Full Prof. für Neuropathologie am College of Medicine der Wayne-U; 19541958 Gründer und Med. Direktor des Michigan Multiple Sclerosis Center.

UH: 13. Aug. 1957 Einsetzung in Rechte e. emeritierten o. Prof.

$Z$ Die Ablehnung der Erteilung eines Lehrauftrags für Experimentelle Pathologie und Histopathologie des Zentralnervensystems an $\mathrm{S}$. begründet das Badische Ministerium des Kultus und Unterrichts in seinem Schreiben vom 24. Nov. 1921 wie folgt: „Wir freuen uns über die ausserordentlich günstige Beurteilung der wissenschaftlichen Leistungen des a.o. Professors Dr. Steiner durch die Direktoren der psychiatrischen Kliniken in Heidelberg und Breslau. Gleichwohl vermögen wir dem Antrag auf Erteilung eines Lehrauftrags an Prof. Dr. Steiner nicht zu entsprechen, da wir grundsätzlich davon absehen müssen, auswärtige Angebote an Privatdozenten zur Grundlage der Erteilung von Lehraufträgen zu machen. Die Aufrechterhaltung dieser Praxis entspricht dem Charakter der Privatdozentur und den Interessen der Privatdozenten sowohl als der Hochschulen. Die Einführung eines Verfahrens zur Abwendung von Wegberufungen von Privatdozenten würde zu durchaus ungesunden Verhältnissen führen“ (aus: PA 1196).

\section{E 1915 Eisernes Kreuz II. Klasse.}

Qu UAH PA 1196, 5969; Rep. 40-425; B-3182/1. GLA Abt. 235, Fasz. 2554. • Briefe: UBH.

$W$ Epilepsie und Gliom. Berlin 1910. - Der Tierversuch in Psychiatrie und Neurologie. Wiesbaden 1914. Entdeckung der Spirochaete argentinensis in: Med. Klinik 13 (1917) S. 1007. (Mitverf.) • Multiple und diffuse Sklerose in: Handbuch der Geisteskrankheiten. Hrsg. von Oswald Bumke. Bd. XI. T. VII. Berlin 1930. S. 289 ff. - Krankheitserreger und Gewebsbefund bei multipler Sklerose. Vergleichend-histologisch-parasitologische Untersuchungen bei multipler Sklerose und anderen Spirochätosen. Berlin 1931. Multiple Sklerose: ihre Ätiologie, Pathologie, Pathogenese und Therapie. Berlin 1962.

L Kürschner (1961) S. 2012; Fischer 2 ( $\left.{ }^{3} 1962\right)$ S. 1500; Chronik Ärzte H (1985) S. 143 f.; WBIS; Peiffer (2004) S. 1188 (Register); UH im Nationalsozialismus (2006) S. 911f. u.ö. • Morgenstern, Hans: Jüdisches biographisches Lexikon. Eine Sammlung von bedeutenden Persönlichkeiten jüdischer Herkunft ab 1800. Wien 2009. S. 787. - Siehe auch https://www.amsel.de/blog/ blogger/Differentialdiagnosen---Abgrenzung-Ue berschneidung/Gabriel-Steiner-1883-1965-Neuro pathologe-MS-Forscher-/ (abgerufen am 26.11. 2017). Deutsche Biographie, s. https://www. deutsche-biographie.de/gnd117253138.html [27.11. 2017]. Malich, Lisa: Die Gefühle der Schwangeren. Eine Geschichte somatischer Emotionalität (1780-2010). Bielefeld 2017. S. 181-186, 193 u. ö.

$P$ Bildarchiv UAH; Chronik Ärzte H; Lexikon jüdischer Einwohner Hs (2011) S. 399.

\section{Steiner, Heinrich}

1865-1866 Phil. Fak. Orientalische Sprachen 1866-1870 Theol. Fak.

Alttestamentliche Theologie, auch Orientalische Sprachen

* 10. Jan. 1841 Zürich

$\dagger$ 19. April 1889 Zürich ref.

V Leonhard S. (1803-1855) Kaufmann

M Maria Elisabeth geb. Heß ( ${ }^{*} 1812 \dagger$ nach 1889 )

$œ$ 30. März 1869 Anna Margaret(h)a Henriette geb. Ehrt (1847-1901)

$\mathrm{K}$ mind. $2 \mathrm{~S}$ 
Vw Schwester: Emilie S. (1842-1919), s. https:// www.myheritage.de/names/emilie_steiner; Ehefrau von Hermann Hitzig (1843-1918), u. a. 1871-1873 Lehrer am Lyceum in $\mathrm{H}$ (heute: Kurfürst-Friedrich-Gymnasium „KFG“), seit 1878 (Habilitation) a. o. Prof. Bern, 1887-1917 o. Prof. für Klassische Philologie an U Zürich, s. Waser, Otto: H.H. in: Biogr. Jahrbuch für Alterthumskunde 42 (1922) S. 11-23; Das „Goldene Buch“ des KFG (1994) S. 91 f.; Sohn von: (siehe) Ferdinand Hitzig.

Lb SS 1859-WS 1862/63 Studium der Theologie und Philologie an U Zürich; 30. April 1863 theol. Examen in Zürich; seit SS 1863 Forts. des Studiums der Philologie an UH, SS 1864 Zürich.

UH: 2. März 1864 Dr. phil.; 2. Mai 1865 Habilitation für Orientalische Sprachen an Phil. Fak.; 21. Febr. 1866 Lizentiatenprüfung an Theol. Fak.; seit 1866 Repetent an Theol. Fak.; 14. März 1866 Habilitation für Alttestamentliche Theologie und damit Fak.Wechsel; seit 24. Dez. 1868 a. o. Prof.; WS 1869/70 letzte Vorlesungsankündigung.

U Zürich: WS 1870/71 (erste Vorlesungsankündigung)-19. April 1889 (†) o. Prof.; 1882-1884 Rektor.

Qu UAH PA 2310; RA 6753; Fak.-Akte H-I-173/ 31. Matrikel Zürich (1999) Nr. 2195; Vorlesungsverzeichnisse der U Zürich WS 1870/71-SS 1889 online, s. http://www.histvv.uzh.ch/. • Auskunft: Universitätsarchiv Zürich.

$W$ Die Mutaziliten oder Die Freidenker im Islam. Leipzig 1865. • Über hebräische Poesie. Basel 1873. Der Zürcher Professor Johann Heinrich Hottinger in Heidelberg 1655-1661. Zürich 1886.

$L$ Furrer, Conrad und Kesselring, Heinrich: Worte der Erinnerung an ... H.S. ... Zürich 1889. • Deutsche Biographie, s. https://www.deutsche-bio graphie.de/gnd117253278.html [27.11.2017].

$P$ UA Zürich (Dozierendendossier AB.1.0967).

\section{Steiner, Isidor}

1878-1888 Med. Fak.

Physiologie

* 03. März 1849 Pleß (Oberschlesien; heute: Pszczyna, Polen)

$\dagger$ 15. (?) Okt. 1914 Köln mosaisch

V N.N., Kaufmann

M N.N.

$\infty$ unbekannt.

Lb Seit WS 1869/70 Studium an U Breslau; 1870/71 Kriegsdienst während des Deutsch-Französischen Krieges.

U Berlin: Seit WS 1871/72 Forts. des Studiums; 2. Aug. 1873 Dr. med.; WS 1873/74 Staatsexamen.

U Halle-Wittenberg: Seit April 1874 Assistent am Physiolog. Inst.

U Erlangen: Okt. 1876-Okt. 1878 Assistent am Physiolog. Inst.; 20. Jan. 1877 Habilitation.

UH: 7. Nov. 1878 Umhabilitation; seit 20. März 1886 a. o. Prof.

Köln: Seit 4. Nov. 1888 niedergelassener Arzt für Nervenkrankheiten und Elektrotherapie.

Geh. Rat

Qu UAH PA 2311; Fak.-Akte H-III-111/89.

$W$ Grundriß der Physiologie des Menschen. Leipzig 1881. 9. Aufl. 1906. - Untersuchungen über die Physiologie des Froschhirns. Braunschweig 1885. • Die Functionen des Centralnervensystems und ihre Phylogenese. 3 Bde. Braunschweig 1885-1898.

L Biogr. Jahrbuch 1 (1914-1916) S. 313; Stübler (1926) S. 314; Fischer $2\left({ }^{3}{ }^{1962)}\right.$ S. 150o; Chronik Ärzte H (1985) S. 144; Kreuter 3 (1996); WBIS; Professoren Erlangen (1999) S. 188 f. (S. 188: irrtümlich 
01. statt 03. März 1849 als Geburts-Tag genannt); Deutsche Biographie, s. https://www.deutsche-bio graphie.de/gnd117657794.html [27.11. 2017].

P Bildarchiv UAH; graph. Slg. UBH.

\section{Steinhausen, Georg}

1932-1933 (Honorar-Prof.) Phil. Fak. Kulturgeschichte

* O2. Juni 1866 Brandenburg an der Havel

$\dagger$ 30. März 1933 Kassel ev.

V Dr. Friedrich Wilhelm Karl Albrecht S. (18401898) Gymnasialdirektor

M Anna Louisa geb. Schneider ( $† 1884)$

๑ 1892 Frieda Gustava Julie geb. von Normann $\left({ }^{*} 1870\right)$

K 1 S ( $\times 1918$ oder $\dagger 1919$ in engl. Gefangenschaft).

Lb Seit WS 1883/84 Studium der Geschichte, Dt. Philologie an U Greifswald, Berlin (2 Semester), zuletzt erneut Greifswald.

U Greifswald: Okt. 1887 Dr. phil.; seit Nov. 1887 Volontär, seit April 1888 Assistent an UB; 24. Sept. 1891 Ablehnung e. Assistentenstelle mit jährl. „500 Thaler Gehalt" an Königl. Bibliothek in Berlin, "deren Annahme [für] mich thatsächlich eine Verschlechterung meiner pecunären und gesellschaftlichen Lage bedeuten würde" (aus: Deile (2008) S. 249).

U Jena: Seit 15. Juli 1892 Kustos, seit 1896 Bibliothekar an UB, s. hierzu Deile, S. $252 \mathrm{f}$.

Kassel: Seit 1. Nov. 1901 Vorsteher, 1907-1931 (Pensionierung) Direktor der Murhardschen Stadtbibliothek; 1905 Verleihung des Titels „Prof.“; 1914 Kriegsfreiwilliger.

UH: Seit 23. März 1932 o. Honorar-Prof.; WS 1932/ 33 Vorlesungsankündigungen, u. a. über Kulturprobleme der Gegenwart auf historischer Grundlage.
Qu UAH PA 5971. - GLA Abt. 235, Fasz. 2555. • Briefe: Staats- und Universitätsbibliothek Göttingen. - Nachlaß: Staatsarchiv Marburg. - Die Geschichtswissenschaft der Gegenwart in Selbstdarstellungen. Hrsg. von Sigfrid Steinberg. 2 Bde. Leipzig 1925-1926. Bd. 1. S. 233-274. (Autobiogr. mit Werkverz.)

$W$ Geschichte des deutschen Briefes. 2 Bde. Berlin 1889-1891. 2. Aufl. Dublin, Zürich 1968. Professoren der Kulturgeschichte? in: Zs. für Kulturgeschichte 2 (1895) S. 192-198. - Kaufleute und Handelsherren in alten Zeiten. Stände und Zünfte im Wandel der Zeit. Leipzig 1899. Nachdr. Düsseldorf 1976. - Geschichte der deutschen Kultur. Leipzig 1904. 4. Aufl. 1936. - Germanische Kultur in der Urzeit. Leipzig 1905. 4. Aufl. 1927. • Kulturgeschichte der Deutschen im Mittelalter. Leipzig 1910. 3. Aufl. 1921. • Die Grundfehler des Krieges und der Generalstab. Gotha 1919. 2. Aufl. 1919 [!]. - Der Aufschwung der deutschen Kultur vom 18. Jahrhundert bis zum Weltkrieg. Leipzig 1920. - Deutsche Geistes- und Kulturgeschichte von 1870 bis zur Gegenwart. Halle/S. 1931.

G, HG 1894-1911 Zeitschrift für Kulturgeschichte, seit 1903 u.d.T.: Archiv für Kulturgeschichte, siehe hierzu Stühn, Andrea: Das „Archiv für Kulturgeschichte" unter den Herausgebern G.S. und Walter Goetz 1903-1958 - seine Vorläufer und seine Entwicklung. Hausarbeit. Köln 1993 (Ex. im Hochschulbibliothekszentrum NRW).

$H G$ Briefwechsel Balthasar Paumgartners des jüngeren mit seiner Gattin Magdalena geb. Behaim (1582-1598). Tübingen 1895. Deutsche Privatbriefe des Mittelalters. Bd. 1: Fürsten und Magnaten, Edle und Ritter. Bd. 2: Geistliche, Bürger. Berlin 1899-1907.

$L$ Wer ist's (1928) S. 1515; Kürschner (1931) Sp. 2891f. - Flaskamp, Franz: Eine Begegnung mit G. S. in: Archiv für Kulturgeschichte (1971) S. 155157. - WBIS. - Vom kollektiven Gedächtnis zur Individualisierung der Erinnerung ... Hrsg. von Clemens Wischermann. Stuttgart 2002. S. 138143 u. ö. - Herold, Jürgen: G.S. und die Kulturgeschichte in: Archiv für Kulturgeschichte (2003) S. 29-70. - Deile, Lars: Drei Niederlagen und ein Neuanfang: G.S. in: Ketzer, Käuze, Queru- 
lanten (2008) S. 249-262; Ders.: Kulturgeschichte als Kulturkritik. Nachfragen bei G. S. München 2008. - Roeck, Bernd: Lebenswelt und Kultur des Bürgertums in der Frühen Neuzeit. 2. Aufl. München 2011. S. 75-77 u. ö. NDB 25 (2013) S. 193 f. • Zeitungsbriefe und Briefzeitungen oder Die Anfänge der Zeitung. Richard Grasshoff (1877), G.S. (1895), Karl Bücher (1893) und Adolf Koch (1910). Eingeführt ... von Hans Wagner. Baden-Baden 2017.

$P$ Die Geschichtswissenschaft der Gegenwart (1925-1926); Deile, Lars (2008); NDB (2013).

\section{Stengel, Adolf Hermann Theodor}

1872-1874 (Honorar-Prof.) Phil. Fak.

1874-189o Phil. Fak.

1890-190o Nat.-Math. Fak.

Landwirtschaftslehre

* o9. Juni 1828 Darkehmen (Ostpreußen; heute: Osjorsk, Russische Föderation)

$\theta \quad$ 22. Nov. 1900 Heidelberg ev.-luth.

V N.N. (†1857) Landrat

M Minna geb. Krieger

$\infty$ ca. 1858 N.N.

๑ 31. Dez. 1875 Rose geb. Grahl (1835-1909) $\mathrm{T}$ von August Friedrich Joachim Heinrich G. (1791-1868) bedeutender Miniaturmaler (Schwiegersohn von Martin Wilhelm Oppenheim (1781-1863) Bankier), s. Allg. Lexikon der Künstler 14 (1921) S. 493 f.; Lehmann, Matthias: Die Malerfamilien Robert Kummer und August Grahl in Dresden. Frankfurt/M. 2010.

$\mathrm{K} \quad 1 \mathrm{~S}$ und $2 \mathrm{~T}$ (aus 1 . Ehe), $1 \mathrm{~T}$ (aus 2. Ehe): Elisabeth (Lili) S. (1881-1986) Ehefrau von: (siehe) Friedrich Voelcker.

Lb Nach 1845 Lehrzeit in Darkehmen; nach 1847 Verwalter auf Gütern in Ostpreußen und Rußland.

Seit 1849 Studium an Königl. Staats- und Landwirtschaftl. Akademie in Eldena (heute: Ortsteil von Greifswald), anschl. an U Berlin (?).
Königl. Höhere Landwirtschaft. Lehranstalt Poppelsdorf (heute: Ortsteil von Bonn): Seit 1852 Assistent; 1855 Habilitation; 1855-1857 Privat-Dozent.

Landwirtschaftl. Akademie Proskau (Oberschlesien; heute: Prószków, Polen): Seit 1857 Privat-Dozent; 8. Okt. 186o Dr. phil. an U Leipzig.

Land- und Forstwirtschaftl. Akademie Tharand (Sachsen): Seit 1862 a. o. Prof.

Landwirtschaftl. Fachschule am Polytechnikum Karlsruhe: Seit 1. Jan. 1865 o. Prof. und Vorstand; SS 1872 Verlegung der Landwirtschaftl. Fachschule an UH.

UH: Seit 30. März 1872 Honorar-Prof. und Direktor des neueingerichteten landwirtschaftl. Laboratoriums (1880 Aufhebung wegen zu geringer Frequentierung) und der Landwirtschaftl. Sammlungen; seit 30. Jan. 1874 o. Prof. • In dieser Zeit:

Berlin: 1876-1881 Mitglied des Dt. Landwirtschaftsrats. - 1881-1882 Mitglied des Dt. Reichstags als Vertreter der Dt. Fortschrittspartei.

1900 Ablehnung der Wahl zum Prorektor der UH wegen e. Augenleidens (14. März 190o-14. März 1901 Prorektor: Heinrich/Harri Rosenbusch); Dekan: 1881/82 Phil. Fak., 1893/94, 1899/190o Nat.Math. Fak. der UH

1891 Hofrat

E 1866 Ritterkreuz I. Klasse, 1871 Ritterkreuz I. Klasse mit Eichenlaub des Ordens vom Zähringer Löwen; 1871 Preußischer Kronenorden.

Qu UAH PA 2312; RA 6571f., 689of. • Auskunft: Universitätsarchive Leipzig und Bonn.

$W$ Welchen Einfluß hat die Tiefe der Ackerkrume auf das Gedeihen des Getreides. Diss. Leipzig 1860 (in Promotionsakte 1860 im UA Leipzig).

$L$ Biogr. Jahrbuch 5 (1900) Sp. 120; Badische Biographien 5 (1906) S. 736-738; Jansen (1992a) S. 169 (Register); WBIS. - Haunfelder, Bernd: Die liberalen Abgeordneten des deutschen Reichstags 
1871-1918. Münster 2004. S. 389. - Deutsche Biographie, s. https://www.deutsche-biographie.de/gn d117658065.html [05.12. 2017]. • Von Professorenzirkeln, Studentenkneipen und akademischem Networking. Universitäre Geselligkeiten von der Aufklärung bis zur Gegenwart. Hrsg. von Matthias Asche und Dietmar Klenke ... Köln 2017. S. 139 und Anm. 79.

$P$ Bildarchiv UAH; graph. Slg. UBH.

\section{Steudel, Friedrich Peter Hermann}

1902-1909 Med. Fak.

Physiologie

* 29. Juli 1871 Stade/Elbe

$\dagger$ 26. Jan. 1967 Bonn

ev.

V Hermann S., Kaufmann

M Adele geb. Lühmann

$\infty$ 14. Aug. 1909 Helene Marie Adeline geb. Koßmann (1881-1941)

$\mathrm{K} \quad 2 \mathrm{~S}, 2 \mathrm{~T}$

$\mathrm{Lb}$ Seit WS 1890/91 Studium an U Freiburg/Br., anschl. Leipzig, Berlin, Kiel; 11. Febr. 1892 ärztl. Vorprüfung in Leipzig; 24. Jan. 1895 Staatsexamen in Kiel; 6. März 1895 Dr. med. an U Kiel.

1895-1896 Schiffsarzt.

Assistenzarzt: Seit Aug. 1896 Infanterie-Regiment 74 Hannover (Militärdienstpflicht als EinjährigFreiwilliger), seit Aug. 1897 Chirurgisch-Orthopädische Privat-Klinik von Dr. Ferdinand Bähr in Kiel, seit April 1898 Städtisches Krankenhaus in Kiel, seit April 1899 Physiolog. Inst. der U Marburg.

UH: Seit April 1901 Assistenzarzt am Physiolog. Inst.; 14. Febr. 1902 Habilitation; seit 11. Jan. 1906 nichtetatm. a. o. Prof.

Friedrich-Wilhelms-U Berlin: Seit WS 1909/10 etatm. a.o. Prof. und Vorsteher der Chemischen Abt. des Physiolog. Inst. der Charité; 28. März
1928-30. Sept. 1936 (Emeritierung) o. Prof. und Direktor des Physiologisch-Chemischen Inst. der Charité; 1946-1949 Wiederaufnahme als o. Prof. und Direktor des Physiologisch-Chemischen Inst. der (seit 1949) Humboldt-U.

E 1941 Goethe-Medaille für Kunst und Wissenschaft.

Qu UAH PA 2314; RA 6191.

$W$ Beschreibung eines Ätherextraktionsapparates in: Hoppe-Seyler's Zs. für Physiologische Chemie 39 (1903) S. 473-476. (Mitverf.: Friedrich Kutscher.) - Physiologisch-chemisches Praktikum. Leipzig 1912. Minimetrische Methoden der Blutuntersuchung. Berlin 1921. 2. Aufl. 1924. (Mitverf.) - Methoden der Stoffwechseluntersuchung. Leipzig 1948.

L Stübler (1926) S. 311; Kürschner (1931) Sp. 2912, (1950) Sp. 2030 f., (1961) S. 2023; Poggendorff 7a (1962) S. 531 f. - Sepke, Ilonka: Zur Geschichte der chemischen Abteilung am Physiologischen Institut der Berliner Universität (1877-1928). Die Beiträge von Theodor Schwann, Albrecht Kossel, ... und H.S. bei der Herausbildung der physiologischen Chemie als selbständige Wissenschaftsdisziplin. Diss. Humboldt-Universität. Berlin 1979. • Höxtermann, Ekkehard: Berliner Botaniker in der Geschichte der Biochemie in: Mitteilungen der Gesellschaft Deutscher Chemiker/Fachgruppe Geschichte der Chemie 7 (1992) S. 21. • Jansen (1992a) S. 169 (Register); WBIS. Exodus von Wissenschaften aus Berlin. Fragestellungen, Ergebnisse, Desiderate. Entwicklungen vor und nach 1933. Hrsg. von Wolfram Fischer ... Berlin 1994. S. 84, 86, 309, 382. - Fruton, Joseph S.: Proteins, Enzymes, Genes. The Interplay of Chemistry and Biology. New Haven 1999. S. 401-403, 411. Hunter, Graeme K.: Vital Forces. The Discovery of the Molecular Basis of Life. San Diego 200o. S. 113f., 185. • Deutsche Biographie, s. https://www.deutsche-bio graphie.de/gnd117658472.html [05.12. 2017].

$P$ Bildarchiv UAH. 


\section{Stollé, Robert Johann Christian Karl}

1899-1935 Nat.-Math. Fak.

Chemie

* 17. Juli 1869 Mülheim am Rhein (heute: Stadtteil von Köln)

$\dagger \quad$ o9. Aug. 1938 Heidelberg

ev.

V Robert S. († vor 1919) Kaufmann (?), später Rentner

M Emilie geb. Hecker

(c) unverheiratet

Vw Bruder: Artur S. (1872-1926) seit 1905 Bergassessor, u.a. geologischer und bergmännischer Sachverständiger: 1908/o9 bei deutsch-englischer Neuguinea-Grenzexpedition, 1910 bei deutsch-holländischer Neuguinea-Grenzexpedition, 1912/13 Leiter der Kaiserin-AugustaFluss-Expedition zur Erkundung des neuguinesischen Flusses Sepik; Geheimer Bergrat, s. WBIS.

Lb Seit WS 1888/89 Studium an U Genf, anschl. Berlin, Bonn.

U Bonn: Okt. 1893 Dr. phil.; Herbst 1893-Ostern 1898 Assistent am Chemischen Inst.

UH: 1899-Febr. 1903 Assistent am Chemischen Laboratorium; 25. Juli 1899 Habilitation; WS 1900/ 01-1913 Lehrauftrag für Pharmazeutische Chemie mit e. Semesterhonorar von 40o.- Mark; seit 14. Febr. 1903 nichtetatm. a. o. Prof. und bis 1935 Abt.-Vorsteher am Chemischen Laboratorium, das SS 1926 erstmals als Chemisches Inst. im Personalverzeichnis der UH bezeichnet wird; seit 5. März 1919 etatm., seit 1920 planm. a.o. Prof.; 1. April 1935 Entpflichtung. • In dieser Zeit:

März-Mai 1913 Kur-Aufenthalt in Dr. Büdingen's Herz- und Kreislaufsanatorium in Konstanz; 19141918 Kriegsdienst.

E 1924 Mitglied der Akademie der Wissenschaften H. 1915 Eisernes Kreuz II., 1917 I. Klasse; 1916 Österr. Militär-Verdienstkreuz III. Klasse mit Kriegsdekoration; 1934 Ehrenkreuz für Frontkämpfer.
Qu UAH PA 6002; RA 5851, 6496, 6886. • GLA Abt. 235, Fasz. 2565.

$W$ Studien mit Hydrazin. Heidelberg 1899. Abhandlung über N-Nitroseverbindungen in: Journal für praktische Chemie 88 (1913) S. 306-314. (Mitverf.); Einwirkung von Acetaldehyd und Benzaldehyd auf Amino-5-tetrazol in: ebd. N.F. 148 (1937) S. 217-220. (Mitverf.) • Siehe auch WBIS.

L Kürschner (1931) Sp. 2931; Poggendorff 7a (1962) S. 558; WBIS; Jansen (1992a) S. 169 (Register); UH im Nationalsozialismus (2006) S. 1152 f.; Deutsche Biographie, s. https://www.deutsche-biographie. de/gnd117286923.html [05.12. 2017].

$P$ Bildarchiv UAH.

\section{Stoy, Carl Volkmar}

siehe Stoy, Karl Volkmar

\section{Stoy, Karl Volkmar}

1866-1874 (Honorar-Prof.) Phil. Fak. Pädagogik

* 22. Jan. 1815 Pegau (Sachsen)

$\dagger$ 23. Jan. 1885 Jena prot.

V Carl Gottlob S. (1774-1830) Pfarrer

M Johanna Sophia geb. Junghannß (1785-1831)

๑ 6. Juni 1845 Johanna Friedericke Dorothea Wilhelmine (Minna) geb. Carl (1826-1905), s. UAH RA 5735

K 2 T, 4 S: u.a. Johann Heinrich S. (1846-1905) seit 1876 Privat-Dozent für Pädagogik Jena, seit 1880 (Wiedereröffnung) Leiter des 1866 geschlossenen Stoy'schen Instituts in Jena; Nachlaß in U- und Landesbibliothek Jena; siehe WBIS; Hellmann, Birgitt u. a.: Jena. Jena 1998. S. 16; Grundig de Vazquez, Katja: Science de l'éducation (2015) S. 326 (Register). - Stephan S. (1856-1930), u.a. 1914-1924 a.o. Prof. für Geschichte Jena, s. Kürschner (1928/29) Sp. 2391; Rede des Geheimrats Prof. ... Linck 
am Sarge des Prof. ... S. S. in der Garnisonskirche am 27. Dez. 1930. Jena 1930.

Lb Seit 9. Mai 1833 Studium der Theologie, Philologie, Philosophie, Pädagogik an U Leipzig, 18371839 Göttingen; 9. Febr. 1837 Dr. phil. an U Leipzig.

Weinheim (Baden): 1839-1842 Erzieher und Lehrer für Griechisch, Geschichte, Deutsch, Latein, Naturgeschichte, Formenlehre und Heimatkunde an Benderscher Privaterziehungsanstalt.

U Jena: 22. Febr. 1843 Habilitation für Philosophie; 9. Dez. 1844-1866 (Auflösung) (Gründungs-)Direktor des Pädagog. U-Seminars unter Anbindung e. Volksschule als Übungsschule (das Seminar verband praktische und theoretische Lehrerausbildung); seit 15. April 1845 a. o. Prof.; seit 1. Mai 1857 o. Honorar-Prof. für Pädagogik. • In dieser Zeit:

Jena: Ostern 1844 (Gründer)-1866 (Schließung) Leiter der vormals Heimburgschen Knabenerziehungsanstalt, jetzt „Stoy'sches Institut“, e. privaten Erziehungs-Inst. mit Schule für 6-17jährige Jungen wohlhabender Eltern, auch aus Großbritannien, Frankreich, USA und Russland; 1858-1866 (Gründungs-)Direktor e. städtischen Seminarschule, der Johann-Friedrichs-Schule, in e. neuen Gebäude am Stadtrand, s. hierzu Soldt, Johannes: K.V.S. und die Johann-Friedrichs-Schule zu Jena. Ein Beitrag zur Geschichte der Pädagogik und Lehrerbildung in Deutschland. Weimar 1935; Coriand, Rotraud: K. V.S. ... und Otto Willmann (1839-1920) - Herbartianer und die Reform der Lehrerbildung in: Klassiker der Pädagogik. Die Bildung der modernen Gesellschaft. Hrsg. von Bernd Dollinger. 3. Aufl. Wiesbaden 2012. S. 152163 u. ö.

UH: 13. April 1866 Ern. zum o. Honorar-Prof. mit e. Jahresbesoldung von 300.- Talern, s. hierzu $Z$ (1); 1. Mai 1874 auf eigenen Antrag Entlassung. - In dieser Zeit:

Nov. 1867-April 1868 von UH beurlaubt: Dez. 1867 Begründer und bis April 1868 Direktor und Lehrer am Ev. Schullehrerseminar in Bielitz (Österreichisch-Schlesien; heute: Stadtteil von BielskoBiała, Polen), des ersten ev. Lehrerseminars für österr. Monarchie; Jan.-Febr. 1871 Berater des österr. Unterrichtsministeriums bei „Errichtung von Universitäts-Seminarien zur pädagogischen Ausbildung der Lehrer an Mittelschulen und Volkslehrerbildungsanstalten“.

U Jena: Seit SS 1874 o. Honorar-Prof. für Pädagogik; Juni 1874 Wiedereinrichtung des Pädagog. USeminars und seit April 1876 mit Anbindung der Übungsschule. • In dieser Zeit:

Jena: Ostern 1879 Mitbegründer und kurzzeitig auch Lehrer an Höherer Töchterschule mit angeschlossenem Lehrerinnenseminar.

Im Aug. 1853 unternimmt S. zusammen mit 5 Lehrern und 22 Schülern eine 8-tägige Wanderung von Jena zum rund $100 \mathrm{~km}$ entfernten Inselsberg im Thüringer Wald; mit dieser ersten Wanderung kreiert S. den noch heute durchgeführten Schul-Wandertag in Deutschland, siehe hierzu auch http://kalenderblatt.blogspot.de/2010/ o1/der-erfinder-des-wandertages.html (abgerufen am 24. Dez. 2017).

$Z$ (1) Am 12. Febr. 1866 teilt badisches Ministerium des Innern der Heidelberger Phil. Fak. mit, Großherzog Friedrich I. vorzuschlagen, S. als o. Honorar-Prof. mit einer Besoldung von 60o.Gulden an UH zu ernennen. Daraufhin gibt Engerer Senat der UH am 14. März 1866 zu bedenken: „Die Creirung besoldeter Honorarprofessoren erscheint uns zwar nicht ganz unbedenklich, wollen wir auch gegen die Ertheilung einer Besoldung an Prof. Stoy uns nicht aussprechen, vorausgesetzt, daß dadurch nicht die Befriedigung eines der verschiedenen von uns bezeichneten und uns dringlicher erscheinenden Bedürfnisse der Universität verhindert werde ..." (aus: UAH PA 2317).

Z (2) Anfang April 1870 stellt S. einen Antrag auf Abhaltung der Fak.-Prüfungen über Pädagogik an Phil. Fak., der abgelehnt wird. Die Begründung des Dekans Gustav Kirchhoff lautet: „... Nach $\$ 8$ der Promotionsordnung hat Prof. Stoy nicht mitzuexaminiren, weil er nicht Mitglied der Fakultät ist, es sei denn, daß er zu diesem Zwecke von ihr beigezogen werde. Ob dieses geschehen soll, muß nach unserer Ansicht lediglich dem Urtheil der Fakultät anheim gestellt bleiben ... Unter die 
Hauptprüfungsfächer hat die (Fakultät) mit gutem Bedacht die Pädagogik nicht aufgenommen; einmal ist der Fall vorgekommen, daß ein Candidat diese Disciplin als Nebenfach gewählt hat; diese Wahl wurde durch besonderen Beschluß von der Fakultät genehmigt und die Prüfung einem ihrer Mitglieder übertragen, welcher auch die Pädagogik vertritt und Vorlesungen über dieselbe hält ..." (aus: Bericht vom 29. April 1870 in: PA 2317).

1857 Geh. Sächsischer Schulrat

E 1869 D. theol. Gießen. 1866 Ritter des Russischen St. Annen-Ordens III. Klasse.

Qu UAH PA 2317; RA 5873, 6855. Mitteilungen: Herr Alfred Stoy $(\dagger)$.

$W$ Der deutsche Sprachunterricht in den ersten sechs Schuljahren. Heidelberg 1842. 3. Aufl. Wien 1868. Encyclopädie, Methodologie und Litteratur der Pädagogik. Leipzig 1861. 2. Aufl. 1878. • Die pädagogische Bildung für das höhere Lehramt. 24 Thesen in: Allg. Schulzeitung 52 (1867) S. 199201. Organisation des Lehrerseminars. Ein Beitrag zur Methodologie. Leipzig 1869. • Pädagogische Bekenntnisse. Jena 1889. Bibliographie in: Coriand, Rotraud: Das Schrifttum K. V.S.s. Weinheim 1999.

HG 1870-1881 Allgemeine Schulzeitung für das gesammte Unterrichtswesen. Darmstadt und Jena.

L Günther (1858) S. 266 f. - Andreae, Carl: Zum Andenken an ... C.V.S. Kaiserslautern 1885. ADB 36 (1893) S. 474-479. • Thüringer Erzieher ... Hrsg. von Günther Franz. Köln u. a. 1966. • Deutsche Lehrerbildung in Bielitz/Ostschlesien. Hrsg. von Julius Stumpf ... Stuttgart 1967. S. $151 \mathrm{ff}$. Lenhart, Volker: Die Pädagogik als wiss. Disziplin an der ... Universität Heidelberg 1803-1970 in: Heidelberger Jahrbücher 15 (1971) S. 159-161. Coriand, Rotraud: K.V.S. und die Idee der pädagogischen Bildung. Würzburg 2000. Musolff, Hans-Ulrich und Hellekamps, Stephanie: Geschichte des pädagogischen Denkens. München 2006. WBIS. - Biographie K. V.S., siehe https:// www.uni-due.de/imperia/md/content/herbartia nismus-forschungsstelle/stoy.pdf (Ausdruck im $\mathrm{UAH}$ ). NDB 25 (2013) S. $463 \mathrm{f}$. Grundig de Vazquez, Katja: Science de l'éducation und Wege professioneller Lehrerbildung ... Bad Heilbrunn 2015. S. 326 (Register). - Deutsche Biographie, s. https:// www.deutsche-biographie.de/gnd115663738.html [05. 12. 2017].

P Bildarchiv UAH; Soldt (1935); NDB 25 (2013).

\section{Strathmann, Hermann Wilhelm Heinrich}

1915-1916 Theol. Fak.

Neues Testament, Kirchengeschichte

* 30. Aug. 1882 Opherdicke (Westfalen; heute: Ortsteil von Holzwickede)

$\dagger$ 29. Nov. 1966 Erlangen ev.-luth.

V Georg Hermann Engelbert S. (1855-1943) Pfarrer, s. Aus der Geschichte der ev. Kirchengemeinde Opherdicke (1176-1925). Opherdicke 1934. S. 82-92; Bauks, Friedrich Wilhelm: G.H.E.S. in: Die ev. Pfarrer in Westfalen (1980) Nr. 6184

M Mathilde geb. Bruch (1854-1927)

$\infty$ 3. Aug. 1911 Maria Bertha Anna Martha geb. Hüttenhain $\left({ }^{*} 1887\right)$

$\mathrm{K} \quad 1 \mathrm{~S}, 4 \mathrm{~T}$

$L b$ Seit WS 1901/o2 Studium an U Tübingen, anschl. Halle/S., Münster; April 1905 I., April 1907 II. theol. Examen in Münster.

U Bonn: WS 1907/08-SS 1908 Forts. des Studiums; Okt. 1908-Sept. 1909 Militärdienstpflicht als Einjährig-Freiwilliger in Bonn; 17. Okt. 1908 Lizentiatenprüfung; 24. Okt. 1910 Habilitation; 15. Okt. 1910-30. Sept. 1914 Inspektor des Königl. Ev.Theol. Stifts an U.

UH: 7. Dez. 1914 Genehmigung des Ministeriums des Kultus und Unterrichts in Karlsruhe zur „Nostrifikation auf 1. April 1915“ (aus: UAH PA 2319); 1. April 1915 Umhabilitierung; seit 1. April 1915 Repetent am Theol. Seminar mit e. Jahresvergütung 
von 1000.- Mark; seit 22. April 1915 nichtetatm. a.o. Prof.; seit 1. April 1915 „Lehrauftrag zur Suppletur im theol. Unterricht insbesondere auf dem Gebiete der Kirchengeschichte" mit e. Jahreshonorar von 2600.- Mark (aus: UAH PA 2319).

U Rostock: Seit 16. Juni 1916 o. Prof.; 1915-1918 (mit 8-monatiger Unterbrechung) Kriegsdienst als Feldgeistlicher in Russland und Frankreich.

U Erlangen: Seit April 1918 o. Prof. für Neutestamentliche Exegese und einleitende Wissenschaften; 1926 3-monatige Studienreise nach Palästina; 1. Nov. 1945 Entlassung durch Militärregierung; 1. April 1946 Emeritierung; 31. Jan. 1947 erneut Entlassung durch Militärregierung; 25. Sept. 1948 Wiederernennung zum o. Prof. unter gleichzeitiger Emeritierung. - In dieser Zeit:

Mitglied: 1918-1920 (Bayer. Mittelpartei), 19461947 (CSU), 1949-1950 (CSU) Bayer. Landtag, 1920-1930, 1931-1932 Deutscher Reichstag.

1918 Mitbegründer der Bayer. Mittelpartei

E 1916 D. theol. Leipzig.

Qu UAH PA 2319; RA 6722, 6753 f. • GLA Abt. 235, Fasz. 2569. - Nachlaß: Landeskirchliches Archiv der Ev.-Luth. Kirche in Bayern, Nürnberg.

$W$ Calvins Lehre von der Buße in ihrer späteren Gestalt. Gotha 1909. • Geschichte der frühchristlichen Askese bis zur Entstehung des Mönchtums im religionsgeschichtlichen Zusammenhange. Bd. 1: Die Askese in der Umgebung des werdenden Christentums. Leipzig 1914. • Was soll die „Offenbarung“ des Johannes im Neuen Testament? Gütersloh 1934. 2. Aufl. 1947. - Wie entstand das Neue Testament? Was ist es uns? Eine erste Fortsetzung von Saladin-Ludendorff im Kampf gegen die Bibel. Essen 1937. 4. Aufl. Velbert 1937.

Übers. Das Evangelium nach Johannes. Göttingen 1932. 10. Aufl. 1963. (Das Neue Testament Deutsch. Bd. 4.)

L Verzeichnis Bonn (1968) S. 306; WBIS. • Bauks, Friedrich Wilhelm: H.W.H.S. in: Die ev. Pfarrer in
Westfalen von der Reformationszeit bis 1945. Bielefeld 1980. Nr. 6185. • Anzeneder, Helmut: Ernst Meier und H.S. Zwei politisch engagierte Erlanger Hochschullehrer in: Erlanger Bausteine zur fränkischen Heimatforschung 41 (1993) S. 99-124. • Hass, Otto: H.S. Christliches Denken und Handeln in bewegter Zeit. Bamberg 1993. • Professoren Erlangen (1993) S. 77 f.; Willett (2001) S. 331, 402 f. u.ö.; Personenlexikon zum dt. Protestantismus (2006) S. 251f. - An der Spitze der CSU. Die Führungsgremien der Christlich-Sozialen Union 1946-1955. Hrsg. von Jaromír Balcar und Thomas Schlemmer. München 2007. S. 655 (Register). Catalogus prof. Rostochiensium online; BBKL (März 2018 in Vorbereitung); Deutsche Biographie, s. https://www. deutsche-biographie.de/gnd119239221.html [31.03. 2018].

$P$ Bildarchiv UAH.

\section{Strauch, Hermann}

1865-1899 Jur. Fak.

Öffentliches Recht, Rechtsphilosophie

* 04. Dez. 1838 Frankfurt/M.

$\dagger \quad$ 28. Sept. 1904 Heidelberg ev.

V Friedrich S., Handelsmann

M Sofia geb. Braunold

$\infty$ unverheiratet.

Lb SS 1857 Studium an U Bonn, seit 19. Okt. 1857 H, seit SS 1859 Wien; 1861 Staatsprüfung in Wien.

Wien: Seit 8. April 1861 Rechtspraktikant am Landesgericht, anschl. Repetitor bei e. Grafen Schoenborn; 15. Juli 1862 Dr. iur. an U; 1862-1864 Mitarbeiter in Kanzlei des Hof- und Gerichtsadvokaten Dr. Franz Schmitt und Mitredakteur der Allg. österr. Gerichtszeitung.

UH: 28. Juli 1865 Habilitation; 1873 Ruf an U Dorpat abgelehnt; seit 27. Febr. 1873 a.o. Prof.; SS 1899 S. läßt sich von Vorlesungsverpflichtung aus Krankheitsgründen entbinden. 
1904: S. richtete ein Legat von 18 ooo.- Mark für eine Strauch-Stiftung an der Universität Heidelberg ein, s. hierzu UAH RA 5309f., GLA 235, Nr. 3938 .

Qu UAH PA 2320; RA 6149, 6761, 6772; Fak.-Akte H-II-111/65. - Teil-Nachlaß: UBH; Institut für Stadtgeschichte Frankfurt/M.

$W$ Ursprung und Natur der Regalien. Heidelberg 1865. - Zur Interventions-Lehre. Eine völkerrechtliche Studie. Heidelberg 1879.

L Badische Biographien 6 (1935) S. 67-70; WBIS; Weigle (1986) S. 89f.; Schroeder (2010) S. 328 f.; Deutsche Biographie, s. https://www.deutschebiographie.de/gnd117311510.html [09.12. 2017].

$P$ Bildarchiv UAH; graph. Slg. UBH.

\section{Strecker, Karl Georg Bernhard Christian}

1924-1933 (Honorar-Prof.) Nat.-Math. Fak. Physik, Mathematik

* 26. März 1858 Mainz

$\dagger \quad$ 24. Aug. 1934 Heidelberg

ev.

V Wilhelm Christian S. (1828-189o) Fabrikant von Schreibmaterialien, s. Die hessen-darmstädtische Beamtenfamilie Strecker. Bearb. nach den Entwürfen ... von Ludwig Strecker ... Darmstadt 1894. 4. T. S. $81 \mathrm{f}$.

M Wilhelmine Katharine Ida geb. Scholz (18391921), s. ebd. S. 81

(1). Okt. 1885 Louise Julie Wilhelmine Anna geb. Sandberger $\left({ }^{*} 1861 \dagger\right.$ nach 1934$) \mathrm{T}$ von Fridolin Carl Ludwig Ritter von S. (1826-1898) seit 1849 Leiter des Naturhistor. Museums Wiesbaden, seit 1855 o. Prof. für Mineralogie, Geologie Polytechnikum Karlsruhe, 1863-1896 (Ruhestand) U Würzburg, s. WBIS; Beckenkamp, Jakob: F. von S. Gedächtnisrede gehalten ... am 24. Nov. 1898. Würzburg 1899; Schnitzer, Walter A., Voßmerbäumer, Herbert: Zur Geschichte von Geologie-Paläontologie in: 400
Jahre Universität Würzburg. Eine Festschrift hrsg. von Peter Baumgart. Neustadt an der Aisch 1982. S. 665-682 u.ö. - Bruder: Adolf Wilhelm August Sandberger (1864-1943) Komponist, seit 1889 Konservator an Bayer. Staatsbibliothek München, seit 1894 PrivatDozent, seit 1900 Prof. für Musikgeschichte U München, s. NDB 22 (2005) S. 415f., Klee, Kulturlexikon (2007) S. 509

K $\quad 1$ T

Vw Tanten: Sophie S. (1829-1891) Schriftstellerin, s. Die hessen-darmstädtische Beamtenfamilie Strecker (1894) S. 82 f.; Ehefrau von Jacob Moleschott (1822-1893) seit 1845 Arzt in Utrecht, seit 1847 Privat-Dozent für Anatomie und Physiologie UH, 1854 Niederlegung der Dozentur nach Verwarnung durch UH wegen unsittlicher und frivoler Äußerungen (M. fordert nach dem Ableben statt Erd- eine Feuerbestattung, um die Asche als Düngemittel sinnvoll zu verwerten), seit 1856 o. Prof. für Physiologie Zürich, seit 1861 Turin, seit 1879 Sapienza Rom, s. Emundts-Trill (1997) S. 252 f., NDB 17 (1994) S. 723-725; Carl Vogt, J.M., Ludwig Büchner, Ernst Haeckel: Briefwechsel. Hrsg. ... von Christoph Kockerbeck. Marburg 1999; Püschel, Ursula: Ein menschlich-historisches Netzwerk anläßlich eines Briefs von J.M. in: Dies.: Bettina von Arnim - politisch. Erkundungen, Entdeckungen, Erkenntnisse. Bielefeld 2005. S. 13-20. Carolina (Lina) Christina Johanna S. (1835-1907), s. Die hessen-darmstädtische Beamtenfamilie Strecker (1894) S. 85-87 u. ö.; Hedwig Pringsheim: Tagebücher. Bd. 4: 1905-1910. Hrsg. ... von Cristina Herbst. Göttingen 2015. S. 841 (Register); Ehefrau von Adolph Strecker (Vetter) (18221871) seit 1849 Privat-Dozent Gießen, seit 1851 Prof. für Chemie Christiania (heute: Oslo), seit 1860 Tübingen, seit 1869 o. Prof. für Organische Chemie Würzburg, s. ADB 36 (1893) S. 555-560, WBIS; Aus der Vergangenheit der Universität Würzburg ... Hrsg. von Max Buchner ... Berlin 1932. S. 663 u. ö.

Lb SS 1877 Studium an U Tübingen, seit WS 1877/ $78 \mathrm{H}$, seit WS 1878/79 Straßburg; 16. Febr. 1881 Dr. phil. an U Straßburg. 
Assistent am Physikal. Inst.: 1881 Straßburg, 18821884 Würzburg.

Berlin: 1885-1886 Physiker bei Dt. Edison Gesellschaft für angewandte Elektricität (später AEG AG).

TH Berlin-Charlottenburg: 29. Okt. 1886 Habilitation für Elektromechanik; seit 1892 Dozent, seit 1899 Prof. für Elektrotelegraphie, insbesondere für Eisenbahnbetrieb; 13. Sept. 1913-1934 (†) Honorar-Prof. für Elektrotechnik und Elektrotelegraphie der Abt. III für Maschinen-Ingenieurwesen mit Einschluß des Schiffbaues, 1922 umbenannt in Fak. III für Maschinenwirtschaft und 1928 in Fak. III für Maschinenwesen. • In dieser Zeit:

Berlin: Seit 1. Okt. 1888 Obertelegraphen-Ingenieur am Reichs-Post-Amt; seit 1. April 1904 vortragender Rat am Reichs-Post-Amt; 1. Juli 1910-28. März 1920 Präsident des Telegraphentechnischen Reichs-Amts.

UH: 21. Sept. 1923 Ern. zum o. Honorar-Prof.; WS 1924/25-WS 1932/33 Vorlesungsankündigungen über Potentialtheorie, Elektrotechnische Messungen, Einführung in die technische Physik.

1900 Geh. Postrat; 1908 Geh. Ober-Postrat

E 1924 Mitglied der Akademie der Wissenschaften H; 1926 Ehrenmitglied des Reichsbundes Dt. Technik. 1922 Dr.-Ing. E.h. TH Dresden. 1921 Siemens-Stephan-Gedenkplakette.

Qu UAH PA 6015. - GLA Abt. 235, Fasz. 2567. Briefe: Staatsbibliothek zu Berlin; Universitätsbibliothek Leipzig. - Auskunft: Universitätsarchiv TU Berlin (Codex Professorum).

$W$ Über die specifische Wärme des Chlor-, des Brom- und des Jodgases. Leipzig 1881. - Hilfsbuch für die Elektrotechnik. Berlin 1888. (Mitverf.) 10. Aufl. 1928. (Verf.) • Die Telegraphentechnik. Berlin 1889. (Mitverf.) 6. Aufl. 1919. (Verf.)

HG 1912-1927 Jahrbuch der Elektrotechnik.
$L$ Wer ist's (1928) S. 1543; Kürschner (1931) Sp. 2947; Arnim 2 (1952) S. 624; NDB 25 (2013) S. 525. • Geschichte der Fernmeldetechnik und Nachrichtentechnik an der TH/TU Berlin, s. http://www. nue.tu-berlin.de/menue/home/geschichte/ (abgerufen am 9. Dez. 2017).

\section{Succow}

siehe Suckow

\section{Suckow, Georg Adolph}

1784-1803 Phil. Fak.

1803-1813 Staatswirtschaftl. Sektion

Staatswirtschaftl. Wissenschaften (Mathematik, Natur- und Tierlehre, Physik, Chemie, Mineralogie, Bergbaukunde, Baukunst)

* 28. Jan. 1751 Jena

$\dagger$ 13. März 1813 Heidelberg

ㅁ 16. März 1813 Heidelberg ev.-luth.

V Lorenz Johann Daniel S. (1722-1801), u.a. seit 1756 o. Prof. für Physik, Mathematik Jena, s. ADB 37 (1894) S. 105, Stolz (2003) S. 303 f., Zimmermann/Neuper (2008) S. $236 \mathrm{f}$.

M Anna Catharina geb. Daries ( $\dagger 1768)$

$\infty$ vor 1785 Regina Elisabetha geb. Meißner († nach 1813)

$\mathrm{K} \quad 2 \mathrm{~T}, 3 \mathrm{~S}$ (davon $1 \mathrm{~T}$ und $1 \mathrm{~S}$ tot geboren), u. a. Dr. med. Friedrich Wilhelm Ludwig S. (17881838) Vorsteher des Naturhistor. Museums Mannheim, s. UAH PA 2328, ADB 37 (1894) S. $106 \mathrm{f}$. (hier irrtümlich 1770 als Geb.-Jahr genannt), WBIS, Erben (2011) S. 30-34

Vw Halbbruder: Wilhelm Carl Friedrich S. (17701848), u. a. seit 1816 o. Prof. für Medizin an U Jena, s. Zimmermann/Neuper (2008) S. $238 \mathrm{f}$. Neffe, $\mathrm{S}$ von Halbbruder Wilhelm Carl Friedrich S.: Gustav S. (1803-1867) seit 1823 Privatdozent, seit 1831 a. o. Prof., seit 1837 HonorarProf. für Chemie, Mineralogie und Geologie Jena, s. WBIS.

MHG 1887-1911 Fortschritte der Elektrotechnik. 
Lb U Jena: Seit 1769 Studium zunächst der Theologie und Orientalischen Sprachen, dann der Medizin; 1772 Dr. med.; SS 1773-SS 1774 S. hält Vorlesungen über Pathologie und Materia medica (Arzneimittellehre).

Lautern (heute: Kaiserslautern): Seit 14. Okt. 1774 Prof. für Naturlehre, Mathematik, Chemie, Physik und Landwirtschaft an „Kameral Hohe Schule“; 1774-1784 auch Sekretär der „Kuhrpfälzisch Physikalisch-Ökonomischen Gesellschaft“; 1784 Verlegung der „Kameral Hohe Schule“ nach $\mathrm{H}$ und Angliederung als Staatswirtschafts Hohe Schule an Phil. Fak. der UH.

Staatswirtschafts Hohe Schule $\mathrm{H}$ und Phil. Fak. der UH: 1784-1803 o. Prof.; Mai 1803 Eingliederung der "Staatswirtschafts Hohe Schule“ in U als Staatswirtschaftl. Sektion.

UH: $1803-1813$ O. Prof. an Staatswirtschaftl. Sektion; 1805-1813 Direktor des Physikal. Kabinetts.

1786/87 Rektor der UH; 1802/o3 Prorektor der UH; 1789 Dekan der Phil. Fak. der UH; 1804/05, 1806, 1807-März 1808 Direktor der Staatswirtschaftl. Sektion der UH; zur Staatswirtschaftl. Sektion der UH, siehe Heinrich Eschenmayer und Ludwig Wallrad Medicus: Einträge unter Z[itat]

Herzogl. Pfalz-Zweibrücker Hofrat; 1805 Großherzogl. Badischer Geh. Hofrat

E 1783 Mitglied der Kurpfälz. Akademie der Wissenschaften in Mannheim; 1798 Mitglied der Dt. Akademie der Naturforscher Leopoldina; 1808 Mitglied der Akademie der Wissenschaften München.

Qu UAH PA 2327 (hier eigenhändige Unterschrift: Suckow); RA 1006, 5622, 5835 u. ö. • Matrikel Erlangen (1918) S. 503 und Anm. 12 (hier Eintrag eines Gleichnamigen am 11. März 1754; S. wäre bei der Immatrikulation 3 Jahre alt). - GLA Abt. 205, Fasz. 517f. - Prozesssachen Freiburg 1489-1867. Bearb. von Stefan Hanke. UA Freiburg/Br. 1997. S. 17: Verleumdungsprozess, Signatur: 80, Vorsignatur 1: III i 72, Laufzeit: 1807; Titel: Forderungen von 302 Gulden 45 Kreuzer der Heidelberger
Professoren Georg Adolf Suckow, Gutterer [wohl Christoph Wilhelm Gatterer] und Martin Tobias Engelbert Semer gegen die katholische Kirchenkommission. Wielands Briefwechsel. Hrsg. von Siegfried Scheibe. Berlin 2007. Bd. 20 (Gesamtregister). S. 633. - Siehe auch Archiv der Dt. Akademie der Naturforscher Leopoldina Halle/S. • Auskunft: Ev.-Luth. Kirchengemeinde - Gemeindekirchenrat - Jena; Ev. Oberkirchenrat - Landeskirchliches Archiv - Karlsruhe.

$W$ Von dem Nutzen der Chemie zum Behufe des bürgerlichen Lebens. Mannheim 1775. • Versuche über die Wirkungen verschiedener Luftarten auf die Vegetation. München 1782. • Anfangsgründe der ökonomischen und technischen Chemie. Leipzig 1783. 2. Aufl. 1789. • Über das Studium der angewandten Botanik in: Vorlesungen der Churpfälzischen Physikalisch-Ökonomischen Gesellschaft in Heidelberg. Mannheim 1787. Bd. 2. S. 125156. Anfangsgründe der Mineralogie. Leipzig 1790. 2. Aufl. 2 Bde. 1803. - Diagnose der Pflanzen-Gattungen nach der neuesten Ausgabe des Linnéischen Sexualsystems. Leipzig 1792. - Anfangsgründe der theoretischen und angewandten Naturgeschichte der Thiere. 4 T. mit mehreren Abt. Leipzig 1797-1801.

$L$ Poggendorff 1 (1863) Sp. 1046 f.; ADB 37 (1894) S. 105 f.; Keller (1913) S. 102 f.; Webler (1922) S. 6567; Kistner (1930) S. 110-113 u. ö. \ Querner, Hans: Naturgeschichte an der Kurpfälzischen Akademie der Wissenschaften in: Heidelberger Jahrbücher 21 (1977) S. 48 ff. • Poller (1979) S. 387 (Register unter Succow); Plettenberg (1983) S. 128-130 u. ö.; Kirschke (2001) S. 449 (Register); WBIS; Cser (2007) S. 145 f.; Zimmermann/Neuper (2008) S. 234f. (hier irrtümlich Mai statt März als Todesmonat angegeben) u. ö. - Landschaften agrarischökonomischen Wissens. Strategien innovativer Ressourcennutzung in Zeitschriften und Sozietäten des 18. Jahrhunderts. Hrsg. von Marcus Popplow. Münster 2010. S. 222-224, 227-230 u. ö. • Biography of G.A.S. in: Contributions to the History of Herpetology. Ed. by Kraig Adler. Vol. 3. Vancouver 2012. • Neuhaus (2014) S. 41, 50, 71, 73, 196. 


\section{Sütterlin, Ludwig}

1890-1913 Phil Fak.

Vgl. Sprachwissenschaft

* 16. Nov. 1863 Heidelberg

$\dagger$ 03. Juli 1934 Freiburg/Br.

ev.

V Johann Georg S., Eisenbahnbeamter

M Barbara geb. Römmig

๑ 2. April 1914 Eugenie geb. Foehr (1877-1969)

$\mathrm{K} \quad 1 \mathrm{~S}$

Lb Seit WS 1883/84 Studium der Vgl. Sprachwissenschaft, der Dt. und Romanischen Philologie an UH, seit WS 1885/86 Leipzig, WS 1886/87 H; 8. Jan. 1887 Dr. phil. an UH.

1887-1888 Hauslehrer bei e. russischen Adelsfamilie während ihrer Reise durch Europa.

H: Frühjahr 1888 Lehramtsprüfung in Deutsch und Französisch als Hauptfächer, Latein und Griechisch als Nebenfächer; 1889 Erweiterungsprüfung in Geschichte als Nebenfach.

Lyceum (seit April 1894 Gymnasium; heute: Kurfürst-Friedrich-Gymnasium „KFG“) in $\mathrm{H}$ : Frühjahr 1888-Aug. 1896 zunächst Lehramtskandidat, anschl. Lehrer.

Höhere Mädchenschule (heute: Hölderlin Gymnasium) und Lehrerinnenseminar in H: Sept. 1896Aug. 1909 Prof., siehe auch $Z$ (3).

Gymnasium in H: Sept. 1909 Versetzung von Höherer Mädchenschule an Gymnasium auf Wunsch der Dt. Kommission der Berliner Akademie der Wissenschaften, „um ihm die Mitarbeit am Deutschen Wörterbuch der Brüder Grimm zu ermöglichen“ (aus: Das „Goldene Buch“ des KFG (1994) S. 113); von Sept. 1909 bis zum Wechsel an U Freiburg/Br. am 1. April 1913 Beurlaubung („S. hat keine einzige Stunde an der Anstalt gegeben“, aus: ebd.). In dieser Zeit:

UH: 21. Nov. 1890 Habilitation ohne Abhaltung e. Kolloquiums, s. hierzu $Z$ (1); seit 25. Juni 1896 nichtetatm. a.o. Prof.; SS 1908-WS 1908/o9, SS
1909-WS 1909/10 Beurlaubung, s. hierzu $Z$ (3); SS 1912 und WS 1912/13 Ankündigung von Phonetischen Übungen, s. hierzu auch $Z$ (4).

U Freiburg/Br.: 20. Dez. 1912 Ern. zum SS 1913 o. Prof.; 1. April 1924 Emeritierung; April 1924-Juli $1934(\dagger)$ Vertreter seiner Professur.

$Z$ (1) Über die Ausnahmeregelungen bei der Habilitation S.s schreibt Dekan Leo Koenigsberger an den Engeren Senat der Universität Heidelberg am 6. Juli 189o: „Da der Candidat die Doctorwürde an der hiesigen Universität mit der ersten Note erlangt hat, so war nach der bisher gültigen Habilitationsordnung von einem Colloquium abzusehen; dem Gesuche [zur Habilitation] sind die Zeugnisse des Candidaten sowie das Gutachten der Facultät über die Habilitationsschrift beigelegt. Von der Forderung des ersten Druckbogens der eingereichten Arbeit bittet die Facultät das hohe Ministerium deshalb Abstand nehmen zu wollen, weil nach der Ansicht der Sachverständigen vor dem Drucke noch einige formale Aenderungen vorzunehmen sein werden" (aus: UAH PA 2329).

$Z$ (2) S. ersucht in einem Schreiben vom 23. Febr. 1906 das Akademische Direktorium (= Prorektor der UH) um Bezahlung der Übersetzung fremdsprachlicher Schriftstücke im Auftrag der Universität: „Im Laufe der letzten Jahre sind mir von der Universitätsbehörde verschiedentlich slavische, besonders russische Schriftstücke zur Übersetzung oder Begutachtung übergeben worden: zunächst ... ein neubulgarischer Aufruf gegen die Türken, ... endlich im Lauf dieses Winters wieder ein langes russisches Schriftstück, eine Verrufserklärung [Verruf $=$ Ächtung] gegen einen russischen Studenten der Bergakademie Freiberg mit angefügtem Bericht über eine vorausgegangene Studentenversammlung.

Da ich erfahren habe, dass derlei Arbeiten sonst vergütet werden, und da ich mich noch zu erinnern glaube, dass im Jubiläumsjahr 1886 sogar zur Übersetzung der eingelaufenen französischen und englischen Glückwunschschreiben ausdrücklich zwei Mitglieder des akademischen Lehrkörpers bestellt wurden, erlaube ich mir ... mitzuteilen, dass ich nichts dagegen hätte, wenn mir ... die aufgewendete Mühe in irgend einer Weise vergütet würde ..." (aus: PA 2329). Am 28. Juni 1906 verfügt 
das Ministerium der Justiz, des Kultus und Unterrichts in Karlsruhe die Auszahlung eines Honorars von 100.- Mark für die von S. „in den Jahren 1902 bis 1906 für die Universität angefertigten Übersetzungen von Schriftstücken aus slavischen Sprachen" (aus: PA 2329).

Z (3) Am 21. Febr. 1908 bittet S. um Beurlaubung zunächst für die kommenden zwei Semester: „... Vor vier Jahren hat mir der vortragende Rat im Preussischen Kultusministerium in Berlin, Herr Geheimer Oberregierungsrat Dr. [Adolf] Matthias, die Aufgabe übertragen, an einem von ihm herauszugebenden mehrbändigen Handbuch des deutschen Unterrichts mitzuarbeiten und darin den Band zu schreiben, der die „Neuhochdeutsche Grammatik" behandelt.

Bis jetzt habe ich zu diesem Werk nur den Stoff sammeln können und möchte in der nächsten Zeit das Ganze einmal ordnen und den Text niederschreiben können ... Der Großherzoglich Badische Oberschulrat hat mich ... auf anderthalb Jahre hinaus in meinem Unterricht an der hiesigen Höheren Mädchenschule und am Lehrerinnenseminar entlastet und meine Pflichtstunden von Ostern 1908 bis Herbst 1909 auf die Hälfte herabgesetzt ..." (aus: PA 2329).

$Z$ (4) Professoren Johannes Hoops, Friedrich Neumann und Wilhelm Braune richten am 5. Dez. 1911 ein Gesuch an Phil. Fak. mit der Weiterleitung des befürworteten Antrags an das Ministerium, „1) dass dem a. o. Professor an der Universität und Professor am Gymnasium in Heidelberg Dr. Ludwig Sütterlin ein fester Lehrauftrag für Phonetik erteilt werde, ...

2) dass Herr Professor Sütterlin zur Förderung seiner Tätigkeit als Forscher und akademischer Lehrer sowie zu Gunsten seiner Mitarbeit am Grimm'schen Wörterbuch dauernd von einem Teil seiner Unterrichtspflicht am Gymnasium entbunden wird und die Kosten für die erforderliche Vertretung aus der Vergütung für den genannten Lehrauftrag bestritten wird“ (aus: PA 2329). Eine Antwort des Ministeriums liegt weder der Personal-, der Rektorats-, noch der Fak.-Akte bei.

S.s nicht mit ihm verwandter Namensvetter Ludwig Sütterlin (1865-1917), ein Gebrauchsgraphiker und Kunstgewerbler, u. a. seit 1917 Prof. an Unterrichtsanstalt des Kunstgewerbe-Museums in Berlin, entwirft 1911 die Sütterlinschrift, siehe WBIS, NDB 25 (2013) S. $688 \mathrm{f}$.

Siehe auch Johannes Rissom: Eintrag unter $Z[\mathrm{i}-$ tat] (2) und Anhang Sporteinrichtungen an $U H$ 1910-1933 und ihre Mitglieder

E 1895 Curtius-Preis vom Kuratorium der Curtius-Stiftung in Leipzig. - Ehrenring des Allg. Dt. Sprachvereins. 1916 Kriegsverdienstkreuz.

$\mathrm{Qu}$ UAH PA 2329; RA 5252, 6680, 6832; Fak.-Akten H-IV-102/115, H-IV-102/128 fol. 100 ff. • Briefe: UBH; siehe auch Int. Germanistenlexikon 3 (2003) S. 1846.

W Zur Geschichte der Verba denominativa im Altgriechischen. Straßburg 1891. - Der Genitiv im Heidelberger Volksmund. Heidelberg 1894. • Die heutige Mundart von Nizza in: Romanische Forschungen 9 (1896) S. 249-586. - Die deutsche Sprache der Gegenwart. Leipzig 1900. 5. Aufl. 1923. - Deutsche Sprachlehre für höhere Lehranstalten. Leipzig 1905. 9. Aufl. 1930. (Mitverf.: Albert Waag.) $\bullet$ Grundriß der deutschen Sprachlehre für die unteren Klassen höherer Schulen. Leipzig 1908. 14. Aufl. 1930. (Mitverf.) Die Lehre von der Lautbildung. Leipzig 1908. 3. Aufl. 1925. • Neuhochdeutsche Grammatik. München 1924. • Siehe auch Int. Germanistenlexikon 3 (2003) S. $1845 \mathrm{f}$.

L Zur Fünfzigjahrfeier der Höheren Mädchenschule, jetzt Mädchenrealschule mit Mädchenrealgymnasium und gymnasialer Abteilung in Heidelberg. Hrsg. von Eugen Ehrmann. Heidelberg 1927. S. 13. Kürschner (1931) Sp. 2979. - Kuhlmann, Walter: Nachruf auf L.S. in: Indogermanisches Jahrbuch 20 (1936) S. 336-343. - WBIS; Lehmann (1967) S. 229f.; Das "Goldene Buch“ des KFG (1994) S. 113; Int. Germanistenlexikon 3 (2003) S. 1844-1846; 100 Jahre Germanistik in Hamburg (2011) S. 95, 112, 480; Riecke (2016) S. 37-40, 125; Deutsche Biographie, s. https://www.deutsche-bio graphie.de/gnd11737239o.html [09.12. 2017].

$P$ Bildarchiv UAH; Das „Goldene Buch“ des KFG (1994) S. 57. 


\section{Sulger, Egon Georg}

1926-1932 (1933) Med. Fak.

Chirurgie

* 16. Juni 1892 Unteruhldingen (heute: Ortsteil von Uhldingen-Mühlhofen) am Bodensee

$\dagger \quad$ 07. Nov. 1964 Aachen kath.

V Josef S. (1864-1895) Schiffsmeister

M Franziska geb. Nipp (1862-1932)

$\infty$ unverheiratet.

Lb WS 1912/13 Zunächst Studium der Mathematik an U München, SS 1913-WS 1919/20 Studium der Medizin an UH; 1915-1918 Kriegsdienst; 23. Dez. 1919 med. Staatsexamen in H; 21. Jan. 1920 Approbation in $\mathrm{H}$.

UH: Seit 1920 Assistent, seit 1928 Oberarzt an Chirurg. U-Klinik; 9. Juni 1920 Dr. med.; 17. Dez. 1926 Habilitation; seit 4. Sept. 1930 nichtplanm. a.o. Prof.; seit 1. April 1932 von U nach Aachen-Forst beurlaubt; 30. Sept. 1933 auf eigenen Antrag U verlassen.
Aachen-Forst: 1932-1956 Chefarzt der Chirurg. Abt. des Krankenhauses.

E 1964 Bundesverdienstkreuz I. Klasse.

Qu UAH PA 1207, 6040. - Mitteilungen: Frau Liselotte Sulger $(\dagger)$.

$W$ Die Behandlung eitriger Entzündungen mittels einer neuen Methode der Röntgenbestrahlung in: Der Chirurg 26 (1929). • Über den Einfluß der Brütungszeit einer Bakterienkultur auf ihre Röntgenstrahlenempfindlichkeit in: Strahlentherapie 36 (1930). - Die postoperative Venenthrombose und Lungenembolie in: Ergebnisse der Chirurgie und Orthopädie 24 (1931).

L Kürschner (1935) Sp. 1391; Chirurgen-Verzeichnis $\left({ }^{4}{ }_{1958)}\right.$ S. 830; WBIS. - Kühl, Richard: Leitende Aachener Klinikärzte und ihre Rolle im „Dritten Reich“. Kassel 2011. S. 63 und Anm. 232 u. ö.

$P$ Bildarchiv UAH. 


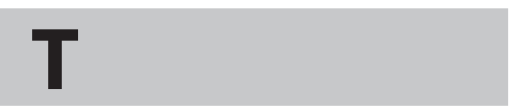

\section{Täubler, Eugen}

1925-1933 (1934) Phil. Fak.

Alte Geschichte

* 10. Okt. 1879 Gostyn (Provinz Posen; heute: Gostyń, Polen)

$\dagger$ 13. Aug. 1953 Cincinnati (Ohio)

mosaisch

V Julius T., Kaufmann

M Rosalie geb. Pinkus

(D) 27. Okt. 1927 Dr. phil. Selma Stern-Täubler geb. Stern (1890-1981) Historikerin, Verf. von „Der preußische Staat und die Juden“ (7 Bde.) und "Jud Süß Oppenheimer“; s. Sassenberg, Marina: S. S.: Das Eigene in der Geschichte. Selbstentwürfe und Geschichtsentwürfe e. Historikerin. Tübingen 2004; Lexikon jüdischer Einwohner Hs (2011) S. 415 f.

$\mathrm{K}$ keine.

Lb Berlin: Seit WS 1898/99 zunächst Studium am Hildesheimer'schen Rabbinerseminar (1 Jahr), seit WS 1899/1900 Studium an Lehranstalt für die Wiss. des Judentums (2 Jahre).

U Berlin: WS 1902/03-SS 1904 Studium der Geschichte, Klassischen und Orientalischen Philologie, Archäologie; 1904 Dr. phil.

Berlin: Seit Okt. 1904 Volontär am Geheimen Staatsarchiv; Okt. 1906-Sept. 1918 Mitbegründer und Direktor des Gesamtarchivs der dt. Juden. • In dieser Zeit:

Berlin: Seit 1910 Dozent für Geschichte und Literatur der jüdisch-hellenistischen und der frühchristlichen Zeit, 1912-1918 Prof. für Jüdische Geschichte an Lehranstalt für die Wiss. des Judentums. In dieser Zeit:

1914 (?)-1916 Kriegsdienst als Soldat an der Ostfront.
U Berlin: Okt. 1918 Habilitation für Alte Geschichte; Okt. 1918-April 1922 Privat-Dozent für Griechische und Römische Geschichte. $\bullet$ In dieser Zeit:

Berlin: 1919-1922 Leiter der von T. mitaufgebauten Akademie für die Wiss. des Judentums.

U Zürich: Seit SS 1922 a. o. Prof. für Griechische und Römische Geschichte.

UH: Seit 1. April 1925 o. Prof. und (bis 1928) Vorstand der Abt. für Alte Geschichte am Archäolog. Inst. als Nachf. von Alfred von Domaszewski; 1928-1934 Direktor des Seminars für Alte Geschichte; 6. April 1933 vorläufige Beurlaubung; Mai 1933 Aufhebung der Beurlaubung; Juli 1933 T. stellt Antrag, „dass mir (auf Grund e. besonderen Voraussetzung) ermöglicht wird, freiwillig auszuscheiden. Die Besonderheit besteht darin, dass ich nicht innerhalb des deutschen Universitätsdienstes zu dem Amt in Heidelberg gekommen bin, sondern im März 1925 ohne mein Zutun aus dem Ausland hierher berufen wurde" (aus: UAH PA 6046); 9. Nov. 1933 endgültige Beurlaubung; 18. Dez. 1933 Beschluß des Reichsstatthalters, T. zum 1. April 1934 in Ruhestand zu versetzen (aus rassischen Gründen).

Berlin: Seit 1938 Dozent an Lehranstalt für die Wiss. des Judentums; 1941 Emigration in die USA.

Hebrew Union College in Cincinnati: 1941-1953 Research Prof.

Am 3. Dezember 2008 eröffnet die Universität Heidelberg die Reihe der Eugen Täubler-Vorlesungen mit e. Vortrag von Prof. David Sorkin, University of Wisconsin, Madison, in der Aula der Alten Universität.

E 1929 (1935 Austritt) Mitglied der Akademie der Wissenschaften $\mathrm{H}$.

Qu UAH PA 6046. GLA Abt. 235, Fasz. 2577. • Briefe: UBH; siehe auch Kalliope. - Nachlaß: Universitätsbibliothek Basel. 
W Imperium Romanum. Bd. 1: Die Staatsverträge und Vertragsverhältnisse. Leipzig 1913 (mehr nicht erschienen). Tyche. Historische Studien. Leipzig 1926. Nachdr. Hildesheim 1979. • Die Archäologie des Thukydides. Leipzig 1927. • Aufsätze zur Problematik jüdischer Geschichtsschreibung 19081950. Tübingen 1977 (posthum erschienen). (Mitverf.: Selma Stern.) - Ausgewählte Schriften zur alten Geschichte. Hrsg. von Géza Alföldy. Stuttgart 1987 (mit Bibliogr.).

HG 1908-1911 Mitteilungen des Gesamtarchivs der dt. Juden.

MHG 1929-1937 Zs. für die Geschichte der Juden in Deutschland.

L Jüdische National-Biographie 6 (1931) S. 88; Kürschner (1931) Sp. 2991; Lehrkörper Berlin (1955) S. 198. Stern-Taeubler, Selma: E. T. and the Wissenschaft des Judentums in: Leo Baeck Institute Year-book Vol. 3. Oxford 1958. S. 40-59. - Friedlander, Albert Hoschander: Umbra Vitae. Zum 10. Todestage E. T.s in: Ruperto Carola 15. Jg., Bd. 33 (1963) S. 121-126. - Herlitz, Georg: Three Jewish historians: Isaak Markus Jost, Heinrich Graetz, E. T. A comparative study in: Leo Baeck Institute Year-book Vol. 9, Issue 1. Oxford 1964. S. 69-90. • Encyclopaedia judaica 15 (1971) Sp. 699; Mussgnug (1988) S. 299 (Register); Historische Zeitschrift 248 (1989) S. 265-303; Geschichte Histor. Seminar UH (1992) S. 222 ff.; Jansen (1992a) S. 169 (Register). • E.T. postumus in: Heuß, Alfred: Wissenschaftsgeschichte und -theorie ... Stuttgart 1995. Bd. 3. S. 1891-1929. Scharbaum, Heike: Zwischen zwei Welten. Wissenschaft und Lebenswelt am Beispiel des deutsch-jüdischen Historikers E.T. Münster 2001. S. 47-55, 100-103, 119-126 u. ö.; Dies.: „Ich habe das Empfinden und das Bewusstsein, (...) ein posenscher Jude zu sein, nicht verloren“. Der Historiker E.T. und sein Verhältnis zum Ostjudentum in: Grenzgänge. Festgabe für Hans Geisser. Hrsg. von Horst Lickert. Zürich 2003. S. 233244. - UH im Nationalsozialismus (2006) S. 1273 (Register); Vertriebene Mitgl. der Akad. der Wiss. H (2009) S. 79-83; WBIS; Krämer (2011) S. 51-62; Lexikon jüdischer Einwohner Hs (2011) S. 415 f.; Wissenschaftsatlas der UH (2011) S. 292; NDB 25
(2013) S. 759 f.; Deutsche Biographie, s. https:// www.deutsche-biographie.de/gnd118620495.html [09.12. 2017].

P Bildarchiv UAH; Ruperto Carola (1963); Vertriebene Mitgl. (2009).

Taylor, George (Pseudonym)

siehe Adolf Hausrath

\section{Teutschländer}

siehe Teutschlaender

\section{Teutschlaender, Otto Richard}

1918-1950 Med. Fak.

Pathologie, Pathologische Anatomie

* 24. Juli 1874 Bukarest

$\dagger \quad$ 05. April 1950 Weinsberg (bei Heilbronn)

ev.

V Willibald Stefan T. (1837-1891) Pfarrer; Autor u. a. von: Geschichte der Ev. Gemeinden in Rumänien mit besonderer Berücksichtigung des Deutschtums. Ein Beitrag zur Kulturgeschichte Rumäniens. Bukarest 1891.

M Jeannette geb. Bossel

$\infty$ 12. Juli 1906 Jeanne geb. Bataillard $\left({ }^{*} 1879\right.$ $\dagger$ nach 1950)

$\mathrm{K}$ keine.

$L b$ Seit WS 1893/94 Studium an U Bern, anschl. Graz, Genf; Mai 1902 med. Diplom in Genf.

1903-1911 Assistent: Patholog. Inst. Zürich, Kantonales Asyl für Altersschwache und unheilbare Irren in Wil (bei St. Gallen), Kantonale Irrenanstalt in Bellelay (bei Biel); 1906 Dr. med. an U Genf.

Düsseldorf: 1911-1913 Assistent am Patholog. Inst. der Akademie für Praktische Medizin. 
UH: 1913-1. April 1924 (Kündigung aufgrund Personalabbaus wegen finanzieller Schwierigkeiten) Assistent an Wiss. Abt. am Inst. für Experimentelle Krebsforschung; Juli 1915 Approbation; 17. Mai 1918 Habilitation; 22. Febr. 1923-1950 ( $\dagger$ ) nichtplanm./ apl. a.o. Prof.; 1924-1927 Assistent am Patholog.Anatom. Inst. im Akad. Krankenhaus; April 19271932 Leiter des Patholog.-Anatom. Laboratoriums und 1932-1945 beratendes Mitglied am Inst. für Experimentelle Krebsforschung sowie Kustos der Sammlung von patholog. Präparaten; für SS 1950 noch Vorlesungsankündigung über „Ausgewählte Gebiete der Krebsforschung“. • In dieser Zeit:

Mannheim: Seit April 1931 Prosektor und Leiter des Patholog. Inst. der Städtischen Krankenanstalten als Nachf. von (siehe) Hermann Loeschcke; 1945 Zerstörung des Inst. bei Luftangriffen.

Heilbronn: 1946-1950 Leiter e. Patholog.-Histolog. Inst.

1933: T. ist Mitglied des wissenschaftlichen Ausschusses im „Reichsausschuss für Krebsbekämpfung" in Berlin sowie 1933 deutscher Vertreter (u. a. auch (siehe) Richard Werner) in der Gründungskommission der Union internationale contre le cancer (UICC) mit Sitz in Genf.

E 1922 Mitglied der Int. Krebsforschungs-Gesellschaft „Leeuwenhoek-Vereinigung" Amsterdam; 1938 Korr. Mitglied des Ärztevereins Budapest.

\section{$Q u$ UAH PA 1210, 6061.}

$W$ Urogenitaltuberkulose in: Beitrag zur Klinik der Tuberkulose (1905/06). • Beitrag zur vergleichenden Onkologie in: Zs. für Krebsforschung (1918-1920); Pechkrebs der Brikettarbeiter in: ebd. (1929). - Lipocalcinogranulomatose in: Rudolf Virchows Archiv für patholog. Anatomie und Physiologie und für klinische Medizin (1935).

L Kürschner (1931) Sp. 3001f., (1950) Sp. 2089f.; Fischer $2\left({ }^{3} 1962\right)$ S. 1558; WBIS; Chronik Ärzte H (1985) S. 144. - Wagner, Gustav, Mauerberger, Andrea: Krebsforschung in Deutschland. Vorgeschichte und Geschichte des Dt. Krebsforschungszentrums ... Berlin 1989. S. 272 (Register). • Eckart
(2000) S. 91 f.; 100 Jahre Krebsforschung (2000) S. 33 u.ö.; UH im Nationalsozialismus (2006) S. 1273 (Register); Friedrich (2009) S. 94f. u. ö.; Deutsche Biographie, s. https://www.deutsche-bio graphie.de/gnd1063754941.html [09.12. 2017].

$P$ Bildarchiv UAH; Chronik Ärzte H.

\section{Thaddäus a Sancto Adamo OCD}

s. Dereser, Thaddäus Anton

\section{Thannhauser, Siegfried Josef}

1924-1927 Med. Fak.

Innere Medizin

* 28. Juni 1885 München

$\dagger$ 18. Dez. 1962 Brookline (bei Boston, Massachusetts)

口 Wolfeboro (New Hampshire) mosaisch

V Joseph Solomon T. (1856-1917) 1882-1916 MitInhaber e. Kunstzinngußwarenfabrik \& Malerei, Glas- und Porzellanwarenfabrik

M Lotte geb. Langermann (1863-1933)

๑ 16. Febr. 1918 Franziska geb. Reiner (18891960), s. Zöllner/Hofmann (2001) S. 23 f., 44 ff.

K 3 T, s. ebd. S. $44-78$

Vw siehe ebd. S. 9-11.

Lb U München: Seit WS 1904/05 Studium der Medizin; 1910 Dr. med.; seit SS 1910 Studium der Chemie; 20. Dez. 1912 Dr. phil. nat.; seit 1912 Assistent, 1920-1924 Oberarzt am U-Klinikum (Friedrich von Müller'sche Klinik); 1914-1918 Kriegsdienst als Stabsarzt; 1917 Habilitation für Innere Medizin; seit 1920 a. o. Prof.

UH: Seit 9. Okt. 1924 planm. a. o. Prof. und Direktor der Med. Poliklinik als Nachf. von Wilhelm Fleiner.

Med. Akademie Düsseldorf: Seit WS 1927/28 o. Prof. 
U Freiburg/Br.: Seit 1. Okt. 1930 o. Prof. und Direktor der Med. U-Klinik; Dez. 1932 Wahl zum Dekan der Med. Fak.; 12. April 1933 Rückgabe des Mandats als Dekan; 17. April 1934 Beurlaubung mit sofortiger Wirkung; Juni 1934 Zurruhesetzung mit Wirkung vom 1. Nov. 1934.

Freiburg/Br.: 1934-1935 Laborassistent an U und Arzt in eigener Praxis; 1934 Ruf an U Ankara abgelehnt; Frühjahr 1935 Einladung an die Boston Dispensary, e. Einrichtung der Tufts College Medical School; 1935 Emigration.

Boston: Seit 1937 Associate Prof., ca. 1939-1962 Clinical Prof. an Tufts College Medical School sowie seit Dez. 1938 Associate Physician-in-Chief am neugegründeten Joseph H. Pratt Diagnostic Hospital; 1946 Ruf an U Freiburg/Br. abgelehnt.

E Mitglied: American Association of Physicians, Academy of Arts and Sciences, 1953 Akademie der Wissenschaften H. • Dr. med. h.c. der U: 1955 München, 1955 Freiburg/Br. • Friedrich-von-Müller-Plakette.

Qu UAH PA 1211, 6063.

W Welcher Weg führt von Tyrosin zur Homogentisinsäure? München 1910. - Lehrbuch des Stoffwechsels und der Stoffwechselkrankheiten. München 1929. 2. Aufl. 1957. - Lipidoses, diseases of the cellular lipid metabolism. New York 1940. 3. Aufl. 1957.

L Kürschner (1931) Sp. 3003, (1961) S. 2086; Fischer 2 ( $\left.{ }^{3} 1962\right)$ S. 1559. - Hess, Benno: S. J. T. † in: Ruperto Carola 15. Jg., Bd. 33 (1963) S. 219 f. • Who was who in America 4 (1968) S. 934; Chronik Ärzte H (1985) S. 144, 273 f. • S. J.T. in: Hellmich, Hermann-Josef: Die Medizinische Fakultät der Universität Freiburg 1933-1935 ... Med. Diss. Freiburg 1989. S. 34-58, 291-304. Z Zöllner, Nepomuk, Hofmann, Alan F.: S. T. Ein Leben als Arzt und Forscher in bewegter Zeit. 2. Aufl. Freiburg/Br. 2001 (mit Bibliogr.). Krasnianski, Michael u. a.: Alfred Hauptmann, S.T., and an endangered muscular disorder in: Archives of Neurology (2004) S. 11391142. Nevins, Michael: Jewish Medicine. What it is and why it matters. New York 2006. S. 93-95.
Seidler/Leven (2007) S. 869 (Register). - Grün, Bernd: Der Rektor als Führer? Die Universität Freiburg im Breisgau von 1933 bis 1945. Freiburg/ Br. 2010. S. 139 f. Huhn/Kilian (2011) S. 252 (Register); Bauer/Ho (2016) S. 47-50. • Über die Familie T., s. https://www.wikitree.com/genealogy/ Thannhauser-Family-Tree (abgerufen am 09.12. 2017; Ausdruck im UAH). - Deutsche Biographie, s. https://www.deutsche-biographie.de/gnd122986 792.html [09.12.2017].

P Bildarchiv UAH; Ruperto Carola (1963); Chronik Ärzte H (1985).

\section{Thibaut, Anton Friedrich Justus}

1805-1840 Jur. Fak.

Zivil- und Kriminalrecht, Römische Rechts-

geschichte

* 04. Jan. 1772 Hameln

$\dagger$ 28. März 1840 Heidelberg

prot.

V Friedrich Wilhelm T. (1735-1790) ArtillerieKapitän, 1784-1788 Major

M Antoinette Friederike geb. Grupen (1747-1815) T von Christian Ulrich G. (1692-1767) Jurist, Rechtshistoriker, 1725-1767 Bürgermeister von Hannover, s. NDB 7 (1966) S. 234 f.; Stadtlexikon Hannover ... Hrsg. von Klaus Mlynek und Waldemar R. Röhrbein. Hannover 2009.

œ 27. Nov. 1800 Henriette (Jette) Dorothea Friederike geb. Ehlers $(1782-1857) \mathrm{T}$ von Martin E. (1732-180o), u. a. seit 1776 Prof. für Philosophie Kiel, s. Professoren Kiel (1956) S. 135 f., NDB 4 (1971) S. 347 f.; Wolgast, Günther: M.E. ... Ein vergessener Pädagoge des 18. Jhdts. in: Pädagogische Bezugspunkte. Exemplarische Anregungen. Hrsg. von Werner Keil ... Regensburg 1995. S. 191-207; WBIS

K 4 T (davon $2 \mathrm{~T}$ früh $\dagger$ ), 3 S: u. a. Carl Ernst T. (1807-1881) 1830-1832 (Niederlegung der Dozentur) Privat-Dozent für Rechtswiss. H, seit 1843 Bibliothekar an UBH, s. UAH PA 91, 2338 f.; Bader (1925) S. 262, Polley (1982) S. 54, Emundts-Trill (1997) S. 235, Zeiler (2008) S. 157; s. auch Johannes Scherrer: Eintrag unter Lb (UBH) 
Vw Bruder: Bernhard Friedrich T. (1775-1832), u. a. seit 1805 o. Prof. für Philosophie, seit 1828 o. Prof. für Mathematik Göttingen, s. Göttinger Gelehrte 1 (2001) S. 84f., WBIS. • Siehe auch Polley (1982) S. 55 u. ö.

Lb Seit 24. Okt. 1791 Studium der Rechtswiss. an U Göttingen, seit 31. Mai 1793 Studium der Philosophie an U Königsberg (Preußen), seit 4. Mai 1794 Kiel.

U Kiel: Ende Nov. 1795 Dr. iur.; vor Ostern 1796 Privat-Dozent für Römisches Recht; seit 22. Nov. 1797 Adjunkt an Jur. Fak. und a.o. Beisitzer des Spruchkollegiums; seit 1798 a. o. Prof.; seit 16. Jan. 1801 o. Prof.; seit 1801 auch U-Syndikus.

U Jena: Seit 26. März 1802 o. Prof.; außerdem Assessor am Hofgericht und am Schöppenstuhl; zwischen 1802 und 18057 Rufe abgelehnt, u.a. an U Greifswald, Halle/S.; 1805 jährl. Besoldung von 2500.- Reichstalern.

UH: Seit 29. Sept. 1805 o. Prof.; Okt. 1805 Dienstantritt; 1805-1831 Beisitzer des Spruchkollegiums der Jur. Fak.; Rufe an U abgelehnt: 1807 Charkiw, 1810 Göttingen, 1828 München, 1829 Leipzig, 1834 Zürich. • In dieser Zeit:

Karlsruhe: April 1819-Juli 1820 Mitglied der I. Kammer des Badischen Landtags als Abgeordneter der UH (siehe auch Carl Salomo Zachariae).

Dez. 1805-März 1807, 1821 Prorektor der UH; 1807, 1813, 1817, 1821, 1824, 1828, 1832, 1836, Jan.-März 1840 Dekan der Jur. Fak. der UH

1811-1833 Leiter e. Singkreises und Begründer e. der größten Notensammlungen seiner Zeit

1805 Kurfürstl. Badischer Hofrat; 1818 Geh. Hofrat; 1826 Geh. Rat II. Klasse

E 1805 Korr. Mitglied der Kaiserlich Russischen Gesetzgebungskommission St. Petersburg; 1837 Mitglied der Académie des Sciences morales et politiques Paris. 1830 Kommandeurkreuz des Ordens vom Zähringer Löwen. • 1829 Ehrenbürger der Stadt Heidelberg.
Qu UAH PA 2337 f.; RA 46, 4921, 5355, 5919, 6761, 6825 u. ö. • Matrikel Kiel (1915) S. 154. - GLA Abt. 205, Fasz. 520. Briefe, u. a. auch Kolleghefte: UBH; siehe auch Kalliope. - Teil-Nachlaß: Musikwiss. Seminar der UH; Musiksammlung Bayer. Staatsbibliothek München; Universitätsbibliothek Tübingen. • Auskunft: Stadtarchiv Hameln. • A. F. J. T. ... in seinen Selbstzeugnissen und Briefen. 3 T. Hrsg. von Reiner Polley. Frankfurt/M. 1982.

$W$ Theorie der logischen Auslegung des römischen Rechts. Altona 1799. 2. Aufl. 1806. Neudrucke 1966, 1999, 2007. - System des Pandektenrechts. Jena 1803. 9. Aufl. 1846. Civilistische Abhandlungen. Heidelberg 1814. • Über die Reinheit der Tonkunst. Heidelberg 1825. 7. Aufl. 1893. Neudr. 1907. - Lehrbuch des französischen Zivilrechts. Berlin 1841. Nachdr. Goldbach 2002. • Bibliographie in: Polley (1982) S. 277-291. - Thibaut und Savigny. Ihre programmatischen Schriften. Mit e. Einführung von Hans Hattenhauer. 2. Aufl. der von Jacques Stern begr. ... Ausg. München 2002. Siehe auch NDB 26 (2016) S. $106 \mathrm{f}$.

MG 1808 Heidelbergische Jahrbücher der Literatur für Jurisprudenz und Staatswissenschaften.

MHG 1821-1840 Archiv für die civilistische Praxis.

$L$ Verzeichniss der von dem verstorbenen Grossherzogl. Badischen Prof. der Rechte und Geheimenrathe Dr. A.F.J.T. zu Heidelberg hinterlassenen Musikaliensammlung, welche als ein Ganzes ungetrennt veräussert werden soll. Heidelberg 1842. - Über A.F.J.T. in: Reichlin-Meldegg, Karl Alexander Frhr. von: Das Leben eines ehemaligen römisch-katholischen Priesters. Heidelberg 1874. S. 114-116 u. ö. - Lautenschlager (1933) S. 640ff., 646-652. • Ehmann, Wilhelm: Der Thibaut-Behaghel-Kreis in: Archiv für $\mathrm{Mu}-$ sikforschung 3 (1938) S. 428-457, 4 (1939) S. 2167. Professoren Kiel (1956) S. 31; Jammers (1964) S. 178 u.ö. - Kitzler, Albert: Die Auslegungslehre des A.F.J. T. Berlin 1986. Heidelberg im säkularen Umbruch (1987) S. 423-440 u. ö. • Pfeiffer, Harald: Heidelberger Musikleben in der ersten Hälfte des 19. Jahrhunderts. Heidelberg 1989. - Weisert (1991) S. 133 u. ö. - Staehelin, Martin: Der MusikStreit zwischen Hans Georg Naegeli und A.F.J.T. in: Helvetien und Deutschland. Kulturelle Bezie- 
hungen zwischen der Schweiz und Deutschland in der Zeit von 1770-1830. [Kolloquium vom 22. bis 26. Oktober 1990 an der Universität Bern.] Hrsg. von Hellmut Thomke ... Amsterdam 1994. S. 221230. - Zywietz, Michael: Das Händel-Verständnis von Bernhard Klein und A. F. J. T. in: Händel-Jahrbuch ... Kassel u. a. 1998. S. 50-63. • Juristen-Lexikon (2002) S. 85-113; Pfeiffer (2004) S. 157. • Schöler, Claudia: Deutsche Rechtseinheit. Partikulare und nationale Gesetzgebung (1780-1866). Köln 2004. Wächter, Karl Georg von: Über die Collision der Privatrechtsgesetze verschiedener Staaten. Frankfurt/M. 2006. S. 291-302. • Senn, Marcel: Rechtsgeschichte - ein kulturhistorischer Grundriss ... 4. Aufl. Zürich 2007. Ruuskanen (2008) S. 127 f.; WBIS; Schroeder (2010) S. 23-25 u. ö. (S. 25: irrtümlich 23. statt 28. als Todestag angegeben); Ders.: „Lange Canapé-Unterhaltung mit Hofrath T." Die Heidelberger Semester des stud. iur. Joseph von Eichendorff (1807-1808) in: Neue juristische Wochenschrift 61 (2008) S. 729735; Ders.: Vom Sachsenspiegel zum Grundgesetz eine dt. Rechtsgeschichte in Lebensbildern. 2. Aufl. München 2011. S. 268 (Register). - Leopold, Silke: "Obgleich Juriste, von Hause aus eine weiche musikalische Natur". A.F.J.T. als Musiker in: Festschrift für Peter Hommelhoff. Hrsg. von Bernd Erle ... Köln 2012. S. 643-659. Rechtsgelehrte der U Jena (2012) S. 77-90; Heidelberger Thesen zu Recht und Gerechtigkeit (2013) S. 67-142. Kaufmann, Dörte: A.F.J.T. ... Ein Heidelberger Professor zwischen Wissenschaft und Politik. Stuttgart 2014. - Schroeder, Klaus-Peter: „T. hat eine Schandschrift geschrieben!" T., der Kodifikationsstreit vor 200 Jahren und die Liebe zur Musik in: Neue juristische Wochenschrift 67 (2014) S. 734738. Lieb, Claudia: Der Streit um die Zukunft des Rechts. Savigny, T. und der Kodifikationsstreit der Jahre 1814 bis 1816 in: Zeitsprünge: Forschungen zur Frühen Neuzeit ... Frankfurt/M. 2015. S. 330347. - Baldus, Christian: A. F.J.T., System of the Pandects' Law (System des Pandecten-Rechts) in: The Formation and Transmission of Western Legal Culture. 150 Books that Made the Law in the Age of Printing. Ed. by Serge Dauchy ... Berlin 2016. S. 330-333. NDB 26 (2016) S. 106 f. • A.F.J.T. ... Bürger und Gelehrter. Hrsg. von Christian Hattenhauer, Klaus-Peter Schroeder und Christian Baldus. Tübingen 2017.

$P$ Bildarchiv UAH; graph. Slg. UBH.
Thode, Heinrich Robert

siehe Thode, Henry

Thode, Henry (eigentlich: Heinrich) Robert

1894-1911 Phil. Fak.

Neuere Kunstgeschichte

* 13. Jan. 1857 Dresden

$\dagger \quad$ 10. Nov. 1920 Kopenhagen

ㅁ Vestre Kirchhof Kopenhagen ev.-luth.

V Robert T. (1825-1898), u. a. 1844-1856 (Verkauf) Mit-Inhaber der Thode'schen Papierfabrik in Friedberg-Hainsberg, Besitzer und Direktor des Bankhauses Robert Thode \& Co. in Dresden (1891 von Dresdner Bank übernommen), 1861-1865 Besitzer des Keppschlosses in Dresden-Hosterwitz, seit 1866 (bis 1917 in Familienbesitz) Eigentümer des Ober-, Mittel- und Kesselgutes sowie des Schlosses von Schoosdorf in Niederschlesien (heute: Ubocze, Polen), s. WBIS, Szylin (1993) S. 304 (Register), http://ubocze66.republika.pl/thode/robert thode.html (abgerufen am 27. Sept. 2016)

M Adolfine geb. Dzondi (1822-1900), s. Szylin, S. 304 (Register)

( 5. Juli 1886 Daniela Senta geb. von Bülow (1860-1940) Pianistin, Wagnersche Andenkenpflegerin, s. auch Z (2); Szylin, S. 304 (Register); Hamann, Brigitte: Die Familie Wagner. Reinbek 2005; Klee, Kulturlexikon (2007) S. 612, Duncan (2016) S. 144f. - T von Hans Guido von Bülow (1830-1894) Pianist, Dirigent, s. NDB 2 (1955) S. 734; Enkelin von Franz Liszt (1811-1886), Stief-T von Richard Wagner (1813-1883). - Scheidung 27. Juni 1914

( 7. Juli 1914 Hertha Christine geb. Teg(e)ner (1884-1946) dänische Violonistin, s. Szylin, S. 304 (Register)

$\mathrm{K}$ keine

Vw siehe Szylin, S. 19f., NDB 26 (2016) S. $155 \mathrm{f}$.

Lb Studium: SS 1876 Zunächst Rechtswiss. an U Leipzig, seit WS 1876/77 Kunstgeschichte, Archäologie an U Wien, WS 1878/79 Berlin, SS 1879 München. 
U Wien: Seit WS 1879/80 Dissertations-Vorbereitung; 19. Juni 1880 Dr. phil.; 1. Nov. 1880 auf Dauer als untauglich zum Militärdienst erklärt; Anfang Dez. 1880-Ende April 1881 Studienaufenthalt in Paris, anschl. Studienreisen durch Nordfrankreich, Belgien und Niederlande; Ende Mai 1881 Rückkehr auf Schloss Schoosdorf.

Seit Mitte Sept. 1881 Studienaufenthalt in Italien; Juli 1883 Habilitationsvorbereitungen an U Berlin; März-Ende Juli 1884 erneut Aufenthalt in Italien; seit Aug. 1884 Forts. der Habilitationsvorbereitungen auf Schoosdorf, seit Ende Dez. 1884 in Berlin.

Berlin: 1885 Redakteur und Hrsg. der neugegründeten Kunstzeitschrift Der Kunstfreund. Beilage zum Jahrbuch der Königlich Preussischen Kunstsammlungen (nur ein Heft erschienen).

Verzögerung des Habilitations-Gutachtens an U Berlin durch Prof. Herman Grimm (1828-1901), s. hierzu Szylin (1993) S. 45 f.; seit Mitte Mai 1886 Wohnsitz in Bonn.

U Bonn: 28. Okt. 1886 Habilitation; 1886-1889 Privat-Dozent; in dieser Zeit mehrere Studienreisen durch Deutschland; 1887 Ablehnung e. durch T.s Vater vermittelten Rufes an Polytechnikum in Dresden.

Frankfurt/M.: Okt. 1889-Okt. 1891 (auf eigenen Antrag Weggang) Direktor der Sammlungen des Städel'schen Kunstinstituts.

1891-1893 Vergebliche Versuche, an U Wien und Straßburg e. Professur zu erhalten; Privatstudien und Wohnsitz in Venedig; seit 1. März 1893 PrivatGelehrter in der angemieteten, 1910 gekauften Villa La Prioria in Cargnacco (am Gardasee; heute: Ortsteil von Gardone Riviera).

UH: 26. Aug. 1893 Ern. zum etatm. a.o. Prof. in Nachf. von Adolf Oechelhäuser und (bis 1910) Vorstand der Abt. für neuere Kunst am Archäolog. Institut mit e. jährl. Gehalt von 3400.- Mark; 1893/ 94 Ruf an U Breslau abgelehnt; 26. April 1894 Beginn seiner Vorlesungen; Urlaubsbewilligungen während des laufenden Semesters: Okt./Nov. 1895, Okt.-Nov. 1896, Jan. 1898, April-Mai 1900, Febr.-
Mai 1904, 30. Jan.-15. Febr. und 15. April-1. Juni 1905, Juli 1908, Dez. 1910-Jan. 1911 (siehe $Z$ (1)); 10. Juni 1896 Ern. zum o. Prof. für Kunstgeschichte; seit 1. April 1899 Jahresbesoldung von 3700.Mark; Nov. 1900 Ruf an U Berlin abgelehnt; jährl. Besoldung: seit 1. April 1901 von 700o.- Mark, seit 1. Jan. 1902 von 90oo.- Mark; 1910 Ablehnung des Direktorats an Nationalgalerie in Berlin; 31. März 1911 auf eigenen Antrag Entlassung.

Nach März 1911 Vortragsreisender und Privat-Gelehrter mit Wohnsitz in der Villa La Prioria in Cargnacco am Gardasee; Sommer 1915 Enteignung der Villa durch ital. Staat; damit Verlust u. a. seiner Bibliothek, Kunstsammlung und seines Schrifttums. La Prioria (heute Teil des Museums Vittoriale degli italieni) war 1921-1938 Wohnsitz des ital. Schriftstellers Gabriele d'Annunzio (1863-1938); siehe hierzu $Z$ (2).

Privat-Gelehrter und Vortragsreisender: Nach Sommer 1915 zunächst ohne festen Wohnsitz mit Aufenthalten u. a. in Kassel, Düsseldorf, Wien; seit Frühjahr 1916 vorübergehender Wohnsitz in Bad Homburg.

\section{Kopenhagen: Seit Sommer 1919 Wohnsitz.}

1903/o4 Dekan der Phil. Fak. der UH

1896: T. ist erster Heidelberger Ordinarius für Kunstgeschichte

Juli 1904: T. und der Maler Wilhelm Trübner (18511917) gründen den Allgemeinen Bund gegen die Wiederherstellung des Heidelberger Schlosses

$Z$ (1) Schreiben des Ministeriums der Justiz, des Kultus und Unterrichts vom 17. Juni 1910 an den Engeren Senat der UH, das Urlaubsgesuch T.s für Dez. 1910 und Jan. 1911 betreffend: „Dem Herrn ... Professor Dr. Thode wird der erbetene Urlaub ... hiermit bewilligt ... Auch wir teilen die von der philosophischen Fakultät ausgesprochene Hoffnung, dass diese Beurlaubung nicht den Abschluss der so erfolgreichen Tätigkeit des Herrn ... Thode an der Universität Heidelberg vorbereiten soll“ (aus: UAH PA 2341). Anfang Nov. 1910 schreibt T. sein Abschiedsgesuch, am 25. Febr. 1911, 20 Uhr, lädt die Universität zu Ehren des scheidenden T.s 
zum Abendessen ins Hotel Prinz Karl am Kornmarkt (heute: Palais Prinz Carl) ein (Preis des Gedecks: 3.- Mark).

Z (2) Karl Hampe, derzeitiger Rektor der UH, schreibt am 19. Dez. 1924 an Phil. Fak.: „Die geschiedene Gattin unseres früheren Kollegen Henry Thode, der ein Jahrzehnt lang höchst erfolgreich an der Heidelberger Universität gewirkt hat, befindet sich, wie von mir angestellte Ermittlungen ergeben haben, seit der Währungskatastrophe in einem Zustande völliger Mittellosigkeit. Henry Thode hatte seinerseits seinen Abschied von dem Universitätsleben ohne Pensionsberechtigung genommen. Ein von ihrem Vater ererbtes Vermögen von 50 ooo.- Mark, von deren Zinsen Frau Daniela gelebt hatte, ist restlos entwertet. Der allgemeine Vermögensschwund hat auch die Familie Wagner überaus stark betroffen, so daß auch Frau Cosima nicht in der Lage ist, ihrer Tochter einen monatlichen Beitrag zu gewähren, der auch nur zur bescheidensten selbständigen Existenz ausreichen würde. Kunstgegenstände und anderer Besitz, der in Gardone noch Eigenthum von Frau Thode war, sind von der italienischen Regierung an Gabriele d'Annunzio überwiesen, der sich nur zur Herausgabe von einigen materiell wertlosen Familienerinnerungen verstanden hat. So ist Frau Thode völlig auf die Gastfreundschaft von Bekannten und Verwandten angewiesen.

Es bedarf keiner besonderen Betonung, daß dies ... ein unwürdiger Zustand ist, dem die Fakultät und Universität, soweit es in ihrer Möglichkeit liegt, abhelfen sollten ..." Dem Antrag auf finanzielle Beihilfe für Daniela Thode bei dem Ministerium des Kultus und Unterrichts wird von allen Lehrenden der Phil. Fak. als „besonders beifallswürdig" (Zitat von Carl Neumann) zugestimmt (aus: UAH H-IV-102/148 fol. 245r-246r). Ob und wieviel Beihilfe Frau Thode erhielt, ist in den Akten nicht überliefert.

1901 Geh. Hofrat; 1911 Geh. Rat II. Klasse

E 1909 Mitglied der Akademie der Wissenschaften H. 1902 Ritterkreuz I. Klasse, 1908 mit Eichenlaub des Ordens vom Zähringer Löwen; 1911 Großoffizierskreuz des Königlich-Italienischen St. Mauritius- und Lazarusordens.
Qu UAH PA 2341; RA 6448, 6728 (Gutachten über T. von 1899), 6850; Quästurakte Rep. 27-1354. • GLA Abt. 235, Fasz. 2586. Briefe: UBH. - Thoma, Hans: Briefwechsel mit H. T. Hrsg. von Josef A. Beringer. Leipzig 1928. - Teil-Nachlaß: Bayer. Staatsbibliothek München; UBH; Museum Vittoriale degli italiani in Gardone Riviera am Gardasee; s. auch Szylin (1993) S. $16 \mathrm{f}$.

W Franz von Assisi und die Anfänge der Kunst der Renaissance in Italien. Berlin 1885. 4. Aufl. 1934. Die Malerschule von Nürnberg im 14. und 15. Jahrhundert. Berlin 1891. - Dichtungen: Federspiele (mit Zeichnungen von Hans Thoma). Frankfurt/M. 1892. 3. Aufl. 1919. - Michelangelo und das Ende der Renaissance. 6 Bde. Berlin 1902-1913. Bd. 1: 2. Aufl. 1912. Bd. 2: 2. Aufl. 1920. Bde. 4-6 u.d.T.: Michelangelo. Kritische Untersuchung über seine Werke. 1908-1913. - Leben oder Tod des Heidelberger Schlosses. Heidelberg 1904. Böcklin und Thoma. Heidelberg 1905. Ein letztes Wort von der Entscheidung über das Heidelberger Schloß. Heidelberg 1906. Hans Thoma. Gemälde. 6 Bde. Frankfurt/M. 1910. - Luther und die deutsche Kultur. München 1915. 2. Aufl. 1934. • Franz von Assisi und die Anfänge der Kunst der Renaissance in Italien. Vollst. Ausg. hrsg. von Woldemar von Seydlitz. Essen 1997.

L Julius Ruska: Lebenserinnerungen. Berlin 1937/ 38. Hrsg. von Thomas Ruska. Online veröffentlicht, s. http://julius.ruska.de/lebenserinnerungen.html/ index.html (Stand: 3. Sept. 2001); hier: 36. Kapitel. • Paatz, Walter: H.T. - einst und jetzt - in: Ruperto Carola 20 (1956) S. 54f. • Verzeichnis Bonn (1968) S. 311; Glockner (1969) S. 277 (Register). • Hans Thoma und H.T. Aspekte einer deutschen Freundschaft. Studioausstellung ... Hrsg. von Anna Maria Szylin. Heidelberg 1988. • Jansen (1992a) S. 169 (Register). - Szylin, Anna Maria: H.T. ... Leben und Werk. Frankfurt/M. 1993. BBKL XI (1996) Sp. 1237-1240; Badische Biographien N.F. IV (1998) S. 294-296; WBIS. - Pachl, Peter P.: Heinrich, Heinz und Henry [Thode] in: Programmheft. Siegfried Wagner: Bruder Lustig (Oper). Theater Hagen. Hagen 2000 (Ausdruck im UAH). • Ladwig, Perdita: Das Renaissancebild der deutschen Historiker 1898-1933. Frankfurt/M. 2004. S. 132143. Metzler Kunsthistoriker Lexikon (2007). • Urbini, Silvia: Somnii explanatio. Novelle sull'arte 
italiana di H. T. Traduzioni di Paola Sofia Baghini. Rom 2014 (mit Bibliographie). - Duncan, Isadora: I've only danced my life. Die Autobiographie der I. D. ... übersetzt von Ute Rall. Berlin 2016. S. 131134, 141-146. • NDB 26 (2016) S. 155-157. • Walcher, Bernhard: Mit Arnold Böcklin und Hans Thoma gegen Frankreich. Kunstkritik als Kulturkritik in H. T.s Heidelberger Vorlesungen (1905) in: Kulturkritik zwischen Deutschland und Frankreich (1890-1933). Hrsg. von Olivier Agard und Barbara Beßlich. Frankfurt/M. 2016. S. 259-273. • Deutsche Biographie, s. https://www.deutsche-biographie.de/gnd119116898.html [10.12. 2017]. • Münkner, Jörn: Grenze, Geister, Gardasee. Franz Kafka, H. T., W. G. Sebald und Bodo Kirchhoff am Benaco in: Der Gardasee und die Deutschen. I Tedeschi e il Garda. Literatur - Kunst - Kommunikation/Letteratura - Arte - Comunicazione. Hrsg. von Alessandro Lombardi ... Frankfurt/M. 2017. S. 107-121.

$P$ Bildarchiv UAH; graph. Slg. UBH; Badische Biographien N. F. IV (1998).

\section{Thoma, Richard Andreas}

1873-1884 Med. Fak.

Pathologische Anatomie

* 11. Dez. 1847 Bonndorf (Schwarzwald)

$\dagger \quad$ 26. Nov. 1923 Heidelberg

kath.

V Dr. Andreas T. (1811-1866) Rechtsanwalt

M Maria Alwine geb. Si(e)gel (1815-1895)

( 21. März 1881 Ida Elisabeth geb. Schmid(t) (1851-1931)

K 3 S: Dr.-Ing. Dieter T. (1881-1942), u. a. seit 1921 o. Prof. für Wasserkraftmaschinen an TH München, s. WBIS, NDB 26 (2016) S. 169f. • Dr. Wilhelm Thoma (1885-ca. 1924) Arzt. • Dr.-Ing. Hans T. (1887-1973), u.a. 1924-1945 o. Prof. für elektr. Anlagen und Hochspannungstechnik TH Karlsruhe, s. WBIS, NDB 20 (2001) S. 671* (Artikel: Prandtl, Ludwig), NDB 26 (2016) S. $168^{*}$.
Lb Studium: Seit WS 1866/67 UH, WS 1867/68 Berlin, seit SS 1868 H, WS 1869/70 Berlin, SS 1870WS 1871/72 H; 1870/71 Kriegsdienst während des Deutsch-Französischen Krieges.

UH: WS $1871 / 72$ Staatsexamen; 26. April 1872 Dr. med. (s. hierzu UAH H-III-111/8o fol. 416r-417r); seit Okt. 1872 Assistent am Patholog.-Anatom. Inst.; 20. Dez. 1873 Habilitation; seit 20. Aug. 1877 a. o. Prof.

Dorpat (heute Tartu, Estland; bis 1889 einzige dt.sprachige U im Russischen Kaiserreich; 1889 einsetzende Russifizierung, u.a. mit Absetzung des Deutschen als Lehrsprache und Durchsetzung der russischen Sprache): Seit SS 1884 o. Prof.

Magdeburg: 1895-1905 Unbezahlter Prosektor am Städtischen Krankenhaus Sudenburg und PrivatGelehrter, da finanziell unabhängig; Begründer e. privaten Patholog. Inst.

H: 1906-1923 (†) Privat-Gelehrter.

Konstrukteur mehrerer med. Apparate (zum Teil im UAH), u.a. des nach ihm benannten Thoma-Mikrotoms, e. Schneidegerät zur Herstellung hauchdünner mikroskopischer Präparate, siehe hierzu Wolff (2012) S. 16of.

1897 Gründungsmitglied der Dt. Pathologischen Gesellschaft, seit 1948 u.d.N. Deutsche Gesellschaft für Pathologie

1894 Kaiserlich-Russischer Staatsrat

E 1886 Mitglied der Dt. Akademie der Naturforscher Leopoldina Halle/S.

Qu UAH PA 796, 2344; Fak.-Akte H-III-111/82 S. 165-177. • Nachlaß: Frau Sibylle Höller, Holzkirchen. - Siehe auch Archiv der Dt. Akademie der Naturforscher Leopoldina Halle/S. • Auskunft: Rat der Stadt Marburg (zu Alwine Thoma geb. Sigel).

W Die Überwanderung farbloser Blutkörper von dem Blut- in das Lymphgefäßsystem. Heidelberg 1873. - Über einige senile Veränderungen des 
menschlichen Körpers. Leipzig 1884. Lehrbuch der pathologischen Anatomie. Stuttgart 1894. • Die experimentell-mathematische Behandlung des Blutkreislaufes in: Handbuch der biologischen Arbeitsmethoden. Abt. 5, T. 4,1 (1921).

$L$ Stübler (1926) S. 327; Arnim 2 (1952) S. 662; Fischer $2\left({ }^{3}{ }^{1962)}\right.$ S. 1562 f. - Walter, Friedrich: R.T. in: Geschichte der Mikroskopie. Leben und Werk großer Forscher. Bd. II: Medizin. Hrsg. von Hugo Freund und Alexander Berg. Frankfurt/M. 1964. S. 389-396. - Verso, M.L.: Some nineteenth-century pioneers of haematology in: Medical History. Vol. 15(1). London 1971. S. 55-67. • Chronik Ärzte H (1985) S. 144; Badische Biographien N.F. III (1990) S. 272 f. • Doerr, Wilhelm: Über wenig beachtete Pioniertaten e. Pathologen ... Erinnerungen an R.T. in: Arzt und Krankenhaus 11 (1992) S. 405-411. - WBIS; Biogr. Enzyklopädie Mediziner 2 (2002) S. 627; Goerttler 2 (2004) S. 107; Von der Forschung gezeichnet (2007) S. 124 u. ö. - Wolff, Horst-Peter: Zur Magdeburger Medizinalchronik und ihren Akteuren ... 3. Aufl. Fürstenberg/Havel 2012. S. 287 (Register). - NDB 26 (2016) S. 168 f.; Deutsche Biographie, s. https:// www.deutsche-biographie.de/gnd117640778.html [10.12. 2017].

$P$ Bildarchiv UAH; graph. Slg. UBH.

\section{Thoma, Richard Emil}

1911-1928 Jur. Fak.

Öffentliches Recht

* 19. Dez. 1874 Todtnau (Südschwarzwald)

$\dagger$ 26. Juni 1957 Bonn

kath., seit ca. 1955 konf.-los

V Berthold T. (1833-1876) Textilfabrikant

M Mathilde geb. Thoma (1845-1919)

๑ 6. Juni 1903 Helene geb. Fieser (1881-1961)

K $1 S$ (im 2. Weltkrieg $X$ ).

Lb WS 1894/95-WS 1895/96 und SS 1898-SS 1899 zunächst Studium der Physik, Mathematik, Chemie, dann der Rechtswiss. an U Freiburg/Br., SS 1896 München, WS 1896/97-WS 1897/98 Berlin;
Spätjahr 1899 I., Frühjahr 1903 II. Prüfung für höheren badischen Justiz- und Verwaltungsdienst; 25. Nov. 1900 Dr. iur. an U Freiburg/Br.

Seit Dez. 1899 Rechtspraktikant, Juni 1903-April 1904 Assessor, zuletzt seit 21. Dez. 1903 am Verwaltungsgerichtshof in Karlsruhe; Mai 1904-April 1906 (Entlassung) Beurlaubung vom badischen Staatsdienst.

U Freiburg/Br.: 26. April 1906 Habilitation für Staats- und Verwaltungsrecht; 1908 Ruf an U Tübingen abgelehnt.

Kolonial-Inst. Hamburg: Seit 1. Okt. 1908 o. Prof. für Öffentl. Recht.

U Tübingen: Seit SS 1909 o. Prof. für Öffentl. Recht.

UH: 25. März 1911 Ern. zum o. Prof. als Nachf. von Georg Jellinek; 1. Okt. 1911 Dienstantritt; Rufe an U abgelehnt: 1920 Bonn, 1921 Berlin. • In dieser Zeit:

1916/17 Kriegsdienst.

U Bonn: Seit 1. Okt. 1928 o. Prof. für Öffentl. Recht und Staatslehre; 25. April 1944 T. beantragt seine Emeritierung; Anfang Okt. 1944 Schließung und 18. Okt. völlige Zerstörung der U; 18. Okt. 1944 T. bittet um Beurlaubung; 31. März 1945 Emeritierung; SS 1946-WS 1949/50 T. hält weiterhin Lehrveranstaltungen $\mathrm{ab}$.

1916/17, 1922/23 Dekan der Jur. Fak. der UH

1948-1949 Berater des Parlamentarischen Rats, der das Grundgesetz der BRD erarbeitet

1918 Geh. Hofrat

E 1914 Ritterkreuz II. Klasse des Ordens vom Zähringer Löwen; 1954 Großkreuz zum Verdienstorden der BRD.

Qu UAH PA 796, 6075. - GLA Abt. 235, Fasz. 2587. Briefe: UBH. - Nachlaß: Bundesarchiv Koblenz. Auskunft: Kath. Pfarramt und Standesamt in Todtnau (Geburts- und Totenbücher). 
$W$ Der Polizeibefehl im badischen Recht. Tübingen 1906. Grundriß der allgemeinen Staatslehre. Bonn 1947. - Über Wesen und Erscheinungsformen der modernen Demokratie. Bonn 1948. • Die Lehrfreiheit der Hochschullehrer und ihre Begrenzung durch das Bonner Grundgesetz. Tübingen 1952. Bibliographie in: Thoma, Richard: Rechtsstaat - Demokratie - Grundrechte. Ausgewählte Abh. aus fünf Jahrzehnten. Hrsg. ... von Horst Dreier. Tübingen 2008. - Siehe auch Wirtschaftswiss. Fak. Tübingen I (2004) S. 408-410.

MHG Handbuch des deutschen Staatsrechts. 2 Bde. Tübingen 1930-1932. Nachdr. 1998. • Siehe Wirtschaftswiss. Fak. Tübingen I, S. 409.

L Verzeichnis Bonn (1968) S. 311. - Rath, HansDieter: Positivismus und Demokratie. R.T. ... Berlin 1981. • Jansen (1992) S. 413 (Register); Ders. (1992a) S. 169 (Register); WBIS. • Sösemann, Fabian: R. T. in: Die Juristen der Universität Bonn im „Dritten Reich“. Hrsg. von Mathias Schmoeckel. Köln 2004. S. 555-580. • Wirtschaftswiss. Fak. Tübingen I (2004) S. 405-411; Kriegstagebuch K. Hampe (2007) S. 1001 (Register). - Schale, Frank: Die Arbeiten von R. T. zur Parteienforschung in: Das Politische. Zur Entstehung der Politikwissenschaft während der Weimarer Republik. Hrsg. von Manfred Gangl. Frankfurt/M. 2008. S. 359-385. • Zeiler (2008) S. 122-126; Ders. (2009) S. 523 (Register). Groh, Kathrin: Demokratische Staatsrechtslehrer in der Weimarer Republik ... Tübingen 2010. S. 70-80 u.ö. • Schroeder (2010) S. 409-413 u.ö.; Baden-Württ. Biographien V (2013) S. 432-435; Maus (2013) S. 460 (Register); Spenkuch (2016) S. 1322 (Register); Deutsche Biographie, s. https://www.deutsche-biographie.de/gn d11862208o.html [10.12. 2017].

$P$ Bildarchiv UAH.

\section{Thorbecke, Andreas Heinrich}

1868-1885 Phil. Fak.

Orientalische Sprachen

* 14. März 1837 Meiningen (Thüringen)

$\dagger$ 03. Jan. 189 o Mannheim

口 Mannheim

ev.

V August Franz T. (1801-1846) Tabakfabrikant, s. Friedhöfe in Mannheim (1992) S. 139

M Amalie geb. Ausfeld (1814-1889) Enkelin von Christian Gotthilf Salzmann (1744-1811) Pädagoge, s. NDB 22 (2005) S. $402 \mathrm{f}$.

๑ 4. Jan. 1869 Emma geb. Bassermann (18421912)

$\mathrm{K}$ keine

Vw Bruder: Dr. phil. August T. (1839-1912) seit 1865 Lehrer, seit 1867 Prof. am Lyzeum in H, seit 1877 (Mitbegründer und) Direktor der Höheren Mädchenschule (heute: Hölderlin Gymnasium) in H, 1886-1892 Privat-Dozent für Geschichte an UH, u. a. Bearbeiter der Statuten und Reformationen der Universität Heidelberg vom 16. bis 18. Jahrhundert. Leipzig 1891, s. UAH PA 2346, RA 6081, Rep. 27-1302; Nachlaß in UBH; WBIS, Das „Goldene Buch“ des KFG (1994) S. 88

Vw Neffen (Söhne von Bruder August T.): Franz T. (1875-1945) 1907-1911 (Entlassung auf eigenen Antrag) Gymnasial-Prof. an Höherer Mädchenschule in Mannheim, 1907/o8 und 19111913 Forschungsreisen nach Kamerun, seit WS 1909/10 Dozent, 1914-1917 nebenamtl. Dozent für Wirtschafts- und Kolonialgeographie an Handelshochschule Mannheim, WS 1913/14 Vertreter des Ordinarius für Geographie an UH: (siehe) Alfred Hettner, seit 1915 PrivatDozent für Geographie UH, seit 1917 o. Prof. an Handelshochschule, seit 1919 U Köln, s. UAH PA 2347; WBIS; Hennings, Rainer: F. T., Afrika-Forscher oder: Was tut ein Mannheimer Professor in Kamerun? Mannheim 1980. Paul T. (1882-1928), u.a. 1913-1919 Oberbürgermeister von Singen. 
Lb Seit WS 1854/55 Studium an U Erlangen, seit 1855 Göttingen, seit SS 1856 Berlin, SS 1857 Jena, WS 1857/58-SS $1858 \mathrm{H}$; Herbst 1858 philolog. Staatsexamen in Karlsruhe; 5. März 1859 Dr. phil. an $\mathrm{UH}$.

1859 Hauslehrer in Hamburg; Eigenstudien: 18601863 München, 1864-1866 Leipzig.

UH: 4. Jan. 1868 Habilitation; seit 14. Jan. 1873 a. o. Prof.

U Halle-Wittenberg: Seit WS 1885/86 a. o., seit 9. Nov. 1887 o. Prof.

UH: 24. Aug. 1889 (zum 1. April 189o) Ern. zum o. Prof. († o3. Jan. 1890 an Typhus) als Nachf. von Gustav Weil, s. hierzu UAH RA 6861.

Qu UAH PA 2348f.; RA 6861; Fak.-Akten H-IV102/56, H-IV-102/68. • Briefe: UBH; siehe auch Kalliope.

W 'Antarah, ein vorislamischer Dichter. Leipzig 1867.

HG Al-Harîrîs Durrat-al-Ġawwâs (Taucherperle). Leipzig 1871. - Miha'il Sabbag's Grammatik der arabischen Umgangssprache in Syrien und Ägypten. Straßburg 1886.

L Socin, Albert: H.T. Nachruf in: ZDMG 43 (1889) [!] S. 707-709. Badische Biographien 4 (1891) S. 465-467; ADB 38 (1894) S. 115-117; Catalogus prof. Hallensis; WBIS. - Mangold, Sabine: Eine „weltbürgerliche Wissenschaft". Die deutsche Orientalistik im 19. Jahrhundert. Stuttgart 2004. S. 329 (Register). - Studien zur Hebräischen Bibel und ihrer Nachgeschichte. Beiträge der 32. Int. Ökumenischen Konferenz der Hebräischlehrenden Frankfurt/M. 2009. Hrsg. von Johannes F. Diehl und Markus Witte. Waltrop 2011. S. 21-24 u. ö.
Tiedemann, Friedrich (seit 1832: von Tiedemann)

1816-1849 Med. Fak.

Anatomie, Zoologie, Physiologie

* 23. Aug. 1781 Kassel

$\dagger$ 22. Jan. 1861 München

ev.

V Dietrich T. (1748-1803), u. a. seit 1786 o. Prof. für Philosophie Marburg, s. Catalogus prof. Marburgensis 1 (1927) S. 285 f., WBIS, Hessische Biografie, s. http://www.lagis-hessen.de/ pnd/11737628o (Stand: 2. Aug. 2016); Michael Hißmann: Briefwechsel. Hrsg. von Hans-Peter Nowitzki ... Berlin 2016. S. 545 (Register).

M Sophie geb. Rothausen, s. Michael Hißmann (2016) S. 235, 481

๑ 30. März 1807 Jenny Rosa von Holzing (17911871)

K 4 S: u.a. Gustav Nicolaus T. (1808-11. Aug. 1849 erschossen) zunächst Direktor der Kriegsschule in Piräus (Griechenland), seit 1848 Revolutionär in Baden, 1849 Gouverneur der Festung Rastatt, s. Badische Biographien 2 (1875) S. 358 f.; Rastatt und die Revolution von 1848/49 (2001) S. 753 (Register). • Zwei Söhne fliehen in die USA, u. a. Dr. med. Heinrich T. (1813-1895) zunächst Arzt in Schwetzingen, seit Mai 1849 Zivilkommissär im Amtsbezirk Schwetzingen, Abgeordneter der Badischen Verfassunggebenden Versammlung, Juni 1849 nach Niederlage der Revolutionstruppen Flucht in die USA; 1850 Verurteilung in Abwesenheit zu e. Haftstrafe von 9 Jahren und Aberkennung des badischen Staatsbürgerrechts; 1860 Mitbegründer e. dt. Hospitals in Philadelphia, s. Betz, Frank-Uwe: Das wahre Leben des Dr. H.T. in: Schwetzinger Zeitung vom 31. Dez. 2012.

K 3 T: u. a. Cunigunda (Kunigunde) Maria Sophia Dorothea T. (1809-1889) Ehefrau von: (siehe) Theodor (von) Bischoff 
Vw Nichte: Johanna Louise geb. Tiedemann $\left({ }^{*} 1825\right)$ Ehefrau von: (siehe) Hermann Kopp. * Siehe auch Betz, Frank-Uwe: Die Tiedemanns - Wissenschaftler und Revolutionäre zwischen Schwetzingen, Heidelberg und den Vereinigten Staaten von Amerika in: ZGORh 163. Jg. (2015) S. 171-187; NDB 26 (2016) S. 257.

Lb Seit Herbst 1798 Studium der Naturwiss., Medizin an U Marburg; praktische med. Ausbildung: seit Frühjahr 1802 Bamberg, seit Herbst 1802 Julius-Hospital in Würzburg.

U Marburg: Frühjahr 1803 Forts. des Studiums; 10. März 1804 Dr. med.; Sommer 1804 Habilitation für Zoologie, Anatomie und Physiologie.

Eigenstudien: Seit Okt. 1804 Würzburg, seit Frühjahr 1805 Paris.

Ludwig-Maximilians-U Landshut: 28. Aug. 1805 Ern. zum o. Prof. für menschliche und vgl. Anatomie, Zoologie mit e. jährl. Gehalt von 1200.Gulden; Okt. 1806-Nov. 1807 (auf eigenen Wunsch Entbindung vom Amt) Hausinspektor der U.

UH: 11. Dez. 1815 Ern. zum SS 1816 o. Prof. als Nachf. von Jacob Fidelis Ackermann; SS 1816Ende Sept. 1849 Direktor des Anatom. Inst.; Rufe an U abgelehnt: 1818 Bonn, 1833 Berlin; 1819-1833 Leiter des „Zoologischen Cabinets“; seit 11. Jan. 1844 Inhaber des II. Anatom. Lehrstuhls, siehe hierzu Jacob Henle; seit 1847 Verschleppung des Baus für e. neues Anatomiegebäude; 30. Jan. 1849 T. unterstellt seinem Kollegen Henle e. Planungsfehler, der von $\mathrm{H}$. entschieden zurückgewiesen wird; T. versucht daraufhin, H. mit „wiederholten Invectiven ... auf meine [Henles] Abstammung aus einer ehedem jüdischen Familie pikant zu machen; er erklärte die Unverschämtheit für eine jüdische und fügte hinzu, daß die Unverschämtheit der Juden eine allgemein bekannte Sache sei“ (Zitat aus: Freudenberg (2010) S. 116 Anm. 296); die vom Ministerium geforderte Entschuldigung seitens T. erfolgt erst im April 1849; 28. Sept. 1849 Ruhestand auf eigenen Antrag („So schmerzhaft es mir ist, aus dem kollegialischen Verband einer Körperschaft zu scheiden, in der ich während einer langen Reihe von Jahren so glücklich war, ... so wird, wie ich hoffe, der akademische Senat gewiß die traurigen Motive zu würdigen wissen, die mich zu diesem Schritte bestimmen“; T. meint vor allem die Erschießung seines Sohnes [Gustav Nicolaus 1849] (Zitat aus: Freudenberg, S. 116 Anm. 297)).

Seit Herbst 1849 Wohnsitz in Frankfurt/M., seit Sommer 1856 in München.

1822, 1842 Prorektor der UH; 1818, 1824, 1830, 1837, 1844, 1848 Dekan der Med. Fak. der UH

1819 gründet T. ein „Zoologisches Cabinet“ im ehemaligen Heidelberger Dominikanerkloster, s. hierzu Moeller, Heinz Friedrich: Zoologisches Museum der Universität Heidelberg. In Zusammenarbeit mit Westermanns Monatshefte. Braunschweig 1985. S. 22-25.

1816 Hofrat; 1820 Geh. Hofrat; 1826 Geh. Rat II. Klasse

$E$ Mitglied der Akademie der Wissenschaften: 1812 München, 1816 Göttingen, 1854 Berlin; 1815 Mitglied der Mineralogischen Gesellschaft Jena; 1828 Mitglied der Dt. Akademie der Naturforscher Leopoldina; 1823 Ehrenmitglied der Sanitätskommission. - 1832 Ritter des Verdienstordens der Bayer. Krone; 1851 Orden pour le Mérite für Wissenschaften und Künste. - 1833 Ehrenbürger der Stadt Heidelberg.

$\mathrm{Q} u$ UAH PA 2352; RA 5342, 5510, 6163, 6165f., 7615; GF 46; KE-120/1-5 (Nachschrift der Vorlesungen F.T.s über die „Physiologie des Menschen“ (1824)). GLA Abt. 205, Fasz. 524f. Briefe: UBH. • Briefe zweier Landshuter Universitätsprofessoren. Eingeleitet und kommentiert von Alfons Beckenbauer. Landshut 1985. Siehe auch Archiv der Dt. Akademie der Naturforscher Leopoldina Halle/S.

$W$ F.T.s Anatomie der kopflosen Mißgeburten. Landshut 1813. Anatomie und Bildungsgeschichte des Gehirns im Fötus des Menschen nebst e. vgl. Darstellung des Hirnbaues an den Thieren. Nürnberg 1816. - Tabulae arteriarum corporis humani. Abbildungen der Pulsadern des menschlichen 
Körpers ... Karlsruhe 1822. • T., F., Gmelin, Leopold: Die Verdauung nach Versuchen. 2 Bde. Heidelberg 1826-1827. 2. Aufl. 1831. Physiologie des Menschen. 3 Bde. Darmstadt 1830-1836. Das Hirn des Negers mit dem des Europäers und Orang-Outangs verglichen. Heidelberg 1837. Faks. Ausg. Marburg/Lahn 1984. • Von der Verengung und Schließung der Pulsader in Krankheiten. Heidelberg 1843. - Siehe auch Freudenberg (2010), NDB 26 (2016) S. 258.

MHG 1824-1835 Zeitschrift für Physiologie.

$L$ Badische Biographien 2 (1875) S. 352-358; Stübler (1926) S. 248-256; Catalogus prof. Marburgensis 1 (1927) S. 210. - Hoepke, Hermann: Die Geschichte der Anatomie in Heidelberg in: Reden bei der Jahrhundert-Feier des Anatomischen Instituts in Heidelberg am 24. und 25. Juni 1949. Berlin u.a. 1951. S. 1-16. Schmitt (1978) S. 72 u. ö.; Renger (1982) S. 306 (Register). • Über F.T. in: T., F.: Das Hirn des Negers mit dem des Europäers ... verglichen. Faks.-Ausg. Marburg/Lahn 1984. S. IX-XXIV. Chronik Ärzte H (1985) S. 144, 274f. - Giese, Christian: Theodor Ludwig Wilhelm von Bischoff ... Anatom und Physiologe. Habil.-Schrift. Gießen 1990. 238 f. u. ö. Z Zimmermann/Drüll (1990) S. 29 f. u.ö. • Beckenbauer, Alfons: Die Ludwig-Maximilians-Universität in ihrer Landshuter Epoche 180o-1826. München 1992. S. 379 (Register). • Biogr. Lexikon der U München (1998) S. 435-437; Weinmann (1999) S. 228; Prückner (2004) S. 305 (Register). Freudenberg, Michael: F. T. Leben und Wirken eines Heidelberger Anatomen im zeitgeschichtlichen Kontext. Diss. Heidelberg 2010. • Roß, R. Stefan: Das Wissenschaftsverständnis F.T.s ... und Leopold Gmelins ... in: Fachprosaforschung - Grenzüberschreitungen Bd. 4/5, 2008/09 (2010) S. 187-212. • Borgards, Roland: Der Affe als Mensch und der Europäer als Ureinwohner. Ethnozoographie um 1800 (Cornelis de Pauw, ..., F. T.) in: Kultur-Schreiben als romantisches Projekt. Romantische Ethnographie im Spannungsfeld zwischen Imagination und Wissenschaft. Hrsg. von David E. Wellbery ... Würzburg 2012. S. 17-42. - Stumm (2012) S. 705 (Register); Hier freut sich der Tod (2013) S. 57-59, 103 f., 159 f. u. ö. - Denk, Claudia, Ziesemer, John: Kunst und Memoria. Der Alte Südliche Friedhof in München ... Berlin 2014. S. 497 f. • Doll (2014) S. 324-327 u. ö.; Hessische Biografie, s. http://www. lagis-hessen.de/pnd/118867733 (Stand: 23. Aug. 2016); NDB 26 (2016) S. 257f.; Doll/Kirsch/Eckart (2017) S. 6, 27, 107; Deutsche Biographie, s. https:// www.deutsche-biographie.de/gnd118867733.html [11.12. 2017].

$P$ Bildarchiv UAH; graph. Slg. UBH; Stübler; Chronik Ärzte H.

\section{Tischler, Georg Friedrich Leopold}

1902-1912 Nat.-Math. Fak.

Botanik

* 22. Juni 1878 Losgehnen (Ostpreußen; heute: Lusiny, Polen)

$\dagger \quad$ o6. Jan. 1955 Kiel

prot.

V Oscar August Julius T. (1847-1903) Rittergutsbesitzer

M Marie geb. Kowalski (1851-1935)

(21. Dez. 1909 Gisela Josepha Hedwig Wanda geb. Freiin von Funck (1878-1959)

K 2 S: Fritz T. (1910-1967) seit 1938 Leiter der vorgeschichtlichen Abt. des Niederrheinischen Museums, 1950-1967 Direktor des genannten Museums in Duisburg, seit 1948 Privat-Dozent, seit 1955 Honorar-Prof. für Vorgeschichte an U Köln, s. Genrich, Albert J.: Nachruf ... in: Die Kunde (1967) N.F. 18, S. 5 f.; Krause, Günter: Archäologische Beiträge zur frühen Geschichte Duisburgs von ersten Anfängen bis heute in: Nomen et Fraternitas. Festschrift für Dieter Geuenich. Hrsg. von Uwe Ludwig. Berlin 2008. S. 393 f. u. ö. - Wolfgang T. (1912-2007) U Kiel: 1939-1950 Assistent am Zoolog. Inst., seit 1941 Privat-Dozent, seit 1957 Wiss. Rat und Prof. für Angewandte Biologie, Ökologie, seit 1963 a. o., seit 1969 o. Prof. für Ökologie, s. WBIS, Kieler Gelehrtenverzeichnis 1919-1965 online; Tischler, WolfHermann: Biographie über W. Otto Georg T. Selbstverlag 2018. (Ex. im UAH.) 
Vw Bruder: Friedrich T. (1881-1945 Suizid vor Einmarsch der Roten Armee) seit 1908 Assessor, seit 1912 Amtsrichter, zuletzt Amtsgerichtsrat in Heilsberg im Ermland (heute: Lidzbark Warmiński, Polen), auch Ornithologe und Verfasser von zwei grundlegenden Werken: Die Vögel der Provinz Ostpreußen. Berlin 1914. Nachdr. 2013 und Die Vögel Ostpreußens und seiner Nachbargebiete. 2 Bde. Königsberg 1941. Nachdr. 2007; siehe WBIS

Vw siehe NDB 26 (2016) S. 307; Tischler, WolfHermann: Das Rittergut Losgehnen in Ostpreußen, dem Land der Störche, Misteln und Seen. Masch.geschr. Quarnstedt 2018. S. 41-55 u. ö. (Ex. im UAH); online, s. http://www.ost preussen.net/ostpreussen/orte.php?bericht $=15$ 11\&gl1498=8\#gl1498 (abgerufen am 31. März 2018).

Lb Seit SS 1896 Studium der Naturwiss. an U Königsberg, seit SS 1897 München, seit SS 1898 Bonn; 24. Juni 1899 Dr. phil. an U Bonn; 2. Febr. 1900 Oberlehrerexamen für Botanik, Zoologie, Chemie, Mineralogie in Bonn.

UH: Seit 15. April 1900 Assistent am Botan. Inst.; 30. Mai 1902 Habilitations-Kolloquium; SS 1902 und SS 1903 Beurlaubung von UH, „da ich von Professor [Jakob] Eriksson [1848-1931] ... [am Pflanzenphysiolog. Inst. der Königl. Schwedischen Landbau-Akademie in Albano bei Stockholm] die Aufforderung erhalten hatte, ihn in die moderne Mikrotomtechnik einzuführen“ (aus: eigenhändigem Lebenslauf in: UAH PA 2353); 28. Okt. 1902 Habilitation (öffentliche Probevorlesung); Ostern 1904 Studienaufenthalt „im Laboratorium von Herrn Professor [Jean Paul] Vuillemin [(18611932) an U] Nancy“ (aus: ebd.); seit 13. Mai 1908 nichtetatm. a.o. Prof.; 1908/o9 Forschungsreisen mit Reichsstipendium nach Java, Malaysien, Ceylon, Südarabien, Deutsch-Ostafrika, Ägypten.

TH Braunschweig: Seit 1. Okt. 1912 etatm. a. o. Prof. und Direktor des Botan. Inst. und Gartens.

Landwirtschaftl. Hochschule Hohenheim (heute: Stadtteil von Stuttgart): 19. April 1917 Ern. zum WS 1917/18 o. Prof.
U Kiel: 1. Okt. 1922-SS 1951 (Emeritierung) o. Prof. an Phil. Fak. und Direktor des Botan. Inst. und Gartens; WS 1931/32 Gast-Prof. an Johns Hopkins U in Baltimore (Maryland); 1946-1951 auch o. Prof. an neugegründeter Landwirtschaftl. Fak.

E Ehrenmitglied: 1947 Naturwiss. Verein für Schleswig-Holstein, 1950 Botanical Society of Japan, 1955 Indische Botanische Gesellschaft der Naturwissenschaften, Portugiesische Gesellschaft der Naturwissenschaften. 1948 Dr. med. h.c. Kiel; 1949 Dr. agr. h.c. Bonn.

Qu UAH PA 2353; RA 6500 (T.s Sammlung tropischer Pflanzenteile), 6502, 6883. - GLA Abt. 235, Fasz. 2595. - Briefe: UBH; im Familienbesitz. • Nachlaß: Universitätsbibliothek Kiel. - Mitteilungen: Herr Wolf-Hermann Tischler (Enkel), Quarnstedt.

$W$ Allgemeine Pflanzenkaryologie. 2 Bde. Berlin 1922. 2. Aufl. in 3 Bden. 1934-1944. Erg.-Bd. fortgeführt von Heinz Diedrich Wulff. Berlin 1963. Tabulae Biologica. 5 Bde. Den Haag 1927-1938. Polyploidie und Artbildung in: Die Naturwissenschaften 30 (1942). • Die Chromosomenzahlen der Gefäßpflanzen Mitteleuropas. Den Haag 1950. • Siehe NDB 26 (2016) S. $307 \mathrm{f}$.

MHG Handbuch der Pflanzenanatomie. Berlin 1934-1955.

$L$ Wer ist wer (1955) S. 1193; Professoren Kiel (1956) S. 164. - Reese, Gerd: G. T. ... in: Berichte der Dt. Botanischen Gesellschaft 74. Jg. H. 11,2 - Generalversammlungsheft (1961) S. 95-102 (mit Bibliogr.). Klein (1968) S. 126. • Universität Hohenheim, Landwirtschaftliche Hochschule 1818-1968. Hrsg. von Günther Franz. Stuttgart 1968. S. 113 f. • Schleswig-Holsteinisches Biographisches Lexikon. Hrsg. von O. Klose. Neumünster 1970. Bd. 1. S. 269271. Brandes, Dietmar: Zur Entwicklung der Botanik an der Carolo-Wilhelmina in: Zur Geschichte der Carolo-Wilhelmina ... Bibliothek der TU Braunschweig. Braunschweig 1988. S. $72 \mathrm{f}$. • Jansen (1992a) S. 169 (Register); WBIS; Kieler Gelehrtenverzeichnis 1919-1965 online; NDB 26 (2016) S. 307 f.; Deutsche Biographie, s. https://www. 
deutsche-biographie.de/gnd117400793.html [11.12. 2017]. Tischler, Wolf-Hermann: Aus dem Leben von G. F. L. T. Selbstverlag 2018. (Ex. im UAH.)

P Bildarchiv UAH; Tischler (2018).

\section{Tobler, Ludwig}

1905-1911 Med. Fak.

Kinderheilkunde

* $\quad$ 02. Mai 1877 Zürich

$\dagger \quad$ 02. Juni 1915 Breslau (heute: Wrocław, Polen) ev.

V Dr. med. Johann Ludwig T. (1827-1895) Gymnasial-Prof., 1873 Begründer der Privatschule mit Internat „Im Morgenthal“ gemeinsam mit seiner Frau

M Henriette geb. Hattemer (1836-1917) T von Heinrich H. $\left({ }^{*} 1809\right.$ Mainz $\dagger 1849$ Biel/Bienne im Kanton Bern) Gymnasial-Lehrer, 1836 Auswanderung in die Schweiz, 1848 Teilnehmer der badischen Revolution, s. ADB 11 (1880) S. $24 \mathrm{f}$., WBIS

$\infty$ 18. Mai 1907 Berta geb. Scholl (1883-1957)

$\mathrm{K} \quad 1 \mathrm{~S}, 1 \mathrm{~T}$

Vw Schwester: Mina T. (1880-1967) Pianistin, s. Demm (2014) S. 247 (Register), Kaesler (2014) S. 1004 (Register); Lepsius, Rainer M.: Max Weber und seine Kreise. Essays. Tübingen 2016. S. 210-231. Onkel: Adolf T. (1835-1910), u. a. seit 1867 Prof. für Romanische Sprachen an U Berlin, s. WBIS, Hausmann (2008) S. 815 (Register).

$L b$ WS 1896/97-SS 1899 Studium an U Zürich, anschl. Kiel, Berlin, Zürich; Nov. 1901 Staatsexamen in Zürich; Frühjahr 1902 (Rigorosum) Dr. med. an U Zürich.

UH: Seit 1903 I. Assistenzarzt an U-Kinderklinik Luisen-Heilanstalt; 8. Nov. 1905 Habilitation; seit 31. Juli 1911 nichtetatm. a. o. Prof.

U Breslau: Seit WS 1911/12 o. Prof. und Direktor der U-Kinderklinik.
Qu UAH PA 2354; Fak.-Akte H-III-111/148. • Matrikel Zürich (1999) Nr. 11317. GLA Abt. 235, Fasz. 2596.

$W$ Allgemeine und pathologische Physiologie der Ernährung und des Stoffwechsels im Kindesalter. Wiesbaden 1914.

$L$ Wer ist's (1914) S. 1718; Biogr. Jahrbuch 1 (19141916) S. 342. Nachruf in: Jahresbericht der Schlesischen Gesellschaft für vaterländische Kultur XCI,1 (1915) S. 39-41. • Stübler (1926) S. 324 f.; Fischer 2 ( $\left.{ }^{3} 1962\right)$ S. 1573. • Wille, Lutz: UniversitätsKinderklinik Luisen-Heilanstalt zu Heidelberg 1860-1985 in: Der Kinderarzt 16. Jg., Nr. 7 (1985) Sp. 1005. - WBIS; Deutsche Biographie, s. https:// www.deutsche-biographie.de/gnd143444336.html [11. 12. 2017].

\section{Traitteur, Johannes Andreas von}

(seit 1790: Ritter, Edler von Traitteur; seit 1824: Graf von Traitteur-Brauneberg)

1785-1795 (1803) Phil. Fak.

Zivil- und Militärbaukunst, Praktische Geometrie

* 30. Juli 1752 Philippsburg (bei Bruchsal)

$\dagger$ 20. Jan. 1825 Bruchsal kath.

V Johannes Adam T. (1707-1772) Fürstbischöfl.Speyerischer Hofrat und Amtmann, s. Waldeck (1921) Sp. 110 f.

M Eva Elisabeth geb. Duras(s) verw. Weber (1720-1785)

$\infty$ 23. Sept. 1777 Anna Maria Walther (†17. April 1798)

(21. Juni 1798 Maria Anna Augusta von Jonner (1771-1848)

$\mathrm{K} \quad 1 \mathrm{~S}, 5 \mathrm{~T}$ (davon $2 \mathrm{~T}$ früh $\dagger$ )

Vw Bruder: Karl Theodor von T. (1756-1830), u. a. seit 1788 Hofbibliothekar in Mannheim, s. $Z$ (9. Dez. 1784).

$L b$ Seit 17. Nov. 1772 Studium der Rechtswiss. an UH; dann Forts. des Studiums am Collège de St. Louis in Metz. 
Vor 1779 Ingenieur und Genieoffizier bei kurpfälz. Kontingent, dann Oberstleutnant der österr. Armee.

UH: $1779-1781$ T. hält Privat-Vorlesungen über Geometrie; 9. Dez. 1784 Ern. zum o. Prof. zunächst ohne Besoldung; Mai 1785 Antritt der Professur; 1. Okt. 1785 als „Oeconomus verpflichtet" und Aufnahme in U-Senat; Okt. 1785 jährl. Besoldung von 100.- Gulden; 1785 T. übernimmt Planung und Leitung des Umbaus in Zusammenhang mit Verlegung der UB-Räume innerhalb der heutigen Alten Universität; 1786 Verantwortlicher bei Restaurierungsarbeiten in der genannten Aula; 1786 Hersteller der Illumination am U-Gebäude anlässlich des 400-jährigen U-Jubiläums für 600.- Gulden Honorar; SS 1795 letzte Erwähnung im Vorlesungsverzeichnis; 24. Dez. 1803 Niederlegung der Professur. • In dieser Zeit:

Seit 1781 Baukommissar in H; 1790 Planer und Ausführender des Trinkwasserleitungen-Baus in Mannheim; 1797 Abbruch der Arbeiten an Wasserleitungen in Mannheim.

1799 Pächter, seit 1812 Besitzer der Saline Bruchsal; außerdem Erblehenträger der Fürstlich-Leiningischen Saline in Mosbach.

1791 Rektor der UH; 1786, 1790 Dekan der Phil. Fak. der UH

1781 Geistl. Administrationsrat; ca. 1790 Kurpfälz. Ingenieur-Major; 1794 Wirkl. Kaiserl. Reichs-Ingenieur-Major

1784: T. lässt erstmals in Leimersheim einen unbemannten Heißluftballon steigen, siehe hierzu Wider, Paul: Menschen und Ballone. Esslingen 1993.

1803: $\mathrm{T}$ erwirbt das ehem. Jesuitengymnasium in der Heidelberger Augustinergasse 15, das 1827 von der Universität gekauft und von 1829 bis 1905 als Universitätsbibliothek genutzt wird.

$Z$ In seinem „Bewerbungsschreiben“ auf eine Professur an der Universität Heidelberg wendet sich T. am 18. Sept. 1784 an Kurfürst Carl Theodor:
„Von Euer Churfürstlichen Durchlaucht hat mein Bruder Theodor Traitteur [siehe Drüll (1991) S. 158 f.] sich die höchste gnade erbetten, als Professor der Geschichte oder sonstigen noch unbesezten fachs bei der Philosophischen Facultät zu Heidelberg aufgestelt zu werden, und Ich hab die unterthänigste Erklärung gethan, daß, wenn dieses gesuch gnädigst genehmiget werden wolte, [ich] willig und bereit seie, bei nemlicher facultaet die professur der civilbaukunst und practischen geometrie ohne Besoldung zu übernehmen ...

(Ich unterfange mich,) anbei zu bemerken, daß, so fern Euer Churfürstliche Durchlaucht mich und meinen Bruder als öffentlich-ordentliche Lehrer bei der philosophischen facultät zu Heidelberg aufzustellen gnädigst geruhen solten, Ich nicht allein das lehramt der civilbaukunst und practischen geometrie ohne besoldung übernehmen, sondern auch im fall über die militairbaukunst kein Ingenieur abgegeben werden kann, dieses fach mit zu besorgen und damit das lehramt der baukunst denen dahier sich zahlreich einfindenden französischen officiers auch dienlich ist und dieselben mehr beigezogen werden, in französisch so wie in deutscher sprache Vorlesungen zu halten ..." (aus: GLA Abt. 205, Fasz. 527).

$\mathrm{Zu}$ o.g. „Bewerbungsschreiben“ erstellen Rektor Dominik Heddäus und die Professoren des Generalstudiums der UH für Oberkuratel in Karlsruhe nachstehendes Gutachten vom 10. Nov. 1784:

„Hiesige hohe Schule wünschte sehr, daß die zu Erlernung nötig und nützlichen Wissenschaften annoch abgängige Lehrstühle mit würdig und geschickten Männern bestellt seyn würden, und die Lehrbegierige Jugend in allen stücken sich zum besten des Staats- und Vaterlands hinlänglich befähigen könnte: Allein der Academische Fiscus ist außer allen stand, sich durch Abgab einiger Besoldung nur den mindesten Last aufbürden zu lassen, jenem fallet es jetzo schon äußerst schwehr, denen dermahligen Lehrern die gnädigst angewiesene Bestallungen in Geld, Wein und Frucht abzugeben, auch die viele Baulichkeiten und sonstige Ausgaben mehr zu bestreiten ...

(Johannes Andreas T.) erbiethet sich ... zur ohnentgeltlichen Lehre der Civil- und MilitairBaukunst ... Wir können dem Gesuch ... um da 
weniger entgegen seyn, als wir bereits von dessen besizenden Geschicklichkeit hinlänglich überzeuget seynd, hiedurch das academische dearium [= diarium] nicht beschwehret wird und jedermann die Gelegenheit verschaffet wird, die Baukunst mit Nuzen erlernen zu können ..." (aus: GLA Abt. 205, Fasz. 527).

Am 9. Dez. 1784 erfolgt die Ernennung des Bruders Theodor von T. (1756-1830) zum o. Prof. für Allg. Geographie an Universität Heidelberg mit der Auflage, sich vor Antritt der Professur an ,auswärtigen Hohen Schulen" weiterzubilden. T. immatrikuliert sich daraufhin am 9. Mai 1785 in Göttingen zum Studium der Weltweisheit. Am 11. Jan. 1786 ordnet Kurfürst Carl Theodor an, T. über das ihm „zugesicherte“ Lehrfach der Allg. Geographie zu prüfen; Prüfung findet wohl nicht statt und T. tritt seine Professur in Heidelberg nicht an. Er wird Anfang 1786 Hofhistoriograph in Mannheim, 1788 zweiter und 1802 erster Hofbibliothekar ebd.

Die "Acta sacrorum secularium“ erwähnen anläßlich der 400-Jahrfeier der Universität Heidelberg 1786 die formale Verleihung des Titels eines Doktors der Philosophie zur Aufwertung einiger Wissenschaftler, die an der Phil. Fak. tätig sind. Zu diesen zählen auch T. und sein Bruder Theodor (vgl. Acta secularium (1787) S. 166, 322 f.).

\section{E 1786 Dr. phil. UH.}

Q $u$ UAH PA 2357; RA 752 [A-160/105 (= I, 3, Nr. 118b) fol. 30or-302v, 452r, v, 517v]. - Acta secularium (1787) S. 315 f., 322 f.; Winkelmann 2 (1886) S. 297 Nr. 2354, 313 Nr. 2475, 318 Nr. 2503, 321 Nr. 2521; Toepke 4 (1903) S. 266, 337 Anm. 5, 345 Anm. 2. GLA Abt. 205, Fasz. 526f., 595, 387, 964. - Briefe: UBH. - Nachlaß: GLA Karlsruhe. • Auskunft: Stadtarchiv Heidelberg (Contractenbuch Bd. 11, S. 122, 470); Kath. Pfarramt St. Maria Philippsburg (Taufbuch); Generallandesarchiv Karlsruhe (Kirchenbücher St. Paul Bruchsal); Privat-Archiv Karl Eichhorn, Bruchsal.

W Die Wasserleitung nach Mannheim ... Mannheim 1790. Die Wasserleitung von Mannheim ... nebst der Nachricht, wie weit das im Jahr 1790 angefangene Werk gediehen und welchen Nutzen seine Vollendung Mannheim gewähren wird. Mannheim 1790. - Landau, die französische Festung, kann durch Inundation mit wenig kosten in kurzer Zeit gewonnen werden. Heidelberg 1793. Die schreckliche Geschichte der Wasserleitung, die unerhörte Behandlung und die schreiende Klage, welche der höchsten Entscheidung Seiner Kurfürstl. Durchlaucht unterlieget. Mannheim 1798. Abhandlung über Wasserbaukunst, in specie über die Dämme gegen Überschwemmungen. Abhandlung über Civil-Baukunst ... Bruchsal 1845 (posthum erschienen; Ex. im Marchivum: Stadtarchiv Mannheim).

L Hautz 2 (1864) S. 300 . Heinze, Rudolf: Heidelberger Universitätsjubiläen ... Heidelberg 1884. S. 39 Anm. 59. - Hirsch, Fritz: Von den Universitätsgebäuden in Heidelberg. Heidelberg 1903. S. 80 f., 90-98. - Walter, Friedrich: Geschichte Mannheims ... Mannheim 1907. Bd. 1. S. 887-892 u. ö. Rosenlehner, August: Zur Lebensgeschichte des kurpfalzbayrischen Bibliothekars und Hofhistoriographen Karl Theodor von Traiteur [!] ... in: Mannheimer Geschichtsblätter 9. Jg. (1908) Nr. 8 und 9, Sp. 171f.; Waldeck, Florian: Alte Mannheimer Familien. III. T. in: ebd. 22. Jg. (1921) Sp. 112114; Ders.: Von Traitteur in: Alte Mannheimer Familien. Mannheim 1922. 2. T.S. 48-64. - Traitteur, Carl von: Ursprung der Familie von Traitteur in: Mannheimer Geschichtsblätter 32. Jg. (1931) Sp. $58-$ 61. Fuchs, Peter: Palatinus illustratus. Die historische Forschung an der Kurpfälz. Akademie der Wissenschaften. Manheim 1963. S. 361, 544, 589. • Frauenfeld, Karl Heinz: Die Quellwasserleitung des J.A. von T. Bau der Wasserleitung von Rohrbach bei Mannheim zur damaligen Residenzstadt Mannheim in: Badische Heimat: mein Heimatland. Zeitschrift für Landes- und Volkskunde ... Freiburg/Br. 1973. 53. Jg. H. 2. S. 207-215. - Sippenbuch der Stadt Philippsburg ... Bearb. und erg. von Wolfgang H. Collum. Hrsg. von Albert Köbele. Grafenhausen bei Lahr 1975. Reihe A. Bd. 62. S. 566. Nr. 5144. - Gantner, Elda: Die Gebäude im Quartier des ehemaligen Jesuitenkollegs ... in: Semper apertus 5 (1985) S. 140 f., 156 Anm. 25; Gensichen, Sigrid: Das Quartier Augustinergasse etc. und das Seminarienhaus in: ebd. S. 120 f.; Juschka, Sabine: Die Alte Universität - Grabengas- 
se 1 in: ebd. S. 51 f.; Dies.: Das Karzergebäude - Augustinergasse 2 in: ebd. S. 74. • WBIS; Drüll (1991) S. 156-158; Wikipedia.

$P$ Bildarchiv UAH.

\section{Traitteur-Brauneberg}

siehe Traitteur

\section{Trautz, Max Theodor}

1910-1934 Nat.-Math. Fak.

Physikalische Chemie

* 19. März 1880 Karlsruhe

$\dagger$ 19. Aug. 1960 Karlsruhe ev.

V Julius Theodor T. (1845-1897) Oberkirchenrat

M Marie Luise Laura Johanna geb. Hauer (18571941)

Ø 22. Mai 1912 Mona Janet geb. Drysdale (18851971)

K 2 S: u.a. Friedrich (Fritz) Alexander Theodor T. (1917-2001), u.a. 1969-1982 o. Prof. für Geschichte U Mannheim, s. UAH PA 686, 3047, 6112, 10840; Baden-Württ. Biographien IV (2007) S. 369-372

Vw Bruder: Friedrich Max T. (1877-1952), u.a. 1926-1930 Leiter des Japaninstituts Berlin, seit 1927 Privat-Dozent, 1933-1939 (seit 1930 beurlaubt) a.o. Prof. für Japanologie U Berlin; 1932 (Gründer), 1934-1938 (auf eigenen Antrag Enthebung vom Amt aus Gesundheitsgründen) Direktor des Dt.-Japanischen Forschungs-Inst. Kyoto, 1938 Rückkehr nach Deutschland, nach 1939 Privatgelehrter, s. Badische Biographien N.F. II (1987) S. 282-285; Walravens, Hartmut: Dokumente zu Leben und Wirken von F.M.T. in: Japonica Humboldtiana 15 (2012) S. 217-250.

Lb Seit WS 1898/99 Studium der Chemie an TH Karlsruhe; 1900 organisches Verbandsexamen, Dez. 1901 physikalisch-chemisches Verbandsexamen in Leipzig.
U Leipzig: Seit WS 1900/o1 Studium der Physikal. Chemie; 3. Aug. 1903 Dr. phil.

U Freiburg/Br.: Seit WS 1903/o4 Assistent am Chemischen Laboratorium; 7. Febr. 1905 Habilitation; seit 7. Febr. 1910 nichtetatm. a. o. Prof.

UH: Seit 1. April 1910 etatm., seit 1920 planm. a.o. Prof. am Chemischen Laboratorium; seit 28. Jan. 1927 persönlicher o. Prof. und Direktor des neugegründeten Physikalisch-Chemischen Inst.

U Rostock: Seit 1. April 1934 o. Prof. für Anorganische Chemie und Direktor des Chemischen Inst.

U Münster: WS 1936/37-1. Okt. 1945 (Emeritierung) o. Prof. und Direktor des Chemischen Inst.; Okt. 1943 Ausbombung des Inst.; Sept. 1944 Ausbombung der T.schen Wohnung und Umzug nach Bomlitz (Lüneburger Heide); bis April 1945 hier Beschäftigung bei der dortigen Pulverfabrik EIBIA $\mathrm{GmbH}$ für chemische Produkte.

Karlsruhe: Seit 1948 Wohnsitz.

1929/30, April-Sept. 1933 Dekan der Nat.-Math. Fak. der UH

E 1921 Mitglied der Akademie der Wissenschaften $\mathrm{H}$; Ehrenmitglied der Physikalischen Vereinigung Frankfurt/M. 1952 Dr. rer. nat. h. c. TH Karlsruhe.

Qu UAH PA 6113f.; RA 5225, 6497, 6886. - GLA Abt. 235, Fasz. 2598. • Briefe: UBH. • Teil-Nachlaß: UAH. Mitteilungen: Herr Prof. Dr. Fritz Trautz $(\dagger)$.

$W$ Studien über Chemiluminescenz in: Zs. für physikalische Chemie 53 (1905) S. 1-115. • Praktische Einführung in die Allgemeine Chemie. Anleitung zu physikalisch-chemischem Praktikum und selbständiger Arbeit. Leipzig 1917. - Galvanische Elemente. Leipzig 1918. - Lehrbuch der Chemie. 3 Bde. Berlin 1922-1924. • Bibliographie in: Baden-Württ. Biographien III (2002) S. 423.

MHG Seit 1949 Zs. für anorganische Chemie. 
L Kürschner (1928/29) Sp. 2471, (1950) Sp. 2120; Poggendorff 7a (1962) S. 705 f. • Binkele, Heinrich Ernst: M.T. und sein Lebenswerk in: ChemikerZeitung - Fachzeitschrift und Handelsblatt für Chemiker, Ingenieure, Pharmazeuten mit Fortschrittsberichten der chemischen Technik. Heidelberg 1964. S. 315-318. • WBIS; Universität Münster (1980) S. 449; Jansen (1992a) S. 170 (Register); Baden-Württ. Biographien III (2002) S. 421-423; Buddrus/Fritzlar (2007) S. 405. - Maier, Helmut: Chemiker im „Dritten Reich“: Die Deutsche Chemische Gesellschaft und der Verein Deutscher Chemiker im NS-Herrschaftsapparat. Weinheim 2015. (Ohne Seitenzahlen.) - Catalogus prof. Rostochiensium online; Deutsche Biographie, s. https://www.deutsche-biographie.de/ pnd11740733X.html [18.12.2017].

$P$ Bildarchiv UAH; graph. Slg. UBH.

\section{Treitschke, Heinrich Gotthard von}

1867-1874 Phil. Fak.

Geschichte

* 15. Sept. 1834 Dresden

$\dagger$ 28. April 1896 Berlin

ev.

V Eduard Heinrich (seit 1821: von) T. (17961867) Husarenlieutenant, später General, s. Fritzsche, Werner: Generalleutnant E.H. von T. Kommandant der Festung Königstein 18591866 in: Offizielles Mitteilungsblatt des Festungsvereins Königstein e. V. ... Dresden 2010. S. 24-28; Deutsche Biographie, https://www. deutsche-biographie.de/pnd117408999.html [18.12. 2017]; zur zeitweiligen Entzweiung von Vater und Sohn aus politischen und religiösen Gründen, s. Gerhards (2013) S. 47-49

M Marie geb. von Oppen (1810-1861)

๑ 18. März 1867 Emma geb. Freiin von Bodman (1836-1901; nach dem Tod des Sohnes 1881 depressiv bis zu ihrem Tod), s. Berbig (2010) Bd. 5. S. 3883 (Register; s. Eintrag unter Qu[ellen])

K $1 \mathrm{~S}(1870-1881), 2 \mathrm{~T}$
Lb Seit SS 1851 Studium der Geschichte, Kameralwiss., Staatswiss. an U Bonn, seit 23. Okt. 1852 Leipzig, WS 1853/54 Bonn, SS 1854 Tübingen, WS 1854/55 H; 20. Nov. 1854 Dr. phil. an U Leipzig.

Eigenstudien: Seit März 1855 Dresden, seit Okt. 1855 Göttingen, seit Frühjahr 1857 Leipzig; 18571858 Mitarbeiter an neugegründeten Preußischen Jahrbüchern in Berlin.

U Leipzig: 10. Dez. 1858 Habilitation; 13. Jan. 1859 venia legendi für Geschichte; 1859-1863 PrivatDozent; in dieser Zeit: April 1861-Jan. 1862 Eigenstudien in München.

U Freiburg/Br.: 25. Juli 1863 Ern. zum a. o. Prof. für Staatswiss.; Juni 1866 auf eigenen Antrag Entlassung und Weggang nach Berlin aus Protest gegen die Kriegsteilnahme Badens auf österr. Seite.

Berlin: Nach Juni 1866 aushilfsweise Mitarbeiter an Preußischen Jahrbüchern; Okt. 1866 Ruf an UH abgelehnt.

U Kiel: 5. Okt. 1866 Ern. zum o. Prof. für Geschichte und Politik.

UH: Seit 25. Juli 1867 o. Prof. als Nachf. von Ludwig Häusser; 22. Okt. 1867 Vereidigung.

U Berlin: 17. Nov. 1873 Ern. zum SS 1874 o. Prof.; seit 1884 vollständige Taubheit.

1871-1888 Mitglied des Dt. Reichstags (nationalliberal; seit 1879 Dt. Reichspartei)

1886 Ern. zum Historiographen des Preußischen Staates

1884 Geh. Reg.-Rat

31. März 2012: Umbenennung der Heidelberger Treitschkestraße in Goldschmidtstraße (T. vertrat antisemitischen Standpunkt; neuer Namensgeber, siehe Victor Goldschmidt)

E 1895 Mitglied der Akademie der Wissenschaften Berlin. 1884 Verdun-Preis; 1887 Orden pour le Mérite für Wissenschaften und Künste. 1896 
Dr. iur. h.c. Berlin. 1874 Kommandeurkreuz II. Klasse des Ordens vom Zähringer Löwen.

Qu UAH PA 2359; RA 6846. • Briefe: UBH; siehe auch Kalliope. Gustav Freytag und H. von T. im Briefwechsel. Hrsg. von Alfred Dove. Leipzig 1900. Nachdr. Bremen 2011. - H. von T.s Briefe 18341896. Hrsg. von Max Cornicelius. 3 Bde. Leipzig 1912-1920. - Wilhelm Dilthey: Briefwechsel 18521882 [u. a. mit H. von T.]. Hrsg. von Gudrun Kühne-Bertram ... Bd. 1. Göttingen 2011. S. 557, $631 \mathrm{f}$. u. ö. Nachlaß: Staatsbibliothek zu Berlin. • Über H. von T. in: Berbig, Roland: Theodor Fontane Chronik. Berlin 2010. Bd. 5. S. 3883 (Register).

$W$ Historische und politische Aufsätze. 4 Bde in mehreren Aufl. Leipzig 1871-1921. • Zehn Jahre deutscher Kämpfe. Schriften zur Tagespolitik. Berlin 1874. 3. Aufl. 1897. - Deutsche Geschichte im 19. Jahrhundert. Leipzig. Bd. 1: 1879. 7. Aufl. 1908. Bd. 2: 1882. 6. Aufl. 1906. Bd. 3: 1885 . 6. Aufl. 1908. Bd. 4: 1889. 5. Aufl. 1907. Bd. 5: 1894. 5. Aufl. 1908. Unsere Aussichten in: Preußische Jahrbücher 44 (1879) S. 559-576 („Die Juden sind unser Unglück“, Zitat aus diesem Aufsatz, der den Berliner Antisemitismusstreit auslöst, s. hierzu: Der Berliner Antisemitismusstreit. Hrsg. von Walter Boehlich. Frankfurt/M. 1965). Das deutsche Ordensland Preußen. Leipzig 1916. Nachdr. 1955. • H. von T.: Aufsätze, Reden und Briefe. Hrsg. von Karl Martin Schiller. 5 Bde. Meersburg 1929.

HG 1866-1889 Preußische Jahrbücher. • 18951896 Historische Zeitschrift.

L Schrader, Ludwig: Kurze Bemerkungen zu H. von T.s „Die Lösung der schleswig-holsteinischen Frage“. 4. Abdr. Kiel 1865. • Joël, Manuel: Offener Brief an Herrn Prof. H. von T. 8. unveränd. Abdr. Breslau 1879. Cassel, Paulus: Wider H. von T. für die Juden. 5. Aufl. Berlin 1880. - Neumann, Carl: Die Vorgeschichte der Berufung H. von T.s nach Heidelberg (1867) in: Historische Zeitschrift 139 (1929) S. 534-556; Bussmann, Walter: T. als Politiker in: ebd. (1954) Bd. 177, S. 249-279. • Professoren Kiel (1956) S. 143; Hoche (1969) S. 76 f. • Wolgast, Eike: Politische Geschichtsschreibung in Heidelberg ... in: Semper apertus 2 (1985) S. 186192. - Weber (1987) S. 606; Giesselmann (1992) S. 77-88; Fuhrmann (1996) S. 104, 107. • Wolgast,
Eike: Die Sicht des Alten Reiches bei T. und Erdmannsdörffer in: Imperium Romanum ... Hrsg. von Matthias Schnettger. Mainz 2002. S. 169-188. • Haunfelder, Bernd: Die liberalen Abgeordneten des Deutschen Reichstags 1871-1918 ... Münster 2004. S. 403 f. - Wölky, Guido: Roscher, Waitz, Bluntschli und T. als Politikwissenschaftler. Spätblüte und Untergang eines klassischen Universitätsfaches in der zweiten Hälfte des 19. Jahrhunderts. Diss. Bochum 2006. Kriegstagebuch K. Hampe (2007) S. 1002 (Register). Reichert, Folker: H. von T. in London in: Wege und Spuren. Festschrift für Joachim-Felix Leonhard. Hrsg. von Helmut Knüppel, Manfred Osten ... Berlin 2007. S. 307-320. - Wulf, Peter: „Unter Normalmenschen“": H. von T. an der Universität Kiel 1866/ 67 in: Forschungen zur brandenburgischen und preußischen Geschichte. Berlin 2008. Vol. 18.2. S. 171-194. • Über H. von T. in: Lönnecker, Harald: „Das Thema war und blieb ohne Parallel-Erscheinung in der deutschen Geschichtsforschung“. Die Burschenschaftliche Historische Kommission ... Eine Personen-, Institutions- und Wissenschaftsgeschichte. Heidelberg 2009. S. 30 f. u. o. Aly, Götz: Warum die Deutschen? Warum die Juden? Gleichheit, Neid und Rassenhass 1800-1933. Frankfurt/M. 2. Aufl. 2011. S. 352 (Register). $\bullet$ Geschichte U Berlin (2012) Bd. 1, S. 665 (Register). • Gerhards, Thomas: H. von T. Wirkung und Wahrnehmung eines Historikers im 19. und 20. Jahrhundert. Paderborn 2013. •Über H. von T. in: Verfassungsgeschichte des Alten Reiches. Hrsg. von Gabriele Haug-Moritz. Stuttgart 2014. S. 283 (Register). Katsch, Hildegard: H. von T. und die preussisch-deutsche Frage von 1860 bis 1866 . Ein Beitrag zur Entwicklung von T.s politischen Anschauungen. Frankfurt/M. (Universitätsbibliothek Johann Christian Senckenberg) 2016 (2 Mikrofiches). - Voigt, Sebastian: Erforderliche Reaktionen. Moritz Lazarus' Erwiderung auf H. von T.s „Unsere Aussichten“ (1879) und Bernard Lazares Auseinandersetzung mit Édouard Drumonts „La France Juive“ (1886) in: Open Peer Review-Publication series ,Nineteenth-Century Anti-Semitism in International Perspective“ (16. Dez. 2016), s. http://antisem19c.hypotheses.org/801 (abgerufen am 24. Sept. 2017).

P Bildarchiv UAH; graph. Slg. UBH. 


\section{Troeltsch, Ernst Peter Wilhelm}

1894-1915 Theol. Fak.

Systematische Theologie

* 17. Febr. 1865 Haunstetten (heute: Stadtteil von Augsburg)

$\dagger \quad$ o1. Febr. 1923 Berlin

ev.

V Dr. Ernst T. (1832-1917) Arzt, s. Troeltsch-Gesamtausgabe 19 (2014) S. 508 (Register)

M Eugenie geb. Köppel (1841-1914), s. ebd.

๑ 31. Mai 1901 Marta geb. Fick (1874-1947), s. ebd.

K 1 S, s. NDB 26 (2016) S. 433.

Lb 1883-1884 Militärdienstpflicht als EinjährigFreiwilliger.

Seit WS 1883/84 Studium u. a. der Logik, Philologie, Physik, Geschichte der Philosophie am Königl. Lyceum in Augsburg, seit Herbst 1884 u. a. Studium der Geschichte an U Erlangen, seit WS 1885/86 hauptsächlich Studium der Theologie, Geschichte an U Berlin, seit 1886 Göttingen, SS 1888 Erlangen.

Herbst 1888 I. (in Ansbach), Juni 1891 II. theol. Examen; 2. Dez. 1888 Ordination; Okt. 1888-Okt. 1889 Predigtamtskandidat am Prot. Seminar in München (1889-1891 für Habilitationsvorhaben beurlaubt).

U Göttingen: 14. Febr. 1891 Theol. Lizentiatenprüfung; 28. Febr. 1891 Habilitation für Kirchen- und Dogmengeschichte mit Berücksichtigung der Systematischen Theologie.

U Bonn: Seit 14. März 1892 a. o. Prof.

UH: 21. Nov. 1893 Ern. zum o. Prof. als Nachf. von Hans Hinrich Wendt; 24. April 1894 Vereidigung; 1894-1895 e. der Hauptlehrer am Ev.-Prot. Theol. Seminar; SS 1895 Aufteilung des Ev.-Prot. Theol. Seminars in Praktisch-Theol. Seminar und Wiss.Theol. Seminar: SS 1895-SS 1909 Lehrer am Praktisch-Theol. Seminar und SS 1895-WS 1914/15 Direktor der Systematischen Abt. am Wiss.-Theol. Seminar; SS 1909 auf eigenen Wunsch Entbindung von der Verpflichtung zur Abhaltung systematischer Übungen im Praktisch-Theol. Seminar, s. Brief des Ministeriums der Justiz, des Kultus und Unterrichts vom 29. Dez. 1908 in: UAH RA 6127; WS 1909/10-WS 1914/15 Lehrauftrag für Philosophie; 1914 Berufung an U Berlin. • In dieser Zeit:

Karlsruhe: 1909-1915 Mitglied der I. Kammer des Badischen Landtags als Vertreter der UH als Nachf. von Wilhelm Windelband.

H: Febr. 1912-März 1915 Stadtverordneter für Nationalliberale Partei.

U Berlin: SS 1915-1923 (†) o. Prof. für Religions-, Sozial- und Geschichtsphilosophie und christliche Religionsgeschichte an Phil. Fak. In dieser Zeit:

Berlin: 1919-1921 Abgeordneter in der Verfassunggebenden Preußischen Landesversammlung; März 1919-Sommer 1920 zunächst Unter-, anschl. Staatssekretär im Preußischen Ministerium für Wissenschaft, Kunst und Volksbildung.

1906/o7 Prorektor der UH; 1898/99, 1904/05, 1910/ 11 Dekan der Theol. Fak. der UH

1918 Mitbegründer des Volksbundes für Freiheit und Vaterland

1906 Geh. Kirchenrat

$E$ Mitglied der Akademie der Wissenschaften: 1909 H, 1912 Berlin, 1914 München. D. theol. der U: 1897 Göttingen, 1921 Oslo; 1903 Dr. phil. h.c. Greifswald; 1911 Dr. iur. h.c. Breslau. 1913 Ritterkreuz I. Klasse mit Eichenlaub des Ordens vom Zähringer Löwen.

Qu UAH PA 236o. - GLA Abt. 235, Fasz. 2599. • Briefe: UBH. $\bullet$ E. T. Briefe an Friedrich von Hügel: 1901-1923. Hrsg. von Karl-Ernst Apfelbacher, Peter Neuner. Paderborn 1974. • Dinkler-von Schubert, Erika: E. T. Briefe aus der Heidelberger Zeit an Wilhelm Bousset 1894-1914 in: Heidelberger Jahrbücher 20 (1976) S. 19-52. - Moretto, Giovanni: E. T. e il Modernismo in: Nuovi studi di filosofia della religione scritti di M. M. Olivetti ... Padua 1982. E. T.s Briefe an Heinrich Rickert. Hrsg. von 
Friedrich Wilhelm Graf in: Mitteilungen der E. T. Gesellschaft 6 (1991) S. 108-128. • E. T.s Briefe und Karten an Paul Wernle. Hrsg. von Friedrich Wilhelm Graf in: Zs. für neuere Theologiegeschichte 2 (1995) S. 85-147. - E. T. Briefe I. (1884-1894). Briefe II (1894-1904). Briefe III (1905-1915). Hrsg. von Friedrich Wilhelm Graf ... Berlin 2013-2016. (E. T. Kritische Gesamtausgabe. 18.-20.) - Nachlaß: Bundesarchiv Koblenz.

$W$ Die Absolutheit des Christentums und die Religionsgeschichte. Tübingen 1902. - Die Bedeutung des Protestantismus für die Entstehung der modernen Welt. München 1911. • Die Soziallehren der christlichen Kirchen und Gruppen. Tübingen 1912. 3. Aufl. 1923. • Der Historismus und seine Probleme. Tübingen 1922. $\bullet$ E.-T.-Bibliographie. Hrsg. ... von Friedrich Wilhelm Graf und Hartmut Ruddies. Tübingen 1982. * The Christian faith. Based on lectures delivered at the University of Heidelberg in 1912 and 1913 ... Ed. by Gertrud von le Fort ... Reprint von 1991. Minneapolis 2010. • E. T. Lesebuch. Ausgewählte Texte. Hrsg. von Friedemann Voigt. Tübingen 2003. - E.T. Kritische Gesamtausgabe. 20 Bde. Berlin u.a. 1998-2016. Siehe auch BBKL XII (1997).

$L$ Catalogus prof. Gottingensium (1962) S. 45; Verzeichnis Bonn (1968) S. 315. • Troeltsch-Studien. Untersuchungen zur Biographie und Werkgeschichte. Hrsg. von Horst Renz und Friedrich Wilhelm Graf. Gütersloh 1982. • Tödt, Heinz-Eduard: Max Weber und E. T. in Heidelberg in: Semper apertus 3 (1985) S. 215-258. - Drescher, HansGeorg: E. T. Leben und Werk. Göttingen 1991 (mit Bibliogr.). - Jansen (1992) S. 413 (Register); Ders. (1992a) S. 170 (Register); Album Professorum der Ev.-Theol. Fakultät Bonn (1995) S. 204-207 u. ö.; Fuhrmann (1996) S. 260, 265; BBKL XII (1997) Sp. 497-562. - E. T. zwischen Heidelberg und Berlin. Hrsg. von Horst Renz. Gütersloh 2001. • E. T. in
Nachrufen. Hrsg. von Friedrich W. Graf. Gütersloh 2002. - TRE 34 (2002) S. 130-143. - Theologische Fakultäten an staatlichen Universitäten in der Perspektive von E. T., Adolf von Harnack und Hans von Schubert. Hrsg. von Hartmut Kress ... Waltrop 2004. - Asketischer Protestantismus (2005) S. 185-200 u. ö. Schwarz, Hans: Theology in a global context. The last two hundred years. Grand Rapids (Michigan) 2005. S. 588 (Register). „Geschichte durch Geschichte überwinden“. E. T. in Berlin. Hrsg. von Friedrich W. Graf. Gütersloh 2006. Personenlexikon zum dt. Protestantismus (2006) S. 93; Kriegstagebuch K. Hampe (2007) S. 1002 (Register). - Sato, Shinichi: Die historischen Perspektiven von E. T. Waltrop 2007. Harant, Martin: Religion - Kultur - Theologie. Eine Untersuchung zu ihrer Verhältnisbestimmung im Werke E. T.s und Paul Tillichs im Vergleich. Frankfurt/M. 2009. - Hauptwerke der Systematischen Theologie. Hrsg. von Rebekka A. Klein ... Tübingen 2009. S. 188-206. - Andersen, Svend: Macht aus Liebe. Zur Rekonstruktion e. luth. politischen Ethik. Berlin 2010. S. 212 ff. • Díaz Cano, Eduardo: Tabula rasa. E. T. y sus escritos iniciales. Madrid 2010. Nix, Echol: E. T. and comparative theology. New York 2010. - WBIS; Badische Biographien N.F. VI (2011) S. 405-409; Geschichte U Berlin (2012) Bd. 1, S. 665 (Register). • Graf, Friedrich Wilhelm: Fachmenschenfreundschaft. Studien zu T. und Weber. Berlin 2014; Ders.: „Nach der Mobilmachung“. E.T.s Sinndeutung des Krieges für Stadt und Universität in: UH während des Ersten Weltkriegs (2017) S. 77-98. - NDB 26 (2016) S. 433 f.; Deutsche Biographie, s. https://www. deutsche-biographie.de/pnd118624024.html [21.12. 2017]. - Siehe auch Mitteilungen der E. T. Gesellschaft unter: http://www.st.evtheol.uni-muenchen. de/troeltsch/mitteilungen/index.html.

$P$ Bildarchiv UAH; graph. Slg. UBH. 


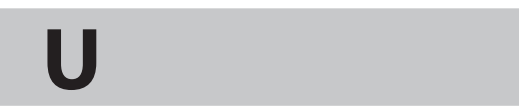

Ubisch, Gerta von

siehe Ubisch, Gertrud von

\section{Ubisch, Gertrud (Gerta) von}

1923-1935 (1936) Nat.-Math. Fak.

Botanik, Vererbungslehre

* 03. Okt. $1882 \mathrm{Metz}$ (Lothringen)

$\dagger$ 31. März 1965 Heidelberg

ㅁ Marburg

ev.

V Dr. Edgar von U. (1848-1927) Berufsoffizier, 1895-1911 Direktor der Ruhmeshalle und des Zeughauses Berlin, s. Kriegserinnerungen e. preußischen Offiziers 1870/71. Berlin 1896. 2. Aufl. 1915 (Autobiogr.); WBIS; Herkenhoff, Michael: Die Sammlung Kriegsbriefe der Universitäts- und Landesbibliothek Bonn (2012/ 13), s. https://www.ulb.uni-bonn.de/de/die-u $\mathrm{lb} /$ publikationen-veranstaltungen/publikatio nen-zur-ulb/dokumente/sammlungen-kriegs briefe; Hettwer (2016) S. 2 (P)

M Anna geb. Goldschmidt (1853-1924), s. Hettwer, S. $2(P)$

$\varnothing$ unverheiratet

Vw Großonkel: (siehe) Levin Goldschmidt

Vw Bruder: Leopold von U. (1886-1965) seit 1927 o. Prof. für Zoologie (Entwicklungsphysiologie) an U Münster, 1935 Emigration nach Norwegen, bis 1940 und nach 1945 Wissenschaftler am Meeresbiolog. Inst. Bergen, s. Kürschner (1961) S. 2130, Heiber II,2 (1994) S. 707-714, Huhn/Kilian (2011) S. 191f. u. ö.; Hettwer, Elisabeth-Maria: Zum Gedenken an L. von U. in: flurgespräche - Universität Münster, s. http:// www.flurgespraeche.de/wp-content/uploads/ 2016/o8/Gedenkblatt_von-Ubisch-Leopold. pdf (2016) (P); Deutsche Biographie, https:// www.deutsche-biographie.de/pnd117249335. html [21.12. 2017].
Lb SS 1904 Studium der Naturwiss. an UH, seit WS 1904/05 Freiburg/Br., seit WS 1905/06 Berlin, anschl. Straßburg; 15. Febr. 1911 Dr. phil. nat. an U Straßburg.

1912-1913 Assistentin an Landwirtschaftl. Hochschule in Berlin-Potsdam; Assistentin am KaiserWilhelm-Inst. für Biologie: SS 1914 Münster, SS 1915 Berlin-Dahlem.

1916-1919 u. a. Saatzuchtleiterin auf Gut Eckendorf in Leopoldshöhe-Schuckenbaum (bei Bielefeld), Gut Falkenrehde bei Potsdam, Gutshaus in Petkus (heute: Ortsteil von Baruth/Mark); April 1919Nov. 1920 Assistentin am Inst. für Vererbungsforschung an Königl. Preussischer Landwirtschaftl. Hochschule in Berlin.

UH: April 1921-April 1933 Assistentin am Botanischen Inst.; 3. März 1923 Habilitation für Botanik und Vererbungslehre; seit 25. Febr. 1929 nichtplanm. a. o. Prof.; WS 1931/32, SS 1932 Lehrauftrag für Vererbungslehre; 6. April-28. April 1933 (Aufhebung) Beurlaubung durch Ministerialerlass; seit Sommer 1933 Tätigkeit im Laboratorium der U Utrecht; seit Sommer 1934 Stipendiatin an U Zürich; Dez. 1934 Ruf als Abt.-Leiterin an Butantan-Inst. in Brasilien; Jan. 1935-Jan. 1936 auf eigenen Antrag für 1 Jahr von U beurlaubt; Febr. 1935 Auswanderung nach Brasilien; 20. Febr. 1936 Streichung ihres Namens im Vorlesungsverzeichnis, da länger als 1 Jahr von U beurlaubt.

Brasilien: Anfang 1935-1938 (Entlassung) Abt.Leiterin am Butantan-Inst. für Vererbungslehre in São Paulo; Annahme der brasilianischen Staatsbürgerschaft; 1939 Mitarbeiterin am Zentrum für landwirtschaftliche Forschung in Rio de Janeiro; seit 1940 Aufenthalt in Rolândia (Bundesstaat Paraná); 1941 Rückkehr nach São Paulo; 1941-1946 von U. lebt von Erspartem und gibt Privat-Unterricht.

Norwegen: Seit Okt. 1946 Wohnsitz in Paradis (bei Bergen) bei ihrem Bruder Leopold.

H: Seit Mai 1952 Wohnsitz; 1. Juli 1953 Zusage e. „jederzeit widerruflich laufenden [finanziellen] Unterstützung" ohne Rechtsanspruch von U; seit 
April 1954 deutsche Staatsbürgerin; seit 1. Juni 1956 (rückwirkend seit 1. Jan. 1954) Auszahlung des Ruhegehalts e. beamteten Dozentin a. D.

G. von U. ist die erste habilitierte Frau an einer badischen Universität und die erste Professorin der Universität Heidelberg (erste Heidelberger Ordinaria ist 1959 Margot Becke geb. Goehring (19142009), s. Drüll (2009) S. 99 f.).

Qu UAH PA 6130. - Mitteilungen von Familienangehörigen. - Aus dem Leben einer Hochschuldozentin in: Mädchenbildung und Frauenschaffen. Jg. 6, H. 10, S. 413-422, Jg. 6, H. 11, S. 498-507, Jg. 7, H. 1, S. 35-45. Hamburg 1956-1957. (Autobiogr.) • Zwischen allen Welten. Die Lebenserinnerungen der ersten Heidelberger Professorin G. von U. Hrsg. von Susan Richter ... Ostfildern 2011.

$W$ Schwingungszahl und Dämpfung im leuchtenden und nichtleuchtenden Na-Dampfe. Leipzig 1911. Beeinflussung der Heterostyliemerkmale von Oxalis stricta durch Ustilago Oxalidis. Amsterdam 1935 .

L Kürschner (1931) Sp. 3059. - Steiner, Gerolf: G. von U. † in: Ruperto Carola 17. Jg., Bd. 37 (1965) S. 174. - Mussgnug (1988) S. 239-243 u.ö. • Baader, Meike, Jansen, Christian: Das Heiligtum mag keine Priesterin. Der Lebensweg G. von U.s ... in: Rhein-Neckar-Zeitung vom 14./15./16. April 1990, Nr. 87, S. 49. • Deichmann (1992) S. 303-309; Jansen (1992a) S. 170 (Register); Frauen im dt. Südwesten (1993) S. 256-262; Heidelberg im Schnittpunkt intellektueller Kreise (1995) S. 445-460. • Saidel, R. G., Plonski, G. A.: How scientists fleeing Nazi Europe contributed to Brazil's new universities in 1933-1945 in: Ibero-Amerikanisches Archiv (Zs. für Sozialwissenschaften und Geschichte). Berlin 1995. Jg. 21. H. 1-2. S. 169-190. * Fischer, Gudrun: Rausgeschmissen und zurückgekehrt ... in: Koryphäe - Medium für feministische Naturwissenschaft und Technik. Oldenburg (Nov. 1998) Nr. 24. S. 2-8. - Baden-Württ. Biographien III (2002) S. 423 f.; UH im Nationalsozialismus (2006) S. 1274 (Register); „Aller Männerkultur zum Trotz“ (2008) S. 354 (Register); Wissenschaft als weiblicher Beruf? (2008) S. 22-29. - Darwins Schwestern. Porträts von Naturforscherinnen und Bio- loginnen. Hrsg. von Gudrun Fischer. Berlin 2009. Lexikon jüdischer Einwohner Hs (2011) S. 422 f. $\bullet$ Zwischen allen Welten. Die Lebenserinnerungen der ersten Heidelberger Professorin G. von U. Hrsg. von Susan Richter ... Ostfildern 2011. S. 225-300 u. ö. Richter, Susan, Pirl, Uwe: G. von U. Physikerin und Botanikerin in: Lebensbilder aus Baden-Württemberg ... Stuttgart 2013. Bd. 24. S. 384-406. Hettwer, Elisabeth-Maria: Zum Gedenken an Leopold von Ubisch in: flurgesprächeUniversität Münster, s. http://www.flurgespraeche. de/wp-content/uploads/2016/o8/Gedenkblatt_ von-Ubisch-Leopold.pdf (2016) S. $8(P)$. • Deutsche Biographie, s. https://www.deutsche-biogra phie.de/pnd119367793.html [21.12.2017].

$P$ Bildarchiv UAH; Ruperto Carola.

\section{Uhlig, Gustav}

1872-1877 Phil. Fak.

1877-1914 (Honorar-Prof.) Phil. Fak.

Klassische Philologie

* o9. Juli 1838 Gleiwitz/Schlesien (heute: Gliwice, Polen)

$\dagger$ 14. Juni 1914 Schmiedeberg/Riesengebirge (heute: Kowary, Polen)

$\square$ Heidelberg ev.

V Carl U. (†1857) Architekt, seit 1844 Regierungs-Baurat

M Auguste geb. N. N. (†1880)

œ Sommer 1870 Hedwig geb. Maresch

K mindestens 2 S: u.a. Carl U. (1872-1938) seit 1900 Vorstand des metereolog. Dienstes von Deutsch-Ostafrika und von dessen Landesaufnahme (u.a. Erforschung des Kilimandscharo), seit 1908 Privat-Dozent Berlin, 1910-1937 o. Prof. für Geographie Tübingen, s. Jaeger, Fritz: C.U. zum Gedächtnis in: Geographische Zeitschrift (1938) Bd. 44, Nr. 11, S. 401408; WBIS, Deutsche Biographie, https://www. deutsche-biographie.de/pnd117279730.html [21.12.2017]. 
Lb Seit WS 1855/56 Studium an U Bonn, seit SS 1858 Berlin; 1860-1864 Eigenstudien; 1. März 1862 Dr. phil. an U Berlin.

U Zürich: Sommer 1864 Habilitation; WS 1864/65 Vorlesungsbeginn; 1869-1872 a.o. Prof.; 1869/70 Beurlaubung für e. Studienreise nach Italien und Griechenland. • In dieser Zeit:

Zürich: Jan. 1865-1866 Zunächst vertretender, dann hauptamtlicher Lehrer am Gymnasium.

Aarau (Kanton Aargau): 1866-1872 Prof. an Kantonsschule.

H: 27. April 1872-31. Aug. 1899 (auf eigenen Antrag Pensionierung, s. hierzu Briefe vom 1. Sept. 1899 und von Herbst 1900 in: UAH PA 2367) Direktor des Lyceums (seit April 1894 Gymnasium; heute: Kurfürst-Friedrich-Gymnasium „KFG“). • In dieser Zeit:

UH: 9. Aug. 1872 Ern. zum a. o. Prof.; 30. Juli 1877 Ern. zum Honorar-Prof.; WS 1877/78-SS 1914 Lehrauftrag für Gymnasialpädagogik und gymnasialpädagog. Übungen mit e. Honorar von 40o.- Mark, seit WS 1886/87 von 750.- Mark pro Semester; Studienreisen in Semesterferien: 1885 Frankreich und England, 1887 Schweden und Norwegen, 1889 Dänemark, Winter 1894/95 Italien, Ägypten, Palästina und Kleinasien; Nov. 1898 Ruf als Leiter der Königl. Preußischen Landesschule in Pforta abgelehnt; 6. Dez. 1898 Ern. zum o. Honorar-Prof.; WS 1899/1900 und SS 1900 Beurlaubung für „Studien in italienischen Bibliotheken und Schulen, auch in den dort neu organisierten Realschulen“ (aus: PA 2367); SS 1914 letzte Vorlesungsankündigungen u.a. über Ratschläge für Unterricht und Erziehung in höheren Schulen, Encyklopädie der klassischen Philologie und über Leben und Werke der bedeutendsten klassischen Philologen seit der Renaissance; Anfang Juni 1914 tödliche Erkrankung während e. Verwandtenbesuchs in Schmiedeberg.

1896 Geh. Hofrat
E 1872 Ritterkreuz I. Klasse des Ordens vom Zähringer Löwen; 1890 Ritterkreuz des Königl. Schwedischen Nordsternordens; 1891 Königl.-Preußischer Kronenorden III. Klasse; 1896 Ritterkreuz des Ordens Berthold I.

Qu UAH PA 2367; RA 6855; Quästurakte Rep. 271325. GLA Abt. 235, Fasz. 2605, 13407-13410. • Briefe: UBH.

$W$ Dionysii Thracis ars grammatica qualem exemplaria vetustissima exhibent ... Leipzig 1883. • Die Heidelberger Erklärung in Betreff der humanistischen Gymnasien Deutschlands ... Heidelberg 1888. Die Einheitsschule mit lateinlosem Unterbau. Heidelberg 1892. Hinz, Vinko: De C. Zangemeisteri vocibus singularibus. Ein Heidelberger Iocosum aus der Feder von G. U. [1887] in: Gymnasium. Zs. für Kultur der Antike und humanistische Bildung (2013) Bd. 120, S. 489-499. - Siehe auch Das „Goldene Buch“ des KFG (1994) S. 92 f.

G, (M)HG 1890-1914 Das humanistische Gymnasium. Zs. für Kultur der Antike und humanistische Bildung (seit 1937 u.d. T.: Gymnasium. Zs. für Kultur der Antike ... ).

MHG Grammatici Graeci. Apollonii Dyscoli quae supersunt ... 3 Bde. Leipzig 1878-1910. Nachdr. 1965.

L Gymnasium zu Heidelberg. Jahresbericht über das Schuljahr 1896-97. Heidelberg 1897. S. 12-16. • Grünwald, Eugen: G.U. in: Das humanistische Gymnasium (1914) 25. Jg., S. 83-103. • Wer ist's (1914) S. 1739; WBIS. • Lenhart, Volker: Die Pädagogik als wiss. Disziplin an der Ruprecht-KarlUniversität Heidelberg 1803-1970 in: Heidelberger Jahrbücher 15 (1971) S. 159, 166 Anm. 57. • Albisetti, James C.: Secondary School Reform in Imperial Germany. Princeton (New Jersey) 1983. S. 364 (Register). • Das „Goldene Buch“ des KFG (1994) S. 92 f.; Deutsche Biographie, s. https:// www.deutsche-biographie.de/pnd117279641.html [21.12.2017].

$P$ Bildarchiv UAH; graph. Slg. UBH. 


\section{Ullmann, Carl Christian}

1819-1829 Theol. Fak.

Neutestamentliche Exegese

1836-1853 Theol. Fak.

Historische und Exegetische Theologie, Dogmatik, Neues Testament

* 15. März 1796 Epfenbach (bei Sinsheim)

$\dagger$ 12. Jan. 1865 Karlsruhe ref.

V Johann Balthasar U. (1764-1846) Pfarrer

M Johanna Charlotta Margaretha geb. Reimold verw. Lorey (1759-1835)

$\infty$ 16. Okt. 1823 Hulda Emma Gisela geb. Mereau (1797-1832) P: Brustbild in Pastell, ca. 1820 von Christian Xeller gemalt (Staatliche Kunsthalle Karlsruhe). - T von Sophie Friederike geb. Schubart gesch. Mereau verh. Brentano (17701806) Dichterin, s. Hammerstein, Katharina von: Sophie Mereau-Brentano. Freiheit - Liebe - Weiblichkeit. Trikolore sozialer und individueller Selbstbestimmung um 1800. Heidelberg 1994. - Stief-T von Clemens Brentano (1778-1842) Dichter, s. NDB 2 (1955) S. 589593; Feilchenfeldt, Konrad: Brentano-Chronik. Daten zu Leben und Werk. München 1978; BBKL XV (1999) Sp. 319-325; Ludwig Achim von Arnim. Briefwechsel 1805-1806. Hrsg. von Heinz Härtl ... Berlin 2011. T. 2. S. 1105 (Register).

(26. April 1835 Thekla Caroline geb. Freiin von Teuffel von Birkensee (180o-1881)

$\mathrm{K} \quad 2 \mathrm{~T}$ (davon $1 \mathrm{~T}$ früh $\dagger$ ), $2 \mathrm{~S}$ : Dr. iur. Carl U. (1824-1901), u.a. Regierungs- und Verwaltungsgerichts-Rat, s. Badische Biographien 5 (1906) S. 779 f. - Hugo U. (1827-1916), u.a. seit 1851 Pfarrer im Diakonissenmutterhaus in Karlsruhe, 1856-1898 (Ruhestand) Pfarrer in Söllingen (heute: Ortsteil von Pfinztal), s. TeilNachlaß im Archiv der Ev. Landeskirche in Baden, Karlsruhe (im Nachlaß von Karl Ludwig Bender, Oberkirchenrat).

Lb Seit 24. Okt. 1812 Studium der Theologie an UH, seit 3. Jan. 1814 Tübingen; Sommer-Spätherbst 1815 Unterbrechung des Studiums wegen e. Brustleidens; Okt. 1816 theol. Examen in Karlsruhe; 12. Jan. 1817 Ordination in Epfenbach.
Kirchheim (heute: Stadtteil von H): 28. Dez. 1816 Berufung zum Vikar.

UH: Seit Ende 1817 Eigenstudien in Philosophie, auch Theologie (Immatrikulation an UH nicht belegt, weder durch Toepke, noch durch Verzeichnis der Studierenden); 25. März 1819 Dr. phil.; anschl. mehrmonatige Reise nach Nord- und Mitteldeutschland, auch nach Berlin; WS 1819/20 Erlaubnis, exegetische Vorlesungen zu halten unter der Bedingung, sich im Laufe dieses Semesters auch zu habilitieren; 15. März 1820 Habilitation für Theologie; Okt. 1820 Bewilligung e. Jahres-Gratifikation von 400.- Gulden (auch rückwirkend) für den Zeitraum 23. April 1820-23. April 1821; 14. Juni 1821 Ern. zum a. o. Prof. mit e. jährl. Besoldung von 400.- Gulden; Aug. 1821 gescheiterte Planung (gemeinsam mit Friedrich Umbreit) e. Biblisch-Exegetischen Seminars mit zwei Abt.: Neutestamentl. (Direktor: Ullmann) und Alttestamentl. (Direktor: Umbreit) durch Einspruch von (siehe) Eberhard Paulus; Ablehnungen: Mai/Juni 1823 Verleihung der Pfarrei Weinheim, 1825 Ruf an Predigerseminar in Wittenberg; 11. Jan. 1826 einmalige Gratifikation von 150.- Gulden; 13. April 1826 Ern. zum o. Prof. mit e. Besoldungszulage von 300.- Gulden; 6. Sept. 1827 Bewilligung des U.schen Gesuchs durch Kurator der U, August Heinrich Froehlich, „statt der ... angekündigten synoptischen Erklärung der 3 ersten Evangelisten, die Dogmatik vortragen zu dürfen“ (aus: Brief vom 6. Sept. 1827 in: UAH PA 2369); 7. Jan. 1828 U. stellt Antrag auf Übertritt von Pfarrwitwenkasse auf Zivildiener-Witwenkasse; Antrag wird zusammen mit e. 6-seitigen, den Antrag unterstützenden Brief des Dekans der Theol. Fak., Friedrich Heinrich Christian Schwarz, an Kurator Froehlich geschickt, s. hierzu Brief vom 17. Jan. 1828 in: PA 2369; Kurator lehnt Gesuch „bei den klaren Bestimmungen der Civildiener Wittwe Casse Ordnung" ab, s. ebd.; 15. März 1829 Kurator Froehlich bedauert Weggang U.s, denn „seine Thätigkeit, sein ausgezeichnetes wissenschaftliches Streben und sein untadelhaftes öffentliches und Privatleben (hat man) anerkannt und zu würdigen gewußt"; man bedauert, „daß die ökonomischen Verhältnisse nicht gestattet hätten, ihm ähnliche Anerbietungen zu machen, wie solche ihm von auswärts zugekommen seien und 
ihn dadurch dem Vaterland und der Hohen Schule zu erhalten“ (aus: Brief vom 15. März 1829 in: PA 2369).

U Halle/S.: 15. Jan. 1829 Ern. zum o. Prof.; 16. Sept. 1836 Weggang, s. hierzu $Z$.

UH: 10. März 1836 Genehmigung Großherzog Leopolds zur Berufung U.s als o. Prof. der „Theologischen und Philosophischen Facultät" (aus: UAH RA 6718 fol. 5v) mit e. Jahresgehalt von 2400.- Gulden, „Aufnahme in die weltliche Wittwenkasse und die gesetzmäßige Pension für seine Wittwe und Kinder nach dem Diener-Edikt und e. Reisegeld von 525.- Gulden“ (aus: Brief des Ministeriums des Innern vom 16. Febr. 1836 in: PA 2369; U. lehrt nur an Theol. Fak.); 10. Mai 1836 U. nimmt Ruf an; WS 1836/37 Vorlesungsbeginn; 31. März 1838 [!] Vereidigung (und Abschrift der Eidesformel, s. PA 2369); 4. Jan. 1842 Ministerium des Innern bedauert, wenn U. den an ihn ergangenen Ruf an U Bonn mit e. Jahresgehalt von 160o.- Reichstalern annähme („die Verhältnisse der Universität Heidelberg gestatten nicht, ihm in pekuniärer Hinsicht Gleiches wie in Bonn zu bieten“), s. hierzu PA 2369; Mitte Jan. 1842 Ruf an U Bonn abgelehnt.

Karlsruhe: 19. Aug. 1853 (Verleihung der Würde)1. Jan. 1861 (Enthebung des Amtes auf eigenen Antrag) Prälat der Vereinigten Ev.-prot. Kirche im Großherzogtum Baden mit e. Gehalt von 1000.Gulden, s. hierzu Brief des Ministeriums des Innern in: PA 2369; seit 19. Aug. 1853 Mitglied des Ev. Oberkirchenrats mit e. Besoldung von 2500.Gulden; 18. Dez. 1856-1. Jan. 1861 (Enthebung auf eigenen Antrag) Direktor des Ev. Oberkirchenrats, s. hierzu Pfisterer (2014) S. 87-106.

1840 Prorektor der UH; 1837, 1840, 1844, 1848, 1852 Dekan der Theol. Fak. der UH

$Z$ 16. Febr. 1836: Ministerium des Innern ermächtigt den Heidelberger Theologieprofessor Friedrich Umbreit, Ullmann in Halle/S. die Professur für Historische und Exegetische Theologie an Universität Heidelberg durch Privatkorrespondenz anzubieten, s. hierzu UAH PA 2369.
1849 Mitbegründer des Badischen Landesvereins für Innere Mission in Karlsruhe-Durlach, s. hierzu Pfisterer (2014) S. $83 \mathrm{f}$.

1836 Großherzogl. Kirchenrat; 1844 Großherzogl. Geh. Kirchenrat

Zur Witwenkasse, -pension, Hinterbliebenenbeihilfe etc., siehe auch Johann Hermann Vossmann, Leopold Weiß, Gerhard Weissenfels, Peter Friedrich Wund

$E 1829$ D. theol. UH. 1842 Ritter des Ordens vom Zähringer Löwen.

Qu UAH PA 2369; RA 6140, 6718 fol. 5v, 6r; Fak.Akte H-IV-102/14 fol. 41r-49r. - GLA Abt. 205, Fasz. 528. Briefe: UBH; siehe auch Kalliope. Vincent, Jean Marcel: Zu Leben und Wirken des späten Wilhelm Gesenius. 10 unveröffentlichte Briefe aus den Jahren 1837-1843 von Gesenius, Eduard Reuss, C. U. und Carl Umbreit. Hermannsburg 1996. - Der Redaktionsbriefwechsel der Hallischen, Deutschen und Deutsch-Französischen Jahrbücher 1837-1844. Hrsg. von Martin Hundt. Bd. 1: Der Briefwechsel um die Hallischen Jahrbücher. Berlin 2010. Apparat: S. 279 (Register). • Teil-Nachlaß: UBH; Archiv der Ev. Landeskirche in Baden, Karlsruhe (im Nachlaß von Karl Ludwig Bender, Oberkirchenrat, s. hierzu Schnaiter, Walter: Der Nachlaß von Oberkirchenrat Karl Ludwig Bender ... mit e. Teilnachlass von ... C. U. im Landeskirchlichen Archiv in: Jahrbuch für badische Kirchen- und Religionsgeschichte. Stuttgart 2011. S. 285-295); im Besitz von Herrn Diplom-Ingenieur Uli Mayer-Ullmann, Karlsruhe.

$W$ Gregorius von Nazianz, der Theologe. Darmstadt 1825. 2. Aufl. 1867. - Reformatoren vor der Reformation. 2 Bde. Hamburg 1841-1842. 2. Aufl. 1866. - Die Sündlosigkeit Jesu. Hamburg 1842. 7. Aufl. 1863. Das Wesen des Christentums. Hamburg 1845. 5. Aufl. 1865.

MG, $M H G$ 1828-1865 Theologische Studien und Kritiken (zus. mit Friedrich Umbreit).

$L$ Wechmar (1846) S. 253; ADB 39 (1895) S. 196200; Biogr. Jahrbuch 1 (1914-1916) S. 316; Arnim 2 
(1952) S. 696; RGG $6\left({ }^{3} 1962\right)$ Sp. 1112; WBIS. • Henß, Walter: Richard Rothe und Karl U., ihr späteres Verhältnis beleuchtet aufgrund von Briefen Rothes in: ZGORh 122. Jg. (1974) S. 311-330. - Pfisterer, Hans: C. U. ... Sein Weg zur Vermittlungstheologie. Karlsruhe 1977. - BBKL XII (1997) Sp. 864876 (Literatur-Ergänzung: 2011). - Ackermann, Helmut: Prälat Dr. C. U. Sohn der Gemeinde Epfenbach. Düsseldorf 2006. Wischmeyer (2008) S. 89, 91, 119. - Steiger, Johann Anselm: „einen ... unpartheyischen Lehrer der kirchlichen Dogmatik“. Ein Brief des reformierten Karlsruher Kirchenmannes Johann Ludwig Ewald (1748-1822) an C. U. ... in: Jahrbuch für badische Kirchen- und Religionsgeschichte. Stuttgart 2011. S. 41-55. • Pfisterer, Hans: C. U. ... Vom Pfarrersbub aus dem kurpfälzischen Odenwald zum badischen Prälaten. Romantik und "positive Vermittlung“ in Theologie und Kirche. Heidelberg 2014. • Leppin, Volker: Transformationen. Studien zu den Wandlungsprozessen in Theologie und Frömmigkeit zwischen Spätmittelalter und Reformation. Tübingen 2015. S. 540 (Register). Catalogus prof. Halensis online (Dez. 2017 in Vorbereitung).

P Bildarchiv UAH; graph. Slg. UBH.

\section{Ulmer, Eugen Richard Karl}

1930-1946, 1946-1955 Jur. Fak.

1934 Wirtschaftswiss. Fak.

1935-1946 Staats- und Wirtschaftswiss. Fak.

Dt. und Ausländisches Privatrecht, Handels-,

Wechsel- und Arbeitsrecht

* 26. Juni 1903 Stuttgart

$\dagger \quad$ 26. April 1988 Heidelberg

ev.

V Dr. h.c. Richard U. (1871-1962) Verlagsbuchhändler, s. Schroeder (2010) S. 486 Anm. 496, NDB 26 (2016) S. 579

M Lilly geb. Hedinger (1882-1969)

$\infty$ 9. Sept. 1929 Elisabeth geb. Linser (1906-1986), s. auch Brief vom 6. März 1952 in: UAH PA 6142; Briefe: UBH
K 1 T, 2 S: Peter U. $\left({ }^{*} 1933\right)$ 1975-2001 o. Prof. für Rechtswiss. H, s. Drüll (2009) S. 629f., NDB 26 (2016) S. 580*. Roland U. $\left.{ }^{*} 1937\right)$ 1961-2007 Leiter des Eugen Ulmer-Verlags Stuttgart, 1970 Mitbegründer der UTB-Verlagsgesellschaft, 1998-2001 Vorsteher des Börsenvereins des Dt. Buchhandels, s. NDB, S. $580^{*}$.

Lb Seit SS 1921 Studium an U Tübingen, anschl. Berlin; Herbst 1924 I. jur. Staatsexamen in Tübingen.

Herbst 1924-Herbst 1927 Referendar in Stuttgart; 1926 Dr. iur. an U Tübingen; Herbst 1927 II. Staatsexamen in Stuttgart; SS 1928 Assistent an Jur. Fak. der U Berlin.

Stuttgart: Herbst 1928-Sommer 1929 Rechtsanwalt. • In dieser Zeit:

U Tübingen: WS 1928/29-SS 1929 Assistent an Volks- und Wirtschaftswiss. Fak.; 28. Dez. 1928 Habilitation für Dt. Recht, Bürgerliches Recht, Handelsrecht.

U Rostock: 1. Okt. 1929-30. Sept. 1930 o. Prof. für Dt. Recht, Arbeitsrecht, Bürgerliches Recht, Dt. Rechtsgeschichte, Dt. und Mecklenburgisches Privatrecht, Handelsrecht, Seerecht, Wechselrecht an Rechts- und Wirtschaftswiss. Fak.

UH: 4. Juli 1930 Ern. zum WS 1930/31 o. Prof. und (Mit-)Direktor des Inst. für Ausländisches Recht (Sept. 1940 Umbenennung in Inst. für Auslandsund Völkerrecht) als Nachf. von Karl Heinsheimer; seit Mai 1934 auch Mitglied der neuerrichteten Wirtschaftswiss. Fak. nach Auflösung der Handelshochschule 1933 in Mannheim, Jan. 1935 (Umbenennung)-8. Jan. 1946 der Staats- und Wirtschaftswiss. Fak.; Rufe an U abgelehnt: März 1940 Breslau, Ende 1941 Hamburg, Jan. 1944 Bonn; 1. Mai 1941-1945 (mit zeitweiligen Arbeitsurlauben, s. hierzu $Z$ (2)) Kriegsdienst (9. Aug. 1945 Entlassung als "Gefolgschaftsmitglied der Universität Heidelberg bei der Wehrmacht bei besonderem Einsatz“, s. UAH PA 6141); 8. Jan. 1946 Entlassung gemäß Erlaß der amerikanischen Militärregierung; 23. April 1946 Erlaubnis der Militärregierung zur Wiederaufnahme der ,amtlichen Tätigkeit“, $s$. PA 6141; 7. Juli 1947 Genehmigung zur Teilnahme 
an Doktor-, Referendar- und Diplomprüfungen durch Präsidenten des Landesbezirks Baden, Abt. Kultus und Unterricht in Karlsruhe, Dr. Heinrich Köhler (1878-1949); 24. April 1946 Wiederaufnahme seiner Vorlesungen, s. hierzu PA 6141; 19. März 1948 Wiedereinstellung in öffentl. Dienst unter Berufung in Beamtenverhältnis auf Widerruf als planm. o. Prof. durch Köhler; 22. Juli 1950 Berufung in Beamtenverhältnis auf Lebenszeit; Sept. 1953-Jan. 1954 Research Fellow und Lecturer an Law School der U of Ann Arbor (Michigan).

U München: 1. April 1955-1. April 1970 o. Prof. und Direktor des Inst. für Gewerblichen Rechtsschutz und Urheberrecht; 1957-1965 außerdem Leiter des Inst. für Ausländisches und Int. Patent-, Markenund Urheberrecht; 1958 Gast-Prof. an Law School der $U$ of Ann Arbor. • In dieser Zeit:

München: 1965-1. Juli 1973 Begründer und MitDirektor des Max-Planck-Inst. für Ausländisches und Int. Patent-, Urheber- und Wettbewerbsrecht.

\section{H: Seit Frühjahr 1986 Wohnsitz.}

1931/32, Nov. 1933-März 1934, Okt. 1939-April 1945, Okt. 1951-Juli 1952 Dekan der Jur. Fak. der UH

$Z$ (1) Pfingsten 1938 erhält U. die Genehmigung zur Teilnahme am Kongreß der Int. Vereinigung für Gewerblichen Rechtsschutz in Prag. Vor Antritt seiner Reise erhält er nachfolgende Anweisung: „... Der Herr Reichsminister der Justiz [Franz Gürtner (1881-1941)], in dessen Händen die Federführung für den Kongreß liegt, hat den Ministerialdirektor Dr. [Erich] Volkmar [18791951] zum Leiter der deutschen Kongreß-Abordnung bestellt. Ich ersuche dem Professor Ulmer aufzugeben, sich unverzüglich mit Herrn Ministerialdirektor Dr. Volkmar in Verbindung zu setzen und dessen Anordnungen und Wünschen als Führer der deutschen Abordnung nachzukommen, damit ein geschlossenes und wirkungsvolles Auftreten der deutschen Abordnung auf dem Kongreß gewährleistet ist" (aus: Brief vom 28. Mai 1938 in: UAH PA 6141).
$Z$ (2) Begründungsschreiben für eine Arbeitsurlaubs-Verlängerung im Ersatzheer während des Zweiten Weltkrieges für U., gegeben vom Rektor der UH, Paul Schmitthenner (siehe Drüll (2009) S. 554f.), an stellvertr. Kommandierenden General und Befehlshaber im Wehrkreis XII, Albrecht Steppuhn (1877-1955): „Feldwebel und O[ffiziers] A[nwärter] Eugen Ulmer ... hat vom 11.1. bis 9. 2. 1943 Arbeitsurlaub ... [er wird] auch weiterhin für die Aufrechterhaltung des Studienbetriebes (200 Studenten) dringend benötigt ..." (aus: Schreiben vom 6. Febr. 1943 in: PA 6141). U. erhält bis 31. März 1943 den erbetenen Arbeitsurlaub. Am 10. Okt. 1943 erfolgt die Ernennung U.s zum Feldkriegsgerichtsrat sowie zum Heeresrichter bei Gericht der Division Nr. 172, Zweigstelle Neckargemünd, s. Brief U.s an UH vom 7. Nov. 1943 in: PA 6141.

Am 10. März 1954 erhält U. den Ruf auf den neu errichteten ordentlichen Lehrstuhl für Bürgerliches Recht und Rechtsvergleichung an der Universität München. Am 7. Juli listet das Stuttgarter Kultministerium Baden-Württemberg u.a. nachfolgende Wünsche auf, „die bei den Erörterungen ... wegen etwaiger Ablehnung der an ihn ergangenen Berufung ... der Genannte [Ulmer] ... zum Ausdruck" brachte:

Errichtung eines Instituts für Urheberrecht und gewerblichen Rechtsschutz.

Bereitstellung eines wiss. Assistenten für das vorhandene Institut für ausländisches Recht.

Eine ganztägige Schreibkraft für das vorhandene und das neu zu errichtende Institut.

Benennung des Lehrstuhls: Deutsches und ausländisches Privat- und Handelsrecht, Urheberrecht und gewerblichen Rechtsschutz.

Entgegenkommende Bereitstellung von Mitteln für Reisen zu Kongressen und aus Anlass fachlicher Interessen.

Protokoll des Engeren Senats der UH vom 20. Juli 1954 vermerkt die einstimmige Bereitschaft der Universität zur Erfüllung der Wünsche 1-5. Allerdings gibt es zum letzten Wunsch folgenden $\mathrm{Zu}$ - 
satz:,$\ldots$ es soll beantragt werden, daß dieser Wunsch aus dem Etattitel des Kultministeriums für Berufungszusagen durch Zurverfügungstellung einer bestimmten Summe oder auch durch Zusage einer laufenden Aufwandsentschädigung erfüllt wird“" (aus: PA 6142).

Jedoch gibt es einen weiteren, hier nicht genannten „Wunsch“ U.s, der in einem Schreiben vom 29. Mai 1954 von Rektor Edmund Schlink (siehe Drüll (2009) S. 538 f.) an seinen Kollegen und Vorsitzenden des Ausschusses für Besatzungsfolgen des Deutschen Bundestages in Bonn, Eduard Wahl (siehe Drüll, S. 644f.), angesprochen wird: „Haben Sie sehr herzlichen Dank für Ihre freundlichen Bemühungen darum, dass das [im Mai 1946 durch die amerikanische Militärregierung beschlagnahmte und General Henning und seiner Familie zugewiesene ${ }^{\star}$ [ [ehemalige Ulmersche] Haus [in der Ludolf-Krehl-Strasse 17] frei gegeben und ihm wieder zur Verfügung gestellt wird. Bitte, lassen Sie in Ihren Bemühungen in dieser Sache nicht ab. Denn es liegt ja nicht nur Ihrer eigenen Fakultät, sondern uns allen, der Universität als ganzer, sehr daran, Herrn Ulmer hier zu behalten. Er ist sehr schwankend und wird gewiss nach München gehen, wenn das Haus nicht zurückgegeben wird ..." (aus: PA 6142). Am 13. Aug. 1954 gibt Walter Dowling, stellvertretender hoher US-Kommissar für Deutschland einen abschlägigen Bescheid, die Freigabe des U.schen Hauses betreffend, an Prof. Dr. iur. Walter Hallstein, Staatssekretär in Bonn; Dowling rät zu einer späteren erneuten Eingabe (aus: PA 6142). [* Aus: Antrag U.s vom 6. März 1952 an Stadtverwaltung und Hauptquartier der U.S. Army in Heidelberg um Freigabe seines Hauses in: PA 6142.]

U. nimmt letztlich den Ruf nach München an: „... Wenn ich mich trotzdem entschlossen habe, ... anzunehmen, so geschah dies in der Erwägung, dass nach annähernd fünfundzwanzigjähriger Tätigkeit in Heidelberg der Wechsel der Wirkungsstätte einer durch die Erfahrung als richtig bestätigten Regel entspreche, unter der wir als akademische Lehrer stehen ... " (Brief U.s vom 9. Dez. 1954 an Heidelberger Rektor Reinhard Herbig (siehe Drüll (2009) S. 269 f.) in: PA 6142).
Vertreter der Bundesrepublik Deutschland bei int. Urheberrechtskonferenzen, u. a. 1952 Welturheberrechtsabkommen, 1961 Rom-Abkommen über den Schutz der ausübenden Künstler, der Hersteller von Tonträgern und der Sendeunternehmungen, 1967 Stockholmer Konferenz für geistiges Eigentum

E Mitglied der Akademie der Wissenschaften: 1940 H, 1959 München. 1965 Dr. iur. h.c. Stockholm. - 1961 Griechischer Phoenixorden; 1966 Bayerischer Verdienstorden; 1968 Großes Bundesverdienstkreuz, 1973 Großes Verdienstkreuz mit Stern.

Qu UAH PA 289, 798, 3051, 6141f. - Archiv der Max-Planck-Gesellschaft Berlin (II. Abt. Rep. 1A PA Ulmer). • Briefe: UBH. - Mitteilungen: Herren Prof. Dr. Eugen Ulmer ( $\dagger$ ) und Prof. Dr. Peter Ulmer, Heidelberg.

$W$ Warenzeichen und unlauterer Wettbewerb. Stuttgart 1929. - Das Recht der Wertpapiere. Stuttgart 1938. - Urheber- und Verlagsrecht. Berlin 1951. 3. Aufl. 1980. - Das Recht des unlauteren Wettbewerbs in den Mitgliedsstaaten der EWG. 5 Bde. München 1965-1968. • Elektronische Datenbanken und Urheberrecht. München 1971. • Die Immaterialgüterrechte im internationalen Privatrecht. Köln 1975. • Siehe NDB 26 (2016) S. 580 f.

$L$ Heuss, Theodor: Die Verantwortung der geistig Führenden: Prof. Dr. E. U. vor der Spruchkammer - Eine grundsätzliche Entscheidung in: RNZ vom 12. Sept. 1946. • Beier, Friedrich Karl: Widmung in: Gewerbliches Rechtsschutz- und Urheberrecht H. 6/7 (1973) S. 211f. • Wer ist wer (1984) S. 1290; WBIS. • E. U. zum Gedächtnis. Hrsg. vom Max-Planck-Institut für Ausländisches und Int. Patent-, Urheber- und Wettbewerbsrecht. Weinheim 1989. - Raehlmann (2005) S. 274 (Register); UH im Nationalsozialismus (2006) S. 1274 (Register). - Deutsch, Erwin: E. U. Ein Zivilrechtslehrer des 20. Jahrhunderts in: Deutschsprachige Zivilrechtslehrer in Berichten ihrer Schüler. Eine Ideengeschichte in Einzeldarstellungen. Hrsg. von Stefan Grundmann, Karl Riesenhuber. Bd. 1. Berlin 2007. S. 206-219. Drüll (2009) S. 629; Schroeder (2010) S. 486-493 u. ö.; Catalo- 
gus prof. Rostochiensium online; NDB 26 (2016) S. 579-581. Deutsche Biographie, s. https://www. deutsche-biographie.de/pnd118763555.html [21.12. 2017]. - Ohnemus, Jan: E. U. - Hochschullehrer und Kriegsrichter in: Täter, Helfer, Trittbrettfahrer (2017) S. 283-298.

$P$ Bildarchiv UAH. - Bildarchiv des Archivs der Max-Planck-Gesellschaft Berlin.

\section{Umbreit, Friedrich Wilhelm Carl}

1820-186o Theol. Fak.

Altes Testament

1820-1829 Phil. Fak.

Orientalische Philologie

* 11. April 1795 Sonneborn (bei Gotha)

$\dagger \quad$ 26. April 1860 Heidelberg ev.-luth.

V Karl Gottlieb Friedrich U. (1763-1829) Organist, Komponist, s. ADB 39 (1895) S. 277, WBIS

M Martha Elisabetha geb. Lampert (1773-1847)

( 31. Mai 1821 Elisabetha Katharina geb. Koch (1801-1884)

K $\quad 3 \mathrm{~T}$

Lb 1814-1817 Studium der Theologie, Philosophie an U Göttingen; Frühjahr 1818 theol. KandidatenExamen in Gotha.

U Göttingen: 1. Aug. 1818 Dr. phil.; seit Herbst 1818 Privat-Dozent für Orientalische Sprachen; Sommer 1819 Eigenstudien in Wien.

UH: 25. Mai 1820 (Ern.)-19. März 1829 a. o. Prof. für Altes Testament an Theol. Fak. und 25. Mai 1820 (Ern.)-30. Mai 1823 a.o. Prof. für Orientalische Philologie an Phil. Fak., s. UAH RA 6718 fol. 6v, PA 2371; 23. Okt. 1821 Beginn der Besoldungs-Auszahlung von 8oo.- Gulden im Jahr; 30. Mai 182330. Sept. 1829 o. Prof. für Orientalische Sprachen an Phil. Fak., s. RA fol. 6v; seit 23. Okt. $1826 \mathrm{Ge}-$ haltszulage von 200.- Gulden; 5. Jan. 1829 U. stellt ergebnislosen Antrag auf Annahme als o. Mitglied bei Theol. Fak. (Diskussionen der Theologie-Professoren hierüber, s. PA 2371); 19. März 1829 Ern. zum o. Prof. für Altes Testament an Theol. Fak. als Nachf. von Carl Ullmann; jährl. Gehaltszulagen: seit 1. Aug. 1829 sowie seit 1. Febr. 1835 von 200.Gulden, seit 18. Jan. 1838 von 30o.- Gulden, seit 1. Aug. 1844 von 200.- Gulden.

In seiner Personalakte (PA 2371) sind außergewöhnlich häufig Anträge U.s auf GenesungsUrlaube überliefert: Herbst 1823 vier Wochen in Gotha, Sommer 1825 vier Wochen in (Bad) Ems, Herbst 1825 in Gotha, Sommer 1834 vier Wochen in Ems, Juli 1839 einige Wochen in Gotha, Sommer 1840 einige Wochen in Ems, Sommer 1854 in der Schweiz, Sept. 1855 und Sept. 1857 einige Wochen in (Bad) Dürkheim, Aug. 1859 einige Wochen in (Bad) Wildbad. Letztendlich leidet U. seit Sommer 1858 an e. fortschreitenden Verfall der körperlichen und geistigen Kräfte, hervorgerufen durch unzureichende Ernährung mit Proteinen und Kohlehydraten (= Marasmus), an dem er 1860 stirbt.

Kuratel-Erlaß vom 11. April 1829 Nr. 130 bestimmt, „daß dem Professor ordinarius Theologiae Umbreit auch die Professur in der Philosophie gesichert sein solle", siehe hierzu UAH RA 6718 fol. 7r; U. wird in den Vorlesungsverzeichnissen nach WS 1829/30 nicht mehr als Ordinarius an Phil. Fak. genannt; er hält allerdings noch in folgenden Semestern Vorlesungen an dieser Fak.: WS 1829/30, SS 1830, SS 1831-SS 1832, SS 1833-SS 1835, SS 1836-WS $1837 / 38$, SS 1845 und SS 1852 .

1832 Prorektor der UH; 1830, 1836, 1839, 1843, 1847 , 1851, 1855, 1859 Dekan der Theol. Fak. der UH

1832 Kirchenrat; 1844 Geh. Kirchenrat

Siehe auch Carl Ullmann

E 1829 D. theol. UH. - Ritterkreuz des Ordens vom Zähringer Löwen.

$\mathrm{Qu}$ UAH PA 2371; RA 603, 5355, 6127, 6140, 6593, 6595, 6718 fol. 6v, 7r, 10v, 11r u.ö., 6849; Rep. 40148. - GLA Abt. 205, Fasz. 529. • Briefe: UBH; siehe auch Kalliope. - Vincent, Jean Marcel: Zu Leben und Wirken des späten Wilhelm Gesenius. 10 unveröffentlichte Briefe ... von Gesenius, ... 
und Carl [F.W.] U. Hermannsburg 1996. - Christophersen, Alf: Friedrich Lücke (1791-1855). T. 2: Dokumente und Briefe. Berlin 1999. S. 498 (Register). Familienarchiv Umbreit im Staatsarchiv Leipzig (Bestand 22413).

$W$ Praktischer Commentar über die Propheten des alten Bundes mit exegetischen und kritischen Anmerkungen. 4 Bde. Hamburg 1841-1846. • Praktischer Commentar über den Hezekiel, mit exegetischen und kritischen Anmerkungen. Hamburg 1843. - Der Brief an die Römer auf dem Grunde des Alten Testaments ausgelegt. Gotha 1856.

MHG 1828-186o Theologische Studien und Kritiken (zus. mit Carl Ullmann).

Übers. Lied der Liebe, das älteste und schönste aus dem Morgenlande. 2. Aufl. Heidelberg 1828.
L Holtzmann, Heinrich Julius, Rothe, Richard: Zwei Reden gehalten am Grabe von F. W. Karl U. ... Heidelberg 186o. • Ullmann, Carl: F. W. C. U. Blätter der Erinnerung. Nebst e. Wort über U.s literärischem Wirken ... Gotha 1862. Catalogus prof. Gottingensium (1962) S. 106, 137; WBIS; BBKL XII (1997) Sp. 904-906. • Über F. U. in: Wüstenberg, Ulrich: Karl Bähr (1801-1874). Ein badischer Wegbereiter für die Erneuerung und die Einheit des ev. Gottesdienstes. Göttingen 1996. S. 51-53 u.ö. • Rauchstein, Maike: Fremde Vergangenheit. Zur Orientalistik des Göttinger Gelehrten Johann David Michaelis (1717-1791). Bielefeld 2017. S. 106.

P Bildarchiv UAH; graph. Slg. UBH. 
V

\section{Valentin, Bruno}

1922-1924 Med. Fak.

Chirurgie

* 20. Sept. 1885 Berlin

$\dagger$ 15. Okt. 1969 Hannover

mosaisch, vor 1922 konf.-los, seit 16. Nov. 1924 ev.

V Heinrich V. (1841-1925) Großkaufmann im Fuhrgeschäft

M Helene geb. Mannheimer (1850-1928)

๑ 4. Juni 1911 Marta geb. Hellmann (1890-1976)

K $\quad 1$ S, 1 T, s. http://mygrandmotherhedi.blogspot. de/ (abgerufen am 2o. Febr. 2018)

Vw Ahnentafel von ... B. V. ..., eingesandt bei der Gesellschaft für jüdische Familienforschung. Berlin ca. 1936-1941, s. Aus den Sammlungen des Jüdischen Museums Berlin (Inventar-Nr: 2000/505/32).

Lb 1904-1905 Militärdienstpflicht als EinjährigFreiwilliger in Berlin; WS 1904/05 Studium an U Berlin, SS 1905 Würzburg, WS 1905/o6 Berlin, anschl. Würzburg, Berlin, zuletzt Würzburg; Dez. 1909 Staatsexamen in Würzburg.

U Würzburg: Seit 1910 Medizinalpraktikant an Chirurg. U-Klinik; 20. Nov. 1910 Dr. med.

1911-1914 Zunächst Volontärarzt an U-Poliklinik für orthopäd. Chirurgie in Berlin, dann Assistenzarzt am Städtischen Rudolf-Virchow-Krankenhaus in Berlin-Wedding.

1914-1918 Kriegsdienst.

U Frankfurt/M.: Jan. 1919-April 1922 Assistent an U-Klinik für Orthopäd. Chirurgie in F.-Friedrichsheim; 18. Febr. 1921 Habilitation; 1921-1922 Privat-Dozent.
UH: Seit Mai 1922 Assistent an Chirurg. U-Klinik; 16. Juni 1922 Umhabilitation; 10. Febr--10. Mai 1923 Austausch-Assistent an U Utrecht; seit 12. Dez. 1924 nichtbeamteter a. o. Prof.

Hannover: 15. Dez. 1924 (Dienstantritt)-31. März 1936 (Entlassung aus rassischen Gründen) Chefarzt der Krüppel-Heil- und Erziehungsanstalt Annastift in H.-Kleefeld; 1930-20. Aug. 1935 (Entlassung) auch Landeskrüppelarzt der Provinz Hannover. • In dieser Zeit:

Tierärztl. Hochschule Hannover: Seit 2. Dez. 1925 Privat-Dozent, 1930-WS 1933/34 nichtbeamteter a. o. Prof. für „Hygiene der Leibesübungen“.

Hannover: Mitte Mai 1936-3. Aug. 1938 (Entziehung der Approbation) Privat-Praxis („ab 15. Mai 1936 befinden sich meine Praxisräume nicht mehr im Annastift, sondern Arnswaldstraße 7 p[arterre]“ aus: Bergner (2016) S. 22).

22. Dez. 1938 Emigration, zunächst mit Aufenthalt in London, 20. Jan. 1939 Überfahrt nach Brasilien.

1939-1967 Wohnsitz in Rio de Janeiro; in dieser Zeit vor allem schriftstellerische Tätigkeit; Okt. 1963 Anerkennung des Antrags V.s über die Entschädigung als Opfer des Nationalsozialismus.

März 1967 Rückkehr nach Deutschland.

Tierärztl. Hochschule Hannover: 1968 Einsetzung in die Rechte e. o. Prof. mit gleichzeitiger Emeritierung.

1931-1934 (Austritt) Vorstandsmitglied, seit 1956 Ehrenmitglied der Dt. Orthopädischen Gesellschaft, heute: Deutsche Gesellschaft für Orthopädie und Orthopädische Chirurgie

2017: Einweihung des Medizinischen Zentrums für Erwachsene mit Behinderung im Annastift in Hannover als Bruno Valentin Institut.

E 1962 Mitglied der Dt. Akademie der Naturforscher Leopoldina Halle/S. 1968 Dr. med. h.c. Tübingen. • 1964 Ernst-von-Bergmann-Plakette. • 1914 Eisernes Kreuz II. Klasse; 1916 Bayer. König 
Ludwigs-Kreuz; 1916 Türkischer Roter Halbmond; 1918 Bayer. Militär-Verdienstorden IV. Klasse mit Schwertern. 1965 Großes Bundesverdienstkreuz.

Qu UAH PA 6156. • GLA Abt. 235, Fasz. 2611. • Siehe auch Archiv der Dt. Akademie der Naturforscher Leopoldina Halle/S.

$W$ Konstitution und Vererbung in der Orthopädie. Stuttgart 1932. - Orthopädie vor 100 Jahren. Die orthopädischen Institute als Vorläufer der heutigen Krüppelheime. Stuttgart 1935. • Die Geschichte des Gipsverbandes. Stuttgart 1956. - Die Geschichte der Orthopädie. Stuttgart 1961. • Geschichte der Fusspflege. Pedicurie, Chiropodie, Podologie. Stuttgart 1966.

HG Dieffenbach an Stromeyer. Briefe aus den Jahren 1836-1846. Leipzig 1934.

L WBIS; Kürschner (1966) S. 2549 f.; ChirurgenVerzeichnis ( $\left.{ }^{5} 1969\right)$ S. 937. - Rütt, August: In memoriam B.V. in: Archiv für orthopädische und Unfall-Chirurgie 67/3 (1970). - Elkeles, Barbara: B.V. ... Die Vertreibung eines hannoverschen Arztes unter der nationalsozialistischen Diktatur in: Niedersächsisches Ärzteblatt 24 (1989) S. 26-30. - Moreno, Beatrice: B.V. - Lebensbilder eines jüdischen Orthopäden in Deutschland in: Geschichte konservativer Verfahren an den Bewegungsorganen. Hrsg. von Ludwig Zichner, Michael A. Rauschmann ... Darmstadt 2001. S. 261-277. Biogr. Enzyklopädie Mediziner (2002) Bd. 2, S. 644. • Hannoversches Biographisches Lexikon. Von den Anfängen bis in die Gegenwart. Hrsg. von Dirk Böttcher ... Hannover 2002. S. 368. • Bergner, Gabriele: Ein Leben für die Menschen ... B. V. ... Hannover 2016; siehe hierzu auch https://www.diakovere.de/mzeb-test/brunovalentin/ (Ausdruck im UAH). - Deutsche Biographie, s. https://www.deutsche-biographie.de/pnd 12943115X.html [23.12. 2017].

$P$ Bildarchiv UAH.

\section{Valentiner, Karl Wilhelm Friedrich} Johannes

1896-1909 Nat.-Math. Fak.

Astronomie

* 22. Febr. 1845 Eckernförde

$\dagger \quad$ o1. April 1931 Berlebeck (heute: Ortsteil von Detmold)

$\square$ Detmold ev.-luth.

V Friedrich Wilhelm V.(1807-1889) Archidiakon, Prediger, s. Deutsche Biographie, https://www. deutsche-biographie.de/pnd117680982.html [23. 12. 2017]

M Catharina Magdalena geb. Fromm (1814-1901)

๑ 28. April 1873 Anna Isis Elisabeth geb. Lepsius (1848-1919) T von Richard L. (1810-1884), u.a. Berlin: seit 1846 o. Prof. für Ägyptologie, 1855 Mit-Direktor, seit 1865 Direktor des Ägyptischen Museums, 1873-1884 Direktor der Königl. Bibliothek, s. Lepsius, M. Rainer: ... R. L. und seine Familie in: Demokratie in Deutschland. Göttingen 1993; Helck, Wolfgang, Otto, Eberhard: Kleines Lexikon der Ägyptologie. Bearb. von Rosemarie Drenkhahn. 4. Aufl. Wiesbaden 1999. S. 171.

K 1 T: Elisabeth V. $\left({ }^{*} 1874\right)$ Ehefrau von Ernst Jost (1877-1945), u.a. als Assistent der Sternwarte in Straßburg 1902-1904 (Gast-)Observator an Sternwarte in Gotha, seit 1909 Observator an Sternwarte und 1918-1944 Prof. für Astronomie an U Königsberg (Preußen), s. WBIS, Tilitzki 1 (2012) S. 558, Deutsche Biographie, https://www.deutsche-biographie.de/ pnd1055409068.html [23.12.2017]

K 3 S: u.a. Siegfried V. (1876-1971), u.a. 19101947 o. Prof. für Physik an Bergakademie Clausthal, s. Kürschner (1966) S. 2550f., WBIS, Deutsche Biographie, https://www. deutsche-biographie.de/pnd117340421.html [23.12. 2017]. - Wilhelm (William) Reinhold Otto V. (1880-1958), u.a. 1924-1945 Direktor des Detroit Institute of Arts, zuletzt Direktor des North Carolina Museum of Art in Raleigh, s. Sterne, Margaret: The passionate eye. The life of W.R.V. Detroit 1980; Mascolo, Marco M.: „Un occhio finissimo“. W. R. V. ... storico dell'arte tra Germania e Stati Uniti. Rom 2017. 
Vw Schwester: Elisabeth Henriette V. (1843-1920) Ehefrau von Carl Christian Bruhns (18301881) zunächst Schlosser, seit 1860 Prof. für Astronomie und Direktor der Sternwarte Leipzig, s. Beneke, Klaus O.T. (Bearb.): C.C.B. Vom Schlosser ... zum Professor ... Ein Zeitzeuge erinnert sich ... unter: http://www.uni-kiel.de/ anorg/lagaly/group/klausSchiver/bruhnsı.pdf; WBIS, Professorenkatalog Leipzig online

Vw Nichte: Dr. Elisabeth V. (1900-1991) Kunsthistorikerin, Ehefrau von Walter Paatz (19021978) 1942-1945, 1947-1967 o. Prof. für Kunstgeschichte an UH, s. Drüll (2009) S. $451 \mathrm{f}$.

Vw siehe auch NDB 22 (2005) S. 504* (Schäfer, Dietrich).

Lb Seit 1863 Studium der Astronomie, Mathematik an U Berlin, anschl. Leipzig; seit Ostern 1867 Assistent bei Sächsischer Gradmessung in Leipzig.

Berlin: Seit Okt. 1867 Assistent am Centralbureau der Europ. Gradmessung; 18. Juni 1869 Dr. phil. an U.

Leiden: 1869-1875 Erster Observator an Sternwarte; 1873-1874 Chef e. deutschen Venusexpedition in Straßburg, Juli 1874-Mai 1875 Studienaufenthalt in China zur Beobachtung des Venustransits.

Mannheim: Seit 16. Juni 1875 Vorstand der Großherzogl. Sternwarte (1880 Verlegung nach Karlsruhe).

Karlsruhe: Seit 22. Nov. 1879 o. Prof. an Polytechnischer Schule und Vorstand der provisorisch eingerichteten Großherzogl. Sternwarte (Verlegung 1898 nach $\mathrm{H}) ; 1887$ Ruf an Sternwarte in Gotha abgelehnt.

H: 23. Nov. 1896-1. Okt. 1909 (Ruhestand) o. Prof. an $\mathrm{U}$ und Leiter der Astrometrischen Abt. an der im Juni 1898 eingeweihten Landessternwarte auf dem Königstuhl.

1902 Hofrat; 1906 Geh. Hofrat

E 1896 Ritterkreuz I. Klasse des Ordens vom Zähringer Löwen; 1909 Ritterkreuz des Ordens Berthold I.
Qu UAH PA 6155. • Briefe: UBH. • Mitteilungen von Familienangehörigen.

$W$ Beiträge zur kürzesten und zweckmäßigsten Behandlung geographischer Ortsbestimmungen mit Hülfstafeln. Leipzig 1869. - Astronomische Bilder. Leipzig 1881. Handwörterbuch der Astronomie. 5 Bde. Karlsruhe 1896-1902. • Veröffentlichungen der Heidelberger Sternwarte, astrometrische Abt. 5 Bde. Karlsruhe 1917.

$L$ Lebensbilder aus der Familie Valentiner zwischen 1830 und 1970. Hrsg. von Elisabeth Paatz. Heidelberg 1976. S. 55-58. - Biogr. Lexikon für Schleswig-Holstein 9 (1991) S. 356-358; Jansen (1992a) S. 170 (Register); WBIS. • Budde, Kai: Sternwarte Mannheim ... 1772-1880. Heidelberg 2006. S. 157-164. • Badische Biographien N.F. VI (2011) S. 414-416; Deutsche Biographie, s. https:// www.deutsche-biographie.de/pnd117340464.html [23.12. 2017].

$P$ Bildarchiv UAH; Lebensbilder (1976). - Sterne, Margaret: The passionate eye. The life of Wilhelm (William) Reinhold Otto Valentiner (1980).

\section{Vangerow, Carl Philip Adolph von}

1840-1870 Jur. Fak.

Römisches Recht (Pandekten)

* 05. Juni 1808 Schiffelbach (Königreich Westphalen; heute: Stadtteil von Gemünden, Hessen)

$\approx$ 19. Juni 1808

$\dagger$ 11. Okt. 1870 Heidelberg ev.-luth.

V Wilhelm von V. (1784-1824) vor 1807 Fähnrich in Kurhessischen Kriegsdiensten, nach 1814 Rittmeister und Provinzial-Kommandant der Kurhessischen Gendarmerie Marburg, s. Lebenslauf im UAH in Aktenordner „Heidelberger Gelehrtenlexikon 1803-1932“, Korrespondenz, Buchstabe V

M Fridericke Wilhelmina geb. von Tilemann genannt Schenck (1785-1862) 
(15. Mai 1834 Dorothea Christiane geb. Graff (1806-1857)

$\mathrm{K} \quad 3 \mathrm{~S}, 3 \mathrm{~T}$ (davon $2 \mathrm{~S}$ und $1 \mathrm{~T}$ früh $\dagger$ ), s. NDB 26 (2016) S. $709 \mathrm{f}$.

$L b$ Seit 7. Mai 1824 zunächst Studium der Philosophie, Geschichte, dann der Rechtswiss. an U Marburg, $1828 \mathrm{H}$ (ohne Immatrikulationseintrag).

U Marburg: 23. Jan. 1830 Dr. iur.; April $1830 \mathrm{Ha}-$ bilitation; seit 6 . Sept. 1833 a. o. Prof.; seit 14. Juni 1837 o. Prof.

UH: Seit 11. Juni 1840 o. Prof. als Nachf. von Anton Friedrich Justus Thibaut; 1. Okt. 1840 Dienstantritt; 3. Nov. 1840 Vereidigung; $1840-1870$ Beisitzer des Spruchkollegiums der Jur. Fak.; abgelehnte Rufe: 1842 und 1849 U Leipzig, 1848 Gießen und Marburg, 1861 Berlin.

1845, 1863 Prorektor der UH; 1843, 1848, 1852, 1858, 1863/64, 1869/70 Dekan der Jur. Fak. der UH

1842 Hofrat; 1846 Geh. Hofrat; 1849 Geh. Rat II. Klasse

E Ritterkreuz I. Klasse des Ordens vom Zähringer Löwen. 1852 Ehrenbürger der Stadt Heidelberg.

Qu UAH PA 2373; RA 6761; Acc. 18/92 (fünf Hefte mit Vangerowschen Vorlesungsmitschriften von 1853/54). - GLA Abt. 205, Fasz. 530-531. • Briefe: UBH. Auskunft: Luth. Gemeinde in Schiffelbach (Taufbuch 1808: hier 15. Juni als Geb.-Datum angegeben; im Civilstands-Register eindeutig der 05. Juni als Geb.-Tag genannt). - Mitteilungen: Herr Dr. phil. Hermann Otto Schwöbel ( $\dagger$ ), Gemünden-Schiffelbach; Frau Carola Noack, Heidelberg.

$W$ Leitfaden für Pandekten-Vorlesungen. 3 Bde. Marburg 1839-1849; dann u.d. T.: Lehrbuch der Pandekten. 7. Aufl. 1863-1868. Neudr. 1875. • Gutachten in Sachen der Miterben am Nachlasse der Rathsverwandten Böhlers Wittwe gegen die Intestaterben des im Hospital Hofheim ledig verstorbenen Balthasar Böhler, Erbschaftsansprüche betreffend. Darmstadt 1846. Siehe auch NDB 26 (2016) S. $710 f$.
$L$ Badische Biographien 2 (1875) S. 382-385; Catalogus prof. Marburgensis 1 (1927) S. 128 f.; Jammers (1964) S. 178 u. ö. - Schermaier, Martin Josef: Die Bestimmung des wesentlichen Irrtums von den Glossatoren bis zum BGB. Wien 2000. S. 764 (Register). Schroeder (2010) S. 143-150 u. ö.; NDB 26 (2016) S. 709-711. - Über C. A. von V. in: Anton Friedrich Justus Thibaut ... Bürger und Gelehrter. Hrsg. von Christian Hattenhauer ... Tübingen 2017. S. 95-99. Wiese, Volker: Alternativität in Schuldverhältnissen. Tübingen 2017. S. 44, $46 \mathrm{f}$., 50-52 u. o.

$P$ Bildarchiv UAH; graph. Slg. UBH.

\section{Vering, Friedrich Heinrich Theodor Hubert}

1857-1875 Jur. Fak.

Römisches Recht, Kirchenrecht

* o9. März 1833 Liesborn (Westfalen; heute: Ortsteil von Wadersloh)

$\dagger$ 30. März 1896 Prag kath.

V Dr. August Ferdinand Maximilian Ludger V. (1805-1835) Arzt, s. Medicinisches Schriftsteller-Lexicon. Bearb. von A.C.P. Callisen. Reprint of the edition Copenhagen 1830-1845. Nieuwkoop 1963. Bd. 20. S. 96.

M Clementine Antonetta geb. Sauer (†1881), s. Schulte, Anton: Zwischen Ems und Lippe (1972) S. $142 \mathrm{f}$.

๑ Juli/Aug. 1868 Elisabeth geb. Molitor (18481916)

K 8

Vw Großvater: Dr. med. h.c. Albert Mathias V. (1773-1829) praktischer Arzt, Gründer e. Privatanstalt für Geisteskranke in Liesborn, Verfasser des ersten vollständigen dt. Lehrbuchs der Psychiatrie: Psychische Heilkunde. 3 T. Leipzig 1817-1821; s. Schulte (1972) S. 140-142; Boerner, Reinhard J.: Temperament - Theorie, Forschung, Klinik. Berlin 2015. S. 24-26.

Lb Seit WS 1850/51 Studium der Philosophie und Rechtswiss. an U Bonn, WS 1851/52-WS 1852/53 
Studium der Rechtswiss. H, seit SS 1853 Bonn; 30. Sept. 1854-30. Sept. 1855 Militärdienstpflicht als Einjährig-Freiwilliger in Koblenz; seit Okt. 1855 Eigenstudien in Bonn; 9. Juli 1856 Dr. iur. an UH; Dez. 1856 Staatsexamen am Königl. Landgericht in Koblenz, s. hierzu auch $Z$.

UH: 8. Mai 1857 Habilitation; seit 21. Juli 1862 a.o. Prof.

Franz-Josephs-U Czernowitz: Seit WS 1875/76 o. Prof. für Kirchenrecht an neugegründeter $U$ in Habsburger Doppelmonarchie.

U Prag: Seit SS 1879 o. Prof. für Kirchenrecht.

Z Im Okt. 1856 befürwortet der Engere Senat der Universität Heidelberg die am 14. August 1856 nachgesuchte Habilitation V.s für Römisches Recht und Kirchenrecht, ohne daß V. die vorgeschriebenen zwei Jahre „praktiziert“ oder auf „wissenschaftlichen Reisen" gewesen ist; das Ministerium des Innern antwortet am 31. Okt. 1856 allerdings abschlägig mit der Begründung: „... Dr. Vering hat nicht allein das Erforderniß einer zweijährigen praktischen Uebung und Ausbildung nach der Vorschrift in Ziffer 3 der Verordnung vom 19. Januar 1835 Nr. 523.524 nicht erfüllt, sondern er hat auch selbst nicht, wie Ziffer 2 dieser Verordnung verlangt, nachgewiesen, daß er die für die Candidaten des Fachs, das er lehren will, vorgeschriebene Staatsprüfung mit Auszeichnung bestanden habe" (aus: UAH PA 2375). Nach Ablegung des Staatsexamens im Dez. 1865 wird V. zur Habilitation zugelassen.

\section{E Dr. iur. can. h.c. Löwen.}

Qu UAH PA 2375; GF 47. - Toepke 6 (1907) S. 141. Auskunft: Kath. Pfarramt St. Cosmas und Damian in Wadersloh-Liesborn; Kreisverwaltung Warendorf; Bischöfliches Generalvikariat - Bistumsarchiv - Münster.

$W$ Römisches Erbrecht in historischer und dogmatischer Entwicklung. Heidelberg 1861. - Geschichte und Institutionen des römischen Privatrechts. Mainz 1865. 4. Aufl. u.d. T.: Geschichte und
Pandekten des römischen und heutigen gemeinen Privatrechts. Mainz 1875. 5. Aufl. 1887. - Lehrbuch des katholischen, orientalischen und protestantischen Kirchenrechts. Freiburg/Br. 1879. 3. Aufl. 1893.

(M)HG Seit 1860 Archiv für kath. Kirchenrecht.

L Raßmann, Ernst: Nachrichten von dem Leben und den Schriften Münsterländischer Schriftsteller des 18. und 19. Jahrhunderts. N.F. Münster 1881. S. 229-232 (mit Werkverz.). Schulte, Anton: Zwischen Ems und Lippe. Vorträge und Aufsätze aus der Geschichte des Beckumer und Warendorfer Landes, aus dem Nachlaß hrsg. von Siegfried Schmieder. Beckum 1972. S. 142 f. • WBIS; Universität Czernowitz (1979) S. 426 (Register); BBKL XII (1997) Sp. 1258f.; Schroeder (2010) S. 207; Deutsche Biographie, s. https://www.deutsche-biogra phie.de/pnd117388556.html [30.11.2017].

\section{Vierordt, Oswald Ernst Ludwig}

1890-1906 Med. Fak.

Innere Medizin

* 05. April 1856 Karlsruhe

$\dagger \quad$ 02. Sept. 1906 Heidelberg

ev.

V Eduard Leopold V. (1830-1900), u.a. Reichsbevollmächtigter für Steuern und Zölle, 18701872 Privat-Sekretär der Großherzogin Luise von Baden (1838-1923), zuletzt Oberfinanzrat an Oberrechnungskammer Karlsruhe, s. Badische Biographien 5 (1906) S. 878, WBIS

M Luise Wilhelmine geb. Goßweiler (1830-1908)

๑ 8. Sept. 1887 Dorothea geb. Schneider $\left({ }^{\star} 1868\right.$ $\dagger$ nach 1906)

K $\quad 1 \mathrm{~S}, 2 \mathrm{~T}$

Lb Seit 1874 zunächst Militärausbildung; 1875 Offiziersanwärter; 1876 Übertritt zur Reserve.

Studium: Seit SS 1876 UH, seit 8. Mai 1880 Leipzig; WS $1880 / 81$ Staatsexamen in Leipzig. 
U Leipzig: 1881 Promotion zum Dr. med; Assistent: seit Jan. 1881 Med. Poliklinik, seit Jan. 1882 Med. U-Klinik; 1884 Habilitation für Innere Medizin.

U Jena: Seit SS 1889 a. o. Prof. und Direktor der Med. Poliklinik mit Lehrauftrag für Kinderkrankheiten.

UH: Seit 29. März 1890 o. Prof. und Direktor der Med. Poliklinik als Nachf. von Theodor von Dusch sowie I. Direktor (II. Direktor: Hermann Lossen) der U-Kinderklinik Luisen-Heilanstalt ebenfalls als Nachf. von T. von Dusch.

1892/93, 1902/o3 Dekan der Med. Fak. der UH

1902 Hofrat; 1905 Geh. Hofrat

E 1896 Ritterkreuz I. Klasse, 1904 Ritterkreuz I. Klasse mit Eichenlaub des Ordens vom Zähringer Löwen; 1899 Ritterkreuz I. Klasse des Königl. Sächsischen Albrechts-Ordens.

Qu UAH PA 2376; RA 5225, 6804. • GLA Abt. 235, Fasz. 2613. - Briefe: UBH.

$W$ Diagnostik der inneren Krankheiten. Leipzig 1888. 7. Aufl. 1905. - Rhachitis und Osteomalacie. Wien 1896. • Die Säuglingsabteilung, Säuglingsambulanz und Milchkühe der Luisen-Heilanstalt (Kinderklinik) zu Heidelberg. Stuttgart 1904.

L Biogr. Jahrbuch 11 (1906) Sp. 68; Stübler (1926) S. 316 f.; Badische Biographien 6 (1935) S. 733-739; Fischer 2 ( $\left.{ }^{3} 1962\right)$ S. 1619; Chronik Ärzte H (1985) S. 144 f. - Wille, Lutz: U-Kinderklinik Luisen-Heilanstalt zu Heidelberg 1860-1985 in: Der Kinderarzt 16. Jg., Nr. 7 (1985) Sp. 1003-1005. - WBIS; Goerttler 2 (2004) S. 110; Peiffer (2004) S. 1120 (Register); 150 Jahre Pädiatrie in H (2010) S. 4046; Freudenberg (2010) S. 17of. u. ö.; Bauer/Ho (2016) S. 33-37; Deutsche Biographie, s. https:// www.deutsche-biographie.de/pnd11741517o.html [23.10.2017].

P Bildarchiv UAH; graph. Slg. UBH; Wille (1985).

\section{Voelcker, Friedrich (Fritz) Valentin}

1902-1919 Med. Fak.

Chirurgie

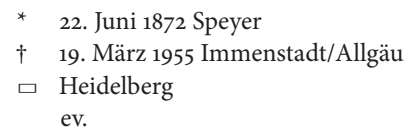

V Friedrich-Jakob V., Goldarbeiter/Goldschmied

M Anna-Marie geb. Rehberger

๑ 1909 Elisabeth (Lili) geb. Stengel (1881-1986) T von: (siehe) Adolf S.

K 3 T: u.a. Rosemarie V. (1910-2003) Ehefrau von Georg Brandt (1895-1968), seit 1921 Assistent von F. V. an Chirurg. U-Klinik, seit 1928 Privat-Dozent, 1935 nichtbeamteter/apl. a.o. Prof. Halle-Wittenberg; Dez. 1935-1945 Chefarzt der chirurg. Abt. des Städtischen Krankenhauses Mainz; 1937 Umhabilitation von Halle/S. an U Frankfurt/M. vom Wissenschaftsministerium abgelehnt (Entziehung von Lehrbefugnis und Professorentitel bis 1948); 1948-1963 (Emeritierung) o. Prof. für Chirurgie und Orthopädie, April 1949-März 1955 Direktor der Chirurg.-Orthopäd. U-Klinik sowie April 1953-Okt. 1963 Direktor der Chirurg. U-Klinik Mainz, s. WBIS, Catalogus prof. Halensis online, Verzeichnis der Professorinnen und Professoren der Universität Mainz, s. http://gutenberg-biographics.ub.unimainz.de/id/a85352e5-1ead-4a6f-8e27-276f94 cd2867.

Lb Seit WS 1890/91 Studium an U München, seit SS 1892 Berlin, seit WS 1893/94 München; 26. Juni 1895 Approbation in München; 15. Juli 1895 Dr. med. an U München; seit Juli 1895 Assistent am Kreiskrankenhaus und an Pflegeanstalt in Frankenthal (Pfalz).

UH: Juni 1897-WS 1905/o6 Klinischer Assistenzarzt an Chirurg. U-Klinik; Okt. 1896-Juni 1897 Militärdienstpflicht als Einjährig-Freiwilliger; 25. Jan. 1902 Habilitation; 2. Juli 1906-30. Sept. 1919 nichtetatm. a.o. Prof.; SS 1906-WS 1906/o7 I. klinischer Assistenzarzt an Chirurg. U-Klinik; seit SS 1907 I. Assistenzarzt, seit WS 1908/o9 Oberarzt 
an klinischer Ambulanz der Chirurg. U-Klinik als Nachf. von Ludwig Arnsperger. - In dieser Zeit:

1906 Begründer e. Privat-Klinik in H. $1915-1918$ Kriegsdienst.

U Halle-Wittenberg: WS 1919/20-WS 1936/37 (Emeritierung) o. Prof. und Leiter der Chirurg. UKlinik.

Wohnorte: Seit 1940 Berlin, seit 1944 Bühl am Alpsee (Allgäu).

V. führt u.a. die Chromozystoskopie (1903) und seine Methode der Pyelographie (1906) ein, siehe Streiflichter aus der Geschichte der Urologie. Hrsg. von Dirk Schultheiss ... Berlin 200o. S. 24-29, 4144, 114 f., 179 f. u. ö.

Mitte der 1930er Jahre spendet V. 500o.- Mark, um jüdischen Verfolgten die Emigration zu ermöglichen

1932 Präsident der Deutschen Gesellschaft für Chirurgie

E 1924 Mitglied der Dt. Akademie der Naturforscher Leopoldina Halle/S.; 1909 Korr. Mitglied des Königl. Ärztevereins Budapest; 1943 Ehrenmitglied der Dt. Gesellschaft für Chirurgie. 1947 Ehrenbürger der Stadt Speyer.

Qu UAH PA 6167. GLA Abt. 235, Fasz. 2614. • Siehe auch Archiv der Dt. Akademie der Naturforscher Leopoldina Halle/S.

$W$ Über Exstirpation der Cardia wegen Karzinoms in: Verh. der Dt. Gesellschaft für Chirurgie 37 (1908). - Die ischiorektale Prostatektomie in: Beiträge zur klinischen Chirurgie 72 (1911) S. 687. • Drei Jahre geheilter Fall von Resection der Cardia wegen Karzinoms in: Zentralblatt für Chirurgie 41 (1914). • F. V. stellt 10 klinische Fälle vor in: Klinische Wochenschrift (2. Mai 1936) 15. Jg., Nr. 18, S. 661.

G, HG 1913-1944 (Erscheinen eingestellt) Zs. für Urologische Chirurgie und Gynäkologie.
MHG Urologische Operationslehre. Leipzig 1921. 2. Aufl. 1924.

$L$ Chirurgen-Kalender (1926) S. 340; ChirurgenVerzeichnis $\left({ }^{3} 1938\right)$ S. 686 f.; Kürschner (1954) Sp. 2462. Boeminghaus, H., Hennig, O.: F. V. † in: Zentralblatt für Chirurgie (1955) S. 287-290. - Fischer $2\left({ }^{3} 1962\right)$ S. 1623 . Kühn, Hildegard: F. V. sein Leben und Werk. Heidelberg 1969. Masch. geschr. Diss. Heidelberg 1969. - Kaiser, Wolfram: Pro memoria F. V. ... Halle/S. 1972. - Leier (1977) S. 86-88. • Linder, Fritz, Amberger, Mechthild: Chirurgie in Heidelberg in: Semper apertus 4 (1985) S. 196. Eberle, Henrik: Die Martin-Luther-Universität [Halle] in der Zeit des Nationalsozialismus 1933-1945. Halle/S. 2002. S. 120 f., 153 f. u. ö. F. V. und die Samenblasenchirurgie in: Illustrierte Geschichte der Urologie. Hrsg. von Jürgen Konert und Holger Georg Dietrich ... Berlin 2004. S. 127-130 u. ö. Demm (2008) S. 383 f. u. ö. $\bullet$ Wenzel, Klaus-Peter: 200 Jahre Hochschulchirurgie in Halle an der Saale (1811-2011). Halle/S. 2011. C Catalogus prof. Halensis online; Demm (2014) S. 248 (Register); Deutsche Biographie, s. https://www. deutsche-biographie.de/pnd117448923.html [30.11. 2017].

P Bildarchiv UAH; Chronik Ärzte H.

\section{Voelcker, Fritz \\ siehe Voelcker, Friedrich}

\section{Vogt, Heinrich}

1921-1929, 1933-1945 Nat.-Math. Fak. 1952-1964 Nat.-Math. Fak.

Astronomie

* 05. Okt. 1890 Gau-Algesheim (bei Bingen am Rhein)

$\dagger$ 23. Jan. 1968 Heidelberg

kath.

V Philipp V. (1852-1917) Landwirt

M Margarete geb. Sturm (1849-1929), s. Schmadel (1997) S. 111 
œ 11. Aug. 1922 Johanna geb. Moot $\left({ }^{*} 1897\right)$ Scheidung 1935

Q 13. Juli 1939 Margarete (Margret) Franziska geb. Braun (1914-1988), s. Schmadel, S. 181

K 1 T, 1 S: Dietmar V. $\left({ }^{*} 1941\right)$ seit 1971 apl. Prof. Mainz, 1973-2009 (Emeritierung) o. Prof. für Mathematik Bergische U Wuppertal, 2004 Alexander-von-Humboldt-Preisträger, s. Kürschner (2011) Bd. 4, S. 4450.

Lb Seit WS 1911/12 Studium der Astronomie, Mathematik, Physik an UH; 1914-1918 Kriegsdienst.

H: Seit 1912 Assistent, 1926-1929 Observator an Landessternwarte auf dem Königstuhl (bei (siehe) Maximilian Wolf).

UH: 14. April 1919 Dr. phil. nat.; 7. Mai 1921 Habilitation; seit 1926 nichtplanm. a. o. Prof.

U Jena: Seit 1. Febr. 1929 o. Prof. und Direktor der U-Sternwarte.

UH: Seit 1. Okt. 1933 o. Prof. und Direktor der Landessternwarte auf dem Königstuhl als Nachf. von M. Wolf; nach 1933 Ruf an U München und Ruf als Direktor des Astrophysikalischen Observatoriums Potsdam abgelehnt; Dez. 1945 (18. Dez. 1945 „Zustellung des Entlassungsschreibens ist erfolgt", aus: UAH PA 6175) Entlassung gemäß Erlaß der amerik. Militärregierung; 1. Okt. 1950 Versetzung in Ruhestand; seit Juli 1952 inaktiver o. Prof. mit Lehrbefugnis; seit 9. Jan. 1957 Rechtsstellung e. emeritierten o. Prof.; SS 1964 letzte Vorlesungsankündigung. • In dieser Zeit:

TH Stuttgart: 1950 Lehrbeauftragter, seit 1953 GastProf.

April-Nov. 1935, März-Sept. 1937 Dekan der Nat.Math. Fak. der UH

1926 Finder des Eindeutigkeitssatzes der Theorie des Sternaufbaus

$E$ Mitglied der Akademie der Wissenschaften: 1935 H, 1939 Berlin; 1943 Mitglied der Dt. Akademie der Naturforscher Leopoldina Halle/S.
Qu UAH PA 6175; Fak.-Akte H-V-6/18; B-3027/2, B-3029/10. Briefe: UBH. - Siehe auch Archiv der Dt. Akademie der Naturforscher Leopoldina Halle/S. - Mitteilungen: Herr Prof. Dr. Dietmar Vogt, Wuppertal.

W Aufbau und Entwicklung der Sterne. Leipzig 1943. 2. Aufl. 1957. - Die Spiralnebel. Heidelberg 1946. Kosmos und Gott. Heidelberg 1951. AuBergalaktische Sternsysteme und die Struktur der Welt im Großen. Leipzig 1960. Die Struktur des Kosmos als Ganzes. Berlin 1961. - Das Sein in der Sicht des Naturforschers. Berlin 1964.

HG Seit 1943 Probleme der kosmischen Physik.

L Poggendorff 7a (1962) S. 781f. - Elsässer, Hans: H. V. † in: Ruperto Carola Jg. 20, Bd. 43/44 (1968) S. 244f. - Jahrbuch HAW für 1969 (1970) S. 4749. - Kollnig-Schattschneider, Erika: H.V. $†$ in: Astronomische Nachrichten (1970) Bd. 292, S. 45. • Schmadel, Lutz D.: Dictionary of minor planet names. 3rd ... Ed. Vol. 1. Berlin 1997. S. 172, 184, 187. • Lexikon der Naturwissenschaftler (2000) S. 408. • Tassoul, Jean-Louis, Tassoul, Monique: A concise history of solar and stellar physics. Princeton (New Jersey) 2004. S. 276 (Register). - Klee, Personenlexikon (2007) S. 643; WBIS. - Gautschy, Alfred: The theorem that was none (Vogt-Russell (VR) theorem) ... online unter http://arxiv.org/ pdf/1504.08188v1.pdf vom 30. April 2015 (Ausdruck im UAH). - Deutsche Biographie, s. https:// www.deutsche-biographie.de/pnd117468002.html [30.11. 2017].

$P$ Bildarchiv UAH; Ruperto Carola 5. Jg., Nr. 11/12 (1953) S. 17.

\section{Vogt, Wolfgang Wilhelm}

1914(-1916) Nat.-Math. Fak.

Mathematik

* 21. Okt. 1883 Breslau (heute: Wrocław, Polen)

X 04. März 1916 Fort Douaumont (bei Verdun, Lothringen)

ev. 
V Heinrich V.(1850-1935) Oberlehrer, 1879-1920 Gymnasial-Prof. für Mathematik, s. Geheimes Staatsarchiv Preußischer Kulturbesitz, XVII. HA, Rep. 206, Nr. 916/446 Provinzialschulkollegium zu Breslau; WBIS

M Gertrud geb. Richter

๑ 31. März 1913 Frida Clara geb. Brauer (18881962) T von Ernst Adolf B. (1851-1934) seit 1876 Privat-Dozent TH Berlin-Charlottenburg; o. Prof. für Maschinenkunde: seit 1883 TH Darmstadt, 1892-1919 (Ruhestand) TH Karlsruhe, s. Kürschner (1931) Sp. 292, WBIS; Zur Geschichte des Maschinenbaus an der Technischen Universität Darmstadt. Hrsg. von Manfred Hampe, Gerhard Pahl. Düsseldorf 2008. S. 1f. - Seit 1921 Ehefrau von: (siehe) Friedrich Pfeiffer

$\mathrm{K}$ keine.

Lb Seit WS 1902/o3 Studium der Mathematik, Physik an U Breslau, SS 1904 Jena, seit WS 1904/o5 Breslau; 1905/o6 preußisches Staatsexamen für höheren Schuldienst in Berlin; 20. Okt. 1906 Dr. phil. an U Breslau.

TH Karlsruhe: Okt. 1907-März 1914 Assistent für Darstellende Geometrie; März 1909 Habilitation.

UH: 27. Febr. 1914 Ern. zum etatm. a. o. Prof. mit e. Jahresgehalt von 3 900.- Mark als Nachf. von Carl Koehler.

Sept. 1914-04. März 1916 (XX) Kriegsdienst.

Qu UAH PA 2382. GLA Abt. 235, Fasz. 2615.

W Korrelative Räume bei gegebener Punktkernfläche. Diss. Breslau 1906 (mit Lebenslauf). • Über algebraische geodätische Linien auf Kegeln II. Ordnung in: Archiv der Mathematik und Physik 19 (1912). - Metrische Untersuchungen der kubischen Hyperbel, insbesondere der gleichseitigen in: Journal für die reine und angewandte Mathematik 141 (1912); Monotongekrümmte Kurven in: ebd. 144 (1914).

$L$ Tiefbewegt teilen wir mit, daß ... W. V., Leutnant der L[andwehr] und Kompanieführer in der Nacht vom 3./4. März bei einem Sturmangriff auf das Dorf Douaumont den Heldentod fürs Vaterland gestorben ist. Heidelberg 1916. - Poggendorff 5 (1926) S. 1316; Math. Institute in Deutschland (1989) S. 162, 181. • Renteln, Michael von: Die Mathematiker an der TH Karlsruhe (1825-1945). 2. Aufl. Karlsruhe 2002. S. 347 f. • Kriegstagebuch K. Hampe (2007) S. 1003 (Register).

\section{Vosmann}

siehe Vossmann

\section{Voß, Johann Heinrich}

1807-1822 Phil. Fak.

Klassische Philologie (Alte Literatur)

* 29. Okt. 1779 Otterndorf (bei Cuxhaven)

$\dagger \quad$ 20. Okt. 1822 Heidelberg

ev.-luth.

V Johann Heinrich V. [sen.] (1751-1826) Dichter, Übersetzer, Hofrat, 1782-1802 (Ruhestand) Rektor der Lateinschule in Eutin, Philologe, kein (Sinekure-)Prof. an UH, s. UAH RA 5857; Briefe in UBH; Der Briefwechsel zwischen Johann Martin Miller und J.H. V. [sen.] Hrsg. von Manfred von Stosch ... Berlin 2012; Reichlin-Meldegg, Karl Alexander Frhr. von: Heinrich Eberhard Gottlob Paulus und seine Zeit ... Stuttgart 1853. Bd. 2. S. 32; ADB 40 (1896) S. 334-349; Heidelberg im säkularen Umbruch (1987) S. 567 (Register); Buselmeier, Michael: Ein Mann wie V. in: DIE ZEIT Nr. 29 (12. Juli 1991) S. 42; J. H. V. ... Beiträge zum Eutiner Symposium im Okt. 1994. Hrsg. von Frank Baudach ... Eutin 1997; Ein Mann wie V. ... Ausstellung zum 250. Geb. von J.H. V. Hrsg. von Frank Baudach ... Bremen 2001; J.H.V. Idylle, Polemik und Wohllaut. Hrsg. von Inka Tappenbeck. Göttingen 2001; Kirschke (2001) S. 450 (Register); Ein Knab auf schnellem Roß (2006) S. 25-29 u. ö.; Schwerin, Kerstin von: J.H. V. Hannover 2013; Einst in Penzlin daheim - heute in der deutschen Literatur zu Hause. Perspektiven auf den Dichter, Schriftsteller und Übersetzer J. H. V. Hrsg. von 
Hans-Joachim Kertscher ... Dettelbach 2014; Seid menschlich, froh und gut. Lieder nach Lyrik von J.H. V. Wien, Gramola 2016. 1 CD, 1 Begleitheft; Vollert, Michael P.: J.H. V. ... Johann Friedrich Abegg ... Zwei Gelehrte an der Universität Heidelberg im frühen 19. Jahrhundert. Rheinbach 2017.

M Ernestine Marie Christine geb. Boie (17561834) Schriftstellerin; Briefe in UBH; s. Stemper, Dagny: Das Leben der schleswig-holsteinischen Schriftstellerin E. V. Eine Analyse zu Biographie und Werk auf der Grundlage ihres autographischen Nachlasses. Frankfurt/M. 2006. - Schwester von Heinrich Christian B. (1744-1806), u.a. 1770-1774 Hrsg. und Redakteur des „Göttinger Musenalmanach“, (Mit-) Hrsg.: 1776-1788 „Deutsches Museum“ und 1789-1791 „Neues Deutsches Museum“, s. H. C. B. Literarischer Mittler in der Goethezeit. Hrsg. von Dieter Lohmeier u. a. Heide 2008.

๑ Unverheiratet.

Lb Seit SS 1799 Studium zunächst der Theologie, dann Philologie an U Halle/S., seit Herbst 1801 Jena; Dr. phil. an U Jena.

Weimar: Seit Ostern 1804 Prof. für Latein und Griechisch am Wilhelm-Ernst-Gymnasium; 1804 Ruf an U Würzburg abgelehnt; 1805 neunmonatige Beurlaubung aus Krankheitsgründen; Okt. 1806 (nach der Schlacht bei Jena und Schließung der Schule in Weimar) Aufenthalt bei den Eltern in $\mathrm{H}$.

UH: Seit Febr. 1807 a. o. Prof.; seit Febr. 1809 o. Prof. für „Alte Litteratur“ (aus: Brief vom 26. März 1813 in: UAH PA 2384) zunächst mit e. Jahresbesoldung von 400.-, zuletzt von 1000.- Gulden; SS 1822 letzte Vorlesungen über Tibulls Elegien (dienstags, donnerstags und freitags, 11-12 Uhr), Erklärung von Aeschylos Supplices, Persern und Sieben vor Thebe (montags, dienstags, donnerstags, 6-7 Uhr abends), Metrik, nach J.H. Voß Zeitmessung der Deutschen Sprache, mit praktischen Übungen (mittwochs und samstags, 11-12 Uhr), Erklärung der Odyssee, Gesang 22-24 (mittwochs und samstags, 6-7 Uhr abends) sowie Unterricht in der spanischen Sprache (in zu verabredenden Stunden).
V. bittet mehrere Male mit Erfolg um Besoldungszulage, so auch am 26. März 1813: „Einem hochverehrlichen akademischen Senate übergebe ich beiliegendes Gesuch [um Gehaltszulage] und bitte es mit der Liebe, die in ähnlichen Fällen jedes Mitglied sich selber schuldig ist, an das Ministerium des Innern zu fördern ..." (aus: UAH PA 2384).

$\mathrm{Qu}$ UAH PA 2384; RA 5857, 6372, 6600; Fak.-Akte H-IV-102/2 fol. 5r. • GLA Abt. 205, Fasz. 534-535. • Briefe von J.H. V. [jun.] in: Voß' [sen.] Übersetzungssprache ... Hrsg. von Anne Baillot ... Berlin 2015. - Teil-Nachlaß: Thüringer Universitäts- und Landesbibliothek Jena; s. auch Kalliope. - Küchmeister, Kornelia: Der Familiennachlaß Boie-Voß in der Schleswig-Holsteinischen Landesbibliothek Kiel in: Johann Heinrich Voß (1751-1826). Beiträge zum Eutiner Symposion ... Eutin 1997. S. 295-305.

Übers. Shakespeare's Schauspiele. 9 Bde. Leipzig 1818-1829 (zus. mit Johann Heinrich Voß [sen.] und Abraham Voß (Bruder), s. hierzu Drewing, Lesley: Die Shakespeare-Übersetzung von Johann Heinrich Voß und seinen Söhnen. Eutin 1999). • Äschylos. Zum Theil vollendet von Johann Heinrich Voß [sen.]. Heidelberg 1826.

$L$ ADB 40 (1896) S. 347 f.; WBIS. • Lautenschlager, Friedrich: Die Übersiedelung von J.H. V. nach Heidelberg in: ZGORh 89. Jg. (1937) S. 154-160. • Heidelberg im säkularen Umbruch (1987) S. 52 f., 314; Kirschke (2001) S. 450 (Register). - Schwinge, Gerhard: Creuzers „Symbolik und Mythologie" und der Antisymbolikstreit mit V. in: Friedrich Creuzer ... Begleitband zur Ausstellung in der UBH ... Hrsg. von Frank Engehausen u. a. Heidelberg 2008. S. 73-88. 200 Jahre Heidelberger Romantik (2008) S. 207-223; Deutsche Biographie, s. https://www.deutsche-biographie.de/pnd1006895 90.html [30.11.2017].

$P$ Bildarchiv UAH; graph. Slg. UBH. 


\section{Vossler, Karl Robert Heinrich}

1899-1909 Phil. Fak.

Romanische Philologie

* o6. Sept. 1872 Hohenheim (heute: Stadtteil von Stuttgart)

$\dagger$ 18. Mai 1949 München

ev.

V Otto (von) V. (1831-1906), u. a. seit 1865 Prof. und 1884-1897 Direktor der Land- und Forstwirtschaftl. Akademie Hohenheim, s. Klein (1968) S. 128; Universität Hohenheim, Landwirtschaftliche Hochschule 1818-1968. Hrsg. von Günther Franz. Stuttgart 1968. S. 331 (Register); Böhm, Wolfgang: Biographisches Handbuch zur Geschichte des Pflanzenbaus. München 1997. - Familienpredigt über O.V. in: Landesbibliothek Württemberg in Stuttgart (unter Vosseler), s. http://www.ahnenfor schung-kunert.de/fname9.pdf (abgerufen am 27. Febr. 2018)

M Anna geb. Faber (1846-1940)

(25. Febr. 1900 Esther geb. Gräfin Gnoli (18681922) T von Graf Domenico G. (1835/18381915), u. a. seit 188 o Prof. für Ital. Literatur an U Turin, seit 1881 Direktor der Nationalbibliothek Vittorio Emanuele in Rom, 1909-1915 Direktor der Biblioteca Lancisiana sowie 1910-1915 Leiter der Biblioteca Angelica in Rom, s. Traniello, Paolo: Dai ruderi di Parigi alla neutralità degli spiriti: tracce di un itinerario culturale di Domenico Gnoli in: Studi e testimonianze offerti a Luigi Crocetti. Milano 2004. S. $443-456$.

$\infty$ 6. Sept. 1923 Emma geb. Thiersch verw. Zeller (1887-1968)

K 2 S: u.a. Otto V. (1902-1987), u.a. 1946-1967 o. Prof. für Geschichte an U Frankfurt/M., s. Hammerstein, Notker: Nekrolog O.V. ... in: Historische Zeitschrift 247 (1988), Muhlack, Ulrich: Nekrolog in: ebd. S. 214-216; Lammers, Walter: Nachruf auf O. V. in: Nachrufe auf Marianus Czerny, Hans Peter ... Hrsg. von der Wiss. Gesellschaft an der Johann-WolfgangGoethe-Universität Frankfurt/Main. Wiesbaden 1992; WBIS, NDB (2018 in Vorbereitung).
Lb Seit WS 1891/92 Studium der Dt. und Romanischen Philologie an U Tübingen, anschl. Straßburg, Rom, WS 1896/97-SS 1897 H.

UH: 15. Okt. 1897 Dr. phil.; seit Okt. 1897 Assistent am Germanisch-Romanischen Seminar; 10. Nov. 1899 Habilitation; seit 15. Okt. 1902 außerdem Lektor für Italienische Sprache; seit 10. Nov. 1902 nichtetatm. a. o. Prof.; 1908/o9 Ruf an U Innsbruck abgelehnt.

\section{U Würzburg: Seit 1. Mai 1909 o. Prof.}

U München: Seit 28. Febr. 1911 o. Prof.; 1926/27 Rektor; Sept. 1937 Emeritierung aus politischen Gründen; WS 1937/38-SS 1938 Vertreter seines Lehrstuhls; Anfang 1944 Vortragsreise durch Portugal und Spanien im Auftrag des Reichswissenschaftsministeriums; 1. März-31. Aug. 1946 Wiedereinsetzung als Rektor. • In dieser Zeit:

1914-1918 Kriegsdienst.

Sept. 1914: V. unterschreibt neben 92 anderen Wissenschaftlern, Schriftstellern und Künstlern das sog. „Manifest der 93“, e. Aufruf vor allem gegen den Vorwurf der deutschen Kriegsschuld und der Kriegsgreuel in Belgien sowie für die Identität von deutscher Kultur und deutschem Militarismus.

E Mitglied der Akademie der Wissenschaften: 1916 München, 1937 Wien, 1949 Berlin. • Dr. h.c.: 1928 Dresden, 1949 Halle/S. 1926 Orden pour le Mérite für Wissenschaften und Künste.

Qu UAH PA 2383; RA 6419, 6872. - GLA Abt. 235, Fasz. 2621. • Briefe: UBH. • Auerbach, Erich: Und wirst erfahren wie das Brot der Fremde so salzig schmeckt. Erich Auerbachs Briefe an K. V. 19261948 ... Warmbronn 2007. Schwägerl-Melchior, Verena: „Mein Verhältnis zur Sprachwissenschaft ist das des unglücklichen Liebhabers“. Der Briefwechsel zwischen Hugo Schuchardt und K.V. in: Grazer linguistische Studien. Graz 2013. S. 181266. - Nachlaß: Bayer. Staatsbibliothek München. - Auskunft: Stadtarchiv Stuttgart (Sterberegister Stuttgart-Mitte Nr. 659/1940: Anna V. geb. Faber). 
W Die Göttliche Komödie: Entwicklungsgeschichte und Erklärung. 2 Bde. Heidelberg 1907-1910. 2. Aufl. 1925. Italienische Literatur-Geschichte. Heidelberg 1914. 4. Aufl. 1927. • Frankreichs Kultur im Spiegel seiner Sprachentwicklung. Heidelberg 1921. 4. Aufl. u.d. T.: Frankreichs Kultur und Sprache. 1929. Geist und Kultur in der Sprache. Heidelberg 1925. - Die romanischen Kulturen und der deutsche Geist. München 1926. Nachdr. 1963. - Lope de Vega und sein Zeitalter. München 1932. 2. Aufl. 1947. - Einführung in die spanische Dichtung des goldenen Zeitalters. Hamburg 1939. • Aus der romanischen Welt. 2 Bde. Leipzig 1940. Neue Ausg. 1950. - Poesie der Einsamkeit in Spanien. München 1940. 2. Aufl. 1950. Gedenkrede für die Opfer an der Universität München. München 1947. - Siehe auch Ostermann, Theodor: Bibliographie der Schriften K. V.s 1897-1951 in: Sitzungsberichte der Bayerischen Akademie der Wissenschaften. Phil.-hist. Klasse. Jg. 1950, H. 11. München 1951.

L Kürschner (1931) Sp. 3130, (1940/41) Sp. 1001f. • Nachruf in: Almanach der Akademie der Wissenschaften Wien 99 (1949) S. 263-277. Arnim 2 (1952) S. 734. - Seidel-Vollmann, Stefanie: Die romanische Philologie an der Universität München. Berlin 1977. S. 278 (Register). • Vergangene Tage. Jüdische Kultur in München. Hrsg. von Hans Lamm. München 1982. S. 420 ff. u. ö. Klemperer, Victor: Curriculum vitae. Jugend um 1900. Berlin 1989. Bd. 2. S. 747 (Register); Ders. (1996) S. 888 (Register); Ders. (1999) S. 955 (Register). Bochmann, Klaus: Sprache und Kultur bei K. V. in: Lebendige Philologie. Leipzig 1999. S. 139-147. - Hutton, Christopher M.: Linguistics and the Third Reich. Mother-tongue fascism, race, and the science of language. London 1999. - Hausmann, Frank-Rutger: Unangreifbare Großordinarien: K.V. und Ernst Robert Curtius in: Ders.: „Vom Strudel der Ereignisse verschlungen“. Deutsche Romanistik im „Dritten Reich“. Frankfurt/M. 2000. S. 117-129. • Trabant, Jürgen: Geist und Kultur in der Sprachwissenschaft. Zur Erinnerung an K. V. in: Beiträge zur Geschichte der Sprachwissenschaft. Bd. 10,2. Münster 2000. S. 253-270. - Storost, Jürgen: K. V. in: 300 Jahre romanische Sprachen und Literaturen an der Berliner Akademie der Wissenschaften. T. 1. Frankfurt/M. 2001. S. 484-491. - Gumbrecht,
Hans Ulrich: Vom Leben und Sterben der großen Romanisten: K. V. ... München 2002. S. 24-48. • WBIS; Universität München im Dritten Reich 1 (2006) S. 670 (Register); Hausmann (2008) S. 816 (Register). Feuerhahn, Wolf, Rabault-Feuerhahn, Pascale: Heidelberg um 1900. Eine Hochburg des Idealismus? Max Weber und K. V. in: Grenzüberschreitende Diskurse. Festgabe für Hubert Treiber. Hrsg. von Kay Waechter. Wiesbaden 2010. S. 279300. Kalkhoff (2010) S. 45 f. (hier ist irrtümlich der 19. Sept. als Todestag angegeben) u. ö. • Killy Literaturlexikon 12 (2011) S. 32-34; Riecke (2016) S. 152 (Register); Deutsche Biographie, s. https:// www.deutsche-biographie.de/pnd118770411.html [30.11. 2017]; NDB (2018 in Vorbereitung). • Ugalde Quintana, Sergio: Traducción de saberes. Alfonso Reyes y la estilística de K. V. in: La traducción desde, en y hacia Latinoamérica. Perspectivas literarias y lingüísticas. Madrid 2017. S. 147-164.

$P$ Bildarchiv UAH.

\section{Vossmann, Johann Hermann Anton}

1804-1805 Phil. Fak.

Mathematik, Naturlehre

* o6. Febr. 1752 Warendorf (Westfalen)

$\dagger \quad$ 04. April 1805 Heidelberg

kath.

V Johann Heinrich V. († vor 1778) Wandmacher (Weber von Wolltuchen)

M Maria Catharina geb. Hoyer

( Anna Maria geb. Lör(t)zlin ${ }^{*}$ ca. $1743 \dagger$ nach 1805)

$\mathrm{K}$ keine.

Lb Vor 1782 Wollweber (siehe Beruf des Vaters).

UH: 10. Dez. 1782 Immatrikulation als „candidatus physices“; 11. Aug. 1783 „Joh. Hermann Fossmann suchet an, ihn als Universitäts-Rechenmeister auf- und anzunehmen“; Beschluß der Oberkuratel: „Ohne hoffnung einer zu erhaltenden besoldung kann solcher als Rechenmeister auf- und angenommen werden" (aus: Toepke 4 (1903) S. 326 Anm. 4); 26. Nov. 1783 Anstellung als Rechenmeis- 
ter, siehe $Z$ (1); seit 1804 a. o. Prof. als Vertreter von Ludwig Wallrad Medicus (s. Drüll (1991) S. 101f.).

Z (1) Franz Gambsjaeger, Rektor der Universität Heidelberg, und Professoren bitten Oberkuratel am 3. Januar 1801 um finanzielle Unterstützung V.s, weil „derselbige in dem Rechnungswesen sowohl als auch in der theoretischen, vorzüglich in der praktischen Mathesi bestens erfahren seie, dies falls auch durch den ... den akademischen Bürgern in vorstehenden Wissenschaften ertheilten Unterricht und dadurch bei denselbigen bewürkten Fortschritt, erwähnter H[er]r Vossmann wegen seiner Geschicklichkeit und langjährig geleisteter Diensten, dermalen aber besonders wegen der äußersten Dürftigkeit zu höchsten Gnaden empfolen zu werden verdient" (aus: UAH PA 2385).

\section{Z (2) „Durchlauchtigster Kurfürst!}

In dem tiefsten Schmerze über den traurigen Verlust meines ... durch den Tod mir entrissenenen Mannes, aber zugleich in dem unbedingtesten Vertrauen auf Eurer Kurfürstl. Durchlaucht [E.K. D.] huldreiche und mitleidsvolle Gesinnungen, wage ich Höchstderoselben mit der flehentlichen Bitte um gnädigste Bewilligung einer Unterstützung, in meiner unglücklichen und ganz verlassenen Lage mich zu nähern.

Nachdem meinem nunmehr seligen Ehemanne durch E.K.D. Gnade die Stelle eines außerordentlichen Professors an der hiesigen Universität zutheil geworden und er hierdurch in den Stand gesetzt war, der Bearbeitung seiner Wissenschaft ganz ausschließlich und einiger Maßen sorgenfreier sich hinzugeben, blieb ihm und mir kein anderer Wunsch mehr übrig, als daß es seinem treuen redlichen Eifer in Erfüllung aller seiner Amtspflichten gelingen möchte, ihm zur Erlangung einer ordentlichen Professur, um dadurch, im Falle die Vorsehung vor mir ihn abrufen sollte, seiner ohne dieß ganz verlassenenen Witwe zum Genusse der Pension zu verhelfen, welche E.K.D. in landesväterlicher Gnade mit jener Stelle zu verbinden geruht haben. Mit Anstrengung aller seiner Kräfte rang er nach diesem Ziele, um die huldreichen Gesinnungen, deren Ausdruck E. K. D. selbst zu erhalten, er vor einem Jahre bei unterthänigster Überreichung einer seiner Schriften das Glück genoß, dessen baldige Erreichung zu erhoffen. Allein vor der Zeit hat der Tod ihn abgerufen und so hinterläßt er mich, seine Witwe, in einer Lage, deren Hilflosigkeit E. K. D. zu schildern ich keine Worte habe. Ohne alles eigene Vermögen, ohne alle Verwandte, auf deren Rath und Unterstützung ich ... rechnen dürfte. Und ohne die Kräfte, mir selbst meinen Unterhalt zu erwerben, würde ich in einem Alter von mehr als sechzig Jahren der bittersten Armuth, dem tiefsten Elende preisgegeben seyn, wenn ich nicht in E.K.D. milder Gnade eine sichere Hülfe erblickte, wenn ich nicht mit der Hoffnung mich trösten dürfte, daß Höchstdieselbe meiner unterthänigsten Bitte, in die unterste Klasse der für die Witwen ordentlicher Professoren bestimmten Pension huldreichst mich einreihen zu lassen, die gnädigste Gewährung nicht versagen werden ..." (Zitat aus e. Brief der Witwe V.s, kurz nach dem Tod ihres Mannes im April 1805 an Kurfürst Karl Friedrich von Baden geschrieben, in: UAH PA 2385). Im Juli wiederholt sie die Bitte um Unterstützung, die „nachdrücklichst“ vom Senat der UH befürwortet wird; ob sie tatsächlich 200.Gulden Pension jährlich erhielt, ist nicht überliefert. Der Personalakte 2385 liegt ein Verzeichnis von Büchern aus dem V.schen Nachlaß bei; diese Bücher wurden von der Universität in einer Auktion „nach dem Ladenpreis mit 10 Procent Abzug gesteigert" (aus: PA 2385 undatiertes letztes Blatt).

Zur Witwenkasse, -pension, Hinterbliebenenbeihilfe etc., siehe auch Carl Ullmann, Leopold Weiß, Gerhard Weissenfels, Peter Friedrich Wund

Qu UAH PA 2385. Toepke 4 (1903) S. 326.

$W$ Handbuch für Ingenieure und Bauleute, enthält die reine Theorie des Drucks der Erde auf allerlei Mauern ... Mannheim 1804.

$L$ Poggendorff 2 (1863) Sp. 1235 f.; Keller (1913) S. 107 f.; WBIS. • J.V. in: Niesert, Franz-Julius und Wallmeier, Wilhelm: Die Geburtsbriefe der Stadt Warendorf 1584-1804. Warendorf 1964. S. 277. • Math. Institute in Deutschland (1989) S. 160, 162. 


\section{Vulpius, Karl Oscar}

1894-1928 Med. Fak.

1894-1928 Chirurgie, 1895-1906 Orthopädie

* 30. Jan. 1867 Boxberg (Baden)

$\dagger$ 28. Juli 1936 (Autounfall) Untereisesheim (bei Heilbronn)

ㅁ Heidelberg ev.

V Dr. Gustav Friedrich Adolph V. (1839-1917) Apotheker, s. Donat (1913) S. 195 f., ApothekerBiographie 2 (1978) S. $716 \mathrm{f}$.

M Amalie Helene geb. Holdermann (1842-1902)

Ø 5. März 1894 Camilla geb. Starck (1869-1936) Schwester von: (siehe) Hugo Starck

K $2 \mathrm{~S}$

Vw Enkel: Dr. iur. Axel V. $\left({ }^{*} 1926\right)$ Ministerialdirigent a.D. im BMBW/BMBF, zuvor 1966-1982 Referatsleiter für Weiterbildung, Bibliothekswesen, Bildungsfernsehen und Fernunterricht; seit 1997 Domherr, seit 2008 Ehrendomherr der „Vereinigten Domstifter zu Naumburg und Merseburg und des Kollegiatstifts $\mathrm{zu}$ Zeitz“, s. http://www.vereinigte-domstifter.de/ de/domkapitel/domkapitel-heute/ (mit $L b, P$ ).

Lb Seit WS 1885/86 Studium an UH, WS 1889/90 Berlin, seit SS 1890 H; WS 1890/91 Staatsexamen; 2. März 1891 Approbation.

UH: 15 . Nov. 1890 Dr. med.; 1891-1896 Assistent an Chirurg. U-Klinik; in dieser Zeit: Winter 1891Herbst 1892 u. a. Studienreise durch Deutschland und Österreich; 1893-1906 Leiter der neuerrichteten orthopäd. Ambulanz, die Juli 1896 auf Initiative V.s in e. U-Poli- und Privatklinik für Orthopäd. Chirurgie, Heilgymnastik und Massage umgewandelt und seit Okt. 1906 als Privat-Klinik von V. weitergeführt wird; 2. Febr. 1894 Verleihung der venia docendi für Chirurgie; 6. Mai 18952. Okt. 1906 (Entziehung, s. hierzu O. V. - Leben und Werk (1997) S. 41-45) Lehrauftrag für Orthopädie, s. hierzu Albert Narath; seit 10. Nov. 1902 nichtetatm., seit 1920 nichtplanm. a. o. Prof.; 19141918 Kriegsdienst als Oberstabsarzt; 24. Febr. 1928
Entziehung der venia legendi, da seit zwei Semestern keine Hörer V.s Vorlesungen besuchen. - In dieser Zeit:

H: Seit Juli 1896 Leiter der (bis 1906 U-)Poli- und Privatklinik für Orthopäd. Chirurgie, Heilgymnastik und Massage in der Luisenstraße 1; 1908 Begründer, 1909-1919 Leiter des Badischen Landesvereins zur Krüppelfürsorge, März 1913(-Okt. 1929) als „Landeskrüppelheim“ in Rohrbach untergebracht (heute: Bethanien-Krankenhaus), siehe hierzu auch Hans von Baeyer; 16. Juni 1912 Mitbegründer und 1912-1932 Leiter der „Sanatorium Solbad Rappenau GmbH“, e. Freiluftklinik für chirurg. Behandlung der Knochen- und Gelenktuberkulose (heute: Vulpius Klinik) in Bad Rappenau.

E 1911 Mitglied der Brasilianischen Gesellschaft für Medizin und Chirurgie Rio de Janeiro; 1914 Korr. Mitglied der Königl. Akademie der Medizin und Chirurgie Barcelona. 1905 Italienischer ReUmberto I.-Preis; 1907 Stiebel-Preis der Dr. Senckenbergischen Stiftung in Frankfurt/M. 1906 Ritterkreuz des St. Mauritius- und Lazarus-Ordens; 1913 Ritterkreuz I. Klasse des Ordens vom Zähringer Löwen.

Qu UAH PA 1228, 6191; Quästurakte Rep. 27-1364; Fak.-Akten H-III-111/114 fol. 161-168, H-III-111/12O fol. 120-128, H-III-111/149, H-III-111/150, H-III-111/ 153 fol. 232-269. GLA Abt. 235, Fasz. 2623. Auskunft: Stadtarchiv Heidelberg. - Mitteilungen: Herren Dres. Günther Vulpius ( $\dagger$ ) und Axel Vulpius, Bonn-Röttgen. - Auszüge aus den Kriegstagebüchern 1914-1918 in: O. V. - Leben und Werk (1997) S. 148-181.

$W$ Die Sehnenüberpflanzung und ihre Verwertung in der Behandlung der Lähmungen. Leipzig 1902. - Die Behandlung der spinalen Kinderlähmung. Leipzig 1910. Orthopädische Operationslehre. Stuttgart 1913. (Mitverf.) 3. Aufl. 1924. Aus 25 Jahren orthopädischer Arbeit. Eine therapeutische Orientierung für den praktischen Arzt. Berlin 1920. 
L Kürschner (1928/29) Sp. 2545; Chronik Ärzte H (1985) S. 145; WBIS. • Jung, Matthias Florian: O. V. sein Lebenswerk und seine Bedeutung für die Orthopädie von damals und heute. Diss. Heidelberg 1995. • O. V. - Leben und Werk ... Hrsg. von Arnim Braun ... Heidelberg 1997. • SchwarzmannSchafhauser, Doris: Orthopädie im Wandel. Die Herausbildung von Disziplin und Berufsstand in
Bund und Kaiserreich (1815-1914). Stuttgart 2004. S. 380 (Register). - Badische Biographien N.F. VI (2011) S. 421-425; Deutsche Biographie, s. https:// www.deutsche-biographie.de/pnd119510375.html [30.11.2017].

$P$ Bildarchiv UAH; graph. Slg. UBH; Chronik Ärzte H. 


\section{Waag, Albert}

1893-1897 (1898), 1911-1918 Phil. Fak. 1918-1921, 1925-1928 (Honorar-Prof.) Phil. Fak. Germanische Philologie

* 10. Juni 1863 Mannheim

$\dagger \quad$ o8. Juni 1929 Heidelberg ev.

V Albert W. $\left({ }^{*} 1820\right)$ Kreiskassier(er)

M Caroline geb. Wolf $\left({ }^{*} 1834\right)$

$\infty$ Maria geb. Ris († nach 1929)

$\mathrm{K}$ keine.

Lb WS $1881 / 82-S S 1883$ Studium an UH, seit WS 1883/84 Freiburg/Br.; 1886 Dr. phil. an U Freiburg/ $\mathrm{Br}$.

Freiburg/Br.: 1886-1889/9o Lehrer.

H: Seit 1889/9o Prof. an Realschule (1896 Umwandlung zur Oberrealschule) (heute: Helmholtz-Gymnasium); 1891-1896 Prof. an Höherer Mädchenschule (heute: Hölderlin Gymnasium); 1896-1897 Direktor der Oberrealschule (siehe oben).

UH: 20. Jan. 1893 Habilitation; SS 1897-WS $1897 /$ 98 beurlaubt; 10. März 1898 Austritt aus Lehrkörper.

Karlsruhe: März 1897-1911 Mitglied des Oberschulrats. • In dieser Zeit:

TH Karlsruhe: Seit 1901 Privat-Dozent, 1909-1911 nichtetatm. a. o. Prof. für Dt. Sprache und Literatur.

H: 1911-1925 (Ruhestand) Direktor der Höheren Mädchenschule (siehe oben) mit Mädchenrealgymnasium und angeschlossenem Lehrerinnenseminar (siehe hierzu: Zur Fünfzigjahrfeier der Höheren Mädchenschule, jetzt Mädchenrealschu- le mit Mädchenrealgymnasium und gymnasialer Abteilung in Heidelberg. Hrsg. von Eugen Ehrmann. Heidelberg 1927). • In dieser Zeit:

UH: 31. Juli 1911 Erneuerung der Habilitation; seit 1. Mai 1918 Ern. zum o. Honorar-Prof.; SS 1921SS 1925 keine Vorlesungsankündigungen; SS 1928 letzte Vorlesung über Übungen zur deutschen Sprachgeschichte.

1908 Geh. Hofrat

E 1902 Ritterkreuz I. Klasse des Zähringer Löwen; 1908 Friedrich-Luisen-Medaille; 1916 Kriegs-Verdienstkreuz.

Qu UAH PA 6192; Fak.-Akte H-IV-102/143. • GLA Abt. 235, Fasz. 2624, 13412 f. • Briefe: UBH.

W Kleinere deutsche Gedichte des 11. und 12. Jahrhunderts. Halle/S. 1890. 2. Aufl. 1916. (Kleinere deutsche Gedichte des 11. und 12. Jahrhunderts. Nach der Auswahl von A.W. hrsg. von Werner Schröder. 2 Bde. Tübingen 1972, s. hierzu Ganz, Peter: Review: Kleinere deutsche Gedichte des 11. ... in: Zs. für deutsches Altertum und deutsche Literatur (1974) 103. Bd., H. 4, S. 169-175); Kleinere deutsche Gedichte ... neu hrsg. von Hans-Joachim Gernentz. 5. Aufl. Halle/S. 1987. • Bedeutungsentwicklung unseres Wortschatzes. Ein Blick in das Seelenleben der Wörter. Lahr 1901. 5. Aufl. 1926. • Deutsche Sprachlehre für höhere Lehranstalten. Leipzig 1905. 9. Aufl. 1930. (Mitverf.: Ludwig Sütterlin.)

L Zur Fünfzigjahrfeier der Höheren Mädchenschule, jetzt Mädchenrealschule mit Mädchenrealgymnasium und gymnasialer Abteilung in Heidelberg ... Heidelberg 1927. S. 13 u. ö. • WBIS; Kürschner (1928/29) Sp. 2545; Burkhardt (1976) S. 41, 43, 121 u. ö.; Riecke (2016) S. 38, 126; Deutsche Biographie, s. https://www.deutsche-biogra phie.de/pnd11707554X.html [30.11. 2017]. 


\section{Wachsmuth, Curt}

1877-1886 Phil. Fak.

Klassische Philologie, Griechische Geschichte

* 27. April 1837 Naumburg/Saale

$\dagger$ 08. Juni 1905 Leipzig

ev.

V Julius W. (1803-1877) Rechtsanwalt, Justizrat, s. Nietzsche Briefwechsel. Kritische Gesamtausgabe. Begründet von Giorgio Colli ... Abt. 2. Bd. 7. Bollinger, Andrea, Trenkle, Franziska: Nachbericht zur 2. Abt. Teilband 3: Briefe von und an Friedrich Nietzsche Januar 1875Dezember 1879. Gesamtregister zur 2. Abt. 2. Halbband. Hrsg. von Annemarie Pieper. Berlin 2001. S. 1375 (Register).

M Clara Antonie geb. Göschel (1816-1873), s. ebd. (2001) S. 1375 (Register)

( Marie Louise Henriette geb. Ritschl (18421903), s. ebd. S. 1375 (Register). - T von Friedrich Wilhelm R. (1806-1876) seit 1833 Prof. U Breslau, seit 1839 o. Prof. Bonn, 1865-1875 o. Prof. für Klassische Philologie Leipzig, s. Verzeichnis Bonn (1968) S. 247, Geschichte U Leipzig 2 (2010) S. 921 (Register)

K 1 S: Richard W. (1868-1941) 1898 Privat-Dozent für Physik U Göttingen, 1898-1905 a.o. Prof. Rostock; Frankfurt/M.: 1908-1914 Prof. für Experimentalphysik Akademie für Sozial- und Handelswissenschaften, 1914 (Gründungsrektor)-1932 (Emeritierung) o. Prof. und Direktor des Physikal. Inst. der U, s. WBIS, Nietzsche Briefwechsel (2001) S. 1375 (Register); Saltzer, Walter G.: Biographie R.W.s, s. https://archive.is/20130429093646/http://ww w.uni-frankfurt.de/fb/fb13/Dateien/paf/paf 1.html (12. Dez. 2008; Ausdruck im UAH); Catalogus prof. Rostochiensium online

Vw Enkel: Werner W. (1900-1990) seit 1930 Privat-Dozent Bonn, seit 1935 Leitender Arzt im Standortlazarett München, 1935 Umhabilitation München, seit 1936 Prof., 1939-1945 Beratender Chirurg und 1940-1944 Leiter des chirurg. Sonderlazaretts des Oberkommandos des Heeres in Brüssel, 1946-1969 (Emeritierung) o. Prof. und Direktor der Chirurg. U-Klinik und Staatl. Luitpoldkrankenhauses Würzburg, s. Ein Leben mit dem Jahrhundert.
Berlin 1985 (Autobiogr.); WBIS, Dt. LiteraturLexikon 26 (2006) Sp. 545 f.

Lb Seit WS 1855/56 Studium der Philologie, Geschichte an U Jena, anschl. Bonn; 14. Febr. 1860 Dr. phil. an U Bonn.

Seit Anfang 1860 Lehrer am Joachimsthalschen Gymnasium in Berlin; seit Herbst 1860 Forschungsreise durch Italien.

Athen: Seit 7. Mai 1861 „Secrétaire interprète“ der preußischen Gesandtschaft, aus: „Bekleidete Dienststellen“ in: UAH PA 2386.

U Bonn: 2. Mai 1863 Habilitation für Klassische Philologie.

U Marburg: Seit WS 1864/65 o. Prof. für Alte Geschichte mit e. jährl. Besoldung von zunächst 2400.- Mark, später 3000.- Mark.

U Göttingen: 4. Febr. 1869 (Ern.) zum SS 1869 o. Prof. für Klassische Philologie und Alte Geschichte mit e. Jahresgehalt von 4200.- Mark, seit April 1873 von 6ooo.- Mark; seit 1. April 1869 auch Prof. für Eloquenz; seit 1869 Mitglied der wiss. Prüfungskommission für Schulamts-Kandidaten mit e. Vergütung von 6oo.- Mark.

UH: 1. Febr. 1877 (Ern.)-31. März 1886 (auf eigenen Antrag Entlassung) o. Prof. als Nachf. von Hermann Köchly mit e. Jahresbesoldung von 9300.- Mark; SS 1877 Direktor, seit WS $1877 / 78$ Mit-Direktor (zus. mit Fritz Schöll) des Philolog. Seminars. In dieser Zeit:

Karlsruhe: 1877-1886 A.o. Mitglied des Oberschulrats mit e. Vergütung von 350.- Mark.

U Leipzig: 18. Dez. 1885 Ern. zum SS 1886 o. Prof. für Klassische Philologie und Alte Geschichte sowie Direktor des Philolog. Seminars und der Altgeschichtl. Abt. des Histor. Seminars.

1880 Geh. Hofrat 
$E$ Mitglied der Akademie der Wissenschaften: 1884 Göttingen, 1886 Leipzig, 1891 Berlin, München. - Ritter des Ordens vom Zähringer Löwen; Ritter I. Klasse des Königl. Sächsischen Verdienstordens.

Qu UAH PA 2386; RA 6394, 6827. • Briefe: UBH. • Franz Overbeck - Erwin Rohde. Briefwechsel. Hrsg. ... von Andreas Patzert ... Berlin 1990. S. 644 (Register). - Nietzsche Briefwechsel (2001) S. 1375 (Register; bibliogr. Angaben: Eintrag unter $[V]$ ater).

$W$ Die Stadt Athen im Alterthum. 2 Bde. Leipzig 1874-189o. - Studien zu den griechischen Florilegien. Berlin 1882. Einleitung in das Studium der alten Geschichte. Leipzig 1895. Antrittsrede C. W.s in: Die Leipziger Rektoratsreden. 1. Die Jahre 1871-1905. Berlin 2009. S. 679-689 u. ö. • Bibliographie in: Weber, Wolfgang: Biographisches Lexikon zur Geschichtswissenschaft in Deutschland, Österreich und der Schweiz. 2. Aufl. Frankfurt/M. 1987.

HG Sillographorum graecorum reliquiae. Leipzig 1885. - Liber de ostentis. Ioannis Lavrentii Lydi Liber de ostentis et Calendaria Graeca omnia ... Leipzig 1897.

$M H G$ Friedrich Nietzsches Briefwechsel mit Fr. Ritschl, J. Burckhardt ... Bd. 3. H. 1. Hrsg. von Elisabeth Förster-Nietzsche und C. W. Berlin 1904.

L Biogr. Jahrbuch 10 (1905). • Lipsius, Hermann: Worte zum Gedächtnis an C.W. in: Berichte über die Verh. der Königl.-Sächsischen Gesellschaft der Wissenschaften. Philolog.-Histor. Klasse. 57,10 (1905) S. 288-297. - Stübe, Rudolf: Worte zum Gedächtnis an C. W. ... Leipzig 1905. - Müller, B. A.: C. W. $\dagger$ in: Biogr. Jahrbuch für Altertumskunde. Leipzig 1907. S. 164-197. - Catalogus prof. Gottingensium (1962) S. 109; Verzeichnis Bonn (1968) S. 324; WBIS. - Die Klassische Altertumswissenschaft an der Georg-August-Universität Göttingen. Eine Ringvorlesung zu ihrer Geschichte. Hrsg. von Carl Joachim Classen. Göttingen 1989. S. 247 (Register). Sachsens Landesuniversität in Monarchie, Republik und Diktatur. Beiträge zur Geschichte der Universität Leipzig vom Kaiserreich bis zur Auflösung des Landes Sachsen 1952. Hrsg. von Ulrich von Hehl. Leipzig 2005. S. 528 f. • Professorenkatalog Leipzig online; Deutsche Biographie, s. https://www.deutsche-biographie.de/pnd11 7077070.html [01.11.2017].

$P$ Seminar für Klassische Philologie der U Göttingen.

\section{Wätjen, Hermann Julius Eduard}

1908-1914, 1918-1919 Phil. Fak.

Geschichte

* 14. Febr. 1876 Bremen

$\dagger$ 05. März 1944 Nimptsch (Niederschlesien; heute: Niemcza, Polen)

$\square$ Bremen

ev.

V Heinrich Eduard W. (1848-1928) Reeder, dann Privat-Bankier, s. Mütter (2010) S. 94

M Helene Adelheid geb. Aselmeyer (1855-1886)

๑ 13. Juli 1905 Ilse geb. Hepner (1876-1949), s. Brief von I. W. an Karl Hampe (1915) in: UBH (Heid. Hs. 4067 III A - 430)

K 1 T, 2 S: u. a. Wilhelm (Willy) Eduard W. (190922. Dez. 1941 in Köln nach Folterung durch Gestapo), s. Mütter, S. 109 und Anm. 66

Vw Bruder: Julius W. (1883-1963) seit 1912 Assistent am Patholog. Inst. U Freiburg/Br., seit Mai 1914 Oberarzt am Patholog. Inst. des Krankenhauses Dresden-Friedrichstadt, seit Aug. 1914 Kriegsdienst, seit 1918 Assistent am Patholog. Inst. U Freiburg, seit 1920 Privat-Dozent ebd., seit 1922 Prosektor U Berlin, seit 1924 planm. a. o. Prof. ebd., seit 1930 o. Prof. für Pathologie U Halle/S., 1945 Entlassung, anschl. erneute Berufung, Jan. 1946-Nov. 1947 Suspendierung nach Denunziationen durch Sowjetische Militäradministration, 1947-1955 (Emeritierung) o. Prof. ebd., s. WBIS; Biographische Enzyklopädie deutschsprachiger Mediziner. Hrsg. von Dietrich von Engelhardt. München 2002. Bd. 2. S. 659; Klee, Personenlexikon (2007) S. 648; Catalogus prof. Halensis online. 
Lb Seit SS 1896 Studium der Rechtswiss. an U Straßburg, SS 1897-WS 1899/1900 Studium der Geschichte an UH; 26. Juli 1900 Dr. phil. an UH.

1900-1901 Militärdienstpflicht als Einjährig-Freiwilliger; 1901-1904 (mit Unterbrechungen) Eigenstudien in Oxford, Dresden, Den Haag; u. a. wiss. Mitarbeiter im Hansischen Geschichtsverein in Hamburg; 1906 erstmals als Privat-Gelehrter in H genannt, s. Adressbuch der Stadt Heidelberg ... für das Jahr 1906. Heidelberg 1906. S. 275.

UH: 31. Okt. 1908 Habilitation; seit 30. März 1914 nichtetatm. a. o. Prof. In dieser Zeit:

Brasilien: Seit Frühjahr 1914 Studien in Nationalarchiv und -bibliothek in Rio de Janeiro.

Großbritannien: Anfang Aug. 1914 Zivilgefangenschaft in Liverpool während W.s Rückreise von Brasilien per Schiff; u. a. durch Bürgschaft englischer Freunde erhält W. die Genehmigung, Quellenkunde im Britischen Museum in London zu betreiben; Sommer 1915-Ende Febr. 1918 Internierung im Lager Wakefield in Yorkshire, s. hierzu Mütter (2010) S. 97 f.; in dieser Zeit: Mitinitiator e. interdisziplinären Hochschule im Internierungslager („Lagerhochschule“).

Ende Febr. 1918 Ausreise aus England nach Holland durch Gefangenenaustausch; Herbst 1918 Rückkehr nach Deutschland.

UH: WS 1918/19 Forts. seiner Lehrtätigkeit.

TH Karlsruhe: Seit 1. Okt. 1919 o. Prof.; in dieser Zeit: Mitglied der Badischen Histor. Kommission in Karlsruhe und Mitglied des Wiss. Rates des Dt. Auslands-Inst. in Stuttgart.

U Münster: 7. Aug. 1922 Ern. zum o. Prof. für Neuere und Mittlere Geschichte insbesondere Wirtschaftsgeschichte; Herbst 1941 Zerstörung des W.schen Privathauses in Piusallee 29 während e. falen).
Bombenangriffs; 10. Febr. 1942 Emeritierung.

Nach Herbst 1941 Wohnsitz bei Lippstadt (West-
1929-1934 Vorsitzender der Histor. Kommission für Westfalen

E Ehrenmitglied: Historisch Genootschap te Utrecht, Matschappij der Nederlandsche Letterkunde te Leiden, 1934 Histor. Gesellschaft des Künstlervereins zu Bremen.

Qu UAH PA 2388; RA 427. - Nachlaß: Universitätsbibliothek Münster. - Mitteilungen: Herr Prof. Dr. Bernd Mütter, Hövelhof.

$W$ Die Niederländer im Mittelmeergebiet zur Zeit ihrer höchsten Machtstellung. Berlin 1909. • Das holländische Kolonialreich in Brasilien. Gotha 1921. Aus der Frühzeit des Nordatlantikverkehrs. Studien zur Geschichte der deutschen Schiffahrt und deutschen Auswanderung nach den Vereinigten Staaten bis zum Ende des amerikanischen Bürgerkriegs. Leipzig 1932. • Der deutsche Anteil am Wirtschaftsaufbau der Westküste Amerikas. Leipzig 1942.

L Kürschner (1931) Sp. 3177, (1940/41) Sp. 1006 f. • Prüser, Friedrich: In memoriam H.W. in: Hansische Geschichtsblätter. Trier 1950. S. 93-97. • Bremische Biographie (1969) S. 543 f.; WBIS; Universität Münster (1980) S. 361f., 373; Weber (1987) S. 633; Heiber I (1991) S. 646 (Register); Kriegstagebuch K. Hampe (2007) S. 1004 (Register). Mütter, Bernd: H. W. ... Ein Reederssohn als Historiker in der Epoche der Weltkriege in: Westfälische Zeitschrift. Zeitschrift für vaterländische Geschichte und Altertumskunde. Hrsg. vom Verein für Geschichte und Altertumskunde Westfalens. Paderborn 2010. 160. Bd. S. 91-140. - Spenkuch (2016) S. 1323 (Register). Deutsche Biographie, s. https:// www.deutsche-biographie.de/pnd117091405.html [01.11.2017].

P Bremische Biographie (1969). 


\section{Waffenschmidt, Walter Georg}

1921-1934 Phil. Fak.

1934 Wirtschaftswiss. Fak.

1935-1946 Staats- und Wirtschaftswiss. Fak.

1946-1947 Phil. Fak.

1947-1970 (Honorar-Prof.) Phil. Fak.

Nationalökonomie

* 10. Febr. 1887 Basel

$\dagger$ 14. Okt. 1980 Heidelberg

ㅁ Zell am Harmersbach

ev.

V Georg W. (1853-1917) Expeditionsassistent an Großherzogl. Badischer Bahn

M Anna Maria Magdalena geb. Heppel (18591917)

๑ Lebenspartnerin: Gertrud geb. Stamm (18901939) Malerin

K 1 T: Felicitas (Fee) geb. Waffenschmidt gesch. Lehmann-Waffenschmidt (1930-2013) Diplom-Psychologin

Vw Enkel: Marco Lehmann-Waffenschmidt $\left({ }^{*} 1956\right)$ seit 1993 o. Prof. für Volkswirtschaftslehre, insbesondere Managerial Economics TU Dresden, s. http://tu-dresden.de/die_tu_ dresden/fakultaeten/fakultaet_wirtschaftswis senschaften/vwl/me/professur/inhaber_lehr stuhl/lw (abgerufen am 18. Dez. 2017). - Sohn von Dietrich Lehmann (1929-2014) seit 1963 Research Fellow U of California Los Angeles, anschl. Senior Researcher Californian Institute of Technology in Pasadena, zuletzt Associate Prof. Department of Visual Science der U of the Pacific in San Francisco, seit 1972 Privat-Dozent, seit 1978 Titular-Prof., 1988-1997 (Ruhestand) Extraordinarius für Neurophysiologie U Zürich, s. Verleihung der (med.) Ehrendoktorwürde an Prof. L. von U Jena in: idw - Informationsdienst Wissenschaft vom 13. Jan. 1997, https://idw-online.de/; Buchner, Helmut: Nachruf in: Klinische Neurophysiologie 45(03) (2014) S. 184; In memoriam D. L. in: Brain Topography - Journal of Cerebral Function and Dynamics (1. Sept. 2014).

$L b$ TH Karlsruhe: Seit WS 1906/07 Studium der Ingenieurwiss.; 1908 math.-naturwiss. DiplomVorexamen.
Forts. des Studiums: WS 1908/o9 TH München, SS 1909 TH Danzig, seit WS 1909/10 TH Karlsruhe; 1911 Diplomprüfung als Bauingenieur in Karlsruhe.

U Freiburg/Br:: Seit WS 1910/11 Studium der Staatswissenschaften; 24. Nov. 1913 (Rigorosum) Dr. rer. pol. • In dieser Zeit:

Freiburg/Br:: Seit 1911 Vorbereitungsdienst zum höheren technischen Staatsdienst als Ingenieurpraktikant (Regierungsbauführer), 1915-1917 Regierungsbaumeister bei Wasser-, Straßenbau- und Eisenbahnbehörden.

TH Karlsruhe: WS 1914/15 Staatsprüfung zum Regierungsbaumeister; 26. Nov. 1918 Rigorosum, 8. Aug. 1919 (Datum der Promotionsurkunde) Dr.Ing.

Karlsruhe: 1917 Versetzung als Regierungsbaumeister an Generaldirektion der Badischen Staatseisenbahnen; Gewerbeinspektor: seit 1919 Gewerbeaufsichtsamt, seit 1920 Badisches Arbeitsministerium; 1921-1924 Regierungs- und Gewerberat sowie Referent für gewerbetechnische Angelegenheiten, Arbeiterschutz- und Arbeitsrechtsfragen im Badischen Arbeitsministerium; 1924-1943 (Zurruhesetzung aus politischen Gründen) Gewerberat (Dienstvorstand) des Gewerbeaufsichtsamtes. • In dieser Zeit:

UH: 5. Nov. 1921 Habilitation für Staats- und Wirtschaftswissenschaften; seit 9. Mai 1927 nichtplanm. a. o. Prof., 10. Okt. 1939 Umbenennung in apl. Prof. für die Dauer der Zugehörigkeit zum Lehrkörper; Mai 1934 Errichtung zunächst der Wirtschaftswiss., Jan. 1935 der Staats- und Wirtschaftswiss. Fak., die 1946 z. T. in Phil. Fak. der UH eingegliedert wird, s. hierzu Weisert/Drüll/Kritzer (2007) S. 113; seit 10. Febr. 1947 Honorar-Prof. an Phil. Fak.; 19581959 kommissar. Direktor des Instituts für Publizistik in Nachf. des verstorbenen Hans von Eckardt (seit Jan. 196o Direktor: Wilhelm Emil Mühlmann, s. Drüll (2009) S. 427-429); Vorlesungen auch: SS 1964-SS 1967 am Dolmetscher-Inst., SS 1964-WS 1970/71 an Jur. Fak. und WS 1970/71 an Wirtschaftsund Sozialwiss. Fak., s. hierzu Weisert/Drüll/Kritzer (2007) S. 114; SS 1970 letzte Vorlesungsankündigung an Phil. Fak. - In dieser Zeit: 
Staatl. Wirtschaftshochschule Mannheim: 9. April 1946 (Ern.)-7. Juni 1947 Staatskommissar für die Wiedererrichtung der ehemaligen Handelshochschule; 20. Nov. 1946 (Ern.)-31. März 1955 (Emeritierung) o. Prof. für Volkswirtschaftslehre; 6. Febr. 1947 Vereidigung; 7. Juni-30. Sept. 1947 kommissar. Rektor; 1. Okt. 1947-30. Sept. 1949 Rektor; SS 1955-WS 1955/56 Vertreter seines Lehrstuhls.

Febr. 1946-Mai 1947 Leiter der Sozial- und Wirtschaftswiss. Fachgruppe an Phil. Fak. der UH, s. hierzu Weisert/Drüll/Kritzer (2007) S. 114

E 1957 Dr. phil. h.c. UH; Dr. rer. pol. h.c.: 1963 Göttingen, 1972 Karlsruhe, 1977 Tübingen. 1957 Schiller-Plakette Mannheim.

Qu UAH PA 290, 6197. - Teil-Nachlaß: UAH. Auskunft: Universitätsarchive Mannheim und Freiburg/Br.; Karlsruher Institut für Technologie (KIT) - KIT-Archiv. Mitteilungen: Herr Prof. Dr. Marco Lehmann-Waffenschmidt, TU Dresden. W. G. W. 1887-1980. Leben und Wirken. Karlsruhe 1987 (z. T. Autobiogr.).

$W$ Die wirtschaftlichen, sozialen und gesundheitlichen Verhältnisse der Zigarrenarbeiter in Baden. Karlsruhe 1925. Technik und Wirtschaft der Gegenwart. Berlin 1952. - Trattato di sociologia generale. (Auszug, deutsch:) Die allgemeine Soziologie von Vilfredo Pareto. Ludwigshafen 1953. • Deutsche volkswirtschaftliche Gesamtrechnung und ihre Lenkungsmodelle. 1949-1955. Stuttgart 1959. - Hinweise auf Bibliographien, s. W.G.W. 1887-1980. Leben und Wirken ... (1987) S. 59.

L Kürschner (1980) S. 4111 (mit Werkverz.). • König, Heinz: Zum Tode von W.G.W. in: Ruperto Carola 33. Jg., H. 65/66 (1981) S. 221. • WBIS; Universität Mannheim (1982) S. 21-24. • Bruch, Kurt: Persönlich Erlebtes mit W.G.W., Rudolf Henn zwischen 1952-1960. Sonderdruck 1987. - W. G. W. 1887-1980. Leben und Wirken. Karlsruhe 1987. • Jansen (1992) S. 414 (Register); Brintzinger (1996) S. 400 (Register); Heidelberg 1945 (1996) S. 345; DBE 10 (1999) S. 273; Enzenauer (2005) S. 185 (Register); UH im Nationalsozialismus (2006) S. 1274 (Register). - Pope, Robin: Beggar-Thy-Neighbour Exchange Rate Regime Misadvice from Misap- plications of Mundell (1961) and the Remedy in: The World Economy 32,2 (2009) S. 326-350. • Hesse, Jan-Otmar: Wirtschaft als Wissenschaft. Die Volkswirtschaftslehre in der frühen Bundesrepublik. Frankfurt/M. 2010. S. 265-267 u. ö. • Schultes (2010) S. 312 u. ö. • Köster, Roman: Die Wissenschaft der Außenseiter. Die Krise der Nationalökonomie in der Weimarer Republik. Göttingen 2011. Baden-Württ. Biographien V (2013) S. 440-443; Deutsche Biographie, s. https://www. deutsche-biographie.de/pnd118628143.html [18.12. 2017].

P Bildarchiv UAH; Universität Mannheim (1982).

\section{Wagemann, Johann Georg Henning}

1811-1820 Phil. Fak.

Neuere Geschichte, auch Staatswirtschaft

* 24. April 1782 Göttingen

$\dagger$ 31. März 1825 Lüttich ev.

V Johann Gottfried Wilhelm W. (1742-1804), u. a. Prediger, Konsistorialrat, $1789-1790$ Privat-Dozent für Theologie Göttingen, zuletzt Generalsuperintendent, s. WBIS, Catalogus prof. Gottingensium (1962) S. 42

M Juliane Elisabeth Friederike geb. Barckhausen (1754-1828)

$\varnothing$ 2. Okt. 1818 Heinrike geb. Planck (1795-1867), s. Nooke, Christoph: Gottlieb Jakob Planck. Grundfragen protestantischer Theologie um 180o. Tübingen 2014. S. 125 Anm. 729, 155, 461; T von Gottlieb Jakob P. (1751-1833), u. a. 17841833 o. Prof. für Kirchengeschichte Göttingen, s. Catalogus prof. Gottingensium (1962) S. 35, BBKL VII (1994) Sp. 705-710, Nooke, Christoph: G. J.P. Grundfragen ... (2014); Urgroßvater von Max Planck (1858-1947) 1919 Nobelpreisträger für Physik; s. auch Ferdinand Fehling: Eintrag unter $\infty$ [Ehefrauen]

K 2 S, 1 T, s. Stumm (2012) S. 294, Nooke (2014) S. 155 Anm. 926 
Vw Schwestern: Carolina Friederike Luise W. (1776-1843) Ehefrau von: (siehe) Christoph Martin. - Johanne Sophie Charlotte Eleonore W. (1784-1859) Ehefrau von Heinrich Ludwig Planck (1785-1831) seit 1809 Privat-Dozent an Phil. Fak., seit 1810 a. o. Prof. für Theologie, seit 1823 o. Prof. für Neues Testament Göttingen, s. Biogr. Jahrbuch (1900) Bde. 4-5, S. 14; Großvater von Nobelpreisträger Max P. • Dorothea (Dorette) Eleonora Wilhelmina Carolina W. (1790-1829), s. Poiss, Thomas: Die unendliche Aufgabe. August Böckh als Begründer des Philologischen Seminars in: Die modernen Väter der Antike. Die Entwicklung der Altertumswissenschaften an Akademie und Universität im Berlin des 19. Jahrhunderts. Hrsg. von Annette M. Baertschi ... Berlin 2009. S. 106 Anm. 109; Ehefrau von: (siehe) August Böckh

Vw Neffe (Sohn von Schwester Johanne Sophie Charlotte Eleonore W.): Johann Julius Wilhelm (von) Planck (1817-190o) seit 1841 Privat-Dozent Göttingen; Ordinarius für Römisches Recht, Zivilrecht, Strafprozeßrecht: seit 1842 Basel, seit 1845 Greifswald, seit 1850 Kiel, 1867-1895 (Ruhestand) München, s. Claussen, Tanja: Johann Julius Wilhelm P. ... Leben und Werk. Frankfurt/M. 2015; Vater von Nobelpreisträger Max P., s. NDB 20 (2001) S. 497-500; Fischer, Ernst Peter: Der Physiker: M.P. und das Zerfallen der Welt. München 2010.

Lb U Göttingen: Seit 6. Mai 1800 Studium der Theologie, Philologie.

Livland: 1803-1809 Informator (Privatlehrer).

UH: 29. Okt. 1810 Dr. phil.; 26. Nov. 1810 Beschluß des General-Direktoriums im Ministerium des Innern in Karlsruhe, W.s Antrag auf e. Privatdozentur für Geschichte und Hilfswissenschaften erst nach seiner Habilitation zu genehmigen; 15. Jan. 1811 Habilitation, siehe hierzu UAH H-IV-102/6 fol. 21-48; seit 3. März 1814 a.o. Prof. mit e. Jahresbesoldung von 300.- Gulden rückwirkend ab 23. Okt. 1813; Herbst 1814 Studienreise nach Großbritannien; 1818 Ruf an U Lüttich abgelehnt; seit
23. April 1818 Besoldungszulage von 300.- Gulden; 23. April 1820 Entlassung auf eigenen Antrag. • In dieser Zeit:

UBH: 1810-1811 Bediensteter: 12. Aug. 1811 W. war „bey hiesiger Universitäts-Bibl[iothek] bisher angestellt und [hat] gute Dienste geleistet", aus: UAH PA 2389.

U Lüttich: Seit SS 1820 o. Prof. für Geschichte und Staatswirtschaft.

Qu UAH PA 2389; RA 5954; Fak.-Akte H-IV102/6. GLA Abt. 205, Fasz. 539. • Briefe: UBH. • Dammann, Oswald: G. W. an August Böckh. Heidelberger Briefe aus den Jahren 1812-1818 in: ZGORh 94. Jg. (1942) S. 676-709.

$W$ De quibusdam causis, ex quibus cum in veteribus tum in recentioribus civitatibus turbae ortae sunt ... 2 Bde. Heidelberg 1810-1811. • Cours de statistique. Lüttich 1823 .

L Meusel, 9. Bd., Suppl. zur 5. Ausg. (1827) S. 295; Wechmar (1846) S. 253 f.; WBIS; Stumm (2012) S. 294; Deutsche Biographie, s. https://www.deut sche-biographie.de/pnd117091863.html [01.11. 2017].

\section{Wagenmann, August Emil Ludwig}

189o-1892, 1910-1935 Med. Fak.

Augenheilkunde

* $\quad$ 05. April 1863 Göttingen

$\dagger$ 12. Aug. 1955 Heidelberg ev.-luth.

V Julius August W. (1823-189o), u.a. seit 1861 o. Prof. für Theologie Göttingen, s. ADB 40 (1896) S. 477-479, Catalogus prof. Gottingensium (1962) S. 36, BBKL (2018 in Vorbereitung)

M Emilie Sophie Charlotte Johanne geb. Göz (1830-1886) 
(0) 19. Sept. 1891 Klara Margarethe Wilhelmine geb. Stellmacher (1867-1945) T von Dr. iur. h.c. Adolf Richard S. (1831-1907), u.a. seit 1864 Staatsanwalt; Oberstaatsanwalt am Oberlandesgericht: seit 1875 Königsberg (Preußen), seit 1879 Celle; 1890-1903 Rat im I. Strafsenat des Reichsgerichts Leipzig, s. Lebenserinnerungen des ... verstorbenen ... A.S. ... für seine Familie und Freunde gedruckt. Jena 1907; WBIS

$\mathrm{K}$ keine

Vw Bruder: Dr. iur. Karl W. (1867-1938), u.a. seit 1893 Pastor an Schloßkirche in Hannover, seit 1896 Konsistorialassessor, seit 1899 Superintendent in Bleckede an der Elbe, seit 1909 in Lüne(-Moorfeld; heute: Stadtteil von Lüneburg); Hannover: seit 1910 Konsistorialrat im Konsistorium, seit 1914 Mitglied des Landeskonsistoriums, 1924-1932 (Ruhestand) Vizepräsident des Landeskirchenamts, s. Meyer, Philipp: K.W. zum Gedächtnis in: Zs. der Gesellschaft für niedersächsische Kirchengeschichte 44 (1939) S. 5-18.

Vw Schwester: Julie (Lulu) W. (1860-1942), s. Scheidle, Ilona: „Fertige Tatsache spricht für sich!“ ... in: Heidelberg. Jahrbuch zur Geschichte der Stadt 2008. Heidelberg 2007. Jg. 12. S. 77; Ehefrau von: (siehe) Paul Jannasch. • Neffen: Julius W. $\left({ }^{\star} 1901\right.$ X 1944) $1925-$ 1937 Privat-Dozent für Kirchengeschichte UH; Vertreter e. Professur: 1935-1936 Gießen, 19361937 Göttingen, 1940-1941 Rostock; 1937-1944 a. o. Prof. Kiel, 1941-1944 Kriegsdienst, s. UAH PA 6200; Die „Murren“ des Hans Freiherr von Campenhausen: „Erinnerungen, dicht wie ein Schneegestöber“. Autobiografie. Hrsg. von Ruth Slenczka. Norderstedt 2005. S. 389 (Register); Kieler Gelehrtenverzeichnis 19191965 online, Buddrus/Fritzlar (2007) S. 420 f., BBKL (2018 in Vorbereitung). • Dr. iur. Karl W. (1905-1982), u.a. Hannover: seit 1933 Mitglied des Landeskirchenamts, seit 1936 Leiter des Finanzdezernats, 1952-1970 (Ruhestand) Präsident des Landeskirchenamts, s. Nachlass im Landeskirchlichen Archiv Hannover (Bestand N 76); Wer ist's (1955) S. 1227.

Lb Seit WS 1881/82 Studium an U Göttingen, anschl. München, Göttingen; WS 1885/86 Staatsexamen in Göttingen.
U Göttingen: 1886 Dr. med.; seit 1. März 1886 Assistent von (siehe) Theodor Leber an U-Augenklinik; 28. Mai 1888 Habilitation.

UH: 3o. Okt. 1890 Nostrifikation; WS 1890/91-SS 1892 Privat-Dozent.

U Jena: Seit WS 1892/93 o. Prof. und Direktor der Augenklinik; vor 1910 Rufe an U abgelehnt: Erlangen, Straßburg.

UH: Seit 30. Juni 1910 o. Prof. und Direktor der UAugenklinik als Nachf. von Leber; 31. März 1935 Emeritierung.

\section{5/16 Dekan der Med. Fak. der UH}

1934 Präsident der Dt. Ophthalmologischen Gesellschaft (DOG); 1917-1935 Hauptschriftführer der DOG

1910 Geh. Hofrat

E Ehrenmitglied: 1936 Ophthalmological Society of the United Kingdom London, 1936 DOG; 1938 Korr. Mitglied der Königl. Gesellschaft der Ärzte Budapest. - 1907 Ritterkreuz II. Klasse des Sachsen-Ernestinischen Hausordens; 1914 Ritterkreuz I. Klasse des Ordens vom Zähringer Löwen. • 1893 von Graefe Preis; 1943 Goethe-Medaille. • 1940 Ehrensenator der Universität Heidelberg.

Qu UAH PA 1230, 2390, 6199; RA 6787; KE 75. • GLA Abt. 235, Fasz. 2628. - Briefe: UBH; siehe auch Kalliope. Auskunft: Stadtarchiv Heidelberg. - Mitteilungen: Frau Diplom-Ing. Architektin Barbara Helbich (Großnichte), Hannover.

$W$ Leber, Theodor, W., A.: Infantile Necrose der Bindehaut mit letalem Ausgang durch allgemeine multiple Streptocokken-Invasion des Gefäßsystems in: Albrecht von Graefes Archiv für Ophthalmologie 34 (1888) Nr. 4, S. 250-271. Die Verletzungen des Auges mit Berücksichtigung der Unfallversicherung. 3 Bde. Leipzig 1913. 3. Aufl. 1924.

MHG 1896-1945 Albrecht von Graefes Archiv für Ophthalmologie. 
L Engelking, Ernst: A. W. in: Ruperto Carola 7. Jg., Nr. 18 (1955) S. 18 f. - Nachruf in: Ärztliche Wochenschrift Bd. 10 (1955) H. 28-57, S. 836. - Serr, Hermann: A.W. in: Albrecht von Graefes Archiv für Ophthalmologie vereinigt mit Archiv für Augenheilkunde Bd. 157 (1955) S. 1f. • Catalogus prof. Gottingensium (1962) S. 94; Chronik Ärzte H (1985) S. 145, 275; WBIS; Jansen (1992a) S. 170 (Register). - Rohrbach, Jens Martin: Augenheilkunde im Nationalsozialismus ... Stuttgart 2007. S. 12, 69, 71, 120 f. u. ö. • Stahl, Dorina Maren: Die Einführung der Chemotaxis der Leukozyten in die Medizin. Eine wissenschaftshistorische Analyse der Laborprotokolle Theodor Lebers zur Entzündungsforschung. Med. Diss. Lübeck 2016. S. 66 f., 105, 131 Anm. 427 u. ö. • Deutsche Biographie, s. https://www.deutsche-biographie.de/pnd11 7091782.html [01.11.2017].

$P$ Bildarchiv UAH; Ruperto Carola; Chronik Ärzte H.

\section{Wahle, Ernst Karl Bernhard Hermann}

1920-1945, 1946-1957 Phil. Fak.

Frühgeschichte

* 25. Mai 1889 Magdeburg

$\dagger \quad$ 21. Jan. 1981 Heidelberg

ev.

V Dr. phil. Hermann W. (1859-1949) Volksschullehrer, später Oberrealschuldirektor, s. Hakelberg (2001) S. $206 \mathrm{f}$.

M Anna geb. Haerter (1861-1948), s. Hakelberg, S. 207

(1) 18. Nov. 1921 Eva Frieda Agnes geb. Baethgen (1897-1967) $\mathrm{T}$ von Friedrich Wilhelm Adolph B. (1849-1905) seit 1884 Prof. für Alttestamentliche Theologie Kiel, seit 1888 Halle-Wittenberg, seit 1889 o. Prof. Greifswald, seit 1895 Berlin, s. NDB 1 (1953) S. 531, WBIS, BBKL I (1990) Sp. 341 f., Tilitzki 1 (2012) S. 36. Schwester von: (siehe) Friedrich Baethgen (1890-1972)

$\mathrm{K}$ keine.
Lb Seit SS 1908/o9 Studium der Archäologie, Geschichte, Anthropologie, Geographie an U HalleWittenberg, seit WS 1908/og Berlin, seit SS $1911 \mathrm{H}$; 28. Juli 1914 Dr. phil. an UH.

H: 1914-1921 (mit Unterbrechungen) Im Auftrag der Stadt Heidelberg richtet W. die vor- und frühgeschichtliche Abteilung der städtischen Sammlungen (des späteren Kurpfälzischen Museums) neu ein. • In dieser Zeit:

1. März 1915-17. Dez. 1918 Kriegsdienst (25. Aug. 1918 schwer verwundet).

UH: 29. April 1920 Habilitation für Prähistorie; WS 1920/21 (bis Juni 1934) erster Stipendiat des Privatdozentenstipendiums in Höhe von jährl. 400o.- Mark; seit 13. März 1922 Lehrauftrag für Vorgeschichte und Dt. Archäologie am Archäolog. Inst.; 1923-1925 (Stilllegung) auch Leiter des von der Josefine und Eduard von Portheim-Stiftung für Wissenschaft und Kunst eingerichteten Prähistorischen Inst. in H, zunächst im Palais Weimar in Hauptstraße 235, dann Brunnengasse 1 (Inst. wird 1927 dem Anthropolog. Inst. der UH zugewiesen); seit 17. Juli 1924 nichtplanm. a.o. Prof.; zwischen 1924 und 1932 mehrere erfolglose Versuche der Phil. Fak. um Einrichtung e. planm. Stelle für W.; 1927 Ruf an U Prag abgelehnt; 1933-1945 (Gründer und) Leiter der Lehrstätte für Frühgeschichte, dem Vorgänger des heutigen Inst. für Ur- und Frühgeschichte; seit 1. Juni 1934 „planm. wiss. Hilfsarbeiter mit der Amtsbezeichnung Professor in der Besoldungsgruppe A 2d“ (aus: UAH PA 6212); 2. Juli 1934 Leistung des Beamteneids; März 1935, erneut Juni 1941 erfolglose Versuche der Phil. Fak. um Einrichtung e. (persönlichen) Ordinariats für W.; seit 1. April 1937 Vertreter des neu eingerichteten planm. Extraordinariats für Vor- und Frühgeschichte; 15. Jan. 1938 Ern. zum planm. a. o. Prof. für Frühgeschichte; 7. Juni 1944 Verleihung der Eigenschaft als Beamter auf Lebenszeit; 19. Nov. 1945 Entlassung gemäß Erlaß der amerikanischen Militärregierung; 22. Nov. 1946 Wiedereinsetzung als planm. a. o. Prof. am Seminar für Frühgeschichte; 30. Sept. 1957 Entbindung von amtl. Verpflichtungen an U. • In dieser Zeit: 
1922-1938 Oberpfleger der frühgeschichtlichen Denkmäler im nördlichen Baden.

W. ist der erste Prähistoriker an der Universität Heidelberg

$E$ Mitglied der Akademie der Wissenschaften: 1935 (als Nichtordinarius) H, 1961 München; Ehrenmitglied: 1936 Royal Irish Academy Dublin, 1979 Kommission für geschichtliche Landeskunde in Baden-Württemberg; Mitglied: 1941 Akademie gemeinnütziger Wissenschaften zu Erfurt, 1944 Akademie der Naturforscher Leopoldina Halle/S.

Qu UAH PA 3061, 6212-6215, 7053. Nachlaß: UBH, s. http://www.propylaeum.de/vor-und-frueh geschichte/themenportale/ernstwahle; http://hei dicon.ub.uni-heidelberg.de/pool/wahle. - Siehe auch Archiv der Dt. Akademie der Naturforscher Leopoldina Halle/S. • W., E.: Und es ging mit ihm seinen Weg. Heidelberg 1980 (mit autobiogr. Charakter).

W Deutsche Vorzeit. Leipzig 1932. Nachdr. 1962. • Frühgeschichte des Germanentums in: Neue Propyläen-Weltgeschichte ... Bd. 2. Berlin 1940. • Zur ethnischen Deutung frühgeschichtlicher Kulturprovinzen in: Abh. der Heidelberger Akademie der Wissenschaften Jg. 1941. • Geschichte der prähistorischen Forschung in: Anthropos 45, Nr. 4-6 (Juli-Dez. 1950) S. 497-538, ebd. 46, Nr. 1-2 (Jan.April 1951) S. 49-112. - E.W. Tradition und Auftrag prähistorischer Forschung. Ausgew. Abh. als Festgabe zum 75. Geb. ... Hrsg. von Horst Kirchner. Berlin 1964. Ur- und Frühgeschichte im mitteleuropäischen Raum. München 1973. 9. Aufl. 1999. - Einheit und Selbständigkeit der prähistorischen Forschung in: Schriften der Gesellschaft der Freunde Mannheims ... 12 (1974).

G 1925 Badische Fundberichte.

MHG 1926-1933 Volk und Rasse. - 1935-1943 Zeitschrift für Rassenkunde.

L Kürschner (1980) S. 4126; WBIS; Jahrbuch der Bayer. Akademie der Wissenschaften (1981) S. 223234. - Gropengießer, Erich: E.W. in: ZGORh 130. Jg. (1982) S. 357-361 (mit Werkverz.). • Jan- sen (1992a) S. 170 (Register). - Hakelberg, Dietrich: E.W. im Kontext seiner Zeit in: Eine hervorragend nationale Wissenschaft (2001) S. 199-310. • Pape, Wolfgang: Zehn Prähistoriker aus Deutschland: Gustav Schwantes, ... E. W. ... in: Reallexikon der germanischen Altertumskunde ... Berlin 2001. Bd. 29. S. 55-88. Magdeburger biogr. Lexikon (2002) S. $766 \mathrm{f}$ • Gross, Uwe: E. W. - Dokumentator verschollener frühmittelalterlicher Funde in: Denkmalpflege in Baden-Württemberg. Nachrichtenblatt des Landesdenkmalamtes (2003) 32, Nr. 3, S. 245-248. - UH im Nationalsozialismus (2006) S. 1275 (Register); Klee, Kulturlexikon (2007) S. 640. - Stephan, Uwe: E. W. versus Gustaf Kossinna ... Marburg 2011. Deutsche Biographie, s. https://www.deutsche-biographie.de/pnd11 8628488.html [01.11. 2017].

$P$ Bildarchiv UAH.

\section{Walch, Georg Friedrich}

1812-1841 Jur. Fak.

Rechtsphilosophie, Römisches Recht

* o7. Jan. 1766 Göttingen

$\dagger \quad$ 16. Juli 1841 Heidelberg

kath.

V Christian Wilhelm Franz W. (1726-1784), u.a. seit 1753 o. Prof. für Philosophie, seit 1754 a. o. Prof., seit 1757 o. Prof. für Theologie an U Göttingen, s. Catalogus prof. Gottingensium (1962) S. 35, BBKL XIII (1998) Sp. 179-183, Göttinger Gelehrte 1 (2001) S. 30 f., WBIS, Kalliope

M Eleonore Franziska (Friderike) geb. Crome

$\infty$ unverheiratet

Vw Großvater: Johann Georg W. (1693-1775), u. a. seit 1728 o. Prof. für Theologie an U Jena, s. BBKL XIII (1998) Sp. 183-186, WBIS, Kalliope

Vw Onkel: Johann Ernst Immanuel W. (1725-1778) seit 1750 a.o. Prof. für Theologie, seit 1754 o. Prof. u. a. für Logik an U Jena, s. WBIS, Kalliope. Karl Friedrich W. (1734-1799) seit 1756 Prof. für Rechtswiss. Jena, s. Rechtsgelehrte der U Jena (2012) S. 67-76 
Vw Vetter: Georg Ludwig W. (1785-1838) seit 1805 Bibliothekar an UB Jena, seit 1808 a. o. Prof. für Klassische Philologie Jena, seit 1811 Gymnasiallehrer in Berlin, 1830-1838 o. Prof. Greifswald, s. ADB 40 (1896) S. 650; Sohn von Karl Friedrich W. (1734-1799).

Lb Seit 1783 Studium an U Göttingen, anschl. Jena; 18. Dez. 1790 (Disputation) Dr. iur. an U Jena.

\section{U Göttingen: Seit 1792 Privat-Dozent.}

UH: Seit 13. Febr. 1812 Privat-Dozent; 3. März 1814 Ern. zum a.o. Prof. mit Besoldung; 11. Okt. 1821 Ern. zum o. Prof. II. Klasse (d.h. ohne Teilnahmeberechtigung an den Fak.-Sitzungen und Doktorexamina); SS 1841 Vorlesungsankündigung: Ein auch für Anfänger bestimmtes Practicum, in welchem einfache Rechtsfälle zur schriftlichen Entscheidung nach römischem Rechte vorgelegt werden: Prof. Walch, wenn es dessen Gesundheit irgend erlaubt, 2 mal wöchentlich in zu verabredenden Stunden.

Qu UAH PA 2393. - GLA Abt. 205, Fasz. 542. • Briefe: UBH.

$W$ Calendarium Palaestinae oeconomicum ... Göttingen 1785. - De negotiis et actibus vi metuve extortis ex iure Romano partim ipso iure nullis partim a praetore rescindendis. Jena 1790 . Emblema Triboniani ... Jena 1790. - Einladung zu einem auch für Anfänger bestimmten Practicum über Gegenstände des römischen Rechts. Heidelberg 1812.

L Wechmar (1846) S. 254. - Über G.F.W. in: Reichlin-Meldegg, Karl Alexander Frhr. von: Das Leben eines ehemaligen römisch-katholischen Priesters. Heidelberg 1874. S. 131. Catalogus prof. Gottingensium (1962) S. 64; WBIS; Weisert (1991) S. 127 u. ö.; Humaniora (2006) S. 290 u. ö.; Baur (2009) S. 162-164; Schroeder (2010) S. 121f. u. ö.; Deutsche Biographie, s. https://www.deutsche-bio graphie.de/pnd117116157.html [02.11. 2017].

\section{Waldberg, Max Freiherr von}

1889-1908 Phil. Fak. 1908-1933 (1935) (Honorar-Prof.) Phil. Fak.

Neuere Dt. Sprache und Literatur

* o1. Jan. 1858 Jassy (Fürstentum Moldau; heute: Iaşi, Rumänien)

$\dagger \quad$ 06. Nov. 1938 Heidelberg mosaisch, seit $1897 \mathrm{ev}$.

V Moses (seit 1884: Freiherr) von W. (1833-1901) Bankier, s. Jüdische National-Biographie 6 (1931) S. 198, Riecke (2016) S. 45

M Anna geb. Kahané (1831-1892)

$\infty$ 21. Dez. 1897 Viola (Violetta) Malwina geb. Platschek (1877-1942 Suizid), s. Lexikon jüdischer Einwohner Hs (2011) S. 426, Riecke, S. 48

$\mathrm{K}$ keine.

Lb Seit WS 1877/78 zunächst Studium der Rechtswiss., dann der Germanistik, Geschichte, Philosophie an U Wien, anschl. Czernowitz.

U Czernowitz: 11. März 1881 Dr. phil. (nicht an U Wien, s. hierzu Universität Czernowitz (1979) S. 157 f.).

U Berlin: 1881-1883 Forts. des Studiums.

U Czernowitz: 29. Juni 1885 Habilitation für Neuere Dt. Literaturgeschichte; 18. Juni 1888 Ern. zum a. o. Prof. für Dt. Sprache und Literatur.

UH: 13. März 1889 Umhabilitation; seit 18. Dez. 1889 a. o. Prof.; 1892 Ruf an U Czernowitz abgelehnt; 1892-1908 nichetatm. a. o. Prof.; 1893-1933 Lehrauftrag für Neuere Dt. Philologie; seit 21. Febr. 1908 o. Honorar-Prof.; 1914-1918 Kriegsdienst als ehrenamtl. Helfer des Dt. Roten Kreuzes; 12. April 1933 auf eigenen Antrag Verzicht auf Lehrtätigkeit, um e. Entlassung durch Gesetz über „Wiederherstellung des Berufsbeamtentums" zu vermeiden; 6. Nov. 1935 Beurlaubung von U; 31. Dez. 1935 Entzug der Lehrbefugnis aus rassischen Gründen.

Am 15. Okt. 1921 ist im Tagebuch der Phil. Fak. der UH vermerkt: Promotionsgesuch von $\mathrm{P}$ [aul] J[oseph] Goebbels; als Hauptprüfer wird M. von W. genannt (aus: UAH H-IV-103/1 S. 94f.); s. hier- 
zu Jakobs (1992) S. 55 Anm. 86; Czapla, Ralf Georg: Ein Leben im Zitat. Joseph Goebbels' Weg vom Germanisten zum Politiker in: akten-kundig? Literatur, Zeitgeschichte und Archiv. Hrsg. von Marcel Atze u. a. 10./11. Jg. 2007/o8. Wien 2009. S. 221-245.

E 1910 Ritterkreuz I. Klasse des Ordens vom Zähringer Löwen.

Qu UAH PA 6219; Fak.-Akte H-IV-102/121 fol. 88r; RA 6419, 6841. • GLA Abt. 235, Fasz. 2632. • Briefe: UBH (sowie ein handschriftl. alphabetischer Zettelkatalog seiner Bibliothek, 1939 ein Geschenk an UBH). • Auskunft: Archiv der Universität Wien. Verbrennung seines Nachlasses durch Ehefrau kurz vor ihrem Freitod.

W Die galante Lyrik. Straßburg 1885. - Die deutsche Renaissancelyrik. Berlin 1888. Goethe und das Volkslied. Berlin 189o. Der empfindsame Roman in Frankreich. Straßburg 1906. Studien und Quellen zur Geschichte des Romans. Berlin 1910.

L Jüdische National-Biographie 6 (1931) S. 198; Kürschner (1931) Sp. 3153; Lehmann (1967) S. 228 f. • Sauder, Gerhard: Positivismus und Empfindsamkeit. Erinnerung an M. von W. in: Euphorion 65 (1971) S. 402 u. ö. Burkhardt (1976) S. 4o f. • Bergstraesser, Dorothea: Die Bibliothek des Germanisten M. von W. ... und die Universitätsbibliothek Heidelberg. Zum Verhältnis von Gelehrtenbibliothek und öffentlicher Bibliothek im Übergang vom 19. zum 20. Jahrhundert in: Bibliothek und Wissenschaft 13 (1979) S. 1-81. • Universität Czernowitz (1979) S. 427 (Register); Mussgnug (1988) S. 299 (Register); Jansen (1992a) S. 170 (Register). Handbuch der historischen Buchbestände in Deutschland. Hrsg. von Bernhard Fabian. Hildesheim 2003. - Int. Germanistenlexikon 3 (2003) S. 1977 f.; UH im Nationalsozialismus (2006) S. 351369 u. ö.; Kriegstagebuch K. Hampe (2007) S. 1004 (Register); Lexikon jüdischer Einwohner Hs (2011) S. 426; Baden-Württ. Biographien V (2013) S. 507509; Riecke (2016) S. 152 (Register); Deutsche Biographie, s. https://www.deutsche-biographie.de/ pnd109834437.html [02.11. 2017]. • Flachs, Olha: M. von W. ... Ein Beitrag zur Geschichte der Germanistik. Heidelberg 2017.

\section{Waldeck, Friedrich Meyer von}

siehe Meyer, Friedrich

Waldow, Erich (Pseudonym)

siehe Boucke, Ewald

\section{Walleser, Max Gebhard Lebrecht}

1911-1934 (1936) Phil. Fak.

Indische Philologie

* 18. Juni 1874 Mannheim

$\dagger$ 15. April 1954 Wiesloch (bei Heidelberg)

口 Heidelberg-Rohrbach kath.

V Martin Jakob W. (1835-1903) seit 1866 Lehrer, seit 1877 Rektor und 1885-1902 (Ruhestand) Direktor der Töchterschule, 1877 umbenannt in Großherzogliche Höhere Mädchenschule (Stiftungsschule; heute: Elisabeth-Gymnasium) in Mannheim; 1902 Hofrat, s. Peschke (2017) S. 27-63, 139-141 u. ö.

M Maria Magdalena geb. Lend (1841-1913), s. Peschke, S. 26, 36, 184 f., 280

๑ 31. Juli 1914 Mathilde (Thilde) geb. Weber (1879-1939), s. Lexikon jüdischer Einwohner Hs (2011) S. 426, Peschke, S. 1167

K 1 T: Adelheid (Heidi) W. (1915-2005), s. Lexikon jüdischer Einwohner Hs (2011) S. 426, Peschke, S. 339, 1115 f., 1199, 1201 f., 1206, 1279 f., 1425 f., 1626 f., 1827, 1833f., 1961-1963, 1971f. • 1 S: Dr. sc. techn. Dr. iur. Friedrich (Fritz) Max Martin W. (1917-2008) 1944-1954 Ingenieur im Werk Bern der Gesellschaft der Ludwig von Roll'schen Eisenwerke AG, 1954-1956 Studium an Jur. Fak. Bern, 1957-1958 Mitarbeiter der Firma Bovard \& Cie., Patentanwälte, Bern, seit 1959 erneut im Werk Bern der Gesellschaft der Ludwig von Roll'schen Eisenwerke AG, s. Peschke, S. 1202-1206, 1279, 1455 f., 1664f., 1668-1676, 1827, 1834, 1917 (1941 Erkrankung an kriegsbedingter Depression), 1918-1922, 1926-1938, 1943-1946, 1949-1953, 1958 f., 3884 u. ö. • Siehe auch Peschke, S. 1847-1902 
Vw Großmutter: Flora Weber geb. Wagner (mosaisch), s. Peschke, S. 1662 f. Schwester: Margarete/Margaretha (Grete) Elisabeth Rosina W. (1878-1960) seit 1901 Lehrerin, 1904-1934 (Ruhestand) Hauptlehrerin an Höherer Mädchenschule in Mannheim, s. Peschke, S. 64-74, 1329 u. o.

Lb Seit WS 1891/92 Studium der Neueren Philologie, Philosophie an UH, WS 1893/94 und SS 1895 Freiburg/Br., 18. Juni 1894-12. Nov. 1894 Genf; 1. Okt. 1892-2. Okt. 1893 Militärdienstpflicht als Einjährig-Freiwilliger im 10. Corps des 2. Badischen Grenadier-Regiments Kaiser Wilhelm I. Nr. 110; 13. März 1896 Staatsexamen in Freiburg/Br. für Französisch und Englisch in den oberen, Lateinisch und Deutsch in den mittleren Klassen.

Lehramtspraktikant (Volontär): Seit 14. April 1896 Großherzogl. Gymnasium in Lahr, seit 4. Sept. 1896 Oberrealschule in Mannheim; seit 14. Apr. 1896 Beamter ohne etatmäßige Anstellung; April 1897 Versetzung an Höhere Mädchenschule in Freiburg/Br.; Juni 1897 Rückversetzung an Oberrealschule in Mannheim; seit 11. Sept. 1898 Lehramtspraktikant am Reformgymnasium in Karlsruhe; 30. Juli-9. Sept. 1899 Studienaufenthalt in England; seit 14. Mai 1900 Lehramtspraktikant an Höherer Bürgerschule in Bühl; seit 11. Sept. 1900 Lehramtspraktikant an Großherzogl. Gymnasium in Offenburg; 7. April-14. Juni 1901 Studienaufenthalt in England; seit 11. Sept. 1901 Lehramtspraktikant an Großherzogl. Gymnasium in Lahr; 30. Nov. 1901-9. Febr. 1902 Aufenthalt in Psychiatr. U-Klinik in H „wegen Geistesstörung“ (aus: Gutachten Prof. Kraepelin in: Peschke (2017) S. 114 Anm. 340); seit 8. Apr. 1902 Lehramtspraktikant an Oberrealschule in Mannheim; 3. Juni 1902 (Rigorosum) Dr. phil. an U Erlangen; 6. März 1903 Ern. zum etatm. Prof. an Höherer Bürgerschule in Säckingen; 1. Juni 1909 Versetzung an Realschule in Kehl; seit 1. April 1911 Prof. an Oberrealschule in Mannheim; Sept. 1912-15. März 1913 (beurlaubt) Prof. der Chinesischen Klasse im Seminar für Orientalische Sprachen an U Berlin. 15. März11. Sept 1913 Verlängerung der Beurlaubung, u.a. für e. Indienreise (Sommer 1913) und Aufenthalt in Italien; 1. Apr. 1913 (Ern.)-31. März 1924 (Ver- setzung in einstweiligen, 30. Apr. 1934 in endgültigen Ruhestand) Prof. am Gymnasium in H (heute: Kurfürst-Friedrich-Gymnasium „KFG“) als Nachf. von (siehe) Ludwig Sütterlin; 24. März-15. Okt. 1923 Beurlaubung aus gesundheitlichen Gründen (chronischer Rachenkatarrh). • In dieser Zeit:

Nach 1893 und in den Folgejahren Einberufung W.s zu Offiziersübungen; seit 3. Aug. 1914 Kriegsdienst; 12.-16. Aug. 1914 Aufenthalt im ReserveLazarett in Lahr; 17. Aug. 1914 Entlassung als feldund garnisonsdienstunfähig zum Ersatz-Bataillon des Regiments Karlsruhe, zuletzt 1. Dez.-20. Dez. 1915 Versetzung zur 4. Kompagnie des Feld-Infanterie-Bataillons 63 .

UH: 2. Nov. 1911 Habilitation für Indische Philologie mit Ausschluss der älteren Zeit; WS 1912/13-SS 1913 Beurlaubung, u. a. für e. Indienreise (Sommer 1913); seit 11. Juni 1918 nichtetatm., seit 1920 nichtplanm. a.o. Prof.; seit SS 1923 Lehrauftrag für Indische und Ostasiatische Religionswiss.; 5. April 1930-1. März 1941 (mit Unterbrechungen) Aufenthalte u. a. in Psychiatr. U-Klinik H, in Heil- und Pflegeanstalt Illenau in Achern, Psychiatr. Klinik in Freiburg/Br., Heil- und Pflegeanstalt Wiesloch (Diagnose: Schizophrenie (katatone Form), s. Peschke, S. 1276 f.); WS 1930/31, SS 1931, SS 1932, SS 1933 Lehrtätigkeit an UH; 1. Jan. 1933 Schreiben W.s an das Ministerium des Kultus und Unterrichts in Karlsruhe mit der Bitte um Verleihung e. o. Professur an U Freiburg/Br. nach Emeritierung von (siehe) Ludwig Sütterlin (Vgl. Sprachwiss.) sowie nach Tod des Honorar-Prof. für Indologie und Jainismus (= indische Religion) Ernst Leumann (1859-1931); 11. Jan. 1933 abschlägiger ministerieller Bescheid mit Hinweis „auf die finanzielle Lage des Staatshaushalts, die zu den weitgehendsten Einschränkungen zwingt, an die Wiedererrichtung des indologischen Lehrstuhls vorläufig und in absehbarer Zeit leider nicht zu denken ist" (aus: Peschke, S. 1247 f. Anm. 2783 und 2785); 28. Febr. 1933 ministerielle Ablehnung des W.schen Antrags auf Verlängerung seines bislang honorierten Lehrauftrags für Indische und Ostasiatische Religionswiss. „wegen dringender Sparnotwendigkeiten“ (aus: Peschke, S. 1248 f. und Anm. 2788); 18. April 1936 Erlöschen der Lehrbefugnis aufgrund Nichtanzeige von Vorlesungen und Übungen seit WS 
1934/35; WS 1937/38 W.s Antrag auf Neuerteilung der Lehrbefugnis wird von Fak. abschlägig beschieden.

April-Mai 1938 Italienfahrt, s. Peschke, S. 17141716; anschl. häufige Aufenthalte in seinem Haus Wieden-Rütte Nr. 7 (heute Nr. 10) im Schwarzwald, unterbrochen von Klinikaufenthalten, u.a. seit 28. Sept. 1938 in Heil- und Pflegeanstalt Illenau in Achern, die am 19. Dez. 1940 im Rahmen der Aktion $\mathrm{T}_{4}$ aufgelöst wird; Verlegung W.s in Heil- und Pflegeanstalt Emmendingen; 1. März 1941 Beurlaubung, 6. Aug. 1941 endgültige Entlassung nach H; März 1941-Okt. 1951 Eigenstudien in H, s. hierzu Peschke, S. 1976-2028.

12. Juli 1951 Erneut Antrag W.s auf Reaktivierung seiner venia legendi an UH mit Aussicht auf Erfolg, s. hierzu Peschke, S. 2075-2080; 19. Okt. 1951 Aufnahme in Psychiatr. U-Klinik in H („schizophrener Erregungszustand“), s. Peschke, S. 2081-2086; zwischen 1951 und 1954 immer wieder Klinik-Aufenthalte; zuletzt seit 20. März 1954 in Heil- und Pflegeanstalt Wiesloch.

26. Sept. 1935-28. Juli 1936 (auf Klage W.s wird Entmündigung durch Landgericht Offenburg wieder aufgehoben) Entmündigung wegen Geisteskrankheit, s. Peschke, S. 1494 f.; 29. Sept. 1936 Ablehnung des Antrags der Direktion der Heil- und Pflegeanstalt Illenau auf Unfruchtbarmachung W.s durch Erbgesundheitsgericht Achern, s. Peschke, S. $1631-1635$.

1924, 1930, 1935 Beiratsmitglied der Görres-Gesellschaft, s. hierzu Peschke, S. 426-462 u. ö.

Am 15. März 1928 gründet W. die „Gesellschaft für Buddhismus-Kunde“, untergebracht in seinem Haus in Heidelberg, Goethestraße 12, s. Peschke, S. 557-615, 632-634, 639f., 643-734, 1972-1975; zu W. s umfangreicher Privat-Bibliothek, s. Peschke, S. $2109-2348$.

E Mitglied: Royal Asiatic Society London, 1929 Akademie der Wissenschaften der UdSSR Moskau. 1935 Ehrenkreuz für Kriegsteilnehmer.
Qu UAH PA 693, 6225; Quästurakte Rep. 27-1380; L-III-01/191 (Krankenakte Männer der Psychiatr. U-Klinik H 1901ff.). • GLA Abt. 235, Fasz. 1612. • Teil-Nachlaß: siehe Peschke (2017) S. 19-21. • Auskunft: Herr Dr. Franz Peschke, München.

W Das Problem des Ich. Diss. Heidelberg 1903. • Die philosophische Grundlage des älteren Buddhismus. Heidelberg 1904. 2. Aufl. 1925. Entspricht Bd. 1: Die buddhistische Philosophie in ihrer geschichtlichen Entwicklung. 4 Bde. Heidelberg 1904-1927. (Siehe hierzu Peschke, S. 354356.) - Die Vollkommenheit der Erkenntnis, nach indischen, tibetischen und chinesischen Quellen. Göttingen 1914. • Edikt von Bhabra. Leipzig 1923. • Zur Aussprache des Sanskrit und Tibetischen. Heidelberg 1926. - Siehe auch Peschke (2017) S. 357365, S. 2351-2376 (Bibliographie).

HG Bhāvaviveka: [Śes-rab-sgron-ma]: Prajñā-Pradipah; a commentary on the Madhyamaka Sūtra. Calcutta 1914. 2. Reprint 2009. - 1923-1940 Materialien zur Kunde des Buddhismus.

L Kürschner (1931) Sp. 3158. - Stache-Rosen, Valentina: German Indologists. Biographies of Scholars in Indian studies writing in German ... New Delhi 1981. - Jansen (1992) S. 414 (Register); Ders. (1992a) S. 170 (Register). Krech, Volkhard: Wissenschaft und Religion. Studien zur Geschichte der Religionsforschung in Deutschland 1871 bis 1933. Tübingen 2002. S. 103 f. u. ö. - Lexikon jüdischer Einwohner Hs (2011) S. $426 \mathrm{f}$; Deutsche Biographie, s. https://www.deutsche-biographie.de/ pnd11712625X.html [25.12. 2017]. - Peschke, Franz: Der Heidelberger Indologe und Buddhologe ... W. und das Problem seines Ich. Eine Biographie. Print on demand (2017), s. http://crossasia-repository. ub.uni-heidelberg.de/4032/1/Walleser_10102017_ End.pdf (weitere Sekundärliteratur, s. S. 2376 f.).

$P$ Bildarchiv UAH. 


\section{Walter, Heinrich Karl}

1923-1932 Nat.-Math. Fak.

Botanik

* 21. Okt. 1898 Odessa (Ukraine)

$\dagger$ 15. Okt. 1989 Stuttgart-Birkach ev.

V Dr. med. Otto W. (1862-1917) Leiter des Krankenhauses für Augenkranke in Odessa

M Clara geb. Stromberg (1866-1956)

๑ 23. Dez. 1924 Dr. rer. nat. (UH, s. hierzu UAH $\mathrm{H}-\mathrm{V}$ Bd. 17) Erna Charlotte Clementine Hedwig geb. Schenck (1893-1992) 1918-1924 u. a. wiss. Assistentin am Botanischen Inst. der UH, Hospitantin an Biolog. Reichsanstalt Berlin-Dahlem, Assistentin an Weinbauschule Oppenheim/Rhein, s. Frahm, Jan-Peter, Eggers, Jens: Lexikon deutschsprachiger Bryologen. Bd. 1. Norderstedt 2001. S. 543. - Erna Schencks Pflanzenfunde sind im Herbarium München aufbewahrt. - T von Johann Heinrich Adolf S. (1860-1927) seit 1889 Privat-Dozent U Bonn, 1896-1918 o. Prof. für Botanik an Polytechnischer Hochschule Darmstadt und Direktor des Botanischen Gartens ebd., s. Botanik an der Technischen Universität Darmstadt 1814-1970. Hrsg. von Ulrich Lüttge, Elke Fischer-Schliers ... Darmstadt 2005.

Vw Onkel (Brüder von Johann Heinrich Adolf Schenck): Johann Adolf Heinrich S. (18571936) U Halle/S.: seit 1889 Privat-Dozent für Geographie, Botanik, seit 1899 Prof., 1918-1922 Honorar-Prof., s. WBIS. - Friedrich (Fritz) Wilhelm Julius S. (1862-1916) Privat-Dozent: seit 1889 Bonn, seit 1890 Würzburg; seit 1899 a. o. Prof. und seit 1901 o. Prof. für Physiologie Marburg, s. WBIS. - Martin Adolf Friedrich S. (1876-1960) seit 1912 Privat-Dozent, seit 1917 Prof. für Physiolog. Chemie (Biochemie) U Marburg; planm. a. o. Prof.: seit 1922 Tierärztl. Hochschule Dresden, 1923-1945 (Entlassung) Veterinärmed. Fak. der U Leipzig, 1952-1955 (Emeritierung) U Leipzig, s. WBIS

$\mathrm{K}$ keine.

Lb Odessa: Sept. 1915-Dez. 1916 Studium der Naturwiss. an U; Febr--Juli 1917 Ausbildung an Artillerieschule; Aug.-Okt. 1917 (Auflösung des
Heeres) Kriegsdienst in Kaukasus-Armee und Rückkehr nach Odessa; seit Sept. 1918 Forts. seines Studiums an U.

U Tartu (Estland; ehem. Dorpat): Seit Anfang 1919 Forts. des Studiums; Mai 1919 Übersiedlung nach Deutschland.

U Jena: SS 1919-WS 1919/20 Forts. des Studiums; 13. Dez. 1919 Dr. phil.

Halle/S.: Seit Febr. 1920 Assistent an Versuchsstation der Landwirtschaftskammer für die Provinz Sachsen.

Planm. Assistent am Botan. Inst. der U: Seit April 1920 H, seit April 1921 Marburg.

UH: Seit April 1922 planm. Assistent am Botan. Inst.; 31. Jan. 1923 Habilitation (Antrittsvorlesung); Juli-Aug. 1928 Teilnehmer an 5. int. pflanzengeographischen Exkursion durch Tschechoslowakei und Polen; seit 5. Febr. 1929 nichtplanm./apl. a.o. Prof.; Sept. 1929-Okt. 1930 Rockefeller Fellow am Desert Laboratory Tucson (Arizona) und am Botanic Institute Lincoln (Nebraska); WS 1931/32 Erteilung e. Lehrauftrags über Pflanzengeographie.

TH Stuttgart: Seit April 1932 planm. a. o. Prof. und Direktor des Botan. Inst. und Gartens; 1933 Ruf an U Ankara abgelehnt; Forschungsreisen: u. a. Aug. 1934-April 1935 Ost-und Südwestafrika, Juli 1937März 1938 Südafrika, 1941 Südwestafrika; 1939-31. März 1941 o. Prof.

SS 1941 Ruf auf Lehrstuhl für Angewandte Botanik und Direktor des Botan. Inst. und Gartens an U Posen angenommen; Stelle nicht angetreten, da Kommandierung zum Kriegsdienst im Rang e. Oberstleutnants an Forschungszentrale für Landund Forstwirtschaft in West-Ukraine; April 1942 Entlassung aus Heeresdienst, Einsetzung als Militärbeamter (Kriegsverwaltungs-Oberrat); Versetzungen: Mai 1942 Kiew (u.a. Betreuung des Geobotanischen Instituts der Ukrainischen Akademie der Wissenschaften), Juli 1942 Simferopol (Betreuung des Nikita-Gartens), Aug. 1942 Hochschule in Worschilowsk (Wiederaufnahme der Vorlesungen), Sept. 1942 Nordkaukasus, 1943 Berlin (Zentrale des Wirtschaftsstabes Ost, Planungs- 
stelle für die Betreuung der landwirtschaftl. Institute im Osten); seit Frühjahr 1943 Angehöriger der Sonderstaffel zur pedologischen Erkundung der Krim (Auswertung der bodenkundlichen Karten in Kiew); Okt./Nov. 1943 Evakuierung nach Posen (Dozent an Reichs-U ebd.); seit Jan. 1944 u. a. Mitarbeiter in Kartiergruppen in Frankfurt/Oder, Erlangen, Wien; Anfang 1945 Verlegung der Sonderstaffel nach Süddeutschland; Ende April-Ende Okt. 1945 in amerik. Gefangenschaft in den Lagern Mundelsheim, St. Avold (Lothringen; hier Rektor e. Lager-U für Kriegsgefangene) und Heilbronn.

Landwirtschaftl. Hochschule Hohenheim (heute: Stadtteil von Stuttgart): 1. Dez. 1945-30. Sept. 1966 (Emeritierung) o. Prof. und Direktor des Botan. Inst. und Gartens; Jan.-März 1947 fristlose Entlassung von $\mathrm{U}$ für 2 Monate auf Befehl der amerik. Militärregierung. • In dieser Zeit:

TH Stuttgart: Mai 1947-Sept. 1966 Honorar-Prof. für Geobotanik.

Gastprof.: 1954/55 Ankara, Mai-Sept. 1969 Logan (Utah); 1964-1966 Gastwissenschaftler am Brookhaven National Laboratory in Upton (New York); Forschungsreisen: u. a. Juli 1958-April 1959 Brasilien, Argentinien, Chile, Dez. 1967-April 1968 Venezuela.

Am 3. April 1924 bittet W. um Zuteilung einer Wohnung in Heidelberg, da er gezwungen ist, „mit meiner Mutter zusammen ... in 2 möblierten Zimmern mit Notküche“ zu leben. „Wir haben nicht einmal ein Aufenthaltszimmer, geschweige denn ein Arbeitszimmer" (aus: UAH PA 6229). Laut „Stadtbuch der Stadt Heidelberg ... für das Jahr 1924/25" lebt W. in der Lutherstraße 47, seit 1926 in der Schröderstraße 49, seit 1929 in der Beethovenstraße 45, wo „wir glücklich (sind) drin zu sein, und ... für die Dauer meines Aufenthaltes in Heidelberg nicht mehr umziehen (werden)" (aus: Briefkarte W.s von ca. 1929 in: PA 6229).

1968 gründen Heinrich Walter und seine Frau die A.F.W. Schimper-Stiftung für ökologische Forschungen in Stuttgart. Seit 1994 wird das ehemalige Wohnhaus des Ehepaars mit der W.schen Privatbibliothek als Forschungsstelle für ausländische Gäste der U Hohenheim genutzt.
E Mitglied: 1962 Dt. Akademie der Naturforscher Leopoldina Halle/S., Akademie der Wissenschaften Buenos Aires, 1967 World Academy of Art and Science, 1969 Akademie der Wissenschaften Wien. 1972 Dr. sc. techn. h.c. Wien. 1932 Int. Rainer-Medaille.

Qu UAH PA 6229. - GLA Abt. 235, Fasz. 2635. Nachlaß: Botanischer Garten und Botanisches Museum Berlin. • Siehe auch Archiv der Dt. Akademie der Naturforscher Leopoldina Halle/S. • Mitteilungen: Herr Prof. Dr. Heinrich Karl Walter $(\dagger)$. Bekenntnisse eines Ökologen. Erlebtes in acht Jahrzehnten und auf Forschungsreisen in allen Erdteilen mit Schlußfolgerungen. Stuttgart 1980. 6. Aufl. 1989. (Autobiogr.)

$W$ W., H., Walter, Erna: Ökologische Untersuchungen des osmotischen Wertes bei Pflanzen aus der Umgebung des Balatons (Plattensees) in Ungarn während der Dürrezeit 1928 in: Archiv für wissenschaftliche Botanik (1929) S. 571-624. • Die Hydratur der Pflanze und ihre physiologische Bedeutung. Jena 1931. Grasland, Savanne und Busch der ariden Teile Afrikas in ihrer ökologischen Bedingtheit in: Jahrbücher für wissenschaftliche Botanik 87 (1939) S. 750-860. - Produktivität der Pflanzendecke und Mitscherlichsche Ertragskurve in: Berichte der deutschen botanischen Gesellschaft (1941) S. 114-120. • Grundlagen des Pflanzenlebens und ihre Bedeutung für den Menschen. Stuttgart 1946. 4. Aufl. 1962. - W., H., Lieth, Helmut: Klimadiagramm-Weltatlas. Etwa $8000 \mathrm{Kli}-$ mastationen, etwa 9000 Diagramme, 33 Hauptkarten, 22 Nebenkarten [mit e. dt. Einleitung und Auszügen in engl., franz., russischer und spanischer Sprache]. 3 Lfg. Jena 1960-1967. • Die Vegetation der Erde in ökophysiologischer Betrachtung. Bd. 1: Jena 1962. 3. Aufl. 1973. Bd. 2: Jena 1968. Vegetation und Klimazonen. Stuttgart 1970. 7. Aufl. hrsg. von Siegmar-Walter Breckle. Stuttgart 1999. Ökologische Systeme der Kontinente. Stuttgart 1976. Ökologie der Erde - Geobiosphäre. 4 Bde. Stuttgart 1983-1991. (Mitverf.) Bd. 1: 2. Aufl. 2008. Bd. 2: 3. Aufl. 2004. Bd. 3: 2. Aufl. 1994.

HG Vegetationsbilder. Jena 1932-1942. 
$L$ Wer ist's (1935) S. 1678; Kürschner (1966) S. 2607, (1983) S. 4472 f.; Klein (1968) S. 129. • Universität Hohenheim, Landwirtschaftliche Hochschule 1818-1968. Hrsg. von Günther Franz. Stuttgart 1968. S. 331 (Register). Kull, Ulrich, Knodel, Hans: H.W. Ökologe, Botaniker, Hochschullehrer in: Jahreshefte der Gesellschaft für Naturkunde in Württemberg 145 (1990) S. 305-311. • Rössler, Mechtild: Wissenschaft und Lebensraum - geographische Ostforschung im Nationalsozialismus. Ein Beitrag zur Disziplingeschichte der Geographie. Berlin 1990. - Jansen (1992a) S. 170 (Register); WBIS; Baden-Württ. Biographien V (2013) S. 456459 (S. 456: hier 1950 als Todesjahr der Mutter Clara angegeben). Lawrence, Adam Christopher: A Member of the Food Chain? Quantifying Primary Productivity from Nazi Germany to the International Biological Program, 1933-1974. Diss. University of California. Los Angeles 2015. S. 91-124 u. ö. Über H. W., s. The International Plant Names Index, http://www.ipni.org/link_to_ipni.html. • Deutsche Biographie, s. https://www.deutsche-bio graphie.de/pnd118628909.html [06.11.2017].

$P$ Bildarchiv UAH; Bekenntnisse eines Ökologen (1980) (Autobiogr.).

\section{Waltz, Ernst Christian Otto}

1868-1875 Phil. Fak.

Allgemeine Geschichte

* 10. Febr. 1844 Heidelberg

$\dagger \quad$ 03. März 1918 Heidelberg

ev.

V Ludwig (Louis) W. (1811-1856) Konditor

M Maria Katharina Elisabeth geb. Mack (18181899/1900)

๑ Karoline Helena geb. Romeiß (†1942)

$\mathrm{K} \quad 1 \mathrm{~S}, 3 \mathrm{~T}$

Lb Seit WS 1862/63 Studium an UH, WS 1864/65 Göttingen, SS $1865 \mathrm{H}$; 4. Mai 1865 Dr. phil. an UH; 1865-1868 Eigenstudien.

UH: 20. Nov. 1868 Probevorlesung, 28. Nov. 1868 Disputation für Habilitation ,unter Erlassung der
Vorlage einer besonderen Habilitationsschrift“ (aus: UAH PA 2398); Sommer 1869 Eigenstudien in Wiener Archiven; Sommer 1873 an 1. Stelle für Professur der Geschichte an U Bern gesetzt, „wurde indeß aus politischen Gründen vom Regierungsrath nicht berufen“, aus: PA 2398; Juni 1874 Anfrage von U Gießen abgelehnt; seit 25. Sept. 1874 a.o. Prof.

U Dorpat (heute: Tartu, Estland; bis 1889 einzige dt.sprachige U im Russischen Kaiserreich; 1889 einsetzende Russifizierung, u.a. mit Absetzung des Deutschen als Lehrsprache und Durchsetzung der russischen Sprache): Seit SS 1875 Dozent, 188oSS 1900 (Ruhestand aus politischen Gründen im Rahmen der Russifizierung) o. Prof. für Allgemeine Neuere Geschichte; hier erster Prof. dieses Fachs an U.

\section{U Bonn: Seit 7. Aug. 1900 Privat-Dozent.}

H: Seit ca. 1908 Wohn- und Alterssitz; in Adressbüchern der Stadt Heidelberg als „Dr. Prof., k[aiserlich] r[ussischer] Wirkl[icher] Staatsrat“, Bergstraße 42, seit 1911 Uferstraße 50 genannt; keine Erwähnung in Vorlesungs- und Personalverzeichnissen der UH als Lehrender.

Kaiserl. Russischer Wirkl. Staatsrat; Wirkl. Geh. Rat (Exzellenz)

Qu UAH PA 2398; Fak.-Akten H-IV-102/70 fol. 122r. • Briefe: UBH. • Auskunft: Stadtarchiv Heidelberg.

$W$ Der Wormser Reichstag im Jahr 1521 und seine Beziehung zur reformatorischen Bewegung. Göttingen 1868. • Die Denkwürdigkeiten Kaiser Karls V. Eine Studie zur Geschichte des 16. Jahrhunderts. Bonn 1901. Fr[ater] Bartolomé de las Casas. Eine historische Skizze. Bonn 1905.

$L$ Lewitzki 2 (1903) S. 399-401; Biogr. Jahrbuch 2 (1917-1920) S. 707. • Tartu ülikooli ajalugu. Ed. K. Siilivask. Bd. 2: 1798-1918. Tallinn 1982. S. 163, 324. - Weber (1987) S. 639 f.; WBIS. • Universitas Tartuensis 1632-2007. Eds. T. Hiio and H. Piirimäe. Tartu 2007. S. 179. - Dubjeva, Ludmila: Research and teaching of history at the university of Tar- 
tu at the end of the $19^{\text {th }}$ and the beginning of the $20^{\text {th }}$ century in: TRAMES. A Journal of the Humanities and Social Sciences published by the Estonian Academy of Sciences and Tartu University ... (2009) 13 (63/58) 2, S. 153-172; hier: S. 158-16o. • Deutsche Biographie, s. https://www.deutschebiographie.de/pnd1012808505.html [06.11. 2017].

\section{Walz, Ernst Friedrich Joseph}

1900-1909 Jur. Fak.

1909-1914 (Honorar-Prof.) Jur. Fak.

Öffentliches Recht

* 19. Juli 1859 Heidelberg

$\dagger$ 18. Dez. 1941 Heidelberg

ev.

V (siehe) Georg W.

M Franziska Antonia Josepha geb. Martin (18281918) Schwester von Walburga Crescentia geb. M., s. Eberhardt, Gunter: Georg Friedrich Walz ... Apotheker, Forscher, Revolutionär. Stuttgart 1990. S. 207 (Register).

$\infty$ 25. April 1889 Margaretha Alberta Emma Helena geb. Becker (1866-1932) T von: (siehe) Otto B.

K $\quad 1$ S, 1 T

Vw Neffe: Ernst W. (1888-1966), u. a. Ministerialrat, 1945-1946 kommissar. Oberbürgermeister von H, 1946-1953 Vize- und Senatspräsident des Verwaltungsgerichtshofs von Württemberg-Baden, 1949-1953 Präsident des Dienststrafsenats Karlsruhe des württ.-badischen Dienststrafhofs, s. Baden-Württ. Biographien II (1999) S. 472-474. • Großnichte: Hannah geb. Walz (1917-2002; T von Neffe Ernst W.) 1945-1985 Geschäftsführerin der Elisabethvon-Thadden-Schule in Heidelberg-Wieblingen, 1947-1980 Mitglied des Gemeinderats (DVP) in H, s. Vogel, Bernhard, Haungs, Peter: Wahlkampf und Wählertradition. Eine Studie zur Bundestagswahl von 1961. Wiesbaden 1965. S. 253f., 274-278, 407-409 u. ö.; Herbstrieth, Nils: „Den Geist von Hannah Walz erhalten“. Thadden-Schule in Wieblingen. Aufgestocktes Gebäude mit sieben Klassenzimmern eingeweiht, das "Hannah Walz Haus“ in: RNZ vom 14. Okt. 2002.
Lb Seit WS 1877/78 Studium an UH; März 1881 I., Juli 1884 II. Examen in H.

1881-1882 Militärdienstpflicht als Einjährig-Freiwilliger im 2. Badischen Grenadier-Regiment Kaiser Wilhelm I. Nr. 110.

1881-1884 (bereits während seiner Militärzeit) Praktikant, 1884-1886 Assessor an Gerichten der Staatsanwaltschaft und Verwaltungsbehörden, u. a. in H, Karlsruhe, Mannheim; 16. April 1886 aus Staatsdienst ausgeschieden.

H: Seit 9. April 1886 II., seit 10. Juli 1886 I. Bürgermeister, 30. Dez. 1913-31. Juli 1928 Oberbürgermeister. $\bullet$ In dieser Zeit:

UH: 14. Juli 1886 Dr. iur.; 24. Okt. 1900 Habilitation; seit 29. Juni 1902 nichtetatm. a. o. Prof.; seit 28. Aug. 1909 o. Honorar-Prof.; WS 1913/14 letzte Vorlesungsankündigung.

1918: Auf Initiative von W. wird die Orthopädische Anstalt in H-Schlierbach der Universität Heidelberg angegliedert (siehe hierzu auch Friedrich Endemann und Johann (Hans) Ritter von Baeyer)

1919-1928 Vorsitzender des Badischen Städteverbandes; 1919-1925 Mitglied des Vorstands des Deutschen Städtetages

1928: Einweihung der Ernst-Walz-Brücke zwischen den Heidelberger Stadtteilen Bergheim und Neuenheim

Siehe auch Johannes Rissom: Eintrag unter $Z[i-$ tat] (3)

E 1948 Dr. iur. h.c. UH. 1899 Ritterkreuz I. Klasse des Ordens vom Zähringer Löwen. 1926 Ehrenbürger der Stadt Heidelberg. 1926 Ehrensenator der Universität Heidelberg.

Qu UAH PA 801, 6235; Fak.-Akte H-II-111/23. • (Personal-)Akten: Stadtarchive Heidelberg und Mannheim. GLA Abt. 235, Fasz. 2636. • Briefe: $\mathrm{UBH}$; siehe auch Kalliope. Auskunft: Ev. Kirchengemeindeamt Heidelberg (Taufbuch 1859). • Lebenserinnerungen. 40 Jahre an der Spitze der 
Stadt Heidelberg. Hrsg. ... von Rudolf Benl. Heidelberg 1991. • Erlebte Geschichte erzählt 19941997 ... Michael Buselmeier im Gespräch mit Hannah Walz am 12. März 1995. Heidelberg 2000. S. 89-103.

W Großherzogtum Baden. Leipzig 1906. (Verfassung und Verwaltungsorganisation der Städte. 4. Bd. 3. H.) (Mitverf.) • Das Staatsrecht des Großherzogtums Baden. Tübingen 1909. • Das badische Gemeinderecht ... Heidelberg 1914.

L Kürschner (1928/29) Sp. 2573, (1940/41) Sp. 1025. Walz, Ernst (Neffe): Zum 100. Geb. von E. W. in: Ruperto Carola 11. Jg., Bd. 25 (Juni 1959) S. 42-47. Badische Biographien N.F. II (1987) S. 305 f.; Jansen (1992) S. 414 (Register); Ders. (1992a) S. 170 (Register); Kriegstagebuch K. Hampe (2007) S. 1004 (Register); Ruuskanen (2008) S. 114 f.; Schroeder (2010) S. 343 f. u. ö. • Graf, Friedrich Wilhelm: Fachmenschenfreundschaft. Studien zu Troeltsch und Weber. Berlin 2014. S. 378-380 u. ö. Deutsche Biographie, s. https:// www.deutsche-biographie.de/pnd11902778X.html [06.11. 2017].

$P$ Bildarchiv UAH; graph. Slg. UBH.

\section{Walz, Georg Friedrich}

1856-1859 Phil. Fak.

1859-1862 Med. Fak.

Pharmazie

* 24. Juli 1813 Heppenheim/Bergstraße

$\dagger$ 29. März 1862 Zwingenberg/Bergstraße (Suizid)

$\square$ Heidelberg

ev.

V Ludwig Friedrich W. (1773-1841) Distriktscommissaire

M Margarethe Elisabeth geb. Hippe/Hiepe (17761855)

(1. Mai 1845 Walburga Crescentia geb. Martin (1825-1848)
๑ 14. Juli 1849 Franziska Antonia Josepha geb. Martin (1828-1918) Schwester von Walburga Crescentia geb. M., s. Eberhardt (1990) S. 207 (Register)

K 4 T, 5 S: u.a. (siehe) Ernst W.

Vw siehe Eberhardt, S. $15 \mathrm{f}$.

Lb Apothekerlehre: Seit Ostern 1828 Fürth im Odenwald, seit Ostern 1831 Wiesloch, seit Ostern 1833 Heidelberg, seit Sept. 1834 Mannheim.

Darmstadt: 28. Juli 1830 Hessische Gehilfenprüfung, 20. Juli 1835 hessisches Apotheker-Examen.

Mannheim: 1835-1837 Apotheken-Angestellter.

H: 1837-1840 Mitinhaber der Schwanen-Apotheke. In dieser Zeit:

UH: Seit 3. Mai 1837 Studium der Naturwiss.; 26. Juli 1838 Dr. phil.; 1840 Ablehnung seines Antrags auf Habilitation für Pharmazie an Phil. Fak. aus formalen Gründen, s. Eberhardt (1990) S. 130 f.

Bamberg: 22. Aug. 1840 Bayer. Apotheker-Examen.

Speyer (seinerzeit bayer. Rheinpfalz): Okt. 1840Aug. 1857 (Verkauf an seinen Neffen Friedrich Vorwerk) Inhaber der Schwanen-Apotheke; 1840 (Gründer)-1856 Leiter e. privaten pharmazeutischchemischen Inst.; 1843-14. Sept. 1850 (Enthebung, s. hierzu Eberhardt, S. 126 f., 157-159) Lehrer an Landwirtschaftl. Gewerbeschule.

UH: 21. Mai 1853 Habilitation an Phil. Fak.; SS 1856 Beginn seiner Vorlesungstätigkeit als PrivatDozent, s. hierzu Eberhardt, S. 133-137; 1857, 1858 und März 1859 W.s Gesuche um e. a. o. Professur werden vom Innenministerium abgelehnt, s. Eberhardt, S. 137-143; seit 6. Aug. 1859 a.o. Prof. an Med. Fak.

H: 1856 Übersiedlung des pharmazeutisch-chemischen Privat-Inst. von Speyer nach H; 22. Juni 1860 badischer Staatsbürger (seit 1857 mehrere erfolglose Beantragungen des Indigenats); Sommer 1861 Ankauf e. größeren Gebäudes für die Unterbringung des Inst. (damit verbunden hohe Schulden); 1861 psychische Erkrankung. 
1850-1862 Vorstand des Allg. Dt. Apotheker-Vereins in Süddeutschland

E 1854 Mitglied der Dt. Akademie der Naturforscher Leopoldina.

Qu UAH PA 2399; Fak.-Akten H-IV-102/34, H-IV-102/49; RA 5815. GLA Abt. 205, Fasz. 546. • Siehe auch Archiv der Dt. Akademie der Naturforscher Leopoldina Halle/S. - Auskunft: Kath. Pfarrarchiv St. Peter in Heppenheim/Bergstraße (Taufbuch; 1813 existierte noch keine ev. Pfarrei in Heppenheim, daher Eintrag im kath. Taufbuch); Staatsarchiv Darmstadt (Todeseintrag sowohl im Sterbebuch des Ev. Pfarramtes in Zwingenberg/ Bergstraße als auch in dem der Kath. Pfarrei Zwingenberg).

$W$ Der Milchsaft des Giftlattichs chemisch untersucht. Heidelberg 1839. - Beiträge zur Cultur des Weinstocks und zur Weinerzeugung vom chemischen Standpunkte aus. Speyer 1846. - Neue Denkschrift über die nothwendigen Reformen der pharmaceutischen Verhältnisse in Deutschland. Hannover 1851. Bibliographie in: Eberhardt (1990) S. 174-186.

MHG 1850-1862 Neues Jahrbuch für Pharmacie und verwandte Fächer.

L Almanach Heidelberg (1886) S. 98. • Wankmüller, Armin: Das Pharmazeutisch-chemische Institut von Apotheker G.F.W. in Speyer und in Heidelberg in: Deutsche Apother-Zeitung 110 (1970). - Stotz (1976) S. 75-78; Apotheker-Biographie 2 (1978) S. 725 f.; Chronik Ärzte H (1985) S. 145; Thomas (1985) S. 173f. - Eberhardt, Gunter: G. F.W. ... Apotheker, Forscher, Revolutionär. Stuttgart 1990. - Stumm (2012) S. 79, 103; Hessische Biografie, s. http://www.lagis-hessen.de/pnd/ 11894858X (Stand: 26. Febr. 2013). • Deutsche Biographie, s. https://www.deutsche-biographie.de/pn d11894858X.html [06.11. 2017].

P Bildarchiv UAH; Chronik Ärzte H.
Wasielewski, Theodor Karl Wilhelm Nikolaus von

1906-1914 (1916) Med. Fak.

Hygiene

* o6. Dez. 1868 Neustadt/Westpreußen (heute: Wejherowo, Polen)

$\dagger$ 30. Jan. 1941 München ev.

V Theodor von W. (1821-1902) Major

M Marie geb. Bardt († vor 1902)

$\infty$ 4. Juli 1905 Johanna Wilhelmine Elisabeth geb. Gründahl (*1874)

K 1 .

Lb Berlin: 1. April-30. Sept. 1888 Militärdienstpflicht als Einjährig-Freiwilliger im Garde-Füsilier-Regiment (erstes Diensthalbjahr); 1. April 1888-1892 Ausbildung an Kaiser-Wilhelms-Akademie für das militärärztliche Bildungswesen; 28. Mai 1892 Dr. med. ebd.; 24. Mai 1894 ärztl. Staatsexamen.

U-Laufbahn:

1. Okt. 1892-23. Aug. 1894 Unterarzt an Charité in Berlin; 2. Juni 1897 (Kommandierung)-30. Juni 1899 Oberarzt (Assistenzarzt) am Hygienischen Inst. der U Halle/S.

Militärärztliche Laufbahn:

Seit 23. Aug. 1894 Unterarzt im Magdeburgischen Füsilier-Regiment Nr. 36 in Halle/S.; 30. Juni 189931. Dez. 1899 Stabsarzt im Infanterie-Regiment Nr. 79 in Hildesheim.

U-Laufbahn:

U Berlin: Seit 1. Jan. 1900 (Kommandierung) Assistenzarzt am Hygiene-Inst.; 6. Febr. 1903 Habilitation für Hygiene; 1903-1906 Privat-Dozent; seit SS 1904 beurlaubt; Okt. 1905-Febr. 1906 fünfmonatiger Urlaub in Italien „zum Abschluß meiner Untersuchungen über Blutzellschmarotzer, insbesondere der Malariaparasiten" (aus: UAH PA 2403). 
Forts. und Beendigung der militärärztlichen Laufbahn:

Seit 16. Febr. 1904 Stabsarzt im 5. Badischen Infanterie-Regiment Nr. 113 in Freiburg/Br.; seit 10. April 1906 Stabsarzt im 2. Badischen Grenadier-Regiment Kaiser Wilhelm I. Nr. 110 II. Bataillon in $\mathrm{H} ; 1907$ als Oberstabsarzt ausgeschieden.

Forts. der U-Laufbahn:

UH: 18. Juni 1906 Umhabilitierung von Berlin; 18. Juni 1906-30. Sept. 1916 Leiter (zus. mit Emil Frhr. von Dungern bis 1913) der Wiss. (Parasitolog.) Abt. am Inst. für Experimentelle Krebsforschung im Samariterhaus, s. hierzu auch Vincenz Czerny; Anfang 1907 Ruf an Kaiserl. Gesundheitsamt in Berlin abgelehnt (s. hierzu auch August Schuberg); seit 5. Febr. 1908 nichtetatm. a.o. Prof.; Juli-Sept. 1913 Beurlaubung „zum Studium der wissenschaftlichen Laboratorien für Krebsforschung und Parasitologie in Frankreich, Belgien und England ... [sowie zu] Kongressen in Brüssel (1. bis 5. August) und London" (aus: Brief vom 14. Juni 1913 in: PA 2403), siehe hierzu auch Z; seit Aug. 1914 Kriegsteilnahme.

Rostock: WS 1916/17-WS 1934/35 (Emeritierung) o. Prof. und Direktor des Hygienischen Inst. der U sowie der Landes-Lebensmittel-Untersuchungsanstalt.

Während des Zweiten Weltkriegs nach 1939 Oberstabsarzt bei Hygienischer Untersuchungsstelle der Wehrmacht in Prag.

Z W. schreibt am 13. Nov. 1913 an Max Wilms, Dekan der Med. Fak.: „Ich bin vom Vorstand der Société de Pathologie comparée aufgefordert worden, in der Festsitzung derselben am 9. Dezember einen Vortrag zu halten. Hierbei bietet sich Gelegenheit, die französischen Krebsforscher, welche der Internationalen Krebskonferenz in Brüssel ferngeblieben waren, persönlich kennen zu lernen und die Pariser Institute zu studieren. Letztere konnte ich auf meiner Studienreise im Sommer nicht aufsuchen, da die verfügbare Zeit für die englischen kaum ausreichte ..." (aus: PA 2403).
E 1908 Korr. Mitglied der Société de Pathologie Paris. 1897 Kaiser-Wilhelm-Gedächtnis-Medaille; 1907 Roter Adler-Orden IV. Klasse.

Qu UAH PA 1232, 2403. - GLA Abt. 235, Fasz. 2640.

W Sporozoenkunde. Jena 1896. Studien und Mikrophotogramme zur Kenntnis der pathogenen Protozoen. 2 Bde. Leipzig 1904-1908. • Der Pockenvirus in: Ergebnisse der Hygiene-, Bakterien-, Immunitätsforschung und experimentellen Therapie 7 (1925).

L Stübler (1926) S. 329; Kürschner (1928/29) Sp. 2581, (1940/41) Sp. 1029; Fischer 2 ( $\left.{ }^{3} 1962\right)$ S. 1644; Chronik Ärzte H (1985) S. 145; WBIS. • Wagner, Gustav, Mauerberger, Andrea: Krebsforschung in Deutschland. Vorgeschichte und Geschichte des Dt. Krebsforschungszentrums ... Berlin 1989. S. 272 (Register). 100 Jahre Krebsforschung (2000) S. 33 u. ö.; Buddrus/Fritzlar (2007) S. 428 f.; Kriegstagebuch K. Hampe (2007) S. 1004 (Register); Friedrich (2009) S. 34 u.ö.; Badische Biographien N.F. VI (2011) S. 426 f.; Grewolls (2011); Catalogus prof. Rostochiensium online; Deutsche Biographie, s. https://www.deutsche-biographie. de/pnd117146587.html [06.11. 2017].

$P$ Bildarchiv UAH.

\section{Wattenbach, Ernst Christian Wilhelm}

1862-1873 Phil. Fak.

Mittelalterliche Geschichte

* 22. Sept. 1819 Rantzau (bei Plön, SchleswigHolstein)

$\dagger \quad$ 20. Sept. 1897 Frankfurt/M. (auf Rückreise von der Schweiz)

ㅁ Heidelberg

ev.

V August Paul Christian W. (†1824) Kaufmann

M Cäcilie geb. von Hennings

$\infty$ 5. April 1885 Auguste Marie Therese Antonie geb. von Hennings (Kusine)

$\mathrm{K}$ keine. 
Vw Schwester: Cäcilie W. (1815-1883) Jugendliebe des Lyrikers Emanuel Geibel (1815-1884), s. N. N. $(\dagger)$ : Eine Jugendliebe E. G.s in: Die Gartenlaube. Hrsg. von Adolf Kröner. Leipzig 1888. H. 4, S. 67; Kohut, Adolph: E. G. als Mensch und Dichter. Mit ungedruckten Briefen, Gedichten und e. Autobiographie G.s. Berlin 1915. Nachdr. Bremen 2017. S. 90-99; E. G. ist Großvater von: (siehe) Ferdinand Fehling, hier Eintrag unter $\mathrm{M}$ [utter].

Lb Seit WS 1837/38 Studium der Philologie, Geschichte an U Bonn, anschl. Göttingen, seit SS 1841 Berlin.

Berlin: 20./22. Juli 1842 Dr. phil. an U; Herbst 1842 Oberlehrerexamen; seit 1842 zunächst Probekandidat, dann Lehrer am Joachimsthalschen Gymnasium; 1843-1854 auch Mitarbeiter an Monumenta Germaniae Historica (MGH); 1847-1848, 1849 Studienreisen nach Österreich. • In dieser Zeit:

U Berlin: 1851 Habilitation; 1851-1854 Privat-Dozent.

Breslau: Seit 16. Nov. 1854 Vorsteher des Provinzial-Archivs.

UH: 15. Nov. 1861 Ern. zum o. Prof.; 25. April 1862 Vereidigung; Osterferien 1866 Reise nach Algier, s. hierzu W., W.: Reise von Heidelberg nach Algier. In den Osterferien 1866 unternommen ... (1866; in: UBH A 5752-1 RES).

U Berlin: Seit WS 1873/74 o. Prof. für Histor. Hilfswissenschaften.

Berlin: 1875-1888 Mitglied der Zentraldirektion und Leiter der Abt. Epistolae der MGH; 1886-1888 kommissar. Präsident der MGH.

$E$ Mitglied der Akademie der Wissenschaften: 1855 Wien, 1860 München, 1865 Göttingen, 1882 Berlin. 1862 Dr. iur. h.c. Breslau. 1862 Ritter IV. Klasse des Königl. Preußischen Roten AdlerOrdens.
Qu UAH PA 2404; RA 6847. Briefe: UBH. Briefe von W. W. an Theodor von Sickel aus den Jahren 1858 bis 1894 . Hrsg. von Leo Santifaller in: Mitteilungen des Instituts für Geschichtsforschung und Archivwissenschaft. 55. Wien 1944. S. 371-431. • Nachlaß: Geheimes Staatsarchiv Preußischer Kulturbesitz Berlin.

W Deutschlands Geschichtsquellen im Mittelalter bis zur Mitte des 13. Jahrhunderts. 2 Bde. Berlin 1858. 7. Aufl. 1904. Neuausg. 3 Bde. 1967-1971. • Anleitung zur griechischen Palaeographie. Leipzig 1867. Nachdr. der 3. Aufl. Leipzig 1895: Hildesheim 1971. Anleitung zur lateinischen Palaeographie. Leipzig 1869. Nachdr. der 4. Aufl. Leipzig 1886: Hildesheim 1971. Peter Luder, der erste humanistische Lehrer in Heidelberg. Karlsruhe 1869. Das Schriftwesen im Mittelalter. Leipzig 1871. 3. Aufl. 1896. Nachdr. Graz 1958. Kleine Abhandlungen zur mittelalterlichen Geschichte. Gesammelte Berliner Akademieschriften 1882-1897. Berlin 1900. Nachdr. Leipzig 1974.

Bearb. Das Leben Kaiser Heinrichs IV. Nach der Ausg. der Monumenta Germaniae übers. von Philipp Jaffé. 2. Aufl. neubearb. von W. W. Leipzig 1893. Nachdr. Whitefish (Montana) 2010.

Redakteur 1875-1888 Neues Archiv für ältere deutsche Geschichtskunde.

Übers. Der Mönch von Sanct Gallen über die Thaten Karls des Großen. Nach der Ausg. der Monumenta Germaniae. Berlin 1850.

$L$ Nachruf in: Almanach der Akademie der Wissenschaften Wien 48 (1898) S. 295-298. - Zeumer, Karl: W.W. $\dagger$ in: Historische Zeitschrift 80 (1898) S. 75-85. Ernst Curtius: Ein Lebensbild in Briefen. Hrsg. von Friedrich Curtius. Berlin 1903. S. 276 f., 282, 309 f., 454, 504, 523. Badische Biographien 5 (1906) S. 795-798; Baier (1937) S. 182184 u. ö.; WBIS; Weber (1987) S. 641; Jakobs (1992) S. 40-46; Fuhrmann (1996) S. 217 (Register). • Wattenbach, Kurt: Wattenbach - Stammfolge aus Mittelfranken in Schleswig-Holstein, Hamburg und London. Nachweis der fränkischen Abstammung des schleswig-holsteinischen Historikers ... W. W. ... und seiner fünf Geschwister im Mannesstamm in: Blätter für fränkische Familienkunde 
25 (2002) S. 101-124. - Der „Berliner Antisemitismusstreit“ 1879-1881. Eine Kontroverse um die Zugehörigkeit der deutschen Juden zur Nation. Kommentierte Quellenedition ... Bearb. von K. Krieger. 2 T. München 2003. S. 554 u. ö.

$P$ Bildarchiv UAH; graph. Slg. UBH.

\section{Weber, Carl David Alfred}

1908-1914, 1919-1933 Phil. Fak.

1946-1958 Phil. Fak.

1908-1914, 1919-1933 Nationalökonomie, Finanzwissenschaft; 1927-1933, 1946-1958 Soziologie

* 30. Juli 1868 Erfurt

$\dagger \quad$ 02. Mai 1958 Heidelberg

ev., seit 1931 konf.-los

V Max W. (1836-1897) Stadtrat, 1875-1877 Reichstagsabgeordneter, siehe Kaesler (2014) S. 1004 f. (Register)

M Helene geb. Fallenstein (1844-1919), siehe Jansen (2002) S. 166-185, Demm (2014) S. 248 (Register), Kaesler (2014) S. 1004 (Register). Schwestern: Henriette Fallenstein (1840-1895), siehe Kaesler (2004) S. 999 (Register); Ehefrau von: (siehe) Adolf Hausrath; Emilie Caroline Luise Emma F. (1846-1922) Ehefrau von: (siehe) Wilhelm Benecke

$\infty$ unverheiratet

$\mathrm{K}$ keine

Vw Großtante: Elisabeth Fallenstein (1827-1901) Ehefrau von: (siehe) Julius Jolly. - Kusine: Pauline (Paula) Helene Mathilde geb. Hausrath (1872-1958) T von: (siehe) Adolf H.; Ehefrau von: (siehe) Georg Schmidt

Vw Bruder: (siehe) Max W.; weitere Geschwister, siehe Kaesler (2014) S. 1004 f. (Register).

Lb Seit SS 1888 Studium der Kunstgeschichte, Archäologie an U Bonn, seit SS 1889 Studium der Rechtswiss., Nationalökonomie an U Tübingen, seit WS 189o/91 Berlin; Okt. 1889-Okt. 1890 Militärdienstpflicht als Einjährig-Freiwilliger in Tübingen; 1. Aug. 1892 I., 26. Juli 1897 II. jur. Examen in Berlin.
Berlin: 1893-1897 Referendar u.a. am Kammergericht; 20. März 1897 Dr. phil. (Nationalökonomie) an U; seit 26. Juli 1897 Assessor am Kammergericht.

U Berlin: 24. Nov. 1900 Habilitation für Staatswissenschaften, Volkswirtschaftslehre.

U Prag: 11. Juli 1904 Ern. zum o. Prof. für Politische Ökonomie.

UH: 29. Juli 1907 Ern. zum o. Prof. und (Mit-)Direktor (mit Unterbrechungen bis 1924) des Volkswirtschaftl. Seminars als Nachf. von Karl Rathgen; 5. Mai 1908 Vereidigung. • In dieser Zeit:

Aug. 1914-Mai 1916 Kriegsdienst; Sommer 1916 (bis Ende Dez. 1918) Einberufung als Mitarbeiter am Kaiserl. Statistischen Amt (seit Nov. 1918: Reichsschatzamt) in Berlin.

UH: 1. Jan. 1919 Wiederaufnahme seiner Lehrtätigkeit; 1924-1933 Leiter des vom Volkswirtschaftl. Seminar in Inst. für Sozial- und Staatswissenschaften (ISoSta) umbenannten Inst.; WS 1925/ 26 Beurlaubung; 1926 Ruf an U Hamburg abgelehnt; 17. Dez. 1926 Übertragung der Vertretung des Lehrstuhls für Soziologie mit Wirkung vom 1. April 1927; SS 1931, SS 1933 erneut Beurlaubung; 1. Aug. 1933 aus politischen Gründen auf eigenen Antrag von Amtspflichten enthoben („emeritiert auf eigenen Antrag nach Regierungswunsch“ aus: UAH PA 6246 letzte Seite).

1933-1945 Privatier.

UH: April-Dez. 1945 Mitglied des Dreizehnerausschusses zum Wiederaufbau der U; Aug. 1945Febr. 1946 Dekan der Staats- und Wirtschaftswiss. Fak., die 1946 z. T. in Phil. Fak. eingegliedert wird, s. hierzu Weisert/Drüll/Kritzer (2007) S. 113 f.; SS 1946 Wiederaufnahme der Lehrtätigkeit als inaktiver o. Prof. für Soziologie und zeitweiliger Direktor des seit 13. Nov. 1948 nach ihm benannten Alfred-Weber-Inst. für Sozial- und Staatswissenschaften an Phil. Fak.; 25. Febr. 1947 erneute Vereidigung; SS 1958 ( $\dagger$ ) letzte Anzeige e. 2-stündigen Kolloquiums über soziologische und staatswiss. Fragen im Vorlesungsverzeichnis. 
1912/13, 1923/24 Dekan der Phil. Fak. der UH; Aug. 1945-Febr. 1946 (Vertrauensmann bei Auflösung der Fak.) Dekan der Staats- und Wirtschaftswiss. Fak. der UH, s. Weisert/Drüll/Kritzer (2007) S. $113 \mathrm{f}$.

1909 Mitbegründer der Deutschen Gesellschaft für Soziologie in Berlin

1925 Mitinitiator und erster Vorsitzender des in Heidelberg gegründeten „Akademischen Austauschdienstes“, e. Vorläufer des DAAD

1946 Mitbegründer der Heidelberger Aktionsgruppe zur Demokratie und zum freien Sozialismus

1949 Mitglied des Deutschen Rates der Europäischen Bewegung

1917 Geh. Hofrat

E Mitglied der Akademie der Wissenschaften: 1922 H, 1948 München; Ehrenmitglied der Dt. Akademie für Sprache und Dichtung in Darmstadt. • 1954 Orden pour le Mérite für Wissenschaften und Künste. 1915 Ritterkreuz I. Klasse mit Schwertern vom Orden des Zähringer Löwen. 1948 Ehrensenator der Universität Heidelberg.

$Q u$ UAH PA 697, 6245-6248; Handakte HAW Nr. 49o. - Briefe, Teil-Nachlaß: Bundesarchiv Koblenz; UBH. - Friedrich Gundolf - Elisabeth Salomon. Briefwechsel (1914-1931). Im Auftrag des DLA Marbach hrsg. von Gunilla Eschenbach und Helmuth Mojem. Berlin 2015. S. 802 (Register). • Auskunft: Universitätsarchiv der Humboldt-Universität Berlin (Phil.Fak.01, Nr. 1224 vom 24. Nov. 1900). Mitteilungen: Herr Prof. Dr. Götz von Olenhusen, Freiburg/Br.; Herr Prof. Dr. Wolfgang Schluchter, Universität Heidelberg.

$W$ Über den Standort der Industrien. 1. T.: Reine Theorie des Standorts. Tübingen 1909. • Die Krise des modernen Staatsgedankens in Europa. Stuttgart 1925. Kulturgeschichte als Kultursoziologie. Leiden 1935. Das Tragische und die Geschichte. Hamburg 1943. Abschied von der bisherigen Geschichte. Hamburg 1946. Prinzipien der Ge- schichts- und Kulturphilosophie. München 1951. • Der dritte oder der vierte Mensch. Vom Sinn des geschichtlichen Daseins. München 1953. - AlfredWeber-Gesamtausgabe. Hrsg. von Richard Bräu ... 10 Bde. Marburg 1997-2003; siehe hierzu Jansen, Christian: Mini-Max oder eigenständige Größe am Soziologenhimmel? Zum Abschluß der A.-W.Gesamtausgabe in: Heidelberg. Jahrbuch zur Geschichte der Stadt 2008. Heidelberg 2007. Jg. 12. S. 199-216.

MG, MHG 1945-1949 (Erscheinen eingestellt) Zs. „Die Wandlung“ (u. a. mit Karl Jaspers), siehe hierzu Waldmüller, Monika: „Die Wandlung. Eine Monatsschrift." Hrsg. von Dolf Sternberger unter Mitwirkung von Karl Jaspers, ... A. W. ... Marbach 1988; Oster, Patricia: Die Zeitschrift als Ort der Konstitution eines "transnationalen" kulturellen Feldes. „Lancelot, Der Bote aus Frankreich“ und "Die Wandlung" in: Am Wendepunkt - Deutschland und Frankreich um 1945 ... Hrsg. von Patricia Oster und Hans-Jürgen Lüsebrink. Bielefeld 2008. S. 231-248.

$L$ Badische Biographien N.F. I (1982) S. 263266. Demm, Eberhard: Zivilcourage im Jahre 1933. A.W. und die Fahnenaktionen der NSDAP in: Heidelberger Jahrbücher 26 (1982) S. 69-80; Ders.: Ein Liberaler in Kaiserreich und Republik. Der politische Weg A.W.s bis 1920. Boppard am Rhein 1990. - Jansen (1992) S. 414 (Register). • Schluchter, Wolfgang: Max und A.W. - zwei ungleiche Brüder in: Ruperto Carola 3 (1994) S. 2935. - Brintzinger (1996) S. 400 (Register). A.W. zum Gedächtnis. Selbstzeugnisse und Erinnerungen von Zeitgenossen. Hrsg. von Eberhard Demm. Frankfurt/M. 200o. - Sombart, Nicolaus: Begegnung mit dem Weltgeist. Heidelberger Reminiszenzen 1945-1951. Frankfurt/M. 2000. • Hausmann (2006) S. 2651 u. ö.; Kriegstagebuch K. Hampe (2007) S. 1005 (Register). • Blomert, Reinhard: A.W. als Politikwissenschaftler in: Das Politische. Hrsg. von Manfred Gangl. Frankfurt/M. 2008. S. 217-230. Demm (2008) S. 390-400; Schönhärl (2009) S. 461 (Register). • Köster, Roman: Die Wissenschaft der Außenseiter. Die Krise der Nationalökonomie in der Weimarer Republik. Göttingen 2011. - Wissenschaftsatlas der UH (2011) S. 114 f. Loader, Colin: A. W. and the crisis of culture. Basingstoke 2012. - Demm, Eberhard: 
Else Jaffé-von Richthofen. Erfülltes Leben zwischen Max und Alfred Weber. Düsseldorf 2014. Intellektuelle in Heidelberg (2014) S. 111-118, 377389 u. ö. - Kaesler (2014) S. 1004 (Register); Kaube (2014) S. 485 (Register). Max-Weber-Handbuch: Leben - Werk - Wirkung. Stuttgart 2014. S. 470 (Register). Deutsche Biographie, s. https://www. deutsche-biographie.de/pnd118765787.html [07.11. 2017].

$P$ Bildarchiv UAH; graph. Slg. UBH; Badische Biographien (1982).

\section{Weber, Heinrich Martin Georg}

1866-1870 Phil. Fak.

Mathematik

* 05. März 1842 Heidelberg

$\dagger$ 17. Mai 1913 Straßburg

ev.

V Schul-Prof. Dr. phil. D. theol. (UH am 26. März 1882, s. UAH Theol. Fak. 47 fol. 281r282r, 288r) Georg W. (1808-1888), u. a. seit 1839 Lehrer, 1848-1872 (Ruhestand) Direktor der Höheren Bürgerschule (heute: Helmholtz-Gymnasium) in $\mathrm{H}$, Historiker, s. ADB 41 (1896) S. 299-302, WBIS; Pfälzer Lebensbilder. Hrsg. von Hartmut Harthausen. Speyer 1987. Bd. 4. S. 179-204; Brauer, Adalbert: G.W. Deutschlands erfolgreichster Universalhistoriker in: Börsenblatt für den dt. Buchhandel. Frankfurter Ausg. Nr. 77 vom 27. Sept. 1988. S. A 360-A 366; Weber, Karsten: G.W. Weltgeschichte für die gebildeten Stände - Königsarbeit des Historikers in: Badische Heimat: mein Heimatland. Zs. für Landes- und Volkskunde ... Freiburg/Br. 1999. H. 4. 78. Jg. S. 622-627; Goldenes Buch der Burschenschaft Allemannia zu Heidelberg. Neubearbeitung zum 150. Stiftungsfest 2006. Hrsg. von Wolf-Diedrich Reinbach ... Heidelberg 2006. S. 256-258; Ruuskanen (2008) S. 171 f.; Werner, Franz: G.W. Winzer und Waldfrevler, Schulleiter und Universalhistoriker in: Jahrbuch des Helmholtz-Gymnasiums (2013/14 und 2014/15) S. 101-125; Ders.: Dr. phil. G.W. ...
Vom Halbwaisen zum Familienvater, Schulleiter und Universalhistoriker. Ein Beitrag zur Schulgeschichte des Helmholtz-Gymnasiums Heidelberg ... Heidelberg 2018 (Arbeitstitel; in Vorbereitung).

M Ida Helene Marie Wilhelmine geb. Becher (1804-1888), s. Roth (2001) S. 198f., 467, 661

๑ 11. Aug. 1870 Emilie geb. Dittenberger (18411901) T von: (siehe) Wilhelm D. [sen.] und Enkelin von: (siehe) Carl Daub

K 2 S: u.a. (siehe) Rudolf Heinrich W. 3 T: u.a. Emilia (Mila) Julia W. (1887-1911) Übersetzerin, s. Scheel (2014) Anm. 109-112, S. 457. • 3 weitere $\mathrm{K}$ früh $\dagger$

Vw Schwester: Sara Henriette Karoline (Lina) W. (1840-1889/97) Ehefrau von: (siehe) Heinrich Holtzmann

Vw siehe auch Scheel, S. 457-459.

Lb Seit WS 1860/61 Studium an UH, SS 1862 Leipzig, WS 1862/63 H, SS 1863-WS 1865/65 Königsberg (Preußen); 19. Febr. 1863 Dr. phil. an UH; 1865 Staatsexamen für Gymnasiallehrer in Karlsruhe; 1865-1866 Vorbereitung auf Habilitation in $\mathrm{H}$ an U Königsberg.

UH: 11. Aug. 1866 Habilitation; seit 20. Juli 1869 a. o. Prof.

Eidgenössisches Polytechnikum Zürich: Dez. 1869 Ern. zum SS 1870 o. Prof.

U Königsberg: 10. Juni 1875 Ern. zum WS 1875/76 o. Prof.

Polytechnikum Berlin-Charlottenburg: Seit SS 1883 o. Prof.

U Marburg: 18. Juli 1884 Ern. zum WS 1884/85 o. Prof. und 1885 Begründer des Math. Seminars.

U Göttingen: 16. April 1892 Ern. zum WS 1892/93 o. Prof.

U Straßburg: SS 1895-SS 1912 (Ruhestand) o. Prof.

1895 und 1904 Präsident der Dt. MathematikerVereinigung 
Ein Teil der W.schen Sammlung mathematischer Modelle und Instrumente befindet sich im Mathematischen Institut der Universität Göttingen, ein anderer Teil ist im Fachbereich Mathematik und Informatik der Universität Marburg untergebracht.

E Mitglied der Akademie der Wissenschaften: 1875 Göttingen, 1896 Berlin, 1903 München; 1883 Mitglied der Dt. Akademie der Naturforscher Leopoldina Halle/S.

Qu UAH PA 2405; Fak.-Akte H-IV-102/61. Die Matrikel der Universität Leipzig. Teilbd. II: Die Jahre 1832-1863. Hrsg. von Jens Blecher ... Weimar 2007. S. 506. Scheel, Katrin: Der Briefwechsel Richard Dedekind - H.W. Hrsg. von Thomas Sonar ... Berlin 2014. - [Weber, Ida:] FamilienGeschichte für Meine Kinder. Nach der Heirath ihrer Eltern. Angefangen 1839. Geschrieben im [Jahr] 1848. Von ihr fortgeführt bis 1887. [51 S.] (Im Privatbesitz von Herrn Dr. Karsten Weber.) • Siehe auch Archiv der Dt. Akademie der Naturforscher Leopoldina Halle/S. Mitteilungen: Herr Dr. Franz Werner, Sandhausen; Herr Dr. Karsten Weber, Mosbach-Neckarelz.

$W$ Theorie der algebraischen Functionen einer Veränderlichen in: Journal für die reine und angewandte Mathematik (1882) S. 181-290. Elliptische Functionen und algebraische Zahlen. Braunschweig 1891. - Lehrbuch der Algebra. 2 Bde. Braunschweig 1895-1896. Bd. 3: 1899. 3. Aufl. Nachdr. 1962. • Encyclopädie der Elementar-Mathematik. Ein Handbuch für Lehrer und Studierende. 3 Bde. Leipzig 1903-1907. (Mitverf.) Mehrere Aufl., zuletzt Bd. 1: 5. Aufl. 1934. Siehe auch Scheel (2014) S. 424-426.

MHG Bernhard Riemann's gesammelte mathematische Werke und wissenschaftlicher Nachlaß. Leipzig 1876. 2. Aufl. 1892.

Bearb. Riemann, Bernhard: Die partiellen Differential-Gleichungen der mathematischen Physik. 2 Bde. Mehrere Aufl. Braunschweig 1900-1919.

Redakteur Seit 1893 Mathematische Annalen.
$L$ Voss, Aurel: H.W. in: Jahresbericht der Dt. Mathematiker-Vereinigung 23 (1914) S. 431-444. • Catalogus prof. Marburgensis 2 (1927) S. 376; Catalogus prof. Gottingensium (1962) S. 112, 140. • Fellmann, E. A.: Hermite - Weber - Neumann. Kleine Briefgeschichte eines großen Irrtums in: Mathematical Perspectives. Essays on Mathematics and Its Historical Development. Ed. by Joseph W. Dauben. New York 1981. S. 47-51. • WBIS; Math. Institute in Deutschland (1989) S. 290 (Register). - Roquette, Peter: H.W., David Hilbert and Königsberg in: Hilbert Seminar, State University of Kaliningrad. Svedlogorsk (1. Juni 1992). S. 111 (S. 2: irrtümlich 17. März statt 05. März 1842 als Geburts-Tag genannt). - Laugwitz, Detlef: Über H.W. in: Bernhard Riemann 1826-1866. Wendepunkte in der Auffassung der Mathematik. Basel 1996. S. 157 f. u. ö. Publikationsstrategien einer Disziplin. Mathematik in Kaiserreich und Weimarer Republik. Hrsg. von Volker R. Remmert, Ute Schneider. Wiesbaden 2008. S. 23f., 31-36 u. ö. • Homo Heidelbergensis mathematicus online; Tilitzki 1 (2012) S. 811 (Register). Biographie H. W.s in: O'Connor, J.J. and Robertson, E.F. online: http://www-groups.dcs.st-and.ac.uk/history/Bio graphies/Weber_Heinrich.html (Juli 2014; Ausdruck im UAH). Lebenslauf von H. W. in: Scheel, Katrin: Der Briefwechsel Richard Dedekind H.W. Hrsg. von Thomas Sonar ... Berlin 2014. S. 31-35, 458 u. ö. (S. 31: irrtümlich 20. Dez. statt 05. März 1842 als Geburts-Tag genannt). • Deutsche Biographie, s. https://www.deutsche-biogra phie.de/pnd1012808513.html [07.11. 2017].

P Siehe Tilitzki 1 (2012) S. 640.

Weber, Carl Emil Maximilian (Max)

1897-1903 Phil. Fak.

(1903-1918 (Honorar-Prof.) Phil. Fak.)

Nationalökonomie, Finanzwissenschaft

* 21. April 1864 Erfurt

$\dagger$ 14. Juni 1920 München

ㅁ München, seit 1921 Heidelberg

ev. 
V Dr. iur. utr. Max W. (1836-1897) Stadtrat, s. Alfred W.

M Helene geb. Fallenstein (1844-1919), s. Alfred W.

๑ 20. Sept. 1893 Marianne geb. Schnitger (18701954) 18. Jan. 1922 Dr. iur. h.c. UH, s. UAH H-II-867/2, H-II-868/3; 1919 Mitglied der II. Kammer des Badischen Landtags in Karlsruhe; siehe Baum, Marie: M. W. zum Gedächtnis in: Ruperto Carola 6. Jg., Nr. 13/14 (1954) S. 46 f. $(P)$; Meurer, Bärbel: M. W. Leben und Werk. Tübingen 2010; Demm (2014) S. 248 (Register); Intellektuelle in Heidelberg (2014) S. 428 (Register); Kaesler (2014); Friedrich Gundolf - Elisabeth Salomon. Briefwechsel (2015) S. 802 (Register); Briefe in UBH

K keine, s. hierzu Kaesler (2014) S. 922, 935

Vw (siehe) Alfred W.

Vw Bruder u. a.: (siehe) Alfred W.

Lb Seit SS 1882 Studium der Rechtswiss., Geschichte, Philosophie, Nationalökonomie an UH, seit WS 1883/84 Straßburg, seit WS 1884/85 Berlin, WS 1885/86 Göttingen.

Okt. 1883-Okt. 1884 Militärdienstpflicht als Einjährig-Freiwilliger bei 2. Niederschlesischen Infanterie-Regiment Nr. 47 in Straßburg.

Mai 1886 I. jur. Staatsexamen vor Oberlandesgericht in Celle; Mai 1886 Referendarexamen in Göttingen; Juni 1886-März 1890 Referendar bei Justizbehörden u. a. in Berlin und Charlottenburg; 1. Aug. 1889 Dr. iur. utr. an U Berlin; 18. Okt. 1890 Assessorexamen in Berlin.

U Berlin: 1. Febr. 1892 Habilitation für Römisches Staats- und Privatrecht; seit SS 1892 Vertreter des erkrankten Ordinarius für Handelsrecht (siehe) Levin Goldschmidt; seit 1. Okt. 1893 nichtetatm. a. o. Prof. für Dt. Recht und Handelsrecht.

U Freiburg/Br.: 25. April 1894 Ern. zum WS 1894/ 95 o. Prof. für Nationalökonomie und Finanzwiss. zunächst an Phil. Fak., seit 1895 Jur. Fak., seit SS 1896 Rechts- und Staatswiss. Fak.
UH: 6. Jan. 1897 Ern. zum SS 1897 o. Prof. als Nachf. von Carl Knies; seit SS 1897 Direktor des neueingerichteten Volkswirtschaftl. Seminars; 25. Juli23. Okt. 1898 Aufenthalt in Heilanstalt für Nervenkranke im Konstanzer Hof in Konstanz; SS 1899 auf eigenen Antrag Befreiung von Lehrtätigkeit aus Krankheitsgründen; 7. Jan. 1900 W.s erstes Entlassungsgesuch; U lehnt ab und bewilligt längeren Urlaub bei fortlaufender Besoldung (bis SS 1903 einschl.); 2. Juli-17. Nov. 1900 Aufenthalt im Sanatorium für Nervenleidende und Erholungsbedürftige in Urach (heute: Bad U.); seit Nov. 1900 Aufenthalte auf Korsika, in Rom, Grindelwald, seit Herbst 1901 u. a. erneut in Rom; 16. April 1903 Entlassungsgesuch W.s aus Krankheitsgründen; SS 1903 letzte Vorlesungsankündigung überhaupt an UH; seit 1. Okt. 1903 Ruhestand (W. verzichtet auf Pension) mit gleichzeitiger Ern. zum o. HonorarProf.

1903-1918 Privat-Gelehrter in H; 20. Aug.-Ende Nov. 1904 USA-Rundreise; Aug. 1914-Sept. 1915 (auf eigenen Antrag Entlassung) Disziplinar-Offizier der Reserve-Lazarettkommission in $\mathrm{H}$.

U Wien: SS 1918 Lehrbeauftragter Prof. (probeweise Vertreter des Ordinarius) für Politische Ökonomie.

U München: Seit 1. April 1919 o. Prof. für Gesellschaftswissenschaften, Wirtschaftsgeschichte und Nationalökonomie.

1909 Mitbegründer der Dt. Gesellschaft für Soziologie in Berlin

E Mitglied der Akademie der Wissenschaften: 1909 H, 1919 München.

Qu UAH PA 2408; RA 1130, 5484f., 6412, 6867; Quästurakte, Vorlesungen betr., s. Rep. 27-1409; Fak.-Akte H-II-319/1; KE 94; Handakte HAW Nr. 492. GLA Abt. 235, Fasz. 2643 f. • Briefe: UBH. • Friedrich Gundolf - Elisabeth Salomon. Briefwechsel (1914-1931). Im Auftrag des DLA Marbach hrsg. von Gunilla Eschenbach und Helmuth Mojem. Berlin 2015. S. 802 (Register). Hinz, 
Uta: Ein Krieg am Schreibtisch. Der Weltkrieg in M.W.s Briefen in: UH während des Ersten Weltkriegs (2017) S. 123-145. - Nachlaß: Geheimes Staatsarchiv Preußischer Kulturbesitz Berlin. • Auskunft: Universitätsarchiv der Humboldt-Universität Berlin (Jur. Fak.o1, Nr. 144 vom 1. Febr. 1892). Mitteilungen: Herr Prof. Dr. Wolfgang Schluchter, Universität Heidelberg.

W Zur Geschichte der Handelsgesellschaften im Mittelalter ... Stuttgart 1889. - Die Verhältnisse der Landarbeiter im Ostelbischen Deutschland. Leipzig 1892. - Die römische Agrargeschichte in ihrer Bedeutung für das Staats- und Privatrecht. Stuttgart 1891. Deutschlands künftige Staatsform. Frankfurt/M. 1919. - Posthum erschienen: Gesammelte Aufsätze zur Religionssoziologie. 3 Bde. Tübingen 1920-1923. - Gesammelte politische Schriften. München 1921. Die rationalen und soziologischen Grundlagen der Musik. München 1921. - Gesammelte Aufsätze zur Wissenschaftslehre. Tübingen 1922. - Wirtschaft und Gesellschaft. Tübingen 1922. Max Weber-Gesamtausgabe. Im Auftrag der Kommission für Sozial- und Wirtschaftsgeschichte der Bayerischen Akademie der Wissenschaften. Hrsg. von Horst Baier ... Bde. $1 \mathrm{ff}$. Tübingen $1984 \mathrm{ff}$.

MHG 1904 Archiv für Sozialwissenschaft und Sozialpolitik.

Redakteur 1909-1920 Handbuch der politischen Ökonomie, seit 1914 u.d.T.: Grundriß der Sozialökonomik (Sammelwerk).

$L$ Weber, Marianne: M. W. Ein Lebensbild. Tübingen 1926. 3. Aufl. 1984. Glockner (1969) S. 278 (Register); Badische Biographien N.F. I (1982) S. 266-269. - Tödt, Heinz-Eduard: M. W. und Ernst Troeltsch in Heidelberg in: Semper apertus 3 (1985) S. 215-258. Obst, Bernhard: Ein Heidelberger Professorenstreit. Die Auseinandersetzung zwischen Adolf Koch und M.W. 1910-1914. Köln 1987. - Heiber I (1991) S. 647 (Register); Jansen (1992) S. 414 (Register); Ders. (1992a) S. 170 (Register). Heidelberg im Schnittpunkt intellektueller Kreise (1995) S. 184-307, 462-484 u. ö. • Brintzinger (1996) S. 400 (Register). Groppe, Carola: Die Macht der Bildung. Das dt. Bürgertum und der George-Kreis 1890-1933. Köln 1997. 2. Aufl.
2001. Reinbach, Wolf: M.W. und seine Beziehungen zur Burschenschaft Allemannia zu Heidelberg. 3. Aufl. Heidelberg 2003. - Roth, Guenther: M. W.s deutsch-englische Familiengeschichte 1800-1950 ... Tübingen 2001. Willett (2001) S. 17 f., 20, 25 u. ö. - Jansen (2002) S. 155-166. • Reichert, Folker: M. W.s Abschied von Heidelberg in: Jahrbuch für U-Geschichte 5 (2002) S. 199215. Asketischer Protestantismus (2005) S. 9-48 u. ö. Radkau, M.W.: Die Leidenschaft des Denkens. München 2005. (Siehe auch Rezensionen zu Radkau in: Heidelberg. Jahrbuch zur Geschichte der Stadt 2006/07. Heidelberg 2006. Jg. 11. S. 209221.) • Raehlmann (2005) S. 274 (Register). • Götz von Olenhusen, Albrecht: M.W. und die Anarchisten in: „... da liegt der riesige Schatten Freud's nicht mehr auf meinem Weg". Hrsg. von Raimund Dehmlow ... Marburg 2006. S. 184-198. Chandler, Nahum D.: The possible Form of an Interlocution: W.E.B. Du Bois and M. W. in Correspondence, 1904-1905 in: The New Centennial Review 6.3 (2007) S. 193-239. Kriegstagebuch K. Hampe (2007) S. 1005 (Register). - Götz von Olenhusen, Albrecht: Ehre, Ansehen, Frauenrechte - M.W. als Prozessjurist in: Das Recht und seine historischen Grundlagen ... Hrsg. von Tiziana J. Chiusi ... Berlin 2008. S. 297-315. • Schönhärl (2009) S. 461 (Register); Moraw (2010) S. 197-222. • Breuer, Stefan: „Herrschaft" in der Soziologie M. W.s. Wiesbaden 2011. - Köster, Roman: Die Wissenschaft der Außenseiter. Die Krise der Nationalökonomie in der Weimarer Republik. Göttingen 2011. • Wissenschaftsatlas der UH (2011) S. 112 f., 128; Geschichte U Berlin (2012) Bd. 1, S. 666 (Register). • Massimilla, Edoardo: M. W. zwischen Heinrich Rickert und Johannes von Kries. Drei Studien. Aus dem Italienischen übers. von Charlotte Voermanek. Köln 2012. • Gerhards (2013) S. 513 (Register). - Scaff, Lawrence A.: M.W. in Amerika. Berlin 2013. Demm, Eberhard: Else Jaffé-von Richthofen. Erfülltes Leben zwischen Max und Alfred Weber. Düsseldorf 2014. Ghosh, Peter: M. W. and the Protestant Ethic: Twin Histories. Oxford 2014. Götz von Olenhusen, Albrecht: Fabelwelt aus Zauberweibern, Anmut, Tücke und Glücksbegier. M. W. und die Anarchisten. Eine Geschichte der Verachtung und Faszination in: Literaturkritik. Rezensionsforum Nr. 5 (Mai 2014), online s. http://www.literaturkritik.de/public/rezension. php?rez_id=19211\&ausgabe=201405. Graf, Fried- 
rich Wilhelm: Fachmenschenfreundschaft. Studien zu Troeltsch und Weber. Berlin 2014. Intellektuelle in Heidelberg (2014) S. 171-188, 391-402 u. ö.; Kaesler (2014); Kaube (2014). - Max-Weber-Handbuch: Leben - Werk - Wirkung. Stuttgart 2014. - Troeltsch-Gesamtausgabe 19 (2014) S. 508 (Register). - Weischenberg, Siegfried: M. W. und die Vermessung der Medienwelt [Elektronische Ressource]. Empirie und Ethik des Journalismus - eine Spurenlese. Wiesbaden 2014. Schluchter, Wolfgang: M.W.s späte Soziologie. Tübingen 2015. - Götz von Olenhusen, Albrecht: M.W. und das Presse-, Medien- und Urheberrecht in: Im Dienste des Architekten-, Bau- und Urheberrechts. Festschrift für Klaus Neuenfeld ... Hrsg. von Inge Gräfin Dohna und Albrecht Götz von Olenhusen. Hamburg 2016. S. 295-311. Lepsius, Rainer M.: M.W. und seine Kreise. Essay. Tübingen 2016. - Bruhns, Hinnerk: M. W. und der Erste Weltkrieg. Tübingen 2017. - Deutsche Biographie, s. https://www.deutsche-biographie.de/pn d118629743.html [07.11. 2017]. - Isenböck, Peter: Sinn, Wert und Erfahrung. Internalismus und Externalismus bei M.W., Alfred Schütz und Niklas Luhmann. Baden-Baden 2017. M. W. and international relations. Ed. by Richard Ned Lebow. Cambridge 2017. M. W.s Economic ethic of the World religion. An analysis. Ed. by Thomas C. Ertman. Cambridge 2017. Recht als Kultur? Beiträge zu M.W.s Soziologie des Rechts. Hrsg. von Werner Gephart, Daniel Witte. Frankfurt/M. 2017. Reichert, Folker: M.W.s Grab in Heidelberg in: ZGORh 165. Jg. (2017) S. 383-402; Ders.: Tod und Verklärung. Das Professorengrab als biographisches Zeugnis in: Historische Zeitschrift 306 (2018) (im Druck). Cochrane, Glynn: M. W.s vision for bureaucracy. A casualty of World War I. Cham 2018.

$P$ Bildarchiv UAH; graph. Slg. UBH.

\section{Weber, Carl Otto}

1865-1867 Med. Fak.

Chirurgie

* 29. Dez. 1827 Frankfurt/M.

$\dagger$ 11. Juni 1867 Heidelberg

ev.

V Ernst Christian Wilhelm W. (1790-1850) seit 1817 Gymnasial-Prof. für Alte Literatur an Kantonschule Chur, seit 1819 Oberlehrer am Königl. Gymnasium Wetzlar, seit 1823 Prorektor und Prof. am Gymnasium Frankfurt/M., seit 1829 Direktor der Gelehrtenschule Bremen, s. WBIS; Schulz, Andreas: Vormundschaft und Protektion. Eliten und Bürger in Bremen 1750-1880. München 2002. S. 780 (Register).

M Bertha geb. Feuer

( 1. Sept. 1858 Julie geb. Gerling $(1837-1891)$

$\mathrm{K} \quad 1 \mathrm{~S}($ früh $\dagger)$.

Lb U Bonn: Seit WS 1846/47 Studium zunächst der Botanik, Geologie, Mineralogie, dann der Medizin; 4. April 1851 Dr. med. et chir.

Seit Nov. 1851 Vorbereitung auf med. und geburtshilfliche Staatsexamina in Berlin; seit Aug. 1852 Studienaufenthalt in Paris nach bestandenen Prüfungen.

U Bonn: 15. Okt. 1852-6. April 1857 Assistent an Chirurg. Klinik; 13. Jan. 1853 Habilitation für Chirurgie und Patholog. Anatomie; seit 6. April 1857 a. o. Prof., seit Nov. 1861 o. Prof. für Patholog. Anatomie; seit 18. Juli 1862 (Gründungs-)Direktor des Patholog.-Anatom. Inst. $\bullet$ In dieser Zeit:

Bonn: Seit 1854 Chirurg am Ev. Krankenhaus der Friedrich-Wilhelm-Stiftung.

UH: Seit 31. März 1865 o. Prof. und Direktor der Chirurg. U-Klinik als Nachf. von Maximilian von Chelius.

Die Ehefrau W.s, Julie geb. Gerling, vermacht der Medizinischen Fakultät der Universität Heidelberg in ihrem Testament 1891 ein Kapital von 10 ooo.Mark („Otto Weber-Stiftung“); die Zinsen „sol- 
len preisgekrönte Bearbeiter der von der medizinischen Fakultät gestellten Preisfrage" erhalten; letzter Vermerk der Stiftung in den Akten ist am 8. Nov. 1917; hier beträgt der jährl. Zinsertrag 550.Mark, s. UAH RA 5303, auch 5309.

Qu UAH PA 2409; RA 6789. GLA Abt. 205, Fasz. 549. - Briefe: siehe Kalliope. - Repertorium der Briefe aus dem Archiv Walter De Gruyter. Ausgewählt von Otto Neuendorff ... Berlin 1999. S. 321.

$W$ Die Knochengeschwülste in anatomischer und praktischer Beziehung. Bonn 1856. Chirurgische Erfahrungen und Untersuchungen nebst zahlreichen Beobachtungen aus der Chirurgischen Klinik ... Berlin 1859. - Krankheiten der Haut, des Zellgewebes, des Lymphgefäßsystems, der Venen, der Arterien und der Nerven in: Pitha-Billroth's Handbuch der allgemeinen und speciellen Chirurgie (1865). - Die Krankheiten des Gesichts. Erlangen 1866. - Über die Anwendung der schmerzstillenden Mittel im Allgemeinen und des Chloroforms im Besonderen. Berlin 1867. Bibliographie in: Noppeney (1968) S. 118-124.

$L$ Badische Biographie 2 (1875) S. 427-434; ADB 41 (1896) S. 343-345; WBIS; Krebs/Schipperges (1968) S. 44-48. - Noppeney, Gertrud: Die Anfänge der pathologischen Anatomie an der Universität Bonn unter besonderer Berücksichtigung von C. O. W. ... Med. Diss. Bonn 1968. • Verzeichnis Bonn (1968) S. 329; Chronik Ärzte H (1985) S. 145. - Linder, Fritz, Amberger, Mechthild: Chirurgie in Heidelberg in: Semper apertus 4 (1985) S. 190-192. Dhom (2001) S. 797 (Register).

$P$ Bildarchiv UAH; graph. Slg. UBH; Chronik Ärzte $\mathrm{H}$.

Weber, Karl Otto

s. Weber, Otto

\section{Weber, Rudolf Georg Heinrich}

1902-1907 Nat.-Math. Fak.

Physik

* 16. Aug. 1874 Zürich

$\dagger$ 03. Aug. 1920 Rostock

ev.

V (siehe) Heinrich W.

M Emilie geb. Dittenberger (1841-1901) T von: (siehe) Wilhelm D. [sen.]

๑ 1907 Helene Gertrud geb. Bauer (1880-1920) T von Max Hermann B. (1844-1917) PrivatDozent: seit 1871 Göttingen, seit 1872 Berlin; o. Prof. für Mineralogie und Geologie: seit 1875 Königsberg (Preußen), 1884-1915 (Emeritierung) Marburg, s. NDB 1 (1953) S. 642 f., WBIS; Bauer, Klaus: Johann Friedrich Widenmann ... und M. H. B. ... in: Württembergisch Franken. Jahrbuch des Histor. Vereins für Württembergisch Franken. Schwäbisch Hall 1991. Bd. 75. S. $238-263$.

K 1 T

Vw Schwager: Walter Bauer (1877-1960; S von Max Hermann B.) seit 1903 Privat-Dozent Marburg, seit 1913 a. o. Prof. Breslau, seit 1916 a. o. Prof., 1919-1945 (Emeritierung) o. Prof. für Neues Testament Göttingen, s. WBIS, BBKL I (1990) Sp. 419

Vw siehe auch Bauer, Klaus: Johann Friedrich Widenmann (1991) S. 216 und Anm. 1, 263.

Lb Ostern 1894-Ostern 1895 Militärdienstpflicht als Einjährig-Freiwilliger.

Seit SS 1895 Studium an U Straßburg, seit SS 1897 Göttingen, seit SS 1898 Straßburg; Mai 1899 Dr. phil. nat. an U Straßburg; SS 1901 Oberlehrerexamen in Physik, Mathematik, Chemie und Mineralogie für Oberklassen in Straßburg.

UH: April 1899-Mai 1907 Assistent am Physikal. Inst. mit e. jährl. Einkommen von 1200.- Mark; außerdem Leiter des Photograph. Kurses am Archäolog. Inst. mit e. Vergütung von 300.- Mark pro Semester; 7. Juni 1902 Habilitation; 19. Dez. 1906 Ern. zum nichtetatm. a. o. Prof. 
U Rostock: Seit 1. Juni 1907 a. o. Prof. für Angewandte Mathematik, insbesondere Analytische Mechanik und Math. Physik nebst Theorie der in ihr angewandten Differentialgleichungen; WS 1907/o8 Vertreter des vakanten Ordinariats für Physik; 13. Nov. 1919 Verleihung des Titels e. o. Honorar-Prof.; 1915-1919 Kriegsfreiwilliger.

Qu UAH PA 2411; RA 6398, 6465. - GLA Abt. 235, Fasz. 2645. • [Weber, Ida:] Familien-Geschichte für Meine Kinder. Nach der Heirath ihrer Eltern. Angefangen 1839. Geschrieben im [Jahr] 1848. Von ihr fortgeführt bis 1887 . [51 S.] (Im Privatbesitz von Herrn Dr. phil. Karsten Weber, Mosbach-Neckarelz.)

$W$ Reversible und umgekehrte Prozesse in: Abh. des Naturwiss. Vereins Rostock 2 (1910). • Magnetische Eigenschaften der Salze und anderer Verbindungen der Fe-Gruppe in: Jahrbuch der Radioaktivität und Elektronik 12 (1915). - Repertorium der Physik. 2 T. Leipzig 1915-1916 (zus. mit Richard Gans).

Übers. Gauss, Carl Friedrich: Allgemeine Grundlagen einer Theorie der Gestalt von Flüssigkeiten im Zustand des Gleichgewichts. Hrsg. von R. H. W. Leipzig 1903. Dt. Übers. von Gauss, C. F.: Principia generalia theoriae figurae fluidorum in statu aequilibrii. Göttingen 1830.

L Kalähne, Alfred: Zum Gedächtnis von R. W. in: Physikalische Zeitschrift 23. Jg., Nr. 4 (1922) S. 8183. - Poggendorff 5 (1925) S. 1340; WBIS. • Bauer, Karl: Stammbaum der Familie Bauer seit Beginn des 17. Jahrhunderts bis Weihnachten des Jahres 1933. Köln 1936. Mahnke, Reinhard: R. H.W. in: Die neue Universität ... Organ der SED-Parteileitung der Universität Rostock. Rostock 1985. S. 6. Über R.H.W. in: Bauer, Klaus: Johann Friedrich Wilhelm Widenmann ... und Max Hermann Bauer ... in: Württembergisch Franken. Jahrbuch des Histor. Vereins für Württembergisch Franken. Schwäbisch Hall 1991. S. 215-263. • Reich, Karin: Die Entwicklung des Tensorkalküls. Vom absoluten Differentialkalkül zur Relativitätstheorie. Basel 1994. S. 330 (Register). - Catalogus prof. Rostochiensium online; Grewolls (2011). Mahnke, Reinhard: Biographie R. W.s, s. www.mathnat. uni-rostock.de/geschichte/kalenderblatt/kalenderblatt-februar-2013/. Hessische Biografie, s. http://www.lagis-hessen.de/pnd/116085614 (Stand: 9. Febr. 2016); Deutsche Biographie, s. https:// www.deutsche-biographie.de/pnd117170798.html [07.11.2017].

P Physikalische Zeitschrift (1922).

\section{Wedekind, Carl Ignaz}

1792-1810 Jur. Fak.

1792-1808 Natur- und Völkerrecht; 1802-181o Dt. Staatsrecht, Privat- und Lehnrecht

* $\quad$ 03. Nov. 1769 Heidelberg

$\dagger$ 21. April 1837 Mannheim kath.

V Georg W. (1739-1789) Prof. für Rechtswiss. H, s. Drüll (1991) S. 167-169

M Sabina geb. Oberkamp

œ Agnes geb. Reuther ( $†$ nach 1837)

K unbekannt

Vw Großvater: Franz Ignaz W. (1710-1782) Prof. für Rechtswiss. H, s. Drüll (1991) S. 165-167.

Lb UH: Seit 7. Dez. 1785 Studium; 24. Nov. 1789 Oberkuratel verfügt, daß W. die Professur seines Vaters übertragen werden soll; WS 1792/93 (erste Erwähnung)-WS 1807/08 (letzte Erwähnung in Anzeigen der Vorlesungen) o. Prof. für Natur- und Völkerrecht als Nachf. seines Vaters; 1802 Übertragung der Professur für Staatsrecht als Nachf. von Georg Friedrich von Zentner (s. Drüll (1991) S. 178-181); bis 1810 Beisitzer des Spruchkollegiums der Jur. Fak.

Mannheim: Seit April 1810 Hofgerichtsrat, seit 1812 Oberhofgerichtsrat, zuletzt Präsident, seit 1. Aug. 1836 auch Kanzler am Badischen Oberhofgericht.

1805 Prorektor der UH; 1800,1804 ? (oder Matthäus Kübel) Dekan der Jur. Fak. der UH

1798 Reg.-Rat; 1805 Geh. Hofrat 
E 1795 Mitglied der Kurmainzischen Akademie gemeinnütziger Wissenschaften zu Erfurt.

Qu UAH PA $2416 \mathrm{f}$; RA 6020 („Fragmente eines gedruckten und zum Theil geschriebenen [49-seitigen] Bücherkatalogs nach Fächern geordnet", vor 7. Juli 1804 von Hofgerichtsrat Wedekind erstellt), RA 5436, 5918, 6477, 6668, 6766, 6779, 7591 u. ö; GF 102. - Toepke 4 (1903) S. 341. GLA Abt. 205, Fasz. 552-554, 556. Auskunft: Kath. Kirchenbuchamt Heidelberg.

W Systematische Darstellung des allg. Staatsrechts. Frankfurt 1794. • Die Aufnahme neuer Kirchen im Staate überhaupt und der Protestanten in Baiern ... Göttingen 1803. - Geist der Zeit, in einer pragmatischen Darstellung der merkwürdigen Ereignisse in der physikalischen, moralischen, literarischen und politischen Welt. 4 T. Freiburg/Br. 1810-1814.

$L$ Wechmar (1846) S. 116 f.; Schneider (1913) S. 115119 u. ö.; WBIS; Jammers (1964) S. 178 u. ö.; Drüll (1986) S. 289 und Dies. (1991) S. 169: irrtümlich W., Franz Ignaz statt W., Carl Ignaz; Weisert (1991) S. 121, 123-126 u. ö. - Schweigard, Jörg: Für Meinungsfreiheit und Menschenrechte. Die Auseinandersetzung um die naturrechtlichen Schriften des Heidelberger Juristen K. I. W. München 2003. • 200 Jahre Heidelberger Romantik (2008) S. 189 f. • Hahn, Thomas: Staat und Kirche im deutschen Naturrecht. Das natürliche Kirchenrecht des 18. und 19. Jahrhunderts (ca. 1680-ca. 1850). Tübingen 2012. S. 213, 222, 269, 285-288 u. ö. Klippel (2012) S. 393 (Register); Schroeder (2013) S. 163-169; Deutsche Biographie, s. https://www.deutschebiographie.de/pnd121645746.html [07.11. 2017].

Wedekind, Karl Ignaz

siehe Wedekind, Ignaz

\section{Weidenbach, Christoph Gottlob (seit 15. Febr. 1813: Edler von Weidenbach)}

1805-1807 Phil. Fak.

Philosophie

* 17. Sept. 1778 Naumburg (Saale)

$\dagger$ 11. Jan. 1843 Augsburg

ev.

V N.N.

M N.N.

$\varnothing$ 12. Aug. 1807 (in Aystetten) Marie Jakobine Barbara geb. Freiin von Münch (1785-1856) T von Christian von M. (1752-1821) Bankier, siehe Wikipedia; 1812-1821 Ortsherr von Buttenhausen (1812 Ankauf von Buttenhausen, das für 65 0oo.- Gulden zum Verkauf aus der Erbmasse der verstorbenen Freifrau von Liebenstein angeboten wurde, s. hierzu Allgemeine Zeitung von 1812. Beilage Nr. 30, S. 120. Augsburg vom 3. Okt. 1812.

K $2 \mathrm{~S}$

Lb U Leipzig: Seit 16. Juni 1798 Studium; 1801 Dr. phil. (W.s akad. Lehrer war Christian Weiß (17741853), u. a. 1796-1797, seit 1799 Privat-Dozent, 18011805 a. o. Prof. für Philosophie an U Leipzig, s. ADB 41 (1896) S. 561 f., WBIS).

Augsburg: Um 1804 Wohnsitz.

UH: 1805 Habilitation (ohne Nachweis in Fak.-Akte UAH H-IV-102/1); seit 6. Okt. 1806 a.o. Prof.; 24. Sept. 1807 auf eigenen Antrag Entlassungsgesuch; 6. Okt. 1807 Genehmigung des Weggangs, s. hierzu $Z$ (1) (1807).

Augsburg: Seit 1807 Gutsbesitzer und Privatier.

Buttenhausen, Schwäbische Alb (heute: Stadtteil von Münsingen): 1812 Erwerb des Guts B. (Meierhof?), s. hierzu $Z$ (2); 1816 Bau des Schlosses; (nach) 1843 Witwe W.s ist "Grundherrin und Patronin“ des Schlosses, s. Königl. Württ. Hof- und Staatshandbuch 1843. Stuttgart 1843. S. 432; Moser, Rudolph: Vollständige Beschreibung von Württemberg, in allen seinen Städten, Dörfern ... Bd. 1. Stuttgart 1843. S. $155 \mathrm{f}$. 
Hexenagger, Oberbayern (heute: Ortsteil von Altmannstein): 1834 W. kauft Schloß Hexenagger, das bis $1951 \mathrm{im}$ Besitz der Familie bleibt.

Z (1) Im Okt. 1806 bittet W. um die Erlaubnis, sich "demnächst" zu verehelichen. Das "Conclusum" der U-Kuratel lautet hierzu: „Da gedachter H[err] Dr. Weidenbach noch in keiner Besoldung stehe, Er aber in seinem Exhibito bemerke, daß zu seiner Verheurathung seine oeconomischen Umstände so beschaffen seyen, daß Er, obwohl eingeschränkt, doch keiner fremden Unterstüzung bedürfe, ... so sey ... die Erlaubniß zu seiner Verheurathung andurch zu ertheilen" (aus: UAH PA 2420). W. heiratet allerdings erst knapp ein Jahr später nach der obigen Erlaubnis, am 12. Aug. 1807.

Am 29. April 1807 moniert der Heidelberger Akad. U-Senat das Fehlen der Vorlesungsankündigung W.s für das SS 1807 am Schwarzen Brett in der Universität. Die U-Kuratel schreibt am 29. April dem Senat zurück, möglicherweise ist „... Prof. Weidenbach vielleicht auf der Reise an einem Orte, wo es ihm nicht möglich sei, Nachricht von sich zu geben, krank geworden ...; [der U-Senat möge] vordersamst auf eine diskrete Weise bei dessen [= W.s] hiesigen Bekannten über seinen jezigen Aufenthalt oder die Zeit seiner Rückkehr Erkundigungen einziehen, um so anschl[ießend] diese nebst einer Anzeige, ob die dem äußerlichen Vernehmen nach in seiner Behausung niedergekommene Frauensperson, wie man vermuthe, ebenfalls verreiset sei, auch, ob Prof. Weidenbach Schulden dahier zurückgelassen, (der U-Kuratel) ... vorzulegen“ (aus: PA 2420).

Der Personalakte W.s liegt der Auszug eines Großherzoglichen Badischen Geheimenraths-Protokolls des Karlsruher Polizeidepartments vom 8. Sept. 1807 bei. Dieses Schreiben wurde auf Erlaß des Heidelberger Akad. U-Senats vom 20. Aug. 1807 verfaßt. Hierin werden die „früher[e]n guten Zeugnisse des Akademischen Senats" sowie „die geistvolle und anständige Sprache" W.s hervorgehoben. Allerdings stünde sein jetziges Verhalten im , auffallenden Contrast“ zu früher, nämlich seine ihm ertheilte Heurats-Erlaubnis auf der einen Seite mit den geheimnisvollen Verhältnissen, und der allen Formen der Dienst-Ordnung und des
Anstands widersprechenden Entfernungsweise und der sonderbaren, nunmehr erfolgten Aufsagung seiner Anstellung auf der anderen Seite ... Professor [Anton Friedrich Justus] Thibaut - unter dessen Prorectorat die bedeutendste Entwicklung der Professor Weidenbachischen Verhältnisse Statt gehabt, und welcher dessen Vertrauen zu besizen scheine -“ wird beauftragt, W. nach München zu schreiben und ihm „die großen Unförmlichkeit[en] seines Betragens bemerklich zu machen und ihm an Handen zu geben, daß er in schicklicher Form um seine Entlassung, die ihm nicht erschwert werde, anzusuchen habe ..." (aus: PA 2420). Am 24. Sept. 1807 schickt W. aus Augsburg das gewünschte förmliche Demissionsgesuch, dem am 6. Okt. durch das Karlsruher „Polizeydepartement" stattgegeben wird.

$Z$ (2) In der Beilage zur Allgemeinen Zeitung Nr. 286 von 1825, S. 1141f. ist die Rezension über die „Beschreibung des Königreichs Würtemberg, herausgegeben aus [!] Auftrag der Regierung, von Professor [Johann Daniel Georg von] Memminger, Stuttgart, in der J.G. Cotta'schen Buchhandlung $1825^{“}$ abgedruckt. Hierin heißt es u. a.: „... Eine niederschlagende Bemerkung ist es, dass in dem Oberamt Münsingen auf den meisten grundherrlichen Orten die Personal- und Lokal-Leibeigenschaft noch lastet und der Zehnte fortwährend auf dem Felde bezogen wird ... Von dieser betrübenden Regel machen nur Hayingen, den Fürsten von Fürstenberg, und Buttenhausen, dem Herrn von Weidenbach gehörig, eine ruhmwürdige Ausnahme; hier ist die Leibeigenschaft aufgehoben. $\mathrm{H}[\mathrm{er}] \mathrm{r}$ v[on] Weidenbach hat überdem durch Verträge den Bauern die vierte Garbe überlassen, neuerlich die Ablösung des Zehnten gegen der Gemeinde vortheilhafte Bedingungen zu Stande gebracht, und, statt der Berechtigung in seinem Walde zu schlagen, durch eine Theilung des Waldes nun der Gemeinde ein eigenes Waldeigenthum gegeben. Ehre den Männern, welche die Ansprüche der Humanität und einer verständigen Oekonomie in Einklang zu bringen wussten! Durch Nachahmung solcher Beispiele würden alle Theile gewinnen. Viel ist in dieser Beziehung noch in Würtemberg zu thun ..." 
Qu UAH PA 2420. - GLA Abt. 205, Fasz. 559. • Teil-Nachlaß: Stadtarchiv Münsingen. • Ergebnislose Anfragen: Stadtarchiv Münsingen; Herr Rechtsanwalt Christoph Edler von Weidenbach, München.

W Über den Gebrauch des Chores in der Tragödie, nach ästhetischen Principien ... Leipzig 1805. (Das Vorwort schrieb W. im Sept. 1804 in Augsburg.)

$L$ Meusel, 4. Bd., Suppl. zur 5. Ausg. (1812) S. 166 f.; WBIS; Schneider (1913) S. 279. • C. Edler von W. in: Genealogisches Handbuch des in Bayern immatrikulierten Adels. Neustadt an der Aisch 1978. Bd. XII, S. 699.

\section{Weidenreich, Franz}

1922-(1924) 1928 Med. Fak.

Anthropologie, Hämatologie

* $\quad$ 07. Juni 1873 Edenkoben (Pfalz)

$\dagger \quad$ 11. Juli 1948 New York

口 Westwood (Bergen County, New Jersey) mosaisch, später konf.-los

V Carl W. (1817-1894) Kaufmann

M Friederike geb. Edesheimer (1831-1903)

@ 15. März 1904 Mathilde geb. Neuberger (18831960)

$\mathrm{K} \quad 4 \mathrm{~T}$ (davon $1 \mathrm{~T}$ früh $\dagger$ ), s. Lexikon jüdischer Einwohner Hs (2011) S. 430 (hier nur $2 \mathrm{~T}$ genannt), Hartkopf (2012) S. 95, 104-106

Vw siehe Hartkopf, S. 95-103.

Lb Seit WS 1892/93 Studium an U München, SS 1895 Kiel, WS 1895/96 Berlin, seit SS 1896 Straßburg; 26. Jan. 1898 Staatsexamen und Approbation in Straßburg.

U Straßburg: 10. Juli 1899 Dr. med.; April 1899März 1903 Assistent am Anatom. Inst.; in dieser Zeit: 1. Dez. 1901-31. März 1902 Assistent am Inst. für Experimentelle Therapie an U Frankfurt/M.; 10. Juli 1901 Habilitation für Anatomie an U Straßburg; April 1903-Nov. 1918 Prosektor am Anatom. Inst.; seit SS 1904 etatm. a. o. Prof. für Anatomie;
1914-1918 auch Mitglied des Straßburger Stadtrats und Präsident der Demokratischen Partei von Elsaß-Lothringen; Jan. 1919 Ausweisung.

Wohnsitz: Nach Jan. 1919-1928 (?): Mannheim, P.7,21.

UH: Seit 3. Jan. 1922 planm. a. o. Prof. und Mitglied der Wiss. Abt. am Inst. für Experimentelle Krebsforschung; 4. Febr. 1922 Vereidigung; 1. April 1924 Emeritierung gemäß Art. 3 der Personal-Abbaubestimmungen des Deutschen Reichs (aus: UAH PA 6275); WS 1927/28 letzte Vorlesungsankündigung über Konstitution und Vererbung, gratis, 1-stündig.

H: 1924-1928 (Aufgabe des Inst.) Leiter des von der Josefine und Eduard von Portheim-Stiftung für Wissenschaft und Kunst eingerichteten Biomechanischen Inst. in der Märzgasse 2 als Nachf. von Josef Spek; in dieser Zeit Eigenstudien: 1925 Zoolog. Station in Neapel, 1926 Biolog. Station des Bergens Museums in Bergen (Norwegen).

U Frankfurt/M.: Seit WS 1928/29 Lehrbeauftragter für Anthropologie, Gründer und Leiter des Inst. für Physische Anthropologie in Räumen des Senckenberg Naturmuseums in Frankfurt/M.; seit 1929 Honorar-Prof. für Physische Anthropologie und Rassenkunde; seit SS 1934 zwangsweise Beurlaubung ohne Bezüge; April-Dez. 1934 Gastprof. am Dept. of Anatomy der U of Chicago; 31. Dez. 1935 Entzug der Lehrbefugnis aus rassischen Gründen.

Peking: Seit 1. April 1935 Gast-Prof. für Anatomie am Peiping Union Medical College und Ehrendirektor des Cenozoic Research Laboratory, einer Abt. des Geological Survey of China; seit April 1939 Studien am American Museum of Natural History in New York; Frühjahr 1940 Rückkehr nach Peking; Herbst 1941 Emigration in die USA nach Entzug der dt. Staatsbürgerschaft.

New York: 1941-1948 Mitarbeiter am American Museum of Natural History. 
E Mitglied: 1904 Dt. Akademie der Naturforscher Leopoldina Halle/S., 1913 Wiss. Gesellschaft Straßburg, 1926 Dt. Gesellschaft für dentale Anatomie und Pathologie.

Qu UAH PA 1238, 6275 (darin: 26. Jan. 1908 Promotion zum Dr. med. an U Straßburg sowie Angabe des Todesdatums mit 21. Juli statt 11. Juli 1948). • GLA Abt. 253, Fasz. 2650 f. • Siehe auch Archiv der Dt. Akademie der Naturforscher Leopoldina Halle/S.

W Die Leukozyten und verwandte Zellformen. Wiesbaden 1911. Das Evolutionsproblem und der individuelle Anteil am Entwicklungsgeschehen. Berlin 1921. - Rasse und Körperbau. Berlin 1927. Ein neuer Pithecanthropus-Fund in China in: Natur und Museum. Die Senckenberg-Naturzeitschrift (1930) Bd. 6o, Nr. 12, S. 546-551. The „Neanderthal Man“ and the ancestors of „Homo sapiens“ in: American Anthropologist (1943) Vol. 45, Issue 1, S. 39-48. - The skull of Sinanthropus pekinensis ... Peking 1943. Bibliographie in: The shorter anthropological papers of F. W. published in the period 1939-1948 ... Ed. by Sherwood Larned Washburn ... New York 1949. S. 257-267.

L Stübler (1926) S. 307; Kürschner (1931) Sp. 3201, (1940/41) Sp. 1503. - Bork-Feltkamp, Adèle J. van: F. W. Amsterdam 1948. Encyclopaedia Judaica 16 (1971) Sp. 374; Mussgnug (1988) S. 300 (Register). • Hammerstein, Notker: Die ... Johann Wolfgang Goethe-Universität ... Bd. 1. Frankfurt/M. 1989. S. 86f. - Juden der Frankfurter U (1997) S. 383385. - Wolpoff, Milford, Caspari, Rachel: Race and human evolution. New York 1997. Hertler, Christine: Anthropologie. Der Humananatom F. W. in: „Exodus der Wissenschaften und der Literatur" ".. Hrsg. von Dirk Reitz. Darmstadt 2004. S. 183-206; Dies.: F. W. und die Anthropologie in Frankfurt ... in: Frankfurter Wissenschaftler zwischen 1933 und 1945. Hrsg. von Jörn Kobes ... Göttingen 2008. S. 111-123. - WBIS; Friedrich (2009) S. 91 f. u. ̈.; Lexikon jüdischer Einwohner Hs (2011) S. 430. - Hartkopf, Herbert: F. W. - ein pfälzischer Weltbürger. Arzt - Politiker - Menschenforscher ... Ubstadt-Weiher 2012. • Deutsche Biographie, s. https://www.deutsche-biographie.de/pn d117239798.html [28.11. 2017].

\section{Weil, Adolf}

1872-1886 Med. Fak.

Innere Medizin

* 07. Febr. 1848 Heidelberg

$\dagger$ 23. Juli 1916 Wiesbaden

mosaisch

V (siehe) Gustav W.

M Auguste geb. Levy (†1851)

$\infty$ Emma geb. Levi

K mind. 1 S: Alfred W. (1884-1946 letzte Erwähnung in USA) Privat-Dozent: seit 1906 Straßburg, seit 1919 Frankfurt/M.; 1921-1935 (Entlassung) a.o. Prof. für Innere Medizin und Röntgenologie Frankfurt/M.; 1935 Emigration in die USA, s. Juden der Frankfurter U (1997) S. $385 \mathrm{f}$.

Lb Seit WS 1865/66 Studium an UH, seit SS 1869 Berlin, anschl. Wien; Nov. 1870 Hauptprüfung in Karlsruhe.

UH: 11. März 1871 Dr. med.; 1872-1876 Assistent an Med. U-Klinik; 24. Juli 1872 Habilitation für Innere Medizin; seit 31. Jan. 1876 a. o. Prof.; 6. Juli 1876 Genehmigung zur Abhaltung von Vorträgen über Physikalische Diagnostik, Syphilis und Hautkrankheiten.

U Dorpat (heute Tartu, Estland; bis 1889 einzige dt.sprachige U im Russischen Kaiserreich): WS 1886/87 o. Prof. für Spezielle Pathologie und Therapie und Direktor der Med. U-Klinik; SS 1887 Aufgabe des Lehrstuhls aus Krankheitsgründen (Kehlkopftuberkulose).

Seit 1887 praktischer Arzt in verschiedenen Badeorten, u. a. (bis 1890) Badenweiler (siehe auch Albert Fraenkel).

Wiesbaden: Seit 1893 niedergelassener Arzt.

1886 Entdecker der sog. Weil'schen Krankheit (Infektionskrankheit), siehe hierzu Enzyklopädie Medizingeschichte. Hrsg. von Werner E. Gerabek u. a. Berlin 2005. S. 1470. 
E 1883 Mitglied der Dt. Akademie der Naturforscher Leopoldina Halle/S.

Qu UAH PA 2421; Fak.-Akte H-III-111/78. - Siehe auch Archiv der Dt. Akademie der Naturforscher Leopoldina Halle/S.

W Die Gewinnung vergrößerter Kehlkopfspiegelbilder. Leipzig 1872. • Die Auscultation der Arterien und Venen. Leipzig 1875. * Handbuch und Atlas der topographischen Percussion. Leipzig 1877. 2. Aufl. 1880. - Über den gegenwärtigen Stand der Lehre von der Vererbung der Syphilis. Leipzig 1878. - Zur Lehre vom Pneumothorax ... Experimentelle, klinische und anatomische Untersuchungen. Leipzig 1882. - Zur Pathologie und Therapie des Typhus abdominalis. Leipzig 1885. • Über eine eigenthümliche, mit Milztumor, Icterus und Nephritis einhergehende acute Infectionskrankheit in: Dt. Archiv für klinische Medizin 39 (1886).

$L$ Biogr. Jahrbuch 1 (1914-1916) S. 371; Stübler (1926) S. 314; Jüdische National-Biographie 6 (1931) S. 222; Fischer 2 ( $\left.{ }^{3} 1962\right)$ S. 1656; Chronik Ärzte H (1985) S. 145 f. • Albert Fraenkel. Ein Arztleben ... Hrsg. von P. Drings u. a. Landsberg/Lech 2004. S. 76. - Cook, Gordon C.: Tropical medicine. An illustrated history of the pioneers. London 2007. S. 110, 236-238. - Von der Forschung gezeichnet (2007) S. 72 f. u. ö.; WBIS. • „Eine raffiniert humane Kur": Hermann Hesse in Badenweiler ... 3. Aufl. Schliengen 2012. S. 14 u. ö. Deutsche Biographie, s. https://www.deutsche-bio graphie.de/pnd117250694.html [28.11.2017]. • Siehe auch Biographie W.s unter http://www.whona medit.com/doctor.cfm/1688.html (abgerufen am 20. Febr. 2018).

$P$ Bildarchiv UAH; graph. Slg. UBH; Chronik Ärzte H.

\section{Weil, Gustav}

1836-1889 Phil. Fak.

Orientalische Sprachen

* 25. April 1808 Sulzburg (Baden)

$\dagger$ 29. Aug. 1889 Freiburg/Br.

mosaisch

V Gottschalk W., Vorsteher der Israelitischen Gemeinde Sulzburg

M Babette geb. Wittersheim

$\infty$ Aug. 1839 Auguste geb. Levy (†1851)

$\infty$ Sept. 1853 Sophie geb. Levy $(\dagger 1886)$

$\mathrm{K}$ 11, u. a. (siehe) Adolf W.

Lb Seit SS 1828 Studium der Geschichte, Philosophie an UH; 1830 Eigenstudien in Paris.

1830-1835 Korrespondent der „Augsburger Allgemeine Zeitung“, auch des „Morgenblatt für gebildete Stände“. • In dieser Zeit:

Aufenthalte: Seit 1830 in Algier (Berichterstattung über Besetzung Algeriens durch Frankreich), Ende Jan.-Juni 1831 in Kairo; Juli 1831-März 1835 Französisch-Lehrer an med. Schule von Abuzabel (bei Kairo); Mai 1832 kurzzeitiger Aufenthalt in Europa; 8. März 1835 Entlassung als Lehrer aufgrund W.s Weigerung, e. Quarantäne-Anordnung Folge zu leisten.

Nach März 1835 Aufenthalt in Konstantinopel (heute: Istanbul).

U Tübingen: 1. Juli 1836 Dr. phil.

UH: 1. Dez. 1836 Habilitation; seit WS 1836/37 Lehrauftrag für Orientalische Sprachen; 14. Aug. 1845 Ern. zum a.o. Prof. durch Regierungsbeschluß gegen den Widerstand der U; seit 7. Aug. 1861 o. Prof.; 30. Mai 1889 auf eigenen Antrag Ruhestand. • In dieser Zeit:

UBH: Seit Sept. 1836 Mitarbeiter („Collaborator“), März 1838-Aug. 1861 Bibliothekar.

1874/75 Dekan, 1875/76 Prodekan der Phil. Fak. der UH 
W. ist der erste jüdische Wissenschaftler in Deutschland, der zum Professor für Orientalische Sprachen (1845) ernannt wird; der erste mosaische Ordinarius an der Universität Heidelberg war 1652 der Mediziner Jacob Israël, siehe Drüll (1991) S. 75; siehe auch Levin Goldschmidt und Sigmund Zimmern

1881 Hofrat

Siehe auch Eduard Röth: Eintrag unter $Z$ [itat] (1)

E 1838 Mitglied der Asiatischen Gesellschaft Paris. 1863 Mauritiusorden; 1863 Königl.-Preußischer Kronenorden IV. Klasse; 1866 Offizierskreuz des mexikanischen Guadelupe-Ordens; 1878 Ritterkreuz I. Klasse, 1888 Kommandeurkreuz des Ordens vom Zähringer Löwen.

Qu UAH PA 2423; Fak.-Akten H-IV-102/32 fol. 185r, v, H-IV-102/57 fol. 464r, v. • Briefe: UBH.

$W$ Mohammed der Prophet, sein Leben und seine Lehre. Stuttgart 1843. Historisch-kritische Einleitung in den Koran. Bielefeld 1844. 2. Aufl. 1878. Geschichte der Chalifen. Nach handschriftlichen, größtenteils noch unbenutzten Quellen. 3 Bde. Mannheim 1846-1851. Forts. u.d.T.: Geschichte des Abbasidenchalifats in Ägypten. 2 Bde. Stuttgart 1860-1862. - Geschichte der islamitischen Völker von Mohammed bis zur Zeit des Sultans Selim. Stuttgart 1866. Bibliographie, s. https://www. islam-akademie.de/islamwissenschaften/bibliogra phie-terminologie/332-gustav-weil-18o8-1889-bi bliographie (Ausdruck im UAH).

Übers. 1001 Nacht, zum ersten male aus dem Urtext vollständig und treu übersetzt von G. W. Hrsg. von August Lewald. 4 Bde. Stuttgart, Pforzheim 1838-1841. Neu bearb. von Karl Heinz Berger ... Stuttgart 2009. Nachdr. Hamburg 2013. - Das Leben Mohammed's nach Muhammed Ibn Ishâk ... Aus dem Arabischen übers. von G. W. 2 Bde. Stuttgart 1864.

L ADB 41 (1896) S. 486-488; Jüdische NationalBiographie (1931) S. 223. • G. W. in: Fück, Johann: Die arabischen Studien in Europa bis in den Anfang des 20. Jahrhunderts. Leipzig 1955. S. 175 f. •
Zollner, Hans Leopold: Mehr als der Übersetzer von "Tausendundeiner Nacht“ in: Beiträge zur Landeskunde ... Beilage zum Staatsanzeiger für Baden-Württemberg 4 (Aug. 1989) S. 13-15. • Grosspietsch, Jost: Vom Markgräfler ins Morgenland. Anm. zu ... G. W. in: Badische Heimat: mein Heimatland. Zs. für Landes- und Volkskunde ... Freiburg/Br. 1999. S. 649 ff. - Heidenreich, Wolfgang: Weißer Kieselstein - schwarzer Obelisk. Erinnerung an ... G. W. in: Alemannisches Judentum. Spuren einer verlorenen Kultur. Hrsg. von Manfred Bosch ... Eggingen 2001. S. 318-328. • Lewis, Bernard: Islam in history. Ideas, people, and events in the Middle East. $2^{\text {nd }}$ ed. Chicago 2001. S. 487 (Register). - Mangold, Sabine: Eine ,weltbürgerliche Wissenschaft". Die deutsche Orientalistik im 19. Jahrhundert. Stuttgart 2004. S. 329 (Register). Marzolph, Ulrich, Leeuwen, Richard van: The Arabian nights encyclopedia ... Bd. 1. Santa Barbara 2004. S. 736 u. ö. • WBIS. • Klenk, Sonja: Gedenkstättenpädagogik an den Orten nationalsozialistischen Unrechts in der Region Freiburg-Offenburg. Berlin 2006. S. 84. Religion(en) deuten. Transformationen der Religionsforschung. Hrsg. von Friedrich Wilhelm Graf, Friedemann Voigt. Berlin 2010. S. 373 (Register). - JohnstonBloom, Ruchama: Jews, Muslims and Bildung. The German-Jewish Orientalist G. W. in Egypt in: Religion Compass 8/2 (2014) S. 49-59. Langguth, Heide: „Träumend in einem irdischen Paradiese“. Der jüdische Gelehrte G.W. brachte den Deutschen die arabische Erzählkunst nahe in: Jewish Voice from Germany Nr. 12 (Okt. 2014) S. 7 f. (auch in engl. Sprache) (hier: seit Juli 1832 Aufenthalt in Konstantinopel). • Bangert, Kurt: Muhammad. Eine historisch-kritische Studie zur Entstehung des Islams und seines Propheten. Wiesbaden 2016. S. 1, 269, 487. - Johnston-Bloom, Ruchama: Analogising Judaism and Islam. Nineteenth- and twentieth-century German-Jewish scholarship on Islam in: Journal of Beliefs \& Values. Studies in Religion \& Education. Vol. 38/3 (2017) S. 267-275. • Schroeder (2017) S. 4, 39, $56 \mathrm{f}$.

$P$ Bildarchiv UAH; graph. Slg. UBH. 


\section{Weinreich, Otto Karl}

1918-1921 Phil. Fak.

Klassische Philologie

* 13. März 1886 Karlsruhe

$\dagger$ 26. März 1972 Tübingen

kath.

V Justus W. (1858-1927) Großherzogl. Kammermusiker, Komponist, u.a. von 3 Suiten für Viola solo. [Erstdruck.] Hrsg. von Bernhard Päuler. Edition-Nr. BP 1110. Amadeus Verlag. Winterthur 2001. - Siehe Sawodny, Wolfgang: J.W. - ein unbekannter Bratschenmeister in: Jahrbuch der Int. Viola-Forschungsgesellschaft (1983) S. 14-18; Deutsche Biographie, https:// www.deutsche-biographie.de/pnd135152836. html [19.12. 2017]

M Elise geb. Dürr ( ${ }^{*} 1865 \dagger 1934$ ?)

๑ 2. Juni 1919 Dora Marie geb. Stadie (1895-1984)

$\mathrm{K} \quad 1 \mathrm{~S}, 2 \mathrm{~T}$

Lb UH: Seit WS 1904/05 Studium; 28. Jan. 1908 Rigorosum, 30. Okt. 1908 (Datum der Promotionsurkunde) Dr. phil.; Apr. 1908-Aug. 1911 Assistent am Archäolog. Inst.; März 1909 badische Oberlehrerprüfung.

Mai 1909-Mai 1910 Gymnasial-Lehramtspraktikant in H; Herbst 1911-Dez. 1913 Eigenstudien und Reisen in Griechenland, Kleinasien und Italien; Jan.-Apr. 1914 Studienaufenthalt in Berlin.

U Halle-Wittenberg: Seit April 1914 Assistent am Philolog. Seminar; 25. Juni 1914 Habilitation; 29. Juli 1914 Antrittsvorlesung.

U Tübingen: 22. Mai 1916 Ern. zum etatm. a.o. Prof.; 14. Aug. 1917 Ruf an U Jena angenommen.

U Jena: Seit SS 1918 o. Prof.

UH: 4. Juli 1918 Ern. zum WS 1918/19 o. Prof. als Nachf. von Fritz Schöll; 12. Dez. 1919 Vereidigung, siehe $Z$.

U Tübingen: 8. Aug. 1920 Ern. zum 1. Okt. 192131. März 1954 (Emeritierung) o. Prof.; 11. Mai 1922 Antrittsvorlesung; 1930 Ruf an U Halle-Wittenberg abgelehnt; 31. März 1954 Entpflichtung; SS 1954WS 1954/55 Vertreter seines Lehrstuhls.

Z Der Text der Vereidigung W.s an UH lautet 1919: „Ich schwöre einen feierlichen Eid zu Gott, dass ich alle Obliegenheiten des mir übertragenen Amtes, den Gesetzen, Verordnungen und Dienstvorschriften entsprechend gewissenhaft wahrnehmen will. Ich schwöre Treue der Reichsverfassung und der Landesverfassung. Dies schwöre ich, so wahr mir Gott helfe“ (aus: UAH PA 6287 fol. $7 \mathrm{r}$ ).

1924-1933 (Aufgabe der Tätigkeit W.s als Musikkritiker) und 1945-1952 erneut Musikkritiker des "Schwäbisches Tagblatt“ in Tübingen, s. Otto Weinreich (1979) S. 534 Anm. 1 (Anhang)

E 1919 Mitglied der Akademie der Wissenschaften H. 1956 Großes Bundesverdienstkreuz. $\bullet$ Siehe auch Otto Weinreich (1979) S. 534 f. (Anhang).

Qu UAH PA 6287; RA 6375, 6396, 6452, 6827; Fak.Akte H-IV-102/143; H-IV-757/4 fol. 693r u.ö. • GLA Abt. 235, Fasz. 2654. • Briefe: UBH. • Dürkop, Martina: Habilitation, Ruf und Inflation. Religionswissenschaft und Klassische Philologie in Briefen O.W.s an Georg Wissowa (1913-1924) in: Archiv für Religionsgeschichte (März 2014) Bd. 15, H. 1, S. 269-384. - Nachlaß: siehe Otto Weinreich (1979) S. 4.

W Antike Heilungswunder. Gießen 1909. Nachdr. 1969. Die Distichen des Catull. Tübingen 1926. Nachdr. 1972. • Der griechische Liebesroman. Zürich 1962. • O. W.: Ausgewählte Schriften ... (19071970). Unter Mitarbeit von Ulrich Klein hrsg. von Günther Wille. 4 Bde (Bd. 4: Zur Musikwissenschaft 1909-1960 und Konzertkritiken 1923-1933 und 1945-1952). Amsterdam 1969-1979.

(M)HG 1916-1939 (Kündigung seitens des B.G. Teubner Verlags) Archiv für Religionswissenschaft, s. hierzu Dürkop, Martina: Das Archiv für Religionswissenschaft in den Jahren 1919-1939 ... Berlin 2013. 1916-1939 Religionsgeschichtliche Versuche und Vorarbeiten. - 1927-1961 Tübinger Beiträge zur Altertumswissenschaft. 
L Kürschner (1966) S. 2645 f.; WBIS. • Wille, Günther: O.W. zum Gedächtnis in: Attempto - Forschungsmagazin der Universität Tübingen - 43/44 (1972) S. 108-113. • Vita O. W.s in: Otto Weinreich: Ausgewählte Schriften III. 1937-1970 (Philologische Schriften). Unter Mitarbeit von Ulrich Klein hrsg. von Günther Wille. Amsterdam 1979. S. 533536 (Anhang). - Bibliographie zur Geschichte der Universität Tübingen. Hrsg. von Friedrich Seck. Tübingen 1980. S. 530. - Borzsák, Stefan: O.W. in: Eikasmós 4 (1993) S. 373-378. • Baden-Württ. Biographien II (1999) S. 479-481; Kriegstagebuch K. Hampe (2007) S. 1005 (Register); Universität Tübingen im Nationalsozialismus (2010) S. 1135 (Register); Catalogus prof. Halensis online. $\bullet$ Deutsche Biographie, s. https://www.deutsche-biographie. de/pnd11880653X.html [19.12. 2017].

\section{$P$ Bildarchiv UAH.}

\section{Weise, Ferdinand Christoph}

(1804) 1805-1808, 1812-1823 Phil. Fak. Geschichte der Philosophie, Rechts- und Religionsphilosophie, Allg. Enzyklopädie der Wissenschaften, Geschichte der Literatur, Natur-, Allg. Staats- und Völkerrecht, Erfahrungsseelenlehre

* 30. Juli 1765 Tübingen

$\dagger \quad$ 14. Juli 1839 Badenweiler ev.

V Friedrich Ferdinand W. (* 1724) Hofgerichtsadvokat

M Magdalene Elisabeth geb. Baur

( 30. Juli 1789 Euphrosine Magdalene geb. Weber(in) († ca. 1857), s. Hauptstaatsarchiv Stuttgart Bestand A 275 Bü 189

K „viele Kinder“, darunter 2 T, s. Brief des Engeren Senats der UH vom 16. Juni 1812 in: UAH PA 2426.

Lb U Tübingen: Seit 5. Okt. 1781 Studium der Rechtswiss.; phil. Magisterexamen; Dr. iur.

Tübingen: Vor 1790 Advokat am Hofgericht.
UH: März 1804 Ern. zum o. Prof. für Philosophie mit e. jährl. Besoldung von 70o.- Gulden, 6 Malter Korn und 9 Malter Spelz (aus: Brief vom 16. Juni 1812 in: UAH PA 2426); 16. Juni 1812 Engerer Akad. Senat der U schreibt an Ministerium des Innern: „... Der Professor W. verfiel gleich nach seiner, um Ostern 1804, erfolgten Ankunft, als er kaum einige Stunden gelesen hatte, in eine so heftige Hypochondrie, daß er zu allen Vorlesungen völlig unfähig geworden ist, und auch sonst nicht die mindeste[n] Dienste leistet. Man hat zwar vor mehreren Jahren ihn bey der Bibliotheck [!] anzustellen gesucht, aber auch von diesem Geschäft hat er sich selbst bald wieder zurückziehen müssen“" (aus: Brief vom 16. Juni 1812 in: PA 2426); WS $1805 / 06$, SS 1806, WS 1806/07-SS 1808, WS $1812 / 13$, SS $1813-S S 1823$ W. kündigt Vorlesungen in „Anzeigen der Vorlesungen ... auf der ... Ruprecht-Karolinischen U ... “ an; WS 1808/o9 „Prof. W. kündigt für diesesmal seiner kränklichen Umstände wegen keine Vorlesungen an“ (aus: „Anzeigen der Vorlesungen ... WS 1808/o9"); SS 1809-SS 1812 W.s Name aus Vorlesungsverzeichnissen gestrichen; 28. Nov. 1811 Akad. Senat wiederholt seine Bitte an Ministerium, „W., welcher sich noch immer in einem Zustande von Geistesschwäche befände, in den Pensionsstand zu setzen“ (aus: Brief vom 16. Juni 1812 in: PA 2426); es folgen bis 1823 weitere Ansuchen des Senats an Ministerium um Pensionierung des kranken W.s; 7. Aug. 1823 Versetzung in Ruhestand.

In einem Brief vom 21. Juni 1816 an den Akademischen Senat der Universität Heidelberg bittet W.s Ehefrau Euphrosine Magdalene um die Bestellung eines „ernstlichen“ Mannes, der künftig - anstelle ihres Mannes - mit ihr gemeinsam die Finanzen regeln soll. Sie beklagt, daß ihr Gatte Geld verschwende, beispielsweise für kostspieliges Drucken seiner Werke auf eigene Kosten, Ankauf von Bibliotheken etc. und damit die Familie in Schulden stürze; Näheres hierzu siehe PA 2426.

1857: Die verstorbene Witwe W.s, Euphrosine Magdalene, hinterlässt dem evangelischen Almosenfonds in Heidelberg eine Stiftung von 500.Gulden, s. Großherzoglich badisches Regierungsblatt. Karlsruhe 1857. 55. Jg. Nr. I-LXII. S. 67. 
1812 Großherzoglich-Frankfurter Hofrat

Siehe auch Jakob Fries

Qu UAH PA 2426; RA 6033f., 7129 (1815 Protest W.s gegen die Übertragung des Dekanats an Jakob Fries), 7168, 7593. GLA Abt. 205, Fasz. 562. • Briefe: UBH. - Auskunft: Ev. Kirchenregisteramt in Tübingen.

W Die Grundwissenschaft des Rechts nebst einer Darstellung und Prüfung aller durch die kritische Philosophie veranlassten Philosopheme über den Ursprung und das Wesen des Rechts. Tübingen 1797. - Systematischer Entwurf der ganzen praktischen Gesetzgebung. Mannheim 1804. Philosophische Entwicklung des Begriffs vom Besitzrechte. Heidelberg 1811. 2. Ausg. 1821. - Aktenmäßige Geschichte der schrecklichen Thaten, welche ... zwischen Laudenbach und Hemsbach an zweyen Schweizer Kaufleuten verübt und an sechs Raubmördern mit dem Schwert bestraft wurden. Heidelberg 1812. - Die Architektonik aller menschlichen Erkenntnisse und Gesetze des Handelns ... Heidelberg 1812. 3. Ausg. 1821. - Erstes dogmatisches System der Philosophie: Die Grundwissenschaft. Heidelberg 1820. Reproduktion Whitefish (Montana) 2010. - Philosophische Religionslehre. Ein Versuch, die edlen Kämpfer Deutschlands um das höchste Gut der Menschheit zu versöhnen. Heidelberg 1820. Reproduktion Charleston (South Carolina) 2011. Allgemeine Theorie des Genie's. Heidelberg 1821. Reproduktion Charleston (South Carolina) 2012. - Organon der Philosophie vom menschlichen Geiste. Bd. 1: Transcendentale und metaphysische Psychologie. Bd. 2: Erstes dogmatisches System der Philosophie. Heidelberg 1835.

L Keller (1913) S. 208; Schneider (1913) S. 84, 90, 100; Weisert (1991) S. 33 u. ö. • Immanuel Carl Diez: Briefwechsel und Kantische Schriften. Wissensbegründung in der Glaubenskrise TübingenJena (1790-1792). Hrsg. von Dieter Henrich. Stuttgart 1997. S. 339, 762. - Klippel (2012) S. 49, 76; Riecke (2016) S. 8; Deutsche Biographie, s. https:// www.deutsche-biographie.de/pnd11727707X.html [19.12. 2017].

\section{Weiser, Artur}

1922-1930 Theol. Fak. Alttestamentliche Exegese

* 18. Nov. 1893 Karlsruhe

$\dagger$ 05. Aug. 1978 Tübingen ev.

V Philipp Ludwig W. (1859-1932) Finanzamtmann, Rechnungsrat

M Josephine Karoline Regine geb. Schmidt (18631921)

@ 18. März 1922 Hilda geb. Autenrieth (18961984)

K $\quad 1 \mathrm{~S}, 1 \mathrm{~T}$

Lb Seit WS 1912/13 Studium an UH, WS 1913/14 Göttingen, SS 1914 Rostock; 2. Aug. 1914-18. Dez. 1918 Kriegsdienst; SS 1919-SS 1920 erneut Studium an UH; Spätjahr 1919 I., Spätjahr 1920 II. theol. Prüfung in H; Spätjahr 1919 Prüfung für Lehrbefähigung in hebräischer Sprache an höheren Lehranstalten.

22. Sept. 1920 Anstellung als Vikar im badischen Kirchendienst; seit 24. Nov. 1920 Vikar in Unterschüpf (heute: Ortsteil von Boxberg, Main-Tauber-Kreis); seit 14. Juni 1921 hauptamtlicher Vikar in Rittenweier (heute: Stadtteil von Weinheim).

UH: 28. Nov. 1921 Lizentiatenprüfung; 10. Febr. 1922 Habilitation; seit 1923 Lehrauftrag für Hebräische Sprache; 1. Aug. -17 . Nov. 1925 Studienreise nach Palästina; seit 6. März 1928 nichtplanm. a.o. Prof.; Rufe abgelehnt: 1930 als planm. a. o. Prof. an U Leipzig und als Direktor des Dt. Ev. Inst. für Altertumswiss. in Jerusalem. • In dieser Zeit:

Gaiberg (bei H): Vor 1928-1930 Pfarrer.

U Tübingen: Seit 1. April 1930 planm. a. o. Prof. für Altes Testament; 1934 als Nachf. von (siehe) Georg Beer an UH vorgeschlagen, s. hierzu UH im Nationalsozialismus (2006) S. 222; 1936 Ern. zum o. Prof.; Mai 1946 Amtsenthebung aus politischen Gründen; 7. Okt. 1949 Versetzung in Ruhestand; 
1. Jan. 1951 Versetzung in Wartestand; seit 1. Okt. 1951 planm. a.o. Prof.; 1961 Umwandlung des Extraordinariats in e. Ordinariat; 31. März 1962 Emeritierung.

E 1930 D. theol. UH. • Eisernes Kreuz II. Klasse.

Qu UAH PA 6289. - Matrikel Rostock online SS 1914, Nr. 38. • GLA Abt. 235, Fasz. 2657. • Auskunft: Universitätsarchiv Tübingen (PA 193/3357).

$W$ Einleitung in das Alte Testament. Stuttgart 1939. 6. Aufl. 1966. • Das Buch der zwölf kleinen Propheten. Göttingen 1949. 4. Aufl. 1963. - Das Buch des Propheten Jeremia. Göttingen. Bd. 1: 1952. 6. Aufl. 1958. Bd. 2: 1955. 6. Aufl. 1968. • The Psalms. A commentary. London 1962. • Siehe auch BBKL XXXII (2011) Sp. 1486.

HG 1934-1943 Zs. Deutsche Theologie.

MHG Das Alte Testament Deutsch. Neues Göttinger Bibelwerk. Göttingen 1949. Mehrere Aufl.

L Kürschner (1976) S. 3444. Kapelrud, Arvid Schou: A. W. † in: Norsk teologisk tidsskrift. Oslo 1979. S. 55. Bibliographie zur Geschichte der Universität Tübingen. Hrsg. von Friedrich Seck. Tübingen 1980. S. 530. • Theologische Fakultäten im Nationalsozialismus. Hrsg. von Leonore SiegeleWenschkewitz ... Göttingen 1993. S. 142-144. • Fix (1994) S. 137; WBIS; Personenlexikon zum dt. Protestantismus (2006) S. 272. • Bultmann, Christoph: A.W. in: Dictionary of Major Biblical Interpreters. Ed. by Donald K. McKim. Downers Grove (Illinois) 2007. S. 1023-1026. • Universität Tübingen im Nationalsozialismus (2010) S. 1135 (Register). Waltke, Bruce K., Houston, James M.: The Psalms as Christian Worship. An historical commentary. Grand Rapids (Michigan) 2010. S. 588 (Register). BBKL XXXII (2011) Sp. 1484-1486; Deutsche Biographie, s. https://www.deutsche-bio graphie.de/pnd118766376.html [19.12. 2017].

$P$ Bildarchiv UAH.

\section{Weiss, Bernhard Wilhelm Johannes}

1908-1914 Theol. Fak.

Neutestamentliche Exegese und Kritik

* 13. Dez. 1863 Kiel

$\dagger \quad$ 24. Aug. 1914 Heidelberg ev.-luth.

V Bernhard Karl Philipp W. (1827-1918), u. a. seit 1852 a. o. Prof. Königsberg (Preußen), seit 1862 o. Prof. für Exegese Kiel, 1877-1908 (Ruhestand) Inhaber des neueingerichteten Lehrstuhls für Neues Testament Berlin, s. Professoren Kiel (1956) S. 6, BBKL XIII (1998) Sp. 666-672, WBIS; https://chran.theologie.huberlin.de/history/history-nt (30. Juni 2014); B.W.: Aus neunzig Lebensjahren 1827-1918. Hrsg. von Hansgerhard Weiß. Leipzig 1927 (posthum erschienen). - Siehe auch: Adolf Deissmann

M Hermine Luise Pauline geb. von Woyna (18361893) $\mathrm{T}$ von Johann Wilhelm Leopold Dewitz von W. (1784-1865), u.a. seit 1817 Direktor, 1836-1841 (Abschied unter Verleihung des Charakters als Generalmajor) Kommandeur des Kadettenhauses in Kulm, siehe ADB 44 (1898) S. 221f., Wikipedia

๑ 10. Aug. 1889 Auguste geb. Ritschl (1864-1945) T von Albrecht R. (1822-1889) U Bonn: seit 1846 Privat-Dozent für Alte Kirchengeschichte, seit 1852 a.o. Prof. für Neues Testament; 1864-1945 o. Prof. für Dogmatik, Kirchenund Dogmengeschichte Göttingen, s. Catalogus prof. Gottingensium (1962) S. 36, WBIS, NDB 21 (2003) S. 649 f.; A. R.s Briefwechsel mit Adolf Harnack, 1875-1889. Tübingen 2010; Axt-Piscalar, Christine: A. R. Eine Würdigung seiner theologischen Grundanliegen aus Anlass seines 125. Todestags in: Kerygma und Dogma. Zs. für theologische Forschung und kirchliche Lehre. Göttingen 2014. S. 285-302.

K 2 T, 2 S: u.a. Dr. iur. Albrecht W. (189o-1961), u. a. seit 1918 Anwalt, 1920-1945 Leiter der Sozialabteilung der I. G. Farbenindustrie in Ludwigshafen, 1938 Gründer der Arbeitsgemeinschaft für betriebliche Altersversorgung, 1940-1945 Redakteur der Werkzeitschrift der I.G. Farbenindustrie „Von Werk zu Werk“; WS 1943/44-WS 1944/45 Lehrauftrag für So- 
zialrecht und Sozialpolitik im Betriebe an Jur. Fak. UH, seit 7. Mai 1956 Honorar-Prof. UH, s. UAH PA 802; Michel, Alexander: Von der Fabrikzeitung zum Führungsmittel. Werkzeitschriften industrieller Großunternehmen von 1890 bis 1945. Stuttgart 1997. S. 296 f. u. ö.; Ruuskanen (2008) S. 98 und Anm. 152; Theodor Heuss: Hochverehrter Herr Bundespräsident! Der Briefwechsel mit der Bevölkerung 1949-1959. Hrsg. ... von Wolfram Werner. Berlin 2010. S. 492-494. - Siehe auch Kriegstagebuch K. Hampe (2007) S. 1005 (Register).

Lb Seit WS 1882/83 Studium an U Marburg, anschl. Berlin, Göttingen; 1886 II. Prüfung in Berlin.

U Göttingen: 18. Febr. 1888 Lizentiatenprüfung; 12. Mai 1888 Habilitation; seit 2. Juni 1890 a. o. Prof.

U Marburg: Seit 15. März 1895 o. Prof.

UH: 12. März 1908 Ern. zum o. Prof. als Nachf. von Adolf Deissmann mit e. Jahresgehalt von 880o.Mark und 1200.- Mark jährl. Wohnungsgeld; 1908-1914 Direktor der Neutestamentl. Abt. am Wiss.-Theol. Seminar als Nachf. von Deissmann; Febr--Mai 1911 Studienreise nach Palästina.

Aus Marburg schreibt W. am 31. März 1908 über seine Ernennung in Heidelberg: „Wie hoch ich die Ehre schätze, der Heidelberger Universität angehören zu dürfen, sollen Euer Magnificenz und meine Herren Collegen daraus ersehen, dass ich den Ruf angenommen habe, obwohl mir in Heidelberg zunächst eine kleinere Wirksamkeit winkt, als ich hier gehabt habe. Ich werde alle meine Kräfte anspannen, um mich der Berufung in eine Arbeitsgemeinschaft würdig zu erweisen, deren Bedeutung und Leistungen unter den deutschen Universitäten in vorderster Linie stehen ..." (aus: UAH PA 2427).

1911/12 Dekan der Theol. Fak. der UH

1908 Geh. Kirchenrat
E 1910 Mitglied der Akademie der Wissenschaften H. 1895 D. theol. Göttingen.

Qu UAH PA 2427. - Briefe: UBH. - Siehe auch Wolfes (1999) S. 642.

$W$ Die Predigt Jesu vom Reiche Gottes. Göttingen 1892. 3. Aufl. 1964. • Das älteste Evangelium. Göttingen 1903. Die Offenbarung des Johannes. Göttingen 1904. - Der erste Korintherbrief. Göttingen 1910. Unveränd. Abdr. 1925. - Stoffels, Wolfgang: J.W. ... Bibliographie einschließlich der Rezensionen und Besprechungen seiner Veröffentlichungen. Bonn 1973.

HG Die Schriften des Neuen Testaments. Göttingen 1906-1907. 3. Aufl. 1917-1918.

$L$ Catalogus prof. Marburgensis 1 (1927) S. 54; Catalogus prof. Gottingensium (1962) S. 41; BBKL XIII (1998) Sp. 659-666. - The Historical Jesus Quest. Landmarks in the Search for the Jesus of History. Ed. by Gregory W. Dawes. Leiderdorp 1999. S. 172-184 u. ö. - Wolfes, Matthias: Protestantische Theologie und moderne Welt ... Berlin 1999. S. 836 (Register). Schmithals, Walter: J.W. als Wegbereiter der Formgeschichte in: Paulus, die Evangelien und das Urchristentum ... Hrsg. von Cilliers Breytenbach. Leiden 2004. S. 328-354. • Kriegstagebuch K. Hampe (2007) S. 1005 (Register); Ruuskanen (2008) S. 96-98. Hochschild, Ralph: Eschatologischer Prophet oder „NonEschatological Jesus". Wissenschaftssoziologische Überlegungen zur Rezeption von J. W. „Die Predigt Jesu vom Reiche Gottes" in: Jesus - Gestalt und Gestaltungen. Rezeptionen des Galiläers in Wissenschaft, Kirche und Gesellschaft ... Hrsg. von Petra von Gemünden ... Göttingen 2013. S. 412-428. Schwarz, Hans: Theologie im globalen Kontext. Die großen Themen und Personen des 19. und 20. Jahrhunderts. 2. Aufl. Gießen 2016. S. 634 (Register). - Carleton Paget, James: Das "Gottesreich" als eschatologisches Konzept. J. W. und Albert Schweitzer in: Jesus Handbuch. Tübingen 2017. S. 55-65. Deutsche Biographie, s. https://www.deutsche-biographie.de/pnd11 8891642.html [19.12. 2017].

$P$ Bildarchiv UAH. 
Weiss, Leopold

siehe Weiß

\section{Weiß, Leopold}

1876-1901 Med. Fak.

Augenheilkunde

* o7. Mai 1850 Gießen

$\dagger \quad$ 02. Febr. 1901 Mannheim

ev.

V Karl Eduard Emanuel Ludwig W. (1805-1851) seit 1828 Privat-Dozent, seit 1831 a. o. Prof., seit 1838 o. Prof. für Öffentl. Recht Gießen, s. Universität Gießen 1 (1907) S. 464, WBIS, Hessische Biografie, s. http://www.lagis-hessen.de/ pnd/117291137 (Stand: 3. Aug. 2017)

M Anna Dorothea geb. Grüninger $\left({ }^{\star} 1807\right)$

$œ$ 14. Dez. 1889 Mary geb. Hoffmann $\left({ }^{*} 1867\right.$ $\dagger$ nach 1925)

$\mathrm{K}$ unbekannt.

Lb U Gießen: SS 1868-WS 1872/73 Studium; seit Juli 1872 Assistent an Geburtshilflicher Klinik; Febr. 1873 II. Examen; 1873 Dr. med.; seit Sommer 1873 Mitarbeiter am Inst. für Physiologie. • In dieser Zeit:

1870/71 Kriegsdienst als Unterarzt während des Deutsch-Französischen Krieges; Febr--Sommer 1873 Militärdienstpflicht als Einjährig-Freiwilliger („um den Rest ... des Dienstjahres abzudienen“, aus: UAH H-III-111/85 fol. 226r).

U Wien: Seit Herbst 1873 Eigenstudien u.a. am Physiolog. Inst.; seit Sommer 1874 Hilfsassistent an U-Augenklinik.

U Tübingen: Seit Herbst 1874 Assistent an U-Augenklinik.

UH: Seit Frühjahr 1875 II. Assistent, Herbst 18751879 I. Assistent an U-Augenklinik; 30. Mai 1876 Habilitation; SS 1878 Beurlaubung, s. Z (1); Juli
1892, erneut Aug. 1894 Gesuche W.' um Verleihung e. a. o. Professur, s. hierzu $Z$ (2); seit 28. Dez. 1894 nichtetatm. a. o. Prof. In dieser Zeit:

Mannheim: Okt. 1878 Umzug von H nach Mannheim mit Zweitwohnsitz in H; 1879-1901 niedergelassener Augenarzt und Ophthalmologe am Städtischen Hospital.

$Z$ (1) Brief W.' vom 26. April 1878 an Großherzogliches Ministerium des Innern in Karlsruhe: „Längeres Unwohlsein im vorigen Winter, von dem ich mich seither nicht vollständig zu erholen vermochte, läßt es mir als wünschenswert erscheinen, einen Urlaub für das Sommer-Semester 1878 zu erhalten ..." (aus: UAH PA 2428). Der Anzeige seines "Todesfalls“ im Heidelberger Tageblatt vom 4. Febr. 1901, S. 3 ist zu entnehmen, dass „sich bei ihm (in den letzten beiden Jahren) durch eine schwere Blutvergiftung viele schwere Leiden einstellten. Schließlich erlag er einer Lungenentzündung".

$Z$ (2) Oswald Vierordt, derzeitiger Dekan der Med. Fak. der UH, weist das W.sche ErnennungsGesuch zum a. o. Professor mit klaren Worten am 1. Febr. $1893 \mathrm{ab}$; Empfänger des Briefes ist das Ministerium der Justiz, des Cultus und Unterrichts in Karlsruhe: „Die Facultät ist der Meinung, daß, wenn ein Dozent durch eine längere Reihe von Semestern nicht nur nicht gelesen hat, sondern überhaupt durch Verlegung des Hauptwohnsitzes und der überwiegenden Praxis an einen anderen Ort außer jeder Fühlung mit der Universität gewesen ist, - es intensiveren und länger dauernden Bemühens bedarf, um die Zugehörigkeit zur Universität, welche nach Annahme der Facultät eine der Vorbedingungen der fraglichen Ernennung ist, thatsächlich wieder zu gewinnen. [Dies steht im Widerspruch zu den Angaben in den Vorlesungsverzeichnissen der UH zwischen 1876 und 1901: W. kündigt von WS 1876/77 bis WS 1900/01 durchgängig Vorlesungen an; laut Heidelberger Adressbücher 1876-1901 unterhält er außerdem eine Zweitwohnung in $\mathrm{H}$, zuletzt seit 1897 in der Märzgasse 5.] Des Weiteren glaubt die Facultät, daß die betr[effende] Ernennung zwar Vortheile für die Praxis des Herrn Dr. Weiss in Mannheim, dagegen nicht, wie Herr Dr. Weiss annimmt, güns- 
tigere Aussichten für die Erlangung des Rufes an eine Klinik nach sich ziehen wird“ (aus: PA 2428).

Das Ministerium der Justiz, des Kultus und Unterrichts in Karlsruhe lehnt daraufhin das Gesuch mit der Begründung ab, „dass wir unter den vorgetragenen Verhältnissen z[ur] Z[ei]t nicht in der Lage sind, einen Antrag auf Verleihung des Charakters als ausserordentlicher Professor an den Privatdozenten Dr. Leopold Weiss Höchsten Orts [= Großherzog Friedrich I.] zu stellen“ (aus: PA 2428).

Z (3) Im Okt. 1925 erhält die jetzt in Darmstadt lebende Witwe „mit Rücksicht auf ihre Notlage ausnahmsweise eine einmalige Beihilfe in Höhe von 200.- Reichsmark aus den für Beihilfen für Hinterbliebene früherer Dozenten vorgesehenen Mitteln“ (aus: PA 2428).

Zur Witwenkasse, -pension, Hinterbliebenenbeihilfe etc., siehe auch Carl Ullmann, Johann Hermann Vossmann, Gerhard Weissenfels, Peter Friedrich Wund

Qu UAH PA 2428; Fak.-Akte H-III-111/85 fol. 213r228r. - Auskunft: Marchivum - Historische Personenrecherche \& AV-Sammlung in Mannheim (1890 sind für W.schen Haushalt 1 Köchin und 1 Dienstmädchen im Mannheimer Wohnungsanmeldebogen eingetragen); Stadtarchiv Heidelberg.

$W$ Über den an der Innenseite der Papille sichtbaren Reflex-Bogenstreif und seine Beziehung zur beginnenden Kurzsichtigkeit in: Albrecht von Graefes Archiv für Ophthalmologie XXXI, 3 (1885) S. 239-321. - Beiträge zur Anatomie der Orbita. 2 Bde. Tübingen 1888-189o. Augenärztliche Demonstrationstafeln. Wiesbaden 1895. * Über das Wachstum des menschlichen Auges und über die Veränderung der Muskelinsertionen am wachsenden Auge. Wiesbaden 1897. U Über das Gesichtsfeld der Kurzsichtigen. Leipzig 1898.

$L$ Badische Biographien 1 (1901) Sp. 115. Hirschberg, Julius: Geschichte der Augenheilkunde. Bd. VI. Nachdr. der Ausg. Berlin 1918. Hildesheim 1977. S. 276 f. - Stübler (1926) S. 323; Fischer $2\left({ }^{3} 1962\right)$
S. 1661; Chronik Ärzte H (1985) S. 146; WBIS; Deutsche Biographie, s. https://www.deutsche-bio graphie.de/pnd117291382.html [22.12. 2017].

P Bildarchiv UAH; graph. Slg. UBH.

\section{Weisse, Ferdinand Christoph} siehe Weise

\section{Weissenfels, Paul Gerhard Karl Heinrich}

1923-1944 (1946) Med. Fak.

Zahnheilkunde

* 19. Juli 1890 Züllichau (Brandenburg; heute: Sulechów, Polen)

$\dagger$ 11. Febr. 1952 Heidelberg ev.

V Prof. Dr. phil. Paul W. (1849-1916) Oberlehrer M Marie Julie Emilie geb. Mühlmann (18531929)

$\infty$ 6. Juni 1919 Hedwig (Hede) Melusine Karoline Charlotte geb. Bärwolff (1887-1977)

$\mathrm{K} \quad 2 \mathrm{~S}($ davon $1 \mathrm{~S}$ früh $\dagger)$.

Lb Seit SS 1908 Studium der Medizin an U Freiburg/Br., SS 1911-SS 1913 Greifswald; 1. Aug. 1910 ärztl. Vorexamen in Freiburg/Br.; 1. Okt. 191031. März 1911 Militärdienstpflicht als EinjährigFreiwilliger in Danzig; 16. Okt. 1913 Staatsexamen in Greifswald; 17. Nov. 1913 Dr. med. an U Greifswald.

Seit 17. Nov. 1913 Ableistung des praktischen Jahres an Med. U-Klinik in Greifswald, anschl. am Stadtkrankenhaus in Osnabrück; 1. Aug. 1914 Approbation in Greifswald.

2. Aug. 1914 (Eintritt in aktives Sanitätsoffizierskorps als Unterarzt)-31. März 1919 Kriegsdienst; März 1920 Pensionierung „wegen eines im Anschluß an ein Pleuraempyem in der Türkei entstandenen Lungenleidens" (aus: eigenhändigem Lebenslauf von 1923 in: UAH PA 1240). 
U Greifswald: Seit SS 1919 Studium der Zahnheilkunde; 1. Mai 1920 zahnärztl. Staatsprüfung; MaiSept. 1920 Assistent an U-Zahnklinik.

UH: Seit 1. Okt. 1920 Assistent (mit e. Grundvergütung von jährlich 8400.- Mark und e. Teuerungszuschlag von 6228.- Mark sowie Kindergeld für 2 S von 960.- Mark jährl.), 24. Nov. 1925-31. März 1938 (auf eigenen Antrag Beendigung) Oberarzt zunächst am Zahnärztl. Inst., 1921 Umbenennung in Zahnärztl. U-Poliklinik, Mai 1927 in Zahnärztl. Klinik und Poliklinik der U (s. hierzu Bauer/ Langsch (1991) S. 383 f. online); 31 . März 1922 zum SS 1922 Erteilung e. Lehrauftrags zur Abhaltung e. einstündigen Kurses für Mediziner mit Übungen im Extrahieren und in zahnärztl. Diagnostik unter Zusage e. Unterrichtsgeldgarantie von 1400.Mark (aus: UAH PA 6297); 26. Juli 1923 Habilitation; seit 12. Febr. 1929 nichtbeamteter a. o. Prof.; 4. Mai 1933-31. März 1935 Vertreter des Lehrstuhls und stellvertr. Direktor der Zahnärztl. Klinik und Poliklinik nach Beurlaubung von (siehe) Georg Blessing und bis Dienstantritt von Karl Schmidhuber (siehe Drüll (2009) S. 542f.); 31. März 1938 Kündigung der Oberarztstelle an Zahnärztl. Klinik und Poliklinik, um ,eine eigene fachärztliche Praxis" zu begründen (aus: Fragebogen der amerikanischen Militärregierung vom 22. April 1945 in: PA 6297); seit 24. Okt. 1939 apl. Prof.; 23. Jan. 1942 Gestellungsbefehl als Stabsarzt in Reservelazarett in Bad Ems (bis 1943); WS 1943/44 letzte Vorlesungsankündigung; 23. Jan. 1946 Entlassung gemäß Erlaß der amerikanischen Militärregierung; 18. Nov. 1948 Ablehnung des Gesuchs W' auf Erneuerung seiner venia legendi von Med. Fak. „aus grundsätzlichen Erwägungen“, da „- von besonderen Ausnahmefällen abgesehen - an solchen (Dozenten, die) aus dem Universitätsbetrieb praktisch ausgeschieden (sind), wohl kaum ein Interesse besteht" (aus: Briefe vom 5. und 20. Nov. 1948 in: PA 1240).

H: 1. April 1938-1952 Fachärztl. Privat-Praxis.

$Z$ (1) Auf die Frage „Welche Vorschläge würden Sie machen, um die Akademische Freiheit der Universität Heidelberg zu sichern?", antwortet W. im oben bereits erwähnten Fragebogen vom 22. April 1945: „Loslösung der wissenschaftlichen Arbeit von aktiver politischer Betätigung“.
$Z$ (2) 1952-1956 bezieht die Witwe W. eine monatliche Unterstützung von 120,- DM durch das Finanzministerium Baden-Württemberg in Stuttgart. Nachdem sie seit 1956 anderweitige Bezüge über monatlich insgesamt 240,96 DM erhält, liegt „eine außerordentliche wirtschaftliche Notlage, die die Weitergewährung der laufenden Unterstützung rechtfertigen würde ... nicht mehr vor" (aus: Brief des Finanzministeriums an UH vom 15. Aug. 1956 in: UAH PA 6297). Seit Okt. 1959 erhält sie nach mehreren Anträgen eine monatliche Beihilfe über 75.- DM aus den Mitteln der „Zentralunterstützungskasse für notleidende Hochschullehrer und deren Angehörige beim Hochschulverband“, s. hierzu PA 6297.

Zur Witwenkasse, -pension, Hinterbliebenenbeihilfe etc., siehe auch Carl Ullmann, Johann Hermann Vossmann, Leopold Weiß, Peter Friedrich Wund

E 1915 Eisernes Kreuz II. Klasse, 1918 I. Klasse; 1918 Kaiserl. Osmanische Kriegsverdienst-Medaille (Eiserner Halbmond); Kaiserl. Osmanische Liakat-Medaille in Silber; 1918 Rote Kreuz Medaille III. Klasse; 1935 Ehrenkreuz für Frontkämpfer.

\section{Qu UAH PA 1240, 6297.}

$W$ Heine-Medin'sche Krankheit und Trauma. Greifswald 1915. - Strahlen- und Lichttherapie in: Fortschritte der Zahnheilkunde (1927-1933) Bde. 3-9, jeweils Lfg. 7. • Die Klinik und Poliklinik für Mund-, Zahn- und Kieferkrankheiten der Universität Heidelberg in: Dt. Zahnärztl. Wochenschrift 32 (1936); Eunarcon in der zahnärztl. Chirurgie in: ebd. 23 (1937). • Siehe Bibliographie 19151937 in: UAH PA 6297.

L Stübler (1926) S. 326; Kürschner (1940/41) Sp. 106o; Bauer/Langsch (1991) S. 387 u. ö. online; UH im Nationalsozialismus (2006) S. 1031, 1036. 


\section{Weizsäcker, Viktor von (seit 1916: Freiherr von Weizsäcker)}

(1917) 1919-1941, 1945-1952 Med. Fak. 1919-1941 Neurologie; 1945-1952 Allg. Klinische Medizin

* 21. April 1886 Stuttgart

$\dagger \quad$ 08. Jan. 1957 Heidelberg ev.

V Karl Hugo Freiherr von W. (1853-1926), u.a. 1906-1918 Präsident des württ. Staatsministeriums, s. Deutsche Biographie, https://www. deutsche-biographie.de/pnd117308153.html [22.12. 2017]. - S von Carl Heinrich von W. (1822-1899), u.a. seit 1861 o. Prof. für Kirchen- und Dogmengeschichte sowie 18901899 Kanzler der U Tübingen, s. Deutsche Biographie, https://www.deutsche-biographie.de/ pnd117308110.html [22.12.2017]

M Viktorie Wilhelmine Sophie Pauline (Paula) geb. von Meibom (1857-1947) T von Victor Reinhard Carl Friedrich von M. (1821-1892), u. a. o. Prof. für Dt. Recht: seit 1858 Rostock (ohne Promotion und Habilitation), seit 1866 Tübingen, seit 1873 Bonn, seit 1875 Rat am Reichsoberhandelsgericht in Leipzig, 18791887 am Reichsgericht ebd., s. NDB 16 (1990) S. 632, Catalogus prof. Rostochiensium online

(13./14. Aug. 1920 Olympia Christa geb. Curtius (1887-1979) Schwester von: (siehe) Ernst Robert C.

K 2 S, 2 T: u. a. Cora Freiin von W. (1929-2009), s. In memoriam Cora Penselin in: Mitteilungen der Viktor von Weizsäcker Gesellschaft Nr. 24 (2009) in: Fortschritte der Neurologie - Psychiatrie 77. Jg. (2009) S. 614f. - Ehefrau von Siegfried Penselin (1927-2014), u. a. 1965-1992 (Emeritierung) o. Prof. für Angewandte Physik Bonn, s. Wer ist wer (2007/o8); Mitteilungen der Viktor von Weizsäcker Gesellschaft Psychiatrie 82. Jg. (2014) S. 727
Vw Bruder: u.a. Ernst von W. (1882-1951), u.a. 1938-1943 Staatssekretär des Auswärtigen Amtes, s. Raulff, Ulrich: Kreis ohne Meister. Stefan Georges Nachleben. München 2012. S. 543 (Register); Ehemann von Marianne geb. von Graevenitz (1889-1983) T von Friedrich (Fritz) Gustav Theodor von G. (1861-1922) zuletzt General der Infanterie, 1914-1918 Militärbevollmächtigter im Großen Hauptquartier, e. mobilen Kommandozentrale der dt. Streitkräfte, s. Euler, Friedrich Wilhelm: Ahnentafel von Weizsäcker - von Graevenitz. Exemplarische Darstellung der prosopographischen Voraussetzungen und Folgen einer gesamtdeutschen geistigen Führungsgruppe. Berlin 1992.

Vw Neffen (Söhne von Ernst von W. und Marianne geb. von Graevenitz): u. a. Carl Friedrich von W. (1912-2007), u.a. seit 1944 o. Prof. für Theoretische Physik Straßburg, seit 1946 Abt.-Leiter am Max-Planck-Inst. für Physik Göttingen, seit 1957 o. Prof. für Philosophie Hamburg, 1970-1980 Direktor (zus. mit Jürgen Habermas) des Max-Planck-Inst. zur Erforschung der Lebensbedingungen der wiss.technischen Welt in Starnberg, s. Hattrup, Dieter: C.F. von W. Physiker und Philosoph. Darmstadt 2004. - Richard von W. (19202015), u. a. 1984-1994 Bundespräsident, s. Hofmann, Gunter: R. von W. Ein deutsches Leben. München 2010; Raulff, Ulrich: Kreis ohne Meister ... (2012) S. 543 (Register); Deutsche Biographie, https://www.deutsche-biographie. de/pnd118766570.html [08.11. 2017]. • Zur Familie von W., s. Wein, Martin: Die W.s. Geschichte einer deutschen Familie. Stuttgart 1988.

Lb Seit WS 1904/05 Studium der Medizin an U Tübingen, anschl. Freiburg/Br., Berlin, SS 1908-SS 1909 H; Herbst 1909 Staatsexamen.

UH: 28. Juni 1910 Dr. med.; Jan. 1911 Approbation; 1911-1914, 1919-1923 Assistent an Med. U-Klinik; 1. März 1917 Habilitation für Innere Medizin; 19201941 Leiter der Nerven-Abt. der Med. U-Klinik; seit 1922 a.o. Prof.; seit 1. Aug. 1923 planm. a.o. Prof. für Neurologie; seit 4. Aug. 1930 o. Prof. $\bullet$ In dieser Zeit: 
1914-1919 Kriegsdienst und Gefangenschaft.

U Breslau: Seit 1. Mai 1941 o. Prof. für Neurologie, Leiter der Neurolog. Abt. des Wenzel-HanckeKrankenhauses und Direktor des Otfrid-FoersterInst. für Neurologie; seit 1941 Leiter e. Lazaretts für Hirnverletzte in B.; Jan. 1945 Marschbefehl nach Dresden; Febr-6. Mai 1945 (Einnahme der Stadt durch Rote Armee) Auflösung der U.

Frühjahr 1945 Beratender Neurologe in Dresden, Leipzig und im Lazarett in Heiligenstadt; 10. AprilHerbst 1945 amerik. Kriegsgefangener.

UH: Seit Sommer 1945 kommissar. Leiter des Physiolog. Inst.; WS 1945/46 V. von W. hält Vorlesungen über Physiologie und Freuds Psychoanalyse in der Medizin und Geistesgeschichte an Med. Fak.; 7. Jan. 1946 (Ern. rückwirkend vom 15. Aug. 1945)30. Sept. 1952 (Emeritierung) o. Prof. für Allg. Klinische Medizin.

E Mitglied: 1932 (1947-1949 Präsident) Akademie der Wissenschaften H, 1942 Dt. Akademie der Naturforscher Leopoldina Halle/S.; 1952 Korr. Mitglied der American Psychosomatic Society. 1936 Erb-Medaille der Gesellschaft der Dt. Neurologen und Psychiater. 1950 Ehrenprofessor der U Valencia (Spanien).

Qu UAH PA 1241, 6298; Fak.-Akten H-III-551, HIII-862/6. - Briefe: UBH. - Achilles, Peter: Die Stimme der Güte. Zu V. von W.s Briefen an Lou Andreas-Salomé in: Sinn und Form (2012) Jg. 64, H. 5, S. 638-648. - Briefedition. Hrsg. von Peter Achilles, Dieter Janz $(\dagger)$... (2018 in Vorbereitung). Teil-Nachlaß: DLA Marbach, s. hierzu Jacobi, Rainer-M.E.: Zum Nachlass V. von W.s in: Mitteilungen der Viktor von Weizsäcker Gesellschaft Nr. 31 (2013) in: Fortschritte der Neurologie - Psychiatrie 81. Jg. (2013) S. 735-737. Familienarchiv in Staatsbibliothek zu Berlin. - Siehe auch Archiv der Dt. Akademie der Naturforscher Leopoldina Halle/S. - Mitteilungen: Herr Peter Achilles, Saarbrücken. • Autobiogr.: Begegnungen und Entscheidungen. Stuttgart 1949. 2. Aufl. 1951; Natur und Geist. Göttingen 1954. 2. Aufl. 1955; Reisebeschreibung 1945 in: Sinn und Form (2007) Jg. 59, H. 6, S. 736-763.
W Soziale Krankheit und soziale Gesundheit. Berlin 1930. 2. Aufl. 1955. Körpergeschehen und Neurose. Analytische Studie über somatische Symptombildungen in: Int. Zs. für Psychoanalyse 19 (1933) S. 16-116 (als Monographie erschienen Stuttgart 1947). - Der Gestaltkreis. Theorie der Einheit von Wahrnehmen und Bewegen. Leipzig 1940. 4. Aufl. 1950 (siehe hierzu: Zybowski, Przemysław: Rezensions- und Rezeptionsgeschichte $\mathrm{zu}$ „Der Gestaltkreis. Theorie der Einheit von Wahrnehmen und Bewegen" von V. von W. Med. Diss. Berlin 2008). Arzt und Kranker. Leipzig 1941. 3. Aufl. 1949. Euthanasie und Menschenversuche in: Psyche 1 (1947) S. 68-102. • Diesseits und Jenseits der Medizin. Stuttgart 1950. Am Anfang schuf Gott Himmel und Erde. Grundfragen der Naturphilosophie. [Vorlesung im WS 1919/20.] Göttingen 1954. 6. Aufl. 1963. • Pathosophie. Göttingen 1956. 2. Aufl. 1967. Neuedition als Ausgabe letzter Hand in: Gesammelte Schriften ... Bd. 10 (2005). • Siehe Gesammelte Schriften in zehn Bänden. Hrsg. von Peter Achilles, Dieter Janz ... Frankfurt/M. 1986-2005. (Bibliogr.: Bd. 1, S. 641-671, erg. in Bd. 10, S. 605-639.)

HG Beiträge aus der Allgemeinen Medizin. $11 \mathrm{H}$. Stuttgart 1947-1956.

MHG (zus. mit Martin Buber und Joseph Wittig) 1926-1930 Die Kreatur. Reprint Nendeln 1969.

$L$ Christian, Paul: Das Personverständnis im modernen medizinischen Denken. Tübingen 1952. $\bullet \mathrm{V}$. von W.: Arzt im Irrsal der Zeit. Hrsg. von Paul Vogel. Göttingen 1956. • Wyss, Dieter: V. von W.s Stellung in Philosophie und Anthropologie der Neuzeit in: W., V. von, Wyss, Dieter: Zwischen Medizin und Philosophie ... Göttingen 1957. S. 181-290. • Auersperg, Alfred: Poesie und Forschung. Goethe, Weizsäcker ... Stuttgart 1965. • Anthropologie als Thema von psychosomatischer Medizin und Theologie. Hrsg. von Michael von Rad. Stuttgart 1974. • Jacob, Wolfgang: Kranksein und Krankheit ... Heidelberg 1978. - Jacob, Wolfgang: Medizinische Anthropologie in: Semper apertus 4 (1985) S. 122160. Henkelmann, Thomas: V. von W. ... Materialien zu Leben und Werk. Berlin 1986. $\bullet$ V. von W. zum 10o. Geb. ... Hrsg. von Peter Hahn ... Berlin 1987. - Reuster, Thomas: V. von W.s Rezeption der Psychoanalyse. Stuttgart-Bad Cannstadt 1990. • 
Schipperges, Heinrich: Medizin in Bewegung ... Heidelberg 1990. - Jansen (1992) S. 414 (Register). Emondts, Stefan: Menschwerden in Beziehung ... Stuttgart-Bad Cannstadt 1993. A Anthropologische Medizin und Sozialmedizin im Werk V. von W.s. Hrsg. von Udo Benzenhöfer. Frankfurt/M. 1994. • Rorarius, Wilhelm: V. von W.s Pathosophie. Stuttgart 1997. • Janz, Dieter: V. von W. als Begründer der psychosomatischen Medizin in: Fortschritte der Neurologie - Psychiatrie (Aug. 2001) Sonderheft 1, 69. Jg., S. 28-33. - Zur Aktualität V. von W.s. Hrsg. von Rainer-M. E. Jacobi und Dieter Janz. Würzburg 2003. • Meinck (2004) S. 29 f.; Scholz/Barth/Pappai/Wacker (2005) S. 530 u. ö.; UH im Nationalsozialismus (2006) S. 1276 (Register). - Benzenhöfer, Udo: Der Arztphilosoph V. von W. Göttingen 2007. Aufsätze über V. von W. in: Gegenseitigkeit. Grundfragen medizinischer Ethik. Hrsg. von Klaus Gahl ... Würzburg 2008. Rasini, Vallori: Theorien der organischen Realität und Subjektivität bei Helmuth Plessner und V. von W. Würzburg 2008. - V. von W. Warum wird man krank? ... Hrsg. von Wilhelm Rimpau. Frankfurt/M. 2008. 3. Aufl. 2009. - Wissenschaftsatlas der UH (2011) S. 118 f., 133. - Raulff, Ulrich: Kreis ohne Meister. Stefan Georges Nachleben. München 2012. S. 543 (Register). • Schmerz und Sprache. Zur Medizinischen Anthropologie V. von W.s. Hrsg. von Rainer-M. E. Jacobi. Heidelberg 2012. Kleinschmidt, Sebastian: Schmerz als Erlebnis und Erfahrung. Deutungen bei Ernst Jünger und V. von W. Warmbronn 2016. • Tolone, Oreste: Alle origini dell' antropologia medica. Il pensiero di V. von W. Roma 2016. • Siehe auch Sekundärbibliographie unter: http://viktor-von-weizsaeckergesellschaft.de/ (Stand: 17.08. 2017). Deutsche Biographie, s. https://www.deutsche-biographie. de/pnd118630733.html [22.11. 2017].

$P$ Bildarchiv UAH; DLA Marbach.

\section{Welcker, Karl Theodor Georg Philipp}

1816-1819 Jur. Fak.

Staatsrecht, Strafrecht

* 29. März 1790 Ober-Ofleiden (heute: Ortsteil von Homberg $(\mathrm{Ohm}))$

$\dagger$ 10. März 1869 Heidelberg ev.-luth.

V Heinrich Friedrich Philipp Christoph W. (1756-1829) Prediger, s. WBIS und WBIS unter Friedrich Heinrich Christian Schwarz

M Johannette Magdalene Dorothea geb. Strack (1757-1829)

(12. Mai 1816 Emma geb. Wiedemann (17981844) $\mathrm{T}$ von Christian Rudolf Wilhelm $\mathrm{W}$. (1770-1840) Prof. für Medizin Kiel, s. Professoren Kiel (1956) S. 76, WBIS; Jonat, Walter u. a.: Universitäts-Frauenklinik Kiel ... 18052005 ... Stuttgart 2005.

K $\quad 2 \mathrm{~S}, 4 \mathrm{~T}$

Vw Bruder: Friedrich Gottlieb W. (1784-1868) 1819-1868 o. Prof. für Philologie an U Bonn, s. Knöpp, Friedrich: Die Brüder W. in: OberOfleiden. 1200 Jahre Gemeinde Ober-Ofleiden. Ober-Ofleiden 1967; Renger (1982) S. 307 (Register); F. G. W. Werk und Wirkung ... Hrsg. von William M. Calder. Stuttgart 1986; BBKL 15 (1999) Sp. 1459-1463, Göttinger Gelehrte 1 (2001) S. $106 \mathrm{f}$., WBIS. • Siehe auch Beiträge zur Geschichte der Familie W. ... Hrsg. von Friedrich Hoffmann. Frankfurt/M. 2006.

Lb Seit 18. Aug. 1806 Studium der Rechts- und Staatswiss. an U Gießen; 20. Okt. 1810 Immatrikulation an $\mathrm{UH}$.

U Gießen: 24. April 1813 Dr. iur.; seit 30. März 1814 a. o. Prof.; 30. Juli 1814 auf eigenen Antrag Entlassung.

U Kiel: 22. Okt. 1814 Ern. zum o. Prof.

UH: 15. Juli 1816 Ern. zum o. Prof.; 23. Okt. 1816 Dienstantritt; 1816-1819 Beisitzer des Spruchkollegiums der Jur. Fak.; 9. März 1819 auf eigenen Antrag Entlassung zum Ende des WS 1818/19. 
U Bonn: 18. Febr. 1819 Ern. zum SS 1819 o. Prof. für Rechtsgeschichte und Naturrecht; Nov. 1821April 1822 Anklagevernehmungen durch Untersuchungsbehörde wegen angeblicher revolutionärer Bestrebungen, s. hierzu Schulz-Retzow (2001); 16. Sept. 1822 auf eigenen Antrag Entlassung aus preußischem Staatsdienst.

U Freiburg/Br.: Seit WS 1822/23 o. Prof., s. hierzu Müller-Dietz (1968) S. 25; Sommer 1832 Anklage wegen Beleidigung der Regierung; 22. Nov. 1832 Verurteilung zu e. zweimonatigen Gefängnisstrafe; 23. Febr. 1833 Aufhebung des Urteils aus formellrechtlichen Gründen durch Oberhofgericht in Mannheim; 12. Sept.-5. Nov. 1832 Schließung der $\mathrm{U}$ durch großherzogl. Verordnung aufgrund verderblichen Einflusses in politischer und sittlicher Hinsicht auf die Studenten; 26. Okt. 1832 Zurruhesetzung W.s wegen politischer Äußerungen, s. hierzu Best/Weege (1996) S. $353 \mathrm{f}$.

Freiburg/Br.: 1832-1840 Freier Schriftsteller.

U Freiburg/Br.: WS 1840/41 Wiedereinsetzung als o. Prof.; 1841 Amtssuspendierung aufgrund unerlaubten Fernbleibens als Mitglied der II. Kammer; 1848 Übersiedlung nach H; 1850 endgültige Pensionierung.

1831-1837, 1839-1847, 1850 Mitglied der II. Kammer des Badischen Landtags in Karlsruhe; 31. März3. April 1848 Mitglied des Frankfurter Vorparlaments; Okt.-Nov. 1848 Mitglied der Reichskommission in Österreich, s. Proklamation der Mitglieder der Reichskommission, Welcker und [Johann Ludwig] Mosle, abgegeben vor ihrer Einreise nach Österreich; Passau, 19. Okt. 1848 in: Sammlung: Gesamtdatenbank des Dt. Histor. Museums (Inventar-Nr. Do 97/149) unter: https://www.dhm.de/datenbank/dhm.php? seite $=5$ \&fld_o=97002304 (abgerufen am 28. Dez. 2017); 1848-1849 badischer Gesandter im Bundestag und Mitglied der Dt. Nationalversammlung, s. hierzu Best/Weege (1996) S. 354.

1819 (bis April) Dekan der Jur. Fak. der UH

1866 Mitbegründer der „Deutschen Partei“
1981 Gründung der C. T. Welcker Stiftung, ein gemeinnütziger Verein zur Förderung der sozialen und beruflichen Rehabilitation im Straf- und Maßregelvollzug in Freiburg/Br.

1828 Hofrat; 1848 Geh. Rat III. Klasse

E 1846 Ehrenbürger der Stadt Heidelberg.

Qu UAH PA 2429. - Toepke 5 (1904) S. 50. • Matrikel Gießen (1957) S. 203. - UA Gießen PA Jur K 8. GLA Abt. 76, Fasz. 8466-8468. • Briefe, Nachlaß: UBH (Signatur: Heid. Hs. 1904-1923). Ergebnislose Anfrage: Landesarchiv SchleswigHolstein in Schleswig. - Auskunft: Ev. Pfarramt Ober-Ofleiden in Homberg (Ohm); Ev. Kirchengemeindeamt Heidelberg (Totenbuch von 1869).

$W$ Die letzten Gründe von Recht, Staat und Strafe. Gießen 1813. - Öffentliche actenmäßige Vertheidigung gegen die öffentliche Verdächtigung der Theilnahme oder Mitwissenschaft an sogenannten demagogischen Umtrieben. 2 Abt. Stuttgart 1823. Wichtige Urkunden für den Rechtszustand der deutschen Nation. Mannheim 1844.

MG, MHG 1832 Zs. „Der Freisinnige“. • Staatslexikon. 15 Bde. Altona 1834-1849. 3. Aufl. 14 Bde. Leipzig 1856-1866, s. hierzu Werner, Eva Maria: Das Rotteck-Welckersche Staatslexikon in: Literatur und Recht im Vormärz. Hrsg. von Claude D. Conter. Bielefeld 2010. S. 205-219.

L ADB 41 (1896) S. 660-665. Wild, Karl: K. T. W., ein Vorkämpfer des älteren Liberalismus. Heidelberg 1913. - Professoren Kiel (1956) S. 32; Jammers (1964) S. 178 u.ö. • Müller-Dietz, Heinz: Das Leben des Rechtslehrers ... K. T. W. Freiburg/ Br. 1968. • Verzeichnis Bonn (1968) S. 332. Gall, Bernd: Die individuelle Anerkennungstheorie von K. T.W. ... Bonn 1971. • Renger (1982) S. 308 (Register). Schoettle, Rainer: Politische Freiheit für die deutsche Nation. K.T.W.s politische Theorie ... Baden-Baden 1985. Heidelberger Strafrechtslehrer (1986) S. 10; Weisert (1991) S. 127 u. ö. Rehbaum-Keller, Adelheid: Ein Oberhesse in der modernsten Datenbank Karlsruhes in: Hessische Heimat. Gießen 1995. S. 61-63. - Zunhammer, Thomas: Zwischen Adel und Pöbel. Bürger- 
tum und Mittelstandsideal im Staatslexikon von Karl von Rotteck und K. T.W. ... Ein Beitrag zur Theorie des Liberalismus im Vormärz. BadenBaden 1995. - Gelehrte in der Revolution (1998) S. 121-154. Schulz-Retzow, Daniel: Kieler Rechtswissenschaftler - K.T.W. Arbeit am Rechtshistor. Seminar. Kiel 2001. - Beyme, Klaus von: Politische Theorien im Zeitalter der Ideologien. 1789-1945. Wiesbaden 2002. - WBIS; Baur (2009) S. 162; Zeiler (2009) S. 523 (Register); Schroeder (2010) S. 125-130 u. ö.; Klippel (2012) S. 394 (Register); Stumm (2012) S. 285; Maus (2013) S. 460 (Register). - Albrecht, Helga: Karl von Rotteck (1775-1840) und K. T. W. ... in: Staatsdenken. Zum Stand der Staatstheorie heute. Hrsg. von Rüdiger Voigt. Baden-Baden 2016. S. 295-299. Hessische Biografie, s. http://www.lagis-hessen.de/pnd/118 63075X (Stand: 10. März 2017). • Siehe auch http:// www.ub.uni-heidelberg.de/helios/fachinfo/www/ gesch/Gesch_Erg/Felseck.htm

$P$ Bildarchiv UAH; graph. Slg. UBH.

\section{Wendt, Hans Hinrich}

1885-1893 Theol. Fak.

Systematische Theologie

* 18. Juni 1853 Hamburg

$\dagger$ 19. Jan. 1928 Jena

ev.-luth.

V Hans Hinrich W. (1813-1862) Prediger, s. Lexikon der hamburgischen Schriftsteller. Hrsg. von Hans Schröder. Hamburg 1879. Bd. 7. S. $607 \mathrm{f}$.

M Maria Friederike Emilie geb. Weber (18281911)

๑ nach 1886 Marie geb. Schulze, T von: (siehe) Hermann S. (seit 1888: von Schulze-Gaevernitz)

K unbekannt.

Lb Seit SS 1872 Studium der Philosophie, Theologie an U Leipzig, anschl. Tübingen, Marburg, zuletzt Göttingen.
U Göttingen: 2. Dez. 1875 Dr. phil.; 1877 theol. Lizentiatenprüfung; Mai 1877 Habilitation für Theologie; seit 20. Juni 1881 nichtetatm. a. o. Prof. für Systematische und Neutestamentliche Theologie.

U Kiel: Seit 1. Sept. 1883 o. Prof.

UH: Seit 1. April 1885 o. Prof. als Nachf. von Daniel Schenkel mit e. Jahresgehalt von 450o.- Mark; 1. Okt. 1885 Vereidigung; 1886-1893 e. der Hauptlehrer am Ev.-Prot. Theol. Seminar; 1. Okt. 1893 Entlassung auf eigenen Antrag.

U Jena: Seit WS 1893/94 o. Prof. für Neues Testament und Systematische Theologie; 31. März 1925 Emeritierung.

1886/87, 1891/92 Dekan der Theol. Fak. der UH

1919 Präsident der Weimarer Landessynode, s. Handbuch der deutschen evangelischen Kirchen 1918-1949. Organe - Ämter - Verbände - Personen. Bd. 1: Überregionale Einrichtungen. Bearb. von Heinz Boberach $(\dagger)$, Carsten Nicolaisen ... Göttingen 2010. S. 22, 487 .

1896 Kirchenrat; 1905 Geh. Kirchenrat

E 1883 D. theol. Göttingen.

Qu UAH PA 2431; RA 6718. - Glanz und Niedergang der deutschen Universität. 50 Jahre deutscher Wissenschaftsgeschichte in Briefen an und von Hans Lietzmann (1892-1942). Hrsg. von Kurt Aland. Berlin 1979. S. 1275 (Register). Nachlaß und Lebenserinnerungen [Sign.: Ms.Prov.q. 186]: Thüringer Universitäts- und Landesbibliothek Jena.

$W$ Die Begriffe Fleisch und Geist im biblischen Sprachgebrauch. Gotha 1878. Christliche Lehre von der menschlichen Vollkommenheit. Göttingen 1881. - Die Lehre Jesu. 2 Bde. Göttingen 1886-1890. 2. Aufl. 1901. - Die Apostelgeschichte. Göttingen 1899. 9. Aufl. 1913. • Das Johannesevangelium. Eine Untersuchung seiner Entstehung und seines geschichtlichen Wertes. Göttingen 1900. • System der christlichen Lehre. 2 Bde. Göttingen 1906-1907. 2. Aufl. 1920. • Die sittliche Pflicht. 
Eine Erörterung der ethischen Grundprobleme. Göttingen 1916. - Fürs innere Leben zur Kriegszeit. Volksschriften zum großen Krieg. 2 H. Berlin 1916-1917. - Johannesbriefe und das johanneische Christentum. Halle/S. 1925. - Zur Gewissensethik. Triebe und Gewissen, Gewissensethik und Werteethik, Gewissen und Glauben. Halle/S. 1928.

Bearb. Kritisch exegetisches Handbuch über die Apostelgeschichte. Begr. von Heinrich August Wilhelm Meyer. 6., ... 7. Aufl. Göttingen 1888.

$L$ Catalogus prof. Gottingensium (1962) S. 41. Schieder, Rolf: Die Berufung Ernst Troeltschs nach Heidelberg in: Troeltsch-Studien. Hrsg. von Horst Renz ... Bd. 1: Untersuchungen zur Biographie und Werkgeschichte. Gütersloh 1982. S. 132144. - WBIS; Jenaer Professoren (1983) S. 99; BBKL XIII (1998) Sp. 752-754. - Wolfes, Matthias: Protestantische Theologie und moderne Welt. Studien zur Geschichte der liberalen Theologie nach 1918. Berlin 1999. S. 836 (Register). • Personenlexikon zum dt. Protestantismus (2006) S. 272 f.; Dt. Literatur-Lexikon 30 (2010) Sp. 575 f. - Fuß, Tilman: Das ethisch Erlaubte. Erlaubnis, Verbindlichkeit und Freiheit in der evangelisch-theologischen Ethik. Stuttgart 2011. S. 168-179 u. ö. • Deutsche Biographie, s. https://www.deutsche-biographie. de/pnd117285625.html [23.12.2017].

$P$ Bildarchiv UAH; graph. Slg. UBH; BBKL.

\section{Wenger, Leopold Johann}

1908-1909 Jur. Fak.

Römisches und Dt. Bürgerliches Recht

* o4. Sept. 1874 Obervellach auf Schloß Trabuschgen (Kärnten)

$\dagger \quad$ 21. Sept. 1953 Obervellach kath.

V Leopold Johann W. (1844-1883) Landwirt, Besitzer des Schlosses Trabuschgen

M Theresia geb. Mulli (1846-1919)
๑ 30. Juni 1906 Hildegard geb. Caspaar ( $\left.{ }^{\star} 1883\right)$, s. Brief von H.W. (28. Mai 1938) im Nachlaß Helmut Berve (Bayer. Staatsbibliothek München, Signatur: Ana 468.B.VII, Wenger, Hildegard)

K 1935 Adoption e. Tochter.

Lb U Graz: Seit WS 1893/94 Studium; 20. Dez. 1897 Dr. iur.

1897-1899 Rechtspraktikant zunächst am Bezirksgericht Obervellach, dann am Landesgericht Graz; 1899-1901 2-jähriges Reisestipendium an U Leipzig (u.a. Student bei Ludwig Mitteis (1859-1921), Vater von: (siehe) Heinrich Mitteis).

U Graz: 28. Jan. 1901 Habilitation; seit 2. Febr. 1902 etatm. a. o. Prof.

U Wien: 4. Juli 1904 Ern. zum o. Prof.

U Graz: Seit 23. Juni 1905 o. Prof.

UH: 14. Juli 1908 Ern. zum o. Prof. als Nachf. von Immanuel Bekker; 1. Okt. 1908 Dienstantritt.

U München: Seit 1. April 1909 o. Prof. und Begründer des Seminars für Papyrusforschung, 1923 umbenannt in Institut für Papryusforschung und antike Rechtsgeschichte.

U Wien: Seit WS 1926/27 o. Prof.; 22. Juli 1927 Ern. zum Honorar-Prof.

U München: 11. Juli 1927 (Ern.)-SS 1935 o. Prof. • In dieser Zeit:

München: 1932-1935 Präsident der Bayer. Akademie der Wissenschaften, s. hierzu Denker, Forscher und Entdecker (2009) S. 273-276.

U Wien: 15. Juni 1935 Ern. zum o. Prof.; 29. Juni 1938 Entbindung von seinen Amtspflichten; 31. März 1939 vorzeitige Emeritierung kurz nach Annexion Österreichs durch Hitler; 15. Okt. 1945 erneut Ern. zum o. Honorar-Prof. für Römische und Antike Rechtsgeschichte; 31. Mai 1946 Ruhestand.

Obervellach: Seit 1939 ständiger Wohnsitz.

1924 Bayer. Geh. Justizrat 
1956: Zusammenfassung der rechtshistorischen Lehrstühle der Münchner Juristischen Fakultät unter der Bezeichnung Leopold-Wenger-Institut für Rechtsgeschichte und Papyrusforschung; den Grundstock der Instituts-Ausstattung bildet W.s Bibliothek (600o Bde.), s. Handbuch der historischen Buchbestände in Deutschland. Bd. 10: Bayern. T. 1: München. Hrsg. von Eberhard Dünninger ... Hildesheim 1996. S. 126 f. u. ö.

E Mitglied der Akademie der Wissenschaften: 1912 München (1932-1935 Präsident), 1926 Wien, Athen, Bologna, Bari, Rom, Brüssel, Berlin. - Dr. iur. h.c. Athen; 1926 Dr. rer. pol. h.c. Wien; Dr. phil. h.c.: 1926 München, 1927 Graz. 1914 Bayer. St. Michaels Orden IV. Klasse mit Krone. 1947 Preis der Stadt Wien für Geisteswissenschaften.

Qu UAH PA 2432; RA 6762. $\bullet$ GLA Abt. 235, Fasz. 2692. - Auskunft: Kath. Pfarramt in Obervellach; Archiv der Universität Wien. • Österr. Geschichtswissenschaft der Gegenwart in Selbstdarstellungen. Bd. I. Innsbruck 1950. S. 133-156. (Autobiogr.) - Turner, Nikolaus: Ein unpublizierter Lebenslauf L. W.s in: Separata Wengers im Leopold-Wenger-Institut München, s. online http:// www.austriaca.at/oxc1aa5576\%200xo01268a1.pdf (abgerufen am 19. Febr. 2018).

W Rechtshistorische Papyrusstudien. Graz 1902. • Allgemeine Rechtsgeschichte. Orientalisches Recht und Recht der Griechen und Römer. Leipzig 1914. (Mitverf.) • Der heutige Stand der römischen Rechtswissenschaft. München 1927. 2. Aufl. 1970. • Die Quellen des römischen Rechts. Wien 1953. Nachdr. Goldbach 2000. Bibliographie in: Thür (2006) S. 2 Anm. 3.

G, (M)HG Seit 1915 Münchener Beiträge zur Papyrusforschung (seit 1922 u.d.T.: Münchener Beiträge zur Papyrusforschung und der Antiken Rechtsgeschichte).

MHG 1939-1944 Zeitschrift der Savigny-Stiftung (Romanistische Abt.).

L Kürschner (1926) Sp. 2128f., (1950) Sp. 2245, (1954) Sp. 2559. - Nachruf in: Almanach der Akademie der Wissenschaften Wien 103 (1953)
S. 320-345 (mit Werkverz.). - Österreichische Geschichtswissenschaft im 20. Jahrhundert. Ein biographisch-bibliographisches Lexikon. Hrsg. von Fritz Fellner ... Wien 2006. S. 448 f. - Thür, Gerhard: L.W. Ein Leben für die antike Rechtsgeschichte in: Gedächtnis des 50. Todesjahres L.W.s. Hrsg. von Gerhard Thür. Wien 2006. S. 1-4. - Nörr, Dieter: L.W. ... Rechtshistoriker, Altertumswissenschaftler und Akademiepräsident 1932-1935 in: Denker, Forscher und Entdecker. Eine Geschichte der Bayer. Akademie der Wissenschaften in historischen Portraits. Hrsg. von Dietmar Willoweit ... München 2009. S. 269-279. • Rechts-, Sozial- und Wirtschaftswissenschaften aus Graz. Zwischen empirischer Analyse und normativer Handlungsanweisung ... Hrsg. von Karl Acham. Wien 2011. S. 273-275, 278-28o, $284 \mathrm{f}$. u. ö. - Deutsche Biographie, s. https://www.deut sche-biographie.de/pnd11880667X.html [23.12. 2017]. - Deutsche und europäische Juristen aus neun Jahrhunderten. Eine biographische Einführung in die Geschichte der Rechtswissenschaft. Hrsg. von Gerd Kleinheyer, Jan Schröder. 6. Aufl. Tübingen 2017. S. 565 u. ö.

$P$ Bildarchiv UAH; Denker, Forscher und Entdecker (2009) S. 268.

\section{Werk, Franz Xaver}

1804-1807 Theol. Fak., kath. Abt.

Moral- und Pastoraltheologie

* 26. Mai 1769 Steinbach (heute: Ortsteil von Baden-Baden)

$\dagger$ 26. Dez. 1856 Freiburg/Br.

kath.

V Johann Michael W., 1777, noch 1786 Fronschreiber, auch Güterverwalter, später Bürgermeister, s. Des hochlöbl[ichen] schwäbischen Crayses vollständiges Staats- und AddreßBuch auf das Jahr 1777 ... Ulm 1777. S. 202; Badenscher gemeinnüziger Hof- und Staats-Kalender für das Jahr 1786. Karlsruhe 1786. S. 211.

M N.N.

$\infty$ unverheiratet. 
Lb U Straßburg: Seit ca. 1784 Studium der Philosophie, 1786-179o der Theologie; 1786 Dr. phil.

Baden (heute: Baden-Baden): Herbst 1791-1795 Lehrer für Grammatik.

2. Juli 1792 Ordination; $1795-1800$ Priester an verschiedenen Pfarreien.

Baden(-Baden): Seit Nov. 1800 Prof. für Moralund Pastorallehre am Lyzeum und Kanoniker am Kollegiatstift.

UH: Seit 27. Aug. 1804 o. Prof. als Nachf. von Marcellian Rüdel; 1807 Verlegung der kath. Abt. der Theol. Fak. nach Freiburg/Br.

U Freiburg/Br.: Seit 28. Mai 1807 (Versetzung) o. Prof. für Pastoraltheologie; 13. Mai 1813 Dr. theol., siehe hierzu Nekrolog in: Freiburger Diözesan-Archiv 10 (1876) S. 313; 14. Aug. 1847 Pensionierung.

Zur Theologischen Fakultät, katholische Abteilung an UH, s. Weisert/Drüll/Kritzer (2007) S. 48, 53

Mitglied der Christentumsgesellschaft (bis 1847)

1818 Großherzogl. Geistlicher Rat

Qu GLA Abt. 205, Fasz. 566. - Briefe: UBH. • Nachlaß: Universitätsarchiv Freiburg/Br. • Auskunft: Erzbischöfliches Archiv in Freiburg/Br.

$W$ Über theologische Specialschulen. Freiburg 1818. - Stiftungs-Urkunden akademischer Stipendien und anderer milder Gaben an der HochSchule zu Freyburg im Breisgau von 1497-1842 chronologisch geordnet ... Freiburg 1842.

$L$ Gelehrtes Baden oder Verzeichniß der im Großherzogtum Baden lebenden Schriftsteller ... H. 1: Literärisches Freiburg im Breisgau oder Verzeichniß der gegenwärtig zu Freiburg im Breisgau lebenden Schriftsteller ... Hrsg. von Cajetan Jäger. Freiburg/Br. 1839. S. 190 f. Reichlin-Meldegg, Karl Alexander von: Das Leben eines ehemaligen römisch-katholischen Priesters. Heidelberg 1874.
S. 29-31. - Nekrolog in: Freiburger Diözesan-Archiv 10 (1876) S. 310-314. Badische Biographien 3 (1881) S. 199f.; ADB 55 (1910) S. 43; Keller (1913) S. 76-78; Schneider (1913) S. 94, $198 \mathrm{f}$ - Staehelin, Ernst: Die Christentumsgesellschaft in der Zeit von der Erweckung bis zur Gegenwart. Basel 1974. S. 154. WBIS; Burkard (1995) S. 254 (Register).

\section{Werner, Richard Victor}

1906-1934 Med. Fak.

Chirurgie

* 22. Juli 1875 Freiwaldau (Schlesien; heute: Jesenik, Tschechien)

$\dagger \quad$ 08. Febr. 1945 (Ermordung) KZ Theresienstadt (Protektorat Böhmen und Mähren; heute: Terezín, Tschechien)

- Nationalfriedhof Theresienstadt mosaisch, seit ca. $1904 \mathrm{ev}$.

V Sigmund W. $\left({ }^{*} 1844\right)$ Kaufmann

M Elisabeth geb. Goldschmi $(e) d(t)\left({ }^{*} 1854\right)$

$\infty$ unverheiratet.

Lb U Wien: Seit WS 1893/94 Studium; 7. Juli 1899 Dr. med.

Seit Okt. 1899 Assistent an Chirurg. U-Klinik H; April 1900-März 1901 Militärdienstpflicht als Einjährig-Freiwilliger (in dieser Zeit: seit Sept. 1900 Assistent an Innerer Station des Garnisonsspitals in Brünn (heute: Brno, Tschechien)); seit April 1901 Assistent an Gynäkologisch-Geburtshilflicher Klinik in Wien.

UH: Seit 15. März 1903 Assistent an Chirurg. UKlinik, seit April 1906 am Inst. für Experimentelle Krebsforschung; 16. Mai 1906 Approbation; 6. Juli 1906 Habilitation; seit 3. Aug. 1910 Oberarzt, 1. Okt. 1916-1934 Leiter des Samariterhauses (Klinische Abt. des Inst. für Experimentelle Krebsforschung, Voßstraße 3) als Nachf. von Vincenz Czerny; seit 22. Juli 1912 a.o. Prof.; 20. April-4. Mai 1933 Beurlaubung aufgrund des Gesetzes zur „Wiederherstellung des Berufsbeamtentums"; 28. April 1933 ministerielle Erlaubnis „e. jederzeit widerruflichen Fortsetzung des Dienstverhältnisses bis 
zur endgültigen Klärung der Voraussetzungen ..." (aus: UAH PA 6325); 16. Febr.-1. März 1934 auf eigenen Antrag Beurlaubung; März 1934 Rücktritt vom Amt des Klinikleiters und Übersiedlung nach Brünn; 1. April 1934 Entlassung aus Staatsdienst auf eigenen Antrag. • In dieser Zeit:

1914-1916 Kriegsdienst.

Brünn: April 1934-März 1939 (Einmarsch der dt. Wehrmacht) Direktor des Krebsinstituts „Haus des Trostes“; 28. Jan. 1942 Deportation nach Theresienstadt.

1906 entwickelt W. den Bestrahlungskonzentrator, s. hierzu Kütterer, Gerhard: Lexikon der röntgenologischen Technik 1895 bis 1925 von Abdeckzunge bis Zylinderblende. Norderstedt 2017. S. 22.

1933: W. ist deutscher Vertreter (u. a. auch (siehe) Otto Teutschlaender) in der Gründungskommission der Union internationale contre le cancer (UICC) mit Sitz in Genf.

$E$ Badisches Verdienst-Kriegskreuz; Preußische Rote Kreuz-Medaille; Ehrenzeichen des Österr. Roten Kreuzes; Kommandeurkreuz des rumänischen Kronenordens.

Qu UAH PA 1244, 6325; Quästurakte Rep. 271454. • GLA Abt. 235, Fasz. 2694.

W Statistische Untersuchungen über das Vorkommen des Krebses in Baden ... Tübingen 1910. Die Kombinationstherapien der Strahlenbehandlung in: Handbuch der gesamten Strahlenheilkunde 2 (1931) S. 213-246. • Bibliographie, s. Kipnis (2014) online.

MG, MHG 1912-1939 Fachzeitschrift „Strahlentherapie".

MHG Die Strahlentherapie in der Chirurgie. Berlin 1925. (Lehrbuch der Strahlentherapie. Bd. II.)

L Stübler (1926) S. 320; Kürschner (1931) Sp. 3242, (1935) Sp. 1523; Fischer $2\left({ }^{3} 1962\right)$ S. 1668; Chronik Ärzte H (1985) S. 146; Mussgnug (1988) S. 300
(Register); WBIS. - Wagner, Gustav, Mauerberger, Andrea: Krebsforschung in Deutschland. Vorgeschichte und Geschichte des Dt. Krebsforschungszentrums ... Berlin 1989. S. 272 (Register). 100 Jahre Krebsforschung (2000) S. 125-127 u. ö. Feuß, Axel: Das Theresienstadt-Konvolut ... Hamburg 2002. S. 76 f. • UH im Nationalsozialismus (2006) S. 1276 (Register); Grüttner/Kinas (2007) S. 174 u. ö.; Friedrich (2009) S. 33f., 118-122; Lexikon jüdischer Einwohner Hs (2011) S. 440. • Kipnis, Alexander: Biographie R.W. online unter http://www.kipnis.de/index.php/alexander/kurz biografien/127-werner-richard-1875-1945-krebsfor scher-radiologe (Stand: 15. Mai 2014; Ausdruck im UAH).

$P$ Bildarchiv UAH; Chronik Ärzte H.

Wette, Wilhelm Martin Leberecht De siehe De Wette, Wilhelm

\section{Wetzel, Albrecht Ludwig}

1919-1924 Med. Fak.

Psychiatrie

* 17. Juli 1880 Tübingen

$\dagger \quad$ 07. Nov. 1947 Stuttgart

ev.

V Karl Gottlob W. ( $\left.{ }^{\star} 1851\right)$ Rechtsanwalt, anschl. I. Syndikus und Direktor des Allg. dt. Versicherungsvereins Stuttgart

M Elisabeth Marie Luise geb. Volz $\left({ }^{*} 1859\right)$

œ 11. März 1916 Elfriede geb. Steffens (1886-1945)

K 5, u.a. $2 \mathrm{~T}$

Lb Herbst 1898-Frühling 1899 Militärdienstpflicht als Einjährig-Freiwilliger (erstes Diensthalbjahr); seit SS 1899 Studium an U Tübingen; Ende WS 1900/1901 ärztl. Vorprüfung in Tübingen; Forts. des Studiums: SS 1901 U München, WS 1901/o2 Berlin, seit SS 1902 Tübingen; WS 1903/04 med. Staatsprüfung in Tübingen; 1904 Dr. med. an U Tübingen; „Ableistung des praktischen Jahres wurde mir erlassen" (aus: Lebenslauf vom 
17. Dez. 1918 in: UAH PA 1245); 1904/05 Forts. der Militärdienstpflicht als Einjährig-Freiwilliger.

Berlin: März-April 1905 Patholog.-anatom. Tätigkeit im Laboratorium des Urbankrankenhauses.

Assistent: Seit 1. Mai 1905 Marien(ho)spital in Stuttgart, seit 1. Mai 1906 Privat-Irrenanstalt „Kennenburg“ in K. (heute: Stadtteil von Esslingen am Neckar).

Aug. 1906-Aug. 1907 Schiffsarzt bei Norddeutschem Lloyd; 1. Sept. 1907-31. März 1908 erneut Assistent an Privat-Irrenanstalt „Kennenburg“.

UH: Seit 1. April 1908 Assistent an Psychiatr. UKlinik; 11. Febr. 1919 Habilitation; Febr. 1919-Sept. 1924 Oberarzt an Psychiatr. U-Klinik; seit 9. Febr. 1922 nichtplanm. a. o. Prof. • In dieser Zeit:

1914-1916 (an der Front), 1916-1918 (als Lazarettarzt) Kriegsdienst.

Stuttgart: Seit Okt. 1924 Ärztlicher Direktor des Bürgerhospitals; Frühjahr 1944 Pensionierung aus Krankheitsgründen.

E 1914 Eisernes Kreuz II. Klasse; 1916 Ritterkreuz I. Klasse des württ. Friedrichsorden mit Schwertern.

Qu UAH PA 1245, 2438; Quästurakte Rep. 27464. - GLA Abt. 235, Fasz. 2696.

$W$ Ein Beitrag zur Frage des toxischen Eiweißzerfalls beim Carcinom. Tübingen 1904. - Geliebtenmörder. Berlin 1913. (Mitverf.: Karl Wilmanns.) (Verbrechertypen. H. 1.) • Über Massenmörder. Ein Beitrag zu den persönlichen Verbrechensursachen und zu den Methoden ihrer Erforschung. Berlin 1920. Die soziale Bedeutung in: Handbuch der Geisteskrankheiten 9, T. 5 (1932) S. 612-667.

MG, MHG 1913-1914 Verbrechertypen. 3 H. (zus. mit Hans Gruhle).

L Kürschner (1935) Sp. 1527; Fischer $2\left({ }^{3} 1962\right)$ S. 1673; WBIS. - Brückweh, Kerstin: Mordlust. Serienmorde, Gewalt und Emotionen im 20. Jahr- hundert. Frankfurt/M. 2006. S. 12, 183, 286 u. ö. • A. W. Über Massenmörder (1920), vervollständigt um die Kasuistik des Massenmords. T. 1 (1914) nebst e. einleitenden Essay und e. biogr. Skizze hrsg. von Michael Farin und Florian Mildenberger. München 2008. Deutsche Biographie, s. https:// www.deutsche-biographie.de/pnd117707562.html [26.12.2017].

$P$ A. W. Über Massenmöder (1920) S. 2.

\section{Wieland, David Hermann}

1925-1929 Med. Fak.

Pharmakologie

* 26. Febr. 1885 Pforzheim

$\dagger \quad$ 07. Mai 1929 Heidelberg ev.

V Dr. phil. Theodor W. (1846-1928) Chemiker, Besitzer e. Edelmetallscheideanstalt

M Elise geb. Blum (1849-1937)

๑ 3. Nov. 1923 Dr. med. Gertrud geb. Polley gesch. Kurtzahn (1893-1931) Ärztin

$\mathrm{K} \quad 2 \mathrm{~S}$ (1 $\mathrm{S}$ davon früh $\dagger$ ), 1 Stief-S aus 1 . Ehe seiner Frau

Vw Bruder: Heinrich Otto W. (1877-1957), u.a. seit 1917 o. Prof. für Chemie TH München, seit 1921 U Freiburg/Br., seit 1925 U München; seit 1917 auch Leiter der neugegründeten wiss. Abt. bei C.H. Boehringer Sohn in Ingelheim; 1927 Nobelpreisträger für Chemie, s. WBIS, BadenWürtt. Biographien III (2002) S. 457-46o, Kazemi (2006) S. 299-302; H. W.: Naturforscher, Nobelpreisträger ... Hrsg. von Sibylle Wieland u. a. Weinheim 2008; Vaupel, Elisabeth: Nützliche Netzwerke und "kriegswichtige“ Forschungsprojekte. Die Handlungsspielräume des Chemie-Nobelpreisträgers H.W. ... im Dritten Reich in: Universität München im Dritten Reich 2 (2008) S. 331-380. 1946) Ehefrau von Albert Boehringer (18611939) Chemiker, 1885 Gründer und Inhaber der Firma Albert Boehringer, chem. Fabrik, s. 125 Jahre Boehringer Ingelheim - Chronik. Ingelheim 2010. 
Vw Neffe: Hermann Theodor Felix W. (1913-1995; S von Bruder Heinrich Otto W., s. oben), u. a. 1951-1968 o. Prof. für Chemie an U Frankfurt/M., 1968-1981 Direktor der Abt. Chemie am Max-Planck-Inst. für med. Forschung $\mathrm{H}$ als Nachf. von (siehe) Richard Kuhn, s. WBIS; Homer, Leopold: Nachruf auf H.T.F.W. in: Sitzungsberichte der Wiss. Gesellschaft an der ... Universität Frankfurt/M. Stuttgart 1999. Bd. 36 Nr. 6. S. 47-49.

Vw Nichte: Eva W. (1915-2002) Ehefrau von Feodor Felix Konrad Lynen (1911-1979), u. a. seit 1953 o. Prof. für Biochemie U München, 19721979 (Emeritierung) Direktor der Abt. Enzymchemie und Stoffwechsel am Max-Planck-Inst. für Biochemie in Martinsried bei München; 1964 (zus. mit Konrad Emil Bloch) Nobelpreis für Physiologie/Medizin, s. Will, Heike: „Sei naiv und mach' ein Experiment." F. L.: Biographie des Münchner Biochemikers und Nobelpreisträgers. Weinheim 2011.

Lb WS 1903/04-SS 1904, SS 1906, SS 1907-SS 1908 Studium der Medizin, Chemie an U München, WS 1904/05-WS 1905/o6, WS 1906/o7 Straßburg; Herbst 1908 med. Staatsprüfung in München; 8. Dez. 1909 Approbation in Straßburg; 21. Dez. 1909 Dr. med. an U Straßburg.

Assistent: Jan. 1910-Okt. 1911 Innere Abt. des Krankenhauses in München-Schwabing, seit Nov. 1911 Pharmakolog. Inst. der U Wien.

U Straßburg: Seit Juni 1912 Assistent am Hygien. Inst., April 1913-Okt. 1918 am Pharmakolog. Inst.; 31. Juli 1915 Habilitation; 1915-1919 Privat-Dozent für Pharmakologie. • In dieser Zeit:

Seit Aug. 1914 Kriegsdienst als Arzt, Ende 1917 (nach Verwundung)-Jan. 1919 Kommandierung an Kaiser-Wilhelm-Inst. für physikal. Chemie und Elektrochemie in Berlin-Dahlem.

U Würzburg: Seit Anfang 1919 stellvertr. Direktor des Pharmakolog. Inst.

U Freiburg/Br.: Seit 1. April 1919 Assistent am Pharmakolog. Inst.; 10. Juli 1919 Umhabilitation.
U Königsberg (Preußen): Seit WS 1921/22 O. Prof.; 1925 Ruf an U Frankfurt/M. abgelehnt.

UH: 29. Juli 1925 Ern. zum o. Prof. und Direktor des Pharmakolog. Inst. als Nachf. von Rudolf Gottlieb und in Nachf. von Philipp Ellinger; 14. Dez. 1925 Vereidigung.

Berater und Mitarbeiter in der 1917 gegründeten und unter der Direktion seines Bruders Heinrich stehenden Wiss. Abt. im Pharmaunternehmen C.H. Boehringer und Sohn in Ingelheim (1921: W. und sein Bruder Heinrich (s.o.) isolieren aus der Pflanze „Lobelia inflata“ Lobelin, e. in der Natur vorkommende chemische Verbindung aus der Gruppe der Alkaloide; Lobelin wird bei Lähmung des Atemzentrums als Stimulans für die Atmung eingesetzt).

Um 1920 testen H.W. und Carl Joseph Gauß (1875-1957; Gynäkologe und Ur-Enkel von Johann Carl Friedrich Gauß (1777-1855; Mathematiker, Physiker, Astronom)) Narcylen, e. hochgereinigtes Acetylen als neues Narkotikum, s. hierzu Heinrich Wieland. Naturforscher, Nobelpreisträger ... Hrsg. von Sibylle Wieland u. a. Weinheim 2008 (Artikel Narcylen).

Seit 1927 Geschäftsführer der 1920 gegründeten Dt. Pharmakologischen Gesellschaft

E 1928 Mitglied der Akademie der Wissenschaften $\mathrm{H}$.

Qu UAH PA 1247, 6353f.; Quästurakte Rep. 271444; Fak.-Akte H-III-12o/2 Nr. 7. GLA Abt. 235, Fasz. 2700.

$W$ Untersuchungen über die lipoiden Substanzen der Magenschleimhaut. Straßburg 1909. Beiträge zur Ätiologie der Beri-Beri. Wien 1912. • Pharmakologische Untersuchungen über Gallensäuren in: Archiv für experimentelle Pathologie und Pharmakologie 85 (1920) S. 199-213, 86 (1920) S. 79-91, 92-103; Über den Wirkungsmechanismus betäubender Gase, des Stickoxyduls und des Azetylens in: ebd. 92 (1922) S. 96-152. - Siehe auch BadenWürtt. Biographien V (2013) S. 511. 
MG, $M H G$ Jan. 1928-1929 Der Schmerz. Dt. Zs. zur Erforschung des Schmerzes und seiner Bekämpfung, zugleich Zentralorgan für Narkose und Anaesthesie (s. hierzu Die Gründung von Der Schmerz in: Tschöp, Michael: Ernst von der Porten 1884-1940 ... Berlin 1986. S. 24 ff.). $1928-$ 1929 Narkose und Anästhesie. Zs. und Zentralorgan für das Gesamtgebiet der Schmerzlinderung und -verhütung (beide Zs. erscheinen 1929-1944 u.d. T.: Schmerz, Narkose, Anaesthesie).

L Kürschner (1926) Sp. 2150; Stübler (1926) S. 329. - Ergebnisse der Chirurgie und Orthopädie. Hrsg. von Erwin Payr und Hermann Küttner ... 21. Bd. Berlin 1928. S. 596 (Register). • Biogr. Jahrbuch 11 (1929) S. 328-332; Poggendorff 6 (1939) S. 2877; Chronik Ärzte H (1985) S. 146; Lindner/ Lüllmann (1996) S. 277 u. ö. • Heinrich Wieland. Naturforscher, Nobelpreisträger ... Hrsg. von Sibylle Wieland u.a. Weinheim 2008. • BadenWürtt. Biographien V (2013) S. 509-511; Deutsche Biographie, s. https://www.deutsche-biographie. de/pnd1012372448.html [27.12. 2017].

P Bildarchiv UAH; Chronik Ärzte H.

\section{Wild, Karl Wilhelm}

1906-1926 Phil. Fak.

(1926 (Honorar-Prof.) Phil. Fak.)

Mittlere und Neuere Geschichte

* 13. Aug. 1866 Neckargerach (bei Eberbach)

$\dagger \quad$ 27. Sept. 1926 Heidelberg

ev.

V Johannes Thomas W. (1825-1902) Pfarrer, s. Badisches Pfarrerbuch 2 (1939) S. 666

M Karoline Friederike geb. Seitz (1829-1886)

( 31. Juli 1920 Julie Luise Pauline geb. Müller verw. Beinert (1886-1951), s. Woltersdorff, Stefan: Johannes Beinert (1877-1916). Ein Leben am Oberrhein ... Meßkirch 2016. S. 113-120, 129f., 133-135, 141 f.; Witwe von o.g. Johannes Beinert, zuletzt Rektor des Großherzogl. Vorseminars in Lahr, s. Woltersdorff (2016)
K 2 S (beide S im 2. Weltkrieg $X X$ ), s. Woltersdorff, S. 202; 2 Stief-S, siehe Badische Biographien N.F. III (1990) S. 294, Woltersdorff, S. 203 f.; u.a. Dr. phil. Berthold Beinert (1909-1981) 1956-1975 Direktor des Dolmetscher-Inst. der UH, s. UAH PA 320, 2588, 7239, 7582; Über B. B. in: Hausmann, Frank-Rutger: „Auch im Krieg schweigen die Musen nicht“. Die dt. wiss. Institute im 2. Weltkrieg. Göttingen 2002. S. 213; Woltersdorff, S. 141f., 169, 201, 203

Vw siehe WBIS, Badische Biographien (1990).

Lb Seit WS 1885/86 Studium der Theologie, Philologie an U Tübingen, anschl. Erlangen, Berlin, WS 1888/89-SS 1890 Studium der Philologie und Geschichte an UH; 1890 theol. Hauptexamen in H.

1890-1892 Lehrer in Großbritannien.

1892 Philolog. Staatsprüfung in H; 1892, noch 1896 Vikar; Lehramtspraktikant: seit 1892 Wertheim, seit 1893 Mannheim, seit 1894 Karlsruhe; 29. Mai 1896 Dr. phil. an UH.

Karlsruhe: 1896-1904 Gymnasial-Prof. an Oberrealschule.

H: 1904-1906 Professor an Höherer Töchterschule (heute: Hölderlin Gymnasium); 1906-1926 Prof. an Oberrealschule (heute: Helmholtz-Gymnasium). • In dieser Zeit:

UH: 26. Mai 1906 Habilitation; seit 29. Dez. 1913 nichtetatm., seit 1920 nichtplanm. a.o. Prof.; seit 14. Aug. 1926 o. Honorar-Prof.

Seine pädagogisch-didaktischen Erfahrungen gab W. in Vorlesungen an Studenten weiter, z. B. durch "Anleitung zu geschichtlichen Vorträgen“ oder „Übungen in der Verwertung des historischen Materials zur wissenschaftlichen Darstellung für Anfänger und Fortgeschrittene" (WS 1910/11 oder SS 1913), Angebote, die zu dieser Zeit unüblich waren.

Qu UAH PA 6359; Studentenakte. - GLA Abt. 235, Fasz. 13416-13418. - Nachlaß: Herr Dr. Wolf-Dieter Beinert, Heidelberg. - Auskunft: Ev. Pfarramt 
in Neckargerach (Geburtsbuch von 1866). - Mitteilungen: Herr Dr. Wolf-Dieter Beinert (Enkel) und Frau Gertrud Döbbeling geb. Müller (Großnichte), Heidelberg.

$W$ Bilderatlas zur Badisch-Pfälzischen Geschichte. Heidelberg 1904. - Lothar Franz von Schönborn, Bischof von Bamberg und Erzbischof von Mainz. Heidelberg 1904. - Staat und Wirtschaft in den Bistümern Würzburg und Bamberg. Heidelberg 1906. Karl Theodor Welcker, ein Vorkämpfer des älteren Liberalismus. Heidelberg 1913. • Bibliographie in: Badische Biographien (1990) S. 296.

$L$ Sauer, Fritz: Geschichte der Heidelberger OberRealschule 1835-1910. Festschrift zum 75-jährigen Jubiläum. Heidelberg 1912. Kürschner (1926) Sp. $2158 \mathrm{f}$. Nachruf in: Historische Zeitschrift 136 (1927) S. 221 f. WBIS; Badische Biographien N.F. III (1990) S. 294-296; Jansen (1992a) S. 170 (Register); Kriegstagebuch K. Hampe (2007) S. 1006 (Register); Reichert (2015) S. 241 f. u. ö.; Deutsche Biographie, s. https://www.deutsche-biographie.de/p nd1012372634.html [27.12.2017].

$P$ Bildarchiv UAH.

\section{Wilke, Ernst Hermann}

1917-1927, 1929-1934 Nat.-Math. Fak.

Chemie

* O2. Nov. 1882 Bielitz (Österreichisch-Schlesien; heute: Stadtteil von Bielsko-Biała, Polen)

$\dagger \quad$ 23. Nov. 1934 Heidelberg ev.

V Severin W. (†1904) Seifenfabrikant

M Bertha geb. Fiber

( 10. Juni 1924 Margarethe geb. Wallach (18981989)
K 1 T, 1 S: Günther W. (1925-2016) 1951 Promotion zum Dr. rer. nat. an UH bei Prof. Karl Freudenberg (s. hierzu auch $Z$ ), u. a. seit 1960 Privat-Dozent TH Aachen, seit 1963 o. Prof. für Organische Chemie Bochum, seit 1967 II., 1969-1993 I. Direktor der Max-Planck-Gesellschaft für Kohlenforschung Mülheim/Ruhr, siehe Die Kaiser-Wilhelm-/Max-Planck-Gesellschaft und ihre Institute ... Hrsg. von Bernhard Vom Brocke ... Berlin 1996. S. 672 (Register); Wer ist wer (2001/o2) S. 1542; Henning, Eckart und Kazemi, Marion: 100 Jahre Kaiser-Wilhelm-/Max-Planck-Gesellschaft zur Förderung der Wissenschaften ... Berlin 2011. S. 1167 (Register); Lebenslauf, s. http:// www.ruhr-uni-bochum.de/vfch/Dokumente/ Wilke.pdf (Ausdruck im UAH).

$L b$ „Aus Gesundheitsrücksichten verhindert, die Schule zu besuchen, wurde ich privat unterrichtet und bestand im Jahre 1900 die Reifeprüfung vor einer militärischen Prüfungskommission" (aus: eigenhändigem Lebenslauf von 1915 in: UAH PA $6362)$.

UH: Seit WS 1900/o1 Studium der Chemie, Physik, Mathematik; 11. Jan. 1905 Dr. phil. nat.; seit 1905 Volontär, 1907-1927 (Entlassung, siehe Z) Assistent am Chemischen Laboratorium. • In dieser Zeit:

1913 Ablegung der Reifeprüfung an Oberrealschule (heute: Helmholtz-Gymnasium) in H; 1915-1917 (als Fernsprechoffizier), 1918 (Versuchs-Abt. im Kriegsministerium in Wien) Kriegsdienst.

UH: 3. Nov. 1917 Habilitation; seit 4. Mai 1922 nichtplanm. a.o. Prof. mit Lehrauftrag für Kolloidchemie; Mai 1927-Mai 1929 auf eigenen Antrag Beurlaubung für zwei Jahre: 1927-1931 Beamter bei I. G. Industriegewerkschaft Farbenindustrie in Ludwigshafen-Oppau, s. Z; WS 1929/30 Wiederaufnahme der Vorlesungstätigkeit; März 1934 Bruttoeinkommen von 30o.- Reichsmark im Monat.

Z Am 12. Nov. 1933 bittet W. in einem Brief an Ministerialrat (siehe) Eugen Fehrle, ihn in „eine gesicherte Staatsstellung [eines Assistenten] rückzuversetzen, denn ab 1935 „wird meine pekuniäre 
Lage ... eine unhaltbare sein, so daß ich auch meinen bisherigen Beruf als Hochschullehrer werde aufgeben müssen“. Begründung: „1927 nach der Übernahme des Ordinariates am chemischen Institut in Heidelberg durch Prof. [Karl) Freudenberg [und Ern. von Max Trautz zum Direktor des neugegründeten Inst. für Physikalische Chemie und Elektrochemie] wurde ich von meinem Assistentenposten entlassen nach 2ojähriger Assistententätigkeit. Durch die Inflation völlig mittellos geworden, war ich gezwungen, in der Industrie einen Broterwerb zu suchen: I. G. Farbenindustrie, Oppau [vermittelt durch Freudenberg] ... 1931 sind bei der I. G. an Stelle von 100 jüngeren Beamten, die abgebaut werden sollten, 40 ältere Herren, darunter 4 Professoren, auch ich, in den Ruhestand versetzt worden.

Die Pensionen entsprechen den Dienstjahren der Einzelnen. Da meine Dienstzeit nur 4 Jahre betragen hat, so ist die Pension sehr gering und deckt nicht den einfachsten Lebensunterhalt einer 4köpfigen Familie ..." (aus: UAH PA 6362). Am 29. März 1934 unterstützen Rektor und Dekan der Naturwiss.-Math. Fak. e. Antrag an Minister des Kultus, des Unterrichts und der Justiz, W. für die Hälfte des zur Verfügung stehenden Betrages der Jubiläumsstiftung in Höhe von etwa 450.- Reichsmark vorzuschlagen (aus: PA 6362). Im Nov. desselben Jahres verstirbt W. Auf die von seiner Witwe erbetene finanzielle Unterstützung von monatlich 140.- Reichsmark antwortet am 15. Sept. 1937 der Reichs- und Preussische Minister für Wissenschaft, Erziehung und Volksbildung in Berlin: „Nach Massgabe der bestehenden allgemeinen Richtlinien bin ich nicht in der Lage, Ihnen aus Landesmitteln eine laufende Unterstützung zu gewähren“ (aus: PA 6362).

E 1912 Mitglied der Dt. Physikalischen Gesellschaft. - 1917 Goldenes Verdienstkreuz mit der Krone am Tapferkeitsband und Schwertern.

$\mathrm{Q} u$ UAH PA 6362; RA 6496; Fak.-Akten H-V-5/2, H-V-6/4. GLA Abt. 235, Fasz. 2702.

W Zur Kenntnis wässriger Kohlensäurelösungen in: Zs. für anorganische und allg. Chemie 119 (1921). - Beiträge zur Theorie der konzentrierten
Lösungen in: Zs. für physikalische Chemie 122 (1926), 125 (1927), 160 (1932), 162 (1932). (Mitverf.) • Über die Leitfähigkeit der Halogen-Wasserstoffsäuren und der Salpetersäure in hohen Konzentrationen in: Zs. für Elektrochemie (1933). • Einwirkung elektrischer Wellen auf Kolloide in: Kolloid-Zs. 65 (1933). (Mitverf.) - Bibliographie 1904-1933 in: UAH PA 6362.

L Kürschner (1935) Sp. 1539. - Nachrufe in: Angewandte Chemie 48 (1935) S. 72 und European Journal of Organic Chemistry 48 (1935) S. 72 . • Poggendorff 6 (1940) S. 2886 f.; Jansen (1992a) S. 170 (Register).

\section{$P$ Bildarchiv UAH.}

\section{Wilken, Friedrich}

1805-1817 Phil. Fak.

Geschichte, Orientalische Sprachen

$$
\begin{array}{ll}
* \quad \text { 23. Mai } 1777 \text { Ratzeburg } \\
\dagger \quad \text { 24. Dez. } 1840 \text { Berlin } \\
\text { kath., (vor) } 1795 \text { ev.-luth. }
\end{array}
$$

V Christian Erich W., Pedell, Kanzlist

M Sophia Maria Magdalena geb. Schmidt

๑ 28. Aug. 1806 Caroline geb. Tischbein (17831843) Zeichnerin, s. Krichbaum, Jörg, Zondergeld, Rein A.: Künstlerinnen von der Antike bis zur Gegenwart. Köln 1979; Stumm (2012) S. 707 (Register); T von Johann Friedrich August T. (1750-1812) Maler, seit 1800 Direktor der Kunstakademie in Leipzig (Johann Friedrich August T. ist Neffe von Johann Heinrich T.d. Ä. (1722-1789) Hofmaler und seit 1777 Prof. an Kunstakademie Kassel sowie Cousin von Johann Heinrich Wilhelm T. (1751-1829), dem „Goethe-Tischbein“), s. Stoll, Adolf: Der Maler Johann Friedrich August T. und seine Familie. Ein Lebensbild nach den Aufzeichnungen seiner Tochter Caroline. Stuttgart 1923; WBIS, Allg. Lexikon der Künstler 33 (1999) S. 206, Pfeiffer (2004) S. 154, Stumm, S. 707 (Register)

K 2 S, 2 T, s. Stumm, S. 283 f. und Anm. 1181 f. 
Lb U Göttingen: Seit Ostern 1795 Studium zunächst der ev. Theologie, dann der Geschichte, Philologie; Ostern 1797-Herbst 1799 Mitglied des Philolog. Seminars; 4. Juli 1798 Gewinner e. Preisfrage mit der historischen Arbeit über „Commentatio de bellorum cruciatorum ex Abulfeda historia“; Herbst 180o-Ostern 1803 Kandidat der Theologie und Repetent an Theol. Fak.; seit 1800 auch Hilfskraft in UB.

April 1803-Sept. 1805 Instruktor und Studienbegleiter des Erbgrafen Georg Wilhelm von Schaumburg-Lippe (1784-1860), u.a. in Leipzig; 1803 Dr. phil. an U Jena; 1805 Privatier in Leipzig.

UH: Seit Herbst 1805 a. o. Prof. als Nachf. von Peter Wolfter; seit Febr. 1807 o. Prof.; Rufe an U abgelehnt: 1810 Berlin, Leipzig und Charkow (Ukraine; heute: Charkiw). • In dieser Zeit:

UBH: Okt. 1808-März 1817 I. Oberbibliothekar (Vorstand) in Nachf. von Engelbert Semer.

U Berlin: 7. Dez. 1816 Ern. zum SS 1817 o. Prof. für Philosophie und Geschichte. - In dieser Zeit:

Berlin: April 1817-24. Dez 1840 ( $\dagger$ ) Oberbibliothekar an Königl. Bibliothek; 1821 Ern. zum königl. preußischen Historiographen; 1831-1840 Leiter der neugegründeten UB (Verwaltung der UB ist bis 1898 in Personalunion mit Königl. Bibliothek).

1815 Prorektor der UH; 1811 Dekan der Phil. Fak. der UH

W. erreicht u. a. die teilweise Rückgewinnung der 1623 von Kurfürst Maximilian I. von Bayern dem Papst geschenkten Handschriften und Bücher der Bibliotheca Palatina, so 181638 Handschriften aus Paris und 852 vor allem deutsche Handschriften aus Rom; 2018 ist die Bibliotheca Palatina zumindest virtuell wieder vereint, s. hierzu http://digi. ub.uni-heidelberg.de/de/bpd/index.html (abgerufen am 2o. Febr. 2018)

1815 Hofrat; 1830 Geh. Reg.-Rat
E 1819 Mitglied der Akademie der Wissenschaften Berlin; 1837 Korr. Mitglied der Russischen Akademie der Wissenschaften St. Petersburg. $\bullet 1815$ D. theol. UH. 1828 Ritter des Königl. Preußischen Roten Adlerordens III. Klasse, 1835 mit Schleife.

Qu UAH PA 2445; RA 4921, 5338, 5974, 6032, 6076, 6108 u. ö. $\bullet$ GLA Abt. 205, Fasz. 504f., 570. • Briefe: $\mathrm{UBH}$. „Leider muß ich klagen und fast verzagen“. Briefe Friedrich Wilhelm Bartholds an F.W. (18321835) und e. unbekannten Freund (1853) in: Baltische Studien. Pommersche Jahrbücher für Landesgeschichte ... Kiel 2015. S. 155-196. - Leopold von Ranke. Briefwechsel. Historisch-kritische Ausg. Bd. 1: 1810-1825. Neu bearb. von Dietmar Grypa. Berlin 2016. S. 878 (Register). - Nachlaß: Staatsbibliothek zu Berlin. - Stoll, Adolf: Der Geschichtsschreiber F.W. Mit e. Anhang, enthaltend Aufzeichnungen von Caroline Wilken, geb. Tischbein, über ihren Vater Johann Friedrich August Tischbein und ihr eigenes Jugendleben. Kassel 1896.

$W$ Institutiones ad fundamenta linguae Persicae. Leipzig 1805. - Geschichte der Kreuzzüge nach morgenländischen und abendländischen Berichten. 7 Bde. Leipzig 1807-1832. Handbuch der deutschen Historie. Heidelberg 1810. Geschichte der Bildung, Beraubung und Vernichtung der alten Heidelbergischen Büchersammlungen. Heidelberg 1817. • Verzeichnis der von F. W. ... hinterlassenen Bibliothek, welche in Berlin ... Mitte Mai d. J. ... versteigert werden soll. Berlin 1841.

MHG 1808-1817 Heidelbergische Jahrbücher der Litteratur.

L ADB 43 (1898) S. 236-241; Keller (1913) S. 213; Schneider (1913) S. 126, 148, 288-291; Bader (1925) S. 282 f.; Catalogus prof. Gottingensium (1962) S. 43; WBIS. - Wolgast, Eike: Politische Geschichtsschreibung in Heidelberg ... in: Semper apertus 2 (1985) S. 158-196. - Weber (1987) S. 663 f. - Schochow, Werner: F. W. ... in: Mitteilungen aus der Staatsbibliothek Preussischer Kulturbesitz 22,2 (1990) S. 165-168. Kirschke (2001) S. 450 (Register). Handbuch der historischen Buchbestände in Deutschland. Hrsg. von Bern- 
hard Fabian. Hildesheim 2003. - Stumm (2012) S. 707 (Register); Riecke (2016) S. 10, 13. Hawicks, Heike, Runde, Ingo: Kriegsbedingte Verluste von Kulturgütern und deren partielle Restitution am Beispiel zweier Papsturkunden der Jahre 1387 und 1816 aus dem Universitätsarchiv Heidelberg in: Homo heidelbergensis. Festschrift für Klaus-Peter Schroeder zum 70. Geburtstag. Hrsg. von Pirmin Spieß ... Neustadt/Weinstraße 2017. S. 303-324.

$P$ Bildarchiv UAH; graph. Slg. UBH.

\section{Wille, Philipp Jacob}

(189o-1898 Phil. Fak.)

(1898) 1899-1928 (Honorar-Prof.) Phil. Fak.

Landesgeschichte, Historische Hilfswissenschaften

* o6. Mai 1853 Frankenthal (Rheinpfalz)

$\dagger \quad$ 22. Juli 1929 Heidelberg ev.

V Johann Ludwig Alexander W. (1814-1878) Gutsbesitzer, 1868-1876 Bürgermeister, s. Laurier, Friedrich Wilhelm: Grabrede, gehalten bei der Beerdigung des Herrn J.L.A.W., früheren Bürgermeisters in Frankenthal am 28. Juni 1878. Frankenthal 1878.

M Apollonia geb. Franz

๑ 1882 Hedwig Rosalie geb. Blesch $\left({ }^{*} 1862 \dagger\right.$ nach 1943)

K mind. 2 .

Lb WS 1873/74 Studium der Geschichte, Klassischen Philologie, Rechtswiss. an UH, seit SS 1874 Bonn, WS $1875 / 76 \mathrm{H}$, seit SS 1876 Leipzig, SS $1877-$ WS $1877 / 78$ München; 16 . Nov. 1876 Dr. phil. an UH; 1878 Prüfung für den Archivdienst in Bayern.

Vorbereitungsdienst zum Archivar: Seit 1878 zunächst UBH (hier war bis 1953 das UA untergebracht), anschl. GLA in Karlsruhe, seit 1881 erneut $\mathrm{UBH}$.

UBH: 28. Febr. 1882 (Ern.)-30. Juni 1902 I. etatm. Bibliothekar als Nachf von Dr. Otto Bender ((18311882) 1859-1882 im UB-Dienst) mit e. jährl. Besol- dung von 2000.- Mark; Jahresgehalt: seit 1. April 1888 2300.-, seit 1. April 1891 3620.-, seit Juni 1894 4020.- Mark; 1. Juli 1902-1. April 1922 (Ruhestand) Oberbibliothekar (= Vorstand, 1911 ersetzt durch Amtsbezeichnung Direktor) als Nachf. von Karl Zangemeister; jährl. Gehalt: seit 1. Juli 1902 von 5000.- Mark zuzügl. 1200.- Mark Wohnungsgeld, seit 1. Juni 1912 8500.-, seit Juli 1914 900o.Mark, seit April 1920 Grundgehalt 16 80o.- Mark plus Ortszuschlag 4000.- und Teuerungszuschlag 10 40o.- Mark, insgesamt 31 200.- Mark; Monatsgehalt: seit Jan. $192134736 .-$, seit April 1921 18 ooo.-, seit Aug. 192142 020.-, seit Okt. 1921 90 ooo.-, seit Jan. 1922100 90o.- Mark; jährl. Ruhegehalt: seit April 192259 40o.- Mark nebst e. Teuerungszuschlag von 11 880.- Mark, seit ca. Mai 1924 nach Ende der Inflationszeit 657,30 Mark. • In dieser Zeit:

UH: 10. Mai 1890 Verleihung des Titels „Prof.“; seit 17. Dez. 1898 Honorar-Prof.; SS 1899 erste Vorlesungsankündigung; seit 21. Febr. 1908 o. Honorar-Prof.; SS 1928 letzte Vorlesungsankündigung.

UAH: 1. Juli 1902-1929 (†) Leiter des UA (in Personalunion als Vorstand der UB) als Nachf. von Zangemeister mit e. jährl. Besoldung von 8oo.Mark, seit April 1922 von 200o.- (Papier-)Mark, seit Okt. 1923 von 200.- Gold- bzw. Reichsmark.

Die Bibliothek W.s mit 900 Titeln befindet sich heute im Bestand des Landesbibliothekszentrums Rheinland-Pfalz, Pfälzische Landesbibliothek in Speyer

1906 Geh. Hofrat; 1918 Geh. Rat II. Klasse

E 1892 Mitglied der Badischen Histor. Kommission; 1905 Ehrenmitglied der Royal Society of Literature London; 1927 o. Mitglied der Akademie der Wissenschaften H. 1926 Dr. phil. h. c. UH. 1913 Ritterkreuz I. Klasse mit Eichenlaub vom Orden des Zähringer Löwen.

Qu UAH PA 97, 6364; RA 5972f., 6113; Fak.-Akte $\mathrm{H}-\mathrm{IV}-102 / 83$; K-Ia-20o/1, K-Ia-481/2. GLA Abt. 235, Fasz. 2703 und 3166. Briefe: u. a. UBH; s. auch Heid. Hs. 4104. - Im Schaffen genießen. Der Briefwechsel der Kulturwissenschaftler Eber- 
hard und Marie Luise Gothein. Hrsg. von Michael Maurer ... Köln 2006. S. 683 (Register). • Nachlaß: siehe Kalliope.

$W$ Philipp der Großmüthige von Hessen und die Restitution Ulrichs von Wirtemberg 1526-1535. Tübingen 1882. Bruchsal. Bilder aus einem geistlichen Staat im 18. Jahrhundert. Karlsruhe 1897. 2. Aufl. 1900. Elisabeth Charlotte, Herzogin von Orléans. Bielefeld, Leipzig 1905. 4. Aufl. 1926. Aus alter und neuer Zeit der Heidelberger Bibliothek. Heidelberg 1906. 2. Aufl. 1908. • Über das Bibliotheks- und Archivwesen. 15-seitiges masch.geschr. Manuskript vom 26. März 1921 sowie W.s 6-seitige masch.geschr. Abschiedsrede vom 1. April 1922 über seine Bibliotheksvorgänger in: UAH PA 6364.

Mitbearb. Regesten der Pfalzgrafen am Rhein 1214-1508. Bd. 1: ... 1214-1400. Innsbruck 1894 (zus. mit Adolf Koch).

HG Die deutschen Pfälzer Handschriften des 16. und 17. Jahrhunderts der Universitätsbibliothek in Heidelberg ... Heidelberg 1903.

Redakteur 1894-1919 Neue Heidelberger Jahrbücher. 1903-1921 Mitteilungen zur Geschichte des Heidelberger Schlosses.

L Kürschner (1925) Sp. 1141f., (1926) Sp. 2161f.; Biogr. Jahrbuch 11 (1929) S. 373. • Sillib, Rudolf: J.W. in: ZGORh 83. Jg. (1931) S. 113-133 (mit Werkverz.). WBIS; Habermann et al. (1985) S. 385 f.; Badische Biographien N.F. IV (1996) S. 322 f. • Handbuch der historischen Buchbestände in Deutschland. Hrsg. von Bernhard Fabian. Hildesheim 2003. Kriegstagebuch K. Hampe (2007) S. 1007 (Register). • Effinger, Maria, Zimmermann, Karin: Die Universitätsbibliothek Heidelberg. Lindenberg 2009. S. 9. • Runde (2012) S. 262; Deutsche Biographie, s. https://www.deutschebiographie.de/pnd117387681.html [27.11. 2017].

\section{Willy, Daniel Heinrich}

1817-1843 (1846) Jur. Fak.

Römisches Privatrecht

* o1. Nov. 1786 Sarepta (damalige Filiale der Herrnhuter Brüdergemeine bei Zarizyn, heute: Wolgograd, Russische Föderation)

$\dagger$ 12. März 1861 Achern (Baden) ev.-luth.

V Daniel W. (1739-1788) Engros-Kaufmann; seit 1760 u. a. Kaufmann im „Ladenhaus“ von Abraham Dürninger (s. BBKL XXIX (2008) Sp. 345-348) in Herrnhut (Oberlausitz), 1761 Aufnahme in Herrnhuter Gemeine ebd., seit 1777 Commissionär der Gemeine Sarepta für Kolonien an der Wolga in Südrußland und Diaspora-Arbeiter (Betreuer von Personen, die außerhalb der Gemeinde leben, aber Kontakt zur Brüdergemeine pflegen), seit 1778 in Sebastianofka, 1786 Rückkehr nach Sarepta als Buchhaltungs-Gehilfe, s. Dienerblatt D.W.s im Unitätsarchiv in Herrnhut

M Christiane geb. Steinhauer (1750-1811) 1764 Aufnahme in Herrnhuter Gemeine, s. Dienerblatt ebd.

œ 1820 N. N. geb. Ehrhardt ( $†$ nach 1861)

K 1 T: Rosalie (Rose/Rosa) Elisabetha Dorothea Euphrosyne Charlotte Jacobine W. $\left({ }^{*} 1828\right.$ $\dagger$ nach 1905), s. Heinrich Heine: Briefwechsel 1815-1856. Register. Bearb. von Christa Stöcker. Berlin 1984. S. 74; in 1. Ehe seit 1850 verh. mit Dr. phil. (Promotion am 15. Aug. 1846 an UH) Richard Georg Spiller von Hauenschild (18251855) Schriftsteller (Pseudonym: Max Waldau), siehe Schumacher, Karl: M. W. ... Leben, Werke und Schicksal e. dt. Dichters ... Berlin 1925; Heinrich Heine: Briefwechsel (1984) S. 74. - In 2. Ehe seit 10. Febr. 1866 verh. mit Graf Arthur Heinrich Wilhelm Anton Eduard von Königsdorff aus dem Hause Peterwitz (2. Febr. 182427. Juni 1866).

Lb UH: WS 1807/o8-WS 1812/13 Zunächst Studium der Medizin, seit SS 1813 der Rechtswiss.; 30. Juli 1817 Dr. iur. und Erteilung der venia legendi, s. hierzu Baur (2009) S. 125; WS 1817/18 erste Vorlesungsankündigung als Privat-Dozent; 6. Jan. 1819 Ern. zum a. o. Prof. mit e. jährl. Besoldung von
Willms, Max

siehe Wilms 
200.- Gulden rückwirkend ab 23. Okt. 1818; seit 16. März 1820 jährl. Gehaltszulage von 300.- Gulden; 11. Okt. 1821 Ern. zum o. Prof. II. Klasse (d.h. ohne Teilnahmeberechtigung an den Fak.-Sitzungen und Doktorexamina); Mitte Nov. 1821 Bestellung zum a.o. Beisitzer des Spruchkollegiums; W. verweigert Mitarbeit in diesem Gremium, s. hierzu Baur (2009) S. 163-165; seit 6. Okt. 1825 Bewilligung e. Gratifikation in Höhe von 150.- Gulden; bereits 1843 Weggang aus gesundheitlichen Gründen, trotzdem zuletzt SS 1845 Vorlesungsankündigung in "Anzeige der Vorlesungen ... im SS 1845", S. 19; erst zum WS 1845/46 Ankündigung „W. ist durch Krankheit verhindert, Vorlesungen anzuzeigen“, s. ebd. ... im WS $1845 / 46$, S. $18 ; 15$. Mai 1846 Beschluß des Kurators der U, Josef Alexander Jakob Karl Magnus Dahmen (1783-1863), zur Versetzung W.s in Ruhestand. - In dieser Zeit:

UBH: Mitte Aug. 1813-1817 Tätigkeit in UB; Dez. 1813 Nennung als Collaborator („Hilfsarbeiter“) mit e. jährl. Vergütung von 50.- Gulden.

Achern: 1843-1861 Aufenthalt in der 1842 gegründeten Irrenanstalt (Heil- und Pflegeanstalt) Illenau, vermutlich die erste Anstalt dieser Art weltweit (siehe Hoche (1969) S. 105).

Zur Herrnhuter Brüdergemeine siehe auch Theodor Plitt

Qu UAH PA 2447; RA 5137 fol. 37r, 39r, v; RA 5970 fol. 21r. • Staatsarchiv Freiburg/Br. (Krankenakte/PA B 821/2 Nr. 337). • Auskunft: Ev. Pfarramt Christuskirche in Achern. - Mitteilungen: Herr Olaf Nippe, Unitätsarchiv - Moravian Archives Herrnhut - in Herrnhut (Dienerblatt des Vaters: ${ }^{*} 1739$ in Chur (Schweiz), $\dagger 1788$ in Sarepta; Mutter Christiane ${ }^{*} 1750$ auf Gut Hermelinshof bei Riga, $\dagger 1811$ in Herrnhut).

W Sammlung von Stellen aus den Quellen des Römischen Rechts. Heidelberg 1834.

L Wechmar (1846) S. 254. - Über D.H.W. in: Reichlin-Meldegg, Karl Alexander Frhr. von: Das Leben eines ehemaligen römisch-katholischen Priesters. Heidelberg 1874. S. 131. • Weisert (1991)
S. 127 f. u. ö.; Schroeder (2005) S. 223; Humaniora (2006) S. 290 u. ö.; Baur (2009) S. 125, 163-165, 167173; Schroeder (2010) S. 122 u.ö.

\section{Wilmanns, Franz Heinrich Karl (Carlos)}

1906-1917, 1918-1933 Med. Fak.

Psychiatrie

* 26. Juli 1873 Victoria de Durango (Mexiko)

$\dagger$ 23. Aug. 1945 Wiesbaden ev.

V Franz Rudolf August W. (1843-1931) Großkaufmann

M Elise Bernhardine Ottilie geb. Delius

๑ 9. Sept. 1909 Elisabeth Johanna Maria Adolpha geb. Meyer (1885-1969), s. UAH Rep. 14-117 (Brief vom 8. Okt. 1927), B-3182/22; Lexikon jüdischer Einwohner Hs (2011) S. 442; T von: (siehe) Victor Meyer

K $\quad 1$ S, 3 T, s. Lexikon jüdischer Einwohner Hs (2011) S. 442 f. • Ruth W. verh. Wilmanns Lidz (1910-1995) 1933 Emigration, u. a. Aufenthalte: Stockholm, 1934 Schweiz, anschl. Istanbul, seit 1937 USA; seit 1937 Assistenzärztin an Henry Phipps Psychiatric Clinic in Baltimore (Maryland), seit 1943 Ausbildung zur Psycho-Analytikerin, anschl. praktizierende Analytikerin, u. a. 1965-1978 (Emeritierung) Prof. für Psychiatrie an Yale University School of Medicine in New Haven (Connecticut), siehe Wilmanns Lidz, Ruth: Von Heidelberg nach Johns Hopkins in: Emeriti erinnern sich ... Hrsg. von Otto M. Marx ... Weinheim 1993. Bd. I. S. 251277; Dies.: Ein erfülltes Leben in: Psychoanalyse in Selbstdarstellungen. Hrsg. von Ludger M. Hermanns ... Tübingen 1994. Bd. II. S. 277311; After Freud Left. A Century of Psychoanalysis in America. Ed. by John Burnham. Chicago 2012. S. 269 (Register); Jüdinnen und Psyche. Hrsg. von Caris-Petra Heidel. Frankfurt/M. 2016. S. 232, 255. - Ehefrau von: Theodore Lidz (1910-2001), u.a. 1951-1978 Prof. für Psychiatrie an Yale University School of Medicine in New Haven (Connecticut), s. Pols, Hans: T.L. in: American National Biography online (May, 2008). 
Vw Onkel: Karl Gustav Heinrich W. (1835-1898) Jurist und 1871-1874 Reichstagsabgeordneter, Antisemit, s. Ferrari Zumbini, Massimo: Die Wurzeln des Bösen. Gründerjahre des Antisemitismus: Von der Bismarckzeit zu Hitler. Frankfurt/M. 2003. - Wilhelm Franz W. (18421911) seit 1877 Prof. für Dt. Sprache Bonn, s. Franck, Johannes: W.W. in: Zs. für dt. Philologie 43 (1911) S. 435-449; Cormeau, Christoph: W.W. und die Einrichtung des Germanistischen Seminars an der Universität Bonn in: Bonn - Universität in der Stadt. Bonn 1990. S. 69-81; Deutsche Philologie an den preuBischen Universitäten im 19. Jahrhundert ... hrsg. von Uwe Meves. Berlin 2011. S. 1120 (Register); Grewolls (2011). - Gustav Heinrich W. (1845-1878) Epigraphiker und seit 1876 o. Prof. für Geschichte Straßburg, s. ADB 43 (1898) S. 304-306, WBIS

Vw Vettern: Dr. med. Richard Karl Paul W. (18801958) seit 1908 Oberarzt, 1925-1949 (Ruhestand) Erster Arzt an chirurg. Abt. der Westf. Diakonissenanstalt Sarepta in Bethel bei Bielefeld, s. Lebenslang als minderwertig abgestempelt. Das Mahnmal zum Gedenken an die Opfer von Zwangssterilisationen während der NS-Zeit in Bethel ... Hrsg. von Bernward Wolf. Bielefeld 2001. S. 17; Schmuhl, Hans-Walter: Ärzte in der Westf. Diakonissenanstalt Sarepta 1890-1970. Bielefeld 2001. • Dr. phil. Ernst W. (1882-1960) Geschichtsdidaktiker, s. Barricelli, M.: Zugriff verweigert? Die Konjunkturen von Kritik, Gemeinschaft und Weltanschauung bei E.W. ... in: Geschichtsdidaktik(er) im Griff des Nationalsozialismus? Hrsg. von W. Hasberg und M. Seidenfuß. Münster 2005. S. 187 ff. • Wolfgang Otto W. (1893-1968) 19341945 o. Prof. für Landwirtschaftl. Betriebslehre Leipzig, 1949-1958 Leiter der Hessischen Lehrund Versuchsanstalt für Grünlandwirtschaft und Futterbau, seit 1951 Honorar-Prof. Gießen, s. WBIS, Professorenkatalog Leipzig online.

Lb Seit WS 1893/94 Studium an U Bonn, anschl. Göttingen, Berlin; 16. Febr. 1897 Dr. med. an U Bonn; 14. Dez. 1898 Approbation in Bonn; Assistent an Staats-Irrenanstalten: seit 1899 Bremen, seit 1900 Bonn.
UH: April 1901-Febr. 1917 Zunächst Assistent von Emil Kraepelin, dann Oberarzt an Psychiatr. UKlinik; 1. März 1906 Habilitation; 19. Jan. 1912Febr. 1917 nichtetatm. a. o. Prof. • In dieser Zeit:

Seit Aug. 1914 Kriegsdienst.

Insel Reichenau (Bodensee): Seit 2. März 1917 Direktor der Badischen Heil- und Pflegeanstalt.

UH: Seit 16. Juli 1918 o. Prof. und Direktor der Psychiatr. U-Klinik als Nachf. von Franz Nissl; zwischen Nov. 1932 und Dez. 1933 mehrmalige Hausdurchsuchungen von NS-Uniformierten wegen despektierlicher Äußerungen W.s über Adolf Hitler und Hermann Göring, s. hierzu Wilmanns Lidz, Ruth: Von Heidelberg ... (1993) S. 252 f. (s. oben Eintrag unter K[inder]); 27. April 1933 Enthebung seines Amtes als Vorsitzender der akad. Krankenhauskommission; 3.-ca. 13. Mai 1933 Inhaftierung; 4. Mai 1933 Beurlaubung mit sofortiger Wirkung; 30. Juni 1933 Entlassung aufgrund des Gesetzes zur „Wiederherstellung des Berufsbeamtentums“; anschl. mehrwöchiger Aufenthalt in e. Zimmer über der Garage e. Freundes in Baden aufgrund telefonischer Todesandrohungen; anschl. für längere Zeit in e. Erholungsheim im Allgäu versteckt, s. hierzu Wilmanns Lidz, Ruth: Ein erfülltes Leben ... (1994) S. 282-284 (s. oben Eintrag unter $K$ [inder]).

Wiesbaden: Seit ca. 1935 Wohnsitz; Arzt, Konsiliarius und Referent; Juli 1945 UH bittet W., seine früheren Rechte als o. Prof. wieder wahrzunehmen; W. lehnt aus gesundheitlichen Gründen ab.

1923/24 Dekan der Med. Fak. der UH

Hans Prinzhorn (1886-1933) ist 1919-1921 Assistent von W. an der Heidelberger Psychiatrischen Universitätsklinik; in dieser Zeit unterstützt ihn W. bei der Sammlung von Kunstwerken Geisteskranker (heutige „Prinzhorn-Sammlung“, Voßstraße 2 in Heidelberg), siehe auch Hans Fehr: Eintrag unter $V w$ [Schwager].

$\mathrm{Qu}$ UAH PA 1248, 1381, 6370; RA 6179, 6326, 6809. Briefe: UBH. 
W Zur Psychopathologie des Landstreichers. Leipzig 1906. - Über Gefängnispsychosen. Halle/S. 1908. - Geliebtenmörder. Berlin 1913. (Mitverf.: Albrecht Wetzel.) (Verbrechertypen. H. 1.) • Säufer als Brandstifter. Berlin 1914. (Mitverf.: (siehe) Hans Gruhle, Georg L. Dreyfus.) (Verbrechertypen. H. 2.) - Die sogenannte verminderte Zurechnungsfähigkeit als zentrales Problem der Entwürfe zu einem deutschen Strafgesetzbuch ... Berlin 1927.

L Stübler (1926) S. 325; Kürschner (1935) Sp. 1542; Große Nervenärzte 2 (1959) S. 15; Fischer $2\left({ }^{3} 1962\right)$ S. 1689. - Über K.W. in: Oettingen, Hans von: Abenteuer meines Lebens. Berlin 1981. S. 86-92 u. ö. • Chronik Ärzte H (1985) S. 146; Klüpfel/ Graumann (1986) S. 46-51. Hermle, Leopold: K.W. ... - biobibliographische Betrachtung einer psychiatrischen Ära in: Fortschritte der Neurologie - Psychiatrie 56 (1988) S. 103-110. - Mussgnug (1988) S. 300 (Register). - Lidz, Ruth, Wiedemann, Hans-Rudolf: K.W. ... einige Ergänzungen und Richtigstellungen in: Fortschritte der Neurologie, Psychiatrie 57 (4) (1989) S. 161f. - Jansen (1992) S. 414 (Register); Ders. (1992a) S. 170 (Register). • Kreuter, Alma: Deutschsprachige Neurologen und Psychiater. München 1996. Bd. 3. S. 1588-1590. • Hoffmann, Klaus: K. W. - Gründer der Heidelberger Schule für Psychopathologie und wegweisender Sozialpsychiater und Kriminologe in: Ars Medici - Schweizer Zs. für Hausarztmedizin 93 (2003) S. 1-5. Lexikon jüdischer Einwohner Hs (2011) S. 442 f. - Mundt, Ch., Hoffmann, K., Wilmanns, J.: K. W. theoretische Ansätze und klinische Praxis. Ihre Bedeutung für die heutige Psychiatrie in: Der Nervenarzt 82 (1) (2011) S. 79-89. • Deutsche Biographie, s. https://www.deutsche-biographie.de/ pnd11929527X.html [27.11.2017]. - Rotzoll, Maike, Röske, Thomas: K.W. ... und die Geburt der Sammlung Prinzhorn aus dem Krieg in: UH während des Ersten Weltkriegs (2017) S. 279-296.

P Bildarchiv UAH; Chronik Ärzte H.

\section{Wilms (Taufeintrag: Willms), Karl Max}

Wilhelm

1910-1918 Med. Fak.

Chirurgie

* 05. Nov. 1867 Hünshoven (Rheinland; heute: Ortsteil von Geilenkirchen)

$\dagger$ 14. Mai 1918 Heidelberg

口 Köln

kath.

V Peter Mathies Willms, Justizrat und Notar

M Emilie geb. Knauer

๑ 18. Nov. 1914 Marie Frieda Else geb. Seyfferth (1880-1974)

K keine.

Lb Seit WS 1886/87 Studium zunächst der Rechtswiss. (1 Semester), dann der Medizin an U München, anschl. Marburg, Bonn, Berlin; 7. Juni 1890 Dr. med. an U Bonn; WS 1890/91 Staatsexamen in Bonn.

Assistent: Seit Jan. 1892 Patholog.-Anatom. Inst. der U Gießen, seit Aug. 1895 Innere Abt. des Augusta-Hospitals in Köln.

U Leipzig: Seit Jan. 1897 Assistent an Chirurg. UKlinik und Poliklinik; 5. Jan. 1899 Habilitation; seit 27. Juni 1904 außeretatm./nichtetatm. a.o. Prof.; 31. März 1907 auf eigenen Antrag Entlassung.

U Basel: Seit SS 1907 o. Prof. und Leiter der Chirurg. U-Klinik.

UH: 30. Juni 1910 Ern. zum o. Prof. und Direktor der Chirurg. U-Klinik als Nachf. von Albert Narath; WS 1910/11 Amtsantritt; 1914-1918 Kriegsdienst (seit Jan. 1915 felddienstunfähig, aber garnisondienstfähig); in dieser Zeit: 15. Okt.-15. Dez. 1914 Georg Hirschel übernimmt stellvertr. die Leitung der Chirurg. U-Klinik.

Nach Wilms sind benannt: W.sche Zotte, W.sche Amputationsmethode, W.sches Symptom bei 
Darmverschluß, W.scher Tumor und W.-Sieverssche Sehnennaht, s. Roche Lexikon Medizin. 5. Aufl. Hrsg. von der Hoffmann-La Roche AG ... München 2003. S. 1974 u. ö.

Seit 1911 Mitglied des Heidelberger Schloßvereins

Hofrat; 1917 Geh. Hofrat

E Königl. Sächsischer Albrechtsorden II. Klasse.

Qu UAH PA 1249, 2448; RA 6789; Quästurakte Rep. 27-1435 (1910-1918). • UA Leipzig (PA 1663). • GLA Abt. 235, Fasz. 2705.

$W$ Die Mischgeschwülste. 3 Bde. (Bd. 1: Die Mischgeschwülste der Niere.) Leipzig 1899-1902. • Zur Technik der Sehnennaht in: Zentralblatt für Chirurgie 32/40 (1905) S. 1057-1059; Die Freilegung des Herzens bei Herzverletzungen in: ebd. 33/30 (1906) S. 817f. - Der Ileus. Pathologie und Klinik des Darmverschlusses. Stuttgart 1906. Zur Stumpfversorgung nach Magenresektion in: Zentralblatt für Chirurgie 38/26 (1911) S. 892-894. • Die Rammstedtsche Operation beim hypertrophischen Pylorospasmus der Säuglinge in: Dt. Zs. für Chirurgie 144 (1918) S. 63.

MHG Lehrbuch der Chirurgie. 3 Bde. Jena 19081909. 7. Aufl. 1923.

$L$ Biogr. Jahrbuch 2 (1917-1920) S. 344-346; Stübler (1926) S. 320; Fischer $2\left({ }^{3} 1962\right)$ S. 1690; Krebs/ Schipperges (1968) S. 72-76. - Hofstetter, Iris: M.W. Leben und Werk eines Heidelberger Chirurgen. Diss. Heidelberg 1975. Leier (1977) S. 8386; WBIS; Chronik Ärzte H (1985) S. 146 f.; Semper apertus 4 (1985) S. 198-200. - Zantinga, Arty R., Coppes Max J.: M. W. ... The man behind the eponym in: Medical and Pediatric Oncology (1992) 2o(6), S. 515-518. • Borgwardt, Götz: M. W. A German surgeon at the beginning of the 2oth century. An appreciation on the centenary of his article „Die Mischgeschwülste der Niere“. Berlin 1999. • Goerttler 1 (2003); Professorenkatalog Leipzig online; Badische Biographien N.F. VI (2011) S. 427430; Raffensperger (2012) S. 313-315 u. ö.; Deutsche Biographie, s. https://www.deutsche-biographie. de/pnd1041335717.html [31. 03. 2017]. • Suson, Kris- tina et al.: A triphasic history of the man, his eponymous tumor, and its evolving treatment in: The Journal of Urology (May 15, 2017) Vol. 197, No. 4S, Supplement, S. e1067f.

P Bildarchiv UAH; Chronik Ärzte H.

\section{Windelband, Heinrich Wilhelm}

1903-1915 Phil. Fak.

Philosophie

* 11. Mai 1848 Potsdam

$\dagger \quad$ 22. Okt. 1915 Heidelberg ev.

V Friedrich Wilhelm W. (†1859) 1849 Reg.-Secretair, zuletzt Rechnungsrat im Oberpräsidium der Mark Brandenburg, s. „Sammlung einiger Daten zum Leben des Königl. Geh. Reg.-Rates Carl August Ferdinand Wichgraf, tätig u.a. in Potsdam und Nowawes, sowie auch einige Angaben zu seiner Familie und Angeheirateten mit den Namen", online unter https://www.janecke.name/gaeste/wichgrafin-potsdam (abgerufen am 30. Dez. 2017)

M Friederike geb. Gerloff ( $\dagger$ ca. 1873), s. Sammlung einiger Daten ...

$\infty$ 10. Okt. 1874 Martha Wilhelmine geb. Wichgraf (1850-1924)

K $\quad 4 \mathrm{~T}$ (davon $1 \mathrm{~T}$ früh $\dagger$ ), u. a. Elly W. (1879-1964) Ehefrau von Dr. iur. Dr. phil. h.c. Ulrich Stutz (1868-1938), u. a. seit 1917 Prof. für Dt. Recht und Kirchenrecht an U Berlin, s. Drüll (2009) S. 486: Biographie Reicke, Siegfried: Eintrag unter $\varnothing$ [Ehefrau]). 2 S: Sigfri (e)d W. $\left({ }^{*} 1883\right.$ X 1914); (siehe) Wolfgang W.

Lb Seit SS 1866 Studium an U Jena, WS $1867 /$ 68 Berlin, SS 1868 ?, seit WS $1868 / 69$ Berlin, WS 1869/70 auch Studium der Physik an U Göttingen; 7. April 1870 Dr. phil. an U Göttingen; 27. Juli 1870-26. Juli 1871 Jäger im Deutsch-Französischen Krieg; anschl. Aufenthalt in Italien.

U Leipzig: 13. Nov. 1872 Habilitationskolloquium; 26. April 1873 Verleihung der venia legendi. 
U Zürich: Seit 12. April 1876 o. Prof. für Induktive Philosophie.

U Freiburg/Br.: Seit 1. April 1877 o. Prof.; seit 3. Apr. 1880 (Gründungs-)Direktor des Phil. Seminars; 1880 Ruf an U Graz abgelehnt; Frühjahr 1881 Forschungsaufenthalt in Paris.

U Straßburg: Seit 1. Okt. 1882 o. Prof.

UH: 16. Nov. 1902 Ern. zum o. Prof. (als Nachf. von Kuno Fischer seit 1906); 6. April 1903 Vereidigung; seit 15. Aug. 1904 (Gründungs-)Direktor, SS 1913SS 1914 Mit-Direktor (zus. mit Emil Lask), seit WS 1914/15 Direktor des Phil. Seminars, das seit 1907 (bis heute) in der Augustinergasse 15/Schulgasse 6 (Seminarienhaus, ehemaliges Jesuitengymnasium) untergebracht ist. • In dieser Zeit:

Karlsruhe: 1905-1908 Mitglied der I. Kammer des Badischen Landtags als Abgeordneter der UH.

1909 Prorektor der UH

1881 Hofrat; 1903 Geh. Rat II. Klasse

Siehe auch Alfred Schmid

Über seine Nachfolge auf den Lehrstuhl Kuno Fischers schreibt W. 1902 an seinen Freund Karl Dilthey (1839-1907; Altphilologe): „... Mit Kuno Fischer habe ich das einfachste Verhältnis: ich übernehme die ganze Professur, und er bekommt dadurch die Möglichkeit, nur noch zu lesen, was ihm passt, Faust und anderes Literaturphilosophisches ..." (aus: Heidelberg im Schnittpunkt intellektueller Kreise (1995) S. 40 und S. 65 Anm. 26).

1.-5. September 1908 Vorsitzender des 3. Int. Kongresses für Philosophie in Heidelberg, s. hierzu Heidelberg im Schnittpunkt, S. 46-52

Neben (siehe) Leo Koenigsberger und (siehe) Friedrich Endemann ist W. maßgeblich an der Gründung der Heidelberger Akademie der Wissenschaften 1909 beteiligt, siehe hierzu UAH Acc. 40/11, Hofer (1993) S. 40-43.
Sept. 1914: W. unterschreibt neben 92 anderen Wissenschaftlern, Schriftstellern und Künstlern das sog. „Manifest der 93“, e. Aufruf vor allem gegen den Vorwurf der deutschen Kriegsschuld und der Kriegsgreuel in Belgien sowie für die Identität von deutscher Kultur und deutschem Militarismus.

Vom 12. bis 14. März 2015 findet ein Int. Symposium: „W.W. 1848-1915“ in Heidelberg statt (Veranstalter: Prof. Dr. Peter König, Dr. Oliver Schlaudt, Philosophisches Seminar der Universität Heidelberg), s. hierzu http://www.philosophie.uni-hd.de/windelband_programm.html (abgerufen am 30. Dez. 2017).

E Mitglied der Akademie der Wissenschaften: 1901 Göttingen, 1903 Berlin, 1904 München, 1909 H; 1910 Korr. Mitglied der Königl. Gesellschaft der Wiss. Göttingen; 1910 Mitglied der Wiss. Gesellschaft Straßburg. • 1893 Königl. Preußischer Roter Adler-Orden IV. Klasse; 1910 Kommandeurkreuz II. Klasse mit Eichenlaub des Ordens vom Zähringer Löwen.

Qu UAH PA 2449; RA 5214, 6432, 6859; Quästurakte Rep. 27-1470; Acc. 40/11. - GLA Abt. 235, Fasz. 2707. UA Leipzig PA 1071. Briefe: UBH. • Vorlesungsmanuskripte aus den Jahren 1878-1900 in Tohoku University Library in Sendai (Japan). • Auskunft: Dr. Jörn Bohr, Universität Wuppertal (DFG-Projekt (HA 2643/14-1) Grundlagenforschung zur Philosophie- und Wissenschaftsgeschichte des 19. und 20. Jahrhunderts am Beispiel W.W. (u. a. Online-Brief-Edition in Bearb. Febr. 2018). Leitung: Prof. Dr. Gerald Hartung, Universität Wuppertal).

$W$ Über die Gewissheit der Erkenntnis. Eine psychologisch-erkenntnistheoretische Studie. Habilitation. Berlin 1873. Reproduktion Saarbrücken 2006. Die Geschichte der neueren Philosophie in ihrem Zusammenhange mit der allg. Cultur und den besonderen Wissenschaften dargestellt. 2 Bde. Leipzig 1878-188o. 3. Aufl. u.d.T.: Lehrbuch der Geschichte der Philosophie. Tübingen 1903. 18. Aufl. 1993. Präludien. Aufsätze und Reden zur Einleitung in die Philosophie. Freiburg/ Br. 1884. 6. Aufl. 1919. Nachdr. Eschborn 1996. Die Geschichte der alten Philosophie. Nördlingen 
1888. 2. Aufl. 1894. • Über Willensfreiheit. 12 Vorlesungen. Tübingen 1904. 4. Aufl. 1923. • Die Hypothese des Unbewußten. Festrede, gehalten in der Gesamtsitzung der Heidelberger Akademie der Wissenschaften am 24. April $1914 \ldots$ in: Die Universität Heidelberg ihren Angehörigen im Felde - Weihnachten 1917. Heidelberg 1917. S. 56-81. Bibliographie in: Chang, Tsun-Hwa (2012).

L Biogr. Jahrbuch 1 (1914-1916) S. 182-184. • Rickert, Heinrich: W.W. Tübingen 1915. 2. Aufl. 1929. - Handels-Hochschule Mannheim 19071932 (1932) S. 29; WBIS; Glockner (1969) S. 278 (Register). - Wiehl, Reiner: Heidelberger Philosophie zwischen Kantianismus und Hegelianismus in: Semper apertus 2 (1985) S. 409-431. Klüpfel/ Graumann (1986) S. 36-38; Jansen (1992) S. 414 (Register); Wennemuth (1994) S. 639 (Register); Heidelberg im Schnittpunkt intellektueller Kreise (1995) S. 32-69. - Ivanov, Vsevolod N.: Im alten Heidelberg (übers. von Alla Meissner) in: Heidelberger Professoren in russischer Sicht. Dokumente aus der Zeit um 1900. Hrsg. von Willy Birkenmaier. Heidelberg 2000. S. 119-131. - Kriegstagebuch K. Hampe (2007) S. 1007 (Register); Ruuskanen (2008) S. 239 f. • Chang, Tsun-Hwa: Wert und Kultur. W.W.s Kulturphilosophie. Würzburg 2012. • Morrone, Giovanni: Valore e realtà. Studi intorno alla logica della storia di W., Rickert e Lask. Soveria Mannelli 2013. Kaesler (2014) S. 1005 (Register). From Hegel to Windelband. Ed. by Gerald Hartung ... Berlin 2015. • Riecke (2016) S. 55 f., 6o-62. - Deutsche Biographie, s. https://www. deutsche-biographie.de/pnd118633635.html [21.07. 2017]. - Fahrenberg, Jochen: Geschichte des Instituts für Psychologie in Freiburg von der Vorgeschichte der Psychologie bis ca. 2000, s. PsyDok http://hdl.handle.net/20.500.11780/3775 (Stand: Aug. 2017). • Gundlach, Horst: W. W. und die Psychologie. Das Fach Philosophie und die Wissenschaft Psychologie im Deutschen Kaiserreich. Heidelberg 2017 (auch online unter DOI: 10.17885/ heiup.203.276). • W.W. ... Studien und Materialien zum Neukantianismus. Hrsg. von Peter König und Oliver Schlaudt. Würzburg 2018.

$P$ Bildarchiv UAH.

\section{Windelband, Wolfgang Martin Adolf}

1914-1925 Phil. Fak.

Neuere Geschichte

* 31. Aug. 1886 Straßburg

$\dagger \quad$ 03. Febr. 1945 Berlin (Suizid) ev.

V (Siehe) Wilhelm W.

M Martha Wilhelmine geb. Wichgraf (18501924)

@ 10. Okt. 1921 Vera geb. Theil $\left({ }^{*} 1897\right)$

$\mathrm{K}$ keine.

Lb Seit SS 1903 Studium an UH, WS 1904/05 Berlin, SS 1905 H, seit WS 1905/o6 Straßburg, anschl. Freiburg/Br.; 4. Juli 1907 Dr. phil. an UH; zwischen 1907 und 1914 Mitarbeiter am GLA in Karlsruhe.

UH: 7. Nov. 1914 Habilitation; vor 1917 kurzzeitiger Kriegsdienst; seit 21. Jan. 1922 nichtbeamteter a.o. Prof.; 22. Jan. 1925 W. hält für Studenten und Besucher aus der Stadt in der Reihe „Vorträge über Vaterlandskunde“ ein Referat über „Der Kampf um den Rhein“ in der Aula der UH; WS 1924/25 letzte Vorlesungen. • In dieser Zeit:

TH Darmstadt: Seit SS 1922 Lehrauftrag für Neuere Staatenkunde und Politik.

Königsberg (Preußen): Seit SS 1925 o. Prof.

U Berlin: Seit SS 1926 Honorar-Prof.; 5. Mai 1933 Ern. zum o. Prof.; Nov. 1935 Verhinderung e. geplanten Versetzung an U Halle-Wittenberg durch Beurlaubung aus gesundheitlichen Gründen; 1936 Entpflichtung. • In dieser Zeit:

Berlin: 1926-1933 Personalreferent im Rang e. Ministerialrats im Preußischen Ministerium für Wissenschaft, Kunst und Volksbildung.

Qu UAH PA 6375; Quästurakte Rep. 27-1471. • GLA Abt. 235, Fasz. 2708. • Briefe: UBH; Staatsbibliothek zu Berlin, Handschriftenabteilung. 
W Die Verwaltung der Markgrafschaft Baden zur Zeit Karl Friedrichs. Leipzig 1916. • Die auswärtige Politik der Großmächte in der Neuzeit 1894-1919. Stuttgart 1922. 6. Aufl. 1964. • Grundzüge der Außenpolitik seit 1871. Berlin 1926. 2. Aufl. 1933. • Bismarck und die europäischen Großmächte, 18791885, auf Grund unveröffentlichter Akten. Essen 1940. 2. Aufl. 1942.

MHG Bismarcks Briefe. Bd. 1: 1822-1861. Bd. 2: 1862-1898. Berlin 1933. (Otto von Bismarck: Die gesammelten Werke. Bde. 14,1 und 14,2.)

L Kürschner (1931) Sp. 3287, (1940/41) Sp. 1102. • Nachruf in: Historische Zeitschrift 172 (1951) S. 661f. - Weber (1987) S. 665 f.; Jansen (1992a) S. 170 (Register). Eberle, Henrik: Die Martin-Luther-Universität [Halle] in der Zeit des Nationalsozialismus 1933-1945. Halle/S. 2002. S. 84 u. ö. • Betker, René: Das Historische Seminar der Berliner Universität im „Dritten Reich“ ... Magisterarbeit an der TU Berlin - Inst. für Geschichtswissenschaft, Fachgebiet Neuere Geschichte. 3. korr. Version 2006 (pdf-Datei). Grüttner/Kinas (2007) S. 157 f.; Kriegstagebuch K. Hampe (2007) S. 1007 (Register). Catalogus prof. Halensis online (hier Sterbedatum: 27. Nov. 1945); Acta Borussica (2016) S. 34, 205 f., 260 f., 1182 u. ö.; Hessische Biografie, s. http://www.lagis-hessen.de/pnd/117400149 (Stand: 31.08.2017; hier Sterbeort: Halle/S.); Deutsche Biographie, s. https://www.deutsche-biographie. de/pnd117400149.html [30.11.2017].

\section{Windisch, Ernst Wilhelm Oskar}

1872-1875 Phil. Fak.

Vgl. Sprachwissenschaft, Sanskrit

* $\quad$ 04. Sept. 1844 Dresden

$\dagger \quad$ 30. Okt. 1918 Leipzig

ev.-luth.

V Wilhelm Louis W., Oberlehrer

M Caroline Sophie geb. Lamm
(18. April 1873 Bertha Ida Caroline Albertine geb. Roscher, T von Wilhelm Georg Friedrich R. (1817-1894) seit 1840 Privat-Dozent, seit 1843 a. o. Prof., seit 1844 o. Prof. Göttingen, 1848-1889 o. Prof. für Staats- und Kameralwissenschaften Leipzig, s. Wölky, Guido: Roscher, Waitz, Bluntschli und Treitschke als Politikwissenschaftler. Spätblüte und Untergang eines klassischen Universitätsfaches in der zweiten Hälfte des 19. Jahrhunderts. Diss. Bochum 2006; Professorenkatalog Leipzig online

K 1 T, 4 S: u.a. Hans W. (1881-1935) seit 1908 Privat-Dozent Leipzig; o. Prof. für Neues Testament und Altchristliche Literatur: seit 1914 Leiden (Niederlande), seit 1929 Kiel, 1935 Halle/S., s. Stephan, Christian: Die stumme Fakultät. Biographische Beiträge zur Geschichte der Theologischen Fakultät der Universität Halle. Dössel 2005. S. 163-166.

Lb U Leipzig: Seit 17. April 1863 Studium der Klassischen Philologie und Sprachwiss.; 1867 Staatsexamen für höheres Lehramt; Sommer 1867 Dr. phil.; 7. Aug. 1869 Habilitationskolloquium.

Leipzig: Ostern 1867-1870 Lehrer an Thomasschule.

London: 1870-1871 Mitarbeiter an Indian Office Library und Eigenstudien; 1871 Ruf an U Bombay (Indien) abgelehnt.

U Leipzig: Seit 1. Okt. 1871 a.o. Prof. mit Jahresgehalt.

UH: 19. Juni 1872 Ern. zum o. Prof. mit e. jährl. Besoldung von 180o.- Gulden; 3. Okt. 1872 Vereidigung; 1. Juni 1874 jährl. Besoldungszulage von 200.- Gulden.

U Straßburg: Seit WS 1875/76 o. Prof.

U Leipzig: WS 1877/78-1918 (†) o. Prof. und Direktor des Indogermanischen Inst.

Königl. Sächsischer Geh. Rat

$E$ Mitglied der Akademie der Wissenschaften: 1883 Leipzig, 1905 München. • D. theol. 
Qu UAH PA 2450; RA 6863. - UA Leipzig PA 1072. - Briefe: u. a. Universitätsbibliothek Leipzig; s. auch Katalog der Handschriften der Universitätsbibliothek Leipzig. N. F. Bd. 1. T. 4. Beschrieben von Detlef Döring. Wiesbaden 2005. S. 209 (Register). - Nachlaß: Bibliothek der Dt. Morgenländischen Gesellschaft in Halle/S. (siehe Universitäts- und Landesbibliothek Sachsen-Anhalt).

W Syntaktische Forschungen. Halle/S. 1871. • Kurzgefaßte irische Grammatik mit Lesestücken. Leipzig 1879. Buddhas Geburt und die Lehre von der Seelenwanderung. Leipzig 1908. - Geschichte der Sanskrit-Philologie und indischen Altertumskunde. 2 T. Straßburg 1917-1920. Nachdr. Berlin 1992. E.W. Kleine Schriften. Hrsg. von Karin Steiner und Jörg Gengnagel. Stuttgart 2001. • Bibliographie in: Festschrift. E. W. zum 70. Geburtstag ... Schriftenverzeichnis zus.gestellt von Ernst Kuhn. Leipzig 1914. S. 366-380.

Redakteur 1880-1893 Zs. der Dt. Morgenländischen Gesellschaft (ZDMG).

L Biogr. Jahrbuch 2 (1917-1920) S. 709. • Förster, Max: Zum Gedächtnis E.W.s in: ZDMG 73 (1919) S. 183-188 (mit Werkverz.). • Hertel, Johannes: Nekrolog in: Berichte über die Verh. der Sächsischen Akademie der Wissenschaften Leipzig. Phil.-Histor. Klasse (1921) H. 2, S. ${ }^{*} 9-{ }^{*} 24$. $\bullet$ WBIS. • Mylius, Klaus: Geschichte der altindischen Literatur ... 2. Aufl. Wiesbaden 2003. S. 34 f., 179 f. u. ö. • Sachsens Landesuniversität in Monarchie, Republik und Diktatur. Hrsg. von Ulrich von Hehl. Leipzig 2005. S. $528 \mathrm{f}$. Geschichte U Leipzig 2 (2010) S. 924 (Register), 4 (2009) S. 1636 (Register); Professorenkatalog Leipzig online; Riecke (2016) S. 24; Deutsche Biographie, s. https://www.deutsche-bio graphie.de/pnd117400564.html [30.11.2017].

P Universitätsbibliothek Leipzig; ZDMG (1919).
Windscheid, Josef Bernhard Hubert (1868: Verleihung des Adelstitels, nicht geführt)

1871-1874 Jur. Fak.

Pandekten, Institutionen, Römische Rechtsgeschichte

* 26. Juni 1817 Düsseldorf

$\dagger \quad$ 26. Okt. 1892 Leipzig

kath., seit 1874 altkath., seit $1891 \mathrm{ev.}$

V Ferdinand W. (1787-1869) königl. Hypothekenbewahrer

M Friderieke geb. Servaes (1795-1852)

๑ 4. Nov. 1858 Auguste Leonore Charlotte (Lotte) geb. Pochhammer (1830-1918) Malerin, seit 1887 (Gründerin) Vorstandsvorsitzende des Vereins für Mädchenhorte zur Betreuung von „dem Straßenleben überlassenen“ Mädchen, s. Theodor Fontane und Martha Fontane. Ein Familienbriefnetz. Hrsg. von Regina Dieterle. Berlin 2002. S. 379, 793; Leyh, Manfred: Charlotte W. geb. P., s. https://www.leipzig.de/ju gend-familie-und-soziales/frauen/10oo-jah re-leipzig-10o-frauenportraets/soziales/sozia les-portraets/ (2015; Ausdruck im UAH)

K 3 T: u. a. Dr. phil. (1895 erste Promovendin an Phil. Fak. der UH, s. Birn, Marco: Bildung und Gleichberechtigung ... Heidelberg 2012. S. 20, 48 f.) Katharina (Käthe) W. (1859-1943) Lehrerin, Frauenrechtlerin und Wegbereiterin für das Frauenstudium, s. Rothenburg, Hannelore: K. W. ... in: Leben ist Streben ... Hrsg. von Johanna Ludwig. Leipzig 2003; Birn (2012) S. 192 (Register). - Charlotte (Lotte) W. (1864-1938) Ehefrau von Paul Oertmann (1865-1938) seit 1892 Privat-Dozent, seit 1896 a. o. Prof. Berlin; o. Prof. für Bürgerliches Recht: seit 1901 Erlangen, 1918-1934 Göttingen, s. Professoren Erlangen (1993) S. $148 \mathrm{f}$., NDB 19 (1999) S. 451 f. • 1 S: Franz W. (18621910) seit 1891 Privat-Dozent für Neurologie, 1901-1910 a. o. Prof. Leipzig, 1900-1910 Chefarzt der Unfallnervenklinik der Sächsischen Baugewerks-Berufsgenossenschaft ebd., s. Angermeyer, Matthias C., Steinberg, Holger: 200 Jahre Psychiatrie an der Universität Leipzig. Personen und Konzepte. Heidelberg 2005. • Siehe auch WBIS, Klein (2014) S. 264 f., 376378, 445-449 u. ö. 
Lb Seit WS 1834/35 Studium der Rechtswiss. an U Bonn, 3. Nov. 1835-8. Aug. 1837 Berlin; 1837 I. jur. Examen; seit Nov. 1837 Auskultator (s. Levin Goldschmidt: Eintrag unter $L b(1851))$ am Landgericht Düsseldorf; Mai-Dez. 1838 Beurlaubung.

U Bonn: 16. Mai 1838 Immatrikulation; 22. Dez. 1838 Dr. iur.

Düsseldorf: Nach 22. Dez. 1838 Rückkehr als Auskultator an Landgericht.

U Bonn: 14. Mai 1840 Habilitation; seit 8. Juli 1847 a. o. Prof. für Römisches und Franz. Recht.

U Basel: Seit 15. Sept. 1847 o. Prof.

U Greifswald: 3. April 1852 Ern. zum o. Prof. für „Processdisciplinen“ und Römisches Recht mit e. Jahresgehalt von 1000.- Reichstalern; Mai 1852 Vorlesungsbeginn.

U München: 26. Juni 1857 Ern. zum o. Prof. für Pandekten, Institutionen und Römische Rechtsgeschichte; WS 1857/58 Vorlesungsbeginn.

UH: 17. Sept. 1870 Ern. zum o. Prof. als Nachf. von Carl Adolph von Vangerow; SS 1871 Amtsantritt; 1871-1874 Beisitzer des Spruchkollegiums der Jur. Fak.; Rufe an U abgelehnt: 1871 Straßburg, 1871/ 72 Leipzig, 1872 Berlin; 1872 Erhöhung des Jahresgehalts von 4800.- auf 600o.- Gulden.

U Leipzig: 20. Okt. 1874 (Vereidigung)-26. Okt. 1892 o. Prof.; 1880 Ruf an U Berlin abgelehnt; WS 1881/82-SS 1883 Beurlaubung; in dieser Zeit:

Berlin: Okt. 1881-Okt. 1883 Mitglied der Ersten Kommission für die Abfassung e. Entwurfs zu e. Dt. Bürgerlichen Gesetzbuch.

U Leipzig: WS 1883/84 Wiederaufnahme der Vorlesungen.

1874 Prorektor der UH; 1872/73 Dekan der Jur. Fak. der UH

1870 Badischer Geh. Rat II. Klasse
Mai 1871 Gründungsmitglied des Heidelberger altkatholischen Komitees, 1874 wohl Mitglied der altkatholischen Gemeinde, s. Keßler (1986) S. 53 Anm. 26 (unter Qu), Klein (2014) S. 331-335.

E Ehrendoktorate: 1888 Bologna, 1888 Leipzig, 1890 Edinburgh. 1866 Ritterkreuz des Bayer. Ordens vom Hl. Michael; 1869 Ritterkreuz des Verdienstordens der Bayer. Krone; 1872 Kommandeurkreuz II. Klasse mit Eichenlaub des Ordens vom Zähringer Löwen; 1878 Ritterkreuz I. Klasse des Königl.-Sächsischen Verdienstordens. 1890 Ehrenbürger der Stadt Leipzig.

Qu UAH PA 2451. • Briefe: UBH. - Schubert, Werner: W.s Briefe an (Gottlieb) Planck und seine für Planck bestimmten Stellungnahmen zum Schuldrechtssystem und zum Besitzrecht der 1. BGB-Kommission in: Zs. der Savigny-Stiftung für Rechtsgeschichte - Romanistische Abt. Bd. 95 (Aug. 1978) H. 1, S. 283-326. - Keßler, Ewald: B. W. an Peter Knoodt (Briefe 1872-1874) in: Int. Kirchliche Zs. 1 (1986) S. 42-54. • Briefe, Nachlaß: siehe Katalog der Handschriften der Universitäts-Bibliothek Leipzig. N. F. Bd. 1. T. 4. Beschrieben von Detlef Döring. Wiesbaden 2005. S. 209 (Register); Klein (2014) S. 466-485; siehe auch Kalliope. Lesener, Hans: B.W.s Tagebuch aus den Jahren 1837-1843 in: Zs. der Savigny-Stiftung für Rechtsgeschichte - Romanistische Abt. Bd. 83 (1966) S. 382-396.

$W$ Die Wirkung der erfüllten Bedingung. Basel 1851. - Die actio des römischen Civilrechts vom Standpunkte des heutigen Rechts. Düsseldorf 1856. - Lehrbuch des Pandektenrechts. 3 Bde. Düsseldorf 1862-1870. 9. Aufl. 1906. Antrittsrede von B. W. in: Die Leipziger Rektoratsreden ... Bd. 1: Die Jahre 1871-1905. Berlin 2009. S. 375-386. • Bibliographie in: Klein (2014) S. 450-459.

MHG 1871-1878 Archiv für die civilistische Praxis.

L Jammers (1964) S. 178 u. ö.; Verzeichnis Bonn (1968) S. 339. - Ober, Jürgen: B.W. und die Reinigung des römischen Rechts. Diss. Köln 1989. • Klemann, Bernd: Sieben kleine Beiträge für eine Windscheid-Biographie in: Rechtsgeschichte in den beiden deutschen Staaten ... Frankfurt/M. 
1991. S. 211-229. • Falk, Ulrich: Der wahre Jurist ... Zum Gedenken an B.W. in: Rechtshistorisches Journal 12 (1993) S. 598-633; Ders.: Ein Gelehrter wie W. ... 2. Aufl. Frankfurt/M. 1999. • Schubert, Werner: Die Anträge von B. W. in der 1. BGBKommission ... in: Festschrift für Rolf Knütel zum 70. Geb. Hrsg. von Holger Altmeppen u.a. Heidelberg 2009. S. 1103-1134. • WBIS; Geschichte U Leipzig 2 (2010) S. 924 (Register); Professorenkatalog Leipzig online; Schroeder (2010) S. 239-242 u. ö.; Grewolls (2011). • Schröder, Rainer: Rechtsgeschichte. 8. Aufl. Münster 2011. S. 140-142, 146148 u. ö. - Geibel, Stefan J.: W.s Einfluß auf das BGB, ausgehend von seinen Heidelberger Jahren in: Heidelberger Thesen zu Recht und Gerechtigkeit. Hrsg. von Christian Baldus ... Tübingen 2013. S. 161-178. Maus (2013) S. 403 f. Anm. 1307 u. ö. • Klein, Friedrich: B. W. ... Leben und Werk. Berlin 2014. - Simon, Dieter: B. W. ... in: Myops. Berichte aus der Welt des Rechts. München 2015. S. 1726. Avenarius, Martin: B. W. ... Der Spätpandektist und seine Wirkung auf das Rechtsdenken des europäischen Auslands in: Zs. für europäisches Privatrecht (2017) S. 396-418. - Polley, Rainer: Thibaut im Urteil seiner Lehrstuhlnachfolger des 19. Jahrhunderts: Karl Adolph von Vangerow, B. W. und Ernst Immanuel Bekker im Vergleich mit zeitgleichen Würdigungen durch praktische Juristen des In- und Auslandes in: A. F. J. Thibaut ... Bürger und Gelehrter. Hrsg. von Christian Hattenhauer ... Tübingen 2017. S. 100-103 u. ö. • Rückert, Joachim: W. - verehrt, verstoßen, vergessen, rätselhaft? in: JuristenZeitung (2017) 72. Jg., S. 662-670. • Schröder, Jan: B.W. ... in: Deutsche und europäische Juristen aus neun Jahrhunderten. Eine biographische Einführung in die Geschichte der Rechtswissenschaft. Hrsg. von Gerd Kleinheyer und Jan Schröder. 6. Aufl. Tübingen 2017. S. 472-476.

$P$ Bildarchiv UAH; graph. Slg. UBH.

\section{Winkelmann, Eduard August}

1873-1896 Phil. Fak.

Mittelalterliche Geschichte

* 25. Juni 1838 Danzig (heute: Gdańsk, Polen)

$\dagger$ 10. Febr. 1896 Heidelberg ev.

V Karl W. († 1850) Goldschmied

M Laura geb. Ulrich

๑ Sommer 1861 Mathilde geb. Christoph ( $†$ nach 1896)

$\mathrm{K}$ mindestens $3 \mathrm{~S}$ (davon $1 \mathrm{~S}$ früh $\dagger$ ), $2 \mathrm{~T}$ : Marie Anna Mathilde W. (1865-1942) Ehefrau von: (siehe) Friedrich Blochmann; Gertrude Mathilde W. (1874-1961) Ehefrau von: (siehe) Eugen von Hippel.

Lb Seit SS 1856 Studium an U Berlin, seit SS 1858 Göttingen, seit SS 1859 Berlin; 1. Dez. 1859 Dr. phil. an U Berlin.

Berlin: Seit Dez. 1859 Mitarbeiter an den Monumenta Germaniae Historica (MGH); Sommer 1860 Oberlehrerexamen.

Reval (Russisches Kaiserreich; heute: Tallinn, Estland): Okt. 1860-Aug. 1865 Oberlehrer an Ritterund Domschule.

U Dorpat (heute Tartu, Estland; bis 1889 einzige dt.sprachige $U$ im Russischen Kaiserreich): 25. Aug. 1865 Habilitation; seit März 1866 etatm. Privat-Dozent; 1867-1869 Präsident der Gelehrten Estnischen Gesellschaft in Dorpat.

U Bern: Seit 28. Jan. 1869 a.o. Prof. und Gymnasiallehrer in Bern; seit 21. Okt. 1869 o. Prof.; 1872/ 73 Italienreise; 1873 Ruf an U Marburg abgelehnt.

UH: Seit 18. Sept. 1873 o. Prof. als Nachf. von Wilhelm Wattenbach; 1877 Italienreise; 1890 (Etatisierung des Seminars)-1896 (†) Mit-Direktor (zus. mit Bernhard Erdmannsdörffer) des Histor. Seminars.

1880 Prorektor der UH; 1877/78, 189o/91 Dekan der Phil. Fak. der UH 
1867 Russischer Hofrat; 1873 Badischer Hofrat; 1886 Badischer Geh. Hofrat

Siehe auch Adolf Koch

E Mitglied der Akademie der Wissenschaften: 1873 München, 188 o Göttingen. $\bullet 1887$ Bayer. Verdienstorden des Hl. Michael.

Qu UAH PA 2453; RA 6847. - UBH Heid. Hs. 3715,28. Bibliothek Winkelmann. Leipzig 1897, s. UBH F 9977-4. • Briefe, Nachlaß: UBH.

$W$ Bibliotheca Livoniae historica. Systematisches Verzeichnis der Quellen und Hilfsmittel zur Geschichte Estlands, Livlands und Kurlands. St. Petersburg 1870. 2. Ausg. Berlin 1878. Nachdr. Hildesheim 1969. Philipp von Schwaben und Otto IV. von Braunschweig. 2 Bde. Leipzig 1873-1878. Nachdr. Darmstadt 1963-1968. - Über die ersten Staats-Universitäten. Rede zum Geburtsfeste ... Grossherzogs Karl Friedrich von Baden ... Heidelberg 1880. • Kaiser Friedrich II. 2 Bde. Leipzig 1889-1897. Nachdr. Darmstadt 1963-1967. • E. W.s Allgemeine Verfassungsgeschichte. Als Handbuch für Studierende und Lehrer hrsg. von Alfred Winkelmann. Leipzig 1901.

HG Acta imperii inedita: saeculi XIII et XIV. Urkunden und Briefe zur Geschichte des Kaiserreichs und des Königreichs Sizilien. Bd. 1: 11981273. Bd. 2: 1200-1400. Innsbruck 1880-1885. Nachdr. Aalen 1964. - Urkundenbuch der Universität Heidelberg ... 2 Bde. Heidelberg 1886.

Übers. Der sächsische Annalist. Nach der Ausgabe der Monumenta Germaniae. Berlin 1864. 3., unveränd. Aufl. neu bearb. von Wilhelm Wattenbach. Leipzig 1941.

L ADB 43 (1898) S. 435-442; Baier (1937) S. 188, 199-201 u.ö.; Catalogus prof. Marburgensis 1 (1927) S. $357^{*}$; WBIS. - E.W. in: Deutschbaltisches biographisches Lexikon 1710-1960. Hrsg. von Wilhelm Lenz. Köln 1970. - Conze, Werner und Mussgnug, Dorothee: Das historische Seminar in: Heidelberger Jahrbücher 23 (1979) S. 135-
137. - Weber (1987) S. 666 f.; Jakobs (1992) S. 4649. - De litteris, manuscriptis, inscriptionibus ... Hrsg. von Theo Kölzer ... Wien 2007. S. 617 f., 632 u. ö. Schmitz, Norbert: Alfred Stern (1846-1936). Ein europäischer Historiker gegen den Strom der nationalen Geschichtsschreibung. Diss. 2008. U Tromsø (Norwegen). Überarb. Fassung, s. https:// munin.uit.no/bitstream/handle/10037/1864/thes is.pdf? sequence $=1$ (abgerufen am 7. Jan. 2018). • Über E. W. in: Otto IV. Traum vom welfischen Kaisertum ... Hrsg. ... von Bernd Ulrich Hucker ... Petersberg 2009. S. $471 \mathrm{f}$.

$P$ Bildarchiv UAH; graph. Slg. UBH; Heidelberger Jahrbücher.

\section{Winkler, Robert}

1922-1935 Theol. Fak.

Systematische Theologie, Religionsphilosophie

* 22. Juli 1894 Kulmbach

$\dagger \quad$ 22. Juni 1983 Ismaning (bei München) ev.

V Johann Georg Caspar W. (1820-(vor) 1864) seit 1847 Zinngießermeister, s. Süddeutsche Zinngiesser. T. II: Künzelsau/Sulzbach. Hrsg. von Erwin Hintze. Neudr. der Ausg. 1921-1931. Osnabrück 1965. Nr. 58 f. (Angebot von zwei Kännchen mit Zuckerdose und zwei Gebäckschalen aus sog. Engelszinn von J.G.C. W., s. Auktionshaus Mehlis in Plauen, 79. Auktion vom 27.-29. 08. 2015, Katalog-Nr. 3556, online unter http://www.mehlis.eu/de/catalogs/7915/ 12/?page $=5$ (abgerufen am 2. Febr. 2018)

M Margarete geb. Förster

œ 27. Juli 1923 Eleonore geb. Roosen

$\mathrm{K} \quad 1 \mathrm{~S}$

Lb UH: SS 1915-SS 1919 (während des Kriegsdienstes von Mai 1915 bis Febr. 1919) Studium der Theologie, WS 1919/20-SS 1921 auch der Philosophie; 28. Juli 1920 Dr. theol.; 1920 Lizentiatenexamen; 1920 I., 1921 II. theol. Examen; 27. Jan. 1922 Habilitation für Systematische Theologie; 24. Febr. 1926 Dr. phil.; seit WS 1928/29 nichtplanm. a.o. Prof. • In dieser Zeit: 
H: 1922-1928 Religionslehrer an Oberrealschule (heute: Helmholtz-Gymnasium); 1928-1932 Lehrer für Religionspädagogik an Lehrer-BildungsAnstalt.

U Breslau: Seit 1. April 1935 (17. Mai 1935 Einführung in die Fakultät) o. Prof. für Systematische Theologie und Religionsphilosophie; Jan.-6. Mai 1945 Einnahme der Stadt durch Rote Armee und Auflösung der U; Vertreibung W.s.

Bad Steben: März 1946-Juni 1947 Amtsaushilfe/ Pfarrverweser in Bayer. Landeskirche.

Bad Kissingen: Juli 1947-1959 I. Pfarrer an Erlöserkirche.

U Erlangen: 1. Juli 1959 Rechtsstellung e. entpflichteten o. Prof.

\section{E 1934 D. theol. UH.}

Qu UAH Fak.-Akte Theol. Fak. 98. - GLA Abt. 235, Fasz. 2662. Auskunft: Universitätsarchiv Erlangen-Nürnberg (PA F2/1 Nr. 2509). • Mitteilungen: Frau Jeannette Mehlis, Plauen.

W Phänomenologie und Religion. Ein Beitrag zu den Prinzipienfragen der Religionsphilosophie. Tübingen 1921. • Die Religion im Urteil der Gegenwartsphilosophie. Leipzig 1926. • Die Mystik der Deutschen Glaubensbewegung und die Mystik des christlichen Glaubens. Bonn 1936. - Siehe auch BBKL.

(M)HG 1929-1934 Christentum und Wissenschaft.

$L$ Wer ist's (1935) S. 1740; Kürschner (1983) S. 4658; WBIS. - Der Kirchenkampf im deutschen Osten und in den deutschsprachigen Kirchen Osteuropas. Hrsg. von Peter Maser. Göttingen 1992. S. 122125 u. ö. - Fix (1994) S. 135f.; BBKL XVI (1999) Sp. 1570-1576. Wolfes, Matthias: Protestantische Theologie und moderne Welt ... Berlin 1999. S. 251-403 u. ö. Große Bayerische Biographische Enzyklopädie. Hrsg. von Hans-Michael Körner ... München 2005. Bd. 3. S. 2115. • Personenlexikon zum dt. Protestantismus (2006) S. 277. • Deutsche Biographie, s. https://www.deutsche-biographie. de/pnd117407194.html [02.12. 2017].

\section{Witkop, Philipp Wilhelm}

1909-1910 Phil. Fak.

Ästhetik, Neuere Dt. Literatur

* 17. April 1880 Kleinenberg (Westfalen; heute: Stadtteil von Lichtenau)

$\dagger$ 17. Dez. 1942 Freiburg/Br. kath.

V Anton W. (*1850 † nach 1910) Kleinbauer, seit 1882 Kolonialwaren-Kaufmann in Gelsenkirchen

M Mathilde Charlotte geb. Drolshagen ( $\left.{ }^{\star} 1850\right)$

๑ 6. März 1912 Hedwig Margarete geb. Hirschhorn ( ${ }^{*} 1889$; mosaisch) Scheidung 1937; siehe Freiburger Phil. Fak. (2006) S. 272 Anm. 29

( 26. Aug. 1937 Anna geb. Krauß $\left({ }^{*} 1904 \dagger\right.$ nach 1988)

K 1 T, 2 S: u.a. Bernhard W. (1917-2010), u.a. 1948-1950 Lecturer an Havard U in Cambridge (Massachusetts), 1957-1987 Leiter des Laboratory of Chemistry am National Institute of Arthritis and Metabolic Diseases in Bethesda (Maryland), siehe Huisgen, Rolf: B. W. $\dagger \ldots$ in: Angewandte Chemie 123 (2011) S. $5723 \mathrm{f}$.

Lb Seit WS 1898/99 Studium der Rechts- und Staatswiss. an U Marburg, anschl. München, Kiel, Tübingen, Freiburg/Br.; Mai 1903 Dr. rer. pol. an U Freiburg/Br.; 1903-1904 literarisches Studium in München.

Berlin: Seit Winter 1904 Mitarbeiter der Zentralstelle für Arbeiterwohlfahrtseinrichtungen.

UH: Seit SS 1905 Studium der Philosophie; 6. Aug. 1907 Dr. phil.; anschl. Studienaufenthalt in München; 16. Jan. 1909 Habilitation; 20. Jan. 1910 Ern. zum nichtetatm. a. o. Prof.

U Freiburg/Br.: 20. Jan. 1910 Ern. zum etatm. a.o. Prof. gegen den Willen der Fak.; 1914 als kriegs- 
verwendungsfähig erklärt, anschl. aber „für arbeitsverwendungsfähig im eigenen Beruf" vom Kriegsdienst zurückgestellt, s. hierzu Freiburger Phil. Fak. (2006) S. 51 Anm. 89; 27. Juli 1922-1942 $(\dagger)$ persönlicher Ordinarius für Neuere dt. Literaturgeschichte (bis 1922 mehrfache Ablehnung seiner Ern. zum o. Prof. durch die Fak.).

E 1932 Goethe-Medaille für Kunst und Wissenschaft, 1932 gestiftet von Reichspräsident Paul von Hindenburg.

Qu UAH PA 2460. • Briefe: UBH; Thomas-MannArchiv an der ETH-Bibliothek Zürich. • Nachlaß, siehe Westfälisches Autorenlexikon 1750-1950 (1997) Bd. 3. - Auskunft: Standesamt Freiburg/Br. (Ehe- und Sterberegister).

$W$ Ein Liebeslied und andere Gedichte. München 1900. - Die deutschen Lyriker von Luther bis Nietzsche. 2 Bde. Leipzig 1909-1913. 3. Aufl. 1925. Die neuere deutsche Lyrik. 2 Bde. Leipzig 1910-1913. Heidelberg und die deutsche Dichtung. Heidelberg 1916. 2. Aufl. 1925. Heinrich von Kleist. Stuttgart 1921. 2. Aufl. 1932. Frauen im Leben deutscher Dichter. Leipzig 1922. • Deutsche Dichtung der Gegenwart. Leipzig 1924. - Tolstoi. Wittenberg 1928. Goethe: Leben und Werk. Stuttgart 1931. - Siehe auch Westfälisches Autorenlexikon 1750-1950 (1997) Bd. 3.

HG Kriegsbriefe deutscher Studenten. Leipzig 1915; seit 1918 u.d. T.: Kriegsbriefe gefallener Studenten. 6. Aufl. München 1933. 1916-1918 Kriegszeitung der 7. Armee. - Johann Peter Hebel. Gedichte, Geschichten, Briefe. Freiburg/Br. 1926.

L Kürschner (1931) Sp. 3305, (1935) Sp. 1552, (1940/ 41) Sp. 1114; Wer ist's (1935) S. 1746. • Gelsenkirchen in alter und neuer Zeit. Ein Heimatbuch. Hrsg. vom Heimatbund. 1. Bd. Jg. 1948. Gelsenkirchen 1949 (im Anhang Lebenslauf P.W.s). • WBIS; Burkhardt (1976) S. 140-147 u. ö.; Badische Biographien N. F. II (1987) S. 313-315. • Hettling, Manfred, Jeismann, Michael: Der Weltkrieg als Epos. P. W.s „Kriegsbriefe gefallener Studenten“ in: Keiner fühlt sich hier mehr als Mensch ... Erleb- nis und Wirkung des Ersten Weltkriegs. Hrsg. von Gerhard Hirschfeld ... Essen 1993. S. 175-198. • Ketelsen, Uwe-K.: „Das ist auch so ein unendlicher Gewinn mitten in der Erfahrung des grässlichsten Todes“... Sammlung von studentischen Briefen aus dem Ersten Weltkrieg in: Bücher haben ihre Geschichte ... Hrsg. von Petra Josting ... Hildesheim 1996. S. 51-61. - Ulrich, Bernd: Die Augenzeugen. Deutsche Feldpostbriefe in Kriegs- und Nachkriegszeit 1914-1933. Essen 1997. - Westfälisches Autorenlexikon 1750-1950 (1997) Bd. 3. • Natter, Wolfgang G.: Literature at war, 1914-1940. Representing the „time of Greatness“ in Germany. New Haven 1999. S. 90-120 u. ö. • Hettling, Manfred: Arrangierte Authentizität. P.W. Kriegsbriefe gefallener Studenten (1916) in: Von Richthofen bis Remarque. Deutschsprachige Prosa zum 1. Weltkrieg. Hrsg. von Thomas F. Schneider ... Amsterdam 2003. S. 51-69. Freiburger Phil. Fak. (2006) S. 267-272 u. ö. - Maurer, Michael: Eberhard Gothein ... Köln 2007. S. 240-244. • Gefallenengedenken im globalen Vergleich ... Hrsg. von Manfred Hettling ... München 2013. - Demm (2014) S. 77, 102, 105. - Redl, Philipp: Dichtergermanisten der Moderne: Ernst Stadler, Friedrich Gundolf und P.W. zwischen Poesie und Wissenschaft. Köln 2016. • Riecke (2016) S. 55 f., 65, 126; Deutsche Biographie, s. https://www.deutsche-biographie.de/pn d117414662.html [03.12. 2017].

$P$ Westfälisches Autorenlexikon 1750-1950 (1997) Bd. 3 .

\section{Wobbermin, Ernst Gustav Georg}

1915-1922 Theol. Fak.

Systematische Theologie

\footnotetext{
* 27. Okt. 1869 Stettin (heute: Szczecin, Polen)

$\dagger \quad$ 15. Okt. 1943 Berlin-Nikolassee ev.

V Albert W. († 1904) Realgymnasiallehrer

M Laura geb. Quandt ( $†$ nach 1935)

( 29. Dez. 1906 Theodora (Dora) geb. Brockhausen $\left({ }^{*} 1879 \dagger\right.$ nach 1954$)$, s. Wolfes, Matthias (1999) S. 837 (Register)

$\mathrm{K}$ keine.
} 
Lb Seit WS 1888/89 Studium der Philosophie und Theologie an U Halle-Wittenberg, seit SS 1890 Berlin.

U Berlin: 2. Mai 1893 I., Sept. 1895 II. theol. Examen; 13. Aug. 1894 Dr. phil.; 2. Aug. 1895 theol. Lizentiatenprüfung. In dieser Zeit:

Berlin: 1893-1895 Sekretär bei Missionswerk, e. 1824 als „Gesellschaft zur Beförderung der ev. Missionen unter den Heiden " gegründeten Vereinigung; Mitte 1893-Mitte 1895 auch Hilfsredakteur bei der Zs. für Missionskunde und Religionswissenschaft; 1. Okt. 1895-30. Sept. 1896 Militärdienstpflicht als Einjährig-Freiwilliger.

Jan. 1897-Jan. 1898 Studienaufenthalt in Griechenland und im Orient.

U Berlin: 10. Nov. 1898 Habilitation für Systematische Theologie und Religionsphilosophie; April 1904 Verleihung des Titels „Prof.“; seit März 1905 Lehrbeauftragter für Symbolik und Apologetik.

U Marburg: 6. Aug. 1906 Ern. zum a. o. Prof.

U Breslau: 31. März 1907 Ern. zum o. Prof.; SS 1907 Vorlesungsbeginn; 1910 Ruf an Yale U in New Haven (Connecticut) abgelehnt.

UH: 24. Dez. 1914 Ern. zum o. Prof. als Nachf. von Ernst Troeltsch; 20. April 1915 Vereidigung; seit SS 1915 Direktor der Systematischen Abt. am Wiss.Theol. Seminar als Nachf. von Troeltsch.

U Göttingen: 4. April 1922 Ern. zum o. Prof.; WS 1922/23 Vorlesungsbeginn; Rufe an U abgelehnt: 1925 Leipzig, 1926 Halle-Wittenberg.

U Berlin: WS 1935/36-WS 1936/37 Zunächst Vertreter der Professur und des Vorstands des Theol. Seminars; seit Juli 1936 o. Prof. und Direktor des Theol. Seminars; 1. Febr. 1939 Emeritierung; W. hält auch nach seiner Emeritierung Vorlesungen; 1. Okt. 1940 Rektor verfügt W.s endgültige Beendigung seiner Lehrtätigkeit.
1916/17, Okt. 1921-März 1922 Dekan der Theol. Fak. der UH

E Mitglied der Akademie der Wissenschaften: 1920 H, 1929 Göttingen. 1907 D. theol. U Berlin. 1913 Königl. Preußischer Roter Adler-Orden IV. Klasse.

Qu UAH PA 2464; RA 6722. GLA Abt. 235, Fasz. 2667. Briefe: UBH. $\bullet$ Wolfes, Matthias: Der Nachlaß G.W.s. Zum Schicksal e. bisher als verschollen geltenden Berliner Theologennachlasses in: Ev. Kirche in Berlin-Brandenburg. Archivbericht. Hrsg. im Auftrag des Konsistoriums der Ev. Kirche ... Berlin 2000. S. 94-99.

W Theologie und Metaphysik. Berlin 1901. • Der christliche Gottesglaube in seinem Verhältnis zur gegenwärtigen Philosophie. Berlin 1902. 3. Aufl. 1912. Monismus und Monotheismus. Tübingen 1911. Systematische Theologie nach religionspsychologischer Methode. 3 Bde. Leipzig 1913-1925. Bde. 1 und 2: 2. Aufl. 1924. Bd. 3: 3. Aufl. 1926. Religionsphilosophie. Berlin 1924. 2. Aufl. 1925. Arthur Titius: Ökumenische Theologie zur Befriedung der Kirche. Eine Gedenkrede. Berlin 1937. • Rassen- und Arier-Fragen in der Kirche in: Deutsches Christentum 3 (1938) Nr. 2. - Bischof von Gloucester. Berlin 1939. 2. Aufl. 1940.

MHG 1921-1939 Theologische Literaturzeitung.

Übers. James, William: The varieties of religious experience ... New York, London 1902. Dt. Übers.: Die religiöse Erfahrung in ihrer Mannigfaltigkeit. Materialien und Studien zu einer Psychologie und Pathologie des religiösen Lebens. Leipzig 1907. 4. Aufl. 1925.

$L$ Catalogus prof. Gottingensium (1962) S. 38; WBIS. - Klünker, Wolf-Ulrich: Psychologische Analyse und theologische Wahrheit. Die religionspsychologische Methode G.W.s. Göttingen 1985. - Jansen (1992a) S. 170 (Register). - Pfleiderer, Georg: Theologie als Wirklichkeitswissenschaft. Studien zum Religionsbegriff bei G.W., Rudolf Otto, Heinrich Scholz und Max Scheler. Tübingen 1992. - Wennemuth, Udo: Über G.W. in: Ostdeutsche Gedenktage 1993. Persönlichkei- 
ten und historische Ereignisse ... Redaktion Peter Mast ... Bonn 1992. S. 154-158. • Fix (1994) S. 117-123; Meier (1996) S. 496 (Register). • Rohls, Jan: Protestantische Theologie der Neuzeit. Bd. 2: Das 20. Jahrhundert. Tübingen 1997. S. 882 (Register). • BBKL XIII (1998) Sp. 1455-1462. - Wolfes, Matthias: Protestantische Theologie und moderne Welt ... Berlin 1999. Reprint 2010. S. 251-403 u. ö. Conrad, Ruth: Lexikonpolitik. Die erste Auflage der RGG im Horizont protestantischer Lexikographie. Berlin 2006. S. 587 (Register). - Personenlexikon zum dt. Protestantismus (2006) S. 277f.; Klee, Personenlexikon (2007) S. 683. - Hege, Brent A.R.: „Zurück zu Schleiermacher! Und von Schleiermacher aus vorwärts!" G. W. and the legacy of Schleiermacher in Weimar ... in: Journal for the history of modern theology (2012) S. 193-216. • Deutsche Biographie, s. https://www.deutschebiographie.de/pnd118769707.html [03.12.2017]. Westrup, Felix: Wissenschaft, Religion und moderne Geisteskultur. Die deutschsprachige Religionspsychologie um 1900. Göttingen 2017. S. 35 f., 67-70 u. ö.

\section{$P$ Bildarchiv UAH.}

\section{Wöhlisch, Edgar Gustav Wilhelm}

1928-1932 Med. Fak.

Physiologie

* o6. Sept. 1890 Danzig (heute: Gdańsk, Polen)

$\dagger$ 22. Nov. 1960 Würzburg

ev.

V Rudolf W., Kaufmann

M Johanna geb. Kaeseberg

( 31. Aug. 1927 Gerda Hildegard Anna geb. Gräfin von Rittberg (1905-1966)

K $\quad 2 \mathrm{~S}$

Lb Seit WS 1908/o9 Studium der Medizin an U München, seit SS 1911 Königsberg (Preußen); Nov. 1911 Physikum in Königsberg; Sommer 1914 med. Staatsexamen; 8. Aug. 1914 ärztl. Approbation in München.
7. Aug. 1914-31. Okt. 1917 (Entlassung) Kriegsdienst (Entlassungsgrund: „Diphtheriebazillenträger", aus: UAH PA 1256).

8. Nov. 1917 Rigorosum, 14. Febr. 1918 (Datum der Promotionsurkunde) Dr. med. an U Königsberg; 1918 Studium der Chemie, Physik, Mathematik an TH Danzig, seit WS 1919/20 Forts. des Studiums an U Königsberg; Mai 1919 anorganisch und organisch-chemisches Verbandsexamen in Danzig; Mai 1921 Dr. phil. an U Königsberg.

U Kiel: Febr. 1920-April 1924 Assistent an Med. UKlinik; 2. März 1923 Habilitation für Innere Medizin.

U Würzburg: 1. Mai 1924 Umhabilitierung für Physiologie; seit 1. Mai 1924 planm. Assistent am Physiolog. Inst.; seit 4. März 1927 nichtbeamteter a.o. Prof.

UH: 1. Okt. 1928 Umhabilitierung; 1. Okt. 192830. April 1932 Assistent am Physiolog. Inst.; seit 1. Okt. 1929 nichtbeamteter a. o. Prof.

U Würzburg: Seit 1. Mai 1932 o. Prof. und Vorstand des Physiolog. Inst.; 1939 Diplom-Chemiker; 1957 Emeritierung.

E 1938 Mitglied der Dt. Akademie der Naturforscher Leopoldina Halle/S.

Qu UAH PA 1256. • GLA Abt. 235, Fasz. 2669. • Siehe auch Archiv der Dt. Akademie der Naturforscher Leopoldina Halle/S.

W 25 Jahre Röntgenstrahlenforschung. Berlin 1922. - Die Physiologie und Pathologie der Blutgerinnung in: Ergebnisse der Physiologie 28 (1929). - Fortschritte in der Physiologie der Blutgerinnung in: Ergebnisse der Physiologie, Biologischen Chemie und Experimentellen Pharmakologie 43 (1) (1941) S. 174-370. - E.W.s Aufladungstheorie des Schlafes und der Erholung in: Müller, Ludwig Robert: Über den Schlaf. 2. Aufl. Berlin 1948. Gehirnvolumen und Liquordruck im Schlafe in: Klinische Wochenschrift 31 (1953) S. 620f. - Blood coagulation. Research 
workers and factors in: Schweizerische med. Wochenschrift 84 (29) (1954) S. 774-776. • Bibliographie 1917-1927 in: UAH PA 1256.

$L$ Über E.W. in: „Ungünstige Laienurteile“ in: Der Spiegel 15 (1953) S. 14. - Professoren Kiel (1956) S. 120; Kürschner (1960) S. 2304. - Marx, R.: In memoriam E.W. in: Blut - Zs. für die gesamte Blutforschung (1961) S. 11f. • WBIS; Fischer $2\left({ }^{3} 1962\right)$ S. 1700. - Kalb, Stefanie: Wilhelm Neumann (1898-1965). Leben und Werk unter besonderer Berücksichtigung seiner Rolle in der Kampfstoff-Forschung. Med. Diss. Würzburg 2005. S. 39 und Anm. 187. - Spörri, Myriam: Reines und gemischtes Blut. Zur Kulturgeschichte der Blutgruppenforschung 1900-1933. Bielefeld 2013. S. 410 (Register). Deutsche Biographie, s. https:// www.deutsche-biographie.de/pnd106746782.html [03.12. 2017].

$P$ Bildarchiv UAH.

\section{Wolf, Max}

siehe Wolf, Maximilian

\section{Wolf, Maximilian (Max) Franz Joseph Cornelius}

1890-1932 Nat.-Math. Fak. Astronomie, Astro- und Geophysik

* 21. Juni 1863 Heidelberg

$\dagger \quad$ 03. Okt. 1932 Heidelberg ev.

V Dr. med. Franz W. (1827-1895) praktischer Arzt

M Elisabeth geb. Helwerth (1840-1924)

๑ 7. Aug. 1897 Gisela geb. Merx (1875-1965) T von: (siehe) Adalbert M.
K 3 S: u.a. Franz W. (1898-1984) TH Danzig: seit 1927 Privat-Dozent, seit 1934 apl. Prof.; TH Karlsruhe: seit 1937 nichtbeamteter a.o. Prof., seit 1940 planm. a. o. Prof., nach 1946 zeitweilig Freistellung auf Anordnung der amerik. Militärregierung, 1950-1966 (Emeritierung) o. Prof. für Physik, s. Vorlesungsmitschriften 1955-1959 in: UAH Rep. 216-20 (Vorlaß Manfred Zimmermann); Kürschner (1983) S. $4697 f$ f; Fritsche, Lothar: Nachruf auf F.W. in: Physikalische Blätter (1984) Jg. 40, H. 11, S. 357; Wikipedia, Deutsche Biographie, https://www.deutsche-biographie.de/pnd117 444081.html [28.12. 2017]. • Werner W. (19061967) 1932-1936 Lektor für Skandinavische Sprachen und Dozent für Dt. und Nordische Philologie an UH, seit 1938 Prof. für Germanistik an Åbo Akademi (Finnland), s. UAH PA 712, 6419; Deutsche Biographie, https://www. deutsche-biographie.de/pnd117446033.html [28.12.2017]

Vw Schwager: (siehe) Julius Ruska.

Lb Seit WS 1882/83 Studium der Mathematik, Physik an UH; Okt. 1882-Aug. 1883 (krankheitsbedingte vorzeitige Entlassung) Militärdienstpflicht als Einjährig-Freiwilliger; WS 1884/85 Forts. des Studiums (hier auch der Astronomie) an U Straßburg; 29. April 1885 erneut Immatrikulation an UH; 18. Dez. 1888 Dr. phil. an UH; Mai-Aug. 1889 (krankheitsbedingte Unterbrechung), Nov. 1889-Ende Jan. 1890 Studien an Akad. Sternwarte in Stockholm bei Prof. Dr. Johan August Hugo Gyldén (1841-1896).

UH: 12. Juli 1890 Habilitation für Astronomie; seit 1. Febr. 1893 nichtetatm. a. o. Prof.; seit 30. Okt. 1893 stellvertr. Leiter, 1896-1932 Leiter des Astrophysikal. Inst. an der 1898 eingeweihten, von W. initiierten Landessternwarte in $\mathrm{H}$ auf dem Königstuhl (vorher Karlsruhe); SS 1893 Studienreisen nach USA und Großbritannien; seit 10. Juni 1896 etatm. a.o. Prof.; 1902 Ruf an U Göttingen abgelehnt; 9. Juli 1902-31. März 1932 (Emeritierung) o. Prof. für Astro- und Geophysik an U und Vorstand der Landessternwarte (April 1921 während der Inflation: 19 ooo.- Mark jährl. Grundgehalt als Direktor der Landessternwarte) in H; 1909-1932 
auch Leiter des Astrometrischen Inst. an o.g. Landessternwarte in $\mathrm{H}$ als Nachf. von Wilhelm Valentiner.

1885: Errichtung e. privaten Sternwarte gemeinsam mit seinem Vater auf der Dachterrasse des elterlichen Wohnhauses in der Märzgasse 16 in Heidelberg, deren Drehkuppel noch heute zu sehen ist.

W. gilt als Pionier der Himmelsphotographie, s. hierzu Freiesleben, Hans-Christian: M.W. Der Bahnbrecher der Himmelsphotographie ... Stuttgart 1962.

1901 Hofrat; 1906 Geh. Hofrat; 1914 Geh. Rat II. Klasse

E 1896 Mitglied der Dt. Akademie der Naturforscher Leopoldina Halle/S.; 1904 Ehrenmitglied der Royal Astronomical Society of England; Mitglied der Akademie der Wissenschaften: 1909 H, 1922 München, 1925 Berlin. 1914 Goldmedaille der Royal Astronomical Society; 1930 Catherine Wolfe Bruce gold medal of the Astronomical Society of the Pacific. 1903 Ritterkreuz I. Klasse, 1909 Kommandeurkreuz II. Klasse des Ordens vom Zähringer Löwen. 1928 Ehrenbürger der Stadt Heidelberg.

Qu UAH PA 6415f. • GLA Abt. 235, Fasz. 2674. • Briefe: UAH; UBH. - Nachlaß: UBH (Signatur: Heid. Hs. 3695); Staatsbibliothek zu Berlin. • Siehe auch Archiv der Dt. Akademie der Naturforscher Leopoldina Halle/S.

$W$ Über die Verwendung gewöhnlicher photographischer Objektive bei der Himmelsphotographie in: Sirius (106) 19 (1891). - Stereoskopbilder vom Sternhimmel. 2 Bde. Leipzig 1906. Bd. 1: 6. Aufl. 1921. Bd. 2: 2. Aufl. 1920. Der Ringnebel und der Dumbbellnebel. Heidelberg 1915. Die Milchstraße und die kosmischen Nebel. Potsdam 1925.

MHG Palisa-Wolf-Sternatlas. Kartenwerk mit 210 Blättern. Wien 1900 (zus. mit Johann Palisa), s. hierzu Schnell, Anneliese: Überholt vom Fortschritt - die Geschichte einer Koproduktion Heidelberg-Wien. Die Wolf-Palisa-Karten (ein früher photographischer Himmelsatlas) in: Beiträge zur Astronomiegeschichte. Bd. 12. Hrsg. von Wolfgang R. Dick ... Leipzig 2014. S. 151-166.

L Kürschner (1931) Sp. 3325. Kopff, August: Zum 9o. Geb. in: Ruperto Carola 5. Jg., Nr. 11/12 (1953) S. 68-70. - Schattschneider-Kollnig, Erika: Die Entwicklung der Astronomie im Raume Mannheim-Heidelberg in: Heidelberger Jahrbücher 17 (1973) S. 147-149. Schaifers, Karl: M. W. in: Semper apertus 3 (1985) S. 97-113. - Jansen (1992a) S. 170 (Register); Wennemuth (1994) S. 640 (Register); Lexikon der Naturwissenschaftler (2000) S. 439-441; WBIS; Badische Biographien N.F. VI (2011) S. 433-437. - Krafft, Fritz: Die bedeutendsten Astronomen. Wiesbaden 2012. S. 215-219. Lemke, Dietrich: „Etwas anderes als Astronom kann man eigentlich gar nicht werden ..." in: Sterne und Weltraum. Zs. für Astronomie ... Heidelberg 2013. H. 7. S. 40-51. - Lemke, Dietrich, Mattila, Kalevi: Freunde im Norden - M. W.s Verbindungen zu Astronomen im Ostseeraum in: Beiträge zur Astronomiegeschichte. Bd. 13. Hrsg. von Wolfgang R. Dick ... Leipzig 2016. S. 217-260. • Deutsche Biographie, s. https://www.deutschebiographie.de/pnd11876988X.html [28.12.2017]. • Krafft, Fritz: M. W.s Eintritt in die „scientific community“ der Astronomen in: In memoriam Hilmar W. Duerbeck. Hrsg. von Wolfgang R. Dick ... Leipzig 2018 (in Vorbereitung).

P Bildarchiv UAH; graph. Slg. UBH; Ruperto Carola (1953); Heidelberger Jahrbücher (1973).

\section{Wolfrum, Philipp Julius}

1884-1919 (Musiklehrer) Theol. Fak. 1888-1897 Theol. Fak.

1897-1917 Phil. Fak.

1917-1919 (Honorar-Prof.) Phil. Fak.

Musikwissenschaft, Theorie und Geschichte der

Musik

* 17. Dez. 1854 Schwarzenbach am Wald (Bayern)

$\dagger \quad$ o8. Mai 1919 Samedan (Kanton Graubünden)

口 Samedan

ev. 
V Johann Heinrich W. († vor 1888) Kantor, Oberlehrer

M Anna Margaretha geb. Schmidt (1833-1863)

(4. Jan. 1887 Regina Sabina geb. von Wallmenich $\left({ }^{*} 1856\right)$ T von Karl von W. $(1816-1895)$ seit 1867 Oberstaatsanwalt, 1886-1895 Oberlandesgerichtspräsident in Bamberg. - Schwester von Clementine von W. (1849-1908) Krankenschwester, Oberin und 1903 Begründerin der ersten Hochschule für Pflege-Oberinnen im Deutschen Reich in München, s. SchmidtMeinecke, Sigrid: Clementine von W. Leben und Vermächtnis einer bedeutenden Frau. München 1981; Wikipedia; Aufbau Ost um 1900. C. von W. gründete die Schwesternschaft Weißensee - im Auftrag der Kaiserin in: Hedwig - Newsletter der DRK-Schwesternschaft Berlin. Ausg. II (2011).

K $\quad 1$ T

Lb Bayern: 1869-1872 Ausbildung am Lehrerseminar in Altdorf; seit 1872 Hauslehrer; seit 1873 Hilfslehrer an Volksschule in Bad Steben; seit 1874 Hilfslehrer am Simultanlehrerseminar in Bamberg; 1876 Prüfung für Volksschullehrer in Bayreuth; 1876-1878 (Abschlußexamen) Studium an Königl. Bayer. Musikschule in München; 18781884 Seminarmusiklehrer in Bamberg.

UH, Theol. Fak.: 28. April 1884-1895 Musiklehrer am Ev.-Prot. Theol. Seminar und bis 1919 UOrganist; 20. Sept. 1885 Verleihung des Titels "Akad. Musikdirektor" und Gründungs-Direktor des Musik-Instituts; z. B. SS 1886 Vorlesungen über Grundlagen und Quellen der prot. Kirchenmelodien, Allg. Musiklehre bzw. Harmonielehre mit Berücksichtigung der alten Kirchentonarten, Chorgesang kirchlicher Tonsätze sowie Orgelspiel (aus: Anzeige der Vorlesungen, welche im Sommer-Halbjahr 1886 auf der ... Universität zu Heidelberg gehalten werden sollen. Heidelberg 1886. S. 4); seit 20. Juli 1888 a. o. Prof., $1892-1897$ nichtetatm. a. o. Prof. (siehe auch weiter Abschnitt: UH, Phil. Fak.); 5. Juni 1891 Promotion zum Dr. phil. an U Leipzig; seit 13. Aug. 1894 etatm. U-Musikdirektor an UH; SS 1895 Aufteilung des Ev.-Prot. Theol. Seminars in Praktisch-Theol. Seminar und Wiss.-Theol. Seminar: 1895-1919 Musiklehrer am Praktisch-Theol. Seminar; 1907 Verleihung des
Titels „Generalmusikdirektor“; WS 1918/19 letzte Vorlesungsankündigung; SS 1919 beurlaubt ( $†$ Mai 1919).

UH, Phil. Fak.: Seit SS 1897 nichtetatm., seit 4. Juli 1898 etatm. a.o. Prof.; 1907 Ruf an U Straßburg abgelehnt; WS 1910/11-SS 1915 Lehrer an der im Juni 1909 neu eröffneten Musik-Akademie, die der UH angeschlossen ist (wohl bis 1915), s. hierzu UAH Quästurakte Rep. 27-1481, Chronik der Stadt Heidelberg für 1907-1909, 15.-17. Jg. (1913) S. 151; WS 1917/18 Ern. zum o. Honorar-Prof.; WS 1918/19 letzte Vorlesungsankündigung; SS 1919 beurlaubt.

1885 Gründer (und bis 1919 Leiter) des Heidelberger Bachchors und Akademischen Gesangvereins

Schüler W.s ist u.a. der Dirigent Frieder Weissmann (1893-1984), s. Bunz, Rainer: Der vergessene Maestro - Frieder Weissmann. Norderstedt 2016. S. $30-32,35,38$.

Noch 1977 gab es ein Museum zur Musikgeschichte an der Universität Heidelberg mit einer Sammlung von Musikinstrumenten, u. a. einer Orgel von 1729, einem Graf-Flügel aus der Zeit Beethovens sowie einiger nachgebauter historischer Streichund Blasinstrumente. Für das Jahr 1961 war zudem eine Schallplattensammlung belegt. Über das weitere Schicksal beider Sammlungen ist nichts bekannt, siehe Webseite der Universitätssammlungen in Deutschland - Das Informationssystem zu Sammlungen und Museen an deutschen Universitäten. Hermann von Helmholtz-Zentrum für Kulturtechnik an der Humboldt-Universität zu Berlin, online unter http://www.universi taetssammlungen.de/sammlung/895/geschichte (Stand: Juni 2015).

1914 Geh. Hofrat

E 1903 Mitglied der Gesellschaft für Geschichte der Musik Amsterdam. 1910 D. theol. UH. 1903 Ritterkreuz I. Klasse des Ordens vom Zähringer Löwen; 1910 Ritterkreuz des Ordens Berthold I. 
Qu UAH PA 2469; RA 586; Quästurakte Rep. 27-1481; GF 48, 154. - GLA Abt. 235, Fasz. 1340. • Briefe: UBH. - Der unbekannte Engelbert Humperdinck im Spiegel des Briefwechsels mit seinen Zeitgenossen (u.a. mit P.W.). Hrsg. von Eva Humperdinck ... Wien 2004. - Teil-Nachlaß: Bayer. Staatsbibliothek München (Signatur: BSB Ana 311/o); siehe hierzu Nachlass von P. W. ... BSB Ana 311/o: Repertorium des Nachlasses von P.W. ... Heidelberg 1970.

$W$ Die Entstehung und erste Entwickelung des dt. ev. Kirchenliedes in musikalischer Beziehung. Leipzig 1890. Nachdr. Walluf bei Wiesbaden 1972. Ein Weihnachtsmysterium op. 31. Heidelberg 1899. - Johann Sebastian Bach. 2 Bde. Leipzig 1910. Nachdr. Hildesheim 1978. • Die ev. Kirchenmusik, ihr Stand und ihre Weiterentwicklung. Bremen 1914. - Orgelwerke. 2 Bde. Hrsg. von Martin Sander. St. Augustin 2004.

L Klauser (1961) S. 323; WBIS. - Nieden, HansJörg: Bachrezeption um die Jahrhundertwende: P. W. München 1976. - Musik in Heidelberg (1985) S. 250 (Register). - Finscher, Ludwig: Bachverein und Universität in: Ruperto Carola 74 (1986) S. 150158; Ders.: Das Musikwissenschaftliche Seminar in: 600 Jahre Ruprecht-Karls-Universität Heidelberg 1386-1986. Geschichte, Forschung und Lehre. Hrsg. vom Rektor der Universität Heidelberg. Redaktion: Hans Krabusch. München 1986. S. 136. • Badische Biographien N.F. III (1990) S. $308 \mathrm{f}$;; Jansen (1992a) S. 170 (Register). • Sander, Martin: Zum 150. Geb. von P.W. in: Forum Kirchenmusik 56. Jg. (2005) Ausg. 3, S. 4-7. • Wolfrum war der Erste in: ruprecht - Heidelberger Studentenzeitung Nr. 103 (Juli 2006) S. 9. • Lebensbilder aus der ev. Kirche (2007) S. 535 (Register). • MGG (Personenteil) 17 ( $\left.{ }^{2} 2007\right)$ Sp. 1130-1133. • Pfeiffer, Harald: „Ich hab' mein Herz in Heidelberg verloren ..." Kleine Heidelberger Musikgeschichte. Leipzig 2011. - Nieden, Hans-Jörg: Musik und Theologie. Ökumenische Perspektiven. Berlin 2013. S. 227-230. Deutsche Biographie, s. https:// www.deutsche-biographie.de/pnd11863495X.html [27.12.2017].

$P$ Bildarchiv UAH; graph. Slg. UBH.

\section{Wolfter, Johann Peter Philipp Ignaz Joseph}

1788-1805 Phil. Fak.

Geschichte, Statistik, Erd- und Länderkunde

$\approx$ 24. Juli 1758 Mannheim

$\dagger \quad$ 28. Juli 1805 Heidelberg kath., seit 1803 ev.-luth.

V Heinrich Benedikt Joseph W. ( $† 1784$, siehe UAH PA 2467 vom 23. Dez. 1794), 1781 als Lizentiat der Rechte, kurpfälz. Hofgerichtsrat und Prokurator bezeichnet in: Seiner Churfürstlichen Durchleucht zu Pfalz etc. Hofund Staats-Kalender ... 1781. München 1781. S. 16o. - H. B. J. W. ist Eigentümer e. Ritterguts im linksrheinischen Oberndorf, ehemals im Besitz der Reichsfreiherren von Reichersberg (aus: UAH RA 7173)

M Sophia Catharina geb. Bezan(i) (†1793) Enkelin des Administrations-Rats Bezani (aus: PA 2467)

๑ Luise geb. Reinhard ( $\dagger 11$. Dez. 1794, siehe PA 2467 vom 23. Dez. 1794)

(D) Luise geb. de Trommer verw. N.N. (1764/651832) Witwe bei der Eheschließung mit P.W., siehe PA 2467 vom 5. Febr. 1796, UAH RA 6020 vorletztes Blatt vom 24. Okt. 1805, UAH PA 2468 vom 31. Juli und 12. Okt. 1805

K 2 S: Carl W. $\left({ }^{\star} 1784\right)$ und Damian W. $\left({ }^{\star} 1786\right)$, siehe PA 2468, Blatt zwischen 1799/180o; siehe auch Bericht W.s vom 28. Sept. 1795 in: PA 2467 sowie PA 2468 vom 25. Mai, 12. Juni und 17. Nov. 1801 und Bittbrief von e. der Söhne vom 23. Okt. 1805 um Anstellung bei UH in: UAH RA 6708.

Lb Wohl vor 1784 Pfalz-Zweibrückischer Hofrat von Herzog Karl II. August Christian von PfalzBirkenfeld-Zweibrücken (1746-1795).

Mannheim: Seit ca. 1784 Wohnort; 1795 Umzug nach Heidelberg.

UH: 28. Nov. 1786 Gesuch um Professur; 16. Juli 1788 Ern. zum a. o. Prof. unter der Bedingung „sich vordersamst gehörig promoviren [zu] lassen“ (PA 2467); 15. Nov. 1788 Immatrikulation als „Dominus Petrus Wolfter, Mannhemiensis, historiarum professor extraordinarius“ (aus: Toepke IV (1903) 
S. 353); zwischen 1788 und 1792 Promotion zum Dr. phil.; 23. Dez. 1794 Gesuch W.s an Kurfürst Carl Theodor „mich zu einem oder dem anderen Fache grosmüthigst anzustellen: ... Schon vor geraumer Zeit überreichte ich S[eine]r Exzellenz dem Herrn Minister eine Bittschrift in Rücksicht der zweiten erledigten Archivarius Stelle, weil ich mir dieselbe zur Ehre des durchlauchtigsten Churfürsts zu versehen getraue, und mein Zweck wäre einmal eine Diplomatische Geschichte eines der wichtigsten und erlauchtesten Fürstenhäuser Deutschlands zu bearbeiten, aber in nichts werde ich erhört, man sucht mich zu hemmen im Wirkungskreise meiner Geschäftigkeit, und darben muß ich, der so bieder für Vaterland denkt, und dem das der höchste Wunsch ist, seinem durchlauchtigsten Churfürsten, und der Pfalz nüzlich zu werden und zu seyn ..." (aus: Brief vom 23. Dez. 1794 in: PA 2467); ein Antwortschreiben auf das Gesuch von 1794 ist nicht überliefert; am 4. Nov. 1797 ordnet Carl Theodor an, würde eine für W. „convenable“ Stelle frei werden, so solle der Supplikant ,in Vorschlag gebracht werden“ (aus: Brief vom 4. Nov. 1797 in: PA 2467); 1795 Umzug nach H; 28. Sept. 1795 Gesuch W.s um 1) Sitz- und Stimmrecht im Akad. Senat, 2) die freigewordene Besoldung des kürzlich verstorbenen Prof. Johannes Schwab (s. Drüll (1991) S. 141f.), ... 4) das Schwabsche Ordinariat an der Phil. Fak.; Begründung für sein $\mathrm{Ge}$ such ist: „Ich will nicht die traurigen Ereignisse erwähnen, die ich durch leztes Bombardement erlitten habe, wo ich kaum mein Leben mit zwei unmündigen Knaben rettete, auch nicht die Schrecknisse schildern, die mich leider zu empfindlich trafen, weil durch diesen betrübten Krieg all das wenige Vermögen unter französischen Händen ist [= das vom Vater geerbte Rittergut im linksrheinischen Oberndorf], und ich nicht das mindeste davon geniese, sondern das Seiner Churfürstl. Durchlaucht unterthänigst vorstellen, daß ich, um ganz meinem Diensteifer gleichsam Grenzen zu sezen, noch von den kleinen Überresten eines väterlichen Vermögens die Bibliothekarienstelle an hiesiger Universität von tit.[uliertem] von Oberkamp um 4000.- Gulden gekauft habe mit Vorbehalt meiner Professur, und um dort jene gerechten Früchte einstens zu ärndten, die jedem meiner Mitbrüder zukömmt. Gnädigster Herr! Durch den
Todesfall des Professors Schwab tritt wirklich die Gelegenheit ein, wo ich, ohne etwas unbilliges zu fordern, nur Höchstdero bekannte Gerechtigkeitsliebe anflehen darf und kann ..." (aus: Brief vom 28. Sept. 1795 an Kurfürst Carl Theodor in: PA 2467); das Gesuch W.s wird vom Akad. Senat aus folgenden Gründen abgelehnt: $\mathrm{Zu}$ 1) „... die erledigte Senatorsstelle ist nach gesezlicher Ordnung durch den ipso Jure eingerückten ältesten professorem ordinarium schon bereits besezet ...," $\mathrm{zu}$ 2) „die Besoldung des seeligen Professors Schwab gebühret dem, welchem sein Lehramt gnädigst wird übertragen werden ..." und $\mathrm{zu} 4$ ) „,das Ordinariat wird gewöhnlich in den facultäten nach dem Alter oder nach dem einer in eine ordentliche Katheder einrücket, ertheilet ..." (aus: Bericht des Akad. Senats an die Oberkuratel vom 4. Januar 1796 in: PA 2467); 2. Sept. 1797 Oberkuratel ordnet an, daß W., „wie vormahls ebenmäsig gelegentlich anderen so gearteter Ereigniß [= Bittgesuche W.s direkt an den Kurfürsten gerichtet] bereits geschehen ist, wiederholter [Malen] bedeutet [wurde], hinkünfftig seine Äusserungen, ohne darmit die höchste Stelle ausser der Ordnung voreilig zu behelligen, anhero [ $=$ an die Oberkuratel] gelangen zu lassen ..." (aus: PA 2467); 26. April 1799 Gesuch W.s an den seit Febr. 1799 regierenden Nachfolger Carl Theodors, Kurfürst Maximilian IV. (17951797 Herzog von Pfalz-Zweibrücken) um die Lehrstelle der Reichs- und Pfälzischen Geschichte: „... $\mathrm{Da}$ ich ... von meinen im Ueberrhein gelegenen Gütern seit 7 Jahren keinen Pacht ziehe, auch als Professor der Geschichte keine Besoldung habe, ... so musste ich nach und nach alles von meinem Hausgeräth, Weiszeug und Effekten an Juden verkaufen [,unter einem Preiße, der sich von solchen Wuchern, die die Noth nuzen, verstehen läßt", aus: Brief W.s vom 22. Sept. 1801 an Akad. Senat in: PA 2468], um dem Hungerstode auszuweichen ... “; W. bittet außerdem um Dispens von der weiteren Abzahlung der verbliebenen 1600.- Gulden für den Ankauf der Bibliothekarsstelle, die er den Kindern des mittlerweile verstorbenen Joseph David von Oberkamp noch schuldet (aus: Brief vom 26. April 1799 in: PA 2468); Mai 1799 W.s „Gesuch ... um die Lehrstelle der Reichs- und Pfälzischen Geschichte“ wird abgelehnt, u. a. „wegen Ermangelung der zum öfentlichen Lehramt so wesentlich erforderlichen Behutsamkeit und Klugheit"; der Akad. Senat regt jedoch an, „daß man dem Herrn Supplican- 
ten eine andere seinen dürftigen Umständen (und äusserst misslichen Gesundheits-Umständen) angemessene Unterstüzung - jedoch nicht zur Last des Fisci academici - angedeihen lassen möge“, s. Bericht des Akad. Senats vom 28. Mai 1799 in: RA 6766; 1. April 1801 Auszahlungsanweisung seitens der U an den „Collector“ (= Verwalter der UEinkünfte aus Gütern, Gefällen) über 300.- Gulden Besoldungsrückstand, die W. am 4. März 1801 einforderte (aus: PA 2468); es folgen weitere Bittgesuche W.s um finanzielle Unterstützung, darunter auch ein Gutachten des Heidelberger Medizin-Prof. (siehe) Franz Karl Zuccarini über W.s schlechten Gesundheitszustand, siehe Gutachten vom 22. Febr. 1803 in: PA 2468; W. stirbt an „Auszehrung“ (aus: Sterbeeintrag im Totenbuch Heidelberg). • In dieser Zeit:

UBH: Seit 18. Mai 1795 Bibliothekar der UB durch Erwerb der U-Bibliothekarsstelle für 4000.- Gulden als letzte pfälzische Bibliothekspfründe (aus: PA 2467) von Joseph David von Oberkamp (Bruder von Franz Joseph und Franz Philipp von O., s. Drüll (1991) S. 116-118); 1795 jährl. BibliothekarsGehalt: 350.- (anschl. gekürzt auf 295.-) Gulden, 12 Malter Korn (aus: PA 2467); 13. Dez. 1796 Hofgericht fällt wegen Verzögerung bei Abzahlung der Bibliothekarsstelle folgendes Urteil gegen W.: Es „... solle demselben an seiner Geld (295.- Gulden) und Frucht Besoldung (12 Malter Korn aus seiner Bibliothekarsstelle) $1 / 3$ tel ... so lang einbehalten werden, bis die Hofgerichts Rathen von Oberkampische Herrn Erben [= die Erben des Hofgerichtsrats von O.] mit ihrer Forderung ad 2000.- Gulden befriedigent sind, diesem nach sind nach deren Fiscalats Rechnungen [bereits] 1/3tel einbehalten, und an die Behörde bezalt worden ..." (aus: PA 2468).

Über den ungeordneten Zustand der Universitätsbibliothek im Jahr 1802 und den Anteil W.s am Ausmaß dieser Vernachlässigung sowie die Einsetzung eines weiteren Bibliothekars, siehe PA 2468, Berichte vom 2. Dez. 1802 bis 16. April 1803.

$\mathrm{Q} u$ UAH PA $2467 \mathrm{f}$; RA 3185, 5975, 6020, 7121, 7173, 7278, 7576, 7579, 7587. • Toepke IV (1903)
S. 353. - GLA Abt. 205, Fasz. 578, 676. - Auskunft: Ev. Oberkirchenrat - Landeskirchliches Archiv Karlsruhe (Sterbeeintrag 1805 im Totenbuch der luth. Providenzgemeinde Heidelberg); Stadtarchiv Zweibrücken; Stadtarchiv Mannheim (Ratsprotokoll von 1795, S. 1515 und 1573 sowie Familienbogen Wolfter).

$W$ Salisch-Pfälzische oder Rheinisch-Fränkische Denkmäler aus dem 9.-12. Jahrhundert. Frankfurt/M. 1786. Geschichte der Veränderungen des teutschen Reichsstaats. Zürich 1789. - Abhandlungen zur Beleuchtung der teutschen Geschichte. Heidelberg 1792. - Geschichte Dr. Martin Luther's und der durch ihn bewirkten Reformation. Mannheim 1805 .

$L$ Wechmar (1846) S. 134, 254; Keller (1913) S. 110 f.; Schneider (1913) S. 24, 27, 146-148; Bader (1925) S. 289; Wolgast (1986) S. 81; WBIS. • Heinstein, Patrick: Klassikrezeption im romantischen Milieu. Schiller und Heidelberg. Eine Revision der Jahre 1782-1810 in: Heidelberg. Jahrbuch zur Geschichte der Stadt 2010. Heidelberg 2009. Jg. 14. S. 11-35, hier: S. 17 .

\section{Wülfing, Ernst Anton}

1908-1926 Nat.-Math. Fak.

Mineralogie, Petrographie

* 27. Nov. 1860 Elberfeld (heute: Stadtteil von Wuppertal)

$\dagger$ 17. Dez. 1930 Bad Wörishofen

$\square$ Elberfeld

ev.

V Friedrich Hermann W. (1811-189o) Rittergutsbesitzer von Volkardey in Ratingen bei Düsseldorf, Mitbegründer der Bergisch-Märkischen Eisenbahn und der Dampfschifffahrts-Gesellschaft für den Nieder- und Mittelrhein, s. Geneanet - Hennings, Peter: Familienstammbaum Wülfing online unter https:// de.geneanet.org/ (abgerufen am 28. Dez. 2017)

M Anna Henriette Auguste geb. Boesner (18291905) 
( 5. Aug. 1893 Erminia Paula Ludovica geb. von Martitz (1871-1969) T von Ferdinand von M. (1839-1921) seit 1864 Privat-Dozent, seit 1868 a.o. Prof. Königsberg (Preußen), seit 1872 o. Prof. Freiburg/Br., seit 1875 o. Prof. Tübingen, 1898-1920 Ordinarius für Staats- und Völkerrecht Berlin; Mitglied: 1898-1903 preußisches Oberverwaltungsgericht, Haager Schiedshof, s. Wer ist's (1914) S. 1077, NDB 16 (1990) S. 309

K 4 S: u. a. Johann Friedrich W. (1894-1945 im Speziallager der sowjetischen Besatzungsmacht in Ketschendorf bei Fürstenwalde/ Spree umgekommen) Teilhaber der Lackfirma „Hermann Wülfing KG“ in Hamburg und Berlin, s. Bergisches Geschlechterbuch (1980) S. 36

Vw Vetter: John Max W. (1859-1929) Stifter von Stipendien an UH, s. UAH B-9589-9591.

Lb Von Militärdienstpflicht als Einjährig-Freiwilliger befreit aufgrund Kurzsichtigkeit; WS 1881/ 82-WS 1882/83 Studium der Chemie und Naturwiss. an U Genf, 26. Mai 1883-4. Nov. 1884 H; 1. Aug. 1884 Dr. phil. an UH; seit WS $1884 / 85$ Forts. des Studiums an U Berlin; 1884-1886 Assistent am Chemischen Inst. der U Berlin; seit WS 1886/ 87 Studium der Mineralogie, Geographie an U Greifswald, seit WS 1887/88 Wien.

UH: Mai 1888-Sept. 1890 Assistent am Mineralog. Inst.

U Tübingen: 14. Mai 1891 Habilitation; seit 29. März 1897 nichtetatm. a. o. Prof.

Land- und Forstwirtschaftl. Akademie Hohenheim (heute: Stadtteil von Stuttgart): Seit 29. Juli 1899 o. Prof. für Geologie und Mineralogie.

TH Danzig: 27. Juli 1904 Ern. zum etatm. Prof. und Leiter des Inst. für Geologie und Mineralogie an neugegründeter $\mathrm{TH}$.

U Kiel: 13. März 1907 Ern. zum o. Prof.

UH: 21. Juli 1908 Ern. zum o. Prof. als Nachf. von Harri Rosenbusch und Gründungs-Direktor des Mineralog.-Petrograph. Inst. mit e. jährl. Gehalt von 600o.- Mark; 7. Okt. 1908 Vereidigung; 1. Okt. 1914 Gehaltszulage von jährl. 30o.- Mark; Jah- resgehalt: 1. Jan. 1921 von 37 976.- Mark, 1. April 1922101 080.- Mark, 1. April 1923803 120.- Mark (während der Inflation), 1. Nov. 1924 946,60 Mark; 31. März 1926 Emeritierung.

1911/12, 1917/18 Dekan der Nat.-Math. Fak. der UH

1918 Geh. Hofrat

Engerer Senat der Universität Heidelberg teilt W. auf seine Anfrage nachfolgenden Bescheid am 20. Okt. 1908 mit: „... bei der Feststellung der Anciennität der ordentlichen Professoren (sind) die Jahre zu rechnen, die der Betreffende als Ordinarius an einer deutschen Universität oder Technischen Hochschule oder an einer Universität deutscher Zunge zugebracht hat ..." (aus: UAH PA 6429).

1983 wird ein Mineral nach W. „Wülfingit“ genannt, s. hierzu: Schmetzer, K., Schnorrer-Köhler, G., Medenbach, O.: Wülfingite, epsilon- $\mathrm{Zn}(\mathrm{OH})_{2}$ and Simonkolleite ... in: Neues Jahrbuch für Mineralogie, Monatshefte (1985) S. 145-154.

E Mitglied: 1909 Akademie der Wissenschaften H, 1925 Akademie der Naturforscher Leopoldina Halle/S. 1927 Dr. rer. nat. h.c. Tübingen. 1904 Schwarzer Adler-Orden III. Klasse; 1913 Ritterkreuz I. Klasse des Ordens vom Zähringer Löwen.

Qu UAH PA 6429; RA 5029, 6489, 6895. - GLA Abt. 235, Fasz. 2677. • Briefe: UBH. • Siehe auch Archiv der Dt. Akademie der Naturforscher Leopoldina Halle/S. • Auskunft: Verband Ev. Kirchengemeinden in Wuppertal-Elberfeld - Verwaltungsamt - (Geburtseintrag).

$W$ Tabellarische Übersicht der einfachen Formen der 32 kristallographischen Symmetriegruppen. Stuttgart 1895. 2. Aufl. 1914. - Die Meteoriten in Sammlungen und ihre Literatur. Tübingen 1897. Reprint 1980. - Mikroskopische Physiographie der petrographisch wichtigen Mineralien. Begr. von Harry Rosenbusch. Bd. 1: Die petrographisch wichtigen Mineralien und die Methoden ihrer Untersuchung. 1. Hälfte: Untersuchungsmethoden. 
4. Aufl. Stuttgart 1904. 5. völlig umgestaltete Aufl. 1921-1924. - Bei badischen Truppen an der Westfront mit einem Liebesgaben-Transport. Vortrag gedruckt. Heidelberg 1916. - Ein neues Polarisationsmikroskop und kritische Betrachtungen über bisherige Konstruktionen. Heidelberg 1918.

$L$ Professoren Kiel (1956) S. 156; Klein (1968) S. 138. - Universität Hohenheim, Landwirtschaftliche Hochschule 1818-1968. Hrsg. von Günther Franz. Stuttgart 1968. S. 92. - Bergisches Geschlechterbuch. Bearb. von Marianne StrutzKödel. Bd. 5. Görlitz 1980. S. 35. • Jansen (1992a) S. 170 (Register); Wennemuth (1994) S. 640 (Register); WBIS; Biogr. Enzyklopädie Naturwissenschaftler 2 (2003) S. 983; Badische Biographien N.F. VI (2011) S. 437-441. - Kipnis, Alexander: Biographie E.W. online unter http://www.kipnis. de/index.php/alexander/kurzbiografien/87-wuel fing-ernst-1860-1930-mineraloge (Stand: 5. Mai 2014; Ausdruck im UAH). - Deutsche Biographie, s. https://www.deutsche-biographie.de/pnd1174321 48.html [26.11. 2017].

$P$ Bildarchiv UAH; graph. Slg. UBH.

\section{Wund}

siehe auch Wundt

\section{Wund, Friedrich Peter}

siehe Wund, Peter Friedrich

Wund, Peter Friedrich (auch: Wundt, Friedrich Peter)

1788-1808 Phil. Fak.

Landesgeschichte, Landesgeographie

* 16. (?) Sept. 1745 Kreuznach (?) (heute: Bad K.)

$\dagger$ 13. März 1808 Wieblingen (heute: Stadtteil von Heidelberg)

$\square \quad$ 15. März 1808 Wieblingen ref.
V Johannes Jacob Wund (1700-1771), u.a. 20. Nov. 1733-30. Juni 1735 Pfarrer und (Schul-)Inspektor in Alzey, seit 1735 I. Pfarrer in (Bad) Kreuznach, 1750-1771 Prof. für Theologie H, s. UAH RA 4738, 4915, 5332, 5906 (= GF 99), 6857, 809o f.; Drüll (1991) S. 172-174, Czer (1997) Anhang, Dt. Literatur-Lexikon 36 (2017) Sp. $342 \mathrm{ff}$.

M Maria Modesta geb. Mieg (1714-1765) T von Ludwig Christian M. (1668-1740), u.a. 17061740 o. Prof. für Theologie UH, s. Drüll (1991) S. 106-108, Maesel (1997) S. 234 u. ö.

(17. Sept. 1778 Christina Magdalena geb. Flies(s)en (1760-1798)

๑ 11. Juni 1804 Carolina Friederike geb. Fischer (1758-1830)

K 13 (davon $8 \mathrm{~K}$ früh $\dagger$ ), u.a. Carl Eduard Ludwig Wundt (1779-1825), u. a. Advokat, seit 1820 Oberamtmann, seit 1824 badischer Ministerialrat im Ministerium des Innern in Karlsruhe und 1825 Mitglied der II. Kammer des Badischen Landtags ebd., s. Neuer Nekrolog der Deutschen. Hrsg. von Friedrich August Schmidt ... 3. Jg. (1825) 2. H. Ilmenau 1827. S. $1529 \mathrm{f}$.

Vw Brüder: (siehe) Daniel Ludwig Wundt. - Johannes Carl Casimir W. (1744-1784), u.a. 1776-1784 o. Prof. für Schöne Wissenschaften, Philosophie, Kirchengeschichte an UH, s. UAH RA 1117, 6716; Drüll (1991) S. 174-178, Maesel (1997) S. 241 u. ö. - Johann Ludwig W. (vor 1741-1758), siehe Briefe aus den Jahren 1755 und 1758 in: UAH RA 6549. - Schwestern: Luise W. (†1797), s. UAH RA 8149 und jüngste Schwester Juliana Margaretha W. verh. Beck, siehe UAH RA 8090-8095

Vw Vetter: Johann Daniel Weber (1757-ca. 1819) Bergbau-Ingenieur, u.a. 1788 Ern. zum II., dann I. Direktor der Königlich-Spanischen Mineralog. Expedition des Königreiches Peru, seit 1797 Direktor des Gebirgs [Silberbergwerks] von Potosíe (heute: Bolivien), aus: Paul, Roland: Vor 250 Jahren: J. D. W., ein pfälzischer Bergbauingenieur, wird in Steinwenden geboren in: Historische Schlaglichter - Institut für pfälzische Geschichte und Volkskunde. Nachricht vom 10. Jan. 2007, s. http://www.pfalzgeschichte.de/johann-daniel-weber/ (abgerufen am 30. Dez. 2017)

Vw Enkel: (siehe) Wilhelm Wundt. 
Lb UH: Seit 3. Okt. 1764 Studium der Theologie; 1766-1772 Inhaber des Stipendiums Schloerianum (Schloerianisches S.) als Nachf. seines Bruders Daniel Ludwig W. • In dieser Zeit:

Sobernheim: 1767 Rezeption; 1767-1772 Pfarrer.

Sinsheim: Seit Anfang 1772 II. Pfarrer, siehe RA 6549.

Lautern (heute: Kaiserslautern): April 1776-1789 I. Pfarrer und Inspektor für den umliegenden Kirchenbezirk Lautern. • In dieser Zeit:

Kameral Hohe Schule Lautern: 1. April 1777-1784 (Verlegung nach $\mathrm{H}$ als Staatswirtschafts Hohe Schule) a. o. Prof. für Allg. und Vaterländische Geschichte.

Staatswirtschafts Hohe Schule H: 1789-Mai 1803 (Eingliederung der „Staatswirtschafts Hohe Schule" in UH, s. hierzu Heinrich Eschenmayer und Ludwig Wallrad Medicus: Einträge unter $Z$ [itat]) Lehrer für Geschichte. In dieser Zeit:

UH: Nov. 1788 (Erste Vorlesungsankündigung)WS 1807/o8 (letzte Vorlesungsankündigung über Geschichte der Großherzoglich Badischen Lande) a. o. Prof. In dieser Zeit:

Wieblingen: 8. Juni 1789-13. März 1808 (†) Pfarrer und „Inspector der Classe Ladenburg“ (aus: ADB (1910) S. 128).

$Z$ Wunds Witwe Carolina Friederike bittet 1809 und erneut 1812 ,wegen der dürftigen Verhältnis-

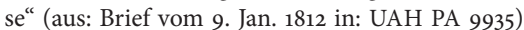
Oberkirchenrat in Karlsruhe vergeblich um eine Pension; angeblich bot vor 1805 die kirchliche Behörde Wund „eine Vergütung für seine Fuhr- und Zehrungs Costen“ an; W. entschied sich „statt dessen [für] eine Pension für seine Wittwe" (aus: Brief des Prorektors Arnold Heise vom 26. Febr. 1809 in: UAH PA 9935). Die Petitionen der Witwe werden vom Oberkirchenrat weitergeleitet an Universität Heidelberg; Prorektor Heise lehnt 1809 eine Geldzuwendung aus der Universitäts-Kasse ab und schreibt u. a.: „... Ueberhaupt muß ich bemerken, $\mathrm{da}$, so große Verdienste der verstorbene Inspector Wundt sich um die Pfälzische Geschichte und
Alterthümer erworben hat, seine Verdienste um die Universität doch von geringem Belange sind, indem er, soviel mir bekannt ist, nur einige Semester hiedurch ein oder zwey Stunden die Woche, vor sehr wenigen Zuhörern Vorlesungen gehalten hat ..." (aus: Brief vom 26. Febr. 1809 in: PA 9935). Dies stimmt nicht ganz, denn zwischen 1788-1808 kündigt W. fast regelmäßig Vorlesungen an.

Zur Witwenkasse, -pension, Hinterbliebenenbeihilfe etc., siehe auch Johann Hermann Vossmann, Leopold Weiß, Gerhard Weissenfels

E 1776 O. Mitglied der Physikalisch-Ökonomischen Gesellschaft.

Qu UAH PA 9935; RA 5138, 6024, 6027, 6549 (hier eigenhändige Unterschrift mit „Peter Friedrich Wund“ am 14. Aug. 1771). Toepke IV (1903) S. 219. - Nachlaß: Badische Landesbibliothek Karlsruhe. Ergebnislose Anfragen: Ev. Kirche im Rheinland - Archivstelle Boppard (Kirchenbücher der ref. Gemeinde Kreuznach); Stadtarchiv Kaiserslautern; Zentralarchiv der Ev. Kirche der Pfalz in Speyer. - Auskunft: Ev. Oberkirchenrat - Landeskirchliches Archiv - Karlsruhe (ref. Kirchenbücher St. Peter Heidelberg (Konfirmationseintrag 1763) und ref. Kirchenbücher Wieblingen (Sterbeeintrag 1808): ohne Nennung von Geburtsdatum und -ort); Standesamt der Verbandsgemeinde Weilerbach (ref. Kirchenbuch der Pfarrei Weilerbach (S. 214: Eheschließung von 1778: ebenfalls ohne Nennung von Geburtsdatum und -ort)).

$W$ Allgemeine pfälzische Bibliothek oder systematisches Verzeichniß der Schriften, welche zur genauern Kenntniß der Landes-, sowohl als der Regierungsgeschichte von der Kurfürstl. Rheinpfalz, den Herzogthümern Oberpfalz, Neuburg und Sulzbach und ehemaligen Herzogthume Zweibrücken dienen; mit den dazu gehörigen kritischen und litterarischen Bemerkungen. 1. Bd. in $3 \mathrm{~T}$. Speyer $1785-1802$ (mehr nicht erschienen). Verzeichniß der katholischen Pfarreien, Schuldiener, Kirchen und Kapellen in dem Kurfürstenthum Pfalz am Rhein in: Magazin für die pfälzische Geschichte 1 (1793) S. 397-416. • Die 
Badische Pfalzgrafschaft, statistisch und topographisch bearbeitet. Karlsruhe 1804. - Geschichte und Beschreibung der Stadt Heidelberg. Bd. 1 (mehr nicht erschienen). Mannheim 1805. Nachdr. Neustadt an der Aisch 1997. - Siehe Dt. LiteraturLexikon 36 (2017) Sp. 339-342.

L ADB 55 (1910) S. 128 f. (unter Benutzung der Kirchenbücher von Heidelberg, Kreuznach und Wieblingen); Keller (1913) S. 111; Schneider (1913) S. 25, 342; Badisches Pfarrerbuch 2 (1939) S. 681; Biundo (1968) S. $521 \mathrm{f}$. Kurzbiographien vom Mittelrhein und Moselland. Hrsg. von der Arbeitsgemeinschaft für Landesgeschichte und Volkskunde ... Koblenz 1968. • Plettenberg (1983) S. 143 f., 177 u. ö.; WBIS. - Czer, Andreas: Zur Biographie von F.P.W. in: Geschichte und Beschreibung der Stadt Heidelberg ... (1997) Anhang. - Kaiserslautern im 18. Jahrhundert. Die Menschen, die in den familienkundlichen Quellen der Stadt erwähnt werden. Einheimische, Eingepfarrte, Fremde. Bearb. von Eugen Reis. Kaiserslautern 2000. Nr. 04203.0.00 (unter „Einheimische“). • Deutsches Familienarchiv 148 (2007) S. 194f., 253-255 (S. 253: hier irrtümlich 13. Mai 1808 als Todesdatum genannt); 200 Jahre Heidelberger Romantik (2008) S. 4 ff.; Dt. Literatur-Lexikon 36 (2017) Sp. 338-342; Deutsche Biographie, s. https://www. deutsche-biographie.de/pnd117728543.html [26.12. 2017].

\section{Wunderlich, Hermann}

1889-1902 Phil. Fak.

Dt. Sprache und Literatur

* 15. Juni $1858 \mathrm{Ulm}$

$\dagger$ 29. Dez. 1916 Frohnau (heute: Ortsteil von Berlin)

ev.

V Karl Friedrich Reinhold W. (1813-1866) Kaufmann

M Sophie geb. Springer (1822-1902)

$\infty$ 12. Aug. 1893 Gertraud geb. Schroeder (18701957), s. Hoffmann (2011) S. 125 f. - T von: (siehe) Richard S.

$\mathrm{K}$ unbekannt.
Lb Seit WS 1876/77 Studium an U Leipzig, dann Tübingen, Berlin; April 1883 Dr. phil. an U Berlin; anschl. längere Reisen in Belgien und Großbritannien; danach Gasthörer an U Bonn; Okt. 1884Juni 1887 Studienaufenthalt in München.

UH: 20. Mai 1889 Habilitation; seit 5. Juni 1893 nichtetatm. a. o. Prof.

Berlin: Seit Okt. 1902 Bibliothekar, seit 1909 Oberbibliothekar an Königl. Bibliothek; seit 1902 auBerdem Mitarbeiter am Dt. Wörterbuch der Brüder Grimm.

Qu UAH PA 2475; Fak.-Akten H-IV-102/123 fol. 33r, 83r, v, H-IV-102/133 fol. 16r. • Otto Hölder, Briefe an die Eltern 1878 bis 1887 ... Hrsg. von Stefan Hildebrand ... Leipzig 2014. S. 342 (Register). • Mitteilungen: Frau Katharina Jahn-Busch, Hamburg.

$W$ Beiträge zur Syntax des Notker'schen Boethius. Berlin 1883. Der deutsche Satzbau. Stuttgart 1892. 3. Aufl. 1925. Unsere Umgangssprache in der Eigenart ihrer Satzfügung. Weimar 1894.

$L$ Wer ist's (1914) S. 1895; Biogr. Jahrbuch 1 (19141916) S. 372; Bader (1925) S. 291; WBIS; Lehmann (1967) S. 227 f. • Behr, Irmtraud: La langue parlée chez H.W. in: DRLAV. Documentation et recherche en linguistique allemande contemporaine. $\mathrm{Pa}-$ ris 1987 . No. 36 f. S. 227-241. • Faber, Marlene: Frühe Beiträge zur Gesprächsforschung von Moritz Lazarus, H.W. ... in: Betriebslinguistik und Linguistikbetrieb. Hrsg. von Eberhard Klein ... Tübingen 1991. Bd. 2. S. 153-162. • Jansen (1992a) S. 170 (Register). Massariello Merzagora, Giovanna et al.: La nostra lingua d'uso nella peculiarità del suo costrutto sintattico: H.W. Pisa 2010. • Riecke (2016) S. 36 f., 125; Deutsche Biographie, s. https:// www.deutsche-biographie.de/pnd117355143.html [26.12. 2017].

\section{Wundt}

siehe auch Wund 


\section{Wundt, Daniel Ludwig}

1787-1805 Theol. Fak.

Kirchengeschichte

* 13. Dez. 1741 Kreuznach (heute: Bad K.)

$\dagger$ 19. Febr. 1805 Heidelberg

ref.

V Johannes Jacob Wund (1700-1771), siehe Peter Friedrich Wund

M Maria Modesta geb. Mieg (1714-1765), siehe ebd.

@ 1767 Luise Katharina geb. Fuchs (1750-1832)

$\mathrm{K} \quad 5 \mathrm{~S}, 4 \mathrm{~T}$ (davon $2 \mathrm{~S}, 3 \mathrm{~T}$ früh $\dagger$ ); siehe Blatt von 1799 in: UAH PA 2476

Vw Brüder, Schwestern und weitere Vw: siehe Peter Friedrich Wund (Bruder).

Lb UH: Seit 20. Nov. 1756 Studium der Philosophie, seit WS 1758/59 Studium der Theologie; 1756-1765 Inhaber des Stipendiums Schloerianum (Schloerianisches S.) als Miegscher Verwandter an U (Stifter des auch für die Miegschen Nachkommen bestimmten Stipendiums war der kurpfälz Geh. Rat und kurfürstl. Vizekanzler in Heidelberg Johann Friedrich Schlör (1569-1637), dessen Tochter Maria Elisabeth Schlör (1616-1658) Ehefrau von Dr. iur. Johann Ludwig Mieg (1609-1671), seit 1664 kurfürstl. Kanzler in Heidelberg, war).

7. Sept. 1761 Pfarrer-Examen; vor Sept. 1763 Bildungsreise nach Lausanne, Genf und Zürich.

Seit 7. Sept. 1763 II. Pfarrer in Ladenburg (bei H) und Pfarrer in Heddesheim (bei Weinheim).

Oppenheim: Seit 17. Juli 1769 I. Pfarrer und Inspektor.

(Bad) Kreuznach: Seit 12. März 1773 I. Pfarrer und Inspektor.

UH: Seit 23. Sept. 1787 (14. März 1787 Ern.) II. Prof. als Nachf. von Dominik Heddäus (s. Drüll (1991) S. 57-59) mit e. jährl. Besoldung von 300.- Gulden, 1 Fuder Wein, 15 Malter Korn, s. hierzu UAH PA 1688 (Heddäus); 28. Okt. 1792 Dr. theol.; seit 13. Nov. 1795 I. Prof. als Nachf. von Heddäus (zur Berufung auf I. Professur, s. UAH RA 6716).
Seit 1797 Mitglied des ref. Kirchenrats

1799/180o Rektor der UH; 1788, 1790, 1792, 1794, 1795, 1796, 1798, 1800, 1801, 1804 Dekan der Theol. Fak. der UH, ref. Abt., s. hierzu Weisert/Drüll/ Kritzer (2007) S. 48

Qu UAH PA 2476; RA 268, 718, 6549, 6716 (eigenhändige Unterschrift), 7822. • GLA Abt. 205, Fasz. 579. Auskunft: Ev. Kirche im Rheinland - Archivstelle Boppard (Kirchenbuch der ref. Gemeinde Kreuznach); Standesamt Alzey (ref. Kirchenbuch für Vater Johannes Jacob W.).

$W$ Nachrichten von etlichen gelehrten Pfälzerinnen in: Carlsruher Beyträge zu den schönen Wissenschaften 2 (1761) S. 170-190. - Grundriß der pfälzischen Kirchengeschichte von der Gründung des Christenthums an bis zum Jahre 1742. Heidelberg 1786. - Versuch einer Geschichte des Lebens und der Regierung des Kurfürsten Karl Ludwig von der Pfalz. Genf, Heidelberg 1786. Kurzer Entwurf seiner Vorlesungen über die Geschichte des jüdischen Volkes ... Heidelberg 1788. • Geschichte des Lazarismus in der Pfalz. Heidelberg 1793. • Siehe Dt. Literatur-Lexikon 36 (2017) Sp. 335-337.

MHG Magazin für die Kirchen- und GelehrtenGeschichte des Kurfürstenthums Pfalz. 3 Bde. Heidelberg 1789-1793 (Bd. 3 u. d. T.: Magazin für die pfälzische Geschichte). - Siehe auch Dt. LiteraturLexikon 36 (2017) Sp. $337 \mathrm{f}$.

$L$ Intelligenzblatt zur Allg. Literaturzeitung Nr. 43 (1805) S. 349-351; ADB 55 (1910) S. 126 f. (unter Benutzung der Kirchenbücher von Heidelberg, Kreuznach und Oppenheim); Keller (1913) S. 78 f.; Schneider (1913) S. 12; Badisches Pfarrerbuch 2 (1939) S. 68of.; WBIS; Maesel (1997) S. 241 und Anm. 69 u. ö.; Carl (2004); Deutsches Familienarchiv 148 (2007) S. 192-194, 227 f.; Deutsche Biographie, s. https://www.deutsche-biographie.de/pn d139872310.html [26.12. 2017]; Dt. Literatur-Lexikon 36 (2017) Sp. 335-338. 


\section{Wundt, Friedrich Peter}

siehe Wund, Peter Friedrich

\section{Wundt, Wilhelm Maximilian}

1857-1874 Med. Fak.

Physiologie, Anthropologie, Med. Psychologie

* 16. Aug. 1832 Neckarau (heute: Stadtteil von Mannheim)

$\dagger$ 31. Aug. 1920 Großbothen (heute: Ortsteil von Grimma)

口 Leipzig

ev.

V Maximilian W. (1787-1846) Pfarrer, s. UAH RA 4724, RA 5137f.; Badisches Pfarrerbuch 2 (1939) S. 681

M Maria Friederike geb. Arnold (1797-1868), s. Lamberti (1995) S. 21 u.ö. - Schwester von: (siehe) Friedrich Arnold

( 14. Aug. 1872 Sophie geb. Mau (1844-1912) Gouvernante, s. Lamberti, S. 87-91, 95f. u.ö.; $\mathrm{T}$ von Heinrich August M. (1806-1850) seit 1839 o. Prof. für Theologie Kiel, s. Professoren Kiel (1956) S. 5, BBKL XXXI (2010) Sp. 849851. - Bruder: August Mau (1840-1909) seit 1873 Sekretär am Dt. Archäolog. Institut (DAI) in Rom, s. NDB 16 (1990) S. $421 \mathrm{f}$.

K 2 T (davon 1 T früh $\dagger$ ), 1 S: Max W. (18791963) seit 1907 Privat-Dozent Straßburg, seit 1918 a. o. Prof. Marburg, seit 1920 o. Prof. Jena, 1929-1945 (Emeritierung) o. Prof. für Philosophie Tübingen, s. Lamberti, S. 96-104, Tilitzki 1 (2002) S. 123-129 u. ö.; Michalski, Mark: Der Gang des deutschen Denkens. Versuche und Programme nationaler Philosophiegeschichtsschreibung ... Würzburg 2010. S. 377-426; Handbuch Christian Wolff. Hrsg. von Robert Theis und Alexander Aichele. Wiesbaden 2018. - Ehemann von Senta Sartorius von Waltershausen (1885-1961) T von August Frhr. S. von W. $\left({ }^{*} 1852\right.$ Göttingen $\left.\dagger 1938\right)$, u. a. seit 1885 o. Prof. Zürich, 1888-1918 (Ausweisung) o. Prof. für Volkswirtschaftslehre, Steuerlehre und Finanzwissenschaften Straßburg, s. NDB 22 (2005) S. 438 f. (weitere Vw)
Vw Großvater: (siehe) Peter Friedrich Wund. Enkel: Wilhelm Wundt, s. Drüll (2009) S. 684 f.

Lb Studium: Seit WS 1851/52 Naturwiss., Philosophie, Medizin an U Tübingen, seit 25. Okt. 1852 Medizin an UH; Herbst 1855 med. Staatsexamen in Karlsruhe; 10. Nov. 1855 Dr. med. an UH; im Sommer 1856 Studienaufenthalt an U Berlin; Aug. 1856 Rückkehr nach $\mathrm{H}$.

UH: 5. Febr. 1857 Habilitation, s. hierzu Lamberti (1995) S. 51f.; 20. April 1857 Blutsturz während der ersten Vorlesung; anschl. knapp einjährige Zwangspause; seit Aug. 1858 Assistent am Physiolog. Inst. bei Hermann Helmholtz; seit 14. April 1864 a. o. Prof. für Anthropologie und Med. Psychologie; 1870 Militärarzt während des DeutschFranzösischen Krieges; seit 10. Aug. 1871 a. o. Prof. mit Besoldung als Vertreter von Helmholtz. In dieser Zeit:

Karlsruhe: 1866-1868 Mitglied der II. Kammer des Badischen Landtags als Abgeordneter der Stadt $\mathrm{H}$ als Mitglied der Badischen Fortschrittspartei.

U Zürich: Seit WS 1874/75 o. Prof. für Induktive Philosophie.

U Leipzig: WS 1875/76-SS 1917 (Rücktritt) o. Prof. für Philosophie; 1879 Gründer des weltweit ersten Inst. für Experimentelle Psychologie, zunächst als Privat-, seit 1883 als U-Einrichtung, s. hierzu Lamberti, S. 121-132 u. ö.

1863-1866 Vorsitzender des Arbeiter-Bildungsvereins Heidelberg, s. hierzu Bringmann, Wolfgang G. et al.: W.W. and the workers' educational movement in: Psychologie und Geschichte 6 (1995) 3/4, S. $233-243$.

Sept. 1914: W. unterschreibt neben 92 anderen Wissenschaftlern, Schriftstellern und Künstlern das sog. „Manifest der 93“, e. Aufruf vor allem gegen den Vorwurf der deutschen Kriegsschuld und der Kriegsgreuel in Belgien sowie für die Identität von deutscher Kultur und deutschem Militarismus.

W.s eigene Bibliothek befindet sich heute zu ca. 7o Prozent in der University Library der Tohoku 
Universität in Sendai, Japan, s. http://www.library.tohoku.ac.jp; im Max-Planck-Institut für Wissenschaftsgeschichte in Berlin ist ein kleiner Ausschnitt davon verzeichnet: Wundts Personal Library (575 Einträge), s. http://vlp.mpiwg-berlin. mpg.de/library/libraries.html?-op_volumeid=eq\& volumeid=lit22218).

Seit 1952: Verleihung der Wilhelm-Wundt-Medaille durch die Deutsche Gesellschaft für Psychologie an besonders verdienstvolle Psychologen (1. Preisträger: (siehe) Willy Hellpach)

1979: Gründung der Wilhelm Wundt Gesellschaft e. V., Sitz der Gesellschaft in Heidelberg, s. hierzu http://www.wilhelm-wundt-gesellschaft.de/ (abgerufen am 29. März 2018)

2016: Gründung des Fördervereins WilhelmWundt-Haus in Grossbothen (bei Leipzig), um zunächst die Nutzungsrechte am ehemaligen Wohnhaus W.s in der Grimmaer Straße 28 zu erwerben, s. hierzu http://userpage.fu-berlin.de/sejutti/muse um/foerderverein/ (abgerufen am 16. Febr. 2018)

1888 Sächsischer Geh. Hofrat; 1909 Wirkl. Geh. Rat (Exzellenz)

$E$ Mitglied der Akademie der Wissenschaften: 1882 Leipzig, 1900 Berlin, 1900 München, 1909 Wien. 1912 Orden pour le Mérite für Wissenschaften und Künste. 1876 Dr. phil. h.c. Leipzig, 1887 Dr. iur. h.c. Göttingen. - Ehrenbürger: 1902 Leipzig, 1907 Mannheim.

$Q u$ UAH PA 2478; Fak.-Akte H-III-111/62 fol. 278r. - Briefe: UBH; siehe auch Kalliope. - Der Briefwechsel zwischen W.W. und Emil Kraepelin ... Hrsg. von Holger Steinberg. Bern 2002. • W.W. im Kreise seiner Schüler. Der Briefwechsel mit Oswald Külpe, Ernst Meumann und Hugo Münsterberg. Hrsg. von Thomas Fuchs und Till Meyer. Leipzig 2017. - Privatarchiv im Universitätsarchiv Leipzig, s. hierzu auch Lamberti (1995) S. 172; Meyer, Till: Das DFG-Projekt. Erschließung und Digitalisierung des Nachlasses von W.W. an der UB Leipzig in: Leipziger Jahrbuch zur Buchgeschichte. Eine Veröffentlichung der UB Leipzig ... Wiesbaden 2015. S. 347-357. • Fahren- berg, Jochen: Wundt-Nachlass. Eine Übersicht über wichtige Archive, Verzeichnisse, Digitalisate, Korrespondenz und Skripten, Biographisches ... Freiburg/Br. 2016. Online, s. https://freidok.unifreiburg.de/data/12409; Dt. Literatur-Lexikon 36 (2017) Sp. 350. - Mitteilungen: Herr Prof. em. Dr. Jochen Fahrenberg, Freiburg/Br. - Erlebtes und Erkanntes. Stuttgart 1920. (Autobiogr.)

$W$ Beiträge zur Theorie der Sinneswahrnehmung. Leipzig 1862. Vorlesungen über die Menschenund Tierseele. Leipzig 1863. 7. Aufl. 1922. 2 Bde. • Lehrbuch der Physiologie des Menschen. Stuttgart 1865. 4. Aufl. 1878. 2 Bde. • Grundzüge der physiologischen Psychologie. Leipzig 1874. 7. Aufl. 1923. 3 Bde. Über die Aufgabe der Philosophie in der Gegenwart. Rede gehalten zum Antritt des öffentlichen Lehramts der Philosophie an der Hochschule in Zürich am 31. Okt. 1874 in: Philosophische Monatshefte 11 (1874) S. 65-68. • Logik. Eine Untersuchung der Prinzipien der Erkenntnis und der Methoden wissenschaftlicher Forschung. Stuttgart. 2 Bde. 1880-1883. 4. Aufl. 1919-1921. 3 Bde. • Ethik. Eine Untersuchung der Tatsachen und Gesetze des sittlichen Lebens. Stuttgart 1886. 4. Aufl. 1912. 2 Bde. System der Philosophie. Leipzig 1889. 4. Aufl. 1919. 2 Bde. Grundriss der Psychologie. Leipzig 1896. 15. Aufl. 1922. • Völkerpsychologie. Eine Untersuchung der Entwicklungsgesetze von Sprache, Mythus und Sitte. Leipzig 1900-1920. (Einzelne Bde. in 3. bzw. 4. Aufl. 1926-1929.) • Einleitung in die Philosophie. Leipzig 1901. 8. Aufl. 1920. - Reden und Aufsätze. Leipzig 1913. 2. Aufl. 1914. - Leibniz. Zu seinem zweihundertjährigen Todestag 14. Nov. 1916. Leipzig 1917. Die Psychologie im Kampf ums Dasein. Leipzig 1917. Siehe W.W.s Werke. Hrsg. von Eleonore Wundt. München 1927. Fahrenberg, Jochen: W. W. - Pionier der Psychologie ... (2011) S. 10-16 u. ö. • Dt. Literatur-Lexikon 36 (2017) Sp. 349.

HG 1881-1903 Philosophische Studien; Neue Folge u. d. T.: Psychologische Studien (HG: 1905-1918).

L Eisler, Rudolf: W.W.s Philosophie und Psychologie. In ihren Grundlehren dargestellt. Leipzig 1902. Biogr. Jahrbuch 2 (1917-1920) S. 626-636. Bringmann, Wolfgang et al.: Helmholtz und W. an der Heidelberger Universität $1858-1871$ in: Heidelberger Jahrbücher 20 (1976) S. 79-88. • Klüp- 
fel/Graumann (1986) S. 8-13 u. ö.; Zimmermann/ Drüll (1990) S. 31 f. • Lamberti, Georg: W. M. W. ... Leben, Werk und Persönlichkeit in Bildern und Texten. Berlin 1995. - Von Neckarau bis Großbothen. Fotographische Impressionen über Leben, Werk und Persönlichkeit von W. W. ... Hrsg.: Förderverein Wundt-Stiftung e.V. Bonn 1995. • DBE 10 (1999) S. 598 f. - Danziger, Kurt: W. and the temptations of psychology in: W.W. in history. The making of a scientific psychology. Ed. by R. W. Rieber and D. K. Robinson. New York 2001. S. 69-94. Goerttler (2004) S. 116; Peiffer (2004) S. 1195 (Register); Ärztelexikon ( $\left.{ }^{3} 2006\right)$ S. $351 \mathrm{f}$. W. W.s anderes Erbe. Ein Missverständnis löst sich auf. Hrsg. von Gerd Jüttemann. Göttingen 2006. • Deutsches Familienarchiv (2007) Bd. 148. S. 195197, 258 f. • Steinberg, H.: Die Bedeutung W. W.s für Emil Kraepelins Person und Werk in: Schriftenreihe der Dt. Gesellschaft für Geschichte der Nervenheilkunde 13 (2007) S. 233-265. • Von der Forschung gezeichnet (2007) S. 126 f. u. ö.; Geschichte U Leipzig 2 (2010) S. 921 (Register), 3 (2010) S. 969 (Register). - Michalski, Mark: Der Gang des deutschen Denkens ... Würzburg 2010. S. 164-181. • Fahrenberg, Jochen: W.W. - Pionier der Psychologie und Außenseiter? Leitgedanken der Wissenschaftskonzeption und deren Rezeptionsgeschichte (2011). Dokumentenserver der Universität des Saarlandes, s. http://psydok.sulb.uni-saarland.de/ volltexte/2011/2901/; Ders.: W.W.s Wissenschaftstheorie. Ein Rekonstruktionsversuch in: Psychologische Rundschau 63 (2012) S. 228-238. Fischer (2012) S. 340-342; Professorenkatalog Leipzig on- line; s. auch http://www.uni-leipzig.de/ psycho/ wundt/chapters/wundt.htm. • Schönpflug, Wolfgang: Geschichte und Systematik der Psychologie. 3. Aufl. Weinheim 2013. - Walach, Harald: Psychologie. Wissenschaftstheorie, philosophische Grundlagen und Geschichte. 3. Aufl. Stuttgart 2013. - Fahrenberg, Jochen: Leibniz' Einfluss auf W.s Psychologie, Philosophie und Ethik (2016). PsyDok Dokumentenserver für die Psychologie ZPID, s. http://hdl.handle.net/20.50o.11780/3675. • Kim, Alan: W.M.W. The Stanford Encyclopedia of Philosophy. Ed. by Edward N. Zalta (2016), s. https://plato.stanford.edu/archives/fall2016/ent ries/wilhelm-wundt/. • Russo Krauss, Chiara: Con Wundt, oltre Wundt. Richard Avenarius e il dibattito sulla psicologia scientifica tra Otto e Novecento. Soveria Mannelli 2016. - Ungerer, Gustav A.: Forschungen zur Biographie W.W.s und zur Regionalgeschichte. Gesammelte Schriften 19781997. Ein „Logbuch“ hrsg. von Katharina UngererHeuck und Yvonne L.S. Ungerer. Ubstadt-Weiher 2016. Wikipedia; Deutsche Biographie, s. https:// www.deutsche-biographie.de/pnd11863562X.html [28.12. 2017]; Doll/Kirsch/Eckart (2017) S. 42; Dt. Literatur-Lexikon 36 (2017) Sp. 348-352. • Fahrenberg, Jochen: W.W. ... Gesamtwerk: Einführung, Zitate, Kommentare, Rezeption, Rekonstruktion. Lengerich 2018 (im Druck).

$P$ Bildarchiv UAH. - Gayk, Ina: Max Klinger als Bildhauer ... Hamburg 2011. S. 205 ff. 


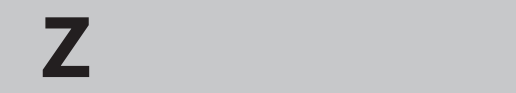

Zachariae, Carl Salomo (seit 1842:

Zachariae von Lingenthal)

1807-1843 Jur. Fak.

Allg. (und seit 1815 Dt.) Staatsrecht, Völkerrecht, Naturrecht, Lehnrecht, Kirchenrecht

* 14. Sept. 1769 Meißen

$\dagger \quad$ 27. März 1843 Heidelberg ev.-luth.

V Johann August Z., Advokat, Gerichtsdirektor

M Friederica Elisabetha geb. Hesse

๑ 1811 Johanna Eleonore geb. Glaeser (1786-1815)

$\mathrm{K} \quad 1 \mathrm{~T}$ (früh $\dagger$ ), $1 \mathrm{~S}$ : (siehe) Eduard Z.

Vw Onkel: Anton Ernst Klausing (1729-1803) U Leipzig: 1755 Habilitation, seit 1767 a. o. Prof. für Kirchliche (Geistliche) Altertümer an Theol. Fak. und 1767-1787 Kustos der UB, s. WBIS, Professorenkatalog Leipzig online. Ehemann von Friedericke Henriette geb. Zachariae (†1799) (im Professorenkatalog Leipzig irrtümlich als geborene Zacharias genannt).

Lb U Leipzig: Seit 7. Mai 1787 zunächst Studium der Philosophie, Philologie, Geschichte, Mathematik, seit 1789 der Rechtswiss.; 30. April 1794 Magisterexamen.

U Wittenberg: Ostern 1792 Immatrikulation als Hofmeister e. Grafen zur Lippe (bis 1794); seit 12. Aug. 1795 amtierender Magister; 30. Juli 1795 Dr. iur.; seit Sommer 1796 Z. hält Vorlesungen u. a. über Theoretische Philosophie, Feudalrecht; seit 27. Nov. 1800 a. o. Prof.; seit 29. Juli 1802 o. Prof. für Lehnrecht; auch Beisitzer der Juristenfak. und des Schöppenstuhles zu W. sowie Beisitzer des Landgerichts in Lübben (Niederlausitz).

UH: 1. Febr. 1807 Ern. zum o. Prof. als Nachf. von Carl Wilhelm Paetz; 23. April 1807 Dienstantritt; 1807-1821, 1834-1843 Beisitzer des Spruchkollegi- ums der Jur. Fak.; Rufe an U abgelehnt: 1817 Göttingen, 1829 Leipzig. • In dieser Zeit:

Karlsruhe: 1820-1823 Mitglied der I. Kammer des Badischen Landtags als Abgeordneter der UH anstelle von (siehe) Anton F.J. Thibaut; 1825-1828 Mitglied der Gesetzgebungskommission; 18251828 Mitglied der II. Kammer des Badischen Landtags als Abgeordneter des Landbezirks Heidelberg.

1817/18 Prorektor der UH (Z. lehnt Wahl zum Prorektor 1833 ab); 1812, 1816, 1820, 1823, 1827, 1831, 1835, 1839, März-April 1840, 1842 Dekan der Jur. Fak. der UH

1807 Hofrat; 1818 Geh. Hofrat; 1825 Geh. Rat II. Klasse

E 1823 Ritterkreuz, 1824 Kommandeurkreuz des Ordens vom Zähringer Löwen.

$Q u$ UAH PA 2480; RA 46, 4921, 5337, 5960, 6108, 6385,6765 . Catalogus Lectionum ... in Academia Vitebergensi ... 1796 in: Universitätsarchiv HalleWittenberg Rep. 1 Nr. 434, S. 43. GLA Abt. 205, Fasz. 581. Briefe: UBH. Biographischer und juristischer Nachlaß von K.S.Z. Hrsg. von ... Karl Eduard Zachariae. Heidelberg 1843. - Auskunft: Universitätsarchiv der Martin-Luther-Universität Halle-Wittenberg.

$W$ Wissenschaft als Gesetzgebung. Leipzig 1806. Nachdr. Goldbach 1997. Handbuch des französischen Civilrechts. 2 Bde. Heidelberg 1808. 2. Aufl. 4 Bde. 1811-1812. 8. Aufl. 4 Bde. 1894-1895. Anleitung zur gerichtlichen Beredsamkeit. Heidelberg 1810. - Staatsrecht der rheinischen Bundesstaaten und das rheinische Bundesrecht. Heidelberg 1810. - Für die Erhaltung der Universität Heidelberg. Im Nahmen der Lehrer der Universität ausgearbeitet von Dr. K.S.Z., derzeitigem Prorector der Universität. Heidelberg 1817. • Vierzig Bücher vom Staate. 5 Bde. Stuttgart 1820-1832. 2. Aufl. 7 Bde. 1839-1843. - Lucius Cornelius Sulla, genannt der Glückliche, als Ordner des römischen Freystaates. 2 Abt. Heidelberg 1834. 
MHG Seit 1797 Journal für Philosophie. • Seit 1829 Kritische Zs. für Rechtswiss. und Gesetzgebung des Auslandes.

L Brocher, Charles: Karl S.Z. Sa vie et ses œuvres in: Revue historique de droit français et étranger 14 (1868) S. 433-447, 15 (1869) S. 295-347 und 430-489. - Über C.S.Z. in: Reichlin-Meldegg, Karl Alexander Frhr. von: Das Leben eines ehemaligen römisch-katholischen Priesters. Heidelberg 1874. S. 128-130. ADB 44 (1898) S. 646-652; Keller (1913) S. 188 f.; Schneider (1913) S. 209, 214; Jammers (1964) S. 178 u. ö.; Heidelberger Strafrechtslehrer (1986) S. 10-14; Weisert (1991) S. 133 u. ö.; Stolleis 2 (1992) S. 169-172 u. ö. • Lang, Thomas: Die Staats- und Verfassungslehre C.S.Z.s. Frankfurt/M. 1996. - Carl (1998) S. 783. - Schroeder, Klaus-Peter: „Aut Caesar, aut nihil“ - Der Heidelberger Rechtsprofessor Karl S.Z. ... in: Festschrift für Erik Jayme. Hrsg. Heinz-Peter Mansel ... München 2004. Bd. 2. S. 1735-1750. • Humaniora (2006) S. 287-289 u. ö.; WBIS; Baur (2009) S. 163 u. ö.; Schroeder (2010) S. 30-38; Ders.: K.S.Z. ... Lehrer des französischen Rechts ... in: 200 Jahre Badisches Landrecht von 1809/1810 ... Hrsg. von Christian Hattenhauer ... Frankfurt/M. 2011. S. 201-215. - Klippel (2012) S. 395 (Register); Volkmer (2012) S. 20-26 u. ö. Reimer, Ekkehart: Das Steuerrecht als Staatsspiegel. Leben und Einsichten des Heidelberger Publizisten K. S.Z. von L. ... in: Heidelberger Thesen zu Recht und Gerechtigkeit ... Tübingen 2013. S. 39-65. • A.F. J. Thibaut ... Bürger und Gelehrter. Hrsg. von Christian Hattenhauer ... Tübingen 2017. S. 377 (Register). • Schroeder (2017) S. 3of., 38-40.

$P$ Bildarchiv UAH; graph. Slg. UBH.

Zachariae, Carl Eduard (seit 1842: Zachariae von Lingenthal)

1836-1843 Jur. Fak.

Römisches Recht

24. Dez. 1812 Heidelberg

$\dagger \quad$ 03. Juni 1894 Großkmehlen (Sachsen; heute: Brandenburg)

ev.-luth.
V (siehe) Carl Salomo Z.

M Johanna Eleonore geb. Glaeser (1786-1815)

(24. Sept. 1840 Louisa Henrietta Carolina geb. Muncke (1820-1877), siehe Stumm (2012) S. 576; T von: (siehe) Georg Wilhelm M.

$\mathrm{K}$ mindestens 1 T, 2 S: u.a. Theodor Z. (18511934) seit 1879 Privat-Dozent, 1883-189o a.o. Prof. für Sanskrit, Indologie Greifswald, WS 1885/86-SS 1887 Vertretungs-Professur Königsberg (Preußen), seit 1890 etatm. a. o. Prof. für Vgl. Sprachwiss., 1921 (auch Emeritierungsjahr) o. Prof. Halle/S., s. http://www.indologie.uni-halle.de/institutsgeschichte/theodor_zachariae/ (Ausdruck im UAH), Tilitzki 1 (2012) S. 646 u. ö.

Lb Zunächst Studium der Philosophie, Geschichte, Philologie, Mathematik, dann der Rechtswiss.: WS 1829/30-WS 1831/32 UH, seit SS 1832 Berlin, SS 1833-WS 1833/34 H; 10. Juni 1834 Dr. iur. an UH; 9. Sept. 1834 Staatsprüfung in $\mathrm{H}$.

Seit Juni 1834 Studienreisen, hauptsächlich zur Erforschung byzantinischer Handschriften in Frankreich, Belgien, Großbritannien.

H: Seit Okt. 1835 Rechtspraktikant am Oberamt (= Verwaltungsbehörde, Landkreisamt).

UH: 16. Jan. 1836 Habilitation; 1837-1838 Studienreisen nach Österreich, Italien, Sizilien, Malta, Griechenland, Türkei, s. hierzu Dr. E. Zachariä’s ... Reise in den Orient in den Jahren 1837 und 1838 über Wien, Venedig ... nach Saloniki, dem Berge Athos, Konstantinopel und Trapezunt ... Heidelberg 1840; seit 7. April 1841 a. o. Prof. und Mitglied des Spruchkollegiums der Jur. Fak.; WS 1842/43 letzte Vorlesungsankündigung.

Großkmehlen: Ca. 1843-1894 (†) Privatier und Besitzer e. Teils des Schlosses G.; Z. richtet hier e. landwirtschaftliche Versuchsstation ein. - In dieser Zeit:

1850 Mitglied des Volkshauses des Erfurter Unionsparlaments; 1852-1855, 1866-1869 Mitglied des Preußischen Abgeordnetenhauses in Berlin. 
Cottbus: 1868 Begründer und Vorsitzender des Komitees für Bahnbau Cottbus-Großenhain; 18701876 Direktor der Cottbus-Großenhainer Eisenbahn-Gesellschaft.

Ruhland: 1874-1876 Mitbegründer und Direktor der Oberlausitzer Eisenbahn-Gesellschaft.

Geh. Reg.-Rat

E 1856 Korr. Mitglied der Russischen Akademie der Wissenschaften Sankt Petersburg; 1866 Mitglied der Akademie der Wissenschaften Berlin.

Qu UAH PA 2479; RA 5017; Fak.-Akte H-II-111/ 31. GLA Abt. 205, Fasz. 580. • Briefe: UBH.

$W$ Historiae iuris Graeco-Romani delineatio, cum appendice ineditorum. Heidelberg 1839. - (Innere) Geschichte des griechisch-römischen Rechts. Leipzig 1856. 3. Aufl. Berlin 1892. Neudr. Aalen 1955. - Ius Graeco-Romanum. 7 T. Leipzig 18561884. - Über Grundrente und deren Ermittelung in: Zs. des landwirtschaftl. Centralvereins für die Provinz Sachsen 18 (1861) S. 48 ff. • Kleine Schriften zur römischen und byzantinischen Rechtsgeschichte. Sammlung der in Zeitschriften und Serienwerken erschienenen selbständigen $\mathrm{Ab}$ handlungen 1840-1894. Leipzig 1973. - Bibliographie in: Fischer, Wilhelm: Verzeichnis der wissenschaftlichen Schriften ... in: Zs. der Savigny-Stiftung für Rechtsgeschichte - Romanistische Abt. Wien 1895. S. 320-332.

L ADB 44 (1898) S. 653-657. - Genealogisches Handbuch des Adels. Hrsg. von der Stiftung Dt. Adelsarchiv ... Bd. 46. Limburg/Lahn 1970. S. 467. • WBIS; Lengemann (200o) S. $203 \mathrm{f}$; Schroeder (2010) S. 105-107; Stumm (2012) S. 576. • Thiel, Hans-Christoph: K.E.Z. von L. als Eisenbahnpionier (Vortrag auf dem 2. Int. Symposium o1.03. Juni 2012 Schloss Großkmehlen: K.E.Z. von L. ... im Spannungsfeld zwischen Sachsen, Preußen und Griechenland; Ausdruck des Vortrags im UAH), online s. auch https://www-docs.tucottbus.de/verkehrswesen/public/Berichte/Thiel/ 2012_06_01_VortragThiel.pdf (abgerufen am 28. Dez. 2017). - Reimer, Ekkehart: Das Steuerrecht als Staatsspiegel. Leben und Einsichten des
Heidelberger Publizisten K. S. Z. von L. in: Heidelberger Thesen zu Recht und Gerechtigkeit. Hrsg. von Christian Baldus ... Tübingen 2013. S. 39-65. • Troianos, Spyros: Die Quellen des byzantinischen Rechts. Berlin 2017. S. 40-44, 144-150 u. ö.

$P$ Bildarchiv UAH; graph. Slg. UBH; Lent (1998) S. 151 .

\section{Zachariae von Lingenthal}

siehe Zachariae

\section{Zade, Martin}

1910-1935 Med. Fak.

Augenheilkunde

* 05. Juli 1877 Bad Polzin (heute: Połczyn Zdrój, Polen)

$\dagger$ 03. April 1944 Shrewsbury (Großbritannien) mosaisch, später ev.

V Joseph Z. (†1905) Landwirt, Rittergutsbesitzer M Laura geb. Arndt

๑ 16. Juni 1916 Maria geb. Oppen (1891-1975), s. Lexikon jüdischer Einwohner Hs (2011) S. 451

K 3 S, 1 T, s. ebd.

Vw Bruder: Adolf Z. (1880-1949) seit 1914 PrivatDozent Jena, 1920-1933 (Entlassung) o. Prof. für Pflanzenbaulehre Leipzig; anschl. Emigration nach Stockholm, s. Wikipedia, Professorenkatalog Leipzig online.

Lb Seit WS 1897/98 Studium an U München, anschl. Straßburg, Freiburg/Br.

U Freiburg/Br.: Febr. 1902 Staatsexamen; Frühjahr 1902 Approbation; 1902 Dr. med.; 1. Okt. 190215. Nov. 1903 Militärdienstpflicht als EinjährigFreiwilliger; Assistent: seit Nov. 1903 Patholog. Inst., seit Aug. 1904 U-Augenklinik.

Assistent: Seit Aug. 1905 Augenheilanstalt in Hagen (Westfalen), seit Juni 1906 U-Augenklinik in Leipzig. 
Seit Aug. 1908 Eigenstudien am St. Mary's Hospital in London, anschl. am Hygien. Inst. in Bonn.

U Jena: Seit März 1909 Assistent an U-Augenklinik; 16. Febr. 1910 Habilitation.

UH: Seit Okt. 1910 Assistent an U-Augenklinik; 29. Okt. 1910 Umhabilitierung; SS 1914-WS 1914/15 Urlaubsgesuch für geplante wiss. Arbeiten auf patholog. Gebiet; Aug. 1914-Nov. 1918 Kriegsdienst; seit 1. März 1916 nichtetatm., seit 1920 nichtplanm. a. o. Prof.; seit 6. April 1933 Beurlaubung aus rassischen Gründen, die im Juli 1933 wieder aufgehoben wird „wegen Teilnahme an Truppenkämpfen“ (aus: UAH PA 6447); 31. Dez. 1935 Entziehung der Lehrbefugnis; März 1939 Flucht in die Niederlande, Aug. 1939 Emigration nach Großbritannien. • In dieser Zeit:

H: 1918-1. Okt. 1938 (Entzug der Approbation für jüdische Ärzte) niedergelassener Augenarzt.

Shrewsbury: Seit 1940 niedergelassener Augenarzt.

Qu UAH PA 1261, 6447; Rep. 14-147 (Freudenberg/ Chrysander). - GLA Abt. 235, Fasz. 1625. A Albert Schweitzer: Theologischer und philosophischer Briefwechsel 1900-1965. Werke aus dem Nachlaß. Hrsg. von Werner Zager ... München 2006. S. $411 \mathrm{f}$.

$W$ Studien über immunisatorische, insbesondere phagocytäre Vorgänge am Auge. Leipzig 1910. • Die Bedeutung der Immunitätslehre für die Augenheilkunde. Leipzig 1911. Blindenwesen und Blindenfürsorge im Kindesalter in: Zs. für Kinderforschung 29 (1924) S. 163; Schielen und Schwachsichtigkeit im Kindesalter in: ebd. 32 (1926) S. 242. Heilpädagogik und Auge. Halle/S. 1928.

L Stübler (1926) S. 323; Kürschner (1935) Sp. 1577; WBIS; Mussgnug (1988) S. 300 (Register); Kuß (2000); Lexikon jüdischer Einwohner Hs (2011) S. 451; Jüdische Ärzte (2014); Deutsche Biographie, s. https://www.deutsche-biographie.de/pnd127266 054.html [10.12. 2017].

$P$ Bildarchiv UAH. C Center for Jewish History. Digital Collections.

\section{Zangemeister, Carl}

siehe Zangemeister, Karl

\section{Zangemeister, Karl Friedrich Wilhelm}

1875-1891 Phil. Fak.

1891-1900 (Honorar-Prof.) Phil. Fak.

Klassische Philologie

* 28. Nov. 1837 Hallungen (bei Gotha)

$\dagger \quad$ 08. Juni 1902 Heidelberg ev.

V Wilhelm Z. (1801-1883) Gutsbesitzer

M Wilhelmine geb. Hattenbach (1810-1878)

$\infty$ 14. Juni 1870 Theresie geb. Hopf (1845-1906)

K 1 T, 1 S: Wilhelm Z. (1871-1930), u. a. seit 1904 Privat-Dozent U Königsberg (Preußen), seit 1910 o. Prof. Marburg, seit 1925 o. Prof. für Gynäkologie und Geburtshilfe Königsberg, s. Tilitzki 1 (2012) S. 395, 646 f. - Siehe auch Zangemeister/Westermann (1907) S. $33 \mathrm{f}$.

Lb Seit 26. April 1857 Studium der Philologie an U Bonn, 1859-1862 Berlin; 1858-1859, 1863 auch Volontär an UB Bonn.

Berlin: 5. April 1862 Dr. phil. an U; 1862 kurzzeitig Gymnasiallehrer; 1863-1868 Mitarbeiter des Projekts Corpus inscriptionum Latinarum: hierfür 1863-1865, 1868 Aufenthalte in Italien.

Gotha: Seit 1868 Bibliothekar an Herzogl. Bibliothek auf Schloß Friedenstein; Ablehnung e. Rufes an UB Freiburg/Br.

UBH: 13. März 1873-8. Juni 1902 Oberbibliothekar (Vorstand) als Nachf. von Christian Bähr.

UAH: 1873-1902 Leiter/Verwalter des Archivs als Vorstand der UBH; 21. Jan. 1889 Prof. Adolf Koch „... ist aus dem Bibliotheksdienst ausgeschieden, um im Auftrag des Großherzogl. Ministeriums bis Jan. 1891 das Universitätsarchiv unter Oberleitung des ... Oberbibliothekars (K.Z.) neu zu ordnen“" (aus: UAH PA 57 (Adolf Koch)). In dieser Zeit: 
UH: 6. Aug. 1875 Verleihung des Titels und Rangs e. o. Prof. in Nachf. von Christian Bähr, s. hierzu $Z$; 9. April 1891 Ern. zum o. Honorar-Prof.; SS 1900 letzte Vorlesungsankündigung über Lateinische Paläographie mit Übungen; 1901 Ruf an U Bonn abgelehnt.

1892 Vorsitzender des geschäftsführenden Ausschusses der Limeskommission in Berlin

1894-1902 Mitglied der Zentraldirektion des Königl. Archäolog. Inst. in Berlin

Z Am 24. Jan. 1874 stellen der Dekan der Philosophischen Fakultät, Otto Ribbeck (Klassische Philologie) und Otto Becker (Augenheilkunde) einen Antrag an Engeren Senat der Universität Heidelberg auf Verleihung der Honorar-Professur an Z.: „Bei den mehrjährigen Verhandlungen über die Neubesetzung des Oberbibliothekariats hiesiger Universitätsbibliothek ging der engere Senat wie die Regierung von dem wichtigen Grundsatze aus, daß der neu zu berufende Vorsteher dieser wichtigen Anstalt nicht durch ein ordentliches Lehramt an der Universität in der Concentration seiner gesammten Kraft auf die Verwaltung der Bibliothek gehemmt sein dürfe. In der Durchführung dieses Princips würde man jedoch nach der Ansicht der Unterzeichneten zu weit gehen, wenn man darauf bestehen wollte, denselben durch die ihm angewiesene Stellung gänzlich außerhalb des akademischen Lehrkörpers gleichsam $\mathrm{zu}$ verweisen ..." Ein Honorar-Professor fühlt sich als „ebenbürtige[r] College der Fachprofessoren ... Eine Stellung dieser Art innerhalb der akademischen Corporation, zugleich ehrenvoll und ohne bindende Pflicht, trägt nicht wenig dazu bei, den Bibliotheksvorstand bei seinen mannigfachen Beziehungen zum Publikum, namentlich auch den Studenten und den Untergebenen gegenüber, so wie nach außen dasjenige Ansehen zu sichern, welches für eine durchgreifende und erfolgreiche Thätigkeit so wichtig ist ... Wenn auch der mitunterzeichnete Vertreter der klassischen Philologie mannichfach [!] Gelegenheit nimmt und nehmen muß, zu paläographischen Studien anzuregen und anzuleiten, so würde er doch eine Ergänzung und Unterstützung dieser Bestrebungen durch einen so kundigen Gelehrten wie Dr. Zangemeister mit Freude begrüßen“ (aus: UAH PA 2481).
Am 20. Febr. 1874 zieht Ribbeck seinen Antrag auf Verleihung der Honorar-Professur an Z. nach der am Vortag stattgefundenen Fakultätssitzung zurück, weil „ihm die Aufrechterhaltung [des Antrags] ... mindestens zweifelhaft geworden ist, jedenfalls aber dadurch die ganze Angelegenheit [einer] völlig neuen ... Behandlung seitens der leitenden Behörde unterzogen werden muß“ (aus: PA 2481).

Am 24. Febr. 1874 begründet Ribbeck den o.e. Widerruf seines Antrags in einem Brief an Phil. Fak.: Ihm [Ribbeck] werde „als ein schweres Vergehen gegen Würde und Selbständigkeit der philosophischen Facultät vorgehalten, daß er keinen Bestand genommen habe, nicht nur in Gemeinschaft mit einem Mitgliede einer anderen Facultät, sondern überhaupt mit einem andern Senatsmitglied einen Antrag im Engeren Senat zu stellen, welches in die Competenz der philosophischen Facultät eingreife. Die von Herrn Geh. Hofrat [Hermann] Kopp [Prof. für Chemie] hierüber empfundene Entrüstung nahm einen Ausdruck an, welcher das Ehrgefühl des Angeschuldigten in hohem Grade verletzen mußte.

Vergeblich wurde meinerseits dagegen erinnert, daß die vorherige Einholung eines Gutachtens von Seiten der philosophischen Facultät in dem Antrage ausdrücklich vorausgesetzt war, daß der vorliegende Fall seiner Natur nach ein ganz besonderer und der Art sei, daß er eine Initiation von Seiten des Engeren Senats verlange. Lebhaft bedaure ich, daß die Bemühung, den von jener Seite angeschlagenen leidenschaftlichen Ton der Debatte im Interesse der Sache auszuweichen, und die momentane Betroffenheit über den m[eines] E[rachtens] unverdienten schweren Vorwurf mich für den Augenblick hinderte, noch folgende Gesichtspunkte gelten zu machen", s. hierzu weiter UAH H-IV-102/78 fol. 216v-22or (Zitat aus: ebd. fol. $216 \mathrm{r}, \mathrm{v}$ ).

Otto Becker hält dagegen seinen Antrag aufrecht, weil „(ich) nur auf diese Weise ... [die] Gelegenheit (erhalte), mich über meine Stellung zu diesem Antrage im Engeren Senate auszusprechen. Ich glaube daher überzeugt sein zu dürfen, daß Eure Magnifizenz [= Prorektor Bernhard Stark] meinem dringenden Wunsche entsprechen werde, den Antrag baldmöglichst circuliren zu las- 
sen und ihn auf die Tagesordnung der nächsten Sitzung des Engeren Senats zu stellen“ (aus: Brief vom 1. März 1874 in: PA 2481).

Am 28. Febr. 1874 zieht Otto Ribbeck über die Angelegenheit „Zangemeister" vor der Phil. Fak. Bilanz: „... Schließlich finde ich bei dem Mangel einer festen Geschäftsordnung das Obwalten differierender Geschichten über die formale Behandlung dieser oder jener Angelegenheit ebenso erklärlich als ich bereit bin, ohne Rechthaberei mich einem Facultätsbeschluß in zweifelhaften Fällen $\mathrm{zu}$ fügen. Nur gegen eine verletzende Behandlung wie ich sie [bei der letzten Sitzung] erlitten, habe ich das Recht mich zu verwahren" (aus: H-IV-102/ 78 fol. 224v).

Am 27. Febr. 1874 stellt Prorektor Bernhard Stark den „Antrag auf Ernennung des Oberbibliothekars Dr. Z. zum Honorarprofessor in der philosophischen Facultät" im Engeren Senat der Universität Heidelberg nach Antrag von Ribbeck, der seinen Widerruf wohl zurückgezogen hatte und Becker (aus: H-IV-102/78 fol. 21or). Im Aug. 1875 wird Z. Titel und Rang e. o. Professors verliehen, 1891 e. o. Honorar-Professur.

1886 Hofrat; 1894 Geh. Hofrat

E 1887 Mitglied der Akademie der Wissenschaften Berlin; Korr. Mitglied des Archäolog. Instituts Rom. 1884 Ritterkreuz I. Klasse des Ordens vom Zähringer Löwen; 1890 Kommandeurkreuz des Ordens der Italienischen Krone.

Qu UAH PA 99, 2481; RA 5859 (Stiftung e. Büste von K.Z. durch Jean Steinel 1908), 5972 f.; Fak.Akte H-IV-102/78. Briefe, Nachlaß: UBH. • Auskunft: Universitätsarchiv Bonn.

$W$ System des Realkatalogs der Universitäts-Bibliothek Heidelberg. Heidelberg 1885. 2. Aufl. 1893. Pfälzische Bibliographie. Heidelberg 1886 . Theodor Mommsen als Schriftsteller. Heidelberg 1887. Neu bearb. von Stefan Rebenich. Hildesheim 2000. - Zur Frage nach der Örtlichkeit der Varusschlacht in: Westdeutsche Zs. für Geschichte und
Kunst (1887) S. 234-252. - Bericht über die Wiedervereinigung der Manessischen Liedersammlung mit den Handschriften der Bibliotheca Palatina in: Akademische Rede zum Geburtsfeste des höchstseligen Grossherzogs Karl Friedrich am 22. Nov. 1888 ... gehalten. Heidelberg 1888. S. 58-62.

HG Pauli Orosii Historiarum adversum paganos libri VII. Wien 1882 und Leipzig 1889. Reprint New York 1966.

MHG Inscriptiones trium Galliarum et Germaniarum Latinae. 3 T. Berlin 1899-1907.

L Wille, Jacob: K.Z. ... in: Neue Heidelberger Jahrbücher 11 (1902) S. 143-152. • Zangemeister/ Westermann (1907) S. 24f. - Westermann, Ascan: Genealogie der Familie Z. ... Marburg 1911. • Bader (1925) S. 292 f.; Badische Biographien 6 (1935) S. 1422 (mit Werkverz.). • Deutsch, Joseph: Oberbibliothekar K. Z. in: Neue Heidelberger Jahrbücher N. F. (1950) S. 19-44. Leyh, Georg: Zur Geschichte der Universitätsbibliothek Heidelberg in: Zentralblatt für Bibliothekswesen 65 (1951) S. 218-221. • Handbuch der historischen Buchbestände in Deutschland. Hrsg. von Bernhard Fabian. Hildesheim 2003. WBIS; Runde (2012) S. 262. • Hinz, Vinko: De C. Zangemeisteri vocibus singularibus. Ein Heidelberger Iocosum aus der Feder von Gustav Uhlig [1887] in: Gymnasium. Zs. für Kultur der Antike und humanistische Bildung (2013) Bd. 120, S. 489-499. - Riecke (2016) S. 34; Deutsche Biographie, s. https://www.deutsche-biographie.de/pn d116964022.html [15.12. 2017].

P Bildarchiv UAH; graph. Slg. UBH.

\section{Zell, Adam Carl Philipp}

1847-1855 Phil. Fak.

Archäologie

* 08. April 1793 Mannheim

$\dagger$ 21. Jan. 1873 Freiburg/Br. kath. 
V Joseph Z. (1756-1798) Stadtgerichtsschreiber

M Antoinette geb. Sartorius (1757-1847)

(2) 27. Jan. 1825 Viktoria geb. Bauchetet (17991863)

$\mathrm{K} \quad 1 \mathrm{~S}, 1 \mathrm{~T}$

Lb Seit WS 1810/11 Studium der Philologie an UH, seit 1813 Göttingen, zuletzt Breslau; Lehrerprüfung.

Rastatt: Seit 29. Okt. 1814 Lehrer am Großherzogl. Lyceum.

U Freiburg/Br.: Seit 17. Mai 1821 o. Prof. für Philologie; seit 3. Sept. 1829 außerdem Oberbibliothekar an UB; 1830 Gründer des Philolog. Seminars, s. hierzu Z., C.: Betrachtungen über die Wichtigkeit und Bedeutung des Studiums der classischen Literatur und Alterthumskunde für unsre Zeit nebst Nachricht über das an der hiesigen Universität neu gegründete philologische Seminarium. Freiburg/ Br. 1830. In dieser Zeit:

Karlsruhe: 1831-1838 Mitglied der I. Kammer des Badischen Landtags als Vertr. der U Freiburg/Br; 1836-1846 Ministerialrat im 1836 neuerrichteten Oberstudienrat (= badische Schulbehörde).

UH: 19. Dez. 1846 zum SS 1847 Ern. zum o. Prof. für Archäologie als Nachf. von Friedrich Creuzer mit e. Jahresgehalt von 200o.- Gulden; Mitte 1848 Einzug der Sammlung archäolog. Hilfsmittel in e. „eigenes Lokal“ in 3. Etage des UB-Gebäudes in Augustinergasse 15, wobei „der Kasten mit der Münzsammlung ... in dem Erdgeschoß der Bibliothek auf einem dort befindlichen Tische" bis Juni 1850 verbleibt (aus: Brief vom 9. Juni 1850 in: UAH RA 6387); Studienreisen: Herbst 1850 Italien, Frühjahr 1851 Paris; 13. März 1855 Ruhestand. • In dieser Zeit:

Karlsruhe: 1847-1855 Ausw. Mitglied im Oberstudienrat; 1848-1852 Mitglied der II. Kammer des Badischen Landtags.

Wohnsitz: Seit 1856 Karlsruhe, seit 1858 Freiburg/ $\mathrm{Br}$.

1851 Prorektor der UH; 1849 Dekan der Phil. Fak. der UH
Am 19. Aug. 1847 weist Joseph Alexander Dahmen (1783-1863), Kurator der Universität Heidelberg, die Universitäts-Bau- und Ökonomie-Kommission an, Z.s „zum Behuf seiner archäologischen Vorlesungen gestelltes Begehren um

1. einen Schlüssel zur Münz-Sammlung beziehungsweise zum Antiquarium Creuzerianum [s. hierzu Friedrich Creuzer]

2. ein Pult und verschließbaren Schrank [für seine bei Vorlesungen unentbehrlichen Kupferwerke, siehe Brief vom 2. Juli 1847 in: UAH RA 6387] in einem Auditorium ... [zu entsprechen und] die beantragten Gegenstände anfertigen $\mathrm{zu}$ lassen ..." (aus: RA 6387).

Am 25. Febr. 1848 erhält Z. auf Anweisung Dahmens 697 Gulden und 33 Kreuzer aus der Universitätskasse zum Ankauf einer Sammlung archäologischer Hilfsmittel; das Jahr 1848 gilt mit dieser ersten Dotation als das Gründungsdatum der Heidelberger Antikensammlung.

Am 29. April 1848 schreibt Z. - bereits die weitere Entwicklung der U-Sammlung im Blick - an das Akademische Direktorium (= Prorektor der UH) kurz vor dem Einzug der archäologischen Sammlung in den 3. Stock des UB-Gebäudes in der Augustinergasse 15: „... Dorthin wäre das schon Vorhandene zu bringen und zugleich die Anordnung jetzt schon zu treffen, daß später bei weiterm $\mathrm{Zu}$ wachs von Gypsabgüssen die dort noch befindlichen Bücher ganz entfernt und die Wände mit einem geeigneten Anstrich versehen würden. Ein Verzeichniß der Münzen und der wenigen andern Stücke liegt vor ..." (aus: RA 6387).

Präsident der Versammlungen der kath. Vereine (heute: Dt. Katholikentag): 1852 in Münster und 1853 in Wien

Siehe auch Bernhard Stark

1846 Geh. Hofrat

E 1824 Dr. phil. h.c. UH. 1838 Ritterkreuz des Ordens vom Zähringer Löwen.

Qu UAH PA 2483; RA 6373, 6377, 6387, 6828. • GLA Abt. 205, Fasz. 583 f. • Briefe: UBH. • Briefe 
von Heidelberger Gelehrten an Franz Joseph Mone. Hrsg. von Friedrich von Weech in: ZGORh 57. Jg. (1903) S. 489-492. Nachlaß: GLA Karlsruhe.

$W$ Ferienschriften. 3 Bde. Freiburg/Br. 1826-1833. N.F. Bd. 1. 1857. 2. Aufl. 1873. - Die Fürstentöchter des Hauses Baden. Karlsruhe 1842. • Über die Iliade und das Nibelungenlied. Neun literarische Abendunterhaltungen in dem Museum zu Karlsruhe. Karlsruhe 1843. Handbuch der römischen Epigraphik. 2 T. Heidelberg 1850-1852. T. 1: 2. Ausg. 1874. - Bilder aus der Gegenwart. Freiburg/Br. 1856. Antwort auf das Sendschreiben der Herren [Ludwig] Häusser, [Daniel] Schenkel, [Karl] Zittel über das Badische Concordat und die Durlacher Conferenz. Freiburg/Br. 186o. - Lioba und die frommen angelsächsischen Frauen. Freiburg/ Br. 1860. $\bullet$ Offenes Sendschreiben an Herrn Elstätter in Sachen des badischen Kirchen- und Schulstreites. Mainz 1868.

Übers. Aristoteles Werke. Organon oder Schriften zur Logik. 4 T. Stuttgart 1836-1841.

HG Aristotelis Ethicorum Nicomacheorum Libri Decem. 2 Bde. Heidelberg 1820.

$L$ Badische Biographien 2 (1875) S. 534-537; ADB 45 (1900) S. 15. - Dor, Franz: Hofrat K.Z. Ein Lebensbild. Freiburg/Br. 1912. - Bader (1925) S. 293; WBIS. • Brechenmacher, Karl: Joseph Beck (18031883). Ein badischer Spätaufklärer. Tübingen 1984. S. 237 (Register). - Morgenblatt für gebildete Stände/gebildete Leser 1807-1865 ... Register der Honorarempfänger/Autoren und Kollationsprotokolle ... Bearb. von Bernhard Fischer. München 2000. S. 495 (Register). - Johann Sebastian Drey: Revision des gegenwärtigen Zustandes der Theologie. Ideen zur Geschichte des katholischen Dogmensystems ... Hrsg. ... von Max Seckler. Editorisch bearb. von Winfried Werner. Tübingen 2015. S. 739-741. • Objekte erzählen Geschichte(n) (2016) S. 130 u.ö.

$P$ Bildarchiv UAH.

\section{Zeller, Eduard Gottlob}

1862-1872 Phil. Fak.

Philosophie

* 22. Jan. 1814 Kleinbottwar (heute: Stadtteil von Steinheim an der Murr)

$\dagger$ 19. März 1908 Stuttgart ev.

V Johann Heinrich Z. (1772-1837) Frhrl. von Kniestedtscher Stabs- und Rentamtmann (= Verwalter grundherrschaftlicher Einnahmen); 1802 Gründer e. Armenstiftung zur Linderung der Not in Kleinbottwar, s. hierzu Zeller, Bernhard: Erinnerung und Auftrag. Betrachtung zu e. Familienjubiläum .... „450 Jahre Zeller aus Martinszell“" in: Nachrichten des Martinszeller Verbandes Nr. 14 (1988) S. $8-15$.

M Johanna Christiana geb. Cam(m)erer (17721850)

$\varnothing$ 22. Juni 1847 Emilie Karoline geb. Baur (18231904) T von Ferdinand Christian B. (17921860) seit 1817 Prof. für Alte Sprachen am Ev.Theol. Seminar Blaubeuren, 1826-1860 o. Prof. für Theologie an U Tübingen, s. BBKL I (1990) Sp. 427 f., Dilthey, Wilhelm (1991) S. 265 f.

$\mathrm{K} \quad{ }_{5} \mathrm{~S}$ (davon 3 früh $\dagger$ ).

$L b$ Tübingen: Seit Herbst 1831 Studium der Philosophie an U, Studium der Theologie am Stift; Herbst 1835 theol. Examen am Stift; 25. Aug. 1836 Dr. phil. an U.

Vikar: Seit Sommer 1836 Nellingen, seit Herbst 1837 Tübingen.

Repetent: Seit Anfang 1838 Theol. Seminar in (Bad) Urach, seit Mai 1839 Königl. Ev.-Theol. Seminar zu Tübingen.

U Tübingen: Herbst 1840 Habilitation für Theologie; 1840-1847 Privat-Dozent.

U Bern: Seit 12. Jan. 1847 a. o. Prof., seit 13. Febr. 1849 o. Prof. für Theologie.

U Marburg: Seit WS 1849/50 o. Prof. für Philosophie. 
UH: 2. Mai 1862 Ern. zum o. Prof.; 8. Okt. 1862 Vereidigung; 1871-1872 Mitglied der I. Kammer des Badischen Landtags in Karlsruhe als Vertreter der UH; 1872 Ruf an U Leipzig abgelehnt.

U Berlin: 17. Juni 1872-30. Sept. 1894 (Ruhestand) o. Prof. für Philosophie.

Stuttgart: Seit 1895 Wohnsitz.

1868 Prorektor der UH; 1865/66, März-Sept. 1867 Dekan der Phil. Fak. der UH

1868 Hofrat; 1872 Geh. Hofrat; 1894 Wirkl. Geh. Rat (Exzellenz)

$E$ Mitglied der Akademie der Wissenschaften: 1864 Berlin, 1873 München, 1890 Wien. • Ehrendoktorate u.a. 1868 D. theol. UH, 1886 Dr. phil. h. c. UH. 1877 Orden pour le Mérite für Wissenschaften und Künste. 1862 Ehrenbürger der Stadt Marburg.

Q $u$ UAH PA 2484. - Briefe: UBH; DLA Marbach; Universitätsbibliothek Tübingen. - Hermann Diels: Briefwechsel ... 2 Bde. Berlin 1992. • Briefwechsel (1849-1895) Heinrich von Sybel und E.Z. Hrsg. von Margret Lemberg. Marburg 2004. • Der Redaktionsbriefwechsel der Hallischen, Deutschen und Deutsch-Französischen Jahrbücher 1837-1844. Hrsg. von Martin Hundt. Bd. 1: Der Briefwechsel um die Hallischen Jahrbücher. Berlin 2010. Apparat: S. 281 (Register). • Wilhelm Dilthey: Briefwechsel 1852-1882 [u. a. mit E. Z.]. Hrsg. von Gudrun Kühne-Bertram ... Bd. 1. Göttingen 2011. S. 622 f. Erinnerungen eines Neunzigjährigen. Stuttgart 1908. (Autobiogr.)

$W$ Platonische Studien. Tübingen 1839. Reprint Saarbrücken 2007. - Die Philosophie der Griechen. Eine Untersuchung über Charakter, Gang und Hauptmomente ihrer Entwicklung. 3 T. Tübingen 1844-1852. 2. Aufl. u.d. T.: Die Philosophie der Griechen in ihrer geschichtlichen Entwicklung dargestellt. Tübingen 1855-1866. Mehrere Aufl. Nachdr. Darmstadt 2013. - Das theologische System Zwinglis. Tübingen 1853. • Über Bedeu- berg 1862. - Grundriß der Geschichte der griechischen Philosophie. München 1883. 14. Aufl. 1928. Nachdr. Aalen 1971. - Friedrich der Große als Philosoph. Berlin 1886. - Philosophische Aufsätze. Leipzig 1887. Nachdr. 1962. • Philosophie- und Wissenschaftsgeschichte im 19. Jahrhundert. Aufsatzsammlung. Hrsg. von Gerald Hartung. Berlin 2010. - Siehe auch E. Z. ... Hrsg. von Gerald Hartung (2010).

(M)HG 1842-1857 Theologische Jahrbücher (zus. mit Ferdinand Christian Baur).

MG 1888 Archiv für Geschichte der Philosophie.

$L$ Nachruf in: Almanach der Akademie der Wissenschaften Wien 58 (1908) S. 342 f.; Catalogus prof. Marburgensis 1 (1927) S. 296 f.; Asmus (1974) S. 67-69 u. ö. - Zeller, Karl August: Die Familie Z. aus Martinszell. Stuttgart 1974. - Gadamer, Hans Georg: E.Z. in: Semper apertus 2 (1985) S. 402408. • E.Z. zum 175. Geb. Hrsg. vom Ev. Pfarramt Steinheim-Kleinbottwar. Steinheim-Kleinbottwar 1989. - WBIS; BBKL I (1990) Sp. 427 f. • Dilthey, Wilhelm: Zur Geistesgeschichte des 19. Jahrhunderts. Portraits und biographische Skizzen ... 3. Aufl. Hrsg. von Ulrich Herrmann. Göttingen 1991. S. 267-278. • Krämer, Hans: Die Bewährung der historischen Kritik an der Geschichte der antiken Philosophie. E.Z. und Albert Schweitzer in: Historisch-kritische Geschichtsbetrachtung. Ferdinand Christian Baur und seine Schüler. Sigmaringen 1994. S. 141-152. - Wischmeyer (2008) S. 210, 285, 293. E. Z. Philosophie- und Wissenschaftsgeschichte im 19. Jahrhundert. Hrsg. von Gerald Hartung. Berlin 2010. • Werle, Dirk: „Lokaler Wissenstransfer“. Theorien literatur- und ideenhistorischer Wirkung an der Berliner Universität (E.Z., ...; Richard M. Meyer, 1860-1914; Julian Hirsch, 1883-1951) in: Zeitschrift für Germanistik (2010) S. 169-185. - Leszl, Walter: From Hegel to Zeller in: The Presocratics from the Latin middle ages to Hermann Diels ... Hrsg. von Oliver Primavesi ... Stuttgart 2011. S. 309-333. - Rössler, Andreas: Aufgeklärte Religion bei E.Z. ... Stuttgart 2014. • Professorenkatalog Marburg, s. https:// www.uni-marburg.de/uniarchiv/pkat/details?id= 2962 (Stand: 19. April 2017); Deutsche Biographie, s. https://www.deutsche-biographie.de/pnd11 8636383.html [12.02.2018]. • Siehe auch Familien- 
stiftungen Paul Wolfgang Merkel und Werner Zeller: Unsere Familie online unter http://merkel-zel ler.de/index.php (abgerufen am 20.02. 2018).

$P$ Bildarchiv UAH; graph. Slg. UBH.

\section{Ziegler, Karl Waldemar}

1926-1936 Nat.-Math. Fak.

Chemie

* 26. Nov. 1898 Helsa (bei Kassel)

$\dagger$ 11. Aug. 1973 Mülheim (Ruhr) ev.

V Dr. Karl August Z. (1858-1933) Pfarrer

M Luise Helene Caroline geb. Rall (1862-1934)

@ 11. März 1922 Maria Mathilde geb. Kurtz (18991980)

K $\quad 1 \mathrm{~T}, 1 \mathrm{~S}$

Lb Seit SS 1916 Studium an U Marburg; SS 1917 I., SS 1918 II. chemisches Verbandsexamen; 1. Juni 1918-Anfang Febr. 1919 Kriegsdienst, s. UAH PA 6473.

U Marburg: 1. Mai 1919-31. März 1925 Assistent am Chemischen Inst.; 28. Juli 1920 Dr. phil. nat.; 18. Dez. 1923 Habilitation.

U Frankfurt/M.: SS 1925-WS 1925/26 Stellvertr. Abt.-Vorsteher am Chemischen Inst.

UH: Seit 24. März 1926 Assistent am Chemischen Inst.; seit April 1927 monatl. Gehalt von 456,96 Reichsmark; 12. Juni 1926 Umhabilitierung; WS 1926/27 Lehrauftrag für Spezielle Chemie aliphatischer Verbindung; seit 12. Jan. 1928 nichtbeamteter a.o. Prof.; Febr.-März 1936 Gast-Prof. an U of Chicago.

U Halle/S.: Seit 1. Okt. 1936 Vertreter des Ordinariats; März 1938 (Ern.)-Sept. 1943 o. Prof. und Direktor des Chemischen Inst.

Mülheim (Ruhr): Okt. 1943-Juli 1969 (Emeritierung) Direktor des Kaiser-Wilhelm-Inst. (KWI) für Kohlenforschung (nach 1948 umbenannt in Max-Planck-Inst. (MPI) für Kohlenforschung). • In dieser Zeit:

TH Aachen: Seit 1947 o. Honorar-Prof.

USA: 1952 Gastvorlesungen an U of WisconsinMadison in Madison und U of Illinois in UrbanaChampaign.

1963 Nobelpreis für Chemie (zus. mit Giulio Natta (1903-1979)), s. http://www.nobelprize.org/nobel_ prizes/chemistry/laureates/1963/ziegler-facts.html

1946-1951 (Mitbegründer und) Erster Vorsitzender der Gesellschaft Deutscher Chemiker (GDCh); 1954-1957 Präsident der Dt. Gesellschaft für Mineralölwissenschaft und Kohlechemie; 1955-1957 Vorsitzender der Chemisch-Physikalisch-Technischen Sektion und Senator der MaxPlanck-Gesellschaft; 1970/71 Gründungspräsident der Rheinisch-Westfälischen Akademie der Wissenschaften in Düsseldorf

Die am höchsten dotierte deutsche Auszeichnung auf dem Gebiet der Chemie ist der 1975 erstmals an Georg Wittig (1979 Nobelpreisträger; siehe Drüll (2009) S. 674f.) verliehene Karl-Ziegler-Preis, s. hierzu Näheres unter https://www.gdch.de/gdch/ stiftungen/ziegler-stiftung.html (abgerufen am 31. Dez. 2017).

Nach seinem Tod stiftet das Ehepaar Karl und Maria Ziegler seinen bedeutenden Kunstbesitz expressionistischer Gemälde und Papierarbeiten 1981 dem Kunstmuseum Mülheim/Ruhr, s. hierzu https://www.muelheim-ruhr.de/cms/stiftung sammlung_ziegler.html (abgerufen am 31. Dez. 2017); Sammlung K. und Maria Z. Städtisches Museum Mülheim a.d. Ruhr. [Sonderausstellung, 6.12.1987-14. 2.1988.] Bestandskatalog. Mülheim/ Ruhr 1987.

Z 1936 sind sowohl Universität Frankfurt/M. als auch TH Karlsruhe an einer Berufung Z.s interessiert; die wissenschaftliche Beurteilung und politische Einstellung Z.s faßt der Heidelberger Prof. Ernst Krieck (siehe Drüll (2009) S. 361 f.) in einem Gutachten an Rektor Wilhelm Groh vom 4. Mai 1936 zusammen: „Ziegler gilt als ein ungewöhnlich 
tüchtiger Chemiker mit der Begabung zum Erfinden und Entdecken. Er hat schon einen sehr guten Namen und man prophezeit ihm eine große $\mathrm{Zu}$ kunft ... Es ist ... für uns eine Notwendigkeit, ... solche Leute nicht nur zu halten, sondern auch $\mathrm{zu}$ fördern, weil sie für den Aufbau der deutschen Wehr und der deutschen Wirtschaft dringlich notwendig sind. Das beste wäre allerdings, wenn man solchen Männern geeignete Forschungsinstitute geben könnte, wo sie auch einen Nachwuchs technischer Art ausbilden können, sie aber im übrigen von der Hochschulerziehung fernhalten würden. Leider ist das in den meisten Fällen nicht möglich, und so kann ich trotz der bestehenden Bedenken zur Berufung Zieglers nach Karlsruhe raten.

Ziegler selbst wurde mir als politisch neutral geschildert, aber es hieß von vornherein, daß seine Frau ihn in Gegnerschaft gegen den Nationalsozialismus abdränge ... In demonstrativer Weise verkehrt er öffentlich fast nur mit einer jüdischen Familie und bei Gelegenheit der Volksfeste bekundet er keinerlei Teilnahme ... Aber ... wir müssen im Augenblick darüber hinwegsehen, ... sonst droht die Abwanderung nach Amerika, und wir müssen solche Leute festhalten ..." (aus: UAH PA 6473).

In einem persönlichen Brief vom 12. Aug. 1936 schreibt Krieck an Rektor Groh: „... Wenn es eine Möglichkeit gibt, Z. in Heidelberg am K. W. I. unterzubringen, so möchte ich das unterstützen ..." (aus: PA 6473). Weder die Universität Frankfurt/M. noch die TH Karlsruhe berufen letztendlich Z. Stattdessen erfolgt zum 1. Okt. 1936 ein Erlaß des Ministers des Kultus und Unterrichts in Karlsruhe an Z. mit dem Auftrag, die Vertretung des Lehrstuhls in Halle/S. zu übernehmen. Weiter heißt es: „... Gleichzeitig hat der Herr Reichserziehungsminister den Umzug des Genannten von Heidelberg nach Halle angeordnet" (aus: PA 6473). Z. bleibt bis 1943 an der Martin-Luther-Universität.

E 1938 Mitglied der Dt. Akademie der Naturforscher Leopoldina Halle/S.; Mitglied der Akademie der Wissenschaften: 1944 München, Göttingen; Ehrenmitglied: 1957 Society of Chemical Industry London, 1958 Chemical Society of Japan. $\bullet 1951$ Dr. rer. nat. h.c. TH Hannover. 1935 Liebig-Medaille; 1952 Carl-Duisberg-Medaille; 1955 Lavoisier-Medaille; 1961 Siemens-Ring. 1959 Ehrenhäuptling der Ponca-Indianer.

Qu UAH PA 6473. - GLA Abt. 235, Fasz. 2681. • Archiv der Max-Planck-Gesellschaft Berlin (II. Abt. Rep. 1A PA Ziegler). - Siehe auch Archiv der Dt. Akademie der Naturforscher Leopoldina Halle/S.

W Zur Kenntnis des „dreiwertigen“ Kohlenstoffs in: Justus Liebigs Annalen der Chemie 551 (1942) S. 127-234. - Präparative organische Chemie. Bd. 1: Wiesbaden 1948. Bd. 2: Weinheim 1953. Methoden zur Herstellung und Umwandlung großer Ringsysteme in: Houben-Weyl: Methoden der organischen Chemie. Allg. chemische Methoden. Stuttgart 1955. T. 2. S. 729-822. - Metallorganische Verbindungen in: Justus Liebigs Annalen der Chemie 629 (1960) S. 1-256. Folgen und Werdegang einer Erfindung. Nobel-Vortrag am 12. Dez. 1963 in: Angewandte Chemie 76 (1964) S. 545-553.

L Poggendorff 7a (1962) S. 1133-1136. - Wilke, Günther: Nobelpreis für Chemie in: Ruperto Carola 16. Jg., Bd. 35 (1964) S. 59-61; Ders.: Nachruf auf K.Z. in: Justus Liebigs Annalen der Chemie (1975) S. 804-833. Catalogus prof. Marburgensis 2 (1979) S. 935 f. Martin, Heinz: Polymere und Patente - Zur wirtschaftlichen Verwertung akademischer Forschung. Weinheim 2001. Eberle, Henrik: Die Martin-Luther-Universität [Halle/S.] in der Zeit des Nationalsozialismus 1933-1945. Halle/S. 2002. S. 22 f., 229 f. u. ö. • Hahn, Ralf: „Weiss der Teufel, was da hinter den Kulissen spielt.“ K.Z.s langer Weg von Heidelberg nach Halle in: Chemie - Kultur - Geschichte. Hrsg. von Astrid Schürmann ... Diepholz 2002. S. 171-185. • Martin, Heinz: Zur wirtschaftlichen Verwertung akademischer Forschung. Weinheim 2002. (Engl. Übers.: Polymers, patents, profits. A classic case study for patent infighting ... Weinheim 2007.) • Wilke, Günther: 50 Jahre Ziegler-Katalysatoren. Werdegang und Folgen einer Erfindung in: Angewandte Chemie 115 (2003) S. 5150-5159. Kazemi (2006) S. 320-323; Klee, Personenlexikon (2007) S. 694. - Remane, Horst: „Einer der begabtesten und erfolgreichsten, jüngeren Chemiker". K.Z. .. 50 Jahre Niederdruck-Polyethylen in: Vorträge 
und Abhandlungen zur Wissenschaftsgeschichte ... Stuttgart 2007. S. 191-216. Catalogus prof. Halensis online. Kipnis, Alexander: Biographie K.Z. online unter http://www.kipnis.de/index. php/alexander/kurzbiografien/49-ziegler-karl-18 98-1973-chemiker (Stand: 5. Mai 2014; Ausdruck im UAH). Historische Stätten der Chemie - K. Z. Mülheim an der Ruhr 2008. Veröffentlicht von der Gesellschaft Dt. Chemiker (PDF-Datei, Ausdruck im UAH). - Rasch, Manfred: K.Z. - ChemieNobelpreisträger, Institutsdirektor und Wissenschaftsmanager in: Mülheimer Unternehmer und Pioniere im 19. und 20. Jahrhundert. Hrsg. von Horst A. Wessel. Essen 2012. S. 328-337. K Katalyse auf dem Kahlenberg: 100 Jahre Max-Planck-Institut für Kohlenforschung. Hrsg. vom MPI für Kohlenforschung. Essen 2015. S. 49-103. - Deutsche Biographie, https://www.deutsche-biographie.de/ pnd119179105.html [12.12.2017].

P Bildarchiv UAH; Ruperto Carola (1964). • Bildarchiv des Archivs der Max-Planck-Gesellschaft Berlin.

\section{Zimmer, Heinrich Robert (seit 1940: Henry Robert Zimmer)}

1922-1938 Phil. Fak.

Indische Philologie

* o6. Dez. 1890 Greifswald

$\dagger \quad$ 20. März 1943 New York

口 New Rochelle (New York)

ev.

V Heinrich Friedrich Z. (1851-1910 Suizid) seit 1878 Privat-Dozent Berlin, seit 1881 Prof. für Indogermanische Sprachwiss. und Sanskrit Greifswald, seit 1901 o. Prof. für Keltische Sprachen Berlin, s. Nachlaß: Archiv der Dt. Akademie der Wissenschaften Berlin; ADB 45 (1900) S. 233-242, WBIS

M Martha geb. Hirt (1864-1926)
๑ 14. Juni 1928 Christiane Maria Anna Katharina Pompilia geb. von Hofmannsthal (1902-1987) zunächst Sekretärin (ihres Vaters Hugo von $\mathrm{H}$. (1874-1929) Dichter, s. NDB 9 (1972) S. 464467; Hergemöller, Bernd-Ulrich: Mann für Mann. Ein biographisches Lexikon. Frankfurt/M. 2001. S. 368-370), 1945-1967 Sozialpädagogin in New York, s. Christiane von H.: Tagebücher 1918-1923 und Briefe des Vaters an die Tochter 1903-1929. Hrsg. von Maya Rauch ... 3. Aufl. Frankfurt/M. 1991; Briefe ... von Hugo von $H . . .$. an ... Christiane von $H$. Mitgeteilt ... von Klaus E. Bohnenkamp. Freiburg/Br. 2005; Gillman, Abigail: Viennese Jewish modernism. Freud, Hofmannsthal ... University Park (Pennsylvania) 2009; Lexikon jüdischer Einwohner Hs (2011) S. 452; Weber, Christian: Max Kommerell - Eine intellektuelle Biographie. Berlin 2011. S. 598 (Register).

$\mathrm{K} \quad 4$ (eheliche) S (davon $1 \mathrm{~S}$ früh $\dagger$ ); $2 \mathrm{~S}$ (davon $1 \mathrm{~S}$ $1945 X$ ) und $1 \mathrm{~T}$ aus e. Beziehung mit Emilie (Mila) Esslinger geb. Rauch (1886-1972) Malerin, s. Südkamp (2007) S. 102 Anm. 19, Lexikon jüdischer Einwohner Hs (2011) S. 453

Vw Schwager: Raimund von Hofmannsthal (19061974) 1933-1939 (Scheidung) Ehemann von Ava Alice Muriel geb. Astor (1902-1956) T von John Jacob (Jack) Astor IV. (1864-1912 bei Titanic-Untergang) Geschäftsmann, 1912 e. der reichsten Männer der Welt, s. Dictionary of American Biography. Ed. by Allen Johnson. Vol. 1. New York 1943. S. 400.

Lb SS 1909 Studium der Kunstgeschichte an U München, seit WS 1909/1910 Studium der Germanistik, Vgl. Sprachwiss., des Sanskrits an U Berlin; 29. April 1914 Dr. phil. an U Berlin.

1914-1918 Kriegsdienst.

Berlin: Febr. 1919 Forts. des Studiums an U; seit 1. April 1919 Assistent bei Orientalischer Kommission der Akademie der Wissenschaften.

U Greifswald: 31. Juli 1920 Habilitation für Indische Philologie.

UH: 6. Mai 1922 Umhabilitation; Juli 1925 Phil. Fak. gewährt Reisestipendium von 1000.- Mark für Studienreisen nach Paris im Herbst 1925, Lon- 
don und Leiden (Niederlande) im Frühjahr 1926; seit 1. Febr. 1926 nichtplanm. a. o. Prof. als Nachf. von Bruno Liebich; Okt. 1936 Verbot, die Leitung e. Reisegruppe nach Indien zu übernehmen aufgrund seiner jüdischen Versippung (Ehefrau war jüdischer Herkunft); 24. Febr. 1938 Entzug der Lehrbefugnis aus rassischen Gründen; März 1939 Emigration.

Oxford (Großbritannien): 1939-1940 Z. hält unvergütete Vorträge am Balliol College.

USA: Mai 1940 Emigration nach New Rochelle; 1940/41 Gastvorlesungen am Inst. for History of Medicine an Johns Hopkins U in Baltimore (Maryland) und Vortragsreisen durch USA; 20. März 1943 Z.s Tod vereitelt zugesagte Stelle als Visiting Lecturer für Indische Philosophie und Religion an Columbia U in New York.

2008: Einweihung e. H.-Z.-Lesesaals in der Bibliothek des Südasien-Instituts der Universität Heidelberg

Qu UAH PA 715, 6483; Fak.-Akte H-IV-102/148 fol. 252r u. ö. • Briefe: UBH. • Briefe aus dem Exil aus der Korrespondenz von H.Z. Hrsg. von Maya Rauch und Dorothee Mussgnug in: Heidelberger Jahrbücher 35 (1991) S. 219-243. Cymorek, Hans: Momentaufnahmen eines Mythos: Heidelberg 1919, Heidelberg 1931. Zwei unveröffentlichte Briefe von Ernst Kantorowicz und H.Z. in: Mitteilungen der Ernst-Troeltsch-Gesellschaft. München 2003. Bd. 16. S. 64-102. - Teil-Nachlaß: Universitätsbibliothek Bremen; DLA Marbach; Bayer. Staatsbibliothek München. - Notizen zu einem Lebenslauf in: Merkur - Dt. Zs. für europäisches Denken - 7. Jg., H. 59 (Jan. 1953) S. 39-54. (Autobiogr.)

$W$ Kunstform und Yoga im indischen Kultbild. Berlin 1926. Neuaufl. Frankfurt/M. 1976. • Der Weg zum Selbst. Lehre und Leben des indischen Heiligen Shri Ramana Maharshi aus Tiruvannamalai. Hrsg. von C. G. Jung. Zürich 1944. Neuausg. hrsg. von Gabriele Ebert. Norderstedt 2013. (Books on Demand.) - Siehe H.Z. Gesammelte Werke. 5 Bde. Zürich 1951-1963.
HG Briefe von Hugo von Hofmannsthal 18901901 (Berlin 1935), 1900-1909 (Wien 1937).

Übers. Dunbar, Sir George: Geschichte Indiens von den ältesten Zeiten bis zur Gegenwart. München 1937. - Zeichen der Liebe. Wie man lieben und die Liebe dichten soll. Ein indisches Lehrbuch für Liebende und Dichter. Die erotische Poetik des Inders Rudrabhatta aus dem Sanskrit-Original des 13. Jhdts nach Christi ... Stuttgart 1948. 4. Aufl. Frankfurt/M. 1987.

L Rossmann, Kurt: H.Z. in: Ruperto Carola 28 (Dez. 1960) S. 39 f. (hier: Todesdatum 20. Febr. 1943). - „Das Vorläufige, das das Notwendige ist ..." Zur Publikationsgeschichte von Hofmannsthals postumem Prosaband „Die Berührung der Sphären“. Dokumente von Hugo von Hofmannsthal, H.Z. ... in: Hofmannsthal-Blätter (1986) S. 26-46. Mussgnug (1988) S. 300 (Register). - Gudden, Ilse: Z., H. R., s. http://kulturpor tal-west-ost.eu/biographien/zimmer-heinrich-ro bert-2 (1990), überarbeitet von Katharina Geiser (2010). - Jansen (1992a) S. 170 (Register). - H.Z. coming into his own. Ed. by Margaret H. Case. Princeton (New Jersey) 1994. - Lexikon Greifswalder Hochschullehrer (2004) S. 248f. • Südkamp, Elisabeth: H.Z. ... „Jahre hindurch suchte ich nach dem „wirklichen“ Indien, „meinem“ Indien“ in: Heidelberg. Jahrbuch zur Geschichte der Stadt 2008. Heidelberg 2007. Jg. 12. S. 89-106. • WBIS; Grewolls (2011). • Die Hofmannsthal-Rezeption und die Goethe- und Kleist-Rezeption im Dialog mit H.Z. in: Weber, Christian: Max Kommerell - Eine intellektuelle Biographie. Berlin 2011. S. 131-224 u. ö. Lexikon jüdischer Einwohner Hs (2011) S. 453 (hier: Todesdatum 23. März 1943). • Geiser, Katharina: Vierfleck oder Das Glück. (Roman u. a. über H.Z.) Salzburg 2015. Riecke (2016) S. 62, 86-88; Deutsche Biographie, s. https://www. deutsche-biographie.de/pnd116993588.html [13.12. 2017]. - Peschke, Franz: Der Heidelberger Indologe und Buddhologe Prof. Dr. Walleser und das Problem seines Ich. Eine Biographie. Print on demand (2017) S. 425 f., 479-49o u. ö., s. http://cros sasia-repository.ub.uni-heidelberg.de/4032/1/Wal leser_10102017_End.pdf.

$P$ Bildarchiv UAH; Südkamp (2007). 
Zimmer, Henry Robert

siehe Zimmer, Heinrich

\section{Zimmermann, Johann Christian}

(1786-1853)

siehe Friedrich Creuzer: Eintrag unter $K$ [inder]

\section{Zimmern, Wilhelm Sigmund}

1818-1825 Jur. Fak.

Römisches Recht, Privatrecht

* 04. März 1796 Heidelberg

$\dagger \quad$ 09. Juni 1830 Heidelberg

mosaisch, seit 11. Sept. 1821 ev.-luth.

V David Heinz Z. (1767-1845) Kaufmann, Bankier, Schutzbürger, s. Mumm (1997) S.11f., 27-30; Ders.: Der Bankier in der Haspelgasse. D.Z. ... in: Pioniere aus Technik und Wirtschaft in Heidelberg. Hrsg. von Peter Blum. Aachen 2000. S. 108-121; Ders.: Nikolaus Lenau: Ein unbeachteter Brief an D.Z. in: Heidelberg. Jahrbuch zur Geschichte der Stadt 2000. Heidelberg 2000. Jg. 5. S. $171 \mathrm{ff}$.

M Sara geb. Flörsheim (1777-1832)

$\infty$ 26. Sept. 1823 Caroline Philippine Adriane geb. Walther (1796-1872), s. Peter, Carl Lorenz (1812-1897; Pfarrer) u. a.: Zur Erinnerung an unsere selig entschlafene Mutter Frau Karoline Z. geb. W. ... Karlsruhe 1873 .

K $1 \mathrm{~S}, 1 \mathrm{~T}$, s. Dt. Juristen jüdischer Herkunft (1993) S. 30

Vw Schwester: Regine (Julie) Z. verw. Neustetel verh. Jolberg (1800-1870), Begründerin u.a. von Kindertagesstätten, s. WBIS, NDB 10 (1974) S. 585 f.; Hauff, Adelheid M. von: Regine Jolberg ... Leben, Werk und Pädagogik. Das ganze Wesen der Kinderpflege ist Liebe. Heidelberg 2002; BBKL XXI (2003) Sp. 718-727; Großmutter von: (siehe) Samuel Brandt
Vw Enkel: Heinrich Friedrich David Z. (18621931) Privat-Dozent für Semitische Sprachen, speziell Keilschriftkunde: seit 1889 U Königsberg (Preußen), seit 1890 Halle-Wittenberg; seit 1894 etatm. a.o. Prof. und 1900-1929 o. Prof. für Assyriologie Leipzig, s. WBIS, BBKL XXXIII (2012) Sp. 1559-1571, Tilitzki 1 (2012) S. 813 (Register). - Weitere Vw, s. Dt. Juristen jüdischer Herkunft (1993) S. 28-30, Mumm (1997) S. 30.

Lb UH: 29. April 1813 Immatrikulation; 3. Febr. 1817 Dr. iur. utr.

Eigenstudien: SS 1817 Berlin, seit WS 1817/18 Göttingen.

UH: 25. Aug. 1818 Habilitation, s. hierzu Schroeder (2010) S. 181 und Anm. 325; 11. Okt. 1821 (nach Übertritt zum ev.-luth. Glauben) Ern. zum o. Prof. II. Klasse ohne Besoldung (d.h. ohne Teilnahmeberechtigung an den Fak.-Sitzungen und Doktorexamina); seit 1821 a. o. Beisitzer des Spruchkollegiums der Jur. Fak.

U Jena: WS 1825/26-WS 1828/29 o. Prof. mit Besoldung; 1825-1829 außerdem Rat am Oberappellationsgericht in Jena; 1827 Ruf an U Breslau abgelehnt; seit 1829 Aufenthalt u.a. in $\mathrm{H}$ aus Krankheitsgründen.

Z. ist 1818 der erste jüdische Privatdozent an einer deutschen Universität; der erste mosaische Ordinarius an der Universität Heidelberg war 1652 der Mediziner Jacob Israël, siehe Drüll (1991) S. 75; siehe auch Levin Goldschmidt und Adolf Weil

1821 Großherzogl. Badischer Rat

Qu UAH PA 2489; Fak.-Akten H-II-111/9, H-II111/14. • GLA Abt. 205, Fasz. 587.

$W$ Versuch einer Würdigung der Angriffe des Herrn Prof. [Jakob] Fries auf die Juden. Heidelberg 1816 (siehe hierzu Beschreibungsversuche der Judenfeindschaft. Zur Geschichte der Antisemitismus-Forschung vor 1944. Hrsg. von HansJoachim Hahn ... Berlin 2015). - Das System der römischen Noxalklagen. Heidelberg 1818. • Rö- 
mischrechtliche Untersuchungen für Wissenschaft und Ausübung. Heidelberg 1821. (Mitverf.: Neustetel, Leopold Joseph.) - Grundriß des gemeinen in Deutschland geltenden Erbrechts. Heidelberg 1823. Geschichte des römischen Privatrechts bis Justinian. 3 Bde. Heidelberg 1826-1829.

L ADB 45 (1900) S. 302; Jüdische National-Biographie 6 (1931) S. 362; Jammers (1964) S. 178 u. ö.; Heidelberger Strafrechtslehrer (1986) S. $16 \mathrm{f}$. • Braun, Johann: S.Z. Ein deutsch-jüdisches Gelehrtenschicksal, dargestellt anhand von Auszügen aus Akten und Briefen in: Zs. der Savigny-Stiftung für Rechtsgeschichte. Germanistische Abt. 108 (1991) S. 210-236. - Weisert (1991) S. 127 f. u. ö; WBIS; Dt. Juristen jüdischer Herkunft (1993) S. 27-43 u. ö. Mumm, Hans-Martin: Das Haus Zimmern und seine Gäste in: Heidelberg. Jahrbuch zur Geschichte der Stadt 1997. Heidelberg 1997. Jg. 2. S. $16-$ 18, 20-24, 30. • Humaniora (2006) S. 290 u. ö.; Baur (2009) S. 162-164 u. ö. - A.F.J. Thibaut ... Bürger und Gelehrter. Hrsg. von Christian Hattenhauer ... Tübingen 2017. S. 35-52. - Schroeder (2017) S. 7, 33-49.

\section{Zipf, Johannes Stephan}

1804-1813 Med. Fak.

Gerichtliche Arzneiwissenschaft, Tierarzneikunde (Veterinärmedizin), Arzneimittellehre, Pathologie

* 16. Mai 1761 Klingenmünster (bei Landau, Pfalz)

$\dagger$ 11. Dez. 1813 Heidelberg

kath.

V Anton Z. (1724-1821) Volksschullehrer, Zollbereiter (reitet die Straßen ab, damit niemand die Zollstation umfährt oder umgeht)

M Elisabeth geb. Ludwig († vor 1790)

$\infty$ 14. Nov. 1785 Felicitas geb. Vornberg $\left({ }^{*} 1762\right)$

$\infty$ Anna Maria geb. Herzberger

K 4 .
Lb 7. Dez. 1778 Immatrikulation zum Studium der Medizin, Philosophie an UH; 17. Aug. 1780 Z. schlägt in Gesellschaft von 5 weiteren Kandidaten „zur Nachtszeit ... auf dem [Schloß-]Berge Fenster ein" (aus: UAH RA 6431 fol. 7ov, 71r); 6. Sept. 1780 Z. entgeht e. mehrtägigen Karzerstrafe bei Wasser und Brot, weil ihm die „erlittene Untersuchungshaft als Strafe" angerechnet wird; allerdings wird ihm die anstehende Promotion zum Dr. med. für dieses eine Mal („pro hac vice“) verwehrt (aus: RA 6431 fol. 77r-74v; siehe auch Toepke 4 (1903) S. 302 Anm. 4).

1780-1784 Praktikant („physices candidatus“ aus: RA 6431 fol. 7ov) an Hospitälern in Straßburg, dann München, Würzburg; in dieser Zeit Promotion zum Dr. phil.

UH: 1784 Genehmigung zur ärztl. Vorprüfung (Tentamen); „mein Examen wurde - nicht aus Anständen wider meine Sittlichkeit oder Wissenschaften, sondern aus gewissen lustigen Veranlassungen, welche sich im Ernste nicht einmal niederschreiben, sondern nur zum lachen erzählen lassen -, verschoben, bis ich die chymischen Collegien bei Professor Herrn [Daniel Wilhelm] Nebel besucht haben würde.

Da mir nun damals schon inconsequent vorkam, daß man ein Tentamen als geschehen und angenommen angesehen, und nur mein Examen verschoben hat, welcher Verschub mich $\mathrm{zu}$ sehr schmerzte, so begab ich mich zur Rettung meiner Ehre kurz darauf auf die Vaterländische Universität zu Ingolstadt, und da wurde ich in der Arzneiwissenschaft nach vorgängigem 5tägigen Tentamen und einem öffentlichen 5stündigen Examen ... für fähig erkannt, und hab ... unter dem 5. Aug[ust] 1784 die Doctorswürde empfangen ..." (aus: Brief vom 25. April 1798 in: UAH PA 2490).

U Ingolstadt: 5. Aug. 1784 Dr. med.

Mannheim: 1785 Examen zum praktischen Arzt und zum Physikus (Amtsarzt) vor Consilium medicum; seit 1785 niedergelassener praktischer Arzt.

Germersheim (Pfalz): 1787 Erstmals als Oberamtsphysikus genannt in: Seiner Churfürstlichen 
Durchleucht zu Pfalz etc. Hof- und Staats-Kalender für das Jahr 1787. München 1787. S. 137.

H: 1794-1804 Oberamtsphysikus; 1794-1813 Stadtphysikus; 1797/98 Z.s Gesuch um Vergabe eines Lehrstuhls an UH, s. Z. • In dieser Zeit:

UH: 14. März 1804 Ern. zum o. Prof.; WS 1812/13 letzte Vorlesungen; SS 1813 „Prof. Zipf wird diesen Sommer hindurch mit höchster Genehmigung wegen widriger Gesundheitsumstände seine Vorlesung aussetzen" (aus: Anzeige der Vorlesungen, welche im Sommerhalbenjahre 1813 .... zu Heidelberg gehalten werden sollten ... Heidelberg 1813 . S. 11).

1806, 1811 Dekan der Med. Fak. der UH

Z Z. bittet in einem Schreiben vom 31. Dez. 1797 Kurfürst Carl Theodor um Übertragung des Heidelberger Lehrstuhls für Gerichtliche Arzneiwissenschaft und Tierarzneikunde "mit der Anwartschaft auf die erste bei der medicinischen Facultaet frei werdenden Besoldung". Dekan Peter Theodor Leveling antwortet im Namen der Medizinischen Fakultät und nennt 12 Gründe für die Ablehnung des Z.schen Antrags, siehe hierzu Brief vom 5. April 1798 in: UAH PA 2490. Einen 13. Grund fügt Prof. (siehe) Franz Anton Mai hinzu: „Zwei fürtreffliche Talente und Professors Söhne, Wedekind und Gattenhof, ... haben wegen ihren schon erprobten Fähigkeiten den gerechtesten Anspruch auf Lehrstühle ...." Z. antwortet in einem 5-seitigen Brief zu seiner „Ehrenvertheidigung" vom 25. April 1798 auf die Einwände der Fakultät und Mais mit Gegenargumenten, siehe hierzu PA 249o. Prof. Mai sieht sich daraufhin genötigt, auf die Feststellung Z.s, Mai sei sein „Gegner“, diesen Punkt im April/Mai 1798 näher zu erläutern: „Wenn ich als Mitglied der medizinischen Fakultät aus Gründen [im Original unterstrichen] bei Ihrem Professors-Gesuch ihr Gegner und Widersprecher sein mußte, so glauben Sie deßhalben nicht, daß Ihnen im Herzen feind ist Ihr aufrichtiger Mai“ (aus: PA 2490). Kurfürst Carl Theodor ordnet in einem Reskript vom 19. Mai 1798 an, „... daß ... Zipf biß zur Vacatur eines solchen Lehrstuhls zur Gedult verwiesen ... werden soll ..." (aus: PA 2490). Nach knapp sechs Jahren, 1804, erhält Z. das erbetene Ordinariat.
Auf Z.s Epitaph in der Heiliggeistkirche Heidelberg heißt es etwas makaber: „Menschenliebe machte ihn zur Leiche“: Z. starb an Typhus; er hatte sich vermutlich bei einem Patienten angesteckt.

Qu UAH PA 2490; RA 5586, 5929, 5987, 6431, 6819, 7125. Toepke 4 (1903) S. 300, Anm. 2, S. 302 Anm. 4. GLA Abt. 205, Fasz. 588 f.

$W$ Lehrbuch der Krankheiten der Thiere und besonders der Pferde. 2 T. Heidelberg 1807-1808.

L Meusel, 9. Bd., Suppl. zur 5. Ausg. (1827) S. 813; Keller (1913) S. 196-198; Schneider (1913) S. 81, 278, 332 f.; Stübler (1926) S. 233-235; WBIS; Prückner (2004) S. 305 (Register).

$P$ Bildarchiv UAH.

\section{Zipff, Zipp}

siehe Zipf

\section{Zöpfl, Heinrich Matthäus}

1828-1877 Jur. Fak.

Allg. Dt. Staatsrecht, Naturrecht, Dt. Staats- und

Rechtsgeschichte, Völkerrecht, Lehnrecht

* $\quad$ 06. April 1807 Bamberg

$\dagger \quad$ 04. Juli 1877 Heidelberg

kath.

V Johann Baptist Z. (1771-1833) AppellationsGerichtsrat, s. WBIS, Schroeder (2010) S. 156

M Catharina geb. Pflaum, s. Schroeder, S. 156

๑ 21. Okt. 1832 Anna Bernhardina geb. Leo (1805-1878)

K 4 T, siehe UAH Fak.-Akte H-II-335/1.

Lb U Würzburg: Seit April 1824 Studium der Rechtswiss., Philosophie; 28. Aug. 1827 Dr. iur.

UH: 14. Nov. 1827 Immatrikulation; 11. Aug. 1828 Habilitation; 1831-1840 Beisitzer des Spruchkollegiums der Jur. Fak.; 8. Nov. 1838 Ern. zum a.o. 
Prof.; 1839-1842 Vorlesungen über Badisches Landrecht und Badischen Zivilprozeß; 1840 Austritt aus dem Spruchkollegium als a. o. Beisitzer, s. hierzu Schroeder (2010) S. 149; 1841 Ruf an U Jena abgelehnt; seit 4. Nov. 1842 o. Prof. II. Klasse (d.h. ohne Teilnahmeberechtigung an den Fak.-Sitzungen und Doktorexamina); 1842-1876 o. Mitglied des Spruchkollegiums; 1843 Ruf an U Dorpat abgelehnt; 25. April 1844 Ern. zum o. Prof. I. Klasse, d.h. mit Teilnahmeberechtigung ... als Nachf. von Carl Salomo Zachariae; 1847 Ruf an U München abgelehnt; u. a. 1850-1856 Mitglied der I. Kammer des Badischen Landtags in Karlsruhe als Vertreter der UH.

1849/50 Prorektor der UH; 1846, 1851, 1857, 1862/63, 1867/68, 1873/74 Dekan der Jur. Fak. der UH

Gutachter und juristischer Ratgeber zahlreicher Fürstenhäuser und Landesherren

1845 Hofrat; 1874 Geh. Hofrat; 1877 Geheimrat II. Klasse

E 1839 Ritterkreuz des Ordens Isabellas der Katholischen.

Qu UAH PA 2492; Fak.-Akte H-II-111/22; GF 49. • GLA Abt. 205, Fasz. 590. • Briefe, Nachlaß: UBH.

$W$ Deutsche Staats- und Rechtsgeschichte. 2 Bde. Heidelberg 1834-1836. 3. Aufl. u.d.T.: Deutsche Rechtsgeschichte. Stuttgart 1858. 4. Aufl. 1872. Nachdr. 1975. Grundsätze des allgemeinen und deutschen Staatsrechts. 2 Bde. Heidelberg 18391841. 5. Aufl. 1863. Constitutionelle Monarchie und Volkssouveränität. Frankfurt 1848. • Deutsche Union und deutsches Reich. Entwurf e. allg. Reichsverfassung mit Inbegriff der deutschen Union. Erfurt 1850. • Alterthümer des Deutschen Reichs und Rechts. 3 Bde. Leipzig 1860-1861. • Die neuesten Angriffe auf die staatsrechtliche Stellung der deutschen Standesherren. Donaueschingen 1867. Grundriß zu Vorlesungen über Rechtsphilosophie. Berlin 1878. 2. Aufl. 1879. • Siehe auch Schroeder (2006) S. 307-311 u. ö.
$H G$ Die peinliche Gerichtsordnung Kaiser Karl's V. nebst der Bamberger und der Brandenburger Halsgerichtsordnung. Heidelberg 1842. 3. Aufl. 1883.

L ADB 45 (1900) S. 432-434; Heidelberger Prof. aus dem 19. Jhdt. 1 (1903) S. 268-270; Jammers (1964) S. 178 u. ö.; Heidelberger Strafrechtslehrer (1986) S. 33; Stolleis 2 (1992) S. 91-93 u. ö.; Lengemann (2000) S. 350 f. - Schroeder, Klaus-Peter: H.Z. - Eine Heidelberger Gelehrtenkarriere mit Hindernissen in: Humaniora (2006) S. 287-314. • Baur (2009) S. 171-175 u. ö.; Schroeder (2010) S. 744 (Register); WBIS; Klippel (2012) S. 395 (Register); Schroeder (2017) S. 372 (Register).

$P$ Lengemann (2000) S. 351.

\section{Zuccarini, Franz Karl}

1788-1809 Med. Fak.

Botanik, Anatomie, Chirurgie

* 24. Febr. 1737 Mannheim

$\dagger$ 15. Nov. 1809 Heidelberg kath.

V Johann Carl (?) Zucherini/Zuccarini M Johanna Barbara geb. Seuffert(in) (?)

œ Franziska geb. Guerdan $\left({ }^{*}\right.$ ca. $1735 \dagger$ nach 1809$)$

K unbekannt.

Lb UH: Seit 12. Dez. 1757 Studium der Logik; 1758 phil. Bakkalaureat; 1760 Magister artium; anschl. Studium der Medizin an UH (?); Febr. 1769 Dr. med.

Mosbach (Baden): Seit ca. 1765, noch Febr. 1769 Gehilfe des Amtsarztes (physicus adiunctus), dann Physikus; vor 1777-1788 Oberamtsphysikus, s. Kurpfälzischer Hof- und Staats-Kalender auf das Jahr nach unseres Herrn und Heilandes Jesu Christi gnadenreicher Geburt ... 1777. Mannheim 1777. S. 131; 1781 erfolglose Bitte um e. a.o. Professur an UH.

UH: 12. April 1788-1809 (†) o. Prof. als Nachf. von Georg Matthäus Gattenhoff; WS 1789/90-WS 
1795/96 Vorlesungen über Heilkunde als Vertreter für Franz Anton Mai; seit 1805 (Begründer) Leiter e. neuen Botanischen Gartens hinter dem ehemaligen Dominikanerkloster an der Ecke Hauptstrasse/Brunnengasse, s. hierzu UAH RA 6514, Wissenschaftsatlas der UH (2011) S. $236 \mathrm{f}$.

1791, 1792, 1796, 180o, 1804, 1808 Dekan der Med. Fak. der UH

1805 Geh. Hofrat

$Z$ In der Allgemeinen Literatur-Zeitung Nr. 9 vom 9. Jan. 1810, S. 71f. heißt es in Z.s Todesanzeige: „... Als Schriftsteller hat er sich, Dissertationen ausgenommen, nicht bekannt gemacht; allein er war ein glücklicher Arzt, so lange er noch einer ungeschwächten Gesundheit genoß, und durch seine Vorlesungen stiftete er vielen Nutzen. Ferne von allem gelehrten Stolze im Umgang, wurde er als Gesellschafter um so mehr geschätzt, da es ihm nicht an dem Talente fehlte, gesellschaftliche Kreise durch muntere Laune zu erheitern."

$\mathrm{Q} u$ UAH PA 2495; RA 3185, 3957, 5810, 6514 (u. a. Testament), 5682, 8089 und 8256 (Übernahme der Vormundschaft von Franz, Josepha und Sophie
Wedekind), 8253. Toepke 4 (1903) S. 186, 494, 497, 579 Anm. 2. GLA Abt. 205, Fasz. 592. • Auskunft: Kath. Kirchenbuchamt Mannheim (Ehebuch 1733; Taufbücher 1727-1738: keinen Eintrag von Franz Karl Z. gefunden); Kath. Kirchenbuchamt Heidelberg (Totenbuch 1809: er starb im 73. Lebensjahr).

$W$ Dissertatio de hypochondria. Heidelberg 1769, s. http://idb.ub.uni-tuebingen.de/diglit/JfII62_qt_9 (abgerufen am 15. Febr. 2018). Siehe WBIS.

$L$ Annalen der deutschen Universitäten. Hrsg. von Karl Wilhelm Justi und Friedrich Samuel Mursinna. Marburg 1798. S. 276 f. (hier: Geburt am 15. Aug. 1738 in Mannheim). Allgemeine Literatur-Zeitung Nr. 9 vom 9. Jan. 1810. S. 71 f. $\bullet$ Meusel, 9. Bd., Suppl. zur 5. Ausg. (1827) S. 827. • Allgemeine Encyklopädie der Wissenschaften und Künste ... Hrsg. von J. S. Ersch und J.G. Gruber. 2. Section. Hrsg. von A.G. Hoffmann. 13. Teil. Nachträge. Leipzig 1836. S. 15, 143. - Schneider (1913) S. 18; Stübler (1926) S. 162 f.; WBIS; Chronik Ärzte H (1985) S. 147; Kirschke (2001) S. 450 (Register); Prückner (2004) S. 305 (Register); DBE 10 (2008) S. 890; Wissenschaftsatlas der UH (2011) S. $236 \mathrm{f}$. 